UMASS/AMHERST

|||||| |||||||||||||||||||||||||||||||||||||||||||||||

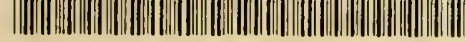

31206600515881 


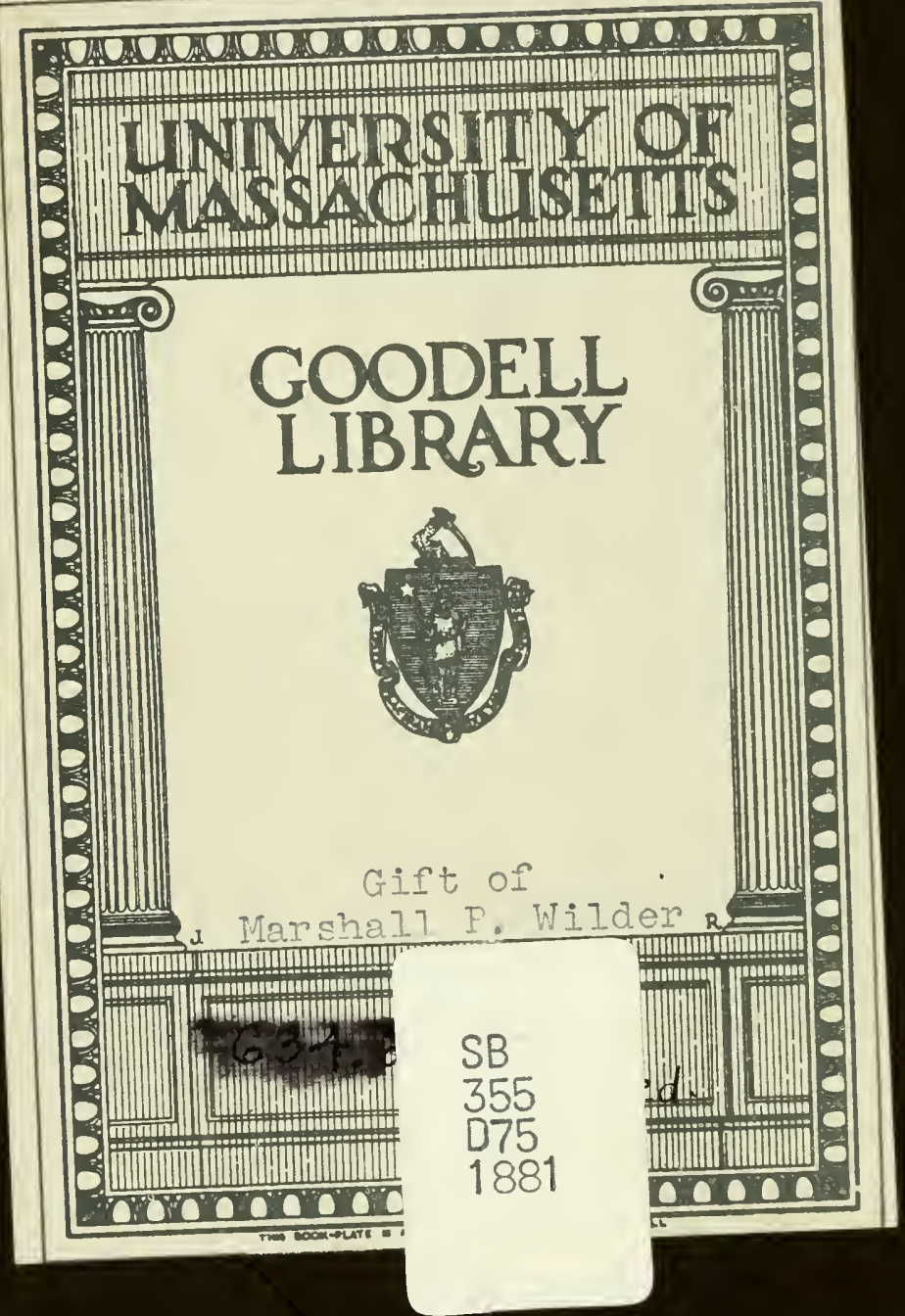


This book may be kept out

\section{TwO WEEKS}

only, and is subject to a fine of THo CENTS a day thereafter. It will be due on the day in. dicated below. 

sesintes tey folm opicy Yor

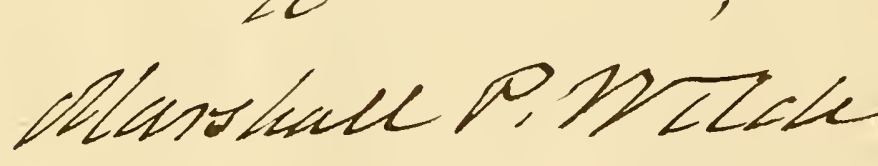
Hetelfor. 



\title{
FRUITS AND FRUIT-TREES
}

\author{
ir \\ A M E R I A;
}

OR

THE CULTURE, PROPAGATION, AND MANAGEMENT, IN THE GARDEN AND ORCHARD, OF FRUIT-TREES GENERALLY;

ห ITI

DESCRIPTIONS OF ALL THE FINEST VARIETIES OF FRUIT, NATIVE AND FOREIGN, CULTIVATED IN THIS COUNTRY.

\section{BY A. J. DOWNING.}

CORRESPONIINO MEMBER OF THE ROYAL BOTANIC SOCIETY OF LONDON; AND OF THE HOKTLULL TURAL BOCleties OF BERLIN, THE LOW COUNTries, MASSACGUSETT8,

penngyltania, indana, cincinnati, etr.

Second Revision and Correction, vith large Additions, including the Appendices of 1872 to 1881 , and contuining many New Varieties.

BY CHARLES DOWNING.

Witir Nearly 400 Outhine Ildustratroxs of Frutt.

NEW YORK:

IOHN WILEY \& SONS. 15 ASTOR PIACE. 1881. 


$$
\begin{aligned}
& 634 \\
& .2 \\
& 175 \\
& 2872 \mathrm{ed}
\end{aligned}
$$

Entered according to Act of Congress, in the year 1872 , by JOHN WILEY \& SON,

In the Affaceof the tibraritin of Congress, at Washington.

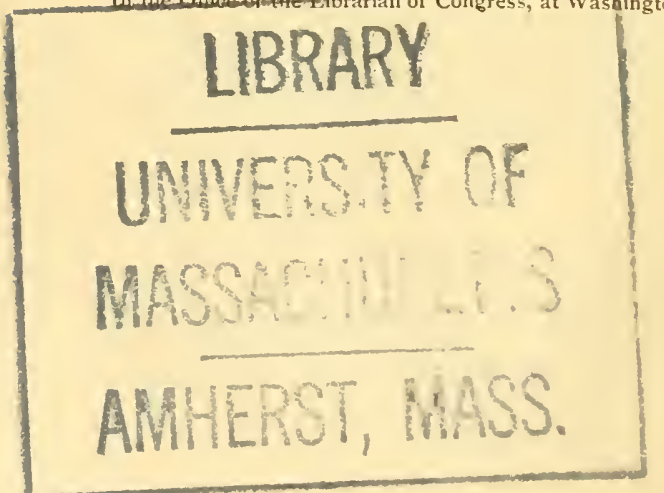

Trow's

Printing and bookbinding Company, 20I-213 East 12th Street, NEW YORK. 
To

MARSHALL P. WILDER, Esq.,

PRESIDENT OF THE

massacilusetT IS hoRticultural society,

TIIS VOLume is Dedicated,

BY HIS FRIEND,

THE AUTHOR. 



\section{A NOTE}

ON TRE

\section{FRUITS OF CALIFORNIA}

Since the publication of the recent edition of this book, the anthor has visited California, and his observations in that newly developed region have elicited the facts that fruit trees grow much faster there, and come into bearing much earlier than with us, and it may be fairly inferred, therefore, that they will not be as long-lived.

The same varieties of Apples, Pears, Peaches, Plums, Apricots, Cherries, \&c., are grown as with us; but all kinds of fruit, especially some kinds of Apples, do not succeed equally well as in the Eastern States. The following sorts were considered most profitable: Williams' Favorite, Early Strawberry, Red Astrachan, Early Harvest, Winesap, Rawles' Janet, Newtown Pippin, White Winter Pearmain, Smith's Cider, Yellow Belflower. Newtown Pippin best and most profitable. The Northern Spy and Baldwin had failed.

The fruit is rather larger, fairer, and handsomer, and the quality equally good, except Strawberries and Blackberries, which were not quite as high flavored. Grapes are grown extensively in many localities, and succeed admirably. They are chiefly of the foreign varieties, and are grown in the open air, withont protection, requiring but little labor, compared with our systern of cultivation. 
They are grown in the tree form on stems or stumps fron wo to three feet high, and those from ten to fifteen years old are from five to six inches in diameter. The vines are planted from seven to eight feet apart, each way. They are pruned, smmually, back to the stems, and when the new shoots have grown five or six inches, all are thimned ont, except ten or twelve of the strongest, and in most rineyards they have no further care till gathering time, except to keep the ground clean.

In some orchards that had been neglected, the trees were failing, and I was told that if the ground was not cultirated and the trees eared for, they soon died.

We found Figs abmudant and of fine quality in nearly every locality we visited. English Walnuts, or Madeira Nuts, Almonds, and Olives are grown successfully in most places.

The climate and soil are favorable for fruit-growing. In the latter, clay predominates. The characteristics of fruit are abont the same as with us. 


\section{CONTENTS.}

PREFACE....................................... IX

Preface to the Second Revision........................ XiI

ABBrevlations AND Books QUOTED ...................... XVII

CHAPTER I.

The Production of New Varieties of Fruit................ 1

The Van Mons Theory............................ 5

Cross-Breeding.................................. 7

CHAPTER II.

Remarks on the Duration of the Varieties of Frutt-Trees.....

CHAPTER III.

Propagation of Varieties, Grafting, Budding, Cuttings, Layers, AND SUCKERS................................... 16

CHAPTER IV.

PrUNLVG.

CIIPTER $\nabla$.

TratNREg.

CHAPTER VI.

Transplanting

CHAPTER VII.

The Position of Fruit-Trees-SoIL AND Aspect

CHAPTER VIII.

General Remarkis on Insects. 
THE APPLE.

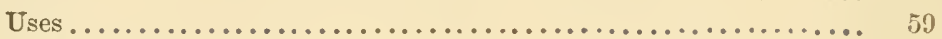

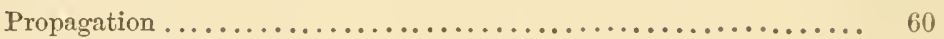

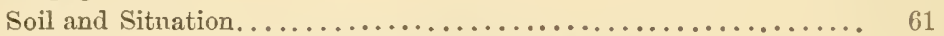

Preparing, Planting, and Cultivation of Orchards............. 62

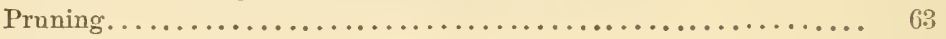

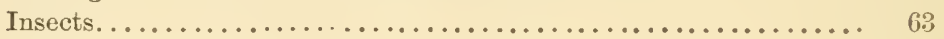

Gathering and Keeping the Fruit..................... 67

Cider .................................... 69

Varieties, Classification, and Terms used in Describing Apples .... To

Descriptive List of Varieties. . . . . . . . . . . . . . . . . . .

Siberian Crabs and Improved Siberian Apples, with Descriptive List 421

Select List of Varieties for Table Use, Cooking, and Keeping; \&c. . . 4 4?

Alphabetical Index to Descriptive Lists.................. $4: 37$

\section{CHAPTER X.}

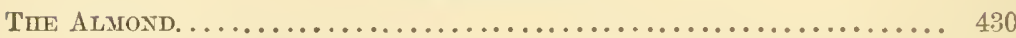

Uses and Cultivation .......................... 430

Descriptive List of Varieties.... . . . . . . . . . . . . . . 431

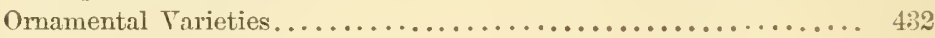

Alphabetical Index to Descriptive List.................. 4:. 437

CHAPTER II.

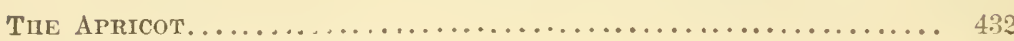

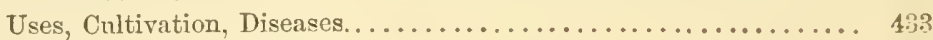

Descriptive List of Varieties..................... 43.3

Curious or Ornamental Varieties.................... 442

Alphabetical Index to Descriptive List................ 1013

\section{CHAPTER XII.}

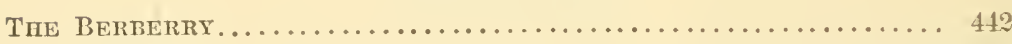

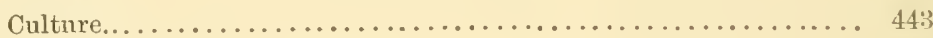

The BuAckrerrt................................ 413

Descriptive List of Varieties. . . . . . . . . . . . . . . . . . 443

Ornamental Varieties. . . . . . . . . . . . . . . . . . . . . $4416^{2}$

Alphabetical Index to Descriptive List................. 1015

\section{CHAPTER XIII.}

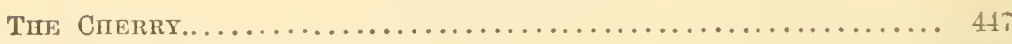

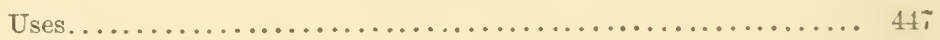

Soil and Situation............................ 44

Propagation and Cultiration...................... 449

Training and Gathering the Fruit................... 450

Descriptive List of Tarieties :

Class I. - Bigarrean and Heart Cherries............... 4.50

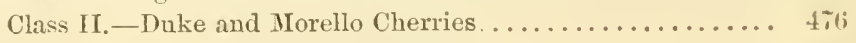

Ornamental Tarieties............................. $4 \$ 0$

Selections of Choice Cherries for Family Use............... 487

Alphabetical Index to Descriptive List. . . . . . . . . . . . . . 101, 


\section{CIHAPTER XIT.}

Tme Currant

Uses, Propagation and Culture, Insects and Diseases.......... 488

Descriptive List of Varieties:

Class I.-Red and White Currants.................. 489

Class II.-Black Currants....................... 492

Ornamental Varieties............................ 493

Alphabetical Index to Descriptive List. ................. 10ミ0

\section{CHAP'TER XV.}

The Cranberrx.................................. 493

Alphabetical Index............................... 1019

\section{CHAPTER XVI.}

THE FIG........................................ 494

Propagation, Soil, and Culture...................... 495

Descriptive List of Varieties:

Class I.-Red, Brown, or Purple.................... 496

Class II._White, Green, or Yellow................. 498

Alphabetical Index to Descriptive List. ................. 1020

\section{CHAPTER XVII.}

THE Gooseberkx ................................. 499

Uses, Propagation, and Cultivation.................. 500

Descriptive List of Varieties......................... 501

American Varieties................................ 50:

Alphabetical Index to Descriptive List.................. 1021

\section{CIIAI'TER XVIII.}

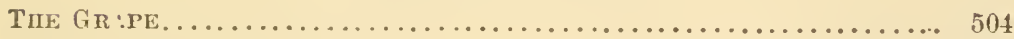

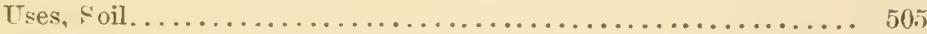

Propagation ...................................... $50 k$

1. Culture of the Foreign Grape................... 506

Renewal Training...................... 507

Culture under Glass without Artificial Heat........... 508

Culture under Glass with Fire Heat. ............... 510

Construction of the Vinery...................... 511

Insects and Diseases....................... 518

Descrptire List of Foreign Grapes.................. 512

2. American Grapes............................. 525

Vineyard Culture ....................... 520

Diseases and Insects, Grafting, Keeping............. 527

Descriptive List of Americun Grapes.................. 528

Selection of Varieties........................... 558

Aly habetical Index to Descriptive Lists of Foreign and American

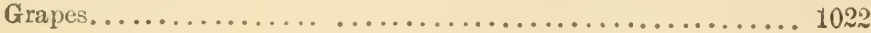




\section{CHAPTER XIX.}

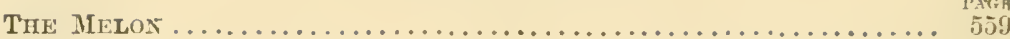

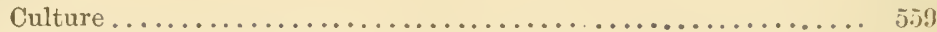

Descriptive List of Varieties. ..................... $56(0)$

Alphabetical Index to Descriptive List ................. 1026

\section{CHAPTER XX.}

THE WATER-Meton............................... 561

Descriptive List of Varieties ...................... 502

Alphabetical Index to Descriptive List................ 1027

\section{CIIAPTER XXI.}

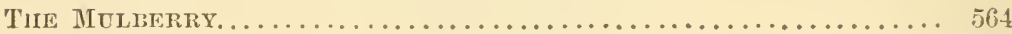

Description of Tarieties. . . . . . . . . . . . . . . . . . . . . . 594

Alphabetical Index.............................. 10?

\section{CIAPTER XXII.}

The Nectarine ................................... 565

Culture ...............................

Descriptive List of Tarieties...................... 566

Alphabetical Index to Descriptive List................ 10:7

\section{CHAPTER XXIII.}

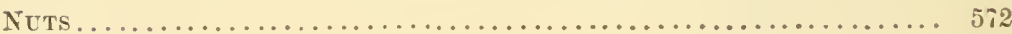

Descriptive List of Tarieties...................... 573

Alphabetical Index to Descriptive List.................. 1028

CIIAPTER XXIV.

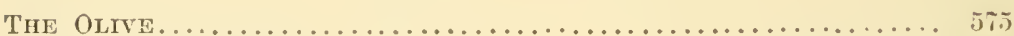

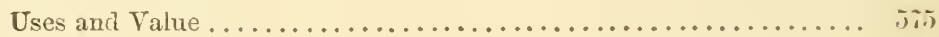

Propagation and Culture............................ 5ij

Varieties. .......................................

Index to Varietics. . . . . . . . . . . . . . . . . . . . . . 1029

\section{CIAPTER XXT.}

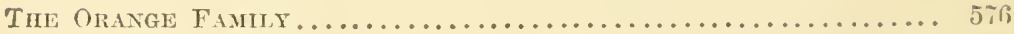

Soil and Culture..................................

Varieties ...................................... 578

Lemons ...................................... 559

The Lime .................................. 579

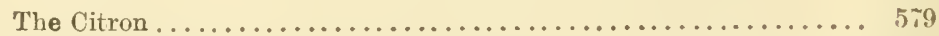

The Shaddock ................................... 579

Index to Tarieties............................. 10:4) 


\section{CHAPTER XYVI.}

Uses....................................... 581

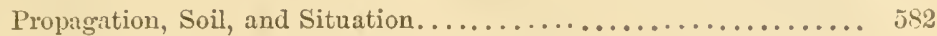

Pruning. . . . . . . . . . . . . . . . . . . . . . . . . . 583

Insects and Diseases. .......................... 586

The Yellows................................. 587

Remedy for the Fellows . . . . . . . . . . . . . . . . . . . . . 591

Raising Peaches in Pots............................ 594

Descriptive List of Varieties. . . . . . . . . . . . . . . . . . . 596

Curions or Ornamental Tarieties......................... 638

Selection of Varieties........................... 639

1lphabetical Index to Descriptive List. . . . . . . . . . . . . . . . 10:

\section{CHAPTER XIVII.}

THE PFAR................................... 689

General Description............................. 639

Gathering and Keeping the Fruit.................... 641

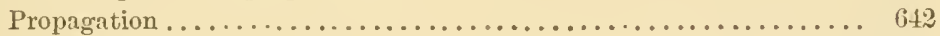

Soil, Situation, and Culture..................... 64:3

Diseases and Insects ............................. 644

The Insect Blight. ........................ 645

The Frozen-sa1, Blight....................... 646

Varieties. ................................... 650

Descriptive List of Varieties. ...................... 651

Select List for Table Use, Marketing, and Cooking . . . . . . . . . 887

Alphabetical Index to Descriptive List. . . . . . . . . . . . . . . . 1033

\section{CIIAPTER XXVIII.}

TIE: PLUM. . . . . . . . . . . . . . . . . . . . . . . . . . . . . 889

Uses............................................... 889

Propagation and Culture.............................. $\$ . \ldots 0$

Suil ; Insects and Diseases ............................. 891

Varieties .......................................... 895

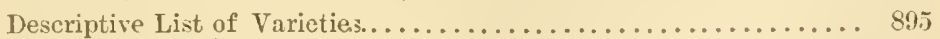

Ornamental Varieties. . . . . . . . . . . . . . . . . . . . . . . . . 9.55

Selection of Tarieties for Table, Marketing, and Cooking........ 9.5.

Alphabetical Index to Descriptive List. . . . . . . . . . . . . . . . 10.56

\section{CHAPTER XXIX.}

The Ponegranate.............................. 956

Propagation and Culture........................ 9.7

Varieties.................................... 957

Alphabetical Index to Varieties...................... 1063

\section{CHAP'TER XXX.}

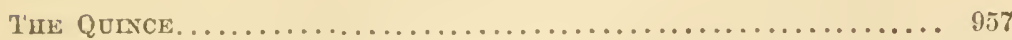

Uses, Propagation, Soil, and Culture.................... 958

Varieties ..................................... 958

Ornamental Tarieties............................ 960

Alphabetical Index to Tarieties..................... 106? 


\section{CHAPTER XXXI.}

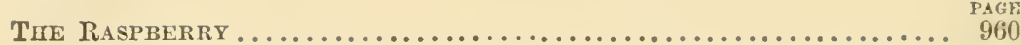

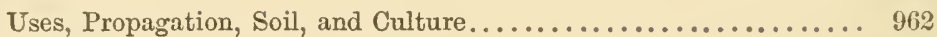

Varieties .......................................... 962

Alphabetical Index to Varieties........................ 1063

\section{CHAPTER XXXII.}

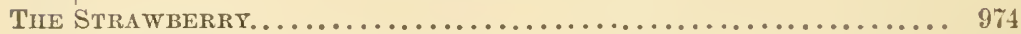

Propagation, Soil, and Culture.................... 975

Varieties........................................ 9iז

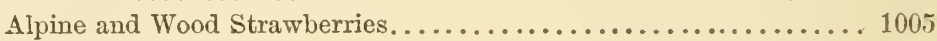

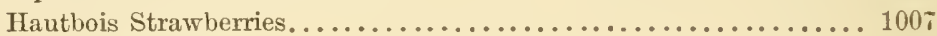

Chili Strawberries.............................. 100t

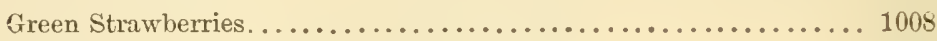

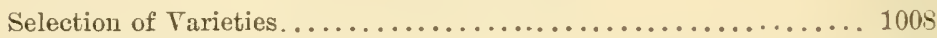

Alphabrical Index to Varieties...................... 1064

Index to the Different FrUits....................... 1013

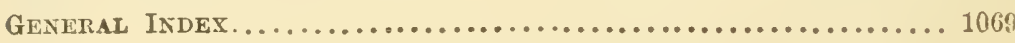

\section{APPENDIXES.}




\section{PREFACE.}

A Mas born on the banks of one of the noblest and most fruitful rivers in America, and whose best days have been spent in gardens and orchards, may perhaps be pardoned for talking about fruit-trees.

Indeed the subjeet deserves not a few, but many words. "Fine fruit is the flower of commodities." It is the most perfect union of the useful and the beautiful that the earth knows. Trees full of soft foliage; blossoms fresh with spring beanty; and, finally,-fruit, rich, bloom-dusted, melting, and luseions, - such are the treasures of the orchard and the garden, temptingly offered to every landholder in this bright and sumny, though temperate climate.

"If a man," says an acute essayist, "should send for me to come a hundred miles to visit him, and should set before me a basket of fine summer fuit, I should think there was some proportion between the labor and the reward."

I must add a counterpart to this. He who owns a rood of proper land in this eountry, and, in the face of all the pomonal riches of the day, only raises crabs and choke-pears, deserves to lose the respect of all sensible men. The classical antiquarian must pardon one for doubting if, anid all the wonderful beauty of the golden age, there was anything to equal our delicious modern fruits-our honeyed Seckels, and Beurés, our melting Rareripes. At any rate, the science of modern horticulture has restored almost everything that can be desired to give a paradisiacal riehness to our fruit-gardens. Tet there are many in utter ignorance of most of these fruits, who seem to live under some ban of expulsion from all the fair and goodly productions of the garden.

Happily, the number is every day lessening. Ameriea is a young orchard, but when the planting of fruit-trees in one of the newest States numbers nearly a quarter of a nillion in a single year; when there are more fleaches exposed in the markets of New York, annually, than are raised in all France; when American apples, in large quantities, command double prices in European markets; there is little need for enter. ing into any praises of this soil and climate generally, regarding the culture of fruit. In one part or another of the Union every man may, literally, sit under his own vine and fig-tree. 
It is fortunate for an author, in this practical age, when his subject requires no explanation to show its downright and direct usefulness. When I say I heartily desire that every man should cultivate an or. chard, or at least a tree, of good fruit, it is not necessary that I should joint out how much both himself and the public will be; in every sense, the gainers. Otherwise I might be obliged to repeat the aúvice of Dr. Johnson to one of his friends. "If possible," said he, "have a good orchard. I know a clergyman of small income who brought up a family very reputably, which he chiefly fed on apple dumplings." (!)

The first object, then, of this work is to increase the taste for the planting and eulivation of fruit-trees. The second one is to furnish a manual for those who, already more or less informed upon the subject, desire some work of reference to guide them in the operations of culture, and in the selection of varieties.

If it were only necessary for me to present for the acceptance of my readers a choice gariand of fruit, comprising the few sorts that I esteem of the most priceless value, the sprace and time to be occupied would be very brief.

But this would only imperfectly answer the demand that is at present made by our cultivators. The comutry abounds with collections of all the finest foreign varieties; our own soil has produeed manr native sorts of the highest merit; and from all these, kinds may be selected which are lighly valuable for every part of the countre. But opinions differ much as to the merits of some sorts. Those which succeed perfectly in one section, are sometimes ill-arlapted to another. And, finally, one needs some accurate description to know, when a variety comes into bearing, if its fruit is genuine, or even to identify an indifferent kind, in order to avoid procuring it again. Hence the number of virieties of fruit that are admitted here. Little by little I have summoned them into my pleasant and quiet court, tested them as far as possible, and endeavored to pass the most impartial judgment upon them. The verdicts will be found in the following pages.

From this great accumulation of names, Pomology has become an embarrassing study, and those of our readers who are large collectors will best understand the difliculty-nay, the impossibility of making a work like this perfect.

Towards settling this chaos in nomenclature, the exertions of the Horticultural Society of London have been steadily directed for the last twenty years. That greatest of experimental gardens contains, or has containerl, nearly all the varieties of fruit, from all parts of the world, possessing the least celebrity. The rast confusion of names, dozens sometimes meaning the same variety, has been by eareful comparison reduced to something like real order. The relative merit of the kinds has been proved and published. In short, the horticultural world ores 
this Society a heary debt of gratitude for these labors, and to the science and acemacy of $\mathrm{M} r$ r. Robert Thompson, the head of its fruit department, horticulturists here will gladly join me in bearing the fullest testimony.

To give additional value to these results, I liave adopted in nearly all cases, for fruits known abroarl, the nomenclature of the London Horticultural Society. By this means I hope to render universal on this side of the Atlantic the same standard names, so that the difficulty and confision which have always more or less surrounded this part of the subject may be hereafter aroided.

These foreign fruits have now been nearly all proved in this country, and remarks on their value in this climate, decluced from actual experience, are here given to the public. To our native and local fruits especial care has also been devoted. Not only have most of the noted sorts been proved in the gardeus here, but I have had specimens before me for comparison, the growth of no less than fourteen of the difierent States. There are still many sorts, nominally fine, which remain to be collected, compared, and proved; some of which will undoubtedly deserve a place in future editions. To the kinduess of pomoiogists in various sections of the comntry I must trust for the detection of errors in the present volume, and for information of really valuable new varieties.*

Of the rescriptions of fruit, some explanation may be necessary. First, is given the standard name in capitals. Below this are placed, in smaller type, the various synongmes, or local names, by which the same fruit is known in various countries or parts of the country. Thus, on page 761 , is the following:

\section{Flemish Benuty.}

\begin{tabular}{|c|c|}
\hline $\begin{array}{l}\text { Bolle de Flandres. } \\
\text { Bosch Nonvelle. } \\
\text { Bosch. } \\
\text { Bose Sire. }\end{array}$ & $\begin{array}{l}\text { Poire Dary. } \\
\text { Impératrice de France. } \\
\text { Fondant du Bois. } \\
\text { Boschpeer. }\end{array}$ \\
\hline
\end{tabular}

Py this is signified, first, that F LEMISI BexuTY is the stenderd name of the pear; secondly, that the others-synonymes-are various local nanres by whith the Flemish Beanty is also known in various places; a.1d, lastly. that by the latter name-Benré spence-it is incorrectly known in some collections, this name belonging to another distinct peat:

It is at once apparent that one of the chicf points of value of a book like this, lies in the acenracy with which these synonymons names

* It is well to remark that many of the so-called new varieties, especially from the West, prove to be old and well-known kinds, slightly altered in appearanee by new soil and different climate. A new varicty must possess very superior qualitieg to entitle it to regard, now that we hav so many fine fruits in our collections. 
are given-since a person might, in looking over different catalogues issued here and abroad, suppose that all ten of the above are different varieties-when they are really all different names for a single pear. In this record of synonymes, I have therefore availed myself of the valuable experience of the London Horticultural Society, and added all the arditional information in my own possession.

Many of the more important varieties of fruit are shown in outliwe. I have chosen this method as likely to give the most correct idea of the form of a fruit, and because I believe that the mere ontline of a fruit, like a profile of the human face, will often be found more characteristic than a highly finished portrait in color. The outlines have been nearly all truced directly from fruits grown here. They are from specimers. mostly below the average size. It has been the custom to choose the largest and finest fruits for illustration-a practice very likely to mislead. I believe the general character is better expressed by specimens of medium size, or rather below it.

It only remains for me to present my acknowlerigments to the numerous gentlemen, in rarious parts of the country, who have kindly furnished information necessary to the completion of the work. The names of many are given in the body of the volume. But to the following I must especially tender my thanks, for notes of their experience, or for specimens of fruits to solve existing doubts.

In Massachnsetts, to Messrs. M. P. Wilder, S. G. Perkins, J. P. Cushing, B. V. French, S. Downer, and C. II. Horey, of Boston; John C. Lee, J. M. Ives, the late Robert Mamning, and his son, R. Manning, of Salem; anr Otis Johnson, of Lymn.

In Comnecticut, to Dr. E. TT. Bull, of Hartford; Mr. S. Lrman, of Manchester'; and the Rev. H. S. Ramsdell, of Thompson.

In New York, to Messrs. David Thomas, of Aurora; J. J. Thomas, of Micedon; Luther Tucker and Isaac Denniston, of Albany ; Alexander Walsh, of Lansingburgh; T. H. Hyatt, of Rochester; R. L. Pell, of Pelham; C. Downing, of Newburgh; and Wm. H. Aspinwall, of Staten Island.

In Ohio, to Professor Kirtland, of Clereland; D1. Hildreth, of Marietta; and Messrs. N. Longworth, C. W. Elliott, and A. H. Ernst, of Cincinnati.

In Indiana, to the Rev. H. W. Beccher, of Indianapolis. In New Jersey, to Messi's. Thomas Hancock, of Burlington, and J. Wr. Hayes, of Newark. In Penusylrania, to Mr. Frederick Brown and Col. C'arr, of Philadelphia. In MIaryland, to Lloyd N. Rogers, Esq., of Baltimore. In Georgia, to James Camak, Esc., of Athens.

A. J. D.

HigmLAND G.RDENS, ?

Newoburgh, N. Y., Muy, 1845. 


\section{PREFACE TO THE SECOND REVISION.}

Tue second revision of the Froits axd Fruit-'irees of America, originally written by my lamented brother, in 1845, has been undertaken with very great hositancy; but the extended increased interest in fruit-culture, and demand for this work, have secmed to require of me such aid in its construction, commensurate with the progress of the age, as I could commanul.

I have therefore, by the assistance of numerous friends in all parts of the States and the Canadas, gathered together material, and embodied, enlarged, and revised the work, trusting that the desire to assist, aid, and continue the advancement of fiuit-culture may be taken as the incentive which has guider my labors; and that imperfections will not be too freely commented upon, withont careful thought of the time and observation, etc., requisite in deciding many points in Pomology. The correcting or deciding relative to the various names under which one fruit is known in different sections, was originally a feature of great difficulty, even when they were brought together and grown in one garden, as by the London Horticultural Society; but when this has to be rlone with the varieties spread over such a wide territory, and with so many varied climates and soils as ours, the task is one of no light character. At the first writing of this book the accumulation of names was snch as to then cause the study of Pomology to be counted as au embarrassing one. What then shall we say of it now, when the list of names has been more than trebled? New varieties have sprung into existence with the magic rapidity belonging to everything of our country; but, unfortunately, regard has not always been had to the qualifications which should have been by them possessed ere their introuluction to our lists; and at this day I may safuly say that not perhaps one in thirty of the recent introrluctions, for the past twenty years, will bear the criticism of a tirst-class fruit.

In my revision I lave endeavored to keep as near as possible the simple arrangement of the original, omitting the arangement of classes and periorls of ripening, and placing the whole alphabetically in order, trusting to the text description to give the information sought by the reader. The nomenclature of the London IIorticultural Society in the original edition has been retrined, and, so far as known, I have continued the original name by which each fruit was first deseribed, as its true name, appenting all others as symonyms.

In the first edition of this work the names of authors who had 
before given descriptions of the fruits were appended to each description, but owing to the great number of names such a record would now make, and to its little practical benefit, I have omitted it.

In the labor of ascertaining synonyms and identifying disputed varieties, much credit is due to the American Pomological, Massachu setts, Western New York, Olio, Illinois, Indiaua, Missouri, and other kindrer Societies, by their gathering and comparing great numbers of specimens from various sources, aud in the acemmulation of knowleclge and opinions here reported as the result of long-continued examinations of private individuals. But the confusion of names yet exists to a large extent, and while much has been done toward correction, order and accuracy can only be arrived at when the different rarieties are well grown in the same soil and locality, a result only to be realized in an experimental garden on a large scale.

The place of origin of each variety has been attached whenever it could be truly traced or known; but many are noted only as having been received from certain States or sections, their origin being possibly in another State. The period of maturity has been giren as its period when fruited here; but it is well known locations South or Nortl cause great changes in this respect, as well as in quality, aud many good longkeeping winter apples of this seetion, when grown in our Southern States, become early autumn and inferior sorts. Again, nearly all rarie. ties of our early summer fruits, aithough ripened at an earlier period, are equal, if not improved, in size and quality when grown at the Soutl.

In the revision of a former edition, as well als in aid of revision of the present, I have received valuable notes, specimens of fruits, de., from a large number of gentlemen, and in here making my grateful acknowledgments, I desire to record all names as a simple tribute, although some have prassed from this land of chaotic terrestriul fruit to that where order and system erer reigus.

In Massachusetts-to Joln Milton Earl, Samuel Colton, George A. Chamberlaiu, and George Jacques, Worcester; J. C. Stone, Shrewsbnir; F. Burr, Hingham; Asa Clement, Lowell: Willis P. Sargent, West Amesbury; O. V. Hills, Leominster: Dr. L. WV. Puffer, North Bridgewater; Joseph Merrill, James D. Black, and N. Page, Danrersport ; Asahel Foote, Williamstown; Col. E. Stone, Dellham; Simon Brown, Concord; J. W. Manning, Reading; Marshall P. Wilder, Dorchester; C. M. Hovey, Boston; J. F. C. Hrde, Newton Centre; N. P. Morrison, North Cambridge; M. Ordway, West Newbury; J. W. Clark, Framingham; J. W. Foster, Dorchester ; Sumner Goss, Millbury; Jonathan Ames, West Bridgewater; Robert Manning, Salem; Joel Kuapl, Wilkinsonville; S. WT. Cole, Chelsea.

In Connecticut-to S. D. Pardee and Prof. Eli Ires, New Haren; Sheldon Moore, Kensington; George Seymour, Norwalk; G. IV. Gager, Sharon; P. S. Beers, southville; D. S. Dewey and D1. G. W. Russell. 
Fartford; S. Tyman, Manchester; Major J. MeLella., Woodstock; I)r. D. W. Coit, Norwich; E. Newbury, Brooklyn.

In Canadia West-to Charles Arnold, Paris; D. W. Beadle, St. Ciltharine's; Wm. Ir. Reed, Port Dallhousie.

In Termont-to Chamney Goodrich and Rev. John Whoeler, Bunling ton; J. M. Ketchum, Brandon; G. W. Marnan, Bennington; Busl Lan. don, Grand Isle; Albert Bresec, Hubbarlton; Solon Burronghs, Walthan.

In New York-to Wm. S. Ferris, Williamsbriclge; T. ML. Yumglove and S. B. Fairchild, Hammondsport; Jacob G. Sickles, Stuyvesant; C'has. G. Benediet, Perry; Wm. Prockshank, Hudson; E. Moody and L. C. IIoag, Lockport; Wm. S. Carpenter, Rye; Dr: James Fonntain, Jefferson Valley; S. P. Carpenter, New Rochelle; William R. Prince, Flushing; Dr. C. WT. Grant, Dr. T. B. Sheltou, James 1I. Ricketts, and A. Saul, Newburgh ; Elisha Dor' and Prof. James Hall, Albany; J. W'. Bailey, Plattsburgh; J. Battey, Keeseville; J. C. Hastings, Clinton; Natthew Mackie, Clyde; Isaac Hildreth, Watkins; T. C. Maxwell Brothers, and IT. T. \& E. Smith, Geneva; Ellwanger and Berry, If. E. Hooker, A. Frost \& Co., and James H. Watts, Foehester; J. B. Eaton, Butialo; Stephen Underhill, Croton Point; $\mathbb{V}^{\top}$. Collins, Smỵrna; M. J. Parrish, Hillsdale; N. T. Arms, Albany; Geo. S. Conuver. West Fayette; H. N. Longworthy, Rochester; Reagles \& Son, Selenectady; James Vick, Rochester; John R. Comstock, Hart's Village; James M. Miatteson, Jacksonville; Dr. E. W. Sylvester, Lyons; F. (. Stulley, Claverick; 1)r. Fenry Reenler, Tarick; Isarc Hicks, Uld Westbury; W. Brown Snitl, Syraeuse; J. 1T. Case, New Martford ; Harvey Green, Jefferson Valley.

In New Jersey-to Lonis E. Berckmanns, Plainfield; William Reid, Elizabethtown: James McLean, Roadstown; William Parry, Cinnanimson: A. G. Baldwin, Newark; Chess. Davis, ju., Philipsburgh ; Marid Pettit, Salem; Joln Neelles, Mt. Lanel; E. Willims, Montclair: A. S. Fuller, Ridgewood; Peter B. Mead, Tenafly.

In Pennsylvania-to Dr. IV. D). Brinckle, Chas. Harmer, and Dr. J. S. Houghton. Phıladelphia; Chas. Kessler and Daniel B. Lorah, Reading; Dr. J. K. Eshleman and Jonathan Baldwin, Duwnington ; Thomas Harvey, West Grove; David Miller, jr., Carlisle; D. H. Waketield, Rostraver; Josiah Hoopes, Westehester; S. WT. Noble, Jenkintown; J. A. Nelson \& Sons, Indian Run; Edward J. Evans, York; O. T. Hobls, Randolph; B. L. Fiyder, Loudon; Mahlon MLon, MLorrisville; Daniel Engle and Engle Brothers, Marietta; Caspar 1Tiller; Conestoga Centre; Luckens Peirce, Coatesville: Wm. Cr. Waring, Tyrone; Sannel Miller, Lebanon; John Hanilton, Jersey Shore; Wilson Den nis, Apllebackville; W. L. Nesbit, Lewisburg; E. H. Coeklin, Shepherdstown; Josiah C. Joungken, Riehland 'Town.

In Ohio-to Robert Buchanau aml A. H. Ernst, Cincinnati; D. C. Richmond, Sanslusky; A. Thompson, Dclaware; M. B. Batcliam, 
Painesville; N. L. Wood, Smitlifield; Isaac Dillen, Zanesville; Samuel Myer's, Salem; I. N. Gillett, Quaker Bottom; J. N. Shepherd, Marion; Rev. J. H. Creighton, Chillicothe; Geo. W. Campbell, Delaware; A. \& R. G. Hanford, Columbus; Chas. Carpenter, Kelley Island; S. S. Jacksun, Cincinnati ; L. S. Mote, West Milton; Prof. J. P. Kirtland, F. R. Elliott, Dr. E. Taylor, and S. B. Marshall, Cleveland; R. J. Black, Bremen; Geo. Hapgood, Warren; W. C. Hampton, MI. Victory ; A. L. Benedict, Ashley; H. P. McMaster, Leonardsburgh.

In Illinois-to Dr. J. A. Kennicott, West Northfield; F. K. Phœnix and C. R. Overman, Bloomington; Arthur Bryant, Princeton; Tyler MeWhorter, Pomeroy; A. M. Lawver, South Pass; J. WT. Stewart, Quincy; E. H. Skinner, Marengo ; Dr. L. S. Pennington, Sterling; J. S. Shearman, Pockford; J. A. Crain, Undulation.

In Kentucky--to H. P. Byram, Louisville; F. Pound, Shortsville; J. S. Downer, Fairview ; D. L. Adair, Hawesville; Dr. S. J. Leavell, Trenton; Geo. C. Curtiss, Maysville; Thos. Kennedy, Louisville; A. I. Woodson, Woodsonville.

In Iowa-to James C. Smith, Des Moines ; Finley \& Dwrre, Davenport; Henry Avery, Burlington.

In Indiana-to Reuben Regan, Nicholsonville; John C. Teas, Raysville; Wm. H. Loomis and E. Y. Teas, Richmond; J. D. G. Nelson, Fort WVayne.

In Maine-to S. I. Goodall, Saco.

In New Hampshire--to Robert Wilson, Keone; Nathan Norton, Greenland, and Charles H. Sanborn, Hampton Talley.

In Nichigan-to T. T. Jyon, Plymouth; Dr. D. K. Underwood, Adrian.

In Delaware--to Edward Tatnail, Wilmington.

In Virginia-to H. R. Roby, Fredericksburgh.

In Missouri-to George Husmam, Hermamn.

In Washington-to Joln Saul.

In Georgia-to William N. White and Dr. M. A. Ward, Athens, Pichard C. Peters and Wm. H. Thurnond, Atlanta; J. Tan Beuren, Clarksville, and P. J. Berckmans, Augusta.

In North Carolina--to G. W. Johnson, Milton; W'estbrooke \& Co., Greensboio; R. I. Stcele, Rockingham:

In South Carolina-to Wm. H. Sumner, Pomona; A. P. Wylie, Chester.

In Alabama-to R. R. Hunley, Harpersville; R. S. Owen, Tuscaloosa.

In Tennessee-to J. IV. Dodge, Pomona.

In Nova Scotia-to C. C. Hamilton, Cornwallis. 


\section{ABBREVLATIONS AND BOOKS QUOTED.}

A"borctum Britamicum; or, The Trees and Shrubs of Britain, pictorially and botanically delineated, and scientifically and popularly described. By J. C. Toudon. London, 1845,8 vols. 8 vo.

Annales de la Socité d'IIorticulture cle Paris.-Paris. In monthly Nos. 8vo. 1827 to 1845.

Annales de l' Institut de Fromont. Par le Chevalier Soulange Bodin. Paris, 8vo. 1829 to 1834,6 vols.

Adlum. A Memoir on the Cultiration of the Vine in America, and the best mode of making Wine. By John Adlum. 12mo. Washington, 1828.

Bon Jarl. Le Bon Jardinier, pour l'Aunée 1844. Contenant des principes généraux de culture, etc. Par A. Poiteun and II. Vilmorin, Paris. 1:mo,yearly volume.

Busby. A Visit to the principal Vineyards of France and Spain. By Jas. Busby. New York, $12 \mathrm{mo}, 183 \tilde{.}$.

Bridgomun. The Young Gardener's Assistant. Bष Thomas Bridgeman. Tenth ed. New York, 1844, 8vo.

Bummrnn's Cut. Catalogue des Végétaux en toub genre disponible dans l'Etab. lissement des Frères Baumann, à Bolwiller, 1842.

Coxe. A View of the Cultivation of Fruit Trees in the United States, and of the Management of Orchards and Cider. By William Coxe. Philadelphia, sंvo, 1817.

Chaptal. Chemistry applied to Agriculture. By John Anthony Chaptal, American ed., 12mo. Boston, 1835.

Cobbctt. The American Gardener. By Wm. Colsbett. London, 1821. 12mo.

Coleman. Reports on the Agriculture of Massachusetts. By IIenry Coleman. Boston, 8vo, 1810-41.

Dom. Giud. 'The Domestic Gardener's Manual. By John Towers. London, 1839, svo.

Duhamcl. Traité des Arbres Fruitiers, par II. Duhamel Dumonceau. Paris, 1768,2 rols. 4 to.

Culticator. The Cultivator, a monthly Journal of Agriculture, \&c. Edited by Luther Tucker. Albany, continned to the present time, 8vo.

Diel. Versuch einer Systematischen Beschreibung in Dentschland vorhandener Kernolsstsorten. Von Dr. Ang. Freidr. Ad. Diel. 12wo. 24 vols., 17991825.

De Candrlle. Physiologie Végétale, ou Fxposition des Forces et des Fonctions vitales des Tégétaux. Par A. P. De Candolle. Paris, 18:32, 3 vols. Svo. 4 rols. 8ro.

$D$ 'Alret. Cours Théorique et Pratique de la Taille des Arbres Fruitiers. Par 1)'Albret. Paris, 1840,8 vo.

Forsyth. A Treatise on the Culture and Management of Fruit Trees. By William Forsyth. 7th ed., London, 1824, 8vo.

FWy. Lindley's Guide to the Orchard. American ed., with additions by Hichael Floy. New York, 183:3, 12 mo.

Fessenden. New Änerican Gardener, containing practical Directions for the Culture of Fruits and Vegetables. By Thos. E. Fessenden. Boston, 1828, $12 \mathrm{mo}$.

Gard. Mug. The Gardener's Magazine eonducted by J. C Loudon. In monthly Nos. 8 vo, 19 vols. to 1844 , London. 
Garl. Chron. The Gardener's rhronicle and Agricultural Gazette, edited by Professor Lindley. A weekly journal, 4to, 5 vols. 1844 to the present time

Hoare. A Practical Treatise on the Cultivation of the Grape Tine on open walls. By Clement Hoare. London, $1810,12 \mathrm{mo}$.

Hort. Soc. C'at. See Thompson.

Hort. Trans. Transactions of the Horticnltural Society of London. London 4 to, 181j, and at intervals to the present time.

Ifinler. Pomona Londonensis. By William Hooker. London, 1S13, 4to.

Huycurl. The Science of Horticulture. By Joseph Hayward. London, 1824,8 vo.

Hurris. A Report on the Insects of Massachusetts injurious to Vegetation. By Dr. T. W. Harris. Cambridge, 1841. 8vo.

Hov. Mag. or $H$. $M$. The Magazine of Horticulture, Botany, and Pural Affairs. Conducted by C. M. Hovey. Boston, 8vo, monthly Jos. $183 t$ to the present time.

Johnston. Lectures on Agricultural Chemistry and Geology. By Jas. W. F: .Tohnston. Americau ed.. New York, $12 \mathrm{mo,} 2$ vols., 1842.

Jurd. Frut. Le Jardin Fruitier. Par Louis Noisette. 2 ed. Paris, 1839, 2 vols. 8 vo.

Knight. Various Articles in the London Horticultural Transactions. By Thomas Andrew Knight, its late President.

Frnoop. Pomologie; on, Description des Arbres Fruitiers. Par Joh. Heım. Knoop. Amsterdam, 1\%\%1, Fol.

Ken. The New Ameriean Orchardist. By William Kenrick. Boston, 1844.

Lollar. A Treatise on Insects injurious to Gardeners, Foresters, and Farmers. By Vincent Kollar. Notes by Westwood. London, 1840, 12mo.

Langley. Pomona; or, The Fruit Garden Illustrated. By Batty Langley. London, 1\%29, Folio.

Loudon. An Encyclopedia of Gardening. By J. C. Loudon. London, 183j, 1 thick vol. 8vo.

An Encyclopedia of Plants. By the same. London, 1836, 1 thick vol. Svo.

An Encyclopedia of Agriculture. By the same. London, 1831, 1 thick vol. Sro.

Hortus Britannicus. A Catalogue of all the Plants in Britain. By the same. Louflon, 8vo.

The Suburban Horticulturist. By the same. London, 1842, 8ro.

The Suburban Gardener and Villa Companion. By the same. London, 18:8, 1842, sro.

Arboretum et Fruticetum Britannicum. By the same. 8 rols., London. 1S:3, 8vo.

Iiebig. Organic Chemistry in its Applications to Agriculture and Physiology. By Justus Liebig. American ed., Cambridge, 184t. 12 mo.

Lind. A Guide to the Orchard and Kitchen Garden; or, an Account of the Fruits and Vegetables cultivated in Great Britain. By George Lindley. Lon don, 1831 . 8vo.

Lindley. An Introluction to Botany. By John Lindley. London, 183:, Svo.

An Introduction to the Natural System of Botany. By John Lindley. I.ondon, 18:35, 2d ed., 8vo.

British Fruits. See Pomological Mugazine-it is the same work.

- The Theory of Horticulture; or, An Attempt to explain the Operation of Gardening upon Physiologieal Principles. By John Lindles. London, Svo, $18+0$.

The same work, with Notes by A. Gray and A. J. Downing. New York, 1841, $12 \mathrm{mo}$

L. or Linnous. Species Plantarum, 5th ed. Berlin, 1810, 5 rols. Sro.

Lebieur. La Pomone Francaise; on, Traits de la Culture Française, et de la Taille des Arbres Frnitiers. Par le Comte Leliemr. Paris, 1s11, \&ro.

Man. The New England Fruit Book. By R. Mamning. 2d ed, enlarged by John M. Ives, Salem, 1844, 12mo.

Man. in $M$. $M$. Manning's Articles in Horey's Magazine.

Bill The Gardener's and Botanist's Dictionary. By Philip Miller. Revised by Professor Martyn. London, 1819, 2 rols. Sro. 
Michaux. The North American Sylva; or, Description of the Forest 'Trees of the United States, Canada, Ec. By A. F. Alichaux. Paris, 1819, 3 rols. Sro.

M' Intosh. The Orchard and Fruit Garden. By Charles MeIntosh, London, 1819,121110 .

N Dul. (The New Duhamel) Trait: des Arbres Fruitiers de Duhamel. Nou. velle éclition augmentée, etc. P'ar MM. Poitean et 'Turpin, Paris. 5 vols. folio, 1,808 , et ser.

Nois. See Jardin Frutier.

Tew Englum Firmer. A weekly periodical, devoted to Agriculture, Horticulture. Sc. Boston, 4to, continued to the present time.

O. Duh. See Duhumel.

Pom. Mrng or P. M. The Pomological Magazine; or, Figures and Descriptions of the most inportant varieties of Fruit cultivated in Great Britain. London, 1828,3 rols. 8 ro.

Pom. Man. The Pomological Manual. By William R. Prince. New York, 18:31, 2 vols. Sro.

Prince. A Treatise on the Vine. By William R. Prince. New York, 1830, Sro.

Prince. A Slort Treatise on Horticulture. By William Prince. New York, 1828, 12mo.

Plillips. Pomarium Britannicum; an Historical and Botanical Account of the Fruits known in Great Britain. By Henry Phillips. London, 1820, Svo.

Pvit. or Poiteau. Pomologie Française. Recueil des plus beaux Fruits cultivés en France. Par Poiteau. Paris, 1838, and continued in 1 to numbers.

Rivers. A Descriptive Catalogne of Pears, cultivated by T. Rivers. Sawbridgeworth, 184:-68, pamphlet, 8vo.

Iion. or Rmalds. Pyrus Mialus Brentfordienses; or. A Concise Description of Selected Apples, with a figure of each sort. By Hugh Ronalds. London, 18:31, 4 to.

Ray. Historia Plantarum, a John Ray, M.D. London, 3 vols., folio, 1636 1704.

Recue Horticole. Journal-des Jardiniers et Amateurs. Audot, Editeur. Paris, 1844, et chaque mois, 12 mo.

Seritzer. The Practical Fruit Gardener. By Stephen Switzer, 1724, 8vo.

Torrey \& Grey. A Flora of North America, containing abridged Descriptions of all the known Plants growing north of the Gulf of Mexico. By John Torrey, M. D., and Asa Gray, M.1). New York, vol. 1st, Sro. New York, 1810, and still in progress.

Thomp. A Catalogne of the Fruits Cultivated in the Garden of the Horticultural Society of London. 3d et., London, 1842. [Prepared with great care by Robert Thompson, the Head of the Fruit Department.]

Thacher. The American Orchardist. By James Thacher, M.D. Boston, 1822, Sro.

Tun Hous. Arbres Fruitiers; ou, Pomologie Belge Exp irimentale et Raisonnie. Par J. R. Tan Mons. Louvain, 18:3i- 1836,2 vols. $12 \mathrm{mo}$.

—- Citalogue des Arbres Fruitiers, Descriptif, Abrigé. Par J. B. Var Mons Louvain, 182??

Witder MSS. Manuscript Notes on Fruits. By M. P. Wilder, Esq., President of the Massachusetts Horticultural Society.

Al. Pom. Album de Pomologie; in which the fruits of Belgimn are figured anu described.

An. Pom. Amals of Pomology ; a periorlical published by royal commission, in which choice fruits are figured and described.

C. II. A. Comice of Horticulture of Angers

IIort. The IIorticulturist of Pural Art and Rural Taste. 22 vols.

Cole. American Fruit liook. By S. II. Cole, Boston, Mass.

Thomas. American Fruit Culturist. Tiy John J. Thomas, Union Springs, New Fork.

Barry. The Fruit Garden. By P. Barry, Rochester, New York.

Wraning. 'The Fruit-Grower's Hank Book By Wm. G. Waring, Boalsburg, Pa

Elliott. American Fruit-Grower's Guide. by F. R. Elliott, Clevcland, O. 
White's Gard. Gardening for the South. By Wm. N. White, Athens, Ga. Hoc. Mreg. The Magazine of Horticulture. By C. M. Hovey, Boston, Mass 33 vols.

N. Y. Hort. Rev. New York Horticultural Review. By C. Reagles, New York. 4d. Int. Rep. Ad Interim Reports of the Pennsylvania Horticultural Society. Ga. Pom. S. Rep. Ad Interim Reports of the Georgia Pomological Society.

Ve. Pom. S. Rep. Annual Report of the Maine Pomological Society.

A. Pom. S. Transactions of the Anerican Pomological Society.

L. E. Berchmen's IIS. Mamuscript Notes by Louis E. Berckman, Augusta, Ga. W. D. Brinclle's IVS. Manuscript Notes by W. D. Brinckle, Philadelphia. R. Mraming's MS. Manuscript Notes by Robert Manning, Salem. Mass. A. II. Emst MS. Manuscript Notes by A. H. Emst. Cincinnati, Ohio. R. Buchanan ISS. Hanuscript Notes by Robext Buchanan, Cincinnati, Ohio.

Wm. $N$. White MS. Manuscript Notes by Wm. N. White. Athens, Ga. J. Tam. Bewren's MS. Maumseript Notes by J. Van Beuren. Clarksrille, Ga. II. R. Robey VS. Manuscript Notes by H. R. Robey, Fredericksburg, Ta. Samuel Miller, Jr., MS. Manuscript Notes by Samuel Miller, Jr., Cumberland, Pa.

J. S. Dooner MS. Manuscript Notes by .J. S. Downer, Elkton, Ky.

Warder. American Pomology. By .. A. Warder.

O. P.S. Ohio Pomological Society Reports.

II. S. H. S. Missouri State Horticultural Society Reports.

Verg. The Verger. By MI. Mas, Paris, France.

Hogg. British Pomology and Hogg's Frnit Manual. By Robert Hogg, London, England.

Pr. Rep. Report of the Pennsylvania Horticultural Society.

Meal. American Grape Culture and Wine-making. By Peter B. Mead, Tenafly, N. J.

Gar. Mom. Gardener's Monthly. Edited by Thomas Meahan, Philadelphia, Pa. 10 vols.

K. Hort. Soc. Transactions of the Kentucky Horticultural Society.

J. of II. Journal of Horticulture, Boston, MIass.

Hismann. The Cultivation of the American Grape, and Manufacture of Americau Wines, by George Husmann, Hermann, Mo.

S. V. M. Theports of the Society Van Mons, Brussels.

Strong. Cultivation of the Grape. Br II. C. Stroug, Brighton, Mass.

Truns. St. L. H. Soc. Transactions of the St. Lonis Horticultural Society.

Am. Hort. An. American Horticultural Ammuai, Orange Judd \& (o., N. Y.

Count. Gent. Country Gentleman. Luther Tucker \& Son, Albany, X. Y. 32 vols. $J a r^{2}$. I. M. Fruits of the Jardin Tan Mous. By A. Birort. Bruxelles.

Wre. Musenm of the Jardin of Fruits. By J. Decaisne.

Liegel. Survey of Plums. by G. Liegel, Braunau, Austria.

$F$. d. $P$. Florist and Pomologist, Lonton. England.

Leroy. Dictionary of Pomology. By André Leroy, Angers, France.

Fulles. Small Fruit Culturist. By A. S. Fuller

Fuller. The Grape Culturist. By A. S. Fnller. Ridgewood. N. J.

P. .J. B. WS. Manuscript Notes of P. J. Berekman, Augusta, Ga.

J. H. Creighton. Manuscript Notes by J. H. Creighton. Chillicothe, U.

Tat. MS. Manuscript Notes by Edward Tatnall. Wilmington, Del.

J. W. Builey. Mamuscript Notes by J. W. Bailey, Plattsburg, N. Y. Arnold. Manuscript Notes by Charles Arnold, Paris, C. WT.

R. R. Hunley, MS. Manuscript Notes by R. R. Hunley, Harpersville, Ala, 


\title{
FRUITS AND FRUIT-TREES.
}

\author{
CHAPTER I. \\ THE PRODUCTIOX OF NEW VARIETIES OF FRUIT.
}

Ix our survey of the culture of fruits let us begin at the begioning. Gradual amelioration, and the skilful practice of the cultivitor, have so filled our orchards and gardens with good fruits, that it is necessary now to cast a look back at the types from which these delicions products have sprung.

In the tropical zone, amid the surprising luxuriance of vegetation of that great natural hot-house, nature ofiers to man, almost without care, the most refreshing, the most delicious, and the most nutritive fruits. The Plantain and Banana, excellent either raw or cooked, bearing all the year, and producing upon a rood of ground the sustenance of a family ; the refreshing. Guava and Sapodilla; the mutritious Bread-fruit; such are the natural finit-trees of those glowing climates. Indolently seated under their shade, and finding a refreshing coolness both from their eververdant canopy of leares, and their juicy fruits, it is not here that we must look for the patient and skilful cultivator.

But, in the temperate clinates, nature wears a harsher and sterner aspect. Plains bounded by rocky hills, visited not only by genial warmth and sunshine, but by cold winds and seasons of ice and snow ; these are accompanied by sturdy forests, whose outskirts are sprinkled with crabs and wild cherries, and festooned with the clambering branches of the wild grape. These native fruits, which at first offer so little to the eye or the palate, are nevertheless tlre types of our garden varieties. Destined in these climates to a perpetnal struggle with nature, it is here that we find man ameliorating and transforming her.

Transplanted into a warner aspect, stimulated by a richer soil, reared from selceted seeds, carefully pruned, sheltered, and watched, by slow degrees the sour and bitter crab expands into a Golden Pippin, the wild pear loses its thorns and becomes a Bergamotte or a Bemré, the Almond is reprived of its bitterness, and the dry and flavorless Peach is at length a termpting and delicious tinit. It is thus only, in the face of obstacles, in a climate where nature is not prodigal of perfections, and in the midst of thorns and sloes, that MLL, THE GARDENER, arises and forces nature to yield to his art.

These improved sorts of fiuit, which man everywhere causes to share his civilization, bear, almost equally with himself, the impress of an exist- 
ence removed from the natural state. When reared from seeds they always show a tendency to return to a wilder form, and it seems only chance when a new seedling is equal to, or surpasses its parent. Removed from their natural form, these artificially created sorts are also much more liable to diseases and to decay. From these facts arises the fruitgarden, with its various processes of grafting, budding, and other means of continuing the sort; with also its sheltered asprects, warm borders, deeper soils, and all its varions refinements of art and culture.

In the whole range of eares and pleasures belonging to this garden, there is nothing more truly interesting than the production of new varie ties of fruit. It is not, indeed, by sowing the seeds that the lover of good fruit usually undertakes to stock his garden and orchard with fine fruit-trees. Raising new varieties is always a slow, and, as generally understood, a most uncertain mode of bringing about this result. The novice plants and carefully watches his hundled seedling pippins, to find at last, perhaps, ninety-nine worthless or indifierent apples. It appear's to him a lottery, in which there are too many blanks to the prizes. $\mathrm{He}$ therefore wisely resorts to the more certain mode of grafting from weilknown and esteemed sorts.

Notwithstanding this, every vear, under the influenees of garden culture, and often without our lesign, we find our fruit-trees reproducing themselres; and oceasionally there springs up a new and delicious sort, whose merits tempt us to fiesh trials after perfection.

To a man who is curious in fruit,- - the pomologist, - who views with a nore than common eye the crimson cheek of a peach, the delicate bloom of a plum, or understands the epithets, rich, melting, butterr, as applied to a pear, nothing in the eircle of eulture can give more lively and unmixed pleasure than thus to produce aud to create-for it is a sort of creation-an entirely new sort, which he believes will prove handsomer and better than anything that has gone before. And still niore: as varieties which originate in a certain soil and climate are found best adapted to that locality, the production of new sorts of fruit of high merit may be looked on as a most valuable as well as interesting result.

Besides this, all the tine new fruits which of late figure so conspicuously in the catalogues of the nurseries and fruit-gardens, bave not been originated at random and by chance efforts. Some of the most distinguished pomologists have devoted years to the subject of the improvement of fruit-trees by seeds, and have attained, if not eertain results, at least some general laws, which greatly assist us in this proeess of amelioration. Let us therefore examine the subject a little more in detail.

In the wild state, every genus of trees consists of one or more species, or strongly marked individual sorts; as, for example, the white bireli and the black birch; or, to confine ourselves more strictly to the matter in hand, the different species of cherry, - the wild or bird cherry, the sonr cherry, the mazard cherry, sc. These species, in their natiral state, exactly reproduce themselves; to use a common phrase, ther "come the same" from seed. This they have done for eenturies, and doubtless will do forever, so long as they exist under natural circumstances oniv.

On the other hand, suppose we select one of these species of fiuit-trees and adopt it into our gardens. So long as we cultivate that individual tree, or any part of it, in the shape of sucker, graft, or bucl, its vature will not be materially altered. It may, indeed, through cultiva- 
tion, be stimulated into a more luxuriant growth; it will probably pro. duee larger leaves and fruit; but we shall neither alter its fruit in tex. ture, color, or taste. It will always be identically the same.

The process of amelionation begins with a new generation, and biy sowing the seerls. Some species of tree, indeed, seen to refuse to yieil their wild nature, never producing any variation by seed; but all fruittrees, and many others, are easily domesticated, and more readily take the impress of culture.

If we sow a quantity of seed in garten soil of the common black mazard eherry (Cerasus avium), we shall find that, in the leaves and habit of growth, many of the seedlings do not entirely resemble the original species. When they come into bearing, it is probable we shall also find as great a diversity in the size, color, and flavor of the firuit. Each of these inclividual plants differing from the original type (the mazard) constitutes a new variety; though only a few, perhaps only one, may be superior to the original species.

It is worthy of remark, that exactly in proportion as this reproduction is frequently repeated, is the change to a great variety of forms or new sorts increased. It is likely, indeed, that to gather the seeds from a wild mazard in the woods, the instances of departure from the form of the original species would be very few; while if gathered from a garden tree, itself some time cultivated, or several removes from a wild state, thongh still a mazard, the seedlings will show great variety of character.

Once in the possession of a variety which has moved out of the natural into a more domesticated form, we lave in onr liands the best material for the improving process. The fixed original habit of the species is broken in upon, and this variety which we have created has always afterwards some tendeney to make further departures from the original form. It is true that all or most of its seedlings will still retain a likeness to the parent, but a few will differ in some respects, and it is by seizing upon those which show symptoms of variation that the inprover of vegetable races founds his hopes.

We have said that it is a part of the eharacter of a speeies to prodnce the same from seed. This characteristic is retained even where the sport (as gardeners term it) into numberless varieties is greatest. Thus, to return to cherries: the Kentish or common pie-cherry is one species, and the small black mazard another, and althongh a great number of varieties of each of these species have been produced, yet there is always the likeness of the species retained. From the first we may have the large and rieh Mayduke, and from the last the sweet and luseious BlackHearts; but a glance will show us that the duke cherries retain the clistinet dark foliage, and, in the fruit, something of the same flavor, shape, and color of the original species; and the heart cherries the broal leaves and lofty growth of the mazard. So too the currant and gooseberry ar' different species of the same genus; but thongh the English gooseberrygrowers have raised thousands of new varieties of this fruit, and shown them as large as hens' eggs, and of every variety of form and color, yet their efforts with the gooseberry have not produced anything resembling the common eurrant.

Why do not varieties produce the same from seed? Why, if we plant the stone of a Green Gage plum, will it not always produce a Green Gage? This is often a puzzling question to the practical gardener, while his every-day experience forces him to assent to the fact. 
We are not sure that the regetable physiologists will undertake to answer this query fully. But in the mean time we ean throw some light on the subject.

It will be remembered that our garden varieties of fruits are not natural forms. They are the artificial productions of our culture. They have always a tendency to improve, but they have also another and a stronger tendency to return to a natural or wild state. "There can be no doubt," says Dr. Lindley, "that if the arts of cultivation were abandoned for only a few years, all the annual varieties of plants in our gardens would disappear and be replaced by a few original wild forms." Between these two tendencies, therefore, the one derived from nature, and the other impressed by culture, it is easily seen how little likely is the progeny of varieties always to reappear in the same form.

Again, our American farmers, who raise a number of kinds of Indian corn, very well know that, if they wish to keep the sorts distinct, they must grow them in different fields. Without this precaution they find, on planting the seeds produced on the yellow-corn plants, that they have the next season a progeny not of yellow corn alone, but composed of every color and size, yellow, white, and black, large and small, upon the farm. Now many of the varietics of fruit-trees have a similar power of intermixing with each other while in blossom by the dust or pollen of their flowers, carried throngh the air by the action of bees and other causes. It will readily occur to the reader, in considering this fact, what an influence our custom of planting the different rarieties of plum or of cherry together in a garden or orchard must have npon the constancy of habit in the seedlings of such fruits.

But there is still another reason for this habit, so perplexing to the norice, who, having tasted a huscious fruit, plants, watehes, and rears its seerlling, to find it, perhaps, wholly different in most respects. This is the influence of grafting. Among the great number of seedling fruits produced in the United States, there is found occasionally a varietr. per. haps a plum or a peach, which will nearly always reproduce itself from seed. From some fortunate circumstances in its origin, unknown to us, this sort, in becoming improved, still retains strongly this habit of the natural or wild form, and its seerls prorluce the same. We can call to mind several examples of this; fine fruit-trees whose seeds have established the reputation in the neighborhood of fidelity to the sont. But when a graft is taken from one of these trees, and placed upon another stock, this grafted tree is found to lose its singular power of producing the same by seer, and becomes like all other worked trees. The stock exercises some, as yet, unexplained power in dissolving the strong natural habit of the variety, and becomes, like its fellows, subject to the laws of its artificial life.*

When we desire to raise new varieties of fruit, the common practice

* The doctrine here advanced has perhaps no foundation in finct, nor has there been any test made that, to oux knowledge, would controvert it. Observation of many years, however, leads to the belief that the mere engrafting a variets lipon another stock in no way affects its habit or capacity for reproducing itself just the same as it would if retained upon its parent roct. The great ritality possessed by some rarieties, their strong character, fre., prerent them, as it were, from receiving impregnation while in flower from any less rigorous sort, and hence, as a strong rariety is oftener than otherwise surrounded by those of less vitality, it mainly fertilizes itself from its own blossoms and thus reproduces its leading qualities. 
is to collect the seeds of the finest table fruits-those sorts whose merits are everywhere acknowledged to be the highest. In proceeding thus, we are all pretty well aware that the chances are generally a hundred to one against onr obtaining any new variety of great excellence. Beforo we offer any advice on rearing seedlings, let us examine briefly the practice and views of two distinguished horticulturists abroad, who have paid more attention to this subject than any other persous whatever; D1. Van Mons, of Belgium, and Thos. Andrew Knight, Esq., the latrs President of the Horticultural Society of London.

\section{The Tan Mons Theory.}

Dr. Van Mons, Professor at Louvain, devoted the greater part of his life to the amtlioration of fruits. His nurseries contained, in 1823 , no less than two thousand seedlings of merit. His perseverance was indefatigable, aud, experimenting mainly on Pears, he suceeded in riising an immense number of new varieties of high excellence. The Beurcé Diel, De Lourain, Frederie of Wurtemberg, de., are a few of the many wellknown sorts which are the result of his unwearied labors.

The Van Mons theory may be briefly stated as follows:

All fine fruits are artificial products; the aim of nature, in a wild state, being only a healthy, vigorous state of the tree, and perfect seeds for continuing the species. It is the object of culture, therefore, to subdue or enfeeble this excess of vegetation; to lessen the coarseness of the tree; to diminish the size of the seeds; and to refine the quality and increase the size of the flesh or pulp.

There is always a tendency in our varieties of fruit-trees to return by their seeds towards a wild state.

This tendency is most strongly shown in the seeds borne by old fruittrees. And "the older the tree is of any cultivated variety of Pear," says Dr. Van Mons, "the nearer will the seedlings raised from it approach a wild state, withont however ever being able to return to that state."

On the other hand, the seeds of a young fruit-tree of a good sort, being itself in the state of amelioration, have the least tendency to retrograde, and are the most likely to produce improved sorts.

Again, there is a certain limit to perfection in fruits. When this point is reached, as in the finest varieties, the next generation will more probably produce bad fruit, than if reared from seeds of an inditlerent sort in the eourse of amelioration. While, in other words, the seeds of the oldest varieties of good fruit mostly yield inferior sorts, seeds taken from recent varieties of bad fruit, and reproduced uninterruptedly for several generations, will certainly produce good fruit.*

With these premises, Dr. Van Mons begins by gathering his seeds from a young seedling tree, without paying much regard to its quality, except that it must be in a state of variation; that is to say, a garden variety, and not a wild sort. These he sows in a seed-bed or nursery, where he leaves the seedlings urtil they attain sufficient size to enable him to judge of their character. He then selects those which appear the most promising, plants them a few feet distant in the nursery, and

* Experience of American growers does not bear ont the supposition here taken. The Seckel, one of the finest and most perfeet pears, has perbaps given more valuable seedlings than any other one kind. 
awaits their fruit. Not discouraged at finding most of them mediocre in quality, thongh differing from the parent, he gathers the first seeds of the most promising and sows them again. 'The next generation comes more rapidly into bearing than the first, and shows a greater number of promising traits. Gathering immediately, and sowing the seeds of this generation, he produces a third, then a fourth, and even a fifth generation, minterruptedly, from the original sort. Each generation he finds to come more quickly into bearing than the previous ones (the fifth sowing of pears fruiting at tlree years), and to produce a greater number of valuable varieties; until in the fifth generation the seedlings are nearly all of great excellence.

Dr. Van Mons found the pear to require the longest time to attain perfection, and he carried his process with this fruit throngh fire generations. Apples he found needed but four races, and peaches, cherries, plums, and other stone fruits were brought to perfection in three successive reproductions from the seed.

It will be remembered that it is a leading feature in this theory that, in order to improve the frnit, we must subdue or enfeeble the original coarse lnxuriance of the tree. Keeping this in mind, Dr. Tan Mons always gathers his fruit before fully ripe, and allows them to rot before planting the seeds, in order to refine or render less wild and harsh the next generation. In transplanting the young seedlings into quarters to bear he cuts off the tap root, and he annually shortens the leading and side branches, besides planting them only a few feet apart. All this lessens the vigor of the trees, and produces an impression upon the nature of the sceds which will be produced by their first fruit; and, in order to continue in full force the progressive variation, he allows his seedlings to bear on their own roots.*

Such is Dr. Van Mons' theory and method for obtaining new varieties of fruit. It has never obtained much faror in England, and from the length of time necessary to bring about its results, it is scarcely likely to come into very general use here. At the same time it is not to be de. nied that in his hands it has proved a very successful mode of obraining new varieties.

It is also undoubtedly true that it is a mode closely founded on natural laws, and that the great bulk of our fine varieties have originated by chance.

The first colonists here, who brought with them many seeds gathered from the best old varieties of fruits, were surprised to find their seedlings producing only very inferior funits. These seedlings had returned, by their inherent tendency, almost to a wild state. By rearing from them, however, seedlings of many repeated generations, we have arrived at a great number of the finest apples, pears, peaches, and phums. According to Dr. Van Mons, had this process been contimed unintermitedly, from one generation to the next, a much shorter time would have been necessary for the production of first-rate varieties.

To show how the practice of chance sowing works in the other hemis-

* - I have found this art to consist in regenerating in a direct line of descent, and as rapidly as possible, an improving variety, taking care that there be no interval between the generations. To sow, to re-sow, to sow again, to sow perpet. ually, in short, to do nothing but sow, is the practice to be pursued, and which cannot be departed from; and in short this is the whole secret of the art I hare employed." -Van Mons' Arbres Fruitiers, 1. p. 22, 22:. 
phere, it is stated by one of the most celebrated of the old writers on innits, Duhamel of firance, that he had been in the habit of planting seeds of the finest table peals for fifty years withont ever having lorodneed a good raliety. 'These seeds were from trees of old varieties of frinit.

The American gardener will easily perceive, from what we hilve stated, a great advantage placed in his hands at the present tine for the amelioration of fruits by this system. He will see that, as most of our Americall varieties of fruit are the result of repeated sowings, more or less constantly repeated, he has before him almost every day at part of the ameliorating process in progress; to which $\mathrm{D}_{1}$. Van Mons, begimning de novo, was obliged to devote his whole life. Nearly all that it is necessary for him to do in attempting to raise a new variety of excellence by this simple mode, is to gather his seeds (before they are fully ripe) from a scedling sort of promising quality, though not yet arrived at perfection. The seedling must be quite young-must be on its own root (not grafted); and it inust be a healthy tree, in order to secure a healthy generation of seedlings. Our own experience leads us to believe that he will seareely have to go beyond one or two generations to obtain fine fruit. These remarks apply to most of our table fruits commonly cultivated.

In order to be most snccessful in raising new varieties by successive reproduction, let us bear in mind that we must avoid-1st, the seeds of old fruit-trees; $2 d$, those of grafted fruit-trees; and $3 d$, that we have the best grounds for good results when we gather our seeds from a young seedling tree, which is itself rather a perfecting than a perfect firuit.

It is not to be denied that, in the face of Dr. Van Mons' theory, in this country new varieties of rare excellence are sometimes obtained at once by planting the seeds of old grafted varieties; thus the Lawrence's Favorite and the Columbia plums were raised from seeds of the Green Gage, one of the oldest European varieties.

Such are the means of originating new fruits by the Belgian mode. Let us now examine another more direct, more interesting, and more scientific process-cross-breeding; a mode almost universally pursued now by skilful cultivators in producing new and finer varieties of plants; and which Mr. Knight, the most distinguished horticultmrist of the age, so successfully practised on fruit-trees.

\section{Cross-breeding.}

In the blossoms of fruit-trees, and of most other plants, the seed is the offspring of the stamenes and pistil, which may be considered the male and female parents, growing in the same flower. Cross-breeding is, then, nothing more than removing out of the blossom of a fruit-tree the stamens, or male parents, and bringing those of another and different variety of fruit, and dusting the pistil or female parent with them,-a process sufticiently simple, but which has the most marked effect on the seeds produced. It is only within abont fifty years that eross-breeding has been practised; but Lord Bacon, whose great mind seems to have had glimpses into every dark corner of human knowledge, finely foreshaniowed it. "The componmling or mixtmre of plants is not found ont, which, if it were, is more at command than that of living creatures; wherefore, it were one of the most notable discoveries touching plants to find 
it out, for so you may have great varieties of fruits and flowers yet un. known."

In Figure 1 is shown the blossom of the Cherry. The central por-

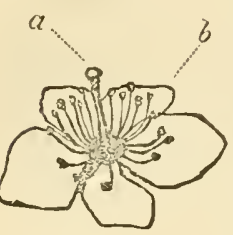

FIG. 1. tion, a, connected directly with the young fruit, is the pistil. The numeroms sumrounding threads, $b$, are the stamens. The summit of the stamen is called the anther, and secretes the powdery substance called pollen. The pistil has at its base the embryo finit, and at its summit the stigma. The use of the stamens is to fertilize the young seed contained at the base of the pistil; and if we fertilize the pistil of one variety of fruit by the pollen of another we shall obtain a new variety, partaking intermediately of the qualities of both parents. Thus, among fruits owing their origin directly to cross-breeding, Coe's Golden Drop Plum was raised from the Green Gage, impregnated by the Nagnum Bonum or Egg Phm; and the Elton cherry from the Bigarrien, inıpregnaterl by the White Heart.* Mr. Kuight was of opinion that the habits of the new variety would always be fomul to partake most strongly of the coustitution and hahits of the female parent. Subserquent experience does not fully confirm this, and it would appear that the parent whose character is most permanent, impresses its form most forcibly on the offspring.

The process of obtaining cross-breed seeds of fruit-trees is very easily performed. It is only necessary, when the tree blooms which we intend to be the mother of the improved race, to select a blossom or blossoms growing upon it not yet fully expanded. With a pair of scissors we cut out and remove all the anthers. The next day, or as soon as the blossom is quite expanded, we collect with a camel's-hair brush the pollen from a fully blown flower of the variety we intend for the male parent, apply. ing the pollen and leaving it upon the stigma or point of the pistil. If your trees are much exprosed to those busy little meddlers, the bees, it is well to cover the blossoms with a loose bag of thin gauze, or they will perhaps get beforehand with you in your experiments in cross-breeding. Watch the blossoms elosely as they open, and bear in mind that the two essential points in the operation are: 1st, to extract the anthers carefully, before they have matured sufficiently to fertilize the pistil ; and $2 d$, to apply the pollen when it is in perfection (dry and powdery), and while the stigma is moist. A rery little practice will enable the amateur to judge of these points.

There are certain limits to the power of crossing plants. What is strictly called a cross-bred plant or fruit is a sub-rariety raised between two varieties of the same species. There are, however, certain species, nearly allied, which are capable of fertilizing each other. The oflspring in this ease is ealled a hybrit, or mule, and does not always produce perfect seeds. "This power" of hybridizing," says Dr. Lindley, "appears to be much more common in plants than in animals. It is, however, in general only between nearly allied species that this intercomse can take place; those which are widely ditferent in structure and constitution not

* The seedlings sometimes most resemble one parent, sometimes the other; but more frequently share the qualities of both. Mr, Coxe describes an Apple, a ross between a Newtown Pippin and a Russet, the fruit of which resemblec exter. nally at one end the Rnsset and at the other the Pippin, and the flavor at eithes end corresponded exactly with the character of the exterior. 
being capable of any artificial union. Thus the different species of Strawbery, of the gourd or melon family, intermix with the greatest facility, there being a great aceorlance between them in general strue. ture and constitution. But no one has ever succeeded in compelling the pent to frrtilize the apple, nor the gooseberry the enrent. And as species that are very dissimilar appear to have some natural impediment which prevents their reciprocal fertilization, so does this obstacle, of whatever nature it may be, present an insuperable bar to the interevirse of the different genera. All the stories that are current as to the intermixture of oranges and pomegranates, of roses and black currunts, and the like, may therefore be set down to pure invention."

In practice this power of improving varieties by erossing is very largely resorted to by gardeners at the present day. Not only in fruittrees, but in olnamental trees, shrubs, and plants, and especially in florists' tlower's, it has been carried to a great extent. 'The great number of new and beantiful Roses, Azaleas, Camellias, Fuchsias, Dahlias, and other flowering plants so splendid in color and perfect in form, owe their origin to careful cross-breeding.

In the amelioration of fruits it is by far the most certain and satisfactory process yet discorered. Its results are more speedily obtained, and correspond much more closely to our aim, than those procured by suecessive reproduction.

In order to obtain a new variety of a certain charaeter, it is only necessary to select two parents of well known habits, and which are both varieties of the same or nearly allied species, and cross them for a new and intermediate variety. Thus, if we have a very early but insipid and worthless sort of pear, and desile to raise from it a variety both early and of fine flavor, we should fertilize some of its pistils with the pollen of the best thavored variety of a little later maturity. Among the seedlings produced we should look for early pears of good quality, and at least for one or two varieties nearly or quite as early as the female parent, and as delieious as the male. If we have a very small but highly flavored pear, and wish for a larger pear with a somewhat similar flavor, we must fertilize the first with the pollen of a large and handsome sort. If we desire to impart the quality of lateness to a very choice plum, we must look out for a late variety as the mother, and eross it with our best flavored sort. If we desire to impart hardiness to a tender fruit, we must undertake a cross between it and a much hasdier sort; if we seek greater beauty of color or vigor of growth, we must insure these qualities by solecting one parent liaving such quality strongly marked.

As the seeds produced by eross fertilization are not found to protuce precisely the same varieties, though they will nearly all partake of the mixed character of the parents, it follows that we shall be most successful in obtaining precisely all we hope for in the new race in proportion to the number of our cross-bred seecilings; some of which may be inferior, as well as some supcrior to the parents. It is always well, therefore, to cross several flowers at once on the same plant, when a single blossom does not produce a number of seeds.

We should abserve here, that those who devote their time to raising new varieties must boar in mind that it is not always by the first fruits of a seedling that it should be judged. Some of the finest varieties require a consiclerable age before thrir best qualities develop themselves, as it is only when the tree has arrived at some degree of maturity that its secre- 
tions, either for flower or fruit, are perfectly elaborated. 'The first fruit of the Black Eagle cherry, a fine cross-bred raised by Mr. Knight, was pronouncel worthless when first exhibited to the London Horticultural Society ; its quality now proves that the tree was not then of sufticient age to produce its fruit in perfection.

\section{CHAPTER II.}

\section{REMARKS ON THE DURATION OF VARIETIES OF FRUIT-TREES.}

It was for a long time the popular notion, that when a good rariety of fruit was once originated from seed, it might be continued by grafting and butding forever,-or, at least, as some old parchment deeds pithily gave tenmre of land-" as long as grass grows and water runs."

About 1830, however, Thomas Andrew Knight, the distinguished President of the Horticultural Society of London, published an Essay in its Transactions tending entirely to overthrow this opinion, and to establish the doctrine that ail varieties are of very limited duration.

The theory advanced by Mr. Knight is as follows: All the constitutional vigor or properties possessed by any variety of fruit are shared at the same time by all the plants that can be made from the buds of that variety, whether by grafting, budding, or other modes of propagating. In similar terms, all the plants or trees of any particular kind of pear or apple being only parts of one original tree, itself of limited ruration, it follows, as the parent tree dies, all the other's must son after die also. "No trees, of any variety" to use his own words, "can be made to produce blossom or fruit till the original tree of that variety has attained the age of puberty; * and, under ordinary modes of juopagation, by grafts and buds, all become subject, at no rery distant period, to the debilities and cliseases of old age."

It is remarkable that such a theory as this should have been offered by $\mathrm{Mr}$. Knight, to whose careful investigations the science of modern horticulture is so deeply indebted-as, however common it is to see the apparent local decline of certain sorts of fruit, yet it is a fumiliar fact that many sorts have also been continued a far greater length of time than the life of any one parent tree. Still, the doctrine has found supporters abroad, and at least one hearty advocate in this country.

Mr. Kenrick, in his new American Orchardist, adopts this doctrine, and in speaking of Pears says: "I shall, in the following pages, designate some of these in the class of old varieties, once the finest of all old pears, whose duration we had hoped, but in vain, to perpetuate. For, except in certain sections of the city, and some very few and highly

* This part of the doctrine has of late been most distinctly refuted, and any one may repeat the experiment. Seedling fruit-trees, it is well known, are usially several years before they produce fruit. But if a graft is inserted on a bearing tree, and, after it makes one season's fair growth, the grafted shoot is bent directly down and tied there, with its point to the stock below, it will the next season-the sap being checked-produce flower-buds and begin to bear, long before the parent tree. 
favored situations in the comutry around, they (the old sorts) have become, either so meertain in their bearing-so baren-so mupodnctive -or so miserably blighted-so nortally diseased-that they are no longer to be trusted; they are no longer what they once were with us, and what many of them are still deseribed to be by most foreign witers."

Mr. Kenrick accordingly arranges in separate classes the Old and New Pears; and while he praises the latter, he can hardly find epithrts sufficiently severe to bestow on the former poor unfortunates. Of the Doyemé he says: "This most eminent of all Pears has now become an onteast, intolerable even to sight;" of the Brown Beurré, "once the best of all P'ean's-now become an outeast." The St. Germain "lias long since become an abandoned variety," \&c., \&c.

Many persons have, therefore, supposing that these delicious varieties hat really and quietly given up the ghost, made no more inquiries after them, and only ordered from the nurseries the new varietics. And this not always, as they have confessed to us, without some lingering feeling of regret at thus abandoning old and tried friends for new-eonerswhich, it must be added, not unfrequently firled to equal the good qualities of their predeeessor's.

But, while this doetrine of Kuight's has found ready supporters, we are bound to add that it has also met with sturdy opposition. At the head of the opposite party we may rank the most distinguished vegetable phrsiologist of the age, Professor De Candolle, of Geneva. Tarieties, says De Candolle, will endure and remain permanent so long as man chooses to take care of them, as is evident from the continued existence to this day of sorts, the most ancient of those which have been described in books. By negligence, or through sucessive bad seasous, they may become diseased, but careful culture will restore them, and retain them, to all appearance, forever.

On own opinion coincides, in the main, with that of De Canclolle. While we admit that, in the common mode of propagation, varieties are constantly liable to lecay or become comparatively worthless, we beliere that this is owing not to natural limits set upon the duration of a variety; that it does not depend on the longevity of the parent tree; but upon the care with which the sort is propagated, and the nature of the climate or soil where the tree is grown.

It is a well-established fact, that a seedling tree, if allowel to grow on its own root, is always much longer lived, and often more vigorous than the same variety when grafted upon another stock; and experience has also proved that in proportion to the likeness or close relation between the stock and the graft is the long life of the grafted tree. Thus a variety of pear srafted on a healthy pear secdling lasts almost as long as upon its own roots. Upon a thon stock it does not endure so long. Upron a monntain ash or quince stock still less; mil the avenage life of the pear-tree when grafted on the quince is rerlucerl to onethird of its ordinary duration on the pear stock. 'This is well known to every practical gardener, and it arises from the want of aftinity between the cyuince stock and the pear graft. The latter is rendered dwarf in its habits, bear's very early, aud perislies equally soon.

Next to this, the ajprarent decay of a variety is often caused by graft. ing upon unhealthy stocks. For although grafts of very vigorous habit have frequently the power of renovating in some meastre, or for a time, 
the health of the stock, yet the tree, when it arrives at a bearing state, will, sooner or later, suffer from the diseased or feeble nature of the stock.

Carelessness in selecting scions for engrafting is another fertile source of degeneracy in varieties. Erery good cultivator is aware that if grafts are cut from the ends of old bearing branches, exhausted by overbearing, the same feebleness of habit will, in a great degree, be shared by the young graft. And on the contrary, if the thrifty straight shonts that are thrown out by the upright extremities, or the strong linbsprouts, are selected for grafting, they ensure vigorous growth, and liealthy habit in the graft.

Finally, unfarorable soil and climate are powerful agents in deteriorating varieties of fruit-tree. Certain sorts that have originated in a cold climate are often short-lived and umproductive when taken to warmer ones, and the reverse. This arises from a want of constitutional fitness for a climite dirierent from its natural one.

Most varieties of apples originating in the climate of the Middle States, if their period of maturity be micl-winter, when taken to the extreme northeru limits lose their value, because of the season not being long enough for their juices to become fully matured. Again, if they are taken to the Southern States their period of maturity is hastened by a greater amount of contimued heat, and the quality impaired.

Varieties, however, that originate at the North, and have their matırity naturally in the warm summer months, are improved by their removal South. But this only proves that it is impossible to pass certain natural limits of fitness for climate, and not that the existence of the variety itself is in any way affected by these local failures.

Any or all of these causes are sufficient to explain the apprarent decay of some varieties of fruit, and especially of pears, orer which some cultivators, of late, have uttered so many lamentations, scarcely less pathetic than those of Jeremiah.

Having stated the theories on this subject, and given an outline of our explanation, let us glance for a moment at the actual state of the so-called decayed rarieties, and see whether they are really either extinct, or on the verge of ammihilation.

Mr. Knight's own observation in England led him to consider the English Golden Pippin and the Nompareil, their two most celebrated varieties of apple, as the strongest examples of rarieties just gone to decay, $01^{\circ}$, in fact, the natural life of which had virtually expired twenty years before. A few years longer he thought it might linger on in the warmer parts of England, as he supposed varieties to fall most speedily into decay in the north, or in a cold climate.

Lindley, however, his contemporary, and second to no one in practical knowledge of the subject, writing of the Golden Pippin, * very frankly states his dissent, as follows: "This apple is considered by some of our moderu writers on Pomology to be in a state of decay, its fruit of inferior quality, and its existence near its termination. I cannot for a moment agree with such an opinion, becanse we have facts annually before our eyes completely at variance with such an assertion. In Corent Garden, and indeed in any other large market in the sonthern or miclland counties of Eugland, will be found specimens of fruit as perfect

* Guide to the Orchard, by George Lindley. 
and as fine as have been figured or described by any writer, either in this or any other conntry whatever. Instuad of the trees being in a state of 'rapid decar,' they may be found of umusually lange size, perfectly healchy, and their crops abmulant; the fruit perfect in form, beatiful in eolor, and excellent in quality." And the like remalks are male of the Nompareil.

Certain French witers, abont this time, gladly seized Knight's theory as an explanation of the miserable state into which several fiue old sorts of pears lat fallen about Paris, owing to bad culure and propagation. They sealed the death-warmat, in like manner, of the Brown Bemré, Doyenué, (hammontel, and many others, and consignerl them to oblivion in terms which MLr. Kenriek lias already al,undantly quoted.

Notwithstanding this, and that ten or fifteen year's have since elapsa ed, it is worthy of notice that the repudiated apples and pears still hold their place among all the best cultivators in both England and France. And the "extinct rarieties" seem yet to bid defiance to theorists and bad cultivator's.

But half the ground is not yet covered. How does the theory work in America? is the most natural incuiry. In this comntry we have soil varying from the poorest sand to the richest alluvial, climate vallying from firigid to almost torrid - a range wide enongh to inclute all fruit-trees between the apple and the orange.

We answer that the facts here, judged in the whole, are recidedly against the theory of the extinction of varieties. While here, as abroat, unfavorable soil, climate, or culture have produced their natural results of a teeble and diseased state of certain sorts of fruit, these are only tho exceptions to the general vigor and health of the finest old sorts in the comitry at large.

liecent experiments have proved that it is not sufficient to bring healthy trees of the old varieties from the interior of the seaboard to insure, in the latter localities, fair and excellent cropss. But, on the other hand, the complete renovation of blighterl trees by the plentiful use of wood-ashes, bone-dust, lime, and blacksmith cinders, along with common manure, shows us listinctly that it is not the age of these varieties of fruit which causes their apparent decline, but a want of that food absolutely necessiury to the production of healthy fruit.*

But there is another interesting point in this investigation. Do the newly originated sorts really maintain in the unfavorable districts the appearance of perfect health? Are the new pears uniformly healthy where the old ones are always feeble?

Undoubtedly this question must be auswered in the negative. Some

* Sinec the writing of this, in 1815, there have occurred seasons when nearly every variety of fruit perfected, and there have also been seasons when the old as well as new varieties hare failed, and that too in almost all soils and in many varied sections of the comutry. To our knowledge, no contimued experiments in the practice of applying special manures as remerlial agents liave been tried, lut, from the fact that old as well as new sorts have frequently failed in our rich westeru soils and inland climates. we lave come to regart the cause of eracking and other cliseases of the pear inore to proceed from climatic or atmospheric influence than form any special.condition or quality of the soil. It is now generally conceded that onr seasons are nore changeable aud the extrenes greater than they were half a century back, and to this influenee do we attribute in a great measure the deterioration noted in oceusional seasons and localitics. 
of the latest Flemish pears already exhibit srmptoms of deear bad health in these districts. Even Mr. Kenrick, with all his enthusiasm for the new sorts, is obliged to make the following admission respecting the Benré Diel pear, the most vigorous and hardy here of all: "I re gret to add, that near Boston this noble fruit is liable to crack badly." We predict that many of the Flemish pears originated by Tan Mons will become feeble, and the frnit liable to crack, in the neighborliood of Boston, in a much less time than did the old rarieties.

And this learls ns to remark here, that the hardiness of any rariety depends greatly unon the circmstances of its origin. When a new variety springs up accidentally from a healthy seed in a semi-natural manner, like the Seckel, the Dix, and other native sorts, it will usually prove the hardiest. It is, as it were, an effort of natme to produce a new individual ont of the materials in a progressive state which garden culture has afforded. Cross-bred seedlings-one parent being of a hardy nature, and both healthy; such as Knight's own seedlings, the Monareh and Dummore pear's-are next in hardiness. Lastly, we rank rarieties reared by Tan Nons' method-that of continually repeated reproductions. This, as Tan Mons disticetly states, is an enfeeblin! processwithout any compensating element of vigor. Hence it follows, as a matter of course, that seellings of the fifth or sixth generation, as are some of his varieties, must in their origin be of feeble habit. Tan Mons limself was fully aware of this, and therefore resorted to "grafting by coprulation," - in fact, root-grafting,-well knowing that on common stocks these new rarieties would, in light soils, soon become feeble and decayed. It is needless for us to add that hence we consider the Belgian mode of producing new rarieties greatly inferior to the English one, since it gives us rarieties often impaired in health in their very origin.

If any funther proof of this is desired, we think it is easily found by comparing the robmst vigor and longevity of many native pear-trees to be formd in the United States-some of them 80 or 100 years old, and still producing large crops of fruit-with the delicate trees of several new varieties now in our gardens from Enrope. Thes varieties are delicate not only with respect to their constitutional vigor, but they are also more susceptible to injury from the severity of our winter"s cold and summer's sum.

There are great advantages, undoubtedly, for soils naturally unfarorable, and for small gardens, in grafting the pear upon quince stocks; yet, as it diminishes the rigor of the tree, it is not impossible that continued propagation from dwarf trees may somewhat lessen the vital powers and the longevity of a giv en rariety.

The decay of rarieties of the Apricot, or Peach, much shorter lived trees by nature, we seldom or never hear of. Tarieties of both are now in cultivation, and in the most perfect vigor, of 200 rears' duration. This, probably, is owing to the more natual treatment these trees receive generally. Tarieties of the rine are said nerer to degenerate, and this is perhaps owing to their having very rarely been propagated by grafting *

* We do not deny that in any given soil there is a period at which a variety of tree or plant exhibits most vigor, and after having grown there awhile it ceases to have its former luxuriance. The same is true of wheat or potatoes, and accordingly farmers are in the habit of " changing their seed." The nutriment for a given variety is after a time exhausted from the soil, and umless it is again 
We are not without remedy for vilieties that have partially decayed in a certain district. If the trees have once been productive of excellent fruit, and are still in a sound condition, though enfeebled, a thorongh renewal of their powers will again restore them to health. To effect this, the soil alout the ronts should be preplaced by new, enriched by manure or peat-compost, and mixed with the mineral substances named in the preceding page. The bark of the trumk and large branches should be well seraped, and, as well as all the limbs, thoronghly washed with soft soap; the head should be moderately pruned; and finally, the tree should be sutfered to bear no fruit for the two following seasons. After this it will generally bear excellent fruit for several yeurs again.

In making plantations of fine old varieties, in districts where the stock has become feeble, something may be gatined by procuing grafts or trees from more favorable localities, where the fruit is still as fair as ever, and care should be exercised in selecting only the healthiest grafts or trees. Nurserymen in unfavorable districts should endeavor to propagate only from trees of healthy character; and if those in their own vicinity are diseased, they shonld spare no pains to bring into their nurseries and propagate only such as they feel confident are healthy and sorind. On them, next to the soil, depends very considerably the vigor or debility of the stock of any given variety in the country around them.

In Mr. Knight's original essay on the Decay of Varieties, he clearly stated a circunistance that most strongly proves what we have here endeavored to show, viz.: that the loeal deeline of a variety is mainly owing to negleet, and to grafting on barl stock. We allurle to the fact repoaterlly verifier, that healthy young shoots, taken from the roots of an old variety in apparent decline, produce trees which are vigorous ant healthy. "The decay," says he, "of the power's of life in the roots of seedling trees is exceedingly slow comparatively with that in the branches. Scions (or shoots) obtained from the roots of pear-trees two hundred years old afford grafts which grow with great vigor, and which are often covered with thorns like young seedling stocks; whilst other grafts, taken at the same time from the extremities of the branches of such trees, present a totally different character, and a very slow and unhealthy growth. I do not conceive that such shoots possess all the powers of a young seedling, but they certainly possess no inconsideral)le portion of such powers."

This is nothing more, in fact, than going hack to the roots-the portion of the tree least exhansted - for the renewal of the health of a variety when the branches of the tree have been exhansted by overbearing, de. It is a simple and easy morle of increasing the vigor of a sort of delicute labit, to take scions from young root-suckers for grafting anow. This can of course only be the with trees that grow on their own roots, or have not been grafted.

supplied the tree must decline. In light soils this speedily happens. In strong clayey or rocky soils, the natural decomposition of which afforls a continual store of lime, potash. Ife., the necessary supply of inorganic food is maintained, and the variety continues healthy and productive. 


\section{CHAPTER IIT.}

\section{PROPAGATION OF VARIETIES - GRAFTING - BUDDING-CUTTINGS, LAYERS, AND SUCKERS.}

After laving obtained a new and choice kind of fruit, which in our hands is perhaps only a single tree, and which, as we have already shown, seldom prodnces the same from seed, the next inquiry is how to continue this variety in existence, and how to increase and extend it, so that other gardens and countries may possess it as well as ourselves. This leads us to the subject of the propagation of fruit-trees, or the continuation of varieties by grafting and budding.

Grafting and budding are the means in most common use for propagating fruit-trees. They are, in fact, nothing more than inserting upon one tree the shoot or bud of another, in such a manner that the two may unite and form a new compound. No person having any interest in a garden should be malle to perform these operations, as they are capable of effecting transformations and improvements in all trees and shrubs, no less valuable than they are beantiful and interesting.

Giafing is a very ancient invention, having been well known and partised by the Greeks and Romans. The latter, indeed, describe a great variety of modes, quite as ingenious as any of the fanciful variations now used by gardeners. The French, who are most expert in grafting, practise occasionally more than fifty modes, and within a few years have succeded perfectly in grafting ammal plants, such as the tomato, the dahlia, and the like.

The uses of grofting and budiling, as apllied to firuit-trees, may be briefly stated as follows:

1. The rapid increase of propagation of valuable sorts of fruit not easily raised by sceds or cuttings, as is the case with nearly all varieties.

2. 'To renew or alter the heads of trees partially or fully grown, producing in two or thee years, by heading-in and grafting, a new head, bearing the finest fruit, on a formerly worthless tree.

3. To render certain foreign and delicate sorts of finit more hardy by grafting them on robust stocks of the same species native to the country, as the foreign' grape on the native; and to produce fine fruit in cliniates or situations not naturally favoral,le, by grafting on another species more lrarly, as in a cooi climate and damp strong soil by working the Peach on the I'lum.

4. To render dwarf certain kinds of fruit, by grafting them on suitable stocks of slower growth, as in the case of the Pear on the Quince, the Apple on the Paraclise stock, ic.

5. By grafting several kinds on the same tree, to be able to have a succession of fruit, from early to late, in a small garden.

6. To hasten the bearing of seedling varieties of fruit. or of such as are a loug time in producing fruit, by grafting them on the branches of full-grown or mature bearing trees. 'Thus a seedling pear, which would not produce fruit on its own root in a dozen years, will generally begin to bear the third or fourth year if grafted on the extremiry of the bear. ing branches of a mature tree.

The proper lime for grafling fruit-trees is in the spring, as soon as the sap is in motion, which commences earliest with the Cherry and 
Plum, and ends with the Pear and Apple. The precise time of course varies with the season and the elimate, but is generally comprised from Fobruary to the middle of April. The grape-vine, however, which suffers by bleeding, is not usually grafted mitil it is ir. leaf. The most farorable weather for grafting is a mild atmosphere with oceasional showers.

The scions are generally selected previously, as it is found, in nearly all kinds of grafting by scions, that success is more complete when the stock upon which they are placed is a little more adranced-the sap in a nore active state than in the scion. 'T'o sceure this, we usually cut the scions very early in the spring, during the winter, or even in the autumn, burying their lower ends in the ground in a shated place, or keeping them in tine soil in the cellar till wanted for nse. In cutting scions we choose straight thrifty shoots of the last year's growth, which may remain entire until we commence grafting, when they may be cut into scions of thrce or four huds each. In seleeting scions from old trees it is always advisable to choose the most vigorous of the last year's shoots growing near the eentre or top of the tree. Scions from sickly and muliealtiy branches should be rejected, as they are apt to carry with them this feeble and sickly state. Scions taken from the lower bearing brarches will produce fruit soonest, but they will not afford trees of so handrome a shape or so vigorous a growth as those taken from the thrifty upright shoots neur the centre or top of the tree. Nurserymen generally take their seions from young grafted trees in the nursery-rows, these being usually in better condition than those taken from old trees, not always in a healthy state.

The stock for graftin! ryon is generally a tree which has been standing, at least for a year previonsly, on the spot where it is grafted, as success is much less certain on newly mored trees.

In the case, however, of very small trees or stocks, which are grafted below the surface of the gromd, as is frerpently the practice with the Apple in Anerican nurseries, the stocks are grafted in the house in winter, or early spring, put away carefully in a clampr cellar, and planted out in the spring; but this method is only snceessful when the root is small, and when the top of the stock is taken off, and the whole root is devoted to supplying the graft with nomishment.

The thenry of grrifting is based on the power of union between the young tissues or organizable natter of growing wool. When the parts are placerl nicely in contact, the ascending sap of the stock passes into and sustains life in the scion; the buds of the latter, excited by this supply of salp and the warmth of the season, begin to elaborute and send down wouly matter, which, passing throngh the newly gramulated substance of the jarts in contact, unites the graft firmly with the stock. "If," says De candolle, "the desceuding sap has only an incomplete analogy with the wants of the stock, the latter does not thrive, though the organic mion may litve taken place; and if the analngy between the albumen of stock and scion is wanting, the organic mion does not operatre, the scion cannot absorb the sajp of the stuck, and the graft fails."

Grofting therefore is confined within certrin limits. A scion from one tree will not, from the want of aflinity, succed on every other tree, but only upon those to which it is allied. We are, in short, only successful in budling or grafting where there is a close relationship and similarity of structure between the stock and the scion. This is the case with varieties of the same species which take most frecly, as the diflerent 
sorts of Apple; next with the different species of a genus, as the Apjie and the Pear, which grow, but in which the union is less complete and permanent; and lastly with the generc of the same natural family, as the Cherry on the Plum, which die after a season or two. The ancients boasted of Vines and Apples grafted on Poplars and Elms; but repeated experiments, by the most skilful cultivators of modern times, have clearly proved that although we may, once in a thousand trials, succeed in effect. ing these ill-assorted unions, yet the graft invariably dies after a few months' growth.*

The range in grafting or budding, for fruit-trees in ordinary culture, is as the following: Apples, on apple or crab seedlings for orchards (standards), or on Paradise apple stocks, for dwarfs; Pears, on pear secdlings for common culture, or Quince stocks for dwarfs, and sometimes on the thorn for clayey soils; Peaches, on their own seedlings for standards or for orchards; on Almonds, for hot and dry climates; on Plums in cold or moist soils, or to secure them against the worm; Apri. cots, on Plum stocks, to render them hardy and prodnctire, or on their own seedlings to render them long-lived. Nectarines are usually worked on the Peach or Plum; and Cherries on mazard seedlings, or on the perfumed Cherry, and on the morello for forming half dwarfs.

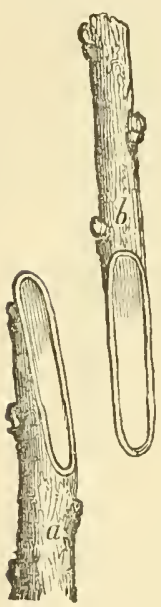

Splice-Grafting.

The mamal operation of grafting is performed in a very easy and complete mamer when the size of the stock, or branch to be grafted, corresponds precisely with that of the scion. In this case, which is called splice-grafting, it is only necessary with a smooth sloping cut, npwrards on the stock a, and downwards on the scion $b$, Fig 2. to make the two fit precisely, so that the inmer bark of one correspouds exactly with that of the other, to bind them firmly together with a strand of matting, and to cover the wounil entirely with grafting clay or wax, aud the whole is finished. In this, which is one of the neatest moles, the whole forms a complete union nearly at once, leaving scarcely any wounded part to heal orer. But, as it is only rarely that the stock is of so small a size as to fit thus perfectly to the scion, the operation must be varied somewhat, and requires more skill. 'The method in most common use to cover all difficulties is called tongue grafting.

We may remark here that grafting the shoots of peaches, Nectarines, and Apricots, owing to therr largc splice-grafting, Fig. 3, has been invented to obviate this. This consists in selecting the scion $a$, so as to leave at its lower enu about a fourth of an inch of two years old wood, which is much firmer. The bottom of

* The classical horticulturist will not fail to recall to mind Pliny's account of the tree in the garden of Lucnllus, grafted in such a manner as to bear Olives, Almonds, Apples, Pears, Plums, Figs, and Grapes. There is little doubt, however, that this was some ingenions deception, as to this day the Itilian gardeners pretend to sell Jasmines, Honersuckles, Jc.. growing together and grafted on Oranges and Pomegranates. This is ingeniously managed, for a short-lived effect, by introdncing the stems of these smaller plants through a hole bored up the centre of the stock of the trees-their roots being in the same soil, and their stems, which after a little growth fill up these holes, appearing as if really grafted. 
the slope on the stock is ent with a dovetail notch, $b$, into which the scion is fitted.

Tongue-grafting (or whip-grafting), Fig. 4, resembles very nearle

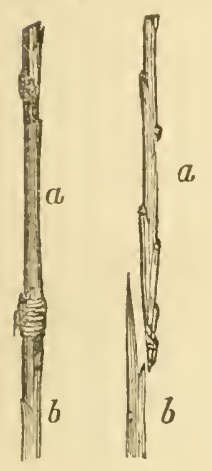

Splice-Grafting the Peach.
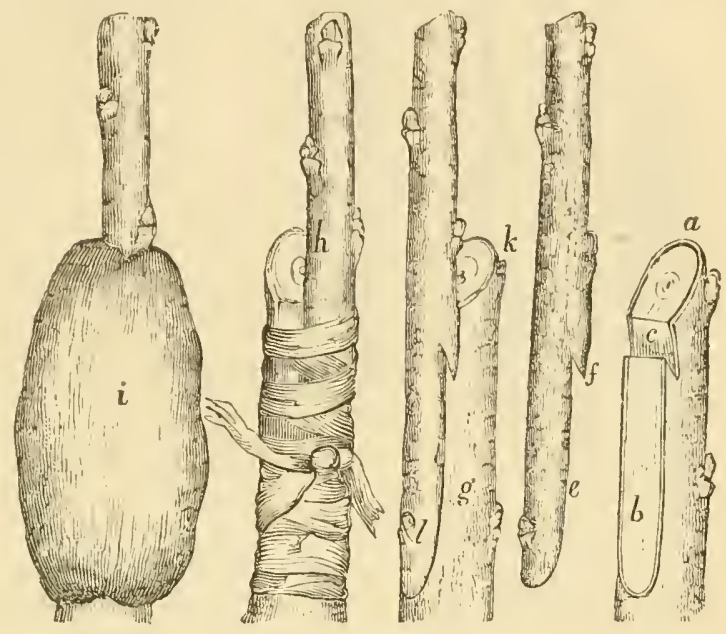

Tongue-Grafting, progressive stages.

splice-grafting, except, instead of the simple splice, a tongue is made to hold the two together more firmly. In order to understand this method, let us explain it a little in detail.

Having chosen your stock of the proper size, cut it off at the point where, $a$, it appears best to fix the graft. If the stock is quite small, it may be within three or four inches of the grouncl. 'Then, with a very sharp linife, make a smooth cut upwards, $b$, about two inches in length. Next make a slit fiom the top of this cut abont one-fourth of the way downwards, $c$, taking out a thin tongue of wood. Cut the scion four or five inches long, or so as to have three buds; then shape the lower end with a single smooth sloping cut, $e$, about the same length as that on the stock, and make the tongue upward, $f$, to fit in the downward slit of the stock. Now apply the scion accurately to the stock, making the inner bark of the scion fit exactly the inner bark of the stock, at lerst on one side, $y$. Without changing their position, tie them together carefully with a piece of bass matting or tape, $h$. And finally cover the wound with well-prepared grafting clay or wax, $i$. This ball of clay shonld more than cover the union, by an inch above and below, and should be abont an inch thick. If grafting-wax is used, the covering need not be above half an inch thick.

American Whip Tongue-Grafting - the morle generally practised by American nurserymen-is similar to the foregoing method, but much more rapid in its execution. The scion and stock are first cut, as represented in Fig. 2, for splice-grafting, and then the knife is passed upward in the scion, $a$, Fig. 5, and downward in the stock, $b$, forming a sliced tongue in appearance, and when joined together, $c$, serves to holil the scion in place. The tying for ont-door grafting is then done by a narrow strip of cloth, say half an inch to an inch wide, one side of which is saturated or coated with grafting-wax, and as each turn lound the 


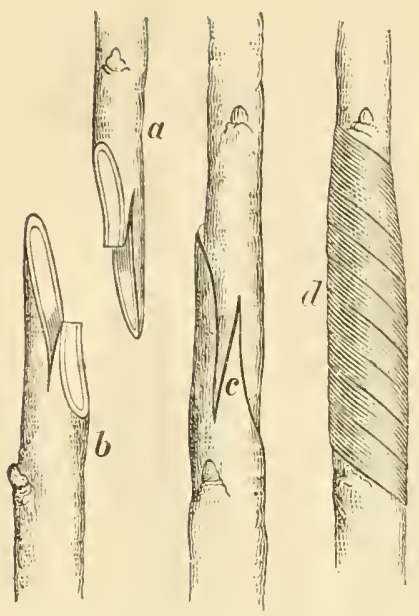
American Thip Tongue-Grafting in its
different stages.

(a). Scion cut for insertion. (b). Stock prepared to receive the scion. (c). Stock and scion united. $(d)$. The same tied np.
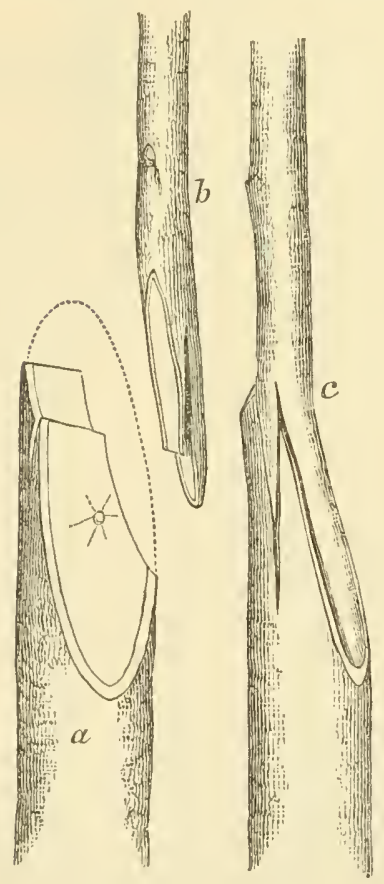

Whip-Grafting large stock.

(a). Stock prepared to receive the scion (b). Scion cut for insertion. (c). Stock and scion united. graft and stock is made, the adhesive power of the wax holds the strip firmly aud render's the work complete $(l)$.

Whip-grafting large stocks is fre quently practised, and is a rery success. ful mamner of operating upon quite large trees in the nursery row. The sloping cut upon the stock, and the forming of the graft, is the same as in the ordinary American whip tonguegrafting, except that one sicle of the stock, opposite that on which the graft is placed, should be cut away upon the same slope as the grafted side, as indicated by the dotted lines in Fig. 6. As sooll as the graft has taken, and commenced expanding its leares and sending out shoots', it will be necessary to mb or cut off all shoots between the ball and the gromud, if it is a small stock, or all those which would rob it of a principal share of nourishment, if upon a large tree. If the scion or stock is rery weak, it is usual to leave one or two other buds for a time, to assist in drawing up the sap. When the graft has marle a growth of two or three inches the ball of clay may be remored, and if the graft is securely united, the bandage may be loosened and retied, or it may be cut partially away at the back of the graft, for the jurpose of permitting the expansion of growth. that otherwise would soon be checked, and cause the graft to break off. In the use of the wax-cloth strips, passing the knife at the back and cutting the tie is all that is requisite. Early in August the angle left at the top of the stock should be cut off smoothly, in order to allow the bark of the stock and the scion to heal neatly over the whole wound.

Though it is little attended to in common practice, the amateur will be glad to know that the success of a graft is always greatly insmred by choosing the parts so that a bud is left near the top of the stock, li, Fig. 4. and another near the bottom of the scion. $l$. These buds attract the rising sap to the portions where they are placed, form woods matter, and greatly facilitate the union of the parts near them; the upper part of 
the stock and the lower part of the scion being the portions soonest liable to perish from a want of nourishment.*

Cleft-yrafting is a very easy though rather chumsy mode, and is in more common use than any other in the United States. It is chiefly practised on large stocks, or trees the branches of which have been headed back, and are too large for tongue-grafting. The head of the steck is first eut over horizonlally with the saw and smoothed with a knife. A cleft about two inches eleep is then made in the stock with a hammer and splitting-knife. The seion is now prepaned by sloping its lower end in the form of is weelge abont an inch and a half long, leaving it a little thicker on the outer edge. Opening the cleft with the splitting-hnife, or a small chisel for that purpose, push the scion carefully down to its place, fitting its inner bark on one sicle to thit of one side of the stock. IThen the stock is large, it is usual to insert two scions, Fig. 7. On withdrawing the chisel, the cleft closes firmly on the scions, when the graft is tied and clayed in the usual mamer.

Apple-stocks, in many American nurseries, are grafted in great quantities in this mode-the stocks being previously taken out of the

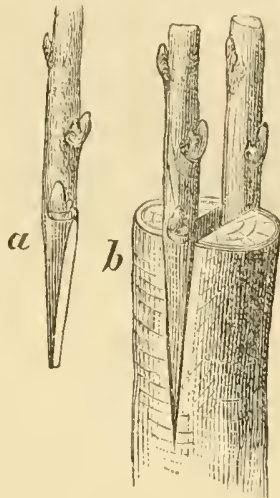

Cleft-Grafting.

(a). Scion ready for insertion. (b). Stock with two scions inserted. ground, hearled down very near the root, cleft-grafted with a single scion, sloping off with an oblique cut the side of the stock opposite that where the graft is placed, and then planted at once in the rows, so as to allow only a single bud of the scion to appear above ground. It is not usual with many either to tie or clay the grafts in this case, as the wound is placed below the surface; but when this plan is adopted, the grafts must be set and the trees planted at once, drawing the wellpulverized soil with great care around the graft. Another way of grafting apjile-stocks, common in western nurseries, consists in tonguegrafting on seedling stocks of very small size, cut back almost to the root.

Large quantities of trees are also propagated by using pieces of roots each three to five inches long, thus forming from the root of one stock sufficient root for two or more grafts. This practice, although quite common, is of very doubtful value, and by some prominent horticulturists considered as tending to dehilitate and reduce vitality - the seat of vital life in fact resting in the natural crown of the seeding, and that once destroyed cannot be renewed. It is therefore apparent that but one healthy permanent tree can ever be grown from a seedling stock. This is performed in winter, by the fireside, the grafts carefully tied, and the

* In grafting large quantities of young trees when stocks are scarce, it is not au unusual practice in some uurseries to tongue or whip-graft upon small pieces of roots of the proper sort of tree, planting the same in the earth as soon as grafted. Indeed $\mathrm{Dr} \operatorname{Van}$ Mons considers this the most complete of all modes, with regard to the proper condition of the grafted sort: 1 st, because the smallest quantity of the stuck is used; and $2 \mathrm{~d}$, because the lower part of the scion being thus pliced in the ground, after a time it throws out fibres from that portion, and so at last is actually growing on its own roots. 
roots placed in the cellar, in sand, till spring, when they are planted, the top of the graft just above ground.

Grafting the Vine is attended with success in the eleft or whip manner, if treated as follows:-Cut your scions during the winter or early spring, keeping them partially buried in a cool datmp cellar till wanted. As soon as the first leaves of the old vine or stock have grown to about two inches in diameter, and all danger of bleeding is past, cut it off smoothly below the surface of the ground, and split the stock and insert one or two scions in the usual manner, binding the cleft well together if it does not close firmly. Draw the soil carefully over the whole, leaving one bud of the scion at the surface. If the root of the stock is a strong native grape, the graft will frequently grow ten or fifteen feet during the first season, and yield a fair crop the second year.

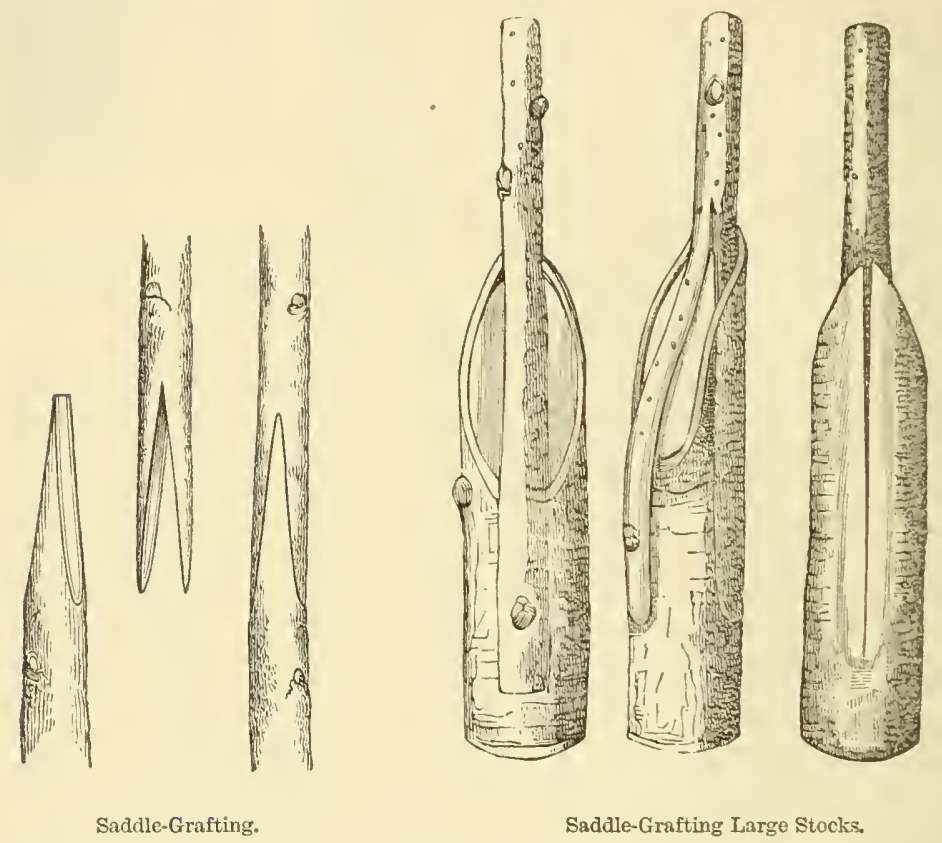

Saddle-grafting, Fig. 8, consists in cutting the top of the stock in the form of a wedge, splitting the scion and thimning away each half to a tongue shape, placing it astride the stock, and fiting the two, at least on one side, as in tongne-grafting. This mode offer's the largest surface for the junction of the scion and stock, and the mion is very perfect. Mr. Knight, who practised it chiefly upon Cherry-trees, states that he has rarely ever seen a graft fail, even when the wood has been so succulent and immature as to preclude erery hope of success by any other mode.

A variety of this mode, for stocks larger than the scions, is practised with much success in England after the usual season is past, and when the bark of the stock separates readily. "The scion, which must be smaller than the stock, is split up between two or three 
inches from its lower end, so as to have one side stronger than the other. This strong side is then properly prepared and introduced between the bark and the wood, while the thimmer division is fitted to the opposite side of the stock." The graft, thus placed, reeeives a large supply of the sustaining fluid from the stock, and the union is rapid; while the wound on the stock is speedily covered by a new layer of bark from that part of the scion which stands astride it.

Side-grafting is a mode deseribed by Elliott, and considered very suecessful for grafting the Magnolia, and other trees difficult of propagation; and also for the greater safety of grafts received or delayed late in spring. It is performed by entting a noteh or slit of about one inch long in the side of the stoek, paring the outer portion, splitting the lower end of the graft and paring the inner portion, then inserting it, so as to form a union of the bark and wood, leaving meanwhile the top of the stock to earry on the cireulation of the sap until the graft becomes united, when the stock is to be eut away.

Grafting-clay is prepared by mixing one-third cow-dung, free from straw, and two-thirds clay, or elayey loam, with a little laair, like that used in plaster, to prevent its eracking. Beat and temper it for two or three days, until it is thoroughly incorporated. When used, it should be of such a consistency as to be easily put on and shaped with the hands.

Grafting-vorx. The common grafting-wax of the Freneh gardeners is of two kinds. The first is melted and laid on with a brush in a fluid state, and is made of half a pound of piteh, half a pound of beeswax, and a pound of cow-dung, boiled together. The second, which is spread while warm on strips of coarse cotton or strong paper, aud wrapped direetly about the graft, answering at onee to tie and to protect it, is composed of equal parts of beeswax, turpentine, and resin. The grafting-wax most commonly used here is made of tallow, beeswax, and resin, in equal parts, or, as many prefer, with a little more tallow to render. it pliable. It may be applied directly around the graft, or it may be spread with a brush, when warm, upon eloth or paper, and afterward the eloth or paper eut into suitable strips for wraping, as indicated in the directions for grafting.

Grafting-wax is a much neater and more perfect protection than grafting-elay.

\section{Budding.}

Budding (inoculating, of the old authors) differs from common graft. ing not the least in its nature or effeets. Every bud is a distinet indiviclual, capable of becoming a tree under favorable cireumstances. In grafting we use a branch composed of several buts, with a considerable quantity of bark and wood; while in burlding we employ but a single bud, with a very small ruantity of the arljoining bark and wood.

The advantages of budding fruit-trees, eompared with grafting, are so considerable that in this country it is ten times as much praetised. These are, first, the great rapidity, with which it is performed; a skilful budder, with a clever boy following him to tie the buds, being able to work from a thousand to twelve huudred young uursery stocks in a day. 2d. The more convenient season at which it is performed in all countries where a short spring erowds garden labors within a small space. $3 \mathrm{~d}$. Being able to perform the operation without injuring the stock in 
case of fithure, which is always more or less the case in stocks headed down for grafting. 4th. The opportunity which it affords, when per-

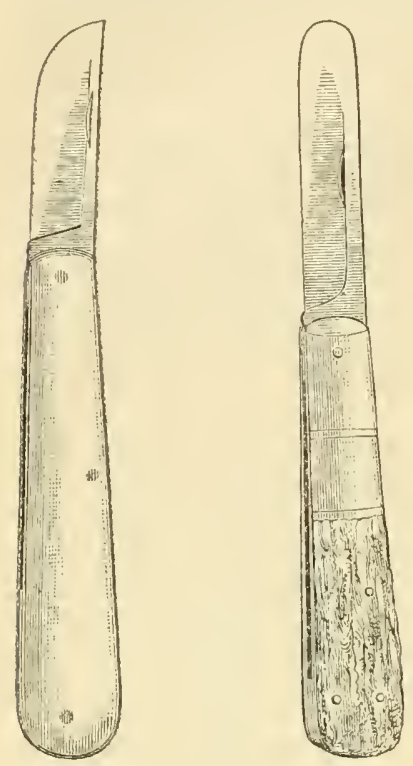

Budding-Knives. formed in good season, of repeating the trial on the same stock. 'T'o these we may add that budding is universally preferred here for all stone-fruits, such as Peaches, Apricots, and the like, as these require extra skill in grafting, but are budded with great ease.

The proper secson for bredding fruittrees in this comntry is from the first of July to the midclle of September'; the different trees coming into season as follows:-Plums, Cherries, Apricots on Plums, Apricots, Pears, Apples, Quinces, Nectarines, and Peaches. Trees of considerable size will require budding earlis than young seerlling stocks. But the operation is always, and only, performed when the barl of the stock provts on separates fiecly fiom the wood, and when the buds of the current year's growth are somewhat plump, and the young wood is growing firm. Young stocks in the musery, if thrifty, are usually planted out in the rows in the spring, and budded the same summer or autumn.

Before commencing you shonld pro-

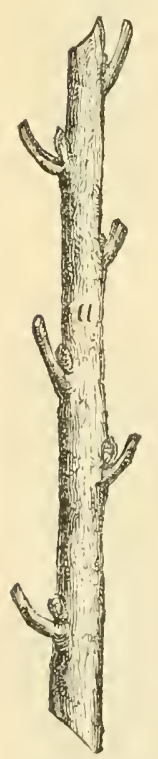

vide yourself with a budding-knife, Fig. 10 (about four and a half inches long), having a round blade at one end, and an ivory handle, terminating in a thin rounded edge called the haft, at the other.

Fig. 11 represents another style or form of buddingknife, by many considered preferable. The cutting portion extends abont one-tlind around the end of the blade, and about two-thirds of its length, leaving the lower part dull. The rounded end of the blade to this knife obviates the necessity of reversing it for opening the. bark when setting a bud, and thus facilitates work.

In choosing your buds, select thrifty shoots that have nearly done growing, and preprere what is called a stick of buds, Fig. 12, by cutting off' a few of the imperfect buds at the lower, and such as may be yet too soft at the upper ends, leaving only smooth, well-dereloped single buds; double buds being fruit-buds.

Great care is essential in selecting buds, as often even on sticks cut from young trees, and especially from bearing trees, many of the single buls will be found develuped into fruit-buds, and are therefore unfitted for use. The for'm of a wood-bud is always long rather than round, and, in the case of peaches, there are sometimes triple buts, $\Delta$ Stick of Buds. the centre one of which is always a wool-hud.

Cut off the leaves, allowing about half an inch of the 
foot-stallis to remain for conveniently inserting the buds. Some strands of bass matting, about twelve or fouteen inches long, and from a quarter to halt an inch in width, moistened in water to render them soft and pliable (or in the absence of these some soft woollen yarn), must also be at hatud for tying the buds.

Shield or 'T-butling is the most approved mode in all countries. A new variety of this method, now generally practised in this country, we shall describe first, as being the simplest and the best mode for fruit-trees.

Lmericum shield-ludeling. Having your stick of buls ready, choose a smooth portion of the stock. When the latter is small, let it be near the gromul, and, if equally convenient, select also the north side of the stork, as less exposed to the sm. Make an upright incision iu the bark from an inch to an inch and a half long, and at the top of this make a cross cut, so that the whole shall form a T. From the stick of buls, vour knife being very sharp, cut a thin, smooth slice of wood and bark containing a bud, Fig. 13, a. With the rounded end of your budling-knife, now raise the bark on each side of the incision just wide enongh to admit easily the preprared bud. Taking holk of the footstalk of the leaf, insert the bud under the bark, pushing it gently down to the bottom of the incision. If the upper portion of the bud projects above the horizontal part of the $\mathrm{T}$, cut it smoothly ofl;, so that it may completely fit $b$. A bandage of the soft matting is now tied over the whole wound. Fig. 1t, conmencing at the bottom, and tying most firmly aloove, leaving the lund and the footstalk of the leaf only exposed to the light air.

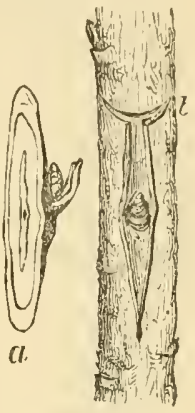

American shieldbudaing.

Common stield-budding, Fig. 15, practised in all gardens in Europe, differs from the foregoing only in one respect-the removal of the slice of wood contained in the bucl. This is taken out with the point of the knife, holding the bud or shield by the leaf-stalk with one hand, inserting the knife under the wood at the lower extremity, and then raising and drawing out the wood by bending it upwards and downwards, with a slight jurk, until it is loosened from the bark;

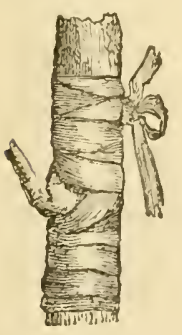
always taking care that a small portion of the wood remains behind to fill up the hollow at the base or lieart of the bud. The bucl this prepared is inserted precisely as before described.

The American variety of shield-buclding is found greatly preferable to the European mode, at least for this climate. Many sorts of fruit-trees, es-

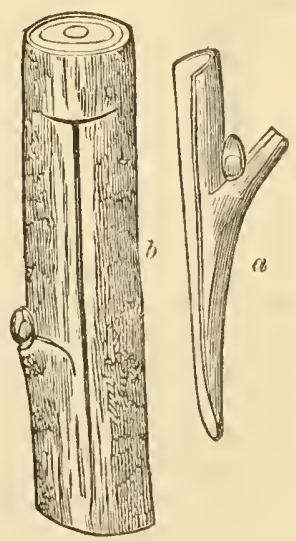
pecially Plums and Cherries, nearly mature their growth, and require to be budded in the hottest part of our summer. In the old method, the but having only a shield of bark with but a particle of wood in the heart of the bud, is much more liabie tc 
be destroyed by heat, or dryness, than when the slice of wood is left behind in the American way. Taking ont this wood is always an operation requiring some dexterity and practice, as few buds grow when their eye or heart-wood is damaged. 'I'he American method therefore requires less skill, can be clone earlier in the season with younger wood, is performed in much less time, and is uniformly more successful. It has been very fairly tested npon hundreds of thousands of fruit-trees in our garlens for the last twenty yeurs, and although practised English budders coming here at first are greatly prejucliced against it, as being in direet opposition to one of the most essential features in the old mode, yet a fair trial has never failed to convince them of the superiority of the new.

After-treatment. In two weeks after the operation you will be able to see whether the bud has taken, by its plumpmess and freshness. If it has failed, you may, if the bark still parts readily, make another trial; a clever budder will not lose more than 6 or 8 per cent. If it has succeeded, after a fortnight more has elapsed the bandage must bo loosened, or, if the stock has swelled much, it shonld be removed altogether, by cutting on the back side opposite the bud. When budding has been performed very late, we have occasionally found it an advantage to leave the bandage on during the winter.

As soon as the buds commence swelling in the ensu-

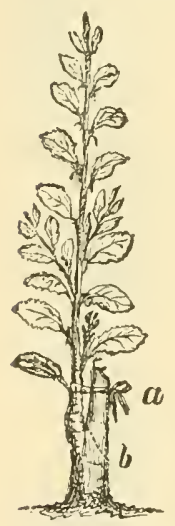

Treatment of the growing bud. ing spring, head down the stock, with a sloping back cut, within two or three inches of the bud. The bad will then start rigoronsly, and all "robbers," as the shoots of the stock near to and below the bud are termed, must be taken ofi' from time to time. To secure the up,right growth of the bud, and to prevent its being broken by the winds, it is tied, when a few inches long, to that portion of the stock left for the purpose, Fig. 16, $a$. During the month of August, if the shoot is strong, this support may be removed, and the superfluous portion of the stock smoothly cut away in the rotted line $b$, when it wili be rapidly covered with young bark.

We have found a great advantage, when budding trees which do not take readily, in adopting Mr. Kunght's excellent mode of tying with two distinct baudages, one covering that part below the bud, and the other the portion above it. In this case the lower bandage is removed as soon as the bud has taken, and the upper left for two or three weeks longer. This, by alresting the upward sap, completes the union of the npper portion of bud (which in plums frequently dies while the lower part is united) and secures success.

Reversed stield-budding, which is nothing move than making the cross cut at the bottom instead of the top of the upright incision in the bark, and inserting the bud from below, is a good deal practised in the south of Enrope, but we have not fouml that it possesses any superior merit for fruit-trees.

An ingenious application of budding, worthy the attention of amateur cultivators, consists in using a blossom-bud instead of a wood-bud; when, if the operation is carefully done, blossoms and fruit will be produced at once. This is most successful with the Pear, though we have often succeeded also with the Peach. Blossom-buds are readily distin- 
guished, as soon as well formed, by their roundness, and in some trees by their growing in pairs; while wood-buds grow singly, and are nore or less pointed. We have seen a curious fruit-grower borrow in this way, in september, from a neighbor ten miles distant, a single blossom-bud of a rare new pear, and produce from it a fair and beautiful fruit the next summer. The bucl, in such cases, should be inserted on a farorable limb of a bearing tree.

Annular budding, Fig. 17, we have found a valuable mode for trees with liard wood and thick bark, or those which, like the walnut, have buds so large as to render it difficult to bud them in the common way. A ring of bark, when the silp is flowing freely, is taken from the stoek, $a$, and a ring of corresponding size containing a bud, $b$, from the scion. If the latter should be too larye a piece must be taken from it to make it fit; or should all the scions be too small, the ring upon the stock may extend only three-fourths the way round, to suit the ing of the bud.

An application of this mode, of great value, occa-

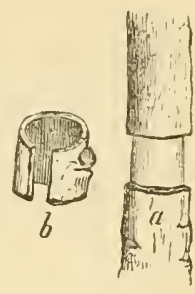

Annular Buōiding.

sionally occurs in this country. In snowy wiuters, fruit-trees in orchards are sometimes girdled at the ground by field-mice, and a growth of tweuty years is thus destroyed in a single day, should the girdle extend quite round the tree. To save such a tree it is only necessary, as soon as the sap rises vigorously in the spring, to apply a new ring of bark, in the annular mode, taken from a branch of proper size; tying it firmly, and drawing up the earth so as to cover the wound completely. When the tree is too large to apply an entire ring, separate pieces, carefully fitted, will answer; it is well to reduce the top somewhat by pruning, that it may not make too large a demand on the root for a supply of food.

Another practice, and perhaps one more easily applicable, is the taking several large grafts or strong twigs of last year's growth, and after splitting them in halves, pare each end down to a thin edge, and insert them underneath the bark of the tree just above and below the wound. Tie around firmly with strong bass matting, and then draw up the earth to cover the whole and keep out the air.

Budding may be done in the spring as well as at the latter end of summer, and is frequently so performed upon roses and other ornamental shrubs by French gardeners, but is only in occasional use upon fruit-trees.

\section{Influence of the stock and graft.}

The well-known fact that we may have a humdred dificrent varieties of pear on the same tree, each of which produces its fruit of the proper form, color, and quality; and that we may have, at least for a time, several distinct though nearly related species upon one stock, as the Peach, Apricot, Nectarine, and Plum, prove very conclusively the jower of every grafted or budded branch, however small, in preserving its identity. To. explain this, it is only necessary to recall to mind that the ascending sap, which is furmished by the root or stock, is nearly a simple fluid; that the leaves digest and modify this sap, furming a proper juice, which re-descends in the inner bark; and that thus every bud and leaf upon a 
branch maintains its individuality by preparing its own proper nourishment, or organizing matter, ont of that general aliment the sap. In deerl, according to De Candolle, * each separate cellule of the inner bark has this power of preparing its food according to its nature; in proof of which a striking experiment has been tried by grafting rings of bark, of difierent allied species, one above another, on the same tree, withont allowing any buts to grow upon them. On entting down and examining this tree, it was found that under each ring of bark was deposited the proper wood of its species, thus clearly proving the power of the bark in preserving its identity, even without leaves.

On the other hand, though the stock increases in size by the woody matter received ili the descending sap from the graft, yet as this descends through the inner bark of the stock, it is elaborated by, and receives its character from the latter; so that, after a tree has been grafted fifty years, a shoot which springs out from its trumk below the place of mion will always be found to bear the original wild fruit, and not to have been in the least affected by the graft.

But whilst grafting nerer effects any alteration in the identity of the variety or species of finit, still it is not to be denied that the stuck does exert certain influences over the habits of the grat'. The most injortant of these are dwarfing, inducing fruitfulness, and adapting the graft to the soil or clinate.

Thus every one knows that the slower habit of growth in the Quince stock is shared by the Pear grafted upon it, which becomes a dwarf; as does also the Apple when worked on the Paradise stock, and, in some degree, the Peach on the Plum. The want of entire similarity of structure between the stock and graft confines the growth of the latter, and changes it, in the case of the Pear, from a lofty tree to a shrub of eight or ten feet in lieight. The effect of this difference of structure is very apparent, when the Peach is grafted on the Plum, in the greater size of the trunk above, as compared with that below the graft; a fact which seems to arise from the obstruction which the desceuding sap of the graft finds in its course through the bark of the stock.

To account for the earlier and greater fruitfulness caused by grafting on a stock of slower growth, Mr. Knight, in one of his able paper's, otfers the following excellent remarks :-

"The disposition in young trees to produce and nourish blossom buds and fruit is increased by this aplarent obstruction of the descending sap; and the fruit, I think, ripens somewhat earlier than upon other young trees of the same age which grow upon stocks of their own species. But the growth and vigor of the tree, and its power to nomish a succession of heavy crops, are climinished, apparently, by the stagnation in the branches and stock of a portion of that sap which, in a tree growing on its own stem or upon a stock of its own species, would descend to nourish and promote the extension of its own roots. The practice, therefore, of grafting the Pear on the Quince, and the Peach on the Plum, when extensive growth and durability are wanted, is wrong; but it is eligible wherever it is wished to diminish the vigor and growth of the tree, and its durability is not so important."

In adapting the graft to the soil the stock has a marked influence. Thus in dry chalky soils, where the Peach on its own roots will scarcely 
grow, it is found to thrive admirably budded on the Almond. We have already mentioned that in clicy soils too heavy and moist for the Peach, it succeeds very well if worked on the Plum. M. Floss, a Prussian gardener, succeeded in growing tine pears in very sandy soils, where it was nearly impossible to raise them before, by grafting them on the Nomntain Ash, a nearly related tree, which thrives on the driost and lightest soil.

A varicty of fruit which is foumd rather tender for a certain climate, or a particular neighborhood, is frecuently acelimatized by grafting it on a native stock of very hardy habits. Thus near the sea-coast, where the finer plums thrive badly, we have seen them greatly improved by being worked on the beech-plum, a native stock adlapted to the spot; and the foreign grape is more luxuriant when grafted on our native stocks.

A slight effect is sometimes produced by the stock on the quality of the fruit. A few sorts of pear are superior in flivor, but many are also inferior, when grafted on the Quince, while they are more gritty on the thor'm. The Green Gage, a Plum of great delicacy of fluvor, varies consiclerably upon different stocks; and Apples raised on the crab, and pears on the IIountain Ash, are said to keep longer than when grown on their own roots.

In adclition to the foregoing, a diseased stock should always be avoiderl, as it will commumieate disease slowly to the graft, unless the latter is a rariety of sufficient vigor to renew the health of the stock, which is hut seldom the case.

The cultivator will gather from these remarks that, in a favorable climate and soi], if we desire the greatest growth, duration, and development in any finit (and this applies to orchards generally), we shonld choose a stock of a closely similar nature to the graft-an apple seedling for an apple; a pear seedling for a pear. If we desire dwarf trees that come into bearing rery young, and take little space in a garden, we employ for a stock an allied species of slower growth. If our soil or climate is unfavorable, we use a stock which is adapted to the soil, or which will, by its hardier roots, endure the cold.

The influence of the graft on the stock seems scarcely to extend beyond the porrer of communicating disease. A graft taken from a tree enfeebled by disease will recover with difficulty, even if grafted on heallhy stocks for a dozen times in repeated succession. And when the disease is an inherent or hereditary one, it will certainly communicate it to the stock. IVe have seen the yellows, from a diseased peach-tree, propogated through hundreds of individuals by budding, and the stock and graft both perish together fiom its effects. Hence the importance, to murserymen especially, of securing healthy grafts, and working only upon healthy stocks.

\section{Propagrtion by Cuttings.}

I'ropagating by cuttings, as applied to fruit-trees, consists in causing a shoot of the previons season's wood to grow. by detaching it from the parent tree at a suitable season, and planting it in the grom under favorable circuinstances.

In this case, instead of uniting itself by wooly matter to another tree, as does the scion in grafting, the descending woody matter becomes roots at the lower end, and the cutting of which is then a new and entire 
plant. Every bud being a distinct individual, capable of forming a new plant, has indeed theoretically the power, if separated from the parent stem, of throwing out roots and maintaining a separate existence; and some plants, as the grape-vine, are frequently propagated by single buds planted in the soil. But in practice it is found necessary, with almost all trees and plants, to retain a considerable portion of the stem with the bud, to supply it with fool until it has formed roots to draw nourishment from the soil.

All fruit-trees may be propagated by cuttings, with proper care and attention, but only a few grow with sufficient facility in this way to render their propagation by cuttings a common mode. These are the Gooseberry, the Currant, the Vine, the Quince, the Fig, and the Mulberry.

Cuttings of the Currant, Gooseberry, and the hardy sorts of Tine will root readily, in a soil not too dry, in the open garden. Currants and Gooseberries are generally taken off in the fall or winter, prepared for planting, and two-thirds of their lower ends buried in the ground till the commencement of spring, when they are planted out, either where they are to remain or in nursery rows. They will succeed nearly as well if taken off in the spring, but, owing to the period at which they commence growing, this must be attencted to very early, if deferred till that season.

A successful practice is to prepare the cuttings of Gooseberries and Currants early in the autumn, and to plant them at once in the position where they are to grow the succeeding summer. In planting, set the cuttings into the ground so deeply that but one bud will be left at or near the surface, and then, as soon as the fiosts of winter come, corer the whole gromul with in light mulch of coarse straw mannre, or other litter three or four inches deep.

In order to raise plants of the Gooseberry and C'urrant,

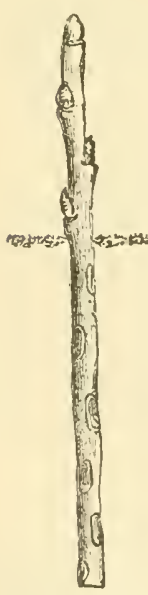
with straight clean stems, which shall not throw up suckers, it is only necessary, before planting the cutting, to cut out every eye or bud to be placed below the surface of the ground, Fig. 18. The cutting should be about a foot long, eight inches of which may be inserted in the ground. To insure greater success in raising the finer sorts of Gooseberry, or other shrubs, it is customary to plant the cuttings on the shaded side of a wall or fence, in deep rich loam, rather damp than dry. Cuttings of the vine are generally prepared when trimming the old plants in autumn or winter; they may then be buried with their lower ends in the ground, or kept in earth in the cellar till spring.

Grape cuttings are also made as soon as it will answer to prune the vines in the autumn; and, being planted at once in the ground, corered as above noted for Gooseberries and Currants, are found to grow successfully.

Scarce sorts of grapes, which it is desirable to multiply extensively, are frequently propagated by joints: that is, by buds having about two inches of wood attached to each--

Gooseberry cutting prepared and jlanted. every bud in this way forming a plant. When this mode is adopted, it is usual to plant the joints about half an inch deep, in light soil, in a common hot-bed prepared for the purpose, or each joint is planted in a pot by itself. In the first way a great number of plants may be grown in a small space. 
Formerly more certain success in propagating the vine by joints was considered gained by halving the joint before planting, as shown in Fig 19; but, recently, operators have practised the simple mamer of prepar ing the cuttings with about two inches of wood below, and half an inch above the bud, and then planting in frames or propagating-houses, by simply placing the eve or entting in a perpendicular position, the burl just level with, or nearly covered in a beil of clean, sharp, building

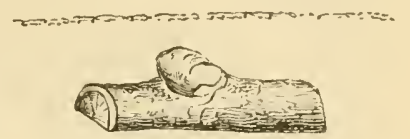

A vine joint prepared and planted. or lake sand. A gentle bottom heat is to be maintained steadily, at the same time keeping the air in the house or frame quite cool until the lower end of the cutting or bud has commenced to form roots, when the air of the surface or rolume of the house may be increased in warmth to stimu. late giowth of rine.

In the method of growing from single eyes, or two-eye cuttings, in out-dloor practice, it is considered best to prepare the cuttings during winter, and pack them in elean damp-not wet-sand, in a cool dark cellar, where they will calius; and then, just as soon in the spring as the ground can be worked, plant the cuttings out, selecting as far as possible a sharp sandy loam for the location, covering the bed half an inch deep with the soil, and then two to three inches deep with mulch of sawdust, tan bark, dtc.

In preparing cuttings of what are termed hard-wood varieties, such as Delaware, Norton's Virginia, dc., it is customary with some propagators to scrape off the outer bark from the lower end of the cutting, and to soften it by suaking in water from ten to twenty hours before placing them in the bed or frame.

The large English black mulberry is propagated by cuttings, as follows: About the last of October take cuttings firom the thrifty shoots of a bearing tree, cut ont all the buis except two or three at the top, and pare off the bottom of the cutting just below a buc. Lay in the cuttings in a sheltered border, burying them so that only the two buds at the top are exposed, and covering them with some loose straw or litter. In the spring make a small hot-bed with rery sandy soil, in which to plant the cuttings on traking them out of the ground, or place each one in a small pot in any hot-bed ready at hand, and in a few weeks they will be found to have marle roots freely.

As a general rule, cuttings succeed best when they are taken off just between the young and the previous year's wood; or, in the case of young side shoots, when they are cut off close to the branch preserving the cullar of the shoot. The lower end should be cut smoothly across just below a bud, the soil should in all cases be pressed firmly about the lower end of the cutting, and it should always be planted before the buds commence swelling, that the wound may in some measure heal before growth and the absorption of fluid commences.

\section{Propagration by Layers and Suckers.}

A layer may be considered as a cutting not entirely separated from the plant.

Layering is a morle of propagation resorted to in increasing some fruit-tree stocks, as the Paradise stock, the Muscle Phnı, and some 
kinds which do not grow so well from the seed. Certain rarieties of native grape, as the Norton's Virginia, which do not root readily by cuttings, are also raised in this way, and it may be applierl to any sort of fruit-tree which it is desirable to continue on its own root withont grafting.

Fruit-trees are generally layered in the spring, and the layers may be. taken off well-rooted plants in the antumn. But they may also be lay. ered with success early in July.

In making layers the ground around the mother plant should be made light and mellow by digging. Being provided with some hooked

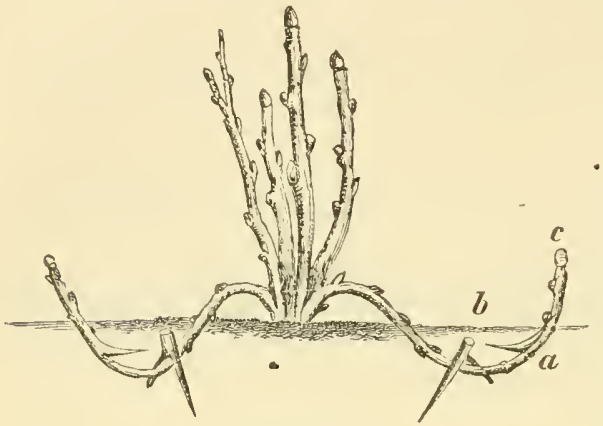

Layering. pegs to fasten down the layers, bend down a branch, so that the end may recline upon the ground. Open a little trench three or four inches deep to receive the young wood to be lavered; make a cut or tongue, Fig. 20, a, half way through the under or upper side of the shoot, legging down the br:mch witli the hooked peg, $b$, to keep it in its place ; press the earth slightly romal the tongue, and, in

filling in the soil, raise nearly upright the end of the layer, $c$, which remains above the surface of the ground.

The descending sap, filled with organizable matter, is arrested by this tongue, accumulates there, and the emission of roots speedily takes place. Ringing, wounding, or fwisting the limb answers the same purpose less perfectly, and indeed many trees root readily from the mere position of the branches as layers, and the moisture of the soil.

A tree or plant which is kept for raising layers is called a stoot, and is headed down both to faeilitate the ronting of the layers and to afford an abundance of shoots near the eartl. Shoots of some of the fruit-tree stocks in the English nurseries are pegged down to the surface before growth commences in the spring, covered abont an inclin deep with soil, and at the end of antmun aftord humdreds of plants; almost erery bud making a sejarate root.

Suckers are shoots sent up from the root, or from prortions of the stem below the surface of the soil, which are easily separated from the parent plant.

Suckers of fruit-trees are frequently used as stocks for budding or grafting upon; but they are greatly inferior to seedlings for this purpose, as they are alvays more liable to jroduce suckers, and ther have not the thrifty, vigorous habit, or the same power of forming as good roots as seedlings. Besides this, should the tree from which they are taken be diseased, they will be likely to cary the malady with them.

Propagating by suckers is an easy and desirable way when we wish to continne a seedling fruit of value on its own root, and some of sur common fruits appear to be more healthy and permanent where growing in that way. It is also a mode for increasing the Raspbery; as is also that of runners, which is a kind of sucker above ground, for the Stramberry. 


\section{Propagation by Picces of Roots.}

Many varieties of trees, and neary all varieties of Blackberries, Raspberies, Gooseberries, Currants, fe., en be readily propagated by small picees of roots. Cut the root into pieces of about two inches in length, any time in autumn or winter, and pack them in noist sand, storing where they will be fiee from frost. In spring prepare a frane with a'gentle bottom heat and plant them, covering about an incle decp, in a sandy loam; as sonn as they have well started they may be tramsplanted out into the open field. Some propagators keep thein in the winter packages until the spring is well advanced and the gromud becomes somewhat wamed, when they plant at once in the open ground, setting the upper end of the piece of root just level with the ground, and then covering the whole surfuce with about three inches deep of some light mulching material.

\section{CHAPTER IV.}

PRUNIXG.

\section{Pmung to promote Growth or modify the From of Frunt-trees.}

Ir this country almost all fruit-trees are grown as standards. In this wa they develop their natural forms, attain the largest size, and produce the greatest quantity of fruit with the least possible care. On bright and powerful sum, reaching every part of the tree, render's the minute systems of pruning and training, which occupy so large a portion of the English works on the subject, of little or no moment to the cultivator here. Pruning is therefore commonly resorted to only for the purpose of increasing the vigor of feeble trees, or to regulate and improve the form of healthy and luxuriant trees.

Pruning has the power of increasing the rigor of a tree in two was. If we assume that a certain amount of nourishment is supplied by the roots to all the branches and buls of a tree, by cutting off one-half of the branches at the proper season we direct the whole supply of nomrishruent to the remaining portion, which will consequently grow with nearly double their former luxuriance. Again, when a tree becomes stunted or enfeebled in its growth, the thinness of its inner bark, with its consequent small sap-ressels (which it must be remembered are the principal channel for the passage of the ascending supply of food), renders the upward and downward circulation tardy, and the growth is small. by heading back or pruning judieiously, all the force of the nourishing fhid is thrown into a smaller number of buds, which make new and luxuriant shoots, larger sap-vessels, and which afford a ready passage to the fluids, and the tree with these renewed encrgies will continue in rigor for a long time.

This treatment is especially valuable in the ease of small trees of feeble or stumted growth, which are frequently eut back to a single bud, and a new shoot or shoots, full of vigor, gires a healthy labbit to the 
trec. In the nurseries this practice of heading down unthrifty trees is frequently pursued, and sma. I orchard trees which have become enfeebled may be treated in the same manner, cutting back the head as far as the place where it is wished that new shoots should spring out. (Ilder trees shonld be headed back more sparingly, unless they are greatly enferbled, and their roots shonld at the same time be assisted by mannie.

A judicions pruning, to modify the form of our standard trees, is nearly all that is required in ordinary practice. Eivery finit-tiee, grown in the open orchard or garden as a common standard, should be reblowed to take its natural form, the whole efjorts of the pruner going no firther than to take ont all veak and croveded branches; those which are filling nselessly the interior of the tree, where their leaves cannot be duly exposed to the light and sun, or those which interfere with the growth of others. All pruning of large branches in healthy trees should be. aroided, by examining them every season and taking out superfluous shoots while smali. Mr. Coxe, the best American anthor on fruit-trees, remarks very truly: "When orchard trees are pruned, they are apt to throw out numerous (superfluous) suckers from the boughs in the following summer' these shonld be rubbed off when they first appear, or they may easily be broken off while young and brittle - cutting is apt to increase their number."

Where pruning is not required to renovate the rigor of an enfeebled tree, or to regulate its shape, - in other words, in the case of a healthy tree which we wish to retain in a state of the greatest luxmiance, lealth, and rigor,-it may be considered worse than useless. Bearing in mind that glowth is always corresponding to the action of the leares and branches, if these are in due proportion and in perfect health, the knife will always be found rather detrimental to luxuriance and constitutional rigor than beneficial. *

The best season for pruning to promote grouth, theoretically, is in antumn, soon after the fall of the leaf. Next to this, winter pruning, performed in mild weather, is best, and in orchards this is the season usually most convenient. In all parts of the country where the winters are not very severe (and always in the Sonthem or Western States) the roots are collecting a certain stock of nourishment during the whole autumn and winter. When a tree is pruned in autumn or winter this whole suppiy goes to the remaining branches, while in the case of sprins pruning it is partly lost. North of the 43 il degree of latitude. howerer, the winters are so severe that winter-pruming should be deferred till the last of Felinary.

We should especially avoid pruning at that period in spring when

* Ignorant cultivators frequently weaken the energies of roung trees, and canse them to grow up with lean and slender stems, by injudicionsiy trinming off the young side shoots and leaves in the growing season. Br talking off these shoots the stem is deprived of all the leaves which would attract and eliborate the sap. thus preparing nourishment for the growth of the stem; and the trunk of the tree does not increase in size half so fast as when the side branches are allowed to remain for a time, pruning them away gradually. It is better. in the use of these young trees, to stop the side branches. when of moderate length, $b r$ pinching out the terminal bud.

+ Experience of many years convinees us that, whaterer theors mas suggest, the best time to prune in order to promote growth, and to have the womnd? healed perfectly, is cery errly in spring, or as soon as the severity of winter has passed. 
the buds are swelling, and the sap is in full flow, as the loss of sap by bleeding is very injmious to most trees, and in some brings on a serious and incurable canker in the limbs.

In pruning large limbs, some composition shonld always be at hand to cover the wound. This will not only prevent its elucking by the cold in winter-pruning, but will keep out the air, and maintain the exposed wood in a sound state mutil it is eovered with a new layer of bark. Many compositions have been in fashion abroad for this purpose, which nneler our summer sun and wintry frosts are nearly worthless, as they generally erack and fall off in a single year. The following is a cheap and adminable application, which we recommend to all eulti. vitors of finit-trees.

Composition for wounds made in pmening. Take a quart of alcohol and dissolve in it as much gunt-shellae as will make a liquid of the consistence of paint. Apply this to the wonnd with a common painter's brush; always paring the wound smonthly first with the knife. The liquid becomes perfectly hard, adheres closely, exchudes the air perfectly, ancl is aflected by no changes of weather'; while at the same time its thinness offers no resistanee to the lip of new bark that gradually closes over the wound. If the composition is kept in a well-eorked bottle, sufficièntly wide-mouthed to admit the brush, it will always be ready for use and suited to the want of the moment.

To prevent mice or rabbits from girdling trees. Great injury is done to young orehards in some distriets by the merulow mouse. This little animal always works under cover, and therefore does its mischief in winter when the snow lies deeply upon the ground. A common and effeetral mods of deterring it is that of treading down the snow firmly abont the stem directly after every fall of suow. But this is a very troublesome affair.

The following mixture will be found to be an effectual prevention. Take one spadeful of hot slaked lime, one do. of ele:un eow-dung, half do. of soot, one handful of Howers of sulphne: mix the whole together with the addition of sufficient water to bling it to the consistency of thick paint. It the approach of winter paint the trunks of the trees sutheiently ligh to he byond the reach of these vermin. Experience has proved that it does no injury to the tree. A dry day should be chosen for its application.

English nurserymen are in the habit of protecting nurseries of smanl, trees from the attacks of rabbits, simply by distributing through the squares of the nursery eoarse matehes made by dipping bunches of rags, or bits of tow, in melterl sulphur, and fastening these in split stakes at comple of feet high. The latter are stuck into the ground, among the trees, at from 12 to 20 feet apart, and are said completely to answer the purpose.

Wrapping the body of the tree with eoarse hardware paper, letting the lower end of the paper go below the soil at the crown of the tree, will effectually prevent the attacks of rabbits.

Wash for the trunlis and branches of finit-trees. The best wash for the stems and branches of fruit-trees is mule by dissolving two pounds of potash in two gallons of water. This is applied with a brush at any season, but perhaps with most effect in the spring. One, or at most, two applications will rid the stem of trees of the bark-louse, and render it smooth and glossy. It is far more efficacious than whitewash, as a preservative against the attacks of insects, while it promotes the growth of the tree, and adds to the natural lively color of the bark. 
The wash of soft soap is also a very good one for many purposes. Though not equal for general purposes to the potash wash, it is better for old trunks with thick and rigid bark, as a portion of it remains upon the surface of the bark for some time, and with the action of every rain is dissolved, and thus penetrates into all the erevices where insects may be lodged, destroying them, and softening the bark itself.

\section{Pruning to induce Fruitfulness.}

There are advantages and disadvantages attending all seasons of pruning, but our own experience has led us to believe that, practically, a fortinight before midsummer is by fur the best season on the whole for pruning in the Northern and Midille states. Wounds made at this season heal over freely and rapidly; it is the most favorable time to judge of the shape and balance of the head, and to see at a glance which branches require removal: and all the stock of organizable matter in the tree is directed to the branches that remain.

When a young fruit-tree is too luxuriant, employing all its energies in making vigorous shoots, but forming few or no blossom buds, and producing no fruit, we have it in our power by different modes of pruning to lessen this over-luxuriance, and force it to expend its energies in fruit-bearing. A successful mode of doing this is by pruning the roots - a proceeding recently brought into very successful practice by European gardeners.

Root-pruning has the effect of at once cutting off a consiclerable supply of the nourishment formerly afiorded by the roots of a tree. The leaves, losing part of their usual foor, are neither able to grow as rapidly as before, nor to use all the nutritious matter already in the branches; the branches therefore become more stunted in their growth, the organizable matter accumulates, and fruit-buds are directly formed. The energies of the tree are no longer entirely carried off in growth, and the returning sap is employed in producing fruit-buds for the next year.

Root-pruning should be performed in autumn or winter, and it usually consists in laying bare the roots and cutting off smoothly at a distance of a few feet from the trunk (in proportion to the size of the tree) the principal roots. Mr. Rivers, an English nurseryman of celebrity, who has practised this mole with great success, digs a trench early in Norember, eighteen inches deep, round and under his trees to be rootprutued, cutting off the roots with a sharp spacle. By following this practice every year he not only throws his trees into early bearing, but torces Apples, Pears, and the like, grafted on their own roots, to become prolific dwarfs, growing only six feet apart, trained in a conical form, full of fruit branches, and prodncing abundantly. Those dwarf trees, thus annually root-pruned, he supplies abundantly with old composted manure at the ends of the roots, thus keeping up their health and rigor. The plan is an admir:ble one for small gardens, or for amateurs who wish to grow a great many sorts in a small surface. Mr. Rivers, in a pamplulet on this subject, enumerates the following among the adran tages of systematic root-pmung:-

"1. The facility of thimning (owing to the small size of the trees), and, in some varieties, of setting the blossoms of shy-bearing sorts, and of thinning and gathering the fruit.

" 2. It will make the gardener independent of the nutural soil of his 
garden, as a few barrowfuls of rich mould will support a tree for a lengthened period, thus placing bad soils nearly on a level with those the most fitrorible.

"3. The capability of remoring trees of fifteen or twenty years' growtl with as much facility as furniture."

In conchusion, Mr. Rivers recommends caution; "enough of vigur must be left in the tree to support its crop of fruit, and one, two, or three seasons' cessation 'from root-pl'uning will often be fomnd necesiatry."

lioot-pruning in this country will, we thiuk, be most valuable in its application to common standard trees, which are thrifty but bear little or 110 finit. They will generally be found to require but a single pruning to bring them into a permanently fruitful condition; and some sorts of l'cars and Plums, which do not usually give a fitir crop till they are twelve or fourten year's old, may be brought into fruit by this means as soon as they are of proper size. Several nearly full-grown peach, pear, and plum trees, on a very rich soil on the Hudson, which were over-luxuriant but bore no fruit, were root-pruned by our advice, and yielded most excellent and abundant crops afterwards.

In the case of Apple orchards, where the permanent valne depends on the size, longerity, and continuerl productiveness of the trees, it is better to wait patiently and not resort to pruning to bring them into bearing, as it camnot be denied that all excessive pruming shortens somewhat the life of a tree. MIr. Coxe, indeed, recommended that the first fruit should never be allowed to ripen on a young apple orchard, as it lessens rery materially the rigor of the trees.

Shortening-in the shoots of Peaches, Nectarines, and Apricots, as wo shall hereafter point out, has a strong tendency to increase the fruitfulness of these trees, since by reducing the young wool the sap accumulates in the remainder of the branch, and many bearing shoots are produced instead of one. And the English practice of spuming-in, which consists in annually shortening the literal shoots of trained P'ears, Apples, and the like, in order to make them throw out short fruit branches $01^{*}$ spurs, is fonnded on the same principle.

Bending down the limhs is an easy and simple means of throwing such branches directly into finit. By this means the circulation is retarded, rapid growth ceases, organizable matter accumulates, and fruit-buds, as before stated, surely follow. The limbs are bent while Hexible, in June or July, and tied down below a horizontal line until they retain of themselves their new position. When this can be easily applied, it is a neverfailing mode of rendering such branches fruitful. It is stated in Loudon's "Gardener's Magazine" that "a very large crop of Pears was obtained by the Rer. Mr. Fisher, in Buckinghamshire, from trees which had not borne at all, by twisting and breaking down the young shoots late in the antumn, when the wood had become tough; and the pendent branches afterwaids continued perfectly healthy."

Dislurking cind limging are two modes that have been recommended by some authors, but of which. except as curious experiments, we entirely disapprove. Disbarking, that is, remoring the outer bark of the trunk in February, May, or March, is and may be practised with good results on trees in very sheltered positions, and under glass, but must always be a somewhat dangerons practice in open orchards, and in a variable climate like ous s; while its grood effects may in a great ine:as. 
ure be attuined by keeping the bark in a healthy state by a wash of soft soap. Ringing, which is nothing more than stopping the descending sap in a branch, and forcing it to organize blossom-buds, by taking ofi a ring of bark, say a fourth or lialf an inch, near midsummer, is : mode always more or less injurious to the health of the branch, and if carried to any extent finally lestroys the tree. It is gradually falling into disuse since root-pruning and other and better modes are becoming known. A ligature or bandage, tightly applied to the limb, will hase temporarily the same effect as ringing, without so much injury to the branch.

\section{Iuducing Fruitfulness by other Means.}

The influence of certain soils on the productireness of fruit-trees is a subject of every-day observation, but the particular ingredients of the soil which insure this abundant bearing are not so well known. Limestone soils are almost invariably productive of all sorts of fruit; and certain strong loams in this country seem to be equally well adapted to this end.

In a curions work called the "Rejuvenescence of Plants," \&c., by" Dr. Schultz, of Berlin, the author, who has deroted considerable time to the subject, states that common salt and chloride of lime contribute greatly to the flowering of most plants, to which, however, they can only be aplilied with safety in small quantities. "Salts of lime," he contimues, "appear to prodnce so nearly the same effect as those of potash and soda, that it is only necessary to place lime within their reach, if there is no deficiency of manure in the shape of general food. Lime will in the main promote, in an astonishing degree, the fruit and Howering of most plants, becutuse calcareous salts promote evaporation and the concentration of silu."

Although we cannot coincide with many of Dr. Schultz's views as expressed in this work, yet the remarks just quoted agree so entirely with facts that have come under our own observation, that we gladly place them before the cultivator of fruit-trees. One of the most productive fruit-gardens in our knowledge is on a limestone soil, and another, more than usually prolific, in a neighborhood not rery fruitful, is every year treated with a top-dressing of coarse salt, at the rate of two bushels to the acre. These facts are surely worth the attention of growers, and should be the subject of more extended and careful experiments.

Rendering trees more fruitful by dwarting, and by adapting tliem to soils naturally mufruitful by growing them upon other and better stocks, we have already placed before the reader under the head of Grafting.

\section{CHAPTER $V$.}

TRAIXIXG.

Training fruit-trees is, thanks to our favorable clinate, a procerding entirely unnecessary in the greater part of the United States. Our tine dry summers, with the great abundance of strong light and sun, are suf 
ficient to ripen fully the fruits of temperate climates, so that the wholo art of training, at once the trial and triumpls of skill with English fruitgatdeners, is quite dispensed with; and in the place of long lines of brick wall and espalier rails, surrounding and dividing the fruit-garden, all covered with carefully trained trees, we are prond to show the open orehard, and the borders in the fruit-garden filled with thrifty and prochuctive standards. Nothing surprises a British gardener more, knowing the cold of onr winter, than the first sight of peaches and other tine fruits arriving at full perfection in the Middle States with so little eare; and he sees at once that three-fourths of the great expense of a fruit-garden here is rendered contirely needless.

Training fruit-trees, in this country, is therefore confined to the colder districts north of the $43^{\circ}$ of latitude, and to the gardens of amateurs. There can, however, searcely be a more beantiful display of the art of the horticulturist than a fine row of trained trees, their branches arranged with the utmost symmetry and regularity, and eovered, in the fruit season, with large and richly colored fruit.

North of the $43^{\circ}$ latitude (or north of the Mohawk) the peach does not ripen well, and this, as well as soem other rather tender trees, will, in such situations, generally yield abundant erops when trained on a common upright trellis, or espalier rail, seven or eight feet high.* Still farther north, as in Maine or Canada, a wall must be resorted to ; but our own observation leads us to believe that, generally, the espalier rail will be found not only cheaper and more easily managed in training, but really preferable to a wall, as full exposure to light is sufficient withont much additional heat. With regard to walls themselves, in the midlle portions of the Union a southern aspeet is almost always the worst, being too hot in midsummer; a wall rumning north and south, and aftording east and west aspects, is much the best. The western aspeet is indeed preferable for all tender fruits, as the blossoms are not there liable to injury from early frosts. A north wall is useful for producing a later crop.

The objects of training are, by a more complete exposure of the leaves and branches to the light and sun, to ripen fruits in a naturally unfarorable climate; to render them more fruitful-lessening vigor and excessive growth by the lateral or horizontal arrargement of the branches; and lastly, economy of space, as trees when trained on a flat surface occupy much less space in the fruit-garden than standards, and lcave the borders more open for cropping with vegetables.

Training conical standards. A very easy and simple mode of training fruit-trees, which has lately come into great favor with amateurs, is the conical standard, or Quenouille (pronounced kenool) of the French. It is applied chiefly to pears, which when treated in this way may be planted about eight feet apart, and thus a great variety of sorts uny be grown in a small garden. A great number of the specimen trees in the London Horticultural Society's Garden are trained in this manner; and Loudon remarks, that in 1840 the Royal Kitehen Garden of Versailles contained two hundred trees trained in the conical manner, with the

* Cedar or loenst posts, set four or eight feet apart, with horizontal bars let in, and crossed by light perpendieular strips of pine from six to twelve inches apart. will form an excellent and durable trellis for espaliers. See Fig 28 . Indeed many gardeners here prefer having a light trellis a few inehes from the wall upon which to train, instead of nailing directly on the wall. 
current year's shoots tied down en quenouille. "They had attuined the height of from six to twelve feet before the branches were hent down; but the effect of this was to cover the shoots with blossom-buds, and to produce the most extraordinary cropss."

To produce Quenonille standards, plant a young tree, three or forr feet high, and, after the first summer's growth, head back the top and cut-in the side branches, as represented by the dotted lines on a. Fig. 21. The next season the tree will shoot out three or four tier's of sicle branches, according to its strength. The lowest sloould be left about eighteen inches fiom the ground, and, by pinching off superthums shoots, others may be made to grow pretty regularly, so as not to crowd the hearl. At the end of this season heal back the leader as in $b$, to strengthen the side shoots. Next season a fresh series of lateral shoots will be produced, four or five of which may be kept every year; and the third or fouth year the lower branches may be bent down in mid.

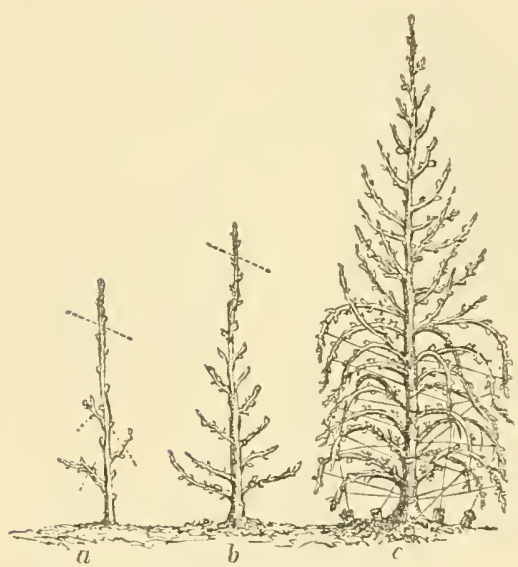

Qnenouille or Conical Training, progressive stages.

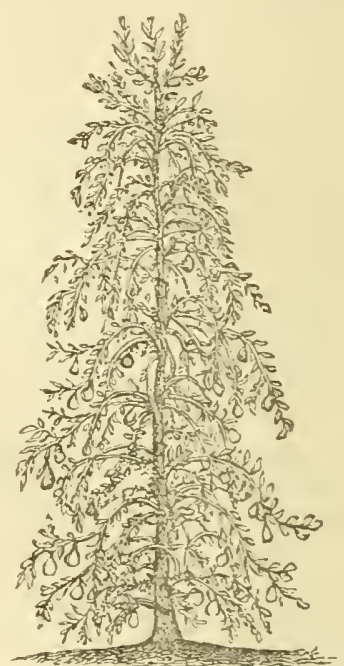

Conical or Quenouille Training, complete.

summer, $c$, and kept in a pendulons position for a year or two, by tring them to stakes diriven in the ground, or to the main stem. This snccessive growth at the top, and arrangement of the limbs below, must be continued till the requisite height-say ten feet-is attained, when, all the branches assuming their final form, the tree will resemble Fig. 2.2 . A moderate pruning to produce new wood, and the occasional tring in of a rambling shoot, will be all that is required. The French quenouille training is performed with dwalf stocks, but the trees are more thrifty and durable when grafted on their own stocks, and kept within proper bounds by root-pruning after Mr. Livers's method, explained in a previous jage.

Pyimids and bushes are trees adapted for small gardens. and not standlards such as are planted in orchards. Mr. Rirers, whose snceess in training and fruiting drarf trees has hardly an equal, gives the following directions:- "If a joung gardener intends to plant, and wishes to train 
tap his trees so that they will become quite perfect in shape, he shonld select plants one year old from the bud or graft, with single upright stems; these will of comse have good huds down to the junction of the gratt with the stock. The first spring a tree of this deseription shonld be healded down, so an to leave the stem about eighteen inches long. If the soil be rich, from tive to six and seven shwots will be produced; one of these must be mate the leader, and if not inclined to be quite prependicular, it must be fastencel to a stake. As soon in summer as the leauling shoot is ten mches long, its end numst br pinched off; and if it pushes forth two or more shoots, pinch off all but one to thee leaves, leaving the topmost for a lealer. The sicle shoots will in most cases assume a regular shape; if not, they may be this first seatson tied to slight stakes, to make them grow in the proper direction. This is best clone by bringing down and fastening the end of each sloot to a slight stake, so that an open pyramid may be formed; for if it is too elose and cypress-like, enough air is not adnitted to the fruit. They may remain impruned till the end of August, when each shoot must be shortened to within eight buds of the stem. This will leave the tree so that no pruning in winter will be required. The second season the tree will nuke vigorous growth; the side shoots which were topped last Angust will each put furth three, four, or more shoots. In Jume, as soon as these hav v made four leaves, they must be pinched off to three leaves, and if these spurs put forth shoots, which they often do, erery shoot must be pinched down to one loaf, all but the lealing shoot of' each siele branch. This must be left on, to exhaust the tree of its superabundant sap, till the end of August. The perpendicular leader must be topped once or twice-in sliort, as soon as it has grown ten inches, pinch off its top, and if it break into two or three shoots, pinch them all but the leader, as direeted for the first season ; in a few year's most symmetrical trees may be formed."

The best modes of training for this comtry, on walls or espaliers, are fan-eordon and horizontal training. The first is the simplest and easiest mode of training the Peach, the Apricot, Nectarine, and Cherry; and the latter is best adapted to the Pear. In training to a wall, the branches are fastened in their places by shreds of leather and nails; and as espaliers, by tying them with slips of bass natting to the rails of the trellis.

Cordon-training has within the past few years become quite a feature among French gardeners, and is now being practised with success by many amateurs in this country. There are a number of varied modes of training en cordon, among which those termed oblique cordon and espalier or lateral cordon are most in use. Oblique cordon training serves to test in a small space a large number of varieties, and may in many cases be adopted with great satisfiction. Dubreil says: "In its practice choose, lealthy and vigoruns young trees of one year's growth, carrying only one stem. Plant them sixteen inches apart, and incline them one over th: other at an angle of sixty degi..s. Cut off about one-thind of the length at or just above a front fruit-bud. During the following summer favor as much as possible the development of the terminal shoot; all the others must be transformed into firut branches by the same means as described for pyramidal trees. The second pruning has for its olject to transform the lateral shoots into fruit-spurs; the new extension of the stem must be cut back one-third. If the terminal extension has grown but slightly, and shows signs of weakness, the cut must le made lower down ou the two-years wood, in order to obtain a more rigorous terminal shoot. By 
the time of the third pruming, the young stem has generally attained two-thirds of its entire length; it must then be inclined to an angle of $45^{\prime \prime}$ "

The same pruning of side branches and terminal shoot must be performed as last year, and continned from year to year until the desired height for covering the wall or trellis is attained; afterwards it must be vearly ent back about two feet, for the purpose of allowing a vigorons shoot to grow fiom the end, and thus keep up a healthy cireulation.

Espalier or lateral cordon training is actapted to the borders of walksi in gardens, and is sniter more to the Aplule worked on the Paradise stock than any other variety of tree. It is termed clouble or single arm cordon, as the trees have arms trained one or both ways. Fig. 23 shows at $a$ a young maiden tree pound for planting, while $b$, shows the same with its limbs tied down to a wire, which is upheld by stakes about one foot above the ground, and secured tirmly at each end of the line.
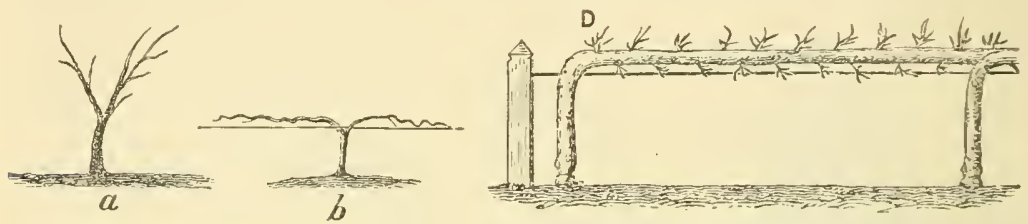

Fig. 24 shows the plants after being two or three years trained in single cordon - the terminal shoot of each tree being united by inarching at the junction with the stem and branch.

The following aeeount of fun-training and horizontal training is so conciselv abridged from the practice of the best English gardens, in the "Snbuban Horticulturist," that we eamuot do better than to place it before the reader.

Fan-traiving in the common English manner. A maiden plant (a tree but one year from the graft) being planted, "is to be hraded down

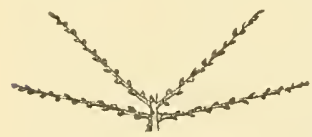

Fan-training, first stage. to four buds or eyes, placed in such a mamner ats to throw out two shoots on each sicle, as shown in Fig. 25. 'The following season the two uplermost shoots are to be headed down to three eyes, placed in such a manner as to throw ont one leading shoot and one shoot on each side; the two lowermost shoots are to be lieaded down to two eyes, so as to throw ont one leading shoot and one shoot on the mpermost side, as shown in Fig. 26. We have now five learling shoots on each side, well placed, to form our future tree. Each of these shoots must be placed in the exact position in which it is to remain; and as it is these shoots which are to form the future tree, none of them are to be shortened. The tree should by no means be suffered to bear any finit this year. Each shoot must now be allowed to produce, besides the leading shoot at its extremity, two other shoots on the uppermost side, one near to the bottom and one about mid. 
way up the stem; there must also be one shoot on the unclermost sille, placerl abont midway between the other two. All the other shoots must be pinched off' in their infant state. 'The tree will then assmme, at the end of the year, the appearance shown in Fig. 27. From this tums it miay be allowed to bara whit ('rop) of finit the gardencr thinks it able to carry; in determining which he onght never to overrate the vigor of the tree. All of these shoots except the lcading ones must at the proper senson be shortened, but to what length must be left entirely to the judgment of the girdener, it of course

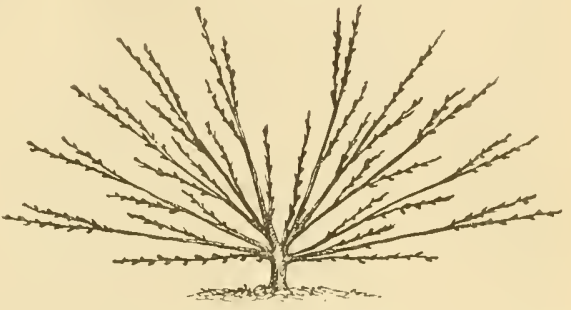

Fan-training, third stage. depending upon the vigor of the tree. In shortening the shoot, care shonld be taken to cut back to a wood-bud that will produce a shoot for the following year. Cut close to the bud, so that the wound maty heal the following season. The following year each shoot at the extremities of the leading branches should produce, besides the leading shoot, one on the upper and two on the under part, more or less, according to the vigor of the tree; whilst each of the secondary branches shonld produce, besides the leading shoot, one other placed near to the bottom; for the grand art of pruning, in all systems to which this class of trees is subjected, consists in preserving a sufficient quantity of young wood at the bottom of the tree; and on no account must the gardener cut away clean any shoots so placed, withont well considering if they will be wanted, not only for the present but for the future good appearance of the tree. The quantity of young wood annually laid in must depend upon

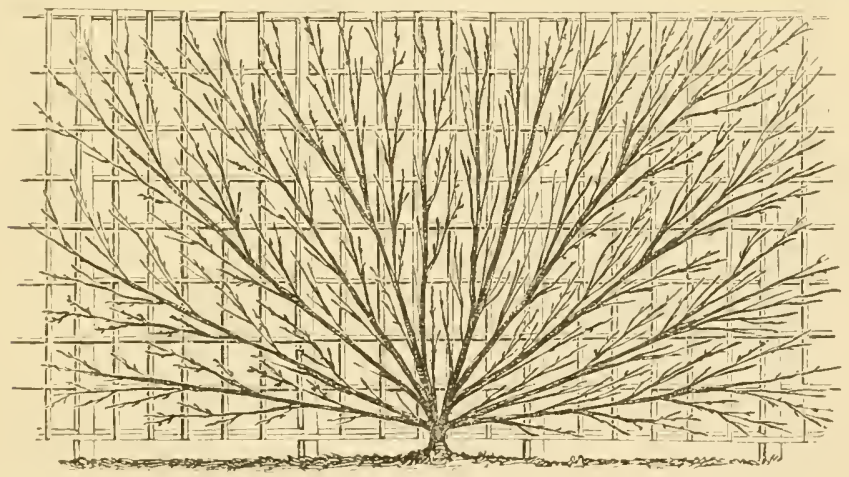

Fan-training, complete.

the vigor of the tree. It would be ricliculous to lay the same quantity into a weakly tree as into a tree in full vigor. The gardener here must use his own judgment. But if any of the leading shoots manifest a disposition to outstrip the others, a portion of young shoots must be laid in, and a greater quantity of fruit suffered to ripen on the over-vigorous branch. At the same time a smaller quantity of fruit than usual must 
be left to ripen on the weaker branch. This will tend to restore the expuilibrium better than any other method. Fig. 28 presents us with the figure of a tree in a more alvanced state, well balanced, and well calculated for an equal distribution of the sap all over its surface. [We have varied this figure by representing it trained on a trellis, instead of a wall.] Whenever any of the lower shoots have advaneed so far as to inconmole the others, they should be cut back to a yearling shoot; this will give them room, and kcep the lower part of the tree in order. In nailing to a wall, eare must be taken not to bruise any part of the shoot; the wounds male by the knife heal quickly, but a bruise often proves incumble. Never let a nail gall any part of the tree; it will endanger the life of the branch. In nailing-in the young shoots, lispose them as straight and regular as possible; it will look workman-like. Whatever system of training is pursued, the leading branches should be laid-in in the exact position they are to remain; for wherever a large branch is brought down to fill the lower part of the wall, the free ascent of the sap is obstructed by the extension of the upuer, and contraction of the lower parts of the branch. It is thus robbed of part of its former vigor, while it seldon fails to throw ont, immediately behind the parts most bent, one or more vigorous shoots."

Horicontal training consists in preserving an upright leader, with lateral shoots trained at regular intervals. These intervals may be from a foot to eighteen inehes for pears and apples, and about nine inches for cherries and plums. "A mairlen plant with three shoots having been

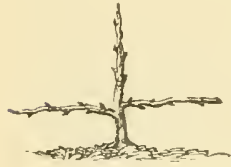

Horizontal training, first stage. procured, the two sicle shoots are laid in horizontally, and the centre one upright, as in Fig. 29 ; all the buds being rubbecl oft' the latter but three, riz. : one next the top for a vertical leader, and one on each side near the top, for horizonal branches. In the conrse of the first summer after planting, the shoots may be allowed to grow without being stoppecl. In the autumn of the first year the two laterals produced are nailed or tied in, and also the shoots produced from the extremities of the lower laterals; the centre shoot being headed town as before, as shown in Fig. 30. But in the second summer, when the main shoot has attained the length of ten or twelve inches, it may be stopled; which, if the plant is in proper vigor, will eause it to throw out two horizontal branches, in addition to those which were thrown out from those of the preceding year. The tree will now be in its second summer, and will have

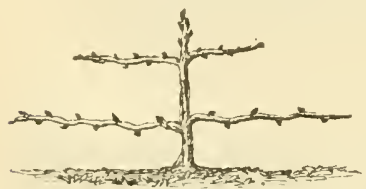

Horizontal training, second stage.

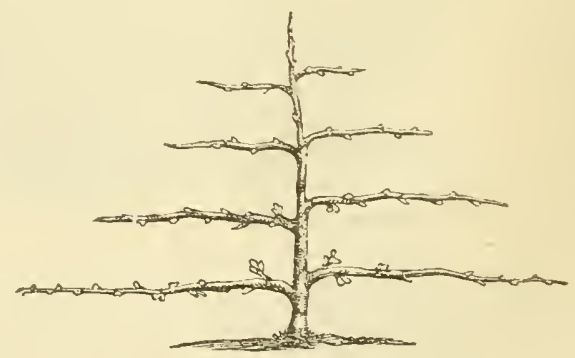

Horizontal training, third stage.

four horizontal branches on each side of the upright stem, as in Fig. 31; and, by persevering in this system, four horizontal bramelies will be 
produced in each year till the tree reaches the top of the wall for espalier), when the upright stem must terminate in two horizontal bianches. Fn the following antumn the tree will have the appearance of Fig. 32." - Suburban IIorticulturist, pl. $363: 372$.

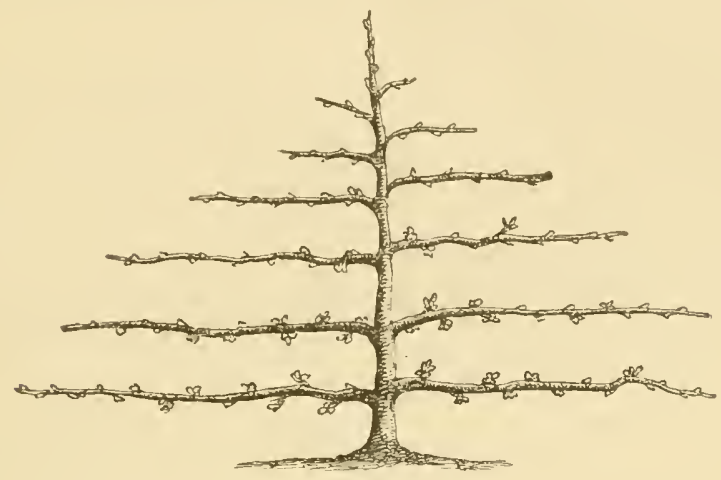

Horizontal training, fourth year.

Training fruit-trees is nowhere in the United States practised to much extent, nor is it considered desirable in the general practice of fruitgrowing. The additional labor is not met by a balance in superior quantity of product, and, while occasionally a few specimens may be procured in this manner of great beanty and excellence, the general crop is not satisfactory or protitable, either to the an ateur or the market-grower.

\section{CHAPTER T'I.}

TRANSPLANTIXG.

As nearly all fruit-trees are raised first in nurseries, and then re moved to their final position in the orchard or fruit-garden; as mpon the manner of this removal depends not only their slow or rapid growth, their feebleness or vigor afterwards, and in many cases even their life, it is evident that it is in the highest degree important to understand and pratetise well this transplanting.

The sersom best adapted for transplanting fruit-trees is a matter open to much difference of opinion among horticulturists; a difference founded mainly on experience, but without taking into account variation of climate and soils, two very important circumstances in all operations of this kind.

All physiologists, howerer, agree that the best season for transplanting deciduous trees is in antum, lirectly after the fall of the leaf. The tree is then in a completely dormant state. Transplanted at this early scason, whaterer wounds may lave been made in the roots commence healing at once, as a deposit direetly takes place of granulons matter from the wound, and when the spring arrives the tree is already sone- 
what established, and ready to commence its growth. Early autumn planting is for this reason greatly to be preferred in all mild climates and dry soils; and even for very hardy trees, as the apple, in colder lat itudes; as the fixed position in the ground, which trees planted then get by the autumnal and early spring rains, gives them an advantage at the next season of growth nver newly-moved trees.

On the other liand, in northern portions of the Union, where the winters commence early, aud are severe, spring planting is greatly preferved. There autumn and winter are not wild enongh to allow this gradual process of healing and establishing the roots to go on ; for when the ground is frozen to the depth of the roots of a tree, all that slow growth and comnection of nutriment by the roots is necessarily at an end. And the more tender sorts of fruit-trees, the Peach and Apricot, which are less hardy when newly planted than when their roots are entire, and well fixed in the soil, are liable to injury in their branches by the cold. The proper time, in such a climate, is as early as the gromid is in a fit condition in the spring.

Early in antumn, and in spring before the buds expand, may as a general rule be consiclered the best seasons for transplanting. It is true that there are instances of excellent snecess in planting at all seasons, except midsmmmer; and there are many who, from having been once or twice snccessful in transplanting when trees were nearly in leaf, avow that to be the best season; not taking into account that their success was probably entirely owing to a fortunately damp state of the atmosphere at the time, and abundant rains after the experiment was jerformed. In the Middle States we are frequently liable to a dry preriod in early summer, directly following the season of removal, and if transplanting is deferred to a late period in spring, many of the trees will perish from drought before their roots hecone establisherl in the soil. Spring planting should therefore alwars be performed as soou as possible, that the roots may have the great benefit of the early and abundant rains of that season, and get well started before the heat of summer commences. For the neighborhood of New York. therefore, the best periods are from the fall of the leaf to the middle of November, in autumn, and from the close of winter to the middle of April, in the slring; thongh commonly the seasons of removal are firequently extended a month beyond these limits.

Taking up the trees is an important part of the operation. A transplanter shonld never forget that it is by the delicate and tender points or extremities of the root that trees take up their food; and that the chance of complete success is lessenerl by every one of these points that is bruised or destroyed. If we could remore trees with erery fibre entire, as we do a plant in a pot, they wonld searcely show any sign of theil change of position. In most cases, especially in that of trees taken from nurseries, this is. by the operation of removal, nearly improssible. But although we may not hope to get erery root entire: we mar, with propres care, preser re by far the larger portion of them, and more particularly the small and delicate fibres. After being taken up, they should be planted directly; or, if this cannot be done, they should be kept from drying by a covering of mats, and, when sent to a distance, by being packed in damp moss.*

* We should notice an inmortant exception to this in the case of trees packed 
Preparing the places. Here is the fatal stumbling-block of all novices and ignorant persons in transplauting. An Fuglish gardener, when he is about to plant finit-trees, talks about preporing his borders; an American savs he will dig his holes; and we camnot give a mole forcible illustration of the ideas of two persons as to the wants of a fruit-tree, or a better notion of the eompanative provision made to supply- these wants, than by contrasting the two phrases themselves. The one looks upon a tree as a living being, whose life is to be renciered long, rigorous, and funitful by a good supply of food, and a soil mellow and easily prenetrated by the smallest fibre; the other consider's it very much in the light of a truncheon or a post, which he thrusts into the smallest possible hole, and supplies with the least portion of manure, trusting to what he seems to believe the inextinguishable powers of natmre to make roots and branches muler any circumstances. It is true that the terms differ somewhat from the nature of the culture and the greater preparation necessary in planting fruit-trees in England, but this is not by any mans sufticient to justify the diflerent modes of performing the same operation there and here.

In truth, in this comntry, where the sun and climate are so favorable, where pruming and training are comparatively so little necessary, the great requisite to success in the ordinary eniture of funit-trees is the proper mepartion of the soil before a tree is planted. lithether a transplanted tree shall struggle several years to recover, or grow moderately after a short time, or at once start into a very luxmiant and vigorous growth, depends entirely upon the amount of care and labor the planter is willing to bestow on the soil for his trees. Wre have seen several instances where, sicle by side, one man planted his trees in large spraces of deeply mored and rich soil, and another in small holes in the common mode, which miformly showed the trees of the first larger after five years than those of the last after twelve.

No fruit-tree should be planted in a hole of less size than three feet square, and eighteen inches to two feet deep. To this size and dejth the soil should be removed and well pulverized, and it should, if necessary, be properly enriched by the application of well-rotted manure, which must be thoroughly mixer with the whole mass of preprared soil by repeated tunings with the spade. 'This preparation will answer' but the most skilful enltirators among us make their spaces fom or five feet in dimmeter, or three times the size of the roots, and it is incredible how much the luxmriance and vigor of growth, even in a poor soil, is promoted by this. No after-mending of the soil, or top-dressings applied to the surface, can, in a climate of dry summers like onrs, equal the effects of this early and reep loosening and enriching the soil. Its effects on the growth and health of the tree are permanent, and the little expense and care necessary in this preparation is a source of early and constant pleasure to the planter. This preparation may be made just before the tree is planted, but in heary soils it is much better to do it sereral months previonsly; and no slatlow plonghing of the soil can obriate the necessity and advantages of the functice where healthy, vigorous orchards or fruit-gardens are desired.

for shipping across the Atlantic. In this case ther should be packed only in dry moss; the moisture of the sea air being sufficient to keep the roots in good conlition. while if packed in damp moss they will be injured by rotting or excessive growth. 
The whole art of transplanting, after this, consists in placing the roots as they were before, or in the most favorable position for growth. Begin by filling the hole with prepared soil, within as many inches of the top as will allow the tree to stand exactly as deep as it previously stood. With the spacle, slape the soil for the roots in the form of a little hillock on which to place the roots-and not, as is commonly done, in the form of a hollow; the roots will then extend in their natural position, not being forced to turn up at the ends. Next examine the roots, and cut off all wounded parts, paring the wound smooth, cutting from the under side. Hold the tree upright on its little mound in the hole of prepared soil; extend the roots, and corer them carefully with the remaining pulverized soil. As much of the success of transplanting depends on bringing the soil in contact with erery filse, so as to leave no hollows to cause the decay of the roots, not only must this be secured by patiently filling in all cavities among the roots, but, when the trees are not quite small, it is customary to pour in a pail of water when the roots are nearly all covered with soil. This carrics the liquid mould to every hidden part. After the water has settled away, fill up the lole, and aroid the common practice of shaking it up and down by the stem. In windy situations it will be necessary to place a stake by the sicle of each tree, to hold it upright, until it shall have taken firm root in the soil, but it is not needful in ordinary cases.

Avoid deep plunting. Hore than half the losses in orchard planting in America arises from this cause, and the equally common one of crowling the eartin too tightly about the roots. No tree should be placed deeper thm it formerly grew, as its roots are stifled from the want of air, or starved by the poverty of the soil at the depth where they are placed. It is much the better and more natural process in fact to plant the tree so that it shall, when the whole is complete, apprear just as deep as before, but standing on a little mound two or three inches higher than the level of the ground about. This, when the mound settles, will leare it nearly on the lerel with the previcus surface.

Wulching is as excellent practice with transplanted trees, and more especially for those which are removed late in the spring. Mulching is nothing more than corering the ground about the stems with coarse straw, or litter from the barn-yard, which by preventing eraporation keeps the soil from becoming dry, and maintains it in that moist and equable coudition of temperature most farorable to the growth of young roots. Very many trees, in a dry season, fail at milsummer, after having made a fine start, from the parched and rariable condition of the earth about the roots. Watering fiequently fails to sare sucl trees, but mulching when they are planted will entirely obriate the necessity of watering in dry seasons, and promote growth under any circumstances. Indeed watering upon the surface, as commonly performed, is a most injurious practice, as the roots, stimulated at one periou of the day by water, are only rendered more susceptible to the action of the hot sum at another, and the surface of the ground becomes so hard by repeated watering that the beneficial access of the air is almost cut ofit. If trees are well watered in the holes, while transplanting is going on, they will rarely need it again, and we may say never, if they are well mulched directly after planting.

The lest manure to be used in preparing the soil for transplanting 
trees is a compost formed of two-thirls muck or black peat earth, retneed by fermenting it several months in a heap with one-tlind fresh barn-yart manure. Almest every farm will supply this, ant it is more fermanent in its effects, ant less drying in its natme, than the common manure of the stable. An admirable manure recently applied with grat success is chareoal- small broken bits and refuse of the clarcoal pits-mixed intimately with the soil. Air-slaked lime is an excellent manure for finit-trees in soils that are not natmully caleareous. 'lwo or three hamelfuls may be mixed with the soil when preparing each space for planting, and a top-dhessing may be applied with advantage ocensionally afterwards, to increase their prodnctiveness. Int whererer large orchards or finit-garlens are to be planted, the muck compost heap should be made realy beforchand, as it is the cheapest, most valuable, aml durable of all manmes for fruit-trees.

Pruning the heads of transplanted trees, at the season of removal, we think generally an injurious practice. It is certainly needless and hurtful in the case of small trees, or those of such a size as will allow the roots to be taken up nearly entire; for as the action of the branches and the roots is precisely reciprocul, and as new roots are rapidly formed just in proportion to the healthy action of the leaves, it follows that hy needlessly eutting ofl the branches we lessen the vital action of the whole tree. At the same time, where trees are transplanted of so large a size that some of the roots are lost in removing them, it is necessiry to cut back or shorten a few of the branches, - as many as will restore the balance of the system, -otherwise the perspiration of the leaves may be so great as to exhanst the smpply of sap faster than the roots can collect it. A little judgment only is necessary to see at a glance how much of the top must be pruned away, before planting the tree, to equalize the loss between the branches and the roots.

When it is necessary to transplant fruit-trees of large size, the best practice is to prepare them previously by digging a trench round the whole mass of roots, undermining them, and cutting ofl all roots projecting beyont this line. The trench should be dug at such a distance from the tree as will include all the large and sufficient ball of roots, and it should be done early in the spring when it is desirable to remove the tree the next year. After all the roots that extent to this circular trench are cut oft; the earth is replaced, and by the season following an abmelance of small fibres is sent out by the amputated roots, which, when the whole is removed, will insure the success and speedy growth of the tree. This is more completely the case when the tree is prepared two years before transplanting. A variation of this mode, which has been found quite as sncessful and less laborious, consists in leaving the trench open and covering it with boards only, or hoards with a top layer of turf. The tree then is somewhat checked in its growth, it throws out an abundance of small fibres into the ball of earth contrining the roots, and is the next season transplanted witl great ease and safety.

The proper sise for transplanting varies somewhat with the sort of tree and the kind of culture intended. It is, howerer, a maxim eqnally well settled, both among theorists and the best practical men, that health, immediate vigor, and duration are all greatly promoted by transplanting fruit-trees of small size-from three to six or seren feet. We are fully aware with what impatience the beginner, or a person who knows 
little of the culture of trees, looks upon trees of this size-one who in eager to plant an orchard and stock a garlen with large trees, thinking to gather a crop the next year. The latter may indeed be done; but the transplanting so affects the tree that its first seanty crop is followed by a long season of rest and feeble growth, while the plantation of young trees is making wood rapilly, and soon comes into healthy and long-continued state of productiveness-often long indeed before the large trees have fairly arrived at that condition. The small tree, transplanted with its sristem of roots and branches entire, suffers little or no check; the older and larger tree, losing part of its roots, repuires several years to resume its former vigor. The constitution of the small tree is healthy and mimpaired; that of the large is frequently much enfeebled. A stont aud vigorous habit-what the nurservmen call a gool stocky plont-is the true eriterion of merit in selecting fruit-trees for transplanting.

Trees intended for orchards, being often more exposed than those in gardens, should be somewhat larger-not less than six, or more than eight feet is the best size. For gardens, all experienced cultivators agree that a smaller size is preferable; we prefer plants two years old from the graft. Most gardeners abroad, when they select trees with more than usual care, take wliat are called maiclen plants, - those one year old from the graft,--and there can be no doubt that, taking into account health, duration, and the ease with which such a tree can be made to grow into any form, this is truly the preferable size for removal into a fruit-garden. 'But we are an impatient people, and it is not till after another century of trial and experience in the culture of finit-trees, that cultirator's generally in this comitry will become aware of the truth of this fact.

The facility with which the different fruit-trees may be transplanted differs considerably. Plums are generally removed witl most success, and after them nearly in the order as follows: Quinces, Apples. Pears, Peaches, Nectarines, Apricots, and Cherries; the latter sncceeling with some difficulty when of large size.

Luying in by the heels is a practice aclopted as a temporary lind of planting when a larger quantity of trees is at hand than can be set out immediately. A trench is opened, and the roots are laid in and covered with soil, the tops being previously placed in a sloping position, inclining to within a few feet of the surface. In this way they are kept fresh and in good order mutil it is convenient to plant them finally. In northern districts, where the autumn is often too severe for planting, and the spring is fiequently too late to receive trees in time from murseries farther south, it is a common and successful mode to procnre trees in antumn, and lay them in by the heels until spring, covering orer the tojs of the more tender sorts, if necessary, with conse litter.*

In planting an orchard, always avoid nlacing the trees in the same spot, or near, where an old tree stood before. Experience has taught mo

* We have often known trees entirely destroyed by want of a little extra care in heading, them in. Select first a dry knoll. or position where no water can stand. and, if possible, sheltered from the southern sun After first digring a trench one foot or more deep, lay the trees down at an angle of about 4.5 . their tops to the sonth; then make the snil mellow and fine, and thorounhly intermingle it with the roots, filling all interstices, ank covering them at least eighteen inches deep.

Trees are sometimes receired in a frozen conlition. They shomk then be placed at once, without nppacking, in a dark cellar, and left mill gradually 
that the growth of a young tree, in such a position, is weak and feeble; the nourishment suitable to that kind of tree laving already been exhansted by a previous growth, and the soil being half tilled with ohl and decayed roots which are detrimental to the health of the young tree.

\section{CHAPTER VII.}

THE POSITION OF FRUIT-TREES-SOIL AND ASPECT.

Ix our favorable elimate many fruit-trees will thrive and produce some fruit in almost any soil, except dry sand or wet swamps. But there is much to be ganined in all elimates by a judicions selection of soil, when this is in our power, or by that improvement which mav generally be effected in inferior soils, where we are necessarily limited to such. As we shall, in treating the culture of each genns of fruit, state more in detail the soils especially adapted to its growth, our remarks here will be confined to the subject of soils generally for the orehard and fruit-garden.

The soils usually selected for making plantations of fruit-trees mav be divided into light sandy loams, gravelly loams, strong loams, and clayey loams; the first having a large proportion of sand, and the last a large proportion of cliny.

The soil most inviting to the eye is a light sandy loam, and as it is also a very common soil, more than half the fruit-gardens in the country are composed of this mould. The easy manner in which it is workeil, owing to its loose and very friable nature, and the rapidity with whieh, from its warmth, erops of all kiuds come into bearing, cause it to be looked upon with almost universal faror. Notwithstanding this, a pretty careful observation tor several years has convineed us that a light sandy soil is, on the whole, the worst soil for fruit-trees. Under the bright skies of July and August, a fruit-tree requires a soil which will retain and afford a moderate and continued supply of moisture, and here the sandy soil fails. In consequence of this the vigor of the tree is ehecked, and it becomes feeble in its growth, and is compraratively short-lived or unproductive. As a tree in a feeble state is always most liable to the attacks of insects, those on a sandy soil are the first to fall a prey to numerous maladies.* The open loose texture of a sandy soil, joined to its warmth, aflords an easy passage and an excellent habitation for all insects that pass part of their lives in the gromul, prepratary to rising out of it to attack the fruit, foliage, or branches of the tree.

thawed out; or they may be at once-if the earth will allow-buried, tops and roots entire, beneath the ground, and there left for a few lays, or until a moist cloudy day occurs for opening and exposing them to the light and air. This latter course is also a good one for trees that are received in a lry or shrivelled state.

* This remark applies to the middle and southern portions of this country. North of the $4: 0^{\circ}$ a light sandy soil is perhaps preferable, as warmer and earlier. 
Such are some of the disadvantages of a light sandy soil ; and in thoronghly examining many of the fruit-gardens of the Middle states the last few seasons, we could not fail to be struck with the fact that, in nine cases ont of ten, where a variety of fruit was musually liable to disease, to blight, or to the attacks of certain fruit-destroying insects, as the curculio, the trees themselves were on sandy soils; while on the other haml, and frequently in the same neighborhood, the same sorts were growing luxuriantly and bearing abmulart crops where the soil was a rather strong loam.* For a few years the growth and productiveness of the trees upon sandy soil is all that can be desired; but the trees are shorter lived, and sooner fall into decay than where the soil is stronger. If there is any exception to this rule, it is only in the case of the Peach; and, judging from the superior flavor of this fruit on stronger soils, we are inclined to cloubt the value of the exception even here.

Grovelly locms are fiequently much better adapted for orchards than sandy, especially where the loam is of a strong quality, and the grarel is not in excess; and the hardier fruits usually do well on this kind of soil.

Strong loams, by which we mean a loam with only just a snfficient portion of sand to make it easily worked, are, on the whole, by far the best for fruit-gatdens in this comntry. A strong loam is ustrally a rleep soil, and affords, during the whole heat of summer, a proper supply of moisture and nomishment to the roots of trees. Fruit-trees do not come into a bearing state so soou in a strong as in a sandy loam, because the growth of wood is more vigorous, and fruit-buds are not so soon formed; but they bear larger crops, are much less liable to many diseases, and their longevity is much greater. The largest and most productive orehards of the Apple and Pear in this comntry are upon soils of this kind.

Cleygy lorms are, when well drained, and when the clay is not in excess, good fruit soils-they are usually strong and deep soils. thongh ratlier heary and difficult to work. Trees that will flomish on these soils, such as the Apple, Pear, Cherry, Plum, and Apricot, usually are very free from disease or insects, and bear large crops. In a moist climate, like that of England, fruit-trees on a clayey loam wonld die of canker, brought on by the excessive quantity of water contained in the soil, but such is not the case umler the high and wan temperature of our summers. The finest, largest, and most productire Plums and Pears within our knowledge, grow in sites on the North River, where the soil is a stift clayey loam, almost approaching a clay. Those fruits that on light sindy soils are almost worthless, from their liability to disease and the attacks of insects, are here surprisingly luxwiant and fruitful.

It is, however, well to remark, that some varieties of fruit, perhaps from the circumstances of their origin, succeed better on sandy soils than any other; thus the Newtown Pippin will only arrive at perfection in a strong loam, while the Summer Queen is finer when grown on a

* As an instance in point, the owner of one of the most highly cultirated gardens in the vicinity of Boston was showing us, in despair. some trees of the Seckel Pear, upon which he could no longer get good crops or fair fruit, and lamenting the degenerucy of the sort. The next day we saw in a neighboring garden beautiful crops of this Pear growing with the least possible care. The garden in the first case was a light sandy loan. in the second, a strong loam. 
sandy, soil. But there are exeeptions to all rules, and what we have already statc l, as to the relative quality of soils, will apply pretty generatly to the whole of this conntry, and it may be added that calcareons. soils, of whaterer texture, are better than soils of the sime yuality where no limestone is present.

Trenching is the most eomplete method of improving a soil too simdy, when the subsoil below is of a loamy or clayey nature. Iropl' subsoil ploughing, by bringing up a suthicient quantity of the stratum below, will answer the same purpose. When the subsoil of a sandy soil is sand or gravel, the surface can only be improved by top-dressings or the application of manures. Top-dressing with elay is the most simple means of changing the nature of such a soil, and it is surprising low moderate a quantity of elay will give a closer texture to light sambly soils. In manuring such soils, we may greatly improve their nature as well as condition by using eomposts of peat or bog earth, swamp muck, or river mul, instead of common barn-yard or stable mamme. 'The former are not only more permanent and better as mamures for fruittrees, but they gradually consolidate and improve the whole texture of the soil.

Indeed no fruit-garden, where the soil is not naturally deep and rich, is in perfect eondition for planting trees, unless the soil has been well trenched two spades in depth. This ereates a matrix for the roots so deep and permanent that they retain their vigor and luxuriance through the droughts of summer, and continue for a long time in a state of health and productiveness.

It is ditheult to give any precise rules as to aspect. We have seen fine fruit-gardens here in all aspects. Perhajs the very best aspect on the whole is a gentle slope to the sonthwest, becanse in such positions the trees when in blossom are somewhat protected from the bad effects of a molning sun after spring frosts. But, to remedy this more perfectly, it is sometimes the practice to plant on the north sides of hills, and this is an eliectual way where early frosts are fatal, and wlere the season is long and wirm enough to ripen the fruit in any exposure. A fine south slope is, sonth of New York, frequently found too warm for many fruit-trees in soils that are light and dry.

Deep valleys with small streams of water are the worst situations for fruit-trees, as the eold air settles down in these valleys in a ealm frosty night, and buds and blossoms are very frequently destroyed. We know a rich and fertile valley of this kind in Connecticut where the Cher'y will scareely grow, and a crop of the Apple or the Pear is not obtained onee in ten years; while the adjacent hill-tops and high cointry, a couple or chree miles distant, yield abundint erops amnually. On the other hand, the borders of large rivers, as the Hudson, or of some of our large inland lakes, are the most favorable situations for fruit-trees, as the climate is rendered milder by large bolies of water. In the garden where we write, a fourth of a mile from the Hudson, we have frequently seen ice formed during the night of the thickness of a dollar, when the blossoms of the Apricot were fully expanderl, without doing the least harm to that tender fruit. This is owing to the slight fog rising from the river in the morning, which, softening the rays of the sun, and dissolving gradually the frost, prevents the injurious effects of sudden thawing. It the sime time, a couple of miles from the shores, this firuit will often be quite destroyed. In short, the season on the lower half of the Hudson may, 
from the ameliorating influence of the river, be said to be a month longer - a fortnight earlier in spring and later in autumn-than in the same latitude a few miles distant; and crops of the more tender firuits are therefore much more certain on the banks of large river's or lakes than in inland districts of the same climate.

As our native forests become cleared away the climate is chimged and becomes more harsh; hence it is found desirable to construct some kind of protection from the point of most destructive harsh winds and storms. Belts of trees, either evergreen or deciduons, or both wingled, and surrounding or placed so as to screen from the northeast, north, and nor'thwest, are considered highly advantageous; and when we consider that foliage is an absorbent and ameliorating agent in tempering climate, we feel that it is the duty as well as interest of every fruit-grower to plant as many such belts as his property and pecuniary means admit.

\section{CHAPTER VIII.}

\section{GENERAL REMARKS ON INSECTS.}

The insects injurious to fruit-trees are numerous, and to consbat them snccessfully requires a minute acquaintance with their character and habits. While considering the culture of cach class of finit in the succeeding pages, we shall point out the habits and suggest means of destroying the most important of these insects; but in the mean time we wish to call attention to some general practical hints on this subject.

In the first place, we cannot too strongly impress upon the attention of the fruit-grower the importance of watching carefully and making an early attack upon every species of insect. It is only necessary to look for a noment at the astonishing rapidity with which many kinds of insects increase, if allowed to get well established in a garden, to become fully aware of this. The common caterpillars are the young of moths or butterflies, and that careful observer of the habits of insects, Dr. Harris, says as each female lays from two to tive hundred eggs, a thousand moths or butterflies will, on the average, produce thrce humdred thousand cater. pillars; if one half this number, when arrived at maturity, are females, ther will give forty-five millions of caterpillars in the serond, and six thousand seven huidred and fifty millions in the third generation.* To take another example: the aphides, or plant-lice, which are freguently seen in great numbers on the tender shoots of fruit-trees, have an almost incredibly prolific power of increase-the investigations of Réaumur having shown that one indiridual in five generations may become the progenitor of nearly six thousand millions of descendants. With such surprising powers of propagation, were it not for the haroc caused among insects by various species preying upon ench other. by birds and other animals, and especially by unfavorable seasons, regetation would

* For much valuable information on the habits of insects injurious to regeta. tion. see the "Treatise on the Insects of Massachusetts," by Dr. T. W. Harris, Cambridge. 
soon be entirely destroyed by them. As it is, the orchards and gardens of eareless and sluvenly cultivators are often over'un by them, and many of the finest crops suffer great injwry or total loss fiom the want of a little timely care.

In all well-managed plantations of fruit, at the first appearance of any injurions insect, it will be inmediately seized upon and destroyed. A tew moments in the first stage of insect life-at the first birth of the new colony - will do more to rid us for the season of that species than whole days of toil after the matter has been so long neglected that the enemy has beeome well established. IVe know how relnctant all but tho experienced grower are, to set ahout cradicating what at first seems a thing of such trifling conseynenere. But such persons should consider that whether it is done at first, or a fortnight after, is frequently the differener beiween ten and ten thousant. A very little time regularly devoted to the extirpation of noxions insects will keep a large place quite free from them. We know a very large garden filled with trees, and always remarkably free from insect ravages, which, while those even in its vicinity suifer greatly, is thus preserved by half an hour's examination of the whole premises two days in the week during the growing season. This is made early in the morning, the best time for the pmorese, as the insects are quiet while the dew is yet upon the leaves, and whole races yet only partially developed may be swept off in a single moment. In default of other more rapid experlients, the old mode of hand-picking, and crushing or burning, is the safest and surest that can be adopted. For practical purposes, the numerous insects infesting fruit-trees may be divided into four classes: 1st, those which for a time harbor in the ground and may be attacked in the soil; 2d, winged and other species, which may be attacked among the branches; $3 d$, aphicles or plantlice, which infest the young shoots; 4th, moths, and all night-flying insects.

Lusects, the laive or grubs of which harbor in the ground during a certain season, as the curculio or plum-weevil, are all more or less affected by the application of common salt as a top-clressing. On a larger scale, in farn crops, the ravages of the cut-worm are frepuently prevented by sowing three bushels of salt to the acre, and we have seen it applierl to all kinds of fruit-grounds with equal success. Salt seems to be strongly disagreeable to nearly all this class of insects, and the grubs perish where even a small quantity has for two or three seasons been alplied to the soil. In a neighborhood where the peach-worm usually destroys half the peach-tress, and where whole crops of the plum are equally a victim to the plum-weevil, we have seen the former preserved in the healthiest eondition by an amunal application of a small handful of coarse salt abont the collar of the tree at the surface of the ground; and the latter mate to hold abundant crops by a top-dressing applied erery spring of packing salt, at the rate of a quart to the surface occupied by the roots of every full-grown tree.

Salt, being a powerful agent, must be applied for this purpose with caution and judgment. In small quantities it promotes the verdure and luxuriance of fruit-trees, while if applied very frequently, or too plentifully, it will certainly cause the death of any tree. 'Two or three years' top-dressing in moderate quimtity will usually be found suflicient to drive away these insects, and then the application need only be repeated once in two or three seasons. Any coarse refuse salt will auswer tho 
murpose; and packing silt is preferable to that of finer quality, as it dissolves slowly by the action of the atmospluere.*

In the reiniged stute most small insects may either be driven away by powerful odor's, or killed by strong decoctions of tobacco, or a wash of diluted whale-oil or other strong soaly. Attention has but recently been called to the repugnance of all insects to strong odors, and there is but little cloulut that before a long time it will lead to the discovery of the means of preventing the attacks of most insects, by means of strong smelling licpuids or ockorous substances. The moths that attack furs, as erery one knows, are divien away by pepper-corns or tubacco, and shond future experimeuts prove that at certain seisons, when our trees are most likely to be attacked by insects, we may expel them by lauging bottles or rags filled with strong smelling liquids in our trees, it will certainly be a very simple and easy way of ridding onrselves of them. The brown scale, a troublesome enemy of the orange-tree, it is stated in the Gradener's Chronicle, has been destroyed by lianging plants of the common chamomile among its branches. The odor of the coal-tar of gasworks is exceedingly oftensive to some insects injurious to finits, and it his been found to dive away the wire-worm and other grubs that attack the roots of plants. The vapor of oil of turpentine is fatal to wasps, and that of tobacco-smoke to the g:een fly. Little as yet is certainly known respecting the exact power of the varions smells in deterring ins rets from attacking trees. What we to know, howerel, gives us reason to believe that much may be hoped from experiments made with a variety of powerful-smelling substances.

Tobacor-router and dilnted whale-oil soap are the two most efficient remedies for all the small insects which feed upon the young shoots and leaves of plants. Tohaceo-water is made by boiling tobacco leares, or the refuse stems and stalks of the tobacco-shops. A liuge pot is crowded full of them, and then filled up with water, which is boiled till a strong decoction is mate. This is applied to the young shoots and leaves with a syringe, or, when the tress are growing in nursery-rows, with a common white-wash brush, dipling the latter in the liquid and shaking it sharply over the extremities or the infested part of each tree. This or the whaleoil soap-stids, or a mixtme of both, will kill every species of plant-lice and nearly all other snall insects to which young trees are subject.

The wash of whale-oil soap is made by mixing two pounds of this soal', which is one of the cheapest and strongest kinds, with fifteen gallons of water. This mixture is applied to the leaves and stems of plants with a syringe, or in any other convenient mode, and there are few of the smaller insects that are not destroyed or driven away by it. The merit of this mixtmre belongs to Mr. David Haggerston, of Boston, who first applied it with great success to the rose-slug, and received the preminm of the Massachusetts Horticultural Society for its discovery. When this soap cannot be obtained, a good sulstitite may be made by turuing into soap the lees of common oil-casks, by the application of potash and water in the usmal way.

Woths am other insects which thy at might are destroyed in large numbers by the following mode, first discovered by Victor Adouin, of France. I flat saucer or vessel is set on the gromid, in which is pliced

* After repeated tests, it is doubtful whether the use of salt is as destructire to insect life as here stated. The use of salt as manure is undoubtedly a good stimulant to regetable life and vigor. 
a light, partially covered with a common bell-glass besmeared with oil. All the small moths are cliretly attracted by the light, fly towards it, anl in their attempts to set at the light, are either caught by the ghntinons sicles of the bell-ylass, or fall inte the basin of vil bencath, and in either ease soon perish. M. Aronin applied this to the destruction of the f'yralis, a moth that is very troublesome in the French vineyards; with two hundred of these lights in a vimevard of four acres, and in at single nigrte 30,000 moths were killed and found dear on or about the ressels. By continuing his process through the season, it was estimated that he had destrojed female moths suflicient to have pro. duced a progeny of orer a million of eaterpillars. In our orebards myriads of insects may be destroyed by lighting small bonfires of shav. ings or any refuse brush; and in districts where the aples are much worm-eaten, if repreated two or three nights at the proper season, this is a very ethicient aud cheap mode of getting rid of the moth which causes so mich mischief. Dr. Harris, knowing low important it is to destroy the caterpillar in the moth state, has recommencled flambeanx, macle of tow wound round a stake and dipped in tar, to be stuck in the finit-garden at night and lighted. Thousands of moths will find a speerly death, eren in the short time which these flambean are burning. The melonbug may be extirpated by myliads in the same way.

A simple and most effectual mode of ridding the fruit-garden of insects of every description, whish we recommend as a general extir pator suited to all sitnations, is the following:- Take a number of common bottles, the wider mouthed the better, and fill them about half full of a mixture of water, molasses, and vinegar. Suspend these among the branches of trees and in various parts of the garden. In a fortuight they will be found full of dead insects of every description not too large to enter bottles-wasps, flies, beetles, slugs, grubs, and a great variety of others. The bottles must now be emptied and the liquid renewed. A zealous amateur of our aequaintanee canght last season in this way more than three bushels of inseets of various kincls; and, what is more satisfactory, preserved his garden almost entirely against their attacks in any shalpe.

The assistance of birls in destroying insects should be duly estimated by the fruit-grower. The quantity of eggs and insects in various states devoured anuually by birds, when they are encouraged in gardens, is truly surprising. It is true that one or two species of these, as the ringtail, annoy us by preying upon the earlier cherries, but even taking this into acconnt, we are inclined to believe that we can much better spare a reasonable share of a few fruits than dispense with the good services of bircis in riclding us of an excess of insects.

The most serviceable birets are the common sparrows, the wren, the red-breast, and in short most of the birds of this elass. All these birds should be encouraged to build nests and inhabit the fruit-garden, and this may most eftectually be done by not allowing a gun to be fired within its boundaries. The introduction of hedges or live fences greatly promotes the domestication of birk, as they afford an almirable shelter for their nests. Our own gardens are usually much more free from insects than those a mile or two distant, and we attribute this in part to our practice of encomaging birds, and to the thorn and arbor vita hedges growing here, sud which are greatly resorted to by those of the feathered tribo which are the greatest enemios of the insect race. 
Among animals, the toad and the bat are great insect destroyers. 'The common bat lives almost entirely upon them, and in its evening sallies devours a great number of moths, beetles, weevils, etc.; and the toad quietly makes away with numberless smaller insects.

\section{CHAPTER IX.}

THE APPLE.

Pyrus Malus. $L$. Rosecere, of botanists.

Pommier, of the French; Apfelburm, German; Apfel, Dutch; Lelo porno, Italian; and Manzana, Spanish.

The Apple is the world-renowned fruit of temperate climates. From the most remote periods it has been the subject of praise among witers and poets, and the old mythologies all endow its fruit with wonderful virtues. The allegorical tree of knowledge bore apples, and the celebrated golden fruit of the orchards of Hesperus, guarded by the sleejless dragon which it was one of the triumphs of Hercules to slay, were also alples, ncording to the old legends. Among the heathen gods of the north, there were apples fabled to possess the power of conferring immortality, which were carefinlly watched over by the godless Iduna, and kept for the especial dessert of the gods who felt themselves growing old! As the mistletoe grew chiefly on the aplyle and the oak, the former tree was looked upon with great respect and reverence by the ancient Druids of Britain; and even to this day, in some parts of England, the antique custom of saluting the apple-trees in the orchards, in the lope of obtaining a good crop the next year, still lingers among the farmer's of portions of Devonshire and Herefordshire. This old ceremony consists of saluting the tree with a portion of the contents of a wassail-bowl of cider, with a toast in it, by pouring a little of the cider about the roots, and even hanging a bit of the toast on the branches of the most barren, the furmer and his men dancing in a circle round the tree, and singing rude songs like the following:

"Here's to thee, old apple-tree.

Whence thon mayst bud, and whence thou mayst blow;

And whence thou mayst bear apples enow,

Ilats full ! caps full-

Bushels and sacks full!

Hazza!"

The species of crab from which all our sorts of Apples have originated, is wild in most parts of Enrope. There are, indeed, two or three kinds of wild crab belonging to this country; as the Pymus coronoriu. or sweet scented crab, with fruit about an inch in diameter, grows in many parts of the United States; and the wild crab of Oregon, $P$. riculuris. bearing a redulish-yellow fruit, about the size of a cherry, which the Chenook Indians use as an article of food; ret none of our cultivated rarieties of Apple have been raised from these native crabs, but from seels of the species brought here, by the colonists, from Europe. 
The Apple-tree is, howerer, most perfectly natmralized in Ameriea, and, in the northern and midhle protions of the United States, sneeeds as well, or, as we believe, better than in any part of the world. The most celebrated apples of Germany and the north of Europe are not superior to many of the varieties originated here; and the American or Newtown Pippin is now juetty senerally admitted to be the tinest ajple in the world. No better proof of the perfect atlutation of our soil and climate to this tree ean be desired, than the semingly spontaneous: production of smeh varieties as this, the Baldwin, the Spitzenberg, or the Swatr-all finits of delicions flavor, and great beanty of appearance.

The Apple is usually a very harly and rather slow-growing finit-tree, with a low-spreading rither irregular head, and bear's an abundance of white blossoms, tinged with red. In a wild state it is very long-lived, but the finest gardeu sorts usually live about fifty or eighty years; though, by proper care, they may be kept healthy and productive much longer. Although the apple generally forms a tree of medium growth, there are many speeimens in this country of enomous size. Among others, we recolleet two in the grounds of Mr. Hall, of Raynlam, Rhode Island, which, ten years ago, were 130 yeurs old; the trunk of one of these trees then measured, at one foot from the gromd, thirteen feet two inch's, and the other twelve feet two inches. The trees bore that season about thirty or forty bushels; but, in the year 1780, they together bore one hundred and one bushels of apples. In Duxbury, Plymouth County, IIass., is a tree which in its girth measures twelve feet five inches, and which has yielded in a single season $121 \frac{1}{2}$ bushels.

In Lehigh County, Pa., there is an apple-tree which measures $17 \frac{1}{3}$ feet in eireunference, one foot above the ground. The tree is fifty-four feet high, and the branches extend thirty-six feet each way from the trunk.

\section{USES OF THE APPLE.}

No fruit is more miversally liked or generally used than the apple. It is exceedingly wholesome, and, medieinally, is considered cooling and laxative, and useful in all inflammatory diseises. The finest sorts are much esteemed for the dessert, and the little eare required in its eulture render's it the most abundant of all firits in temperate climates. As the earliest sorts lipen about the last of June, and tire latest can be preserved until that seasun, it may be considered as a fruit in perfeetion the whole rear. Besicles its merits for the dessert, the value of the apple is still greater for the kitchen; and in sances, pies, tarts, preserves, and jellies, and roasted and boiled, this fruit is the constant and invaluable resource of the kitchen.

In seasons of seareity, the small and usually eonsidered refuse apples may be stewerl, and then rubburl through a eullender, separating the seeds and skins from the pulp, forming a delicious sauee.

Apple-butter, made by stewing pared and slieed sweet apples in new cicler mutil the whole is soft and pulpy, is a common and excellent artiele of food in many farmers' finniliss, and is freenently made by the barrel. In France, nearly the same pieparation is formed by simmering apples in new wine until the whole becomes a sort of marmalade, which is called Raisine. The juice of the apple unfermented is, in some parts of the country, boiled down till it Jeeomes molasses. When fermented it forms cider; and if this is carefully made from the best cider apples 
it is ne:trly equal to wine; in fict, many hundreds of barrels of the cider of New Jersey have been mannfactured, in a single year, into an imita. tion champange, which is searcely distinguished by many from that made from the grape.

Apples are also made into jelly, by grinding and pressing in the ordinary way for cider, then passed, in a thin and nearly continuous cirrent, orer an intensely heated clarifying or evaporating pan, such as is ordiwarily used in the manufacture of molasses from the sorgho sugar-cane. About eight gallons of the apple-juice, or cider, will make one gallon of a very delicious jelly.

Dried aplles are also a considerable article of commerce. Farmers zustally pare and quarter them by hund, and dry them in the sun; but those who pursue it as a matter of tracle pare them by machinery, and dry them slowly in ovens. They are then packed in bags or barrels, and used either at home, in sea stores, or are exported.

In perfumery, the pulp of this fruit, mixed intimately with lard, forms pomatum. The wood is employed for lasts, and for other purposes, by turners; and, being fine-grained and compact, is sometimes stained black and used for ebony by cabinet-makers.

The quality of an apple is always judged of by the use to which it is to be applied. A table or dessert apple of the finest quality should be of medium size, regular form, and fine color; and the flesh should be fine-grained, crisp, or tender, and of a sprightly or rich flavor and aroma. Very large-sized, or coarse apples are only admired by persons who have little knowledge of the true criterion of excellence. Apples for kitchen use should have the property of cooking evenly into a tender, pulpy consistence, and are generally acid in flavor ; and, although there are many good cooking apples unfit for the table, many sorts, as the Fall Pippin and the Greening, are excellent for both purposes. To this we may add, that for the common apple-sance made by fapmers, a high-Havored sweet apple, which boils somewhat firm, is preferred, as this is generally made with cider. The very common use made of this cheap preserve at the North and West, and the recent practice of fattening hogs, horses, and other animals upon sweet apples, accounts for tha much greater number of varieties of sweet apples held in esteem here than in any other country. In fact, so excellent has the saccharine matter of the apple been found for this purpose, that whole orchards of sweet apples are frequently planted here for the purpose of fittening swine and cattle, which are allowed to run at large in them.

Cider apples are varieties frequently useless for any other purpose. The best for this purpose are rather tough, piquant, and astringent; their juice has a high specific quality, and they are usually great bearers, as the Harrison, the Red Streak, and the Virginia Crab.

\section{PROPAGATICN.}

The Apple for propagation is usually raised from seeds obtained from the pomace of the cider-mills, and a preference is always given to that from thrifty young orchards. These are sown in antumn, in broad drills, in good mellow soil, and they remain in the seed-bedsattention being paid to keeping the soil loose, and free from weeds, from one to three years, according to the richness of the soil. When the seedlings are a little more than a fourth of an inch in diameter, they 
should be taken up in the spring or antumn, their tap-roots shortened, and then planted in unsery rows, one foot ajust, and three to four feet between the rows. If the plants are thifty and the soil good, they may be bukler the following antmmu, within one or two indes of the mpond, and this is the most sperdy morle of obtaining strong, straight, thifty plants. Grafting is gencrally perforned when the stocks are about hali an inch thick; and for several moles of performing it on the Aple, see the remanks on grafting in a previoms page. When young trees are fechle in the nursery, it is usual to hear them back two-thirds the length of the graft, when they are three or four feet high, to make them throw up a stroug, vigorous shoot.

Apple-stocks for dwatis are raised by layers, as pointed out in the article on Itayers.

Apple-trees for transplanting to orchards should be at least two rear's budded, and six or seven fect high, and they should have a proper 'balance of head or side branches.

\section{SOIL AND SITUATION.}

The Apple will grow on a great variety of soils, but it seldom thrives on very hy sands, or soils saturated with moisture. Its favorite soil, in all comntries, is a strong loam of a calcareous or limestone nature. A deep, strong, gravelly, maly, or clayey loan, or a strong sindy loam on a gravelly subsoil, protuces the greatest crops and the highest-flarored fruit, as well as the utmost longerity of the trees. Such a soil is moist rather than dry-the most farorable comlition for this fruit. Too damp soils may often be rendered tit for the Apple by thorough draining, and too dry ones by deep subsoil plonghing, or trenching, where the subsoil is of a heavier texture. And many apple orchards in New England are very fiourishing and productive on soils so stony and rock-covered (though naturally fertile) as to be unfit for any other crop.*

As regards site, apple orchards flomish best in sonthern and middle portions of the comntry on north slopes, and often even on the steep north sicles of hills, where the climate is hot and diry. Farther north a southern or southeastern aspect is preferable, to ripen the crop and the wood more perfectly

We may here remark that almost every listrict of the country has one or more rarieties which, having hat its origin there, seems also peculiarly alapted to the soil and climate of that locality. Thus the Newtown Pippin and the Spitzenberg are the great apples of New York; the Baldwin and the Roxbury Rinsset, of Nassachusetts; the Bellflower and the Rambo, of Pennsylrania and New Jersey; and the Peck's Pleasant

* Blowing sands, says Mr. Coxe, when bottomed on a dry substratum. and aided by marl or meadow mur, will he found capalste of prodneing very fine Apple-trees. Goor cultiration and a system of high manuring will always remunerate the proprietor of an orchare, excrpt it be planted on a quicksand or a cold clay ; in sueh soils, no management can prevent an early deeay. One of the most turifty orehards I possess, was planter on a blowing samd, on which I earted three thousand loads of mud on ten acres, at an expense of abont tiventy-five dollars per acre, exclusive of much other manure; on this land I have raised gool wheat and clover. Of five rows of the IInesap Apple planted mpon it eight years ago, on the summit of a sandy kuoll, not one has died ont of near an hunilred trees-all abundant bearers of large and fair apples. - I'iew of $H^{\prime} I^{\prime} u$ t Tiees, p. 31. 
and the Seek-no-further, of Connecticut; and though these apples are cultivated with greater or less success in other parts of the country, yet, nowhere is their flavor and productiveness so perfect as in the best soils of their native districts-excepting in such other districts where a soil containing the same elements and a corresponding climate are also to be found.

PREPARING, PLANTIYG, AND CULTIYATION OF ORCHARDS.

With the exception of a few early and very choice sorts in the fruit. garden, the orchard is the place for this tree, and indeed, when we consicler the great value and usefulness of apples to the farmer, it is easy to see that no fium is complete without a large and well-selected apple orchard.

The distance at which the trees shonld be planted in an orchard, depends upon the mode in which they are to be ireated. When it is desired finally to corer and derote the whole ground to the trees, thirty feet apart is the proper interval; but where the farmer wishes to keep the land between the trees in grain and grass, fifty feet is not ton great a distance in strong soils. Forty feet a part, however, is the usual distance at which the trees are planted in orehards.

Before transplanting, the ground should be well prepared for the trees by plonghing deeply and subsoiling the whole field one year or more previous to planting. Poor soils require manure; and turning under green crops, such as clover, peas, etc., serves to lighten and make porous, open, and emrich the soil. Where the subsoil is a heary clay, it is best to thoroughly underdrain the whole by means of tile drains, at distances of two or three rods, and at the same time the surfuce clrains should alwars be kept open, to prevent any water standing about the roots of the trees.

Vigorous, healthy young trees should be selected from the nurseries. $\Delta$ s there is a great difference in the natural growth, shape, and size of the various.sorts of apple-trees, those of the same kind should be planted in the rows together or near ench other; this will not only facilitate culture and gathering the fruit, but will add to the neatness and orderly appearance of the orchard.

It is an indispensable requisite in all young orchards to keep the ground mellow and loose by cultication; at least for the first few years, until the trees are well established. Indeed, of two adjoining orchards, one planted and kept in grass, and the other plonghed for the first fire years, there will be an incredible difference in faror of the latter. Not only will these trees show rich, dark, luxuriant foliage, and clean smooth stems, while those neglected will have a starved and sickly look, but the size of the trees in the cultivated orchard will be treble that of the others at the end of this time, and a tree in one will be ready to bear an abumdant crop before the other has commenced yielding a peck of good fruit. Fallow crops are the best for orchards-potatoes, beets, carrots, bush beans, and the like; while grains, such as rye, wheat, oats, ete., are very injurious; but whatever crops may be grown, it should constantly be borne in mind that the roots of the tree require the sole occupancy of the ground, so far as they extend, and therefore that an area of more than the diameter of the head of the tree should be kept clean of crops, weenls, and grass.

When the least symptom of failure or decay in a bearing orchard is 
perceived, the ground should have a good top-1lessing of manure, and of minl, or mild lime, in altermate years. It is folly to smpose ilat so stronggrowing a tree ats the apple, when planted thickly in an orchard, will not, after a few heavy erops of fruit, exlaust the snil of much of its proper ford. If we rlesire our trees to continue in a lealthy boaling state, we should therefore manure them as regularly as any other erop, and they will amply repay the expense. 'I'here is scarcely a farm where the wasto of barn-yad manme, the urine, etc., if properly economized by mixing this animal exerement with the muck-heap, would not he amply sufficient to keep the orehards in the lighest condition. And how may noss-corered barren orehards, formerly very productive, do we not every day see, which only require a plentiful new supply of food in a substantial tope-dressing, thorough scraping of the stens, and wasling with cliluted soft soap, to bring them again into the finest state of rigor and productivene'ss.

The bearing year of the Apple, in common culture, only takes place evcry alternate year, owing to the excessive crops which it usually produces, by which they exhaust most of the organizable matter laid up by the tree, which then requires another season to recorer and collect a surficient supply again to form fruit-buds. When laalf the firuit is thinned ont in a young state, leaving only a moderate crop, the apple, like other fruit-trees, will bear every year, as it will also if the soil is kept in high condition. The bearing year of an apple-tree, or a whole orcharr, maty be changed by picking oft the fruit when the trees first show good crops, allowing it to remain only in the alternate seasons which we wish to make the boaring rear.

\section{PRUNING。}

The Apple in orchards requires very little pruning if the trees, while the orchard is young, are carefully inspected every year early in March, and all crossing branches taken ont while they are small. When the heads are once properly adjusted and well balanced, the less the pruming-saw and knife are used the better, and the cutting out of dead limbs, and removal of such as may interfere with otleers, or too greatly crowd up the hear of the tree, is all that an orchard will usnally require. - But wherever a limb is pruned away the surface of the wound should be neatly smoothed, and if it exceds an inch in diameter, it shonld be covered with the liquid shellac previously noticed.

\section{IXSECTS.}

There are several inseets that in some parts of the eountry are very destructive or injurious to this tree; a knowlerlge of the habits of which is therefore very important to the orchardist. These are chiefly the horer,t] e caterpillar, and the canker-wor'm.

The Alple-borer is, as we usually see it in the trunks of the Apple, Quince, and thorn trees, a Heshy white grub, which cnters the tree at the collar, just at the surface of the gromul, where the bark is tender, and either girclles the tree or perforates it through every part of the stem, finally causing its death. This grub is the larva of a brown and white striped beetle, half an inch long (sipperda bivittata), ant it remains in this grub state two or three years, coming out of the tree in a butterfly 
form early in June-flying in the night only, from tree to tree, after its food, and finally depositing its eggrs, during this and the next month, in the collar of the tree.

The most effectual mode of destroying the borer is by picking it ont with the point of a knife, or, when it cannot thus be reached, killing it by thrusting a flexible wire as far as possible into its hole. Dr. Harris recommends placing a bit of camphor in the month of the aperture and plugging the hole with soft wood. But it is always better to prevent the deposit of the egg, by placing about the trunk, early in the spring, a small mound of ashes or lime; or by drawing away the soil an inch or two deep at the base of the tree and wrapping with coarse hardware paper, tying it, and then replacing the earth; and where orchards have already become greatly infested with this insect, the beetles may be destroyed by thousands in June, by building small bonfires of shavings in varjous parts of the orchurd. The attacks of the borer on mursery trees may in a great measure be prevented by washing the stems in Mar, quite down into the ground, with a solution of two pounds of potash in eight quarts of water.

The Caterpillar is a great pestilence in the Apple orchard. The species which is most troublesome to our fruit-trees (Clisiocampa americana) is bred by a sort of lackey moth, different from that most troublesome in Europe, but its habits as a caterpillar are quite as annoying to the orchardist. The moth of our common caterpillar is a redlish brown insect, whose expanded wings measure about an inch and a half. These moths appear in great abundance in midsummer, Hying only at night, aud often buzzing about the candles of our houses. In laying tlieir eggs they choose principally the Apple or Cherry, and they deposit thousands of small eggs about the forks and extremities of the young branches. The next season, about the middle of MIay, these eggs begin to hatch, and the young caterpillars in myriads come forth, weaving their nests or tents in the fork of the branches. If they are allowed by the careless cultivator to go on and multiply, as ther soon do incredibly fast, they will in a few seasons, sometimes in a single year, increase to such an cxtent as almost to cover the branches. In this caterpillar state they live six or seven weeks, feeding most ferocionsly upon the leares, anil often strip'ping whole trees of their foliage. Their effect upon the tree at this period of the season, when the leares are most inportant to the health of the tree and the growth of the fruit, is most deplorable. The crop is stunted, the health of the tree enfeebled, and, if they are allowed to remain unmolested for several seasons, they will often destroy its life, or render it exceedingly decrepicl and feeble.

To destroy the caterpillar various modes are adopted. One of the most effectual is to touch the nest with a sponge, artached to the end of a pole, and dipped in strong spirits of ammonia or naphtha from coaloil retinings; the sponge should be tmrned slowly round in the nests, and every insect coming in contact will be instantly killed. This should be done early in the season. Or they may be bronght down and destroyed with a round brush fixed to the cind of a pole, and rorked about in the nests. On small trees they may be stripled ofl with the hand, and crushed under the foot; and by this plain and simple mode, begun in time, with the aid o $\mathrm{f}$ a ladder, they mar in a larce orchind be most effectually kept under by a few moments" daily labor of a single man. As they do not leave their nests until nine in the morning, the 
extiupator of caterpillars should always be abroad and busy hefore that time, and while they are all lying quietly in the nests. And let him never forget that he may do more in an hour, when he commences early in the season, than he will in a whole dily at a later periorl, when they are thoroughly scattered among the trees. If they ane allowed to remain ummolested, they spin their cocoons abont the midlle of .June, and in a fortnight's time comes forth fiom them a fiesh brood of moths, which, if they are not put an enul to by bontires, will again lay the egges of an infinite number of caterpillars for the next spring.

The Canker-uorn (Anisopteryx pometreria of Harris) is in some parts of the comntry one of the worst enemies of the Apple, destroying also its foliage with great rapidity. It is not yet common here, but in some parts of New England it has become a serions enemy. The male is a moth, with pale ash-colored wings, with a black dot, a little more than an incli across. The female is wingless, oval, clark asll-colored above, and gray beneath.

The canker-worm usually rises out of the ground very early in the spring, chiefly in March, as soon as the ground is free from frost; thongh a few also find their way up in the antumn. The females, having no wings, climb slowly up the trunks of the trees, while the winger males hover abont to pair with them. Very soon after this, if we examine the trees we shall see the egos, of which every female lays some sixty or a humdred, glued over, closely arranged in rows, and placed in the forks of branches and among the young twigs. About the twentieth of Miay these eggs are hatched, and the cankel-worms, dusky brown, or ash-colored, with a yellow strije, make their appearance, and commence preying upon the foliage. When they are abundant ther make rapid progress, and in places where the colony is firmly established, they will sometimes strip an orcharl in a few days, making it look as if a fire had passed orer it. After feeding about four weeks, they lescend into the ground three or four inches, where they remain in a chrysalis form, to emerge again the next season. As the female is not jrovided with wings, they do not spread very rapirlly from one place to another.

The attacks upon the canker-worm shonld be chiefly made upon the female in her way from the gromul up the trunk of the tree.

The conmon mode of protecting Apple-trees is to surround the trunk with a belt or banclage of canvas, four or five inches wicle, which is then thickly smeared with tar. In order to prevent the tar from soon becoming dry and hard, a little coarse train-oil must be well mixed witli it; and it should be watched and renewed as often as it appears wecessary. This tarred belt catches and detains all the females on their upward journey, and prevents them from ascending the tree to lay their egess. And if kept in orler it will very effectually deter and destroy them. When the canker'worm is abundant it is necessary to alply the tarred bandage in October, and let it remain till the last of May, but usually it will be sufficient to use it in the spring. It is probable that a mixture of coal-tar and comnfon tar would be the best application, as it is more offensive, and will not so easily diy aud become nseless by exposure to the air and sun. Some persons apply the tar directly to the stems of the tree, but this has a very injurious efiect upon the trunk. Old Inctia rubber, melted in an iron vessel over a very hot fire, forms a very adhesive thiid which is not affected ly exposure to the weather, and is considered, by those who have made use of it, the best substance 
for smearing the bandages, as being a more effectual barrier, and seldom or nerer requiring renewal.

Mr. Jonathan Dennis, Jun., of Portsmouth, Rhode Island, has invented and patcnited a circular leaden trough, which smrounds the trunk of the tree, and is filled with oil, and stops effectnally the ascent of the canker-worm. There appear, however, to be two objections to this trough, as it is frequently used; one, the escape of the oil, if not carefully used, which injures the tree; and the other, the injurious effect of nailing the troughs to the bark or trunk. They should be sup. ported by wedges of wood driven in between the trough and the trumk. and the spaces completely filled up with liquid elay, put on with a binsh. The insects must be taken ont and the oil renewed from time to time. For districts where the canker-worm greatly abounds, this leaden trough is probably the most permanent and effectual remedy yet employed.

Circular strips of zine or tin, abont four inches wide, passing around the trunk of the tree, the lower end standing out in a flaring manner, resembling a bowl bottom u, ward, proves an effectual preventive remedr, as the insects camnot pass the lower rim.

Experiments made by the Hon. John Towell, and Professor Peck, of Massachusetts, lead to a belief that if the ground under trees which suffer from this insect is dug and well pulverized to the depth of five inches, in October, and a good top-dressing of lime applied as far as the branches extend, the canker-worm will there be almost entirely destroyed. The elm, and linden-trees in many places, suffer equally with the Apple from the attacks of the canker-worm.

The bark-louse, a dull white, oval, scale-like insect, abont a tenth of an inch long (a species of coccus), which sometimes appears in great numbers on the stems of young Apple and Pear trees, and stunts their growth, may be destroyed by a wash of soft soap or the potash solntion. The best time to apply these is in the month of June, when the insects are young, or when the tree is devoid of foliage.

The woolly Aphis (aphis lanigera), or American blight* is a dreadful enemy of the Apple. It makes its appearance in the form of a minute white down in the crotches and crevices of the branches, which is composed of a great number of very minute woolly lice, that if allowed will increase with fearful rapidity, and produce a sickly and diseased state of the whole tree. Fortunately, this insect is easily destroyed. "This is effected by washing the parts with diluted sulphuric acid, which is formed by mixing three-fourths of an onnce by measure of the sulphuric acic of the shops with seven and a half ounces of water. It should be rubbed into the parts affected by means of a piece of rag tied to a stick, the operator taking care not to let it touch his clothes. After the bark of a tree has been washed with this mixture, the first shower will redissolve it, and convey it into the most minute crevice, so its effectually to destroy all insects that may have escaped."-(Lonulor's Wayazine, ix., p. 336.) It is the more common practice to destroy it by the use of whale-oil, soal' or lime wash.

The Apple-worm or Codling moth (Carpocapsa promonellie of European writers) is the insect introduced with the Apple-tree from Europe

* It is not a little singular that this insect, which is not indigenous to thiz country, and is never seen here except where introduced with imported trees, should be called in England the American blight. It is the most inveternte enemy of the Apple in the north of France and Germany. 
which appears in the early worm-eaten Apples and Pears in the form of a reddish white grob, and causes the finit to fall prematurly from the trees. The perfect insect is a small moth, the fore-wings gray, with a large round brown spot on the hinder margin. These moths appear in the greatest numbers in the warm evenings of the first of June, and lay their eggs in the eve or blossom-end of the young fruit, especially of the carly kinds of Apples and Penrs. In a short time these egrgs hatch, and the grub burrows its waly till it reaches the core; the fruit then rijens prematurely, and drops to the gromm. Here the worm leaves the fruit and creeps into the erevices of the bark and hollow of the tree, and spins its cocoon, which usmally remains there till the ensuing spring, when the young moth again emerges from it. The readiest way of destroying them, when it can be done conveniently, is to allow swine and ponltry to run at large in the orchards when the premature fruit is falling; or otlerwise the fruit may be picked 11 , daily and placed where the worms will be killed. It is said that if an old cloth is placed in the crotch of the tree about the time the fruit begins to drop, the Apple-worm will make it a retiring-place, and thousands may be eanght and killed from time to time. As the cocoons are deposited chiefly under the old loose bark, the thorough cultivator will take care, by keeping the trunks of his trees smooth, to afford them little harbor; and by seraping and washing the trunks early in the spring, to destroy such as may have alrearly taken "lp their quarters there.

When the fruit of orchards is much liable to the attacks of this insect, we cannot too much insist on the efficacy of small bonfires lighterl in the evening, by which myriads of this and all other mothis may be destroyed before they have time to deposit their eggs and canse wormeaten fruit.

A simple preventive remedy, or method of trapping the inseet when in the grub form, has been introduced by Dr. J. P. Trimble, of New Jersey, and consists in twisting a band or rope of hay, long euough to pass three or four times around the body of the tree, and putting it thereon, "securing its ends so as to prevent its becoming lonse; as soon as the fruit shows signs of the worms being at work, or from the mirldle to the last of June. They shomld be examined every two weeks, as long as the warm weather lasts, the earlier broods of worms becoming moths and producing a second erop. If the orehard is pastured, the bands must of course be put ont of the reach of animals. Sometimes it may be necessary to place them around the limbs; in that case the seales of rough bark on the body of the tree below them should be seraped oft."

The Blight, which occasionally kills suddenly the cunds of the limbs of the apple and the quince, is caused by an insect (Bostrichus bicoudatus) which affects the small twigs, by penetrating the wood at the axil of a leaf, and causing it to wither. It is designated the 'Trig blight. Little or no injury results, but it is always well to cut away the injured twig just below the wound.

The Apple-barls Beotle (Tomicus mali), deseribed by Fitch, is a small, smooth, black or chestnut-red beetle; the darva feed under the bark and then enter the wood, sometimes killing the young tree.

\section{GATIERING AND KEEPING THE FRUIT.}

In order to secure soundness and preservation, it is indispensably 
necessiry that the funit should be gathererl by hand. For winter fruit the gathering is ilelayed as long as possible, aroiding severe frosts: and the most sncessful practice with our extensire orcharrists is to place tho good fruit directly, in a cureful manner, in mew, tight four-barrels as soon as gathered fion the tree. These barrels should be gently shaken white filling, and the head closely pressed in: they are then placed in a cool, shaty exposme, under a shed open to the air, or on the north side of a building, protected by corering of boalds orer the top, where they remain for a fortuight, or until the cold becomes too serere, when they are carefully tramsferred to a cool, dry cellar, in which air can be admitted oceasionally in brisk weather.

Auother method, by some regarded as superior, and tending to keep the fruit longer and better, is to gather earefully, in a dry day, as late as possible in the fall, ancl plice the fruit on a floor, or in open bins, from one foot to sixteen inclies in depth. After abont a week examine, and if the dampuess, commonly called sweat, has passed off, prepare a good clean barrel, and as each fruit is placed in the barrel, see that it is made perfectly dry by wiping it with a soft cloth. As soon as the barrel is filled, head it ru securely and place it in a cool, dry cellar.

A cellar for this prirpose should be dug in cly, gravelly, or sancly soil, with, if possible, a slope to the north; or, at any rate, with openings on the north sille for the admission of air very rarely in weather not excessively cold. Here the barrels should be placed in tiers on their sides, and the cellar should be kept as dark as poswible. In such a cellar, one of the largest apple-growers in Dutehess County is able to keep the Greening Apple, which, in the fruit-room, usually decays in Jinuarr, until the 1st of April, in the freshest and finest condition. Some persons place a layer of clean rye-straw between every layer of apples, when packing them in the barrels.

Apples are frequently kept by farmers in pits or ridges in the ground, covered with straw and a layer of earth, in the sime mamner as potatoes; but it is an inferior method, and the fruit rery speedily decars when opened to the air. 'The English apple-growers lay their fruit in heaps, in cool, dry cellars, and cover them with straw.

Tarious plans and methods have been designed for the keeping of fruit, few, if any of which are found practically adapted to the general wants of a family. Among those most prominent is the Roberts Fruit Honse, which is constructed br forming a room inside of an ice-house, having the ice around the sides and overhead; and with an arrangement for drainage below, by means of a piue beneath the floor, and a condensing-tube insicte the chamber or fruit-room.

The Nyce Fruit House is constructed with upright walls, sheeted on the inside and outside with sheet-iron, nailed to upright studding, and having the inside space ciosely packed with sawdust or chaft. Ahore the frnit-room is a floor of galranized iron, on which ice, five to six feet in clepth, is packed, and from it a tube or pipe is led off, for the purpose of convering the water as the ice melts. Below the floor of the finitroom, which is also of galvanized iron, shavings three feet thick are tirst laid, and then coated with tar and pitch, to prevent any rise of moisture from below. The temperature is kept at all seasons at just above the freezing-point, and the moisture from the finit engendered in the room is absorbed by the use of "bittern" from salt-works. This absorp. tion of moisture by means of chloride of calcium, or the waste bittern of 
salt-works, is the principal feature of novelty in this house. Put while upon a large seale these fruit-homses are fomd of value, their artoption involves too much of expense in their tirst comstruction, and too arrat 'are, to meet the wants of the general fruit-growes. When a fruithouse or room is to be constructed, aside from the cellar, muler the ban or dwelling, select a location where complete dhainage can be had. Fxcarate so ats that the lower fruit-room will be albont two-thirds of its lecight moler gromel fay the outside vall, and then, leaving a space of four inches, lay another inside enenent wall. Constrouct windews so as to give free eirenlation, and yet keep the room dark by having blinds on the outer side, and sash opening on the imer wall. For winter, donble sash will be repuired. For the uper room, the same principle of forming a clonble wall, leaving a space of at least four inches, is to be continned, and the armangent of shelves or drawer's throngh the contre, keeping a passage opmen all aromul, may bo macke to meet the wants for which the room is to be used.

When apples are exported, each fruit in the barrel should be wapped in elean soft paper, and the barrels should be placed in a dry, airy place between decks.

\section{CIDER.}

To make the finest eider, Apples should be chosen which are especially snited to this purpose. The fruit should be gathered abont the first of November, and earrse eloths or straw should be laid under the tree, to seeure them against bruising when they are shaken from the tree. If the weather is fine the fruit is allowed to lie in heaps in the open air, or in airy sheds or lofts for some time, till it is thoronghly ripened. All immature and rotten fruit shonld then be rejeeted, and the remainder ground in the mill as nearly as possible to a miform mass. This pulp should now remain in the vat from $2+$ to 48 hours, or even longer if the weather is cool, in order to heighten the color and increase the saceharine principle. It is then put into the press (without wetting the straw), from whenee the liquor is strained, through hinir-eloth or sieves, into perfectly elean, sweet, somnd casks. The eisks, with the bung out, are then placed in a cool cellar, or in a sheltered place in the open air. Here the fermentation eommenees, and as the pomace and froth work out of the bunghole, the casks must be filled up every day with some of the same pressing, kept in a cask for this purpose. In two or three weeks this rising will cease, when the first fermentation is over, and the bung shonld at first be put in loosely - then in a day or two driven in tight-leaving a small venthole near it, which may also be stopped in a few clays after. If the easks are in a cool airy cellar the fermentation will cease in a day or two, and this state may be known by the linuor becoming clear and bright, by the cessation of the discharge of fixerl air, and by the thick erust which has collected on the surface. The elear eider shomld now be diawn off and placed in a elean cask. If the ciler, which must be carefully watched in this state, to prevent the fermentation going too far, remains ruiet, it may be allowed to stand till spring, and the addition at first of about a gill of finely powdered charcoal to a barrel will secure this end; but if a scum collects on the surface, and the fermentation seems inclined to proceed further, it must be immediately racked again. The vent-spile nay now be driven tight, but "xamined occasionally. In the begining of Harch 
a final racking sluuld take place, when, should the eider not be perfectly fine, abont three-fourths of an onnce of isinglass should be dissolved in the cider and poured in each barrel, which will render it perfectly clear. It may be bottled now, or any period before the biossoming of the Apple or afterwards, late in May. When bottling, fill the bottles within an inch of the bottom of the cork, and allow the bottles to stand an hour before the corks are driven. They should then be sealed and kept in a cool cellar, with clean dry sand up to their necks, or laid on their sides in boxes or bins, with the same between each layer.

\section{VARIETIES.}

The varieties of the Apple at the present time are very numerous. The garden of the Horticultural Society of London, which contains the most complete collection of fruit in the world, enumerates now, 1845 , about 900 varieties, and nearly 1500 have been tested there. Of these the larger proportion are of course inferior; but it is only by comparison in such an experimental garden that the value of the different rarieties for a certain climate can be fully ascertained.

The European Apples generally are, in this climate, inferior to our first-rate native sorts, though many of them are of high merit also with us. There is much confusion in regard to names of Apples, and the variation of fruits fiom soil, location, or other causes, makes it difficult to identify the kinds, and mitil they are brought together and finited on the same ground the certainty of their nomenclature will not be established. New varieties of Apples are constantly springing up in this country from the seed, in favorable soils; and these, when of superior quality, may, as a general rule, be considered much more valuable for orchard culture than foreign sorts, on account of their greater productiveness and longevity. Indeed every State has some tine Apples pecnliar to it, and it is therefore impossible in the present state of pomology in this comntry to give a complete list of the finest Apples of the Tnited States. To do this will require time, and an extended and careful examination of their relative merits collected in one garden. The following descriptions comprise all the finest American and foreign varieties yet known in our gardens.

\section{CLASSIFICATION.}

The distinctive characters of fruits have, during the past quarter of a century, become so much interningled and hybriclized that, after carefully studying them, and comparing them with the order's of classification adopted by anthors, we have come to the conclusion that no definite order can safely be made to embrace them. Forms. colors, growths, and periods of ripening are so much interwoven and distributed as to defy all arlbitrary rules of chassification, and hence we have withont hesitation abandoned it entirely, substituting in our work the simple order of the alphabet as confined to uames, believing such course will prove the most available and useful.

\section{TERMS USED IN DESCRIBING APPLES.}

In identifying fruits, not only certain forms and features of the fruit itself are desirable, to have a definite description under plain and intelli- 
gihle terms, but often the form of the growth of the tree, as well as the color of its young wood, are essential to a clear knowledge for decision. The form and general appearance of a finit may be changed by soil or climate, but the general habit of growth and color of the yomig wood is always the same, and in the ensuing pages this latter point has been kept in view and recorded, so far as knowledge could be obtained, resprecting valuable varietius.

The terms used we have sought to make simple and uniform, and within the comprehension of all, rather than scientitic. In describing trees, the character designed to be represented is that of the orchard, or tres in a healthy bearing condition, and the growth is said to be strong and vigorous, as the Rhode Island Greening, or Baldwin; vigorons and slender, as the Jonathan or Winesap; stout and stort-jointed, as Jersey Sweet or Primate; medium and vigorous, as Famense, or Maiden's Blush. And for the general form of the tree, the word upright spreading is used to designate such as Baldwin; spreading, as the Rhode Island Greening; round-headed, as in the Early Harrest; upright, as with Benoni. In describing fruits, the word base means that part of the fruit in which the stem is planted; and apex, the blossom end, or crown, as it is sometimes termed. Forms are so much interwoven, as it were, one with another, that we have selected but four as the primary bases on which all others are built, and are subsidiary.

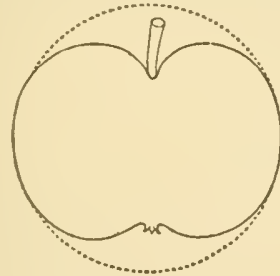

Oblate.

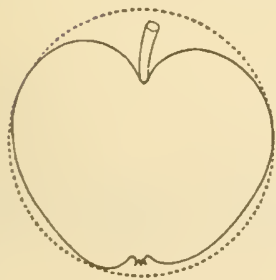

Conical.

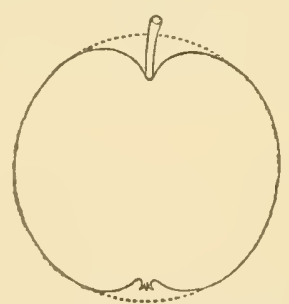

Roundisl.

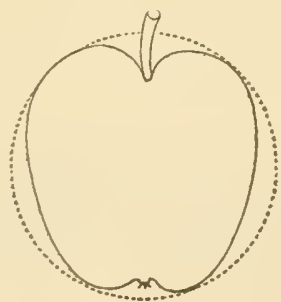

Oblong.

These primary forms are roundish, oblate, conical, and oblong. The terms rourd, roundish, or globular, are sometimes used in connection, rather as qualifying expressions than as distinctive; for while the word roundish, which indicates the height and diameter as ncarly equal, ap- 
plies to many fruits, there is no perfectly round or globular apple known.

Oblute indicates the height as much less than diameter. Crnical, is when the fruit is roundish, laving the apex end contracted. Oblong, is when the fint is longer than broad, and having the apex and base of nearly the same brealth. Connected and subsidiary terms, snch as roundish, conical, or conic, are when the Apple unites the two primary forms of roundish and conical; or elongated conical, or conic, when the length is consiclerably beyond the breadth. Truncate conic, is when the fruit is Hattened at the apex. Ribbed, or obscurely ribbed, when the surface has rising lines and channels from apex to base. Ollique, is when the fruit rresents the appearance as of being one-sicled, or when the axis is inclined to one side. Ublate, not symmetric, or sides unerquel, when one side is less than the other. Comugated, having depressed lines, furrows, or wrinkles. Acute, when narrowing to a sharp point. Obtuse, round or blunt. Abrupt, when the depression breaks off suddenly.

In designating the quality of firuits, the terms of the American Pomological Society have been adopted; but it must be remembered that these terms apply strictly and only to the actual quality of the fruit as a dessert sort.

Sume varieties classed as best, and which are strictly of the highest quality as fruit, are, nevertheless, unprofitable as varieties to grow, except by the amateur, while many to which the term very good, or very yood to best, is applied, are known to be highly valuable and protitable for market, as weli as excellent for the dessert.

\section{APPLES.}

\section{Aввотт.}

Origin unknown.

Fruit medium, oblate, inclining to conic, obscurely ribbed, greenishyellow, shaded and striped with red, few light and brown dots. Stalk long, cavity broad, slightly russeted. Calyx closed. Basin small, uneven. Flesh whitish, crisp, tender, juicy, subacid. Core medium. Very good. December to March.

\section{ABbott's Sweet.}

Origin, New Hampshire.

Fruit rather above medium, roundish, conical, yellow, covered with stripes and blotches of red, and many white dots. Flesh white, tender, juicy, and pleasant. Very sweet. Good to very good. December to March.

\section{Abrott's Frve-Sided Spice.}

Origin unknown.

Fruit medium, roundish oblate conic, pale yellow, splashed and striped with two shades of red, light-gray dots. Flesh whitish, moderately juicy, mild subacid. Good. Core small. October and November. 


\section{A BRAN.}

Origin unknown. Grown extensively in Eastern Virginia and North Carolina.

Fruit below medium, roundish, yellow shaded, and splashed with red. Many light dots. Flesh white, teucler, subacid. "Good." December to Miarch.

\section{Aclilan's Ruesset.}

Aclemy Russet.

Origin, Acklam, England.

Fruit medium or below, roundish oblate, pale yellowish green, some gray russet and yellowish-gray specks. Flesh whitish, firm, crisp, sub. acid. "Good." Norember to February.

\section{ADAMIS.}

Originated with James Aclams, Union, Penn. Tree quite strong, vigorous, spreading. Young shoots dull reddish brown. Very productive.

Fruit large, roundish, oblate, slightly oblique, yellow, shaded and splashed with red and russet netting. Stalk short. Cavity large, deep. Calyx generally open. Segment long, reflexed. Basin large, abrupt. Flesh yellowish, tender, juicy, slightly aromatic. Very good. January to April.

\section{Adams Pearmain.}

\section{Norfolk Pippin. Matchless.}

Origin unknown. Tree a free, healthy grower. Young shoots. Good bearer.

Fruit medium or below, roundish conical, inclining to oblong, pale yellow, shaded, mottled and splashed with red, with many light dots. Fjesh yellow, erisp, firm, juicy, rich, brisk, subacid, slightly aromatic. Very good. December to February.

\section{Agate D'Exchinuysen.}

Origin, Enckhuysen, Holland. Tree upright. Young shoots slender, dark reddish.

Fruit small or medium, conieal, clear yellowish green, and with many small dots. Calyx large, open, or nearly so. Segments large. Basin deep. Stalk short, stont. Cavity acute, deep. Flesh white, very fine grained, rather firm, juicy, sugary, perfumed. January to Marel. (Verg.)

\section{Agatile.}

Pomme Double Agathe.

Origin, Limbourg, Holland. Tree vigorous, productive. Fruit medium or large, conical oblate, deep yellow in the shade, bright redcheek in sun. Many conspicuois gray dots. Flesh yellowish-white, 
sometimes slightly rose-colored, tender, juicy, subacid, pleasant. Core large, open. October to February. (An. Porn.)

\section{AgNes's.}

Origin, Lancaster Co., Pa. Fruit rather below medium, oblate, somewhat oblique. Skin yeliowish, striped, and sharled with red, and sprinkled with light brown dots. Stalk short and small, inserted in a large cavity. Calyx closed, in a medium basin. Flesh tenter, with a spicy, pleasint, subacid flavor. "Guod." September, October.

\section{Ailues.}

Origin, Chester Co., Pa., of vigorous growth, and productive. Fruit large, oblate, yellowish, shaded and striped with red. Stalk short. Cavity narrow. Calyx in a round moderate basiu. Flesh yellow, fine, crisp, juicy, with a rich vinous flavor. Good. Highly esteemed for cooking, not in eating till spring, and will keep till midsummer.

\section{ALANT.}

\section{Pomme d'Aunee.}

Probably of German origin. Tree slender, short jointed. Young shoots reddish-brown.

Fruit medium, truncated conic, greenish-yellow, with indistinct dots. Calyx small. Basin deep. Stalk short. Carity deep. Flesh yellow, teuder, juicy, with a cinnamon aroma. Winter. (Verg.)

\section{Alexander.}

\section{Emperor Alexander. Russian Emperor. Aporta.} Victoria, incorrectly.

A very large, showy Russian variety. Tree vigorous, spreading, productive. Fruit very large, regularly formed, conical. Skin greeuishyellow, faintly streaked with red on the shaded side, but orange, brilliantly streaked, and marked with bright red in the sun. Calyx large, set in a deep basin. Stalk rather slender, three-fourths of an inch long, planted in a deep cavity. Flesh yellowish-white, crisp, tender, and juicy, with a rather pleasant flavor. Good. October to December.

\section{Alfriston,}

\section{Lord Gwydr's Newtown Pippin. Shepherd's Pippin. \\ Oldaker's New \\ Baltimore, incorrectly.}

A third-rate Apple, valued in England for cooking. Fruit large, roundish, a little ribbed, and rather broadest at the base, pale greenishyellow. Flesh yellowish-white, crisp, tender, with a tolerable, somewhat acid flavor. Good. October to Jammary.

\section{Allemand.}

Pepin d'Or Allemand.

Of Hanoverian origin. Tree a slender grower. Fruit small, concal truncated, pale yellow, with pearl-color spots. Flesh yellow, fine, tender, sugary vinous. Winter. (Virg.) 


\section{Allex's Croice.}

Origin, Pennsylvania. Fruit medium, oblate, sides unequal, yel. low, mostly shaded, and striped with red. Flesh white, stained with red, coarse, crisp, juicy, aromatic. "Good." January.

\section{AlLeN's Pirpin.}

Origin, Chatham, N. C. 'Tree upright, productive. Fruit medium, oblate, greenish-yelluw. Flesh whitish, tender, mild, subacid. Good. Octuber to December.

\section{AlL-HALLOWS.}

Origin from seed by Richard H. Graves, Ireland. Fruit medium, roundish, handsome. Flesh tender, juicy, very pleasant. October and November. A new variety, not yet fully tested in this country.

\section{Ard,-SUMMER.}

Origin, Lancaster Co., Pa. Tree slow growth, spreading, an annud] bearer, and very productive. Fruit small, oblate, greenish waxy yellow, slight tinge of red in sun. Stalk slender. Calyx small, closed. Flesh white, tender, pleasaut. Almost "very good." July and August.

\section{A LLUM.}

\section{Hallum. Tockingham Red.}

Much grown in norther'n N. Carolina; valuable chiefiy because of its productiveness and for its keeping properties. Fruit medium, oblate, irregular, deep red. Flesh whitish, crisp, tender, juicy, with a brisk acid flavor. Good. January to April.

\section{Alsace.}

Origin, Alsace Township, Pa. Fruit medium, conical, whitish-yellow, blush in sun. Flesh whitish, juicy, pleasant. "Good." January to March. (Pa. Hort.)

\section{AMELIA.}

Of European origin. Fruit medium, roundish, conical, paie yellow, shaded, and obscurely splashed with two shades of crimson. Flesh whitish, firm, tender, juicy, mild subacid. Good. January and February.

\section{Americax Beauty.}

\section{Sterling Beauty. Beauty of America.}

Origin, Sterling, Mass. Tree vigorous, productive, an anmual bearer. Wood dull reddish brown, slightly downy.

Fruit large, form roundish, slightly inclining to conic, obscurely ribbed. Color a yellow ground mostly covered with red, which is quite dark in the sun, thickly sprinkled with small light and brown dots. Stalk rather short, somewhat slender. Cavity medium, with russet, the rays of which sometimes extend out over a portion of the fruit. Calyx small, 
closed. Segments medium, slightly recurver. Basin medium, nueven. Flesh yellowish, rather compact, tender, juicy, rich mild, subucid, aro. matic. Core small. Very good. December to April.

\section{American Goldex Pippin.}

Golden Pippin.

Ribbed Pippin. Golding.

\section{New York Greening.}

Newtown Greening.

Golden Apple.

This old Apple is one of our finest American fruits, and seems not to be generally known. It has been cultivated more than fifty years, and is considered one of the most profitable for orchard culture and marketing; it is also a suprerior Apple for family use. Growth strong, similar to R. I. Greening, but less drooping, making a round, sprearling head; does not bear young, but very productive when a little advanced, and a popular fruit where known. Wood dark reddish, downy, with prominent flattened buds.

Fruit medium to large; form roundish oblate, inclining to conic, obscurely ribbed; color yellow, sometimes a brownish blush in sun, thinly

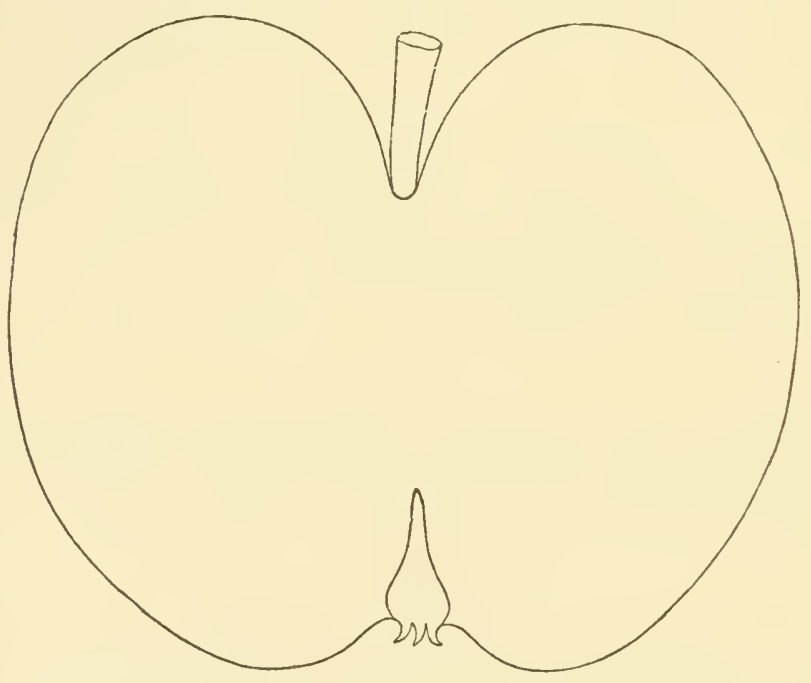

Ameriean Golden Pippin.

sprinkled with gray dots, often slightly netted with thin russet. Stalk short, moderately stont. Cavity large, deep. Calyx closed. Segments pointed, slightly recurved. Basin broad, open, slightly corrugated. Flesti yellowish, breaking juicy, rather coarse, rich, aromatic, subacid. Core rather large. Very good. November to February.

\section{Anierican Golden Russet.}

\section{Golden Russet. . Bullock's Pippin. Sheep Nose. Little Pearmain.}

The American Golden Russet is one of the most delicious and tender 
Apples, its fiesh resembling more in texture that of a buttery Pear than that of an ordinary Apple. It is wideiy cultivited at the WVest and in New Eughud as the Golden Rinsset, and though neither handsome now large, is still a miversal firorite, from its great productiveness and adminable flavor. The nucontl name of Coxe, Sherphose, is nearly obsolete, except in New Jerser, and we therefore adopt the present one, to which it is well entitled. 'The tree is thrifty, with upright shoots, dull redelish grayish brown.

Fruit below melinm size, roundish-ovate, dull yellow, sprinkled with a very thin russet. Stalk rather long and slender. Callyx closed, and set in a rather narrow hasin. . Flesh yellowish, very tender, juicy, with a mild, rich, spicy flavor. Best. Oetober to Jamiary.

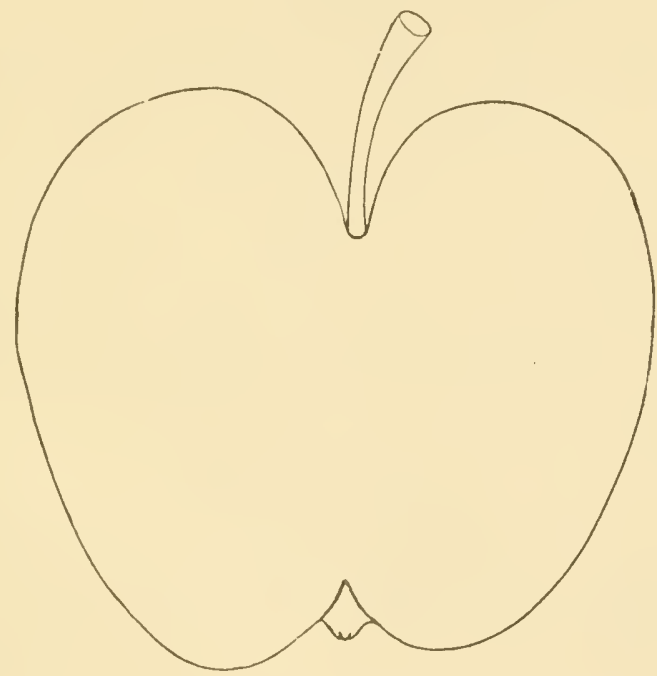

American Golden Russet.

\section{Aderican Nonpareil.}

Origin unknown. Tree vigolons, round, and regular. Fruit mediun, oblong conic, yeliow, streaked with lively red. Flesh white, crisp, juicy. August. (Coxe.)

\section{American Pippin.}

\section{Stone. Grindstone.}

Tree thrifty, spreading, with crooked shoots. Valuable only for its late keeping and for cider.

Fruit of medium size and regular form, oblate, dull red in patches and stripes, on a dull green ground. Flesh white, firm, juicy, with a somewhat brisk, acid flavor. Good. Keeps till June.

\section{American Plate.}

Origin unknown. Tree of slow growth, lardy, very productive. 
Fruit small, roundish, oblate, greenish, with a brown tinge. Flesb crisp, juiey, pleasant. Decenber and Jamnary. (Ron.)

\section{American Summer Pearmaix.}

Warly Summer Pearmaiu.

A rich, highly-flavored fruit, much esteemed where it is known. It appears to be quite different from the Summer Pearmain (of the English), and is probably a seedling raised from it. It ripens gradually from the tenth of August to the last of September. Tree moderately rigorous, with slender branches, round-headed. Young shoots dull reddish-brown.

Fruit of medium size, oblong, widest at the crown, and tapering slightly to the eye. Skin red, spotted with yellow in the shade, but streaked

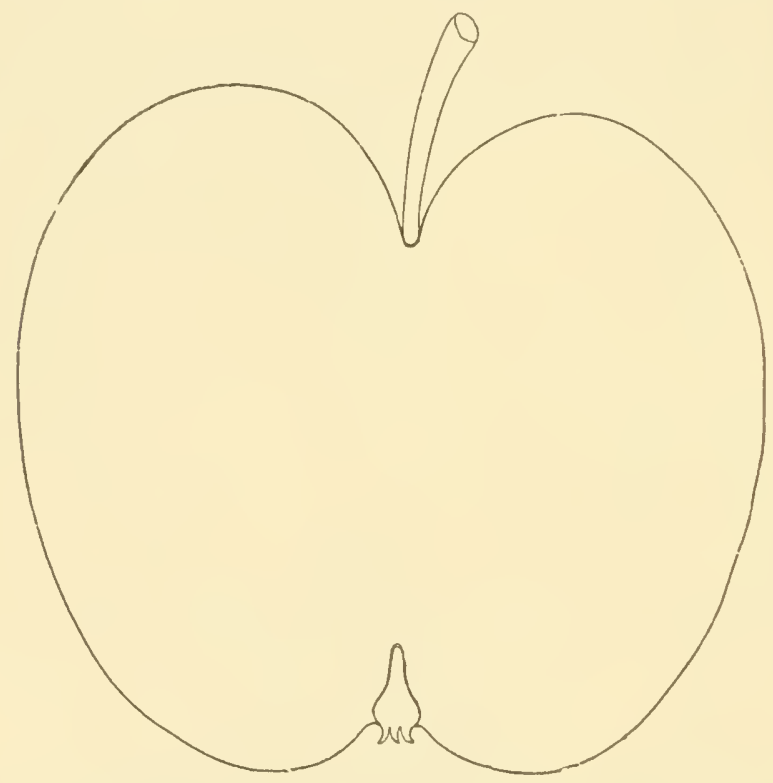

American Summer Pearmain.

with livelier red and yellow on the sunny side. Stalk three-fourths of an inch long, and pretty deeply inserted. Eye deeply sunk. Calyx closed. Segments short, erect. Basin abrupt, slightly corrugated. Flesh yellow, remarkably tender, with a rich and pleasant flaror, and often bursts in falling from the tree. Quality best. Core nedium.

\section{Ananas.}

\section{Rother Ananas. Bromelia Ananas.}

Tree vigorous, productive.

Fruit medium, roundish, yellow, streaked with bright red in the sun, brown spots in shade. Stalk long, slender. Cavity deep, open. Calyx 
irregular, open. Basin deep. Flesh white, tender, juicy, subacid, perfimed. Excellent. October. (Al. Pom.)

\section{Aravas de Liege.}

\section{Calville Ananas de Liege. Lutticher Ananas Calville.}

Originated in Belgium. 'l'ree moderately vigorous, with long, jointed, dark-redilish shoots.

Fruit large, conical, truncated, greenish, with patches of brown or brownish russet. Calyx large. Basin deep, abrupt. Stalk short. Cavity large and deep. Flesh white, half-tine, firm, a little dry, subacid. Cooking. January, February. (Terg.)

\section{ANGLE.}

Medium, roundish, yellow, nearly covered with stripes and splashes of light and dark red, with white dots. Flesh yellow, tender, sweet and good, fair and handsome. Good. First of September.

\section{Axglo-American.} tive.

Raised by WT. IT. Read, Canadia West. Tree vigorous and produc-

Fruit medium, oblate, yellowish, marbled, striped and splashed with bright red. Stalk short, rather slender, inserted in a cavity of moderate depth. Calyx closed. Segments long, partly recurved. Flesh white, tender, juicy, sweet, slightly aromatic. Very good. August, September.

\section{Archiduc Axtorne.}

Tree upright, vigorous. Toung shoots reddish.

Fruit medium, roundish, yellow green, dotted with inconspicuons small brown dots. Calyx half open. Basin small. Stalk rather long. Cavity deep. Flesh whitish yellow, fine, tender, juicy, subacid. Early winter. (Verg.)

\section{Aromatic Carolina.}

Origin, Pomaria, South Carolina. Tree vigorous, hardy, productive.

Fruit large, roundish, oblate, sides unequal, light yellow, slightly streaked with pale rerl. Flesh moderately firm, crisp, pleasant, mild, subacid, aromatic. Very good. Angust and September. William Sumner says this is exceedingly tender and melting, and in season all July.

\section{Aromatic Russet.}

An English Apple, of vigorous, upright, rather slender growth, hardy and productive.

Frnit medium, rounclish, truncate conic, greenish, with a thin gray russet, and a tinge of dull red in the sum. Flesh greenish white, firm, brisk, subacid, aromatic. November, February. (Lind.)

\section{AsILAND。}

Origin, Clermont Co., O. Tree upright, moderate grower, a good and annual bearer. 
Fruit medium, approaching conic, truncate, yellowisli, striped and shated with earmine, and considerably sprinkled with large light dots. Stalk small and short, inserted in a large open eavity surrounded by greenish russet. Calyx open, set in a round, abrupt basin. Flesh yeilow, tender, juiey, with a very pleasant, mild, subaeid flaror. Tery good. January to April.

\section{Asmead's Kersel.}

A variety from Gloncestershire, England. Tree hardy and productive.

Fruit small, roundish, oblate, greenish yellow, with tinge of biownish orange in the sun. Flesh yellowish, firm, erisp, juicy, aromatic. November to May. (Lind.)

\section{AsHMORE.}

\section{Red Ashmore.}

Origin unknown. Tree vigorous, upright, spreading. Young shoots dull reddish brown.

Fruit medium, form ronndish oblate, inelining to conical, generally regular; color whitish yellow, washed or shaded with rich bright red, obseurely splashed, moderately sprinkled with light and gray dots. Skin glossy, smooth. Stalk medium; eavity broal, deep, slightly russeted. Calyx small, finely closed. Segments ereet. Basin deep, open, slightly uneven. Flesh white, tender, juiey, mild, subaeid. Core small. Tery good. October, November.

Striped Ashmore is elaimed by some as a distinct variety, differing only in its coloring.

\section{Asterus.}

D'Asterus. Strifling d'Hiver.

An English variety, valuable for cooking.

Fruit large, roundish, green, with some dull red streaks. Flesh firm, rich, subacid or acid. January to April. (Ron.)

\section{Augustine.}

Large, roundish, conic, yellow, striped with red, sweet and diy. August.

\section{Augustus Pearirais.}

An English variety. Fruit small to medium, roundish conical, yellow, with streaks of red, deepest in the sun. Calyx small, closed. Stalk short, and having a knobly attachment. Flesh tender, juiey, vinous, aromatie. November, December. (Hogg.)

\section{Aunt Anva.}

Aunt Anna's Seedling.

Introduced by John Reeder, South Charleston, Ohio. Fruit medimm, oblate, yellow, finely striped with red. Flesh yellow, tender, rather dry. (O. P. S. Riep.) 
Aunt's Apple.

Origin mknown. Tree small, delicate, very productive. Fruit. large, oblong, yellow, mostly covered and streaked with a lively red Flesh yellow, breaking, juicy, not rich. Norember. (Coxe.)

\section{Aunt Mannah.}

Origin, Fssex Co., Mass. Tree of slow growth. Fruit medium, oblate, nearly globular. Skin golden yellowish, sprinkled witlı russet. Stem short, inserted in a cavity surrounded by russet. Calyx closed. Basin very shallow. Flesh yellow, fine-grained, with a rich peeuliar flavor, slightly musky. Good. December to February.

\section{Auxt Susax's Favorite.}

Originated from seed, by Mrs. Susan Tippet, in Missouri, about twenty-tive year's since. Tree hardy, thrifty, vigorous, round open head, good aud regular bearer. Fruit large, roundish, flattened, light yellow, shaded and striped with shades of deep and light red. Stalk short. Cavity deep. Calyx closed. Flesh white, tender, juicy, mild, subacid. Good. August. (II. S. H. Soc.)

\section{Austin Sweet.}

Origin, Mercer Co., Pa. Tree irregular spreading.

Fruit medium, roundish, inclining to conic, jale yellow, sprinkled with a few brown dots and patches of russet. Stalk short and small; cavity, wicle open, deep, russeted. Calyx open. Segments short, erect. Basin abrupt, deep, uneven. Flesh white, moderately juicy, rich, sweet. Very good. Core medium. September to December.

\section{Autuma Golden Pippin.}

An old English variety. Tree vigorous. Fruit small, lemon-yellow, little russeted. Flesh rich, and delicious flavor. (Ron.)

\section{Autuain Pearmain.}

\section{Winter Pearmain.}

A slow-growing tree, but attains a large size. Branches slender, spreading. Fruit of medium size, roundish, narrowing gradually toward the eye. Color brownish-yellow, mixer with green on the shaded side, but next the sun reddish, blended with yellow, streaked with deeper red, and sprinkled with numerous small brown specks. Stalk short, obliquely planted under a fleshy lip. Calyx small, set in a broad slatlow basin, which is sometimes scarcely at all sunk, and obseurely plaited. Flesh pale yellow, crisp, firm, a little dry, but rich and high flavored. Core 1 itlier small. Quality very good. October to March.

\section{Autuma Romante.}

Originated on the farm of Jacob Nicely, Cumberland Co., Pa. Fruit medium, round, somewhat flattened, beautiful red. Flesh yellow, pleasant. September. (A. Pom. S. Rep.) 


\section{Autunn Rose.}

\section{Roseau d'Automne.}

An old English variety. Tree vigorous, spreading. Fruit medium, red on bright rich yellow, russet at the stem. Flesh yellow, rich, juicy, tender, ligh flavored. September. (Coxe.)

\section{Autumal SwaAr.}

\section{Fall Swaar of West.}

Origin unknown. Tree hardy, vigorous, spreading. Fruit large, roundish, conic, orauge-yellow, netted with r'usset, and sprinkled with starshaped dots. Stalk rather short. Cavity broad, deep, slightly russeted. Calyx small and closed. Basin deep, abrupt, and corrugated. Flesh yellow, juicy, tender, with a pleasant, rich, mild, slightly aromatic subacid flaror. Core small. Very good. September.

\section{Autumn Sweet Bough.}

\section{Late Bough. Sweet Bellflower. Fall Bough. Philadelphia Sweet.} White Sugar?

Origin unknown. Tree vigorous, upright, round-headed, very productive. One of the very best dessert sweet Apples of its season. Fruit medium, conical, angniar, smooth, pale yellow, sprinkled with a few brown dots. Stalk of medium length, rather slender, inserted in a deep narrow cavity. Calyx closed. Segments long. Basin deep, conrugated. Flesh white, rery tender, with a sweet, refreshing, vinous flaror. Very good. Last of August to first of October.

\section{Autumal Sweet SwaAR.}

\section{Sweet Swaar. Sweet Golden Pippin.}

Origin unknown. Tree vigorous, spreading, productive. Fruit medium, oblate, inclining to conic, deep yellow, with occasional blush in sum. Stalk rather long, slender. Cavity broad and even. Calyx closed. Basin round, open, corrugated. Flesh yellow, tender, moderately juicy, rich and sweet. Core medium. Very good. September, October.

\section{Autunin Seek-No-FARTHer.}

Dr. Watson.

Origin unknown. A variety considerably grown in Indiana, where it is much esteemed. Tree moderately rigorous, spreading, productire. Fruit medium, oblate, sides sometimes mequal. Color greenish-white, shaded, and splashed in the sun with dull crimson. Stalk of medium length. Carity broad, uneven. Calyx open. Basin large, rather deep. Flesh whitish-yellow, rather firm, juicy, rich, subacid. Core mediun. Very good. September, October. 


\section{AVERILL.}

Wolf's Den.

Origin, Pomfret, Conn. Tree vigorous, productive. Fruit rather large, irregularly conic, angular, greenish yellow, striped and shaded with red. Stem short and stout, inserted in a narrow cavity. Calyx closed, set in a very shallow slightly furrowed basin. Flesh whitish, tender, juicy, with a pleasant subacid flavor. Good. February to June.

\section{Baccolinus.}

Origin unknown. Tree vigorous, very productive. Fruit small, roundish to roundish oblong, whitish, shaded and splashed with light and liark red. Fiesh firm, moderately juicy, vinous. Core small. Good. Jinuary to April.

\section{BaChelor's Blush.}

Origin unknown. An annual moderate bearer. Fruit rather large, form oblate depressed, often obscurely ribbed, color yellowish with blush in sun, sprinkled with a few light and gray dots. Stalk very short. Cavity large, deep. Calyx open. Segments short, erect. Basin medium, uneven. Flesh white, tender, crisp, juicy, rather rich, subacid. Core small. Very good. August and September.

\section{BACHELOR'S GLORY.}

An English variety. Fruit large, roundish, irregularly ribbed, golden yellow with crimson stripes. Calyx closed. Segments flat. Stalk medium. Cavity deep, funnel-shaped. Flesh yellow, tender, juicy, pleasant. October, November. (Hogg.)

\section{Backhouse's LoRd Nelson.}

Origin, York, England. Tree vigorous.

Fruit large, roundish conic, yellowish with dull green shade. Flesh tender. Good. December to January. (Ron.)

\section{Baddow Pippin.}

Ribston Pippin, Spring.

An English dessert Apple, valued for its keeping properties. Fruit medium, roundish oblate, ribbed, yellowish green, with dull red in the sun, Stalk short. Calyx large, open Flesh whitish, firm, crisp, rich vinous. Good. April to May.

\section{Bailey's Golden.}

Origin, Kennebec Co., Maine. Tree productive. Fruit large, oblong, flattened at base and crown, yellowish, slightly russeted, with a warm cheek. Stalk short, surrounded by russet in a broad deep cavity. Calyx large and open. Basin shallow. Flesh white, with a pleasant subacid flavor. Good. January to March. 


\section{Bailey's Spice.}

Origin, Plattsburg, N. Y. Tree moderately vigorous and productive. Fruit medium, roundish conical, light yellow, sometimes a faint blush. Stalk rather long, slender. Cavity rather deep. Calyx closed. Basin abrupt, corrugated. Flesh whitish, tender, juicy, lively subacid, slightly aromatic. Core large. Nearly very good. September and October.

BaIley's SweEt.

Edgerly's Sweet. Howard's Siceet. Paterson's Sweet.

Origin unknown, introduced by J. Edgerly of Perry, Wyoming Co., N. I. Tree hardy, vigorous, upright, spreading, productire.

This rariety is regarded as profitable for all purposes, althongh perhaps a little too tender skin for shipping long distances. Fruit large, form roundish conical, often approaching oblong, obscurely ribbed, color yellowish, mostly shaded and obscurely striped with red, and thickly sprinkled with minute dots. Stalk short and rather small, inserted in a narrow cavity. Calyx small, closed, set in a narrow irregular basin. Flesh white, tender, not very juicy, almost melting, with a honeyed sweet flavor. Core rather large. Very good. November to March.

\section{BAKER.}

\section{Scott.}

Origin, Pidgefield, Ct. Trec vigorous, spreading, abundant bearer, young wood reddish brown, with prominent round buds. In its native locality this Apple is highly esteemed both for market and cooking purposes.

Fruit large, roundish oblate, inclining to conic, yellowish, mostly shaded and splashed with shades of crimson. Stalk short, moderately stout. Cavity regular, medium. Calyx closed. Segments slightly recurred. Basin shallow, slightly corrugated. Flesh yellowish, rather coarse, often tinged with crimson near the skin, pleasant subacid. Very good. Core small. October to February.

\section{BAKER'S SWEET.}

\section{Winter Colden Sweet. Long Stem Sweet. Late Golden Sweet.}

An old fruit of Conmecticut and Massachusetts, and much cultivated there. 'Tree moderately vigorous, slender, somewhat resembling Jonathan. Wood clear reddish brown.

Fruit medium, roundish, of a golden yellow color, with some patches of russet. Stalk long, inserted in a large smooth cavity. Calyx closed. Rather large basin. Flesh yellow, rich, exceedingly saccharine and pleasant. Good to very good. November, December.

\section{BALM.}

Origin, Vermont. Tree rigorous, productive.

Fruit medium or above, roundish, oblate conical, yellowish, mostly corered with red. Stalk slender. Flesh whitish. tencier, moderately juicy, mild, pleasant. Good. October. 


\section{BALDWIN.}

$\begin{array}{cll}\text { Woodpceker. } & \text { Pecker. } & \text { Steele's Red Winter. } \\ \text { Felch? } & \text { Red Baldwin. } & \text { Butters. }\end{array}$

The Baldwin stands at the head of all New England Apples, and is unquestionably a first-rate fruit in all respects. It is a native of Massachusetts, and is more largely cultivated for the Boston market than any other sort. It bear's most abundintly with us, and we have har the satisfaction of raising larger, more beautiful, and lighly flavored specimens here than we ever saw in its native region. The Baldwin in flavor and generil characteristics evidently belongs to the sane family as our Esopus Spitzenberg, and deserves its extensive popularity.

Tree vigorous, upright spreading, productive. Young shoots dull reddish brown.

Fruit large, roundish, and narrowing a little to the eye. Color yellow in the shade, but nearly covered and striped with crimson, red, and orange in the sun, dotted with a few russet dots, and with radiating streaks of russet abont the stalk. Calyx closed, and set in a rather narrow plaited basin. Stalk half to three-fourths of an inch long, rather slender for so large a fruit, planted in an even, moderately deep cavity. Flesh

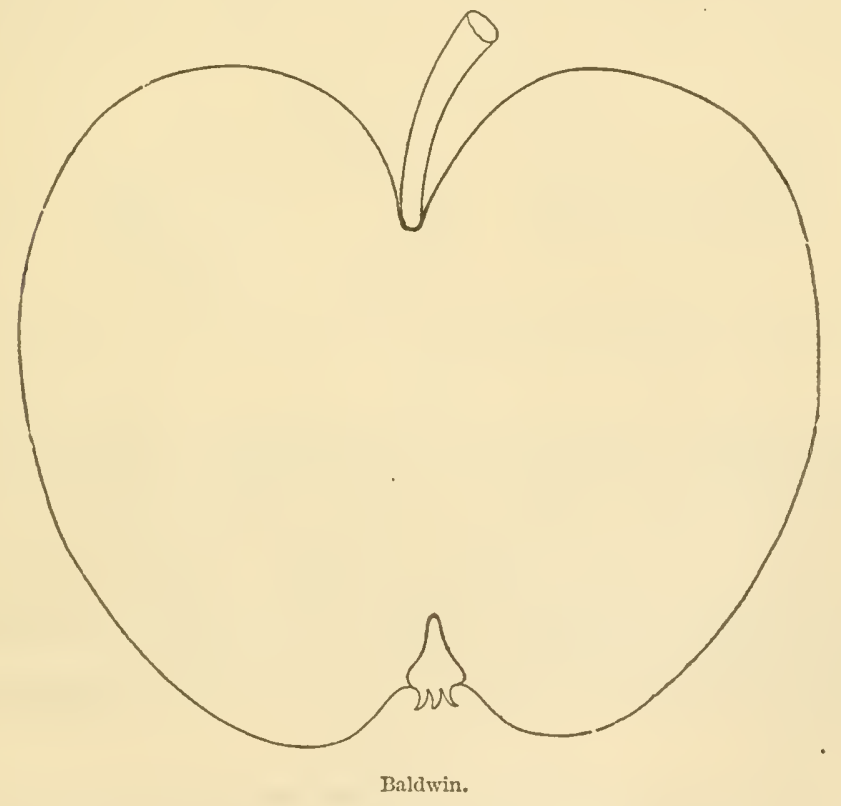

yellowish white, crisp, with that agreeable mingling of the saccharine and acid which constitutes a rich, high flavor. Very good. The tree is a vigorous upright grower, and bears most abundantly. Ripe from November to March, but with us is in perfection in January.*

* The Baldwin, like nearly all other varieties of winter fruits, originated in the Northern and Eastern States; when grown in Southern latitudes they become 


\section{Baldowin SweEt.}

Fruit rather large, roundish, yellow, striped and shaded with red Flesh yellow, rather compact, sweet and good. Productive. October. January.

\section{BaLtimore.}

Cable's Gilliflower. Baltimore Pippin. Royal Pippin

Origiu unknown. Tree healthy, hardy, moderately vigorous, making a round head that when loaded with fruit appears almost drooping. Young shoots slender, dull reddish brown. A profitable variety for market or table use.

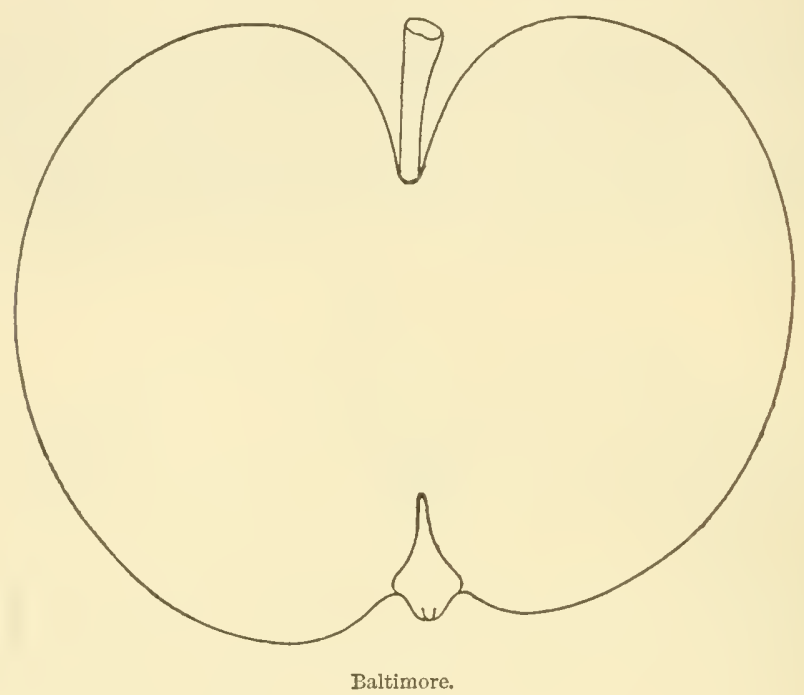

Fruit medium. Form roundish, conical, regular. Color pale yellow, shaded with light red, striped and splashed with dark red, almost purplish, having a grayish appearance of bloom, large light dots, with a dark centre. Stalk short. Cavity medium size, rather thinly russeted. Calyx small, closed. Segments drawn to a point. Bitsin shallow, nearly smooth. Flesh whitish, tender, juicy, mild, subacid. Core medium. Very good. December to April.

An apple received from Maryland as Baltimore proves identical with Fallawater.

\section{Baltimore Greening.}

Origin unknown. Specimens received from John Edgerton, Coal Creek, Iowa.

Fruit large, globular flattened, greenish yellow, with a brownish

autumn or early winter sorts, and lose more or less of their sprightliness and good qualities as table fruits. On the other hand, the summer-ripening varieties, origipating North, are greatly improved when grown at the South. 
blush cheek in sun, some slight stripes of russet, and a few small raised gray dots. Stem short. Cavity broad, open, and deep. Calyx closed, or nearly so. Basin open, deep, slightly furrowed at base. Flesh yellowish, rather coarse, tender, mild, subacid. Very good. Core medium. December. (Elliott's Notes.)

\section{Baltzby}

From Virginia. Tree spreading, productive. Fruit large, oblate, yellowish white, with a faint blush; dots scattered, snall, white. Flesh white, firm, somewhat tough, juicy, almost sweet. Grood. October.

\section{BAR.}

A large, fair apple, slightly tinged with red next the sun. Flesh white, juicy, sweet, and agreeable. Good. An early fall fruit, and keeps well through the winter.

\section{Barbour.}

Originated with J. Barbour, Lancaster Co., Pa. Fruit medium roundish, oblate, inclining to conical, mottled, and striped with red of different hues on a grayish ground, with numerous gray specks. Flesh yeliowish, white, tender, juicy, flavor pleasant. Quality very good. (Pa. Rep.)

\section{Barceloxa Pearmain.}

Speckled Golden Reinette.

Polinia Pearmain

Reinette Rouge.

Glace Rouge.

Kleine Casseler Reinette.
Speckled Pearmain

Reinette Rousse.

Reinette des Carmes.

Cassel Reinette.

A foreign variety of uncertain origin, which from its good qualities there, has evidently been widely grown under many mames. Tree hardy and productive.

Fruit medium, roundish oblong, pale yellow, mostly covered with red, and many star-like russet specks. Flesh yellowish white, firm, crisp, rich, aromatic, subacid. November to March.

\section{Barchard's Seedling.}

An English variety, valuable for kitchen use. Fruit medium, roundish oblate, yellow striped with red. Flesh white, sugary. October. (I. H. S.)

\section{Barnhan's Sweet}

Origin, Connecticut. Fruit medium, roundish, pale yellow, rough, russet. Flesh yellowish, rather dry, rich, sweet. Good for baking. November, December.

\section{BARIIILT,}

American, small, conical, yellow, striped with red. Flesh white, tough, dry. Octcber, November. 


\section{Bark Apple}

Originated with the Messi's. Ronalds, England, and there regarded valuable for culinary use. Fruit medium, roundish conical, greenish yellow, blush in sun, some russet. Flesh firm, crisp, juicy acid. November to Feloruary. (Hogg.)

\section{BARRE.}

\section{Colville Barre.}

Origin unknown. Introduced from Angers in 1848. Fruit large, roundish conieal, yellow, with spots or patches of greenish. Flesh yellowish white, juicy, acid. Decèmber. (An. Tom.)

\section{BARRETT.}

Origin, Kensington, Conn. Fruit medium to large, conic, yellow, striped and splashed with carmine. Flesh yellow, juicy, tender, with a very pleasant vinous aromatic flavor, almost sweet. Good. January to March.

\section{Bars.}

Origin, Rhode Island. Fruit rather large, round, pale yellow, marbled, and nearly covered with red and a few russet spots. Stalk long, slender. Cavity small. Calyx closed. Segment slightly recurr. ed. Basin medium, furrowed. Flesh whitish, tender, juicy, mild, subacid. Core small. Very good. September.

\section{BaRTLETT.}

Origin unknown. Fruit large, roundish, ribbed, striped and splashed with bright red on yellow. Flesh whitish, mild subacid. Good. (Count. Gent.)

\section{BARTON.}

Originated with Michael Aikman, in the township of Barton, C. W. Fruit medium, oblate, slightly conic, light yellow, with light red cheek. Stalk short. C'avity even. Calyx small, regular. Basin medium. Flesh white, fine-grained, tender, juicy, mild, subacid. Core small. Tery good. September October. A new variefy promising of value for dessert. (Tat. Mss.)

\section{Barton's Incomparable.}

An English variety, regarded abroad as of the highest excellence for the dessert. Tree healthy and productive. Fruit below medium, roundish conical, five ribbed, yellowish green, with patches and speeks of russet, orange in sun. Flesh yellowish white, crisp, juicy, sprightly, vinous. October to February. (Hogg.)

\section{Bauman's Reinette.}

\section{Reinette Bauman.}

Of Flemish origin, introduced and named by Tan Mons. Fruit medium, roundish oblate, yellowish green, with numerous distinet brown rlots. Flesh yellowish white, fine, firm, sugary, perfumed. January. (L. H. S.) 


\section{B.ater's Pearuian.}

From Norfolk, Englaud. Tree hardy, vigorous, productive. Fruit large, roundish, elongated conical, pale green, with shades and streaks of red in the sun. Fiesh yelluwish, firm, brisk, sprightly subacid. Valuable for all purposes. November to March. (Hogg.)

\section{Beacheminel Seedling.}

Motteux's Seedling.

From Norfolk, England. Tree hardy, vigorous, productive. Fruit below medium, roundish, yellowish, with faint stripes and splashes of red, brown patehes. Calyx and stalk prominent. Flesh yellowish white, tender, brisk, subacid. December to March. (Ron.)

\section{BEADELL.}

Hanover Seedling.

Originated on the farm of Edward Beadell, Westchester Co., N. Y. Tree strong, vigorous, spreading, good bearer. Fruit resembles the MIcLellan in form, color, size, and similar in Havor. Good to ver'y good. Ripe in October.

\section{BeAN SweET.}

Originally sent out by Julge Buel. Fruit medium, oblong rounded, nearly white. Flesh crisp, juicy. October to March. Baking. (Elliott.)

\section{Bear SweEt.}

Origin unknown. Fruit medium, roundish, conical, yellowish, shaded and splashed with red. Flesh moderately tender, juicy, pleasant, sweet. Good for cooking. November.

\section{BEAU.}

Distributed by Judge Buel. Fruit large, roundish, oblate, yellowish green, with blush in sm, and white dots. Flesh white, erisp, juicy, acid. August to October. Culinary. ' (Ken.)

\section{BEAUTY OF KENT.}

A showy English sort for culinary uses. The tree grows very strong and upright, moderately productive.

Fruit very large, roundish, but flat at the base, and narrowing distinctly to the eye, where it is slightly ribbed, smooth, greenish-yellow, marked with large, broken stripes of purplish red. Stalk short, slender, deeply planted in a round, russeted, corrugated cavity. Calyx small, set in a narrow basin. Flesh juicy, crisp, tender, with a simple subacid tlavor. Good. Oetober and November.

\section{Beauty of tile West.}

\section{Western Beanty. Ohio Beauty. Musgrove's Cooper.}

Origin unknown. First sent out and noticed by Judge Buel some 
thirty or more years since, and yet but little known. The tree is a strong, vigorous grower, forming a large spreading head, moderately productive. Young wood dull reddish brown.

Fruit large, roundish, oblate, conical, greenish yellow, nearly covered with pale dull red, striped with a darker shade, and dotted with large yellow specks. Stalk short. Calyx large, balf open. Flesh greenishwhite, not firm, tender, mild, subacil. Good. November to February.

\section{Bedfordshire Founding.}

Cambridge Pippin.

A large green English Apple, excellent for kitchen use. Fruit large, roundish, obscurely ribbed, deej green, paler at maturity. Flesh yel. lowish, tender, juicy, with a pleasant, acid flavor. Good. October to February.

\section{Beefsteak.}

Garden Apple of some, incorrectly.

Origin, farm of Joel Davis, Amesbury, Mass. Habits similar to Baldwin, very productive.

Fruit medium, oblate, inclining to conical. Sides sometimes unequal. Skin whitish-yellow, shaded and splashed with light and dark red over two-thirds its surface, large areole dots. Stalk medium and slender, often with bracts. Cavity rather large, slightly russeted. Calyx closed. Segments slightly recurved. Basin medium, nearly smooth. Flesh white, crisp, tender, juicy, mild, subacid. Core medium. Very good. Uctober, November.

\section{Beeler's Russet.}

Origin unknown. Fruit medinm to small, round, truncated, russeted. Flesh yellow, crisp, tender, juicy, subacici, aromatic. November, December. (Warler.)

\section{Belden or Red Cineek}

Origin unknown. 'Tree vigorous, upright, moderately productive. Fruit large, roundish, conic, greenish-yellow, with patches of russet, sometimes a little bronzed cheek. Flesh yellow, crisp, subacid, pleasant. Good. October, Feluruary.

\section{Belden Sweet.}

Grown in Connecticut, very prolific. Fruit medium, or below, roundish conic, light yellow, with a warm cheek. Stalk medium, in an acute, deep cavity. Calyx closed, in a small basin. Flesh white, tender, juicy, saccharine, with a pleasant, aromatic flavor. Core large. Good. December to March.

\section{Belle Bonde. \\ Billy Bond. Belly Bounder.}

This variety is somewhat grown in Central New York, and claimed as having originated in France, in 1790, and brought tinere by one John 
Deidens. Tree hardy, vigorous, spreading. Fruit medium, or above, roundish conical, pale-yellow, striped and splashed with red, and with large light dots. Flesh whitish, a little coarse, tender, brisk, subacid. Good for cooking. January and February.

\section{BeLle BonNF。}

Winter Belle boon. Winter Belle and Bonne. Rolland.

Fruit large, roundish, flattened, greenish-yellow, with a few reddish streaks in the sun. Flesl firm, juicy. October to January. Culinary. (Hogg.)

An old variety, first described by Parkinson, in 1629, and which is probably identical with the Belle et Bonne above described.

\section{Belle D'Axgers.}

Origin in doubt. Fruit large, roundish conical, pale-yellow, splashed and shaded with dull red. Flesh yellow, juicy, crisp, brisk, subacid, aromatic. Core medium. Very good. October.

\section{Belledge.}

\section{Belledge Pippin.}

Origin, Derbyshire, England. A dessert and culinary apple. Fruit below medium, roundish oblate, lemon yellow, tinged with pale brown in sun, many embedded gray dots. Flesh firm, crisp, pleasant, aromatic, acid. October, December. (Lind.)

\section{Belle et Bonne. \\ Tenon Hills.}

A large, fine apple, having a great reputation in the vicinity of Hartford, Conn., a vigorous grower and productive. Shoots dull reddish brown.

Fruit very large, roundish oblate, golden yellow, thickly sprinkled with small dots. Stalk short, inserted in a broad, deep cavity, surrounded by thin russet. Calyx closed. Basin moderate and uneven. Flesh yellow, coarse, juicy, with a pleasant, rather rich, subacid flavor. Good. A profitable variety for market. October to March.

\section{Belle Grideline.}

\section{Belle Grisdeline.}

An old variety, originated at Norwich, England. Tree healthy, vigorous. Good bearer. Fruit medium, round, regular, yellow, marbled, and washed with lively red, gray russet in sun. Flesh white, crisp, brisk, subacid. November to March. (Hogg.)

\section{Bellflower Pippin.}

Originated with Joseph Curtis, Edgar Co., Ill. Tree resembles Yellow Bellflower, but more slender in its branches. 
Fruit medium, or above, oblate, orange-yellow, sometimes shaded with crimson in the sun, thinly sprinkled with gray dots. Flesh yel lowish, crisp, tender, juicy, rather rich, subacid. Core small. Very . good. December, January.

\section{Beliont}

Gate.

White Apple.

Namma Beam.

Waxen of some.

Golden Pippin of some. Kelley White.

Origin, near Strasburgh, Lancaster Co., Pa., in the garden of Mrs. Beam, at her" gate, hence the names "Gate Apple," and "Mamma Beam." It was taken to Ohio by Jacob Neisley, Sen., and became

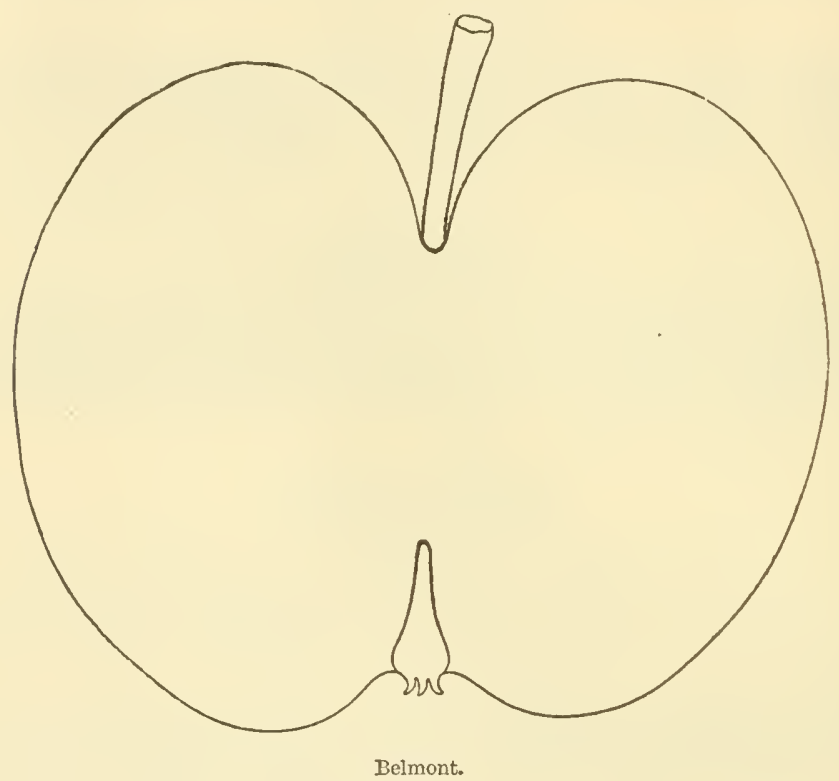

very popular in Belmont Co., and we retain this name as being the most universal one. Tree vigorous, healthy, and very productive. Wood smooth, light reddish brown.

Fruit medium to large, globular, a little flattened and narrower towards the eye, sometimes oblong. Color light, waxen-yellow, often with a bright vermilion cheek. Stalk short. Cavity generally large. Calyx usually closed. Basin rather deep, corrugated. Flesh rellowish, crisp, tender, juicy, sometimes almost melting, of a mild agreeable flavor. Very good. Norember to February.

\section{BELPRE KeEPER.}

Fruit below medium, roundish, pale greenish-white, some shades of crimson in sun. Flesh greenish, .crisp, tender, pleasant, subacid. Good. January to March. 


\section{Belvoir Pippin.}

Of English origin. Fruit small, roundish oblate, yellow with crimson in sun, russet at the stalk. Flesh pale yellow, firm, crisp, rich brisk acid. November, December. (Lind.)

\section{BeLzER.}

Fruit medium, roundish, yellow striped with red. Flesh white, fine, sub-acid. Good. Micidle August. (Hov. Mag.)

\section{Ben Davis.}

New York Pippin.

Victoria Pippin.

Victoria Red.

Red Pippin.

Kentucky Pippin.
Baltimore Red.

do. Pippin.

do. Red Streak.

Carolina Red Streak.

Funkhouser.

The origin of this apple is unknown. J. S. Downer of Kentucky writes that old trees are there found from which sucker's are taken in way of propagating. The tree is very hardy, a free grower, with very

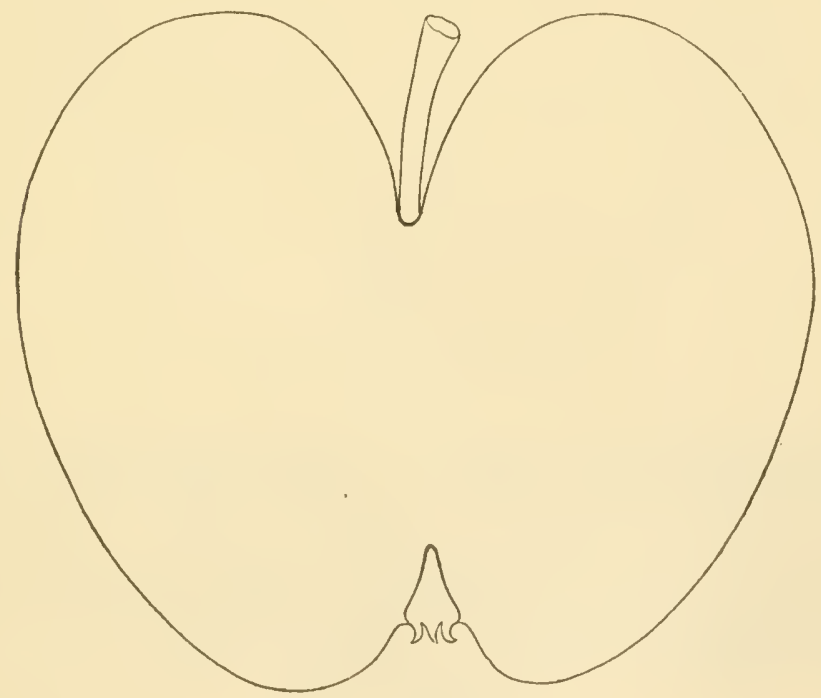

Ben. Davis.

dark reddish brown, slightly grayish young wood, forming an erect round head, bearing early and abundantly. In quality it is not firstrate, but from its early productiveness, habit of blooming late in Spring after late frosts, good size, fair even fluit, keeping and carrying well, it is very popular in all the Southwest and West.

Fruit medium to large. Form roundish, truncrted conical, often sides unequal. Color ycllowish, almost entirely overspread, splashed, and striped with two shades of red, and dotted sparsely with areolo dots. Stalk medium, rather slender. Cavity narrow, deep, russeted. 
Calyx partially open. Basin wide, abrupt, slightly corrugated. Flesh white, tender, moderately juicy, pleasant, subacid. Core medium to large. Good to very good. December to March.

\section{Bennet.}

Origin, Herefordshire, England, where it is valued for cider. Fruit medium, elongated, oblong, conical, dingy russet gray, orange, and muddy red. (Lind.)

\section{BeNoni.}

This excellent early apple is a native of Dedham, Mass. The tree is of vigorous, upright, spreading habit; hardy and productive; light reddish brown. It is a valuable variety for market or table use.

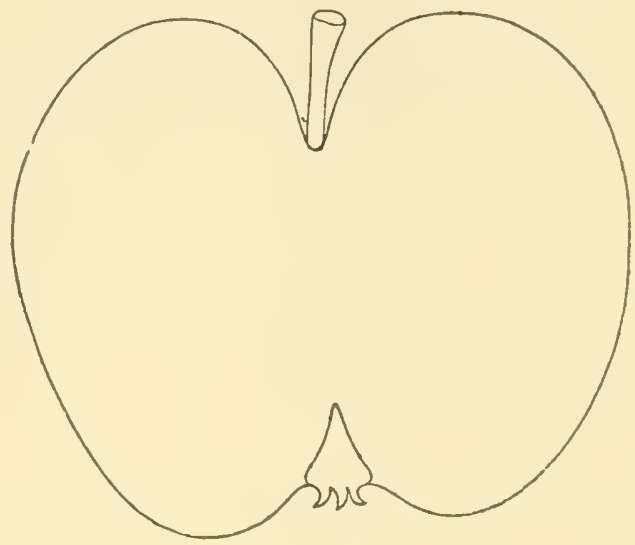

Benoni.

Fruit rather below medium size. Form roundish oblate conical. Color pale vellow, sharled, striped, and marbled with dark crimson, and thinly sprinkled with bright dots. Stalk short, slender. Cavity deep russeted. Calyx closed. Segments persistent, sometimes a little recurved. Basin abrupt, quite deep, somewhat uneven. Elesh yellow, juicy, tender, pleasant, subacid. Core small. V'ery good. Angust.

\section{Bentlex's Sweet.}

Origin unknown. Supposed Virginia. Tree moderately vigorous, hardy, good bearer and keeper, valuable in the Southwest in rich soils.

Fruit medium, roundish, flattened at ends, sometimes slightly oblique, and sometimes sides unequal, pale yellowisk green, shaded with pale red and moderately sprinkled with light and brown dots. Stalk long, slender, curred. Cavity smooth, deep. Calyx large, closed, or partially open. Segments medium length, erect, sometimes a little recurved. Basin large, deep, corrugated. Flesh fine, whitish, compact, sweet, some. what honeyed flavor. Core small. Very good. January to May. 
Bexwell's Pearmats.

An English variety. Fruit medium, roundish conical, dull green, with stripe of red. Filesh yellowish white, crisl', juicy, brisk, aromatic. December, Jannary. (Hogrg.)

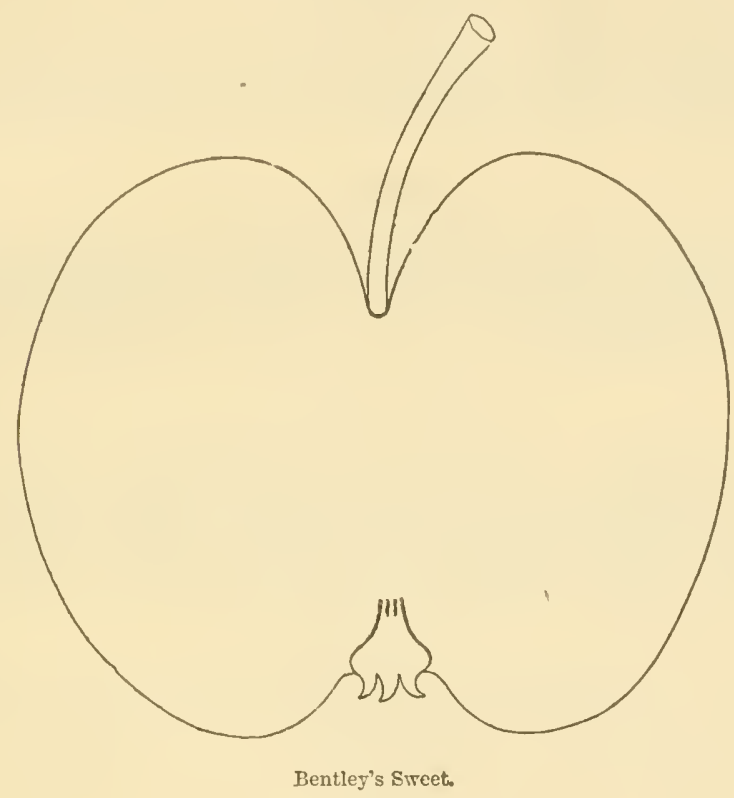

Bere Court Pippix.

Origin, Berkshire, England. Fruit medium round, slightly oblate, yellowish with stripes of red in sun. Flesh erisp, juicy, brisk, acid. September and October. (Hogig.)

\section{Bergner.}

Originated with G. Bergner, near Hermann, Mo. Tree a rapid grower, with strong branches, somewhat drooping; hardy and an abundant bearer.

Fruit large, roundish oblate. Color a rich yellow ground, mostly covered, striped and splashed with shades of maroon red, with some yellow gray or russet dots. Stalk short. Cavity open, regular, deep. Calyx small, closed. Basin abrupt, deep, slightly plaited at hase. Core small. Flesh yellow, crisp, juicy, sprightly, aromatic, quince-like. Very good. February to A pril.

\section{Bess, Poot. \\ Best Pool.}

Origin, Warwickshire, Englaud. Tree hardy, vigorouts, productive. 
Fruit above medium, roundish, conical, regular, yellow, washed and striped with clear red. Flesh white, tender, juicy, vinous, subacid. The stem almost always has a fleshy protuberance on one side. November to Narch. (Hogg.)

\section{Best Bache.}

Bache's Kernel.

Origin, Herefordshire, England, where it is grown mostly for cirlermaking. Fruit medium, oblong, yellow, shacled and streaked with pale reu. (Hogg.)

\section{Betsey.}

An English variety, there regarded as a valuable dessert Apple. Fruit small, roundish oblate, conical; pale yellow with brownish russet in sum. Flesh greenish yellow, tender, juicy, rich, and sugary. Norember to January. (Hogg.)

\section{Betsr's Faxcy.}

Origin unknown. A free grower, rather spreading, good bearer.

Fruit scarcely medium, oblate, yellowish, shaded with dull red. Stem short, inserted in a moderate cavity. Calyx closed. Basin shallow and umeven. Flesh compact, tesider, pleasant, mild, subacid flavor: Good to very good. December to Narch.

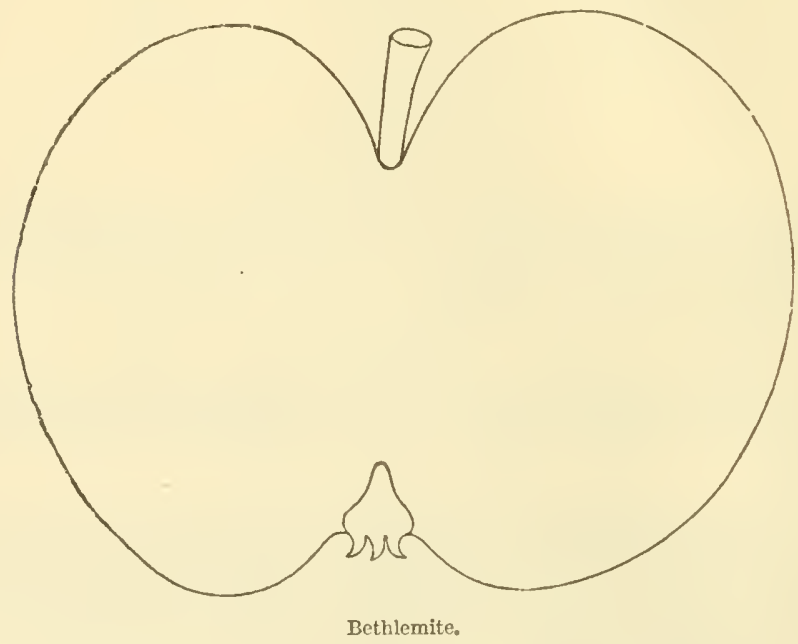

BethleMite.

The origin of this fine apple is unknown. It was first brought to notice from the town of Bethlehem, in Ohio, and is undoubtedly a seedling of the Newtown Spitzenberg, which it much rescmbles. "Tree an 
mpright, strong, stocky, short-jointed grower, with young shoots, dull redulish brown, quite downy. A productive bearer, the fruit keeping and carrying well; very valuable for all purposes.

Fruit, medimu, oblate, inclining to conical, regular. Color pale yellow, striped, shaded and splished with shardes of light and liak red nearty orer the whole surface, thin grayish tinge, and pretty thickly sprinkled with light and brown dots. Stalk rather short, slender. Cavity large, considerably russeted. Calyx open or purtially closed. Segments large and generally erect. Basin large, slightly corrugated. Flesh white, compact, crisl', juicy, rich, milı subacid, slightly aromatic. Core small. Very good. December to March.

\section{Better than Good.}

Origin uncertain. Tree thrifty, but rather slender, very productive. Fruit nedium, oblate, pale yellow, with a few brown dots. Stalk short, inserted in a broad cavity. Calyx closed. Basin large and open. Flesh yellowish, rery tender, juicy, with a mild, pleasant, subacid llavor. Good to very good. November to January.

\section{BEVAN'S FaYORITE.}

Origin, Salem, New Jersey, where it is a favorite. Tree vigorous and productive. Fruit medium, oblate, slightly conic, yellow, striped and splashed with red. Flesh white, tirm, crisp, subacid. Good. August.

\section{Bigg's Noxsuch.}

Origin, Middlesex, England. Tree hardy and productive. Fruit medium, round, broadest at base, yellow, striped with bright crimson. Flesh yellowish, tender, juicy. Culinary use. October to December. (Hogg.)

\section{Billi BakKer.}

Originated on the farm of $\mathrm{Wm}^{\mathrm{m}}$. Barker, Wake Co., N. C. Tree uppright grower and good bearer. Fruit large, green, oval, elongated: Flesh yellowish, juicy, tender, brisk, vinous. August. (Gar. Mon.)

\section{Billy's Pippin.}

Fruit large, round ovate, smooth, shaded and indistinctly striped with rich red on yellow. Flesh subacid. Tery good. (Coun. Gent.)

\section{Binminghim.}

Of moderate growtl, prolnclive. Fruit medium, obliquely oblate, yellow, sprinkled with a few whitish dots. Stalk long, slender, in a broad, deep cavity. Calyx closed, in a large cormgated basin. Flesh yellowish, tender, rather acid, good for cooking. September.

\section{Birmingiman Pippix. \\ Grumas Pippin. \\ Stone Pippin. \\ Brummage Pippin. Grummage Pippin.}

Tree of small growth, with short, stout shoots, produetive. Fruit small, roundish flattened, lingy yollow, with gray russet, esjecially 
russetcd at base. Flesh greenish, crisp, juicy, brisk, pleasant. January to June. (Lind.)

\section{Bischoff's ReINetTe.}

Fruit medium, roundish conical, lemon yellow, with marblings of russet. Fleslı whitish-yellow, juicy, sugary, vinous, aromatic. Norember to March. (Hogg.)

\section{Bishop's BOURNE.}

Received from C. C. Hamilton, Cornwallis, Nova Scotia. Fruit medium, roundish conical, pale yellow, shaded, and obscurely splashed and striped on the sumny side, few gray and light dots. Stalk medium, slender. Cavity slightly russeted. Calyx partially closed. Segments long, erect. Basin abrupt, deep, corrugated. Flesh white, crisp, tender, juicy, mild, subacid, slightly aromatic. Very good. Core small. November, December.

\section{BLACK COAL.}

\section{Welcome. Baltimore Red. Baltimore Red Streak.}

Origin unknown. Tree vigorous, very productive. Frnit rather large, roundish, deep red, almost black, with a slight bloom, and many white rots. Flesh white, slightly tinged with red, crisp, agreeable, moderately juicy. Good. Core medium. November to February.

\section{BLACK OXFORD.}

Originated in Maine, where it is by many highly esteemed, especially as a good keeper and great bearer.

Fruit medium, roundish oblate, slightly conic, yellow, nearly covered with shades of red, numerous light-colored dots. Flesh whitish, com1act, not very juicy, mild subacid. Good. March to May.

\section{BLACK JACK.}

Received from W. C. Hampton, Ohio. Fruit medium, oblate, slightly conic, yellowish, mostly overspread with dark rich red, few light gray dots. Flesh whitish-yellow, rather dry, rich, sweet. Good for baking. January, February.

\section{BLACK WARRIOR.}

Origin, Alabama. Fruit medium or small, roundish, inclining to conic, regular, greenish, with a few brown dots. Flesh whitish, modelately juicy, ruther firm, subacid. good. Core small. November, December.

\section{Blackstone Valley Sweet.}

Originated in Massachusctts. Tree productive. Fruit medium, oblate, often depressed, inclining to conic, greenish-rellow, some nettings of russet, gray and green dots. Flesh white, finc-grained, sweet, and rich. Good for cooking. August. Core small. 
BuAck ANsette.

An old variety, consiclerably grown in some parts of the Eastern States. Tree a good bearer. Fruit medium, small, roundish, dark red. Flesh white, tender, negative in character, pleasant. Good. November, December.

\section{Black Apple.}

- Small Black. Jersey Black. Black American.

An old variety, described and put out by Coxe, and now found in many sections. The trees are healthy, moderate growers, forming medium-sized, spreading round heads, with diooping limbs. It is a pleasant table fruit, although not of high or rich flavor.

Fruit medium. Form roundish oblate, deep red, with a bloom. Flesh white, sometimes slightly stained with pinkish red. Good. November to February:

\section{BuACK Gilliflower.}

Medium size, oblong conical. Skin very dark, dull red. Flesh white, dry, mild, subacid. Good. November to February. Very productive, and some cail it a profitable market fruit.

\section{Buand's Jubilee.}

Originated in Norwich, England. Fruit large, round, slightly conical, obscurely ribbed, clear yellow, with many large russet dots or patches, and russet at the calyx. Flesh yellowish, tender, crisp, juicy, sugary, perfumed. October to January. (Hogg.)

\section{BLAKE.}

Originated in Westbrook, Cumberland Co., Maine. Fruit medium to large, roundish, greenish yellow, quite yellow at maturity. Flesh frm, fine, crisp, juicy, subacid. Good. October to January. (Me. Rep.)

\section{Blakely.}

Origin, Pawlet, Vermont, on the farm of Mr. Blakely. Vigorous, up right growth, regular bearer.

Fruit lar'ge, regularly oblate, slightly conie, yellow, with a sunny cheek thinly sprinkled with reddish dots. Stalk small and short, inserted in $\varepsilon$ broad cavity of moderate depth. Calyx nearly closed. Basin small and shallow. Flesh tender, juicy, with a very pleasant, mild, subacid flavor. Good. January, Narch.

\section{BLECKENSDERFER.}

Originated at Zoar, Olio. Fruit medium, oblate, inclining to conic, yellow, shaded and splashed with two shades of red or crimson. Flesh white, rather firm, tender, juicy, subacid. Hardly good. November to February.

\section{Bledsoe Pippin.}

Raised by John Blodsoe, of Carroll Co., Kentucky. Growth moderate, rather spreading, productive, a promising winter Apple for the South. 
Fruit very large, reguiar, roundish, flattened at the base, tapering to the apex, greenish yellow, very obscurely strijed. Stalk short. Cavity cleep, slightly russeted. Calyx partly closed, in a somewhat fur. rowed basin. Flesh white, fine texture, crisp, juicy, with a mild, pleasant subacil Havor. Good. December to April. (Ky. Hort. Soc.)

\section{Blenheim Pippin.}

Blenheim.

Blenheim Orange.

Northwick Pippin.

Kempster's Pippin.

Woodstock Pippin.

An old variety, originated at Woorlstock, in Oxfordshire, England. Tree a strong and vigorous grower, a regular and abundant bearer.

Frnit large, romdish oblate, conical, yellowish, becoming deep orange, stained on the sumny side with dull and dark red stripes. Stalk short and stont, in a deep cavity. Calyx large, open, in a deep broad basin. Flesh yellow, breaking, very sweet, pleasant. Good. October, December.

\section{Burnkoxyy.}

\section{Blinkbonny Seedling.}

Raised by —_Cleghorn, Montreal, Canada. Tree vigorous, upright spreading, very productive. Fruit medium or below, roundish oblate, pale whitish yeliow. Stalk long, slender. Calyx closed. Flesh white, rather firm, pleasant, subacid. Core small. Good. September.

\section{BLOCKLET.}

\section{Blockley Pippin.}

Origin, ne:ur Philadelphia. Growth upright, moderate, a good bearer.

Fruit medium or large, roundish oblate. Color fine yellow, sometimes with a faint blush, thinly sprinkled with brown dots. Sंtalk short, rather stout, inserted in a cleep russeted cavity. Calyx partially closed, set in a broad, deep, corrugated basin. Flesh yellowish, compact, rich, sprightly, mild subicid. Good. November to Jannary.

\section{Blondr.}

Originated with Reuben Ragan, Indiana. Fruit rery large, oblate, mequal, greenish yellow, splashed and striped with red, dots large gray Flesh greenish yellow, tender, juicy. October, Norember. (ITarder.)

\section{Blooming Orajge.}

Under this name WT. G. Waring, of Centre Co., Pi., has introduced an Apple said to have been brought from Herefordshire, England. ITe have been unable, from the few specimens examined, to identify it with any known sort. Tree vigorous, with strong, smooth shoots, resembling the Rhode Island Greening in color, but of upright growth.

Fruit large, roundish oblate, imelining to conic, yellowish, striped, splashed, and shaded with dull red, with large whitish and gray dots. Flesh white, juicy, pleasant subacid. Good to very good. Core merlium. November and December. This may yet prove to be somo known kind but as we have not fruited it ourself, cannot decide. 


\section{Blue Mountain.}

\section{Trout Aple or Forelle. Blauberger.}

Introduced by W. G. Wring. Tree hardy, moderate grower, forming a small round head. Young shoots, slender, dark brown.

Fruit rather large, roundish oblate, whitish, with broken splashes and stripes of light red, dotted with few gray dots. Stalk rather short. Calyx small and closed. Bitsin medium, corrugated. Flesh white, crisj', juicy, brisk subacid. Core lauge. Good to very good. Novenber to February.

\section{Blue Mountain Sweet.}

Origin unknown.

Fruit medium size, roundish, slightly oblate, greenish yellow, with a shade of brown. Flesh fine-grained, solid, sweet. Very good. (Count. Gent.)

\section{Blue Pearmain.}

Fruit of the largest size, roundish, regularly formed, very slightly conical. Color stripes of dark purplish-red, over a dull ground, and appearing bluish from the white bloom. Flesh yellowish, mild, rather rich, aromatic, and very good. 'The tree grows strongly, and bears moderate crops. October to February.

\section{Bluff Sweet.}

From the banks of the White River.

Fruit medium to small, round, regrular, smooth, green. Flesh green ish white, sweet. Good. July. (Warder.)

BoAs.

Kelter.

A Pennsylvania Apple, introduced by Rev. Mr. Boas, of Berks Co. Tree a strong grower and productive.

Fruit medium, oblate or roundish oblate, pale yellow, shaded and indistinctly splashed and striped with crimson over most of its surface. Stalk short and stout. Cavity medium. Calyx closed or partly open. Basin slightly corrugated. Flesh whitish yellow, fine-grained, juicy, pleasant, brisk subacid. Core small. Very good. Jannary to March.

\section{BoAlsburg.}

A seedling of Centre Co., Pa. I targe, oblong, inclining to conical, delicately mottled, and striped with red on a yellow ground. Stem short, thick, inserted in a deep acuminate russeted cavity. Basin deep, moderately wide. Flesh yellow, juicy, sprightly. Good. February

\section{Bollaxinan.}

\section{Buchanan.}

A Southern fruit introduced by Lewis Sanders, of Kentucky. T'ree upright sprearing, young shoots, light reddish brown. Good regular bearer.

Fruit rather large, rounrish oblate, approaching conic, fine yellow, with a bright crimson cheek in the sun. Stalk slender, inserted in a round, 
uneven, slightly russeted cavity. Calyx closed in a narrow abrupt basin. Flesh yellow, tender, juicy, with a fine spicy subacid flavor. Cor' large. Good culinary. September, August.

\section{Boyum.}

\section{Magnum Bonum.}

Raised by Squire Kinney, Davidson Co., N. C. Tree upright spread. ing, hardy and vigorous, an early and abundant bearer. Young shoots, smootli reddish gray.

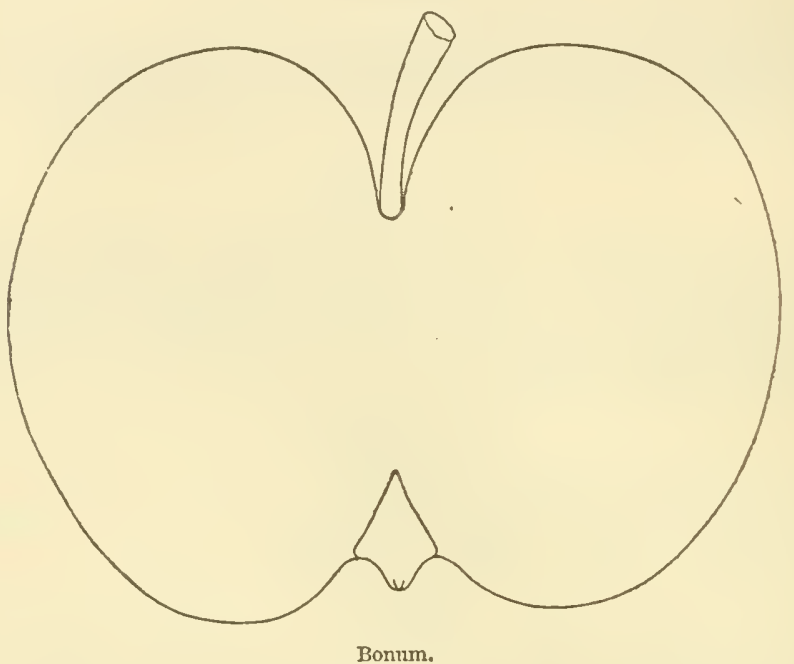

Fruit medium, oblate, yellow, mostly shaded with deep erimson, and indistinct stripes and splashes of dark red, rather thinly sprinkled witl pretty large light dots, a portion of them having a dlark centre. Stalk long and slender. Cavity medium to large, often with a little green russet. Calyx closed. Segments rather long and sometimes recurved. Basin shallow, slightly corrugated. Flesh white, often stained next the skin, firm, tender, juicy, rich, mild subacid. Core small. Very good. November to December.

\section{Borden's Early.}

Origin unknown. Tree vigorous, spreading, productive.

Fruit medium, roundish oblate, conical, vellow, striped, and splashed with two shades of red. Flesh yellowish, crisp, juicy, mild subacid. Core large. Good. A desirable cooking apple.

\section{BorOYTSKY.}

A. Russian Apple of medium size, roundish, angular. Skin pale whitish yellow, faintly striped. Flesh white, firm, subacid. August.

There may be a distinct variety under this name, but, so fiur as re ceived by me, it has proved to be identical with Duchess of Oldenburg. 


\section{BORSDORFFER.}

Bursdorff.

Queen's.

Wdler Winter Borsdorffer.

Garret Pippin.

Le Grand Bohemian Borsdorffer.
King George the Third.

Reinette Bitarde.

Bursdorfler.

King.

Reinette de Misnie.

A small celebrated German Apple.

Fruit roundish oval, narrowing at the eye. Skin pale yellow, with a full red cheek, sprinkled with a little russet. Flesh yellowish white, very firm and crisp, with a rich, brisk, perfumed flavor. November to February.

\section{BORSDORF OgNOx.}

\section{Reinette Plate. Zweibel Apfel.}

Of German origin. Tree with short, stocky, yellowish-brown shoots, regular roundish head.

Fruit small, greenish yellow, with large, distinet gray spots. Flesh white, firm, subacid, perfumed, rich flavol. Winter. (Verg.)

\section{Bonne Virginie.}

A Belgian variety.

Fruit medium, roundish, flattened at base, glossy greenish yellow, with red in the sum. Flesh white, firm, sugary, slightly acid, agreeably perfumed. October. (Alb. Pom.)

\section{Bossoy.}

Originated at Petwortl, England.

Fruit large, conical, pale greenish yellow, very much russeted, and with bright red on sunny side. Flesh yellowish, erisp, juicy, sugary, subacid. Valuable as a cooking-apple. November to March. (Lincl.)

\section{BOTIGNE.}

\section{De Boutigne.}

Of Belgic origin. Tree vigorous, upright, with large reddish-brown shoots, downy at the end.

Fruit rather large, oblong conical, yellow, washed over with carmine red, and marbled with spots of gray and black. Flesh yellowish, firm, very juicy, sugary. Core long, irregular. November to March. (Alb. Pom.)

\section{Bottle Greening.}

This variety was found near the Vermont and New York State line, and takes its name from a hollow in the original tree, where workmen were accustomed to keeping their bottle. It was introdneed to notice and disseminated by Eben Wight, of Dorehester, Mass. Tree a fine grower, vigorous, spreading. Young wood reddish yellow. .

Fruit nedium, oblate inclining to conic, greenish-yellow, shaded with dull crimson in the sun, a slight bloom, and thinly sprinkled with light dots. Stalk rather short. Cavity broad. Calyx elosed. Basin small, corrugated. Flesh white, subacid, almost melting. Core small. Very good. January, February. 


\section{Bourassa.}

A foreign variety, succecds well at the North, apt to shrivel, aud does not keep well.

Fruit medium, roundish conic, ribbed, yellowish, rich orange russet on the sumy side. Flesh white, sometimes stained, tender, with a pleasant aromatic flavor. Good. November, December.

\section{Bowyer's liusset.}

An Fnglish variety. Valuable for desert there in September. Tree healthy and productive.

Froit small, roundish conical, yellowish, russeted. Flesh yellow. ish white, crisp, brisk, aromatic. September. (Lind.)

\section{BOWKER.}

Tree vigorous, rather spreading, good bearer.

Fruit medium, roundish flattened, slightly conic, pale yellow, tinged with crimson, sparsely covered with brown, and gray dots. Flesh white, tender, juicy, pleasant, mild, subacid. Good. October.

\section{BOWLING'S SWEET.}

From Spottsylvania Co., Va. A very vigorons grower and very productive.

Fruit medium, roundish. Color dull red, on a rellow ground. Flesh rich, juicy, sweet, and entirely free from acid. Good. October to January.

\section{BOXFORD,}

Fruit medium, oblate. Skin whitish, striped with red. Flesh compact, crisp, juicy, subacid. Good. September, October.

\section{Braddick's Noxpareil.}

Originated at Surrey, England.

Fruit small, roundish conical, or flattened at base, yellowish, with brownish red in the sum, and russet near the calyx. Flesh yellowish, rich, sugary, aromatic. October, December. (Lind.)

\section{Bradley's Autumin.}

Originated in orchard of Mr. Bradley, Plymouth, Mich. Tree thrifty, with a spreading top, productive.

Fruit large, roundish oval, somewhat ribbed, whitish-yellow, shaded where exposed to the sm with fine crimson, and pretty thickly sprinkled with brown dots. Stalk r'ather short and small. Cavity uneven, acute. Calyx closed. Segments ereet. Basin rather abrupt, fiurowed. Flesh white, moderately juicy, brisk, subacid. Core large. Good. Excellent for cooking. October to January.

\section{Brajdywine.}

Origin mknown.

Fruit above medium, roundist conical, slightly ribbed, a little ob. 
lique, rellowish, sharled, splashed, and striped with red over half tc two-thirds its surface, many large, light dots. Stalk short and small. Cavity deep. Calyx elosed, or partially open. Basiu large. Flesh yellowish, crisp. juicy, tender, mill, somewhat rich, subacid, slightly aromatic. Core suall. Ciood to very goorl. November to February.

\section{Brabayt Bellflowter.}

\section{Brabant Belle-fleur. Iron Apple.}

The Brabant Belle-fleur is a variety from Holland. The habit of the tree is sprealing, and it requires to be grafted high to make a good head.

Frnit lange, roundish oblong, slightly ribbed. Skin pale yellow, much striped with red. Calyx large, set in a pretty wide, irregular basin. Flesh firm, juicy, with a rich, pleasant, subacid flavor. Good. Valuable for cooking. October to Jamary.

\section{Breedon Pippin.}

A variety from Berkshire, Eugland. 'Tree hardy, slender, productive.

Fruit small, roundish oblate, dull yellow, tinged with orange, becoming red in the sun, with traces of russet. Flesh yellowish, firm, with a vinous brisk flavor. October, Novenber. (Lind.)

\section{Brencainan.}

Raised by Mr. Bremnaman, Laneaster Co., Pa. Tree vigorons, upright, productive. Toung wood short-jointed, reddish-brown, somewhat downy.

Fruit rather above medium size, roundish oblate, yellowish, nearly covered with red stripes, and splashed. Stem short, in a large cavity. Calyx closed in a deep basin. Flesh white, tender, juicy, with a pleasant, subacid flavor. Good. Excellent for cooking. August, Septexuber.

\section{Brewer.}

From Massachusetts, a good grower, an annual bearer.

Fruit very large, roundish, yellow, with a slight blush. Flesh yel. lowish, tender, pleasant, mild, sụbacid. Good. October, November.

\section{Brewer's Pippin.}

An English variety.

Fruit medium, rounlish, brownish yellow, with red stripes. Flesh white, crisp, tender, subacid. Cooking. November. (L. H. S.)

\section{Bricklex Seedlixg.}

Of English origin. Tree hardy, productive.

Fruit small, roundish conical, greenish yellow, red when exposed to the sun. Flesh yellowish, firm, rich, sugary. January to $\Lambda_{\text {Iuil. (Lind.) }}$

\section{Brigg's Auburn.}

Origin, Anburn, Me. Tree lıardy, vigorous, and productive ; fruit large, oblatw, somewhat ribberl, whitish yellow, blnsh in sun, with a few light and gray dots. Flesh white, firm, pleasant, mild, subacid. Core medium. Good. September, October. 


\section{Bridgewater Pippin}

An old English culinary sort.

Fruit large, roundish, slightly flattened, ribbed, deep yellow, with blush of red in sun and near the stalk. Flesh yellowish, brisk, pleasant. October, December. (Hogg.)

\section{Brill's Seedlixg.}

A chance seedling of Francis Brill, Newark, N. J. Tree a rapid up. right grower, with light-colored shoots.

Fruit large, oblong conical, much ribbed, yellow, moderately sprinkled with gray dots. Skin oily. Stalk rather short. Calyx closed. Basin large, corrugated. Flesh yellowish, tender, juicy, sprightly, subacid. Core very large and open. Good to very good. November. An apple of good promise as a profitable market sort, being large and showy.

\section{BrIMER.}

\section{Yoder.}

Of Pennsylvania origin.

Fruit medium, oblate inclining to conic, sides sometimes unequal and slightly ribbed, whitish yellow, with a tinge of red in the sun, and thinly sprinkled with gray dots. Flesh whitish, crisp, rather tender, juicy, pleasant, subacid. Good to very good. Core small. February, March.

\section{Brixckley White Sweet.}

Unknown origin.

Fruit small, roundish oblate, pale whitish green, dull red on the sunny side, few gray dots. Flesh white, crisp, tender, juicy, sweet, honeyed tlavor. Very good. October.

\section{Bringewood Pippin.}

Originated with Thomas Andrew Knight, Esq., Herefordshire, Eng. land. Trce hardy, but a slender grower.

Fruit small, roundish, rich yellow, dotted and marked with russet.

Flesh yellowish, fir'm, crisp, sugary, aromatic, dry. October to March. (Lind.)

\section{Bristol Pearmain.}

Origin, Hampshire, England.

Fruit small, oblong, ribbed, dull yellowish green, stripes of crimson and patches of gray russet. Flesh yellow, firm, not juicy or of much value. October to February. (Hogg.)

\section{Bristol.}

An old variety, much grown in Connecticut many years since. A pleasant but not rich fruit. Tree hardy, rather slender, drooping when in fruit.

Fruit medium or below, roundish, inclining to conic, dark rich crim. son red. Flesh very white, often stained under the skin, tender, juicy. Good to very good. Core rather large. January to March. 


\section{Brittle Sweet.}

Origin unknown. Tree moderately vigorous, very productive. This valuable apple is little known; in beauty and quality it may be classed as among the best, and deserves more attention.

Fruit above medium, roundish, approaching conical. Color pale yellow, shaded, splashed and marbled over nearly the entire surface, with shades of light and dark crimson red, many small gray and white dots. Stalk ruther short, slender. Cavity regular, broad, moderately deep. Calyx closed. Seginents small, often recurved. Basin small corrugated. Flesh yellowish, crisp, tender, juicy with a peculiar honeyed sweet, and slightly aromatic. Core rather large. Very good. October and November.

\section{BroAd-End.}

Winter Broading. Kentish Broading. Broading.

An old English culinary apple, in use from November to Christmas. Tree strong, vigorous, productive.

Fruit large, roundish oblate, yellowish green, red in sun, with patches of russet. Flesh yellowish white, firm, crisp, subacid. (Hogg.)

\section{Broad-Ere Pippin.}

Another old English sort for culinary use.

Fruit large, oblate, greenish yellow, tinged with red in the sun. Flesh yellowish white, firm, crisp, brisk, juicy. January. (Hogg.)

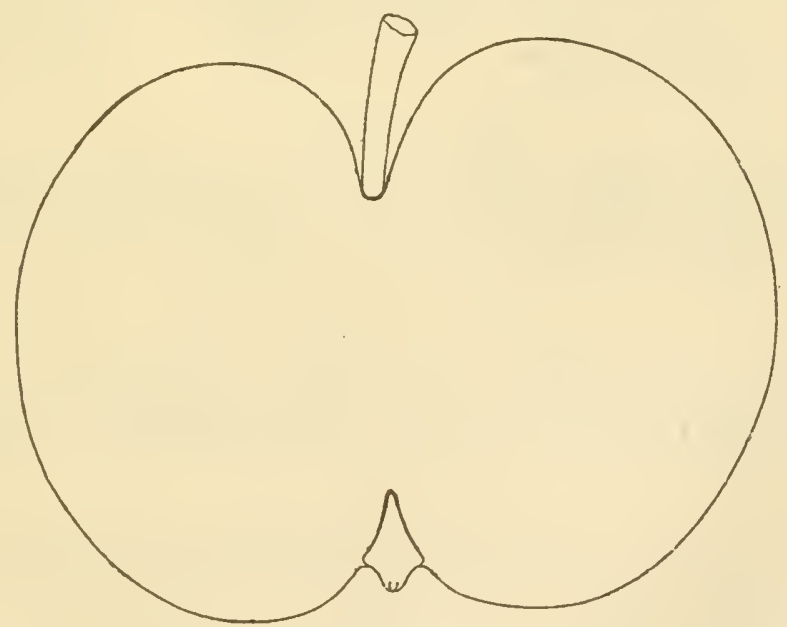

Broadwell.

BROADWELL.

Broadwell Sweet.

Originated with Jacob Broadwell, near Cincinnati, O. An extremely valuable sweet apple, either for the table or cooking. 'l'ree vigorous, quite hardy, very spreading, irregular, productive. Young shoots dull reddish brown, downy. 
Fruit medium, oblate, somewhat conic. Color clear bright yellow, brownish blush in the sun exposure, with carmine spots. Dots few, greenish, sutfused beneath. Stalk rather short. Cavity broad, russeted. Calyx closed, with short segments. Basin abrupt, regular. Flesh whitish, firm juicy, rich, sweet. Core small. Very good. November to February.

\section{Brookes.}

An old Norman Apple. Tree a free but slender grower, abundant bearer.

Fruit small, conical, golden orange, with bright red next the sun, some russet. Flesh yellowish, firm, rich, sweet, aromatic. October to February. (Ron.)

\section{Bronson SweEt.}

Origin unknown. This variety was many years since carried by a Dr. Bronson from Connecticut to Ohio, without name, and there received its present title. Tree a moderate grower, making a round head.

Fruit medium, oblate, sometimes oblate conic, yellowish, mostly overspreal, striped, and splashed with red. Flesh white, compact, moderately juicy, pleasant, sweet. Good. October, November.

\section{Brown.}

A Pennsylvania Apple.

Fruit medium, oblate, slightly ribbed, yellow, striped, splashed and shaded with light and dark crimson over two-thirds the surface. Flesh yellowish, erisp, tender, juicy, rather rich, subacia. Very good. Core small. October, November.

\section{Brown Kentixg.}

An English dessert apple.

Fruit above medium, roundish, slightly ribbed, yellowish, with russet marblings and brown russet in the sur. Flesh yellowish, crisp, brisk, aromatic. October to December. (Hogg.)

\section{Brown's Summer Beauty.}

Origin, Slough, Englind. Tree vigorous, good bearer.

Fruit medium, roundish conical, dull greenish yellow, with a red cheek. Flesh delicate, rich, juicy. A tine table apple. September. (Ron.)

\section{Brownlee's Riusset.}

\section{Brownlee's Seedling Russet. Reinette Grise Brownlee's.}

An English variety. Tree vigorous.

Fruit large, roundish, flattened greenish, with brownish red next the sun. Flesh greenish white, tender, juicy, sweet, aromatic. Good for cooking or the dessert. From Jan'ary to May. (Hogg.)

\section{Browite.}

\section{Brown's Winter.}

Origin, supposed Delaware. 'Tree a regular grower, with spreading branches. 
Fruit below medium, roundish oblong, conical. Flesh tender, crisp, sprightly. Mid-winter: (Coxe.)

\section{Brozghtor.}

A valuable Fuglish dessert Aplule.

Fruit small, eonical, regular, greenish yellow, covered with lively red, becoming deep red in sun, and with many russet dots. Flesh greenish yellow, tender, brisk, rieh flavor. October to Deeember. (Hogg.)

\section{Buchuxay's Pippin. \\ Buchanan's Seed!ing.}

Raised by Robert Buchiman, Cineinnati, O. Tree vigorous, round. hearlerl, very productive.

Fruit medium, oblate or roundish oblate. Color yellow, splasherl and striped with light and dark crimson, in the sun clark crimson maroon, many light conspienous dots. Stalk short and suall. Cavity medium to large, russeted. Calyx partially closed. Segments medium erect, or partially recurved. Basin rather abrupt, slightly corrugated. Flesh yellowish, rather firm, crisp, juicy, pleasant, slightly aromatic, subacid. Core elose and small. Tery good. January to April.

\section{Buctisghair.}

Queen.

Fall Queen.

Winter Queen.

Kentucky Queen.

Lexington Queen.

Frankfort Queen.

Ladies' Farorite of Tenn. Henshaw.
Sol. Carter.

$\begin{array}{ll}\text { Byer's. } & \text { Winter Queen. } \\ \text { Ox-Eye of some in } \mathrm{K} y \text {. Ne Plus Ultra. }\end{array}$

Bachelor. King.

Merit. Byer's Red.

Red Gloria Mundi of some.

Red Horse of some.

The origin of this Apple appears all unknown. It lias been long grown in Tirginia, Kentucky, and other Southwestern States, and is there a protitable and popular variety, valuable either for market or table use. It matures often in Norember, but will keep into February. Tree hardy, healthy, moderately vigorous and productive, forming a roundheaded spreading tree of medium size. Yroung shoots rather slender, dull reddish brown.

Fruit medium to large. Form oblate, inclining to conic. Color greenish rellow, mostly covered, shaded, striped, and splashed with two shitdes of crimson or purplish red, many light brown dots. Stalk short. Civity broad, deep, slightly russeted. Calyx closed. Segments to a point. Basin rather large, deep, slightly corrugated. Flesh yellowish, rather coarse, breaking, tender, juicy, mild, sprightly, subacid, Core small. Tery good to best. November to February.

\section{Bucks Coustr Piprix.}

Origin, Bucks Co., Par. Tree upright, spreading. Young shoot pretty stout, short-jointed, redilish brown, downy, with prominent downy buds.

Fruit rather large, oblate or roundish oblate, oblique, greenish yellow, sometimes with a dull blush in the sun, brown dots. Stalk short. C'avity large, irregular. Calyx closed or partially open. Basin abrupt, 
slightly furrowed. Flesh yellowish, crisp, juicy, tender, brisk, subacid Very good. November to Marcl.

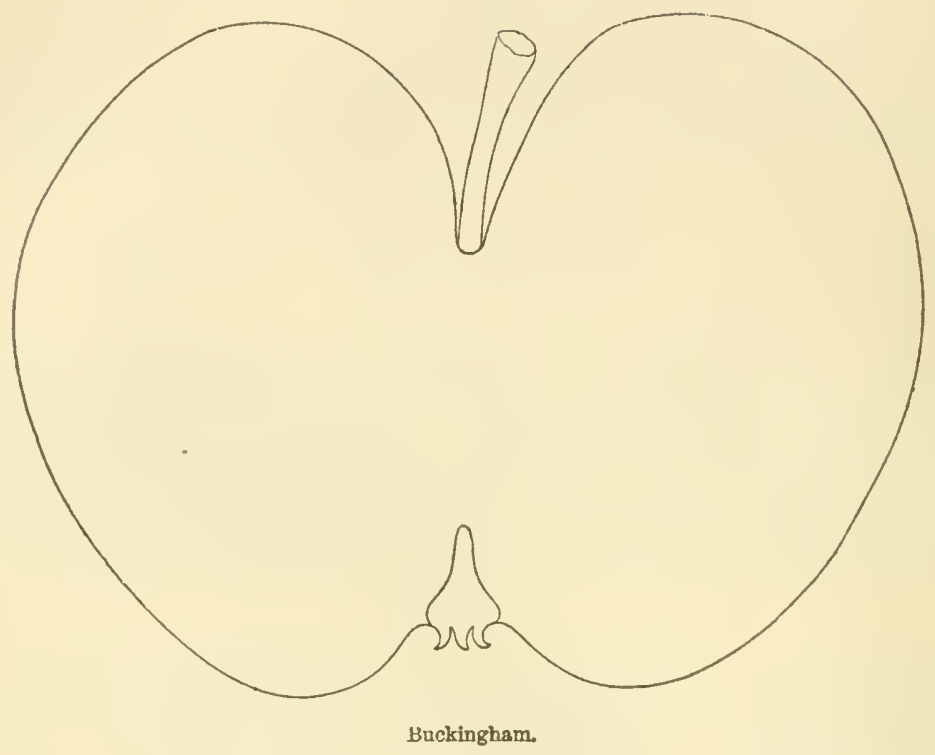

Buck Meadow.

()igin, Norwich, Conn:, productive.

Fruit above medium, roundish, lightly conic, yellow, marbled and streaked with red. Flesh yellowish, tender, juicy, with a rather rich, pleasant, vinous flavor: Good. November to March.

Buel's Fayorite.
Spotted Pippin.
Gray Pippin.

Fruit medium, roundish, greenish yellow. Flesh white, firm. November. Hardly good.

\section{Buel's SWeET.}

Fruit small, roundish conical, yellow, shaded with rich deep red in sun, brown dots. Flesh white, cou pact, not tender, moderately juicy, not quite good. Winter.

\section{Buffington's Early.}

Origin said to be on the Brandywine, Pa. Tree of good upright growth, bears moderately.

Fruit medium or below, oblate, yellowish white, sometimes a faint blush. Stalk short. Cavity large, slightly russeted. Calyx closed. Basiu shallow, slightly corrugated. Flesh tender, juicy, with a sprightly subacid flavor. Good. Middle of Angust. 
BuFF.

Granny Buff.

Origin, Haywood Co., N. C. 'lree vigorous, upright, productive.

Fruit large to very large. Form roundish oblate, irregular. Sides unequal. Color whitish yellow, orerspread with broad, Jroken splashes and stripes of dark crimson. Stalk short, rather slender. Cavity large, deep, much russeted. Cirlyx open or partially elosed. Seginents medium length, separated and partially reeurved. Basin deep, abrupt, slightly corrugated. Flesh white, rather coarse, breaking, subacid. Core medium. Good. December and January.

\section{Bull's Golden Reinete.}

An English variety. Fruit medium, roundish oblate, yellowish, highly colored with crimson red in the sun. Flesh yellowish, tender, juicy, sweet. December, Jamuary. (Hogg.)

\section{BuLlETT.}

\section{Bartlett. Priestly of some.}

An old variety, origin unknown. Fruit medium, oblong truncated, bright red and yellow. Flesh light yellow, subacid. Good. Valuable only as a long keeper. January to June.

\section{Bullett.}

\section{Green Abram. North Carolina Greening.}

An old rariety of Southern origin, formerly much grown in Virginia, Kentucky, and North Carolina, but now superseled by better sorts. Tree hardy, a slow, rather slender grower, of a drooping habit, productive.

Fruit medium, oblate, oblique, greenish, mostly overspread witlı stripes and shades of red and grayish russet. Flesh white, firm, moderately juicy, peculiar subacicl. Good. Core small, compact. January to June. Valuable only for its long keeping quality.

\section{Burrell's Red.}

An English Apple of robust growth and productive. Fruit above medium, conical, red, approaching scarlet. Flesh juicy, agreeable acid. November to January. (Ron.)

\section{Burr's Seeding}

Origin, Marlborongh, England. Fruit medium roundish, slightly conical, rellow, blush red in the sun, patches and dots of russet. Flesh yellowish, tender, juicy, subacid. October to December. (Hogg.)

\section{Burr's Wixter Siveet.}

Raised by Elisha Burx, Hingham, Mass., a good grower, comes early into bearing, prodnctive.

Fruit medium, oblate inclining to conic, yellow, marbled and striped with light and dark red. Stalk short, inserted in a large eavity. Calyx closed. Basin small. Flesh yellowish, tine grained, tender, juicy, 
with a sugary aromatic flavor. Very good. Core small. November to March.

\section{Burst Opex.}

Origin unknown. Frnit medium, oblate, much ribbed, pale whitish yellow, splashed and striped with light and dark crimson, few gray and light dots. Flesh whitish, tender, mocrately juicy, mild subacid. Good Core medium. November.

\section{Burroughs Greenisg.}

Origin, farm of Stephen MI. Burroughs, Vergennes, Vt. Gond grower, tree spreading, and regular bearer. Medium, nearly globular, inclining to conic. Skin greenish, yellow. Stem long, slender. Calyx closed. Basin funowed. Flesh solid, juicy, crisp, with a pleasant spicy subacid flaror. Good. Jamuary and February.

\section{Busir's Beauty.}

Origin on the furm of Henry Bush, near Sandusky, O. Tree spreading, a yearly abundant bearer. Fruit medinm, roundish, flattened at base. Surface irregular, creamy white, striped and splashed with rermilion pink, a little russet toward the stalk. Flesh whte, crisp, tender, acid. Good. September, October. Valuable for market.

\section{Bush.}

Origin, furm of Christian Dale, near Boalsburg, Centre Co., Pa. Rather above medium, oblate inclining to conical, light rellow, faint blush in the sum, brown dots. Flesh white, rather firm, mild subacid. Nearly very good. Core smail. September.

\section{BusmWHACKER.}

A variety found wild near Nyack, N. J. Fruit large, roundish conical, yellow. Good. February to May.

\section{Butter.}

From Pennsylvania. Tree vigorous, upright, very productive. Fruit above medium, roundish, yellow, fain. Stalk short. Cavity deep and romul. Calyx small, closed. Basin large and open. Flesh whitish, very sweet and rich, valuable for cooking, and esteemed for making apple-butter. September and Octobor.

Another Butter apple is described in Elliott as follows:- "Frnit below medium, regular roundish, red marbling and orerspreading rellow, few yellow russet dots, russet near and in cavity of stem. Stem long, slender. Cavity narrow, deep. Calyx half closed. Basin abrupt, ribbed. Core medium. Seeds roundish orate. Flesh yellowish white, tender, sweet. Very good. November to February."

Another Butter is thus described by Warder, with Fulkerson's as a synonym:- "Fruit small, very regular, oblate. Surface rery smooth and so coverel with mixed red as rarely to show the yellow gromil color; mon this are laid darker stripes of deep red. Dots minnte and inconspicuous. Basin medium, regular, folded. Eye rather large, closed. Carity acnte. Stem of medium thickness, rather long. Core wide; large, plump pointed 
seed. Flesh vellow, tender, fine-grained, juicy, with a sweet rich and aromatic flavor. October to January."

There are, besides these, three or four different varietics under the nane of Butter, which appears to be a favorite name with some to apply to any good sweet apple fior sauce or cooking.

\section{Bran's SweEt.}

()

Fruit medium, oblate, inclining to conic, yellowish, with a shade of red in the sun, gray dots. Flesh whitish, rather tender, juicy, lively, sweet pleasant tlavor. Core small. Very good. October.

\section{Brson Wood Russet.}

\section{Byson Wood.}

An English Apple, there esteemed for dessert.

Fruit below medium, oblate, greenish yellow, covered with gray russet. Flesh greenish, firm, crisp, juicy, brisk, sugary, aromatic. December to February. (Hogg.)

\section{CABASHEa.}

\section{0-Ounce Pippin. King.}

Origin unknown. Tree a vigorons grower, poor bearer, and unprofitable. Young shoots very dark reddish brown, downy.

Fruit very large, roundish oblate, conical, yellow striped and splashed with dull red. Flesh whitish, coarse, subacid. Poor. December to February.

\section{Cabbage-Head.}

Probable origin, New Jersey. Tree a vigorous grower and good bearer.

Fruit large, oblate conical, golden yellow, with a few gray dots. Flesh yellow, a little coarse, crisp, juicy, brisk, subacid. Good. Core medium. December.

\section{CACHE.}

A native of Pulaski Co., Ill. Tree healthy and productive.

Fruit medium, roundish conical, greenish, with a shade of brownish crimson in the sun, gray dots. Flesh white, close-grained, not very juicy, mild subacid. Good to very good. Core small. November.

\section{Cake Aprle.}

\section{Connecticut Cake.}

Origin, Connecticut. Medium, oblate, much depressed, yellowish, with a blush. Flesh juicy, tender, pleasant, subacid, almost sweet. Good, sometimes very good. A great keeper, and in some localities considered viluable on account of its productiveness, fair even size, and keeping quality. January to March.

\section{Caleb Sweet.}

Of Pennsylvania origin. Tree vigorous and very productive. 
Fruit medium, oblate conical, yellow, with a tinge of brown in sun. Flesb yellowish, crisp, rich, sweet. Core small. Good. September.

\section{Calville Blancie ì Cote's.}

Of French origin. Tree vigorous, prodnctive, with long jointed branches of reddish brown.

Fruit medium, conical, Hattened at base, lemon yellow, with. red in sun. Flesh white, fine-grained, tender, acid. December to May. (Verg.)

\section{Calville Malixgre.}

Pomme de Malingre, and many other synonyms.

An old rariety. Origin in doubt.

Fruit very large, elongated, ribberl, yellow, deep red next the sun, with stripes of darker red. Flesh white, delicate, juicy, agreeable, acid. A culinary apple. From July to April. (Hogg.)

\section{Calville Rouge de Micoud.}

This is an old French Apple, said to blossom and get three crops of fruit in a season.

The fruit is large to small in size, mostly covered with red, with a yellowish-white sweet flesh. (Lind.)

\section{Calef's Sweet.}

Origin, Kingston, N. H.

\section{Magoun Apple.}

Fruit large, roundish flattened, yellow, with gray dots and crimson specks. Flesh white, rery rich and sweet. November to January. (Maine Report.)

\section{Camack's Sweet:}

\section{Camack's Winter Sweet. Grape Vine.}

Origin, Macon Co., N. C. Tree a slow grower, with small wiry branches, irregular spreading, an early and abundant bearer.

Fruit medium, roundish, sometimes conical, light yellow gren, red in sun. Flesh yellowish, firm, juicy, brisk, pleasant, saccharine. Good. Core small. February.

\section{Camprell.}

This new variety is an accidental seedling in the grounds of George WT. Campbell, Delaware, $O$. He describes the tree as a vigorous strong grower, open spreading habit, shoots stout, blunt, leares large and abundant, at good regular bearer.

Fruit medium, roundish, oblate, a little oblique, pea green, with broken dull red stripes in the sum or toward the stalk end, and with more or less of russet from the stalk cavity; scattering rough distinct dots. Stalk short. Cavity deep, open, narrow, russeted. Calrx closed with broken segments. Basin very deep, slightly furrowed. Flesh greenish white, crisp, breaking, half tender, mild, juicy, subacid, pleasant. Crood to rery good. Core small. Slightly hollow in centre. Seeds dart blackish, pointed. December to February. 


\section{Cambusnetuan Pippin. \\ Winter Red Streak. Watch Apple.}

A Scotch variety, medinm, roundish, light yellow, striped and shadeō with crimson and dark red. Flesh yellowish, juicy, subacid. Good to rery good. Septeuber, December.

\section{Campfield.}

Newark Sweeting. Sweet Maiden's Blush.

A capital New Jersey cider apple, ranking next to the Harrison. It iorms a fine large tree, with straight, spreading limbs, and is very productive. Fine for baking and stock feeding.

Fruit of medium size, roundish, rather flattened. Skin smooth, washed and striped with red, orer a greenish-yellow ground. Flesh white, tather dry, firm, rich and sweet. Good. April, May.

Cax.

A very old Apple, originated in Schenectady, N. Y. Tree a good bearer.

Fruit above medium, oblong, yellow, shaded with erimson. Flesh ahitish, not juicy, pleasant. Good. November.

\section{PANY.}

Winter Sweet Bough. Winter Bough. Sweet Cann.

Tree vigorous and productive.

Fruit large, roundish, conic, greenish yellow, with a dull crimson cheek, slightly sprinkled with brown dots. Flesh white, compact, not very juicy, rich, sweet, and pleasant. Core large. December to Mareh. A good cooking and market apple.

\section{Chinad Reinette.}

Canadian Reinette.

Grosse Reinette d'Angleterre.

Pomme du Caen.

Reinette du Canada Blanche.

Reinette Grosse du Canada.

Reinette du Canada à Cortes.
De Bretagne.

Portugal.

Januarea.

Wahr Reinette.

Praire Rambour Reinette.

It is easy to see that the Canada Reinette is a popular and highly esteemed variety in Furope, by the great number of synonyms under which it is known. It is donbtful, notwithstanding its name, whether it is truly of Canadian origin, as Merlet, a French writer, rleseribes the same fruit in the 17th century, and some authors think it was first brought to this continent from Normandy, and earrierl back under its new name. At any rate, it is a very large and handsome fruit, a good bearer, and of excellent quality in all respects. Wherever grown in this country it sustains its foreign reputation, the tree being of vigorous habit, spreading, open, and productive. Young shoots clear reddish-brown, slightly downy.

Fruit of the largest size, oblate conical, flattened; rather irregnlar, with projeeting ribs; broad at the base, narrowing towards the eye, four inches in diameter, and three deep. Skin greenish-yellow, slightly washed with brown on the sunny side, sprinkled with dots and russet 
patches. Stalk short, inserted in a wide hollow. Calyx short and large, set in a rather deep, irregular basin. Flesh nearly white, rather firm, juicy, with a rich, lively, subacid flavor. Very good to best. Ripe in December, and, if picked early in autumn, it will keer till April.

The Canada Reinette Grise is very much like the above, and nay prove identical.

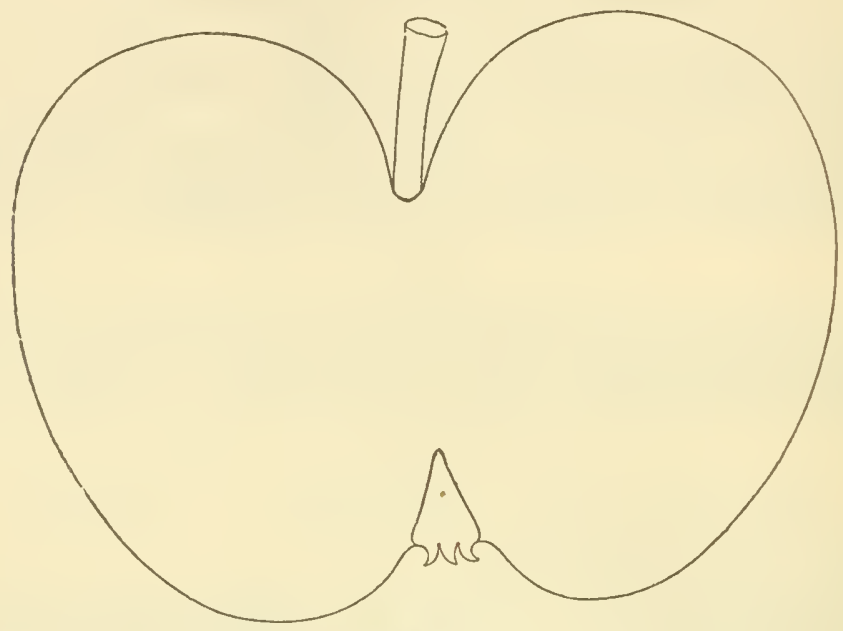

Canada Reinette.

\section{Cane Creek Sweet.}

Origin, Burke Co., on Cane Creek, N. C.

Fruit medium, roundish, pale greenish-yellow, shade of brown. Flesh white, rather firm, mild, sweet. Core medium. Good. July, August.

\section{Cannon Pearmain.}

Tree vigorous, spreading, and productive; much grown in North Caro lina, and some portions of the West.

Fruit medium, roundish conic. Color yellow, striped, and marbled with red and dark crimson, with large grayish dots. Stalk short. Cavity small, russeted. Calyx large, open. Basin large, round, deep, and open, corrugated. Flesh yellow, firm, with a rich, brisk, subacid flavor. Verý good. December to March.

\section{Canterbury Reinette.}

\section{Reinette de Cantorbery.}

Tree moderately vigorous.

Fruit large, roundish oblate, conical, greenish-yellow. Stalk long. Cavity deep. Calyx closed. Flesh white, coarse, juicy, sharp, acid. January to March. (Alb. Pom.) 


\section{Capital.}

Origin, Indiana.

Fruit small, globular, truncate, deep red on greenish yellow. Flesh yrellow, breaking, juicy, subacid. Good. December to January. (Warder.)

\section{Caplon's Pleasant.}

Fruit mclium, or above, roundish oblate, greenish yellow, with a brownish tinge. Stalk ratler stout, inserted in an open cavity, slightly russeted. Calyx large, closed, in a medium basin. Flesh yellow, juicy, tender, mill, subacid, and very agreeable. Good. Core small, September to October.

\section{Caraway Russet.}

From England.

Fruit below medium, oblate, pale brown russet, with an orange tinge in sun. Flesh firm, erisp, juicy, sweet. February. (Hogg.)

\section{Carbage.}

Medium, roundish conic, yellow. Flesh tender, juicy, sweet, without much flaror. September, October.

\section{Cardinal Red.}

Of European origin.

Fruit medium, oblate, inclining to eouic ; sides unequal; very dark red, almost blackish next the stalk; some light gray dots. Flesh white, rather firm, juicy, sprightly subaeid. Good. Core small. January, February.

\section{Carer's Seedling.}

Ohio origin.

Fruit small, roundish, yellow, slight blush in sun. Flesh yellowish white, tender, subacid. Good. October, November.

\section{Carlisle Codlin.}

A dwarf variety of the old English Codlin. Tree hardy, and abundant bearer.

Fruit above medium, ovate, flattened at base, pale yellow with a few russety specks. Flesh white, tender, erisp, juicy. A good cooking apple from August to September. (Hogg.)

\section{Cardel Sweet.}

Speckled Sweet.

A native of Carmel, Putnam Co., N. Y. Tree vigorous, upright, spreading. Very productive. Young shoots dull redelish brown, smooth.

Fruit medium, oblate, greenish yellow, with a blush, many fine red dots. Flesh white, juicy, teuder, sweet, and rich. Very good. October, November.

\section{Carvahan's Favorite.}

Origin, with Mr. Carnahan, Cincimnati, O. Tree vigorous, produc- 
tive. Fruit large, roundish conic. Color yellowish, striped and shaded with red, and much sprinkled with green or russet dots. Flesh fine grained, juicy, with a very pleasant vinous flavor. Good. December to March.

\section{Carnation.}

Fruit medium size, a delicious subacid apple, fully first-rate, darkred, splashed with russet. Flesh white, brittle, and very juicy. Both the calyx and stem are sunk in deep depressions. 10th of August. (White's Gard.)

\section{Caroline.}

Said to have originated near Tremont, O. Tree a strong upright grower and abundant bearer.

Fruit medium, roundish, slightly oblate, pale lemon yellow, brownish blush in the sun. Calyx large. Stalk slender. Flesh white, teuder, mild, subacid. Core rather large. Very good. September.

\section{Ciaroline.}

\section{Carolina Baldwin.}

Origin, premises of A. G. Baldwin, Hanover, N. J. Tree vigorous and productive.

Fruit medium, oblate, yellowish, mostly shaded with maroon, obscurely striped, and splashed with ligit and dark red, and thickly covered with light dots. Flesh yellowish, crisp, juicy, mild, subacid, rather rich. Very good. Core medium. December to March.

\section{Caroline.}

From Norfolk, England.

Fruit above middle size, roundish, rich yellow, streaked with red. Flesh firm, brisk juice, high flavor. Cooking. November to February. (Lind.)

\section{Caroline Auguste.}

Of Belgic origin. Tree vigorous, with upright reddish brown shoots.

Fruit medium, roundish, pale green with spots of brown. Flesh white, tinged with rose on the sunny side, fine acid, with a pine-apple perfume. September. (Verg.)

\section{Carolina Red June.}

Knight's Red June. Red June.

\section{Blush June. Georgia June.}

Wilson's June.

Origin somewhat uncertain, supposed to be Carolina. Tree very vigorous, upright, an early and abundant bearer, much esteemed at the South and Southwest as their best early Apple, ripe a few days after Early Harvest, not equal to it in flavor, but more profitable as an orehard fruit.

Fruit medium or below, oval, irregular, inclining to conic. Srin mooth, nearly the whole surface shaded with deep red, and almost of a purplish hue on the sunny side, and covered with a light bloom. Stalk 
rariable in length, inserted in a small narrow cavity. Calyx closed. Segments long, reflexed. Basin narrow, plaited. Flesh very white, tender, juicy, with a brisk subacid thavor. Core rather large. Tery good.*

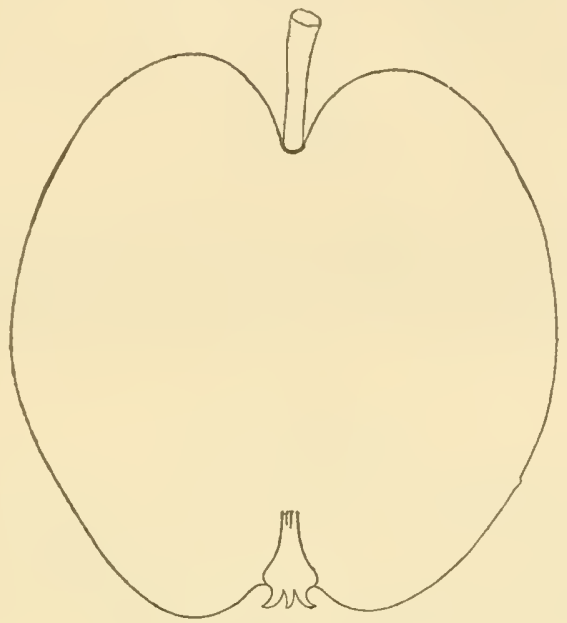

Carolina Red June.

\section{Carolina Sweet.}

Fruit rather large, roundish, a little flattened, yellow, slightly shaded in the sun. Flesh yellow, dry, sweet. Poor. August.

\section{Carolina Watson.}

Of Southern origin.

Fruit large, oblate conical, greenish, shaded, splashed and striped with dull red, large light dots, with dark centres. Flesh white, coarse, mild, subacid. Good. August.

\section{Carpeyter.}

Originated from a sced of the Belmont, with Charles Carpenter, Kelley Island. Tree a moderate grower, forming a medium-sized round, spreading head.

Frvit medium roundish oblate, yellow, oily surface, shaded with a brownish crimson in sun, and occasional marblings of russet. Flesh yellowish, rather firm, rather rich, pleasant subacid. Good, or almost rery good. Core small. Productive. Good keeper. January to March.

* Carolina Striped June-(Carolina June). This is generally confounded with the above, and is scarcely distinguishable except that, as it ripens, it be. comes striped. One is doubtless a seedling from the other. 


\section{Carpentin Reinette.}

Kleine Graue Reinette. Der Carpentin.

A Crerman Apple. Tree a free grower and good bearer.

Fruit small, ronndish oblong, yellowish green, striped and washed with red, dark red in the sun. Flesh yellowish white, tender, juicy, vinous, aromatic. December to April. (Hogg.)

\section{Chrter.}

\section{Royal Pippin.}

Origin, farm of Nath. Carter, Leominster, Mass. A vigorous grower and productive.

Fruit above medium, roundish oblate, yellow, slightly shaded, striped, and marbled with red. Stalk short, inserted in a deep eavity. Calyx closed, set in a large basin. Flesh tender, rather coarse, juicy, pleasant, subacid. Good to very good. Core small. October to January.

\section{Carter's Blue.}

\section{Lady Fitzpatrick.}

This variety originated at Mount Meigs, near Montgomery, Ala. 'Tree a fine upright grower, an early bearer. Young shoots reildish brown, very close grained.

Fruit large, roundish oblate, greenish, washed and striped with dull red and covered with a blue bloom. Stalk slender. Calyx closed. Flesh yellowish white, crisp, sugary, rich, aromatic. Very good. September to November.

\section{CARver.}

Origin, Norristown, Pa. Tree productive.

Fruit large, roundish, lemon yellow. Stalk short. Calyx small, closed. Flesh yellowish, juicy, tender, vinous, subacid. Good. August.

There is also a Carver Apple from Montgomery Co., which is red, and a winter fruit.

\section{Cary's Summer.}

Of unknown origin. Probably an old variety.

Fruit large, round, flattened, rich yellow, splashed with crimson. Flesh yellow, tender, juicy, subacid. Good. Core medium. June to September. (Warder.)

\section{CASE.}

An Apple somewhat grown in Connecticut.

Fruit medium, roundish oblate, light and dark red, striped and splashed. Flesh whitish, juicy, tender, crisp, aromatic, pleasant, subacid. Good. Norember.

\section{Cash SWeEt.}

Medium size, oblate, conic. Skin whitish, with a blush. Flesh white, sweet, and rather dry. September. 


\section{CASTLLE MIAJOR.}

An Englisl cooking Apple.

Fruit unedium, roundish oblate, greenish yellow, with white specks. Flesh firm, juicy, brisk, acid. January to April. (Lind.)

\section{CATFACE.}

From Kentucky.

Fruit large, conical, truncated, greenish yellow, with streaks of red. Flesh white, tender, brisk, subacid. Good. February, March.

\section{Catifead Sweet.}

Tree hardy, good bearer.

Fruit large, roundish conic, greenish yellow, slight blush. Flesh white, tender, sweet, not rich. Good. October.

\section{Catline.}

Gregson Apple.

Origin, Maryland. Tree of slow growth, very productive, much esteemed in the lower part of Delaware. Below medium size, oblate, yellow, bright red cheek, with stripes. Flesh tender, rich, juicy, and sweet. Good. October to December.

There is also a White Catline, which is smallex in size, oblate, greenish white, and maturing in September and October. It is juicy, tender, pleasaut. Good.

\section{CATSheAd.}

\section{Round Catshead. Cathead Greening.}

A very large Apple, cultivated for drying in some parts of the country, but of little other value except as a cooking apple.

Fruit of the largest size, romd, quite smooth, pale green. Flesh tender, with a subacid juice. Good. October and November.

\section{Cato.}

Origin, probably Maryland.

Fruit small, oblate, white shaded, and splashed with bright red, deep in sun, few light dots. Flesh white, often stained next the skin, tender, sprightly, subacid. Good. January to March.

\section{Catooga.}

\section{Corbin. Cattoogaja. Cuttugaja.}

A Southern variety.

Fruit large, roundish, sides unequal, yellow, with brown dots. Flesh whitish yellow, tender, juicy, subacid. Good. Cooking fruit. Norember.

\section{CAYWOOD.}

Origin, Ulster Co., N. Y. Only valued as a keeper.

Fruit medium, oblate. Skin bright yellow, with a tinge of red on the sunny side. Stalk rather long, in a broad, shallow cavity. Calyx 
small, closed. Basin broar and wrinkled. Flesh yellowish, rather firm, pleasant, but not juicy or rich. Good. December, May.

\section{Cedar Falls.}

A native of Forsyth Co., N. C.

Frnit medium to large, a little oblate in form, deep yellow, nearly covered with purplish red; patch of russet around the stalk. Flesh yellow, firn, aromatic, subacid. November to February. (White.)

\section{Celestia.}

Originated with L. S. Note, Miami Co., O. A new variety of good promise as an amateur sort.

Fruit large, form roundish, conical, slightly ribbed. Color pale yellow, moderately sprinkled with gray or brown dots, and sometimes large dots of red. Stalk rather short and slender. Cavity deep, uneven. Calyx closed. Segments long, slender, partially recurved. Basin rather small, furrowed. Flesh yellowish, crisp, tender, juicy, very pleasant, rich, mild, subacid. Core rather large. Very good. October.

\section{Cellini.}

An English culinary Apple.

Fruit medium, roundish oblate, deep yellow, with streaks and mottlings of dark crimson. Stalk short. Cavity slightly russeted. Calyx large, open. Basin corrugated. Flesh white, tender, juicy, brisk, and pleasant. Very good. September, October.

\section{Challenge.}

Raised by D. C. Richmond, Sandusky, O. A thrifty grower, and exceedingly prodnctive. Wood grayish brown.

Fruit large, oblate, slightly conic, deep yellow, sprinkled with brownish dots. Stalk rather short. Cavity large, slightly russeted. Calyx closed. Basin deep, corrugated. Flesh yellowish, tender, juicy, sweet. Very good. October to June.

\section{Champaigne Reinette.}

\section{Reinette de Champagne. Soskrieger.}

Origin unknown.

Fruit medium, roundish oblate, greenish yellow, with more or less of russet. Flesh yellowish, mild, subacid, vinous. Very good. December to January. (Verg.)

\section{Chandler.}

\section{Late Chandler.}

Of Connecticnt origin, where it is a favorite. Tree moderately vigorous, great bearer.

Fruit large, roundish, slightly flatteneci, and one-sicled or angular in its form, obscurely ribbed on its sides, thickly streaked and overspread with dull red with a few streaks of bright red, on a greenish yellow ground, the red sprinkled with light gray dots. Core and seeds small. Flesh greenish white, tender juicy, with a moderately rich, subacid flavor. Good. November to February. 


\section{Chaner.}

A Penusylvania Apple, valuable mainly as a lor g keeper. Treo a straggling grower, vigorous and good bearer.

Fruit medium, oblate or roundish oblate, inclining to conic, pale yel. low, shaded in the sun with crimson, and sprinkled with light giay dots. Flesh whitish, firm, moderately juicy, with a sprightly subacid flavor. Good to rery good. Core small. December to March.

\section{Cimaparax's Orange.}

Fruit small, deep orange, juicy, rich, subacid. October.

\section{Charley's Winter.}

Raised by H. R. Robey, Fredericksburgh, Va.

Fruit medium or below, oblate inclining to conic, pale yellow, often shaded with crimson in the sun. Flesh yellow, compact, juicy, crisp, brisk subacid. Good. January, February.

\section{Cirase's Seedlixg.}

Origin, Maine.

Fruit medium, roundish, pale yellow, splashed and marbled orer neariy the entire surface with red. Flesh white, teuder, moderately juicy, mild subacid. Good. September.

\section{Chattahoochie.}

A Southern variety from the banks of the Chattahoochie River, Ga. Tree vigorons, upright, productive.

Fruit medium or below in size, roundish oblate, oblique, slightly conic, greenish yellow, faint brownish blush in sun. Stalk very short. Cavity large, ojen, deep, somewhat russeted. Calyx partially open, with short segments, broad, divided, sometimes closed, sometimes erect. Basin deep, broad, abrupt, slightly furrowed. Flesh yellowish white, breaking, crisp, partially tender, subacid, pleasant. Good. Season, December to April.

\section{Cineese.}

Origin, Lewisburgh, Pa. Tree strong, vigorous, spreading, productive aunually.

Fruit medium to large, oblate, greenish, mostly overspread and striped with red, small grayish dots. Flesh white, fine-grained, tender, subacid. Good. November to February.

\section{Cheeseborough Russet.}

$\begin{array}{ll}\text { Pumpkin Sweet of some. } & \text { Kingsbury Russet. } \\ \text { Forever Pippin. } & \text { Cheeseboro. } \\ \text { Howard Russet. } & \text { York Russet. }\end{array}$

Sweet Russet.

An old fruit of little value, large, conical, green russet. Flesh roarse, dry, mild, subacid, almost sweet. Poor. October, November.

\section{Cinelteninam. \\ Calf Pasture.}

The Cheltenham is a handsome and popular market variety that origi. 
nated at Cheltenham Township, Nontgomery Co., Pa., in a field where calves were pastured, and hence the synonym by which it is locally known It is a moderate grower, but very productive.

Fruit medium, roundish, striped and marbled with red on a yellow ground. Stalk short. Cavity narrow. Calyx small, closed. Basiu deep. Flesh whitish yellow, tender, juicy, pleasant. Good. September.

\section{Chenaygo Strawberry.}

$\begin{array}{lll}\text { Frank. } & \text { Sherwood's Favorite. } & \text { Jackson Apple. } \\ \text { Buckley. } & \text { Strawberry. } & \text { Smyrna. }\end{array}$

Originated in the town of Lebanon, Madison Co., N. Y. It is an apple pleasant to the taste and much esteemed as a table fruit wherever grown. Tree is vigorous, spreading. Young wood light reddish brown, downy.

Fruit medium, oblong conic or oblong truncated conic, indistinctly

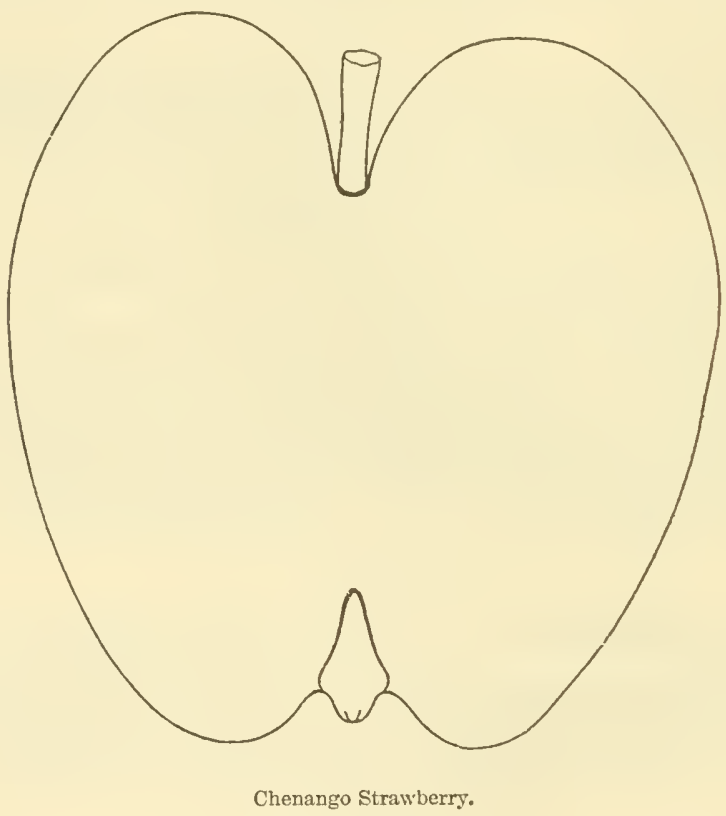

ribbed. Color whitish, shaded,.splashed and mottled with light and dark crimson over most of the surface, light dots. Stalk rather short small. Cavity acute, somewhat meven. Calyx closed, or partially open. Segments erect. Basin rather large, abrupt, slightly corrugated. Flesh white, tender, juicy, peculiar mild, subacid. Core rather large. Very good. Septemier and October.

\section{Cheney.}

Originated on the old Cheney farm, South Manchester, Comn. Tree upright, spreading, an early and regular bearer. 
Fruit medium, oblate, yellow shaled with rich crimson over the whole surface. Flesh white, tender, juicy, pleasant, subacid, slightly aromatic. Good to very gool. September and October.

\section{Chestatee.}

A Southern fruit of unknown origin. Tree vigorous, upright, spreading. Wood smooth, reddish gray, with very small redelish bucls.

Fruit medium, oblate inclining to conic, pale yellow with a slight blush in the sun. Flesh whitish, crisp, juicy, sprightly subacid. Good. November.

\section{Chester.}

Chester Red Streak.

Origin, Cliester Co., Pa.

Fruit medium, oblate, whitish yellow, sometimes with a sunny check and sprinkled with carnine dots. Flesh white, tender, juicy, plensant, subacid, aromatic. Good. November to December.

\section{Ciester Pearmain.}

An English dessert Apple. Tree hardy, free grower, attaining a considerable size, good bearer.

Fruit medium, oblate, conical, pale vellow, striped with crimson in the sum, some russet. Flesh yellowish white, tender, juicy. Secondrate. October to December. (Hogg.)

\section{Chester Spitzenberg.}

A Pennsylvania Apple. Tree a good grower and productive. Young wood dark dull reddish brown, very stout.

Fruit medium, roundish, inclining to oblate, yellowish, splashed and striped nearly over the whole surface with light and dark red. Flesh yellowish, rather compract, moderately juicy, subacid, slightly aromatic. Good. February to April.

\section{Chestoa.}

\section{Rabbit's Head.}

A Southern variety.

Fruit large, elongated conical, irregular at apex end, deep rich yellow, striped, splashed and shaded with red, and with many minute dark specks. Flesh whitish, crisp, juicy, rather rich, vinous, aromatic. Very good. November to March.

\section{CineF Good. \\ Summum Bonum.}

From Kentucky, near Louisville.

Fruit merlium to large, roundish, flattened at base, light yellow, streaked and mottled with red. Flesh white, tender, juicy, subacid, aromatic. September, October. (Elliott.)

\section{Cirristiaxi.}

Origin, on the premises of John R. Brinckle, near Wilmington, Del. Fruit medium, oblate, splashes and stripes of rich crimson red over a 
yellow ground. Flesh yellowish white, moderately juicy, sprightly, mild, subacid. Good tu very good. November.

\section{Christie's Pippin.} bearer.

Origin, Kingston-on-Thames, England. Tree of slender growth, good

Frnit medium, oblate, lemon yellow, with faint red strijes, russety dots. Flesh yellowish, tender, agreeable, mild subacid. December to February. A dessert apple of the first ruality. (Pon.)

\section{Christ's Gold Pininete. \\ Christ's Deutsche Goldreinette.}

Of German origin.

Fruit above medium, oblate, golden yellow, red cheek in sun, and much cinnamon-colored russet. Flesh fine, juicy, aromatic, vinous. November to May. (Hogg.)

\section{Chrontcat.}

Cotton Apple.

This variety originated on the farm of John Cotton, Putnam Co., Ind. It is a thrifty grower, with a rather upright sprealing habit, very hardy, and a moderate anmual bearer. It is valued much for properties euabling it to be kej,t in good condition for two ycars withont extra care.

Fruit medium, roundish, slightly conical, greenish yellow, with splaslies and stripes of dull red, few light dots with dark centres. Flesh yellowish white, compact, firm, mild subacid. Core small, close. Good.

\section{Cinurchill Greenisg.}

Origin uncertain. Tree vigorous and productive.

Fruit large, oblate, somewhat conic, ribbed, yellowish green, shaded with dull red, and thickly sprinkled with green dots. Flesh yellow, tender, granular, with a brisk, vinous, almost saccharine flavor. Good. December to February.

\section{Church's Late Sweet.}

A Sonthern Apple of unknown origin.

Fruit medium, roundish inclining to conic, rich rellow, with occasionally a shade of crimson in the sun. Flesh yellowish, compact, rather rich, mild subacid, almost sweet. Good. February to May.

\section{Gitron des Carmes.}

A French Apple. Fruit small, oblong, light dull brown, dry. Poor. December. (Ron.)

\section{Citronen Reinette.}

\section{Reinette de Citron.}

An Apple of German origin, there regarded as of value for the dessert. Fruit large, roundish conical, bright yellow, with blush in the sun. Flesh very white, fine-grained, juicy, brisk, sugary, vinous. De cember to June. (Hogg.) 


\section{Clatper Flat.}

Flat Apple.

Origin, town of Bethlehem, Albany Co., N. Y. Tree productive.

Frnit above medimn, oblate inclining to conic, prale yellow, mostly covered, shaderl and splashiced with deep red. Flesh yellowish, moderately juicy, tender, pleasant subacid. Good. Ilighiy valued for cooking September, October.

\section{Clara Pippin.}

Origin, Cranford, England.

Fruit snall, roundish ovate, orange, with brownish red in the sun. Fleslı deep orange, firm, rich, brisk, sngary. December to May. (Hogg.)

\section{Clatke.}

A new variety originated with J. N. Clarke, Naples, N. Y., who states it a strong grower, with an open top, and annually productive.

Fruit merlium or above, roundish inclining to conic, slightly angular, pale whitish yellow, sliaded, striped and splashed with light and clark crimson, few gray dots. Stalk short, slender. Cavity narrow, rather deep. Calyx small, closed. Segments slightly recurved. Basin small, a little corrugated. Flesli white, tender, juicy, splightly, vinous, subacid. Very good. October, Norember.

\section{Charke's Delaware.}

Originated with John C. Clarke, Maryland. Tree very productive.

Fruit nearly medium size, rommdish, inclining to oblong, oblique, smooth, yellow, shaded in the sun with orange red, many gray dots. Flesli whitish, moderately tender, juicy, mild subacid. Almost very good. December to Marcli.

\section{Clarkf. Pearinats.}

Yellow Pearmain. Gloucester Pearmain.
Columbian Russet. Golden Pearmain.

From North Carolina, an old variety. Tree of slow growth, very productive.

Fruit medium, roundish oblate, slightly conical, greenish yellow, sharled, striped and marbled with red and russet dots. Stalk very short. Cavity small, slightly russeted. Calyx closed. Basin small. Flesh yellow, rather firm, crisp, rich, subacid. Tery good. Core small. December.

\section{Clarksox}

Originated on the premises of David Clarkson, Plymouth, Wayne Co., Nich. Tree a good grower and bearer.

Fruit above merlium, ollate conic, elear white, shaded with crimson in the sun, with light and brown dots. Flesh white, fine-grained, tender, juicy, sharp subacid, slightly aromatic. Cure rather large. Cood. Valuable for cooking and drying only. 


\section{Claygate Peararais.}

An English Apple.

Fruit medium, roundish conical, greenish yellow, nearly covered with brownish red. Flesh yellow, tender, rich, aromatic. Good. Norember to March.

\section{Clayton.}

Origin, Indiana.

Fruit large, conical, flattened, regular, greenish yellow, covered, striped, and splashed with dull red. Flesh yellow, breaking, subacid. Good. Kitchen and market. January to March. (Warder.)

\section{Clepington.}

An English dessert Apple. Fruit small, round oblate, yellow. September.

\section{Cley Pippin.}

Also an English dessert Apple, there counted as of first-rate quality. Fruit small, roundish, yellow. October to March. (H. S. C.)

\section{Cluster.}

Tree productive.

Fruit small, yellow, oblate, sweet. November.

Another Cluster Apple is small, roundish conical, or oblong conical, greenish white. Flesh white. Poor. December, February.

\section{Cluster Goldex Pippix. \\ Cluster Pippin. Twin Cluster Pippin. Thickset,}

An old variety. A hardy tree, slender grower, good bearer, producing its fruit in clusters, and often with two frnits uniled or grown togetlier.

Fruit small, round, flattened, yellow, with orange in the sun, and patches of gray russet. Flesh yellowish, firm, crisp, subacid perfumed. November to March. (Hogg.)

\section{Cluster Pearalais.}

Introduced by R. Ragan, of Indiana.

Fruit full medium size, round, flattened, regular, inclined, yellowish green, mixed and striped light red, dots large, gray and yellow, white bloom. Flesh yellowish white, breaking, grinular, subacid, aromatic. Good to very good. An autumn fruit, acceptable as a substitute for Rambo. (Warder.)

\section{Clyde Beautr.}

Mackie's Clyde Beauty.

Raised by Mr. Mackie, Clyde, ITayne Co., N. I. Tree vigorons, upright, very productive.

Fruit large, roundish, conic, angular, greenish, oily. sprinkled and mottled with dull red and bright red in the sun. Stalk sliort, sleuler, inserted in an acute cavity. Calyx closed, set in a smali corrugated basin. Flesh white, tender, juicy, brisk subacid. Good. October to Jamnary. 


\section{Conhas.}

From Kent, England. Tree hardy, vigorous, and productive.

Fruit medium to large, roundish oblate, dull yellowish green, faint red in the sum, some light russet. Flesh pale yellow, erisp, saccharine, aromatic. November, December. (Lind.)

\section{Cobourg Pippin.}

An Apple originated in Warwickshire, England.

Fruit small, oblate conical, pea green, with large russet dots. Elesh firm, rich, acid. March. (Ron.)

\section{Coccagee. \\ Cocko Gee.}

An Irish Apple, mostly valued for cider.

Fruit medium, roundish, conical, pale yellow. Flesh yellowish, acid. October, December. (Hogg.)

\section{Cockle Pippin.}

\section{Nutmeg Cockle. Nutmeg Pippin. \\ White Cockle. Brown Cockle.}

A variety from Sussex, England. Tree healthy, hardy. Shoots moderately stout, chestnut colored.

Fruit medium, roundish conical, slightly ribbed, green, with brown russet. Flesh yellowish, firm, crisp, aromatic. Good. January to April.

\section{Cocklin's Favorite.}

Grandfather.

Introduced by Jacob Cocklin, York, Pa. Tree a good upright grower productive.

Fruit below medium, roundish oblate, whitish, thinly shaded with light erimson in the sun, moderately sprinkled with light dots. Stalk medium, very slender. Cavity, large, deep, sometimes thinly russeterl. Calyx closed. Segments medium, erect, sometimes slightly recurver. Basin abrupt, deep, rather uneven. Flesh white, very tender, juicy, mild, pleasant subacid. Very good. Core small. November.

\section{CockPIT.}

Origin, North of England.

Fruit medium, roundish oblate, truncated, yellow. Flesh tender, brisk, a pleasant apple for table or kitchen. November, December. (Ron.)

\section{Coe's Goldex Drop.}

An English Apple, the origin of which is in doubt. Tree hardy, free upinght grower, and proluctive.

Fruit small, roundish conical, fine yellow, with a shade of crimson in the sun. Flesh yellowish, erisp, juicy, rich, brisk subacid, slightly aromatic. Good to very good. November, February. 


\section{Cogswell.}

Cogswell Pearmain.

This excellent Apple originated in the town of Griswold, near Norwich, Ct., on a farm which came into the possession of William Cogswell about the year 1798. The original tree was then about forty or fifty years old. The fruit was first exhibited in 1816 or ' 18 , before the Massachusetts Horticultural Society.

It is an extremely valuable variety wherever grown, either for table or market purposes, a good keeper, and bears carriage to market long distances without apparent injury. Tree a vigorous, upright, spreading grower, an abundant bearer of very regular, even-sized fruit. Young shoots dark reddish brown, somewhat downy.

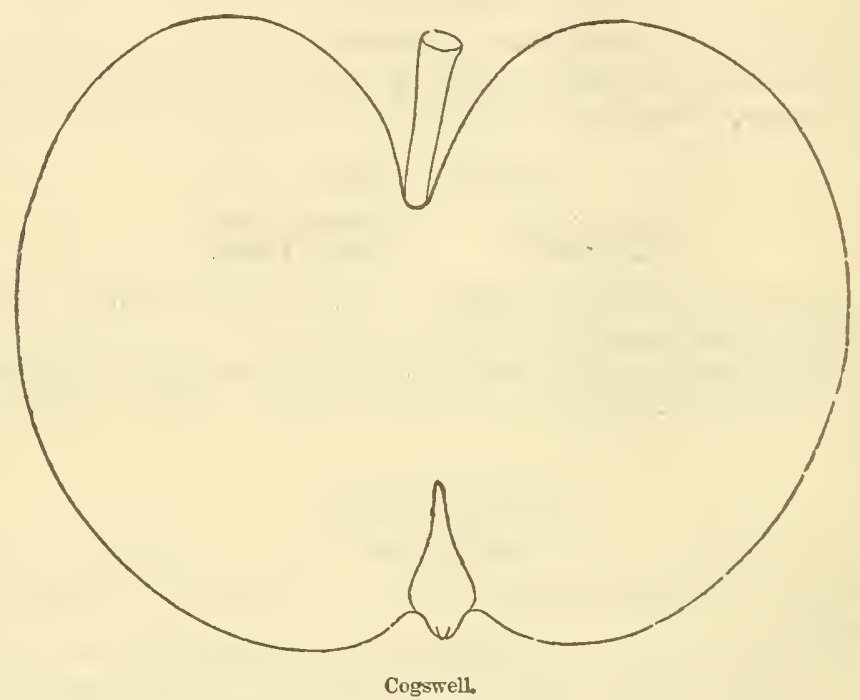

Fruit size above medium. Form roundish oblate, regular. Color rich yellow, nearly covered with red, marked and streaked with bright red, pretty thickly sprinkled with areole dots. Stalk short, rather slender. Cavity large, thinly russeted. Calyx small, nearly closed. Basin small, shallow. Flesh yellowish, fine-grained, tender, juicy, scarcely subacid, rich aromatic. Core small. Very good to best. December to March.

\section{COIE.}

Scarlet Perfume.

Duling ?

A variety from England, of second quality, but admired for its beauty of appearance.

Fruit medium, roundish oblate, conic, ribbed. Color deep crimson on a yellowish ground, or sometimes entirely red, with a little russet. Stalk medium, woolly, planted in a cavity broad and deep. Calyx large, in a broad basin. Flesh white, rather firm, juicy, yellowish, somewhat rich and agreeable. Nearly rery good. September and October. 


\title{
Columbiav.
}

Received from Pennsylvania.

Fruit medium, oblate, slightly inclining to conical, yellowish, shaded, splashed and striped with light and dark crimson, few light gray dots. Flesh whitish yellow, tender, juicy, sprightly subacid, slightly aromatic. Very good. Core small. October, November.

\section{Colvert.}

\section{Prussian.}

An old variety, of uncertain origin, valued mainly for cooking. Tree a strong grower, and an enormous bearer.

Fruit large, oblate, inclining to conic, greenish yellow, striped and shaded with dull red in sun. Flesh greenish white, tender, brisk subacid. Good. October, November.

\section{Conant's Red.}

Much cultivated in Southern Ohio.

Fruit full medium, regular, oblate, sometimes nearly round, yellow, obscurely mixed with red, on which are streaks of russet, dots fawncolored. Flesh yellow, fine-grained, juicy, subacid to sweet, aromatic. September, December. (Warder.)

\section{Condit SweEt.}

A New Jersey Apple.

Fruit small, roundish, whitish yellow, tinge of brown in the sun. Flesh yellowish, tender, juicy, pleasant, sweet. Good. September.

\section{Congress.}

\author{
Jackson Apple. Tyler Apple.
}

A Massachusetts variety, cultivated in the New England States for half a century or more. Tree very vigorous, sprearling, abundant bearer. Fruit valuable mainly for cooking or market.

Fruit large to very large, roundish oblate, slightly conic, yellowish, splashed, striped, and marbled with red. Flesh whitish, coarse, juicy, tender, brisk subacid. Good. Core large. November, December.

\section{Connecticut Summer Sweet.}

Fruit medium, roundish, yellow and red striped. Flesh yellowish, sweet, tough. August. (Elliott.)

\section{Coxietr's Sweet.}

Tree strong, upright grower, early and abundant bearer.

Fruit large, romndish, flattened, yellow, mostly covered with dark red. Flesh yellow, fine-grained, tender, sweet. Very good. December to MIarch. (Elliott.)

\section{Contin Reinette.}

From Ross-shire, Scotland. Tree hardy, a slender grower, and sure bearer. 
Fruit medium, roundish, dull yellow, red in the sun. F'lesh yellowish, firm, pleasant, acid. October, November. (Hogg.)

\section{CONWAY.}

Origin unknown.

Fruit medium, oblate, obscurely ribbed, greenish yellow, with a bronzed cheek in the sun, few brown gray dots and traces of russet. Flesh yellowish, crisp, juicy, vinous, slightly aromatic. Very good. December to April.

\section{CoOK's ReD Winter.}

Fruit medium to large, produced by Jacob Cook, Edisto, S. C. Tree vigorous and regular bearer. October to April. (Summer Notes.)

\section{Cooledge's Favorite.}

Said to have originated in Cambridge, Mass. Tree productive.

Fruit medium, roundish conical, deep yellow, splashed and narbled with red, becoming brilliant in the sum, r'nsset at the sten, and with whitish specks over the whole. Stalk long, slender. Cavity deep, broad. Calyx in a shallow plaited basin. Flesh tine-grained, tender, and juicy, pleasant subacid. Very good. September, October. (J. of H.)

\section{COOPER.}

\section{Beauty Red. Lady Washington.}

Origin unknown; supposed to be an old Eastern rariety, as yet unreeognized. Thrives well at the West, and much esteemed there by many. Growth vigorous, upright, and productive.

Fruit large, roundish oblate, sides unequal. Color greenish vellow, with a few stripes and splashes of bright red, thickly sprinkled with brown dots. Flesh tender, juicy, vinous, with a pleasant but not high flavor. Good. October to December.

\section{CoOper's EArly White.}

Grown in Illinois and other Western States, where it is regarded by many as productive and profitable.

Fruit medium, roundish, little Hattened, pale yellow with faint blush, tinge of green at the stem. Flesh white, crisp, sprightly. September aud October. (Elliott.)

\section{- CoOper's MARKet.}

\section{Cooper's Redling. Rigley. Redling :}

Tree hardy, vigorous, upright, with loug slender branches, very productive and a late keeper. Taluable for market in New Jersey.

Fruit medium, oblate conic, yellowish, shaded with red and striped with crimson, Stalk short. Cavity deep, narrow. Calyx closed. Basin small. Flesh white, tender, with a brisk subacid flaror. Good. December to May.

\section{Cooper's Russeting.}

Originated in Gloucester Co., N. J. Tree irregular in form, healthy grower, abundant bearer. 
Fruit small, oblong, conical, pale yellow mixed with russet. Flesh rich, sweet, dry. Valuable for cooking or for cider. October to December.

\section{Corlie's Sweet.}

Origin on the farm of A. Corlies, Shrewsbury, New Jersey. Tree vigorous, round-header, great bearer.

Fruit medium, roundish, conical, whitish yellow, light blush in smo. Flesh white, firm, moderately juicy, pleasant sweet, tine for cooking. Hirdly good. September, November.

\section{Corvelu's Fanct. \\ Cornell's Favorite.}

From Penusylvania. Tree vigorous and productive.

Fruit medium, oblong, conical. Color waxen yellow, shaded and splaslied with crimson. Stalk of medium length. Cavity rather large. Calyx closed, abrupt, corrugated. Flesh white, tender, crisp, juicy, with a pleasant subacid Haror. Core medium or large. Very good.

\section{Cornfietd.}

A Southern variety from J. S. Downer.

Fruit medium, roundish oblate, truncate regular, yellow, covered with mixed deep red, striped. Flesh yellow, fine-grained, tender, rather dry, subacid. Good. December. (IVarder.)

\section{Corisish Aromatic.}

An English Apple.

Fruit of medium size, roundish, angular. Color rich red, much marked with russet yellow dots, on a pale russet groumd. Flesh yellow, with a rich, aromatic, subacid flavor. Good. October to December.

\section{Cormisil Gilliflower.}

Cornish July-flower. Pomme Regelans. Red Gilliflower?

Calville d'Angleterre. Cornwallisser. Nelken Apfel.

An old English Apple. Tree a poor grower and shy bearer.

Fruit medium size, roundish, conical, narrowing much to the eye where it is ribbed, dull green, or dark yellowish green, with a sunny side of brownish red, intermixed with a few streaks of richer red. Flesly yellorrish, firm, with a rich, ligh flavor, and a slight aromatic perfume. Good. November to April.

\section{Conxism Spice.}

Origin unknown.

Fruit small, oblate, pale yellow, slight sharle in sun. Flesh yellow ish, crisp, juicy, slightly aromatic, subacid. Good. November.

\section{Corse's Favorite.}

A Canadian Apple, valuable for stering.

Fruit medium, oblate, depressed, yellowish green. Flesh whitish, juicy, brisk, subacid. Good. September. 


\section{Cos, or CAas.}

A native of Kingston, N. Y., where in is productive and highly esteemed.

Fruit large, one-sided or angular, roundisis, broad, and flattened at the stalk, narrowing a good deal to the eye. Skin smooth, pale greenish yellow in the shade, but red in the sun, with splashes and specks of bright red, and a few yellow dots. Flesh white, tender, with a mild, agrecable flavor. Good to very good. December to March.

\section{COSTARD.}

\section{Coulthard. Prussian Pippin.}

An old English culinary Apple mentioned by Lawson in 1597, and was in the fruiters' bills in the time of Edward the First, 1292, under name of Pomme Costard. Tree hardy, strong, vigorous, with downy shoots, productive.

Fruit large, roundish oblong, prominently ribbed, dull yellowislı green, embedded all orer with gray specks. Flesh greenish white, tender, juicy, brisk, subacicl. October to December. (Hogg.)

\section{Cotsville Spitzenberg.}

A variety received from Nelson \& Son, Mercer Co., Pa., by whom it was obtained as a scedling of the Rambo, from Ohio. It looks much like the Baltinore, on p. 86, and may prove identical.

Fruit medium, roundish, slightly conical, whitish, covered over with deep crimson in the sun, lighter in the shade, a little misset, and pretty thickly sprinkled with light dots. Flesh whitish, sometimes a little stained, tender, juicy, pleasant, mild subacid, slightly aromatic. Core small. Very good. December to February.

\section{Coral Buush.}

From Ross-shire, Scotland. 'Tree hardy, vigorous, upright, productive.

Fruit medium, roundish, pale yellow, dull red in the sun. Flesh yellowish, crisp, juicy, brisk. A good culinary sort. December. (Lind.)

\section{Court Pendu de Tournay.}

Reinette d'Orleans.

Originated in Holland. Tree vigorous, productive.

Fruit small to medium, roundish, conical. Flesh creamy white, ten. rer, fine, aromatic. (An. Pom.)

\section{Court Pendu Plat.}

Court-pendu.

Courti-perdu plat rougeâtre.

Capendu.

Garnon's Apple.

Court-pendu Extra.

Rond Gros.

Rose.
Court-pendu MIusqué.

Coriandre Rose.

Rouge Mnsqué.

Pomme de Berlin.

Wollaton Pippin.

Russiau.

Princess Noble Zoëte.

A popular French variety.

Fruit of medium size, regularly formed, and quite flat. Skin rich, deep crimson on the sumny side, with a little pale greenish yellow in the 
shade. Stalk sliort, inserted in a very deep cavity. Calyx large, set in a wide shallow basin. Flesh yellow, erisp, with a rich brisk aeid flavor. Good. The tree bears young aud plentifully. November to February.

\section{Court Pexpu Rose.}

\section{Court Pendu Rosat.}

Of French origin. Tree vigorous, productive.

Fruit small, roundish, flattened, yellow, marked with gray dots, and shaded with bright red around the stem. Flesh white, fine, juicy, vinous, aeid, perfumed. (An. Pom.)

\section{Court of IVICK.}

Court of Wick Pippin.

Court de Wick.

Golden Drop.

Wood's Huntingdon.

Barlow.

Transparent Pippin.
Philip's Reinette.

Knightwick Pippin.

Week's Pippin.

Yellow.

Fry's Pippin.

A highly-flavored English dessert Apple of the Golden Pippin class, which does not sueeeed well with us.

Fruit below the middle size, regularly formed, roundish oblate, some. what flattened, greenish yellow in the shade, but becoming a warm orange, with a little red in the sun. Flesh yellow, crisp, and juicy, with a high poignant flavor. Very good. Oetober to February.

\section{Cowarne Ped.}

Origin, Herefordshire, England.

Frnit medium, roundish, narrowing to the crown, pale yellow, bright red where exposed to the sun, sometimes deep purplish crimson. VTaluable for cider. (Hogg.)

\section{Cowarne's Queening. \\ Northern Greening.}

Tree upright, compact, an abundant bearer.

Fruit very large, roundish, conical, golden yellow, red in the sun. Flesh white, tender. Fine for eooking or drying. November to January. (Ron.)

\section{Cox's Orange Pippin.}

An English variety much esteemed for dessert. Tree is well adapted for dwarfing on the paradise stock, and a free bearer.

Fruit medium, oblate, yellowish, shaded, splashed and slightly mottled nearly over the whole surfaee with crimson. Flesh yellowish, rather firm, juicv, brisk, rieh, subacid. Core small. Very Good. September, October.

\section{Cox's Pomoxa.}

A variety from England, valuable as a culinary apple.

Fruit medium, oblate, somewhat eonie, greenish yellow, shade of crim son in the sun. Flesh white, crisp, juiey, brisk subacid. Good. Cort small. October.

\section{Cracking.}

Origin, farm of Henry Barger, Harrison Co., O. Tree spreading, vigorous, aud productive. Toung shoots redlish brown, slightly downy. 
Fruit fair, large, roumdish, slightly flattened, inclining to conic, ob. scurely ribbed, pale yellow, with a slight tinge of red, thinly sprinkled with large dots. Stalk medium, in a rather deep slightly russeted cavity. Calyx closed in a corrugated basin. Flesh yellowish white, crispl, tender, juicy, subacid. Good. Core large. Valuable for cooking. October, .November.

\section{Cray on Krav.}

An old fruit nearly out of use and not worth cultivating.

\section{Cranberry.}

\section{From Georgia.}

Fruit medium, roundish conical. Color yellow, brightly striped with carmine on the unexposed side, and of deeper red on the side next the sun. Many gray russet dots. Calyx small, closed. Flesh whitish. Good.

\section{Cranberry Pippin.}

This strikingly beantiful Apple was found growing on a farm near Hudson, N. $X$. It is only second-rate in point of flaror-but it is an excellent cooking and market apple.

Fruit medium, roundish oblate, regular. Skin very smooth, light yellow, with a bright scarlet cheek. Flesh white, moderately juicy, brisk subacid. Good. November to February.

\section{Cranberry Russet.}

Introduced to notice by J. Austin Scott, Toledo, O.

Fruit medium to large, oblate, compressed. Surface rough, russeted, blushed carmine, meven. Flesh breaking, tender, not very juicy, acid. Good. Said to be stiperior for cooking. Novenber, December. (Warder.)

\section{Crawford.}

Of unknown origin.

Fruit medium, roundish oblate inclining to conic, yellowish, with a tinge of crimson in the sun, few grayish dots. Flesh yellowish, tender, juicy, rather rich, slightly aromatic, subacid. Tery good. November to March.

\section{Crawford's Keeper.}

Originated in Lawrence Co., $\mathrm{O}$. Tree strong grower and a great bearer. Young shoots slender, clear, smooth, light reddish brown.

Fruit above medium, roundish truncated conical, oblique. Color light yellow, mostly overspread with a rich red, large light gray specks. Stem very short. Cavity large, deep, acutc, slightly russeted. Calyx closed or nearly so. Segments divided. Basin very deepr, broad, abrupt, slightly furrowed. Flesh yellowish white, breaking moderately juicy, mild, sweet, subacid. Good to rery good. January to March.

\section{Cray Pippin.}

Piaised in Kent, Englan t, where it is said to be a valuable dessert App:e.

Fruit below medium, conical, pale yellow, tinge of red in the 
sun. Flesh yellow, crisl, sweet, and highly flavored. October. (Hogg.)

\section{Crayton.}

Fruit medium to large, fine flaror. Norember to April. (Sumner's MIS.)

\section{Crean.}

Origin, Queens Co., L. I., N. Y. Tree a vigorous grower, forming a compact head, an early bearer, and by some thought valuable for dessert or eulinary purposes.

Fruit medium or below, roundish oblate, yellowish, thickly sprin. kled with brown and gray dots. Flesh yellowish, fine-grained, tender, juicy, pleasant, sweet and rich. September and October.

\section{Creed's Marigold.}

Raised from seed of the Scarlet Nonpareil, in Kent, England.

Fruit medium, roundish, deep rich yellow, orange in the sun, covered and striped with shades of rich red. Flesh yellow, tender, juicy, sugary, richly flavored. October, Norember. (Hogg.)

\section{Crede's QuittexreinetTe.}

Credo's Gutten Reinette.

A German variety of medium size, roundish, lemon yellow with starlike russety dots. Flesh white, very fine and juicy, sugary, vinous, quince flavor. December to March. (Hogg.)

\section{Creek.}

A native of Hellam township, Tork. Pa., where it is highly prized on account of its quality and extraordinary productiveness. Tree vigorons, upright, slightly spreading.

Fruit medium, oblate, slightly conical, greenish yellow, obscurely striped and splashed with light and dark red. Flesh wlite, tender, juicr, mild, pleasant, subacid. Core small. Very good. December to March.

\section{Creeper.}

Common in Berkshire, England.

Fruit below medium, roundish, somewhat conical, dark green, nearly overspread with red, striped in the sun with darker shades. Flesh white, tender, juicy, sweet, slight aroma. September. (Hogg.)

\section{Crego Red Streak.}

From Columbia Co., N. Y. Tree very prodnctive.

Fruit medium, roundish oblate, whitish, with stripes and shades of red. Flesh white, sharp subacid. Hardly good. September.

\section{Crimson Qteening.}

\section{Scarlet Queening. Red Queening. \\ Summer Queening. Herefordshire Queening.}

A second-rate English raticty.

Fruit mediun size, conical, wustly covered with deej crimson. Flesh 
white, with a red tinge under the skin, tender, juicy, sweet, aromatic December to March. (Hogg.)

\section{Crispis.}

Of unknown origin.

Fruit large, roundish, oblong truncated, greenish, shaded and striped with shades of red. Flesh whitish, dry, compact, subacid. Not quite good. December to May.

\section{CritTendex.}

A new variety, seedling from Kentucky, introduced to notice by J. C. Teas, of Indiana. Tree a sure and prolific bearer.

Fruit medium size, roundish, dull red on vellow. Flesh juicy, very sweet. Good. Keeps until May or June.

\section{Crofton Pippin.}

An Apple from Ireland. Tree blossoms late, and bearing its fruit at ends of the branches gives it a drooping appearance.

Fruit below medium size, roundish oblate, greenish, mostly overspread with red. Flesh firm, rich, juicy. December, January. (Ron.)

\section{Crook's Seedling.}

From the county of Way, Indiana, where it is esteemed as a market sort. Tree forms an open round head, a great bearer.

Fruit full medium size, red striped on yellow ground. Good. October.

\section{Cropsey's Fayorite.}

Originated with D. W. Cropsey, Plainfield, Will Co., Ill.

Fruit full nedium, roundish, yellow, mixed and splashed with carmine. Flesh yellow, breaking, fine-grained, juicy, subacid. December. (Warder.)

\section{Crotcher.}

Supposed to be a native of Dorchester Co., Md. Tree moderate, rather upright grower, producing large erops of rery eren-sized finit.

Fruit medium, oblate conical, slightly truncated. Color waxen white, with a slight blush, and thinly sprinkled with light and green dots. Stalk short. Cavity deep, large, partially russeted. Culyx closed. Basin rather large, abrupt, a little uneven. Flesh whitish, crisp, tender, juicy, refieshing, subacid. Very good. August.

\section{Crow EGG.}

An old variety of not very good quality, oblong oval, long stem, greenish yellow, tender, sweet, large core. October, November.

There is also another Crow Egg in Kentucky, of conical form, yellow, striped with dull red. Stem short. Flesh yellow, compact, subacid. Good. December, January.

\section{Crow Nest.}

Originated at Kelley's Island, O., in the orchard of Chas. Carpenter. Tree vigorous, productive. 
Fruit full medium, round, trumeated, greenish yellow, thinly covered with russet. Flesh green, teuder, breaking, subacid, only good for cooking. November to Jamuary. (W arder.)

\section{Cullasaga.}

Raised by Miss Ann Bryson, Macon Co., N. C. Good grower, and a standard winter fruit for the South. Very productive.

Fruit medium or large, roundish, inclining to conic, sides sometimes unequal. Skin yellowish, mostly shated and striped with dark crinsun, and sprinkled with whitish dots. Stalk small and short, inserted in a deep cavity, surrounded hy russet. Calyx open, set in a shallow eorrugated basin. Flesh yellowish, rather compact, moderately juicy, mild subacid. Good. November to April.

\section{Culiawhee.}

A Southern seedling, with slender wood. Tree resembling the Buff.

Fruit medium, or above, oblate, slightly inclining to conic, pale yellow, nearly overspread, shaded and splasherl with two shades of red, light erimson and dark dots. Flesh white, tender, juicy, brisk subacid. Good. December to March.

\section{Culp.}

Origin, Jefferson Co., O. Introdueed by George Culp. Tree very vigorous, spreading, productive.

Fruit medium, roundish oblate, conic, waxen yellow, shaded with blush or dull erimson. Flesh firm, crisp, juicy, agreeable, subacid. Good December to March.

\section{Cumberlaxd Seedling.}

Supposed to have originated in Cumberland Co., Pa. Tree a fine grower and great bearer.

Fruit medium, oblate inclining to conic, sides unequal, pale yellow, mostly splashed and shaded with dark crimson, few large light dots. Flesh yellowish, rather firm, juicy, brisk subacid. Good to very good. Oetober, December.

\section{Cumberland Spice.}

From Cumberland Co., N. J. Tree thrifty, upright, spreading, productive.

Fruit rather above medium, roundish conic, pale yellow, rarely with a blush, sprinkled with brown dots. Flesh white, tender, juicy, and pleasant subacid; apt to shrivel. Good. Core large and hollow. December to February.

\section{Curry's Red Winter.}

Origin unknown. Came from Eastern North Carolina. Tree vigorous and very productive.

Fruit medium, oblong. Color yellow ground nearly covered with palo red and russet dots. Stalk rather short, slender set in a small cavity. Calyx large and open. Basin large. Flesh white, and solid, and keeps well into Jamuary. (So. Cult.) 


\section{Curtis Greening.}

Origin uncertain, found in Illinois.

Fruit medium to. large, oblong, truncated, axis inclined, yellow brouzy. Flesh yelfow, breaking, subacid. Good. January to February. (Warder.)

\section{Curtis Sweet.}

Introduced to notice by Joseph Curtis, St. Alban's, Vt. Tree vigorous, upright, productive, and hardy.

Fruit large, roundish, conical, ribbed, pale yellow, sprinkled, marbled, and splashed with crimson, and thickly covered with crimson dots. Flesh white, fine-grained, very tender, with a very pleasant sweet flavor. Core large. Good. August to October.

\section{Custard.}

Originated in the grounds of L. B. Langworthy, Greece, Nonroe Co., N. Y. Tree productive.

Fruit medium, to small, roundish, or roundish oblate, inclining to conic, greenish yellow, faintly marbled and splashed with dull red, deeper in the sun. Flesh whitish, very tender, juicy, very mild, almost sweet, agreeable, good for the amateur. Core small. Very good. November, December.

\section{Cut Pippin,}

West's Spitzenberg.

Honemaker Pippin.
Haymaker. Hommacher Apfel.

From Western Pennsylvania. Tree vigorous, prochctive.

Fruit medium to large, greenish. Flesh greenish, juicy, subacid. Good. December to April. (Elliott.)

\section{DAHLONGEA.}

Of Southern origin, but precise locality unknown.

Fruit medium, roundish conical, light greenish yellow, shaded, splashed, and marbled with crimson, a slight bloom, and thickly sprinkled with light dots. Flesh whitish, moderately tender, juicy, subacid. Good. February to March.

\section{Dahltox.}

Dahlton Pippin.

Origin unknown. So far as we know, only grown in Massachusetts.

Fruit medium, oblate, greenish yellow, shight blush in the sun, greenish dots. Flesh whitish, juicy, tender, mild subacid. Good. September, October.

\section{Dane JeañetTe.}

\section{Joannetten's Reinette.}

Of French origin.

Fruit small to medium, roundish, conical, yellowish, with a bronzed cheek in sun. Stalk slender. Calyx large. Flesh white, reined with yellow, mild sı bacid, perfumed. December. (Verg.) 
DANA.

Origin, near Cincinnati, O. Tree large, productive.

- Fruit small, flat rich, yellow partially covered with mixed red, distinctly striped with earmine, white bloom. Flesh yellow, finegrained, subacid. August. (Wareler.)

\section{Dara Greening.}

Fruit medium or below, oblate, greenish yellow, few gray dots. Flesh whitish, crisp, pleasant subacid. Good. December to March.

\section{Dana's Striped Sweet.}

From Ohio.

Fruit medium or below, oblate, sides sometimes unequal, yellowish shaded, and striped with red. Flesh white, crisp, juicy, mild, pleasant sweet. Good. December to March.

\section{DANIEL.}

From Henry Co., Ind.

Fruit medium, roundish oblate, greenish yellow, partially striped and splashed with dull crimson. Flesh white, fine-grained, tender, juicy, pleasant subacid. Good. August and September.

\section{DANiEL'S A PPLE.}

An old variety. Origin unknown, of no value.

Fruit medium, roundish conical, greenish, with dull crimson. Flesh white, coarse, tencler, juicy, subacid. Core large and hollow. October.

\section{Dan Pearmain.}

Originated in Indiana.

Fruit medium to small, round, flattened, yellow, covered, mixed, and striped with bright red. Flesh yellow, breaking, tender, mild subacid, rich. Too small for profit. Deeember to March. (Warder.)

\section{Danvers Winter Sweet.}

Epse's Sweet.

Origin, Massachusetts, in the town of Danvers, from which this variety takes its name, it has been for a long time one of the best market apples, but we think it inferior to the Ladies' Sweeting. It is an abundant bearer, and a very rapid tree in its growth. Young shoots dark grayish brown, slightly downy.

Fruit of medium size, roundish oblong. Skin smooth, dull yellow, with an orange blush. Stalk slender, inclining to one sille. Calyx set in a smooth, narrow basin. Flesh yellow, firm, sweet, and rich. Very good. It bakes well, and is fit for use the whole winter, and often till April.

\section{DAPPER,}

From Georgia.

Fruit small; rounlish, truncate, yellow, with crimson specks. (Pa. Rep.) 


\section{Darlington.}

\section{Darlington Russet.}

Native of Northern Ohio.

Fruit medium, roundish, smooth russet. Flesh - hite. Hardly very good. January to June. (Elliott.)

\section{Darling Pippin.}

An old English sort, described in 1665 .

Fruit medium, oblate conical, lemou yellow, small pearly specks. Flesh yellowish, firm, juicy pleasant subacid. November to January. (Lind.)

\section{Dartmouth Sweet.}

An old Massachusetts variety.

Fruit medium, oblate, yellow, sprinkled with brown dots. Flesh yellowish, moderately juicy, tender, sweet. Good. October.

\section{Davis.}

Origin, Plymouth, Wayne Co., Mich., on the farm of Jehiel Davis. Tree vigorous, upright, bears annually.

Fruit small, roundish, flattened at base and crown, yellowish, shaded, and obscurely striped with crimson, russeted at the crown, and sprinkled with gray dots. Flesh whitish, fine-grained, compact, juicy, crisp, sprightly, subacid. Good. April, May.

\section{Davis's Sweet.}

Origin said to be Monroe Co., O. Tree vigorous, productive.

Fruit medium, roundish oblate, sometimes rather conical, regular. Color yellow, shaded with mixed red, splashed crimson, numerous large gray or fawn-color dots. Skin not smooth, thick. Stem long, slender. Cavity acute, regular. Calyx medium, closed. Basin small, abrupt, russeted. Flesh yellow, fine-grained, rather sweet. Core medium. Quality good. April to July. (A. Pom. S.)

\section{Dawson's Cluster.}

From Clark Co., O.

Fruit medium, oblong, truncate, pale yellow, blushed lightly with brown. Flesh yellowish white, tender, juicy, subacid. Good. Norember. (Warder.)

\section{DAY.}

\section{Royal Pippin.}

A native of Kentucky.

Fruit large, round, somewhat conic, yellow striped, splashed, and nottled with bright red. Flesh white, firm, breaking, subacid. Foor. January. Kitcheu use.

From Maine.

\section{DAYTON.}

\section{Haley.}

Fruit medium, roundish conic, whitish rellow, marbled and striped with red. Flesh juicy, tender, subacid. Good. Core large. December. 


\section{Defiaxce.}

Originated witl H. N. Gillett, Ohio, from seed of Prycr's Recl.

Fruit medium, oblate conical, yellow, nearly overspread, shaded, splashed, and striped with rich red. Flesh white, tender, not juicy, rich peculiar aroma. Good. August, September.

\section{Delaware.}

\section{Trumpington.}

Of unknown origin, supposed American, although heretofore found described only in Ronalds.

Fruit of medium size, oblate, golden yellow, blotched with deep red. Flesh firm, rich, high-flavored. October to December.

\section{Delight.}

From Robert Buchanan, Cincinnati, O.

Fruit medium, roundish oblate, yellow, some russet, and a red cheek in the sun. Flesh yellowish, firm, mild subacid, almost sweet. Good. December to March. (Elliott.)

\section{Denocrat. \\ Varick.}

An Apple consideraly grown in Tompkins Co., N. Y., the origin of which cannot be correctly traced. The trees are great bearer's, fruit keeping well, and always meeting a ready sale in market. Tree an up. right, good grower, annually productive. Young shoots reddish brown.

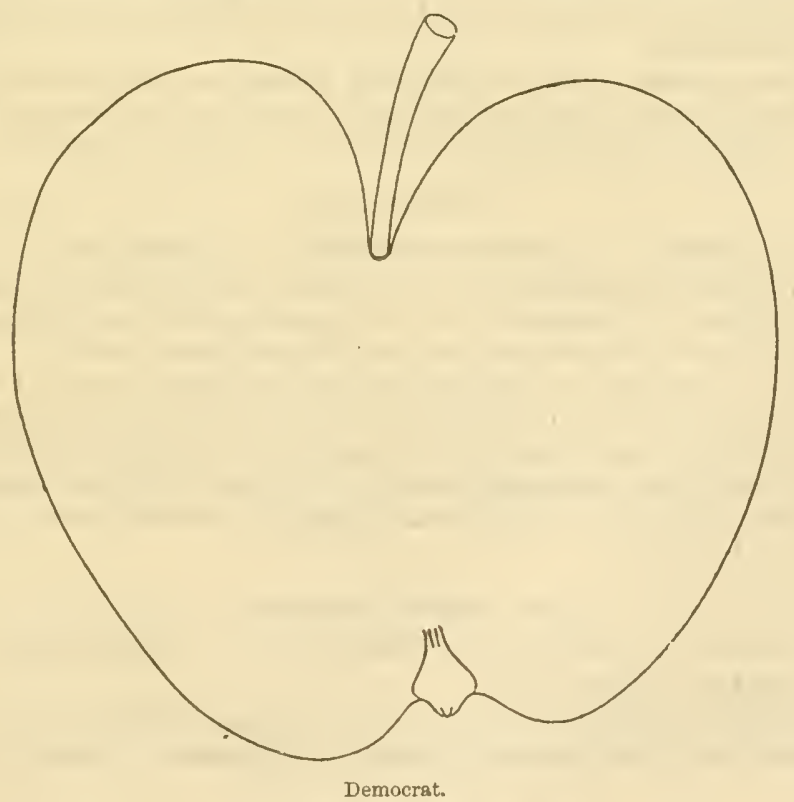

Fruit-size medium, or alove; form roundish conical, obscurely ribbed. Color pale whitish yellow, shaded, partially striped, and splashed nearly over the whole surface with light and dark crimson, and pretty 
thickly sprinkled with small light dots. Stalk medium, slender. Cavity large, deep, acute. Calyx small, closed. Segments small and short to a point. Basin medium, rather deep, corrugated. Flesh white, sometimes a little stained next the skin, very tender, juicr, mild, pleasant subacid. Very good. Core large. December to March.

\section{Democrat.}

Warder describes an Apple under this name obtained of George Powers, Perrysburgh, O., as follows:

Fruit medium, roundish conic, yellow, blushed scarlet. Dots minute. Flesh yellow, breaking, juicy, subacid, aromatic. Good to very good. October, December.

\section{Derry Noxsuch.}

\section{Dinsmore.}

Londonderry.

Origin unknown, from Keene, N. H., and held in estimation there. Tree thrifty and productive, a late keeper.

Fruit above medium, oblong or conic, yellow, sprinkled, shaded, and splashed with crimson. Stalk short, in a moderate cavity. Calyx large, closed. Basin shallow, uneven. Flesh yellowish, juicy, tender, slightly aromatic, agreeably subacid. Good. January to April.

\section{Detrolt Black.}

Crimson Pippin.

Black Detroit.
Grand Sachem.

Washington Pearmain.

A showy, large, dark, blood-red fruit, but rather coarse, and scarcely worth cultivation.

Fruit very large, roundish, distinctly ribbed, and irregular in its outline. Skin smooth, deep, dingy red orer the whole surface. Flesh white, rather dry, and withont much tiaror. Good. September.

\section{Detrolt Red.}

\section{Detroit. Black Apple of some. Large Black.}

This fruit, commonly known in Western New York and Michigan as the Detroit, is supposed to have been bronght to the neighborhood of Detroit by early French settlers, and thence disseminated.

Fruit of medium or rather large size, roundish, somewhat conical, bright crimson at first, but becoming dark blackish purple at maturity, somewhat dotted and marbled with specks of fawn color on the sunny side. Flesh white (sometimes stained with red to the core in exposed specimens), crisp, juicy, of agreeable, sprightly subacid flaror. Good. October to February.

\section{Devosshire Butcklaid.}

\section{Dredge's White Lily. White Lily. Lily Buckland.}

An Euglish culinary Apple.

Fruit above medium, roundish oblate, waxen yellow. Flesh rel. low, crisp, juicy, brisk, sweet. October to February. (Hogg.)

\section{Devoxsinke Goldex Ball.}

An English Apple, described by Ronalds as follows:

Fruit large, globular, straw-colored, with flesh of unstriped carmine. 
A beautiful sance apple, with an agreeable acid. January and February. Tree grows well and beats freely.

\section{Devoxhmbe Quarbexdex.}

Red Qnarrenden.

Sack Apple.

An English fruit, scurcely of medium size, roumdish, flattened, and slightly narrowed at the eyc. Skin rich sleep crimson, with lighter crimson, sprinkled with numerous green dots. Flesh nearly white, crisp, juicy, with a pleasant subacid flavor. Good. lipe duing all August and september.

\section{Deronshire Queen.}

Ronalds describes this as a favorite apple in the West of England.

Fruit rather large, roundish oblate, straw-colored, with bright red stripes. Flesh juicy, high flarored, for table or sauce.

\section{Devonsinre Red Streak.}

Another old West of England fruit, which, when grown in the States, becomes increased in size.

Fruit medium, roundish conical, yellowish with many stripes of red, few brown dots. Flesh yellow, tender, brisk, subacid. Good. Core large, hollow. November, December.

\section{Devonsuire Wilding.}

A cider Apple much valued in North Devon, England. Tree a strong grower and free bearer.

Fruit medium, roundish, yellowish green. Flesh firm, sharp, acid.

\section{Diel's Reinetete.}

Reinette Diel.

Diel Kernobst.

This variety was raised by Van Mons. Tree strong, healthy, vigorous grower, and alundant bearer.

Fruit below medimn, roundish oblate, orange yellow at maturity, with erimson and russety dots and spots. Flesh white, firm, crisp, juicy rich, spicy. December to March.

\section{Dickson's Eyperor.}

\section{From Scotland.}

Fruit large, slightly ribbed, yellow, with dashes of carmine, dull red in sum. Flesh yellowish white, juicy. Good. November, January. (Elliott.)

\section{Dieksiril.}

This Apple was first found among the Duteh, on the west end of Long Island. It is valued where known for being an early and regular bearer; but is not an attractive market fruit.

Fruit medium, oblate, grcenish yellow, mostly covered, shaded and splashed with dull red. Flesh whitish, crisp, juicy, tender, mild, almost sweet, subacid. Good. November, December.

\section{Dietzer Rothe Mindel Reinette.}

A German dessert Aple, which should bear the test of American 
palates before being highly praised. Tree a fine grower and productive. Hogg thus describes it:-

Fruit medium, roumdish, clear yellow, with iight red, slightly broken into stripes in the sun. Flesh fine, yellowish, firm, juicy, rich, aromatic, subacid. December.

\section{DiLLINGHAM.}

Raised by D. C. Richmond, of Sandusky, O. Tree moderately vigorous, productive, and particularly excellent for baking. Wood light reddish brown. Buds prominent, downy.

Fruit medium, roundish, inclining to conic, greenish yellow, with green and red dots. Stalk short. Carity deep. Calyx closed in a medi $\mathrm{m}$ basin. Flesh yellowish, fine-grained, juicy, sweet. Good. Norember to February.

\section{Disharoon.}

Origin, Habersham County, Georgia, growth upright and vigorous, productive.

Fruit medium, roundish conical, greenish white, covered with gray dots. Flesh yellowish white, juicy, tender, with a pleasant subacid flavor. Good. November to December.

\section{Dobe's Kernel Golden Pippix.}

From Gloucester, England, and only estimated orer the old Golden Pippin because of more free growth, and more productive.

- Fruit small, oblate, rich, golden yellow. Flesh firm, crisp, sharp subacid. March to April. (Ron.)

\section{DOCTOR.}

Red Doctor. De Witt.

A Pennsylvania Apple; the tree is rather an inclifferent grower and bearer.

Fruit medium, roundish oblate, yellow, striped and washed with two or three shades of red, with a few darker spots. Flesh tender, juicy, breaking, sligh tly aromatic, subacid. Good. October, January.

\section{Doctor Helshan's Pippis.}

From Norfolk Co., England. Tree slender, productive.

Fruit medium, roundish conical, yellowish green, slight red in sun. Flesh white, sweet, slightly aromatic. August, September. (Lind.)

\section{Doctor Fulcher.}

Origin, Todd Co., Ky. Tree thrifty, an early abundant bearer. Shoots slender.

Fruit medium, globular, trumeated, yellow marbled, and splished with carmine. Flesh yellow, tine-grained, tencler, juicy, subacid. December, Jamury. (Warder.)

\section{Donge's C'Rmsor.}

Cumberland Black.

Originated with .J. W. Dodge, Pomona, Tenn. Tree a free grower, making a round or spreading head, with sleuder limbs, which droop 
with the weight of the fruit. Ioung shoots very dark brown; an annual and great bearer.

Fruit medium, roumdish conical, deep rich red, almost purplish, few small light dots. Flesh white, sometimes stained a little next the skin, firm-grained, tender, juicy, sprightly, vinous. Good to very good. December, Jannary.

\section{DOMINE.}

English Rambo of some.

Hogan.

English Red Streak.

\section{Wells.}

Striped R. I. Greening.

English Beauty of Pa.
Cheat.

Cling Tight.

This Apple, extensively planted in the orchards on the Hudson and west, so much resembles the Rambo externally, that the two are often confounded together, and the outline of the latter fruit (see Rambo) nory be taken as nearly a fac-simile of this. The Domine is, however, of a livelier color, and the flavor and season of the two fruits are very dintinct,-the Rambo being rather a high-flavored early winter or antumn apple, while the Domine is a sprightly, juicy, long-keeping winter fruit.

Fruit of medium size, flat. Skin lively greenish yellow in the shade, with stripes and splashes of bright red in the sun, and pretty large russet specks. Stalk long and slender, planted in a wide cavity and inclining to one side. Calyx small, in a broad basin, moderately sunk. Flesh white, exceedingly tender and juicy, with a sprightly pleasant, though

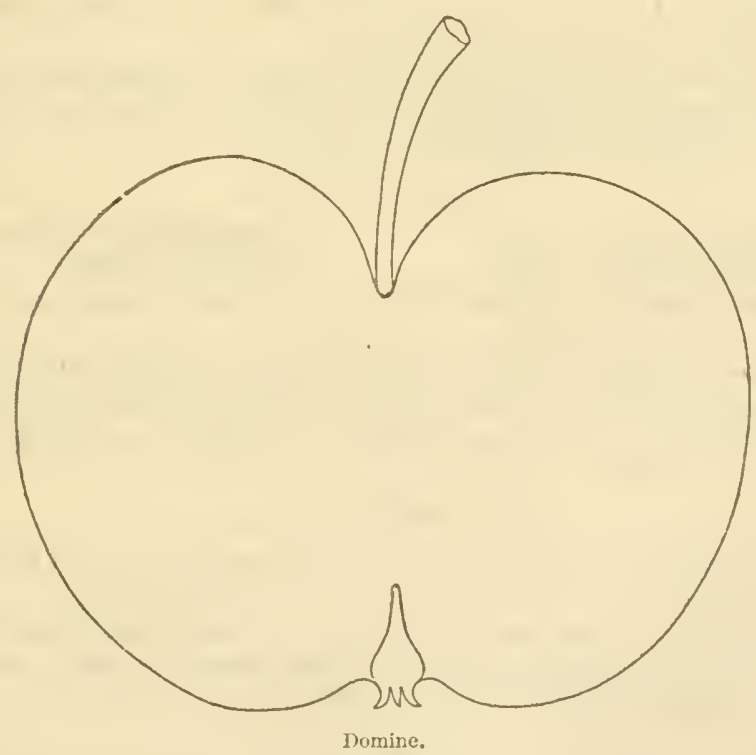

not high flavor. Young wood of a smooth, lively light brown, and the trees are very hardy, and the most rapid growers and prodigious early bearers that we know-the branches being literally weighed down by the rope-like clusters of fruit. 
The Domine does not appear to be describer by any foreign author. Coxe says that he received it from England, but. the apple he describes and figures does not appear to be ours, and we have never met with it in any collection here. It is highly probable that this is a native fruit. It is excellent from December till April.

\section{Donnelan's Seedlixg.}

Of American origin.

Fruit medium, roundish, greenish yellow, dull red stripes. Flesh yellowish, dry, subacid. September. (Elliott.)

\section{DOUX D'ARGENT.}

\section{Doux d'Angers. D'Eve. Ostogate.}

Supposed French origin. Tree rigorous, productive, with straight, downy young shoots.

Fruit medium, oblate, conical, waxen vellow, bright red in the sun. Flesh white, firm, crisp, not very juicy, partially sweet. December, January.

\section{Dowell's Pippin.}

An old Berkshire, England, dessert Apple.

Fruit medium, roundish, conical, green, with russet and brownish red in the sun. Flesh firm, crisp, juicy, aromatic. October.

\section{Downing's Paragon.}

Raised by A. G. Downing, near Canton, Ill. Growth upright, not very strong. Bears regularly and well.

Fruit above medium, roundish, truncated. Skin light rellow, with a sumny cheek. Flesh whitish, juicy, tender, sweet, rich, aromatic. Good to very good. September to December.

\section{Downton Pippin.}

\section{Elton Pippin.}

Knight's Golden Pippin.
Downton Golden Pippin. St. Mary's Pippin.

A rather early variety of the English Golden Pippin, raised by Mr. Kniclit, of Downton Castle.

Fruit a little larger than the Golden Pippin, about two and a quarter inches in diameter, roundish, flat at the ends. Skin smooth, rellow. Flesh yellowish, erisp, with a brisk, rich tart flavor. Tery good. October and November.

\section{Dow's Winter Pippix.}

Origin, on the grounds of V. P. Dow, Greenbush, near Albany, N. Y. Tree productive.

Fruit large, oblate, green inclining to yellow, slightly shaded in the sun with erimson, few brown dots. Flesh greenish, tender, juicr, brisk subacid, slightly aromatic. Good. November.

\section{Drap D'Or.}

Fennouillet Jaune. Bay Apple. 
most French authors, which is quite a small apple; but it is the Vrai Drap d' $O r$ of the old Dulimel, pl. xii. Fig. 4.

Fruit large, romdish oblate. Skin smooth, yellow or dead gold color, with distinet small brown dots or sjecks. Flesh eris], juicy, mild subacid. Good. Angust to Oetober.

There are two or three apples under this name-one is similar in size to the above, but the tree is of stronger growth, dropping its fruit before mature, which is rather coarse, spongy. Flesh quite inferior.

Another variety, the Drap d'Or of Knoop, is small, bright yellow, firm and erisp.

\section{Dredge's Fair Maid of Wishford.}

A varicty from near Salisbury, England. Tree a free grower, and good bearer.

Fruit medium, roundish, yellow, with patehes of brown russet, and streaks of red in sun. Flesh yellowish, tirm, brisk, juicy, sugary. December to March. (Hogg.)

\section{Dredge's Fame.}

Tree hardy, vigorous grower, productive.

Fruit medium, roundish, dingy yellow, patches of thin russet, pale red in the sun. Flesh greenish yellow, firm, erisp, brisk, sugary, aro. matic. December to Mareh. (Hogg.)

\section{Dredge's Golden Pippin.}

Ronalds deseribes this as a little larger than the original, flattish in shape, clear yellow, firm, and sweet. February to March.

\section{Duchesse de Brabant.}

\section{Reinette Duchesse de Brabant.}

Thee very vigorous.

Frnit large, variable in form, yellow, spotted with reddish gray dots, crimson cheek in the sun. Flesh yellowish white, firm, crisp, juicy, acid. September to December. (An. Pom.)

\section{DUCHESS OF OLDENBURGI.}

Smith's Beauty of Newark. New Brunswick.

This liandsome Russian Apple proves one of the most hardy and profitable varieties in cultivation, and especially in our northwestern sicetions. The tree is vigorous, forming a roundish, upright, spreading heal, requiring little or no pruning, and producing abundantly a fruit of fair, even, and regular size, that, although not of the first quality, always commands a ready sale, as it is valuable for narket and cooking, and passably good for dessert. Young shoots smooth, reddish.

Fruit medium size, regularly formed, roundish oblate. Skin smooth, finely washed and streaked with red on a golden or yellow ground. Calyx 
pretty large and nearly closed, set in a wide, even hollow. There is a faint blue bloom on this fruit. The flesh is juicy, sprightly subacid. Ripens early in September.

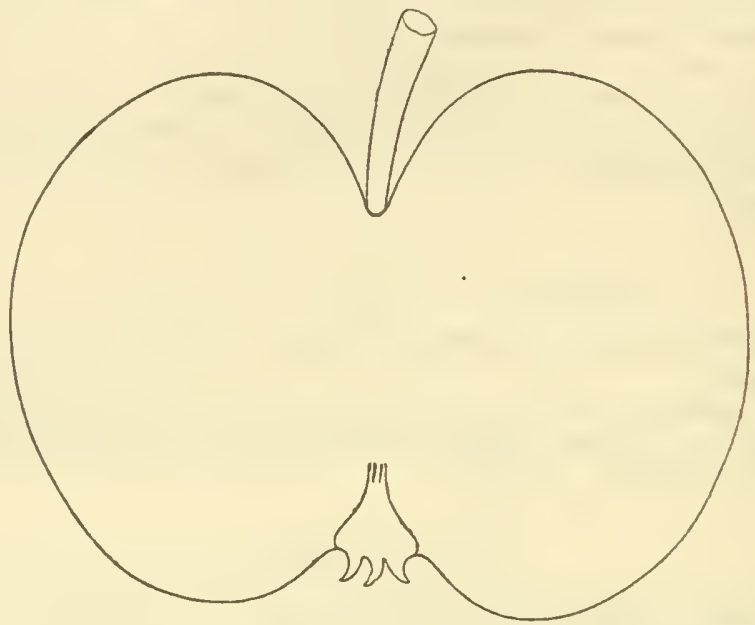

Duchess of Oldenburgh.

\section{DUCKETT.}

A Southern fruit.

Fruit rather large, oblate, light waxen yellow, often with a crimson cheek. Flesh white, tender, juicy, pleasant, aromatic. Good. Very good at the South, where it is ripe October to November.

\section{Duffield PippiN.}

Probably an old variety, claimed as a seedling of the Rev. George Duffield's ancestors.

Fruit medium, roundish oblate, pale yellow, with shade of light crimson in the sun. Flesh yellowish, juicy, tender, pleasant, subacid. Good. November.

\section{Du Halder.}

Probably a Holland variety. Tree vigorous, very productive.

Fruit large, roundish conical, golden yellow, with gray white dots. Flesh white, fine, semi-tender, sugary acid. November to May. (An. Pom.)

\section{Duke of Beaufort's Pippin.}

Fruit large, roundish oblate, ribbed, greenish, with faint streaks in the sun of pale red. Flesh greenish white, crisu, and subacid. Norember, December. (Lind.)

Duke of Devonshire.

An English dessert Apple. 
Fruit of medium size, roundish, lcmon yellow, with a dull red eheek. Flesh yellowish, crisp, juiey, rich, sugity, fine aroma. F(b. ruary to Miay. (Hogg.)

\section{Dulce Doman.}

\section{Sweet IIome.}

Introduced by E. H. Cocklin, Cumberland Co., Pa. Tree of upright growth, moderately vigorous and productive.

Fruit medium, oblate, greenish yellow with a shade of red in the suu. Flesh firm, yellowish, moderately juicy, mild honeyed sweet. Good to very good. Baking and stewing. November, February.

\section{Dumelow's Seedling.}

\section{Wellington. Dumelow's Crab.}

English, rather large, roundish, yellow, with a blush. Flesh yellow, crisp, brisk, acid. Good. November to March.

\section{DUMPL.ING.}

Crooked Limb Pippin. French Pippin of Indiama. Watrous Dumpling.

Fruit large, roundish oblong, light yellow, blush in the sun. Flesh white, indifferent. October, December. (Elliott.)

\section{DUNCAN.}

Fruit medium, roundish oblate conical, ribbed, yellow, with rieh deep red in the sun. Flesh yellowish white, crisp, juicy, pleasantly acid. November to January. (Hogg.)

\section{Dusten.}

Of unknown origin, but grown in Weare, N. H.

Fruit medium, oblate, whitish yellow, few gray dots. Flesh white, tender, juicy, pleasant subacid. Good. November.

\section{Dutch Codin.}

\section{Chalmer's Large.}

A very large kitchen Apple, valued only for cooking, from August to September.

Fruit of the largest size, irregularly roundish, or rather oblong, strongly marked by ribs extending from the base to the eye. Skin pale yellow, becoming orange yellow on the summy side. Flesh white, subacid, and moderately juicy. Good.

\section{Dutch Mignoxie.}

Reinette Dorée. Pomme de Lak. Grosser Casselar Reinette. Paternoster Apfel. Settin Pippin. Copmanthorpe Crab.

A popular Apple from Holland. Tree moderately vigorous, upright, spreading, young wood dirk brown, downy, productive.

Fruit medium, roundish oblate, slightly conic. Skin rather rough, yellow, shaded, striped, and splashed with shades of light and darls 
rich red, and moderately sprinkled with light and brown dots. Stalk medium, slender. Cavity large, often russeted. Calyx partially open. Segments erect. Bisin large, slightly corrugated. Flesh yellowish, a little coarse, tender, juicy, slightly subacid. Core small. Good to very good. December to March.

'The foregoing is not the Dutch Mignonne which was described in the first edition of this book. That variety difiers in being a more vigorous grower, forming a very large spreading tree, and bearing its fruit singly and very evenly distributed over the whole of the branches. We are uncertain of its true name. Young wood rery stout, dark reddish brown.

Fruit large, often very large, roumdish oblate. Skin dull orange, half covered or more with rich, dull red, dotted and mottled with large yellow russet specks. Calyx very large. Segments divided and reflexed. Basin very broad, large, and deep, slightly colrugated. Flesh yellowish, a little coarse, breaking, tender, rich, aromatic. 'Very good. Yovember to February.

\section{Duzexpury.}

This valuable new Apple originated on the farm of Charles Duzenbury, Phillipstown, Putnam Co., N. Y. The tree is a vigorous grower, forming a handsome spreading head, producing abundantly a mediumsized, regtilar, miform fruit, which keeps and retains its flaror until May. Young wood, dark brownish red.

Fruit medium; form romdish conical, truncated; color greenish yellow, shaded and rather obscurely splashed with dull red over nearly two-thirds its surface, and sprinkled with a few gray and light dots. Stalk rather short. Cavity rather large and deep. Caly closed. Segments medium, erect to a point. Basin rather abrupt, slightly corrugated. Flesh whitish yellow, crisp, tender, moderately juicy, rery mild, and pleasant subacid, almost sweet. Core small. Tery good. February to May.

\section{Dyer, or Pomie Royale.}

Golden Spice.

White Spice.

Smithfield Spice.

Mygatt's Bergamot.

Beard Burden.

\author{
Pinneo's Favorite. \\ Woodstock. \\ Tompkins. \\ Coe's Spice. \\ Bullripe.
}

A popular dessert Apple, very sprightly, tender, and excellent. Tree a moderate grower. Young wood grayish brown. It is supposed to be of French origin, and to have been brought to Rhode Islund more than a hundred years ago. It was renamed Dyer by the Massachnsetts Horticultural Society, who supposed it to be a seedling of Mr. Dyer, of Rhode Island, but the old aud familiar name of Pomme Roycle should be preferred.

Fruit of medium size, roundish, pretty regularly formed. Skin smonth, pale greenish vellow, with a faint blush and a few dark specks on one side. Stalk about half an inch long, set in a smooth, round cavity. Calyx closed. Basin plaited, moderately deep. Core round, hollow. Flesh white, very tencler and juicy; flavor very mild and 
amreeable, aromatic, slightly subacid. Very good to best. September Oetober.

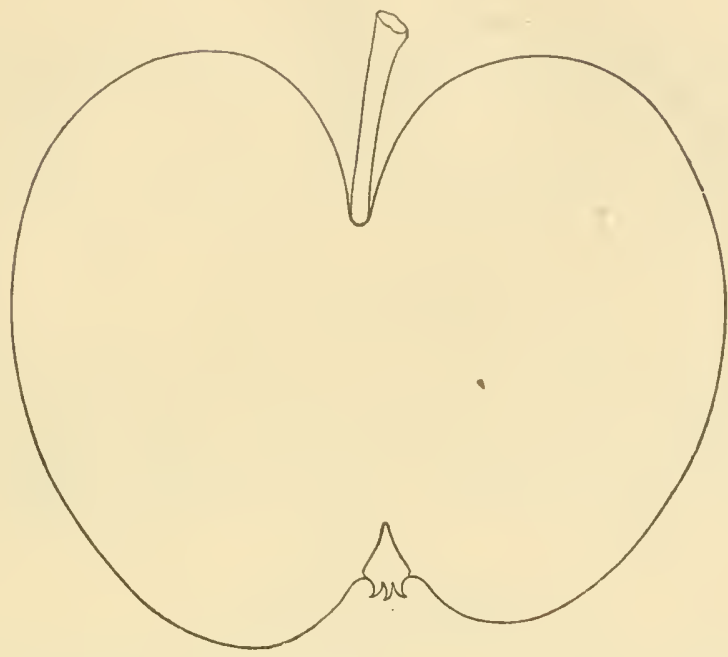

Dyer, or Pomme Royale.

\section{Eardi Chandler.}

Fruit medium or small, roundish. Color mostly shaded and striped with fine red on yellow ground. Stalk short, in a regular cavity. Calyx closed, in a large basin. Flesh yellow, tender, juicy, with a pleasant subacid flavor. Fine for cooking, too acid for eating. Good. Angust.

\section{EARLY HARVEST.}

Prince's Harvest, or Early French Reinette, of Coxe.

July Pippin.

Yellow Harvest.

Tart Bough.

Early French Reinette.

Large White Juneating. Sinclair's Yellow.

An American Apple; and taking into account its beanty, its excellent qualities for the dessert and for cooking, and its productiveness, we think it the finest early apple yet known. It begins to ripen abont the first of July, and continues in use all that month. The smallest collection of apples should comprise this and the Red Astrachan. Tree moderately vigorous, upright, spreading. Young shoots reddish brown.

Fruit medium size. Form roundish, often roundish oblate, medium size. Skin very smooth, with a few faint white dots, bright straw-color when fully ripe. Stalk half to three-fourtlis of an inch loug, rather siender, inserted in a hollow of moderate depth. Calyx set in a shal- 
low basin. Flesh very white, tender, and juicy, crisp, with a rich. sprightly subacid tlavor. Very good to best. Core small.

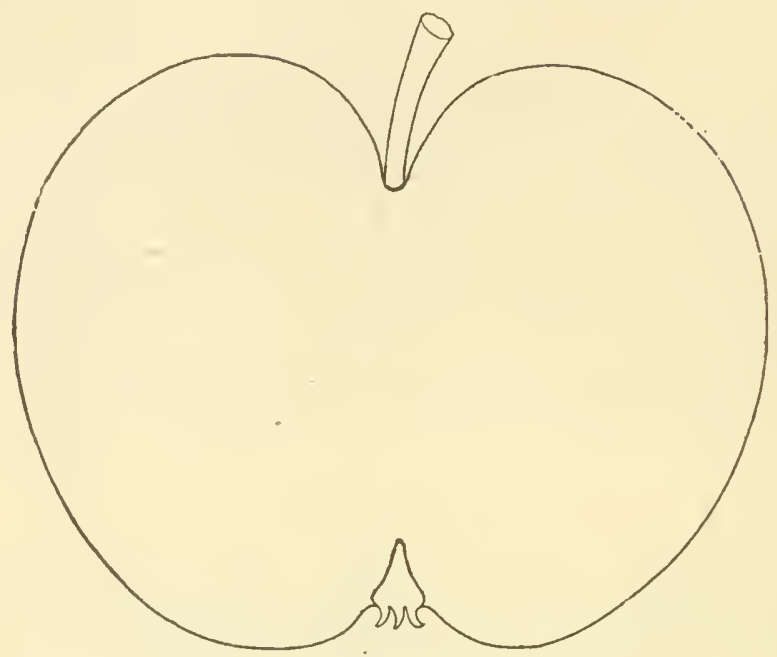

Early Harvest.

EARLY JoE.

Origin, orchard of Heman Chapin, Ontario Co., N. Y. Tree of slow growth, productive, requires high culture for fair fruit.

Fruit below medium, oblate, very slightly conic, smooth, yellowish,

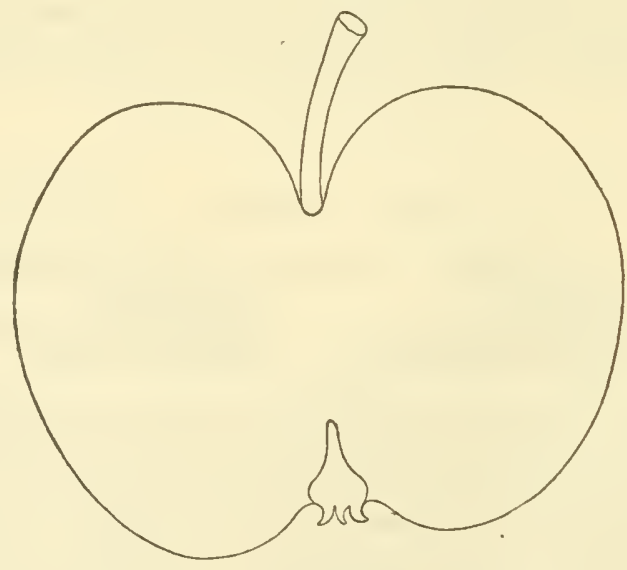

Early Joe.

shaded and striped with red, and thickly sprinkled with greenish spots. Stalk of medium length, inserted in a large cavity surrounded by russet. Calyx closed. Basin moderate. Flesh whitish, tender, juicy, with a 
very agreeable vinous flavor. Best. Ripe middle of August to middle of september.

There is a Luce's Early Joe which is distinet from this, being larger, and not as good quality.

\section{Early Julien.}

This Apple is of Scoteh origin, the tree healthy and hardy, and a good bearer.

Fruit medium size, roundish, slightly flattened, pale yellow, deepening in the sun. Flesh yellowish white, juicy, brisk subaeid, pleasant. August. (Lind.)

\section{Early Lojg Strem.}

Early Spice.

Origin unknown. Speeimens received from Henry Avery, Burlington, Iowa.

Fruit small, oblong eonical, slightly ribbed. Skin greenish yellow. Stem long, slender, in a large cavity, slightly russeted. Calyx closed. Basin shallow, eorrugated. Flesh white, tender, juicy, slightly aromatic, subacid. Good. August.

\section{Early Marrow.}

A large Scotch Apple, roundish conical, ribbed. Skin yellowish white, with a tinge of red in the sun. Flesh tender, and bakes well; productive. Good. September and October.

\section{Early NoNpareil.}

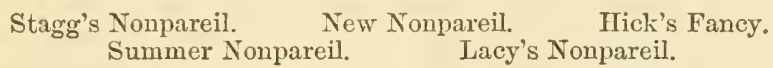

Originated about 1780, in Norfolk, England. Tree a free upright grower, hardy, early, and abundant bearer.

Fruit medium, roundish oblate, dull yellow with gray russet, and russet dots. Flesh yellowish white, tender, juicy, brisk, rich, aromatic. October, November. (Lind.)

\section{Early Nonpareil.}

A variety grown in Illinois, the origin of which we eannot learn. It is barely possible that this may prove identical with the foregoing.

Fruit medium to large, roundish oblate, strongly ribbed, whitish, thinly shaded, striped and splashed with red gray dots. Flesh white, sometimes stained next the skin, very tender, juicy, sprightly subacid. Good, Core large. September.

\begin{tabular}{ll}
\multicolumn{2}{c}{ Earty Pexyock. } \\
Shakers' Yellow. & Indian Queen. \\
August Apple. & New Jersey Red Streak. \\
Warren Pennoek. & Harmony.
\end{tabular}

A very productive and favorite variety with many at the West.

Fruit large, roundish eonic, ribbed, light yellow, splashed, mottled, and shaded with light red. Flesh whitish, a little coarse, subacid. Good. Core large. Last of August and September. 
Tree hardy, an early and abundant bearer. The fruit, however, is only showy, and salable in market where a better quality of fruit is unknown.

\section{Early Queening.}

Fruit medium or below, roundish, yellow, striped and mingled with red. Flesh whitish, slightly subacid. August. Tree rather spreading, with light brown shoots.

\section{Early Red Margaret.}

$\begin{array}{ll}\text { Margaret, or Striped Juneating. } & \text { Striped June. } \\ \text { Early Red Juneating. } & \text { Striped Juneating. } \\ \text { Red Juneating. } & \text { Eve Apple of the Irish. } \\ \text { IIargaretha Apfel of the Germans. }\end{array}$

An excellent early Apple, ripening about the middle of July, or directly after the Early Harvest. The tree while young is rather slen. der, with reddish brown upright woolly shoots. It is a moderate bearer.

Fruit below medium size, roundish ovate, tapering towards the eye. Skin greenish yellow, pretty well covered by stripes of dark red. Flesh white, subacid, and, when freshly gathered from the tree, of a rich, agreeable flavor. Good.

\section{Early Red Streak.}

Fruit medium, roundish, yellowish, mostly covered with red, marbled and splashed. Flesh white, tender, juicy, crisp, subacid. August, September.

There are a number of distinct apples under the name of Earl $>$ Red, or Early Red Streak, and we have been unable to decide perfectly as to which the name truly belongs. None of them, however, are more than moderately good. One, under name of Philadelphia Queen, is also similar to Early Red, and may be the same. The origin is variously claimed, but all unknown.

Fall Stripe may also prove identical with one of the above.

\section{Early Red Sweet.}

From Pennsylvania.

Fruit medium, roundish, sweet. Not desirable.

\section{Early Ripe.}

Supposed Pennsylvania origin, but unknown. Tree a free grower, and productive.

Fruit medium, roundish oblate, pale rellow, sprinkled with a few gray dots. Stalk long, in a slightly musseted cavity. Calyx small, closed. Flesh white, tender, juicy, subacid. Good. August.

'There is also another apple under name of Early Ripe, which is small, oblate. Stalk short. Flesh brisk subacid.

\section{Early Spice.}

An English culinary Apple. Fruit medium, roundish, pale rellow. Flesh white, marrowy, poor. August. (Hogg.)

There is also an Early Spice originated in Chatham, N. C., which is 
small, round, yellow. Flesh yellow, dry, igh flavored. Tree produc tive. Young shoots slender.

\section{EARty Strawberry.}

American Red Juneating. Red Juneating.

A beautiful variety, which is said to have originated in the neigh. borhood of New York, and appears in the markets there from July till September. It is quite distinct from the Early Red Margaret, which has no fiagrance, and a short stem.

Fruit roundish, narrowing towards the eye. Skin smooth and fair,

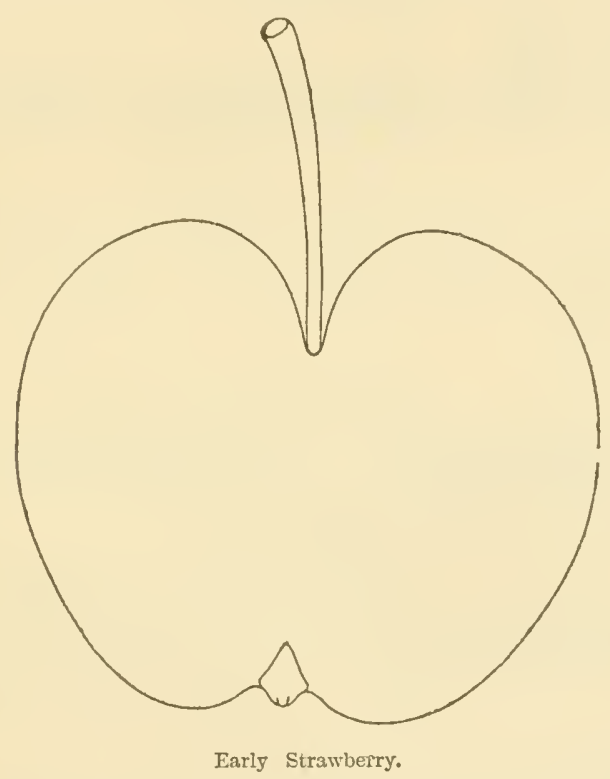

finely striped and stained with bright and dark red, on a yellowish white ground. Stalk an inch and a half long, rather slender and uneven, inserted in a deep cavity. Calyx rather smali, in a shallow, narrow basin. Flesh white, slightly tinged with red next the skin, tender, subacid, and very sprightly and brisk in flaror, with an agreeable aroma. Very good.

\section{EArly Sifeet.}

Originated with WV. C. Hamptun, Ohio. Tree upright, productive. Fruit medium or below, roundish, whitish yellow. Flesh white, tender, moderately juicy, sweet Goorl. August.

\section{Early Tart.}

Supposed seedling of Lancaster Co., Pa. Tree productive.

Fruit mediur, roundish, inclining to conic, pale yellow, light shade of 
crimson in sum. Stalk short. Calyx closed. Flesh white, tender, juicy, brisk subacid. Good for cooking. August.

\section{Early Tart Harvest.}

Tree moderateiy vigorous, productive.

Fruit mediun, oblate, slightly conic, obscurely ribbed, waxen white, sometimes greenish, rarely a blush in sun. Stalk medium. Calyx closed. Flesh white, very tender, juicy, brisk subacid. Tery good. Core medium. Ripe about two weeks later than Early Harrest.

\section{EARLY WAX.}

Wax Apple.

An English variety.

Fruit below medium, oblong, roundish, somewhat ribbed, waxen yellow. Flesh yellowish white, tender, sofr, sweet. August. (Hogg.)

\section{Early Yellow PieinetTe.}

\section{Reinette Jaune Hatif.}

Fruit medium, conical, yellow and red. Flesh rich and juicy. August.

\section{Easter Pippin.}

Young's Long Keeping. Claremont Pippin.
Ironstone Pippin.

French Crab. Forsyth (not of Coxe).

Remarkable for keeping sound and firm two years. It is an English variety.

Fruit of medium size. Skin deej green, with a pale brown blush. Elesh very firm, and though not juicy, of a good subacid flavor.

\section{East Grinstead.}

Ronalds describes this as a Sussex Apple of great excellence for table or kitchen.

Fruit medium, roundish conical, dull greenish yellow, with splashes of dull faint red. Elesh white, juicy, acid. March to May.

\section{EAton.}

Origin unknown, found a grafted tree in the garden of J. B. Eaton, Buffalo, N. Y., and described in the Am. Pom. Soc. Reprints, 1854.

Fruit large, oblong conical, dull green, striped with dull red, deeper when exposed to the sun. Stalk rather slender. Calyx large. Flesh white, tender, juicy, subacid. Good to very good. November, December.

\section{EDEL KöNIG.}

$$
\text { Rú-Très-Noble. }
$$

A German cuinary Apple of first-rate quality.

Fruit large, roundish conical, truncated, ribbed, yellowish green, 
deep purplish crimson in sum. Flesh white, tinged with pink, tender, juicy, sugary, raspberry tharor. October, November. (Hogg.)

\section{Edgar's.}

An English Apple, which Ronalds describes as of medium size, roundish, yellow laced with bright red striping. A bear tiful fruit, ex cellent for the dessert or kitchen. Norember, December.

\section{EDward's.}

Origin, Chatham Co., N. C.

Fruit nearly medium, roundish oblate, greenish yellow, lightly striped with delicate red. Flesh rich, juicy, firm. One of best keepers. (Con. Gent.)

\section{EgGernont.}

\section{Eggermont's Calville.}

Fruit medium, oblate. Skin glossy, lemon yellow, slight lines of russet. Flesh white, firm, juicy, marrowy, sugary, vinous. November. (Hogr.)

\section{EGG ToP.}

Ere. Sheep Nose. Round Top. Wine of some.

Fruit medium, elongated, oblong, conic ovai, mostly overspread, and splashed and striped with shailes of red. Flesh white, tender, moderately juicy, subacid. Scarcely good. November, December.

\section{Egrptian Belle.}

From J. M. Smith, of Greenville, Ill.

Fruit large, roundish flattened, yellowish white, striped, stained, and splashed with light and deep carmine. Flesh juicy, white, fine-grained, subacid. August. (Gar. Mon.)

\section{Egyrtian Russet.}

\section{Bagby liusset.}

From Southern lllinois, origin unknown. This Apple is much esteemed where known for its rich, high flavor, and as a good keeper. Some think it the best of all the russets. The tree forms an upright, symmetrical, round head, with grayish reddish brown, somowhat downy young shoots. Productive.

Fruit merlium. Form roundish, approaching conical, slightly ribbed. Color golden yellow, netted and patched with russet over half or twothirrls of its surface, often with a chcek of crimson or fitwn in the sun, and inoderately sprinkled with brown dots. Stalk short and small. Cavity medium or rather broarl. Calyx open or partially closed. Segments short. Basin medium. Flesli yellowish, tender, juicy, rich, slightly aromatic, plcasant subacid. Very good. December to March.

\section{Eldon Pipeis.}

Fruit small, round, somewhat oblate, ribbed near the calyx, yellow 
shaded or covered with crimson next the sun. Flesh yellowish, very juicy, sweet, rich, aromatic. December to April. (Hogg.)

\section{Elford Pippin,}

Hogg describes this as a dessert Apple of first quality. Tree a healthy rigorous grower and good beurer.

Fruit roundish, ribbed near the calyx, yellowish green, with markings of russet in the shade, red, and striped with darker red next the sum. Flesh yellowish, crisp, brisk, sugary, vinous. October, December.

\section{Elicke's Winter Sweet.}

Origin, Lebanon Co., Pa. An upright grower and a good bearer.

Fruit above medium, obliquely depressed, yellow, striped and mottled with crimson. Flesh yellowish, a little coarse, tender, noi very juicy, but very sweet, and excellent for apple butter. Good. December to January.

\section{Ellijay.}

From Clarksville, Ga.

Fruit large, oblique, roundish conic, pale yellow, often a blush red cheek in sun. Flesh white, rather tender, juicy, subacid. Hardly good. Core large and hollow. Most ralued for cooking. Norember, December.

\section{ElLis.}

From Connecticut. Small, roundish, greenish fellow, brown cheek. Flesh firm, juicy, pleasant, a long keeper. Ciood. April, MIay.

\section{Elloworth}

Miller's Seedling.

Originated in Columbia Co., N. Y., on the furm of John C. Miller.

Tree pretty vigorous growth, erect, young wood, much like Swaar in color, very productive.

Frnit medium, roundish, fine yellow, sometimes a shade of crimson in the sun. Nettings of russet and gray dots. Stalk long, slender. Cavity rather large, russeted. Calyx closed. Segments small, short, erect. Basin medium, slightly corrugated. Flesh white, firm, tender, juicy, rich, sprightly subacid. Tery good or best. Core small. January to March.

\section{EMPEROR.}

Described by Verry Aldrich in the Prairie Farmer as follows :-

Fruit medium, romdish, one-sided, orange striped aud shaded with red on the sun side, covered with white specks. Stalk short and slender. Cavity deep. Flesh white, fine-grained, tender, juicy, plea. bant, almost sweet.

\section{ENE's WTiNTER SWEeT.}

A Southern Apple, introduced by J. S. Downer, Elkton, Ky. 
Fruit medium, oblate, greenish yellow, blushed in sun, russeted Flesh yellow, fine-grained, sweet. Good. December.

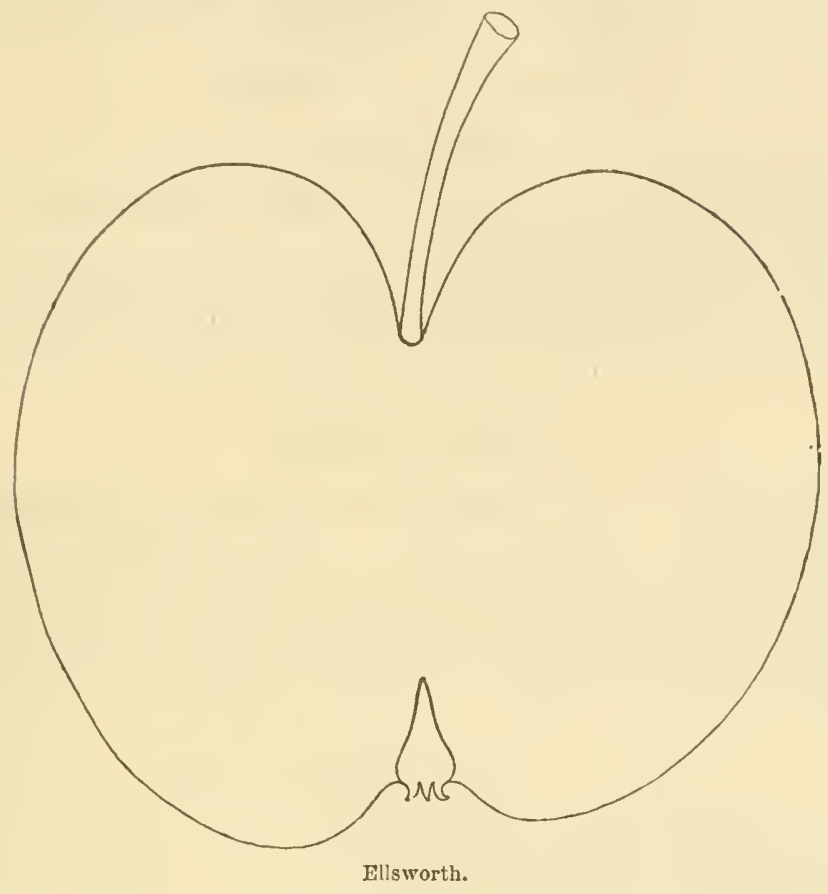

Enfield Pearmain.

A moderate grower and a fair bearer.

Fruit below medium, nearly globular, deep red, sprinkled with minute dots. Stalk long and slender, in a large cavity, surrounded by thin russet. Calyx partially closed, in a broad, shallow basin. Flesh tender, fine-grained, juicy, with a pleasant, mild, rich flavor, resembling Seekno-Further. Good. December to February.

\section{Exglish Beauty.}

Origin unknown.

Fruit large, romdish oblate, slightly conical, yellow, mostly overspread, striped, shaded and splashed with crimson, and sprinkled with light and brown dots. Flesh whitish, tender, juicy, sprightly mild subacid. Almost very good. December to March.

\section{Eyglish Crab.}

Fruit small, oblate, yellow with dark red. Flesh deep yellow, mild subacid. Good. January.

\section{Exglish Gilliflower.}

Origin unknown.

Fruit large, roundish oblate, approaching conic, slightly ribbed, 
light yellow, splashed, striped, and shaded with crimson and thickly sprinkled with brown dots. Stalk very short. Cavity russeted. Calyx nearly closed. Basin abrupt. Flesh yellowish, tender, juicy, mild subacid. Almost very good. November, December.

\section{English Granat Peinette.}

Pomme Granate.

Hogg describes this as a first-rate German dessert Apple. Tree a medium grower and great bearer.

Fruit medium, roundish oblate, lemon yellow, two-thirds overwashed and striped with crimson. Flesh yellowish white, ver'y fine, firn, crisp, juicy, very lich vinous, aromatic. December to March.

\section{English Rennette.}

\section{Reinette d'Angleterre.}

This is distinct from Grosse Reinette d'Angleterre, or from English Golden Pippin.

Fruit medium, roundish, inclining to conical, slightiy ribbed, yellow shaded, marbled, and indistinctly splashed on the sunny side with light crimson. Stalk rather long. Calyx open. Flesh yellow, crisp, juicy, with a rather rich brisk subacid. Very good. December, Jannary.

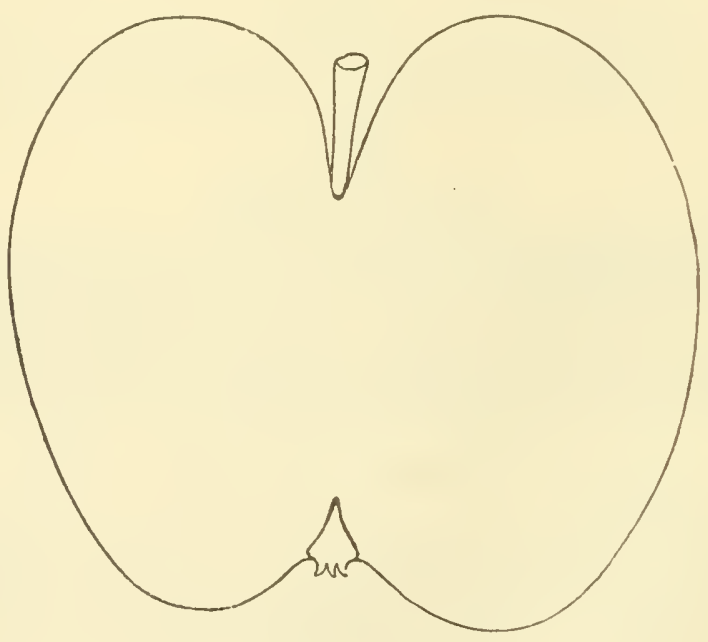

Engiish Russet.

\section{Exglisir Russet.}

Poughkeepsie Russet.

Po'keepsie Russet.

The English Russet is a valuable, long-keeping varicty, extensively cultivated, and well known by this name, but which we have not been able to identify with any English sort. It is not tit for use until Feb. 
mary, and may be kept till July, which, together sith its great produc. tiveness and good flaror, render's it a very valuable market fruit.

The trees grow rery straight, and form upright heads, and the wood is smootlr and of a reddish brown.

Fruit of medium size, roundish, slightly conical, and very regularly formed. Skin pale greenish yellow, abont two-thirds covered with russet, which is thickest near the stalk. Calyx small, closed, and set in an even, roum basin, of moderate depth. Stalk rather smail, projecting eren with the base, and pretty deeply inserted in a narrow, smooth cavity. Flesh yellowish white, firm, erisp, with a pleasant, mild, slightly subacid flavor. Good. Jannary to May.

The Eng'ish Russet described by Warder is entirely distinet, being, as he describes, large, globular, flattened, somewhat one-sided. Surface uneren, green. In season fiom December to January.

\section{Exglisit Sweet.}

Ramsdell's Sweet.

Ramsdell's Red Pumpkin Sweet.

Randall's Red Winter.
Ramsdell's Sweeting. Red Pumpkin Sweet.
Hurlbut Sweet?

Avery Sweet.

This old variety is esteemed where grown for the large crops which it bears, and as a showy sweet apple for market, and profitable for stock feeding, as well as superior for cooking.

The tree is very vigorous, grows remarkably straight and upright, comes early into bearing, and vields every year enormonsly. Young shoots clear ruddish brown, slightly grayish.

Fruit rather above medium size, oblong, regularly shaped, and tapering slightly towards the eye, dark red, dotted with fawn-colored speeks, and covered with a blue bloom. Flesh yellowish, very tender and mellow, umsually sweet and rich. Good to very good. In weight the apple is light. Oetober to February.

\section{EPSY.}

From Vermont. A handsome productive fruit, small, elongated conic, deep red, almost crimson. Flesh whitish, brisk subacid. Scarcely good. December, January.

\section{Eptings Prenium.}

Large, greenish, with red stripes. Flesh juicy and excellent. (Sumner's IIS.)

\section{Eptings Red Winter.}

Large, beautiful red, resembling Carolina Red June. Flesh yellow, with rich pine-apple flavor. Keejs well to Christmas. (Sumner's MS.)

\section{Erie Sweet.}

From Erie, $\mathrm{Pa}$.

Frnit merlium, roundish oblate, whitish yellow. Flesh white, tender, juicy, mild, pleasant sweet. Good. Septeinber, October. 


\section{Essex Pippin.}

An English variety.

Fruit small, roundish oblate, yellowish green, tinge of red in the suri. Flesh yellowish, firm, crisp, brisk, sugary. October to February. (Hogg.)

\section{Esopus Spitzenburgh,}

\section{Esopus Spitzenberg. Asopus Spitzenburg. \\ True Spitzenburgh.}

The Esopus Spitzenburgh is a handsome, truly delicious Apple, and is generally considered by all good judges equal to the Newtown Pippin, and unsurpassed as a dessert fruit by any other variety. It originated at Esopus, a famous apple district, originally settled by the Low Dutch, on the Hudson. But throughout the whole of New York it is considered the first of apples. The tree has rather slender shoots, and when in bearing has long and hanging limbs.

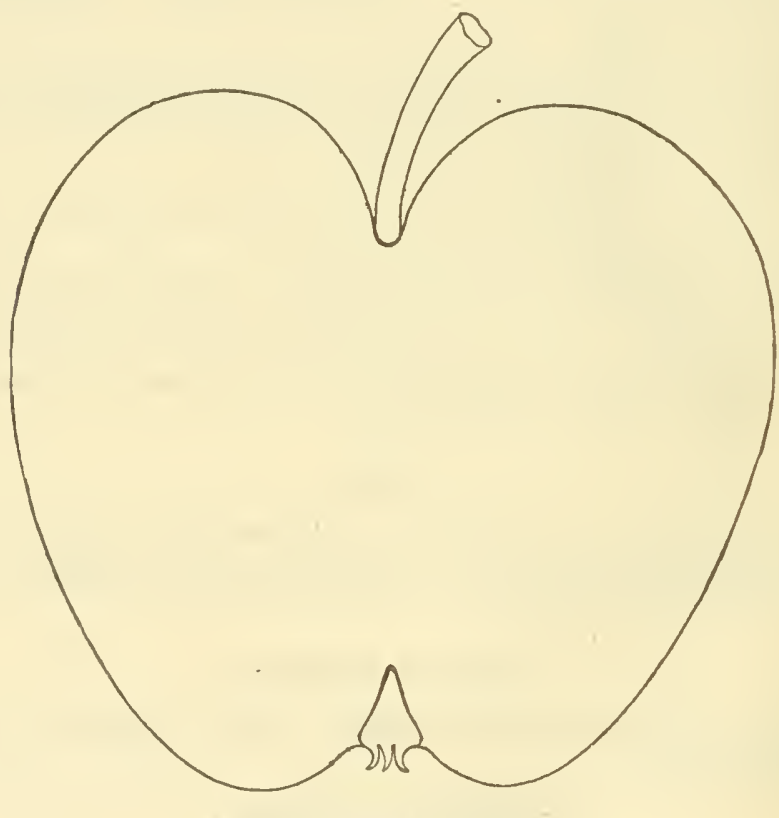

Esopus Spitzenburgh.

Fruit large, oblong, tapering roundly to the eye. Skin smooth, nearly covered with rich, lively red, dotted with distinct yellowish russet dots. On the shaded side is a yellowish ground with streaks and broken stripes of red. Stalk rather long-three-fourths of an inchand slender, projecting beyond the base, and inserted in a wicle cavitr. Calyx small, and closed, set in a shallow basin, which is slightly furrowed. Flesh yellow, rather firm, crisp, juicy, with a relicious rich, brisk flavor. Best. Seeds in a hollow core. I)ecember to Februarr. 


\section{Esten.}

Origin, Rhode Island. Tree vigorous, productive.

Fruit large, rumdish, slightly ribbed, smooth, yellow, sometimes with a blush. Dots large, green and light. Flesh ycllowish, crisp, juicy, slightly aromatic, mild subacid. Good. November.

\section{ETOILE.}

\section{Calville Etoille. Reinette Etoile.}

Origin supposed Holland. Tree vigorous, very productive.

Fruit large, rouudish oblate, rich red, with gray shade, and many gray dots. Flesh white, veined with red, tender, sugary, slightly acid. November to February. (Alb. Pom.)

\section{Eustis.}

Ben Apple.

Origin, South Rcading, Mass. Moderate grower, a good bearer.

Fruit rather large, roundish oblate, slightly conic, yellow, striped and shaded with fine red, and sprinkled with greenish dots. Stalk medium, inserted in a deep cavity, surrounded by russet. Calyx partially open. Basin narrow, rather deep. Flesh yellowish, firm, crisp, mild subacid. Very good. November to January.

\section{Evening Party.}

Origin, Berks Co., Pa. Tree vigorous, roundish, upright spreading, with slender branches. Young shoots dark grayish brown, many small dots.

The fruit hangs well to the tree, and the foliage remains until fliite late.

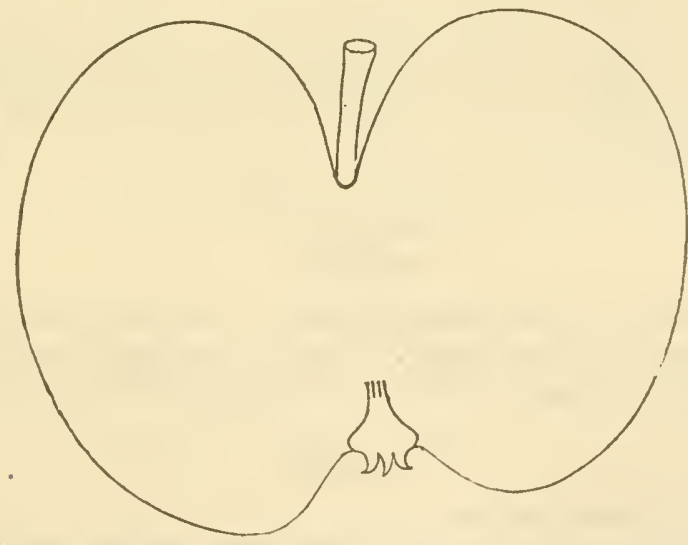

Evening Party.

Fruit small or medium, oblate, sicles often unequal, yellow, chiefly shaded, splishled, and striped with red, becoming dark red in the sur, 
pretty thickly studded with light dots, especially near the calyx. Stalk short, inserted in a round, deep, acute cavity, sometimes russeted. Calyx closed. Basin rather large and even. Flesh juicy, whitish, tender, crisp, with a brisk saccharine, somewhat vinous, aromatic flavor, an excellent dessert fruit. Very good. December and Jaruary.

\section{EwaLT.}

Bullock's Pippin of some.

Origin, Bedford Co., Pa. Tree very vigorous, upright spreading.

Fruit large, roundish, approaching conic, obscurely ribbed, bright yellow, shades of crimson in the sun. Stalk short, stout. Carity deep, irregular. Basin abrupt, deep, furrowed. Flesh white, tender, brisk subacid. Good to very good. November to March.

\section{ETER's GreeniNg.}

Lindley describes this fruit as of middle size, somewhat round, pale green, tinged with brown in the sum. Flesh green, sweetish subacid. Culinary. November to March.

\section{EXCEL.}

Origin, Sharon, Conn. A strong grower and a good bearer.

Fruit large, oblate conic, yellowish, marbled, splashed, and shaded with red, some nettings and patches of russet. Fleshe yellow, tender, juicy, brisk, subacid. Core large. Good to very good. December to February.

\section{ExQuisite.}

Origin, orchard of A. G. Downing, Canton, I1l. Growth moderate, upright, and very productive.

Fruit below medium, oblate. Skin yellow, striped and marked with red. Stem short and small, surrounded by russet, in a deep, broad cavity. Calyx small, partially closed, set in a shallow basiu. Flesh white, juicy, melting, with a very rich, vinous Haror, almost saccharine. Good to very good. A delightful apple for the table. Septem. ber to November.

\section{FaIL.Me-Nerer.}

Neverfail.

A Scottish Apple for cooking purposes. Tree hardy and productive. Fruit above medium, oblate, ribbed, red, becoming deep red in the sun. Flesh white, sugary. Good. November, March. (Liud.)

\section{FAIRBANKS.}

Origin, Winthrop, Maine.

Fruit medium, oblate conic, light yellow, striped with red, and patched with russet. Stem long. Cavity broad and shallow. Flesh yellowish, juicy, with a rich, vinous flavor. Good. Scptember to Oc tuber. (IIe. P. S. R.) 


\section{Fairfield Sumier Quees.}

Origin unknown.

Fruit medium, roundis! oblate conic, obseurely ribbed, pale yellow, striped, splashed, and shaded with two shades of red. Stalk long, slender. Cavity large. Calyx elosed. Basin uneren. Flesh yellowish, juiey, tender, brisk subacid, slightly aromatic. Very Good. Core small. September.

\section{Fair Maid.}

From Pennsylvania.

Fruit rather large, roundish oblate, striped with carmine, subacid. Inferior.

\section{Fair maid of Tauntox.}

An English Apple.

Fruit small, roundish oblate, straw color, with faint red in the sun. Flesh yellowish white, tender, juicy, sweet. November to February. (Hogs.)

\section{Fair's NoNpareiL.}

Fruit small, roundish, yellow, with tinge of red in the sun. Flesh firm, crisp, juicy, vinous. November to February. (Hogg.)

\section{Faliawater.}

Falwalder.

Fornwalder.

Tulpehocken.

Pfarrer Walter.

Baltimore, erroneously. Brubacker.

\section{Pim's Beauty of the West. Winter Blush}

Pound.

Mountain Pippin.

Fall de Walldes.

Fallawalder.
Green Mountain Pippin

Molly Whopper.

Falder.

Fallawalder.

A favorite Apple of Pennsylvania, of which State it is a native. Tree a strong grower and very productive.

Fruit very large, globular, inclining to conic. Skin yellowish green, shaded with dull red, and sprinkled with large gray dots. Stalk very short, inserted in a deep cavity. Calyx small and closed, set in a slightly plaited basin. Flesh greenish white, juicy, crisp, rather tender, pleas. ant, subacid flavor. Good. November, February.

\section{Fall Butter.}

There are dozens of this name. Warder describes one from Indiana as :

Fruit large, globular, greenish yellow. Flesh yellowish white, juicy, sweet. December, January.

\section{Fall Greening.}

The original tree of this variety was found on the grounds of S. M. Van Wyck, Claverack, Columbia Co., N. Y. 'T'ree a moderately vigorous grower, round-headed, almost pendent, very productive, valuable. 
Fruit medium, roundish oblate, greenish yellow. Flesh greenish white, tender, pleasant, subacid. Good to very good. December to February. Tree a good grower and bearer, and sells well in market.

There is another Fall Greening, which is more oblate in form. Similar color. Flesh whitish yellow, juicy, sprightly subacid. Sep. tember to November. The tree a poor grower.

\section{Fall Harver.}

A fine large fall fruit from Essex Co., Mass., highly esteemed in that neighborhood. We do not think it comparable to the Fall Pippin.

Fruit large, roundish, a little flattened, obscurely ribbed or irregular about the stalk, which is rather slender, an inch long, set in a wide, deep cavity. Calyx closed, small, in a rather shallow corrugated basin. Skim pale straw yellow, with a few scattered dots. Flesh white, juicv, crisp, with a rich, good flavor. Good to very good. October and November.

\section{Fall Jenneting,}

Summer Jenneting.

Tree vigorous, and very productive.

Fruit large, oblate, slightly conic, almost ribbed, pale greenish jellow, with a blush. Flesh whitish, tender, juicy, brisk subacid. Good. September and October.

\section{Fall Limibertwig.}

Origin unknown.

Fruit medium, roundish oblate conic, pale yellow, shaded and splashed with red. Flesh whitish, tender, juicy, brisk subacid. Good. November.

\section{Fall Orange.}

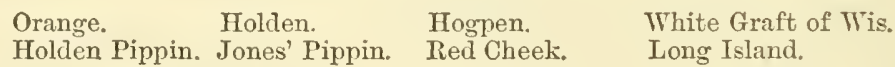

Origin, Holden, Mass. A very strong, erect grower, good bearer, and hardy. Young shoots smooth, dark brownish red.

Fruit fair, large, roundish, pale yellow, sometimes with a dull red cheek and sprinkled with brownish dots. Stalk short, inserter in at deep, narrow cavity, very slightly surrounded by russet. Calyx large, partially closed, basin rather deep, narrow. Flesh white, tender, juicr, subacid. Too acid for a dessert, good for cooking. October, Norember.

\section{Fall Pearmain.}

Tree thrifty, moderate bearer. From Connecticut.

Fruit fair and handsome, medium, roundish conic, slightly angular. Skin yellow, striped, splashed, and shaded with crimson, and sprinkled with gray and green dots. Stalk medium, in a deep, slightly russeted cavity. Calyx partially closed. Basin rather deep, slightly corrugated. Flesh white, tender, juicy, subacil, rather rich flaror. Good to very good. September, October. 
Fall Pipess.

York Pippin. Pound Pippin.
Episcopal.

Philadelphia Pippin. Golden Pippin, erroneously. Pound Royal of some. Cathead, incorrectly.

'The Fall Pippin is, we think, decidedly an American variety. It is rery probably a seedling raised in this country from the White Span-

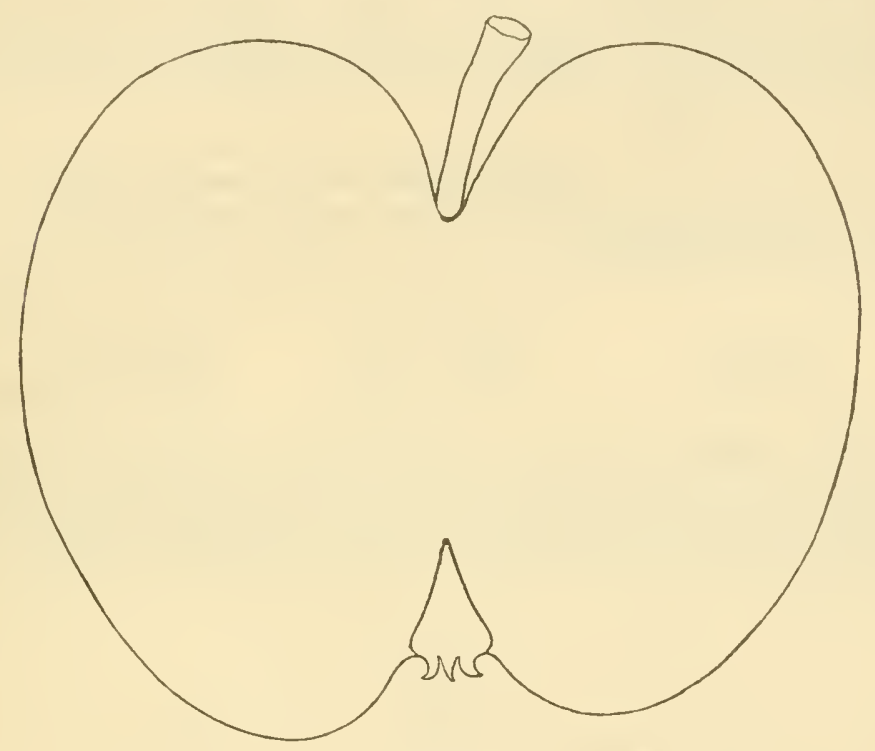

Fali Pippin.

ish Reinette, or the Holland pippin, both of which it so much resembles, and from which it, in fact, differs most strongly in the season of maturity. The Fall Pippin is a noble fruit, and is eonsidered the first of autumn apples in the Michlle States, where its beauty, large size, and its delicious flavor for the table or for cooking, render it very popular.

The tree is a very vigorous, strong grower, upright spreading. Young shoots reddish brown.

Fruit very large, roundish, generally a little flattened, pretty regular, sometimes with obscure ribs at the eye. Stalk rather long, three-fourths of an inch, projecting considerably beyond the fruit (which distinguishes it fiom the Holland Pippin), set in a rather small, shallow, round cavity. Calyx open, not very large, rather deeply sunk in a round, narrow basin. Skin smooth, yellowish green, becouning a fine yellow, with often a tinge of brownish blush on one side, and with a few scattered dots. Flesh white, very tender and inellow, with a rich, aromatic flavor. -Very good to best. Oetober to December.

\section{Fall Spitzexburgit.}

From Vermont. Tree a fair grower and good bearer. 
Fruit medium, roundish conic, red striped. Flesh tender, juicy, pleasant subacid. Good. October, Norember.

\section{FadL Seek-yo-Further.}

Winter Seek-no-Further.

Origin unknown. Tree much the habit of the Rhode Island Green. ing, thrifty and productive.

Frnit very large, oblate, yellow, mostly shaded with red, striped with darker red, and covered with numerous grayish dots. Flesh whitish, tender, moderately juicy, with a pleasant subacid flaror. Good. October and November.

There is another apple unler name of Fall Seek-no-Further which we have received from Iowa, of medium size, roundish, greenish, with slight blush in the sun. Flesh white, tender, mild, subacid. Very good and keeps till M.Larch.

\section{Fall Wise.}

Sweet Wine.

Ohio Wine.
Sharpe's Spice.

Uncle Sam's best.
Musk Spice.

Hower or House.

Origin unknown, probably an old Eastern fruit called " Wine" or "Sweet Wine," but not now much cultivated on account of the fruit being defective. In the rich Western soils it thrires admirabls, producing fine fruit, yet in a few localities they complain of its being knumy. Tree healthy, but of rather slender growth, bearing moderate crops amnually.

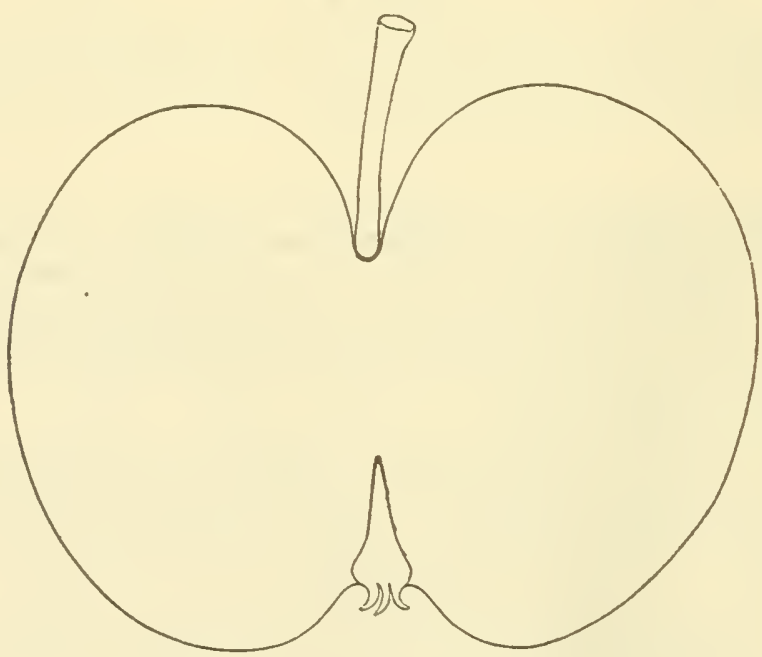

Fall Tine.

Fruit above medinm. Stem rather long, slender, in a broad. deep cavity, surrounded by clear waxen yellow. Calyx partially closed in a broad, deep, corrugated basin. Slin striped and shaded witl red, 
on a light ground, with numerous russet dots. Flesh yellowish, juiey, tender, with a rich, aromatic, very mild, subacid flavor, almost sweet Very good to best. September, November.

\section{Fall Winesap.}

A Western variety, the origin of which is unknown.

Tree a fiec elcan grower, moderately spreading, somewhat drooping as the tree acquires age, productive and an early bearer.

Fruit medium, roundish, sometimes slightly eonical, yellowish green, with considerable blush in the sun. Flesh white, fine-grained, tender, juicy, subacid. Good. October, December.

\section{Fania gusta.}

An old English sort. Tree rigorous, straggling in habit.

Fruit medium to large, roundish oblong conical, deep yellow, faint red in sun. Flesh yellowish, tender, sweet. Good for cooking. November, December.

\section{Fameuse.}

\section{Pomme de Neige. Sanguineus. Snow Chimney. Snow.}

A very celebrated Canada fruit (probably an old Freneh variety), whieh has its name from the snow-white color of its flesh, or, as some say, from the village from whence it was first taken to England. It is an excellent,

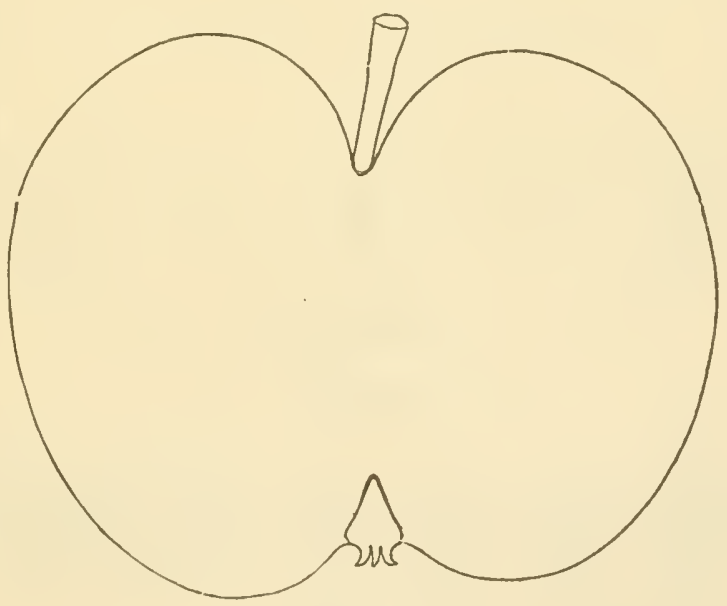

Fameuse.

productive, autumn apple, and is especially valuable in northern latitudes.

Tree moderately vigorous, round-headed, hardy. Young shoots reddish brown.

Fruit of medium size, roundish, somewhat flattened. Skin with a 
ground of pale greenish yellow, mixed with faint streaks of pale red on the sliady side, but marked with blotches and short stripes of darker red, and becoming a fine deep red in the sun. Stalk quite slender, haif an inch long, planted in a narrow funnel-shaped cavity. Calyx small, and set in a shallow, rather narrow basin. Flesh remarkably white, very tender, juicy, and with a slight perfume. Very good, almost best. Ripe in October and November. A regular bearer and a handsome dessert fruit.

There is a variety under name of Striped Fameuse, claimed to be distinct, the fruit being more striped and less highly colored.

\section{Fayily.}

McLoud's Family.

A native of Georgia. Tree a fine regular grower and productive. Fruit medium, oblate conical, yellowish, shaded, striped, and splashed

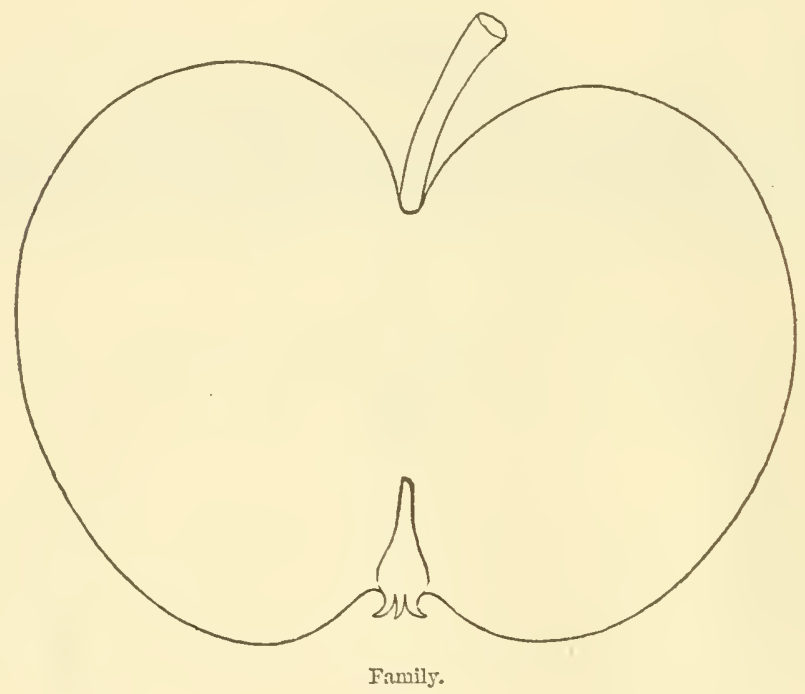

with dull red over half or more of its surface, thickly sprinkled with large light dots. Stalk short and small. Cavity pretty large, slightly russeted. Calyx closed. Segments medium, partially recurved. Basin medium, a little wrinkled. Flesh white, tender, juicy, mild, pleasant, sukacid. Very good. August, September.

\section{FAITCHER.}

Origin unknown.

Fruit large to very large, globular, regular. Surface smooth, rellow, blushed. Flesh white, fine-grained breaking, juicy, very sweet. Good to very good. Baking. September, October. (Warder.) 


\section{Fanvy,}

Originated near Strasburgh, Lancaster Co., Pa., on the farm formerly owned by Jacob Beam. Tree vigorous, spreading, very productive. Young wood dark grayish purple, two shades darker than Red Astrachan, and grayish.

Fruit large, roundish oblate, slightly conic, deep rich erimson red,

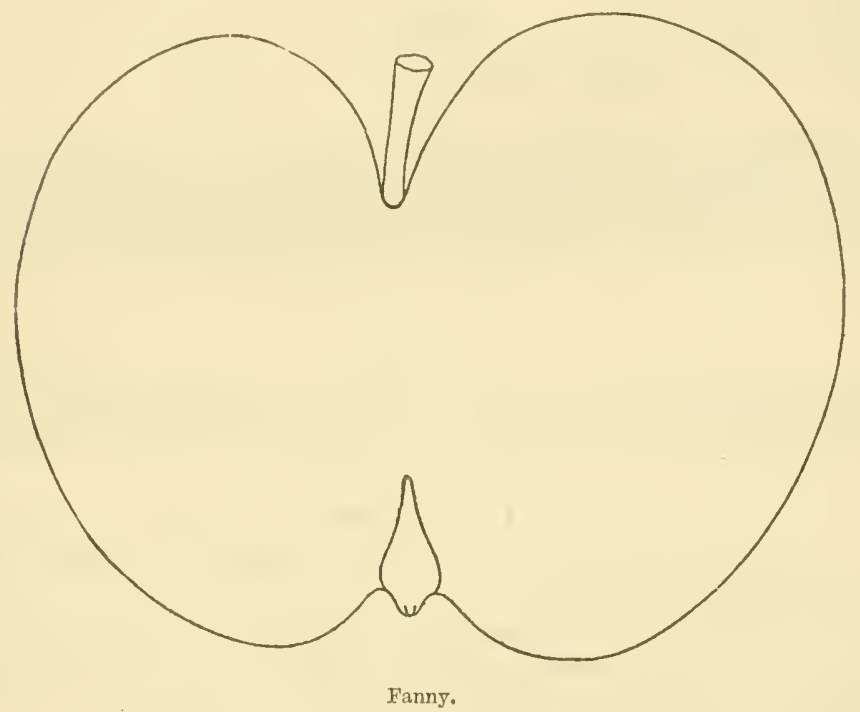

moderately sprinkled with light dots. Stalk short, small. Cavity large, deep. Calyx closed. Segments short. Flesh white, a little stained next the skin, tender, juicy, pleasant subacid. Very good. Core small. August. A new Apple of great promise as a market sort.

\section{Farleigh Pippin.}

\section{Farley Pippin.}

Originated at Farleigh in Kent, England. Tree strong, vigorous, upright, hardy, productive.

Fruit medium, oblong conical, ribbed, yellowish, brownish red in the sun. Flesh greenish, firm, rich, and sugary. January to April. (Lind.)

\section{Firley's Red.}

A native of Oldham, Ky. Tree a moderate grower, hardy and productive.

Fruit roundish, inclining to conic. Skin yellowish, shaded and striped with deep crimson, and specked with light dots. Flesh whitish, very firm, erisp, juicy, with a pleasant vinous flavor. Good. January, April. 


\section{FAtmer.}

A seedling originated about 1795 by General Amos Hall, in West Bloomfieid, Ontario Cu., N. Y. Tres a thrifty, upright grower, forming a handsome head, a good and constant bearer.

Fruit medium, nearly oblate, more or less ribbed, greenish yellow. Flesh whitish, very tender and iuicy, subacid. Good. November, De. cember.

\section{FaUsT}

Faust's Winter.

Foust.

Origin, Torth Carolina.

Fruit medium, roundish, yellow, sometimes faintly shaded with red in the sun, and thinly sprinkled with light dots. Stalk short, stout. Calyx nearly closed. Flesh whitish yellow, moderately juicy, pleasant subacid. Guod, almost very good. November, December.

\section{FAYORITE.}

From Kentucky.

Fruit small, roundish, yellow, striped and splashed with red. Flesh yellow, juicy, mild subacid. Good. November, January. (Elliott.)

\section{Fay's Russet.}

Origin, Bennington, Vt., on the farm of Mr. Fay. Tree moderate grower and very productive.

Fruit rather below medium size, oblate conic. Color light yellow, mostly covered with russet, having a crimson cheek obscurely striped. Stalk slort and small, inserted in a moderate acute cavity. Calyx partially closecl. Segments long, in a shallow somewhat furrowed basin. Flesh white, tender, sprightly, pleasantly subacid. Tery good. April, June. Core small.

\section{Fearns Pippin.}

Clifton Nonsuch. Ferris Pippin. Florence Pippin.

An English variety, not as desirable here as there. Tree upright, vigorous, hardy, and productive.

Fruit medium, roundish oblate, greenish yellow, becoming red in the sun. Flesh yellowish white, firm, juicy, rich, and pleasant. November, March. (Liud.)

\section{Federal Peariain.}

An old English sort, once prized for the dessert.

Fruit small, loundish conical, yellowish, with red and streaks of red in the sun, patches and dots of russet. Flesh fine, delicate, rery juicy, rich sugary, vinous. December to March. (Hogg.)

\section{Fell's Winter Sweet.}

A variety received from $\mathrm{F}$. K. Phcenix, of Illinois. Origin unknown. Tree a great bearer. 
Fruit medium, romulish, greenish yellow, with cheek of brown crimson in the sun. Flesh white, mild, rich, sweet. Good. Valuable for cooking and keeping only.

\section{Fexley.}

Finley. Findley. Horse, erroneously.

This Apple originated in Kentucky, and was first brought into notice by the gentlemin after whose name it has been callecl. It is grown to considerable extent South and West, and counted valuable, especially for kitchen nse. Tree vigorous, upright, and productive. Joung wood dark reddish, grayish, downy.

Fruit large, oblate, slightly conic, pale yellow or yellowish, sprinkled with a few brown dots. Stalk short. Cavity broad, russeted. Calyx closech. Basin pretty large. Flesh yellow, crisp, juicy, pleasant subacid. Good to very good. September.

\section{Fenoulleter Gris.}

Fruit small, roundish. Skin light russet on yellow ground. Flesh firm, with a saccharine, perfumed flavor. Good. December to February.

\section{Fexouillet Jaune.}

Embroidered Pippin. Drap d'Or. Pomme de Caractère.

A French fruit, which has not proved of much value here.

Fruit small, roundish, yellow gray russet network. Flesh white, firm, aromatic flaror. Good. October to Mareh.

\section{Fexouillet Rouge.}

Burdin.

Court-pendu Gris.

Fruit small, roundish. Skin rongh, grayish, with dark brownish red. Flesh firm, sugary. Goocl. Oetober, January.

\section{Ferdinatd.}

A seedling of Pomaria, S. C. Tree vigorous, upright.

Fruit large, oblate, deep orange yellow, moderately sprinkled with large brown dots. Stalk short. Calyx large, closed. Flesh yellow, moderately juicy, tender, mild subacid. Good to very good. November to Mareh.

\section{Ferris.}

\section{Rhode Island Seek no Further. Westehester Seek no Further.}

An old variety of mknown origin, brought into Westchester Co., N. Y., about sixty years ago, where it is quitc extensively grown and consiclered a profitable market apple. The tree makes an upright, round, rather open hearl, a great bearer every other year, and moderate bearer in alternate years.

Fruit large, oblate, inclining to conic, whitish green, shaded, splashed, and striped orer most of the surfice with shades of erimson. Flesh 
white, tender, juicy, refreshing, vinous, mild subacid. Very good. November, December.

\section{EERris.}

Origin, Wilmington, Del., where its value is mainly for its keeping qualities and productiveness.

Fruit below medium, roundish oblate, slightly conic, whitish, shaded and indistinctly splashed with dark red. Flesh greenish white, rather firm, juicy, subacid, good. March, April.

FETT.

Fat Apple.

Origin unknown.

Frvit small to medium, roundish oblate, red shaded and striped with crimson. Stem slender. Cavity almost closed, or appearing as if full. Flesh white, sometimes stained under the skin, crisp, subacid. Good. January.

\section{FIELD.}

Originated in York Co., Pa. Tree an upright grower, productive.

Fruit medium, roundish, whitish shaded, splashed, and striped with crimson. Flesh yellowish, crisp, juicy, pleasant, mild subacid, half spicy quince-like flavor. Good. November, January.

\section{FINK.}

\section{Fink's Seedling.}

Origin, farm of Joseph Fink, Somerset, O. Tree a strong, vigorous, upright grower and a profuse bearer.

Fruit small, oblate, whitish yellow, with a crimson cheek in the sun. Flesh whitish, fine-grained, compact, moderately pleasant, aromatic, subacid. Good to very good. A long keeper, often the fruit of two years' growth being shown at the same time.

\section{First and Last.}

An English culinary Apple.

Fruit medium, roundish, narrowing toward each end, yellow with crimson in the sun, and brown russet. Flesh yellowish, tender, sweet, brisk, spicy aroma. September to May. (Hogg.)

\section{Fishkilt Beauti.}

Origin, Fishkill, N. Y. Tree vigorous, spreading.

Fruit medium or above, roundish oblate, whitish yellow, blush in the sun. Flesh white, very tender, juicy, mild subacid. Good. September, October. Apt to decay on the tree.

\section{Fish's Seedlixg.}

Origin, Keene, New Hampshire. Tree vigorous and productive, bighly estecmed in its locality 
Fruit medium, oblate, obliyuc, deep red on the sunny sirle, indistinctly striped with darker red and yellow, and sprinkled with yellow dots. Flesh greenish white, tender, melting, vinoms, saccharine flavor. Good. ()etober', Norember.

Fisise.

Origin unknown. Tree productive.

Fruit large, romdish oblate, palc yellow, shaded, and faintly splashed with slades of crimson. Flesh white, crisp, tender, juicy, pleasant, subacid. Good to very good. December to March.

\section{FLAKE's FALL.}

Originated with the late Col. Flake, of Mercer, Pa, where it is esteemed a valuable and profitable apple, either for market or the table. Tree a moderate grower, rather upright, a good bearer.

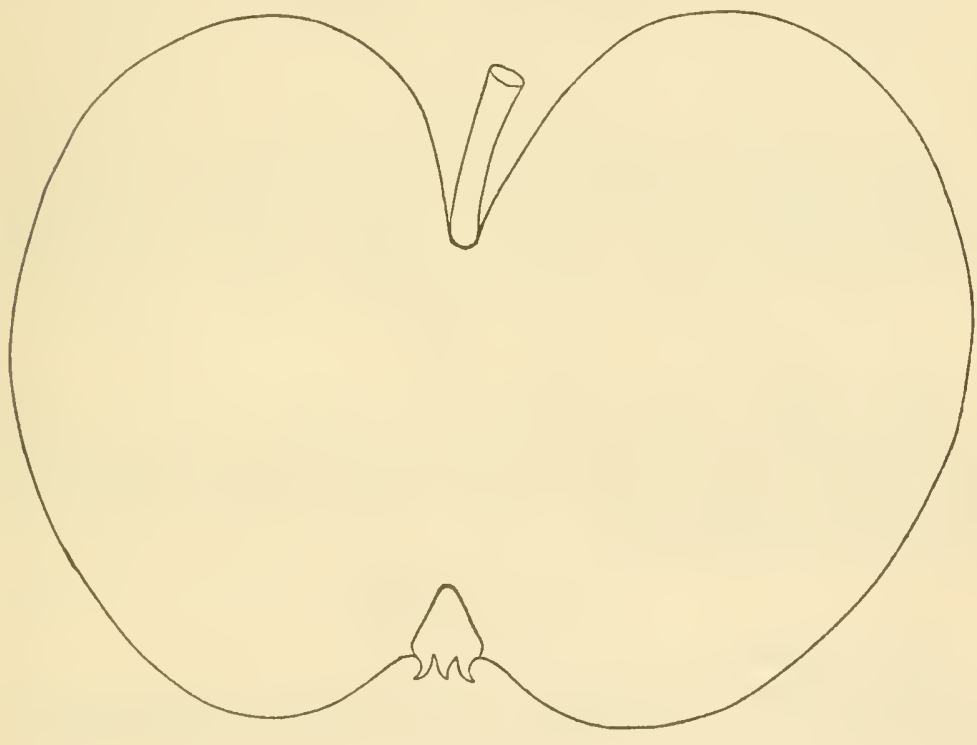

Flake's Fall.

Fruit large, form oblate, shightly conic. Color yellowish, orerspread, shaded, striped, and splashed with light and dark crimson, becoming very dark in the sun, thickly sprinkled with light and russet dots, some with dark centre. St ilk very short, and rather stout. Cavity large, deep, russeted, the splashes and nettings extending outside. Calyx open, or partially closed. Segments large, to a point, and rather separated. Basin medium, uneven. Flesh white, tender, moderately juicy, mild subacid, peculiarly aromatic. Core sinall. Very good. October, November.

\section{Flaxders Pippin.}

From Berkshire, England. 
Fruit medium, oblate, ribbed, greenish yellow, dull red in the sun. Flesh white, tender, juicy, brisk subacid. Cooking. October, November. (Ilogg.)

\section{Flanders Reinette.}

\section{Reinette de Flandre.}

Tree vigorons, productive.

Fruit medim, roundish, yellow, with grayish red in the sun and near the stalk. Flesh yellowish white, firm, sugary. December to Jamuary. (Alb. Pom.)

\section{Flat Pippin.}

\section{Needles.}

Orimin, Ohio.

Fruit large, oblate, ribbed, greenish white, tinge of red in the sun Flesh whitish, jnicy, subacid. Good. November, December.

\section{Flat Sweet.}

An old Eastern finit, and much valued where known.

Frnit large, oblate, slightly conic, yellow, sometimes with sunny cheek, and slight russet. Flesh white, tender, juicy, with a fine, rich, saccharine flaror. Good. Vahned for baking. October to March.

\section{Flat Sweet.}

From Illinois.

Fruit medinm or below, oblate, yellow, splashed, striped, and shaded with light and dark crimson over ali, few large light dots. Stalk short. Flesh white, stained next the skin, firm, juicr, mild subacid, scarcely sweet. Good. September.

\section{Fleet's Nonpareil.}

Origin unknown.

Fruit medium, oblate, slightly conic, pale yellow or whitish. Flesh white, crisp, juicy, brisk subacid. Good for cooking. September.

\section{Fleiser.}

Of German origin. Tree vigorons, upright, productive. Nood dull redılish brown, slightly grayish.

Fruit medium, oblong conical, whitish yellow, shaded with crimson in sun. Flesh white, tender, juicy, brisk sharp subacid. Good. Octoher, Norember.

\section{FtorA.}

A Southern Apple.

Fruit medium, oblate, yellowish, shaded, splashed, and mottled with crimson. Flesh whitish, nild subacid. Hardly good. Angust. 


\section{FLORY.}

\section{Flory's Bellflower.}

Sheep Shire.

Origin, Montgomery Co., Ohio. A new variety, highly regarded in the vicinity of its origin. Tree upright grower, abundant bearer.

Fruit medium, roundish conical, rich yellow, with small patches of russet and minute raised russet dots. Flesh yellowish, tender, moder. ately juicy, subacid. Good. October, November.

\section{Flower of Kext.}

A large and handsome English Apple, chiefly valued for baking and kitchen use.

Fruit quite large, roundish eonic, tawny yellow, washed with dull red, with oeensionally a few strijes of brighter red. Flesh greenish yellow, abounding with a lively subaeid juice. Good cooking. October to January.

\section{Flushing Spitzenburgh.}

This variety has been confounded with the Esopus Spritzenburgh, but is really quite distinet. The tree makes strong reddish brown shoots, different from the slender yellowish ones of that sort.

The fruit is roundish eonical. Stalk set in a narrow eavity projecting beyond the fruit. Skin nearly eovered with red, on a greenish yellow gromnd, dotted with large fawn spots, and coated with a slight bloom. Cilyx small, in an even basin. Flesh white, juicy, exisp, nearly sweet, and of pleasant flavor, but without the brisk richness or yellow color of the Esopus Spitzenburgh. Good. October to February.

\section{Focht.}

A seedling of Iebanon Co., Pa. Tree forms a low open head, productive.

Fruit large, oblate, slightly conic, pale yellow, sometimes with a blush. Flesh white, tender, juicy, good, subacid. October, December. Exeellent for eulinary purposes.

\section{Foote's Nonpareit.}

Origin, farm of Jonathan Foote, Lee, Mass. Tree thrifty, vigorons, spreading, an annual bearer.

Fruit small, oblong conic truncated, yellow shaded and indistinetly splashed with erimson. Flesh firm, juicy, pleasant aromatic subaeid. Very good. Core large. November.

\section{Foratge.} bearer.

Origin, Fairfield Co., Ohio. Tree good grower, round head, good

Frnit large, pale yellow. Flesh white, fine-grained, rich sweet. Good. September.

\section{Ford Apple.}

Origin, farm of Darid Ford, Canaan, Columbia Co., N. Y. 
Fruit large, roundish, slightly conical. Color rich yellow. Flesh yellowish white, solid, moderately tender, with a high, rich, rather acir] flavor. Good. October, January.

\section{Forest.}

Red Codlin.

This variety we received from J. S. Foster, New Hartford, N. Y., who does not claim it as original, but that it is probably a foreigner. We have not been able to identify it with any known sort. Tree of upright growth, very hardy, and an aunual bearer.

Fruit above medium, roundish oblong conical, often ribbed, rellow, mostly overspread, shaded, splashed, and striped with faint reddish crimson, and many large light dots. Stalk rather short. Cavity deep, irregular. Calyx small, closed. Basin small, abrupt, furrowed. Flesh yellow, crisp, tender, juicy, rich, pleasant, slightly aromatic, subacid, almost sweet. Core small. Tery good. December to March.

\section{Forest Strre.}

\section{Styre. Stire.}

A cider fruit, from Gloucestershire, England. Tree upright, willowlike in growth. Fruit small, roundish oblate, pale yellow, blush in sun. Flesh firm, brisk acid. (Lind.)

\section{Forge.}

Origin, Sussex Co., England. Tree strong, stocky, short-jointed, forming a spreading open hcad, productive.

Fruit small to medium, roundish oblate, obscurely ribbed, whitish yellow, overspread, shaded, splashed, striped, and mottled with red. Flesh yellowish white, tender, juicy, pleasant, subacid. Tery good. October, December.

\section{Forman's Crew.}

An old dessert Apple, originated in Glamorganshire, England. Tree healthy, upright. Young wood reddish chestunt, downy.

Fruit below medium, oblate conic, yellowish green, brownish in sun. Flesh greenish yellow, juicy, rich subacid. November, February. (Lind.)

\section{Fort Miami.}

Origin near Fort Miami, Ohio. Tree thrifty, healthy, productive, but not an early bearer.

Fruit medium, roundish oblong conic, truncated, pale yellow with a brownish tinge, considerably russeted in the sun. Stalk rather short. Cavity medium, acute, deep. Calyx open. Basin abrupt, colrugated. Flesh yellowish, fine, crisp, juicy, rather rich subacid, aromatic. Tery good. March to May.

\section{Foster Sweet.}

Origin unknown. Introduced by J. W. Foster, Dorchester, Mass 
Fruit medium, roundish oblate, slightly conic, obseurely ribbed, whitish rellow, shaded with dark red and stripes and splashes in the sun, few linhit lots. Stalk short. Cavity small. Calyx closed. Basin rather deep. Flesh whitish, juicy, tender, mild subacid, almost swet. Good to very good. Core medium. September.

\section{Fouldon Peariain. \\ Ilorrex's Pearmain.}

Origin, Norfolk, England.

Fruit medium, roundish, pale yellow, blush in the sun. Flesh yellowish white, firm, crisj, brisk, shar' subacid. November to March. (Lind.)

Found Ling.

\section{Shirley. Groton.} tive.

Origin, Groton, Mass. Tree moderately vigorous, spreading, produc-

Fruit above medium, roundish oblate, inclining to conic. Color yellowish green, striped and shaded with deep rich red. Stalk short, slender, in a large, somewhat furrowed carity. Calyx closed. Busin small, furrowed. Flesh yellow, teuder, juicy, with a pleasant, rich vinous aroma. Very good. August, September.

\section{Fourth of JuLy.}

Siberian August. Stewart's Nonpareil ?

Tetofsky, erroneously. McAdow's June. August Apple.

A German Apple, introduced by C. F. Jaeger, of Columbus, Ohio.

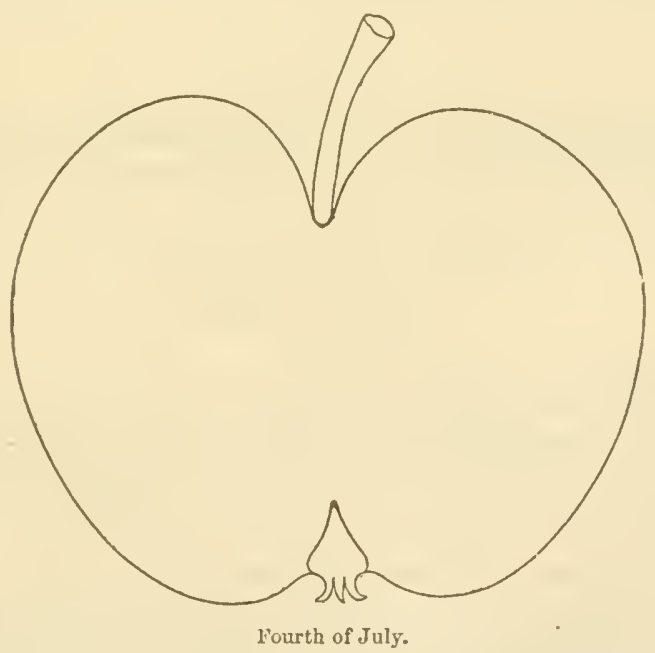

Valuable mainly for its hardiness and early maturity as a cooking or market variety. Tree a strong upright grower, forming a fine liead. Young shoots long dark reddish brown. 
Fruit medium or below, roundish oblate conical, slightly ribbed, whitish yellow, covered with a thin whitish bloom, and striped and splashed with bright red, large light dots. Stalk rather short ana slemeler, often with bracts. Carity medium, regular. Calyx closed. Segments rather long, generally recurved. Basin small, slightly uneven. Flesh white, juicy, sprightly, brisk subacid. Good. Core small. July. In fruit this closely resembles the Tetofsky, but the color of the wood, habit of growth, and foliage of old trees render its distinctiveness plain.

\section{FOX-WTHELP.}

An old English cider Apple.

Fruit medium, roundish, ribbed at crown, yellow and red mixed, and streaked. Flesh firm. October, November. (Lind.)

\section{Fraise.}

Of French origin. Tree moderately vigorous, productive.

Fruit small, roundish conical, yellow, mostly orerspread, and washed with bright red. Flesh fine-grained, tender, subacid. (Soc. T. M.)

\section{Framboise.}

Framboos. Calville Rouge d'Automne, incorrectly.

Of German origin.

Fruit medium to large, roundish oblong, truncated, somewhat ribbed, greenish yellow, spotted and striped with shades of bright and deep red, much red in sun. Flesh white, fine, tender, mellow, juicy, sugary. September. (An. Pom.)

\section{Fraxchot.}

Originated in Otsego Co., N. Y. Tree productive.

Fruit medium, roundish conical, yellow, shaded and splashed with red. Flesh yellowish, juicy, crisp, pleasant, aromatic. Good. October to January.

\section{Franklin's Goldex Pippix.}

\section{Sudlow's Fall Pippin.}

Dr. Hogg says: This is an American Apple, and was introduced into England by Joln Sudlow.

Fruit of medium size, roundish, slightly conic, very regular in shape, rather broadest at the base, deep yellow, freckled with numerons dark spots. Flesh pale yellow, crisp, juicy, rich subacicl. Good to very good. The tree grows freely, and forms an upright head. October.

Under the name of Franklin Golden Pipgin we have received an apple from Illinois, and now somewhat grown there, which is quite distinct from the above. It was introduced TVest from Pemsrlvamia, under name of Golden Pippin, but in its new locality has had attached, by whom we know not, the prefix of Franklin. There are so many Golden Pippins that it is difficult to decide which shall be entitled tc priority of name. 
Fruit metlium, roundish conical, slightly ribbed, pale lemon yellow moderately sprinkled with light and gray dots. Stalk short, shemeler. Cavity deep. Calyx firmly closed. Basin corrugated. Flesh yellow isl, tenter, moderately juicy, mild subacid. Tery good. November December.

\section{Flieendis.}

Origin, New Jersey. Tree productive.

Fruit medium, ovate truncated conical, mottled and splashed with red. Flesh white, often stained next the skin, tender, slightly subacid, nearly sweet. Good to very good. Vilued mainly as a late keeper.

\section{Freeze aNd Thaw.}

Of Penusylvania origin.

Fruit medium, oblate, slightly conic, light yellow, with shades and splashes of red. Flesh whitish, rather firm, subacid. Poor. Norember to February.

\section{Fremoxt Pippis.}

Originated on the farm of James Armitage, Soleberry, Pa.

Fruit medium, roundish conical, ribbed, lemon yellow, slightitly shaded with crimson in the sun. Stalk long. Carity deep. Calyx small, closecl. Basin small. Flesh white, crisp, juicy, brisk subacid. Very good. Core medium. January, February.

\section{Frexch.}

An old New England variety, origin unknown.

Fruit medium to large, oblate, slightly conical, yellow, striped and splashed with red. Flesh yellow, crisp, rich acid. Good. November.

\section{Frejch Bellflower.}

Bellefleur de France. Double Bellefleur.

I)obbel Bellefleur.

A French Apple, described in the Annals of Pomology as:-

Fruit very large, roundish, slightly conical, yellowish, with carmine red cheek in the sun. Flesh yellowish white, half·tender, melting, sweet, subacid.

\section{Frexch Crab.}

Ronalds describes this as follows: Tree very hardy, somewhat pondent in its growth, and bears well. A long keeper.

Fruic alsove medium, globular, green, becoming yellow at maturity. Flesh firm, pleusant, brisk.

\section{French Noxpareil.}

Oricin unknown. Tree vigorous, moderately productive.

Fruit medium, roundish oblate, sides unequal, greenish yellow, shaded, splashed, and marbled with red. Flesh whitish, crisp, juicy, pleasant, mild subacid. Good to very good. Core small. October, Tovember. 


\section{Frexch Pippix.}

Of unknown origin. Tree hardy and vigorous, with dark reddish brown shoots.

Fruit rather large, roundish oblate, greenish yeliow, with a faint dul: cheek, thinly sprinkled with large brown dots, and traces of russet. Flesh yellowish, tender, pleasant, subacid. Good. Core small. October, January.

Quite distinct from Newark or French Pippin, which has slender branches. There are several apples under name of Erench Pijpin, and it is difficult to decide which has priority to the name, except as connected with the oldest description.

\section{French Reinette.}

Reinette Franche.

Reinette Blanche. Weisse Reinette.

Reinette Blanche, dite Prime. Franz Remmette. Franz sische Edelreinette. Reinette de Normandy.

An old French Apple described by various anthors, valued mainly as a long keeper. Coxe says the tree is handsome, of rigorous growth and an abundant bearer.

Frnit large, roundish oblong conical, truncated, yellow, with some russet, and red in sun. Flesh firm, yellowish white, rich and sprightly subacid.

\section{French Russet.}

French Pippin.

This old Apple is described in Ronalds as a sauce or cooking fruit of medium size, globular, yellowish, with faint red in the sun, considerably lusseted. Flesh white, tender, subacid. November, January.

\section{French's SWeet.} tive.

Origin, farm of B. V. French, Braintree, Mass. Tree very produc-

Fruit above medium, roundish oblate, yellow, with a shade of brown in the sun. Flesh yellowish, crisp, moderately juicy, compact, rich, sweet. Valued for cooking. October, November.

\section{Friar.}

An English cider Apple, described by Hogg as of good size, some. what conical, greenish, with dull red in the sun. Tree vigorous and productive.

\section{Frisland Reinette.}

\section{Reinette de Frisland.}

Of German origin, described in the Album of Pomology. Tree vigorous, productive.

Fruit large, roundish oblate conical, bright yellow, brownish red in the sun, reddish gray near the stalk. Flesh white, firm, agreeable, suuacid. December to Jannary. 


\section{Fronchin.}

Originated in Laneaster Co., Pa., where the original tree is supposeci to be orer one humbred years old. It is a rapid grower, bearing profusely even when young, but the fruit is lather too acid to please many tastes.

Fruit below medium, oblate, whitish, shuled and splashed with rich red. Flesh yelluwish white, tender, juicy, sharp subacid. Good. September, Norember.

\section{Front Door.}

From Mlichigan, origin unknown.

Fruit molium to large, oblate, yellow, striped and splashed with red. Flesh whitish, teuder, juicy, subacid. Good. Scptember.

\section{Fullerton Sweet.}

Origin unknown, found in the orchard of William Fullerton, Orange Co., N. Y. It much resembles the Autumn Sweet Bough.

Fruit below medium, roundish conical, pale yellow, with a few brown dots. Flesh white, juicy, tender, honeyed sweet. Very good. Core small. October, November.

\section{Fulton.}

A Western finit, originated in the orchard or nursery of A. G. Downing, Canton, Fulton Co., 1ll., a vigorous grower, hardy, regular in for'm, an annual and productive bearer. Young shoots slender, clear light reddish brown.

Size about medium, oblate, light yellow, sprinkled with green or gray dots, having a blush on the sumny sicle. Stalk three-fourths of an inch, rather slender, inserted in a broad deep cavity. Calyx large, open. Segments small, recurved, in a pretty large basin. Flesh yellowish, juicy, tender, mild subacir, almost sweet. Good to very good. Core small. November to February.

\section{Fulton S'trawherry.}

Origin same as the Fulton. Tree vigorous, stout, spreading grower, hardy, does not come early into bearing. Young wood grayish brown, slightly downy.

Eruit medium, oblate, whitish, mostly overspread, striped, splashed, aud mottled with shades of red. Flesh whitish, tinged with pink, juicy, pleasant suJacid. Good. Core small. Surtember:

\section{FULWOOD.}

\section{Green Fulwood.}

Lindley and Hogg both describe this culinary Apple as large, roundish, ribbed, green, with broken stripes of dull red in sun. Flesh greenish white, firm, crisp, brisk acirl. November to March.

There is also a White Fulwood described which is probably identical with the above. 


\section{Gabriel.}

Ladies' Blush.

Tree of rather slender growth, productive.

Fruit medium, roundish oblate, whitish green, shaded and splashed with erimson, and spriukled with gray dots. Stalk medium, inserted ir a eavity of moderate depth. Calyx partially closed, set in a moderate uneren basin. Flesh yellowish, tender, juicy, rich subacid. Core small. Good to very good. October and Norember.

\section{Gaesdonker Gold Reinette.}

A German dessert Apple.

Fruit below medium, oblate, golden yellow, reddish cheek in sum, and some russet. Calyx partially elosed, with long, pointed segments. Flesh yellowish, fine, firm, juiey, rich aromatic subacid. December to March. (Hogg.)

\section{Gaxges.}

Fruit pretty large, oblong, green, with red in the sun. Flesh yellowish, subacid. Cooking. (Lind.)

\section{Gardex.}

Originated with Hezekiah Ellis, in Spottsylvania Co., $\mathrm{T}_{\text {il. }}$

Fruit small, oblate, yellow, shaded, splashed, and striped with two shades of red nearly over the whole surface, moderately sprinkled with light and gray dots. Stalk long, sleuder. Cavity meclium, thinly russeted. Calyx elosed. Segments ruther long, partially recurvecl.' Basin abrupt, slightly corrugated. Flesh white, a little stained next the skin, crisp, juicy, mild subacid. Good to rery good. November, December.

Warder, in lis American Pomology, page 435, describes a Garden Apple, and gives at the same time Garden lioyul as a synonym, which latter must be erroneous, as there is a distinct finit moler that name. Warder's description is as follows:

Fruit pretty large, roundish flat, regular. Surface smooth, yellowish green, slightly shaded red, seattered stripes earmine, dots minute black. Basin wide, regular, small, closed. Carity deep, acute, regular, green. Stem short to medium, sometimes knobby. Core wide, closed or open, regular, clasping the eye. Flesh pale reliow or whitish, tender, fine-grained, juicy, subacid, aromatic, saceharine, agreeable. August to October.

\section{GARDEN.}

Comstock's Garden.

Origin uncertain. Tree moderately vigorous, produetive.

Fruit medium size, roundish oblate. Skin whitish, nearlr corered with narrow stripes of light and dark red, and thickly sprinkled with conspicuous light dots. Stalk short and slencler. Calyx nearly closed. Basin medium, slightly furrowed. Flesh white tinged with red, not very tender, but valuable as a cooking fiuit. September, October.

\section{Garden Royil.}

Originated on the farm of ——Bowker, Sudbury, Mass. Tree of 
morlerate, very upright growth, forming a beantiful roundish, regular even head, very productive. Young shoots dark dull rectetish brown, siightly grayish or imperfect downy.

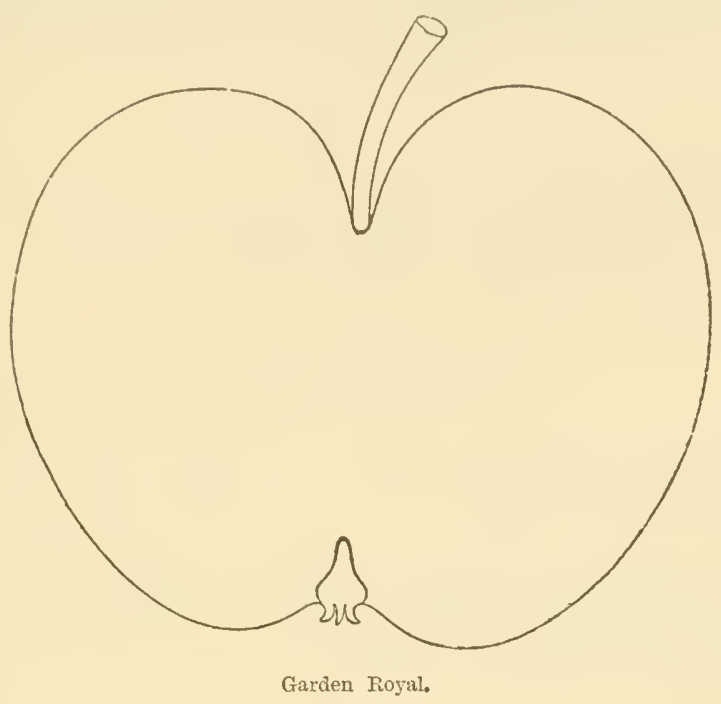

Fruit medium or below. Form roundish oblate, very slightly conic. Color greenish yellow, shaded, striped, and splashed with rich red, a little dull or grayish toward the stalk. Sprinkled with light and gray dots. Stalk medium, slender. Cavity deep, acute. Calyx open or partially closed. Segments sometimes a little recurved. Basiu shallow, slightly uneven. Flesh yellow, very tender, juicy, rich, mild subacid, aromatic. Best. Core small. Last of Angust, September.

\section{GARden Stripe.}

Tree moderately vigorons, spreading, and drooping.

Fruit below medium, roundish oblate, yellowish, broadly striped, splashed and shaded with shades of deep red. Flesh tender, juicy, subacid. Good. September.

\section{GARDEN SWEet.}

A New England Apple. Tree hardy, thrifty, and productive. Young shoots strong, light redulish brown, slightly downy.

Fruit medium, roundish oblong conic. Color yellow, shaded and splashed with crimson nearly over the whole surface, many light and gray dots. Stalk rather short and small. Cavity acute. Calyx closed. Segments partially recurved. Basin large, abrupt, corrugated. Flesh yellowish white, tender, juicy, rich, sweet. Very good. Core medium. September and Octoher. I valuable variety for cooking or stock feeding, continuing a long time in use. 


\section{Gardier Sweet.}

Gardner Sweeting.

Kemick says: Tree grows slow, but is very productive.

Fruit above medium, roundish, pale color, covered with small specks, bright blush next the sun. Flesh firm, sweet. December to March.

\section{Gardxer's Sweet Pearmain.}

An old Long Island Apple.

Fruit medium, oblate, sides unequal, yellowish, shaded, splashed, and striped with light and dark red nearly over the whole surface, thickly sprinkled with light dots. Flesh whitish, tender, juicy, sweet, and pleasant. Good. Core small. September.

\section{Garrettson's Early. \\ Somerset Harvest.}

Originated on the farm of Jno. Garrettson, Somerset, N. J. Tree rigorous, upright spreading, productive. Young wood brown, slightly downy.

Fruit medium, roundish conic, yellowish, thickly covered with light specks. Stalk short. Cavity deep, acute. Calyx closed, in a small, abrupt, furrowed basin. Flesh white, tender, juicy, brisk subacid. Good, valuable for cooking. September.

\section{GARTER.} red.

A cider fruit of England. Fruit medium, oblong, pale yellow and

\section{Gault's Bellflower.}

Fruit large, roundish, pale yellow. Flesh white, coarse. October, December. (Elliott.)

\section{Gaumoxt.}

Supposed French origin.

Fruit large, roundish oblong oblate, ribbed, golden yellow with a few light gray dots. Stalk short. Calyx open. Basin very deep. Flesh yellow, compact, juicy, rich subacid. October, November.

\section{General Hashell.}

Origin said to be Graves Co., Ky. Tree a good grower and productive. Fruit medium, red, esteemed for its fine appearance and being a Iong keeper.

\section{Gevesee Chief.}

Origin unknown. Tree a strong, vigcrous grower.

Fruit large, roundish conical, meven or ribbed, whitish, almost waxen, shaded with crimson in the sun, few faint dots. Flesh white, tender, juicy, subacid. Good. Core large. September. Cooking. 
Gexeva Pippin.

Winter Pippin of Genera.

An Apple bearing the above local name was found growing in the garden of Mrs. Crittendon, Geneva, and is deserving of notice. 'Thu appearance of the tree and fruit is strikingly like that of the Fall Pip. pin, but is a late keeper, continuing in perfection until May. Toung wood reduish brown, slightly downy.

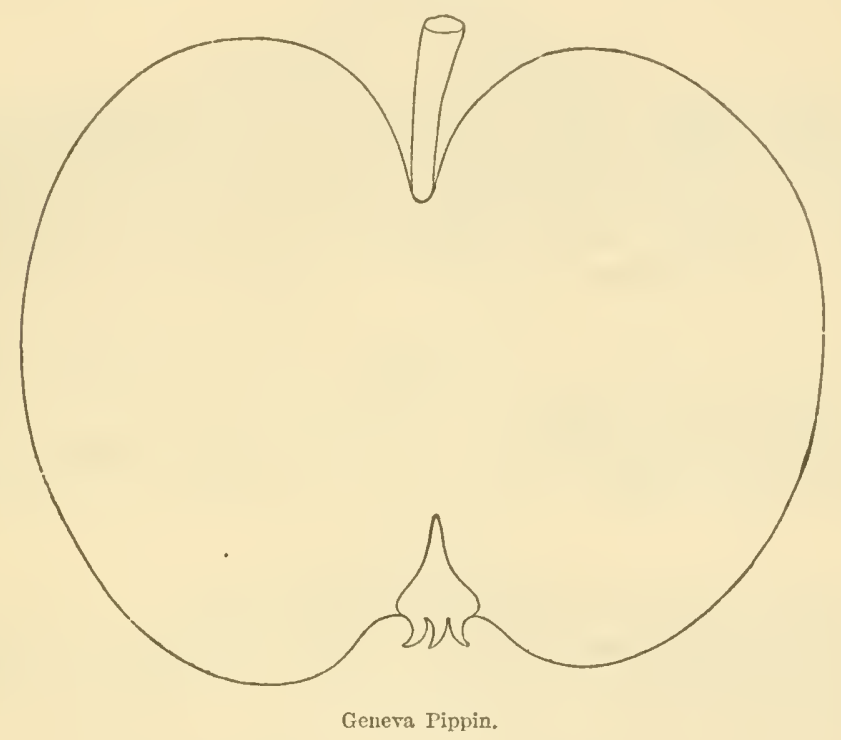

Fruit large, roundish oblate, fine yeliow, with rarely a bronzed cheek, sparsely covered with gray dots. Stalk short and small, inserted in a narrow cavity. Calyx open. Segments long. Basin open. Flesh yellow, tender, juicy, vinous. Very good or best. January to May.

\section{Gentle's Large Red.}

Origin unknown.

Fruit large, roundish, slightly conic, sides unequal, yellow, shaded, splashed, and striped with dull red, many light and brown dots. Stalk long and slender. Calyx closed. Flesh whitish, juicy, tender, mild, pleasant subacid. November. Goud.

\section{GEORGE。}

Origin, Muskingum Co., Ohio. Tree healthy, spreading, an abundant bearer.

Fruit merlium, roundish oblate, pale yellow, with considerable misset specks and markings. Calyx large, open. Flesh whitish, firm, juicy, mild acid. Good. July. 


\section{Gestreifter Sominer ZimimetapfeL.}

La Canelle.

An excellent little German dessert Apple described by Hogg. Tree a good grower and bearer.

Fruit small, roundish oblate, lemon yellow, with crimson stripes in the sun. Flesh yellowish white, fine, juicy, very aromatic, cinna. mony. Angust and September. (Hogg.)

\section{Gewiss Good.}

Gewiss Guth. Indeed Good.

Origin, Berks Co., Pa. Tree vigorous, upright spreading.

Fruit medium, roundish oblate, often conic, light yellow, slightly shaded with carmine. Stalk short, inserted in a deep, narrow, slightly russeted cavity. Calyx partially closed. Basin deep', slightly corrugated. Flesh juicy, tencler, crisp, with a somewhat spicy, subacid flavor. Good. December, February.

\section{Giant。}

A Pennsylvania variety.

Fruit large, roundish conical, dull red, striped. Flesh greenish white, tender. Poor.

\section{GiLes.}

Elliott describes this as from Wallingford, Conn.

Fruit medium, conical, dark red. Flesh tender, juicy. Very good. October, November.

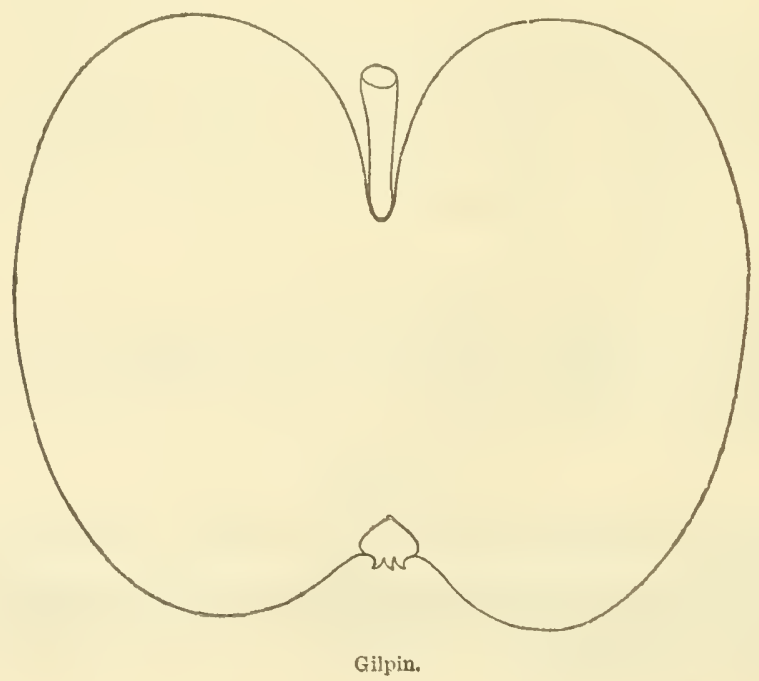




\section{Cimpix.}

Carthouse.

Small Romanite.

Gray Romanite.

Roman Kñight.

Romanite of the West.

Little Romanite.

A landsome cider fruit, from Tirginia, which is also a good table fruit from Eebruary to May. A very hady, vigorous, and frutful tree.

Fruit of medium size, roundish oblong. Skin very smootl and hand. some, richly streaked with deep red and yellow. Stalk short, deeply in serted. Calrx in a roumd, rather decy basin. Flesh yellow, firm, juicy and rich, becoming tender and sprightly in the spring. Good.

\section{Gipson's Kentucky.}

\section{Gipson's Kentucky Seedling.}

Originated on the farm of A. Gipson, Calhoun Co., Ky.

Fruit below medium, roundish, sides unequal, greenish, with dark red in the sun. Flesh pale yellow, juicy, sprightly subacid. Jannary to April.

\section{GLADNEY's ReD.}

Originated in Mississippi.

Fruit medium, roundish, yellowish, shader, mottlerl, and obscurely striped with light red nearly over the whole surface, and covered with a thin bloom. Stalk long and slender. Calyx elosed, with long reflexed segments. Flesh yellowish, rather firm, moderately juicy, slightly aromatic, subacid. Core small. Good. Jannary, February.

\section{Guanz Reinette.}

Tyroler Glanz-reinette.

A beautiful waxen-like Apple of German origin.

Tree a stroug grower, folming a round head, very productive.

Fruit medium, roundish oblate, waxy lemon yellow, blush of red in the sum. Stalk long. Cavity russeted. Basin furrowed. Flesh snow white, fine, juicy, rich, sugary, vinous. December. (Hogg.)

\section{Gleasoy Sweet.}

Fruit medium, roundish conical, yellow, shaded and splashed with crimson over most of the surface. Flesh white, tender, juicy, scarcely sweet. Good. Core small. November.

\section{GLENDALE.}

Warder says: "Believed to lave originated near Glendale, Hamil. ton Co., Oliio." Tree vigorous, thrifty, spreading, productive.

Fruit large, roundish, somewhat conical, yellow, striped and clonded with bright red, dots small, russet. Flesh yollowish, mild, subacid, almost saccharine. Cood. September, October.

\section{Gloria Muxdi.}

Monstrous Pippin.

Glazenwood Gloria Mundi. Paltimore Pippin.

American Nammoth.
Belle Josephine.

Mississippi?
Baltimore of some.

New Tork Gloria Mundi. Ox Apple.

Origin unknown. Tree vigorous. Not productive or profitable. 
Frnit very large, roumlish oblate, ribbed, greenish yellow. Flesh coarse, tender, with a pleasant acid flavor. Good. October to January.

\section{Glory of Exglatio.}

Fruit large, oblate, ribbed, yellow, with streaks and dots of crimson, whitish specks and some russet. Flesh greenish yellow, tender, soft, juicy, sprightly acid. Cooking. (Hogs.)

\section{GLory of THE WEst.}

Tree a strong vigorous grower and great bearer.

Fruit large, oblate, ribbed, yellow, red in the sun, minute russet dots. Flesh yellowish white, firm, juicy, brisk, slightly perfumed, acid. October, December. (Hogg.)

\section{Gloucester White.}

Origin, Gloncester Co., Va. Tree vigorous and very productive.

Fruit medium, roundish oblate, fine yellow. Flesh yellow, juicy, crisj, pleasant, subacid. Good. October, November.

\section{Goble Russet.}

Sweet Seek-no-Further.

Origin unknown. Elliott describes the fruit as medium to large, oblong flattened, yellow russet, marbled with red. Flesh whitish yellow, dry, sweet. October to December.

\section{Gogar Pippin.}

\section{Stone Pippin.}

A variety from Ediuburgh, Scotland.

Fruit medium, roundish, obscurely ribbed, greenish, with brownish red in the sun. Flesh greenish white, juicy, brisk acid. January, February.

\section{Golay.}

Originated near Tevay, Indiana.

Fruit medium, oblate, somewhat conic, truncated, yellow, mixed, striped with purplish red, dots minute, gray, scattered, indented. Flesh yellowish white, breaking tender, juicy, rich subacid. Good to best. January to May. (Warder.)

\section{Golder.}

Fruit medium, roundish, ribbed, light sellow. Flesh yellowish, acid. July. (Elliott.)

\section{Goldex Ball.}

Origin, Conn. Tree a vigorous grower, but only a moderate bearer. Fruit large, roundish, somewhat ribbed, golden yellow, with a few dots. Flesh crisj, tender, subacid. Good, December, Narch. 


\section{Goldis Burr.}

\section{Burr Knot.}

Ronalds describes this as a rariety easily grown from euttings, becanse of the knots or joints on the shoots.

A large aple, romulish, yellow, with flush of faint red in the sun. Useful for kitchen. November, December.

\section{Goldex Goss.} ductive.

Received from Western New York. Tree vigorons, upright, pro-

Fruit rather large, roundish conical, slightly ribbed, golden yellow, faintly shaded in the sum with red. Flesh white, firm, juicy, mild sul, acid. Good to very good. November, Decenuber.

\section{Goldex Harvey.}

Brandy Apple.

An excellent, high-flavored little dessert Apple from England, of slender growth.

Fruit small, irregularly round. Skin rather rough, dull russet over a yellow ground, with a russety red cheek. Flesh yellow, of fine texture, with a spicy, rich, subacid thavor. The fruit is apt to shrivel. December to April.

\section{Golden Kivob.}

Tree vigorous, productive.

Fruit small, roundish oblate, golden yellow, some russet and tinge of red in sun. Flesh greenish white, crisp, juicy, brisk, sweet. December to March.

\section{Golden Lustre.}

A culinary Apple from England.

Fruit medium, conical, yellow, with patches and stripes of bright red in the sum. Flesh pale yellow, firm, subacid. November to April.

\section{Golden Monday.}

Monstow's Pepping.

Hogg describes this as from the Berkshire orchards, as a dessert Apple of first-rate quality.

Fruit small, roundish oblate, golden yellow, with crimson' dots in the sun. Nettings and lines of thin brown russet. Flesh yellowish white, crisp, sugary, brisk, perfumed. October, December.

\section{Golden Noble.}

An old English variety, valuable for cooking. Iindley descrihes it as pretty large, roundish conical, bright yellow with a few small reddish spots and patches of russet. Flesh yellow, tender, pleasint, subacid. November, December. 


\section{Goldex Noxpareit.}

Fruit small, roundish, golden yellow, with russet and blush red in the sun. Flesh crisp, sharp acid. October, December.

\section{Goldex Pearmain.}

Dutch Pearmain. Ruckman's Pearmain. Red Russet of some.

An old English Apple. Tree upright, very productive.

Fruit medium, roundish conical, yellow, orange in sun. Patches and dots of russet. Flesh yellowish, firm, crisp, juicy, sweet. Tery good. November.

Ronalds describes an entilely different Apple under this name, as follows :

Fruit small, oblong roundish conical, yellow, with some slight russet and a good deal of red striping. Flesh firm, rich, and high-tlavored. December, January.

\section{Goldex Pippix.}

Golden Pippin.

Old Golden Pippin.

Balgone Pippin.

Milton Golden Pippin.

Russet Golden Pippin.

Herefordshire Golden Pippin. Koening's Pippelin.

Reinette d'Angleterre.
London Golien Pippin.

Warter's Golden Pippin.

Bayfordbury Golden Pippin.

Pepin d'Or.

Pomme dor.

The Golden Pippin of the English is the queen of all dessert Apples, in the estimation of the English comnoissemrs, as it mites the qualities of small size, fine form, and color, with high flaror and durability. It is a very old variety, being mentioned by Erelyn in 1660 , but it still thrives well in many parts of England.

Fruit small, round, and regularly formed, gold color, dotted with gray russety dots, with also obscure white specks imbedded under the skin. Flesh yellowish, crisp, rather acid, but with a rich, brisk, ligh flavor. Very good. A great bearer, but requires a strong, deep, sandy loam. November to March. Does not sncceed well here.

There are many varieties of the English Golden Pippin, differing but little in general appearance and size, and very little in flaror, from the old sort, but of rather more thrifty growth; the best of these are Hughes', and Kirke's new Cluster Golden Pippins.

\section{Goldex Pippix.}

\section{Pittstown Pippin.}

This is an old Apple, grown many rears ago in Adams. Mass.. from whence it was brought to Pittstown, and has been recently chistened after that place. The tree is an upright rigorous grower, with large strong branches. Shoots dull brownish red, slightly downy.

Fruit rather large, roundish oblate, sometimes conic, and sides unequal, greenish yellow with a blush in sun exposure. Flesh rellowish. tender, juicy, sprightly subacid. Core rather large. Good for cooking. September and October. 


\section{Golden Pirpin.}

Pound Royal of some. Butter Pippin.
York Pippin.

Large Golden Pippin.

Mammoth.

This Apple is considerably grown in the New England States and Western New York, and is one of the largest of its class, specimens sometimes weighing 20 ounces. Tree very vigorous and very productive on deep rich soils; on light soils it is often a shy bearer, the finit much smaller.

Fruit very large, roundish, ribbed, greenish yellow, becoming quite rellow at full maturity, slight blush of brown crimson in sun-exposed specimens. Flesh yellowish, coarse, juicy, tender, mild subacid. Core small. Grod to very good. November, December.

There is arrother Golden Pippin sometimes known as Porter in Michigan, which is of medium size, roundish oblate, greenish yellow, mild subacid. Ripe in September and October.

'There are also several other Apples under this popular name, many of which doubtless will be found identical with named sorts.

\section{Golden ReD.}

From Long Island. Origin unknown.

Fruit medium or below, roundish oblate, yellow, shaded, splashed, and mottled nearly over the whole surface. Flesh yellowish, crisp, moderately juicy, pleasant subacid. Core small. December, January. Fruit liable to rot on the tree, not profitable.

\section{Goldex Reinette.}

\author{
Reinette, Golden. \\ Aurore. \\ Kirke's Goliten Reinette. \\ Fellow German Reinette. \\ Reinette d'Aix. \\ English Pippin. \\ Court pendu Doré.
}

\author{
Wyker Pippin. \\ Elizabet. \\ Wygers. \\ Megrinch Favorite. \\ Dundee. \\ Reinette Giden. \\ Princesse Noble, of the French.
}

The Golden Reinette is a very popular dessert fruit in England and on the Continent, combining beauty and high flavor.

Fruit below medium size, very regularly formed, roundish, a little flattened. Skin smooth, golden yellow, washed and striped with fine soft red on the sunny side, mingled with seattered russet dots. Flesh yellow, crisp, with a rich, brisk subacid. Good. October to January.

\section{Goldex Reinette of Tanderlaaxs.}

Reinette dor'e de Tan der Laans.

Originated with Van der Laans of Rynland, in Holland. Tree strong, stout branches.

Fruit medium, roundish conical, greenish, with indistinct grayish brown spots. Calyx laige, half open. Stalk short. Cavity deep. Flesh greenish white, fine, firm, perfumed, subacid. October to December. (Terg.) 

above.

The German Golden Reinette may possibiy prove identical with the

\section{Golden Russet.}

English Golden Russet. English Golden. Russet Golden.

This is an old English Apple described by Ronalds and Lindley as Golden Russet, and as that is its commonly accepted name in this country we have followed it. It is one of the popular Apples, succeeding in nearly all sections, and especially in rich Western soils. The tree is thrifty, vigorous, spreading, lather irregular, forming a bushy head. Young shoots slender, dull reddish brown, slightly downy, with numerous small white dots. An early bearer.

Fruit medium or below, roundish, or roundish oblate. Skin rough. Color yellow, mostly covered with dull russet, and having a bronzed cheek in the sun. Stalk short, small. Cavity medium, or rather deep. Calyx closed. Segments rather long, often a little recurved. Basin broad, rather large, slightly corrugated. Flesh whitish jellow, tinegrained, rather compact, sprightly, mild subacid. Good to very good. December to March.

\section{Golden Russet, of Massachusetts.}

Tree vigorous, upright, and productive. Young shoots clear reddish brown.

Fruit medium, roundish oblate, conic. Skin golden russet, with a sunny cheek. Stalk small and short, inserted in a deep cavity. Calyx nearly closed. Segments small, recurved. Basin deep, round, and open. Flesh yellowish white, tender, rich, mild, sweet subacid. Tery good. January, April.

There are many Golden Russets about the country, and it is difficult to identify them. This is from Massachusetts, and distinct from those grown in New York, and West.

\section{Golden Seedling.}

Supposed origin, Missouri.

Fruit large, roundish oblate, greenish yellow blush in the sun. Flesh yellowish, juicy, sharp subacid. February to May.

\section{Golden Streak.}

A cider Apple from Somersetshire, England.

Fruit medium, roundish oblate, clear yellow, with stripes of red. Flesh yellow, brisk, pleasant acid. (Hogg.)

\section{Goldex Sweet.}

\section{Orange Sweeting. Early Golden Sweet.}

A celebrated Connecticut fruit. Tree very vigorous, spreading, forming a tree of moderate size, hardy and very productive. Young shoots reddish brown.

Fruit above the medium size, roundish, scarcely flattened, fair, and well formed; when fully ripe, pale yellow or straw color. Stalk about 
an inch long, slender at its junction with the fruit. Calyx closed, and set in a basiu of moderate depth. Flesh tender, sweet, rich, and excel. lent. Good to very good. August and september. A valuable sort for cooking, warket, or stock feeding.

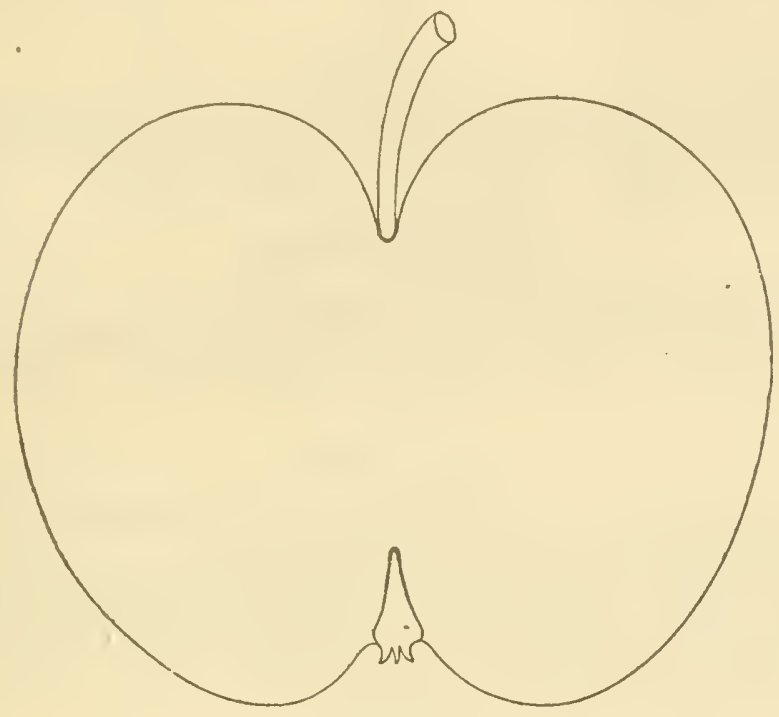

Golden Sweet.

\section{Goldex WiLding.}

Origin, near Fayetteville, N. C. Tree thrifty, upright, productive.

Fruit medium, roundish oblate, a little oblique, golden yellow, thickly sprinkled with brown dots. Stalk rather short and small. Cavity deep, russeted. Calyx open. Flesh yellow, firm, crisp, brisk subacid. Core small. Good. November to March.

\section{GOLDEN WORCESTER.}

A small dessert Apple described by Ronalds as perfectly round, ricb golden, slightly tinged with red. Flesh firm, yellow. January.

\section{Gold Reinette yox Bordeaux. \\ Bordeauer Gold Reinette.}

Hogg describes this as a valuable and beautiful sort. We do not know of its laving fruited in this country.

Fruit very large, obtuse pearmain shaped, greenish, becoming rich yellow and washerl with bright red in the sun, traces of russet, and gray russet dots. Stalk short, Hleshy. Calyx open. Flesh yellowish white, fine, tender, juicy, rich aromatic. December to March. 


\section{Goodrear.}

Goodyear's Seedling.

Origin, Cumberland Co., Pa. Tree a fine grower, and productive.

Fruit medium, roundish, fine red. Flesh tirm, juicy, subacid. Good. December to April.

\section{Gooseberri:}

An Euglish cooking Apple. Tree vigorous, spreading.

Fruit large, roundish conical, greenish yellow, sometimes slight tinge of red in sun. Flesh yellowish, crisp, juicy, brisk subacid. Good to very good for cooking. Core large. December, February.

\section{Gooseberry Piprix.}

A handsome little English dessert Apple.

Fruit small, roundish, yellow, with splashes and marblings of red. Flesh fine-grained, tender, juicy, brisk, sweet subacid. November to Eebruary.

\section{Gould's SweEt.}

Origin unknown. First brought to notice from Mercer Co., Pa. Tree of rather slow spreading growth, productive.

Fruit medium, romdish oblate conical, yellow, deep orange in the sun, brown dots. Flesh yellowish, moderately tender, juicy, mild, rich, sweet. Core rather small. A good cooking fruit." December to March.

\section{Goverior.}

American. Large, yellowish, tinged with red, juicy, acid, cooking. October, January. (Elliott.)

\section{Goverisor Charter.}

Governor Charter's Seedling.

A variety described in the Prairie Farmer as a raluable market Apple. Tree hardy and prodnctive.

Fruit medium, roundish conical, obscurely ribbed, light yellow, with blush in the sur. Flesh white, firm, juicy, pleasant, scarcely acid, slightly aromatic. Core small. October.

\section{GraCer.}

Origin, Greenville, Ill.

Fruit abore medium, roundish conical, light green, with greenish white specks. Flesh greenish white, coarse, mild subacid. August. (Gar. Mon.)

\section{Grange.}

Origin, Herefordshire, England. Tree hardy and productive.

Fruit below medium, roundish, yellow. Flesh yellow, firm, crisp) brisk. October, November. (Ron.) 


\section{Gratge's Pearmaix. \\ Grange's Pippin.}

An Euglish enlinary Apple. Tree hardy, produetive.

Fruit large, roundish conieal, yellow, with broken stripes of red. Flesh yellowish white, tender, juiey, brisk pleasant acid. November, February. ( (Iogg.)

\section{Grantwinisle.}

Originated in one of the eastern counties of New Jersey. Tree vigorous, mpright, spreadiug, productive.

Fruit medium, rounclish, slightly conical, yellowish, shaded with light red, and striped and splashed with a deeper shade. Flesh white, fine-grained, juicy, moderately tender, rich pleasant honeyed sweet. Core small. Very good. Taluable for stock, eider, or for cooking. October to December.

\section{Granite Beauty.}

Aunt Dorcas. Grandmother's Apple. Clothes-yard Apple.

Origin, on the farm of $Z$. Breed, Weare, N. H. Tree hardy, rigorous, upright, sprealing. An annual bearer. Young wood light reddish brown, slightly downy.

Fruit medium to large, roundish oblong, largest at the centre, and narrowing toward stalk and ealyx, uneven surface, or obsemely ribbed. Skin somewhat oily. Color pale yellow, mostly overspread, striped, splashed, and mottled with two shades of red, brown dots. Stalk short, slender. Cavity uneven, or ribbed, acute. Calyx closed. Segments short, erect. Basin medium, corrugated. Flesh whitish, tender, juicy, mild pleasant subacid. Core large, open. Good to very good. December to February.

\section{Granny Earle.}

Fruit small, roundish oval, green, striped and splashed with red. Flesh white, crisp, tender. Very good. November, January. (Hov. Mag.)

\section{Gravenstein.}

\section{Grave Slije.}

A superb-looking German Apple, which originated at Gravenstein in Holstein, and is thought one of the finest apples of the North of Europe. It fully sustains its reputation here, and is, unquestionably, a fruit of first-rate quality. Tree very vigorous, spreading, forming a large, broul head. Very productive. An early bearer. Young wood redilish brown.

Fruit large, rather flattened, and a little one-sicled or angular, broadest at the base. Stalk quite slinrt and strong, deeply set. Calyx large, closed, in a wide, leep, lather irregular basin. Segments long, irregular, recurvel. Skin greenish yellow at first, but becoming bright yellow, and beantifully dashed and pencilled, and marbled with light and 
deep red and orange. Flesh tender and crisp, with a high-flavored, somewhat aromatic taste. Very good. September and October. A valuable apple for market or cooking, succeeding admirably wherever grown.

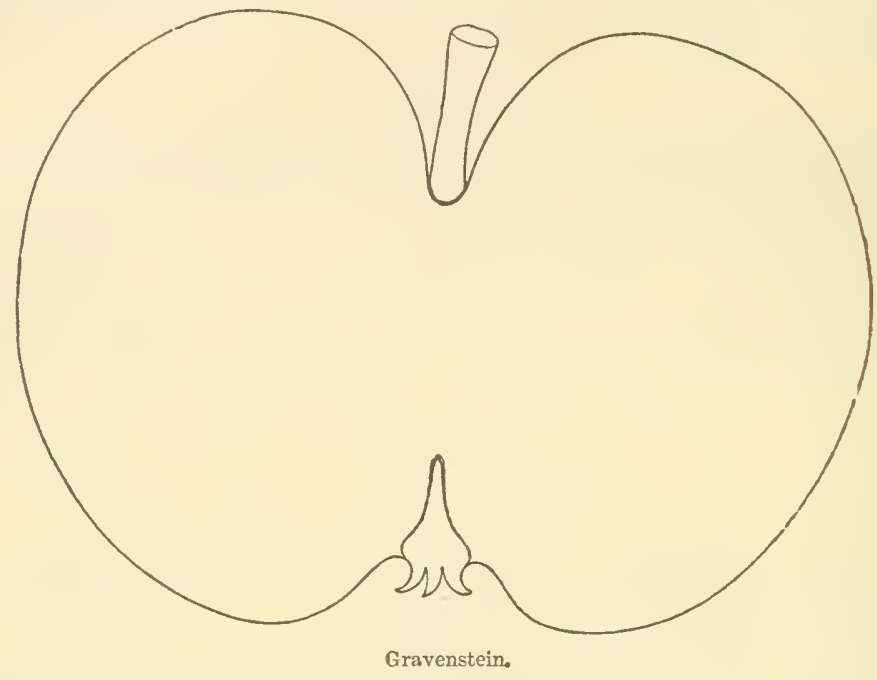

Great Unknown.

Origin unknown. Found in the orchard of S. McDowell, Ma. con, Ga.

Fruit large, regular, oblate roundish, inclining to comic, yellow shaded and marbled with carmine. Stalk slender. Calyx open. Flesh yellowish, tender, juicy, subacid. Very good. December. (White.)

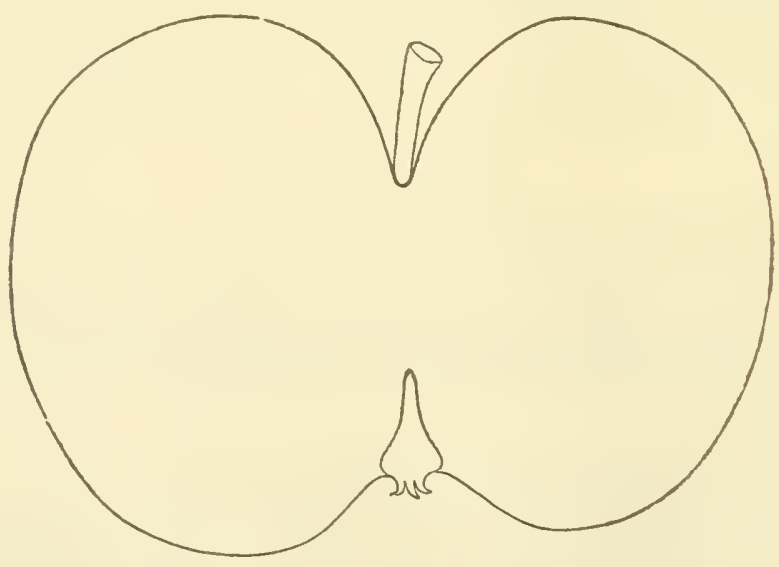

Green Cheese. 


\section{Green Cineese.}

Green Crank. Sonthern Golden Pippiu. Winter Greening. Green Skin.

Yellow Crank.
Winter Cheese. Greening.
Southern Greening. Carolina Greening. 'I'urner's Cheese.

An old variety, grown largely in Kentucky and other Soutliwestern States. It has been extensirely propagated by suckers, but the exact place of the original tree is mknown. Although not best in quality, it has so many good properties adapting it to the South and Southwest, that it is widely disseminated under the various synonyms given above.

Tree moderately vigorous, upright, and has the habit of blooming late, which gives it a special value. A good bearer and long keeper. Ioung shoots slender, grayish brown.

Fruit merlium, oblate, oceasionally oblique, pale greenish yellow, moderately sprinkled with brown dots. Stalk short, slender. Cavity large, deep, russeted. Calyx closed. Segments slightly reeurved. Basin broad, deep, uneven. Flesh vellowish white, tender, erisp, juicy, rich, sprightly subacid. Core small, compact. Very good. Novem ber to March.

\section{Green's Choice.}

Origin, Chester Co., Pa. Tree vigorous and productive.

Fruit medium, roundish conical, yellow, striped with red. Flesh tender, juiey, very mild subaeid, or almost sweet. Good. Ripe last of August and first of Septeniber.

\section{Green Douine.}

Fruit medium, oblate, greenish yellow, washed or obscurely striped with dull red. Flesh whitish, firm, with a pleasant, peculiar flavor. Good. December, February.

\section{Green Mlountain Pippin.}

From Geortgia, and much grown there as a market. fruit.

Fruit medium, roundish, inclining to oblong, flattened at base and crown, greenish yellow. Flesh white, crisp, juicy, tender, pleasant subacid. Good. November, February.

\section{Greex Newtown Pippin.}

Hunt's Fine Green Pippin. Newtown Pippin. American Newtown Pippin. , Brooke's Pippin? Green Winter Pippin. Petersburgh Pippin.

Inunt's Green Newtown Pippin?

The Newtown Pippin stands at the head of all Apples, and is, when in perfection, acknowledged to be unrivalled in all the qualities which constitute a high-flavored dessert apple, to which it combines the quality of long keeping without the least shrivelling, retaining its ligh flavor to the last. It commands the highest priee in Covent Garden Market, London. This variety is a native of Newtown, Long Island, and it requires a pretty strong, deep, warm soil to attain its full perfection, and in the orchard it should be well manured every two or three years. The tree 
is of rather slender and slow growth, and even while young is always remarkable for its rough bark.

Fruit of medium size, roundish, a little irregular in its outline, caused by two or three obscure ribs on the sides-and broalest at the base, next the stalk; about three inches in diameter, and two and a half deep. Color dull green, becoming olive green when ripe, with a faint, dull brownish blush on one side, dotted with small gray specks, and with delicate russet rays around the stalk. Calyx quite small and closed, set in a narrow and shallow basin. Stalk lialf an inch long, rather slender, deeply sunk in a wide, funnel-shaped cavity. Flesh greenish white, very juicy, crisp, with a fine aroma, and an exceedingly high and delicious flavor. Best. When the fruit is not grown on healthy trees, it is liable to be spotted

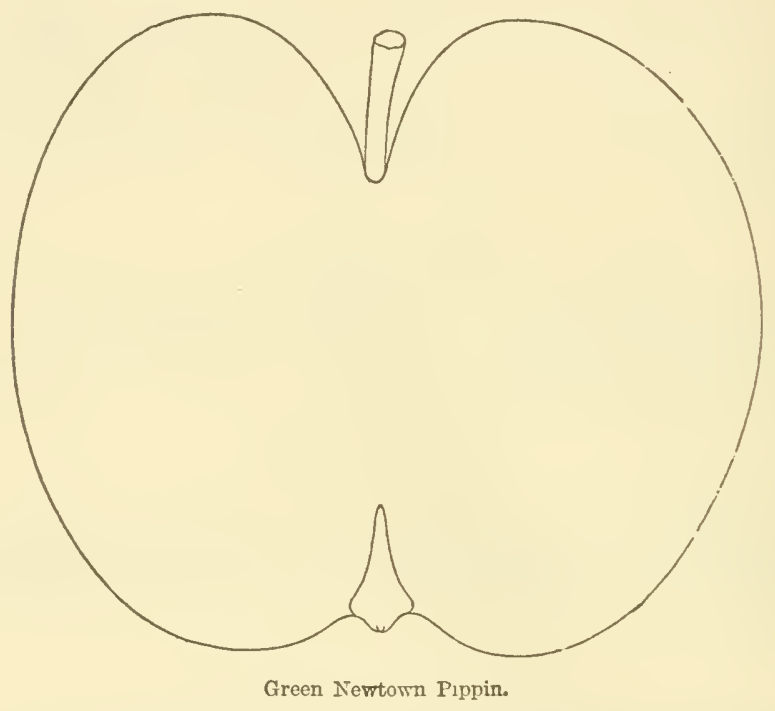

with black spots. This is one of the finest keeping apples, and is in eating from December to May, but is in the finest perfection in March.

This is entirely distinct from Yellow Newtown Pippin.

\section{Green Reinette.}

Reinette Verte. Groene Renet.
Groene Franse Renette. Grune Reinette.

Tree vigorous and healthy, a good bearer.

Fruit medium, roundish, flattened at base, ribbed at apex, yellowish green with a tinge of red. Flesh yellowish white, tender, juicy, aromatic. December to May. (Hogg.)

\section{Green Seek-xo-Further.}

White Seek-no-Further. Flushing Seek-no-Further. Seek-no-Further of Coxe.

Origin in the garden of the late W'm. Prince, Flushing, L. I. 
Tree while young rery slow in its growth, but makes a compact, well. formed head in the orchard.

Fruit apt to be knotty and unfair. Rather large, roundish conical, yellowish green, sprinkled with gieen and brown dots. Stalk short, in a moderate carity. Calyx closed, in a rather deep basin. Flesh white, crisp, tender, juicy, pleasant, mild subacid. Very good. October, January.

\section{Green Tiffix. \\ Mage's Johnny.}

From Lancashire, England. Tree a fair grower and bearer.

Fruit medium, round conical, yellowish green with a few russet and red dots. Flesh white, crisp, tender, acid. September, December. (Hogg.)

\section{Green SWEeT. \\ Honey Greening.}

Tree vigorons, upright spreading, and prodnctive.

Frnit medium, roundish oblate, somewhat conic. Skin green, sometimes becoming a little yellow at maturity, covered with greenish or light russet dots. Stalk of medium length. Cavity rather deep, covered with russet. Basin shallow and abrupt, somewhat furrowed. Flesh whitish, tender, juicy, sweet, pleasant. Good. December to March.

\section{Green Sweet of Indidid.}

This Apple is somewhat grown in Indiana, and we have not met with it elsewhere.

Fruit medium to large, roundish conical, greenish yellow, with brown dots. Flesh yellowish, tender, jnicy, sweet and pleasant. Good. September.

\section{Greenup's Pippin.}

\section{Greenus's Pippin.}

'This English Apple is described by Hogg as popular and highly esteemed, the tree being hardy and an abundaut bearer.

Fruit above medium, roundish, with on one side a prominent rib, pale straw color, bright red next the sun. Flesh pale yellowish white, tender, juicy, sweet, brisk. October to December.

\section{Green WoOdCock.}

Origin, Sussex, England ; described by Hogg as follows :

Fruit medium, roundish oblate yellowish, mottled and striped with red in the sim. Flesh white, tender, juicy, brisk. October, December.

\section{Greist's Fine Winter.}

From York, Pa. Tree a strong grower, regular, moderate bearer.

Fruit rather large oblate or roundish oblate, yellow, splashed and shaded in sun with light red. Flesh yellow, compact, crisp, juicy, brisk subacid. Good. December, February. 


\section{Grey Canada Reinette.}

Canada Reinette Gris.

Origin unknown.

Fruit large, oblate, yellow, covered with yellow russet, and moder ately sprinkled with gray dots. Flesh white, crisp, brisk subacid. No vember, December.

\section{Grey French Reinet'te. \\ Reinette Grise. Reinette Franche Grauwe. Reinette Grise Française.}

There are a number of varieties of Reinette Grise, or Gray Reinette. The one here, however, is consiclered by Lindley as distinct, and among the most valuable of its class. It is of French origin. Tree a moderate grower and good bearer. Foung wood of a chestnut color.

Finit nedium, roundish oblate, broadest at base, covered with brownish gray russet. Flesh yellow, moderately juicy, rich subacid. November, December.

\section{Grevilouse.}

Hoopes. Hopsey.

Origin, supposed New Jersey. Has been long grown and highly valued for cider-making. Tree strong, erect grower, and productive.

Fruit mediun, oblate, nearly globular, dull red, with faint stripes. Flesh firm and dry, poor in quality. A long keeper.

\section{Grey Leadington.}

\section{Leadington's Grauer Pippin. Grey Leadington Pippin.}

A favorite Scottish Apple. Tree vigorous, hardy, and productive.

Fruit medium, roundish oblong conical, greenish yellow, with cinnamon russet and red in the sun. Flesh white, firm, tender, very juicy, aromatic. October, December. (Linrl.)

\section{Grey Pininette.}

Reinette Grise Extra.

Reinette Grise d'Hiver.
Reinette Grise. Prager.

Belle Fille.

An old Fiench Apple.

Fruit medium, roundish, yellowish green, with brownish red in sun. Flesh yellow, firm, crisp, brisk subacid. November, February. (Hogg.)

\section{GRIFFITH.}

Sweet Maiden's Blush.

Raised by Caleb Mendenhall, West Milton, near Dayton, O. Tree hardy, spreading, productive.

Fruit medium, roundish oblate, clear pale yellow, with light blush red eheek in the sun. Stalk short. Cavity rather large. Basin small. Flesh fine-grained, tender, juicy, a little tart. September. (L. S. Mote's MSS.) 


\section{Grimes' Goldex Pippin.}

Grimes Golden.

This valuable Apple originated many years since, on the farm of Thomas Grimes, Brooke Co., Val. In its native locality it is highly prized for the peculiar handihood of the tree, withstanding minjured the most serere winters, and nerer breaking in its limbs. Also for its uniform regular anmual productireness.

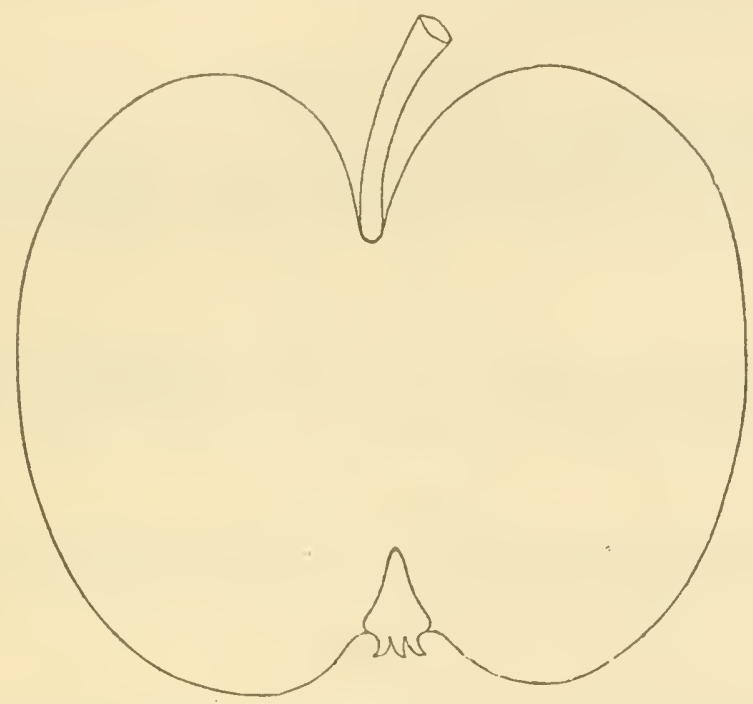

Grimes' Golden Pippin.

Tree vigorous, hardy, upright spreading, very productive, branches with peculiar knobs at the base of each, connecting it with the main limbs. Young wood dark dull red brown, grayish.

Fruit medium, roundish oblate, slightly conical. Skin meven. Color rich golden yellow, sprinkled moderately with small gray and light dots. Stalk rather short and slender. Cavity rather deep), sometimes slightly russeted. Calyx closed, or partially open. Basin abrupt, uneven. Flesh yellow, compact, crisp, tender, juicy, rich, sprightly, spicy subacid, peculiar aroma. Core rather small. Very good to best. December to March.

\section{Gros Faros.}

Faros.

Fruit medium, oblate, roundisl, yellow, with considerable red in the sun. Flesh greenish white, juicy, sweet subacid. December, January.

\section{Grosir.}

Originated in Snufftown, Lancaster Co., Pa, Tree upright, with stout brown shoots; an ammial bearer. 
Fruit very large, oblate, oblique, greenish white, striped with light and dark red. Flesh white, loose, soft texture, juicy, acid. September, Good. Cooking. (Gar. MIon.)

\section{Grovzier.}

Received from New Jersey. Origin unknown.

Fruit medium, roundish conical, greenish, partially striped and splashed with light red. Flesh whitish, tender, juicy, mild subacid. Good. November, December.

\section{Grooveland Sweet.}

Origin unknown.

Fruit mediun, roundish oblate, slightly conic, a little oblique, sides unequal, yellow, a tinge of red in the sun. Flesh whitish, crisp, tender, juicy, mild, pleasant, sweet. Good. December to March.

\section{Gruver's Early.}

Originated on the furm of - Nayer, Springfield, Pa.

Fruit medium, roundish, whitish yellow, with stripes and splashes of red. Flesh whitish, juicy, pleasant, mild subacid. Goorl. August.

\section{Guernsey Pippin.}

Fruit small, roundish, brown russet on yellow, bronzed in the sun. Flesh firm, crisp, juicy, brisk sweet. December, Jannary.

\section{Gullett.}

Origin unknown.

Fruit large, oblate conical, greenish yellow, with dull stripes. Flesh juicy. February.

\section{Gully.}

Origin, Lancaster Co., Pa.

Fruit small, white blush in the sun. Flesh white, juicy. August.

\section{Habershay's Pearmain.}

Tree of upright growth.

Fruit medium, ovate form, bright crimson. Stalk short, slender. Calyx medium. Flesh white, rather dry, firm, subacid. September. (White.)

\section{Hagioe Crab.}

This is a celebrated old English cider fruit.

Fruit small, ili-shaped, something between an apple and a crab, more long than broad, wide at the base and narrow at the crown, which is a little sunk, aud the eye flat, pale yellow, a little marbled in different directions, with a russet gray, and having a few red specks or streaks on the sunny side. 


\section{Hague Piprin.}

Originated in 1816 , by Samuel Hague, Centreville, Ind. Tree hardy, vigorous grower, and productive. Young shoots strong, light reddish brown, slightly downy.

Fruit medium to large, roundish conieal, pale yellow, mostly covered, shated, splashed and striped with red, thickly sjurinkled with light dots. Stalk short. Flesh rather coarse, yellowish, erisp, moderately juicy, wild subacid. Core large. Good. January, Cebruary.

\section{HAIN。}

Origin, Berks Co., Pa. A rigorous grower and profuse bearer.

Fruit litge, globular, inclining to oblong, yellow, striped, marbled, and mottled with red. Flesh white, juicy, tender, rich sweet. Good. Novcmber, Mitreh.

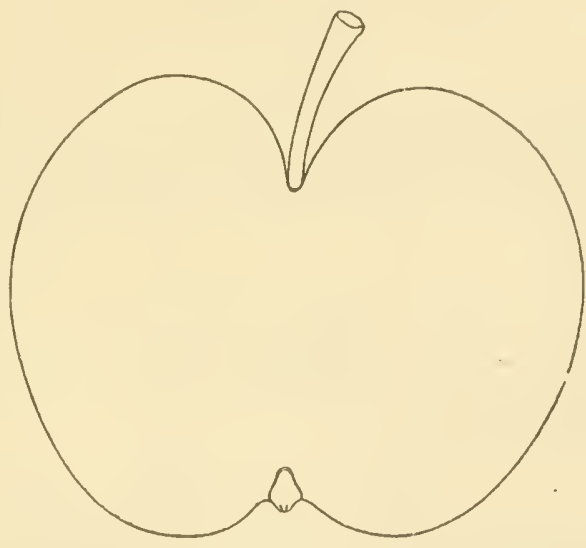

Hall.

\section{. HALL.}

\section{Hall's Seedling. Hall's Red. Jenny Seedling'.}

Origin, on the grounds of Mr. Mall, Franklin Co., N. C. Tree of moderate growth, lravdy, rpright, with long, slender, reddish brown, grayish branches, and remarkably firm wood. The tree never attains a very large size; is very productive, and is considered in Nortl Carolina the hest long-keeping dessert apple they cultivate.

Fruit small, oblate, slightly conic. Skin smooth, thick, mostly shaded with crimson, and covered with various colored dots. Stalk of medium lengtl, slender, curved, inserted in a round, decp, open cavity. Calyx closed, gencrally in a small uneven basin. Flesh yellowish, finegrained, juicy, with a very rich, vinous, saccharine, aronutic flavor. Very good. December to April.

\section{HATL DOOR.}

An English Aple lo described by Ronalds as desirable for cooking. 
Fruit large, oblate, greenish, with few red stripes. Flesh white, coarse, subacid. December, January.

\section{HALL'S SWEeT.}

Of unknown origin.

Fruit large, roundish oblate, yellow, shaded, striped, and splashed with red, many light dots. Flesh sometimes a little stained, not very juicy, rich, sweet. Good. September.

\section{Hambledon Deux Axs.}

Origin, Hampshire, England.

Eruit medium, roundish oblate, yellow, mostly orerspread and indistinctly splashed with red. Flesh yellowish, juicy, pleasant subacid. Good. November.

\section{HaMiLToN.}

Wonder?

Origin unknown. Came from the South.

Fruit large, roundish, irregular, somewhat ribbed, red on rellow, splashed with puple. Dots large, yellow. Calyx large, open. Flesh rellow, breaking, rather juicy, subacid. Good. September, October. (Am. Hort. An.)

\section{Hainioxd.}

Fruit medium to large, green. Flesh juicy. Norember, and keeps to March (Sumuer, MS.)

\section{Haypton Beliflomer.}

A seedling from the Bellflower, grown by WT. C. Hampton, Mt. Tictory, Oliio.

Fruit large, light yellow gromnd, speckled and splashed with carmine, red in the sun, few russet gray dots and marblings. Stalk medium. Calyx partially open. Segments recurved and with fine points. Basin open, slightly uneven at base. Flesh white, tender, breaking, rather coarse, mild pleasant subacid. Good. Core small. November and December.

\section{Hampton's Fall Sweet.}

Origin, W. C. Hampton, Olio.

Fruit medium, roundish, yellow, striped with red. Flesh tender, sweet, rather dry. Good. October.

\section{Hanpton's HoNex SWEET.}

Origin, W. C. Hampton, Ohio.

Fruit medium, elongated truncate conic, rellow, fuintly striped with red. Flesh white, tender, sweet. Good. December to iluil. 


\section{ITAMPTON's LATE SweET.}

Sweet Jersey.

Origin, W. C. Hampton, Olio. 'Tree vigorous, with slender branches, hardy and productive.

Fruit medium, roundish conic, whitish, splashed, striped, and shaded with red. Flesh white, stained next the skin, tender, juicy, pleasant subacid. Good to very good. October.

\section{Hanpton's Russet.}

Origin, W. C. Hampton, Ohio.

Fruit medium to small, roundish conical, yellowish, thinly covered with light russet, splashes and stripes of red. Flesh yellowish, tender, juicy, lively subacid. Good. November, January.

\section{MANCOCK.}

Originated in Chester $\mathrm{Co}, \mathrm{Pa}$. Tree a strong upright grower, not an early bearer.

Fruit large, roundish, yellowish green, shaded and rather indistinctly splashed with light red. Flesh yellowish, compact, moderately juicy, roarsc, pleasant subacid. Core small. Good. December to March.

\section{Hanvair.}

Origin unknown.

Fruit medium to large, roundish, pale yellow, with stripes and splashes of dull red. Flesh white, coarse, breaking, subacid. Hardly good. Cooking only. October, November.

\section{HANWELL SOURING.}

Origin, Oxfordshire, England.

Fruit medium, oblate conic, greenish yellow, faint blush in the sun. Flesh white, crisp, fine, brisk acid. Good. Cooking. December to April.

\section{HARE.}

\section{Watermelon.}

We received this desirable Apple from New Jersey, but have been unable to learn its history. Tree moderately vigorous, upright. Wood grayish brown.

Fruit large, roundish oblate, slightly conic, greenish, sprinkled with a few gray dots. Stalk short, slender. Calyx small, closed. Flesh white, very tender, juicy, mild pleasant sweet. Tery good. Core rather large. October, November.

\section{Tharbord's Pippin.}

Colored Harbord's Pippin.

Origin, Norfolk, England.

Fruit large, roundish conical, pale yellowish green, partially russeted. Flesh white, soft, juice, brisk, acid. November to March. (IJogg.) 


\section{Hargreare's Green Sweet.}

An English variety, somewhat valued there.

Fruit medium, roundish, ridged at apex, yellow, with faint streaks of red in the sun. Flesh yellowish, tender, juicy, sweet. September, October.

\section{HARNisH.}

From Pennsylvania, said to have originated in Lancaster Co.

Fruit medium, roundish oblate, mostly shaded with dark red, and sprinkled with grayish dots. Flesh compact, tender, not juicy, almost sweet, pleasant. Good. September to October.

\section{HARRIS.}

\section{Ben Harris.}

Originated with Marston Harris, Rockingham Co., N. C. Tree vigorons, erect, productive, popular in its native locality. Foung wood grayish brown, slightly lowny.

Fruit large, roundish oblate, bright straw color, occasionally with a pink blush. Stalk very short and stout. Cavity deep. Basin large and deep. Flesh white, coarse, pleasant subacid, contimues a long time, valuable for market and culinary purposes. Good. September to November.

\section{IIARRISON.}

New Jersey is the most celebrated cider-making district in America, and this Apple, which originated in Essex County of that State, has long enjoyed the highest reputation as a cider fruit. Ten buslıels of the Apples make a barrel of cider. The tree grows thriftily and bears very large crops.

Fruit medium size, ovate or roundish oblong. Skin yellow, with ronghish, distinct black specks. Stalk one inch or more long. Flesh yellow, rather dry and tongh, but with a rich flaror, producing a highcolored cider, of great body. The fruit is rery free from rot, falls easily from the tree about the first of November, and keeps well.

\section{HARRY SWEet.}

Originated in Nercer Co., Pa. Tree of slow, upright growth.

Fruit medium, roundish, inclining to conic. Sides sometimes ur. equal. Skin thick, greenish yellow, dull blush in the sun, and nettings of russet. Flesh whitish, crisp, a little coarse, moderately juicr, mild sweet. Good. December to April.

\section{Hartford Sweet.}

\section{Spencer Sweeting. Keney's Sweet.}

Origin, farm of Mr. Spencer, near Hartford, and introdnced by Dr. E. IV. Bull. Tree moderately vigorous, hardy, and modnctive.

Fruit rather large, roundish, slightly flattened. Skin smooth and 
fair, almost covered and striper with fine red over a yellowish green ground, and sprinkled witlı small gray dots. Stalk nearly three-quarters of an inch long, slender, inserted in a rather shallow, round cavity. Calyx broad, closed, with few segments, set in a slightly uneven basin which is but little sunk. Flesh yellowish, very juicy, tender, rich sac charine. Good. December to May or Jume. A valuable market apple.

\section{Harvest Red Streak.}

Early Red Streak.

Striped Harvest.

An old variety, origin unknown. Thee a free grower, upright, spreading, productive.

Fruit medium, oblate, whitish, striped and splashed with two sharles of red. Flesli white, coarse, tender, juicy, brisk subacid. Valuable for cooking. August and September.

\section{HARVEY.}

\section{Doctor Harvey.}

One of the oldest of English Apples.

Fruit large, roundish oval, greenish yellow, with russet tracings. Flesh whitish, firm, brisk subacid. Good for cooking. October to January. (Lind.)

\section{"Hlarver's Pippix.}

Dredge's Beauty of Wilts.

\section{bearer."}

Of English origin. Hogg says :- "Tree a free grower and excellent

Fruit medium, roundish, yellow, washed with fine red, and marked with crimson dots. Flesh firn, crisp, juicy, rich. December to February.

\section{Harvey's Wirtshire Defiance.}

This Apple is described by Hogg as very handsome and of first-rate quality.

Fruit very large, conical, distinctly five-ribbed, yellow, with many minute russety dots, and some patches of russet. Flesh yellowish, firm, erisp, juicy, sugary, vinous. Core very small. October to January.

\section{Haskell Sweet.}

\section{Sassafras Sweet.}

Origin, farm of Deacon Haskell, Ipswich, Mass. 'Tree vigorous, upright, spreading and productive. Young wood light grayish brown.

Fruit medium or above, oblate. Color greenish yellow, sometimes with a blush. Stalk short, inserter in a rather broad, deep cavity. Calyx closed. Basin broad and large, of medium depth. Flesh yellowish, tender, juicy, very sweet, rich, aromatic. Tery good to best. Sieptember, Oetober. 


\section{Haute Bonté.}

\section{Reinette grise haute bonté. Blandilalie.}

An old French dessert Apple.

Fruit medinm, roundish, ribbed, yellow, with faint tinge of red in the sun. Flesh greenish white, tender, juicy, brisk subacid. Decem ber to February.

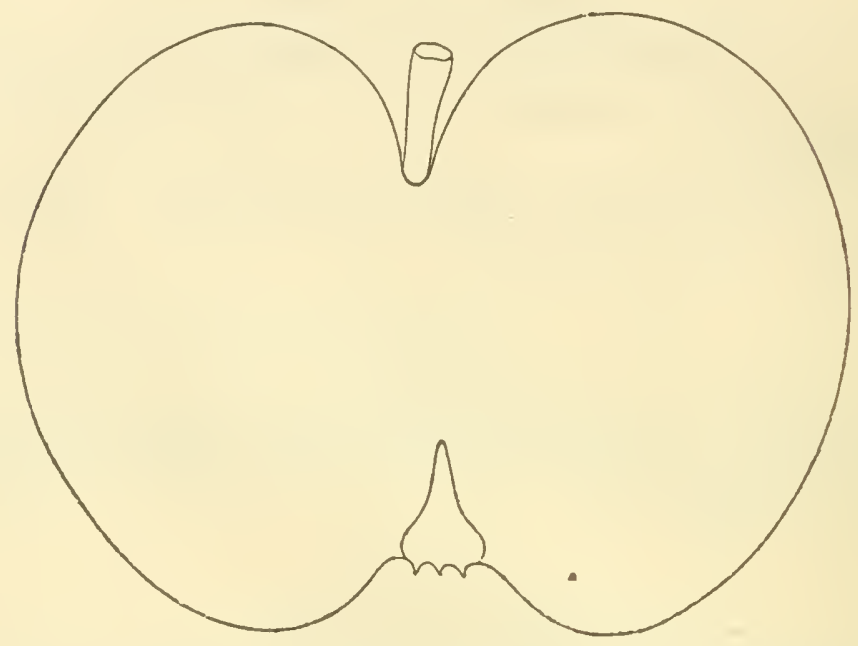

Haskell Sweet.

HaWLey.

Origin, Columbia Co., N. Y. Tree vigorous, and bears annually.

Fruit large, roundish oblate conic. Skin fine yellow, somewhat wa cen or oily, and considerably dotted. Stalk short, inserted in a rather deep cavity. Calyx small, nearly closed, in a moderate, somewhat furrowed basin. Flesh whitish, very tender, juicy, rich, mild subacicl. Ripe September.

A fruit of very good quality, but as it soon decays, its value is thereby much depreciated.

\section{HAWTHORNDEx.}

White Hawthornden.

A celebrated Scotch Apple, which originated at Hawthornden, the birthplace of the poet Drummond. It resembles, somewhat, our Maiden's Blush, but is inferior to that fruit in flaror. An excellent bearer, a handsome fruit, and good for cooking or drying, and exceedingly profitable for market.

Tree vigorous, upright, spreading, and, when in bearing, somewhat pendulous. Young shoots very short-jointed, dull reddish' brown. Buds prominent. 
Fruit rather above the medium size, pretty legularly formed, roundish, lather flattened. Skin very smooth, pale light yellow, nearly white in the shade, with a fine blush where exposed to the sun. Flesh white, juicy, of a simple, pleasint flavor. Crood. September.

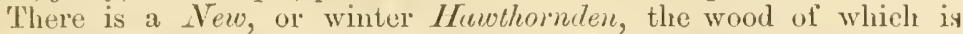
brownish red, tree more robust, the fruit larger, and a longer keeper than the above.

\section{HAY Bors.}

Fruit large, oblate, pale yellow. Flesh yellow, breaking, sweet. Good to very good. August. (IVarder.)

\section{HECTOR.}

A seedling of Chester Co., Pa.

Fruit large, roundish, conical, striped and mottled with red on a yellow ground. Flesh yellowish, breaking, subacid, pleasant. Good. December to Mareh.

\section{Helen's Favorite.}

From Troy, Ohis.

Fruit medium, roundish, dark red shades. Flesh white, streaked with red, tender, juicy. January, February. (Elliott.)

\section{HeMphilL.}

From Person Co., N. C. An erect, vigorous grower, and bears profusely.

Fruit oblate, slightly conic, whitish yellow, very much shaded with red, and thickly sprinkled with grayish dots. Flesh yellowish white, compact, mild subacid. Good. November, May.

\section{Henry Apple.}

A strong, vigorous grower, and productive, from Vermont.

Fruit large, oblong conic, yellow, with a slightly bronzed cheek, and many small, grayish dots. Flesh yellow, tender, not very juicy, pleasant. Good. Oetober, January.

\section{HeNwOOD.}

Originated in Incliana. Tree in growth and appearance much resembling Yellow Belleflower.

Fruit large, oblong conical, clear smooth yellow, with rarely a blush in the sun. Stalk long, slencler. Calyx small. Basin corrugated. I'lesh yellowish white, crisp, tender, juicy, sharp subacid. Very good. January to April.

\section{Hepler.}

Raised by Mr. Ifepler, of Reading, Pa. 
Fruit medium, roundish. Color light yellow, shaded with dull red. Flesh white, juicy, pleasant subacid. Good. December to April.

\section{Herefordshire Peariais.} Royal Pearmain, of some. Parmin Royal. Old Pearmain.
Royale d'Angleterre.

An old and popular Engiish Apple, about which, as connected with other Pearmains, there is much confusion. The variety we have received, and grown for many years, is of a strong, vigorous, spreading growth. Young shoots dull grayish brown, slightly downy, moderately strong.

Fruit medium, roundish conical. Color yellow, shaded, splashed, and marbled with dark red, and thickly sprinkled with conspicuous light areole dots. Stalk short. Cavity medium, slight russet. Calyx partially open. Basin rather abrupt, cleep, corrugated. Flesh yellowish, crisp, juicy, rich, slightly aromatic, subacid. Very good. November to February.

\section{Herman.}

Origin, farm of Mr. Herman, Cumberland Co., Pa. Tree vigorous and spreading, quite prolific.

Fruit medium, oblong conic, red striped on green ground. Flesh greenish, tender, juicy, subacid. Good. November to February.

Tliere is also another Hermann, which originated at Hermann, Mo., from seed of Rawles Janet. Tree a fine grower, upright, and rery productive.

Fruit medium, conical, bright red, with gray dots. Flesh whitish, juicy, pleasant subacid. December to May.

\section{Hess.}

Origin, Lancaster Co., Pa.

Fruit medium, form variable, sometimes roundish, often conical, red, in stripes of different hues. Flesh greenish white, tender. Good. December, February.

\section{Hetterich.}

Origin, Pennsylvania. Tree an irregular grower.

Fruit medium to large, roundish oblate, yellow. Flesh whitish, tender, acid. Good. November, January.

\section{Hewe's Tirginia Crab. \\ Hughe's Virginia Crab.}

The Virginia Crab makes a very high-flavored dry cider, which, by connoisseurs, is thought unsurpassed in flaror by any other, and retains its soundness a long time. It is a prodigious bearer, and the tree is very hardy, though of small size. 
Fruit quite small, about an inch and a lialf in diameter, nearly romd. Skin dull red, dotted with white speeks, and obseurely streaked with greenish yellow. Stalk long and slender. Flesh fibrous, with an acid, rough, and astringent flavor, and, when ground, rums elear and limpirl from the press, and ferments very slowly. The Virginia Crab is often mixed with rich pulpy apples, to which it impants a good deal of its fin: quality.

The Roane's White Crab is a sub-variety of the foregoing, about the same size, with a yellow skin. It makes a rieh, strong, bright liquor, and keeps throughout the summer, in a well-bunged eask, perfectly sweet.

\section{Hewit's SweET.}

Large, oblate, yellow, splashed with red. Flesh whitish, sweet, tender and pleasant. Good. Oetober, Normber. Productive.

\section{HICK's.}

\section{Buckram.}

Originated with Isaac Hicks, North Hempstead, L. I. Tree an upright, strong grower, an early and abundant bearer. Young shoots stout, very short-jointed, dark brown, fine downy. Buds broad, Hat, prominent, especially at ends.

Fruit medium or above, roundish, color pale greenish yellow, somewhat striped and splashed with crimson, thinly sprinkled with light and gray dots. Stalk rather short. Civity deep, slightly russeted. Calyx closed. S'egments short, often a little reeurved. Basin rather large and uneven. Flesh whitish, tender, moderately juicy, rieh, sweet, slightly aromatic. Core rather large. Very good. August. A new Aplile, of good promise.

\section{Hiester.}

$\begin{array}{lll}\text { Heaster. } & \text { Heister. } & \text { Baer. } \\ \text { Stehly. } & \text { Miller. } & \end{array}$

Originated in Reading, Berks Co., Pa. Tree large, rigorous, spreading, productive. Young shoots very dark blackish brown.

Fruit medium, roundish oblate, yellowish, shaded and indistinctly splashed and mottled with two shacles of red, few light gray dots. Flesh white, erisp, juiey, tender, pleasant subacid. Good. November to March.

\section{Higey Sweet.}

\section{Lady Cheek Sweet. Ladies' Blush.}

Originated in Trumbull Co., $\mathrm{O}$. This is one of the most delicate of sweet Apples, valuable either for the table or market. Tree a thrifty, upright grower, an early and good hearer. Young shoots rery shortjointed, innderately stout, dark rich redish brown, with very few light specks.

Fruit medium, roundish, slightly conical, sometimes oblique. Color 
light waxen yellow, shaded with fine clear rich red in the sun, thinly sprinkled with gray and light dots. Stalk short. Cavity acute, rather deep, sometimes a little russeted. Calyx closed. Segments short, erect. Basin narrow, deep, uneven. Flesh white, very tender, juicy, sweet, excellent. Core small. Very good to best. November to January.

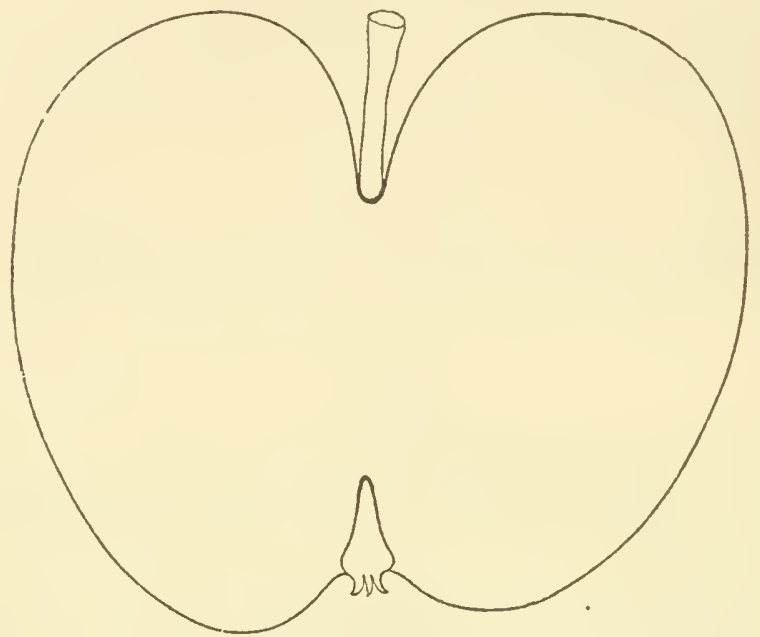

Higby Sweet.

\section{HighlaNder.}

Origin, Sudbury, Vermont. Tree a good grower. vers productive.

Fruit medium, oblate, approaching conic, greenish, mottled, and striped with red. Flesh white, juicy, tender, with a pleasant rinous flavor. Good. September, October.

\section{Hightop.}

Supposed origin, Wayne Co., Tnd.

Fruit medium to large, flat, roundish, regular. Surface smooth, mixed dull red, striped carmine, dots scattered, minute. Flesh pale vellow, fine-grained, tender, juicy, subacid, aromatic. December, January. (Warder.)

\section{Hightop Sweet.}

Summer Sweet.

Sweet June.

Origin, Plymouth, Mass. An old variety, highly prized at the West. Growth upright, vigorous. T'ree hardy, very productive, light reddish brown shoots.

Fruit medium or below, roumdish, regular. Skin very smooth. Color light yellow, partially covered with green dots. Stalk medium, inserted in a deep narrow cavity, surromeded by thin russet. Calyx small, 
closed. Basin shallow, slightly furrowed. Flesh yellowish, very swcet, not very juicy, but pleasant and rich. Very good. August.

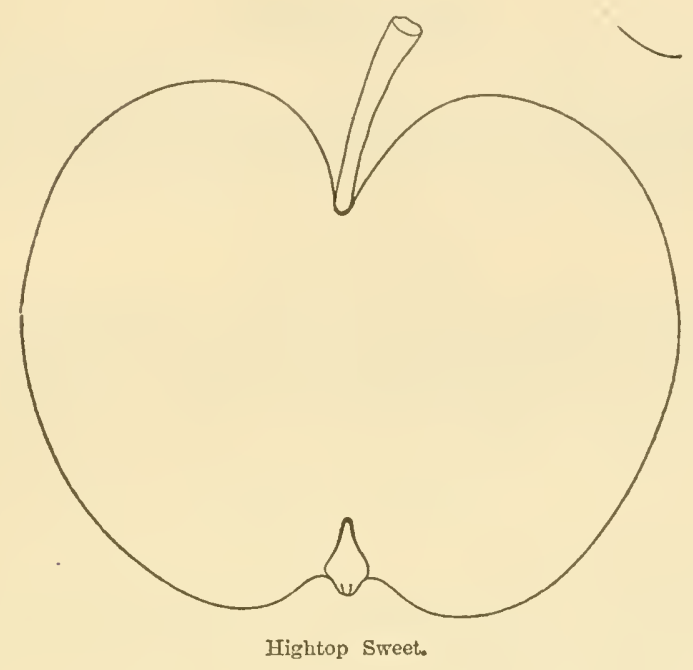

Hill's Favorite.

Origin, Leominster, Mass. A thrifty grower, and very productive.

Fruit medium, roundish oblate, slightly conic, yellow, mostly shaded and striped with red, covered with thin bloom and numerous whitish dots. Stalk short. Cavity medium, uneven. Calyx closed. Basin small, shallow. Flesh yellow, fine-grained, tender, juicy, pleasant, slightly subacid, aromatic. Good to very good. Niddle of September, and in use for a mouth.

\section{Hill's SwEeT.}

Of unknown origin. Tree a strong, upright grower, very productive. Fruit medium, oblate or roundish oblate, jellow, mostly covered with two shades of red, many light dots. Stalk short. Cavity large, deep. Calyx closed. Basin large, uneven. Flesh yellowish white, tender, moderately juicy, rich, sweet, jleasant. Good to very good. Core small. January to April.

\section{HiLToN.}

Origin, Columbia Co., N. Y. Tree vigorous and productive.

Fruit large, roundish, yellowish green. Flesh tencler, juicy, subacid, excellent for culinary purposes. Good. September to October.

\section{Hinjersley.}

Origin, Bucks Co., Pa.

Fruit rather small, roundish oblong conical, greenish, thickly sprink. 
led with light and brown dots. Flesh greenish white, fine-grained, rather tender, moderately juicy, mild subacid. Good. December to March.

\section{Hoary Moristg.}

Dainty Apple. Downy. Sam. Rawlings.

An English fruit for culinary purposes, large, oblate conic, yellow, splashed and striped with red, and covered with a bloom. Flesh white, firm, brisk subacid. Good. October, December.

\section{Hobbs' SweET.}

Originated on the farm of Samuel Hobbs, Randolph, Pa. Tree hardy, vigorous, with a round head, productive, raluable for cooking.

Fruit large, roundish oblate, greenish yellow. Flesh tender, sweet. October, November. (Hobb's MS.)

\section{HocketT's SWEET.}

Origin, North Carolina. Tree a good bearer, and the fruit profitable for stock feeding.

Fruit medium, roundish oblate, yellow, shacled, splashed, and striped with deep red. Flesh yellowish white, moderately juicy, erisp, rather rich, sweet. Good. December to March.

\section{Hodge's Limber Twig.}

Origin unknown.

Fruit small, roundish, whitish, thinly shaded, splashed, and striped in the sun. Flesh white, rather firm, juicy, sprightly subacid. Very good. October, December.

\section{Hog IsLaNd SWEET.}

\section{Canada Sweet. Sweet Pippin. English Sweet, erroneously.}

Origin, Hog Island, adjoining Long Island. Tree vigorous and productive. Wood dark brown, slightly downy, short-jointed, valuable for family use and stock feeding.

Fruit of medium size, oblate, yellow, striped with red, with a bright crimson cheek. Stalk rather short, slender, inserted in a deep, abrupt cavity. Calyx closed, set in a broad basin of moderate depth. Flesh yellow, juiey, crisp, tender, slightly aromatic, with a rery sweet, rich, excellent flavor. Good to rery good. September, October:

\section{Holbert's Victoria.}

An English Apple, described by Mogg as small, ovate, yellow, with pale gray russet. Flesh yellowish, firm, juiey, vinous, aromatic. De cember to May.

\section{HoLCONB.}

Fruit medium, oblate, yellow, shaded and obscurely splashed with 
red in the sun. Flesh whitish, fine, tender, moderately juicy, pleasint, almost sweet. Good. December to Mareh.

\section{HoLlady.}

Raised by Joln Hollady, Spottsylvania Co., Va. A very thrifty, up. right grower, a good bearer.

Fruit medium, oblate. Color yellow, with a faint blush, and sprinkled with gray dots. Flesh yellowish, compact, tender, aromatic. Good. November to DIarch.

\section{HollaxdBury.}

$\begin{array}{lll}\text { Hollingbury. } & \text { Trawberry Pippin. } & \text { Horsley Pippin. } \\ \text { Beau Rouge. } & \text { Bome Ronge. } & \text { Howbury Pippin. }\end{array}$
Kirke's Scarlet Admirable.

An old English enlinary Apple. Tree strong, vigorous grower. Frnit very large, roundish, flattened, ribbed, yellow, much red in the sun. Flesh white, tender, juicy, brisk subacid. October, December.

\section{Holland Pippix.}
Reinette d'Hollande.
Summer Pippin.
Pie Apple.

This and the Fall Pippin are frequently confounded together. They are indeed of the same origin. One of the strongest points of ditterence lies in their time of ripening.

The Holland Pippin begins to fall fiom the tree and is fit for pies about the middle of Angust, and from that time to the first of November is one of the rery best kitchen apples.

Fruit very large, roundish, a little more square in outline than the Fall Pippin, and not so much flattened, though a good deal like it, a little narrowed next the eye. Stalk half an inch long, thick, deeply sunk. Calyx small, elosed, moderately sunk in a slight plaited basin. Skin greenish yellow or pale green, becoming pale yellow when fully ripe, washed on one side with a little dull red or pale brown, with a few scattered, large, greenish dots. Good.

\section{Holland Sweet.}

Fruit medium, conic, green, with stripes of dull red. Flesh firm, sweet, and valuable for long keeping and eulinary uses. Good. January to May.

\section{Hollow Core.}

There are two varieties under this name. One grown in New Jersey, of medium size, roundish oblong, yeliow, with shado of light red. Flesh whitish, tender, juicy, sprightly subacid. Good. Core very large and lollow. December, Janniry.

The other, rlescribed by Hogrg, is melimm size, conical, ribber, green. i: h, with pale red next the sum. Flesh white, tender, brisk, pleasant. Core very large, with open cells. September. 


\section{Hollow Crows.}

Hartford. Tyler. Kelsey.

An old New England Apple, commonly grown there, origin un. known. Tree a strong, upright grower.

Fruit large, roumdish, slightly conic, yellow, splashed, striped, and marbled with red, thinly sprinkled with light dots. Flesh yellowish, somewhat coarse, crisp, tenter, juicy, pleasant, brisk subacid. Good. November, December. Valuable for cooking or market.

\section{Hollow Crown Pippin.}

Hollow-Eyed Pippin.

An English culinary Apple.

Fruit medium, roundish oblate, yellowish, with a blush cheek in the sun. Flesh firm, juicy, subacid. October, Norember.

\section{Holly.}

\section{Hardskin. Northern Hardskin. Persimmon. Simmon.}

Origin, Georgia. Tree moderately vigorous, upright, healthy, and an early bearer.

Fruit medium size, roundish oblate, red, on a yellow ground, somewhat striped. Calyx closed. Flesh deep yellow, firm, juicy, sweet, aromatic. Good. November to March.

\section{HOLMES.}

This is an old variety, first described in Thatcher's Treatise on Orcharding, and yet considerably grown in Massachusetts. The tree is vigorous and very productive.

Fruit medium, roundish, slightly oblate, pale vellow, with bright blush in the sum, and many large russet specks. Stalk short, slender. Cavity shallow. Calyx large, partially open. Basip ribbed. Flesh yellowish, tender, fine, juicy, swet subacid. December, January.

\section{Holves's SWEet.}

Origin, Niagara Co., N. Y. Tree vigorous, productive. Toung shoots dark reddish brown.

Eruit medium, roundish conical, waxy yellow, red cheek in the sun. Stalk medium. Cavity deep. Calyx open. Basin shallow. Flesh yellow, tender, rather juicy, spicy, sweet subacid. Very good. November and February.

\section{Holstex Sweet.}

Origin unknown.

Fruit medium to large, round, greenish rellow, bronzy. Flesh whitish yellow, fne-grained, tender, jucy, very sweet, aromatic, rich, December, February. (IVarder.) 


\section{Honey Greening.}

Poppy Greening. Honey Swcet, incorrectly.

Origin uncertain. Tree vigorous, of rather a stragghing, spreading habit, very productive. Ionng shoots light clear reddish yollowish brown.

Fruit medium to large, roundish oblate, greenish yellow, a slight blush in the sun, few light and gray dots. Stille rather long, slender. Cavity leep. Calyx closed. Basin abrupt, corrugated. Flesh white, fine-grained, very tender, moderately juicy, with a honeyed sweet. Very grood. Core small. Norember, February.

\section{HoNeY SWEET.}

Origin unknown. There are a number of sorts under name of Honey Sweet, it being a popular application for every good sweet apple. The one we now describe, however, we have fomd more generally grown than any other, and therefore our application of the name to it.

Tree very upright, vigorous. Toung shoots light reddish brown.

Frut medium, roundish oblate, inclining to conic, pale vellow; bronzed, crimson in the sun, with a few green and grely dots. Stalk rather long. Cavity large, russeted. Calyx elosed. Basin corrugated. Flesh white, moderately juicy, rather compact, honeyed sweet. Good. Valuable for baking or stock. August.

\section{Hoon}

Hood's Seedling.

A nice and handsome little fruit, oblong conical in form, yellow, mottled, marbled, and splashed with two sharles of red. Flesh whitish, firm, pleasant, sweet. November, December.

\section{HOOKER.}

Origin, Windsor, Conn. Gṛowth upright, rigorous, prodnetive.

Frnit inedium, conic, slightly oblique, greenish yellow, shaded with dull crimson, striped with red, and sprinkled with large russet dots. Flesh greenish, tender, juiey, pleasant subacid. Good. November to January.

\section{HoOver.}

Wattaugah.

Originated in South Carolina. It is pretty extensively disseminated and nuch favored where grown. The trees are quite distinct, having large foliage and retaining it until quite late into winter. It forms a heautiful upright spreading tree. Tonng shoots clear realdish brown, slightly downy.

Fruit medium, roundish, sometimes roundish oblate, slightly ohlique, jellowish, mostly overspread, splashed, and striped with two shades of red, some conspieuous light dots, and patches of russet. Stalk rather long. Cavity large, thinly russeted. Calyx open. Lasin slightly fur. 
rowed. Flesh yellowish, rather firm, tender, juicy, rich subacid. Core small. Very good. November to February.

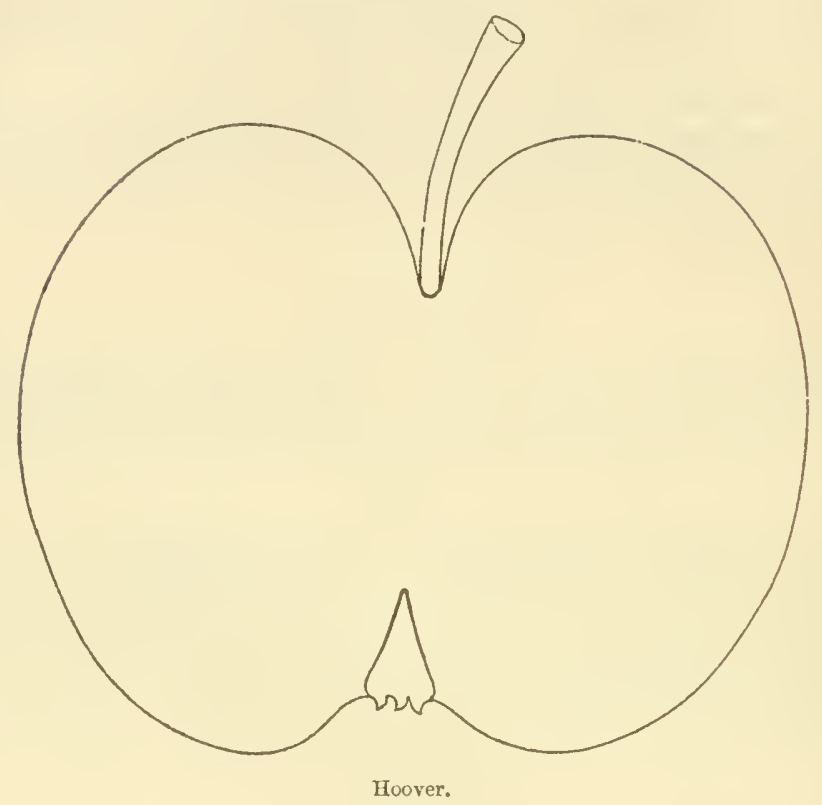

\section{Hopkins.}

Supposed origin, Maryland. Tree vigorous, spreading, not an ear'ly bearer.

Fruit medium or below, roundish oblate, sometimes with unequal sides, yellowish, shaded, splashed, and mottled with light and dark red. Stalk rather short. Calyx small. Flesh white, crisp, juicy, pleasant subacid. Good to very good. October, Norember.

\section{Hopper.}

From South Carolina.

Fruit large, roumdish, flattened, sides unequal, greenish jellow, with a brown orange cheek in the sum, and a little russet about the stem. Flesh white, firm, moderately juicy, subacicl. Good.

\section{Hormead Pearilair.}

\section{Arundel Pearmain. Hormead Pippin.}

An English variety, jet but little grown in this country.

Fruit medium, roundish, or nearly roundish conical, pale rellow, moderately sprinkled with gray dots. Stalk medium, slender. Carity russeted. Calyx nearly closed. Basin shallow, corrugated. Flesh white, crisp, tender, juicy, brisk subacid. Good to very good. Norem. ber, December. 


\section{Hons.}

Leech's Red Winter.

Origin unknown. 'Tree vigorous, with stout diverging branches.

Fruit medium or below, oblate, sides unequal, whitish yellow, shaderl and obscurely striped with light red, many small light dots. Flesh yellowish white, half teuder, moderately juicy, mild subacid. Good. December to March.

\section{Horse APPLE.}

Haas.

Summer IIorse.
Yellow Hoss.

Trippc's Horse.

Origin supposed to be North Carolina. Tree vigorous, an annual, early and abundant bearer, valuable for drying and culinary purposes. Toung wood light reddish brown.

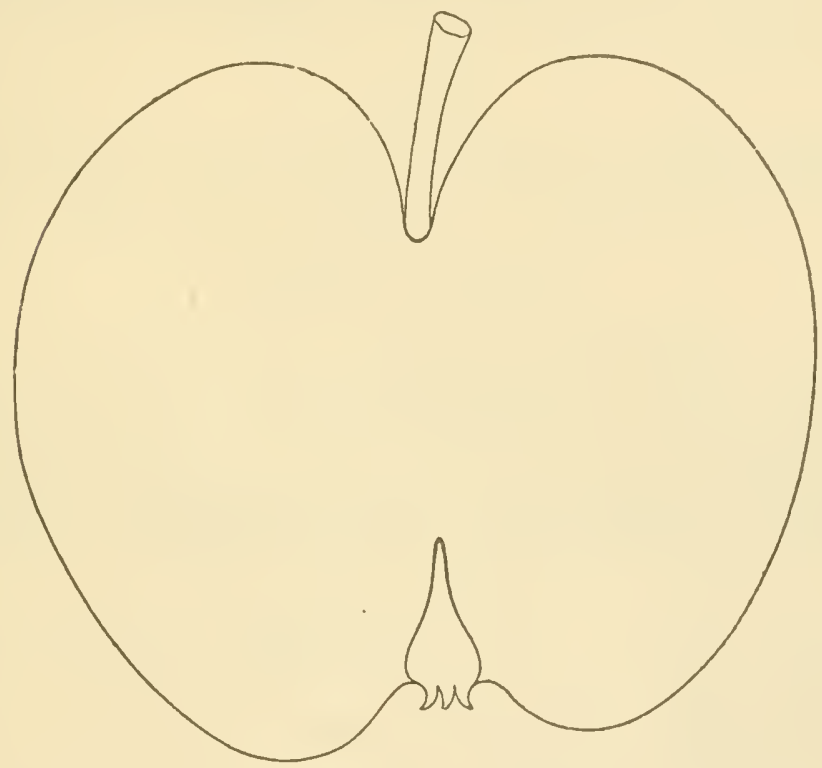

Horse.

Fruit large, roundish, yellow, sonetimes tinged with red, and small patches of russet. Flesh yellow, rather firm and coarse, tender, pleasant subacid. Good. Last of July and first of August.

'There is said to be another Horse Apple, ripening a month or more later; we have not examined it.

\section{HoRshiy RusseT.}

Origin, Norwich, England. Tree hardy and productive.

Fruit sinall, roundish, warm yellowish gray russet, bronzed in sur. Flesh white, firm, erisp, brisk subacid. November, Decemher. 


\section{Hosisreiger. \\ Heidelocher.}

Fluit large, oblate, yellowish green, with streaks of red in the sun: Flesh white, tender, brisk subacid. Norember, March. (Hogg.)

\section{Housum's Red.}

Originated in Berks Co., Pa.

Fruit medium, roundish oblong, rellow, shaded and obscurely splashed with red, light dots. Flesh white, rather compact, crisp, mod. erately tender, juicy, pleasant subacid, slightly aromatic. Tery good. Core suall. December, February.

\section{Howard's EDgexonT.}

Origin, Pennsylvania.

Fruit large, roundish oblate, greenish yellow, partially splashed and striped with red, light gray dots. Flesh yellowish, crisp, tender, juicy, sprightly subacid. Good. November, December.

\section{HUBBARD.}

Origin unknown. Tree vigorous, productive.

Fruit rather large, roundish oblong conic, yellow, with a few brown dots. Flesh yellow, tender, juicy, pleasant subacid. Good. October.

\section{Hubbard`s Pearilais.}

\section{Hubbard's Russet Pearmain. Golden Vining.}

This little English fruit is rescribed by Lindley as one of the richest of dessert Apples. Tree healthy, with slender young wood of a pale grayish brown color.

Fruit small, roundish conical, regular, yellow, sometimes corered with pale brown russet, mottled red. bronzed in the sun. Flesh yellow, firm, very rich, sugary, aromatic. Norember to Mareh.

\section{Hubbard's Sugar.}

Origin, Guilford Co., N. C. Tree upright, moderately vigorous. Young shoots, light reddish brown.

Fruit medium, oblate, greenish yellow, striped with red. Flesh rich, juicy, and fine. September.

\section{Hubbardston Nosencir.}

John May. Old Town Pippin. Hubbardston.

A fine, large, early winter fruit, which originated in the town of Hubbardston, MIass. The tree is a vigorous grower, forming a handsome branching head, and bears rery large crops. Joung shoots dull grarish brown, slightly downy. It is worthy of exter. ive orchard culture.

Fruit large, romdish oblong, much narrower near the ere. Skin smooth, striped with splashes, and irregular broken stripes of pale and bright red, which nearly cover a yellowish ground. The calyx open, and the stalk short, in a russeted hollow. Flesh yellow, jricy, and teu- 
der, with an agreeable mingling of sweetness and acidity in its flavor Vory good to best. Oetober to January.

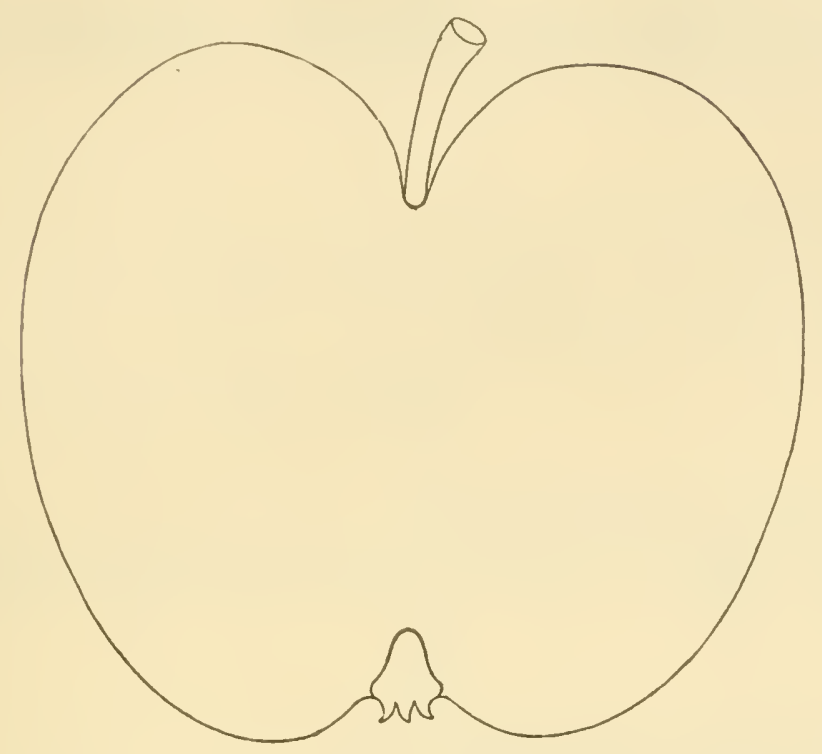

Hubbardston Nonstich.

\section{Hubbardton Pippin.}

Origin uneertain. Tree thrifty, spreading, irregular, strong grower, and produetive. Young shoots clear reddish brown.

Fruit large or very large, variable in form, globular, inclining to conic, slightly oblique, yellow, shaded and striped with red. St:tlk short, inserted in a moderate cavity. Calyx closed. Basin small, corrugated. Flesh tender, yellowish, crisp, juicy, pleasant subacid, slightly aromatic. Core large and open. Very good. November to March.

\section{HuGIIES.}

Origin, Berks Co., Pa. Tree upright, spreading, vigorous, said to be an abundant bearer.

Fruit large, roundish, greenish yellow, with a blush, and numerous gray dots. Flesh fine, tender, juicy, agreeable, saccharine without being sweet. Good. Mareh, April.

\section{Hegires' Goldex Pippin.}

An English Apple, described by Ronalds as an exeellent table sort. Tree hardy, with long slender shoots, produetive.

Fruit below medium, ronndish oblate, yellow, with some russet patehes and dots. Flesh yellowish white, firm, rich, brisk, spicy aromatic. December, January. 


\section{Hull Blosson.}

Origin unkıown.

Fruit medium, roundish, slightly conic, pale yellow, much shaded, splashed and striped with red, many light dots. Flesh whitish, tender, juicy, pleasant, sweet. Good. October.

\section{Hull Sweet.}

Of unknown origin.

Fruit medium, roundish oblate, mostly overspread with sliades of light and dark red, few large light dots. Flesh whitish, juicy, tender, rich, pleasant, sweet. Good to very good. October.

\section{HuxaE.}

\section{Hunger}

Origin uncertain, popular, and long cultivated in North Carolina. Tree vigorons and very productive.

Fruit large, roundish, green, with a blush. Flesh soft, subacid, pleasant, valuable for drying and culinary uses. Good. September, October.

\section{Hunt.}

Supposed origin, Eastern Indiana.

Fruit merlium, roundish oblate, yellow, mixed, striped, bright red, numerous yellow dots. Flesh yellow, fine-grained, juicy, subacid, aromatic. December, January. (Warder.)

\section{Huxthouse.}

A Yorkshire English Apple.

Fruit medium, roundish oblate conical, yellow, tinged with red in the sun, and crimson dots and faint streaks. Flesh white, firm, coarse, acid. December. (Hogss)

\section{Hunq's Consecticut.}

Guttry.

Baldwin, erroneously.

An old variety. Origin unknown.

Fruit large, round oblate, yellow, marbled and shaded with dull red, gray specks. Stalk short. Cavity often musseted. Calyx large. Basin quite shallow. Flesh yellowish, rather dry, breaking, subacid. Good. Norember to March.

\section{Hunts Deux Axs.}

An English dessert Apple, which has the character of Feeping two vears.

Fruit medium, roundish oblate conical, russeted, with gray and large brown russet dots in the sun. Flesh yellowish white, firm, juicy, aromatic. 


\section{Hiat's Duke of Gloucester.}

\section{Hunt's Nonpareil?}

This viriety is elaimed by Hogg as distinct from Hunt's Nonpareil, which is a synonym given it by Lindley. We have not examined them.

Fruit below medium, roundish, greenish, almost covered with thin russet, reddish brown in sun. Flesh white, crisp, juicy, high flavored December January.

\section{Hunt's Russet.}

Supposed to have originated with the Hunt family, of Concord, Mass, many years since. Tree hardy, moderate grower, upright, spreading when in bearing, an annual and good bearer. Young shoots light reddish brown, slightly grayish.

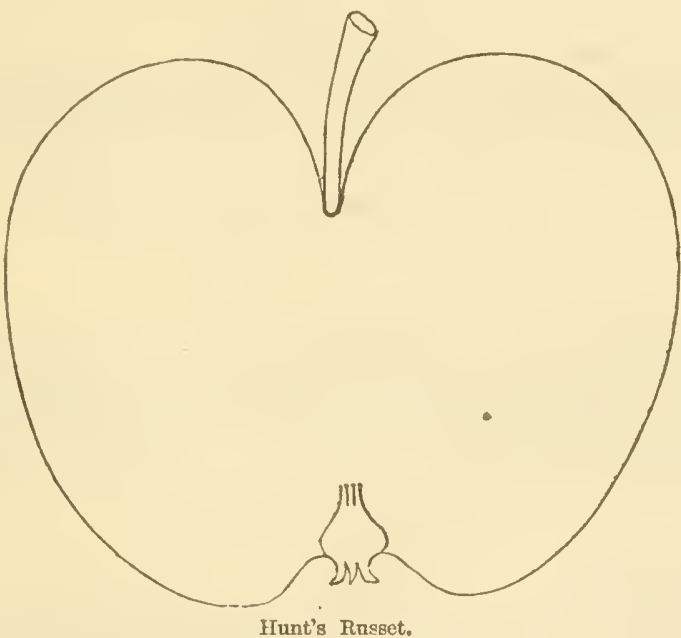

Fruit medium, or below, roundish oblate, slightly conic. Color yellow, mostly covered with thin dull russet, with a blush of bright rich red in the sun, few brown dots. Stalk varying in length. Carity large, deep, acute. Calyx partially open. Segments medium, a little reflexed. Basin medium, slightly corrugated. Flesh yellowish white, fine-grained, tender, juicy, rich, brisk subacirl, slightly aromatic. Very good or best. Core compact. January to April.

\section{Hurlbut.}

\section{Hurlbut Stripe.}

Origin, farm of General Hurlbut, Winchester, Conn. Tree very vigorous, and great bearer. Young wood dark brownish red, slightly downy. Buds prominent.

Fruit medium, oblate, slightly conic, angular. skin yellow, shaded 
with red stripes, and splashed with darker red, and thinly sprinkled with light dots. Stalk short, rather slender, inserted in a broad deef cavity, surrounded by russet. Calyx closed. Basin rather shallow. Flesh white, erisp, tender, juicy, mild, sprightly subacid. Good to very good. Core small. October, December.

\section{Hutcheson.}

Origin, supposed Logan Co., Ky. Tree of rather slow growth, healthy and productive. Esteemed, where known, for its fine appearanct and long keeping.

Fruit medium, roundish, inclining to conic, yellow, overspread with rich red, large light dots. Stalk short. Cavity narrow. Calyx elosed. Basin abrupt, deep. Flesh white, firm, moderately juicy, mild subacid, almost sweet. Core small. Grood to very good. December to April.

\section{Hutton Square.}

A coarse culinary Apple, from England.

Fruit large, roundish, sides unequal, yellowish, with dull red in the sun. Flesh white, coarse, brisk; sweet. Good. November, December.

\section{IJPERIAL.}

Magnifique. Maltranche.

Of French origin.

Fruit medium, oblate, inclining to conic, yellow, shaded, splasherl, and striped with light and dark red, deepest in the sun. Stalk short. Caly.- cosert. Flesh white, crisp, tender, juicy, refreshing subacid. Good. October, November. (Warder.)

\section{INDIANA Beauty.}

Origin, Indiana.

Fruit large, roundish, oblong, unequal, sellow, partially corered mixed scarlet, splashed carmine. Flesh yellowish, breaking, juicy, subacid. Good. September, November.

\section{INDIANA FaYorite.}

Supposed to have originated on the farm of Peter Morrits, Fayette Co., Indiana. Growth healthy, spreading, and a good bearer.

Fruit medium or large, roundish, flattened at the ends, slightly onesided, yellowish, shaded and streaked with red, and covered with russet specks. Flesh white, tender, juicy, vinous, almost sweet, and very pleasant. Good. January to April.

\section{Indian Prince.}

Fruit medium, roundish, deep red, sprinkled with whitish dots. Flesh yellowish, rather firm, juicy, with a pleasant aromatic flavor, Hardly good. September, October. 


\section{INGRAM.}

A new variety, grown from seed of Jawls Janet, by Martin Ingram, of Greene Co., Mo. 'Tree productive, and the firuit especially valued for its long keeping.

Fruit medium or below, roundish oblate, orange yellow, mostly overspreal with broken stripes of rich warm red, gray russet dots, and slight marblings. Stalk slender. Calyx small. Flesh yellowish white, moderately juicy, crisp, mild subacid. Curc above medium. Seeds dark brown. Felfuary to Jume. (Hort.)

\section{Irish Peacil APple.}

\section{Early Crofton.}

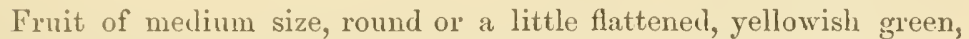
with small dots in the shade, washed and streaked witl brownish red in the sun. Flesh white, tender, juicy, and pretty well flavored. Hardly good. August.

\section{Irish Reinette.}

An English culinary Apple.

Fruit medium, roundish oblong, ribbed, yellowish green, dull brownish in the sun, and with patches of russet. Flesh yellowish white, crisp, juicy, brisk sharp acid. Hardly good. November to February.

\section{ISLAND BEAUTY.}

\section{Chicago?}

Origin unknown. Tree vigorons, upright, spreading.

Fruit large, roundish, pale yellow, with a shade of brown in the sun, moderately sprinkled with indistinct light dots. Flesh whitish, tender, juicy, brisk subacid. Good. Core rather large. September.

\section{Iste of Wight Pippin.}

Isle of Wight Orange. Orange Pippin. Pommo d'Orange.

A very old Apple, described in Ronalds as fine for dessert.

Fruit small, roundish, yellow, bright orange in sun, with sometimes a brownish cheek. Flesh firm, juicy, rich, aromatic, acid. January, February.

\section{Isleworth Crab. \\ Brentford Crab.}

Fruit medium, roundish conical, yellow, brownish tinge in sun. Flesh white, crisp, juicy. Poor. October.

\section{Italian Rose.}

Weisse Italianische Rosmarinapfel.

An Italian dessert Apple.

Fruit medium, roundish oblong conical, yellow, with pale red, somy- 
what striped in the sun. Flesh white, teuder, juicy, sugary, vinous. December. (Diel.)

\section{JABE.}

Originated in Boxford, Mass. Tree thrifty, hardy, and a regular, abundant bearer.

Fruit small, oblate, light straw color, beautiful blush cheek, and crimson spots in the sun. Flesh yellowish white, fine-grained, tender, juicy, pleasant subacid. September, November. (Me. Rep.)

\section{JABEZ SWEET.}

Originated on the premises of Jabez Barnes, near Middletown, Conn. Tree healthy, vigorous, and productive.

Fruit medium, roundish conical, yellow, with a few dark specks. Flesh white, tender, juicy, rich, sweet. Good to very good. December, February.

\section{JACKSON.} brown.

Origin, Bucks Co., Pa. Tree upright grower. Young wood dark

Fruit medinm, roundish oblate, greenish yellow, with many dark green blotches and gray dots, a very few faint stripes, and warm mottled brown cheek. Flesh greenish, fine texture, tender, juicy. Good to very good. October, February.

\section{JACques Lebel.}

An English fruit of much beanty, but ordinary quality.

Fruit large, roundish oblate, lemon yellow, shaded with red in the sun, many gray dots. Stalk large. Cavity deep. Calyx half closed. Flesh white, tender, mild subacid. January. (Alb. Pom.)

\section{JANE.}

Origin, Bucks Co., Pa. Tree of medium upright growth, an annual bearer.

Fruit medium, roundish, rellowish, shaded with deep red in the sun, lighter in the shade, some obscure splashes and stripes, few light and gray dots. Flesh yellow, compact, moderately juicy, mild subacid, almost sweet. Good. December to March.

\section{JARMINITE.}

Origin, Highland Co., Ohio. Tree vigorous, rery productive.

Fruit medium, oblate roundish, green, partially covered with mixed and striped dull red. Flesh breaking, firm, mild subacid, almost sweet. December to March. (Warder.)

\section{JEFFERIS.}

Origin, Chester Co., Pa. Growth moderate, rery productive. A fir 
and handsome fruit of excellent quality, in use all of September. Young wood light reldish brown, smooth.

Fruit medium, oblate, inclining to conic, yellow, shaded and splashed with crimson, and thickly covered with large whitish dots. Stalk rery short, inserted in a lather lirge cavity. Calyx closed, set in a round open basin. Flesh white, tender, juicy, with a rich, mild, subacid tliavor. Very goou. September.

\section{Jeffersoy County.}

Origin, Jefferson Co.. N. Y. Tree vigorous, hardy, sprealing, an early and great bearer. Ioung wood dull grayish brown.

Fruit medium, roundish oblate, slightly conic, yellow, splashed and shaded with fine red, minute light dots and some blotches of russet. Flesh whitish yellow, juicy, tender, pleasant subacid. Good to very good. Core small. Uetober, November.

\section{Jexkiss.}

Originated with John M. Jenkins, Montgomery Co., Pa.

Fruit small, roundish ovate, red, interspersed with numerous large white dots on yellowish ground. Flesh white, tender, fine texture, juiev, arreenbly saccharine. Good. January to March.

There is another . Jenkins apple which ripens in summer. It is small, roundish, yellow, striped with red.

\section{Jenvings Sweet.}

Uriginated at Marietta, Ohio. Tree vigorous, productive.

Fruit large, roundish oblate, yellow, striped with bright red. Flesh whitish, sweet, fine for baking or stock. Good. October, November.

\section{Jersey Pippin.}

Foreign.

Fruit medium, round oblong conical, yellowish green, stripes of red in the sun. Flesh greenish yellow, juicy, vinous, subacid. Good. November, February. (Elliott.)

\section{Jerser Sweeting.}

Origin unknown. Tree moderately vigorous, forming a handsome round head, productive. Young wood dark reddish brown, downy.

A very popular Apple in the Middle States, where it is not only highly valued for the dessert, but, owing to its saceharine quality, it is also planterl larely for the fattening of swine.

Fruit medium size, roundish ovate, tapering to the eye. The calyx is small, closed, very slightly sunk, in a small plaited basin. Stalk half an inch long, in a rather narrow cavity. Skin thin, greenish yellow, washed and streaked, and often entirely covered with stripes of pale and dull red. Flesh white; fine-grained, and exceedingly juicy, tender, sweet, and sprishthty. Good to very good. Young wood stont, and short-jointed. This apple commences maturing about the last of August, aud continues ripening till frost. 


\section{JewetT's Best.}

Origin, farm of S. W. Jewett, Weybridge, Vt. Same habit as Rhode Island treening.

Fruit large, oblate or nearly globular, yeilowish green, mostly shaded with deep red. Stalk short, inserted in a large cavity. Caiyx closed, set in a very small basin. Flesh yellowish white, juicy, almost melting, pleasant, rich subacid. Very good. December to February.

\section{JewetT's Fine Red.}

\section{Nodhead.}

Origin, Hollins, New Hampshire. Tree of moderate growth, and productive, requires high culture to produce fair fruit.

Fruit medium, roundish oblate, greenish white, striped, splashed, and shaded with erimson, having a dull grayish bloom. Stalk short, inserted in a broad, deep cavity. Calyx firmly closed, in an exceedingly small basin. Flesh tender, juicy, very pleasant, sprightly, almost sweet. Good to very good. November to February.

\section{JOEL.}

Of Pennsylvania origin.

Fruit small, oblate, greenish yellow with patches of russet and russet dots. Flesh greenish yellow, dry, and poor.

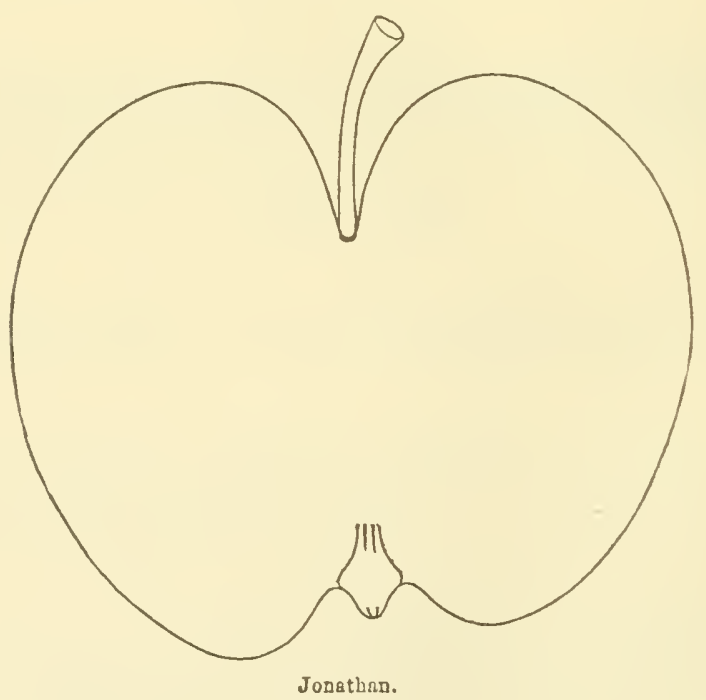

\section{JoNathaN.}

King Philip.

Philip Rick.

The Jonathan is a very beautiful dessert Apple, and its great beautr, good flavor, and productiveness in all soils, unite to recommend it to 
crchard planters. The original tree of this variety is growing on the farm of Mr. Philip Rick, of Kingston, New Tork. It was first described by the late Judge Buel, and named by him, in compliment to Jonathan Hasbrouck, Esq.. of the same place, who made known the fruit to him. It suceeeds wherever grown, and proves one of the best in quality, and most protitable either for table or maket. The tree is hardy, moderately rigorous, forming an upright spreading, round head. Young shoots rather slender, slightly pendulous, grayish brown.

Fruit of medium size, regularly formed, roundish conical, or tapering to the eye. Skin thin and smooth, the ground clear light yellow, nearly covered by lively red stripes, and deepening into brilliant or diuk red in the sun. Stalk three-fourths of an inch long, rather slender, inserted in a deep, regular cavity. Calyx set in a deep, rather broul basin. Flesh white, rarely a little pinkish, very tender and juicy, with a mild, sprightly, vinous flavor. This fruit evilently belongs to the Spitzenburgh cliss. Best. November to March.

\section{JOHN CARTER.}

Origin uncertain, grown in Connecticut. Tree vigorous and pro-

Fruit large, roundish conic, yellow, marbled, striped, and splasherl with crimson. Flesh white, tender, juicy, with a mild subacid flavor: Good. September.

\section{JoHnson.} bearer.

Origin, Brookfield, Conn. A strong, upright grower, and a good

Fruit above medium, roundish conic, smooth, striped with red on a yellow ground, dark red in the sun. Flesh remarkably tender, crisp, and juicy, with a brisk, sweet flavor, very soon hecomes mealy after ripening. Good. Middle of August to middle of September.

There is another Johnson Apple which is said to have originated in Massac Co., Ill., and deseribed in the Chicago Repullican. We liave not seen it.

Fruit medium to large, roundish flattened, greenish yellow, almost entirely corered with rich dark red. Flesh yellow, subacid. December to March.

\section{Johyson Russet.}

Origin unknown. Tree a crooked grower, moderate bearer.

Fruit medium, oblong roundish conical, light golden russet, few light and gray lots. Flesh white, tender, dry, poor, mealy. December, February.

\section{JOIN'S SWEET.}

Origin, Lyndshoro, New Irmpshire. Tree a good grower, somewhat straggling, a prolific bearer. Young shoots, reddish brown.

Fruit medium, roundish eonic, whitish yellow, sprinkled, striped, and splashed with red. Stalk short, inserted in a narrow eavity, surrounded by lusset. Calyx closed, set in an abrupt basin. Flesh juicy, tender, sweet. Good. January to May. 


\section{Jolly Beggar.}

Hogg describes this as a first-rate early cooking Apple. Tree a pro digious and carly bearer.

Fruit medium, roundish, pale yellow, becoming orange in the sun. Flesh white, teuder, brisk subacid. August to October.

\section{Jubilee Pippin.}

From Norwich, England.

Fruit medium, roundish, yellowish, with gray and brownish specks. Flesh white, crisp, mild, almost sweet. Core large, open. October, December. (Lindley.)

\section{JUDGE ANDREWS.}

Origin unknown.

Fruit medium, roundish, pale yellow. Flesh tender, aromatic. Good. August.

\section{Juicy Bite.}

Origin, Pennsylvania.

Fruit medium, roundish, inclining to conic, pale yellow, mostly overspread, shaded and splashed with red. Flesh white, crisp, tender, lively subacicl. Good. Sentember.

\section{JULIAN.}

Juling. Julien.

An Apple of Southern origin. Tree moderately vigorous, very productive. Young shoots light reddish brown, somewhat grayish, many white dots.

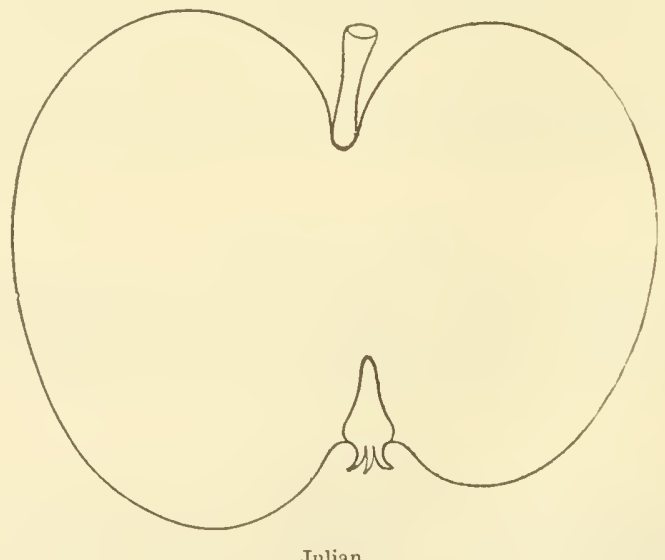

Fruit above medium, roundish, inclining to conic. Sides unequal. Color waxen whitish, striped, splashed, and mottled with rich red, 
moderately sprinkled with light dots, some having dark centres. Stalk short, small. Cavity deep, sometimes russeted. Calyx small, closed. Segunents long, slender, slightly recurved. Basin decp, slightly com'u. gated. Flesh yellowish white, tender, juicy, pleasunt subacid. Good to very good. July and August.

\section{JUNALUSKEE.}

\section{Junaliska. Journalaskia.}

Origin, North Carolina. Tree moderately vigorous, spreading. Young shoots dark brownish, slightly downy.

Fruit medium to large, roundish oblate, yellow, lightly shaded on the sumny side, and sprinkled with brown and gray dots. Stalk short. Cavity large, a little green l'usset. Calyx small, closed. Basin abrupt, nearly smooth. Flesh yellowish, rather compact, moderately juicy, rich subacid. Good to very good. Core small. November to March.

\section{Kaighn's Syitzenburair.}

Red Pearmain.

Red Spitzenburg.

Red Winter Pearmain, erroneously.

Long P'earmain.

Lady Finger, erroneonsly.

Scarlet Pearmain, erroneously.
Long John.

Red Pippin.

Red Phœnix.

Sheeprose of some.

Iiussim.

Hudson Red Streak.

Crigin, Gloncester Co., N. J. Tree vigorous, spreading or straggling habit, productive, and valued only becanse of its showy fruit.

Fruit rather large, oblong oval, approaching conic, whitish yellow, mostly shaded and striped with red, and thickly sprinkled with minute dots. Flesh yellowish, coarse, crisp, juicy, pleasint subatid. Good. November to January.

\section{KANE.}

\section{Cane. Cain}

Origin, Kent Co., Delawąe. Tree moderately vigorous, upright. A beantiful little Aple, of pleasant flavor.

Fruit small, oblate, slightly conical, regular, whitish yollow, waxen, beautifully shaded and lightly striped with fine crimson. Flesh whitish, juicy, crisp, with a pleasant Haror. Good. October, November.

\section{Keddeeston Pippin.}

An English dessert Apple, described by Ronalds.

Fruit small, conical, straw color, slightly russeted. Flesh yellowisb, juicy, sugary, aromatic. Octobor to January.

\section{Keepixg Red Streak.}

An English culinary sort.

Fruit medium, roundish oblate, yellowish, mostly striped with two shades of red, some russet and gray dots. Flesh greenish yellow, firm, brisk subacid. December, February. (Ilogs.) 


\section{Keeping Russet.}

This is a dessert Apple described by Hogg as of first quality.

Fruit medium, roundish, pale yellowish brown russet, with a red cheek in the sun. Flesh yellow, firm, juicy, rich mellow flavor. Oc. tober, Janumy.

\section{KEIM.}

Origin, Berks Co., Pa. Tree moderately vigorous. Toung shoots reddish brown.

Fruit small to medium, oblate. Color light waxen yellow, thickly sprinkled with light russet dots. Stalk long, slender, in a broad, shallow cavity. Calyx closed. Basin shallow and meven. Flesh white, tender, crisp', fine, brisk, delicate aromatic subacid. Very good. December to March.

\section{KEIser.}

Red Seek-no-Further.

An old variety, much grown in Jeflerson Co., Olio, and highly prized; growth of tree like Rambo.

Fruit medium, roundish oblate, slightly oblique, angular. Skin pale yellow, shaded with red, indistinctly striped and thickly sprinkled with large, grayish dots. Stalk short, inserted in a large cavity. Calyx small, closed, in a broad, shallow, corrugated basin. Flesh yellowish, not very juicy, but mild subacid. Good. November to February.

\section{KELSEY.}

Origin, Berks Co., Pa., on the premises of John Kelsey.

Fruit medium, roundisl oblate, sometimes inclining to conical, greenish yellow, with occasionally a faint blush, and numerous gray dots. Flesh tender, fine textmre, greenish white, mild subaicl. Good. March.

\section{KeLsey SWeET.}

Origin, Connecticut. Tree moderately vigorous, upright.

Frnit medium, roundish, greenish yellow, with a tinge of brown in the sum, green and gray dots. Flesh greenish white, moderately tender, juicy, sweet. Good. October, November.

\section{Kexnebec Russet.}

From Maine. Tree vigorous, upright.

Fruit medium, roundish conical, yellow, partially netted with russet, and sprinklerl with brown dots. Stalk long, slender. Calyx small, closed. Flesh moderatcly tender, juicy, brisk subacid. Good. November, December.

\section{Kennedy's Red Winter.} bearer.

Originated in Pennsylvania. Tree an upright grower and regular

Fruit large, roundish conical yellow, shaded, splashed, and striped 
with light and dark red, large light dots. Stalk short. Calyx closed. Flesh whitish, mockerately juicy, a little coarse, pleasant subacid. Ciood. December, February.

\section{Kensey.}

From Connecticut.

Fruit medium or below, roundish oblate, greenish yellow, sharled and splashed with red, large light dots. Flesh white, rather tender, moderately juicy, mild subacid. Good. Core small. Decembry to Narch.

\section{KENRICK.}

Kenrick's Autumn. Kenrick's Red Autumn.

Origin, on the farm of Mr. Kenrick, Newton, Mass. Tree moderately vigorous, compact, very prouluctive.

Fruit large, roundish, pale yellowish green, strijed and stained with bright red. Flesh white, a little stained with red, tender, juicy, sprightly acid. Goorl. September.

\section{KeNTish Broading.}

A fine slowy old English Apple. Tree a free grower and good bearer.

Fruit large, roundish oblate, yellow, with broken stripes or splashes of clear red. Flesh white, tender, a little coarse, subacid. Good. November, December.

ǨENT.

Originated on the premises of Walker Kent, near Plymouth, Mich. Tree a strong grower, and very productive.

Fruit large, roundish, pale greenish yellow, sometimes a slight blush cheek, few greenish dots. Stalk short. Calyx closed. Flesh white, tender, juicy, sprightly, subacid. Core rather large. Good to very good. October.

\section{Kentisir Fill-Basket.}

\section{Potter's Large Seedling. Lady de Grey's.}

An immense English truit, properly named, and much armired by those who like great size and beanty of appearance. 'The $f$ avor is tolerable, and it is an excellent cooking Apple. The tree grows strongly, and bears well.

Fruit very large-frequently four and a half inches in diumeter-roundish, slightly ribbed or irregular. Color yellowish green in the shade, but pale yellow in the sun, with a brownish red blush on the sunny side, slightly streaked or spotted with darker red. Flesh tender, juicy, with a subacid, sprightly flavor. Good. Oetober to January.

\section{Kentisil Pippin.}

Red Kentish Pipnin.

Vaun's Pippin.

An old English Apple esteemerl alroad for cooking, but is liere crute good for dessert. Tree hardy, vigorous, and a good bearer. 
Fruit medium, roundish oblate, sides often unequal, greenish jellow, with a slight blush next the sun, small gray dots. Stalk short, small. Cavity deep, large, and with thin russet extending out upon the fruit. Calyx partly open. Flesh yellowish white, crisp, tender, juicy, rich, brisk subacid. Good. Core small. December to May. Valuable as a late keeper.

\section{KENTUCKY.} bearer.

Of unknown origin, and probably a local name. An early and abundant

Fruit large and very uniform, roundish, slightly conical. Color yellowish, marbled and mottled, with dull red in the sun, with irregular greenish splashes or specks. Cavity narrow, acuminate. Calyx large, in a narrow abrupt basin. Flesh not very fine, but juicy, very tencler, agreeable subacid. Good. October.

\section{Kentucky Cream.}

Originated in Todd Co., Ky. Tree moderately vigorous, upright, an early and abundant bearer.

Fruit medium to large, roundish, largest at the crown or apex, and tapering slightly toward the stalk, yellowish mostly overspread with rich clear red, thickly sprinkled with large areole dots, and some grayish warblings next the stalk. Stalk sleucler. Cavity narrow, acute. Calyx large. Segments partially closed, divided. Basin broad, deep, somewhat corrugated. Flesh yellowish, breaking, not very juicy, rich, mild subacid. Good to very good. December to March.

\section{Kentucki King.}

From Kentucky.

Fruit above medium, oblate, yellow, mixed and striped with carmine. Flesh yellow, breaking, fine-grained, juicy, subacid, aromatic. Good to very good. December, February. (IVarder.)

\section{Kentucky Red Streak.}

\section{Winter Red Streak? \\ Bradford's Best. \\ Selma?}

Origin obscure, supposed Tennessee. Tree upright, rigorous, and productive ammually.

Fruit medium, roundish, slightly inclining to conic, greenish yellow, shaded with dull purplish red, and indistinctly splashed and striped, thickly sprinkled with large light dots, having gray centres, sometimes the number of dots give apnearance almost as if mottled. Stalk medium. Calyx closed. Flesh whitish, tender, juicy, mild subacid. Core small. Good to very good. December to Miarch.

\section{K ENTUCKY SWEET.}

A Southern Apple of unknown origin.

Fruit medium, conic, regular, deep red, stripes obscured and scarcely visible. Dots scattered, large, yellow. Flesh jellow, tender, finegrained, juicy, very sweet, rich, slightly perfumed. Norember, January (Warder:) 


\section{Kerity Piprin.}

Edmonton's Aromatic Pippin.

An Trish dessert Apple.

Fruit middle size, oval, a little flattened at the eje, pale yellow. Flesh yellow, tender, eris], with a sugary flavor. Good. Ripens in September and October.

\section{Keswiek CoDlis.}

A noted Fnglish cooking Apple, which may be gathered for tarts as early as the month of August, and continues in use till November. It is an early aud a grent bearer and a vigorous tree, and is one of the most profitable of orehard sorts for cooking or market. Tree very hiurdy; forming a lirge, regular, upright, spreading, round hear.

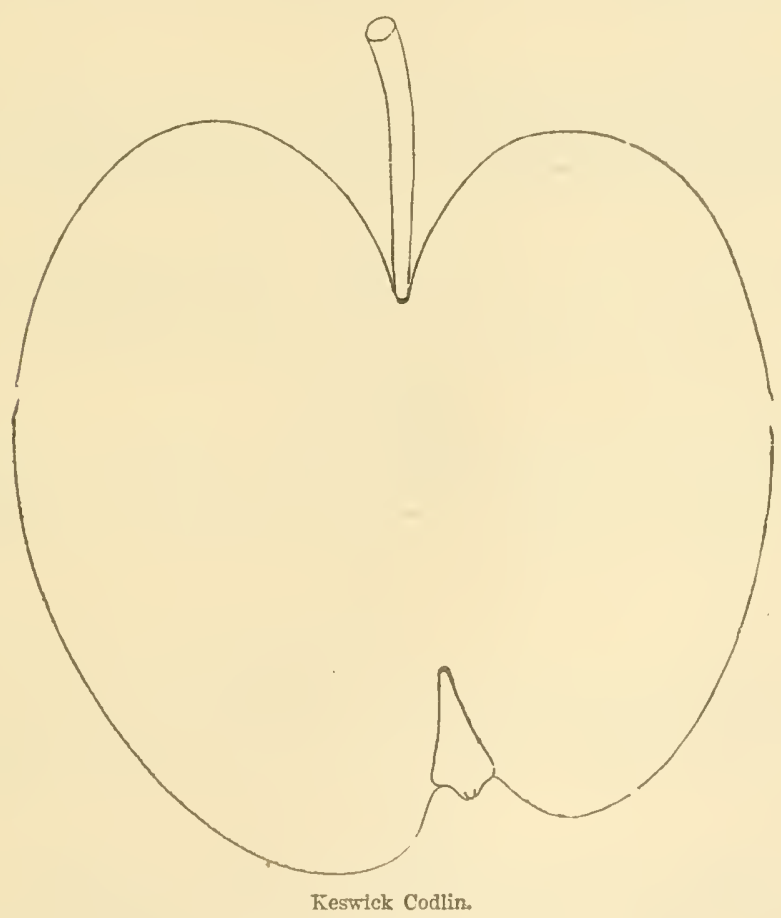

Fruit a little above the middle size, rather conical, with a few obsenre ribs. Stalk short and deeply set. Calyx rather large. Skin greenish yellow, washed with a faint blush on one side. Flesh yellowish white: juicy, with a pleasint acid flavor.

\section{Ketciteri's Fatorite.}

Origin, farm of $M T r$. Ketchum, in Sudbury, $V^{\top}$ t. Tree vigorous and productive.

Fruit medium, roundish oblate, liglit waxen yellow, slightly shaded 
with rosy blush, irregularly sprinkled with carmine dots. Flesh white, mild, tender, juicy, subacid. Good. September to Janury

\section{KIKITA.}

Origin unknown. Tree moderately vigorous, spreading.

Fruit medium, roundish, slightly oblate, greenish yellow, shaded with dull red in the sun. Flesh whitish, tender, moderately juicy, mild sweet. Good. November, December.

\section{Kilimali Hirl.}

A native of Essex Co., Mass., laised by Daniel Kilham.

Fruit pretty large, roundish, ribbed, narrowing to the eye, pale yellow, slightly splashed with red in the shade, deep red in the sun. Flesh of sprightly, rather high flavor, but is apt to become dry and mealy. Good. September.

\section{Kineluar.}

From Ross-shire, Scotland.

Fruit medium, roundish conic, yellowish green, some red in the sun. Flesh white, firm, juicy, pleasant. Good. December, January.

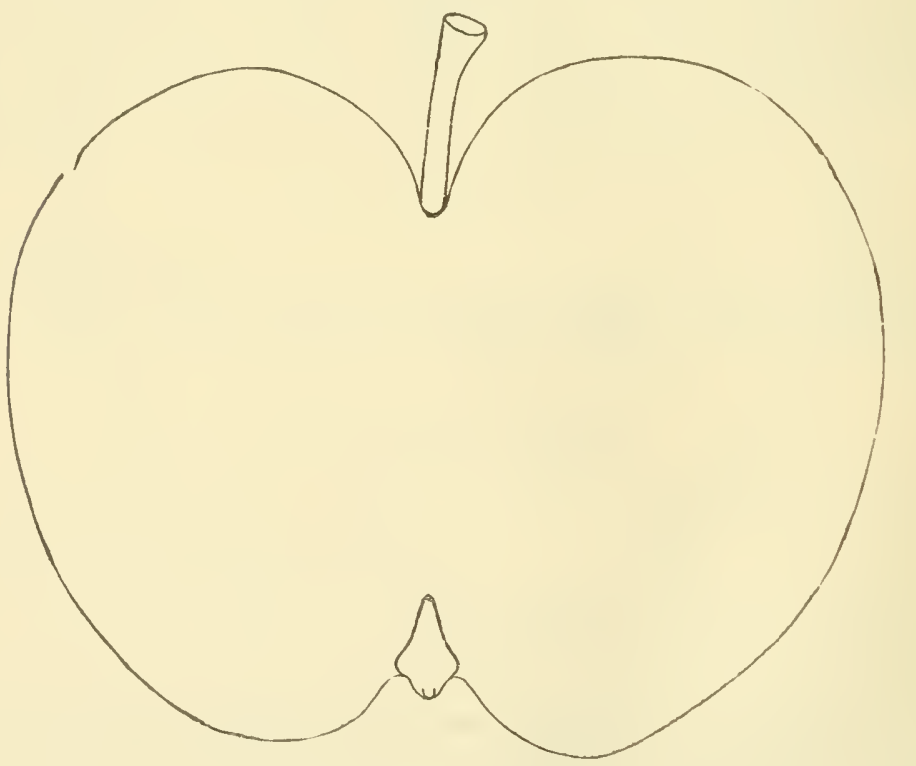

King of Tompkins County.

King of the Piptins.

Hampshire Yellow.

An English fruit of poor quality, medium size, roundish óblate, paie vollow, washed and striped with red. Flesh very firm, sharp subicid, Good. October, November. 


\section{King of TompKins County. \\ King Apple. \\ Toms Red. \\ Tommy Red.}

Origin uncertain; said to have originated with Thomas Thacher, Warren Co., N. J. A valuable market fruit. 'liee very vigorous, sprealing, an abundant bearer anumally. Toung shoots very dark reddish brown, quite downy, especially toward the culls.

Fruit large, globular, inclining to conic, sometimes oblate, angular. Color yellowish, mostly shaded with red, striped and splashed with crimson. Stalk rather stont and short, inserted in a large, somewhat irregular cavity. Calyx small and closed, set in a medium, slightly corrugated basin. Flesh yellowish, rather coarse, juiey, tender, with an exceedingly agreeable, rich, vinous flavor, delightfully iromatic. Very good to best. December to March.

\section{KINGSLEY.} bearer.

Crigin, Monroe Co., N. Y. Tree an erect moderate grower, an early

Fruit medium, rounclish, yellowish, striped and splashed with red. Flesh tine-grained, juicy, melting, subacid. Very good. November, February.

\section{Kingston Black.}

A small English cider fruit of little value.

Fruit roundish, pale yellow, striped with red. Flesh white, stained with red, tender, juicy, sweet. November, December.

\section{KIvg Tour.}

From North Carolina. Origin unknown. Tree a crooked, twisting, tangled grower, forming a low head, with stout, distinct, blunt shoots.

Fruit medium, roundish, orange yellow. Flesh yellow, rather tough, spicy. August. (Ga. Hort. S. Rep.)

\section{KINNEX.}

A Southern variety, little known.

Fruit medium, roundish conic, greenish yellow, thickly sprinkled with gray dots and some russet. Stalk long, slender. Calyx elosed. Flesh yellowish, rather firm, moderately juicy, subacid. Good. November, December.

\section{KIRKBRIDGE WHITE.}

Tree of rather slow upright growth, an early and abundant hearer.

Fruit below medium, oblong orate, very irregular, ribbed, yellowish white. Stalk short and small, in a narrow cavity. Calyx small and closed. Seginents long, reflexed. Basin narrow. Flesh white, tender, juicy, subacid. Core rather large. Good. Angust and September.

\section{KirTLAND.}

\section{Kirtland's Seedling.}

Tree rigorous, and a good bearer.

Fruit large, oblong, deep rich vellow at maturity. Flesh yellowish,

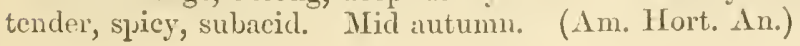




\section{Kirk's LoRd Nelson.}

English.

Fruit large, roundish, light yellow, striped and mottled with bright red. Flesh firm, juicy, but not rich. October, November.

\section{Kittageskee.}

A Southern Apple of unknown origin. Tree moderately vigorous, spreading. Young shoots short-jointed, grayish.

Fruit below medinm, oblate, sides unequai, fine yellow, with a tinge of brown in the sum, few dark or brown gray dots. Stalk rather short and slender. Cavity broad, sometimes a little russeted. Calyx partially closed. Basin broad, shallow, furrowed. Flesh yellow, crisp, tender, brisk, mild subacid, slightly aromatic. Core small. Good to very goorl. November to March.

\section{KLAPROTH.}

This beautiful Apple, a native of Lancaster Co., Pa. (on the farm of Mr. Brennaman), was brought into notice by Dr. J. K. Eshleman, of Downington, Pa., and promises to be an excellent fruit, especially for market purposes. It bears carriage remarkably well, a most prolific

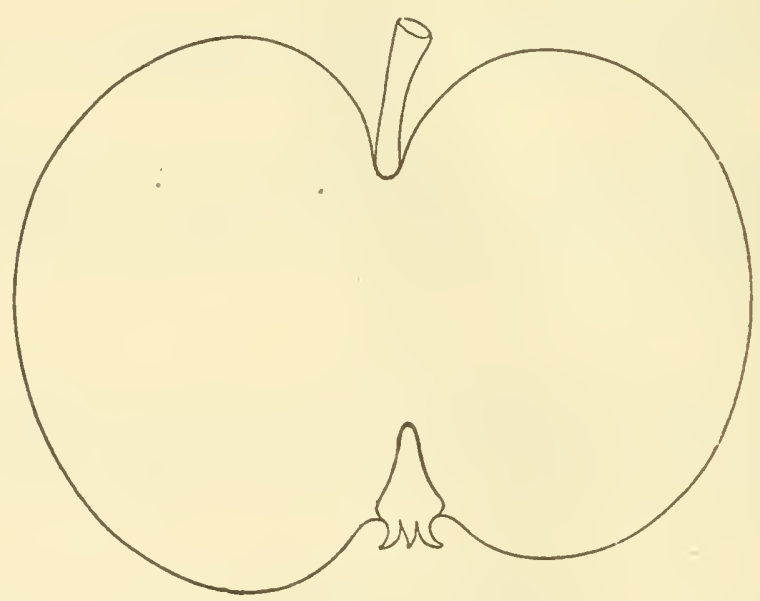

Klaproth.

bearer and vigorous grower. We give the Dr.'s description. Young wood very grayish dull reddish brown. Size medium, form oblate. Skin greenish yellow, streaked and stained with red, deepened on the sumn side, dotted all over with light specks, and occasional russet spots near the stalk, which is short and inserted in a smooth deep cavity. Caly small and closed. Segments reflexed, set in a wide, regular, and wellformed basin. Flesh white, very crisp, juicy, tender, and pleasant sub. acid flavor, and until quite ripe acid predominates. Very good. August so October. 


\section{KNICKERBOCLER.}

Origin unknowu.

Fruit medium or above, rounalish oblate, greenish yellow, sjrinkled with brown dots. Stalk medium. Cavity large, deep, uneven. Calyx closed. Basin broad, shallow, meven. Flesh whitish, juicy, erisp, brisk subacid, pleasant aromatic. Good to very good. September, October.

\section{KNobey Russet.}

\section{Knobbed Russet. Old Maid's. Winter Rnsset.}

A dessert Apple from Sussex, England, which Lindley describes as of medium size, roundish oval, yellow, nearly covered with russety kuobs or warts. Flesh yellowish, crisp, not juicy, but sweet and high flavored. December to March.

\section{KNowles' EARLy.}

\section{Oat Harvest ?}

Introduced by John Knowles, near Philadelphia. Tree of moderate growth, forming a round head, an early, anmual, and abundant bearer, and the fruit contimmes in use a long time.

Fruit small, roundish oblate, smooth, pale greenish yellow, partially striped and splashed with dull crimson. Stalk long, slender. Calyx closed. Flesh whitish, very tender, moderately juicy, mild subacid. Good to very good. Angust.

\section{Krox Russet.}

Found in the orchard of J. Knox, Pittsburgh, Pa. Origin unknown. Tree spreading, productive, shoots slender.

Fruit small to medium, globular, somewhat conic, yellow green, blushed, covered with light russet. Flesh yellow, fine-grained, mild subacid, aromatic. Good to very good. December, January.

\section{KонL.}

From Germany. Tree thrifty, forming a regular top, a good and regular hearer.

Fruit small, roundish, crisp, juicy. Good keeper. (A. Fom. Rep.)

\section{König's Reinette.}

\section{Reinette Dorée. Reinette du Roi. \\ Royale. Winter Citronenapfel.}

This is said to be a beautiful long-keeping dessert Apple, of German origin.

Fruit above medium, roundish oblate, ribbed, lemon yellow, with a rich red cheek. Flesh ycllowish white, very fine, firm, and juicy, rich subacid. December to March. (Diel.)

\section{Krauser.}

\section{Krowser. Krouser.}

Origin, Berks Co., Pa. Tree vigorous, a handsome grower and an abundant and regular bearer. Young wood dark reddish brown. 
Fruit medium, roundish conic. Color whitish yellow, strijed and splashed with bright red. Stalk rather short, inserted in a medium cavity. Calyx elosed. Basin small and corrugated. Flesh white, tender, mild subacil. Good to very good. December, March.

\section{Krauter Reinette.}

A German Apple, highly praised in its own home.

Fruit medium, roundish oblate, greenish yellow. Stalk long. Cavity russeted. Flesh white, very fine, juicy, highly aromatic. December to March.

\section{LABUTE.}

Of French origin. Tree vigorous, upright.

Fruit large, ronndish conical, sides unequal, yellow, mostly shaded, and somewhat splashed with rich red. Stalk rather short. Cavity deep. Calyx closed. Basin small, corrugated. Flesh white, crisp, rather firm, juics, pleasant subacid. Good. Core large. October.

\section{LACKER,}

\section{Laquier.}

Origin, Lancaster Co., Pa.

Fruit medium, oblate, sides sometimes unequal, pale red, striped and splashed with crimson. Stalk short, slender, inserted in a narrow russeted cavity. Calyx closed. Basin wide, deep, corrugated. Flesh white, tender, crisp, juicy, pleasant subacid. Good. November to March.

\section{LADY APPLE.}
Api.
Api Petit.
Pomme Rose.
Pomme d'Api Ronge. Petit Api Rouge. Gros Api Rouge.

An exquisite little dessert fruit, the pretty size and beautiful color of which render it a miversal favorite; as it is a great bearer, it is also a profitable sort for the orchardist, bringing the highest price of any

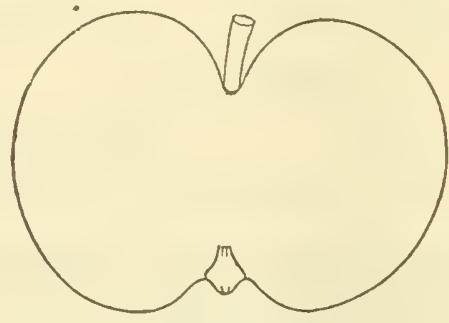

Lady Apple.

fancy apple in the market. It is an old French variety, and is nearly always known abroad by the name of $A p i$; but the name of Lady Apple has become too universal here to change it now. No amateur's collection should be withont it. 
Fruit quite small, but regularly formed and flat. Skin smooth and glossy, with a brilliant deep red cheek, contrasting with a lively lemon yellow gromel. Stalk of medium length, and deeply inserted. Calyx small, sunk in a basin with small plaits. Flesh white, crisp), tender, and juicy, with a pleasant flavor. The tree has upright, almost black shoot., with small leaves; forms a very upricht, small head, and beals its fruit in bunches. 'The latter is very hardy, and may be left on the tree till severe frosts. The Larly Apple is in use from December to Mlay.

The A pi Noir, or Black Lady Apple, differs from the foregoing sort only in the color, which is nearly black. In shape, size, souson, and thavor, it is nearly the same. It is, from its unusually dark lue, a singrular and interesting fruit-poor flavor.

The true Api Etoile, or Star Lady Apple, figured and deseribed by Poiteau, in the Pomologie française, is another very distinct variety; the fruit is of the same general character, but having five promineut angles, which give it the form of a star. This variety is rather searce, the common Lady Apple being frequently sent out for it by French nurserymen. It keeps until quite late in the spring, when its flavor beeomes excellent, though in winter it is rather dry. The growth of the tree resembles that of the other Apis.

The Api Gros, or Large Lady Apple, is of a similar habit in growth of the tree to the true Lady Apple, the fruit a tritle larger, more romolish, less brightly colored, and quite inferior in quality.

The A pi Gros Pomme de Rose, or Rose-colored Larly Apple, is also another variety, with fruit of medium size, roundish, pale yellow, washed with bright rosy red. Flesh yellowish white, fine-grained, iuicy, crisp, aromatic.

\section{LAdY Blush.}

Received from Pennsylvania.

Fruit rather large, roundish, whitish yellow, shaded in the sun with bright red, many light and gray dots. Stalk medium. Cavity deep. Calyx elosed. Flesh yeilowish, rather firm, moderately juicy, pleasant subacid, slightly aromatic. Gnod. Norember, December.

Elliott describes a Lady or Lady's Blush as medium, yellow, with red blush. Elesh dry.

\section{LADY FiNGER。}

Under this name Hogg describes an Apple as:

Fruit below medium, pyramidal, rounded at base, dull greenish yel. low, with minute gray russety dots, dull blush and spots of lively red in the sun. Flesh yellow, tender, juicy, pleasantly acid. November to March.

Coxe describes an apple as Jady Finger or I Long Pippin, as remarkably long, greenish yellow. Flesh pleasant, early winter, but dues not keel, well.

Elliott describes under name of Lady Finger, synnnym Sheep Nose, an apple as medium size, olılong, pale yellow, faint blush. Flesh firm, watery. November, December.

We have also reccived an apple from Naryland under this name which is of medium size, roundish conical, yellowish, shaded over the whole surface with deep erimson, thinly sprinkled with light duts. Stalk 
short. Cavity rather deep. Calyx closed. Basin large, deep, curru. gated. Flesh white, tender, moderately juicy, pleasant subacid. Good to very good. Core small. August.

\section{Lady Haley's Nonsuch.}

An Eastern variety, of unknown origin. Tree vigorous, productive.

Fruit medium, roundish oblate, ribbed, light waxen yellow, shade of red in the sun. Stalk short and stout. Cavity large. Calyx closed. Basin medinm, corrugated. Flesh rather firm, pleasant, slightly aromatic. Good. Cooking. September.

\section{LADY OF THE WEMrYss.}

A large and handsome Scotch Apple.

Fruit roundish, pale green, red next the sun. Flesh white, juicy, subacid. October, December.

\section{Lady's Delight.}

An English culinary Apple, the habit of the tree like that of the Weeping Willow.

Fruit medium, roundish oblate, ribbed, greenish yellow, with red next the sun. Flesh white, crisp, juicy, brisk, aromatic. October, December. (Hogg.)

\section{LAdY's Faxcy.}

\section{King of some.}

Origin unknown. Much grown in Vermont, Northern New York, and Canada.

Fruit above medium, oblong conical, whitish yellow, splashed, shaded, and mottled with light and dark red, light dots. Stalk short. Cavity narrow. Calyx closed. Flesh white, crisp, tender, juicy, agreeable, subacid. Core large. Good. November to February.

\section{LADY's SEedling.}

Origin, Delaware Co., Pa. Tree moderately vigorous, upright, spreading.

Fruit medium, oblate, greenish yellow, with a blush cheek. Flesh whitish, juicy, pleasant subacid. October.

\section{LADY'S SWEET.}

\section{Pommeroy. Lady's Sweeting. Roa Yon. Ladies' Sweet.}

We consider this one of the finest winter sweet Apples for the dessert yet known or cultivated in this country.

Its handsome appearance, delightful perfume, sprightly flaror, and the long time which it remains in perfection, render it miversally admired wherever it is known, and no garden should be withont it. It is a native of this neighborhood. The wood is not very strong, but it grows thriftily, and bears very abunlantly, making a round spreading head. Young shoots reddish brown, downy. Bucls small. 
Fruit large, roundish ovate, narrowing pretty rapidly to the eye. Skin ver'y smooth, nearly covered with red in the sun, but pale yellowish green in the shade, with broken stripes of pale red. The red is sprinkled with well-marked yellowish gray dots, and covered, when fisst gatllered, with a thin white bloom. There is also generally a faint marbling of eloudy white over the red, on the shady side of the fruit, and

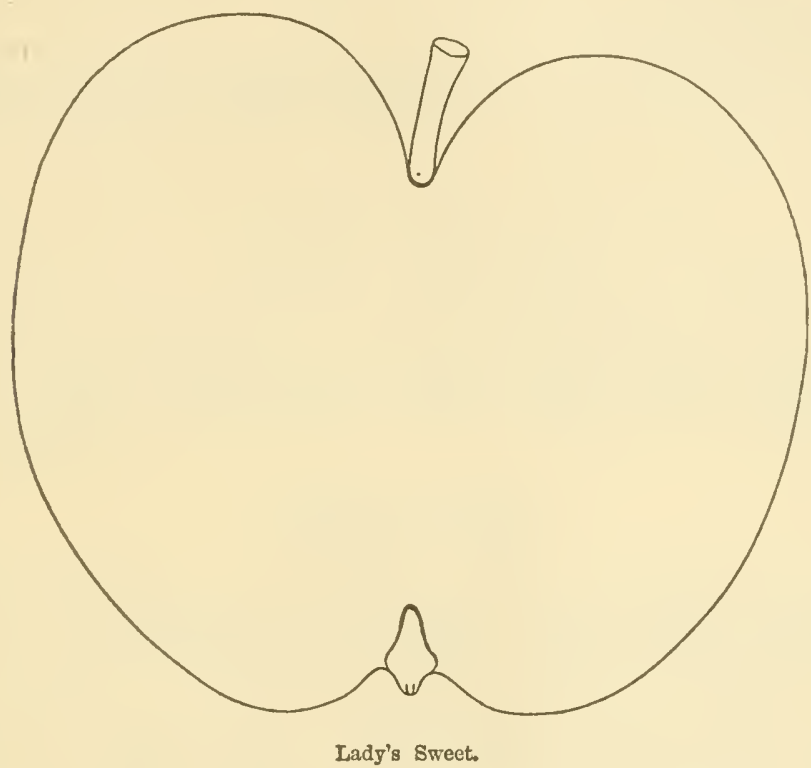

rays of the same around the stalk. Calyx quite small, set in a narrow, shallow, plaited basin. Stalk half an inch long, in a shallow eavity. Flesh greenish white, exceedingly tender, juicy, and crisp, with a delicious, sprightly, agreeably perfumed flavor. Very good or best. Keeps without shrivelling, or losing its flavor, till May.

\section{LADY'S WHITE.}

Origin, Franklin Co., O. Tree a good grower and bearer.

Fruit medium or below, roundish, whitish, very smooth and fair. Flesh white, tender, juicy, subacid. December to February.

\section{LAFAYETTE.}

Originated in Chester, N. H., on the farm of William Jenney, and first fruited in 1821, the year of General Lafayette's visit to this country, hence its name. It is much esteemed in its native locality, but has been little disseminated. 'Tree a good grower and an ammal bearer.

Fruit medium, roundish, whitish yellow, shaded, splashed, and mar. pled with erimson, moderately sprinkled with light dots. Stalk rather 
long, slender. Cavity medium. Calyx closed. Segments rather short to a point. Basin abrupt, corrugated. Flesh white, juicy, tender, pleasant, mild subacid. Good to very good. December to Febrnary.

\section{LAKE.}

Origin, D. C. Richmond, Sandusky, O. Tree of strong upright growth, productive. Young shoots stout, short-jointed, dull reddish brown, slightly downy.

Fruit medium, roundish oblate conical, yellow, striped, splashed, and shaded with deep red. Flesh yellowish, tender, juicy, rich, pleasant subacid. Good to rery good. Core small. Ripe September and October.

\section{Lamb Abbey Pearman.}

\section{Laneb Abbey Pearmain.}

An old variety, from Kent, England. Tree not healthy.

Fruit medium, roundish, yellow, shaded, splashed, and striped with two shades of red. Flesh whitish, compact, juicy, subacid. Good. November.

\section{Latcaster Greening.}

\section{Lancaster Pippin.}

Origin, Lancaster Co., Pa. Tree hardy, vigorous, spreading. Young wood smooth, reddish brown. Buds prominent, flattened.

Fruit medium, roundish oblate, approaching conic. Color greenish, but when fully mature quite yellow, occasionally a blush of crimson in the sun, and pretty thickly sprinkled with russet and crimson dots and patches of russet. Stalk slender. Cavity deep, sometimes russeted. Calyx small, closed. Basin very shallow, corrugated. Flesh yellowish, compact, moderately juicy, pleasant, mild subacid. Tery gool. December to May. Much valued as a long keeper.

\section{LANCASTER SweEt.}

Origin, probably Pennsylvania. Tree vigorous, productive.

Fruit medium, roundish conic, whitish, splashed and marbled with red. Flesh whitish, not very tender, juicy, sweet. Good. September, October.

\section{LANDOS.}

Origin uncertain, found on the farm of Bnel Landon, Grand Isle. $V t$, and by him introduced to notice. Tree vigorous, with low spreading branches, and bears moderately every year.

Fruit medium, roundish, inclining to conic. Color reliow, mottleck and shaded with red or deep crimson, and corered with numerons gray ish dots. Stalk short. Cavity large, surrounded by russet. Calyx open, basin corrugated and shallow. Flesh yellowish, firm, crisp, juicy, with at rich, mild subacid flavor, aromatic. Tery good. February to Mlay. 


\section{LANe's Red Streak.}

Origin, orchard of Mr. Lane, Eilgar Co., Illinois. Tree of modcrate growth.

Fruit large, round conical, regular. Color yellow, with very fine short stripes, and specks of bright red, beantiful. Flesh white, fine, ten. der, pleasant subacid, of fair quality. Good. October.

\section{ILANE'S SีWEET.}

Origin, Boylston; Mass. Tree a good grower and productive. Young shoots smooth, light reddish brown.

Fruit medium, roundish conical, yellow, shaded, splashed, and striped with red, moderately sprinkled with large light dots. Stalk medium, slender. Calyx closed. Basin corrugated. Flesh white, crisp, teuder, juicy, pleasint sweet. Good to very good. September.

There is another Lane's Sweet which originated in Hingham, Iass. Tree vigorous and productive. Young shoots dark reddish brown, slightly downy.

Fruit medium, oblate, slightly conic. Color fine yellow, with a suuny cheek. Stalk short. Cavity large, russeted. Calyx closed, basin small, open. Flesh yellowish, not very tender, juicy, sweet, aromatic. November to March.

\section{LANSINGBURGH.}

Origin unknown. Tree upright, spreading, vigorous, moderately productive.

Fruit medium, roundish oblate, yellow, largely overspread with gras-

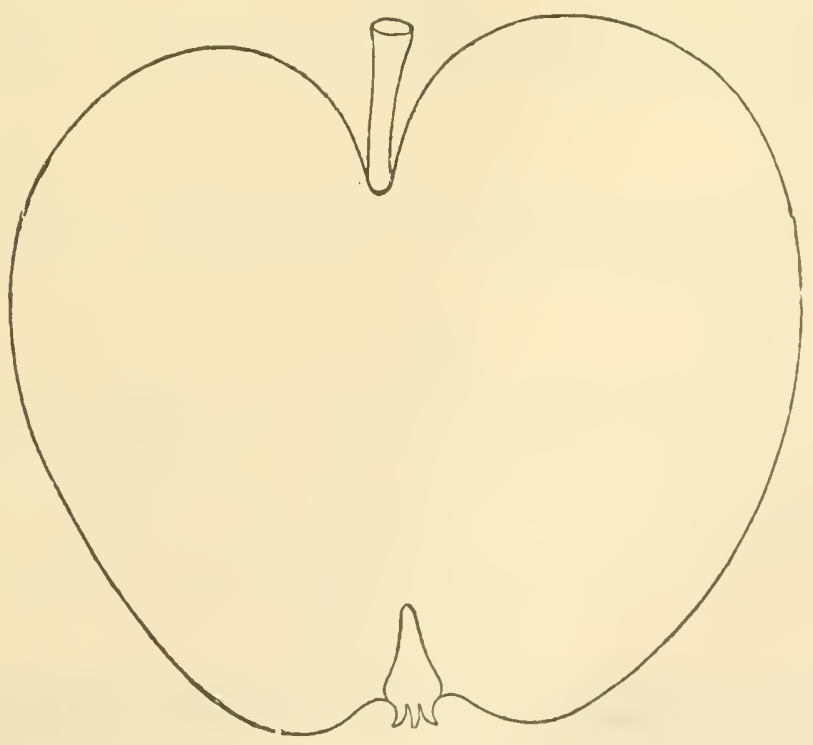

Lirge Jellow Dough. 
ish red. Flesh firm, mild subacid. Good. Valuable mainly because of its long keeping qualities.

\section{Large Yellow Bough.}

Early Sweet Bough. August Sweet.
Sweet Harvest.

Washington, incorrectly.
Bough.

Sweet Bough.

A native Apple, ripening in harvest time, and one of the first quality, only second as a dessert fruit to the Early Harvest. It is not so much esteemed for the kitchen as the latter, as it is too sweet for pies and sance, but it is generally much admired for the table, and is worthy of a place in every collection.

Fruit above the middle size, and oblong ovate in form. Skin smooth, pale greenish yellow. Stalk rather long, and the eye narrow and deep. Flesh white, very tender and crisp when fully ripe, and with a rich, sweet, sprightly flavor. Ripens from the middle of July to the tenth of August. Tree moderately vigorous, bear's abundantly, and forms a round head. Young shoots grayish brown, very slightly downy.

\section{Larue's Big Green.}

Origin, Hardin Co., Ky.

Fruit very large, yellow. Flesh vinous, sprightly subacid. Feb. ruary, March. Superior for cooking. (Ky. Hort. Soc. Trans.)

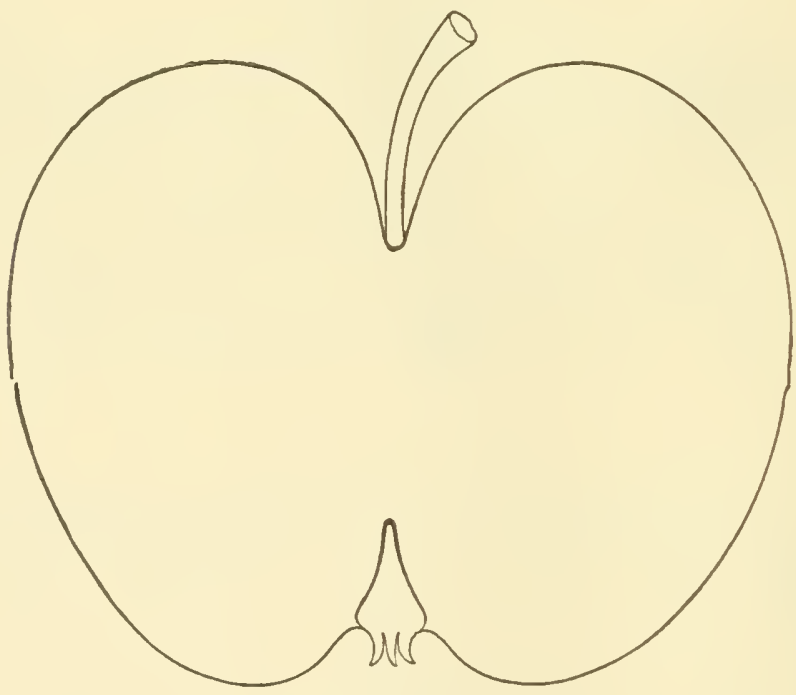

Late Strawberry.

LAte Strawberry.

Autumn Strawberry.

Origin, Aurora, N. Y., on lands formerly owned by Judge Phelps. Tree vigorous, upright, spreading, hardy. Ioung wood smooth, reddish brown, a regular and early bearer. 
Fruit medium, roundish, inclining to conic, sometimes obscurely rib. bed. Color whitish, striped and splashed with light and dark red, and often covered with a thin bloom. Stalk rather long, slender, eurved. Cavity large, deep, slightly russeted. Basin abrupt, eorrugated. F'lesh yellowish white, tender, juicy, pleasant vinous, subacid. Very good. Uctober, December.

\section{Late Sweet.}

A variety somewhat grown in Connecticut, origin unknown.

Fruit medium, roundish, yellow, mostly shaded, splashed, and mar. bled with red, light and gray dots. Flesh white, compact, not juicy, sweet. December, March. A long keeper and good for cooking. -

\section{LATE Wine.}

A very excellent Apple, the origin of which we have been unable to trace, nor can we identify it with any known sort. Tree upright, vigorous, an early and abundant bearer. Young shoots smooth, light reddish brown, with buds large, round, and prominent.

Fruit rather below medium, roundish conical. Sides unequal. Color mostly shades of light and dark crimson, sometimes almost purple, a thin light bloom and light dots. Stalk short, slender. Cavity acute, slightly russeted, sometimes lines or traces of russet outwards. Calyx small, elosed. Basin abrupt, furrowed. Flesh white, very tender, juicy, mild, pleasant subacid. Very good, October, November.

\section{LATHAM.}

Origin, Sag Harbor, Long Island, N. Y. Tree a good grower, very productive.

Fruit medium, oblate conic, sides unequal, yellow, almost entirely overspread with light and dark red, small light dots. Flesh white, tender, juiey, pleasant, mild subacid. Good. November, December.

\section{Lauren's Greening.}

Origin, Laurens Co., Ga.

Fruit large or above medium, oblate, greenish, with tinge of red in the sun. Flesh white, crisp, acid, pleasant. Good. September.

\section{LAWVER.}

Origin uncertain. Introduced by George S. Park, of Parkville, Mo., and said to have been found in an old Indian orchard in Kansas. Tree vigorous, spreading, an early and annual bearer, a beatifnl fruit, and a long keejer.

Fruit large, roundish oblate. Color dark bright red, covered with small dots. Stalk medium. C'avity deep, regular. Calyx small, elosed. Basin nedium, furrowed. Flesh white, firm, crisp, sprightly, aromatic, mild subacid. January to May. (Prairie Farmer.)

\section{TEAVER.}

Received from South Carolina. Tree remarkably vigorous and at good bearer. 
Fruit medium, roundish, slightly conical, yellow, shaded and obsimely striped and splashed with red. Stalk slender. Calyx nearly closed. Flesh yellowish, firm, crisp, juicy, rich, slightly aromatic sub acid. Good to very good. Core small. Nurember to March.

\section{IEDGE SweET.}

Portsmouth Sweet.

Origin, Portsmouth, N. H. Tree vigorous, productive, regular bearer.

Fruit medium, oblate, whitish yellow, thinly shaded with red, splasked and striped with dark red, thinly sprinkled with light and gray dots. Stalk very short, stout. Cavity broad, not deep. Calyx closed. Segments short. Basin medium, slightly corrugated. Flesh yellowish, a little coarse, tender, juicy, mild, half sweet, pleasant. Core small. Good or very good. December to March.

\section{Leicester Sweet.}

Potter Sweet.

Origin, Leicester, Mass. Tree vigorous, not very prodnctive.

Fruit rather large, flattish, greenish yellow and dull red. Flesh tender, rich, excellent, fine for lessert or baking. Winter.

\section{Leithemer Streifling.}

Of German origin.

Fruit large, roundish conical, lemon yellow, overspread, shaded, and striped and splashed with varying shades of red. Calyx closed. Basin ribbed. Flesh white, tinged with red, firm, aromatic, sweet. December.

\section{LELAND SPICE.}

\section{Leland Pippin. New York Spice.}

Origin, Sherburne, Mass. Tree vigorous, productive.

Fruit large, roundish. Color yellow, ncarly covered with bright red. Stalk short, inserted in a narrow cavity. Calyx small, closed. Basin shallow. Flesh yellowish, rather tender, juicy, with a very rich aromatic subacid flavor, excellent for dessert or kitchen. Good to rery good. September, October.

\section{Ienion Pippix.}

Kirke's Lemon Pippin. Pepin Limon de Galles?

An English variety, of medium size, oval. Skin lemon yellow. Flesh firm, brisk subacid. Good. October.

\section{LESHER.}

Origin, Berks Co., Pa.

Fruit medium to large, oblate, sjdes unequal, whitish, shaded in the sun with light purplish crinuson, few small gray and light dots. Flesh white, crisp, moderately tender, pleasant subacid. Good. December so February. 
LEWIS.

Origin, Putnan Co., Ind. A good grower, and productive.

Fruit melium, oblate conic. yellowish, striped with crimson, ancl partially corered with thin eimimon lusset, and sprinkled with grat and brown dots. Stalk short, inserted in a deep cavity. Calyx chosed or nearly so, in a moderate basin. Flesh yellow, compact, with a rick subacid flavor, not very juicy. Good. November, February.

It is claimed by some that there is another Lewis, but our experience in fruiting them does not enable us to so decide.

\section{LEWIS'S IXCOMPARABLE.}

An English sort, mostly valued for cooking. Tree vigorous, prodinctive.

Fruit medium to large, roundish oblate, yellow, with streaks and shades of red. Flesh yellowish white, firm, crisp, brisk subacid. De. cember.

\section{LIBERTY.}

Originated in Delaware Co., O. Tree vigorons, spreading, and productive. Toung shoots smooth, reddish brown.

Fruit medium, roundish oblong, oblate, oblique, conical, yellowish, shaded, splashed, and striped with shades of dull red. Flesh yellowish, rather firm, nild subacid. Core small. Good. Valuerl mainly for its keeping qualities. December to May.

\section{LiGoz.}

Origin unknown.

Fruit large, roundish, yellow, shaded, splashed, and striped with shades of red. Flesh whitish, a little coarse, juicy, crisp, pleasant subacid. Good. Core small. December, January.

\section{Limber Twig.}

\section{James River. $\quad$ Red Limber Twig ?}

An Apple much cultivated South and West. Origin, supposed North Carolina. Tree hardy and productive, roundish, sjreading, somewliat ilrooping.

Fruit medium or above, roundish oblate, inclining to conic, greenish rellow, shaded and striped with dull crimson, and sprinkled with light dots. Stalk of medium length, inserted in a broad, deep carity, smrrounded by thin, green russet. Calyx closer, set in a small, uneven basin. Flesh whitish, not very tender, juicy, with a brisk, sulbacid flavor. Good. January, April.

\section{Lincolisinire Hollind Pipper.}

Striped Holland Pippin.

A second-rate cooking Apple.

Fruit above medium, roumlish, slightly oblate, yellow, stripes of red in the sun. Flesh white, subacid. November, Jaumary. 


\section{LINDENWALD.}

Origin, orchard of J. G. Sickles, Stuyvesant, N. Y. Tree moderately vigorous, upright.

Fruit medium, roundish oblate, surface oily, yellow, light shades of red in the sun, few indistinct dots. Stalk short. Cavity deep, often russeted. Calyx closed. Basin deep, slightly furrowed. Flesh yellowish, crisp, juicy, pleasant subacil. Good to very good. September.

\section{LINDLEY's NoNPAREII.} bearer.

Origin, Chatham, N. C. Tree delicate, slender, poor grower, great

Fruit small, oblate, yellow, blush in the sum. Flesh yellowish, rich, crisp, aromatic, nearly sweet. Good to very good. August, September.

\section{LIPPINCOTT SWEET.}

Origin, New Jersey.

Fruit medium, roundish conical, pale yellow, thin shade of crimson in the sun, many brown and russet dots. Flesh white, tender, moderate!y juicy, pleasant mild sweet. Good. Core small. December to March.

\section{Litciffield Pippix.}

Raised by Wm. Hutchins, of Litchfield, Me.

Fruit medium to large, oval, yellow, with red in sun. Flesh white, mild subacid. (Me. Rep.)

\section{LitTLe Beauty.}

This little Apple, says Ronalds, has the property of holding firmly to the branches, so as not easily to be dislodged. Tree upright, and a great bearer.

Fruit small, roundish oblate, yellow bronzed in the sum. Flesh yellowish, rich, but rather dry. December, February.

\section{LOAN'S PEARMAIN.}

An old variety. Tree a poor grower.

Fruit small, roundish oblong, greenish, with stripes of dark red. Flesh firm, juicy, crisp. Good. September to November.

\section{LOCY.}

Fruit globular, sometimes inclining to oblate, and sometimes oblong or conic, greenish, sharled and striped with dull red. Flesh greenish, crisp, tender, juicy, pleasant. Hardly good. November, February.

\section{Lodgemore NoNpareil.}

\section{Clissold's Seedling.}

An English dessert Apple.

Fruit medium, roundish, deep yellow, with blush in sun. Flesh yellowish, firm, crisp, juicy, aromatic. February, March. (Hogg.) 
Loxpox Pippix.

Five-Crowned Pippin. New London Pippin. Royal Somerset.

A very old English Aple, mostly valued for cooking or drying. rree a moderate grower, productive.

Funit large, roundish, slightly conical, flattened at base, yellow, with a tinge of red in the sun. Calyx small, closed. Flesh white, rather firm, subacid. Good. Norember to February.

\section{LONDON SWEET.}

Heieke's Winter Sweet. Clark's Seedling.
Mrs. Weaver's Sweet?

London Winter Sweet.

Origin supposed near Dayton, O. Tree vigorous, productive, valnable in rich deep soils. Toung wood, dull grayish brown.

Fruit medium or large, roundish oblate, pale yellow, with very slight indications of russet, a little green russe! around the stalk, and sparsely covered with brown specks. Stalk short, in a large eavity. Calyx closed, set in an abrupt, open, slightly uneven basin. Flesh whitish, juicy, tender, fine, delicate, sweet, slightly aromatic. Good to very good. November to February.

\section{Long Island Peariain.}

\section{Hollow Crown Pearmain.}

An old variety, described by Coxe, and while it is somewliat extensively grown, has been sometimes confounded with IVinter Pearmain, which is an entirely different fruit.

Fruit large, roundish oblong, having a large hollow basin or crown, yellow, splashed and streaked with red, and some faint russet spots. Flesh coarse, tender, somewhat dry, aromatic. Good. October to February.

\section{Losg Island Pippix.}

Origin unknown. Specimens from T. T. Lyon, Plymouth, Mich.

Fruit large, roundish, flattened, yellowish green. Flesh greenish yellow, breaking, fine-grained, juicy subacid. Almost best. January. (IVarder.)

\section{Loxa Istand Russet.}

An old Apple, much grown in New Jersey and Long Island, anit valued highly for cicler purposes. Tree vigorous, spreading, and productive.

Fruit below medium, roundish, yellow, mostly oversprearl with dull I'usset, black spots or blotches when fully ripe. Flesh yellowish, tongh, . rather dry, alunost sweet. October to February.

\section{LONG JoHN.}

Of unknown origin.

Fruit large, conical, greenish yellow. Flesh yellowish white, rather dry, subacid, valuable only for its size and long keeping quality. Marel to May. 


\section{ToNg's ReD Winter.}

H. R. Robey, of Fredericksburg, says this was found in the forest about fifteen miles from that place.

Fruit medium to large, roundish oblate, yellow, striped and splashed with bright red, sprinkled with a iew brown dots. Flesh yellowish, tender, juicy, crisp, subacid. Good to very good. December to Feb ruary.

\section{LONG StaRT.}

Westmoreland Longstart.

An. English culinary Apple.

Fruit medium, roundish, yellow, mostly overspread and streaked with red. Flesh white, crisp, tender, pleasant subacid. October, December.

\section{Loxg Sten.}

There are four distinct Apples under this name, easily disting inished by the wood of the young slioots.

'The Iong Stem of Comnecticut is, perhaps, the oldest variety. The young shoots are dull reddish brown, somewhat downy, with prominent rounderl, flattened buds.

Fruit medium, romudish oblate, yellow, with greenish dots, and small patches of russet. Calyx small, in a small basin. Flesh yellow, fine-grained, somewhat spicy, sweet, and rich. Good. September to January.

The Long Stem of Massachusetts has rather slender young shoots of reddish brown, somewhat grayish, and slightly downy, with small clear red buds.

Fruit medium, roundish oblate, yellow, with a slight blush in the sun, moderately sprinkled with light and gray dots. Calyx medium, closed. Flesh yellowish, tender, juicy, sprightly subacid, aromatic. Good. October, February.

The Long Stem of Pennsylvania has young shoots, of a yellowish brown, with very small short buds.

Fruit medium or below, roundish, inclining to oblong, truncated, vellowish, shaded, splashed, and striped with red mostly orer the whole surface, many small light and gray dots. Stalk long, slencler, curred, with bracts. Calyx closed. Segments a little recurved. Basin corrngated. Flesh whitish, crisp, tender, mild subacid, slightly aromatic. Good to very good. Norember to February.

The Long Stem of Kentucky has redilish grayish brown young wood, slightly downy, with short, round, flattened buds.

Frnit medinm, roundish oblate, greenish, shaded, mottled, ancl rather indistinctly splashed and striped over all with dull dark r.ed, and with many large light gray dots. Flesh greenish white, rather compact, mild, almost sweet, subacid. Core small. Good to very good. December to March.

\section{LONGVilLE'S KERNEL.}

Sam's Crab.

English. Fruit rather below medium size, oval, rather flattened, 
greenish rellow, streaked with pale brownish red, with a few streaks of bright red. Flash tirm, yellow, slightly perfumed, subicid. Good August and September.

\section{Lord Burleigh.}

\section{Lord Burghley.}

A new eclebrated English clessert Apple, as yet untested here.

Fruit medium, ronndish, slightly oblate, and ribbed, yellow, with a bright crimson cheek, and many russet speeks. Flesh yellowish, tender, juicy, sweet pino-apple Havor. January to May. (Hogg.)

\section{LoRd StFFiELD.}

A valuable English kitchen Apple, described as an improvement on Keswick Codlin. The tree lardy, and a great bearer.

Fruit above medium, conical, greenish yellow, with a tinge of red in the sun. Flesh white, firm, tender, brisk subacid. August and September.

\section{Lorick Cluster.}

Said to have originated in Georgia. Tree a poor grower, but at great bearer and keeper.

Fruit small, roundish conieal, pale green, with a brown tinge in the sul. Flesh greenish white, pleasant, mild subacid. Good. Core small. January to April.

\section{Loring SweET.}

Fruit medium, oblate, greenish yellow, shaded with red, and sprinkled with brown specks. Flesh tender, juicy, sweet, and rich. Good. November to June.

\section{Loudon Pippin.}

\section{White's Loudon Pippin. Lady Washington?}

Origin, farm of Mrr. White, Loudon Co., Va, and much cultivated and valued in that seetion. Tree very vigorous, upright spreading.

Fruit large, oblate, approaching eonic, light vellow, sometimes bluslı of red in the sun, sprinkled witl a few grayish dots. Stalk short, inserted in a large eavity, surrounded by russet. Calyx large, open. Batsin smooth and even, rather deep. Flesh yellowish, compact, tender, juicy, subacid. Good to very good. December to February.

\section{Louise Rienard.}

Originated in Belgium.

Fruit medium, roundish oblate, conical, yellow, shaded with bright red in the sun, small reddish gray spots. Stalk short. Cavity deep, irregular. Calyx open. Flesh very white, tender, subacid, aromatic. (An. Pom.) 


\section{LovetT's SweEt.}

Origin, Beverly, Mass.

Fruit medium, roundish oblate conic, Skin yellow. Flesh yellow, moderately juicy, sweet and pleasant. Good. October to February.

\section{LOWELL.}

Queen Anne. Orange.
Michigan Golden. Tallow Apple.
Greasy Pippin.

Golden Pippin of some.

Origin unknown. Tree hardy, vigorous, spreacing, productive. Young wood reddish brown.

Fruit large, roundish oval or conic, bright waxen yellow, oily. Stalk of medium length. Cavity deep, uneven. Basin deep, abrupt, and furrowed. Calyx closecl. Flesh yellowish white, with a brisk, rich, rather acid flavor. Good to very good. September, October.

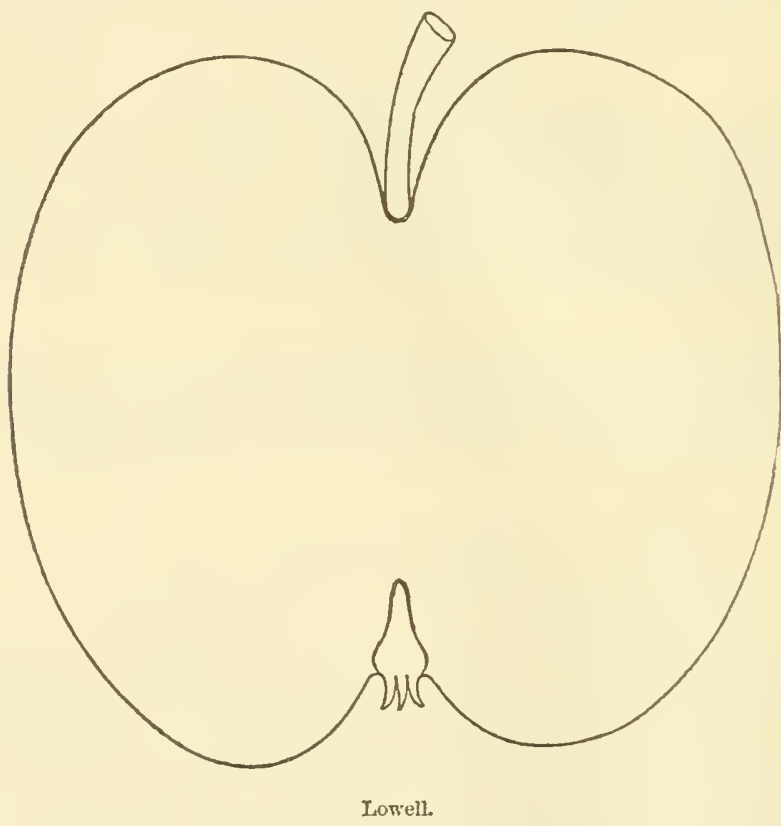

Lowre QUEEN.

Loure Queen.

Origin unknown, somewhat extensively grown in Central Ohuo. Trees upright, early bearers.

Fruit medium, roundish, flattened, rellow, striped and splashed with dull red. Flesh rellowish white, tender, juicy. Very good. November, February. (Ellioti.) 


\section{Luce's Early Joe.}

Early Joe, incorrectly.

Origin unknown.

Fruit medium, roundish oblate, whitish, with a blush in the sun, few brown dots. Flesh yellowish, tender, crisp, juicy, mild, pleasant subacil. Good. September.

\section{Lucombe's Pine-A pple.}
Pine-Apple.
Pine-Apple Pippin.

An English Apple, rather below medium size, orate conical, obscurely ribbed, pale yellow, bronzed in the sun. Flesh yellowish white, tender, juicy, subacid, aromatic. Good. October, December.

\section{Lucombe's SEedLing.}

English. Fruit large, roundish, angular, whitish, striped and splashed with red. Flesh firm, juicy, good for cooking. October, November.

\section{LUDWIG.}

\section{Haas.}

Originated on the land of - Ludwig, Bucks Co., Pa., and considerably grown in its native locality.

Fruit large, roundish, slightly conical, whitish, splashed, mottled, and shaded with light red, many dots, with dark centres. Stalk short, slender. Cavity rather large, a little greenish russet. Calyx closed. Basin slightly coluugated. Flesh white, sometimes a little stained next the skin, fine-grained, juicy, mild subacid. Core rather small. Good to very good. November to March.

\section{Lyman's Large Summer. \\ Large Yellow Summer.}

A large and handsome American fruit, introduced to notice by Mr. S. Lyman, of Manchester, Conn. . The bearing trees are easily recognized ky their long and drooping branches, which are almost wholly withont fruit-spurs, but bear in clusters at their extremities. They bear poorly until the tree attains considerable size, when it yields excellent crops.

Fruit quite large, roundish, flattened at the ends. Skin smooth, pale yellow. Flesh yellow, tender, subacid, and good for the table or for cooking. Last of August.

\section{LxoN's SWEET.}

Originated in Connecticut. Tree a good grower and great bearer.

Fruit medium, roundish, inclining to conic, yellow, shaded, striped, and splashed with red, light and gray dots. Stalk short. Calyx closed. Flesh whitish, rather compact, juicy, tender, sweet. Good. December.

\section{Lxscom.}

Osgood's Farorite.

Matthew Stripe.

Origin, Massachusetts. Tree vigorous, upright, spreading. Young shoots dark brown, downy 
Fruit large, roundish, grcenish yellow, with a few broken stripes or splashes of red. Stalk short, planted in a deep, round, even cavity.

Calyx large, in a broad, plaited basin. Flesh fine-grained, and exceed. ingly mild and agreeable in flavor. Good to very good. September tc November.

\section{MCAfee's Nonsuch.}

McAfee's Red.

Originated at McAfee's old Fort in Kentucky. Good grower, very productive. Young shoots smooth redlish brown.

Fruit large, globular, inclining to oblate. Skin yellowish green, shaded and striped with crimson and covered with a thin bloom. Stalk short, inserted in a large cavity. Calyx closed, set in a small basin. Flesh whitish, solid, crisp, subacid. Good to very good. December to March.

\section{MuCoy's Pippin.}

Origin, Loulon, Mercer Co., Pa. Tree of medium upright growtl, productive, valued as a showy market sort, and also for cooking.

Fruit large, oblate, a little oblique, greenish white, a shade of dull led in the sun, brown dots. Flesh white, crisp, tender, moderately juicy, pleasant, mild subacid. Good. Core small. October, December.

\section{McDaniel.}

Origin, Green Co., Ohio.

Fruit full medium, regular, oblate, yellow, covered with rich crimson, indistinct stripes. Dots light gray. Flesh yellow, solid, juicy, subacid, rich, piquant. October, November. (Warder.)

\section{McDowelt's Sweet.}

Origin, North Carolina.

Fruit medium or above, roundish oblate, fine yellow, mostly overspread, shaded, and splashed with light and dark red, almost purplish in the sun. Stalk short. Calyx small, closed. Basin narrow, corrugated. Flesh whitish, tender, juicy, mild, refreshing, sweet. Good to very good. October, December.

\section{McHenky.}

Origin, Elizabethtown, Indiana. Growth upright and free, moderately productive. Color and quality similar to American Summer Pearmain. September to December.

\section{Machay Sweet.}

Origin, Massachusetts. Tree a good grower and productive.

Fruit medium, roundish oblate conic, yellow, slight tinge of red in the sun. Stalk short. Cavity large, slightly russeted. Calyx small, closed. Flesh whitish, tender, juicy, mild, sweet, pleasant. Good. Core small. December to March. 


\section{MUKin's VANDERVERE.}

Origin, on the grounds of Robert McKim, Centre Co., Pa. 'l'reo vigorous, upright.

Fruit medium, roundish oblate, deep yellow, splashed, striped, and mottled with shades of red, light and brown dots. Flesh white, tender, not very juicy, acid. Good. September, November.

\section{McKinLeY.}

Fruit medium, roundish flattened, slightly conic, dull red on greenish yellow. Stripes indistinct. Flesh breaking, fine-grained, juicy, sub. acid. Good. December, January.

Maclean's Fayorite.

An English Apple of little value.

Fruit medium, roundish, yellow. Flesh crisp, acid. November to February.

\section{McLellan.}

Martin.

Origin, Woodstock, Conn. Tree thrifty, upright, very productive, annual bearer, and handsome. Young shoots, dull grayish red dish brown, slightly downy.

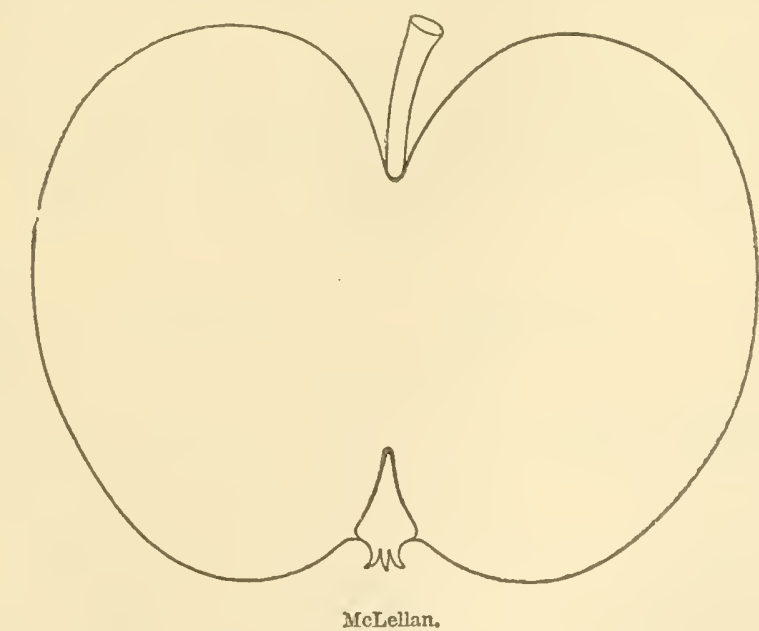

Fruit medium or above, roundish oblate, slightly conic, very regular, and fair. Color yellow, mostly striped, marbled, and splasherl with red. Stalk short, inserted in a rather deep cavity. Calyx small, nearly closed. Basin moderate, slightly uneven. Flesh white, very tender, juicy, with a fine vinous flavor, almost saccharine. Very good. December to March. 


\section{MACOMBER.}

Origin, Guilford, Maine. Tree a good annual bearer.

Fruit full medium, oblate, angular, yellowish, shaded and striped with red. Stalk short. Cavity large. Calyx closed. Basin large and regular. Flesh white, fine-grained, tender, subacid. Good. Core small. December, January.

\section{Magnolia.}

Origin, Bolton, Mass. Growth moderate, productive.

Fluit medium, roundish oblate conic, yellow, beautifully striped and mottled with crimson. Stalk short, in a broad, unereu cavity. Calyx closed. Basin small. Flesh white, tender, juicy, brisk, aromatic, subacid. Good to very good. October.

We have also received from J. W. Dodge, Tennessee, an apple under this name, the origin of which cannot be well traced. It is large, roundish oblate, inclining to conic, irregular, yellow, striped, mottled, and splashed with red. Flesh yellow, a little coarse, tender, juicy, pleasant, slightly aromatic. Very good. December, January.

\section{Maidex's Blush.}

A remarkably beautiful Apple, a native of New Jersey, and first described by Coxe. It begins to ripen about the 20th of August, and continues until the last of October. It has all the beauty of color of the pretty little Lady Apple, and is much cultivated and admired, both for the table and for cooking. It is also very highly esteemed for drying.

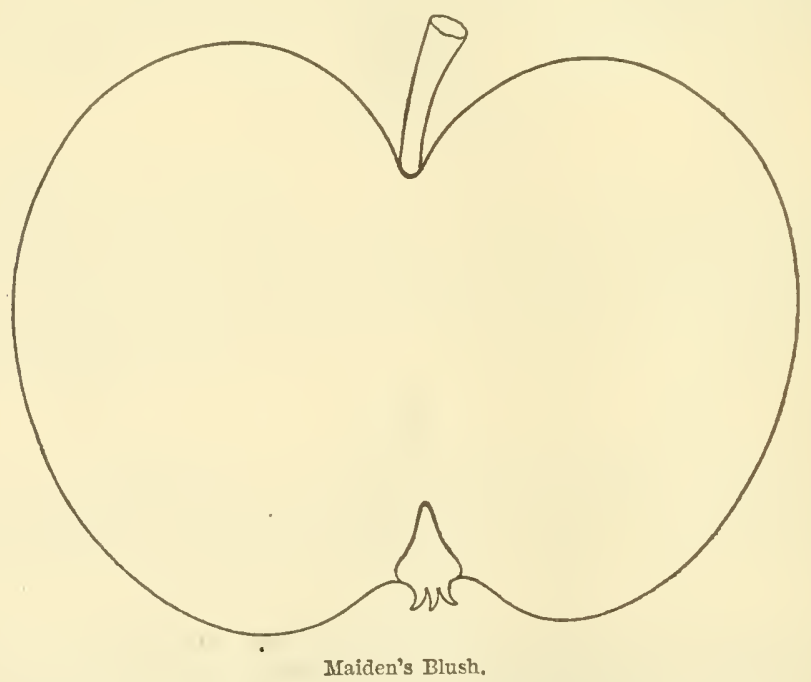

This variety forms a handsome, rapid-growing tree, with a fine spreading liead, and bears large crops. It is very valuable as a profita. ble market sort. 
Fruit of medium size, very regularly shaped, and a little narrower towards the eye. Skin smooth, with a delicate waxen aplearance, palo lemon yellow in the shade, with a brilliant crimson cheek next the sum, the two colors often joining in brilliant red. Stalk short, planted in a rather wide deep hollow. Bisin moderately depressed. Calyx closed. Flesh white, tender, sprightly, pleasant subacid. Good.

\section{Maiden's Favorite.}

Maiden's Apple.

Origin, farm of J. G. Sickles, Stuyvesant, N. Y. Its delicacy and beauty will make it desirable for the amateur. Tree of rather slow growth, npright slender branches, an annual and good bearer. Young shoots smooth, clear reddish brown.

Fruit medinm or below, roundish, sometimes slightly eonic, generally eylindrie, but often rery obseurely ribbed, whitish or pale waxen yellow, shaded and sometimes slightly mottled with erimson, and sparsely sprinkled with minnte dots. Stalk short, small, surrounded by thin russet, in a deep, uniform eavity. Calyx firmly closed. Basin slightly corrugated, deep, open. Flesh whitish, tender, erisp, with a pleasant, very delicate, vinous subacid. Good to very good. Core small. October to Jauuary.

\section{MAJOR.}

Originated with Major Samnel McMahon, Northumberland Co., Pa. This is a showy market Apple of really excellent quality. The tree is a rapid and vigorous grower, with rather irregular, upright, spreading shoots, reddish brown, slightly grayish.

Fruit large. Form roundish, often oblate, shightly inelining to conic. Sides sometimes mequal. Color greenish, shaded and rather obseurely striped and splashed with deep red, many light russet gray dots. Stalk short. Carity deep. Calyx large, with stiff, short segments. Basin large, broad, and furrowed. Flesh yellowish, rather firm, crisp, jnicy, rich subacia. Core small. Very good. November to April.

\section{Mila Carle.}

$\begin{array}{ll}\text { Pomme Finale. } & \text { Charles Apple. } \\ \text { ILela di Carlo. } & \text { Mela Carla. }\end{array}$

Pomme de Charles.

The Male Carle is the most eelebrated of all Apples in Italy and the South of Europe, whence it comes. Here or in New England it does not always attain perfection, but south of New York it beeomes beanti. ful and fine, as it needs a warm and dry soil.

Fruit of medium size, very regularly shaped, a little narrow towards the eye. Skin smooth, with a delicate waxen appearance, pale lemon rellow in the shade, with a brilliant crimson cheek next the sun, the two colors often joining in strong contrast. Flesh white, not very juicy, but tender, and with a delicate, slightly rose-perfuned flavor. Good. September to January.

\section{MaMMA.}

A Suuthern Apple of unknown origin. Tree a rery thrifty, compact grower. Young wood reuldish. 
Fruit above medium, oblate, crimson red. Flesh yellowish, rich, aro matic subacid. October, November.

\section{Mamoth June.}

Origin, Christian Co., Ky. Tree an upright, moderate grower; not an early bearer.

Fruit medium, roundish oblate conic, whitish yellow, striped and splashed with shades of red, light dots. Flesh very white, tender, not very juicy, mild subacid. Good. July, August.

\section{Manaen.}

This variety was grown from seed of the Talman Sweet, by F. P. Niller, Sugar Grove, Warren Co., Pa., and first fruited in 1867. The tree is said to be a thrifty, upright grower. Toung wood dark reddish brown, with a few white raised dots, and slightly downy. Leaf broad, roundish oval, coarsely serrated.

Fruit medium size, romdish oblate conical, irregular, or partially ribbed, pale whitish yellow, with deep carmine dots and marblings in sun, russet lines radiating from the stalk, scattering minute, raised, grar, or russet dots in the shade. Stalk slender. Cavity deep, broad, open, russeted. Calyx partially closed, with erect recurved, divided segments. Basin rather deep, abmut, generally irregular in form, usually clean and smooth, but occasionally with russeted broken lines. Flesh yellowish white, granulated, tender, moderately juicy, mild sweet, aromatic. Very

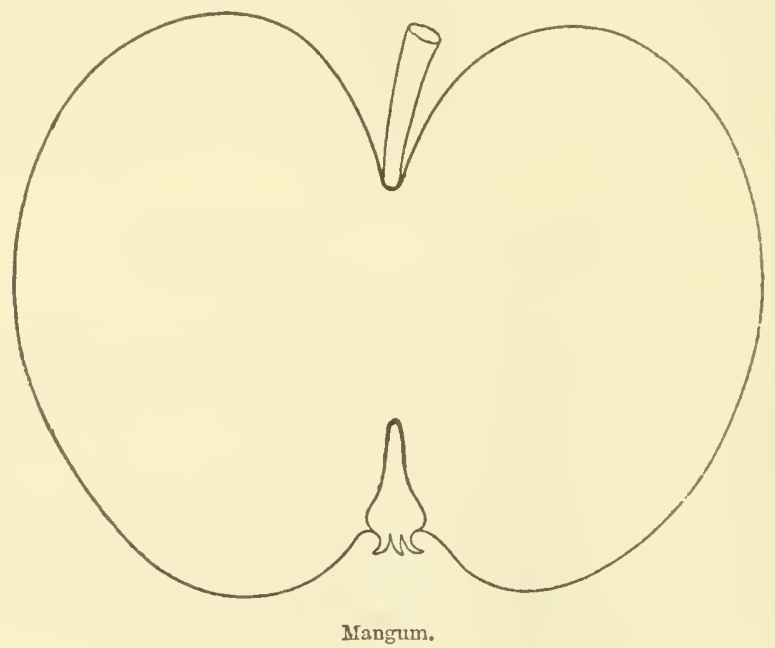

good. Core small. Seeds dark rich brown, oblong, pointed. Season, last of Augnst and September. A new rariety of fine promise as an amateur's fiuit. (Rural New I'orker.) 


\section{Maxguar.}

$\begin{array}{lll}\text { Fall Cheese of Va. } & \text { Cheese. } & \text { Seago. } \\ \text { Gully. } & \text { Carter of Ala. } & \text { Maxfield. } \\ \text { Carter's Wintcr. } & \text { Patton. } & \text { Johnston's Favorite. } \\ \text { Alabama Pearmain? } & \text { Sam Wingard. } & \text { Blakely. }\end{array}$

A Southern variety of uncertain origin. It is extensively cultivated South, where it is counted as one of the most desirable and reliable apples. Tree a good, fair grower, with young shoots of a grayish brown, very productive.

Fruit medium, oblate, slightly conic, yellowish, striped and mostly shaded with red, thickly sprinkled with whitish and bronze lots. Stalk short and small, inserted in a broad cavity surrounded by russet. Car lyx partially closed. Basin slightly corrugated. Flesh yellow, very tender, juicy, mild subacid. Tery good to best. October, November.

\section{MIANK'S Codlin.}

Irish Pitcher.

Eve of Scotland.

\section{Frith Pitcher. \\ Frith Pipuin.}

Irish Codlin.

An old English culinary Apple, long cultivated and esteemed here as well as abroad for its productiveness, hardiness of tree, and early bearing habit.

Fruit medium, roundish oblong conical, one side of apex end higher than the other, clear pale yellow, with a bronzed cheek in sun. Flesh yellowish white, fine crisp, brisk subacid. Good. August to November.

\section{Minnington's Pearmaix.}

Origin, Sussex, England. A dessert fruit of considerable esteem abroad, and here fully sustains its foreign character. Tree hardy, and early bearer.

Fruit below medium, roundish conical, truncated, yellow, partially russeted, shaded and splashed with red, prominent, rongh, light gray dots. Flesh yellowish, crisp, tender, brisk subacid. Very Good. Core medium. October, December.

\section{MaNonet.}

Horse Block.

Manomet Sweet.

Origin, Plymouth, Mass. Tree vigorous and productive. Young shoots dark reddish brown. This is one of the finest of sweet apples, esteemed highly wherever grown.

Fruit medium, roundish oblate, fine yellow, with a richly shaded chcek. Stalk rather slenrler, inserterl in a shallow cavity, slightly surrounded by russet. Calyx closed. Basin shallow, corrugated. Flesh tender, juicy, swest, and rich. Very good. Core small. August, September.

\section{Missfield Risset.}

Brought into notice by Dr. Joseph Mansficld, of Groton, Mass. Tree vigocous, upright, and very productive. 
Fruit small, roundish oblong, inclining to conic, cinnamon russet. Stalk long, inserted in a deep furrowed carity. Calyx partially closed, set in an open basin. Flesh not very juicy, rich, aromatic, saccharine, vinous. Good to very good. Keeps till April or May.

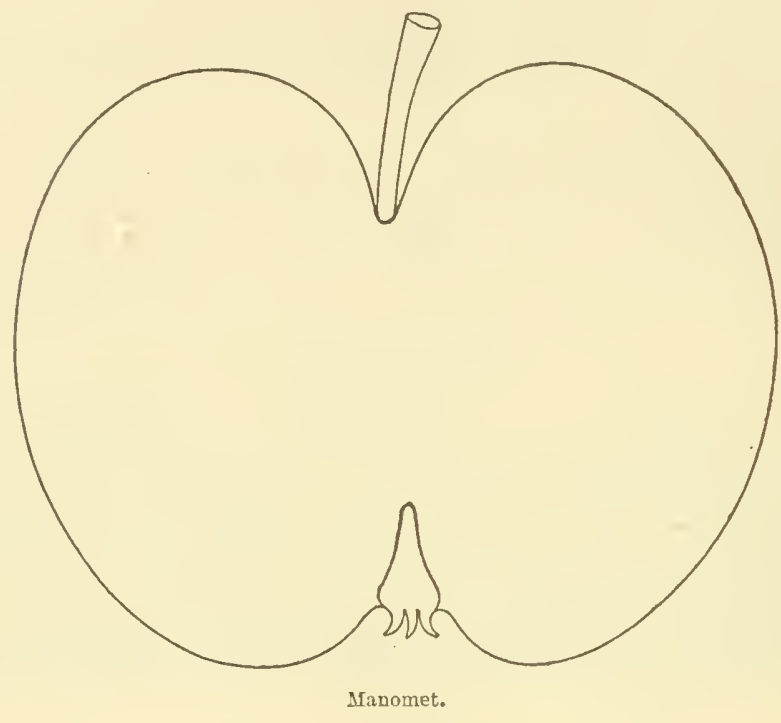

Marble Sweet.

Virginia Sweet.

McIntire's Sreeting.

Fruit medium to large, roundish orate, marbled dull red and yellow. Flesh sweet, dry. November, February. (Elliott.)

\section{March's Red Wixter. \\ March's Red Seedling.}

Origin, on the farm of George B. March, near Chillicothe, Ohio. Tree a moderate grower.

Fruit medium or below, roundish, yellow, overspread and shaded with rich bright red. Flesh yellowish, tender, moderately juicy, pleasant subacid. Good. November to January.

\section{MIARGIL。}

Neverfail.

Munche's Pippin.

An old English dessert Apple, of slender growth.

Fruit small, roundish oblate, yellow, striped with red. Flesh yel low, firm, aromatic. Goorl. October, November.

\section{Maria Bush.}

Origin, Lancaster, Co., Pa. A healthy grower and good bearer. 
Fruit large, roundish oblate, yellow, shaded, striped, and splashed with red, and thinly sprinkled with russet dots. Sten slender. Cavity large. Basin abrupt and open. Flesh white, very tender, juicy, subacid Good. October, November.

\section{MLARKs.}

Origin, Berks Co., Pa., on the lands of Mr. Klinger. Tree vigorous, upright, productive.

Fruit medium size, roundish, tapering slightly to the crown, yellowish white, with a few russet dots, and nearly covered with a faint orange blush. Flesh whitish, tender, brisk subacid. Good. Jannary to March. The fruit drops bally.

\section{Marmalade Pippin.}

\section{Althorp Pippin。 Welsh Pippin.}

This is an English Apple, from Derbyshire. Tree hardy, and profuse bearer.

Fruit medium to large, roundish obloug, truncated, yellowish, bronzed in the sun, numerous dots and some pearly white specks. Flesh yellowish white, firm, juicy, sweet. October to February. There is another apple under this name, which is striped with red and ripens in August.

\section{MARSILALL。}

Largely grown in some parts of New Hampshire, as a profitable market Apple, on account of its productiveness and very late keeping.

Fruit above medium, roundish, a little flattened, deep green, mostly overlaid with a fine thick sprinkling of whitish green specks, a little blush and crimson specks next the sun. April, May. (Me. Riep.)

\section{MLARshaLl's SWEet.}

Originated with S. B. Marshall, Ohio. Tree a moderate stocky grower, forming a round head.

Fruit medium or below, roundish oblate conic, sides unequal, yellow, splashed and striped with light and dark red. Flesh white, a littlo strined next the skin, tender, moderately juicy, pleasant, sweet. Good. November, December.

\section{Marstox's Red Wister.}

Origin, Grecnland, N. H. Tree hardy, of moderate growth. Toung slloots reddish brown, slightly downy. Great bearer, and keeps as well as Baldwin.

Fruit above medium size, roundish ennic. Stalk rather slender, in a narrow, deep, compressed, slightly russeter cavity - sometimes with a lip. Calyx partially closed. Segments long, in a deep eorrugated basin. Color whitish yellow, shaded and striperl with bright red and erimson, thickly sprinkled with minute dots. Flesh whitish yellow, rery juicy, tender, sprightly subacid. Good to very goot. December to Miarch. 


\section{Martin.} tive.

Origin, supposed Ohio. Tree thrifty, vigorous, spreading, produc-

Fruit medium to large, roundish oblate, yellow mixed and striped red. Stalk short. Flesh light yellow, rather tender, juicy, subacid, agreeable. Almost good. August, September. (Am. Hort. Au.)

\section{Martin Noxpareil.}

An English Apple. The tree a vigorous grower, hardy, and a good bearer.

Fruit small, roundish or roundish oblate, vellow, with many traces and patches of russet, and small gray and brown dots. Flesh yellow, complact, juicy, brisk, rich subacid. Very good. Core small. November to March. Too small for profit.

\section{MARY.}

Origin unknown.

Fruit below medium, roundish, yellow, overspread with light red, striped and splashed with erimson, few light dots. Stalk short, small. Calyx small, closed. Flesh whitish, rather firm, crisp, tolerably juicy, mild subacid, almost sweet. Good to rery good. Core small. January to March.

\section{Marylajd Beauty.}

Origin unknown.

Fruit medium, oblate, whitish shaded, splashed and marbled with light and dark red, light dots. Flesh whitish, rather coarse, tender, juicy, brisk subacid. Good. Core large. October, November.

\section{MASTEN.}

Masten's Seedling.

Originated on the farm of R. C. Masten, Pleasant Talley, Dutchess Co., N. Y. Tree vigorous, with a broad, spreading, well-formed head, productive. Young shoots grayish brown.

Fruit rather below medium, roundish conical, oily, yellow, brownish or faint blush in the sum, brown and light dots. Stalk short, small. Cavity narrow. Calyx closed. Basin small, uneven. Flesh whitish, fine-grained, rather juicy, pleasant subacid. Good. December to March.

\section{MAster's.}

\section{Master's Seediling.}

An old Kentish, England, Apple. Tree hardy, vigorous, and productive.

Fruit medium, round, yellowish green, red cheek in the sun. Flesh white, firm, acid. November, January. 
Matlock's Summer.

Fruit large, oblate, white, sometimes with a blush or indistinct splashes and stripes. Flesh tender, juicy, almost sweet. Good August.

\section{MIATson.}

Fruit large, red streaked, showy, acid, cooking. (A. Poin. S.)

\section{Matpanuskeet.}

Origin, Eastern Nortlı Carolina. Tree vigorous, productive. Young wood dull reddish brown, slightly downy.

Fruit medium, roundish oblate conic, yellow, shaded and splashed with light and dark red. Flesh whitish yellow, crisp, brisk subacid. Good. December to March. Valued principally for its keeping qualities.

\section{MAUCK.}

A Pennsylvania Apple.

Fruit large, conical, greenish yellow, blush in the sun. Flesh tender, pleasant. Good. Core large, hollow. October, November.

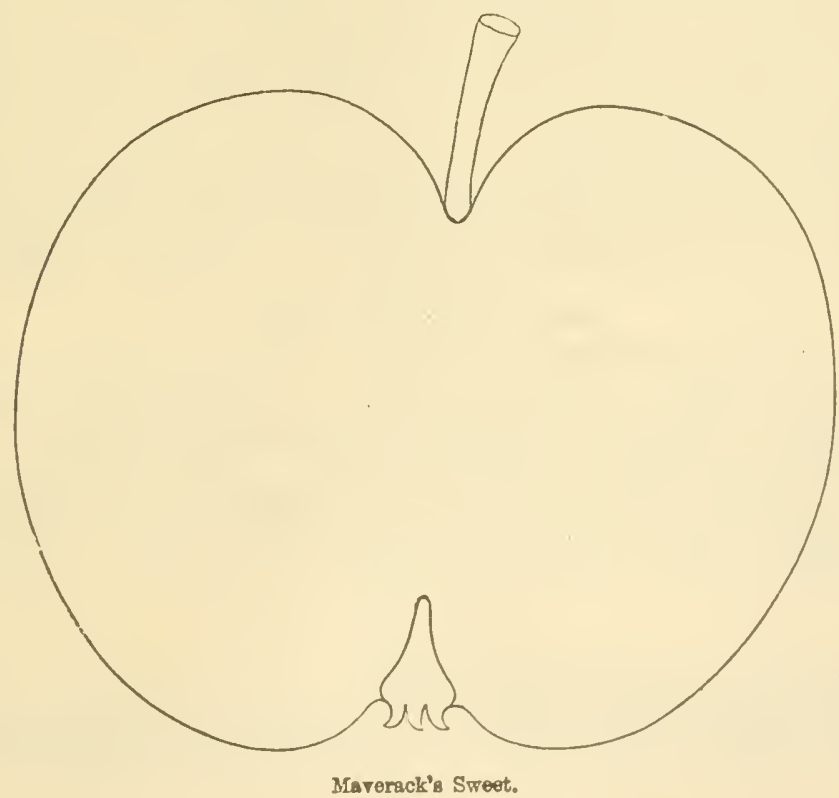

Maverack's SweEt.

Raised by Dr. Maverack, Pendleton District, S. C. Tree vigorous upright, spreading, sometimes irregular, an early and good bearer. Young shoots redelish gravish brown, slightly downy. 
Fruit large, roundish oblate, yellow, mostly shaded with rich deep red, and sprinkled with gray dots. Stalk short, inserted in an open cavity. Calyx open, set in a deep corrugated basin. Flesh yellowish, rather coarse-grained, breaking, tender, rich, sweet. Good to very good. Core small. November to February. A valuable sweet apple for market or cooking.

\section{MAxer.}

This variety we received from A. L. Woodson, Hart Co., Ky., by whom the tree is described as a good grower, an annual but not early bearer, producing fair, even-sized fruit, that keeps well into May and June.

Fruit above medium, roundish, approaching conical, light greenish ground, with broken red stripes and splashes, from the stem end, of pinkish red, light dots and indistinct dark specks. Stalk medium length and size. Cavity regular, round, smooth, lightly russeted. Calyx large, open, with divided recurved segments. Basin shallow, broad, regular. Flesh whitish, not very juicy or tender, subacid. Good. Core small. May to July.

$\begin{array}{lcc} & \text { MaY. } \\ \text { May Apple. } & \text { Pillkin. } & \text { Plymonth Greening. } \\ \text { Rhenish May. } & \text { Winter May. May of Myers. } & \text { May Seek-no-further of some. }\end{array}$

An old Apple, considerably grown at the West. Origin unknown. Its only value is because of its long keeping quality. Tree a poor grower, but a good bearer. Young shoots dark reddish brown, downy somewhat towards the end.

Fruit medinm, roundish conical, pale greenish yellow, slight brownish in sun. Flesh whitish, fine-grained, compact, not very juicy, mild subacid. Core rather large, and open. Good. February to June.

\section{May Seeik-xo-Farther.}

\section{Lop-sided Pearmain. Pilliken. Mray, erroneously.}

Origin unknown. Considerably grown in some parts of the West, and valued only because of its productiveness and long keeping.

Tree spreading, hardy, productire.

Fruit medium, oblate, oblique, dull greenish, mostly overspread and shaded with obscure stripes and marblings of dull dingy red. Flesh firm, dry, subacid. Good. February to May.

\section{MEACH.}

From J. M. Ketchum, Brandon, V't.

Fruit large, roundish, slightly conic, greenish yellow, striped and mottled with light red, and sprinkled with brown dots. Flesh yellowish, rather fine, juicy, mild subacid. Good. October, November.

\section{MEadow SweEt.}

Origin unknown.

Fruit medium, oblate or roundish oblate, pale yellow, gray and light slots. Flesh whitish, moderately tender and juicy, rather rich, sweet. Core smaall. Good. November, Febinary. 


\section{MEAR's SWEET. \\ Mear's Seedling.}

Origin, near Cineinnati, Olio.

Fruit below medium, roundish oblate, greenish yellow, brownish in the sum. Stalk long. Calyx closed. Flesh whitish, juicy, tender, mild, sweet subacid. Core sinall. Good. Jamuary to March.

\section{Meister.}

From Berks Co., Pa.

Size below medium, roundish conical, greenish yellow, striped with red, witl numerous white spots, and russet dots. Flesh tender, pleasant subacicl. Good. October.

\section{Melon.}

\section{Norton's Melon. Watermelon.}

Origin, East Bloomfield, N. Y. Tree of rather slow growth while young, a good bearer. Young shoots dull grayish redclish brown. One of the best and most valuable sorts for the dessert; a little too tender for shipping long distances.

Fruit medium or above. Form roundish oblate, slightly conic, obscure ribs towards apex. Color pale yellow, nearly covered with light

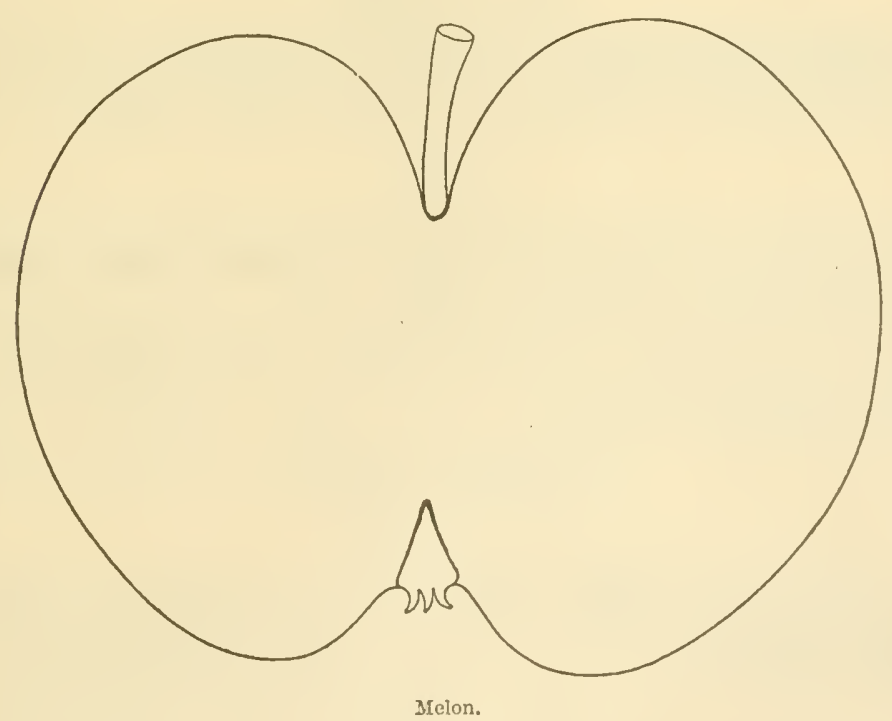

crimson, splashed, striped, and mottled witl carmine, some traces of russet, and moderately sprinkled with light and brown dots. Stalk medium, slender. Cavity large, deep, regular, often eonsiderably russeted. Calyx partially closed. Segments medium, erect, sumetimes a little re- 
"urved. Basin rather abrupt, slightly corrugated. Flesh white, very tender, juicy, refreshing, lively vinous subacid. Core small. Best November to March.

\section{MELrose.}

White Melrose.

An old Scotch Apple little known. Tree a strong, healthy grower and a free bearer.

Fruit large, roundish oblate conical, much ribbed toward the apex, pale yellow, becoming deeper in the sun, and at times many crimson spots. Flesh yellowish white, firm, sweet subacid. October, De. cember.

\section{MeLt in the Mouth.}

Origin, Chester Co., Pa. Tree moderately rigorous, spreading. Young shoots long, slender, dark reddish brown, downy at ends.

Fruit medium or rather below, roundish, slightly conic, deep red, splashed and marbled on a yellow ground, with a few small white dots. Stalk long, very slender, curved, in a small cavity. Calyx closed, in a rather abrupt basin. Flesh yellowish white, tender, juicy, with a mild, rather rich, pleasant subacid, somewhat resembling summer Pearmain. Very good. September to November.

\section{Melvin SweEt.}

Origin, Concord, Mass. Tree vigorous and productive.

Fruit medium, roundish, yellowish green, striped with pale red. Flesh rich and sugary. November to February. (Hov. Mag.)

\section{Menagère.}

We received this fruit from Mr. Manning, who, we believe, had it from Germany ; it is only fit for cooking.

Fruit very large, regularly formed, but verr much flattened, pale yellow, with sometimes a little red in the sun. Flesh tolerably juicy. Good. September to January

\section{Menonisten Reinette.}

\section{Reinette des Mrenonites.}

A German dessert Apple.

Fruit medium, roundish oblate, yellow, some russet, and a flush of red in the sun. Flesh tine, firm, juicy, aromatic, brisk subacid. No. vember, February.

\section{Mensfeld Calville.}

Calville d'Hiver de Mensfeld. Mensfelder Gulderling.

Mensfelder Winter Calville.

Originated in Mensfeld, in the Duchy of Warsaw. Tree a strong, rigorous grower, with long jointed branches. 
Fruit large, roumdish oblong, slightly ribbrd, yellowish green, with distinet small brown dots. Calyx large. Stalk short. Flesh half firm, rather tender, sutgary, vinous. Ciood for table or cooking. December to February. (Ver.)

\section{Merrer.}

Origin unknown. Specimens received from Western New York.

Fruit medium, roundish oblate, pale yellow, sprinkled with a few gray dots. Stalk rather short. Calyx closed. Flesh white, tender, juicy, crisp, pleasant subacid. Good. Core small. Oetober.

MÈre DE MÉNAGE.

Fruit very large, conical, yellow, overspread, shaded, and striped with red. Flesh firm, erisp, brisk, juicy, subacid. October, December. A very showy market Apple, and good for cooking.

\section{Merrill's.}

Merrill's Apple.

Origin, Smyrna, N. Y.

Fruit medium, roundish, yellow, with a briglt red cheek. Flesh yellow, rather firm, rich, spicy, subacid. Good. December to March.

\section{Merritt's Sweet.}

Fruit medium, oblate, yellow, sometimes with a blush. Flesh compact, rery sweet, good for culinary use and stock feeding. Good. Last of August. Productive.

\section{MERWIN.}

Fruit nedium to large, roundish oblate, pale yellow, faintly striped, splasherl, and shaded with red. Flesh yellowish, rather compact, moderately juicy, pleasant subacid. Good. December to March.

\section{MeTHodist.}

From Connecticut. Tree vigorous and productive, medium size, oblong oval, greenish, marbled and striped with red. Flesh white, tender, mild subacid, not rich. Good. November

\section{MEtoiríe.}

French Crab.

An old variety, of litle value. Tree of moderate growth, holding its fruit quite late in autumn.

Fruit medium, oblong, yellow, shaded over with red. Flesh juicy. Good flavor for baking.

\section{Mexico.}

Origin, Canterbury, Conn. Tree of moderate growth, productive, hardy. Young shoots dull grayish brown, downy. 
Fruit medium, roundish oblate, crimson, striped, splashed, and shaded with very dark red, a little yellow in the shade, with a few large light dots. Stalk medium length. Cavity broad, shallow, russeted. Calyx closed in a narrow basin. Flesh whitish, stained with red, tender, rather juicy, pleasant subacid. Good to very good. Core small. Septamber, October.

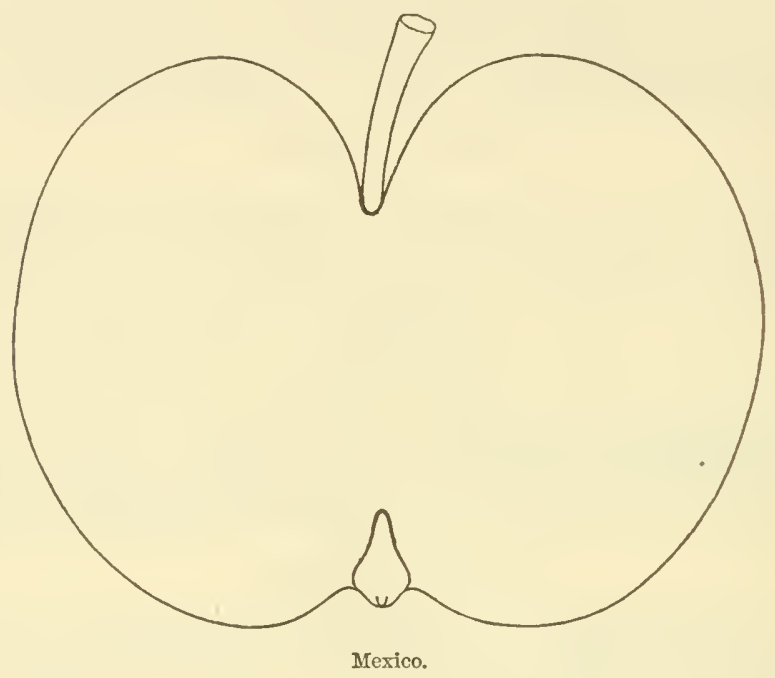

Michael Henry Pippin.

Rariton Sweet.

A New Jersey fruit, a native of Monmouth County, first described by Coxe. The tree forms a very upright head, with pretty strong șoots. Very productive.

Fruit of medium size, roundish oblong ovate, narrowing to the eye, when ripe, of a lively yellowish green. Stalk short and rather thick. Calyx set in a narrow basin. Flesh greenish white, very tender, juicy, mild tame sweet. Good. November to March.

\section{MidDle.}

\section{Mittel.}

Origin, Herkimer, N. Y. A moderate grower, not very productive.

Fruit medium or below, roundish oblong, inclining to conic, greenish yellow. Flesh white, tender, juicy, brisk, mild subacid. Good. December, February.

\section{Middlebourg Reinette.}

\section{Reinette de Middlebourg.}

A new variety, originating in Holland. Tree upright, productire. 
Fruit medium, roundish oblong, grecnish yellow, with many grayish spots. Calyx small, half closed. Stalk short. Flesh yellowish white, tine, firm, rather dry, subacid. December to March. (Ver.)

\section{Miffin King.}

Origin, farm of Mr. Koffinan, Miftlin Co., Pa.

Fruit small, oblate, whitish with a slight blush and a few gray dots. Stalk short, sniall. Calyx small, closed. Flesh white, crisp, tender, juicy, pleasant, lively subacid. Good. November and December.

\section{Mignonne D'Hiver.}

A new varietv, probably of French origin.

Fruit medium or below, oblate depressed, slightly conic, greenish yellow, with shade of rich bright red in the sun, few light and gray dots. Stalk short. Calyx nearly closed. Flesh whitish, rather firm, moderately juicy, mild, pleasant, almost sweet. December, February.

\section{MiLan.}

Harrigan. Winter Pearmain of some. Blair. Thomas. Rusty Coat Milam?

Origin uncertain, much grown in some sections at the West, very productive, and keeps well.

Fruit medium or below, roundish, greenish, shaded and striped with red. Flesh rather firm, pleasunt, subacid, not rich. Good. December, March.

\section{MILCH.}

Braunschweiger Milch.

Milch Apfel.

An extremely beautiful German Apple, recently introduced.

Fruit medium to large, roundish, waxy white, with crimson stripes and dots on the sunny side. Flesh white, tender, crisp, subacid. August.

\section{Miller.}

Origin, Berks Co., Pa. Tree moderately rigorous, very productive. Young shoots grayish dull redrlish brown, downy.

Fruit below medium, roundish oblate, whitish yellow, shaded, splashed, and striped with shades of rerl. Flesh white, sometimes stained with red next the skin, juicy, tenter, mild subacid. Goorl. Core large. September, November.

\section{Miller.}

Introrluced by James O. Miller, Montgomery, Orange Co., N. Y Tree vigorous and productive. Young wood smootl, light reddish brown.

Fruit rather large, roundish oblate, inclining to conic, yellow, sharler?, striped, and splashed with rich red, large light or areoledots. Situlk shorit. 
Cavity deep. Calyx large, partially closed. Basin deep, furrowed Flesh yellowish, tender, crisp, pleasant subacid. Good to rery good October, Norember.

\section{Minchall Crab.}

$\begin{array}{ll}\text { Minshul Crab. } & \text { Mincham's Crab. } \\ \text { Lazcashire Crab. } & \text { Lancaster Crab. }\end{array}$

An English Apple, valued mainly for cooking. Tree hardy, and abundant bearer.

Fruit above medium, roundish oblate, yellowish, with traces of misset, and sharles of red in the sun. Flesh white, crisp, juicy, brisk acid. November, February. (Ron.)

\section{Misier's Dumplixg.}

An English cooking Apple. 'Tree a strong grower and good bearer. Fruit large, roundish, slightly ribbed, greenish, with dull red in the sun. Flesh firm, juicy, subacid. Norember, February. (Lind.)

\section{Minister.}

A New England variety, introduced to notice by the late R. Manning. It originated on the farm of Mr. Saunders, Rowles, Mass. Tree moderately vigorous, upright spreading, very productive. Young shoots dark reddish brown.

Fruit large, oblong, tapering to the eye, around which are a few furrows-and resembling the Yellow Belle-Flenr in ontline. Skin striped and splasherl vear the stalk, with bright red on a greenish yellow ground. Stalk an inch loug, slender, curved to one side, and pretty deeply inserted. Calyx small, closed, inserted in a rery narrow plaited or furrowed basin. Flesh yellowish white, rery tender, with a somewhat acid, but very agreeable flaror. Good to very good. Core large and open. October to February.

\section{MINKLER.}

Brandywine?

This is an old variety which was first exhibited before the lllinois Horticultural Society, and because it could not be identified, received, for the time being, the name of its exhibitor. At some future time it will probably be found identical with some variety long since named and described. Tree an irregular grower, good bearer and keeper.

Fruit medium, roundish oblate, slightly conic, pale greenish yellow, striped and splashed with two shades of red. Flesh rellowish, compract, moderately juicy, mild, pleasant subacid. Good. Core small. Jannary to March.

\section{MishleR's SWEet.}

From Pennsylvania. Origin unknown. Tree vigorous and productive. Young shoots light reddish brown, somewhat downs.

Fruit large, roundish oblong ovate, greenish yellow few gray dots 
Flesh white, tender, juicy, mild, pleasant sweet. Good. Core large. October.

\section{MituHELSON.}

Mitchelson's Seedling.

An English Apple, described by Hogg as beatiful, and suitable for dessert or cooking.

Fruit above medium, roundish conical, deep yellow, slight patches and traces of russet, with a reddish cheek in the sun. Flesli yellowish, firm, crisp', brisk rich subacid. December, February.

\section{MoLAsses.}

Origin unknown. Tree upright, vigorous, and hardy.

Fruit medium, oblate. Skin thick, rough, greenish yellow, shaded with dull red, thickly covered with large crimuson or lilac dots, and dull lilac bloom. Flesh yellow and exceedingly sweet. January to April.

'There are, besides the above, three or four distinct apples under this name. One is claimed to have originated in Peunsylvanial.

Fruit medium, roundish, pale yellow, tinge of crimson in the sun. Flesh yellow, compact, not very juicy, sweet. Tree a sluw grower. October, November.

Elliott describes a Molasses, giving as synonyms, Priest's Sweet, Butter, Blue Siveet.

Fruit small, roundish, red. Flesh dry, sweet. October.

Another we have met is roundish conical, yellow, mostly shaded, splashed, and marbled with dark red. Flesh rich, sweet. Fine for cooking. None of this elass are valued, except for the purpose of cooking and feeding stock.

\section{Monarch.}

Monarch Sweet.

Origin unknown. Tree vigorous, a good and eariy bearer.

Fruit medium, roundish oblate, regular. Skin light red, splashed and striped with dark red, and numerous light dots. Flesh juicy, not very tender, but rich, pleasant subacid. Good. September, Oetober.

\section{Monkland Pippin.}

Fruit small, roundish, greenish yellow. Flesh greenish white, soft, coarse. Poor. November.

\section{MoNK's FaYorite.}

Origin, Indiana. Tree rigorous, upright sprearling.

Fruit large, roundish, yellowish, striped and splashed with red. Flesh yellowish white, tender, juicy, subacid. Good. November, Deeember.

\section{Monktor.}

A cider Apple from Somersetshire, England.

Fruit below medium, obkate, slightly ribled, clear red, with stripes of crimson. Flesh yellow, juicy, brisk acid. (Horgo.) 


\section{Monaouth Pippix.}

Red Cheek Pippin.

A native of Monmouth Co., N. J., of moderate upright growth, and productive. Young shoots dark olive.

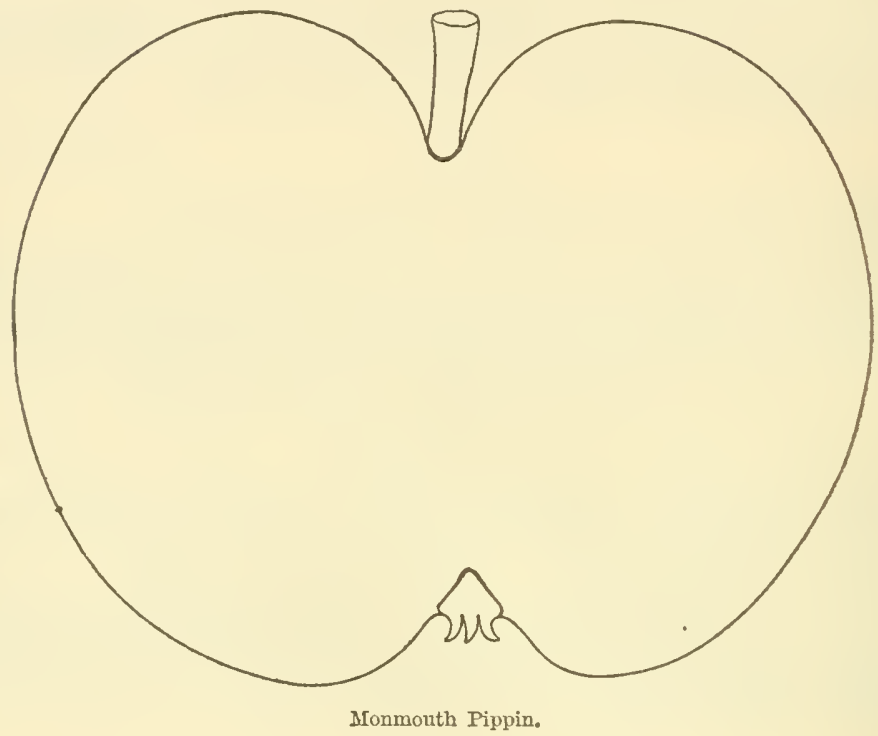

Fruit large, oblate, a little inclining to conic, obscurely five-angled, slightly flattened at base and crown. Color pale yellow, with a beautiful warm cheek, and numerous russet dots. Stalk rather short, inserted in a large, slightly russeted cavity. Calyx partially closed. Basin deep, abrupt, and corrugated. Flesh juicy, fine, brisk, aromatic subacid. Tery good to best. November to March.

\section{Monstrous Bellflower.}

An old variety, little grown. Tree a strong, irregular, rigorous grower, not profitable.

Fruit large, roundish oblong, ribbed, pale yellow blush in the sun. Flesh whitish, brisk, juicy, subacid. Good. Core large. October, Norember.

\section{Montalivet.}

Of French origim. Tree vigorous, upright spreading.

Fruit medium or below, roundish, deep rellow, with small russet dots. Flesh yellow, firm, juicy, pleasant subacid. Good. January, February. Core small. 


\section{MOORE.}

Moore's Seedling

A good culinary Apple.

Fruit large, roundish oblate conical, greenish yellow, with broken streaks of red. Flesh yellowish, tender, pleasantly sweet. Uctober, December. (Hogg.)

\section{Moore's Extra.}

Origin, Ohio. Tree vigorous, not an early but a good benrer.

Fruit medium to large, roundish, slightly conical, flattened at base. Color yellow, shaded, splashed, and striped with light and dark red, large light dots. Stalk short, small. Cavity narrow, deep. Calyx open. Segments short, erect, separated. Basin large, deep, irregular: Flesh vellow, tine-grained, juicy, tender, mild subacid. Core small. Very good. December, March.

\section{Moolre's Greening.}

Raised by R. Moore, of Southington, Conn. Very productive.

Fruit medium, globular, inclining to oblong or conic, greenish yellow, sometimes with a slight blush. Flesh white, juicy, tender, with a brisk, rinous Havor. Good. December, Marcl.

\section{Moore's S'WEET.}

Sweet Pippin.

Red Sweet Pippin.
Polhemus.

Pound Sweet of some.

Tree moderately vigorous, very productive. Although not a firstclass Apple, it is a very profitable and valuable one for all cooking or stock-feeding purposes.

Fruit medium, roundish oblate, dark dull red, with a slight bloom, small light-colored dots. Flesh yellowish, rich, pleasant sweet. Good. Core small. November to May.

\section{MIoorhex Pippin.}

An English dessert Apple, below medium size, roundish oblate, greenish, with splashes of red and rosset in sun. Flesh firm, rich, pleasant. January to April. (Ron.)

\section{MORELAND。}

Origin, Montgomery Co., Pa. Tree very productive.

Fruit medium, yellow, with a red cheek, plcasant acid. Good for cooking. October.

\section{Morgan White.}

Origin unknown.

Fruit large, globular, somewhat flattenerl, irregularly ribbed, uneven, grecnish, marked with gray stripes, rarely a fint blush. Dots white, large. Flesh greenish white, breaking, tender, juicy, acid to subacid. Good. September to January. (Warter.) 


\section{MTorrison's Red.}

Origin, supposerl to be a native of Medtield, Mass., on the farm of Mr. Fisher. Tree rigorous and productive. Young shoots dull grayist. brownish red, slightly downy.

Fruit medium, roundish conic, light yellow, shaded and obscurely striped with deep red. Stalk very short, stout. Carity small. Calyx closed, in a very small basin. Flesh tender, crisp, with a very mild, pleasant subacid. Very good. November to March.

\section{Morrison Sweet.}

Origin, Clinton Co., N. I. Tree small, hardy, round regular head, good bearer.

Frnit medium, roundish oblate, greenish, with slight blush in sun Flesh white, rather dry, sweet. Poor. October, November.

\section{Morris's Court of WICK.}

A variety esteemed in England, too small for Americans.

Fruit small, oblate, greenish, with light red in the sun. Flesh firm, tender, juicy, rich, vinous. October, January.

\section{Morris's Riusset.}

Origin, Brentford, England.

Fruit below medium, roundish, brownish russet, becoming ruddy in the sim. Flesh firm, tender, juicy, brisk, aromatic, subacid. October, February. (Hogg.)

\section{Mortos.}

\section{Morton's Seedling.}

Origin, supposed Clermont Co., Ohio. Tree vigorous, upright spreading, productive.

Fruit large, roundish, slightly oblate, greenish yellow, with a reddish blush in the sun. Flesh whitish, tender, juicy, mild, sweet subacid. Grood. November, December.

\section{Moses Wood.}

Origin, Winthrop, Maine. Tree vigorous and productive.

Fruit medium, roundish, yellow, striped with red. Cavity and basin shallow. Flesh white, tender, juicy, pleasant subacid. Good. Sentember, October.

\section{Moss's Ifcomiparable.}

Originated in England. Tree vigorous, productive.

Fruit large, roundish conical, golden yellow, washed with pale red, and splashed with bright red in the sun, nany small dark brown specks.

Stalk slender. Cavity large. Flesh yellowish white, tender, soft, aromatic subacid. January to February.

An apple of good promise. (An. Pon.) 
Motr's SWEET.

Originated on the property of L. S. Mote, Miami Co., Olio. A ralua. hle, but as yet comparatively new Apple. Tree vigorous, upright spreading, productive. Ioung shoots light reddish brown, downy.

Fruit large. Form romdish, somewhat romulish oblate conic. Color pale whitish yellow, with a tinge of red in the sum, and moderately sprinkled with gray dots. Stalk medimm, slender. Cavity large, deep. Calyx closed or partially open. Segments short, erect. Basin medimm, uneven. Flesh yellowish, tender, moderately juicy, rich honeyed sweet. Very good. Core small. September, October.

\section{MLOTHER.}

\section{Queen Anne,}

Gardener's Apple.

Origin, Bolton, Mass. Tree moderately vigorous, upright, and productive. Young shoots grayish brown, downy. One of the best of Apples for the dessert, rather too tender for shipment.

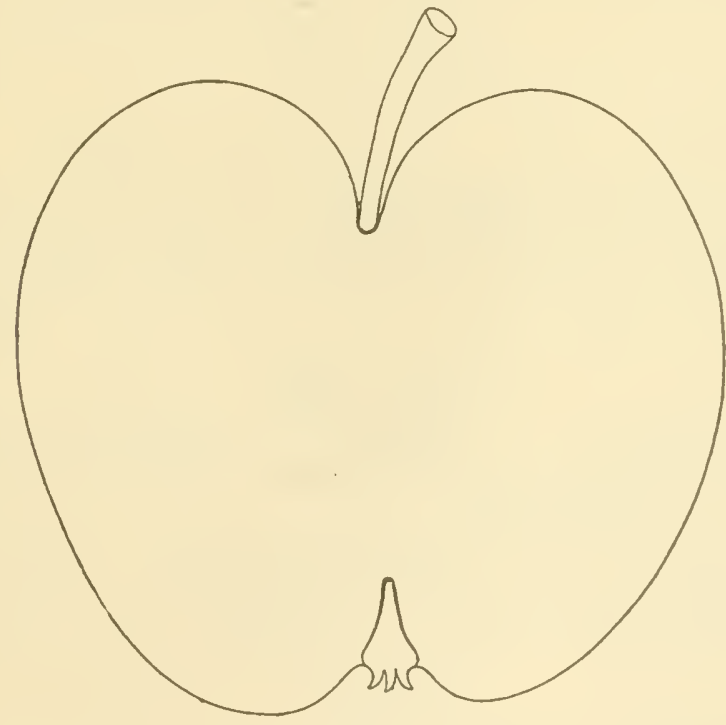

Mother.

Fruit medium. Form roundish, slightly conical. Color yellow, almost entirely orerspread with light, clear, rich red, splashod and marbled with many deeper shades, many minute light dots. Stalk short, small. Cavity acute, often a little russeted. Calyx closecl. Basin small, corrugated. Flesh yellow, tender, juicy, rich, aromatic subacid. liest. November, February. 
Mother Davis.

From Pennsylvania.

Fruit medium, roundish conical, whitish yellow, shaded and op. scurely splashed with light red, many small and large light dots Stalk short. Calyx small, closed. Flesh fine, yellowish, tender, juicy, sprightly, pleasant subacid. Good to very good. Core rather small. November, December.

\section{Mountain Belize.}

A native of Habersham Co., Ga.

Fruit medium to large, oblate conical, orange ground, shaded and striped with red. Stalk short. Cavity deep. Calyx medium. Flesh white, hard, juicy, tough, subacid. Good. November to May. (White.)

\section{Mountain Sweet.}

\section{Mountaineer.}

From Pennsylvania.

Fruit large, oblate, light yellow. Dots minute. Calyx small, closed Stalk short, slender. Flesh white, breaking, very tender, fine-grained, juicy, sweet. Good to very good. December. (Warder.)

\section{Mouse Apple.}

Moose Apple.

Origin, Ulster Co., N. Y. Tree vigorous and productive.

Fruit, in weight, light; in size, large, roundish, slightly conical, pals greenish yellow, with a brownish blush on one side, and a few scattered, russety gray dots. Flesh very white and fine-grained, moderately juicy, delicate, faintly perfumed, mild subacicl. Good. October, November.

\section{Munson Sweet.}
Orange Sweet.
Ray Apple.
Meachem Sweet.

Origin uncertain, probably Massachusetts. Tree vigorous, spreading, an annual and abundant bearer.

Fruit medium, oblate, pale yellow, sometimes with a blush. Stem short. Cavity large. Calyx closed. Basin small. Flesh yellowish, juicy, sweet. Good. September to February.

\section{Murphy.}

Raised by Mr. J). Murphy, of Salem, Mass. Tree moderate grower, spreading, tolerably productive.

Fruit pretty large, roundish, pale red, streaked with darker red, and mark od with blotches of the same color. Flesh white, tender, with an agreeable flavor. Good. Norember to February.

\section{Muscat Rennette. \\ Reinette Musquée.}

A new German Apple, said to be superior. 
Fruit medium, roundish conical, yellow, much striped with red. Flesh yellowish white, juicy, rich, aromatic, subacid. November tc March. (Iogg.)

\section{Muster.}

Origin unknown.

Fruit oblate, yellow, mostly covered with mixed red and splashes of crimson. Flesh yellow, fine-grained, tencier, juicy, subacid, aromatic Best. Core small. August and September. (Warder.)

\section{Naigle's Winter.}

Origin, Missomi. 'l'ree upright while young, becoming drooping when in fruil ; very productive.

Fruit medium, roundish, flattened at ends. Color a bright yellow, covered with two shades of red, many large yellow gray dots, light blue bloom. Calyx closed. Stalk short. Flesh white, crisp, tender, juicy, mild subacid. Core small. Very good. December, February. (Hort.)

\section{NAXNY.}

An English Apple, which Hogg describes as of excellent quality. Tree at morlerate grower and good bearer.

Fruit medium, roundish, yellow, striped and splashed with shades of deep red, russet dots. Flesh yellow, rather soft, juicy, subacil. October.

\section{Nantahlatee.}

\section{Maiden's Bosom.}

Originated in Macon Co., Ala. Tree a rapid grower, of rather a straggling, drooping habit. Young shoots dull grayish reddish brown.

Fruit medium, broad oblate conic, often contracted near the apex, ribbed, pale yellowish green, sprinkled with a few gray dots. Stalk medium. Cavity large, uneven. Calyx elosed. Segments rather long, a little recurved. Basin small, corrugated. Flesh white, tender, juicy, sprightly acid. Good. Core large. July, August.

\section{NECTAR.}

Origin, near Raleigh, N. C.

Fruit medium, oblate, green. Calyx closed. Stalk short. Flesh yellowish, juicy, rich, saccharine. August. (Gar, MIon.)

\section{NED. \\ Saylor. Libhart.}

Originated at Marietta, Pa. Tree vigorous, rather straggling, with slender shoots, dark redilish brown, slightly grayish, very productive.

Fruit medium, roundish oblate, slightly conic, yellow, shaded, striped, and splashed with two shades of dark rich red, and sprinkled with large light conspicuous dots. Stalk short, slender. Calyx large. Flesh white, tender, juicy, mild, pleasant subacid. Core small. Good to very good. December to February. 


\section{Needle.}

Supposed an old English Apple, not yet identified.

Fruil below medium, roundish oblate, greenish yellow, with small brown dots. Stalk short. Calyx closed. Flesh white, juicy, mild, pleasant subacid. Cor'e small. Good. December, January.

\section{Neisley Bellflower.}

Neasley Bellflower.

From Salem, Columbiana Co., O. Tree rather upright, vigorous.

Fruit medium to large, roundish oblate, pale whitish yellow, shaded, splashed, and striped with light and dark red, few light and gray dots. stalk short. Calyx open. Flesh yellowish, moderately juicy, mild subacid. Good. Core small and close. December to March.

\section{Nelsor.}

Origin unknown.

Fruit medium to large. Form roundislı oblate, regular. Color dull green, becoming yellow, sometimes bronzed with dull brown. Stalk rather long, slender. Cavity medium, acute, regular, green. Calvx medium, closed. Segments reflexed. Basin small, uneven. Flesh greenish yellow, firm, fine-grained, juicy, sweet. Core medium. Good. May to July. (Am. Jour. of Hort.)

\section{Nelison's Codlin.}

\section{Backhouse's Lord Nelson.}

A culinary English Apple.

Fruit large, roundish oblate, light yellow, deepening in the sun and with russet specks and traces. Flesh yellowish white, tender, brisk, sharp subacid. Good. October, November.

\section{Nequassa.}

\section{Nequassa Sweet.}

Origin, Franklin, Macon Co., N. C. Tree vigorous, upright.

Fruit large, oblate. Color yellow, striped with red. Stalk of moderate length, inserted in a large, open cavity. Basin smooth and open. Flesh white and very sweet. Good. November to January.

\section{Neversink,}

Origin, Berks Co., Pa. Tree vigorous, upright spreading.

Fruit large, roundish, inclining to conic, beantiful waxen orangeyellow color, with a few russet dots, and a delicately striped and richly mottled carmine cheek. Stalk short. Cavity narrow, acuminate, shallow. Calyx large. Basin deep, rather wide, furrowed. Flesh yellowish, somewhat tough, moderately juicy, subacid, quince-like. Good. December to March.

\section{NeWark King.}

\section{Hinckman.}

Origin, New Jersey. The tree is spreading, and bears well. 
Fruit medium, roumclish conieal, smooth, red, with a few yellow streaks and dots on a greenish ground. (alyx set in a narrow basin. Flesh tender, with a rather rich, pleasant flaror. Good. November to February.

\section{NewakK Pippix. \\ French Pippin. Tellow Pippin.}

A handsome and excellent early winter variety, easily known by the crooked, irregular growth of the tree, and the drooping habit of the branches. Not profitable. Young sloots slencter, dull brownish red, smooth.

Fruit rather large, roundish oblong, regularly formed, greenish rellow, becoming a fine vellow when fully rije, with elusters of small black dots, and rarely a very faint blush. Calyx in a regular and rather decp basin. Stalk moderately long, and deeply inserted. F'lesh yellow, tender, very rich, juicy, and high flavored. Trery good. November to February.

\section{Newburx. \\ Cat's Head.}

Origin uncertain.

Fruit large, oblong conic, greenish, with a brownish cheek in the sun. Stalk short. Calyx small. Flesh greenish, coarse. Core large. Poor. December, February.

\section{New Late Reinette.}

\section{Reinette Tardive Nonvelle.}

Fruit medium, roundish oblate, rellow, striped, splashed, and veined with redclish brown and shaded with gray. Calyx half closed. Flesh yellowish, fine, tender, juicy, agreeable, aromatic, subacid. April to June. (Alb. Pom.)

\section{From England.}

\section{New Rock Pippis.}

Fruit below medium, dull green, becoming brownish in the sun, slight tinge of red and considerable russet. Flesh yellow, firm, rich, sweet. Good. November to February.

\section{New Suall Lemox Pippin.} ductive.

An old English Apple, described by Ronalds. Tree hardy and pro-

Fruit below medium, roundish oblong, clear yellow, with many small red dots. Flesh whitish, firm, juicy, pleasant sublacid. Good. November, December.

\section{Newtowy Spitzesiburgir.}

$\begin{array}{ll}\text { Vandevere of New York. } & \text { Spitzenburgh. } \\ \text { Ox Eye. } & \text { Kurlington. } \\ \text { Matchless. } & \text { Kountz. } \\ \text { Joe Berry. } & \text { Barrett's Spitzenburgh. } \\ \text { Spiced Ox Eye. } & \text { Winc, crroncously. }\end{array}$

This old and raluable A pple las heen long known in New Tork as the Vandevere, but as it was first described by ('oxe as Newtown Spit. 
Lenburgh, we continue that name. It had its origin in Newtown, Long Island. Tre'e moderate, vigorous, spreading, and productive in rich, light soil, of most excellent fruit, which is suited to more tastes than any other Apple of its season.

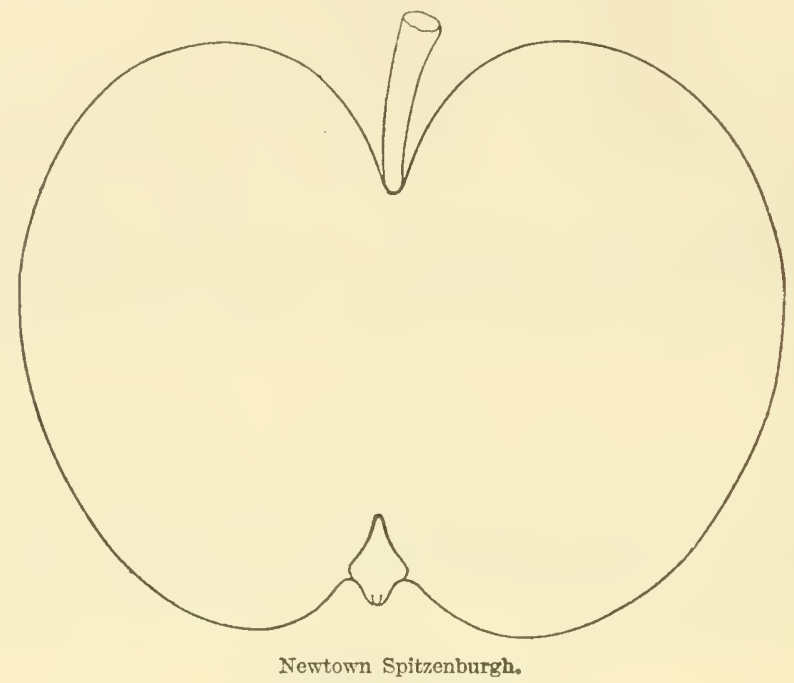

Fruit medium, oblate, slightly conic, fine yellow, washed with light red, striped and splashed with deeper red, and richly shaded with car. mine on the sumny side, covered with a light bloom, and sprinkled with peculiar gray specks. Stalk short, inserted in a wide cavity. Calyx small, closed, set in a regular basin of moderate depth. Flesh yellow, crisp, tender, with a rich, sprightly, vinous flavor, scarcely subacicl. Best. October to February.

\section{Nichols Sweet.}

Origin unknown.

Fruit medium, roundish, slightly conic, yellow, shaded and faintly splashed with red, few light dots. Flesh whitish, compact, moderately juicy, sweet. Good cooking. Core small. December, January.

\section{NICKAJACK.}

Caroline.

Berry.

Summeromi,

Accidental.

Red Pippin.

Howard.

Hubbard.

Mobbs.

Cheataw.

Fdward Shantee.

Pound.

Wall.

$\begin{array}{ll}\text { Aberdeen. } & \text { Alleghany. } \\ \text { Trenham } & \text { Chaltram Pippin. } \\ \text { Big Hill. } & \text { Gowden. } \\ \text { Carolina Spice, } & \text { Graham's Red Wa } \\ \text { Cheatan Pippin. } & \text { Walb. } \\ \text { Chatham Pippin. } & \text { Winter Horse. } \\ \text { Winter Rose. } & \text { Missouri Pippin. } \\ \text { Red Hazel. } & \text { Nissour Red. } \\ \text { Wander. } & \text { Leanham. } \\ \text { Red Warrior, erroneously } & \text { Winter Horse. } \\ \text { Forsythe's Seedling. } & \text { Tackson Red. } \\ \text { Ruckman's Red. } & \text { World's Wonder. }\end{array}$

This Apple is very widely disseminated in sections of the South and 
Southwest, it having as it were the halbit of reproducing itself from seed, or at least so nearly identical as to be impossible to distinguish the seedling from the parent, hence one cause of so many symonyms. The first dissemination of it known was by a Colonel Summerour, of lineoln Comnty, N. C., under the name of Winter liose; but as it was founcl on Nickajack Creek, it soon took that name, and is now best known thereby. The habit of the tree is upright spremling, forming a very large head. On branches two, three, or fonr years old, there are woody knobs or warts of various sizes, which, when cut from the branch, are found to contain kernels entirely detached fiom the regular grain of the wood. The grent ralue of the variety consists in the hardihood and productiveness of the tree rather than the elazacter of the fruit, which is not more than good in quality. Young shoots bright clear dark reddish.

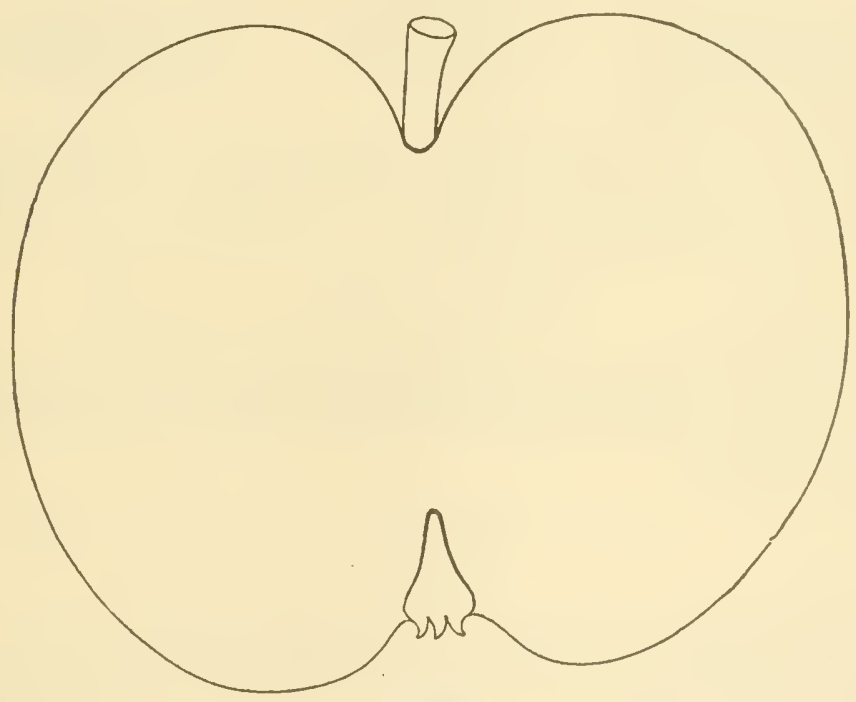

Nickajack.

Fruit large. Form roundish to roundish oblate, slightly eonic, some. times oblique. Coior yellowish, striped, shaded, and splashed with two slades of red, and with a grayish appentance, as if eovered with a thin bloom, many large areole clots. Stalk short. Cavity large, medium deptl. Calyx partially open. Basin medium, slightly corvugated. Flesh yellowish, compract, moderately tender and juicy, negative subacid. Good. Core small, closed. December to A rril.

\section{Niemax's Ris Reinette.}

Nieman's Rothe Reinette. Reinette Rouge de Nieman.

Originated at Hanover, Germany. Tree a strong, vigorous grower. Fruit medium, roundish conical, ycllow, mostly overspread and splashed with red. Stalk short. Calyx open. Flesh white, tender, juicy, vinous, subacid. November, February. (Verg.) 


\section{Nix Grees.}

Queen Apple, erroneously.

Origin, Habersham Co., Ga. Tree profuse bearer.

Fruit medium, oblate roundish, greenish yellow, with many light dots. Stalk short. Calyx small, closed. Flesh white, firm, tender, pleasant subacid. Good. November, February.

\section{Noblesse de Gand.}

An English sauce Apple, described by Ronald as large, roundish, slightly conical, straw-colored. Flesh firm, heary, brisk subacid. January, February.

\section{Nonpareit.}

English Nonpareil.

Hunt's Nonpareil.

Nonpareil d'Angleterre.
Old Nonpareil. Loveden's Pippin. Duc d'Arsel.
Original Nonpareil. Tieinette Nonpareil. Grune Reinette.

An old English variety. Tree free upright grower, productive.

Fruit medium, roundish conical, yellowish green, with patches of dull russet, and red in the sum. Flesh crisp, juicy, vinous, aromatic, mild acid. Goor. December, March.

\section{Nonpareil Russet.}

Of English origin. Tree vigorous, spreading, productıve.

Fruit small, roundish oblate, conical, greenish yellow, covered with thin dull russet. Flesh white, crisp, juicy, sprightly subacid. Good. Jannary to May.

\section{Nonsucir.}

Nonsuch.

An old English sort, valuable as a sance Apple; productive.

Fruit of medium size, regular form. flat, greenish vellow, striped and spotted with dull brick red. Flesh white, soft, with a plentiful subacid juice. Grood. September, November.

\section{NorFolk.}

From Massachusetts.

Fruit small, flat, yellow, pleasant. August. (Cole.)

\section{Norfolk Beaufix.}

Read's Baker. Catshead Beaufin. Norfolk Beefing.

A large English fruit, only fit for cooking purposes, dull red, on greenish ground. Flesh firm, subacid. Good. January to May.

\section{Norfot:k Paradise.}

An English dessert Apple.

Fruit medium, oblong, greenish yellow, brownish red in sun, will 
stripes. Flesh white, furm, juicy, rich subacid. Oetober to Fubruary (Lindley.)

\section{Nonfolk Stone Pipers.}

Stone Pippin. White Stone Pippin. White Pippin.

A valuable long-keeping cooking fruit. Tree a free grower and abundant bearer.

Fruit below medium, roundish, yollowish green, slight tinge of rea in the sun. Flesh white, firm, brisk, rich, sweet. November to March.

\section{Norfolk Storing.}

An English Apple, valuabie for market or cooking.

Fruit large, roundish oblate, yellowish green, with yellow red cheek in the sun. Flesh white, tender, juicy, crisp, brisk subacid. Novem. ber, January.

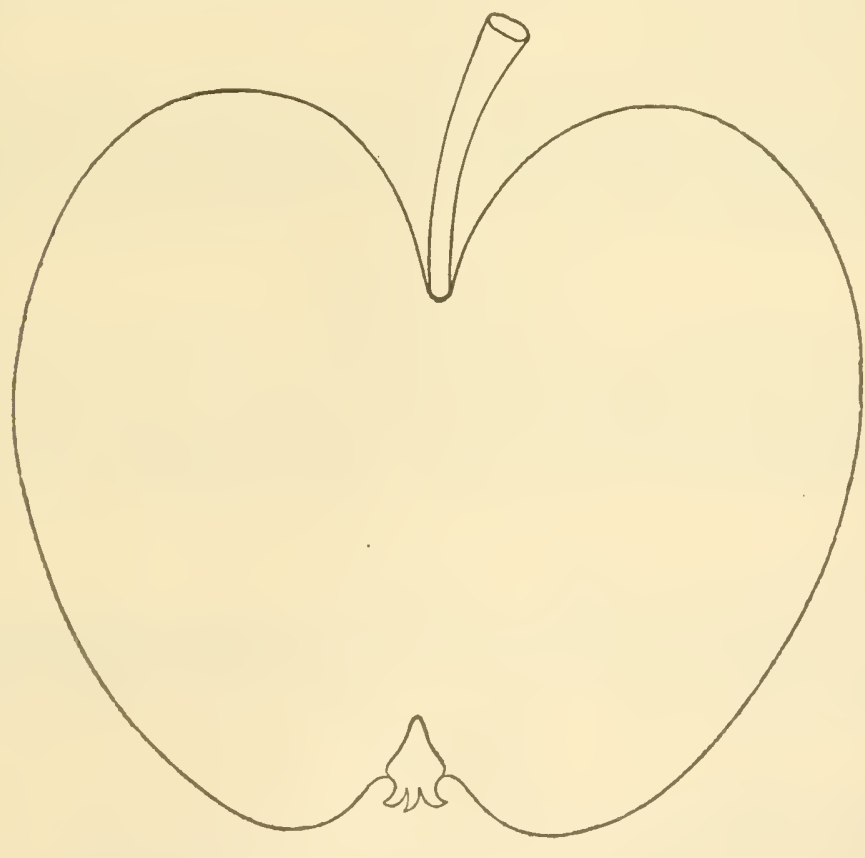

Northern Spy.

\section{Northery Sipy.}

This beautiful American fruit is one of the most delicions, fragrant, and sprightly of all late dessert apples. It ripens in .January, keeps till June, and always commands the lighest market price. The tree is of rapid, upright growth, and bears moderate crops. It originated on the 
farm of Heman Chapin, of East Bloomfield, near Rochester, N. Y. The trees require high culture, and open heads to let in the sun, otherwise the fruit is wanting in flavor, and apt to be imperfect and knotty. Young shoots dark reddish brown. The tree blooms late, often escaping rernal frosts.

Fruit large, roundish oblate conical. Skin thin, smooth, in the shade greenish or pale yellow, in the sun covered with light and dark stripes of purplish red, marked with a few pale dots, and a thin white bloom. Stalk three-fourths of an inch long, rather slender, planted in a very wide, deep cavity, sometimes marked with russet. Calyx small, closed. Basin narrow, abrupt, furrowed. Flesh white, fine-grained, tender, slightly subacid, with a peculiarly fresh and delicious flavor. Core large and open. Tery good to best. December to June.

\section{Northers SweET.}

Northern Golden Sweet.

Golden Sweet.

Origin, on the farm of the late Nathan Lockwood, of St. George, Chittenden Co., Vt. Tree healthy, spreading, and productive, but needs high culture for the perfect development of the whole crop. Toung wood reddish, smooth.

Fruit medium, roundish oblate, yellow, sometimes with a blush. Stalk rather long, in a moderate cavity. Calyx small and closed, in a narrow, abrupt, corrugated basin. Flesh wbite, tender, juicy, sweet, rich, and excellent. Core medium. September, October. Not profitable.

\section{Northfield Beauty.}

Origin unknown. Tree a vigorous grower. Young shoots rick reddish brown, with few prominent dots.

Fruit large, roundish oblate. Sides mequal, whitish yellow, with stripes, shades, and splashes in the sun. Flesh white, crisp, brisk subacid. Core small. Good for cooking. August, September.

\section{Nottingham Pippin.}

Tree vigorous, productive.

Fruit medium, roundish oblate, yellow, with slight markings of russet. Flesh white, warrowy, sugary, vinous. Norember to February. (Hogg.)

\section{Nursery.}

Origin unknown.

Fruit below medium, roundish, inclining to conic, greenish yellow, slight blush or brown in the sun, gray dots. Stalk short, slender. Catlyx closed. Basin slightly corrugated. Flesh yellowish, compact, moderately juicy, mild subacid, almost sweet. Core small. Good. Decem. ber to February.

\section{OAKES.}

From Danvers, Mass. Origin unknown. Tree a strong, vigorous grower, and fair bearer. Young shoots clear reddish, smooth. 
Fruit medium, roundish oblate, greenish yellow, with a shacle of red in the sun, few gray dots. Stalk short, slender. Calyx elosed. Flesh yellow, juicy, temler, pleasant subacid. Core small. Good te very good. November, Jamiary.

There is an English eulinary Apple of this name described by Lindley, which is medium, roundish, with ribs, pale sreen, with broken streaks of pale brown, and russety specks. Flesh soft, greenish white, slightly sweet. Norember, December.

\section{Oconee Greening.}

Origin, banks of the Oconee river, a little below Athens, Ga. Tree vigorous and abundant bearer.

Fruit large, roundish flattened, yellow, a little brownish in the sun, russet about the stem, with a few scattered russet dots. Calyx open, in a shallow, slightly furowed basin. Stalk very short, in a rather regular, decp cavity. Flesh yellowish, fine-grained, crisp, abounding in a delightful aromatic, lively, subacid juice. Good to very good. October, November.

\section{OFINE.}

Of English origin. Tree vigorous, prodnctive.

Fruit large, roundish oblate conical. Skin oily. Color lemon yellow, washed and splashed with red in the sun, many large reddish gray spots. Stalk large, short. Calyx open. Flesh white, firm, tender, sweet subacid, aromatic. November. (An Pom.)

\section{Ogdexsburgh.}

Originated with A. B. James, Ogdensburgh, N. Y.

Fruit medium, roundish oblate conic, whitish yeilow, brownish red in sun, few light and brown dots. Flesh white, juicy, tender, very mild subacid. Very good. Core medium. New. November, Decembel. (Elliott's Notes.)

\section{OGLEBY.}

From Spottsylvania Co, Va. Tree a rapid grower.

Funit below medium, roundish oblate, yellow, sometimes a slight blush in sum, with gray and green dots. Flesh yellowish, compact, crisp, juicy subacid. Grood. October, November.

\section{Onio Noxpareit.}

Myer's Nonpareil.

Western Beauty, erroneously.

\section{Cattell Apple.}

Rusty Core.

This is one of the most valuable of autumn Apples, whether for market or table use. Its origin is in doubt, the first known trees of it being in the orchard of - Bowman, Massillon, Ohio. The young trees are very vigorous, with stout, straight shoots, while the orchard trees are very wide, regular, open, spreading, requiring little or no thinning, and bearing the fruit evenly ovor the whole tree, and all fair sized, smooth frult. Young shoots smooth, rich, dark reddish brown. 
Fruit medium to large. Form roundish oblate. Color yellow, shaded, marbled, and splashed with two shades of rich red, thinly sprinkled with light and gray dots. Stalk medium, rather slender. Cavity large, deep, regular. Calyx rather large, partially open. Segments rather short. Basin medium. Flesh yellowish white, fine-grained, tender, juicy, rich. slightly aromatic subacid. Core small. Very good. October, Noven ber".

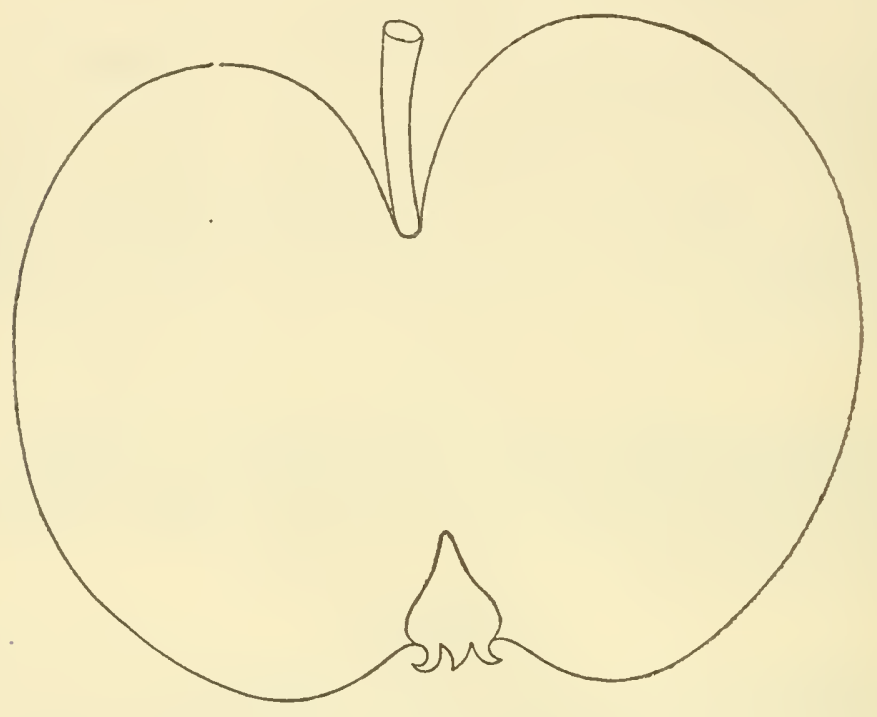

Ohio Nonpareil.

Оніо Pippis.

Ernst's Pippin.

Shannon.

Origin in doubt. Supposed Dayton, Ohin. It was first disseminated by the late A. H. Ernst, of Cincinnati. Tree healthy, vigorous, spreading, moderately productive. Toung shoots strong, dull reddish brown, quite downy.

Fruit large, roundish oblate, yellow, with mottled red in the sun. Flesh yellowish, moderately juicy, pleasant, sharp subacid. Good. Core small. November, January.

\section{Ohio Red Streak.}

Originated with James Mansfield, Jefferson Co., O. Giowth vigor ous, upright.

Fruit medium, oblate, yellow, shaded, splasher, and striped with red. Stalk short. Cavity large, russetea. Calyx large, closed. Basin shallow, uneven. Flesh rather compact, juicy, rich subacid. Good. January to A pril. 


\section{OHLIXiger.}

Origin, Pennsylvania, Berks County.

Fruit below medium, yellow, with a brownish check, with many areole specks. Flesh yellowish white, tender, subacid. Good. October:

\section{Old English Codlin.}

\section{English Codlin. Trenton Early?}

The trees are very vigorous and fruitful. A large and fair cooking Apple, in use from July to November.

Fruit generally above nedium size, oblong or conical, and a little irregular, clear lemon yellow, with a faint blush next the sun. Stalk stont and short. Flesh white, tender, and of a rather pleasant subacid. Much esteemed for cooking, ripens gralually upon the tree.

\section{Old Field.}

Origin, Connecticut. A good grower, bears well, an old variety.

Fruit medium, oblate conic, yellow, with a slight blush. Flesh yellowish, tender, pleasant, mild subacid. Good. January to April.

\section{Old House.}

Origin, Bucks Co., Pa. Tree vigorous, upright.

Fruit medium, oblate, inclining to ob.-conic, yellow, with a blush. Flesh tender, fine texture, juicy, flavor agreeable, aromatic. Good. December.

\section{Old Hundred.}

Origin unknown. Specimens received from J. W. Manning, Reading, Mass. Tree upright grower and good bearer.

Fruit medium, roundish oblate conic, yellowish, striped, splasherl, and marbled with shades of red. Flesh whitish, crisp, tender, juicy, sprightly subacid. Good. November to February.

\section{Old Royal Russet.}

Leather Coat Russet.

Fruit medium, roundish, gray russet on green. Flesh greenish white, sharp subacid. November, February. (Elliott.)

\section{Old Town Crab.}

\section{Spice Apple of some}

Fruit small, greenish yellow, with brown specks. Flesh crisp, juicr, sweet. December, March.

\section{Old Town Pippis.}

Of unknown orïgin.

Fruit above medium, roundish ollate, light yellow, shaded and splashed with red, few brown dots. Elesh yellowish, firm, not rery juicy, pleasant subacid. Good. Cooking. January to March. 
OLINE.

Tree vigorous, productive.

Fruit very large, roundish, yellow, washed with red. Flesh tender, fine, subacid. Very good. November, December. (Soc. V. M.)

\section{Olive.}

Origin, Wake Co., N. C. Tree vigorous, upright grower.

Fruit medium, slightly conical, crimson, with gray dots. Calyx open. Stalk long, stout. Flesh erisp, juiev, subacid. October, 广ovember.

There is another Olive Apple, from Vermont, which is medium, oblate, inclining to conic, yellowish, shaded, splashed, and striped with shades of red, few areole dots. Stalk short. Calyx closed. Flesh white, tender, juicy, mild subacid. November to January. (Gar. Mon.)

\section{Omar Pasma.}

An English cooking Apple.

Fruit above medium, roundish oblate, deep yellow, dotted with russet. Calyx open. Stalk short. Flesh white, firm, crisp, juicy, pleasant acid. December to Mareh.

\section{ORANGe.}

There are several Apples under this name; but as it is almost impossible to decide which has prior right to the name, we enumerate and describe in the order they are known to us.

The Oraxge of New Jersey origin is a vigorous grower, and moderately productive. Young shoots clear, reddish brown, buds reddish, prominent.

Fruit above medium, roundish oblate. Skin orange vellow, with a few gray dots, and sometimes patches of russet. Stalk short, in a large cavity. Calyx closed. Basin moderate. Flesh yellow, juicy, subacid, pleasint. Very good. September, October.

The Orange of Readiug, Pa., has fruit roundish, slightlr oblate, faintly ribbed, of a warm yellow orange color. Flesh yellowish, sprightly. Good.

The Orange of France, received from A. Leroy, Angers, is of medium size, rounclish, fine yellow, shaded with crimson in the sun, moderately sprinkled with gray and light dots. Stalk short. Calyx small, closed. Flesh white, tender, juicy, mild, pleasant subacid. Good. October, November.

\section{Orange Pippin.}

Marigold Pippin.

Isle of Wight Orange. fruit.

An old Apple, originated in Normandy, and ralued mainly as a cider

Fruit medium, roundish, rich orange yellow. Flesh firm, crisp, pleasant acid. October to January.

There is also an Orange Pippin grown in New Jersey differing from this, but we have been unable to obtain its history or description. 


\section{Orange Sweet.}

There are several rarieties under this name, but we have heen unable to examine and compare them elosely. The one we have most known came from (thio, and has young shoots of a light roddish brown, smooth, the fruit linge, roumlish, greenish yollow, sometimes traces of russet, few gray and green dots. Calyx small, closed. Flesh whitish, tender, juicy, pleasant, sweet. Good. Valuable for baking. Octolser, November.

Another we have from Massachusetts, is a good grower and bearer. Yommg shoots smooth, very dark reddish brown. Buds very small.

Fruit medium, oblate, greenish yellow. Calyx small. Flesh vellowish white, ratler coarse, but rich, sweet. Good for cooking. August and september.

Another Orange Sweeting, grown in Maine, is deseribed as a tree of upright liabit, healthy, thrifty, and productive. Young shoots dark brownish red.

Fruit medium, roundish ovate, bright yellow, with a blush cheek in the sun, small greenish dots in shade, and crimson dots in the sun. Flesh yellowish, tender, sweet, and rich. Suptember, October.

Warder, in his American Pomology, describes an Oronge Sweet or Russet as large, round, greenish yellow, bronzy orange russet. Flesh green, rather tough, tine-grained, sweet. Good for baking. December.

\section{ORD.}

\section{Ord's Apple. Simpson's Pippin. Simpson's Seedling,}

An English Apple, grown from a seed of the Newtown Pippin.

Fruit medimm, oblong conical, somewhat ribbed, dull green, washed and splashed with dull red, and many star-like russet specks. Flesh greenish white, tender, crisp, brisk subacid. December to April.

\section{Orleaxs Reinette.}

\section{Reinette d'Orleans.}

Fruit large, roundish oblong, deep yellow, with stripes of bright red in the sun. Flesh yellowish, fine, juicy, brisk acid. December.

\section{ORNDORF.}

Origin, Muskingum Co., O. Tree a vigorous, spreading, upright grower, productive.

Eluit medium, roundish oblate, yellow, shaded, striped, and splasleed with two shades of red. Stalk short. Calrx small, closmel. Flesh whitish, tender, mild subacid. Good. Core small. Oetober, Norenber.

\section{ORNE'S EARLY.} ing.

Origin unknown, supposed foreign. Tree vigorous, upright spread-

Fruit medium, roundish. Color whitish, thickly sprinklerl with gray and light dots. Stalk long and slender. Calyx small, elosed. Flesil white, tender, fine-grained, moderately juicy, pleasant, sprightly sul. acid. Good. Core small. August, September. 


\section{Ortley.}

Ortley Pippin.

Woolman's Long.

Greasy Pippin.

White Bellefleur.

Van Dyne.

Nelting Pippin.

Yellow Pippin.

Woodward's Pippin.
White Bellflower.

White Detroit.

Hollow Cored Pippin.

Green Bellflower

Jersey Greening.

Crane's Pippin.

Inman.

Davis W'hite Belltlower. Irarrow Pippin.

Ohio Favorite.

Willow Leaf Pippin.

White Pippin.

Detroit.

Davis.

Warren Pippin.

Golden Pippin.

Thite Seek-no-Further. Tod's Golden Pippin.

Origin, orchard of Michael Ortley, South Jersey. It grows pretty strongly, with upright slender shoots, and bears abundantly.

Fruit medium to large, roundish oblong conic, greenish rellow, becoming fine yellow at maturity, sometimes with a sunny cheek. Stalk slender, of medium length, inserted in a deep, acute cavity, smounded by l'usset. Calyx closed, set in an abrupt, somewhat corrugated basin. Flesh white, fine-grained, tender, juicy subacid, very pleasant. Good to very good. Core large. November to F€bruars.

\section{OSCEOLA.}

Origin, Putnam Co., Ind. Tree vigorous, upright spreading. Young shoots dark reddish brown, grayish.

Fruit medium, roundish oblate conic, sides unequal, pale yellow, shaded, splashed, and striped with red, large light dots. Stalk short. Cavity slightly russeted. Calyx closed. Basin deep, uneven. Flesh whitish, firm, juicy, pleasant, mild subacid. Good to very good. January to March.

\section{OSKaLOOSA. \\ Jack Apple.}

Origin unknown. Tree a moderate grower, forming a handsome head, an early but not an abundant bearer.

Frnit medium, round, somewhat Hattened, yellow. Flesh juicy, mild subacid. November. (Gard. MIonth.)

\section{OSLIN.}

\section{White Oslin. Arbroath Pippin.}

An excellent Scotch Apple. Tree rigorous and productire.

Fruit below medium size. Form oblate. Skin rather tough, clear lemon yellow when quite xije, and sprinkled with a few grayish green dots. Flesh yellowish, firm, crisp, juicy, spicy aromatic. Good. September.

\section{Osxabrucker ReinetTe.}

\section{Reinette d'Osnabruck. Grau Osnabrucker Reinette.}

A foreign variety, not apparently of much value.

Fruit small, roundish, rich rellow ground, somewhat russeted, with a red cheek in sun. Stalk long, slender. Calyx large. Flesh white, fine, juicy, perfumed. Very good. December, February. (Ter.) 


\section{Osterley.}

Osterley Pippin.

A seedling of the Ribston Pippin, from Middlesex, Fngland, describer by Ronalds as a free grower and good bearer.

Fruit below medium, romelish oblate, dull green, with thin russet and red in the sum. Flesh greenish yellow, firm, erisp, juicy, brisk, aromatic, sharp subacid. November to February.

\section{Ostogate.}

Supposed French origin. Tree vigorous and productive.

Fruit medium, roundish oblite, yellow, with many gray russet dots. Stalk slender. Civity narrow, deep. Calyx open. Elesh whitish yellow, fine, aromatic, sweet subacid. November. (An. Pom.)

\section{OVERMLAN's SwEeT.}

Origin, Tllinois. Tree laardy, spreading, productive.

Fruit medium, roundish oblate conical, yellowish, shaded, mottled, and splashed with red, many light aud gray dots. Stalk short. Calyx closed. Flesh whitish, not very tender, moderately juicy, mild, sweet. Core small. Good. Norember, March.

\section{OVIATT.}

Origin, Warren Co., O.

Fruit large, roundish oblate conic, greenish yellow, shaded with red in the sun, few brown dots. Stalk short. Calyx closed. Elesh whitish, a little coarse, temler, pleasant subacid. Good. September.

Ox.

From Pennsylvania.

Fruit large roundish conical, whitish, slightly bronzed in the sun, few gray dots. Stalk long, slender. Calyx closed. Flesh white, crisp', tencler, juicy, sprightly subacid. Good. Core small. November to January.

\section{Oxiead Pearmaix.}

Earl of Yarmouth's Pearmain.

From England. Tree hardy, with slender drooping branclies, productive.

Fruit small, conical. greenisl, with a thin russet, brownish in the sun. Flesh greenish white, firm, crisp, xich, acid. November, February.

\section{OX SwEET.}

From Massachusetts. Tree very virorous, mpright spreading.

Fruit above medium, ponndish oblite, greenish, sometimes a little bronzed in the smu, many light and gray dots. Stalk short. Calyx closed. Elesb rellowish white, juicy, tender, sweet, and pleasant. Good. Core rather large. October, Novernber. 


\section{Padley's Pippis. \\ Compote. Padley's Royal George Pippin.}

An old English Apple, of moderate growth, but quite productive Young shoots grayish chestnut red.

Fruit medimu, or small, roundish oblate, dull greenish yellow, yel low in the sun, with some russet. Flesh yellowish, juicy, rich, brisk acil. December, Januiny.

\section{Pandex Sweet.}

Oiigin unknown.

Fruit medium, oblate, yellow, with a tinge of red in the sun, some gray and red dots. Stalk short. Calyx small, closed. Flesh white, compact, crisp, sweet. Good. Cooking. Norember.

\section{PARK SPICE.}

Park Apple.

Origin, Westchester Co., N. Y. Tree thrifty, upright spreading, very productive. Young shoots pretty smooth, dark reddish brown.

Fruit medium, romuchish oblique, whitish yellow, shaded with red, obscurely splashed and striped, moderately sprinkled with light and browu dots. Stalk short, slender. 'alyx small, closed. Flesh yellowish, rather firm, moderately juicy, mild subacid, slightly aromatic. Core medium. Very good. December to March.

\section{Parmentier Rieinette.}

Of French origin. Tree vigorous, upright spreading.

Fruit large, roundish, golden yellow, dotted with reddish gray, and striped with bright red in the sm. Flesh yellowish white, firm, sharp subacid, aromatic. March to May. (S. T. M.)

\section{Parrot Reinette.}

Supposed of German origin.

Fruit above medimm, roundish oblate, pale rellow, lightly splashed, shaded, and marbled with light red, few brown dots. Stalk medium, rather slender. Cavity broad, deep. Calyx closed, or partially open. Flesh whitish, tender, juicy, brisk subacid. Good. Core large and open. New, promises valuable for market or cooking.

\section{Parrits Pearuats.}

An English dessert Apple.

Fruit small, roundish oblong, truncated, greenish yellow, shaded and striped with red in the sum. Flesh firm, juicy, rich, and sweet. Good to very good. Jamuary to March.

\section{Passe Ponne d'Autonne.}

Passe Pomme Rouge d'Antomne.

Pomme d'Outre Passe.

Herbststrich Apfel.
Generale.

Passe Pomme Cotellee.

Rother He:bststrichapfel.

Of German origin. Tree vigorons, productive.

Fruit medium, roumdish, slightly oblate, ribberl, yellowish, slıded 
and striped with rich red in the sum. Flesh very white, tinged with red, tender, juicy, vinous, excellent for cooking. September. (Hogrer.)

\section{Passe Ponne Rouge.}

Rother August Apfel.

Rothe Sommerpasspomm.

Tree slender grower, harly, productive.

Fruit snuall, roundish oblate, yellow, cntirely orerspread and shaded with red. Flesh white, tinged with red next the skin, erisp, juicy, soon decars. Poor. August.

\section{Patch's Russet.}

Of English origin.

Fruit below medium, roundish oblate, greenish yellow, with thin gras russet. Calyx small. Stalk long. Flesh yellowish white, crisp, brisk aromatic. Good. November, December. (Lind.)

\section{Patersox's Sweet.}

Origin unknown. Considerably grown in Western New Tork, and esteemed valuable for its season. Tree upright, thifty, productive.

Frnit medium, roundish oblate, rellow, mostly covered and indistinctly splashed and striped with dark rich red, many conspicuous light dots. Flesh white, tender, juicy, pleasant, sweet. Good to very good. September, October.

\section{PAWPAW.}

Western Baldwin. Bubicon. Ball Apple.

Origin, Pawpaw, Nich, Tree hardy, a good and regular bearer. Foung shoots dull grayish reddish brown.

A new Apple, esteemed in its place of origin for its productiveness and beauty of appearance.

Fruit medium, roundish oblong, slightly oblique, yellow, shaded and mostly overspread with bright rich red, faintly splashed and mottled, moderately sprinkled with areole dots. Stalk medium. Cavity deep, narrow. Calyx partially open. Segments a little recurred. Flesh yellowish, juicy, firm, rich, brisk subacid. Very good. December to June.

\section{PAWSAN.}

An English cider Aprle.

Fruit medium, roundish, dull green, with network of russet. Flesh frrm, juicy, acid. October.

\section{PEACH.}

Origin unknown, Tree moderate grower.

Fruit below medium, oblate, inclining to conic, pale yellow, will blush of red in the sun, and thickly sprinkled with gray dots. Stalk short. Calyx closed. Flesh white, erisp, tender, juicy, lively brisk subacid. Good to very gool. Core small. December to Apil. A good keeper. 


\section{Peach-Pond Sweet.}

This is a most excellent autumn variety, from a small village of this name in Dutchess Co., N. Y. It appears well worthy of a more general dissemination. Tree vigorous, spreading. Young shoots dull grayisle brown.

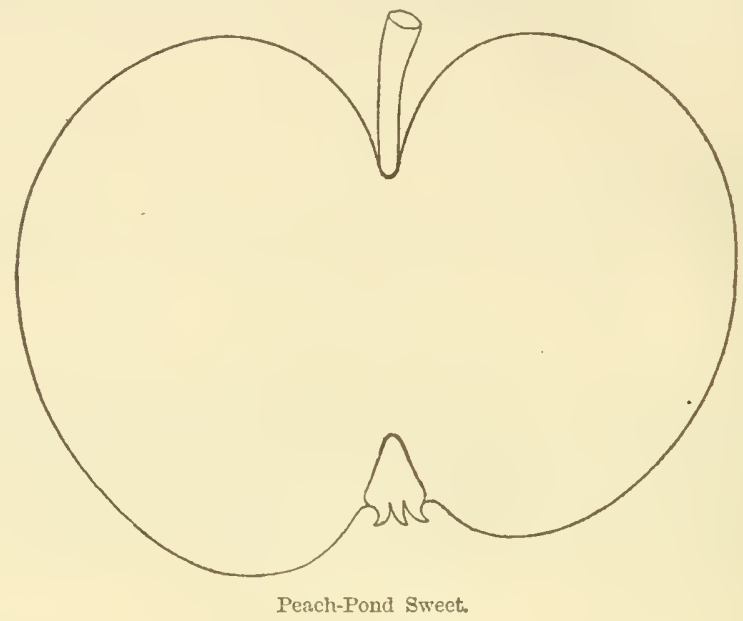

Fruit of medium size, rather flat, striped light red. Stalk long and slender. Flesh tender or very mellow, moderately juicy, very rich, sweet, and agreeable. Very good. September to Noveraber.

\section{Pear.}

Pear-Apple.

From Pennsyltania.

Fruit medium or below, roundish oblong, pale yellow, with a blush in the sun, few gray dots. Flesh white, crisp, juicy, pleasant subacid. Good. Core small. December, February.

\section{Pearsalt's Sweet.}

Supposed to have originated in Queens Co., Long Island. Tree upright spreading, quite productive.

Fruit rather large, roundish, sometimes oblique, rellow, shaded, splashed, and mottled with light red. Stalk short. Calyx closel. Flesh yellowish, a little coarse, moderately juicy, sweet. Good. Core large and open. November, January. A good keeper, and raluable for baking.

\section{Pearson's Early.}

Fruit medium or above, roundish, pale jellow. Flesh jellowisb white, sharp subacid. August, September. (Elliott.) 


\section{Pearson's Plate.}

A rariety from England, which has a very bigh reputation.

Fruit small, about two and a half inches in diameter, regularly formed, flat, greenish yellow, becoming yellow, with a little red in tho sun. Flesh white, crisp, tender, sprightly subacid. Good. February, March. Core small.

\section{Peck's Pleasant. \\ Waltz Apple.}

A first-rate fruit in all respects, belonging to the Newtown Pippin class. It has long been cultivated in Rhode Island, where, we think, it originated, and in the northern part of Connecticut, and deserves extensive dissemination. It considerably resembles the Tellow Newtown Pipjun, with more tender flesh, and is scarcely inferior to it in flavor.

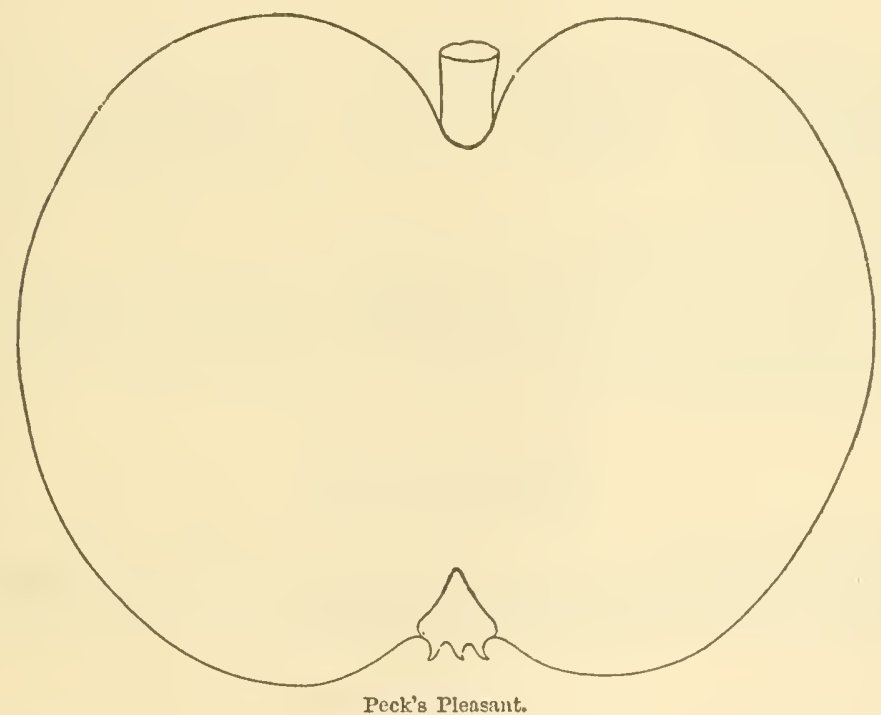

The tree is a moderate, upright spreading grower, but bears regularly and well, and the fruit commands a high price in the market. Tho apples on the lower branches of old trees are flat, while those on the upper branches are nearly conical. Young shoots reddish brown, slightly downy.

Fruit above medium size, roundish, a little ribbed, and slightly flattened, with an indistinct furrow on one side. Skin smooth, and when first gathered, green, with a little dark red; but when ripe a beantiful clear yellow, with bright blush on the sumny side and near the stalk, marked with scattered gray dots. The stalk is peculiarly fleshy and flattened, short, and sunk in a wide, rather wavy cavity. Calyx woolly, sunk in a narow, abruptly, and pretty deeply sunk basin. Flesh yellowish, fine-crained, juicy, crisp and tender, with a delicious, high anomatic sprightly subacil. 'Tery good or best. November to March. 


\section{Pelifan Sweet.}

Green Sweet.

From Massachusetts. Tree a fair grower and good bearer.

Fruit below medium, roundish oblate conic, greenish, sometimes shaded with red in sun, splashes and patches of russet. Stalk short. Calyx closed. Flesh yellowish, moderately tender, sweet. Good. Core small. December to March.

\section{Pennington's Seedling.}

An English finit of medium size, nearly flat, a little angular, mostly covered with rough yellow russet, with a little pale brown in the sun. Flesh yellowish, firm, crisp, with a brisk acid juice. Hardly good. Norember to March.

\section{Pexnock.}

Pomme Roye. Large Romanite. Prolific Beauty. Roman Knight.
Big Romanite.

Neisley's Winter Penick. Pelican

Red Ox.
Red Pennock Pennock's Red Tinter. Gay's Romanite.

Origin, Pennsylvania. Tree a strong, vigorous, upright spreadiug grower, and very productive.

Fruit quite large, oblique, generally flat, but occasionally roundish oblong, fine deep red, with faint, indistinct streaks of yellow. Flesh yellow, tender, and juicy, with a pleasant half sweet flavor. Good. November to March.

\section{Pennsyluania Sweet.}

Pennsylvania Sweeting.

Origin unknown.

Fruit large, oblong, greenish yellow. Flesh tender, fne-grained, very sweet. Good. Early winter. (Warder.)

\section{Penngylyania Wine Sap.}

Origin unknown.

Fruit large, conical oblate, truncated, yellow, blushed, very little splashed. Flesh yellowish white, tender, juicy, subacid. Good. December, January. (Warcler.)

\section{Teople's Chojee.}

Melt-in-the-MIouth of some.

A Pennsylvania fruit. Tree molerately rigorous, upright. Young shoots grayish reddish brown.

Fruit medium, oblate, inclining to conic. Color red, sometimes obscurely striped, thickly sprinkled with large whitislı dots of peculiar appearance. Flesh yellowish, firm, juicy, hrisk, rich subacid. Good. December to March. 
Pejix Russe.

Fruit medium, roumdish ollate, yellow, with reddish gray dots, bright red in the sun. Flesh fine, half firm, yellowish white, subacid. Deeeuber, Jamuary. (S. T. Ml.)

\section{Perry Russet.}

\section{Golden Russet.}

The origin of this is in obscurity. It was, many years since, carried from Perry, Wroming C'u., N. Y., to the West, under the name of Golden Russet, but as it was entirely distinct from the true Golden. liusset, it soun hecame known as the Perry Russet, which nane we contimue. It is of "good" quality for table or kitchen, but does not keep late, and sometimes drops its fruit from the tree early. Thee a moderate, upright spreading grower, hardy, an early and abundant bearer. Young shoots light brownish red.

Fruit medium, ronndish conical, sometimes a little oblique, pale yellow, netted with russet on the sumy side, and sometimes brownish. Stalk short, eavity narrow, sometimes witl a lip. Calyx elosed. Basin abrupt. Flesh yellowish, rather firm, juicy, brisk subacid. Good. November, December.

\section{Petit Jean.}

From Jersey, England. Tree an abundant bearer.

Fruit small, roumlish oval oblate, pale yellow, sharled and striped with red. Flesh white, tender. Good. November, February.

\section{Petworti Nonpareil.}

Green Nonpareil.

Ronalds describes this Euglish fruit as larger than the old Nonpareil, of the same shape, green. Flesh crisp, juicy. February, March.

\section{Pilllitipi.}

Origin, supposed Berks Co., Pa. Tree vigorous. Young shoots redilish brown, slightly downy.

Fruit medium, oblate conical, greenish yeliow, with numerous blotehes and gray dots, and a bhish on the exposed side. Stalk short and slender, inserted in a wide, deep cavity, Calyx small, closed, set in a narow superficial basin. Flesh tender, fine texture, juicy. Good to very good. Uctober to Jinuary.

\section{Pinllips' Sweet.}

Originated on the farm of Creorge Phillips, Coshocton Co., Ohio. Tree thrifty, upright, very productive. Young wood smooth, light, clear reddish brown.

Fruit unerlium or above, romndish oblate, inclining to enuir, whitish yellow, sharled witl, light red, and stripred and splashed with dark, 
large light dots. Stalk long, slender. Cavity deep. Calyx closed. s'egments short. Basin abrupt, deep. Flesh white, erisp, tender, juicy, rich, pleasant, sweet. Good to very good. Core small. December, Mareh.

\section{Phanix.}

From Illinois. Origin unknown.

Fruit medium, roundish, shightly oblate, light yellow, faintly shaded, splashed, and striped with rich red, few brown and light dots. Flesh yellowish, coarse, moderately juicy, subacid. Good. December, March.

\section{Pickard's Reserve.}

Origin, Parke Co., Ind. Tree hardy and productive.

Fruit rather large, oblate, sides unequal, jellow, shaded with red in the sun, few gray dots. Stalk short. Cavity large. Calyx closed. Basin large, deep, corrugated. Flesh yellowish, crisp, rather tender, juicy, slightly aromatic subacid. Good to very good. Core small. December, January.

\section{Pickian.}

\section{Pickman Pippin.}

Origin, Massachusetts. Tree vigorous. Young shoots dull brown, downy. Buds knobby at base.

Fruit medium, roundish oblate, jellow, with scattered shades of -russet, and small russet dots. Stalk short. Cavity medium. Calyx closed. Flesh yellowish white, crisp, pleasant subacid. Good to very good. January, April.

\section{Pifer. \\ Pfeifer.}

Origin, Bucks Co., Pa. Tree rapid grower, upright spreading.

Fruit below medium, roundish, sparsely streaked with red on a yellowish green ground, fawn-colored next the sun. Flesh white, tender, subacid. Good. January to July.

\section{Pigeon.}

Jerusalem.

Gros Counr de Pigeon.

Rother Taubenapfel.

\section{Cour de Pigeon.}

Passe Pomme.

Arabian Apple.
Pigeon Rouge.

Duif Apfel.

This old Apple is described by Ronalds as a free but not robust grower.

Fruit medium, oblong conical, straw color, flushed with red in the sun. Flesh white, delicate, crisp, lleasant subacid. December to February.

\section{Pigeonette.}

Pigeonet Blanc.

Pigeonette Gros de Rouen.

American Peach.
Pigeonette Blanc d'Été.

Museau de Levre.

Taubenfarbige Apfel.

This is described by Hogg as of only second quality, and here probably of little value. 
Fruit below medium, oblate roundish, rellow, striped and rayed witl red. Flesh white, delicate, agreenble acid. Angust, September.

\section{Pigeonette de Rouex.}

This is described in the Aunals of Pomology, by MI. Bivort, as tree very productive.

Fruit large, oblong conical, truncated, p'ale yeilow, spotted with gray, washed and blotched with bright red. Flesh white, tender, sulyrid. Good. December to March.

\section{Piketon Russet.}

Origin, near Piketon, Olio.

Fruit large, conical, reddish green, and russety. February to April. (O. P. S. Rep.)

\section{Piles Russet.}

Pyles Russet.

An old English Apple. Tree vigorous, productive.

Fruit medium, roundish oblate, dull green, covered with russet, becoming dull brown or orange in the sun. Flesh greenish, breaking, brisk, slightly aromatie subaeid. November to April. (Lindley.)

\section{Pine Apple Russet.}

\section{Hardingham's Russet.}

Tree of moderate growth, fruit not fair or very raluable.

Fruit medium, conic, angular. Skin whitish yellow, faintly striped. Stalk rather long and slender. Carity uneven, and slightly russeterl. Calyx closed. Basin shallow, corrugated. Flesh whitish, juicy, tender, subacid, slightly aromatic. Very good. Last of September and Octolser.

\section{Pine Creek Sweet.}

\section{Hamilton.}

Origin, Pine Creek, Clinton Co., Pa. Tree very vigorous, upright spreatding.

Fruit large, roundish conieal, pale whitish yellow, sprinkled with a few brown dots. Stalk short. Cavity deep, large, uneven. Calyx small, closed. Basin abrupt, deep, slightly colrugated. Flesh white, crisp', tender, juicy, rich honeyed sweet. Tery good. Core small. October.

\section{Pine Strawberry.}

Tree healthy, vigorous, upright.

Fruit inedium to large, eonical, pale yellow, blushed and splasherl, light earmine. Dots large, yellow. Calyx open. Stilk short. Flesh yellow, tough, jnicy, sweet. Good. Winter. (Am. Hort. A11.)

\section{Pink Sineeting.}

Originated with William Kreller, Cumberknd Co., Pa. Tree vigorous, sprealing, producing enormous crops. 
Fruit small, greenish, nearly covered with bright red, perfect in form, rich, pleasant, sweet. Good. September, October.

Pinner.

Carrell's Seedling.

Pinner Seedling.

Origin, Middlesex, England.

Fruit medium, roundish, ribbed slightly, yellowish brown russet, becoming reddish brown in the sun. Flesh yellowish, crisp, tender, brisk subacid. December, February.

\section{Pioneer.}

From Pennsylvania.

Fruit medium, roundish oblate conic, yellow, shaded with light red, and splashed and striped with dark red, many small light and gray dots. Stalk rather short. Calyx closed. Flesh whitish yellow, tender, juicy, pleasant subacid, slightly aromatic. Good. Core small. October, November.

\section{Pitulaston Golden Pippin.}

Fruit small, round, rough, pale yellowish brown russet. Flesh deep yellow, crisp, tender, juicy, sweet. December. (Hogg.)

\section{Pitmaston Nonpareil.}

St. John's Nonpareil. Pitmaston. Russet Nonpareil.

Origin, near Worcester, England.

Fruit medium, roundish oblate, dull green, with russet and faint red in the sun. Flesh greenish yellow, firm, rich, aromatic subacid. November, December. (Lind.)

\section{Pitmaston Pine-Apple.}

Fruit small, conical, yellowish brown l'usset. Flesh yellowish, firm, crisp, sugary. December, January. (Hogg.)

\section{Pittsburgh Pippin.}

$\begin{array}{lll}\text { Flat Pippin. } & \text { Swiss Pippin. } & \text { Swiss Apple. } \\ \text { Father Apple. } & \text { William Tell. } & \text { Schwitzer Apple. } \\ \text { Greasy Back. } & \text { Pippin. } & W_{J} \text { the. }\end{array}$

Origin, supposed to be Pittsburgh, Pa. In irregular grower, somewhat drooping in habit, and generaliy a good bearer. Joung shoots dull reddish brown, downy.

Fruit large, oblate, obscurely ribbed, pale rellow, rarely with a blush, sparsely sprinkled with brown clots. Stalk short and surall, in a large cavity, sometimes a little russeted. Calyx nearly closed. Basin broad and corrugated. Flesh whitish, juicy, tender, sprightly subacid. Good to very good. November to April.

\section{Platt's Sweet.}

Origin, Addison Co., Vt. Tree a strong grower, and productive. 
Fruit medium, roundish conical, sides unequal, greenish yellow, shaded and striped with dull red. Flesh yellowish, juicy, peculiar, sweet. Good. Core small. January to March.

\section{Pleasaxt Valley Pippin.}

Of unknown origin. Received from New Jersey. Tree moderately vigorous, upright spreading.

Fruit medium, roundish, inclining to conie, greenish yellow, with brown or gray dots. Calyx small, elosed. Flesh yellowish, tender, juicy, mild, pleasant subacid. Good to very good. October, Novembes.

\section{Plum.}

Origin unknown.' Tree upright, moderately vigorous.

Fruit medium, roundish oblate, greenish yellow, with a tinge of red in the sun. Flesh white, fine, tender, juicy, mild, pleasant subacid. Very good. Core small. August.

\section{Polish.}

\section{Red Polish.}

Originated in the neighborhood of Boston, Mass. Tree very productive, moderately vigorous, upright spreading.

Fruit medium, roundish eonical, yellow, shaded, splashed, and striped with dark rich red, light gray dots. Stalk rather short, slender. Calyx closed. Flesh whitish, sometimes stained next the skin, juicy, pleasant subacid. Good to very good. October, Norember.

\section{Polly Bright.}

Origin supposed to be Virginia. Tree vigorons, upright spreading.

Fruit elongated conic. Skin light yellow, shaded with carmine, obscurely striped. Stalk of mediun length, in an acute cavity, russeted. Calyx in a small furrowed basin. Flesh tender, juicy, witl a pleasant subacid flavor. Good. September, October.

\section{PoMeroy.}

\section{Taunton.}

There are two Pomeroy Apples from England-one from Somersetshire and one from Lancashire; neither of them proves of much value here. The first is medinm, roundish conical, greenish yellow, with stripes of red and russet in the sun. Flesh yellow, firm, juicy, sugary. October, December.

The second is medium, roundish oblate, ribbed at apex, pale yellow, shaded cheek of red in the sum, russet dots. Flesh whitish, tender, bi isk subacid. September, Oetober.

There is another Pomeroy from Massachusetts, which is of medium sizc, roundish oblate, yellow, shaded, splashed, and marbled in sun with light and dark red. "Stalk short. Calyx closed. Flesh white, tenler, moderately juicy, pleasant subacid. Good or very good. October, November. 


\section{Ponde Grise.}

Pomme de Cuir. Gray Apple.
Grise.

Leather Apple of Turic.

A small gray Apple, from Canada, probably of Swiss or French origin, and undoubtedly one of the finest dessert Apples for a northern climate. It is not a strong grower, but is a good early bearer, and has an excellent flavor. Young wood reddish brown.

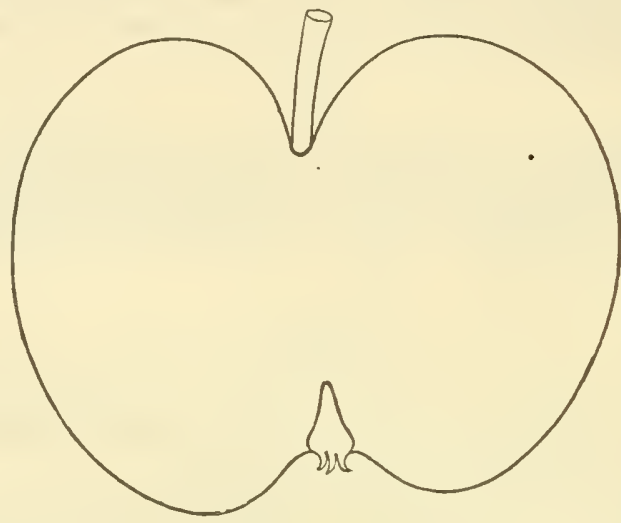

Pomme Grise.

Fruit below medium size, oblate roundish. Skin greenish gray or cinnamon russet, with a little red towards the sun. Calyx small, set in a round basin. Flesh tender, rich, and high-flavored. Very good to best. December to February.

There is an Apple under name of Pomme Gris d'Or which is claimed as of more upright growth. The fruit more oblong and quite distinct. We have been unable to so decide.

\section{Pomme Water。}

\section{Pomme Water Sweet.}

An old Apple, described in Kenrick, Hogg, and others. It has travelled considerably, but is not.generally known, nor very highly appreciated. 'Iree vigorous, spreading, moderately productive.

Fruit medium to large, roundish, slightly conical, greenish jellow, shaded and splashed with red or crimson in the sun. Stalk rather short. Calyx closed. Flesh yellowish white, breaking, juicy, pleasant, sweet. Good to very good. Fine for baking. October, December.

\section{Ponto Pippin.}

An English variety, described by Hogg as of medium size, roundish, slightly conical, greenish yellow, red in the sun, with spots of dark russet. Flesh greenish white, crisp, tender, brisk subacid. Norember to February. 


\section{Poorilouse.}

A new variety, received from $\Lambda$. L. Woodson, of Kentucky, by him obtained from Tennessee.

Fruit large, roundish oblate, pale yellowish green, with russet dots Stalk short. Flesh yellowish, compact, morlerately juicy, mild subacid. Very good. December. Promises a good keeper.

\section{Pope.}

Pope's Apple.

This is described by Hogg as originating in Kent, England, and there highly esteemed. The tree an early and abundant bearer.

Frnit large, roundish oblate conical, clear yellow, with patches of green, dark dots and streaks of red in the sun. Flesh yellowish, sugary, juicy, rich, and excellent. November to March.

\section{Porter.}

A first-rate New England fruit, raised by the Rev. S. Porter, of Sherburne, Mass., and wherever grown a decided favolite. The tree is hardy, a moderately vigorous grower, forming a low, round, spreading head and

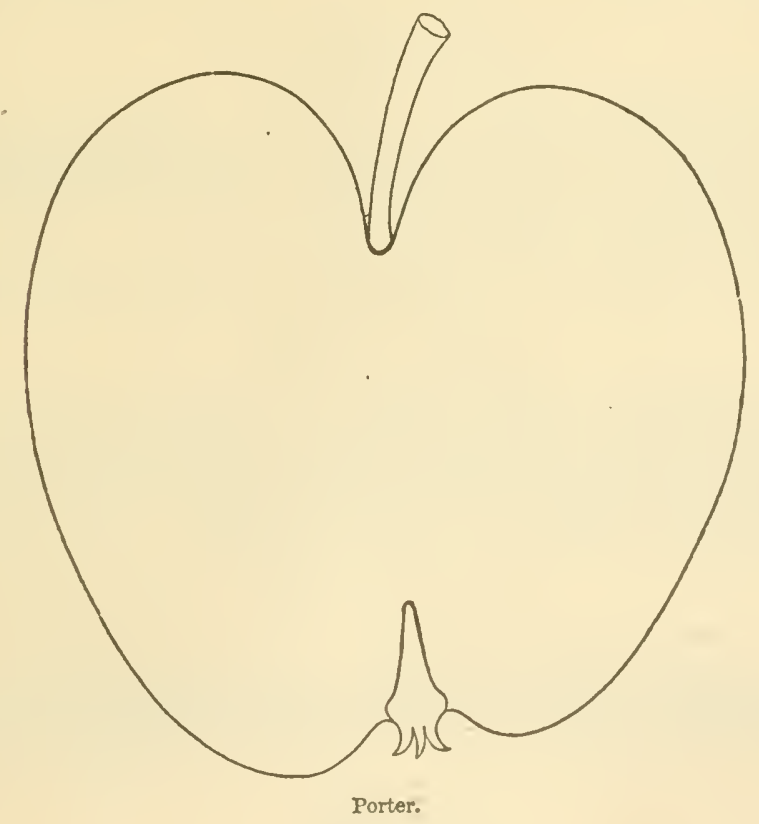

producing abundantly, if in good soil, a fruit uniformly fair and even in size and form. It is a valuable market fruit, and continues a long timo in use. 
Fruit rather large, regular, oblong, nartowing to the eye. Color clear glossy bright yellow, and, when exposed, with a dull blush next the sum. Calyx closed. Segments irregular, set in a narrow and deep basin. Stalk rather slender, not three-fourths of an inch long. Flesh fine-grained, and abounding with juice, sprightly, agreeable aromatic subacid. Very good to best. Ripens in September, and deserves general cultivation.

\section{Porter Spitzenburgh.}

Origin uncertain. A free grower and very productive. Tree moderately vigorous, upright spreading.

Fruit large, globular, slightly inclining to conic, red, shaded with deep crimson. Stalk very short, inserted in a large cavity, surrounded by thin russet. Calyx small, closed, set in an open basin. Flesh white, much stained, very complact, crisp, juicy, pleasant, brisk subacid. Good to very good. November to March.

\section{Portugal Gray Reinette.}

Reinette Grise de Portugal. Graue Portugiesische Reinette.

Origin unknown. A very singular-colored fruit, small to medium, green, covered with a peculiar dirty reddish brown. Calyx large, closed. Flesh greenish white, tender, pleasant subacid. January, February.

Poser's Red.

Posey's Red Winter Sweet.

Origin unknown.

Fruit medium or below, rounclish oblate, yellowish, shaded, splashed, and striped with red. Flesh whitish, tender, mild subacid, almost sweet. Good. Core small. November to April.

\section{Posteley.}

Posteley's Seedling.

Origin unknown. Tree a fair grower and good bearer.

Fruit medium, roundish, inclining to conic, greenish yellow, shaded in the sun with dull red, many gray dots. Stalk short. Cavity large. Calyx closed. Flesh yellowish, compact, juicy, brisk subacid. Good to very good. Core medium. December to March.

\section{PotTer's LARge.}

Potter's Large Apple.

Potter's Large Seedling.

A very large English sance Apple, roundish oblong conical, obscurely ribbed, greenish yellow, with a blush red in the sum, and many red and gray dots. Flesh white, subacid. October to December.

\section{Pottinger.}

Big Red.

Origin and distinctiveness uncertain. Tree rigorous, large. Branches upright. Shoots purple, warty. Buds long, pointed. 
Fruit large, regular, oblate, dull red, shaded and striped, covering the yellow ground. Dots small, prominent, with some ronghness. Flesh yellow, breaking, granular, juicy, subacid, aromatic. Only good for kitchen and drying. December, January. (Warder.)

\section{Pound Cake.}

\section{Royal Pearmain?}

A Southern Apple, not much known.

Fruit large, roundish oblate, inclining to eonic, golden yellow, mottled and shaded with red, netted and patched with russet. Flesh yellow. ish, rather crisp, tender, a little granular, vinous, pleasant. Good to very good. November, December.

\section{Pound Royal.}

\section{Winter Pound Royal.}

Probably of French origin. Fruit apt to be unfair, unless with high culture. Tree spreading, with long slender branches. Young shoots light biown.

Fruit large, roundish oblong conical, with a slightly uneven surface, pale yellowish white, rarely with a faint blush, and niaked when ripe with a few large ruddy or dark speeks. Flesh very tender, breaking, fine-grained, with a mill, agreeable, aromatic subacicl. Giood. In use from December to April.

\section{Pound's July.}

Origin, Kentucky. Tree vigorous, upright spreading. Young shoots light reddish brown.

Fruit large, roundish conic, sides unequal, greenish white, with a dull blush, and thinly sprinkled with brown dots. Stalk very short. Cavity deep, russeted. Calyx elosed. Basin small, narrow. Flesh white, fine-grained, tender, not very juicy, rich, pleasant, sweet. Good to very good. July, August.

\section{Pound Sivent.}

There are several sorts under this popular name, as applied to any large sweet apple. One is large, roundish conical, greenish yellow, with slight red in sun. Flesh yellowish, tender, moderately juicy, sweet. September, October. Another is large, roundish, red. Flesh whitish, moderately juiey, aromatic, sweet.

\section{Poveshon.}

An old New Jersey Apple, valued mainly for making early cider.

Fruit sinall, oblate, deep red. Flesh yellow, dry, sweet. Good. September, October.

\section{Powell's Russet.}

A little English Apple, deseribed by Ronalds as roundish oblate, light brown russet. Flesh white, firm, brisk subacid. December, January. 


\section{Powers.}

Miller's Apple.

Origin, Perrysburgh, Ohio.

Fruit large, roundish oblate, waxy yellow ground, shaded with red, and splashed with carmine. Stalk short. Cavity deep, acute. Calyx elosed. Basin abrupt, somewhat corrugated. Flesh white, fine-grained, jnicy, mild, aromatic subacid. Very good. October, November. (O. P. S. Trans.)

There is another Powers, or Powers Seedling, which originated on the farm of C. W. Powers, Amenia, Dutchess Co., N. Y.

Fruit medium, roundish, inclining to conic, whitish, shaded, splashed, and striped with red, light dots. Flesh white, a little stained next the skin, crisp, juicy subacid. Good. November.

\section{Pownat Spitzengurgir.}

Origin, Vermont. An old variety, not much esteemed. Tree a rapid grower, but late coming into bearing.

Fruit above medium, roundish oblate, sometimes inclining to conic, yellow, marbied and striped with red. Flesh yellowish, not very tender, pleasant subacid. Good. December to March.

\section{Prairie Calville.}

Calville des Prairies. Tenetten. Tilden $\Lambda$ pfel.

Fruit medium, roundish oblate, light yellow, overspread and blotched with red. Flesh white, tender, juicy, subacid. November, December. (An. Pom.)

\section{PratT's Sweet.}

Origin, on the farm of Daniel Pratt, Richland, Oswego Co., N. I. lree vigorous, with an open spreading head, an annual bearer, and procluctive. Toung shoots dark reddish brown.

Fruit large, roundish conical, with broad yet slight ribs. Color rich pale yellow ground, marbled, striped, and shaded orer two-thirds the surface, with two shades of clear bright pinkish red, and dotted with inconspicnous light dots. Stalk rather short, slender. Cavity deep, broad, and open. Calyx closed. Basin abrupt, moderately deep, round, and slightly corrugated. Flesh yellowish white, crisp, breaking, tender, rather fine-grained and juicy, mild, pleasant, rich, sweet. Tery good. C'ore medium. December to March.

\section{President.}

Origin, farm of Capt. John White, Salem, N. H. Tree rigorous, productive.

Fruit large, roundish oblate, pale yellow, with a tinge of red in the sun, few gray dots. Flesh yellow, firm, juicy, subacid. Good. Septem. ber, Octuber.

The original tree of the President is said to have been in bearing at the inauguration of Washington as President, and to be yet in a healthy conclition. 


\section{Presidext De Fiy's Dumoxceau.}

Origin, Belginm. Tree vigorous aud prodnetive. A new variety, of good promise.

Fruit very large, oblate, broadly ribbed, rich yellow, splisshed and marbled with bright red in the sun. Stalk slender. Calyx small, elosed. Flesh rellowish white, tender, sugiry, acicl. November, February. (Ail. Pow.)

\section{Press.}

Origin, Bucks Co., Pa. Tree upright, vigorons.

Fruit rather large, oblate. Skin whitish yellow, striped and splashed with red. Flesh juicy, tender, pleasant, mild subacid. Good. Mareh.

\section{Press Ewing.}

Originated in Christian Co., Ky., and introduced to notice by J. S. Downer. Tree lardy, vigorous, irregular, spreading. Young shoots dark brown, productive.

Frnit medium, oblate, yellow, shaded and obsenrely splashed with crimson, and thickly eovered with dots, having a dark centre. Stalk medium, inserted in a broad, deep carity. Calyx closed, set in an uneven, deep, abrupt basin. Flesh yellowish, firm, juicy, crisp, tender, mild, agreeable subacid. Good to very good. February till Ipril.

\section{Priestly.}

Priestley's American.

Origin, Pennsylvania. Tree vigorous, upright, and productive.

Fruit large, roundish oblong, smooth, dull red, with small streaks of yellowish green. Flesh white, moderately juicy, with a spicy, agreeable Hlavor. Hardly good. December to March.

\section{Priest's Sweet.}

Blue Sweet.

Molasses Sweet.

Origin, Leominster, Mass. - Tree vigorous and very productive.

Fruit medium, globular inclining to conic, yellow, chiefly corered with dull red stripes and numerous red dots. Stalk short, set in at rather deep cavity. Calyx closed. Basin small. Flesh white, tine, tender, and pleasant, not very juicy, a late keeper. Good. January to May.

\section{Primate.}

\author{
Pough and Ready. \\ Sour Harrest. \\ July Apple. \\ Scott.
}

\author{
Early Tart Harvest. \\ Zour Bough. \\ Powers.
}

North American Best.

The true origin of this delicious amateur's A pple is unknown. It apr pears to have been long known and grown in viulons sections of our States under different names. The tree is harily, a strong and stocky 
grower, and forms a beautiful head, very productive. Young shoots short-jointed, reddish brown, quite downy. Buds rather prominent.

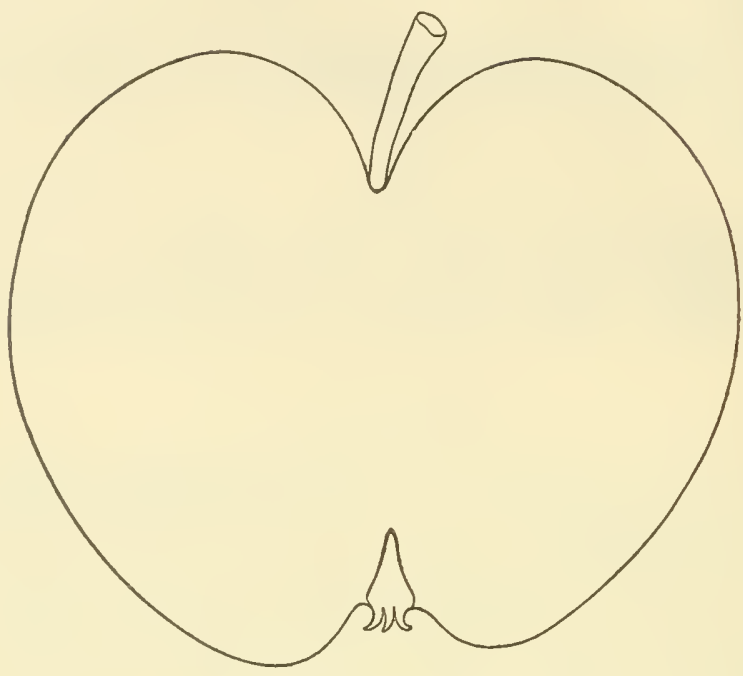

Primate.

Fruit medium, roundish oblate conic, greenish white, witl a crimson blush on the exposed side. Stalk of medium length, inserted in a rather large, deep, irregular cavity. Calyx closed in an abrupt, opren, somewhat corrugated basin. Flesh white, rery tender, sprightly, refreshing, mild subacid. Very good or best. An excellent dessert Apple, ripening the last of Angust, and continuing in use till October.

\section{Princely.}

Origin, Bucks Co., Pa. Tree a good grower and good bearer.

Fruit medium, oblate, sometimes inclining to conic, yellow, shaded, marbled, and indistinctly splashed with red, small light dots. Stalk short. Calyx open. Flesh yellowish, tender, juicy, pleasant, mild almost sweet subacid. Core small. Good to very good. October, January.

\section{Prince of Orange.}

Tree vigorous, very productive.

$\mathrm{Fr}^{\circ}$ it medium to large, roundish oblong, ribbed, pale yellow, with blotches of red. Flesh yellowish white, tender, soft, subacid. Good. October, November. (An. Pom.)

\section{Princesse Noble.}

Grosser Edler Prinzessinapfel. bearer.

An excellent Dutch Apple. Tree a good grower, an early and good 
Fruit medium, roundish, somewhat conical, yellowish, with many broken stripes of red. Flesh yellowish white, firm, juicy, pleasant, vi. nous. November. (Hogg.)

\section{Princesse Noble des Chartreaux.}

Origin unknown.

Fruit medium to large, bright green, with many indistinct spots, greenish brown around the stalk. Stalk short. Calyx small. Flesh yellowish white, firm, sugary, agrecable acid. January, February. (Verg.)

\section{Prinz.}

Of German origin. New. Tree vigorous, upright, a good grower, and productive. Young shoots reddish brown, downy.

Fruit large, roundish conical, obscurely ribbed, yellow, shaded with pale red in the sun, few brown dots. Stalk short. Calyx closed. Flesh yellowish, juicy, tender, breaking, mild, pleasant subacid. Good to very good. October, November.

\section{Progress.}

\section{"Esquire Miller's Best Sort."}

A native of Middlefield, Conn. Tree a moderate grower, and forms a handsome head, bears early, and very productive. The original tree stands on the land of Enoch Coe, formerly of Isaac Miller Esq., and for some time was called "Esquire Miller's best Sor't."

Fruit medium, roundish oblate. Stalk short, inserted in a round cavity, surrounded by russet. Calyx large, partially closed, set in an open basin. Skin smooth, yellow, with a sunny cheek, sometimes with a few scattered gray dots. Flesh solid, tender, crisp, juicy, refreshing, subacid. Good to very good. Core small. Ripe, October to April.

\section{Proliferous Rieinette.}

An English Apple, describèd by Hogg as :

Fruit medium, roundish, obscurely ribbed, dull yellow with broken stripes of crimson, small russety specks. Flesh yellowish white, juicy, rich brisk flavor. October, December.

\section{Prolific Beauty.}

Origin unknown.

Fruit large, roundish oblate, yeilowish, with dull stripes of red. Flesh whitish yellow, tender, acid. Poor. September, December.

\section{Prolific Sweet.}

From Connecticut. Tree a good grower, very productive, fine for cooking.

Fruit roundish ennic. Skin greenish. Flesh whitish, tender, with a pleasant, sweet, spicy flavor. November to February. 


\section{Prop.}

From Pennsylvania.

Fruit medium, oblate oblique, pale yellow, with a few large splashes ancl stripes of light red, few large brown dots. Stalk short. Calrx large, open. Flesh whitish, tender, juicy, mild, pleasant subacid. Good. Core small. December.

\section{Pryor's Fed.}

Pitzer Hill. Big Hill. Prior's Red.

Origin unknown. Tree upright, spreading, not very vigorous, nor an early bearer, requires a deep, rich soil, and a warm season or a south. ern climate for the full development of its excellence. Young wood and buds clear reddish brown, many large conspicuous gray dots.

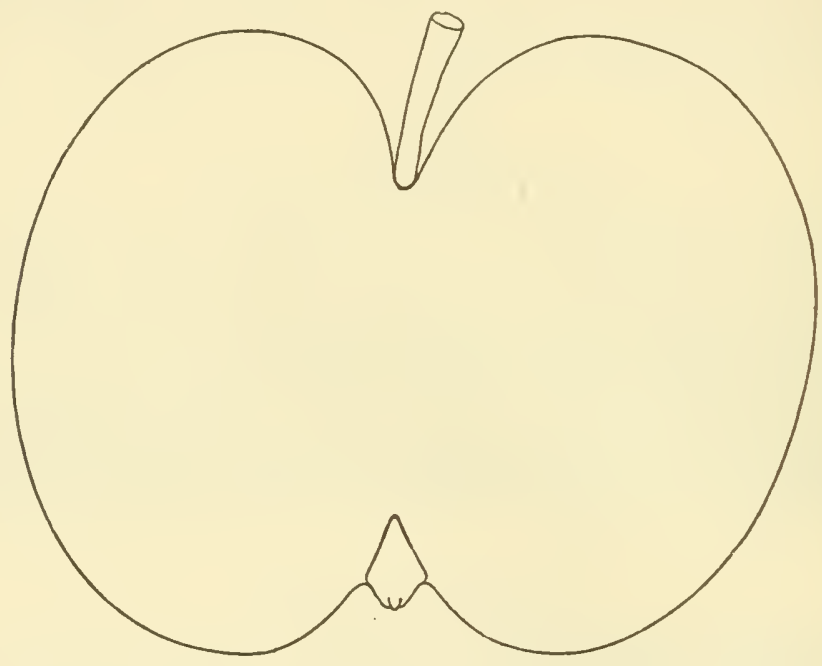

Pryor's Red.

Fruit medium, somewhat globular oblate, obliquely depressed. Color greenish yellow, shaded with red, striped with dark crimson, and thickly sprinkled with greenish gray dots, and some seasons much covered with russet. Stalk short and thick, inserted in a small acute cavity, surrounded by traces of russet, which sometimes considerably orerspread the fruit. Calyx firmly closed, set in a small basin. Flesh yellowish, tender, juicy, very rich, pleasant subacid. Tery good. January to March.

There is an apple under name of Prror's Blue, which may be distinct from the above, and may prove identical.

\section{Pucker Exd.}

From Long Island. Tree thrifty and productive. Fruit large, roundish, inclining to conic, pale yellow, often shaded with crimson in 
the sun, few dark gray dots. Stalk short, stont. Calyx closed. Flesh yellowish, erisp, juicy, subacid. Crood. Core large. Oetober.

\section{Pumpin Riesset.}

\section{Sweet Russet. Pumpkin Sweet. Flint Russet. York Russet.}

Origin unknown. Trees large and sprearling.

Fruit large, round. Flesh pale yellowish green, slightly corered with russet. Stalk long, set in a wide, shallow eavity. Eye narrow, slightly sunk. Flesh exceedingly rich and sweet. Gool. September" to January.

\section{Pumpin Swelet.}

\section{Vermont Pumpkin Sweet. Lyman's Pumpkin Sweet. Pound Sweet.}

A very large sweet Apple, which we received from M[r. S. Lyman, of Manchester, Comn. It is, perhilps, inferior to the Jersey Sweet or the Summer Sweet Paralise for the tahle, but is a very valuable apple for baking, and deserves a place on this account in every orchard. Tree upright, spreating. Young woor brown.

Fruit very large, roundish, more or less furrowed or ribbed, especially near the stalk. Color pale green, with obseme whitisll streakis near the stalk, and numerous white dots near the eye, sometimes beconing a little ycllow next the sun. Flesh white, very sweet, but not very juicy. Good. September to December.

There is also in Comecticut and MLassachusetts another Pumplin Sweet, the tree of which is a strong, upright grower, and very produc. tive. Young wood redelish brown, slightly downy.

Fruit large, roundish oblate, rich yellow, frequently with consiler. able russet. Flesh yellowish white, breaking, rich, sugary, sweet, ripening in September and October. Very valuable for baking or stock feeding.

There are also several other Apples under the name of Pumpkin Sweet, but we consicler the two abuve deseribed as the best we have known.

\section{Pusimataila.}

\section{Sloau's Seedling.}

Originated near Tuscaloosa, Ala. Tree stont, upright, modcrately sprearing head, early and abundant bearer. Young shoots grayish, downy at end.

Fruit medium or below, roundish ollate, inclining to conic, pale yellow, shaded, splashed, and striped with rich red, few hrown dists. Stalk medium, slender. Calyx closed. Flesh yellowish white, juicy, mild, pleasant subacid. Good. Core small. November to January.

\section{Putray Harver.}

Origin unknown.

Fruit medium to large, roundish oblate, greenish, with patches of msset. Flesh white, crisp, tender, juicy, subicid. August, September. (Elliott.) 


\section{Putxay Keeper.}

Fron Kentucky. Tree vigorous, upright spreading.

Fruit large, oblate, yellowish, shaded and splasherl with red. Stalk rather long. Calyx closed. Flesh yellowish, crisp, juicy, pleasant sub. acid. Good. Core small. December to March.

\section{Putxay Sweet.}

Originated near Marietta, Ohio.

Fruit large, flat, regular, surface smooth, mixed, splashed, and striped deep red. Dots numerous, large. Calyx small, closed. Stalk short. Flesh tender, sweet, very good. Kitchen, stock. August, September. (IVarder.)

\section{Putanite.}

Fruit medium, roundish, light yellow, coarse, dry, acid. December, January. (Elliott.)

\section{QUAKER.}

An old Apple. Origin unknown. Tree vigorous, spreading, an early and great bearer, regarded by some as a valuable market sort.

Fruit medium, roundish, inclining to conic, yellow, splashed and striped with rich rel, light dots. Stalk medium, slender. Carity large. Calyx closed. Flesh whitish, crisp, juicy, pleasant, slightly aromatic subacid. Good. November, February.

\section{Quaker Pippin.}

Fruit medium, greenish yellow. Very acid. Poor. October. (Elliott.)

\section{Queen Charlotte.}

An old German Apple, described by Ronalds as:

Fruit small, conical, greenish, with a facing of brown in sun. Flesh brisk, pleasant. March, April.

\section{Queen of SaUce.}

A culinary Apple, described by Hogg as:

Fruit large, oblate, greenish yellow, striped and flushed with red, patches and specks of russet. Calyx open. Flesh yellowish, firm, crisp, juicy, sugary, brisk, pleasant. Good. November, January.

\section{QueEN OF THE Pippiss.}

Reine des Reinettes.

Origin unknown. Foreign.

Fruit medium, roundish conical, truncated, fine rellow, shaded, splashed, and marbled with red, few gray dots. Stalk slender. Calrs open. Basin large. Flesh yellowish white, firm, crisp, slightly aro. matic. Good to very good. November, December. 


\section{QUEEx OF THE TALLex.}

Origin unknown. Receivel from Commerticut. Tree vigorons, np. right spreading. Young shoots hownish, slightly gravish.

Fruit rather large, roundish conical, yellow, nostly shaded, striped, and splashed with rich red, many whitish dots. Stalk short. Calyx closed. Flesh whitish, juiey, tenider, pleasant subacid. Good to very good. November, December.

\section{Quince.}

\section{Seneca Spice? Pear Apple.}

Origin uncertain; first deseribed by Coxe. In appearance this Apple is much like a large yellow Newtown Pippin; grown at the West it is larger than in New England, of a rich high flavor, and by some estecmed very highly. Tree liardy, vigorous, uppright spreading, and productive. Joung shoots dull reddish brown. Buds small, reddish, pointed.

Fruit medium to large, roundish oblate, yellow, rarely with a blush, somewhat broadly ribbed. Stalk short. Cavity broad, open, deep. Calyx closed. Basin large, rather deep, furrowed or uneven. Flesh yellowish white, crisp, tender, a little coarse, with a brisk, pleasant subacid quince aroma. Core rather large. Very good. October, December.

There is another Quince, or Coles Puince, which is claimerl to have originated in Cornish, Maine. The fruit of the two is rery similar, and we have at times questioned its identity. The young wood is, however, different in shade of color, being clear rich reddish brown, with buds short, abrupt, prominent.

\section{R.BBINE.}

This English Apple is described by Hogg as valuable for culinary or dessert purposes.

Fruit above medium, roundish oblate, ribbed, greenish vellow, mottled, splashed, and striped with red in the sun. Flesh yellowish, tender, crisp, sugary, brisk, pleasint acid. Uctober, December.

\section{RigaN.}

\section{Ragan's Red.}

Originated with Reuben Ragan, Putnam Co., Ind. Tree hardy, vigorous, and fruitful. Toung wood dull reddish brown, grayish.

Fruit medium to large, roundish conic. Color marbled and striped with red on a green ground. Stalk medium length, inserted in a rery rleep, namow cavity. Calyx small, closed, set in a deep, abrupt basin. Elesh yellowish white, juicy, pleasant, rather rich, spicy, subacid. Goort to very good. October to November.

\section{P.גino.}

Fall Romanite.

Gray Romanite.

Striped Rambo.

Delaware.

\section{Romanite. \\ Seek-no-Further. \\ Bread-and-Cheese Apple. Rambouillet.}

Trumpington?

Jarge Rambo?

Terry's Redstreak.

The Rambo is one of the most popular autumn or ealy wiuter 
fruits. It is a highly valuable Apple for the table or kitchen, and the tree thrives well on light sandy soil, being a native of the banks of the Delaware. The tree is of a vigorous, rather spreading habit, quite productive.

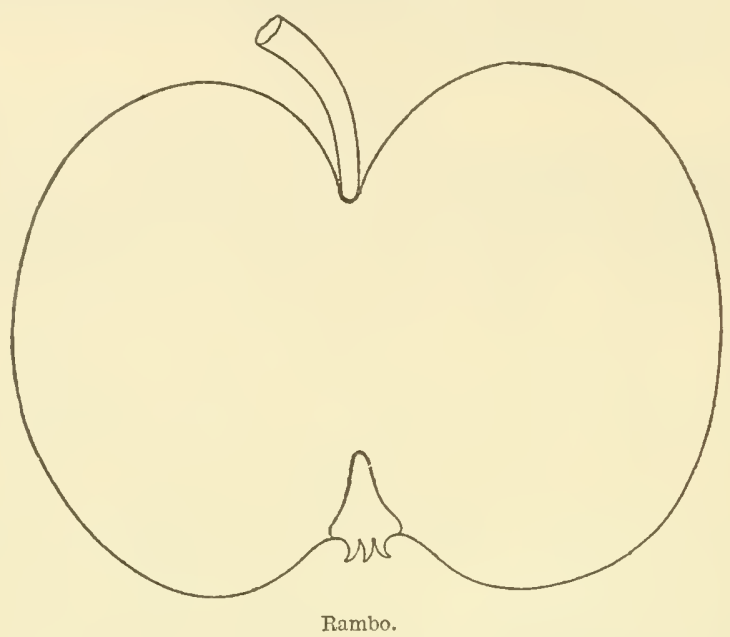

Fruit of medium size, flat, smooth, rellowish white in the shade, streaked and marbled with pale yellow and red in the sun, and speckled with large rough dots. Stalk long, rather slender, curved to one side, and deeply planted in a smooth funnel-like carity. Calyx closed, set in a broal basin, which is slightly plaited around it. Flesh greenish white, very tender, rich, mild subacid. Tery good. October to December.

There is claimed to be a distinct or sub-variety of this, called Recl Rambo, the fruit of which is more red, otherwise there is no perceptible ditference.

\section{Rambour Gros.}

An old Apple, described by Romalds as :

Fruit large, roundish oblong conical, slight projecting ribs, yellow, marbled and faintly striped with rich warm red. Flesh white, crisp, juicy, sharp subacid. Good. December, January.

\section{Rambour Papeleu.}

Rambourg Papeleu.

Of Russian origin. Tree vigorous, productive.

Fruit large, roundish oblate conical, deep rich rellow, spotted, striped, and splashed with shades of rich red, small light russet dots. Stalk medium. Calyx closed. Flesh yellowish white, rather coarse, breaking, sharp subacid. Goor. November, January. An Aple of good promise for market. 
Rambolr Rose.

Rambour Ronge. La Mère des Pommes. Kool-appel. ductive.

Tree moderately vigorous, with lurge strong branches. Tery pro.

Fruit large, roundish conical, truncaterl, rieh yellow, mostly over. spread, splashed, and shaded with rich red, traces of fawn russet. Stalk large, short. Flesh greenish white, half crisp, sugary acid, agree-

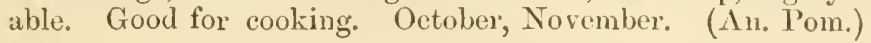

\section{RAMl's HonNS.} of use.

A large dark red Apple, imperfectly described by Cole. Poor. Out

\section{Randel's Best.}

\section{Randel Best.}

Origin unknown.

Fruit medium, roundish, slightly flattened, greenish yellow, mostly striped and overspread with dark red. Stalk short. Calyx small. Flesh white, tender, sweet. November, February. (Elliott.)

\section{RASCIIE.}

Originated with W. Rasche, near Hermann, Mo. A new variety, of good promise. Tree a strong grower, productive, and hardy. Young wood dark brown red, with prominent buds.

Fruit medium, roundish oblate, obsemre ribs. Color greenish yellow, with small irregularly scattered gray dots, a shade of deeper green suffused, faint traces of russet at the stem end. Stalk short. Calyx closed. Flesh yellowish, crisp, juicy, mild subacid. Very good. December tc March.

\section{Rattle-Box.}

\section{Hollow Core.}

Origin unknown.

Fruit below medium, roundish, greenish yellow, thinly striperl and splashed with red. Flesh white, tender, jucy, mild subacid. Good. Core large. August.

\section{Ravelston Pippin. \\ Revelstone Pippin.}

An Apple from Seotland.

Fruit medium, roundish oblate, irregularly ribbed, greenish yellow, with stripes of reil, and many russet dots. Stalk short. Calyx elosed. Flesh yellow, firm, sweet, pleasant. Good. Angust.

PAWLE'S JANET.

Missouri Janet?

Tied Neverfail?

Rawle's .Jannet.

Raule's . Tannetting.

Rawle's Genet.
Roek Remain.

Rock Rimmon.

Yellow Janett.

Winter Jannetting.

Jeniton.
Jennett.

Neverfail.

Indiana Jannetting.

Raul's Gennetting.

Originated in Amlierst Co., Va., on the farm of Caleb Rawle. Treo 
hardy, vigorous, spreading; it puts forth its leaves and blossoms much later than other varieties in the spring, and consequently avoids injury by late frost; it is, therefore, particularly valuable for the South and Southwest, where it is much cultivated. Young wood clear reddish biown.

Fruit rather large, oblate conic, yellowish, shacled with red and striped with crimson. Stalk short and thick, inserted in a broad oper.

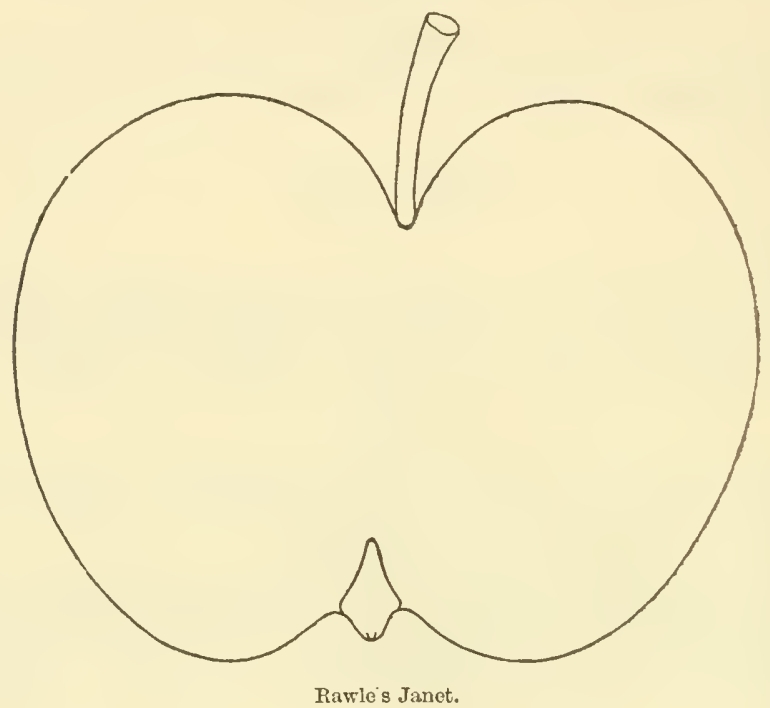

cavity. Calyx partially open, set in a rather shallow basin. Flesh whitish yellow, tender, juicy, pleasant subacid. Good to very good. February to June. So far has not succeeded well at the North.

\section{Rawlixg's Red Streak.}

Rawling's Fine Red Streak.

Red Streaked Rawling.

An old English sauce Apple, described in Ronalds.

Fruit large, roundish, yellow, striped with red. Flesh yellowish, tender, juicy, sweet. Good for cooking. December to March.

\section{Rebecca.}

\section{Daddy.}

An old variety, originating with a family by name of Stidham, in Delaware. Tree upright spreading. Young shoots dull grayish brown. Terminal bud large, blunt. Productive.

Fruit medinm, oblate, whitish yeliow, sometimes with a crimson cheek. Stalk short, inserted in a deep, narrow carity. Calyx closed. Basin broad and deep. Flesh tender, juicy, pleasant subacid. Good to very good. August, September. 
Red ANd Grees Sweet.

Red Pound Sweet.

Wheelock Sweet.

Prince's Large Red and Green Sweet.
Bedford Sweet.

Large Farly lied.

Origin unknown. Tree a good grower, upright spreading, a moderate anmual bearer.

Fruit very large, oblong conic, ribbed, greenish white, with stripes of red. Flesh white, tender, sweet; a good fruit for baking and stock feeding. Middle of August to middle of September.

\section{Red Aprle.}

Origin, Berks Co., Pa.

Fruit below medium, roundish oblate, striped and marbled with bright red. Stalk long, slender. Calyx large. Flesh whitish, slightly stained with red, tender. Good. January to March. (Am. P. S. Rep.)

\section{Red Astrachan.}

Deterding's Early. Astrachan Rouge.

Vermillon d'Été. Abe Lincoln.

Rother Astrakan.

A fruit of extraordinary beauty, first imported into England, with the White Astrachan, from Sweden, in 1816. It bears abundantly with us, and its singular richness of color is heightened by an exquisito bloom on the surface of the fruit, like that of a plum. It is one of the

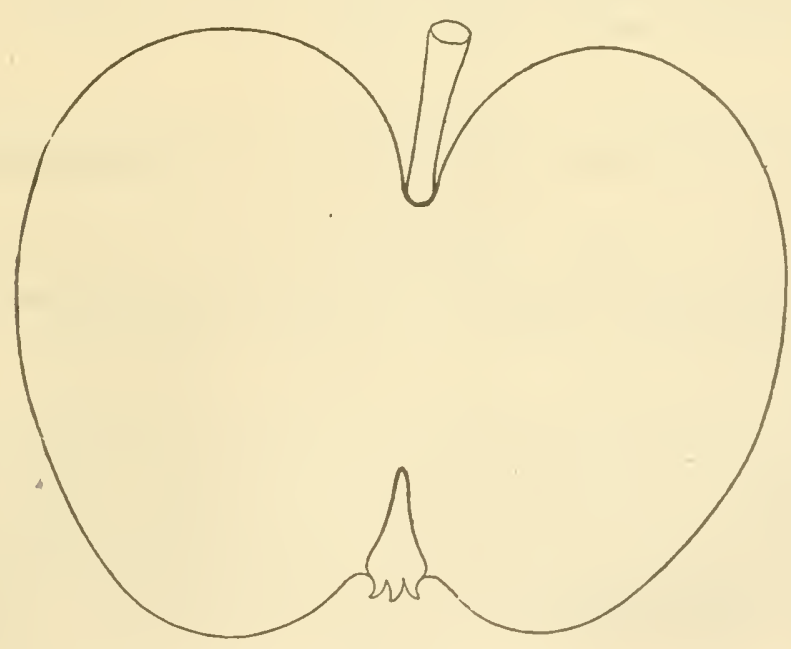

Red Astrachan.

handsomest dessert fruits, and its quality is good, but if not taken from the tree as soon as ripe it is liable to become mealy. Tree a vigorous 
grower, upright spreading. An early and abundant bearer. Young shoots elear reddish brown.

Fruit pretty large, rather above the midlle size, and very smooth and fair, romelish, a little narrowed towards the eye. Skin almost en. tirely covered with deep crimson, with sometimes a little greenish yellow in the shade, and occasionally a little russet near the stalk, and covered with a pale white bloom. Stalk rather short and deeply inserted. Calyx partially closed, set in a slight basin, which is sometimes a little irregular. Flesh quite white, crisp, moderately juiey, with an agreeable, rich, acid flavor. Good to very good. Ripens from last of July to middle of August.

\section{Red Autujn Calville.}

Calville Rouge d'Automne.

Calville d'Automne.

Erd Beere, or Strawberry of Switzerland. Rosseau, incorrectly.

An old French Apple of unknown origin. Tree vigorous, productive. Yourig wood dark reddish brown.

Fruit large, romdish conical, deeply ribbed, pale yellowish, washed and overspread with shades of rich dark, or very dark red. Flesh white, tender, juicy, often stained with red, sprightly aromatic, subacid. Good. September to December. An unprofitable variety.

\section{Red Belle-Fleur.}

Belle-Fleur. Striped Belle-Fleur. Belle-Fleur Rouge. Wigwam.

A French variety, scarcely worth eultivation.

Fruit large, regular, oblong conieal, pale greenish yellow, but nearly covered with red, striped with dark red. Flesh white, tender, of tolerably mild flavor, apt to become mealy. Poor. November to January.

\section{Red Canada.}

Old Nonsuch, of Mass.

Poland.

Richfield Nonsuch.

Steele's Red Winter.

An old fruit, formerly much grown in Connecticut and Massachnsetts, but is not now much planted, on aceount of its small size and poor fruit; sneceeds well in Western New York, Ohio, and Michigan. Tree thrifty, but of slender growth; very productive. Young wood brownish olive.

Fruit medium, oblate, inelining to conic. Skin yellow, mostly shaded with deep red or crimson, somewhat striped or splashed on tho sunny side, and thickly sprinkled with gray, and sometimes greenish dots. Stalk short, inserted in a broad, deep earity. Calyx closed. Segments long, in a small, narrow, somewhat irregular basin. Core small, elose. Flesh white, tender, crisp, abounding with a brisk, refreshing juice, and retaining its fine, delicate flavor to the last. Very good to best. January to May.

\section{Red Cathead.}

Cathead of some.

Tree upright, vigorous, and productive, extenswely grown in the 
eastern and southwestern counties of Virginia. Young wook dull rerl. dish brown, downy.

Fruit large, roundish conic, yellow, partially shaded with dull red, and sometimes deeper red in the shadie, and thickly sprinkled with whitish dots. Stalk short, inserted in a deep cavity. Calyx open, set in a large basin. Flesh yellowish, tender, juicy, pleasant subacid. Good to very good. Oetober, November.

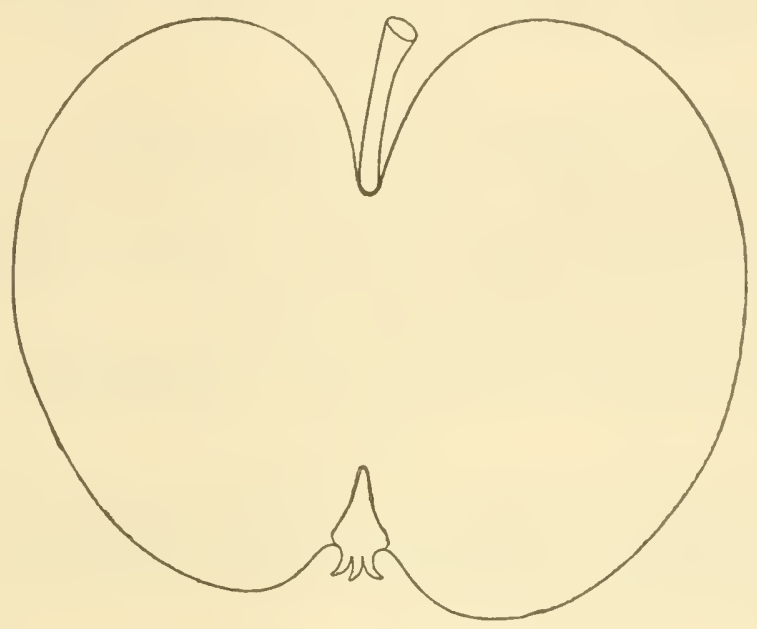

Red Canadia

\section{Red Cedar.}

Origin unknown. Tree moderately vigorous, upright spreading.

Fruit medium, dark rich red. Flesh yellow, mild subacid. Falued for its long keeping quality.

\section{Red Cheек.}

There are claimed to be three distinct Apples under this name. One is said to have originated on the farm of Mull, Sharon, Conn.; the tree forming a sinall branching head, a great bearer, and the fruit a long keeper.

Fruit medium, roundish oblate conic, whitish, shaded in the sun with light red. Calyx small, closed. Flesh white, tender, juicy, pleasant mild subacid. Core medium. Deeember to February.

Another Red CheEk is said to have originated near Dracut, Mass.

Fruit medium, roundish eonical, whitish, shaded with crimson in the sun, few gray ciots. Calyx closed. Flesh white, tender, juicy, pleasant subacid. Core rather large. November, December.

Another comes from New Jersey.

Fruit medium, roundish oblong oval, inclining to conic, whitish yellow, shaded with erimson in the sun, gray and light dots. Stalk short. Calyx partially closed. Flesh white, tender, juicy, sulueid. Core ratlice small. December, January. 


\section{Red Fayorite.}

Origin near Carlisle, Pa.

Fruit medium, oblate, juicy, subacid. (A. Pom. S. Rep.)

\section{Red Gilliflower.}

Red Seek-no-Farther.

Harkness New Favorite.

Fruit medium, oblong conical, fine red. Flesh white, mild, rich sub. acid. November to January. Tree a poor bearer. (Elliott.)

\section{Red Horse.}

Reseived from Kentucky. Tree of upright growth.

Fruit medium, oblate, with broad ribs, mostly covered with dark red, and obscure splashes and stripes, and pretty thickly sprinkled with light gray dots, and nettings of misset. Stalk short. Cavity large; irregular. Calyx open. Flesh yellowish, crisp, tender, juicy, mill sub. acid, aromatic. Very good. Oetober, January.

We have had but little opportunity of comparing this with other varieties, and it may prove a variety known by another name.

\section{REDICK.}

An old Connecticut Apple. Tree moderately vigorous, productive.

Fruit below medium, roundish oblate, yellow, shaded, splashed, and striped with dark red. Flesh yellowish, tender, juicy, pleasant. Good. Core small. Novenber, December.

\section{Red Ingestrie.}

Raised by Mr. Knight. This is greatly admired as a dessert Apple in Fingland, but not liere.

Fruit small, oblong or ovate, with a wide basin at the ere, and a short and slender stalk. Bright yellow, tinged and mottled with red on the sunny side. Flesh very firm, juicy, and high flavored. Good. Ripens in September and October.

\section{FiEd JEWELI.}

Originated in Told Co., Ky. Tree a good and hant'some grower, an early bearer, and uniformly prodnctive. A new promising sort.

Fruit small, roundish oblate. Sides often unequal. Color very dark crimson red, with many white conspicnons dots. Stalk slender. Calyx closed, or partially open. Flesh yellowish, firm, compact, juicy, mild, pleasant subacid. Good to very good. December to February.

\section{Red June Sweet.}

June Sweeting.

Origin unknown. Received from Pennsylvania. Tree a fine grower and abundant bearer, continuing a long time in use.

Fruit medium, roundish inclining to oblate, greenish yellow, striped, splashed, and shated with dull red. Stalk short. Calyx closed. Flestr 
white, tender, moderately juicy, rich, pleasiut, sweet. Tery Gooul. July, A ugust.

\section{RED Mokxios.}

From Pennsylvania. Tree vigorous, upright spreading, productive.

Frnit medimm, ublate, yellowish, shaded and indistinctly splished with red, small dots. Stalk long, slender. Calyx closed. Flesl: yellowish, tender, juicy, slightly aromatic subacid. Good to very good. Core small. January to March.

\section{Red Must.}

An old Herefordshire (England) cider fruit, of large size, roundish oblate, yellow, with red cheek in the sun. Flesh rich. October, November.

\section{Red Rance.}

Origin unknown. Tree a vigorous, upright spreading grower, productive.

Fruit medium or below, roundish, slightly conic. Color fine yellow, shaded with red and thickly covered with whitish dots. Stalk slor't, inserted in a small cavity. Calyx closed, set in a broad, shallow basin. Flesh rellowish, firm, juicy, rich, with a mild Spitzenburgh flavor. Good to very good. December, February.

\section{Red Republican.}

Origin, Lycoming Co., Pa. Tree vigorous, spreading, moderately productive.

Fruit large, roundish oblate. Skin yellowish, striped and shaded with red, and sprinkled with large whitish dots. Stalk short, in a large: cavity. Calyx closed. Basin broad, deep, and furowed. Good. Flesh coarse, tender, juicy, subacid. December, January.

\section{Red Romarin.}

Pomme Romarin Jange. Mela di Rosmarino rossa.

An Italian fruit.

Fruit large, oblate oblong conic, bright yellow, shaded with red, and dotted with small brown spots. Stalk slender. Calyx closed. Flesh white, fine-grained, crisp, sugary aeid, perfumed. Core small. Decentber to Mareh. (An. Pom.)

\section{Red Russet.}

Origin, farm of Mr. Sanborn, Hampton Falls, N. H. Tree rers vigorous, upright spreading, and productive. Foung wood clear redilish irown.

Fruit large, roundish conic, rellow, shaded with dnll red and level calmine in the sun, and thiekly covered with gray dots, with a slight alp. l. sarance of rough russet on most of the surface. Stalk rather short aud thick, inserted in a medium cavity, surrounded with thin russet. Callyx nearly closed. Segments long, remrved, in a narrow, uneren hasin. Flesh vellow, solid, crisp, tender, with an excellent rich, subieid flaror, somewhat resembling Ballwin. Tery grod. January to April. 


\section{Red SeEi-No-Farther.} bearer.

Origin unknown. From Pennsylvania. Tree open, spreading, good

Frnit medinm, oblate, greenish yellow, splashed, striped, and shaded with red. Flesh whitish green, crisp, tender, juicy, pleasant, mild sub. acid. Core small. Good. December, January.

\section{Red Streak.}

Herefordshire Red Streak. Scudamore's Crab. Johnson.

A capital English cider Apple, which thives admirably in this conntry, and is very highly esteemed, as it makes a rich, high flavored, strong liquor. It is a handsome grower, and a great bearer.

Fruit of medium size, roundish. Calyx small, set in a rather deep basin. Stalk rather slender and short. Skin richly streaked with red, with a few yellow streaks and spots. Flesh yellow, rich, firm, and dry. Good,

\section{Red Stripe.}

English Red Stripe. Carolina Red Stripe. Rockhill's Summer Queen.

Origin unknown. Comes to us from Indiana. Tree hardy and productive. Valuable fruit for market or cooking.

Fruit medium, oblong conical, almost ribbed, whitish, considerably striped, splashed, and mottled with crinison. Stalk short and slender. Calyx closed. Flesh white, tender, juicy, pleasant subacid. Good. A ugust. Core large and open.

\section{Red SweET.}

Origin, on the farm of D. C. Richmond, Sandusky, O. Tree upright, vigorous, and productive.

Fruit medium, roundish oval, yellowish, striped and shaded with light red, and sprinkled with greenish dots. Flesh whitish, very tender, juicy, sweet, and excellent. Good. November to Fepruary.

\section{RED WARRIOR.}

Origin, North Carolina. Distinct from Nickajack, which is some. times grown under this name. Tree upright, with young shoots dark redclish.

Fruit large, roundish oblate, yellow, striped and marbled with two shades of red. Flesh yellowish, crisp, juicy. Good. November to Narch.

\section{Ren Wister Cantille.}

Calville Royale d'Hiver. Calville Rouge d'Hiver. Calville Ronge Normande. Calville Rouge d'Anjou. Calville Ronge. Caillot Rosat.

\section{Red Calville.} Sanguinole.

Cushman's Black? Calville vraie des Allemands.

An old French variety, quite superseded.

Fruit medium, roundish conic, ribbed, pale and dark red. Flesk tender, mild subacid. Poor. November to February. 


\section{Red Winter Pearmain.}

$\begin{array}{lll}\text { Red Lady Finger. } & \text { Bunembe. } & \text { Rer Fall Pippin } \\ \text { Bunkum. } & \text { Red Vandevere. } & \text { Meig's. } \\ \text { liobertson's Pearmain. } & \text { Batehelor. } & \text { Tinson's Red. } \\ \text { Jaekson's Red. } & \text { Sonthern Fall Pippin. L'wers. }\end{array}$

Origin unknown. An old valiety. Tree of moderate upright growtlı; a regular bearer. Young shoots clear rich reddish brown, slightly downy.

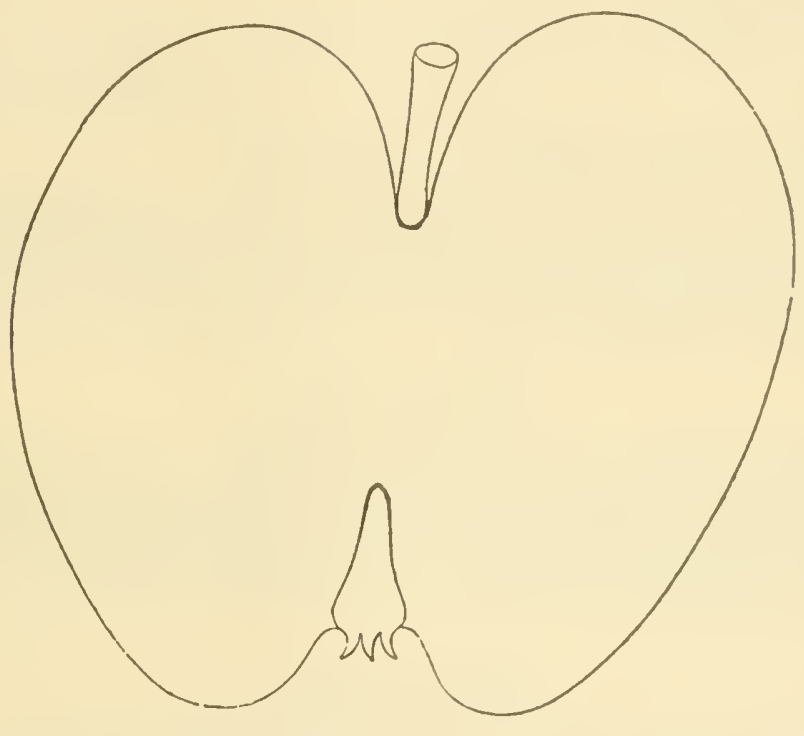

Red Winter Fearmain.

Fruit medium size, roundish oblong conic, yellowish white, mostly shaded with maroon and thickly sprinkled with linge light dots. Sitalk very short, in an acute deep eavity, slightly russeted. Calyx closerl, set in a small, rount, open basin. Flesh whitish yellow, tenter, juicy, mild subacisl, or nearly sweet, slightly aromatic. Good to very good. January to March.

\section{Red Whater Sweet.}

Origin unknown. Specimens from Kentucky, although the fiuit is there stated to have come from Virginia or Maryland.

Fruit medium, roumdish conic, de'p crimson on yellow, with indistinct splashes and stripes, large and small light dots. Stalk short. Cavity small. Cillyx small, closed. Flesh yellow, a little coitrse, rich, honeyed sweet. Fine for cooking. Decembir, February.

\section{Reed.}

Originated on the premises of Creorge Reed, Leerlsville, 1)utchess Co., N. Y. 
Fruit medium, roundish, whitish, shaded, splashed, and mottled with light and dark red. Stalk medium. Calyx small, closed. Basin shallow. Flesh white, a little stained next the skin, tender, juicy, pleasant subacid. Good. Norember.

\section{Pieinette Calville.}

Fruit medium, roundish, inclining to oblong, rich yellow, with broad stripes of dull red in the sun. Flesh yellowish, tender, juicy, perfumed. November January. (Diel.)

\section{Reinetre Coulor.}

A new Apple, originating with M. L. Coulon, Liege, in 1856. Tree vigorous, with dark reddish gray young shoots.

Frnit very large, roundish oblate, slightly conic, golden yellow, washed and splashed with rich bright red, many prominent reddish gray dots. Stalk stont, short. Cavity deep. Calyx closed. Basin rather (leep. Elesh creamy white, semi-crisp, brisk subacid, agreeable. Core open, large. November, January. (Ar. Pom.)

\section{Reinette Daniel.}

Origin unknown. Tree vigorous, spreading.

Fruit above medium, romelish oblate. Sides unequal, whitish yellow, nearly covered with thin dull russet. Stalk short. Calyx small, closed. Flesh whitish, moderately tender, juicy, brisk, sharp subacid. Good. November to February.

\section{ReINeTte D'ANjot.}

Of French origin. New. Tree vigorous, upright spreading,

Fruit medium or above, roundish, slightly oblate, yellow, shaded and indistinctly splashed with rich red, few light or areole dots. Stalk rather slender. Cavity shightly russeted. Calyx large, open. Basin shallow. Flesh yellow, crisp, tender, juicy, brisk, rather rich subacid. Very good. Core medium, hollow. December, February.

\section{Reinette de BaYeti.}

A Belgian Apple of unknown origin. Tree vigorous and productive.

Fruit large, roundish, stightly conical, golden yellow, shaded with red around the stalk, and with scattered red dots. Stalk short. Cavity large. Calyx half closed. Flesh white, half tender, sharp subacid. December to January. (An. Pom.)

\section{Reinette de Breda.}

Fruit medium, roundish oblate, rich yellow, witlı russet an d red in the sun. Flesh yellowish white, frm, crisp, juicy, vinous, aromatic. December to March. (Diel.) 


\section{Reinetee de Caux.}

Of French origin. Tree vigorons, productive.

Fruit large, roundish, slightly ohlate, yellow, splashed and moteled with bright red in the sum, many gray dots. Stalk slender. Callyx lalf closed. Flesh yellowish white, tender, juicy, agreeable aromatic, sul,acid. January, February. (Alb. Pom.)

\section{Reinette de Clalieval.}

Of French origin.

Fruit melium, roundish oblate, clear lemon yellow, with a slight tinge of red in the sun. Flesh fine, white, firm, juicy, aromatic, vinons. December, MIarch. (Diel.)

\section{Reinette de Hoxgrie.}

An old Apple, described by Lindley as :

Fruit medinm, roundish oblate, rough gray russet, with faint orange in the sun, numerous warty specks. Flesh greenish white, firm, cris]', aromatic. November to April.

\section{Reinette de Tioror.}

Supposed to have originated in Holland. It is described in the An. nals of Pomology as a vigorous, upright, productive tree.

Fruit medium to large, roundish truncated, rellowish, washed, shaderl, and mottled with bright red, glay dots. Stalk long, slender'. Calyx with long segments. Flesh creany white, tender, juicy, rich subacil. December.

\section{Reinette Doré.}

Reinette Jaune Sardive.

Reinette Rousse.

Of French origin.

Fruit mediun, roundish, pale yellow, with a tinge of red in the sun, nettings of russet, and large brown dlots. Stalk short. Calyx closed. Flesh whitish, not very juicy, firm, subacid. Good. Core small. October, November.

\section{REINETTE DU Tigan.}

Of foreign unknown origin. Tree vigorous, hardy, and productive.

Fruit medium, roundish conical, rich yellow, with many red and gray dots, fuint blush of red in the sun. Stalk slender. Calyx small, closeri. Flesh rellow, tinted with rose, fine-grnined, firm, juicy, rich subucid. Decenuber to March. (An. Y'om.)

\section{Peinette Grais dor.}

Tree vigorous, prorluctive.

Fluit large, roundish oblute, vellowish, with grav spots and dots, bronzed in the sun. Stalk slendor. Calyx closed. Flesh yrllowish, furm, juicy, brisk subacid. Decenber, Janualy. (Alb. Pom.) 


\section{Reinetre Pippin.}

Origin, supposed France.

Fruit medium, oblate, inclining to conic, pale yellow, with light and gray dots. Stalk short. Cavity large. Calyx small, closed. Basin medium or small, corrugated. Flesh white, crisp, moderately juicy, brisk subacid. Good. Core rather large. December, January.

\section{Reinette Quarrendon.}

French origin.

Fruit medium to large, roundish oblate, golden yellow, washed and splashed with two shades of red, small black dots. Stalk slender. Calyx closed. Flesh white, half crisp, sugary acid. December. (Alb. Pom.)

\section{ReinetTe St. LaMbert.}

Supposed to have originated in Liege.

Fruit medium to large, roundish oblate, yellow, mostly overspread with brilliant rich red or crimson, with a tinge of purple. Stalk short. Calyx in a deep basin. Flesh yellowish white, fine, juicy, delicate, perfumed. September. Of good promise. (An. Pom.)

\section{Reinette Triomphante.}

Victorious Reinette.

A German early winter Apple.

Fruit large, oblong, pale yellow, thickly dotted with white specks and rough, projecting warts. Flesh yellow, firm, juicy, pleasant aromatic. Good. The tree is of thrifty growth, and is said to bear well.

\section{Reinette Tervaene.}

Originated at Ledeberg-les-Gand. Tree spreading. Ioung nood brownish, downy.

Fruit medium, oblate, yellowish, mottled and shaded with brick reel. Flesh greenish white, fine-grained, sharp subacid. Good. November.

\section{Riepublicax Pippin.}

Origin, Lycoming Co., Pa. First discovered by George Webb, who gave it the name. Tree of strong, but crooked growth, only moderately productive.

Fruit large, irregularly oblate, dull yellow, mostly shaded with red, somewhat striped and marbled, and thinly sprinkled with large gray dots. Stalk long, slender. Calyx small, closed. Flesh whitish, tender, juicy, pleasant subacid. Good. Cooking and drying. September, October.

\section{Rhode Island Greesisg.}

Burlington Greening. Jersey Greening.
Russine. Grünling von Rhode Island.
Bell Dubois,

The Rhode Island Greening is such a universal fatorite, and is sc generally known, that it seems almost superfluous to give a description 
of it. It sneceeds well in ahmost all of the northern sections of the States, and on a great variety of soils, and where it does snceed is one of the most esteened and profitable among early winter fruits. In Southern Ohio, Indiana, and farther south it drops too early. Tree a very vigorous, strong, spreading grower. Young shoots reddish brown. Tery productive.

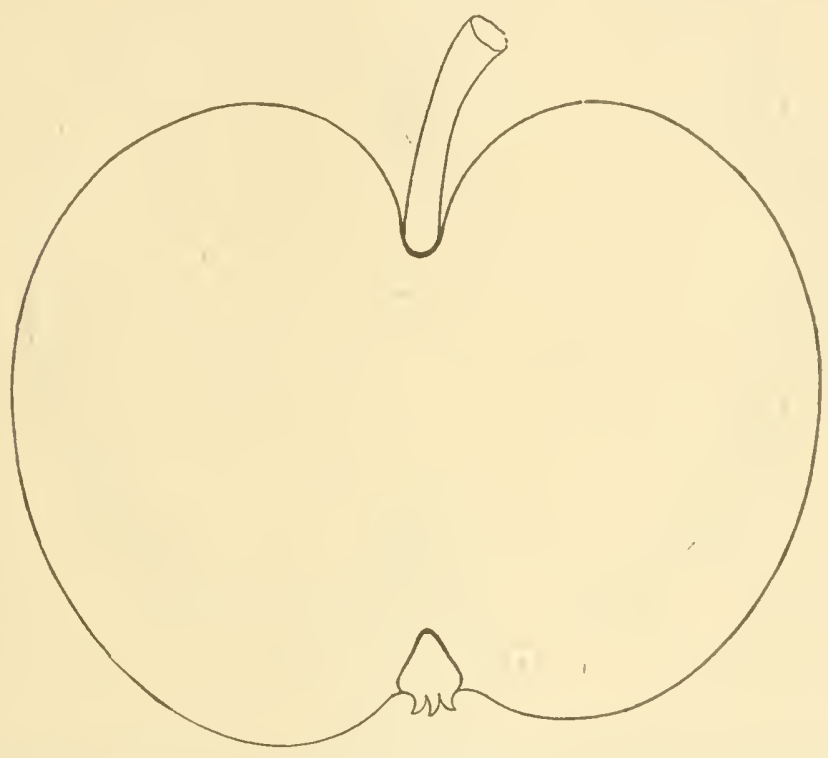

Rhode Island Greening.

Fruit large, roundish, a little flattened, pretty regular, but often obseurely ribbed, dark green, becoming greenish yellow when ripe, when it sometimes shows a dull blush, near the stalk. Calyx small, woolly, closed, in a slightly sumk scarcely plaited basin. Stalk three-fourtlis of an inch long, eurved, thiekest at the bottom. Flesh yellow, fine-grained, tender, erisp, with an abundance of rich, slightly aromatic, lively, acid juice. Very good. November to February.

\section{Pihode's Oraxge.}

Raised by Col. Nercer Rhorles, Newton Co., Ga. Tree a slow grower, spreading, productive.

Fruit inedium, roundish oblate, yellowish, washed, striperl, and mot. tled with light red, many light and gray dots. Stalk rather long. Calyx small, closed. Flesh whitish, tencler, juicy, pleasant subacid. Good. Core small. August.

\section{Rimston Pippix.}

Glory of York. Travers'. Formosa Pippin. Rockhill's Russet

The Ribston Pippin, a Yorkshire Apple, stands as high in rireat Britain as the Bank of England, and to say that an Aple lias a Ribston 
flavor is there the highest praise that can be bestowed. But it is scarcely so much esteemed here, and must be content to give place with us to the Newtown Pippin, the Swaar, the Spitzenburgh, or the Baldwin. In Maine, and parts of Canada, it is very fine and productive.

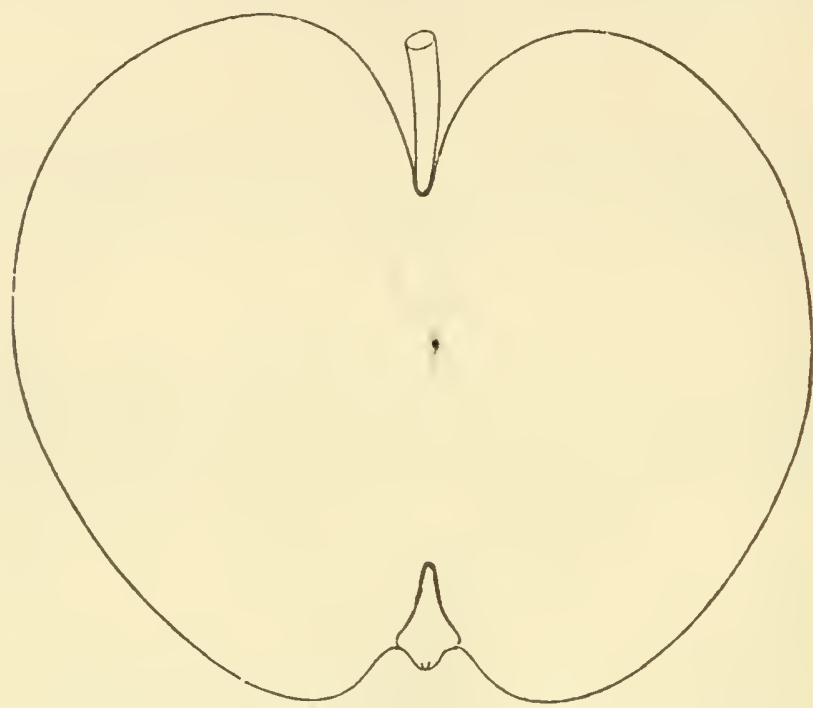

Ribston Pippin.

Fruit of medium size, roundish, greenish yellow, mixed with a littlo russet near the stalk, and clouded with dull red on the sunny side. Stalk short, slender, planted in a rather wide cavity. Calyx small, closed, and set in an angular basin. Flesh deep yellow, firm, crisp, with a sharp, rich, aromatic flavor. Very good. The tree forms a spreading top. November to April.

\section{Richari's Graft.}

Derrick's Graft. Strawberry.
Red Spitzenburgh. Wine.

\section{I) $\in$ rrikinan.}

Dirck's Graft.

Originated at Greenport, Columbia Co., N. Y. An excellent fall Apple, worthy of extended cultivation. Tree a free, upright spreading grower, productive. Young shoots very dark reddish brown, downy.

Fruit medium, roundish oblate. Color yellow, nearly covered with splashes, marblings, and shades of rich red. Stalk medium length, slender. Cavity large. Calyx small, closed. Segments sometimes recurved. Basin medium, slightly uneven. Flesh yellowish, tender, juicy, pleasant, rich, aromatic subacid. Very good. September, Octower.

\section{RiCHARDSON.}

Origin, farm of Ebenezer Richardson, Massachusetts.

Fluit large, roundish conic, mostly covered with red, bright in the 
sun, with numerous large, light specks. Stem rather stont, in a largo cavity. Calyx large, open, in a deep narow basin. Flesh greenish white, remarkably tender, juicy, with a fine, rieh, ahmost sacehaine tavor. Goud. Last of August and Sep̧tember. (Cole.)

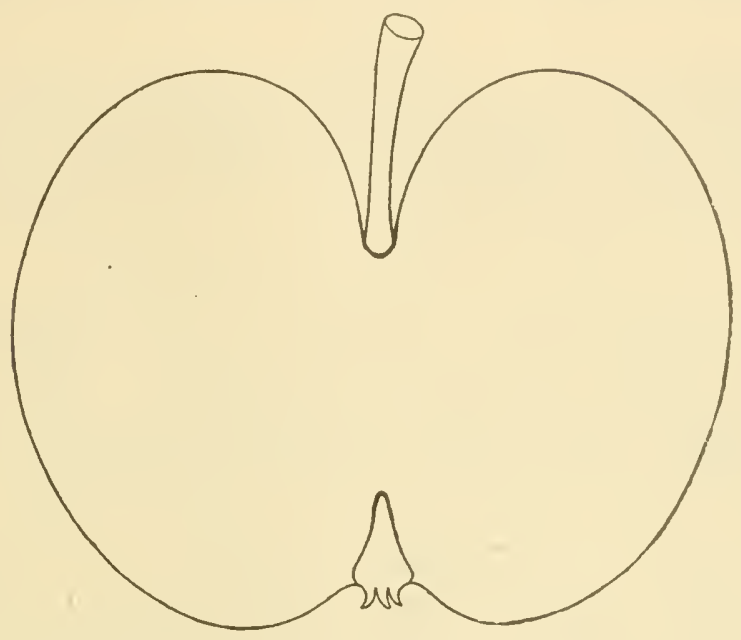

Richard's Graft.

\section{Pichuond.}

Origin, farm of D. C. Richmond, Sandusky, O. Tree a free grower, and a profuse bearer.

Fruit large, oblate, light yellow, striped, splashed, and marbled with crimson, and thickly sprinkled with light brown dots. Stalk short. Calyx open. Flesh white, tender, juicy, vinous, sweet, and rich. Good. October to February.

\section{Ridge Pippin.}

Origin unknown, supposed Pennsylvania. 'l'ree a good grower and hearer.

Fruit rather large, roundish conical, very much ribbed. Tollow, very slightly shaded,- sprinkled with russet and crimson dots. Stalk rather short, inserted generally in a large eavity. Calyx closed, set in an alb. rupt uneven basin. Flesh yellowish, juicy, crisp, with a mild, alnost saccharine, slightly aromatic Havor. Good. Mareh, April.

Valued mainly as a long keeper and salable in market.

\section{Riest.}

From Simon S. Riest, Lancaster, Pa.

Fruit large, roundish, ribbed at apex, fair yellow. Flesh fine, pleasant. Good. August. 


\section{Riglex.}

From Penusylvania. Tree moderately vigorous, upright.

Fruit medium, roundish conicai, pale yellow, shaded and splashed with shades of red. Stalk medium. Calyx closed. Flesh whitish, moderately juicy, subacid. Goorl. Core small. December to March.

\section{Ritter.}

Origin, Berks Co., Pa. Tree moderately vigorous, upright spreading.

Fruit medium, roundish oblate, yellow, striped and splashed witk two shades of red. Stalk short. Calyx closed. Flesh white, tender, juicy, mild, pleasant subacid, almost sweet. Good. September.

\section{River.}

Origin, Massachusetts. Tree of slow growth, but productive.

Fruit medium to large, oblate, slightly conic, ribbed, yellow, striped and shaded with dark red, with a slight bloom. Stalk medium, deeply planted. Calyx open, set in a basin of moderate depth. Flesh juicy, tender, pleasant subacid. Good. August, September.

\section{Roadstown Pippin.}

Introduced to notice by James McLean, of Roadstown, N. J., and originated in that town. A strong, erect grower, and makes a large tree; a good bearer, and a profitable market fruit, large and uniformly fair, excellent for cooking and drying. Size large, oblate oblique. Calyx small, and closed. Skin greenish yellow, sparsely sprinkled with green dots. Flesh white, tender, sprightly subacid. Good to rery good. Middle of April to the middle of September.

\section{Roane's White Crab.}

An old Virginia cider Apple; valuable only for that purpose. Fruit small, round, yeliow. September, October.

\section{Roberson's White.}

Origin said to be Culpepper Co., Va., where it is popular. Tree upright, of rapid growth, and bears regular crops.

Fruit merlium, roundish oblate. Color greenish yellow, with many dark dots. Flesh yellowish, fine-grained, crisp, juicy, subacid. Good. October to December.

\section{Robert Bruce.}

Origin, Wake Co., N. C. Tree of vigorous, upright growth, and good bearer.

Fruit rather above medium, oblate, crimson shaded. Calyx open. Stalk short. Flesh white, rather coarse, juicy, pleasant. August. (Gar. Mon.) 


\section{Ronents.}

Roberts Seedling.

Origin, Nuskingum Co., O.

Fruit medium, roundish oblate, pale yellow, with blush cheek in sun. Flesh white, tender,' juicy, pleasant subacid. Very good. November, December.

\section{Robex.}

Robey's Seedling.

Raised by H. R. Robey, Fredericksbmrgh, Va. Tree vigorous and produetive.

Fruit large, round, tapering to the eye. Color lively red, faintly striped, on a scarcely pereeptible yellow ground, thickly covered with creamy spots. Flesh yellow, juicy, pleasant subacid. Good. November, December.

\section{Robis.}

This is a new Apple, originated in the garden of Mr. Roivin, at Corbeil, and deseribed in the Annals of Pomology.

Fruit medium to large, oblate conic, yellowish, mottled and reiner with vermilion red in the sun. Stalk short. Calyx large. Flesh white, firm, juicy, perfumed subacid. April to May.

\section{Robinsox's Pippin.}

An old English Apple of little value.

Fruit small, roundish oblate, greenish yellow, bronzed in the sun. Flesh greenish, tender, juicy, sharp subacid or acid. December, February.

\section{Robinsox's Superb.}

Farrar's Summer.

An Apple from Virginia. Tree upright, productive.

Fruit large. Flesh erisp, juicy. September, October.

\section{Riobinsox's Sweet.}

Origin, Vermont. Tree upright, vigorous, productive.

Fruit medium, round, light red, stripe!. Flesh fine-grained, juicy, sweet. 'Too mueh of the finit imperfeet to make it desirable.

\section{Rochelle Reinetre.}

\section{Reinette de la Rochelle.}

Tree vigorons, productive.

Fruit large, roundish ullong eonical, pale yellow, brownish blush in sim, many large gray and red spots or dots. Flesh whitish, rathel cuarse, tender, juicy, mild subaeid. January. (Am. Pom.) 


\section{Rock.}

Oriciu, Peterborough, N. H., recommended by Robert Wilson, of Keene, as an excellent fruit. Tree vigorous, with long, slender branches, very productive.

Fruit large, roundish, slightly flattened, striped and splashed with dark anu bright red on a yellowish ground. Flesh white, tender, juicr, Haror subacid. Good. September, October.

Another Rock Apple comes from Pennsylvania.

Fruit medium, oblate, inclining to conic, whitish, sprinkled with a few indistinct gray and light dots. Flesh white, tender, juicy, lively subacid. Good. Core sinall. Angust.

\section{Rock PIPpis.}

Lemon. Walnut Stem.

From Ohio.

Fruit medimm, oblong conical, yellow, bronzed in sum. Flesh firm, and a good keeper, and in spring profitable market fruit. (O. P. S.)

\section{RockPort SWEET.}

Origin, Massachusetts. Tree a strong grower and productive. Young shoots reddish brown, smooth.

Fruit medium, roundish oblate, greenish, becoming waxen yellow, with a dull red cheek. Stalk rather long, inserted in a cavity somewhat ribbed, surrounded by russet. Calyx large, ne:irly closed, set in a broad, open basin. Flesh whitish, juicy, brisk, sweet. Good to rery good. January to April. Core small.

There is claimed to be another Rockport Sweet, originating in Olio, but we fail to discover the distinction by means of the fruit.

\section{Rock SWEET.}

Origin, farm of Elihu Pearson, Newbury, Mass. Tree hardr, vigorous, and a constant bearer. Young shoots reddish olive.

Fruit, medium or below, roundish oblate, slightly conic, reddish, shaded, striped, and splashed with darker red, and sprinkled with large whitish dots. Stalk short, set in a broad, deep, russeted carity. Calyx closed. Basin shallow, corrugated. Flesh white, tender, juicy, rich, sweet, and pleasant. Good to very good. September.

\section{ROLEN'S KEEPER.}

Rowland.

Fruit medium, round, regular, splashed red on russet. Dots scattered, small, white. Calyx small, closed. Fosh greenish rellow, fine-grainech acid, rich. Good to very good. March, Arril. (Warder.)

\section{Rollix.}

\section{Rolla?}

Origin. Franklin Co., N. C. Tree of moderate growth, bears ai :u. dantly. 
Fruit medium, roundish oblate, yellow, stained and striped with dull red. Stalk long. Cavity wide and deep. Basin shallow. Flesh compact, fune-grained, subacid. Good to very good. October to January.

\section{Romanite.}

Broad River. Southern Romanite.

The origin of this Apple is unknown. It has been sometimes con. founded or placed as identical with Shockley in North Carolina, where it is much grown, but it is quite distinct. It is also distinct from Gil-

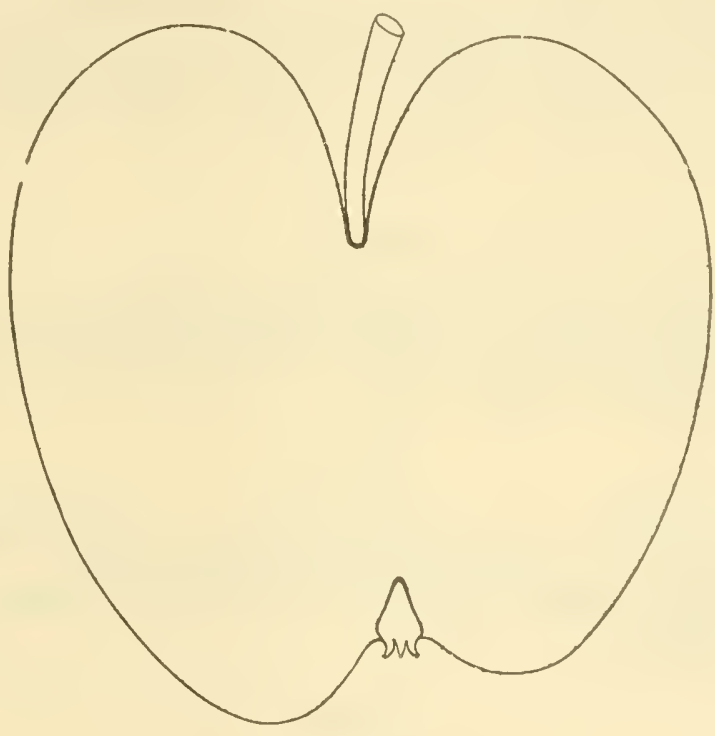

Romanite.

pin, sometimes known as Romanite. Tree vigorous, spreading, very productive. Branches slender. Wood short-jointed, dull grayish brown.

Fruit small, roundish conical, truncated, yellow ground, mostly overspread with clear, light, handsome red, indistinct light dots. Stalk slender. Calyx in an abıut basin. Flesh yellowish, finc-grainerl. juicy, mild, pleasant subacid. Gond to very good. February, April. Taluable as a keeper, and for the eremness of its fruit.

\section{Roman Stem.}

Originated at Burlington, in New Jersey, and is much esteemed in that neighborhood. Tree very productive, morlerately vigorous, spreading, irregular.

Fruit scarcely of medium size, roundish, whitish yellow, with a faint brownish blush, sprinkled with patches of dark russet, and, when ripe, having a few reddish specks, unless the fruit is very fuir. Stalk 
three-fourths of an inch long, inserted in a shallow cavity under a Heshy protuberance. Calyx set in a rather narrow basin, with a few plaits. Core hollow. Flesh tender, juicy, with a rich, pleasant, musky flavor. Very good. November to March.

\section{Rome Beauty.}

\section{Gillett's Seedling.}

Origin, Southern Ohio. Tree a moderate grower, succeeds well at the Southwest. Young wood clear reddish brown, slightly downy or gray. A late bloomer.

Fruit large, roundish, approaching conic, yellow, shaded and striped with bright red, and sprinkled with light dots. Stalk an inch long, inserted in a large, deep cavity, surrounded by greenish russet. Calyx partially closed, set in a narow, deep basin. Flesh yellowish, tender, juicy, sprightly subacic. Good. Core rather large. October to December.

\section{RosA.}

An old French Apple. Tree moderately vigorous.

Fruit large, roundish, light yellow, shaded and splashed with red in the sun, reddish gray dots. Flesh white, fine, tender, juicy, subacid. December, January. (Alb. Pom.)

\section{Riose.}

Coxe calls this the Rose Apple of China, and says he imported it from England. Tree vigorous, upright, abundant bearer.

Fruit large, rather oblong, striped red and green. Flesh pleasant, juicy. October:

\section{Rostiu.}

Foreign. Tree poor grower and unprofitable.

Fruit large, dark red, irregular in size and fornt. Flesh crisp, juicy, rich. Good. November, February.

\section{Roseau D'Autonse.}

Tree large, vigorous grower, spreading.

Fruit medium, rounclish ovate, flat at base, yellow, russet at stem, blush red cheek. Flesh yellow, juicy, tender, rich, firm. September. (Coxe.)

\section{Rose Calville.}

From France.

Fruit medium, roundish inclining to conic, rellowish, shaded and rather indistinctly splashed with crimson. Stalk short. Calyx closed, or partially open. Flesh whitish, tender, juicy, subacid. Good. No. vember, January. 


\section{Rose de Hollande.}

Rose de la Benange. Rose Tendre. Pomme de Collillao

'Tree vigorons.

Fruit medium to large, oblate eonical, gollen yellow, spotted anó veined with rosy earmine. Stalk small, short. Calyx half open. Flesh yellowish white, tender, sugary, acid. Winter. (An. Pom.)

\section{Rosemary.}

\section{Rosemary Russet.}

An old Apple described by Ronalds as of medium size, roundish conieal, greenish, with a little red russet. Flesh tirm, yellowish, rich, and good for table or kitchen use. December, February.

\section{Ross NoxpareiL.}

An Trish fruit, rather below medium size, roundish, narrowing a little to the eye, eovered with a thin mellow russet, and faintly stained with red on the summy side. Flesh greenish white, tender, with a rich aromatic flavor. Very good. A profuse bearer. Very subject to rot before ripening. Unprofitable. Oetober.

\section{Rostocker.}

$\begin{array}{lll}\text { Stetting Rouge. } & \text { Annaberger. } & \text { Mratapfel. } \\ \text { Rothe Stettiner } & \text { Rothe Hernapfel. } & \text { Bodickheimer ? } \\ & \text { Berliner Glossapfel. } & \end{array}$

A large and favorite German Apple, says Hogg, valuable for culinary jurjoses.

Fruit oblate, ribbed, yellowish, deep red next the sun. November to May.

\section{Rosy Red.}

An old variety, origin unknown. It is grown in Michigan, where it is elaimed as a seedling of Western New York, and in Indiana, and there claimed as a seedling of Cambridge, Ia.

Fruit medium, roundish oljlate, slightly eonieal, yellow, shaded, splashed, and marbled with light and dark red, light dots. Stalk medium, slender. Cavity deep, aente. Calyx elosed, medium, irregular. Flesh yellowish, breaking, sometimes a little stained, mild subaeid. Good. November, January.

\section{Round Winter Nonesuch.}

A variety deseribed by $\mathrm{Hogg}$ as an exeellent bearer, and valuable for market.

Fruit large, roundish oblate, obseurely ribbed, greenish yellow, with broken stripes and spots of red, some russet dots. Calyx large, closed. Stalk short. Flesh greenish white, tender, juiey, sweet. November tc Mareh. 
Rowe.

Rowe's Seedling.

An old Devonshire sauce Apple, described by Ponalds as:

Fruit large, roundish conical, light green. Flesh greenish white, juicy, pleasant. August, September.

\section{Roxbury Russet.}

$\begin{array}{ll}\text { Reinette Rousse de Boston. } & \text { Boston Russet. } \\ \text { Howe's Russet. } & \text { Putnam Russet. } \\ \text { Marietta Russet. } & \text { Warner Russet. } \\ \text { Belpre Russet. } & \text { Sylvan Russet. }\end{array}$

This Russet, a native of Massachusetts, is one of the most popuiar ruarket fruits in the country, as it is excellent, a prodigious bearer, and keeps till late in the spring wherever the soil and climate suit it. South and West it drops its fruit too early, and is therefore not valuable. The tree is healthy, moderately vigorous, spreading, with young shoots of a reddish brown, downy.

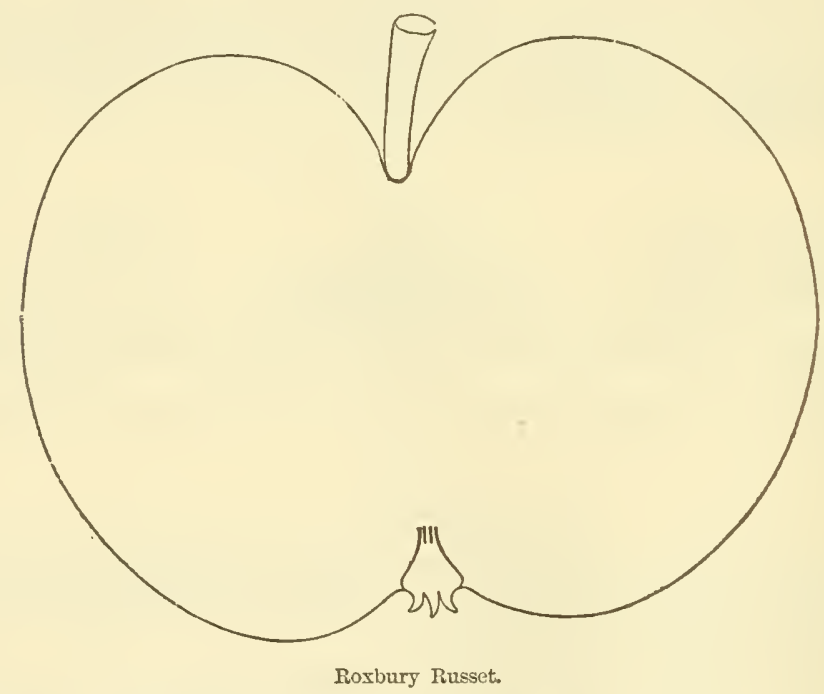

Fruit of medium size, often large, roundish, a little flattened, and slightly angular. Skin at first dull green, covered with brownish vellow russet when ripe, with, rarely, a faint blush on one side. Stalk near!y three-fourths of an inch long, rather slender, not deeply inserted. Calyx closed, set in a round basin of moderate depth. Flesh greenish white, moderately juicy, with a rather rich subacid flavor. Good to very good. Ripens in January, and may be brought to market in June.

\section{Royal Pearmaix.}

Merritt's Pearmain.

An old Apple described by Coxe and Romalds. It is to be found 
in the old orchards of New Jersey, Pennsylvania, and Ohio. The tree a moderately vigorous grower, very productive, the fruit kecping well.

Fruit merlium, roundish conical truncated, yellow, mostly overspread and indistinctly striped with red, wam romgh russet at the apex. Ftalk slender. Carity russeted. Calyx with short divided semments. Basin irregular or broadly furrowed. Flesh yellowish, firm, rich, mild sulacid, when fully ripe almost sweet. Tery good. November to Mareh.

\section{Roval ReinetTe.}

Royal Grise Reinette.

From Sussex, England. Described by Lindley as : tree an abundant bearer.

Frnit rather small, conical, yellow, striped with red, many gray spots. Flesh pale yallow, firm, juicy, brisk subacid. November to May.

\section{Royal Russet.}

Leathercoat Russet. Reinette de Canada Grise.
Reinette de Canada Platte. Passe Pomme de Canada.

An old varisty. Tree hardy, vigorous, and productive.

Frait mediun, roundish oblate conical, yellowish green, mostly covered with brownish russot, which is bronzed in the sun. Flesh greenish white, firm, rich acid. Gool. November, February.

\section{Royal Shepherd.}

A culinary Apple, described in Hogg as:

Fruit above medium, roundish oblate, greenish yellow, dull red in the sun. Flesh greenish white, crisp, brisk, pleasant acid. November.

\section{Royal Somerset.}

Fruit medium, roundish oblate, pale yellow, with broken streaks of red in the sum. Flesh yellowish, tender, juicy, pleasant subacid November to March. Cooking: (Hogg.)

\section{Rules Sumer Sweet.}

Origin, Cumberland Co., Pa.

Fruit medium, oblong, yellow. August. Poor. (A. Pom. S. Rep.)

\section{Rum Apple.}

Origin, Pawlet, Vt., on the farm of Brownley Rum. Tree upright, rigorous, an early and profuse bearer.

Fruit medium, oblate, yellow, slightly shaded with crimson. Stalk short. Cavity moderate. Calyx partiuly closed. Basin broad and shallow. Flesh whitish, juicy, tender, sprightly subacid. Goud. Norember to March.

\section{RUNAELLS.}

Origin, Naine. Profitable as a market fruit from its great productiveness and long kecping. 
Fruit medium, roundish, deep green in the shade, mostly covercd with purplish brown. Flesh firm. Moderately good. April to June (Me. Rep.)

\section{Piushock Pearifain. \\ Charles Pearmain.}

An English Apple.

Fruit below medium, roundish, yellow, with cimnamon russet, becon ing brownish in the sun. Flesh yellowish, firm, crisp, juicy, brisk subacid. December, April. (Hogg.)

\section{Russet Peariain.} ductive.

An old variety from Comnecticut. Tree moderately vigorous, pro-

Fruit medium, roundish conical, yellow, mostly covered with russet, and a brownish red cheek. Flesh yellowish, breaking, rich, brisk subacid. Good. December to March.

\section{Russet Table Pearmaix.}

A little dessert Apple, from Englaud. Tree of slender growth, pro. ductive.

Fruit small, roundish conical, yellowish green, slightly russeted, with a bright red cheek in sun. Flesh yellowish, firm, rich, aromatic, subacid. Very good. November to February. (Ron.)

\section{Russian Traysparent.}

- Ronalds describes this as forming a large broad tree, but a poor licarer.

Fruit large, roundish conical, ribbed at apex, golden yellow, faced with a flush of rose, and speckled with dark points. Flesh sweet, peculiar. Good for cooking. November, December.

\section{RrMer.}

\section{Caldwell. Green Cossings. Newbold's Duke of York. \\ Cordwall. Newbold's Admiral Duncan.}

of foreign origin. Tree vigorous, productive.

Fruit medium, roundish oblate, pale yellow, shaded with deep red, light dots. Flesh yellowish, rather firm, tender, subacid. Good. De. cember to April.

\section{Sable Sweet.}

Origin, Vermont. Tree good grower, spreading, productive.

Fruit medium, roundish oblate conic, whitish yellow, partially splashed and mottled with red. Flesh whitish, tender, juiey, mild swect, subacid. Good. August. 


\section{SACK AND Sugar.}

Morris's Sack and Sugar. bearer.

A little, old, early English Apple. 'Tree a fine grower, and good

Fruit small, roundish conical, pale yollow. Flesh white, soft, juicy sweet. Good. Angust.

\section{Sailly Autums.}

Salle?

Origin, Plattsburgh, N. Y., on the farm of J. It. Samborn. Tree upright, vigorous, and productive.

Fruit medim, roumdish oblate conic, greenish yellow, the exposed side frequently deep red. Stalk short, in a medium cavity. Calyx small, closed. Bisin small, narrow. Flesh very tender. Subacid. Good. September.

\section{SAINT Julien}

Saint Julian. Seigneur d'Orsay.

Heilige Julian's Apfel. De Saint Julien.

Concombre des Chartreaux. Pomme de Saint Julien.

An old variety, probably of French origin. Tree a strong, vigorous grower, productive.

Fruit medium, roundish conical, obtusely ribbed, yellowish russet green, slight tinge of red in sun. Flesh yellowish white, firm, rich, sweet: December. (Lind.)

\section{St. Lawrexce.}

Origin uneertain. Tree vigorous, upright, productive. Young shoots smootli, redldish brown.

Fruit large, oblate, tapering towards the eye, yellowish, striperl and splashed with carmine. Stalk of medium length, inserted in a large cavity. Calyx firmly closed. Basin small and deep. Flesh white, lightly stained, crisp, juicy, tender, and vinous. Good to very good. September, Octolver.

\section{Saint Sauveur.}

\section{Calville Saint Sauveur. Pomme Saint Sauveur.}

Originated in France.

Fruit large, roundish oblong conical, pale yellowish, faint blush in the sum, many light dots. Stalk short. Flesh milk white, tender, juiey, aromatic, acid. Good. November. (An. Pom.)

\section{SALEM.}

\section{Salem Sweet.}

An old Massachusetts Apple, somewhat grown in Ohio and west. ward. Tree a good grower and productive.

Fruit medium or above, roundish oblate conic, rongh, yellow, with brown and green dots, sometimes a blush in sum. Flesh yellowisl, crisp, tender, mild, almost sweet. Cooul. Core small. October, December.

\section{Saloplax Prppix.}

A Silnophine Apple, deseribed by Ronalds. Tree a eomprat grower, constant bearer: 
Frnit medium, oblate, yellowish green, faint bronzed cheek in sun, many small brown specks. Flesh white, juicy. Talued for cooking October, December.

\section{SiM Young.}

Irish Russet.

Origin, Treland.

Fruit small, slightly flattened and regularly formed, bright yellow, a good deal covered with gray russet. Flesh greenish, quite juicy and tender. Good. Norember to January.

Saxtouchee.

Panther.

Wildcat.

Origin, North Carolina. Tree vigorous, upright grower, productive. Young shoots grayish brown, with prominent buds.

Fruit large, roundish conical, oblique, waxen white, with brown dots. Stalk medium, slender. Cavity large, furrowed. Calyx partially closed, small. Basin narrow. Flesh white, crisp, tender, juicy, subacid. Good. November to February.

\section{SAPSON.}

Sapsonvine.

An old but very nice little dessert Apple. Tree an abundant bearer.

Fruit small, roundish, crimson red, stained and striped with purplish crimson. Flesh white, stained with piuk, crisp, juicy, pleasant subacid. Good. August to October.

\section{Sarthis's Yellow.}

Pomme de Jaune. Pomme d'Argent. Pomme de Jaune de Ia Sartha.

Of French origin. Tree vigorous, productive.

Fruit small or medium, roundish, yellow, spotted with brown spots. Stalk short. Calyx small, closed. Basin furrowed. Flesh yellowish white, firm, crisp, juicy, subacid. (An. Pom.)

\section{Savage's Cheese.}

Origin, Columbia Co., Ga. Tree moderately vigorous, spreading, a good bearer.

Fruit medium, oblate, yellow, marked and striped with red. Flesh white, juicy. October. Good bearer.

\section{SAYewell.}

Putnam's Savewell.

Cornell's Sarewell.

Origin, Westchester Co., N. Y. Tree vigorous, spreading, productive.

Fruit medium, roundish oblate, inclining to conic, pale rellow, often shaded with dull red. Stalk short. Calyx closed. Flesh rellowish, srisp, tender, juicy, pleasant subacid. Good. February, March. Valu able keeper. 
SAWYER.

Origin, Amos Sawyer, Hillsborongh, Ill. Tree vigorous, upright, 3arly bearer.

Fruit medium. Form conic truneated, regular. Color waxy ycllow, with faint blush of crimson, thinly sprinkled with small gray dots. Stalk medium, slender. Cavity medium, acute. Calyx rather large, somewlat open. Segments reflexed. Basin deep, abrupt, regular. Flesh yellow, breaking, tender, juicy, subacid. Core small. Quality good. April to July. (Am. Joul. of Hort.)

\section{SAWYer SiWEeT.}

Origin unknown, Tree a strong, healthy grower, upright spreading. Young wool reddish brown, grayish, slightiy downy.

Fruit large, greenish, with blush in the sun. Flesh white, sweet. Gool. Oetober, November.

\section{Scarlet Crofton.}

Red Crofton.

An Irish Apple.

Fruit medium, oblate, yellowish russet, red in the sun. Flesh firm, crisp, rich, sugary. October, December. (Lindley.)

\section{Scarlet Leadington.}

Of Scottish origin.

Fruit above medium, roundish conical, four-sided, vellow and red striped. Flesh yellowish, veined with pink or lilac, film, cris], juicy, brisk, sugary. November, February. (Hogg.)

\section{Scarlet Noxpareil.}

\section{New Scarlet Nonpareil.}

Foreign; medium size, roundish oblate conical, whitish, striped and shaded with red. Flesh yellowish white, firm, juicy, subacid. Very good. November, December.

\section{Scarlet Pearmain.}

\section{Bell's Scarlet Pearmain. Sigler's Red? Oxford Peach.}

A showy dessert Apple, of English origin.

Fruit medium sized, pearmain or conical shaped. Skin light crimson or yellow in the shade, rich crimson on the sunny side. Stalk nearly an inch long, deeply set. Flesh white, stained with a tinge of pink, crisp, juicy, subacid. Very good. In cating from the last of August to the tenth of October. A plentiful bearer.

\section{Scarlet Siweet.}

Origin, Ohio. Tree vigorous, productive. Young wood dark brownish red, downy.

Fruit medium, roundish oblate, inclining to conic, yellow, sbaded 
and intistinctly striped and splashed with light scarlet, many light dots Stalk varying. Cavity open, deep. Calyx small, open. Flesh yellowish white, tender, juicy, mild pleasant sweet. Core small. Good to very good. October to February.

\section{Scarlet Tiffing}

A culinary Apple, from Lancaster, England.

Fruit above medium, roundish, inclining to oblate, pale yellow, mostly orerspread with deep scarlet in the sun. Flesh pure white, tender, crisp, juicy, pleasant acil. Norember, December. (Hogg.)

\section{SChAFFER's EARLY.}

\section{Schaffer's Early Red. Schaffer's Garden.} bearer.

Origin, Lehigh Co., Pa. Tree an upright thrifty grower, and a good

Fruit medium, oblate, slightly conic, pale yellow, striped, splashed, and marbled with red, sometimes only a red cheek. Stalk short. Calyx closed. Flesh whitish, juicy, tender, pleasant subacid. Good, or very good. Core small. August, September.

\section{SCHOOXMAKER. \\ Schoolmocker.}

An old Apple. Origin unknown. Tree moderately vigorous, upright spreading.

Fruit large, roundish oblate, yellow, bronzed blush in the sun. Flesh yellowish white, crisp, brisk subacid. Good to very good. January to March.

\section{Schreveton Goldex Pippix.}

From Nottinghamshire, England.

Fruit small, roundish, yellowish, marked with russet. Flesh rel lowish, tender, crisp. Good. December, April.

\section{Sciota Beautr.}

Origin, Ohio. Tree moderately rigorous, upright spreading.

Fruit below medium, roundish ovate, whitish yellow, shaded, splashed, and striped with two shades of red. Flesh white, tender, juicy, pleasant subacid. Good. Core small. January to April.

\section{Scollop Gilliflower.}

\section{Scolloped Gilliflower. Striped Gilliflower?}

This, according to Elliott, is an entirely distinct variety from Red Gilliflower. Origin unknowr.

Fruit medium to large, roundish conical, flattener at base, tapering towards the eve, alwars much ribbed or scolloped, light yellow, striped and splashed with shades of light and dark red. Stalk short, slencher. Carity deep, russeted. Calyx with long segments. Basin abrupt, deep, ribbed. Flesh yellowish, firm, tender, juicy, slight tinge of sweet. Core large, hollow. Good. November to February. 


\section{Scoteh Bringet.}

A cooking fruit, Lancister, England.

Fruit medium, romnlish oblate, ribbed or knobhed at apex. Flesh white, tender, soft, juicy. October, January. (Hogg.)

\section{Sсотт's Bist.}

Origin, farm of Luther Scott, Hinsulale, Cattarangus Co., N. Y. Tree moderately vigorous, spreading.

Fruit medium to large, roundish oblate, yellowish, shaded and mot. thed with light red, striped and splashol with crimson. Stalk variable, slender. Cavity shightly r'usseted. Calyx nearly closed. Flesh whitish, tine-graned, tender, juiey, agreeuble, slightly aromatie, subacid. Ciood to very good. November, Decenber.

\section{Scrivener's Red.}

An admired cider fruit in some parts of Maryland and Delawire.

Fruit medium, roundish oblong conical, bright red, with dark stripesw Flesh juicy, breaking, rich. Octoker.

\section{Seaconk Siweet.}

An old Commectient Apple. Tree strong grower, very procluctive.

Fruit medium, roundish oblong conic, reil, with stripes of clarker reel, few small white dots. Flesh yhite, compact, sweet. Good. January to April.

\section{SEAMAN's Sweet.}

From Long Island.

Fruit medium, roundish oblate, whitish, splashed, striperl, and shaded with red. Calyx closed. Stalk very short. Flesh white, not tencler, juicy, sweet. Good. Baking. October.

\section{Séaver Sweet. \\ Grafton Sweet.}

Origin unknown. 'Tree vigorous, productive, spreading. Toung wood light reddish brown, slightly downy.

Fruit medium, roundish oblong conical, pale yellow, blush of rerl in the sun, few gray dots. Stalk medium, slender. Calyx closed. Flesh yellowish, moderately tender, juicy, sweet. Good. Core small. Junuary to April.

\section{SEEDLESS.}

Origin in the grounds of Alfued Smith, Addison, Vt. Thee drooping habit, healthy and prorluctive.

Fruit below medium, oblate roundish, light grcenish yellow, with dark carmine clreek in sum. Stalk slender. Cavity open, deep. C'alyx small, closed. Flesh white, dire, very mild subacid. Only good. Coreo without seeds. November, December. 


\section{SEEver.}

Seever's Red Streak.

From Coshocton Co., O.

Fruit medium, globular, lemon yellow, striped with bright clear red Stalk short, slender. Calyx with long segments. Basin deep, open Flesh yellowish, juicy, subacid. October to Norember. (EIliott.)

\section{Selby Bellflower.}

A seedling from the Yellow Bellflower. Tree hardy and productive. Fruit large, roundish, approaching eonic, pale vellow on rather a greenish ground. Stalk medium, slender. Calyx medium. Basin shallow. Flesh yellowish white, tender, juicy, mild, spicy, subacid. November to March. (Gar. Mon.)

\section{Selua.}

From Clark Co., O.

Fruit medium to large, roundish flattened, yellow, with pale russet patches, especially around the stem, dull faint red in sun. Flesh yellowish white, breaking, mild subacid. Very good. November, December. (Elliott.)

\section{SeLwood's ReinetTe.}

From Lancaster, Fingland. Tree a healthy grower and a good bearer.

Fruit large, roundish oblate, greenish, mostly covered and striped with red. Flesh greenish white, tender, brisk, pleasant. Cooking. December, March. (Hogg.)

\section{SePtember.}

Pride of September.

Origin, Centre Co., Pa., received from W. G. Waring. Tree hardy and vigorous, a good and regular bearer. Young wood smooth, reddish brown. Buds prominent.

Fruit large, globular, somewhat depressed, very slightly conic, Jellow, slightly shaded and thinly sprinkled with brown dots. Stalk short, inserted in a deep, abrupt cavity, surrounded by thin russet. Calyx partially closed, set in an open basin. Flesh yellowish, tender, juicy, very agreeable subacid. Very good. October.

\section{Sergedit's SweEt.}

Origin, Massachusetts.

Fruit medium, round, straw color, with a blush next the sun. Flesh tender, very sweet, superior for baking. October. (Kenrick.)

\section{Shaker Greexixg.}

\section{Hampshire Greening? Shaker Pippin.}

Origin, Enfield, N. H. Tree vigorous, upright spreading, very productive.

Fruit medium, oblate conic, greenish yellow. Flesh yellowish, ten: der, crisp, juicy, brisk subacid. Good. March, November. 


\section{SHAKESPEAKE.}

An English rlessert Apple, deseribed ly Hogg as of medium suze, roundish oblate conic, greenish, with brownish red next the sun, few broken stripes of darker red, many russety dots. Flesh greenish yellow tirm, crisp, juicy, brisk, vinous. December to April.

\section{Sirarpe's Greextivg.}

Origin, North Carolina. Tree thrifty, and upright grower.

Fruit medium, oblate, greenish yellow, with a blush cheek. Flesh juicy, subacid. Good. January to March.

\section{Sheepsose.}

There are several Apples to which this name has been applied : some are proved identical with well-known varieties; others, of which no ori gin ean be traced, may yet prove only synonyms of well-known kinds.

Warder describes a sheemose as:

Fruit medium, romd, slightly conic, irregular, greenish yellow, white strix about the base. Dots minute. Flesh yeilowish white, breaking, tender, juicy, subacid. Good. December, February.

Another Sheepnose is grown in New Jersey and Pennsylvania, which is medium size, roundish conical, yellow, sometimes a blush in sun. Calyx closed. Flesh yellow, rather firm, juicy, subacid. Good. Novęmber, December.

\section{SHELL.}

Supposed origin, Virginia.

Fruit large, romdish, greenish yellow, becoming clear yellow in the sun. Flesh yellowish, juicy, rich. August. New.

\section{Silepherd's Faine.}

Fruit large, roundish oblate, ribbed, pale yellow, streaked with a deeper shade and rich red. Flesh yellowish, soft, tender, sweet. October, Nareh. (Hogg.)

\section{SHEPPARD's SwEET.}

Origin, Windham Co., Conn. Tree thrifty, upright, and a great bearer.

Fruit medimm, roundish, approaching eonic, yellow, striped with red. Stalk long, slender, inserted in an acute caivity. Culyx firmly closed, set in a small basin. Flesh, white, tender, sweet and pleasant. Good. Oetober, November.

\section{SHiaWassee Beautr.}

\section{Michigan Beauty.}

Originated in Shiawassee Co., Mich. T'ree a strong upright grower. until in full bearing, when it becomes partially pendent, very purluctive. Young wood dull redilish brown, slightly downy. This viriety resembles Famense, but its rood shows its distinctiveness. 
Fruit medium, oblate, whitish, shaded, marbled, splashed, and striped with rich resl, few light dots. Stalk rather short. Cavity large. Calyx small, closed. Basin large, open, slightly corrugated. Flesh firm, very white, tender, juicy, brisk, refreshing subacid. Very good. October, Jannary.

\section{SHipley GreeN.}

Origin, Maryland.

Fruit medium, oblong, red, and very acid. Good for cooking and keeping only.

\section{Shippex's Russet.}

Originated in Philadelphia. It is often found at the T'est, and as a market sort profitable, but inferior in quality to the Roxbury liusset. The tree is very vigorous, forming a large round spreading heal, productive.

Fruit large, oblate, irregular, yellowish green, somewhat russeted. Flesh greenish, rather diry, soft, mild subacid. Good. Norember, February.

\section{SHOCKLEY.}

Origin, Georgia. Tree moderately vigorous, upright, very pro. ductive, bearing young and regularly. Young wood reddish, grayish on under side.

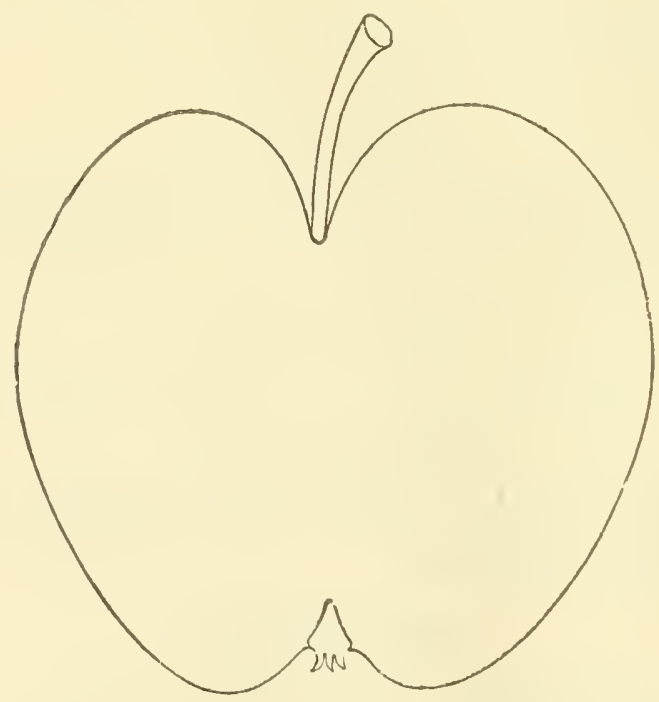

Shockley.

Fruit below medium, roundish conical, pale yellow overspread with red, inconspicuous minute dots. Stalk long, slender, inserted in a deep 
acute cavity. Calyx partially closed, set in a sliallow corrugated basin. Flesh crisp, juicy, rich, saccharine, slightly vinons, and pleasant. Good. April, May.

This is one of the most profitable varietios at the Sonth, where it not only bears abundantly, but keeps and sells rentirkably well.

\section{Simpson Sweet.}

Origin, Mercer Co., Pa. Tree vigorous, upright.

Fruit medium, roundish oblong, thattened at base and crown, greenish yellow, with a tinge of brown in the sun. Calyx small, closed. Flesh white, moderately juicy, sweet, and pleasant. Gool. Core small. December.

\section{SINE-QUA-NON.}

A native of Long Island, namerl by the late $\mathrm{Wm}$. Prince.

Fruit roundish conical, abont medium size, smooth, pale greenish yellow. Stalk slender. Flesh white, very tender, juicy, and of a delicate and very sprightly flavor. Good. The young trees are rather slow and crooked in growth. August.

\section{SiNk.}

Origin, Boalsburg, Centre Co., Pa. Tree vigorous, upright spreading, productive.

Fruit medium, roundish, inclining to conic, whitish, splashed and marbled with red. Flesh very white, stained next the skin, tender, juicy, brisk subacid. Good. September.

\section{Șir William GibBons.}

An English cooking Apple.

Fruit large, roundish oblate, ribbed, yellow, streaked with light and dark red. Flesh yellowish white, crisp, juicy, slightly acid. November, January.

\section{ShunK.}

An old New Jersey Apple.

Fruit large, yellow, resembling Newtown Pippin, with red spots and blotches. Flesh yellowish, juicy, pleasant. Good. November, Decem. ber. (Coxe.)

\section{Sleeping Beautr.}

Winter Sleeping Beauty. Sleeper.

Tree an excellent bearer.

Fruit inedium, roundish, somewhat flattened, straw-color, washcd with lively red. Flesh yellowish white, crisp, tender, juicy, acid. November, February. (Hogg.)

\section{Sleight's Lady A PPLE.}

This valuable Apple was raised hy Edyar s'leight, Dutchess Co., N. Y. It is almost a perfect fac-simile of Ladly $A$ plyle, exeept being nearly twice as large. Tree somewhat more vigorous and spreading than the Lady Apple, and very productive. The fruit a little earlier in ripeuing. 


\section{Slingerland Pippin.}

Raised by Mr. Slingerlaud, of Albany Co., N. Y. Tree vigorous, spreading.

Fruit medimm to large, roundish, often oblique, yellow, shaded with red and sprinkled with minute dots. Stalk short. Calyx small, partially closed. Flesh white, teucler, juicy, brisk, rather rich subacid Good to very good. December, February.

\section{SMALLEY.}

\section{Spice.}

From Kensington, Conn. Tree vigorous, spreading, a good bearer.

Fruit medium size, oblate conic, yellow, with a slight blush. Stalk short. Calyx closed. Flesh tender, juicy, brisk, pleasant aromatic. Gond. September, October.

\section{Silall's Admirable.}

This is described by Hogg as an immense bearer, and adapted for dwarf culture.

Fruit above medium, roundish ovate, flattened, lemon yellow. Flesh firm, yellowish, crisp, subacid. November, December.

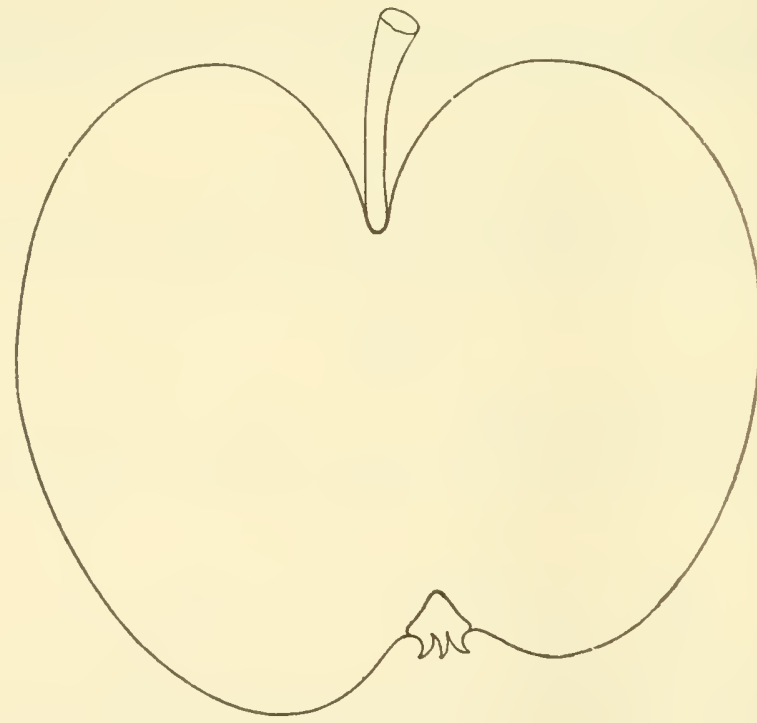

Smith's Cider.

\section{Suith's Cider.}

Smith's. Fuller.
Pennsylvania Cider. Fowler.

Origin, Bucks Co., Pa. This Apple is widely grown, and much es teemed as a profitable market sort. The tree is a very vigorous, strag- 
gling, spreading grower, and productive. Yourg wood a rich dark brown.

Fruit medium to large, roundish oblate conic, yellow, shaded and striped with red, sparsely covered with gray dots. Stalk slender, of weclium length, inserted in a deep, rather narrow cavity. Calyx closed, set in a broad, rather shallow basin. Flesh whitish, tender, juicy, crisp', pleasant, mild subacid. Good. December, March.

\section{Syokemouse.}

Millcreek Vandevere. Red Vandevere. English Vanderere.

Origin, Lancaster Co., Pa., near Millcreek, grew on the farm of Gibbons, near his smokehouse, hence its name. An old variety and popular in Pennsylvania. It somewhat resembles the old Pennsyl. vania Vandevere, and is supposed to be a seedling of it.

Tree moderately vigorous, with a spreading head, a good bearer. Young wood dull dark reddish brown.

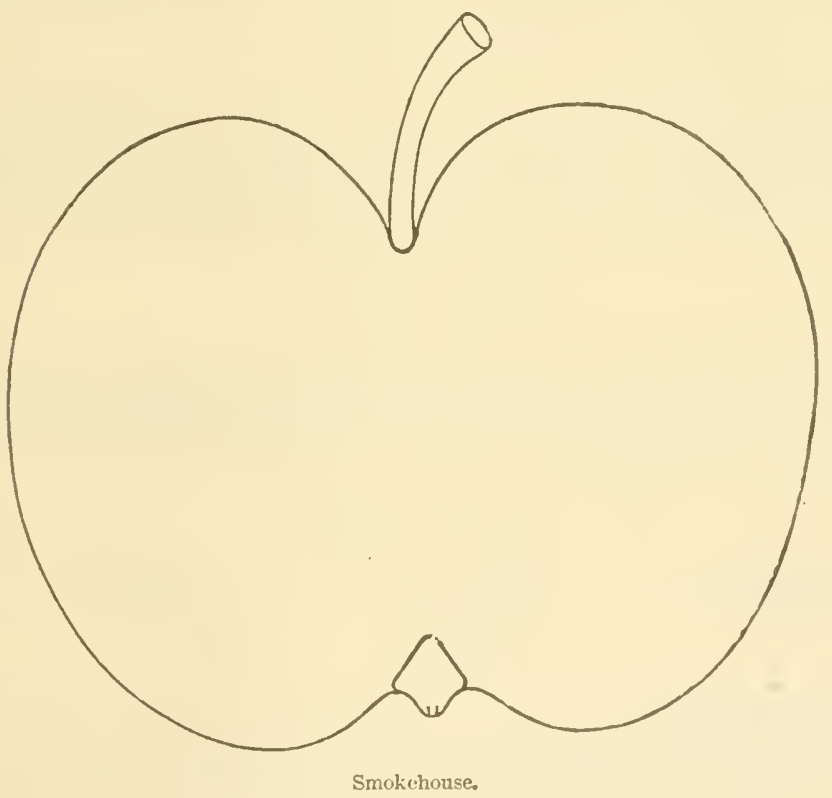

Fruit rather above melium, roundish oblate, skin yellow, shaded and splashed with crimson, and thinly sprinkled with large gray and brown dots. Stalk rather long, curved, inserted in a broad cavity. Calyx closed, set in a wide basin, of moderate depth, shightly corrugated. Flesh yellowish, somewhat firm, juicy, erisp', rather rich subacid. Good. September to February. Valued for culinary uses.

\section{SNEDIKER.}

Origin unknown. Tree an upright vigorous grower, productive. 
Fruit large, roundish conical, sides unequal, yellow, marbled with large red dots, few gray dots. Stalk very short. Calyx closed or par. tially open. Basin slightly corrugated. Flesh yellowish, crisp, juicy, tender, brisk subacid. Core rather small. Good. December, February

\section{Sxepps'.}

Jno. Snepps'. ductive.

Supposed origin, Edinburgh, Ia. Tree vigorous and sufficiently pro-

Fruit above medium, almost large, flat, dull green, becoming pale yellow, with many dark dots that often give it a gray appearance. Calyx large, closed. Stalk stout. Flesh yellowish, breaking, fine-grained, juicy, agreeably sweet. December, March. (Warder.)

\section{Somerset.}

Origin, Somerset Co., Me. Tree very vigorous, upright spreading.

Fruit large, roundish, somewhat flattened, bright yellow, mostly covered with splashes and stripes of bright red. Flesh yellowish, sometimes a little stained with red, tender, juicy, agreeable subacid. September. (Me. Rel.)

There is another Somerset grown in Western New York, the fruit of which is medium or below, roundish conical, whitish yellow, partially netted with russet. Flesh yellow, tender. Good. August, September. The wood as well as fruit of these is quite distinct, the former being reddish brown, the latter dull grayish reddish brown, downy.

\section{Someremet Lasting.}

A fine showy English Apple, described by Ronalds as large, roundish oblate, clear yellow, with a blush red cheek. Flesh white, tender, brisk, sharp subacid. Valuable for cooking or market. December to March.

\section{SOPS OF WINE.}

$\begin{array}{lll}\text { Red Shropsavine? } & \text { Worden's Pie Apple. } & \text { Hominy. } \\ \text { Bell's Early? } & \begin{array}{l}\text { Washington. } \\ \text { Bennington. }\end{array} & \text { Dodge's Early Red. }\end{array}$

An old European variety. Tree vigorous, upright, an early and productive variety.

Fruit medium, roundish, yellow and red, splashed and shaded with deep red, and sprinkled with white and gray dots, and a thin bloom. Stalk slender, in a narrow cavity. Calyx closed. Basin rather shallow, uneven. Flesh white, often stained, not very juicy, mild, pleasant subacid. Good. August, September.

\section{Souisson Russet.}

Origin unknown.

Fruit medium, roundish conic, yellow, shaded with rich red or crim. son in the sun, and splashes and blotches of russet in the shade, and sometimes russet mixed with the red. Flesh whitish, tender, juicy, rich, brisk subacid. Very good. Core small. February, March. 
Sour Boygit.

An old variety, grown in Westehester Co., N. Y. Tree thrifty, upright.

Fruit medium, roundish conic, yellow, morlerately sprinkled with gray and light dots. Flesh whitish, brisk subacid. Good for cooking. september. Often knotty and inprofitable.

\section{Southern Lady.}

From North Carolina.

Fruit small, oblate, whitish, much shaded with bright crimson, many light dots. Stalk short and small. Calyx closed. Flesh yellowish, tender, . uicy, very mild subacid, aromatic. Very good. September, October.

\section{Sovereign.}

A little Apple from England, described by Ronalds as :

Fruit small, oblong oblate, light yellowish brown, with a small thush of red. Flesh firm, rieh, and sweet. February, April.

\section{SPAFFord Russet.}

Origin, Ohio.

Fruit medium, roundish conical, flattened at ends, yellowish, slightly russeted. Flesh greenish white, soft, moderately juicy, mild subacid. Hardly good. December, February.

\section{Spark's Late.}

\section{Spark's.}

A variety somewhat grown in Southern Illinois, its origin unknown. Tree an upright grower, hardy, and good bearer.

Fruit large, roundish oblong conic, greenish yellow, rarely with a shade of crimson in the sun, brown dots. Stalk slender. Calyx closed. Flesh whitish, half tender, pleasant, mild subacid. Good. Valuablo for cooking.

\section{SPECKLED。 \\ Westbrook.}

Origin uncertain. Tree a rapid grower and annual bearer.

Fruit liuge, roundish oblong, yellowish white, red in the sun, small russet dots. Flesh white, terider, subacid. Good. October, January.

\section{Speckled Olex.}

From Berks Co., Pa.

Fruit medium, roundish, greenish yellow, striped and mottled with red, large white dots. Flesh white, moderately juicy. Hardly good.

\section{Spectator.}

Originated by J. W. Bailey, Plattsburgh, N. Y. Tree spreading, very productive. 
Fruit medium, roundish oblong oval, ribbed, yellow, shaded with red in the sun. Flesh white, tender, juicy, subacid. Hardly good September.

\section{Spice Russet.}

Sweet Russet of some, erroneously.

Origin unknown. Tree a good grower and productive.

Fruit below medium, roundish flattened, light yellow russet, with numerous small fine dots, exposed to the sun carmine and yellow bronzed. Stalk slender. Calyx closed. Flesh whitish, fine-grained, juicy, almost sweet, aromatic subacid. December to March. (Elliott.)

\section{SPICE SweET. \\ Berry Bough.}

Tree vigorous, productive, medium, oblate, smooth, pale jellow. Flesh rather firm, sweet, highly aromatic, apt to be knotty and unfair. August, September.

\section{SPONGE.}

There are two varieties under this name, neither of which is at all valuable.

One is: Fruit large, roundish oblate. Skin greenish, striped with dull red, dotted with whitish spots. Flesh white, coarse, subacid. A kitchen fruit. October and November.

The other is: Fruit medium, oblong conic, green, splashed with red. Flesh white, moderately juicy. Poor. November.

\section{Sprague.}

Fruit rather small, oblong oval, slightly conic, yellow. Flesh yellow, juicy, tender, sprightly subacid. Scarcely good. October.

\section{SPRINGER.}

Springer's Seedling.

Origin, Ohio.

Fruit small, roundish oblong, yellowish green, with faint stripes of red. Flesh firm, negative character. Jamuary to May. (Elliott.)

\section{Spring Grove Codin.}

An old English cooking Apple.

Fruit medium, roundish conical, greenish jellow, deeper in the sun. Flesh greenish yellow, crisp, juicy, brisk, sharp subacid. October.

\section{Spring Pippin.}

Springport Pippin.

Origin, Springport, Cayuga Co., N. Y. Tree upright, thrifty, unpro sluctive.

Fruit above mediun, roundish oblong, yellowish green. Flesh rellow ish white, crisp, sprightly subacid. December to May. (Elliott.) 
Soune's Grelanisg.

An English enlinary Apple.

Fruit iescribed by iTogg as above medium, roundish, flattened, green, with dull brownish red in the sun. Flesh yellowish white, firm, brisk subacid. December to April.

\section{STALT'S Sireet.}

Originated in Somerset Co., N. J. Tree a strong, upright, vigorous grower, with eurved erect branches, forming a beantiful head, productive.

Fruit medium, roundish, slightly eonieal, greenish yellow, shaded, splashed, and overspread mostly with light and dark red. Stalk short. Calyx large, open. Flesh yellowish white, breaking, juicy, mild, pleasant, sweet. Good to rery good. December to February.

\section{STACK.}

Origin, Indiana.

Fruit medium to large, roundish eonical, red, striped with deep rerl. Dots minute and few. Stalk long, slender. Calyx medium, elosed. Basin medium. Flesh light yellow, fine-grained, juicy. Good. Core large, open. December to January. (Inc. Trans.)

\section{Stackyard.}

Originated in Montgomery Co., Pa. An old variety.

Fruit medium, oblate, greenish yellow, covered and marbled with yellow and red, and speckled with small spots and patches of russet. Wlesh white, erisp, tender, juicy. Good. November, December.

\section{Stamford Pippin.}

An English Apple, deseribed by Hogg as first-rate for dessert.

Fruit abore medium, roundish, yellow, tinge of orange in sum. Flesh yellowish, firm, tender, erisp, sweet, brisk, pleasant aroma. December to Narch.

\section{Stajarn.}

\section{Stanard's Seedling.}

An Apple extensirely dissminated in Illinois and WTest, from Colonel B. Holge, through "The Grove" nurseries. The tree is extremely hardy, euduring uninjured the nost severe changes of the prairies. It is a erooked, spreading, irregular, hnt ripil grower; a young, abundant, and annual bearer. Joung wood redilish brown, lowny.

Finit mediun to large, roundish oblate, slightly eonical, dull green, changing to yellow at maturity, splashed and striped with reel, lange l'usset specks. Stalk in a depj eavity. Calyx closed. Flesh yellowish white, rather eoarse, very juicy, rather rich subacicl. Tery goxl, De. cember to March. Superior for cooking. 


\section{StANLEY.}

\section{Stanley's Seedling.}

Originated in Alabama. Tree moderately vigorous, upright.

Fruit large, romdish conical, greenish yellow. Flesh whitish, ten der, moderately juicy, subacid. Good. October, November.

\section{Stanley's IVinter Sweet.}

Origin, Winthrop, Me. Tree productive.

Fruit large, oblate, red, streaked and specked with purple. Flesh iuicy, sweet. December to March. (Me. Riep.)

\section{STANSILL.}

Origin, North Carolina. Tree a good grower and early bearer.

Fruit medium, roundish oblate, yellowish green, sometimes a blush in sun, and occusionally indistinctly striped. Flesh yellow, subacid. Good to very good. January.

\section{STAR.}

An old variety, grown in Dutchess Co., N. Y.

Fruit medium, roundish oblate, yellowish, shaded and indistinctly splashed with crimson, large light dots. Stalk short. Calyx closed. Flesh white, pleasant, mild subacid. Good. November.

\section{STARK.}

Origin unknown, grown in some parts of Ohio, and valued as a long keeper and profitable market fruit. Tree vigorous, upright, spreading. Young shoots dark brownish red.

Fruit large, roundish, inclining to conic, sometimes a little elongated, and sometimes slightly oblique. Skin greenish yellow, shaded, splashed, and striped with light and clark red nearly over the whole surface, and thickly sprinkled with light and brown dots, a portion of them areole dots. Stalk short, rather stout, inserted in a medium carity. Calyx closed. Basin rather large, slightly corrugated. Flesh yellowish, a little coarse, moderately juicy, mild subacid. Good. Core small. January to May.

\section{STARR.}

From New Jersey.

Fruit medium to large, roundish oblate, greenish white. Stalk slender. Flesh whitish, pleasant subacid. July to September. Cooking only.

\section{Star Reinette.}

\section{Reinette Etoile.}

Calville Etoile.

A Belgian Apple. Tree vigorous, productive.

Fruit medinm, roundish, ribbed at apex end, washed and shaded with red, distinct white dots. Flesh white, tender, subacid. Novem. ber. (Alb. Pom.) 


\section{Steel's Sweet.}

Origin, Connecticut; productive, keeps well, but not always fair.

Fruit medium, globular, yollowish, slight blush. Flesh white, compact, juicy, with a peculial saccharine flavor. Wecenber to March.

\section{Steirienson's Winter.}

Origin, Marshall Co., Miss. Tree a moderate grower and a good bearer. Ioung shoots smooth, reddish brown, slightly grayish.

Fruit medium, roundish oblate, greenish yellow, shaded and sometimes striped with red. Stalk long, slender. Calyx open. Flesh whitish, rather firm, juicy, pleasant, brisk subacid. Core small. Good. January to April.

\section{Stevens' Gilliflower.}

Originated in Sweden, Me. Fruit large, roundish conical, dull whitish ground striped with red. Flesh white, tender, pleasant subacid. November to February. (Cole.)

\section{Stillian's Early.}

Origin, Cliuton, Oneida Co., N. Y. Tree of moderate upright growth, productive.

Fruit small, roundish conic, yellow, sometimes a slight blush, and a few brown dots. Stalk long. Calyx closed. Flesh yellow, tender, pleasant subacid. Good. Last of July and first of August.

\section{STILLWATER SWEeT.}

\section{Grandmother.}

Originated by Caleb Menclenhall, near Dayton, O. Tree an upright grower, productive. Young shoots elear recldish brown, very slightly downy.

Fruit medium, roundish, slightly conical, faintly ribber, greenish yellow, shaded, mimte black dots, sometimes in the sun it hats a pale red cheek. Flesh yellowish white, fine-grained, tender, sweet. Good to very good. September, October.

\section{Stirzaker's Early SQUare.}

A Lancaster, Fngland, varisty, deseribed by Hogg as:

Fruit below medium, rounciish, ribbed, pale yellow, overspread and mottled with a dingy brown russet. Flesh white, tender, pleasant. August, September.

\section{Stockade Sweet.}

Origin, Marietta, Ohio. 'Tlec thrifty, very upright, and productive.

Fruit below medium, roundish oblate, yellow, shaded, splashed, and striped witl rerl. Stalk slender. Calyx elosed. Flesh whitish, compact, moderately juicy, rich, sweet. Coresmall. Cood. Valuable for baking and keeping. Jecember to May. 


\section{Stone Pippin.}

White Stone Pippin.

A Norfolk, England, Apple, described by Lindley as worthy of culti. vation. 'Tree vigorous, hardy, and abundant bearer.

Fruit medium, oblong conic, pale green, becoming yellow. Flesh rery firm, almost sweet. November to May.

\section{Stonewall Jachson.}

A new Southern Apple, mostly valued because of its long-keeping quality. Tree an upright, stout grower, productive.

Fruit medium, roundish conical, sides unequal, whitish yellow, shaded, and obscurely striped and splashed in the sun with light red. Stalk small. Flesh white, firm, not very juicy, brisk subacid. Good. A long keeper.

\section{Stoyor PARK.}

An English dessert Apple, described by Ronalds as of medium size, conical, yellow, with faint stripes and shades of red. Flesh white, tender, brisk subacid. Good. November.

S'TRAUDT.

Origin, Berks Co., Pa.

Fruit large, roundish, inclining to conical, deep crimson, with stripes of paler red, and numerous light dots. Stalk short. Calyx small, closed. Flesh tine-grained, tender, white, subacid, pleasant. Grood. November.

\section{STRAWX.}

Strawn's Seedling.

Raised by James Strawn, Tirginia. Tree a thrifty grower and good bearer.

Fruit rather large, reddish stripes on a pale yellow ground, creamcolored spots. Flesh yellow, juicy, slightly acid. Good. December to April.

\section{Strealied Pippis.}

\section{Red Pippin. Hempstead. Quaker of some. \\ Skunk, erroneously.}

Origin, Westbury, Long Island, N. I. 'Tree thrifty, hardy, vigorous, sprearling, and prodnctive.

Fruit large, roundish oblong, pale jellow, stuaded, splashed, and striped with rich reel, few light and gray dots. Stalk short, small. Carity narrow, sometimes russeted. Calyx closed. Basin slightly corrugated. Flesh yellow, a little coarse, tender, juicy, pleasant subacid, shightly aromatic. Good to very good. November to January.

\section{STRIPED BEAUFIN.}

An English Apple. Tree hardy, productive.

Fruit large, roundish oblate, browlly ribbed, greenish yellow, corered 
and mottled with broken stripes and dashes of deep red. Flesh yollow ish white, firm, juicy, pleasant acid. October to May. (Lindley.)

\section{Striped Beile et Bonye.}

An old Eastern Apple. Origin unknown. Tree vigorous, upright sprealing, productive. Toung shoots dull reddish brown, somewhat dowuy. A profitable market raricty.

Fruit large, roundish wblate, whitish yellow, mostly corered, striped, splashed, and mottled with light and dauk red, few light brown dots. Stalk short. Calyx closed. Flesh white, crisp, brisk subacid, moderately juicy. Good. Core rather small. August, September.

\section{Striped Holland Pippis.}

An old Holland fruit. Tree a free grower, and productive; valued mainly for cooking.

Fruit large, roundish, obscurely ribbed, yellow, striped with red. Flesh white, subacid. October, December. (Lindley.)

\section{Striped MoHAWK.}

Fruit above medium, roundish, red striped on jellow. Flesh dry, poor: Late autumn. (Elliott.)

\section{Striped Moxstrous Reinette.}

An English cooking Apple. Tree a strong grower, productive.

Fruit large, roundish, with irregular rilis, terminating in strong wrinkles around the eye, greenish yellow, mostly covered, striped, and blotched with red. Stalk small. Flesh tender, juicy, agreeable acicl. October, November. (Ronalds.)

\section{Striped PortFr.}

Fruit large, roundish oblong conical, yellow, with stripes and splashes of red, red and russet specks. Stalk slender. Cavity deep, russeted. Basin wrinkled. Elesh white, crisp, juicy, subacid. October. (N. E. Far.)

\section{Striped Siropsavine.}

Curtiss Early Stripe.

Fruit small, oblong conic, pale yellow, striped with bright red. Flesh crisp, pleasant. July, August. A poor grower.

\section{Striped Winter Pearmais.}

Striped Sweet Pippin.

Snorter.

Winter Pearmain of some.

Nissonrian?
Large Striped Winter Pearmain. Striped Pearmain.

Missouri Keeper?

An olil rariety, which can only be traced to Korstucky. It is con. siderably grown now all through the W West, and luredy under the mame of Striped sweet Pippin. 'Tree harly, vignous, sprealing, prod cotive. Joung shoots clear reddish brown, slight bluom on ends. 
F1uit medium to large, roundish, inclining to oblate, yellow, striped, splashed, and sharled with shades of recl, numerous gray dots, giving it somewhat appearance of bloom. Stalk medium or short, and small, in.

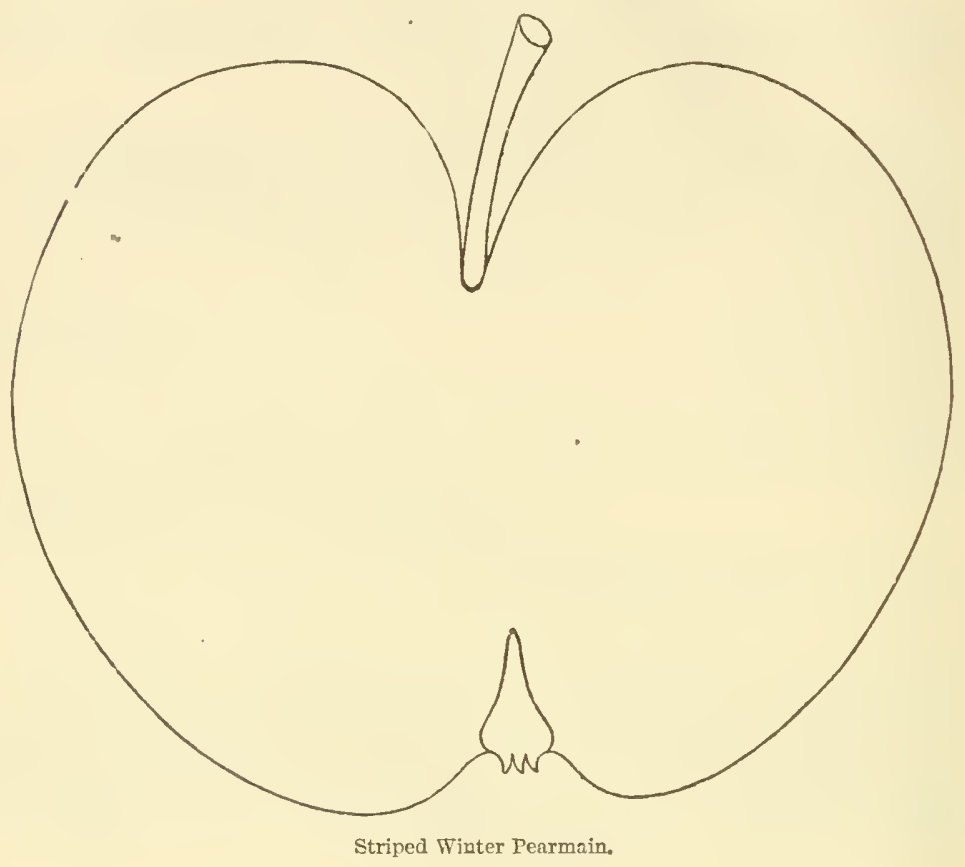

serted in a large cavity surrounded by russet. Calyx small, closed, set in a broad, uneven basin. Flesh yellow, juicy, crisp, tender, very mild, rich, pleasant, scarcely subacid. Very good. October to January.

\section{STroat.}

\section{Straat.}

An Apple formerly in high esteem among the descendants of the Dutch settlers on the North River. Not profitable.

Fruit above the middle size, roundish, and tapering a little to the eye, yellowish green. Flesh yellow, very tender, brisk subacid. Good. September to December.

\section{Strode's Birmisghay.}

Strode's. tive.

Origin, Chester Co., Pa. A vigorous, upright grower, very produc-

Fruit rather below medium, oblong oval or conic, yellow, sprinkled with a few gray dots. Stalk slender, set in a deep, narrow cavity. Basin broad, shallow, corrugated. Flesh yellow, moderately juicy, sub acid. Good to very good. September. 


\section{Strubel.} tive.

Origin, Pennsylvania. Tree a moderate grower, hardy, and produc.

Fruit medium to large, roundish oblong conic, yellowish, sharted, splashed, and marloled with rich red. Stalk short. Cilyx closed. Flesh compact, yellowish, juicy, subacid, slightly aromatic. Good. Core suall. November to March.

\section{Stump.}

Supposed origin, Delaware. Tree spreading, productive.

Fruit medium, oblate, yellowish, shaded with light red nearly over the whole surface. Stalk short, small. Calyx closed or partially open. Flesh whitish, rather firm, crisp, juicy, tender, sprightly subacid. Good. Core small. September, Uctober.

\section{Sturier Pippin.}

An Euglish fruit. Below medium, oblate, approaching conic, yellow, with a bronzed or crimson cheek. Stalk of medium length, inserted in a large cavity. Calyx closed. Segments long. Basin shallow and uneven. Flesh compact, rich subacid. Good. January, May.

\section{Stymus.}

This new and really excellent Apple originated on the farm of Jacob Stymus, Dobb's Ferry, N. Y. Tree moderately thrifty, upright, and productive. Young shoots dull reddish brown, slightly downy.

Fruit medium, oblate, inclining to conic, yellowish, shaded, splashed, and striped with light and dark crimson. Stalk short, small. Cavity large, deep. Calyx closed or partially open. Segments short, erect. Basin large, deep, meven. Flesh whitish, fine, tender, juicy, mild, pleasant subacid, slightly aromatic. Core small. Very good. October, November.

\section{STYRE.}

\section{Forest Styre.}

A famons old English eider fruit, of merlium size, roundish, pale yellow, with an orange cheek. Flesh firm, and makes $a^{\circ}$ high-colored liquor. October, January.

\section{SudBury SWEeT.}

Origin unl zown. Tree vigorous, upright, a good bearer.

Fruit medium, roundish, inclining to conic, yellow, faintly splashed, marbled, and striped witlı dull red, many light and gray dots. Flesh whitish, rather tender, moderately juicy, rather rich, swect. Good. December, January.

\section{Suffolk Beauty.}

A new variety from H. H. \& E. L. Brown, Deer Park, Long Island. Tree a free grower and abundant bearer.

Fruit medium, roundish oblate, yellowish white, with a few dark green dots, and a hittle russet near the stalk. Stalk slender. Calyx 
small. Flesh white, agreeable subacid. August, Sertember. (Gar. Mon.)

\section{Sugar and Brandr.}

A Lancashire, England, Apple.

Fruit medium, roundish, slightly conical, rib on one side, deep dull yellow, pale red in the shade, bright orange red in the sun. Flesh deep yellow, spongy, juicy, very sweet. August, September. (Hogg.)

\section{Sugar Loaf Pippin.}

Hutching's Seedling.

A. foreign sort. Tree of grood growth and productive.

Fruit of medium size, oblong or conical, smooth, clear pale yellow, becoming nearly white on one sicle when fully ripe. Flesh white, firm, very slightly acid, and moderately juicy. Good. Ripens the latter part of July, and is very showy on the tree.

\section{Sugar SweEt.}

From Massachusetts. Tree vigorous, upright, a moderate bearer.

Fruit large, roundish oblate conic, yellow, mostly shaded with red, and a dark maroon cheek. Flesh white, fine-grained, not very tender, but with a rich, honeyed sweetness. Good. December to February.

\section{Suisse.}

\section{Pomme Suisse. Pomme Rubanee. Pomme de Perroquet.}

An old rariety, described in 1665 .

Fruit medium to large, roundish, slightly conical, greenish, and striped in the shade with yellowish green, which in sum becomes dull reddish. Stalk slender. Calyx small. Flesh white, tender, moderately juicy, subacid. Good.

\section{Summer Bellflower.}

Origin, farm of J. R. Comstock, Dutchess Co., N. Y. Tree vigorous, upright, productive. Young shoots clear reddish brown.

Fruit medium or above, oval, inclining to conic, elear yellow, with rarely a faint orange blush on the side of the sun. Stalk an incli long, in a shallow cavity. Calyx closed, with small reflexed segiments, slightly five-sided basin. Flesh white, fine-grained, tender, excellent subacid. Good. Middle of August to middle of September.

\section{Sumaer Bellflower of Pexysylyayia}

is quite distinct from the above, and very much resembles Tellow Bell. flower in shape and color, but has a rery wide and deep carity, and closed calyx. Flesh yellowish white, firm and fine texture, not very juicy, with a brisk, agreeable, pleasant subacid. Good. Last of August and first of September. Young shoots light reddish brown, downy. 


\section{Sumer Broldex.}

\section{Summer Colman. Summer Broadend.}

An old Norfolk, England, cooking A pple.

Fruit above medium, romnlish oblate, dull greenish yellow, tinged on the sunny side with dull pale brown. Flesh greenish white, subacid. October, November. (Lindley.)

\section{Sumier Cheese.}

Cheese Apple. Maryland Cheese. Prather Apple. Findlay Apple.

An old variety, of poor quality. Origin unknown. Tree a strong grower, spreading, not an early bearer, but moderately productive when old.

Fruit medium, oblate, sides sometimes unequal, yellow, oceasionally with a tinge of red in the sun. Flesh whitish, tender, juicy, subacid. August, September.

\section{Summer Goldex Pippin.}

A nice little English dessert Apple, but inferior to many of our own.

Fruit small, ovate, flattened at the eye, bright yellow, with a little orange next the sun. Flesh yellow, firm, erisp, and rich. Good to very good. August.

\section{Sumaer Hagloe.}

\section{Hagloe.}

An old sort. Tree vigorous, but slow in its growth while young, thick blunt shoots, productive. Young shoots clear light reduish brown.

Fruit large, roundish oblate, whitish yellow, striped and splashed with bright red, and covered with a thin bloom. Stalk short and thick, inserted in a broad, open cavity. Calyx elosed, set in a small, round basin. Flesh white, rather coarse, tender, juicy, subacid. Good to very good. An excellent culinary and table variety. Angust, September.

\section{Summer Harvey.}

Origin unknown. Tree thrifty, spreading, very productive, an early and abundant bearer.

Fruit large, roundish oblate, greenish yellow, sometimes nettings of russet and red eheek in the sun, thickly sprinkled with light and green dots. Flesh whitish, tender, juicy, brisk subacid. Good. August.

\section{Summer Jaxet.}

Fruit medium, round truneated, regular. Surfuce smooth, pale yellow, mixed red, striped darker red. Dots seattered, gray. Flesh yellow, tender, fine-grained, subacid, aromatic. Good. September. (IVarder.)

\section{Sumaer Limbertwig.}

A Southern fruit from Greenshoro', N. C. Fruit medium, Hat, regular, pale vellow, mixed link, striped dark red. 
Flesh white, tender, fine-grained, juicy, subacid, aromatic. August, September. (Warder.)

\section{Summer Marigold.}

An old English Apple. Tree a good grower and great bearer.

Fruit medium, roundish conical, yellow, striped with two shades of red. Flesh breaking, juicy, pleasant subacid. August.

\section{Summer Pippix.}

Sour Bough.

Walworth.

Haverstraw Pippin.

Paper Apple.
Calkin's Pippin.

Tart Bough.

Champlain.

Large Golden Pippin.
Underdunk.

Nyack Pippin.

Geneva Pearmain.

Origin unknown. An old fruit, much cultivated in Rockland and Westchester Counties, N. Y.; a valuable market fruit. Tree vigorous, forming a beautiful round head, a regular and good bearer. Young shoots dull reddish grayish brown, slightly downy.

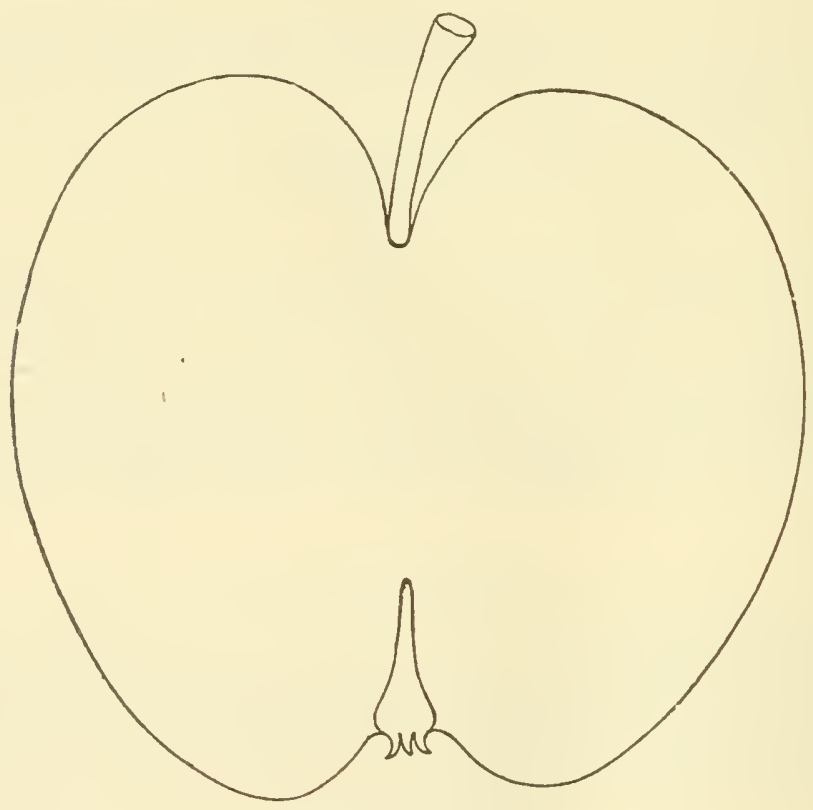

Summer Pippin.

Fruit medium to large, variable in form, generally roundish oblong, inclining to conic, pale waxen yellow, shaded with a delicate crimson blush, and sprinkled with green and grayish dots. Stalk raries in length and thickness, inserted in a deep, abrupt cavity. Calyx closed, set in a deep, abrupt, corrugated basin. Flesh white, tender, moderately juicy, pleasant, refreshing, subacid, valuable for culinary uses, and 
profitable for market. Ripens the middle of Augnst, and continnes a month or more.

There is another Summer Prppix which we have received from Lowa. Tree very vigorons, productive.

The fruit is medinm, oblate, inclining to conic, yeliowish, shaderl, splashed, and striped with crimson in the sun, large light dots. Stalk rather long. Calyx closed. Flesh white, pleasant subacid. August, September.

\section{Sumier Pound Royal.}

Pound Royale.

Summer R. I. Greening.
Pound Royal of the Putnam List. Orange.

An old variety, the origin of which has not been traced. It is now pretty widely disseminated in some parts of Michigan, Ohio, and in the South and West. Tree a stroug, vigorous, upright spreading grower, hardy and productive. Young shoots very dark brown.

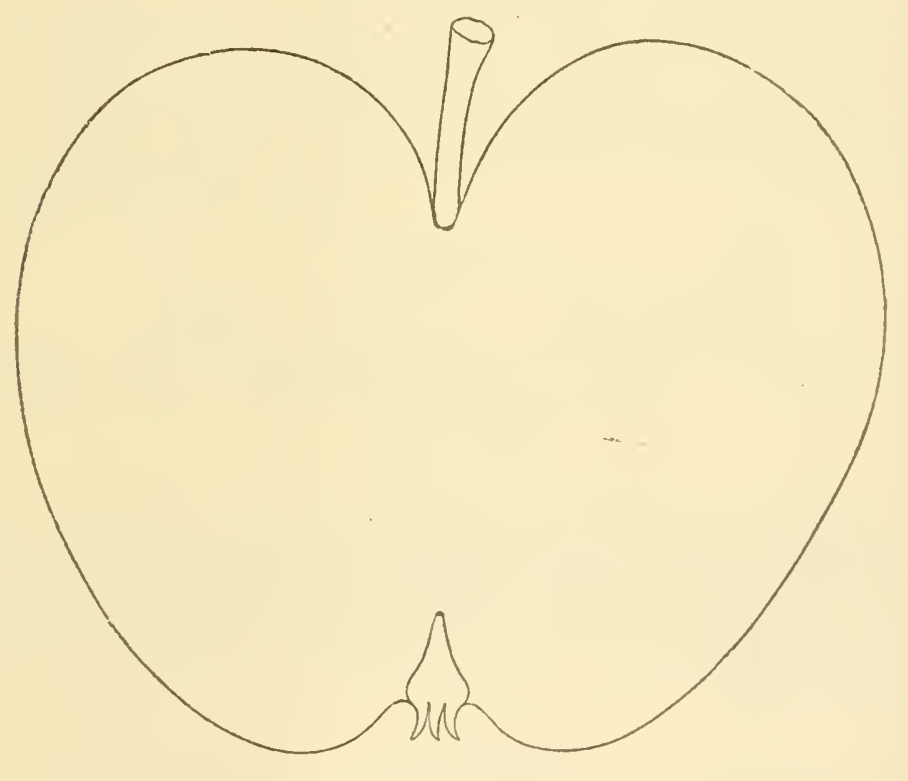

Bummer Pound Royal.

Fruit large, roundish conical, sometines roundish oblate conicul, greenish white, and moderately sprinkled with green and light dot: Stalk rather short. Cavity large, decp, silightly russeted. Calyx closed Segments medium, erect. Basin abmut, mither deep. Flesh white finc-grained, tender, juicy, mikl, sprightly subacid. Good to very good. Core small. August, September. A profitable orchard and nurket variety. 


\section{Sumyer Queex.}

Sharpe's Early. Lancaster Queen. Polecat.

This variety forms a large tree with somewhat pendent boughs, and is a profitable sort for orcliards and marketing over a large territory.

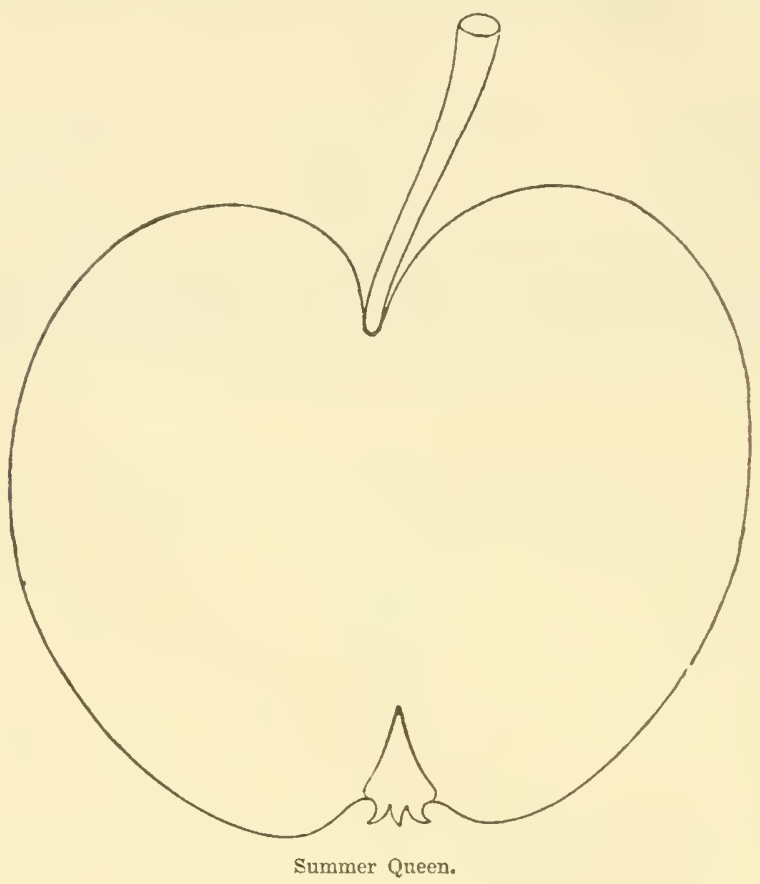

The fruit is large and broad at the crown, tapering towards the eye. The stalk is rather long, and is planted in a pretty deep cavity, sometimes partially elosed. Calyx but little sumk, in a narrow plaited basin. Skin fine deep yellow in its ground, though well striped and clonded with red. Flesh aromatic, yellow, rich, and of good flaror. August and September.

\section{Sumier Rambo.}

Rambour Franc. Rambour Gros. Frank Ramboux.

Summer Rambour. Rambour d'Été.

This is an old French Ajple which was pretty freely distributed many years since, and the old trees of which everywhere prove hardy and profitable for early marketing. Tree vigorous, spreading, open round head.

Fruit a little above medium size, flat, generally evenly formed, but oceasionally a little irregular, pale greenish rellow, stained and streaked with red on the sunuy side. Flesh ratlier soft, sprightly subacid. Good. Ripens early in september. 


\section{Sumar Ried Carvilue.}

Calville Rouge d'Eté. Calville d'Eté. Madeleine.

Rother Sommercalville.

An old French Apple of medinm size, roundish conical, ribbed, yellowish white, streaked and stained with red, becoming very bright in the sum. Flesh white, soft, tender, tinged with red, mild subacid. Good. July, August.

\section{Summer Red Streak.} tive.

Origin, Columbia Co., N. Y. Tree moderately vigorous, produc-

Fruit medium, roundish oblate conical, yellowish, shaded, splashed, and striped with rich red. Stalk small. Calyx closed. Flesh white, sometimes a little stained next the skin, juicy, brisk subacid. Good. Valued for cooking. September.

\section{Sumer Reinette.}

Weisse Wack's Reinette. Weisse Sommer Reinette. Reinette d'Été Blanche.

A beantiful German Apple.

Fruit very large, roundish oblate. Skin oily. Color clear yellow, faintly washed with clear bright red. Calyx half open. Stalk very short. Cavity russeted. Flesh white, fine, juicy, vinous, sweet, aromatic. September, October. (Diel.)

\section{Sumyer Rose.}

Woolman's Harvest.

Lippincott's Early.

A very pretty and very excellent Apple, highly esteemed as a dessert fruit. 'Tree moderately vigorous, productive.

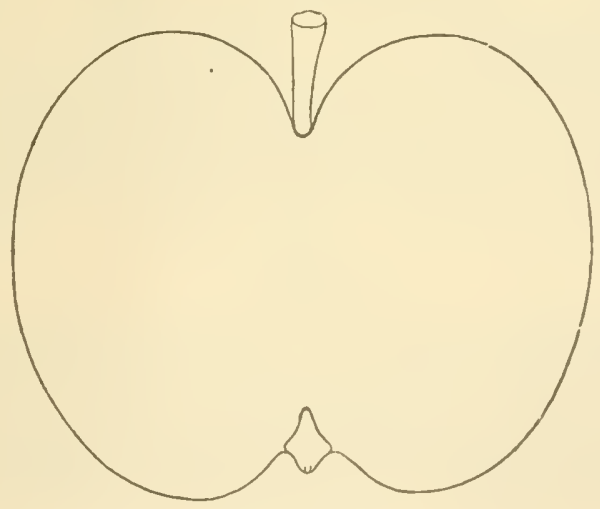

Snmmer Rose.

Fruit scarcely of medium size, roundish, smooth, rich waxen yellow, streaked and blotched with a little red on the sumy side. Stalk 
rather short and slender. Calyx closed, set in an even basin. Flesh tender, abounding with sprightly juice. Ver'y good or best. Ripens early in August.

\section{Summer Sweet.}

An old Comnecticut Apple. Tree vigorous, very spreading, and produetive.

Fruit medium, oblate, inclining to conic, yellowish, netted with russet. Stalk short and small. Calyx closed. Flesh whitish, crisp, tender, moderately juicy, rich, sweet. Excellent for baking. Core small. September:

\section{Summer Sweet Paradise.} tive.

Originated in Pennsylvania. Thee very vigorous, spreading, produc-

Frnit quite large, round and regular in its form, a little flattened at both ends. Skin rather thick, pale green, sometimes faintly tinged with yellow in the sun, and very distinctly marked with numerous large dark gray dots. Stalk strong, and set in an even, moderately deep hollow. Flesh tender, crisp, very juicy, sweet, rich, aromatic. Good to very good. Ripe in August and September.

\section{Summer Thorte.}

Thorie. Thoral Pippin. Whorle Pippin. Watson's New Nonsuch.

A farorite Scotch Apple. Tree a free grower, rather pendent, very productive, bearing in chisters.

Fruit small, oblate, rich yellow, with mottled stripes of rich red. Stalk short. Calyx half open. Flesh yellowish white, tirm, crisp, juicy, brisk subacid. August, September. (Ron.)

\section{Sumer White Calyille.}

Calville Blanche d'Été. Calville Blanc.
White Calville.

Wahrer Weiser Sommercalville.

An old variety. Tree a strong grower and productive.

Fruit medium, roundish oblate, with prominent ribs, pale straw color, with traces of delicate russet in the sun. Flesh white, tender, delicate, sweet, and pleasant. August, September. (Hogg.)

\section{SUPER B.}

Origin, Franklin Co., N. C. Tree tolerably vigorous, spreading, and a prodigious bearer.

Fruit medium or abore, roundish oblate, regular. Skin green, rarely with a blush. Stalk of medium length, in a shallow carity. Calyx large and open. Flesh yellow, solid, slightly coarse-grained, ricl, subacid. Good to very good. November to March.

\section{Superb Sweet.}

Raised by Jacob Deane, Mansfield, Mass. Tree vigorous, productive. 
Fruit rather large, roundish, inclining to conic, pale yellow, shaded, splashed and mottled with red. Stalk long, inserted in a reep eavity. Calyx large, open. Basin broad. Flesh white, very tender, juicy, sweet, rich. Core large. Good to very good. S'cptember, October.

\section{SURPRISE.}

A small, round, whitish yellow Apple, of little or no valne, but admired by some for its singularity, the flesh being stained with red. November to January.

\section{Surrey Flat Cap.}

Hogg describes this as a very excellent dessert Apple.

Fruit above medium, roundish oblate, pale bluish green, rough veing russet, and deep red next the sum. Flesh yellow, firm, rich, and sugary. October, January.

\section{SUSANTAH}

Large, oblong oval, greenish yellow. Flesh crisp, rich, aromatic. November to April. (Sumner MIS.)

\section{Susax's Spice.}

Originated in Franklin Co., Pa. Tree moderately vigorous, upright.

Fruit medium, compressed, glossy light crimson, deeper in the sum, with fawn-colored dots. Stalk short. Flesh yellowish white, stained occasionally with red, juicy, pleasant, aromatic. October. (Gar. Mon.)

\section{Suttox Beauty.}

Beauty.

Origin, Sutton, Mass. Tree upright, thrifty, and very productive.

Fruit medium or above, roundish oblate conic, waxen yellow, shadel, mottled, and obscurely striped with fine crimson, and thinly sprinkled with whitish dots. "Stem rather short, inserted in a medium cavity, slightly surrounded by greenish zusset. Calyx partially closed, set in a moderate, uneven basin. Flesh whitish, crisp, tender, juicy, sprightly subacid. Very good. Norember, February.

\section{SWAAR。}

Hardwick.

This is a truly noble American fruit, produced by the Dutch settlers on the Hudson, near Esopus, and so terned from its unusual weight, this word, in the Low Dutch, meaning heary. It requires a decp, rich, sandy loam to bring it to perfection, and, in its native soils, we hare seen it twelve inches in circumference, and of a deep golden vellow color. It is one of the finest flavored apples in America, and descrios extensive cultivation in all favorable positions, though it does not snceed well in damp or cold soils.

Fruit large, regularly formed, roundish or 1 oundish oblate. Skin greenish yellow when first gathererl, but when entirely ripe of a fine, 
dead gold color, dotted with mumerous distinct brown specks, and some. times faintly marbled with gray russet on the side and round the stalk. Stalk slender, three-fourths of an inch long, inserter in a very round cav. ity. [Sometimes this cavity is partially closed.] Calyx small, greenish,

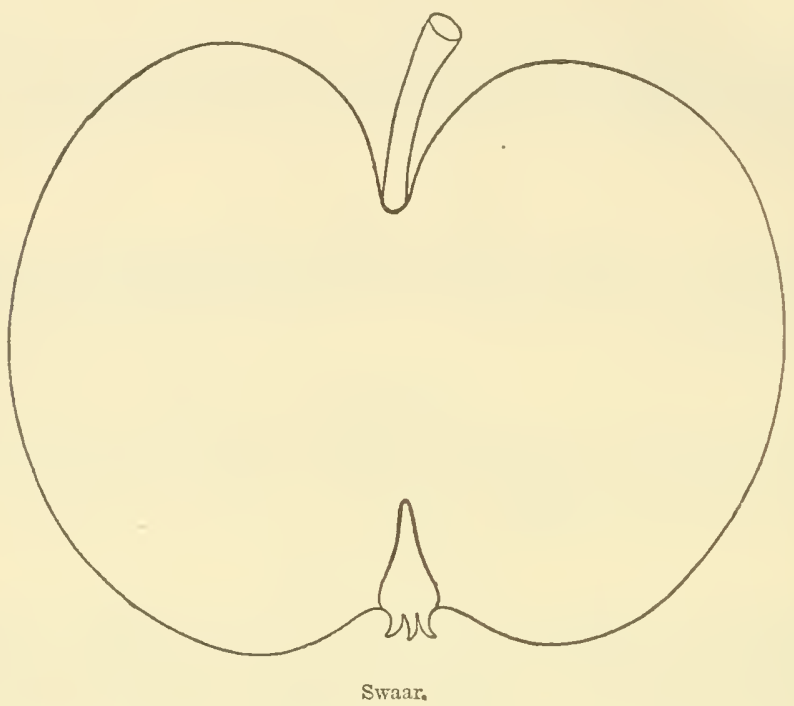

set in a shallow basin, scarcely plaited. Flesh yellowish, fine-grained, tender, with an exceedingly rich aromatic flavor and a spicy smell. T'ery good to best. Core small. The trees bear fair crops, and the fruit is in season from December to March.

\section{SWASEY.}

Supposed origin, Ohio. Tree hardy, but a poor grower.

Fruit small, oblate, yellow, with a red cheek in the sun. Flesh whitish, crisp, tender, subacid. Good. Core small. December, January.

\section{SweEney Noxparjil.}

An English Apple. Tree a good grower and bearer.

Fruit above medium, roundish conical, greenish, with patches of russet and brilliant red cheek in sun. Flesh firm, crisp, juicy, acid. January to April. Cooking.

\section{SWEET AND SOUR.}

Origin unknown. Tree vigorous, spreading, productive.

Fruit large, oblate, ribbed, the ribs being green, and the intervening hollows light yellow; the ribs bearing the flaror of the fruit, which is acid, the intervening hollows being almost flarorless, but sweetish; this jortion not having its juice well elaborated. December, February. 


\section{SWEFT BALDWT.}

Origin unknown. Tree very vigorous, upuight spreading, procluctive.

Fruit medium, roundish oblate, yellowish, shaded, splished, and striped with light and dark red, thin bloom, light dots. Flesh yellowish, moderately juicy, mild, sweet. Good. Octuber.

\section{Sweet Belle Bonve.}

Belle et Bonne.

A very old Apple. Origin unknown. Tree a spreading, moderately upright grower, and an anmul bearer. Young shoots redclish brown, somewhat grayish, slightly downy.

Fruit medium to large, roundish oblate conc, yellow, with nettings and patches of russet, few large brown dots. Calyx small, closerl. Flesh yellow, moderately juicy, rich, sweet. Good. October, December.

\section{Sweet Bellflower.}

\section{Sweet Butter? $\quad$ Butter of some.}

Of unknown origin. Tree vigorous, spreading.

Fruit above medinm, roundish oblate, slightly ribbed, greenish yellow, with a few brown dots, slight blush in the sun. Stalk rather long, slender. Calyx closed. Flesh yellowish white, tender, aromatic, sweet. Good. October, November.

\section{Sweet Bellflower of W'yaxdot Couxtr.}

The origin of this Apple is unknown, but as Elliott has first described it as of II yandot Connty, we follow him until its history is disclosed. The variety is a profitable market sort. Tree a good grower, somewhat drooping in finit. Young wood reddish brown.

Fruit rather large, roundish oblong conic, rough greenish yellow netted and patched with russet. Stalk rather short. Calyx closed. Flesh yellowish, moderately juicy, half tender, sweet. Good. October, Norember.

\section{SWEET Doctor.}

From Pennsylvania. Tree vigorons, upright spreading.

Fruit medium, roundish oblate, yellowish, shaded, splashed, and striped with light and dark red. Stalk slender. Calyx closed. Flesh white, tender, juicy, rich, sweet. Good. Core small. Oetober.

\section{Sweet Fali Pippix.}

Grown in Westchester Co., N. Y. Tree vigorous, productive.

Fruit large, oblate, greenish yellow, slightly sprinkled with brown dots. Stalk short, in a lange cavity. Calyx closerl, in a very shallow basin. Flesh juicy, sweet, and rich. Cood. October, Nurember.

\section{Swhet Greexinf.}

Origin unknown. Tree vignrous, spreading, proluctive.

Fruit large, roundish oblate, greenish yelluw, with dull bronzed real 
in the sun, many irregular scattered rough dots and marblings of russet. Stalk medium. ('avity broad, acute, regular. Calyx in a broad, decp, slightly furrowed basin. Flesh white, loose-grained, mild, sweet, rather dry. Good. Core small. December to February.

\section{SWEET JANET.} ductive.

Origin, Indiana. Tree healthy, vigorous, spreading, annually pro-

Fruit large, round, somewhat conical, covered with rich red or crimson, mixed and striped. Stalk short. Calyx small, closed. Flesh yellow, breaking, not juicy, sweet. Good. December, January. Fine for laking, and the tree claimed to bloom late in season and thus escape frosts. (O. P. S.)

\section{Sweet Kixg.}

Origin, Oyster Bay, Long Island. Tree a stout, erect grower, an early and abundant bearer. Young wood reddish brown, slightly grayish.

Fruit medium, roundish conic, yellowish, shaded, striped, and splashed with red, few light gray lots. Stalk varying. Calyx large, open. Flesh white, tender, juicy, sweet. Good to very good. October to March.

\section{Sweet Mari.}

Originated with J. W. Dodge, Pomona, Tenn. Tree a vigorous, upright grower, and a great bearer. Toung shoots dull grarish brown.

Fruit above medium, roundish conicul, whitish yellow, very smooth, sprinkled with a few light brown dots. Stalk rely short. Calyx closed. Flesh yellowish white, tender, juicy, sweet. August, September.

\section{SWEet Pear.}

Origin unknown. Tree a vigorous, upright grower, very hardy and productive.

Fruit medium, roundish conical, pale yellow, with dull blush red in the sun. Stalk short. Calyx closed. Flesh white, tender, juicy, sweet, aromatic. Very good. September, October.

\section{Sweet Peiriatis.}

An old variety, of unknown origin. Tree a strong, upright grower, and good bearer.

Fruit medium, roundish, slightly conic. Stalk short. Carity broal, deep. Calyx small, closed. Basin shallow. Flesh whitish, juicy, tender, brisk, rich, sweet, aromatic. Very good. Jamury to April.

\section{SWeEt Pippin.}

An old variety. Tree productire.

Fruit medium, roundish oblate or oblate, rellowish, with red in the sum. Stalk short. Elesh firm, morlerately juicy, sweet. Good. Norera her, December. 
Swert Quees.

Dalc's Sweet Fall Queen.

Origin, Peunsylrania. 'l'ree a fair grower, and productive.

Fruit large, elongated conic, ribbed at apex, whitish, shiuled, striped, nnd splashed with shates of red. Flesh white, tender, pleasant, sweet. Scarcely good. November.

\section{SWEFT Raybo.}

Origin, supposed Pennsylrania. Tree stout, upright, rigorous, not an early bearer.

Fruit medium, roundish ollate, yellow, mostly shaded with red, and thickly covered with large gray dots, a little elevated above the surface. Stalk slender, inserted in a deep cavity, surrounded by russet. Calyx closed, set in an open basin. Flesh whitish, juicy, pleasant sweet. Core small and close. Good to very good. Octuber to December.

\section{Sweet Ribbed Gilliflower.}

An old Comnecticut rariety.

Fruit large, roundish elongated conic, ribbed, mostly covered with light red, striped and splashed with dark. Stalk short. Calyx closed. Flesh white, rather compact, morlerately juicy, half tender, sweet. Good. Core large. November, December.

\section{Sweet Roulanite.}

\section{Red Winter Sweet? Sweet Nonsuch.} bearer.

Origin unknown. Tree a strong, upright grower, hardy, moderate

Fruit medium, ronudish oblate, greenish yellow, shaded, splashed, and striped with red, light dots. Stalk short, slender. Calyx closed. Segments erect, slightly recurved. Basin corrugated. Flesh yollowish white, compract, tender, juicy, rich, sweet. Good to very good. Core small. November to March.

\section{Sweet Russet.}

Summer Russet.

Received from Parsons it C'o, Flushing, Long Island. Origin unknown. A nice little Apple. Tree moderately rigorons, productive. Young wood redlish olive.

Fruit small, roundish, inclining to conic, sometimes oblate, yellow, mostly covered with light russet, aud spriukled with brown misset dots, tinge of red in the sum. Stalk slender. Calyx closed. Elesh whitish, crisp, very tender, juicy, rich, sweet, aromatic. Tery good. Sieprtember.

Another SweEt licssem is grown in Massachusetts, Now York, and elscwhere. The tree an un inght, sprealing grower, productive. Grood for cooking.

Fruit medium, oblate, yellow, mostly covered with nettings and patches of musset. Fleshl whitish, lualf tender, ricll, sweel. Cioorl November, Narch.

Another Sweet Russet of Kentucky, is described hy Warder as: 
Fruit small, conical, truncated, rough, dark russet. Dots minute, white, prominent. Flesh yellowish white, fine-grained, not tender, sweet. Scarcely good. December, February.

\section{Sweet Seek-no-Farther.}

Origin, Hanover, N. H. Tree a good grower, an early and abundant bearer.

Fruit above medium, roundish conical, yellowish green, with a red cheek next the sun. Flesh firm, juicy, sweet. Grood. A long keeper.

\section{Sweet Sponge.}

Origin unknown.

Fruit medium, oblate, yellowish white. Flesh white, tender, sweet. July. (Warder.)

\section{SWEET WTLIIE.}

Origin, Todd Co., Ky. Tree a good grower, and productive.

Fruit large, greenish, mostly covered with stripes of red. Flesh fisegrained, tender, juicy, rich, sweet. Good to very good. Norember, December.

\section{SWEET ITINESIP.}

Henrick Sweet? Henry Sweet. Ladies Sweet, of some. Sweet Pearmain, of some. Red Sweet Winesap.

From Pennsylvania. Tree of molerate, upright growth, productive.

Fruit medimm, oblate, slightly approaching conic. Color red, splashed with deep crimson. Stalk long and slender, inserted in a deep cavity, surnounded with russet. Calyx pirtially open, set in a rather deep, open basin. Flesh tenter, juicy, very sweet, rich. Good to rery good. November to Narch.

\section{SWEET TANDERVERE.}

\section{Sweet Redstreak.}

Sweet Harvey.

Origin unknown. Tree of erooked growth, a profuse bearer.

Fruit medium, roundish oblate, yellow, shaded and striped with dull red. Stalk short, rather slencler, inserted in a large, irregular cavity. Calyx partially closed, set in a broal, open basin. Flesh tender, juicy, mild, sweet, aromatic. Good. November, March.

\section{Sweet Wixter Pexiock.}

From Ohio, supposed origin Belmont Co. Tree moderately vigorous, upright, rather slender, a moderate bearer.

Fruit medium, oblate, greenish yollow, shaded and striped with red. Flesh whitish, moderately juicy, mild sweet. Poor. December, January.

\section{SwISS REINET'TE.}

\section{Reinette Suisse.}

Of foreign origin. Tree moderately vigorous, spreading.

Fruit medium or above, oblate, inclining to conic, tine yellow, moder. 
ately sprinkled with gray and rather indistinct light dots. Stalk short. Carity large, slightly russeted. Calyx closed. Basin abrupt, de'pl, slightlr corrugated. Flesh yellowish, crisp, rather tender, juicy, pleasant subacid. Very good. December, February.

\section{Sike-House Russet.}

A Yorkshire Apple. Tree spreading, productive.

Fruit medium, oblate, yellowish, mostly covered with light brown russet. Flesh yellowish, firm, erisp, sprightly, juicy, subacid. Novenber, February. (Ron.)

\section{STLTESTER.}

Originated on the farm of Dr. E. WT. Sylvester, Lyons, N. X. Tree vigorous, forming a beautiful open, round, spreading head, a profuse bearer. Young shoots dark reddish brown, slightly grayish or downy.

Fruit below medium, roundish oblate, regular, waxen white, beautifully shaded on the sunny side with bright erimson, thinly sprinkled with minute light and brown dots. Stalk small, short. Cavity regular. Calyx closed. Basin rather shallow. Flesh very white, tender, crisp, juicr, brisk subacid. Tery good. September, October. Excellent for cooking and drying.

\section{Table Greening.}

Origin, Cornish, Me. I'ree vigorous, upright spreading, productive.

Fruit medium, roundish, dull green. Flesh juicy, mild, pleasant subacid. Good. December to Narch.

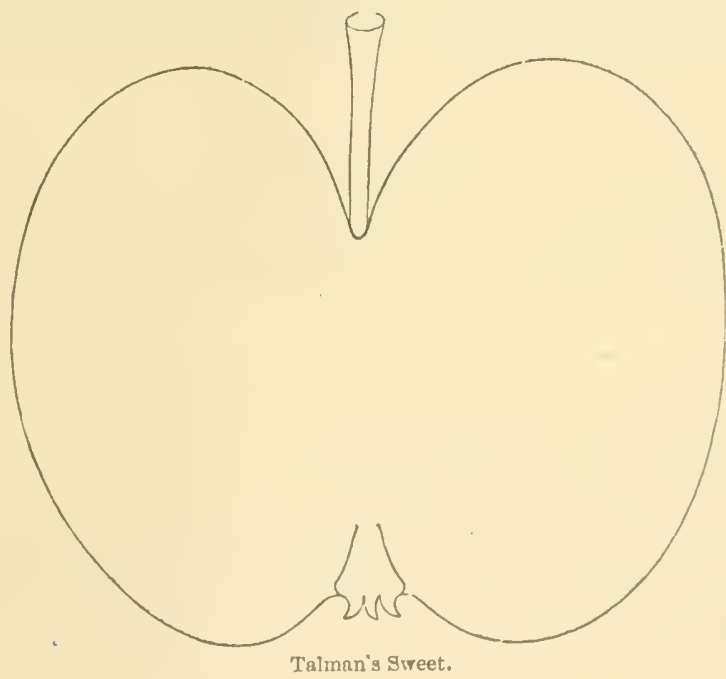

'Thunas's SWEeT.

Tolman's Sweeting. Tallman's Sweeting. Brown's Golden Sweet.

A native of Rhode Island. In quality the fruit is scarerly second rate as a table sort, but it is a very popular and profitable oreliad sort, 
from the hardihood of the trees, their great productiveness, and its value for stock feeding and various culinary uses. Tree an upright spreading grower, vigorous.

Form nearly globular. When fully ripe, whitish yellow, with a soft blush on one side, and generally a line rumning from stem to calyx. Stalk rather long and slender, inclining to one side, and inserted in a rather wide, shallow, but regular cavity. Calyx set in a small basin, slightly depressed. Flesh quite white, rather firm, fine-grained, with a rich sweet flavor. November to April.

\section{TARDIVE DE JoNCRET.}

Originated in Belgium. Tree vigorous, very productive.

Fruit medium to large, roundish conical truncated, ribbed, golden yellow, with bright red on the sun side. Dots and splashes of gray. Stalk short. Calyx closed. Basin deep. Flesh white, tender, sweet subacid. December, February. (An. Pom.)

\section{Tart Boughr.}

Sour Bough of some.

An old variety, originally disseminated, so far as we can learn, by Judge Buel, of Albany, N. Y. It much resembles Early Harvest in the fruit, but the trees are more rapid in growth, and it ripens much later, is more acid, and not considered profitable.

There is amother Tart Bougr, the fruit of which is small, romdish conical, whitish, thickly sprinkled with dots. Stalk long, slender. Calyx closed, with long segments. Basin shallow. Flesh white, firmgrained, tender, juicy, sprightly, pleasant subacid. Good. Core small, August.

\section{Tarvey CODlin.}

Raised from seed of the Manks Codlin.

Fruit large, conical, dull olive green, with yellow and yellowish red, much spotted with broken rows of blood-red dot, next the sun. Flesh white, juicy. A good culinary apple. November, December. (Hogg.)

\section{Tauntox.}

Origin unknown. Some claim it for Alabama, others Georgia. The tree is a vigorous but straggling grower, very productive. Young shoots redlish brown, slightly downy.

Fruit rather large, oblate conic, greenish yellow, striped ancl splashed with red, darkest on sun side, large light dots. Stalk slender. Cavity deep, russeted. Calyx closed. Segments loug, slender. Basin slightly corrugated. Flesh whitish, tender, juicy, aromatic, acid. Good. September, October.

\section{Taunton Golden Pippin.}

Tree hardy and productive.

Fruit below medium, roundish, rich yellow, markings and freckles of russet in shade, clouded red, and streaked in sun. Flesh yellow, firm, crisp, delicate, brisk, vinous. December to March. (Hogg.) 
Texperskix.

Of Southern origin. Tree very vigorous, healthy, and productive Young wood reddish brown, downy, rery short-jointed, with prominent butcs.

Fruit below medium, roundish conical, yellow, striped and splashed somewhat with red, some bloom. Stalk long. Calyx closed. Flesh yellowish, tender, very juicy, pleasant subacid. Good to very good. November to Jamary.

\section{Tex Siilllings.}

Fruit medium, roundish oblate, greenish yellow, covered with pale brown russet orange streaked with red in the sun. Flesh yellowish white, tender, sweet acid. November. (Hogg.)

\section{Texterden Park.}

Fruit medium, roundish, yellowish green, mostly covered with deep red, striped with a still deeper shade in the sun. Flesh greenish white, tender, crisp, brisk, juicy, not rich. Oetober, February. (Hogg.)

\section{Terral's Late.}

A Southern Apple of unknown origin. Tree very productive.

Fruit large, oblong oblique, whitish, shaded with light red, striped and splashed with dark red, thickly sprinkled with light brown dots. Stalk very short. Cavity narrow, deep, partially russeted. Calyx small, closed. Segments small, erect. Basin abrupt, deep. Flesh white, tender, juicy, pleasant subacid. Good. Core small. October, Norember.

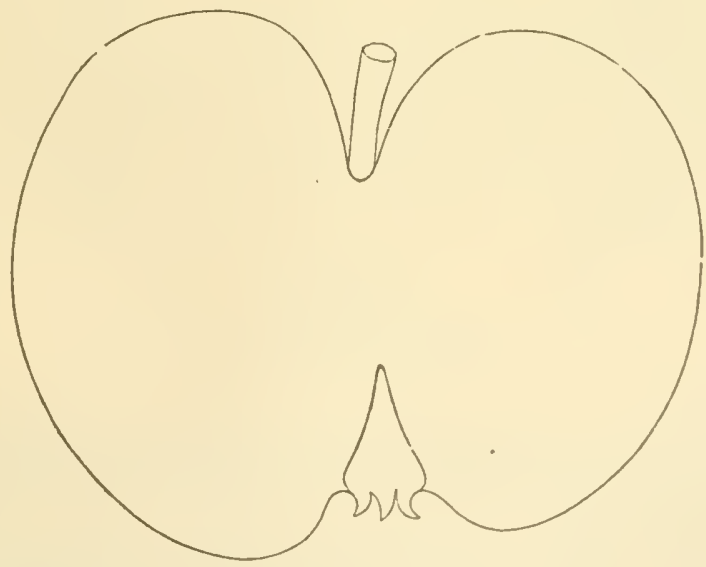

Tetorsky.

Tetofsky.

The Tetofsky is a Russian Summer $A_{p}$ ple, which proves profitable for market growing. The tree is an upright sprearling grower, forming 
an open head, comes early into bearing, and produces annually. Very hardy. Young shoots yellowish reddish brown, leaves very large.

Fruit of medium size, oblate conic, sometimes nearly round, smooth, th a yellow ground handsomely striped with red, and, like most pples of that country, covered with a whitish bloom, under which is a shining skin. The flesh is white and juicy, sprightly acid, fragrant, and agreeable. Good. Angust. Succeeds at the North.

\section{Teuchat's EgG.}

\section{Chucket Egg. $\quad$ Summer Teuchat Egg.}

Fruit below medium, varying in shape from ovate to conical, irregularly ribbed, pale yellow, washed and streaked with red. Flesh tender, juicy, pleasant. September. (Hogg.)

\section{Tewkesbury Wixter Blush.}

\section{Tewkesbury Blush.}

Coxe says this Apple was bronght from Tewkesbury, Hunterdon Co., N. J.

It is a handsome, fair fruit, with more flavor and juiciness than is usual in long-keeping apples. They may be kept till Angust, without

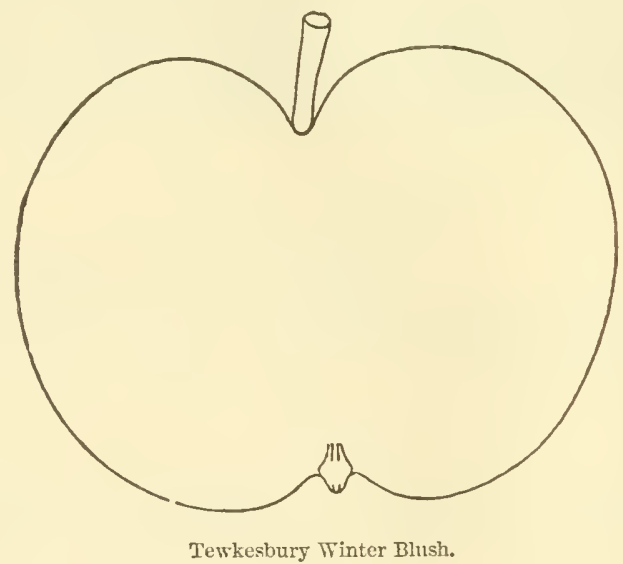

particular care, quite plump and somd. The tree grows rapidly and straight, and the fruit hangs till late in the autumm. Young shoots grayish reddish brown.

The size is small, rather flat. The skin smooth, yellow, with a red cheek. Flesh yellow, with more juice and Haror than any other long. keeping variety. Mild, pleasant subacid. January to July.

\section{Them's Red Streak.}

Fruit medium, roundish, pale green, with red stripes. Flesh acid Winter. (Hov. Mag.) 


\section{T'HoMis.}

An old unknown viriety, carried many years since from Mra yland to Tllinois, where it has received the mame of Thomas. The tree is rery hardy, moderately vigorous, forming a handsome-shaped top, anmually productive.

Fruit large, roundish conical truncated, greenish, becoming yellow when fully matured. Skin thin. Flesh soft, tender, juicy, pleasant subacid. December to February. (N. Lyon: MS.)

\section{TIFT'S S'WEET.}

Origin, New England. Tree vigorons, upright spreading.

Fruit medium, oblate, green, netted with russet, sometimes with a dull brown cheek. Flesh yellowish, exceedingly swect and rich. A regular, but not profuse bearer. Unprofitable. September, October.

\section{Tillaqua.}

\section{Big Fruit.}

Origin, North Carolina. Tree vigorous, upright spreading.

Frnit above medium, roundish ublate or oblate, yellowish ground, nearly covered, shaded, splashed, and striped with red, moderately sprinkled with large light dots. Stalk short. Calyx closed. Flesh whitish, moderately juicy, brisk subacid. Good to very good. November to March.

\section{Tixmoutil.}

\section{Teignmonth. Vermont Pippin.}

Origin, Tinmouth, Vt. This fine Apple is much esteemerl in the region of its origin. The tree is a good grower, very productive, and a profitable sort. Young shoots dull brownish red, slightly downy.

Fruit above medium, oblate, whitish yellow, considerably shaded with carmine, and sprinkled with a few brown dots. Stalk short, inserted in a deep cavity. Calyx partially closed, set in a deep open basin. Flesh whitish, juicy, tender, pleasant, mild subacid, with a peculiar melon-like aroma. Good to very good. November to February.

\section{Titus Pippix.}

\section{Well Apple. Hans-On. Timothy. Timothy 'Titus Sort.}

Origin, near Hempstear, I ong Island. Tree an upright, thrifty grower, productive, and profitable for market.

Finit large, roundish oblong conic, somewhat ribbed, pale yellow, rarely with a biush. Stalk rather slencler. Calyx open. Flesh whitislı yellow, a little coarse, breaking, juicy, tenter, brisk subacicl. Good. Core large and open. December to February.

\section{ToCCOA.}

Muskinelon.

Originated in Habersham Co., Giı.

Fruit medium, roundish conical, yellow, with a light shade of crim- 
son in the sun, few gray dots. Stalk slender. Calyx closed. Basin small, corrugated. Flesh yellowish, tender, mild subacid. Good. Angust, September.

\section{ToKer's Ixcomparable.}

An English culinary sort.

Fruit large, roundish oblate, ribled or five-sided, yellowish green, with traces and streaks of red in the sun. Flesh yellowish, firm, crisp; tender, juicy, brisk, pleasant acid. November, December. (Hogg.)

\section{'Tolber't.}

From Pennsylvania.

Fruit medium, roundish, deep red, with indistinct stripes, and light dots. Stalk short and small. Cavity narrow, a little russeted. Calyx closed. Flesh yellowish, moderately juicy and tender, mild subacid. Good. Core small. Sevtember.

\section{Toy PotTer.}

A Devonshire, England, Apple, described by Ronalds. Tree healtiny, but uncertain bearer.

Fruit medium, roundish oblate conical, yellow, shaded and striped with red in the sun. Flesh juicy, high-flavored. September, October.

\section{Toole's Indian Rareripe.}

Origin unknown. Tree stout, upright, short-jointed, forming a dense round head, moderately productive. Ioung shoots smooth clear reddish.

Frnit large, roundish slightly conic, greenish yellow, with a tinge of red in the sum. Stalk very short. Calyx small, closed. Basin medium, uneven. Flesh greenish white, tender, brisk subacid, valuable for cooking. Core large. September, October.

\section{Tower of Glaymis.}

Glammis Castle. Late Carse of Gowrie. Carse of Gowrie.

A fine culinary Apple from the Clydesdale orchards, Scotland. Tree an excellent bearer.

Fruit large, roundish conical, sides sometimes unequal, pale yellow, shaded with crimson in the sun. Stalk rather slender. Calyx large, open. Basin slightly corrugated. Flesh white, tender, juicy, sharp subacid. Good. December, January.

\section{Tower's GLorY.}

A cooking Apple, described by Hogg as of medium size, roundish, with obtuse angles, ycllow, corered in sun with red, and streaked with darker shades. Stalk very short. Calyx large, open. Flesh yellowish, tender, juicy, brisk, acid. October to April.

\section{Towrsexp.}

Hocking.

Seager.

Originated in Bucks Co., Pa., found orer one hundred years ago, in 
an Indian clearing by Stephen Townsent, when he first sottled in that then wild comtry. 'Thee healthy, vigorous, upright spreading, produc: tive. Young wood redelish brown, slightly downy.

Fruit medium, oblate, slightly conic, pale yellow, striperl and splashed with red, and covered with a thin bloms. Stalk ratliex loner, slender, inserted in a medium cavity. Calyx elosed, set in a busin of moderate depth. Ilesh white, tendere very mild, agreeable, subacid. Good to rery good. Ripe middle of August to middle of september.

\section{Townevo's Suling Beautr.}

An excellent kitchen Apple.

Fruit large, roundish oblate, ribbed, yellow, with a brownish red cheek. Calyx closed. Flesh tender, fine-grained, juicy, agıecable acid. October to April. (Hogg.)

\section{Trader's Faxct.}

Originated in the uurseries of Solomon Phillips, Washington Co., Pa. Tree a vigorous grower, a good and regular bearer, and popular where known; valued as a late keeper and market fruit at the Southwest. Young wood dull reddish brown.

Fruit mediun, roumilish oblate, greenish yellow, striped and shader with dull red, covered with a bloom. Stalk short, slender. Calyx closed. Basin broad and corrugated. Flesh whitish, crisp, tender, juin, with a mild, pleasant, subacid flavor. Good to rery good. January to May.

\section{Trasspareat Codlix.}

Lindley describes this as a handsome Aple, forming a spreading tree, and an excellent bearer.

Fruit medium, roundish oblong conic, lcmon yellow, tinged with salmon or red in the sun. Flesh tender, semi-transparent, juicy, sweet. September, November.

\section{Traxsparext de Zurior.}

Eruit small or medium, beautiful waxen white, elear, translucent. Sejtember. (Elliott.)

\section{Transport.}

Origin, Tndiana. Tree poor in the nursery, good in the orchard, very productive.

Fruit large, globular, flattened, angular, pale yellow, blushed cal:mine. Dots scattered, green, with white bases; purple where exposed, hloom white. Flesh rellowish white, tender, melting, fine-grainerl, juicy, mild subacid. Good to very good. December to Fubrury. Not very profitable. (Warder.)

\section{Trextoy Earuy?}

A variety somewhat grown in Ohio anci the Wrest, the origin or identi- 
$\mathrm{ty}$ of which has not yet been discovered. The tree is a moderately vigorous grower, hardy, and quite prodnctive. Young wood reddish brown.

Fruit above inedium, irregular, ribbed. Color yellowish, with siight undulations orer the surface, which are green. Skin snooth and oily Cavity wide. Basin furrowed. Flesh not very fine-grained, very light and tender, with a pleasant, subacid flaror. Good. August.

\section{Trescott Russet.}

Originated in Sharon, Conn. Tree a strong grower, good bearer; and the fruit keeps well, but inclines to shrivel.

Fruit roundish conic oblique, yellow russet, with a dull red cheek. Stalk short, thick. Calyx closed. Flesh tough, mild subacid, vinous, almost sweet. Crood. February, April.

\section{Trumbull. S'Weet.}

Fenton Sweeting.

Trumbull Sweeting.

Originated in the orchard of Aaron Fenton, Trumbull Co., Ohio. Tree a healthy, spreading, vigorous grower, an early and good bearer.

Fruit medinm, romulish oblate, whitish yellow, with a blush in the sun, and a few brown and indistinct green or gray dots. Stalk rather short and slender. Cavity broad, uneven. Calyx closed. Flesh white, juicy, tender, mild, sweet. Very good. Core rather large. September, Octoler.

\section{Trumpeter. \\ Treadle-Hole.}

An Apple esteemed in the orchards of Lancaster, England.

Fruit large, oblong, ribbed, pale green, with a tinge of yellow in the sun. Elesh greenish white, crisp, juicy, sweet subacid. October, December.

\section{TucKer.}

A cooking Aple, described by Cole as medium, flattish round, greenish yellow, crisp, juicy, acid. July, August.

\section{Tuebrer's Cider.}

Origin, Missouri. Talned only for cider.

Fruit below medium, roundish trumcated, dull yellowish red. Flesh vellow, acid. October.

\section{Tuzbsek's Goldex.}

Originated in Missouri.

Fruit small, roundish, yellow. Flesh acid. Talned only for its productiveness. September.

\section{Tuft's.}

Tuft's Baldwin.

Originated in Cambriclge, Mass. The tree is vigorous, forming a handsome head, and besring ammally. Toung wood dark brown. 
Fruit large, roundish ohlate, yellowish, much shaded and somotine's stripred with red. Stalk in a large cavity. ('alyx elosed, in a plititred basin of moderate alepth. Flesh crisp, rather juicy, with a flavor searecly subacid, and slightly aromatic. Ciovi. September, Uctuber.

\section{'Turis.}

Tulp. Tulpen. Dutch Tulip. Calville Tulipee. Tulipen Calville.

A Dutch Apjle.

Fruit medium or below, roundish, yellow, nearly overspreat with deep, almost purplish red. Stalk slender. Calyx open. Flesh yellow ish white, juicy, tender, sweet subacid. Good. November, January.

\section{Turkey Greening.}

From Connecticut. Tree vigorous, very prosluctive.

Fruit fair and very productive, large, oblate, slightly conic. Skin green, with a dull blush and many light dots. Flesh greenish, tender, juicy, subacid, not valuable. Januars, February.

\section{Turk's Car.}

A cooking Apile, described by Hogg as :

Fruit large, roundish oblate, ribbed, golden yellow, some russet and a brownish tingn of red in the sun. Calyx large, open. Stalk long. Flesh yellow, firw, crisp, juicy, pleasant subacid. November, December.

\section{TURA OFF LANE.}

\section{Winter Strawberry.}

Origin, Salem, N. J. Tree noderately vigorous, upright, a regular and good bearer.

Fruit medium or below, oblate, inclining to conic, rellow, striped and shaded with red. Flesh white, tender, brisk, sprightly subacid. Good Prized in the neighborhood of its origin as a late kecper.

\section{Tuscaloosa.}

Tuscaloosa Seedling.

A variety originated by Andrew Clements, of Tuscaloosa Co., Ala. I new seedling of good promise as a market sort for the South. 'Tree morlerately vigorons, spreading, productive.

Fruit medium to large, romudislı oblate, slightly conic, yollow, sliarled, striped, and marbled with red russet near the stalk, few graly dots. Stalk slencler. Cavity slightly russeted. Calyx closed. Basin corrugated. Flesh yellowish, firm, juicy, mild subacid. Crood to very good. Coro small. Octolser to Feloruary.

\section{Tuscaloosa Sweet.}

Supposed a native of Kentucky. Tree moderately vigorous, wiright, spreading.

Fruit large to very large, oblate, slightly ribberd, ycllowish green, becoming deep yellow in the sum, small white suflused specks surrounded with crimson red. Stalk medium. Carity broad and rusncted. Calyx 
small, closed. Flesh yellowish white, crisp, tender, brisk, sparkling; sweet. Core medium, compract. Tery good. October, December.

\section{Tutrue.}

Origin unknown. A strong, vigorous, upright, spreading grower.

Fruit above medium, roundish, slightly conic, yellow, mostly shaded and splashed with dark and light red, few whitish dots. Stalk rexy short and stout. Cavity small, russeted. C'alyx closed. Flesh whitish, rather firm, tender, juicy, pleasant, mild subacid. Good to very good. December, February.

\section{Twenty Ounce.}

Morgan's Favorite.

Twenty Ounce Apple.

Eighteen Ounce Apple. Aurora.

\section{Coleman}

Cayuga Red Streak.

Lima.

TWine of Connecticut.

A very large and showy Apple, well known in Caynga Co., N. Y., but an old fruit from Commecticut. It is a good, sprightly fruit, though not very high flavored, but its remarkably liandsome appearance and large size render it one of the most popular fruits in market. The tree is thrifty, and makes a compact, neat head, bears regular crops, and the fruit is always fair and handsome. Young wood rich brownish red.

Fruit very large, roundish, slightly uneven, greenish yellow, boldly splashed and marbled with stripes of purplish red. Stalk short, set in a wide, deep cavity. Calyx small. Basin moderately deep. Flesh coarse-grained, sprightly, brisk subacid. Good to rery good. October to January.

\section{Twix.}

A rariety introduced and disseminated in Michigan by a nursersnan, who, having lost its true name, applied the above, because of its hearing its fruit in pairs. It has not yet been identified, but will probably prove some old variety.

Fruit above medium, oblate, yellowish white, nearly corered with bright red, shaded and striped with dark red, usually a patch of russet next the stalk. Flesh fine-grained, crisp, juicy, with occasional pink lines or threads through it, aromatic. October, November. Core small, close. (T. T. Lyon, MS.)

\section{'Twitchell's Sweet.}

Origin, Dublin, N. H.; a vigorous grower, with slender branches, and very productive.

Fruit medium, roundish conic, red, shaded with purple, and partially sprinkled with small gray dots. Stalk long and slender, inserted in a deep cavity. Calyx small and closed, set in an abrupt, plaited basin. Flesh very white, veined with red under the skin, and sometimes at the core, tender, very sweet and pleasant. Good. Norember, De. cember.

\section{Trre Bencty.}

A new variety, originated on the farm of Jason Smith, Tyre, Seneca 
Co., N. Y. Tree a gooul grower, productive of fruit uniformly even in size, inul viluable as a market sort.

Eruit medium size, romulish vblate, pale yellow, with broken liness and splashes of deep erimson, shaded and mabied intermediate, monlily bloom, lisht gray dots. Stalk short. Cavity deep. Calyx with almost erect segmunts. Basin deep. Flesh white, erisp, tender, breaking, slightly acicl, pleasant. Good. Core small. Seeds broad, pointed. Season, eirly September. (Rural New Yorker.)

\section{Tyroler Pippin.}

Reinette der Tyrol.

A Swiss Apple.

Fruit small to medium, roundish, yellow, with dull red, broken stripes in the sun. Flesh white, veined with green, firm, sugary. Winter. (Ver'g.)

\section{UXCLE JOHN.} ductive.

Origin, Eastern Pennsylvamia. Thee a strong, upright grower, pro-

Fruit medium, oblate oblique, whitish, shaded with light, and splashed and striped with dark red or lake, thickly sprinkled with large light dots. Stalk short and small. Calyx closed. Flesh quite white, tender, juicy, mild subacid. Good to very good. Core small. November, December.

\section{UXIQUE.}

A French Apple.

Fruit medium, oblong conic, ribbed, pale yellow, lightly shaded in the sun with red, and thickly sprinkled with small gray and liglit dots. Stalk short. Cavity medium. Calyx small, closed. Segments short to a point. Basin small, abrupt. Flesh white, firm, moderately juicy, subacid. Good. Core small. Norember, December.

\section{UNion.}

Originated in the County of Way, Ia. Tree a good bearer.

Fruit medium, roundish oblong conical, yellow, with pale red stripes. January. (Lewis Jones' MS.)

\section{UPDEGRAFF.}

From Pennsylvania. Tree vigorous, spreading.

Fruit medium, oblate or roundish oblate, inclining to conic, pale yellow, shaded, splashed, and strijed with light and clark red, darkest in sul, few areole dots. Stalk slender, Calyx large, open, or partinlly closed. Basin corrugated. Flesh white, tender, juicy, pleasant subacid. Core small. Good. Norember.

\section{UTTER.}

A popular Apple in Wisconsin and some other Western scetions. Tree a regular bearer, and hardy 
Fruit medium to large, oblate, lemon yellow ground, nottled, shaded and striped with light red, small russet dots. Stalk short and slender. Calyx small, closed. Basin open, furrowed. Flesh white, tender, juicy, mild, pleasant subacid. Good. Norember, December.

\section{Vale Mascal Peariain.}

Frnit below medium, roundish, greenish yellow, with bright red in the sum, and many spots of russet. Flesh yellow, crisp, sugary. (Hogg.)

\section{VAN Buren.}

A Southern variety.

Fruit merlium to large, globular, a little conical, yellow, shaded with dark red, specks and patches of russet. Stalk short, fleshy. Carity narrow. Calyx small, closed. Basin shallow. Flesh yellow, juicy, tender. Good keeper. October to April. (White.)

\section{VANCE's HarVest.}

Vance's Early.

Origin, Edgar Co., Ill. Tree vigorous, productive.

Fruit small, oblate, inclining to conic, yellow, shaded with orange red in the sum, few gray and light dots. Cavity russeted. Calyx closed. Flesh yellowish, tender, juicy, pleasant subacid. Good. August. Core small.

\section{VANDENABEELE.}

Originated in Flanders. Tree vigorous, prodnctive.

Fruit large, oblong conical truncated, ribhed at apex, golden yellow, splashed and marbled with red in the sun, many gray dots and shades. Stalk short. Cavity deep. Calyx large, open. Flesh yellowish white, half tender, agreeable subacid. December to February. (An. Pom.)

\section{VANDERNOOT.}

One of Tan Mons' seedlings.

Fruit large, roundish conical, clear yellow, splashed and clonded with deep rich red in the sun, greenish monid toward the apex. Stalk long. Cavity deep. Calyx open. Basin furrowed. Flesh white, tender, juicy, subacid. November, December. (Alb. Pom.)

\section{TANDERSPIEGEL.}

Seek-no-Further of some.

Origin, Bennington, Vt. Tree a good grower, and productive.

Fruit below medium, roundish conic trmneated, rellowish, shaded an splashed with red, few light dots. Calyx partially closed. Flesh yellowish, crisp, juicy, pleasant subacid. Good. December, February. 


\section{VANDEVELE.}

White Vandevere.

Little Vandevere of Indiana.

Vanderveer.

Pennsylvania Vandevere.
Vandevere of Pa.

Stalcluhs.

Yellow Vandervere. Striped Vandervere.

Lasting Vandervere? Fall Vandevere? Red Vandevere.

The Tanderere is an old fruit, a native of Wihmington, Dcl, and took its name from a family there by name of Tamoiver, which should be by right the name of the Apple; but it lias so loug been known and grown under the spelling Vimderere, that we deem it best not to change it. There is much confusion existing respecting this Apple and its sub-rarieties, which possibly some of those may be, srown miler what we give as synonpus. Tree of moderate horizontal growth, not very productive. 'Young shoots smooth, dark grayish reddish brown, with bold, full, projecting, rounded conical buds.

Fruit of nedium size, oblate. Stalk about an inch long, inserter in a deep cavity. Calyx small and closed, set in a rouml, moderate bisin. Color waxen yellow, striped with red, and covered with nmmerous green dots. Flesh yellowish, compact, but tender, with a fine, rich, subarid flavor. Good. October to Jaunary. Valuable for culinary purposes.

There is a Tanderere which we have received from Virginia, the young wrod of which is slender, with rery small inconspicuous buds.

\section{Thideriere Pippin.}

Indiana Yandevere.

Mountain Vauderere.

\section{Watson's Vandevere.} Imperial Vaudevere?

Big Vandevere.

Origin unknown. Tree a strong, rapid grower, sprealing, a moderate bearer. Young wood smooth, light reddish brown, medium sized, buds reddish.

Fruit large, oblate, approaching conic, yellow, flaked all over with wrl, striped on the sumny side, and covered with rongh brown dots. Stalk short, inserted in a broad, deep cavity, often russeted. Calyx partially closed, set in a moderate basin. Flesh crisp, with a brisk subacid Havor. Good. September to February. Taluable for cooking and drying.

\section{TANDINE.}

Origin unknown. Tree upright, vigorous grower, productive. Young wood smootī, brownish.

Fruit large, roumdish, slightly conic, yellowish, with a tinge of red, and slightly surinkled with brown and reddish dots. Stalk rather slender, in a lange cavity. Calyx closed, in a deep, uneven basin. Flesh white, tender, juicy, subacid, agreeable. Crool Septemler, October.

\section{VAx Moxs ReINeTte.}

\section{Reinette Van Ions.}

Origin unknown.

Fruit small, roundish oblate, slightly conic, rich wollow, with a rich red cheek in sun, considerable russet. Stalk rither short. I'alyx closed. Flesh yellow, rich subacid. Tery good. I'(crmber. March Not profitable. 


\section{VAughi's Winter.}

Origin, Christian Co., Ky. Tree hardy, vigorous, and productive Introduced by J. S. Downer, of Elkton, Ky.

Fruit medium, oblate. Sides unequal, whitish, waxen yellow, shaded with erimson and lilac, and sometimes obscurely striped, and thickly covered with conspicuous light dots. Stalk small and short. Deep, uneven cavity. Calyx closed. Basin deep, abrupt, open, slightly corrugated. Flesh yellowish, tender, juicy, mild subacid. Good. January to March.

\section{Vaughis's Piptin.}

Colonel Taughn's.

Fruit small, conical, waxen yellow, with bright crimson in the sun. Calyx small, closed. Stalk short. Flesh white, tinged with red under the skin on the side, crisp, juicy, swcet. September, October. (Hogg.)

\section{VAUgoveau.}

\section{Cadeau du General.}

Origin unknown. Tree vigorous.

Fruit large, roundish conical, flattened at base, dull yellow, shaded and splashed with red, spotted with gray. Stalk short. Cavity deep. Calyx half closed. Flesh white, tender, juicy, subacid. December to March. (An. Pom.)

\section{Veruillox Royée.}

A French Apple.

Fruit medium, roundish oblate, inclining to conic, yellow, mostly rovered, shaded, splashed, and strijed with red, few gray dots. Stalk short. Cavity russeted. Calyx large, open. Flesh yellow, crisp, juicy, brisk subacid. Very good. Core small. December, March.

\section{Versilllaise Reinette.}

Reinette Versaillaise.

Of French origin. Tree vigorous, upright spreading.

Fruit medium, roundish, slightly conic, yellow, mostly corered with dull russet, a slight tinge of red in the sun. Stalk rather short. Calyx closed. Basin corrugated. Flesh white, fine, tender, moderately juicy, brisk subacid. Good to very good. Core small. Decamber, Febrnary.

Victuals and Drink.

\section{Big Sweet. Pompey.}

An old Apple, which originated in the neighborhood of Newark, N. J., about 1750. T'ree of vigorous, upright spreading habit, and a morlerate bearer.

Fruit large, oblong, rather irregular, and varies a good deal in size. Skin thin, but rough, dull yellow, marbled with r'usset, with a faint 
risset blush on the sumny side. Stalk moderately long and slender, deeply inserted in an irregular cavity. Calyx small, set in a rathrer shallow basin. Flesh rellowish, tender, breaking, rieh, sprightly, swert. Tery good. In perfection from October to January, but will keep till April.

\section{VIOLETTE.}

A sance or cooking Apple, described by Ronalds as of medium size, oblong conical, dark copper or purple color, covered with a fine bluisli bloom. Flesh white, tinged with red under the skin, juicy, brisk acid. December to March.

\section{Virginia Greenisg.}

Ross Greening. Green Mountain Pippin. Virginia Pippin?

Origin unknown, supposed Southern. Tree a vigorous grower and very productive.

Fruit large, oblate, greenish yellowish, thinly covered with large brown dots, and a slight blush. Stalk rather long, in a large cavity. Calyx open. Basin broad, corrugated. Flesh yellow, compact, a rather pleasant subacid. Esteemed at the South as a late keeper and a good market apple.

\section{Tirginia Quaker.}

Origin not known. Tree vigorous, upright.

Fruit quite small, glolular, slightly conic, greenish yellow. Dots scattered, minute, black. Calyx small, closed. Flesh yellowish white, firm, breaking, subacid. Good. Midsummer. (Warder.)

\section{Tirginia Spice.}

Origin unknown. Tree an erect, slender, moderate grower.

Fruit medium, oblate conie, whitish, thinly sprinklerl with brown dots. Stalk very short. Cavity russeted. Calyx small, elosed. Pasin small. Flesh yellowish, juicy, erisp, sprightly subacid. Good. Sepr tember, October.

\section{VOSS' WINTER.}

Southern.

Fruit medium to large, globular, unequal, smooth white, with leather aracking, and a heary bloom. Dots minute, brown. Calyx small, slosed. Basin abrupt, deep, wavy. Stalk long. Cavity deep. Fleslı whitish yellow, firm, juicy, subacid. Good. December. (Warder.)

\section{WABASII.}

Wabash Bellflower.

Origin, Pennsylrania.

Fruit large, roundish oblong, or somewhat conical, drep rellow, cov ered with clear orange red, brightest on the sumy side, and streaked with russet in the cavity arounil the stalk. Stalk short, slencler. Calyx 
rather large, open. Flesh white, firm, crisp, tender, subacid. Core large. November, December. (Hov. Mag.)

\section{WTADDELL HALL.}

A Southern Apple of unknown origin. Tree moderately vigorous. Young wood brownish.

Fruit small, roundish conical, pale yellow, shaded, striped, and sj)lashed with light red. Stalk long, slender. Calyx closed. Flesl: whitish, juicy, tender, pleasant subacid. Good. December to March.

\section{Wadhurst Pippix.}

Origin, Wadhurst, Sussex, England. A valuable cooking Apple.

Fruit large, roundish conical, ribbed at apex, yellow, splashed and marbled with red in sun, small gray dots. Stalk very short. Calyx closed, with long segments. Flesh yellowish, crisp, juicy, brisk acid. November, February.

\section{TIGENER.}

Origin, Penn Yan, Yates Co., N. Y. Tree thrifty, upright, hardy, and early bearer; requires thinning to produce good-flavored fruit; when grown in the shade is wanting in flavor. Young wood light reddish brown, slightly downy. Buds prominent.

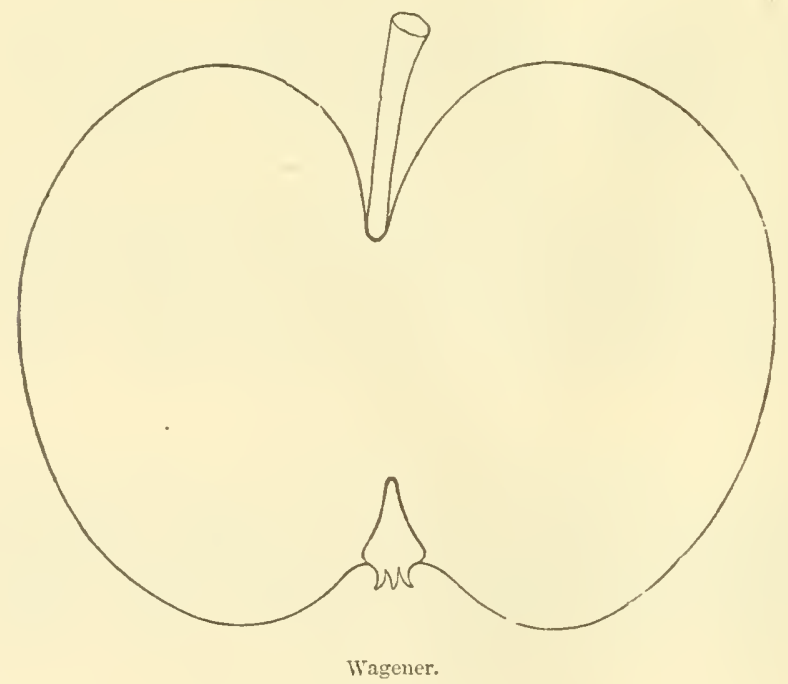

Fruit medium or above, roundish oblate, rellow, mostly shaded with crimson, obscurely striped, and sprinkled with light dots. Stalk nearly an inch long, rather slender, inserted in a large, broad, irregular carity: Calyx small and closed, set in a rather abrupt somewhat corrugated basin. Flesh yellowish, very tender, juicy, excellent, brisk, somewhat vinous Very good to best. A very delicate apple. Ripe, November to February 


\section{ThakeR's Yellow.}

\section{Walker's Winter.}

This Apple is a native of Pulaski Co., Georgia, and introduced by Gieorge $\mathrm{W}$ allker. Tree uplight, vigorous.

Fruit large, roundish conie, fine golden yellow, with a faint blush on the sumny side. Stalk of moderate length, in a deep, acute cavity. Basin small. Flesh yellowish white, juicy, hard, rather too acid for a dessert fruit. Good. November to April.

\section{WALPOLE.}

Origin, Walpole, Mass. Tree moderately vigorous. Ioung wood grayish.

Fruit medium, roundish, rellow, shaded and striped with bright red. Stalk short. Cavity large. Calyx elosed. Basin shallow. Flesh rellowish, tender, juicy, sprightly subacid. Very good. Last of August and first of september.

\section{Waltilair AbBey. \\ Waltham Abbey Seedling}

Origin, Essex, England.

Fruit large, roundish, slightly conie, yellow, with dull red in the sun, many minute russet dots. Stalk short. Cavity russeted. Calyx large, open. Flesh yellowish, tender, juicy, sweet. October, January. (Lindley.)

\section{WANSTALL.}

Green Street Apple.

Originated in Kent, England.

Fruit medium, roundish, slightly conical, ribbed at apex, golden yellow, striped and mottled with dark red in the sum, patches and veins of russet, and russet dots. Calyx half open. Basin furrowed. Flesh yellow, firm, crisp, juicy, sugary, rich. December to May. (Hogg.)

\section{WARD.} tive.

Origin, Westville, Champagne Co., Ohio. Tree healthy and produc-

Fruit large, oblong, flattened at ends, vellow, streaked and spotted with mottled red. Flesh yellowish white, subacid. (O. P. S.) Forsyth describes an apple unrler this name as of medium size, flat, green, with some red in sun, shaip acid, and keeps till June.

\section{WARFIELD。}

Originated in Muscatine, Ia. Tree hardy, tluifty, vigorons grower, an early and abundant bearer.

Fruit meditum, roundish oblate, light waxen yellow, with a blush in the sun, moderately sprinkled with gray dots. Stalk slender. Cavity slightly russeted. Calyx large, open. 'Segments short. Flesh whitish, moderately juicy, milil subacid. Good. Core small. Taluable for cooking. September, Oetolser. 


\section{WARAER'S KING.}

Tree a free and vigorous grower, and a good bearer; hardy, valua. ble for culinary use.

Fruit very large, roundish ovate, deep yellow, with russet dots and patches. Stalk short. Calyx small, closed. Flesh white, tender, crisp, brisk subacid. November to March. (Hogg.)

\section{WarRaschiKe DE Guben.}

A Russian variety, new.

Fruit medium to large, roundish oblate, slightly conical, greenish yellow, with considerable brownish red at apex end. Flesh white, fine, tender, mild, sweet, agreeable. Early Winter. (Ver.)

\section{WashiNgton Royal. \\ Palmer Greening.}

Originated in Leominster, Mass. Tree vigorous and productive.

Fruit above medium size; roundish oblate, rellowish green, with numerous small gray dots, and a clear red in the skin. Calyx closed, in a broad basin. Stalk short. Flesh whitish, crisp, juicy, subacid, slight. ly aromatic. Core small. Good to rery good. Keeping till July.

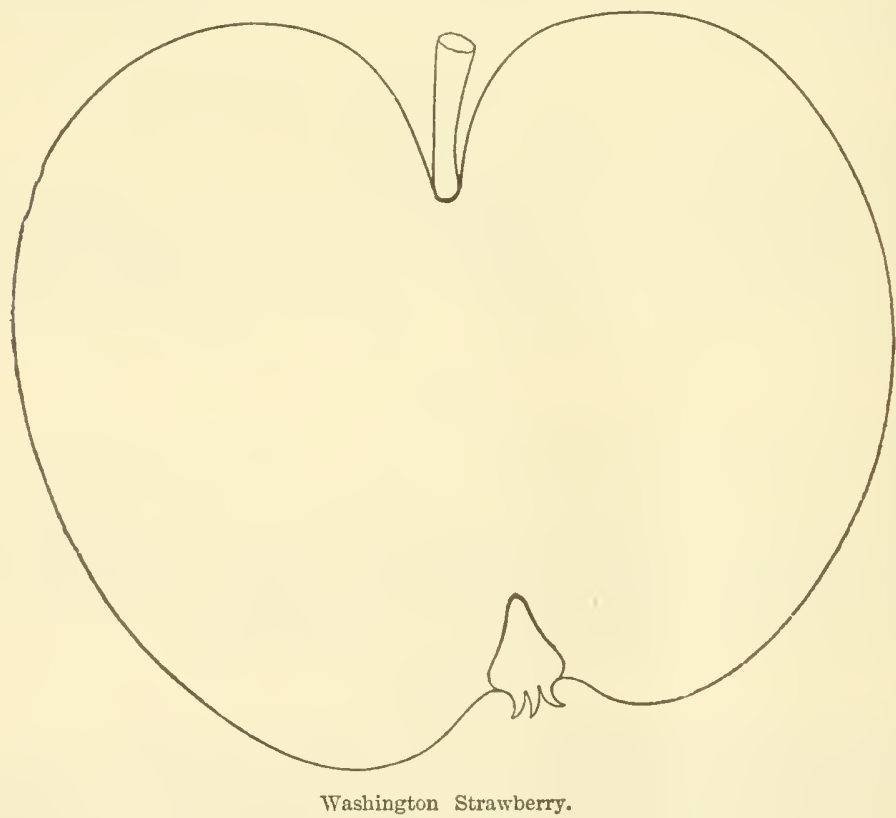

\section{WASHixgtoN StraWberRT.}

Originated on the farm of Job Whipple, Union Springs, Washing- 
ton Co., N. Y. Tree hardy, vigorous, mpright spreading, an early and abundant bearer. Toung wool reddish. Finds jurominent, rounderl.

Fruit large, rommlish eonical, thattened at base, yellow, shacled, splashed, and mottled with rich reel, or crimson. Stalk short. C'arity thinly russeted. Calyx elosed. Segments rather long, reflexed. Basin abrupt, deep, furrowerl. Flesh yellow, a little coasse, crisp, tender, juicy, brisk subacid. Very good. September, October.

\section{Wasmingtox SweEt.}

Origin, Berlin, Mass. Tree a thrifty grower and annual bearer. Ioung wood reddish brown, slightly downy.

Frnit below medium, romdish, slightly oblong conie, flattened at ends, yellow oceasionally with erimson check in the sum, few green dots. Stalk slender. Calyx closed. Flesh yellowish, crisp, juicy, pleasant sweet. Good. October, November.

\section{WATER.}

Originated in Durham Township, Bucks Co., Pa. Tree vigorous, erect, forming a round somewliat close head, blooms nearly two weeks later than other varieties, and produces abundantly every other year. Toung wood very dark, blackish brown.

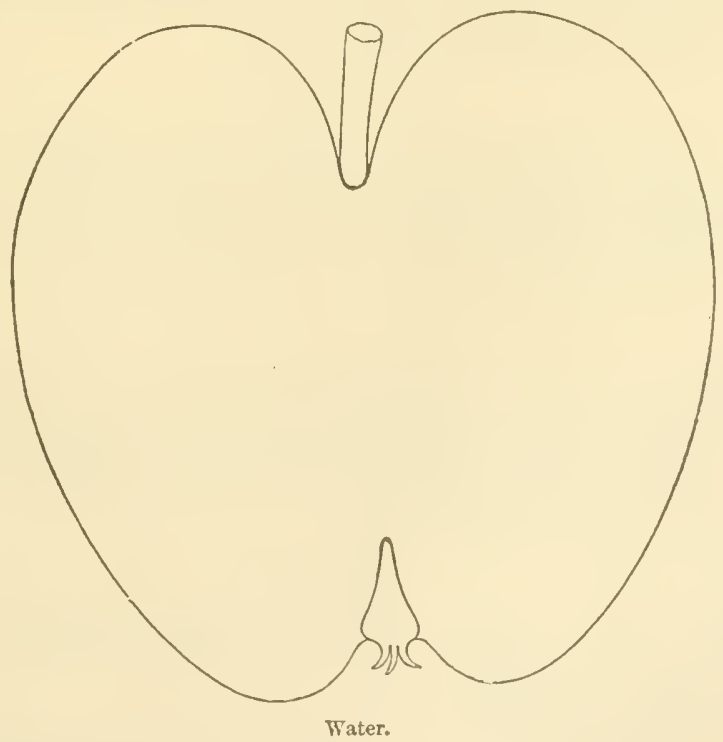

Fruit merlium, roundish couical, sometimes oblong conic truneated, whitish yellow, shaded with rich purplish crimson in the sun, few brown dots. Stalk short, slender. Calyx elosed. Basin small, abrupt, slightly corrugated. Flesh white, rery tender, juiey, pleasant subacid. Very good. Oelober, Norember. 


\section{WATERMAN's SWEET.}

Fruit medium, oblate inclining to conic, yellow, sharled, splashed, and mottled with crimson, few light gray clots. Stalk slender. Calrx small, closed. Flesh yellowish, crisp, tender, jui y, moderately sweet. Good. December to -.Iarch.

\section{Watson's Dumpling.}

A large English kitchen Apple, nearly round, yellowish green, faintly striped with dull red. Flesh juicy, pleasant, subacid. Good. October to January.

\section{Watson's FAYORITE.}

From Maine.

Fruit medium, roundish oblate, reddish blush on yellow. Flesh yellowish, juicy, pleasant subacid. V' ${ }^{\top}$ ry good. (Cont. Gent.)

\section{Waugir's Crab.}

Claimed to have originated in Culpepper. Co., Va. Tree thrifty, very productive, valued mainly for cider and long keeping.

Fruit small, roundish conic truncated, shaded with light red, splashed and striped with deep red in the sun. Stalk long, slender. Calyx in an abrupt basin. Flesh whitish, very firm, moderately juicy, sweet subacid. Geod. February to April.

\section{WAX.}

Fruit large, roundish oblate, yellowish green, slightly shaderl with red. Stalk short. Calyx closed. Flesh white, a little cuarse, sweet. Good. December, February.

\section{WAYEN.}

Origin, supposed to be Virginia. Tree thrifty. Young wood dark. Fruit medium, roundish, slightly oblate, pale yellow, oily, sprinkled with a few dots. Stalk slender, in a deep cavity. Calyx closed. Basin shallow. Flesh whitish yellow, crisp, tender, juicy, sprightly, mild subacid. Good. Norember, December.

\section{WEALTHY.}

A new variety originated by Peter M. Gideon, near St. Paul, Minn., from seed gathered in Maine about 1860. So far the tree has proved bardy, vigorous, and healthy.

Fruit medium, oblate or roundish oblate, whitish rellow groumd, shaded with deep rich crimson in the sum, obscure broken stripes and mottlings in the shade, sometimes entirely corered with crimson, many light dots. Stalk short to medium, slender. Cavity green, russet. Calyx partially closed. Basin deep, abrupt, uneren. Flesh white, finegrained, stained with red, tender, juicy, lively, rinous, subacid. Tery good. Core small. Season, December, February. 


\section{E.ALTIIY's FAVORITE.}

Winter Seedling.

Bradley's Winter.

Origin, Town of Plymouth, Mich.

Fruit medium, roundish oblate, pale waxen yellow, shaded in sun with crimson, and thinly sprinkled with brown and white dots. Stalk short. Cavity deep, acute. Calyx closed. Basin abrupt, uneven. Flesh whitish yellow, tender, juicy, mild subacid, pleasant. Tery good. December to February. An amatemr's fruit.

\section{WEBD'S WINTER.}

A Southern, probably Mississippi, variety. 'Tree slender, with drooping branches.

Fruit medium, roundish, yellow, shaded and rather faintly splashed and striped with red. Stalk long, slender. Calyx closed. Flesh whitish, tine-grained, moderately tender, juicy, pleasant, mild subacid. Good. Core small. December, February.

\section{Wellford's Y'Ellow.}

Origin, Essex Co., Virginia. A rapid grower and a 'reat bearer.

Fruit rather small, roundish flattened, pale yellow, with faint reed streaks on one side. Flesh yellow, fine-grained, juicy, subacid, aromatic. Keeps well until June.

\section{WELL'S SWEET. \\ Sweeting, Well's.}

Origin unknown. Tree upright spreading, productive.

Fruit of medium size, roundish, broadest in the middle, and lessening each way, pale dull green, with a dull red or brownish cheek. Stalk rather slender and short. Calyx short, set in quite a shallow basin. Flesh very white, and very tender, abounding with a rich, agreeable, sprightly juice. Gool to very good. November to Jamury.

\section{Westers SPY.}

Origin, farm of John Mansfield, Jefierson Co., O. Tree a slender spreading, moderate grower, but very productive.

Fruit rather large, romulish oblate, yellow, often much shaded with crimson. Stalk short and stout, inserted in a large cavity. Calyx open, set in an abrupt basin. Flesh rellowish, tender, juicy, brisk subacid. Excellent for cooking. Grood. October to Jume.

\section{Westeleld SeFk-jo-Furtiler.}

Connecticut Seek-no-Further. Seek-no-Further.

The Westfield Seek-no-Further is the Seek-no-Further of Connecticut, and is an old and highly estcemed varicty of that district. It has a jearmain flavor.

Fruit large, pretty regularly round conical, pale or dull red over a prale slouded green ground-the red sprinkler witl oloscure russeted yel 
low dots. Stalk very slender, three-fourths of an inch long; inserted in an even cavity. Calyx closed, or with a few reflexed segments, and set

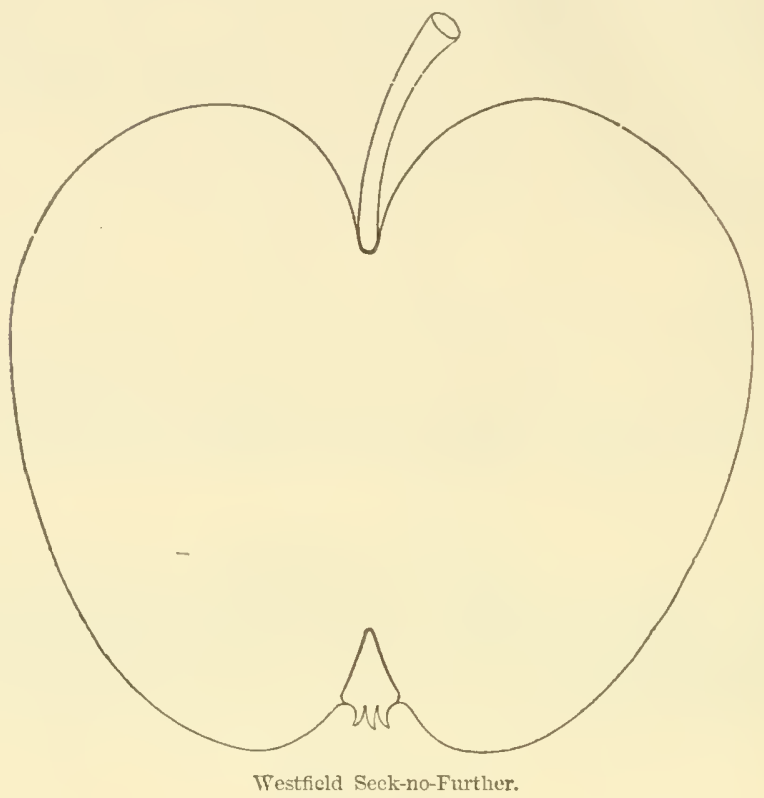

in an even basin of moderate depth. Flesh white, fine-grained, tender, with a rich pearmain flavor. Very good or best. A tirst-rate fruit. October to February.

\section{West Grissteld Pippix.}

East Grinstead. lence.

A Sussex, England, Apple, described by Ronalds as of great excel-

Fruit medium, roundish conical, greenish, with broken stripes and splashes of red brown dots. Stalk short. Calyx open. Flesh greenish white, soft, tender, brisk subacil. Norember, February.

\section{WESTON.}

Origin, farm of Major Weston, Lincoln, Mass. Tree rigorous, spreading.

Fruit medium, roundish conieal, light yellow, shaded, striped, and splashed with red. Flesh white, moderately juicy, mild pleasant flavor. Good. Corn large. October.

\section{WhEeler's Extreme.}

Origin, Gloucester, England.

Fruit small, oblate, greenish yellow, shaded and mottled with red, and traced with russet. Flesh yellowish white, temler, sweet. No vember, February. (Hogg.) 


\section{WheElen's Russet.}

An Apple originated in Gloncester, Fngland, and described by Lindley, as :

Fruit medium, roundish oblate, yellowish, gray russet brown in the sun, and darker russety specks. Flesh firm, greenish white, brisk, saccharine. November to Miarch,

\section{WHEELER's SWEET.}

Origin, Harding Co., O.

Frnit medium, roundish conic, yellow, with a red cheek in the sun, minute brown and light dots. Stalk short. Cavity deep, furrowed. Calyx closed. Basin abrupt, deep. Flesh yellowish, rather firm, moderately juicy, pleasant, sweet. Good. Core rather small. October, November.

WIIIG.

From Pennsylvania. Tree moderately vigorous, spreading.

Fruit below medium, oblate, inclining to conic, often oblique, vellow, sharled, splashed, and striped with light and dark red, sometimes very dark, large light dots, often with a brown centre. Stalk short, small. Cavity russeted. Calyx elosed. Flesh white, tender, juicy, mild subacicl, almost sweet. Cood. Core small. December.

\section{WHITte AsTraCHAN.}

$\begin{array}{ll}\text { Pyrus Astracanica. } & \text { Transparent de Moscovie. } \\ \text { Glacé de Zélande. } & \text { Weisser Astrakan. }\end{array}$

Astracanischer Sommerapfel.

A nearly white, semi-transparent Russian Apple.

Fruit of medinm size, rounclish. Skin very smooth, nearly white, with a few faint streaks of red on one side, and covered witl a white bloom. Flesh quite white, partially transparent, tender, and of delicate Havor, but rather dry. Poor. First of August.

\section{WHITE BeAUtY.}

Origin, Ashtabula Co., O. Tree a good grower, young shoots, reddish, with gray specks,

Fruit medium, roundish, smooth, dull greenish, with grayish specks. Flesh very white, tender, sprighlitly subacid. Crood. September, December. (Elliott.)

\section{Thite Calville,}

White Winter Calville. Calville Blanche d'Hiver.

Weisser Winter Calville.

The White Calville is a celebrated old French sance and cooking Apple; lut, like most others of its class, is not worthy of eultivation.

Fruit medium, roundish eonic, ribbed, yellow, faint bhsh. Flesh coars', tender, pleasint. Hardly good. November, February. 


\section{WHITE DOCTOR.}

Origin, Pennsylvania. A profitable market sort, and valuable for culinary uses. Tree vigorous and prodnctive.

Fruit large, romdish oblate, greenish yellow. Stalk short, set in an acute carity. Calyx closed. Basin shallow and furrowed. Flesh white, tender, brisk subacid. Good. September, October.

\section{WHITE INCONPARABLE.}

\section{Large White Incomparable Crab.}

An Apple described by Ronalds as above medium size, clear creamy yellow. Stalk slender. Flesh crisp', juicy, acid. October, December. Valuable for culinary uses.

\section{TVHTE JUNEATING.}

Joanneting.

Juniting.

Gennetting.

Primiting.

May of Virginia.
Owen's Golden Beauty.

Jennetting.

Juneting.

May Pipjin.

Caroline.

Early Mlay.
Juneating.

Ginetting.

Early Jennetting.

Yellow Mlay.

Carolina of some.

This is an old variety, mentioned by Erelyn in 1660, and described by Ray in 1688, and is a very tolerable little Apple, ripening among the very earliest, during the last of Jume and the first of July. It is very distinct from the Early Harrest, sometimes called by this name. Tree a moderate grower, and forms a roundish upright spreading head. Productive.

Fruit small, round, a little flattened. Calyx closed. Stalk rather long and slender. Pale green at first, light yellow, with sorietimes a faint bhush on the sumny side. Flesh crisp and of a pleasant flavor, but soon becomes dry. Good.

\section{TVHite NoxpareiL.}

Tree vigorous and productive.

Fruit medium, roundish, depressed at the ends. Skin greenish rellow, almost entirely corered with reddish gray. Flesh white, half firm, sugary, acid. May. (Soc. V. Mon.)

\section{Winte Paradise.}

\begin{tabular}{|c|c|}
\hline $\begin{array}{l}\text { Paradise Pippin. } \\
\text { May. }\end{array}$ & $\begin{array}{l}\text { Lady's Finger. } \\
\text { Egg. }\end{array}$ \\
\hline
\end{tabular}

A Scotch fruit of some beauty, but of little value except for culinary use. Tree a free grower, and productive.

Fruit medinm, oblong roundish conical, broadest at base, clear yel low, splashed and inottled with red, brown russety dots. Elesh yellowish, tender, crisp, pleasant acid. October.

\section{White Piptin. \\ Canada Pippin.}

'This Apple is much cultivated at the West, but of unknown origitu. 
It is of the Newtown Pippin elass, distinct from Canada Reinette. Trees thrifty, upright, a regular and good bearer. Toung shoots dark clear recldish brown, downy.

Fruit large, form variable, roundish oblate, slightly oblique, greenish white, waxen, sprinkled with green dots, and becoming pale yellow at maturity, sometimes having a dull blush and a few brown dots. Stalk short, inserted in a large cavity, surrounded by green russet. Calyx

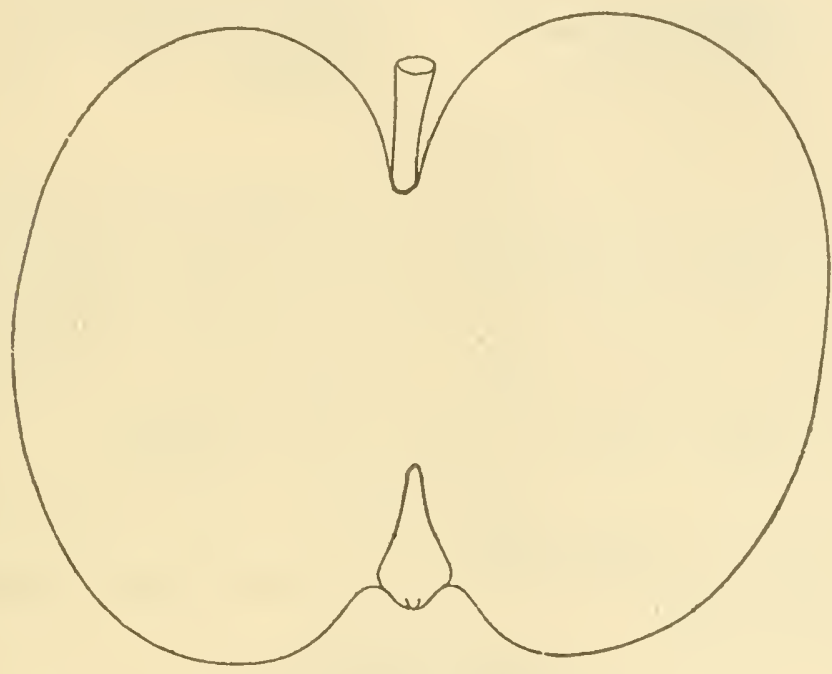

White Pippin.

small, nearly closed, set in an abrupt furrowed basin. Flesh white, tender, crisp, juicy, fine, rich subacid. Very good to best. Core small. Jamuary to Marcl.

\section{White Rambo.}

Origin, Huntington Co., Pa. Tree of medium growtl. Branches remarkably slender. Very productive.

Fruit medium, oblate, approaching conic, yellowish white. Stalk sliort, in a russeted cavity. Calyx closed. Basin shallow, surrounded by prominences. Flesh yellowish, fine, pleasant subacid. Good. Core smiall. November.

\section{VIIIte RoMarin.}

\section{Romarin Blanche.}

An Italian Apple.

Fruit medium, oblong conical, clear light yellow, faint red in the sun, large gray dots. Stalk slender. Calyx closed. Flesh yellowish white, fine, aromatic subacid. Core large, open. December to March. (An. Pom.) 


\section{White Russet.}

An Irish dessert Apple.

Fruit large, roundish oblate, yellowish russety green, intermixed with white, and having a little light red on the sunny side. Stalk short. Flesh firm, good. Apt to grow mealy. November. (Lindley.)

\section{White Spanish Rieinette.}

D'Espagne.

Fall Pippin, erroneously.

Large Fall Pippin.

Cobbett's Fall Pippin.
Reinette Blanche d'Espagne.

Reinette d'Espagne.

Camnesar.

Elgin Pippin?

A very celebrated old Spanish variety.

Fruit very large, roundish oblate, with broad ribs on its sides, terminating in an uneven crown, where it is nearly as broad as at the base. Calyx large, open, very deeply sunk in a broal-angled, oblique, irregular basin. Stalk half an inch long, set in a rather small, even cavity. Skin smooth, yellowish green on the shaded side, orange, tinged with brownish red next the sun, and sprinkled with grayish dots. Flesh yellowish white, crisp, tender, wich subacid. Very good. The tree has the same wood, foliage, and vigorous habit as our Fall Pippin, and the fruit keeps a month longer. 'This is quite distinct from Fall Pippin.

\section{White Spice.}

Origin, Cumberland Co., Pa.

Fruit large, roundish oblate. Flesh subacid, good. September. (A. Pom. S. Piep.)

\section{White SPITZENBerg.}

Origin, Northampton Co., Pa. Tree an annual productive bcarer.

Fruit medium, roundish oblong, yellow, interspersed with large gray dots, with a blusli on the exposed sides. Stalk short, in a deep, open cavity. Calyx small, closed, harrow basin. Flesh breaking, sufliciently juicr, subacid, agreeable aroma. Good. December to March.

\section{WHITE'S RED W'INTER.}

Southern.

Fruit large, oblong, shaded and striped with red. Flesh rich, juic5. Good keeper. (Cont. Gent.)

\section{White Suminer Pippis.}

An early dessert Apple, described in Ronalds as of medimm size, roundish, straw color, mottled and variegated with some russet and purple spots. Flesh tender and delicious, if eaten of the tree in August.

\section{White SWEET.}

Witherill's White Sweet.

Honer Sireet of some.

Mrigin, supposed New Jersey. Tree vigorous, productive.

Fruit medium, roundish oblate conic, whitish with a blush of crim. 
son in the sm. Stalk slender. Calyx closed. Flesh white, not rery tender, moderately jnicy, mild sweet. Good. September, October, Traluable for stock, cider, and cooking.

\section{WiIte VIRGIN. \\ Scotch Virgin.}

A culinary Apple, described by Hogg as:

Fruit medium, oblate, pale yellow to rich orange, and streaked with red in the sun, a few dark dots and veins of russet. Stalk short. Calyx large, closed. Flesh white, soft, tender, juicy, brisk acid. October to February.

\section{WHITE'S WINTER.}

Origin, Guilford Co., N. C. Tree thrifty, a great and early bearer.

Fruit medium, roundish oblate, yellowish white, somewhat rich, juicy, and very good. Keeps well. (Count. Gent.)

\section{Whitewater Sweet.}

From Southern Ohio. Tree moderately vigorous, spreading.

Fruit small, roundish oblate, yellowish green, with a few gray and many indistinct light dots. Calyx closed. Flesh whitish, compact, juicy, crisp, mild sweet. Good. December to IIarch.

\section{WHITE WINE.}

Fruit medium, roundish conical, yellowish, with rays, patches, and specks of russet. Stalk short and fieshy. Calyx open. Flesh white, firm, crisp, pleasantly acicl. October, December.

\section{WHITE WINTER.}

Origin, farm of Mr. Cocklin, Cumberland Co., Penn. Tree moderately vigorous, very productive.

Fruit small, nearly globular, light yellow, with a dull crimson cheek. Stalk medium, in an acute cavity. Calyx firmly closerl, a little sumk, in a very small basin. Flesh whitish, juicy, almost buttery, mild subacid. Good. January to May.

\section{White Winter Pearmain.}

\section{Campbellite.}

Origin unknown, by some thought to be an old Eastern variety, highly esteemerl at the West. 'Tree sprealing, hardy, and thrifty, it regular and good bearer. Young shoots very short-jointed, dull redidish brown, slightly grayish or downy at end.

Fruit medium or above, roundish oblong conic, somewhat oblirue. Stalk short, in a deep cavity. Calyx nearly closed. Segments long. Iiasin uneven. Skin pale yellow, with a slight blush or wam cheek, thickly 
sprinkled with minute brown dots. Flesh yellowish, tender, crisp, juicy; very pleasant subacid. Very good. January to April.

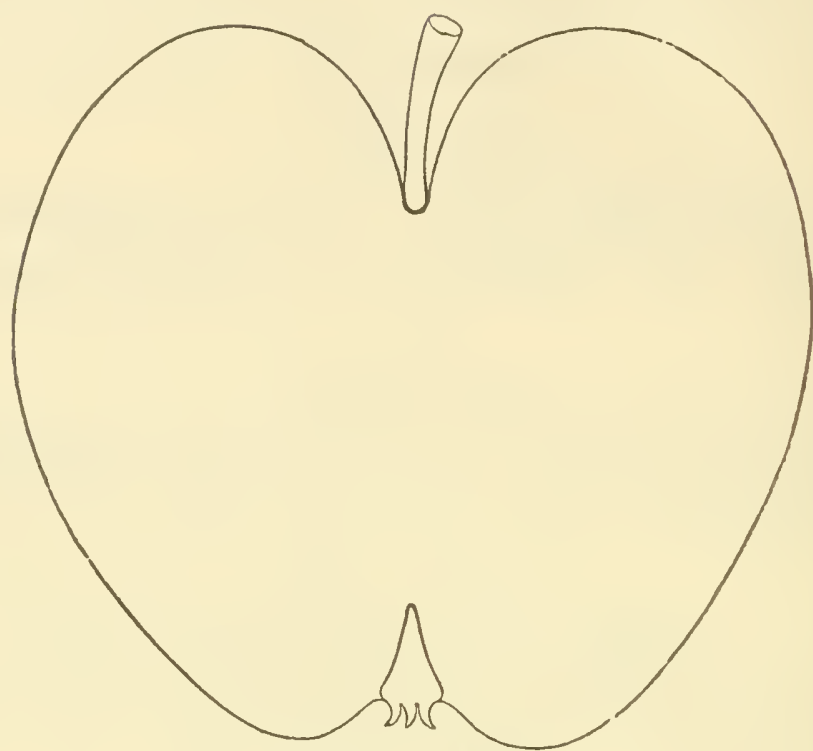

White Winter Pearmain.

\section{Wintmax.}

From South Abington, Mass.

Fruit a little above medium, oblong, greenish yellow, with russet blotches. Stalk slender. Flesh sweet. December. (N. E. Farm.)

\section{Whitmore's Pippin.}

Fruit medium, conical, ribbed, yellowish green, dark green specks, and slight tinge of red in the sun. Flesh whitish green, breaking, lurisk, slight aromatic. November, January. (Lindley.)

Whitney Russet.

Origin unknown. Supposed Canadian. Tree a vigorons grower, productive. Young shoots reddish brown, grayish.

Fruit small, oblate, slightly inclining to conic, yellow, mostly covered with thin light russet, sometimes a shade of crimson in the sun. Stalk long, often with bracts. Cavity large, deep. Calyx closed. Basin slightly corrugated. Flesh yellowish, tender, jnicy, rich, mild subacid. Very good. Core small. December to April.

\section{Wickham's Peardain.}

Wick Pearmain.

This variety, says Hogg, was grown at Wickham, near Winchester, Hampshire, England. J t is an excellent dessert Apple. 
Fruit small, roundish conical, flattened at base, yellow, tinged and shaded with red, patches and speeks of russet. Flesh greenish yellow, tender, crisp, juicy, high flavored. Oetober to December.

\section{Wier SiWeet.}

Origin unknown. Tree moderately vigorous, forming it round, regular head, productive.

Fruit medium, oblate, greenish yellow or yellow, often with a sharle of bronze in the sun, moderately sprinkled with brown dots. Stalk slender. Calyx closed. Flesh whitish, tender, juicy, mild, pleasant, rather rieh sweet. Good. Core medium or rather small. December' to Niarch.

\section{WILFONG.}

From North Carolina. Tree vigorous, spreading.

Eruit below medinm, oblate, dejressed, greenish yellow, shaded with dark purplish red, indistinct splashes and stripes, light dots. Stalk short, stout. Calyx closed. Flesh whitish, rather firm, moderately juicy, tender, pleasant subacid. Good. Core small. December to Marcl.

\section{Willifin Pexn.}

From Columbia, Pa. Tree vigorous, upright spreading.

Fruit medium, roundisl oblate, inclining to conic, yellow, shaded, splashed, striped, and mottled with bright red, many light dots. Stalk very short. Cavity considerably russeted. Calyx closed. Basin large, deep, slightly corrugated. Flesh yellowish, crisp, juicy, pleasant sul,acid, slightly aromatic. Good to very good. Core small. December to March.

\section{Williaj's Favorite.}

\section{William's Early. William's Red.}

A large and liandsome dessert Apple. It originated at Roxbury, near Boston, Mass., bears abundantly, and ripens fiom the last of July to the first of September: An excellent market variety.

Fruit of medium size, roundish oblong conic, and a little one-sicled. Stalk an inch long, slender, slightly sunk. Calyx closed, in a furowed basin. Skin very smooth, of a light red ground, but nearly coveres with a fine dark red. Flesh yellowish white, and of a very mild and agreeable flavor. Good. Requires a strong, rich soil.

\section{Willian's Pippix.}

Fruit below medinm, somewhat conical, pale yellow, mottled with pale red in the sun. Flesh pale yellow, soft, pleasant subacid. Good to eat from the tree, and for baking and roasting. October, December. (lindley.)

\section{WILLIAM'S W'HTE.}

Origin, supposed Cumberlam Co., Pa.

Fruit medium or helow, oblate, slightly conie, whitish yellow, sprin- 
kled witl a few brown dots. Stalk short. Calyx small, closed. Flesh light yellow, tender, juicy, pleasant subacicl. Good. August, September.

\section{Willis's Russet.}

Origin, farm of Mr. Willis, Sudbury, Mass. Tree hardy, vigorous. and an abundant bearer.

Fruit small, oblate conic, russet on a yellow ground, and occasionally a sunny cheek. Stalk loug, slender, curved, set in a large cavity. Calyx closed. Basin shallow. Flesh tencker, juicy, with a rich pear-like flavor. Very good. December, January.

\section{WILLIS SWEET.}

Pear Lot. Pear-Tree Lot.

Origin on the farm of Edward Willis, Oyster Bay, Long Island. Tree a vigorous, spreading grower, productive. Young shoots lich, warm brown, slightly grayish.

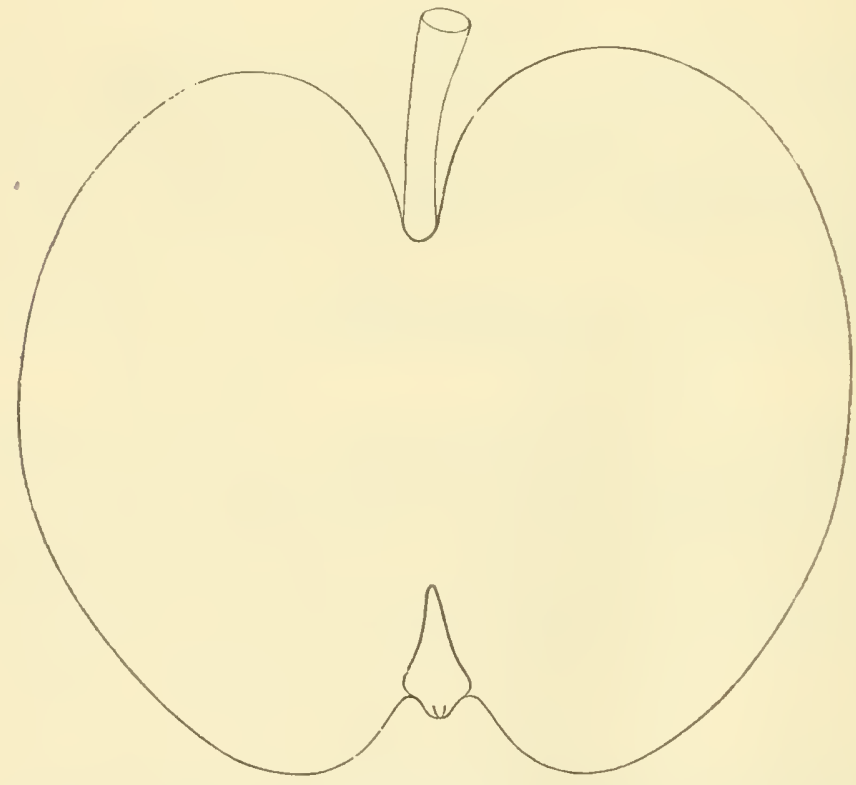

Willis Sweet.

Fruit rather large, roundish, whitish, somewhat shaded with a thin light red, and blotched with erimson, few brown dots. Stalk short and stout. Calyx small, elosecl. Basin abrupt, furrowed. Flesh whitish, crisp, juicy, tender, sweet, and rich. Tery good. C'ore large. August, september. Valuable for table, market, and culinary purposes. 


\section{WILLOW TWIS.}

\section{Willow. James River.}

Of unknown origin. The tree is a poor grower in the nursery, but makes a good sprealing, somewhat drooping, orchard tree, quite hardy, and very productive, and aithough of only good quality, its keeping qualities, productiveness, and hardihond make it a profitable market Apple for rich prairie and bottom lands in the West. Young shoote stender, reddish brown, downy. Buds inconspicuous.

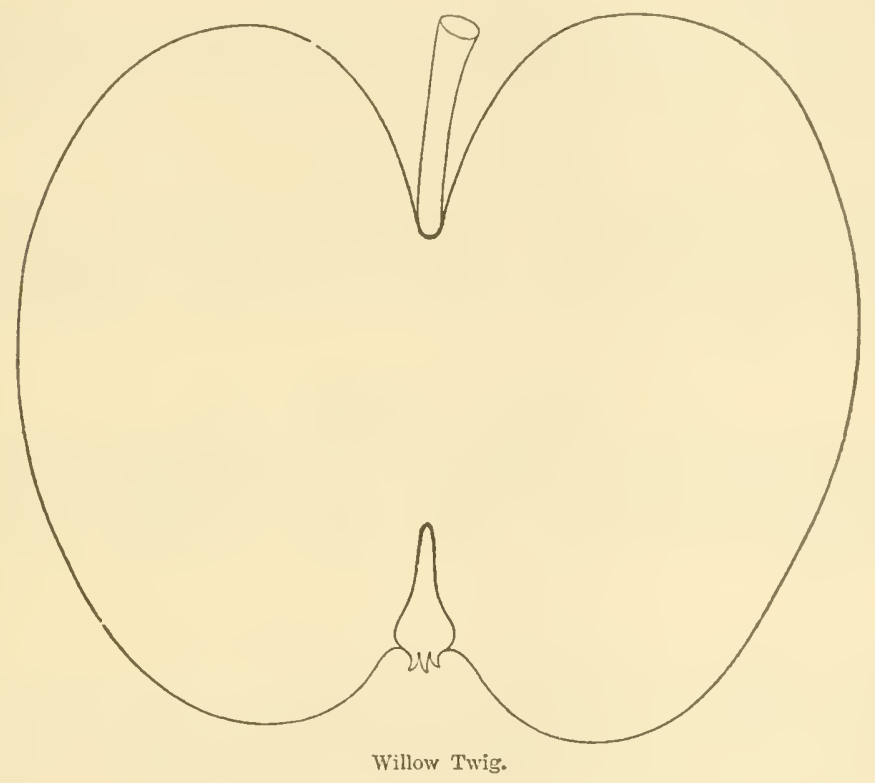

Fruit medium size, roundish, slightly conie, somewhat ob]ate, light yellow, shaded and marbled with dull red, and sprinkled with numerons russet dots. Stalk rather short and slender. Cavity narrow, sometimes partially closed, with a lip. Calyx partially elosed, in a somewhat corrngated abrupt hasin. Flesh yellowish green, not very tender, pleasant subacid. Good. Viluable for late keeping.

\section{WiLLsBoro.}

Supposed origin, Willsboro, Essex, Co., N. Y.

Fruit mediun, roundish eonic, yellow, sharlerl, mottled, and marbled mostly with dull red. Flesh yellowish white, juicy, erisp, tender, sprightly subacid. December, February. (J. W'. Bailey.)

\section{WiLsiot.}

\section{Wilmot's Seedling.}

A sance or cooking Apple described by Ronalds. Tree an upright, strong grower, productive. 
Fruit medium, conical, yellow, with marblings of gray, and splashes of red. Flesh white, tender, juicy, fragrant subacid. July, August.

\section{W'ILSON.}

Of Michigan.

Fruit large, round, slightly conic, regular. Surface smooth, golden yellow. Dots scattered, dark. Flesh yellow, breaking, fine-grained, juicy, subaeid, rich. January, February. (Warder.)

The same author describes another Apple under this name as from Western Virginia.

Fruit small, roundish oblate or oblate, smooth, nearly covered with very deep red, in which the stripes are almost obscured. Dots minute, white. Flesh white, tine-grained, crisp, tender, juicy, mild subacid. January.

\section{Wilson's Summer.}

Origin, Forsyth Co., N. C. Tree upright, productive.

Fruit medinm, roundish, slightly conic, greenish yellow, thickly striped with elear red. Flesh rich, juicy, fine-flarored. Angust, September. (Count. Gent.)

\section{Wilson's V'olunteer.}

Fruit large, globular trumcated or flattened, regular, yellow, mostly covered with mixed red, striped darker. Dots large, gray, and yellow. Flesh greenish yellow, tender, juicy subacid. December, February. (WTarder.)

\section{WIXCHELl SWEET.}

Origin, Hartford Co., Conn.

Fruit medium to large, oblate, greenish yellow, with a brownish shade in the sun, moderately sprinkled with gray dots. Stalk short. Calyx closed. Flesh whitish, rather firm, moderately juicy, sweet, and rich. Good. Core small. February to May. Taluable for cooking.

\section{WINDhaM Russet.}

An Aple from Massachusetts. Tree vigorous, upright spreading.

Fruit medium, roundish, inclining to conic, yellow, mostìy covered with dull rough russet, often mixed with red in the sun, gray rough or raised dots. Stalk medium. Cavity deep, large. Calyx partially open. Flesh yellowish, rather firm, moderately juicy, mild subacid. Gond. Core small. December to April.

\section{TYINE.}

\section{Hay's Winter. Winter Wine. Pennsylrania Red Streak.} English Red Streak, incorrectly.

The Wine Apple is a very handsome, and an admirable winter fruit, a most abundant bearer, and a hardy tree. It is a native of Del. aware. The tree has small leares, grows thriftily, and makes a fine spreading head. Young shoots smooth grity ish redilish brown. 
Eruit rather above medimm size-in rich soils large; form regular, nearly round, a little thattened at the ends. Skin smooth, of at lively deep red over a yellow gromul, or more frequently with a few indis. tinet stripes of yellow. Stalk short, iuserted in a rourd, smooth cavity, with a little russet around it. Flesh yellowish white, juicy, and erisp, with a rather vinous, rich, and pleasant flavor. Good to very good. Core small. Oetober to March.

\section{TINESAP.}

\section{Wine Sop? Potpie Apple.}

'This is not only a good Aplule for the table, but it is also one of the very finest cicler fruits, and its fruitfulness renders it a great fitvorite with oreharelists. 'The tree grows rather irregularly, and does not for'm a handsome liead, but it bears ealy, and the apples have the good quality of hanging late mpon the trees without injury, while the tree thrives well on sandy, light soils. The tree is very hardy, and one of the most protitable orehard varieties wherever grown. Young wood reddish brown, with smooth red buds.

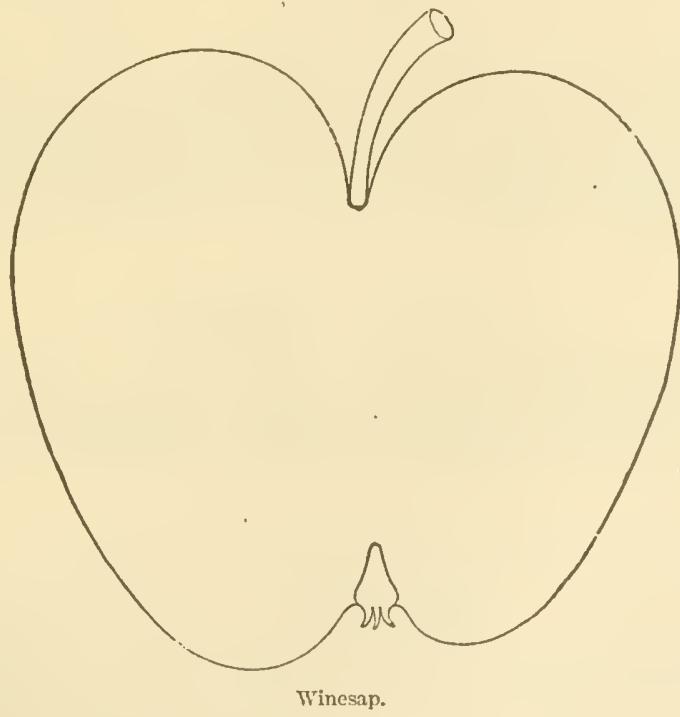

Fruit of medium size, rather roundish oblong. Skin smonth, of a fine dark red, with a few streaks, and a little yellow ground, appearing on the sliady side. Stalk nearly an incli long, slender, set in an irregular earity. Calyx small, placed in a regular basin, with fine plaits. Flesh yellow, firm, crisp, with a rich, high flavor. Very good. November to May.

\section{WING SWEET.}

An old variety, of ruknown origin, profital,le for stock fecling and cooking. Tree a moderate grower, spreading, and productive. 
Frnit mediun or below, romdish oblate conical, yellow, mostly shaded, splashed, and striped with dark red. Stalk long, slender Calyx closed. Basin slightly cormgated. Flesh yellowish, tender, moderately jnicy, sweet, lich, and pleasant. Good to very good. September to December.

\section{Wixx's Russet.}

Origin, Sweden, Me. Tree of slow growth, hardy and productive.

Fruit large. Cavity deep. Basin broad and shallow. Color dark russet, with obscure stripes of red, covered with whitish spots. Flesh fine-grained, subacid. Good. Keeps till May.

\section{WinsLow.}

From Virginia.

Fruit large, globular, flattened at base, dark and light red streaked, light brown speeks and dark flakes. Stalk short, slender. Calyx open. Flesh yellowish white, tender, juicy, subacid. Fall and early winter. (Elliott.)

\section{Winter Cónlis.}

An English culinary Apple. Tree vigorous, upright spreading.

Fruit medium, roundish conic, whitish yellow, partially splashed, striped, and marbled with light red, few gray dots. Calyx closed. Basin slightly furrowed. Flesh white, rather firm, moderately juicy, subacid. Good. Oetober to Mareh.

\section{Winter Colman.}

\section{Norfolk Colman. Norfolk Storing.}

A culinary Apple, described by Lindley as:

Fruit rather large, roundish oblate, paie yellow, deep red in the sun. Flesh firm, crisp, sharp subacid. November to Mareh.

\section{Winter Gray Reinette.}

Reinette Grise d'Hiver. Prager.

\author{
Reinette Grise Extra. \\ Reinette Grise. \\ Reinette Grise Française. \\ Belle Fille. \\ Grauwe Franse Rennett.
}

Among the Reinettes there is a world of confusion, and we feel no confidence in colrectuess until such time as they my be gathered and grown all in the same grounds. The present description of this variety is taken from Hogg. Tree healthy, vigorous, prodnctive.

Fruit medium, romdish, flattened on the sides, broadest at base, dull yellowish green in the shade, with a patch of thin dull brownish red in the sum, which side is so covered with brown russet that little color is visible. Stalk very short. Calyx closed. Flesh yellow, firm, crisp, rich, juicy, sugary. November to May.

We have received and fruited a Winter Gray Reinette from Rivers, which is small, oblate, depressed, dull yellowish gray russet, indistinct raised dots. Stalk long, slender. Calyx closed. Flesl whitish, firm, moderately juicy, rich, brisk subacid, Good. December to May. 
The Album of Pomology also describes a Winter Gray Reinette as large, roundish, dull pale yellow, overhaid with dull gleenish russet.

\section{Wister Harvet.}

Winter Pippin. Autumn Pippin.

An old Eastern variety. Tree vigorous, mpright, spuending, produc. tive. Young shoots dark grayish redclish brown.

Fruit medium, roundish conic, slightly ribhed, greenish yellow, rarely with a shade of dull red in the sum. Stalk rather short. Calyx partially closed. Flesh white, tender, juicy, pleasant, mild subacid. Good. Core rather small. Jamuary to March.

\section{Winter Hog Island Sweet.}

Crigin, Long Island. Tree moderately vigorous, productive.

Fruit mediun or below, ollate inclining to conie, slightly ribbed, pale yeliow, striped, splashed, and shaded with light and dark red, few light and brown dots. Stalk rather short. Calyx closed. Flesh yellowish, tender, moderately juicy, rather rich sweet. Good. Core sniall November to February.

\section{Winter IAding.}

A sance Apple, from Sussex, England.

Fruit medium, roundish conical, green, with patches and dots of thin russet. Flesh greenish white, juicy, tender, sweet subacid. Oeto. ber, December. (Hogg.)

\section{Wixter Mamen's Buusii.}

From Bucks Co., Pennsylvania.

Fruit medium, oblong conic, yellow, covered witl large, distinct, carnine dots. Stalk short. Calyx elosed. Flesh white, crisp, tender, subacid. Vrery good. Core large. (Gar. MLon.)

\section{WHATER MAJETTIN.}

A Norfolk, England, Apple, described by Lindley as valuable for culinary uses.

Fruit medium, roundish ovate, ribbed at apex, vellowish green, with a dull brownish red in sun exposure. Flesh greenish white, tirm, brisk, sharp subacid. Tecember, February.

\section{Winter PeAryain.}

$\begin{array}{ll}\text { Old Pearmain. } & \text { Parmain d'Hirel. } \\ \text { Pearmain. } & \text { Great Pearmain. } \\ \text { Pepin Parmain d'Hiver. } & \text { Pepin Parmain d'Angleterre. }\end{array}$

Peremenes.

This is one of the oldest $A_{\text {plples }}$ on record. The tree a free and liealthy grower, and produetive.

Fruit medium, conieal, greenish, with lively deep red in the sun, russety lots. Flesh yellowish, firm, crisp', juicy, slightly aromatic. Nuverimber to March. 
There is grown in Illinois, and other. Western States, an Apple under the varions names of Wintre Pearmaln and Red Pearadix, entirely distiuct fiom above. The tree is vigorons, spreading, with slender branches. roung shoots moderately slender, grayish reddish brown, with downy buds.

Frnit modium, oblate, a little inclining to conic, yellowish, sbaded, splashed, and striped with light and dark red. Staik short. Calyx closed. Flesh yellowish, rather firm, crisp, juicy, rich subacid. Good. Core small. November, February.

There is another IVinter Peanuan, grown in Pennsylvania, the fruit of which is below medium, oblate or roundish oblate, yellow, shaded and obscurely splashed with brownish red, few light dots. Stalk short. Calyx open. Flesh yellow, compact, moderately juicy, mild subacid. Good. Core small. 'Janniry to May.

\section{Winter Pipin of T'eriont.}

Origin unknown, much cultivated in Vermont; a fair grower and productive.

Frnit large to very large, nearly globular, inclining to conic, obscurely ribbed, greenish yellow, sprinkled with star-like crimson dots, cheek sladed with dull crimson. Stalk short, inserted in a decp compressed carity. Calyx small, nearly closed. Segments long, in a rather deep, uncven basin. Flesh white, tender, and agreeable. Good. Novermber to March.

We have received a Winter Pippin from Michigan, where it was introduced from Westem New York, but have diot sufficiently tested it to decide as to its identity with the above.

\section{Winter Reinette.}

Weisse Antillische.

Winter Reinette.

A beantiful and excellent Geman dessert Apple.

Fruit large, oblong conical, lemon yellow, with blush red in the sun. Flesh yellowish, firm, juicy, sugary, vinous. December to March. (Diel.)

\section{Winter STraWBERry.}

This variety is described by Ronalds as above medium size, roundish, yellow, splashed, shaded, and striped partially orer with rich red. Flesh whitish, tender, juicy, subacid. December, January.

\section{Winter Sweet Paradise.}

\section{Paradise Winter Sweet. Grandmother.}

From Pennsylvania. The Winter Swect Paradise is a productive and excellent orchard firuit, always fair, and of fine appearance. Tree hardy, upright, vigorous, not an early bearer. Toung shoots reddish gray.

Fruit rather large, regularly formed, roundish oblate. Color dull green when picked, with a brownish blush, becoming a little piler at 
maturity. Stalk short, set in a ronnd cavity, often russeted. C'alyx closed, small. Basin rather decp, slightly corrugatod. Flesh white,

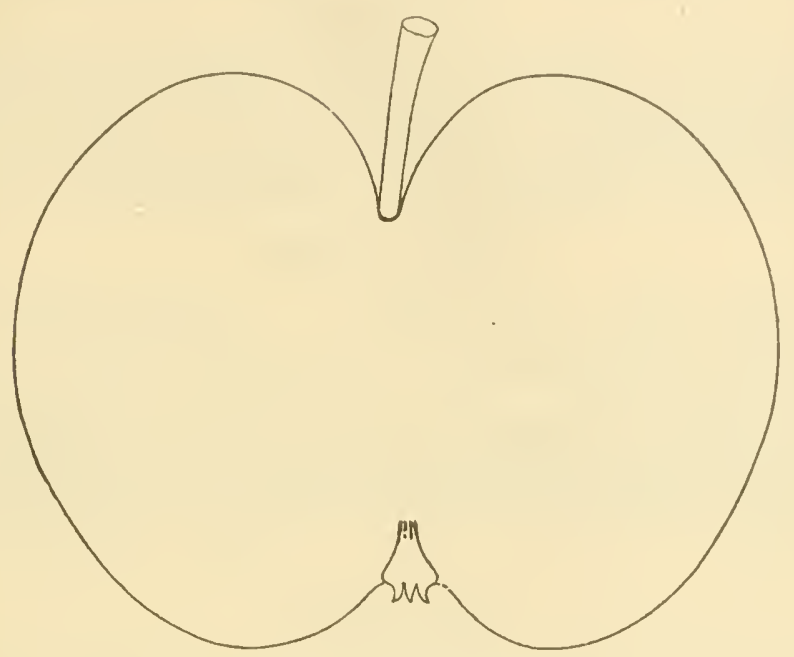

Winter sweet Paradise.

fine-grained, juicy, swcet, sprightly, and very good. Core rather small November to March.

\section{WistmRop Greening.}

Lincoln Pippin.

Howe Apple.

Origin, Winthrop, Ne. Tree vigorous, upright spreading.

Fruit large, oblate, slightly ribbed, greenish yellow, with nettings and patches of russet, thickly sprinkled with light and gray dots. Stalk rather short. Calyx large, open. Elesh white, tencler, juicy, rather rich subacid. Good. Core small. September.

\section{Wintilrop Pearmain.}

Origin, Winthrop, Mc. Size large, roundish orate. Skin yellow, striped with red, and decp red in the sun. Strm in a large cavity. basin shallow. Flesh white, juicy. Flavor spicy and pleasant. September to January. (Me. P. S. R.)

\section{WISNER.}

Originaterl on the furm of - Wisner, Mildletown, Orange Co., N. Y. Fruit small, conical, greenish, shaded and striped with dull red. Flesh tender, juicy, pleasant subacid. Good. Decumber, March.

\section{WOODTAND.}

A Sonthern variety.

Fruit full medium, oblate, yellowish green, sometimes striped red. 
Dots few, minute. Calyx small, closed. Stalk medium to long. Flesh yellow, rather tough, but juicy, subacid. Good. Midwinter. (Am. Hort. An.)

\section{WOODRING.}

Originated in Fairfield Co., O. Tree a moderate grower, slender branches, early bearer.

Fruit below medium, roundish, yellow, mostly covered with red Flesh white, juicy, subacid. Good. January to Míarch.

\section{Wood's Greening.}

Coate's Greening.

Onstine.

Cooke's Greening.

A native of New Jersey. Tree a moderate grower, hardy, somewhat spreading, productive.

Fruit medium, roundish oblate, yellowish green, with rough spots or patches. Stalk short. Calyx large. Flesh greenish white, fine-grained, tender, juicy, slightly subacid. Very good. Core small. January, February.

\section{WOOD's SweEt. \\ Hyde's Sweet.}

Origin, Sudbury, Vt., and there considered the best fall sweet Apple in cultivation. Growth nearly equal to Baldwin, and productive.

Fruit large, irregularly oblate. Color whitish vellow, waxen or oily, shaded and striped with fine rich red. Stalk rather short, inserted in a broad, deep, furrowed cavity. Calyx small, closed, set in a rather deep open basin. Flesh white, tender, juicy, rich saccharine. Good to very good. September, November.

\section{THOOLFOLIS.}

Supposed Kentucky origin.

Fruit full medium, truncated, regular, yellow green, scattered gray dots. Flesh white, tender, breaking, juicy, subacid. Good. Tiable, kitchen. December to March. (Warder.)

\section{Worisley Pippin.}

\section{Knight's Codling.}

An English fruit, middle-sized, roundish, tapering a little towards the eye, pale green or straw color, darker next the sun. Flesh white crisp, firm, with a sharp subacid juice. Good. September.

\section{WIIGHT.}

Origin, Hulbardton, T't. Tree vigorous and pioductive. Toung wood olive brown.

Fruit merlium, roundish oblate, lemon yellow. Stalk short, inserted in a deep cavity. Calyx closed. Basin rather large and corrugated. 
Flesh white, rery tender, juicy, vinous, ahmost sweet, aromatic. Good to very good. Middle of September to middle of October.

\section{WRIGHT'S JANET.}

Supposed to have originated near St. Louis, Mo.

Fruit medium to large, round, sometimes that, regular, waxen yellow, mixed, striped, splashed carmine. Dots minute, prominent, scattering. Flesh deep yellow, breaking, fine-grained, juicy, sulacid. Good to very good. January to June. (IVarder.)

\section{WYKex P'IPPIN.}
Warwickshire Pippin.
Girkin Pippin.
Arley.

An old rariety, originated near Coventry, England. Tree upright, hardy, and productive.

Fruit below medium, oblate conical, greenish yellow, with ilull orange blush in sun, mottled and marbled and dotted with light russety patches and dots. Flesh yellowish, tender, juicy, sweet subacid.- December, February. (Rou.)

\section{YАCHT.} bearer.

Origin, Montgonery Co., Pa. Tree of moderate growth, a regular

Fruit medium, oblate, yellowish, shaded, splashed, and striped with two shades of red, large light dots. Stalk medium. Calyx partially closed. Flesh white, tender, pleasant, mild subacid. (rood. Core small. Norember, January.

\section{YADKIN.}

Sonthern.

Fruit large, round, regular, red striped. Flesh white, dry, subacid. Only good. August. (Warder.)

\section{YAHOOLA.} bearer.

Origin, Lumpkin Co., Ga. Tree with slender, wiry limbs, a good

Fruit merlium, oblate, yellow green, specked and streaked with russet. Stalk long, slender. Calyx and basin medium. Flesh juicy. Good. September to January. (White.)

\section{YANKEE SPY.}

\section{Seedsville Sweet? Dutchess County Sweet. Ox Sweet.}

Of unknown origin. Tree vigorous, upright spreading, productive.

Fruit medium, oblate, sometimes a little conic, deep ycllow, sometimes a tinge of red in the sun, large brown dots. Stalk medium. Calyx closed. I Basin furrowed. Flesh yellowish, moderately juicy, rich, sweet. Good. C'ore small. October, Lovember. I valuable culinary sort. 


\section{YATES.}

Originated in Fayette Co., Ga. Tree very upright grower, great bearer and good keeper.

Fruit suall, oblate or oblate conic, whitish yellow, overspread, sharled, splashed, and striped with shades of red, many light dots. Stalk slender. Cavity large, slightly russeted. Calyx small, closed. Flesh white, sometimes stained next the skin, tender, juicy, pleasant subacid. Good. March to May.

\section{Yellow Bellflower.}

Bellefleur Yellow.

Belle Fleur.

Bishop's Pippin of Nova Scotia. Lady Washington.

Reinette Musque.

Warren Pippin.

The Yellow Belle Fleur is a large, handsome, and excellent wintes Apple, everywhere highly esteemed in the United States. It is most abuudantly seen in the markets of Philadelphia, as it thrives well in the sandy soils of New Jersey. (Joxe first deseribed tlis fruit; the original tree of which grew in Burlington, N. J. Tree a moderately rigorous grower, forming a spreading, roundish, rather drooping head. Young wood yellowish brown. A regular and excellent bearer.

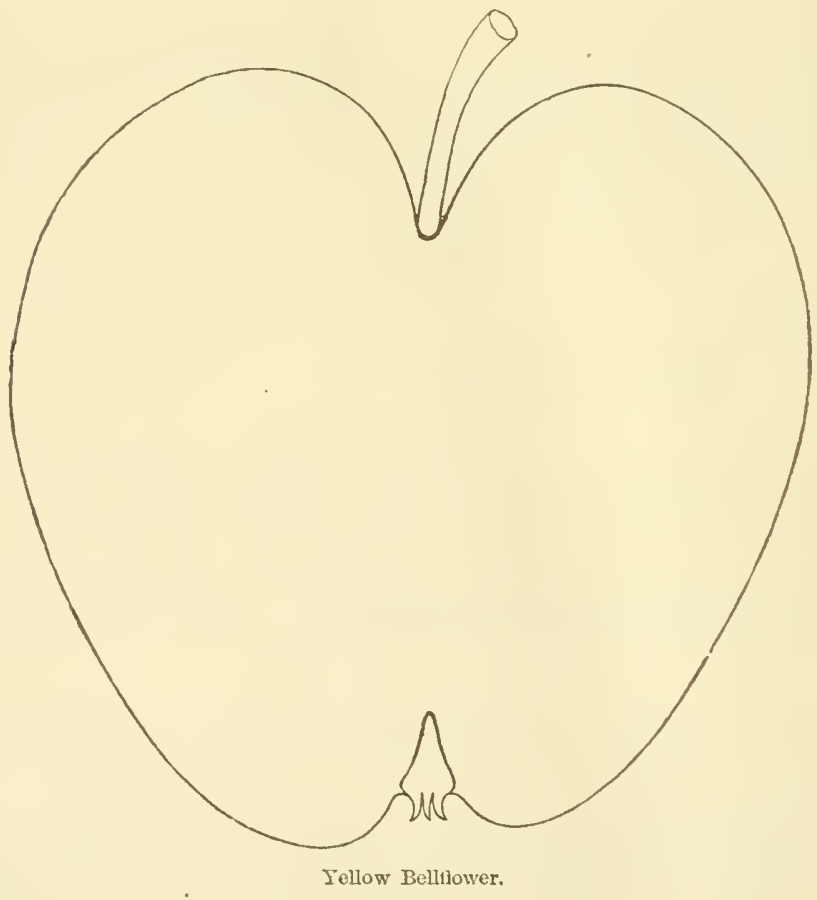

Fruit very large, oblong, a little irregular, tapering to the eye. Skin smooth, jale lemon yellow, often with a blush next the sum. Stalk long 
and slender, in a deep eavity. Calyx closed and set in a rather narrow plaitrel basin. Seeds in a large hollow capsule or core. Flesh tender, juicy, crisp, with a sprightly subaeid flavor; before fully ripe it is considerably acid. V'ery good. December, February.

\section{Yellow Foster.}

Origin unknown. Received from Ohio. 'Tree very vigorous, spreading.

Fruit below medium, oblate, yellow, thinly sprinkled with brown and green dots. Stalk short. Calyx closed. Flesh yellowish, rather coarse, moderately juicy, mild subacid. Good. October, November.

\section{Yellow Ingestrie.}

Fruit small, roundish oblate, clear bright gold color, without red. Flesh tender and delicate, with a plentiful juice when freshly gathered from the tree. Gook. Oetober.

\section{YeLLOW JUNe.}

White June.

Of unknown Southern origin. Tree vigorous, upright grower, and ahundant bearer. Young wood light reddish brown, slightly downy, very small buts.

Fruit below medium, roundish oblate, pale yellow, thickly sprinkled with green and brown dots. Stalk long, slender. Cavity slightly russeted. Flesh white, tender, juicy, brisk, sprightly subacid. Good. Core small. June, July, South. August at North.

\section{YeLLOW MeAdow.}

A Sonthern fruit.

F'uit large, oblate, greenish yellow. Stalk rather slender, in a deep, irregular cavity. Calyx large and open, in a shallow basin. Flesh yellow, compret, vinous. Goorl. November.

\section{Yellow Newtowy Pippin.}

Albemarle Pippin.

The Yellow Newtown T'ippin is haudsomer in appearance, and has a higher perfume than the Green or Newtown Pippin, and its flesh is rather firmer, and equally high flavored; while the Green is more juicy, crisp, and tencler. The Yellow Newtown Pippin is rather Hatter, medsuring only about two incles deep, and it is always quite obliquelrojecting more on one side of the stalk than the other. When fully ripe it is yellow, sometimes with a rather lively red cheek, and a smooth skin, few or none of the spots on the Green variety, but with the same russet marks at the stalk. It is also more highly fragrant before and after it is eut than the Green. 'The flesh is firm, crisp, juicy, and with a very rich and high flavor. Both the Newtown Pippins grow alike, and they are botl excellent bearers. 'This variety is rather hardier and suceeeds best. February to May.

YEITOW SWEET.

A native Apple of unknown origin. 
Fruit small, roumdish, light yellow, with a few gray dots. Flesh white, rather tender, pleasant, sweet. Good. October, November.

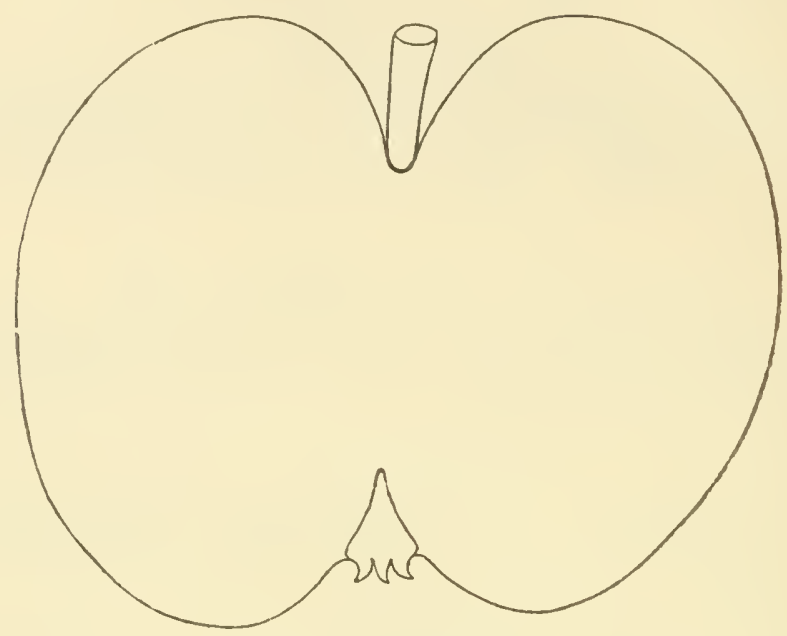

Yellow Newtown Pippin.

Yopp's FAYORITE.

From Georgia. Tree moderately vigorous, upright spreading.

Fruit large, roundish, slightly conic, greenish yellow, with a blush in the sun, sprinkled sparingly with russet dots, and a little russet about the stem. Calyx open, in a deep basin. Stalk short. Cavity deep. Flesh white, fine-grained, tender, juicy, subacid. Good. Core small. November.

\section{YORK.}

From Massachusetts. Valuable for culinary purposes.

Fruit medium, roundish conic, pale yellow, with a slight shade of red in the sun. Stalk short. Calyx closed. Flesh whitish, tender, juicy, sprightly subacid. Good to very good. Core small. October, November.

\section{Tork IMPERIAL.}

\section{Johnson's Fine Winter.}

Origin thought to be York Co., Pa. Tree moderately vigorous, productive. Young wood rich brown, downy.

Fruit medium, oblate oblique, whitish, shaded with crimson in the sun, thinly sprinkled with light and gray dots. Stalk short. Calyx closed or partially open. Basin large, deep. Flesh yellowish, firm, crisp, juicy, pleasant, mild subacid. Good to very good. Core compact, small. November, February. 


\section{Torkshire Greening.}

Coate's.

Yorkshire Goose Sauce.

An English culinary Apple. Tree very vigorous and productive.

Fruit large, oblate, slightly ribbed, greenish, with shades and stripes of dull red, specks and traces of russet. Flesh greenish white, firm, crisp, brisk subacid. Good. October, November.

\section{YosT.}

A native of Berks Co., Pa. Tree large and spreading.

Fruit oblate, very much flattened, yellow, striped and shaded with crimson, thinly dotted with brown. Stalk sliort. Cavity slightly russeted. Calyx partially elosed. Flesh yellowish, rather coarse, tender, juicy, pleasant subacid. Good. December, January.

\section{ZANE.}

Zane Greening.

Origin, Virginia.

Fruit large, roundish, dull greenish yellow. Flesh greenish white, tender, soft. Poor. February to June. (Elliott.)

\section{ZIEBER.}

Origin, Reading, Pa.

Fruit below medium, roundish, yellow, with a striped red cheek. Flesh dry, pleasant, hardly good.

\section{Zodr Greening.}

Origin, Ohio.

Fruit large, roundish conic, greenish, faintly shaded with dull red in the sun. Flesh white, tender, moderately juicy, pleasant subacid. Good. Core small. November, December.

\section{SIBERIAN CRABS AND IMPROVED SIBERIAN APPLES.}

True varieties of Siberian Crab Apples (Pyms Laccatc) have, heretofore, been mainly valued for their handsome flowers and the beantiful appearance of the tree when loaded with fruit.

Within the past year or two, however, considerable attention has been given to their cultivation by fruit-growers in om. Western and Northwestern States, beeause of the superior hardihood of the trees. Large numbers of seedlings have been grown, some bearing full evidence of the paternity of the $P y / v$ s bacrata, others possessing more or less of the Pyrus malus, apparent more in the flesh and improved quality of the fruit, than in the habit of the trees. They are all valuable for cider, preserves, and cooking, and some of the improved varieties, more 
truly, perhaps, Siberian Apples than Crabs, are quite pleasant and rick. for the dessert. The great hardihood of the trees, and their produc. tireness, make them highly valuable for sections where the better varieties of the Pyrus malus do not succeed. In description of these varieties the terms "medium, large, or small," must be considered as applied in comparison with the Siberian Crab.

The common Siberian Crab is a beautiful little fruit, which is produced in rich clusters on the branches, and, at a distance, resembles large and handsome cherries. It is highly esteemed for preserving, and almost every large garden contains a tree of this variety. It forms a rigorous, neat tree, of rather small size, and its blossoms, which are white, are produced in beantiful profusion in spring, and a large crop of fruit regularly follows.

\section{AKIN'S WTITER.}

From Minmesota.

Fruit medium or small, roundish oblate, light, pale yellow, with a rich clear curnine red cheek in sun. Stalk long and slender, set in an open acute cavity, often russeted. Calyx closed. Basin deep, broad, and somewhat furrowed. Flesh yellowish white, juicy, crisp, somewhat too acid for a pleasant table apple, but not too much so for cooking. December.

\section{Astracax.}

\section{Evergreen Apple Crab.}

Fruit medium, oblate, compressed, green, specked with white dots. Flesh greenish white, juicy. Inferior.

\section{Astrichas.}

This is one of the very largest sized of the old varieties.

Fruit medium to large, roundish conical, bright rich rlear red, with a fine light bloom. Calyx with long segments, prominent. Flesh whitish, crisp, juicy, sharp, brisk acid, tender. September.

\section{Chase's Wixter Sweet.}

Fruit medium size, roundish oblate, rich warm rellow ground, mostly overspreal with dark rich red, minute dots. Stalk long, slender. Cavity broad, open, deep. Calyx half closed, with short, almost erect segments. Basin shallow, corrugated. Flesh yellowish, very firm, moderately juicy, mild, sweet. December.

\section{Cherri.}

Fruit small, roundish ovate, pointed, light yellow, spotted and shaded with red. Flesh crisp, juicy, pleasant, hangs long, almost even to drying on the tree. September, October.

\section{Chicaro.}

Origin near Mrarengo, Tll.

Fruit similar to Coral in general ap pearance--a little longer or more 
completely oblong. Flesh not as deep colored as Coral, but quite crisp', sprightly sulucid, and by many wonld be preferred to Coral, although it is not as rich. December to March.

\section{Coral.}

This valiety has the same origin as Chicago.

Fruit small, conical thattened at ands; rich warm yellow ground, with a vermilion cheek. Stalk long, slender, set in a narrow, aente car. ity, slightly russeted. Calyx closed, smrounded with corrugated ridges, but with little or no basin. Flesh yellowish, crisp, sprightly, juicy, rich, mild subacid, almost tender. An early winter sort, keçing until about February.

\section{Currats Crab.}

The fruits of this kind are of the size of emrants, and are borne like them in clusters; they are round, a little compressed towards the ends. Color red, slightly striped with eleepred. It is ormamental in its flowers as well as its fruits.

\section{Docble Flowerixg Chinese Crab.}

Double Flowering Apple.

This very beantiful crab-tree from China, which produces a small green fruit, of no ralur, is highly admired for its showy blossoms. These are large, tipped with deep led in the bud, but when open are of a pale rose color, semi-donble, large, and produced in fine chusters. It is an exceedingly ornamental, small tree, growing from ten to twenty feet in height.

\section{Double White Siberiay Crab.}

Fruit roundish, irregular, swollen on one side. Color red carmine on the sunny side, green on the sharded side, covered with a white bloom. Flowers large double white, very ornamental.

\section{Foxlex Crab.}

Raised by Thomas Andrew Knight, England, from seed of the Cherry Cral). Tree hardy. Fruit prodnced in chisters.

Fruit medinm, roundish oblate, golden yellow. Stalk long. Flesh yellow, crisp, juicy, subaricl.

\section{Fragrint.}

The flowers of this varicty are very fragrant. Fruit small, oblate, green, with whitish dots. Flesh inferior.

\section{Gexiral Grant.}

Size large for a crab, rouml, olblate, warm yellow ground, with broken stripes of dark, becoming, on the sul1-exposed sicle, entircly red, and very diuk, almost black red, with a few minute lieglit dots. Stalk slencis: C'arity olwn, moderately deep. Calyx eluscd. Basin broal, 
not deep, but conspicuonsly furrowed. Flesh white, moderately finegrained, not juicy, very mild subacid. Core large for size of fruit. late Autumn.

\section{GOLDEN.}

Fruit large, roundish oblate. Skin golden yellow. Stalk long, slender. Cavity medium. Calyx elosed. Segments long, slender, recurv. ed. Basin medium. Tlesh white, moderately juicy, brisk acid. September.

\section{Hampton's Siberian Crab.}

A beautiful variety, originated with Wm. C. Hampton, Hardin Co., O. Fruit large for a Siberian Crab, ovate conical, deep rich crimson, blotched and indistinctiy striped with clear orange and yellowish red. Blossoms large. This is one of the most beantiful of all the crabs, especially when in bloom.

\section{Hutchison's Winter Sweet.}

Fruit medium size, roundish oblate, light yellow ground, with a blush red cheek in the sun, and many minute dots. Stalk long, slender, in a deep open cavity. Calyx closed, with long pointed segments. Basin broad, deep, corrugated. Flesh yellowish white, dry, sweet. November.

\section{HYSLOP.}

This variety has been long and pretty extensively cultivated. The trees are hardy, the growth strong, rather spreading. Wood light colored, a little downy.

Fruit large, prodnced in clusters, roundish orate, dark rich red, covered with a thick blue bloom. Stalk long, slenrier. Calyx closed. Flesh yellowish, subacid, good for culinary uses and for cider.

\section{LADY Crab.}

This is a foreign variety, of great beauty, and the tree a vigorous, upright grower, much resembling the Larly Apple. T'ery productive. Ioung wood grayish reddish dark brown, with conspicuous white or gray dots.

Fruit sinall, roundish oblate, a little oblique, rich dark red, with traces of russet, and many apparently rough russet dots. Stalk medium length for a crab, quite slender. Cavity open, broad, deep russeted. Calyx almost closed, with connected lalf-recurred segments. Basin broal, shallow, distinctly corrugated next the calyx. Flesh yellowish, moderately juicy, mild subacid. Novenber, December.

\section{Larige Red Siberian Crab.}

This varlety is about twice the size of the common Siberian Crab, roundish ovate, with a large and prominent calyx, and a pale red and yellow skin. It forms a larger tree. with rather coarser foliage than the common variety, and is esteemed for the same purposes. Scptember and October. 


\section{Latige Yellow Siberian Crab.}

Fruit similar in size to the foregoing, roundish oval, flattened at baso and crown, light clear yellow often inclining to amber, with a warn check.

\section{Maiden's Buésh.}

Fruit small, flat, somewhat ribbed, pale clear yellow, with clear bright earmine red in sun. Calyx large, half elosed. Basin broad, slightly furrowed. Flesh yellowish white, rather diy, almost sweet. Late Autumn.

\section{MARENGo.}

The discoverer of this variety, as well as its identity with the Siberian Crabs, Pyrus baccute, as a tree, is attributed to James F. Lester, Marengo, Ill. It is said to be a seedling found in the rows of an old seedling nursery of apple-stocks. The original tree is thought to bo about eighteen years old. Young shoots vigorous, reddish brown, with the gray specks, bloom and scaly cuticle peculiar to the siberian.

The fruit is large for its class; in form roundish, flattened at blossom end, bright warm red on yellow ground, smooth, with a few scattered gray or light russet dots. Flesh yellowish white, erisp, juicy, a little harsh until fully ripe, when it is a mild and pleasant subacid. Stalk long, slender, set in a narrow caritv. Calyx closed. Basin broad, open, corrugated. Early Winter to late in Spring.

\section{MeAdER'S WINTER.}

Fruit medium size, roundish oblate; warm, light yellow ground, shaded with clear rich red, many large gray dots. Basin deep, broad, slightly ribbed or furrowed. Flesh yellowish, moderately juicy, crisp?, tender, rich, sharp subacid. Season, Winter. A valuable cooking sort, and rich for cider.

\section{Montreal Beauty.}

This is one of the most beautiful of all Crabs, in appearance.

Fruit large, roundish oblate, bright yellow, nostly covered and shaded with rich red. Flesh yellowish, rich, firm, acid. September, October.

\section{Obloxg-Fruited Siberiax Crab.}

Fruit elongated conic, light yellow, almost white, washed, narbled, and striped witl crimson and carmine, and covered witl a thin bloom.

\section{ORAYGE.}

Fruit medium, round, slightly flattened at ends; light, warm yellow, or light orange-colored. Stalk slender. Cavity open, decp. Calyx closed. Basin furrowed. Flesh yellowish white, mild subacid, „I leasant, a little diy. 


\section{Powers' Large.}

Originated with Hiram Powers, Catskill, N. Y. Tree vigorous, hardy, and productive.

Fruit large, roundish oblate, waxen white, shaded and striped with carmine, crimson, and yellow, and covered with a lilac bloom. Flesh sliarp, yet mild acil. Fine for cooking. Early Oetober.

\section{Purple Siberian Crab.}

Fruit oblate. Color beantiful redklish purple on the sunny side, covered with a bloom, the shaded side less brilliant, and the whole sur face speckled with some gray dots. Flesh, like all the erabs, coarse and harsh.

\section{Red Siberian Crab.}

Fruit about three-fourths of an inch in diameter, rery regularly formed, and rather flat. Skin smooth, of a lively scarlet over a clear yellow gromed, and, when the bloom is rubbed off, is highly polished. Stalk nearly two inches long, and very slender. Calyx small, slightly sunk. Fit for preserving in September and October.

\section{Rouex Transparext Crab.}

Fruit small, oblate, bright earmine red on light yellow. Stalk slen. der, very long, set in a decp wide carity. Flesh yellowish white, acid. September:

\section{SIIOWY Crab.}

Frunt small, roundish oval, rellow, dotted with red in sun. Stalk very long. Flesh dry. Not valuable.

\section{SOLLIRD.}

A sort of little value exeept in appearance. It is said to have originated near St. Lonis, Mo.

Fruit medium, oblate, elear smooth greenish yellow, with many minute, sufinsed, dark green dots. Stalk short for a crab, slender, narrow cavity. Calyx small, closerl. Basin medium, shightly conugated. Flesh white, bitter, astringent, unfit for anything except eider.

\section{Stripen Siberiax Crab.}

Fruit medium size, roundish. Color rose yellowish, red striped all over, earmine on the sunny side, more yellow towards the stalk, covered with a fine white bloom.

\section{Transcexdest.}

This is one of the best of early antumn rarieties.

Frnit nedium to large for its class, roundish oblong, flattened at it conds, slightly but regularly ribbed, golden yellow, with a rich crimson, 
red eheek in the sun, corered with a delieate white bloom; when rully ripe the red nearly cover's the whole surface. Stalk long and slender, set in an open, deep cavity. Cialyx clused, with long reflexed segments. Flesh ereany yellow, crisp, subacid, a little astringent until fully mellow, when it is pleasant and agrceable. Early Autumn.

IVARFEL Crab.

Originated with John Warfel, Laneaster, Pa. Tree vigorous.

Fruit medium size, oblate, yellow, beantifully striped with red and crimson.

\section{WHITE WINTER.}

Fruit medium size, roundish oblate, light pale yellow, with a faint blush and a few scattering, irregular-sized, dark curmine dots in sun. Stem short. Carity very broad, open, yet rleep, slightly russeted. Calyx closed, with short segments. Basin slallow, with slight broal furrows. Flesh yellowish white, crisp, moderately juicy, sharp acid. December and January.

\section{Yellow Siberiax Crad.}

\section{Amber Crab.}

This scarcely differs from the common Siberian Crab except in its fruit, which is rather larger, and of a fine amber or golden yellow. Both this and the red are beantiful ornaments to the fruit garden in summer and antumm, and are equally esteemed for preserves and jellies. September.

\section{SELECT LIST OF TARIETTES FOR TABLE USE, MARKETING, COOKING, AND KEEPING.}

Ir this list it is not assumed that all against which the word market is written are equally profitable, but that their size and appearance will generally command for them a ready sale. Again, some varieties are classerl as market sorts mainly beeanse of their long keeping, and therefore coming into use when there are hut few sorts with which to compete. Soil and climate make so great a cluange in the growth, culality, and period of maturity of varieties, that it is impossil,le to mals a list adapted to general cultivation; and so, kinds which, because of their gond quality (like the American Golden Linsset), which we mark as only for table nse, in some localities are found also profitable for market. The planter, in selecting from this list, should be guided somewhat in arlopting kinds by a record of the place of origin of the variety, which nay be found on the page where the spple is described in the bonk.

Wo have appenderl the words "Sonth" and "Nortll" to some varieties, to desiguate them as of most value in our southem or Northeru States. 
American Golden Pippin. 'Table and market.

American Golden Russet. Table.

American Summer Pearmain. Table.

Baldwin. Table and market.

Baltimore. Table and market.

Belmont. 'Table.

Ben Davis. Market, South and Southwest.

Benoni. Table and market.

Bentley Sweet. Market and keeping.

Bethlehemite. Table and market.

Bonmm. Table aud market.

Broadwell. Table and market.

Buckingham. Table and market.

Campfield. Cider, market, and keeper

Canada Reinette. Table and market.

Carolina Red Jume. Table and market.

Cogswell. Table and market.

Domine. Table and market.

Dutchess of Oldenburgh. Cooking and market.

Dyer. Table.

Early Harvest. Table and market.

Early Joe. Table.

Early Strawberry. Table and market.

English Russet. Market and keeper.

Esopus Spitzenburgh. Table and market.

Evening Party. Table and market.

Fallowater. Market and cooking.

Fall Pippin. Table and market.

Fall Wine. Table.

Fantense. Table and market.

Garden Royal. Table.

Gilpin. Market and keeper.

Golden Sweet. Market and cooking.

Gravenstein. Market and cooking.

Green Cheese. Table and market, South.

Grimes' Golden Pippin. Table and market.

Hall. Table and market, South.

Haskell Sweet. Table.

Higby Sweet. Table.

High Top Sweet. Market, West.

Horse. Market and cooking, South.

Hubbardston Nonsuch. Table and market.

Hunt's Russet. Table.

Jersey Sweet. Table and market.

Jonathan. Table and market.

Keswick Codlin. Narket and cooking.

King of Tompkins Co. Table and market.

Klaproth. Table and market.

Lady Apple. Table and market.

Lady's Sweet. Table and market.

Large I'ellow Bough. Table and market.

Late Strawberry. Table and market.

Lowell. Market and cooking. 
McLellan. Table.

Maiden's Bhsh. Market and cooking.

Mangum. 'Jable, Soutlı.

Maverack Sweet. Market and cooking, South.

Melon. 'Table.

Monmonth Pipjin. Table and market.

Mother. Tiavle.

Newtown 1'ippin. Table and market.

Newtown Spitzenburgh. 'Table and market.

Nickajack. Market and keeper, South.

Northern Spy. Table and market.

Ohio Nonpareil. Table and market.

Peach Pond sweet. Table, market, and cooking.

Peck's Pleasant. Table and market.

Pomme Grise. Table and market, North.

Porter. Table and market.

Primate. Table.

Pryor's Red. 'Table and market, South and West.

Raumbo. Table and market.

Rawles Janet. Table, market, and keeper, Southwest.

Red Astrachan. Market and cooking.

Red Canada. Table and market.

Rhode Island Greening. Market and cooking.

Pibston Pippin. Table and market, North.

Roxbury Russet. Market and keeper, North and West.

Shockley. Market and keeper, South.

Smith's Cider. Market.

Smokehouse. Market and eooking.

Striped Winter Pearmain. Table and market, South and Southwest.

Summer Pippin. Market and cooking.

Summer Queen. Market.

Summer Rose. Table.

Swaar. Table.

Tetofisy. Market and cooking.

Tewksbury Winter Blush. Table, market, and keeping.

Tolnan's Sweet. Market and cooking.

Wagener. Table.

Washington Strawberry. Table and market.

Westfield Seek-no-Further. Table and market.

White Pipjin. Table and market.

Willis Sweet. Cooking, table, and market.

WVillow Twig. Narket and keeper, West and South.

Winesal. Table, market, and keeper.

Winter Sweet Paradise. Table.

Yellow Bellflower. Table and market.

Yellow Newtown Piplin. Table and market. 


\title{
CHAPTER $\mathrm{X}$.
}

\author{
THE ALMOND.
}

Amygdalus communis, Dec. Rosacex, of botanists. Amandier, of the French ; Mandclbaum, German ; Mandorlo, Italian ; Almendro, Spanish.

The Almond-tree, which is a native of the north of Africa and tho mountains of Asia, has long been cultivated, and is mentioned in Scripture as one of the charms of the fertile land of Canaan. It so strongly resembles the peach-tree that it is difficult to distinguish it by the leaves and wood only ; indeed, several botanists are of opinion, from experiments made in raising the almond from seed, that this tree and the peach are originally the same species, and that the rich and luscious peach is the effect of accidental variation, prodnced by culture on the almond. The chief distinction between the two in our gardens lies in the fruit, which, in the almond, consists of little more than a stone corered with a thick, dry, woolly skin, while the peach has in addition a rich and luscious tlesh. The blossoms of the almond resemble those of the peach, but are larger; they are produced in great profusion, early in the season, before the leaves, and are very ornamental.

$U$ ses. The kernel of the sweet almond is highly esteemed as an article of food, and is largely used as an ingredient in confectionery, cookery, and perfumery: It is raised in great quantities in the south of Europe, especially in Portugal, and is an important article of commerce. The bitter almond is used in cookery and confectionery, and in medicine; it furnishes the prussic acid of the shops, one of the most powerful of poisons. From both species an oil is also obtained.

In France the almond is preferred as a stock on which to bud and graft the peach, which in a very dry climate or chalky soil, it is found, renders the latter more healthy and fruitful than its own bottom. The sweet hard-shelled variety (Jouce à coque dure) is preferred for stocks by French nurserymen.

Cultivation. The almond thrives best in a warm dry soil, and its general cultivation in this comtry is precisely like that of the peach. The sweet almond is the only variety considered of value here, and it is usually propagated by budding it on Plum stock, or on the bitter. almond seedlings. It is rather more loardy at the North when budded on the former, and as the buds of the sweet almond are rather slender and small, the plum stocks to be budded should be thrifty seedlings, not more than a fourth of an inch in diameter at the place where the bud is inserted.

The Common Almond, the Hard-Shell Sweet Almond, and the Bitter Almond, are hardy in the latitude of New York, and will bear tolerable crops without care. 'The Soft-shell Sweet Almond, or Ladies' Almond, will not thrive well in the open garden, as a standard, north of Philadclphia; but they succeed well trained to a wall or on espalier rails in a warm situation, the branches being slightly protected in winter.

There is no apparent reason why the culture of the almond should not be pursued to a profitable extent in the warm and favorable climate 
of some of the Southern States. Fspecially in the valley of the Ohio and Temessee it would be likely to sueceed admirably.

\title{
BitTer Aliond.
}

The Bitter Almond has large pale blossoms, differing little from the common almoud except in the kernel, which is bitter. There are two rarieties, one with a hard, and the other with a brittle shell. The fruit, which is produced abundantly, ripens in September. 'The leares aro longer and of a darker green than those of most of the sweet-firuited varieties.

\section{Comion Almond.}

\author{
A. c. dulcis. Amande commune. \\ Amandier à Petit Fruit. Common Sweet. \\ commun.
}

This is the common Sweet Almond of France and the South of Europe, and is one of the most hardy and productive sorts here. Nuts hard, smooth, about an inch and a quarter long, compressed and pointed, of an agreeable flavor, but inferior to the following. Flowers expand before the leaves. Ripens last of September.

\section{Peach Aliond.}

Pècher:

Amandier-Pécher.

Peach Almond.

A rather indifferent variety, nearly sweet, but often slightly bitter. It is a true cross between the peach and the ahmond, and in its leaves, Howers, and stone strongly resembles the peach; the fruit is also pulpy and of tolerable flavor, like an indiflerent peach. The nut scarcely ever ripens well as far north as this.

\section{Pistacina Sweet A limond.}

Amande Pistache.

Amandier Pistache.

A variety of Almond with a very small pointed fruit, about the size and shape of that of a Pistachia, enclosing a kernel of a delicate sweet flavor. The shell not quite so soft as the Soft-Shell Almond. This is scarcely known yet in this country, but is worth further trial at the South.

\section{Soft-Silell Siweet Alyoyd.}

Doux ì coque tendre. Sultan à coque tendre. Amandicr a coque tendre. des Dames.
Amandier des Dames, Ou Amande Princesse. Ladies' Thin Shell.

The Soft-Shell or Ladies' Almond is the finest of all the Almonds. It is the very variety common in the shops of the confectioners, with a shell so thin as to be easily crushed between the fingers, and the kernel of which is so higrhly esteemed at the ressert. It ripens carly in tho season, and is also highly estecmed in a roung or fresh state, heing served on the table for this purpose about the middle of July in T'aris. The 
blossons of this rariety expand at the same time with the leaves, and are more decply tinged with red than the foregoing. Sereral varieties are made of this in France, but they are (as quoted above) all essentially the same.

Fruit two inches long, oral, compressed. The nut is more than an inch long, oval, pointed, one-sided, with a light-colored, porous, very temler shell. The kernel sweet and riz̧ch.

On the plum stock, in a favorable aspect, this Almond succeeds, with a little care, in the Mildle States.

\section{Sultaya SweEt A LMoxd.}
Amande Sultane.
Amandier Sultane.

Sultian.

A tender-sheller Almond of excellent quality, with smalier fruit and narrower kernel than the Soft-sheil Almond, but of equally excellent flavor, and which is preferred by many. It is thought by Poiteau to be scarcely different from the Soft-shell or Ladies' Almond.

\section{The Toxg Hard-Simell Alyond.}

Amandier à gros fruit.

Amandier à gros fruit dur.

A variety with landsome, large, pale rose-colored flowers, opening before the leaves, and large and long tinit, a third longer than other varieties. The stone is about as large as the soft-shell variety, but the kernel is larger and plumper. This is a good hardy sort, and it is very ornamental when in blossom. Kipeus abont the last of September.

Orvamental Varieties. The Dwart Double Flowering Almond (Amygdalus prmile. Lin. Prmms sinensis of some) is a beautiful, well-known low shrub, extremely ornamental in spring. being covered with a profusion of small pink blossoms, very double. There is also a Double White, similar in habit of growth.

The Large Double Flowering Alinond (A. à grand Aleni, 1. Dull.) (A. communis pleno) is a beautıful French variety, with large nearly. white flowers, two inches in diameter. It also bears a good small hard. shell Almond.

\section{CHAPTER XI.}

TIIE APRICOT.

Armeniuce Vulgaris, Dec. Resnece, of botanists.

Abricotier, of the French; Apritosenburm, German; Abercoco, Italian ; Albaricoque, Spanish.

The Apricot is one of the most beantiful of stone fruit-trees, easily known by its glossy heart-shoped follage, large white blossoms, and smooth-skinned golden or ruddy fruit. In the fruit-garden it is a 
highly attractive objoct in early spring, as its charming flowers are the first to expant. It forms a the sprealing tree of about twouty feet in height, and is barrly "nough to bear as an open stamelard sonth of the izd degree of latitude in this country.

The native conntries of this tree are Armenia, Arabia, and the higher regions of Cuntral Asia. It is largely euttivated in Chima and Japan ; and, indeed, according to the aceomts of (trosier, the momntains west of Tekin are corered with a natural growth of apricots. 'The names hy which it is known in varioms Emropean countries all seem to be corruptions of the original Arabic term Berkoche.

UsFs. A very handsome and delicions dessert fruit, only inferior to the peach, ripening abont midsmmmer, aftex cherries and before plums, at a season when it is peculialy acceptable. Foi preserving in sugar or brandy, for jellies or pastries, it is highly esteemed, and, where it is abundant, an arlmirable liquor is made from the froit; and it is also dried for winter use. In some parts of Germany, the fiee-bearing sorts - the Turkey, Orange, and Breda-are largely cultivated for this pmpose.

Cintrition. This tree is almost always budred on the plum stock (on which in July it takes readily), as it is foumd more haudy and durable than upon its own root. Many nurserymen bur the apricot on the peach, but the trees so protuced are of a very inferior quality-short lived, more liable to diseases, and the finit of a second-rite Havor. Buclded on the plum they are well adapted to strong soils, in which they always hold their fruit better than in light sandy soils.

A pricots generally grow very thiltily, and soon make fine heads, and produce an abundance of blossoms and young fruit; but the crop of the latter frequently falls off when half grown, from being stumg by the plum-weevil or curculio, to which the smooth skin of this fruit seems highly attractive. To remedy this, the same course must be pursued as is directed for the plum. Seedling apricots are ustrally more hardy and proluctive here than the finer grafted sonts.

This is a farorite tree for training on walls or espaliers, and, in town gardens especially, we often see it trained against the sides of brick houses, and yielding most abundantly. As it bears its fruit in the same Way ats the peach, and requires the same management, we must refcr our readers to the latter head for direction as to pruming and training. As the apricot, however, expands its blossoms rery early, it should not be placed on an east wall, or in a situation where it is tor much exposed to the full morming sum.

Disenses. When budded on the Plum, this tree is but little liahle to diseases, and may be considered a hardy fruit-tree. In oreler to render it fruitful, and kcep it for a long time in a productive state, we canmot too strongly nrge the artvantages of the shortering-in system of pruming recommeuded for the peach.

\section{Albergifr.}

Alberge.

This is a rariety very common in the interior of France, where it is constantly reperduced with lut little variation from the sced-Allorge being the name of the apricot in some of the provinces. It is a free grower, and bears well, but is neither so large nor tine as many other 
varieties. The leaves are small, and often have little wing-like ears at the base. The Albergiers are much used for stocks in France.

Fruit small, roundish, deep yellow. Flesh reddish, firm, with a brisk, rinous flavor. Stone compressed. Kernel bitter. Esteemed for preserving. Ripe niddle of August.

\section{Axgoumots.}

Anjou. Riouge. Violet.

Fruit small, oval, flattened at the apex. Skin elear deep yellow on the shaded side, but dark rusty brown on the side next the suu. Flesh deep orange, juiey, and melting, separating from the stone, rich, sugary, and briskly flavored, but when highly ripened eliarged with a fine aroma. Back of the stone impervious. Kernel sweet. End of July. (Hogg.)

\section{BeAtge.}

A foreign variety very much resembling the Moorpark, but ripening a little later.

\section{BLACK.}
Amygdalus dasycarpa. Violet.
Purple Apricot.
Du Pape.
Noir.

This remarkable little Apricot so strongly resembles a dark round plum, that at a little distance it might easily be mistaken for one. (It was indeed called Prunus dasycarpa by the old botanists.) It is pretty good, and very hardy, and its unique appearanee renders it sought after by amateurs. The tree has a rough, somewhat crooked trunk, and small, oval foliage.

Fruit about an inch and a half in diameter, round. Skin pale red in the shade, bnt dull reddish purple in the sum, eovered with a slight down. Flesh pale red next the skin, yellow near the stone, adhering somewliat to the stone, juicy, with a pleasant, slight astringent flavor. Kernel sweet. August.

\section{Bred.}

\section{De Hollande. \\ Amande Areline. Ananas. \\ Persique. \\ Hasselnussmandel,}

This is a rery excellent small Apricot, said to be originally from Africa, whieh bears well with eommon culture, and deserves a place in all gardens, as it is not only a high-flavored dessert sort, but it makes one of the riehest preserves. The blosson buls are tinged with deep red before they expand.

Fruit rather small, about an ineh and a half in diameter, roundish, sometimes rather four-sided. Suture well markecl. Skin oringe, becoming dark orange in the sum. Flesh deep orange, rich, high-flavored, and rather juicy-separating freely from the stone. The kernel, which is sweet, is eaten in irance, whence the name imande dieline. First of August. 


\section{Browy's E.mLx.}

Origin, Chelsea, Mass.

Fruit large, short oval, yellow, bright red cheek. Flesh yellow, melting, rich, juicy, luscious flavor. Season, widdle to last of July. (Cole.)

\section{BRUSSELS.}

The Brussels Apricot is not a fine fruit in this country, but it is a good bearer in light soils.

Fruit of medium size, rather oval, and flattened on its side. Skin pale yellow, dotted with white in the shade, but often marked with a little russety brown in the sun. Suture deep next the stalk. Flesh yellow, wather firm, with a lively but not rich flavor. Kernel bitter. Midulle of August. The Brussels of some collections is the Breda.

\section{Burlington.}

Raised by Mrs. Woolman, Burlington, N. J. Tree vigorous.

Fruit medium to large, oblong, somewhat compressed at the sides, with a distinct suture. Skin golden yellow, with numerous red spots and a ruddy tint on the sicte exposed to the sun. Flesh yellowish, sweet, and fine. Middle of July to the tirst of August. This variety is probably out of existence.

\section{Canino Grosso.}

A variety from the Papal States of Italy, introdneed by Thomas Rivers, Sawbridgeworth, England. Tree hardy and a vigorous grower.

Fruit quite large. Skin orange, becoming red in the sun. Flesh rich reddish yellow, melting, high-Havored. Hiddle July.

\section{Claude Bidot.}

From France. Tree vigorous and productive.

Fruit medium, roundish ovate, deep suture, half round. Skin deep orange yellow, spotted and shaded with deep red. Flesh deep yellow, slightly colored with red on the side of the sun. Flesh fine, melting, sugary, aromatic. Stone medium, ronndish ovate. Kernel very sweet. (An. Pom.)

\section{Conice de Toulon.}

Of French origin.

Fruit large, roundish ovate. Skin very downy, jellow, becoming orange in the sun, with deep carmine dots. Flesh orange yellow, fine, juicy, aromatic. Kernel sweet. Early July. (An. Pom.)

\section{Des Farges.}

Originated near Lyons, France.

Fruit medium to large, ronndish oval, golden yellow, covered with a short down. Flesh orange yellow, fine, juicy, musky perfumed. Stone large. Separates free from the flesh. Last of June. (Verg.) 


\section{Early Golden.}

Dubois' Early Golden.

Origin unknown. Introduced by Charles Dubois, Fishkill Landing. N. I. Tree vigorous, with long, rather slender branches.

Fruit small, roundish oval, with the suture well marked, and extending half-way round. Skin smooth, pale orange. Flesh yellow, mo. derately juicy and sweet, with a very good flavor-separates from the stone. Middle of July.

\section{EArLy MIoorpark.} earlier.

A variety much resembling the Moorpark, but ripening some weeks

Fruit roundish, inclining to oval, deep suture on one side, extending from the base to the apex. Skin yellow, mottled and dotted with crimson on the exposed side. Flesh in all respects resembling that of the Moorpark. Stone oblong, with a covered channel along the back, which is pervious. Kernel bitter.

\section{Golden Drop.}

This new Apricot is described by Rivers as having been raised from seed of the Musch-Musch, and is about the size of an Orleans Plum, bright orange and crimson. Flesh melting, with a delicious pine flavor. Ripe middle July.

\section{Heuskirke.}

A large and beantiful English variety, of the finest quality. It strongly resembles the Moorpark, from which it is known by its stone not being perforated like that variety. It also ripens a little earlier.

Fruit large, roundish, but considerably compressed or flattened on its sides. Skin orange, with a red cheek. Flesh bright orange, tender, rather more juicy and sprightly than the Moorpark, with a rich and luscions plum-like flaror. Stone rather small, and kernel bitter. End of July.

\section{JAQUES.}

Origin unknown. Tree vigorous, hardy.

Fruit small, ovate. Skin with a fine short down or bloom, greenish yellow. Flesh orange yellow, melting, juicy, sugary, perfumed. Stone medium. July, August.

\section{KAISHA.}

A variety from Syria, of high reputation abroad, but we have found the tree tender and unhealthy.

Fruit medium, roundish, with a deep suture toward the stalk, pale vellow, mottled and tinged with red in the sum. Flesh tender, juicy, pale yellowish, parting freely from the stone, sugary, high-flarored Stone small, roundish. Kernel sweet. July and first of A ugust.

\section{LAFAIETTE.}

Origin, City of New York. Tree remarkably vigorous. 
Fruit very large, oval. Skin light yellow, marbled with red next the sum. Flesh high-Havored and excellent. Ripens in dugust. (IV. R I'rince.)

\section{Carge Early.}

$\begin{array}{ll}\text { Gros Précoce. } & \text { De St. Jean. } \\ \text { Gros d'Alexandrie. } & \begin{array}{l}\text { Gros Fruhe. } \\ \text { De St. Jean Rouge. }\end{array}\end{array}$

I fine, large, early variety from France, of vigorous growth, and ono of the best of the early sorts.

Fruit of medium size, rather oblong, and compressed. Suture deep. Skin slightly downy, pale orange in the shade, fine bright orange with a few rudily spots in the sum. Flesh separating readily from the stone, orange-colored, rich, and juicy. Kernel bitter. Middle of July.

\section{LARGE RED,}

\section{Gros Rouge.}

Gros Rouge Hâtif.

This is a variety of the Peach Apricot, the tree hardier than the Moorpark.

Fruit large, deep orange red. Flesh rich, juicy, separating freely from the stone. Kernel bitter. Last July.

\section{Liabaud.}

Origin, near Lyous, France.

Fruit large, ovate, depressed at ends. Skin dull yellow, shaded with orange in the sun. Flesh orange yellow, translucent, fine, melting, sugary. Stone ovate, obtuse at summit. July. (Verg.)

\section{LUIZET.}

Originated near Lyons, France. 'Tree vigorous.

Fruit large, ovate truncated at apex. Skin thick, orange yellow, washed and dotted with deep crinson. Flesh yellow, firm, sugary, perfumed. Stone large. Freestone. July. (Verg.)

\section{Mexico.}

Oricinated near Lyons, France.

Fruit usclinm, ovate elongated. Skin thick, greenish yellow, washed with roddish brown. Flesh pale yellow, fine, tender, sugary, musky. Stone ubtuse at apex end. July. (Verg.)

\section{Moxtganet.}

\section{Crotte. Alberge de MIontgamet.}

Fruit small, oval, somewhat compressed on the sides, and marked with a shallow snture. Skin pale yellow, with a slight tinge of red on the side next the sum. Flesh yellowish, firm, adhering to the stone, juicy, and agreeably acil. When well ripened, highly perfumed. Stone roundish. Kernel bitter. Fnd of July. (Hogg.) 


\section{Moorpark.}

Auson's.

Oldaker's Moorpark.

Walton Moorpark. Dummore's Breda.

Dunmore.

Sudlow's Moorpark. De Nancy.

Temple's.

Hunt's MIoorpark.

This fine variety is the most popular and widely disseminated in this eountry, except the Breda. It has its name from Moorpark, the seat of sir. William Temple, in England, where it was cultivated more than one hundred and forty years ago. It is only a moderate bearer here, and espeeially requires the shortening-in mode of pruning, as recommended for the peach.

Fruit large, roundish, about two inches and a quarter in diameter. each way, on a standard tree; rather large on one side of the suture than the other. Skin orange in the shade, but deep orange or brownish red in the sun, marked with numerous dark specks and dots. Flesh quite firm, bright orange, parting fiee from the stone, quite juicy, with a rich and luscious flavor. Stone peculiarly perforated along the back, where a pin may be pushed through nearly from one end to the other Kernel bitter. Ripe early in August.

\section{Muscir-Musch.}

\section{D’Alexaudrie.}

This delicious little Apricot takes its name from the eity of Musch, on the frontiers of Turkey in Asia; but it is also commou about Alexandria, and in northern Egypt it is said to be raised in such abundance that the dried fruit is an article of commerce. The tree is rather delicate, and requires a sheltered position.

Fruit rather small, about an inch and a half in diameter, round. Skin deep yellow, with a little orange red on the sunny side. Flesh yellow, with a translucent pulp, tender, melting, and very sweet. Ker. nel sweet.

\section{Newhall's Earis.}

Origin, Lynn, Mass.

Fruit medium, short oval, bright orange, deep red eheek, tender, juicy, rich delicious flavor. Clingstone. Last July. Early August (Cole.)

\section{OraNge:}

Early Orange. Royal Orange.
Persian.

Royal Persian.
Royal George.

An Apricot of only tolerable quality for the dessert, but it is much esteemed by many for preserving; and it makes delicious tarts, even before the fruit begins to acquire color.

Fruit of medium size, roundish, with a well-marked suture, deeply nollowed near the stalk. Skin firm, orange, sometimes tinged with a ruddy tint in the sun. Flesh dark orange, moderately juicy, but of ten rather dry and insipid (unless ripened in the house), not separating entirely from the flesh. Stone small, roundish. Kernel sweet. Micklle of July. 


\section{Oulliss Early Peach.}

A rariety of the Peach Apricot, diflering only in time of ripening.

Peacir.

$\begin{array}{lll}\text { Anson's Imperial. } & \text { Royal Peach. } & \text { Piehe. } \\ \text { Abricot Pêche. } & \text { De Nancy. } & \text { Du Luxembourg. } \\ \text { Piche Grosse. } & \text { Wurtemburg. } & \text { P'firsiche. }\end{array}$

The Peach Apricot, originally from Piedmont, has long been considered the finest variety; and it is with us the larest and most excellent sort cultivated-being often as large as a Peach-of medium size, handsome, and of delicious thavol. It very strongly resembles the Moorpark, but the two are readily distinguished by the eye when standing near each other, and the fruit of the Peach is rather larger and finer, and a few days earlicr.

Fruit of the largest size, about two and a half inches in diameter, roundish, rather flattened, and somewhat compressed on its sirles, with a well-marked suture. Skin yellow in the shade, but deep orange, mottled with dark brown, on the sumny side. Flesh of a fine yellow saffron color, juicy, rich, and high-flarored. Stone with the same pervious passage as the Moorpark, and with a bitter kernel.

\section{Pine Apple.}

\section{Ananas.}

Fruit large, roundish, flattened. and marked with a rather shallow suture. Skin thin and delicate, deep golden rellow in the shade, witl a high-colored red cheek where exposed to sun, and speckled with large and small red specks. Flesh reddish yellow, somewhat firm, juicr, rich pine-apple flavor. Stone oval. Kernel bitter. Middle August. (Hogg.)

\section{Portugat.}

\section{Male.}

Fruit small, resembling in shape and size the Red Masenline, round, divided on one side by at deep suture. Skin pale yellow on the shaded side, decp yellow tinged with red, and marked with brown and red russet spots next the sun. Flesh deep yellow, tender, melting, rich sugary; musky, adhering somewhat to the stone. Stone almost round. Kernel bitter. Middle of A ugust. (Hogg.)

\section{Provexce.}

Abricot de Provence.

Fruit small, crmpicssed on the sides, with a deep suture, higher on one sicle, yellow, with red in the sun. Flesh yellow, melting, rich, rather dry, pleasint. Kernel sweet. End of July. 


\title{
Ried Masculine.
}

Early Masculine. Brown Masculine. Abricotier.
Apricot Précoce.

Apricot hâtif Musquée.

Frühe Muscateher.

A small early sort, harly, very productive, of tolerable flavor, but not rich, growth upright, slender.

Fruit small and nearly rourd, scarcely an inch and a half in diameter, with a well-marked suture on one sicle. Skin bright yellow, tinged with deep orange and spotted with dark red on the sunny side. Flesh yellow, juicy, with a slightly musky, pleasant fla vor. Stone thick, obtuse at the ends. Flowers smaller than in most other sorts. Kernel bitter. Ripe about the 12 th of July.

\section{RINGOLD.}

Originated in Athens, Ga.

Fruit large, roundish, a little oblong, suture slight. Skin light orange, darker in the sm, where it is beantifully dotted with carmine. Flesh deep yellow, juicy, and excellent. Ripens just after the orange, hardy and productive.

\section{Roman.}

\author{
Abricot Commun. \\ Grosse Germine. \\ Germine. \\ Transparent.
}

This is with us one of the largest growing and hardiest Apricot trees, and produces good crops every year in cold or mnfarorable situations, where none of the other sorts except the MLasculine succeed. It is therefore, though inferior in Havor, a raluable sort for northern situations. The blussoms will bear quite a severe frost without injury.

Fruit middle-sized, oblong, with the sides slightly compressed, with lunt little or no suture. Skin entirely pale yellow, or very rarely dotted with a few red sprots on one side. Flesh dull yellow, soft, rather dry. When ripened by keeping a few days in the house, the flavor is tolerably good. Stone oblong, with a bitter kernel. Ripe the last of July and first of Angust.

There is a Blotened-Leaved Romax (commun à ferilles panacliés, of the French), precisely like the foregoing in all respects, except the white or yellow stain in the leaf-but it is quite distinct from the blotehedleaved Turkey, cultivated here.

\section{ROYAL.}

A fine large French variety, raised a few years since at the Royal Luxembourg Gardens. It is nearly as large as the Mloorpark, but with larger leaves boune on long footstalks, and without the perrious stone of that sort. It is quite as high flavored, and ripens a week or ten days earlier.

Fruit rommdish, large oval, slightly compressed. Skin dull yellow, with an orange cheek, very faintly tinged with red, and a shallow suture. Flesh pale orange, firm and juicy, with a rich vinous flaror. Ripe the latter end of July. 


\section{ST. AmbroIse.}

This is a large early Apricot, almost the size of and earlier than the Moorpark. It is compressed, of a derp yellow color, reddish next tho sur. Flesh juicy, rich, aud sugary. Niddle August. (Hogg.) ,

\section{SARDINIAN.}

\section{De Sardaigne.} culine.

Tree a great bearer, ripening its fruit as early as the Red Mas.

Fruit small, with a deep suture on one side. Skin white, with a few crimson spots, and sometimes a flush of red. Flesh juicy, sprightly, sweet, pleasant. Stome small. Kernel bitter.

\section{SIIIPLEY's.}

Blenheim.

Shipley's Large.

A very good early variety, of small or medium size, of vigorous but rather slender growth.

Fruit medium, oval, orange, with a deep yellow, juicy, and tolerably rich flesh. Stone roundish, impervious, with a bitter kermel. Ripens liere about the 25th of July.

\section{Suker Para.}

\section{Green Gage.}

From Syria.

Fruit medium, roundish, smooth skin, small stone, delicious, rather dry, very sweet flesh.

\section{TExAs}

Originated with Dr. M. A. Ward, Athens, Ga.

Fruit small, round. Color dark maroon, darker in the sun. Suture slight, a mere line. Flesh juicy and pleasant, except at the stone, where it is astringent. Adheres to the stone. (W. N. White, MS.)

\section{'TURKEY.}

\section{Large Turkey. De Nancy of some.}

The Turkey Apricot is a fine old variety, which is seldom seen in our garrlens, the sort generally sold under this name being the Roman. It is quite a late sort, ripening after the Moor lark, from which it is easily known by its impervious stone and sweet kernel.

Fruit of middle size, nearly round, not compressed. Skin fine deep yellow in the shade, mottled with brownish orange in the sum. Flesh jale yellow, firm, quite juicy, with a flavor in which there is an excellent mingling of sweet and aeid. Kernel nearly as swert as that of an Almonul, which, as woll as the form and color, distinguishes this sort from the Rormus. Ripe tho midalle of A ugust.

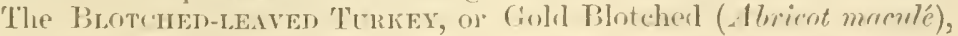
is a sub-vallicty, very well known here, resembling the common Thrkey 
in all respects, except that it has in the centre of each leaf a large yel. lowish spot. It is a thrifty tree and bears delicate fruit. Ours is not iclentical with the Turkey, as the last edition of the L. H. S.'s Cata. logne arranges it, but is a globular fruit, and a true variation of the Turkey.

\section{White Masceline.}

White Apricot.

Abricot Blane.

Abricotier Blanc.
Early White Masculine.

Blane.

White Algiers?

This scarcely differ's from the Red Masculine before described, except in color. It is four or five days later.

Fruit small and roundish. Skin nearly white, rarely with a little reddish brown on one side. Flesh white, delicate, a little fibrons, adheres a little to the stone, and has a delicate, pleasant juice. Kernel bitter.

Curious or ornamental varieties. The Brisxçon Apricot (A. brigantiaca, Dee.), a very distinct species, so inuch resembling a phum as to be called the Briancon Plum by many authors (Prune de Briancon, Poit.), is a small irregular tree or shrub, ten or twelve feet high, a native of the Alps. It bears a great abundance of small, round, yellow, plumlike fruit in clusters, which are scarcely eatable; but in France and Piedmont the kernels of this variety make the "huile de marmotte," which is worth double the price of the olive oil.

The Double flowerixg Apricot is a pretty ornamental tree, yet rare with us.

Selection of Apricots for a small garden. Large Early, Breda, Peach, Moorpark. Breda.

Selection for a cold or northem climate. Red Masculine, Roman,

\section{CHAPTER XII.}

\section{TH E B E R B E R R 。}

Barberis vulgaris, L. Berberacea, of botanists.

Epine-vinette, of the French; Berberitzen, German; Berbero, Italian ; Berberts, Spanish.

Tine Berberry (or barberry) is a common prickly shrub, from eight to ten feet high, which grows wild in both hemispheres, and is particularly abundant in many parts of New England. The flowers, the roots, and the inner wood are of the brightest yellow color, and the small crimson fruit is borye in clusters. It is a popular but fallacious notion, entertained both here and in England, that the vicinity of this plant, in any quantity, to grain fields, canses the rust.

The barberry is too acid to eat, but it makes an agreeable preserve 
and jelly, and an ornamental pickle for garnishing some dishes. From the seedless sort is made in liouen a celebrated sweetmeat, confitur, d'épine-vinette. The inner bark is used in Frunce for dyeing silk and cotton a bright yellow.

Culturi. The culture is of the easiest reseription. A rieh light soil gives the largest fruit. It is easily propagated by seed, layers, or suckers. When fine fruit of the barberry is desired, it should be kept trained to a single stem-as the suckers which it is liable to produce frequently render it barren or make the fruit small.

\section{Common Red.}

This is too well known to need description. In good soils it grows twelve or fifteen feet high, and its numerous chister's of bright oval berries are very ornamental in antumn. There is a Iarge Red variety of this, which is only a variation produeed by eultivation in rich soil. There are also varieties of this in Europe with pale yellow, white, and purple fruit, which are not yet introduced into this country, and which scarcely differ in any other respect than the color. And there is a socalled sweet rariety of the eommon Berberry from Austria (B.v.dulcis), but it is searcely less acid than the common.

A variety with purple foliage differs but little in the fruit, which is perhaps not quite as fleshy, but the foliage is extremely ornamental.

\section{THE BLACKBERRY.}

There are sereral species of the Bramble indigenous to this conntry, which produce eatable fruit, but the best for the table, or for cooking, are the Low Blackberry, a trailing shrub, and the following varieties of the High Blackberry.

The fruit is larger than that of the Raspberry, with fewer and larger grains, and a brisker Haror. It ripens about the last of July or early in August, after the former is past, and is mueh used by all elasses in this eountry. There is no doubt that varieties of much larger size, aud greatly superior flavor, might be produced by sowing the seeds in rich garden soil, especially if repeated for two or three successive generations.

Their cultivation in gardens is similar to that of the Raspberry, except that they require to be planted at greater distanees apart, say from six to eight feet. (See page $9(j 1$.

\section{Adair's Claret.}

Originated with D. L. Adair, Hawesville, Ky. The plant is not quite hardy.

Finit medium size, claret color, soft, with a mild pleasant flavor.

\section{A I.Biox.}

A wildling found and introduced by John B. Orange, of Albion, Ill. Although described as large and productive, we have never been able tc gather more than half a crop from our plants, and the fruit of only fair size, imperfect, and without flavor. 


\section{CAPE MAY.}

Fruit large, black, sweet, quite soft, loses color soon after gathering. not valuable.

\section{Coloner WiLder.}

Introduced by John B. Orange.

Fruit of medium size, oblong, light cream color, moderately firm, does not fill well.

\section{Crystal White. \\ Orange's Crystal.}

Introduced by John B. Orange, Albion, Ill. It is a vigorous grower, suckers fieely, and not hardy. Does not set its fruit well.

Fruit medium, oblong oval, light creamy white, translucent, sweet. Good. Only desirable as a curiosity.

\section{Cumberland}

A New Jersey variety, productive, hardy.

Fruit medium, black, sweet, early.

\section{Cut-Leaved.}

Parsley Leaved.

An old European variety, valued more for its curious foliage than for the amount of its fruit.

Fruit roundish, black, sweet, with a musky peculiar flaror.

\section{Cutter's Mulberry.}

Introduced by G. B. Cutter, Newtown, Mass.

Fruit long, slender, remarkably sweet. (Hov. Mag.)

\section{DOCTOR W'ARDER.}

Introduced by John B. Orange.

Fruit rather shorter and thicker than the Albion, nearly as large. Color dark rosy red. (Hov. Mag.)

\section{DORCHESTER.}

Introduced to notice by the late Capt. Lovett, of Beverlr, Mass. Nearly equal in size to New Rochelle, of a more elongated form, grains rather smaller, somewhat sweeter, and producing large crops of highflavored fruit, a vigorous grower.

Fruit large, oblong conic, sometimes measuring an inch and a quarter in length, of a deep shining black. The berries should be fully matured before they are gathered; it bears carriage well. Ripens about the first of August. 


\section{DUNCAN'S FALLS.}

Introduced by J. C. Neff, Duncan's Falls, O. An upright, very vig orous grower. tested.

Fruit large, black, moderately firm, juicy, sweet. New, not fully

\section{FARLEY.}

Origin nuknown. New.

Fruit nearly as large as New Rochelle, black, sweet, and ripcns two weeks earlier. (Hort.)

\section{FELTON.}

Introduced by Oscar Felton, of Camden, N. J.

Fruit large, long, slightly conical, sweet. Good. Ripens early, moderately productive.

\section{HoLconb.}

Introduced by E. A. Holcomb, of Granbs, Conn. Canes hardy and productive. early.

Fruit large, roundish, black, moderately firm, well flavored. Ripens

\section{KЕNTLCKY WTITE.}

Introduced by D. L. Adair, Kentucky. Plant tender.

Fruit medium size, oblong oval, light dirty white. Imperfect.

\section{Kiтt.АTinsy.}

A native wildling from the Kittatinny Mountains, Waren Co., N.J. It has within a few years become widlely disseminated, and everywhere proves of the highest value. Canes quite hardy, and very productive; ripening early, and continuing a long time.

Fruit large to very large, ronndish conical, rich glossy black, moderately firm, juicy, rich, sweet, excellent.

\section{Low BlAckBerry.}

Trailing Blackberry. Dewberry. Rubus Canadensis.

A low trailing, prickly shrub, prorlucing large white blossoms in May, and rery large roundish oblong black finit in midsummer. Leaflets from three to five in number. The fruit, when in good soil and fully exposed to the sum, is high-flavororl, sweet, and excellent.

\section{Mason's MIountain.}

A new variety. Canes hardy.

Fruit large, conical, black, sweet, rich.

\section{Missouri MTAMoth.}

A variety recently disseminated from Missouri. It has not yet 
fruited here, but is described as "bearing fruit of the very largest size, quite black, firm, rich, juicy, sweet, without any core. Ripens very early, and continues a iong time in bearing."

\section{Newnin's Thornless.}

A new variety, discovered by Jonas Newman, Ulster Co., N. Y. Promises to be valuable. Growth not so vigorous as New Rochelle and Dorchester, but prodnces good-sized oval berries of excellent flavor. The canes have but few spines or thorus in comparison to the others. Ripens about the first of Augnst.

\section{New Rochelle.}

Seacor's Mammoth.

Lawton.

This remarkable variety was found by Lewis $A$. Seacor, in its natıve wildness by the roadside, in the town of New Rochelle, Westchester Co., N. Y. It is of very vigorous growth, with strong spines which belong to the bramble, is luarly and exceedingly productive.

Fruit very large, oval, and, when fully xipe, intensely black. When mature the fruit is very juicy, rather soft and tender, with a sweet, excellent flavor; when gathered too early it is acid and insipid. The granules are larger, consequently the fruit is less seedy than any other variety. Ripens about the first of Augnst, and continues in use five or six weeks.

\section{Sable Queen.}

Introduced by J. W. Manning, Reading, Mass., who describes it as in size, beauty, and fruitfulness, equal if not superior to Dorchester or New Rochelle. We have not seen it.

\section{WACHUSETT.}

Found growing wild on Monadnock Mountain. Canes hardy, nearly thornless.

Frnit medium, oblong oval, moderately firm, productive. (J. of H.)

\section{WASHITGTON.}

Raised by Prof. C. G. Page, Washington, D. C.

Fruit large, black, sweet. Good. New.

\section{Wrison's EarLY.}

Introduced by Joln Wilson, Bullington, N. J. A hardy, productive, very early ripening market sort.

Fruit large, oblong oval, black. Flesh firm, sweet. Good.

Ornamental Varieties.-The "Double White Blossomed" and "Double Pink Blossomed Brambles" are beautiful climbing shrubs, of remarkably luxuriant growth, which may be trained for a great length 
in a season, and are almirally adipted for covering walls and unsightly buildings. The flowers are like small double roses, and are prowheed in numerous chusters in June, having a very pretty efieet. North of $\mathrm{New}_{\text {Tork }}$ these climbers are rather tender in severe winters.

The liose flowering Bramber (Rubus odoratus) is a very pretty native shrub, with liuge broad leaves, and pleasing rose-colored flowers, and gronjs well with other shrubs in ornamental plantations.

\section{CHAP'TER XIII.}

\section{The Cherry.}

Cerasus syluestris, and $C$. vulgaris, Arb. Brit. Rosacece, of botanists. Cerisier, of the French; Kirschenbrum, German; Ciriego, Italian; Cerezo. Spanish.

Tre Cherry is a fine, ỉxuriant fruit-tree, with smooth, light-colored bark, and generally of rapid growtl. The valieties of the black and heart-shaped cherries are always vigorous, and form fine large spreacling heads, forty or fifty feet in height; but those of the acid or red cherry are of lower, more busliy, and tardy growth. In the spring the cherrytree is profusely covered with clusters of snow-white blossoms, and earlier in summer than upon any other tree, these are followed by abundant crops of juicy, sweet, or acid fruit, hanging upon long stalks, and enclosing a smooth stone

The Cherry comes originally from Asia, and the Roman general, Lncullus, after a victorious experlition into Pontus, has the reputation of liaving brought it to Italy frum Cercusus, a town in that province, in the year 69 B.c. According to Pliny, the Romans, 100 years after this, had eight varieties in cultivation, and they were soon afterwards carried to all parts of Europe. The seeds of the cultivated cherry were brought to this country very early after its settlement, both fiom England and Holland.

Usss. As a pleasant and refreshing dessert fruit, the cherry is ererywhere highly esteemed. The early season at which it ripens, its juiciness, delicacy, and richness, reuder it always acceptable. While the large and fleshy varieties are exeedingly sweet and luscious, other's which are more tender, and more or less acid, are very valuable for pies, tarts, and various kinds of cookery. The fruit of the Kentish or Eirly Richmond is excellent when stoned and dried, and the Mazzard, and our wild Virginia cherries, are used to give a lavor to brandy. When camned they rotain their character and are very delicions. The Dukes or Morellos are best for the purpose.

The celebrated German Kirschwesser is made by distilling the liquor of the common black mazzard or gean (in which the stones are ground and broken, and formented with the julp), and the delicious Ratrific cordial of Girnoble is also marle from this fruit. Maresclino, the most celebrinted liqueur of Italy, is distilled from a small gean or mazzard with which, in fermenting, honey and the leares and kernels of the fruit are mixed. 
The gum of the Cherry is nearly identical with gum arabic, and there are some marvellous stories told of its nutritive properties. The wood of the cherry is hard and durable, and is therefore valuable for many purposes; but the best wood is afforded by our common wild or Virginia cherry, which is a very good substitute for mahogany, taking a fine polish.

The larger growing sorts of black cherry are the finest of all fivuit. trees for shade, and arc, therefore, generally chosen by farmers, who are always desirous of combining the useful and the ornamental. Indeed the Cherry, from its symmetrical form, its rapid growth, its fine shade, and beautiful blossoms, is exceedingly well suited for a roadsido tree in arricultural districts. We wish we conld induce the planting of aremues of this and other fine-growing fruit-trees in our country neighborhoods, as is the beantiful custom in Germany, affording ornament and a grateful shade and refreshment to the traveller at the same moment. Mr. Loudon, in his Arboretum, gives the following account of the cherry aremes in Germany, which we gladly lay before our readers:-

"On the Continent, and more especially in Germany and Switzerland, the cherry is much used as a roadside tree; particularly in the northeru parts of Germany, where the apple and pear will not thrive. In some comntries the roal passes for many miles together through au avenue of cherry-trees. In Moravia, the road from Brumn to olmutz passes through such an avenue, extending upwards of sixty miles in length; and in the autumn of 1828 , we travelled for several days through almost one continuous avemue of cherry-trees, from Strasburg by a circuitons ronte to Munich. These avennes, in Germany, are planted by the desire of the respectire govermments, not only for shading the traveller, but in order that the poor pedestrian may obtain refreshment on his journey. All persons are allowed to partake of the cherries, on condition of not injuring the trees; but the main crop of the cherries, when ripe, is gathered by the respective proprietors of the land on which it grows; and when these are anxious to preserve the fruit of any particular tree, it is, as it were, tabooed; that is, a wisp of straw is tied in a conspicuous part to one of the branches, as vines by the roadsicles in France, when the grapes are ripe, are protected by sprinkling a plant here and there with a mixture of lime and water, which marks the leaves with couspicuous white blotches. Every one who has travelled on the Continent in the fruit season, must have observed the respect that is paid to these appropriating marks; and there is something highly gratifying in this, and in the humane feeling displayed by the princes of the difierent comntries in cansing the trees to be planted. It would indeed be lamentable if kind treatment did not prodnce a corresponding return."

Sorl Axp Situation. A diy soil for the cherry is the universal maxim, and although it is so hardy a tree that it will thrive in a great variety of soils, yet a good sandy or gravelly loam is its farorite place. It will indeed grow in much thimner and clryer soils than most other fruit-trees, but to obtain the finest fruit a deep and mellow soil, of good quality, is desirable. When it is forced to grow in wet places, or where the roots are constantly damp, it soon decays and is rery short lived. And we have seen this tree, when forced into too luxuriant : growth in our over-rich W'estern soils, become so gross in its wood as to bear little or no fruit, and split open in its trumk, and soon perish. It is a rery 
hardy tree, and will bear a great rariety of exposures withont in. jury. In deep warm valleys, liable to spring frosts, it is, howerer, well to plant it on the north sides of hills, in order to retard it in the spring.

Proparation. 'The fince sorts are nearly always propagated ly budding on seellings of the common black mazzard, which is a very common kind, producing a great abundance of fruit, and very healthy, free growing stocks. 'To raise these stocks, the cherries shonld be gathered when fully ripe, and allowed to lie two or three days together, so that they may be partially or wholly freed from the pulp by washing them in water. They should then be planted immediately in drills in the seed plot, corering them about an inch deep. They will then vegetate in the following spring, and in good soil will be fit for planting out in the nursery rows in the autumn or following spring, at a listance of ten or twelve inches apart in the row. Many persons preserve their cherry stones in sand, either in the cellar or in the open air, until spring, but we have found this a more precarious mode; the cherry being one of the Inost delicate of seeds when it commences to vegetate, its ritality is frequently destroyed by leaving it in the sand twenty-four hours too long, or after it has commeneed sprouting.

After planting in the mirsery rows, the seedlings are generally fit for budding in the month of August following. And in order not to have weak stocks orerpowered by vigorous ones, they should always be assorted before they are planted, placing those of the same size in rows together. Nearly all the cherries are grown with us as standards. The English nurserymen usually bud their standard cherries as high as they wish them to form heads, but we always prefer to bud them on quite young stocks, as near the ground as prissible, as they then shoot up clean, straight, smooth stems, showing no elumsy joint where the bud and the stock are mited. In gond soils the buds will frequently make shoots, six or eight feet high, the first season after the stock is headed back. Grafting of the cherry may be performed the same as with the alple and pear, but the work, to be successful, should always be performed early in the season, before the frost is well out of the grounl. If omitted until the buds begin to swell strongly the chances for sucess are less than those of failure.

When dwarf trees are required, the Morello seedlings are used as stocks, or the Perfumed Cherry (Cerasus Mahàleb) is employed; but as standards are almost universally preferred, these are seldom scen here. Dwarfs in the mursery must be headed back the second year, in order to form lateral shoots near the gromed.

Cultivation. The cherry, as a standard tree, may be said to require little or no cultivation in the llidlle States, further than oceasionally supplying old trees with a little manure to keep up their vigor, pruning out a dearl or crossing branch, and washing the stem with soft soap) should it become hard and bark-bound. P'uning, the cherry very little needs, and as it is always likely to produce gum (and this deeay), it should be aroided, except when really required. It should then be done in midsummer, as that is the only season when the gum is not more or less exuded. The eherry is not a very long-lived tree, but in filvolable soil the finest varieties generally endure about thirty or forty years. In the County of Perrs, Ohio, there is a tree of the Plack Mlazzarl vuriety which is cighty fuet in height, and four foet one inch in civiv. 
meter of main trumk, while the length of the largest limb or branch is forty-two feet.

it large cherry-tree at Walworth, N. Y., is recorded as measuring fourteen feet six inches in circumference, sixty feet in height, and having a spread of over four rods. It has produced forty bushels of fiuit in one season.

Twenty feet apart for the strong, and eighteen feet for the slowgrowing kinds is the proper distance for this tree.

Trunisg the Cherry is very little practised in the United States. The Heart and Bigarreau Cherries are usually trained in the horizontal nanner, explained in pages 44,45 . When the wall or espalier is once filled, as there directed, with lateral branches, it is only necessary to cut uff, twice every season-in the month of May and July-all additional shoots to within an inch or so of the branch from which they grew. As the trees grow older, these fruit-spurs will advance in length, but by cutting them out whenever they exceed four or five inches, new ones will be procluced, and the tree will continue to keep its proper shape and rield excellent fruit. 'The Morello Cherries, being weaker growing sorts, are trained in the fan manner (parges 42, 43).

Gathering tue Fruit. This tender and juicy fruit is best when freshly gathered from the tree, and it should always be picked with the stalks attached. For the dessert, the flavor of many sorts in our climate is rendered nore delicious by placing the fruit, for an hour or two previous, in an ice-house or refrigerator, and bringing them upon the table cool, with dew-drops standing upon them. For market or transportation long distances, they should be gathered only when perfectly dry.

VARIETIES. Since the first publication of this work was written, the number of varieties has greatly increased, and become so hybridized that no distinct line can now be drawn separating many of the Heart Cherries (tender and half tender) from the tirm-fleshed or Bigarreat varieties, each cluss insensibly approaching and intermingling with the other. We have therefore made but one class of these, whose main characteristic is the large, vigorous growth of the trees. The Duke and Morello Cherries, also wanting a natural division, we make to constitute another class, and in these two have comprised all the cherries.

\section{CLASS I.}

\section{BIGARREAU AND HEART CHERRIES.}

Adan's Crown.

Uf English origin.

Fruit medium, round heart-shape, pale red. Flesh tender, juicy, agreeable. Middle of Jume.

A Mber.

Imperial English Amber?

A variety desrribed by Coxe as large, round. Skin glossy cream color, faint blush. Flesh firm, lnscious. Ripens late in June. Tree grows large, regular, sprealing. 


\section{Amber Gean.}

\section{Gean Amber.}

Of foreign origin, exccedingly productive, ripens late, and liangs til. the middle of July.

Fruit small, oval or obtuse heart-shape. Skin very thin, color pale yellow, partially overspread with a very faint red. Stalk long and slender, very slightly inserted. Flesh white, juicy, melting, of a sweet and pleasant tia ror.

\section{AMBREE.}

Cerise Ambrée.

An English variety, deseribed in Lindley as of rather tender habit in tree.

Fruit large, round, flattened next the stalk. Skin thick, of a fine amber color, mottled with red and yellow. Flesh pale yellow, slightly tinged with red, juicy, exeellent. Middle of July.

\section{Americhan Amber.}

\section{Bloodgood's Amber. Bloodgood's Honey. Bloodgood's New Honey.}

Raised by the late Daniel Bloodgood, of Flushing, Long Island. A vigorous tree, productive.

Fruit of medium size, roundish heart-shaped, slightly indented at the apex. Skin thin, smooth, light amber, delicately mottled and overspread with bright red. Stalk long and slender, inserted in a slight narrow cavity. Flesh tender, abounding with a sprightly, though not highflavored juice. Ripe about the 25 th of June.

\section{Aimerican Heart.}

Its origin is uncertain. The tree is quite luxuriant, with widespreading branches. Prodnctive.

Fruit pretty large, heart-shaped, often nearly four-sided, and irregular in its outline--borne in elusters. Skin at first pale, not becoming covered with light red or pink, mixed with very little amber. Stalk latiler long and slender, inserted in a small and shallow cavity. Flesh half tender and crackling, adhering to the skin, which is rather tough. Juice abundant, and in dry seasons sweet aud excellent, but rather wanting in sweetness in cool or wet seasous. Ripens early in Jume.

\section{ANNE.}

A very productive early variety. Received from A. V. Bedford, Paris, $\mathrm{Ky}$.

Fruit medium to small, bright red, tender, juiey, very sweet, and excellent, a good amateur's fruit, growth modernte. Ripe with Early White Heart, or soon after.

Argental's Late.

\section{Bigarreau Tardive d'Argental.}

A Cherry from France, of rather spreading haljit, with irregular, rather slender branches, the fruit in form unlike any other cherry. 
Fruit medium, elongated oval. Sides compressed, narrow suture. Stalk medium, slender, in a small cavity. Skin deep purplish black. Flesh half tender, juicy, sweet. Very good. Stone small, narrow, elongated oval. Ripens July 10.

Baumany's MTay.

Bigarreau de Mai.

Wilder's Bigarreau de Mai.

Of foreign origin. A very productive, early variety; of vigorous growth, of good quality, but not equal to E. P. Guigne.

Fruit rather small, oval heart-shaped, and rather angular in outline. Skin deep rich red, becoming rather dark when fully ripe. Stalk an inch and three-fourths long, pretty stout at either end, and set in a very narrow and rather irregular cavity. Flesh purplish, tender, juicy, and when fully ripe, tolerably sweet and good. Ripens here the 20th of May.

\section{Belle Agathe.}

\section{Autumn Bigarreau. Belle Agathe de Novembre.}

A variety from Belgium. Tree vigorous, hardy, good bearer.

Fruit small, roundish oval, depressed at ends, yellow, mostly covered with red. Flesh firm, hard, sweet, moderately juicy. Stone large Valuable only because of its time of ripening, late in August.

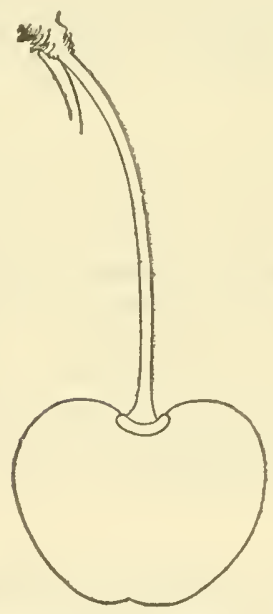

Belle d'Orleans.

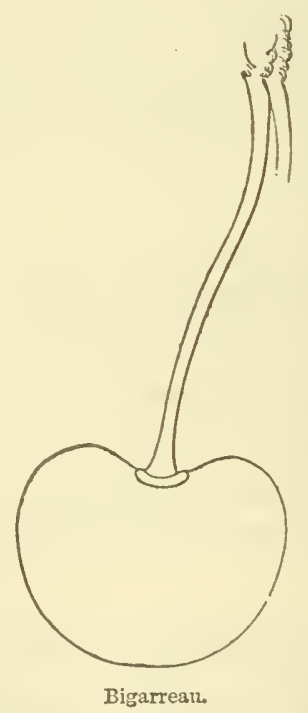

BELLE D'ORLEANS.

A foreign variety, ripening just after the Early Purple Guigne. Tree a vigorous grower, spreading habit, productive, and a valuable addition to the early kinds.

Fruit above medium size, roundish heart-shaped. Color whitish yellow, half covered with pale red. Flesh tender, very juicy, sweet, and excellent. Ripens early in June. 
Bigarreau.

Graffion.

White Bigarreau.

Turkey Bigarreau?

Italian Heart.

West's White IIeart.

Groote Princess.

Prinzessin Kirsche.
Yellow Spanish.

Amber. or Imperial.

Bigarreau Royal.

Bigarreau Gros?

Bigarreau Tardif.

Hollandische Grosse.

Cerise Ambrée.

This noble fruit is unquestionably one of the largest, most beantifu?, and delicious of Cherries.' It was introduced into this country about the vear 1800, by the late William Prince, of Flushing, and has been very extensively disseminated under the names of Yeliow Spanish, Graffion, and Bigarreau. The tree is short, but thrifty in growth, making strong lateral shoots, and forming a large and handsome head with spreading branclies.

Fruit very large, and of a beautiful waxen appearance, regularly formed, olstuse heart-shaped, the base a good deal flattened. Stalk stout, nearly two inches long, inserted in a wide hollow. Skin pale whitish yellow on the shaded side, bordered with minute earmine dots, and deepening into bright red, finely marbled on the sunny side. Flesh pale yellow, quite firm, juicy, with a rich, sweet, and delicious flavor if allowed fully to ripen. In perfection the last of June.

\section{Bigarreau Gros Ceeuret.}

Large Heart-shaped Bigarreau. Bigarreau Gros Monstrueux. Bigarreau Coeur de Pigeon. Bigarreau Marcellin.

Gros Cœuret.

This, the true Large Heart-shaped Bigarreau, is a French variety only rarely seen in the fruit gardens of this country.

Fruit large, roundish heart-shaped, with a suture line frequently raised, instead of being depressed. Skin at first yellowish red, marked with deeper red streaks, but becoming, when fully ripe, a dark shiniug red, almost black. Stalk inserted in a shallow hollow. Stone oval and rather large. Flesh firm, purplish, a little bitter at first, but of a sweet flavor when fully matured. Ripe first week in July.

\section{Bigarreau Jaboulay.}

Bigarreau de Lyon.

This is a fine large, early Bigarreau. Skin covered with elear red. Stalk an inch and a half long. Flesh firm, juicy, richly flavored, and delicious. End of June. (Hogg.)

Some years since we receiverl a Bigarreau de Iyyon from Lewis B. Eaton, of Buftalo, N. Y., he having purchased it from a lot of imported French trees. The label being lost, the above name was given, and as it has been so disseminated, we continue it and give description to aid in its identity. The tree is a free grower, with long, sprending, somewhat pendulous branches.

Fruit liurge, heart-shaped, somewhat irregular compressed. Suture slight. Skin deep red, almost black at maturity. Stalk rather loug, slender, curved, set in a round narrow cavity of moderate depth. 
Flesh reddish purple, half tender, juicy, sweet, rich. Very goorl. Early July.

\title{
Bigarreau of Mezel.
}

\author{
Great Bigarreau? \\ Great Bigarreau of Mezel. Mlonstrous de Mezel. \\ Bigarreau Gaubalais.
}

A foreign variety of the largest size, and, so far as we can judge, iden tical with Great Bigarreau and Large Red Prool. This is however doubted by some. The tree is a very vigorous grower, forming a wide. spreading open head, bearing its fruit on spurs along the limbs or branches.

Fruit very large, obtuse heart-shaped. Surface uneven, dark red, or quite black at maturity. Stalk long and slender. Flesh firm and juicy, but not ligh-Havored. Ripe last of June and beginning of July.

\section{Bigarreau Riverchon.}

A late Cherry, described by Rivers as large, dark red, nearly black. Flesh rich. July.

\section{Bill axd Coo.}

A variety that originated on the grounds of Prof. J. P. Kirtland, Cleveland, O., and took its name from the tree being the haunt of two young lovers. Tree vigorous and productive.

Fruit medium, regular, heart-shaped, flattened at apex. Stalk long, slender: Sides high. Color amber yellow ground, marbled with clear rich red. Suture

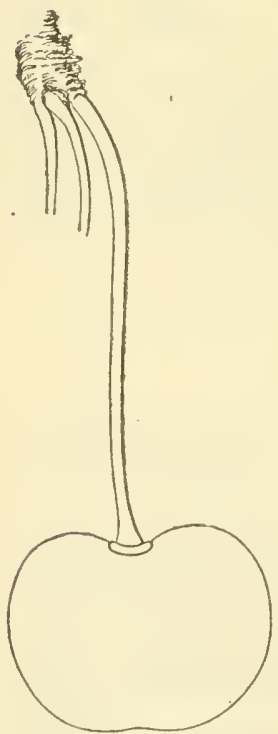

Black Eagle. half round, broad, opposite sicie knobby. Flesh rich, delicate, sweet. Early in June, but hangs a long time without decaying. (Elliott's Notes.)

\section{Black Bigarreat of Savoy.}

New Large Black Bigarreau. Bigarreau Noir de Saroi. Bigarreau Noir.

An Italian varietr, of very vigorous growth; hardy and productive. Toung wood (juite dark.

Fruit large, regularly heart-shaped, very slightly obtuse. Skin smooth and even on the surface, not very glossy, quite liack at maturity. Stalk an inch and three-fourths long, rather stout, set in a narrow even hollow. Flesh purple, quite firm and solid, with a rich but not abundant juice. Stone rather large. Ripe middle of July.

\section{Black EAgLe.}

A very excellent English variety, raised by the daughter of $\mathrm{Mr}$. Knight, at Downton Castle, in 1806 , from the seed of the Bigarrean fertilized by the Maycluke. It ripens at the begimning of July, or a few days later than the Black Tartarian. 
Frnit rather above medium size, borne in pairs and threes, olntuse heart-shaped. Skin decp purple, or nearly black. Stalk of mediun length, and rather slencler. Flesh deep purple, tender, with a rich, high-flavored juice, superior to the Black Heart. Branches strong, with large leaves. Moderate bearer.

\section{BLACK HAWK.}

Originated with Dr. J. P. Kirtland, Cleveland, Olio. The tree is of healthy, vigorous, spreading habit, with much of the general character of Yellow spanish. As a table fruit, its high flavor will always commend it; while as a market fruit, its size and productive habit of tree place it among the rery best.

Fruit large, heart-shape, often obtuse. Sides compressed. Surface uneven. Color dark purplish black, glossy. Flesh dark purple, half tender, alnost firm, juicy, rieh, sweet, fine flavor. Stason from 20th June to 1st July.

\section{BLACK HEART.}

Early Black.

Ansell's Fine Black.

Spanish Black Heart.

Black Russian.
Black Caroon.

Guinier à fruit noir.

Guigne grosse noir.

Grosse Schwarze Hertz Kirsche.

The Black Heart, an old varic $y$, is better known than almost any other Cherry in this country, and its great fruitfulness and good flavor, together with the hardiness and the large size to which the tree grows, render it everywhere esteemed.

Fruit above medium size, heart-shaped, a little irregular. Skin glossy, dark purple, becoming deep black when fully ripe. Stalk an inch and a half long, slender, set in a moderate hollow. Flesh, befors fully ripe, half tender, but finally beeoming tender and juicy, with a rich, sweet flavor. Ripens the list of June, about ten days after the Mayduke.

\section{Black MAZZard.}

Mazzard.

Common English.

- Wild English Cherry.

Black Honey.

Iiristol Cherry.

Cerasus avium.

Will Black Fruited.

Small Wild Black.

\author{
Whixley Black. \\ Merry Cherry. \\ Herisier à petit fruit. \\ Merisier à petit fruit noir. \\ Corone. \\ Caroon. \\ Couronue. \\ Large Wild Black.
}

This is the wild species of Europe, being common in the forests of France and some parts of England; and it has now become naturalizerl, and grows spontaneously throughout most portions of the settled States. It is the original speeies from which nealy all the fine Heart and other sweet elerries have sprung. It is small, and of little value for eating, retaining, umless very ripe, a certain bitterness; but it ripens and langs on the tree until the niddle or last of July, so that it then becomess somewhat arceptable.

Fruit small, roundish or oval heart-shaped, flattened a little on both sides. Stalk long and very slenrler; inserted in a small depression. 
Skin thin, and when fully ripe, jet black. Flesh soft and melting, purple, with an abundant somewhat bitter juice.

'The Wrute Mazzand of Mr. Manning is a seedling raised by that pomologist, which differs little except in its color.

\section{Black Tartarian.}

Tartarian.

Black Circassian.

Ronald's Heart.

Fraser's Tartarische.

Bishop's Large.

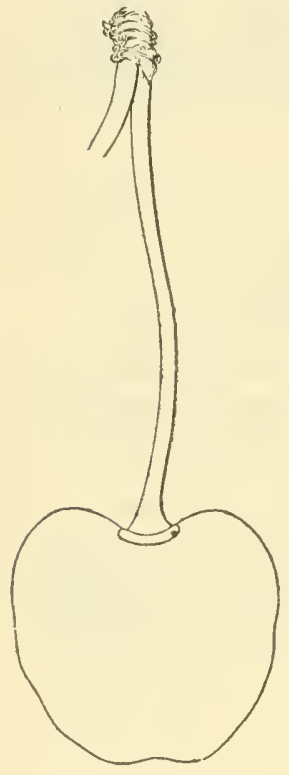

Black Tartarian.

Fraser's Black Tartarian. Ronald's Large Black Heart. Superb Circassian. Fraser's Black Heart. Schwal'ze Herz Kirsche. Circassian.

Fraser's Black.

Black Russian.

Double Heart.

This superb fruit has become a general favorite in all our gardens; and in size, flavor, and productiveness it has no superior among black cherries. It is a Russian and West Asian variety, introduced into England about 1796, and brought thence to this country. It is remarkable for its rapid, vigorous growth, large leaves, and the erect habit of its head. The fruit ripens about the middle of June, a few days after the Maydeke.

Fruit of the largest size, heart-shaped (sometimes rather obtuse), irregular and uneven on the surface. Skin glossy, bright purplish black. Elesh purplish, thick (the stone being quite small), half-tender, and juicy. Flesh very rich and delicious.

\section{Boliemian Black Bigarreau.}

Bigarreau Radowesnitzer.

Foreign.

Fruit very large; roundish heart-shape, very even and regular in outline. Skin shining jet black. Stalk short, stout, dark green. Flesh quite black, firm, juicy, richly flavored and delicious. Season early July. (Florist and Pomologist.)

\section{Bowyer's Eirly Heart.}

Medium size, obtuse heart-shaped. Skin amber, mottled and shaded with red. Elesh tender, juicy, with a pleasant vinous flaror, Distinct from Early White Heart. lipens immediately after.

\section{Braxdiwe.}

Originated near Wilmington, Del. Tree vigorous, spreading, productive.

Fruit large, roundish obtuse heart-shape, almost without suture. Skin yellowish, beantifully mottled and marbled with light crinson mud lake, small light dots. Stalk long, slender, in a moderate cavity. Flesh tender, juicy, sprightly acidulous. Fine for culinary uses. Stone rather large. Last of June. 


\section{Brant.}

Origin, Cleveland, Olico. 'Tree vigorous, with large foliage and spreading, of rather round, regular form.

Fruit large, rounded angulir heart-shape. Sides slightly eompressed. Color reddish black. Flesh dark purplish red, half tender, juicy, sweet, and rich. Very good. Season early or middle of June.

\section{Brown's SEedlixg.}

Origin, Connecticut. Tree vigorous, upright.

Fruit medium, obtuse heart-shaped, compressed witl a line and slight suture. Stalk in a broad cavity. Skin whitish, shaded and mottled with red. Flesh half tender, juicy, sweet. Good. Early July.

\section{Burr's Seedling.}

Origin, Perrinton, Monroe Co., N. Y. Tree a vigorous spreading grower, productive.

Fruit large, heart-shaped, whitish yellow shaded with light red, and isometimes mottlęd. Flesh nearly tender, with a sweet, rich, excellent flavor. Very good. Ripe the last of June.

\section{'Buttaer's Black Heart.}

From Germany. 'Tree a vigorous grower.

Fruit large, heart-shaped, almost black. Flesh purplish, firm, juicy, not very rich. Good. Fipe middle of July.

\section{ButTixer's Yellow.}

Büttner's Wachs-Ǩnorpel Kirsche.

Büttner's Gelbe-Knorpel Kirsche.

Raised by Biittner, of Halle, in Germany, and one of the few Cherries entirely yellow.

Fruit of medium size, roundish. Skin pale yellow. Flesh firm, yellowish, sweet, aud not of much value. Ripe first week in July.

\section{Carmine Stripe.}

Raised by Prof. J. P. Kirtland. Tree vigorous, healthy, spreading. Very productive.

Fruit above medium, heart-shaped. Suture lialf round, followed by a line of carnine. Color amber yellow, shaded and mottled with bright, lively carmine. Flesh tender, juicy, sweet, sprightly, and agreuable. Very good. Stalk varies. Season, last of June.

\section{Caroline.}

One of Prof. J.P. Kirtland's originating. Tree a vigorous, somewhat upright spreading habit, very productive, and an exceedingly delicious fiuit for the dessert.

Fruit above merlium, round oblong, one side eompressed slightly. Color pale arnher, mottled with clear light red, and when fully exposed to the sun becomes rich recl. Flesh very tender, juicy, sweet, and delicate. Very good or best. Season last of June. 


\section{BrRxsville.}

Origin, Dutchess Co., N. Y. Tree vigorous, spreading, productive.

Fruit medium to large, nearly globular, slight apex. Skin yellowish, shaded and mottled with light and dark red. Stalk medium or short. Flesh rery tender, juicy, brisk subacid. Good. Last June.

\section{Champagne.}

Originated at Newburgh, N. Y. Tree of moderate growtl, and forms a round head.

Fruit of medium size, roundish heart-shaped. Color lively brick red, inclining to pink, a little paler on the shaded side. Stalk of moderate length and size, inserted in a rather flat shallow dejression. Flesh amber-colored, of a lively rich flavor, a mingling of sugar and acid, something between Downer's Late and a Duke cherry, a good bearer, and ripens uniformly and hangs some time on the tree. Tery good. Season last of Jine.

\section{China Bigarreau.}

\section{Chinese Heart.}

Eruit of medium size, roundish heart-shaped, light amber, mottled and shaded with bright red. Flesh firm, with a sweet, peculiar flavor. Good. Ripe last of June.

\section{Clevelaxd.}

Cleveland Bigarreau.

Raised by Professor J. P. Kirtland, a thrifty strong grower, spreading, productive, and a fine fruit.

Fruit large, round heart-shape. Suture pretty broad, nearly halfround. Color bright clear red on yellowish ground. Flesh fine, juicy, rich, sweet, and fine flaror. Ripe a few days before Black Tartarian. Very good.

\section{Cocklis's Favorite.}

\section{Late Amber.}

Origin unknown. Introciuced by E. H. Cocklin, Shepherdstown, Pa. Tree upright, conical, vigorous, and exceedingly productive.

Fruit large, roundish, regular, a little compressed, somew hat flattened al base, almost without suture. A pex sunk. Skin yellowish shaded, and somewhat mottled in the sun with light crimson. Stalk long and slender, in a deep smooth cavity. Flesh tender, juicy, sweet, vinons. Very good. Stone very small. Ripens a little later than Downer's Red.

\section{Cof's Traxspaliext.}

Originated with Curtis Coe, of Middletown, Conn. A productive and valuable addition to the amateur's collection, but rather too tender for carriage to market. 'T'ree vigorous and hardy, with a round and somewhat spreading head. 
Fruit of medium size, remarkably round and regular in form. Skin thin, wax-like, of a very lelicate pale amber, nearly covered with pale cornelian red in the sun, and marked with delicate pale spots or blotches, which gire it a mique appearince. Stalk set in a deep depression of moderate deptl. Flesh very tender, melting, and jnicy, with a delicate but sweet and excellent flavor. Best. Ripens just before Black Tartarian.

\section{Columeis.}

Origin mknown. Tree vigorous, spreading, productive. Fruit medium, heart-shaped, inclining to a point. Surfice angular and uneven. Sides compressed. Suture dee.p and niurow. Stalk long and slender, in a large deep eavity. Skin whitish yellow, shiaded and mottled with light red. Flesh whitish, slightly stained with pink, tender, juicy, pleasant. Good. Larst of Jume.

\section{Conestoga.}

Origin, Lancaster Co., Pa. Introduced by Caspar Hiller. Tree a very vigorous spreading grower, and abundant bearer.

Fruit medium, obtuse, heart-shaped, slightly compressed. Suture shallow. Apex small. Stalk long. Cavity deep, large. Skin deep red or purplish, somewhat mottled. Flesh reddish, almost tender, juicy, brisk. Good. Early July.

\section{CORNELia.}

Originated by Charles Pease, near Cleveland, $\mathrm{O}$. Tree rigorous, u1). xight sprending, very productive.

Fruit medium to large, heart-shaped, compressed. Suture slight. Skin whitish yellow, shaded with rich bright crimson when fully exposed to the sun. Stalk long, in a narrow deep earity. Flesh light yellow, tender, juicy, sweet, and lively flavor. Very good. Stone small. Last of June.

\section{DACOTAIr.}

A new variety, originated by Charles Pease, Sen., near Cleveland, O. The tree resembles Rockport in habit of growth, very productive.

Fruit medium to large, heart-shapeul, compressed. Suture shallow, with projection and dark line on the opposite side. Stalk long, slender, pretty deep, rather narrow cavity. Skin rich dark rerl, almost black. Surfice a little uneven. Flesh purplish, tender, juicy, sweet. Very good. Stone medium. Ripe just after Black Tartarian.

\section{DAVENPORT.}

\section{Davenport's Early Black. Davenport's Early. New Mayduke.}

Origin, Dorchester, Mass. Tree of moderate upriglit growth, dis. tinct frum Blick Heart, an early aud good bearer. 
Fruit above medium size, roundish heart-shaped. Stem an inch and a half long, rather stout, in a medium cavity. Color dark purplish black. Flesh tender, juicy, and pleasant. Ripe about the time of Mayduke or just before. Trery good.

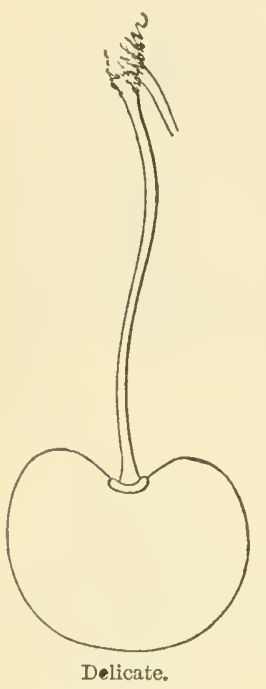

\section{Delicate.}

Raised by Prof. J. P. Kirtland, Cleveland, O. Tree thrifty, rather spreading habit, productive, and its beautiful appearance and delicate flaror will make it a favorite for family use.

Fruit rather above medium size, roundish, slightly depressed. Stem medium length, in a rather broad deep cavity. Color fine amber vellow in the shade, with a rich bright red on the sunny side. Flesh tender, juicy, sweet, with a delicate rich flavor. Best. Ripens the last of June.

\section{DOCTOR.}

The Doctor:

Tree a free grower, somewhat spreading, very productive, apt to be small unless well cultivated.

Fruit of medium size, roundish heart-shaped. Stalk of medium length, in a round regular cavity. Color light yellow, mostly shaded with bright red. Flesh tender, juicy, and pleasant. Tery good.

Ripens early in June.

\section{Doulin Bigarreau?}

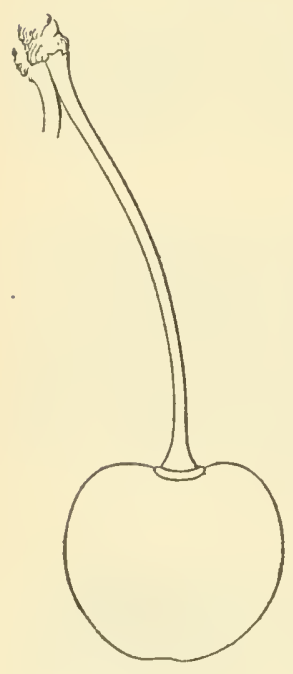

A foreign variety, which may be distinct, but doubtful. Tree a rapid, spreading grower, an early bearer.

Fruit large, heart-shaped, compressed on one side. Suture slight. Stalk slender, curved. Cavity deep. Skin dark purplish red. Flesh pinkish, rather tender, juicy, sweet, pleasant. Good to very good. Early June.

\section{DOWXER's LATE.}

\section{Downer. Downer's late Red}

This valuable late Cherry was raised by Samuel Downer, Esq., an ardent cultivator, of Dorchester, near Boston. It is a very regular and great bearer, ripens about a week after the Cherry season, and hangs for a considerable time on the tree.

Fruit of medium size, roundish heart-shaped, inclining to oval. Skin very sinooth, of al soft but lively red, nottled with a little amber in the 
shade. Stalk inserted with a very slight depression. Fruit borne thick. ly, in clusters. Flesh tender, melting, with a sweet and luseious flavor. Ripens from the 4 th to the loth of July.

\section{Downixg's Red CIIEeK.}

Originated at Newburgh, N. Y. Tree vigorous, upright spreading, productive.

Fruit rather large, regularly obtuse heart-shaped, with a pretty distinct suture. Skin thin, white, with a rich dark crimson cheek (somewhat mottled). Stalk an inch and a lialf loug, set in an even hollow of moderate depth. Flesh yellowish, half tencler, and of a very delicate sweet. Very good. Ripens about the 14th of June.

\section{Dowrtos.}

A variety raised by T. A. Knight, Esq., of Downton Castle, from the seed, it is believed, of the Elton. Tree having a round spreading head, moderately productive.

Fruit large, very blunt heart-shaped, nearly roundish. Stalk one and a half to two inches long, slender, set in a pretty deep, broad hollow. Skin pale cream color, semi-transparent, delicately stained on one side with red, and marbled with red dots. Flesh yellowish, withont any red, tender, adhering slightly to the stone, with a delicious rich flavor. Very good. Last of June.

\section{Drogan's Thite Bigarreau.}

Bigarreau Blanc de Drogan.

Fruit heart-shaped, pointed at apex, flattened on one side, yellow, mottled and flushed with red in the sun. Stalk stout. Flesh firm, sweet.

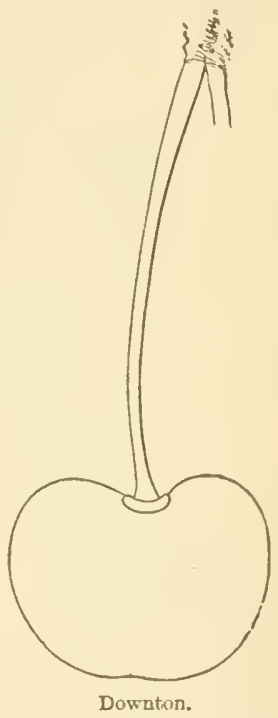
(Hogg.)

\section{Drogan's Yrllow BigarreaU.}

Bigarreau Jaune de Drogan.

Drogan's Gelbe Knorpelskirsche.

Fruit large, round. Skin clear pale yellow. Flesh very juicy, sweet, and pleasant. Middle July. (Hogg.)

\section{Early Buack Bigarreau.}

Fruit larg?, heart-shapel. Skin jet black. Stalk rather long. Flesh dark purple, firm, sweet. Ripe middle of June. (Hogr.)

\section{Early Lamaurie.}

A variety described by Rivers, not yet finited in this country.

Fruit large, dark purple. Flesh rich, juicy, excellent. il week earlier than Early Purple Guigne. 


\section{EARly Ltons.}

Rose de Lyons.

This, to our knowledge, has not yet been introduced to this country. Rivers, the celebrated English pomologist, deseribes it as :

Fruit very large, light red and yellow. Flesh juicy, rich, excellent. Ripens about a week later than Early Purple Guigne.

\section{Early Prolific.}

Raised by Dr. J. P. Kirtland, Cleveland, Ohio. An excellent earì, very prolific variety, of moderate growth.

Fruit medium size, round obtuse heart-shape, light yellow ground, shaded and mottled with bright red. Stalk long. Flesh half tender, juiey, rich, sweet, and very goor. Ripe about a week before Mayduke.

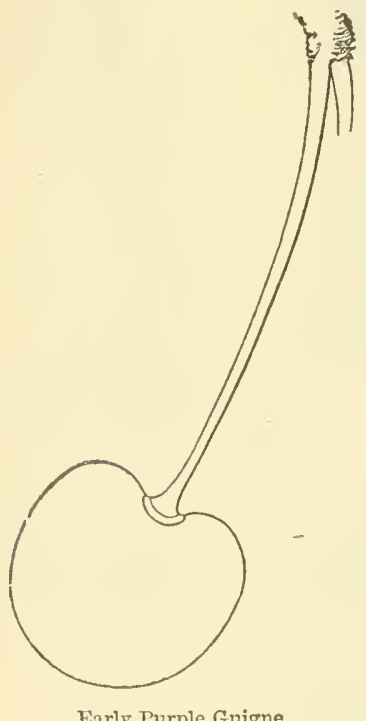

Early Purple Guigne.

\section{Early Purple Guigne.}

Early Purple Griotte.

German Mayduke.

Trempe Précoce.

Origin unknown. An exceeclingly early variety, ripening the last of May in favorable seasons. Tree hardy, free grower, spreading, somewhat pendent, and the leaves have longer petioles than most other sorts; a good bearer, and indispensable among the early rarieties.

Fruit medium size, roundish heart. shaped. Stem long, inserted in a rather shallow cavity. Suture indistinct. Skir smooth, dark red, becoming purple at maturity. Flesh purple, tender, juicy, with a rich and sweet flavor. Grood to very good.

Has proved hardy at the West, and well adapted to that climate.

\section{Early Red Bigarreau.}

Bigarrean Rouge de Gouben.

An excellent early Cherry, the tree somewhat of the habit of a Duke in its growth.

Fruit large, heart-shape, bright red, translucent. Stalk long. Flesh firm, rich, sweet, cxcellent. Early June. (Hogg.)

\section{Early White Heart.}

$\begin{array}{ll}\text { Arden's Early White Heart. } & \text { White Transparent. } \\ \text { White Heart. } & \text { Amber Heart. } \\ \text { Dredge's Early White Heart. Swedish. }\end{array}$

Herefordshire White.

An old variety. Tree vigorous, roundish upright, although a good early fruit. It is not equal to Belle D'Orleans, Early Prolific, and others of the same season. 
Fruit below medium size, rather heart-shaped-often a little onesiderl. Suture quite distinct. Stalk an inch and three-fourths long, rather slender, inserted in a wide shallow cavity. Skin dull whitish rellow, tinged and speckled with pale red in the sun. Flesh half tender, inless fully ripe, when it is melting, with a sweet and pleasant. flavor.

Good. First of June. Manning's Early White siniiar to above.

\section{Elizabetif.}

Originated by Caleb Atwater, Ohio. Tree vigorous, upright, very prólific.

Fruit medium to large, heart-shaped. Skin rich dark red when fully ripe. Flesh half-tender, juicy, pleasantly sweet. Good. Ripe middle to last of June.

\section{ELTox.}

Bigarreau Conleur de Chair.

Flesh-colored Bigarreau.

Gros Bigareau Couleur de Chair.

Grus Bigarreau Blanc.

Bigarreau à Gros Fruit Blanc.

Large Heart-shaped Bigarreau.
Bigarreau de Rocmont.

Cueur de Pigeon.

Belle de Rocmout?

Elton Kirsche.

Elton's Bunte Knorpelkirsche.

The Elton, a seerlling raised in 1806, by the late President of the London Horticultural Society, is certainly one of the first of Cherries in all respects. The trees grow very vigorously, and are readily known, when in foliage, by the unusually dark red color of the foot-stalks of the leaves.

Fruit large, rather pointed heart-shaped. Skin thin, shining, pale yellow on the shaded side, but with a cheek next the sun delicately mottled and streaked with bright red. Stalk long and slender. Flesh somewhat firm at first, but becoming nearly tender, juicy, with a very rich and luscious flavor, not surpassed by any large Cherry known. Ripens about the middle of June, or directly after the Mayduke.

\section{Esperey Bigatreate. \\ Bigarreall d'Eapcrin. \\ Ligarreau des Vignes.}

Tree vigorous, rather sprealing, productive.

Fruit large, roundish heart-shaped. Skin yellowish white, mottled and sharled with bright rich red. Stalk long, rather slender, inserted in a large cavity. Flesh rather firm, juicy, and good thavor. Gool. Ripe midlle of July. This may yet prove the same as Napoleon Bigarreau.

\section{FATORITE}

\section{Elliott's Favorite.}

'Tree vigorous and productive.

Fruit snall to mediun. Stalk long, rathei slender, in a slight de• 
pression. Color pale yellow, with a light red cheek, somewhat marbled. Flesh tender, juicy, sweet, and of a delicate flavor. Very good. Ripe last of June.

\section{Florence.}

\section{Knerett's Late Bigarreau.}

A most excellent Cherry, originally brought from Florence, in Ialy, which considerably resembles the Bigarrean, but ripens a little later, and has the additional good quality of hanging a long time on the tree.

Fruit large, roundish heart-shaped, flattened at base, pale anber, mottled or mostly covered with bright red. Flesh amber color, firm, rich, sweet, fine Havor. Very good. Stone small. Middle July.

\section{Frogurore Early Bigarreau.}

An early Cherry of recent introduction. It is described in the Lon. don Florist as "large, obtuse heart-shaped. Skin with a brilliant red cheek, dotted with minute yeilow points. Flesh delicate, translucent, tender, juicy, rich sweet flavor. Ripens before any fruit of its class."

$$
\text { GAS:OITNE'S HEART. }
$$

Bleeding Heart.

Red Heart.
Herefordshire Heart. Guigne Rouge Hâtive.

An old English variety.

Fruit of medinm size, long heart-shaped, small drop or tear at the end. Skin dark red. Flesh reddish, half tender, with only a tolerable

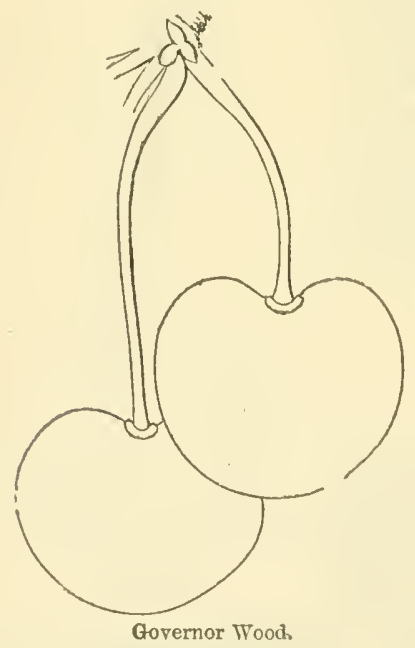

GrIDLET. Havor. Poor. Ripe the last of June. A bad bearer.

\section{Gifford's Seedling.}

Small, roundish heart-shaped. Light red, very sweet. Hardly good. Pro. ductive, last of June.

\section{Gortertor Wood.}

Raised by Professor Kirtland, Cleve. land, 0 . It deserves a place in every good collection. Tree vigurous, forming a round, regular head, rery productive.

Fruit large, roundish lieart-shaped. Skin light yellow, shaded and marbled with bright red. Suture half round. Stem an incl and a half long, in a broad cavity. Flesh nearly tender, juicy, sweet, rich, and delicious. Tery good to best Ripe about the middle of June.

Apple Cherry.

Fruit mediun, roundish, black. Flesh firm, not very juicy nor rich. Ripens last of Jume. Poor. Productive. Origin, Massachusetts. 


\section{Grosse de W AGNellee.}

Originated in Belgium. Tree vigorous, productive.

Fruit large, oval. Skin yellow, washed and spotted with red. Flesh tender juicy, sweet. July. (Alb. T'om.)

\section{Guigne Très Précoce.}

Rivers says of this :

Fruit rather small, round, dark purple. Stalk very short. Flesh very sweet. One of the earliest to ripen, and a great bearer.

\section{Hexsel's EARLY.}

Origin, Lancaster, Pa. Tree a moderate grower, hardy, and productive.

Fruit roundish, obtuse at base. Stalk slender. Flesh half tender, moderately juicy. Good. Early June. (Hort.)

\section{Hildesheim Bigarreau.}

Bigarreau Tardif de Hildesheim.

Bigarreau marbr' de Hildesheim.

Bigarreau Blanc Tardif de Hildesheim.

Hildesheimer ganz Späte Knorpel Kirsche.

Hildesheimer späte Herz Kirsche.

Späte Hildesheimer Marmor Kirsche.

The Hildesheim Bigarreau is a German vatiety which ripens here in August.

Fruit of medium size, heart-shaped. Skin yellow, mottled and marbled with red. Flesh pale yellow, firm, with a sweet and agreeable flavor. Good.

\section{Hoadley.}

Raised by Prof. Kirtland. Tree of healthy, vigorous habit, forming a round, spreading head.

Fruit above medium, regular round heart-shape, light clear carmine red, mottled and striped on pale yellow. Flesh tender, juicy, rich, sweet, and delicious. Very good. Season, 20th to last of June.

\section{Honey.}

Large Honey.

Yellow Honey.
Late Honey.

Mérisier à fruit blanc.

A small, late, very sweet fruit, formerly much esteemed.

Fruit small, roundish, yellow and red. Flesh tender, very sweet. Middle of July.

\section{Hovey.}

Originated with C. M. Horey, Boston, Mass. Tree vigorous, upright spreading, productive. 
Fruit lirge, heart-shaped, compressed on one side with a distinct line from apex to stalk. Stalk medium. Cavity deep. Skin whitish yellow, shaded and mottled with rich shades of red. Flesh rather firm, juicy, sweet, pleasant. Very good. Middle of July.

\section{Hrde's Late Black.}

Origin, Newton, Mass. Strong grower and good bearer.

Fruit medium, obtuse heart-shaped, purplish black. Flesh half firm, juicy. Good. Ripe first week in July.

\section{Hrde's Red Heart.}

Origin, Newton, Mass. Tree vigorous, productive.

Fruit medium, heart-shaped. Skin pale, but becoming a light red at maturity. Flesh tenrler, sprightly. Ripe last of June.

\section{Foreign.}

\section{Jaune de Prusse.}

Tree vigorous, with long slender branches, productive, small, heart-shaped, light yellow,

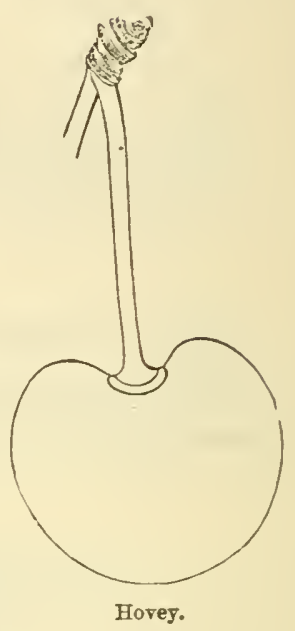
translucent. Stalk long and slender. Flesh yellowish-white, tender, juicy sweet, a little bitter before fully ripe, which is soon after Downer's Late.

\section{Jocosot.}

Origin near Cleveland, $\mathrm{O}$.

Fruit large, very regular, uniform heart-shape, slightly obtuse, anıl with a deep indenture at apex. Surface uneven. Color rich glossy dark liver color, almost black. Flesh tender, juicy, with a rich sweet flavor. Very good. Season, near the last of Jume.

\section{KехNicotт.}

Raised by Prof. Kirtland. Tree vigorous, hardy, spreading. Very productive.

Fruit large, oval heart-shape, compressed. Suture shallow, half round. Color amber yellow, mottled and much overspread with rich, bright, clear, glossy red. Flesh firm, juicy, rich, aud sweet. Very good. Season, 8th to 10th July.

\section{КЕокUK.}

Originated by Prof. J. P. Kirtland. Tree a strong, vigorous grower, forming a large tree.

Fruit large, heart-shaped, dark purplish black. Flesl half tender, rather coarse, and deficient in Havor. Hardly good. Its chief merit a market variety. Ripe early in July.

\section{Kirthayd's Mamuoth.} bearer.

Originated by Prof. Kirtland. Tree vigorous grower, but poor 
Fruit of the largest size, obtuse heart-shaped. Color bright clear yellow, partially overspread and marbled with rich red. Flesh almost tender, juicy, swcet, with a very tine high flavor. Very good, or best. Season, last of June.

\section{Kirtland's Mary.}

Raised by Prof. Kirtland. Tree a strong, upright grower, suid to be one of the best of his seedlings, and desirable either for the dessert or market purposes.

Fruit large, roundish heart-shape, very regular. Color light and dark rich red, deeply marbled and mottled on a yellow ground; grown fully in the sun, is mostly a rich, dark glossy red. Flesh light yellow, quite firm, rich, juiey, sweet, and very high flavored. Very good or best. Season, last of June and first of July.

\section{Knight's Early Black.}

A most admirable early Cherry, resembling the Black Tartarian, though much more obtuse in form, but ripening nearly a week earlier. Tree spreading. Moderately productive.

Fruit large, a little irregular in outline, obtuse heart-shaped. Stalk of moderate length, rather stout, and inserted in a deep open cavity. Skin dark purple, becoming black. Flesh purple, tender, juicy, with a rich and sweet juice of high flavor.

\section{LADY OF THE LAKE.}

Originated by Charles Pease, Sen., near Cleveland, $\mathrm{O}$. Tree vigorous, upright spreading, productive.

Fruit medium to large, roundish obtuse conic, compressed, shallow suture, a knob, and line on opposite side. Skin light yellow, shaded and marbled with rich bright crimson. Stalk medium, in a deep cavity. Flesh half tender, pale

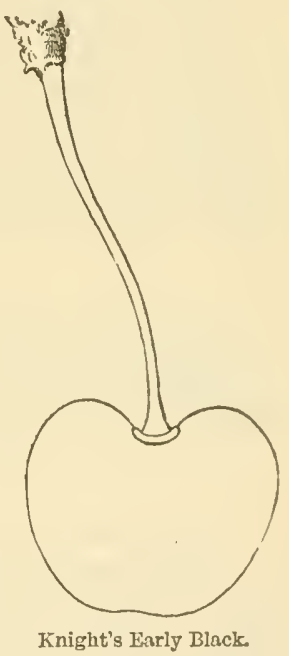
ye'low, juicy, sweet. Very good. Midlle to last of June.

\section{Lady Southaypton's Yellow.}

Lady Southampton's Duke. Golden Drop.

\section{Yellow or Golden.} Spanish Yellow.

Fruit of medium size, heart-shaped. Skin yellow. Flesh firm, not very juicy. Ripens about the middle of July.

\section{Large Red Bigarreau.}

Gros Bigarreau Rouge.

Bigarreau à Gros Fruit Rouge.

Fruit large, oblong heart-shape. firm. Early in July. Poor bearer.
Bigarreau à Gros Fruit Rouge. Belle de Rocmont.

Skin dark red in the sun. Flesh 


\section{Late Bigarreau}

Origiuated by Prof. Kirtland. Tree thrifty, moderate growth, rather spreading, productive.

Fruit large, obtuse heart-shaped. Skin deep yellow, shaded on the sumny side with bright red. Stalk long, inserted in a broad open carity. Flesh almost firm, juicy, sweet, pleasant flavor. Very good. Ripe last of Jume and first of July.

\section{Late Purple Guigne.}

A new foreign variety. July.

Fruit large, roundish, dark red. Flesh firm, juicy, sweet. Middle

\section{LAURA.}

Originated with Charles Pease, Sen., Cleveland, O. Tree spreading upright, productive.

Fruit medium to large, heart-shaper, globular, sometimes one-sider. Color pale yellow ground, mostly overspread with rich, bright red, without suture. Stem nedium or short, in a shallow depression. Flesh peach-blow white, radiating lines wavy, juicy, sweet, very rich, and high flavor, excellent, half or nearly tender. Pit medium to small. Season early in June, but hangs well.

\section{Leather Stocking.}

Raised by Professor Kirtland. Tree vigorous, upright spreading.

Fruit medium, heart-shaped, redclish black. Flesh firm, sweet. Middle to last of July.

\section{LiNCOLN.}

Originated near Cleveland, O. Tree vigorous, spreading.

Fruit large, oblong heart-shape, pointed. Color when ripe a brown red. Suture rather broad, shallow, half round. Stalk long. Cavity deep. Flesh almost firm, veined and marbled with shades of red, sprightly, juicy, sweet, and pleasant. Good. Stone above medium. First to midclle of July. A good market sort. (Elliott.)

\section{LINDLEY.}

Origin, near Cleveland, O. Tree vigorous, moderately prolific.

Fruit large, heart-shaped, dark purplish red. Flesh almost firm, tinged with red, juicy, but only good. Early July. (Elliott.)

\section{LOGAN.}

Originated with Prof. Kirtland.

Fruit medium or above, obtuse, sometimes regular heart-shaped, with a hollow indenture at apex. Color purplish black when ripe. Flesh nearly firm, juicy, sweet, and rich flavor. Very good. Season middle to last of June. 


\section{LuDWIG.}

Ludwig's Bigarreau. Bigarreau de Ludwig.

A Clierry of recent introlnction, not yet, to our knowlerge, fruited in this country. It is deseribed as large, heart-shaped, or pointed, with a deep suture on one side, bright rich red. Flesh pale yellow, half ten. der, juicy. Early June.

\section{Lundie Gean.}

Fruit medium, roundish, purplish black. Flesh tender, juicy. July,

\section{Madisox Bigarreau.}

Raised by Robert Manning, of Salem, Mass. Tree healthy, very prodictive.

Fruit of medium size, fair quality, roundish. Skin yellow, shaded with red. Flesh half teuder, juicy, with a pleasant flavor. Ripe middle or last of June. Good.

\section{Maritig's Early Black Heart.}

Raised by Robert Manning, of Salem, Mass. Tree vigorous, spreading.

Fruit medium, similar to the Black Heart, rather earlier and smaller in size. Ripe abont the middle of June.

\section{Manning's Late Black.} ductive.

Raised by Robert Manning, of Salem, Mass. Tree vigorous, pro-

Fruit large, roundish, deep purple or nearly black. Flesh purplish, half tender, very juicy, sweet, and excellent. Good. Ripe the last of June. Tree vigorons.

\section{MAxisg's MotTled.}

\section{Mottled Bigarreau.}

Raised by Robert Manning. It is a most abundant bearer. Tree vigorous, upright spreading.

Fruit rather large, roundish heart-shaped, Hattened on one side, with distinct suture lines. Skin amber color, finely mottled and overspread with red, with a semi-transparent, glossy appearance. Stalk slender, inserted in a shallow hollow. Flesh, when fully ripe, yellow, tender, with a sweet and delicious juice. Yery good. Ripens the last of June.

\section{Merveille de Septemire.}

Tardive de Mons.

A French variety, ripening in $A$ ugust, vigorous grower. Fruit small, firm, rather dry, sweet, but of little value.

\section{Moyer's Honey Heart.}

Originated in Bucks Co., Pa. Tree a strong grower, forming a round head. 
Fruit small or medium, obtuse heart-shape, slightly compressed. Suture small. Apex slight. Skin whitish, shaded and mottled with rich red. Stalk long, slender. Flesh yellow, juicy, sweet, pleasant, often adheres to the stone. Good. Middle July.

\section{Nancy.}

Originated by Charles Pease, Sen., Cleveland, O. Tree a vigorous, rather upright spreading grower. Very productive.

Fruit large, obtuse heart-shape. Suture slight. Stalk long, stout, in a large cavity. Skin palé yellow, shaded and mottled with crimson. Flesh tender, juicy, rich, and sweet. Very good. Stone small. Last of June.

\section{Napoleon Bigarreau.}

Bigarreau Lauermann.

Lanermann's Kirsche.

Lauermann's Grosse Kirsche.

Clarke's Bigarreau.
Lauermann's Herz Kirsche.

Holland Bigarreau?

Clarke's Superb.

The Napoleon Bigarreau is large, well-flavored, handsome, and pro ductive.

Fruit of the largest size, very regularly heart-shaped, a little inclining to oblong. Skin pale yellow, becoming amber in the shade, richly dotted and spotted with very deep red, and with a fine marbled dark crimson cheek. Flesh very firm (too much so), juicy, with an excellent flavor. Stalk very stout, short, and set in a narrow cavity. Ripens a few days after the Bigarrean, about the first of July, and is a good and constant bearer. Good. The fruit is not so obtuse as the Bigarreau.

Holland Bigarreau is so much like the above that we think it identical.

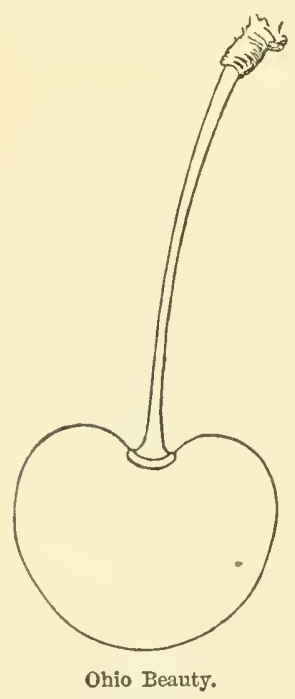

\section{Omo Beautr.}

Originated by Prof. Kirtland. Tree a vigorous grower, with a rather spreading head, and has proved so far a productive, valuable kind.

Fruit large, obtuse heart-shaped. Light ground, mostly covered with red. Flesh tender, brisk, juicy. Very good. Ripe about the middle of June.

\section{OSCEOLA.}

Originated with Prof. Kirtland. Moderate bearer and medium growth.

Fruit above medium, heart-shaped. Color fine dack red, approaching to black. Flesh juicy, tender, sweet, and excellent. Very good. Ripe last of June.

\section{Ox-Heart.}

Lion's Heart.

Bullock's Heart.
Very Large Heart.

Ochsen Herz Kirsche.

Fruit large, obtuse heart-shaped. Skin dark red. Flesh red, 
half tender, with a pleasant juice, of second quality in point of flavor. Good. Ripens last of Jume.

\section{Pierce's Late.}

Originated with Amos Pierce, Massachusetts. Growth free, rather upright, with a round head.

Fruit medium, obtuse heart-shaped, dark red and mottled, light amber in the shade. Stalk rather short and slim. Flesh soft, tender, very juicy, sweet. Good. Stone small. Ripe the last of July.

\section{Pontiac.}

Originated with Prof. Kirtland. Tree vigorous, round headed, upright spreading. Very productive. Valuable either for table or market purposes.

Fruit large, obtuse heart-shaped. Sides com-

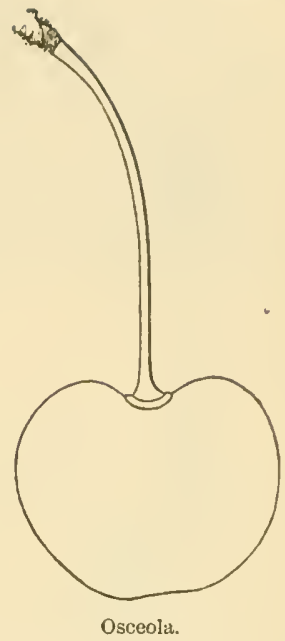
pressecl. Color dark purplish red, approaching to black when fully ripe. Flesh half tender, juicy, sweet, and agreeable. Very good. Season, last of June.

\section{Powhattan.}

For profitable market purposes this is one of the very best, the fruit ripening late, and all being uniform and regular in size. Originated with Prof. Kirtland.

Fruit medinm size, uniform, roundish, flattened or compressed on sides. Surface irregular. Color liver-like, highly polished. Suture half round. Flesh rich, purplish red, marbied, half tender, juicy, sweet, pleasant but not high flavor. Good. Season late, Sth to 15 th of July.

\section{President.}

Tree vigorous, spreading, productive.

Fruit medium to large, regular heart-shape, slightly compressed, slight suture, followed by an indistinct line. Skin amber color, mottled and shaded with carmine and yellow. Flesh tender, juicy, and sprightly sweet. Very good. Last June.

\section{Prince's Black Heart.}

Originated by Wm. R. Prince, Flushing, Long Islaucl. Tree vigorous, upright spreading.

Fruit medium to large, heart-shaped, slightly compressed. Apex small. Suture small. Surface somewhat uneven. Flesh purplish, rather tender, juicy, sweet, and good to very goorl. Last of June.

Proudfoot.

Raised by D. Proudfoot, Cleveland, O. Tree vigorous. 
Fruit large, heart-shaped, dark purplish red. Flesh firm, juicy, sweet. Ripe 15th to last of July.

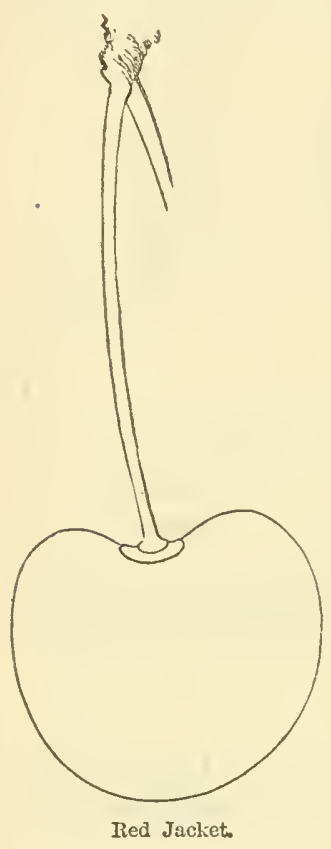

RED JACKET.

One of Prof. Kirtland's seedlings. A freegrowing; rather spreading, late, and productive variety. Very profitable for market.

Fruit large, regular, obtuse heart-shaped. Color amber, mostly covered with light red. Flesh half tender, juicy, good but not rich flavor. Stalk long, slender, in a moderate basin. Ripe about the tiune of Downer's Red.

\section{Piemington.}

Remington White Heart. Remington Heart.

Fruit small, heart-shaped. Skin yellow, rarely with a faint tinge of red on one side. Flesh yellowish, dry, and somewhat bitter. Middle and last of August.

\section{RichaRdson.}

Raised by J. R. Richardson, Boston. Tree vigorous, productive.

Frnit large, heart-shaped, dark red, inclining to black. Flesh deep red, half tender, juicy, sweet. Good. Last of June.

\section{Rival.}

An English variety. Its principal value being from its period of late maturity. Tree vigorous, productive.

Fruit medium, obtuse heart-shape, compressed one side. Suture distinct. Skin purplish black, or black. Flesh firm, sweet. Good. August.

\section{Rivers's EArty Ayber.}

Raised by Thomas Rivers, England.

Fruit medium size, heart-shaped, prolific, a sub-variety of old Early White Heart, but not as early.

\section{Rivers's Early Heart.}

Raised by Thomas Rivers, England.

Fruit medium size, heart-shaped, ripening just after Belle d'Orleans. Very much inferior. 


\section{Roberts' Red Heart.}

Originated in the garden of David Roberts, of Salem, Mass. Tree hardy, free grower, hears abundantly.

Fruit of medium size, roundish heart-shape. Skin of a pale amber grouml, but nearly overspread with pale red, mottled with deeper red. Suture quite distinct. Flesh juicy, sweet, and well flavored. Stalk long, slender, set in a moderate depression. Very good. Ripe last of June

\section{Rockport.}

\section{Rockport Bigarreau.}

Raised by Dr. Kirtland, Cleveland, O. Tree vigorous, healthy, up. right, forming a beantiful pyramidal head; a good betrer, and worthy of a place in every good collection.

Fruit large, roundish obtuse heart-shaped. Color, when fully ripe, a beatiful bright red, shaded with pale amber. Flesh rather firm, juicy, sweet, rich, with an excellent flavor. Very good or best. Ripens early in June, or just before Mayduke.

\section{Sparhawk's HoNey.}

Sparrowhawk's Honey.

Raised by Edward Sparhawk, of Brighton, near Boston. A profuse bearer. Vigorous grower.

Fruit of medium size, roundish heartshaped, very regular in form. Stalk of moderate length, rather slender, set in a round, even depression. Skin thin, of a beartiful glossy pale amber red, becoming a lively red when fully ripe. Flesh juicy, with a very sweet flavor. Ripe the last of $J$ une.

\section{Strass's Early Black.}

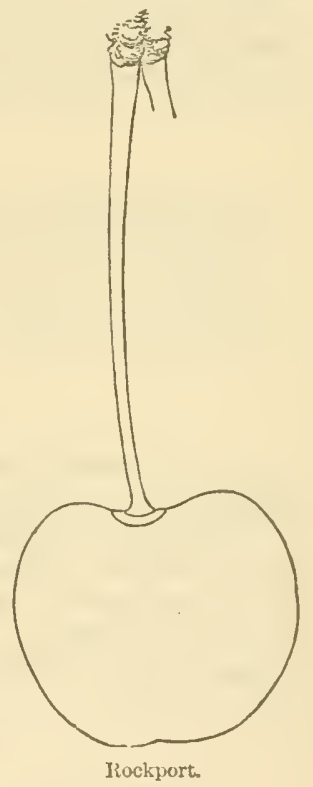

\section{Noir Précoce de Strass.}

Fruit small, heart-slıape, black. Flesh juicy, sweet. Very early iu ripening, and an abundant bearer. New.

\section{SuMNER's HoNey.}

Originated by Clement Summer, Dorchester, Mass. Tree a vigorous grower and good bearer.

Fruit merlium, roundish heart-shape. Skin amber, lıalf covered and marbled with pale red. Flesh rather firm, juicy, rich, sweet. Good. Last of June. (Cole.) 


\section{Sineet Montarorency.}

Allen's Sweet Montmorency.

Raised by J. F. Allen, Salem, Mass. Tree hardy, vigorous growth, good bearer.

Fruit of medium size, round, flattened. Skin pale amber in the shade, light red, slightly mottled, in the sun. Stalk an inch and threefourths long, rather slender, inserted in a small, shallow, even hollow. Flesh yellowish, tender, sweet, and excellent. Ripens here middle July.

\section{TECUMSEH.}

One of Prof. Kirtland's varieties. Tree moderately vigorous, productive.

Fruit medium to large, obtuse heart-shaped. Skin reddish purple. Flesh dark red, half tender, with a brisk vinous flavor. Good to very good. Ripe towards the end of July.

\section{Tobacco-Leaved.}

Four to the Pound.

Bigarreautier à Feuilles de Tabac.

Guignier à Feuilles de Tabac.

Leaves very large.

Fruit small, hard, of no value.
Cerisier de 4 à Livre.

Bigarreautier à Grandes Feuilles.

Vier auf ein Pfund.

\section{Townsexd.}

Tree a strong, vigorous grower, productive, and promises well. Raised by W. P. Townsend, Lockport, N. Y.

Fruit large, obtuse heart-shaped, high-shouldered, compressed. Suture distinct. A pex depressed. Stem long, somewhat slender, set in a broad, rather deep depression. Color light amber, mottled and shaded with carmine. Flesh almost tender, juicy, rich, sprightly, re. freshing flavor. Pit small. Good to very good. Ripe last of June.

\section{Tradescant's Black Heart.}

\section{Elkhorn.}

Large Black Bigarreau.

Bigarreau Gros Noir.

Gross Schwarze Knoorpel.
Elkhorn of Maryland.

Tradescant's.

Guigne Noir Tardive.

Kirsche mit Säftigen Fleisch.

It is an European variety, but a tree, growing about forty years since in the garden of an inn in Maryland, attracterl the notice of the late Wm. Prince, who propagated it under the name of Elkhorn, by which it was there known. The bark is of a peculiarly gray color, and the growth quite vigorous.

Fruit large, heart-shaped, with a very irregular or uneven surface. Skin deep black, glossy (before fully ripe, deep purple, mottled with black). Stalk rather short, set in a pretty deep hollow. Flesh very solid and firm, dark purple, moderately juicy. Good. Ripe first and second week in July. 


\title{
Transparent Guigne.
}

Trunsparent Gean. Transparent.

It is a pretty variety for the dessert, hanging late on the tree.

Fruit small, regular, oval heart-shaped. Skin glossy, thin, yellowisk white, delicately blotched with fine red, distinct suture line on both sides. Stalk long and slender. Flesh tender, when fully ripe very sweet, luingled with a very slight portion of the piquant bitter of the Mazzard class of Cherries. Good. First of July.

\section{Triumph of Cumberland.}

$\begin{array}{ll}\text { Monstrous May. } & \text { Brenneman's Early. } \\ \text { Street's May. } & \text { Cumberland Seedling. }\end{array}$

Origin, Carlisle, Cumberland Co., Pa. Tree vigorous and spreading, moderately productive.

Fruit large, obtuse heart-shape, one side compressed. Suture slight. Stalk rather long. Skin deep crimson, almost black when fully ripe. Flesh purplish, rather firm, juicy, sweet, not high-flavored. Good. Last of June.

\section{WarRen's 'Trassparen't.}

Origin, Brighton, Mass.

Fruit small, roundish heart-shape, pale yellow and red. Flesh tender. Good. Early July. (Cole.)

\section{WATERLOO.}

An English variety. Tree a moderate grower and bearer.

Fruit large, obtuse heart-shaped, deep suture half round. Skin dark purplish black. Stalk ratler short. Flesh purplish red, juicy, half tender, sweet. Good. Middle June.

\section{WeLLisgton.}

Fruit medium, roundish, obtuse heart-shape, purplish black. Flesh almost firm, juicy, sweet. Good. Early July.

\section{Wexdell's Mottled Bigarreau.}

Originated with Dr. H. Wendell, Albany, N. Y. Tree upright, thrifty growth.

Fruit large, obtuse heart-shaped, dark red, nearly black at maturity, mottled. Flesh dark red, firm, and ligh-flavored. Good to very good. Ripe about the time of Downer's Late.

\section{Werder's Early Black Heart.}

\author{
Werdsche Frühe Schwarze. Herz Kirsche.
}

An early variety. Tree vigorous, spreading, moderately productive. Fruit large, roundish heart-shaped. Skin black. Flesh purplish, 
tender, sweet, and excellent. Very good. Ripens early in June, or just before Mayduke.

\title{
White Bigarreau.
}

\author{
White Ox-Heart. \\ Harrison Heart? \\ Ox-Heart. \\ Large White Bigarreau. \\ Bigarrean blanc? \\ White Bigarreau. \\ Turkey Bigarreau.
}

The White Bigarreau is inferior to the Bigarreau or Graffion in hardi. ness, and in the circumstance that it is a very poor bearer while the tree is young, though it bears fine crops when it has arrived at from twelve to fifteen years' growth. Growth upright.

Fruit of the largest, size, heart-shaped, with a rather irregular outline, and a pretty distinct suture line on one side. Skin yellowish white, overspread with marbling of red. Flesh firm, but scarcely so much so as that of the Bigarreau, and when fully ripe half tender, and more luscious than the latter Cherry. Good to very good. It is very liable to crack after rain. Middle and last of June.

\section{White Frevchi Guigse.}

A foreign sort, of vigorous growth.

Fruit small, roundish obtuse conical, a little compressed, slight suture. Skin whitish yellow, translucent, sometimes a tinge of crimson in the sum. Stalk long, slender. Flesh tender, juicy, sweet, pleasant. Good. Middle July.

\section{White TARTARiaN.}

Fraser's White Tartarian. Fraser's White Transparent. Amber à petit fruit.

Fruit of medium size, obtuse heart-shaped. Skin pale yellow. Stalk slender. Flesh whitish yellow, half teuder, and very sweet. Good. Early June.

\section{Wilikinsox.}

Fruit medium, heart-shape, compressed, slight suture. Skin deep red, almost purplish. Flesh purplish, tender, juicy, pleasant. Good. Stone large. Early July.

\section{CLASS II.}

\section{DUKE AND MORELLO CHERRIES.}

\section{Admirable de Solssors.}

De Soissons.

Belle de Soissons.

A Cherry of the Morello class, good for culinary uses.

Fruit medium or above, broadly heart-shaped, slightly compressed, slight suture half round. Skin shades of red on yellow. Stalk rather long. Flesh tender juicy, brisk subacid. Last of June. 


\section{ArCII DUKe.}

Griotte de Portugisl. Portugal Duke.
Late Arch Duke.

Late Duke of some.

Tree rather more vigorous and upright than the Mayduke, liardy and prolific.

Fruit large, obtuse heart-shaped. Suture distinet on one side. Skin at first bright red, but becoming very dark when mature. Stalk an inch and a half long, slender, inserted in a rather deep open cavity. Flesh light red, melting, juicy, rich subacid flavor. Very good. Ripe the tirst and second week in July.

\section{Belle de Choisy.}

Belle Audegoise?

Cerise Doucette.
Ambrée de Choisy.

Cerise de la Palembre.

Schöne von Choisy.
Ambrie à Gros Fruit.

Cerise ì Noyau Tendre.

In our estimation, there is no Cherry for the dessert more delicious than the Belle de Choisy. It comes from the viliage of Choisy, near Paris, where it was raised in $\mathbf{1 7 6 0 .}$. The habit of the tree is nearly that of the Mayduke, the leaves dark, and the head upright. It is hardy, a molerate bearer.

Fruit round or slightly depressed. Skin very thin and translucent, showing a net-like texture of flesh beneath; in color, pale amber in the shade, but in the sun finely mottled with yellowish red-the fruit fully exposed becoming a bright cornelian red. Flesh amber-colored, very tender and melting, of a delicate sweet flavor. Stalk rather short, swollen at the upper end. Best. Middle of June, or directly after the Mayduke.

\section{- Belle de Sceaux.}

\section{Chatenay.}

A Morello, from France.

Fruit round, deep red. Flesh yellowish, juicy, acid. Last of Jume.

\section{Belle Magnifiote.}

Belle et Magnifique. Magnifique de Sceaur.

Belle de Sceaux. Belle de Chatenay.

\section{Planchoury?}

Tree hardy, moderately vigorous, productive, a beautiful and excellent late variety. Useful for culinary purposes, and good table fruit when pretty ripe.

Fruit large, roundish, inclining to lieartshape. Stalk long, slender, in an open mcdium eavity. Skin a fine bright red. Flesh juicy, tender, with a sprightly subacid flaror, one of the best of its class. Ripe middle of July till the middle of August.

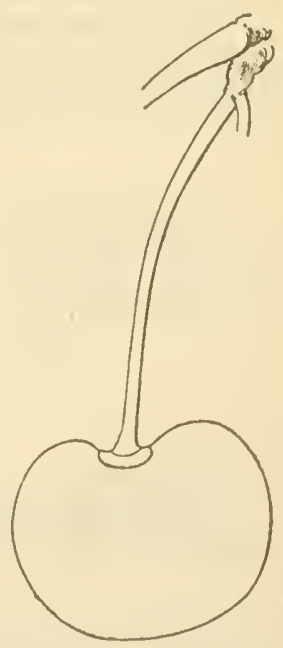

Belle Magnitique. 


\section{Buttner's October Morello.}

A foreign sort. Small, late, acid, and of little or no value.

\section{Carnation.}

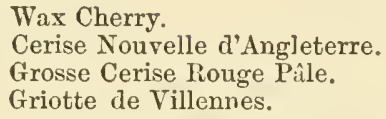

Crown.

Cerise de Portugal.

Griottier Rouge Pâle.

A very handsome, light red, large Cherry, highly esteemed here for brandying and preserviug.

Fruit large, round. Skin yellowish white, mottled with red, becoming a lively red slightly marbled. Stalk stout. Flesh tender, a little more firm than most of this division, but juicy, and when fully ripe of a sprightly and good subacid flavor. The foliage is pretty large, and the wood strong, but the tree has a spreading, rather low habit. It is a moderate but regular bearer, and the fruit hangs a long while on the branches without decaying. Good. Ripe the middle and last of July

\section{Cluster.}

$\begin{array}{lll}\text { Cerise à Bouquet. } & \text { Cerisier à Trochet. } & \begin{array}{l}\text { Cherreuse. } \\ \text { Commune à Trochet. }\end{array} \\ \begin{array}{l}\text { Très-Fertile. } \\ \text { Bouquet Amarelle. }\end{array} & \begin{array}{l}\text { Trauben Amarelle. } \\ \text { Flandrische Weichsel. }\end{array} & \begin{array}{l}\text { Büschel Kirsche. } \\ \text { Busch Weichsel. }\end{array}\end{array}$

A very curious fruit, growing closely clustered around a common stalk, small size, borne in clusters of from two to six; round, of a lively red. Ripens the last of June. The tree is small in all its parts.

\section{Coz's Late Carnation.}

A promising late variety.

Fruit above medium size, roundish. Suture shallow, with a line. Color amber, mostly shaded and mottled with bright red. Flesh juicy and sprightly subacid. Ripe from the middle till the last of July.

\section{Dauphine.}

Of the Morello class. Tree vigorous, productive.

Fruit medium, roundish, without suture. Skin bright crimson, mottled. Stalk long, slender. Flesh tender, juicy, less acid than most of the Morellos. Very good. Stone small. Last June.

\section{De Chaux. \\ D'Allemagne.}

A Morello.

Fruit large, roundish oblate. Skin dark red. Stalk long, slender. Flesh dark, tender, juicy, brisk subacid. Middle July.

\section{Decheraut.}

A fine large Cherry of the Duke class, ripening about the same time as Mayduke. 
Fruit large, roundish heart-shape, broad at the stalk, rather flattened. Suture slight. Skin rich red. Stalk long, in a deep eavity. Flesh tender, suceulent. (Hogg.)

\section{De Kleparow.}

Belle Polonaise.

A Morello.

Fruit medium, roundish, dark red. Stalk long. Flesh dark, tender, juicy, rich subacid. Middle July. (Hogg.)

\section{De la Toussaint.}

A variety of little value except as ornamental. It flowers almost continuously, and produces fruit the whole season, so that ripe and green fruit and flowers are upon the tree all at the same time.

The fruit is small, round, deep red, firm, acid.

\section{Donva Maria.}

A Morello Cherry, forming a small tree, but very prolific.

Fruit of medium size, roundish, dark red, tender, juicy, rich acid. Valuable for cooking. Middle July. (Elliott.)

\section{Double Natte.}
Doppelte Natte.
Kirsch von der Natte.

Fruit rather large, roundish, a little compressed and inclining to ovate. Skin brownish black. Stalk slender, very long, and bearing leaves. Flesh very red, tender, juicy, brisk, sprightly acid. Early July. (Hogg.)

\section{Duchesse de Palluau.}

A vigorous tree of the Duke class.

Fruit medium size, roundish heart-shaped, compressed, very dark purple. Stem long and slenter, in a large open cavity. Flesh dark red, tender, juicy, mild acid. Ripe middle of June.

\section{EARLy MAY.}

Nay Cherry.

Small May.

Cerisier Nain ì Fruit Rond.

- Précoce.

Griottier Nain Précoce.

Hâtive.
Précoce.

Petite Cerise Rouge Précoce.

Königliche Amarelle.

Frühe Kleine Runde.

Z Zwerg Weichsel.

Cerise Indulle.

An early Morello of rather dwarf habit. Ripening about the first of June. ncid.

Fruit sulall, round, slightly flattened, lively red, tender, juicy,

This is an old variety from abroad. The Early May of Illinois and the West is probably a distinet sort, and by some considered as identical with our Kentish or Early Richmond. We have had no opportunity of comparing them. 


\section{Excellente Douce Tardive.} productive.

Originated at Jodoigne, France. A Morello of vigorous habit and

Fruit medium to large, roundish flattened at ends. Skin deep red. Stalk large and long. Flesh yellowish, melting, acid. Stone small. Ans. (An. Pom.)

\section{Flexish.}

Montmorency.

Cerise à Courte Queue.

Gros Gobet.

English Wreichsel?

Double Volgers.

Kentish of some.
Montmorency à Gros Fruit.

Gobet à Courte Queue.

A Courte Quene de Provence.

Weichsel mit ganzkurzen Stiel.

Early May of some.

This is a very odd-looking fruit, being much flattened and having a very short stalk.

Fruit rather large, very much flattened both at the top and base, and generally growing in pairs. Stalk stout, short. Skin shining, of a bright lively red. Flesh yellowish white, juicy, and subacid. Good for preserving; but, unless very ripe, scarcely rich enough for table use. Last of July.

\section{Great Cornelian.}

Double Glass.

Fruit large, oblate, deep suture half round. Skin thin, translucent, at first light becoming dark red. Flesh yellowish, tender, juicy, subacid, vinous. Iast June. (Hogg.)

\section{Guigne Noir Luisante.}

Black Spanish.

Fruit medium size, round heart-shaped, glossy, blackish red. Flesh reddish purple, tender, juicy, rich, acid. Rije middle to last of July.

\section{Hâtive MaLgre Tout.}

A Duke Cherry from France.

Fruit medium, roundish obtuse heart-shape. Skin rery dark red, nearly black when fully ripe. Flesh dark red, juicy, subacid. Jume. (Alb. Pom.)

\section{Holmax's Duie.}

A variety of the Duke class, which has been confounded with Mayduke. It is very similar, but ripens later. The tree has short, erect shoots.

Fruit large, round oblate, deep red, almost black. Flesh tender, juicy, rich, excellent. Tery good. Niddle to last of July.

\section{INPERATrICE EugénIE.}

\section{Empress Eugénie.}

A French Cherry of the Duke family, rather dwarf in habit, shoots pretty stout, very productive. 
Fruit laige, romudish flattenel. Skin rich dark red. Suture broad, shallow. Stalk rather short, in a deep cavity. Flesh reddish, tender, rich, juicy subacid. Very good. Stone small. Niddle of Jume.

\section{Imperial Momello.}

A productive and early bearing variety.

Fruit medium size, roundish, lark purplish red. Flesh tender, juicy, acil. List of July.

\section{JeFFrey's DÜKE.}

Jeffrey's Royal. Jeffrey's Royal Caroon. Royale.

Fruit of medium size, round, or a little flattened at the apex and basin. Skin of a fine lively red. Stalk moderately long. Flesh yellowish amber, scarcely red. Juice abumdant, and of a rich flavor. The trees are of a distinct habit of growth, being very compact, and growing quite slowly. The buds are rery closely set, and the fruit is borne in thick clusters. Middle and last of June.

\section{JuNe DUke.}

\section{Wetherill. Shippen.}

A variety described by Coxe as a vigorous grower.

Fruit of large size, very rich, tree abundant bearer. We know little of it, having only heard of it as the Wetherill, grown near Philadelphia.

\section{Kentish.}

Virginian May?

Early Richmond. Kentish Red.

Cominune.

Muscat de Prague.

Cherry Cluster I IIay Cluster $\zeta$ of Virginia.

\section{Common Red}

Pie Cherry.

Montmorency.

Montmorency à longue queue.

Sussex.

De Kalb.

The true Kentisll Cherry, an old Europen sort, better known here as the Early Richmond, is one of the most valuable of the acid Cherries. It begins to color about the 20th of May, and may then be used for tarts, while it will hang upon the tree, gradually growing larger, and losing its acility, until the last of June, or in dry seasons even uutil July, when it becomes of a rich, sprightly, and excellent acirl flaror. The tree grows about eighteen feet ligh, with a roundish spreading head, is exceelingly producive, and is from its early maturity a rery profital,le market fruit, being largely planted for this purpose. This kind is remarkable for the tenacity with which the stone adheres to the stalk. Advantage is taken of this to draw

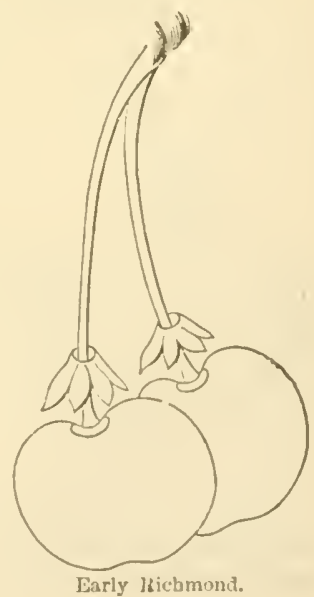


unt the stones. The firut is then exposed to the sun, and becomes one of the most excellent of all dried fruits.

Fruit when it first reddens rather small, but, when fully ripe, of medium size, round, or a little flattenerl borne in pairs. Skin of a fine bright red, growing somewhat dark when fully ripe. Stalk an inch and a quarter long, rather stout, set in a pretty deep hollow. Flesh melting, juicy, and, at maturity, of a sprightly rather rich acid flavor. Very good.

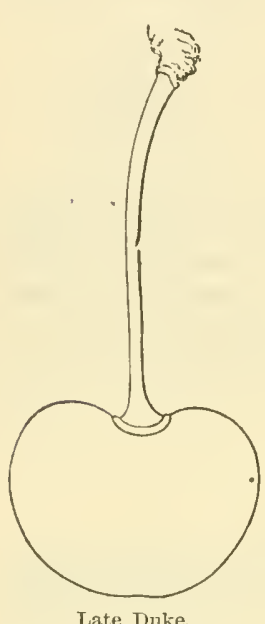

Late Duke,

\section{Kirtland's Morello. \\ Kirtland's Large Morello.}

One of Prof. Kirtland's seedlings. Tree a spreading, rather drooping grower, moderate, regular bearer.

Fruit pretty large for a Morello, roundish, dark red. Flesh juicy, acid, when fully ripe rich. Very good. Stone small. Middle July.

\section{LATE DUKE.}

\section{Anglaise Tardive.}

A very large and fine Duke Cherry, ripening later than the Mayduke, and therefore a very valuable sort for the dessert or for cooking. The tree is of vigorous growth for its class.

Fruit large, flattened or obtuse heart-shaped. Color, when fully ripe, rich clark red (but at first white, mottled with bright red). Stalk rather slender, inserted in a shallow hollow. Flesh yellowish, tender, juicy, with a sprightly subacid flavor, not quite so sweet and rieh as the Mayduke. Ripens gradually, and hangs on the tree from the middle of July till the

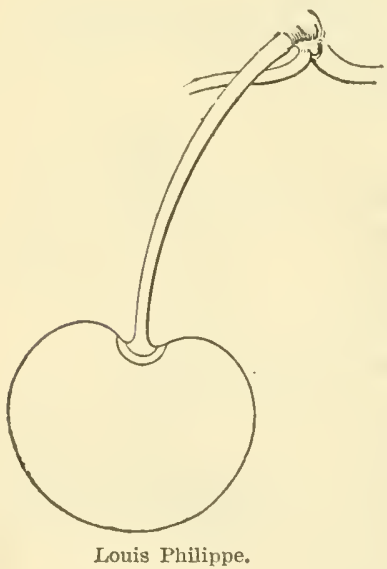
10th of August.

\section{Late Kextistr.}

\section{Common Red. \\ Pie Cherry. \\ Common Sour Cherry. Kentish Red.}

This Cherry, a rariety of the Kentish, is better known among us than any other acid Clierry.

It is emplatically the Pie Cherry of this country, being more generally grown than any other sort.

Fruit medium, round, flattened. Skin deep lively red, when fully ripe. Flesh very tender, and abounding with a highly acid juice. Ripens middle July.

\section{Louis Philippe.}

From France. Tree upright spreading, habit between the Dukes and Morellos, Vigorous and very productive. 
Fruit large, romulish regular. Stalk rather short, stout, set in a broat even regular eavity, usually grows in clusters. Skin rich dark, almost purplish black red. Flesh red, tender, juicy, sprightly, mild acicl. Stone small. Very good or best. Middle to last July.

\section{Love APrLE.}

Tomato.

A. Cherry from Spain of the Duke class.

Fruit large, roundish obtuse heart-shape, shallow sutures. Skin clear red. Flesh pale, tender, juicy. Good.

\section{MAYduke.}

Royale Hâtive

Cherry Duke of some.

Cerise Guigne.

Coularie.

De Ilollande.

D'Espagne.

Griotte Grosse Noire.

Griotte d'Fispagne of some.

Griotte Précoce of some.
Early Duke.

Large Mayduke.

Morris Duke.

Morris's Early Duke.

Benham's Fine Early Duke.

Thompson's Duke.

Portugal Duke.

Buchanau's Early Duke.

Millet's Late Heart Duke.

This invaluable early Cherry is one of the most popular sorts in all countries, thriving almost equally well in cold or warm elimates. This, the Black Heart, and the Bigarrean, are the most extensively diffiused of all the finer rarieties in the United States. And among all the new varieties nowe has been found to supplant the Mayduke. Before it is fit for table use, it is admilably adapted for cooking, and when fully ripe it is, perhaps, the richest of the subacid Cherries. In the gardens here, we lhave noticed a peculiar habit of this tree of producing very frequently some branches which ripen much later than the others, thus protracting for a long time the period in which its fruit is in use. The Mayduke is remarkable for its upright, or, as it is called, frustiginte hend, esjecially while the tree is young, in distinction

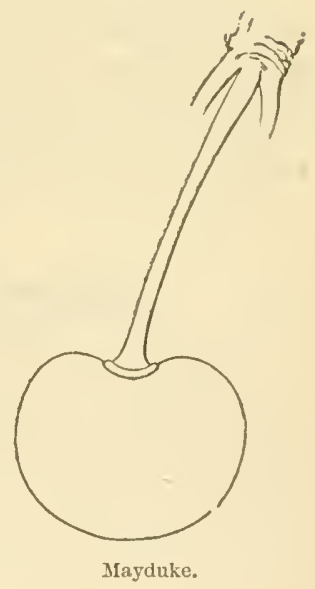
to other sorts, which produce many lateral branches.

Frnit roundish or obtuse heart-shaped, growing in chusters. Skin at first of a lively red, but when fully ripe of a rich dark red. Flesh reddish, tender, and melting, very juicy, and at maturity rich and execllent in flavor. This fruit is most frequently pieked while it is yet red, and partially acid, and before it attains its proper color or flavor. It begins to color, about New York, in favorable seasons, the last of May, and ripens during the first lalf of June.

Mayduke is said to be a corruption of Médoc, the province in France where this variety (the type of all the class now called Dukes) is believed to have originated. 


\section{Morello.}
Milan.
English Morello.
Cerise du Nord.
Large Morello.
Griotte Ordinaire du Nord.
Dutch Morello.
September W'eichsel Grosse.
Ronald's Large Morello.

The Morello is a fine fruit. Its name is said to be derived from the dark purple color of its juice, which resembles that of the Morus or Mulberry. It is highly valuable for all kinds of preserves, and is an agreeable addition to a dessert.

Fruit of pretty large size, round or slightly obtuse heart-shaped. Skin dark red, becoming nearly black when fully ripe. Flesh dark purplish red, tender, juicy, and of a pleasant subacid flaror when quite mature. Ripe 20 th of July.

The Common Morello of this country is a smaller variety of the foregoing, and a little darker in color. Little esteemed.

\section{Morello de Charmeux.}

This is a very late variety of the Morello, with a milder flavor, ripening middle of August.

\section{Nouvelue Rorale.}

This recently introduced variety of the Duke class of Cherries is stated to possess great size and beauty of fruit, while the tree is of a pyramidal form, very handsone when grown upon the Mahaleb stock.

Fruit large or very large, roundish, flattened at the stalk. Skin brilliant glossy red, somewhat mottled with large dark red dots. Flesh tender, melting, juicy, sprightly, sweet, acid. 5th to 15 th July.

\section{Ostinem.}

\section{Zwerg Kirsche. Ostheimer Weichsel. \\ Frankische Wucher Kirsche. Ostheimer Kirsche.}

A small growing tree of the Morello class.

Fruit large, roundish oblate, slightly compressed one side. Skin red, quite dark at maturity. Stalk long. Flesh liver-color, tender, juicy, rich, almost șweet subacid. Very good. Middle July.

\section{Paramidar.}

\section{Baramdam.}

A tree of very dwarf habit.

Fruit small, round, pale red. Flesh pale, tender, agreeable, lirely acid. Middle July. (Hogg.)

\section{Plumstone Morello.}

Tree of slow growth, makes a fine pyramid. A productire, hardy. and valuable sort.

Fluit large, roundish, inclining to heart-shape. Skin deep red. Stalk an inch and a half long, rather slender and straight, set in a hollow of moderate depth. Flesh reddish, tender, juicy, and when well 
matured, of a sprightly and agreeable flavor. Good. Stone long and pointed. Ripe last of July and first of A:igust.

\section{Reine Hontexse.}

Monstreuse de Bavay. $\quad$ Belle de Bavay.
Lemercier.

French origin, of Duke habit. 'Tree a healthy and handsome grow er, productive, and a very desirable variety.

Fruit very large, roundish elongated. Skin a bright lively red, somewlat marbled and mottled. Suture distruetly marked by a line without any depression. Flesl tender, juicy, very slightly subacid and delicious, best of its season. Ripe from the uiddle to the last of July.

\section{Roral Duke.}

Royale Anglaise Tardive.

Growth upriglit, compact head, branches less slender than Mayduke. Moderate bearer.

Frnit large, roundish, and distinctly oblate or flattened. Skin dark red. Flesh reddish, tender, juicy and rich. Good. Ripens in the last of June.

\section{Rumsey's Late Morello.}

Origin unknown. Tree moderately vigorous. Ripens gradually through August and September. Not of much value except to the curious amateur.

Fruit large, roundish heart-shaped. Color rich lively red. Flesh juicy, with too much acid for the table.

\section{Shaxpon.}

'This is a Morello raised by Prof. Kirtland.

Fruit slightly above medium size, globular, flattened at junction with stem, dark purplish red when ripe. Flesh tender, reddish purple, juicy, acid. Stone small. Stalk long, slender, inserted in an open arvity. Good. Season middle of July.

\section{VaIl's August Duke.}

A very late Cherry, of the Duke class. Originated with Henry Vail, Esq., Troy, N. Y. Tree very productive, and of vigorous growth.

Fruit large, obtuse heart-shaped. Stalk modium, in rather deep out narrow cavity. Skiu rich bright red on the shaded side, and of a lively cornelian red in the sun. Flesh tender, subacid, much like the Mayduke in flavor. Very good. Ripe the last week in July, and the first week or two in Anginst. 


\section{ORNAMENTAL VARIETIES.}

\section{Chinese Double-Flowering.}

\section{Yung To. Cerasus serrulata. Serrulated Leared Cherry.}

This is a variety from China, with the leaves cut on the edges in the manner known as serrulate by botanists. Its flowers, which are borne in fascicles, are white, slightly tinged with pink, and nearly as double as those of the Large Double-Flowering. The tree considerably resembles the sour cherry-tree, and appears rather dwarfish in its growth.

\section{Dwarf Double-Flowering.}

\section{Double-Flowering Kentish. Small Double-Flowering.} Cerisier à Fleurs Doubles.

This is a double-flowering variety of the sour or Kentish Cherry, and has the more dwarfish habit and smaller leaves and branches of that tree-scarcely forming more than a large shrub, on which account it is perhaps more suitable for small garclens. The flowers are much like those of the Large Double-Flowering, but they are not so regular and beautiful in their form.

\section{Large Double-Flowerixg.}

Double French Cherry. Prunus cerasus pleno.
Mérisier à Flenrs Doubles. Cerasus sylvestris, flore pleno.

The double-blossomed Cherry bears no fruit, but whoever adnires a beautiful flowering tree camot refuse a place in his garden to this one, so highly ormamental. Its blossoms, which aplear at the usual season, are produced in the most showy profusion; they are about an inch and a half in diameter, and resemble clusters of the most lovely full double white roses. The tree has the habit and foliage of the Miazzard Cherries, and soon forms a large and lofty head.

\section{Virginjan Wild Cimerry.}

Wild Cherry of the United States.

Cerisier de Virginie.
Cerasus Tirginiana.

Virginische Kirsche.

Our native wild Cherry is too well known to need minute description. It forms a large and lofty forest-tree with glossy, dark green leaves, and bears currant-like bunches of small fruit, which are palatable, sweet, and slightly bitter when fully ripe, at midsummer. They are, however, most esteemed for preparing cherry bounce, a farorite liqueur in many parts of the country, made by putting the fruit, along with sugar, in a demijohn or cask of the best old rum.

The black wild Cherry ( $C$. serotina, Torrey and Gray), which ripens the first of September, is the best kind. The other species ( $C$. T $r$ ginicuna), which is commonly known as the Choke Cherry, bears reddish colored fruit, which is more astringent, and ripens a month earlier. 


\section{Whepixg, on All-saints.}

Ever-Flowering Cherry.

Cerise le la Toussainte.

Cerise Tardive.

Cerise de st. Martin.

Martin's Weichsel.
C. vulgaris, sempertlorens.

Guignier ì rameaux pendaus.

Cerisier Pleurant.

St. Martiu's Amarelle.

Monats Amarelle.

Allerheiligren Kirirsche.

This charming little tree, with sleuder, weeping branches, elothed with small, almost myrtle-like folinge, is a very pleasing ornament when introduced on a lawn. Its fruit is a small, deep red Morello, which is acid, and in moist seasons is produced for a considerable period successirely. When grafted, as it generally is, about the height of one's heid, on is straight stem of the common Mazzard, it forms a beantiful parasol-like top, the ends of the branches weeping half way dow'll to the ground.

\section{SELECTIONS OF CHOICE CHERRIES FOR FAMILY USE, TO RIPEN IN SUCCESSION.}

Early Purple Guigne, Belle d'Orleaus, Mayduke, Bigarreau, Roekport, Black Tartarian, Elton, Gov. Wood, Coe's Transparent, Osceola, Delicate, Downer's Late, Reine Hortense, Belle Magnifipue, Kentisl.

The hardiest Cherries are the Kentish (or Early Richmond), the Dukes, and the Morellos. These succeed well at the farthest limits, both North and South, in which the Cherry can be raised; and when all other varieties fail, they may be depended on for regular crops.

\section{CHAPTER XIV.}

THE CURRANT.

Ribes rubrum, Lin. Grossulacere, of botanists.

Groseillier commun, of the French; Die Johunnisbcere, German; Albesscbonn, Dutch ; Ribes rosso, Italian; and Grosella, Spanish.

The name Currant is said to be derived from the resemblance in the fruit to the little Corinth grapes or raisins, which, under the name of Crurants, are sold in a dried state in such quantities by grocers; the latter word being only a corruption of Corinth, and the fruit of this little graje being faniliarly known as such long before the common currants were cultivater.

The Currant is a native of Britain, and the north of Europe, and is, therefore, au exceedingly hardy fruit-bearing shrub, seldom growing 
more tham three or four feet high. The finit of the original wild species is small and very sour, but the large garden sorts produced by eultivation, and for which we are chiefly indebted to the Dutch gardener's, are large, and of a more agreeable subacid flaror.

The Black Currant (Ribes nigrum) is a distinct species, with larger leaves, and coarser growth, and which, in the whole plant, has a strong odor, disagreeable, at first, to many persons.

Uses. The cooling acid flavor of the Currant is relished by most people, in moderate quantities, and the larger varieties make also a pretty appearance on the table. Before fully ripe, currants are stewed for tarts, like green gooseberries, and are frequently employed along with cherries or other fruits in the samo way; but the chief value of this fouit is for making curront jelly, an indispensable accompaniment to many dishes. Currant sturb, made from the fruit in the same manner as lemonate, is a popular summer drink in many parts of the country, and corresponds to the well-known Paris beverage, en de groseilles. I sweet wine of very pleasant taste is made from their expressed juice, which is very popular among farmers, but which we hope to see displaced by that afforded by grapes, - which every one may make with less cost and trouble, and which is intinitely more wholesome, because it requires less additions, of any kind, to the pure juice.

The fruit of the Black Currant is liked by some persous in tarts, but it is chietly used for making a jam, or jelly, much valued as a domestic remedy for sore throats.

The season when Currants are in perfection is midsummer, but it may be prolonged until October by covering the bushes with mats, or sheltering them otherwise from the sun.

Propagation and Culture. Nothing is easier of culture than the Currant, as it grows and bears well in any tolerable garden soil. To propagate it, it is only necessary to plant in the autumn, or early in the spring, slips or cuttings, a foot long, in the open garden, where they will root with the greatest facility. The Currant should never be allowed to produce suckers, and, in order to insure against this, the superflnous eyes or buds should be taken out before planting it, as has been directed under the head of Cuttings. When the plants are placed where they are finally to remain, they should always be kept in the form of treesthat is to say, with single stems, and heads branching out a few inches from the ground. The after treatment is of the simplest kind; thinning ont the superfluous wood every spring is all that is required here. Those who desire berries of an extra large size stop, or pinch out, the ends of all the strong growing shoots about the midlle of June, when the fruit is two-thirds grown. This forces the plant to expend all its strength in enlarging and macuring the fruit. And we may add to this, that it is better not to continue the cultivation of curant-trees after they have borne more than six or eight years, as finer fuit will be obtained, with less trouble, from young plants, which are so easily raised.

For field culture many prefer to grow them from suckers, but when this mode is adopted, care shonid be taken to thin ont the oldest branches annually, and dig in old nanure about the roots.

Inseuts AND Diseases. Within a few years the Currant and Gooseberry have been affected by the ravages of an insect described by Dr. Asa Fitch, in his reports to the New York State Agricultural 
Society, under the name of Abraxis ribearia. The moths are of a dull nankeen yellow, and make their appearance in June-depositing their eggs upon the leaves. 'These soon change to small worms, and rapilly eat up the foliage. The best remedy yet known is, to dust thoroughly with powdered white hellebore.

The Curmut-bores, Prenocerus supernatatus, is another inseet that sometimes creates damage by boring its way through the centre of young shoots and thus destroying them. By examining the young shoots in winter, such as are injured or contain the worm will be found of a brown color or shrivelled. Cutting away soon ehecks them.

There are, nominally, many sorts of Currants, but the following sorts comprise all at present known worthy of eultivation.

\section{CLASS I.}

\section{RED AND WHITE CURRANTS.}

\section{A trtractor.}

A variety from France. Growth rather slow, spreading, very productive. Leaves small, sharply serrate or toothed, and three-lobed.

Fruit medium, yellowish white. Bunches medium, short.

\section{Buist's Loxg-Bunched.}

Originated by Robert Buist, Philadelphia, Pa. A very vigorous upright grower, and very productive.

Fruit of large size. Bunches very loug, tapering, nuch like Red Dutch in flavor and color.

\section{Chanpagne.}

Pheasant's Eye.

Groseillier à Fruit Couleur de Chair.

A large and handsome Currant, of a pale pink or flesh color, exach ly intermediate in this respreet between the Red and White Dutch. It is quite an acid sort, but is admired by many for its pretty appearance.

\section{Cherry,}

A strong-growing variety, with stout, ereet, short-jointed shoots. Leaves large, thick, and clark green. Not any more productive than other Currants, but a valuable one for market on accomnt of its size.

Fruit of the very largest size. Bunches short. Berries deep red, and rather more acid than Red Duteh.

\section{Fertile de Palluau.}

A varieiy of rather recent introduction from France. A vigorous 
upright grower, productive. Fruit large. Bunches long, bright red, moderately juicy.

\section{Gondouis Red.}

Red Provens.

From France. Red. Vigorous grower, very productive.

Fruit not as large nor as good as Red Dutch, fails to ripen well, quite acid and worthless.

\section{Gondourn White.}

Fruit large, whitish yellow, quite sweet, more so than any other sort. Branches rather long, strong growth, productive.

\section{Knight's Early Red.}

The merit of this variety is in its ripening a few days earlier than other sorts.

\section{Knight's Large Red.}

Fruit very large, bright red. Bunches very large, very productive, an excellent sort.

\section{Knight's Sweet Red.}

This is not a sweet Currant, but is considerably less acid than other red Currants, not as sweet as White Dutch.

Frnit nearly as large as Red Dutch, rather lighter in color. Productive.

\section{La Fertile.}

From France. A vigorous upright grower, and productive. Dutch.

Fruit large. Bunches long, dark red. Flavor similar to Red

\section{La Hâtrve.}

Hâtive de Bertin.

A variety from France. Plant vigorous, foliage not as large as the cherry.

Fruit large, dark rec. Bunches medium length, tapering. In quality about equal to Red Dutch.

\section{LaA Versaillaise.}

\section{Macrocarpa.}

Fertile d'Angers.

\section{Caucase.}

Imperial Red.

A variety from France. A very vigorous grower, with large, coarsn foliage, productive.

Fruit of the largest size, dark red. Bunches resembling Cherry Currant, but occasionally longer.

We have received this Currant under the various names above given: 
but have been unable to discover any difference. There may bo dis. tinct sorts under these names, but we have failed to obtain them.

\section{Long-Bunched ReD.}

Grosse Rouge de Holland.

Fruit large. Bunches long. Berries deep red, much like Red Dutch. with a little larger clusters, and "ather larger fruit. Very productive.

\section{Prixce Albert}

Moderately vigorous grower, large foliage, late in ripening, produc. tive and valuable.

Fruit large, similar in color to Victoria.

\section{Red Dutch.}

$\begin{array}{ll}\text { Large Red Dutch. } & \text { Large-Bunched Red. } \\ \text { New Red Dutch. } & \text { Morgan's Red. }\end{array}$

Groseillier Rouge à Gros Fruit.

An old, well-known sort, thrifty, upright growth, very productive.

Fruit large, deep red, rich acid tlavor, with clusters two or three inches long.

\section{Short-Bunched Red.}

Much like Rerl Dutch, with rather shorter bunches. Fruit not quite as large, but similar in quality.

\section{Striped-Fruited.}

Grosse Weiss und Rothgestreifte Johaunesbeere. Silver-Striped.

A fruit from Germany. Distinctly striped, small, poor bearer, and of no value except as a curiosity. Gloire des Sablons is similar to the above, and both without value except for ornament.

\section{Transparent.}

Blane Transparent.

A French Currant.

Fruit very large, yellowish white, similar to White Grape in growth and fruit, and we are somewhat disposed to consider them identical. Very productive.

\section{VICTORIA.}

$\begin{array}{lll}\text { May's Victoria. } & \text { Raby Castle. } & \text { Houghton Castle. } \\ \text { Goliath. } & \text { Red Grape. } & \text { Wilmot's Red Grape. }\end{array}$

A very excellent, rather late sort, with very long bunches of bright red fruit, and is an acquisition to this class of fruits. Berries as large as Red Dutch. Bunches rather longer, of a brighter red, growth moie slow, sprearling, and very productive. Will hang on the bushes some two weeks longer than most Currants. 


\section{Winte Dutch.}

New White Dutch.

White Crystal.

White Clinton.
Reere's White. Morgan's White. White Antwerp.
Dana's New White?

White Leghorn.

This is precisely similar to Red Dutch in habit, but the fruit is larger, with rather shorter bunches, of a fine yellowish white color, with a very transparent skin. It is considerably less acid than the Red Currauts, and is therefore much preferred for the table. It is also a few days earlier. Very productive.

\section{White Grape.}

Imperial White.

Impérial Blanc.

Bunches moderately long. Berries very large, whitish yellow, sweet and good. Very productive. Branches more horizontal than White Dutch, and less vigorous.

\section{White Provence.}

A strong, upright growing variety, leaves often silvery edged.

Fruit yellowish white. Bunch short, tapering. Not as productive or profitable as WVhite Grape.

\section{CLASS II.}

\section{BLACK CURRANTS.}

B.ANG UP.

A variety similar, and no way superior, to the Black English.

\section{Black Grape.}

Ogden's Black Grape.

Very much resembling Black Naples, but the plant, perhaps, a stronger and more vigorous grower.

\section{Black Naples.}

The Black Naples is a beautiful fruit, the finest and largest of all Black Currants, its berries often measuring nearly three-fourths of an inch in diameter. Its leaves and blossoms appear earlier than those of the Common Black, but the fruit is later, and the clusters, as well as the berries, are larger and more numerous.

\section{Comiron Black.}

Black English.

Casis.

The common Black English Currant is well known. The berries are quite black, less than half an inch in diameter, and borne in clus. ters of four or five berries. 
Several varieties of Yellow and Blick Currants, which we have re. ceived from Utah, have not fruited sutliciently for us to decide upon their values.

Slickotion of Curraxts. Red Dutch, White Dutch, White Grape, La Versaillaise, Victoria, ('herry.

Orsanextal Varieties. There are several very ornamental species of Currant, among which we may here allude to the Missouri Currast (Ribes Anreum), bronght by Lewis and Clarke from the Rocky Mommbains, which is now very common in our gardens, and generally admired for its very fragrant yellow blossoms. Its oval blne berries, which are prodnced in great abundance, are relished by some persons. But there is a Lurge-Frnited Missomi Cmrant, a variety of this, which bears berries of the size of the Black Naples, and also some with yellow fruit of large size, almost equalling small cherries.

The Red Flowerixg Cunkaxt (R. sanguineum) is a very beautiful shrub from the westeru coast of America, with foliage somewhat like that of the Common Black, but which bears very charming clusters of large light erimson blossoms in A pril.

There are several other varieties, as $R$. sanguineum, fl. pl., R. sanguineum atro-purpurea, and $\mathbf{R}$. Gordoni. They are not quite hardy enongh to stand our winters withont protection, but at the South will make a valuable addition to their shrubbery.

\section{CHAPTER XV.}

\section{THE CRANBERRY.}

Oxycoccus, Arb. Brit. Ericacere, of botanusts. Aire"le, of the French; Die Wonsebeere, German; Teen bessen, Dutch; osicocen, Italian.

THE Cranberry is a familiar trailing shrub, growing wild in swampy, sandy meadows and mossy bogs, in the northern portions of both hemispheres, and produces a round, red, acid fruit. Our native species ( $O$. macrocurpus), so common in the swamps of New England, and on the borders of qur inland lakes, as to form quite an article of commerce, is much the largest and finest sprecies; the Emropean: Cranberry (O) prabstris) being much smaller in its growth, and prolucing frut inferior in size and quality. Also the Russian (O. viridis), a medimm-sized variety.

Of the 0 . macrocarpus, there are three varicties:-The "TBellshaped," which is the largest and most valued, of a very dark, bright red color. The "Cherry," two kinds, large and small; the large one" the best, of a round form, a fine dark red berry, nearly or quite equal to the Bell-shaped; and the Bugle, Oval, or Erg-shaperl, two kinds, large and small, not so high-colored as the Bell and Cherry-not so much prized, but still a fine variety.

The value of the common Cramberry for tarts, preserves, and other 
culinary uses, is well known, and in portions of the country where it loes not naturally grow, or is not abmolantly produced, it is quite worth while to attempt its culture. Althongh, naturally, it grows mostly in mossy wet land, yet it may be easily cultivated in beds of peat soil, made in any rather moist situation; and if a third of old thoronghly decayed mamme is added to the peat, the berries will be much larger and of more agreeable flavor than the wild ones. A square of the size of twenty feet, planted in this way, will yield three or four bushels annually-quitc sufficient for a family. The plants are easily procured, and are generally taken up like squares of sod or turf, and planted two or three feet apart, when they quickly cover the whole beds.

In some parts of New England, low and coarse mearlows, of no value, have been drained and turned to very profitable account by planting them with this fruit. In New Jerser, on Long Island, and elsewhere, large tracts of light sandy soils have been planted to Cranberries, and grown with profit and success. The Cranberry grows freely in light soils, but it is necessary to cover the surface, after ploughing, a depth of several inches, with clean sand. The average product is from eighty to one hundred bushels of cranberries, and the care they require after the laud is once prepared and planted is scarcely any at all, except in gathering. Some of the farms in Massachusetts yield large crops, partly from nitural growth, and partly from cultivated plantations. The Cranberry grows wild in the greatest abundance on the sandy low necks near Barnstable, and an annual Cranberry festival is made of the gathering of the fruit, which is done by the mass of the population, who turn ont on the day appointed by the authorities, and make a general gathering with their cranberry rakes, a certain portion of the crop belonging, and being delivered, to the town.

A laborer will gather about thirty bushels of the fruit in a day with a cranberry rake.

\section{CHAP'TER XVI.}

THE FIG.

Ficus Carven, L. Arb. Brit. Trticacen, of botanists ; Figuier, of the French; Fitjenbrum, German ; Fico. Italian ; Higuera, Spanish.

THIs celebrated fruit-tree, whose history is as ancient as that of the world, belongs properly to a warm climate, thongh it may be raised in the open air in the Middle States, with proper care.

In its native countries, Asia and A frica, near the sea coast it forms a low tree, twenty feet in height, with spreading branches, and large, rleeply loberl, rough leaves. It is completely naturalized in the sonth of Europe, where its cultivation is one of the most important occupations of the fruit-grower.

The fruit of the Fig-tree is remarkable for making its appearance, growing, and ripening, without being preceded by any apparent blossom. The latter, however, is concealed in the interior of a tleshy receptacle 
which is called, and futally hecomes, the fruit. The flavor of the fig is excecelingly sweet aud liscious, so much so as not to be agreeable to nuany persons when tasted for the first time; but, like most fruits of this kind, it becomes a ireat firorite with all after a short trial, and is really one of the most agreerble, wholesome, and nutritions kinds of foorl. It has always, indeed, been the favorite fruit of warm countries, and the ideal of earthly happiness and content, as typified in the Bible, consists un sitting under one's own fig-tree.

Its cultivation was carried to great perfection among the ancient Romaus, who had more than twenty varieties in their gardens. But the Ithenians seem to have prided themselves most on their figs, and even made a law forbidling any to be exported from Attica. Simuggling, however, seems to have been carried on in those days, and a curious little piece of etymological history is connected with the fig. The informers against those who broke this law were called sukophantai, from two words in the Greek, meaning the "discoverer's of figs." And as their power appears also to have been used for malicions purposes, thence arose our word sycophant. The fig was first introduced from Italy about 1548 , by Cardinal Poole, and to this country about 1790 , by $\mathrm{Wm}$. Hamilton, Esq.

Propagatios. This tree is very readily increased by cuttings taken off in the month of March, and planted in a light soil in a hot-bed, when they will make very strong plants the same season. Or they may be planted in a shady border in the open air, quite early in April, with tolerable success. In either case the cuttings shonld be made eight or ten inches long, of the last year's shoots, with about half an inch of the old "r previous year's wood left at the base of each.

SoIL AND CULTURE. The best soil for the fig is one moderately deep, alid neither too moist nor diy, as in the former case the plant is but too apt to rim to coarse wood, and in the latter, to drop its fruit before it is fully ripe. A mellow calcareous loam is the best soil in this climate -and marl, or mild lime in compost, the most suitable manure.

As in the Middle States this tree is not hardy enongh to be allowed to grow as a standard, it is the policy of the cultivator to keep it in a low and shrub-like form, near the ground, that it may be easily covered in winter. The great difficulty of this mode of training, with us, has been that the coarse and over-luxuriant growth of the branches, when kept lown, is so great as to render the tree mufruitful, or to rob the fruit of its due share of nomishment. Happily the system of root-pmurng, recently found so beneficial with some other trees, is in this elimate most perfectly adapted to the fig. Short-jointed wood, and only moderate vigor of growth, are well-known accompaniments of fruitfuluess in this tree; and there is $n 0$ ineans by which firm, well-ripened, short-jointed wood is so easily obtained as by an amual pruning of the roots-cutting aff all that project inore than half the length of the branches. In this way the fig-tree may be kept in that rich and somewhat strong soil ne. cessary to enahle it to hold its firuit, and rijen it of the largest size, without that courseness of growth which usually happens in such soil, and but too frequently renders the tree barren. T'he morle of performing root-pruning we have already described, but we may add here that the operation should be performed on the fig early in November. When this mode is adopted but little pruning will be necessiry, beyond that of keeping the plant in a somewhat low and regular sliape, short- 
ening-in the branches occasionally, and taking out old and decaying wood.

In winter the branches of the fig must be bent down to the ground, and fistened with hooked pegs, and covered with three or four inclies of soil, as in protecting the foreign grape. This covering should be removed as soon as the spring is well settled. Below Philadelphia, a covering of straw, or branches of evergreens is sufficient-and south of Virginia the fig is easy of cuiture as a hardy standard tree.

Two crops are usually produced in a year by this tree: the first, which ripens here in midsmmmer, and is borme on the previous season's shoots; and the second, which is yielded by the young shoots of this summer, and which rarely ripens well in the Middle states. It is, therefore, a highly advantageous practice to rub off all the young figs of this second crop after midsummer, as soon as they are formed. The consequence of this is to retain all the organizable matter in the tree, and to form new embryo figs where these are rubbed off, which then ripen the next season as the first crop.

Ripening the Fruit. In an unfavorable soil or climate, the ripening of the fig is undoubtedly rendered more certain and speedy by touching the eye of the fruit with a little oil. This is very commonly practised in many districts of France. "At Argenteuil," says London, "the maturity of the latest figs is hastened by putting a single drop of oil into the eye of each fruit. This is doue by a woman, who has a phial of oil suspended from her waist, and a piece of hollow rye strnw in her hand. This she dips into the oil, and afterwards into the eye of the fig."

We have ourselves frequently tried the experiment of touching the end of the Fig with the finger dipped in oil, and have always found the fruits so treated to ripen much more certainly and speedily, and swell to a larger size than those left witouched.

There are forty-two varieties enumerated in the last edition of the London Horticultural Society's Catalcgue. Few of these have, however, been introduced into this comntry, and a very few sorts will comprise all that is most desirable aud excellent in this fruit. The following selection includes those most suitable for our soil and climate.

Fruit nearly all ripen in August.

\section{CLASS I.}

RED, BROWN, OR PURPLE.

\section{BuACK GExOA.}

The fruit of this Fig is long ohovate, that portion next the stalk being very slender. Skin dark purple, becoming nearly black, and covered with a purple bloom. Pulp bright red, flavor excellent. Habit of the tree moderateily strong.

\section{Blacti tsomita.}

Early Forcing. Blue Ischis.

One of the most fruitful sorts, and pretty hardy. 
Frnit of medium size, roundish, a little flattened at the apex. Skin dirk violet, beeoming almost. hlack when fully ripe. Elesh deep red, and of very sweet, luscious thitror.

\section{Bnown Ischin.}

Chestuut. Chestnut-colored Ischia.

A good variety, with, howerer, a rather thin skin, rendering it liable to crack or burst open when fully ripe. It is hardy, of good halit, and a very excellent bearer.

Fruit of molinm size, roundish oborate. Skin light or chestnut brown. Pulp purple, very sweet and excellent.

\section{Brow TerKey.}

$\begin{array}{lll}\text { Brown Italian. } & \text { Large Blue. } & \text { Italian. } \\ \text { Brow n Naples. } & \text { Murrey. } & \text { Lee's Perpetual. }\end{array}$

This is undoubtedly one of the very best for this country, and for open air culture, as it is perhaps the very hardiest, and one of the most regular and abundant bearers.

Frnit large, oblong or pyriform. Skin dark brown, covered with a thick blue bloom. Flesh red, and of very delicious flavor.

\section{Brunswick.}

$\begin{array}{llll}\text { Madonna. } & \text { Hanover. } & \text { Brown Hamburg. } & \text { Black Naples. } \\ \text { Clementine. } & \text { Bayswater. } & \text { Red. }\end{array}$

One of the largest and finest purple Figs, well adapted for hardy culture.

Fruit of the largest size, pyriform in shape, with an oblique apex. Eye consiclerably sunk. Stalk short and thick, of a fine riolet brown in the sun, dutted with small pale brown specks, and, on the shaded sicle, pale greenish yollow. Flesh reddish brown, slightly pink near the centre, and somewhat transparent. Flavor rich and excellent. The only fault of this variety for open air culture is, that it is rather too strong in its growth, not being so easily protected in winter as more dwartish sorts.

\section{MaLta.}

\section{Small Brown.}

A small, but rery rich Fig, which will often hang on the tree rintil it begins to shrivel, and becomes "a fine sweetmeat."

Fruit much compressed at the apex, and very much narrowed in towards the stalk. Skin light brown. Pulp pale brown, and of a sweet, rich flavor. Ripens later than the foregoing, about the last of August.

\section{Sintl Brown Iscimia.}

A very hardy sort, which, in tolerably warm places south of Philadelphia, will make a small standard tree in the open air, bearing pretty good crops, that ripen abont the first of September. 
Fruit small, pyriform, with a very short footstalk. Skin light brown. Pulp pale purple, of high flavor. Leaves more entire than those of the common Fig.

\section{Violette.}

A very good sort from the neighborhood of Paris, where it produces two crops annually.

Fruit small, roundish obovate, flattened at the apex. Skin dark violet. Pulp nearly white, or a little tinged with red on the inside, aud of pleasant flavor.

\section{Violette de Bordeaux.}

\section{Bordeaux.}

A Fig which is much cultivated in France, being quite productive, though of inferior flaror to many of the foregoing sorts.

Fruit large, pyriform, about three inches long and two in diameter. Skin deep violet when fully ripe, but at first of a brownish reu. Pulp reddish purple, sweet, and good.

\section{CLASS II.}

FRUIT, WHITE, GREEN, OR YELLOW.

Axgélique.

Concourelle Blanche.

Mélitte

This little Fig is a very abundant bearer, and a pretty hardy sor't.

Fruit small, obovate. Skin pale greenish yellow, dotted with lighter colored specks. Pulp white, but only tolerably sweet. It will usually bear two crops.

\section{Large White Gexoa.}

Fruit large, roundish obovate. Skin thin, pale yellow. Pulp red, and well flavored.

\section{Marseilles.}

White Marseilles.

White Naples.

Pocock.
Ford's Seedling.

White Standard.

Figue Blanche.

A very favorite sort for forcing and raising under glass, but which does not succeed so well as the Brown Turkey and the Ischias for open culture.

Fruit small, roundish obovate, slightly ribbed. Skin nearly white, with a little yellowish green remaining. Flesh white, rather dry, but sweet and rich.

\section{NERII.}

A fruit rather smaller and longer than the Marseilles, and which, from a mingling of siight acicl, is one of the most exquisite in its flaror. 
Fruit small, roundish obovate. Skin pale greenish yellow. Pulp red. Flavor at once delicate and rich. 'This is a very farorite variety according to Loudon, "the richest fig known in Britain."

\title{
Pregussata.
}

A sort lately introduced from the Tonian Isles into England. It is tolerably har ly, quite productive, and succeeds admirably umder glass.

Fruit of medium size, roundish, a good cleal thattened. Skin purplish brown in the shade, dark brown in the sun. Pulp deep red, with a luscious, high flavor. Seeds unusually small. lipens gradually, in suecession.

\section{White Ischia.}

\section{Green Ischia.}

A very small Fig, but one of the hardiest of the light-colored ones.

Fruit about an inch in dianeter, roundish obovate. Skin pale yellowish green, very thin, and, when fully ripe, the darker-colored pulp appears through it. Pulp purplish, and high flavored. A moderate grower and good bearer.

\section{CHAPTER XVIT.}

THE GOOSEBERRY.

\begin{abstract}
Ribes Frossularia, Arb. Brit. Grossulacea, of botanists.
Groseillier, of the French; Starhelbeerstmuch, German; Uia Spino, Italian ; G'rovella, Spanish.
\end{abstract}

The Gooseberry of our gardens is a native of the north of Europe, our native species not having much improved by garden culture. This low prickly shrub, which in its wild state bears small round or oval f:uit, about half an inch in diameter, and weighing one-fourth of an onnce, has been so greatly improved by the srstem of successive reproduction from the seed, and high culture hy British gardeners, that it now bears fruit nearly or quite two inches in diameter, and weighing an ounce and a half. Lancashire, in England, is the mericlian of the gooseberry, and to the Lancashire weavers, who seem to hare taken it as a hobby, we are indebted for nearly all the surprisingly large sorts of mod. ern date. Their annual shows exhibit this fruit in its greatest perfection, and a Gooseberry Book is published at Manchester every year, giving a list of all the prize sorts, etc. Indeed the climate of England seems, from its moistness and coolness, more perfectly fitted than any other to the growth of this fruit. Under our more clear and hot suns, lowever, the best rarieties of English sorts do not snceed well, suffering from inildew of the fruit and foliage in nearly every location. A few varietics of the Euglish sorts, and some few sorts of American origin, steceud, and their growth near large cities is considerad quite protitable. 
Uses. This fruit is, in the first place, a very important one in its green state, being in high estimation for pies, tarts, and puddings, coming into use earlier than any other. The earliest use made of it appears to have been as a sance with green goose, whence the name, goose-berry. In its ripe state it is a very agreeable table firuit, and in this country, following the season of cherries, it is always most acceptable. Tnripe gooseberries are bottled in water for winter use (placing the bottles, ncarly filled, a few moments in boiling water, afterwards corking and sealing them, and burying them in a cool cellar, with their necks downward). They are also canned, the same as with cherries, peaches, and other fruits.

As a luxury for the poor, $\mathrm{M}_{1}$. London considers this the most valuable of all fruits, "since it ean be grown in less space, in more unfaror. able circumstances, and brought sooner into bearing than any other."

Propagation. Gonseberry plauts should only be raised from enttings. New varieties are of course raised from seed, and the production of new Anerican varieties of large size and fine quality altords a field of oecupation which we should rejoice to see abundantly filled.

In preparing euttings seleet the strongest and straightest young shoots of the emrent year, at the end of October (or very early in the ensuing spring); ent out all the louds that you intend to go below the ground (to prevent future suckers), and plant the cuttings in a deep rich soil, on the north side of a fence, or in some shaded border. The cuttings should be inserted six inches deep, and from three to six or eight inches should remain above gromnl. The soil should be pressed very firmly about the cuttings, and, in the case of antumn planting, the cuttings should be inserted into the ground level with the upper buds, and then covered with a mulch of coarse mamme, to be taken away in the following spring, when they should be examined, and the earth pressed to render it firm again should the cutting lave been raised by severe frost. After they have become well rooted-generally in a year's time-they may be transplanted to the borders, where they are finally to remain.

Comtivation. The Goosebery in our elimate is very impatient of drought, and we have uniformly found that the best soil for it is a deep strong loam; or at least whatever may be the soil, and it will grow in a great variety, it should always be deep-if not naturally so, it should be made deep by treneling and manuring. It is the most common error to plant this fruit shinb under the branches of other trees for the sake of their shade-as it always renders the fruit inferior in size and flavor, and more likely to become monldy. On the contrary, we would always alvise planting in an open border, as, if the soil is sufficiently deep, the plants will not suffer from dryness, and should it unfortumately lue of a dry nature, it may he rendered less injurious by corering the ground under the plants with straw or litter. In any case a rich soil is necessary, and as the Gooseberry is fond of manure, a pretty heavy top-dressing should be dug in every year around bearing plants. For a later crop a few bushes may be set on the north side of a fence or wall:

For the Cooseberry, regular and pretty liberal pruming is absolutely necessarly. Of course no suckers should be allowed to grow. In November the winter pruning should be performed. The leaves now being off, it is easy to see what proportion of the new as well as old wood may be taken away; and we will here remark that it is quite impossible 
to obtain fine gooseberies here, or anywhere, without a very thorough thimning ont of the branches. As a greneral rule, it may safely be said that one-half of the head, including old and young branches (nore especially the former, as the best fruit is borne on the youmg wood), should now he taken out, leaving a proper distribution of shoots thronghont the bush, the heal being sufficiently thimed to admit freely the lingt and air. An additional pruning is, in England, pertormed in June, which consists in stopping the growth of lowg showts by pinching out the extremities and thiming out superthous branches; but if the ammal pruning is property performed this will not be found necessary, except to obtain fruit of extraorelinary size.

We do not think that this fruit shrub can be said to bear well for more than a half-dozen years successively, when grown in the single stem or tree form. In large plantations of acres, and where cultivation is given by means of the horse and plough, the system of growing in the bush form is by many considered most profitable; and when so done, all that is requisite, from year to year, for many years, is to cut away dead wood, head hack vigorous shoots, and keep the form open.

A succession of young plants should be kept up by striking some cuttings every season.

VArieties. The number of these is almost endless, new ones being produced by the prize growers every year. The last edition of the London Horticultural Society's Catalogue enumerates 149 sorts consiclered worthy of notice, and Lindley's Guide to the Orchard gives a list of more than seven hundred prize sorts. It is almost neerlless to say that many of these very closely resemble each other, and that a small number of them will comprise all the most valuable.

The sorts bearing fruit of medium size are generally more highly flavored than the very large ones. We have selected a sufficient number of the most valuable for all practical purposes.

\section{Red Gooseberries.}

Bodrduax's British Crowx. Fruit very large, roundish, hairy, handsome and good. Branches spreading.

Chanpagse. A fine old variety, of very rich flavor. Fruit small, ronndish oblong, surface hairy, pulp clear; branches of very upright growth.

Capper's Top SAwyer. Fruit large, roundish, pale red, hairy; rather late; flavol very good. Brauches drooping.

Farkow's Rodrixig Liox. An immense berry, anil hangs late. Fruit oblong, smooth ; flavor excellent; branches drooping.

Hartsionx's Laxcasirjne Lad. Fruit large, roundisli, dark red, hairy ; flavor very good; branches erect.

Kews's Seedlixg. Fruit of medium size, oblong, hairy; flavor first-rate; branches drooping. Farly and productive.

Leigir's Riflemax. Fruit large, roundish, hairy; flavor first-rate ; • branches erect.

Mereixa's Crowx Boß. Fruit large, oblong, hairy; flavor firstrate; branches sprearling.

MIss Bos, Fruit of medium size, roundish, surface downy ; flavor excellent; branches spreading. 
Red Wrarringtox. Fruit large, roundish oblong, hairy; flavor first-rate; branches drooping.

\section{Yellow Gooseberries.}

Buerdaslu's Duckwivg. - Fruit large and late, obovate, smooth; flavor good; branches ereet.

CAp’er's Bunker Hill. Fruit large, roundish, smooth; flavor good; branches spreading.

GonTon's VIPER. Fruit large, obovate, smooth; flaror good; branches drooping.

Hill's Goldes Gound. Fruit large, oblong, hairy; flaror good ; branches drooping.

Part's Golden Fleece. Fruit large, oval, hairy; flavor first-rate; branches spreatiug.

Propner's Rockwood. Fruit large and early, roundish, hairy; flavor good; branches erect.

Inelow Champagae. Fruit small, roundish, hairy; flavor firstrate; branches erect.

Yellow Ball. Fruit of middle size, roundish, smooth; flaror firstrate; branches erect.

\section{Green Gooseberries.}

Colrier's Jolmy Axquen. Fruit large and late, oblong, downy; flavor first-rate; branches erect.

BerRy's GreENWood. Fruit large, oblong, smooth; flaror good; branches drooping.

Early Grees Hatry (or Green Gascoigne.) Fruit small and early, roumd, hairy ; flavor excellent; branches spreading.

EDWard's Jolly TAr. Fruit large, obovate, smooth; flavor first. rate; branches drooping.

Glenton Green. Fruit of middle size, oblong, hairy; flavor excellent; branches drooping.

Greex Waldut. Fruit middle size, obovate, smooth; flavor firstrate; branches spreading.

Hepburn Green Prolific. Fruit of mildle size, roundish, hairy ; flaror first-rate; branches erect.

Massey's Heart of OAK. Fruit large, oblong, smooth; flavor first-rate; branches drooping.

Parkinson's Laurel. Fruit large, obovate, downy; flavor firstrate; branchès erect.

Pituaston Green Gage. Fruit small, aud hangs .long, obovate, smooth; flavor rich and excellent; branches erect.

Wainyax's Green Ocean. Fruit very large, oblong, smooth; flavor tolerably good; branches droopiug.

\section{White Gooseberries.}

Cleworti's IVinte Lion. Fruit large and hangs late, obovate, downy ; flavor first-rate. Branches drooping.

Crompton Sheba Queer. Fruit large, obovate, downy; flaror firstrate. Branches erect. 
Cook's Wirte Eagle. Fruit large, obovate, snooth. Flavor firstrate. Brinches ereet.

Cappen's Boxyy Lass. Fruit large, oblong, hairy. Flavor gool. Branches spreading.

ILAluer's LADY of TIIE MLAxon. Fruit large, roundish oblong, hairy. Flavor good. Branches erect.

Siduninks' Cheshine Lass. Fruit large and very early, oblong, downy. Flavor excellent. Branches erect.

WOoDWands Wmitesutu. Fruit large, roundish oblong, downy. Flavor first-rate. Branches erect.

Weldxigox's Glons. Fruit large, rather oval. Very downy. Skin quite thin. Flavor excellent. Branches erect.

White Hoxey. Fruit of middle size, roundish oblong, smootl. Flavor excellent. Branches erect.

'Taýlor's Brigite Vexus. Fruit of middle size, hangs a long time, obovate, hairy. Flavor first-rate. Branches erect.

The following list of selected sorts, from one hundred varieties, is prepared by Thomas Rivers, Sawbridgeworth, England :-

\section{Red Gooseberries.}

Atlas, late.

Echo, late.

Guido, very large.

Huntsman, early.

Hopley's Companion.

Overall, late.

\section{White Gooseberries.}

Freedom.

Lady Delamere.

Ostrich, early.

Queen Caroline.

Smiling Beauty.

Riley's Tallyho.

\section{Green Gooseberries.}

Conquering Hero, late. Husbandman, late. Jolly Cutler, late. Riley's.

Elijah, early.

Green River, late.

Keepsake.

Thumper, very late.

\section{Yellow Gooseberries.}

Banks Dublin.

Broom Girl.

Briton.
Husbandman, late.

Marigold, early.

Pilot, early.
Prince Albert, early.

Prince Regent, early.

Young Wonderful.

\section{AMERICAN VARIETIES.}

Favorite.

Iudependent.

Profit, late.

Wistastoa Hero, early.

\section{Downing.}

A seedling of Houghton, originated at Newburgh, N. Y. Upright vigorous growing plant, very productive.

Fluit somewhat larger than Houghton, roundish oval, whitish green with the rib reins listinct. Skin smooth. Flesh rather soft, juicy, very grood. Excellent for family use. 


\section{HoBbs' SEEDLING.}

A variety claimed to have originated by $\mathrm{O}$. J. Hobbs, of Randoly, Pa. It is light pale green, roundish, slightly oval, smooth. Flesh medium firmness. A good keeper, and nearly one-half larger than Hougiton's.

\section{Houghton's Seenlixg.}

Originated with Abel Hunghton, Lynn, Mass. A vigorous grower. Branches rather drooping, slender, very productive, generally free from mildew. A desirable sort.

Fruit medium or below, roundish, inclining to oval. Skin smooth, pale red. Flesh tender, sweet, and very good.

\section{Mountain Seedling.}

Originated with the Shakers at Lebanon, N. Y. Plant a strong straggling grower. An abundant bearer.

Fruit large, the largest of any known American sort, long oval, dark hrownish red, with long stalk. Skin smooth, thick. Flesh sweet. A good market sort.

\section{Pale Red.}

\section{American Red. Robert's Sweet Water. Ohio Seedling. Dutch Joe.}

American Seedling.

Ohio Prolific.

St. Clair.

Cluster.

A variety of unknown origin. Bush more upright than Houghton. Slender wood. Very productive.

Fruit small or medium, or size of the Houghton; darker in color when fully ripe. Hangs a long time upon the bush. Flesh tender, sweet, very good.

\section{Suith's IMPRoved. \\ Smith's Seedling.}

A new variety recently introduced. Grown from seed of the Honghton, by Dr. Smith, of Vermont, and in growth of plant more upright and vigorous than its parent; the fruit is larger and somewhat oval in orm, light green, with a bloom. Flesh moderately firm, sweet and good.

\section{CHAPTER XVIII.}

THE GRAPE.

Titis vinifera, L. Vitacece, of botanists.

Vigne, of the French; Weintrauben, German; Vigna, Italian ; Tid, or Tina, Spanish.

THe history of the Grape is almost as old as that of man. Growing in its lighest perfection in Syria and Persia, its luscious fruit, and the 
unrivalled beverage which its fermented juice affords, recommonded is to the especial care of the patriachal tillers of the soil, and rinevards were extensirely planted long before orehards or collections of other fruit-trees were at all common.

The grapes of the old world are all varieties of the wine grape (I Titis vinifere), which, though so long and so miversally cultivated and naturalized in all the mildle and southem portions of Europe, is not a native of that continent, but came originaliy from Persia. From the lat ter country, as cirilization advanced westward, this plant accompanied it - first to Egypt, then to Greece and sicily, and gradually to Italy, Spain, France, and Britain, to which latter comntry the Romans carried it about two hundred years after Christ. To America the seeds and plants of the European varieties were brought by numerous emigrants and colonists within the first fifty years after its settlement.

The wild grapes of onr own cumtry are quite distinct species from the wine grape of Europe-are usualiy stronger in their growth, with larger and more entire foliage, and, in their native state, with a peculiar foxy odor or flavor, and more or less lardness of pulp. These traits, however, disappear in process of cultivation, and we have reason to hope that we shall soon obtain from the wild type new varieties of high quality, and of superior hardiness and productiveness in this climate.

The grape-vine is in all cases a trailing or climbing decirhous shrub, living to a great age, and, in its native forests, clambering over the tops of the tallest trees. In the deep rich alluvial soils of western America it is often seen attaining a truly prodigious size, and several have been measured on the banks of the Ohio the stems of which were three feet in circumference, and the branches two hundred feet long, enwreathing and festooning the tops of huge poplars and sycamores. In a cultirated state, however, it is found tliat tine flavor and uniform productiveness require the plants to be kejt p'med within a small compass.

Uses. The grape in its tinest varieties, as the Hamburgh and the Muscat, is in flavor hardly surpasserl by any other fruit in delicacy and richness, and few or none are more beantiful in the dessert. Dried, it forms the raisin of commerce, the most excellent of all dried fruits, everywhere esteemed. And wine, the fermented juice, has always been the first of all exhilarating licuors. Some idea of the past consumption of this product may be formed from the fact that more than $500,000,000$ imperial gallons have been made in France in a single year; aud as a data to julge of its value we mar add that, while a great proportion of the vin ordinaire, or common wine, is sold at 10 or 12 cents a bottle, on the other hand, particular old and rare vintages of Madeiras or Sherries will not unfrequently command twenty or thirty clollars a gallon.

Soıt. The universal experience in all countries has established the fact that a dry and warm soil is the very best for the vine. Where vineyards are cultivated, a limestone soil, or one composed of deciying calcareous rocks, is by far the best; but where, as in most gardens, the vine is raised solely tor its fruit, the soil should be highly emriched. The foreign grape will scarcely thrive well here on a heavy soil, though our native varieties grow and bear well on any strong land; but the essence of all that can be said in grape culture respecting soil is, that it be dry and light, deep and rieh. Frequent top-dressings of well-rotted 
manure should be applied to vines in open borders, and this should. every third or fourth year, be alternated with a dressing of slaked lime.

Propagation. The grape-vine makes roots very freely, and is, therefore, easy of propagation. Branches of the previous or eurrent year's wood, bent down at any time before midsummer, and covered witl earth, as layers, root very freely, and make bearing plants in a couple of years, or very frequently indeed bear the next season.

But the finer varieties of the vine are almost miversally propagated by cuttings, as that is a very simple mode, and an abundance of the cut tings being afforded by the annual trimming of the vines.

When cuttings are to be planted in the open border, a somewhat moist and shaded place should be chosen for this pupose. The cuttings should then be made of the youmg wood of the previous year's growth, cut into lengths about a foot long, and having two or three buds -one near the top, one at the bottom, and the third in the middle. Before planting the eutting, pare off its lower end smoothly, close below the buds, and tinally plant it in mellow soil, in a slit made by the spade, pressing the earth firmly about it with the foot.*

The rarer kinds of foreign grapes are usually grown by cuttings of shorter length, consisting only of two buds; and the most successful mode is to plant each cutting in a small pot, and plunge the pots in a slight hot-bed, or place the cuttings at once in the mould of the bed itself. In either case they will make strong plants in the same season.

But the most approved way of raising vine plants in pots is that of proplagation by eyes, which we have fully explained in the first part of this work. This, as it retains the least portion of the old wood, is manifestly the nearest approach to raising a plant from the seed, that most perfect of all modes with respect to the constitution of a plant. In the case of new or rare sorts, it ofters us the means of multiplying them with the greatest possible rapiclity. As the grape usually receives its anmual pruning in autumn or winter's the cuttings may be reduced to nearly their proper length, and kept in earth, in the cellar, until the ensuing spring. The hardier sorts may be buried in the open ground.

The foreign and the native grapes are very different in their habits in this climate, and therefore must be treated differently. The native sorts are eultivated with searcely any further care than training up the branches to poles or a trellis, and are, on this account, highly valuable to the farmer; while the European varieties are of little value in this climate except with especial care, and are therefore confined to the garden.

\section{Culture of the Froreign Grape.}

The climate of the temperate portion of this country, so farorable to all other fruits, is, unfortunately, not so for the foreign Grape. This results, perhaps, from its variability, the great obstacle being the mildex.

* In sandy or dry soils, to insure greater success, cover the upper end of the cutting with grafting-wax, or something of the kind, to prevent evaporation. The practice of growing grapes from single eses, by making cuttings of one eye each, and callosing them in sand, in the cellar or pit, has been recently renewed. The cuttings are made of one eye each, placed in sand, in a cool cellar or shed. free from frost, and in spring plunted out, covering the bud half an inch or so with soil, and over the whole spreading a mulch of tan-bark or sawdust one or two inches deep. 
which, seizing upon the young fruit, prevents its further growth, eanses it to erack, and renders it worthless. Unwilling to believe thist this was not the fault of bad culture, many intelligent cultivators, and anong them men of eapital and much practieal skill, have attempted vineyari culture with the foreign sorts in various sections of the country, mider the most firvorable ciremimstances, and have miformly failed. On the other hand, the very timest Grapess are produced under glass, in great quantities, in our first-rate gardens. In the small yards or gardens of om cities, owing to the more miform state of the atnosplere, the foreign Grape thrives pretty well; and finally, in all gardels of the Middle States the hardier kinds may, moler certain modes of culture, be made to bear good fruit.

Withont rntering into any inquiries respecting the particular way in which the millew (which is moloubtedly a parasitical plant) is canserl, we will endeavor to state concisely some practical truths, to which our own observation and experience have led us, respecting the hardy culture of the foreign Grape.

In the first place, it is well known to gardeners here that young and thrifty vines generally bear one or two fair crops of fruit; second, that as the vine becomes older, if it is primed in the common mode (that is to say, the spurring-in more of shortening the side branches, and getting fresh bearing shoots trom main branches every year), it soon bears only mildewed and imperfect fruit; and, finally, that the older and larger the vine, the less likely is it to produce a good crop.

This being the case, it is not difficult to see that as the vine, like all other trees, is able to resist the attacks of disease or mfarorable climate just in proportion as it is kept in a young and highly vigorous state, it follows, if we allow a plant to retain only young and rigorous wood, it must necessarily preserve much of the necessary vigor of constitution. And this is only to be done, so far as regards training, by what is called the renewal system.

The renewal system of training consists in annually providing in fiesh supply of young branches, from which the bearing shoots are produced, eutting out all the branches that have borne the previous year. Fig. 37 represents a bearing vine treated in this manner, as it would appear in the spring of the year after having been pruned. In this figme a represents the two branches of last year's growth trained up for bearing the present year; $b$, the places ocenpied by the last year's wood, which, having borne, has been eut down to within an inch of the main arn, $c$.

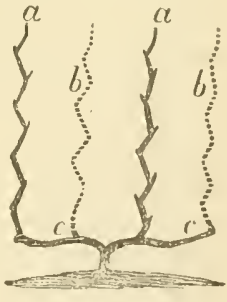

Renewal Training. The present year, therefore, the two branches, $c$, will throw out side shoots, and hear a good crop, while the young branches will be trained up in the places of $b$, to bear the next year whes a are in like manner cut down.

This renewal training will usually produce fair fruit, chicfly, as it appears to us, because the aseent and eireulation of the sap, being mainly carried on through young wood, is vigorous, and the plant is liealthful and able to resist the mildew; while, on the contrary, the circulation of the sap is more feeble and tardy though the more compact and rigid sap-ressels of a vine full of old wood.* 
The above mode of training is very easily understood, but we may arld here, for the benefit of the novice: 1st, that vines, in order that ther may bear regularly and well, should always be kept within small bounds; 2l, that they should always be trained to a wall, building, or ujriglit trellis; $*$ and $3 \mathrm{~d}$, that the leares shonld never be pulled otf to menote the ripening of the fruit. The ends of the bearing shoots may be sionped (pinched oft) when the fruit is nearly half grown, and this is usually all the summer pruning that, under our bright sun, the grapevine properly treated requires.

Following out this hint, that here the vine only bears well when it is young, or composed mainly of young wood, an intelligent cultivator near us secures every year abundant crops of the Chasselas by a srstem of renewal hy layers. Every year, from his bearing vines, he lays down two or more long and clean shoots of the previous year's growth. These root freely, are allowed to make another season's growth, and then are male to take the place of the old plants, which are taken out; and by this continual system of providing young plants by layers he always succeeds in obtaining from the same piece of ground fair and excellent grapes.

Citlure cinder Glass without Artificial Heat. The great superiority of this fruit when raised under glass, renders a vinery an indispensable feature in every extensive garden. Even without firelieat grapes may, under our bright sum, be grown admirably ; the sudden changes of the weather being gnarded against, and the warmth and miformity of the atmosphere surrounding the vines being secured. Cheap structures of this kind are now very common, and even the Muscat of Alexandria, and other sorts which are usually thought to require fire-heat, ripen regularly and well with moderate attention.

A vinery of this lind may be erected so as to cost rery little, nearly after the following manner: Its length may be thirty feet; its width sixteen feet; height at the fiont two feet; at the back twelve feet. This part of the structure may all be built of wood, taking for the frame ceclar or locust posts, setting them three and a half feet in the ground, the portion rising above the ground being squared to four or five inclies. On these posts (which are placed six feet apart) nail, on both sides, matched and grooved planks, one and a quarter inches thick. The space between these planks not ocenpied by the post, fill in with dry tan, which should be well rammed down. The rafter's should be tixed, and from three to four feet apart. The sashes forming the roof (which are all the glass that will be necessary) should be stationary, ventilation being given by small windows at the top of the back wall, titted with linges, to be opened or shut at pleasure by means of a pulley cord. The building will, of course, front the south, and the door may be at either end.

The border for the grapes should be made partly on the inside and partly on the outside of the frout wall, so that the roots of the rines may extend through to the open border. A trellis of wire should be fixed to the rafters, about sixteen inches from the glass, on which the vines are to be trained. Early in the spring the vines, which should be two-year-old roots, may be plinted in the inside border, about a foot from the front wall, one vine below each rafter.

* And never on an arbor, except for the purposes of shade. 
Solt. The border should be thoroughly prepares and pulverized before planting the grapes. Two-thirds of mollow samily loam, nixed with one-third of a compost formed of woll-femented mame, bits of broken rhareonl, and a little lime rubbish, forms an excellent soil for the grape in this climate. If the soil of the garden is old, or is not of a proprer quality for the basis of the border, it is best to preprare some for this purpose by rotting and reducing beforehand a quantity of loamy turf from the roal-sides. The depth of the border neer not exceed two feet, but if the subsoil is not dry at all seasons it shonk be well drainerl, and filled np half a foot below the border with small stones or brick-bats.

I'rixis. Decidedly the best mode of pruning for a cold house, or vinery without fire-heat, is what is called the long or renewal mode, which we have already partially explained. Supposing the honse to be planted with good young plants, something like the following mode of training and puming may be adopted. The first season one shoot only is allowed to proceed from each plant, and this, at the end of the first seasom, is eut down to the second or third eye or bucl. The year following two leading shoots are encomaged, the strongest of which is headed or stopped when it has extended a fuw joints beyond the middle of the house or lafter, and the weaker about half that length. In Norember these shoots are reduced, the strong one having four or fire joints ent from its extremity, and the weaker one to the third eye from its lower end or latace of origin. In the third season one leading showt is laid in from each of these, the stronger one throwing ont side shoots on which the fruit is produced, which sicle shoots are allowed to mature one bunch of grapes each, and are topped at one or two joints abore the fruit. No side shoots are allowed to proceed from the weaker shoot, but it is laid in to produce finit the ensuing season, so that, by the third season after planting, the lower prart of the honse or rafters is furnished with a crop of fruit proceeding from wood of the preceding year. At next antumn pruning the longest of these main shoots is short ened alout eighteen inches from the top of the rafter, and the next in strength to ibout the midille of the rafter, and all the spin's which har bone fruit are removed. Each vine is now fumished with two shoots of bearing wood, a part of old bamen wood which has already prodnced fruit, aud a spur near the bottom for prorlueing a roung shoot for the following vear. In the fourth summer a full crop is preincerl, both in the lower and upjer part of the louse, the longer or oldest slioot producing fruit on the upper part of its length, and the shorter on its whole length; from this last a leading shoot is lairl in, and mother to suceed it is produced from the spur near the hottom. At the next antumn pruning the oldest or longest shoot, which has now reached the top of the house, is entirely cut ont and remover, and replaced by that which was next in succession to it, and this in its turn is also eut ont and replaced by that immediately belinel it, a succession of a yoarly shout beines olstained from the lower part of the old stem. (I/C Inivesh.) 'This is decidedly the most sucerssful mode for a vincry withont hent, producing abmudant and fair crops of frout. Hoare, who is one of the most experienced and ingenious writers on the grape, strongly recommends it, and suggests that "the old wool of a vine, or that which has previusily produced fruit, is not only of no further use, but is a positive injury to the fertility of the plant. The truth of this remark depends 
on the fact that every branch of a vine which produces little or nc foliage alpropriates for its own support a portion of the juices of the plant that is generated by those branches that do prodnce foliage."

Routine of rulture. In a vinery withont heat this is compara tively simple. As soon as the vines commence swelling their buds in the spring they should be carefully washed with mild soap-surls, to free them from any insects, soften the wood, and assist the buds to swell re-. gularly. At least three or four times every week they should be well syringed with water, which, when the weather is cool, should always be done in the morning. And every day the vine border should be duly supplied with water. During the time when the vines are in blossom, and while the fruit is setting, all sprinkling or syringing over the leaves must be suspended, and the house should be kept a little more closed and warm than usual, and should any indications of mildew appear on any of the branches it may at once be checked by dusting them with Hower of sulphur. Air must be given liberally every day when the temperature rises in the house, beginning by opening the rear windows a little in the morning, more at mid-rlaty, and then gradually closing them in the same manner. To guard against the sudden changes of temperature out of doors, and at the same time to keep up as moist and warm a state of the atmosphere within the vinery as is consistent with pretty free admission of the air during sunshine, is the great object of culture in a vinery of this kind.

Thinning the finit is a very necessary practice in all vineries, and on it depends greatly the flavor as well as the fine appearance and size of the berries and bunches. The first thinning usually consists in taking off all superfluous blossom-burls, leaving only one bunch in the large sorts, or two in the small ones, to each bearing shoot. The next thinning takes place when the berries are set and well formed, and is performed with a pair of scissors, taking care not to touch the berries that are left to grow. All this time one-third of the berries should be taken off with the point of the scissors, especially those in the centre of the cluster. This allows the remainder to swell to double the size, and also to form larger bunches than would otherwise be prodnced. There the bunches are large, the shoulders should be suspended from the trellis by threads, in order to take oft" part of the weight from the stem of the vine. The last thimning, which is done chiefly to regulate the form of the bunch, is done by many gardeners just before the fruit hegins to color-but it is scarcely needed if the previous thinning of the berries has been thoroughly done.

The regular antumnal pruning is best performed about the middle of November. The vines should then be taken down, laid down on the border, and covered for the winter with a thick layer of straw or a slight covering of earth.

Culture unuer Glass With Fire-meat. As the foreign Grape is almost the only fruit of temperate chimates which cannot be raised in perfection in the open air in this climate, we shall give some concise directions for its culture in vineries with artificial heat. Those who only know this fruit as the Chasselas or Sweetwater appears, when grown in the open air, have little idea of the exceeding lusciousmess, high Havor, size, and beauty of such varieties as the Black Hamburgh or Muscat of Alexandria, when well grown in a first-rate vinery. By the aid of artificial heat, which in this climate is, after all, chiefly required 
in the spring and antumm, and to comnteract any sudden cold changes of atmonphere, this most admirable fruit may easily be producer for the dessert from May till lecember. Indeed, by vineries emstructed in divisions, in some of which vines are forced and in others retarded, somo have (iripes nearly every month in the year.

Construction of the Finery. The vinery with fire-heat may bo built of wood, and in the same simple mamer as just described, with the addition of a the above the surface of the ground, ruming close along the end, two feet from the front wall, and about a foot from the back wall, and returning into a chimney in the back wall over the furnace.*

For the sake of permanence, however, a vinery of this kind is usually built of brick; the ends and front wall eight inches thick; the back wall a foot thick-or eight inches, with occasional abutments to increase its strength. In fig. 38 . (I) is shown a simple plan of a vinery of this kind. In this the surface of the ground is shown at $a$, below which the foundation walls are sunk three feet. Above the surface the front wall, $b$, rises two feet, the back wall, $c$, twelve feet, and the width of the honse is fourteen feet. On these walls are placed the rafters, from three to four feet distant.

In the present example the flues are kept ont of the way, and the space clear, by placing them in a square walled space direetly under the walk; the

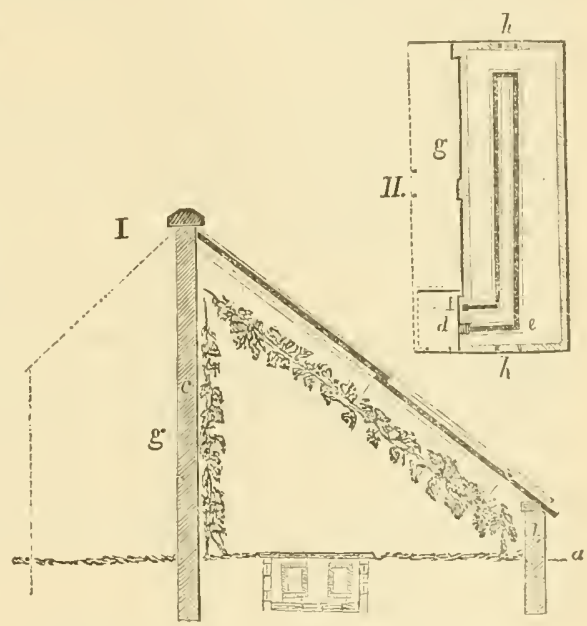

Plan and Section of a Vinery, with Fire-hent.

walk itself being formed by an open grating or lattice, though which the beat rises freely. The arrangement of the the will be better muderstood by referring to the ground plan (11). In this the furnace is inticated at $d$, in the back wall ; from this the flue rises gradually to $e$, whence it continues nearly the length of the house, and returuing cnters the chimmey at $f$. For the convenience of shelter, firing, etc., it is usual to have a back shed, /, behind the back wall. In this shed may be a bin for wood or coals, and a sunk area (shown in the dotted lines around $l, f)$, with stepss to descend to the furnace and ash-pit. There are two doors, $h$, in the vinery at either end of the walk.

* Heating by hot water is eonsidered more successful in its results, hecause of enabling a more even and steady temperature to be maintainer. The expense is somewhat greater at first-but in the end, perhaps, most economical.

$f$ This furmace should be ylaced two feet below the level of the flue at $\rho$, in order to secure a dranght, after which it may be earried quite level tili it enters the chimney. An aix-chamber may be formed round it, with a register to admit heated air to the house when necessary. A furnace fourteen inchts square and deep, with an ash-pit below, in which anthracite coal is burned. will be found a very easy and perfect mode of heating a house of this wilth, and thirty fect long. 
The border should be thoroughly prepared previously to planting the vines, by excavating it two feet cleep and filling it up with suitable compost. 'I'his is best formed of one-lualf loamy turf, well rotted by having been previonsly laid up in heaps (or fresh and pure loamy soil from an old pasture or common) ; one-third thoroughly fermented horse or cow manume. which has lain in a turf-covered heap for three months; and one-third broken pieces of charcoal and old line rubbish: the whole to be thoroughly mixed together before planting the vines.

The vines themselves shonld always be planted in a border prepared insirle of the house; and in order to give the vines that extent of soil which is necessary for them, the lest cultivators make an additional. border, twelve or fourteen fect wide ontside, in front of the vinerr. By building the fomdation of the front wall on piers, within a comple of inches of the surface, and supporting the wall above the surface on slabs of stone reaching from pier to pier, the roots of the vines easily penetrate to the border on the outside.

The vines should be planted early in the spring. Two-year-old plants are preferalule, and they may be set eighteen inches from the front wall-one below each rafter, or, if the latter are over three feet apart, one also in the intermediate space.

The pruning and training of the vines we have already described. The renewal system of pruning we consider the best in all cases. The spm. system is, however, practised by many gardeners, with more or less success. This, as most of our readers are aware, consists in aliowing a single shoot to extend from each root to the length of the rafters; fiom the sides of this stem are produced t're bearing shoots every rear ; and every antumn these spurs are shortened back, leaving only one bud at the bottom of each, which in its turn becomes the bearing shoot, and is again eut back the next season. The fruit is abundantly produced, and of good flavor, but the bunches are neither so large nor fair, nor do the rines continue so long in a productive and healthy state as when the wood is anmally jenewed.

The essential points in prming and training the vine, whatever mode be adopted, according to Loudon, "are to shorten the wood to such an extent that no more leaves shall be produced than can be fully exposed to the light; to stop all shoots produced in the summer that are not likely to be required in the winter prming, at two or three joints, or at the first large healthy leaf from the stem where they originate; and to stop all shoots bearing bunches at one joint, or it most two, beyond the bunch. As shoots which are stopped generally push a second time from the terminal bud, the secondary shoots this produced should be stopped at one joint. And if at that joint they push also, then a third stopping must take place at one joint, and so on as long as the last terminal bud continues to break. Bearing these points in mind, nothing can be more simple than the pruning and training of the vine."

When early forcing of the vines is commencel, the heat should be applied very gently for the first few days, and afterwards very gradually increased. Sixty degrees of Fahrenheit's thermometer may be the maximum till the buds are all nearly expauded. When the leaves are expanded, sixty-five may be the maximum and fifty-five the minimum temperature. When the vines are in blossom, serenty-five or eighty in mid-day, with the solar heat, should be allowed, whth an alundance of 
air, and somewhat about this slould be the arerage of mid-day temperature.

To insure a good crop of Grapes, we are satisfied that they inust liave -plenty of heat-plenty of air-plenty of mosture-severe thinning of bunches-and serere thinning of berries. T'he vines, also, must be pruned often, and kept free; the wood never crowded. Great attention must be paid to the airing of the house, which must be done gradnally, that there may be at no time a sudden change in the temperature.

With such attention, and the prerequisite of a rich border, on a dry subsoil, good crops of fine Grapes are always to be obtained. The vines require much moistme until they have completed their last swell, when the moisture should be withdrawn.

Ixsects axp Diseases. When poperly grown under glass the Grape is a very vigorous plant, liable to few diseases. The bleeding whieh often hapjens at the commencement of growtl, usually ceases without loing harm when the foliage begins to expand. If excessive, it mav be stopped by a mixtme of three parts of cheese-parings and one part hime applied to the wound. The red spider, which sometimes infests vinerios kept at a high temperature, is usually destroyed by coating over the flues with a wash of quick-lime and sulphur, after which the house must be kejt closed for half a day. The smaller insects which occtsionally prey on the young shoots are easily kept down by syringing the parts aflecterl with a solution of whale-oil soap.

VARIETIES. There are in the catalogue a vast number of names of Grapes, many of which beloug to the same fruit. But there are really only twenty or thirty varieties which are at all worthy of cultivation in gardens. Indeed, the most experienced gardeners are satisfied with a dozen of the best sorts for their vineries.

We will describe some of the finest foreign Grapes that have been introduced.

\section{Alepro.}
Switzerland Grape.
Striped Muscadine.
Variegated Chasselas.
Chasselas panaché.
Maurillan panaché.
Raisin Suisse.
Maurillan noir panaché.

A very singular Grape, the berries being mostly striped with white and black in distinct lines. The foliage is also prettily striped in autumn.

Bunches rather below medium size. Berries medium size, roundish. Skin thin, striped with white and dark red, or black. Flesh juicy, and of a rich and excellent flavor.

\section{Alicante.}

Black Tisbou.

Black Palestine.

Meredith's Alicante.

Alicantenivein.

Schwarzer Spanischer.
Blaek St. Peters.

Black Spanish.

St. Peters.

Blauer von Alicante.
Black Portugal.

Black Valentia.

Espagnin Noir.

Sanct Peter's Traube.

All excellent late viriety, which is large and showy, and hangs well. 
Bunches large, sometimes shouldered. Berries large, oval. Skin tough, rather thick, jet black, with a blue bloom. Flesh tender, juicy.

\section{Black Cilampion.}

Bumch large, long, shouldered. Berries large, roundish oval, deep black with a slight bloom. Flesh firm, juicy, sweet, rich. Ripens earlier than Black Hamburgh. A good variety for a cold vinery.

\section{Black Cluster.}

Black Morillon.

Fianc Pineau.

Pineau.

Raisin de Bourgne.

Black Burgundy.

Schwarzer.
Morillon noir.

Auverna.

Vrai Auvernas.

Small Black Cluster.

Rother.

\author{
Auverne. \\ Auvernas Fouge. \\ True Burgundy. \\ Burgunder. \\ Early Black.
}

This is readily distinguished from Miller's Burgundy, by the absence of the down on its leaves. The fruit is very sweet and excellent.

Bunches swall, compact (i. e., berries closely set). Berries middle sized, roundish oval. Skin deep black. Juice sweet and good. Ripens in the open air abont the 20th of September.

\section{Black Frontigran.}

Muscat Noir.

Nuscat Noir Ordinaire.

Black Froutignac.

Black Constantia of some.

Muscat Noir de Jura.
Sir William Rowley's Black.

Purple Frontignau.

Purple Constantia.

Bourdales des Hautes Pyrénées.

An excellent Grape, originally from the town of Frontignan, in France, where it and other similar sorts are largely cultivated for making the Muscadine or Frontignan wine.

Bunches rather long. Berries of medium size, round, quite black. Skin thm. Flavor musky and rich. Ripens in October. A good bearer.

\section{Black Hayburgh.}

Warner's Black Hamburgh.

Purple Hamburgh.

Red Hamburgh.

Brown Hamburgh.

Dutch Hamburgh.

Victoria.

Salisbury Violet.

Hampton Court Vine.

Valentine's.

Gibraltar.

Frankendale.

Black Frankenthall.
Frankenthaler.

Frankenthaler Gros Noir.

Trollinger.

Blue Trollinger.

Troller.

Welscher.

Fleisch Traube.

Hudler.

Languedoc.

Mohrendutte.

Weissholziger Trollinger.

The Black Hamburgh has long been considered the first of black Grapes for the vinery, but it will very rarely perfect its fruit out of doors. Its very large size and most luscious flavor render it universally esteemed.

Bunches large (about nine inches deep), and mostly with two shoulders, making it broad at the top. Berries very large, roundish, slightly inclining to oval. Skin rather thick, deep brownish purple, becoming 
nearly black at full maturity. Flavor very sugary and rich. A good and regular bearer.

\section{Btacki Lombardy.}

West's St. Peters.

Raisin de Cuba.
Poonah.

Money's.
Raisin des Carmes.

Bunches large and long, with shoulders. Berries large, roundish oval. Skin thin, very black at maturity. Flavor very rich and sugary. The leaves are rather small, and turn purple as the fruit ripens. It requires a pretty ligh temperature, and is then a great bearer.

\section{BLACK MOROCCO.}

I.e Cœur.

Black MIuscadel.

Ansell's Large Oval Black. Raisine d'Espagne.

A large and showy Grape, ripening late, but requiring a good deal of heat. The blossoms are a little imperfect, and require to be fertilized with those of the Black Hamburgh, or some other hardy sort.

Bunches large. Berries very large, oval. Skin thick, dark red, Flavor tolerably sweet and rich.

\section{Black Muscadine.}

Black Chasselas.

Chasselas Noir.

A pretty good black Grape, scarcely succeeding well, however, in the open air, and inferior to other sorts for the vinery.

Bunches of medium size, compact. Berries roundish oval. Skin thick, black, overspread with a blue bloom. Juice sweet, and of pretty gooil tharor.

\section{Black Muscat of Alexandria.}

Red Muscat of Alexandria.

Nuscat Hamburgh.
Red Frontiguac of Jerusalem.

Bunches large and shouldered. Berries large, oval. Skin thiek, of a reddish eolor, becoming black at maturity. Flesh quite firm, with a rich musky flavor. Requires a vinery with fire-heat.

\section{Black Prince.}

Boston. Pocock's Damascus.

Sir A. Pytches' Black. Steward's Black Prince.

The Black Prince is very highly esteemed. It is hardier than the Black Hamburgh, bearing profusely, with the easiest culture, in the vinery.

Bunches long and not generally shouldered. Berries large, rather thinly set, oval. Skin thick, black, covered with a thick blue bloom. Flesh tender, juicy, rich sugary, sprightly.

\section{Brack Sweetwater.}

Water Zoet Noir.

Bunches small, compact. Berries small, round. Skin thin, with a sweet and pleasant juice. A second-rate, but rather hardy sort. 


\section{Black Tripoli.}

Black Grape from Tripoli.

This Grape is said to be a large and very excellent one, ripening late, and well worthy of a place in the vinery. It requires some fireheat.

Bunches of medium size, shouldered, rather loose. Berries large, round, often slightly tlattened. Seeds quite small. Skin thin, purplish black, slightly covered with bloom. Flesh tender and sweet, with a very high-flavored rich juice.

\section{BoWOOD Muscat.}

Tynningham Muscat.

A new variety, claimed as a seedling from the Muscat of Alexandria which it closely resembles, but has rather shorter-jointed wood, and sets its fruit and bears well.

\section{Burchiardt's Prince.}
Aramon.
Plante Riche.
Ugrie Noir.

A late variety that hangs well.

Bunches long, tapering. Berries medium, round, a few incliving to oval. Skin of a deep black color, covered with a thick bloom. Flesh rather firm, juicy, rich, piquant, vinous.

\section{Canoy Hall Muscat.}

A variety differing from its parent, the Muscat of Alexandria, in being of stronger growth and more tapering bunches. Berries large, roundish oral, whitish, juicy, rich. Requires special care to grow it well.

\section{Chaptat.}

A French Grape, a great bearer, and adapted to a cold vinery.

Bumches large and long. Berries large, round, amber color when ripe. Flesh sweet, juicy.

\section{Charlsworth 'Tokay.}

A variety from England, reputed to be of superior quality.

Bunches long, compact. Berries large, oval. Skin thick, white. Flavor rich and excellent, with a Muscat perfume.

\section{Citasselas Musqué.}
Musk Chasselas.
Le Cour.
St. Albans.

A very delicious Grape, the highest flavored Chasselas, having much of the flavor of the Muscat of Alexandria.

Bunches of medium size, long and rather loose. Berries middle 
size, round. Skin thin, yellowish white. Flesh tender, with an abund. aut juice, of a rich musky flavor. Leaves smaller and deeper green than those of the Sweetwater or Muscadine. Requires heat.

\section{Chasselas Royal.}

A new and excellent Grape.

Bunches short and thick, with shoulders. Berries large, round, pale amber color when ripe. A great bearer. (Rivers.)

\section{Chasselas Vibert.}

A strong grower, well suited to a cold vinery.

Bunches long. Berries large, rouud, golden amber when ripe. Flesh juicy, rich. (Rivers.)

\section{Duchess of Buccleugh.}

A Grape of recent introduction, and highly praised. It is said to be a cross between the Muscat and Chasselas Musqué.

Bunches large, loug, tapering, slightly shouldered. Berries medium, roundish. Early, and an abuudant bearer. Suited for a hot or cold vinery.

\section{Early Black Bordeaux.}

One of the best very early sorts.

Bunches medium, short, shouldered. Berries medium, round, quite black, with a thin bloom. Flesh teuder, melting, rich, sweet.

\section{Early Black July.}

$\begin{array}{lll}\text { July Grape. } & \text { Madeleine. } & \text { Madeleine Noir. } \\ \text { Raisin Précoce. } & \text { Morillon Hâtif. } & \text { De St. Jean. } \\ \text { Schwarzer Frübzeitiger. } & \text { Burgundcr. } & \text { August Traube. } \\ & \text { Jacob's Traube. } & \end{array}$

The earliest of Grapes, and chiefly valued for the dessert on that account. In the open air it ripens here the last of July, or early in August. The leaves are rather small, and light green above and bo. neath.

Bunches small and compact. Berries small, quite round. Skin thick, black, covered with a blue bloom. Flavor moderately sweet, but not rich or perfumed.

\section{Early Golden Frontignan.}

A variety adapted to hot or cold vineries.

Bunch long, medium, not shouldered. Berries medium, round, yellow, with minute dark dots. Flesh juicy, sprightly, melting, sweet.

\section{Early Saumur Frontignax.}

Muscat de Saumur.

Madeleine Musque de Courtiller.
Muscat Hâtif de Saumur. Précoce Musqué.

A very early variety, ripening well in a cold vinery.

Bunches small, compact, shouldered. Berries medium, youndish 
flattened. Skin thin, translucent amber color at maturity. Flest juicy, with a pleasant, slight Muscat flavor.

\section{Early Silyer Frontignan.}

Bunch medium to large, shouldered. Berries large, roundish oval, whitish yellow, with a silver bloom. Flesh very tender, melting, rich, very juicy, and agreeable. An early and productive sort, suited to hot $o r$ cold vinery.

\section{Early Sayrna Frontignax.}

Muscat de Smyrne.

Isaker Daisiko.

One of the earliest sorts, well suited for a cold vinery.

Bunches medium, well set, not shouldered. Berries medium, round, bright amber. Flesh melting, rich, juicy, delicious.

\section{Early White Malvasia.}

Morna Chasselas.

Early Chasselas.

Grove End Sweet Water.

White Melier.

Early Kienzheim.
Mornair blanc.

Le Melier.

Melier blanc.

Blane de Bonneuil.

A nice early Grape, and a good bearer, which is in fact only an earlier variety of the Chasselas. It bear's very well in the open air.

Bunches, in size and form, much like those of the White Chasselas or Royal Muscadine. Berries round, yellowish white. Skin thin. Flesh sweet, juicy, and agreeable in flavor. Ripens in August. The leares are pale green on the upper side, slightly downy below, cut into five rather deep lobes.

\section{Esperione.}

Turner's Black. Hardy Blue Windsor. Cumberland Lodge.

'I the Esperione is a hardy, luxuriant, and prolific Grape, growing as well in the open air as the Muscadine, and even better in many situations.

Bunches large, shouldered, like the Black Hamburgh in size. Berries round, or occasionally flattened, and often indented with a groove. Skin thick, dark purple, powdered with a thick blue bloom. Flesh adLeres to the skin, of a pleasant, sprightly flavor, not very rich.

\section{Fintindo.}

This Grape is of Italian origin, brought to notice by M. De Bavay, of Vilvorde, who received it of Major Esperen, and is said to have been discovered by the French army in Naples. Its growth is vigorous. Peduncle very stout.

Bunch large, compact, and shouldered. Berries of the largest size, nearly round, slightly oval. Skin dark violet. Flesh abounds in a sugary juice, and has a peculiarly pleasant aroma. It has a resemblance to the Black Hamburgh, but is considerably earlier. 


\section{Foster's White Seedling.}

A new variety, described as superior to the Royal Muscudine, and ripening at the sime time.

Bumches large, sets well. Berries above medium, roumdish oval, yel. lowish amber. Flesh tender, melting, sweet, and rich Havored. Said to have the character of hanging withont shrivelling.

\section{Golden Cimampion.}

A new variety but just introduced. It is deseribed in the Gardener's Dlagazine as remarkably free and robust in growth, and of as easy eulture as Black Hamburgh.

Bunches large, of a slightly-tapering form, and heavily shouldered. Berries extra large, obovate or ovate, slightly pointed-in some instanees almost round. Flesh firm, yet remarkably juiey, tender, and rich Havor.

\section{Golden Hamburgit.}

Busby's Golden Hamburgh. Stockwood Park Golden Hamburgh.

A new white Graps of excellent quality. Requires careful eultivation, as it soon deeays after ripening.

Bunches large, somewhat loose, shouldered. Berries large, roundish oval, rich yellow. Skin thin. Flesh tender, juiey, rieh, melting, sweet.

\section{Grees's Prolific.}

A new variety, originated by W. R. Green, Newburgh, N. Y. Vine a stroug grower, very productive, and sets well.

Bunch large, long, shouldered, very compact. Berry medium, round, deep black, blue bloom, raised a little at apex. Flesh juicy, melting, sweet, vinous.

\section{Grizzly Frontignas.}

Red Frontignan. Muscado Rosso. Muscat Rouge.

\section{Muscat Gris. \\ Red Constantia. \\ Graver Muscateller.}

This delicious Grape requires to be grown in a vinery, when it is, to our taste, seareely surpassed.

Bunches rather long, with narrow shoulders. Berries round, of medium size, and growing eloser upon the bunches than those of the White Frontignan. Skin thick, pale brown, blended with pink and yellow. Flesh very juicy, rich, musky, and high flavored.

\section{Gros Maroc.}

\section{Marocain.}

An excellent variety, ripening after Black Hamburgh. A great bearer, well suited to a cold vinery.

Buuches large, long, shouldered. Berries large, oval, covered with a thick bloom. Skin thiek, deep reddish purple. Flesh tender, sweet, rich. 


\section{Jura Muscat.}

Muscat Noir de Jura.

A valuable Grape. Vine very prolific.

Bumches long, tapering, slightly shouldered. Burries above medium oval, and well set. Skin purplish black or dark chocolate, with a thin blue bloom. Flesh solid, tender, juicy, richly flavored, with a fine Muscat aroma.

\section{Knight's Variegated Chasselas. \\ Variegated Chasselas.}

A hybrid seedling, raised by Mr. Knight from the White Chasselas impregnated by the Aleppo. A curious and pretty fruit, but not first. rate in flavor.

Bunches rather long, unshouldered. Berries below the middle size, round, loosely set. Skin quite thin, white, shaded with bluish riolet, sometimes becoming purplish in the sum. Flesh tender, sweet, and pleasaut.

\section{LADY DOWNE's.}

\section{Lady Downe's Seedling.}

This rariety was grown from seed of the Black Morocco crossed by the Chasselas or Sweetwater. It is among the most valuable, ripening its fruit and hanging a long time-Hogg says, from August until March.

Bunches large, rather loose, shouldered. Berries above medium, roundish oval. Skin rather thick, reddish purple, becoming quite black, with a delicate bloom. Flesh dull white, firm, sweet, and richly flavored.

\section{LOMBARDY.}

Flame-Colored Tokay. Rheinish Red. Wantage. Red Grape of Taurida.

The Lombardy is remarkable for the very large size of the bunches, which are frequently twelve to eighteen inches long. It is a handsome fruit, the berries thickly set (so much so as to need a good deal of thinning), and it requires fire-heat to bring it to full perfection.

Bunches very large, handsomely formed, with large shoulders. Berries large, roundish. Skin thick, pale red or flame-colored. Flesi firm, sweet, with a sprightly, very good flavor.

Miller's Burgundy.

$\begin{array}{lll}\text { Miller Grape. } & \text { Müller. } & \text { Le Meunier. } \\ \text { Mrullevrebe. } & \text { Morillon Taconné. } & \text { Morone Farinaccio. } \\ \text { Fromenté. } & \text { Pulverulenta. } & \text { Aleatica du Po. } \\ \text { Farineux noir. } & \text { Sauvignien noir. } & \text { Noirin. }\end{array}$

A variety that ripens pretty well in the open air, and is readily known by the dense covering of cottony down which lines both sicles of the leaves, whence the name Miller's Grape.

Bunches short, thick, and compact. Berries roundish oral, very closely set together. Skin thin, black, with a blue bloom. Flesh tender, abounding with a sweet, high-flarored juice. Each berry contains two small sereds. 


\section{Mescat of AlexandRIA}

Alexandrian Frontignan.

Charlesworth Tokay Malaga.

Mnseat Lischolata.

Musciat Crec.

Mruseat of Jerusalem.

Mnscat of Lumel.

Muscat lionuain.
Moscatel Gordo Blanco.

P’anse Musquéc.

Passe Musquée.

Tottenham Park Muscat.

Uva Salamana.

White Muscat of Alexandria.

Muscat Esculata?

A well-known Grape which furnishes the Muscatel Raisins, from Spain. It requires a high temperature to ripen it thoroughly.

Bunches very large, long, loose shouldered. Berries large, oval, unequal in size. Skin thick, pale amber, thin white bloom. Flesh firm, moderately juicy, sweet and rich, fine Muscat flavor.

\section{Pitulastox White Cluster.}

A pretty hardy Grape, raised in Pitmaston, England, from the Black Cluster, ripening rather earlier than the Sweetwater, of good yuality, and well deserving a place where the foreign Grapes are cultivated in the open air.

Bunches of medium size, compact, and shouldered. Berries middle. sized, round. Skin thin, amber color, oceasionally tinged with a little russet when fully ripe. Flesh tender, juicy, sweet, and excellent.

\section{Primavis Frontignan.}

An early ripening variety that sets well and is productive.

Bunches large, long, shouldered, berries medium to lirge, round, amber. Flesh rather solid, tender, juicy, sweet, and rich. One of the finest of the Muscat Chasselas family. Early.

\section{Red Chlasselas.}

Red Muscadine.

Chasselas Rouge.
Chasselas Rouge Foncíe.

Cerese Septembro.

This Grape a good deal resembles the White Chasselas, except that the berries are slightly colored with red. Ver:y rarely, when over ripe, they become a dark red.

Bunches loose, not large. Berries medium size, round. Skin thin, at first pale green, but when exposed to the sun they become red. Flesh tender, sweet, and very good.

\section{Reeves' Muscadine.}

An excellent variety for the cold vinery.

Bumches large, conical, loose, shouldered. Berries large, nearly round, amber color. Flesh tender, rich, juicy, sweet.

\section{Rorar MUscadive.}

Amber Muscadine

Early White Teneriffe.

Golden Chasselas.

White Chisselas

Chasselas doré.

Chasselas blanc.
Chasselas de Fontainebleau.

D'Arbois.

Raisin de Champagne.

Amiens.

Campanella Bianca.

White Nice, or Xeres.

A truly excellent Grape in all respects-one of the very best for 
harly culture in this climate, or for the vinery. It is everywhers highly esteemer, and is the Chasselas par excellence of the French.

Bunches large and shouldered. Berries larger than those of the Sweetwater, round. Skin thin, at first grcenish white, but turning to an amber eolor when fully ripe. Flesh tender, with a rich and delieious tlavor. Ripens here about the 20th of September. Wood and foliage stronger than those of the Sweetwater.

\section{Scotch White Cluster.}

Blacksmith's White Cluster.

Laan Hàtif.

Van der Laan Prícoce.
Diamant.

Diamant Traube.

This Grape was raised by a blaeksmith of Edinburgh in 1812.

Bunches of middle size, compaet. Berries medium-sized, roundist. oval. Skin white, thin. Flesh tender, juicy, sweet, and excellent.

\section{Syrian.}

Jews.

Palestine.

Terra de la Promise.

This is believed to be the Grape mentioned in the Seriptures as found by the Isratelites on the brook of Esheol, the bunches of which were so large as to be borne on a staff by two men. It is a very superblooking fruit, and has been grown in this country to very large size. In England bunches of it have been protueed weighing $19 \frac{1}{2} \mathrm{lbs}$.

Bunches enormonsly large, and regularly formed, with broad shoulders. Beries large, oval. Skin thick. white at first, but becoming a tawny yellow or amber when at full maturity. Flesh firm and solid, moderately juicy and sweet, though not rieh. Will hang till Christmas in a vinery. The wood and foliage are very large.

\section{Trebbiaxo.}

Trebbiano Bianco. Trebbiano Vero. Erbalus. Ugni Blanc.

A variety that requires a tolerably high temperature, especially during the fall months. It is a late sort, and hangs well.

Bunches very large, hroad, shouldered. Berries medium, roundish, oval. Skin thick, somewhat alhering to the flesh, whitish, with a delicate bloom. Flesh firm, sweet, rich.

\section{Trextian BLack.}

\section{Long Noir d'Espagne.}

A fine variety, well suited to the cold vinery. It ripens with Black Hamburgh, but will hang plump and fresh long after that variety has shrivelled.

Bunches large, tapering, and shouldered. Berries above medium, oval. Skin tough, jet black, eorered with a thin bloom. Flesh melting, juicy, rich, sugary, vinous. 
Troveren Frontignax.

Troveren. IInscat Troveren. MIuscat Troveren Blane.

This, says Rivers, is one of, if not the finest of all the Frontignans. A great bearer, and with a rich Muscat flavor in the fruit.

Bunches large. Berries rery large, xomndish oval, greenish, changing to pale amber. Flesh firm and crackling, juicy, sweet, and acid. liequires tire heat.

\section{Tringham Muscat.}

A late variety that sets well and is very productive.

Bunches very liuge, double-shouldered. Berries large, oval, amber yellow, slight bloom. Flesh solid, juicy, sweet, and of a rich Muscat Havor:

\section{VERDELHO.}

Verdal. Verdilhio. Madeira Wine Grape.

A vigorous growing Grape, of good quality, from Madeira, which is largely used in that island for making the best wines.

Bunches rather small, loose. Berries small, rather unequal in size, and often without seeds. Skin thin, semi-transparent, yellowish green, a little tinged with russet when very ripe. Juice a little acid at first, but rich and excellent at matuity.

\section{Wimte Frontignan.}

White Constantia.

Muscat Blanc.

Moschata Bianea.

Muscateller.

\section{White Frontniac. Raisin de Frontignan. Moscado Bianco.} Weisser Aluscateller.
Nepean's Constantia.

Museat Blane de Jura.

Moscatel Commun.

Weisse Nuscaten Traube.

The White Frontignan is a very favorite Grape, as the many names quoted ahove, by which it is known in various parts of Enrope, sufficiently prove. Its harly habit, uniform productiveness in the vinery, and most luscious flavor, make it everywhere esteemed.

Bunches of medium size, or pretty long, and without shoulders. Berries middle-sized, round, rather thickly set. Skin thin, dull white or yellow, covered with a thin bloom. Flesh tender, with a rich, perfumed, musky flavor.

\section{White HANBURGII.}

White Lisbon. White Portugal. White Raisin.

This is the Portugal Graje of commeree, which is so largely exported to different parts of the world in jars. It is not a high-flavored though a very showy grape, and will hang a long time on the vines after maturity. It requires fire-heat.

Bunches very large and loose. Berries large oval. Skin thick, greenish white. Flesh solid, sweet, and sometimes with a slight Muscat flavor. Bunches of this variety weighing over three pounds have been grown near Boston. 


\section{WHITE NiCE.}

A vely large and showy fruit, and, in a vinery with fire-heat, a very excellent sort. MIIntosh, an English gardener of reputation, has grown bunches of this the White Nice to the enormons weight of eighteen pounds, and considers it "one of the noblest of grapes."

Bunches very large, with loose shoulders. Berries roundish, medium size, thinly distributed over the shonlders and sicles of the bunch. Skin thin, rather tough, greenish white, becoming, finally, a little yellowish. Flesh erisp, sweet, and of very good flavor. Leaves and wood very strong, the latter remarkably downy beneath.

\section{White Piessling.}

Schloss Johannisberg. Petit Riessling.
Rudesheimerberg.

Grosser Riessling.

Kleiner Riessling.
Riessling.

Rössling.

The most celebrated Grape of the Rhine, producing the celebrated Hock wines.

Bunches of medium size, compact. Berries rather small, round. Skin thin. Elesh tender and juiey, with sweet and sprightly pleasant flavor.

\section{WHite SWEETWATER.}

Early White Muscadine. Stillward's Sweetwater. Chasselas Royal.
White Muscadine.

Dutch Sweetwater.

Water Zoete Blane.
Early Sweetwater. Chasselas Prc coce.

This Grape is better known and more commonly cultivated than any other in this country, although it is inferior to the Royal Muscadine. It differs from the latter in having weaker wond, and open, loose bunches of a paler color.

Bunches middle-sized, loose or open, usually with many small imperfect berries, shouldered. Berries of the middle size, round. Skin thin, clear watery green, rarely becoming amber, except very fully exposed to the sun. Flesh crisp, watery, sweet, but not high-flavored. Ripens in the open air from the 20th to the last of August-a fortnight earlier than the Royal Muscadine.

\section{White ToKaY.}
Genuine Tokay.
Gray Tokay.
Tokai blane.

This is the fruit fiom which the delicious Tokay wine of Hungary is made. Its flavor is good, and its aroma peculiarly agreeable.

Bunches of medium size, compact. Berries rounded oval, closely set. Skin thin, of a dull white. Flesh very delicate, sweet and perfumed.

\section{YEDDO.}

A variety from Japan, introduced with high praise, but proved of ittle value.

Bunches medium. Berries medium, brownish. Flesh rich and sweet. Not good enough for the vinery, and liable to mildew in the open air. 


\section{AMERICAN GRAPES.}

The better varieties of the native Grapes are among the most valuable of fruits in the Middle States. Mardy, vigorous, and proluctive, with a moderate amount of care they yield the farmer and the common gardener, to whom the finer foreign sorts, requiring much attention and consiclerable expense in culture, are denied, the enjoyment of an abundance of rery good fruit.

The grape region has been latcly greatly extended by the addition of new varieties, which, in consequence of ripening their fint much earlier than the Isabella and Catawba, are suited to two or three degrees of latitude farther north than the limit of the enltivation of these varicties.

The garden culture of the hardy native grapes, althongh not very difficult, cammot be accomplished so as to give the fruit in perfection, withont some attention to their habits and wants. The soil should be dry, deeply worked, and well emricherl, always bearing in mind that it is an essential point to secure a perfectly open, smmy exprosure, as it mar always be assumed that with ns no atmosphere can be too warm or bright for the grape; for although it will make the most vigorous shoots in the shade of trees or buildings, yet the crops will be small, the fruit poor and uncertain, and the vines likely to fall a prey to mildew.

In the second place, the vines should be kept within moderate bounds, and trained to an upright trellis. The Isabella and Concord are so rampant in their growth, when young, that the indulgent and gratified cultivator is but too apt to allow them to overbear; the border should always be given to the exclusive occupancy of the vines, and the roots shonld be allowed space proportional to the branches they are to carry. By observing these directions, and not suffering the vines to overbear, they may be continmed a long time in full vigor and prodnctiveness.

The system of pruning and training these grapes generally pursued is the upright mole, with the spur mole of training. The first season's growth of a newly planted vine is cut back to two buds the ensuing fall or spring. These two buds are allowed to form two upright shoots the next summer, which at the end of the season are brought down to a horizontal position, and fastened each way to the lower horizontal rail of the trellis, being shortened at the distance of three or four fect from the root-or as fur each side as the plant is wished to extend. The next season, upright shoots are allowed to grow one foot apart, and these, as soon as they reach the top of the trellis, are also stopped. 'The next rear, the trellis being filled with the vines, a set of lateral shoots will he produced from the upright leaders, with from one to three bunches upon each, which will be the first crop. The vine is now perfect, and, in the spur mode of pruming. it is ouly necessary at the close of every season, that is, at the autumnal or winter pruning, to cut back these lateral shoots or fruit-spurs to within an inch of the upright shoot from which they sprang, and a new lateral producing fruit whll annually sup ply its place, to be again cut out at the winter pruning.

After several years' bearing, if it is found that the grapes fail in size or flavor, the vines should be ent down to the main horizontal shoots at the bottom of the trellis. They will then speedily make a new set of npright shoots which will produce very alumdantly, as at first.

It cannot be denied that the renewal system of training (507) is 
certain of yielding always the largest and finest fruit, though not sc large a crop-as half the surface of the vine is every year occupied with young wood, to take the place of that annually cut out.

WThat we have already stated $(509)$ respecting pruning will ap. ply equally well here. If the vine is fully exposed to the sun it will require very little summer jruning; in fact, none, except stopping the young shoots three joints beyond the farthest bunch of grapes, at mid. summer - for the leaves being intended by nature to elaborate the sap, the more we can retain of them (without robbing the fruit unduly of fluids expended in making new growth) the larger and higher flavored will be the fruit; careful experiments having proved that there is no more successful mode of impoverishing the crop of fruit than that of pulling otf the leaves.

In the axils of the leaves by the side of the buds which are to send forth shoots for next season's crops, branches called laterals push forth, -hich should be pinched off at the first leaf, and at the next leaf where they start again; generally the second stopping will be sufficient.

The annual pruning of the hardy grajes is usually perforned during mild days in February or March-at least a month before regetation is likely to commence. Many cultivators prefer to prume their vines in November, and, except for cold latitudes or exposures, this is undoubtedly the better season.

Vineyard Culture. The vineyard culture of the native grape is very simple. Strong, loamy, or gravelly soils are preferable-limestone and clay shale being usually the best-aud a warm, open, sunny expo. sure being indispensable.

In preparing the soil, if it is loamy or gravelly, a simple deep ploughing is all that is requisite; but if it is clay, or underlaid with a clay hard-pan, the subsoil should be thoroughly broken to a depth of not less than sixteen inches. This, on most linds, can be done by means of a plongh and team. Steep sidehills or slopes must of course be prepared by hand labor, digging and trenching the ground thoroughly with the spade.

The vines are planted in rows, the distance from plant to plant varying according as it is a strong and vigorous grower like Concord, or a moderate short-jointed grower like Delaware. The first are generally planted eight by eight feet or eight by ten feet apart, and the latter four by six feet; while varieties of intermediate vigor are placed at six by eight feet. The renewal system of pruning is generally practised, and the vines are trained both on stakes and wire trellis, the latter being most generally considered as the best and most economical.

The ordinary culture is as simple as that of a field of Indian cornone man and horse with a plough, and the horse cultivator, being able to keep a pretty large surface in good order. The annual pruning is performed in autumn or winter, top-dressing the vines when it is necessary in the spring; and the summer work, thinning, tying, and gathering being chiefly done by women and children.

The summer work is one requiring some care and watchfulness, although attendant with light labor, and, as we have said, may be performed by women and shildren. In vineyard culture the long renewal system is most practised; by it the vine the first year is permitted to make but one leading shoot, all the buds likely to form other shoots being rubbed off early in spring, or as soon as they have fully developed. The second 
year this one cane, or the furst year's growth, is ent down to two buds, and these are grown to two long canes, all others, as the first year, heing rubbed otf. 'The third rear one of these canes of the second year's growth is cut down to two buls, and the other to four buds--the former again permitted to make two gool long stont cames, and the latter allowed to produce about four or six elusters of fruit, all the gromed shoots being rubbed away. When the buds break in spring, as soon as they are about one inch long the bearing canes are to be eximined, and all but one shoot at each axil he rubled out, otherwise there will be a mass of small shoots and elusters withont any perfect finit. It is also in some varieties deemed advisalhle to rub out entire all the huds of ach alternate joint, leaving only one-half the natural qumtity to fruit. Wher this is doun the winter pruning of the bearing eane should be somewhat longer than when each bud is allowed to fruit.

The two buds or canes for the next year's fruiting are allowed to grow as long as they will, and are trained upright; the other, on which the firtit is grown, is carried of at an angle of about fortr-tive degrees, and when it has male its shoots, set its fruit, and grown so that there are three or four leares or joints beyond the fruit they are stopped by pinching, as we have alvised in the training of foreign glapes, the only point of difference bring in permitting our native sorts more liberty and foliage. The following season, or fourth year, the cane which has this vear borme fruit is cut down to two luds, and the two canes of this year's growth are ent to four or more buds for fruit-bearing, and trained at an angle of forty-five degrees each way, while the two buds on the bearing cane of last year make canes for the sncceding year's hearing.

Diseases axd Ixsects. The mildew and rot are diseases which most affect the success of grape eulture in this country. Many theories and suggestions as to their origin, eanse, cte., lave been promulgated and printed, but we feel that as yet no elear and full explanation or cause has been adduced. Sudden changes of temperature, a cold night or two in the month of August, a few days of foggy warm rain, followed by elear sunshine, often producing the disease, with serious results, without regard to the most thorough practices of prevention as advised by theorists.

The beetles which sometimes infest the grape-rines in smmer, especially the large brownish yellow vine beetle (Pelidnotr punctutu), and the grape-vine flea-bectle (ITultion chelyber), are very destructive to the foliage and buds, and the nost effectual remedy is hand-picking when takon in time.

Gantixs the grape may be performed, and often quite successfully. Operator's differ in their opinom as to the best season. some prefering the antum, some early spring, anct some cuite late spring. But, whatever time is takmin, it must be remembered that the nuion of the graft and stock should always be covered with earth, leaving the top or upper bud of the graft level with the ground.

KeEprow. Giapes may he kept into misl-winter or even spring. They should be gathered in a dry day, latid in tirrs of two binches deep on shelves for a comple of days, then aired, and each bunch carefully wripped in soft paper aul packed in boxes, not over five or six inches deep, and laid away in a cool dry room. Anotler plan is to pack them in layers with tine soft hay, ent by a cutting machine into abont inchlong bits, laying a layer of hay, then grapess and then hay again. If 
grapes are gathered before they are fully matured, they do not have as good flavor, nor are they as rich and sweet as when fuliy ripe. In nandling, be careful to take them always by the stem.

\title{
VARIETIES.
}

\section{ADIRONDAC:}

The original vine of this Grape was riseovered in the grounds of $\mathrm{J}$. C. Witherbee, l'ort Henry, Essex Co., N. Y., and was introdneed to notice by J. W. Bailey, of Plattsburgh, N. Y. The growth and foliage is mueh like lsabella, but not as vigorous.

Bunches larere, complact, shouldered. Berries large, round. Skin thin, dark pmplish black, covered with a delicate white boom. Flesh very tender, juicy, mild, pleasant, sweet, not rich. Ripens a week or ten dilys carlier tham lsabellat.

\section{AgAWAM.}

Rogers' No. 15.

Raised by E. S. Rogers, of Salem, Mass. Vine very vigorous, very productive, but subject to rot hadly in unfarorable seasons.

Buncl large, moderately eompract, shonldered. Berry large, roundish, dark red ol maroon. Flesh ahmost tender, juicy, rinous, with a little of the native aroma. Rijens soon after the Concord.

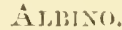

Garber's Albino.

Raised hy .T. B. Garber, Colmmlia, Pa.

Bunch small. Berry nearly round, slightly oval, yellowish or amber color. Flesh acid, tongh, too late for the North.

\section{ALEXANDEI's.}

Schuylkill Muscadel.
Cape Grape.
Gnringmill Constantia.
Clifton's Constantia.
Madeirn, of York, Pa.?
Tasker's Grape.

\author{
Winne. \\ Schuylkill Madeira. \\ Constantia. \\ Black Caure. \\ York Lislon. \\ Teray. \\ Rothrock, of Prince.
}

This Grape, a natural seedling, was first discovered by Mr. Alex. under, gardener to (iov. Penm, before the war of the Revolution. It is not umfrequently fomd, as a scedling, from the wild Foxglape, on the borders of omr wooks.

Bunches rather compact. Berries of nedium size, romdish oval. Skin thick, quite black. Flesh with a very firm pulp, but juicy, rather harsh. October.

The White (ape is similar to above, differing only in its color, which is greenish white.

\section{A LLAlR.}

Bunch small, loose. Berry medium, redelish brown. Flesh pulpy: harsh, poor. 


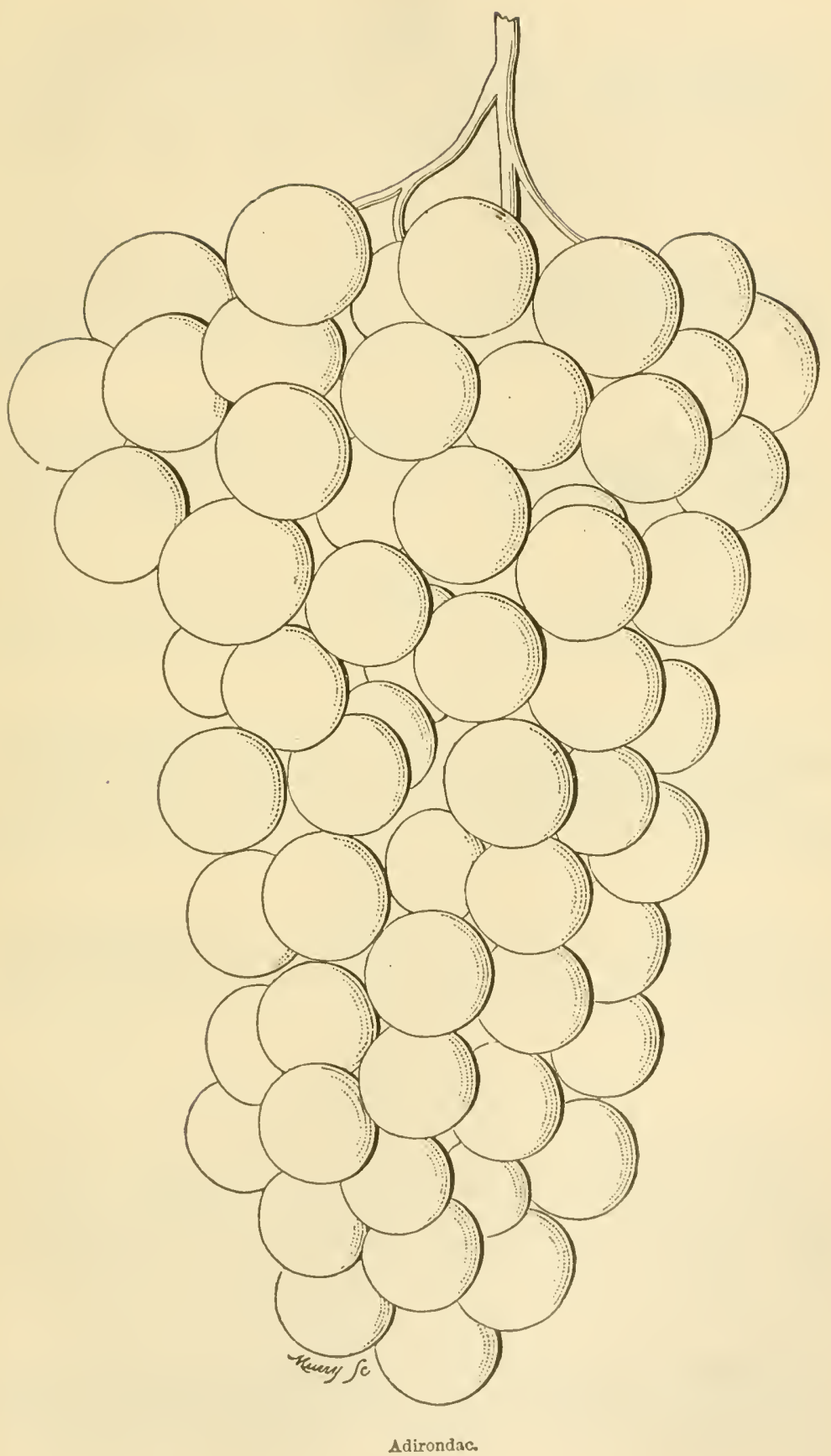




\section{Alvey.}

Hagar.

Introduced by Dr. Harvey, of Hagerstown, Md. Vine vigorous, moderately productive.

Bunclies above medium, long, and shouldered. Berries medium or snall, roundish, black. Flesh tender, refreshing, vinous. Ripens middle to last of September.

\section{Arciler.}

Origin, Philadelphia, Pa.

Bunch large. Berries medium, roundish, greenish white, amber in the sun, white bloom. Flesh juicy, sweet, pleasant. Very good. Nov. (Hort.) Ripens too late for the North.

\section{Arkansas.}

A small black variety from the Southwest, that is said to plomisf well for making of red wine.

Bunch compact. Berry round, black. Flesh juicy, rich. Ripens with Catawba.

\section{A RCOTT.}

Resembles Cassady. Liable to cast its foliage. Skin thick. Taluable only for wine. (Miss. Rep.)

\section{Aughwick.}

A new variety, described as having originated with Wm. A. Fraker, Shirleysburgh, Huntingdon Co., Pa.

Bunches and berries similar to Clinton in size and form and color. Flesh dark red, juicy, making a lark wine. We have not seen the Grape.

\section{August Pioneer.}

Origin unknown. It is one of the coarsest of native sorts, large, black, with a firm, hard, pulpy flesh, fit only for stewing. Middle of August.

\section{Autuchon.}

Arnold's No. 5 .

Originated in 1859, by Charles Arnold, Paris, C. W., from seed of C'linton crossed with Golden Chasselas. Leaf deeply lobed.

Bunch quite long, moderately compact, often shouldered. Berries medium, greenish white with a golden tint when fully ripe. Skin thin. Flestl void of pulp, resembling WThite Chasselas, but more sprightly and rich. Ripens with Delaware. (C. Arnold, MS.)

\section{Baldwin te Noir.}

Originated at West Chester, Pa.

Bunches small, rather loose. Berries small, quite dark, almost black. Flesh somewhat pulpy, brisk, rough acil. May rlo for wine; not desirable for table use. October. 


\section{BARNES.}

Origin, Parker Barnes, Boston, Mass.

Bunches shouldered. Berries medimm, oval, black, sweet, good September 5th, or nearly as early as Martiord. New. (Strong.)

\section{BARRY.}

Rogers' No. 43. tive.

Raised by E. S. Rogers, of Salem, Mass. Vine vigorous, produc-

Bunch rather large, short, broad, compact, often shouldered. Berry large, roundish, black. Flesh tender, nearly fiee from pulp, juicy, sweet, pleasint. Ripens about the time of Concord.

\section{BAXTER.}

A late ripening variety from the Sontl.

Bunch long, loose. Berries small, black, juicy, not mnch pulp, but quite acid here at the Nortl. May be better. Soutl. Very late in ripening.

\section{BIRD's Erg.}

Bunch long, pointed. Berry long oval, whitish, with brown specks. Flesh pulpy. Only good. Curiosity.

Brack HawK.

Originated at Lebanon, Pa., from seed of Concord vine. Strong, vigorous, hardy.

Bunch medium to large. Berry large, nearly round. Flesh somewhat mllyy, like its parent. Comparatively new and untesterl.

\section{BLACK JULy.}

$\begin{array}{lll}\text { Lincoln. } & \text { Sherry. } & \text { McLean. } \\ \text { Devereux. } & \text { Thurmond. } & \text { Hussou. } \\ \text { Sumpter. } & \text { Hart. } & \text { Lenoir, incorrectly. } \\ \text { Blue Grape. } & \text { Tuley. } & \end{array}$

Origin uneertain. A small black Grape, a half-hardy vive, not an early bearer.

Bunches small, compact. Berries small, lark bluish black. Flesh tender, juicy, vinous, somewhat prized South for wine.

\section{BLAND.}

Bland's Virginia. Bland's Madeira. Red Scuppernong of some.

Bland's Pale Red. Powell.

The Bland does not ripen well North, except in favorable situations, and should always be planted in a warm exposure. It is said to have been found on the eastern shore of Virginia, hy Col. Bland of that State.

Bunches rather long, loose, and often with small imperfect berries. Berries round, on long stalks, hanging rather thinly. Slin thin, at first pale green, but pale red when ripe. Flesh slightly pulpr, of a pleasant, sprightly, delicate flavor, and with little or no musky scent, but a slight astringency. Ripens late. 


\section{BLOOD'S BIACK.}

A native fox Grape, healthy, hardy, and productive of fruit, quite harsh and foxy.

Bunches short, compact, shouldered. Berry round, black. Ripens about with Hartford, and inferior.

\section{Blue Favorite.}

A Sonthern Grape that does not ripen well North. Vine vigorous, productive.

Bunch above medium. Berries medium, round, blue black, sweet, vinous, much coloring matter. Ripe Sonth early in September, and there said to be much esteemed for wine-making.

\section{Blue Imperial.}

Origin uncertain. Vine vigorous, free from mildew, not productive.

Bunches medium, short. Berry large, round, black. Flesh with a hard acid centre or pulp. Ripens with Hartford. Inferior.

\section{Brandywine.}

Origin, Wilmington, Del.

Bunch large, shouldered, rather compact. Berry oral, greenish white. Flesh tender. Middle September. (Gar. Mon.)

\section{Brant.}

Arnold's No. 8.

Raised by Charles Arnold, Paris, C. W., from seed of Clinton fructified with mixed foreign pollen. Vine strong, healthy grower. Foliage of a dark reddish green, deeply lobed. Smooth on both sides.

Bunch and berry medium, black. Flesh free from pulp, very juicy, sweet, and, when perfectly ripe, rich and aromatic. Ripens early. (C. Amolil, MS.)

\section{Brinckle.}

Raised by Peter Raabe, near Philadelphia. Vine tender.

Bunch large, rather compact, sometimes shouldered. Berries round, black. Flesh slightly pulpy, vinous, saccharine. Good. Ripens Sept.

\section{Brown.}

Very much like Isabella, and ripens with it.

\section{BURROUGHS.}

From Vermont. Vine allied to the Clinton.

Bunch small. Berry round, black, thick bloom. Flesh harsh, acid, austere. Ripens a little earlier than Isabella.

\section{Burton's Earty.}

A large early, poor Fox Grape. Unworthy culture.

Of the fox class.

\section{CAMDEN.}

Bunch medium. Berry large, greenish white. Flesh with a hard centre, acid, poor. 


\section{Canada.}

Armold's No. 16.

Raised from seed of Clinton crossed with pollen of Black St. Peter's. $V$ ine and foliage somewhat like Clinton. The fruit also resembles Clinton in appearance of bunch, but larger berry.

Bunch and berry above medium, shouldered. Skin thin, black, with a fine bloom. Flesh free from pulp, juicy, with a distinet foreign flavor, and aromatic. Ripens with Concord. (Chas. Arnold, MS.)

\section{Carter.}

Of a foxy character. Berries round, large, almost black. Ripens with Lsabella, and inferior.

\section{Cassady.}

An accidental seedling that sprang up in P. H. Cassady's yard, in Philadelphia.

Bunches medium size, tolerably compact, and sometimes shouldered. Berry below medium, round, greenish white, with occasionally a faint salmon tint, and thickly covered with white bloom. Flesh juicy, little pulp, pleasant, peculiar honey swect.

\section{Catawba.}

$\begin{array}{ll}\text { Red Muncy. } & \text { Catawba Tokay. Saratoga? } \\ \text { Michigan. } & \text { Fancher? }\end{array}$

This excellent native Grape was first introduced to notice by Major Adlum, of Georgetown, D. C., and was found by him in Maryland.

The Catawba is too late in ripening for general cultivation in the Eastern and Northern States; but where it does succeed few Grapes are its superior. Clay shale soils appear to give most richness to the fruit; but very handsome cluster's are grown in gravelly or sandy soils. It is a popular and profitable market sort. Vine harily and productive.

Bunches of medium size, somewhat loose, shouldered. Berries round (or sometimes slightly oval), pretty large. Skin rather. thick, pale red in the sharle, but pretty deep red in the sum, covered with a lilac bloom. Flesh slightly julyy, juicy, very sweet, with an aromatic, rich, musky flavor. Ripe from the 1st to the middle of Oetober, and sliould be allowed to liang till fully ripe.

Meal's Seedling; and Mammoth Catawba, and Poeschel's Mammoth are claimed as seedlings of the Catawba; but they are so nearly identical as not to require distinct descriptions. The Zane, White Catawba, Pond's Seedling, James' Seedling, Clermont, also belong to this class.

\section{Cifallexge.}

Raised by Rev. Asher Moore, from a cross between Concord and Royal Muscadine. Vine hardy and thrifty.

Bunches short, compact, shouldered. Berries rather large, round, fale red like Catawba. Flesh slightly pulpy, juicy, sweet. Ripens before Concord. (W. F. Basset.)

\section{Charter Oak.}

A very large, coarse, native Fox Grape, quite worthless except for size. 


\section{Chippewa.}

A variety found growing on the banks of the (hippewa Creek, and described in 1858 by $\mathrm{W}^{\mathrm{m}} \mathrm{m}$. H. Read.

Bunches good size, compact, heavily shouldered. Berries medium, black, covered with bloom. Flesh tender, melting, sweet, and excellent. We have never seen the vine or heard of it since the first above-pullished deseription in the "Country Gentleman."

Clara.

A chance seedling in grounds of Peter Raabe, Philadelphia, Pa. Vine rather tender.

Bunch medium, loose, shouldered. Berry medium, roundish, pale yellow, translucent. Flesh tender, juicy sweet. A fine anateur sort. Ripens with Catawba.

\section{Claret.}

A seedling of Chas. Carpenter, Kelly Island, O. Vine vigorous. Bunch aud berry medium, claret red, acid. Not valuable.

\section{Clinton.}

Worthington.

Origin uncertain, said to have originated in Western New York. Growth vigorous, hardy, and productive.

Bunch medium, shouldered, long and narrow, somewhat irregular, but compact. Berries round, rather below medium size, black, covered with a thick bloom, juicy, with some acidity and toughness in its pulp, but with a brisk vinous flavor. Colors early, but does not fully ripeu until quite late, or after frost.

\section{Clover Street Black.}

A seedling raised by Jacob Moore, from Diana crossed by Black Hamburgh.

Bunches large, compact, shouldered. Berrics large, roundish, black, with a dark violet bloom: Flesh tender, sweet. Tine moderately vigorous. Ripens with Concord. (Hov. Mag.)

\section{Clover Stheet Red.}

Same origin as the preceding.

Bunches larger than Diana, loose, occasionally with a similar long stalk or shoulder appended to the top. Berries large, roundish oval, crimsou when fully ripe, with a slight Diana flavor. Vine a strong grower. Ripens with Diana. (Hov. Mag.)

\section{Columeia}

This Grape is said to have been found by Mr. Adlum on his farm at Georgetown, D. C. A vigorous grower, productive.

Bunch small, compact. Berry small, black, with a thin bloom, with very little hardness or acility in its pulp, not higl-flavored, but pleas. ant and vinous. Ripe last of September. 
THE GRAPE.

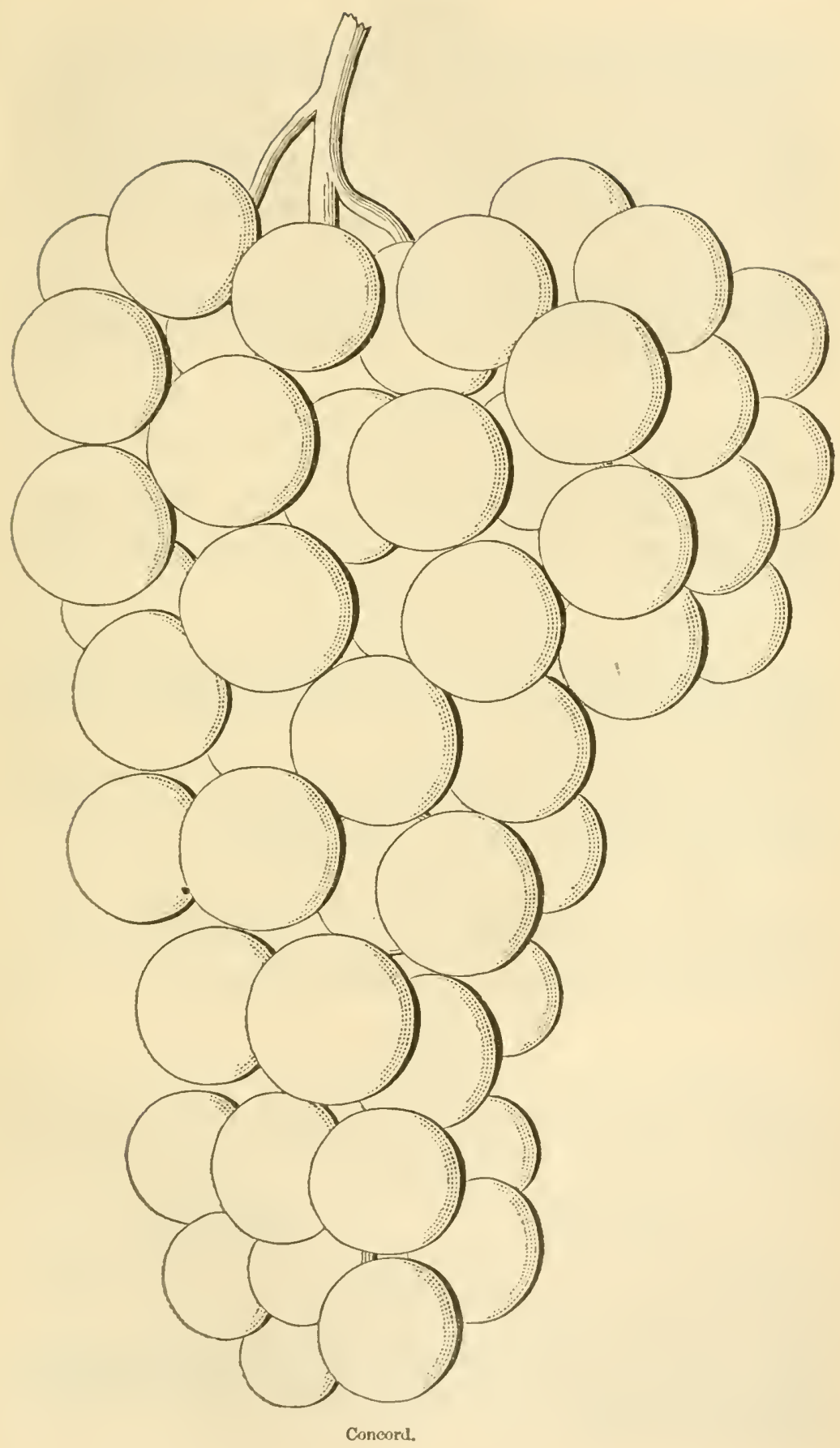




\section{Coxcord.}

This fine hardy native Grape was raised from seed by E. W. Bull, Concord, Mass. It is of very healthy, vigorous habit, and productive.

Bunch rather compact, large shouldered. Berries large, globular, almost black, thickly covered with bloom. Skin rather thick, with more of the native pungency and aroma than the Isabella, which it resembles, but does not quite equal in quality. Flesh somewhat buttery, moderately juicy, sweet, with considerable toughness and acidity in its pulp. It is more hardy than the Isabella, and ripens, about ten days earlier, consequently it is a very valuable variety for a large northern range where the Isabella does not ripen. It is very popular, but as a market sort the fruit, if left to ripen before gathered, does not carry well long distances, and is liable to drop from the bunch after a few days.

\section{Conqueror.}

A cross between Concord and Royal Mnscadine, grown by Rev. Asher Moore. Vine hardy, thrifty, productive.

Bunches rather long, loose, shouldered. Berries medium to large, son:ewhat pear-shaped, glossy, black, with a fine bloom. Flesh slightly julpy, juicy, sweet. Ripens with Concord. New. (IV. F. Bassett, MSS.)

\section{Corvicopia. \\ Arnold's No. 2.}

Raised in the year 1859, by Charles Arnold, from seed of Clinton, crossed with St. Peters. Vine very healthy and vigorous. Leaves large, dark green, smooth on both sides. Wood short-jointed. Tery productive, and a long keeper.

Bunch large, compact, shouldered. Berry above medium, very black, with a fine bloom. Skin thin. Flesh juicy, no pulp. Ripens with Concord, which ripens early. (C. Amold, MISS.)

\section{Cottage.}

This is a new variety, originated with E. W. Bull, and by him described as:

Fruit black, and ripening two weeks before Concord.

Cowax.

McCowan.

A native.

Bunch and berry medium, black, rather harsh and austere. Not desirable.

\section{Crevelling.}

Catawissa Bloom.

Columbia County.
Bloomburg.

Laura Beverly?

Claimed to be of Pennsylvania origin. Vine hardy and rigorous, moderately productive. It has imperfect blooms, but is said to be quite productive when grown side by side with Concord.

Bunch medium to large, long, loose, shonldered. Berries medium, nearly round, black, with a blue bloom. Flesh tender, very little pulp, juicy, sweet, and moderately rich, more so than Concord. Ripens soon after Hartford Prolific. 


\section{Ćrotos.}

A new variety, originated by Stephen Underhill, Croton T'oint, N. Y., from seed of Delaware crossed by Chasselas. The vine is a fine grower, hardy.

Bunch medium, shouldered, moderately compact. Berries small to medium, light greenish yellow. Skin thin. Flesh juicy, sprightly, sweet, pleasint, rich. Ripens abont with Hartford Prolific.

\section{Cunnisgham.}

\section{Long.}

Said to have originated with Jacob Cunningham, Prince Edward Co., Va. Vine vigorous healthy. A variety of value for wine, South and Southwest.

Bunch medium, brownish, compact, often, not always, shouldered. Berries small, round, black. Flesh juicy, rich. Not quite hardy at the North, and ripens later than Catawba.

\section{Cengahoga.}

\section{Wemple.}

A chance seedling found and grown by - Wemple, Collamer, Cuyahoga Co., O. Vine strong grower, requires a warm sandy soil and exposure to make it desirable at the North; but when well grown is of fine quality. South it casts its foliage, and is not valuable.

Bunch medium, compact. Berry medium, dull greenish amber when fully ripe. Flesh tender, juicy, rich, vinous, sweet. Ripens with Catawba or a little later.

\section{Cinthlana.}

\section{Red River.}

Of unknown origin, said to be Kansas. A distinct and raluable variety for making of red wine South and West, or wherever the Catawba will ripen. Vine very vigorous, hardy, and prodnctive. It much resembles Norton's Virginia, and is perhays superior:

Bunches moderately compact, shouldered. Berries small, round, black, blue bloom. Flesh juicy, the juice not quite as dark in color as Norton's Virginia.

\section{DArA.}

A seedling grown by Francis Dana, of Roxbury, Mass., and described in the "Massachusetts Horticultural Transactiuns."

Bunch merlinu, shouldered, compact, with a peenliar red stem. Berries rather large, nearly round, red, with a rich heavy bloom, so that when fully ripe they appear almost black. Flesh as free from pulp as Delaware; not so sweet, but more spirited and vinous, yet not acid. Ripe last of September.

\section{DELAWARE.}

Heath.

Italian Wine.

The precise origin of this Grape is not known. It was found many years since in the garden of Paul H. Provost, Frenchtown, Hunterion Cu., N. J. - It is moderately vigorous in growth, with short-jointed 
wood. Quite hardy, requires rich soil, open, and well drained, to pro. duce the finest of fruit. One of our most, if not the most, valuable sorts for general cultivation. Very productive.

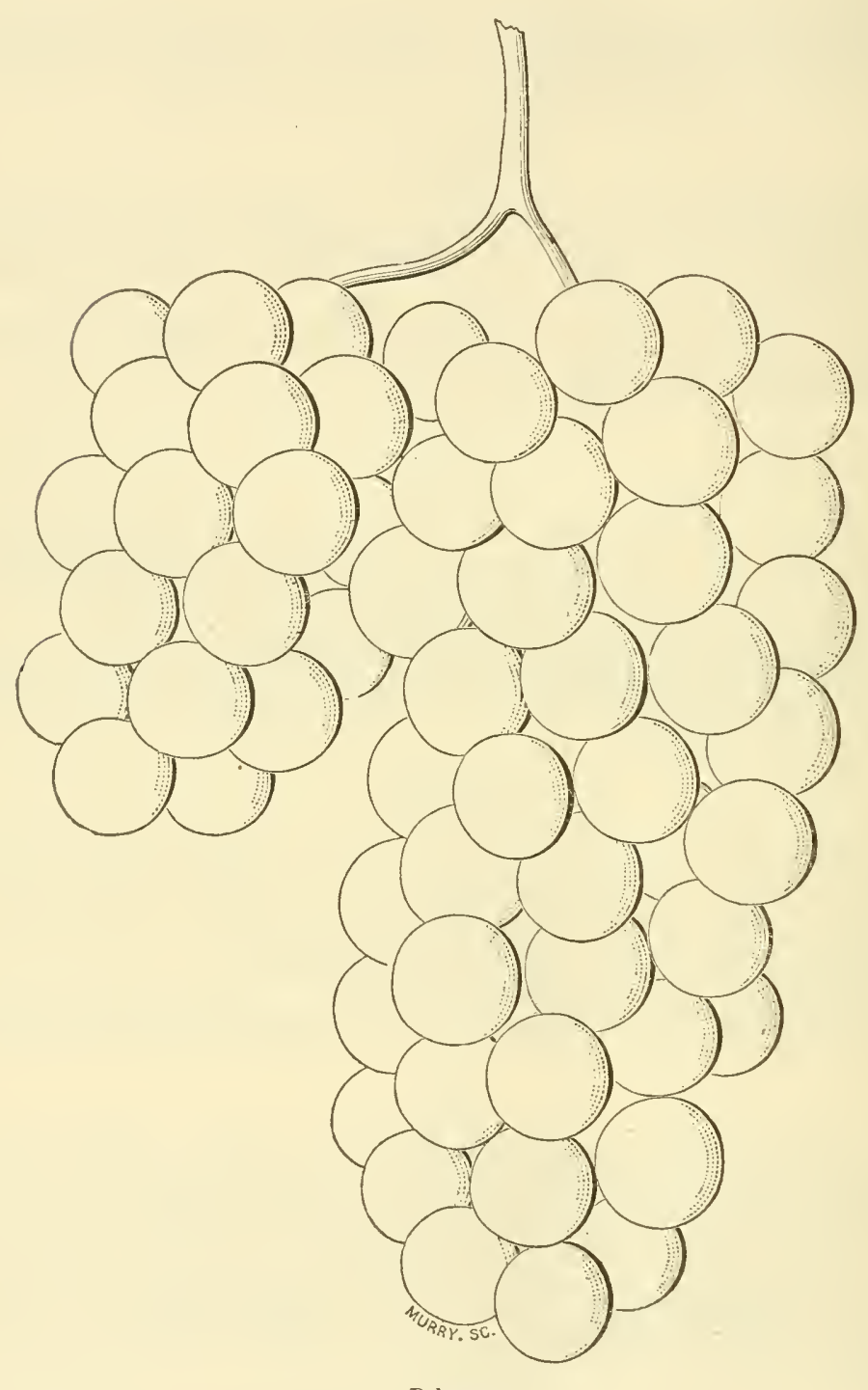

Delaware.

Bunch small, very compract, and generally shorldered. Berries rather small, round. Skin thin, of a beautiful light red, very translucent. It is without hardness or acility in its pulp, exceedingly swet but sprightly, vinous, and aromatic. 


\section{Deтriolt.}

This rariety is supposed to be a seedling. It was found in a garden in Detroit, Mich. Not having seen the fruit, we copy from description in the Horticulturist: "Vine very vigorous and hardy. Foliage resembling Catawba. Wood short-jointed.

"Bunches large, compact. Berries very lark, rich brown claret, with a light bloom, romel and regular. Flesh with rery little pulp, rich and sugary. Ripens earlier than Catawba."

\section{Diana.}

A seedling of the Catawba, raised by Mrs. Diana Crehore, of Brostom. It is a very fine fruit when well ripened, but while it colors early, cloes not ripen much, if any, earlier than Catawba. It is a very vigoi ous vine, requiring much room and long pruning, and increases in productiveness and good quality as the vines get age. It does not require a rery rich soil.

Bunches large, very compact, and heavy, not properly shouldered, but often having a small bunch appended by a long branch of the peduncle.

The color is a fine reddish lilac, thickly covered with bloom. The berries round. The fruit when fully ripe abounds in fine rich juice, vinous, and aromatic, from which all the offensive native odor has disappeared. It hangs long on the vines, is not injured by severe frosts, and keeps admirably for winter nse.

\section{Diana Hayburgif.}

Originated from seed of Diana, crossed with Black Tamburgh, by Jacob Mloore, Rochester, N. Y. Vine a fair grower, with short-jointed wood, tolerably healthy, sométimes disposed to mildew. We have seen but little of it, and think it not suited for ont-door culture.

Bunch large, moderately compact, shouldererl. Berries roundish oval, rich red, with a blom. Flesh tender, sweet, somewhat aromatic, like Diana. Ripens nearly with Isabella.

\section{Dracut Amber.}

Originated by J. W. Manning, Draent, Mass. Vine very vigorous, of the Fox Grape class, productive.

Bunch large, compact, often shouldered. Berry large, round. Skin thick. Flesh quite pungent and foxy. Ripens about with Concord.

\section{Early Hudsox.}

A round black Grape, early, and of little value, except as a curiosity, inasmuch as some of the berries contain no seed.

\section{ELI\%ABFTII.}

Originated on the farm of Joseph ILart, near Rochester, N. Y., and deseribed in the Rural New Yorker.

Bunches large, compact. Berries large, roundish oval, greenish white, with a sligbt purple tinge in the sun. Flesh rather pulpy, acid. 


\section{Etsingburgh.}

\section{Smart's Elsingburg. Elsenborough. Elsir boro.}

A very nice little Grape for the dessert, perfectly sweet and melt ing, without pulp, originally brought from a township of this name in salem Co., N. J. It is not a great deal larger than the common Frost Grape in the size of the berry. A moderate, but regular bearer, ripens well, and much esteemed by many for the talle.

Bunches pretty large, loose, and shouldered. Berries small, round. Skin thin, black, covered with a blue bloom. Flesh entirely without pul ${ }^{\prime}$, melting, sweet, and excellent. The leaves are deeply five-lobed, pretty dark green, and the wood rather slender, with loug joints.

\section{Emily.}

Raised by Peter Raabe, near Philadelphia.

Bunch large, not very compact, occasionally shouldered. Berry below medium, from three-eighths to one-half an inch in diameter, round, pale red. Flesh very juicy, with little or no pulp. Tender vine.

\section{Eumelas.}

A chance seedling, originated at Fislıkill, N. Y. Tine hardy, productive, and ripens early.

The bunch of good size, compact, shouldered. Berry medium size, nearly round, of a deep purple or bluish black color, covered with a light bloom. Flesh tender, melting, ripening to the centre, sweet, sprightly, vinous.

\section{Flora.}

Origin, Philadelphia, Pa.

Bunch small, compact. Berry small, roundisb oval, purplish red. Flesh somewhat pulpy, acid at centre, juicy, vinous. Ripens about with Isabella. Vine hardy and productive.

\section{Frantín.}

Vine much the habit and growth of Clinton. Not as good a bearer.

Bunch small, not very compact. Berry small, black, juics, quite acid, austere. Unworthy.

\section{Garrigues.}

Raised by Edward Garrigues, Kingsessing, Philadelphia. A vigorous grower, hardy and productive, very mnch resembles Isabella, and no doubt a seedling of it. Ripens a few days earlier.

\section{Goetine.}

Rogers' No. 1.

Raised by E. S. Rogers, of Salem, Mass. Vine vigorous, productive, and has more of the foreign character in it than any other of his seedlings. It does not ripen here, except in farorable seasons. It is siril to succeed well South and Southwest. 
Bunch large, moderately compact, shouldered. Berry very large, oval, yellowish green, often blotched with dull ved. Flesh tencler to the centre, juicy, sweet, pleasant, slightly aromatic.

\section{Goldex Chintos.}

\section{King.}

A seedling of Clinton, and resembles that variety, except in color of fruit, which is yellowish white. Not as productive as Clinton.

\section{Graifam.} phia.

An accidental seedling, introduced by William Graham, of Philadel.

Bunch of medium size, shouldered, not compact. Berry half an inch in diancter, round, purple, thickly corered with a blue bloom, contains little or no pulp, and abounds in juice of agreeable flavor. A poor grower and bearer.

\section{HALL.}

A variety grown by David Hall, of Urbana, O. Berries medium, dark, almost black, better than Clinton, not equal to Isabella, but earlier. May be better south.

\section{Hartford Prolific.}

\section{Seneca? $\quad$ Framingham.} ductive.

Raised by Mr. Steel, of Hartford, Conm. Hardy, vigorons, and pro-

Bumch large, shouldered, rather compact. Berry large, globular, with a good deal of the native perfume. Skin thick, black, covered with a bloom. Flesh sweet, moderately juicy, with considerable toughness and acidity in its pulp. Ripe among the very earliest. An early variety for marketing, but too liable to drop its fruit from the bunch as soon as fully ripe.

\section{HATTIE.}

There are two Grapes under this name. One originated with Mrs. N. R. Haskell, Monroe, Nich. Is a medium-sized bunch, rather long and loose. Berries medium, slightly oval, bright clear red, trans. lucent, with a bloom. Flesh juicy, with hittle pulp, pleasantly vinous, not rich. Ripens with Concord. "The other Hattie, or Hettie, is of unknown origin. Bunch small. Berry black. Flesh somewhat pulpy, a poor grower and bearer, but ripens early.

\section{HeRBEMONT.}

Niarren.

Herbemont's Madeira.
Tirrenton.

Neil Grape.

Origin claimed for many localities, but not yet fully ascertained. It is, however, a Southern Grape, a vigorous grower, a good bearer, and particu. 
larly fitted for those Southern latitudes that are liable to injury from late frosts in spring, as it flowers very late. It is highly esteemed as a wine grape in Missouri, Temessee, and other Southeru and Southwestern sections. At the North it does not ripen its fruit except in warm, sheltered sitmations.

Bunch large and compact, shouldered. Berries below medium, round, dark blue or violet, covered with a thick light bloom. Skin thin, which is filled with a sweet, rich, vinous aromatic juice of so little, consistence that it cannot be called flesh.

\section{Hine.}

Originated with Jason Brown, of Put-in-Bay, O., from seed of Catawba.

Bunch large, compact, slightly shouldered. Berries ınedium, round, irregular in size, dark claret red. Flesh juicy, rich and sweet, slightly pulpy. Ripens about with Concord.

\section{HoWELL.}

Origin unknown.

Bumch and berries medium, oval, black. Skin thick. Flesh with firm pulp, pleasant. Good. Middle September.

\section{Hudson.}

Originated in the garden of Mr. Calkins, Hudson, N. I. Growth similar to Isabella.

Bunch and berry much the same, but less sprightly and not quite so rich.

\section{Hyde's ElizA.}

Originated with Eliza Hyde, Catskill, N. Y. Vine moderately vigorons, and productive.

Bunch medium, compact, often with a small shoulder. Berry medium size, romud, black, covered with a thin, light bloom. Flesh tolerably juicy, somewhat buttery, with a pleasant vinous flavor. Ripe a few days before Concord.

\section{IONA.}

Originated by Dr. C. W. Grant, Iona 1sland, N. I. Vine vigorous, productive. A superior grape when in perfection.

Bunch medium to large, shouldererl, sometimes double-shouldered. Berries medium, roundish oval, light clear red, fine bloom. Skin thin. Flesh soft, tender to the centre, juicy sweet, vinous. Ripens a few days after Delaware, and continues a long time in use.

\section{ISABELLA.}

Paign's Isabella.

Woodward.

Payne's Early.
Christie's Improved Isabella.

Saubornton?

This very popular Grape, a native of South Carolina, was brought to the North and introduced to the notice of cultivators about the year 
THE GRAPE.

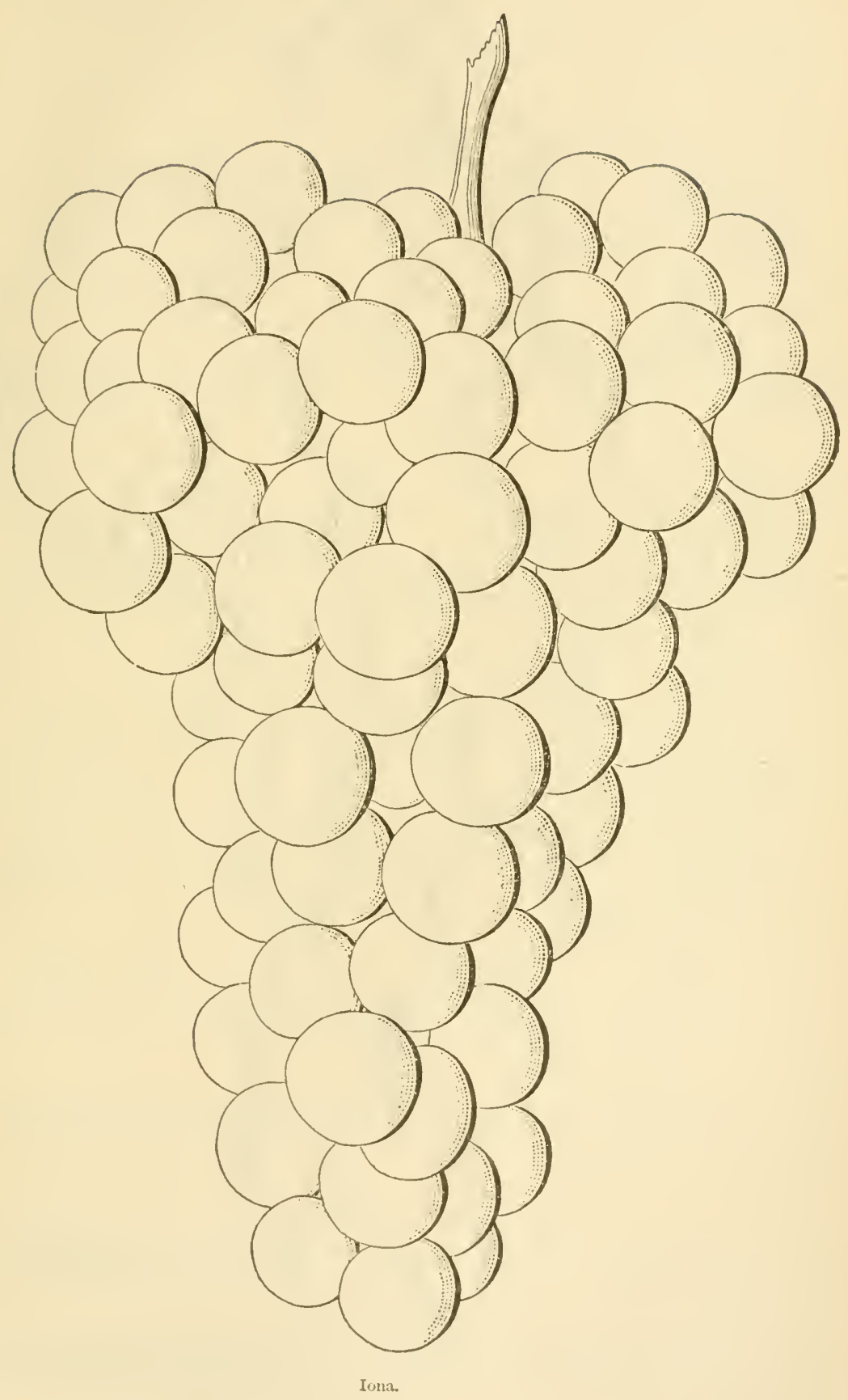


THE GRAPE.

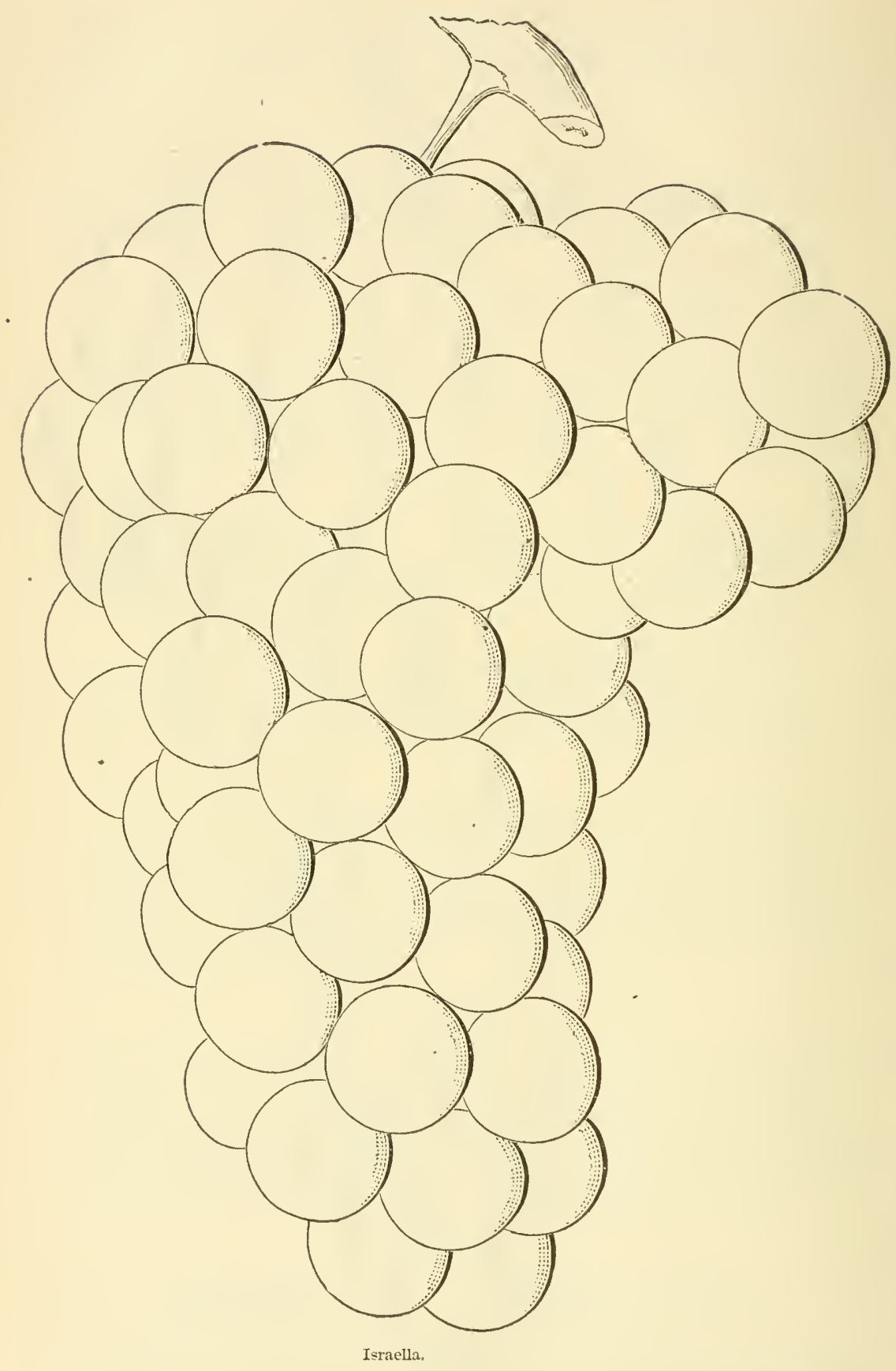


1818, by Mrs. Tsabella Gibbs, the wife of George Gibbs, Fisq., in honor of whom it was named. Its great vigor, hardiness, and productiveness, with the least possible care, have caused it to be most widely disstminated. It is, perhisps, a little more hardy, and ripens earlier thin the Ciatiawba.

Tumches of good size-five to seven inches long, rather loose, shouldered. Berries oval, pretty large. Skin thick, dark purple, becoming it last nesly liack, eovered with a blue bloom. Flesh tender, with some pulp, which nearly dissolves when fully mature; juicy, sweet and rich, with slight musky aroma.

This Grape is frequently picked as soon as it is well colored, and long before it is ripe.

Many seedlings of the Isabella have been grown, differiug very little in form, size, or quality of firuit, or in growth and productiveness. and therefore we prefer to class them as sub-varieties. They are Cloanthe, Aiken, Richmond, Baker, Bogue's Eureka, Sanbornton, Wright's Isahella, Lee's, \&c., dc.

\section{ISRAELLA.}

Originated with Dr. C. W. Grant, of Iona Island, N. Y. Vine rigorous, hardy, and productive.

Bunch medinm to large, shonldered, compact. Berries large, slightly oval. Skin rather thin. Flesh tender, juicy, free from pulp, sweet. Ripens soon after Hartford Prolific.

\section{TVes.}

\section{Ires' Seedling. Ives' Madeira. Kittredge.}

Raised by Henry Ires, of Cincimnati. Vine vigorous, productive. Has lately come into pretty high repute as a valuable wine Grape in its native locality.

Bunch medium size, compact, shouldered. Berry medium, black, roundish oval. Flesh with some pulp, juicy, sweet, a little too harsh for table use. Ripens with Isabella.

\section{Kilvington.}

Origin unknown.

Bunch medium, tolerably compact. Berry small, round, dull red, with a bloom. Flesh pulpy, half tender, vinous.

\section{Kingsessing.}

Bunch long, loose, shouldered, Berry medium, round, pale red, with a bloom. Flesh pulpy.

\section{KitcheN.}

Seedling from Franklin.

Bunch and berry medium. Berry round, black. Flesh acid, juicy.

\section{IABE.}

Bunch rather small, short, oblong. Berries medium, loosely set, black. Flesh half tender, pulpy, sharp sweet. 


\section{LAKE.}

Iden.

Bunch and berry small, black, early, acid, harsh.

\section{LENOIR.}

This Grape takes its name from Lenoir Co., N. C. It lras been confounded with Black July, but is distinct, as shown in foliage. The toliage of this has lobed leaves.

Bunch medium, compact, shouldered. Berry small, round, dark, almost black. Flesh tender, vinous, juicy, sweet. A good variety South, but too late in ripening for the Nortl.

\section{LINDLEY.}

Rogers' No. 9.

Raised by E. S. Rogers, of Salem, Mass. Tine vigorous, very productive.

Bunch medium, rather long, compact. Berry medium, roundish, red or reddish. Flesh tender, juicy, sweet, slightly aromatic. Ripens a little before the Concord.

\section{LOGAN.}

Supposed origin, Ohio. Vine a moderate grower and bearer.

Bunches medium, shouldered. Berries roundish oral, black. Flesh juicy, sweet, some pulp at centre. Ripens just after Hartford Prolific.

\section{Loulsa.}

Raised by Samuel Miller, Calmdale, Lebanon Co., Pa.; hardy, vigorous grower.

Bunch medium, rather compact, occasionally shonldered. Berry round, inclining to oral, black, with a blue bloom similar to Isabella, and ripe a few days earlier.

\section{LOIISIANA.}

A variety from Louisiana, by some considered a native; others say it is foreign. George Husman says:

"It can hardly be distinguished from the Rulander in appearance, but has a more sprightly flavor. Ripens at the same time."

\section{ITPIA.}

A chance seerlling, originated on Kelly Island, and introduced by Chas. Carjenter. Vine about with Isabella in growth and hardihood, int not a good bearer.

Bunches short, compact, roundish. Berries large, greenish white, inge of yellow when fully ripe. Skin thick. Flesh juicy, ricl, sweet, with very little pulp, and free of native aroma. Ripens with Delaware. 


\section{LYMAN.}

Origin unknown. A Northern variety, said to have been brought from Quebec upwards of fifty years ago. Harly and productive.

Bunch small, rather compact. Berry round, medium or below, black,

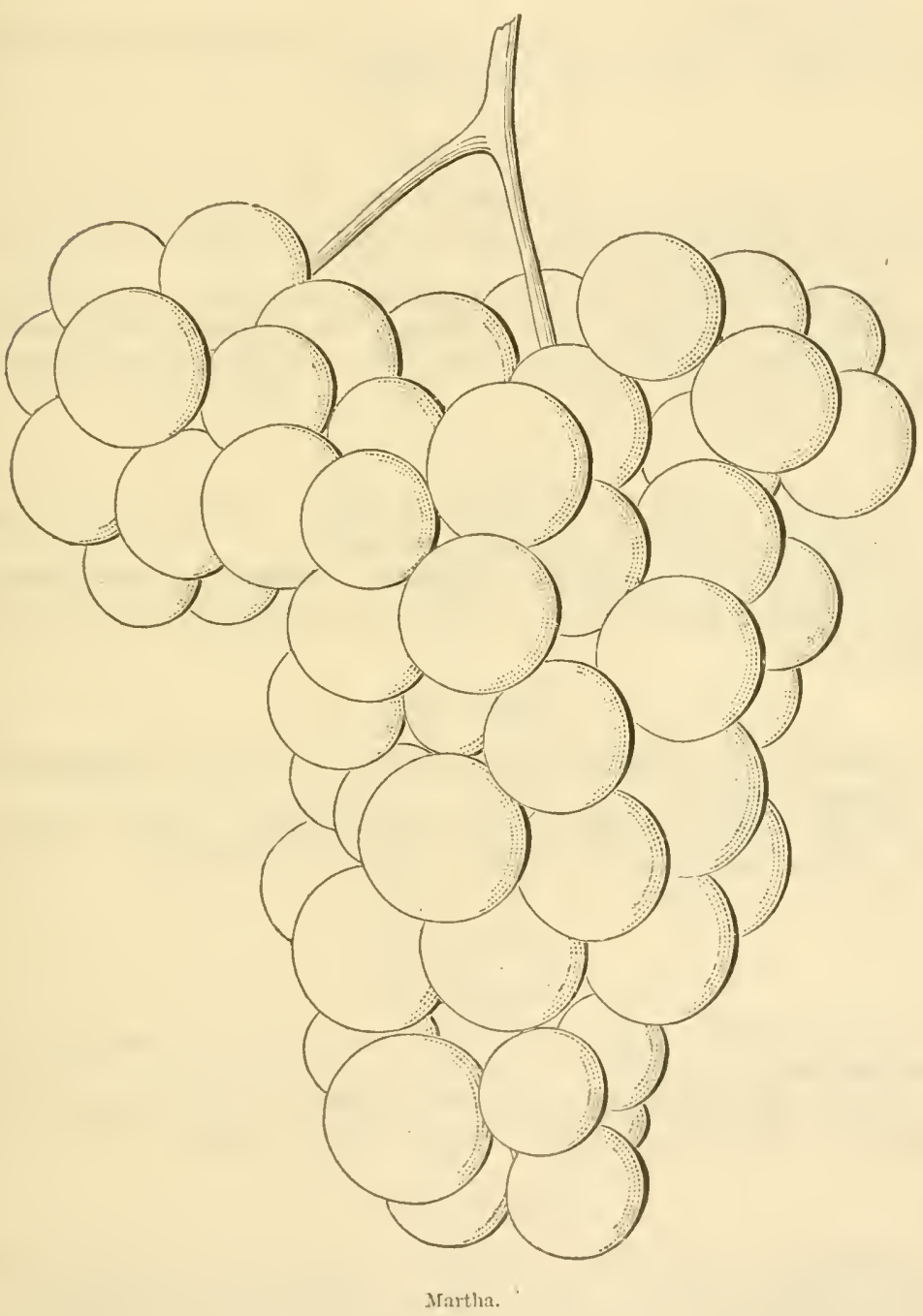

covered with a thick bloom, similar in flavor to Clinton, and ripens about the same time.

Sirermax and M[CNeIL are varieties grown from the above, but hardly to be distinguished from it. McCoun is another of this class. 


\section{ManhatTan.}

Originated near New York. A poor bearer.

Bunches small. Berries medium, round, greenish white, with ? bloom. Flesh sweet, rather pulpy.

\section{MARION.}

Origiu unknown.

Bunch large, compact. Berries roundish oval, purplish black, tongh centre, austere. Colo's early, but ripens late.

\section{Martita.}

Raised by Samuel Miller, Blufiton, Mo. The habit of the vine is much like Concord, but it has not yet been tested, as we think, suticiently to deride on its productiveness.

Bunches medium, not very compact, shouldered. Berry large, roundish, greenish yellow, with a bloom. Flesh similar to Concord, perhaps a little sweeter. A promising new sort, ripening a few days earlier than Concord.

\section{Mary.}

Raised by Charles Carpenter, Kelly Island. Vine hardy, strong grower. Fruit ripens too late for the North.

Bunch medium, moderately compact. Berries medium, round, greenish white, with a bloom. Flesh tender, slight pulp, juicy, sweet, brisk flavor.

\section{Mary Ann.}

Raised by J. B. Garber, Columbia, Pa. An early Grape, hardy. Not equal to Isabella.

Bunch medium, moderately compact, shouldered. Berry medium, oval, black, pulpy acid, foxy. Ripens about with Hartford.

\section{Massasolt.}

Rogers' No. 3.

Raised by E. S. Rogers, of Salem, Mass. Vine moderately vigorous, productive.

Bunch medium, rather loose, short, shouldered. Berry large, round, claret red. Flesh tender, juicy. Ripens before Concord.

\section{Maxatawney.}

Originated at Eagleville, Montgomery Co., Pa., in 1814. Vine healthy, vigorous, hardy, and productive. Requires a warm situation at the North, but Southwest proves one of the finest of White Grapes.

Bunch medium, not generally shouldered, somewhat loose, occasion. ally compact. Berries medium, roumdish oval, greenish white, with an amber tint when ripe. Flesh tender, not pulpy, very sweet and deli cious. Ripens last of September. 
THE GRAPE.

\section{MERrimack,}

Rogers' No. 19.

Raised l,y E. S. Roggers, of Salem, Mass. Vine very vigorous, very productive.

Bunch rather large, short, and broad, compact. Berry large, rouni,

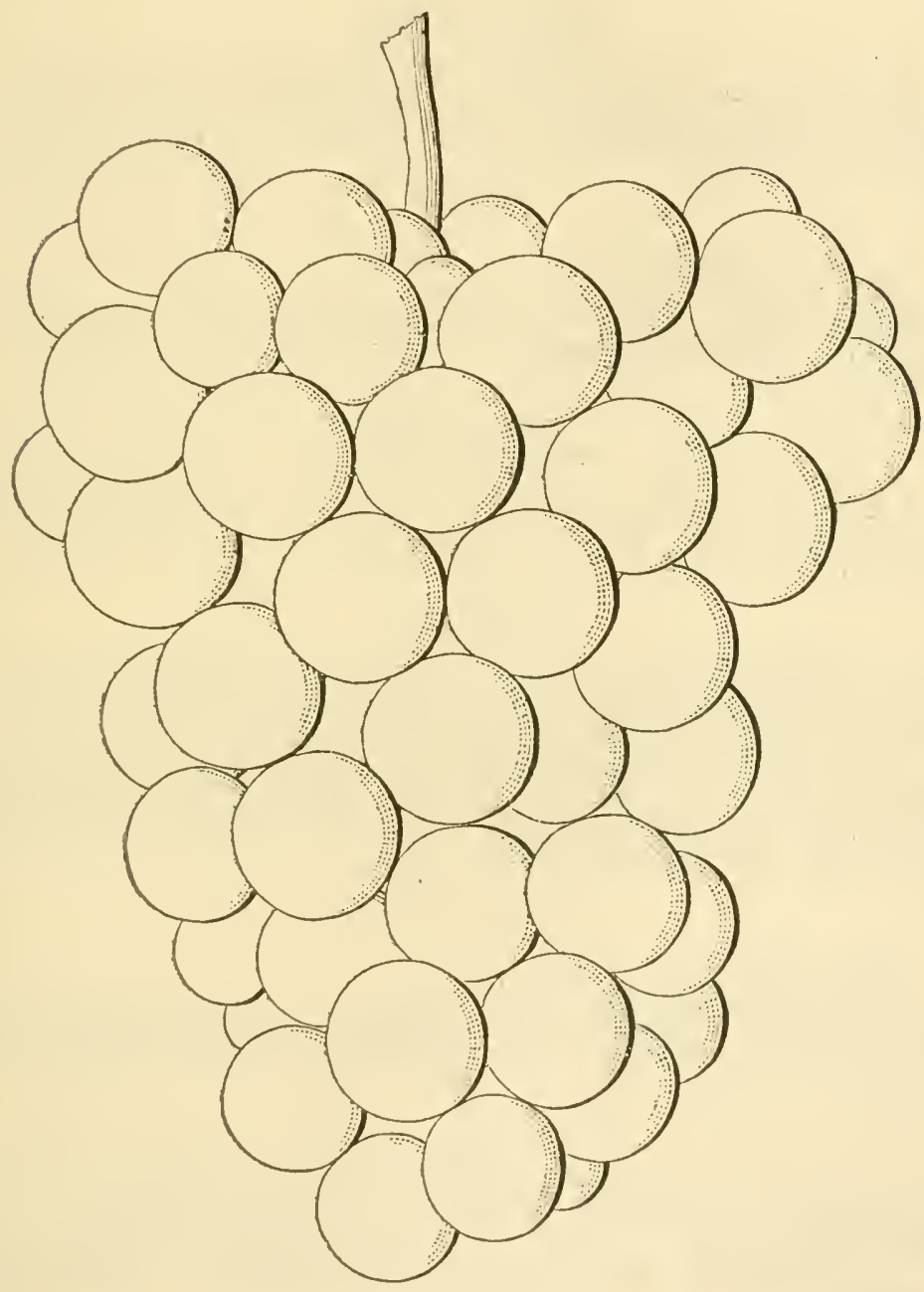

Mottled.

black, with a slight bloom. Flesh tender nearly to the centre, jucy, sweet, and very much like the Wilder, and ripens at the same time. 
Miles.

Origin, Westchester Co., Pa. Vine a moderate grower, hardy, anu productive.

Bunch small, rather compact. Berry small, round, black. Flesh tender, slight pulp at centre, brisk viuous, pleasant. Ripens amoug the earliest, but does not hang long.

\section{Missouri.}

\section{Missouri Seedling.}

A native sort, with short-jointed wood, and only moderate grower Bunch small, moderately conpact. Berries small, round, nearly black Flesh juicy, rather pulpy, vinous, pleasant when well ripeued. Ripens about with Isabella.

\section{Modexa.}

A new variety, raised by A. J. Caywood, of Poughkeejsie, N. Y., from seed of the Concord.

Bunch medium. Berries medium, roundish, black, something like Concord, but richer in saccharine. Pipens about with Concord.

\section{Montgonery.}

\section{Merritt's Seedling.}

A variety of undoubted foreign parentage. It is a large, showy bunch, and matures tolerably well in the open ground while the plants ale young.

\section{MotTled.}

A seedling grown by Charles Carpenter, Kelly Island, O. Tine hardy, very short-jointed. A profuse bearer, ripening with Delaware. It will hang a long time after ripe, and keeps unusually well.

Bunch medium, slightly shouldered, close, compart. Berries round, medium size, maroon red, with spots that when held to the light give it a mottled appearance, hence its name. Flesh tender. Pulp small. Juice sweet, rich, vinous, abundant.

\section{Mount Lebaxon.}

Origin, Columbia Co., N. Y.

Bunch larger than Northern Muscadine. Berry round, reddish Flesh pulpy, tough, sweet, perhaps a little better than Northern Mus. cadine.

\section{NEFF}

Keuka.

Origin, on the farm of Mr. Neff, near Keuka, on Crooked Lake, New York.

Bunch medium. Berry medium, dark copper red. Flesh pulpy, and somewhat foxy. Good native. Early.

\section{Noxantum.}

A new seedling, grown by Francis Dana, near Boston, and de scribed as : 
"Finch small, shouldered. Berry good size, oval, similar to lsabedla. Entirely free fiom pulp. Good tlavor:"

\section{Norti Amirica.}

Tine vigorous, unproductive.

Bunch snall, shouldered. Berry round, black, juicy. Ripens abont with Hartfosd Prolitic.

\section{North Carolina.}

North Carolina Seedling.

Bunch xuedium to large, shoullered, compact. Berry large, black, oblong, pulpy, but sweet and gool. Ripens only a few days after Hartford V'iolitic. Vine very productive, hardy, and healthy. Strong grower. (Husman.)

\section{Northery Muscadine.}

Raised by the Sliaker's, at New Lebanon, Columbia Co, N. Y.

Bunches small, short, compact. Berry large, round, ehocolate or brownish red. Skin thick, with a pungeney and odor common to the IVild Fox Grape, and is a very little, if any, improvement on it. The beries fall from the bunch as soon as ripe, which is about two weeks. before Isabella.

\section{Nortox's Virginia.}

\section{Norton's Seedling.}

A variety introduced by Dr. D. N. Norton, of Richmond, Va, It is a most productive Grape in garden or vineyard, bearing very large erops (especially at the South, where many kinds rot) in all seasons. It is valued for making a red wine.

Bunch medium, shouldered, somewhat compact. Berries small, round. Skin thin, dark purple. Elesh tender, wiih a brisk, rather rough tlavor. Ripens with Catawba.

\section{O1110.}

Cigar-Box Grape. Jack. Black Spanish Alabama.

Longrworth's Ohio. McCandless. Jacquez.

The origin of this Grape is mknown. It is said to have been brought from the Straits of Gibraltar, in 1805, to Oakland, Ala. Vine vigorous, long-jointed, not hardy at the North.

Bunches large and long, fiom six to ten inches, and often fifteen inches in length, rather loose, tapering, shouldered. Berries small, round. Skin thin, purple, with a blue bloom. Flesh tender and melting, without any pulp, brisk and vinous.

\section{ONOXDAGA.}

Originated in Fayetteville, Onondaga Co., N. Y., with Lewis Hueber, from a cross between Diana and Delaware.

Bunches about the size and form of Diana, compact. Berry medium: 
amber color when ripe. Flesh delicate, sweet, rich, without any of the native aroma. Ripens with Delaware. (W. Brown Smith, MSS.) .

\section{OPORTo.} well.

A strong, vigorous growing vine, should be long pruned to produce

Bunch small, slightly shouldered. Berries medium, round, black. Flesh purple, pulpy, austere.

\section{OSMOND.}

A seedling from the Franklin, by O. T. Hobbs, Raudolph, Pa. harsh.

Bunch and berry small, round, black, blue bloom. Flesh vinous,

\section{Othello.}

Canadian Hamburgh. Arnold's No. 1. Canadian Hybrid.

Raised in 1859, by Charles Arnold, Canada West. A good, strong grower and very productive. Leaves deeply lobed, smooth.

Bunches large, shouldered, compact. Berries large, round. Flesh solid, crisp, free from pulp, juicy, sprightly. Ripens with Delaware.

\section{Pauline.}

Burgundy of Georgia.

Red Lenoir.

A Southern Grape, of little value at the North, where it does not ripen or grow well.

Bunch large, long, tapering, shouldered. Berries small, very com. pact, colper color or violet, with a lilac bloom. Flesh brisk vinous, sweet, aromatic at the South.

\section{Perkins.}

Vine vigorous, productive.

Bunch medium, compact, shouldered. Berry full medium, roundish oval, light red at first, becoming quite copper color at maturity, covered with a light bloom. Flesh rather pulpy, foxy, showy. Ripens before Isabella.

\section{PoLLOCK.}

Raised by Mr. Pollock, Tremont, N. Y.

Bunches large as Concord, compact. Berries large, dark purple or black. Flesh free of pulp, vinous, not too sweet. (Strong.)

\section{RAABE.}

Raised by Peter Raabe. Vine moderately vigorous, not profitable.

Bunches small, compact, rarely shouldered. Berry below medium size, round, dark red, thickly covered with bloom. Elesh very juics, with scarcely any pulp. Ripens about with Concord. 


\section{REBECCA.}

Originated iu the garlen of E. M. Peake, of Hudson, N. Y. Vine moderately vigorous, a nice amateur Grape. Succeds finely in some localities.

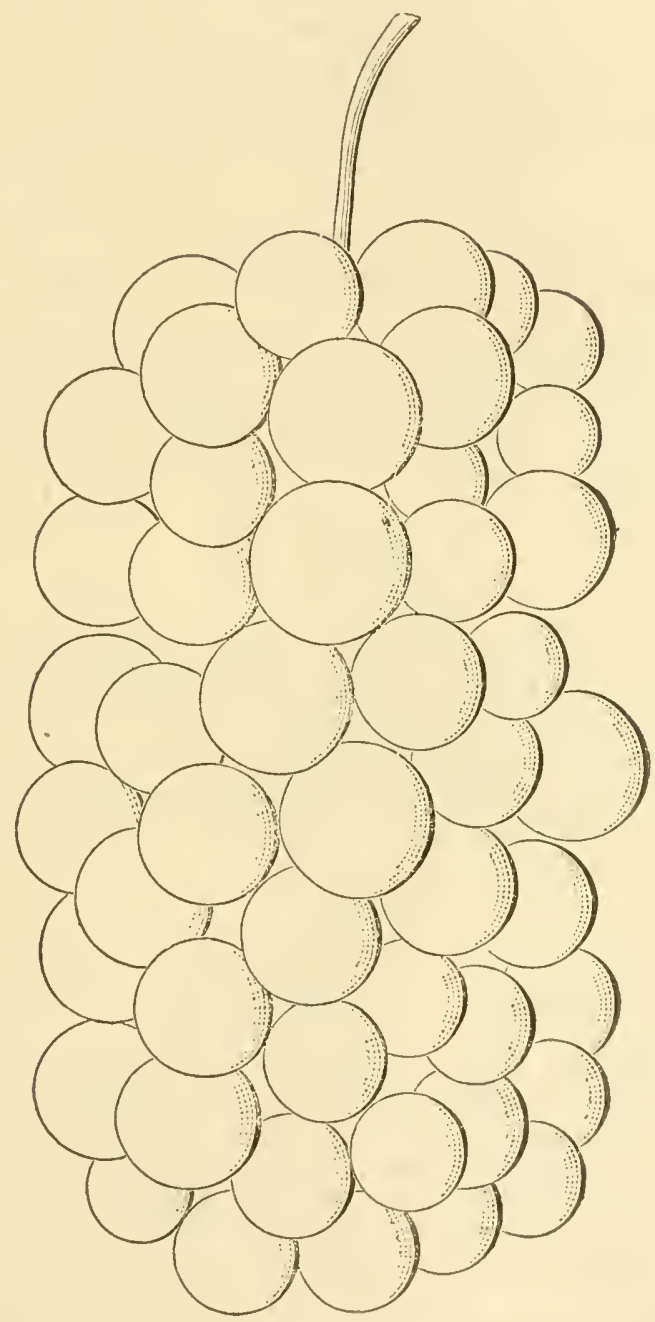

Rebecca.

Bunches medium, very compact, rarely shouldered. Berries of fun medium size, roundish oval, strongly adhering to the peduncle. Color light green in the shade, auburn or golden in the sun, and eovered with a light bloom, considerably transhurent. Flesh of some consistence, juicy, sweet, and delicious, with a perceptible native perfune, but very agreeable. Ripens with Isabella, and kefps well. 
Rentz.

Origin, Cincinnati, $\mathrm{O}$.

Bunch large, loose. Berzy rouud, purplish red. Flesh pulpy, foxy May do for wine.

\section{St. Catherine.}

Raised by James W. Clark, Framingham, Mass.

Bunch large, rather compact. Berries large, chocolate color, rather sweet, tough, foxy. Not of much value.

\section{S't. Genevieve.}

Rulander. $\quad$ Amoureux. Red Elben.

Au old Southern variety, and valuable in the South and Southwest. Vine vigorous, short-jointed, does not succeed North.

Bunch nedium to small, shouldered, compact. Berry small, roundish oval, dark purple or black, tender, juicy, sweet, and rich at the South, where it ripens last of July.

\section{SALEM.}

Rogers' No. 22.

Raised by E. S. Rogers, of Salem, Mass. Vine healthy, vigorons, and productive. We have not fruited it sufficient to express a decided opinion of it, more than it promises well.

Bunch large, short, and broad, compact. Berry large, round, a shade or two darker in color than Catawba. Flesh tender, juicy, nearly free from pulp, sweet, aromatic, and well-flarored. Ripens soon after Delaware.

\section{Scupperiong.}

Bull or Bullet.

American Muscadine.
Roanoke.

Vitis rotundifolia.
Titis Vulpina.

The Scuppernong Grape is a very distinct Southern species, found growing wild, from Virginia to Florida, and climbing the tops of the tallest trees. It is easily known from every other Grape by the small size of its leaves, which are seldom over two or three inches in diameter, and by their being glossy and smooth on both the under and upjer surfaces. These leaves are roundish and eoarsely serrated, and the young shoots are slender; the old wood is smooth, and not shaggy, like that of most vines.

We have made several trials with the Scuppernong Grape, but find it quite too tender for a Northern elimate, being killed to the ground by our winters. At the South it is a very hardy, productive, and excellent wine grape. The White and Black Scuppernong seareely differ, except in the eolor of the fruit. The tendrils of each correspond in hue with the fruit.

Bunches small, loose, seldom eomposed of more than six berries. Berries round, large. Skin thick, light green in the white, dark red in 
the black variety. Flesh quite pulpy, except wheu very thoroughly ripe, juicy and sweet, but with a strong musky scent and davor.

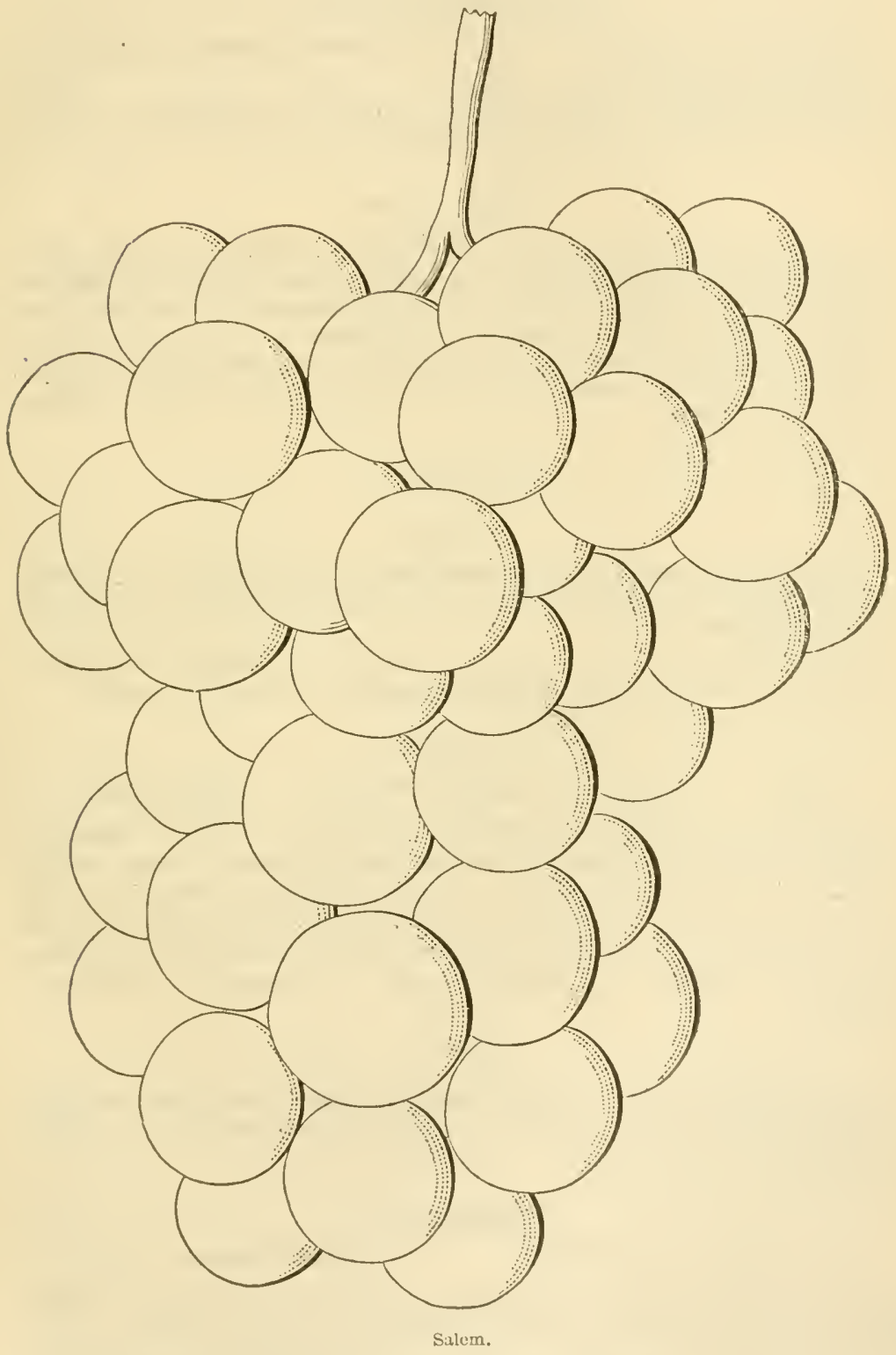

Sheppard's Dilaware.

Raised from seed of Catawba by J. N. Sheppard, in 1853, from whom, 
with its history, we received it. The vine and fruit are similar in all respects to Delaware.

\section{ShurtlefF's Seedling.}

Raised many years ago by Dr. S. A. Shurtleff, Brookline, Mass. We copy Coles' description:

"Bunches large. Berries medium, oval. Skin thick, lilac. Flesh of a sweet rich flavor. Ripe early September."

\section{'TAYlon's Bullet.}

A variety introduced by Judge Taylor, of Henry Co., $\mathrm{Ky}$. It is a very strong, rampant grower, and requires long space and training to produce good fruit. Confined to single stakes or low trellis it does not set well at the North, but does better South.

Bumches small, short, compact, shouldered. Berries small, greenish white to pale amber, round, sweet, and nearly free from pulp. Ripens about with Isabella.

\section{Telegrapi.}

Christine.

This variety was found in a yard near Philadelphia, Pa. A hardy and vigorous vine. Fruit of fair quality, ripening early or about with Hartford Prolific.

Bunch above medium to large, compact. Berry large, round, black. Flesh juicy, with some pulp, similar in quality to Hartford Prolific.

\section{To Kalox.}

\section{Wyman. Carter. Spofford Seedling. The Beautiful.}

Raised by Dr. Spofford, of Lansingburgh, N. Y. Vine vigorous, hardy, and productive, but is inclined to rot, and does not ripen well.

Bunches large and shouldered. Berries varying in form from oval to oblate, very dark in color and profuselv covered with bloom. Its fruit, when ripe, is very sweet, buttery, without foxiness in its aroma, or but little toughness or acidity in its pulp. Ripens a little earlier than Catawba.

\section{UNA.}

Originated with E. W. Bull, Concord, Mass., who describes it as hardy and prolific. Earlier than Concord, and the berries pure white, changing to golden amber.

\section{UXDERHILL.}

\section{Underhill's Seedling. Underhill's Celestial.}

Originated at Charlton, Saratoga. Co., N. Y., by Dr. A. K. Under hill. It is an improved variety of Fox Grape, large and showy. Tine hardy.

Bunch large. Berries large, round. Skin thick, clear dark red, without bloom. Flesh pulpy, hard at centre, sweet. Ripens about with Concord. 


\section{UNION VILLAGE.}

Shaker Grape. Ontario. Imitation Hamburgh.

Origin claimed among the Shakers of Union Village, O. It is perhaps the largest berry of any good native Grape. Vine very vigorous and coarse grower, but a little tender at the North-requires pro tection.

Bunches large, eonpact, shouldered. Berries very large, round, deep blaek, slight bloom. Flesh, when fully ripened, without any hardness, juies, vinous, pleasant, not rich. Ripens with Isabella.

\section{URBANA.}

Bunch medium, short, shoultered. Berry medium to large, round, white, yellowish in the sun, juiey, vinous aeid, hard centre, aromatic skin. Ripens about with Isabella.

\section{Tenango.}

Miner's Seedling.

An old viriety, said to be eultivated by the French at Fort Venango, on the Alleghany river, some eighty years since. A very vigorous grower, and hardy.

Bunel compat, if a fine lilac color, with the toughness of pulp belonging to the native varieties, but with a peculiar aromatic flavor. Ripens earlier than Catawba.

\section{WALTER.}

Originated with A. J. Caywood, Ponghkeepsie, N. Y., from seed of Delaware erossed with Diana. As yet it has only been fruited in the hands of its originator, where it promises to be valuable.

Bumch mediun, shouldered, moderately compact. Berries medium, round, light red. Fleslı juicy, sweet, not quite tenrler at the centre. Ripenș about with Concord.

\section{WILDER。}

Rogers' No. 4.

Raised by E. S. Rogers, of Salen, Mass. Vine vigorous, very productive. 'This is one of the best of Roger's' seedlings, adheres well. 'The bunch keeps well after it is gathered, and is a promising variety for market.

Bunch large, compaet, shouldered, sometimes double-shouldered. Berry large, round, blaek, slight bloom. Flesh tender nearly to the centre, juicy, sweet, rich, slightly aromatic. Ripens about the time of Concord.

\section{WHLMNGTON.}

Originated on the farm of $\mathrm{Mr}_{\mathrm{r}}$. Jeffries, near Wilmington, Del. Tine very vigorous, hardy.

Bumehes large, loose, sometimes shouldered. Berries large, round, 
inclining to oval, greenish white, or when fully ripe, yellowish. Flesh acid, pungent, not desirable at the Nortl, may be better South. Ripens late.

\section{WINSLOW.}

This originated in the garden of Charles Winslow, Cleveland, $O$. The vine resembles Clinton, is hardy and productive; the fruit matuses very early, and is less acid than Clinton.

Bunch medium, compact. Berries small, round, black. Flesh red. dish tinge, some pulp, vinous, sweet, juicy.

\section{Wroning Red.}

\section{Hopkins Early Red.}

The origin of this Grape is uncertain. It is said to have been found in the Wyoung Valley, Pa. The leaf and woor are described as similar to Delaware, only more vigorous. 'The fruit is also similar in color, but the berries are larger, and by some thought richer in quality.

Another Grape has been described as Wyoming, the fruit of which is black. We have not seen either of the above.

\section{York MADEIRA.}

$\begin{array}{lll}\text { Canby's August. } & \text { Large German. } & \text { Marion Port. } \\ \text { Black German. } & \text { Small German. } & \text { German Wine. } \\ \text { Wolfe. } & \text { Monteith. } & \text { Tryon. }\end{array}$

Supposed origin, York Co., Pa. Vine hardy, short-jointed, moderately vigorous and productive.

Bunch medium, compact, shouldered. Berry medium, roundish, black, sweet, sprightly, pleasant. Colors early, but does not ripen quité as early as Is.tbella.

\section{SELECTION OF TARIETIES.}

The Grape varies so much in its values when grown in different localities, that it is difficult to make a selection of varieties. The Concord has proved almost universally successful, but is not a grape of high character. Wilder, or Rogers' No. 4, is a better grape, and so far a success when grown.

Delaware and Mottled are two sorts of fine quality, hardy vines, but the Delaware especially requires rich soil and good cultivation. Rebecca and Allen's Hybrid are varieties among the White Grapes, most valuable, so far as tested, for private gardens.

Adirondac, Iona, Isabella, Massasoit, or Rogers' No. 3, Crevelling, Catawba, Isabella, Elsingburgh, Maxatawney, are valuable fruits, and where they are found to succeed, and ripen well, should be freely planted. 


\title{
CHATER XIX.
}

\author{
THE IIELUN゙.
}

\author{
Cucumis _Velo, L. Cucurbitncer, of botanists \\ Milon, of the French; Mcloma, German; Melcon, Dutch; Melone, Italian, \\ and Melon, Spanish.
}

True Melon (or M[uskmelon) is the richest and most luscious of ail herbaceous fruits. The plant which bears this fruit is a trailing annual, supposed to be a native of Persia, but which has been so long in enltivation in all warm elimates that it is quite doubtful which is its native country.

The climate of the Middle and Southern States is remarkably favorable for it-indeed far more so than that of England, France, or any of the temperate portions of Europe. Consequently Melons are raised as field crops by market gardeners, and in the month of Angust the finest citrons or green-fleshed Melons may be seen in all the markets of the States in immense quantities. Warm dry soils are peculiarly favorable to the growth of Melons, and even at low prices the prorhict is so large that this erop is one of the most profitalle.

Culture. The culture of the Melon is very easy in all except the most northern portions of the United States. Farly in May a piece of rich, light soil is selected, well manured, and thoronghly dug or prepared by deep plonghing and harrowing. Hills are then marked out, six feet apart each way. These hills are preprared by thigging a foot deep and two feet across, which are filled half full of good, well-rotted manure. Upon the latter are thrown three or four inches of soil, and both manure and soil are then well mixed together. More snil, well pulverized, is now thrown over the top, so as to complete the hill, making it three inches higher than the surface. Upon this plaut cight or ten grains of seed, corering them about half an inch deep.

When the plants have made two rough leaves, thin them so as to leave but two or three to each hill. Draw the earth nicely around the base of the plants with the hoe. In case the striped bug (Golereucuco vittala) attack the plants, which it often does, the best remedy is to hand-pick them early in the morning and then draw earth up even with the base of the leaves. The cucumber flea-beetle is kept off by dusting the vines early in the morning, daily, for a period, while they are yet moist with dew, using either dry fine soil, soot, or plaster.

As soon as the runners show the first blossom-buds, stop them by pinching out the bud at the extremities. This will cause an inereaserl production of lateral shoots, and add to the size of the firuit. Nothing more is necessary but to keep the surface free from weeds, and to stir the soil lightly with the hoe, in field culture. In gardens, thimning the fruit, and plicing lits of slate or blackencel shingles under each fruit, improve its size and flavor.

'To retain a fine sort of Melon in perfection, it should be grown at some distance from any other sort, or even from any of the cucumber family, otherwise the seeds of the next generation of firuit will be spoiled by the mixture of the pollen.

Varieties. A large number of viricties are enumerated, but many 
of these do not succeed without extra care, which their quality is not found to repay. Indeed what is popularly known as the Citron Melon, one of the finest of the green-fleshed class, is the greatest favorite with all American gardeners. It is high-flavored, uniformly gool, very productive, and in all respects adapted to the climate.

Melons have become so intermingled cluring the past ten or fifteen years that it is almost impossible at this time to classify them, as was once done. As before said, however, the Citron or Fine Netted, being types of the Green-Fleshed, are among the highest Havored and most delicate.

\section{Alten's Superb.}

A variety of the Nutmeg, a trifle larger than the old Nutmeg, round, considerably netted. Flesh green, and sweet. Esteemed as profitable for market growing.

\section{Alvord's Hybrid.}

This variety varies much in form, from round to oval. Color of skin pale whitish green, deeply ribbed, moderately netted, sometimes almost smooth. Rind moderately thick. Flesh whitish green Good but not rich. Ripeus medium season.

\section{BEECIIWOOD.}

Fruit of medium size, quite dark green, roundish oval. Skin greenish yeliow. Flesh green, very sweet. A fine variety for growing in frames under glass.

\section{Christiana.}

Originated in Beverly, Mass. Requires a little extra care, but when well grown one of the finest.

Fruit medium size, roundish, yellowish green. Flesh yellow, sweet rich, juicy. Ripens early.

\section{Green Citron.}

This is much the finest Melon for general culture.

Fruit rather small, roundish, flattened at the end, regularly ribbed and thickly netted. Skin deep green, becoming pale greenish yellow at maturity. Rind moderately thick. Flesh green, firm, rich, and highflavored. Ripens pretty early and bears a long time.

\section{ISPAHAN.}

This is large, handsome, with flesh of a light sulphur yellow, not rich or sweet.

\section{JENNY LIND.}

A variety somewhat resembling the foregoing, but not quite as large, of a rich, delicious sweet flavor. Ripens quite early and produces abun. dantly. 


\section{Thare Musk Cantelope.} its size.

An old and well-known variety, harlly worth growing except for

Fruit large, long oval, deeply ribbed. Flesh thick, light salmon color, swect, juicy. It is early and productive, and often used for making mango pickles.

\section{Nutueg.}

An old variety, often seen impure, but when in perfection very melting and excellent.

Fruit large, roumdish oval. Skin very thickly netted, pale green, slightly but distinetly ribbed. Rind rather thin. Flesh pale green, very melting, sweet and good, with a high musky flavor. Medium season.

\section{Persian.}

There are several sorts under this name. The best among them has long oval-shaped fruit, with a thin and delicate skin, and llesh quite tender, juicy, rich, and sweet. Mledium season.

\section{Pine-Apple.}

A dark-green oval Melon, of medium size, rough-netted. Flesh thick, firm, juicy, and sweet.

\section{Skillilan's Fine Netted.}

Earliest of the green-fleshed Melons, small, rough-netted, flattened at the ends. Flesh green, very thiek, firm, sugary, and of the most delicious flavor.

\section{WHITE JAPAN.}

Comparatively new. Originally from Japan.

Fruit small to medium, ribbed, sometimes slightly netted, color creamy white. Flesh thick, juiev, sweet, and well-Hivored.

Besides the foregoing there are Winter Melons from the South of Europe, very commonly cultivated in Spain, whieh, if suspended in a dry room, may be kept till winter. The Grees, VAlescia, and the D.mpsis are the three principal sorts; they are oval, skin netted, flesh white, sugary, and good.

\section{CHAPTER NX.}

THE WATER-MELON.

Cucurbita citrullus, I. Cucurbitacec, of botanists.

Pasteur, of the French; Hasser Melone, German; Cocomero, Italian.

Tre Water-melon is a very popular and generally cultivated fruit in this country. The rine is a training annual of the most vigorous 
growth, and the fruit is very large, smooth, and green, with a red or yellow core. Though far inferior to the Melon in richness, its abundant cooling juice render's it very grateful and refreshing in our hot midsummer days. Inmense fields of the Water-melon are raised, and their culture is very easy throughout all the Middle and Southern States.

The cultivation of the Water-melon is precisely similar to that of the melon, except that the hills must be eight feet apart. The finest crops we have ever seen were grown upon old pieces of rich meadow land, the sod well turned under with the plough at the last of April, and the nelons planted at once.

The following are its best varietics:-

\section{APPLE-SeEned.}

Medium roundish, slightly oval, dark rich green. Rind thin. Flesh scarlet, crisp, sweet, and very good. Early and prolific. Seeds very small, dull reddish brown. A nice little melon, but only desirable for the amateur.

\section{BAUGH.}

Received from Kentucky.

Fruit large, long oval, pale green. Flesh red, nearly solid, juicy, sweet. Rind thin. Rather early. Seeds reddish.

\section{Black Spanish.}

A rich and very excellent Wrater-melon.

Fruit large, roundish oblong. Skin very dark, blackish green, slightly marbled. Rind moderately thick. Flesh red, solid, rich, and very sweet. A late vilriety.

\section{BRADFORD.}

Originated in South Carolina.

Fruit large, oblong. Skin usually dark green, with gray longitudinal stripes, mottled and streaked with green. Rind half an inch thick. Flesh red to the eentre, with a fine sugary flaror, of the besù quality.

\section{Carolina.}

The large common variety.

Fruit very large, oblong. Skin dark green and white marbled. Rind thick. Flesh deep red, hollow at the centre, sweet and good. Sceds large, black.

There is also a sub-variety, with pale yellow flesh aud white seeds.

\section{Clarendon.}

Origin, Clarendon District, South Carolina.

Large, oblong. Skin mottled gray, with dark-green longitudinal stripes. Rind half ar anch thick. Fiesh scarlet to the centre, with a sugary and exquisite flavor, "best" quality. Seeds yellow, with a black 
stripe around the edge, and from one to threr black spots on each side; the form and number corresponding on the two sides.

\section{CitroN WATER-NHA,ON.}

This is a small, round, pale green, marbled sort, ripening late, and esteemed by many for preserving.

\section{ICE-CREAM.}

A fine variety, large, round, early and prolific. Skin very light green. Rind rather more than half an inch thick. Flesh white, cris]', sugary, and excellent. Seeds white.

\section{IMPERIAL.}

A remarkably fine-flavored and very productive sort, from the Mediterranean. Keeps a long time after it is ripe.

Frnit of medium size, nearly round. Skin pale green and white, marbled. Rind remarkably thin. Flesh solid to the centre, light red, crisp, rich, and high-flavored. Seeds quite small, reddish brown.

\section{Mountain Sprout.}

Large, long oval, striped with light and dark green. Flesh scarlet, a little open in the centre. Rind thin. Seeds light fawn-color, one of the best.

\section{Mountain Sweet.}

Similar to the above, except it often has a mammelonne neck. Flesh rather more solid, and of excellent flavor. This is grown extensively for the markets.

\section{Odfll's IaARge White.}

Very large, round. Skin gray, with green network. Rind threequarter's of an inch thick. Flesh pale red, of a very good quality. Keeps a long time after being gatherel.

Originated with Col. A. G. Sumner, South Carolina.

\section{ORANGE.}

Peculiar for the division of its flesh from the rind, unedium size, roundish oval, light green, with shades of darker greeu. Rind half an inch thick. Flesh red, not very solid, of good quality, but not equal to Mountain Sweet and Imperial.

\section{Ravenscroft.}

Origin, South Carolina.

Large, oblong, dark green, faintly striped, and inarked with lighter green. Rind half an inch thick. Flesh red to the centre, with a delicions sugary flavor, of the best quality. Seeds crean-color, having a brown stripe alound the edge. 


\section{SOUTER.}

Large, oblong, sometimes roundish. Skin peculiarly marked with grayish dots, and pale and dark green stripes. Rind half an inch thick. Flesh deep red to the centre. Flavor sugary and delicions, of tho best quality. Seed cream white, with a faint russet stripe around the edge. Very productive.

Originated in south Carolina.

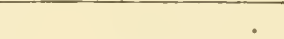

\section{CHAPTER XXI.}

\section{THE MULBERRY.}

Morus, Tourn. Trticacer, of botanists.

Murier, of the French; Maulbeerbrum, German; Moro. Italian; Morel, Spanish

The Mulberry is a hardy, decidnous fiuit-tree, but little cultivated in this country, though it is really a very considerable acquisition to our list of summer fruits, and every garden of considerable size ought to contain one or two trees. The fruit ripens in July, very soon after the season of cherries. It is rarely picked from the trees, as it fatls as soon as ripe, and it is therefore the custom to keep the surface below it in short turf, and the fruit is picked from the clean grass. Or, if the surface is dug ground, it may he sown thickly with eress seed, six weeks previously to the ripening of the fruit, which will form a temporary carpet of soft verdure.

The Black Mulberry, or English Mulberry (Morus nigra, L.), is a very celcbrated old fruit-tree, originally from Asia, more or less commonly cultivated in all parts of Europe, but yet quite rare in this country. Its growth is slow, and it seldom attains a height of more than twelve or fifteen feet, forming a low, branching tree, with lobed leaves, but it is very long lived, and there is a specimen in England, at the seat of the Duke of Northmmberland, 300 years old. In this comntry it is scarcely hardy enough north of New York, except in sheltered situations. An occasional extreme cold winter kills them; they are also suljject to canker and die off.

The fruit is incomparably larger and finer than that of the Red Mulberry, being an inch and a half long, and nearly an inch across-black, and of delicious flavor.

Everbearing. Originated here from seed of the Multicaulis. Tree very vigorous and very productive, an estimable variety, and surpassed by none except the Black English, and possesses the same rich subacid flavor. It continues in bearing a long time.

Fruit cylindric, one and a quarter of an inch long, and nearly half an inch in diameter. Color maroon, or an intense blue black at full maturity. Flesh juicy, rich, sugary, with a sprightly vinous flaror. Hick's Everbearing, from Kentucky, is similar to the above.

Jornsos, a seedling from Ohio. Fruit very large, oblong cylindric; blackish color, subacid, and of mild, agreeable flavor. Growth of the wood strong and irregular. Leaves uncommonly large. 
The Red Morberry (Momes mbra, L.) is a native species, more or less common in onr woods, with large, rough, lient-shaped or lobed leaves. The finit is about an inch long, and very pleasant and palatable, though much inferior to the Black English. It bears transplanting well. or is easily raised from seed, and may, undoubtedly, be greatly improved by repeated reproduction in this way. As it forms a large ornamental tree, with a fine spreadling heard, forty feet ligh, it is well deserving a place on the lawn, or near the house, in ornanental plantations.

There are many varieties of the White Mulbery, commonly cultivated for silk, but which procluce firuit of no value.

The best soil for the Mulberry is a rich, deep, sandy loam. The tree requires littlo or no proming, and is of very easy culture. It is usually propragated by cuttings, three feet long, planted in the spring, half their lepth in the gromnd; cuttings made of pieces of the roots will also send up shoots and become plants.

\section{CHAPTER XXII.}

\section{THE NECTARINE.}

\section{Persica vulgaris (v.) Lavis, Dec. Rosacea, of Butanists.}

Tre Nectarine is only a variety of the peach with a smooth skin (Pêche lisse, or Brugnom, of the French). In its growth, babit, and general appearance, it is impossible to distinguish it from the peachtree. The fruit, however, is rather smaller, perfectly smooth, without down, and is one of the most wax-like and exquisite of all produetions for the lessert. In flavor it is perhaps scarcely so rich as the finest peach, but it has more piquancy, partaking of the noyau or peach-leaf flavor.

The Nectarine is known in Northern India, where it is called moondla aroo (smooth peach). It appears to be only a distinct, accidental variety of the peach, and this is rendered quite certain since there are several well-known examples on record of both peaches and nectarines having been produced on the same brauch - thus showing a disposition to return to the natural form. Nectalines, however, usually produce nectarines again on sowing the seeds; but they also occasionally produce peaclies. The Boston Nectarine originated from a peach-stone.

The Nectarine appear's a little more shy of buring in this comntry than the peach, lut this arises almost always fiom the destruction of the crop of fruit by the curculio, the destroyer of all smooth-skinned stone fruit in sandy soils. It is quite hady here wherever the peach will thrive, though it will not generally bear large and fine fruit, unless the branclies are shortened-in anmully, as we have fully directed for the peach-tree.

With this easy system of pruming, good crops are readily obtained wherever the cureulio is not very prevalent.

The culture of the Neetarine is in all respects preciscly similar to that of the peach, and its habits are also completely the same. 


\section{VARIETIES.}

The same characters are used as in describing peaches, $\mathrm{f}(\mathrm{I}$ which the reader is referred to that part.

\section{Albert.}

A variety raised by Thomas Rivers, of Sawbridgeworth, Englant. It is one of the finest of Nectarines, but requires a warm location and soil to ripen it well.

Leaves with reniform glands. Flowers large.

Fruit large, round. Skin greenish white, with a pale red cheek. Flesh pale red next the stone, juicy, melting, brisk, vinous. Separates freely from the stone. Season middle of August.

\section{Balgowax.}

\section{Balgone. De Balgone.}

A variety allied to Violette Hîtive, but more hardy and vigorous.

Leaves with reniform glands. Flowers small.

Fruit very large, roundish, inclining to ovate. Skin pale green, mottled with red on the sladed side, corered with deep hright red next the sun. Flesh greenisin, veined with red at the stone, rich, melting. Season middle August. (Hogg.)

\section{Boston.}

\section{Lewis's. Perkins' Seedling.}

This American seedling was raised from a peach-stone by Mr. T. Lewis, of Boston. The fruit, though not of high Havor, is excellent, the tree very hardy and productive, and one of the best for general standard culture. Leaves with globose glands. Flowers small.

Fruit large and handsome, romdish oval. Skin bright yellow, with very deep red cheek, shaded off by a slight mottling of red." Flish yellow to the stone (which is small and pointed), sweet, though not rich, with a pleasant and peculiar flavor. Separates from the stone. Ripe first of September.

\section{BROOMFIELD.}

Lewis (incorrectly of some).

A handsome clingstone Nectarine, of second quality. It is an accidental seedling, which sprang up in the garden of Hemry Broomfield, Esq., of Harvard, Mass. Leaves with obscure, reniform glands. Flowers small

Eruit large, roundish. Skin rather dull yellow, with a dull or rather dingy red cheek. Flesh yellow, and adheres closely to the stone, juicy, rather pleasant, but not high-flavored. First to the middle of September.

\section{Chauvière.}

A variety originated in France. 
Fruit medium, roundish, depressed at base. Skin smooth, colored with carmine or deep purple aud dotted with gray in the sun. Flesh white, firm, juicy, vinous, aromatic, freestone. Season last of August. (Alb. l'om.)

\section{DOWTON.}

The Downton is a seedling raised by Mr. Knight. It is in quality, appearance, and season, an intermediate variety between the Violette Hattive and the Elruge, ripening a few datys earlier than the latter. Leaves with reniform glands. Flowers small.

Fruit large, roundish oval. skin pale green, with a deep violet rod cheek. Flesh pale green, slightly red at the stone; melting, rich, and very good. Separates from the stone. Ripens about the 25th of August.

\section{Dư du Tellier's.}
Duc Tilliers.
Due de Tello.
Duke de Tilley.
Du Tilly's.

A very excellent Nectarine, considerably resembling the Elruge, but a much greater bearer. Leaves with reniform glands. Flower's small.

Frnic rather large, roundish oblong, being shightly narrowed at the top, and broad at the base or stalk. Skin pale green, with a marbled purplish-red cheek. Flesh greenish white, pale red at the stone, melting: „uicy, sweet, and good. Separates from the stone. Last of August.

\section{Early Newingtos.}

$\begin{array}{ll}\text { Early Black Newington. } & \text { Lucombe's Black. } \\ \text { New Dark Newington. } & \text { Lucombe's Seedling. } \\ \text { New Early Newington. } & \text { Early Black. }\end{array}$

Black.

The Early Newington is one of the best of clingstone Nectarines. It is not only a richer flavored fruit than the old Newington, but it is larger, dark-colored, and earlier. Leaves serrated, without glands. Flowers large.

Fruit large, loundish ovate; a little enlarged on one side of the suture, and terminating with an acute swollen point at the top. Skin pale green in its ground, but nearly covered with bright red, much marbled and mottled with rery dark red, and coated with a thin bloom. Flesh greenish white, but deep red at the stone, juicy, sugary, rich, and very excellent. Beginning of September.

\section{ELRLGE.}

$\begin{array}{ll}\text { Common Elruge. } & \text { Anderson's. } \\ \text { Claremont. } & \text { Temple's. } \\ \text { Oatlands. } & \text { Peterborough. } \\ & \text { Spring Grove. }\end{array}$

The Elruge is everywhere esteemed as one of the very finest Nectarines. It is an English variety which has been a good while cultivated, and, with the Violette Hative, is considered indispensahle in every collection. In this country, when the young wood is annually shortened-in, it hears good crops on standard trees, which ripen finely. 
Without this precaution, like almost all othex Nectarines, the fruit is small, poor, and ripens imperfectly. Leaves with reniform glands. Flower's sinall.

Fruit of medium size, roundish oval, the suture slight except at the top', where it is distinctly marked. Skin with a pale-green ground, but when fully exposed it is nearly covered with deep violet, or blood-red, dotted with minute browuish specks. Flesh pale gieen to the stone, or slightly stained there with pale red; melting, very juicy, with a rich, high flivor. Stone oval, rough, of a pale color. Separates from the stune. Last of August and beginning of September.

\section{FaIrChild's.}

Fairchild's Early.

A very small, indifferent sort, only valued for its earliness, aud scarcely worth cultivating. Leaves with reniform glands. Flowers small.

Fruit small, about an inch and a fourth in diameter, round, slightly flattened at the top. Skin yellowish green, with a bright red cheek. Flesh yellow to the stone, rather dry, with a sweet, but rather indifterent flavor. Separates from the stone. Beginning of August.

\section{FELIGNY.}

\section{De Feligny.}

Du Hainaut. .

Leaves with coarse serratures and reniform glands.

Fruit medium, roundish oval. Skin smooth, carmine red on rich yellow, reddish gray in sun. Flesh white, shaded with purplish red next the stone, juicy, vinous, perfumed. Early September. (An. Pom.)

\section{Galopin.}

A variety from Belgium.

Fruit large, roundish, Hattened next the stem. Skin thick, firm, yellow, covered with violet in the sun. Flesh greenish, tinted with red, juicy, slightly acil, sugary. August. (Verg.)

Gathoye.

From Belgium.

Fruit small to medium, roundish. Skin yellowish green, marbled with reddish puiple. Flesh white, melting, juicy, sweet. Augnst. (Verg.)

\section{Goldex.}

Orange.

Fine Gold-fleshed.

An old English variety. Leaves with reniform glands. Flowers sinall.

Fruit of medium size, roundish ovate. Skin of a fine bright, waxen yellow color, with a small scarlet cheek. Flesh orange yellow, firm, juicy, sweet, and tolerably good. It ripens about the 10th of September. Clingstone. 


\section{HARDWICKE.}

\section{Hardwicke's Seedling.}

Was raised at Hardwicke House, in Suffolk, Eugland, and has tho reputation of being "one of the best and hardiest of Nectarines, and a very excellent bearer." Leares with globose glands.

Frnit very large, romolish, inclining to oval, and resembling the Elrnge. Skin pale green, with a deep, violet red check. Flesh pale green, slightly marked with red at the stone, juicy, melting, rich, and high-thivored. End of August. Freestone.

\section{Hunt's 'TAWry.}

\section{Hunt's Large Tawny. Hunt's Early Tawny.}

This is the best very early Nectarine. It is a very distinct sort, with serrated leaves, and was originated in England abont fifty years ago. It is worthy of general cultivation, as it is not only early but hardy, and an abundant bearer. Leaves serrated, wilhout glands. Flower's - sinall.

Fruit nearly of medium size, roundish ovate, being considerably narrowed at the top, where there is a prominent swollen point; and the fruit is slightly enlarged on one side of the suture. Skin pale orumge, with a dark-red cheek, mottled with numerous russety spectss. Flesls deep orange, juicy, melting, rich, and very good. Separates from the stone. It ripens firom the 5th to the 15th of August.

\section{LORD NAPIER.}

New. Raised by Thomas Rivers, England.

Fruit medium, jale cream-color, with a red cheek. Flesh melting. Separating from the stone. Glands kidney-shape. Flowers large. Ripens first week in August. (Rivers.)

\section{Muffrum.}

Of unknown origin.

Fruit small, roundish, deep suture half round. Skin smooth, golden yellow, shaded and dotted with rich purplish red. Flesh yellow rich, juicy, sweet. Separates fiom the stone. Early September. (Alb. Pom.)

\section{Murrey.}

Murry.

Black Murry.

The Murrey is an old English Nectarine, which, though of goud quality, is rather a poor bearer. Leaves with reniform glands. Flowers small.

Fruit of medium size, roundish ovate, slightiy swollen on one si.le of the suture. Skin pale green, with a dirk-red cheek. Flesh greenish white, melting, sweet, and of good flavor. Stone almost smooth. Sepra1ates freely. Ripens about the 20 th of August. 
Newington.

\begin{abstract}
Scarlet Newington.
Scarlet.

Old Newington.

Smith's Newington.

French Newington.
\end{abstract}

Sion Hill.

Anderson's.

Anderson's Round.

Rough Roman.

Brugnon de Newington.

D'Angleterre.

A very good clingstone Nectarine, of English origin. It should be allowed to hang on the tree till it begins to shrivel, when the Havor is much improved. Leaves serrated, without glands. Flowers large.

Fruit rather large, roundish. Skin pale greenish yellow, nearly covered with red, marbled with dark red. Flesh firm, pale, but deep red next the stone, juicy, sweet, and rich, with an excellent vinous Hiavor. Ripens about the 10th of September.

\section{New WHite.}

Neat's White. Cowdray White.
Flanders.

Large White.
Emerton's New White.

The New White is a fine light-skimned variety. Leaves with reniform glands. Flowers large.

Fruit rather large, nearly round. Skin white, with oceasionally a slight tinge of red when exposed. Flesh white, tender, very juicy, with a rich, vinous flavor. The stone is small. Separates freely. Ripens early in September.

\section{OLD Winte.}

This Nectarine is supposed to hare been introduced from Asia into England abont sixty years ago. It is much like the foregoing in Havor, perhaps a little richer, but it is less hardy and productive. Leaves with reniform yiands. Flowers large.

Fruit rather large, roundish oval. Skin white, slightly tinged with red. Flesh white, tender, juicy, and rich. Separates fireely from the stone. Early in September.

\section{Peterborough.}

Late Green.

Vermash.

This is the latest Nectarine known. It is rather small, and of inferior quality, and scarcely deserves cultivation exeept to make complete a large collection. Leaves with reniform glands. Flowers small.

Fruit rather small, roundish. Skin mostly green, or slightly tinged with dingy red on the sumny side. Flesh greenish white to the stone, somewhat juicy, and of tolerable flavor. Separates freely from the stone. It ripens early in October.

\section{PINE-APPLE.}

Raised by Thomas Rivers, England. 
Fruit large, nearly oval, pointed. Color deep orange and erimson. Ripens a week later than P'itmaston Olange. (livers.)

\title{
Pitulaston ORANGe.
}

\author{
Williams' Orange. \\ Williams' Seedling.
}

The Pitmaston Orange, which is consiclered the best yellow-fleshed Neetarine, was raised in 1816 by John Williams, of Pitmaston, near Woreester, England. The tree is rigorous. Leaves with globose glands. Flower's large.

Fruit large, romedish ovate, the base (towards the stalk) being broal, and the top narrow, and ending in an ante swollen point. Skin rici orange yellow, with a dark brownish-red cheek, streaked at the union of the two colors. Flesh deep yellow, but red at the stone; melting, juicy, ricl, sweet, and of excellent flavor. The stone is rather small, separates freely. Ripens middle and last of August.

\section{lied Rovax.}

$\begin{array}{ll}\text { Old Roman. } & \text { Bruguon Violette Musquée. } \\ \text { Roman. } & \text { Brugnon Nusque. }\end{array}$

The Red Roman is a very old European variety, laving been enu. merated by Parkinson in 1629 . It is one of the richest and best of clingstone Nectarines. "The tree healthy and productive. Leaves with reniform glands. Flower's large.

Fruit large, roundish, a little fhattened at the top. Skin greenish yellow, with a brownish, mudely red cheek, which is somewhat rough, and marked with brown russety specks. Flesh firm, greenish yellow, and deep red at the stone, juiey, with a rich, high vinous Havor. Ri. pening early in september.

\section{Rivers' Orayge.}

New variety, produced by Thomas Rivers, England, from seed of Pitmaston Urange. It is described as much resembling its parent, but higher flavored, and ripening a week or so later. The tree is a great bearer, robust, and hardy. Leaves with uniform glands. Flow. ers large.

\section{Rivens' White.}

Originated in 1857, by Thomas Rivers, England.

Fruit large, rounclish. Skin smooth, whitish, with slight shades of red in sum, white bloom. Flesh melting, juicy, vinous. Gluuds reniform. Flowers large. Earlier than New IV hite.

\section{STANWICK.}

A new late valiety. At the South, probably, it will prove an acquisition.

It was grown in Englund from a stone brought from Syria, and is deseribed in the Jomrnal of the London Hortieultural Society as above mediun size, roundish oval, slightly heart-shiped at base. Skin pale 
greenish white, shaded into deep rich violet in the sun. Flesh white, tender, juiey, rich, sugary, and without the slightest trace of prussic acid tlaror.

\section{VICTORIA.}

Raised by Thomas Rivers, Sawbridgeworth, England, from seed of Tiolette Hâtive fertilized by Stanwiek.

Fruit large, roundish, thattened at top. Skin greenish yellow, crimson on the sumny side. Flesh rich, sweet, one of the best. Glands re niform. Flowers small. Middle of August. New.

\section{VIOLETTE HÂtive.}

Eariy Violet.

Violet.

Eariy Brugnon.

Brugnon Red at the Stone.

Hampton Court.

Large Searlet.

New Scarlet.

Aromatic.
Petite Tiolette Hative.

Brugnon Hâtif.

Violette Angervilli res.

Tiolette Musqu e.

Lord Selsey's Elruge.

Violet Red at the Stone.

Violet Musk.

The Violette Hattive, or Early Violet Neetarine, everywhere takes the highest rank among Neetarines. It is of delicious flavor, fine appearance, hardy, and productive. Externally the fruit is easily confounded with that of the Ehuge, but it is readily distinguished by its dark-eolored stone, and the deep red flesh sumounding it. The fruit is usually rather darker eolored. It is of French origin, and has heen long cultivated. Leaves with reniform glands. Flower's rather small.

Fruit rather large, roundish, narrowed shightly at the top, where it is also marked with a shallow suture. Skin pale yellowish green in the shade, but when exposed nearly eovered with dark purplish red, mottled with pale-brown dots. Flesb whitish, but much rayed with red at the stone. The latter is roundish, the furrows not deep, and the surface reddish brown. The flesh is melting, juiey, rich, and rery highflavored. It ripens about the last of August.

The Violette Grosse (Thomp.) resembles the foregoing in leaves and flowers, and general appearanee. The fruit is, however, larger, but not so richly flavored.

Selection of choice hardy Nectarines for a small Garden.- Tiolet Hative, Elruge, Hardwicke, Hunt's Tawny, Boston, Roman, New White.

\section{CHAPTER XXIII.}

NUTS.

The Chestaxt (Castanea vesca, W.; Chataignier, of the Freneli; Fistanienbaum, German; Castagno, Italian) is one of our loftiest 
forest-trees, common in most parts of the Uuited States and Furope, and bearing excellent Nuts. The foreigu variety best known in this conntry is the spanish Chestnut, with fruit nearly as large as that of the HorsiChestnut, and which is excellent when boilerl or roasted. It thrives rery well here, but is not quite hardy to the north or east of this. One or two English varieties have been produced, of considerable excellence, among which the Downton is considered the best. The French cultivite " dozen or more varieties of greater or less excellenee, but thongh some of them have been introduced, we have not yet fairly tested them in this country.

The Cumpuapr, or Dwarf Chestnut, common in some parts of the Middle and southern states, is a dwarf species of the chestmut, msually growing not more than six to ten feet ligh, and bearing fruit of half the size of the common ehestunt, with the same flavor. It is worth a place in a small fruit-garders as a curiosity.

All the chestmuts are very casily enltivated in any good, light soil, and may be propagated by grafting and by sowing the seeds.

The Evropeax Waliut (Juglans regia, L.; Toyer, of the French; Wulnussbaum, German; Noce, Italian; and Noyal. Spanish), better known liere as the Mudeira $\Gamma^{\prime} u t$, is a fine lofty growing tree, with a handsome sprealing head, and bearing crops of large and excellent muts, enclosed like those of om native black walnut in a simple lusk. It stands the winter very well here, and to the south of this it wonld undoubtedly be a profitable fruit to plant for the market. The fruit in a green state is very highly esteemed for pickling, and the great quaritities of the ripe nuts anmully inported and sold here, prove the estimation in which they are held for the table. There are several varieties reputed to be of rather finer quality, which, however, have not displaced the original species, even in the gardens of Europe, and have not yet borne fruit here.

This tree is usually propagated by the seed, and transplanted from the nuseries when from three to six feet high. But it may also be grafted, with due care, on the common hickory-nut. A number of distinct rarieties have been produced from seed and perpetuated by grafting. Among them the following are regarded as of the most value :-

\section{Dwarf Prolific.}

Early-Bearing. Fertile. Precocious.

This is a dwarf-growing and rery early bearing variety, rery desirable for small fruit-gardens, as it may in our Northern States be easily protected in winter. The trees commence bearing when not more than three feet high, and, like the common walnut, it reproduces itself nearly always fiom seed.

\section{I.HRE-FRTITED.}

\section{Double. French. De Jauge.}

This is the largest of all, and of little ralue except as its size maker it attractive, or its shell may be of value for forming toys. 


\section{Thix-SHetled}

\section{A Coque Tendre.}

This is an oblong-shaped nut with a tender shell, well filled, one of the best.

The Filbert (Noisette, of the French; Haselstaule, German; Avellano, Spanish) is an improved variety of the common hazel-nut of the woods of Europe (Corylus acellana, L.). The finit is three or four times as large as that of our common hazel-nut, and from its size and excellent Haror is admired for the dessert. The old Spanish filbert, common in many of our gardens, is a worthless, nearly barren variety; but we have fonnd the better English sorts productive and excellent in this climate, and at least a few plants of them should have a place in all our gardens. They are generally raised from layers, made in the spring, but they may also be grafterl readily on the common hazel-nut, or the S sumish mut. When planted ont they should not be permitted to sucker, and should bo kept in the form of bushes with low heads, branching out about two feet from the ground, and they should be annually pruned somewhat like the gooseberry, so as to preserve a rather thin, open head, shortering back the extremities of the young shoots one-half, every spring.

The following are the best filberts known:-

Cosford. Nut large, oblong. Husk hairy. Shell remarkably thin, and kernel of excellent flavor. A goorl bearer.

Frizzlen. Easily known by jts handsome, deeply cut husk. Nut of medium size, oval, compressed. Husk hairy. Shell thick. Kernel sweet and good.

Lambert (Kentish Cob, Filbert Cob). This is perhaps the best of all the nuts, some of them being an inch or more in length. Husk nearly smooth. Nut large, oblong, and somewhat compressed. Shell pretty thick, of a brown color. Kernel full and rich. A great hearer.

Prarsox's Prolific (Ducarf Prolific, Nottingham Prolific). Nut medium size, obtusely ovate. Shell rather thick. Kernel full.

Purple Filbert (Purple-leaved). This is an ornamental shrub, as well as productive of excellent fruit. Its fruit is much like the Red Filbert, but the foliage is of a deep purple or red color.

Nortinampoxshire Prolific. Ripens early. Nut of medium size, oblong. Husk hairy. Shell thick.

Red Filbert. Easily known from other sorts by the crimson skin of the kernel. Fruit of medium size, ovate. Shell thick. Kernel with a peculiar, excellent flavor.

Włitse Filbeist. Resembles the last, but with a light yellow or white skin. The tree is also quite bushy. Nuts ovate. Jusk long and tubular.

The English generally call those varieties with long husks, filberts (full-beards), and those with short husks, simply nuts.

The Hirkony-Nut (Carya alba), or shell-bark, the Black Walnut (. ruglans nigra), and the Butternnt (.T. cinerea), are native nut-bearing trees, common in our forests, and too well known to need description here. There are occasionally found in the woods accidental varieties of the shell-bark hickory of much larger size and finer flavor thin the 
common species, whirh are highly wortly of cultivation, as we confess, to our own taste, this nut is much superior to the European walnut. 'There is indeed no dount that, with a little care in reprodustion by seed, the shell-bark may be trebled in size, and greatly improved in flavor.

\section{CHAP'TER XXIV.}

THE OLIVE.

Olen Europer, L ; Oleina, of botanists.

Olivier, of the French; Oehlucum. German; Ulivo, Italian; Olivo, Spanish.

Tne Olive, which, as Loudon justly remarks, furnishes, in its invaluable oil, the eream and butter of spatin and Italy, will undoubtedly one day be largely cultivated in our Sonthern States.

The uses and value of the olive-oil are still comparatively unknown in this conntry. In the Sonth of Europe it is more valuable than bread, as, to saty nothing of its wholesomeness, it enters into every kind of rookery, and rencless so large a quantity of vegetable food fit for use. A few olive-trees will serve for the support of an entire family, who wonld starve on what could otherwise be raised on the same surface of soil ; and hry cuevices of rocks, and almost otherwise barren soils in the deserts, when planted with this tree, become flourishing and valuable places of habitation.

The olive is a native of the temperate sea-coast ridges of Asia and Africa; but it has, time ont of mind, been cultivated in the South of Europe. It is a low evergreen tree, scarcely twenty feet high, its lead spreading, and clothed with stiff, narvow, bluish-green leaves. Its dark green or black fruit is oval, the hard fleshy pulp enclosing a stone. In a pickled state the fruit is highly esteemed. The piekles are made by steepring the mmipe olires in lye-water, after which they are washed and bottled in salt and water, to which is often added femel, or some kind of spice. The oil is made by crusling the fruit to a paste, pressing it through a coarse lempen bag into het water, from the surface of which the oil is skimmed off." The best oil is marle fiom the pulp alone: when the stone also is crusher, it is inferior.

Proparation AND Culture. A rery eommon mole of propagating the olive in Italy is by means of the nocoli (little eggs). 'These are kuots or tumor's, which form in considerable numbers on the bark of the trunk, and are easily detached by girdling then with a pen-knife, the mother-plant suffering no injury. They are planted in the soil like bulbs, an inch or so deep, when they take root and form new trees. It is also propagated by cuttings and seeds. The seedlings form the strongest and thriftiest trees; they are frequently some months in vegetating, and should therefore be buried an inch derp in the soil as soou as ripe.

'The wild American olive (Olea Americana, I.) or Devil-wood, a tree 
that grows more or less abundantly as far north as Virginia, will undoubtedly prove a good stock on which to ingraft the European olive. It is of a hardier habit, and, though worthless itself, may become valuable in this way.

The olive-tree commences bearing five or six years after being planted. Its ordinary crop is fifteen or twenty pounds of oil per annum, and the regularity of its crop, as well as the great age to which it lives, renders an olive plantation one of the most valuable in the world. With respect to its longerity we may remark, that there is a celebrated plantation near Terni, in Italy, more than five miles in extent, which, there is every reason for believing, has existed since the time of Pliny.

The Olive is not a very tender tree. It will thrive farther north than the orange. The very best sites for it are limestone ridges, and dry, crumbling, limestone rocky regions always produce the finest oil. The tree, however, thrives most luxuriantly in deep, rich, clayey loams, which should be rendered more suitable by using air-slaked lime as manure. It requires comparatively little pruming or care when a plantation is once fairly established.

Varieties. There are numberless varieties enumerated in the French catalognes, but only a few of them are worth the attention of any but the curious collector. The common European Olive is, on the whole, much the best for general cultivation, yielding the most certain and abundant crops.

The sub-variety most eultivated in France is the LoxG-LeAved OLIVE (Olea, e. longifolia), with larger and longer leaves; the finit nearly of the same size as that of the common olive.

The farorite sort in Spain is the Broad-Leaved Olive (Olea e. latifolia). Its finit is nearly double the size of the common Olive, and yields an abundance of oil, but the latter is so strong in flavor as to be more relished by the Spaniards than ly strangers.

The Olivier à Frutt Arnoxui (Olea splerica, N. Duh.) is a hardy French variety, which, in a moist, rich soil, yields most abundant crops of tine oil.

The Olivier Picmoline (Olea oblonga, N. Duh.) yields the fruit most esteemed for pickling. It grows quite readily in any tolerable soil, and is one of the hardiest varieties.

The Olivier Pleureur (Olea eranimorpha, N. Duh.), or Weeping Olive, is one of the largest and finest trees. Its branches are pendent, its fruit excellent, and the oil pure and abundant. It is a rery hardy sort, and grows best in damp valleys.

\section{CHAPTER XXV.}

THE ORANGE FAMILY.

Citrus, L. Aurantiacece, of botanists.

'TuE (jrang family includes the common orange (Cilrus aurantium); the Jemon ( $C$. limonum); the Iime (C'. limetta); the shaddock ( $C$. 
aecumanr): and the Citron ( $C$. medica); all lifferent species, with the same general liabit.

'The: Orange, a native of Asia, is the most attractive and beantiful of fruit-trees, with its rich, dark evergreen foliuge and its golden fruit, and it may woll therefore rnjoy the reputation of being the Golden $\Lambda_{\text {p }}$ ple of the Hespcricles. When to these chandus we and the delicions fragrance of the blossoms, surpassing that of any other fruit-tree, it must be enneded that, though the orang must yield in flavor to some other finits, yet, on the whole, nothing suppisses an oringe grove, ol orchard, in its eombination of attractions-rich verolure, the delicious aroma of its flowers, and the great beauty of its finit.

The south of Europe, Chinit, and the West Indies, furnish the lar gest suplines of this fruit. But it has, for a considerable time, been curtivated pretty largely in Florida, and the orange groves of st. Angustin: yield lange anid protitable crops. Indeed the enltivation may be extended over a consiclerable portion of that part of the Uniom borlering on the Gulf of Mexico: and the southern pant of Lomisiana, and part of Texas, are highly favorable to orange plantations. The Bitter Urange has become quite natmalized in parts of Florida, the so-called Wild Orange seedling; furnishing a stock much more hardy than those produced by sowing the imported seels. By continnally sowing the seed of these Wild Oranges, they will furmish stoeks suited to almost all the Southern States, which will in time render the better kinds grafted upon them comparatively hardy.

North of the latitucle where, in this country, the orange can be grown in gloves or orchards, it may still be protitably enltivated with partial protection. The injury the trees suffer from severe winters arises not from their freezing--for they will bar, withont injury, severe frost-bnt from the rupture of sap-ressels by the sudden thawing. A mere shed, or covering of boards, will gumel against all this mischief. Accordingly, towards the sonth of Europe, where the chimate is protty severe, the orange is grown in rows against stone walls or banks, in terraced gardens, or trained loosely against a sheltered trellis; and at the approach of winter they are covered with a slight movable shes, o ${ }^{*}$ frame of boards. In mild weather the sliting doors are opened, and air is aimitted freely--if very severe, a few pots of charcoal are placed within the enclosure. This covering remains over them four or tive months, and in this way the orange may be grown as far north as Baltimore.

Sorl AND Centure. The lest soil for the orange is a deep rich loam. In propagating them, sow, early in the spuing, the seeds of the naturalized or wild bitter orange of Florida, which gives much the hardiast stock. They may be ludded in the mun'sy-row the same season, or the next, and for this pmipose the earliest time at which the operattion can be performed (the wood of the binls being sulliciently timn), the greater the success. Whip or splice grafting nay also be resorted to early in the spring. Only the hardiest solts should he chosen for orchards or grores; the more delicate ones can be grown easily with slight covering in winter. Fifty feet is the maximm height of the orange in its native country, but it rarely forms in Florida more than a compact low tree of twenty feet. It is better, therefore, to plant them so near as partially to shade the surface of the cromel.

wiskits. The orange plantations of Florida have suffered very 
severely from the attacks of the scale insect (Corcup hisperidum), which in some cases has spread over whole plantations. and gradually destroyed all the trees. It is the same small, oral, brownish insect, sc common in our greenhouses, which adheres closely to the bark and undersicle of the leaves. A wash of sal soda or potash water, applied with a brush to the bodies and limbs of the trees, is the most certain and surc remedy for destroying this insect that we have known. Repeating this once or twice will probably efiectually rid the trees of the sealed insect.

Varieties. From among the great number of names that figure in the European catalognes, we select a few of those really deserving attention in each class of this fruit.

\section{The Oraxge.}

The Orange (Oicunger, French ; Pomeranzenbaum. Crerman; Arancio, Italian; and Vuranjo, Spanish) is, on the whole, the finest tree of the genus. Its dark-green leaves have winged foot-stalks, its fruit is round, with an orange-colored skin. It is one of the longest lived finit-trees, as an instance of which we may quote the celebrated tree at Versailles, called "the Grand Bombon," which was sown in 14:1, and is at the prescut time in existence, one of the largest and tinest trees in France.

The fruit of the orange is miversally esteemed in its ripe state. The bitter orange is used for marmalades; the green fruits. eren when as small as peas, are preserved, and used in various ways in confectionery; the rind and pulp are used in cooking; and the orange flowers, distilled, give the orange-flower water, so highly esteemed as a perfume and in cookery.

Besiles the Conmox Sweet Oraxae, the most esteemed sorts are the MALTEse and the BLOOD-RED, both of excellent flavor, with red. pulp. The MIANDARIN orange is a small, thattened fruit, with a thin rind separating very easily from the pulp, frequently parting from it of itself, and leaving a partially hollow space. It comes from China, and is called there the Mandarin, or noble orange, from its excellent quality. The Hesh is dark orange-colored, juicy, and very rich.

The Berganot orange has small flowers and pear-shaped finit. The leaves, flowers, and fruit being peculiarly flagrant, it is highly esteemed by the perfumer, and yields the bergamot essence. "The rind, first dried and then moistened, is pressed in moulds into small boxes for holding sweetmeats, to which it communicates a bergamot flavor."

The Havasi or common sweet orange is a well-known fruit, of good size and moderately rough rind, pulp well filled with delicious juice.

The St. Aucustine oranges are a large yariety of the Havana, much better than those brought from Cuba.

The ST. NIcHAEL's orange is a small fruit, the skin pale rellow, the rind thin, the pulp often seedless, juicy, and luscionsly sweet. It is cunsidered the most delicions of all oranges, and the tree is a most abundant bearer.

The SEville, or bitter orange, is the hardiest of all the varieties, enduring very hard frosts withont injury. It has the largest and most firgrant flowers; the pulp, however, is bitter and shirp. and is valued chiefly for marmalades. The Double Bigurade is a French variety of this species, with fine double blossoms. 
Besides the above, the Fingered, Sweet-stinned, P'eatr-shaped, and Ribbed oranges, are tho most striking sorts-all chiefly cultivated by curious amateurs.

\section{LENONS.}

The Lemon (Limonier, of the Freneh and German ; Limone, 1talian; Limon, spanish) has longer, paler leaves than the orange, the footstalks of which are naked or wingless; the flowers tinged with red externally, and the fruit is oblong, pale yellow, with a swollen point, and usually an aeid pulp. Its principal use is in making lenronade, punch, and other cooling acid drinks.

Besicles the common Lemon, there is an Italian variety, ealled the SWEET Lexos, the pulp of whieh is sweet and good.

\section{TIIE LIME,}

The Lime (Limettier, of the French) differs from the Lemon by its smaller, entirely white flowers, and small, roundish, pale yellow fruit, with a slight protuberance at the encl. The acid, though sharp, is searcely so rich and high as that of the lemon, and is used for the same purposes. The green fruit is more esteemed than any other for preserving. The Italians cultivate a curiously marked variety ealled Pomo d'Ademo, in which Adam is said to have left the marks of his teeth.

\section{THE CITRON.}

The Citron (Cédratier, of the French; Citronier, German; Cedrato, Italian) is one of the finest growing trees of this family, with large, oblong, wingless leares, and flowers tinged with puple externally. The fruit, shaped like that of the lemon, is much larger, of a yellow color, warted and furrowed externally. The rind is very fragrant and very thick, the pulp is subacid, and is used in the same way as that of the lemon. It is ehiefly valued, however, for the rich sweetmeat or preserve, called citron, made from the rind.

The Madras citron is considered the largest and best variety.

\section{THE SIIADDOCK.}

The Shaddoek (Pampelmous, French; Irancio massimo, Italian) may be considered a monstrous orange, with a comparatively tasteless pulp. It is a native of China and Japan, and has its name from Inr. Shaddock, who first earried it to the Wrist Indies. The leaves are winged, like those of the orange, the flowers white, and the funit globular. Its size is very large, as it often weighs six or eight pounds. 'The pulp is sweetish, or subacid, and the juice is rather refreshing. It is, however, more showy than useful, and certainly makes a magnificent appearance in a collection of tropical fruits. 


\title{
CHAPTER XXVI.
}

\author{
THE PEACH.
}

\section{Persica vulgaris, Dec. Rosacere, of botanists. \\ Pecher, of the French; Pfirschbrim, German; Persiclikeboom, Dutch; Persico Italian ; and $e l$ Melocotom, Spanish.}

The Peach-tree is a native of Persia and China, and was lorought from the former country to Italy by the Romans in the time of the Emperor Clandius. It was considerably cultivated in Britain as early as the year 1550 , and was introduced to this comtry by the early settlers somewhere about 1680. From Persia, its native country, its name in all languages--Persico-Pêcher-Peach-has evidently been derived.

The peach is a rather small frnit-tree, with narow, smooth, serrated leaves, and pink blossoms. It is nore tencler and of shorter duration than most other of the fruits usually grown in temperate chimates. It is never raised in England, and not generally in France, without the aid of walls. Even at Montreuil, near Paris, a village whose whole population is mainly employed in cultivating the peach for market, it is grown entirely upon white-washed walls. China and the United States are, therefore, the only temperate countries where the peach and the apple both attain their highest perfection in the open orchard. The peaclies of Pekin are celebrated as being the finest in the world, and of double the usual size.

It is a curious fact in the history of the peach, that with its delicicus flavor were once compled, in the East, certain notions of its poiscnous qualities. This idea seems vaguely to have accompanied it into Europe, for Pliny mentions that it was supposed that the king of Persia had sent them into Egypt to poison the inhabitants, with whom he was then at war. As the peach and the almond are closely related, it has been conjectured by Mr. Knight that the poisonons peaches referred to were swollen almonds, which contain a considerable quantity of prussic acid. But it is also worth remarking that the peach-tree seems to hold very much the same place in the ancient Chinese writings that the tree of knowledge of the old Scriptures, and the golden Hesperides apples of the heathens, do in the early history of the western nations. The tratitions of a peachtree, the fruit of which when eaten conferred immortality, and which bore only once in a thousand rears-and of another peach-tree of knowledge, which existed in the most remote period, on a mountain guarded by a hundred demons, the fruit of which produced death-are said to be distinctly preserved in some of the early Chinese writings. Whatever may have been the nature of these extraordinary trees, it is certain that, as Lord Bacon says, "not a slip or sucker has been left behind." We must therefore content ourselves with the delight which a fine peach of modern times affords to the palate and the eye.

We believe there is at the present time no country in the world where the peach is grown in such great quantities as in the United States. North of a line drawn from the Mohawk river to Boston, comprising most of the Fastern States, they do not indeed flourish well, requiring some artificial aid to produce regnlar cropss; but in all the Middle, Southern, and Western States, they grow and produce the 
heaviest crops in wery garden and orchard. Thousands of acres are deroted to this crop for the supply of the markets of our large cities. The market price usually varies according to the abundanee of the crop, imd to the earliness or lateness of the seison at which they are oflereal. Many growers have orchards of from 10,000 to 100,000 trees of different ares, and send to maket in good seasons as many bushels of fruit from the bearing trees. When the crop is not universally abundant, the protits are very large; if the contrary, they are often very little.

The very great facility with which the peach grows in this country, and the numerous crops it produers, almost withont eare, have led to a arrelessness of cultivation which has greatly enfecbled the stock, and, as we shall presently show, has in many places produced a disease peculial to this comutry. This renders it neeessary to give some arlitional are and attention to the cultiration of the peach; and with very trifling care this delicions fruit may be produced in great abundance for many successive years.

Úses. Certainly no one expects us to write the praisess of the peach as the most delicions of fruits. "To gild refined gold" would be a task yuite as necessary, and if any one doubts the precise rank which the parch should take among the different fruits of even that comucofian month-september--and wishes to convince us of the higher flavor of a Seckel or a Belle Lucrative pear, we will promise to stop his month and his argument with a smuny-cheeked and melting "George the Fourth," or luscious "Rareripe!" No man who lives uncler a warm sun will hesitate about giving a due share of his garlen to peaches, if he have no orehard; and even he who lives north of the best Indian con'n limits onght to venture on a small line of espalier for the sake of the preach. In pies and pastry, and for various kinds of preserving, the peach is everywhere lighly esteemed. At the South and $W^{2}$ est a considerible quantity of peach brandy is ammally distilled from them, lut we believe by no means so much as formerly. Hogs are fattened, in such districts, on the refuse of the orduard and distillery.

In most parts of the country where peaches are largely cultivated the fruit is dried, and in this state sent to market in very large quantities. The drying is performed, on a small seale, in spent ovens; on a large scale, in a small drying-house heated by a stove, and fitted up with ventilated drawers. These clawers, the bottoms of which are formed of laths, or narrow strijes sufficiently opere to allow the air to circulate through them, are filled with peaches in halves. They are cut in two without being peeled, the stones taken ont, and the two halves placed in as single layer with the shin clownward. In a short time the heat of the drying-house will complete the drying, and the drawers are then rearly for a second filling. Farther south they are spread upon boards or frames, and dried in the sun merely; but usually with the previons preparation of dipping the peaches (in baskets) for a few minutes in boiling water before halving them.

The leaf of the peach, hruised in water and distillecl, gives the peach watter, so much esteemed by many for flaworing articles of delicate cookery ; and steeped in brandy or spirits, they communicate to it the flavor of Soyau. Indeed a very good initation of the celebrated Noyau is made in this way, by using the best white brandy, which, after being thin: flarned, is sweetenerl with refined sugar mixed with a small quantity of milk, and afterwards decanted. 
Propagatron. The peach is the most easily propagated of all fiuit. trees. A stone planted in the autumn will vegetate in the elisuing spring, grow three or four feet high, and may be budded in Angust or September. Two years from this time, if left undistubed, it will usually produce a small crop of fruit, and the next season bear very abundantly, mless the growth is over-luxuriant.

In nursery culture it is customary to bury the pedch-stones in autumn, in some exposed spot, in thick layers covered with earth. Here they are allowed to lie all winter. As early in the spring as the ground is in fine friable condition, the stones are taken out of the ground, cracked, and the kernels sown in mellow prepared soil, in the numsery rows where they are to grow. They should be corered abont an inch deep. Early in the following September they will be fit for budding. This is performed with great ease on the peach, and grafting is therefore seldom or never resorted to in this country, except at the South The buds should be inerted quite near the ground. The next season the stock should be headed back in March, and the trees will, in good soil, grow to the height of a man's head in one year. This is by far the best size for transplanting the peach-one year old from the bud.

In England the plum stock is mniversally employed. The advantage gained thereby is, a dwarfer and neater habit of growth for their walls. In France, some of the best cultivators prefer the almond stock. Healthy peach stocks afford the most natural foundation for the growth of standard orchard trees. At the same time we must protest against the indiscriminate employment of peach-stones from any and every sonce. With the present partially diseased state of many orcharels in this country, this is a practiee to be seriously condemmed; and more especially as, with a little care, it is always easy to procure stones from sections of country where the Yellows is not prevalent.

For rendering the peach quite dwarf, the Mirralle plum stock is often employed abroat.

Sorl and Situntox. The very best soil for the peach is a rich, deep, sandy loam; next to this, a strong, mellow loam; then a light, thin, sandy soil; and the poorest is a heary, complact clay soil. We are very well aware that the exteusive and profitable apipropriation of thousands of acres of the lightest sandy soil in New Jersey and Delaware, has ler many to believe that this is the best soil for the preach. But such is not the fact, and the short duration of this tree in those districts is unquestionably owing to the rapidity with which the soil is impoverished. We have, on the contrary, seen much larger, finer, and richer flavored peaches produced for a long time successicely on mellow loam. containing but little saml, than mpon any other soil whatever.

It is a well-founded practice not to plant peach orchards successively upon the same site, but always to choose a new one. From sixteen to twenty-five feet apart may be stated as the limits of listance at which to plant this tree in orchards, more space being required in warm climates and rich soils than under the contrary circumstances. North of New York it is better always to make plantations in the spring. and it should be done pretty early in the season. South of that limit it may usually be done with equal advantage in the antumn.

In districts of country where the fruit in the blossom is liable to be cut oft' by spring frosts, it is found of great advantage to make plantations on the north sides of hills, norther'n slopes or elevated grounds, in 
preference to warm valleys and soutlern as ects. In the colter expostues the vergetation and blossoming of the tree is retarled motil aftror all clanger of injury is past. Situations near the binks of large rivers and inlaud linkes are equally adnirable on this account, and the blossoms are not injured once in a dozen years; while on lerel grommls, distant but a little way, they are destroyed every fouth or fifth season.

With regard to the eulture of peach orchards, there is a seeming disparity of opinion between growers at the Nolth and fonth. Must of the cultivators at the South say, never plongle or cultivate an orchard after it lias borne the first crop. Ploughing bruises the ronts, (nffeet)les the trees, and lessens the crop. Enrich the ground by tophliesings, and leave it in a state of rest. 'The best northern grower's say, always keep' the land in good condition, mellow and loose by cultivation, and erol' it very frequently with the lighter root and field cropss. Both are correet, and it is not diticult to explain the seeming ditterence of opinion.

The majority of the peach orchards south of Philadelphia, it will be recollected, grow upon a thin, light soil, previously rather impoverished. In such soils it is necessarily the case that the roots lie near the surface, and most of the food derived by them is from what is applied to the surface or added to the soil. Ploughing, therefore, in such soils, wounds and injures the roots, and croppingr the ground takes fiom it the scanty fond ammally applied or alrealy in the soil, which is not more than sufticent for the orchard alone. In a stronger and deeper soil the roots of the peach-tree penetrate farther, and are mostly out of the reach of serious injury by the plough. Instead of losing by being opened and exposed to the air, the heavier soil gains greatly in value by the very act of rendering it more friable, while at the same time it has naturally sufficient heart to bear judicious eropping with advantage rather than injury to the trees. The growth and luxuriance of an orchard in strong land, kept under tillage, is suprisingly greater than the sinne allowed to remain in sod. The difference in treatment, therefore, slrould always adapt itself to the nature of the soil. In ordinary eases, the duration of peach orchards in the light sandy soil is rarely more than three years in a bearing state. In a stronger soil, with proper attention to lle shortening system of pruning, it may be prolonged to twenty or more years.

Proxisg. It has always been the prevailing doctrine in this comntry that the peach requires 110 pruning. It has been allowed to grow, to bear heary cropss, and to die, pretty much in itsown way. This is rery well for a tree in its mative climate, and in a wild state : but it must be rememlered that the peach comes from a warmer country than ours, and that our peaches of the present day are artificial varieties. They owe thoir origin to artificial means, and require therefore a system of culture to correspond.

In short, we view this absence of all due care in the management of the peach-tree, after it comes into berning, as the principal original cause of its present short duration, and the discase which preys upon it in many of the older parts of the country. We therefore earnestly desire the attention of peach-growers to our brief hints upon a regular system of pruning this raluable tree. Of course we speak now of common standard trees in the orehard or garden.

A peach-tree, left to itself after being planted, usually comes intc bearing the third or fourth year, and has in well-shaped rounded head, 
full of small bearing branel es, and well garnished with loaves. It must be borne in mind that the fruit is unly borne on the voung shoots of

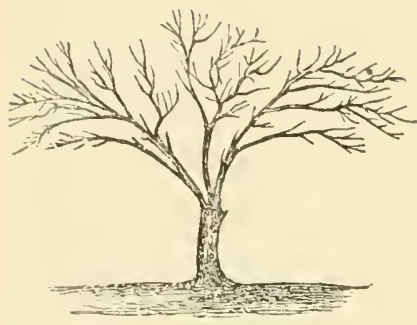

A peacli-tree without pruning, as commonly seen. the previous summer's growth. In a young tree these are properly distributed throughout. But in a conple of seasons, the tree being left to itself, the growth being mostly produced at the ends of the principal branches, the young shoots in the interior of the hrad of the tree die ont. The consequence is, that in a slort time the interior of the tree is filled with long lean branches, with only youngshoots at their extremities. Any one can see that such a tree can he provided with but half the numlier of healthy, strong shoots for bearing, that one would have if tilled throughout with vigorous young wool. The sap flows tardily through the long and rigid lomeles, and not half leaves enough are providerk to secure the proper growth of the fruit. And, finally, all the fruit which the tree vields being allowed to remain at the ends of the branches, they often break under its weight.

Now, we propose to substitute for this what is generally known as the shortenim/-in system of pruning. We affirm, both from its constant success abroad, and from on own experience and observation in this conntry, that, putting its two diseases out of the question, the peach may be continued in full vigor and production, in any good soil, for from ten to thirty years.

Let us take a healthy tree in the orchard or garden, in its first blos. soming year. It is usually about six to eight feet ligh, its well-shaped head branching ont about three feet * from the ground. It has never yet been trimned, except to regulate any cleformity in its shape, and this is so much the better.

At the end of February, or as early in the spring as mar be, we commence pruning. This consists only of shortening-in. i.e. cutting oft herlf' the lust yeur's grouth over the whole ontside of the head of the tree, and also upon the inner branches. As the usual average growth is fron one to two feet, we shall necessarily take off from six to twelve inches. It need not be done with precise measnement; indeed, the strongest shoots should be shortened back most, in order to bring up the others, and any long or projecting limbs that destroy the balance of the head should be eut back to a nuiform length. This brings the tree into a well-1'ounded shape. By reducing the young wood one-half, we at the same moment reduce the coming crop one-half in number. The remaining half, receiving all the sustenance of the tree, are of dunble the size. The young shoots, which start out abundantly from every part of the tree, kerp it well supplied with bearing wood for the next year, while the greater luxuriance and size of the foliage, as a necessary consequence, produces larger and higher flarored fruit. $†$ Thus, while we have

* We think Imo heads much preferable to high ones on many accounts. They shade the root. and are more within reach both for luming and gathering.

+ It is well. in shortening-back, to cut off the shoot close above a mond-bud rather than a blossom-bul. Few persons are aware how much the size and 
secured agranst the prevalent evil, an over-crop, we have also provided for the fuli nomrishment of the present year's fruit, and incluced a supuly of fruit-bearing shoots througlont the tree for the next seison.

This course of punting is followerl regularly, every year, for the whole life of the tree. It is done much more rapidly than one would suppose; the pruncel wounds are too small to eatuse any gum to flow; and it is clone at the elose of winter, when labor is worth least to the cuitivator.

The appearance of a tree pruned in this way, after many yoars of bearing, is at very striking contrast to that of the poor skeletoms usually seen. It is, in fact, a fine objecet, with a thick, low, bushy head, filled

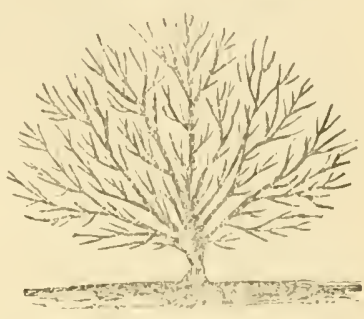

A peach-tree pruned by the shorten ing-in mode. with healty young wood, and in the summer with an abundance of darkgreen, healthy foliage and handsome fruit. Can any intelligent man hesitate about adopting so simple a course of treatment to secure such valuable results? We recommend it with entire contidence to the pratice of every man in the country that cultivates a peach-tree. After lia has seen and tusted its good effects, we to not fear his laying it aside. *

Training the peach-tree against walls or espalicrs is but little practised in this comntry. Espalier and cordon training, on a small scale, is, however, highly worthy of the attention of persons desiring this fiuit

beanty of the fruit depend on the size and vigor of the leaves. We have seen two peach-trees of the same age side by side, one mpruned, and the other regnlarly shortenrl-in, and both bearing about four bushels. That of the latter was, however, of double the size, and incomparably finer.

* Our attention has been drawn to the following remarkable examples of the goot effects of regulin pruning. which we trauslate from the leading French jourual of horticuiture. We ask the attention of our readers to these cases, especially after perusing our remarks on the Yellows and its canse.

* MI. Durilliers laid iefore the Roy:al Society of Horticulture an account of some old peach-trees that he had litely seen at the Chateru de Villiers, near Fert-Aleps (Seine-et-Oise). These trees, eight in number, are growing upon it terrace wall, which they eover perfectly, and yield abundant crops. 'T'he gardener assured H. Duviliers that they had been under his care durirg the thirty years that he had been at the chitean; that they were as large when he first saw them as at present, and that he smplosed them to bo at least sixty yerrsold. II' cannot dumbt (says the editor) thut it is to the ammunl pruming that these porach-

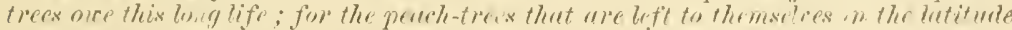

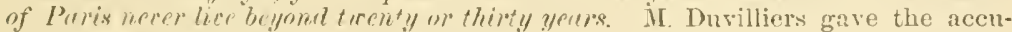
rate measurement of the trunks and branches of these trees, anil stater, whit it is more interesting to know, that although all their trunks are hollow, like those wi oll willows. yot their vigor aml l'ertility are still quite mimpaired." (Anurles

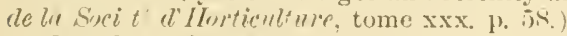

In volume 25 . page $6 \%$, of the same jomrnal, is an account of a remarkable pench-tree in the demesne of M. Jumbert, nesu Villeneuve le lioi (d partement de l'Yonne). It is trained against one of the winss of the mansion, covers a large space with its branches. and the eirenuference of its trunk. taken at some distixuce from the ground, is two feet and a hall. It ix linown to br. arourlly. of "nor. than :): yenrs? youth, and is believerl to he more than 100 years old. It is still in perfect health and vigor. It is growing in strong soil. but it lias been regularly suljected to a uniform and severe sistem of pruning, equivalent to our shortening-in mode. Where can any peach-tree of half this ago be found in the United States, naturally a much inore favorable elimate for it than that of France? 
in the colder parts of the country, where it loes not snceeed well as a standard. Everywhere in New England excellent crops may be pro. duced in this way. Full directions for training the peach en espalier and cordon, with illustrations, are given in pages 42 and 43 .

Cordon or low fan training is practised by some cultivators at the North, and in sections where the crop of the peach is nncertain by reason of extreme cold in winter or late spring frosts destroying the buds. When the cordons or low fans are kept within one to two feet from the ground the trees may be readily protected in winter by covering with corn-stalks, straw, or brush of evergreens.

Inse ts AND Diseases. For a considerable time after the peach was introduced into America, it was grown everywhere south of the $40^{\circ}$ of latitude, we may say literally, withom cultivotion. It was only necessary to plant a stone in order to obtain in a few years, and for a long time, an abundance of fruit. Very frequently these chance seerllings were of excellent quality, and the finer grafted varieties were equally luxuriant. Two maladies have appeared within the last twenty years, which, becanse they are little understood, have rendered this fine fruit-tree comparatively short-lived and of little value. These are the Peach-borer and the Yellows.

The Peacri-boner or Peach-worm (_Egeria exitiosa, Say) does great mischief to this tree by girdling and devouring the whole circle of bark just below the surface of the ground, when it soon languishes and dies.

The insect in its perfect state is a slender, dark-blue, four-winged moth, somewhat like a wasp. It commences clepositing its eggs in the soft and tender bark at the base of the trunk, usually about tibe last of Jume, but at different times from Jume to October. The egg hatches and becomes a small white borer or grub, which eventually grows to threefourths of an inch long, penetrates and devours the bark and sap wood, and, after passing the winter in the tree, it enfolds itself in a crcoon under or upon the bark, and emerges again in a perfect or winged form in June, and commences depositing its eggs for another generation.

It is not difficult to rid our trees of this enemy. In fact, nothing is easier to hin who is willing to levote a few moments every season to each tree. The eggs which produce the borer, it will be recollected, are deposited in the soft portion of bark, just at the surface of the earth. Experience has conclusively proved that if a quantity of leached ashes, charcoal, or even common soil, be heaped to the height of one foot around the trunk of each tree at the end of May, and suffered to remain till October, the peach-borer will not attack it. It has been tried most successfully in large orchards, where the protected trees have long remained sound, while those unprotected have been speedily destroyed by the borer. The remelly undoubtedly lies chiefly in covering the most vulnerable portion of the tree from the attack of the insect. These mounds or heaj's of earth, ashes, etc., should be spread over the surface every autumn on approach of winter, thus exposing the larve of the insect, if any have entered the tree, to cold and destruction.

Another simple remedy is in spring to first draw away a little earth from the crown of the tree, then wral, the body up, one foot from the ground, with strong coarse paper, securing it with tying, and replace the earth.

Many careful and rigid cultivatcrs prefer a regular examination of 
the trees every spring and autumn. On removing the earth for a fow inches, the appearance of gum or castings quickly inclicates where the horel has male his lodgring. A few momeuts with the knife will then eradicate the insect for the season.

T'ue Yellows. This most serious malady seems to belong exclu sively to this country, and to attack only the peach-tree. Although it has been the greatest enemy of the peach-planter for the last thirty years, - reudering the life of the tree uncertain, and frequently spreating over and destroying the orchards of whole districts, - still little is known of its nature, and nothing with eertainty of its cause. Many slight observers have confonuded it with the effeets of the peach-burel, but all persons who have carefully examined it know that the two are totally distinct. Trees may frequently be attacked by both the yellows and the borer, but hundreds die of the yellows when the most minute inspection of the roots and branches ean diseover no insect or visil,ls cause. Still we believe proper eultivation will entirely rid our gardens and orehards of this malady ; and this belief is in jart borne out by experiments under our own inspection. In order to combat it successfully, it is necessary that the symptoms should be clearly understood.

symptoms. The Yellows appears to be a constitutional disease, no external cause having yet been assigned for it. Its infallible symptoms are the following:-

1. The production upon the branches of very slender, wiry shoots, a few inches long, and bearing starved diminutive leares. These shoots are not protruded from the extremities, but from latent buds on the main portions of the stem and larger branches. The leaves are very narrow and small, quite clistinet from those of the natural size, and are either pale yellow or destitute of color.

2. The premature ripening of the fruit. This takes place from two to four weeks earlier than the proper season. The first season of the disease it grows nearly to its natural size; the following season it is not more than half or a fourth of that size; but it is always marked externally (whatever may be the natural color) with specks and large spots of purplish red. Internally the flesh is more decply colored, especially around the stone, than in the natural state.

Either of the foregoing symptoms (and sometimes the second appears a season in advance of the first) are undeniable signs of the Yellows, and they are not produced by the attacks of the worm or ather maledy. We may add to them the following additional remarks:-

It is established beyond question, that the Yellows can always be propagated by budding or grafting from a diseased tree; that the stock, whether peach or alnond, also takes the disense, and finally perishes; and that the seeds of the diseased trees produce young trees in which the Yellows sooner or later breaks out. To this we maly add that the peach, budited on the plum or apricot, is also known to die with the Yellows.

Tery frequently only a single branch, or one side of a tree, will he affected the first season. But the next year it invariably spreads through its whole system. Frequently trees badly affected will die the next year. But usually it will last, growing more and more feeble every year, for several seasms. 'The loots, on digging up the tree, do not appear in the least diseased. 
The soil does not appear mater ially to increase or lessen the liability to the Yellows, though it first originated, and is most destructive, in light, warm, sandy soils.

Lastly, it is the nearly universal opinion of all orchardists that the Tellows is a conterjous disease, sprealing grahnally, but certainly, from tree to tree through whole orehards. It was conjectured by the late William Prince that this takes place when the trees are in blossom, the contagion being carried from tree to tree in the pollen by bees and the wind. This view is a questionable one, and it is rendered more donbtful by the fact that experiments have been made by dusting the pollen of diseased trees upon the blossoms of healthy ones without commmicating the Yellows.

We consider the contagious nature of this malady an unsettled point. Theoretically, we are disinclined to believe it, as we know inothing analogous to it in the vegetable kinglom. But on the other land it would alpear to be practically true, and for all practical purposes we would base our alvice mon the supposition that the dismase is contagious. For it is only in those prarts of the Atlantic states where every vestige of a tree showing the Yellows is immediately destroyed, that we have seen a return of the normal health and longerity of the tree. *

Cause of the Tellows. No writer has yet ventured to assign a theory, supported by any facts, which would explain the catuse of this malady. We therefore adrance our opinion with some difhiclence, but yet not without much confidence in its trutl.

We believe the malady called the Yellows to be a constitutional taint existing in many American varieties of the Peach, and produced, in the first place, by bad cultivation and the conseguent exhaustion arising from suceessive orer-erops. Afterwards it has been established and perpetuated by sowing the seeds of the enfeebled tree, either to obtain varieties or for stocks.

let us look for a moment into the history of the Peach eulture in the United States. For almost a hmmlred years after this tree was introduced into this comntry it was lingely cultivited, especially in Virginia, Maryland, aud New Jersey, as we have already stated, in perfect frectom from such disease, and with the least possible care. The great

* The following extract from some remarks on the Yellows by that eareful observer, Noyes Darling, Esq., of New Haven, Ct., we recommend as worthy the attention of those who think the disease contagions. They do not seem to indicate that the disease spreads from a given point of contagion, but breaks out in spots. It is elear to our mind that in this, and hundreds of other similar cases, the disease was inherent in the trees, they being the seedlings of diseased parents.

"When the disease commences in a garden or orehard containing a considerable number of trees, it does not attack all at once. It breaks out in ju!ch * which are progressively enlarged, till eventually all the trees become victims to the malady. Thus, in an orchard of two and a half acres, all the trees were healthy in 182\%. The next year two trees on the rest vide of the orchurd. within a lod of each other, took the Yellows. In 15:!), six trees on the erre wicl of the orchard were attacked; five of them standing within a circle of four rous diameter. A similar fact is now apparent in my neighborhood. A fine lot of 200 young trees. last year in perfect health, now show disease in two spots nen the opposite ends of the lot, having exactly six diseased trees in each pateh contignons to each other; while all the other trees are free from any marks of dis. eise." - C'ultivator. 
natural fertility of the soil was unexhansterl, and the land oecupied by orchards was seirlom or never cropperl. Mlost of the scoil of these States, however, though at first naturally rich, was light and sandy, and in course of time became compantively exhansted. The perth-tree, always proluctive to an excess in this climate, in the imporerisherl soil was no longer able to recruit its energies by ammal growtl, and gratdually became more and more (nfeebled and short-lived. Ahont 1,isor), or a tew years before, attention was attracted in the neighborhos of Philadelphia to the sudden deeny and death of the orchards without apparent canse. From Philadelphia and 1)elaware the disease grahually extemlial to New Jersey, where, in 1814, it was so previlent as to destroy a considerible part of all the orcharls. About three or four years later it appeared on the banks of the Hudson (or fiom 181: ts 1815), gratually and slowly extending northward and westwarl to the remainder of the State. Its progress to Comnecticut was taking place at the same time, a few trees here ant there showing the disease, until it became well known (though not ret generally prevalent) thoughunt. most of the warmer pants of New Eugland.

It should be here remarked, that thongh the disense had been considerably noticed in Maryland and thr Midhle States previonsly, yet it was by no means general until about the elose of the war of $181 \%$. At this time wheat and other grain crops bore very high prices, and the failing fertility of the peach orehard soils of those States was sudlenly still more lowered by a heavy system of eropping between the trees without returning anything to the soil. Still the peach was planted, prodiced a few heavy erops, and declined from sheer feebleness and want of sustenance. As it was the eustom with many orcharelists to raise their own seedling trees, and as almost all nurserymen gathered the stones $i$ discriminately for stocks, it is evicient that the constitutional debility of the parent trees would naturally be inherited to a greater or less degree by the seedlings. Still the system of allowing the tree to exhaust itself by heary and repented crops in a light soil was athered to, and generation after generation of seedlings, each more enfeebled than the former, at last produced a completely sickly amd feeble stock of peach-trees in those districts.

The great abundance of this fruit caused it to find its way more or less into all the markets on the spa-coast. The stones of the enfecbled Southern trees were thus cirried north, and, being esteened by many better than those of home growth, were ererywhere more or less planted. They brought with them the enfeebled and tainted constitution derived from the parent stock. They relroduced almost always the same disease in the new soil; and thus, littlo by little, the Yollows spread from its original neighlorhood, below Pliladelplial, to the whole northern and eastern sections of the Union. At this moment, 18.5, it is slowly but gradually moving West; thongh the rich and reep soils of the Western alluvial bottoms will, perhaps, for a consiclemable time, even without care, overpower the original taint of the trees and stones received from the East.

Let ns now look a little more closely into the nature of this enfeebled state of the peach-tree which we call the Yollows.

Every gool gardener well kuows that if he desires to raise a healthy and vigorous seedling plant, he must select the seed from a parent plant that is itself deciledly healthy. Lindley justly and concisely re- 
marks: "All seeds will not equally produce vigorous seedlings; but the healthiness of the new plant will correspond with that of the seed from which it sprang. For this reason it is not sufficient to sow a seed to obtain a given plant; but in all cases, when any importance is attached to the result, the plumpest and healthiest seeds should be selected, if the greatest vigor is required in the seedling, and feeble or less perfectly formed seeds, when it is desirable to check natural luxuriance." *

Again, Dr: Van Mons, whose experience in raising seedling fruit-trees was more extensive than that of any other man, declares it as his opinion that the more frequently a tree is reproduced continuously from sees, the more feeble and short-lived is the seedling produced.

Still more, we all know that certain peculiarities of constitution or habit can be propagated by grafting, by slips, and even by seeds. Thus the variegated toliage, which is a clisease of some sort, is propragated forever by budding, and the disposition to mildew of some kinds of peaches is continued almost always in the seedlings. That the peachtree is peculiarly constant in any constitutional variation, the $\Gamma^{\text {ecturine }}$ is a well-known proof. That fruit-tree is only an accirlental variety of the peach, and yet it is continually reproduced with a smooth skin from seerl.

Is it not evident, from these premises, that the constant sowing of the seeds of an enfeebled stock of preaches would natrirally produce a sickly and diseased race of trces? The seedlings will at first often appear healthy, when the parent had been only partially diseased, but the malady will sooner or later show itself, and especially when the tree is allowed to produce an over-crop.

That poor soil and over-bearing will produce great debility in any fruit-tree, is too evident to need much illustration. Even the apple, that hardiest orchard tree, requires a whole year to recover from the exhaustion of its powers caused by a full crop. The great natural luxuriance of the peach enables it to lay in new fruit-buds while the branches are still loaded with fruit, and thus, except in strong soil, if left to itself, it is soon enfeebled.

There are some facts in our every-clay observation which may be adduced in proof of this theory. In the tirst place, the varieties of this tree always most subject to this disease are the yellow percles; and they, it is well known, also produce the heaviest crops. More than ninetenths of the victims, when the disease first appeared, were the yellowfleshed peaches. On the other hand, the white-Heshed kinds (those white and red extermally) are much more rarely attacked; in some parts of the country never. They are generally less vigorous, and bear more moderate crops. And it is well worth remarking that certain fine old sorts, the ends of the branches of which have a peculiar mildeved appearance (such as the old Red Rareripe, the Early Anne, fcc.), which seems to check the growth without impairing the health, are rarely, if ever; attacked by the Yellows. Slow-growing and moderately productive sorts, like the Nutmeg peaches, are almost entirely exempt. We know an orchard in the adjoining county where every tree has gradually died with the Yellows, except one tree which stood in the centre. It is the Red Nutmeg, and is still in full vigor. It is certainly true that these sorts often decay and suddenly die, but we believe chiefly from the neg. 
lect which allows them to fall a prey to the Peach-borer. Indeer the frequency with which the Borer lans been confounded with the Yeliows by ignorant observers, renders it much more difficult to arrive at any correct conchions respecting the contagious nature of the latter disease.*

It may be said, in objection to these views, that a disease which is only an enfeeblement of the constitution of a tree, would not be suflicient to alter so much its whole nature and duration as the Kellows hats done that of the peach. The answer to this is, that the debility produced in a single generation of trees probably would not have lect to such effects, or to any settled form of constitutional disease. But it must be borne in mind that the same bad management is to a great extent going on to this day, the whole comntry over. Exery year, in the month of Angust, the season of early peaches, thousands of bushels of fruit, showing the infallible symptoms of the Yellows, - a spotted skin, dr.,-are exposed and sold in the markets. Every year more or less of the stones of these peaches are planted, to produce, in their tun, a generation of cliseasech trees, and every successive generation is even more feeble and sickly than the linst! Even in the North, so feeble has the stock become in wany places, that an excessive crop of fine fruit is but too frequently followed by the Yellows. In this total absence of proper care in the selection both of the seed and the trees, followed by equal negligence of good cultivation, is it surprising that the peach has become a tree comparatively difficult to preserve, and proverbially short-lived?

Abroad, it is well known that the peach is always subjected to a regular system of pruning, and is nerer allowed to produce an overcrop. It is not a little singular, both that the Yellows shonld never have originated there, and that, notwithstanding the great number of American varieties of this fruit that have been repeatedly sent to England and are now growing there, the disease has never extended itself, or been communicated to other trees, or even been recognized by English or French horticulturists. We must confess, these facts appear to us strong proofs in favor of our opinion as to the nature and origin of the malaty.

Remedy for the Iellows. It may seem to many persons a difficult task to rid omrselves of so wide-sjuread a malady as this, yet we are conficlent that a little perseverance and care will certainly accomplish it. In the present uncertainty with regard to its contagious nature, it is much the wisest to reject "the benefit of the doubt," and act unon the principle that it is so. We know at the present monent several gardens where the trees are maintained in good health by immediatcly rooting out and destroying every tree as soon as it shows marked symptoms of the malarly.

1. We would therefore commence by exterminating, root and branch, every tree which has the Yellows. And another tree should not be planted in the same spot without it lapse of several years, or a thorough removal of the soil.

2. The utmost care should be taken to select seeds for planting from perfectly healthy trees. Nurserymen, to secure this, should gather them

* All knowledge relating to the Yellows appears to us as much in obscurity as when this was written. In our experience no one rariety seems more liable to be attackel than another, the most vigorous trees being as ofteu affected ag iv sse of moderate growth.-C. D. 
from the latest ripening vareties, or procure them from districts of the country where the disease is not known.

3. So fir we have aimed only at procuring a healthy stock of trees. The most important matter remains to be stated-how to preserve them in a healthy state.

The answer to this is emphatically as follows: pursue steatily, from the first bearing year, the shortening-in system of fruncing alleady ex plained. This will at once secure your trees against the possibility of over-hearing and its consequences, and maintain them in rigor and productiveness for a long time.* It will, in short, effectually prevent the Yellows where it does not alpeady exist in the tree. 'To whoever' will follow these precuntions, pursue this mode of cultivation, and atopt at the same time the remedy for the Borer already sugrested, we will confidently insure healthy, vigorous, long-lived trees, and the tinest fruit. Viil any reasonable man say that so fine a fruit as the peacl does not fully merit them?

Whether the system of shortening-in and careful culture will pre. rent the breaking out of the Yellows, when constitutionally latent in the tree, we-will not yet undertake to say. In slight cases of the dis ease we believe that it may. Of one thing, however, we are certain : it has litherto failed entirely to reclaim trees in which the malady har once broken out. Neither do we know of any well-attested case of its cure, after this stage, by any means whatever. Such cases hare indeed been reported to us, and published in the jouruals, but, when investigated, they have provel to be trees sutfering by the effects of the borer only.

A planter of peach-trees must, even with eare, expect to see a few cases of Yellows occasionally appear. The malaly is too wiclely extended to be immediately vanquished. Occasionally trees liasing the constitutional taint will show themselves where least suspected: but when the peach is nuce properly cultivated these will every day hecome more rare, nutil the original health and longerity of this fruit-tree is again establishet.

The CorL is the name commonly given to a malady which often attacks the leaves of the peach-tree. It usually appears in the month of May or June. The leaves curl up, become thickenel and swollen, with hollows on the under and redlish swellings on the upper sicte, and finally, after two or three weeks, fall ofi. They are then succeerled br a new and healthy crop of foliage. Although it does not appear materially to injure either the tree or the crop, yet it greatly distigures it for a time.

Innumerable seedlings have been produced in this country, and some of them are of the highest excellence. It is very desirable to reduce the collection of peaches to reasonable limits, because, as this fruit neither offer's the same variety of flavor nor the extent of season as the apple and pear, a moderate number of the choicest kinds, ripening from

* The following remarks, directly in point, are from London's last work "The effect of shortening the shoots of the peach is not merely to throw more sap into the fruit, but to add vigor to the tree generally by increasing the power of the roots relatirely to the branches. The peach being a short-lired

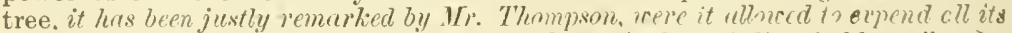

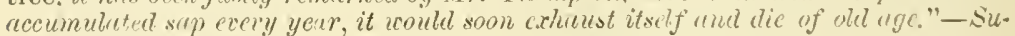
burban Ilorticult urist. 
the earliest to the latest, is in every respect better than a great variety, many of which must necessilily he second-rate.

It is worthy of renark, that most of our American varieties of the first quality have porved second-rate in England. This is owing to tho comparative want of sun and heat in their climate. Indeed, om finess late paraches will not ripen at all except under glass, and the early varieties are much later than with us. On the other hand, many of the best Enropean sorts are finer here than in England, and we have lately endeavored to introduce all of the foreign sorts of high prality.

In the arscriptim of perches and nectatines the form and outliness of many kinds are so nearly similar that we are obligerl to resort to olher charateristies to distingnish the varieties. The two mest matmal classes into which the kinds of this firuit are divided are firestomes and clingstomes (molter's ant pricies, of the English); the flesli of the fonmen parting freely from the stone, that of the latter atlrering.

Next to this, the stromgest matural distinction is fomd in the lenes of the peacli. At the base of the leaves of certain kinds are always found small glamels, ejther roumd and regular, or oblong and irregular, while the leares of ex'tain other kinds have no glands, but are more deeply cut or serrated on the margin. These peculiarities of the foliage are constant, and they aid us greatly in recognizing a variety by fonming three distinct classes, viz. :-
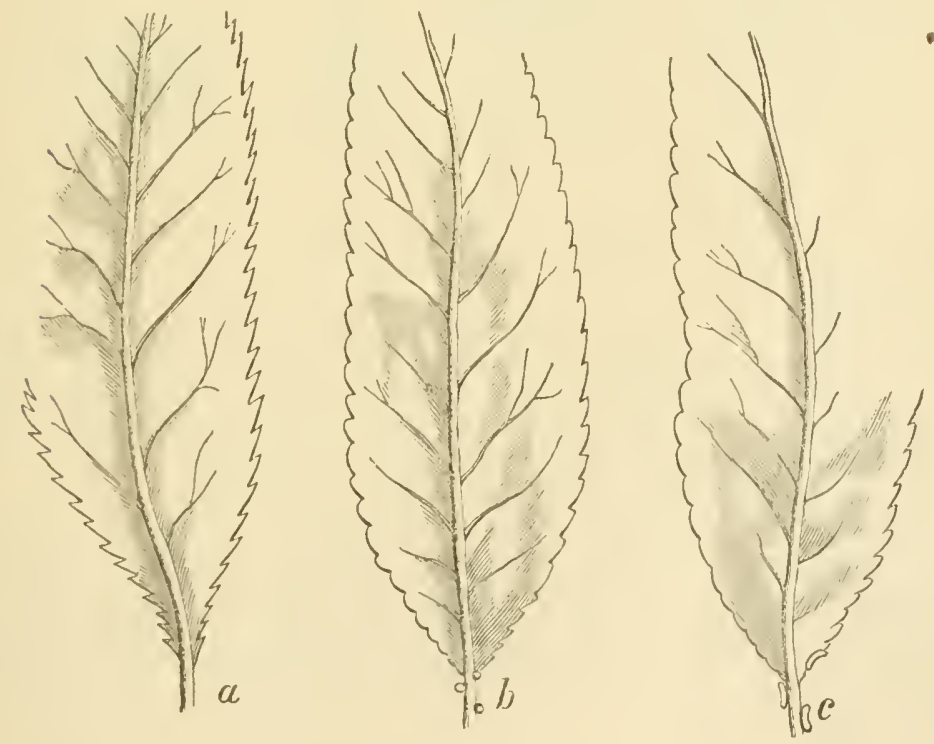

Characters in the leaves of peaches.

1. Leaves serrated and without glamels, a. 2. Leaves with small round or glolose glands, $b$. 3. Leaves with large, irregular, reniform glemels, $c$.

This distinction of leaves is valuable, because it not only assists us 
when we have the fruit before us, but it may be referred to, for the sake of verifying an opinion, at any time during the season of foliage.

There is also another elass of characteristics to be found in the blos. soms, which is constant and valuable, though not so much so as that of the leaves, because it ean ouly be referred to for a few days in the spring. The blossoms atiord two well-marked subdivisions: Ist. Large Howers, always red in the centre, and pale at the margin ; 2d. small flowers, tinged with dark at the margin.*

The most desirable peaches for market-growers in this conntry are very early and very late kinds. These command donble the price in market of kinds ripening at the middle season. For New England and the North only the earliest kinds are desirable, as the late ones seldom mature well.

In describing peaches we have embodied their character as Freestones or C'lingstones in the text clescriptive.

Raising Peacires ix Pots. The uncertainty of peach culture in the olen air has become so eommon in many sections where once the crop was as sure as that of the aljle, that many persons are resorting to orchard houses, or artiticial in-door criture, both for supply of families aur? also as a profitalle item of fruit-growing for market.

"Two modes are adopted: one withont fire-heat, the erop maturing a little earlier than in conmon orchards; the other, where by the use of fire-heat the fruit is obtained two or three montlis earlier than in open ground." The former mode has been succersfully prosecuted by Messis. Ellevanger and Barry, Rochester, N. Y. ; and the following, written by P. Barry and published in Thomas' Americur F Frit C'nlurist, we copy":

"We have now frniting in wooden boxes, ten by ten inches, fifty-three viricties of peaches, eleven varieties of nectarines, and seren of apicots.

"Age, Potting, and Soit. The trees are now three years fiom the bud. They were taken up in the fall of 1861: heeled-in and covered during winter; potted early in spring-March, I think: soil a mixture of abont three parts yellow sandy loam and one part of old hotbed manure.

"Summer Care. After potting they were kept in a cool house, partly covered with glass, until they had made shoots four or five inches long, and the danger of cold weather over. They were then plunged to the rim of the boxes in an open border until the fall. They were carefully watered when necessary during summer, and the shoots kejt as much as possible in uniform vigor by pinching.

"Pruming. When potted the rearling trees were cut back to six or" eight inches, and in some cases to four inches, or only two or three buds above the union of bud and stock, the object bing to grow them in the form of bushes. We now find that those ent back farthest are the best trees. [Fig. 350 represents the yearling tree; Fig. 351 the same, ent back; Fig. 352 the tree set in a jot; and Fig. 3.53, the same after a year's growth.]

"Tintering. On the approach of very cold weather. or just before the freezing of the ground so as to prevent ont-door work, they were

* Lindley makes a third dirision, embracing a few sorts with blossoms of an intermediate size. But it is of no practical value, as any doubt as to which of the two divisions any blossom belongs is immediately set at rest by the color of the blossom. 
removed tc a shed, where ther were plunged, as they had been during summer, up to the edges of the tubs.

"syming Treatment. On the return of mild spring weather abmulance of air was admitted, and they remained there till 1st May, when they were placed under glass, the buds at this time being ahont to expand. Here they were kept till the 15th of June, at which time the fruits were set, and all clanger of cold to affect the foliage past.

"I'entilation and Wutering. During the period they were under
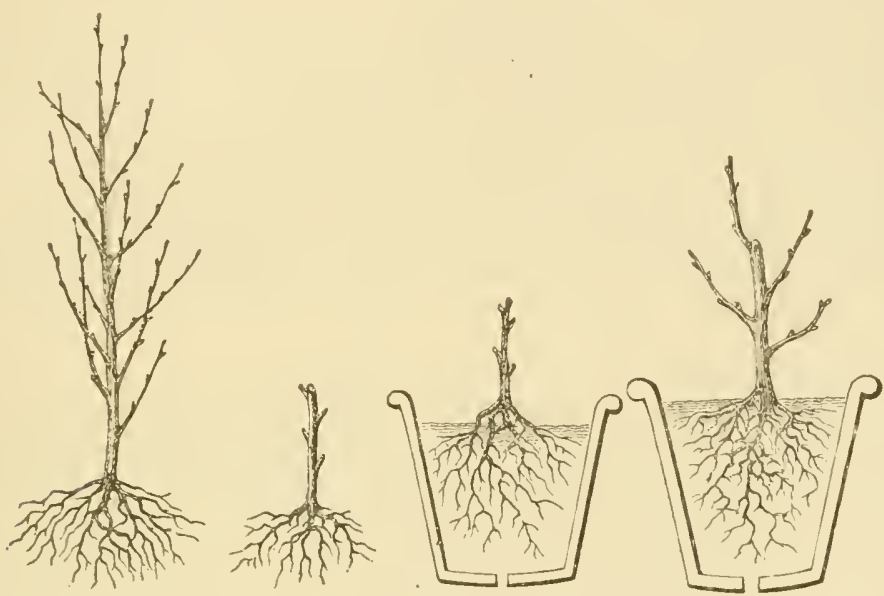

glass, May lst to Jume $15 \mathrm{th}$, the principal points of management were VExtilatios, which was ample, and watenixg-the latter being one of the most important points in the treatment of all trees and plants in pots. Careless watering will ruin any plant, no matter how skilfully or carefully other points may be managed. DAILr watering is necessary, and, as soon as out of bloom, a free use of the syringe night and morning.

"Siummer Trectment. On the 15th June, when all danger of cold was orer, and the fruits set, they were removed from the glass corering and plunged in an open but sheltered border, and mulcherl with old hot-bed manure. Since that time they have received no eare but watering, except an occasional pinch to regulate the growth of shoots.

"There has not been a single leaf curled on any one of all these trees, showing conclusirely that the curl is due to unfarorable changes of weather. Each tree now is a bush about two and a lalf feet high, and oceupies about three feet square of space.

"The first winter we had potted trees we kept them in a collar, but most of the buds dropped, and we changed to the eool dry shed, the boxes plunged, and this has been suceessful."

In houses where fire-heat is userl, and the frut brought forward so as to ripen in May and onward, the pots are either immersed in beds of tan bark over the flues or heating pipes, or placed on platforms or shelves, the pot containing the tree inside of onp, two, or thres sizes 
larger, and the space between filled with moss; this serves to keep the roots at a more even temperature than would be the case were they tu stand withont this double potting. The trees are generally prejared by training one or two years before being brought into fruit, forming a hearl at about one foot to sixteen or eighteen inches of stem. This is done l,y a systematic system of pinching or summer pruning, removing the end of each shoot as fast as it grows to form three or four leaves. This pinching gives to the hear a compact round form, and supplies it with numerous spurs or bearing shoots. The trees or pots are kejet in the lonse all winter, and the thermometer in no instance allowed to go below zero, as the buds are more easily affected than those of out-door culture. It is usual to commence heating by artificial means about the middle of January, increasing it as the season adrances and the natural growing season and influence of the sun's rays are ircreased, giring all the time attention to rechcing the temperature at night and increasing it by lay, as in the natural life out of doors. Great heat nay be maintained in a peach-house, but it must be always accomprnied by abundant watering, or the trees will be liable to drop their fruit before mature. Some growers place their trees in warm, sheltered situations ont of doors a few days before fall ripening, believing it affects and increases the flavor of the fruit.

Growing peaches in pots without the aid of glass structures or fireheat has also been strcessfully practised. The rrees are prepared, pruned, and grown the same as for house culture, and during the growing season the pots are plunged in the open gromm in a warm, sheltered prosition in the garden, due attention being giren to watering. Just before the approach of severe winter, say about the middle of Torember, they are removed into a cool, light cellar or pit fiame, there to remain during winter. In spring they are returned to the gardsu, and should there be any sign of fiost or cold, to injure the blooms, they are protected by means of a cloth awning, arranged so that it can be drawn over them at a moment's notice.

\section{VARIETIES.}

The varieties of peach are almost in numerable, new seedlings being produced in this country with great facility, and, after being heralded for a season, are suffered to pass out of existence and their places occupied with still later prorluctions. A few of the old sorts remain as good today as when this work was first witten, and oceasionally a new variety is found of superior merits. In the following pages descriptire we have endeavored to record all of much value, omitting many which are inferior, and others perhaps that, although gool, were not sufficiently so to make them desirable, and therefore they are rare to be found in any collection.

\section{A BeC.}

Mignonne à Bec.

Pourprée à Bec.

This is a new variety, ripening early in August. The leares have globose glands. Flowers large. 
Fruit large, roundish, uneven in its outline, having a bold blunt nipple at the apex. Suture shallow, highest on one sisle. Skin thin, of a lemon yellow, with erimson cheek. Flesh white, slight tinge of red next the stone, tender, melting, sweet. Freestone. (Hogg.)

\section{ABRICOTÉE.}

Yellow Admirable. Apricot Peach.
Grosse Jaune Tarlive. D'Abricot.

Admirable Jame. D'Orange. (Orange Peach.)

The Apricot Peach (or Fellow Admivable, as it is more fiecuently called) is an old French variety, but little cultivated in this comitry, thongh deserving of attention in the Midelle States. It ripens very late, and is thought to have a slight apricot flavor. It grows with moderate rigor, and bears ahmondantly. Leaves with reniform glands. Flowers large.

Fruit large, roundish oval, with a small suture ruming on one side only. Skin elear yellow all over, or fuintly touched with resl next the sun. Flesh yellow, but a little red at the stone, firm, rather dry, with a sweet and agreeable flavor. Stone small. Ripens at the begiming of Oetober.

\section{AcTON SCOTT.}

The Acton Scott is an English Peach, raised by Mr. Knight. It is an excellent early fruit, and will thrive and ripen well at the North. Leaves with globose glinds. Flowers large.

Frnit of medium size, rather narrow and depressed at the top, with a shallow suture. Skin rather woolly, pale yellowish white, with a marbled bright red cheek. Flesh pale quite to the stone, melting, sugary, and rich, with sometimes a slight bitter Havor. Niddle of Angust.

\section{Albert's Late Rareripe.}

A Southern variety. Glands globose.

Fruit large, roumclish. Suture slight. Skin not very downv, yellowish white, sprinkled with red dots and a marbled red elieek. Flesh pale, light red at the stone, juicy, sweet. Freestone. September. (White.)

\section{Alexandra.}

\section{Alexandra Noblesse.}

Seedling Noblesse.

This variety was raised by Thomas Rivers, from the Old Noblesse, and, unlike the old variety, the tree is not subject to mildew. Glamels globose. Flowers large.

Fruit of the largest size, round, and marked with a deep suture. Skin covered with a rough down, pale, with a few clusters of red dots on the side next the sum. Flesh white, quite pale at the stone, tender, melting, juiey, rieh, vinous. Freestone. Early in August. (Hogg.)

\section{A LIDA.}

Originated with Charles Carpenter, Kelly Island, O.

Fruit large, round, dark red. Flesh yellow, juiey, good. September. Freestone. 


\section{Allex.}

An old sort, cultivated in Massachusetts. It has the babit of reproducing itself true from seed.

Fruit small, roundish, white, with a red cheek. Flesh white, juicy, pleasant. Freestone.

\section{Anelia.} $\begin{array}{ll}\begin{array}{l}\text { Stroman's Carolina. } \\ \text { Orangeburg. }\end{array} & \begin{array}{l}\text { Rayzer's June. Nolly's Peach. } \\ \text { Sonesuch of North Carolina. }\end{array}\end{array}$

This Peach originated with Mr. Stroman, in Orangeburg District, S. C. Glands reniform. Flowers small.

Fruit large, roundish oblong. Suture large and deep, extending nearly round. Skin pale whitish yellow, shaded and marbled with crimson in the sum, downy. Flesh white, juicy, melting, sweet, rich, vinous. Freestone. Last of August. Ripens at the South with Early Iork.

\section{Ayelia.}

This fine large Peach originated with George Husman, Hermann, Mo. It is much like Columbia, but later in ripening. Leaves with indistinct globose, almost reniform glands.

Fruit large, round. Suture well defined, deepest towards the apex, which has a rounded point. Skin rich yellow, marbled with dull red. Elesh thick, rich, juicy, sweet. Ripe a few days later than Columbia. Freestone. (Hort.)

\section{Aremie.}

Origin, Pomaria, S. C.

Fruit very large. Flesh yellow, juicy, high-flavored. 10th August. Clingstone. (Summer's MIS.)

Astor.

An American Peach, which originated in New York. It is good, but hardly first-rate; not very productive. Flowers large. Leares with globose glands.

Fruit large, rather flattened or broad, and slightly sunk at the top. Suture well marked. Skin pale yellowish white, with a deep red cheek. Stone small. Flesh melting, very juicy, sweet, and of excellent flavor. Ripens the last week in August. Freestone.

\section{Atwood.}

Originated with Roscius Atwood, Newberry, S. C.

Fruit large. Quality bsst, productive. Clingstone. (Sumner's MS.)

\section{Austin's Late Red.}

Glands reniform. Flowers large.

Fruit large, oblong, white, with a red cheek. Flesh white, juicr, vinous, and well-flavored. Clingstone. Ripens middle of October. ( $\dot{\mathrm{P}}$. J. Berckman, MIS.) 


\section{BALDWIN'S LATE.}

Glands reniform. Flowers small.

Fruit large, oblong, with a distinct swollen point. Skin greenish white, with a slight red cheek. Flesh very firm, juicy, melting, and well-flavored. Freestone. Ripe the last of Oetober at the South. Disseminated by Dr. Baldwin, of Mlontgomery. (White's Gird.)

\section{Barrington.}

Buckingham Mignonne.

Colonel Ausley's.

A handsome, very fine, and very hardy English Peach. The tree is vigorous and healthy. The fruit ripens at the medium season, about it week after the Royal George. Leaves with globose glands. Flowers large.

Fruit large, roundish, inclining to ovate, and rather pointed at the top, with a moderate suture on one side. Skin pale yellowish white, with a deep-red marbled cheek. Flesh but slightly tinged with red at the stone, melting, juicy, very rich, and of the first quality. Stone rugged, dirk brown. Beginning of September. Freestone.

\section{BATCHELder.}

Origin, Haverhill, Mass. Mardy and productive; said to produce the same from seed.

Fruit large, round. Skin white, with a deep blush. Flesh white, melting, juicy, very pleasant vinous Havor. Last of September. (Cole.)

\section{BAUGH.}

Leaves with reniform glands.

Fruit medium, roundish, terminated with a small point. Suture obscure. Skin pale yellow, almost white, with a shight blush towards the sun. Flesh yellowish white, pure white at the stone, melting and juicy, with a sweet, pleasant flavor. Separates from the stone. Ripens the first of October. (White's Gard.)

\section{- Belle Bausse.}

Belle Bauce.

Pourprée Vineuse.

Vineuse Hâtive.

Pourpre Hâtive Vmeuse.

Vineuse de Fromentin.

This delicious Peach is a variety of Grosse Mignomme, but larger, and ripens ten days later. Glands globose. Flowers large.

Fruit large, somewhat flattened at extremities. Suture distinct, higher on one side than the other. Skin thin and delicate, covered with fine down, highly colored almost over the entire surface with deep' ied. Flesh white, with a rosy tint round the stone, tender, melting, vinous. Freestone. Early September.

\section{Belle Cienveuse.}

Glands reniform. Flowers small.

Fruit elongated, with a bold niplele at summit. Skin downy, yel- 
lowish, marbled with red in the sun. Suture distinct. Flesh whitish yellow, red at stone, sweet, and juicy. September. (Hogg.)

\section{Belle de Beaucaire.}

A Sonthern variety. Glands globose. Flower's small.

Eruit large, roundish, with protruding point. Suture shallow. Skin light yellowish green, with cheek slightly reddened. Flesh pale greenish yellow, red at the stone, a little coarse, melting, rich. Freestone. Ripe last of July, South. (White's Gard.)

\section{Belle de Doue.}

\section{Belle de Douai.}

A large melting Peach, an early variety of Bellegarde. Flesh vinons, rich flavored. Freestone. Glands globose. Flowers small. Middle A ugust. (Hogg.)

\section{Belle de la Croix.} small.

A new Peach raised at Bordeanx. Glands reniform. Flowery

Fruit large, round. Flesh sweet and rich. Middle August. (Hogg.)

\section{Belle de Vitriy.}

Admirable Tardive.

Bellis.

This is not the Belle de Vitry of most of our gardens, which is the Early Almirable; it is quite distinct, also, from the Late Admirable; but is the Belle de Vitry deseribed by Duhantel, and is a rery firmHeshed and excellent French variety, little known in this country. Leaves serrated without glands. Flowers small.

Fruit middle size, rather broad, with a deep suture, and the top depressed. Skin pale yellowish white, tinged and marbled with bright and dull red. Flesh rather firm, red at the stone, melting, juicy, and rich. Ripens here the last of september. Freestone.

\section{Belle et Bonse.}

A foreign variety. Leaves withont glands. Flowers large.

Fruit large, roundish. Suture deep). Skin downy, clear yellow, shaded with hright red in the sun. Flesh white, fine, melting, lighly perfumed. Freestone. August. (An. Pom.)

\section{BELlegarde,}

Galande.

Noir de Montrenil.

French Royal George.

Smooth-leaved Royal George.

Early Royal George.
Red Magdalen.

Brentford Mignonne.

Fonald's Hignonne.

Early Garlande.

Belle de Fillemont.

This very excellent French Peach is the one most highly esteemed hy the Montreuil grower's, who supply the Paris markets, and it is 
equally valued by the English. It is also one of the handsomest and mosi delicions fruits here. Leaves with globose glands. Flowers small.

Finit large, round, and regular, the suture shallow, the top slightly hollowed, and having a little projecting point. Skin pale yellowish green, with a rich red eheek, often streaked with darker purple. Flesh slightly marked with red at the stone, a little firm, but very melting, juicy, rich, and high-flavored. Stone rather large. End of August and first of september. Freestone.

\section{Bergex's Yellow.}

One of the best of the yellow-fleshed Peaches, hut not a good bearer, and therefore unprotitable. Leaves with reniform glands. Flowers small.

Fruit large (often measming nine inches in circumference), globular, depressed, and broad; the suture well marked, and extending more than half romul. Skin deep olange, dotted with some red, and with a very broad, dark-red cheek. Flesh deep yellow, melting, juicy, and of rich and luscious flavor. Ripens at the begimning of September. Freestone.

\section{Blanton Cling.}

\section{Yellow Blanton Cling.}

Leaves large. Crlands reniform. Flowers small.

Fruit large, and shaped like Lemon Cling, with the same projecting, swollen point. Skin rich orange, with a slightly redclened cheek. Flesh oringe yellow, firm, but full of a delicions vinous juice. Later and better than Lemon Cling. Reproduces itself from seed. Ripens 10th August. (White's Gard.)

\section{Blood Clangstone.}

\section{Indian Blood. Claret Clingstone. Blood Cling.}

The Blood Clingstone is a very large and peculiar fruit, of no value for eating, but esteemed by many for jickling and preserving; the flesh very red, like that of a beet. This is an American seelling, raised many years ago from the French Blood Clingstone-Sungunoue i Cmarr ADHérexte. It is a much larger fruit than the original sort, which has large flowers; otherwise they are the same in all respects. Leaves with reniform glands. Flowers small.

Fruit often very large, roundish oval, with a distinct suture. Skin very downy, of a dark, dull, clonderl, purplish ıed. Flesh deep red throughont, firm and juicy-not fit for eating. September to (letober.

There is a Frexcin Buond Freestone (Sanguinole, sanguine, Cardinale, or Betrue, Duh., Thomp.) of the sane nature, and nsed for the same purpose as this, but smaller in size, and not erual to it for cooking. Leares withont glands.

There is also a Blood Freestone, raiser by Joln M. Ives, Salem, Mass., which is of medium size. Blood red throughout. Tree hardy and a good bearer.

\section{Bonse Gros DF Noisette.}

Originated witlı M. Noisette, Paris, France. 
Fruit large, roundish, depressed. Suture deep. Skin nearly smooth, white, with faint marblings of red in the sun. Flesh yellowish white, red at the stone, juicy, vinous, aromatic. Freestone. September.

\section{Bordenux Cllixg.}

Raised in New Bordeaux, Abbeville District, S. C., from a stone brought from Bordeaux. Glands reniform. Flowers large.

Fruit large, oblong or oval, a little one-sided. Suture shallow. Skin very downy, lemon yellow, with a red cheek. Flesh yellow, red at the stone (to which it clings), juicy, melting. A showy market sort. First of August. (Wm. N. White, MS.)

\section{BREYOORT.}

Brevoort's Morris.

Brevoort's Seedling MIelter.

One of the richest and most delicious of American Peaches, and one of the favorite sorts for garden cultivation. It was raised by Henry Brevoort, of New York. Bears regular, moderate crops. Leaves with reniform glands. Flowers small.

Fruit medium or large, round and rather broad, with a distinct suture, deep at the top. Skin pale yellowish white, often a little dingy, with a bright red cheek. Flesh rather firm, slightly red at the stone, rich, sugary, and high-flavored. Freestone. First of Seltember.

\section{Briggs.}

Origin, Delham, Mass. Hardy and productive.

Fruit large, roundish. Suture continned almost round it. Skin white, nearly covered with bright red. Flesh white, tinged with red at the stone, very juicy, of a rich, sweet, slightly vinous flavor. Freestone. From first to middle of September. (Cole.)

\section{Cable's Late.}

Cable's Late Melocoton.

Originated with E. Cable, Cleveland, O. A seedling of the Red Cheek Melocoton, and resembles Crawford's Late, somewhat larger, and ripening a little earlier. Tree a gool bearer. Freestone. (Elliott.)

\section{Cambridge Belle.}

\section{Hovey's Cambridge Belle.}

Raised by Hovey \& Co., Boston, Mass.

Fruit large, roundish. A beautiful Peach, with a clear waxen skin, and a blush on the exposed side, and of a rich, brisk, delicious flavor. Freestone. Ripe early in September. (Hov. Mag.)

\section{Canary.}

An American variety. Glands globose. Flowers small.

Fruit medium, roundish oblong. Skin thin, beantiful bright rellow Flesh yellowish, melting, juicy, rich, and good. July, South ; August, North. Freestone. 


\section{Carpenter's White.}

Raised by William S. Carpenter, New York City. Tree vigorous and productive, with globose glands. Flowers small.

Fruit large and round. Skin white, with a slight sharle of green. Flesh white to the stone, juiry, melting, and of good flavor. Separates from the stone. Ripens about the middle of October.

\section{Catherise.}

\section{Congress.}

The Catherine Cling is an old English variety, of excellent quality, but not, we think, equal to the Lmge White Clingstone, a native seedling, so much esteemed in the Middle States. Leaves with reniform glands. Flower's small.

Fruit large, roundish oval, more swollen on one sicle than the other, and terminated by a small swollen point at the top. Skin pale yellowish green, mueh sprinkled with red dots, the exposed eheek of a bright lively red, streaked with darker red. Flesh firm, yellowish white, but dark red at the stone, to which it adheres rery closely, juicy, rich, and good. Middle and last of September.

\section{Chascellor.}
Chancellière.
Gtewart's Late Galande.
Noisette
Late Chancellor.
Edgar's Late Melting.

The Chancellor is said to have been originated by M. de Seguier, of Paris, then Chancellor of France. Leaves with reniform glands. Flowers small.

Fruit large, oval, with a well-marked suture. Skin pale yellowish white, with a dark crimson cheek. Flesh very deep red next the stone, melting, and possessing a rich vinous flavor. Stone oblong. Freestone. Middle of September.

\section{Chisese Ching.}

Reniform glands. Flowers small.

Fruit large, globular. Sides compressed. Suture quite shallow. Skin creamy white, sharled and marbled with fine red. Flesh white, red at the stone (which is adherent), very juicy, melting, with a rich, excellent vinous flavor. Ripens first to middle of September; at the South, from the middle of July to the first of August.

\section{Christidia.}

Originated at Pomaria, S. C.

Fruit large, beautiful. Flesh white to the stone. Flavor delicious. Ereestone. September. (Sumner's MS.)

Clemence Isaure. small.

A new French Peach. Leaves with large reniform glands. Flowerg 
Fruit large, roundish oval. Suture well marked. Skin envered with a gray down, whitish yellow, deep puple in the sun. Flesh deef yellow, purplish next the stone. Freestone. September. (Verg.)

\section{Clintox.}

A native variety, of second-rate flavor. Leaves with globose glands. Flowers large.

Fruit of medium size, roundish, a little depressed at the top, but nearly without suture. Skin pale yellowish white, with a reel cheek marked by broken stripes of dull red. Flesh scarcely stained at the stone, juicy and good. Last of Angust. Freestone.

\section{Cole's Early Red.}

An American Peach, which is a very fruitful and excellent variety for market culture. Leaves with globose glands. Flower's small.

Fruit of medium size, roundish, with but little suture. Skin pale in the shade, but nearly all covered with red, becoming dark red on the sunny side. Flesh melting, juicy, rich, and very sprightly. Beginning to the middle of August. Freestone.

\section{Columbia.}

Indian Peach.

Pace.

Mulatto.

The Columbia is a singular and pecmliar Peach. It was raiserl by Mr. Coxe, the author of the first American work on fruit-trees, from a seed brought from Georgia. It is a very excellent fruit, which every amateur will desire to have in his garden. The tree is not a verr rapid grower, and bears only moderate crops, being, of course, all the less surbject to speedy decay. The young wood is purple. Leaves with reniform glands. Flower's small.

Fruit large, globular, broad and much depressed, the suture distinct, extending half way round. Skin rough and rather thick, dull dingy red, sprinkled with spots and streaks of darker red. Flesh bright rellow, of the texture, as Coxe remarks, of a very ripe pine-apple, rich, juicy, and of very excellent flavor. Ripens from the begiming to the middle of September. Freestone.

\section{Columbus, June.}

Glands globose. Flowers small.

Fruit medium to large, flattened or shightly hollowed at the apex. Suture shallow. Skin pale yellowish white, with a rich reed cheek. Flesh slightly red at the stone, melting, juicy, and high-flavored, excellent. Pipens here in Georgia 20th Jume. Free. (White's Gard.)

\section{Conet.}

Raisel by Thomas Rivers, of England, from the Salway. Glands reniform. Flowers small.

Fruit large, round. Skin pale yellow, with a crimson cheek. Flesh pale yellow, separating freely from the stone, juicy, melting. Early October. (Hogg.) 


\section{Comtesse de Hainaut.}

Originated in Belgium. Flowers large.

Fruit large, romulish. Suture distinct, not deep. Skin covered with a light down, elear yellow, red in the sum. Flesh yellowish white, red at the stone, juicy, melting. Stone large. Freestone. September. (An. Pom.)

\section{Conlenge's Favorite.}

Cooledge's Early Red Rareripe.

This most popular early New England Peach was raised from seed by Mr. J. Cooledge, of Watertown, Mass. It is musually productive, and a very bright-colored handsome Peach, of excellent quality; and its hardiness renders it valuable at the North. Leaves with globose glands. Flowers small.

Fruit large, roundish (the suture prominent at the top only), lut rather the largest on one side. Skin clear, smooth, white, with a fine crimson mottled cheek. Flesh rrey melting and juicy, with a rich, sweet, and high flavor. Middle of August. Freestone.

\section{Covits'.}

Originated with H. H. Counts, Lylesford, S. C.

Fruit large, white, with red cheek. Flesh white, rich, juiey, superior. Clingstone. (Smmer, MS.)

\section{CraWfold's Early.}

Early Crawford.

Crawford's Early Melocoton.

This is the most splendid of all early yellow-fleshed Peaches, and is scarcely surpassed by any other variety in size and beanty of alpearance. As a market finit it is perhaps the most popular of the day. It was originaterl by Willian Crawford, Esq., of Middletown, N. J." The tree is vigorous, very fruitful, and hardy. Ieaves with globose glinds. Flowers small.

Fruit very large, oblong, the swollen point at the top prominent; the suture shallow. Skin yellow, with a fine red cheek. Flesh yellow, melting, sweet, rich, and very excellent. It ripens here the last week in August. Freestone.

\section{Crawford's LAte.}

\section{Crawford's Superb Malacatune.}

Crawford's Late Melocoton, from the same source as the foregoing, is one of the most magnificent Anerican Peaches. We think it deserving of universal cultivation. As a splendid market fruit it is umivalled, and its size and beanty will give it a place in every garden. Leaver with globose glands. Flowers small.

Fruit rery large, roundish, with a shallow but distinct suture. Skin yellow, with a fine dark-red check. Flesh deep yellow, but red at the stone, juicy and melting, with a very rich and exeellent vinous flavor. Ripens from the 20t's to the last of September. Freestone. 


\section{Crimson Gailande.}

Crimson Mignonne.

Glands globose. Flower's small. Fruit medium, roundish, faint suture, pitted at apex. Skin almost covered with dark crimson, nearly black. Flesh tender, melting, blood red at the stone, juicy, rich. Freestone. (Hogg.)

\section{Crockett's Late White.}

A late-maturing white Peach, originated in New Jersey, where it is popular as a market sort. Leares with reniform glands.

Fruit medium to large, oblong. Skin greenish white, occasionally some red in sun. Flesh prale, sweet, not very juicy. Last September. Freestone. (Gar. MIon.)

\section{DAGMAR.}

A new Peach raised by Thomas Rivers, England. Glands globose. Flowers small.

Fruit round, marked with a shallow suture, deepest at apex. Skin tender, very downy, pale straw-color, nearly covered wicis minute crimson dots, giving a mottled appearance. Flesh white, very teuder, melting, juicy, rich, vinous, sweet. Freestone. Angust. (Hogg.)

\section{De Beurre.}

A French Peach. Teaves without glands. Flowers small.

Fruit medium, oval, depressed at apex. Skin easily detached from the flesh, covered with a short, fine down, whitish yellow, washed with brownish red in the sun. Flesh fine, melting, pulplish next the stone, sweet, vinous. August. Freestone. (Terg.)

\section{De Boxlez.}

A Belgian variety. Flowers large.

Fruit large, round, depressed. Siture deep. Skin downy, yellowish, deeply colored with red in the sum. Flesh firm, yellowish, red at the stone. September. Freestone. (Alb. Pom.)

\section{Desse Tardive.}

Glands globose. Flowers small.

Fruit large, round, flat at top, deep suture next the stalk. Skin pale yellow, faint tinge of rosy red next the sun. Flesh greenish white, slightly tinged with red next the stone, melting, juicy, sweet. September. Freestone. (Hogg.)

\section{De Zeiners.}

Fruit medium, round. Suture deep, large. Skin downy, yellow, more or less colored with bright red. Flesh white, melting, juicy, sweet. August. Freestone. (Alb. Pom.) 


\section{Docton IIoG.}

Originated with Thomas Rivers, England. It is described as the largest early Peach known. Glands reniform. Flowers large.

Fruit large, round. Suture distinet. Skin lemon yellow, dotted with crimson, and a crimson cheek in the sun. Flesh yelluwish white, somewhat firm, but melting and juicy, stained witl red at the stone. Last of $\mathrm{Jull}_{\mathrm{l}}$ or early August. Freestone.

\section{D'Oignes.}

Originated in Belgium. Leaves serrated.

Fruit medium to large, roundish. Suture large and shallow. Skin downy, greenish yellow, with red in the sun. Flesh yellowish white, much colored arouud the stone, melting, juicy. September. Freestone. (An. Pom.)

\section{Doxaioo Cling.}

From Mr. Donahoo, Clark Co., Ga. Glands reniform. Flowers small.

Fruit very large, roundish. Suture quite deep on one sicle, and risible entirely around the frnit. Apex depressed. Skin ereamy white, lotted and tinged with red in the sun. Flesh white to the stone, exceedingly juicy, rich, and luscious. Ripens from 10th to 20 th September.

\section{Double Montagne.}
Double Mountain.
Montagne.
Montauban.

A Peach much resembling the Noblesse, of French origin. Leaves serrated, without glands. Flowers large.

Fruit of medium size, roundish, but somewhat narrower at the top. Skin pale greenish white, with a soft red cheek, which is marbled with darker red at maturity. Flesh. white to the stone, very delicate and melting, with a plentiful and high-flavored juice. Stone orate and rugged. Middle of August. Freestone.

\section{Druid Hill.}

Originated by Lloyd N. Rogers, Esq., of Druil Hill, near Baltimore. The tree is musually vigorons, the shoots and leaves very large, and it bears abundantly. The very late sason of its maturity remeler it valuahle, as most of the luscious sorts are then gone. Leaves witr. globose glands. Flowers small.

Fruit large, roundish; the cavity of the stalk rather narrow, the sur ture very slight, and the swollen point distinct, but smarecly prominent. Skin pale greenish white; clonded with red on the sumy side. Flesh greenish white, purple at the stone, very juicy and melting, with an exceredingly rich, high vinous flavor. Stone long and rather comprescol, much furrowed. Ripens from the 20th of September to tho Ist of October. Freestone. 


\section{Duff Yellow.}

Glands globose. Flowers small. An excellent early market Peach Fruit very large, round, with a sharp point. Skin yellow, with a red cheek. Flesh yellow, juicy, and pretty well flavored, a little acid, red at the stone. Clingstone. Ripens early in July. (P. J. B., MS.)

\section{Duperron.}

A seedling of M. Duperron. Promises of value. Leases with globose glands. Flowers small.

Fruit large to very large, roundish, depressed at end. Suture shallow. Skin downy, golden yellow, more or less washed with pale red. Flesh yellow. Clingstone. October.

\section{Dwarf Orleaxs.}

\section{Italian Dwarf.}

This variety, introduced many years since, and described by $\mathrm{WT}^{\mathrm{m}} \mathrm{m}$. Prince, in 1828, has recently been brought out anew under the name of Italian Dwarf. It forms a diminutive tree of about two feet in height, is a slow grower, with short-jointed wood, suited as a curiosity for protgrowing. Leaves long. Flowers large.

The fruit is nearly as large as the Nutmeg Peach. White flesh, juicy. Freestone.

\section{Early Aduirable.}
Admirable.
Belle de Titry.
L'Admirable.

A very excellent French Peach, wrong]y known by many in this country as the Belle de Vitry, which is a distinct variety. We find it early, and rery prolitic. Leaves with globose glands. Flowers large.

Frnit not quite round. Skin pale yellowish white, with a lively red cheek. Flesh red next the stone, melting, and juicy, with a good, rich, sweet flavor. Middle of August.

\section{Early Alberto}

An early Peach raised by Thomas Rivers, of England. Glands globose. Flowers small.

Fruit above medium, roundish, frequently one sicle of suture higher than the other, pittech at apex Skin greenish rellow, shaded with deep crimson. Flesh white, teuder, melting, with a faint brick red tinge next the stone, rich juicy. Freestone. Last of July. (Hogg.)

\section{EArty Alfred.}

Praised by Thomas Rivers, from seed of Hunt's Tawny Nectarine. Glands globose. Flowers large.

Frtit rather large, marked with a deep suture. Skin straw-color, mottled with crimson in the sun. Flesh white, melting, vinous, rich. Early August. (Hogg.) 


\section{EARLY ANNE.}

Anne. Green Nutmeg.

The Early Anne is an old and familiar English sort. The tree is of slender growth. Juaves serrated, without glands. Flower's large, nearly white.

Fruit rather small, roumd. Skin white, with a faint tinge of red next the sun. Flesh white to the stone, soft, nelting, sweet, and of pleasant flavor. Last of July and first of August.

Way's Early Anne, a seedling of the above, by Lincoln Fay, of Cliautauque Co., N. I., is larger and better. Ripens a week or two later, and just before Early York (serrate). Slkin whitish, sometimes slightly tinged with red. Flesh white, juicy, melting, and very gool.

\section{Ehrly Beatrice.}

This Peach, says its originator, Thomas Rivers, Sawbrilgeworth, England, is the earliest sort known, dipening from 5th to 11th of July. Leaves with reniform glands. Flowers large. juicy.

Fruit medium size, with a mạabled red eheek. Flesh melting, rery

\section{Farly Chelisfokd.}

\section{- Mammoth.}

Leares glandless.

Fruit large, roumlish. Suture elear round, deep on one side. Skin white, with a bright red cheek. Flesh white, rery melting and juicy, of a very delicious, slightly vinous fluvor. Freestone. 20th to last of August.

\section{Early Grosse Migroxine.}

Grosse Mignonne Hâtive.

Mignonne Hầtive.

This is a very fine Peach, ripening early in August. Glands globose. Flowers large.

Fruit melium, roundish, pitted at apex. Nipple one side, and shiullow suture. Skin witl a pale red eheek in the sun, dotted thiekly with bright erimson dots. Flesh white, veined with red, very juicy, vinous, sweet. Freestone. (Hogg.)

\section{EARLY Louise.}

Seedling of Thomas Rivers. Glinds renifor'm. Flowers small.

Fruit medium, bright red. Flesh melting, juicy, excellent. Freestone. July 12th to 16th. (Rivers' Cat.)

\section{Early Maldex.}

Raised by James Dougall, Canada West. Flowers small. Leaves glandless.

Fruit medium, roundish, one side enlarged. Suture distinet on one side. Skiu whitish, mostly shaded with red in the sun. Flesh white, juicy, melting, sprightly. Freestone. Midale of August. 


\section{Early Newington Freestone.}

Newington Peach.

Early Newington.
Smith's Early Newington.

Smith's Newington.

This is a large and exceedingly high-flavored early Peach; indeed we consider it without a superior at its season. It is quite distinct from the other Newingtons, which are clings and rather late, while this is early and generally parts from the stone, though it frequently lappens that some of the finit on the same tree aclheres partially wh wholly to the stone ; and this peculiarity (comnon, so far as we know, to but one other kind) is one of its constant characteristics. The tree is only a moderate bearer. Leaves with globose glands. Flowers smali.

Fruit rather large, round, with a distinct suture, and one-half the finit always the larger. Skin pale yellowish white, dotted and streaked with red, the cheek a rich red. Flesh white, but red at the stone, to which many particles alhere. If not fully ripe it has the habit of a cling. Flesh juicy, melting, with a rich vinous flavor. Ripens directly after the Early Tork, about the 2th of August.

\section{EARly Rivers.}

Glands reniform. Flowers large.

Fruit large, pale straw-color, with a delicate pink cheek. Flesh melting, remarkably rich and racy. Middle July. (Hivers" Cat.)

\section{EARLY Silver.}

Raised by Thomas Rivers, in 1857, from seed of the White Nectarine. Glands reniform. Flowers large.

Fruit very large, roundish ovate, sometimes a nipple at the apex. Skin cream-color, with a slight blush in the sun. Flesh white, melting, juicy, brisk. Middle August. Freestone. (Hogg).

\section{EARLY SWEET WATER.}

Sweet Water.

Large American Nutmeg.

It is an American Peach, raised from a stone of the Early Anne. The tree is thrifty and productive, with pale shoots, and nearly white blossoms. Leaves with globose glands. Flowers large.

Fruit of medium size, sometimes large, roundish, with a slight suture. Skin pale white, very seldom with a faint blush when fully exposed. Flesh white, slightly stained at the stone, melting, juicr, sweet, and of very agreeable flavor. Ripe about the Sth of Angust. Stone small.

Early Sweet Water (Prince's) is distinct from this, and, Mr. Prince says, equally valuable.

\section{Early Tillotson.}

The Early Tillotson was first introduced to notice by J. J. Thomas, of Macedon, Wayne Co. It is considered a native of that part of the State.

This has not succecled well here, and most cultivators at the Forth lave discontinced it. It mildews bally, grows slowly, and is not pro- 
ductive. At the South it is one of their very best early peaches, and in many localities it has proved fine. Leaves deeply selrated, withont glands. Flower's small.

Fruit of medium size, round. Skin nearly covered with red, the ground color, pale yellowish white, being thickly dotted with red, and the exposed cheek being a dark red. Flesh whitish, but red at the stone, to which, though a freestone, it partially adheres, melting, juicy, with a rich, highly excellent flavor. It ripens the middle of Angust.

\section{Early V'tetoria.} York.

Raised by Thomas Rivers, England. Mueln like its parent, Early

\section{EARLY York.}

Early Purple. Pomprée Hâtive. Serrate Early York.

The Early York has long been the most popular of early Peaches in this country. It is at least a week earlier than the (true) Royal George, more melting and juicy, though not quite so rich, and deserves a place in every garden. In unfavorable soil, the ends of the branches are a little liable to mildew; but the tree is very hardy and productive. There are one or two newer seedlings raised from this, and bearing the same name, in New Jersey, which are rather more thrifty for the orchard, but do not possess the high flavor of the old kind. They are easily known from it by the absence of glands in the leaves and by the large flowers of the true sort. It is quite distinct from the Red Rareripe, which is large, broader, deeply markerl with a suture, later in ripening and richer flavored. Leaves serrated, without glands. Flowers large.

Fruit of medium size, romndish, inclining a little to ovate, with a slight suture only. Skin very thin, pale red, thickly dotted over a pale ground in the shade, but quite dark red in the sun. Flesh greenish white, remarkably tenrler and melting, full of rich, sprightly juice. Ripens about the 18th of August.

\section{EAstburn.}

Eastburn's Choice.

American.

Fruit large, roundish, pale yellow, with red on the sunny side. Flesh yellowish, red near the stone, juicy. Freestone. September. (Elliott.)

\section{Eatox's Golden.}

Origin, North Carolina. Glands reniform. Flowers large.

Fruit above medium, round. Suture shallow. Skin golden yellow, with occasionally a few faint pink spots near the base. Flesh golden yellow, sweet, juicy, with a marked apricot flavor. Clingstone. Ripo middle of September. (P.J. B., MIS.)

\section{Eliza Peach.}

Origin, Philadelphia. Leaves large, with reniform glands. 
Fruit medium, round, terminating in a nipple. Skin yellow, with a mottled red cheek. Flesh yellow, red at the stone. Last of Sep tember. Freestone.

\section{Elmira Chisg.}

Originated with M. W. Phillips, Mississippi. Glands reniform Flowers small.

Fruit large, oval, depressed. Suture rather shallow on one side. Skin white, with a greenish yellow tinge, quite downy. Flesh white, tinged with red at the stone, to which it adheres. Sweet and good. Early in August.

\section{Eimperor of Ritssia.}

Cut-Leaved. Serrated. New Cut-Leared. Tnique.

A very ricl and fine-flarored Peach, raised by Mr. Floy, in 1812. Its growth is slow, and its shoots are inclined to become mildewerl. It is rather a shy bearer. The leares are rery deeply cut. or serrated on the edges. Leaves serrated, without glands. Flowers small.

Fruit large, romdish and broad, with one half more swollen than the other. Skin downy, dull yellowish white, with a dark-red cheek. Flesh yellowish white, rather firm, rich, and high-flarored. Last of August.

\section{Erxoult.}

This is a singnlarly formed and colored Peach, from Belgium. Leares with globose glands.

Fruit large, roundish, depressed. Snture shallow in the middle of the fruit, deeper at ends, and peculiarly wrinkled pit at apex. Skin downy, clear ycllow, shaded with deep reddish purple in the sun. Flesh white, some red next the stone, melting, juicy, xich. Freestone. (An. Pom.)

\section{Exquisite.} small.

A variety that originated in Georgia. Glands globose. Flowers

Fruit large, roundish oval. Sutnre distinct. Nipple at apex. Skin yellow, mottled with crimson in the sun. Flesh deep yellow, red at stone, tender, melting, juicy, vinous. September.

\section{FATORITE.}

Farorite Red.

A capital orchard fruit, of large size, hardy, and a most abundant bearer. It is a very good native Peach, though not of high flavor. Leares with obscure globose glands, often with none. Flowers small.

Frnit large, oblong or oval. Skin white, rather downy, much corared with red, which becomes a very dark red when fully exposed in the sun. Flesh red at the stone, a little firm, but juics, with a good, vinous, but not rich flaror. Second week in Septembsr. 
Fluteir's St. John.

Yellow St. John.

A new variety, of Southern origin, said to be one of the most pro mising of the enrly varieties.

Fruit large, somewhat resembling Early Crawford, but deeper color. Flesh yellow, juicy, sweet. Freestone. Ripens a little before Early Tillotson. (R. R. Hunley, MS.)

\section{Flewellen Cling.}

Fruit large, globulitr, depressed at the apex. Skin downy, yellowish white, mostly overspread with shades of red, dark dull purplish red in the sun, the lighter tints of red somewhat in stripes. Flesh yellowish white, red at the stone, to which it firmly adheres, very juicy, sweet, and high-flavored. A desirable early cling for the south. First of August.

\section{Fox's Seedling.}

A good and productive late Peach, a native of New Jersey. Leaves with globose glands. Flowers small.

Fruit round, a little compressed. Cavity at the stalk narrow. Skin white with a red cheek. Flesh melting, juicy, sweet, and good. Middle of September. Freestone.

\section{Freeman.}

This Peach originated in South Pass, Ill., and was brought to notice by P'arker Earle. It is there esteemed as highly valuable for late market, ripening considerably later than the Smock. Leaves with globose glands.

Fruit large, round, yellow, with red in the sun. Flesh yellow, red next the stone, juicy. Freestone.

\section{Fruitlind.}

\section{Fruitland Seedling.}

A new variety, originated at Augusta, Ga.

Fruit large, obovate to a point, greenish white, with a pale mottled red cheek. Flesh greenish white, very juicy, vinous, a little red at the stone. Freestone. Early September. (P. J. Berckman's Cat.)

\section{Fulierson.}

Fulkerson's Early. tive.

Originated with R. P. Fulkerson, Ashland, O. Hardy and produc-

Fruit medium, obtuse, rounded. Sides irregular, unequal. Suture half round. Skin whitish, rich red cheek. Flesh whitish yellow, tinged with red at the pit, juicy, lich, sweet, and high-flarored. Freestone. 20th August. (Elliott.) 


\section{GAYLORD.}

Originated by Dr. M. W. Phillips, Mississippi. Glands globose. Flowers small.

Fruit large to very large, round, with a sharp point. Skin roseate, with a red cheek. Flesh white, juicy, rich, and superior. Freestone. Ripe midlle of August. (P. J. B., MS.)

\section{George the Fourth.}

This is certainly the most popular Peach for garden culture in the United States. It is large, bears regular and moderate crops, is of the highest flavor, and the tree is musually hardy and rigorous, succeeding well in all parts of the country. No garden should be without it. The original tree stood in the garden of Mr. Gill, Broad Street, New York. Leaves large, with globose glands, often obsenre. Flowers small.

Fruit large, round, deeply divided by a broad snture, and one hals a little larger than the other. Skin pale yellowish white, finely dotted with bright red, and deepening into a rich dark-red cheek on one side. Flesh pale, marked with red at the stone (which is small), melting, very juicy, with a remarkably rich, luscious flaror. Ripens the last of August. Freestone.

\section{Goode's October.}

Belongs to the Indian type. Origin, Sonth Carolina.

Fruit large, round or slightly oblong. Skin white, veined with red, and quite downy. Flesh white, with red near the stone, very juicy, vinous subacid. Clingstone. Ripe early October. (P. J. B., MS.)

\section{Gorgas.}

Originated with Benjamin Gullis, Philadelphia. Growth vigorous. Leaf glandless. Flowers small.

Fruit rather large, roundish, with a small swollen point at the apex. Skin yellowish white, clonded and blotched with red on the exposed surface; dull greenish on the shaded parts. Suture indistinct. Flesh whitish, slightly stained at the stone, juiey. Freestone. Mliddle September.

\section{Great Easters.}

Origin, Fruitland Nursery, Augusta, Ga. A very large fruit. Glands globose. Flowers small.

Fruit very large, lound, sometimes a little flattened. Skin greenish white, with a red cheek. Flesh white, juicy, and well-flavored. Ripe middle of July. (P. J. B., MS.)

\section{Gregory's Late.}

A very late variety. Leaves with globose glands. Flowers small. Fruit large, ovate, pointed. Skin paie green, with a dark red cheek Flesh melting, vinous, sweet. Early October. Freestone. (Hogg.)

\section{Greex Catharine.}

Origin uncertain. Glands globose. Flowers smail. 
Fruit large, roundish. Skin pale green, with a red cheek only when exposed to the sun. Flesh greenish white, red at tho stone, very juicy, melting, and very good flavor. Freestone. Requires a warm season to bring it to perfeetion. Ripe fiom the first to middle of September.

\section{Grosse Mignoxie.}

Royal Kiensington.

Grimwood's lioyal George.

- New Roval George.

Large French Mignonne.

French IIignomue.

Swiss Miguonne.

Purple Arant.

Early Purple Arant.

Early May.

Early Vineyart.
Neil's Early Purple.

Johnson's Larly Purple.

Nignome.

Telontie de Merlet.

Pourprie de Tormandie.

La Royale.

Pourprie Hitive.

Ronald's Seedling Galande.

Royal Sovereign.

Superb Royal.

The Grosse Mignonne is certainly the "world-renowned" of Peaches. It is everywhere esteemed as one of the most delicious of varieties. Leaves with globose glands. Flowers large.

Fruit large, roundish, always somewhat depressed, and marked with a hollow suture at the top. Skin pale greenish yellow, mottled with red, and having a purplish-led eheek. Flesh yellowish white, marked with red at the stone, melting, juicy, with a very rich, high, vinous flavor. Stone small, and very iough. Niddle of August, before the Royal George. Ereestone.

\section{Haines' Early Red.}

An early Peach, originated in New Jersey, of very fine flavor, and so hardy aurl productive as to be a popular orchard fruit. Leaves with glohose glands. Flowers small.

Fruit of medium size, round, depressed at the top, with a wellmarked suture exteuding round the truit, which is always one lialf larger than the other. Skin pale white, marked with red, and nearly covered with deep red. Flesh greenish white, very juicy, melting, sweet, and well-flarored. Middle of August.

\section{Male's Early.}

\section{Early German.}

This very early and profitable market Peach was originated in Summit Co., O., by a German, and was first distributed under the name Farly German. The tree is quite hardy and productive, maturing thes earliest of any good sort. Leaves with globose glands. Flowers large.

Fruit medium size, nearly round. Skin greenish, mostly covered and motted with red when ripe. Flesh white, melting, juicy, rich, swret. Freestone. Last of July.

\section{Harker's Seedling.}

Origin, New Jersey. Glands globose. Flowers small.

Fruit large, roundish, mostly covered with red. Flesh yellowish, sweet, juicy. Early September. Freestone. (Elliott.) 


\section{Hastings' Rareripe.}

Origin unknown. Globose glands. Flowers small.

Fruit above medium, round, often a little flattened. Skin yellowish white, having a purplish-red cheek on the smnny side, shaded of witk specks of the same color. Productive, juicy, and of delicious flavor. Middle of September. Freestone.

\section{HATCH.}

Originated with S. O. Hatch, Franklin, Conn. Hardy and valuable at the North. Glands globose.

Fruit roundish, pointed. Suture shallow. Skin deep yellow blush in the sun. Flesh yellow, melting, sweet, and excellent. Freestone. First of September. (Cole.)

\section{HÂtive de Ferrières.}

An early French variety. Leaves without glands.

Fruit medium, roundish. Suture shallow; one side a little enlarged. Skin white, nearly eovered with rich red. Flesh white, slightly tinged at the stone, juicy, melting, with a sweet, rich, vinous flavor. Freestone. Ripe last of August, just after Early York.

\section{НеAтH.}

Heath Clingstone. Fine Heath. White English. Ted Heath.

The most superb and most delicious of all late Clingstones. It seldom ripens in New England, but here, and to the southward, it is one of the most valuable kinds, of very large size, and the very finest flavor.

Coxe informs us that this is a seedling produced in Maryland from a stone brought by Mr. Daniel Heath from the Mediter'ranean; and it is frequently still propagated from the stone, withont variation. The tree is vigorous, long-lived, and moderately productive; with the shoitening-in mode of pruning, the fruit is always large and fine, otherwise often poor. This tree is well deserving of a place on the espalier rail, or wall, at the North. Leaves nearly smooth on the edges, with reniform glands. Flowers small.

Fruit very large, oblong, narrowing to both ends, and terminating at the top with a large swollen point; the suture distinct on one side. Skin dowur, eream-colored white, with a faint blush or tinge of red in the sun, or a brownish cheek. Flesh greenish white, very tender and melting, exceedingly juicy, with the richest, highest, and most luscious flavor, surpassed by no other variety. It adheres very closely to the stone. It ripens in October, and frequently keeps for a month after being gathered.

\section{Henry Clay.}

A Southern Peach, introduced and described in the Horticulturist by Rev. A. B. Lawrence, Woodville, Miss.

Fruit very large. Skin deep purple in the sun, shading to loright 
pink and creany white. Flesh grayish white, delicate, tender, peculiar Havor, partaking slightly of pine-alpple and strawberry. First of August: September at the Nortl. Freestone.

\section{HOFFYER.}

Hoffner's Seedling.

Originated near Cincinnati, O. Glands globose.

Fruit medium to large, roundish. Skin greenish white, red in the sum. Flesh yellowish white, juicy. August. Freestone.

\section{HONEY.}

\section{De Montigny.}

This is undonbtedly a variety that peproduces itself from seed with great exactness. The one grown mostly in this country was raised by Charles Downing, many years since, from seed bronght from China and presented to him.

Hogg describes a Honey as having originated at the "Jardin dea Plantes," and from Chinese seed. Glands reniform. Flowers large.

Fruit small, oval, compressed, with a pretty deep suture along one side, and turning the point to the opposite side, giving it the apprearance of a beak. Skin whitish yellow, washed and marbled with tine red in the sum. Flesh creany white, fine, juicy, melting, with a peculiar honeyed, rich, delicious sweet flavor. Freestone. Last of August

\section{Horton's Delicious.}

Frnit large, roundish, inclining to oval, depressed at apex, point very small, and within the depression. Suture shallow. Skin morle. rately downy, of a rich creany white, with a faint blush in the sum. Flesh white to the stone, with the exact flavor of a Heath Cling. From first to middle of October. (Clingstone.)

\section{Huli's A thenian.}

From Henry Hull, Jr., Athens, Ga.

Fruit very large, oblong, depressed at apex. Suture a mere line. Skin very downy, yellowish white, marbled with dull red in the sim. Flesh white, pale red at the stone, rather firm and rich. October. Clingstone.

\section{HrSLOP.}

Hyslop's Clingstone.

Origin unknown. An American variety, hardy and productive. Glands reniform. Flowers small.

Fruit large, roundish, inclining to oval. Skin white, with a crim. son cheek. Flesh very juicy, melting, with a rich vinous flavor. Adheres to the stone. First of ()ctober. 


\section{INCOMPARABLE.}

Pavie Admiralle.

Late Admirable Cling.

Larger than the Catherine, which it resembles. Leaves with reni form glands. Flowers small.

Fruit large, roundish, one side enlarged. Skin pale yellowish white, light red on the exposed side. Flesh yellowish white, red at the stont, juicy, melting, and of agreeable Havor. Last of September.

\section{JaCkson Cling.}

Raised by Mrs. L. A. Franklin, Athens, Ga.

Fruit large, oblong, with a very large, swollen point. Skin rich dark yellow, covered with dark red in the smm. Flesh rather firm, orange yellow, and dark red at the stone; juicy, sprightly. Iast of August.

\section{JaCroues' Ridiertpe.}

Jacques' Yellow Rareripe.

Origin, Massachusetts. A large yellow Peach of medium quality, and productive. Glands reniform. Flowers small.

Fruit large, roundish, compressed. Suture shallow. Skin dark yellow, mostly shaded with dull red. Flesh yellow, red at the stone, juicy, slightly subacid. Freestone. Midule of september.

\section{JANE.}

Baxter's Seedling, No. 1.

Irish Jane.

Origin, Philadelphia, Pa.

Fruit large, roundish oblate, greenish vellowish-white, with a red cheek. Good. Last of September. Freestone.

\section{Jones' EArLy.}

Ritised by S. T. Jones, Staten Island, N. Y. Globose glands.

Fruit nedium, romdish. Sutme shallow, distinct, extending around the fruit. Skin yellowish white, tinged with pale red in the sum. Flesh yellowish white, slight red at the stone, juicy. Middle of August. Freestone.

\section{Jones' LARge EArly.}

Raised by S. T. Jones. Glauds reniform.

Fruit large, roundish, flattened at each end. Suture deep, one half a little larger than the other. Skin delicate white, broadly shaded with deep crimson in the sun. Flesh white, pink at the stone, very juicy, rich, sprightly, and delicious. Freestone. Middle of August." (Hov. Mag.)

\section{Jose SweEt.}

Glands globose. F'lowers small.

Fruit medium, roundish. Suture deep. Skin greenish white, wtt a dull red cheek, juicy, delicious. Last September. Freestone. 


\section{JULIA.}

Origin, South Carolina.

Fruit medium, white, with a slight red cheek. Fleslı white, juiey, vinous. One of the best late sorts for the Soutli. November. Freestone. (Y'.J. Berekman's Cirt.)

\section{KenRick's Heatil.}

Freestone Heath.

Heath Free.

White Heath.

A large, showy, oblong Peach, often growing to the largest size, and a very hardy tree, but the quality of the fruit is only second-rate. 'This sort, which is a native of New England, is rigorous, and hearsi large crops. It is quite distinct from the eelebrated Heath Cling. Leaves with reniform olands. Flowers small.

Fruit very liuge, ohlong, with a slight suture, and a small swollen point at the top. Skin pale greenish white, witl a purplish red eheek. Flesh greenish white, deep red at the stone, a little coarse, melting, quite juicy, with a pleasant subacid Havor. Middle of September.

\section{Lady Palmerston.}

One of 'Thomas Rivers' new varieties, and described by him as having reniform glands. Flowers small.

Fruit large, greenish yellow, marbled with erimson. Flesh pale yellow, melting. Very good. Ripe last of September.

\section{Lady Parhan.} small.

Originated with Thomas Aftleek. Glands reniform. Flowers

Fruit medium, roundish, one side larger than the other, depressed at the summit. Suture distinctly marked, the swollen point small. Skin yellowish white, downy. Flesh pale, red at the stone, firm, rich, vinous. Middle of Oetoler. Freestone.

\section{La Grange.}

The La Grange is a white freestone Peach, of very late maturity, large size, and fine flavor. It was originated from seed in the garden of Mr. John Hulse, Burlington, N. J.

Its late period of maturity, its color, its productiveness, and size, have given it quite a reputation among the extensive growers of New Jer'sey, and it is undoubtedly a most valuable fruit, not only for the table, lut for preserving at the most desirable period for this purpose, late in the season. Leaves with reniform glands. Flowers small.

Fruit large, oblong, shaped somewhat like the Heath Cling. Skin greenish white, with oecasionally some red on the summy side. Flesh pale, juicy, melting, very rich, sweet, high-flavored, and delicious. Last of September and beginning of Oetober. Freestone.

\section{Large Early York.}

Honest John.

New York Rareripe.

A valuable variety, so much like Haines' Early and Walter's Early 
that it is difficult to decide whether they are not identical. Leaves with globose glands. Flower's small.

Fruit above medium, roundish. Skin whitish, with marblings and dots of red, clear rich red-cheek in the sun. Flesh almost white, finegrained, juicy, rich, mild, excellent. Freestone. Last of August.

\section{Large White Clingstone.}

New York White Clingstone.

Williamson's New York. Selby's Cling.

The Large White Clingstone is one of the most popular of this class of P'eaches. We think it superior to the Catherine and Old Newington, and only surpassed in flavor by the Oldmixon Cling and the Hcath Cling.

'This variety was raised by David Williamson, in New York. The light color aud excellent quality of this fruit render it the greatest farorite for preserving in brandy or sugar. It bears reguiar and good crops. Leaves with globose glands. Flower's small.

Frnit large, round, the suture sliglit, and the swollen point at the top snall. Skin white (inclining to yellow only when orer-ripe), dotted with red on the sumny side, or with a light-red cheek when fully txposed. Flesh whitish, tender, very melting, full of juice, which is very sweet, luscious, and high-flarored. Beginning and mildle of september.

\section{Late Admirable.}

La Royale.

Pêche Foyale

Teton de Venus.

French Bourdine.
Judd's Melting.

Motteux's.

Pourpre Tardive, i incorrectly

Late Purple, $\quad \int$ of some.

"The Late Admirable" is one of those delicious sorts that, originating a long time ago in France, have received the approval of the best cultivators everywhere. It is harly and productive in this climate. Leaves with globose glands. Flowers small.

Fruit very large, romdish, inclining to oval, with a bold suture dividing the fruit pretty deeply all round, and a small, acute, swollen point at the top. Skin pale yellowish green, with a pale red cheek, marbled with darker red. Flesh greenish white, but red at the stone, very juicy, melting, and of delicate, exquisite flaror. Middle of September.

\section{Late Red Rareripe.}

\section{Prince's Red Rareripe.}

This American fruit is one of the finest of Peaches. Its large size, and its productiveness and vigor, mite to recommend it to universal favor. The rather grayish appearance of the fruit serves to distinguish it, at first sight, from all others. Leaves with globose glands. Flowers small.

Fruit large and heavy, roundish oval. Suture depressed only at the top, where the swollen point is distinctly sunken. Skin clowy, pate grayish yellow, thickly marbled and covered with reddish spots; the cheek dull, deep red, distinctly mottled with fawn-culored specks. Flesh white, but deep red at the stone, very juicy, melting, and of rich, higk fiavor. First to the 10th of September. Freestorre. 
Thate Yellow AlberGe.

October Yellow. Algiers Yellow. Algiers Winter.

A very late Clingstone, originally introducerl fiom the South of Fanee, but now abandoned. Leaves with reniform grlands. Flowers large.

Frut of medium size, roundish oval. Skiu towny, green, bacoming yellow. Flesh yellow to the stone, very firm, lather juicy, sweet October.

\section{T.emon Clingstone.}

Kennedy's Carolina.

Kennedy's Lemon Clingstone.

Largest Lemon.
Long Yellow Pine-apule. Pine-apple Clingstone. Yellow Pine-apple.

Allison.

The Lemon Clingstone is one of the largest ancl most beautiful of all the rellow-fleshed clings. It is originally at native of Sonth Carolina. There are now many seedlings reproduced from it. This is a very poductive, laardy tree. Leaves long, with reniform glands. Flowers small.

Fruit large, oblong, narrowed at the top, and having a large, projecting, swollen point, much like that of a lemon. Skin fine yellow, with a dark brownish-red cheek. Flesh firm, yellow, slightly red at the stone, adhering firmly, with a rich, sprightly, vinous, subacid flavor. Middle and last of September.

\section{LENOIR.}

Fruit medium, round, with one side projecting. Skin white, smoot!, washed and splashed with red. Flesh white, juicy, perfumed. Freestone. Ripe milldle August.

\section{LEOPOLD I.}

A Belgian Peach. Leaves serrated, with slight reniform glands. Flowers large.

Fruit large, roundish. Suture well marked. Skin downy, clear yellow, shaded with red in the sun. Flesh fine, melting, juicy. September. Freestone.

\section{I.INCOLN,}

Origin, Lineoln, Mass. Very hardy and prodnctive. Glands globose.

Fruit large, loundish. Suture large. Skin rich yellow, mostly covered with dark purplish red, much downy. Flesh yellow, with a tinge of red at the stone, juicy, of a very rich, swcet, and excellent flavor. Freestone. From first to list of September.

\section{Lord Palmerston.}

This is another of Thomas Rivers' new solts, grown, as he says, from seed of the Princess of Wales, and resembling in size its grandparent, the MIonstrous Pavie of Pompone. Glands globose. Flowers large.

Fruit rery large. Skin whitish, with a pink cheek. Flesh firm, yet melting, juicy, and rieh. Nicldle to end of serternber. 
LYoN.

An accidental seedling, originating on the grounds of George Husman, Hermann, Mo.

Fruit rather large, round, somewhat irregular, largest on one side. Suture slight, marked with a red streak. Skin smootl, little down, yellowish white, nearly covered and marbled with beautiful rerl, hecoming deep purple in the sun. Flesh veined with red, deep red at the stone, juicy, sweet, vinous. "One of the best among thirty of ny varieties." Early August. Freestone. (Husman, MS.)

\section{Madame D'AxDrimont.}

Originated in Belginm. Leaves glandless. Flowers large.

Fruit large, romolish, depressed at ends. Sutnre shallow. Skin downy, pale yellow, bright red in the sun. Flesh white, marbled with bright purple next the stone. August. Freestone. (V'erg.)

\section{Madeleine de Courson.}

$\begin{array}{ll}\text { Red Magdalen, } & \begin{array}{l}\text { French Magdalen. } \\ \text { True Red Magdalen. }\end{array} \\ \text { Rouge Paysame. } & \text { Madeleine Rouge. }\end{array}$

The Red Magdalen of Courson is a favorite old French Peach. Leaves serrated, without glands. Floweis large.

Fruit of medium size, or rather below it, round, flattened, with a deep sutme on one sicle. Skin pale yellowish white, with a lively red cheek. Flesh white, slightly red at the stone, juicy, and melting, with a rich, vinous flavor: Middle and last of August. Freestone.

\section{Malta.}

Pêche Malte. Malte de Normandie. Italian. Belle de Paris.

An old European Peach. The tree is not a great bearer. The fruit of the Malta keeps well after being gathered. Leaves serrated, without glands. Flowers large.

Fruit of rather large size, romdish, flattened, with a broar, shallow suture on one side. Skin pale dull green, markerl on the sunny side with broken spots and blotches of dull purple. Flesh greenish, with a little dark red at the stone, very juicy and melting. Last of August. Freestone.

\section{Merriam.}

Glands globose.

Fruit very large, short oval. Skin light yellow, bright red cheek. Flesh yellow, red at the stone, melting, very jnicy, of a sweet luscious flavor. First of October. (Cole.)

\section{Migmoxne Dubarle.}

Glands globose. Flowers large.

Fruit of medium size, roundish, inclining to oval. Nipple at apex. Suture distinct. Skin nearly covered with bright red in the sun. Flesh tender, melting, juicy, rich. Middle August. Freestone. (Hogg.) 


\section{Mis. Huveter.} snall.

Origin, Fruitland Nursery, Augusta, Ga. Glands reniform. Flowers

Fruit medium to large, one-siclel, pale yellow, with oceasionally a little red near the base. Flesh ycllow, rich, melting. Ripens last of September. (P. J. B., MIS.)

Mrs. Poinsette. glands.

Origin, South Carolina. Tree vigornus and productive. Globoses

Fruit large, globular, with a regular suture. Skin yellowish, inclining on the exposed side to a brownish tint, reined with red. Flesh of rich yellow, juicy, melting, aud of first quality, partially adherent. Ripens from lst to leth of Angust in Sonth Carolina. (William Siummer.)

\section{MIontgoneri's Late.}

Southern origin. Glands reniform. Flowers large.

Fruit large, round, depresserl at apex. Suture shallow, but distinct. Skin downy, yellowish white, dotted with red, and having a dull red cheek. Flesh pale white, red at the stone, very juicy, melting. Ripens the first of September, continues nearly all the month. Freestone.

\section{MOLDEX'S WHITE.}

Origin, Molden Mountain, on the Chesapeake. A fine white Peach, valuable for its lateness. Glands reniform. Flowers small.

Fruit large, roundish oval. Suture distinct. Skin creamy white, rarely with a tinge of red. Flesh white to the stone, juicy, sweer, melting. Ripe last of September. Freestone.

\section{MoORE's Farorite.}

Origin, garden of H. R. Moore, Chelsea, Mass. Tree hardy, vigorous. Glands globose.

Fruit large, roundish. Suture rount the fruit. Skin white, with a broal, bright blush. Flesh white, fine, juicy, of a rich vinous flaror. Stone small, free. September 1 st to 15th. (Cole.)

\section{MOORE'S JUNE.}

Origin, Atlens, Ga. Glands reniforn. Flowers small.

Fruit helow medium, globular. Suture shallow. Skin yellowish, with red dots and marblings, and deep red in the sun. Flesh white, marbled with red from the skin to the stone in the darker-colored ones, but red only at the stone where grown in the shate; juicy, vinous. Last of June and first of July. Freesione.

\section{MorRis.NIA Pouxd.}

\section{Hoffman's Pound.}

Morrison's Pound.

A very large varicty, originated many years ago, ly Martin Hoff. man, but first disseminated from the garden of Gourernem Morris, of 
Morrisania, near New Tork. It is a gool fruit, but its place has been taken, of late, by other more popular sorts. Leaves with globose glands. Flowers small.

Fruit very large and heary, nearly round. Skin dull greenish white, with a brownish-red cheek. Flesh pale rellow, firm, juicy, sugary, and rich in flavor. Ripens the middle and last of September. Freestone.

\section{Morris's Red Rareitipe.}

Morris Red. Red Rareripe. Large Red Rareripe.

This rery propular and well-known American Peach has been justly esteemed for its acknowledged good flavor, beatyty, and productiveness. Leares with small globose glands. Flowers small.

Fruit large, rouncish, a little depressed at the top, with a moderately well-maked sutme. Skin tine pale greenish white, a little dotted, and with a lively, rich red cheek. Flesh pale greenish white, quite red at the stone, very melting and juicy, with a sweet and rich flaror. Last of August. Freestone.

\section{Morris's White Rareripe.}

Morris's White.

White Rareripe

Luscious White Rareripe.

Lady Ann Steward.
White Melocoton

Cole's White Melocoton.

Freestone Heath

Morris's White Freestone.

Momis's White Rareripe, a native, is the most popular and wellknown white Peach, and is everywhere cultivated in this comtry, either muler this or some of the other names quoted above. It is a rich fruit in a warm climate, but is not quite so ligh flarored at the North or East. The tree is rigorous and healthy, and bears fair crops. In some sections tender and rariable in quality. Leares with reniform glands. Flowers small.

Fruit rather large, oval. Suture only of moderate deptli, swollen point small. Skin rather downy, greenish white on all sides at first, but white with a creamy tint when fully ripe, and, when fully exposed, sometimes with a slightly purple cheek. Flesh white to the stone, a little firn, melting juicy, sweet, and rich. Middle of September.

\section{Napoleox}

Supposed to have originated near MTacon, Ga. Glands reniform. Flowers small.

Fruit medium to large, round, very downy. Skin almost dark red. Flesh pink, reined with red, juicy, rich. Freestone. Ripens last of July. (P. J. B., MIS.)

\section{Nectarine Peach.}

Raised from stone of a Dutch Nectarine, by Thomas Rirers. Glands reniform. Flowers large. 
Fruit large. Skin smonoth. Flesh melting, rich, peculiar, fine flavor Midlle Séptember. (liver's' Cart.)

\section{NIVETTE.}

Nirette Veloutée. Velout'e Tardive. Dorsetshire.

The Nivette is an execllent French variety, much resembling the Late Aduirable. Luras with globose glands. Flowers small.

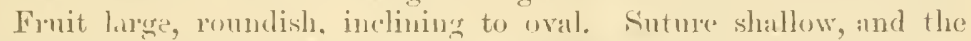
top slightly depressed. Skin pale inderen, with a lively real clicek. Flesh pale green, but deep red at the stone, juicy, melting; and very rich. Boginning and iniddle of seprtember.

\section{Nonlesse.}

\section{Vanguard. Mellish's Favorite. Lord Montague's Noblesse.}

An Enchish Peach, estecmed wherever known, as one of the laresest and most valuable varieties. Leares serrated, withont glands. Flowers large.

Fruit large, romulish oblong, a little nurowed at the top, and terminated by an acute swollen point. Skin slightly lowny. pale groen thronghont, marked on the eheek with delicate red, cloudeil with darker red. Flesh pale greenish white to the stone, melting, very juicy. Liast of Angust. Freestone.

\section{Oldimon Chingatone.}

\section{Oldmixon Cling.}

The Oldmixon C'lingstone is certainly one of the highest flavored of all Peaches known in this country, where it is raised in perfection, and should have a place in every goorl garden. Indeed we considel thic. the Large: White Cling, and the Heath Cling, as being the sorts anon!? the most desirable of this class of Peaches for small enllections. Icares with globose glands. Flowers small.

Fruit large, romulish oval. The snture distinct only at the top, on one side of which tle fronit is slightly enlalged. Skin yellowish white dotted with resl, or with a red cheek, varying from pate to lively real. Flesh prale white, very melting and juicy, with an exceedingly rich, lus. cions, high flavor. First of September:

\section{Oldmixon Frentone. \\ Oldmixon Clearstone.}

A large American Peach, of late maturity and rich flavor. It was, we believe, raised eithor from a stone of the Catherine (thing or the Ohmixon Cling, the latter having been brought to this country many years ago by sir John () dchixixon. It hears good crops, and is a valuable variety for market or garden. Leaves witl globose glands. Flower's small.

Fruit large, romelish or slightly oval, one sile swollen, and the suture visible only at the top. Cavity hut slightly sumk at the stalk. Skin prate yellowish white, marbled with red, the cheek a deep red. Flesh white, but quite red at the stonc. tender, with an excellent rich sugary, and vinous flavor. Beginning of september. 


\title{
Oi.D Newingtox.
}

\author{
Newington. Large Newir gton.
}

A celebrated English Clingstone, which has been in cultivation more than two hundred years, and still is perhaj's the best in the Enghish climate. Although excellent, it is not so generally estermed here as the Large White Cling and Oldmixon Clingstone. Leaves serrated, withont glands. Flowers large.

Fruit large, roundish, the sutme slight. Skin pale yellowish white, with a fine red cheek, marked with streaks of darker red. Flesh pale yellowish white, deep red at the stone, to which it always adheres rery firmly; melting, juicy, and rich. Ripens about the 15 th of September.

\section{Orange Clingstone.}

The Orange Cling is a very large, handsome, and excellent fruit, somewhat resembling the Lemon Cling in color, but globular in form, rather richer in flavor, and quite a distinct sort. Leaves large, serrated, without glands Flowers small.

Fruit large, round, the suture distinctly marked, and extending nearly round the fruit, swollen point at the top, none. Skin deep orange, with a rich dark-red cheek. Flesh dark vellow, rather firm, juicy, with rich, vinous flavor. September.

\section{OSCEOLA.}

Origin, Macon Co., Ga. Belongs to the Indian type. Flowers large.

Fruit medium, round. Suture medium, golden vellow, with an orange cheek, and a few reddish reins. Flesh yellow, stained and streaked with dull red, sweet, pleasant. Freestone. Last of September.

\section{Owes.}

\section{Owen's Lemon Rareripe.}

Origin, garden of J. Owen, Cambrilge, M[ass. Glands globose. Flower's small.

Fruit large, roundish. Suture large. Skin rich yellow, mostly covered with dark red or purplish red in the sum. Flesh rellow, red at the stone, tender, very juicy, of a delicious saceharine and slightly subacid flavor. Freestone. Middle to last of September.

There is ancther Owex, originated in Habersham C'o., Ga., which is described as having globose glands.

Fruit medium. Skin creamy white, downy. Flesh white to the stone,juicy, melting, sweet, and rich. Freestone. September.

\section{Paye de Poipone.}

$\begin{array}{ll}\text { Monstrous Pomponne. } & \text { Parie Rouge de Pomponne. } \\ \text { Monstrous Pavie. } & \text { Pavie Camu. } \\ \text { Parie de Pomponne Grosse. } & \text { Gros Melocoton. } \\ \text { Pavie Monstmenx. } & \text { Gros Persique Rouge. }\end{array}$

A large old French Clingstone. The fruit is very solid in flesh. The tree is of very strong growth. Leaves with reniform glands. Flow. ers large. 
Fruit very large, roumelish oval, with a well-marked suture extending to the top, and terminating there in an obtuse swollen point. Skin yellowish white, a good deal covered with the broad very deep red color of its cheek. Flesh fim, yellowish white, deep red at the stone, to which it adheres vecy firmly, and which is rather small, juicy. Flavor sweet and good. First of Oetober.

\section{Piçuet's Late.}

Originated with Antoine Piequet, Bell Air, Ga. Glands reniform. Flowers large.

Fruit large to very large, round, sometimes a little flattened and onesided. Skin yellow, with a red cheek. Flesh yellow, melting, sweet, rich, and perfumed. Tery good. Freestone. Eirly september. (P. J. B., MS.)

\section{Poole's Targe Yellow.}

Poole's Late Fellow Freestone. glands.

A very large Peach, of the Melocoton family. Leaves with reniform

Fruit large, roundish, with suture. Skin deep yellow, dark-red cheek. Flesh yellow, but red at the stone, juicy. Last of September. Freestone.

\section{President.}

One of the best of om Peaches, and a capital variety. Originated, several years ago, on Long Island. Leaves with globose glands. Flowers small.

Fruit large, roundish oval, the suture shallow. Skin very downy, pale yellowish green, with a dull red cheek. Flesh white, but deep red at the stone, very juicy, melting, rich, and high-Havored. Stone very rough. Middle of September. Freestone.

\section{President Church.}

Raised by the Rev. A. Churelı, President of Franklin College, Ga. Glands reniform.

Frnit large, roundish, inciining to oval. Suture shallow, often a mere line, with a small point at the apex, which is rarely depressed. Skin pale red in the shade, beantifully mottled and washed with dark red in the sun. Flesh white, pale red at the stone, very juicy, melting. Freestone. Ripe middle September.

\section{Princé of Wales.}

A late Peacl grown from seed of Pitmaston Orange Nectarine, by Thomas Rivers, England. Glands reniform. Flowers small.

Fruit very large, roundish, rather flattened. Skin downy, green in shade, but dark red in sun. Flesh greenish white, stained with red next the stone, tender, melting, juicy. Middle September. Freestone. (Hogg.) 


\section{Prince's Climax.}

Origicated on the farm of George Mitchell, Flushing, Long Island: very productive.

Fruit large, oval. Skin yellow, with a crimson cheek, and two thirds mottled with crimson. Flesh yellow, very rich, aromatic, pine apple flavor; adheres to the stone. Ripens the middle and end of Sep. tember.

\section{Prince's Excelsior.}

Originated with William R. Prince, Flushing, Long Island.

Fruit large, round. Suture slight, little abortive mamelon. Skin creamy white, shaled with erimson. Flesh yellow, rich, aromatic, sweet and rich; separates freely from the stone. Lipens middle of October.

\section{Prince's Paragon.}

Tree very vigorous and very productive.

Fruit large, oval. Skin yellowish green, shaded with red. Flesh juicy, luscions, and fine flavor. Separates from the stone. Ripens about the middle of September. (Wm. R. Prince, MS.)

\section{Princess of Wales.}

Raised by Thomas Rivers, fiom seed of Pavie de Pompone. Glands globose. Flowers large.

Fruit very large, round, terminated by a nipple. Skin cream-colored, very slightly shaded with blush. Flesh meling, juicy, rich, deep red at the stone. Freestone. October. (Hogg.)

\section{Pucelle de Malines.}

A foreign variety not much known here. Leaves without glands. Flowers large.

Fruit large, round. Suture distinct. Skin downy, yellow, becoming red in the sun. Flesh yellowish white, stained with red round the stone, melting, juicy, sweet. Early September. Freestone.

RAY.

Originated by Dr. H. Ray, of Tallobusha Co., Miss. Glands reniform.

Fruit medium, roundish, with a nipple. Skin cream white, spotted with purple. Flesh juicy. Late in August. South. (Gar. MIon.)

\section{Paymackers.}

A foreign variety. Leaves serrated.

Fruit large, round. Snture deep at ends. Skin downy, clear yel. :ow, largely colored with carmine. Flesh white, melting, vinous. Sept. Freestone. (Alb. Fom.) 


\title{
Red-Cheer Melocoton.*
}

Malagatune.

Milacatune.

Hogg's Melocoton.
Yellow Malocoton.

Yellow Malagatune.

Red Cheek Malocoton.

The Nelocoton (or Malagatune, as it is commonly called) is almost too well known to need description. Almost every orehard and garden in the country contains it, and hundreds of thousands of bushels of the fruit are raised and sent to market in this country every year. It is a beautiful and fine fruit in farorable seasons, though in nufavorable ones the acid frequeutly predominates somewhat in its flavor. It is an American seedling, and is constantly reproducing itself under new forms, most of the varieties in this section having, directly or indirectly, been raised from it; the finest and most popular at the present time being Crawford's Eirly and Late Melocotons, both greatly superior, in every respect, to the original Melocoton.

l'ettit's Imperial, Mirldleton's Imperial, Scott's Nompareil, and Tice, are seedlings of this variety, but not sufficiently distinct and valuable to merit cultivation. Leaves with globose glands. Flowers small.

Fruit large, roundish oval, with a swollen point at the top. Skin yellow, with a leep red cheek. Flesh deep yellow, red at the stone, juicy, melting, with a good, rich, vinous thavor. First of September. Freestone.

\section{Red Nutueg.}

\author{
Avant Ronge. \\ Avant Pêche de Troyes. \\ Red Avant. \\ Early Red Nutmeg.
}

The Red Nutmeg is a very small and inferior Peach, which has lonz been cultivated solely on account of its earliness. It is now seldom seen in our garlens, being abaudoned for better sorts. It is iesirable, howerer, in a complete collection. The tree grows slowly, and is of dwarf habit. Leaves small, with reniform glands. Flowers large.

Fruit small, roundish, with a distinct snture, terminating in a small, round, swollen point at the top. Skin pale yellow, with a bright, rich red cheek. Flesh yellowish white, red at the stone, with a sweet and rather pleasant flavor. Niddle and last of July. Freestone.

\section{Red Rareripe.}

\section{Large Red Rareripe, of some.}

Early Red Rareripe.

This Peach strongly resembles the Royal George, and we believe it an American seedling from that variety, which is, however, distinct, and superior in flavor.

It must be observed, that this is totally different both from the Errly Fork and Morris's Red Rrereripe, with which it is often confounded by some. 'The fruit is larger, broader, and a week later than the first; and its serrated leaves, and different flavor, separate it widely from the latter. Ends of the branches sometimes slightly mildewed. Leaves serrated, without glands. Flowers small. 
Fruit rather large, globular, but broad, depressed, and marked with a deep, broad sutmre, extending nearly round the whole fruit. Skin white, mottled, and marked with numerous red dots, and the cheek of a rich dark red. Flesh whitish, but red at the stone, melting, juicy, very rich and high-flavored. Middle and last of August. Freestone.

\section{Reeves' Favorite.}

Raised by Samuel Reeves, Salem, N. J. A hardy and productive kind. Glands globose. Flowers small.

Frnit large, roundish, inclining to oval, with a swollen point. Skin yellow, with a fine red cheek. Flesh deep yellow, red at the stone, juicy, melting, with a good, rinous tlavor. Freestone. Middle of September.

\section{Reine Des Vergers.}

\section{Monstrueuse de Doue. Orchard Queen.}

An old French Peach but little known in this comntry. Leaves with reniform glands. Flowers small.

Fruit lirge, roudish, narrowing a little at stem end. Snture nearly round. Skin whitish, mostly covered with dull deep purplish red in the sum. Flesh whitish red at the stone, juicy, melting, vinous. Last September. Freestone.

\section{Rivers' Early Tork.}

Leaves with globose glands. Flowers large.

Fruit medium. Skin marbled with red. Flesh melting, juicr, Nectarine flavor. Not liable to mildew. Early Angust. Freestore. (Rivers' Cat.)

\section{RoduAN's RED. \\ Rodman's Cling.}

An American Clingstone, not of the richest quality but very showy for market. Leaves with reniform glands. Flowers small.

Fruit large, roundish oblong. Skin mostly covered with fine red. Flesh white, juicy, rather firm, vinous. Last of September.

\section{Rose Aronatic.}

Originated with J. F. Nesmith, Indian Town, S. C.

Fruit medium, oblong. Suture distinct, one side enlarged. Skin yellow with dark orange eheek, washed with red, very downy. Flesh white, red near the stone, rather dry, with a peculiar rose aromatic perfume. Freestone. Ripe last of July. (P. J. B., MIS.)

\section{Rosebank.}

Raised by James Dougall, Windsor, Canada West. Tree healthy, moderate bearer.

Fruit large, round. Suture deep. Skin greenish white, with a beantiful dark red mottled cheek. Flesh whitish, juicy, melting, rich, and excellent. Separates from the stone. Last of August. 


\section{Royal Charlotte.}

New Roral Charlotte.

Grimwood's Royal Charlotte.

New Early Purple.

Lord Nelson's.
Lord Fanconberg's Mignonne.

Marleleine Ronge 'Tarrive.

Madeleine Romge it Moyenne Fleur

Madeleine is Petite Flenr.

A very excellent Peach, and a favorite valety with all Europoar gardeners. Its leaves are nore coarsely and deeply serrated than those of other varieties. Leaves serrated, without glants. Flowers small.

Fruit rather large, inclining to ovate, being rather broader at the base than at the top; the suture of moderate size. Slin pale greenish white, with a deep red mabled cheek. Flesh white, hut pale red at the stone; melting, juicy, rich, and excellent. Beginning of reptember. Freestone.

\section{RoYAl George.}

Early Roval fieorge.

Millet's II Iignonne.

Lockyer's Mlignonue.

Griffin's Mignome.

Superb.

\section{Red Magrlalen.}

Madeleine Rouge à Petite Flenr French Chancellor, incorrectly, of some.

Early Bourdine,

Double Swalsh,

Few of the early Peaches surjass in flavor and beanty the Royal George. It is one of the finest Luropean varieties. It is a regular and moderate bearer. Leaves serraterl, without glands. Flowers small.

Fruit above the midlle size, or rather large, globular, broad, and depressed, the suture deep and broad at the top, and extending romul twothirds of the fruit. Skin pale or white, thickly sprinkled with red ats, and the cheek of a broud, rich, deep red, slightly marbled. Flesh whitish, lut very red at the stone, melting, juicy, very rich, and of the highest Havor. "Erom the 20th to the last of August. Freestone.

\section{Scott's Early Pied.}

Scott's Early Red is a variety of a very exceilent flavor, and a pro lific bearer, which was received from New Jersey. Leaves with obscure globose glands. Flowers small.

Fruit of medium size, roundish, a little depressed, the suture distinctly marked, but not deep. Skin pale greenish white, but much covered with red, which is mottled with fiwn-colored dots. Flesh whitish, very juicy, with a rich and luscious flavor. Middle of August. Freestone.

\section{Siott's Magaate.}

A noble variety of the Red Rareripe. Glanrls reniform.

Fruit very large, round, depressed. Skin pale yellow, with a darkred cheek. Flesh white, huscious, and well-flavored. Ripens early in September. (Prince's Mis.)

\section{Scott's Nectar.}

Another very fine seedling from the Red Rareripe. Glands glolose.

Fruit large, round, somewhit depressed. Color red shaded on pales yellow ground, and bright red next the sum. Finsh white, very sweet, aud of the highest thavor. Ripens carly in september. (1'rince's MS.) 


\section{S:OTT'S OCTOBER.}

Originated with Jacob C. Lrons, Colnmbia, S. C.

Fruit medinm to large, pale dingy lemon yellow. Flesh firm, with a lemon flavor. Last of Uctober. Clingstone. (Sumner, MIs.)

\section{Shatghate.}

Trees of this variety and Chinese Cling were sent to this country by the late Mr. Winchester, while British Consul at Shanghae. Tree vigorons. Glands reniform. Flowers large.

Fruit large, oval, trumcate. Sutme distinct, extending from the base to beyoul the apex, deepening very much at the apex, so as to form quita a cavity. Skin greenish yellow, quite downy, sometimes a little mottled or shaded with pale red. Flesh greenish yellow, rery melting, juicr, adhering to the stone, with a high, vimous flavor. Ripens from first to midcle of September. At the South, last of July and fir'st of August.

\section{Silth's Favorite.}

Grown by Calvin Smith, Lincoln, Mass. Glands reniform.

Fruit large, roundish. Suture deep. Skin yellow, mostly covered with deep rich red. Flesh yellow, juicr, sweet. Freestone. Middle to last of September. (Cole.)

\section{Suith's Newiagton.}

Early Newington. Smith's Early Newington. Farly Newington.

This is one of the best early Clingstone Peaches. The Early Jewington of our gardens as generally known (see Early Newington Freestone), is earlier and a very much tiner variety, with renifurm glands; veing a partial Clingstone, but most frequently parting from the flesh, has quite supplanted it. Leares serrated, without glands. Fluwers large.

Fruit middle-sized, rather oval, narrower at the top, and one half at little enlarged. Skin pale straw-color, with a lively led cheek streaked with purple. Flesh firm, pale yellow, but light red at the stone, to which it adheres closely; juicy, and of very good quality. Last of August.

\section{Suock Freestone.}

\section{St. George.}

This was originated by Mr. Smock, of Middleton, N. J. Leares with reniform glands.

Fruit large, oval, narowed towards the stalk, and rather compressed on the sides. Skin light orange rellow, mottleel with red, or aften with z dark-red cheek when fully exposed. Flesh bright rellow, but red at the stone, moderately juicy and rich. Ripens last of September and tirst of October.

\section{SNow.}

The snow Peach is a remarkably fair and beantiful fruit. of American origin. The fruit and blossoms are white, and the foliage and wood of a light green. Leaves with reniform glands. Flowers small.

Fruit large, globular. Suture faintly maked, cxcept at the top 
Skin thin, clear, beautiful, white on all sicles. Flesh white to the stone, juiey and melting, with a sweet, rich, and sprightly flavor. Begiming of September. Freestone.

\section{Stephexson Clixg.}

From 'Thonas Stephenson, Clark Co., Gia.

Fruit large, roundish. Suture distinct. Skin very downy, of a creamy tint, sharled with flesh-color-the tint decpening in the smo to a dark, dull, purplish red where fully exposed. Flesh white, somewlat tinged with red, and deep red at the stone. Flesh very tender, melting, juicy. September tirst.

\section{STetson's SEedLixc.} small.

Raised by N. Stetson, Bridgewater, Mass. Globose glands. Flowers

Fruit large, roundish. Suture indistinct. Skin greenish white, marbled and shaded with erimson in the smo. Flesh white, pink at the stone, very melting, juicy, brisk, rieh. Freestone. Rijens from middle to last of September. (Hov. Mag.)

\section{StrRAwBerRy.}

Rose.

The Strawberry Peach we received from the late Thomas Ifancoek, of Burlington, N. J. It is esteemed one of the very finesi earty varieties for orchard culture in that State. It is quite distinet from the Early York. Leaves with reniform glands. Flower's small.

Fruit of medium size, oval, the cavity at the stem deeply sunk, the suture exteuding half round. Skin marbled with deep red over almost the whole surface. Flesh whitish, melting, juicy, rich, and of very delicious flavor. Middle of August.

\section{Stump the WORLD.}

A native of New Jersey, large and showy, and profitable for market growing. Flowers small. Glands globose,

Fruit very large, romulish, a little oblong. Skin creamy white, with a bright red cheek. Suture shallow, rather more than lalf round. Flesh white, juicy, and high-flavored. Last of September. Freestone.

\section{STURTEVANT.}

Raised from seed by E. T. Sturtevant, Clevelaurl, O., in 1826. It is one of, if not the, best yellow-fleshed Peaches grown.

Fruit medium or above, roundish, compressesl. Broarl shallow suture half romm, followed by a ilark line. Skin downy, rich yellow, mostly eovered with dark rich red, very dark in the sum. Flesh yollow, red at the stone. Stone very small. Freestone. Last of August to irst of September. (Elliott.)

\section{Sumelis's Early.}

Fruit melium to large, beautiful blush. Flesh white, firm, bears 
transportation well. Early and valuable for market. Freestone. (Summer's MS.)

\section{Sunner's White Free.}

From South Carolina. Flowers large.

Fruit large, nearly round, slightly depressed. Sides unequal. Suture large, half round. Skin whitish green, a shade of red in sun, downy. Flesh white to the stone, juicy, sweet. Last of August, early September.

\section{Susquehaxia.}

Griffith Malacotune. Griffith. Griffith Mammoth.

Originated with $M[r$. Griffith, on the banks of the Susquehama. A large, hamblsome fiuit, and a favorite in that section.

Fruit large, nearly globular. Suture half romd. Skin rich yellow, with a beautiful red check, nearly corering the whole surface. Flesh yellow, sweet, juicy, with a rich vinous flaror Ripens from the first to the middle of September. Freestone.

\section{Tinley's OCtOBER.}

Origin, Macon, Ga. Glands reniform. Flowers large.

Fruit medium, slightly ollong, white, with a light wash of red. Flesh white, jnicy, vinous, very good. Ripe middle of October. (P. J. B., MS.)

\section{TIPPECANoE.}

\section{Hero of Tippecanoe.}

A large and handsome Clingstone, originated by George Thomas, of Philadelphia. Its lateness and beauty render it a valuable kind. Leaves with reniform glands. Flowers small. The shoots dark purplish red.

Fruit very large, nearly round, a little compressed on the sides. Skin yellow, with a fine red cheek. Flesh yellow, juicy, with a good vinous flavor. It ripens from the 20 th to the last of September.

\section{Titus.}

Originated with Mrs. Sarah Titus, Philadelphia.

Fruit large, roundish. Skin fair yellow, with a rich cneek. Flesh yellow, red next the stone, juicy. Maturity middle to last of September. Freestone.

\section{Troth's Early Red.}

A New Jersey Peach, valued as an early sort, profitable for market. Glands globose. Flowers small.

Fruit medium, roundish. Skin whitish, bright red in the sum, Flesh white, red at the stone, juicy, sweet. Freestone. Ripens early in August. 


\section{Tufts' Rarertpe.}

Originated with Bermard T'ufts, Billerica, Mass. Very hardy, vigorous, and productive. Glands globose.

Fruit medium, roundish. Skin yellowish, with a bright red cheek. Flexh yellow, melting, rery sweet and luscions. Freestone. Middle to last of September. (Cole.)

\section{Tax Burex's Goldex DWarf.}

An accidental seedling found in the grounds of J. V an Buren, Clarksville, Gar. The habit of this is somewliat dwarfed, and it is well suited for pot culture. Flowers small.

Fruit medinm, roundisl ovate, pointed at apex. Skin golden yellow, with a crimson cheek in sun. Flesh yellow, firm, juicy, sprightly. Clingstone. September to early October.

\section{Yax ZaNDT's Superb.}

Originated in the garden of L. B. Van Zandt, Long Island. Flowers small.

Fruit medium size, oval. Skin nearly smooth, white, delicately marbled with red, giving it a waxen hue; the beauty and smoothness of the skin approximate in appearance to that of a nectarine. Flesh melting and delicious; separates fiom the stone. Ripens in August.

\section{Walburtor Adminabe.}

An English variety, which is found very good here. Flowers small.

Fruit large, roundish. Suture medium. Skin greenish white, finely shaded with dark red in the smo. Flesh white, a little stained at the stone, juicy, melting, with a rich sweet flavor. Middle and last of September. Freestone.

\section{WALTER'S EARLY.}

Wraiter's Early is esteemed as one of the most popular early varieties for orchards in New Jerser, where it originated. It is remarkably well adapted to the light sandy soil of that State, bearing abundant crops of excellent fruit. Leaves with globose glands. Flowers small.

Fruit large, roundish. Skin white, with a rich red clieek. Flesh whitish, a little touched with red at the stone, melting, juicy, sweet, and of very agreeable flavor. Ripens about the 20th of August.

\section{WARD'S LATE FreE.}

A fine late American variety, vigorous and productive, valuble for market. Glands reniforn. Flowers small.

Fruit rather large, roundish, inclining to oval. Skin white, with a beautiful crinson cheek. Flesh white, slightly tinged with red at the stone, juicy, melting, rich, and excellent. Freestone. First of Octolver.

\section{WASIIYGTON.}

Washington Red Freestone.

The Washington is a landsome and very delicious Peacl, of American origin. It was named and first introduced to notice by Michael Floy, 
New York. The fruit ripens late ; the tree is vigorous, hardy, and pro. cluctive, and it is altogether a valuable variety. Leaves with globose glands, Flower's small.

Fruit large, broad, depressed, with a broad, deep suture extending nearly round it. Skin very thin, vellowish white, with a deep crimson cheek. Flesh pale yellowish white, very tender, juicy, and melting, with a sweet, rich, and luscious flavor. It often adheres shightly to the stone, which is quite small. Niddle of September. Freestone

\section{Washington C'lingistone.}

An American variety, juicy and sweet. It is neither handsome nor prepossessing externally. Leaves with reniform glands. Flowers small.

Fruit of medium size, roundish. Skin yellowish green, marked with gray specks, and with a slight tinge of red on the sunny side. Flesh very juicy, tenter, and melting, with a very sweet and luscions flavor. I ast of 'September.

\section{White BALL.}

Originated in Massachusetts. Leaves with reniform glandis. Flowers large.

Fruit medium, roundish, siightly depressed. Suture medium, half round. Skin greenish white, shaded and marbled with red in the sun. Flesh white to the stone, juicy, melting, sweet. Early September. Freestone.

\section{White-Blossoned Trconparable.}

\section{White Blossom. Willow Peach.}

This is a native fruit, of second quality. much inferior both in flavor and appearance to the Snow Peach. Leaves with reniform glands. Flowers large, white.

Fruit large, oval. Skin fair, white throughout. Flesh white to the stone, melting, juicy, pleasant. September.

\section{White IMPeriar.}

The White Imperial is a fruit of most estimable quality. This fino Peach originated in the garden of David Thomas, of Cayuga Co., N. I., long known for his skill and science as an amateur hortieulturist. Leaves with globose glands. Flower's small.

Fruit rather large, broad, depressed, hollowed at the summit, with a wirle, deep cavity at the stem; the suture moderately deep, and the finit enlarged on one of its sicles. Skin yellowish white, with only a slight tinge of red next the sun. Flesh nearly white, very melting and juicy, of a very delicate texture, and the flaror sweet and delicious. Ripens last of August. Freestone.

\section{WiItTe MAgDalexe.}

Made Blanche. Madeleine Blanche de Loisel. MIontagne Blanche.

A foreign variety. Leaves without glands. Flowers large.

Fruit mediun, roundish, flattened at base. Suture deep. Skin 
slips casily from the flesh, yellowish white in the sharle, marked with red in the sum. Flesh white, with yollowish veins, and red next the stone. Juicy, melting, sweet, vinous. Lipe middle August. Freestone.

\section{Wilite Nutueg.}

\section{Early White Nutmeg.}

The White Nutmeg is the smallest of Peaches, the flavor is inferior, and it is only esteemed by curious amatens as ripening a few days earlier than any other variety. Leaves serrated, withont glands. Flowers large.

Fruit rery small, rather oval, with a deep suture extending a little more than half round. Skin white, or rarely with pale blush. Flesh white to the stone, with a sweet and slightly musky, pleasant flavor. Ripens about the 10th or 15th of July. Freestone.

\section{Winte Pace.}

A Southern Peach, a variety of the Indian or Pace Peach, but with a comparatively white skin. Flesli yellowish, juicy, sweet. August. Freestone.

\section{VIOLET HÂtIVE.}

English Galand.
Hardy Galand.

A rariety of Bellegarde. Glands globose. Flowers small. Fruit similar to Bellegarde, but smaller and paler in color.

\section{Yellow Alberge.}

$\begin{array}{lll}\text { Alberge Jame. } & \text { Gold-Fleshed. } & \text { Red Alberge. } \\ \text { Píche Jaune. } & \text { Tellow Rareripe. } & \text { Golden Nignonne. } \\ & \text { Purple Alberge. } & \end{array}$

The Tellow Alberge is an old French variety, and one of the earliest of the vellow-fleshed Peaches. It is, no doubt, the original solt from which our Melocotons and Iellow Rarreripes have sprumg in this comn. try. It has only a second-rate flavor, except in rich, warm soils, and is not comparable to the Yellow Rareripe in size or quality. Leaves with globose glands. Flower's small.

Fruit of medium size, roundish, with a well-marked furrow ruming hilf round. Skin vellow, with a deep purplish-red cheek. Flesh vellow; lut deep red at the stone, soft, juicy, sweet, with a pleasant vinous flavor. Widdle of $A$ ugust. Freestone.

The Rosixsi, Alberge Taune Tardif of many French gardens, ant Tellow Alberge of some gardens here, differs firom the above only in having reniform glands and ripening ten or twelve days later. Flavor second-rate.

Barnard's Early and Yellow Honest John are probably identical, or, if seedlings, so near like the parent, Yellow Alberge, as to be unworthy particular attention. 


\section{Yellow RARERTPE.}

Large Yellow Rareripe.

Red and Yellow Rareripe.
Marie Antoinette. Cutter's Tellow

One of the finest very early yellow-fleshed Peaches. It is in Aneri. can seedling, and well deserves the extensive cultivation it receives both in the orchard and garden. Leaves with globose glands. Flowers small.

Fruit large, romdish, the snture shghtly depressed, extending nore than half round, the swollen point at the toj small. Skin deeprorange yellow, somewhat dotted with red, the cheek rich red, shated off in streaks. Flesh deep yellow, but red at the stone, juicy, melting, with a rich and excellent vinous flavor. Ripens from the 25th to the 30th of August. Stone small. Freestone.

\section{CURIOUS OR ORNAMENTAL TARTETTES.}

\section{Double-Blossomen.}

Double-Flowering Peach. Rose-Flowering.
Pécher à Fleurs Doubles. Pêcher à Fleurs Semi-Doubles.

The T)onble-Blossoned Peach is, when in full bloom, one of the gayest and nost beautiful of finit-trees, and blooming with its lovely companion, the Double-Flowering Cherry, finds a place in all our pleasmegronnds and ornamental plantations. Its flowers are of a lively rose color, nearly full double, and so thickly disposed on the branches as to be rery striking and showy. They are prodnced at the nsual season. or a few days later. This sort is rendered more dwarf for shrubberies by budaling it upon the Mirabelle or the Cherry Plum stock. The leaves have reniform glands.

The fruit, which is sparingly produced, is romelish oval, pale greenish vellow, faintly tinged with red. Freestone, and of indifferent flarur.

The Crimsos or Cameldia-floweren, with large double-Howers of a rich crimson hne, especially attractive and showy, the CARxitiosFLOWERED, with flowers striped like a carnation, and the TARIEGATEDFLOWERED, with flowers of different hues on the same tree, are among the more recent introductions, and, gromped with the older varieties, are very effective.

\section{Flat Peach of Chisa.}

Chinese Peach. Java Peach. Peen To.

A very singular variety, from China, where the gardeners affect all manner of vegetable curiosities. The fruit is of small size, about two inches in cliameter, and so mnch flattened at the ends that only the skin and the flat stone remain, the fleshy part being crowded on either side. The tree is of rather dwarfish habit, and holds its leaves very late. The fruit is of very good flavor, and is well worthy of a place in the gardens of the curions. * Leaves with renifor'm glands. Flowers large.

Fruit small, so much flattened as to form a deep hollow at both ends, having at the top a singular broad, rough, five-angled eye. skin pale

* Should any one of our amateurs now possess it, we shall be much gratified to receive buds of it. 
yellowish green, mottler with red on one side. Flesh pale yellow, with a circle of red round the stone (from which it separates), swcet, juicy; witis a slight noyal Havor. IBeginning of September.

\section{Whepis: Peich.}

Reid's Weeping Peach.

A peculiar variety, with penclent, weeping branches, and a habit much like that of the weeping ash. It was originated ly the late Wm. Reid. 'To display itself to adrantage it should be grafted six or eight feet high, on the clean stem of a peach or plum stock. Reniform glands. Flowers large.

Selection of chnice Penches, to furnish in sucepsion. Fieestomes: Hale's Early, Early Tork (serrate), Early Newington, Coolerlge's Favorite, George the Fonth, Grosse Mignome, Craw ford's Early, C'ruwford's Iate, Olimixon Free, Morris' IThite, Tan Zaukt's Superb, Ward's Late Free, Noblesse, Late Red Rareripe, Druid Hill. Clingstones: Lirge White, Oldmixon and Heatlı Clings.

\section{SELECTION OF VARIETIES FOR TLE SOUTH.}

With no actual personal knowledge of the success and value of varieties at the South, we have compiled the following list from a summing up of majorities of leating Southern pomologists in their faror.

\section{Freestones.}

$\begin{array}{lll}\text { Amelia } & \text { Early Tillotson. } & \text { Picquet's Late. } \\ \text { Columbia. } & \text { Grosse Mignonne. } & \text { President Church. } \\ \text { Crawford's Early. } & \text { Lady Parham. } & \text { Susquehanna. }\end{array}$

Stump the World.

\section{Chingstones.}

Chinese

Eaton's Golden.
Heath.

Lemon.

Washington.
Oldmixon.

Tinley's October.

\section{CHAPTER XXVII,}

TIIE PEAR.

Pyrus communis, L. Rosacer, of botanists.

Poirier, of the French; Biruebum, German; Peer, Dutch; Pero, Italian; and I'err, Spanish.

The Pear is undeniably the farorite fruit of modern times and modern cultivators. Indeed, we believe the Pear of modem times, 
thanks to the science and skill of horticulturists, is quite a different morsel for the palate from the pear of two or three centuries ago. In its wild state it is one of the most austere of all fruits, and a choliepear of our fields, realiy a great improvement on the wild type, seizes one's throat with such an mmerciful gripe as to leare belind it no soothing remembrances of nectar and ambrosia.

So long ago as the earliest time of the Romans the pear was considerably enltivated. It was common in Syria. Egrpt, and Greece, and from the latter comitry was transplanted into Italy. "Theophrastus speaks of the productiveness of the old pear-trees, and Tircil mentions some pears which he received from Cato. Pliny in his 15 th hook describes the varieties in cultivation in his time as exceedingly numerous; and mentions a number which were namert after the countries from which they were received. Of all pears, he says, the Costumine is the most delicate and agreeable. The Falernian wear was esteemed for its juice; and the Tibemian, because it was preferred by the Emperor Tiberins. 'There were 'proul pears,' which were so ealled because they ripened early and would not keep, and "winter" pear's, pears for baking, as at the present day." None of these old Poman varieties have been handed down to us, and we might believe some of them approached the buttery hecionsmess of our modern pears, did not Pliny pithily ad, most unfortunately for their reputation, "all pears whatsoever are but a heavy meat, mless they are well boilerl or baked."

In fact, the really delicions qualities of this fruit we'e not dereloped until about the serenteenth century. And within the last sixty vears the pear, subjected to constant prodnetion from seed by $\mathrm{T}$ an Nons and his followers, and to hybriclizing or cronsing by MIr. Kinight and other Enghish cultirators, appear's at length to have reacher alnost the smmmit of perfection in beanty, duration, and flaror. Of I'rofessor Van Mons and his labors of a whole life. almost devotel to jwerse, we have already spoken in our first chapter. From amoug the so, $00(1$ seedlings raised by himself, and the many thousands reared ly other zealous cultivators abrond, especially in Belgium-the Elen of the perartree-there have been selected a large number of virieties of ligh excellence. In this comitry wo are contimually adiling to the number. as, in our newer soil, the pear, following the natural laws of successive reproduction, is constantly applaring in new seedling forms. The high thavor of the Seckel Pear, an American variety, as yet mmonpased in this respect by any European sort, proves the natural congeniality of the climate of the Northeru states to this fruit.

The pear-tree is not a native of North America, lunt was introrluced from the othel eontinent. In Enrope, Western Asia, and China it grows wild, in compiny with the ajple, in hedges and woody wastes. In its wild state it is hardier and longer lived than the apple, making a taller and more prramidal head, and becoming thick in its trunk. There are trees on record abroal of great size and age for fruit-trees. M. Bose mentions several which are known to be near 400 rears old. There is a very extraordinary tree in Holme Lacy, Herefordshire. Eng. land-a perry pear-from which were made, more than once, lis hougsheadis of perry in a single year. In 180,5 it covered more thain lialf an acre of land, the branches bending down and taking root, and, in turn. prodncing others in the same way. Lomdon, in his work on trees, says that it is still in fine health, thongh reduced in size. 
One of the most remarkable pear-trees in this country is growing in Illinois, alont ten miles north of Vincemes. It is not believer to be more than forty years old, having been planted by Mrs. Ockletree, about 1805 . The girth of its trunk one foot alowe the somml is twete? feet, and at nime feet from the gromul, six amel a half feet; and its branches extend over an area ninety-fonl feet in dianeter. In 183. it yielded $18+$ bushels of pears; in 1840 it yielded 140 bushels. It is enormonsly productive always; the fruit is pretty lange, ripening in early antumn, and is of tolerable flivor.

The tree came into hearing at the fifteenth yoar from its plinting, but grafts from it prorluce in about four or five years. Like the ilix, it is almost thomless, and it is remarkable that no blight. of any kincl has ever affected it.

The Stnyvesant Pear-Thee, which was destroyed in 1867, was originally planted by the old governor of the Dutch colony of New York, more than two lundred years ago, on what was once his fumm, but in now part of the eity, quite thickly covered with houses.

Along the St. Clair river, below Detroit, and on the banks of the Mississiplyi, near St. Louis, are found many large old pear-trees vying in health and vigor with those of recent p'anting.

Uses. The great value of the Peall is as a dessert fruit. Next to this, it is highly esteemed for baking, stewing, preserving, and minmalades. In France and Belginm the fruit is very generally dred in ovens, or much in the same way as we do the apple, when it is yuite an important article of food.

Dessert pears should have a melting, soft texture, and a sugary, aromatic juice. Kitchen pears, for baking or stewing, shonlal be large, with firm and crisp Hesh, moderately juicy.

The juice of the pear, fermented, is called Perry. This is mado precisely in the same way as cider, and it is richer, and more estermod by many persons. In the midland counties of England, and in varions parts of France and Germany, what are called Perry Pears-rery hariy productive sorts, having an anstere juice-are largely cultivated for this purpose. In several places in onr Eastern States, we understand, perry is now annually made in considerable quantities. The fruit should be ground directly after being gathered, and requires rather more isinglass (say $1 \frac{1}{2} \mathrm{oz}$. to a barrei) to fine it, on racking, than cider. In snitable soil the rield of perry to the acre is usually about one-third more than that of cider.

The word of the Pear-tree is heavy and fine-grained, and makes, when stained black, an excellent imitation of ebony. It is largely employed by tmmers for making joiner's' tools. The leaves will dye yellow.

Gatherixg axd Keepling the Frutt. The pear is a peculiar fruit in one respect, which shonld always be kept in mind: viz., thert most varieties wie much finer in fluvor if picled from the tree and ripened in the house, than if allowerl to bceome fully matured on the tree. There are a few exceptions to this rule, but they are rery few. And, on the otler hand, we know a great many varieties which are only second or third-rate when ripened on the tree, but possess the highest and rich est flavor if gathered at the proper time and allowerl to mature in the house. 'This proper season is easily known, first, by the ripening of a fow full-grown but worm-eaten specimens, which fidl soonest fiom the tree; and, secontly, by the ehange of color and the readiness of the 
stalk to part from its branch on gently raising the fruit. The fruit should then be gathered-or so much of the crop as aypears sufficiently natured-and spread ont on shelves in the fruit-room.

So important is the ripening of pears in the house, that most amateurs of this fruit find it to their advantage to have a small roorn set apart and fitted up with shelves in tiers, to be nsed solely as a finit-irnm.

In absence of any room sprecially devoted to the jupose. shallow drawers, say four inches deep, and from one and a half to two feet in diameter, should be procured, and into the bottom of each lis a suft woollen cloth, then a layer of pears. but so that they may not totich each other; then over them lay another soft woollen cloth, and place the rhawers in a cool dry room. In a period rarying from three clays to as many weeks, according to the rariety, the fruit will be fonnd to have ripened to a delicions richness, and to have taken on a high golden color, seldom or never obtained when allowed to ripen on the tree. Some r.trons use the common lunsks called "short." from the flouring-miils. to corer thie pears in place of the woollen cloths, and with pertaps equally good results, but it is not as neat or conrenient a practice.

Many sorts which, ripened in the smo and open air. are rather dirg, when ripened within doors are most abundantly melting and juicy. They will also last for a considerably longer period if ripered in this way-maturing gradnaily, as wanted for nse, and leing thus beyond the risk of loss or injuy by violent storms or high winds.

Winter dessert pears should be allowed to hang on the tree as long as possible, until the nights hecome frosty. They shomld then be wrapped separately in paper, packed in kegs, brirels. or small braps, and placed in a cool, dry room, free from frost. Some rarieties, as the I) Aremberg, will ripen tinely with no other care than placing them in barrels in the cellar like apjles. But most kinds of the tinc(r. winter dessert pears should be brought into a warm al artment for a couple of weeks before their usial season of maturity. They should be kejt covered, to prevent shrivelling. Many sorts that are comparatively tongh, if ripened in at cold apartment, become very melting, buttery, and juicy when allowed to mature in a room kept at the temperature of 60 or 70 degrees.

Proparatiox. The finer sorts of pears are continuter or increased by grafting and budding, and the stocks on which to work are either seedlings or suckers. Sucker stocks have usualls snch indifierent roots. they are so liable to prodnce suckers continually themselves, and are so much less healthy than seedlings, that they are now seldom nseil by good cultivators; though, if quite young and thrifty, they will often make good stocks.

Seedlings, however, are by far the best stocks for the pear in a!l cases; and seedlings from strong-growing, healt hy pears, of common quality - suc 1 as grow abont most farmer's' gardens-are preferahle for stocks to those aised from the best varieties, being more hardy and vigorons.

As it is nsually fonnd more diflicult to raise a good supple of seedling pear-stncks in this comtry than of any other fruit-tree, we will here lemark that it is absolutely necessary. to insure snccess, that two points be observed. The first is, to clean and sow the seed as soon as may be after the finit is well matmed; the second, to sow it mly in deep ridh soil. It shonld be previonsly trenched-if not natmally deep-at least $t w \in$ nty inches or two feet deep, and entiched with mamure or compost mixed 
with ashes. This will give an abundant supply of nutriment to the young seedlings the first year, without which they become starved and parched, after a few inches' growth, by our hot and diy summer, when they frequently fall a prey to the apluis and other insects at the root and top. A mellow, rich soil, whose depth insures a supply of moisture, will give strong seedlings, which are always, at two years growth, fit to gro into the mu'sery-rows for budding; while a dey, thin soil will seldom produce good stocks, even in half a dozen years.

The seeds should be sown precisely like those of the apple, in broal drills, and the treatment of the stocks, when planted in the wows for budding, is quite similar. Budding is almost miversally prefered by us for propangiting the pear, and this tree tikes so readily that very few fililures (an happen to an experienced hand. A bont the first of August, in this latitude, is the proper season for prerforming this operation.

We may add here, that one-year-old pear seedlings are often winterkilled when the antumn has not been such as to ripen the wond tholoughly. A few branches of evergreens, or some slight covering lais along the rows will prevent this. Or they may be lail in by the heels in a sheltered place.

The thom makes rery good stocks for the peir, except that if grafted above ground the tree is often apt to be broken off at the point of union by high winds. This is obviated by grafting a little below the surface. Grafting on the thorn is a very useful practice for strong clayey soils. as on such stocks the pear may be glown with snccess, when it would not otherwise thrive. It also comes rather earlier into bearing. The mountain ash is thought hy some to be a valuable stock for light sandy soils, but care should be taken that the graft or bud be inserted low down near the crown of the stock, so that when transplanted the whole of the stock can be covered with soil, otherwise the borer will soon destroy it. The pear is sometimes budded on the apple, but it is then usually very short-lived.

For rendering the pear dworf, the Quince stock is almost niviversally used, as the pear unites rearlily with it, becomes quite dwillf in habit, and bears very early. Some large-growing pears-as the Dncliess of Angonlème-extremely liable to be blown off the tree, bear much better on the quince stock, and others are considerably improved in flivor by it. The dwarf pear, however, it must be confessed, rither belongs to the small garden of the amatem than to the orehardist, or him who desires to have regular large elops and long-lived trees. The dwarf tree is usually short lived, scldom enduring more than fifteen or twenty years in bearing-but it is a protty and economical way of growing a good many sorts, and getting fruit speedily, in a small garden. *

The pear, not being very abundantly supplied with fibrous roots, should never be transplanted, of large size, from the nursery. Small thrifty plants, five or six feet high, are much to be proferrecl.

Soll, Situatros, axd Culture. The best soil for this fruit-tree is a strong loam of moderate depth on a diry subsoil. 'The pe:ur will, in-

* Whether the Pear can he successfully cultivated on the Quince for market is jet a debatable question; some growers, owing perlaps to suil and climate, having succeeded satisfactorily, while others lave entirely failer. That dwarfs are a great acquisition to the garlen where large standards are inadmissible is unquestioned. We believe the promise of some varieties on quinec warrants the expectation that they will be found profitable for general cultivation. 
deed, adipt itself to as great a variety of soils as any fruit-tree, but in unfarorable soils it is more liable to suffer from disease than any other. Soils that are wet during any considerable portion of the year, are entirely unfit for the pear-tree; and soils that are over-rich and leep, like some of the Western alluvials, force the tree into such orer-luxmiant growth that its wood does not ripen, and is liable to be killed by winter blight. Soils that are too light, on the other hand, may be improved by trenching if the subsoil is heavier, or by top-dressing with heary muck and liver mud if it is not.

In a climate rather cold for the pear, or on a cold soil, it is actrantageous to plant on a Southern slope; but in the Middle states, in warm soils, we do not consider a decidedly Southern exposme so good as other rather cooler ones.

The Pear suceeeds so well as an open standard, and requires so little care for pruning-less, indeed, in the latter respect than any other fruit-tree-that training is seldom thought of except for dwarfis, or in the garlens of the curious or skilful. The system of quenomille or distrif training, an interesting mole of rendering trees very poluctive in a small space, we have alreacty fully deseribed in p. 40, as well as rootpruning for the same purpose in 1). 36 .

The mamer of growing and training dwarfs in this country. on at large seale, for orchards, is, however, more as bushes or low-headed trees than as pyramils, quenouille, or espalier ; and while the same general principles are maintained, it is necessary to head back the leading shoot more severeiy; and unless time can be given in the smmmer season to checking the growth, and forming a thick, round, open head by means of summer pinching, then, in orrler to maintain liealth and vigor in dwarfs, they must be ammally shortened back from one-half to $t$ tothirds of the preceding year's growth. The best time for this is immediately at the close of winter.

In orehard culture the pear is usually planted about thirty feet distant ench way; in fruit-gardens, where the heads are somewhat kept in by pruning, twenty feet is considered sufficient by many.

Pear-trees in a bearing state, where the growth is no longer luxuriant, should have, every autum, a moderate top-chessing of manure, to keep them in good condition. This, as it promotes steady and regular growtl, is far jreferable to ccasional heary mamming.

Diseases. As a clawback to the otherwise easy cultivation of this fine fruit, the pear-tree is, unfortunatcly, liable to a very serions disease called the peor-tree blight or fire blight, appearing irregularly, and in most parts of the country; sometines in succeeding seasons, and again only after a lapse of several years; attacking sometimes only the extremities of the limbs, and at other times destroying the whole tree; producing, occasionally, little clamage to a few brauches, but often also destroying, in a day or two, an entire large tree; this disease has been, at different times, the terror and despair of peargrowers. Some parts of the country have been nearly free from it, while others have suffered so much as almost to deter persons from extending the cultivation of this fine fruit. For nearly at hundred years its existence has been remarked in this country, and all notions of its charaeter and origin have been so vague as to lead to little prac. tical assistance in removing or remedying the evil.

Careful observations for several years past, and repeated comparison 
of facts with accurate observers in various parts of the country, have led us to the following conclusions:-

1st. That what is popularly ealled the pear blight, is, in fact, two distinet discases.

2. $l$. That one of these is caused by an insect, and the other by surl. den freezing and thawing of the sap in unfavorable antumns. The first we shall therefore call the insect blight, and the second the firnzen-sory, blighte

1. The Ixsect Buigit. The symptoms of the insect blight are as follows: Jn the month of June or July, when the tree is in full hixuriance of growth, shnots at the extremities of the branches, and often cxtcurling down two seasons' growth, are observed sudclenly to trim brown. In two or thee days the leares become quite black and dry, :und the wood so shrivelled and hard as to be cut with difficulty with a knife. If the branch is allowed to remain, the disease sometimes extends a short distance farther down the stem, but usmally not much firther than the point where the insect had male his lodgment. The insect which canses this blight was first discovered by the Hon. John Lowell, of Boston, in 1816, and was described by Professor Peck under the name of Scolytus myri. It is very minute, being scarcely one-tenth of an incll long: and it escaues from the branch almost as soon as, by the withering of the leaves, we are aware of its attack; lence it is so rarely seen hy careless observers. In the perfect state it is a very small beetle, deep brown, with legs of a paler color. Its thorax is shor, convex, rongh in fiont, and studded with erect bristles. The wing-covers are marked with rows of punctured points, between which are also rows of bristles, and they appear cut off very obliquely behind.

This insect deprosits its egg some time in July or August, either behind or below a bud. Whether the eng hatches at once, we are not aware, but the following spring the small grub or larva bores through the sap-wond or tender albumum, begimning at the root of the bud, and burrows toward the centre of the stem. Aromd this centre or pith it forms a circular passage, sometimes devoung it altogether. By thus perforating, sawing off, or girdling, intemally, a considerible portion of the ressels which convey the ascending sap, at the very period when the rapid growth of the leares calls for the largest supply of fluid from the roots, the growth and the vitality of the branch are checked, and finally extinguished. The larva about this time completes both its trausformation and its passage out, and, in the beetle form, emerges, with wiugs, into the air, to seek out new positions for laying its eggs and continuing its species. The small passige where it makes its exit may now more easily be discovered, below or by the side of the bud, resembling a hole bored with a needle or pin.

It is well to remark here that the attack of this blight insect is mot confined to the Pear, but in some parts of the country we have observed it preying npon the Apple and the Quince in the same manner. In the latter tree, the shoots that were girdled were shorter, and at the extremi ties of the branches only; not leading, therefore, to such serious consequences as in the Pear.

The ravages of the insect blight, we are inchined to think, do not extend much below the point where the insect has depositerl its egg,-a material point of difference from the firnzen-sep blight, which often poisons the system of the whole tree if allowed to remain, or if origin ally very extensive. 
The remedy for the insect blight is rery distinct. It is that originally suggested by Mr. Lowell, which we and many other's have pursued with entire success, when the other form of the rlisease was not also present. The remedy consists, at the very first indicatious of the existence of the enemy, in eutting off and burning the diseased branch, a foot below the lowest mark of discoloration. The insect is usually to be found at the bottom of this blackened point, and it is very important that the branches be removed early, as the scolytus is now about emerging from his burrow, and will speedily eseape us, to multiply his mischief elsewhere. If there is much appearance of the insect blight, the tree shonld be examined every noon, so long as there are any indications of disease, and the amputated branches carried at once to the fire.

2. 'Tine Frozen-sap Buight. We give this term to the most folmidable phise of this disease that aflects the pear-tree. Though it is by ordinary ubservers often confounded in its affects with the insect blight, yet it has strongly characteristic marks, and is far more fatal in $i$ is effects.

The symptoms of the frozen-sap) blight are the following: First. The appealance, at the season of winter or spring pruning, of a thich clemmy sap, of a sticky nature, which exucles from the wommels made by the knife; the ordinary cut showing a clean and smooth surface.

Second. The appearance in the spring, on the bark of the trunk or branches, often a considerable distance from the extremities, of black, slirivelled, deal patches of lark.

Third. In early summer months the disease fully manifests itself by the extremities shrivelling, turning black, and decaring, as if suddenly killed. If these diseased parts are cut ofl, the immer bark and heart-wood will be found dark and discolored some distance below where it is fresh and green outside. If the tree is slightiy affected only, it may pass off with the loss of a few branches; but if it has been seriously tainted, the disease, if not arrested, may, sooner or litter, be carried through the whole system of the tree, which will gradually decline or entirely perish.

To explain the nature of this disease we must first premise that, in every tree, there are two currents of sal carried on: 1st, the mpwarl current of salp, which rises through the outer wood (or alburnum), to be digested by the leaves; $2 \mathrm{l}$, the downwad eurrent, which descends through the inner bark (or liber), forming a deposit of new wook on its passage down.*

Now let us suppose, anterior to a hlight season, a very sudden and early winter succeeding a damp and warm antumn. $\dagger$ 'The summer having been dry, the growth of trees was completed early, but this excess of lampness in autumn forces the trees into a vigozous second growth, which continues late. While the sap-ressels are still filled with their fluids, a sharp and sudden freezing takes place, or is, perhaps, repeater several times, followed, in the daytime, by bright sum. The desecnding current of sap becomes thick and clammy, so as to desecend with

* Being distributed towards the centre of the stem by the medullar rars which communicate from the inner bark to the pith.

+ Which always happens previously to a summer when the blight is very prevalent, and will be remembered by all as having hecn eslecially the case in the autumn of 1813 , which preceded the extensire blight of the nex season. 
difficulty ; it chokes vitality, and becomes dark and discoloned, and in some cases so poisonous as to destroy the leaves of other plants when applied to theme. Here, along the immer bark, it Jerlges, and remains in a thick, stick state all winter. If it happens to flow down till it meets with any oli. struction, and remains in any considerable pumtity, it frexzes again beneath the hark, rmptures and lestroys the silp-vesscls, and the liatk and sone of the wood beneatl it shrivels and dies.

In the ensuing spring the npwated current of sap rises throngh it: ordinary channel, - the onter wool or alburnum, - the leaves expand, and. for some time. nearly all the upward enrent being tatsen rip to form leaves and new shoots, the tree alpeal's tlomisling. 'Towall the hegin loing of summer, however, the leaves commence sencling the downwarl current of sial to inerease the wooly matter of the stem. This current, it will be rennembered, has to gass downwald through the inner bark on liber, along which still remain portions of the poisoned salp, arrested in its comser the provions antmm. This poison is alihterl, and taken "1] by the new downwal current, distributed towad the pith, and along the new layers of allmmum, thus tainting all the neighboriug parts. should any of the adjacent silp-ressels have been ruptured by fiost, so that the poison thus becomes mixed with the still ascending current of sap. the branch above it inmediately tmons black and dies, preciscly as if poison were intmoluced muler the bark. And very frespently it is accompanied with precisely the odor of decaying frost-bitten regetation.* *

The foregoing is the worst form of the disease, and it takes place when the poisoned sap, stagnated under the bark in spots, remains throngh the winter in a thick, seni-tluid state, so as to be caprible of being taken mp in the descending emrent of the next summer. When, on the other hand, it collects in sufficient quantity to fieeze again, bust the salp-vessels, and afterwards dry out by the influence of the sum and wind, it leaves the patehes of dead bark which we have ahrealy descingel. As part of the wondy channels which convey the ascending salp pobably remain entire and uninjured, the tree or branch will perhaps concinue to grow the whole season and bear fruit, as if nothing harl halpened to it, irying down to the shrivelled spots of bark the next spring. The effect in this case is precisely that of girdling only, and the branch or tree will die after a time, hut not suddenly.

From what we have said, it is easy to infer that it would not be diffcult, on the occurrence of such an autumn, when sudden congelation takes place in minipened wood, to predict a blight season for the following

* We In not know that this form of blight is eommon in Europe, but the following extract from the celebrated work of Duhamel on fruit-trees, publisher in 1 ifis, would seem to indicate something very similar a long time ago.

"The sap corrupted by putriel water, or the excess of mamure, bursts the cellular memhranes in some places, extends itself between the woor and the sark, which it separates, and earries its poisonous acrid influence to all the neighboring liuts; like a gangrene. When it attacks the small hranclies, they should be cut off; if it appears in the large branches or boly of the tree, all the cankered parts must he ent out down to the sound worl, and the wom eovered with composition. If the evil be produeed by manure ur stagnant water (and it may be produced by other causes). the old earth must he removed from the rnots, and fresh soil put in its place, and means taken to lraw off the water from the roots. But if the disease has male mnch progress on the trunk, the tree is lost."-Truite des Arbres Fruitiers, vol. 11, 1. 100. 
summer. Such has several times beeu done, and its fulfilment may bo looked for with certainty in all trees that had not previously ripened their wood.*

So also it would and does naturally follow, that trees in a damp, ric! soil, are much more liable to the frozen-say blight than those upon a drier soil. In a soil over-moist or too rich, the pear is alwars liable to maks late second growths, and its wool will often be canglit nmipened ly an early winter. For this reason this form of blight is vasty more extensive and destructive in the deep rich soils of the Western states than in the drier and poorer soils of the East. And this will always be the case in over-rich soils, nuless the trees are checked in then luxuriance hy root-pruning.

Again, those varieties of the pear which have the habit of matuing their wood early, are rery rarely affected with the frozen-saj, blight. But late-growing sorts are always more or less liable to it, esprecially when the trees are young, and the excessive growth is not reduced by fruit-bearing. Every nuseryman knows that there are certain lategrowing sorts which are always more liable to this bight in the nursery. Among these we have particularly noticed the Passe Colmar and the Forelle, though when these sorts become bearing trees they are not more liable than many others. The seckel pear is less subject to hlight than others, which we attribute entirely to its liabit of making slort-jointed shoots, and ripening its wool very early.

'To distinguish the blight of the frozen-sap from that caused by the attack of the Scolytus pym is not difficult. The efiects of the latter cease below the spot where the insect has perforated and eaten its burrow in the branch. The former spreads gradually down the branch, which, when dissected, shows the marks of the poison in the discoloration of the inner bark and the pith, extending down some distance below the external marks of injury. If the poison becomes largely ditrinsed in the tree, it will sometimes die ontright in a day or two: but if it is only slightly present, it will often entirely recorer: The presenec of black, dry, shrivelled spots of bark on the bianches, or soft sappy spots, as well

* Since the above was written, we have had the pleasure of seeing a highly interesting article by the Rev. H. W. Beecher, of Indiana, one of the most intelligent observers in the country. Mr. Beecher not only agrees in the main with us, but he fortifies our opinion with a number of additional facts of great value. We shall extract some of this testimony, which is rouched for by Mr. B., and for the publication of which the cultivators of pears owe him many thanks.

"IIr. R Ragan, of Putnam Co., Ind., has for more than twelve rears suspected that this disease originated in the fall previous to the summer on which it declares itself. During the last winter Mr. Ragan predicted the hlight, as will be remembered by some of his acquaintances in Warue Co., and in his pearorchards lie marked the trees that would suffer, and pointed to the spot which would be the seat of the disease, and his prognostications were strictly rerified. Out of his orchard of 200 pear-trees, during the previous hlight of isis. only four escaped, and those had been transplanted, and had, therefore, made little or no growth.

$\therefore$ Mr. White, a nurseryman near Mooressille. Ind, in an orchard of orer - 150 trees, had not a single case of blight in the year 1844 , though all aroumd him its raves were felt. What were the facts in this case? His orchard is planted on a mould-like piece of ground, is high, of a saudy. gravelly soil: earlier by a week than uursery soils in this country; and in the summer of 1843 , his trees grew through the summer, ripened and shed their leaves carly in tir fall, and during the warm spell made no second growth." 
as the appearance of thick clammy sap in winter or spring pruning, are the infallible signs of the frozen-siap blight.

The most successful remedies for this disastrous blight, it is very evident, are chiefly preventive ones. It is, of course, improssible for us to avoil the oecisional arenrence of rany, wam antumus, which have a tenclency to moe the trees into late secomd growth. The principal means of escaping the danger really lies in always sturlionsly avoiling a wet soil for the fruit-tree. Tery level or hollow surfices, where heavy early antumnal rains are al to lie and saturate the gromol, shombl also he shmmet. And any summer top-dressing or enriching caldenlated to stimulate the tree into late growth is pernicions. A rich, dhy soil is, on the whole, the best, because there the tree will make a groor growth in time to ripen fully its woorl, aurl will not be likely to nuke second glowtl. A rich, wet soil will. on the contrary, serve continually to stimulate the tree to new growth. It is in accordance with this that many persons have remarked, that those pear-trees growing in common matow land were free from bight in seasons when those in the rich garden soils were continually suffering fiom it.

The first print, then, should bo to secme a rich, but dly, well-drained soil. Cold aspects and soils should be avoided, as likely to retard the growth and ripening of the wood.

The second is to reject, in blighted districts, such varieties as have the habit of making wood late, and eloosing rather those of early habit, which ripen the wood fully before autumn.

Severe summer-pruning, should it he followed by an early winter, is likely to induce blight. and should therefore be avoided. Indeed, we think the pear should always be pruned in winter or early spring.

As a remerly for blight actually existing in a tree, we know of no other but that of freely cutting out the cliseased branches at the earliest moment after it apjears. The amputation should be continned as fur down as the least sign of discoloration and consequent poisoning is perceptible, and it should not be neglected a single day after it manifests itself. A still better remely, when we are led to suspect, during the winter, that it is likely to break ont in the ensuring summer, is that of earefully looking over the trees before the buds swell, and entting ont all branches that show the discolored or soft salply spots of bark that are the tirst symptoms of the disease.

Finally, as a preventive, when it is evident, from the nature of the season anil soil, that a late antumnal growth will take place, we recommend laying bare the roots of the trees for two or three weeks. Rootpruning vill always cleck any tendency to over-luxuriance in particular sorts, or in young hearing trees, and is therefore a valuable assistance when the discase is foarcd. And the use of lime in strong soils, as a fertilizer, insteal of mautre, is worthy of extensive trial, because lime lats a tendency to throw all fruit-trees into the production of shortjointerl firit-spurs, instearl of the luxmiant woody shoots indreed by animal inanure.

In gardens where, from the natrial rampuess of the soil or locality, it is nearly impossible to escape blight, we recommend that mode of dwarfing the growth of the trees-conical stamiluds, or quenomilles, described in the section on prming. 'This morle can scarcely finl tc secme a grood crop in any soil or climite where the pearl-tree will Hourish. 
After the blight, the other discases which affect the pear-tree are of little moment. They are chietly the same as those to which the apple is liable, the same insects occasionally affecting both trees, and we therefore refer our reader's to the section on the apple-tree.

There is, however, a sluy-worm, which occasionally does great damage on the leares of the pear-tree, which it sometimes entirely destroys. This shug is the Selcendrine cercesi of I Larris. It appears on the upjer sicle of the leares of the pear-tree, from the middle of June to the midhle of July. It is nearly lialf an inch long when fully grown, olive-colored, tapering from the head to the tail, not much unlike in shape a miniature tadpole. The best destructire for this iusect is ashes, plaster, dry dust, or quicklime, sifted or sprinkled over the leaves, early in the morning.*

\section{VARJETIES.}

The varieties of pear have so multiplied within the last thirty years that they may almost be considered endless. ()f the new varieties, Belgium has produced the grreatest number of high quality; England and France many of excellence; and, lastly, quite a number of valuable sorts have originated in this eountry, to which some additions are made amnually. The latter, as a mutter of course, are found even more generally alapted to our clinate than any foreigi sorts. But we believe the climate of the Middle States is so nearly like that of Belgium, that the pear is grown here as a standard to as gieat perfection as in any other country.

More than one thousand kinds of pears, collected from all parts of the world, have been fruited here, but unly a small proportion of these have been found of first-rate quality, and a very large number of them are of little or no value. The great difticulty seems to be, to decide which are the really valuable sorts, worth universal cultivation. ITe shall not, perhaps, arrive at this point, in this country, for several rears, not until all the most deserving sorts have had repeated trials, ancl the difficulty is always increased by the fact of the difference of climate and soil, and the continnous increase of new rarieties. A rariety may prove of superior merit in one locality and quite inditierent in anothes; owing to the influence of soil and climate. This, however, is true only to a very limited extent, as the fact that most sorts of the first character receive nearly the same praise in Belgium, England, and all parts of this country, clearly proves. High flavor, handsome appearance, productiveness, and uniformly good flavor in all seasons--these are the criterions of the first class of pears.

- Many theories and speculative opinions have beell promulgated Auring the past twenty or more years since these remarks on blight were written, but, so far ns we can learn, nothing conclusive is yet known. There are many persons holding the views here expressed. while nthers support a theory of atmospherio fungoid blight with equally good reasoning.

$\uparrow$ The most sncessful cultivator of pears in this country. whose collection comprises hundreds of varieties. lately assured us that if he were asken to name all the sorts that he considered of unvarying and unquesinmble cheplence in all respects, he could not count more than twenty! It may. then, be asket. Why do all cultivate so large a variety? We answer, because the yuality of many is yet not fully decided; again, there is a great difference in taste, as to the 
Most of the finer varieties of pears lave not the necessary harli. hood to enable them to resist, perfectly uninjured, the violent atmos. pheric changes of our climate, exiept under favoralble cireunstances; consequently the finit is more or less variable in quality; and this i: more particulaly true of some that come to nis fiom abous with promise of the highest exerlenee, and to pronomee an abiding jurlsment upon their merits requires many yeas' experience and careful cobservation under ditberent circumstances and in varions logalities. And it must be borne in mind, that althongh yomig trees give finit of nearly or quite full size and beanty, yet perfection of Havor is only to be expeeted from trees of more matme age. The inference is not logitimate that a variety which exhibits great excellence in Belgium. or some of the districts of France, will exhibit generajly in all localitics in th. United Stites the same excellence; bnt the supposition is fair, and borne ont by some experience, that those which prossess excellence of a garticular character in an eminent degree in Europe, will generally exlibit the same in particnlar localities in this country. We would instance such rigorons growers, with pretty solid flesh, as the following:- Belle Lucrative, liostiezer, Dnchess d'Angonlême, Benré Harly, dr. To produce satisfactory resulis in the cultivation of peass, some of its wants must always be eomplied with, such as good depth of soil, sulticient drainage, and proper emichment.

In describing pears, we shitl, as usual, designate the size by comparison, as follows:-Large, as the Benré 1)iel or Bartlett; medimn, as the Doyemé or V'irgalien; small, as the Sockel.

With regard to form, these are so mmmerous and complicated that it is difficult to rleterminie upon any terms that can be always preserved: but with a view to mity, and with a belief that they are the best now in use, we have adopted those establisher] by the Massachusetts Horticultural Society. (See pages 65:2 and 653.)

As with ilpples and other finits, we contime the alphabetical system of arrangement, it being the most readily applicable for general use; an!, as with apples, have, in designating the quality of flesh, contimued the terms adopted by the American Pomological Society, as "best," "ver"/ "good," and "good." The latter term, although in many cases laving reference only to the quality of the fruit as a dessert pear, may be often formd attached to one of great value for cooking, or highly profitable for market.

\section{Abre de Beaunont.} France.

Originated in the commercial gardens of Ambre Ijeroy, Angers,

Fruit medium, obtuse, pyriform. Stalk short. Calyx large, npen. Skin grecnish yellow, narbled with fawn-color and washed with red in the sun. Flesh white, fine, juicy, melting, rough or gritty at corr, vinous, sweet. August, Sejtember. (Leroy.)

merits of a given sort; there are also some sorts so produc'ive, or handsome, fc., that they are lighly esteemed, though only second-rate. In a work like the? present. we are also obliged to deseribe many sorts of seconr ruality, in orier to assist in identifying them, as they are already in gencral cultivation. 


\section{SIMPLE FORMG.}

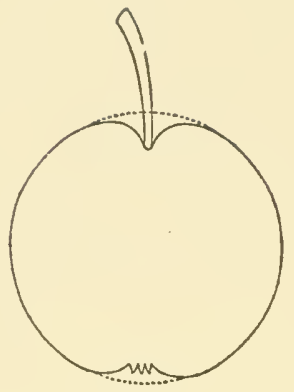

Globular.

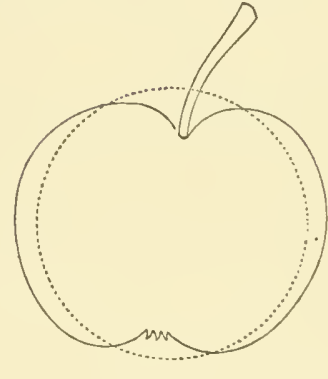

Oblate.

COMPOUND FORMS.

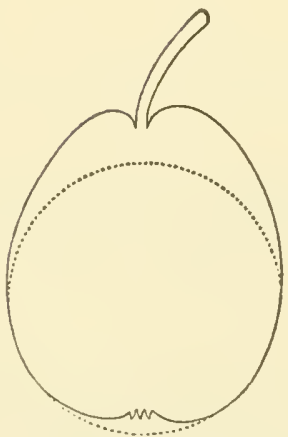

Globular, obtuse pyriform.
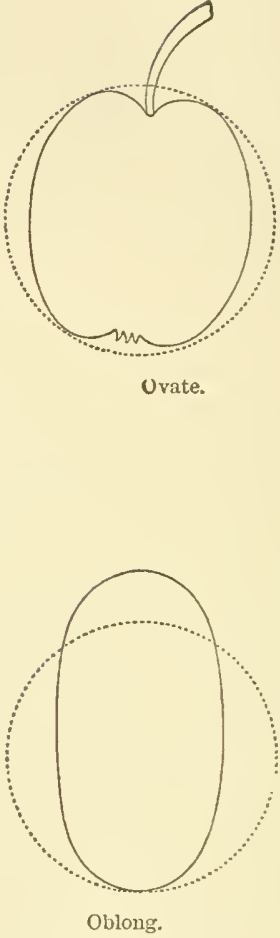

Oblong.

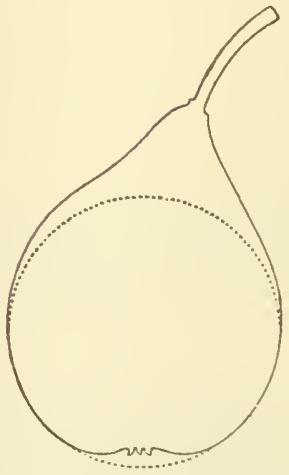

Globular, acute uyriform. 
TIIE PEAR.

\section{COMPOUND FORMS-Continued.}

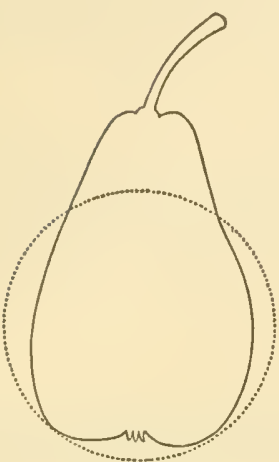

Ovate, pyriform.

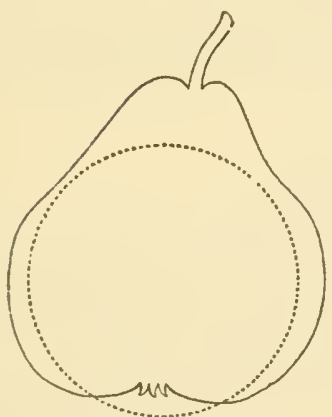

Obovat , obtuse pyriform.

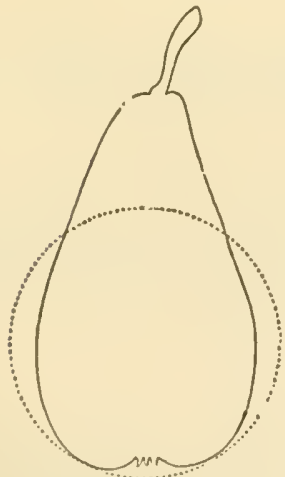

Oblong, ovate pyriform.

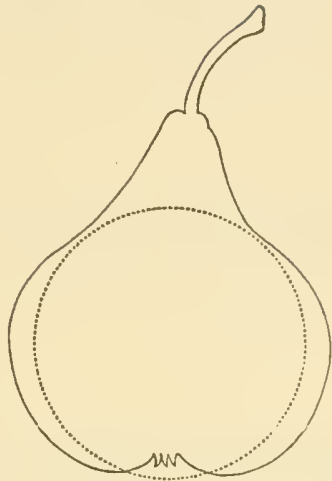

Obovate, acute pyriform.

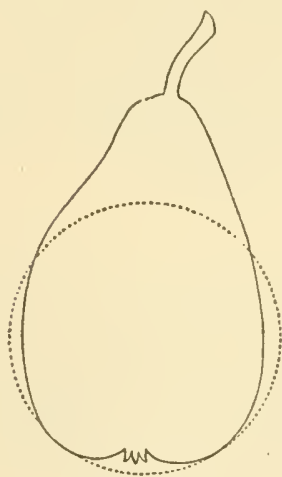

Oblong pyriforn.

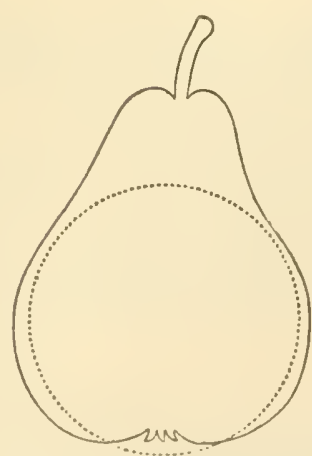

Oblong, obovate pyriform. 


\section{Abré Edouard.}

One of Van Mons' seedlings. 'Tree vigorous, spreading.

Fruit medium size, roundish obtuse pyriform, rich clear green, becoming yellow at matmity, with a russet cheek. Flesh white, half ten. der, melting, juicy, sweet, pleas:mt. Ripens in November.

\section{A BBÉ Perez.}

'This Pear originated in Germany, and was introdnced in 1862.

Fruit small to nedium, oval oblate. Skin yellowish green. splashea and dotterl with red, shaded with fawn-color at the apex. Flesh whitish, firm, melting, juics, harsh at the core, vinous, sweet. November, February. (Leroy.)

\section{A BвоTт.}

Origin, Providence, R. I., on the farm of Mrs. Al,bott. A vigorons grower, and the fruit, although not of tirst quality, is mifurmly good and beantiful. Foung wood reddish olive.

Fruit of metium size, oblong obovate prriform. Skin yellowish, considerably shaded with crimson, sprinkled with gray and crinson dots, and having a few russet patches. Stalk medium, inserted by a lip or ring in a slight depression surrounded by russet. C.llys open, with segments persistent, in a broad open basin. Flesh white, granular, buttery, juicy, melting. Flavor sweet, pleasant, and perfumerl. Ripens last of Sejtember.

\section{A BERCROMB:}

Abercromby's Seedling.

An American chance seerlling that was found in Tailapoosa Co., Ala. Tree a vigorons, stout grower, an early and abundint bearer.

Fruit medium size, globular obovate obtuse priform, greatest breadth at centre. Skin rather rongh, greenish rellow, netted and patched with russet, and with a mottled red cheek. Stalk short. Calyx large and open. Flesh whitish, coarse, granular, moderately juiey, and sweet, slightly vinous. Good. Ripens early in August.

\section{ADAMS.}

Raised by Dr. H. Adams, of Waltham, Mass. Tree a vigorous grower, with an upright, erect habit, making a pyramidal head. Young woorl reddish yellow brown.

Frut large, obovate pyriform, rargest at centre. Surface uneven. Skin pale yellow shaded with light erimson in the sun, with many brown, green, and reddish dots. Stalk short, often set with a russeted lip. Calyx closed. Basin very shallow. Flesh white, very juicy, melting, vinous. Tery good. Ripens earky September.

\section{ADÉLAIDE DE RÈYES.}

Madame Adélaide R:ves.

From Belgium. Tree vigorous. Young shoots very stont, rellow ish brown red. 
Fruit large, oblong, obovate acute pyriform, yellowish green with a shade of red in the sur, aml russet specks and blotelies, and russet at base of stalk. Flesls white, half tine, nelting, juicy, viuous, sweet Good. October.

\section{Anèle Lixcelot.}

A Belgian Pear of recent introduction. Tree vigorous.

Fruit medium to large, pyriform. Skin clear green yellow, shaded with red in the sum. Flesh white, not very juicy or rich. Good. Ostober.

\section{ADMIRABLE.}

\section{Dana's Admirable.}

Originated with Francis Dana, Boston, Mass., and first exhibited before the Massachusetts Horticuitural society in 1853. Tree a vigrorous grower, somewhat irregular, and, according to Hovey, tardy in coming into bearing. Ioung wool olive brown.

Fruit merlium to large, roundish ovate, narowing towarl the stalk. Surface uneven. Skin rellowish, partially russeted and thickly sprinkled with russet dots. Stalk nedium, a little inclined, planted in a small cavity, and sometimes with a liv. Calyx open. Segments short, erect. Basin medium, rather abrupt, uneven. Flesh juicy, melting, vinous, a little astringent. Good. S'entember.

\section{Admiral Farragett.}

This new American Pear originated with Dr. Shurtleif, Boston, Mass, who deseribes the tres as strong, rigorous, productive. Shoots long, medium size.

Fruit very larre, long pyriform, green with many dots, and blush in the sun. Stalk stont, curved. Calyx mediun. Basin shallow. Flesh melting, juicy, fine-grained, subacid, pleasant. Season last of September. (J. of H.)

\section{Adolpire Catchet.}

Origin, gardens of M. André Leroy, Angers, France.

Fruit medimm, obtuse pyriform, rich yellow, clotted and splashed with red in the sum. Flesh white, juicy, vinous, sweet, harsh and gritty at core. August, September. (Leroy.)

\section{Anolphise Ricitard.}

A Belgian Pear of recent introduction.

Fruit medium, pyriform, elear yellow, with shates and patches of brown red. Flesh white, half fine, juicy, vinous, sweet. Good. No. rember.

\section{Agtane Grégotre.}

A Belgian variety, of rigorous and productive lialit.

Fruit medinm, obtuse pyiform. skin yellow, dotted and sploshed 
with reddish brown. Flesh yellowish white, half fine, half melting juicy, perfumed. Good. February, March. (Jardin Van Mons.)

Ah ! Mon Dieu.

\author{
Poire d'Abondance. \\ Mon Dieu. \\ Beurré Sprin.
}

MIandieu.

The my-God Pear.

Esperine.

An old French Pear. Tree vigorous, upright. prodnctive.

Fruit medium, obovate acute jyriform. skin pale yellow, smooth. nearly covered with red. Flesh white, juicr, slightly vinous, and sweet. Good. Uetober.

\section{A lexander.}

Origin, town of Alexander, N. I. Tree moderate growth. Ioung wood light olive lorown.

Fruit medium, obovate obtuse pyriform, somewhat one-sided. Skin yellowish green, dotted, netted, and splashed with russet. Stalk slender, rather long, curred, fleshy at its insertion. Calyx large, closed. Flesh white, a little eoarse and gitty, rery juiey, melting. sugary, and rich. Vury good. Ripe last of September and early October.

\section{Alexandre Buort.}

A seedling of Esperen in 1848. Tree rigorous, of a bushy habit. Young wood reddish brown.

Fruit merlium, obtuse prriform. Skin pale yellow, with a few jatches and traces of russet. Stalk rather long. set in a small cavity. Caly small, open. Segments slender, partly recurved. Basin large, abrupt, corrugated. Flesh whitish, a little coarse, moderately juicy, half tender, sweet, and pleasant. Good. December to February.

\section{Alexaxdre Lambere.}

One of Van Mons' seedlings. Tree rigorons, spreading. Branches long, slender.

Fruit medium, oblate obtuse pyriform, vellowish, netted and patcl. ed with russet, brown red in sum. Flesh yellowish pinkish white, juicy, sweet, a little astringent. Good to rer'y good. October, Decemler.

\section{Alexasmisis.}

\section{Alexandrina Bivort.}

A Belgian Pear, too small in size to be of much valne at its seasou of ripening.

Fruit medium or below, oblate prriform, light yellow, shaded witl red in the sun, netted and dotted with russet. Stalk long. Calyx open. Flesh white, juicy, melting, sweet. Good to rery good. Septemher.

\section{Alexasdrise Dociltard.}

\section{Douillard.}

This comparatively new Belgian Pear has size to commend it, and may prove valuable. Tree vigorous, productive, and comes warly intc bearing. Young wood dull yellowish brown. 
Frnit large, obovate obtuse pyriform. Skin pale yelluw, slightly netted and traced with russet. Stalk varying in length, inserted in a slight cavity, sometimes with a lip. Calyx partly closed. Basin abrupt, uneven. Flesh white, juicy, melting, slightly vinous. Very good. October:

\section{Alexandrine Mas.}

A seedling of M. Mis, France, fiom seeds of Passe Culmar in 18.50.

Fruit large, obtuse pyriform, light yellowish green, with shades and patches and dots of russet. Stalk stout, set without depression. Calyx liuge. Segments ereet. Flesh white, translucent, juicy, sweet, perfuncel. Late winter. (Verg.)

\section{A LPH.}

A Belgian seedling. Tree vigorous, productive.

Fruit medium or below, obovate, slightly oblong. Skin smooth, pale, yellowish green, dotted with reddish points, and liaving a thin, pale brown blush. Stalk about an inch long, inserted in a slight depression. Calyx stiff, open, set in a rome basin of moderate size. Flesh white, fine-grained, buttery. Good. October.

\section{Alphosse Kark.}

Originated with Mr. Louis Berckmans. Tree vigorous. Young wood dull olive.

Fruit medium, obovate obtuse pyriform, golden yellow, netterl, marbled, and dotted with msset. Flesh whitish, fiue, melting, juicy, slightly vinous, sweet. November, December.

\section{Althorpe Crassane.}

Fruit medium, roundish ovate. Skin pale green. Flesh white, buttery, and quite juicy, not rich, slightly perfumed. Good. October, Norember.

\section{AvaDotre.}

Madotte.

Antumn Superb.

De Graine Damadote.

Beurré Knox? Dame Houdotte.

Beurré Blanc des Capucins.

Fruit rather large, pyriform. Skin pale yellow. Stalk mediun. Carity small. Calyx open. Basin shallow and uneven. Flesh whitish, coarse, juicy, vinuus, rariable, sometimes astringent. Hardly good. Ripe October.

\section{Amandine de Rouen.}

A new French Pear, as yet little known.

Fruit medium, obtuse pyriform, greenish yellow, with splashes of tawn russet. Flesh white, half fine, melting, juicy, sweet. Gocxl. Sejtember, October. (Leroy.) 


\section{A.mbrette.}

Ambrette d'Hiver.

Ambre Gris.

Ambrette Gris.

Belle Gabrielle.
Trompe-valet

Ambret.

Winter Ambret.

Cheat servant. Tilton.
'Thorny Ambrette. Ambrette avee epines. Ambrette épineuse De Chine.

A very old Pear-tree, very hardy and productive.

Fruit medium to small, roundish oval, yellowish green, with russet spots and black blotches. Flesh whitish, a little coarse, melting, sweet. Good. December to March.

\section{A merosia.}

\section{Early Beurré.}

A French Pear of medium size, rommlish obovate. Skin greenish yellow, a little russeted. Flesh buttery, without much flaror. Harlly good. September.

\section{Ainerica.}

An American Pear, originated with Francis Dana, Boston, Mass. l'ree a strong vigorous grower.

Fruit uledium to large, roundish oblats obtuse pyiform. Skin yellow, with traces, dots, and patches of russet. Stalk long, in a small cavity. Calyx open. Flesh whitish, a little coarse, half melting, sweet, sugary, pleasant. Good. November, December.

\section{Amelie Leclere.}

A seedling of the late Leon Leclerc, of Laval, France. Tree moderately vigorous, sprealing, with long slender shoots.

Fruit merlium, roundish, inclining to obtuse prriform. Slin green. ish yellow, with a shade of red in the smm, and slight nettings of russet. Flesh white, juicy, melting, sweet, slightly vinous. Good to very good. October.

\section{A Miral Cécil.}

Originated in France, of moderate growth, productive.

Fruit medium or below, roundish ovate, yellowish, with fawn-color marblings in the sum. Flesh whitish, juicy, melting, harsh and gritty at centre. Crood. Octuber, December.

\section{Auire Johiset.}
St. Jean.
St. John's Pear.
Amiré Tohannet. Joannette. Petit Johannet.
Petit St. Jean.

This fruit is one of the earliest, ripening at the beginning of Jaly -in France, whence it originally comes, about St. John's dar. whence the name Joannet. It is a pleasant fluit, of second quality, and lasts but a few days in perfection. It opens the pear season, with the Little Muscat, to which it is superior.

Fruit below the mildle size, regularly pyriform, tapering to the stalk, which is an inch and a half long, and thickest at the point of junction. Skin rery smooth, at first light green, but becomes bright 
lemon-color at maturity-very rarely with a faint blush. Calyx large, with reflexed segments, even with the surface. Flesh white, sugary, delicate and juicy at first, but soon beeomes mealy.

Axour.
Trésor.
Poire d'Amour.
Love Pear.
Trésor d'Amour.
Treasure.

An old Pear, valued ouly for eooking.

Fruit very large, oblong obovate pyriform. Skin rough, dull yel. lowish green, brownish in sun. Flesh white, coarse, larsh, astringent. Good for stewing. December to March.

\section{Ananas de Courtrai.}

Ananas de Courtray.

What we have received as Ananas de Courtrai from three or four sources, both here and in Europe, have proved to be Ananas d'Eté ; and

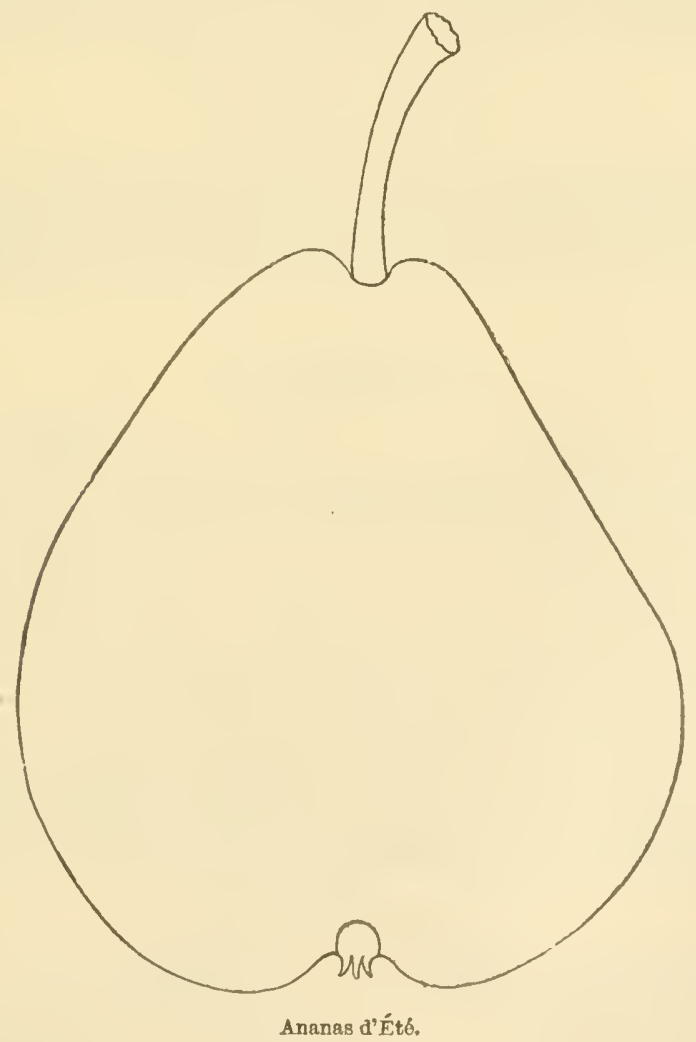

as there is said to be a distinct Ananas de Courtrai, we insert Leroy's deseription. 
Fruit large, pyriform, slightly obtuse, surface uneven. Skin pale yellow, with a warm brown red clieek in the sum, more or less marbled, some dots and patches of russet brown. Flesh white, fine, juicy, mild, sweet, musky, delicate perfume. Very good. Last of August and earlv in September.

\section{ANavas D'ÉtÉ.}

Ananas (of Manning and of Leroy).

Ananas Francais. Du Bouchet.

Favori Musqué. Summer Pine-apple.

An old variety, from Holland, which here is one of our best late summer or early autumn Pears. Tree very vigorous. Young shoots strong, of a rich redclish-yellowish brown, with prominent sharp-pointed buds, and oblong white specks.

Fruit rather large, pyriform, or occasionaily obtuse at the stalk. Skin pale yellow, with a little brown on one side, and much corererl with large, rough, brown russet dots. Stalk an inch and a quarter long, inserted sometimes in a blunt cavity, sometimes without depression, $\mathrm{b}_{\mathrm{y}}$ the side of a lip. Calyx open, with short divisions. Basin shallow. Flesh fine-grained, buttery, and melting, with a sweet, perfumed, and high flavor. V'ery good. September and October.

\section{Axdré Desportes.}

Originated in the gardens of M. André Leroy, in France, 1854.

Fruit medium, obovate obtuse pyriform, oblique. Skin greenish yellow, with patches of fawn and bronze in the sun. Flesh yellowish white, fine, juicy, melting, granulous at the core, sugary acid. July. (Leroy.)

\section{ANDREWs.}

\section{Beurré Oudinot? Amory. Gibson.}

The Andrews is a favorite native seedling, found in the neighborhood of Dorchester, and first introduced to notice by a gentleman of Boston, whose name it hears. It is of excellent flavor, but variable and subject to rot at the core.

Fruit rather large, priform, nne-sided. Skin smooth, and rather thick, pale yellowish green, with a dull red cheek, and a few seattered dots. Stalk abont an inch and a quarter long, curved, and set in a rery shallow, blunt depression, or often without deprescion. Calyx open, llaced in a small basin. Flesh greenish white, full of juice, melting, with a fine vinons flavor. Good to very good. Early in September. The Beurré Ondinot, as we have received it, has always proved identical with our Anchews, but Leroy claims it a distinct sort.

\section{Argélique de Bordeaur.}

Gros Franc Real d'Hirer. Cristalline.
St. Martial.

Molle Bouche d'Hirer.

A variety from France.

Fruit medium, obtuse pyriform. Skin yellowish green in the shade, b:ownish red in the sun, with brown dots. Stalk fleshy at insertion. 
Culyx small. Flesh tender, juicy, buttery, melting. January to April. (Hogg.)

\section{Avgélique Leclerc.}

Originated with Leon Leclerc, of Laval. 'Tree productive.

Fruit mealium to large, oblong obtuse pyriform. Stalk short. Ca. lyx small, open. Skin greenish yellow, shaded and dotted with red in the sun. Flesh white, very close, melting, juiey, rough at the core, sweet, aromatic. October, December. (Leroy.)

\section{Angleterre.}

\author{
English Beurré. \\ Beurré d'Angleterre. \\ Beurré Amande. \\ Almond Pear.
}

\author{
Monkowthy. \\ Longue de Narkouts. \\ Beurré Judes. \\ Amande Double.
}

An old French fruit of unknown origin. Tree vigorous, productive.

Fruit medium, acute pyriform. Skin dull light green, slight nettings of russet. Stalk long, slender, curved, fleshy at its junction with the fruit. Flesh white, buttery, and melting, full of juice, and of pleasant though not high fiavor. Good. Middle of September.

\section{Axgleterre D'Hiver.}

Angoisse blanche.

An old Pear of little value, except as a keeper and for cooking.

Fruit large, acute pyriform, greenish yellow, with a brownish red tint in sun, inany small russet and black specks. Flesh firm, rather dry, slightly acid. February to April.

\section{Axgleterre Nain. \\ Angleterre Parfumé.}

Origin, Paris, France.

Fruit small to medium, obovate obtuse pyriform. Stalk long. Calyx half closed. Skin rough, dull green, dotted with red in the sum. Flesh whitish, fine, juicy, luarsh near the core, musky. September, October. (Leroy.)

\begin{tabular}{|c|c|c|}
\hline & & \\
\hline $\begin{array}{l}\text { Mansuette. } \\
\text { Solitaire.' }\end{array}$ & $\begin{array}{l}\text { Gros Angobert. } \\
\text { De Sainte Catherine. }\end{array}$ & $\begin{array}{l}\text { Beurré de Semur. } \\
\text { Double Mansuette. }\end{array}$ \\
\hline
\end{tabular}

A very old variety, described in 1660, and then, as now, considered one of the best of cooking Pear's.

Fruit large, or very large, irregular obtuse pyriform, greenish yellow. Flesh half melting, juicy, somewhat astringent. A cooking pear, September.

\section{Anva Audisson.}

Doyenné Anna Audisson.

Beurró Anna Audisson.

Originated at Angers, France.

Fruit medium, roundish obtuse prriform, yellowish green, with patches of russet and brownish red in the sun. Stalk short and stont. 
Cavity slight, sometimes a lip. Calyx open. F esh whitish, juicy, melting, sweet, and pleasant. Good to very good. October.

\section{Apple PEar.}

Pomoire. Poire-Pomme. Beurré de Rackenheim.

Fruit below medium, round or roundish oblate. Skin covered with cinnamon russet, unless in the shade, when it is a dirty yellow green, witlı russet marblings. Flesh yellow, tender, melting, juicy. Good. October.

\section{Arbre Courbê.}

Amiral.

Colmar Charnay.

Tree vigorous, with irregular crooked branches. Young wood yellowish brown, with many specks, angled or bent from joint to joint.

Fruit medium or large, oval pyriform. Skin greenish yellow, with patches and russet dots. Stalk large and fleshy. Calyx open. Basin broad and shallow. Flesh whitish, coarse, lialf buttery, melting, juicy, slightly astringent. Good. Ripe last of September.

\section{Arlequin Musqué.}

An old Pear, but little known.

Fruit large, obovate pyriform. Skin yellowish green, with marblings and dots of brown. Calyx large, open. Flesh white, buttery, melting, sweet. Good. Last of September.

\section{Arthur Bivort.}

One of Van Mons' seedlings. 'Tree vigorous.

Fruit above medium, oblong obtuse pyriform, green, becoming reilowish at maturity, dotted with red in the sum. Stalk curved in a slight cavity. Calyx open. Flesh white, half fine, melting, juicy, vinous. October. (Alb. Pom.)

\section{Aston Town}

Fruit small, roundish turbinate. Skin pale yellowish, with brown specks. Flesh soft, buttery, moderately sweet, perfumed. Hardly good. Middle and last of September.

\section{Audibert.}

\section{Belle Audibert.}

Fruit large, obovate obtuse pyriform, pale yellow, orange in sun. Flesh white, breaking, granulated, acidulous. Good for stewing only. November.

\section{Auguste Jurie.}

A seedling of M. Fortune, Willermoz, Jirance. Tree moderately vigorous, very productive.

Fruit small, oblate pyriform, yellow, shaded with dark red in the sum. Flesh white, half melting, juicy, slightly vinous, and slightly musky. Good. August. 


\section{Avcinste Royer.}

Tree very vigorous and productive, and promises to loe a valuable orehard finit.

Fruit medium, roundish. Skin greenish yellow, eovered with russet-fawn. Flesh whitish, half melting, juice abundant, sugaly, and pleasantly perfumed. Good. lípe October.

\section{AUgustiNe Lejieuti.}

Anguste Lelieur.

A variety from Belginm, but of unknown origin.

Fruit below medimm, oblong ovate priform. Skin greenish, with patehes and nettings of russet, russet dots, and a blush-red eheek in sun. Stalk long, 'urved. Calyx closed, hasin snall, corrugated. Flesh white, buttery, juicy, half-melting, sweet, and pleasant. Cood. Oetor ber, Norember.

\section{Augustus Dana.}

An Ameriean Pear, originated with Francis Dana, Boston, Mass. The tree is a good but not strong or a handsome grower. Young shoots of a light redilish brown eolor.

Fruit medium, varying in form from acute pyriform to ohtuse pyriform. Skin yellow, netted and patched with russet, and russet dots. Stalk often one side of a true axis, enrved, and set with slight depression. Calyx open. Flesh whitish, juicy, melting, sweet, shightly aromatic. Good to very good. October.

Aurate.

An old variety.

Fruit small, pyriform, pale yellowish green. Flesh juicy, rich. Very good. Last of July.

\section{A utuma Bergamot.}

\section{English Bergamot. \\ Common Bergamot.}

York Bergamot.

English Autumn Beroramot.

Fruit small, roundish, and flattened. Skin roughish green. Flesh greenish white, eoarse-grained at the eore, jiicy, sugary. September.

The Bergamotte d'Automne of the French is a distinet fruit from this. Skin light yellowish green, brownish red eheek. Flesh breaking, juicy, and refieshing, but not high-flavored. A second-rate frnit.

\section{Autuma Colmar.}

A Frenelı Pear, of fair quality and a good bearer.

Frnit of medium size, oblong or obtuse pyriforn, a little meven. Skin pale green, dotterl with numerous russety specks. Stalk about an inch long, straight, planterl in a small, uneven cavity. ('alyx small, closed, set in a slight basin, a little furrower. Flesh a little gritty at the core, buttery, with a rich and agreeable flavor. Good. October. 


\section{Autumx Nelis.}

Graham's Autumn Nelis.

Graham's Bergamot.

An English Pear. Tree much the habit of Winter Nelis, very harly and poductive. Yomng wood hight olive.

Fruit medium, obovate pyriform. Skin greenish yellow, mostly overspread and netted with russet. Flesh yellowish, fine-grained, melt. ing, rich aromatic. Tery good. October.

\section{Avrit.}

D'Avril. Poire d'Arril.

Tree a vigorous grower, productive.

Eruit large, roundish, obtuse pyriform. Skin greenish yellow, slightly shaded and somewhat spotted with russet, and thickly covered with russet dots. Stalk long and curved, inserted usualiy in a clepression. Calyx closed, basin deep and irregular. Flesh whitish, compart, coarse, granular, juicy, half-melting, sweet, and agreeable. A good baking pear. November to February.

\section{Barbanetnet.}

Origin, Nursery of Audre Leroy, Angers, France. Tree vigorous, sprealing, upright, productive. Young wood light brown.

Fruit medium oblong acute pyriform, greenish yellow, with a brownish shade in the sun, sometimes slightly netted and patched with russet, and sprinkled with dots. Stalk medium, fleshy at junction. Calyx partially open. Segments short. Basin small. Flesh white, juicy, melting, slightly vinous. T'ery good. September.

\section{Barbe Nelis.}

Raised by Gregoire, of Belgium. Tree very vigorous, moderately productive. Young wood stout, light yellowish brown.

Fruit. small, oblare obtuse pyriform, greenish yellow, shaded and marbled with dull leer in the sun, many green dots, and a few nettings and patches of russet. Stalk long, slender, eurved, often with bracts in a slight cavity. Calyx open. Flesh white, butters, juicy, half-melting, sweet, pleasant. Good. Last of August.

\section{Baron Deman De Lexiek.}

A Belgian Pear, too small to be of great ralue at its season.

Fruit small, roundish to roundish oblate, greenish yellow, with net. tings and traces of russet, especially near the calrx, and many russet tots. Calyx large, open. Flesh white, coarse at centre, juicr, halfmelting. Good. Norember, December.

\section{Baronne de Mello.}

Adèle de St. Denis. Ad le de St. Cerras.
St. Cerran.

Beurré Tan Mrons.

A Belgian Pear, first described by Biyort, in Album Pomology. 'Treo 
hardy, vigorous grower, and productive. Young wood light olive brown with many specks.

Fruit medium, irregular in form, varying from curved pyriform to long acute pyriform, occasionally roundish acute pyriform. Skin yel-

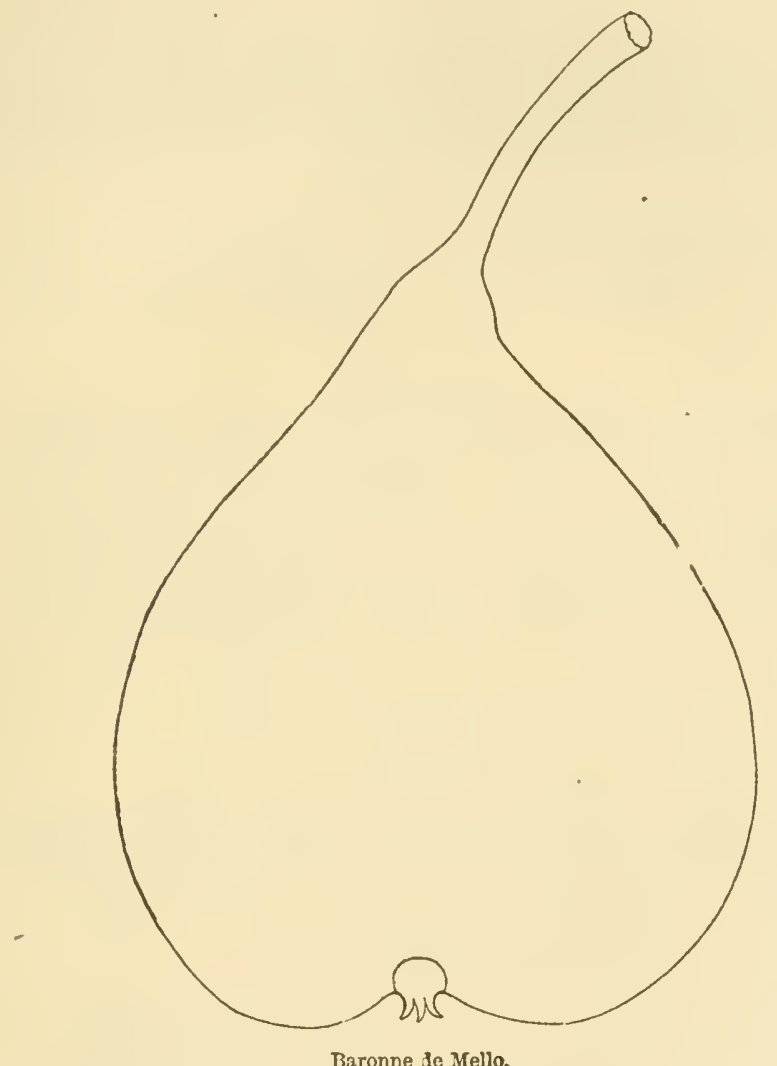

Baronne de Mello.

lowish, nearly covered with brown russet, and thickly sprinkled with russet dots. Stalk long, curved, inclined, fleshy at base, and often with z lip. Calyx partially closed. Segments short, erect. Flesh whitish, a ittle coarse, juicy, melting, vinous subacid. Very good. October.

\section{BARRY.}

\section{De Lestumieres. Doyenné Barry.}

An old variety, lately introduced and renamed.

Fruit medium, oblong obovate pyriform, greenish yellow, netted and shaded and dotted with russet. Stulk short, obliquely inserted, short. Calyx large, open. Flesh whitish, juicy, sweet, pleasant. Good to very good. October. 


\section{Bartlett, or Williahs' Boxchreties.}

Bartlett. of all American Gardens.

Williams' Bonchrétien.

Clement Doyenné.

Poire Guillaume, of the French.
Barnett's William.

Bonchrétien Barnett.

Delarault.

This noble Pear is, justly, one of the most popular of all the stmme1 varieties. Its size, beanty, and excellence entitle it to this estimation, apart from the fact that it bears very early, regulariy, and abundantly. It is an English variety, originated about 1770, in Berkshire, and was afterward propagated by a London grower by the name of ITil.

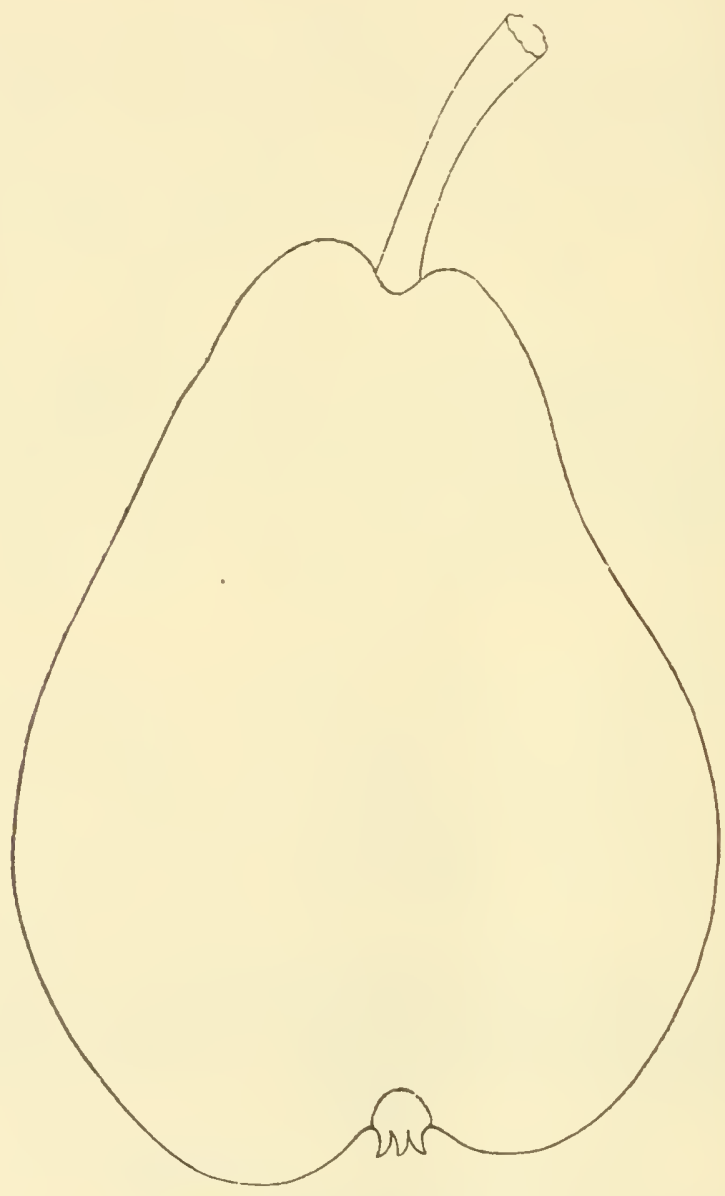

Bartlett, or Williams' Bonchrêtien.

liams. When first introduced to this country its name was lost, and having been cultivated and disseminated by Enoch Butlett, Esin.. of Dorchester, near Boston, it became so universally known as the Burtlett 
Pear, that it is impossible to dispossess it now. It suits our elimate adminably, ripening better here than in England, and has the unusua? property of maturing perfeetly in the house, even if it is picked before it is full-grown. It has no competitor as a summer market fruit. The tree grows upright, with thrifty, yellowish brown shoots, and narrow, folded leaves.

Fruit of large size, oblong, obtuse pyriform. Surface moven. Shin very thin and smooth, elear yellow (with a soft blush on the smmy side in exposed specimens), rarely narked with faint russet. Stalk one to one and a half inches long, stout, inserted in a shallow cavity. Calyx open. Segments short, erect, set in a very shallow, obscurely plaited basin. Flesh white, and exceedingly fine-grained and huttery ; it is full of juice, sweet, with a highly perfumed viuous thavor. (Li damp or unfarorable soils it is sometimes slightly acid.) Ripens from last of August to middle and last of September.

\section{BARTRAM.}

Origin, an accidental seedling on the premises of the late Miss Anna Bartram, near Philadelphia, Pa. Tree an irregular grower. Young wook slender, reddish yellow brown.

Fruit me linm, obovate, obtuse pyriform, pale lemon yellow, thickly sprinkled with brown gray dots and traces of russet. Stalk inclined in a narrow eavity. Calyx partially open. Flesh white, fine-grained juicy, melting, rich, slightly vinous. Tery good. September.

\section{Beadelel.}

\section{Beadnell's Seedling.}

Foreign. 'Tree vigorous. Shoots long, bright thestnut.

Fruit medium, pyriform, pale yellowish green, blushed red in the sun. Flesh melting, juicy. Good. Last September. (Elliott.)

\section{Beau Présent d'A rtois.}
Présent Royal de Naples.
Présent Royal de Nanues.

A foreign rariety, by some persons highly esteemed. Tree vigorous, with long branches. Toung wool dull brown, with white oblong specks.

Fruit large, oblong pyriform, greenish yellow, dotted and patcher with russet. Stalk long, rather stont, inclined, little or no depression. Calyx partially closed. Basin shallow, meven. Flesh buttery, juicy, melting. Good to very good. September.

\section{Beauvalot.}

\section{Augière. Augert. Auger.}

A foreign variety of indifferent quality.

Frnit medium or above, obovate obtuse pyriform, greenish yellow, sprinkled and patched with russet and many russet dots. Flesh juicy, vinous, pleasant. November, December. 


\section{Belle de Bruxelles.}

Belle d'Août.

Petit Certean.

Beauty of Brussels.

De Coq.
Gros Muscadille.

Bellisime d'Automne.

MInscadille.

Vermilion

Des Dames.
Beurré de Bruxelles.

Muscat Rouge.

Vermillon des Dames.

Vermillor d'Automne.

A large and handsome fruit, of poor quality.

Fruit medium, acute pyriform. Skin pale yellow, with a soft red cheek when fully exposed. Flesh white, sweet, and slightly perfumed. Middle of August.

\section{Belle de Figuier.}

Originated at Angers, France, in 1860.

Fruit medium to large, globular obtuse pyriform. Skin rough, greenish red, with fawn-colored spots. Stalk short. Calyx large, open. Flesh white, juicy, melting, sweet aromatic acid, gritty at core. December, January. (Leroy.)

\section{Belle de l'Orient.}

A foreign variety, showy but of poor quality.

Fruit large, oblong obtuse pyriform, greenish yellow, netted and dotted with russet. Flesh white, tencler, rots at core before ripe. October.

\section{Belle de Thouars.}

Coulon de Saint Maro.

Belle de Troyes.

Belle de Prague.
Belle de Thouarse.

Saint Marc.

Belle de Jersey.

A foreign variety, of indifferent or poor qualitv.

Fruit medium to large, oblong abtuse pyriform, yellow, covered with a thin cinnamon russet. Flesh white, dry, sweet. December, January.

\section{Belle ÉpiNe Dumas.}

Duc de Bourdeaux.

Epine du Rochoir.

Épine de Limoges.

Epine Dumas.

Beurré de Rochoir.
Beurré Rochechourt

Beurri: St. Louis.

Colinar de Lot.

Comte de Limoges.

Emile de Rochois.

Beurré d'Elberg.

Tree vigorous, pyramidal form, good bearer. Young wood dull velLow brown, with sharp-pointed buds.

Fruit medium, obovate obtuse prriform. Skin green, becoming greenish yellow when ripe, with small russet brown dots. Stalk long, set in a very small depression. Calyx partially closed, in a shallow, regular basin. Flesh white, buttery, half melting, juicy, sweet, and of a peculiar Havor. Very good. November and December.

\section{Belle Julie.}

Tilloy - .

St. Germain du Tilloy.
St. Germain Dutilleul.

St. Germain du Tillay.

St. Germaiu de Graines.

A Belgian Pear. Tree very vigorous, and productive. Young rood rather slender, light yellowish brown. 
Fruit medium, globular olstuse pyriform, sometimes inclinerl. Skin rather rough, greenish yellow, considerably netted and patched with russet, esprecially aroumd the stalk and callyx. Stalk generally curved, set in a slight repression, often withont and sometimes with " $\mathrm{li}_{1}$. Calyx open. Flesh whitish, buttery, juicy, melting, slightly vinous. Good to very good. October.

\section{Belle Moutinoise.}

Originated at Monlins, France, and introdnced in 1864.

Frnit large, oblong obtuse priform. Skin rongh, greenish, dottral and marbled in the sum, with fawn-color mear the stalk. Stalk long. large, curved. Calyx large, open. Flesh whitish, fine, firm, juicy, crisp, sweet, musky. February, Mitrch. (Leroy.)

\section{Belle Rouexyase.}

A French Pear, introducer in 1856.

Fruit medium, roundish oblinue acute pyriform. Skin lemon yellow, covered with russet dots. Calyx large, half open. Stalk stunt. Flesh white, tender, meling, juicy, rich, sugary, with a delicate aroma. Early in October. (Hogg.)

\section{Belle Williams.}

A foreign varuety little known. Tree a very erect, vigorous grower. Young wood olive, slightly yellow, glossy.

Fruit melimn to large, oblong pyriform, with a groove or sunken line from stem to calyx, yellowish, with traces and nettings of lusset. Stalk long, curved, set in a slight depression by a lip. Calyx prartially closed. Flesh whitish, not juicy or rich. Good for cooking. Decenber to March.

\section{Belitissine D'Itiver.}

Vermillon d'Hiver des Dames.

Bellisime du Bur.
Du Bur.

Belle Noisette.

An old P'ear, valuable only for cooking.

Fruit large, obovate obtuse prriform, greenish yellow, with sharle of red in the sun, and many russet dots. Flesh white, fine, sweet, breaking, not gritty. November, January.

\section{BeLMoNT.}

An English kitchen Pear.

Fruit rather large, obtuse pyriform. Skin yellowish green, a lit. tle brownish next the sum. Flesh rather coarse, juicy, and sweet. October.

\section{Berganotere Bousstìre.}

One of Van Mons' seedlings.

Fruit bolnw medium, romulish oblate pyriform, yellowish green Flesh white, juicy, harsh at centre. Good. October, December. 


\section{Bergamotte Bufo.}

Bergamotte Caprand.

Crapaud.

An old French Pear, heretotore confounded with Bercamotte Cadet Tree vignous, productive. Joung wood light reddish yellow brown.

Fruit medium, roundish oblate, greenish yellow, netted and patched with russet, and thickly sprinkled with russet dots. Stalk long, in a broad, rather shallow cavity. Calyx open. Flesh yellowish, juicy, melting, sweet, slightly vinous. Ciood. Octobar.

\section{Berganotte Cadet.}

Poire de Cadet. De Cadet. Milau de Bourdeaux.

A good Bergamot from France. Productive. Toung wood clear light yellowisli brown.

Fruit mildle-sized, romdish inclining to oblate. Skin smooth, pale rellow, rauely with a pale red cheek. Stalk an inch long, thick set in an angular, shallow cavity. Calyx small, open. Basin nearly lat. Flesh buttery and juicy, sweet and rich. Crood. October and Torember.

\section{Berganotte d'Esperéx.}

A seedling of Esperin, in 1830. Tree vigorous, productive. Toung wood warm rich dark yellow brown, with small white specks.

Frnit medium, oblate, excedingly repressed, sides often mequal. Skin greenish yellow, thick and rough, covered with russet dots and patches. Stalk long and stont, thickened at its insertion in a small cavity, at an inclination. Calyx small, closed in a rather deep slightly furrowed basin, surounded by russet. Flesh greenish yellow, juicy, buttery, sweet, and rich. Good. December to February.

\section{Berganotte de Millipieds.}

Said to have originated by Goubalt, at Millipieds, France, and first fruited in 1852 .

Fruit medium, roundish ovate, ribbed at apex, pale yellow, moderately splinkled with small brown dots. Stalk long, stont. C'avity small. Calrx open. Segments erect. Basin deep, abrupt, meven. Flesh white, a little coarse, juicy, half melting, sweet. Good to very good. November.

\section{Bergamotte Dussart.}

A Belgian variety, described by various authors.

Fruit medium, obovate pyriform, greenish yellow, with gray dots and traces of russet. Flesh half melting, juicy, sweet, rinous. "Good. December, January.

\section{Bergamotte Gatdry.}

Gandry.

A foreign Pear of little ralue.

Fruit small, roundish oval oblate, greevish yellow; partially netted 
and patched with misset, and many russet dots. Stalk long. Flesh whitish, coarse, breaking, gritty at core, pleasant, vinous. Hardly good. October.

\section{Bergamotte Heimbotra.}

Raised by M. Bivort. Thee vigorous and rery productive.

Fruit large, Bergamotte-shaped. Skin rough, green, changing to lemon-yellow when ripe, dotted with brown, and tinged with red next the sun. Flesh white, very fine, somewhat buttery, juice abundant, sugary, pesfumed. Ripe early in October. (Gard. Cliron.)

\section{Bergaliotte Leseble.}

A Pear of Freneh origin, only good in quality. Tree vigorous and productive.

Fruit medium, oblate, or Borgamotte-shapad. Skin yellow, with a smmny cheek, mmerous small dots, and russeted patches. Stalk long. curved, inserted in a depression. Calyx open, broad. Pasin irregular. Flesh juicy, buttery, melting, sweet, and pleasant. October.

\section{Berganotte Parthenax.}

Bergamntte de Parthenay. Beurré Parthenay.
Poire Poriault.

Bergamotte Stoffels. Bergamotte Poireau.
Parthenay.

Poireau.

An old French Pear, large, and valuble only for cooking.

Fruit large, oblate obtuse pyramidal, olive yellow, with fawn-colored specks. Flesh white, firm, juicy, subacid, astringent. January to May.

\section{Berganotte Piquot.}

Origin unknown. Tree vigorous, productive.

Fruit medinm, rounilish, broard obtuse pyriform, pale yellow, tinge of red in the sun, traces of russet and russet dots. Flesh white, juicy, melting, sweet, shightly vinous. Good. Rots at core. September.

\section{Bergamote SAgeret.}

\section{Sageret.}

A French Pear, of vigorous growth of tree.

Fruit medium, romolish, greenish, very thickly sprinkled with brown and russet dots. Stalk fleshy at insertion. Calyx large, open. Flesh white, juicy, melting, sweet, pleasant. Good. October.

\section{Berganot Seckel.}

Raised by William Pitmaston, England. Tree moderately vigorous, productive.

Fruit medium or below, roundish, regnlar. Skin red,lish-brown, russet speeks. Stalk short, thick, inclined without depression. Cilyx short, stiff. Basin shallow. Flesh white, juicy, sugary, with all tho ipicy flavor of the Seckol. (Gard. Chron.)

\section{BERGEY.}

A chance seedling found in a hedge on land formcrly belonging to 
Simon Bergen, of New Utrecht, Long Island. Tree moderately vigo. rous, npight. Young wood reddish, an early and good bearer, but not profuse.

Fruit large, elongated, obtuse pyriform, often with siles not symmetric, angular. Skin waxen, lemon yellow, finely shaded with crimson and fawn where exposed to the sum, and thickly sprinkled witt brown and crimson dots. Stalk long, rather stont, curved, inserted in a moderate repression by a fleshy ring. Calyx small, open. Segment: stiff. Basin small, surrounded by a wary border. Flesh whitish, reined with yellow, a little coarse and gritty, buttery, juicy, melting, with a sweet aromatic flavor, delicately perfumed. Good to very good. Ripe last of September and beginming of October:

\section{Berriats.}

Poire de Berriays.

This is a rew French rariety, obtained from seed in 1861, by M. Boisbunel. Tree moderately vigorous, productive. Toung shoots reildish.

Fruit medium, surface a little uneven, roundish oborate obtuse. skin pale greenish yellow, sometimes a shade of brown in the sun, and thickly sprinkled with brown and green dots. Stalk long, set in a small cavity. Calyx closed. Segments short. Basin small, nneven. Flesh white, a little coarse at the core, juicy, melting, refreshing, shightly vinous. Good to very good. September.

\section{BeUrré Axtorye.}

Saint Germain Fondant.

Originated in 1822, and was rebaptized in 1849, under name of the present synolym. Tree vigorous.

Fruit melinm or above, oblong pyriform, sometimes with a suture one side. Skin pale greenish yellow, sprinkled with green and brown dots. Stalk long, curved, inserted in a small eavity. Calyx large, open. Flesh white, buttery, not rery juicy or meltirg, but sweet. Good. Last September.

\section{Beurré Axroinette.}

A Belgian Pear, originated in 1846. Tree vigorons and produc. tive.

Fruit medinm, roundish acute prriform. Skin greenish yellow, slightly netted with russet, and thickly sprinkled with russet dots. Stalk long, slender, inserted generally with a lip. Calyx open. Flesh yeliowish, juicy, buttery, sweet, pleasant, a little perfumed. Slightly vinous. Good. Septeinber.

\section{Beurré Assomption.}

Beurré de l'Assomption.

Originated near Nantes, in France. Tree vigorous, very productive.

Fruit large, irregular, generally oblong priform, obtuse, yellow, dotted, marbled, and splashed with red in sum. stalk short. Calyx large, cpen. Flesh white, half fine, melting, jnicy, rough next the core. acid sweet. July, August. (Leroy). 


\section{Beurré Aunexiere.}

Origin, supposed France. Thee vigorous, productive. Young wood dull yellowish brown.

Fruit medium, roundish oblong pyriform, pale yellow, with a few traces of russet, and sprinkled with brown dots. Stalk stout. Calyx partially open. Segrments short, erect. Flesh white, juicy, melting, sweet, aroulitic. Croor. Latst September.

\section{Beurré Barhelter.}

Bachelier.

Chevalier.

A French Pear, introduced in 1845. Tree vigorous. Young wood rich dark biown.

Fluit undium or above, obovate obtuse pyriform. Skin greenisls yellow, with brown dots and patch of muset next the stalk. Stalk shortish, very much inclined in a moderate depression by a lip. Calyx parially closel, set in a shallow basin. Flesh buttery, juicy, melting, with a brisk, vinous, aromatic flavor. Very good. November and December.

\section{Beurré Balley.}

A variety that originated in France, and first fruited in 1848 .

Fruit large, irregular, elongated prriform, yellow, dotted with greenish gray, and with fawn color next the calyx. Flesh white, fine, halt melting, juicy, sugary, rough near the core. Uctober, November. (Leroy.)

\section{Beurré Beauchamps.}

$\begin{array}{ll}\text { Beanchamps. } & \text { Hagliens d'Hiver. } \\ \text { Biemont. } & \text { Bergamotte Beauchamp. }\end{array}$

One of Tau Mous' seedlings. Tree vigrorons. Young shoots stont, dark dull olive yellow, many long whitespecks, and patches of whitish giay.

Fruit nedium, roundish obovate. Skin rough, light yellow, slightly netted and patched with russet, and with many brown and crimson dots. Stalk pretty stout, long and curved, set in a moderate cavity, sometines by a lip. Calyx open. Basin rather narrow, abrupt, and uneven. Flesl white, juicy, melting, a little buttery, very sweet, gritty, pleasant. Good. November.

\section{Beurré Beaulieu.}

Fruit medium, rounclish pyriform. Skin greenish yellow, mostly covered with russet. Stalk short, inclined, without cavity. Calyx open. Basin shallow. Flesh whitish, somewhat conse, buttery, molting, with a brisk vinous flavor, resembling Brown Beurré. Good. October.

\section{Beumé Beguines.}

A small but very uich Pear, one of Van MLons' seedlings, too small for the season.

Fruit small, obovate oblate. Skin rougl, nearly covered with dull misset. Stalk long. Calyx open. Flesh whitish, juicy, coarso, melt ing, sweet. Goorl. October. 


\section{Jjeurré Bexvert.}

From Belginm.

Fruit small, rommlish oblate pyriform, pale yellow, sometimes shaded and mottled with fawn and erimson in the sum, and often netted amil patched with russet. Stalk long, slemeler. Cilyx open. Flesh whitish or light rose color, juicy, molting, it little coilsse, sweet, perfumed. Crod. November, December.

\section{Beurhé Bexolst.}

Beurré Augnste Benoit. Benoist. Beurré Benoist Nouvenu.

Tree morlerately vigorous, sprealing, very productive. Young word redelish, with sharp spur-like buds.

Fruit medium, roundish inclining to aente pyriform. Skin yellow, spotted and shaded with brown lusset, red cheek in sun. Stalk of morlerate longth, inserted by a fleshy ring or lip. ('alyx open, in a regular basin. Flesh white, fine, melting, juice abundant, sugary, ancl well perfumed. Very good. Ripe end of September.

\section{Betrok Berchans.}

Alexandre Berckmans.

One of Major Esperen's seedlings, derlicated to II. Tonis Berekmans, onee a colaborer in pemology. Tree vigorons, upright, very productire. Young wood very stout, blunt at ends, yellowisl olive.

Fruit merlium or above, obovate priform, sometimes olovate acute pyriform. Skin yellowish, rough, chiefly covered with russet. Stalk uf medimm length, fleshy, very mueh inclined. Calyx small, open, in a shallow furlowed basin. Flesh white, juicy, very buttery, melting, with a rich, lighly perfuned flaror. Very good. October, November.

\section{Beurré Boisbunet.}

Originated with I. MI. Boishmel, at Ronen, France, in 1835. Tree moderately vigorous and productive. Young wood dull yellowish howll.

Fruit medinm, obovate pyriform. Skin greenish yollow, with traces of russet, and thickly sprinkled with russet dots. Sitalk long, slender, curved, set in a small eavity, sometimes by a lip. Calyx smali, open. Flesh whitish, rather coarse, juicy, melting, sweet, shightly perfuned. Good. September.

\section{Betrié Bollwiller.}

A winter eooking Pear, of good guality.

Fruit large, ohevate olotuse pyriform. Skin rellowish, with spots of grayish brown and russet near the calrx, shitle of red in the sum. Flesh white, half tine, j licy, sweet, agreeable. Good. January, March.

\section{Bevrré Bosc.}

Bosc's Flasch mbime. Callebasse Bosc. Canuellc.

The Beurré Bose is a Pear to which we gire our mqualified praise. 
It is large, handsome, a regular hearer, always perfect, and of the highest flavor. It bears singly, and not in clusters, looking as if thinned on the tree, whence it is always of fine size. It was raised in 1807 , by V an Mons, and named Calebasso Bose in honor of M. Bose, a distinguished Belgian enltivator. Having also been received at the garden of the

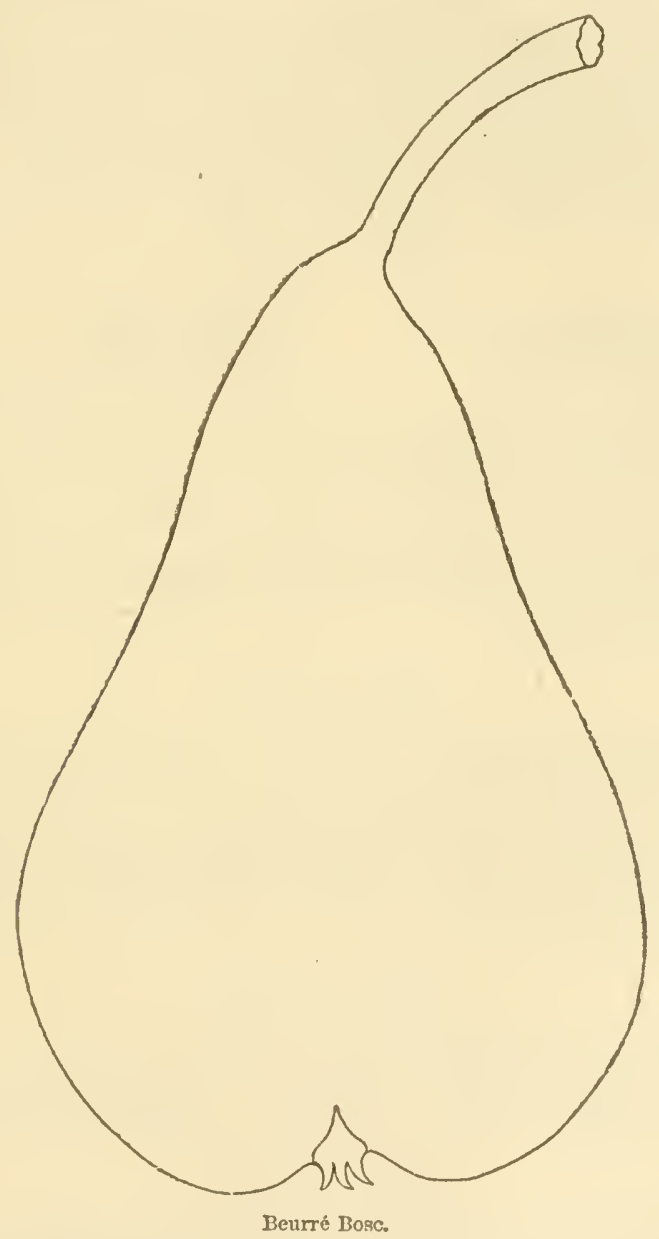

Horticultural Society of London under the name of Beurré Bosc, Mr. Thompson thought it best to retain this name, as less likely to lead to a confusion with the Calebasse, a distinct-fiuit. The tree grows vigorously. Shoots long, brownish olive.

Fruit large, pyriform, a little uneven, often tapering long and giadually into the stalk. Skin pretty smooth, dark yellow, a goorl deal covered with streaks aud dots of einnamon russet, and slightly trucherl with red on one side. Stalk one to two inches long, rather sleucler, 
curved. Calyx short, set in a very shallow basin. Flesh white, melt ing, very buttery, with a rich, delicious, and slightly perfuned flavor. Best. Ripens gradnally from the last of September to the last of October.

\section{Beurré Brettouneau.}

Docteur Brettouneau.

One of Major Esperen's seedlings, originated in 1818. Tree vigorous, but comes late into bearing. Young wood yellowish brows.

Fruit large, variable in form, generally obovate pyriform. Skin rough, light green, golden yellow at maturity, reddish brown in the sun. Flesh fine, yellowish white, not juicy, half melting, sugary, vinous, pleasantly perfumed. Good. March and April.

\section{Beurré Bruneau.}

Crassane d'Hiver de Bruneau.

Bergamotte Crassane d'Hiver.

Crassane d'Hiver.
De Saint Herblain.

Crassane Bruneau.

Bergamotte Crassane de Bruneau.

This variety, we believe, was originally figured and described in the Anmals of Pomology as Bergamotte Crassane d'Hiver, but having received it as Beuré Brunean, we prefer to continue that name as the most simple. It is not a variety of much excellence, althongh the treet is hardy and productive.

Fruit medium, short obtuse pyriform, dull yellow, spotted and shaded with grayish brown. Flesh white, juicy, vinous a little acid. Good November, December.

\section{Beurré Burnice.}

Originated and first fruited with Major Esperen, in 1846. Tree ris. orons, spreading, irregular, productive. Young wood reddish brown.

Fruit medium, globular acute pyriform. Skin rellowish, partially netted and patched with russet, and sprinkled with russet dots. Stalk medium, fleshy at insertion. Calyx generally open. Basin small, uneven. Flesh whitish, juicy, melting, vinous, slightly astringent. Good. October.

\section{Beurré Charrox.}

Originated at Angers, France, in 1838.

Fruit medium, roundish, yellowish, with many gray dots. Stalk long. Calyx small, closed. Basin deep. Flesh juicy, melting, buttery. Very good. October.

\section{Beurré Chatexay.}

A French Pear, too small for profit, but rery good in quality.

Fruit small, varying in form from oborate to ovate prriform, pale yellow, netted and patched with russet, occasionally a red cheek in the sun. Stalk rather short. Calyx partially open. Flesh white, half fine, juicy, sweet, vinous. October.

\section{Beurré Citron.}

From Belgium, one of T'an Mons' seedlings. Tree vigorous. Young wood reddish brown. 
Frinit medium or below, obovate oblate. Skin whitish yellow, shade of red or crimson in the sun, traces of russet and many russet dots. Stalk long, a little curved, set in a small cavity, sometimes with a slight lip. Calyx open. Flesh white, half melting, juicy, sweet, a little perfumed. Good to very gool. Last Neptember and October.

We have received another and quite different pear under this name, the wood of which is vellowish brown.

Fruit medium or below, irregular, sometimes obovate obtuse pyiform, and again ovate acute pyriform. Skin pale yellow, slightly netted with lusset, and with small brown or russet dots. Stalk mediun, fleshy at insertion. Calyx open. Flesh yellowish, coarse, not juicy or melting. Harily good. November, December.

Leroy makes General Lamoricière identical witl Beurré Citron, but as we have receivod them thay are quitc distinct.

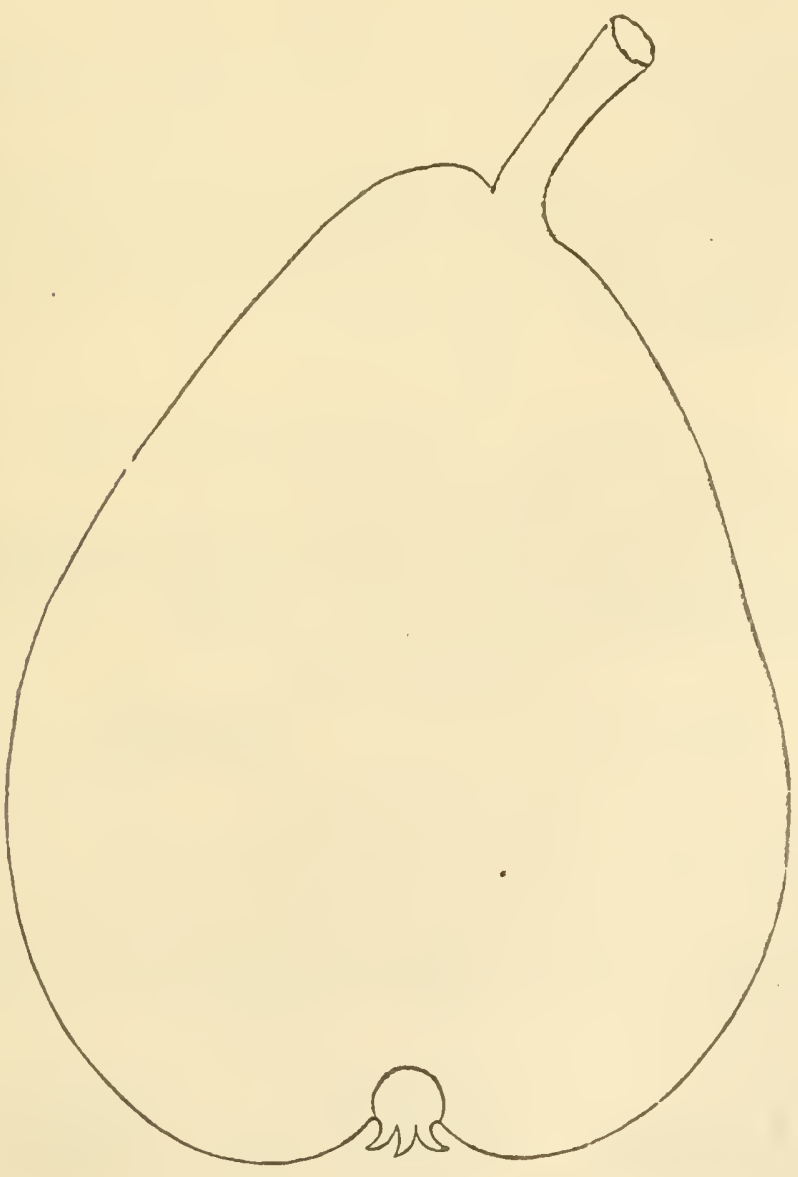

Benn’o Clairgcru. 


\section{Beurré Clatrgeau.}

\section{Clairgeau. Clairgeau de Nantes.}

Raised by Pierre Clairgeau, of Nantes, France. Tree very vigorons, forming a beautiful pyramid. Young wood reddish brown, very productive.

The size, early bearing, productiveness, and beanty of this Pear renlder it a profitable market sort.

Fruit large, pyriform, but with unequal sides. Skin warm yellow, inclining to fawn, shaded with orange and crimson, thickly covered with russet dots, and sometimes sprinkled with russet. Stalk short, stout, and fleshy, inserted by a lip at an inclination almost without depression; when the lip is absent the cavity is uneven. Calyx open. Segments stiff, in a shallow furrowed basin. Flesh yellowish, buttery, juicy, somewhat granular, with a sugary, perfumed, vinous flavor. Good. October to January.

\section{Beurré Colmar.}

\section{Beurré Colmar d'Automne.}

Beurré d'Enghien of France.

It is one of Dr. Van Mons' seedlings, and is quite distinct from the Autumn Colmar.

Fruit of medium size, oval obovate, regularly formed. Skin smootir, pale green, becoming yellowish at matnrity, with a bhush next the sun, and thickly sprinkled with dots. Stalk an inch long. Calyx expanded, and set in a very shallow, narrow, irregular basin. Flesli very white, slightly clisp at first, but becoming very juicy and melting, with a slightly perfumed flavor. Good. October.

\section{Beurré Coloni.}

\section{Beurré du Coloma. Capucine d'Automne Coloma.}

The trees of this foreign Pear are good growers.

Fruit small to medium, long oval pyriform, greenish yellow, with a tinge of red in the sum, and many green and brown dots. Stalk medium, inserted withont cavity. Calyx open. Flesh whitish yellow, juicy, melting, slightly astringent. Good. October.

\section{Beurré D'At.BREt.}

Poire d'Albret.

Dalbret.
Beurré Delbret.

Calebasse d'Albret.

A foreign variety. Tree vigorous and productive. Young wood reddish.

Fruit medium or above, elongated pyriform, angular, often with a suture on one side. Skin yellow, mostly covered with cinnamon russet. Stalk short, thick, and fleshy, much inclined at its insertion br a lip. Calyx small, open, or prartially closed. Basin small and uneren. Flesh greenish white, exceedingly juicy, buttery, meiting, with a rich vinous Havor, highly perfumed. Very good. October.

\section{Beurré n'Amanlis.}

Hubard.

Beurré d'Amaulis.

Beurré d'Amalis.

Kessoise.
Kaissoise.

Thiessoise.

A Belgian Pear, very productive, variable. Succeeds best in cold latitudes. 
Fruit large, obovate, not very regular, a little swollen on its silles. Skin rather thick, dull yellowish green, with a pale reddish brown cheek,

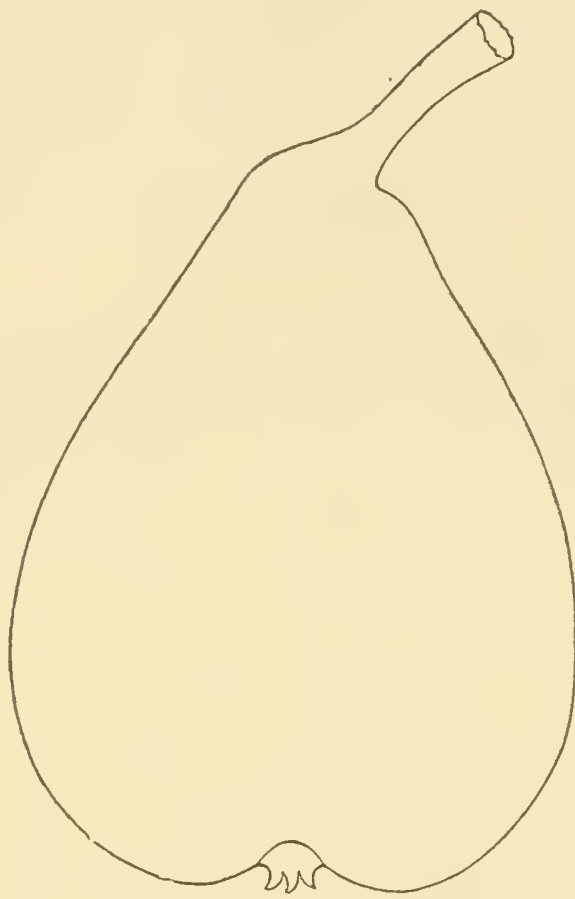

Beurré d'Albret.

overspread with numerous brown dots and russet streaks and patches. stalk a little more than an inch long, set rather obliquely in a shallow, ir. regular cavity. Calyx open, with broad divisions. Basin shaliow. Flesh yellowish, somewhat coarse, but buttery, melting, abundant, rich, with slightly perfumed juice, often astringent and poor. September.

Beurre d'Amanlis Panachée differs from the above only in itsskin, having green and greenish yellow shades and stripes.

\section{Beurré D'ANJou.}

Ne Plus Meuris of the French.

A noble fruit, said to be of French origin. Tree vigorous. Young shoots yellowish brown, very productive.

Fruit large, obtuse pyriform. Stem short, thick, and fleshy, inserted in a cavity, surrounded by russet. Calyx very surall, open, stifl, in an exceedmgly smali basin, surrounded by musset. Skin greenish, sprinkled witl russet, sometines shaded with dull crimson, and sprinkled thickly with brown and crimson dots. Flesh whitisl, not very finc, melting, juicy, with a brisk vinous flavor, pleasantly perfumed. Very good to best. October, November. 
This is one of the most profitable varieties for orcharding, bearing abundantly and evenly, whether grown on quince or pear stocks.

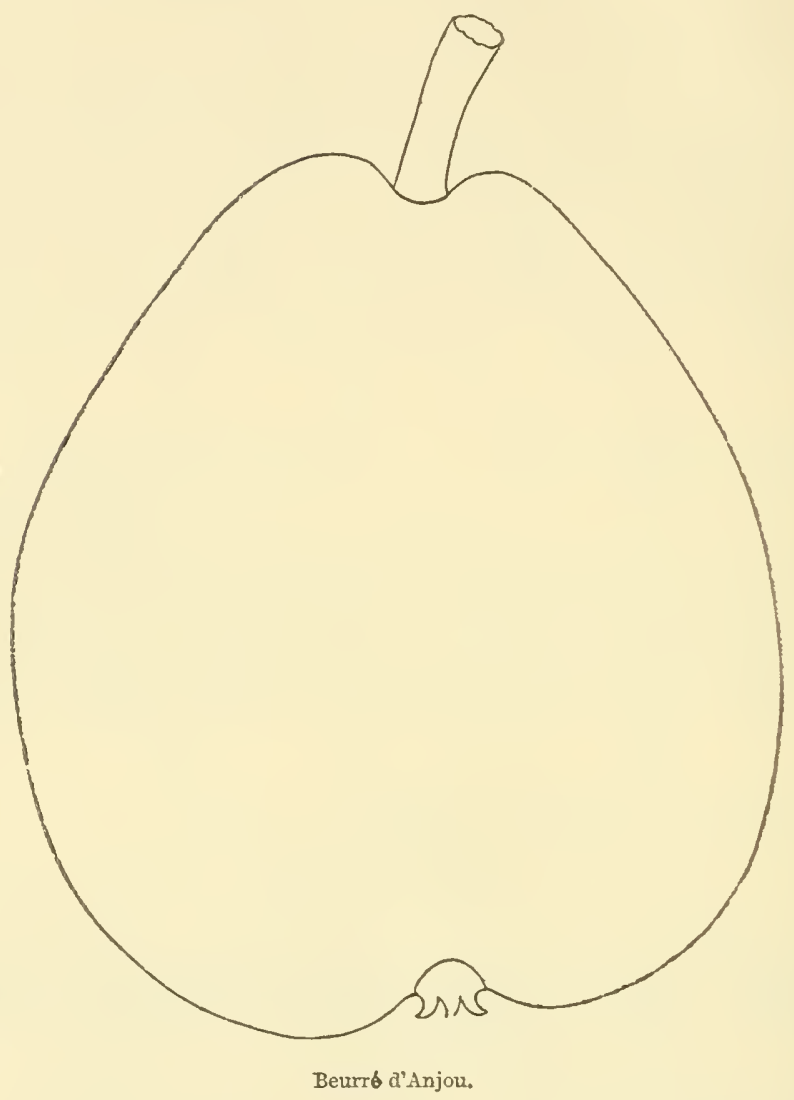

Beurré D'Aremberg.

Duc d'Aremberg.

Deschamps.

Colmar Deschamps.

D'Aremberg Parfait.

L'Orpheline.
Beurré des Orphelines.

Beurré Burcharit.

Orpheline d'Enghien.

Beurré Deschamps.

Délices des Orphelins.

The Beurré d'Aremberg is a fine fruit, high-flarored, bears most abundantly, and always keeps and matures with perhaps less care than most other winter fruits in the house.

The Beurré d'Aremberg was laised by the Abbé Deschamps, in the garden of the Hospice des Orphelines, at Enghien. . The Beuré d'Aremberg of many French catalngtues is the Glout MIorceau. The two sorts are easily distinguished. The fruit of the d Aremberg has a short, or thicker stalk, usually bent to one side; its flaror is rinous instead of 
sugary, and its wood not so strong, with more decply serrated leaves, Branches clear yellowish brown, dotted with pale specks. Tree un healthy and subject to canker.

Fruit obovite, but narowing a gool deal to the stalk. Skin thick, rather uneven, pale greenish yellow, becoming yellow at maturity, with many tracings and spots of light russet. Stalk short, half an inch to an inch long, thick, and very fleshy, especially where it joins the fruit, and usually planted very obliquely. Calyx short and small, set in a deep basin. Flesh white, huttery, and meltiug, with an abundant, rich, delicions vimons juice. Very good. December.

\section{Beurré d'A rolne.}

A variety of comparatively recent introduction from Belgium.

Fruit medimm, obovate. Skin greenish yellow, with a few patches and nettings of russet, and some russet lots. Stalk medium. Calyx closed. Flesh whitish, juicy, melting, sweet, and pleasant. Good to very good. October.

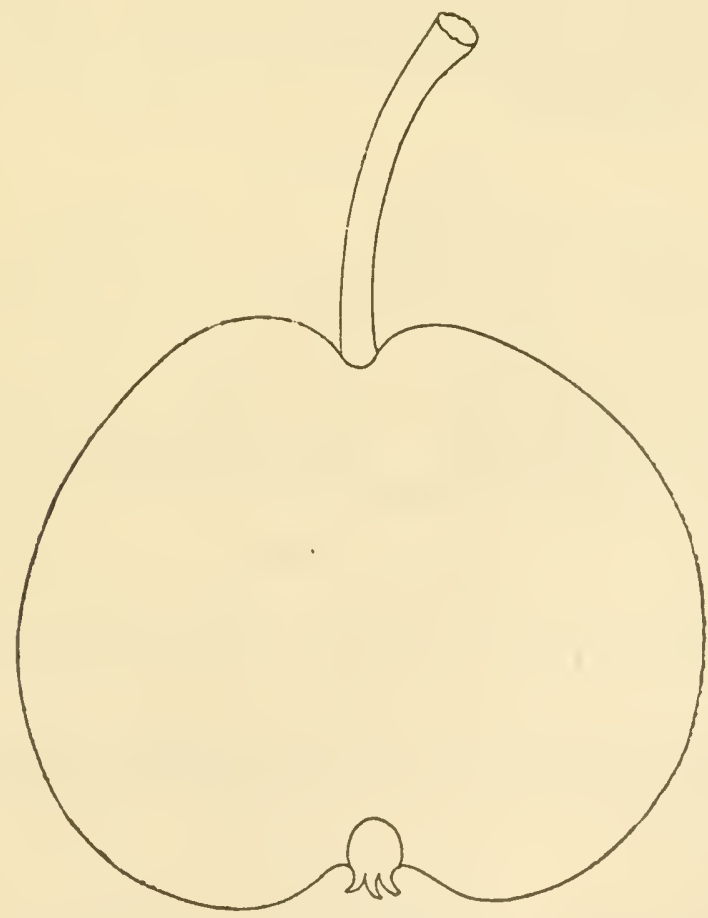

Beurré de Brignais.

Beurré de Brigials.

Des Nonnes. Poire des Nonnes. Nun's Pear. De Nonne.

A valuable variety, the origin of which we cannot learn. Tree 
vigorous, hardy, and productive. Young wood rich dark yellowish brown.

Fruit medium, roundish oblate. Skin greenish, with numerous gray dots. Stalk long, curved, inserted in a narrow, uneven carity. Calrx closed. Basin shallow, corrugated. Flesh white, juicy, melting, with a brisk, perfumed, high flavor. Very good. Ripe middle and last of September. Core small, continnes a long time ere it decays.

\section{Beurré de Capialiont.}

Capiumont. Aurore.

\section{Beurré Aurore.}

De la Glacière.

Calebasse Vasse.

A Flemish Pear, very fair and handsomely formed, and a capital bearer, hardy in all soils and seasms; sometimes first-rate; but when the tree is heavily laden, it is apt to ba slightly astringent. It grows freely. Branches a little pendent, grayish yellow.

Fruit of medium size, long turbinate, very even, and tapering regularly into the stalk. Skin smooth, clear yellow, with a light cimnanonred cheek, and a few small dots and streaks of russet. Calyx large, with spreading segments prominently placed, and not at all sunk. Stalk from three-fourths to an inch and a half long, curved. Flesh fine-grained, buttery, melting, sweet, and, when not astringent, of high flavor. September and Uctoher:

\section{Beurré Defais.}

Beurré Audusson d'Hiver.

Beurré Defays.

A French Pear. Tree productive, and a strong, vigorous grower. Young shoots rieh elear reddish brown, with a large pointed bud at end.

Fruit rather large, oblique obtuse pyriform. Skin fine rellow, slightly netted with russet, and a few russet dots. Stalk varying in length, set in a narrow cavity. Calyx small, partially open. Flesh white, juicy, melting, sweet, slightly aromatic. Good. October.

\section{Beurré de Fétrier.}

This winter Pear originated in Rouen, France, and is classed as a superior variety; we have not fruited it, and give our description from Leroy.

Fruit medium, oblong obtuse pyriform. Skin greenish rellow, with clear spots of red in the sun. Flesh white, half fine, melting, slightly granulous, juicy, sweet with a vinous perfume. January, February.

\section{Beurré de Ghelix.}

\section{Beurré Fromentel.}

Raised by M. Fontaine de Shelin, near Mons, Belgium. Tree rigorous, productive.

Fruit large, very irregular in its outline, often romdish oblong oval, yellowish, with some few marhlings of russet. Stalk short. Carity irregular. Flesh yellowish white, half tine, juicy, sweet, agreeable October, December. (Leroy.) 


\section{Beurre d'Hardenpont d'Autome.}

\section{Wilfred?}

Tree upright, vigorous. Foung wood grayish reduish brown.

Fruit rather large, oblong obovite obtuse pyriform. Skin pale yel low, netted and patehed with russet, and many large russet dots Stalk long, eurved. Calyx open. Basin narrow, abrupt. Flesh yel lowish, juicy, sweet, slightly aromatic. Good to very good. Octo. ber.

\section{Beurré de Johyge.}

Originated in the garden of M. Gambier, near Brussels. Treo hardy, prouluctive.

Eruit mediun to large, obovate acute pyriform, fleshy next the stem. Skin pale yellow, a tinge of red in the stm, considerably netted and patched with russet, and many russet dots. Stalk short, inclined. lip at base. Calyx open. Segments short. Basin rather small and

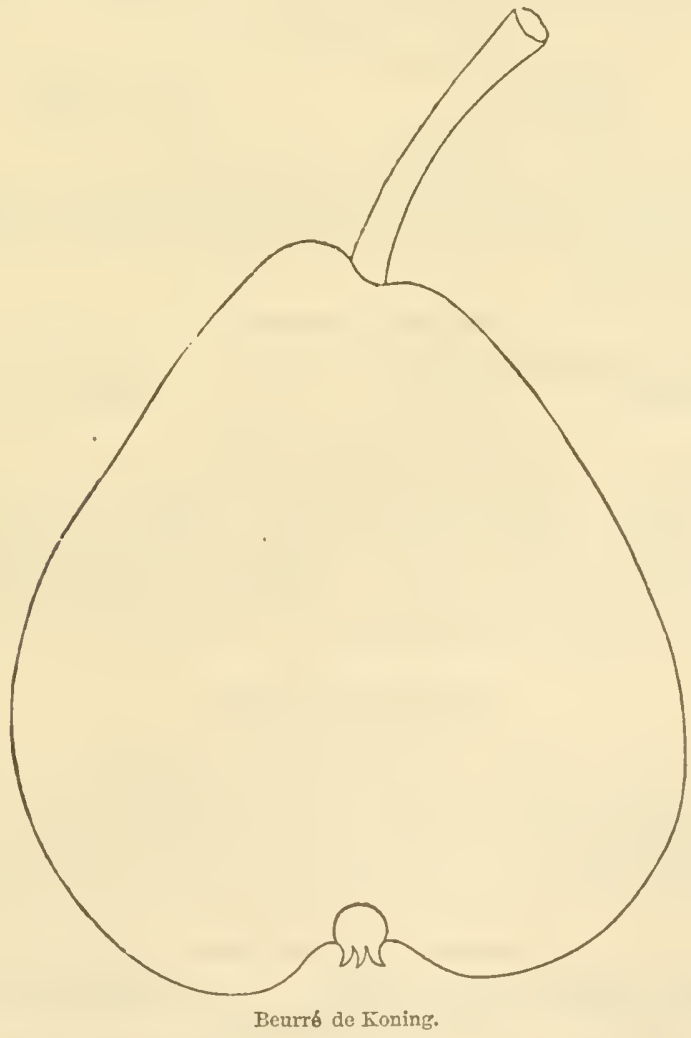

uneren. Flesh whitish, juicy, melting, swest, rich, a little perfumer. Good to very good. December, January. 


\section{Beurré de Koning.}

Beurré Koninck.

Beurré de Conick.

Auguste de Mlaraise?

Beurré Conning.

A Belgian Pear. Tree moderately vigorous. Young shoots slen der, olive reddish yellow.

Fruit medium, obovate, slightly obtuse pyriform. Skin yellowish green, with russet and brown dots and marblings. Stalk medium, stout. Calyx open, in a broad basin. Flesh white, juicy, melting, vinous Good to very good. October.

\section{Beurré Delannoy.}

\section{De Launay.}

Originated with Alexander Delannoy, of Tournai. Tree vigorous, productive. Young shoots dull reddish-yellowish brown.

Fruit large, obovate obtuse pyriform. Skin greenish yellow, a little brownish in the sun, with patches and traces of russet and many russet dots. Stalk varying, a little curved and inclined. Calyx open. Flesh whitish, melting, refreshinglv sweet. Very good. October, November.

\section{Beurré Delbecq.}

$\begin{array}{ll}\text { Delbecque. } & \text { Ficur de Mars. } \\ \text { Fondante Delbecq. } & \text { Beurré Delberg. }\end{array}$

A Belgian varicty. Tree vigorous and productive.

Fruit medium, oval obovate, golden yellow, splashed and dotted with red in the sun. Flesh white, fine, melting, juicy, sweet. Good. September, October.

\section{Beurré Delfosse.}

Beurré Philippe Delfosse. Delfosse.

\section{Bourgmestre Delfosse.}

Delfosse Bourgmestre. Philippe Delfosse.

Raised by M. Gregoire, of Belgium. Tree vigorous, productive. Young shoots very stout, rich warm yellow brown.

Fruit medium to large, obovate obtuse pyriform, sometimes only obovate, greenish yellow, netted and patched with russet, and many russet dots. Stalk curved, set in a small cavity. Calyx open. Flesh white, juicy, melting, sweet, pleasant. Good. October, November.

\section{Beurré de Mons.}

\section{Beurré de Mans.}

A foreign Pear of little value, as it rots at the core.

Fruit small, roundish obovate, yellowish, with a shade of brownish red in the sun, many green and gray dots. Stalk long, slender. Calyx open. Flesh whitish, coarse, juicy, astringent. Poor. August.

\section{Beurré de Montgeron.}

New Frederick of Wurtemburg.

De Montgeron.

Beurré de Montigeron.

A variety obtained by MI. Guyot, of Villenenve, in 1830. Tree vigorous, moderately productive. Young wood dull yellow brown. 
Fruit medium, broad pyriform. Skin yellow, shaded with fine rich red in the sun, and sprinkled with mimnte light brown dots. Stalk long, curved. Calyx open. Basin furrowed. Flesh whitish yellow, juicy, melting, with a pleasint vinous flavor. Good to very good. August.

\section{Beurré de Nantes.}

\section{Beurré Nantais.}

Beuré Blanc de Nantes.

Raised by François MLaisonnenve, at Nantes, France. Tree very vigorous, upright, healthy, and comes early into bearing. Foung wood olive.

Fruit lirge, elongated pyriform or pyramidal. Skin greenish yellow, with a red cheek and mimute dots. Stalk ratlier long and large, inserted by a lip almost without cavity. Calyx large, open. Busin broad and furrowed. Flesh juicy, sweet, melting, and pleasantly perfumed. Tery gool. October.

\section{Beurré de Nivelles.}

A Belgian Pear, as yet but little known.

Fruit medium, obtuse pyriform. Skin yellow, with brownish red in the sun, netted, patched, and dotted with russet. Stalk set in a small carity. Calyx small, nearly closerl. Basin small, narrow, abrup,t. Flesh whitish, juicy, melting, vinous. Good. October.

\section{Beurré de Quexast.}

We have received several Pears under this name, one of which has proved identical with Louise Bon de Jersey, and as we lave doubts of the others, we copy description from the Annals of Pomology, as follows:-

Fruit medium, roundish oblong pyriform, slightly acute, greenish yellow, with patches of russet, and russet next the stalk and calyx. Elesh white, melting, juicy, sweet, and pleasantly perfumed. October.

\section{Beurré Derouineau.}

A French Pear of small size and poor quality.

Fruit small, obovate, yellowish, sprinkled with russet patches. Flesh white, sweet. October, Novemluer.

\section{Beurré je S.int ArNaud.}

\section{Beurré de Saint Arnand.}

A Belgian Pear, originated in 1853. Tree vigorous.

Fruit below medium, roundish obovate, yellow, becoming brownish red in the sun. Flesh white, fine, buttery, juicy, agreeable. Cood. October.

\section{Beurré des Mouchouses.}

Origin, France.

Fruit large, roundish obtuse obovate, vellow, with many gray dots Flesh white, fine, melting, juicy, vinous. July, August. (Leroy.)

\section{Beurrí DE W WTterex.}

This Pear was discovered by Louis Berekmans, in his garden at 
Heyst-op-den-Berg, among a number of wild pear-trees of his sowing. Tree vigorous, very thorny, suitable for a pyramid.

Fruit middle size, turbinate. Stalk medium, with some small plaits around its insertion. Eye in a wide even cavity. Skin completely covered with russet, and slightly colored next the sun. Flesh fine, yellowish white, half melting, buttery, with an abundant sugary, agreeabiy perfumed, muskr inice. February. (An. Pom.)

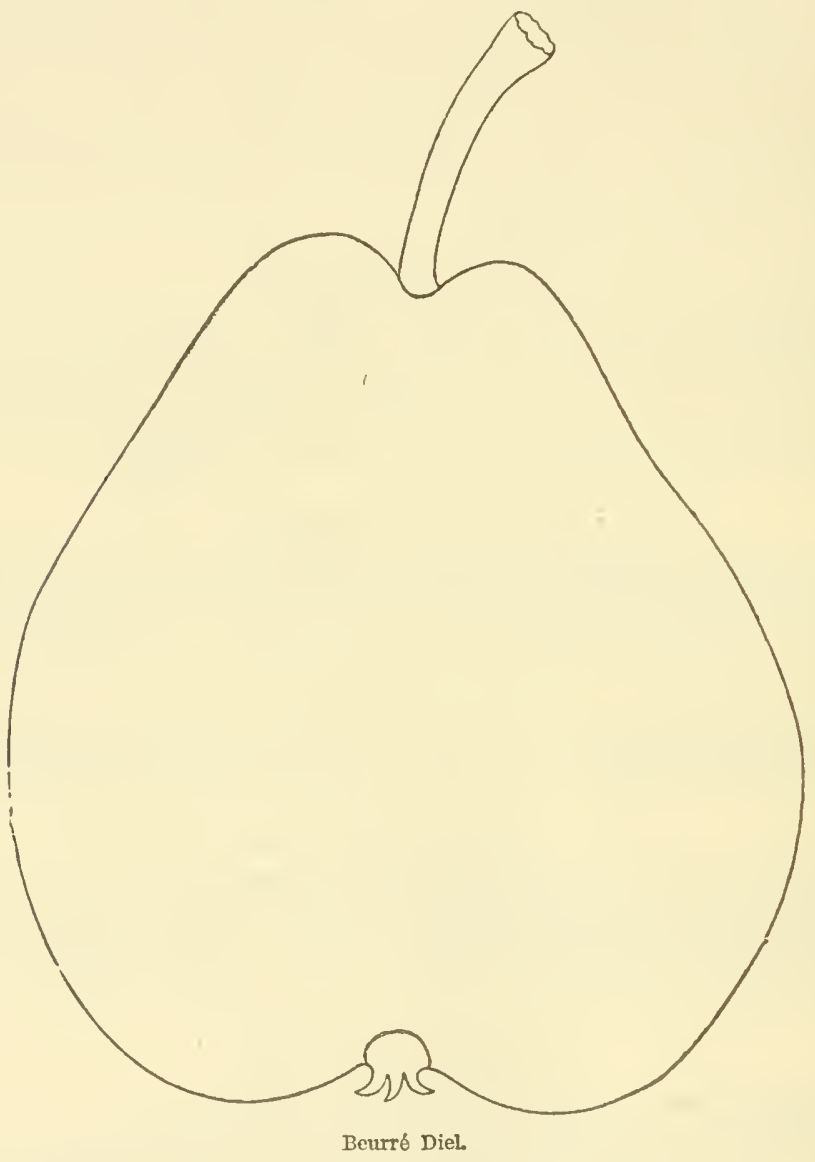

Beurre Diel

Diel's Butterbirne.

Diel.

Dorothée Royale.

Grosse Dorothée.

Sylvanghe vert d'hiver.

Beurré Royale.

Dorothée Royale.

Gros Dillen
Dillen.

Des Trois Tours.

Mabille.

Benrré d'Tielle.

De Melon.

Nelon de Kops.

Beurré Magnifiqne.

Beurré Incomparable.
Beurré de Gella. Dillen d'Hirer.

Dry Toren.

Gracioli d'Hirer.

Fourcroy.

Guillaume de Nassau.

Beurré Tert.

A chance seedling near Brussels, Belgium, dedicated by Tan Mons, 
and named in honor of his friend Dr. Augustus Frederick Adrien Diel, a clistinguished German pomolugist. Its vigor, productiveness, and beauty have made it already a general favorite with ou planters. It is in every respect a first-rate fruit in favorable situations, but on very young trees and in cold soils it is apt to be rather coarse and astringent. The tree has long, very stout, twisting banches, and is uncommonly vigorons. Jomng shoots redelish yellow grayish brown.

Fruit large, varying from obovate to obtuse prriform. Skin rather thick, lemon yellow, becoming orange yellow, makkel with large biewn dots, and mathlings of msset. Stalk an inch to an inch and thee-guarters long, stout, curved, set in a rather uneven arvity. Calyx nearly closed, and placed in a slightly furrowed basin. Flesh yellowish white, a little coarse-grained, especially at the core, but rich, sugary, half melt. ing, ant, in good speeimens, buttery and delicious. Very good. In cating, in this country, from s'eptember to December, if picked and ripened in the house.

\section{Beurré du Cercle.}

\section{Beurré de Cercle. Pratique de Rouen.}

A new French Pear little known. Tree moderately vigorous.

Fruit medium or below, very irregular in form, varying from obovate to oblong acute prriform. Skin yellow, mostly covered with golken russet, and shade of red in sum, and many russet dots. Stalk rather short. Calyx open. Flesh yellowish, coarse, juicy, melting, swect, slightly vinous. Good. October.

\section{Beurré Duhaune.}

Tree a moderate grower, productive. Young wood yellowish brown.

Fruit medium, oblate turbinate, very much depressed, with a suture along one sicle. Skin rough, covered with thin russet, and thickly sprinkled with russet dots. Stalk short, thick, and fleshy, inserted by a lip at an inclination. Calyx open. Segments stiff. Basin irregular. Flesh coarse, buttery, juicy, melting, with a pleasant vinous flavor. Good. November to February.

\section{Beurre Dunont.}

Beurré Dumon.

A Belgian variety, raised by Joseph Dumont. Tree a vigorous grower, with rather slenter branches.

Fruit rather large, obovate pyriform obtuse. Skin pale yellow, with a shade of red in the sun, and a fow nettings and patches of rus. set and russet dots. Stalk rather stont, set in a slight carity. Calyx open. Flesh white, a little coarse, juicy, melting, refreshing, sweet Good. September and October.

\section{Beurré Dumortier.}
Du Mortier.
Dumontier.
Dumoustier.

A Belgian Pear.

Fruit mediun, roundish obovate pyriform, often with unequal 
sides. Skin rough, greenish, partially netted and patched with russet, and many russet dots. Stalk generally inelined and without depression. Calyx open. Segments long, recurved. Flesh greenish white, juicy, sweet, melting, it little vinous. Good to very good. October.

\section{Beurré Durand.}

Originated at Angers, France, and introdnced in 1855.

Fruit medium, oblong obtuse pyriform, yellow, dotted and marbled with fawn-color and splashed with red in the sun. Stalk short. Calyx half closed. Flesh white, fine, melting, sugary, vinous. September, October. (Leroy.)

\section{Beurré Duyal.}

Duval. Dwael. Roi Louis Nouveau. Audibert.

A Belgian Pear, raised by M. Duval. Tree rigorons, productive. Young wood pretty stont, grayish olive brown.

Fruit medium to large, varying in form from ohovate to oblong obtuse pyriform. Skin warm yellow, dull brown in the sun, and with patches and nettings of russet and many brown dots. Stalk moderately stout, with little or no depression. Calyx open. Flesh whitish, juicy, melting, sweet, pleasant. Good to rery good. October.

\section{Beurré Duvivier.}

\section{Duvivier. Général Durivier.}

A coarse, poor French Pear.

Fruit small, obovate, greenish with russet. Flesh white, coarse, sweet, pleasant, hardly good. Rots at core. Sejtember.

\section{Beurré Flon.}

Originated near Angers, France, in 185.

Fruit large, oblong oborate obtuse pyriform. Sides unequal. Skin rough, thick, citron yellow, mostly overspread, marbled, splashed, and dotted with red. Stalk short, set in a shallow cavity. Calyx open. Flesh white, half fine, tender, juicr, a little rough, sweet, aromatic. September, October. (Leroy.)

\section{Beurré Fougiere.}

A foreign Pear, introdnced by J. C. Lee.

Fruit of medium size, obovate. Skin greenish yellow, with patcher and points of light russet, and some dark green spots. Flesh yellowish white, coarse-grained, a little gritty at the core, melting, juicy, sweet, and good. October. (Rob. Manning's MS.)

\section{Beurré Gexdron.}

\section{Poire Gendron.}

A large foreign Pear, fine for cooking.

Fruit large, irregnlar, oblong obovate obtuse priform, rellowish, with a shade of brownish red in the smu. Flesh white, coalse, breaking, juicy, sweet, vinous. January, March. 
Beurre Gens.

A Belgian Pear. Tree vigorous and productive. Young wood yel. lowish hrown.

Fruit medium, roundish obovate, obscurely pyriform. Skin yellow, shaded with bright red and sprinkled with russet dots, and netted and patched with russet. Stalk short. Calyx small, partially closed. Biasir narrow. Flesh white, tine, juicy, melting, sweet, vinons, aromatic, ‘ little gritty at the core. Very gool. October.

\section{Beurré GifFard.}

Poire Giffard.

Giffart.

A chance seedling, originated with M. Giftard, Angers, France. Tree of moderate growth, with slender reddish-colored shoots.

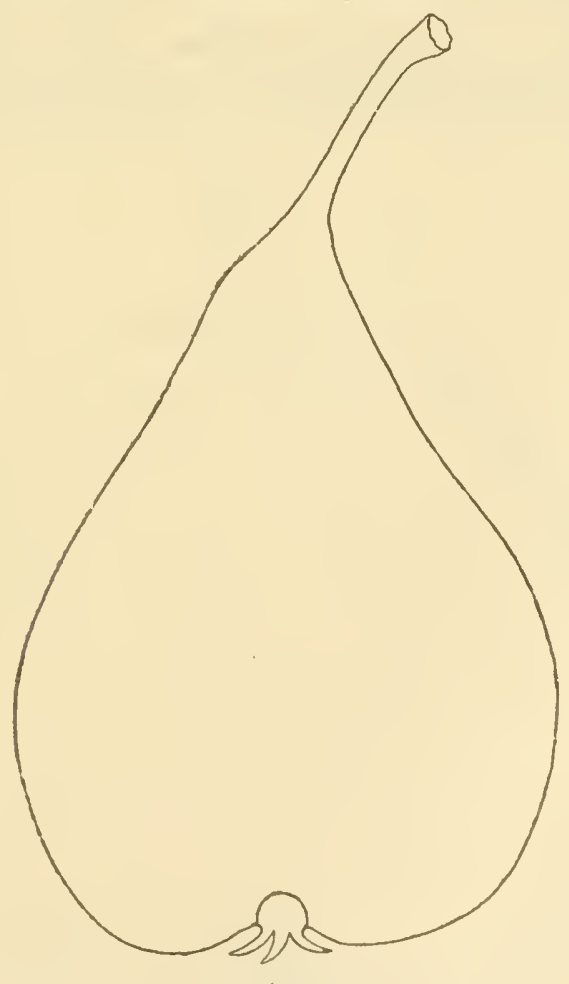

Beurré Giffard.

Fruit medium in size, pyriform, tapering to the stem, which is rather long. Skin greenish yellow, marbled with red on the sunny side. Culfx closed. Segments stiff, set in a very small hasin. Flesh white, melting, juicy, with an excellent vinous flavor, delightfully perfumol. An eirly Pear of value, but refuires to be gathered carly, and does not contiune long. Trery good. Ripening mildle of A ugust. 


\section{Beurré Goubalt.}

Poire Goubalt.

Originated in France, in 1842. 'Tree vigorous, an early. bearer, and productive.

Fruit small, irregularly obovate. Skin greenish yellow, with gray lines. Stalk long. Calyx large. Flesh juicy, melting, pleasant, but not rich. Good. September.

\section{Beurté Gris D'Hiver Nouveau.}

Beurré Gris d'Hiver.

de Iucon.

Supirieur.
Beurré de Fontenay.

d'Hiver.

de Lucon.

Tree moderately vigorous, productive. Young wood dark sellowish redrlish brown.

Fr'uit medium, roundish obtuse pyriform. Skin golden russet, with a fiue sunny cheek, and sprinkled with dots. Stalk very stout, rather

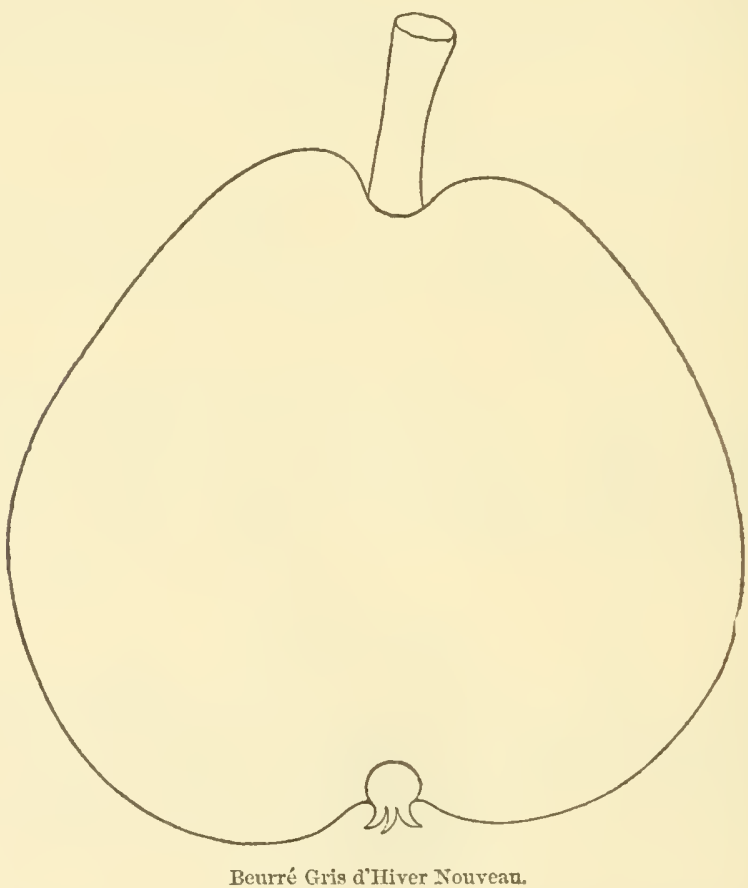

short, inclined, sometimes inserted in a large cavity, at others with a lip. Calyx very small and open. Segments small, slightly reeurred. Basin shallow, uneven. Flesh somenhat granular, juicy, buttery, melting. Flavor rich and sugary, with a very peculiar aroma. Tery good. November, February. 


\section{Beurre Haffier.}

A Belgian Pear, by some confounder with Flemish Beauty, from which it is entirely distinct. Tree vigorons, productive. Young wood clear reddish yellow biown.

Frnit medium, oborate pyriform. Skin greenish yellow, often with a shade of red, netted and patched with russet, and many russet dots. Stalk rather long, enrved, set in a small cavity, sometimes with a lip. Calyx large and open. Flesh whitish, a little coarse, juicy, melting, sweet, pleasant. Very good. September, October.

\section{Beưrré Hanecher.}

A Pear from Belgium.

Fruit medium, roundish prriform. Skin pale yellow. Stalk large, long, curved. Calyx small and closed. Flesl dry, sugary. Poor. October, November.

\section{Beurré Hardy.}

Tree vigorous, productive. Young wood dark grayish olive brown. Fruit large, obovate obtuse pyriform. Skin greenish, covered with

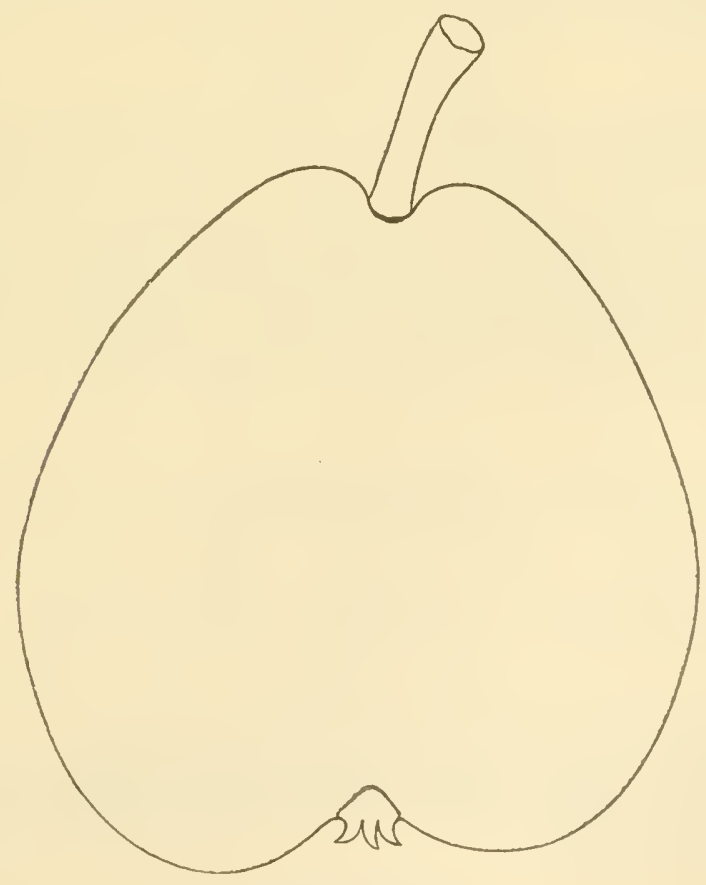

Beurro Hardy.

light russet, consıderably sliaded with brownish red, and sprinkled with brown dots. Stalk about an inch long, a little swollen at its insertion, at an inclination, in a small, rather uneven cavity. Calyx open. Seg- 
ments long, recurved in a broad, shallow basin. Flesh buttery, melt ing, juicy, brisk, vinous, and highly perfurned, slightly astringent nexi the skin. Very good. September and October.

\section{Beurré Jalais.}

Originated in 1848 with M. Jacques Jalais, of Nantes. Tree very productive.

Fruit large, roundish obovate pyriform, golden yellow, with marblings and veins of reddish brown in the sun. Stalk short, curved. Calyx small, half closed. Flesh whitish, fure, melting, rough at the core, juicy, sweet, perfumed. September, October. (Leroy.)

\section{Beurré Jeax Thax Geert.} 1864 .

Originated in Belgium with MI. Jean Van Geert, and introduced in

Fruit large, oblong pyriform. Skin yellow, dotted and marbled with fawn, and washed with relmilion red in the sum. Stalk short. Calyx half closed. Flesh white, half fine, melting, jnicy, rough at the core, sweet, aromatic. October, November. (Leroy.)

\section{Beurré Kennes.}

A Belgian Pear, a seedling of Van Mons, introduced and described by Bivort in 1846. Tree vigorous, productive. Young wood brownish red.

Fruit medium, roundish acute pyriform. Skin greenish rellow, mostly covered with thin russet, shaded with crimson. and thickly sprinkled with russet and crimson dots. Stalk of medium length, thick, and inclined, fleshy at its insertion, by a large ring or lip. Calyx partially closed, set in a broad, shallow basin. Flesh whitish, butters; jnicy, melting, with a very sweet, rich, perfumed flavor. Tery good. October.

\section{Beurré Kéentick.}

No. 1599 of Tan Mons.

A Flenish seedling, of medium size. Skin greenish sellow, russet spots. Flesh juicy, sweet, and buttery. Poor. September.

\section{Beurré Kxox.}

A Flemish variety, of vigorous growth, prodnetive.

Fruit large, oblong obovate. Skin pale green, russet on one side. Flesh tender and soft, juicy and sweet, but not high-flarored, lardly good. Last of September.

\section{Beurré Kossuth.}

A variety from Belgium. Tree of moderate vigor, productive.

Fruit large, very variable in form, generally prriform obtuse. Surface uneven. Stalk long, curved. Calyx small. Basin moderately deep and 
round. Skin dull yellowish green, traced and freckled with gray or bronze, dotted with sprecks of the same eolor, shade of red in the sun. Flesh very fine, melting, buttery, sngary, a little vinous. Good. September, Oetober.

\section{Beurré Langelier.}

\section{Langelier's Beurré.}

Raised by M. Langelier of Jersey. 'Tree vigorous, productive. Young wood dull ye]low brown.

Fruit medim, obovate obtuse pyriform. Skin pale yellow, slightly shaded with crimson and blotehed with russet, and covered with russet dots. Stalk short and fleshy, inserted often by a lip without depression. Calyx open or partially closed. Segments persistent. Basin somewhat irregular, shallow, and open. Flesh white, juicy, melting, somewhat gramular, with a very brisk, rich, vinous flavor. Very good. November to January.

\section{Beurré Le Fevre.}

Beurré de Mortefontaine. Lefevre.

A French Pear of large size, roundish or romdish obovate, greenish yellow, with brownish orange in the sun. Flesh white, gritty, course. October.

\section{Beurré leon le Clerc.}

Tree vigorous, upright, produetive. Young wool yellow brown.

Fruit merlium or alove, roundish oblong obtuse pyriforn. Skin pale yellow, partially netted and patehed with russet, and many russet dots. Stalk rather long, eurved. Cavity small. Calyx open. Segments broad. Basin abrupt, furrowed. Flesh whitish, juicy, buttery, melting, sweet, pleasant, aromatic. Very good. October.

\section{Beurré Luizet.}

Originated with M. Luizet, France, in 1847. Tree very productive.

Fruit above medium, oblong obtuse pyriform. Skin greenish yellow, shades of red in the sun, fawn-color next the stalk. Flesh white, fine, juicy, melting, sweet, vinous. Oetober, November. (Leroy.)

\section{Beurré Mauxion.}

Tree vigorous. Young wood grayish yellowish brown.

Fruit medinm, roundish, inelining to pyriform. Skin yellow russet, with a bright rerl eheek. Stalk short, morlerately stout, swollen at the extremities, inserted in a shallow eavity. Calyx open, stiff, set in a very shallow basin. Flesh fine, buttery, melting, abounding in juice, sugary, with a spicy vinous flavor, pleasantly perfumed. Very good. Ripe in september.

\section{Beurre Mevaud.}

Beurré Menand.

A French Pear of recent origin.

Fruit medium to large, long obovate. Skin pale lemon yellow. 
Stalk stout. Calyx open. Flesh tender, buttery, melting, very juicy, brisk. October. (Hogg.)

\section{Beurré Millet of Axgers.}

Origin, Angers, France. Tree vigorous and very productive. Young wood yellowish brown.

Fruit medium, roundish obovate. Skin greenish, covered with russet and thickly sprinkled with minute russet dots. Stalk medium, stout, curved, inserted in a rather abrupt cavity. Calyx open, set in a deep irregnlar basin. Flesh whitish, somewhat buttery, juicy, melting, with a brisk vinous flavor. Good to very good. November to January.

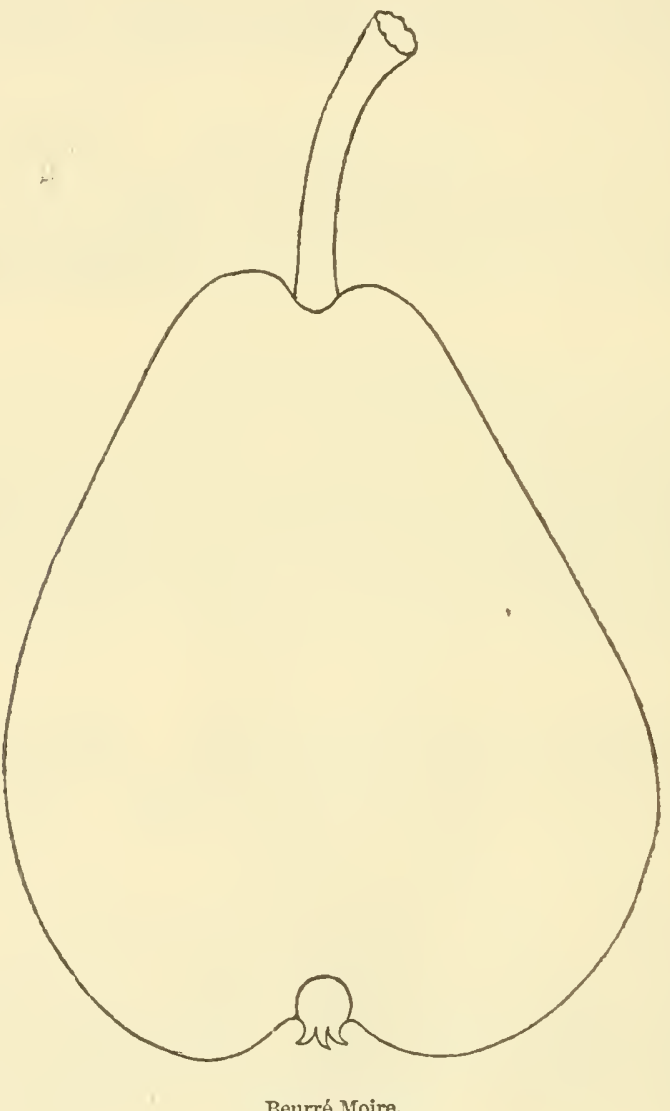

Beurré Moire.

Beurré Moiret. Moire. Belle de Moire.

A French Pear of vigorous and productive habit. Young wool redilish yellow olive brown. 
Fruit large, oblong obtuse pyriform. Skin greenish yellow, profusely sprinkled with yellow dots, sometimes a tinge of red in the sum. Stalk nedium, stout, curved, inserted in an mueven depression. Calyx small. Basin shallow. Flesh yellowish, a little gramular, buttery, melting, with a fine rich brisk flavor, highly perfumed. Good to very good. October.

\section{Beurré Moxdelue.}

A Belgian Pear, but little known.

Fruit medimm, roundish oblate obovate, or pyriform. Skin greenish yellow, netted and patched and mostly covered with cinnanon russet, and many russet dots. Stalk long, curved, sometimes set in a small cavity, sometimes by a lip. Calyx open. Bisin broad, uneven. Flesh yë́lowish, coarse, juiey, melting, aromatic. Good. October.

\section{Beurrê Navez.}

Beurré de Wael. Colmar Navez.
Beurré Noisette.

Duc de Nemours.

One of Van Mous' seellings, introduced first by M. Bunvier. Tree vigorous and productive.

Frnit large, obovate acute pyriform. Skin yellow, inclining to cinnamon, with numerous gray dots. Stalk long, thick, fleshy, inserted in an inclined carity. Calyx small, open, set in a shallow basin. Flesh white, juicy, melting, pleasant. Good. October.

\section{Beurré Paimpol.}

A French Pear, recently introduced, of only good quality. Tree vigorous and productive.

Fruit medium, obtuse pyriform, greenish yellow, patches nettings and dots of russet. Flesh white, juicy, half melting, sweet. Good. September.

\section{Beurre Pointelle de Roux.}

A Belgian Pear, showy, but of second quality.

Fruit medium, ovate obtuse pyriform. Skin greenish, dotted, splashed, and shaded with red in the sun. Flesh white, half tender, melting, juicy, sweet. Good. October. (Leroy.)

\section{Beurré Preble.}

A Pear named by Mr. Manning in honor of Commodore Edward Preble, U.S.N., and raised from seed by Elijah Cooke, of liaymond, Me.

Fruit medium, oblong obovate. Skin greenish yellow, mottled with russet and green spots. Stalk about an inch long, very stout, set in a noderate hollow. Flesh white, buttery, and melting, with a rich, high Havor. Good. October and Norember:

\section{Beurré Precocee.}

Precocee Goubault.

Bezi Precocee.

Raiserl by Mr. Goubault, Angers, France. Tree moderately vigorous, productive. 
Fruit melium, obovate, inclining to pyriform. Skin greenish yel low, slightly netted and patched with russet. Stalk long, curved. Calyx nearly closed. Basin abrupt, corrngated. Flesh whitish, juicy, melting, vinous, a little astringent. Good. Middle of August.

\section{Beurré Rance.}

Beurré Ranse.

Hardenpont du Printemps.

Beurré Épine.

Beurr: de Flandre.

Josephine, incorrectly of some.

Beurré de Ranz.

Noirchain.

Beymont.
Bon Chr'tien de Rans.

Beurr de Noirchaiu.

Beurr's de Rhin.

Benrr: d'Hiver.

Beurrs Bon Chrétien.

Gastelier.

Jenart.

The Bemre Rance is considered by all Fnglish cultivators the best very late Pear yet generally known. The wood is dull grayish brownisli yellow, straggling in growth, and rather pendulous when in bearing, and when the tree has attained a moderate size it bears well.

Fruit of medium size, obtuse pyriform. Skin clark green, even at maturity, rather thick, and dotted with numerous russet specks. Stalk rather slender, an inch and a lialf long, set in a slight blunt depression, or often without any carity. Calyx quite small, and set in a basin very little sunk. Flesh greenish white, melting, a little gritty at the core, full of sweet, rich juice, of excellent flavor. Sncceeds in England, Belgium, and France, but does not in this country, except at the South, or in warm soils and particular localities.

Beymont is doubtless a seedling of Beurre Rance, but so identical in every respect except its wood as to make a second description unnecessary.

\section{Beurrê Richelieu.}

Tree vigorous. Young shoots dull olive reddish brown.

Fruit large, obtuse pyriform truncate. Skin greenish, inclining to yellow, sprinkled with dots. Stalk short, inserted by a slight lip in a hroad depression. Calyx firmly closed, set in a broad, shallow furrowed basin. Flesh buttery, juicy, melting, with a fine sweet, aromatic flavor, sometimes astringent. Good to very good. December.

\section{Beurré Robert.}

Originated near Angers, France, in 1860 or 1861. The tree is vigorous and promising of considerable value.

Leroy describes the fruit as large, oblong obtuse pyriform. Skin greenish yellow, covered with small gray rots, and with a brownish red next the stalk and calyx. Flesh white, melting, fine, juicy, sweet, vi. nous, delicate perfume. November, December.

\section{Beurré Romaix.}

\section{Fondante de Rome.}

Beurré de Rome.

La Reine.

An old variety, variable in quality. Thee morlerately vigorous.

Fruit of merlium size, obovate pyriform. Skin pale vellowish green. Flesh white, juicy, sweet, and agreeable. Good. September to October. 


\section{Beurré Rovge d'Anjou. .}

Rouge d'Anjou.

A French Pear. Tree a good grower and productive. Young wood dull olive brown.

Fruit mediun or below in size, roundish obovate pyriform. Surface uneven. Skin yellow, partially netted and patched with russet, a tinge of crimson in the sun, sprinkled with many green and brown dots. Stalk medium, set in an acute cavity, sometimes with a lip. Calyx open. Basin uneven. Flesh whitish, half melting, not juicy, sweet. Good. October.

\section{Beurré Scheidweiler.}

Grosse Sucre.

Tree stout and rigorous, inclining to a pyramil, good bearer.

Fruit medium, obovate pyriform. Skin green or dull green, with a few traces of russet, changing very little at maturity. Flesh buttery, sweet, and pleasant. Good. September and October.

\section{Beurré Seutix.}

Fruit medium, pyriform, inclining to oval, irregular or angulas. Color green, sprinkled with russet, sometimes sladed with dull crimson. A late-keeping, dry, cooking pear.

\section{Beurré Six.}

\section{Poire Six}

Originated in Belgium. Tree vigorous and productive.

Fruit below medium, priform, pale greenish yellow, sprinkled with green and brown dots. Stalk long, rather stout, little or no depression. Calyx open. Basin small. Flesh whitish, juicy, melting, vinous. Good. Sisptember.

\section{Beurré Soulange.}

Size medium to large. Form acute pyriform. Stalk an inch or more in length, fleshy at its junction. Color pale clear yellow, with occasional traces of russet. Flesh melting and very juicy, flavor rich, sugary, with a peculiarly pleasant aroma. Season-October, November. (Wil(ler's Rep.)

\section{Beurré Spae.}

A Belgian Pear, figured and described in the Illustration Horticole, from which we copy. Tree vigorous, productive.

Fruit large, roundish pyriform, pale yellowish, spotted and mottled with brown in the sun. Stalk curved, inserted in a furrowed cavity. Flesh very juicy, fine, sugary, melting, perfumed. Very good. November.

\section{Beurré Spence.}

Many varieties having been received from Europe for Beurré Spence and proved incorrect, we give description of one which we have received, 
and presume to be the true variety, originated by Tan Mons. Tree moderately vigorous. Young shoots reddish. Very productive.

Fruit medium, short pyriform, inclining to turbinate. Skin greenish, becoming yellow at maturity, shaded with dull crimson, thinly sprinkled with russet, and thickly covered with russet dots. Stalk long, fleshy at its insertion, which is often at an inclination by a lip. Calyx smali, elosed, in a deep, rather abrupt basin. Flesh juicy, melting, with a fine rich, vinous flavor. Good to very good. Core small. September

\section{Beurré Sterkmaxs.}

Doyenné Sterkmans. Belle Alliance. Calebasse Sterkmans.

A Belgian Pear. Tree vigorous, with stout yellowish-brown shoots, productive.

Fruit medium, oblate, remotely pyriform. Skin green, speckled with russet, and shaded with crimson. Stalk about an inch long, stout,

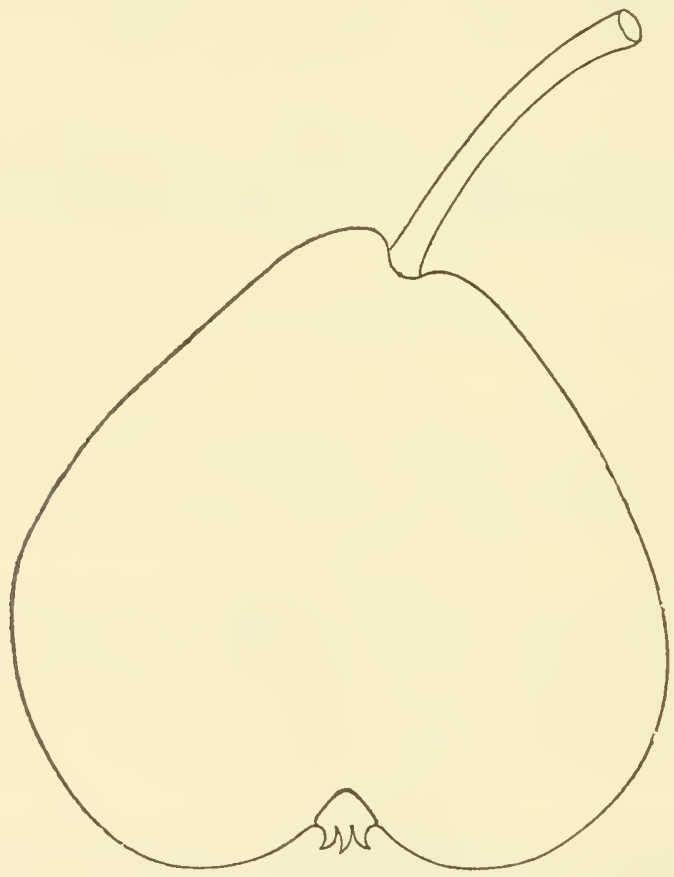

Deurre Sterkmans.

inserted in a small, uneven cavity. Calyx open. Segments stift, set in a broad, uneven basin, slightly russeted. Flesh yellowish white, fine, very melting, juicy, sugary, vinous, pleasantly perfumed. Good to rery good. October and November.

\section{Beurré Superfin.}

This really good Pear originated in France, in 1837. The tree is. 
very healthy, hardy, and moderately vigorous, not an carly, but a good berarer when at full age. Young shoots slender, light yellow brown.

Fruit medium, romndish pyriform. Skin yellow, slightly shaded with crimson on the sunny side, and partially covered with russet, and

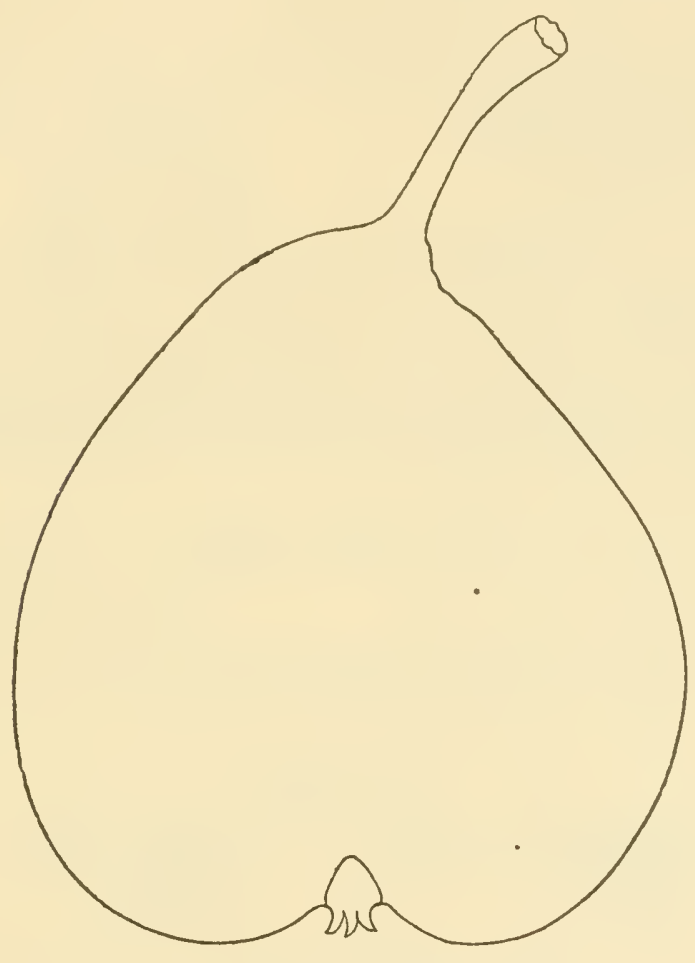

Beurré Superfin.

thickly sprinkled with minute dots. Stalk stout, rather long, inserted without depression by a fleshy enlargement. Calyx partially closed, in an abrupt, small basin. Flesh exceedingly juicy, buttery, melting, with a brisk vinous or subacid flavor. Very good to best. Ripe all of October.

\section{Beurre Vax Driesscite.}

Originated in Belgium, and but recently introduced. We find no description of it except in Leroy, which we copy.

Fruit above medium, oblong obtuse pyriform, dull yellow, dotted with clear brown, and shaded with the same next the stem. Flesh whitish, half fine, half melting, rough at centre, juicy, sweet, vinous. Excellent. February, May.

\section{Bezi de CAEN.}

This Pear is of recent introduction, and promisos to be valuable as a midwinter variety. Young wood dull yellow brown. 
Fruit medium, pyriform. Skin dull brown, with smooth russet on greenish yellow. Stalk set withont depression. Calyx open. Segments short. Flesh white, fine-grained, melting, juicy, sweet, vinous. Very good. December, January.

\section{Bezi de Caissoy.}

Bezy de Quessoy.

Roussette d'Anjou.

Petite Beurré d'Hiver.

Wilding of Caissoy.

Terreneuvaise.
Nutineg Pear.

De Quessoy.

Small Winter Beurré.

Besi de Quassoy.

Besi de Bretagne.

An old Pear, said to have been discovered in the forest of Caissoy, in Bretagne. Tree hardy and very productive. Young wood slender, dull olive yellow.

Fruit small, roundish pyriform. Skin yellow, reddish brown in sun and numerous russet specks. Stalk short, set in a rather deep cavity. Calyx open. Flesh white, tender, buttery, sweet and aromatic. Very good. November to February.

\section{BEZI de CAISSOY D'ÉtÉ.}

Bergamotte Quessoy d'Été.

Besi Quessoy d'Été.

This variety resembles in all respects the preceding Bezi de Caissoy, only in maturing its fruit early in September instead of winter.

\section{Bezi d'Heri.}

\section{Bezi Royal.}

Französische Rumelbirne.

Besidery.

Bezi de Hery.
Wilding of Hery.

Besi d'Airy.

De Henri.

De Bordeaux.

This is a very excellent winter stewing pear, which bears most abundantly. It is of no value for the dessert.

Fruit medium, roundish. Skin greenish yellow, with a reddish blush. Flesh tender, juicy, free from grit, with an anise-like flaror. Fit for cooking from October to January.

\section{Bezi DE LA MotTe.}

Bein Armudi.

Beurré blanc de Jersey.

The tree is exceedingly vigorons and productive, and the gravish olive shoots, like the fruit, have a peculiarly speckled appearance. It ripens gradually, and may be kept a good while.

Fruit of medium size, bergamot-shaped, roundish, flattened at the eye. Skin pale yellowish green, thickly sprinkled with conspicuous risset green dots. Stalk about an inch loug, green, slightly curved, and inserted in a slight flattened hollow. Calyx small, open, set in a shallow, rather abruptly sunken basin. Flesh white, very fine-grained, but tery, juicy, with a sweet, delicate perfumed flavor. Good. October. 


\title{
Bezi DE LA T'IERRE.
}

Besi de la Pierre.

Originated at Anvergne, France. Introduced in 1862. Tree pror ductive.

Fruit small to medium, oval, citron-yellow, marbled, dotted, and splashed with fawn-eolor. Stalk short, curved. Calyx halt closed. Flesh whitish, laalf tine, melting, juicy, rough at core, vinous. ()etober, November: (Leroy.)

\section{BEZI* DE MIONTIGXY.}

\author{
Trouré de Montigny. \\ Dovenni: Musque. \\ Benrré Cullem. \\ Louis Bose. \\ De Montigny. \\ Comptesse de Lunay.
}

A pleasant juicy fruit, with a musky flavor, but not first-rate. The skin is remarkibly smooth, and the pear is evenly formed. It is a good bearer. Toung wool olive brown.

Fruit of medium size, very regularly obovate. Skin pale vellowish green, with numerous gray dots. Stalk stont, thickest at the point of insertion, an inch long, inserted in a snall shallow carity. Calyx small, half open, reflexer, in a very smooth basin, scarcely sunk. Flesh white, melting, juier, half buttery, with a sweet, musky Havor. Good. First of October.

\section{BEZI des TÉTÉRANS.}

\section{Banuean. Des Vétérans.}

A Belgian Pear, of vigorous thrifty habit, and productive. Young wood olive biown, with many specks.

Fruit large, olstuse prriform. Skin light yellow, thickly sprinkled with gray dots, and slight patches of russet. Flesh firm, not tender; chiefly for cooking. December to February.

\section{Bezi Esperex.}

\section{Bezy d'Esperen. Besi Esperen.}

Raised by Major Esperen. Tree a moderate grower and good bearer. Young wood olive brown.

Fruit large, roundish obtuse prriform. Skin dull yellow, sprinkled and patcherl with russet, and thickly covered with l'usset rlots. Stalk rather long, stout, inserted by a ring or lip, at an inclination, in a small, irregular cavity. Calyx open, set in a deep, acute basin, surrounded by russet. Flesh juicy, with a sprightly vinous flavor. Good. Oetuber; November.

\section{Bezi Goubault.}

A French Pear, originated in 1845.

Fruit medium size, irregular in form, generally roundish obovate. Skin yellow, mostly covered with cinmamon russet, and many russet dots. Flesh temler, half melting, grity at core. Ciood. February, March. France.

* Bezi signifies voilding, i.e., natural seedling found near MTontigny, a town in 


\section{Bezi Mai.}

Besi de Mai.

Raised by J. De Jonghe, Brussels, and first fruited in 1856. It is a winter fruit, said to mature from April to May. As vet it has not fruited here. The tree is hardy, a good grower, and described as productive. Young wood yellow brown.

Fruit large, obtuse oval, dull yellowish green, with brown dots. Stalk nearly an inch long. Calyx small, with short, stiff, erect segments. Flesh buttery, juicy, sugary, rich, very firm. February, April.

\section{Bezi VAET.}

$\begin{array}{lll}\text { Beurré de Beaumont. } & \text { Besi Va. } & \text { De Saint Waast. } \\ \text { Besi Vaat. } & \text { Besi Vath. } & \text { Besi Waet. }\end{array}$

Besi de St. Waast.

The Bezi Taet lias been considerably cultivated in this comtry, but is not generally considered more than a good second-rate Pear. The young shoots are reddish olive brown.

Fruit of medium size, obovate, narrowing to the stalk. Skin roughish, pale green, becoming yellowish, with many russety spots and a brownish cheek. Stalk an inch or more long, inserted in a slight cavity. Calyx set in a small basin. Flesh yellowish white, melting, juicy, with a sweet, somewhat perfumed flavor. Good. November to January.

\section{Bezy Sanspareil.}

Bergamotte Sanspareil. Nonpareille.

Sans Pareille.

Besi Incomparable.

Sans Pair.

An old French Pear, of little value and only good for cooking.

Fruit large, obscurely pyriform. Skin yellowish green, covered with numerous brown dots. Stalk fleshy at its insertion, in a slight cavity, at an inclination. Calyx open in a moderate uneven basin. Flesh coarse and granular, buttery, juicy, melting, with a brisk vinous flavor. October to December.

\section{Bismop's Thumb.}

A long, oddly shaped English Pear.

Fruit rather large, ollong and narrow, and tapering irregularly. Skin dark yellowish green, having a russet red cheek. Flesh juicy, melting, with a vinous flavor, somewhat astringent. Good. October.

\section{Brack WoRCester.}

Black Pear of Worcester. Parkinson's Warden. Iron.

A market fruit esteemed for cooking. The branches incline downwards with the weight of the fruit. Young shoots dark yellow olive, diverging.

Frnit large, obovate or oblong pyriform. Skin thick, rough, green, nearly covered with dark russet. Flesh hard and coarse, but stews and bakes well. November to February. 
Bu.ixquet Anastere.

Blanquet Anasterque.

Blanquet d'Austrasia.

A French Pear, of poor quality.

Fruit small, pyriform, yellowish green, with a tinge of brown in the sum. Flesh white, coarse, breaking, rots easily. August.

\section{BLEecker's MEADOW.}

$\begin{array}{lll}\text { Large Seckel. } & \text { Heidelherg. } & \text { Meadow Feaster. } \\ \text { Feaster. } & \text { Spice Butter. } & \text { Frankford. }\end{array}$

A native fruit, said to have been found in a meadow in Pemsylvania. It is a handsome, hardy fruit, and bear's large crops, but it has been overpraised as to quality.

Fruit small, roundish. Skin bright clear yellow, with crimson dots on the sunny side. Flesh very white, firm, with a peculiar musky or wasp-like aroma and spicy taste, but mostly remains erisp and hard. Stalk straight and stiff Basin shallow. Calyx open and reflexel. Good. October and November.

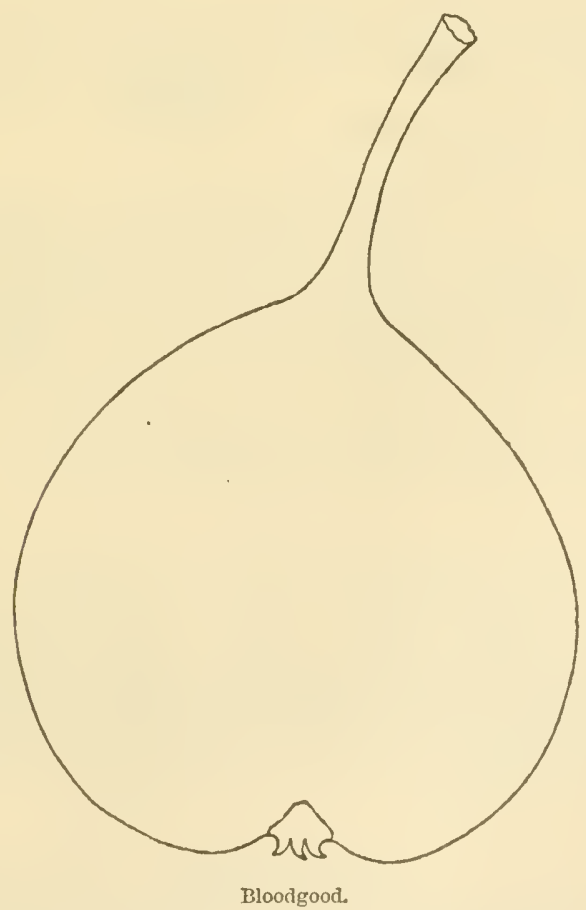

BLOODGOOD.

Early Beurré.

The Bloodgood is the highest flavored of all early Pears, and do. 
scrves a place eren in the smallest garden. It was named from the cir cumstance of its laving been bronght into notice, about 18.35, by the late James Bloodgood, murseryman, Flushing, L. I. The sort was brought to that nursery as a new variety, without a nane, however, by some person on Long Island, mknown to Mr. B., who was never able afterward to trace its history further. The tree is rather short-jointed, with deep reddish brown wood, grows moderately fast, and bears early and regularly. The fruit, like that of all early pears, is better if ripened in the house. It surpasses every Emropean variety of the same season, and together with the Dearborn's Seedling, another native sort, wil supplant all inferior early pears.

Fruit of medium size, turbinate, inclining to obovate, thickening very abruptly into the stalk. Skin yellow, sprinkled with russet dots and network markings, giving it a russety look on one side. Calyx strong, open, set almost withont depression. Stalk obliquely inserted, without depression, short, dark brown, fleshy at its base. Flesh yellowish white, buttery, and melting, with a rich sugary, highly aromatic flavor. The thin skin has a musky aromatic perfume. Tery good. Core small. Ripe from the 5 th of July to the 10tll of August.

\section{Bon Chrétien Fondante.}

Bon Chrétien de Bruxelles.

Pionlice.

Bon Chritien Fondante Musquó.

Bon Chritien d'Été Musqué.
Bon Chrétien Musqué Fondante. Bugiarda.

Petit Musqué.

A Flemish Pear, abounding with juice, and having a refreshing, agreeable flavor. In good seasons it is first in quality, and it bears early and abmudantly. Toung shoots slender, diverging, olive gray.

Fruit pretty large, romdish obovate, regularly formed. Skin pale green, sprinkled with small russet dots, and considerably corered with russet. Stalk three-fourths of an inch lomg, curved, insertęd in a slight depression. Calyx suall, set in a narrow hollow. Flesh yellowish white, gritty round the core, exceedingly juicy, tender, and melting, with a rich and pleasant tlavor. Tery gooil. October.

\section{Bow Chrétien Joseph Lamarque.}

Originated in Liege, Belgium. Tree very vigorous and productive.

Fruit large, oblong obtuse pyriform. Skin rough, yellowish, with a sharle of brown red, and spotted and dotted with black and dark brown specks. Stalk rather stont, curved, set in deep furrowed carity. Calyx open. Flesh white, buttery, melting, juicy, delicate perfume. October. (An. Pom.)

\section{Bon Gustare.}

Raised by Major Esperen. Tree very vigorous, with stont shoots.

Fruit mildlle size, regular, pyriform. Stalk medium. Calyx open. Basin shallow. Skin light green, corered with russet. Flesh white, fine, buttery, juicy, sugary, and perfumed. Rije Deconber, January (Garcl. Clur.) 


\section{Boxwe Axtorse.}

Fruit very large, conical or pyriform obtuse, yellowish. green, with spots, marblings, and patches of brown. Flesh white, fine, slightly graiulous, juicy, sweet, lerfumed. First quality. Octuber, November. (Leroy.)

\section{Boxwe C'inalóte.}

Tree vigorous and productive.

Fruit of moderate size, variable in form, generally resembling Doy emé. Skin smootl, pale rellow, with green dots. Stalk long. Galyx open. Flesh morleratrly fine, more buttery than melting, singary, and strongly perfumed. Good. Should be gathered early. Middle of A ilgust.

\section{Boxxe d'Ezée.}

Bonne des Haies.

Bonne de Zies.
Bonne de Longueval. Belle et bonne d'Ezée.

A French Pear. Tree moderately vigorous, productive. Young wood dull yellow brown.

Fruit large, oblong obtuse pyiform. Skin light yellowish green, with russet palches and dots. Stalk large, long, curved, inserted in a broad cavity. Calyx small, open. Basin narrow, of little deptlı. Flesh white, juicy, melting, sugary, brisk, rich. Good to very good. September and October.

\section{Boxye DE JALAIS.}

Beurré de Jalaise.

A French Pear, originated at Nantes in 1857.

Fruit medium, roundish pyriform. skin golden rellow, washed, splashet, and dotted with red. Stakk rather long, largest at junction with the tree, inclined. and set in a shallow carity. Flesh white, fine, melting, juicr, aromatic, sweet. Good. October:

\section{Boxye de la Chapelle.}

Beurrí de la Chapelle.

This rariety was found by a gardener in the wood of La Chapellesur-Erdre, near Nantes, in 1845. Tree moderately rigorous and pro ductive.

Fruit medium, varying in form from roundish oblate to oblate pyri. form. Skin greenish yeilow, with nettings and patches of russet, and distinct brown dots. Stalk long, slender, curvet. Calyx open. Flesh yellowish, moderately juicy, ratler coarse. Good. November, December.

\section{Boxyeserre de Shixt Dexis.}

Originated with André Terny, Angers, France, in 1863. Tree very [roductive. Foung wood reddish brown grayish.

Fruit medium to larese, romdish obovate, yellowish green, dottec and splashed with red. Stalk short. Calyx large, half closed. Flesl: white, fine, melting, juicy, rough at the rore, sweet, vinous, delicious perfume. December, Jamary. (Leroy.) 


\section{Bonne de Soulers.}

De Soulers.

Beurré de Soulers.
Bergamotte de Soulers. Soleure.

An old variety, described in 1675 . Tree moderately vigorous, productive.

Fruit medium, oval. Skin pale greenish yellow, dull red in the sun. Flesh white, juicy, half melting, sweet, slightly vinous. Good. Janwary to March.

\section{Bonve SopHi. \\ Bonne Saplier.}

Fruit rnedium, acute pyriform. Skin pale greenish yellow, with a shade of crimson, a few patches and nettings of russet, and many sm ull

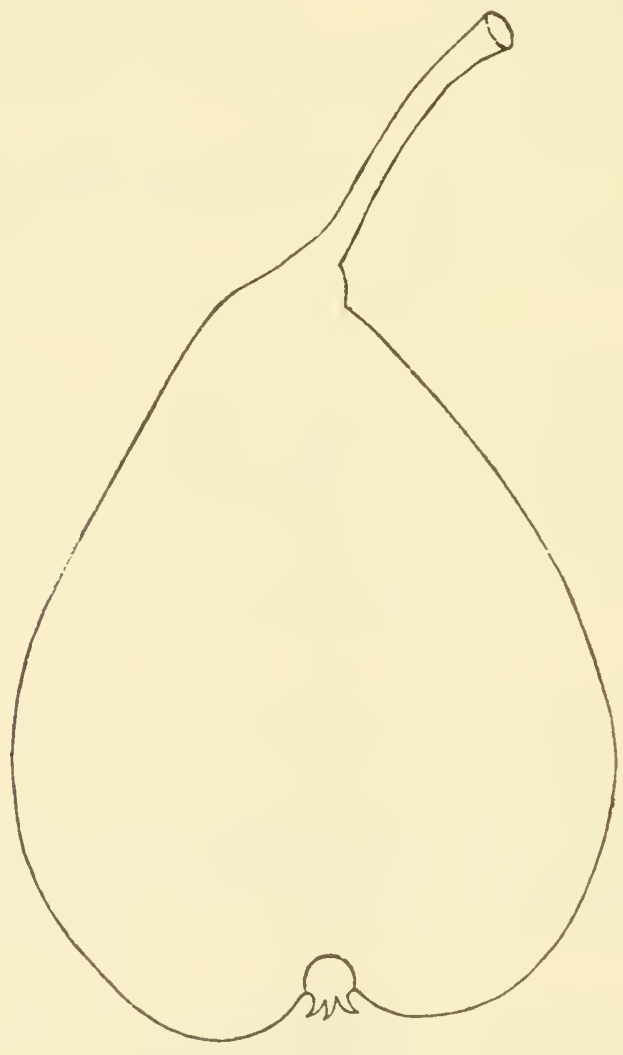

Bonne Sophir.

brown dots. Stalk long, inclined, fleshy at insertion. Calyx open. Flesh white, fine, juicy, melting, sweet, slightly perfumed. Very good. New and promising. October. 


\section{Boxne Túḱrése.}

Originated in Ma.ines, France.

Fruit medimm, roundish ovil. Skin greenish yellow, marbled with red at the stalk. Stalk short, straight. Calyx small, open. Flesh very white, fine, melting, juicy, sweet, perfumed. October. (Leroy.)

\section{Bovcouia.}

\section{Beurré Boucquia.}

A Flemish Pear.

Fluit rather large, oval turbinate. Skin pale yellow. Flesh yellowish white, rather istringent, and liable to rot at the core. October.

\section{BOURGEMESTER.}

Bouvier Bourgemestre.

Fruit large, pyriform. Skin pale yellow, witl large gray dots, russeted around the eye. Flesh tender, juicy, and astringent. November. Wood cracks and cankers badly.

\section{BRACONOT.}

Poire Braconot d'Epinal.

Originated in 1840 or 1841, with M. Leclerc-Epinal, France. new Pear, very showy and promising. Young wood yellow brown.

Fruit very large. Skin pale yellow, washed with a brown shade in sun. Stalk long and stont. Calyx large, open. Flesh yellowish white, tine, crisp, juicy, sweet, perfumed. October.

\section{Brande's Saint Germain.}

Brande's.

Bran de St. Germain.

Urigin uncertain, said to be a scedling of Van Mons. Tree a slow grower, with slender branches, spreading.

Fruit of medium size, oval, narrowing towards both ends. Skin ycllowish green. Elesh melting, juicy, with a rich and excellent flavor. Good. November and December.

\section{BRAYDYWINE.}

Found on the farm of Eli Harvey, on the banks of the Brandywine, Delaware Co., Pa. Tree vigorous, upright, uniformly productive. Young wood dull yellow brown.

Fruit medium, varying in form from oblate depressed pyriform to clongated pyriform. Skin dull ycllowish green, considerably dotted and somewhat sprinkled with russet, having a warm cheek on the sicle of tho sun. Stalk is fleshy at its junction with the fruit, and generally surrounded by folds or rings. Calyx open. Basin smooth and shallow. Flesh white, juicy, melting, sugary, and vinons, somewhat aromatic. Good to very good. Ripe last of August and first of September. 


\section{Brewer.}

Fruit medium, obovate pyriform. Skin lemon-yellow, thickly sprinkled with minute brown dots. Stalk very long, curved, set in a small eavity. Calyx open. Basin rather small, slightly corrugated. Flesh white, eaarse, not juicy or melting, but sweet and pleasant. Good October.

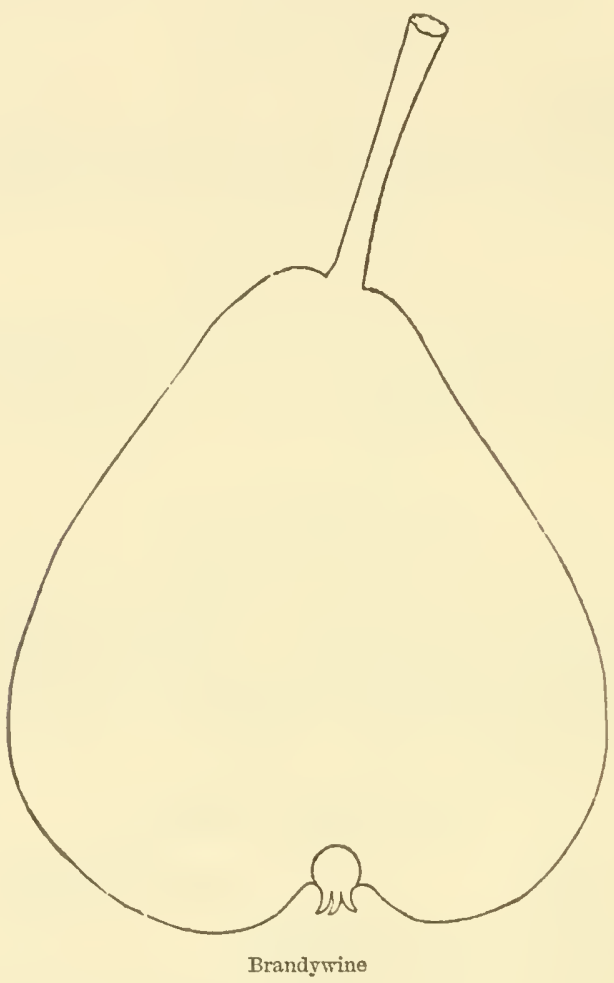

Brialmonion.

A Belgian Pear, of recent introduction and good promise. Young wood olive brown.

Fruit medium, ovate, greenish yellow, with traces of russet and many green and brown dots. Stalk rather short, set in a small eavity. Calyx open, with long recurved segments. Flesh white, juicy, buttery, melting, pleasant. Very good. Oetober.

\section{BRIFFAUT.}

Originated with M. Briffaut of Sèvres. Tree rery productive.

Fruit large, oblong aeute pyriform. Skin greenish, with fawn rolored shades, especially around the stalk, bright red cheek in sun. Stalk long, straight, without depression. Calyx large and open. Flesh white, juicy, melting, rough at the core. July, August. (Leroy.) 


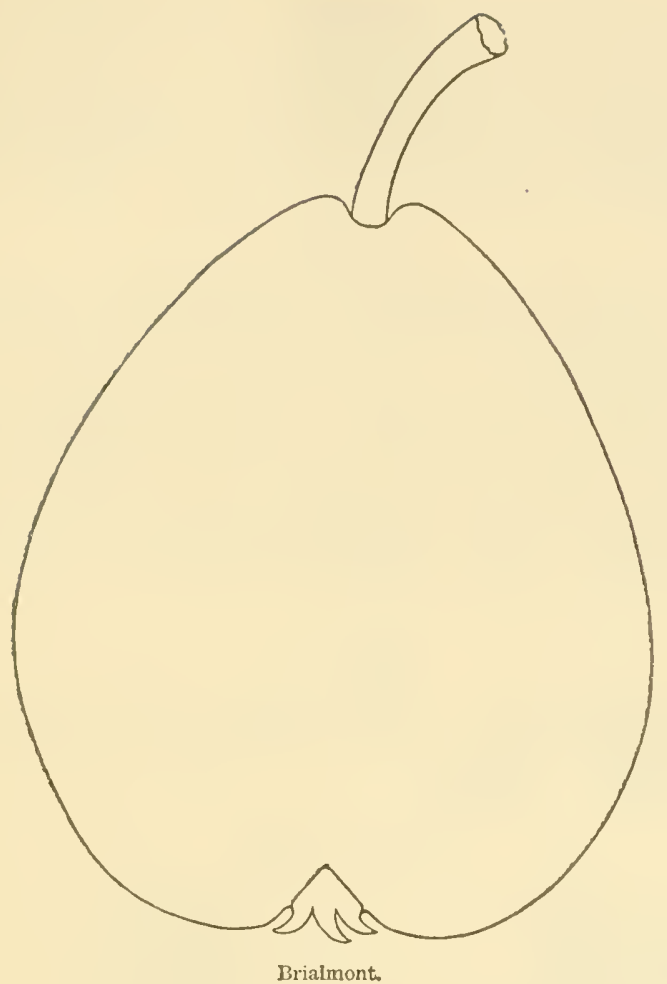

Brimpamour.

An old rariety, which originated in Vienne, France. Tree vigorous and productive.

Fruit medium, roundish pyriform. Skin bronzed, marbled, and sharlerl with fawn and green. Stalk short, set without depression. (Galyx large, open. Flesh whitish, fine, fibrous, melting, watery, sugary acid, perfuned. November, December. (Leroy.)

\section{BrixgeWood.}

A foreign Pear, deseribed in Hovey's Magazine, from which we copy, not having scen the fruit:-

"Fruit medium, pyriform, yellowish hrown and russet. Stalk long and slender. Calyx open. Flesh yellowish white, gritty at core, the rest buttery. Very good. November."

\section{British Queen.}

An English Pear, raised at Frogmore, supposed from seed of Mario Louise. Tree a vigorous grower. Young woor rery strong, clear rich redlish brown. It is deseribed in IJogr as follows :- 
"Fruit large, obovate pyriform, the outline umrlulating and bossed. Skin smooth, and almost entirely covered with a thin coat of cinnanoncolored russet, but on the side next the sun it has a blush of rosy crimson. Calyx rather small, with short, narrow segments. Stalk stout, obliquely inserted in a round, narrow cavity. Flesh yellowish white, very fine-grained, buttery, melting, rich, sngary. October, November."

\section{Bronx.}

A new American Pear, raised in 1850, by James P. Swain, of Bronxville, N. Y. The tree is an upright pyramidal grower, with reidish brown young shoots.

Fruit medinm, obovate pyriform. Skin dull greenish yellow, partially netted and patched with russet, and thickly sprinkled with russet and brown dots. Stalk long, rather sleuder, curved, and set in a small cavity. Calyx small, open. Segments short, erect. Basin small, uneven, and much russeted. Flesh whitish, juicy, melting, sweet, a little pelfumed. Good to very good. Early September.

\section{Brougham.}

An English variety.

Fruit roundish oblate. Skin greenish yellow, some russet. Flesh coarse, astringent. November.

\section{Brown Beurré.}

\author{
Benrré Gris. \\ Peurré Rouge. \\ Beurré d'Or. \\ Beurré Dorée. \\ Beurré d'Amboise. \\ Beurré d'Amblense. \\ Beurré du Roi. \\ Poire d'Amboise. \\ Isambert. \\ Isambert le Bon. \\ Beurré. \\ Goldtn Beurré.
}

\author{
Red Beurré. \\ Badham's. \\ Gray Beurré. \\ Beurié Vert. \\ Red Butter. \\ Beurré Rousse. \\ Beurré Roux. \\ Gisambert. \\ Beurré d'Isambert le Bon. \\ Beurré Gris d'Automne. \\ Eisenbart. \\ Beurré de Caen.
}

The Brown Beurré, almost too well known to need description, was for a long time considered the prince of Pears in France, its native country, and for those who are partial to the high vinous flavor-a rich mingling of sweet and acid-it has, still, few competitors. It is, however, quite variable in different soils, and its variety of appearance in different gardens las giveu rise to the many names-gray, brown, red, and golden-under which it is known. Shoots diverging, dark reddısh brown.

Fruit large, oblong obovate, tapering convexly quite to the stalk. Skin slightly rough, yellowish green, bui nearly covered with thin russet, often a little reddish brown on one side. Stalk from one to one and a half inches long, stout at its junction with the tree, and thickening obliquely into the fruit. Calyx nearly closed in a shallow basin. Flesh greenish white, melting, buttery, extremely juicy, with a rich subacid flavor. Very good. September. 


\section{Buffum.}

\section{Buffam.}

The Buffam is a native of Rhode Island, and from its general resem blance to the Doyenné, it is, no doubt, a seelling of that fine sort. It is an orchard Pear of the first quality, as it is a very strong, uprightit grower, with reddish or reddish brown young shoots, bears large, regular crops, and is a very handsome and salable fruit. It is a little varialule in quality. We liave frequently eaten them so fine as scarcely to be distinguished from the Doyené, and again when rather insipid. It may be considered a beantiful and good, though not first-rate variety.

Fruit of medium size, oblong obovate, a little smaller on one side. Skin fair, deep yellow (brownish green at first), finely suffused over

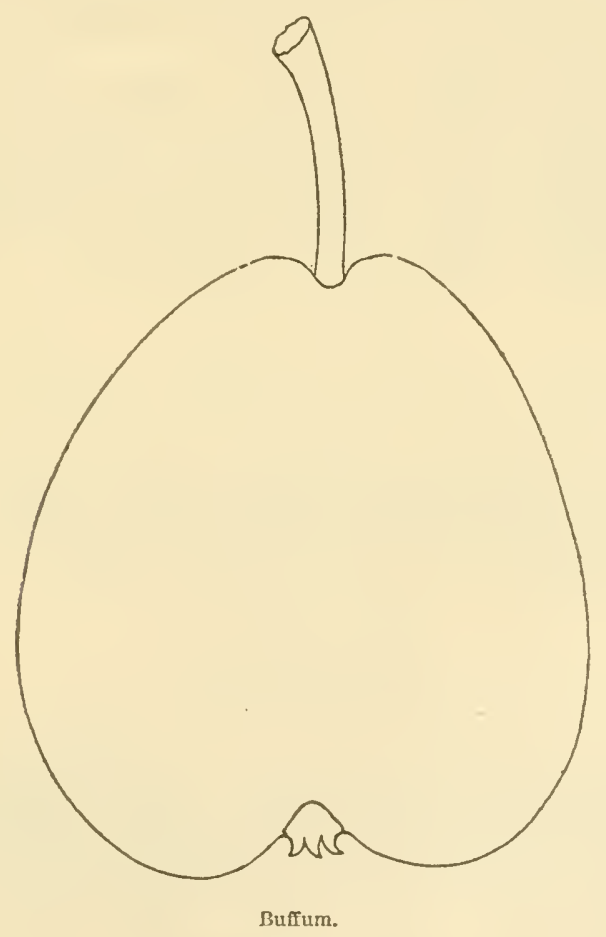

half the fruit, with bright red, sprinklerl with small brown dots, or a little russet. Stalk an inch long, inserted in a very slight cavity. Calyx with small segments, and basin of moderate size. Flesh white, buttery, not so juicy as the Doyemé, but sweet, and of excellent flavor' The strong upright reddish brown shonts, and peculiar brownish green appearance of the pear before ripening, distinguish this fruit. V'ery good. September.

\section{Butilivgane.}

A Pear of quite indifferent quality that originated in Ohio. 
Fruit small or medium, roundish oblate, yellow, shaded with red in the sun. Flesh coarse, not juicy, sweet. Poor. September.

\section{BurnetT,}

Raised by Dr. Joel Burnett, of Southborough, Mass.

Fruit large, obtuse pyriform. Skin pale yeliow. Flesh greenish ite, a little coarse-grained, but juicy, sweet. Good. First of Oeto$\because$

\section{САвот.}

Originated from the seed of the Brown Beurré, by J. S. Cabot, Esq., of Salem, Mass. It has a goor deal of the flavor of its parent, and is an agreeable subaeid fruit. The tree grows upright and very strong, and produces amazing crops.

Fruit small to medium, roundish turbinate, narrowing rather abruptly to the stalk, which is bent obliquely, and inserted on one side of a tapering summit. Skin roughish, bronze yellow, pretty well covered with cinnamon pusset. Calyx small, open. set in a round, smonth basin. Flesh greenish wlite, breaking, juicy, with a rich subacic Lavor. Good to very good. Middle and last of September.

\section{Cadet de Vaux.}

Origin unknown. Tree very productive. Young wood yellow brown.

Fruit large, obtuse pyriform, irregular. Skin ochre vellow, dotted with brown, and shaded with fawn and pale red in the sun" Stalk short, large, curved. Calyx large. Flesh yellowish white, fine, almost melting, sweet, juicy, perfumed. Good. December to March.

\section{Caen de France.}

Doyenné de Bruxelles, erroneously.

A foreign Pear promising great value. Tree vigorous, productive.

Frnit merium, regular, ovate obtuse priform. Skin rough, yellow, overspread with a dull rnsset, and with many mough russet dots. Stalk rather short and stont, a little inclined, and set in a small carity. Calyx "losed, or partially open. Segments short. Basin rather small, meven. Flesh whitish, fine-grained, juicy, melting, vinous, slightly aromatic. Very good. December, February.

\section{Caleb.asse.}

Culebasse Double Extra. Calebasse d'Hollande. Calebasse Mrusquée.

The Calebasse is a very grotesque-looking Belgian fruit, named from its likeness to a calabash or gourd.

Fruit of medium size, oblong, a little crooked and irregular or tnobby in its outline. Skin rough, dull yellow, becoming orange russet 
on the sunny side. Flesh juicy, crisp, a little coarse-grained, but sugary and pleasant. Good. Middle of September.

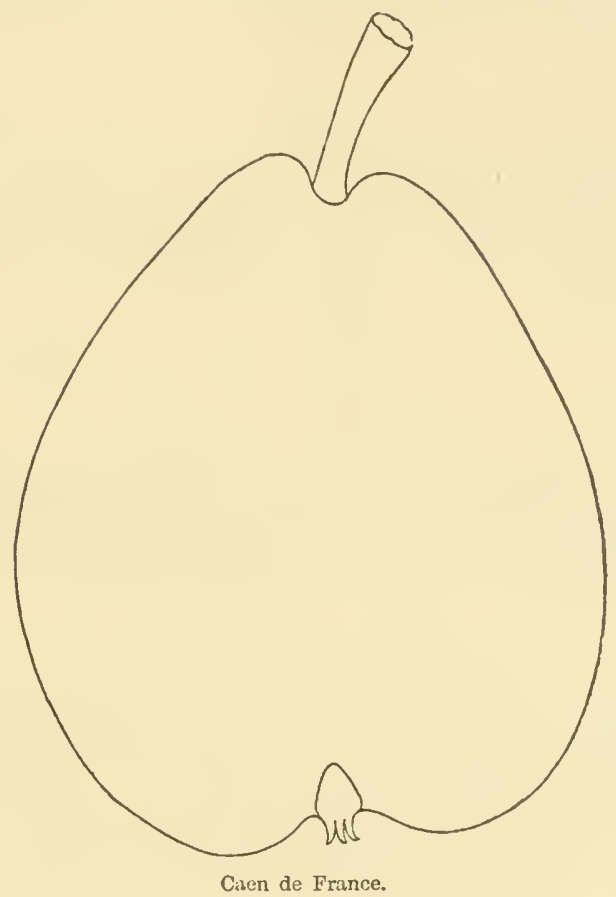

Calebasse D'Été.

Belle de Forêts.

A variety raised from seed by Major Esperen. Tree moderately vigorous. Not desirable.

Fruit medium, oblong acute pyriform, greenish yellow, mostly covered, netted, and patehed with russet, and many russet dots. Stalk long, stont, fleshy at base. Calyx large, open. Flesh whitish, vinous, astringent. Poor. Early September.

\section{Calebasse Delvigne.}

Origin uncertain. Tree vigorous and productive.

Fruit medium, lyriform, broad at calyx. Skin yellow, slightly rus seted, sometimes shaded on the sumuy sicle. Stalk short, thick at its junction with the fruit. Calyx open. Segments stiff, in a very shallow, uneven basin. Flesh white, conrse, buttery, juicy, melting, perfumed, slightly astringent. Grod. Oetober.

\section{Calebasse Tougard.}

A Belgian Pear raised by Van Mons. Tree vigorous, productive 
Fruit medium, oblong pyriform, sometines acute, sometimes obtuse Skin gicenish yellow, mostly covered with rough russet, and thickly sprinkled with russet dots. Stalk curved. Calyx open. Basin small, uneven. Flesh yellowish, rather coarse, juicy, melting, sweet, aromatic. Good to very good. October.

\section{Calhour.}

Raised by the late Governor Edwards, New Haven, Corin.

Fruit medium, roundish, obliquely oblate. Skin yellowish, shaderl with dull crimson, sprinkled with russet, russet dots. Stalk short. Calyx open. Flesh white, coarse, granular, buttery, melting, pleasant. Good. October.

\section{Camerling.}

Camerlyn.

Camerlingue.

Camerling d'Allemagne.

A Flemish Pear. Tree vigorous and productive.

Fruit medium, pyriform. Skin yellow, with numerous brown dots and a slightly marbled cheek. Stalk long, slightly inclined, in a small cavity surrounded by r'usset. Calyx open. Flesh juicy, melting, sugary, with a peculiar aroma. Good. September, October.

\section{Camilule de Roiman.}

Prince Camille de Rohan.

A foreign Pear, with thorny yellow olive brown shoots, hardy.

Fruit medium, roundish obovate. Skin yellow, considerably nettel and patched with russet, and sprinkled with large russet dots. Stalk long, slender. Calyx partially closed. Basin medium. Flesh white, fine-grained, melting, vinous. Good. Norember, January.

\section{Canaidatigua.}

Catherine.

Origin uncertain, supposed to lave been brought from Connecticut to Canandaigua about the year 1806 , vigorous and productive.

Fruit rather large, irregular, elongated acute pyriform. Surface uneven, resembling Bartlett. Skin lemon-yellow, sometimes a shade of red in the sum. Stalk medium, or rather short, inclined. Calyx open. Basin narrow and deel. Flesh whitish, coarse, melting, vinous. Good. September.

\section{CANTELope.}

A seedling of the late Gov. Edwards. Not valuable.

Fruit below medium, nearly globular, pale yellow, sometimes a blush in the sun. Flesh whitish, coarse, breaking, dry. Good only for cooking. October.

\section{Capsueaf,}

\section{Cops Heat.}

A native of Rhodle Island. It is a very agreeable fruit. Young shoots stout, upright, yellowish brown. 
Fruit of medinm size, oblong oborate pyriform. Skiu deep yellow, with patches and traces of cimmamon russet. Stalk an inch long, stout, inclined, inserted in a shallow lıollow. Calyx small. Basin slightly sunk. Flesh white, juicy, and melting, very sweet and pleasant. Good. October.

\section{Carucis.}

Capuchin.

Capucin Van Mons.

One of Van Mons' seellings. Tree a moderate grower.

Fruit medium, oval pyriform, greenish yellow, marbled and sharled in the sun with fawn and red, slightly netted with russet, and with many russet cimson dots. Stalk slender, set in a slight depression by a lip. Calyx open. Flesh whitish, melting, juicy, vinous. Good to very good, Octuber to December.

\section{Cassaste de Mars.}

A variety from Malines, said to be a seedling of Major Esperen. It may be a clistinct sort, but as we have received, it has proved iclentical with Winter Nelis. We coly description from the Album Pomology :-

"Tree vigorous.

"Fruit, which is borne in clusters, resembles Doyenné blanc. Skin smooth, bright green, becoming golden yellow at maturity, striped and shaded with fawn. Flesh when in full perfection is half melting, juicy, sugary, vinous, and well perfumed. Ripe December to April."

\section{Casserule.}

Of foreign origin. We have fruited it but once.

Fruit medium to large, oblong obovate pyriform. Skin rough. Color yellowish, covered with a dull yellow brown russet. Stalk short, withont depressions, often oblique. Calyx large, open, round, with connected segments. Basin medium, regular. Flesh whitish, coarse, granulated, especially next the core, dry, and without flavor. Good. December, January.

\section{Casteline.}

A Belgian Pear, described by foreign authors as first quality, here it has only proved good.

Fruit medium, roundish obtuse pyriform, pale greenish yellow, with slight nettings and patches of russet, and sprinkled with dots. Stalk long, largest at junction with the tree, curved, set in a shallow cavity. Calyx open, with long recurved segments. Basin shallow, meven. Flesh yellowish, juicy, buttery, melting, sweet. Good. November, December.

\section{Catilarine Gardette.}

Raised by Dr. W. D. Brinckle, of Philadelphia. Young shoots shortjointer, vellow brownish olive.

Fruit medium, roundish obovate. Skin fair, yellow, with numerous 
small carmine dots on the exposed sicle. Stalk curved, inserted by a fleshy termination into a slight depression. Calyx small, set in a rather deep basin. Flesh yellowish, coarse, juicy, sweet. Good. September.

\section{Catuerine Lanbre.}

One of the new Belgian Pears that promises to sustain here its foreign reputation. It originated with Van Mons, aud was named and introduced by Bivort. The tree is very vigorous and hardy, and a good bearer, with long, strong, dark rich yellow brown shonts.

Fruit medium or above, oblong obtuse pyriform. Skin smootl, greenish yellow, shaded in the sun with red, and dotted with bronze specks. Stalk medium, set without depression, inclined. Calyx large, open. Flesh whitish, half fine, juicy, melting, sweet. Very good. October, November.

\section{Catillac:}

Grand Monarque.

Grand Mogol.

Carlillac.

Katzenkop.

Groote Mogul.

40 Ounce.

Bon Chrétien d'Amiens Chartrense.

Monstrueuse de Landes.

Cotillard de Livre.

Besi de Maraise.

De Citrouille.

De Tout Temps.

Gros Thomas.

De Bell Argentine.

Tête de Chat.

Gros Ratean.

Grand Tamerlan.

De Gros Ratean Raisenette?

Roi de Lonvain.

Gros Rateau gris.

The Catillac is an old French baking and stewing Pear, of very large size, and of good quality for these purposes. In rich soil the fruit is often remarkably large and handsome.

Fruit very large, broadly turbinate (flattened-top shaped). Skin yellow, dotted with brown, and having sometimes a brownish red cheek at maturity. Stalk stout, about an inch long, curved, and placed in a very narrow, small cavity. Calyx short and small, and set in a wide, rather deep plaited basin. Flesh hard and rough to the taste. November to March.

\section{Catinka.}

Raised by Major Esperen. Tree of vigorous growth. Branches rather slender, productive. Young wood dull yellow brown.

Fruit small to medium, obovate pyriform. Stalk very long, inserted by a ring in an nueven cavity. Calyx large and open, with segments persistent. Basin shallow. Skin pale yellow, netted, patched, and thickly sprinkled with xusset dots. Flesh coarse, granular, buttery, melting, juicy, with a refreshing vinous flavor. Good to rery good. October to December.

\section{Cendariere.}

Originated in the grounds of W. C. Bryant, Roslyn, Long Island.

Fruit small, nearly globular. Skin pale greenish yellow, with russet nettings and dots. Stalk rather short, curred. Calyx open. Flesh white, juicy, melting, sweet. Good. August. 
Certeau D'Été.

Gros Certeau d'Été.

Rorrges des Vierges.

Emmanitel.
Courte de Ersol.

Colorée d'Anût.

De Champague d'Été.

This showy Pear is by some authors attributed to Van Mons. Others say it was described in .15t0. 'Tree vigorous and productive. Young wood redilish yellow brown.

Fruit medium, oblong acute pyriform. Skin smooth, almost waxen rellow, sharled with brigh terimson over most of the surface, and sprinkled with light dots. Stalk long, curved, fleshy at its insertion. Calyx small, open. Basin small. Flesh white, juicy, melting, pleasant, sweet. Good to very good. Last of August.

\section{Cirancellor.}

Supposed to be a native of Germantown, Penn., on the grounds of Mr. Chancelior. Branches hơrizontal, not very vigorous, spreading. Young wood reddish brown.

Fruit rather large, obovate obtuse pyriform. Skin greenish yellow, sometimes rerl in sun, rough, somewhat inclining to russet, thickly covered with dots. Stem medinm, curved, rather stont, fleshy at its insertion lyy a lip, inserted in a rather broad carity. Calyx small, set in a moderate basin. Flesh whitish, juicy, buttery, melting, sugary, perfumed. Good. October, November.

\section{Cimapun.}

An American Pear of poor quality, unworthy.

Fruit medium, obovate pyriform, yellow, dotted with brown and green. Flesh white, half melting, astringent. September.

\section{Cilaptal.}

\section{Beurré Chaptal.} good.

An old French Pear, that sometimes is very good but often only

Frnit medium to large, oblong obovate obtuse pyriform, greenish yellow. Stalk stout, in a slight cavity. Calyx large, open. Flesh white, breaking, juicy. December.

\section{Charles Basiner.}

A foreign Pear which we have not yet fruited. Toung wood liglit yellow. Buds projecting, prominent. Hogg deseribes it as :-

"Fruit obovate, pale yellowish green. Stalk long, slender. Calyx small, open. Flesh white, juicy, sweet. October."

\section{Cimarles Bivort.}

A Belgian Pear, an early bearer, but only good in quality. Young shoots dark rich yellow brown.

Fruit medium, oborate obtuse, pale whitish yellow, with a few 
patches and nettings of russet, and conspicnous russet dots. Stalk rather short, curved, set in a small cavity. Calyx open. Flesh white, coarse, juicy, half melting, sweet, and pleasant. Good. October.

\section{Charles Frederick.}

One of Tan Mons' seedlings. Tree vigorous and productive.

Fruit medium, roundish obovate pyriform, sometimes obtuse oblong. Skin prale vellow, shaded and mottled with red in the sun, patches, nettings and dots of russet. Stalk short to medium, sometimes in a small cavity, others withont. Calyx open. Easin shallow. Flesh white, buttery, sweet, slightly vinous. Good. Sejtember.

\section{Charles Silet.}

Charles Smith.

One of Van Mons' seedlings. Tree a vigorous grower. Young wood dull olive grayish brown.

Fruit medium, pyriform, broad at the crown. Skin yellowish, considerably russeted. Stalk long, curved, fleshy at its insertion. Calyx open, small. Basin narrow. Flesh juicy, sweet, and highly perfuméd. Cood to very good. Jaunary, February.

\section{Cimarles Van Hoogitev.}

Fruit large, varying in form from obovate acute pyriform to roundish obtuse obovate. Skin yellow, netted and patched with russet, and with many russet dots. Stalk varying, always Heshy at insertion. Calyx open. Basin shallow. Flesh rather coarse, sweet. Good. Early October.

\section{Cimarlotte de Brower.}

One of Esperen's seedlings. Tree of moderate vigor, and of great productiveness.

Fruit medium or above, obovate roundish pyriform. Skin yellow, slightly netted and patched with russet, and with many russet dots, and slightly shaded in the sun with crimson. Stalk stout and fleshy at its insertion. Calyx open. Basin medium. Flesh whitish, juicy, melting, vinous. Good. October.

\section{Chaumontel.}

Bezi de Chaumontelle.

Winter Beurré.

Beurré d'Hiver.

Shaumontel.
Oxford Chaumontel.

Bon Chrétien de Chaumontel.

Beurré de Chaumontel.

Shaw-montel.

This old French Pear takes its name from the village of Chaumontelle, in France, and succeeds well in Europe, but has not proved good here, except in very favorable situations. It may be valuable Sonth. Tree a good and vigorous grower. Young shoots yellow brow gravish olive.

Fruit large, priform. Skin a little rough, yellowish in the shade, dotterl with many brownish russet dots, and brownish red or rich deep 
red in the sun. Stalk about an inch long, inserted moderately deep, in an angular basin. Flesh buttery and melting, sugary, with a peculiar and agreeable perfume. Crool. November to February.

\section{Cinelisford.}

Tynsboro'.

Mogul Summer.

Origin, Chelmsford, Mass. Tree vigorous, productive.

Fruit large, roundish ohtuse pvriform, yellow, red cheek. Flesh coarse, sweet, good for cooking. I tast of september.

\section{Cholsmakd.}

Originated with M. Choisnard, Ormes, France.

Fruit medinm to large, oblong obtuse lyriform. Skin rongh, dull yellow brown in the sun, and with many fawn-colored dots. Stalk rather long. Calyx large, open. Flesh yellowish white, half crisp, halt fine, rough at centre, juicy, delicate musky flavor. Jannary, MIarch. (Leroy.)

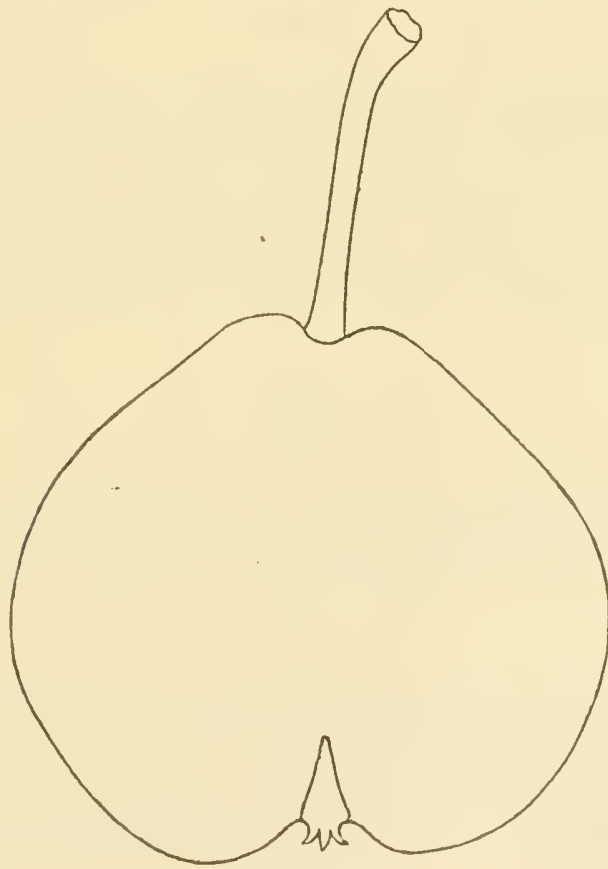

Church.

Churcir.

Clarke?

This really good Pear originated on land belonging to the Trinity Church, at New Roclielle, N. Y.; henee its name. The habit of the Church Pear is somewhat spreading in its growth, uniformly productive, 
and the fruit unvarying in its quality. Young wood dull yellow, or brown.

Fruit rather below medium size, generally clepressed, somewhat angular. Stalk rather long, stont at its insertion, in a small eavity surrounded by russet. Calyx small and closed, in a broad, rather shallow basin. Skin green, becoming yellow at maturity. Flesh white, very buttery, juicy. melting, with an exceedingly rich, sweet, and highly perfumed flavor. Tery good. Core small. Ripens slowly, and continues in use all of September.

\section{Citrina.}

Originated with Dr. __ Shurtleff, Boston, Mass., first fruited in 1862. Tree productive. Wood slender, grayish.

Fruit medium, pyriform, bright yellow. Surface slightly knobby and uneven. Stalk medium. Calyx small. Basin corrngated. Flesh nearly whitc, rather coarse. Gritty at the core. September. (Journal of $\mathrm{H}$.)

\section{Citron.}

A seedling of the late Governor Edwarts, a vigorous, uprichlit grower, producing large crops, but inclined to rot at the core.

Fruit small, nearly globnlar, approaching turbinate. Stalk short, rather stout, set in an abrupt, uneven cavity. Calyx closed. Basin broad, shallow, irregular. Skin greenish, slightly shaded with dull crimson. Flesh greenish, rather coarse, juicy, melting, sugary, vinons, with a musky perfume. Good. Ripe from middle of August to middle of September.

\section{Ciara.}

Claire.

Une of Van Mons' seedlings. It is of medium size, oval prriform. Skin clear yellow, dotted with red. Flesh white, melting, very juicr, and sweet, relieved by a slight acid. Hardly good. September and October.

ClaP.

This variety was raised from seed, by Capt. Nilliam Clap, of Massachusetts.

Fruit below medium, acute prriform, yellowish green, with a brownish blush in the sun. Flesh whitish, buttery, juicy, aromatic. Middle of Angust. (Prince.)

\section{Clapp's Fatorite.}

This extremely fine and valuable Pear was raised from seed by the late Thaddens Clapp, of Dorchester, Mass. The tree is m upright spreading, vigorous grower, forming an open, well-shaped lead, on which the fruit is evenly distributed and almost uniform in size. Verg pro. ductive. Yomig shoots dark reddish brown. 
Frnit large, obovate ovate, slightly obtuse pyriform. Surfece un even. Skin thin, pale lemon yellow, marbled and faintly splasherl with erimson and fiwn when filly exposed to the sun, thickly sprinkled with brown dots, and sometimes patches and traces of russet. Stalk nearly

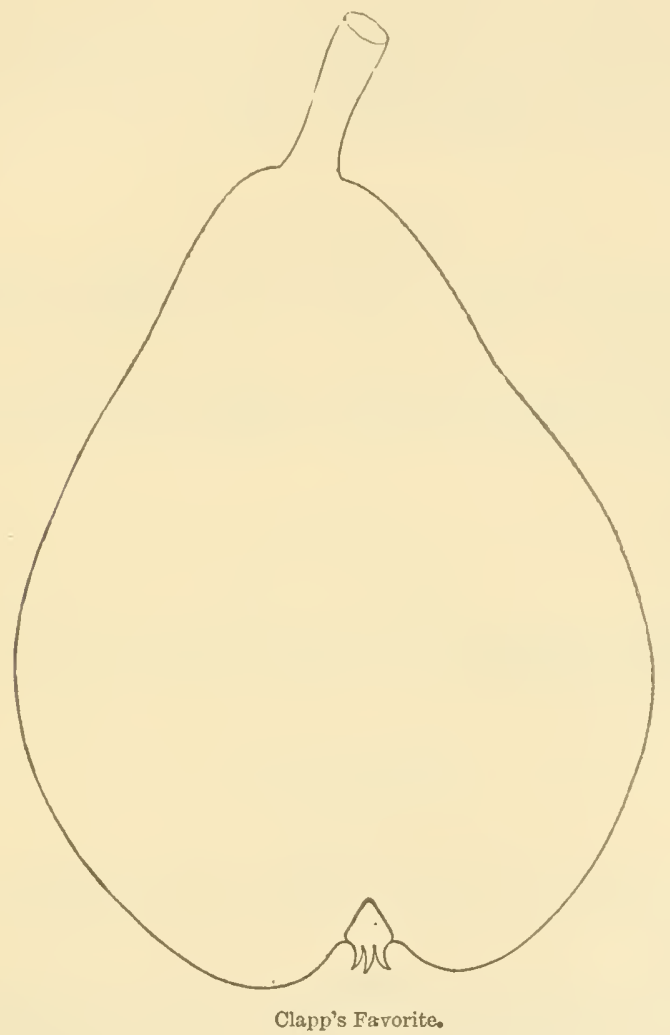

an inch long, a little inclined, stout, and somewhat fleshy, inserted in a slight depression. Calyx partially closed. Segments stift, erect. Basin shallow, shightly corrugated. Flesh white, fine-grained, juicy, buttery, melting, rich, sweet, vinous, a little perfumed. Very good. Last of August or early September.

\section{ClaY.}

\section{Sponge.}

Raised by the late Governor Edwards.

Fruit medium, roundisl oblate, sometimes pyriform. Skin waxen vellow, shaded with erimson, and sprinkled with brown or crimson dots. Stalk medium. Calyx closed. Flesh whitish, ratlice coarse, granular, juicy, sweet. Good. October. 


\section{Clfaience.}

Clementine.

A seedling of Van Mons, originated in 1833. Young wood olive brown.

Fruit medium, acute pyriform, sometimes obovate acute pyriform, pale yellow, shiderl and mottled with crimson, and patched and netted with russet, few brown dots. Stalk short, curved, Heshy at insertion. Calyx open. Basin shallow, uneven. Flesh white, fine, juicy, sweet, melting, pleasant. Vury good. September.

\section{Clenent Bivort.}

A Belgian Pear that we have not yet finited. Young shoots smooth, short-jointed, yellow brown. It is described by the Société $\mathrm{V}$ an Mons as:-

"Fruit medium, romulish oblate. Skin golden yellow, shaded with red in the sun. Flesh white, fine, melting, juicy, sweet, perfumed. Novenilier."

\section{Clinton.}

Van Mons, No. 1238.

A poor fruit, of medimn size, light yellow skin. Flesh soft, buttery, and goorl, but not high-flavored. Middle of November.

\section{Colt's Beurré.}

\section{Deurré Coit.}

Originated with Col. Coit, Collamer, near Cleveland, O. Tree a healthy, good grower, productive. Young wood brownish olive, with rough specks.

Fruit medium, obtuse pyriform. Skin yellow, inclining to russet, sometimes with a smny cheek, thickly covered with dots, which become crimson on the exposed side. Stalk short, rather stout, set in a small cavity, sometimes inclined by a lip. Calyx large, open. Flesh white, a little coarse, juicy, melting, rich, vinous. Tery good. September, October.

\section{Collins.}

$\begin{array}{ll}\text { Watertown. } & \text { Colin Noir. } \\ \text { Charbonnière. } & \text { Malconnaître. }\end{array}$

Raised by A. Collins, of Watertown, Mass., and first exlibited before the Massachusetts Horticultural Society in 1848. Tree of moderate growth, with reddish brown shoots.

Fruit medium, roundish, slightly acute pyriform. Skin greenish yellow, with russet spots, and frequently a blush on the smmy side. Stalk short, thick, inserted at an inclination withont cavity. Calyx small, and very little smo. Flesh fine, melting, juicy, with a brisk, 
sugary flavor, resembling white Doyenné. Very good. Ripens first of October.

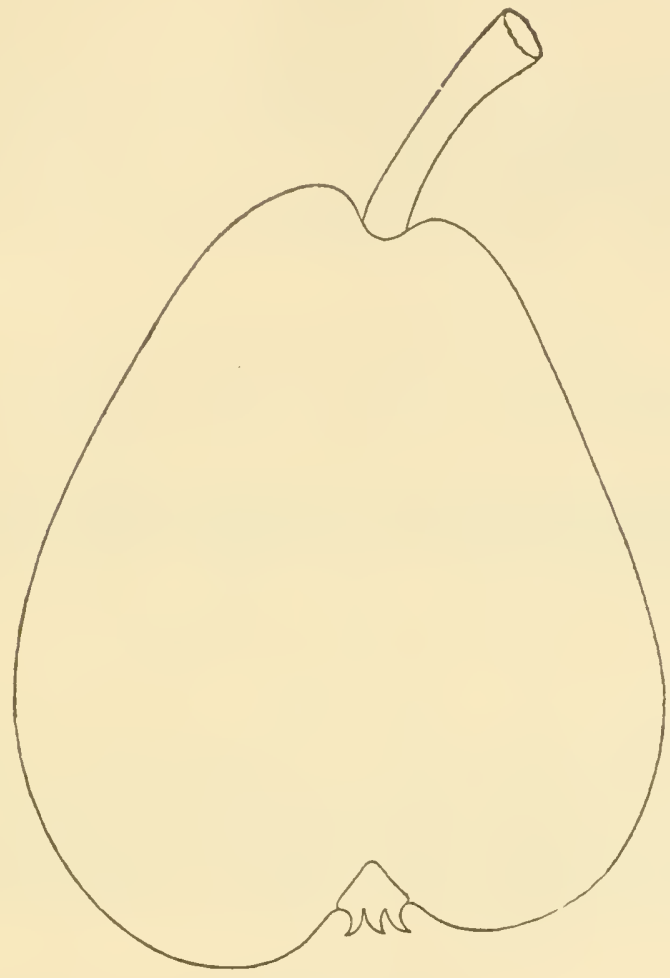

Coit's Beurré.

\section{Colmar.}

De Naune.

Incomparable.

Winter Virgalieu.

Bergamotte Tardive.

Colmar Dorée.
Belle et Bonne d'Hirer.

Colmar d'Hiver.

Commodore.

Bergamotte Rojal d'Hiver.

An old Belgian Pear. The tree hardy, vigorous, and productive. Valuable for cooking, often very good in quality.

Fruit medium or large, obtuse pyriform. Skin light yellow. Flesh melting, half buttery, juicy, sweet. December, February.

\section{Colmar artoisenet.}

A Belgian Pear of vigorous growth, and a good bearer. Young shoots reddish olive brown.

Fruit large, irregularly oblate obtuse pyriform. Skin pale vellow, often with a brownish cheek, netted and patched with cinnamon russet, aod with many russet dots. Stalk short, inserted in a slight depression, 
often with a lip. Caly small, closed. Basin furrowed. Flesh whitish, coarse, juicy, melting, brisk, vinous. Good. September, October.

\section{Colmar d'Alost.}

Délices d'Alost.

A Belgian Pear, said to have originated with M. Hellinck in 1840. Young wood dark olive brown.

Fruit large, roundish oblong obtuse pyriform, greenish yellow, brownish in the sun. Flesh white, half melting, juicy, gritty at core, sweet, vinous. Good. October, November.

\section{Colmar d'Aremberg.}

Kartofel.

Cartofel.

A large Belgian Pear, mainly to be ralued for its size and for cooking.

Fruit large to very large, roundish obtuse pyriform. Skin green, becoming yellow at maturity, with nettings of russet and dots. Flesh whitish, half fine, granulous, sweet, vinous. Good. November, December.

\section{Colmar d'Automne Nouteau.}

Received from France. Tree vigorous. Young shoots light yellow brown.

Fruit medium, obtuse pyriform, sometimes inclined. Skin pale rel. low, sometimes a shade of crimson in the sun, partially patched and net. ted with traces of russet, and russet brown dots. Stalk long, inclined, set in a small eavity, often by a lip. Calyx open. Segments long, recurved. Basin rather abrupt. Flesh whitish, juicy, melting, rich, vinous. Very good. Last September.

\section{Colmar d'Été.}

\section{Colmar Précoce. Autumn Colmar}

A Belgian Pear, originated in 1825, and ranked high among foreign pomologists; here it proves only good, or rather poor, and rots at the cole.

Fruit medium, roundish obtuse pyriform. Skin greenish sellow, sometimes a slight blush in sum, patches of russet, and brown dots. Stalk long, a little inclined, set in a small curity. Flesh white, coarse, astringent. Early in September.

\section{Colmar de Joxgite.}

Originated with M. J. De Jonghe, Belgium, and not having fruiterl it, we copy from his description:- "Tree hardy, robust, vigorous, and productive, rather upright. Young wood nut brown, with a few gras specks.

"Fruit medium, pyriform. Skin greenish yellow, mostly covered with reddish brown blotches. Stalk thick, set without depression. Calys open. Flesh white, fine, juicy, vinous, sweet, and aromatic. SejtemDer." 


\title{
Coluar de Meester.
}

Demeester.

Originated in Belgium.

Fruit medium, roumdish obtuse pyriform. Skin pale yellow, a few nettings of russet, and sprinkled with many brown and green dots. Stalk long, a little inclined. Calyx large, open. Wlesh white, coarse, juiey, half melting, slightly vinous. Scarcely gook. Octuber.

\section{Colmar des Jymalides.}

\author{
Poire des Invalides. \\ Beurré de Printemps. \\ Ta Deux Ans. \\ Colmar Van MIons.
}

Gros Colmar Tan Mons.

This Belgian Pear is said to have been raiserl at Enghien in 1808 . It is large and showr, but only valuable for cooking. Young wood reddish olive yellow brown.

Frnit large, obtuse pyriform. Skin yellow, slightly marbled with crimson in the sum, and sprinkled with russet and brown dots and traces. Stalk rather short, set in a small cavity. Calyx large and open. Segments long, reeurverl. Flesh whitish, coarse, juicy, breaking, sweet. November to February.

\section{Coluar Épine.}

An agreeable juicy Pear, sent to this country by $V$ an Mons, and originated by him. Young shoots stout, upright, brown.

Fruit large, roundish oblong, tapering gradually to an obtuse point at the stem, which is one inch long. Color greenish yellow. Flesh white, sweet, melting, juicy, and good. Middle of September.

\section{Coloree de Juillet.}

Originated in Pouen, France.

Fruit below nedium, obovate obtuse pyriform. Skin yellowish, with a shade of brownish red in the sun, and small patches and dots of brown l'usset. Stalk medium or stout, set in a shallow eavity. Flesh white, half tender, juicy, a little gritty at core, sweet, perfumed. Good. July.

\section{Columbia.}

\section{Columbian Tirgalieu.}

Columbia Virgalonse.

The original tree grows on the farm of Mr. Casser, in Westehester Co., N. Y. The tree grows upright. Young wood stout, upright, olive brown.

Fruit large, regularly formed, obovate, usually a little oblong, and always broadest in the middle. Skin smooth and fair pale green in antumn, but when ripe of a fine golden yellow, with oceasionally a soft orange tinge on its cheek, and dotted with small gray dots. Stalk rather more than an inch long, slightly curved, placed towards one side of a narrow depression. Calyx of medium size, jartially open, set in a very shallow basin. Flesh white, not very finr-grained, but melting, inicy, with a sweet aromatic flavor. Good. November to January. Very apt to rrop' from the tree previous to ripeniug. 


\section{Commissaire Delmotte.}

Originated in Belgium by Gregoire.

Fruit medium, obtuse pyriform. Skin greenish yellow, sometimes a shade of crimson in the sum, netted, patched, and dotted with russet. Stalk medium, curved, set in a small cavity. Calyx open, or partially closed. Basin rather abrupt, uneven. Flesh whitish, juicy, half molting, sweet. Good. January to March.

\section{Comprette.}

A Flemish seedling of little value.

Fruit small, obtuse pyriform. Skin yellowish green. Flesh white, buttery, with a sugary perfumed juice. October, November.

\section{Conte D'Egmont.}

Fruit small, obovate, lemon yellow, covered with dots of reddish brown russet, forming almost a patch. Stalk stout, inserted without depression. Calyx small, open. Flesh yellow, melting, slightly gritty, very rich, sugary, and delicious. Last of October. (Hogg.)

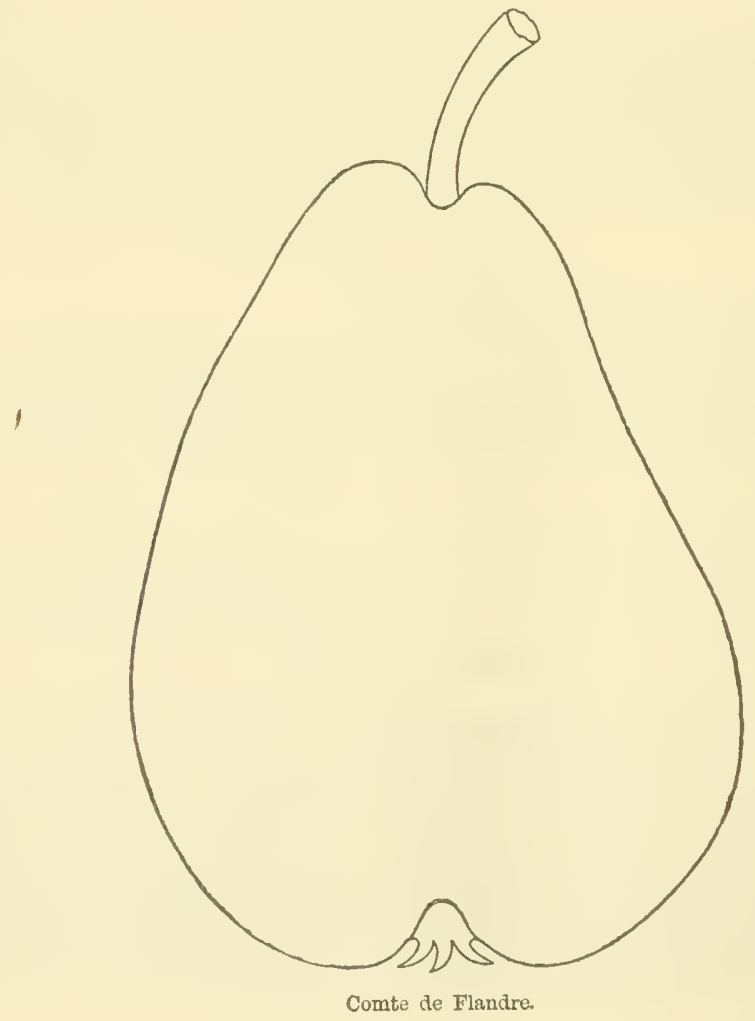




\section{C.MTE JE FlaNdie.}

St. Jean Baptiste.

St. Jean Baptiste d'Hiver.

One of Tan Mous' seedlings. 'T'ree vigorous, prorluctive. Toung wood redelish yellow brown.

Fruit large, elongated pyriform, obtuse. Skin yellowish, considerably covered with msset. Stalk long, much inclined, and inserterl hy a lip in a small eavity. Calyx open, set in a shallow, comugater basin. Flesh very buttery, melting, juicy, granular, sweet, and rich Good to very good. Oetober, November.

\section{CoMstock.}

Comstock Wilding.

A couse cooking Pear that originated in Dutchess Co., N. Y.

Frnit of medium size, regularly formed, obovate. Skin smooth and glossy, bright yellow, with a crimson cheek. Flesh white, crisp, and, if well ripened, with a sweet and sprightly tiavor. November.

\section{CoNte DE LAMY.}

Beurré Curtet. Dingler.

\section{Beurré Quitelet.}

Bis Curtet.

Henri Van Mons, erroneously.
Comte Lamay.

Beurré Cutter.

Originated in Belgium in 1828. Tree vigorous, spreading.

Frut of medium size, oblate pyriform. Skin yellow, with a brownish red cheek, and sprinkled with patches and small russety dots. Stalk an inch long, straight, obliquely inss-ted under a lip, or planter in a slight cavity. Calyx open, set in a shallow basin. Flesh white, fine-grained, buttery, melting, sweet. Good. Last of September to middle of October.

\section{Conte de Paris.}

One of Tan MIons' seedlings. Tree pyramidal, very vigorous. Young shoots reddish brown grayish.

Fruit medium, obtuse pyriform, often elongated. Skin greenish yellow, a little netted and patched with russet, and dotted with conspicuons russet and green dots. Stalk long, slender, curved, set in a shallow eavity, sometimes by a lip. Calyx large, open. Segments long. Basin small. Flesh whitish yellow, juicy, melting, brisk, slightly vinous, musky. Good to very good. September.

\section{C'onte Lelieur.}

\section{Frederick Lelieur.}

Of Belgian origin. Tree vigorous, upright, moderately productive. Yumng wood redlish olive brown.

Fruit large, pyriforu. Skin yellowish green, with a brownish-res check, specklerl with gray, netted and pateherl with russet. Stalk short, curved, inclinerl, set by a lip. Flesh yollowislı white, a little coarscgrained, melting, juicy, sweet. Good to very gool. September. 


\section{Comtesse d'A Lost.}

A Belgian Pear, highly commenderl abroad, but here proves only good. Tree vigorous. Young wood dull reddish yellow brown.

Fruit large, oblong ovate pyriform, sometimes acute. Skin pale yellow, slightly netted and patched with russet, and many brown dots, shade of red in the sun. Flesh yellowish, juicy, half melting, vinous, astringent. Scarcely good. Norember.

\section{Contesse de Chambord.}

Originated at Poictiers, France. Tree moderately vigorous. Young woor olive yellow brown. Leroy describes the fruit as follows:-

"Fruit small to medinm, obtuse pyriform. Skin yellowish green in the sharle, bright golden in the sm, reined, rlotted, and marbled with yellowish gray. Stalk short. Calyx large, half closed. Flesh yellowish white, melting, rough at centre, sweet, vimous, clelicate aroma." November, December.

\section{Congress Pomologique.}

Triomphe de Pomologique.

Originated with M. Boisbunel, at Ronen, in 18.56. Tree a vigorous grower, with moderate-sized young shoots, long-jointed, and of a dull yellowish-brown color, with many rough specks. Productive.

Fruit medium, obtuse pyiform. Skin rather rough, greenish yellow. with traces of yellow, and sprinkled with brown dots. Stalk long, slender, with bracts, set in a shallow carity. Calyx large, open. Segments long, recurved. Basin broad, shallow, uneven, russeted. Flesh whitish, buttery, juicy, melting, sweet, pleasant. Good to very good. October, November.

\section{Conklin.} tive.

Originated in Westchester Co., N. Y. Tree vigorous and produc-

Fruit rather large, oblate obtuse pyriform. Skin greenish or pale yellow, netted and patched with russet, and dotted with green and brown dots. Stalk medium, fleshy at insertion. Calyx partially elosed in a deep, abrupt basin. Flesh yellowish, coarse, juicy, half melting, sweet. Good. September.

\section{Coxseiller Ranwez.}

One of Van Mons' seedlings. Tree vigorous, very productive. Young wood dull olive reddish brown.

Fruit large, very irregular in form, obovate obtuse, obscurely prriform. Skin greenish yellow, rough, with a few patches of russet, and many brown dots. Stalk inserted in a broal cavity, by a slight lip or fleshy ring. Calyx open, stiff, set in a furrowed basin. Flesh coarse, a little granular, juicy, melting, perfumed, sweet, vinous, slightly astrin: gent. Good. October. 


\section{Copta.}

A Philadelphia seedling.

Fruit large. Skin yellow. Flesh rather coarse, but sugary. Poor. September to October.

\section{Corywell.}

Cluster?

An old Pear, origin unknown, transferred by travelling grafters from the New England States, and may yet prove some named sort.

Fruit small, nearly globular, greenish yellow, netted and patched with light russet. Flesh yellowish white, juicy, vinous, a little astringent. Good. Early September.

\section{COTER.}

One of Van Mons' seedlings, of moderate growth and productive.

Fruit medium or below, irregular in form, varying from obtuse to acute pyriform. Skin yellowish, with numerous russet dots, some patches of russet, and russet around the calyx and stem. Stalk slightlw curved, and enlarged at its insertion, without cavity, and inclined. Calyx open, set in an abrupt, not very deep basin. Flesh whitish, not very fine, juicy, vinous. Good. December.

\section{Crassane.}

Bergamotte Crassane. Crísane. Bergamotte Crassane d'Automme. Beurré Plat. Flat Butter. Crassane d'Automne.

An old variety, cultivated as long ago as 1667. Tree hardy, vigo: rous, and productive. Young wood light reddish.

Fruit medium to large, roundish oblate. Skin yellow, rarely with a blush, dotted with russet dots. Flesh coarse, rather dry, sweet, pleasant. Good. October, November.

\section{CratwFord.}

Bancrief.

Lammas of the Scotch.

A Scotch finit, of second quality; the chief merit of which is its hardiness in a cold climate.

Fruit middle-sizerl, obovate. Skin light yellow, tinged with brown in the sun. Flesh white, buttery, sweet, and of a tolerahly pleasint flavor. August.

\section{Croft Castle.}

An English variety, peculiar in its shape, and especially so in its Alavor; very productive.

Fruit medium. Skin pale greenish yellow. Flesh juicy, crisp, and sweet. Scarcely good. October. 
Cross.

Originated on the premises of Mr. Cross, of Newburyport, Mass. Branches l'ather slender, of slow growth.

Fruit of medium size, roundish oblate. Skin smooth, deep yellow, with a red cheek, and marked with numerous russet dots, and patches of russet around the eye. Stalk planted in a slight depression. Flesh coarse, white, melting, juicy, and sweet. Good. In eating from the last of November to the middle of Jannary, but chiefly in December.

\section{Crouch.}

Originated at Colchester, Conn. Tree vigorous. Young wood dull yellow brown.

Fruit below medium size, roundish inclining to oblate. Skin pale yellow, consilerably netted and patched with russet, many russet dots. Stalk slender, curverl. Calyx open. Flesh whitish, juicy, melting, sweet, pleasant. Good. Early September.

\section{CumberLand.}

A native fruit, in Cumberland, Rhode Island.

Fruit rather large, obovate pyriform. Skin orange yellow, pale red cheek. Flesh white, buttery, and tolerably juicy. Good. September and October.

\section{Cushixg.}

The Cushing is a native of Massachusetts, having originated on the grounds of Colonel Washington Cushing, of Hingham, about forty years ago. It is a very sprightly Pear, and, like many of our native varieties, it produces most abundaint crops. Branches rather slender, diverging, olive yellow brown.

Fluit medium size, obovate, tapering rather obliquely to the stem. Skin smootl, liglit greenish yellow, sprinkled with small gray dots, and occasionally a dull red cheek. Stalk an inch long. planted in an abrupt cavity. Calyx rather small, set in a basin of moderate size. Flesh white. fine-grained, buttery, melting, sweet, sprightly, perfumed. Goorl. Midcle of September.

\section{DALIAS.}

Raised by Governor Elwards, of New Haven, Conn. Tree upright, vigorous. Young wood redrlish brown. A profitable Pear to grow, as it produces abundantly and keeps long after gathering.

Fruit ralher large, ovate obtuse pyriform. Skin yellow, with a sumy cheek, thickly sprinkled with crimson and russet dots. Stalk large, long, inserted by a shight lip in a very moderate cavitr. Calyx open. Basin shallow, corrngated. Flesh buttery, juicy, with a sweet, rich, pleasant $9^{-o m a t i c ~ f l a v o r . ~ T e r y ~ g o o d . ~ R i p e ~ O c t o b e r ~ a n d ~ N o v e m b e r . ~}$

\section{DAXA'S HoVEY.}

Raised by Francis Dana, of Roxbury, Mass. Tree vigorous, hardy: 
and productive. Young wool olive yellow brown, retains its foliage late in season. This is one of the highest-flarored Pears, next to tho Scckle, that we have known. It lacks in size for a market variety, but as an amateur sort is one of the most desirable.

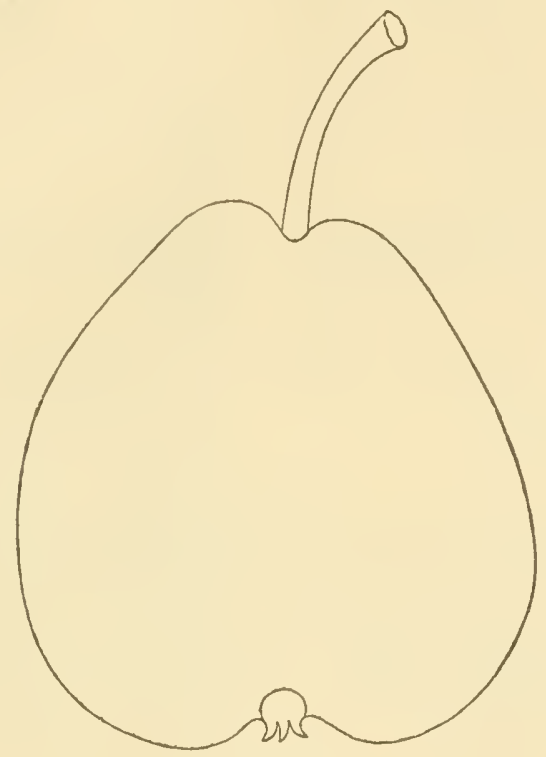

Dana's Hovey.

Fruit small, obovate obtuse pyriform, regular. Skin greenish yeslow or pale yellow, considerably netted and patched with russet, and sprinkled with many brown dots. Stalk rather short, a little. curved, set in a slight cavity, sometimes by a lip. Calyx open. Basin small, uneven, and slightly russeted. 'Flesh yellowish, juicy, melting, with a sugary, rich, aromatic flavor. Best. November to January.

\section{DARLINGTON.}

An American variety, the origin of which we have been unable to learn. Tree very vigorous, upright grower, productive. Young wood yellow brown.

Fruit large, oblate obtuse pyriform, pale yellow, with sometimes a shade of crimson in the sun, nettings and patches of russet, and russet dots. Flesh whitish, coarse, sweet. Not quite good. Rots at core. Early September.

\section{Davis.}

Introduced from Delaware Co., Pa. The only claim this Pear has is that some specimens are almost, or entirely, seedless.

Fruit small, obovate obtuse, yellowish, netted and patched witl russet dots. Stalk short, in a small cavity. Calyx partially open. 
Flesh rellowish, rather coarse, not juicy, melting, sweet. Good. September. This is similar to and may be identical with Elton.

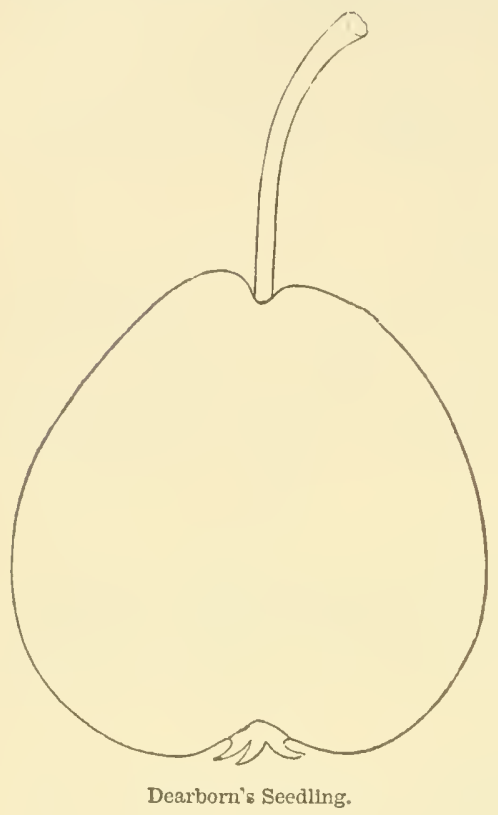

\section{Dearboris's Seedlisg.}

\section{Nones. Dearborn's Sanding.}

A very admirable early Pear, of first quality, raised in 1818 , by the Hon. H. A. S. Dearborm, of Boston. It bears most abundant crops, and is one of the most desirable early varieties, snceeding the Bloodgood, and precerding the Bartlett. Young shoots long, reddish brown.

Fruit scarcely of medium size, roundish priform, and very regularly formed. skin very smooth, clear light yellow, with a few minute dots. Stalk slender, rather more than an inch long, set with very little depression. (alyx with delicate spreading segments, set in a very shallow basin. Flesh white, rery juicy and melting, sweet and sprightly in fla vor. Very good. Ripens about the micldle of August.

\section{De Bavay.}

Poire de Baray.

One of Van Mons' seedlings. Tree a moderate grower. Young wood dull olive brown.

Fruit medium, obtuse pyriform. Skin yellowish, netted and patched with russet, and sprinkled with large russet dots. Stalk stout, curred, a little inclined, set in a small cavity. Calyx open. Basin shallow, uneven, often russeted. Flesh ye!lowish, rather coarse, juicy, melting, sweet, a little aromatic. Good to very good. October.

\section{De Deux Folx Laxe.}

A small foreign Pear, handsome but of poor quality.

Fruit small, oblate pyriform, irregular, or a little inclined, lemon yellow, with a crimson-red cheek, fawn and russet nettings and dots. Flesh white, coarse, rather dry, sweet. Poor. August.

\section{Délices de Charles.}

We have received two Pears under this name, one as of Tan Mons, the other of Bouvier.

The former is medium in size, irregular in form, varying from oborate to obovate pyriform. Skin greenish yellow; netted and patched 
with russet, and sprinkled with russet dots. Stalk rather long, inclined, set in a slight depression, often with a lip. Calyx open. Flesh yellow. ish, juicy, melting, vinous, sweet. September, October.

'The latter is above medium in size, obovate obtuse. Skin greenish, with traces of russet, and sprinkled with brown dots. Stalk long, curved, set in a rather large cavity. Flesh whitish, buttery, rots at core. Middle of September.

\section{Delices de Froyennes.}

This variety was obtained by M. de Comreelle, of Lille, near Tour. nay.

Fruit medium, acute pyriform. Skin a little rough, clear fawn-color. Stalk straight, stout. Calyx open. Flesh white, fine, melting, juicy, sweet, perfumed. November, December: (Revue Horticole.)

\section{Délices d'Hardenpont of Angers.}

\section{Beurré des Hautes.}

Beurré Lasalle.
Vignes.

Délices d'Angers.

Tree of moderate growth, productive.

Fruit medium, roundish, greenish, becoming yellowish at maturity, with a warm cheek, sprinkled and patched with russet. Stalk short and thick, inserted by a ring or lip at an inclination, in a shallow cavity. Calyx open. Segments short, stitt, in a small, uneven basin. Flesh yellowish, nearly melting, juicy, sugary, aromatic. Good to very good. October, November.

\section{Délices d'Hardenpont of Belgium.}

\section{Fondante Pariselle.}

Délices d'Ardenpont.

Archduke Chorles.
Charles d'Autriche.

Pariselle.

Tree moderately vigorous, upright, with long, slender shoots of dull olive brown color.

Fruit medium, truncate conic or pyramidal, angular. Skin rough, greenish, covered with small brown dots, becoming yellowish at maturity. Stalk short and thick, inserted in a sinall uneven cavity at an inclination. Calyx large, set in a shallow furrowed basin. Flesh white, buttery, juicy, melting, sweet, with a fine aromatic perfume. Grood. November, December.

\section{Délices de Jodoigne.}

This Belgian Pear originated in $18+6$, but it is yet little known. Tree moderately vigorous. Young wood reddish brown.

Fruit rather large, varying from obtuse to acute pyriform. Skin pale yellow, rich brownish crimson in the sun, netted and patched and dotted with russet. Stalk medium, sometimes with a slight depression at insertion, again fleshy, without eavity. Calyx open. Segments re curved. Basin small, shallow. Flesh white, iuicy, Juntery, half melting. Good to very good. October. 


\section{Délices de la CaCAudière.}

This variety originated in France, in 1846 . We do not know of its being fruited in this country, but its size and period of ripening are promising of value.

Fruit large, obovate pyriform, yellow green, shaded with red in the sum and many small dots. Stalk long, stout, set without depression. Fleslı white, a little coarse, half melting, juicy, sweet. Ripens early in August. (Verg.)

\section{Délices DE. LoutexJaL. \\ Jules Bivort.}

An old variety, yet little known in this country. Tree moderately vigorous and very productive.

Fruit medium or above, obovate obtuse pyriform, greenish yellow, with patches of russet and many small green and russet dots. Stalk rather stout, curved. Calyx small. Basin shallow. Elesh juicy, melting, sweet, rich, vinous. Good to rery good. October, Norember.

\section{DÉlices VAX MoNs.}

Délices de Mons.

Délices de la Meuse.

The clate of origin of this Pear is unknown. So far as we can learn, it was first described simply as Délices. The tree is a healthy free grower, with young wood of a dull grayish yellow brown.

Fruit medium, ovate obovate pyriform. Surface somewhat uneren. Skin pale yellow, with a shade of crimson in the sun, nettings of russet, and numerons brown dots. Stalk rather long. Carity small, russeted. Calyx small, closed. Segments short. Basin small, slightly russeted. Flesh white, coarse at the core, juicy, melting, sweet, pleasant, slightly vinous. Good or very good. October.

\section{De Lourais.}

Poire de Louvain. Bezy de Louvain.

\section{Gros Quere.}

Parabelle Musqué.
Valandrée.

Raised by Van Mons in 1827 .

Fruit of medium size, obovate, inclining to pyriform, and tapering to the stalk. Skin rather uneven, clear light yellow, a little marked with russet, and dotted with brown points, which take a ruddy tinge next the sun. Stalk about an inch long, stout, inserted obliquely withont depression, or by the side of a fleshy lip. Calyx placed in a very narrow, shallow basin. Flesh white, buttery, and melting. Good. Uctober.

\section{DEMOCRAT.} tive.

Originated in Pennsylvania. Tree a vigorous grower and produc-

Fruit medium or below, oborate roundish. Skin greenish rellow, nettings and patches of russet, and dotted with conspicuous russet and brown dots. Stalk long, slender, curved, set in a small carity. Calyx large, open. Basin abrupt, uneven. Flesh half melting, juicy, sweet, pleasant. Grood. September. 
I)ES Chussetirs.

$\begin{array}{ll}\text { Chasseurs. } & \text { Sportsmán. } \\ \text { Prive des Chasseurs. } & \text { Hunter. }\end{array}$

This Belginn Pear is supposed to be one of Van Mons' seedlings. The tree is moderately rigorous, somewhat spreading, productive. Young shoots walm rellow brown.

Fruit medium, priform, sometimes obtuse. Skin greenish yellow, covered with minute dots, and a few patches of russet. Stalk long. enlarged at its junction, without depression. Calyx small. Basin shallow. Flesh buttery, juicy, slightly gramular, perfumed. Good to very good. October.

\section{Désirée Cornelis.}

\section{Comelis.}

Raised by M. Bivort. Tree vigorous, productive. Young wood cinnamon russet brown.

Fruit medium to large, oblong obovate pyriform, slightly obtuse. Skin greenish rellow, with nettings of russet and irregular conspicuous brown dots. Stalk curved. set in a slight cavity. Calyx partially closed. Basin small. Flesh whitish, juicy, half melting, sweet. Tery good. Early September.

\section{Désirée Van MoNs.}

One of Van Mons' seerllings, originated in 1836.

Fruit medium to larce, obtuse pyriform. Skin dull greenish, with a few traces and patches of russet, especially around the stalk, minute marblings and dots of black. Stalk slender, curved, set in a very slight depression. Flesh white, half melting, juicy, sweet, perfumed. Good. September, October.

\section{De Sorlus.}

One of Tan Mlons' seedlings. Tree vigorous, very productive.

Fruit medium or above, oblong obtuse pyriform. Skin greenish yellow, slightly netted and patched with russet, and sprinkled with minute green and brown dots. Stalk rather long, generally straight, set with little or no cavity, sometimes by a ring or enlargement at base. Calyx open. Basin small, uneven. Flesh whitish, a little coarse, not juicy or melting. Good. November.

\section{DE TONGRES.}

Poire Durandeau.

This fine fruit was raised by M. Durandean, of T'ongres, France. Tree vigorous, with long slender hranches, pyriform, bears young and abundantly. Toung shoots olive yollow brown.

Fruit large, obovate acute pyriform, slightly irregular. Skin pale yellow, covered with rich cinnamon russet, which becomes crimson on 
the sun-exposed side. Sprinkled with russet and brown dots. Stalk long, curved, inserted without depression, often by a lip. Calyx small, open, or partially closed. Segments short, erect. Basin shailow, abrupt, mneven. Flesh white, fine, melting, juicy, vinous, rich saccharine. Tery good. October.

\section{Deux Saurs.}

Des Deux Sœurs.

The Two Sisters.

A chance seedling found near Malines, France, and named by Major Espereu. Tree vigorous, thorny, hardy, productive.

Fruit medium, oblong oval, irregular. Skin greenish yellow, sprin. kled with brown dots. Stalk rather short, set in a slight depression or by a lip. Calyx open. Flesh white, coarse, moderate-y juicy, sweet. Good. October, November.

\section{Devergates.}

$\begin{array}{ll}\text { Belle } d u \text { Vernis. } & \text { Duvernay. } \\ \text { Belle } d u \text { Vernie. } & \text { Duvernis. }\end{array}$

Beurré Duvernay.

A Belgian Pear, originated at Hainault in $181 \%$.

Frnit medium, roundish short pyriform. Skin dull yellow, shaded and blotched with brownish red in the sun, dark russet dots and specks. Stalk curved, set in furrowed cavity. Calyx large. Basin furrowed. Flesh whitish, half fine, sweet. Good. December.

\section{DICKERMAN.}

Pardee's No. 2.

Raised by S. D. Partee, New Haven, Conn. Tree vigorous anu productive. Young wood dark rich brown.

Fruit medium, roundish oblate. Skin rellowish, shade of bright cinnamon in the sun, thickly covered with minute dots. Stalk curved, fleshy at its insertion, in a moderate cavity. Calyx nearly closed. Segments persistent. Basin broad and uneven. Flesh whitish, buttery, juicy, melting, perfumed. Good to rery good. Ripe from the middle of September to the middle of October.

\section{Dieudonate Axtholne.}

A variety from Enghien, Belgium. Tree vigorous, moderately productive.

Fruit medium, roundish obtuse pyriform. Skin light yellow, varying to a cinnamon yellow, with occasionally a flush of red in the sun. Flesh whitish, melting, juicy, sugary, vinous, perfumed. October. (An. Pom.)

\section{Diller.}

A Pennsylvania Pear. Tree a slow and poor grower. Young wood light brownish yellow.

Fruit below medium, nearly globular. Skin yellowish, sprinkled 
and pateherl with russet. Stalk long, inserter in a very slight cavity by a fleshy ring. Calyx closed, set in a rather broad, shallow basin. Flesh whitish, coarse, and gramular, juiey, buttery, melting, with a very sweet, aromatic perfumed thavor. Good to very good. Ripe last of August and first of September.

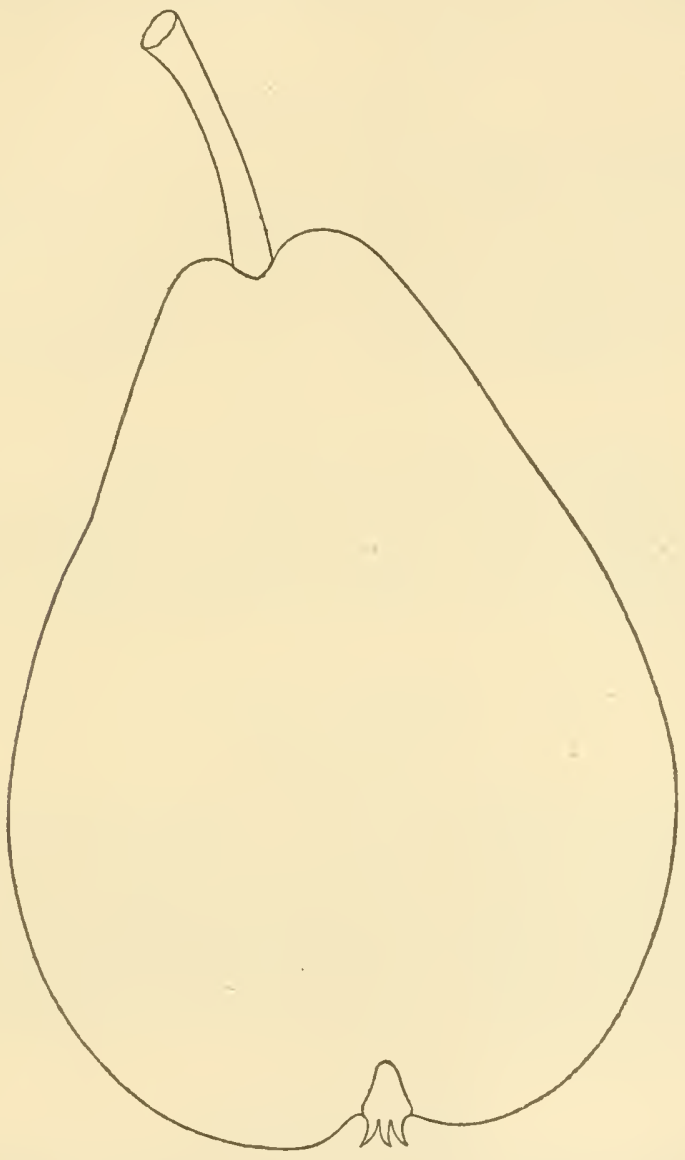

Dis

Dix.

Lewis, erroneously of the French.

The Dix is, unquestionably, a fruit of the highest excellence, and deserves the attention of all planters. It is one of the hardiest of peartrees, but the tree does not come into bearing until it has attained considerable size. The young branches are dull olive yellow brown, upright, and slender. The original tree stands in the garden of Madam Dix, Buston. It bore for the first time in 1826 . 
Fruit large, oblong, or long pyriform. Skin roughish, fine deep sellow at maturity, marked with distinct russet dots, and sprinkled with russet around the stalk. Calyx small for so large a fruit. Basin narrow, and scarcely at all sunk. Stalk rather stout, short, thicker at each end, set rather obliquely, but with little or no depression. Flesh not ver'y fine-grained, but juicy, rich, sugary, melting, and delicious, with a slight perfume. Tery good to best. Uctober and Norember.

\section{Docteur Bouvier.}

A vigorous tree, forming a beautiful pyramid, very productire. Toung wood yellow reddish brown.

Fruit medium, roundish obovate pyriform. Skin greenish, becoming slightly vellow at maturity, sprinkled, shaded, and dotted with rinsset, sometimes sightly crimson and fawn in the sun. Stalk curved, set withont depression. Calyx open. Flesh a little coarse, juicr, melting, brisk, vinous, slightly perfuned. Good to rery good. December.

\section{Docteur Caprox.}

One of Van Mons' seedlings, originated in 1842 .

Fruit medium, regular, ovate pyriform. Skin pale rellow, a little brownish in the sun, with nettings, patches, and dots of russet. Stalk medium, inclined, set in a slight depression, russeted. Calrx open. Flesh yellowish, juicy, half melting, sweet, pleasant. Good. October, November.

\section{Docteur Lextier.}

Doctor Lenthier.

A Belgian Pear, originated about 184i, and named after M. Lentier, a physician. Tree vigorous, productive. Young shoots olive brown.

Fruit medium, obovate, sometimes acute pyriform. Skin greenish or pale yellow, with traces and yatehes of russet, especially next the stalk, sometimes a shade of crimson in the sum, and sprinkled with minute brown dots. Stalk varying, set without depression. Calyx partially closed. Basin small. Flesh yellowish, juicy, melting, sweet, pleasant. Good. Neptember, October.

\section{Docteur Trousseau.}

Raised from seed at Saint Remy, France, in 184R. Tree a vigorous grower, with long, strong, rather spreading branches. Foung wood dull dark red brown.

Fruit medium to large, roundish obtuse prriform. Skin greenish vellow, partially netterl and patched with russet, and thickly sprinkled with russet dots. Stalk variable, curved, set in a slight depression or advity, sometimes by a lip. Calyx open. Elesh rellowish. juicy, melting, rinous, a little astringent. Good to very good. November.

\section{Doctor Nelis.}

Another Belgin variety, originated in 1847, and named and de- 
dicated to a plysician. Tree moderately vigorous and productive. Young wood olive yellow brown.

F'uit medium, roundish pyriform, slightly obtuss. Skin greenish yellow, with a shade of red in the sum, somewhat patched and netted

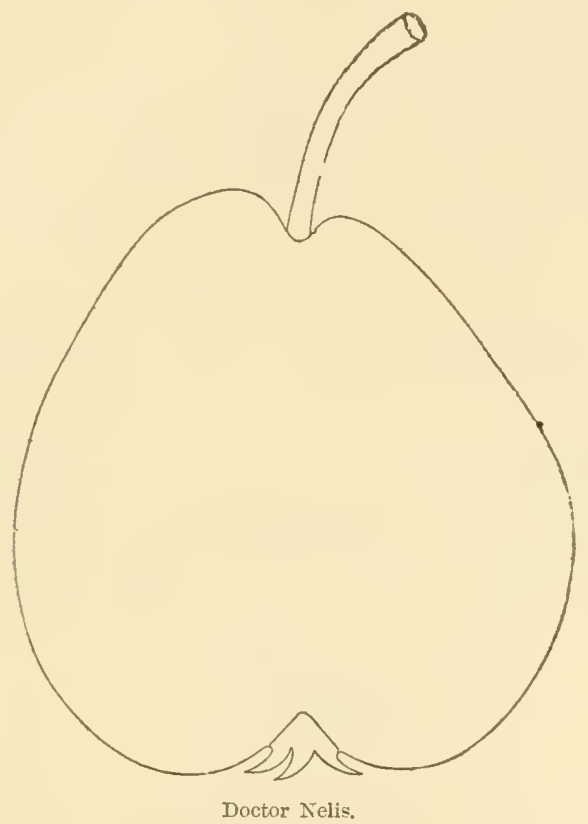

with russet, and sprinkled with russet green lots. Stalk short, a little inclined, set in a small, russeted cavity. Calyx large, open. Flesh whitish, juicy, melting, sweet, pleasant, slightly vinous. Tery gooul. Last of September.

\section{DOCTOR REEDER.}

\section{Reeder's Seedling.}

Raised from seed of the Winter Nelis by Dr. Henry Reeder, Varick, Seneca Co., N. Y. Tree very hardy, healthy, vigorous, spreading, open frim, an excellent bearer. Toung shoots warm olive brown.

Fruit small to medium, roundish ovate obtuse pyiform, compressed, rften apparently slightly furrowed on one side. "Skin yellow, netted and patched with russet nearly over the whole surface, and thickly sprinkled with russet dots. Stalk long and slender, slightiy curver, a little inclinerl, in a small eavity. Calyx large and open. Segments large, lying flat on the fruit. Basin merlium, nearly regular. Flesh fine, juicy, melting, buttery, a little granular, very sugarr, vinous, with u high musky perfune. Very good to best. November. 


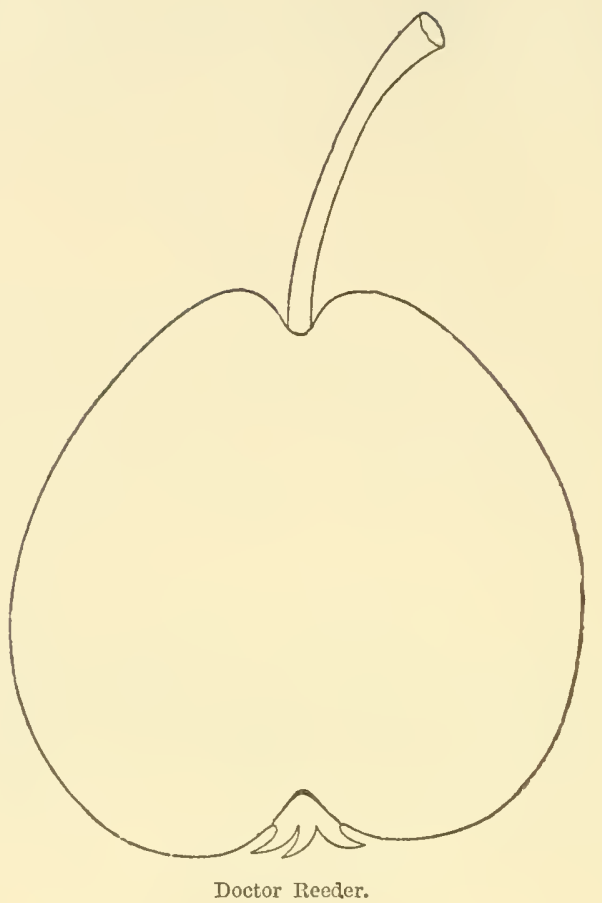

Doctor TurNer.

A Connecticut Pear, origin unknown. Tree a moderate spreading grower. Young wood a dark olive brown.

Fruit large, acute obtuse pyriform. Skin pale yellow, sometimes with a slight blush, and thickly sprinkled with green and brown dots, a few traces of russet. Stalk long, curved, set in a slight depression by a ring or lip. Calyx closed. Basin rather small. Flesh white, juicy, half melting, slightly vinous, somewhat astringent. Good. August.

\section{Dorothée Rotale Nouvelle.}

Fruit about medium, pyriform, uneren. Skin smooth, clear deep temon yellow, with here and there a patch of cinnamon russet. Calyx open. Stalk stout. Flesh vely fine, melting, juicy, rich. Last of October. (Hogg.)

\section{Dorsoris.}

American Beauts.

Origin unknown. Introduced by Isaac Coles, of Glen Core, Long Island. Tree a vigorous, upright, spreading grower, and an early bearer. Young wood reddish yellow brown.

Fruit medium, roundish pyriform. Skin pale yellow, shaded with 
bright rich crimson in the sun, and sprinkled with brown and green dots. Stalk medium. Calyx nearly closed. Flesh white, buttery, sweet, pleasant. Good. August.

Dow.

Raised by Dr. Eli Ives, New Haven, Conn. Tree upright, vigorous, productive.

Fruit rather above medium, obovate, acutely pyriform, sometimes turbinate. Skin rough, yellowish green, sprinkled with russet dots, and a few small patches of russet. Stalk long, inserted at an inclination in a very slight cavity. Calyx large, open, set in a very small basin. Flesh white, buttery, juicy, melting, with a good vinous flavor, sometimes slightly astringent. Good. September, October.

\section{Doyen Dillen.}

\section{Deacon Dillen.}

Doctor Dillen.

One of Van Mons' Pears. Tree vigorous, productive. Young wood olive yellow brown.

Fruit rather large, oblong pyriform. Skin fine yellow, inclining to russet, thickly sprinkled with 'usset specks. Stalk short, thick, and fleshy, strongly fixed, without any depression. Calyx small, rarely open. Basin of moderate depth. Flesh juicy, buttery, sweet, and rich. Very good. October, November.

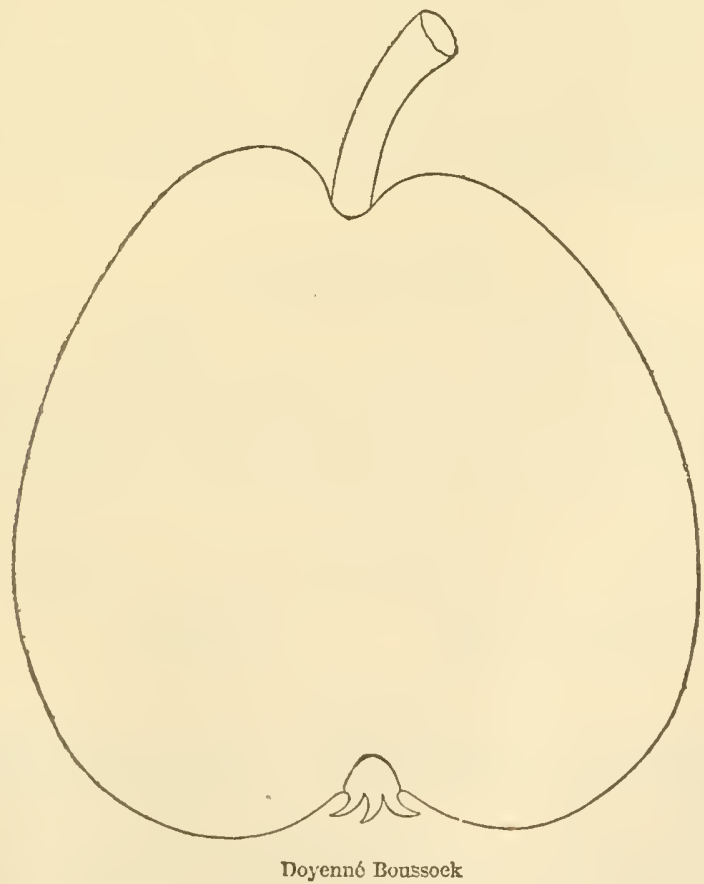




\section{Doyenné Boussock.}
Doyenné Boussouck Nouvelle.
Beurré de Merode.
Double Philippe.
Bossoch.
Beurré Boussock.
Albertine.
Beurré de Tresterloo.
Beurré MIagnifique.

Doyenmé de Merode.

This Belgian Pear proves one of the most vigorous of trees, and profitable as a market sort. Tree vigorous, upright, spreading. Young wood dull reddish brown.

Fruit varying in form, obovate inclining to pyriform, or roundislı obtuse obovate. Skin rough, deep yellow, netted and clouded with russet, with a warm cheek. Stalk rather short and stout, inserted in a round carity. Calyx open. Basin shallow. Flesh buttery, juicy, melting, sweet, aromatic, and excellent. Very good. September and October.

DELPIERE, as we have received it, proves identical with the above.

\section{Doyexné D'Alexçox.}

$\begin{array}{ll}\text { Đoyenné d'Hiver d'Alencon. } & \text { Doyenné Marbré. } \\ \text { Doyenné Gris d'Hiver Nouveau. } & \text { Doyeuué d'Hiver Noureau. }\end{array}$

St. Michael d'Hiver.

A foreign Pear, of mnknown origin. Tree moderately vigorons and productive. Young shoots dull olive browu.

Fruit medium, roundish oval, inclining to obovate or prriform. Skin rough, yellow, shaded with dull crimson or carmine, sprinkled, netted, and patched witlı russet brown dots. Stalk of mocierate length, pretty large, inserted in a medium cavity. Calyx open. Segments persistent. Basin deep, round, upright. Flesh somewhat granular, but. tery, juicy, sugary, very rich, sprightly, and highly perfumed. Very good. December to April.

\section{Doyenné de Cercle.}

\section{Doyenné de Cercle Pratique de Rouen.}

Fruit medium, nearly round, inclining to pyriform. Sides unequal. Skin greenish yellow, with a blush of crimson in the sun, a few traces and nettings of russet, and thickly sprinkled with large brown dots. Stalk varying, set in a small curity. Calyx open. Basin uneren, slightly russeted. Flesh whitish, juicy, melting, slightly vinous. Good. October.

\section{DOYENyé D'Été.}

Summer Doyenné.

Doyenné de Juillet.

St. Michael d'Été.
Jolliemont.

Roi Jolimont. Jolimont.

\section{Wolivet.}

One of Van Mons' seedlings, obtained in 1823. Tree vigorous, upright, an early and abundant bearer. Toung shoots reddish yellow brown.

Fruit small, roundish obovate, slightly prriform. Skin smootl, fine yellow, often shaded with bright red, anrl covered with numcrous 
gray or russet dots. Stalk rather sloort and thick, fleshy at its junetion with the fruit, almost witlout depression. Calyx small and open, ire a

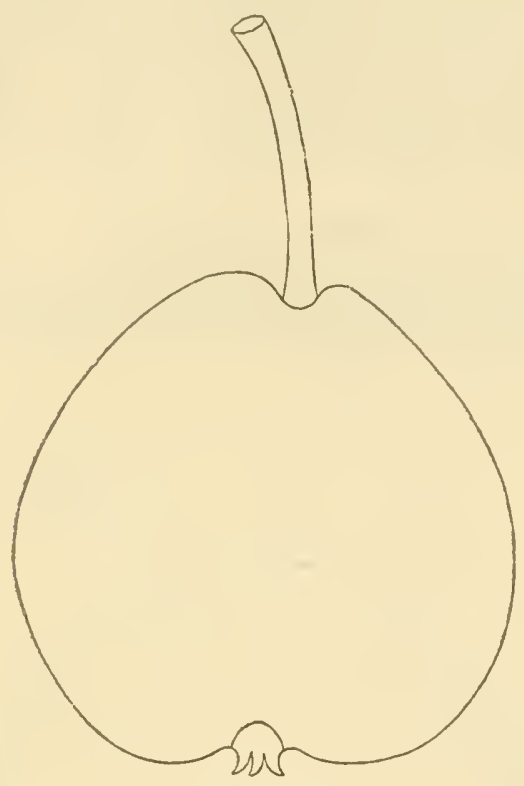

Doyenne d'Été.

very shallow, slightly corrugated basin. Flesh white, melting, juicy, with a sweet, pleasant flavor. Good to very good. Last of July.

\section{Doyenjé Defais.}

Defays.

Doyenné d'Affay.

Originated at Angers, France. Tree moderately vigorous. Young wood dull olive brown, with many white specks.

Fruit medium or below, roundish oblate. Skin pale yellow, sometimes a slight shade of red in the sun, traces of russet and spfinkled with brown dots. Stalk short, a little curved, in a broad eavity. Calyx open. Basin abrupt, furrowed. Flesh white, juicy, melting, sweet, pleasant, slightly aromatic. Good to very good. October.

\section{Doyexat DE SAUMUR.}

Tree vigorous. Young wood gravish olive.

Fruit medium or below, roundish ovate. Skin pale whitish yellow, thickly sprinkled with large green and brown dots. Stalk medium. curved. Calyx open. Flesh wlite, juicy, melting, sweet, pleasant. Good to very good. September. 


\section{Doxenxé DoWning.}

Raised by André Leroy, and dedieated to the late A. J. Downing Tree morlerately vigorous. Young wood slender, dark rusty brown.

Fruit medium, obovate obtuse pyriform, inclining to turbinate. Skin greenish yellow, sprinkled and netted with russet, very slightly shaderl with crimson, and thickly covered with russet dots. Flesh time, buttery, juicy, melting, with a sweet, vinous, rich, perfumed flavor, somewhat aromatic. Good to very good. October.

\section{DoYenje dU Conice.}

A French Pear, of comparatively recent introduction, which promises to be of much value. Tree moderately vigorous, upright. Young wood rich warm reddish yellow brown.

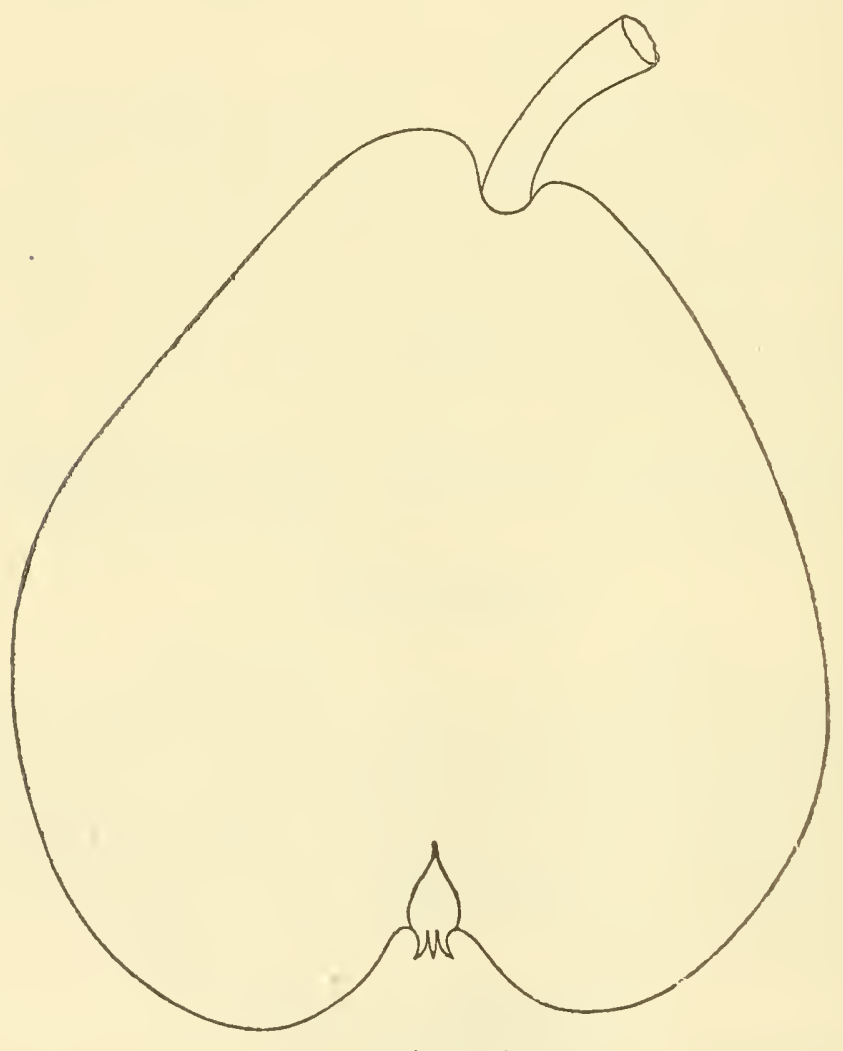

Dojenné du Comice.

Fruit large, varying, roundish pyriform or broad obtuse pyriform, sometimes obtuse. Skin greenish yellow, becoming fine yellow at maturity, often lightly shaded with crimson and fawn in the sum, slight net- 
tings and patches of russet, and thickly sprinkled with russet dots. Stalk slort, stont, inclined and set in a shallow eavity, often russeted. Calyx small, open. Bisin large, deep, and uneven. Flesh white, fine, melting, a little buttery, juicy, sweet, rich, slightly arouatic. Very good or best. Core small. October, November.

\section{Dorenné Goubault.}

Origin, Angers, France. Of slow growth, and rather slender branches. An improfitable sort.

Fruit medium, occasionally large, obovate acute pyriform. Stalk short. Calyx small. Skin rull pale yellow, with a few traces of russet, particularly around stem and calyx. Flesh meltingand juicy, sweet, uromatic. Good to very good. Ripe December to February.

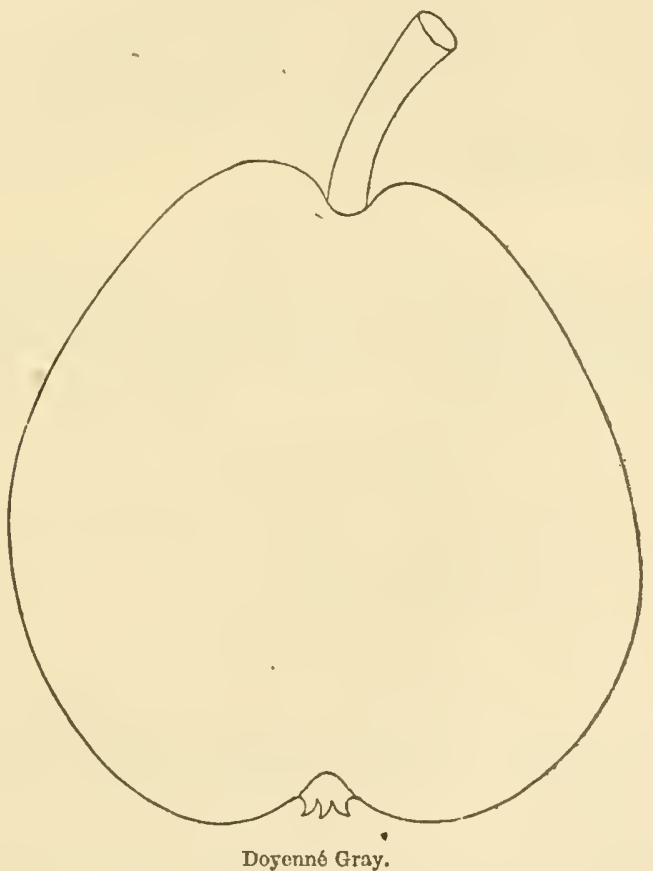

Doyenté Gray.

Gray Butter Pear.

Gray Deans.

Gray Doyenné.

Red Doyenné.

St. Michel Doré.

Doyenné Galeux.

Doyenné Boussouck, of some.
Doyenné Gris.

Doyenné Rouge.

Doyenné Roux.

Doyenné d'Automne.

Red Beurrí, , incorrectly

Beurré Rouge, $\int$ of some.

Le Beurré.

The Gray Doyenné strongly resembles the White Doyenné in flavor and general appearance, except that its skin is covered all over with a 
fine, lively cinmamon musset. It is a beautiful Pear, usually keeps a lit the longer, and is considered by many rather the finer of the two. Shoots upright, grayish brown.

Fruit of medium size, orate obovate, but usnally a little rounder than the White Doyenné. Skin wholly covered with smooth cinnamon rus. set (rarely a little ruddy next the sim). Stalk half to tliree-fourths of an inch long, curved, set in a narrow, rather deep and abrupt cavity. Calyx small, closed, and placed in a smooth, shallow basin. Flesh white, tine-grained, very buttery, melting, rich, and delicious. Best. Iidlle of October, and will keep many weeks.

\section{DOYenné RoBin.}

Beurré Robin.

Raised by MI. Robin, Angers, France. Tree vigorons. Young wood olive brown.

Fruit medium, roundish oblate. Skin greenish yeliow, netted, patchel, and thickly sprinkled with russet and gray dots. Stalk long, stout, inserted in a broad deep carity. Calyx partly closed. Flesh whitish, rather coarse, juicy, melting, somewhat granular, vmous, perfumed. Good. September.

\section{Doyesné Rose.}

Fruit above medium, obovate, obscurely pyriform. Skin yellow, beautifully shaded with crimson. Stem short. Cavity small. Calyx small; deel, regular basin. Elesh white, coarse, grannlar, with very little flaror: Rots at the core. Poor. Last of October.

\section{DOXENNÉ SANTELLET.}

A fine handsome Pear from Flanders.

Fruit above medium, obtuse prriform, greenish rellow, with marblings and sprecks of gray russet. Flesh white, a little gritty, tender, musky perfume. October. (Lindley.)

\section{Doyexxé Sieulle.}

Sieulle.

Beurré Sieulle.

Bergamotte Sieulle.

A hardy tree, and a profitable market Pear in some sections. Raised by II. Sieulle. Tree vigorous and productive. Ioung wood olive yellow brown.

Fruit medium, roundish oblate. Skin greenish rellow, thickly sprinkled with green or brown dots, shacled with crimson and firwn in the sun. Stalk curved, stont, inserted in a broad cavity by a ring or hip. Calyx open in a small shallow basin. Flesh white, coarse, very buttery, juiey, with a rich vinons, slightly aromatic flaror. Good. October, November.

\section{Du Breull Pìre.}

A seedling grown by M. Alphonse Du Brenil.

Fruit medium, ronudish oblate pyriform. Skin greenish, with marblings and rays of brown in sum. Flesh white, fine, melting, juicy, sweet, vimous. Middle September. (Leroy.) 


\section{Duc Alfreis De CRUY.}

Fruit large, obtuse pyriform. Skin smooth, greenish yellow, with a thin crust of brown russet over the surface; on the side next the sun it is tinged with pale brown. Stalk fleshy at base, set withont depression. Calyx open. Flesh yellowish, not very juiey, buttery, rich, spicy, November, December. (Hugg.)

\section{Dú D'Aumale.}

Gèdeon Paridant.

A seedling of Van Mons', of vigorous growth and produetive habit. Young wood rectdish yellow brown.

Friit medium, slightly obtuse pyriform. Skin pale yellow, shaded and marbled with brownish red in the sum, slight netting and patches of russet, and many russet dots. Stalk rather long, a little curved. Calyx large, open. Flesh whitish, juicy, sweet, aromatic. Good to rery good. September.

\section{Duc de Brabant.}

Fondante des Charneuse. Miel d'Waterloo.

\author{
Jamin. \\ Beurré Charneuse. \\ Beurré d'Waterloo.
}

A Belgian Pear. Tree hardy, vigorous, productive. Young wood olive brown grayish.

Fruit large, oblong pyriform, sometimes acute, sometimes obtuse. Skin greenish, shaded with crimson on the sunny side, and thickly sprinkled with greenish dots. Stalk long, eurved, and twisted, somewhat fleshy at its insertion, in a very small cavity. Calyx large and open. Segments persistent, in an irregular ribbed basin. Flesh whitish green, very juiey, buttery. melting, with a refreshing vinous flaror. Very good. Oetober, November.

\section{Duchesse D'ANgoulêne.}

\section{Beurré Soule.}

A magnificent large dessert Pear, sometimes weighing a pound and a quarter, named in honor of the Duchess of Angoulême, and said to be a natural seedling, found in a forest heilge near Angers. Whien in perfection, it is a most delicious fr'uit of the highest quality. We are compellerl to add, however, that the quality of the fruit is a little mcertain on young stanclard trees. 'The tree is a strong grower, the shoots upright, reidish yellow brown.

Fruit very large, oblong obovate, with an uneven, somewhat knobby surface. Skin dull greenish yellow, a good deal streaked and spotted with russet. Stalk one to two inches long, very stout, bent, deeply planted in an irregular cavity. Calyx set in a somewhat knobby basin. Flesh white, buttery, and very juicy, with a rich and very excellent flavor. Very good. October.

\section{Duchesse D'Aremberg.}

A French Pear, the fruit of which we have seen but once. Tree a vigorous grower and sarly bearer.

Fruit medium, roundish obtuse prriform, dull greenish. Stalk long, slender, curved, set in a broad, rather deep cavity. Calyx partially 
closed. Basin shallow. Flesh whitish, rather coarse, tender, juicy Good. . September.

\section{Duchesse de Berry d'Été.}

Duchesse de Berry.

Duchesse de Berry de Nantes.

Originated at Nantes, France. Tree vigorous, upiright. Young wood dark reddish.

Fruit small, roundish oblate, obscurely pyriform. Skin yellow, shaded with light red, nettings and patches of russet. Stalk short, in

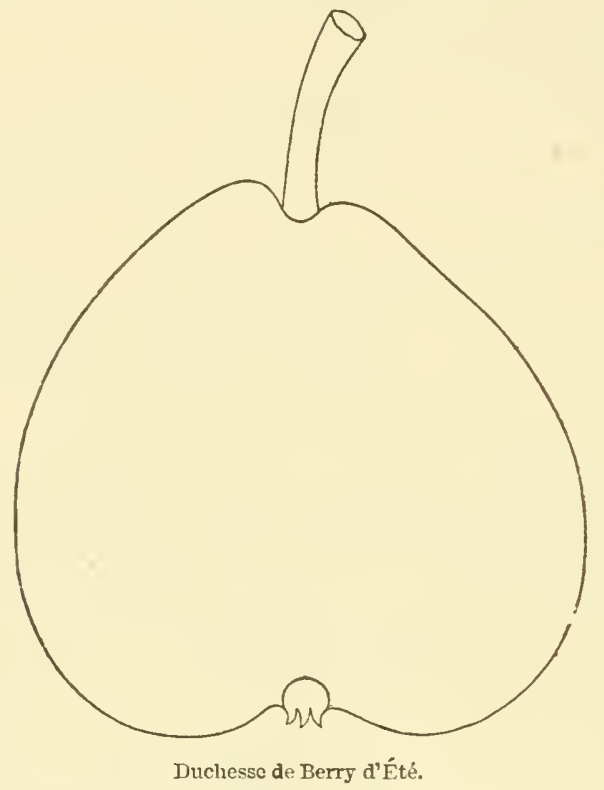

serted in a small cuvity. Calyx partially open, set in a broad shallow basin. Flesh juicy, melting, with a good vinous flavor. Good to very good. Ripens last of August.

\section{Duchesse de Bourdeaux.}

Beurré Perrault.

Originated with M. Secher, near Angers, France, in 1850. Tree moderately vigorous. Young wood dull olive brown.

Fruit medium, roundish, inclining to obtuse pyriform. Skin yellow, netted and traced with russet, and surinkled with rthsset dots. Stalk long, stout, fleshy at insertion, often by a lip. Calyx open. Basin medium, uneven. Flesh white, moderately juicy, sweet, pleasant. Good. December to February.

\section{Duchesse de Brabant. (Durieux.)}

Tree very vigorous.

Fruit of good size, turbinate pyriform, sometimes elongated. Skin rough, bright green, becoming moderately yellow at ripening, much chaded with bright russet. Flesh whitish yellow, fine, melting, juice 
abundant, sugary, vinous, finely perfumed. Fruit of the first quality, ripeuing at the end of October: (An. Pom.)

\section{Ducifesse de Brabant. (Capenick.)}

Thee vigorous and productive.

Fruit medium, roundish, depressed at crown, clear yellow, tinged with bright red in the sun. Stalk long, inserted in a small contracted cavity. Calyx open. Flesh white, rather firm, but melting, juicy, rich, sweet. October. (Hovey Mag.)

There is also another Duchesse de Brabant, the origin of which is unknown. We have fruitel, but are in doubt of the correctness of our tree.

\section{Duchesse D'Hiver.}

Tardive de Toulouse.

Winter Duchess.

Originated with M. Barthere, at Toulouse, France. Tree a vigorous handsome grower, and an early bearer. Young wood olive yellow brown.

Fruit large, obovate pyiform, uneven surface, dull greenish, with brownish dull russet shades and spots. Stalk stout, set in a slight uneven cavity. Flesh white, juicy, pretty fine-grained, mild, sweet, pleasant. Very good. December to April.

\section{Duchesse DE MARs.}

\section{Comtesse de Lumay.}

A French Pear, first described in 1850, by M. Prevost, in Album Pomologie. Tree hardy, branches rather slender. Young wood very dark redilish yellow biown.

Fruit medium or below, oblong obovate, obtuse pyriform, yellowish brown, with considerable russet and russet specks. Stalk short, set in a rather cleep cavity. Flesh whitish, melting, juicy, sweet, vinous. Very good. Core small. October, November.

\section{DuChesse D'OrLEANS.}
Beurré St. Nicholas.
St. Nicholas.
Duc d'Orleans.

A French Pear, of which the precise location of origin is unknown. Tree a good grower, upright, with long jointed wood. Young shoots dull olive brown, slightly grayish.

Fruit rather above medium, elongated prriform, narrowing towards the basin. Skin yellowish green, sometimes a sumny cheek, with brown dots. Stalk long, pretty large, eurved. Calyx nearly closed, set in a shallow uneven basin. Flesh juicy, melting, slightly aromatic, with a very good flavor. Trery good. Sejtember, October

\section{Duchesse Hélène d'Orleats.}

Princess Helen d'Orieans.

Reine de Vierge.

According to the Album Pomologie this variety was first ilescrilued in 1847. It has been, by some, confounded with Maréchal de la Cour, and also with Duchesse d'Orleaus, but is found by its giowth of wood, more than by its fruit, to be distinct. The tree is a vigorous grower, with long jointed, stout wood, the young shoots of a rich warm reddish 
brown color, with scattered, nearly oblong, light gray specks. Buds sharp pointed.

Fruit large, varying from oblong pyriform to oblong obovate pyriform, whitish yellow, considerably netted and patched with russet, and thickly sprinkled with russet dots. Stalk inedium or rather stout, a little inclined, set in a small cavity, sometimes with a lip. Calyx open, or partly so. Segments short, erect. Basin small, corrugated. Flesh white, juicy, melting, sweet, pleasant, a little rinous. Good to very good. September, October.

\section{DumONT DuMORTIER.}

This is a Belgian variety. Not having fruited it, we copy description from Hovey. "Tree a moderate grower and a good bearer.

"Fruit large, romulish obovate, romuding to an obtuse point at stem. Dull green, nearly covered with dark russet, reddish in sum, and dotted with russet specks. Stalk rather short, straight. Cavity moderately rleep. Calyx large, open. Basin shallow. Flesh white, melting, juiey, pleasant, slightly vinouś. Good. Core large. October."

\section{DUNDAS.}

Eliott Drundas. Rousselet Jamin.
Félicité Dundas.

Rousselet de Jamin.

A Belgian variety, sent to this country by Tan Mons, in 1834. Tree an nuritht, vigorous grower, an early and good bearer.

Fruit medium size, roundish obovate pyriform, yellow, shaded with crimson in sun, thickly sprinkled with brown russet dots, and a few nettings and patches of russet. Stalk medium, curved. Cavity small, sometimes a lip. Calyx open. Segments small, persistent. Flesh white, juicy, melting, sweet, agreeable. Good to very good.

\section{DUxMORE.}

The Dummore is a large Pear, raised br Knight. It is a stronggrowing tree, and bears exceedingly well. Young wood gravish.

Fruit large, oblong obovate, rather swollen on one side, greenish, dotted and speckled with smootl brownish-red russet, and nettings and patches of russet. Stalk rather long, eurved, inserted in a slight depression by a lip. Calyx open, with reflexed segments. Basin shallow. Flesh yellowish white, juicy, melting, rich, vinous, sometimes gritty, and rots at core unless gathered early and carefully ripened. Tery good. September.

\section{Dupuy Chlarles.}

A variety produced by Louis E. Berckmans, in 1847, and br him dedieated to Charles Dupuy, Loches, France. By deseription, in 1850, the tree is vigorous, half upright in growth, and productive.

Fruit below medium, acute pyriform, yellow, netted and patehed with russet, and sprinkled with russet dots. Stalk varying in length, surved, set without depression. Calyx open. Basin small, shallow, uneven. Flesh yellowish, juicy, melting, sweet, pleasant. Good. Oc. tober. 


\section{DITนÉE.}

Durée's Secdling.

The original tree of this valiety was found on the furm of Whitehead Duree, Westbury, Long Island, N. Y., by Isate Hicks, and by him introduced. Tree it vigrorous, spreading grower, and an early beaver. Young wood duil dark olive brown.

Fruit medium, oblong acute pyriform, pale yellowish, considerably netted and patched with russet, and thickly sprinkled with russet dots. Stalk long, curved, without depiession. Calyx open. Busin uneven. Flesh whitish, half melting, juicy, vinous, sweet, slightly musky. Good to very good. October.

\section{Early Berganot.}

A second-rate French sort.

Fruit me:lium, roundish. Skin pale yellowish greon. Flesh quite juicy, crisp, with a pleasant, sweet Havor. Ripe abont the 20th of August.

\section{Early Butter (of Cinctinati).}

\section{Early Summer Butter.}

Mear's Summer Butter.

A variety somewhat grown around Cincimmati, $O$. Origin unknown. Tree upright, and a good grower.

Fruit small, oval, inclining to obovate, light yellow, with a tinge of red in the sun, brown and green dots. Stalk rather long, curved. Calyx large, with long recurved segments. Flesh white, juicy, buttery. Good. Last of July.

\section{Easter Berganot.}

Bergamotte de Pâques.

Bergamotte d'Hirer.

Bergamotte de Bugi

Bergamotte de Toulouse.

Robert's Keeping.

Winter Bergamotte.

Paddrington.

Royal Tairling.

Terling.
St. Herblain d'Hiver.

Bergamotte de la Grillire.

Bergamotte de Carême.

Bergamotte Ronde d'Hiver.

Bergamotte Soldat-Nabours.

Anderson's Favorite.

Cape May.

Bonner's Pope's Pear.

An old French variety. Tree vigorous and productive, keeps well, and a good cooking fruit. Toung wood olive, with round white specks.

Fruit medium, roundish obovate, narrow at the stalk. Skin smooth, pale green, thickly speckled with conspicuous light gray dots, and becoming pale yellowish at maturity. Flesh white, crisp, juicy, with a sprightly flavor. Goorl for cooking. February to May.

\section{Eister Beurré.}

Bermamotte de la Pentecîte.

Beurré de la Pentec te.

Beurré d'lliver de Bruxelles.

Doyenn: d'Hiver

Doy̌cnné du Printemps

Beurré Roup :

Du P'itre.

Merreille de la Nature.
Pastorale d'Iliver.

Beurrí de Pàues.

Philippe de Púques.

Bezi Chaumontelle très-gros.

('hammontelle tris-gros.

Camning.

Seigneur d'Iliver.

Caming d'Hiver.

The Easter Beurré is consilereel abroal one of the very lest late 
winter or spring Pears. It seems to require a rather warmer climate than that of the Eastern States to arrive at full perfection, and has dis. appointed the expectations of many cultivators. It bears well here, but

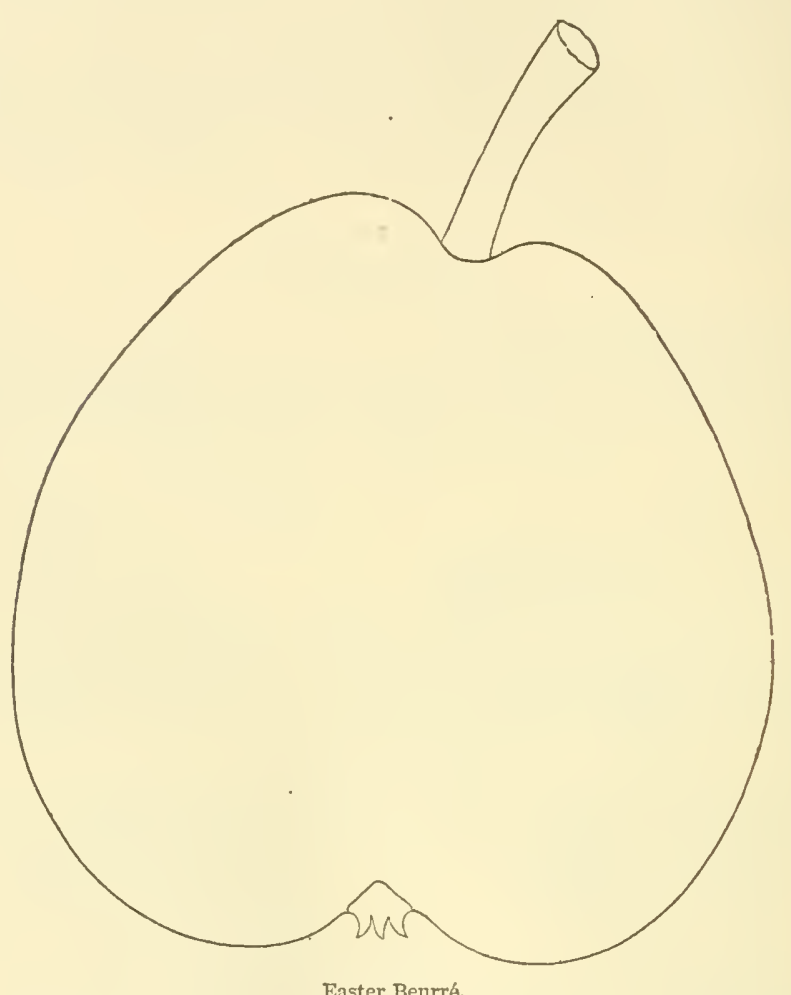

is rather variable in quality. In good seasons, if packed away in boxes and ripened off in a warm room, it is a delicious, melting, buttery fruit. The tree grows upright, and thriftily, with reddish yellow shoots. It requires a warm exposure and a rich soil to give fine fruit as an opeu standard tree. It is said to succeed well at the Sonth.

Fruit large, roundish obovate obtuse, often rather square in figure. Skin yellowish green, sprinkled with many russety dots, and some rtisset, which give it a brownish cheek in some specimens. Stalk rather short, stout, planted in an abruptly sunken obtuse cavity. Calyx small, closed, but little sunk among the plaited folds of the angular basin. Flesh white, fiue-grained, very buttery, melting and juicy, with a sweet and rich flavor: January to March.

\section{Eastior Castle.}

Fruit medium, roundish. Skin green and thick. Flesh greenish white, juicy, melting. December. 
Euthaserie.
Beri d'Echnssey.
L'Echasserie.
Winter Long Green.
Jezi l'Echasserie.
Jaglhirne.
Bezi de Chasseray.
Verte Longue d'Hiver. Winter Green Long.
Besidery Sandry. Landry W'ilding.

A French Pear of second quality, productive.

Fruit of medium size, roundish oval. Skin smooth, pale green, yellowish at maturity, slightly dotted with gray. Flesh melting, buttery, with a sweet perfumed Havor:" Jannary to April.

\section{EDMonds.}

Origin, town of Brighton, N. Y. A chance seedling on the farm of

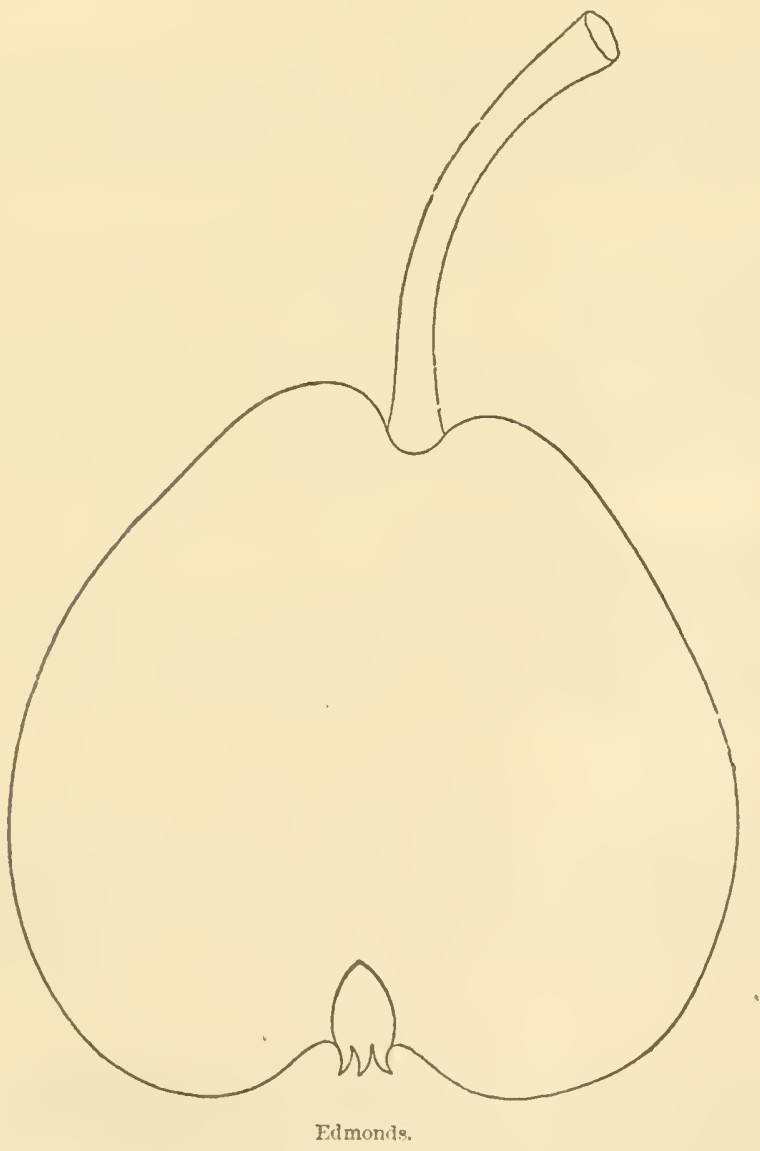

Eliphalet E Imonds. Tree a strong grower. Toung shoots yellowish redilish bro $r n$, with large spots.

Fruit large, obovate obtuse pyriform. Surface uneven, yellow, 48 
bronzed red in sum, and slight nettings of r'usset and russet dots. Stalk long, inclined, curved, Heshy at insertion. Cavity broad, uneven. Calyx open. Segments short, erect. Basin abrupt, corrugated. Flesh tine-grained, whitish, juicy, half melting, sweet, with a peculiar flavor. V'ery good. September.

\section{Edward Morrex.}

A foreign variety, the origin of which we have not traced. Tree vigorous and productive. Yomng wood rich brownish olive.

Fluit small, roundish, greenish, with brownish cheek, sprinkled with green and brown dots. Stalk long. Cavity small, often a lip at base if stem. Calyx open. Basin shallow. Flesh white, juicy, half melting, sweet, pleasant. Good to very good. November.

\section{EDWARDS.}

Raised by Governor Edwards. A very gool baking fruit.

Fruit medium, obovate obtuse pyriform, yellow, sometimes shaded with crimson. Stalk short and thick. Calyx closed. Basin deep, uneven. Flesh coarse, granular, not tender. September.

\section{EDWards' Elizabeth.}

Edwards' Elizabeth is a seedling raised by Ex-Governor Edwards, of New Haven, Conn.

Fruit of medium size, often large, oblate obtuse pyriform, angular, and oblique at the base, the stalk frequently planted in a fleshy protn. berance like a fold, vellowish green, very fine, and a peenliar waxen ap pearance. Flesh white, buttery, slightly subacid, and good. Oetober.

\section{Edwards' Sieedlixe St. Germais.}

Raised by Dr. WV. D. Brinckle.

Fruit medinm, globular pyriform, yellow, with nettings and patches of russet, russet green clots. Stalk rather stout, set often with a lip. Calyx open. Basin medium. Flesh whitish, rather coarse, juicy, half melting, sweet, pleasant. Good. October to December.

\section{Eleoxie Bouvier.}

A Belgian variety, as yet little known. Tree vigorous, productive.

Fruit medium or below, oblong obovate pyriform, clear yellow, shaded with crimson and fawn, patches and netiings of russet, and many russet dots. Stalk medium, fleshy at insertion. Cavity slight. Culys open. Flesh white, rather coarse, sweet. Good. September.

\section{Eliza D'Heist.}

A French variety, introduced and described by Major Esperen in 1844. Tree a good grower. Toung wood olive yellow brown.

Fruit medium size, obtuse pyriform, greenish yellow, slarle of brown in sull, nettings and patches of russet, many brown russet dots. Stalk rather stont, often curved, set in a slight eavity with a lip. Calyx open. Segments short, erect. Basin small. Flesh whitish, juicy, melting, sweet, pleasant, aromatic. Good to very gool. Janumy to March. 


\section{Elliott's Meleivg.}

Raised by Betsey Elliott, Carlisle, Pa., some sixty years since. Tree vigorous, spreading.

Fruit below medium, nearly globular, oblique, greenish, netted with russet, especially at the ends. Stalk short. Cavity narrow, small. Basin small, regular. Flesh whitish, juicy, melting, sweet, aromatic, pleasant. Good to very good. September:

\section{ELLIS.}

Raised from seed of the Seckel, by Mrs. Ellis, of New Bedford, Mass., in 1843 . The tree is a vigorous grower, hardy, and prolific. Young shoots dull yellow brown, with long gray specks.

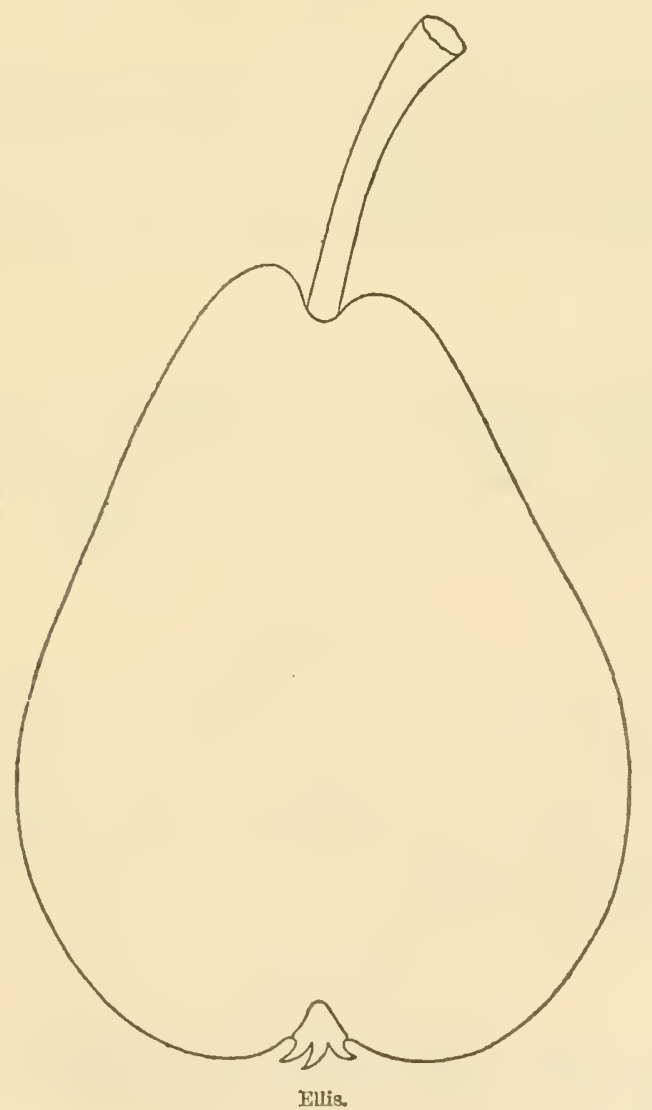

Fruit large, oblong obovate obtuse pyriform. Surface somewhat uneven, greenish yellow, patched and mottled with russet, and sometimes a sharle of crimson in the sun, many russet dots. Stalk rather liuge, 
long, curverl, and set in a small cavity. Calyx open. Segments long, recurved. Basin uneven. Flesh whitish, juicy, melting, sweet, slightly rinons, aromatic. Very good. Sentember and October.

There is another Pear under the name of Ellis, grown in Westeru New York, entirely distinct.

Fruit medium, acute pyriform, greenish yellow, shaded with crim. son red in sun, mauy small brown dots. Flesh white, juicy, melting, vinous, and often astringent, and disposed to rot at the core. Good. August and early September.

\section{Eltsworth.}

Origin unknown.

Fruit merlium, globular pyriform, greenish yellow. Flesh whitish, coarse, sweet. Only to be valued for cooking. October.

\section{ELTON.}

According to Lindley, the original tree of this variety grew in Herefordshire, England, and must be now nearly two and one-half centuries old. The fruit is stated by Hogg to be frequently without core or seeds, the flesh being solid throughont.

Fruit medium, oval oborate, greenish, with russet, shaded with orange red in sun. Flesh firm, crisp, juicy. Very good. September.

\section{Emeratid.}

A Belgian variety, variable, sometimes good.

Fruit medium size, obtuse py riform, oblique. Surface uneren, yellowish, with a brown eheek in sun, and brown dots. Stalk rather stout, curved. Calyx partially elosed. Flesh white, melting, rather coarse, juicy, subacid, vinous. Good. November, December.

\section{EMeraice.}

Emerance Birort.

A foreign variety, the tree of which grows strong but somewhat rambling.

Fruit large, obovate acute pyriform. greenish yellow, shaded with reddish crimson in the sum, patehes and nettings of russet, and many brown dots. Stalk curved, inserted with a knob or rim, fleshy. Calyx partially open. Basin medium. Flesh white, juicy, melting, sweet, pleasant. Good. September.

\section{Enilie Bryort.}

\section{Emily Birort.}

A Belgian variety, dedicated by its first describer, Bouvier, to the daughter of the distinguished pomologist, A. Bivort. Young wood olive brown.

Fruit medium or below, roundish irregular, sometimes oblate, rellow, blotched and patched with russet, and many russet dots: sometimes nearly the whole surface is covered with cinmamon russet. Stalk wedi- 
um. Cavity shallow. Calyx partially open. Basin abrupt, deep, fulrowed. Flesh whitish, juicy, melting, sweet, rich, slightly aromatic. October: Tery good.

\section{Finile D'Heyst.}

This fruit was dedicated by Major Esperen to the son of his friend L. E. Bercknans, of Georgia. It is of Belgian origin, and is one of the very best. The tree is hardy and productive, so much so as to require thimning to obtain full-sized fruit. It holds its foliage quite late in autumm, and holds its fruit well. Tree vigorous, spreading. Young wood olive color.

Fruit large, obloug obovate pyriform, angular and irregular. Skin cliar yellow, with brownish orange cheek in sum, netted and patched with

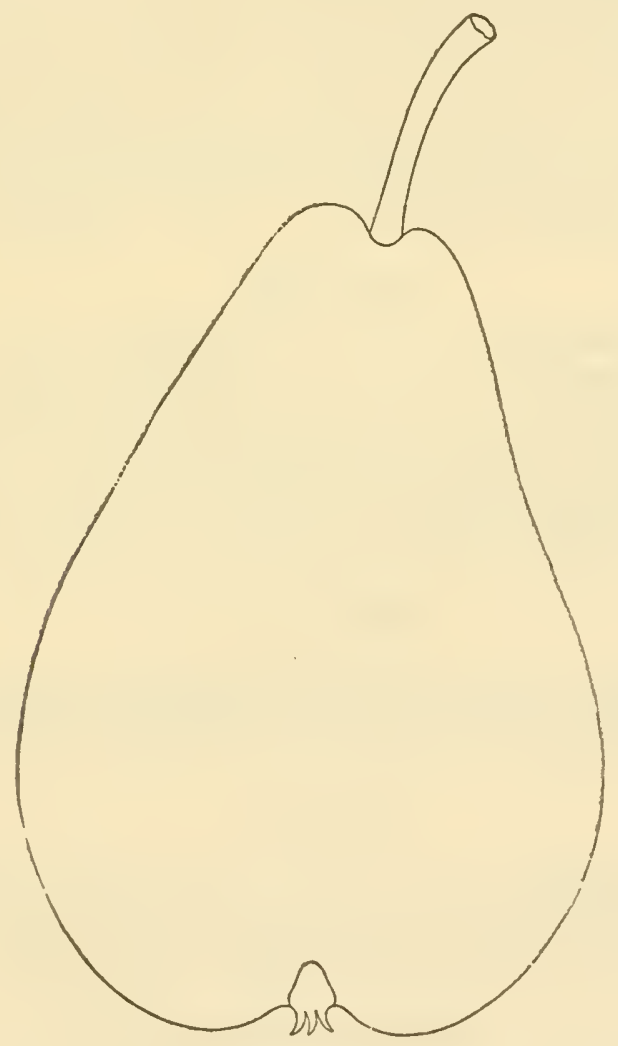

Emile d'Heyst.

russet, and thickly sprinkled with large russet dots. Stalk medium to long, inclined, curved. Cavity slight, often with a lip or fleshy ridge at base of stem. Calyx small, closed. Segmeuts short. Basin medium, somewhat furrowed. Flesh yellowish white, fine-grained, juicy, 
melting, sweet, slightly vinous and aromatic, rich and excellent. Very good to best. November, December.

\section{English Jargonelie.}

\author{
Epargne. \\ Grosse Cuisse Madame. \\ Beau Présent. \\ Poire de tables des princes. \\ Saint Sampson. \\ Saint Lambert. \\ Belle Verge. \\ Sparbirne. \\ Frauenschenkel. \\ Real Jargonelle.
}

\author{
Sweet Summer. \\ Chandelle. \\ Chopine. \\ Certean Madam. \\ Beurré de Paris. \\ Espargne. \\ Reserve Pear. \\ Jargonelle de Knoop. \\ Sicile. \\ Long Island Summer.
}

An old variety, variable in quality and decays at the core soon after maturity. If gathered early is very good. Tree a strong grower, with a rather straggling, pendent habit.

Fruit pretty large, long pyriform, tapering into the stalk. Skin greenish yellow, smooth, with a little brownish color on the sumny side. Stalk nearly two inches long, rather slender, curved, obliquely set. Calyx open, with quite long projecting segments, and sunk in a small and furrowed basin. The flesh is yellowish white, rather coarse-grained, juicy, with a sprightly refreshing flavor. Good. August.

\section{ÉPINE D'ÉTÉ.}

\section{Summer Thorm. \\ Fondante Musquée. Satin Vert.}

Petite Epine d'Été.

Bugiarda.

Bugiarda des Italiens.

Tree moderately vigorous, spreading, productive.

Fruit medium, pyriform. Skin greenish yellow. Flesh tender, melting, with a sweet, musky, peculiar flavor. Good. Last of August and first of September.

\section{Épine Royale.}

A French Pear. Tree vigorous, very productive.

Fruit medium, pyriform, yellowish, with bright red in the sun. Flesh fine, melting, juicy, sweet, vinous. October. (S. V. MI.)

\section{Eruesinde.}

A French variety.

Fruit large, oblong ovate pyriform, dull greenish, mostly covered and netted with russet, few dark blackish dots. Flesh white, fine, melting, juicy, sweet, agreeable. October. (Alb. Pom.)

\section{Ernestine Auzolie.}

Of French origin.

Fruit small, roundish pyriform, sometimes acute prriform, greenish yellow, with a shade of brown in sun, often netted and patched with russet. Flesh rather coarse, yellowish, moderately juicy, half welting, sweet. Good. September, October. 


\section{ESPERINE.}

This variety originated with Van Mons, and by him was dedicated to Major Esperin, of Malines. Tree vigorous, productive.

Fruit large, pyriform, greenish yellow, red in the sum, and shaded and specked with cimmamon r'nsset. Stalk medium, set with a lip or inclined. Calyx with open, short, half erect segments. Flesh white, buttery, melting, very juiey, and sweet. Good to very good. October. (s. T. Ml.)

\section{Essex.}

Introduced by Jonathan Batty, fiom the garden of Wm. Flack, Essex, Essex Co., N. Y. Tree vigorous and healthy.

Fruit below medium, oblong obtuse pyriform, greenish yellow, with many brown and green dots, marbled with carmine in the sun. Stalk long. Cavity large. Basin russeted. Flesh whitish, juiey, melting, granular, sweet. Good. September.

\section{Esturion.}

A foreign variety.

Fruit small, obovate pyriform, yellow, shaded with erimson in the sun, russet around the calyx. Flesin white, coarse, not juicy, hardly good. September.

\section{Excelsior.}

Dana's Excelsior.

A seelling of Francis Dana, Boston, Mass. Tree a strong upright grower, and good bearer. Young wood rich olive brown.

Fruit medium, obovate obtuse pyriform, sometimes irregular, greenish yellow, with traces of russet and many brown dots. Stalk long, curved, rather slender. Cavity small, russeted. Calyx open. Segments a little recurved. Basin small. Flesh juiey, melting, sweet, pleasant. Good to very good. September.

\section{EYEWOOD.}

A seedling of Mr. Knight's. Tree vigorous and hardy.

Fruit of medium size, oblate or Hattened. Skin much eovered witl russet. Flesh buttery, rich, and excellent.

\section{FAMENGa.}

A foreign variety.

Fruit medium, obovate, greenish yellow. September. (Elliott.)

\section{FEast.}

Feast's Seedling.

Originated with Samuel Feast, of Baltimore, from seerl of Seckel. Fruit medium, obovate pyriform, greenish yellow, with brown dots Flesh whitish, juicy, sweet. Good. September.

\section{Felix de Leim.}

A Belgian variety, but little known.

Fruit medium, roundish obovate lyriform, often inclined, yellowish 
green or pale yellow, marblings and traces of russet, many small russet green dots. Stalk medium, rather slender, set inclined in a small cavity with a lip. Calyx with long reflexed segments. Flesh whitish, juicy, uelting, sweet, ar mmatic. Good. October.

\section{Figue.}

Figue d'Alençon.

Verte longue de la Mayenne.

Verte longue d'Angers.

Figue d'Hiver.

Bonnisseme.

Bonnirsima de la Sartha.

Sylvange d'Hiver.
Petaless.

Figue d'Hiver d'Aleņ̧on.

Pettalless.

Figue d'Alençon d'Hiver.

Pistolette.

Grosse Figue?

Originated in the town of Alençon, France. Tree vigorous, pro. dnctive. Young wood reddish or reddish brown on the upper side, olive yellow brown underneath, prominent pointed buds.

Fruit large, oblong ovate acute pyriform, inclining by a lip over the stalk, greenish yellow, sometimes with a brownish cheek, partially netted and patched with russet, and thickly sprinkled with russet green dots. Stalk short, stont, fleshy at insertion by a lip, often russeted. Calyx open. Segments stift, long, recurved. Basin small, shallow, uneven. Flesh greenish white, juicy, half melting, sweet, slightly vinous. Very grood. October to December.

\section{Figue de Napies.}

Beurré Bronzée. Comtesse de Frenol.
Fig Pear of Naples. De Vigne Pelone.

Fourcroy?

A Belgian Pear. Tree vigorous, with upright brown shoots.

Fruit medium, oborate pyriform, greenish yellow, shaded and marbled with red in the sim, netted and patched witl russet, many russet-green dots. Stalk long, slender, generally curved and enlarged at junction of fruit, and a little inclined. Calyx open. Basin small, shallow, and uneven. Flesh yellowish, juicy, melting, sweet, pleasant. liood or very good. October.

\section{Fine Gold of Summer.}

Fin Or d'Été.

Fruit small, roundish, yellow, with a beautiful red cheek. Flesh iuicy, good flavor, not rich. Very productive. Good. Middle of Aug ist.

\section{Flemish Beauti:}

Belle de Flandres.

Bosch Nouvelle.

Bosch.

Bose Sire.

Poire Davy.

Imperatrice de France.

Fondante du Bois.

Boschpeer.

Beurré Spence (err me ously).

Brilliant.

Brillante.
Bergamotte de Flandre.

Beurre Foidard.

Petersilie Peer.

Bemrri de Bourgogne.

Beurré St Amour.

Belle des Bois.

Benrre de Deftinge.

Beurré Deftinghern.

Beurré Dary.

Poire de Persil.

Molle Bouche Nouvelle.

A:1 old Pear, supposed of Belgian origin, although foreign authors 
conflict in regard thereto. The tree is very luxuriant, hardy and bears early and abundintly; the young shoots njught, reddish olive lorown. The fruit reyuires to be gathered sooner than most pears, even before it parts readily from the tree. If it is then ripened in the house it is always fine, while, if allowed to mature on the tree, it usualiy becomes soft, thavorless, and decays soon.

Fruit large, obovate obtuse pyriform. Surface a little rough, the ground pale yellow, but mostly covered with marblings and patches of

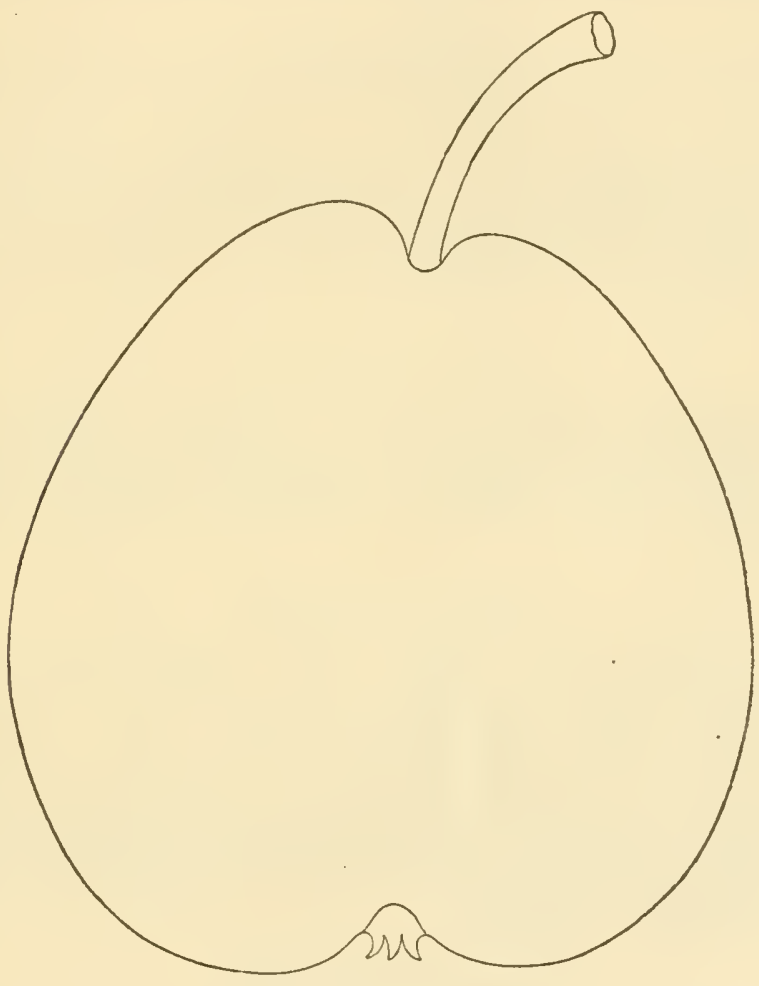

Flemish Beanty.

light russet, becoming reddish brown at maturity, on the sunny side. Stalk rather short, from an inch to an inch and a half long, and pretty deeply planted in a peculiarly narrow, round cavity. Calyx short, open, placed in a small round basin. Flesh yellowish white, not very fine-grained, but juicy, melting, very saccharine and rich, with a slightly musky flavor. Very good. Last of September.

\section{Flemisi Bon Chréties.}

Bon Chrétien Turc.

Bonchretien Yernois.
Turkish Pear. Turkish Bonchrétien.

The Flemish Bon Clurétien is an excellent cooking Pear, not very prochuctive. 
Fruit of medium size, obovate pyriform, yellow, russeted near the calyx, alid with many large russet dots. Flesh whitish, coarse, juicy; stews very tender. November to March.

\section{Florent Scoumax.}

Fruit large, pyriform, clear green, striped and spotted with brown ish red. Flesh very fiue, melting, juicy, sweet. October to December, (S. V. M.)

\section{Florinoxd Parent.} tility.

One of Van Mons' seedlings. Tree of moderate vigor and fer-

Fruit very large, pyramidal, swelled towards its centre, green, pointed and striped with brown russet, becomes deep jellow at maturity. Flesh coarse, melting, juicy, sugary, and agreeably perfumed. Good. Ripe at the end of September.

\section{Fondante Agréable.}

Fruit medium, roundish obovate. Color dull yellowish green, slightly russeted. Stalk planted at an inclination, and fleshy at its junction with the fruit. Flesh juicy and melting. Flavor very pleasant and refreshing, with a delicate aroma. Ripe last of August." (Wilder in Hort.)

\section{Fondante D'Albret.}

Received from Erance. Tree a vigorous upright grower, productive. Young wood yellow brown.

Fruit above medium, nearly globular, a little oblique, pale yellow, slightly netted and patched with russet, thickly sprinkled with green and russet dots, a bronzed red cheek in sun. Stalk rather short, stout. Cavity broad. Calyx large, open. Basin large. Flesh whitish, a little coarse, juicy, half melting, sweet, pleasant, vinous, slightly musky. Good to very good. September.

\section{Fondante D'Automane.}

Belle Lucrative. Seigneur d'Esperin. Bergamotte Fiévéc. Gresillier.

Du Seigneur.

Beurré Lucrative. Seigneur.
Arbre Superbe.

Lucrate.

Fondante de Maubege.

Antumn Melting.

Esperin's Herrezbirne.

Bergamotte Lucratire.

This Flemish Pear is, when grown in perfection, one of the rery best; but if the trees are overloaded, soil unsuited, or a dull, cloudy, rainy season, it is only second-rate. The tree is moderately vigorous, healthy and productive. Toung shoots yellowish brown.

Fruit medium size, variable in form, from obovate obtuse pyriform to globular. Pale yellowish green, slightly russeted. Stalk little more 
than an inch long, stout, often fleshy, obliquely inserted in a slight, irregular cavity. Calyx very short, open, with few divisions, set in a

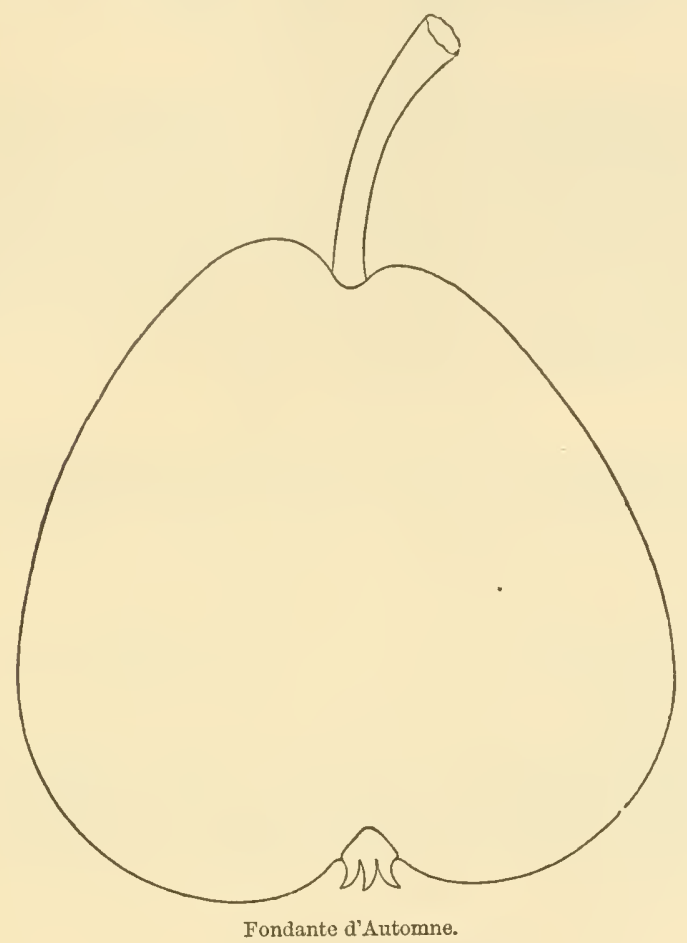

basin of moderate depth. Flesh juiey, melting, sugary, rieh, and delicious. Very good to best. Last of Sejtember.

\section{Fondante de Cuerne.}

A French variety, said to be superior to, and ripening with, Beurré Giffard. We have not fruited it, and therefore copy description:-

Fruit mediun, oblong obovate pyriform, pale greenish yellow, with traces of russet and russet brown in the sun. Stalk rather short, varying. Calyx small, open. Flesh white, juicy, melting, buttery, sweet, agreeable. August. (An. Pom.)

\section{Fondante d'Ingendal.}

Fruit small, acute pyriform, greenish yellow, a little brownish in sun, with green and gray dots. Stalk long, curved, fleshy where joined to the fruit. Calyx open. Segments long. Flesh whitish, juicy, melting, sweet, a little vinous, perfumed. Tery good. September. 
Fondante de la Mâitre d'École.

A foreign variety.

Fruit medium, pyriform, yellow, dotted with green. Flesh yellow half melting. December, January. (Hov. Mag.)

\section{Fondaxte de Malines.}

Oue of the seedlings of Major Esperen, of Belgium. Tree vigorous, somewhat imegular in habit. Young wood dull yellow brown.

Fruit medium, obovate pyriform, lemon yellow, with a tinge of crimson and fawn in the sun, sometimes russet patches and thickly sprinkled with brown russet dots. Stalk long, often curved, set in a shallow cavity by a lip. Calyx large, open, stiff segments. Basin rather abrupt, un. eren. Flesh white, a little coarse, juicy, melting, sweet, a little aromatic. Good to very good. Sejtember, October.

\section{Fondante de Nees.}

Fruit large, deep yellow, mottled and dotted with pale brown russet. Flesh yellowish, buttery, not juicy. Second-rate. October. (Hogg.)

\section{Fondante de Nö̈L.}

Belle de Noël.

Belle après Noël.

Of French origin. Tree vigorous and a good bearer. Young wood olive brown.

Fruit large, obovate obtuse pyriform. Surface nneven, fine yellow, mostly covered with cinuamon russet, and a brownish cheek in the sun, many russet dots. Stalk short, fleshy at insertion. Calyx open. Flesh yellowish, coarse, juicy, melting, brisk, a little astringent. Good. September.

\section{Fondante des Prés.}

A seedling of Van Mons'. Tree vigorous, productive. Young wood rich warm brown.

Fruit medium, varying from obovate obtuse to obovate acute pyriform, pale yellow, often with red cheek in sun, many brown dots. Flesh buttery, melting, agreeable. Only good. October.

\section{Fondaxte du Comice.}

Originated at Angers, France, abont 1849. The tree is a good grower, with olive brown young shoots.

Fruit large, ovate pyriform, sometimes obovate pyriform, yellow, with a warm cheek, inclining to russet, with russet dots. Stalk varying, sometimes curved, inserted in a depression. Calyx open, set in a rather deep, open basin. Flesh juicy, buttery, with a rich, sugary, vinous tlavor. Good to very good. October, November.

\section{Fondaste Van Moxs.}

Raised by Dr. Van Mons, and first introduced by Mr. Manning. It bear's abundantly. Young wood brick red. 
Fruit nearly of medium size, roundish, a little depressed. Skin pale yellow. Stalk stout, an inch anil a half long, planted in a rather deep cavity. Calyx set in a pretty deep basin. Flesh white, juicy, nelting, sweet, and of very agreeable Havor. Only good. First of November.

\section{Foote's SECKEL.}

Raised by Asahel Foote, of Williamstown, Mass., from seed of the Seckel. A very promising new variety, ripening a week or two later than its parent, and a little more vinous. Tree healthy, vigorous, more spreading than Seckel. Young wool dark rich brown.

Fruit small, oblate obtuse pyriform, yellow, shaded with brownish crimson in the sun, nearly covered with rich crimson r'usset. Stalk short, fleshy.

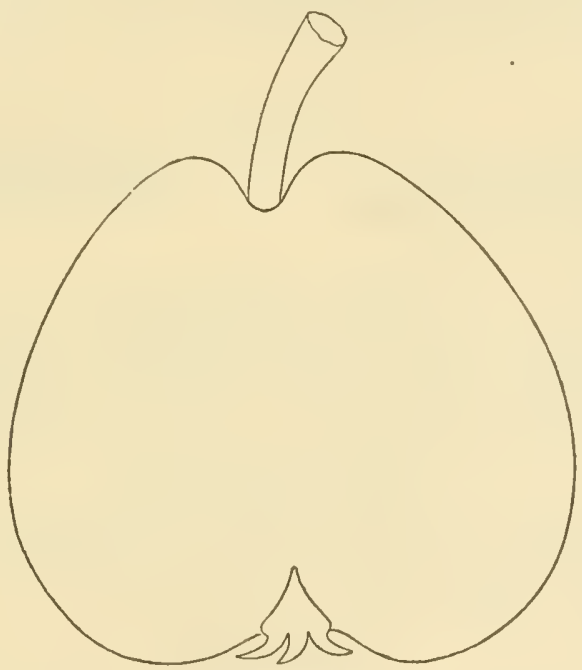

'Foote's Seckel

Cavity small. Calyx open. Basin medium, rather deep. Flesh whitish, fine, juicy, melting, sugary, slightly vinous. Very good. Scptember.

\section{Forelle.}

$\begin{array}{lll}\text { Forellen-birne. } & \text { Corail. } & \text { Petit Corail. } \\ \text { Grave de Corail. } & \text { Poire Truite. } & \text { Trout Pear. }\end{array}$

This exyuisitely beautiful German Pear-called in that language Frrellen-birne, $i . e$. , trout pear, from its finely speckled appearance-is ore of the most attractive lessert fruits. Young shoots long, with few aud rark-colored branclies.

Fruit oblong ovate, inelining to pyriform, smooth, at first green, but when fully ripe lemon yellow, washed with rich deep red on the sunny sile, where it is marked with large, margined, crimson specks. Stalk rather slender, slightly eurved, shallow, meven cavity. Calyx rather small. Basin abruptly sunk. Flesh white, fine-grained, buttery, melt- 
ing, slightly vinous. Good. Beginning of November, and may be kept, with care, till Christmas.

\section{Forme de Bergajotte Craesane.}

One of Van Mons' seedlings.

Fruit medium, oblong ovate pyrifor'm, pale yellow, a tinge of red in sun, slightly netted and patched with russet, many small russet dots. Stalk rather stout, inclined, curver, set in a depression, often with a lip. Calyx large, open. Flesh whitish, juicy, pleasant, a little astringent. Good. January to April.

\section{Forme. de Délices.}

A Flemish Pear, received from the London Horticultural Society.

Fruit medium, obovate. Skin rough, yellowish, with dull russet. Flesh buttery, melting, somewhat dry, but sweet. Good. Last of Oc. tober.

\section{Fortunée.}

Episcopal.

La Fortunée de Paris.

La Fortunée de Parmentier.

Bergamotte Fortunée.
Surpasse Fortunée.

Fortunée de Remme.

Beurré de Remme.

An old variety, raised by M. Parmentier, of Enghien, and raluable and protitable to grow for sale as a cooking Pear.

Fruit medium or below, roundish oblate, greenish vellow, slightly netted and patched with russet, many russet dots. Stalk short. Calyx open. Flesh whitish, melting, sweet. November, December.

\section{Foster's St. Michael.}

Fruit medium, roundish ovate. Stalk medium, in a small cavity. Calyx nearly closed, stift. Basin shallow. Skin yellow. Flesh coarse, sweet. Good. September.

\section{Franchinont.}

Supposed French origin.

Fruit below medium, roundisl oblate, yellow, shade of red in sun, netted and patched with russet, many russet dots. Flesh yellowish, juicy, half melting, sweet, slightly aromatic. Good or very good. September, October.

\section{Frangois Bergia.}

A new French sort.

Fruit medium, obtuse obovate, golden yellow, with large russet dots. Flesh coarse-grained, not very juicy, brisk, and not good. October. (Hogg.)

\section{Franc Feal D'Fiver.}

Franc Réal. Fine Gold of Winter. Golden End of Winter. Fin Or d'Hiver. Gros Micet.

The Winter Franc Réal is a good cooking Pear, hears well, and grows upright. 
Fruit of merliun size, roundish, slightly pyriform. Skin yellow, speckled with russet brown, and having a brownish cheek. Flesh crisp and firm. In use firom December to March.

\section{FRANGIPANE.}

Franchipane.

An old variety.

Fruit small, roundish pyriform, yellow, with some light russet. Stalk short, fleshy at base. Flesh whitish yellow, juicy, melting, sweet. Good. September, October.

\section{Fréderic de Wurteamura.}

Frederick of Wurtemburg. Vermillon d'Été.

\section{Roi de Wurtemberg. Médaille d'Or. King of Wurtemberg.}

Origin disputed by authors. A very handsome and sometimes very good fruit, but often poor.

Fruit large, one-sided, pyriform, rather uneren in its surface. Skin deep yellow at maturity, with a remarkably lich crimson cheek. Flesh white, juicy, melting, and sweet, and when in perfection, buttery and good. September.

\section{Frederick Leclerc.}

A French Pear, described in the Album Pomologie by L. F. Berckmans, and dedicated to Doctor Leclerc. Tree moderately vigorous. Young wood olive.

Fluit medium or above, oblong obovate pyriform, greenish yellow, with thin traces of russet. Stalk slender. Cavity narrow, acute. Flesh whitish yellow fine, melting, juicy, sweet, perfumerl. November, December.

\section{Frederika Bremer.}

Introduced by J. C. Hastings, of Clinton, Oneida Co., N. Y. Tree vigorous.

Fruit medium, irregularly obtuse pyriform, sometimes Bergamotteshaped, greenish yellow. Flesh whitish, melting, buttery, sweet, and vinous, sliglrtly perfumed. Good. October.

\section{Frenchi Jargonelle.}

Bellissime d'Étí.

Bellissime Suprême.

Bellissime .Jargonelle.

Vermilion l'Été.

Red TIuscadel.

Sabine d'Été.

Summer Beauty.

English Red Cheek.

Red Cheek.

Udal.

Laurentienne.
Saint Laurent.

Muscadet d'F́té.

Bassin.

Just.

Belle Comelie.

Butler's Harrest.

Cuisse Madame.

Summer Jargonelle.

Cuisse Dame d'Été.

Fusce d'Été.

This, which ML'. Thompson calls, by way of distinction, the French Srergonelle, because it is most commonly received under that name 
from France, is a higher colored and handsomer fruit than the Englist Jargonelle, though much inferior in quality, and, in fact, lasts only a day or two in perfection, and is often mealy and overripe, while the exterior is fair and tempting. The tree is of very strong, upright growth.

Fruit of medium size, obovate in form, light green, becoming lemon color, with a very rich, deep red cheek. Flesh white, coarse, breaking, sweet, and soon rots at the core. Ripens the last of July and first of Angust.

\section{Fultos.}

This American Pear is a native of Mraine, and is a seedling from the farm of Mrs. Fulton, of Topsham, in that State. It is very hardy, and bears every year abundantly. Tree moderately vigorous. Young shoots rather slender, and yellowish reddish brown.

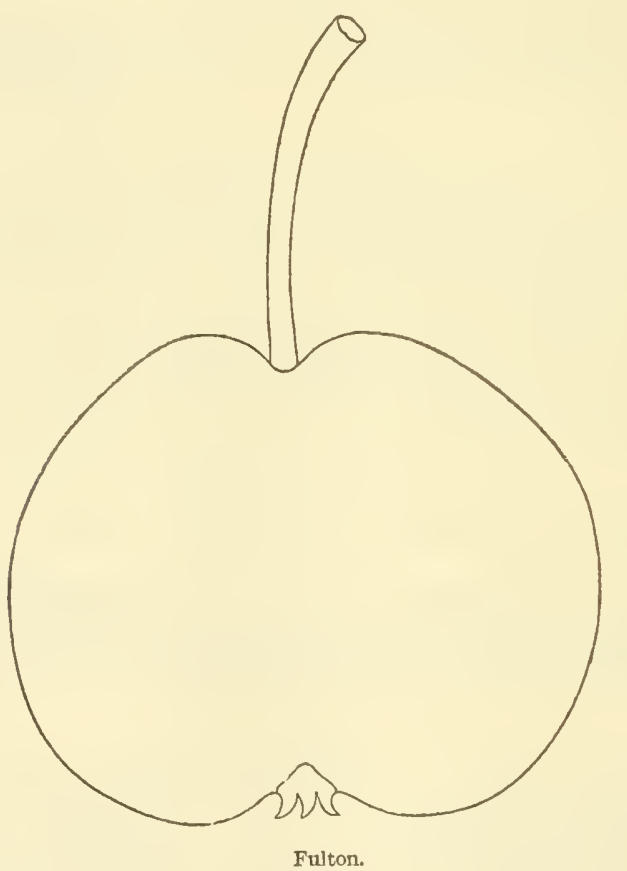

Fruit below medium size, roundish, flattened. Skin at first entire. ly gray russet in color, but at maturity of a dark cinnamon russet. Stalk one to iwo inches long, slender, planted in a narrow cavity. Calyx with long segments sunk in an uneren hollow. Flesh half buttery moderately juicy, with a sprightly, agreesble flaror. Very good. Oc. tober and November. 


\section{Gansel's Bergamotte.}

Brocas Bergamot.

Ives's Bergamot.

Staunton.
Bonne Rouge.

Gurle's Benrré.

Diamant.

Gansel's Berganotte is an old Peal', raised from seed of the Antumn Bergamotte, by the English Lientenant-General Gansel, of Donneland Hall. Tree moderately vigorous, spreading in habit, and productive. Young wood dull grayish brown.

Fruit large, roundish obovate, but much flattened. Skin roughish brown, becoming yellowish brown at naturity, tinged sometimes with a

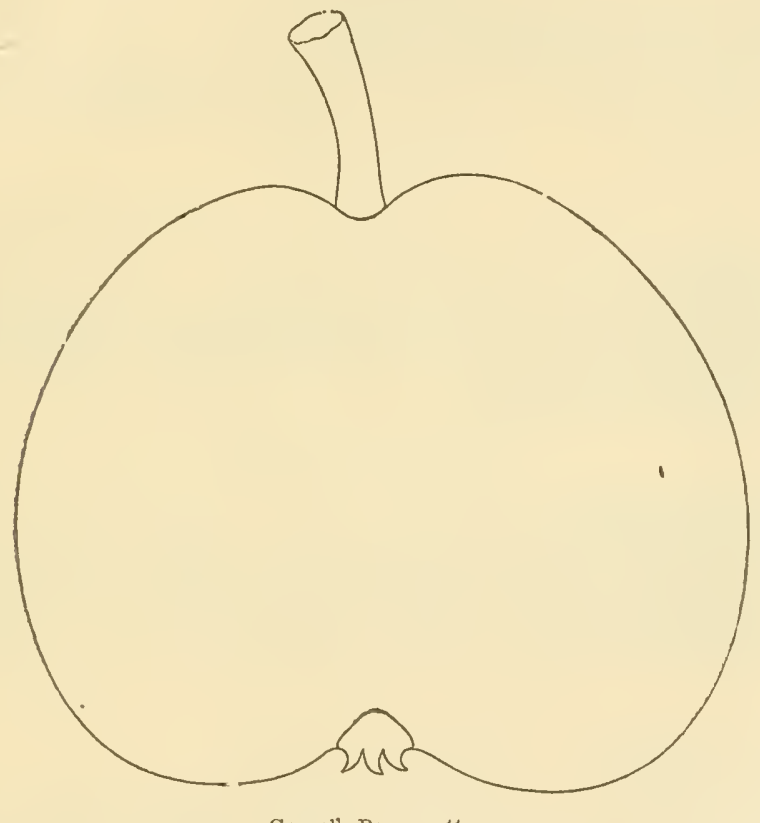

Gansel's Bergamotte.

russet red cheek, and sprinkled with spots of russet. Stalk short, fleshy at both ends. Cavity moderate. Calyx short and small, placed in a smooth, moderate hollow. Flesh white, melting, very juicy, rich, sweet, and aromatic. Very good. Ripens during all September.

\section{Gaxsei’s Late Berganotte.}

Raised by Mr. Williams, of Pitmaston, England. Of vigorcus growth. Young wood grayish yellow brown.

Fruit roundish oblate. Skin greenish, rough, sprinkled with russet. Stalk much enlarged at its insertion in a pretty deep cavity. Calyx large, open. Basin broad and shallow. Flesh juicy, granular, melting, sugary, and rich, vinous, highly perfumed with musk. Goorl to very good. December, January. 


\section{Gaxsel's Seckel.}

Raised by Mr. Williams, of Pitmaston, England. Growth much like Seckel, although with a more rough bark. Young shoots dull olive brown.

Fruit medium or small, oblate, much depressed. Skin yellow, rough, and uneven, mostly covered with thin russet. Stalk short and stout, inserted in a broad, shallow cavity. Calyx closed, set in a broad, deep basin. Flesh coarse, buttery, juicy, melting, slightly vinous, with a rich aromatic perfumed flavor. Very good. November.

\section{Gardex Pear. \\ Poire du Jardin.}

An old variety, valued for cooking.

Fruit large, roundish obovate, yellow or yellow green, with a blush of broken stripes, red in sun. Flesh rather coarse, gritty at the core, sweet. December.

\section{Gevdeshein.}

Verlaine. Verlaine d'Été. Gendebien.

A Flemish Pear, of not very good quality.

Fruit small, obovate obtuse pyriform, pale greenish yellow, a little russet. Flesh rather gritty near the core, elsewhere buttery. Hardly good. October and Noveuiber.

\section{Geveral Bosquet.}

of French origin.

Fruit medium size, ovate acute prriform, greenish, thickly sprinkled witl green and brown dots. Stalk long, rather slender, curved, set without carity. Calyx with stiff, erect segments. Basin small, corrugated. Flesh white, tender, juicy. Good. September.

\section{General Cajrobert.}

A French Pear.

Fruit medium size, orate acute pyriform, greenish, with traces of russet and many brown dots. Stalk inclined, fleshy at junction. Carlyx open. Flesh yellowish, buttery, not juicy or melting, without flavor. Hardly good. November.

\section{Geveral de Louriel.}

Of French origin.

Fruit small to medium, roundish, greenish brewn in sun, with patches and traces of russet, especially at apex, and many brown dots. Stalk variable, sometimes stout, and again long and curved. Calyx open. Segments long, recurved. Basin meven. Flesh juicy, half melting, sweet. Good. November.

\section{Geveral Dutilleul.}

Of Belgian origin.

Fruit below medium or small, oblong ovate pyriform. pale rel 
low, shade of crimson in the sum, nettings and patches of russet. Stalk short, moderately stout. Calyx open. Basin shallow. Flesh yellowish white, juicy, melting, sweet. Good. November.

\section{General Lamoricière.}

A French Pear, the tree very vigorous, very productive. Young wood dark dull olive brown.

Fruit medium size, irregular pyriform, inclined. Sicles often unequal. Surface rough greenish yellow, considerably netted and patched with russet, especially at base of stalk, and thickly sprinkled with large lusset dots. Stalk rather stout, sometimes curved, set inclined in a small cavity. Calyx open. Segments recurved. Basin small and uneven. Flesh whitish, buttery, juicy, melting, slightly viuous. Good to very good. October.

\section{Geseral Taylor.}

\section{Homewood.}

Keyports.

We have no doubt of this being a native American seedling. It was first introduced by L. N. Rogers, of Baltimore, who found it in the town of Franklin, Md. Afterwards it was said to have been brought from Germany by a man named Keyports, but we ean find nothing resembling it in any foreign pomological work. Tree vigorous, upright. Young wood reddish browu grayish.

Fruit medium, obovate obtuse pyriform, sometimes oblate obtuse pyriform, yellow, sharled in the sun with thin light rich crimson, partially netted and patched with russet, inuch russet near the calyx, and many russet dots. Stalk medium length and thickness, a little inclined in a small cavity. Calyx partially open. Basius lightly corrugated. Flesh whitish, a little coarse, juicy, melting, sweet. Good to very good. October.

\section{General Totleben.}

\section{General Todleben.}

Paised by M. Fontaine, of Gheling. First fruited in 1855, and first described by $\mathrm{M}$. Adolphe Papeleu, in 1858. Tree a vigorous grower, irregular, spreading, productive. Young wood reddish yellow brown.

Fruit above medium or large, obovate obtuse pyriform, greenish yellow, patched and netted with russet, and many russet brown dots. Stalk lather stout, often eurver. Cavity small. Calyx small, closer, with short, segments. Basin large, deep, uneven. Flesh whitish yellow, a little coarse, juicy, melting, sweet, shightly vinous, and aromatic. Very good. October and early November.

\section{Geraxdo.}

\section{Poire Gerando.}

A foreign vari ty. Tle vigorous, sireading.

Fruit above mediu n, roundish obtuse pyriform. Surfare knobby; 
yellow, mostly overspread with cinnamon russet, dnil red in the sun. Flesh yellowish, rather coarse, granular, buttery, sugary, vinous, shightly astringent. Good. October.

\section{Gerardin.}

Girardin. Gerardine. Girardon. La Girardin.

A foreign variety. Tree a vigorous grower. Young wood dull grayish brown.

Fruit medium, roundish, somewhat irregular. Skin yellow, with many spots and patches of rough russet, and a reddish tint towards the sun. Flesh coarse, buttery, astringent, granular. Tolerably good. Septrmber.

\section{German Muscat.}

Muscat d'Allemagne.

Almain.

Muscat l'Alleman.

Muscat Allemand. Muscat l'Allemand.

Muscat Lallemand.

Muscat of Germany.

Colmar Boise.

An old variety, described by La Quintinge in 1690. Tree vigorous, spreading. Young wood yellowish brown.

Fruit medium, obovate obtuse pyriform, pale yellow, partially netted and patched with russet. Flesh whitish, a little coarse, juicy, sweet, slightly astringent. Good. October to December.

\section{GILOGIL.}

Bergamotte Geerard.

Bellegarde.

Beurrí Geerards.

Cir e r'Hiver.

Garde Ecorce.

Gile-o-gile.

Poire à Gobert.

Garde d'Écosse.

Jilogil.

Gilot.

Gobert.
Gros Gilot

Gros Gobet.

Téton de Vénus.

Fontarabie acure.

Girogille.

Gros Franc Réal.

Gros Guy Grillaud.

Livre de Burgoyne.

Pequini.

Poire de 16 Ounces.

Ris de Lomp.

A large showy French Pear, only fit for cooking.

Frui large, roundish. Skin thickly covered with russet, with a reddish russet cheek. Flesh very firm and crisp. November to February.

\section{Glory of Coubrone.}

Supposed of French origin. Tree a fine grower, healthy, and hardy and productive.

Fruit above medium, or nearly large, oblong prriform, yellowish, mostly overspread, marbled, and dotted with warm brownish yellow rus. set. Stalk molcrately stout. Carity siight. Calyx medinm. Seg-. ments open, reflexed. Basin medium, regular. Flesh whitish rellow: gramulated, almowt luttery, melting, juicy, sugary, delicions. Last of September an.? early October. (Elliott.) 


\section{Glou-morcenu.}

Gloux M[orceaux.

Bemré d'Hardenpont.

Harlenjont d'Hiver.

Linden d'Automne.

Beurré d'Aremberg.

Goulu Morceau.

Kronprinz Ferdinand.

Beurré de Cambron.

Got Luc de Cambron.

Woolaston.

Potts.
Trimble.

Goulue MIorceau de Chambrcn.

Beurré de Kient.

Glou Miorceau de Cambron.

Beurré d'Hardenpout de Cambron.

Beurre Lombard.

leurré d'Ardeupont.

Glout Morceau.

Hardempont.

Victoria.

Langlier's Vietona.

Au old Flemish Pear, originated with M. d'Ardempont, canon of Tournay. The growth of the tree is distinct, having dark olive shoots, spreading in habit.

Fruit rather large, varying in form, but usually obovate orate obtuse pyriform, smooth, thin, pale greenish yellow, marked with small green dots, and sometimes with thin patches of greenish brown. Stalk rather slender and straight, an inch or more long, planted in a small, regular cavity. Calyx usually with open divisions, set in a moderately deep basin. Flesh white, fine-grained, and smooth in textmre, buttery, very melting, with a rich, sugary thavor, with no admixture of acid. Sometimes astringent in heary soils. Good to very good. December.

\section{Golden Beurré of Bilboa.}

Hooper's Bilboa.

Driver ?

Beurré Gris de Portugal.

Beurré Dore de Bilbon. Bewré Gris de Bilboa.

The Golden Beurré of Bilboa was imported from Bilboa, Spain, about 1827 , by Mr. Hooper, of Marblehead, Mass. Its European name is mknown. The tree is healthy, hardy, and a vigorous grower, forming a beantiful upright, round head, and producing abundantly. It is a profitable orchard sort. Shoots stout, upright, light yellowish brown.

Fruit medium, regular obovate pyriform, golden yellow, evenly dotted with small brown dots, and a little marked with russet, especially round the stalk. Stalk about an inch and a half long, rather slender, set in a small cavity. Calyx small, closed, placed in a slight basin. Flesh white, very buttery and melting, and fine-grained, with a slightly vinous flavor. Very good. First to the middle of September.

\section{GOODALE.}

Goodale's Seedling.

Saco.

Raised from seed of the McLaughlin, by Enoch Goodale, Saco, Me. Its size and period of ripening make it promise of high value as a market sort. The tree is very hardy, a vigorous, thrifty grower, spreading upright in habit, and uniformly productive. Ioung wood very stout, olive.

Fruit large, oblong obovate obtuse pyriform, light vellow, shaded with crinson and fawn in the sun, slightly netted and patched with rus. 
set, and thickly sprinkled with small russet brown dots. Stalk rather suort and set in an inclined cavity of considerable depth, sometimes a projection one side. Calyx small, closed. Segments thick. Basin

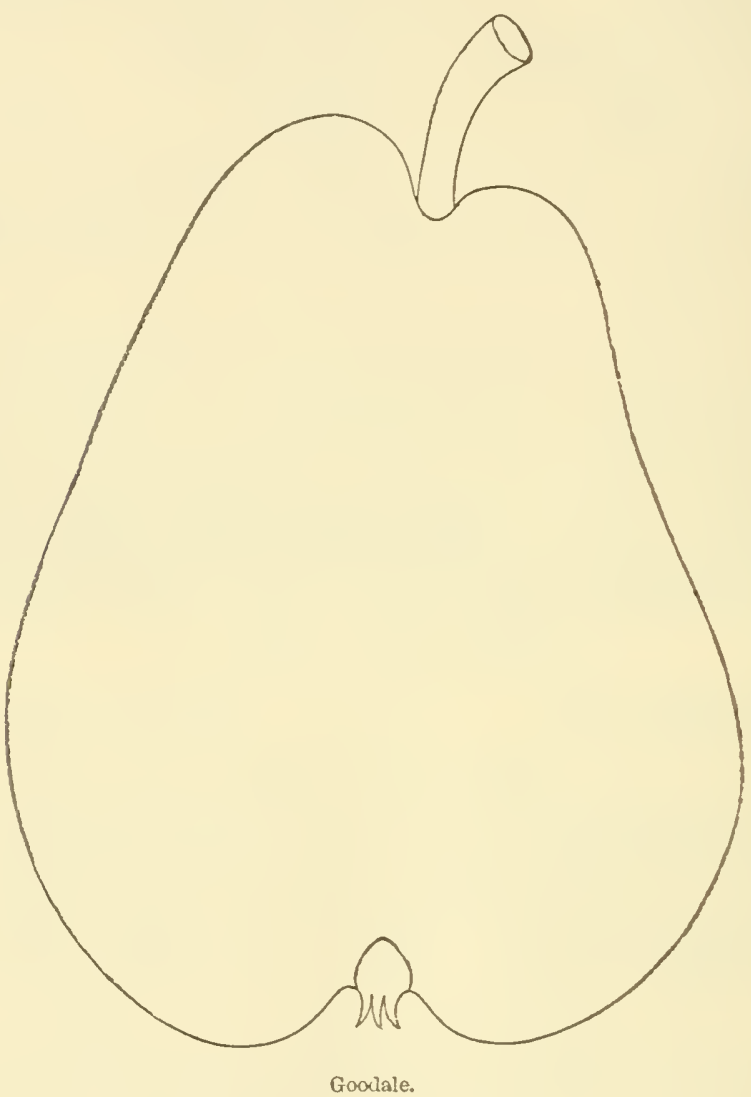

rather deep and uneven. Flesh whitish, juicy, melting, a little gritty a* the core, sweet, slightly vinous, with a brisk refreshing musky perfume. Very good. October.

\section{Graxd Bretagne.}

Great Britain.

Supposed of Belgian origin.

Fruit medium or below, obovate acute pyriform, pale yellow, shaded and mottled with red in the sun, nettings and patches of russet, and russet dots. Flesh yellowish, coarse, gritty, juicy, sweet. Not quite good. January, February. 


\section{Grand Soleil.}

Introduced by Major Esperen, of Malines. Tree vigorous and pro. ductive. Young wood dull dark yellow brown.

Fruit medium, roundish lyriform, pale yellow, mostly covered with cinnamon russet and fawn, and a red cheek in sum, many russet dots. Stalk medium, in a small cavity. Calyx small, nearly closed. Basin abrupt, deep, a little furrowed. Flesh whitish, a little coarse, juicy, half melting, sugary, slightly vinous. Very good. October, November'

\section{Graslin.}

of French origin. Tree vigorous. Young wood olive yellow brown, very productive.

Fruit medium, obovate ovate obtuse pyriform, greenish yellow, sprinkled with brown dots and sometimes traces of russet. Stalk rather long and stout, set in a slight cavity, sometimes by a lip. Calyx open. Segments large, reflexed. Basin simall, slightly furrowed. Flesh yellowish, juicy, buttery, sweet, slightly vinons. Good. October, November.

\section{Great Blanguetete.}

Blanquet de Florence.

Grosse Blanquet.

Roi Louis.

Grosse Roi Lonis.
Musette d'Anjou.

Grosse Blanquette.

Great Blanket.

Bagpipe of Anjou.

An old French Pear, of little value.

Fruit small, ovate acute pyriform, yellowish green. Flesh melting, juicy, sweet. Good. August.

\section{Great Citron of Bohemia.}

Citronenbirne Bümische grosse, punctirte.

Fruit small, oblong, yellow. Flesh sugary, juicy, a little coarsegrained, and not much flavor. Ripens the last of September.

\section{Green Chisel.}

Madeleine Vert.

Hativeau.
Guenette.

Petit muscat batard muscade.

An old English Pear. The tree is very productive, erect, fruiting in clusters.

Fruit small, roundish ovate, greenish. Flesh white, melting, juicy, sprightly. Good. Middle August.

\section{Green Mountain Box.}

An $\Lambda$ merican variety.

Fruit medium, roundish obovate or oborate pyriform, golden yellow, with lussety brown specks. Flesh yellowish, melting, juicy, sweet. Very gool. Octuber. (Elliott.) 


\section{Green Pear of Yair.}

Green Yair.

The Green Pear of Yair is a European fruit, which proves but lit tle worthy of eultivation here.

Fruit of medium size, oborate. Skin green. Flesh juicy, but not high-flavored or rich. Good. September.

\section{Groon's Princess Royal.}

Matthews Eliza. Princess Royal. Bergamotte Mratthews Eliza.

An English fruit, raised by Mr. Groom, the famous tulip-grower. Young wood olive yellow brown.

Fruit of medium size, roundish. Skin greenish brown, with a tinge of brownish red, and sume russet tracings. Stalk short and thick, set in a very trifling depression. Calyx small, open, set in a shallow basin. Flesh buttery, melting, a little gritty near the core, but sweet and highflarored. Very good. January and February.

\section{Gros Rousselet d'Aốt.}

A seedling of Van Mons. Catalogued in 1823. Tree vigorons, os pyranidal form, very productive.

Fruit medium, pyriform. Skin green, hecoming golden yellow at maturity, shaded with russet and spotted with fawn. Flesh whitish, fine, melting, very juicy, sugary, vinous, deliciously perfumed. Ripens in August. (Al. Pom.)

\section{Grumirower.}

Grumkower Winterbirnie.

This variety is described by Lindley as of middle size, in shape like a Bon Chrétien, witl obtuse angles or ribs. Flesh melting, juicy, sweet, musky. Norember, December.

\section{Gustave Bivort.}

A French variety.

Fruit medium, roundish, pale yellow, patches and nettings of russet, shade of red in sum. Flesh white, juicy, half melting, sweet, slightly perfumed. Good or' very good. August.

\section{Gustale Burgore.}

Fruit large, oblong obovate obtuse pyriform, greenish vellow, a little brownish in the sun, slightly netted and patched with russet, sometines nearly covered, and thickly sprinkled with russet dots. Stalk set in a shallow cavity. Calyx open. Flesh whitish, juicy, melting, sweet, pleasant. Good. September, October.

\section{Gustin's Suminer.}

An American variety, of little value. Originated in New Jerses. 
Fruit small, roundish. Skin yellow. Flesh white, sweet, without much flavor. First of September.

\section{Hacon's Incomparable.}

Celestus.

Downham Seedling.

An English fruit, raised by Mr. Macon, of Downlam Market, Nor. folk. It is a lardy, productive tree, with rather depending branches. Young shoots rather slender, diverging, olive-colored.

Frnit rather large, roundish, incliming to turbinate. Skin slightly rough, pale, and dull yellowish green, mixed with pale brown, sprinkled with numerous greenish russet dots and russet streaks. Flesh white, buttery, melting, with a rich vinous flaror. Good. October and November.

\section{HADDINGTON.}

Raised by J. B. Smith, Philadel,hia. Tree vigorous, spreading.

Fruit above medium, obovate or pyriform. Color greenish yellow, with a brownish cheek. Stalk slender, inserter in a small cavity. Calyx small, in a round, shallow basin. Flesh yellow, crisp, juicy, with an aromatic flavor. Good. Jannary till April.

\section{HAGAR.}

A French Pear, of poor quality. Tree very vigorous, upright.

Fruit meảium, obovate obtuse pyriform, pale yellow, sharle of red in sun, some russet. Flesh coilrse, dry, sweet. October.

\section{H.IGHT.}

An American variety. Thee moderately vigorous, spreading.

Fruit of medium size, roundish pyriform, yellow, shaded and mottled with red in the sum, small brown dots and traces of russet. Stalk long, a little curved, fleshy at insertion, set in a small cavity. Calyx open. Basin broad and nneven. Flesh white, pink at centre, a little coarse, breaking, juicy, sweet, and pleasant. Good. October.

\section{HAMLTON.}

\section{Hamilton Seedling.}

An American Pear, originated in South Carolina, where it is said to be of very good quality, but here at the North it is astringent and poor.

Fruit medium, oblate. Surface rough, yellowish, slightly patched and blotched with russet, and many lusset dots. Flesh yellowish, coarse, not juicy, slightly astriugent. November.

HAyON.

Besi Fondante. Besi ITamon. Beurré Seringe?

Originated by M. Nerard, Tyons, France, in 1837. Tree vigorous, productive. 
Fruit medium or below, irregular, oval, dull pale green, tinged with yellow. Stalk long, curved. Flesh white, halt melting, juicy, swcet. Good. August.

According to Leroy, Beurré Seringe should be a synonym of Doyr:ané de Saumur; but our trees received of these varieties are not ident a al. According to the Jardin Fruiterer, Beurré Seringe is identical r, ih Hamon. Not having trees of that variety with which to compar..., we for the present place it here.

\section{Hampden's Berganot.}

Bergamotte d'Angleterre.

Fingal's.

Scotch Bergamot.

Ellanrioch.

Milan Vert.

Longueville d'Écosse.

Hampden.

Benzard.

Belle et Bonne.

Belle sans Pepius

Belle de Luxembourg.
Bergamotte de Bruxelles. Bergamotte d'Été Grosse. Bergamotte de Paysans.

Gracieuse.

Fanfareau.

Great Bergamotte.

Deutsche National Bergamozte

Poire sans Pepins.

Belle de Bruxelles.

Sans Pepins.

Schöne and Gute.

An old variety, the origin of which is unknown.

Fruit large, roundish oblate, a little rising at the stalk end, greenish yellow, with traces and patches of thin russet, and greenish russet dots. Flesh white, a little coarse, tender, half buttery, sweet, agreeable. Good. September.

\section{Hanptox's Berganot.}

Originated with W. C. Hampton, Mt. Victory, Ohio.

Fruit small, roundish oblate, yellow, netted and sprinkled with russet and green dots. Flesh whitish, coarse, juicy, half melting, vinous. Good. September.

\section{Hayptoy's Cluster.}

\section{Haḿpton. \\ Cluster Pear.}

Raised by W. C. Hampton, Ohio.

Fruit borne in clusters, very small, roundish, greenish yellow, shaded with dull red in the sum, and netted with russet. Flesh juicy, melting, sweet. Very good. September.

\section{Hamptox's Virgalieu.}

A seedling of W. C. Hampton, Ohio.

Fruit medium, roundish pyriform. Surface uneven, green, slightly yellow at maturity, sometimes with a warm cheek in sun, patches, nettings, and dots of russet. Flesh yellowish, slightly gritty, juicy, melt. ing, brisk, vinous. Very good. Óctober.

\section{Haviers'.}

Hannas.

Originated in the garden of Mr. Hanners, Boston, Mass. Tree an upright good grower and bearer. Young shoots dull olive. 
Fruit large, oblong, very obtuse pyriform, greenish yellow, slightly netted and patcher with lusset, ancl many green and russet dots. Stalk varying, sometimes long, pretty stont, set in a eavity, often with a lip. Calyx open. Segments long, slender', reeurved. Basin shallow, uneven, slightly russeted. Flesh whitish, juicy, melting, pleasant, sweet, a little perfumed. Very good. September.

\section{HANOYER,}

From Hanover Furnace, N. J.

Fruit below medium, roundish obovate. Skin green, with dull green l'usset markings, and a brown cheek. Stalk medium. Cavity shallow and angular. Calyx open, in an irregular basin. Flesh greenish yellow, exceedingly melting and juicy. Flavor pleasant. Good. Ripe October. (Ad. Int. Rep.)

\section{HaRris.}

\section{Speckled Harris?}

Received from Georgia. Tree vigorous, productive.

Fruit medium, obovate obtuse to obovate acute pyriform, pale yellow, deep red in the sun, many green and brown dots. Flesh whitish, buttery, not juicy, sweet. Good. September.

\section{Harrison's Large Fall.}

Rushmore's Bon Chrétieu. Large Swan's Egg.

Richmond. Englebert Lott.
Lott's Pear.

An American variety, a strong, rapidly-growing tree, comes early into bearing, and produces abundantly.

Fruit large, irregular, inclined, obovate obtuse pyriform, pale yellow, with a red cheek. Valued as a cooking fruit. August, September.

\section{HARVARD,}

\section{Boston Eparme. Cambridge Sugar Pear. Belle de Flushing.}

The Harvard produces enormous crops, of fair quality. The tree is remarkably hardy and vigorous, with upright shoots forming a fine head. It originated at Cambrictge, Mass.

Fruit rather large, oblong pyriform, russety olive yellow, with a brownish-red cheek. Stalk rather stout, inserted rather obliquely on the narrow summit or in a small cavity. Calyx set in a narrow basin. Flesh white, tender, juicy, and melting, of excellent flavor, but liable, if not picked early, to rot at the core. Beginning of September.

\section{Harvest.}

\section{Early Sugar. Sugar Pear. Wolcott's Early?}

An American variety. Tree an upright round spreading head, a good grower and bearer. Young wood olive yellow brown.

Fruit below mediun, or small, roundish, pale yellow, brown tinge of red in the sun, and sprinkled with brown and green dots. Flesh whitish, not rery juicy or melting, but sweet, pleasant. Good. July. 


\section{HAWES' Winter.}

\section{Morgan. Hewes' Winter.}

Origin, King and Queens Co., Va., on the farm of the Hawes family: Tree vigorous, productive.

Fruit medium or below, roundish, greenish yellow, with traces anc spots of russet. Flesh whitish, buttcry, half melting, juicy, sweet Good. November.

Heathcot.

\section{Gore's Heathcot}

The Heathcot originated on the farm of Governor Gore, in Waltham, Mass., by Mr. Heathcot, then a tenant; the original tree came into bearing in 1824. Tree moderately vigorous. Young shoots upright, recldish brown.

Fruit of medium size, regularly obovate, pale greenish rellow, with a very few dots, and a few russet streaks. Stalk an inch long, planted in a very small cavity. Calyx closed, and set in a rather narrow and shallow basin. Flesh white, buttery, and melting, molerately juicy, with an agreeable vinous flavor. Good to very good. Middle and last of september.

\section{HEBE。}

Raised by William Sumner, Pomaria, S. C. Tree thrifty, thorny, hardy, productive, and retains its foliage late. Young wood slender, grayish.

Fruit large, round, obovate, with irregular protuberances, greenish lemon yellow, dotted with russet specks and blotches. Flesh sprightly, melting, buttery, slightly vinous. Seldom forms seeds. December. (Hort.)

\section{Hegemas.}

\section{Hegerman. Heggerman. Hampton.}

Originated on the farm of Andrew Hegeman, North Hempstead, Long Island, Tree vigorous, upright in habit, not an early bearer, but when mature bears heavily. Joung wood olive brown.

Fruit medium, roumlish ovate, variable in form, greenish yellow, netted and dotted with russet. Stalk short. Cavity shallow, uneren. Calyx large, open. Basin shallow. Flesh yellowish, juicy, melting, sweet. Good to very good. October.

\section{Hélèxe Grégoire.}

Raised by M. Grégoire, of Jodoigne, Belgium. Tree vigorous and productive. Young wood dull realdish brown.

Fruit large, ovate, light greenish yellow, slightly colored in the sun, russet patches and spots. Stalk short, set in a namow cavity. Calyx large. Basin furrowed. Flesh fine, melting, half buttery, juicy, sweet, perfumed. October. (An. Pom.) 


\section{HEXKEL.}

Cumberland of Belgium.

One of Tan MLons' seedlings. Growth vigorous, upright, productive. Young wood dull grayish brown.

Fruit rather large, broad obtuse pyriform, greenish yellow, netted and patched with russet, and spriukled with green and brown dots. Stalk

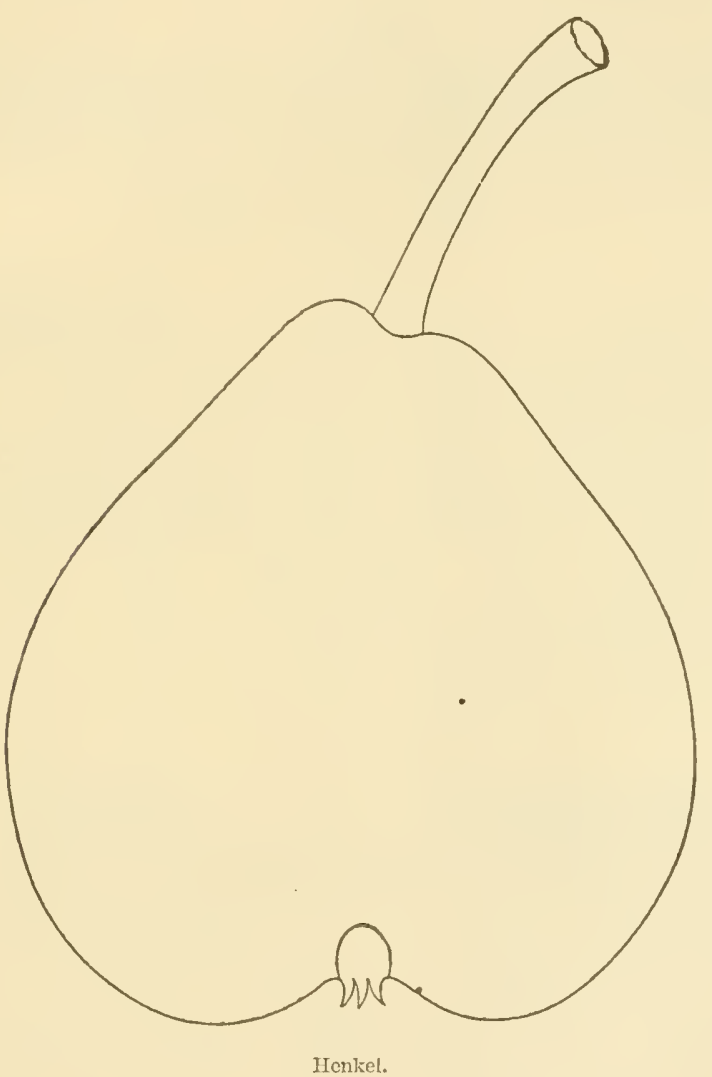

inclined, rather stout, fleshy at insertion by a ring or lip. Calyx par. tially open. Segments short, stiff, sometimes reflexed. Basin rather large, slightly uneven, russeted. Flesh whitish, juicy, melting, with a rich, slightly vinous flavor. Very good to best. September.

\section{Henri Bivort. \\ Henri (Birort.)}

A Belgian ariety. Tree vigorous.

Fruit medium, obovate pyliform, greenish yellow, few patehes of 
russet, and many green and brown dots. Flesh whitish, juicy, half melting, sugary. Good. September.

\section{Henri Desportes.}

A seedling of André Leroy's.

Fruit large, pyriform. Flesh white, juicy, one of the best summer Pears. (Leroy.)

\section{Hexrietti.}

Raised by Gov. Edwards, of New Ifaren, Conn. Tree a free grower, of upright form, a good bearer. Toung wood reddish brown.

Fruit medium, roundish oval, greenish or greenish yellow, a little netted and patched with russet, tinge of red in the sun. "Flesh whitish green, juicy, half melting, sweet. Good. September.

\section{HeNriette.}

Belle Henriette. Henriette Bouvier. Henriette d’Orleans.

Raised by M. Simon Bonvier, of Jodoigne, Belgium. Tree a fine grower. Young wood reddish.

Fruit medium, oblate, nearly globular, pale greonish yellow, a little shaded with fawn or dull red in the sun, thinly netted with russet, and thickly sprinkled with russet dots. Stalk long, slender, a little inclined, Heshy at insertion, or with a mamelon neck. Calyx open. Segments long, slemter, often recurved. Basin very shallow, slightly uneren. Flesh a little coarse, whitish, juicy, half melting, sweet, perfumed. Good to very good. November.

\section{Henri Vax Mons'.}

Bergamotte Rouge Tardif. Beurré Ronge Tardif.
Fleur de Neige.

Snow Flower.

One of Van Mons' earliest seedlings. 'Tree very vigorous, hardy, holding its foliage late in the season, and an abundant bearer. Young wood clear olive.

Fruit medium to large, elongated acute pyriform, pale yellow, shaded and mottled with brownish red or crimson in the sum, netted and patched with russet, and thickly sprinkled with russet dots. Stalk long, rather slender, curved, without cavity. Calyx open. Segments long, generally recurved. Basin small, meven. Flesh yellowish, juicy, melting, sweet. Good to very good. October.

\section{Hexry the Fourth}

$\begin{array}{ll}\text { Henri Quatre. } & \text { Jaquin. } \\ \text { Favori Musqué du Conseiller. } & \text { Beurré Ananas. } \\ \text { Ananas. } & \end{array}$

The tree of this French Pear is a good grower, hardy and productive. Young wood dull yellow brown, with many specks.

Fruit below mediun size, roumdish prriform, pale greenish rellow, dotted with small gray specks. Stalk rather more thąn an inch long, slender. Calyx small, placed in a shallow abrupt basin. Flesh whitish. 
not very fine-grained, but musually juicy and melting, with a rich, delieately perfmed flavor. It should always be ripened in the house. Good to very goud. Early in s'prember.

\section{HERICART.}

A second-rate Belgian Pear, witlı a pleasant, perfumed juice, ripening early in autumn. Tiee rery vigorous aml productive.

Fruit of medium size, obovate, often rather oblong and irregular, yellow and russety. Stalk an ineh or more long, wather slender, set in a small cavity. Calyx set in a shallow basin. Flesh white, fine-grained, buttery, not rich, hut with a delicate, peculiar aroma, gritty, and slightly astringent. Good. The firuit ripens the last of september.

\section{Hericart de Thury.}

Raised by $T$ an Mons. A good grower, of peculiar habits and ap. iearance, rather pyramidal, but with diverging crooked limbs. Not an early nor a very profuse bearer. Young wood dull reddish olive brown.

Fruit medium or above, obtuse ovate pyriform, yellow, thinly shaded with red in the sum, slightly netted, and thickly sprinkled with russet dots. Stalk long, rather slender, curved. Cavity small. Calyx closed. Segments short. Basin small, nueven. Flesh white, not very inicy, and slightly astringent. Good. December.

\section{HERKIMER。}

Earl Pear.

Originated on the farm of S. Enl, Herkimer, N. Y. The tree is a vigorous grower, hardy and produetive. Toung wood warm reddish brown.

Fruit medium or above, ronndish oblate. Surface a little uneren, pale greenish yellow, clouded with dull red in the sun, and many green ilots. Stalk pretty stout, eurved. Carity doep, round. Calyx with flat reflexed segments. Basin vitrying from shallow to moderately deep. Flesh white, a little coarse-grained at the core, juicy, sweet, melting, and agreeable. Good. September, October.

\section{Hessel.}

Hazel.

Hasselbirn.

A Scotch Pear, very productive.

Fruit small, obovate. Skin yellowish green. Flesh whitish, juicy, of little or no value. First of September.

\section{Hixginy.}

Originated in Hingham, Mass. Tree vigorous, spreading.

Eruit melium, obovate acute prriform, pale yellow, shaded with red in the sum, many brown dots. Stalk long. Calyx partially closed. Flesh whitish, juicy, melting, vinous. Good. October. 


\section{Holiande Berganotte.}

Holland Bergamot.

Beurre d'Alencon.

Begamotte d'Alencon.

Jardin de Jougers.

Bergamotte de Fougère.

Amoselle.

Lord Cheeney's.
Hollandische Bergamotte.

Bergamotte d'Holland.

Sarah.

Bergamotte d'Hiver d'Holland.

Beurré Extra.

Lord Chêney.

Musquine de Bretagne.

An old variety, the origin unknown. An excellent kitchen fruit which will keep sound till May ol Jume. Shoots stout, diverging. olive brown.

Fruit rather large, roundish, green, much marbled and covered with thin brown russet, but becoming yellowish at maturity. Flesh white, crisp, with an abundant, sprightly, agreeable juice.

\section{Holiand Green.}

An old variety, described by Coxe, and sometimes called Holland Table Pear.

Frnit large, irregular, green, with spots of russet. Flesh juicy, melting, delicate, delicious. September. (Coxe.)

\section{Honey.}

\section{European Honey.}

This Pear is considerably grown in many parts of the comtry, and although an old sort, its origin seems nnknown, and to our knowledge is not noted by any American author. The tree is an upright, good grower, and a great bearer.

Fruit mectium or below, roundish, sometimes roundish priform, pale yellow, shaded and mottled with red in the sun, with many light misset lots, and sometimes patches of musset. Stalk short, rather stont. Calyx oper. Basin broad, shallow. Flesh whitish, coarse, breaking, moderately juicy, sweet, pleasant. Gooct. Angust.

\section{Hosexschexc'R.}

Hosenshenck.
Shenk's.
Watermelon.
Smokehonse.
Butter Pear.

Queen of August.

MIoore's Pound.

Eshleman.

Moore's Pear.

This Pear originated on the farm of John Schenck, Weaver Town. ship, Pa. Tree vigorous, productive. Ioung wood grayish olive brown.

Fruit of medium size, rountish oblate. Skin light yellowish green, miely with a blush. Stalk about an inch long, rather stont, inserted without mucl depression, sometimes by a lip. Calyx small. Basin deep. Flesh rather coarse, tender, juicy, slightly virous, melting, with a pleasant flavor. Good to very good. Ripens the last of August.

\section{Hover.}

\section{Doyenné Forer.}

Raised by Andlé Leroy, and cledicated to C. M. Hovey, of Boston, 
Mass. Tree a rigorous, upright grower. Young shoots clear yellow brown.

Fruit medium or above, varying in form from oblong oval to obo. vate obtuse priform, yellow or greenish yellow, slightly sprinkled, netted, and patehed with russet. Stalk medium, moderately stout, inserted without earity. Calyx with short, stiff segments. Basin shallow, lightly furrowed and slightly russeted. Flesh yellowish, buttery, juicy, melting, sweet, aromatic. "Very good. October, November.

\section{HOWARD.}

Receired from D. W. Coit, Norwich, Conn. Tree vigorous, upright, productive, with olive yellow brown young shoots.

Fruit medium, roundish obovate, pale yellow, patches and traces of russet, and thickly sprinkled with russet dots. Stalk long, curved. Carity small. Calyx open. Basin meven, slightly russeted. Flesh white, juicy, melting, sweet, rich, slightly perfumed, pleasant. Very good. September.

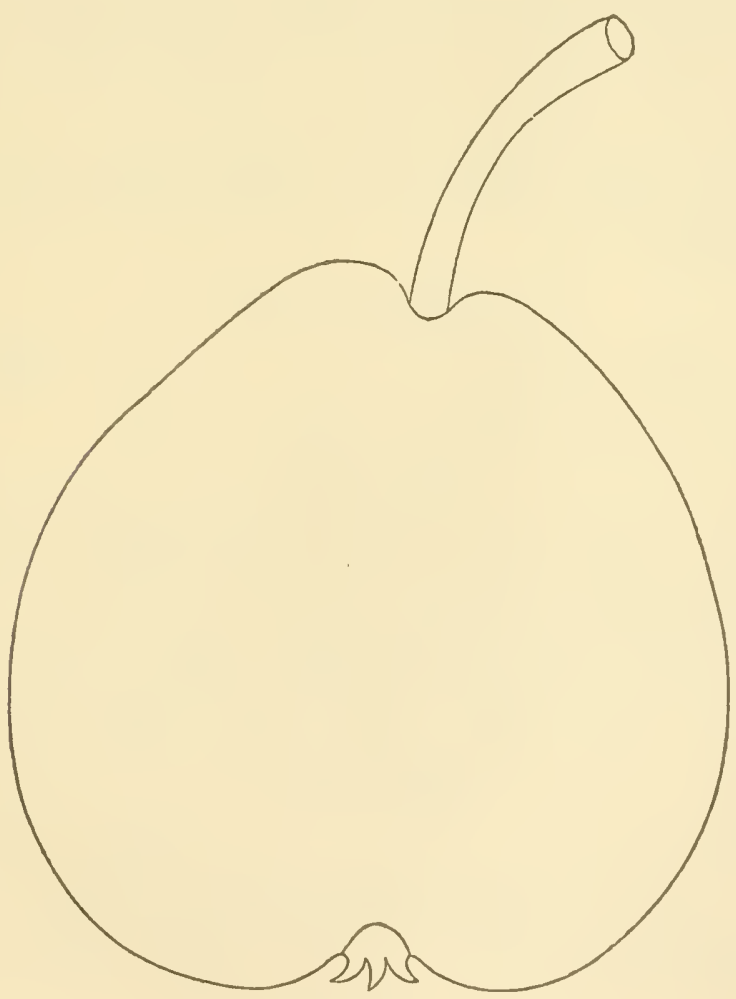

Howell.

\section{HowelL.}

Raised by Thomas Howell, of New Haven, Conn. A valuable 
variety. Tree an upright and free grower. Young shoots reddish yel. low brown, an early and profuse bearer.

Fruit rather large, roundish pyriform, light waxen yellow, often with a finely shaded eheek, thickly sprinkled with minute russet dots, and some russet patches. Stalk medinm, inserted without eavity, sometimes by a ring or lip, sometimes in a small cavity. Calyx open. Segments recurved. Basin ratler large and uneven. Flesh whitish, juicy, melting, brisk, vinous. Very good. September, October.

\section{HLGUENot.}

A fruit originated by $\mathrm{Mr}_{\mathrm{r}}$. Johonnot, of Salem, Mass. It bears abundantly, but is rather dry, aud not worthy of general eultivation.

Friait medium, romish, pale yellow, sprinkled with large spots of bright red. Flesh white, fine-grained, half breaking, sweet, but wanting in flavor and juice. Grool. October.

\section{HuLl.}

Originated in the town of Swanzey, Mass. Tree vigorous, somewhat rambling in habit, with long sloots of a rich reddish yellow brown.

Fruit medium, oblong oborate obtuse pyriform, greenish yellow, netted and patehed with russet, especially near the stalk, thickly sprinkled with russet dots. Stalk long, rather stout, inserted by a ring in a shaliow cavity. Calyx partially elosed. Segments short, erect. Basin small, uneven. Flesh white, juicy, melting, slightly vinous. Yery Good. Septenher.

\section{Huxgerford's Osirego.}

Received from Oswego, N. Y.

Fruit medium, roundish, yellow, with brown dots. Flesh white, buttery, juicy, melting, gritty, swcet. Good. October.

\section{Huxtixetos.}

Origin, New Roehelle, and brought to our notice by S. P. Carpenter. It was found by $\mathrm{M}_{1}$. Huntington, and now stands on his grounds. Tree vigorous, forming a pyramid, an early and profuse bearer. Young shoots olive color.

Fruit nearly medium in size, roundish oblate, rongh yellow, often shaded with eriunson, thickly eorered with gray and crimson dots, and russet patches. Stalk medium or long, nearly straight. Carity broad and meven. Calyx open. Segments stifl" Basin broad and open. Flesh white, very juiey, melting, buttery, with a very sweet, vinous flavor, delicately perfumed. Very good. September.

\section{Hunt's Connecticett.}

An American fruit for kitehen use. Medium, oblate, yellowish green, eoarse, dry, and sweet.

\section{Huyshe's Prince Coxsort.}

Raised by Rer. John Huyshe, of Clythesdon, Devon, England, from seed of Bewré d'Aremberg, fertilized by Passe Colmar. This is one oi 
a series of four new Pears, originated by Mr. Huyshe, all of which are said to be of smperior exeellence. 'The tree is a vigorous grower, with short-jointed young shoots of a dark dull reddish brown, and indistinct white specks. Hogg describes the finit as large, oblong obovate pyriform, grass green, much covered with russet and russet dots. Stalk loug, stont. Calyx small, open. Basin deep, uneven. Flesh yellowish, coar'se-grained, juicy, melting, sweet, vinous, with a peculiar flavor unlike any other pear. November.

\section{Hurshe's Prince of IVales. \\ Huyshe's Bergamot.}

Originated at Clythedon, England, by Rev. John Huyshe, from seed of Marie Lnuise crossed with Gansel's Bergamot. Tree vigorous, spreading. Young wood reddish brown.

Fruit large, roundish oval, lemon yellow, mostly covered with cinnamon-colored russet. Stalk stout and woody, somewhat obliquely inserted in a round and rather open cavity. Calyx small, open, with erect tooth-like segments. Flesh yellowish white, tender, melting, juicy, and lichly flavored. November to Janumry. (Hogg.)

\section{Hurshe's Prixcess of Wales.}

Origin, Clythedon, England, by the Rev. John Huyshe.

Fruit mediun, oblong, abrupt at stalk, lemon yellow, with patches, veins, and dots of cinnamon-colored russet. Stalk long, stout, woody, somewhat obliquely inserted in a round and rather wide cavity. Calyx small, open, with narrow, erect segments. Flesh deep yellow, finegrained, very melting, juicy, rich, and highly aromatic. Last of November. (Hogs.)

\section{Huxshe's Victoria.}

This Pear is of the same origin as Muyshe's Prince of Wales. It has fruited in several collections in this country. Tree a good grower, spreading. Young wood dull brown.

Fruit medinm size, ovate pyriform or ovate acute pyriform, yellow, considerably prtched and netted with russet, and thickly sprinkled with green and brown dots. Stalk medium length, stout, inclined, and joined to the fruit without depression. Calyx open. Basin medium, uneven. Flesh yellowish, juicy, melting, a little vinous. Good to very good. November.

\section{IrCominumicable.}

A Flemish Pear.

Fruit above medium, obtuse pyriform, grass green, with russety specks. Flesh yellowish white, a little gritty, melting, swcet. October. (Lind.)

\section{Inconnue Van Mons.}

\section{L'Inconnue.}

One of Van Mons' seedlings. Tree hardy, vigorous, upright, very productive. 
Frnit medium or below, broad oval pyrifurm, light yellow, netted and putched with russet, and many russet dots. Stalk long, curved, inclined, and set in a slight depression, sometimes by a lip. Calyx open. Segments long, recurved. Basin shallow, uneven. Flesh white, juicy, melting, very sweet, rich, and pieasant. Good to rery good. December to March.

\section{INOONSTANT.}

\section{L'Inconstant.}

Fruit medium, ovate obovate acute pyriform, pale yellow, slight traces and patches of russet, sharle of red in the sun, many dots. Flesh white, juicy, half melting, a little astringent. Good. October.

\section{Jris Grégolre.}

A Belgian Pear, as yet little known in this country. Tree moderately vigorous, productive.

Fruit inedium to large, oblong acute pyriform, clear light yellow, with shades and marblings of red rnsset. Stalk short, with two or more fleshy rings at its connection with the fruit. Flesh white, fine-grained, melting, buttery, sweet, perfumed. December, Jantary. (An. Pom.)

\section{ISABELIA.}

Raised by Dr. S. A. Shurtleff, Brookline, Mass. Tree thrifty, upright.

Fruit medium size, pyriform, light green, red in sun. Flesh white, juicy, sprightly, agreeable. October. (J. of H.)

\section{ISLAND.}

Originated at New Utrecht, Long Island. Tree moderately vigorous, upright. Young wood olive yellow brown.

Fruit medium, roundish pyriform, pale yellow, netted, sprinkled, and patched with russet. Stalk short. Calyx open. Flesh white, a little granular, juicy, melting, sweet, slightly perfumed. Good. October.

\section{Ires' August.}

Originated with Dr. Eli Ives, New Haven, Conn.

Fruit medium, oblong obtnse pyriform, greenish, with a brownish red cheek. Flesh greenish white, juicy, half molting, a little astringent. Good. Angust.

\section{[VES' BERGAMOTTE.}

Raised by Dr. Eli Ives, New Haven, Comn. Tree closely resembles the Seckel, and is very productive.

Fruit medinm or small, roundish, greenish yellow, with slight traces of russet. Stalk short and thick. Flesh rather coarse, buttery, melting, juicy, vinous. Good. Ripens first of September.

\section{IVES' PEAR.}

Raised by Dr. Eli Tres, New Haven, Conn. Tree vigarous and relt productive. 
Fruit small, oval oblong pyriform, greenish, with a brownish-red cheek. Stalk long. Calyx open. Busiu very small. Flesh juicy, melt. ing, sugary, and good. Ripens first of September.

\section{IVES' SEEDLING.}

Raised by Dr. Eli Tres, New Haven, Conn.

Fruit neary medium, somewhat globular, greenish yellow, shaded with crimson. Stalk short and thick. C'ilyx small, nearly closed. Basin shallow and irregnlar. Elesh whitish, coarse, and grannlar, juiey, melt. ing, with a refreshing sugary flavor, well perfumed. Good. Ripe about the first of seprtember.

\section{Tres' V'rRgalieu.}

Raised by Dr. Eli Ives, New Haven.

Fruit below melium, aeute pyriform, broad at calyx, greenish, shaded with dull erimson. Stalk inserted by a lip. C'alyx open. Basin shallow and irregular. Flesh whitish, rather coarse and granular, buttery, juiey, and melting, with a sweet vinous flavor. Good. October.

\section{IVES' W'TITER.}

Raised by Prof. Ires, New Haven.

Fruit medium, depressed pyriform, yellowish, sprinkled with russet. Stem large and long, in an abrupt eavity. Calyx open, in a large basin. Flesh white, coarse, and granular. Couking. December.

\section{IYES' YALE.}

Raised by Dr. Eli Ires, New Haven, Conn.

Fruit medium, roundish, mamelon at base of stem, dull greenish yellow, brownish erimson in the sun. Flesh greenish white, moderately juey. Good. Early August.

\section{JACKSON.}

Origin, New Hampshire. Tree rigorous and productive. Young wood clull reddish brown.

Fruit medium, obovate, short pyriform, pale yellow, somewhat russeted. Stalk long and eurved, fleshy at its junction, inserted in a slight carity. Calyx small and open, set in a rather deep abrupt basin. Flesh white and juicy. Flavor brisk and vinous. Good to very good. Ripens the last of September.

\section{JACKSON'S ELIZABETH.}

Mrs, Jackson,

Jackson.

Originated with S. S. Jackson, of Cincinnati, O. Tree moderately vignrous, very productive. Yoning wood rechlish brown.

Fruit medium size, romdish obovate pyriform. Skin greenish yellow, shaded with erimson in the sme, and thickly sprinkled with russet dots. Stalk medinm, set in a slimht depression. Calyx small, partially elosed. Basin small, regular. Flesh whitish, juicr, melting, sweet, pleasant, slightly aromatic. Good to very good. List of September. 


\section{JALOUSIE.}

De Pucelle.

An old Belgian Pear.

Fruit rather large, roundish to obovate, and more frequently pyri form. Skin rough, of the deepest russet, ruddy in the sun. Flesh a little coarse-grained, soft, sweet, and of pleasant flavor. Good. Last of September.

\section{Jalousie de Fontexay Vexdée.}

De Fontenay Vendée. Jalousie de Fontenay. Belle d'Esquermes.

The tree of this French Pear is vigorons, and an early and abundant bearer. Young shoots a dull olive brown color.

Fruit medium, oblong obovate, slightly acute pyriform, dull rellow and green, considerably marked with russet patches and dots, and tinged with a red cheek. Stalk about an inch long, set obliquely, without depression, on an ohtuse point. Calyx with stitt segments, set in a shallow, round basin. Flesh white, butterr, melting, with a rich-flavored juice. Very good. First of October.

\section{JAHINETE.}

Sabine.

D'Austrasie.

Beurré d'Austrasie.

Belle d'Austrasie.
Wilhelmine.

Josephine.

Colmar Jaminette.

Crassane d'Austrasie.
Bergamotte Cheminette.

Sabine Tan Mons.

Beurré Saint Helier.

Tyrolle.

Raised by M. Jaminette, of Metz, very productire, and in favorable seasons an excellent winter fruit. Young wood dull yellow brown.

Fruit of medium or large size, varying in form, but mostly obovate, a good deal narrower at the stalk, clear green, paler at maturity, considerably marked with russety brown, especially near the stalk, and sprinkled with numerous brown dots. Stalk scarcely an inch long, rather thick, and obliquely planted, without any depression. Calyx open, set in a basin of moderate depth. Flesh white, a little gritty near the core, but very juicy and buttery, sweet. Good to rery good. November to Jannary.

\section{JAPAN.}

This peculiar Pear originated with Gideon Ross, of Trestfield, X. J., from seeds brought from Japan, and is similar to Chinese sand pear. 'The tree is a very vigorous grower, with very large thick leaves, an early and abundant bearer. Young wood ricl clear brown, with long white specks. It lias a hard flesh, with a peculiar quince-like aronia, and is only valued for cooking.

Fruit medium, oblate, cinnamon yeliow russet, with many large light-colored specks. Stalk very long. Cavity open, deep. Calyx inconspicuous. Basin deep, open, broad. Flesh coarse, gritty, tirm, in consistence and flavor much like a delicate quince. Very fine for cook. ing. October, December.

\section{Jean Baptiste Biyort.}

A new Belgian Pear. Tree vigorous.

Fruit large, oblong pyriform, yellowish, nearly overspread witl 
cinnamon red and reddish specks. Stalk long, slender. Cavicy narrow. small. Flesh white, melting, huttery, juicy, sweet, slightly jerfumed November. (An. Ponr.)

\section{JEAN DE: WITTE.}

Dial. Beurré de Hamptienne. Passe Colmar François.

Tree vigorous, "uright grower. Toung shoots very dark olive.

Fruit medium, roundish obovate pyriform, yellowish green, dotterl sprinkled, and netted with rnsset, and slightly shaded with fawn (1) erimson in the sum. Stalk long, curver, inclined, set in a small cav. ity. Cilyx open. Segments stitt. Basin rather abrupt. Flesh white, juicy, melting, sweet, pleasant. Good to very good. November, De. cember.

\section{JeFFERSON.}

Origin, Mississippi. Tree very vigorous, an early bearer, and very productive.

Fruit large, roundish obtuse pyriform, straw color, shaded with red in the sun, and dotted with small green dots. Flesh white, not juicy, sweet, coarse, decays quickly at core, not high-flavored. A uigust.

\section{Jersey Gratioli.}

Gracioli of Jersey. Bedminster Gratioli. Norris Pear.

Originated in the Isle of Jersey. Tree a moderately vigorous grower and a good bearer. Young wood short-jointed, dull reddish brown.

Fruit medium, roundish obovate pyriform, greenish yellow, netted and patched with russet, many brown russet clots. Stalk short, rather stout, inclined, in a small cavity, msseted. Calyx, open. Segments rather long and slender, recurved. Basin abrupt, deep, nueven. Flesh whitish, juicy, melting, rich vinous. Very good. September.

\section{John Griffith.}

Originated in Westchester Co., N. Y.

Fruit medium, roundish obovate obtuse pyriform, greenish yellow, with many brown dots, and some nettings and patches of russet. Flesh whitish, coarse, not very juicy, melting, sweet, pleasant. Goorl. September.

\section{JoHONxот.}

\section{Franklin.} Mass.

Originated in the garden of George S. Johonnot, Esq., of Salem,

The fruit is of merlinm size, of a roundish and peculiar irregular form, dull yellowish. Stalk short and thick, planted by the side of a swollen protuberance. The flesh is melting, buttery, and good. Septem. ber, Detober. 


\section{Jolie Fille de Gust.}

This "pretty girl of Cust" is of Belgian origin.

The fruit is small, roundish acute pyriform, pale yellow, shaded with crimson in the sum. Stalk long. Calyx open. Flesh white, coarse, dry; its beauty its only value. September.

\section{Joly de Bonneau.}

Fruit above medium size, obovate, pale green, with spots and reins of brown russet. Stalk long, obliquely inserted, stout, woody, and inserted without depression. Calyx open. Flesh white, with a pink tinge, fine-grained, melting, juicy, sweet, vinous. December. (Hogg.)

\section{JoNES.}

Jones's Seedling.

Origin, Kingsessing, near Philadelphia. This is one of the good Pears, and, were it a little larger, would be one of the most valuable. The tree is vigorous and upright in growth, and productive. Young shoots of a dull alive browa.

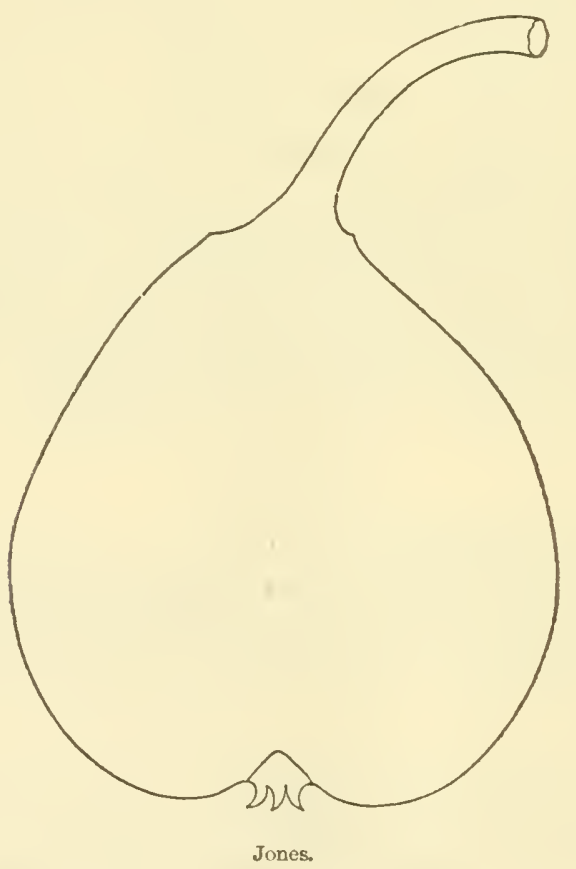

Fruit medium or below, pyriform, broad at calyx, tapering to the stem, which meets it by a fleshy junction. Skin yellow, shaded with russet, bright cinnamon on the smmy side. Calyx open, in a broar. shallow, meven basin. Flesh coarse, granular, buttery, sugary, brisk. and vinous. Very good. Octuber. 


\section{Josephise Bourier.}

Frnit medinm, ovate, green, with a few patches and nettings of rus set, and many brown dots. Stalk medium length, curved. Cavity shal. low. Calyx partially open. Segments recurved. Flesh white, coarse, juicy, melting, sweet, withont flavor. Jamuluy.

\section{Josepitine de Malines.}

Raised by Major Esperen, of Malines, and proves one among the best of winter varieties. Tree moderately vigorous and prodnctive. Young wood olive yellow brown, very short-jointed. Buds iround, projecting.

Fruit medium, roundish oblate, slightly pyriform, pale greenish yel. low, netted and patched with russet, especially around the stalk, and

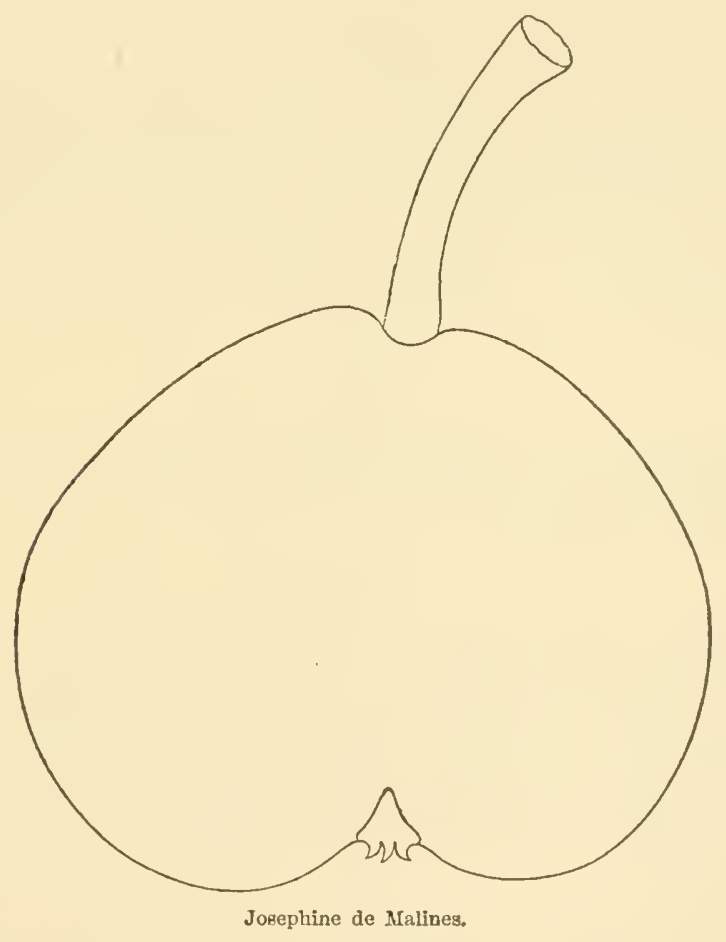

with many minute brown dots, particularly around the calyx. Stalk cnlarged at both ends, curved, sometimes set in a small eavity. Calyx sinall, open. Segments short, stiff, nearly erect. Flesh pinkish white, juicy, melting, sweet, with a delicate aroma. Very good. January, February.

\section{Joseph Staquet.}

A new variety, from Belgium.

Fruit above medium, oblong pyriform, pale yellow, with patches and 
dots of green and russet. Stalk fleshy at insertion, set without depression. Flesh white, melting, buttery, rery juicy, sweet, with a musky perfume. September, October. (An. Pom.)

\section{JUdGE ANDREWS.}

Andrews' Kingsessing.

Uriginated in Pemnsylvania.

Fruit medium, oblong obovate yriform, yellowish, traced and mot. tled with red in the sum. Flesh coarse, breaking, dry. Poor. Sep. tember.

\section{JUi.IENAE.}

A handsome summer Pear. It is a productive fruit, and comes into bearing very early. It is often of excellent flavor, and of the first quality ; but, unfortunately, it is variable in these respects, and some seasons it is comparatively tisteless and insipid. In the Southern States, and in rich, warm, and dry soils at the North, it is almost always fine. The tree is of thrifty, upright growth, with light yellowish-brown shoots.

Fruit of small size, but varying in different soils; obovate, regularly formed, clear bright rellow on all sides. Stalk light brown, speckleil with yellow, a little more than an inch long, pretty stout, inserted in a very shallow depression. Calyx open, set in a basin shightly sumk, but often a little plaited. Flesh white, rather firm at first, half buttery, sweet, and moderately juicy. Ripens all the month of August.

\section{KEISER.}

Fruit medium size, pyriform, vellowish green, with small gray russet specks, and russet round the stalk. Flesh greenish white, a little gritty, melting, sweet. October. (Lind.)

\section{KELSEY.}

Originated in the garden of Wm. Kelsey, Columbus, O. Treo up. right, partially spreading, vigorous. Young wood dull yellow brown.

Fruit medium, roundish obovate, dull green, becoming yellowish when well ripened, marblings of russet near the calyx. Dots of russet. Stalk slender. Calyx small, open. Segments short, erect. Basin slightly furrowed. Flesh greenish yellow, melting, sweet, buttery, vinous; slightly aromatic. October to February. (Hort.)

\section{King.}

Originated at Oswego, N. Y.

Fruit medium or below in size, roundish oblate prriform, gneenish brown in the sun, with many green and brown dots. Flesh whitish, coarse, half melting, sweet. Good. September, October.

\section{Kixg Edward's.}

Jackman's Melting.

Fruit large, pyriform, tapering gradually to the stalk, rellow, red 
cheek. Flesh yellowish, buttery, melting, and good, when the stason is favorable. Good. October.

\section{Kingsessing.}

Leech's Kingsessing.

Originated in the tamily burving-ground of Isaac Leeell, near Plii ladelphia. 'Tree upright and of vigorous growth, with dark olive yel low brown shoots. Buds broatly shouldered, prominent.

Fruit large, obtuse prriform, greenish yellow, thiekly sprinkled with minute green or gray ciots. Stalk medium or long, curved, and fleshy at its insertion in a broud, uneven eavity. Calyx set in a lange, irregular, corrugated basin. Flesh whitish, somewhat coarse and granular, juiey, buttery, and melting, with a sweet perfumed flavor. Good to very good. September.

Kisg. -

King's Seedling.

Medium size, oblate uneven, yellowish green, rough. Stalk in a cavity. Calyx open. Basin shallow. Flesh greenish white, granular, juicy, sugary, aromatic, perfumed. Good. October.

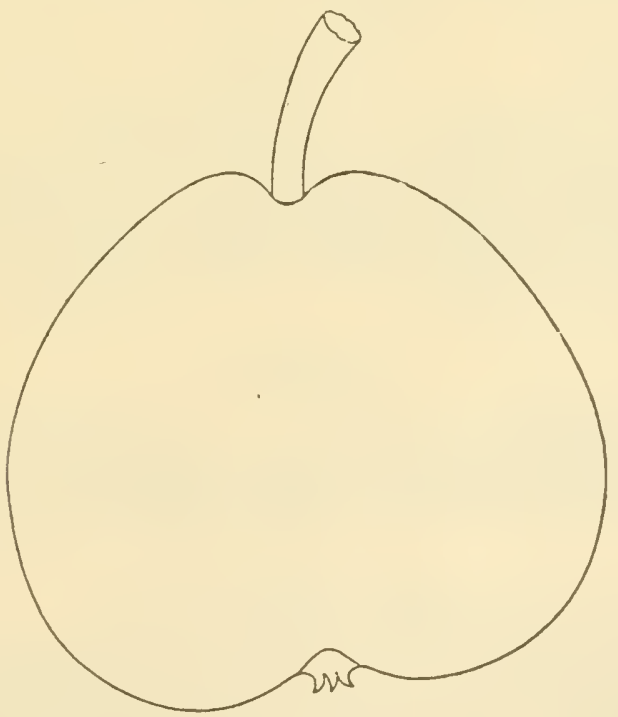

Kirtland.

\section{KirTLAND.}

Kirtland's Seedling. Hadley. Kirtland's Seckel. Kirtland's Beurre.

Raiserl by H. T. Kirtland, Poland, O. Tree moderately vigorous Young wood olive yellow brown.

Fruit medium or below, obtusely oborate, sometimes obseurely pyri 
form, fine yellow, mostly covered with bright cimnamon russet, occa sionally mottled and streaked with red on the sumny side. Stalk rather short and stout, inserted in a small cavity, often by a ring or lip. Calyx partially open, persistent. Basin shallow and broad. Flesh melt. ing, juicy, sweet, aromatic. Very good. Ripe first of September.

\section{KNight's Monarcir. \\ Monarch.}

An English Pear, raised by Thomas Andrew Knight, which has not proved of mnch value at the North. In the Southern States it promises well. Tree vigorous, hardy, and productive.

Fruit medium, roundish, yellowish green, with brown russet and many gray russet specks. Flesh yellowish, lnelting, sweet, agreeable. Good. December, January.

Kvigit's.

\section{Knight's Seedling.} tive.

Raised by Mr. Knight, of Rliode Island. Tree vigorous, produc-

Fruit medium, oblate pyriform, yellowish green, rough. Stalk long, inserted by a slight cavity. Calyx closed, in a shallow basin. Flesh juicy and sweet. Good. October.

\section{KOPERTSCHER.}

Kossertscher.

Princière de Kopertsh.
Beurré Prince de Schwarzenberg.

Supreme Coloma.

A foreign Pear, of uncertain origin. Tree vigorous and productire.

Fruit medium or below, nearly globular, greenish yellow, with a few patches of russet, and many green and brown dots. Stalk short. Calyx large, open. Flesh whitish, juicy, buttery, melting, swcet, pleasant. Good. October.

\section{LAFAYETTE.}

Origin, Connecticut.

Fruit small, roundish pyriform, pale yellow, with light russet, and dotted with brown russet dots. Flesh yellowish, buttery, juicy, half melting, sweet, lacking flavor. Good. November.

\section{LA HÉrARD.}

One of Van Mons' seedlings, originated in 1825.

Fruit medium, oblong obovate pyriform, pale yellowish green, with reddish cheek in sun, and sprinkled with many brown dots. Stalk rather long, curved. Cavity small. Calyx partially closed. Segments short, erect. Basin small, slightly furrowed. Flesh whitish, juicy, melting, sweet, a little perfumed. Very good. September.

\section{LA Juive.}

Juire.

Jewess.

One of Major Esperen's introduction. Tree vigorous and productivo. Young wood yellow brown. 
Fruit medium, ovate obovate, pale yellow, consilerably russeted, netted, and patched, and with many hrown russet dots. Stalk short, stont, fleshy at base. Cavity small. Calyx open. Regments persistent, often a little recurved. Basin shallow, meven. Flesh yellowish, a little con'se at the core, juicy, half melting, sweet, a little aromatic. Good t.o rery good. Oetober.

\section{LANARTINE.}

De Lamartine.

Of foreign origin.

Fruit small, roundish oblate. Surface rough, greenish yellow, mostly covered with a light thin russet, and with many brown dots. Stalk short and small. Cavity small. Calyx small and open. Basin rather deep. Flesh whitish, a little coarse, juiey, melting, rieh, sweet. Very good. November.

\section{Lamis.}

\section{Huntingdon.}

An old variety, described by Lindley as an erect, strong grower, hardy, good bearer, and profitable for the market. We do not know of its ever fruiting in this comtry.

Fruit small, lyriform, pale yellow, tinged with red in the sun. Flesh juicy, melting, agreeable. Good. August.

\section{La Moulinoise.}

A foreign variety, that we have fruited but once.

Fruit large, oblong pyriform, greenish yellow, partially netted and patehed with russet, and thickly sprinkled with brown russet dots. Stalk long, rather stout, inserted by a lip. Calyx partially open. Segments erect. Flesh yellowish, juicr, melting, sweet, slightly vinous. Tery góod. September.

\section{LANSAC.}

De Lansac.

Dauphine.

Satin.

This Pear is described by Lindley as below merlium size, nearly globular, yellowish green. Flesh yellowish, melting, sugary, slightly perfumed. November and Deeember.

\section{Large Round Blanguet.}

Grosse Blanquette Ronde.

Gros Blanquet Rond.

An old fruit of little value, small size, round, yellowish, shade of red in the sum. Flesh whito, half breaking, sweat. İast of July.

\section{La Sayourese.}

Probably of German origin.

Fruit below merlium, roundish oblate, green, with some marblings and patches of russet. Staik long, slender. Flesh greenish white, but. tery, sweet, agreeable. Early winter. (Verg.) 


\section{Las CANAS.}
Bon Parent.
Bouvier.
Bow Parent.

A Belgian Pear, possessed of many of the best rualities that make up a good fruit. The tree is a good grower, an early bearer. and the fruit keeps well.

Frnit melinm or below, ovate acute pyriform, pale or greenish yel. low, netted and patcher with golden russet, and thickly dotted with russet gray dots. Stalk medium, inclined, fleshy at base, or inserter! br a lil, without depression. Calyx small, open. Basin shallow, russeted. Flesh yellowish white, buttery, melting, juicy, slightly astringent, and aromatic. Very good. October.

\section{La Seur Grégoire. \\ Sœur Grégoire.}

Raised by M. Grégoire.

Frnit large, oblong. Surface uneven, rich golden yellow, mostly overspread with dull briek red. Flesh fine, vellowish white, melting, buttery, juicy, sweet, with a delicate aroma. November, January. (An. Pom.)

\section{LAURE DE Glymes.} tive.

A seedling of Van Mons'. Tree of moderate growth, very produe-

Fruit medium or below, roundish oval, inclining to obovate. Surface rough, yellow, nearly covered, netted, and patched with russet, many russet dots. Stalk rather stout, fleshy at insertion. Calyx partially open. Segments recurved. Basin shallow, corrugated. Flesh yellowish, a hittle coarse, buttery, not very juicy, slightly vinous, and a little astringent. Good. September, Oetober.

\section{LAWRENCE.}

Originated at Flushing, Long Island. Tree hardy, a moderate grower, an early and abundant bearer. Young shoots dull rellow brown. A valuable sort for oreharding, and unsurpassed in its many good qualities among our early winter Pears.

Fruit medium size, obovite obtuse pyriform, nearly regular. Color lemon yellow, with traces and occasional patehes of russet, and thickly dotted with minute brown dots. Stalk of medium length and rather stont, set in an irregular russeted cavity. Calyx open. Segments short, persistent. Basin broad, shallow, uneven, or slightly corrugated, and thinly russeted. Flesh whitish, juicy, melting, sweet, and aromatic. Very good or best. December.

\section{LE Breton.}

The origin of this Pear is unknown.

Fruit medium size, irregular, obovate obtuse prriform, yellow, netted and patehed with russet, and many russet dots. Flesh rellowish, 
rather coarse at the enre, melting, juicy, sweet, aromatic. Good to very good. November to Jamuary.

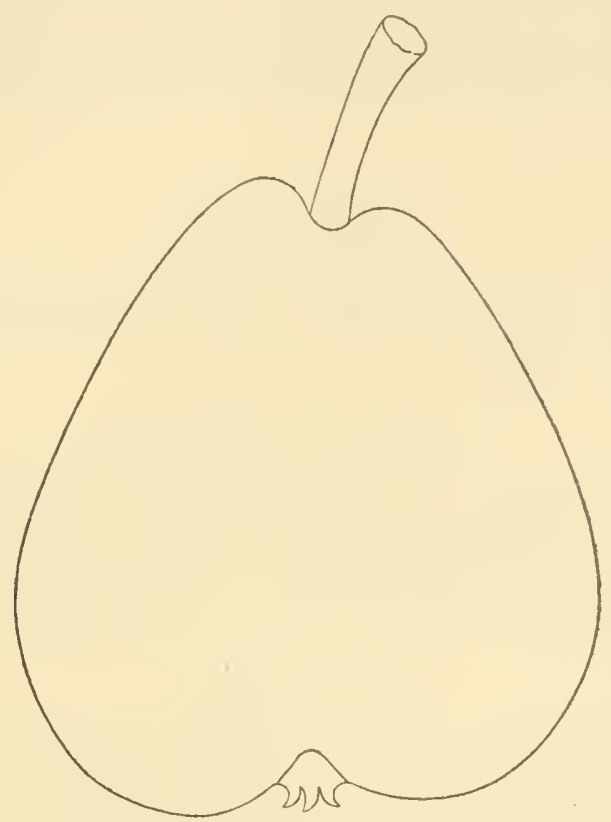

Lawrence.

If Brux.

Uriginated in Troy, France.

Fruit of medium size, oblong ovate pyriform, yellowish, with brown and fawn shades. Flesh white, melting, juicy, sweet, with a musky perfume. September, October. (Leroy.)

\section{LEE.}

Lee's Seedling.

Originated at Salem, Mass.

Fruit small to medium, roundish oval, greenish, russet brown in stur. Flesh white, juicy, coarse. l'oor. September. (Elliott.)

\section{TEFETRE.}

Beurré le Fevre.

Beurré de Mortefontaine.

An old French Pear, nriginated about 1740.

Fruit very large, rumnlish oval, dull green, dull brown in sun, with numerous conspicuous large gray dots. Stalk stout. Calyx with reflexed segments. Flesh greenish white, fine, melting, juicy, vinous, perfumed. October. (Jitr.) 


\section{LENAWEE.}

Origin unknown. Received from Dr. D. K. Underwood, of Adrian, Michigan. Tree at first upright, becoming straggling, and twisting irregular.

Fruit medium, oblong pyriform. Surface uneven, light yellow, with a crimson cheek in sun, dotted with small russet specks. Flesh buttery, not very juicy, slightly aromatic. Good. September.

\section{Lent Saint Germaix.}

\section{Easter Saint Germain.}

Fruit pretty large, oblong oval obovate, pale green, full of small white specks. Flesh firm, breaking, with a rery good flavored juice. March, A pril. (Lind.)

\section{Leochine de Printeirs.}

This is one of the new foreign varieties, which we have fruited but once.

Fruit medium, obovate pyriforn, yellow, netted and patclied with russet, and sprinkled with russet dots. Stalk short. Calyx open. Flesh white, firm, not very juicy. Gool. Late Winter.

\section{LÉOX GrêGOIRE.}

This new Pear is described in the Annals of Pomology as:-

Fruit large, oblong, obtuse pyriform, greenish yellow, marbled, mottled, and shaded with reddish brown, and reddish gray dots. Flesh yellowish white, melting, buttery, sweet, vinous, agreeable. December, January.

\section{LÉonie Pinchart.}

A new Belgian variety.

Fruit of medium size, roundish oborate, greenish yellow, much cor. ered, netted, and patched with yellow russet, and minute lusset dots. Stalk short, stout. Calyx open. Segments recurred. Basin rather shallow, uneven. Flesh whitish, juicy, sweet, melting. Very good. September, October.

\section{Léoy Le Clerc LAYAL.}

\section{Blanc-per-ne.}

One of Tan Mons' seedlings. A good cooking Pear, large size, and very distinct from the celebrated "Van Mons Léon le Clerc." In favorable seasons it is of tolerable quality for the table.

Fruit large, obovate pyriform, yellow, tinge of red in the sun, with russety spots at either end, and some large dots. Calyx large, with long, straight, narrow divisions, and placed in a broad shallow basin. Stalk an inch and a half long, pretty stout, swollen at its point of insertion. Flesh yellowish white, juicy, crisp, and rather tirm, sweet, pleasant Goorl. December to April., 


\section{Léox te Clenc Louvain.}

A secrlling of Vin Mons', Belgium. 'Tree of moderate growth, very productive.

Fruit large, pyriform, russet, on greenish yellow ground. Stalk long and eurved, iuserted in a slight cavity by a lip. Calyx open. Basin shal. low. Flesh white, juicy, buttery, melting, rich, and exeeedingly sugary. ()etober, November.

\section{LÉon Rey.}

\section{Beurré Léon Rey.}

A new variety, obtainer by Rey at Toulouse.

Fruit medium size, roundish pyrifon'm. Flesh melting, juicy. Angust. (Teroy.)

\section{LEOTOLD I.}

A Belgian Pear, little known, and, so far as we have fruited it, not specially valuable. Tree moderately rigorous.

Fruit medinm, oblate obtuse pyriform, yellow, partially netted and patched with russet. Many russet dots. Stalk stout. Carity small. Calyx open. Basin small, uneven. Flesh yellowish, juicy, melting, sweet. Good to very good. (Dec.)

\section{IEOPOLD Rícin.}

One of M. de Jonghe's seerllings.

Fruit rather large, obtuse obovate pyriform; yellow, thickly dotted with large cinnamon russet dots. Stalk slender. Calyx open. Basin shallow. Flesh rather coarse-grained, crisp', very juicy, rich, sweet, with a fine almond flavor. Norember. (Hogg.)

\section{LEPINE.}

De Lepine. Delepine. Poire de Lepine.

Tree of moderate growtl, very productive.

Fruit small, oblate, yellowish, shaded with crimson, slightly russeted. Stalk long. Cavity broad and shallow. Calyx small, open, in a corrugated basin. Flesh coarse, granular, melting, juicy, brisk, vinous. Good. November, December.

\section{LEWIS.}

This Pear originated on the farm of John Lewis, of Roxbury, Mass. It bears enormous crops. The tree grows vigorously, and has long, drooping branches of olive brown color.

Fruit scarcely of melium size, obovate, dark green in autumn, palc green at maturity, witl numerous russety specks. Stalk long and slender, inserted nearly even with the surface. Calyx lange, with white spread divisions. Basin alnost level. Flesh yellowish white, rather coarse-grained, melting, juicy, and rich in flavor, with a slight spicy perfume. Good. November to February.

\section{LiBFRALE.}

Of Belgian origin. Tree a vigorous grower. Toung wood dull brown 
Fruit medium, obovate olstuse pyriform, greenish yellow, shade of brown in the stm, sprinkled with brown or russet dots, and with patches of russet. Stalk long, curved, inserted in a cavity at an inclination. Calyx large and open. Basin broad and shallow. Flesh yellowish, juicy, melting, sweet, rich, and peculiarly aromatic. Very good. October.

\section{LIEBART.}

\section{Chamoisine.}

Beurré Liebart.

A foreign variety, the origin of which is unknown. Tree a very vigorous grower, and an early bearer.

Fruit large, obovate obtuse pyriform, pale yellow, shade of red in the sum, a few large patches of russet and russet dots. Stalk rather stont. Cavity slight. Calyx open. Basin shallow. Flesh white, coarse, breaking, not juicy. Poor. September.

\section{Lieuterant Poitevin.}

\section{Lieutenant Poidevin.}

A French Pear, introduced in 1853. Tree vigorous, and an early bearer, valuable as a cooking fiuit.

Fruit large, broad at calyx, obtuse pyriform, yellow, overspread, netted and patched with cinnamon russet, many russet dots, sometimes shade of crimson in sun. Stalk short. Calyx small, closed. Flesh white, rather firm, juicy, breaking, rather coarse. November to MLarch.

\section{LimoN.}

\section{No. 10. Van Mons. Beurré Haggerston. Bergamotte Louise.}

A fine sprightly Belgian Pear, originated by Van Mons. The young shoots are long, stender, reddish brown.

Fruit rather small, obovate, yellow, with a faint red cheek. Stalk an inch and a half long, rather stout, set in a moderately depressed round eavity. Calyx set in a rather shallow round basin. Flesh white, buttery, melting, and juicy, with a sprightly high flaror. Tery good. Middle of August.

\section{Little Blanguet.}

\author{
Petite Blanquette. \\ Petit Blanquet. \\ Poire à la Perle. \\ Blanquet Petit. \\ Pearl Pear.
}

Little Blanket.

Musk Blanquet or Blanquette. Small Blanquet. White Pear.

An old variety, superseded.

Fruit small, pyriform, yellowish white. Flesh half-breaking, pleasant. Good. Early Auguist.

\section{Little Muscat.}

Little MIusk.

Petit Muscat.
Primitive.

Inscat Petit.
Sept-en-gueule. Chiot.

This very little French Pear, well known in many of our gardens, is 
allowed a place there, chiefly becanse it is the earliest of all Pears, ripening at the beginning of July.

Fruit very small, turbinate, yellow, with a dull red cheek. Flesh breaking, sweet, with a slight musk flavor. Good. Very productive.

\section{Livingston Virgalieu.}

An old variety, somewhat grown along the Hudson River, origin unkıown.

Fruit medium, roundish obovate, greenish yellow, patched and dotted with russet. stalk short. Calyx small, open. Flesh whitish, juicy, nearly melting, sweet, pleasaut. Good. September.

\section{LOCKE.}

Locke's New Beurré. Mass.

This is a native fruit, originated by James Locke, West Cambridge,

Fruit medium, romndish obovate, dull yellowish green, slightly mottled with spots of rlarker green and bits of russet. Flesh greenish white, melting, and juicy, with a sprightly vinous flavor. Good. November and December.

\section{LODGE.}

\section{Smith's Bordenave.}

The Lodge Pear is a native of Pennsylvania, and is understood to have originated near Philadelphia. It is a very agreeable subacid Tear, and has so much of the Brown Beurré character, that we suspeet it is a seedling of that fine old variety.

Fruit of medium size, pyriform, tapering to the stem, and one-sided, greenish brown, the green becoming a little paler at maturity, and much covered with patches of dull russet. Stalk an inch and a fourth long, obliquely planted at the point of the fruit, which is a little swollen there. Flesh whitish, a little gritty at the core, which is large, juicy, and melting, with a rather rich flavor, relieved by pleasant acid. Very Good. September and October.

\section{LoNdon Sugar.}

An English Pear, described by Lindley.

Fruit small, pyriform, pale yellow with a brownish tinge in sun. Flesh tender, melting, sweet. Good. Last of July.

\section{Long Green.}

Verte Longue. Mouille Bouche. Mouthwater.

An old variety, described by Duhamel. Tree very vigorous and produetive.

Fruit small, obovate acute pyriform. Stalk of medium length, nearly perpendicularly inserterl. Calyx small, alınost without basin. Skin remains green when fully ripe. Flesh melting, juicy, with a pleasant spicy flavor. Good. September. 


\section{Long Greex of Autumx.}

Verte longue d'Automne.

Mouille bouche d'Automne.
Autumn Mouthwater.

Coule Soif d'Automne.

The Long Green of Autumn is said to be even an older variety than Long Green. The fruit of this sort is later in maturing.

Fruit medium, oblong ovate acute pyriform, smooth, pale green, with occasional patches of russet, and thickly sprinkled with small brown clots. Stalk long, slender, curved. Calyx open. Segments almost joined, short, persistent. Basin shallow, uneven. Flesh greenish white, buttery, juicy, half melting. Good. October.

\section{LoNg GREen of Esperin.}

\section{Verte Longue of Esperin.}

We received this variety from $I$. E. Berckmans. It is of Belgian origin.

Fruit medium, oblong ovate pyriform, greenish yellow, with a shade of crimson in the sun, and patches and nettings of russet, and many brown dots. Stalk rather short, moderately stout, set in a small cavity. Calyx open. Segments recurved. Basin shallow, furrowed. Flesh yellow: ish white, juicy, half melting, vinous. Good. September.

\section{Loxg Green Paxacile.}

Culotte de Suisse.

Verte longue panache.

This differs from Long Green only in being striped with yellow.

\section{Long-Stalken Blaxguet.}

Blanquette à longue queue.

Blanquette à longue queuen.

Long-Tailed Blanquette.

\section{Suchrin blanc d'Été.}

Long-Stalked Blanket.

Sucrée blanche.

Gillette longue.

A very old variety, now entirely superseded.

Fruit small, roundish, greenish or greenish yellow. Flesh white, half breaking, delicate, sweet, vinous. Good. Early August.

\section{Louise Boxye.}

\section{Louise Bonne Réal.}

St. Germain Blanc.

An old French winter Pear.

Fruit large, pyriform, a little rounded towards the stalk, smooth, pale green. Flesh white, rather coarse-grained, melting, sweet. Gooul. December.

\section{Louise Bonne de Printemps.}

This variety was raised by M. Boisbunel, of Rouen, France, as he supposed, from seed of Lonise Bonne de Jersey, which in appearance the fruit much resembles. The tree is a vigorous grower and productive. Young wood olive yellow brown.

Fruit large, oblong ovate pyriform, rich clear yellow, with a red cheek in sun, and a little of russet, especially near the stalk. Stalk short, set in a narrow, furrowed carity. Calyx with short persistent segments. Basin rather deep, furrowed. Flesh white, melting, juicy, but tery, sweet, and slightly perfumed. February, March. (An. Pom.) 
Lovise Bonne of Jersey.

Bonne de Longueval.

Touise Bomme d'Avranehes.

Lonise Bomne de Jersey.

Beurré or Bonne Louise d'Araudoré.

William the Fourth.

Bergamotte d'Arranches.

De Jersey.
Beurré d'Araudore.

Bonne Lonise d'Araudore.

Beurré d'Avranches.

Bome d'Avranches.

De Louise.

William.

Originated in France, near Avranches, succeeds admirably on the quince, forming a fine pyramid-not of the first quality, but profitable. Tree vigorous, upright, very productive. Fruit of better quality on tl.e quince than on the pear. Young wood dull olive brown.

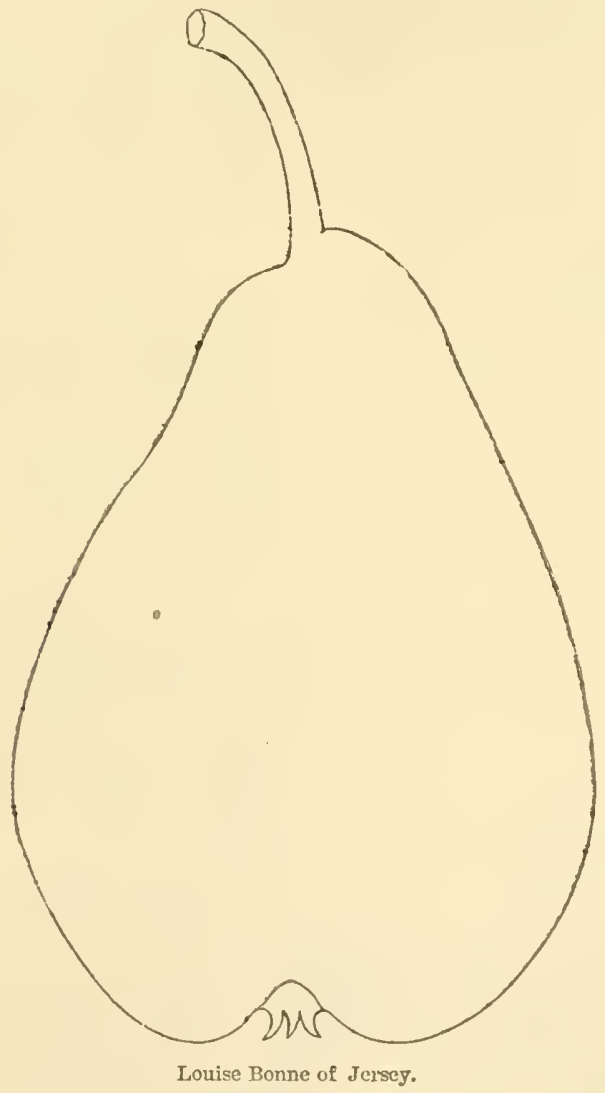

Fruit large, oblong pyriform, a little one-sided, glossy, pale green in the shade, but overspread with brownish red in the sun, and dotted with numerous gray dots. Stalk about an inch long, curved, rather obliquely inserted, without depression, or with a fleshy, enlarged base. Calyx open, in a slatlow, uneven basin. Flesh greenish white, very juicy and melting, with a rich and excellent flavor. Good to very good. Sep. tember and October. 


\section{Louise of Bovlogie.}

Of Belgic origin.

Fruit medium size, roundish obovate, greenish yellow, sprinkled with brown dots. Stalk long, a little curved, rather slender. Cavity small, russeted. Calyx open. Basin small and uneven. Flesh whitish, light jink at centre, juicy, melting, sweet. Good to rery good. October, November.

\section{Louis Grégoire.}

A seedling raised in 1832 by M. Grégoire, of Jodoigne. Tree a rigorous, somewhat upright grower, and productive. Young wood dull yellowish olive brown.

Fruit medium size, roundish oborate pyriform, greenish yellow, considerably covered with russet, and thickly dotted with russet dots. Stalk varying, set with little or no depression. Calyx ojen. Segments large,

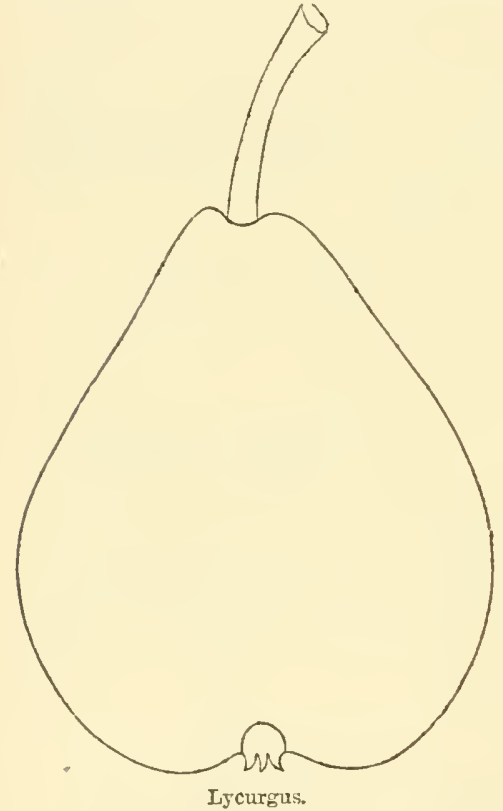
persistent. Basin small and rather shallow. Flesh yellowish white, juicy, melting, sweet, slightly vinous. Good. October, Norember.

\section{Ltciex Leclerce.}

A seedling of Tan Mons' that first fruited in 1844 .

Fruit medium size, ovate, pale green, with russet patches and russet near the stalk, distinet rough dots. Flesh fine, white, melting, sweet. Norember. (Alb. Pom.)

\section{LYeERGES.}

Originaterl with George Hoadley, of Clevelund, O., from seed of Winter Nelis. It is one of the best in quality of late Winter Pears. The tree is a moderate, rather spreading grower, productive. Young wood dark rich olive hrown.

Fruit small, oblong prriform, greenish yellow, mostly covered with a thin brownish russet, many large grayish dots. Stalk medium length, a little curved, set with little or no depression. Calyx open. Segments short, erect. Basin small, uneven. Flesh yellowish, juicy, melting, sweet, rich, a little aromatic, and slightly perfumed. Very good. December to February.

\section{LYTIA TuIL̀RARD.}

Raised by M. Jules Thièrard, Bethel, France. Tree very rigorous, productive.

Fruit is of Bergamotte shape. Stalk of medimm size, curved, a littlo fleshy at the base, in a large and uneven depression. Calyx small, open. Basin large, deep, regular. Skin thin, clear green, thickly 
sprinkled with small brown dots, and russet spots near the calyx Flesh fine, melting, juicy, sugary, and highly perfumerl. Core large. Season, December to January. (Revue Horticole.)

\section{LYON.}

Originated at Newport, R. I. Tree unright, vigorous, hardy, and productive.

Fruit medium, oblong obovate, yellow, with a crinson blush on one side, minute dots, russet near the stalk. Calyx small. Segments persistent. Basin narrow, shallow. Flesh white, coarse, gritty at the core, melting, moderately juicy, sweet. Good to very good. October. (Hov. Mav.)

\section{MuLaughlin.}

A native of Maine, introduced by S. I. Goodale, of Saco. Tree hardy and vigorous. Young wood light dull red.

Fruit large, obtuse pyriform, greenish, mostly eovered with russet,

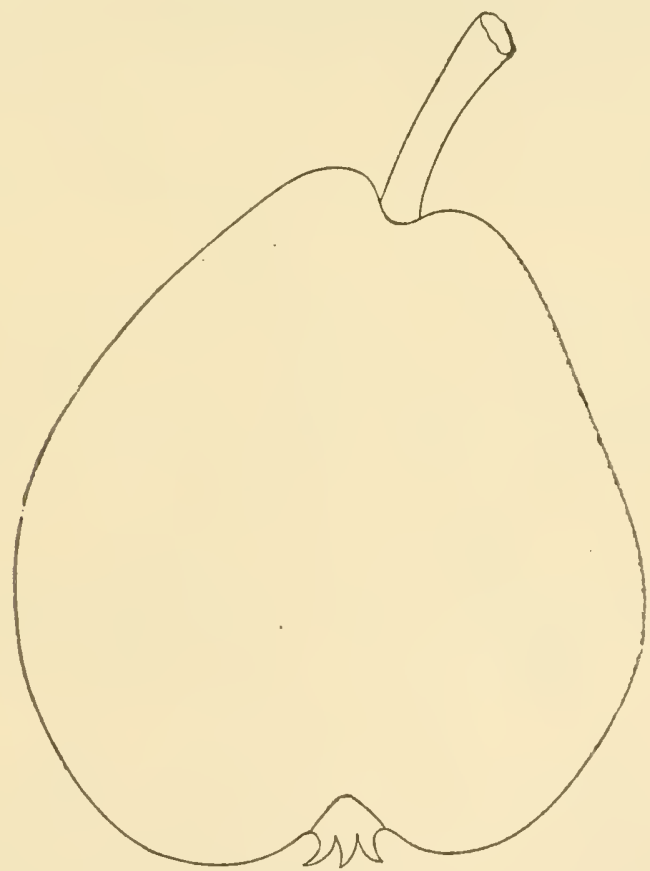

McLaughlin.

which becomes yellowish at maturity, with a warm sunny cheek. Stalk short, inserted at an inclination, with some appearance of a lip. Calyx open, set in a shallow corrugated basin. Flesh whitish, not very fine, juiey, and melting. Flavor sweet, rich, and perfumed. Good to very good. November to Januiny.

\section{MCVEAN.}

Origin, Monroe Co., N. Y. Tree very vigorous, very productire Young wood giayish light yellow biown. 
Fruit large, obovate acute pyriform, yellow, with nettings and patches of russet, and numerous green and brown dots. Stalk short, rather stont, fleshy at insertion, and often set inclined, and with a lip. Calyx partially closed. Basin slightly corrugated. Flesh coarse, not juicy, or melting, sweet. Good. September.

\section{Madame Durieux.}

A Flemish variety.

Fruit medium or below, obovate acute pyriform, yellowish, netted and patched and dotted with russet. Stalk long or very long, and slender. Flesh white, buttery, melting, juicy, sweet. Very good. October.

\section{Madaje Ducar.}

Introduced by M. Esperen. Tree vigorous, productive.

Fruit medium, obovate pyriform, pale lemon yellow, with a few rus. set lots. Stalk long, fleshy at insertion. Cavity medium, somewhat

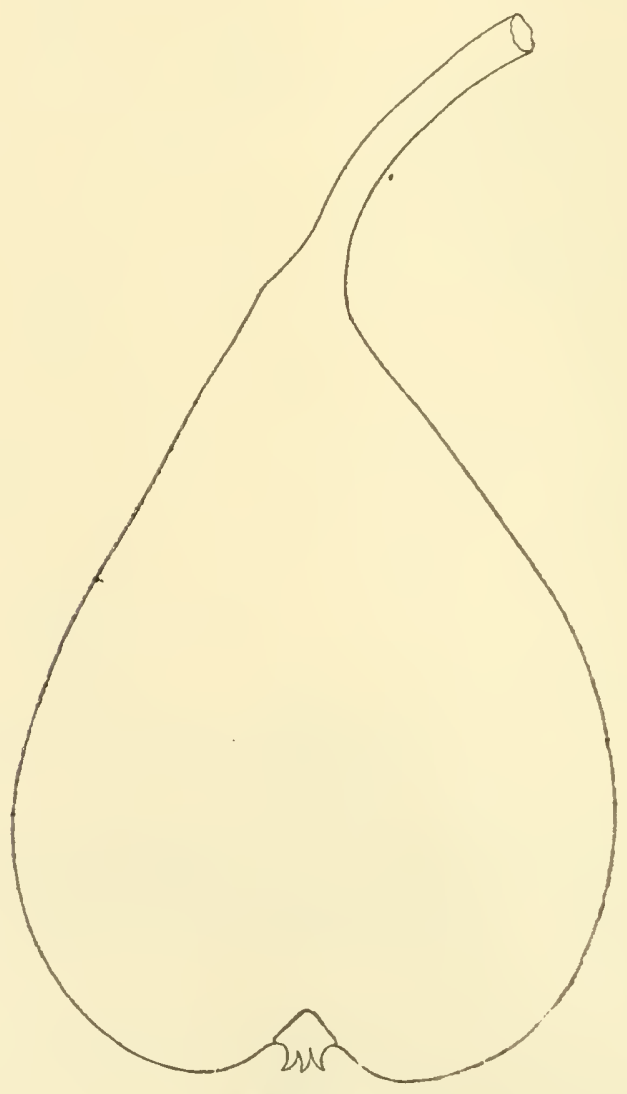

Ma.ame Elizis. 
ribbed. Calyx open, Basin abrupt, uneven. Flesh white, juicy, melting, pleasant, slightly vinous. T'ery good. September.

\section{Midime Eliza.}

One of Bivort's seedlings, and named in honor of the wife of the well-known pomologist, L. E. Berckmans. The tree is vigorons, rather open and irregular in form, productire. Toung woorl dull olive yellow brown. It is a l'ear described as excellent in Belgium, and so far liere sustaius its foreigu character.

Fruit larse, oblong ovate acute pyriform, pale whitish yellow, a few traces of russet, and thickly sprinkled with small russet dots. Stalk long, inclining, fleshy at insertion, or by a lip. Calyx small, partially closed. Segments small, erect. Basin abrupt, meven, russeted. Flesh white, fine, juicy, melting, sweet, cielicately perfumed. Very good. ()etober.

\section{Madame Millet.}

Tree moderately vigorous. Joung wood olive brown.

Fruit medium, obovate pyriform, pale yellow, nuch covered, netted, patched, and dotted with light russet. Stalk long, stout, curved, set in a slight cavity with a lip. Calyx open. Segments short, erect. Basin rather small, uneven. Flesh whitish, juicy, not melting, slightly vinous, a little aromatic. Good. November to April.

\section{Madane Gregoire.}

Of Belgian origin, seedling of Grégoire of Jodoigne, and dedicated to his wife.

Fruit large, oblong obtuse pyriform, greenish yellow, netted, patched, and dotted with brown russet. Stalk rather loug, fleshy at base. Ca. vity rather deep. Flesh white, tinted with rose, half melting, sweet, vinous, perfumed. November, December. (An. Pom.)

\section{Madane Henri Desportes.}

Fruit roundish, obovate, yellow, mostly corered with dark cinnamon-colored russet. Stalk short, stont. Calyx large, open. Flesh yellow, buttery, rich, sweet, juicy. October. (Hogg.)

\section{Madane Treyve.}

\section{Souvenir de Madame Treyve.}

Raised by MI. Treyve, of 'Trevons, France, and dedicated to his wife. Tree vigorous.

Fruit medium, obovate pyriform, pale yellow, with a red cheek in the sun, some l'usset, and dotted with minute brown dots. Stalk slender. Cavity nurow. Calyx small, open. Basin narrow, round, regu• lar. Flesh white, melting, juicy, rich, sweet, with a delicate aroma. September. (Verg.)

\section{Madeleine, or Citron des Carmes.}

Madeleine.

Citron des Carmes.

Early Chaumontelle. Magrlelen.
Sainte-Madelaine.

Grune Sommer Magdalena.

Grune Magdalena.

The Madeleine is one of the most rofreshing and excellent of the 
early Pears. It takes its name from its being in perfuction, in France, at the feast of Ste. Mateleine. Citron des Carmes comes from its being tirst cultivated by the Carmelite monks. The tree is fruitful and vigorous, with long, erect, olive-colored branches.

Fruit of medium size, oborate pyriform. Stalk long and slender, often nearly two inches, set on the side of a small swelling. Pale yellowish green (very rarely with a little brownish blush and russet specks around the stalk). Calyx small, in a very shallow furrowed basin. Flesh white, juicy, melting, with a sweet and delicate flavor, slightly perfumed. Good to very good. Middle and last of July.

\section{Malconnaître d'Haspix,}

Fruit large, form roundish obovate. Stalk one inch long, inserted in a slight depression. Calyx closed, set in a rather deep irregular basin. Skin tull yellow, with a brownish red cheek, stippled with coarse dots, and russeted at the calyx. Flesh juicy, tender, and melt. ing. Flavor rich subacid, perfumed. Tree vigorous, hardy, and productive. October, November. (Wilder's Rep.)

\section{Manchester.}

Manchester Iate.

Manchester October.

A native variety, originated in Providence, R. I.

Fruit medium, obovate pyriform, yellow, with a blush of crimson in the sun, traces and many dots of russet. Stalk rather long. Calyx open. Flesh white, moderately juicy, half melting, sweet, pleasant. Good. October.

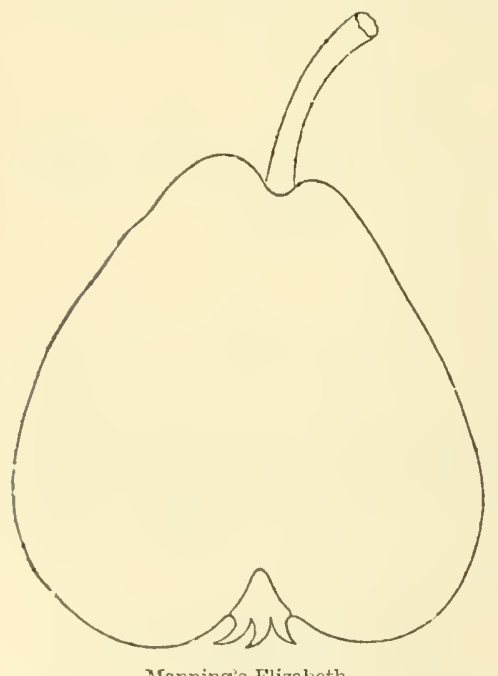

Manning's Elizabeth.

\section{Manimag's Elizabeth.}

Van Mons, No, 154.

Elizabeth Tan Mions.

Manning's Elizabeth, a seed. ling of Dr. Tan NLons', named by Mr. Maming, is a rery sweet and sprightly Pear, with a peculiar flavor. A beautiful dessert fruit, productive, growth moderate, shoots dull reddish. One of the most desirable Pears of its season, for amateur growing.

Fruit below medium, obovate obtuse pyriform, bright yellow, with a lively red cheek, dotted with brown and red dots. Stalk one inch long, set in a shallow. round cavity. Calyx open, set in a broad shallow basin. Flesh white, juicy, and very melting: witn a saccharine but very.sprightly aromatic character. Tery good or best. Last of August. 


\title{
Maxsfield.
}

A native valiety, origin uncertain. Tree vigorous and productive. Young wood reddish brown.

Fruit medium, roundish oblate, yellowish green, with considerable russet and many green and brown dots. Stalk rather long. Cavity narrow, small. Calyx open, with recurved segments. Basin broal, meven. Flesh whitish, coarse, buttery, melting, sweet, a little astringent. Crood. September.

\section{MARAsquine.}

A Belgian Pear, obtained of Major Esperen.

Ernit medium, oblong ovil, light pale yellow, greenish in shade, with fiwn russet in the sum. Stalk long, slender. Calyx open. Basin shallow. Flesh white, fine, melting, slightly sweet, perfumed. August. (Verg.)

\section{March Berganotte.}

One of Mr. Knight's seedlings.

Fruit small or medium. Color green, with small gray dots, and large patches of russet. Stalk long, straight, in a cavity like that of. an apple. Flesh coarse, greenish, of no decided excellence.

\section{Maréchal de la Cour.}

\author{
B. O. de la Cour. \\ Baud de la Cour. \\ Conseiller de la Cour. \\ Grosse Marie.
}

Maréchal Decours.

One of Van Mons' seedlings. Dedicated to his son in 1845. Tree moderately vigorous, holding its foliage late in season. Young shoots olive reddish brown, with many speeks.

Fruit medium to large, oblong obovate pyriform. Skin greenish yellow, with a slight netting and few patches of russet, and russet dots. Stalk rather long, sometimes inclined, set in a moderate cavity, somewhat russeted. Calyx open, in a narrow basin, russeted. Flesh yellowish white, buttery, juicy, melting, rich vinous, very good. October.

\section{Maréchal Dillen.}

\section{Dillen d'Automne.}

One of Van MLons' seellings. Tree vigorous and productive.

Fruit large or very large, oblong obtuse pyriform, dull greenish vellow, mottled with fawn, shades and traces and dots of russet. Stalk short, set in a broad shallow cavity. Flesh white, melting, buttery, juicy, sweet. October, November. (An. Pom.)

\section{MIargaret.}

Raised by Clnistopher Wiegel, Cleveland, O. Tree a vigorous, up. right grower, productive, and an early bearer. Young wood dull redulish.

Fruit small to medium, oblong obovate, yellow, mostly overspread with deep dull red, small russet dots. Stalk inedium, inserted with. 
out depression. Calyx large, open. Segments long, reflexed. Flesh white, juicr, vinous, sweet, good, early. August. (Hort.)

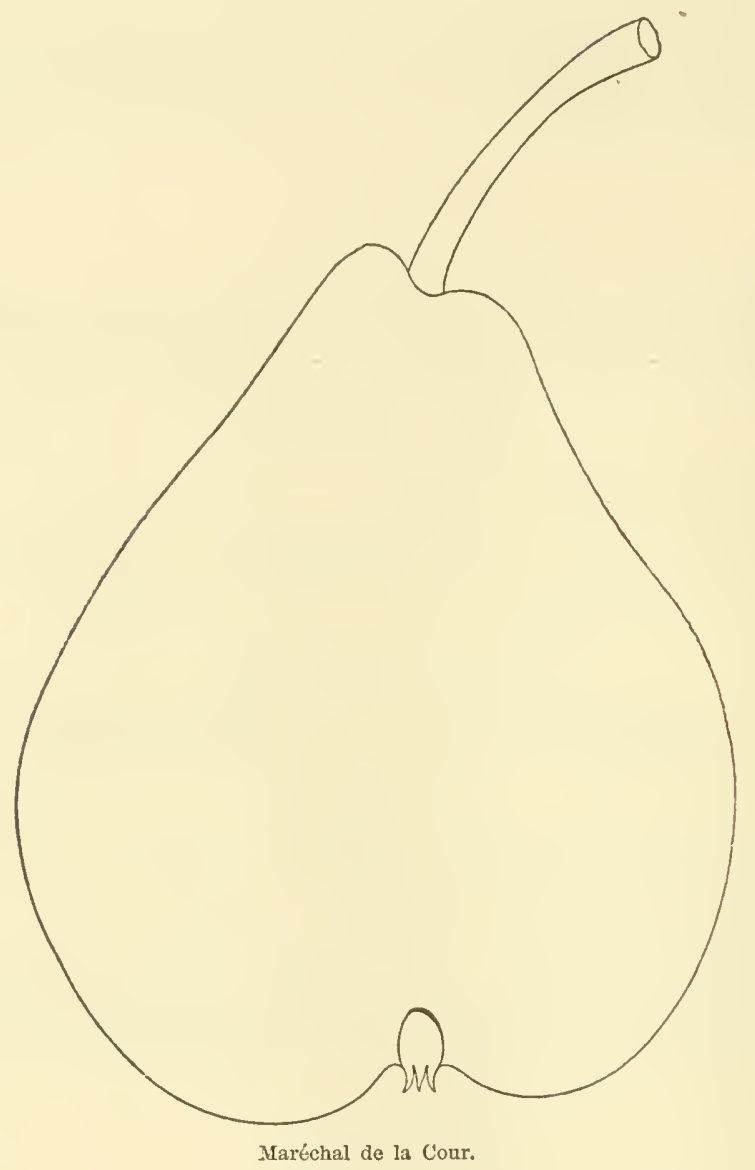

MLarianne de Nancy.

Raised by Van Mons.

Fruit medium or above, oblong obovate pyriform, yellowisb green, netted and dotted with fine dull russet. Stalk short, stout. Calys open. Flesh white, buttery, lualf melting, juicy, vinous, sweet. Octo ber. (Alb. Pom.)

\section{Marie de Nantes.}

A French Pear, originated by M. Garnier, in 1853. Tree moderately vigorous. Young wood olive brown.

Fruit small, obovate acute pyriform, yellow, shade of brownish an in sun, and partially netted and patehed with russet, especially neax 
the base. Stalk short, set in a narrow, furrowed, shallow eavity. Calyx small, open, with short segments. Basin small. Flesh whitish, juicy, melting, sweet. Very good. November, December.

\section{Mhrie Guisse.}

This variety is said to have been grown from seed of St. Germain, in 1834 , near the town of Metz, France. It was twenty years before it fruiterl.

Fruit merlium size, obovate oblong pyriform. Surface uneven, ycllow, with shades of red in sun, and large, dull, dark specks. Stalk rather long and moderately stont, set in a narrow furrowed cavity. Flesh yellowish white, granular, melting, sweet, vinous. December, February. (V erg.)

\section{Marie Louise.}

Forme de Marie Louise.

Marie Chrétienne.

Princesse de Parme.

Braddick's Field Stanclard.

Marie Lonise d'Elcourt.

Tan Doukelear.
Marie Louise Donkelar. Marie Lonise Nouvelle. Mavie Lonise de Jersey. Corchorus.

Marie Louise Delacourt. Van Donckelaer.

A Belgian variety, of first quality in its native country, and here, in some seasons, fuliy sustains that character; but it is so uncertain, so variable in seasons, as greatly to detract from its value. Tree a vigorous but straggling grower. 'Young wood redlish olive brown.

Fruit pretty large, oblong pyriform, rather irregular or one-sicied in figure, pale green, but at maturity rich yellow, a good deal sprinkled and mottled with light msset on the exposed side. Stalk an inch and a half long, obliquely planted, sometimes under a slightly raiser lip, sonetimes in a very small one-sided cavity. Flesh white, exceedingly buttery and melting, with a rich, saccharine, and vinons flavor. Very good. Last of September and middle of October.

\section{Marie Louise d'UCCle.}

'This rariety was raised from a seed of the MIarie Louise, by M. Gambier, in a village (Uccle) near Brussels. 'Tree a vigorous, upright grower. Toung wood dark brown.

Fruit above medium, roundish obovate pyriform. Surface rough, yellow, with a shade of brown in the sun, considerably netted, patched, and numerously dotted with russet. Stalk merlinm, inclined, curved, set in a small cavity, sometimes by a lip. Calyx large, partially open, with persistent segments. Basin large, meven. Flesh white, juicy, melting, vinous, a little astringent. Good to very good. September, October.

\section{TLarie Louise NovA.}

This variety was sent by Van Mons to Mr. Manning. It will by no means bear a comparison with the Marie Louise, though in some seasons a very good fruit. 'The wood is rery strong and dark colored.

Fruit medium, regular acute jyriform, yellow, with a brownisis. red cheek. Flesh at first melting, juicy, but quickly decays. Good last of september. 
Marie Parext.

Sophia Beekmans.

Ferdinand de Meester.

Roussellet le Meester.

Paised by M. Bivort, in 1844, from seeds of the last generation of Tan Mons' seedlings. It first fruited in 1851 . Tree moderately rigo. rous. Young wood dull grayish-redidish brown.

Fruit medium, obovate lyriform to obovate acute pyriform, green. ish yellow, with shade of red in the sun, and traces of russet, and many minute brown dots. Stalk medium, generally inserted withont cavity. Calyx large, open. Flesh whitish, juicy, vinous. Good. September.

\section{Marquise de Bediax.}

Of foreign origin.

Fruit medium or below, roundish pyriform, pale greenish yellow, with a fow traces and patches of russet, and many green and brown dots. Stalk long, slender. Cavity small. Calyx open. Flesh white, sweet, rather firm. Good. September.

\section{MARMION.}

A Belgian variety.

Fruit small, roundish pyriform, pale yellow, some russet. Flesh whitish, coarse, sweet, dry and poor. November.

\section{Martha Ans.}

Dana's No. 1.

Raised by Francis Dana, of Roxbury, Mass.

Fruit medium, obovate obtuse pyriform, yellowish green, with patches and dots of russet. Flesh coarse, juicy, astringent. Poor. October.

\section{Martix Sec.}

Rousselette d'Hiver Dry Martin.

Winter Rousselette.
Martin Sec d'Hiver.

Troken Martin.

Martin Sec de Champagne.

An old variety, of which the origin is unknown. Tree vigorons, very productive.

Fruii small, ovate, yellow, shaded with crimson in the sun, some russet. Flesh arse, granular, juicy, half breaking, agreeable. Chiefly valued for cooking. Winter.

\section{MARTin SiRe.}

Certeau Musqué d'Hiver.

Sire Martin.

A very old sort, valued only for cooking.

Fruit large, pyriform, greenish yellow, with a shade of red in the sun. Elesh crisp, gritty near the core, juicy, swcet. December to February. 


\section{MLARulis.}

Iarcellis.

Foreign.

Fruit small, roundish, greenish yellow. Poor. September. (Elliott.)

\section{MiRY.}

Originated in the grounds of William Case, Cleveland, O. Tree an upright, vigorous grower, with brownish, short-jointed young wood. An carly and procluctive bearer.

Fruit snall to medium, roundish pyriform, yellow, mostly overspread with rich red, a little russet, and many gray dots. Stalk short. Calyx large. Erect segments. Flesh white, juicy, almost buttery, sweet. Very good. Iast of July. (Hort.)

\section{MATHER.}

Originated with John Mather, near Jenkinstown, Montgomery Co., Pa. Tree a moderate grower. Young wood olive grayish brown.

Fruit below medium, roundish ovate, greenish yellow, slight blush in sun, and many minute brown dots. Stalk short, stout. Calyx open. Flesh white, a little coarse, not juicy, sweet, pleasant. Good. August.

\section{Maynard.}

Origin mknown, grown in Lancaster Co., Pa.

Frnit medium, obovate pyriform. Skin yellow, with russet dots and a crimson cheek. Stalk obliquely inserted, fleshy at its junction. Calyx open, in a slight depression. Flesh white, juicy, and sugary. Scarcely good. Ripe last of July.

\section{Meluish.}

Fruit below medium, roundish pyriform, pale yellow, netted, patched, and dotted with russet. Stalk long, slender. Calyx partially closed. Elesh whitish, juicy, melting, sweet, pleasant. Good to very good. October.

\section{MERriam.}

Origin, Roxbury, Mass. Tree vigorous and very productive. Young wood reddish yellow brown; a good market sort.

Fruit merlium, roundish oblate; dull yellow, covered with pale rus. set around the stem and calyx, and entire surface somewhat netted with russet. Stalk short, moderately stont, in a small carity, with one pro. tuberant side. Calyx closed. Basin shallow and furrowed. Flesh yel. lowish, coarse, melting, and juicy, slightly vinous, musky. Good to rery good. Octolver.

\section{Messire JeAN.}

Chaulis.

Enmilacour.

Marion.

Monsieur Jean.

Messire Jean Gris.

Messire Jean Blanc.
Messire Jean Doré.

Mr. John.

John.

Communauté.

Coulis.

Courent.

An old Frencl 1 Pear, but rather coarse-grained and gritty. 
Fruit of medium size, turbinate, yellow, nearly covered with brown russet. Flesh gritty, white, crisp, juicy, and breaking, with a very sweet flavor. Good. November and December.

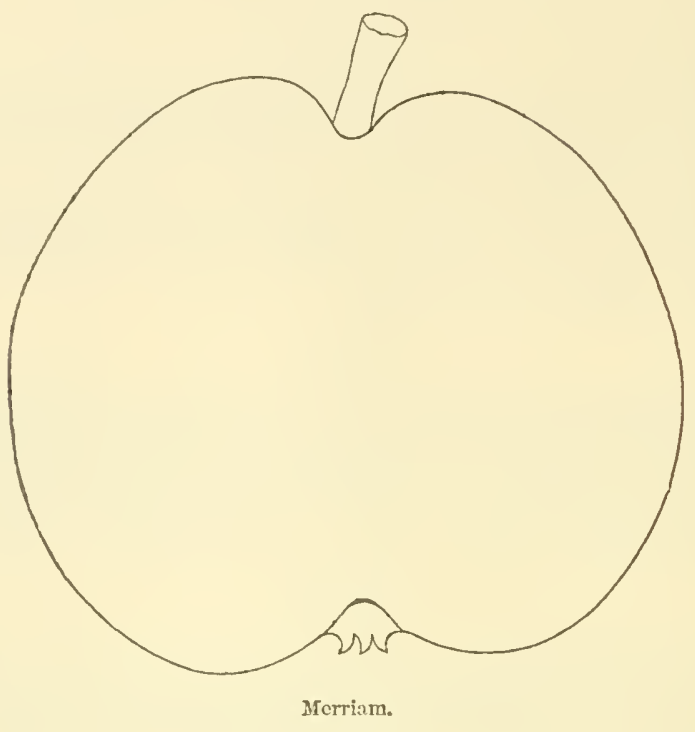

Michati.

Comte de Michaux.

Fruit of medium size, nearly round prriform, light yellowish green, with a faint blush on the smnny side. Flesh white, coarse, half buttery, juicy, sweet, but second-rate. Poor. September and October.

\section{Migronase D'Hiver.}

An old Belgian variety, often very good.

Fruit medium, ovate obovate to oblong ovate prriform, light yellow, mostly covered with thick rongh russet, and veined with crimson and fawn. Stalk rather stout. Calyx open. Flesh yellowish, a little granular, juicy, melting, sweet, vinous, aromatic. Good. November, December.

\section{Mithan de Rouen.}

A Flemish Pear, little known and not of much ralue.

Fruit medium, roumdish, greenish yellow, with nettings, patches, and dots of russet. Flesh white, coarse, juicy, melting, vinous. Septem ber.

\section{MILlotot de NANor.}

One of Van Mons' seedlings, named after M. Millot, a resident of Nancy, France. Tree productive. Ioung sloots reddish brown. 
Fruit medium, oblong ohovate, greenish yellow, with many brown dots. Stalk medium, eurved, often inclined, and set in a small cavity. Calyx partially open. Segments short, erect. Flesh yellowish, not juicy melting, sweet. Good. Norember.

\section{Mitchell's Russet.}

()igin, Belleville, Ill.

Fruit medium or small, roundish, slightly pyriform, rough, yellow brown russet, thickly covered with gray dots. Stalk long. Calyx open. Flesh juicy, melting, astringent. Searcely good. October.

\section{Moccas.}

Originated by Mr. Knight. A good grower, productive, but not of good quality.

Frnit medium, obovate, green, sprinkled with small dots. Flesh juicy. Poor. December.

\section{Moliet's Guernset Beurế.}

\section{Mollet's Guemsey Chaumontelle.}

An English variety, raised by Charles Mollet, Esq., of the Island of Guernsey.

Frnit of medium size, oval pyiform. Skin rather uneven, yellow and rellowish green, nearly covered on one side with dark cimnamon brown russet, in stripes and tracings. Flesh yellowish, melting, and buttery, with a rich vinous flavor. Grood. December.

\section{Monseigneur Affre.}

(Ine of Bivort's introducing. Tree hardy, vigorous, and productive. Young wood dull olive brown.

Fruit below medium, roundish, greenish, considerably covered with thick russet, and thickly sprinkled with russet dots. Stalk long, curved, inserted in a morlerate cavity. Calyx small, open, persistent. Basin broad. Flesh white, rather coarse, melting, sweet, pleasant. Good. November.

\section{Monseigneur des Hoxs.}

A new summer Pear, from Troyes, France. Tree vigorous, spreading. Young wood reddish brown.

Fruit medium, oblong ovate pyriform, rich warm yellow, veined with green, and shaded with a warm red cheek in the sur. Stalk medium, inserted withont depression. Calyx open. Basin shallow. Flesh laalf finc, melting, aromatic, sweet. Early Augnst. (An. Pom.)

\section{Monseigneur Sibour.}

A now French Pear, described in the Annals of Pomology :--

"Frnit medium, obtuse pyriform, pale yellow, with greonish shades, mottlcd, shaded, and dotted with warm red or crimson. Stalk long, 
slender. Calyx large, open. Flesh yellowish white, half fine, melting, juicy, sweet. Novemher."

\section{MOREL.}

An English Pear, mainly valued for cooking.

Fruit medimm, obovate, yellow, freckled with lirge russet spots, Flesh yellowish white, crisp, juicy, and sweet. December to April. (Hogg.)

\section{Mount Vernon. \\ Walker's Seedling.}

A chance seedling, originated in the grounds of Samuel Walker, Roxhury, Mass., aud by him named Mount Ternon. The tree is a rigorous grower, and an early bearer. Young wood yellow redilish brown.

Fruit medium or above, varying in form, but generally roundish obtuse pyriform, light russet on a yellow ground, brownish red in the sun. Stalk short, inserted by a lip, with little or no depression. Calyx small, closed, with short segments. Flesh yellowish, granulated, juicy, melting, slightly vinous and slightly aromatic. Very good. Norember, December.

\section{Moramensing.}

\section{Smith's Early Butter.}

Origin in the garden of J. B. Smith, Philadelphia, Moyamensing District. Tree vigorons and productive.

Fruit medium, roundish oblate, lemon or greenish yellow, with patches, marblings, and dots of russet. Stalk short. Calyx nearly closed. Flesh whitish, coarme, juicy, melting, swect, pleasant. Good. Angust.

\section{Muscadine.}

The MInscadine is renarkable for its high musky aroma. Its history is mncertain, and it is believed to be a native. It bears very heavy crops, and if the fruit is picked early, and ripened in the honse, it is a good Pear of its season. Tree vigorons, upright in growth. Toung shoots stont, dark gray brown.

Eruit of medium size, roundish obovate, regularly formed, pale rellowish green, a little rough, thickly sprinkled with brown dots. Stalk about an inch long, set in a well-formed small cavity. Calyx with reflexed segments, set in a shallow basin. Flesh white, buttery, half melting, with an agreeable, rich, musky flavor. Good to very good. Last of Angust and first of September.

\section{Miuscat Robert.}

Poire à la Reine.

D'Ambre.

St. Jean MIusquée Gros.

Miusk Robine.

Early Queen.

Queen's Pear.

Beurré à la Reine.

Robine.

Muscat Robine.
Queen's Amber.

Virgin of Xaintonge.

Muscat d'Ambre.

The Princess.

Great Musk Pear of Cone.

Maiden of Flanders.

Maiden of Xaintonge.

Robert's MIuskateller.

An old Pear, of unknown origin. Tree very prochuctive. 
Fruit small, roumdish priform, inclining to ovate, greenish yellow, with a dull erimson. Stalk long, sometimes inserted by a lip, and sometimes in a slight eavity. Calyx large, open. Flesh breaking, juicy, sweet. Grood. Iast of July.

\section{MUSKIxguir.}

Origin, supposed Ohio. Tree very vigorous, upright, hardy, and productive. Toung wood dull reddish olive brown.

Fruit medium, roundish, greenish yellow, much dotted with russet and green. Stalk long. Cavity small. Calyx open. Basin very shallow. Flesh melting, with a pleasant, brisk flavor. Good. Ripe midlle and last of August.

\section{NApoleoN.}

Médaille.

Sucrée Dorée.

Poire Liard.

Roi de Rome, erroneously.

Bonaparte.

Belle Canaise

Charles.

Poire Napoleon.

Gloire de l'Empereur.

Captif de Sainte Hélìne.
Melon.

Benrré d'Autien.

Jiart.

Mabille.

Mailanderin Grosse Grune.

Napoleon d'Hiver.

Bois Napoleon.

Napoleon Vrai.

Bon Cbrétien Doré.

The Napoleon is hardy, thrifty, and bears abundant crops, even while very roung. In poor soils, or unfavorable exposures only, it is astringent. The tree is thrifty, and a vigorous grower. Shoots upright, olive colored. It was raised from seed, in 1808, by M. Liard, gardener at Mons.

Fruit pretty large, obtuse pyriform, clear green at first, but beeoming pale yellowish green at maturity. Stalk varying from half an inch to an in ellong, pretty stout, set in a slight depression or under a swollen lip. Calyx set in a basin of moderate depth. Flesh white, melting, juicy, sweet, sprightly. Good. September.

\section{Napoleon Sartinien.}

This is a new French variety, resembling Napoleon in appearance but maturing later in the season.

Fruit medium, obovate acute pyriform, yellow, partially netted and patched with russet, and thickly sprinkled with russet dots. Stalk short. Calyx large, open. Segments reflexed. Basin large, uneven. Flesh whitish, rather coarse, juiey, half melting. Good. January.

\section{Naumikeag.}

A native of Salem, Mass.

Fruit nedium, roundish. Skin yellow russet. Flesh juicy, melting, but rather astringent in flavor. Good. October.

\section{Navez Peintre.}

Fruit medium, ovate, yellowish green, with brownish red in the sun, and bands of brown russet. Calyx open. Flesh yellowish, multing, juicy, liquant, sugary. Last of September. (Hogg.) 


\section{Negley:}

This is supposed to be a seedling originated near Pittsburgh, Pa. Introduced by J. S. Negley. Tree vigorous, upright, and an early bearer. Joung wood reddish brown.

Fruit medium or above, obovate obtuse pyiform, waxen yellow, slightly netted with russet, beautifully shaded with bright crimson in the sum, and thickly spriukled with minute brown russet dots. Stalk mediun. Cavity deep, regular. Calyx open. Segments persistent. Basin shallow, a little russeted. Flesh white, a little coarse, juicy, halfmelting, sweet, pleasant, slightly aromatic. Good to very goorl. Early Sejtember.

\section{Ne Plus Meuris.}

This is a Belgian Pear, one of Dr. V'an Mons' seedlings, named in allusion to Pierre Menris, his gardener at Brussels. The tree grows upright, has short-jointed, olive-colored shoots.

Fruit medium or rather small, roundish, usually very irregular, with swollen parts on the surface, dull yellowish brown, partially covered with iron-colored russet. Stalk quite short, set withont depression, in a small cavity. Flesh yellowish white, buttery, with a sugary and agreeable flavor. Good. January to Mirch.

\section{New Bridge.}

Fruit below medium, pyriform, dull gray, covered with gray russet brown in the sun. Flesh melting, a little gritty, a sngary juice without flavor. October. (Lindley.)

\section{Newhall.}

Raised from seed by Thaddeus Clapp, Dorchester, Mass. Tree hard5, healthy, and prolific. Young wood quite reddish.

Fruit large, obtuse pyriform, inclining to oval. Surface a little meven, yellow at maturity, with a few traces or blotches of russet, sometimes a blush cheek in sun. Stalk inserted without much cavity Calyx small, partly closed, set in a corrugated basin. Flesh melting, very juicy, buttery, and tender, sweet, with a musky aroma. Very good. October. (Jomm. of Hort.)

\section{NewTOWN}

\section{Newtown Seedling.}

Originated at Newtown, Loug Isiand.

Fruit medium, roundish obovate, lemon yellow, netted and patched with russet. Flesh whitish, rather coarse, half melting, sweet, and pleasant. Good. September.

\section{Nickersor.}

This variety originated in Readfield, Me., from seed planted by ex-Governor Huntoon.

Fruit large, oblong pyriform, greenish yellow, with a dull red cheek in sun. Flesh white, juicy, melting, vinous, swcet. Good. October. 


\section{NIELI.}

Beurró Niell.

Poire Niell.
Colmar Bose.

Fondante du Bois, incorrectly.

Colmar Niel.

A large and handsome Belgian variety, raised by Van Mons, from seeds sown in 1815, and named in honor of Dr. Niell, of Edinburgh, a distinguished horticulturist and man of science. The tree bears plentifully.

Frnit large, obovate, inclining to pyriform, rather shortened in figure on one side and enlarged on the other, tapering to the stalk, which is about an inch long, obliquely planted, with little or no cavity, pale rellow, delicately marked with thin russet, fiuely dotted, and sometimes marked with faint red. Flesh white, buttery, sweet, with a plentiful and agreeable juice. Good to very good. Last of September.

\section{NiLES?}

A foreign variety, imported by John M. Niles, Hartford, Conn. The original name having been lost, it has not yet been identified. Young wood whitish gray.

Fruit large, ubtuse pyriform. Color yellow at maturity, thickly eovered with russet dots. Stalk long, inserted in a deep, abıupt, uneven cavity. Calyx closed, set in a deep roumd basin. Flesh juicy, buttery, sweet, and pleasant. December. (Ad. Int. Rep.)

\section{Nonpareil.}

A seedling raised by Judge Livingston, of New York. Tree vigorous, productive.

Fruit small, roundish oblate, russety yellow, specked with red. Flesh fine, melting, sugary, juicy, rich vinous. December. (Hov. Mag.)

\section{Notarie Minot.}

One of Van Mons' seedlings. Tree vigorous and productive.

Fruit medium, obtuse pyriform, greenish yellow, mostly overspread and shaded with red in sim, and bright fawn russet in shade. Stalk slender. Cavity rather deep, narrow. Flesh yellowish white, melting, juicy, sweet, perfumed. November. (Alb. Pom.)

\section{Nouveau Porteau.}

Tombe de l'Amateur. Choix d'un Amateur.

A seedling of Van Mons', a very vigorous grower, forming a beautiful pyramil; very productive. Young wood brownish red. An early bearer.

Fruit large, obovate, inclining to pyriform, green, with numerous russet dots, and sometimes patches of russet. Stalk rather short, curved, inserted in a small eavity. Calyx partially elosed, set in a narrow basin of moderate depth. Flesh whitish, buttery, juicy, melting, with a sugary, vinous, and vory refreshing flavor. Good to very good. Ripo November. 


\section{Nouvelle Fulvie.}

Fulvie Grégoire.

This new Belgian Pear is described in the Annals of Pomology as :-

Fruit very large, pyriform. Surface uneven, rich light yellow, shaded and marbled with brown red in the sun, and an occasional fawn russet patch. Stalk stout, inserted as it were by a neck. Calyx large, in a round, regular basin. Flesh yellowish white, melting, buttery, juicy, sweet, with an exquisite perfume. January and February.

As we have received and fruited this Pear it is only of mediun size, roundisl, slightly pyriform, and ripens in November.

\section{OAK-LEAVED IMPERIAL.}

Imperial.

Imperial Oak-leaved.
Impériale à feuilles de chêne.

Oak-leaved Imperial.

An old Pear, of unknown origin and of little ralue, except as a curiosity, from its peculiar foliage somewhat resembling the oak.

Fruit below medium, ovate pyriform, deep green, with some nettings and patches of russet. Flesh whitish, half melting, juicy, sweet. Good. December to March.

\section{OAkley Park Bergajotte.}

One of Knight's seedlings. It is described by the London Horticultural Society as :-

Fruit medium sizt, roundish obovate, greenish yellow, with some russet. Flesh buttery, melting. October.

Euf.

Fruit small, oval, greenish yellow, with light red in the sun, and gray russety dots. Stalk long. Calyx small, open. Flesh whitish, tender, melting, sweet, musky. Ripe in August, and will keep three weeks without decaying. (Hogg.)

\section{OKEx.}

Oken d'Hiver

Winter Oken.
Cent Couronnes.

Beurré Oken.

A Belgian Pear, of little value.

Fruit medium, roundish oblate, yellowish, with a little brown in sun. Flesh white, juicy, melting, slightly vinous. Hardly good. October.

\section{Oliver's Russet.}

Originated in the grounds of - Oliver, Lynn, Mass.

Fruit below medium, roundish, cinnamon russet on sellow ground, with a blush. Stalk in a cavity. Basin small. Flesh whitish, cosrse, without much flavor. Last of September.

\section{Olivier de Serres.}

Originated with M. Boisbunel, Rouen, France. Tree rigorous, 
rather spreading, and very productive. Young wood slender, rich yel. low brown. A new sort, reputed of first quality in France. It has not yet fruited here.

Fruit medium to large, irregular in form, generally roundish. Deep yellow, with shade of rough musset, and many reddish russet dots in sum. Flesh white, fine, melting, rich, juicy, sweet, delicate perfume February, March. (V erg.)

\section{ONEIDA.}

Origin, Western New York.

Fruit medium or below; roundish, pale yellow, partially netted and patched with light russet. Flesh white, coarse, juicy, half melting, pleasant. Good. September.

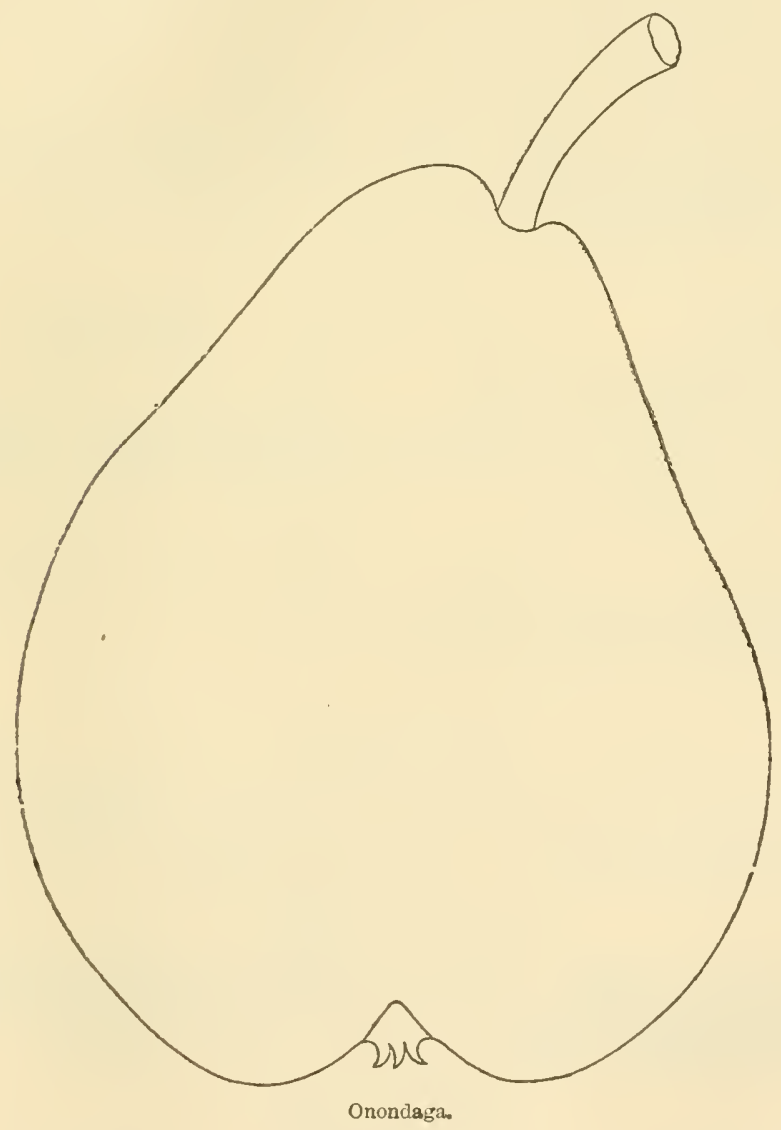

ONONDAGA.

Swan's Orange.

Kilmer.

Supposed to have originated in Farmington, Conn. Tree very vigo- 
rous and productive. Young wood olive brown. A profitable market variety.

Fluit large, ovate obovate obtusely pyriform. Skin somewhat course and uneven, thickly covered with russet dots, fine rich yellow at maturity, generally with some traces of russet, and sometimes with a sumny cheek. Stalk rather stout, of medium length, inserted in a small eavity, at an inclination. Calyx small, firmly closed, set in a narrow, somewhat nneven basin. Flesh buttery, melting, abounding in juice, slightly granular, and when in perfection with a fine, rich, vinous flavor. A variable fiuit. Good to very good. September to November.

\section{ONTARIO.}

Origin, Geneva, Ontario Co., N. Y. Tree vigorous and prorluctive. Young wood light yellow, a shade of red next the buds.

Fruit medium, oblong ovate pyriform, pale yellow, thickly dotted with minute brown and green dots, and slightly netted with russet. Stalk long, inserted in a small cavity, with a ring or lip. Calyx open, with long recurved segments. Flesh whitish, slightly veined with yellow, melting, juicy, buttery, slightly granulous, sweet. Good to very good. Last Neptember.

\section{Orange.}

Red Orange.

Orange d'Automne.

Orange Rouge.

An old variety of little value.

Fruit medium, nearly globular, pale yellow, with a few traces of russet and brown dots. Flesh white, laalf melting, sweet. Early September.

\section{Orange Berganotte.}

Fruit medium, obovate pyriform, yellow. Flesh firm, rather acid for eating, but excellent for baking. September.

\section{Oraxge D'HuVer.}

\section{Winter Orange.}

Fruit medium; an old Pear, very productive; not desirable for table, but a good baking Pear. November, December.

\section{Orange Maxdarine.}

Fruit about medium, roundish, golden yellow, with many brown russet dots, and a warm glow on the side next the sun. Flesh yellowish, very tender, melting, acidulous, sugary. October. (Hogg.)

\section{Orayge Mugquée.}
Orange Musk.
Musk Orange.
Orange d'Été.

Fruit medium, round, yellow, marbled and shaded with red in tho sun. Flesh breaking, with a musky juice. Good. Last of August. 


\section{Oraxge T'Ulupée.}

Poire aux Mouches.

Striped Orange.
Tuliped or Fly-Pear.

Great Orange.

Fruit pretty large, oval pyriform, green, shaded in sun with brown. ish red. Flesh melting, juice agreenble. Soptember. (Lind.)

\section{Orpheline Colmar.}

One of Tan Mons' Belgian Pears, as yet little known in this country. Tree vigorous, very fertile. Young wood dull olive brown.

Fruit very large, priform, bright green, somewhat yellow, dotted with grar, brown, and black, and shaded with russet, fawn on the sumny side, and around the calyx and stem. Flesh whitish yellow, fine, melt. ing, a little granular around the core, juicy, sweet, and perfumed. October. (An. Pom.)

\section{Osband's Summer.}

Osband's Favorite.

Summer Virgalieu.

Origin, Wayne Comnty, N. Y. Tree moderately vigorous, upright, an early and prolific bearer. Young wood rich vellow brown.

Fruit small, roundish ovate obovate pyriform, clear yellow, thickly dotted with small greenish and brown dots, with a warm cheek on the side of the sun, and some traces of russet, particularly around stalk and calyx. Stalk of mediun length, rather strong, inserted in an abrupt cavity. Calyx open, set in a broad, shallow basin. Flesh white, juicy, melting, with a rich sugary flavor and pleasant musky perfume. Very good. Ripens early in August.

\section{OSBORNE.}

Origin, Economy, Ind. Productive and a free grower.

Fruit medium, short pyriform, yellowish green, with numerous gray dots. Stalk rather long. Basin broad and shallow. Calyx partially closed. Flesh white, juicy, brisk, vinous. Hardly good. Midlle of Sep tember.

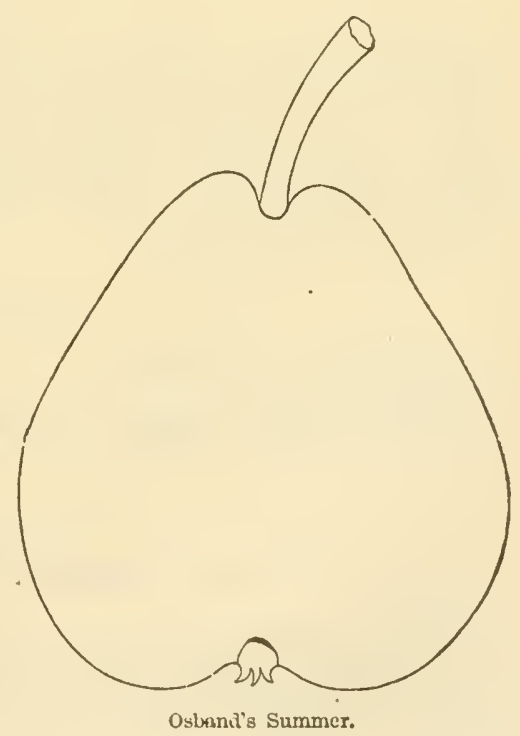

\section{Oswego Beurré.}

Read's Seedling.

Paised by Walter Read, of Oswego, N. Y. Tree vigorous, hardy, and productive. Toung wood olive yellow. 
Fruit medium, oblate, sometimes inclining to conic, yellowish green, streaked and mottled with thin russet, but becomes a fine yellow. Stalk rather short, inserted in a deep, round eavity. Calyx elosed, set in an even, shallow basin. Flesh buttery, juicy, melting, with vinous, aro uratic flavor. Good to very good. October, November.

\section{Oswego Tycomparable.}

Originated at Oswego, N. Y. Tree very vigorous.

Fruit rather large, obtuse obovate pyriform, yellow, slightly netted and patched with russet, a tinge of erimson in the sum, and many russet dots. Flesh whitish, juicy, half melting, sweet, pleasant. Good. September.

\section{OTr.}

A seedling of the Seckel; originated with Samuel Ott, Montgomery Co., Pa. Tree moderately vigerous, very produetive. Young wood reduish olive-brown.

Fruit small, roundish obovate, greenish yellow, partially netted with russet, reddish on the sumny side. Stalk long and curved, inserted in a slight depression. Calyx open, in a round, open basin. Flesh melting, sugary, rich, perfumed, and aromatic. Ripe middle of August. An excellent little pear, somewhat variable. Good to very good.

\section{OTt's SEEDLiNG.}

Originated by Dr. W. D. Brinckle, from seed of the Ott. Tree moderately vigorous. Young wood reddish yellow brown.

Fruit small, globular obtuse pyriform, greenish, shaded with dull crimson in the sun, and thickly spinkled with green and light dots. Stalk stout, incliued in a slight depression by the lip. Calyx small, closed. Segments short. Flesh whitish, juiey, sweet, rich. Good to very good. Last of Angust.

\section{OWEN.}

Originated in the garden of John Owen, Cambridge, Mass. A fine cooking Pear.

Fruit medium, roundish oval, dark green. Flesh tender, delicious, finely colored. October to December. (Cole.)

\section{Paddock.}

Received of Chauncey Goodrieh, of Burlington, Vt. Tree vigorous, spreading.

Frnit rather below medium, oblong ovate pyriform, light yellow, sometimes with a faint blush. Stalk medium. Calyx in a rather broad, shallow basin. Flesh fine-grained, melting, sweet, but not rery high flavor. Good. Ripe last of July.

\section{Pailleau.}

A Belgian Pear of good quality, but rather coarse-grained.

Fruit medimm, turbinate, greenish yellow, with patehes of russet Flesh juicy, sweet. Good. Early in September. 


\section{Paradise D'Automine.}

Calebasse Bose.

Maria Nouvelle.

Princesse Marianne.

Faux Spreciew.
False Spreciew.

Marianne.

Calebasse.

Calebasse Prineesse Marianne.

A Belgian Pear, of uncertain origin. Tree very vigorous. Shoots long and twisting, dull reduish brown, thickly sprinkled with very conspicnous dots.

- Fruit large, oblong obovate acute pyriform, yellow, mottlerl, and often entirely orerspread with bright cinnamon russet. Surfaco

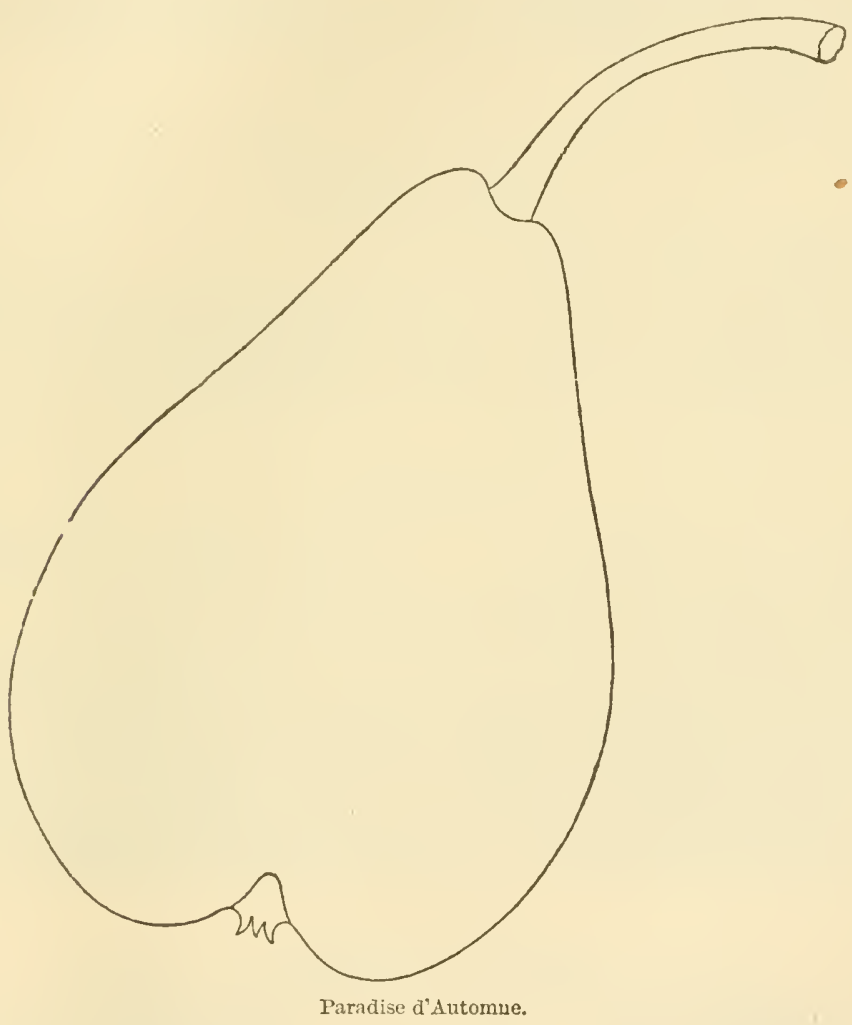

uneren. Stalk long, enlarged at both enrls, and inserted without much cavity, often by fleshy wriukles or folds. Calyx open. Basin abrupt, and sturounded by prominences. Flesh moderately fine, sometimes slightly granular, juicy, melting, with a rery rich vinous, aromatic flavor. Very good. September, October.

\section{Pardee's Seedling.}

Raised by S. D. Pardee, New Haven, Comn. Tree vigorous, very prorluctive. Young shoots slender, grayish red brown. 
Fruit small, roundish, greenish yellow, ehiefly covered with russet. Stalk nuedium. Cavity large, deep. Calyx open. Basin furrowed. Flesh eoarse, granular, buttery, juicy, melting, vinous, slightly aromatic. Good to very good. Oetober.

PARfun D'Aốt.

Perfumed.

August Perfume.

An'old sort, of little value.

Fruit small, pyriform, light yellow, deep red in the sun, with many dark yellow dots. Flesh white, rather coarse, musky, juicy. Hardly good. August.

\section{Parfun de Rose.}

A Belgian variety, of little valne.

Fruit small, oblong ovate acute-pyriform, yellow, nearly covered with light russet, and with numerous brown and gray dots. Flesh yellowish, moderately juicy, half melting, sweet, pleasant. Oetober.

\section{Parsonage.}

Origin, New Rochelle, N. Y. Tree a fine healthy grower, produces large crops of perfect fruit annually, making it, although not of first quality, a profitable market sort. Young wood dull olive brown.

Fruit medinm or large, obovate obtuse priform, often inclined, orange yellow, rough, generally shaded with dull crimson, netted and patched with russet, and thickly sprinkled with russet dots. Stalk short and thick, fleshy at its jumction, inserted in a small cavity, russeted. Calyx partially open, stiff, set in a shallow, slightly russeted basin. Flesh white, slightly coarse, somewhat granular, juicy, melting, with a refreshing vinous flaror. Good. Ripe all of September.

\section{Passans du Portugal.}

Summer Portugal.

Miller's Early.

Butter of Michigan.
Poire Chenille.

Chenille.

A delicate and pleasant. Pear, which comes early into bearing, and produces very large crops. Shoots grayish recldish brown.

Fruit small, roundish oblate, pale yellow, with a cheek of fairest brown, becoming red in the sun. Stalk nearly an inch long, inserted in a round, regular hollow. Calyx stiff. Basin moderately sunk. Flesh v lite, juicy, breaking, of very delicate, agreeable flavor. Ciood. Last of August. 
Passe Colmar.

Ananas d'Hiver.

Passe Colmar Epineaux.

Colmar fixis.

Passe Colmar Gris

Benrú Colmar Gris, dit préeel.

Précel.

Fondante de Mons.

Beurré d'Argenson.

legintin.

Colmar IIardenpont.

Présent de Malines.

Marotte Sucrée Jaune.

Sourcraine d'Hiver.

Colmar Sonveraine.
Gam!ier.

Cellite

Colmar Preule.

Pucelle Condésienne.

Bergentin.

Colmar Epineanx.

Beuré Chapman.

Chapman's.

Colmar Bonnet.

Passe Colmar Vineux.

Colmar de Silly.

Prenl.

Impératrice.

Souveraime.

The Passe Colmar is a Belgian Pear, raised by the Comsellor Jlar. denpont. Vigorous growth, and abundant bearer. It grows indeed almost too thriftily making long bending shoots, and owing to this overluxmiance the fruit is often seeond-rate on young trees, but on old trees, with high eultivation, it is sometimes of the best quality. It is a very variable fruit, and often poor. The young shoots are of a dark olive yellow brown.

Fruit rather large, varying considerably from obovate to obtuse pyriform. Skin rather thick, yellowish green, becoming yellow at matuity, a good deal sprinkled with brown russet, especially aronnd the stalk and ealyx. Stalk an inch and a lualf long, inserted in an obtuse, meven carity, or sometimes without depression. Calyx open. Basin shallow. Flesh yellowish white, buttery, and juicy, with a rich, sweet, aromatic flavor. Good to very good. Decenber, January.

\section{Passe-Colmar Musqué.}

\section{Colmar IIusqué. Passe-Colmar Musqué d'Automne.}

Raised by Major Esperen of Malines.

Fruit medimm size, varying from roundish oblate to roundish ovate pyriforn, greenish yellow, netted and patched with russet, and thickly sprinkled with green and brown dots. Stalk rather short. Calyx small, partially elosed. Basin shallow, uneven. Flesh white, very buttery, juicy, melting, pleasant perfumed. Good. October.

\section{Passe Crassixe.}

Surpasse Crassane.

Neue Crassane.

Originaterl in France. Tree moderately vigorous. Young woot yellow olive brown.

Fruit medimm, obtuse pyriforın, yellow, with slight nettings and patches of russet, and thickly sprinkled with russet dots. Stalk long, rather stout, inclined. Cavity metium. Calyx small and closed. Basin abrupt, uneven. Flesh yellowish, gritty near the core, juicy, melting, slightly vinous. Good. December, January.

\section{Passe Tardive.}

One of Major Esperen's seedlings.

Fruit molium, oborate acute pyriform. Surface uneven, pale yel 
low, tinge of red in the sum, and thickly sprinkled with gray brown dots. Stalk stout, Heshy at insertion, and without cavity. Calyx open Flesh white, juicy, breaking, sweet, pleasant. Good. January to Mărch.

\section{Pater Noster.}

Paul Thielens, erroneously.

An old variety, of which the origin appears unknown. It was in Tan Mons' catalogue in 1823.

Fruit large, variable in form, from obovate obtuse pyriform to irregular obovate acute pyriform, greenish yellow, mottled and shaded in sum with red, netted, patched, and dotted with russet brown. Stalk stout, nsinally planted with a lip. Basin shallow, uneven. Flesh white, juicy, melting, slightly vinous. Good to very good. October, Novem. ber.

\section{Paul Amire.}

The origin of this Belgian variety is unknown.

Fruit medium, roundish or roundish oval, pale greenish yellow, often shaded and mottled with crimson in the sun, sometimes netted with russet, and thickly sprinkled with russet brown dots. Stalk medium, set in a small cavity. Calyx large, open, with long, broad, recurved segments. Basin shallow, smooth. Flesh whitish, juicy, buttery, melting, sweet. Cood to very good. October.

\section{Paul Thielens.}

One of Tan Mons' seedlings, first fruited in 1844. Tree vigorous and productive. Young wood olive yellow brown.

Fruit medium or below, roundish oblate, pale yellow, slightly netted and patched with russet, and sprinkled with russet dots, light shade of crinson in the sun. Stalk medium length, pretty stout. Cavity broad, irregular. Calyx small. Segments persistent. Basin small, abrupt, uneven. Flesh whitish, coarse, juicy, melting, a little astringent. Good. October.

\section{Payenche.}

Poire de Payency.

De Périgord.

Payenchi.
Paquency.

Payenchi de Périgord.

Pasency.

This Pear was first discorered in the village of Parenche, in 1830 . Tree a moderately vigorous grower and an early bearer.

Fruit medium size, oblong ovate prriform, light yellow, with a rich warm red cheek in the sun, much netted and specked with rongh russet. Stalk stout, curved, often a little inclined, and set with a scarcely per. ceptible cavity. Calyx rather large, open. Basin small, abrupt. Flesh yellowish white, a little coarse, melting, iriey, sweet, slightly aromatic Good to very good. October. 


\section{PENII PEAR.}

Poire Pìche. Peach. Ifirsichbirne.

A seedling of Esperen, of moderate growth and productive. Young wood dult redelislı brown.

Fruit medium, obovate prriform, greenish vellow, netted and patched with russet, and thickly sprinkled with russet dots. Stalk rather long, curved, fleshy at insertion, by a lip: Calyx partially open. Basin small, uneven. Flesh whitish, juicy, melting, brisk, rinous, sometimes astringent. Good. August.

\section{Penbertox.}

General Banks.

Originated with S. A. Shurtleff, of Boston, Mass.

Fruit medium size, roundish, obtuse at the stem, nearly smooth, yellowish green, shade of red in the sun, and dotted with greenish specks. Stalk short, stout. Calyx large, open. Basin shallow, ribbed. Flesh yellowish white, fine, melting, jucy, with a rich bergamot aroma. Early september. (Hov. Mag.)

\section{Penderson.} bearer.

Raised by Samuel Penderson, of New Haven, Conn. Tree a great

Fruit medium, roundish, greenish yellow. Flesh white, crisp, half melting, brisk, somewhat astringent. Good. October.

\section{Pexdletox's Early York.}

Raised by Mrs. Jeremiah York, of Pendleton Hill, Conn. Tree noderately vigorous, and very produetive.

Fruit medium or below, obovate, varying to obtuse pyrifor'm. Skin vellow, sometimes with a faint blush, a few patches and traces of russet, and many green and brown dots. Stalk inserted in a moderate ca:ity, Calyx, open. Basin irregular. Flesh white, not melting, sweet, slightly perfumed. Good. liipens last of July.

\section{Pexgethly.}

One of Mr. Knight's seedlingss.

Fruit medium, inclining to oval. Stalk long, rather slender. Calyx large. Segments quite long and narrow. skin light green, thickly sprinkled with dark dots, yellowish on the side of the sun, sometimes a red elleek. Flesh somewhat conse, but juicy, sweet, and good. February, Miu'ch. (Robert Mamning's MS.)

\section{Pexs.}

Fraser or Butter Pear.

Railroad Fuss.

A variety originated in Bordentown, N. J., near the old Penn Manor, hence the name. Tree vigorous, "uright, an ammul bearer.

Fruit medium, oblate, sometimes roundish oblate, pale lemor 
yellow, thickly sprinkled with small grayish and russet dots, and some. times a few patches and dots of russet around the calyx. Stalk rather stont, enlarged at insertion. Cavity slight, meven. Calyx open. Seg ments short, erect. Basin slightly furrowed. Flesh white, a little coarse, jucy, melting, sweet, pleasant, slightly aromatic. Good to very good. October.

\section{Pexpeluania.}

Smith's Pennsylvania.

The Pemnylvania is a seedling originated by J. B. Smith, Esq., of Philadelplia, a well-known amatem.

Fruit of nedium size, roundish obovate, brown russet, nearly covering a dull yellow ground, and becoming russet red on the sumy side. Flesh yellowish white, not very fine-grained, juicy, half melting, sweet, perfumed, musky flavor. Hardly good. Middle and last of September.

\section{Perpetuat.}

Origin, Long Island, N. Y. Tree vigorous.

Fruit medium, obovate obtnse pyriform, greenish yellow, slight tinge of red in the sum. Flesh whitish, firm, mocterately juicy. A good cook. ing Pear. Keeping to May.

\section{Peters.}

Raised in 1848, by Rer. Absalom Peters, of Williamstown, Mass. Tree vigorous grower, and an anmul abundant bearer.

Fruit medium, roundish obovate obtuse pyriform, greenish vellow, shaded with brownish red in the sun. Flesh white, coarse, moderately juicy, half melting, sweet, pleasant. Good. Augnst.

\section{Perré.}

An American Pear. The original tree is growing in that interesting place, the old Bartram Botanic Garrlen, near Philatlelphia. The tree is not a rapicl grower, but produces very regular and abundant crops. Young wood slender, yellowish brown.

Fruit of medium size, or rather large obovate, pule yellow, sometimes marked with greenish russet, and sprinkled with russet about the eye. Stalk stiff and strong, about an inch long, stont at the lower end, and set in a peculiar, abruptly fiattened cavity. Calyx small, set in a narrow but smooth basin. Flesh whitish, fine-grained, buttery, and very melting, with a perfumed, slightly musky, high flavor. Good to very good. October.

\section{Philadelphita.}

\section{Latch. Orange Bergamot, erroneonsly.}

Origin, near Philadelphia. Tree healthy, vigorous. Young shoote light yellowish brown, productive. Fruit sometimes cracks.

Fruit large, roundish obtuse priform, yellow, thickly sprinkled with green or gray dots, sometimes netted with russet. Stalk of mediux 
length, stout at its insertion, in an abrupt eavity. Calyx open, set in a broad, uneren basin. Flesh contse, juiey, buttery, melting, with a sugary flavor, slightly perfumed. Good. Śeptember.

\section{Pinluppe Goes.}

A Belgian variety, much resembling Baronne de Mello. Tree vigorons and productive. Soung wood dark olive brown.

Fruit small to medim, romelish acute pyriform, yollow, covered with brownish russet. Stalk long, eurved, fleshy at insertion. Calyx small, partially closed. liasin small. Flesh whitish, melting, juiey, rinous, slightly aromatic. Good to very good. September.

\section{Picciola.}

Of Belgian origin. Tree vigorous, spreading, productive. Toung woorl reddish yellow brown.

Fruit small, romdish oblate, greenish yellow, sometimes a slight blush in sun, and traces of russet. Stalk long, eurved, set in a carity somewhat furnowed. Calyx small, open, with short, ereet segments. Flesh whitish, rery juiey, melting, with a vinous flavor. Guod to very good. September.

\section{PiE IX.}

A Belgian Pear, quite variable in quality, but almost always smooth and handsome. 'lree vigorous. Young wood olive yellow brown.

Fruit above medimm, romdish acute pyriform, slightly inclined, yellow, netted and patched with russet, espeeially at each end, and thickly sprinkled with russet dots. Stalk stont, joined insensibly as it were to the fruit. Calyx open. Segments short, persistent. Basin broad, shallow. Flesh white, a little firm, juicy, melting, brisk, vinous. Good to very good. September, October.

\section{Pixneo.}

$\begin{array}{ll}\text { Boston. } & \text { Early Denzelona. } \\ \text { Graves. } & \text { Hebron. } \\ \text { Silliman's Russet. } & \text { Lebanon. } \\ & \text { Summer Virgalien. }\end{array}$

An old Ameriean variety, said to have originater in Columbia, Tolland Co., Conn. Tree a morlerately vigorous grower, a good bearer. Young woorl light rerldish brown.

Fruit below medium, roumdish oblate, slightly pyriform, pale yellow, netted, patched, and dotted with russet, and often a warm red eheek in sun. Stalk rather long, nearly straight, sometimes curved. Cavity medium or small. Calyx partially open. Basin broad. Flesh white, fine, juiey, melting, sweet, pleasant. Guod. Last of August.

\section{Pitmastox Duchesse D'Angoulême.}

This is the unfortunate name given to a Pear raised by Joln Wil liams, of I'itmaston, England. Tree vigorous.

Fruit very large, oblong obovate, yellow, with light russet near the stalk. Jlesh yellowish white, melting, buttery, juicy. October, Novenber. (Gard. Chron.) 


\section{PitT's Prolific.}

Pitt's Surpasse Marie.

Surpass Muria Louise, incorrectly.

An English fruit of melium size, oblong pyriform. Skin yellow, a little russeted. Flesh juicy, soft, sweet, rather coarse, and of indifferent quality. September.

\section{Plantagenet.}

A new Belgian Pear. Young wood redclish yellow brown.

Frnit medium, pyriform, greenish yellow, netted, patched, and dotted with russet. Stalk long, slender, set in slight cavity, with a lip. Calyx open. Segments partially recuved. Flesh whitish, juicy, melting. Good to very good. November.

Platt.

Plact's Seedling.

Origin on the farm if the late Thomas Tredwell, Beckmantown, ( linton Co., N. Y. Tree vigorons, hardy, and produstive. Young wood grayish redılish brown, with many specks.

Fruit medium, roundish, inregular oblate, pale yellow, netted and patched with russet and sprinkled with russet dots. Stalk medium. ('alyx small, closed. Flesh whitish, juicy, buttery, half melting, pleasilnt. Good. October.

\section{Pocahontas.} brown.

Origin, Quiney, Mass. Tree moderately vigorous. Young wood olive

Fruit below medium, obovate pyriform, yellow, netted, patched, and lotted with russet, sometimes shaded in the smm with bright crimson. Stalk rather long, stout, set withont carity by a lip. Calyx open. Basin small, slightly russeted. Flesh white, juicy, melting, sweet, slightly musky, pleasant. Good to very good. September.

\section{Pollax.}

A Pennsylrania Pear.

Fruit below medium, nearly globular, greenish yellow, with a shade of brown in the sum. Flesh whitish, a littlc coarse, moderately juicy, vmous, pleasant. Good. August.

\section{POPE'S QUAKER.}

Origin, Long Island, N. Y.

Fruit very fair, middle-sized, oblong pyriform, smooth, yellow rus. set, juicy, melting, and pleasant. Hardly good. October.

\section{Pope's Scarlet Major.}

Origin, Long Island, N. Y.

Fruit rather lar ce, obovate, yellow, with a bright red cheek. Flesh wlite, breaking, and rather dry. Poor. Last of August. 
Pouxd.

Uredale's St. Gezmain.

Winter Bell.

Bretingne le Cour.

Belle Angevine.

Belle de Jersey.

Du Tonneau.

Royal d'Angleterre.

Beauté de Tervueren.

Pickering Pear.

Lent St. Germain.

Cortelier.

Anderson.

Ansora ?

D'Horticulture.

Berthebirn.

Bolivar.

Faus-Bolivar.
Bolivar d'lliver.

Comtesse de Terweuren.

Duchesse de Berry d'Hiver

Gros fin or long d'Hiver.

Union.

Grosse de Bruxelles.

La Quintinye.

Grosse Dame Jeanne.

Louise Bonne d'Iliver.

Bellissime d'Hiver, du Bur.

Abbé Mongein.

Chamber's Large.

Dr. Udales Warden.

German Baker.

Pickering's Warden.

Piper.

The Pound, or Winter Bell Pear, valued only for cooking, is an abundant bearer, and a profitable orchard crop. The trees are strong and healthy, with very stout, upright, dark-colored wood.

Fruit large, pyriform, swollen at the crown, and narrowing gradually to a point at the insertion of the stalk. Skin yellowish green, with a brown cheek (yellow and red when long kept), and sprinkled with numerous brown russet dots. Stalk two inches or more long, stont, bent. Calyx crumpled, set in a narrow, slight basin. Flesh firm and solid, stews red, and is excellent baked or preserved.

\section{Prairie de Pond.}

Introduced by A. H. Erust.

Fruit small, nearly globular, greenish yellow, with many brown and green dots. Flesh whitish, moderately juicy, half melting, vinous, astringent. Poor. September.

\section{Pratt.}

A native of Rhode Island. Tree a vigorous upright grower, very productive. Young wood olive brown.

Fruit medium, obtuse pyriform. Skin greenish yellow, sharled with crimson, and sprinkled with numerous russet and conspicuous dots, frequently patched and netted with russet. Stalk long, slender, curved, inserted in a regular cavity. Calyx open, set in a broad, shallow basin. Flesh white, juicy, melting, briskly vinous, and saccharine, variable, hut when in perfection of great excellence. Good to very good. Ripens last of september.

\section{Precilly.}

A Belgian Pear. Tree very vigorous, productive.

Fruit medium to large, oborate acute pyriform, greenish yellow, netted roud patched with russet, and sprinkled with brown dots. Elesh yellowish white, coarso, juicy, breaking. Good for cooking. Os. tober. 


\section{Prémices de Wagelwater.}

Fruic below medium, roundish obovate pyriform. Sides unequal Skin vellow, a few traces of russet, and thickly sprinkled with browr dots. Stalk long. Calyx open. Flesh whitish, juicy, melting, very sweet. Good to very good. October.

\section{Presidents.}

Raised by Dr. S. A. Shurtleff, Brookline, Mass., and first clescribed in the New England Farmer, 1862.

Fruit very large, roundish obovate, somewhat irregular. Skin slightly rough, greenish yellow, pale red in the sim, considerable of russet next the base of stalk, and traces of russet and conspicuous russet dots over all. Stalk short, rather stout. Calyx medium, with short, stiff, closed segments. Basin medium. Flesh yellowish white, rather coarse, juicy, slightly vinous. Good. Early Norember.

\section{President Felton.}

Originated with Dr. W. D. Briuckle. Tree moderately vigorous. Young wood olive yellow brown.

Fruit medium, roundish oblate, pale yellow, with a crimson cheek in sm, nettings, traces of russet, and many brown and gray dots. Stalk short. Calyx open. Flesh fine, juicy, yellowish, half melting, slightly vinous, sweet. Good. October.

\section{President Mas.}

A new Belgian variety.

Fruit large, oblong obovate obtuse pyriform. Skin greenish yellow, with some patches and traces of russet. Flesh yellowish white, fine, juicy, melting, buttery, sweet. December, Jamuary. (Transom's Cat.)

\section{Prevost.}

\section{Poire Prercst.}

A French Pear. Tree vigorous, very productive. Ioung wood stout, olive yellow brown.

Fruit medium size, obovate pyriform. Skin pale yellow, with a tinge of red in the sme, and thickly sprinkled with minute brown dots. Stalk medium length, moderately stout. Calyx open. Flesh white, a little coarse, juicy, breaking, sweet, and pleașant. Good. February.

\section{Prince Albert.}

One of Van Mons' late seedlings. Tree rery vigorous. Young wood olive yellow brown.

Fruit rather large, oblong oborate pyriform. Skin yellow, some. times brownish yellow in the sun, nettings and patches of russet. Calyx 
open. Flesh yellowish, juicy, valuable as a cooking pear. December to March.

\section{Prince de Joinville.}

A Belgian Pear, first fruited in $18 t 8$.

Fruit medium, roundish, greenish yellow, with a red cheek in sun, and more or less of shades and patches of fawn russet. Stalk slender. Cavity medium. Caiyx small, closed. Flesh yellowish white, half fine, melting, juicy, vinous, sweet, with a peculiar perfume. November. (Alb. Pom.)

\section{Prince Imperial de France.}

One of M. Grégoire's seedlings. 'Tree vigorous, irregular spreading, productive.

Fruit large, obovate ovate pyriform. Skin clear warm greenish yellow, becoming golden or brownish in sun, with small patches and dots of fitwn russet. Stalk medium. Cavity deep, acute, furrowed. Flesh white, slightly tinged with rose, melting, juicy, sweet, with an agreeable perfume. October. (An. Pom.)

\section{Prixce Napoleon.}

Introdueed by M. Boisbunel, Rowen, France. Tree moderately vigorous and very productive. Young wood dull brown, slightly reddisb.

Fruit meslium, roundish, slightly pyriform, dull greenish, much shaded with thin brown russet, and russet patches. Stalk short, stout. Flesh greenish white, fine, juicy, sweet, perfumed. December. (Verg.)

\section{Prince's Harvest.}

Raised by William Prince, of Flushing, Long Island, N. Y. Tree vigorous, upright, and productive. Young wood reddish yellow brown.

Fruit smald, ovate pyriform. Skin pale yellow, rarely a brownish blush, red cheek in sun, sprinkled with brown dots, and sometimes patched with russet. Stalk medium, fleshy at insertion, by a large liv and rings. Calyx open. Flesh white, firm, breaking, moderately juicy, sweet, slightly musky. Good. Last of July.

\section{Prince's Pear.}

\section{Poire de Prince. Cher Adame. Chair a Dame,}

An old variety, of unknown origin, and of little value.

Fruit small, lyriform, roundish, greenish yellow, mostly covered with dull reddish russet, with some gray specks. Flesh crisp, sweet, juicy. Last of August.

Prince's St. Germain.

Brown St. Germain.

New St. Germain.

Originated with William Prince, Flushing, Long Island, Tree a 
moderately vigorons grower, and an abundant bearer of fruit, in qualit very good, and possessing a good keeping character. Young wood dull redilish brown.

Fruit of medium size, obovate, inclining to oval pyriform. Skin nearly covered with brownish russet over a green ground, and bccoming

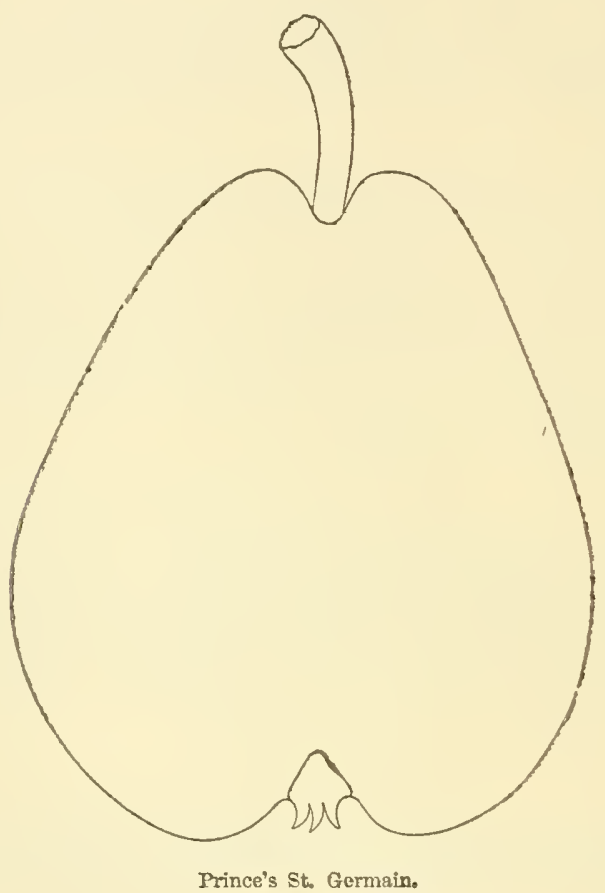

dull red next the sun. Stalk an inch or more long, a little curved, and placed in a medium uneven cavity. Calyx large, open, firm, and nearly without divisions, set in at smooth, nearly flat basin. Flesh yellowish white, juicy, melting, with a sweet, somewhat vinous, and very agreeable flavor. Very good. November to Lareh.

\section{Princess Charlotte.}

Raised by Major Esperen. A vigorous tree, productive. Young wood dull yellow brown.

Fruit mediun, oblate pyriform. Color greenish. Stalk stont and long in a slight cavity. Basin broad and shallow. Flesh yellowish pink ish at centre, melting, juicy, sweet, pleasant. Good. November.

\section{Princess Maria.}

One of Van Mons' seedlings. 
Fruit medium or below, ovate obovate pyriform. Skin yellow, considerably covered with rough dull russet, and thickly sprinkled with dots. Stalk long, sleuder. Calyx small, elosed. Flesh whitish, rather coarse, juicy, melting, vinous, aromatic. Gool. September.

\section{Princess of Orange.}

Princesse d'Orange.

Princesse Conquite.

A Flemish variety, raised by the Count Coloma, in 1802.

Fruit medium, roundish. Skin cinnimon russet in the shade, bright reddish russet in the sum. Flesh pale yellowish white, erisp, juicy, astringent. Poor. Oetober and November.

\section{Professeur Hennat.}

A new Flemish Pear. Tree vigorous and productive.

Fruit medium or above, ovate pyriform. Skin yellowish, mostly covered with warm reddish brown in sun, and dotted with munerous small and large dots. Stalk very short, inserterl, inclined, with a ring or lip. Flesh white, half fine, melting, juicy, sweet. December. (An. Pom.)

\section{Pulsifer.}

Raiser by Dr. John Pulsifer, of Hennepin, Tll. An upright and vigorous grower. Young wood light yellow brown.

Fruit small, obovate pyriform. Skin pale vellow, slightly netted and patehed with russet, and thickly sprinkled with russet brown dots, sometimes sharled with erimson in the sun. Stalk medium. Cavity small. Calyx partially open. Basin small, uneven. Flesh whitish, a little coarse, juicy, melting, slightly vinous. Good. August.

\section{Puvis St. Germain.}

\section{Saint-Germain-Puvis}

A French Pear, as yet little known in this country.

Fruit large, oblong obovate acute pyriform, dull green or greenish yellow, with nettings, patches, and specks of dull russet. Stalk stout, curved, set with a knob or lip. Flesh greenish white, fine, half melting, juicy, vinous, sweet. September. (Terg.)

\section{Queen of the Low Countries.}

Reine des Pays Bas.

A seedling of Van Mons'.

Fruit large, often very large, broad acute pyriform. Skin in the shade dull yollow, dotted and russeted around the eye, and overspread with fine dark red on the side next the sun. Flesh white, buttery, melting, and juicy, with a rich, subacid, vinous flavor. Tariable, sometimes poor. Early in October. 


\section{QUILLETETTE.}

An odd-looking, late antumu fruit, received from Van Mons.

Fruit nearly of medium size, roundish, a little flattened. Skin greenish, nearly covered with dull iron-colored russet. The flesh is white, buttery, and melting, sweet and perfumed. Scarcely good. November.

\section{Quins.}

\section{Knight's Seedling.}

This variety was imported by Prof. Mapes, and the name being lost when the fruit was shown before the American Institute Farmers' Club, it was newly christened as above.

The fruit is below medium size, acute pyriform. Skin inclined to golden russet. Flesh juicy. Good. January. (Hort.)

\section{Piallay.}

An old variety, of unknown origin.

Fruit small to medium, globular acute pyriform. Skin rongh, dull vellow, dnil reddish cheek, and over all spots of russet. Flesh yellowish white, breaking, juicy, gritty. Good. November, December: (Elliott.)

\section{Rapelje.}

Introduced by Professor Stevens, Astoria, Long Island. Tree vigorous and productive.

Fruit medium, obovate, sometimes obtuse, and sometimes acute pyriform. Skin yellowish, covered with cimmamon russet. Stalk long, rather thick, generally inserted by a lip. Calyx large and open, set in a very shallow basin. Elesh whitish, somewhat granular, juicy, and melting, with a sweet, vinons, aromatic flaror. Fariable, sometimes poor. september.

\section{Ravenswoon.}

Origin, Ravenswood, Long Island. Tree a rigorous grower, witi: grayish olive brown, young shoots.

Fruit small, obovate pyriform. Skin pale yellow, sometimes a tinge? of red in the sun, and thickly sprinkled with green dots. Stalk short, Calyx partially closed, with persistent segments. Flesh whitish, slight ly coarse, juicy, meiting, slightly vinous. Good to very good. Early August.

\section{RAYMOND.}

The Raymond is a native of Maine, and originated on the farm of D1. I. Wright, in the town of this name. Tree of slow growth. Toung shoots slender.

Fruit of medium size, obovate prriform. Skin yellow, marked with russet near the stalk, and tinged with a little red towards the sum, and thickly sprinkled with russet dots. Stalk an inch or more long, inserted with little or no depression. Calyx round, firm, open, set in a shallow basin. Flesh. white, buttery, melting, juicy, sweet, aromatic. (iooi to very good. Septemker. 
RiE.IDING.

Originated in Oley Township, Berks Co., Pa. Tree vigorous and productive. Young wood dull brown grayish, with conspicnous appa. rently rough dots.

Fruit melium to large, obovate pyriform. Skin yellow, thickly dotted with brown and gray dots and sprinkled with russet. Stalk long, curved, enlarged and ribbed at its insertion, generally in a depression. ('alyx open. Segments strong, in in exceedingly shallow basin. Flesh whitish, granular, melting, with a brisk, rinous llavor. Good. January to March.

\section{Red Berganot.}

$\begin{array}{ll}\text { Bergamotte Ronge. } & \text { Du Colombier. } \\ \text { Bergamotte Musqué. } & \text { De Sicile Musquée. } \\ \text { De Sicile. } & \text { Crassane d'Été. } \\ \text { Petit Museat d'Automne. } & \text { Bergamotte Dorée. }\end{array}$

A very old Pear, of little vilue.

Fruit below medimm, roundish, sometines obovate acute pyriform, pale yellow, mostiy orerspread with dull red in sun. Flesh soft, melting, juicy, sweet. "September.

\section{Ried Garden.}

Raised by Josiah Youngken, of Richlandtown, Pa. Tree a good grower and bearer.

Fruit medium, obovate pyriform, pale yellow, shaded and mottled with a few crimson dots in sun, netted and patehed with russet, and thickly sprinkled with brown dots. Stalk rather long, slender. Calyx partially open. Segments short. Flesh whitish, a little coarse, juicy, melting, sweet, pleasant. Good or very good. September.

\section{REGINE.}

(ine of Tan Mlons' seedlings.

Fruit medimm, roundish pyriform. Skin greenish yellow, with slight nettings of russet, and thickly sprinkled with green and brown dots. stalk long, inclined. Calyx open. Flesh white, juicy, melting, sweet, pleasant. Good. September.

\section{Rinine Caroline.}

A Europeau Pear, only fit for cooking.

Fruit of medium size, narrow pyriform. Skin yellow, with a brownish red cheek. Flesh white, cris]', rather diy and indifferent in quality. Norember.

\section{Reive D'Hryer.}

Fruit small, roundish oblate. Skin yellow, with a brownish tingo in sim, and nettings, patches, and dots of xusset. Flesh yellowish, juicy, melting, swert, pleasant. Good. November. 


\section{Reine des Poires.}

A French Pear, of ponr quality.

Fruit medium or abore, obovate pyriform. Skin pale yellow, shaded and mottled with crimson in the sun. Flesh white, coarse, breaking. not juicy. Scarcely good except for cooking. October.

\section{Reine Victoria.}

Supposed a seedling of Van Mons'.

Fruit medium, obovite acute pyriform, greenish yellow, with shades and patches of fawn. Flesh white, tinted with rose, tine, melting, juicy, sweet. December. (Alb. Pom.)

\section{Retour de Roye.}

One of Tran Mons' seedlings. Tree vigorous. Young wood reddisl brown, with oblong white specks.

Fruit medium, roundish obovate acute pyriform. Skin yellowish, blotched with russet, and thickly sprinkled with russat dots. Stalk short, and stout at its insertion in a small inclined cavity. Calyx partially closed, in a round narrow basin. Flesh whitish, coarse, granular, melting, juicy, with a rich vinous flavor, sligltly astringent. Good. September.

\section{Pegyaer Beernaert.}

One of Van Mons' seedlings. 'Tree vigorous.

Fruit medium, roundish pyriform. Skin golden yellow, dotted with red. Flesh melting, juicy, sweet. December: (Soc. V. M.)

\section{Richards.}

Origin, Wilmington, Del. Tree moderately rigorous. Young wood olive brown.

Fruit medium, obovate acute pyriform. Skin yellow, with nuinerous smali russet dots, and traces and patches of russet. Stalk of inedium length, curved, inserted by a fleshy ring in a slight depression. Calyx partially closed. Basin very small. Flesh buttery, melting: granulated, with a sweet, pleasant, vinous flavor. Good. Ripens first of October.

\section{Ridelle's.}

Poire Ritelle.

Tree of moderate vigor, productive.

Fruit medium, oblate turbinate, remotely pyriforn. Skin yellow. covered nearly all over with bright red. Stalk short. Calyx open. Flesh not very fine, rather juicy, uot melting or delicate in flaror Scarcely good. September. 


\section{Rivers' Winter Beurré.}

Winter Beurré (Rivers).

Raised by 'Thomas Rivers, England. Tree moderately vigorous, spreatling, an early and abundant bearer. Young wood dull yellow brown.

Fruit medium, roundish elongated pyriform. Skin greenish, rough. spotted, netted, and patched with russet. Stalk stout, curved, inclined at its insertion. Calyx partially closed, set in a shallow irregular basin. Flesh white, tine-grained, gritty at core, melting, buttery, vinous or subacid. Good. January, February.

\section{Roe's Bergayot.}

Raised by William Roe, Newburgh, N. Y. Tree moderately vigorous, very productive. Young wood reddish yellow brown.

Fruit medim, oblate or Bergamotte-shaped. Skin smooth, yellow, with minute yellow dots in the shade, mottled and clouded with reel on the sumny side. Stalk short, inserted in a narrow, abrupt cavity. Calyx small, with short stiff segments, set in a narrow basin. Flesh rather coarse, melting, with a sweet, rich, brisk, well-perfumed flavor. The flavor of this excellent new Pear is extremely like Gansel's Bergamotte, but much more sugary. Good to very good. September.

\section{Ror D'ÉtÉ.}

Gros Rousselet. Great Rousselet, Riusselet.
Large Rousselet.

The Rousselet.

King of Summer.

An old variety, of little value.

Fruit medium, obovate pyriform, pale green, dull red in the sun, with numerous gray russety speeks. Flesh half buttery, melting, agreeable subaciel. Last of August. (Liud.)

\section{RoI DE RoMe.}

This variety was found in a province of Hainault, Belgium, by M. l'Abbé Duquesnes, and first fruited in 1810. Under the name of Roi de Rome, the Napoleon has been repeatedly received in this conntry, but, as described in the Annals of Pomology, is entirely a distince fruit.

Fruit very large, regular, oblong ovate pyriform. Skin clear yellow, marbled with erimson in the sum, specked with russet, and dotted with many small gray dots. Stalk short, set with little or no cavity, but surrounded with slight furrows. Flesh yellowish white, half fine, melting, juicy, sweet, agreeable. October, November.

\section{RoITELET.}

A Flemish Pear.

Fruit small, roundish, yellow, netted, shaded, and sprinkled with russet. Flesh whitish, half melting, juicy, sweet. Good. Scptember. 


\section{RoKeBY.}

Raised by M. Bivort, Belgium. Tree vigonous, very prolific. Young wood dark olive brown, with narrow oblong white specks.

Fruit below medium, obovate pyriform. Skin yellowish, sometimes a tinge of red in the sun, netted, patched, and dotted with rnsset. Stalk short. Cavity shallow. Calyx open. Flesh white, half melting, vinous, astringent. Poor. Early September.

\section{RONDELET.}

Fruit below medium, roundish oblate. Skin greenish yellow, shaded with brown russet, tinged with red in the sun, and speckled with large gray dots. Stalk an inch long, iuserted in a narrow cavity. Flesh finegrained, buttery, melting, juicy, rich, sweet, with a musky perfume. November. (H’ogg.)

\section{RoNville.}

Martin Sire (incorrectly) Lord Martin Pear.

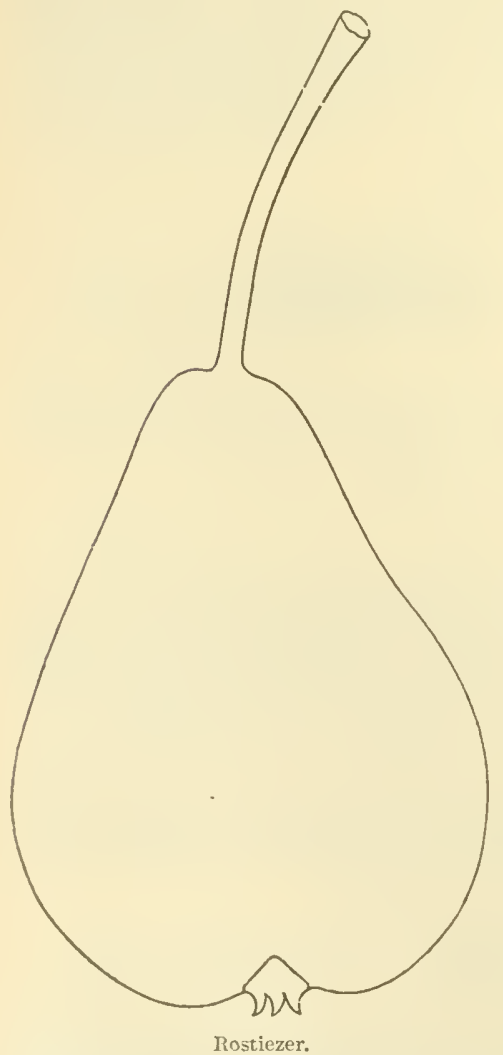

Hocrenaille. Poire de Bunville.

An old Belgian Pear, of little value.

Frnit medium to large, ovate, yellowish green, russeted at end, dotted with gray l'usset specks. Flesh white, breaking, gritty at core, sweet, pleasant. October. (Prince.)

\section{Ropes.}

Origin, garden of Mr. Ropes, Salem, Mass.

Fruit mediun, orate obovate. Color cinnamom r'usset, slightly tinged with red on the sumny side. Stem short, in an inclined cavity. Calyx small, open. Basin shallow. Flesh whitish, coarse, melting, and juicy, sugary, and good, with a perfume. Good. October, November.

\section{RosLy.}

Found on the place of $\mathrm{W}$. C. Bryant, of Roslyn. Loug Islimel. Tree vigorous. Yommg wood reddish yellow brown.

Fruit nedium, nearly globular. Skin yellow, netted, patched, and dotted with russet. Ftalk long. Calyx partially closer. Flesh whitish, juicy, meltin, slightly

vinous. Good or very grood. Lasi of August. 


\section{ROSTIEZER.}

A foreign variety, which is scurcely melimm in size and has not generally moli beauty of color, yet combines an assemblage of excellences that places it in the rank before any other of its season. Tho young trees produee but few shoots of strong growth, and require severe shortening to bring them into a fine symmetric form. The color of the roung wool is dirk olive brown. It is healtly and vigotous in its habit, an early and most profuse bearer, and in flavor is only expalled by the Seckel, which ripens six weeks later.

Fruit medium or below, obovate oblong pyriform. Skin dull yellow green, mixed with reddish hrown on the smonny side. Stalk long and slender, curved, and inserted with very little depression. Calyx open, persistent. Basin small and corrugated. Flesh juicy, melting, somewhat buttery, exceedingly sugary, vinous, aromatic, and pleasantly perfumed. Best. Niddle of August to middle of September.

\section{Rousse Jench.}

Fruit lurge, oblong oval. Skin lemon yellow, with a slightly russeterl covering. Flesh yellow, buttery, juicy, sugary, pretty well flavored. January, February. (Hogg.)

\section{Rousselet Aelexs.}

A Belgian Pear of medium size, obovate acute pyriform, yellow, with shade of red in sun, patches of russet, and dots of grayish red. Stalk inserted without cavity. Flesh yellowish white, half fine, melting, juicy, sweet, perfnmed. (An. Pom.)

\section{Rousselet Bivort.}

A Belgian Pear, raised from seed of the Simon Bonvier in 1840.

Fruit modium, ovate obovate pyriform. Skin pale yellow, slightly netted and patcled with russet, and sprinkled with brown dots. Stalk rather long, with a fleshy fold at insertion. Calyx partially open. Basin small, furrowed. Flesh yellowish, fine, juicy, buttery, melting, sweet. Good to very good. November.

\section{Rousselet Decoster.}

Rousselet de Coster.

Decoster's Russelet.

A seedling of Van Mons', dedicated to M. Decoster, of Louvain. Tree morlerately vigorous. Young wood dull reddish brown.

Fruit small, roumdish obovate pyriform. Skin pale greenish yellow, patched and blotched with russet, especially around the stalk and calyx, thickly sprimkled with russet dots, and sometimes a brownish cheek in sum. Stalk ratlier loug. Cavity small. Calyx open. Segments stiff. Basin sluallow, meren. Flesh coarse, yellowish, juicy, melting, slightly vinous, aromatic. Gool. September.

\section{Rousselet de Jaiviep.}

Of Belgian origin.

Fruit small, obovate pyriform. Skin yellowish. Flesh fine, half melting, wuttery, perfumed. January. (soc. V. M.) 


\section{Rousselet DE JoNGHe.}

Fruit small, curved obovate, nueven and irregular in its outline. Skin smooth lemon color. Calyx rery large, open. Flesh yellow, fine. grained, firm, melting, juicy, rich, sugary. November, December. (I Iogg.)

\section{Rousselet de Rhems.}

\section{Rousselet.}

Petit Rousselet.

Spice or Mrusk Pear.
Rousselet Musqué.

Late Catherine

Autumn Catherine.

This French Pear, originally from Rheims, is supposed to have been the parent of our Seckel. There is a pretty strong resemblance in the color, form, and Havor of the two fruits, but the Seckel is much the most delicious. The growth is quite different, and this Pear has remarkably long and thrifty dark brown shoots. It is sugary, and with a peculiarly aromatic, spicy flavor, and if it were only buttery and melting, would be a fisst-rate fruit.

Fruit small, obovate, inclining to pyriform. Skin yellowish green, with brownish red and russety specks. Flesh breaking or half buttery, with a sweet, rich, aromatic flavor. Ripe at the beginning of September, subject to rot at the core.

\section{Rousselet Exfant Prodigue.}

Nectarine ?

Enfant Prodigue.

One of Tan Mons' seedlings. Tree vigorous, productive.

Fruit medium, pyriform. Skin thick and rough, green, covered with russet, sometimes with a sunny cheek. Stalk of medium length, in an inclined cavity. Calyx large. Basin shallow. Flesh yellowish, juicy, granular, with a vinous flavor, highly perfumed with musk. Good. October, November.

\section{Roussejet Esperex.}

Rousselet Donble.

Tree very vigorous, and very productive

Fruit medium, obovate pyriform. Skin yellow, with reddish gray and white dots, and covered wilh russet around calyx and stalk. Flesh whitish, half fine, half melting, juicy, sugary, vinous, and perfumed. Ciood. September.

\section{Rousselete Hâtif.}

$\begin{array}{ll}\text { Early Catharine. } & \text { Early Rousselet. } \\ \text { Kattern. } & \text { Perdreau. } \\ \text { Cyprus Pear. } & \text { Poire de Chypre. }\end{array}$

The Rousselet IIâtif is productive, with long slender branches, of dark dull reddish brown color.

Fruit rather small, acute pyriform. Skin, when fully ripe, yellow, with a brownish-red check. Flesh a little coarse-grained, swect, pleasant, and slightly perfimed. Ripens the middle of August. Apt to int at the core. 
Rotsstetet St. Nicholds.

A Belgian Pear, so fur as we lave scen it, of little value.

in puit below medium, romdish oblate, yellow, shaded with rimson in the sun, netted, patched, and dotted with l'usset. Flesh whitish, juicy, melting, sweet, vinous. November.

\section{Roussetev S'TUTTraRT.}

Poire de Stuttgard.

Stuttgarter Geishirtel
Chevriers de Stuttgardt. Bellisime de Provence.

Originated in the envirous of Stuttgardt in 1759. Tree a vigorous, upright, healtly grower, and a good beares. Foung wood reddish jurple.

Fruit holow medium, pyriform. Skin greenish yellow, netted and patched with russet, and sprinkled with russet and green dots, brownish crimson in the sun. Stalk rather long, curved, enlarged at its insertion, senerally without depression. Calyx open. Basin shallow. Flesh ratler coarse, juicy, half melting, with a sweet, rich flavor, spicy aroma. Pipe last of August.

\section{Rousselet VAiderwecien.}

Raised by MI. Grégoire, of Jodoigne, Belgium. A pyramidal tree of medium vigor, but very productive.

Fruit small, varyiug in form from Doyenné to Bergamotte. Skin vellow at time of maturity. Flesh white, fine, melting, juice abundant, sugary, and strongly aromatic, like that of the Rousselet. Fruit quite of first quality, and ripe first of November. (An. Pom.)

\section{Rousseline.}

Russelin.

An old variety, now superseded by larger and better Pears.

Fruit small, nearly globular. Pale yellow, shaded with red in sun, and sprinkled with inany risset dots. "Flesh white, melting, sweet, musky. Good. Norember.

\section{Rousselor.}

Raised by Major Esperen in 18+6, and figured and deseribed by L. E. Berckmans in 1851 . 'Tree of medium vigor, grows well as a pyramid.

Fruit merium, shaped like a Dorenné. Skin citron yellow at matu. rity, dotted with russet, and highly colored on the side of the sum. Flesh fine, half melting, sufficiently juicy, sugary, vinous, with an agreeable perfume. February. (An. Pom.)

\section{RoYAL.}

\section{Peck's Seedling.}

A seedling raised by Thomas R. Peck, Waterloo, N. Y. Tree a vigorous grower, productive. Young wood vellow brown.

Fruit medium, roundish pyriform. Skin vellow, mostly covered with thin crimson russet, and a shade of crimson in the sun, sprinkled with 
brown and russet dots. Stalk medium. Carity small Calyx partially closed. Segments short. Flesh white, juicy, melting, sweet. slightly aromatic. Good to very good. September.

\section{Royale d'Hiver.}

Winter Royal.

Royal Winter.

Spina di Carpi.

An old rariety, of unknown origin.

Fruit rather large, obovate pyriform, or nearly pyriform. Skin yellow, with fine red in the sun, markled with numerous brown specks and dots. Flesh yellowish, half buttery, melting, juicy, sweet, well flavored. December to February. (Lind.)

\section{Rutter.}

Raised by John Rutter, of Westchester, Pa. Tree a moderate grower, a good bearer, with young wood of a dull olive yellow brown color.

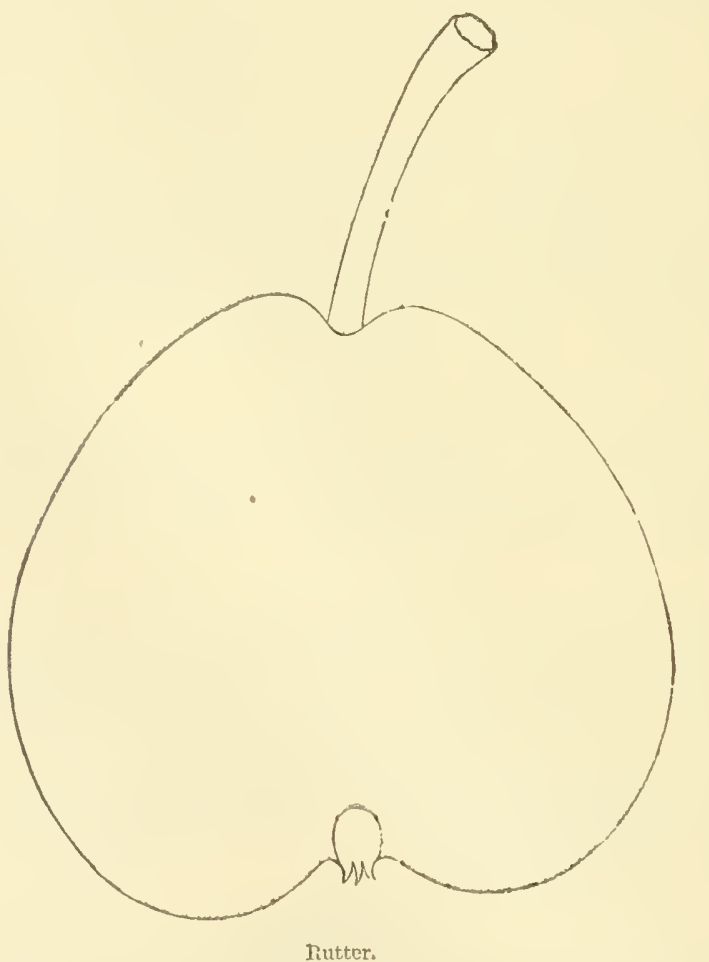

Fruit medium to Irrge, nearly globular, remotely pyriform. Skin rough, greenish yellow, sprinkled and netted with russet, and numorous musset dots. Stalk large, long, and woody. Carity small. Calys 
small, closed. Segments narow, nearly erect. Basin rather small, mueven. Flesh white, moderately juicy, half fine, somewhat gritty, nearly melting, sweet, slightly vinous. Very good. October, November.

\section{SACANDAGA.}

Van Franken.

Sacandaga Seckel.

Found on the farm of $\mathrm{Wm}_{\mathrm{m}}$. Tan Tranken, Erlinhurgh, Saratoga Co.; N. Y. Tree an upright moderate grower. Young wood rich warm brown.

Fruit small, nearly globular. Skin pale greenish yellow, shader with brownish arimson, and netted and dotted with russet. Sitalk medium. Cavity small. Calyx open. Segments rather long, ercet. Flesh white, juicy, melting, sweet, rich, a little perfumed. Good to very good. September.

\section{SaINT ANDRé.}

Imported by Mr. Manning, from the Brothers Bammann, of Bolwyller. Wood often cracks and cancers.

Fruit medium, obovate. Skin light greenish yellow, somewhat dotted with red. Flesh white, fine-grained, buttery, melting, and good. Early in september.

\section{Saint Crispix.}

A seedling raised by Israe? Buffum, of Lymm, Mass. Tree a strong grower, and an abundant hearer. Young wood yellow brown grayish.

Fruit large, irregular.in ontline, generally oblong obovate pyriform. Skin a little lough. Surface meven, greenish yellow, with tinge of red in sun, and russet patches. Stalk rather long. Calyx large, closed. Flesh yellowish white, a little coarse, melting, juicy, subacid. October. (IIov. Mag.)

\section{SAint Denis.}

Tree vigrorons, with long dark reddish branches.

Fruit small, turbinate angular. Skin yellowish, considerably shaded with crimson, thickly sprinkled with crimson dots. Stalk long. Calyx open; broad, shallow, uneven basin. Flesh breaking, a little coarse, sweet, and aromatic, rots at the core unless gathered early. Last of August.

\section{SAINT DoRotiée.}

Royale Nouvelle.

Of forcign origin. Tree vigorous. Young wood grayish brown.

Fruit rather large, oblong obovate jyriform. Skin greenish yellow, netted and patcherl with russet, and thickly sprinkled with russet dots. Stalk long, curved, inserted by a fleshy lip in a small cavity. Calyx open. Segments rather lirge, recurverl, set in a rather abrupt basin. Flesh whitish, fine, juicy, melting, with a sugury, viuous, peculiarly per. funcd flitor. Cioud to rery good. October. 


\section{Sant Geriain.}

St. Germain Gris.

\section{- Jamue.}

Inconnue la Fare.

Lafare.

St. Germain Doré.

Franklin.

Hermansbirne.
Saint Germain blanc.

Arteloire.

Richmond.

Saint Germain brun.

vert.

d'Hiver.

This is a well-known old French variety. The tree is rather a slow grower, with a dense head of foliage. The wood slencler, and light ulive colored.

Fruit large, pyriform, tapering regularly from the crown to the stalk. Skin yellowish green, marked with brownish specks on the sunny sirle, and tinged with a little biown when ripe. Stalk an inch long, strong, planted obliquely by the side of a small fleshy swelling. Calyx open, set in a shallow basin. Elesh white, a little gritty, but full of refreshing juice, melting, sweet, and agreeable in flavor. November and December.

The Striped Germain (St. Germain Panachée) is a pretty rariety of this fruit, differing only in being externally striped with yellow.

\section{Satnt Geruian de Pepins.}

A foreign variety. Tree a good grower and an early bearer.

Fruit medinm, nearly globular or obovate, slightly pyriform. Skin pale yellow, lightly sharled or mottled with crimson in the sun, netted and patched with russet, and thickly sprinkled with russet dots. Stalk rather long and stout, largest at jumction with the tree. Carity small, irregular, russeted. Calyx partially closed. Basin inregular, corrugated. Flesh yellowish, coarse and gitty, with a hard core. Good. Feluruary.

\section{Saint Ginslain.}

Quinnipiac.

A most excellent Belgian Pear. When in perfection it is of the highest quality, but on some soils it is a little varialile. The tree is remarkable for its nprightness, and the great benuty and rigor of its growth. Young shoots olive brown, with oblong white specks.

Fruit of unedinm size, pyriform, tapering to the stalk, to which it joins by fleshy rings. Skin pale clear yellow, irith a few gray specks. stalk an inch and a half long, curved. Calyx rather small, open, set in a shallow basin. Core small. Flesh white, buttery, and juicy, with a rich sprightly flavor. Good to very good. September; Ociober.

\section{SAINT LEZIN.}

Fruit very large, pyriform. Skin dull greenish yellow, covered with flakes of russet. Stalk long. ('alyx open. Flesh firm, crisp, juicy, sweet. A cooking Pear. September, (Hetoler. (Hogg.)

\section{Saint Mexix.}

\section{Omer Pacha.}

His Poiteau.

Poire His.

'Tree a vigorous grower. Toung wood grayish olive.

Fruit rather large, obovate obtuse pyriform. Skin pale rellow; 
slightly brown in the sun, netted and patched with russet, and thickly dotted with eonspicuous russet dots. Stalk short. Cavity deej. Calyx closed. Basin abrupt. Flesh whitish, juicy, molting, sweet, slightly aromatic. Good to very good. September.

\section{Saint Michael Archangel.}
St. Michel Archange.
Plombgastel.
Dusnas.

A French Pear, of unknown origin. Tree vigorous and productive Young wood yellowish olive.

Fruit large, ovate obovate pyriform. Skin pale yellow, slightly net. ted and patched with russet, and thickly sprinkled with green and russet dots. Stalk rather stout, a little inclined in a small cavity by a Heshy ring or lip. Calyx partially closed. Negments rather short, stiff: Basin uneven, furrowed. Flesh whitish, buttery, juicy, melting, slightly aromatic. Good to very good. October.

\section{Salnt Vincext de Paul.}

A new foreign Pear. Tree moderately vigorous. Young wood a very dark rieh olive brown.

Fruit medium, oblate pyriform, broad at calyx. Skin light yellow, mostly covered with thin light russet, and thickly sprinkled with russet dots. Stalk long, slender. Calyx with short erect segments. Basin abrupt. Flesh tirm, juicy, melting, not sweet. Good. Novenber.

\section{Salisbury Seeding.}

A native of IVestern New York. Tree vigorous.

Fruit nhtuse pyriform. Skin rough, somewhat covered with russet, and thickly sprinkled with russet dots. Stalk short and thick. Calyx 1:artially closed, in a deep, uneven basin. Flesh coarse, white, sweet, breaking, not juicy or melting. Scarcely good. September.

\section{Salviata.}

Forniquet. Eerfumed. Épine Rose Gris.

An old variety, now superseded by better sorts.

Finit below medium, obovate ovate obtuse pyriform, light yellow, dotted with russet. Fiesh breaking, juicy, musky. Good. Last of August.

\section{SAND PEAR.}

\section{Chinese Sand Pear.}

This variety is valued mainly as a curiosity, although it is good for cooking. The tree is remarkably vigorous, with large, glossy foliage.

The fruit is of medium size, roundish pyriform, dull yellow, covered with a rough, sandy-like russet. Flesh firm, moderately juicy, cooks well, and acquires a fine color. September.

\section{Sanguixole.}
Sanguine d'Italie.
Bloody.
Grenade.

An ancient Pear, of unknown origin. As an amateur euriosity it is only desirable. 
Fruit small to medium. Form roundish, pale yellow, brownish in sun, with irregular-shaped brown dots and specks. Flesh white, tinged with red, juicy, melting. Good. September.

\section{Saxguixole de Belgique.}

Fruit medium, ovate prriform. Skin greenish, mottled and dotted with red in the sun, netted and patched with russet, and sprinkled with red and brown dots. Stalk long, curved. Flesh stained with rerl, which renders it a curiosity, that being its only value. September.

\section{Siritr.}

Raised by Thaddeus Clapp, Dorchester, Mass. Tree of an erect habit, hardy, healthy, and productive. Young wood rich olive sellow brown.

Fruit medium size, rom dish obovate pyriform. Skin pale greenish yellow, partially netted and patched with russet, and thickly sprinkled with brown dots. Stalk medium, a little inclined, set with a slight depression by a ring or lip. Calyx partially closed. Segments short, erect. Basin shallow, meven. Flesh white, fine, juicy, melting, sweet, rich, aromatic. Very good. Octobes:

\section{SCHUMAN.}

A native of Buck's Co., Pa.

Fruit medium, roundish obovate. Pale yellow, shacle of red in sun. Flesh coarse, pasty. Poor. September.

\section{SEAL.}

From Pennsylvania.

Fruit medium or below, roundish. Skin pale yellow, lightly shaded with crimson in the sun, and thickly sprinkled with green and russet dots. Stalk medium length, largest at ends, inserted by a ring or lip. Calyx open. Segments persistent. Flesh white, coarse, moderately juicy, melting, slightly astringent. Good. Last of A ugust.

\section{Sebastopol.}

Sebastopol d'Été.

A Belgian Pear, described by Alexander Birort as :-

Fruit of medium size, ovate obovate, greenish yellow, dotted with grayish brown. Flesh white, half fine, melting, a little granulous, sweet, vinous, perfumed. Agreeable. August. (Jar. Van Mons.)

\section{SECKEL.}
Seckle.
Srckle.
Sickel.
Red-Cheeked Seckel.
New York Red Cheek. Shakespeare.

We do not hesitate to pronounce this Ameriran Pear the richest 
and most exquisitely flavored variety known. In its highly concei trated, spicy, and honeyed flavor it is not surpassed, nor indeed equalled, by any European variety. When we add to this, that the tree is the healthiest and hardiest of all pear-trees, forming a tine, compact, symmetrical head, and bearing regular and abundant crops in cluster's at the ends of the branches, it is easy to see that we consider 110 garden complete without it. Indeed we think it indisprensable in the smallest garden. The stout, short-jointed, olivebrown colored wood distinguishes this variety, as well as the peculiar reddish brown color of the fruit. The soil should receive a top-dressing of manure frequently, when the size of the Pear is an object. The Seckel Pear originated on the farm of Mr. Seckel, abont four miles fiom Philadelphia.*. It was sent to Europe by

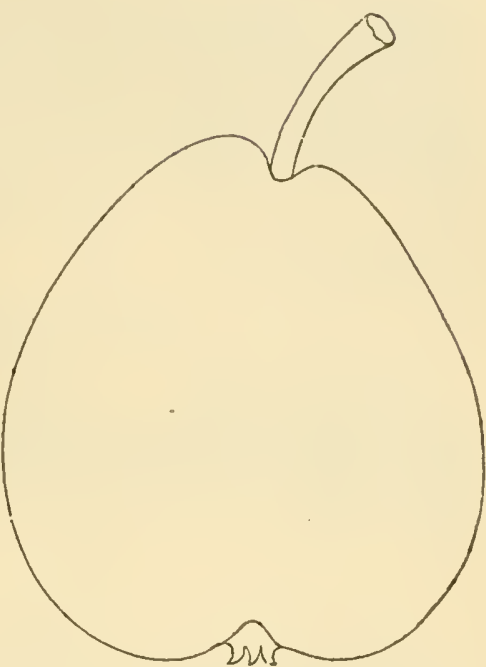

Seckel. the late Dr. Hosack, in 1819 , and the fruit was pronounced by the London Horticultural Society exceeding in flavor the richest of their autumn Pear's.

Fruit smali, regulai $y$ formed, obovate. Skin brownish green at first, becoming duil yeirish brown, with a lively russet red cheek. Stalk half to three-fourths of an inch long, slightly curved, and set in a tritling depression. Calyx small, and placed in a basin scarcely at all sunk. Flesh whitish, buttery, very juicy and melting, with a peculiarly rich spicy flavor and aroma. It ripens gradually in the house from the end of August to the last of October.

* The precise origin of the Seckel Pear is unknown. The first pomologists of Europe have pronounced that it is entirely distinct from any European variety. and its affinity to the Rousselet, a well-known German Pear, leads to the supiosition that the seeds of the latter Pear, having been brought here by some of the Germans settling near Philadelphia, by chance produced this superior seedling. Howerer this may be, the following morcerul of its history may be relied on as authentic, it having been related by the late venerable Bishop White, whose tenacity of memory is well known. About 80 years ago, when the 13ishop was a lad, there was a well-known sportsman and cattle-dealer in Philadelphia, who was familiarly known as "Dutch Jacob." Every season, early in the autumn, on returning from his shooting excursions, Dutch Jacob regaled his neighbor: with pears of an unusually delicions flavor, the secret of whose place of growth, lowever, he would never satisfy their curiosity by divulging. At length the Holland Land Company. owning a considerable tract south of the city, disposed of it in pareels, and Duteh Jacob then seenred the ground on which his farorite pear-tree stood, a fine strip of land near the Delaware. Not long afterwards it became the farm of $\mathrm{Mr}$. Seekel, who introduced this remarkable fruit to public notice, and it received his name. Afterwarls the property was added to the vast estate of the late Stephen Girard. The original tree still exists (or did a few years ago), rigorous and fruitful. Specimens of its pears were quite lately exhibited at the annual shows of the Pennsylrania Horticultural Society. 


\section{Selleck.}

Origin somewhat uncertain. 'The oldest bean g tree stands on the grounds of Columbus Selleck, Sudbury, Vt., and is of healthy growth, and rery productive. Young wood grayisl olive brown.

Fruit large, obovate obtuse pyriform. Surfuce uneven, fine yellow, sometimes witl a crimson cheek, and thickly sprinkled witin russet dots. Stalk long and curved, fleshy at its insertion in a moderate carity. Calyx nearly closed, in a rather small uneven basin. Flesh white, a little coarse, juicy and melting, sweet, aromatic. Good to rery good. September, October.

\section{Sexateur Mosselmax.}

A foreign variety.

Fruit medium or below, roundish, slightly obovate. Skin greenish yellow, shaded in the sun with orange and crimson, and numerous brown and russet dots. Flesh yellowish, firm, moderately juicy, sweet. Good. February, March.

\section{Seraphine Oris.}

A Belgian variety, originated in 1854. Tree vigorous, making long ammual shoots, pretty stout, of olive brown, with oblong white siecks.

Fruit medium, ronndish obtuse pyriform, jale yellow, nottled and marbled in the sun with crimson, numerously dotted with large conspicrous russet and gray dots or specks. Flesh yellowish white, half tine, lialf melting, buttery, juicy, sweet, slightly aromatic, musky. Good. S'eptember.

\section{SERrtrier.}

Serrurier d'Automme.

Fondante de Millot.

Fondante Sermurier de Millot.
Noureau Maison.

Noureau Mauxion.

A seedling of Professor Van MIons'. Tree vigorous, healthy, productive. Young wood light yellow brown.

Fruit medium, roundish obovate obtuse. Skin pale rellow. with a tinge of red in the smm, considerably netted and patched with msset, and numerously sprinkled with russet dots. Stalk medium, inserted in a small cavity, often russeted. Calyx open. Basin small. Flesh yellowish white, a little coarse, juicy, melting, vinous, slightly astringent. Good to very good. October.

\section{Seutix.}

Poire Seutin.

A seedling of M. Bouvier's.

Fruit medium or above, ovate, green, with a brownish shade in sun, marblings, pateles, and dots of dull russet. Stalk quite long. Calyx large, with short persistent segments. Flesh half fine, white, melting, juicy, sweet, perfumed. September, October. (Alb. Pon.) 


\section{SIIAWMT.}

Originated with Francis Dana, Roxbury, Mass. Tree an upriglit, moderately vigorous grower. Young wool grayish reddish brown.

Fruit large, obtuse pyriform. Skin nearly smooth, dull yellow, dot. ted with large round russet specks. Stalk long, fleshy, and wrinkled at base. Calyx open. Basin broad, decp. Flesh yellowish, coarse, melt. ing, jnicy, vinous, sprightly, musky perfume. October. (Hov. Mlag.)

\section{SHELDON.}

Wayne. Hland. Huron. Wisner.

An accidental seedling on the furm of Norman Sheldon, in the town of Huron, Wayue Co., N. Y. Tree vigorous, erect, hardy, and a good bearer. Young wood yellow brown.

Fruit medium, roundish obtuse obovate. Skin greenish yellow, mostly covered with thin light russet, a little brownish crimson in the

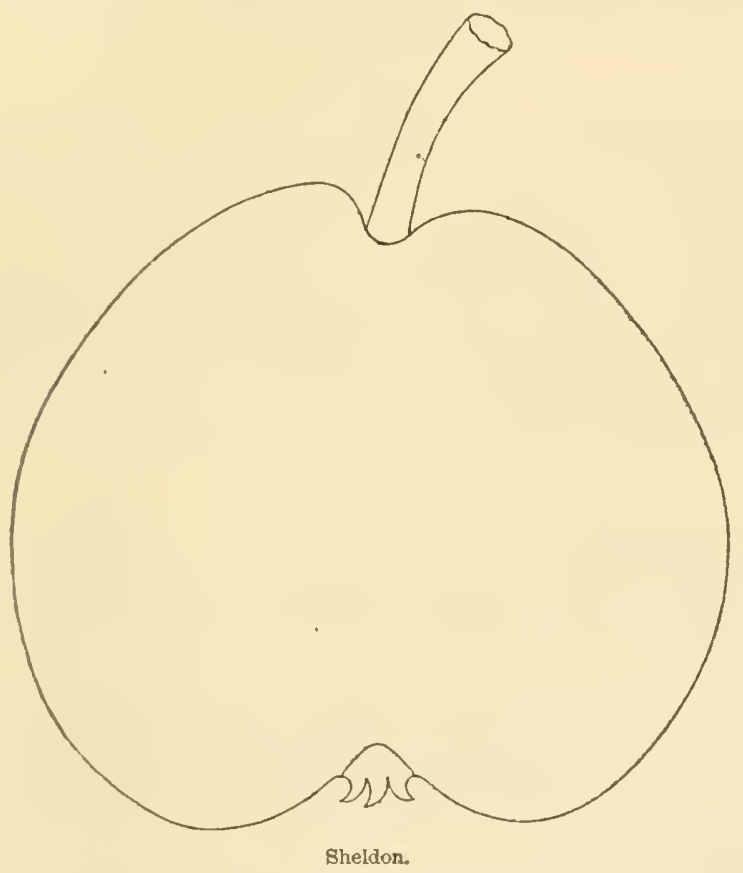

sun, dotted with russet. Stalk short, stout. Cavity deep. Calyx open. Segments partly recurved. Basin broad, large. Flesh whitish, very juicy, melting, sweet, vinous, rich aromatic. Very good. October.

\section{Simeppard.}

Ritised by James Sheppard, of Dorchester, Mass.; introduced to notice by $D_{r}$. L. W. Puffer. Tree $a$ free grower, and very productive Young wood grayish olive brown. 
Fruit large, obovate pyriform. Skin rough, yellow, sometimes with a brownish red cheek, slightly sprinkled with russet dots, and with some patches of russet. Stalk short and stout, in a depression, often inclined, surrounded by russet. Calyx partially closed, set in a very shallow furrowed basin. Flesh whitish, coarse and grannlar, buttery, melting, juicy, vinous, perfumed. Good to very good. Ripens last of September and tirst of Oetuber.

\section{Sinion Bourier.}

\section{Souvenir de Simon Bouvier.}

Originated in 1833, with M. Grégoire, of Jodoigne, Belgium. Tree moderately vigorous. Young wood rich brown.

Fruit medium or abore, obovate obtuse pyriform. Skin rough, yellow, netted, patched, and dotted with russet, and a few specks and marblings of erimson in the sun. Stalk short, inserted in a shallow, broad cavity. Calyx open. Segments reflexed. Flesh white, buttery, melt. ing, juicy, sweet, perfumed. October, November. (Al. Pom.)

\section{SKINLESS.}

\section{Poire sans Peau. \\ Fleur de Guignes. \\ Sanspeau. \\ Precoee de Glady. \\ Frihe Rousselet.}

The Skinless is a rery nice little Pear, with a remarkably thin, smooth skin, and a delicate perfumed flavor. It bears in clusters, and very regularly. It is not first-rate, but is esteemed by many.

Fruit below medium size, long pyriform. Skin very smooth and thin, pale green, becoming light yellow, speckled with light red in the sum. Stalk long, slender, curved, inserted in a very trifling cavity. ('alyx closed, set in a small basin. Flesh white, juicy, half melting, with a sweet and slightly perfumed flavor. Good. Middie of August.

\section{Soldat Laboureur.}

\section{Anguste Van Krans. Blumenbach. Soldat Esperen.}

A seedling of Major Esperen's, produced about 1820. Tree vigorous, mpright, an early and abundant beares. Young wood dull grayish reddish brown.

Fruit rather large, roundish olovate pyriform. Skin yellow, patched, netted, and dotted with russet. Stalk rather stout, long and curved, inserted in a small, abrupt cavity. Calyx open, scarcely sunk. Basin very small. Flesh yellowish, slightly granular, melting, juicy, with a sugury, vinous, perfumed flaror. Good to very good. October, November.

\section{Souvenir du Coxgress.}

This Pear was originated by M. Mlorel, of Lyon-Taise, Erance, and by him dedicated to the Pomological Congress of France. Tree vigorous and fertile, pyramidal in form.

Fruit large to very large, resembling in form the Bartlett. Skin smooth, of a handsome yellow at maturity, washed with bright red, or carmine, on the side exposed to the sum. Flesh much like the Bartlett, having the musky flavor, though in a less degree. Its maturity com mences in August and continues in September. (Rorue Horticole.) 


\section{Souvexir d'Esperen.}

This seedling Pear of Major Esperen's proves one of the very best, cither for amateur or market cultivation. Tree vigorous, healthy, hardy, and productive, and holds its foliage well and late. Young wood olive redulish yellow brown.

Fruit large, oblong pyriform. Surface meven. Skin grennish yellow, mostly covered with dull rough russet, especially around the stalk

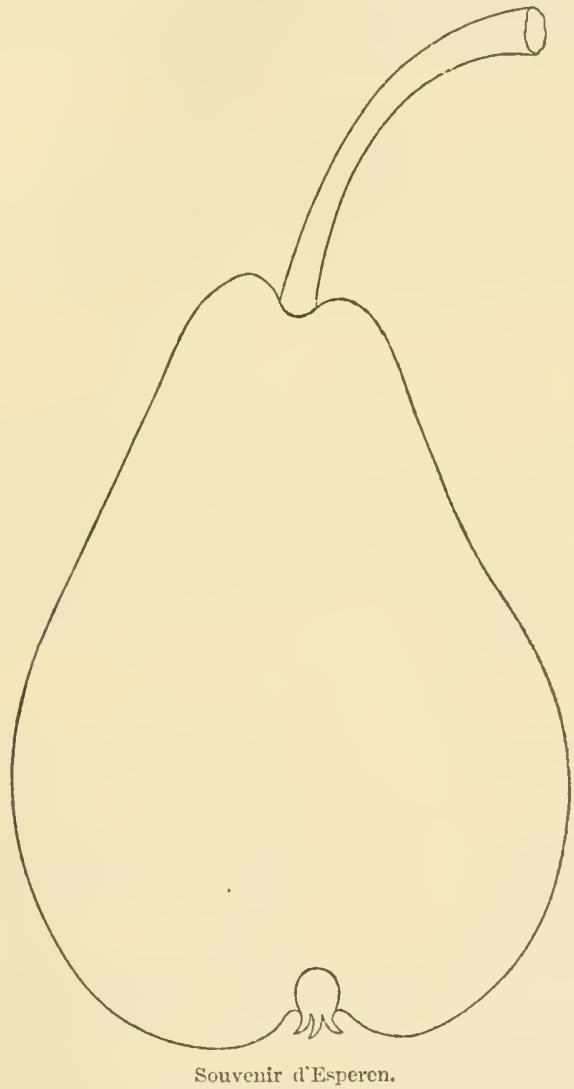

and calyx. Stalk long, inclined, set in a slight carity, sometimes by a lip. Calyx open. Segments medium, erect, sometimes a little recurved. Basin small, narrow, uneven. Flesh yellowish, juicy, vinous, aromatic. Very gool. October, November.

\section{Souvexir de la Reise des Belges.}

A Belgian Pear seedling of M. Grégoire. Tree vigorons and productive.

Fruit above medium, acute prriform, pale yellow, tinged witl crim. son brown in sun, patched and dotted with thin russet. Stalk short, 
enlarged at end, and inserted by a ring. Flesh yellowish white, half fine, melting, juicy, sweet, perfumed. Uctober, November. (An. Pom.)

Souvenir Favre.

A French Pear, originated with M. Favre in 1850, and first fruited in 1857. Young wood reddish olive brown.

Eruit above medium, oblong obtuse pyriform, pale yellow, deeper in the sun, and dotted with many gray dots, or reddish in the sun. Stalk rather stout, inserted with a slight eavity. Calyx open, with long halferect segments. Flesh a little coarse, half melting, juicy, sweet, and perfumed. November, December. (An. Pom.)

\section{Souveraine D'Ét'É.}

Fruit below medinm, roundish obovate pyriform. Skin light yellow, with numerous dots, which are crimson on the sunny side. Stalk short, in a narrow cavity, frequently by a lip. Calyx partially closed. Basin medium. Elesh whitish, juicy, melting, sugary, vinous, aromatic. Good. Ripens first of September.

\section{Souveraine de Printemps.}

\section{Poire de Printemps.}

A French Pear. Young wood dark olive reddish brown.

Fruit medium, irregular in form, genexally roundish obovate, slightly pyriform. Skin rough, greenish yellow, partially netted and patched with rough dark russet, and thickly sprinkled with russet dots. Stalk curved, enlarged at insertion, in a small carity, sometimes a lip. Calyx large and open. Flesh whitish, juicy, melting, sweet, pleasant. Good to very good. October.

\section{Spanish Bon Chrétien.}

Bon Chrétien d'Espague.

Spina.

De Janvry.

Bon Chrétien d'Automne.

Gratiole d'Automne.

Pri sident d'Espagne.

Safran d'Antomne.

Safran rosat d'Automne.

Bon Chr tien Janne d'Antomne.

Blanche.

Grosse Grande Bretagne.

Bon Chretien Spina.
Bon Chrétien doré d'Espagne.

Van Dyck.

Compagnie dOstende.

Janvry.

Grosse Grande Bretagne dorce.

Vermillon d'Espagne d'Hiver.

Gracioli de la Toussaint.

Vandyck.

Good Christian of Spain.

Spanish Warden.

Autumn Bon Chritien.

A very old variety. Tree a good bearer, and the fruit highly valned for cooking.

Frnit large, pyriform. Skin at maturity deep yellow, with a brilliant red cheek, and dotted with reddish brown sperks. Elesh white, crisp, or half breaking, good for cooking. December to Jannary.

\section{Steinuta Catilerine.}

A Pennsylvania Pear. Tree very vigorous and productive.

Fruit medium or small, oblong pyriform, greenish, with a tnnge of brown in the sm. Flesh white, moderately juicy, half melting, vinous Ciood. September. 


\section{Steinitit SPre.}

Origin, Pennsylvania.

Fruit small, roundish pyriform, greenish yeliow, with nettings, patches, and lots of russet. Flesh whitish green, juicy, melting, sweet. pleasant, aromatic. Good. September.

\section{STERLING:}

De Mott.

Origin, Livingston Co., N. I.; grown from seed brought from Cor. neeticut. Tree vigorous, upright. Young wood grayish-yellowish brown, an early bearer, and productive.

Fruit medium, nearly round, sliglitly oval, very obscurely pyriform.

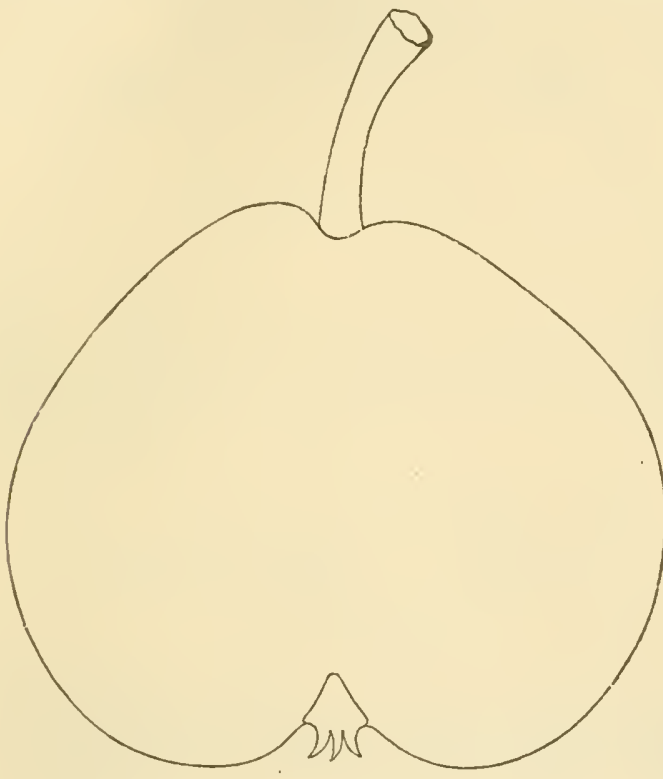

Sterling.

Skin yellow, sometimes with a few small patches of russet, aud on the sunny side a mottled crimson cheek. Stalk rather stout, inserted in a slight cavity, sometimes by a ring. Calyx open, in a medium, rather uneven basin. Flesh rather coarse, juicy, melting, with a very sugary, brisk Havor. Good to very good. Ripens last of August and first of Septem. ber:

\section{Stevexs' Gevesee.}

Guernses.

Louise de Prusse.

Crottée.

Doyeun: Galeux.

Saint Michel Crotté.
Philippe Strits,

Doyenné Crotté.

Passa-tutti.

Stephen's Genesee.

Genesee.

Beurré des Belges.

This admirable Pear, combining in some degree the excellence of tho 
Doyenné and Bergamotte, is reputed to be a seedling of Western New Tork. It originated on the farm of Mr. F. Stevens, of Lima, Living ston Co., N. Y. Althongh placed among autumn pears, it frequently ripens here at the end of August, among the late summer varieties. Young shoots diverging, lark gray.

Fruit large, roundish, and of a yellow color. Stalk about an

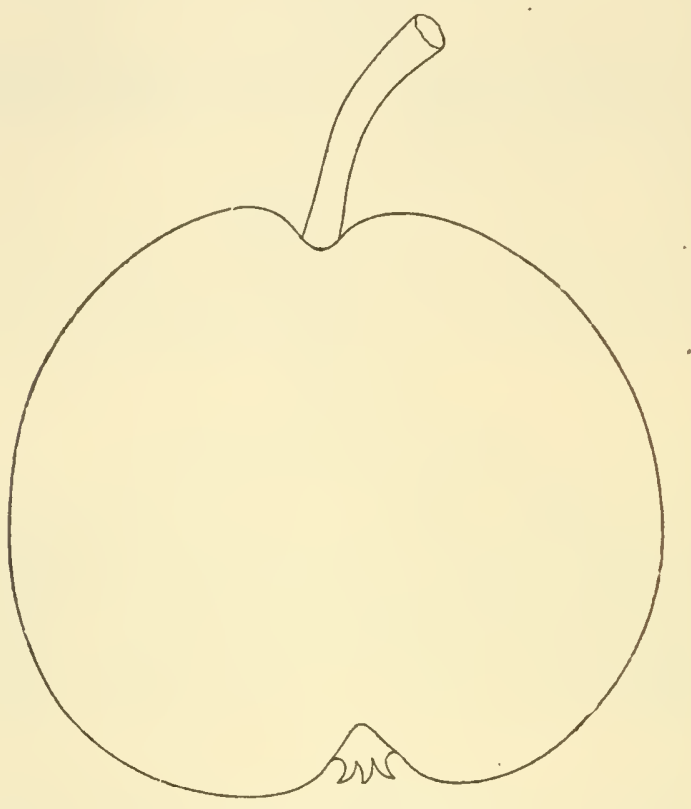

Stevens' Genesec.

iuch long, stout, thicker at the base, and set in a slight, rather onesided depression. Calyx with short, stiff divisions, placed in a smooth basin of only moderate depth. Flesh white, half buttery, with a rich aromatic flavor. Good to rery good. First of September.

\section{STONE.}

Origin, Ohio. Tree vigorous and productive.

Fruit large, roundish pyriform, uneven. Skin bright yellow with a sunny cheek. Stalk large, long, and curved. Calyx large. Basin open, broad, and shallow. Flesh white, somewhat buttery, slightly astringent. August.

\section{STYER.}

Origin uncertain, introduced by Alan W. Corson, of Montgomery Co., Pa. Tree a very vigorous grower. Shoots stout and short-jointed, productive. Young wood olive yellow brown.

Fruit medium or below, roundish oblate. Skin pale rellow, netted, patched, and dotted with cimnamon russet. Stalk rather short, inserted 
in a small, shallow eavity. Calyx almost obsolete. Basin narrow, mo. derately deep. Flesh yollowish white, somewhat gritty at the core, buttery, melting. Good to very good. Ripens middle of September.

\section{Strrian.}

\section{Keele Hall Beurré.}

This very bright-colored and exeellent Pear enmes from England. Tree vigorous and productive. Young shoots dull grayish olive brown.

Fruit medium or above, obovate pyriform. Skin pale yellow, lightly shaded with erimson in the sum, traces and patches of russet, and numerous brown dots. Stalk rather long, inched, eurved, set in a small cavity, sometimes by a lip. Calyx partially closed. Segments a littlo recurved. Basin uneven. Flesh white, a little coarse near the core, juicy, melting, sweet, aromatic. Good. September.

\section{Sucre de Tertolax.}

Sncre d'Antomne de Tertolen. Sucre Vert d'Automne de Tolsdnyn.

Originated in Holland.

Fruit below medium, roundish pyriform, pale green, mostly coverel, netted, patched, and dotted with russet. Stalk rather long. Flesh white, tinged with yellow, half melting, juicy, sweet, perfumed. Last September, early October. (Verg.)

\section{SUCREE DE HOYERSWERDA.}

\section{Sugar of Hoyersworda. Sucre Noir d'Été. Sucre-vert d'Hoyerswerda.}

A pleasant German Pear, of peculiar flavor, good when ripened in the house. It bears immense crops.

Frnit small, roundish pyriform. Skin pale yellowish green, thickly sprinkled rith greenish l'usset dots. Elesh white, quite juicy, with a sweet and piquant flavor. Scarcely good. It does not keep loug. Last of Angust.

\section{Sucrée du Comice.}

This Pear comes from France, and is described in the Catalogne of the Hort. Soe. of Angers as :-

Fruit of medim size, irregularly formed. Skin rellow, covered with green and russet dots. Flesh tender, sugary. Ripe in September and Octobes.

\section{SUCre Tert.}

Green Sugar. Bayonmaise. Gris de Chine. Verdette. Sukerey d'Automne.

An old Pear, of unknown origin.

Fruit medium or small, obovate pyriform. Skin green. Stalk me. dium, fleshy at its insertion in a very slight cavity. 13asin shallow. Flesh juicy, molting, sweet, and plussant. Good. October. 


\section{SufFolk Thorx.}

An English Pear, raised from seed of Gansel's Berganot.

Fruit small, roundish pyrifornı. Skin yellowish, mostly covered witk thin russet. Flesh rather coarse, juicy, melting. Good. Ostober.

\section{Sugar Top.}

July Pear. Prince's Sugar. Prince's Sugar Top.

Fruit roundish, top-shaped. Skin smooth, yellow. Flesh white, somewhat juicy and breaking, sweet, but with little flaror. Last of July.

\section{Sullivan.}

Van Mons, No. 889.

Sent to this country by Van Mons, and named by Mr. Manning. Young shoots slender, diverging, reddish brown.

Frnit of medium size, oblong pyriform. Skin pale greenish yellow. Stalk an inch and a half long, stont, tapering to the stalk. Flesh juicy, melting, sweet, and pleasant. Good. September.

\section{Summer ArchitKe.}

Archiduc d'Été.

Amire ronx.

Ainire roux de Tours.

De-la-mi-Juillet.
Gros Ognonet.

Ognonet.

Ognonnet.

Oignonet.
Archduke of Summer.

Brown Admired.

Great Onion Pear.

Ornonet Musqué.

Fruit medium, obovate pyriform. Skin smooth, yellowish green, covered with dark brownish red next the sun. Calyx open. Basin shallow. Flesh whitish, rather gritty, juicy, and sweet. Ripe early Angust. (Hogg.)

\section{Sumier Bergamot.}

\section{Bergamotte d'Étó.}

The Summer Bergamot is an old foreign variety, of small size and second quality. The tree is of feeble growth.

Fruit quite small, round. Skin yellowish green. Flesh juicy, and pretty rich in flavor, but quickly becomes mealy and dry. Last of July.

There is a Large Stmaner BERGmot, quite distinct from the above. Flesh breaking and half buttery, not rich. September. The tree grows and bears finely.

\section{Sumier Betrré d'Aremberg.}

Raised by Thomas Rivers, of Sawbridgeworth, Herts, England. Tree hardy, moderately vigorous, upright, very productive.

Fruit medium or below, somewhat turbinate or short obovite. Skin of a lemon color, slight nettings and patches of russet, particularly around the stem. Stalk rather long, inserted in a small cavity. Calrx very smail. Basin deep and narrow. Flesh tender, melting, juicy, brisk, vinous and perfumed, apt to rot at the core unless gathered early. First of September. (Gard. Chron.) 


\title{
Sumber Bon Cinrétuex.
}

\author{
Bon Chritien I'Et: \\ Gratioli \\ Gratioli d'Étí. \\ Gratioli di Roma. \\ Summer Good Christian. \\ Husk Summer lion Chritien. \\ Sommer Apothekerline. \\ Sommer Gute Christenbirue. \\ Die Sommer Christebirne. \\ Lirge Sugar, of soine. \\ Gros Bon Chritien. \\ Beauclere.
}

Safran d'Étí.

Sichelis

Cracioli rouge.

Jon chritien d'Et'́ .Jaune.

Canclle d'ité.

De Dneliesse.

Gros bon Chritien d'Etó.

Lom Clır tien Gratioly.

Gros bon Chr tien Beauclerc.

William Powell.

Stuyversant.

Eniticott.

Richards lieurri, of some.

This is one of the oldest Pears, having been cultivated for the last Shree centuries all over Europre.

Fruit large, irregularly bell-shaped or pyriform, with swcollen, \{nolby sicles. Skin yellow, with an orange blush. Flesh yellowish, coarse-grained, very juicy, aud of a pleasant, rich, swest flayor. Good. Last of Angust, or early in September.

\section{Simaler Crassane.}

Crassane d'Été.

Fruit small, roundish oblate, pale yellow, covered with crimson russet. Flesh half uelting, very juicy, sweet, and aromatic. Last of A ugust. (Hogg.)

\section{Sumaer Frixc Réat.}

Franc Réal d'Étè.

Fondante.

Gros Mieet d'Ét’́.

Milan Blane,

Bergimotte d'Ets on Milan Blanc.

Milan de le Beurri re.

Beurrí d'Été.

Royale.

Hâtiveau Blanc.

Conle Soif.

Gros Mouille Bouche.

Great Nonthwater.

Beurré Blanc.

The origin of this Pear is unknown.

Fruit of medium size, obovate, but largest in the midlle, and tapering each way. Skin pale yellowish green, dotted with small brownish green dots. Flesh white, fine-grained, buttery, sugary. Good. Ripe early in September.

\section{Sumuer Rose.}

Epine Rose.

Caillot Rosat d'Été.

Thorny Rose.

poire de Rose.

Epine d'Ét' Couleur Rose.

Caillot Rosat.

Rosenbirne, of the Germans,

The Riose Pear.

Rose Epine Rose.

De Caillean.

De Caillot.

Calua Rosat.

Caillou Rozat.
De Monsieur.

De la IIontières.

Ognon de Xiaintonge.

Rozatte du Dauphine.

Viliane d'Anjou.

Rozatte d'Ingrandes.

Benrr' Ilutif.

D'Eau Rose.

bigarride.

'Tulip'e.

Brute Bonne d'Automne.

Caillaurozat.

Caillorozar.

Peral del Campo.

Fruit meditim, roundish. Skin fuint yellow, with a red musset cherk. Flesh white, coarse. Last of August, not eatable. 


\section{Sumier St. Germaix.}

Short's Saint Germain.

Saint Germain de Martin.

Saint Giermain d'Été.
Joli-mont of some.

Hoe-Langer Hoe-Lievrr.

Jargonelle des Prorençaux. crops.

A pleasant, juicy summer Pear, of second-rate flavor, bearing large

Fruit of medium size, obovate pyriform. Skin pale green all over the surfice. Stalk an inch and a quarter long, obliquely inserted Calyx large, in a basin scarcely sunken. Flesh juicy, tender, with a very slight acid. Poor. Last of August.

\section{Sumer Virgaliet \\ Powell's Virgalieu.}

Origin unknown. Tree moderately vigorous, productive.

Fruit merlium, roundish pyriform. Skin yellow, slightly netted and patched with russet, and thickly sprinkled with russet dots. Stalk rather long, often eurved, set in a small eavity. Calyx open. Segments recurved. Basin shallow, uneven. Flesh yellowish, juicy, melting, a little vinous. Good. Augnst.

\section{Superfondante.}

Fruit of medium size, obovate. Skin smooth, pale yellow, marked with russet. Flesh white, buttery, melting, and good. October.

\section{SUPREME DE QUimper.}

This nice little Pear is of Belgian origin. Tree moderately vigorons, upright and productive. Young wood olive yellow brown, rery shortjointed.

Fruit medium, roundish, slightly pyriform. Shin fine, clear yellow, richly sharled with red, somewhat specked and netted with russet. Stalk rather short, obliquely inserted, without cavity. by a slight appearance of a lip. Calyx open or partially closed. Basin shallow. Flesh whitish, juicy, melting, sweet and perfumed. Good to rery good. Ripe early in August. Should be gathered very early, or it becomes dry.

\section{Strpasse Mletris. \\ Ferdinand Demeester.}

A seedling of Van MLons'. Tree vigorous, very productive.

Fruit medium, roundish, slightly oral. Skin greenish yellow, sometimes shaded with dull erimson in the sun, and thickly sprinkled with brownish dots. Stalk stont, Heshy at insertion, in a shallow depression. Calyx large, open. Segments long, recurved. Basin shallow, meren. Flesh whitish, juicy, buttery, half inelting, sweet. Good. November.

\section{Surpasse Trirgaliet.}

\section{Surpasse Virgonleuse. Colmar Van MIons, erroneously.}

The precise origin of this very delicious fruit is not known. It was first sent out from the nursery of the late Mr. Andhew Parmentier, of Brooklyn, under this name, and is, perhaps, an unrecognized foreigu 
Pear, so named by him in allusion to its surpassing the favorite Virga. ?ien (White Doyenué) of New York.

Fruit rather large, romulish, sometimes romolish obovate. Skin smooth, pale lemon yellow, with a rery few minute dots, and rarely a little faint red on the sumy side. Stalk rather more than an inch long, not deeply planted in a cavity rather higher on one sile. Calyx rather small, and pretty firm, set in a slight, smooth basin. Flesh white, ex. ceedingly fine-giained and buttery, abounding with delicious, ligh. flavored, aromatic juice. Very gooul. October.

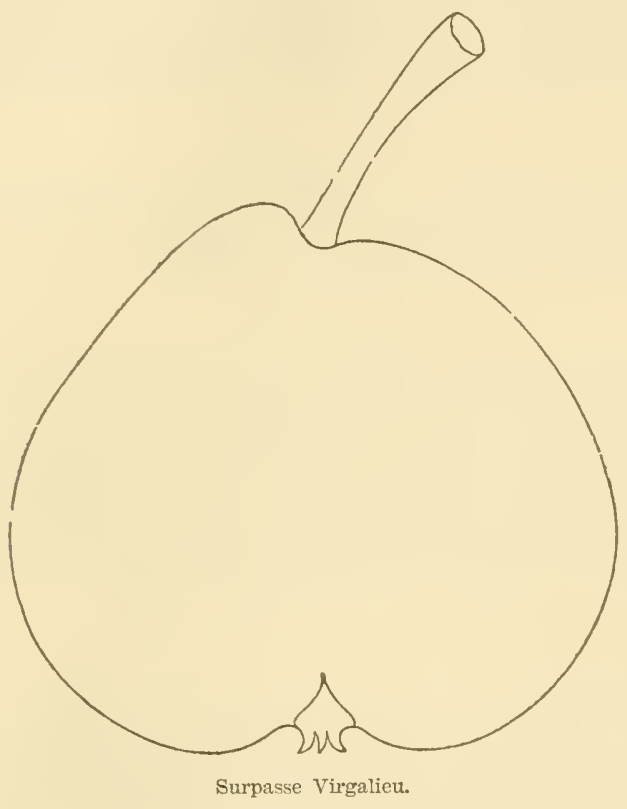

SuzeTte DE BAVAY.

Raised by Major Esperen. Tree vigorous, and very produetive.

Fruit small, roundish oblate. Skin yellowish, sprinkled with minute dots, and some traces of russet. Stalk curved, inserted in a small cavity. Calyx open. Basin shallow and uneven. Flesh whitish, melting, sweet, and pleasint. Good. Only valuable for cooking. J Jauuary to March.

\section{Swan's EgG.}

Noor-fowl Egg, incorrectly.

A very old Pear, unworthy cultivation.

Fruit small, oval. Skin pale green, washed with pale brown on the sunny side, and dotted with brownish specks. Flesh soft, juicy, with a sweet, somewliat musky tlavor. October.

\section{Swiss Berganot.}

Bergamotte Suisse. Striped Bergamot. Bergamot Rayée.

A very pretty, roundish, striped Pear. Branches often striped. 
Fruit of medium size, roundish, a little inclined to turbinate. Skin smooth, pale green, striped with yellow and pale red. Flesh multing, juicy, sweet, aud pleasant. Good. October.

\section{SILYANGE.}

$\begin{array}{ll}\text { Bergamotte Sylvange. } & \text { Bergamot Sylvanche. } \\ \text { Green Syivange. } & \text { Silvanbirne. } \\ \text { Sylvanche. } & \text { Silvange Pierard. }\end{array}$

A foreign variety, superseded.

Fruit roundish obovate. Skin rough, pale green, with a slightly darker green cheek. Flesh greenish white, juicy, tender, and melting, with a sweet, agrceable fiaror. Good. October, and keeps a long time.

\section{TARDJF DE MoNs.}

Fruit oblong obovate. Skin yellow, with an orange tinge in sun, and strewed with large russety dots. Flesh white, tender, buttery, melting, very juicy, rich, sugary. November. (Hogg.)

\section{TARQUIN.}

An old variety, which we have never fruited. The description by Prince resembles that of Belle Williams, recently received as new.

Fruit large, oblong pyliform, with a shallow groove from one end of the fruit to the other: "Skin greenish yellow, marbled orer with fawn. Stalk medium length, enlarged, with a fleshy appearance near its junction with the fruit. Flesh breaking without being dry, rather delicate, and lass a slight acidity. Good. Ripens April, May.

\section{Tarquix des Pyréxées.}

Tree vigor'ous.

Fruit large, pyriform. Stem long, stout, fleshy at its junction, without cavity. Calyx large, open, with persistent segments, in a broad, irregular basin, surrouncled by russet. Skin green, sprinkled or patched - with russet, and thickly covered with brown dots. Flesh of poor quality, a very long keeper, and said to keep two years. Only a cooking Pear.

\section{Thylor Pear.}

\section{Merriweather.}

Originated won the farm of Mr. Merriweather, near Charlottesville, Albemarle Co., Va. Tree vigorous. Young wood clear olive brown, productive.

Fruit medium, roundish oblate. Skin light green, mottled with dark green, netted and dotted with russet. Stalk medium. Cavity shallow. Calyx small, open. Flesh yellowish, coarse, buttery, juicy, half melting, sweet, and pleasant. Good. November, December.

TEA.

Raised by Mrs. Ezra Merchant, of Milford, Conn. The seed was found in a pound of tea, which she purchased at the store, hence its name. Tree vigorous and productire. Young wood olive yellow. 
Fruit medium, obovate, inclining to pyriform. Skin lemon yellow, with numcrous small brown dots, and sometimes a reddish cheek, netted and patehed with russet. Stalk rather stout, inserted obliquely under a lip in a very small cavity. Calyx half closed. Basin shallow. Flesh white, fine, juicy, melting, and rinous. Good to very good. Ripens last of A ugust to middle of September.

\section{Theodore VAN Moss.}

'This Belgian Pear, supposed one of Van Mons' seedlings, originated about 1827 , but was not brought to notice until about 1843 . The tree is a vigorous, upright grower, quite productive. The young wood light yellow reddish brown.

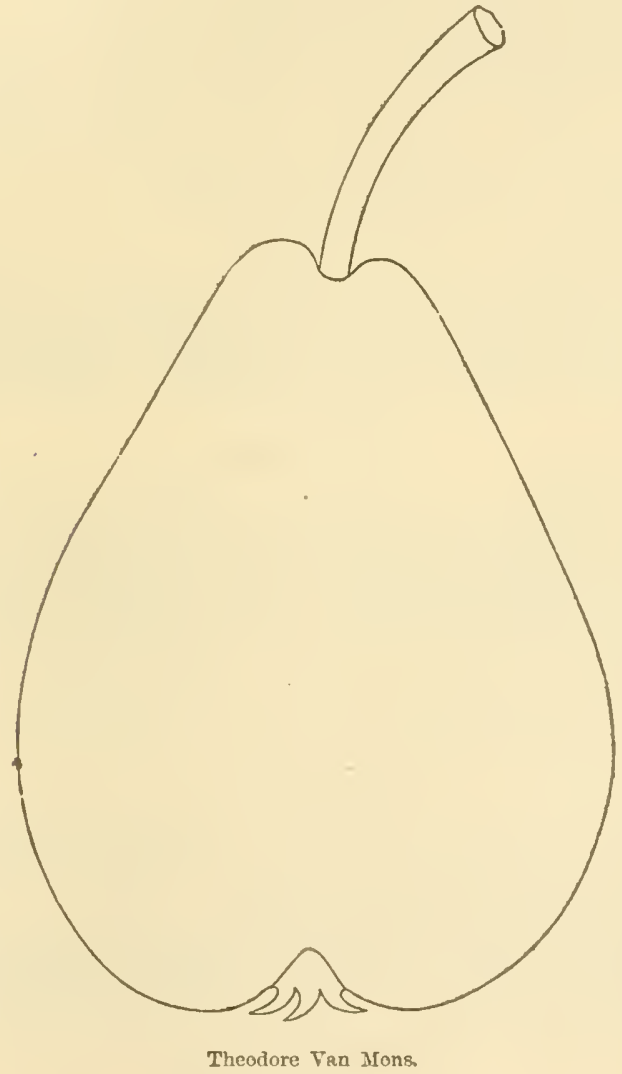

Fruit medium or above, oblong pyriform. Skin greenish or pale yellow, with traces and patches of russet, and many gray and green dots. Stalk eurved. Cavity slight, russeted. Calyx open. Segments reflexed. Flesh whitish, rather coarse, juicy, melting, vinous. Good to very good september, Oetober. 


\section{Thérèse Kumps.}

A Belgian Pear, introdnced in 1847. Tree vigorous, productive.

Fruit medium, oblong pyriform, pale yellow, slightly tinted with brownish in sm, small patches, large specks and dots of thin russet. Stalk medium, rough, inserted with rings at base. Calyx with short, almost erect segments. Flesh yellowish white, half fine, melting, jnicy, sweet, vinous, perfumed. Norember. (An. Pom.)

\section{Tifompson's.}

This Pear, received by us from the Horticultural Society of London, was named in honor of Mr. Rober't Thompson, the head of the firuit de. partment in the Śociety's garden, to whose pomological acumen the hor. ticultural world is so largely indebted. Tree vigorous and productive. Fruit variable. Young wood reddisls yellow brown.

Fruit of mediun size, oborate lyriform, slightly irregular in surface. Skin pale lemon yellow, with a few small russety dots and patches and streaks. Stalk pretty stont, an inch or more long, inserted in a blunt, uneven carity. Calyx open, stiff, often without divisions. Basin abrupt, uneven. Flesh white, buttery, molting, sugary, slightly aromatic. Good to very good. October and November.

\section{Thoonis.}

A Belgian Pear, introduced in 1854, and morthy cultivation.

Fruit below medium, oval, pale yellow, thickly sprinkled with brown dots. Elesh white, coarse, dry, sweet, and poor. Early September.

\section{Thuerlinckx.}

Tuerlinckx.

Beurré Tuerlinckx.

This variety was grown from seed and first exhibited in 1848, by M. Thuerlinckx, of Malines, Belgium. Tree moderately vigorous.

Fruit very large, regular oblong obovate pyiform. Skin dull greenish, with a shade of brown at ends, and marblings of dull dark green and brown. Stalk medium, inserted without depression by a ring. Flesh white, butter'y, acidulous. Norember, December. (Al. Pom.)

\section{Tillixgtox.}

Raised in the village of Tillington, near Hereford, England, and first exhibited by T. A. Knight, Fsq., before the London Horticultural Society, in 18:0. Tree hardy and productive.

Fruit medium size, short pyriform, greenish yellow, with light brown russet dots. Stalk short. Calyx open. Flesh yellowish, tender, but tery, melting, not juicy, vinous, aromatic. Good. October.

\section{TOTTEN'S SEEDLING.}

Raised by Colonel Totten, of New Haven, Conn. Tree vigorous. Young wood dull olive yellow brown.

Fruit small, roundish pyriform, pale yellow, with a shade of crimson in the smu, traces, patches, and dots of riisset. Stalk long. Calyx open, Flesh white, sweet. Poor. September. 


\section{TRESCOTT.}

Originated on the furm of Niles Trescott, Cranston, R. I.

Fruit melium size, roundish obovate, orange yellow, with patches of cinnamon russet. Flesh fine-graned, melting, juicy, pleasant rood, Last September. (Hort.)

\section{'T'RIOMIPIE DE JODOIGNE.}

A Pelgian Pear, seedling of M. Bonvier in 1830, introduced in $18+3$. T'ree vigorons and productive. Young wood short-jointed, dull grayish brown.

Eruit lirge, obovate ovate obtuse pyriform. Surface meven. Skin pale greenish yellow, shaded and mottled with crimson in the sum, patches, nettings, and traces of russet, and thickly sprinkled with brown and green dots. Stalk rather long, a little inclined, fleshy at its insertion by a ring. Cavity small. Calyx open. Segments short and stiff. Basin small, uneven. Flesh whitish, coarse, juicy, half melting, sweet. Good to very good. October.

\section{Trionpile de Louvais.}

Of Belgian origin. Tree vigorous, productive, an early bearer.

Fruit medium, roundish oblate. Skin rather rough, greenish yellow, mostly covered with thin dull russet, with a dull red cheek in sun, many russet brown dots. Stalk rather short, stout. Cavity medium. Calyx large, open. Segments recurved. Flesh whitish, coarse, not juicy or melting, sweet. Good. September.

\section{Truckhili Bergamot.}

Fruit medium or above, roundish oblate. Skin yellow, with erimson and fiwn in the sum, sprinkled with gray and green dots. Stalk rather short. Cavity deep. Calyx open. Basin deep, abrupt, uneven. Flesh laalf melting, somewhat coarse and gritty, moderately juicy. Good. October.

\section{Twexty-fifti Annifersaire de Leopold I.}

This Pear, with its unfortunate long name, is a seedling of M. Grégoire, Jodoigne, Belgium. The tree is of medium vigor, and very pro. iluctive.

Fruit medium to large, oval obovate pyriform. Skin pale greenish yellow, with a few patches of crimson in the sun, and netted, patched, and dotted with russet. Stalk medium or slender. Cavity narrow. Calyx with half-erect segments. Flesh white, fine, melting, buttery, juicy, sweet, with a delicious perfume. November. (An. Pom.)

\section{Tyler.}

An Ameriean variety. Tree moderately vigorous. Young wood reddish vellow brown.

Fruit below medium, roundish pyriform, yellow, netted and patshed and rotterl with russet. Stalk long and slender, in a moderate cavity. 
surrounded by russet. Calyx open. Basin shallow and uneven. Flesh white, coarse, granular, buttery, melting, juicy, brisk, and vinous. Good. Octobcr.

\section{Trson.}

A nutive seedling, found in a hedge on the farm of Jonathan Tyson, of Jenkintown, near Philadelphia. Tree an upright, vigorous grower, but a tardy bearer, very productive. Young wood olive yellow brown.

Fruit medium or below, acute pyriform. Skin clear, deep yellow at full maturity, slightly russeted, with a fine crimson cheek, and numerous

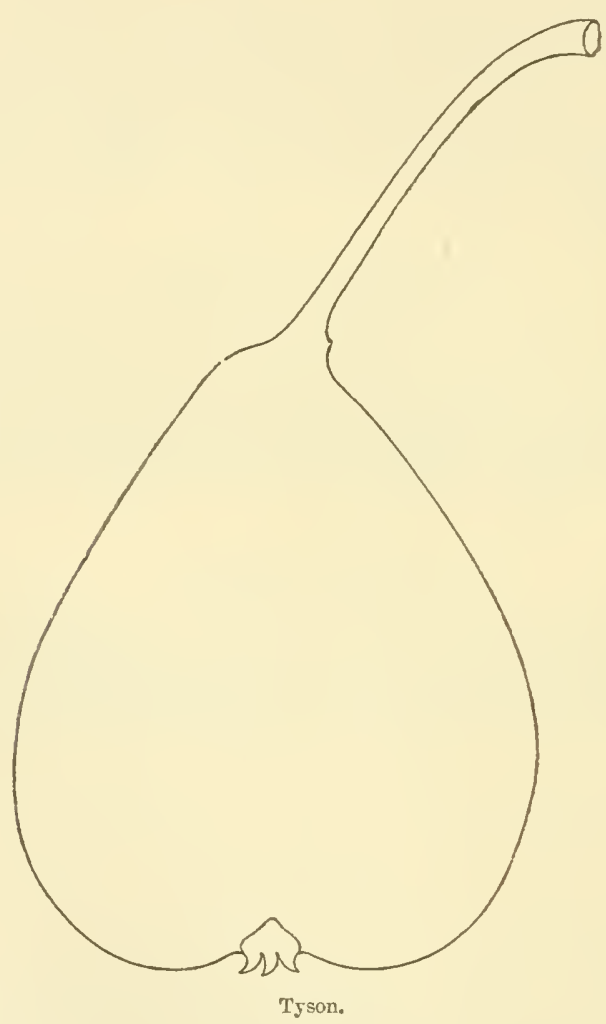

minute brown dots. Stalk long and curved, generally inserted by a fleshy ring or lip. Calyx open. Basin shallow. Flesh rather fine, juicy, melting, very sugary, and somewhat aromatic. Very good to best. Ripens last of August and first of September.

\section{UPPER Crust.}

A seedling of South Carolina, and introduced by Colonel Sumner. Fruit below medium, roundish. Skin greenish, covered with dots 
and patches of russet. Stalk rather short and stout. Cavity broul, shallow. Calyx large, open. Flesh gramular, not juicy, rots at core P'oor. Angust.

\section{URBANISTE.}

\begin{tabular}{ll} 
Count Coloma. & Louise d'Orleans. \\
St. Nare? & Piequery. \\
Beurré Piequery. & Louis Dupont. \\
\hline Coloma d'Automne. & Henkel d'Iliver. \\
\hline
\end{tabular}

The Urbaniste is a fruit which, in its delicious flavor, compares perhaps more nearly with the favorite old Doyenus or Virgalieu than any other fruit, and adds, when in perfection, a delicate perfume peeuliarly its own. Its handsome size and remarkably healthy habit eommend it for those districts where the Doyenne does not flowrish. The tree is a

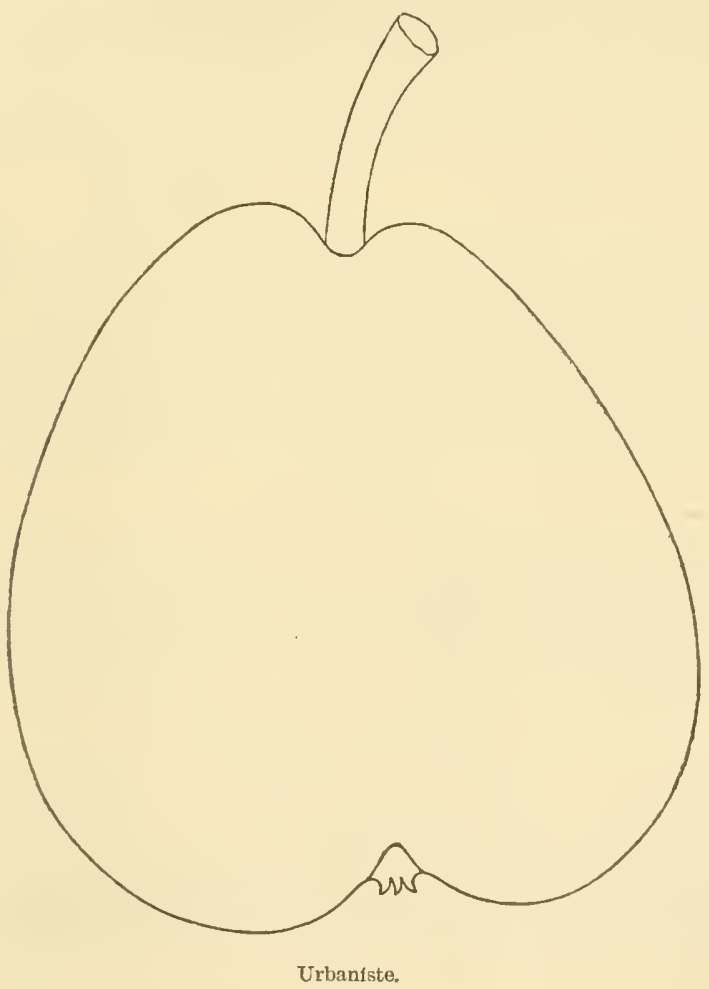

moderately vigorous grower, and though it does not begin to bear so early as some varieties, it yields abundant and regular crops, and gives every indication of a long-lived, hardy variety. For the orchard or garden in the Middle States, therefore, we consicler it indispensable. With so many other fine sorts, we owe this to the Flemish, it having 
been originated by the Count de Coloma, of Malines. It was first intro. duced into this country in 1823. Young shoots upright, short-jointed, olive vellow brown.

Fruit of medinm size, often large, obovate pyriform. Skin smooth and fair, pale yellow, with gray dots, and a few russet streaks. Stalk about an inch long, rather stont, and inserted in a well-marked or rather lroad depression. Calyx small, closed, and set in a narrow basin, which is abruptly and rather deeply sunk. Flesh white, yellowish at the core. buttery, rery melting and rich, with a copious delicious juice, delicately perfumed. Very good or best. Ripens from the last of September till the end of November, if kept in the house.

\section{URSULA.}

Fruit below medium size, oblong acute pyriform. Skin yellow, much shaded with fine crimson in the sum, partially netted and patched, and thickly sprinkled with russet dots. Stalk stout, Heshy at base, inclined, set without carity. Calyx open. Flesh yellowish, coarse near the core, juicy, half melting, sweet, pleasant. Good to rery good. October, November.

UWCHLAN.

Dowlin.

Round Top.

Origin on the premises of widow Dowlin, Uwchlan township, Pa., near the Brandywine. Tree of moderate growth.

Fruit below medium, roumlish, inclining to obovate. Skin yellow, mostly covered with golden russet. Stalk long, curved, in a slight lepression. Calyx open. Basin shallow. Flesh white, melting, juicy, slightly vinous, with a fine aromatic flavor. Good to very good. If not picked early it is disposed to rot at the core. Ripens last of August.

\section{VALENTINE.}

Originated on Long Island.

Fruit above medium, oblong acute pyriform, pale yellowish green, tinge of red in the sun. Flesh white, juicy, melting, sweet, pleasant. Good. August.

\section{Vallée Franciie.}

De Vallée.

Bonne de Keinzheim.

De Keinzheim.

An old variety, unworthy cultivation.

Fruit medium, obovate pyriform. Skin yellowish green. Flesh white, not fine-grained, quite juicy, but not buttery, and of a simple sweet flavor. Last of August.

VAN Assche.

Tan Assene.

Tan Asshe.

'This Flemisl Pear is quite handsome but of variable quality. Tree vigorous, productive. Toung wood reddish yellow brown.

Fruit medium to large, roundish oborate pyriform. Skin pale whit- 
ish yellow, shaded, mottled, and dotted with crimson, and thickly covered with conspicnous brown lots. Stalk eurved, inclined, set in a shallow eavity, sometimes by a lip. Calyx partially elosed. Segments short, erect. Basin abrupt, large, deep, slightly corrugated. Flesh white, juicy, melting, sweet, pleasant. Ciood to very good. September.

\section{Thas Burex.}

An American seetling, raised by Governor Edwards, of New Haven, Comn. Only valuable for cooking.

Fruit medium, roundish oblate. Skin clear yellow, with a rich orange-red blush next the sum, legularly dotted with conspricuous brownish specks, and slightly tonched with greenish and russet spots. Flesh white, crisp, sweet. October.

\section{ThN Defenter.}

Origin, New Jersey. Tree very vigorous, very productive.

Fruit rather small, oblong ovate lyriform, greenish yellow, shaded with brownish red in the sur, with many gray and green dots. Stalk inclined, inserted by a lip, and sometimes rings. Calyx partially closed. Basin shallow. Flesh whitish, juicy, tender, half melting, sweet, pleitsant. Good. Milllle August.

\section{TAY de W'eyer BAtes. \\ Vandeweyer Bates.}

Fruit below medium, rounlish obovate, pale lemon yellow, covered with small brown dots, and a few veins of the same color. Calyx large, open. Flesh yellow, buttery, juicy. rich, sugary, with a pleasant aroma One of the finest late Pears. March to May. (Hogg.)

\section{Vax MakUM.}

$\begin{array}{ll}\text { Beurré Yan Marum. } & \text { Calebasse Carafon. } \\ \text { Grosse Calebasse du Nori. } & \text { Calebasse MIuustre. } \\ \text { Bouteille. } & \text { Calebasse Mlonstrueuse du Nord. } \\ \text { Monstrueuse du Nord. } & \text { Calebasse Royale. } \\ \text { Triomphe du Nord. } & \text { Calebasse de Holland. } \\ \text { Triomphe de Hasselt. } & \text { Calebasse Imp riale. } \\ \text { Poire Vau Marum. } & \text { Calebasse du Nord. } \\ \text { Calebasse de Nerckman's. } & \text { Calebasse Monstrue use. }\end{array}$

Originated with Van Mons. Tree a vigorous grower, productive. Young wood reddish brown.

Fruit, large to very large, oblong pyriform. Skin yellow, rarely with a little red. S alk rather long and slender, inserted in a flattened cavity. Calyx large, set in a regular shallow basin. Flesh white, liable to rot at the core, half melting, not very juicy, but sweet and pleasantly perfumed. Good. October.

\section{Vay Moss Léon le Claerc.}

Van Mons Léon le Clere was originated by M. Léon le Clere, an amateur cultivator, of Laval, in France, who, in naming it, desired to comple his own name with that of his friend, Dr. Van Mons-- "le grand prêtre de Pomona." Its young shoots are strong, upright, olive-colored. 
Fruit large, oblong obovate. Skin yellowish, much mingled with brown orer nearly the whole surface, and slightly russeted near the stalk. Stalk an inch and a half long, rather stout, obliquely inserted, witl little depression. Calyx small, open, set in a shallow basin. Flesh yellowish white, buttery, and melting, with a sugary flaror. Good to very good. October and November.

\section{Vax Mons Str. Germar.}

\section{St. Germain Nouveau.}

A seedling of Professor: Van Mons', and considered a great acquisition to the list of fine Pears. Tree vigorous, productive.

Fruit ratlier above medium, regular, oblong obovate pyriførm, green ish yellow, shaded with dull green, and with fawn russet patches and minute black dots. Stalk long, inserted with scarcely any depression, surrounded by a few folds. Flesh white, lalf fine, melting, juicy, sweet, perfumed. September. (Al. Pom.)

\section{VAUQUELIT.}

Poire Vauquelin.

Saint Germain Tauquelin.

A variety from Rouen, France. Tree a vigorous grower. Young wood reddish brown.

Fruit medium, obovate pyriform, sometimes oblong obovate pyriform. Skin greenish, a little brownish in the sun, some patches and traces of russet, and russet dots. Stalk stout, inserted with little or no cavity, and base enlarged. Flesh whitish, juicy, melting, vinous, astringent. Good. December, January.

\section{Verlaine.}

\section{Verlaine d'Été ?}

One of Van Mons' seedlings.

Fruit mediun, oblong obovate pyriform, pale yellow orange in sun, with patches and dots of brownish red. Stalk slender, inserted in a small cavity. Calyx with short, stiff segments. Flesh white, halt fine, melting, juicy, sweet, vinous. September. (An. Pom.)

\section{Vermillon d'ex Hat'.}

A foreign variety. Tree vigorous, with strong young shoots of a light olive yellow brown.

Fruit medium size, obovate pyriform, greenish yellow, shaded with red in the sun. Flesh fine, melting, juicy, sweet. September.

\section{VERMIONT.}

Vermont Seedling.

A supposed seedling, taken from Vermont to near Oswego, N. Y., where it has fruited. Tree an upright grower. Young wood glayish olive.

Fruit medium or below, ovate obovate obtuse pyriform, pale whitish 
yellow, slight red in the sum, traced, netted, and dotted with russet. Stalk slender. Cavity deep. Calyx with erect segments. Flesh whitish, juicy, melting, sweet, pleasant. Good to very good. October.

\section{Verulaim.}

Black Beurres.

Spring Beurré
Buchanan's Spring Beurré.

New Spring Beurré.

An old variety, valuable only for cooking.

Fruit large, obovate, dull green, covered with thin russet in the shade, and reddish brown in the sun, thickly dotted with gray dots. Stilk slender. Calyx open. Flesh crisp, coarse-grained, and when stewed assumes a fine rose color. January to March. (Hogg.)

\section{Vezouziere.}

This is a seedling raised by M. Léon le Clere, from seeds of the Van Mous Léon le Clerc. Tree a vigorous grower, productive. Young wood reddish olive brown.

Fruit medium or below, nearly globular, slightly oblate. Skin yellowish, sprinkled with minute gray and green dots. Stalk long, curved, inserted in a broad, shallow cavity. Calyx open, persistent, in a wide, uneren basin. Flesh very juicy, melting, sweet, and agreeable. Good to very good. September.

\section{VICAR OF WINKFIELD.}

Le Curé.

Monsieur le Caré.

Clion.

Belle de Berry.

Belle Hèloise.

Bon Papa.

De Clion.

Monsieur.

Belle Andreane.

De Monsieur Le Curé.

Belle Adrienne.

Vicaire de Winkfield.
Missive d'Hiver.

Cueillette d'Hiver.

Comice de Toulon.

Du Curé.

Grosse Allongée.

Du Pradel.

Wicar of Wakefield.

Pradello de Catalogne.

Curette.

Jouffroy.

Messire d'Hiver.

This large and productivè Pear was discovered, as a natural seed ling, in the woods of Clion, France, by a French curate, whence it obtained in France the familiar name of Le Curé, or Monsieur le Curée. A short tine after it became known at Paris, it was imported into England by the Reverend Mr. Rham, of Winkfield, Berkshire, and cultivated and disseminated from thence, becoming known in the neighborhood of London as the Vicar of Winkifield. With regard to its merits there is some difference of opinion-some persons considering it a tine fruit. It is always remarkably large, fair, and handsome. TVe think it always a first-rate baking Pear. Occasionally we have tasted it fine as a table Pear, but generaily it is astringent, and only third-rate for this purpose. If ripened off in a warm temperature, however, it will generally prove a good second-rate eating Pear. But its great productiveness, hardiness, and fine size, will always give it a prominent place in the orchard as a profitable market cooking Pear. The tree grows thriftily, with drooping fruit branches. Shoots diverging, dark olive biown. 
Fruit large and long pyriform, often six inches long, and a little onesided. Skin fair and smooth, pale yellow, sometimes with a brownish

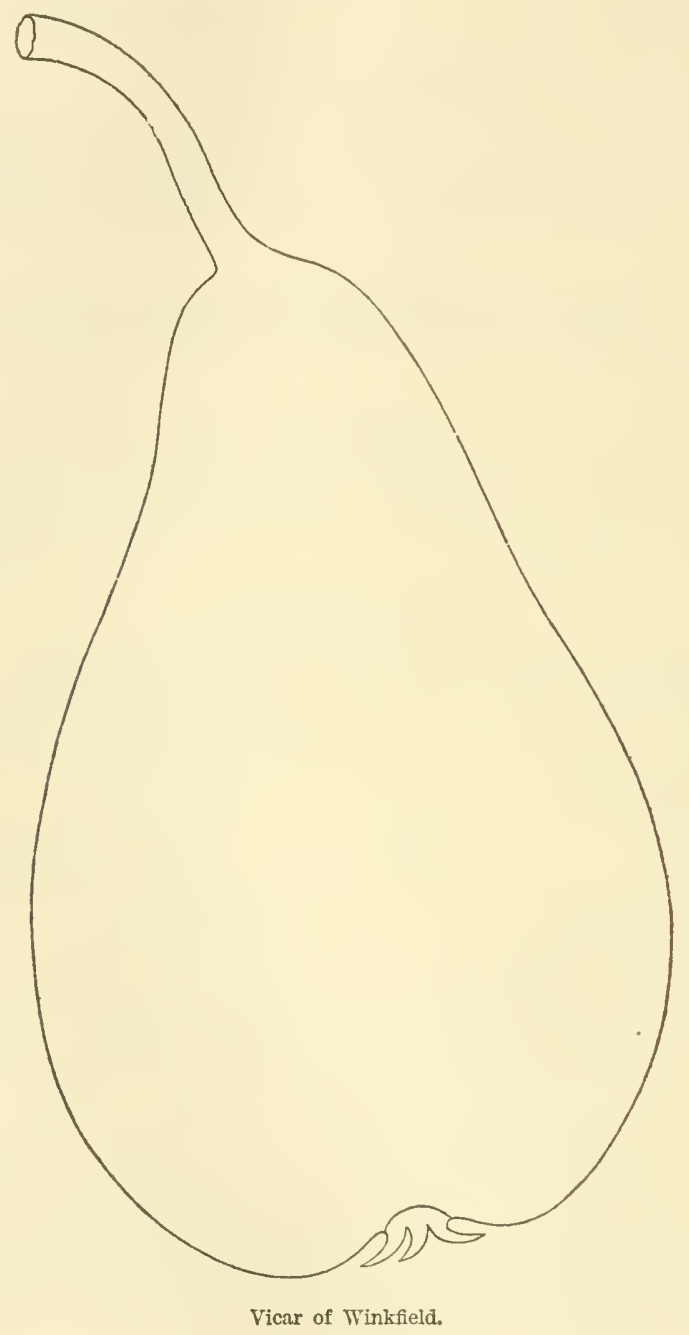

cheek, and marked with small brown dots. Stalk an inch or an inch and a half long, slender, obliquely inserted without depression. Calyx large, open, set in a basin which is very slightly sunk. Flesh greenish white, generally juicy, but sometimes buttery, with a good, sprightly Havor. November to January. 


\section{Vicomte de Spoelbercir.}
De Spoelberg.
Beurré de Spoelberg.
Despoilberg.

A seclling of Tan Mons', deseribed in 1830, and dedicated to M. le Ticomte de spoelberg de Lowenjoul. Tree vigorous, productive. Young wood reddish yellow brown.

Fruit medimm, romulish acnte pyriform. Skin pale yellow, coverer with nmmerous small dots, and small patehes of russet. Stalk eurved, theshy at its insertion, with slight russet. Calyx open. Basin small, Flesh white, brttery, juicy, melting, not high flavored. Good. Novenher, December.

\section{TINEUSE.}

Vineuse d'Esperen.

A seedling of Major Esperen's, first introduced in 1840. Tree vigorous, with slender wood, noductive. Yomng wood reddish olive biown.

Frnit medium or above, obovate ovate slightly obtuse pyriform. Skin greenish, slightly bronzed in the sun, a few patches and nettings of russet, and many small brown and green dots. Stalk medimm. Cavity small. Calyx large, open. Basin broad, shallow. Flesh coarse, juicy, melting, acid. Good. Oetober.

\section{VIRGOULEUSE.}

$\begin{array}{lll}\text { Poire-glace, } & \text { Le Virgoule. } & \text { Poire de Glace. } \\ \text { Chambrette. } & \text { Virgolese. } & \text { Ice Pear. } \\ \text { Bujaleuf. } & \text { Chambrette d'Hiver. } & \text { La Virguleuse. }\end{array}$

An old French variety, of little value.

Fruit medium, pyriform. Skin very smooth, yellowish green at maturity, sprinkled with numerous gray or reddish dots. Flesh white, l. uttery. Good. November to Jamuary.

\section{VOY ZUGLER,}

A new Belgian variety. Tree slender. Young wood olive. Produetive.

Fruit medium size, roundish acute pyriform. Skin yellow, nearly covered with cinnamon russet. Stalk rather short, inclined in a slight depression by a fleshy lip. Calyx small, open. Segments short, ereet. basin small. Flesh white, juicy, melting, sweet, slightly aromatic. Very grood. September.

\section{IVADLEIGH.}

Origin, New Hampshire

Fruit medium, nearly globular. Fine yellow, slightly netted and matehed with russet. Stalk short, stont, inserted in a slight eavity, sometines by a fold or lip. Calyx with small short segments. Flesh white, fine, a little gritty, juicy, melting, pleasant. Good. September.

\section{WALKER}

No. 13i, Van Mons.

This is a seedling of Van Mous', and sent to Robert Manning, of 
Salem, Mass., in 1834-5, muder number. The tree is a vigorous, lealthy grower, upright habit. The young wood grayish.

Fruit large, oblong pyriform. Śkin greenish rellow, sometimes a shade of crimson in the sum. Slight nettings and patches of russet, and thickly sprinkled with brown dots. Stalk long, fleshy at insertion, in a slight cavity by a ring. C'alyx open or partialiy closed. Segments short, erect. Basin small. Flesh white, a little coarse, juicy, half nelting, vinous, a little astringent. Good to very good. October.

\section{WASHINGTON.}

Robinson. Naaman's Creek. Trobertson. Namen's Creek.

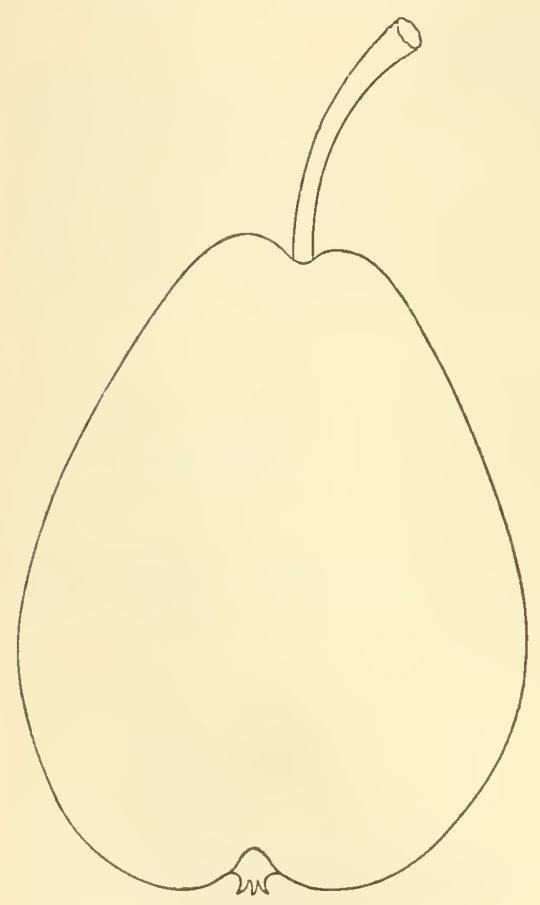

Washington.

A beautifnl American Pear, of rery excellent quality, which is a native of Delaware. It was discovered there in a thorn hedge, near Naaman's Creek, on the estate of Colonel Robinson. It is one of the most attractive and distinct of our native des sert Pear's. Young shoots slender, diverging, reddish jellow brown.

Fruit of medium size, oval obovate, regularly formed. Skin smooth, clear lemon yellow, with a sprinkling of reddish dots on the sunny side. Stalk about an inch and a half long, inserted even with the surface, or with a slight depression. Calyx small, partly closed, and set in a shallow basin. Flesh white, very juicy, melting, sweet, and agreeable. Tery good. Middle of September.

\section{WATSON.}

An American rariety, of poor quality.

Fruit below medium, roundish slightly obovate, yellowish, corered mostly with russet. Flesh whitish, coarse, moderately juicy, sweet. Early September.

\section{WEBSTER,}

Originated at Hudson, N. Y. Tree a moderate grower, productive. Young wood reddish brown.

Fruit medium, globular obtuse pyriform. Skin yellow, sometimes a tinge of crimson in the sun. Traces and nettings of russet, and many minnte brown dots. Stalk long, slender, inclined, set in a small russeted cavity. Calyx open. Segments long, reflexed. Flesh white, juicy, melting, sweet, slightly aromatic. Good to very good. November. 


\section{Welbeck Berganot.}

Hepworth.

Fruit above medium, roundish, meven in ontline, bossed abont the stalk, lemon yellow, blush of light crimson in the sun, and thickly sprinkled with large russet specks. Calyx small, open. Basin shallow. Wlesh white, rather coarse-grainer, half melting, juicy, sweet, without flavor. November. (Hogg.)

\section{WELLINFTON.}

Raised by _ Wellington. Braintree, Mass., and first shown before the Massachinsetts Horticulturai Dociety in 1864.

Fruit large, oblong obovate obtuse pyiform. Skin clear pale yellow, cloucher with green. Stalk very short. Calyx open, with short, stiff; slightly incurved segments. Basin shallow. Flesh yellowish white, little coise, juicy, melting, sweet, with a peculiar aroma. November. (Hov. Mag.)

\section{WTEXDELL.}

A seedling of Tan Mons', named in honor of Dr. H. Wendell, Albany, N. Y. Tree vigorous, npright.

Fruit rather small, roundish pyriform, pale yellow, shaded in sun with erimson, and sprinkled with dots. Calyx small, partially open. Flesh whitish, fine-grained, juicy, melting, buttery, sweet, pleasant. Goorl. September.

\section{WESTCOTT.}

A native of Rhorle Island. Tree vigorons, an early bcarer, very prodnctive.

Fruit medinm, irregular globular. Stalk long, curved, rather stont, Heshy at its insertion, in a cavity of moderate depth, with a lip. Calyx rery small, in a shallow furrowed basin. Color light yellow, with numerous gray dots. Flesh white, juicy, nearly melting, coarse, granu lar, sweet, and agreeable. Good. September, October.

\section{WETXIORE.}

Raised by E. B. Wetmore, Westmoreland, N. Y. Tree upright, vigorous. Toung wood reddish yellow brown.

Fruit small, roundish oral. skin pale yeliow, with nettings and patches of russet, and thickly sprinkled with russet dots. Stalk long, slender, set in a small eavity, sometimes by a lip. Calyx open. Segments short, erect. Basin shallow, slightly corrugated. Flesh white, juicy, melting, sweet, aromatic. Good to very good. October.

\section{WHARTOX's EARLY.}

Origin unknown. Tree vigorous. Toung wood olive yellowish brown.

Fruit medium size, obovate oblong acute pyriform. Skin pale yellow, traces of russet, and thickly sprinkled with russet dots. Stalk long, curved, rather slender, set in a slight eavity, sometimes by a lip. Calyx open. Serments short, erect. Basin small, meven. Flesh whitish, juicy, melting, sweet, slightly musky. Cood or very good. August. 


\section{WHEELER.}

Originated in Greenwich, R. I. Tree vigorous, upright. Young wood olive yellow brown.

Fruit medium, roundish oborate. Skin greenish yellow, a few traces and patches of russet, and numerous gray and green dots. Stalk medium. Cavity small. Calyx open. Basin abrupt, uneven. Flesh white, juicy, melting, sweet, pleasant. Good. August.

\section{as WIIELDON.}

Whieldon's McLellan.

McLellan.

Originated in the garden of Wm. WT. Whieldon, Concord, Mass The tree is moderately vigorons, and a profuse bearer.

Fruit medium or above, obovate obtuse, slightly pyriform. Skin pale vellowish green, with a tinge of red in the sun, numerous russet nettings and dots. Stalk long, rather slender, a little inclined, set in a shallow carity. Calyx open. Segments a little recurved. Basin medimm, uneven. Flesh whitish, a little gritty near the core, juicy, melting, buttery, sweet, pleasant, slightly aromatic. Good to very good. September.

\section{White Doyense.}

Doyemné White.

Tirgalieu, of New York.

St. Michael. of Boston.

Putter Pear, of Philadelphia.

Virgaloo.

Bergolon.

Yellow Butter.

White Beurré.

White Antumn Beurré.

Dean's.

Warwick Bergamot.

Pine Pear.

St. Michel.

Reigner:

Doyenn:

Doyenné blanc.

Beurré blanc.
Poire de Limon.

Valencia.

Citron de Septembre.

Bonne-ente.

A courte queue.

Kaiserbirne.

Kaiser r'Automne.

Vieisse Herbst Butterbirne.

Dechantsbirne.

Nonvelle d'Onef.

Edwige.

Carlisle.

White or Autumn Butter.

Talentia or Talencia

Poire du Doyen.

Garner or Gardner.

Sublime Garnotte.

The White Doyenne is, unquestionalbly, one of the most perfect of autumn Pears. Its miversal popularity is attested br the great number of names by which it is known in varions parts of the world. As the Tirgalien in New Tork, Butter Pear in Philadelphia, and St. Hichael's in Boston, it is most commonly known; but all these names, so likely to create confusion, shondd be laid aside for the true nne, White Doyenné** It is an old French variety, having been in cultivation over two hmulred years. The branches are stroug, upright, yellowish gray or light brown.

Fruit of medinm or large size, regularly formed, oborate. It raries considerably in difierent soils, and is often shorter or longer on the same

* Virgalien seems an American name, and is always liable to be confounded with the Virgouleuse, a very different fruit. The Dovenné (pronounced drooyannriy), literally derchstip, is probably an allusion to the Dean by whom it was first brought into notice. 
tree. Skin smooth, clear pale yellow, regularly sprinkled with small dots, and often with a tine red cleek. Stalk brown, from three-fourths to an inch and a fourth long, a little curved, and planted in a small, round caviry. Calyx always rery small, closed, set in a shallow basin, smooth or ilelicately plaited. Flesh white, fine-grained, very buttery,

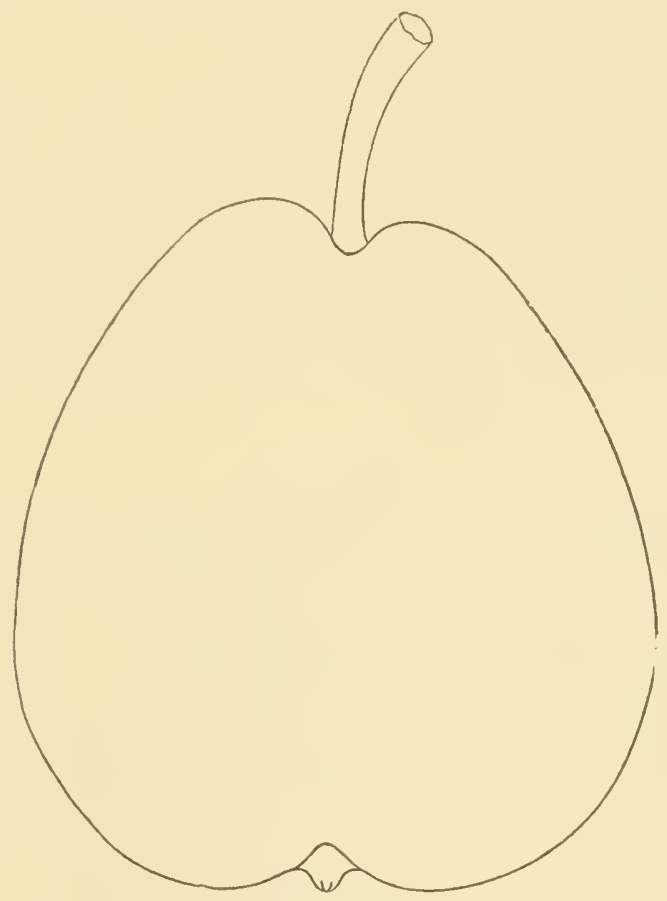

White Doyenné.

melting, rich, high-flavored and delicious. Best. September-and, if picked early from the tree, will often ripen gradually till December.

The Dorexne Pandue, or Striper Dean, is a variety rather more narrowing to the stalk, the skin prettily striped with yellow, green, and red, and dotted with brown. Flesh juicy, melting, but not high-flavored. Octoher.

\section{WIITE'S SEEDLING.}

Drigin, New Haven, Conn. Tree a vigorous grower, very productive. Joung wood olive brown.

Fruit nedium, oblong ovate obovate. Skin yellow, sometimes with a brownish blush in the sun, considerably netted and patehed with russet, and many russet dots. Stalk long, inclined, set in a sliallow eavity, jften by a Heshy lip. Calyx open. Segments short, ereet. Basin small, nineven. Flesh yellowish, juicy, melting, sweet, aromatic. Good to very grood. October to Febmary. 


\section{WIEST.}

From Pennsylvania. Tree a vigorous grower. Young wood reddish yellow brown, with oblong gray specks.

Fruit medium or below, roundish oval, green, shaded with dull red, and sprinkled with green and gray dots. Stalk rather stont. Calyx small, closed. Segments to a point. Flesh whitish green, juicy, meltings, snbacid. Good. September.

\section{W'ILEUR,}

The Wilbur is a native fruit, which originated in Somerset, Mass. shoots slender, light olive brown.

Frit below nedium size, roundish ovate, pale yellow, slightly netted and patched with russet, and thickly sprinkled with russet dots. Stalk small in a small cavity. Calyx open. Segments long. Basin small. Flesh yellowish, juicy, melting, slightly astringent. Good. Seytember.

\section{WIIKINSON.}

The original tree grows on the farm of Mr. J. Wilkinson, Cumberland, R. I. The tree is very thrifty, hardy, and a regular bearer. The shoots are long, upright, stout, olive yellow, with oblong white suecks.

Fruit of medium size, obovate, inclining to oval. Skin smooth and glossy, bright yellow, dotted with brown points. Stalk an inch and a ynarter long, rather stout, inserted with little or no depression. Calyx snall, open, and firm, set in a shallow basin. Flesh rery white, juicy, melting, sweet, and rich, with a slight perfume. Good. October to December.

\section{Willeryoz.}

This Belgian Pear was produced in 1848. The tree is an extremely fune grower, with young shoots dark dull olive brown, very productive.

Fruit large, obovate obtuse pyriform. Skin greenish yellow, nettings and some large patches of russet, and many small russet dots. Stalk medium or rather stout, inclined, set in a small carity. Calyx open, or partially closed. Basin abrupt. Flesh whitish, bntiery, juicy, melting, consse at core, slightly vinous. Good to rery good. November, January.

\section{WiLlia EDWARds.}

A seedling of Ex-Governor Edwards, of New Haven, very productive, and a good baking fruit, but not juicy or melting enough for the dessert.

Fruit of medium size, obtuse pyriform, terminating rather abruptly at the stalk. Skin vellow, and at $m$ iturity profusely dotted with red and russet points or dots on the sunny side. Flesh yellowish white, buttery, sugary. September. 


\section{William Prince.}

Origin unknown. Thee vigorous, upright, productive.

Fruit medimm, roundish lyriform. Skin greenish yellow, with a sharle of erimson in the sum, and many brown dots. Stalk rather short. Calyx open. Basin shallow. l'lesh white, juicy, melting, swcet. Good to rery goorl. September, October.

\section{Williams' Earlo.}

A native fruit, which originated on the farm of Mr. A. D. Williams, of Roxbury, Mass. Tree a moderate grower. Young shoots brown recl.

Fruit small, roundish slightly pyriform. Skin bright yellow, thickly sprinkled with rich searlet dots on the sumny side. Stalk an inch and a lialf long, straight, a little fleshy where it joins the fruit. Calyx very short, open. Basin shallow and slightly plaited. Flesh yellowish white, a little coarse-grained at first, but, when ripe, very juicy, half buttery, with a slightly musky flaror. Grood. First to the midlle of September.

\section{WILLIAMSON.}

Origin on the farm of Nicholas Williamson, Long Island. Tree hardy, vigorous, and a good bearer.

Fruit medium, roundisl oblate. Skin greenish yellow, a few patches and traces of russet. Stalk rather stout. Calyx open. Basin uneven. Flesh white, coarse, juicy, half melting. Good. October.

\section{WILMINGTON.}

A seedling of Passe Colmar, raised by Dr. Brinckle, of Philadelphia. Tree a moderate grower. Young wood dull yellow brown.

Fruit medimm, obovate obtuse pyriform. Skin greenish yellow, netted and patched with russet, and thickly sprinkled with russet dots. Stalk long, set in a small cavity, often by a lip. Calyx open. Segments persistent. Basin shallow, uneven. Flesh whitish green, juicy, buttery, melting, sweet, pleasant, slightly aromatic. Good to very good. September.

\section{WINDSOR.}

Summer Bell.

Konge.

Madame.

Iadame de France.
Belle d'Etée.

Lady Thigh.

Bell Tongue.

Bellissime.

Watermelon, of some.

Green Windsor.

Grosse Jargonelle.

Supreme.

Water, of some.

The Windsor is an olı European Pear, very commonly known in some parts of this country as the Summer Bell Pear. It is a profitable market sort, bearing regularly large crops, and selling well, althongh in quality it is, from its astringeney, almost uneatable, and to be valued only as a cooking fruit. The tree is remarkable for its stont, perfretly upright rlark brown shoots.

Fruit large, Iyriform or bell-shaped, widest above the micldle, nar- 
rowing to the eye. Skin yellowish green. Flesh white, tender or soft, coarse-grained, with a somewhat astringent juice. Rots at the core. Last of August.

\section{Winsitip.}

Winship Seedling.

Originated in the nurseries of the Messrs. Winship, Brighton, Mass. Tree vigorous. Young wood rich dull yellow reddish brown.

Fruit merlium size, oblong acnte pyriform. Skin greenish yellow, with traces and patches of russet. Stalk long, rather stout, and uneren. Calyx large. Segments short, erect. Basin small, corrugated. Flesh white, coarse, not juicy or melting. Poor. Angust.

\section{Winter Boychrétien.}

Bon Chritien d'Hiver.

Poire d'Angoise.

Good Christian of Winter.

Winter Good Christian

Bon Chrétien de Constantinople.

Panchresta.

Poire d'A pothécaire.

Crustemenie.

A Tetine.
De Dos.

De Fesses.

De Bon Crustemenien.

De Chritien.

Bon Chritien de Tours.

Bon Chrétien de Ternon.

Bon Chrétien.

Bon Chrétien d'Auch.

De Saint-Martin.

This is perhaps one of the oldest Pears known, having been deseriber in 1485 . Its value is only for cooking.

Funit large, obovate obtuse pyriform. Skin dull yellow, tinge of brown in the sum, and sprinked with russet dots. Stalk medium. Cavity small. Calyx open. Basin deep. Flesh white, crisp, juicy, sweet, perfumed. December to March.

\section{Winter Nélis.}

\section{Nélis d'Hiver.}

Bonne de Malines.

Beurré de Malines.

La Bonne Malinaise.

Milanaise Cuvelier.
Etourneau.

Bergamotte Thouin.

Colmar Nélis.

Thouin.

Colmar d'Hiver.

The Winter Nélis holds, in our estimation, nearly the same ranli among winter Pears that the Seckel does among the autumnal rarieties. It is a very hardy and thrifty tree, and bears regular crops of pears, which always ripen well, and in succession. Branches direrging, rather slender, dark reddish brown. It is a Flemish Pear, and was originater by M. Nélis, of Mechlin.

Fruit of medium size, or usually a little below it, roundish oborate. narrowed-in near the stalk. Skin yellowish green at maturity, dotted with gray russet, and a good deal covered with russet patches and streaks, especially on the sunny side. Staik an inch and a half long, bent, and planted in a narrow cavity. Calcx open, with stiff, short divisions, placed in a shallow basin. Flesh reilowish white, fine-grained, buttery, and very melting, abonnding with juice of a rich. saccharine, aromatic flavor. Best. In perfection in December, and kecps til] the middle of January. 


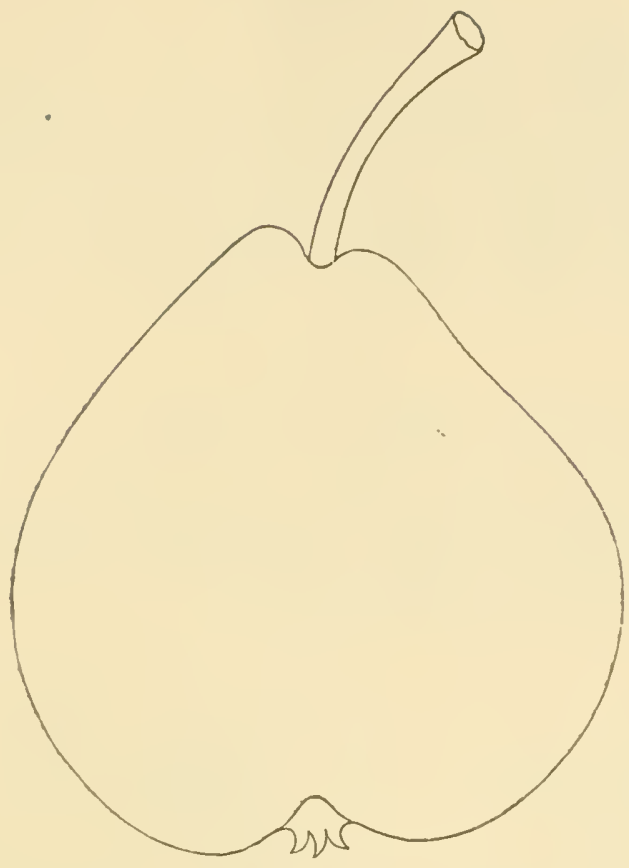

Winter Nélis.

Winter Secked.

Origin, near Frederickshurg, Va. Introduced by H. R. Roby.

Eruit small, obovate, yellow, with a brownish eheek in sun, patehes and nettings of russet, and many large green and brown dots. Stalk slenfler. Calyx large, open. Flesh white, a little coarse at core, juicy, half melting, sweet. Good. Janiuary to March.

\section{Wister Thors.}

Épine d'Hiver.

Épine Rose d'Hiver.

Fruit medium, roumlish obovate, yellowish green, with grayish brown dots. Calyx small, open. Flesh whitish, tender, buttery, sweet, musky. November, January. (Hogg.)

\section{WOOdBribGe's SECKEL.}

Originated at Detroit, Mich. Tree moderately vigorous.

Fruit small, ovate pyriform. Skin pale yellow, sloarled and marbled with crimson in the sun, and thickly sprinkled with brown and crimson dots. Stalk long, slender. Calyx open. Flesh yellowish, juicy, melting, sweet, vinous. Very good, but rapidly decays at the core. September. 


\section{WOODSTOCK.}

Origin, Vermont. Tree moderate grower, very productive. Young wood olive brown.

Frnit meclium or below, varying in form from roundish obtuse to obovate pyriform. Skin pale yellow, netted and patched, and thickly sprinkled with russet dots. Stalk long, rather slender, inserted in a small cavity, often by a lip. Calyx open. Segments loug, slender, persistent. Basin abrupt. Flesh white, juicy, melting, sweet, pleasant, slightly musky. Good to very good. September.

\section{WREDOW.}

This is of unknown origin, probably French. Tree moderately vigorous, very froductive. Young wood dark olive.

Fruit medium, obovate pyriform. Skin greenish yellow, shade of crimson in the sun, netted, patched, and dotted with rich golden russet. Stalk long, slender, inserted in a small cavity, sometimes by a lip. Calyx open. Segments recurred. Flesh whitish, juicy, melting, brisk, vinous. Good to very good. September.

\section{YAT.}

Yutte.

Beurré Gris d'Été.

De Hollaude.

Gute Fraue.
Graue Sommer Butterbirne.

Jutjesbirne.

Jut-peer.

Jutte.

Originated in Holland, of little value. Tree vigorous. Young sood redtish yellow brown.

Fruit small, obovate pyriform, green, with some large, round, lightcolored specks, brown russet in sun. Flesh white, tender, juicy, sweet. Rots quickly. September.

\section{ZEPHERIN Locis.}

Zepherin Louis Grégoire.

Originated and first described by MI. Grégoire, of Jodoigne, Belgium. Tree a moderate healthy grower.

Frnit medinm, roundish obovate. Skin dull greenish rellow, clonded with brownish red, and shades of russet. Staik very short. Carity narrow, round. Calyx small. Flesh yellowish white, tinge of green, half melting, juicy, sweet, slightly aromatic. January. (Al. Pom.)

\section{Zephirin GréGOIRE.}

Raised by M. Grégoire, of Jodoigne, in 1843. Tree a free grower. Ioung wood smooth, light olive yellow brown.

Fruit medium, irregular, roundish acute priform. Skin greenish yellow, reddish in the sum, with patches of russet, and manr green and gray dots. Stalk short, fleshy, very fleshy at insertion, and without a cavity. Calyx open. Segments loug. Flesh whitish, melting, juicy, perfuned. Good to rery good. October, Norember. 


\section{ZoAR BeaUtr.}

\section{Zoar Seedling.}

A native of Ohio. Tree vigorous, dark brown shoots, an early and abundint bearer.

Fruit medium, acute pyriform. Skin yellow, with a beantiful crimson or carmine cheek in snn, thickly dot ${ }^{2}$ ed with minute green dots. Stalk long. curved, fleshy at iusertion, often by a ring or lip, in a suall cavity. Callyx open. Segments erect, sometimes recurverl. Flesh white, gramular, half breaking, moderately juicy, sweet, aronatic, perfumed. Uuless gathered early it rots at core. Good. Early August.

\section{SELECT LIST OF PEARS FOR TABLE USE, MARKETING, AND COOKING.}

Ananas d'Eté. Talle and market.

Baron de Mello. Table and market.

Bartlett. Table and market.

Beurré d'Albret. Table aud market.

Beuré d'Anjou. Table and market.

Beurré Bose. Table and market.

Beurré Brignais. Table and market.

Peurré Clairgeatr. Market.

Beurré Diel. Table and market.

Beurré Giffart. Table.

Beuré Gris d'Hiver Nouveau. Table and market.

Reurré Hauly. Table and market.

Beurré Koning. Table and market.

Beuré Sterckmans. Table and market.

Beuré Superfin. Table and market.

Black Worcester. Market and cooking.

Bioodsood. Table.

Brandywine. Table.

Brialnont. Table and narket.

Buffum. Table and market.

Catillac. Market and couking.

Church. Table.

Clapp's Favorite. Table and market.

Coit's Beuré. Table and market.

Dana's Ilovey. Table and market.

Dearborn Secedling. Table.

Dix. Table and market.

Doetor Reeder. Table.

Doyemué Boussock. Table and market.

Doyemné (fonnies. Table ant market.

Doyenné l'Été. Table and narket.

Doyenué Giris. Table and market. 
Duchesse D'Angoulême. Table and market. Duchesse D'Orleans. Table and market.

Edmonds. Table and market.

Emile d'Heyst. Table and market.

Flemish Beanty. Table and market.

Fondante d'Automne. Table and market.

Foote's Seckel. Table.

Fulton. Table and market.

Gansel's Bergamotte. Table and market.

Henkel. Table and market.

Howell. Table and market.

Jones' Seedling. Table and market.

Josepline Malines. Table and market.

Law rence. Table and market.

Léon le Clerc Laval. Market and cooking.

Louise Bome de Jersey. Table, narket, and cooking.

Lycurgus. Table.

McLauglilin. Table and market.

Madime Eliza. Table and market.

Maming's Elizabeth. Table.

Maréchal de la Cour. Table and market.

Merviam. Table and market.

Onourlaga. Table and market.

Paradise d'Automne. Talble and narket.

Pound. Market and cooking.

Prince's st. Germain. Table and market.

Riostiezer. Table and market.

Putter. Table and market.

Seckel. Table and market.

sheldon. Table and market.

Sonvenir a'Esperen. Table and market.

Spanish Bon Clrétien. Market and cooking.

Stevens' Genesee. Table and market.

Surpasse Virgalieu. Table and market.

Tyson. Table and market.

Urbaniste. Table and market.

Vicar of Winkfield. Market and cooking.

Washington. Table and market.

White Doyemné. Table and market.

Winter Bonchrétien. Market and cooking.

Winter Nélis. Table and market. 


\title{
CHAP'TER XXVIT.
}

\author{
TIIE PLUM.
}

Prunus domesticu, I. Tísacer. of botanists.

Prunier, of the French; Pflumentum, German; Prugno, Italian; Ciruelo, Spanish.

Trie original parent of most of the cultivated Plums of our gardens is a native of Asia and the Southern parts of Europe, but it has become naturalized in this conntry, and in many parts of it is produced in the greatest abmolance* That the soil and climate of the Middle States are admirably sulted to this firit is sufficiently proved by the almost spontaneons production of such varieties as the Wrashington, Jefierson, Lawence's Farorite, ice.; sorts which equal or surpass in beanty or Haror the most celebrated Plums of France or England.

UsEs. 'The finer kinds of plums are beautiful dessert fruits, of rich and luscious flivor. They are not, perhaps, so entirely wholesome as the peach and the pear, as, from their somewhat cloying and flatulent nature, unless when very perfectly ripe, they are more likely to disagree with weak stomachs.

For the kitehen the plum is also very highly esteemed, being prized for tarts, pies, canning, sweetmeats, etc. In the South of France an excellent spirit is made from this finit fermented with honey. In the western part of this State, where they are very abundant, they are halverl, stoned, and dried in the stur or ovens in large quantities, and are tben excellent for winter use. For eating, the plum shonld be allowed to hang on the tree till perfectly ripe, and the fruit will always be finer in proportion as the tree has a more sumny exposure. 'The size :mul quality of the fruit is always greatly improved by thinning the fruit when it is half-grown. Indeed, to prevent rotting, and to have this fruit in its highest perfection, no two plums should be allowed to touch each other while growing, and those who are willing to take this pains, are amply repaid by the superior quality of the fruit.

* There are three species of wild pium indigenons to this country-of tolerable flavor, but seldom cultivated in our gardens. They are the following :-

I. The CHICkisaw Plcm. (Prumus Chicasa, Michaux.) Fruit abont threefourths of an inch in diameter, round, and red or yellowish red, of a pleasant, subacid llaror, ripens pretty early. Skin thin. The branches are thorny, the hear rather bushy, with narrow lanceolate serrulate leaves, locking at a little distance somewlit like those of a peach-tree. It usually grows about 12 or 14 feet high; hut on the Prairies of Arkansas it is only 3 or 4 feet high. and in this form it is also emmon in Texas. The Dw.13F TExas PLum described by Kenrick is only this species. It is quite ornamental.

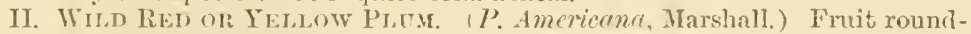
ish oval. skin thick, reddish nrange, with a juicy, yellow, subacid pulp. The leaves are ovite. coarsely serrate, and the old branches rougl and sonewhat thomy. Grows in hertges, and loy the banks of streams, from Canata to the ('vulf of Mexico. Tree from 10 to 1.j feet high. Fruit ripens in July and Augrist.

III. "J'he Pfficr PLIM, or Sand Plum. (P. Wrevitimu, Wang.) A low shrub with stout stragrling branches, fonnd mostly on the sancly sea-coast, from Massachunts to Virginia, and selifom ripening well elsewhere. Fruit roundish, searcely an inch in diameter, rerl or purple, covered with a bloom. Pleasant, but scmewhat astringent. Leaves oval, finely serrate. 
One of the most important forms of the plum in commerce is that of munes, as they are exported from France to every part of the world. We quote the following interesting account of the best mode of preparing prunes from the siboretum Britannicum:-

The best prunes are made near Tours, of the St. Catherine Plum and the Prune d'Agen; and the best French plums (so called in Eng. land) are mate in Provence, of the Perdrigon blane, the Brignole, and the Prume d'Ast; the Provence plums being the most fleshy, and having always most bloom. Both kinds are, however, made of these and other kinels of plums, in various parts of France. The plums ares gathered when just ripe enough to fall from the trees on their being slightly shaken. They are then laid, separately, on frames or sieves marle of wicker-work or laths, and exposed for several days to the sun, till they hecome as soft as ripe medlars. When this is the case they are put into a spent oven, shut quite close, and left there for twentyfour homs; they are then taken out, and the oren being slightly reheated, they are put in again when it is rather waner than it was before. The next day they are again taken ont, and turned by slightly shaking the sieves. The oren is heated again, and they are put in a thind time, when the oven is one-fourth degree hotter than it was the second time. After remaining twenty-four hours, they are taken out, and left to get quite cold. They are then romded, an operation which is performed by turning the stone in the plum without breaking the skin, and pressing the two ents together between the thimb and finger. They are then again put upon the sieves, which are placed in an oven fiom which the breal has been just drawn. The door of the oven is closed, and the crevices are stopped round it with clay or dry grass. An hom afterwards the plums are taken out, and the oven is again shut, with a cup of water in it, for alout two hours. When the water is so wam as just to be able to bear the finger in it, the prunes are again placed in the oven, and left there for twenty-four hours, when the opreration is finished, and they are put loosely into small, long, and rather deep boxes, for sale. The common sorts are gathered by shaking the trees; but the finer kinds, for making Frumch plums, must be gathered in the morning, before the rising of the sun, by taking hold of the stalk between the thumb and finger, withont tonching the fruit, which is laid gently on a bed of vine-leaves in a basket. Then the baskets are filled, withont the plums touching each other, they are removed to the fruit-room, where they are left for two or three clays exposed to the sun and air ; after which the same process is employed for the others; and in this way the delicate bloom is retained on the fruit, even when quite dry.

Prophation axd Culture. The plum is usually propagated in this comtry by sowing the seeds of any common free-growing variety (avoiding the Damsons, which are not readily worked), and budding them, when two years old, with finer sorts. The stones shonld be planted as soon as gathered, in broatd drills (as in planting peas), but about an inch and a half deep. In good soil the seedlings will reach eighteen inches or two feet in height the next season, and in the antumm or the ensuing spuing they may be taken from the seed-beds, their tap-roots rednced, and all that are of suitable size planted at once in the nursery rows, the smaller ones being thickly bedded until after anotlier season's growth. 
The stocks planted out in the nursery will ordinarily he ready for working about the ensuing milsummer, and, as the plum is quite diffi. cult to buel in this dry elimate, if the exact season is not chosen, the budkler must wateh the condition of the trees, and insert his buds as raly as they are sntheiently firm, - sar, in this neighborhood, abont the loth of July. Insert the buds, if possible, on the north side of the stock, that being more protected from the sum, and tie the bandage rather more tightly than for other trees.

The English propagate very largely, by layers, three varieties of the common phun-the Muscle, the Brirsels, and the P'erer Plum, which al't almost exclusively employed for stocks with them. But we have not found these stocks superior to the seedlings raised from onr conmon plums (the Bhue Gage, Horse Plum, de.), so abundant in all our gardens. For dwarting, the seedlings of the Mirabelle are chiefly emjloyed.

"Open standard culture is the universal mode in America, as the plum is one of the hardiest of fruit-trees. It requires little or no pruning berond that of thimning out a crowded head, or taking away dectyed or broken branches, and this should be clone before midsummer, to prevent the flow of gum. Old trees that have become barren may be renovated by leading them in pretty severely, covering the wounds with a solution of gum shellac, and giving them a good top-dressing at the roots.

SolL. The plum will grow vigorously in almost every part of this comitry, but it ouly baars its finest and most abundant erops in heavy loams, or in soils in which there is a considerable mixture of clay. In sandy soils the tree blossoms and sets plentiful crops, but they are rarely perfected, falling a prey to the curculio, an insect that harbors in the soil, and seems to find it difficult to penetrate or live in one of a heary texture, while a warm, light, sandy soil is exceedingly favorable to its propragation. It is also undonbtedly true that a lreary soil is naturally the most farorable one. The suppising facility with which su perior new rarieties are raised merely by ordinary reproduction from seed, in certain parts of the valley of the Hudson, as at Hudson or near Alhany, where the soil is quite clayey, and also the delicions flavor and great protuctiveness and health of the plum-tree there, almost without any care, while in adjacent districts of rich sandy land it is a very uncertain bearer, are very convincing proofs of the great importance of clayery soil for this fruit.*

Where the whole soil of a place is light and sandy, we would recommend the employnent of pure yellow loam or vellow clay in the place of manure, when preparing the border or spaces for planting the plum. Tery heary clay, burned slowly by mixing it in large heaps with brush or fagots, is at once an admirable manure anil alterative for such soils. Swamp nnuck is also one of the best substances, and especially that from salt-water marshes.

Common salt we have found one of the best fertilizers for the plumtree. It greatiy promotes its health and luxurianer.

INSECTS AND Diseases. There are but two drawbacks to the culti-

* When this was written it was generally supposed that the curculio would not attack the fruit of plums growing on trees in clayey soils; but practical ex. perience has shown that such is not the fact.--REvisou. 
vation of the phum in the United States, but they ase in some districtin so great as almost to destroy the value of this tree. These are the cur. culio and the knots.

The curculio, or plum-weeril (Rhynchenus Venuphar), is the un. compromising foe of all smooth-stone fruits. The cultivator of the Plum, the Nectarine, and the Apricot, in many parts of the country, after a tlattering profusion of snowy blossoms and an abundant promise in the thickly set young crops of fruit, las the frequent mortification of seeing nearly all, or indeed, often, the whole crop, fall from the trees when half or two-thirds grown.

If he examines these falling finits he will perceive on the surface of each, not far from the stalk, a small semi-circular scar. 'This scar is the erescent-shaped insignia of that little Thrk the curculio-an insect so small as, perhaps, to have escaped his observation for years, unless pa.ticularly drawn to it, but which nerertheless appropriates to himself the whole product of a tree, or an orchard of a thousand trees.

The habits of this curculio, or plum-weevil, are not yet fully and entirely ascertained. But careful observation has resulted in establishing the following points in its history :--

The plum-weevil is a small, dark biown beetle, with

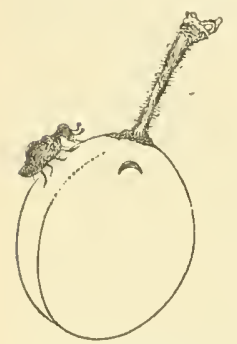

The curculio, and its mark. spots of white, yellow, and black. Its length is scarcely one-fifth of an inch. On its back are two black liumps, and it is furnished with a pretty long, eurved throat and snout, which, when it is at rest, is bent between the forelegs. It is also provided with two wings, with which it flies through the air. How far this insect flies is yet a dispnted point, some enltivators aftirming that it scarcely goes finther than a single tree, and others believing that it flies over a whole neighborhool. Our own observation inclines us to the belief that this insect emigrates just in proportion as it finds in more or less abmudance the tender fruit for lepositing its eggs. T'ery rarely do we see more than one puncture in a plum, and, if the insects are abundant, the trees of a single spot will not atford a sufticient number for the purpose; then there is little doubt (as we have seen them flying through the air) that the insect flies farther in search of a larger supply. But usually, we think, it remains nearly in the same neighborhood, or migrates but slowly.

About a week or two after the blossoms have fallen from the trees, if we examine the fruit of the plum in a district where this insect abounds, we shall find the small, uewly formed fruit beginning to be junctured by the proboscis of the plum-weeril. The insect is so small and shy, that unless we watch closely it is very likely to escape on notice. But if we strike or shake the tree suldenly, it will fall in consiclerable numbers on the ground, drawn up as if dead, and resembling a small raisin, or, perhaps more nearly, a ripe hemp-seed. From the first of April until August this insect may be found, though we think its depredations on fruit, and indeed its alpearance in any quantity, is confined to the months of May and June in this climate. In places where it is very abmomit, it also attacks to some extent the cherry, the pach, and even the apple and pear.

Early in July the punctured plums begin to fall rapidly from the 
tree. The egg drposited in each, at first invisibl', has become a white grub or larra, which slowly eats its way towards the stone or pit. As soom as it reaches this print the fruit falls to the gromol. Jlere, if left umlisturbed, the grub soon finds its way into the soil.

There, aceording fo most cultivators of fruit, and to our own ohservations, the gmos or lanve remain till the ensuing spring, when in their perfect form they again emerge as beetles and renew them ravages on the fruit. It is true that Warris amd some other naturalists have proved that the insect does sometimes muderoro its final transformation and enerese form the ground in twenty days, but we are inclined to the opinion that this only takes place with a small portion of the brood, which, perhaps, have peretrated but a very short distance below the surfite of the soil. These making their apprearance in midsmuner, and finling no young fruit, deposit their eggs in the young branches of trees, etc. But it is undeniable that the season of the plum-weevil is early spring, and that most of the larve which produce the annual swa'm, remain in the soil during the whole period intervening since the fall of the previous year's finit. Plum-trees growing in hard trodken court-yurds usually bear plentiful crops.

The modes of destroying the plum-weevil are the following :- -

1. Shatimg the tree aml. killing the beetles. Watch the young finit, and you will perceive when the insect makes its appearance hy its punctures upon them. Spread some sheets under the tree, and strike the trunk pretty sharply several times with a wooden mallet. The insects will quickly fall, and should be killed immediately. This should be repeated daily for weeks, or so long as the insects continue to mak their alpearance. Repeated triais have proved, beyond question, that this rather tedious mode is a very effectual one if persisted in.* Coops of chickens placed about under the trees at this season will assist in destroying the insects.

Dr. E. S. Ifull, of Alton, Illinois, has invented a machine for catching the cureulio on a large seale for orchard culture, but not having seen it, we copy an extract from the Klocth and Home:

"This is nothing but a gigantic white umbrella, tumed bottom up ward, momted upon an immense wheelbarrow, and split in front to receive the trumk of the tree which is to be operated mpon. At the imterior end of the split in front is a padeled bumper, which strikes against the trmnk as the operator wherls the barrow, first against one tree, and then against another, and with two or three sudden jars fetches all the insects off the boughs into the white mmbrella, which gines widely open to receive them. Really, it is a most magnificent institution, but for it:

* Merely shreting the tree is not sufficient. The following memorandum, as additional proof, we quote from the Goncsec Frmur :- "Under a tree in a remote part of the fruit-garden, having spread the sheets, I made the following experiment. On shaling the tree well I canght five curculios; on jarring it with the hand I eaurht twelve more; and on striking the tree with a stone, eight more dropped ou the sheets. I was now convinced that I had heen in error ; and calling in assistance and using a lammer to jar the tree violently, we caught, in less than an hour, more than two hnnclred and sixty of these insects." We will add to this, that to prevent injury to the tree a large wooden mallet should be sulistituterl for a hammer, and it is hetter if a thick layer of choth is bound orer its head. A sharp stumning blow is found necessary to readily dislolge the insect, and as such. when given directly upon the bark of the tree, ofteu canses a bruise, it is found to be a good practice to saw of a tmall limb and strike tho Llow upon the stump. 
practical snccess three things are necessary: 1st. That the land should be decently clean, and not overgrown with rank weeds fonr or five feet high. "2l. That the orchard be a sufficiently large one to pay the interest on the prime cost of the machine. 3d. That the trees have a clean trunk of some three or four feet."

For those wishing a full description of the machine, we refer them to the Inctor"s own statement in the American Entomologist for Jnly, 1860.

2. Crathering the firut and destroying the farre. As the insect, in its larva or gub form, is yet within tlie plums when they fall prematurely from the tree, it is a very obvious mole of exterminating the next rear.s brood to gather these fallen fruits daily, and feed them to swine, boil, or otherwise destroy them.

A simple and easy way of covering the difficulty, where there is a plum orchard or enclosure, is that of turning in swine and fowls during the whole season, when the stung plums are droplying to the ground. The fruit, and the insects contained in it, will thus be devoured together. 'This is an excellent expedient for the farmer, who bestows lis time grudgingly on the cares of the garden.

The luots a black gum. In some parts of the comntry this is a most troublesome disease, and it has, in neighborhoods where it has been suffered to take its course, even destroyed the whole race of Plum-trees.

The lnots is a disease attacking the bark and wood. The former at first lecomess swollen, afterwards bursts, and, finally, assumes the appearance of large, irregular, black lumps, with a lard, cracked. uneven surfice, quite dry within. The prassage of the sap "y,wards becomes stopped by the compression of the branch by the tumor, and, finally, the poison secms to disseminate itself by the downward flow of the sap through the whole trunk, breaking out in various parts of it.

The soits of plum most attacked by this disease are those with purple fruit, and we have never known the green or yellow fruited rarieties infected, until the other sorts had first become filled with the knots. The common Horse Plum and Damson alpear to be the first to fall a prey to it, and it is more difficult to eradicate it from the in than from most other sorts. The common Morello cherry is also very often injured by the same disease, and, in some districts, the sweet cherry also.

Thre is yet some doubt respecting the precise cause of these knotty excrescences, though there is every reason to think it is the work of an insect. Professor Peck and Dr. Harris believe that they are caused by the same curculio or plum-weevil that stings the fruit; the second brood of which, finding no fruit ready, choose the branches of this tree and the cherry. This olservation would seem to be confirmed by the fact that the grubs or larve of the plum-weeril are fiequently found in these warts, and that the beetles hare been seen stinging the branches.

On the other latud, the following facts are worthy of attention. First, in some parts of the country, where the cureulio has been troublesome for many years, the knots liave never been known. Secondly, in many cases, the knots have been abundant on Plum-trees, when the fruit was entirely fair and uminjured by the curculio, even upon the Eame branches.

These facts seem so irreconcilable with the opinion that the curculio produces both these effects, that we rather incline at present to the belief, that though the curculio deposits its eggs in the tumors on the 
branches while they are yet soft and tender, yet it is not to the curculic, but to some other inseet or anse that wo owe this mojoghty clisease.

Practically, lowever, this is of little account. The experience of many persms, besicles ommelres, hats pored most sit istatetorily that it is easy to extirpate this malacly, if it is taken in season and momittingly pursted. As early as possible in spring the whole of the infected trees shond be examined, and every bianch anel twig that shows a tumor should be ent off and immediately burned. Whatever may be the insect, we thus destroy it, and, as exporience has tanght ns that the malady spucads lapjidy, wo will thus effectualiy prevent its increase. If the trees atre comsiderably attacked by it, it will probably be neeessary to go over them again about the midlle of May, bnt, nsmally, once a rear will be sufficient. If any of the trees are very much covered with these knots, it is better to heat hack the shoots severely, or aig them up and burn them ontright, and it will be necessary to prevail upon your neighbors, if they are near ones, to enter into the plan, or your own labors will be of little value. P'usue this simple and straightforwarl practice for two or three seasons (covering any large wounds male with the sohtion of gum shellac), and the knots will be found to disappear, the curculio to the contrary notwithstanding.

Tarietres. There are now a pretty large number of fine plums, and some most important additions liave been made by the seedlings raised in this country. The Green Gage still stands at the hearl of the list for high flavor, thongh several other sorts are nearly or quite equal to it. The IVashingtum, the Jefferson, and the Nadison are among the largst and most beautiful; and Coe's Golden Drop and Reine Claude de Baray are very desirable for their late maturity.

In describing Plums, the surfice of the young wood, when just ripened, is an important character; as it is smooth in some varieties, and downy, or covered with soft hairs, in other's. In some varieties the tlesh purts from the stone, while in others it arlheres. And, finally, the depressed line or ehannel which rums down one side of the exterior surface of the plum is called the suture, and the proninence or absence of this featme enables us to distinguish many kinds at first sight.

\section{VARIETIES.}

\section{Abricotée de Braunau.}

Branches smooth.

Fruit large, roundish, inclining to oval, rather fiattened on the sicles, and marked with a suture which is deep towards the stalk, and higher on one sicle than the other. Skin whitish green, covered with a thick white bloom on the shaded side, and reddish, with some spots of a deeper red on the side next the sun. Stalk an inch long, thick. Flesh yellow, firm, juicy, sweet, sugary, and rieh flavored, separating from the sture. Iipe midale of September. (Hogg.)

\section{A LBATY BenUtY.}

Denniston's Albany Beauty.

Origiuaterl with Tsaac Denniston, Albany, N. Y. Tree moderatcly vigorous. Branches smooth. 
Fruit rather below medium size, rommlish oval, with an obscure su ture. Skin pale whitish green, maked with numerous small purplish dots, and covered with a thin bloom. Stalk an inch or more long, slen. der, very slightly inserted. Flesh vellow, moderately juicy, rich, and sweet; separates from the stone, which is small and pointed. Good to very gool. Ripe August.

\section{Americax Mugnem Bontm.}

A native variety, quite common, but its origin unknown. Tree rery vigorous, with strong, downy bianches.

Fonit rather large, oval. Suture broad, shallow. Skin deep pur. ple, covered with a thick blue bloom. Stalk rather long, curved, set in a moderately deep cavity. Flesh greenish yellow, juicy, sweet, and pleasant; adheres to the stone. Crood. Early september.

\section{American Wheat.}

Tree moderately vigorous, productive. Branches smooth, grayish brown.

Fruit quite sinall, roundish, with a shallow sutme. Stalk slender. Skin greenish, shaded with violet pmple, and covered with a thin blue bloom. Flesh greenish, juicy, sweet. Good. Adheres partially to the stone. Last of August.

\section{Angelina Burdett.}

An English variety, raised by MIr. Dowling. Sonthampton. Tree moderate grower, productive, hardy. Branches smooth.

Fruit abore medium, ronnd, with a suture deepest next the stalk. Skin thick, dark pmple, thickly corered with brown dots and a blue bloom. Flesh yellowish, juicy, well flavored; sejarates from the stone. Good. Early september.

\section{AxNA MARLA.}

Raised by S. D. Pardee, New Ilaven, Conn. Tree molerately vigorous, rather spreating, very productive. Branches slightly downy, gray, short-jointed.

Fruit below medium, roundish oval, without suture. Skin jale greenish vellow, splasher with darker green, and covered with a thin blue bloom. Stalk mather short, in a small carvity. Flesh pale green, very juicy, melting, rich, sugary. Good to very good. Adheres slightly it one edge of the stone. List of Angust.

\section{Apple Plux.}

From the garden of D. U. Pratt, Chelsea, Mass.

Fruit medium, roundish flattened, a little swollen on one side. Suture medium. Skin reddish purple, with a blue bloom and light dots. Flesh greenish yellow, a little coarse, sreet, sprightly, with considerable austerity at the skin; allheres partially to the stone. Goou. Seprtember.

\section{Apricot}

Apricot Plum of Tonrs. Abricot e de Tours.

\section{Abricotíe.}

Tellow Apricot. Abricotée Blane.

\section{Abricotée Blanclie.} Old Apricut.

Branches quite downy, nearly white. 
Fruit above medium size, roundish, with a deep suture or furrow. Skin vellow, dotter and tinged with red on the sumly side, eovered with a white bloom. Flesh yellow, rather firm, separates from the stone; slightly bittor, until fully ripe, when it is melting, juicy, and high-flavored. Grood. Lipe the middle of August.

\section{A Uubur.}

A mative of Western New York. 'T'ree vigorous. Branches smooth, redulish.

Fruit medium, oval. Suture shallow. Skin light reddish purple, with a thin lilac bloom. Stalk rather short. Flesh rather coarse, orango ycllow, not juicy, swret, pleasant; separates from the stone. Good. Early Angust.

\section{Attonne de Scimanili.}

Prune d'Automne de Schamili. Damascena Schamali. D'Antomne de Schamal.

A German variety. Tree vigorous. Branches upright, smooth, light reddish brown.

Fruit large, oval, with a long, peculiar mamelon neck, one sisle sometimes enlarged. Suture large, deep, two-thirds around. Skin light reddish purple, with a light lilac bloom. Stalk long and stont. Flesh orange yellow, juicy, sweet; atheres firmly to the stone. Good. September.

\section{Autums Compote.}

This variety was grown by Thomas Rivers, Sawbridgeworth, Englind, from seed of Cooper's Large. 'Tree vigorons, moderately productive. Brauches smootl.

Frnit large, oblong oval, narrowing to the lower end. Suture broad and shallow, one sille often swollen. Skin dull whitish yellow, with light crimson on the smmny side, and covered with a thin lilac bloom. Stalk long, set in a smali narow cavity. Flesh yellow, a little coarse, juicr, sweet, pleasantly mixed with acil; adheres partly to the stone. Good to rery good. Siertember.

\section{Autunn Giag.}

Roe's Antumn Gage.

Reine Claude d'Antomne.

Riaser by WTm. Roe, of Newburg. Of good quality, a very abun. dant hearer. Branches smooth. Tree vigorons, spreading.

Fruit medium size, oval, rather broadest towards the stalk. Stalk three-fourths of an inch long, inserterl without any depression. Skin 1:le yellow, corered with thin whitish blowm. Flesh gecenish yellow, s'pratating from the stone, juicy, sweet, and of delicate, pleasant flavor. frood to rery good. Stune long, compressed, pointed at both ends. sejptember.

\section{Bayay's Green Gage.}

\section{Reine Claude de Bavay. Mlonstrueuse de Bavay. Saint Clair.}

Paised by Major Esperen, and dedieaterl to M. De Bavay, of Til. rorde. A very vigorous grower, very poductive, and a valuable addition to the late varieties. Branches smooth. 
Fruit large, roundish, slightly depressed. Skin greenish yellow, with stripes and splashes of green, covered with a thin bloom. Su. ture medimn. Apex dimpled. Stalk short and stont, set in a small

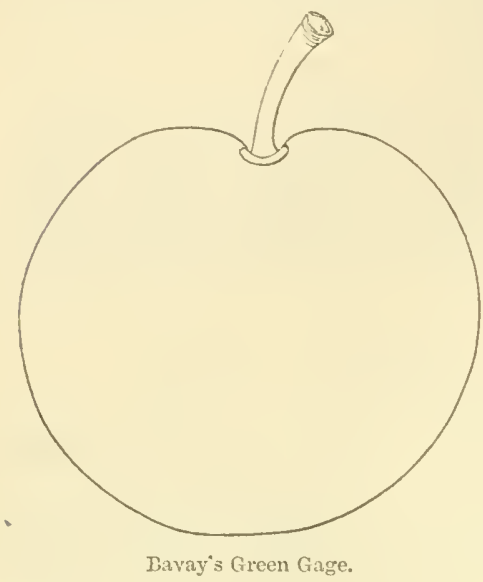

stone. Good. Last of August. carity. Flesh rellow, juicy, melting, with a sugary, rich, excellent flavor; separates from the stone. Best. Last of september and first of Oetober:

\section{Bejoxitères.}

Prune des Bejonnières.

A foreign variety. Tree rigorous. Branches smooth, reddish brown.

Fruit medium or below, oral, often with a slight neck. Suture broad, shallow. Skin pale yellow, with a thin light bloom. Stalk rather stout, in a small carity. Flesh greenish yellow, juicr, sweet, slightly vinous; separites from the

\section{Belgiax Purple.}

Blen de Belgique.

Bleu de Perque.

From Belgium. Tree vigorous. Branches smooth. Buds prominent.

Frut rather large, roundish oval. Suture shallow. Apex sunken. Skin deep brownish purple, corered with a blue bloom. Stalk half inch long, rather slender. Cavity large. Fiesh a little coarse, greenish, juicr, rich, sugary: adheres to the stone. Tery good. Early september.

\section{Belle de Louvais,}

Prune de Lourain.

A Belgian variety, of unknown origin. Tree vigorous, productive. Branches stont, smooth, grarish brown.

Fruit large, long ovat. Suture deep. skin purplish red, corered with a thin bloom. Flesh rellow, a little coarse, juicy; agreeable; separates from the stone. September. (Al. Pom.)

\section{Belly de Septembre.}

Tan Mons' Red?

Tan Yons' lied Gage?

Autumn Beantr.
Reine Clande Rouge de Septembre.

Reina Nora.

Gros Rouge de Septembre.

Reine Claude Rouge Tan IIons?

A variety introduced from Brussels. 'Tree vigorous and productive. Branches smooth.

Fruit medium, roundish, inclining to oval. Sicles unequal. Suture large, extending a little berond the apex. Skin light reddish purple, covered with a thin blue bloom. Stalk short, slencler. Cavity small. 
Flesh orange yellow, juicy, sweet, vinous; adheres to the stone. Good to very gooul. September.

\section{BeNEDICT.}

Origin, Pa. Tree vigorous. Branches smooth, brownish.

Fruit small, oval, one sile a little enlarged. Suture distinct, extend. ing a little beyond the apex. skin pale yellow, covered with a thin white blom and a few red dots and blotehes on the sunny side. Stalk of medium length, inserter in a small cavity. Flesh pale yellow, juicy, sweet and pleasant. Good. Adheres to the stone.

\section{BingIIAY.}

A native fruit, originally from Penusylvania, and named after the Bingham family. Tree vigorons, productive. Branches downy.

Fruit large, long oval, rather widest towards the stalk. Skin deep yellow, somewhat spotted with rich red on the smmy side. Stalk slightly inserted. Flesh yellow, adhering to the stone, juicy, and of rich and delicious flavor. V'ery good. Last of August and first of September.

\section{Bleecker's Gage.}

\section{German Gage. Bleeker's Ycllow. Bleecker's Yellow Gage.}

A fruit of the first quality, not only excellent but remarkably hardy, and a good and regulur bearer. It was raised by the late Mrs. Bleecker, of Albany. Tree very vigorous. Branches downy.

Fruit of merlium size, roumlish oval, very regular. Suture seareely perceptible. Stalk quite long, an inch $\mathrm{Ol}^{\circ}$ more, straight and pretty stout, downy, slinhtly inserted. skin yellow, with mliñuxums imbedded white specks, and a thin white bloom. Flesh yellow, jich, sweet, and luscious in flavor; sipurates almost entirely from stone, which is pointed at both ends. Very good. Easily distingnisher from Tellow Gage hy its longer and stonter stalk. Tery good. Last of A ngust.

\section{Blue Gage.}

\section{Azure Hative.}

Little Blue Gage.

Black Perdrigon. Cooper's Blue Gage.

An orlinary little round blue Plum, the Azure Ilative of the French. Branches slender and downy.

Fruit quite small and round. Skin rlark blue, covered with light blue bloom. Flesh greenish, juicy, a little acici, somewhat rich, and separates from the stone. Grod. liipe middle of August. 


\section{Brice IMPÉratrice.}

$\begin{array}{lll}\text { Impíratrice. } & \text { Violette. } & \text { limpress. } \\ \text { Víritable Impératrice. } & \text { Impératrice Violet. } & \text { Violet Empress. }\end{array}$

The true Blue Imperatrice is an admirable Plum, one of the fiuest of the late plums, hanging for a long time on the tree, and may be kept in the fruit-room a considerable period after being gathered. It is rich, sugary, and excellent. The branches are long, smooth, and sleuder, and the smaller twigs start out

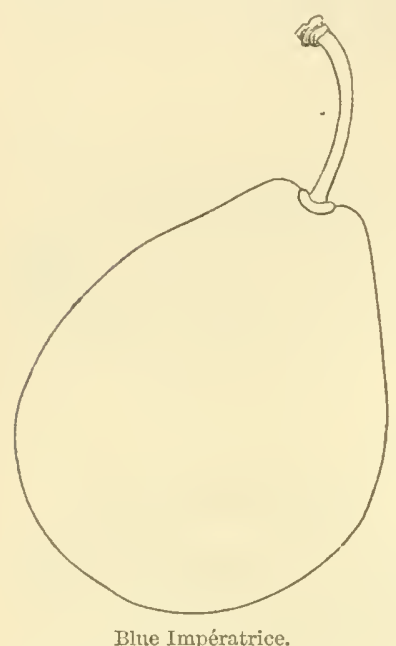

Blue Impératrice. at nearly right angles with the main brauches.

Fruit of medium size, oval obovate, obtuse, tapering most towards the stalk. Stalk nearly an inch loug, set in a slight hollow. slin deep purple, covered with a thick blue bloom. Flesh greenish yellow, pretty firm, rather dry, but quite rich and sugary, adhering closely to the stone. Tery gool. Pipens in October, and will hang, in sheltered situa. tions, till the middle of November.

\section{Blue Perdrigor.} Violet Perdrigon. Perdrigon Violette.
Brignole Violette.

A very old variety from Italy. Brauches downy.

Fruit of medium size, oval. Skin reddish purple, with many brown dots, and a very thick whitish bloom. Flesh greenish yellow, rather firm, sugary; adhering to the stone. Good. Last of August.

\section{BuUe Plum.}

From the South. Propagated by suckers. Tree productive. Branches smooth.

Fruit medium, roundish, scarcely oval. Suture obscure. Skin dark blue, with light blue bloom. Flesh yellowish green, juics, sweet; adheres to the stone. Early August. (Wirite.)

\section{Butro}

This is supposed to be a seedling of North Carolina. The Country Gentleman describes it as:-

"Fruit full medium or rather lar'ge, oval. Color dull orange, with numerous small brown dots. Suture distinct. Stalk short. Carity narrow. Flesh yellowish brown, fine-grained, very juicy. Tery good. July, Angust."

\section{Boñet D'EvêQte.}

Tree vigorous, upright. Branches smooth.

Fruit nedium, obovate. Skin dark purple. Flesh rich, separating from the stone. October. (Hogg.) 


\section{Boulouf.}

Fruit large, roundish, red or reddish violet, with spots. Flesh yellow, fine, juicy, slightly acid, perfumed. September. (S. V. M.)

\section{Bradsinaw.}

Black Imperial.

Blue Imperial.

'Tree an upright, vigorous giower. Branches smooth, brownish.

Fruit large, oval obovate, sometimes with a slight neck. Sutmre

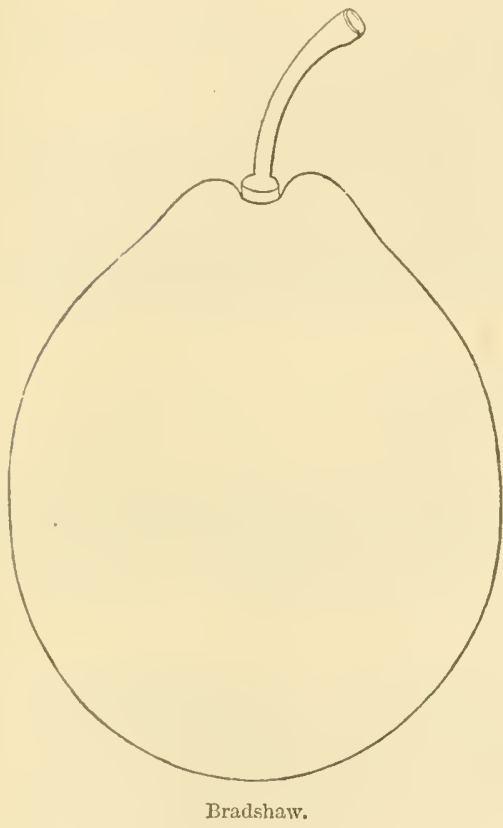
half round, broad, shallow. A pex a little sunk. Skin redelish purple, covered with a light blue bloom. Stalk rather stout, curved, set in a small cavity. Flesh yellowish, coirse, juicy, brisk, pleasant; adheres partialiy to the stone. Grood to very good. August.

\section{Brahy's Green Gage.}

Reine Claude de Brahy.

Tree vigorons, with stont, smooth branches, brownish purple.

Fruit large, romudish, inclining to oval. Suture half round, large. Skin greenish yellow, splasked with darker green, and covered with a pretty thick light bloom. Flesh greenish yellow, sugary, rich; adheres to the stone. Very good. September.

\section{Brevoort's Purple.}

New York Purple.

Brevoort's Purple Bolmar.
Brevoort's Purple Wrashington.

Washington Purple.

Raiserl by Henry Brevoort, New York. Tree vigorous. Branches long, smootl.

Fruit large, oval. Skin reddish, covered with a violet bloom. Flesh yellowish, soft, juicy, not very sweet, but with considerable vinous flavor; adheres closely to the stone. Good. Ripe the first of So'ptember.

\section{BricetTa.}

Petit Bricette. Bricet. Mirabelle Tardive, Mirabelle d'Octobre.

Tree moderately vigorous. Branches smooth.

Fruit medium, roundish oval. Skin yellow, with spots of red. Stalk of medium length, set in a small cavity. Flesh yellow, rather 
firm, very juicy, sugary, and excellent; adheres to the stone. (rood. Ripens micllle of September.

\section{Bryanstor's Gage.}

Fruit medium, oval, with a shallow suture. Apex a little sunk. Skin clull pale yellow, with a bronze cheek in the sun, covered with a light bloom. Stalk rather stout. Cavity medium. Flesh yellow, a little coarse, juicy, sweet, pleasant; adheres partially to the stone. Good to very good. October.

Buel's FaYorite.

An excellent Plnm, raised by Isaac Deuniston, of Albany, I. Y. Tree moderately vigorous. Branches smooth, reddish.

Fruit pretty large, ovate, broadest towards the stalk. Suture quite distinet for half the circumference. Stalk nearly three-quarters of an inch long, rather stont, slightly inserted. Skin pale green, thickly sprinkled with lighter dots, and speckled with a little red next the stalk. Flesh greenish yellow, rather firm, juicy, and quite rich and highfiarored; adheres to the stone, which is long and pointed. Good. Last of Angust.

\section{Burgundy Pruxe.}

Prune de Bourgogne.

Fruit medium, egg-shaped, with a neck. Suture indistinct. Skin reddish black, with a blue bloom, covered with numerous small dots. Stalk long, set in a very small carity. Flesh tine, juicy, sugary, very pleasant; separates from the stone. Good. Middle of September.

\section{Burlixgtoy Gige.}

Origin, Burlington, Vt. Tree hardy, vigorous, spreading, irregular grower, productive even when young. Wood yellowish gray.

Fruit medium size. Form rom dish oral. Color dark purplish blue, with rich bloom. Flesh greenish yellow, juicy, rich. Freestone. Good, Angust.

\section{Bunettes.}

Raised by M. Grégoire. Tree of medium vigor, very fertile.

Fruit large, long oval. Skin dull yellow. Flesli very delicate, melting, abounding in juice, very sweet, with a delightful aroma. Ripe the end of Septmmber. (Al. Pom.)

\section{Bifield.}

Tree moderately vigorons. Branches smooth.

Fruit small, round. Skin light yellow. Flesh yellow, of good fla. vor; adheres to the stone, which is thick. Good. Middle to last of Angust.

\section{Caldwell's Goldex Drop.}

An American variety. Tree vigorous. Branches smooth. 
Fruit large, oval, one side often enlarged. Suture hatf round, large. Skin yellow, marbled with erimson in the sun, thin bloom. Stalk slender. Cavity small. Flesh yellow, juicy, sugary, rich; allheres to the stone. Good. August.

\section{Caldwell's White Gage.}

Americau. Tree productive. Branches smooth or slightly downy; grayish.

Fruit medium, oval, narrowing a little to the apex. Suture slallow. Point at anex. Skin greenish vellow, dotted with purple in the sum, covered with a thick bloom. Stalk long. Flesh greenish yellow, rather coarse, juiey, sugary ; adheres to the stone. Good. September.

\section{CAMBELL.}

\section{Cambeil's Seedling.}

McCauley's Seedling.

Tree vigorous. Branches smootle.

Fruit rather larse, oval. Suture shallow. Skin pale yellow, splashed with green, dotted and marbled with crimson in the sun, light bloom. Stalk long. Cavity small. Flesh pale vellow, a little coarse, juicy, sweet; acheres partially to the stone. Good. September.

\section{Chapin.}

Originated with Aaron Chapin, Hartford, Comm. Tree vigorous grower.

Fruit medium, oval. Suture shallow. Skin light reddish purple or chocolate, blue bloom. - Stalk long, slender. Cavity deep. Flesh yellow, juier, and vinous; adheres partially to the stone. Crood. Late Uctober.

\section{Early Scarlet.}

II robolan.

Virginia Cherry.

\section{Cherry.}

De Virginie.

D'Amerique Ronge.

Prunus Myrobolana.
Prunus Cerasifera.

Miser Plum.

The Cherry Plum or Early Scarlet is a very distinct species. Tree grows rapidly, forming a bushy head, with slender branches and small leares. A beantiful early fruit. Good for preserving or market.

Fruit is round, about an inch in diameter, of a lively red, with very little bloom, ant a rer'y slender, short stem, set in a narrow cavity. The Hesh is greenish, melting, soft, rery juicy, with a pleasant, lively, sulbacill favor-neither rich nor high flavored-and adheres elosely to the stone. It ripris about the niddle of July, before most other plums, and this, and its pretty appearance at the dessert, are its rhief merits. Brauches smootli. 'The common ('herry Plum, or Mrroisolax, of Europe, is rather larger, and shaped like a lieart. In all other respects the same.

\section{Chester Cousty Pruse.}

Origin, Chester Co., Pa. Tree vigorous, upright, with long, sleniler branches, smooth, and of a light grayish brown.

Fruit mediun or below, long oval or oblong oval, almost withont suture. Skin black, with a thick blue bloom. Stalk rather long, slender. Cavity small. Flesin greenish, swoet; separates freely from the stone. Grood. Early September. 


\section{Chestos.}

Matchless.

Diaprée Violette.

Violet Diaper.

A pleasaut early Plun, but superseded now by better ones. Branches downy.

Fruit rather smail, oval. Skin dark purple, with a blue bloom. Stalk quite short, set without depression. Flesh yellow, firm, sweet, and rather surightly; separating from the stone. Good. Last of July and first of August.

\section{Cleatixger.}

A native of Philadelphia Co., Pa. Tree vigorous, spreading. Branches downy.

Fruit rather large, oval. Suture distinct, one side often enlarged. Skin deep purple, thick blue bloom. Stalk moderately stont. Cavity deep. Flesh orange rellow, coarse, juicy, vinous, subacid; adheres to the stone. Crool. Last of Angust.

\section{Coe's Goldex Drop}

Burr Seedling.

Coe's Imperial.

New Golden Drop.

Eair's Golden Drop.

Golden Gage.
Waterloo of some.

Goutte d'Or.

Coe's Plum.

Prune Goutte d'Or.

Raised by Mr. Coe, an English gardener, near London. Tree mo. derately rigorous, productive; requires a warm, late season to ripen. it north of $\pm 1^{\circ}$ latitucle. Branches smooth.

Fruit of the largest size, ovit, witl a well-urarked suture, on one side of which it is a little more swollen than the other, the outline warrowing towards the stalk. Skin light yellow, with a number of rich dark red spots on the sumnr sicle. Stalk nearly an inch long, rather stiff, set on the end of the finits. Flesh yellow, rather firm, adhering closely to the stone, which is quite pointed. Flavor rich, sweet, and delicious, Very good. List of September.

\section{Coe's Late Red.}

Saint Martin.

Saint Martin Ronge.

Prune de St. Martir.

Red Suint Martin.

Tree vigorous, with long, rather slender branches, rery productive. A good late variety. Branches downy.

Eruit of medium size, nearly round, with a mell-marked suture 
running along one sile. Skin light purplish rod, with a thin blie bloom. Stalk juetty stout, three-fonths of an inch long, set nearly even with the surfice. Flesh vellowish, rather firm and crisp, juicy, with a rich vinous thar"; separating almost entirely from the stone. Good to very good. Uctober and Norember.

\section{('OE'S VIOLET.}

Coe's Golden Drop Violette.

Tree vigorous. Branches smooth, dark brown.

Fruit large, oval. Suture large, extending a little beyond the apex Skin light redilish, thickly sprinkled with brown dots and a lilac bloom. Sitalk rather loug and stout. Cavity small. Flesh rellowish, juicy, sweet; willeres to the stone. Good to very good. September.

\section{Columbia.}

Columbian Gage.

Piaised by L. U. Lawrence, Hudson, X. Y. Tree rigoroms, productive, but subject to rot.

Frut of the largest size, six or seren inches in circumference, nearly globular, one latf rather larger than the other. Skin brownish purple, dotted with numerous firwn-colored specks, and covered with much blue bloom, throngh which appears a reddish brown tint on the shaded side. Stalk about an inch long, rather stont, inserted in a narrow, small carity. Flesh orange, not rery

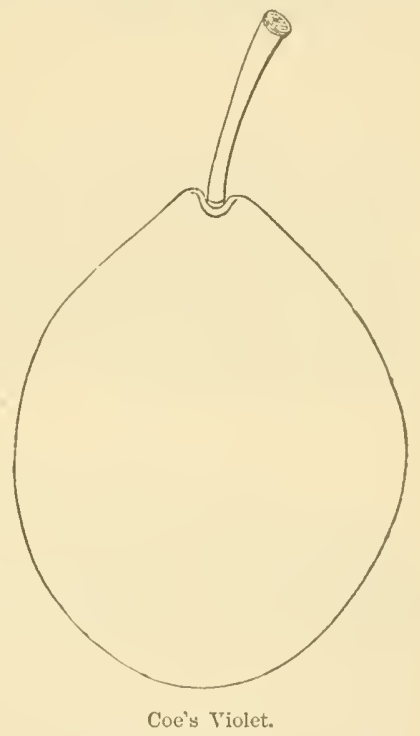
juicy, but when at full maturity very rich, sugary, and excellent; it separates freely from the stone, except a little on the edge. 'The stone is quite small and compressed. Good. Last of August.

\section{Compe Gustave d'Egger.}

An Austrian variety, originated with M. Liegel, of Braunau, from secd of the Alrieotée. Tree morlerately vigorons. Branches downy.

Fruit sma:l or medimu, oblong oval. Sntme half round, broad, deep, distinet. Skin pale yellow, bronzed in sun and tinged with violet. Flesh yellowish, tine, sweet, juicy, delicions; separates fiom the stone. September. (An. Poin.)

Conper's Tharge.

\section{Cooper's Large Red. Cooper's Large American. La Délicieuse?}

Coxe, who first described this Plum, says it was raised by Mr. Joseph Cooper, of New Jersey, from a stone of the Orleans. He con. 
siclers it as a fine large plum, but exceedingly liable to rot upon the tree. Tree vigorous. Branches smootb, dark brown.

Fruit large, oval. Sides unequal. Suture broad, large, often extending beyond the apex. Skin deep bluish purple, pretty thickly covered with a blue bloom. Stalk medium. Cavity large, deep. Flesh jellowish, not very juicy, sweet, slightly vinous ; adheres to the stone. Good. September.

\section{Cope.}

Raised by John Cope, near Philadelphia.

Fruit large, long oval, dark purple. Flesh not juicy, acid; senarates from the stone. Guod for cooking.

\section{COPPER.}

French Copper.

An old Plum, very productive and profitable. Tree vigorous. Branches smooth. Very prodnctive and a good market sort.

Fruit medium or below, oval, withont suture and with a slight mameIon neck. Skin deep colper color, covered with a thick blue bloom. Stalk rather long, slender, set on a point without depression. Flesh greenish, juicy and acid; adheres to the stone. Good. Tahed for conking. Last September.

\section{Corse's Aduriral.}

Raised by Henry Corse, of Montreal, Canada. Branches downy.

Fruit above medium size, oval. Skin light pmple, covered with a pale lilac bloom. Flesh greenish yellow, juicy and sprightly, but secondrate in flavor, and adhering closely to the stone. Gool. September.

\section{Corse's Fiejo Marshal.}

Skin lively purplish red. Raised by Hemry Corse, Montreal, Canada.

Fruit rather large, oval. Flesh greenish yellow, juicy, but a little tart; adheres closely to the stone. Ripe middle of August.

\section{Corse's Nota Bexe.}

Raised by Ilenry Corse, of Montreal, Canada. Tree verr vigorous, very productive, and hardy. Branches smooth.

Fruit of rather large size, romul. Skin pale lilac or pale brown, often dull green on the shaded side, with much light blue bloom. Stalk half an inch long, set in a round hollow. Flesh greenish, rather tim, juicy, sweet, and rich, and separates from the stone. Good. First of September.

\section{Cox's Seedlixg.}

Raised by Mrs. Cox, York, Pa. Tree a rigorons upright grower. Branches smooth.

Fruit very large, roundish oval, slightly compressed. Snture broad, shallow. Skin yellow, sometimes a little splashed with green, and cove 
ered with a light bloon. Stalk rather stout, in a narrow, rather deep cavity. Flesh greenish yellow, a little coarse, juicy, sweet; separates from the stone. Good. Early Angust.

\section{Croft's Early.}

Fruit small, reddish blue. Flesh yellow, diy, devoid of flavor. dugust. (Elliott.)

\section{Creger`s Schrlet.}

Cruger's. Cruger's Seedling. Cruger's Scarlet Gage.

Raised by Henry Cruger, of New York. Tree of free growth. Branches long, downy, rery productive.

Fruit rather larger than a Green Gage, roundish oval, with an obseure suture. Skin, when fully exposed, a lively red, but usually a bright lilac, covered with a thin bluish bloom, and speckled with numerous golden dots; in the shade it is pale fawn-colored on one side. Stalk half an inch long, set in a shallow depression. Flesh deep orange, not very juicy nor rich, but with a very agreeahle, mild, sprightly tlavor. It hangs well after ripening. Good. Last of August.

\section{DAMSON.}

Common Damson. Black Damson.
Purple Damson.

Early Damson of many.

The common oval Blue Damson is almost too well known to need description, as every cottage garden in the country contains this tree, and thousauds of bushels are anmually sold in the market for preserves. The tree is enormously productive, but in the hands of eareless cultivators is liable to be rendered worthless by the knots, which are easily extirpated if the diseased branches are regulary burned every winter or sprins. Branehes slender, a little thorny aud downy.

Fruit sinall, oval, about an inch long. Skin purple, covered with thick blue bloom. Flesh melting and juicy, rather tart; separates partially from the stone. September.

As the Damson is frequently produced from seed, it varies somewhat in character.

The shropshre or Prexe Dursox is an English purple rariety, rather obovate in figure, but little superior to our common sort. The SweEt DAmsor resembles the common Damson, and is but slightly acid.

The Late Black Damsox, Late Plrple Dansox, Princés Early Dasson, Silall Red Daysox, Shall White Damsoy, Lakge Wimte DAysox, are also varieties not of sufficient value or distinctness to render separate description necessary.

The Wrater DArsox is a valuable market sort from its extreme lateness. It is small, round, purple, covered with a very thick light blue bloom. Flesh greenish, acid, with a slight astringency, but nakes good preserves. It bears enormous crops, and will hang on the tree till the iniddle of November, six weeks after the common Damson, uninjured by the early frosts. 


\section{Daxa's Tellow Gage.}

A New England variety, raised by the Rev. Mr. Dana, of Ipswich: Yass. It is a very hardy and healthy tree, and bear's abundantly. Branches smooth.

Fruit of medium size, oval, pale yellow, with a very thin bloom, the skin clouded like that of the Imperial Gage. Flesh adheres to the stone, juicy, sweet, with a lively pecular Havor. Good. Last of August and first of September.

\section{Date Plum.}

\section{Prune Datto. Prune d'Autriche. D'Autriche. \\ Quetsche de Hongrie. \\ Quetsche Datte. \\ Dattelzwetsche.}

Fruit small, nearly round. Suture distinct, rather flat. Skin rellow, marked with touches of bright red in the sun, and covered with a whitish bloom. Flesh yellow, soft. Early September. (Pom. Mag.)

\section{DE DÉLICE.}

A foreign variety of excellence. Tree moderately vigorous and productive. Branches snooth.

Fruit medium, roundish oval, with a slight neck, a little swollen on one side. Suture small. Skin green, marbled and shaded with violet, and covered with a thin bloom. Stalk three-fourths of an inch long, rather stout, very slightly inserted. Flesh orange yellow, juicy, melting, with a rich, sugary, luscious flavor; adheres slightly to the stone. Vury good. Ripens the last of September.

\section{De MoxtFort.}

A seedling of Prevost. Tree of moderate growth, spreading, very productive. Branches smooth.

Fruit medium size, roundish oval. Snture large, extending to apex. Skin dull purple, with russet dots and strijes, a thin blue bloom. Stalk nearly an inch long, rather stout, without depression. Flesh greenish, juice afondant, sweet, and rich; separates from the stone. Tery good. Ripens last of August.

\section{Dennistox's Red.}

Raised by Isaac Demiston, Albany. Tigorous grower, productive. Branches smooth, lark colored.

Fruit rather large, roumdish oval, narrowed towards the stall. Suture running half round. Skin of a beantiful light red, sprinkled with many small, fawn-colored dots, and dusted with a very light bloom. Stalk very long and slender, slightly inserted. Flesh amber color, juicy, rich, and sprightly, with an excellent flavor. It separates from the stonc, which is small, oval, and compressed. Good. Last of August.

\section{DenNiston's SEPERB.}

\section{Madison.}

An excellent stedling, from Mr. Denniston's famous plum orchard, 
near Alhany, N. Y., of the Green Gage family, a third larger than the latter vinicty, and nearly as rich in flavor. Tree very vigorous and productive. Branches downy.

Fruit round, a little tlattened, and having a distinct suture, often extending quite round the fruit. Skin pale yellowish green, markerl with a few large purple bloteliess and dots, and overspread with a thin bloom. Stalk rough, theefourths of an inch long, set in a eavity of molerate size. Flesh rerr thick (the stone being small), moderately juicy, with a rich vinous flavor; stone parts readily, and is roundish and thick. Best. Midille and last of August.

\section{DIAMOND.}

English origin. Branches long,

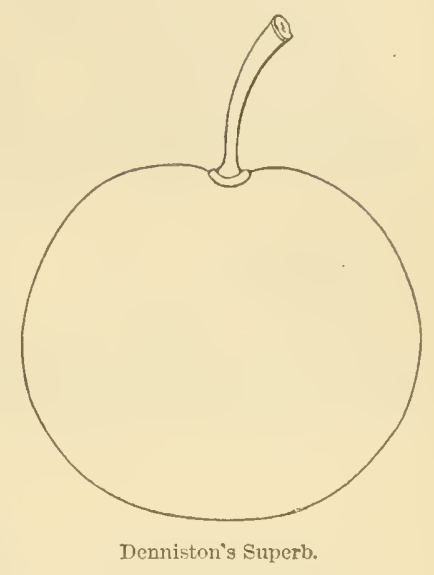
downy.

Fruit of the largest size, oval. Skin black, covered with a blue bloom. Flesh deep yellow, coarse-grained, and rather dry, a little acid, and without flavor; separates from the long-pointed stone. Scarcely good. Valuable for cooking only. First of September.

\section{Dictator.}

Raised by Henry Corse, of. Montreal. Tree vigorous and hardy.

Fruit very litge, brownish purple, covered with a bloom. Flesh juicy, rich, and high-flavored. (Hov. Mag.)

\section{Domine Dull.}

Dutch Prune.

Dutch Quetzen.

This good American Prune was raised from a seed brought from Holland by the Rev. Mr. Dull, a Dutch minister, who afterwards re. siderl at Kingston, N. Y. The prarent tree was the common Dutch Prune. Branches long and smooth.

Fruit of medimm size, long oval, with little or no suture. Skin very dark purple, nearly black, dusted with some blue bloom. Stalk nearly an inch long, inserted with very little cavity. Flesh yellow, quite juicy at first, but if allowed to hang on the tree becomes dry, rich, and sweet; it adheres closely to the stone. Good. A prodigions bearer, and a really good fruit. September.

\section{DORR'S FAVORITE.}

Originated with Elisha Dorr, Albany, N. X. Tree moderately vigorous. Branches smooth, brownish.

Fruit large, oval, with a slight neck. Suture broad. A pex a little sunk. Skin yellowish, marbled and dotted in the sun with purplish crimson, thin lilac bloom. Stalk long. ('avity small. Flesh yellowish, a little coarse, juicy, sweet; allheres to the stone. Good to rery good. Last of September. 


\section{DOWNixg's EARLY.}

Originated at Newburgh, N. Y. Tree moderately vigorous. Branches short-jointed, slightly downy.

Fruit medium, oral. Suture half round. Skin yellow, slight blush, and minute crimson dots. Flesh yellow, sweet; adheres slightly to the stone. Good. Early September.

\section{DOWNTON IXPÉRATRICE.}

Raised by Mr. Knight. A strong, upright growing tree. Branches long, smooth.

Fruit of medium size, oval, marrowing a little to the stalk. Skin pale yellow, quite thin. Flesh yellow, melting, and sweet when fully ripe, with a little acidity before ; adhering to the stone. Good to rery good. Ripens last of september, and haugs some time on the tree.

DraP D'OR.

Mirabelle Double. Mirabelle Grosse. Tellow Perdrigon.

The Drap d'Or, or Cloth of Gold Plum, is about the size and figure of the Green Gage, but of a fine golden yellow, and ripens a week earlier. Branches slightly downy.

Fruit below medium size, round, with an indistinct suture, and a dimpled or pitted apex. Stalk slender, half an inch long. Skin rich bright yellow, with a few erimson specks when fully exposed. Flesh yellow, sugary, and rich: separates freely from the stone. Good to very good. Early in August.

\section{Droset DAMASK.}

Damas Dronet.

Branches sinooth.

Fruit small, oval. Skin yellowish, with a thin light bloom. Flesh greenish, sweet; separates from the stone. Good. Late August.

Duane's Prrple.

\section{Purple Magnum Bonum.}

Pourprée Duane.

Raised by James Duane, of Duanesburgh, N. I. Tree very vigorous, distinet from the Fied Magnum Bonum of Europe. Branches very downy.

Fruit very large, oval or oblong, considerably swollen on one side of the suture. Skin reddish purple in the sum, but a very pale red in the sharle, sparingly dotted with yellow specks, and corered with lilac bloom. Stalk three-fourths of an inch long, slender, set in a narrow carity. Flesh amber-colored, juicy, sprightly, moderately sweet; actheres partially to the stone. Good. Ripens with the Washingtou (or a littlo before), abont the 1utlu of Angust.

\section{DUXMORE.}

Dumore.

Foreign origin.

Fruit small, oblong oral. Skin thick and green, becomes golden 
yellow at maturity. Flesh vellow, fine, very juicy, sweei, very arona tic; separates fiom the stone. Ripens the first of October. (A]. Pom.)

\section{E.sRLY Ayirer.}

Fruit small, somewhat oblong, broadest at apex. Skin pale greenish rellow, with small crimson specks in sun, covered with a thin whitish hloom. Flesh greenish yellow, juicy, subacid; adheres to the stone. Early Angust. (Lind.)

\section{Fiarty Aprínt.}

\section{Abricote Hâtif. Abricotée Hâtice.}

Fruit small, romdish. Skin prle red, darker in the sun. Flesh rellowish green, moderitely juicy, acid; adheres to the stone. Good. Early Aluginst.

\section{Early Cross.}

Originated with Mrr. C'ross, Salem, Mass. Tree moderately vigorous, produetive.

Fruit small to medium, roundish. Skin reddish purple, covered with a thick bloom. Stalk half an inch long. Flesh greenish yellow, juicy, sweet, and good; adheres to the stone. Good. Ripens the second week in August.

\section{Early Fatorite.}

Rivers's Early Favorite.

Rivers' No. 1.

Raised by Thomas Rivers, England. Tree moderately vigorous. Branches rather slender, slightly downy.

Fruit sinall to medimm, roundish oval, with a shallow suture. Skin almost black, sprinkled with russet dots, and covered with a blue bloom. Flesh greenish yellow, juicy. sweet, vinous, not quite as early as Janne Hâtive, separates from the stone. Good. First of Angust.

\section{Early Green Gage.}

Reine Claude Hâtive.

Fruit small, ronnd, flattened at top. Skin yellowish green, with a red cheek, and a few dots. Stalk about half an inch long. Flesh yellow, very tonder, juicy, sweet, rich; separates from the stone. Last of . July. (Hogrg.)

\section{Early OrLeans.}

New Early Orleans.

New Orleans.

Grimwool's Early Orleans.

Inampton Court.

Nonsieur Hitif.
Monsieur Itâtif de Montmorency.

Wilmot's Orleans.

Wilmot's Farly Orleans.

Farly Monsieur.

Monsieur IIâtive.

Tree a moderate grower. Branches downy.

Fruit of the size and color of the common Orleans, a litile more 
oval, and with a more shallow suture. Skin a little marbled. Flesh yellowish green, of brisk flaror, rather richer than the old Orleans, and separates from the stone. Good. Last of August.

\section{Early Prolific.}

Early Rivers. Rivers' Early Prolific. Rivers' Early No. 2.

Raised by Thos. Rivers, England. A prolific early Plum. Tree moderately vigorous, with smooth grayish branches.

Fruit medim, roundish oval. Skin reddish puple, covered with as tine blue bloom. Stalk about half an inch long, set in a very small cavity. Flesh yellowish, juicy, sweet, and pleasant; separates from the stone. Good. First of August.

\section{Early Rojal of Nikita.}

A German variety. Tree moderately vigorous. Branches smooth, gray.

Fruit small, roundish oval, narrowing towards the stalk. Skin vio let purple, with a thin blue bloom. Stalk set with little or no cavity. Flesh orange yellow, juicy, sugary, rich; adheres to the stone. Good to very good. Early September.

EArLy St. Joins.

Prune de St. Jean.

St. Jean.

Tree modelately vigorous. Branches slightly downy.

Fruit medium, ronndish, blong. Suture shallow, distinct. Skin reddish purple. Flesh grem, firm, sweet, sprightly; separates from stone. Good. Last of August.

\section{Earty Y alow Prune.}

A foreign sort. Tree vigorous and very productive. Branches dowity.

Fruit rather large, oval. Skin yellow, with a very slight bloom, and dotted with red in the sun. Stalk of riedium length, inserted in a small cavity. Flesh yellow, sweet, juicy, with somewhat of a melon firvor. Separates from the stone. Good. Midlle of Angust.

There is another Early Iellow Prune that originated in Bedford Co., Pa., which difiers but little from the above either in appearance or quality.

\section{Enouard Sexectatze.}

Branches downy.

Fruit very small, obovate, narrows toward the stalk. Skin clear golden yellow. Flesh very tender, sweet, and rich; separates freely from the stone. July. (Hogg.)

Ethrey.

Elfry's Prune.

Branches smooth.

Fruit small, oval. Skin blue. Flesh greenish, tery steet, dry, and frm ; parting very freely from the stone. Good. Last of Angust. 


\section{Fanerald Drop.}

O)rigin, Newburgh, N. Y. Tree moderately vigorous, and very productive. Branches long and smooth.

Fruit of medium size, long oval. Suture strongly marked, and the fruit larger on one of its siles. Skin pale yellowish green, sometimes dull green only in the sliacle. Stalk three-fourtlis of an inch long, inserted with seareely any depression. Flesh greenish yellow, very juicy ; aclheres somewhat to the stone, which is long and pointed. Crood. Last of Angust.

\section{ENGLSH WheAT.}

\section{Wheat Plum. Wheaton. Whitlow, Nutmeg.}

Fruit mediun, roundish oval. Suture moderate. Skin reddish purple, with a blue bloom, covered with mumerous white dots. Stalk half an inch long, rather strong, set in a rather deep cavity. Flesh yellow, a little coarse. juicy, sweet, with a lich flavor. It adheres to the stone. Good. Last of Augnist.

\section{Exglatsh Teltow Gace.}

\section{Little Queen Claude. Theine Claude Blanche. Small Green Gage. \\ Petite Reine Clande. - $\quad$ petite espèce. Gomme's Green Gage. White Ginge.}

This Plum, formerly known, we believe, as the little Queen Claude, but which has now received the sobriquet of Yellow Gage, we suppose for good reasons, from the hear of the fruit department in tìe London Horticultural society's garden, is an old French variety described by Duliamel. Branclies smooth and rather long.

Fruit below medium size, round, with a distinct suture on one side. Stalk half an inch long, rather slender, inserted in a slight hollow. Skin pale yellowish green, speckled with a few reddish dots, and overspread with a good deal of bloom. Flesh pale yellow, sweet, and pleasant; separates freely from the stone. Good. Niddle of Iugust.

\section{Eugene Furst.}

\section{Sweet Damson, Quetsche Précoce de Furst.}

A new German variety. Branches smooth.

Fruit small, obovate pointed. Skin dark purple, witl a thick bloom. Flesh yellowish, juicy, sweet; separates from the stone. Good. Last of August.

\section{Fine Boxté.}

This variety originated at MLselle, France. Tree vigorous. Branches smooth.

Fiuit swall, oval pointed. Skin reddish puple or lilac, bluc bloom. Fleslı grcenish yellow, juicy, sweet; separates from the stonc. Jast of July. (Vergr.)

\section{Foote's Early Orleaxs.}

Raised by Asahel Foote, Williamstown, Mass. Tree vigorous, sprearling. Liranches slightly downy, grayish. 
Fruit medium, roundish, inclining to oval, dot at apex. Skin deep black covered with a blue bloom. Stalk medium, slender, set in a duep civity. Flesh greenish, moderately juicy, sweet, pleasant; adheres tc the stone. Good to very good. Early August.

\section{Foote's Goldex Gage.}

Same origin as the preceding. Tree very vigorous, upright. Branches slightly downy, reddish brown.

Fruit large, nearly globular. Suture shallow, half round. Skin golden yellow, with obscure splashes of green, and shaded with red in the sun; thin bloom. Stalk slender. Cavity small. Flesh yellow, juicy, sweet, slightly vinous; adheres very slightly to the stone. Very grood. Early September.

\section{Fotherisgham.}

Sheen. Fotheringay. Grove House Purple.

An old English Plum of good ruality. Branches smooth.

Fruit of medium size, obovate, with a distinct suture. Skin reddish purple, covered with a pale blue bloom. Flesh pale greenish yellow, juicy, sprightly, and rich; separating from the stone. Good. Middle of August.

\section{- Frost Gage.}

Frost Plum.

A late Plum, scarcely yielding to any other late variety in the cxcellence of its flavor. It appears to have originated in Fishkill, Dutchess Co., N. Y., where it has for many years past been most extensively cultivated for market; but of late has been so subject to kuots that it is not now much grown. Branches smooth.

Fruit rather below medium size, roundish oral, with a distinct suture on one side. Skin deep purple, with a few brown specks, and a thin blonm. Stalk half to three-fourths of an inch in length, inserted with little or no depression. Flesh greenish yellow, juicy, sweet, rich and melting; adhering to the stone. Good to very good. First of October.

\section{Fultox.}

Origin uncertain. Found at Johnstown, Fulton Co., N. Y. Tree vigorous and productive. Branches smooth, redish.

Fruit rather large, roundish oval. Suture shallow, half round. Skin whitish yellow, covered with a bloom, blotched and marbled in the sun. Stalk rather stont. Cavity large. Flesh golden yellow, juicy, sugary, vinous. Good to very good. Separates from the stone. Early October.

\section{Galbraith.}

Originated with Mr. Galbraith, near Boalsburg, Pa. A straggling grower. Tree very vigorous. Branches smooth, brownish gray.

Fruit medium to large, roundish oval. Suture shallow. Skin purple. Sralk medium. Cavity deep. Flesh tender, juicy; adheres to the stone. Good. August. 
GEM.

Originated near Albany, N. X. Tree vigorous. Branches downy.

Fruit small, roundish. Suture slight. Apex a little sunk. Skin whitish, mostly shaded and mottled with violet in the shade and purple in the sum, covered with a blue bloom. Stalk rather long. Cavity large. Flesh yellow, juicy, sweet, adheres partially to the stone. Its beauty its only merit. Last of Angust.

\section{Gexi. HAND.}

Origin mucertain : supposed to have originated on the farm of Genl. Hanl, new Lancaster, Pa. Tree very vigorons. Branehes smooth.

Fruit very large, roundish, oval. Suture-obscure, running half round. Skin deep golden yellow, slightly marbled with greenish yellow. Stalk long, set in a shallow cavity, the whole of that end being flattened. Flesh coarse, pale rellow, moderately juicy, sweet and good, but not high flaror; separates freely fiom the stone. Good. September.

\section{Germas Prune.}

Common Quetsche.

True Large German Prune.

Turkish Quetsche.

Leipzic.

Sweet Prune.

Damask.

Impératrice Tiolette.

Impératrice Violette Grosse.

Damas Violet Gros.

Zwetsche.
Quetsche Grosse.

Prune d'Allemagne.

Quetsche d'Allemagne Grosse.

Damas Gros.

Covetche.

Early Russian.

German Quetsche. Conetsche.

Koetsche.

Quetzen.

Large German Prune.

So many Plums are cultivated under the name of German Prune that it is clificult to fix this fickle title, a circumstance owing to the fact that the prume frequently comes the same, or nearly the same, from seed, and in prune-growing districts this is a popular way of increasing them, while it, of course, gives rise to many shades of eharieter. It is a valuable class of plums, of fair ruality for the table, but most esteemed for drying and preserving-abundaut bearers, and lianging long ou the tree. Branches smooth. 'The common German Prune is deseribed as follow: :-

Fruit long oval, nearly two inches long, peculiarly swolleu on one side, and drawn out towards the stalk. Suture distinetly marked. Skin purple, with a thick blue bloom. Stalk three-fourths of an inch long, slender, slightly inserted. Flesh firm, green, sweet, and pleasant; separates from the stone, which is flat, very long, and a little curved. Goorl to very good. 10th of September.

'This jume is, perhajs, the most universal and most valuable fruit-tree in Germany, Hnngary, Sixony, and all Central Europe. Preserved, it is used in winter as a substitute for

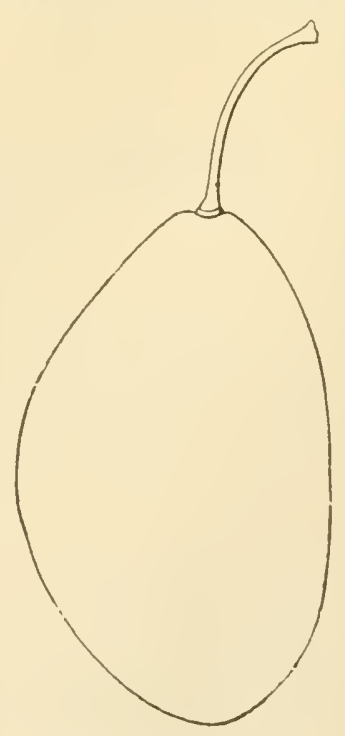

German Prune. 
butter by the laboring peasantry; and dried, it is a source of large profit in commerce.

The Austrian Quetsche, Thomp. (Quetsche de Brême, Bremen Prune), is a sub-variety, much like the foregoing, purple, a frenstone, of rather better flavor, and ripening somewhat later.

ST. JAMEs' QueTscme is another variety, with smooth branches, and oblong fruit of medium size. Flesh purple, adheres to the stone, of very good flavor. It yields good crops. September.

\section{Ghiston's Early.}

Branches smootl, short-jointed.

Fruit large, oval. Skin clear yellow, with a light bloom. Flesh yellow; separates from the stone. Poor. Middle of August.

\section{Giffond`s Lafajette.}

Tree very vigorous, and very productive.

Fruit medium, long oval, purple, with a bloom. Flesh greenish, coarse, juicy, not rich; adlieres to the stone. Poor. Last of August.

\section{Gisporne's.}

Gisborne's Early.

Paterson's.

Tree a moderate grower, spreading, productive. Branches downv.

Fruit medium, oval. Suture distinct, one side often enlarged. Skin gneenish yellow, with red next the sun, marbled and spotted, thin bloom. Stalk medium. Cavity deep. Flesh yellowish, rather coarse, moderately juicy; separates from the stone. Grood. Last of August.

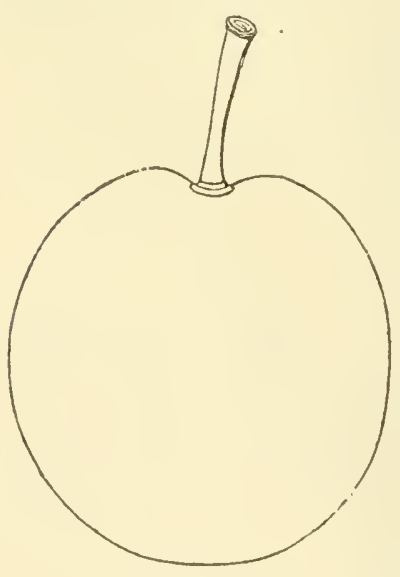

Golden Esperin.

\section{Goldex Cherry Plum.}

Raised by Samuel Reeve, Salem, N. J. Tree vigorous, productive.

Fruit small to medium, roundislı. Skin fine waxen yellow, becoming bronzed in the sun. Flesh yellowish, juicy, brisk, subacid; adheres to the stone. July.

\section{Goldex Esperex.}

Cloth of Gold Esperen. Drap d'Or Esperen.

Raised by Major Esperin. Tree of moderate growth. spreading. Buds large, pointed, a promising variety. Branches smooth, reddish brown

Fruit large, roundish oval. Skin golden vellow, with light streaks of green beneath, covered with a thin bloom, and a few crimson dots on the sunny side. Suture shallow. Stalk short and rather stout, in a small carity. Flesh light yellowish, rather coarse, very juicy, sugary, and rich. Good to very good. Adheres partially to the stone. Ripens last of August. 


\section{Goliath.}

Caledonian.

Steers's Emperor.
Saint Cloud.

Wilmot's late Orleans.

A large and handsome Plum. It is eusily distinguished from the Nectarine Plum, witl which it has been confounded, by its gray, very downy shoots.

Frut large, roundish oblong, enlarged on one side of the suture. Skin a fine deep red, approaching purple, a little paler in the shade, dusted with a thin blue bloom. Flesh yellow, adheres considerably to the sivne, rather juicy, with a brisk, spriglitly Haror. Good. Last of Aligust.

\section{GoNTE.}

\section{Prune Gonne.}

A large and handsome Belgian Plum. Tree vigorous productive. Brimelies downy.

Fruit large, roundish oval. Snture distinct. Skin reddish purple, with carmine dots and specks in sun, thin bloom. Flesh yellowish, rather coarse, juiey, melting, sweet; separates from the stone. Early September. (An. Pom.)

\section{Great Damasi Violet of Tours.}

\section{Gros Damas de Tours Largest Damask of Tours. \\ Damas de Tours gros.}

This Frenel Plum is described by Lindley, whom we copy. Branches downy.

Fruit medium, somewhat oval. Skin dark blue, covered with a violet bloom. Flesh yellow, and loosely adheres to the stone. Early August.

\section{Greex Gage.}

Bruyn Gage.

Jradford Gage.

IVilmot's Green Gare. Louis Brum

Dauphive.
Abricot Tert.

- New Green Gage. Abricotie Sageret?

-..- Late Green Gage. Ida Gage.

Brugnon Gage.

Reine Claude.

Grosse Reine Claude

Grosse Reine

Damas Vert.

sucrin Vert.

Vert Bonne.

Ida Green Gage.

Queen Claudia.

Rensselaer Gage.
Schuyler Gage; incorrectly .

Trompe Garcon.

Trompe Valet.

Terducia.

Terdochio.

Verte Tiquetée.

Murray's Reine Claudia.

Huling's Reine Claudia.

Goring's Golden Gage.

Grent Green Damask.

Reine Claudia blanche la grosse.

Gros Damas vert.

Mirabelle Vert Double. Livingston Manor.

Reine Claude Dorée.

The Green Gaige is miversally admitted to hold the first rank in flavor among all Plums, and is everywhere lighly esteened. In France this variety is generally known as the Reine Claide, having, it is said, bet: introluced into that country by Queen Clande, wife of Francis I. During ahe last century an English fumily by the name of Gage obtained a number of fruit-trees anong the monks of Chartreuse, near Paris. Annong them was a tree of this plum, which, having lost its name, was 
called by the gardener the Green Gage. It is pronounced, by Lindley. the best plum in England, and we must admit that we have no superior to it here.

The Green Gage is a very short-jointed, slow-growing tree, of spreading and rather dwarfish habit. It is an

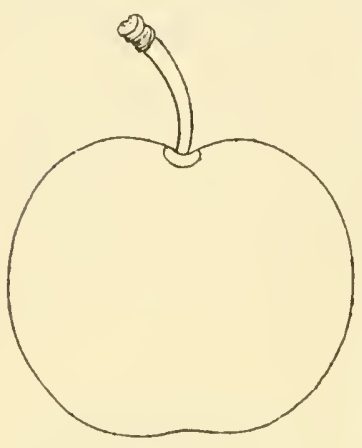

Green Gage. abundant and pretty regular bearer, though the fruit is a little liable to crack upon the tree in wet seasons. Branches smooth. Buds with large shoulder's.

Fruit round, rather small, seldom of medium size. Suture faintly marked, but extending from the stalk to the apex. Skin green, or yellowish green at full maturity, when it is often a little dotted or marbled with red. Stalk half to three-fourths of an inch lone, slender, very slightly inserted. Flesh pale greeu, exceedingly melting and juicy, and usually separates fieely from the stone. Flavor at once sprightly and very luscious. Best. Ripe about the michlle of August.

There are several seedling varieties of this Plum in various parts of this country, but none superior or scarcely equal to the old.

\section{Gundaker Pruse.}

Groundacre.

Raised by Samuel E. Guntaker, of Lancaster, Penn.

The Gundaker Prune is of a yellowish white color, nearly as large as the Blue Prume, and of the same oval shape, very high-flavored, and a good bearer.

\section{Gundaker Plim.}

Same origin as the Prune, of a purple color on one side, and the other a light color, heart-shaped, resembling a Plum called Golden Urop, but larger in size, and a great bearer. (Gundaker in Hort.)

\section{Guthrie's Apricot. \\ Guthrie's Golden.}

Raised by Mr. Guthrie, Scotland. Tree very vigorous, hardy, productive. Branehes smooth.

Fruit rather large, roundish oval. Suture rery slight. Skin yelJow, sprinkled with a few crimson dots, and covered witl a thin bloom. Stalk rather long, set in a small depression. Flesh yellow, coarse, juicy, sweet, but not ligh-flavored; atheres to the stone. Good to very good. Ripens the last of August.

\section{Guthrie's Aunt Axy.}

\section{Aunt Ann.}

Same origin as the preceding. Tree vigorous, upright. Branches smooth, reddish.

Fruit medium, oval. Suture shallow, a little more than half round. 
Apex a little sunk. Skin pale yellow, somewhat splashed with green, covered with a thin bloom. Stalk rather long. Cavity moderate. Flesh yellow, juicy, sugary, slightly vinous; adheres to the stone. Good to very good. Early September.

\section{Guthriès Late Green.}

\section{Minette.}

Raised by' Mr. Guthrie, Scotland. A rery rapid grower. Branches sinonth.

Fruit medium, globular, swollen on one side. Skin yellow, with splashes of green, and covered with a thin bloom. Stalk three-fourths of an inch long, inserted in a small carity. Flesh greenish yellow, juicy, sugary, rich; allheres to the stone. Very good. Early Sertember.

\section{Guthrie's Russet.}

Another of Mr. Guthrie's originating. 'Tree vigorous. Branches smooth, brownisls

Fruit large, oval. Suture large, half round. Skin yellow, covered with a thin bloom, sometimes marbled in the sum with crimson. Stalk long, slender. Cavity small. Flesh yellow, juicy, sweet, rich; adheres to the stone. Good to very good. Last of Angust.

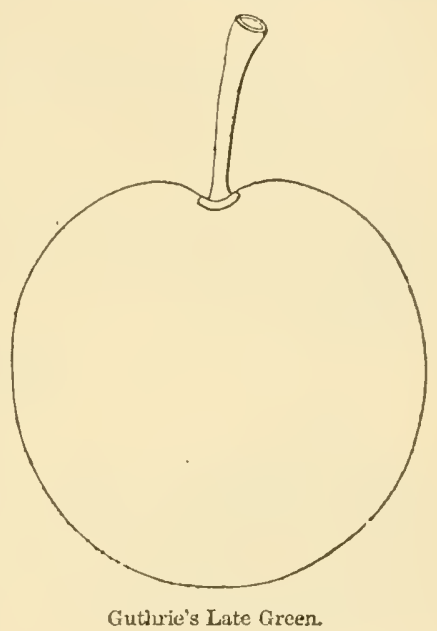

\section{Guthrie's Taybank.}

Same origin as above. Branches smooth, short-jointed.

Fruit large, roundish oval. Skin greenish yellow. Flesh yellowish, juicy. Good. Last of September. (Elliott.)

\section{Guturie's Topaz.}

Raised by Mr. Guthrie, Scotland. Tree a moderate grower, with smooth reddish brown branches, very productive.

Fruit medium, oval, with a slight neek, one side somewhat swollen. Suture moderate. skin golden yellow, with a thin bloom. Stalk an inch long, slentler, curved, inserted in a small deep cavity. Flesh yellow, juicy, sweet, not very rich, but pleasant; adheres to the stone. Good. Middle of September.

\section{GWalsiI.}

Fruit large, oblong oval. Suture shallow. Skin deep purple, with 
a bloom. Stalk rather short, slightly sunk. Flesh greenish, coarse, not very juicy, sweet, and pleasant; adheres to the stone. Cood. First of september.

\section{HALLEXBECK.}

Originated with Hemy Hallenbeck, East Greenbush, Rensselaer Co., N. Y. Tree vigorous, with upright stout shoots and prominent buds. rather slow growth. Branches smooth or slightly downy.

Fruit large, roundish oval, one side often enlarged." Suture broar, shallow. Skin deep reddish purple, sprinkled with mumerous minute dots, and covered with a grayish blue bloom. Stalk stont. Cavity large. Flesh greenish yellow, very juicy, sugary, with a brisk flavor; adheres clusely to the stone. Good. Last of August.

\section{Hartwiss' Yellow Prene.}

A German variety. Tree vigorous, very productive.

Fruit nedium, oval, narrowed toward the stalk, next which is a slight mamelon neck. One side compressed. Skin fine yellow, slightly blotched and dotted with crimson, thin light bloom. Stalk long, slender. Cavity small. Flesh yellow, a little coarse, iuicy, sugary. Separates freely fiom the store. Good to very good. Early September.

\section{Hexrietta Gage.}

\section{Early Genesee.}

Originated in the town of Henrietta, Monroe Co., N. Y. Tree of rather slow growth. Branches brownish gray, shightly downy.

Fruit medium, roundish oval. Suture shallow, a little more than half round. Skin pale yellowish white, with a thin white bloom. Stalk rather short, stout, in a small cavity. Flesh yellow, not very juicy, sweet; adheres to the stone. Good. Early August.

\section{Hexry Clay.}

Raised by Elisha Dorr, Albany, N. Y. Tree vigorons and productive. Its great beanty will make it desirable. Branches smooth.

Fruit medium, somewhat oval, inclining to a neck, with a slight suture. Skin yellow, with a light bloom, and the cheek beautifully marbled and shaded with red. Stalk long, siender, inserted in a small cavity. Flesh yellow, juicy, and sweet; adheres sightly to the stonè. Good to very goorl. Last of August.

\section{Highlaxder.}

Origin, Newburgh, N. Y. Tree vigorous and rery productive. Branches gray, smooth.

Fruit large, irregularly ovate, somewhat swelled on one side. Suture moderate, half round. Skin deep blue, inclining to reddish brown, covered with a thin bloom, and thickly sprinkled with brown dots. Stalk rery short, inserted in a slight cavity. Flesh gremish yellow, juicy, sugary, rich, vinous; adheres slightly to the stone. Good to very good. Last of September. 
Hollavd.

Blue Folland.

Holland Prune.

Tree vigorous. Branches clowny, rather slender.

Fruit round, slightly flattened. "Skin blue or light reddish purple, covered with a bluo bion, Flesh juicy, melting, sweet, and pleasant; separating freely from the stone. Cood. Last of August to the middle of September.

\section{Homse Plum.}

Large Early Damson.

Sweet Damson.

Tree vigorous, upright. Branches downy.

Fruit of medium size, oval, with a deep suture on one side. Skin purple in the sun, reddish on the shaded side, with blue bloom. Flesh greenish yellow, rather dry and acid, separates from the stone. Scarcely good. Last of Angust.

HOWARD'S FAVORITE.

Raised by E. Dorr, Albany, N. Y. Tree a vigorous grower, very froductive. Branches smooth.

Fruit large, oval, narrowing toward the stalk, and flattened at apex. Suture shallow, a little more than half round. Skin pale ycllow, dotted and marbled witl camine in the sun, covered with a thin lilac bloom. Stalk rather long. Cavity small. Flesh yellow, juicy. sweet; adheres to the stone. Good to very good. September.

\section{Howell's Early.}

Sea. Early Purple. Chapin's Early.

Origin unknown; brought from Tirginia. Tree of ratlier slow growth. Wood slender, gray, and downy.

Fruit rather below medium size, oral, without any snture, one side a little enlarged. Skin pale red, recidish purple in the sun, covered with a light lilac bloom. Stalk short, stout, with a slightly elerated collar. Flesh yellow, juicy, rich, sweet; separates from thes stone. Good to very good. Early August.

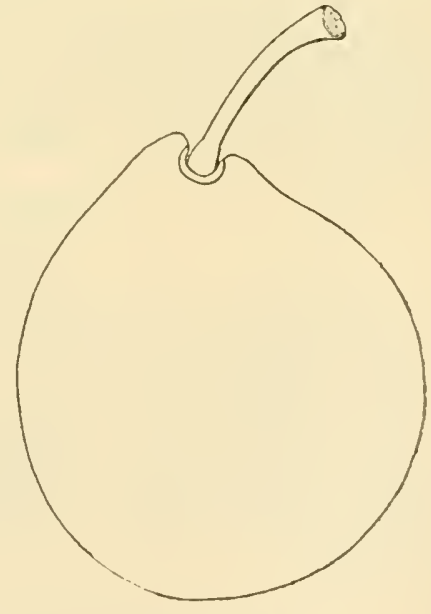

Iloward's Farorite.

\section{How's AMBER.}

Origin, Portsmouth, N. H. Tree vigorous, productive.

Fruit medium, roundisl, slight suture. skin amber-colored in the shade, mottled with rose, thinly covered witlı pale violet bloom. Stalk of medium length, inserted without cavity. Flesh coarse, rellow, melting, juicy; adliering to the stone. First of September. (Hov. Mag.) 


\section{Hudson Gage.}

\section{Reine Claude d'Hudson.}

Raised by L. U. Lawrenee, of Hudson, N. Y. Tree thrifty, produc tive. Branches downy.

Fruit of medium size, oval, a little enlarged on one side of the ob scure suture. Skin yellow, clouded witl

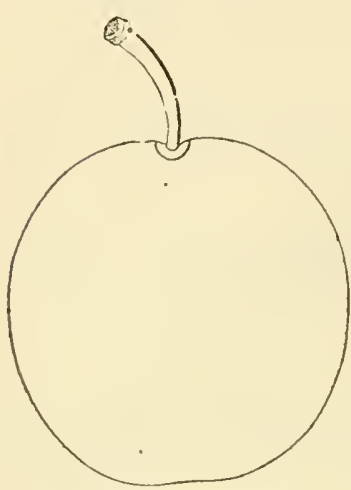

Hudson Gage. green streaks under the skin, and covered with a thin white bloom. Stalk sholt, little more than half an inch long, inserted in a moderate hollow. Flesh greenish, very juiey and melting, with a rich, sprightly, excellent flavor. It separates firm the stone (adhering very slightly). Very good. First week in Augnst.

\section{Hulings' Superb.}

\section{Keyser's Plum. Gloire de New York.}

Raised by Mr. Keyser of Pennsylvania, and brought into notice by Dr. W. E. Hulings of that State. Tree very vigorous, upright, large foliage, blunt shoots, large-shouldered buds, moderate hearer. Branches downy.

Fruit very large, roundish oval, with a distinet though shallow suture. Stalk strong and stont, set in a round, small cavity. Skin rather dull greenish yellow, thinly covered with pale bloom. Flesh greenish yellow, rather coarse, but with a rich, brisk, sprightly flavor. Good. It adheres to the stone. Middle of August.

\section{ICKWORTH IMPÉRATRICE.}

Knight's No. 6.

Raised by Mr. Knight, of Downton Castle. It hangs a long while on the tree, and if gathered and wrapped in soft paper, will keep many weeks. Branches smooth.

Fruit lather above medium size, obovate. Skin purple, peculiarly traced or embroidered with streaks of golden fawn color. Stalk moderately long and thick. Flesh greenish yellow, sweet, juicy, and rich, mostly adhering to the stone, which is rather small. Very good. Early in Oetober.

\section{Tipériale de Milax.}

\section{Prune de Milan.}

Tree vigorons, rather spreacing. Branches smooth.

Fruit rather large, roundish oval. Suture broad, extending twothirds around one side, often enlarger. Skin deep purple, covered with a thick blue bloom. Stalk stout, set in a small eavity. Flesh greenish, juicy; sugary, allieres to the stone. Good. Early September. 


\section{Iatperiat Gage.}

Flushing Gage.

White Gage.

Prince's Imperial Gage.

Superior Green Gage.
Reive Claude Impíriale.

Prince's Gage.

Admiral de Rigny?

Prince's White Gage.

Prince's Imperial.

The Imperial Gage has long enjoyed the reputation of one of the most execllent and productive of Plums. It was raised at Prince's Nursery, Flushing, N. I., from the seed of the Green Gage, and the fitet of the fruit of a single tree near Boston having produced finit to the value of nearly fifty dollars ammually, has often betn repeated as a proof of the profit of its cultivation for market. The tree grows freely and rises rapidly, and has long dark shoots, slightly downy.

Fruit rather above medium size, oval, with a distinct sutme. Stalk rearly an inch long, slightly hairy, and pretty stont, inserted in an even hollow. Skin pale green until fully ripe, when it is tinged with yellow, showing a peculiar marbling of dell green stripes, and covered with

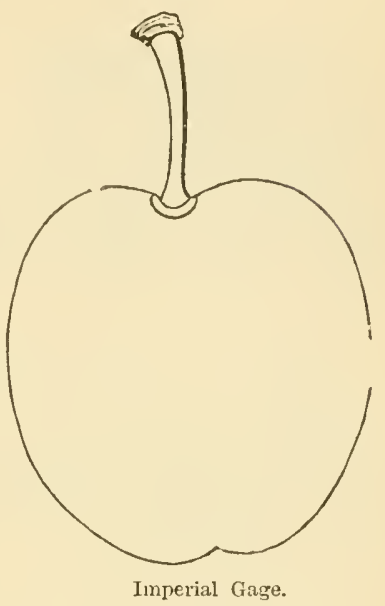
copious white bloom. Flesh greenish, very juicy, melting, and rich, with a very slightly agreeable flavor; it separates pretty freely from the stone. The latter is oval, and pointed at both ends. Best. Early September.

\section{IMPERIAL OTtOMAN:}

A very neat early Plum, of good flavor, and a prolific bearer. It has the reputation of having been brought from Turkey, but it is uncertain whether this is correct. 'Tree vigorous, upright. Branches long, slightly downy.

Fruit scarcely below medimm size, roundish, between Green Gage and the American Yellow Gage in appearance, and having a suture on one side, from the stalk half way down. Stalk downy, slender, enrved, threefourths of an inch long, inserted in a very slight carity. Skin dull yellow, clouded with darker streaks, and covered with a thin bloom. It adheres considerably to the stone. The flesh is juicy, sweet, melting. Good to very good. Last of July.

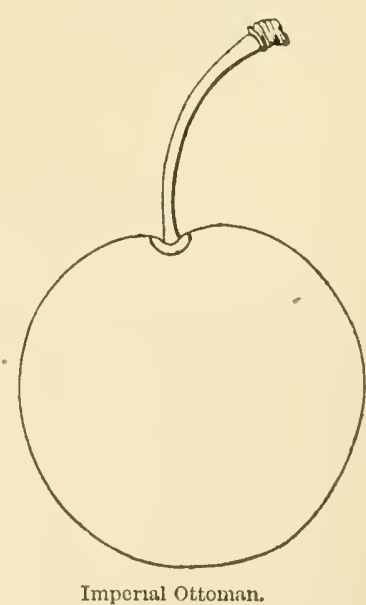

Imperial Purpie

Originated with Wm. R. Prinee, Flushing, L. I. Tree vigorous, very productive. Branches smooth. 
Fruit nedium, roundish oval, one side slightly compressed. Suture slight. Skin reddish purple, covered with a pretty thick lilac bloom. Stalk rather short, slencler. Cavity small. Flesh greenish, juicy, sweet; adheres to the stone. Good to very good. Last of August.

\section{INCOMPARABLE.}

\section{Tonpareil. Incomparable Prune.}

A German Prune Plum. Tree vigorous, upright, with long slender smootli bi'tunches.

Frnit medium or below, long oval, narrowing at ends. Sutme shallow, pointed at apex. Skin deep puplish black, covered with a thick Whe bloom. Stalk long, slender. Cavity small. Flesh yellowish, sweet; adheres slightly to the stone. Good. Last of September.

\section{ISABELLA.}

This is an attractive-looking English Plum. Branches quite downy and gray.

Fruit medium size, oval, ratler narrower towarls the stalk. Skin dark dull red in the sum, paler in the shade, and thiekly sprinkled with darker colored dots. Stalk three-fourths of an inch long, a little hairy, set in at molerate hollow. Flesh yellow, rich, juicy, with a smart flavor, and adheres to the stone. Good. Last of August.

\section{ITALIAN DAMASK.}

Damas d'Italie.

Tree thrifty, vigorous.

Fruit medium, roundish oval. Suture shallow. Apex slightly sunken. Skin purplish black, covered with a thick blue bloom. Stalk rather stout. Flesh light green, a little firm, moderately juicy, slightly vinous; separates from the stone. Grood. Late August.

\section{Italiax Prune.}

$\begin{array}{ll}\text { Prune d'Italie. } & \text { Altesse Double. } \\ \text { Fellenberg. } & \text { Italian Quetsche. } \\ & \text { Quetsche d'Italie. }\end{array}$

Tree vigorous, spreading. Branches smooth.

Fruit medimm, oval. Suture moderate. Skin dark blue, with a bloom. Stalk an inch long, rather stont, inserted in a very small cavity. Flesh dark yellow, juicy, sweet, and good; separates fiom the stone. Good. First of October.

\section{Ives.}

Ives' Washington.

Ives' Seedling.

Raised by J. M. Ives, Salem, Mass. Tree of moderate growth, straggling and irregular, prominent buds. Branches smooth.

Fruit merlinm, oval. Suture a mere line. Skin pale yellow, with a light thin bloom. Stalk long, slender. Flesh yellow, melting, juicy; sejarates from the stone. Good. Early September. 


\section{JACOB.}

Tree moderately vigorous. Branehes smooth.

Fruit medium, oval, with a neck, one side enlarged. Suture large, Skin violet purple, covered with lilac bloom. Stalk long, slender. Cavity small. Flesh greenish, juicy, sweet; separates from the stome. Good. September.

\section{Farly Yellow.}

Catalonian.

White Primordian.

. Taune de Catalogne.

Prume de st. Barnabe.

D'droine.

\section{JALNE HÂTIVE.}

$\begin{array}{ll}\text { Amber Primordian. } & \text { Prune de Catalogne. } \\ \text { Jean Hntive. } & \text { Avant Prune blanehe. } \\ \text { Early John. } & \text { Cerisette Blanche } \\ \text { Jilboa. } & \text { P'ickett's July. } \\ \text { St. Barmabée. } & \text { P'rune Monsieur Jaune. } \\ \text { Loudon Plum. } & \text { Prune d'Altesse blanche. }\end{array}$

The earliest of Plums, which is its chiref recommendation. It is a very old variety, from Catalonia and the sonth of Franee, and has been in eultivition more than two hundred years. It is a pretty little fruit, and is worthy of a place in the garden of the anatenr. The tree has long, sleutler, downy branches.

Fruit small, oval or obovate, with a shallow suture on one sicle. Stalk slender, half an inch long. Skin pale yellow, thinly coated with bloom. Flesh yellow, tolerably juiey, and melting, of sweet and pleasant flavor; seprates from the stone. Good. From the 10 th to the micklle of July.

\section{JEFFERSON.}

If we were asked which we think the most desiral,le and beautifn] of all dessert Plums, we should undonbtedly give the name of this new

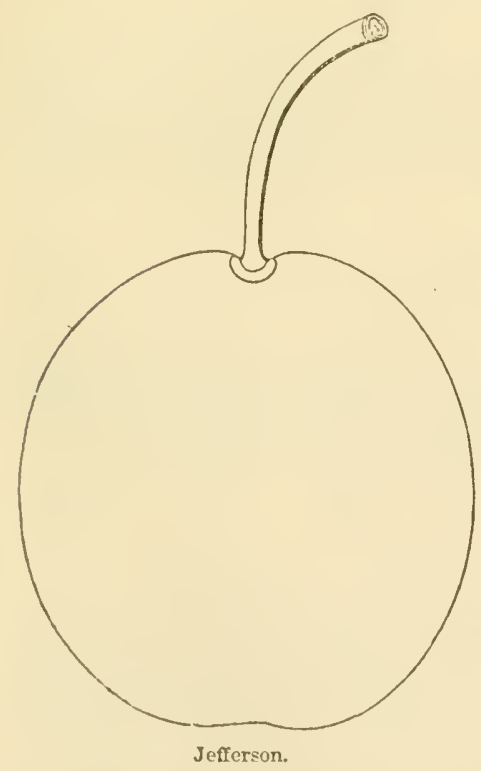
variety. When fully ripe, it is nearly equal in flavor to the Gireen Gage, that unsurpassable standard of flavor. But when we contrast the small appearance of the Green Gage with the unusual size and beanty of the Jefferso11, we must admit that it takes the very first rank. It is about ten days or a fortnight later than the Washing ton, ripening the last of Angust.

We received the Jefler'son Plum, a few years ago, from the late Judge Buel, by whom it was raised and named. It is a good moderate grower and regular bearer, and the crop is very handsome on the tree. Branches slightly downy.

Fruit large, oval, slightly namowed on one sicie towards the stalk. Skin golden vellow, with a beantiful purplish-red cheek, and covered with a thin white bloom. Stalk an inch long, pretty stont, very slightly inserted. Suture indistinct. Flesh deep orange; parts fiecly, and al. most entirely from the stone, which is long and pointed. Very rich, juicy, luscions, and high-flavored. Best. 


\section{Jeirusalem.}

Prunier de Jerusalem. Violette Jerusalem.
Prune Violet de Jerusalem. Gil de Bœuf.

De Bordeaux.

Fruit large, long, egg-shaped. Skin dark purple, covered with a dense blue bloom. Stalk an inch long, hairy. Flesh tirm, sweet, brisk; separates from the stone. Mildle September. (Hogg.)

\section{Jodoigne Greex Gage.}

Boulouf. Reine Claude de Jodoigne. Royal de Vilrorde.

'ìee vigorous. Branches smooth, stout. short-jointed.

Frut large, round, inclining to oblate. Suture shallow, haif round. Skin thin, greenish yellow, with blush red strewed green and yellowish dots on the side next the sun, and covered with a thin blue bloom. stalk half an inch long. Flesh whitish yellow, firm, very juicy, tender, sugary, rich. Late September. (Hogo.)

\section{JuDSOx.}

Raised by Mr. Judson, of Lamsingburgh, N. I. Tree thrifty and productive. Branches smooth.

Fruit large, long oval. Suture broad, rather deep. Skin reddish purple, covered with a thin blue bloom. Stalk long, stout. Flesh greenish, rather coarse, not very juicy, sweet; adheres partially to the stone. Scarcely good. Last of August.

\section{July Greex Gage.}

Reine Claude de Bavay Hâtive.

Early Bavay.

Fruit medium, roundish, slightly oblong. Suture distinct, a little more than half round. Skin greenish yellow, tinged with purple in the sum, thin bloom. Stalk rather stout. Cavity broad, shallow. Flesh yellow, juicy, sweet; separates from the stone. Very good. Last August.

\section{Kester's Green Gage.}

Raised by W Weaver, Mt. Pleasant, Westmoreland Co., Pa. Tree vigorous, productive.

Fruit small, nearly globular, one side enlarged. Suture rather large. Skin pale yellowish green, with splashes of deeper green, slight bloom. Stalk of medium length, inserted in a large cavity. Flesh greenish, juicy, sugary, rich. Very good. Adheres slightly to the stone.

\section{Kester's Yellow Gage.}

Raised by W Weaver, Mt. Pleasant, Westmoreland Co., Pa. Tree vigorous, upright. Branches smooth.

Fruit mediun, roundish oval. Suture broad and shallow. Skin pale yellow, splashed with green, and covered with a thick white bloom. Stalk of medium length, inserted in a small cavity. Flesh greenish yellow, juicy, sugary, rich. Very good. Adheres partially to the stone.

\section{KinkE'S.}

Kirke's Plum is a variety which came to us from England, where 
it was first brought into l.otice by Mr. Kirke, the nurseryman, at Brompton. Binche's smooth.

Frut of medimm size, romnlish oblong, with very little suture. Skin dark purple, with a few golden dots, and coated with an unusually thick blue bloom, which adhores pretty closely. Stalk three-forrths of an inch long, inserted in a very slight depression. Flesh greenish yellow, firm, and very rich in flavor. It separates freely from the stone, which is flat and bioal. Cood to rery good. Last of August and first of Soptember.

\section{KOLENKAMP.}

Originated in the garden of W. Kolenkamp, Philadelphia, Pa.

Fruit lirge, oval, red. Flesh yellowish, dhy; seprarates from the stone. Last of Neptember. (Am. P. Soc.)

\section{L.ADY PIUN.}

Raised by Isaac Denniston, Albany, N. Y. Tree of slender growth, productive. It is quite a pretty fruit, esteemed highly for preserving, this being its chief quality. It is a rampant grower, an abundant bearer.

F'uit quite small, ovil. Stalk short and stout. Color light yellow, spotted with red. Stone free and small. Flavor acid. First of September. (E. Dorr in Cult.)

\section{LANGDON.}

Langdon's Seedling.

Raised by Reuben Langdon, of Hartford, Comn. Tree vigorous and productive. Branches smooth.

Fruit rather large, roundish oval, with a moderate suture. Skin reddish purple, covered with a thick lilac bloom. Stalk three-fourths of an inch long, inserter in a rather deep cavity. Flesh greenish yellow, coarse, juicy, sprightly, subacid, and alheres mostly to the stone. Good. Last of August.

\section{Large, Green Dritia. \\ Knight's Large Drying.}

A late variety, raised, we believe, by Mr. Knight, and introduced here from the garden of the Horticultural Society of London. The tree is vigorous, and the branches are smooth.

The fruit large, round, greenish yellow. The flesh yellowish, morlerately juicy, sweet. Grood. Adheres to the stone. Middle of September.

\section{Late Black Orleans.}

Tree vigorons, with long and slender smooth branches; very productive.

Fruit medium, nearly round. Suture broad, slabllow. Dot at apex. Skin deep black, covered with a thick blue hloom, and thickly sprinkled witl minute lrowa dots. Stalk rather stout. Cavity small. Flesh (leep) yellow, juicy, sugary; adheres firmly to the stone. Good. Last of September. 


\section{Late Bolmer.}

Winter Bolmar.

Fruit medium, roundish. Skin yellow, mottled with red next the sun. Flesh yellow, rather firm, sweet, but not rich; separates from the stone. Good. Middle of September.

\section{Late Rivers.}

A seetling of Thomas Rivers, England. Branches smooth.

Fruit below medium size, romul, slight snture. Skin dark purple, almost black. Stalk an inch or more long, slencier. Flesh yellow, juicy, sweet; adheres to the stone. Goorl. Last of October. (Hogg.)

\section{Lawrexce's EARLy.}

A foreign rariety.

Fruit medium size, roundish oral, flattened at ends. Skin dark pur. plish red, covered with a thick bloom. Flesh juicy; separates from the stone. Good. Middle August.

\section{LAWRExCE'S FAYORITE.}

\section{Lawrence's Gage.}

Reine Claude de Lawrence.

Lawrence's Faronite is a fruit of high merit, raised by MIr. I. U. Lawrence, of Hudson, N. Y., from a seed of the Green Gage.

The general appearance of the fruit is like that of its parent, except

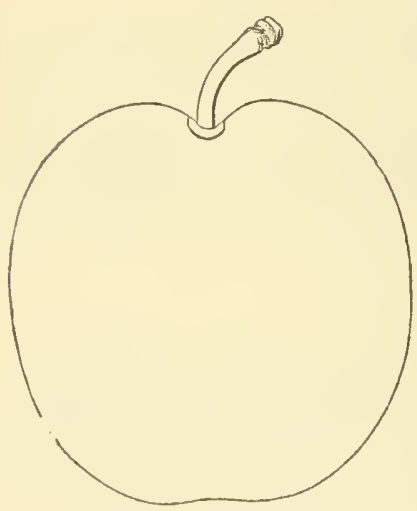

Lawrence's Favorite. that it is much larger. It haugs well on the tree, and its size, flavor, and productiveness should give it a place in every garden.

Lawrenee's Favorite forms an upright tree of thrifty growth: Young branches smooth.

Fruit large, heavy, roundish, al little flattene l at either end. Slin dull yellowish green, clonded with strenks of a darker shade beneath, and corererl with a light bluish-green bloom. The upper' part of the fruit, when fully ripe, is covered with a peruliar bromish netrork. and a few reddish dots. Stalk short, only half an incl long, slender, inserted in a narrow cavity. Flesh greenish, resembling that of the Green Gage, remarkably juicy and melting, perhaps scarcely so rich as the latter, but with a rery rich, sprightly vimous tlavor, and one of the most delicious of plums. The flesh sometimes adheres a little when not fuily ripes, but then separates fieely. Best. Mildle of Angust.

\section{LAWSON'S GOLDEx.}

Damas Lawson.

Golden Gage Lawson.

Tree vigorous, productive. Branches smooth.

Fruit medium, roundisin oval. Suture very shallow. Skin pale yel. 
low, lightly shaded and mottled in the sun with dull crimson, covered with a thin bloom. Stalk long, slender. Carity small. Flesh yellow juicy, sweet. Adlueres to the stone. Clood to very good. Last of August.

\section{LEWISTOX EGG.} downy.

Origin, Lewiston, N. Y. Tree vigorous and productive. Branches

Fruit medinn size, oval. Skin pale yellow, with a bloom. Flesh vellow, adhering closely to the stone, not very sweet, and only seconclrate flavor. Goorl. Last of August.

\section{LIEGEL'S APRICOT.}

Abricotée de Braman Nouvelle.

Branches downy.

Fruit mediun, rommlish. Sutme deep. Skin like Green Gage, covered with a white bloom, beconning yellowish as it ripens. Flesh greenish yellow, melting, juicy, sugary; separates from the stone. Last of September. (Hogg.)

\section{LOMBARD.}

\section{Bleecker's Scarlet. Beekman's Scarlet. Montgomery Prune.}

Tree very vigorous, hardy, has strikingly crimpled leaves, bright purple glossy shoots, very profluctive, popular.

It was called the Jombird Plum by the Massachusetts Horticul. tural Society, in compliment to Mr. Lombard, of Springfield, Mass., who first brought it into notice in that State: and it is said to have been received by him from Judge Platt, of Whitesborough, N. Y., who raised it from seed. Bul it was previously well known here by the name of Bleecker's syrulet. Never having been described under that name, however, we adopt the present title.

Fruit of medium size, roundish oval, slightly flattened at either end. Suture obscure. Stalk quite slender, scarcely three-fourths of an inch long, set in a broad, ahruptly narrowing cavity. Skin delicate violet red, paler in the shade, dotted with red, and dusted thinly with bloom. Flesh deep yellow: juicy, and pleasant, but not rich ; adhering to the stone. Good. Middle and last of

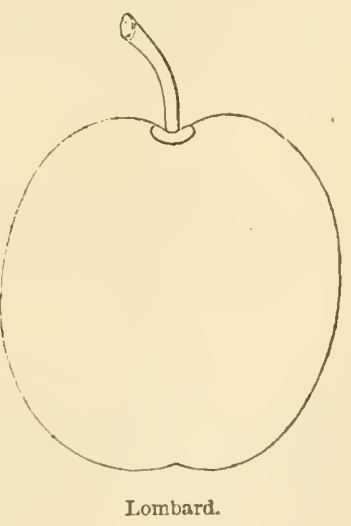
August.

\section{Loyg SraRLET.}

\section{Scarlet Gage. Red Gage, incorrectly.}

American. Tree very vigorous, aud very produetive. Shoots downy.

Fruit of medinm size, oblong abovate, swollen on one side of the suture, and tapering to the stalk. Skin bright red in the sun, pale yellowish reel on the shady side, covered with a fine lilac bloom. Flesh deep yellow, juicy, acid at first, but, if allowed to hang, it becomes rather rich and sweet. It adlheres to the stone. Goul. List of August. 


\section{Louisa.}

From Missouri. Tree vigorous, very productive, spreading. Branches evidence of its native wild character.

Fruit medium, nearly round, yellow, nearly covered with purplish red, gray dots, thin bioom. Suture slight. Flesh yellow, juicy. Good. Adheres to the stone. Last of Angust. (Musmann.)

\section{Le'conbe's Nonesuch.}

An English 1'lum, raised by Lncombe, of the Exeter Nursery. Tree moderately vigorons. Branches smooth.

Fruit ahove medium size, roundish, shaped and colored much like the Green Gage, but much more distinctly streaked with yellow and orange, and covered with a whitish bloom. Suture broad. Stalk straight, thires-fouths of an inch long, set in a wide hollow. Flesh pretty firm, greenish, and adheres to the stone. Good. Last of September.

\section{MULAUGILIN.}

Raised by James McLanghlin, Bangor, Me. Tree hardy, vigorous, and productive, a valuable varicty, nearly or quite equal to Gireen Gage. Branches smooth.

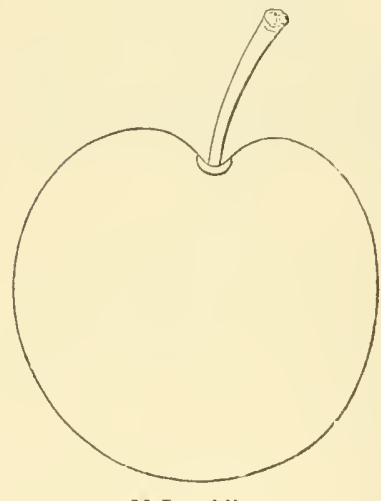

MeLaughlin.

Fruit large, nearly round, oblate, flattened at both ends. Suture slight. Stalk three-fonths of an inch long, inserted in a small cavity by a ring. Skin thin and tender, yellow, dotted and marbled with red on the sumny sicle, and covered with a thin bloom. Flesh dull yellow, rather firm, juicr, very sweet and luscious, perfumed. It alheres to the stone. Best. Last of August.

\section{MLAMelonité.}

IIamelon Sageret.

A seedling of Sageret, near Paris. Tree moderately rigorous. Branches smooth, brownish gray.

Fruit of reluarkible shape. having a nes or (mamelon) at the base of the stock. It is of excellent quality, hardy and prolific. Fruit of medium size, ovial, tapering towards the apex, and a well-marked suture on one side. Stalk small, inserted withont depression. Skin pale yellow, a few splashes and streaks of green, dotted and marbled with crimson in the sun, covered with a thin light bloom. Flesh yellow, juicy, sugary, rich; separates from the stone. Good to very good. Middle Angust.

\section{Mannixg's Loxg Bute Prune.}

\section{Manning's Prune. Large Long Blne. Manning's Long Blue.}

Origin unkuown. Tree vigrorous, with long dark-colored shoots, rery productive. Branches smooth.

Fruit quite large, long oval, a little one-sided, with an obseure suture. Stalk very long and slender, set in a very trifling depression. Skin dark purple, with it thick bhe bloom. Flesh greenish yellow, firm, rather 
juicy, with a sweet, sprightly, pleasant flavor. It separates pretty readily from the stone, which is long and pointed. Cood. First to last of Sep tember. Ripens gradually and bears carriage well.

\section{Many's Imperial, \\ Brandy Gage. Mann's Brandy Gage.}

This fruit is a small form of Coe's Golden Drop, of rich flavor, but very much earlier. It alifiers from Coe's Golden Irop by having downy shoots. (Hogg.)

\section{Marten.}

Marten's Seedling.

An accidental seedling in the garden of Mr. Marten, Schenectady, N. Y. A very vigorous, mpright grower, productive. Branches smooth, grayish.

Fruit large, roundish oblong, irregular suture, rather deep from stalk to apex, which is a little sunk. Skin yellow, somewhat streaked with green, and dotted with red on the sumny sicle. Stalk nearly an inch long, set in a suall eavity. Flesh yellow, a little coarse, juicy, with a brisk sprightly flavor. Separates from the stone. Good to very good. First of September.

\section{Maugeron.}

Damascene Maugeron.

Damas de Mangeron.
Mangeron.

Maugeron Damask.

Branches smooth.

Fruit large, round, depressed. Skin purplish, dotted with yellowish dots, and covered with a blue bloom. Flesh whitish yellow, not very juicy, breaking, sweet; separates from the stone. Early September. (Liegel.)

\section{Mediterraxeax.}

Tree vigorous, productive. Branches smooth, quite redølish.

Fruit medium, ovate-necked. Suture medium. Skin light crimson. Stalk long, slender. Cavity small. Flesh yellow, sweet, sprightly; separates from the stone. Good. Early September.

\section{Meigs.}

Fruit large, roundish oval. Suture indistinct. Skin dull reddish purple, with numerous gray dots. Stalk long, eurverl, slender, set in a small carity. Flesh greenish yellow, juicy, rich, sugary and exeellent; adheres to the stone. Good. Last of September.

\section{Miner.}

\begin{tabular}{|c|c|}
\hline Hinckley. & Gillett. \\
\hline
\end{tabular}

This is an impored rariety of the wild or Chickasaw Plum, originated with Mr. Miner, Lancaster, Pa. Branches smooth, dark red.

Fruit medium, ol,long, pointed at apex. Skin dark purplish red, with a fine bloom. Flesh soft, juicy, vinous; adlieres to the stone. Early October. 


\section{Mirabejle.}

Mirabelle Petite. Mirabelle Jaune. Mirabelle Blanche. Mirabelle Perle.
Mirabelle de Vienne. White Mirabelle. Mirabelle Précoce. Prune de Mirabelle.
Gelbe Mirabelle. Small Mirabelle. Little Hirabelle. Petit Drap d'Or.

A very pretty little fruit, exceedingly ornamental on the tree, the branches of which are thickly sprinkled with its abundant crops. The tree is small in all its parts, and although the fruit has a tolerable flavor, yet from its size and high perfume it is chiefly valued for pre serving. Branches downy.

Fruit quite small, obovate, with a well-marked suture. Stalk half un inch long, slightly inserted. Skin of a beautiful yellow, a little spotted with red at maturity, and covered with a white bloom. Flesh orange, sweet, and sprightly, becoming dry when over-ripe, and separates from the stone. Good. Middle of Angust.

\section{Mirabelle de Naxcy.}

A variety resembling the foregoing, except in its maturing later.

Fruit snall, nearly round, rich yellow, dotted with red. Flesh juicy. September. (Hogg.)

\section{Mitchelson.}

Mitchelson's.

Raised by - Mitchelson, England. Tree hardy, productive. Branches smooth.

Fruit above medium size, oval, withont suture. Skin black, dotted with a few minute fawn-colored dots, covered with a thin blue bloom. Stalk stout. Flesh yellow, tender, juicy, sweet; separates from the stone. Good. Early September. (F. and P.)

\section{MONROE.}

Monroe Egg.

Raised by Miss Dunham, Penfield, Monroe Co., N. Y. Tree rery vigorons and productive. Branches smooth.

Fruit medium or above, oval. Skin greenish jellow, with rarely a blush. Stalk rather long, with rery little depression. Flesh greenish yellow, not very tender, sweet. Good. First of September.

\section{Morocco.}
Early Moroceo.
Black Morocco.
Early Black Morocco.
Early Damask.

A good early Plum, of rather slow growth, and a moderate bearer. Branches downy.

Fruit of medinm size, roundish, with a shallow suture on one side, a little flattened at both ends. Skin dark purple, corered with a pale thin bloom. Stalk half an inch long, rather stont. Flesh greenish yellow, adhering slightly to the stone, juicr, with a smart, rich flavor, becoming quite sweet at maturity. Good. First to middle of $\mathrm{A} u$ gust. 
Motret's Gage.

Reine Claude Mogret.

A new Freneb Plum, originated by M. Moyret, at Neuville-sur-Ain. Tree vigorous. Branches slightly downy.

Fruit medium, romedisls. Suture half round, distinct, not deep Skin light reddish, covered with an amber-blue bloom. Stalk rather stout, set in a eavity rather de.p. Flesh greenish yellow, fine, juicy, sweet, perfumed; seprates from the stone. Early August. (V erg.)

\section{MU LeERTY.}

Raised by Isaac Demniston, of Albany. The tree is a vigorous grower.

Fruit large, oval, somewhat narrowest towards the stalk. Skin pale whitish yellow, sprinkled with white dots, and dusted with a pale bloom. Stalk an inch long, rather slender, very slightly inserted. Flesh greenish yellow, juicy, sweet, good; adheres slightly to the stone. Good. First of September.

\section{Musche.}

This variety is only valuable for stocks on which to propagate other sorts.

Fruit small, oblong, dark red. Stone large.

\section{Musk Damask.}

Prune de Malthe.

De Chypre.

\section{Musqué de Malta?}

Damas Musqué.

Prune de Chypre.

Tree vigorous, upright. Branches smooth or slightly downy.

Fruit below medium, roundish. Suture distinct. Skin deep purple or bluish black, covered with a thick blue bloom. Flesh yeliow or greenish yellow, juicy, sugary, musky. Good. Adheres slightly to the stone. Last of August.

\section{Nectarine.}

$\begin{array}{ll}\text { Caledonian. } & \text { Peach Plum, erroneously. } \\ \text { Howell's Large. } & \text { Prune Pêche. } \\ \text { Jenkins' Imperial. } & \text { Louis Philippe. }\end{array}$

Tree rigorous, upright, stout, blunt, purplish shoots, nearly smooth. A fune-looking fruit, of foreign origin, but only of second quality.

Fruit of the largest size, regularly formed, romulish. Stalk about half an inch long, lather stout, and set in a wide shallow depression. Skin puple, dusted with a blue bloom. Flesh dull greenish yellow, becoming tinged with red at maturity, a little coarse-grained, with a rieh, brisk flavor, and adhering partially to the stone. Good. Middle of August.

\section{Neison's Victory. \\ Knevett's Late Orleans.}

Tree very vigorous, an abundant bearer. Branches smooth.

Fruit medium-sized, round, marked with a shallow suture. Skın deep purple, covered with a blue bloom. Stalk half an inch long, set 
in a shallow cavity. Flesh firm, rather coarse, sweet, briskly flavored; adhering to the stone. Middle September. (Hogg.)

\section{Newmax.}

A variety of the Chickasaw family, that has recently come into notice through D. L. Adair, of Kentucky. Tree healthy, hardy, vigorous, and productive.

Fruit medium, roundish oval. Skin light scarlet, with a thin bloom. Flesh soft, light pinkish, vinous, juicy; arlheres to the stone. Early Aligust.

\section{Norbert.}

Prune de Lepine. Prune de Prince.

Branches slightly hairy.

Fruit very small, round, inclining to oblate. Skin dark purple, covered with a thick, clear, light blue bloom. Flesh greenish yellow, firm, sweet, not juicy. Separates from the stone. (Hogg.)

\section{Norman PERdrigon.}

\section{Perdrigon Normand.}

A French variety.

Fruit medium, nearly romd. Skin light purple, considerable bloom, marked with fawn-colored dots. Flesh yellowish, melting, juicy, sweet; adheres to the stone. Last of Angust. (Pom. Man.)

\section{Nonth.}

North's Seedling.

Raised by Professor North, Clinton, N. Y. Tree very vigonous, very productive. Branches slightly downy.

Fruit large, roundish oblong oval. Skin reddish purple, with a thin bloom. Flesh yellowish, juicy, moderately sweet, perfuncd. Good to very good. Early September.

\section{Nouvelle de Dorelle.}

Prune Grosse Quetsche Nouvelle. Prune Nourelle de Dorrel.
Dorelle's Neue Grosse Zwetsche. Quetsche de Dorelle Nouvelle Grind.

\section{Dorelle's New Purple Prune.}

A German variety. Tree molerately vigorous. Branches downy.

Fruit large, oval, somewhat pointed at the stalk. Suture shallow, distinct, one side often a little enlarged. Skin violet purple, covered with y thin blue bloom, and pretty thickly sprinkled with whitish brown dots. Stalk rather long and stout, set in a small cavity. Flesh yeliow, juicy, sugary, vimous; alheres to the stone. Good to rery good. Last of August.

\section{Oberley.}

Oberley's Greenwood.

Originated in Northampton Co., Pa., on the farm of - Oberley. Tree a thrifty, upright grower, very productive. Branches smonth: greenish. 
Fruit medium size, roundish. Suture shallow. Apex a little sunk. Skin amber, nearly covered with rosy red, thin light bloon. Stalk medium, slender, set in a moderate cavity by a ring. Flesh yellow, juicy, vinous, rather sweet; adheres to the stonc. Good. Last of August.

\section{October Greey Gate.}

Late Green Gige. Reine Clande Tardive. lieine Claude d'Octobre.

Tree very vigorous. Young wood smonth, stont, and short-jointed.

Fruit small, ronndish. Sutue molerate. Apex dimplerl. Skin gremish yellow, covered with it thin white bloom, nottled with crimsol: in sun. Stalk stout, rather long. Flesh green, juicy, sngary, and rich; separates from the stone. Cood to very good. First of Octolner.

ORANGE.

Orange Gage. Wager.

Origin, Rhinebeck, Dutehess Co., N. Y. Tree a vigorous grower, productive. Branches stout and smooth.

Fruit very large, wal, flattened at both exds. Skin bronze yellow, maked with roughish white dots and douded with puplish red near the stalk. The latter is thes-fourths of an inch long, rather rough, inserted in a narrow round cavity. Flesh deep yellow, a little coarsegrained, moderately juicy, sugar and acid combined. It adheres a little to the stone. Good. Last of August.

\section{OrLEAss.}

MIonsieur.

Monsieur Ordinaire.

Old Orleans.

Red Damask.
Anglaise Noir. English Orleans. Prune d'Orleans. Late Monsieur.
Prune de Monsieur. Common Orleans. Red Orleans.

A populı English market Plum, being hardy and uniformly prodnetive. Tree vigorous. Branches gray, and rery downy.

Fruit midilie-sized, round, a little enlarged on one side of the distinct snture. Skin dark recl, becoming purple in the sun. Flesh yellowish, sweet, mixed with acid, and separates freely from the stone. Good. Midrlle of Angust.

\section{Oullix's Goldex.}

Reine Claude d'Oullins. Reine Clande Prícoce.
Oullin's Golden Gage. Monstruense d'Oullins.

Ouillin's Gage.

This is a German Plum, large and showy. Tree very vigorous and productive, with smooth branches, stont, short jointerl.

Fruit large, roundish oblong. Suture very shallow. Skin rich yellow, flecked and sharled with green, small erinson dots in sun, and covered with a thin white bloom. Stalk inserted in a broad, moderately deep cavity. Flesh yellow, very tender, juiey, sugary; allering slightly to the stone. Very good. Middle of August. (Hogg.) 


\section{Parsonage.}

Origin, Rhinebeck, Dutchess Co., N. Y. Tree very vigorous, upright, productive. Branches smooth.

Fruit medium to large, oval. Skin pale yellow, lightly splashed with green. Stalk of medimn length, inserted in a small depression. Flesh yellow, juicy, with a rich sugary flavor. It separates freely from the stone. Good. First of september.

\section{Peach Pluy.}

Prune Pêche. Large Peach. Reine Claude Berger?

Tree upright, rigorous, only a moderate bearer. Tree rather tender at the Nortlr. Branches smootl.

Fruit very large, shaped more like a peach than a plum, roundish, inuch flattened at both ends. Suture shallow, but strongly marked. Apex much depressed. Skin light lnownish red, spuninkled with obscure dark specks, and covered with a pale bloom. Stalk short, rather stout, set in a shallow narrow cuvity. Flesh pale yellow, a little coarse-grained, but juicy, and of pleasant sprightly flavor when fully ripe; separates freely from the stone. Good. Last of July.

\section{Penomscot.}

Raised by James Mcfamghlin, Bangor, Me. Tree vigorous, hardy, productive. Branches smootl.

Fruit large, oval. Suture distinct. Stalk three-fourths of an inch long, set in a small cavity. Skin yellow, tinged with green and a faint reel cheek. Flesh yellow, sweet, and pleasant; adheres to the stone. Guod. First of September.

\section{Peoly's Early Blue.}

This is a native fruit, of medium quality. Branches very downy.

Fruit middle-sized, roundish. Suture scarcely visible. Skin very dark bluc, covered with light blue bloom. Flesh yellow, of pleasant Havor, adhering partially to the stone. Good. Early August.

\section{Pehdigon Violet Hâtif.}

Tree hardy, vigorous, prorluctive. Branches downy.

Fruit medium or below, roundish, slightly oval. Suture half rounct, shallow. Apex a little sunk. Skin violet or reddish purple, sprinkled with brownish dots and covered with a blue bloom. Stalk short, stout. Cavity small. Flesh yellowish, moderately juicy, with a sugary pleasant Havor; separates from the stone. Good or very good. Middle August.

\section{Pershone.}

An English varietv. Branches smooth.

Fruit above medium size, obovate. Skin yellow, with a golden tinge. Flesh tender, with a fue subacid flavor; alhering to the stone. I ast of August. (Hogg.) 


\section{Peter's Yeliow Gage.}

Tree moderately vigorous, with short branches, which are downy.

Fruit medium, nearly globular, a little depressed at base. Suture broad, shallow. Apex broad, shallow, smuken. Skin pale yellow, sometimes with crimson dots in the smm and a thin light bloom. Stalk rather shor't and stout, set in a large cavity. Flesh yellowish, juiey, sngary ; adheres slightly to the stone. Good to very good. Middle August

\section{Poxis's Seeduing.}

\section{Pond's Purple.}

American origin. Tree very vigorous. Branches downy.

Fruit middle-sized, romdish. Skin purple. Flesh yellowish, rather dry, seprates from the stone, sweet, mingled with acid. Good. Early in Angust.

\section{Pond's Seenlixg.}
Plum de l'Inde.
Fonthill.
Pond's Purple.

English origin. Tree very vigorous and productive; a beautiful fruit. Branches smooth, grayish.

Fruit very large, oval, tapering a little towards the stalk, sometimes with a mamelon neck. Skin vellowish, nearly covered with bright red or carmine, having a thin whitish bloom, and sprinkled with brownish dots. Flesh yellow, a little coarse, juicy, and sugary, but not rich. Good. Middle of September.

Précoce de Tours.

Early Violet.

Violette Hâtive.

Early Tours.

Perdrigon Violet.

Blue Perdrigon.

Violet de Tours.

Noire Hâtive.

Prune de la Madelaine.

Damas de Tours.

Pruns de Gaillon.

Of foreign origin. Tree vign rous, with long, slender branches, moderately productive. Branches downy.

Fruit ratler more than an inch in diameter, oval, with a shallow su-

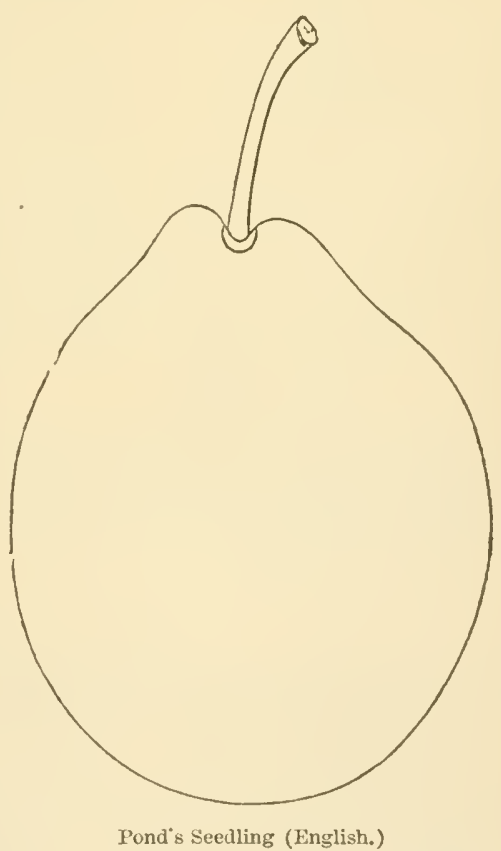

Pond's Seedling (English.)

ture. Skin deep purple, covered with a thick azure bloom. Stalk laalf an inch long, set in a narrow cavity. Flesh at first greenisl, but becoming dull yellow at matuity ; a little filrous, but juicy, sweet, melt. ing, and shightly perfumed; it adheres considerably to the stone. Good. Eirst of August. 


\section{Précoce de Bergthold.}

Tree moderately vigorous, very productive.

Fruit small, nearly globular. Suture shallow, but distinct point at apex. Skin pale yellow, sometimes witl marblings of green, and covered with a thin white bloom. Stalk short, stont. Cavity shallow. Flesh yellow, juicy, sugary; adheres slightly to the stone. Good. Early August.

\section{Prince Exglebert.}

From Belgium. This is a promising variety for market growing, as

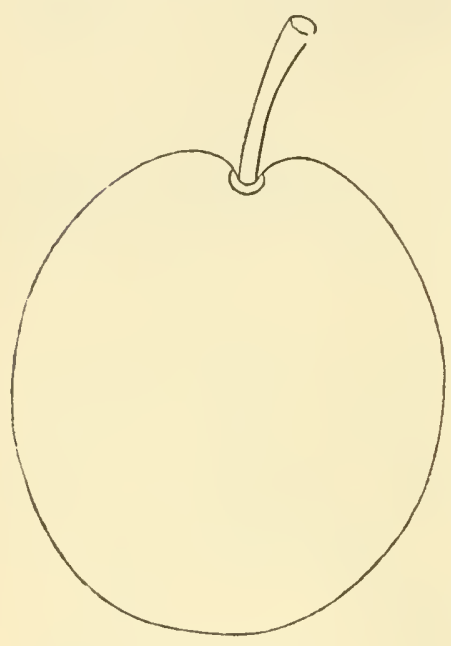

Prince Engrelbert. the tree is a great bearer, and the fruit valuable for dessert and cooking. Tree vigorous. Branches smooth.

Fruit large, oblong oval. Suture very slight, one sicle a little enlarsed. Skin very deep purple, sprinkled with brown dots, and covered with a deep, blue bloom. Stalk rather stout, setin a deep cavity. Flesh yellowish green, juicy, sugary; separates from the stone. Tery good. Last of Au gust.

\section{Prisce of Wales.}

Chapman's Prince of Wales. Priuce Albert?

English origin. 'Tree very vigorous, very productive. Branches smooth or slightly downy.

Fruit large, globular, inclining to oblong, with a moderate suture on one side. Skin roddish purple, with brownish yellow dots, and a thick bloom. Stalk short and stout, set in a moderate cavity. Flesh a little coarse, greenish yellow, juicy, sweet, and sprightly, not rich, partially arlhering to the stone. Good. First of September.

\section{Privee's Orange Egg.}

Raised by William Prince, Flushing, Long Island, N. Y. Tree very vigorous and productive. Branches smooth.

Fruit rather large, oval. Skin rellow, covered with a thin bloom. Stalk three-fourths of an inch long, rather stont, set in a small carity. Flesh golden yellow, coarse, juicy, sprightly, subacid, not rich; adheres to the stone. Grood. Middle of september.

\section{Prince's Orange Gage.}

Fruit medium, roundish oval. Suture modcrate. Skin yellow. 
Stalk loug, set in an open cavity. Flesh ight yellow, coarse, juicy, pleasant, but not rich; alleres to the stone. Good. First of Sep: tember.

\section{Prince's P'rimordian.}

Prince's Blue Primordian.

Originated with William Prince, of Flushing, L. I. Branches slender, grayish.

Fruit snall, oral, blue. Flesli pleasant; its principal value is its early maturity. (Pom. Man.)

\section{Prince's Yellow Gage.}

American Yellow Gage of some.

White Gage of some.

The Yellow Gage was raised so long ago as the year 1783 , by the elcler Mr. Prince, of Flushing, L. I. Its great bardiness and productiveness, joined to its rich, sugary flavor, make it a fuvorite sort. Branches smonth, short-jointed, and the tree forming a large spreading head.

Fruit a little above medium size, oval, rather broarlest towads the stalk. Suture a mere line. Skin golden yellow, a little clouded, and covered with a copious white bloom. Stalk an incl long, inserted in a small round cavity. Flesh deep yellow, rich, sugary, and melting, though sometimes rather dry; jarts freely from the stone. Tery good. Early in August.

\section{Provence Damask.}

Damas de Provence.

Early Damask of Provenee.

Damas de Provence Hútif.

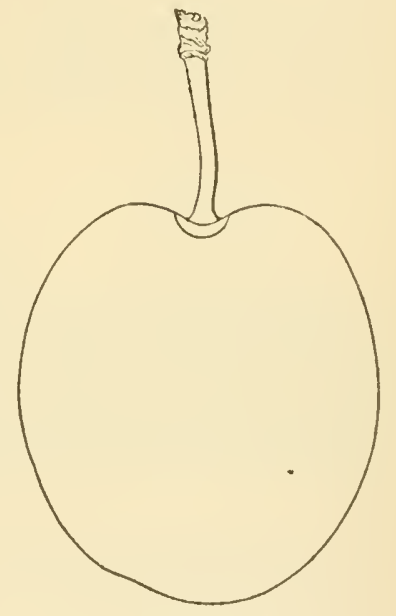

Prince's Yellow Gage.

Tree vignrous, branches downy.

Frnit ahove medium, roundish. Suture deep. Skin reddish purple, covered with blue bloom. Flesh yellowish green; separates from the stone. Good for cooking. Last of July.

\section{Prune d'Agev.}

$\begin{array}{lll}\text { D'Agen. } & \text { Rohe de Sergent. } & \text { St. Maurin. } \\ \text { Prune d'Ast. } & \text { Agen Datte. } & \text { Prine de Brignole of some. }\end{array}$

Prune du Roi

A foreign variety of excellent quality. Tree of moderate growth, Brauches smonth. V'ery moductive.

Fruit medium size, oval, slightly necked. Suture small. Skin vio. 
let purple, covered with a thick bloom and numerous small dots. Stalk nearly an inch long, a little curved, set in a small depression. Flesh greenish yellow, juicy, sugary, rich, and delicious, slightly adherent tc the stone. Best. Middle and last of September.

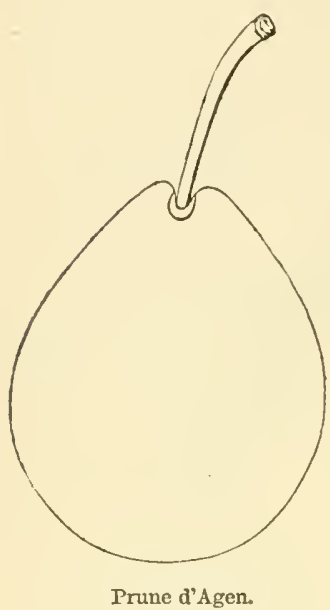

\section{Purple Favorite.}

This delicious fruit received its name from us some years ago. The tree from which the stock now in this eountry was derived, stood for many years (until it died of old age) in the eentre of the principal garden here, and was planted by the father of the author. 1ts origin we were never able to learn, and we have not been able during all our pomological researehes and comparisons to identify it with any other sort.

The Purple Favorite, when in perfection, is not surpassed ly any other Plum in luscions flavor. It is more juicy and melting than the Purple Gatge, and has some affinity to the Diaprée Ronge, or Mimms. It shovild have a place in every garden, as it bears' well, and is very hardy. In the nursery it has the dwartish habit of the Green Gage, but more slender' shoots. Branches nearly smooth, short-jointed.

Fruit medium size, often large, roundish obovate. Suture none. Skin light brown in the shade, brownish purple in the sun, dotted with numerous golden specks, and dusted with thin, light blue bloom. Stalk three-fourths to one inch long, set in a very slight depression. Flesh pale greenish, very juicy, tender, melting, with a luscious sweetness. Parts freely from the stone, which is very small and roundish. Best. Begins to ripen about the 20th of Angust, and will hang for a fortnight on the tree.

\section{Purpleg Gage.}

Reine Claude Violette.

Violette Queen Claude.

Die Violette Königin Claudie. Violet Gage.

The Purple Gage holds the first place for high flavor among purple 
plums abroad. Althongh it is well known in France under the title of the Reine Claule Violette, as in England under that of the Purple Gage, yet its native comtry is not precisely determined. Tree moderately vigorons. Branches smooth, much like those of the Green Garge.

Fruit medium sized, shaped like the Green Gage, roundish, a little flattened. Snture shallow, but distinct. Stalk an inch long, rather thick, set in a narow earity. Skin a little thick, violet, dotted with pale yellow, and covered with light blue bloom. Flesh greenish yellow, rather firm, rich, sugary, and very high-flavored; separates from the stone, which is oval and compressed. Ripens rather late, and will hang on the tree-shrivelling a little, but not eracking - all the month of September. Very good.

\section{QZCACKEnBoss.}

Introluced by Mr. Quackenboss, of Greenbush, N. Y. Origin in the garilen of S. C. Groot, Albany. A very rapid upright grower, and productive. Branches smooth.

Frnit large, oblong roundish. Skin deep purple, covered with a bluish bloom. Suture scareely apparent. Stalk lons, slender, and set in a slight depressed cavity. Flesh greenish yellow, sprightly, juicy, a little coarse-grained, sweet, and subacid adheres slightly to the stone. Good. September.

\section{Queen Mother.}

Red Queen Mother. Pigeon's Heart. Damas Violet.

A neat little redish Plum, long known in European gardens. Branches smooth, rather feeble in growth.

Frnit rather small, romul, abont an inch in diameter. Skin dark, purplish red in the sun, pale reddish amber in the shade, with many refldish dots. Stalk half an inch long. Flesh yellow, sweet and rich, separating freely from the stone. Gool. September.

\section{Reagle's Axciext City.}

Originated at Scheneetady, N. Y., by C. Reagles. Tree very rigorous. Branches smooth.

Fruit large, roundish oval. Skin elonded orange, red in the sun. Sutme distinet. Flesh yellow, juicy, sweet; separates fiom the stone. Good. Last of August.

\section{Reagle's Gage.}

Another of the seedlings raised by C. Rivigles, Schenectarly, N. Y., from soerl of the Washington. Tree vigoroms, mpright. Branehes smooth. Fruit medium, nearly glubular. Suture broad and shallow. Apex

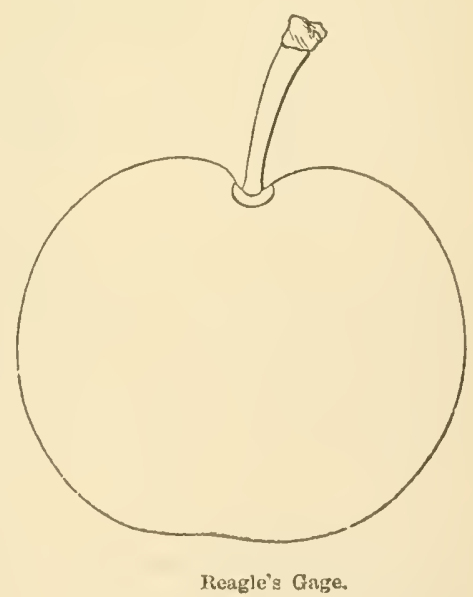


sunken. Skin greenish yellow, with splashes of darker green, and covered with a bloom. Stalk medium in length and thiekness. Cavity large. Flesh greenish yellow, juicy, sweet, slightly vinous; separates from the stone. Tery good. List of August.

\section{Reagle's Union Purple.}

Same origin as the preceding. Tree vigorous, branches smooth.

Fruit large, roundish oval. Skin reddish purple, covered with a thin bloom, snture only perceptible near the sialk and apex. Stalk short, stout. Flesh greenish, a little coarse, vinous, sweet; adheres to the stone. Good. September.

\section{RED APRICOT.}

Abricotée Rouge.

A French variety. Tree moderately vigorons. Branclies smooth. Fruit of medium size, roundish oval. Skin of a fine elear red in the shade, violet in the sun. Flesh orange color, sweet, but rather dry, and withont much flavor; separates freely from the stone. Good. Last of August.

\section{Red Diaper.}

Diaprée Rouge. Roche Carbon.
Mimms.

Imperial Dindem.

The Diaprée Ronge, or Red Diaper, is a very large and handsome French Plum. A rather slow grower: Branches almost smootl.

Fruit large, obovate. Skin of a reddish purple, with a few golden specks, and a light blue bloom, easily rubhed off." Stalk three-fourths of an inch long, slender, hairy, slightly inserted. Flesh pale green, juicy, very melting, rich, and delicions, separating from the stone, which is quite small. Good to very good. Last of Angust.

\section{Red Gage.}

An American Plum, of delieious flavor, very luardy, and a prodigions bearer. It is a seedling raised from the (treen Gage by the elder $W^{\top} \mathrm{m}$.

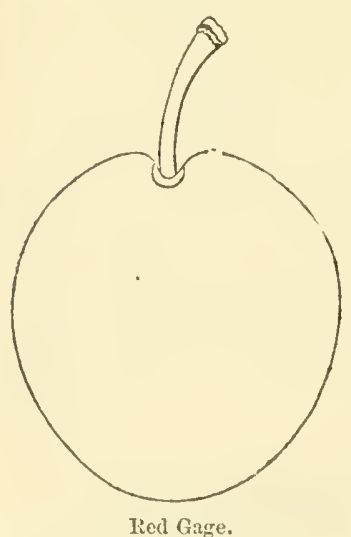

vigorous, upright, productive. Prince, of the Flushing Nirseries, in 1790. It grows. very vigorously, and is distinguished, when young, by its deep green crimpeel foliage. Branches dark reddish, smooth.

Fruit about as large as the Green Gage, but more oval, regularly formed. Skin brownish or brick red, with little bloom. Stalk rather slender, set in a narrow eavity. Flesh greenish amber, very juicy, melting, sugary, and luscious. It parts freely from the stone, which is small. Best. Vidulle of August.

\section{Red Gage of Duteness Coustr.}

A seedling of Dutchess Co., N. I. Tree Branches slightly downy. 
Fruit medium, romulish oval, a little compressed. Suture large, often extending two-thirds around the fruit. Skin yellowish, nearly rovered with a light redclish purple, and with a thin lilae bloom, thickly sprinkled with brown dots. Slalk short, stout. Cavity large. Elesh yellow, juicy, slightly vinous; adheres to the stone. Good. Jast of August.

\section{Rei Magney Bontur.}

Purple Egg.

lied Imperial.

Imperial.

Piurple Magnim Bonum. Florence.

\author{
Imperial Violet. Prune d'Guf. \\ Imperiale Violette. Tied Erg. \\ Imp riale Ronge. Askew's Purple Egg. \\ Dame Aubert Violette. Die Rothe Eiperflanme. \\ Imp riale.
}

A foreign valiety of morluate growth, slender smooth sloots, dis tinct from the American variety, which is a vigorons grower, with downy sloots.

Fruit large, oval, with a stroug suture, on one side of which the fruit is more swollen. Skin rather pale in the sliade, but deep red in the sun, sponinkled with many gray dots, and dusted with but little pale bloom. Stalk an inch or more long, slender, set in a narrow cavity. Flesh greenish, rather firm and coarse, with a subacid flavor, selarating from the stone, which is oval and pointed. Good. First of September.

\section{Red Perdrigon.}

Perdrigon Rouge.

Forcign. Branches downy.

Fruit of medium size, roundish. Sides often meqnal. Skin fine deep reel, much lilac bloom. Stalk long, slender. Flesh pale yellow, a little coarse, moderately juicy and sweet, and parts from the stone. Good. Last of August to the micldle of September.

\section{Red Prinordian.}

Originated with William Prince, Flushing, L. I. Tree vigorons, upright, with long, smooth, brownish gray branches.

Fruit medium or small, oval, somewhat pointed, slightly necked. Skin light lilac or chocolate, and covered with a thin, hight lilac bloom. Stalk rather long, slender, set in a small ring. Flesh yellowish, moderately juicy, with a slight acid flavor; seprarates from the stone. Goorl. Early Angust.

\section{Reine Victoria.}

This is a French variety, and quite distinct from the Victoria. Branches downy. It is of short oval shape, much like Kirke's, but not quite so round. Skin dark reddish purple. Flesh very juicy, rich, and agreeable, and separating from the stone. It is from two to three weeks later than Kirke's. (Hogg.) We think this may yet prove to be Sharp's Emperor.

\section{Rilizenstein's Yellow Prune.}

An Ttalian fruit. Tree very vigorous and productive. Branches smooth. 
Fruit medium size, oval, narrowing at both ends, often enlarged or one side and swollen on one edge. Small mamelon neck. Suture large, extending beyond the apex. Skin fine yellow, often much shaded and marbled with rich crimson, and covered with a thin lilac bloom Stalk long, rather slender. Cavity small. Flesh golden yellow, juicy, sweet; adheres closely to the stone. Good to very good. Last September.

\section{Rinxebeck Yeltow Gage.} smooth.

Origin, Rhinebeck, N. Y. Tree very strong and vigorous. Branches

Fruit large, oval. Suture deep. Skin yellow. Stalk rather long, inserted by a fleshy ring without depression. Flesh coarse, juicy, sweet, and pleasant; adheres to the stone. Good. First of September.

Rhue.

Rhue's Seedling. downy.

Origin, Pennsylvania. Tree vigorous, productive. Branches slightly

Fruit larse, oval. Suture shallow, broad, half round. A pex slightly sunk. Skin reddish purple, covered with a blue bloom. Stalk rather short, stont. Cavity cleep. Flesh greenish yellow, rather coarse, juicy, sweet, vinous; adheres partially to the stone. Good. Middle Augirst.

\section{Richland.}

nriginated on the farm of Randall Elien, Richland, Bucks Co., Pa. 'l'ree upright, vigorous. Branches smooth, long, slender:

Fruit medium size, oral, a little pointed at apex. Skin reddish purple, covered with a thin blue bloom. Stalk in a small cavity. Elesh greenish yellow, juicy, sugary ; adheres partially to the stone. Good. Last of August.

\section{RoBY's YeLLOW.}

A seedling raised by H. R. Roby, Fredericksburgh, Va. Tree moderately vigorous. Branches smooth.

Fruit rather small, romdish. Sutnre broad, shallow. Sides unequal. Skin greenislı yellow, covererl with a copious light bloom, and a few red dots in the sum. Stalk short. Cavity small. Flesh greenish yellow, juicy, sweet; adheres to the stone. Good. Last of Angust.

\section{Roltande Galloppi.}

Tree very vigorous, upright. Branches smooth.

Fruit medium, elongated oval, witl a large neck. Suture large, half round. Skin pale yellowish green, dotted and marblen with crimson in the sun, and covered with a thin light bloom. Stalk slender. Carity small. Flesli yellowish green, juicy, sweet; adheres to tlee stone. Gond. Iast of September. 


\section{Roxald's Faxcy.}

Fruit medium or above, oval. Suture half round. Skin yellow, striped, marhled, and splashed with green, and covered with a thim light, bloom. Stalk half inch long. Cavity moderate. Flesh greenish yellow, juicy, sugary, vinous, sprightly; separates from the stone. Good. Early October.

\section{RostraVe BeLL.}

Originated with John D. Steplens, Westmoreland Co., Pa. Tree very vigorous and productive. Branches smooth.

Fruit large, roumlish oval. Suture broad, shallow, two-thirds round, one side enlarged. Skin reddish purple, many brown dots, and covered witl a blue bloom. Stalk medium. Cavity large, rather deep. Fleslı vellowish, coarse, not very juicy, vinous; adheres partially to the stone. Gool. Early September.

\section{Royale.}

La Royale. Royal.

\section{Royal Red.}

Sir Charles Worsley's.
French Royal. Prune Royale.

The Royale, a French variety, is remarkable for the exceedingly thick coat of bloom which envers the skin. The tree is a slow grower, forms a bushy, spreading hearl, and its very lowny shoots have a gray or whitish appearance. It bears regularly, but molerately, asid though not fit for the orchard, it is a first-rate garilen finit.

Fruit of medium size, often quite large, romd, lessening a little towards the stalk. Suture distinct at the apex on one sicle only. Skin reddish purple, dotted with light brown specks, and covererl with a thick jale bloom, which adheres elosely. Stalk three-fourths of an inch long, downy, set in a narow cavity. Flesh dull yellow, rather firm, but melting, very juicy, with an exceedingly lich, vinons flavor; it sejutrates from the stone, which is small, rommlish, pointerl at boilh ends. Good to very good. Last of August, till the mildle of September.

\section{RoYale DE Tours.}

\section{Royal Tours.}

A French variety, received from several sources, but they do not agree, neither lo the anthorities; some say a freestone, and others a cling. Branches always quite downy.

Fruit large, roundish, lont marked with a large and deep sutmre extending quite half round, and enlarged on one side. At the apex is a small, white, depressed point. Skin lively red in the shade, deep violet in the sun, witl many minute golden dots, and coated with a thick blue bloom. Stalk hilf to three-fourths of an incli long, stout, set in a narrow cavity. Flesh greenish, rather firm, with a rich, high-flarored, abundant juice. Goud to rery good. Micllle Angust.

\section{Royale HÂtite.}

Early Royal.

An early Plum, of French origin. Tree vigorous, with stout short branches. Branches very downy.
Marian. 
Fruit of medium size, roundish, a little wider towards the stalk Skin light purple, dotted (and faintly streaked) with brownish yellow, and covered with a blue bloom. Stalk half an inch long, stout, in. serted with little or no depression. Flesh yellow amber, with rich, high flavor, and parts from the stone (adhering slightly till ripe). Ver'v good. Early August.
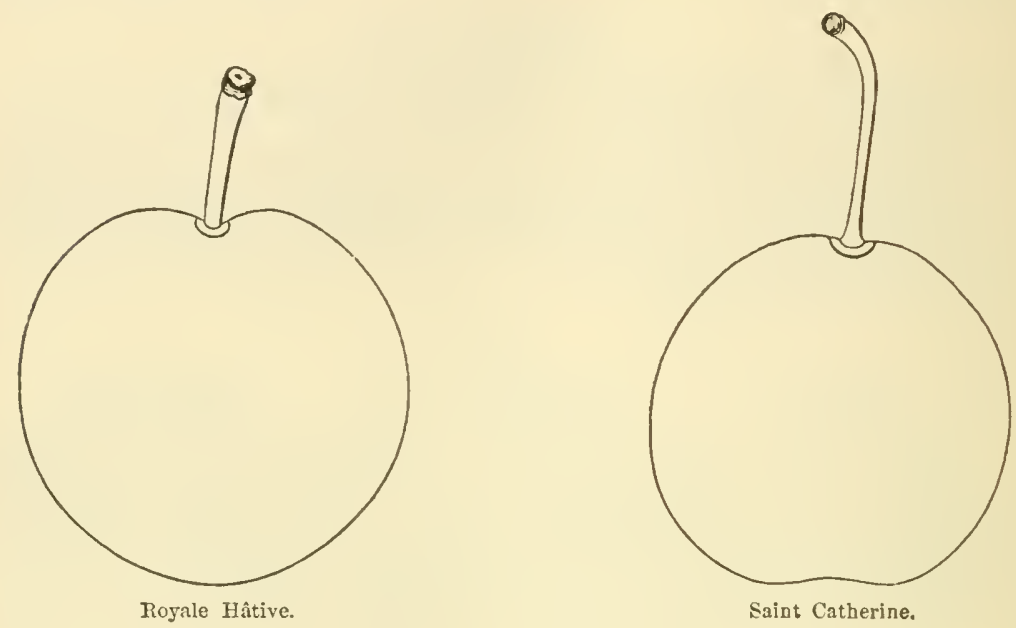

Saint Catilerine.

Among the fine old varieties of late Plums the St. Catherine is one of the most celebrated. In France it is raised in large quantities, in some districts making the most delicate kind of prunes. It is also much esteemed for preserving, and is of excellent quality for the clessert. Branches smooth, upright, rather slender.

Fruit of medium size, obovate, narrowing considerably towards the stalk, and having a strongly marked suture on one side. Stalk three. fourths of an inch or more long, very slender, inserted in a slight cavity. Skin very pale yellow, overspread with thin white bloom, and occasionally becoming a little reddish on the sunny side. Flesh yellow, juicy, rather firm, and adheres partially to the stone. In flavor it is sprightly, rich, and perfinmed. Very good. Middle to last of September:

\section{SAist ETIENxe.}

Tree of moderate growth. Branches smooth.

Fruit medium, roundish heart-shaped. Suture shallow, half round. Skin yellow, shaded, marbled, and dotted with rich dirk crimson. Stalk short, rather slender. Carity small. Flesh fine yellow, juicr, sweet, and rich; separates firom the stone. Good to very good. Jast of August.

\section{SAINT Juliex.}

Common St. Julien.

French St. Julien.

Petit St. Julien.

St. Julien petit.

Fruit small, oval, dark violet, covered with bloom. Flesh greenish, slightly acid; seprarates from the stone. Last of August. (Pom. Man.) 


\section{Saint Martin's Quetsche.}

A very late variety of Prune from Germany. Hardy and a grood bestrer. Bramehes smooth.

Fruit of medium size, ovate, or considerably broadest towarls the stalk. Suture broad, shallow. Skin pale yellow, covered with a white bloom. Flesh yellowish, with a rich and excellent flavor, and separates readily from the stone. Good. First of Oetober, and will hang a montl.

\section{Schenectady Catherine.}

Origin, Schenectady, N. Y. Tree vigorous, very productive. Branches smooth, grasish.

Fruit medium, roundish oval. Suture shallow on one side. Skin reddish purple, covered with a thin blue bloom. Stalk of medium length, slender, set in a small cavity. Flesh greenish yellow, very juicy, sugary, and rich; separates freely from the stone. Very good. First of September.

\section{Schuyler Gage.}

Originated with Gen. Sehuyler, Albany, N. Y., from a seed of the Green Gage. Tree upright, very vigorous and productive. Branches smocth.

Fruit medium, oval. Suture moderate. Skin yellow, with small green splashes, dotted and washed with carmine on the sunny side, and eovered with a thin bloom. Stalk long, curved, inserted in a small eavity. Flesh yellow, juiey, sweet, rich, and

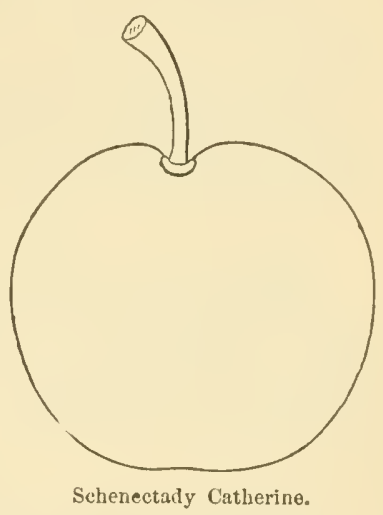
excellent; separates from the stone. Very good. Last of September.

\section{Semiata of Boston.}

Blue Impératrice of some.

This is quite distinet from the Semiana of Europe. It is probably a native fruit. Tree moderately vigorous, with slender shoots nearly smooth, very productive, late, keeps well - a good market finit.

Fruit medium, oval, with a slight rise or neck next the stalk. Skin deej purple, covered with blue bloom. Stalk short. Cavity very suall. Flesh greenish, juicy, suljacid, not rich; adheres to the stone. Good. Last of September and first of October.

\section{September Damask.}

\section{Damas de Septembre. Prune de Vacance. Prunier des Vacances,}

Branches downy.

Fruit small, roundish oval. Suture distinct. Skin dark purple, covered with a thick blue bloom. Flesh greenish yellow, sweet; separ rates from stone. Poor. Last of September. 


\section{Sharp's Emperor.}

Dolphin.

Dauphin.
Denyer's Victoria.

Alderton.

Impérial de Sharp.
Tictoria.

Royal Dauphine.

A beautiful Plum, brought into notice by Denyer, of Sussex, England. Tree vigorous and productive. Branches strong, downy, and foliage large.

Fruit large, roundish oval. Suture shallow, but distinct. Skin light yellow, marblerl, spotted, and shaded with light lilac and purple, thickly sprinkled with light and gray dots, and covered with a thin lilac bloom. Stalk medinm length, rather stout, set in a rather leep carity. Flesh golden yellow, coarse, not very juicy or sugary, a little vinous; separates from the stone. Good. Middle September.

\section{SiIELDON.}

Originated on the farm of Wareham Sheldon, Huron, Wayne Co., N. Y. Tree a rapid grower, and very productive. Branches smooth, stout.

Fruit large, oval. Suture shallow. Skin deep purple, thick blue bloom. Stalk short, in a small cavity. Flesh greenish, juicy, slightly acid; separates from the stone. Good. September.

\section{SiAMESE.}

Branches long, slender, and smooth.

Fruit mostly in pairs, distinct, but closely joined on one side, mediumsized obovate. Skin pale yellow, with a white bloom. Flesh yellow, juicy, and sprightly, of second-rate flaror, and adheres to the stone. Good. Early September.

\section{SMITH's OrLLAXS.}

Violet Perdrigon, incorrectly.

Red Magnum Bonum of some.

Smith's Orleans, the largest and finest of this class of Plums, is a native variety raised from the old Orleans by Mr. Smith, of Gowanns,

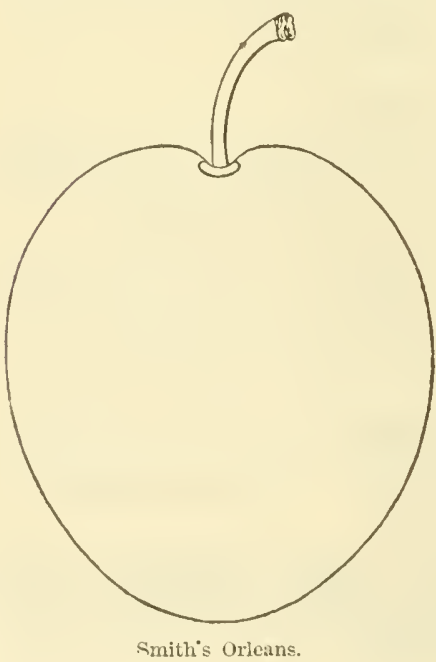

Toug Island. It is one of the most vigorous of all plum-trees, making straight, glossy, reddish pmple shoots. with rlark green crimped leares. Very proluctive. Bearing branches smooth, or nearly so.

Fruit large, often of the largest size, oval, rather widest towarks the stalk, a little irregular, with a strougly marked suture on one side. Stalk quite small and slender, little more than half an inch long, inserted in a deep narrow carity. Skin realdish purple, covererl with a deep blue bloom. Flesh deep rellow, a little firm, very juicr, with a brisk, rjch vinous flavor (not sweet and cloving), and adheres to the stone. Good to very good. 201h to the last of $\mathrm{Au}$ gust. 


\section{SPANISII DAMASK.}

\section{Damas d'Espagne.}

Fruit small, nearly round. Skin deep purple, covered with bloom. Flesh yellowish, not rich, mild, sweet; separates from the stone. Last of August. (Pom. Man.)

\section{Spotted Gage.}

Tree vigorous, very productive. Branches downy.

Fruit nedium or above, oval. Suture shallow. Skin greenish yellow, sharled, mottled, and patched with crimson and lilac, numerous light dots, and covered with a thin bloom. Flesh coarse, yellow, sugary, juicy, a little vinous; adheres purtially to the stone. Good. Early September.

\section{Stajdard of Exgland.}

Said to have been raised by $\mathrm{Mr}$. Dowling, of Southampton, England. Tree vigorous. Branches smooth or slightly downy.

Fruit medium, ovate, slight character of neck. Suture shallow. Skin purplish lilac, many dots, aul covered with a thin bloom. Stalk inserted in a small cavity. Flesh greenish, juicy, moderately sweet; separates from the stone. Good. Early September.

\section{STONELESS.}

Kirke's Stoneless. Sans Noyau. Pitless.

Branches downy. Of no value except as a curnosity.

Frnit small, oval. Skin dark purple, covered with blue bloom. Flesh greenish, harsh acid. Kernel without any stone surrounding. Early september.

SUISSE.

$\begin{array}{ll}\text { Simiana. } & \text { Swiss Plum. } \\ \text { Monsieur Tardif. } & \text { Monsieur Tardive. } \\ \text { Prune d'Altesse. } & \text { Switzer's Plum. }\end{array}$

A foreign variety, of free growth, with long, slender, smooth branches, distinct fiom Semiana of Boston.

Fruit rather small, roundish oval. Skin violet red, covered with a thick hloom. Flesh greenish yellow, firm, rather dry, but sweet, and seprates from the stone. Good. Last of September.

\section{THomas.}

A handsome native fruit, orifrinater in the garden of William Thomas, of Boston. A free grower, and bears abundantly. Branches slightly downy.

Fruit large, roundish oblong, a little irregular, and rather compressed in the dircction of the suture. Stalk hairy, half an inclı or more long, stout, set in a small narrow eavity. Skin salmon color, with numerous dots, and a soft red check. Flesh pale yellow, a little coarse-grained, but with a mild pleasant flavor; separating freely from the stone. Good. Last of August. 


\section{Thorndyke Gage.}

A native fruit, originated near Newburgh, N. Y. Tree moderately vigorous. Branches downy.

Fruit below medium, roundish. Suture slight. Skin pale green, with a blue bloom. Flesh greenish, juicy, sweet, pleasant; adheres to the stone. Good. Early September.

\section{Tomlinson's Charlotte.}

Charlotte.

A seedling raised by Judge 'Jomlinson, Schenectady, N. Y. Tre甘 vigorous.

Fruit large, oval. Skin yellow. Flesh sweet, agreeable. August. (Pom. Man.)

\section{Transparent Gage.}

Reine Claude Diaphane. Diaphane Laffay.
Prune Diaphane Laffay. Reine Claude Transparent.

Diaphane.

A French variety, evidently from seeds of the Green Gage, raised by M. Laffay, of Paris. Tree vigorous, with loug, stout, and smooth branches.

Fruit above medium, roundish oblate. Suture shallow, distinct. Apex sunk. Skin greenish yellow, marbled and specked in the sun with carmine red. Stalk mediun. Cavity small, rather deep. Flesh greenish yellow, tender, juicy, sugary, rich. Very good or best. Mirldle of September:

\section{Trouvée de Voueche.}

Found in the woods by Grégoire, and by him introduecd. Tree moderately vigorous and very fertile.

Fruit medium or small, regularly oval. Skin thick, redilish violet with a shady side, and a violet bloom on the sunny side. Flesh juicy, sweet, and very good. Last of August. (Al. Pom.)

\section{ULYSSES.}

A variety from Western New York. Branches smootl.

Fruit above medium, roundish oval. Skin whitish, shaded and mottled with violet purple, thin blue bloom. Flesh yellowish, juicy, sweet; adheres to the stone. Good. Farly September.

\section{VIRGIN.}

Virginale Blanc. White Virginale.
Tirginal Blanc.

Virginal à gros Fruit blanc. Virginal à Fruit blanc.

A foreign variety, of fiee growth. Branches smooth, ratlier slender

Fruit medium, roundish. Skin reddish purple, with a thick bloom. Flesh greenish, very juicy, sweet. Good to rery good. Adheres slightly to the stone. First of Srptember. 


\section{WANGENHEIM.}

A German variety. Tree a moderate grower. Branches smonth. Fruit medium, oval. Suture shallow. Apex a little sunk. Skin decp purple, covered with a thick blue bloom. Statk rather short. Cavity sunall. Flesh rather firm, greenish yellow, juicy, sugary, rich. Separates from the stone. Good to very good. Last of August.

\section{WASHINGTON,}

$\begin{array}{lll}\text { Bolmar. } & \text { Bolmer's Washington, } & \text { Parker's Mammoth. } \\ \text { Bolmer. } & \text { Franklin. } & \text { Washington Jaune. } \\ \text { New Washingion. } & \text { Irving's Bolmar. } & \text { Philippe I. }\end{array}$

The Washington, although not equal to the Green Gage and two or three others in high flavor, yet its great size, its beanty, and the vigor and hartiness of the tree, are qualities which liave brought this noble fiuit into notice everywhere. The parent tree grew originally on Delancey's firm, on the east sicle of the Bowery, New York, but, being grafted with another sort, escaped notice until a sucker from it, planted by Mr. Bolmer, a merchant in Chatham street, came into bearing about the year 1818, and attracted unirersal attention by the remarkable beanty and size of the fruit. In 1821 , this sort was first sont to the Horticultural Society of London, by the late Dr. Hosack.

The Washington has remarkably large, broad, and glossy foliage, is a strong grower, and forms a liandsome round head. Wood light brown, downy.

Fruit of the largest size, roundish oval, with an obscure suture,

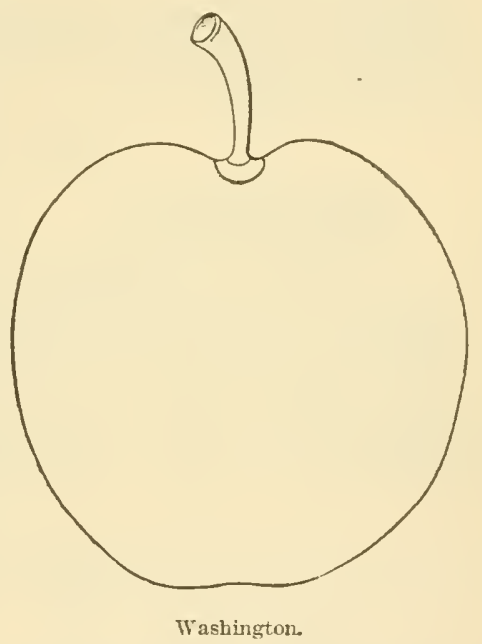
except near the stalk. Skin dull yellow, with faint marblings of green, but when well ripened, deep yellow, with a pale crimson blush or dots. Stalk scarcely three-fourths of an inch long, a little downy, set in a sliallow, wide hollow. Flesh yellow, firm, very sweet and luscious, sejarilting frecly from the stone. Good to very good. Middle to the last of August.

\section{WAX.}

Raised by Elisha Dorr, Albany, N. Y. Tree moderately vigorous and productive.

Eruit medium, roundish oval. Suture slight, broad, shallow. Skin yellow, with a bright carmine cheek, and covered with a thin whitish bloom. Stalk long, slender, set without carity. Flesh yellow, juicy, subacid, sprightly; selarates from the stone. Good. Early October. 


\section{White APRICot.}

Abricote Blanc.

Abricot'e Blanche.

Fruit medium, roundish, yellow. Flesh rather firm, slightly acid separates from the stone. Good. Middle August.

\section{White Bullace.}

Branches downy.

Fruit small, round. Skin yellowish white, mottled with red in the sum. Flesh firm, juicy, sweet; adheres to the stone. Cooking. Early Oetober.

\section{White DaMask.}

\section{Damas Blanc. Damas Blanc Gros. Damas Blanc Hâtif Gros.}

Branches smooth.

Fruit below medium, romndish oval. Skin greenish yellow, with white bloom. Flesh sweet, pleasant; separates from the stone. Cooking. Last of September.

\section{White Danisos.}

$\begin{array}{ll}\text { Late Yellow Damson. } & \text { White Damascene. } \\ \text { White Prune Damson. } & \text { Late Cl:ster. } \\ \text { Shailer's White Damson. } & \text { Frost Plum. }\end{array}$

White Winter Damson.

Branches smooth, and of thrifty growth, very productive.

Fruit small, oval. Skin pale yellow, with a white bloom, ancl sprinkled with reddish-brown spots at maturity. Flesh adheres closely to the stone, is yellow, and when fully ripe of a rich, sprightiy, subacid, agreeable flavor: Good. Last of September.

\section{White Diaper.}

Diapre Blanc.

Diaprée Blanche.

Fruit small, ronnd. Skin whitish green, covered with bloom. Flesh rather firm, pale yellow, sweet. Good. Last of August.

\section{WIITE IYPérATRICE.}

White Empress.

Impératrice Ilanche.

In the habit of the tree, appearance and flavor of the fruit, and season of maturity, it strongly resembles the St. Catherine, but is a freestone. It is not equal to the latter in flavor. Branches smooth.

Fruit of medium size, obovate, a little thattened at the ends. Suture rather obseme. Skin bright yellow, covererl partially with a thin white bloom, and spotted with a little red. Stalk a little more than half an inch long, set in a narrow cavity. Flesh yellow, rery juicy, crisp, sweet, and quite transparent in texture; separates freely from the stone. Good. Eariy in September. 


\section{White PERdRigon.}

Perdrigon Blanc. Maitre Clande. Brignolo.

'Tree rather a slow grower. Branches lowny.

Eruit mildle-sized, oval, narowing towards the stalk. Skin palo greenish yellow, a few erinson dots in the sun and numerous small white dots, and thinly coated with bloom. Flesh pale yellow, sweet, with a slight perfume, and adheres slightly to the stone. Good. Last of Aigust.

\section{WILDE'S.}

Fruit medium, roundish oblong, dark brownish orange, covered with a white bloom. Flesh sweet, not juicy; separates from the stone. Early August.

\section{IVILD GoOse.}

\section{Nolen Plum.}

An improved rariety of the Chickasaw, evident in the greater vigor of the tree and increased size of the fruit, which is nearly as large as a Green Gage. Skin purple, with a blue bloom. Flesh juicy, sweet; adheres to the stone. Last of July.

\section{TiLKinson.}

Tree vigorous. Branches smooth, rather slender.

Fruit medium, oval, slightly neeked. Skin reddish purple, covered with a thick bloom. Stalk medium, set in a small cavity. Flesh dark yellow, rather firm, sweet, not rich or high flavored; adheres partially to the stone. Good. Last of July.

\section{Winesour.}

\section{Rotherham.}

An English Plum, valued for cooking. Branehes downy.

Fruit below medium, oblong oval. Skin dark puple. Flesh greenish yellow, acid; adheres to the stone. September.

\section{Woolstox's Black Gage.}

Of same origin as Angelina Burdett and Standard of England. Tree vigorous. Brauches smootl.

Fruit medium, roundish, with a shallow sutmre. Skin very deep purple, with many small dots, and covered with a blue bloom. Flesh melting: juicy, sugary; separates from the stone. Good. Karly Septem. ber.

\section{Tellow Damask.}

\section{Damas Jaune.}

Branches smooth.

Fruit helow medium, nearly round. Skin yellow, with a fine white bloom. Flesh very juicy, separating from the stone. Early October. (Hogg.) 


\section{Yellow EGG.}

White Magnum Bonum.

Askew's Golden Egg.

Eqg Plum.

White Egg.

Magnum Bonum.

Yellow Maguum Bonum.*

White Mogul.

Wentworth.
White Imperial.

White Holland.

Dame Aubert.

Dame Aubert blanche.

Dame Aubert jaune.

Imp riale blanche.

Grosse Luisante.

Prune d'Inde blanc.

The White Magnum Bonum, or Egg Plum, as it is almost universally

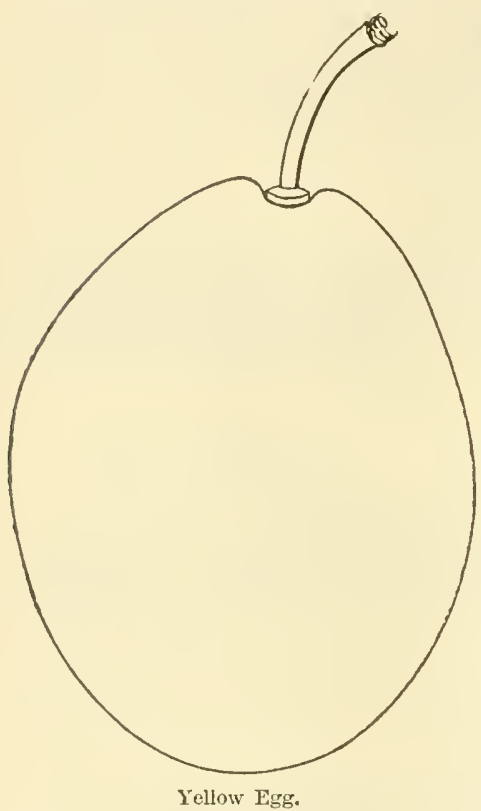

bearer, though apt, in light soils, known here, is a very popular fruit, chiefly on account of its large and splendid appearance, and a slight acidity, which reuders it admirably fitterl for making showy sweetmeats or preserves. When it is raised in a fine warm sitnation, and is fully maturerl, it is pretty well flarored, but ordinarily it is considered coarse, and as belonging to the kitchen and not to the dessert. Branclies smootl, long.

Fruit of the largest size, measuring six inches in its longest circumference, oval, narrowing it good deal to both ends. Sutnre well marked. Stalk about an inch long, stout, inserted without carity in a folded border. Skin yellow, with numerous white dots, covered with thin white bloom-when fully ripe, of a deep gold color. Flesh yellow, adhering closely to the stone, wather acid until very ripe, when it becomes sweet, though of only second-rate flaror. Stem long, anil pointed at both ends. A pretty good Middle of August.

\section{Yellow Impératrice.}

Altesse Blanche.

Monsieur à fruits Jaune.

Branches smooth.

Fruit large, roundish oval, marked with a sutnre, deep at apex, shallow at the stalk. Skin deep golden yellow, with a few streaks of red about the stalk. Flesh yellow, juicy, melting, sugary, rich, arleres to the stone. Middle of August. (Hogg.)

YoHe's EagLe. $\mathrm{Pa}$.

An accidental seedling in the garden of Caleb Tohe, Bethlehem,

* There is really no practical difference between the White and the Yellow Magnum Bonum. The fruit is precisely similar in appearance and quality, though the growth of the two trees may not fully agree. 
Fruit large, roundish, oblong oval. Skin greenish yellow, slight red cheek in sun, thin white bloom. Flesh firm, yellow, melting, juicy, sweet; separates from the stone. Good. Early September.

Young.

Young's Seedling.

From Penusylvania. 'Tree vigorous. Branches smooth.

Fruit medium, roundish oval, deep reddish purple, with a blue bloom. Flesh yellow, not juicy, swcet; separates from the stone. Crood. Last of August.

\section{ORNAMENTAL VARIETIES.}

There are few varieties of Phuns which are considered purely ornamental. One, however, is a remarkable exception to this, as it is scarcely cxceeded in beanty in the month of May by any other flowery shrubwe mean the Dovble-Flowering Sloe. It is a large shrul, only 10 or 12 feet high, with quite slender shoots and leaves, but it is thickly sprinkled, every spring, with the prettiest little donble white blossoms about as large as a sixpence, resembling the Lady Banks' Roses. It is one of the greatest favorites of the Chinese and Japanese-those flowerIoving people.

The Common Exglish Sloe, or Blackthom (Prums spinosre), is rather an ornamental tree in shrubbery plantations. The branches are more thorny than those of the common Damson, and the fruit is nearly round, quite black, but covered with a thick blue bloom. In the spring this low tree is a perfect cloud of white blossoms.

The Double-blossoned Puum has large and handsome double white flowers. Except in strong soils, however, they are apt to legenerate and become single, and are, indeed, always inferior in effect to the Double sloe.

The Cherry Plum we have already described. It is one of the fruitbearing sorts.

\section{SELECTION OF VARIETIES FOR TABLE, MARKET, AND COOKING.}

Bavay's Green Gage. Table anl market.

Bleecker's Gage. Table and market.

Bradshaw. Market and cooking.

Coe's fiolden Drop. Table, market, and cooking.

I)enniston's Superb. Table and market.

German P'rume. Narket and cooking.

Green Giage. Table and market.

Howarl's Favorite. Table and market.

Hudson Gacre. Table and market.

Inperial Gage. Table and market.

Inperial Ottoman. Table and market.

Jeffer'son. Table and niarket.

Jawrence's Favorite. Table and market.

Lombircl. Market and cooking. 
McLaughlin. Table and market.

Pond's Seedling (English). Market and market.

Prince Engelbert. Table and market.

Prinee's Yellow Gage. Table and market.

Prune d'Agen. Table and market.

Purple Favorite. Table.

Smith's Orleans. Table and market.

Trausparent Gage. Table and market.

Washington. Table and market.

Yellow Egg. Market and cooking.

\section{CHAPTER XXIX.}

\section{THE POMEGRANATE.}

Punica granatum, L. ; Granatacea, of Botanists. Grcnadier, of the French; Granatenburm, German; Melagrane, Italian; Granado, Spanish.

'THrs unique fruit, the most singularly beautiful one that ever appears at the ressert, is a native of China and the South of Europe. It grows and bears very readily in this country, as far north as Maryland and the Ohio River, though the fruit does not always mature well north of Carolina, except in sheltered places. It is even hardy enough to stand the winter here, and will bear very good fruit if trained as an espalier and proteeted in winter.

The fruit is as large as an apple. Its skin is hard and leathery, of a yellowish orange color, with a rich red cheek. It is erowner in a peculiar manner with the large ealyx, which remains and increases in size after the flower has fallen. There is a pretty bit of mythological listory told by Rapin, the French poet, respecting this fruit. Bacchus once beguiled a lovely Scythian girl, whose head had been previously turned by the diviners having prophesied that she would some diay wear a erown, and who therefore lent a willing ear to his suit. The fickle god, however, not long after abandoned her, when she soon died of grief. Touched at last, he metamorphosed her into a pomegranate-tree, and placed on the summit of its fruit the crown (calyx) which he had denied to his mistress while living.

The fruit of the eommon Pomegranate is acid, but the cultirated variety hears fruit of very agreeable, sweet flavor. The interior of the fruit consists of seeds enveloped in pulp, much like those of the gooseberry, but arranged in compartments, and of the size and color of red currants. Medicinally, it is cooling and much esteemed, like the orange, in fevers and inflammatory disorders.

The tree is of low growth, from twelve to twenty feet, with numerous slender, twiggy branches, and is rery ornamental in garden scenery, either when elad with its fine scarlet flowers or decked with fruit, which hangs and grows all summer, and does not rijen till pretty late in the season. It is well worthy of a choice sheltered place at the 
Forth, on a wall or espalier rail, where it can he slightly proteeted with mats or straw in winter ; and it deserves to be mueh more poptular than it now is in every Southern garden. If raised in large quantities there, it would become a valuable finit for sending to the Northern cities, as it is now constantly sent from the Sonth of Europe to Paris and London Hedges are rer'y often marle of it near Genoa and Niee.

Propacatiox and Culture. This tree is rearlily propagated by cuttings, layers, suckers, or seeds. When by seeds, they should be sown directly after they ripen, otherwise they schlom regetate. Any goorl rich garden soil answers well for the Pomegranate; and, as it produces little excess of wool, it needs little more in the way of pruning than an ocensional thinning out of any old or decaying branches.

TArimtes. There are several varieties. The finest, viz.:-

1. Tire Sweer-Fruted Pomegranate (Grenadier it Fruit Doux), with sweet and juicy jul]).

2. The Subicid Ficited Pomegranate; the most common variety eultivated in gardens.

3. The Wirm or AclD-Fruted Pomegranate, with a sharp, acid flavor, which makes an excellent syrup.

Besicles these, there are several clouble-flowering varieties of the Pomegranate, which are rery beautiful, but bear no fronit. They are also rather more tender than the fruit-bearing ones. The finest are the Docble Red Pomegranate, with large and rery splendid scarlet blossoms, and the Dorble WHite Pomegranate, with flowers nearly white. There are also the rarer varieties, the TElcow Flowened and the Tariegated Flowered Pomegranate, seldom seen here, except in choice green-huuse collections.

\section{CHAPTER XXX.}

TIIE QUINCE.

Cydonia vulgaris, Dec.; Rosncer, of Botanists.

Coignassier, of the French; Quittenbarim. German; Kivepeer, Dutch ; Cotogno, Italian; and Menubrillo, Spanish.

'l'ne: Quince is a well-known hardy, decidnous tree, of small size, crookerl branches, and spreading, bushy head. It is indigenous to Germany and the South of Europe; and it apjears first to have attracted notice in the city of Cydom, in Crete or Candia, whence its botanical natue, Cyclonia. "The fruit is of a fine golden vellow, and nore nearly resemlyles that of the orange than any other. It was even more highly esteemerl by the Greeks and Romans, for preserving, than by us. "Quinces," sars Columella, " not unly vield pleasure, but heakh."

The Quince seldom grows higher thim fifteen feet, and is usually rather a shrub than a tree. Its large white and pale pink blossoms, which appear rather later than those of other fruit-trees, are quite ornamental; and the tree, properly grown, is very oruamental when laden in October and Norember with its ripe golden fruit. 
Uses.-The Quince is, in all its varieties, unfit for eating raw. It is, however, much esteemed when cooked. For preserving it is everywhere ralued, and an excellent marmalade is also made from it. Stewed, it is very frequently used to communicate additional flavor and piquancy to apple-tarts, pies, or other pastry. In England, wine is frequently made from the fruit by adding sugar and water, as in other fruit wines; and it is a popular notion there that it has a most beneficial effect upon asthmatic patients. Dried Quinces are excellent.

In this country large plantations are sometimes made of the Quince; and as it is in good soil a plentiful bearer, it is considered one of the most valuable market fruits. The Apple Quince is the most productive and salable; but as the Pear Quince ripens and can be sent to market much later, it frequently is the most profitable. The Angers is also a profitable market sort, producing abmolantly, and keeping equally as well as the Pear-shaped.

Propagation.- The Quince is easily propagated from seed, lavers, or cuttings. From seeds the Quince is somewhat liable to vary in its seedlings, sometimes proving the apple-shaped and sometimes the prarshaped variety. Cuttings prepared in the autumn, heeled-in, and protected during winter, and planted in a shaded situation early in the spring, root very easily, and this is perhaps the simplest and best way of continuing a good variety. Another way is to bud upon free growing sorts, as that of the Angers.

Quince stocks are extensively used in engrafting or budding the pear, when it is wished to render that tree dwar' in its habit.

Soil and Culture.-The Quince grows naturally in rather moist soil, by the side of rivulets and streams of water. Hence it is a common iclea that it should always be planted in some damp, neglected part of the garden, where it usually receives little care, and the fruit is often knotty and inferior.

This practice is a very erroneous one. No tree is more benefited by manning than the quince. In a rich, mellow, deep soil, even if quite dry, it grows with thrice its usual vigor, and bears abundant crops of large and fair fruit. It should therefore be planted in a deep and good soil, kept in constant cultivation, and it should have a top-rlressing of manne every season when fair and abundant rops are desired. As to pruning or other care, it requires rery little indeed-an occasional thinning out of crowding or decayed branches being quite sufficient. Thinning the fruit when there is an orercrop improves the size of the remainder. Twelve feet apart is a suitable distance at which to plant this tree.

The Quince, like the apple, is occusionally subject to the attacks of the borer and a few other insects, which a little care will prevent or ilestroy. For their habits we refer the reader to the Apple.

\section{VARIETIES}

\section{Angers.}

This is the variety most generally used for stocks on which to bud the pear. It is only within a few years that its value as a fruit has been 
known. The tree is one of the most thrifty growing, and an abundant bearer. It does not cook quite as tender as the apple, but will keep, much longer. In form it is much like the alple, but the flesh is a littlo harsher and more acid.

\section{APPLE-Shaped QuiNeE.}

\section{Orange Quince.}

'This is the most popular variety in this country. It bears large roundish fruit, shaped much like the apple, which stews quite tender, and is of very excellent flavor. It also bears most abundant crops. Leaves oval.

There are sereral inferior varieties of the Apple Quince. The true one bears fruit of the size of the largest apple, fair and snooth, and a fine golden color.

\section{New UPRIGHT.}

Paris de Fontenay.

This is an upright growing variety, forming quite small, compact little trees. Of little or no value as a fruit.

\section{Pear-shaped Quince.}

\section{Oblong Quince.}

The Pear-shaped Quince is drier and of firmer texture than the foregoing. It is rather tough when stewed or cooked, the flesh is less lively in color, and it is therefore much less esteemed than the apple-shaped variety. The fruit is of medium size, oblong, tapering to the stalk, and shaped much like a pear. The skin is yellow. The leaves are oblong ovate. It ripens about a fortnight later than the apple-shaped, and may he preserved in a raw state considerably longer.

\section{Portugal Quince.}

The Portugal Quince is rather superior to all others in quality, as it is less larsh, stews much better, and is altogether of milder flavor, though not fit for eating raw. For marmalade and baking it is much esteemed, as its flesh turus a fine purple or deep crimson when cooked.

The leaf of the Portugal Quince is larger and broader than that of the common quince, and the growth of the tree is stronger. The fruit is of the largest size, oblong ovate, obtuse. The skin is in color not so deep an orange as that of the other sorts.

The Portugal Quince is unfortmately a shy bearer, which is the reason why it has never been so generally cultivated as the Apple Quince.

\section{ReA's SeEdLiNG.}

Van Slyke.

A new seedling, raised by Joseph Rea, Coxsackie, Greene Co., N. Y. It is a superb firut, averaging one-third larger than the apple or 
orange quince, of the same form and color, fair and handsome, and equally as good, and by some preferred to the apple quince for culinary purposes. Tree healthy, a thrifty grower, and moderately productivean acquisition.

Omamental Turieties.--There are two or three ornamental varieties of the Quince, which are natives of China and Japan, and are now among the most common and attractive of our garden shrubs. They are the following :-

\title{
Cinjese Quisce.
}

We have had this pretty shrub in our garden for several years, where it flowers abundantly, but has as yet produced no fruit. The leaves are oral, somewhat like those of the common Quince, but with a shining surface. The flowers are rosy red, rather small, with a relicate violet odor, and have a very pretty eflect in the month of May, though much less showy than those of the Japan Quince. The fruit is described as large, egg-shaped, with a green skin and a hard dry flesh, not of any value for eating. The leaves assume a beautiful sharle of red in autumn.

\section{JAPAN QUINCE.}

Cydonia Japonica.

Pyrus Japonica.

The Japan Quince is a low thorny shmb, with small dark green leaves. It is the most brilliant object in the shrubbery during the month of April, the branches being clothed with numerous clusters of blossoms, shaped like those of the Quince, but rather larger, and of the brightest scarlet. The fruit which oceasionally succeeds these flower's is dark green, very hard, and having a peculiar and not unpleasant smeil. It is entirely uscless.

The White, or Buush JAPAx Quxce $(C$. jap. $f$. albo) resembles the foregoing, except that the flowers are white and pale pink, resembling those of the common apple-tree.

\section{CHAPTER IXXI.}

THE RASPBERRY.

\begin{abstract}
Rubus Ideeus, 4 ; Rosaced. of botanists
Framboisier, of the French; Himbecrstrauch, German; Firmbocs. Dute ; Rown ideo, Italian; and Frombucso, Spanish.
\end{abstract}

THE Rasplerry is a low decidnous shrub, which in several forms is common in the woods of both Europe and America. The large-fruited varieties most esteemed in our gardens have all originated from the long cultivated Rumes Ldaus, or Mount Jda bramble, which appears first to have been introduced into the gardens of the South of Europe from Mount Ida. It is now quite natualized in some parts of this country. 
Besides this, we have in the woods the common black raspber ry, of thimbleberry (Rubus aceiclentalis, L.), and the red rasplberry (Rubus strignsus, Jichx.), with rery good fruit.

The name raspherry (licrspo, Italian) is probably from the rasping romghness of prickly woorl. The term rospis is still used in Sootland.

Tses.-The maphery is held in general estimation, not only as one of the most refoeshing and agrecable subacid fruits for the dessert, but it is employed by almost every family in making preserves, jams, ices, sances, tarts, and jellies; and on a larger scale by confectioners for making syrups, by distiller's for making rasplocry brandy, rasplerry vinegar, de. Raspluery wine, marle in the same way as that of eurant, is considered the most fragiant and delicions of all home-made wines.

Snecerding the strawberry at the begiming of summer, when there is comparatively little else, this is one of the most invaluable fruits, and, with the strawlery, generally commands the attention of those who have scarcely room for fruit-trees. It is, next to the strawberry, one of the most wholesome herries, and not being liable to undergo the acetous fermentation in the stomach, it is considered beneficial in cases of gout or rhemutism.

Propatitinx.-The raspberry is miversally propagated by suckers, or offsets, springing up from the main roots. It naty also be grown from pieces of the roots, two to three inches long, and planted in a light samly soil early in the spring, covering about one inch deep, and adding a slight coat of light mulch to prevent the earth from drying or baking. The Black Cajs, Yellow Caps, and the Purple Came varieties are grown from burying the tips of canes in the latter part of August or September, or as soon as the ends of the canes stop growing abont one inch deep, when they will form roots and make good plants for transplanting the following spring. Seeds are only planted when new rarieties alre desired. The seedlings come into bearing at two or three year's of age.

Sold axd Culture.-The best soil is a rich deep loam, rather moist than dry, but the rasprberry will thrive well in any soil that is rich and deep.

In nuking a plantation of raspberries, plant the suckers or canes in rows, from three to four feet aprart, according to the vigor of the sort. Two or three suckers are generally planted together, to form a group or stom!, and these stools may be three feet apart in the rows, or they maty be set one plant in a place, at distances of one foot to eigliteen inches along in the row.

The plantation being male, its treatment cousists chiefly in a single pruning crery rear, given early in the spring. To perform this, examine the stools in April, and leaving the strongest shoots or suckers, say about thee or five to each stool, cut away all the old wood and all the other suckers. The remaining shoots should have about a foot of their ends ent ofl, as this pat of the wood is feeble and worthless. It is also an good plan som after the fruit is gathered to ent ont the old canes, which have fruited so as to give the new a better chance to ripen. With a light top-ellessing of manure, the gromml should then be dug over, and little other care will be reguisite during the seasun, except keeping down the weeds.

When very neat culture and the largest fruit are desired, more space is left between the rows, and after being pruned the canes are tied to 
long lines of rods or rails, like an espalier, by which means they are more fully exposed to the sum and light.

For field culture, the European varieties ought to be planted four or five feet apart each way, which gives room for the plow and cultivator to work both ways. The Black Cap varieties should be five or six feet each way, and the growing eanes of these should be stopped or shortenerl in when about three fect high, which canses them to grow stocky and throw ont lateral shoots, and these should be cut back to within eighteen inches or two feet the following sping.

A tine crop of the antumnal varieties of raspberries is readily obtained by cutting down the canes over the whole stool, in the spring, to within a few inches of the ground. They will then shoot up new rood, which comes into bearing in August or September.

We have found a light application of salt, given with the top-dressing of manure in the spring, to hive a most beneficial effect on the vigor of the plants and the size of the fruit.

A plantation of rasplberries will be in perfection at the third rear, and after it has borne about eight or ten years it must be broken up and a new one formed on another plot of ground.

All the rasplberries except the hardy Ameriean varieties should be pruned in the fall. After which bend the canes gently on the ground, and cover them an inch or two deep with earth; let them remain in the spring until the cold winds are over, or until the buds begin to swell, then take them up and tie them to stakes or frames.

Tarieties.-The finest raspberries in general enltivation for the dessert are the Hudson River Antwerp, Fastollf, Orange, Belle de Pallan, Knevett's Giant, French, Franconia, and Clarke.

The common American Red is most esteemed for flaroring liqueurs or making brandy, and the American Black is preferred by most persons for cooking and dhying. The Ever-bearing rarieties are raluable for prolonging the season of this fruit till late fiosts.

\section{Allex.}

Allen's Antwerp. English Red Cane. False Red Antwerp.

The origin of this variety is unknown. It is said by F. R. Elliott to have been brought to Cleveland by an English gardener, and was, by Mr. Elliott, sent to W. H. Sotham, Black Rock, N. Y., fiom whose garden Lewis F. Allen obtained it. Canes strong, vigorous. upright, somewhat branc ing. Spines purplish, quite numerous. This and the following, in foliage and fruit, are similar to American Red, and no doubt are improved seedlings of it, or a cross between it and some foreign sort. both throw ul' a large guantity of suckers, which should not be allowed to grow if a crop of fruit is wanted.

Fruit medium, nearly globular; light red, juicy, not very firm; separates freely; milel, pleasant flavor.

\section{Allex's Red Prolific.}

Same origin as the preceding. Canes strong, upright, without branches. Spines whitish, rather scattering.

Fruit medium, nearly globuiar, light red or erimson, rather juicr, not very firm, seprarates freely, productive. 


\section{A MERTCAN BLatik.}

Common Black-Cap.

Thimbleberry.
Black Raspberry.

Rubus Occidentalis.

This Raspberry, common in almost every field, with long, rambling, purple shoots, and flattened, small, black berries, is everywhere known. It is frequently cultivated in gardens, where, if kept well pruned, its fruit is much larger and finer. Its rich acid flavor renders it, perhaps, the finest sort for kitchen use-tarts, puddings, dc. It ripens a little earlier than most of the European sorts.

\section{Anerican Red.}

\section{Common Red.}

Stoever.

The Common Red Raspberry is a native of this and all the Middle States. It ripens nearly a week earlier than the Antwerps, bear's well, and though inferior in flavor and size to these sorts, is esteemed by many persons, particularly for flavoring liqueurs.

Fruit of medium sizc, roundish, light red, pleasant subacid in flavor. Shoots very vigorous, long, upright, and branching, grows from four to six feet ligh. Light shining brown, with purplish spines. Leaves narrow, light green.

\section{A verican White.}

Yellow Cap. Golden Cap.

A variety resembling the American Black in all respects, except in the color of its fruit, which is pale yellow or white, and the flavor not as rich or sprightly.

\section{Arsold's Orange.}

Originated with Charles Arnold, Paris, Ontario, C. W. Canes strong, branching, yellowish brown, almost smooth, and produces but few suckers.

Fruit large, somewhat shorter than Brinckle's Orange, and of a darkel orange color, unsurpassed by any for rich flavor. (Arnold's MS.)

\section{ArNold's ReD.}

Same origin as the preceding. A strong grower. Canes strong branching, dark purple, somewhat drooping. Spines slightly purple, sitout, quite numerous.

Fruit large, red, about the size and shape of Philarlelphia, but of superior flavor. An enormous bearer both in July and September. (Amold's MS.)

\section{Algust Black.}

This variety was received from Thomas Rivers, Fugland. Canes strong, branching. Spines greenish, quite numerous.

Fruit medium size, ronndish oblate, dark red, slight bloom, rather soft, subacid.

\section{A UTUMa BLACK.}

Raised by Thomas Rivers, Fngland. It is said by its author to be propagated only from seeds. We quote his description of the fruit:able."

"Fruit medium size or large, dark purple, very juicy and agree- 


\section{Bagley's Perpetual.}

Fruit medium, oblate, crimson, brisk subacid. Of poor quality.

\section{Barnet.}

Cornwall's Prolific.

Cornwall's Seedling.

\section{Barnet Cane.}

Lord Exmouth's.

Large Red.

An old English variety. Canes long, yellowish green, branching. vor.

Fruit large, roundish conical, bright purplish red. Pleasant fla

\section{Belle de Fontenay.}

Belle d'Orleans.

A variety producing its fruit mainly in the autumn. Ic suckers freely, and requires to be carefully thinned out. The canes should all be cut down in spring in order to obtain good crops. Canes strong, stout, branching. Spines purplish, short, and stiff, quite numerous.

Fruit large, long conical. Grains large, dark crimson, thin bloom. Flesh moderately firm, juicy, sprightly; adheres slightly to the core.

\section{Belle de Paluau.}

A new French variety, of good promise. Canes strong, vigorous, upright. Spines short, purplish, rather slender, and numerous at base.

Fruit very large, conical, a little obtuse, bright light crimson. Grains large, regular, a few hairs. Flesh quite firm, juicy, rich. Tery good. Separates freely from the germ in picking.

\section{BLACK.}

\section{English Black,}

This is a hybrid from England. An old variety. Canes moderately vigorous, with numerous purple spines.

Fruit medium, roundish, dark crimson or purplish. Grains medium or small, compact. Flesh rather firm, brisk subacid, separates freely.

\section{Brentford Cane.}

English.

Fruit medium, oval conical, dull dark red. Inferior to the best. Not productive.

\section{Burlington.}

Prosser.

Originated by Benjamin Prosser, of Burlington, N. J. There is some coufusion as to this kind, two or three having been sent out under this name. The one we have is moderately vigorous and productive. Spines greenish white, with a brownish tinge, slender, and more numerous than any kind we have ever seen.

Fruit large, roundish conical. Grains rather small, compact, scarlet. Flesh quite firm, juicy sweet and good.

\section{Canada Black Cap.}

A variety of American Black, which we have not seen, but said to have been brought from Canada to Piqua, Ohio, where it is popular. 


\section{Carter's Prolific.}

\section{Prolific (Carter's).}

An English variety. Canes strong, with purplish spines.

Fruit large, roundish or obtuse conical, deep scarlet, slight bloom. Grins medium compact. Flesh rather firm, molerately juicy, sweet, pleasant. Ciood.

\section{Catawissa:}

A native of Columbia Co., Penn. Vigorous and very productive. This is especially vahued in some localities as an autumn or late-benring variety. In order to obtain the best crops, the canes should all be ent away in spring, and as the new spronts grow they should be thinnerl to four to six cancs only. It is a little tender, and should always be corered in winter.

Fruit mediun size, flattened, dark crimson, covered with thick bloom. Flavor sprightly, rather acid, more suited to the amateur than for general cultivition. Commences ripening about the first of Angust, and continues in use a long time.

\section{Clarke.}

Raised by E. E. Clarke, New Haven, Conn. Canes very strong, vigorors, upright. Spines purplish, rather loug and stiff. Foliage large, flat, and thick, and endures heat and cold better than any European kind we have. It is not entirely lardy, but more so than any foreign sort, and produces better crops by being covered. It is better suited to light saudy soils than any of its class.

Fruit large, conical, regular. Grains large, quite hairy, bright crimson. Elesh rather soft, juicy, sweet, and excellent.

\section{COL. WILDER.}

Originaterl with Dr. Brinckle, Philadelphia. Strong white spines. Leaf much crimped. Productive, and a good grower.

Fruit large, roundish, semi-transparent, yellowish white or cream color, pleasint flavor, but not rich.

\section{Cope.}

Raised by Dr. Brinckle. Canes strong, upright. Spines short, punplish, numerous.

Fruit large, obtuse conical, or nearly globular. Grains compact, scarlet, with a slight bloom. Flesh firm, moderately juicy, swect, and pleasant.

\section{Cretan Rien.}

A rather late variety, of merlium quality.

Fruit of mediun size, ylobular, inclining to conical, deep purplish red, subacid, and good.

\section{Cưsing}

Originated with Dr. Brinckle, Philadelphia. Canes moderately vigorous. Prorluctive. Spines purplish, long, stiff, rather numerous.

Fruit roundish conical, regular in form, crimson, with a thin bloom, sprightly rich acid flavor. Yarts freoly from the gerw. 


\section{Dayson's Thornless.}

Thormless Black Cap.

Said to have originated in the garden of Mrs. Mercy Davison, Go. wanda, Angola, Erie Co., N. Y. It differs from the American Black Cap only by its ripening a few days earlier. It is nearly as vigorous, and about as productive, not quite as large, but a little sweeter and the canes without spines, except a small one on the leaf stalk.

\section{Doolit'tle.}

\section{American Improved. Joslyn's Black Cap. Doolittle's Black Cap. Joslyn's Improved. Joslyn's Improved Black Cap.}

Introluced by Leander Joslyn, of Phelps, Ontario Co., N. Y. Canes very vigorous, branching. Spines whitish, stout, and numerous. Very productive.

Fruit similar to American Black, but an improvement on it, and is one of the best of its class for market.

\section{Double-Bearing.}

\section{Perpetual Bearing.}

Late Liberian.

A variety of the Antwerp, formerly esteemed for its habit of bearing late in the season; but is now surpassed by better kinds.

Duhrixg.

Originated with Henry Duhring, Philadelphia, Pa. Canes strong. Spines slightly purplish, not very strong, but quite numerous.

Fruit large, roundish obtuse, deep red or crimson. Grains large, rather soft, sweet. Good. Separates freely.

\section{Ellisdalle.}

Described by H. A. Terry as having been found growing wild upon the Ellisdale Farm, in Iowa. It is a variety of the Purple Cane Family, but of stronger growth.

Fruit large, clarker in color, with a little more bloom, and about the same quality.

\section{Eum City.}

A hardy sort, size and flavor much like Philadelphia. Eight to ten days earlier than other sorts. (F. Trowbridge, MIS.)

\section{Elsie.}

A seedling raised by Samuel Miller, of Bluffton, Mo, who describes it as very large and excellent. We have not fruited it.

\section{EMILY.}

A seedling firom the Col. Wilder. White spines.

Fruit large, conical, sometimes round, often shouldered, which distinguishes it from the other varieties; light yellow.

\section{Exglisit Globe.}

Canes strong. Spines short, purplish, moderately numerous.

Fruit large, obtuse conical, dark crimson. Flesh soft, juicy, sweet. 


\section{FASTOLLF.}

Filby.

The Fastollf Rasplbery is an English variety of high reputation. It derives its name from having originated near the mins of an old castie, so cilled, in Great Yarmontl. Cines strong, rather erect, hranehing, light yellowish brown, with few pretty strong bristles.

Fruit very large, obtuse or roundish conieal, bright purplish red, rieh and high-thavored, slightly allering to the germ in picking.

\section{Fraticosia.}

Abel.

This was imported from Vilmorin, of Paris, under this name, by S. G. Perkins, Esq., of Boston, some years ago. Its erops are abundant, the frnit is finn, and benrs carriage to market well, and it ripens about a week later than Red Antwerp. It is one of the finest for preserving. Canes strong, spreading, branching, yellowish brown, witl seattered, rather stont purple spines. Leaves rather large, very deep green.

Fruit large, olstuse conical, dark jurplish red, of a rich acid flavor, much more tart and brisk than that of the Red Antwerp.

Naomi so elosely resembles this in growth, fruit, \&c., that we ar. unable to see any difference, yet it is claimed to be a seedling, differing in the canes being more hardy and the grains of less size, \&c.

\section{Frexch.}

Vice-President French.

nriginaterl with Dr. Brinckle. A little later than most sorts, a very productive, vigorous grower. Cines very strong, tall and upright. Spines purplish, stont and short, numerous at base, few at top. Foliage large, deep green, with many deep veins.

Fruit medium to large, roundish or very obtuse conical, inclining to oblate, deep crimson, slight bloom. Grains large. Flesh rather firm, sweet and very good. Separates freely.

\section{Fultox.}

A seedling of the French. Raised by Dr. Brinckle.

Fruit large, round, crimson, productive; a vigorous grower, reel sIilites.

\section{Garder.}

Doolittle's Red Flavored Black Cap.

A variety of the Black Cap, lighter in color, more acid. Good cooking sort.

\section{Gex. Pattenson.}

A seerlling of the Col. Wilcler. Raised by Dr. Brinckle; vigorous grower, very proluctive, red spines.

Fruit large, round, erimson; does not part readily from the sten.

\section{Golden 'Tholingess.}

A large variety of the Anerican white or yellow, introduced from the west by Pudy and Johnston, of Palnyra, X. Y. It is moderately vigorous, very productive, and has but few spines. 
Fruit equal in size to the MeCormick, oblate, oceasionally conical, slight bloom, dull orange or darker than the American yellow, rather firm, juicy, sweet and pleasant.

\section{HILDRETH.}

Introduced by Isaac Hildreth, of Big Stream Point, Yates Co., N. Y. as a native sort near that place. It does.not grow readily from the tips of the canes and produces but few suckers. Canes rather strong. Spines purplish, stiff, numerous.

Fruit merliun, roundish oblate, dull red or maroon, thick bloom, half firm, juicy, sweet, subacid and similar to Purple Cane in flaror.

\section{HORNET.}

Raised by Souchet, near Paris, very productive. Canes very strong, vigorous, upright. Spines purplish, rather stout, and numerous at the base.

Fruit very large, conical, often irregular. Grains large, quite hairy, compact, crimson. Flesh rather firm, juicy, sweet, and good. Separates freely.

\section{Hudson River Antwerp.}

New Red Antwerp.

Origin unknown, but as fal as we have been able to trace it, was first brought to this country by the late Mr. Briggs, of Ponghkeepsie, N. Y. Its firmness of flesh and parting readily from the germ, together with its productiveness, render it the most popular variety for market. Canes short, but of sturay growth, almost spineless, of a rery peculiar gray or mouse color.

Fruit large, conical. Flesh firm, rather dull red, with a slight bloom, not very juicy, but of a pleasant, sweet flavor.

\section{Huntsuan's Giaxt.}

Raised by Prof. T. W. Huntsman, Flushing, I. I. Fuller describes it as similar to the Franeonia in size, shape, and quality, but the canes taller, and having a peculial grayish white bark.

\section{IMPERIAL.}

A large French variety. Canes pale green, nearly white, with a pale red blush. Mon.)

Fruit large, roundish, bright red. Flesh firm, excellent. (Gar.

\section{Imperial Pied.}

Red Imperial.

A variety grown in New Jersey, where it proves hardy.

Fruit medium, roundish, scarlet, half firm, juicy, pleasant.

\section{JoUET.}

A French variety. Canes yellowish green. Spines whitish, numerous.

Fruit small, long conical, bright lemon yellow, with a whitish bloom. Flesh soft, sweet. Only good. 


\section{KintulND.}

\section{Cincinnati Red?}

Origin unknown. A vigorous, upright grower, not much branclied. Spines whitish, not very stont nor munerous; the earliest to ripen, suckers freely.

Frut medium, roundish or obtuse conical, inclining to oral. Grains small, light crimson, slight bloom. Flesh tender, soft, not very juicy, nor high flavored; separates fieely.

\section{Kinevet's Giant.}

This is one of the strongest growing varieties. Very prorluctive, and of excellent flavor. Canes strong, erect. Spines snall, reddish, very few.

Fruit of the largest size, obtuse conical, deep red, firm in texture, and hangs a little to the germ in picking. Berries sometmes double, giving them a cock's-comb appearance.

\section{LArge-Fruited Monthly.}

Rivers' New Large Monthly.

Canes moderately strong, upright. Spines red, stout, and numerous.

Fruit above medium size, roundish conical, crimson. Flesh soft, sweet, and excellent.

\section{LINDLEY.}

Raised by Joseph B. Lindley, of Newark, N. J. Canes strong, tall, upright, much branched. Spines greenish and stout, numerous; snckers too freely.

Fruit medium to large, conical, a little obtuse, crimson. Grains medium to large, compact. Flesh rather soft, juicy, sweet, and good; adheres slightly.

\section{Lum's Ever-Bearing.}

Autumn Black Raspberry.

Raised by H. B. Lum, of Sandusky, O. This variety is much like the Ohio Ever-bearing Black C'ap', and is increased bylayers from the tips of the canes. Like the Catawissa, it is advisable, when a full autumn crop is desired, to cut away the canes in spring. It is similar in size to the Black Calp, but not quite as firm.

\section{McCormick.}

Miami Black Cap. Larce Miami Black Cap. Mammoth Cluster. Collinsville Miami. Improved Miami. Superior Miami.

A variety of the American Black Cap, with stronger and nore vigorons canes, laving fewer spines, and more productive, and is the largest and best Black Cap we have yet seen.

Fruit similur in form to Anerican Black Cap, but of much larger size, of decper color, more bloom, juice, and sweetness. 


\section{Magnum Bonum.}

A white or yellowish fruit, of large size, rather firm flesh, and finely flavored, similar to the Old Yellow Antwerp. Very productive and vigorous.

\section{Miami Black.}

Little Miami Black Cap.

A common Black Cap, originally found growing along the Miami River, in Ohio, from whence its name. It is of less value than the MeCormick, but very vigorous, very productive, of a more brownish red, not quite as sweet, and not quite as late in ripening.

\section{Mrs. Wood.}

Originated with Mrs. Reuben Wood, near Cleveland, O. Supposed a hybrid between the Black Cap and Purple Cane families. Canes very strong, much branched, productive.

Fruit medium, roundish obtuse, purplish red, with a bloom. Flesh moderately firm, juicy, sprightly subacid; separates freely. Matures its erop quite late, and is on that account valuable.

\section{Mote's Ever-BeArixg.}

Raised by L. S. Mote, of West Milton, O. A new Ever-bearing variety, of vigorous growth, somewhat like Catawissa. Canes of a brownish color, branching. Spines slender, but sharp, and quite numerous at the base, few at the top.

Fruit medium, roundish obtuse, dark red, with a bloom. Grains quite large, rather firm, juicy, subacid; separates freely.

\section{Northumberland Fill-Basket.}

A foreign variety. Canes strong, vigorons, with numerous rather strong crimson-colored spines.

Fruit somewhat globular or obtuse conical. Grains large, compact, deep red, with a good, pleasunt, slightly acid flavor; adheres a little to the core.

\section{Nottingham Scarlet.} Havor.

An old English variety, of medium size, obtuse conical, red, good

\section{Octomer Red.}

Merveille de Quatre Saisons.

A French variety. Requires the canes to be cut down in spring in order to prochuce much fruit. Canes strong, upright. Spines purplish.

Frnit medium, roundish, inclining to conic or obtuse conical, crimson. Flesh rather soft, juicy, sweet, and separates freely.

\section{October Yellow.}

Merveille de Quatre Saisons.

This is of same origin and similar to the above, except that the fruit is of a yellow color and not quite as firm. 


\section{Ohio Ever-Bearixg.}

Ohio Raspberry.

This is a native of Ohio. It is precisely like the American Black Raspberry, or Black Cap, in all respects, except tlat it has the valuable property of bearing abundant erops of fine fruit till late in the season.

\section{ORANGE.}

\section{Brinckle's Orange.}

Originated with Dr. W. D. Brinckle. It is unquestionably the largest and finest Havored light-colored Raspberry yet known, and deserves a place in every garden. Canes strong, branched. Strong white spines. T'ery productive.

Fruit large, conical, sometimes ovate, beautiful orange color. Grains large. Flesh juicy, a little soft, sweet, rich. Excellent.

\section{Philadelpuila.}

Supposed a chance native variety, found wild in the connty of Phila. delphia, Pa. The canes have proved hardy, very productive, and well suited to light soils in the sonthern portions of the Middle States. C'anes vigorous, tall, branching, almost free from spines.

Fruit medium, roundish, dark crimson or purplish red. Flesh rather soft, moderately juicy, mild subacid; separates freely. Goorl.

\section{Pilate.}

This is a French variety, of good flavor. Canes moderately strong, with a tinge of purple. Spines purplish.

Fruit large, conical, crimson, with a slight bloom. Flesh moderately firm, juicy, sweet. Good. Separates frecly.

\section{Prince of Whles.}

\section{Cutbush's Prince of Wales.}

An English variety. Canes strong, nearly upright. Spines purplish.

Fruit large, conical, somewhat obtuse. Grains small, rather compact, regular, quite hairy, crimson. Flesh moderately firm. Sweet and very good. Separates freely.

\section{Prince's Globose.}

Raised by Wm. R. Prince, Flnshing, L. I. Canes strong, upright, branching. "spines long, very stout, and numerous. Sucker's numerons.

Fruit large, nearly globular or very obtuse conical. Graius very large, dull red, with a deep bloom. Flesh coarse, rather dry, crumbling. Not valuab'e.

\section{Purple Cane.}

Purple Prolific.

Huntsville.

\section{English Purple. English Red.}

Red Prolific.

Allen, erroneously.

A native variety. Canes strong and tall, often branching, reddish purple. Spines rather long, stiff, and moderately numerous. 
Fruit medium size, oblate, purplish maroon, slight bloom. Elesh soft, juicy, and rich.

\section{Red Antwerp.}

Old Red Antwerp.

Knevett's Antwerp.

True Red Antwerp.
Howland's Red Antwerp. Framboisier à Gros Fruit. Burley.

This is the common Red Antwerp of England and this country, and is quite distinct from the North River variety, which is shorter in growth, and has a conical fruit. Canes strong and tall. Spines light red, rather numerous, and pretty strong.

Fruit large, nearly globular or obtuse conical. Color dark red, with large grains, and covered with a thick bloom. Flesh juicy, with a brisk vimous flavor.

\section{Red Pearl.} good.

Fruit medium, roundish conical, light red, moderately firm. Scarcely

\section{RILEY's EARLY.}

From New Jersey. It is described as of medium size, good flavor, and quite early. We have not seen it.

\section{Rivers' Orange.}

\section{Large Orange.}

Raised by Thomas Rivers, England. Canes strong, branching. Spines greenish, stout, not numerous.

Fruit medium to large size, roundish conical, pale reddish orange or deep orange. Grains large. Flesh soft, juicy, subacid, but not rich; separates freely.

\section{Russell's Red.}

Raised by Dr. G. W. Russell, of Hartford, Conn. Belonging to the Antwerp family. Canes strong. Spines short, stout, whitish, prochetire.

Fruit large, conical, scarlet. Grains medium, compact. Flesh rather firm, juicy, sweet; separates freely.

\section{Semper Finelis.}

An English variety. Canes strong, upright. Spines purplish, short, and stiff.

Fruit large, conical, somewhat irregular, dull red, with a thick bloom. Grains medium, compact. Flesh firm, not very juicy, subacid. Good.

\section{Seneca Black Cap.}

A variety of the American Black Cap, raised by Mr. Dell, of Seneca Co., N. Y. It is larger aud later than Doolittle, very vigorous, very productive. Spines reddish, strong, and numerous.

Fruit rather larger than Doolittle, not as black, but with a shade of purple, light bloom, juicy, and sweet. 


\section{SouchetTi.}

White Transparent.

A French variety, raised by M. Souchet, near Paris, France. Canea morlerately strong. Spines greenish, short, slender, scattering.

Fruit rather large, conieal, a little elongated. Grains medium, compat, pale creamy yellow. Flesh rather soft, moulcrately juicy, mild sweet, not rich; sejarates freely.

\section{Sumait.}

Of the American Yellow Cap class, raised by O. T. Hobbs, Rar dolph, Pa. Canes strong, branching. Spines stout and numerous.

Fruit large for its elass, roundish oblate, orange color, with pink at the base of most of the grains, which are rather small and compact. Much like Yellow Cap in form, but the flesh firmer and richer.

\section{Surprise.}

This is another variety of the American Black Cap, found wild and introduced to notice by George Husman, of Bluffton, MIo. In growth its caues have few and short spines, and have stiff upright branches.

The fruit is larger, more conical, darker in color, with a peculiar deep bloom, and fewer seeds than the Common Black Cap.

\section{Sineet Yellow Antwerp.}

An old English variety, sweet but unprofitable. Canes slender.

Fruit medium, roundish obtuse conieal, light yellow. Grains small. Flesh soft, juicy, sweet.

\section{THunderer.}

Foreign. Strong grower. Canes erect. Spines red, not numerous, productive.

Fruit rather large, obtuse conical, deep red, rather acid flavor.

\section{TIĆTORIA.}

\section{Roger's Victoria.}

An English variety, of rather dwarf and delicate habit. It is an autumn-bearing sort.

Fruit rather large, dark red. Good.

WALKER.

Raised by Dr. Brinckle. Canes strong, with few roddish spines.

Fruit large, round, deep erimson, solid, atheres firmly to the stem, keeps long in perfection on the plant, bears carriage well.

\section{White CANADA.}

Raised hy Charles Arnoll, Paris, Ontario, C. W. Canes vigorous, upright, brownish yellow. Spines white, quite stout, numerous.

Fruit about the shape of Brinckle's orange, pale yellow, of a decid. edly Antwerp flavor. (C. Arnold, MS.) 


\section{WOODSIDE.}

Originated in New Jersey. One of the Black Cap family. Canes light crimson or dark scarlet. Spines few and scattering.

Fruit very large, globular, black, with little bloom, sweet, juicv, and good. Produces a second crop in autumn. (Fuller.)

\section{WOODWARD.}

Raised by Dr. Brinckle. This is one of the smallest varieties, though larger than the ordinary wild Raspberry.

Fruit round, sometimes roundish ovate, crimson, ripens quite early.

\section{Yellow ANTwERP.}

White Antwerp.

Double-Bearing Yellow.

The Yellow Antwerp is a large, light-colored Raspberry, and, with high cultivation, a good sort, but greatly surpassed by the Orange. Canes strong and vigorous, light yellow, sometimes with many bristles or' spines, often nearly smooth. Productive.

Fruit large, nearly conical, pale yellow, sweet, and of good flavor.

\section{Yellow Pearl.}

A variety of the Yellow Cap. More vigorous, very productive, often produces a fall crop. flavor.

Fruit darker in color, with a slight bloom, and more sprightly in

\section{CHAPTER XXXTI.}

THE STRAWBERRY.

Fragaria (of species). L. Rosncerp, of botanists.

Fraisier, of the French; Erdbeerpthuze, German; Aadbezie, Dutch; Pianta di Fragolu, Italian; and Fresa, Spanish.

The Strawberry is the most delicious and the most wholesome of all berries, and the most miversally cultivated in all gardens of temperate climates. It is a native of the temperate latitudes of both hemispheres, -of Europe, Asia, North and South Americn,-though the sprecies found in different parts of the workl are of distinct habit, and have each given rise, through cultivation, to different classes of fruit.

The name of this fruit is by some molerstood to have arisen from the common and ancient practice of laying straw between the plants to keep the fruit clean. Another reason of the origin of the name comes from the custom of children stringing the berries on straws.

In the olden times the rariety of strawberies was very limited, and the garden was chiefly supplied with material for new plantations from the woods. Old Tusser, in his "Five Hundred Points of Good Husbandrr," points out where the best plants of his time were to be had, and turns 
them over with an abrupt, farmer-like contempt of little matters, to feminine hands:---

"Wife, into the garden, and set me a plot

With strawherry roots, of the best to be got;

Such growing abroad, among thorns in the wood,

Well chosen and picked, prove excellent good."

The Strawberry, though well known, is of comparatively little value in the South of Europe. Old Roman and Greek poets have not, therefore, sung its praises ; but after that line of a northern bard,

"A dish of ripe strawberries, smothered in cream,"

which we consider a perfect prestoral idyl (as the German school would say) in itself, nothing remains to be wished for.

Ripe, blushing Strawberies, eaten from the plant, or served with sugar and cream, are certainly Areadian dainties witl a true paradisincal flavor, and, fortunately, they are so easily grown that the poorest owner of a few feet of ground may have them in abundance.

To the confectioner this fir is also invaluable, communicating its flavor to ices, and forming several delicate preserves. In Paris a cooling drink, bavaroise ì la grecque, is made of the juice of strawberies and lemons, with the addition of sugar and water.

The Strawberry is perhaps the most wholesome of all finits, being very easy of digestion, and never growing acicl by fermentation, as most other fruits do. The often quoted instance of the great Linneus curing himself of the gout by partaking fieely of strawberries-a proof of its great wholesomeness - is a letter of credit which this tempting fruit has long enjoyed, for the consolation of those who are looking for a bitter concealed under every sweet.

Proparation and Soll. The strawberry propagates itself very lapislly by rmmers, * which are always taken to form new plantations or beds. These are taken off the parent plants early in spring, or in Angust and September, and at once planted in the rows or beds where they are to finit.

The best soil for a strawberry is a deep rich loam. Deep it must be, if linge berries and plentiful crops are desired; and the wisest course, therefore, where the soil is naturally thin, lies in trenching and manuring the plot of ground thoroughly before putting ont the plants. But even if this is not necessary, it should be dug deeply, and well cnricherl with strong manmre betorehand.

The best expusure for strawberies is an open one, fully exposed to the sum and light.

('UuTre ix Rows. The finest strawberies ale always obtained when the plants are kept in rows, at such a distance apart as to give suffieient sprace for the roots, and abundance of light and air for the leaves.

In planting a plot of strawherries in rows, the rows should be two feet apart, and the plants of the largi-growing kiuds, two feet from each other in the rows; of the smaller growing kinds, fron one foot to eighteen inches is sufficient. The rumners must be kept down by cutting them off at least three times a year, and the gromel inust be inaintained in good order by constant dressing. During the first year a row

* Excepting the Bush Alpines, which have no runners, and are propagated by division of the roots. 
of any small vegetables may be sown in the spaces between the rows Every autumn, if the plants are not luxuriant, a light coat of manure should be dug in between the rows; but if they are very thrirty it should be omitted, as it would cause them to run too much to leaf.

A light top-dressing of leaves, or any good compost, applied late in the fall, wreatly promotes the vigor of the plants, and secures the most tender kinds against the effects of an unusually cold winter. Before the fruit ripens the ground between the rows should be covered with straw, or light new-nown grass, to keep it clean.

A plantation of this kind in lows will be found to bear the largest and finest fruit, which, being so fully exposed to the sun, will alwars be sweeter and higher flavored than that grown in crowded beds.

Cultelie in alteriate Strips. A still more easy and economical mode is that of growing the strawberry in strips.

Early in A pril, or in August, being provided with a good stock of strong young plauts, select a suitable piece of good deep soil. Dig in a heavy coat of stable manure, pulverizing well and raking the top soil. Strike out the rows, three feet apart, with a line. The plants should now be planted along each line, about a foot apart in the row. They will soon send ont rumners, and these rumers should be allowed to occupy a width of one foot, leaving an alley of two feet, which is kept clear from weeds, and is used to walk in when gathering the fruit.

The occupied strip or bed of muners will now give a heary crop of strawheries, and the open strip of two fect will serre as an alley from which to gather the fruit. After the crop is over, dig and prepare this alley or strip for the occupancy of the new rmmers for the next season's crop. The rumer's from the old strip will now speedily cover the new space allotted to them, and will perhaps require a partial thinning ont to have them evenly distributed. As soon as this is the case, say about the middle of Angist, dig moler the whole of the olf plants with a light coat of manme. The surface mas be then sown with tumips or spinage, which will come off before the next season of fruits.

In this way the strips or beds ocenpied by the plants are reversed every seasoll, and the same plot of ground may thus be continued for years, but less productive than when new land is taken.

It may be remarked that the Alpine and European Wood strawherries will do well and bear longer in a rather shaded situation. The Bush-Alpine, an excellent sort, having no runners, makes one of the neatest borders for quarter's or beds in the kitchen garden, and produces considerable fiuit till the season of late frosts. If the May crop of blossoms is taken off, they will give a moderate crop in September.

To accelerate the ripening of early kinds in the open garden, it is only necessary to plant rows or beds on the sonth side of a wall or tight fence. A still simpler mode, by which their matmity will be hastened ten days, is that of throwing up a ridge of soil three feet high, running east and west, and planting it in rows on the south side. (The north side may also be planted with later sorts, which will be somewhat re. tarded in ripening.)

Ilermophrodite and Pistillate Plants.-A great number of experiments have been male, and a great deal has been written lately, in this country, regarding the most certain mode of producing large crops of this fruit.

Cultivators divide all Strawberries into classes, characterized by their 
blossoms. The first of these they all staminate (or male), from the stamens being chiefly developed. The seennd they call hermajhiodite (or perfect), from their having both stamens and pistils developed. The third are called pistillate (or female), from the pistils being chictly developed.

'The first class really does not exist among eultivated varieties, hecause a pure male variety, or one producing only male flowers, cannot bear fruit.

In planting strawherry berls it is important, therefore, to the cultivator to know which are the perfect, or hermaphodite, and which are the pristillate varicties-as they are found to be permanent in these characters. We have accorlingly designated these traits in the descriptions of the varieties which follow.

Upon the relative proportion of hernaphrodites, cultivators are not absolntely agreed. Some considering one plant of a hermaplerudite sullicient to inpregnate ten or twulve pistillates; others again set twenty pistillates to one. The hermaphrodite, or perfect flowering sorts, require no special care of this kind, and are generally preforred by planters, and are considered fully as productive as an entire pistillate, even when most advantageonsly impregnated.

STRAWBERTY BLOSSOMS.

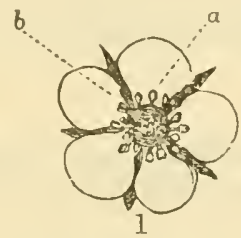

Perfect or Hermaphrodite blossom.

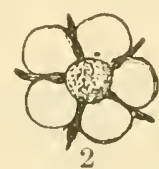

Pistillate blossom.

Nothing is casier than to distinguish the two classes of strawberies when in blossom. In the IIermaphrodite, the long yellow anthers $(a)$, bearing the fine clust or pollen, are abundant. In the pistillate, only the cluster of pistils (b), looking like a very minute green strawbery, is visiole (that is, to the common observer, for the male organs are merely rudimentary, and not developed), while the perfect, or hermalnodite flower, as seen in the drawing, has both stamens and pistils developed.

\section{VARIETIES.}

The varieties of this fruit are very numerous, indeed quite unnecessarily so for all useful purposes. They were formerly divided into classes, designated as the pine and scarlet, but the introductions of late years have become so intermingled as to make reference thereto of no prac. tical value, if indeed it ean be done correctly.

The characters of the flowers corresponding with the above are noted in the text by the words Hermaphrorlite and Pistillate.

As before remarked, the varieties of the Strawberry are very numerous. They are also compratively evanesent. We have therefore omitted to nume or describe many sorts once recorded, because of a doubt as to their present existence. Again, others lave perhaps only a 
local habitation and name, and, possessing no superior qualities, are not worthy of perpetuation, and are therefore omitted.

ADAIR,

Nimorod.

An English variety. Hermaphrodite.

Fruit large, conical, dark red. Flesh deep red, soft, hollow at core.

\section{Admiral Dundas.}

An English variety, of vigorous habit. Hermaphrodite.

Fruit large. Color pale scarlet. Flesh moderately firm, juicy, with a good but not high flavor.

\section{Agriculturist.}

Abraham Lincoln.

President.

Raised by Seth Boyden, Newark, N J. Plant vigorous, foliage dark green; hardy and very productive. Pistillate.

Fruit large, roundish conical, elongated, often with a neck. Surface somewhat meven; first berries often cock's-comb shape, deep crimson. Flesh clark red, quite firm, juicy, sweet, and rich.

\section{AJAX.}

An English variety. A large dark-colored fruit, of a blunt ovate form, with a deep-colored flesh, well tlavored and good. Vines not hardy. (Hov. Mag.)

\section{Alice Maud.}

Princess Alice Mand.

A foreign variety. Hermaphrodite.

Fruit large, conical. Color dark glossy scarlet. Flesh light scarlet, juicy, rich, and excellent.

\section{Ambrosia.}

An English variety. (Hogg.)

Fruit large, roundish, dark shining crimson. Flesh juicy, rich.

\section{Auerica.}

Raised by J. Koech, Waterloo, N. Y., who informs us they ripen nearly all at the same time, and quite as early as the Early Scarlet.

Fruit large, obtuse conical, often wedge shape, crimson. Flesh quite firn, juicy, rich subacid.

\section{Ariadne.}

Pistillate.

Fruit rather large, conical, slight neck, light scarlet, sweet, fine fla. vor. (Hov. Mag.) 


\section{AUstin.}

Austin Seedling.

Austin Shaker.

Shaker's Seedling.

Originated at the Shaker Settlement, near Albany, N. Y. Hardy and productive. Hermaphrodite.

Fruit large, roundish conical, light scarlet. Flesh white, rather soft, acid, and deficient in flavor.

\section{Barnes Mammotir.}

Raised by D. H. Barnes, of Poughkeepsie, N. Y. Plant very vigorous, very productive, and said to be one of the best for market.

Fruit very large, roundish obtuse conical. Surface somewhat uneven; crimson. Flesh scarlet, firm, juicy, sprightly subacid.

\section{Baron Deman de Lennick.}

Frnit very large, elongated flattened cone, light scarlet. Flesh pink, solid, sweet. (Fuller.)

\section{Bicolor.}

Foreign.

Fruit large, conical, rich blush red. Flesh moderately firm.

\section{Bicton Pine.}

Barnes' White.

Virgin Queen.

An English variety, but too tender for our climate.

Fruit large, roundish. Color white, with a tinge of pink on the sumny side. Flesh tender, delicate, mild and pleasant, but not rich.

\section{Bıол.}

Raised by M. De Jonghe. Not profitable.

Fruit medium, conical, bright crimson or scarlet. Flesh white, firm.

\section{Bishop's Oraxge.}

Bishop's New.

Orange Hudson Bay.

Pistillate. Vines hardy, vigorous, and productive.

Fruit medium, conical, regular. Color light scarlet, approaching orange. Flesh rather firm, rich, and excellent.

\section{Black Prince.}

Black Imperial. Cuthill's Black Prince. Mralcolm's Aberdeen Seedling.

A foreign variety, and, when in perfection, of the best quality. Variable. Pistillate.

Fruit large, regular roundish or ovate depressed. Color very deep crimson, almost black, glossy. Flesh deep crimson, rather firm, rich, and high-flavored. 


\section{Black Roseberry.}

Fruit medium, nearly round, dark red or purplish, pleasant flavor, moderate bearer.

Bonté de ST. Julian.

A foreign variety.

Fruit medium size, roundish conical, bright scarlet. Flesh tinged with red, rich, sugary.

\section{Boston Pine.}

\section{Bartlett.}

Raised by C. M. Hovey, Boston, Mass. This fine Strawberry, to have it in perfection, requires rich, deep soil, and to be grown in lills or bunches eighteen or twenty inches apart each way. Hermaphrodite.

Fruit rather large, roundish, slightly conical. Color deep glossy crimson. Flesh rather firm, juicy, rich, and of excellent flavor-an uncertain variety in many places.

\section{BoudiNOT.}

Originated with H. Boudinot, Alexandria, Licking Co., O. Hermaphrodite.

Fruit large, roundish conical, rich clear scarlet. Flesh firm, good flavor, and productive.

\section{Boule D'Or.}

\section{Boisselot.}

Plant robust, moderately productive.

Fruit very large, roundish flattened, bright glossy orange scarlet. Flesh white, sweet. (Fuller.)

\section{Boyden's MIAMMOTH.}

Raised by Seth Boyden, Newark, N. J. Plant vigorous, not very productive.

Fruit large, roundish, often dejressed, dark crimson.

\section{Boydex's No. 30.}

Raised by Seth Boyden, of Newark, N. J. Plant vigorous, very productive. Its large size, productiveness and firmness give promise as a valuable market variety.

Fruit very large, roundish obtuse conical, regular, often with a short neck, bright crimson. Flesh quite firm, juicy, rich subacid.

\section{Brewer's Euperor.}

English. Hermaphrodite. Medium size, ovate, dark red, good flavor.

Brightox Pine.

Raised by T. Scott, of Brighton, Mass. Said to be early, hardy, and productive.

Fruit medium to large, conical, light crimson, rich sprightly flavor. 


\section{Brilliant.}

Raised by Wm. R. Prince, Flushing. Hermaphrodite.

Fruit large, conical, deep crimson.

\section{Britisir Queen.}

Myatt's British Queen.

Raised by Mr. Myatt, England. Flowers hermaphrodite. Plant vigorous, rather tender, requires deep, rich cultivation.

Fruit very large, roumdish conical, occisionally cock's-comb-shaped, of a beautiful shining searlet. Flesh rather firm, juicy, rich, and excellent.

\section{Brooklyn Scarlet.}

Raised by A. S. Fuller. Hermaphrodite.

Fruit medium to large, elongated, a little compressed, bright scarlet. Flesh rather soft, sweet, rich.

\section{Bryan's Satisfaction.}

A new sort. Originated with S. Bryan, Vineland, N. J.

Fruit small, heart-shape pointed, glossy crimson. Flesh firm.

\section{Burr's New Pine.}

Raised by Zera Burr, Columbus, O. Vines moderately vigorous, productive. Flowers pistillate.

Fruit medium, regular roundish conical. Color light crimson. Flesh tender, juicy, with a sweet, rich, aromatic flavor.

\section{Burr's SeEdling.}

\section{Burr's Old Seedling. Burr's Staminate.}

Raised by Zera Burr, Columbus, O. Hermaphrodite. Vines hardy, vigorous, and productive.

Fruit rather large, romish, inclining to conic. Color light scarıer. Flesh tender, juicy, with a mild, pleasant flavor.

\section{Caleb Cope.}

An American variety. Pistillate.

Fruit large, pointed, scarlet. Flesh white.

\section{Capt. Cook.}

An English variety, of large size, somewhat resembling the British Queen, but not quite so large; the color is dark and rich. Poor bearer.

\section{Carolina Superba.}

An English variety. Plant hardy and productive.

Fruit very large, ovate, sometimes cock's-comb shape. Seeds not deeply embedded, pale red. Flesh clear white, firm, solid, rich. (Hogg.) 


\section{Champion. ,}

Originated by Dr. J. C. Neff, Carlisle, Cumberland Co., Pa. Her maphrodite.

Fruit large. Flesh firm, melting, sweet. (Dr. Neff.)

\section{Ciharles Downing.}

Raised by J. S. Downer, Fairview, Ky. Plant very vigorous and very productive. Hermaphrodite.

Fruit very large, nearly regular, conical, deep scarlet. Seeds brown and yellow, rather deep. Flesh quite firm, pink, juicy, sweet, rich.

\section{Charles Favorite.}

A seedling from Hovey's Seedling. Size, shape, flavor, and color similar, but ripens ten days earlier. (Hov. Mag.)

\section{Charlotte.}

Pistillate.

Fruit large, obovate, dark scarlet. Flesh sweet.

\section{Chrlutiax.}

Pyramidal Chillian, or Newland.

Raised by Mr. Newland, in New Jersey.

Fruit medium, conical, bright crimson. Flesh rather firm, mild acid, late. Productive, sometimes very good.

\section{Chorlton.}

Charlton Prolific.

Raised by William Chorlton, Staten Island, N. Y. Hermaphrodite.

Fruit large, roundish obtuse, slight neck, scarlet. Flesh light scarlet, rather acid.

\section{Crinton.}

Raised by Elias Camfield, near Newark, N. J. Plant hardy, healthr, vigorous, productive, rather early, and said to be a valuable market sort.

Fruit large, roundish, crimson. Flesh quite firm, juicy, rich, sprightly subacid.

\section{Cockscoms.}

Obtained in the Royal Gardens, Windsor, England.

Fruit very large, ovate, oceasionally cock's-comb-shaped. Skin pale varlet. Flesh white, with a rosy tinge, rich. (Hogg.)

\section{Colfax.}

From Indiana. Plant very vigorous, very productive, but too small to be of much value.

Fruit small size, round, dark crimson. Flaror subacid, with a peculiar spicy taste. 
Colonel Ellswortit.

Raised by A. S. Fuller, Ridgewood, Bergen Co., N. J. Plant moderately vigorous, productive, the foliage often burns with the sun. Hermaphrodite.

Fruit medium, roundish conical, somewhat obtuse, slight neck, dark scurlet. Flesh rather firm, not very juicy, sweet.

\section{Columbus.}

American. Pistillate. Large, roundish, hardy, productive, dark red, tender, and sweet.

\section{Coyte de Flandre.}

Fruit large, conical, bright crimson, fine flavor. Excellent bearer. (Gar. Mon.)

\section{Comte de Paris.}

Fruit large, obtuse heart-shaped. Skin scarlet, becoming deep crimson. Flesh pale red, and solid thronghout, with a brisk acid flavor. (Hogg.)

\section{Cornucopia.}

Raised by $W^{\top} m$. R. Prince, Flushing, I. I. Plant vigorous, moderately productive.

Fruit large, conical, bright scarlet. Flesh rather soft, sweet. Good.

\section{Criason Cluster.}

An English variety.

Fruit medium size, roundish, sometimes cock's-comb shape, dark red. Flesh firm, juicy, sweet. (Hogg.)

\section{Crimson Cone.}

\section{Scotch Pineapple. Dutchberry. Scotch Rumner.}

An old and beautiful variety, a hardy, vigorous grower, productive. Pistillate.

Fruit medium, irregular elongated conic. Color deep crimson. Seeds deeply embedded. Flesh rather firm, sprightly, with a rich acid flavor, rather late in ripening. One of the best for preserving.

\section{Cringon Favorite.}

Originated with A. S. Fuller. Plant vigorous, not productive.

Fruit large, roundish obtuse conical, somewhat irregular. Color crimson. Flesh rich, juicy, sweet, sometimes hollow.

\section{Crimson Queen. \\ Doubleday's No. 2.}

An English variety, moderately prodnetive.

Fruit medium to large, cock's-comb shape, irregular, bright scarlet. Flesh firm, brisk acid. 


\section{Culverwell's Seedling.}

An English variety.

Fruit long, tapering, much furıowed, very dark red, almost black. Flesh firm, and rich Havored. (Hogg.)

\section{Cushing.}

Raised by Dr. W. D. Brinckle, Philadelphia.

Fruit medium, roundish conical. Color light scarlet. Flesh tender, witl a sprightly, pleasant flavor.

\section{Cutter's Seedling.}

\section{Bunce.}

Originated in Massachusetts. Plant vigorous, productive. Hermaphrodite.

Fruit medium to large, roundish obtuse conical, slight neck, bright scarlet. Seeds yellow and brown. Flesh scarlet, rather soft, juicy, sweet.

\section{DE BATH.}

Fruit large, roundish oval. Color pale rose, or white tinted with rose. Flesh white, fine, sweet, juicy, excellent. (Al. Pom.)

Not productive.

\section{Délices D'Automse.}

Fruit large, roumdish, light scarlet, sweet, rich, high-flavored.

\section{Deptford Pine.}

\section{Myatt's Deptford Pine.}

English. Hermaphrodite. Large, wedge-shaped, bright glossy scarlet Flesh solid, rich, subacid. Shy bearer.

\section{DIADEM.}

Raised by William R. Prince. Pistillate. Large, showr, rouuded, beautiful light scarlet, pleasant flavor, a fine and beautiful berry. (WV. R. P., in Hort.)

\section{Doctor HogG.}

This variety is from Nottingham, England. It is described by for eign authors as very hardy, holding its foliage well, and one of the finest.

Fruit very large, cock"s-comb-shaped. Skin pale ued. Flesh pale red, sweet, very rich flavor.

\section{Doctor Nicaise.}

This is a French variety, of recent introduction, often produciug fruit of extra large size. It is hermaphrodite; not productive.

Fruit very large, irregular cock's-comb shape, bright clear scarlet red. Flesh moderately firm, juicy, sweet, a little hollow at centre.

\section{Downer's Prolific.}

Raised by .J. S. Downer, Kentucky. Hermaphrodite. Plant vigorous, very productive, early. Valuable for near market growing. 
Fruit medium to large, roundish conical, light clear bright scarlet. Flesh ruthes soft, juicy, rich, but a little acid.

\section{DOWNTON.}

Knight's Seedling.

English. Hermaphrodite. Medium, with a neck, ovate, dark pur. plish scurlet, good flavor. Poor bearer.

\section{Duc de Brabant.}

From Belgium.

Fruit large, conical, bright scarlet, good flavor, tolerably productive, and early.

\section{Duc de Malakoff.}

Frnit large, handsome, roundish, a cock's-comb shape, deep red. Flesh red, sweet.

\section{DUKE OF KeNT.}

\begin{abstract}
Austrian Scarlet
Nova Scotia Scarlet.

Globe Scarlet.
\end{abstract}

Early Prolific Scarlet.

Oatland's Scarlet.

Duke of York Scarlet.

English. Plant vigorous, productive. Hermaphrodite.

Fruit small, roundish conical, bright scarlet. Flavor sharp and good. Ripens early, which is its chief merit.

\section{DUNDEE.}

A Scotch variety. Pistillate. Medium, roundish oval, light scarlet, rich acid flavor, productive, late.

\section{DURAND.}

Durand's Seedling.

Raised by Elias W. Durand, Trvington, N. J. Plant moderately vigorous, not very productive. Hermaphrodite.

Fruit large, irregular in form, from conis to oblong. Color scarlet. Flesh somewhat firm, juicy, nearly white.

\section{Echipse.}

Reeve's Eclipse.

Fruit above medium size, conical. Seeds small. Skin glossy red, shining as if varnished. Flesh firm, solid, white. (Hogg.)

\section{Crystal Palace.}

Nyatt's Eleanor.

An English variety, of vigorous growth, hardy, and requires plenty of room.

Fruit large, very conical, ragular, brilliant glossy scarlet. Flesh firm, fine-grained, juicy, and high-flavored. 


\section{Elton.}

Elton Seedling.

Elton Pine.

An old English variety, that ripens quite late.

Fruit large, ovate, frequently cock's-comb shape, bright shining crim. son. Flesh red, firm, brisk subacid.

\section{Elton Improven.}

Raised at the Royal Garden at Frogmore, England.

Fruit large, conical, bright glossy crimson. Flesh solid, sweet, and good. (Fuller.)

\section{EMily,}

An English variety. Plant hardy, not very productive.

Fruit large, round, pale red. Flesh white, juicy, and sweet.

\section{Evima.}

One of M. de Jonghe's raising; vigorous, moderately productive.

Fruit medium size, obtuse conical, bright deep red. Flesh whitish, juicy, moderately sweet.

\section{EMpress Eugévie.}

A variety from France. Not valuable. good.

Fruit large, irregular in form, deep red. Flesh red, sweet, tolerably

\section{English Lady Finger.}

Fruit medium size, oblong, orange scarlet. Flesh white, sweet, and good.

\section{Fairy Queex.}

Raised in the Royal Gardens at Frogmore, England.

Fruit large, conical. Skin pale scarlet, slining as if varnished. Flesh pure white, tender, juicy, sweet, very rich. (Hogg.)

\section{Frerdisande.}

This is a French variety, of good promise.

Fruit large, regular obtuse conical, rich deep scarlet red. Seeds light yellow. Flesh firm, juicy, rich, and high-flavored. (Am. Pom.)

\section{Filbert Pine.}

\section{Myatt's Seedling.}

An English sort, that is said to succeed finely in light soils. Vines prolific, matures late.

Fruit above medium size, conical, occasionally cock's-comb shape, dull red. Flesh pale pink, tirm, rich, brisk, with a tine aroma. (Hogg.) 


\section{Fill-Basket.}

An English variety, very large, roundish, dark scarlet, beautiful, good flavor.

\section{Fillimore.}

Raised by Samuel Feast \& Sons, Baltimore, Md. Plants moderately vigorous. Pistillate. In deep rich soils, under high culture, this is one of value for amatem cultivation ; not profitable for market.

Fruit medium to large, obtuse conical, rich deep scarlet. Seeds yellow: and near the surface. Flesh moderately firm, rich acid.

\section{Fleming.}

Originated in Pennsylvania. Plants vigorous, moderately productive. Pistillate.

Fruit large, roundish obtuse conical, deep scarlet. Seeds yellow, not deep. Flesh rather soft, sweet, and rich.

\section{Florence.}

Raised by Wm. R. Prince; vigorous, moderately productive. Hermaphrodite.

Fruit large, conical, scarlet, fine flavor.

\section{Frexch.}

French's Seedling.

From MLorestown, N. J. Plant vigorous, moderately productive. Hermaphrodite. A fine early variety for private gardens.

Fruit medium to large, roundish obtuse conical, light bright scarlet. Flesh rather soft, rich, and good.

\section{Frogione Late Pine.}

Raised by Mr. Ingram, at the Royal Gardens, Frogmore, England.

Fruit large, conical or cock's-comb shape, with a glossy neck, bright, rich dark red. Flesh juicy, rich, high-flavored. Late. (Hogg.)

\section{Garibaldi.}

An American variety, raised by W. A. Burgess, near New York. Hermaphrorlite.

Fruit medium size, roundish obtuse conical, light scarlet. Seeds yellow. Flesh soft, rich, sweet.

\section{Genesee.}

Raised by Ellwanger \& Barry, Rochester, N. Y. Hardy, vigorous, moderately productive. Hermaphrodite.

Fruit rather large, roundish, somewhat oblate, largest at centre, tapering towards base and apex, generally necked. Color scarlet, inclining to crimson. Flesh tender, juicy, mild, and pleasant, not rich. 


\section{General Scott.}

Raised by W. A. Burgess, near New York. Plant vigorous, pro. ductive.

Fruit large, roundish obtuse, deep searlet, rather soft, rich, subacid.

\section{Globe.}

Myatt's Globe.

English. Large, rich scarlet, excellent flavor, moderately productive.

\section{Globose Scarlet.}

Raised by Wm. R. Prince, Flushing, Long Island, N. Y. Plant vigorous, moderately productive. Pistillate.

Fruit large, roundish, light scarlet. ( $\mathrm{Pr}$.)

\section{Golden Seeded.}

Raised by W. H. Read, Port Dalhousie, C. W. Poor bearer.

Fruit medium, conical, rich crimson, bright yellow seeds. Flesh half fir'm, juicy, rich, mild, pleasant.

\section{Goliath.}

Kitley's Goliath.

An English variety. Hermaphrodite. Plant vigorous, hardy, and moderately productive.

Fruit very large, irregular, often cock's-comb shape, bright scarlet, rich, high flavor, and, like all the English varieties, requires plenty of room and high culture.

\section{Great Eastern.}

Plants vigorous, not very productive. Hernaphrodite.

Fruit large, broadly conical, light crimson. Flesh whitish, rather furm, sweet, not high-flavored, a little hollow.

\section{Green Prolific.}

Newark Prolific.

Raised by Seth Boyclen, Newark, N. J. Plant hardy, very vigorous, very productive, and is highly valued by some as a market sort. Pistillate.

Fruit large, roundish obtuse conical, orange scarlet. Surface soft, centre of flesh firm, rather acid.

\section{Grove End Scarlet.}

Atkinson's Scarlet.

Aberdeen Beehive.

English. Hermaphrodite. Medium, globular, bright scarlet, rather acid, early, productive. 


\section{Haquix.}

This foreign variety is of good rich quality, but not productive. Hermaplirodite.

Fruit large, broadly conieal, sometimes irregular, bright scarlet. Seeds yellow brown. Flesh pinkish, rather firm, juicy, rich.

\section{Harlem Orange.}

Originated near Baltimore, Md. Pistillate.

Fruit orange color, pineapple shape, glossy. Good. (Hov. Mag.)

\section{HATHAWAY.}

Hathaway's Seedling.

Raised by B. Hathaway, Little Prairie Ronde, Mich. Plant vigo. rous, very productive. Hermaphrodite.

Fruit large, roundish obtuse or oblate. Seeds yellow and brown. Color deep scurlet. Flesh searlet, juicy, moderately firm, rich acid.

\section{Hendry.}

A new foreign variety, very beautiful.

Fruit large, long ovate, slight neck, light red or pale red at point, glossy. Flesh moderately tirm, juicy, rich, sweet.

\section{Mero.}

Fruit large, regular, globular, bright red. Flesh carmine, very sweet. Early. (Fuller.)

\section{Highland Chief.}

This variety, Hogg writes, "deserves universal cultivation." It is worthy of trial here. We copy his description :-

Fruit large, romish ovate, and somewhat flattened. Seeds not deep. Skin fine, clear red, becoming dark red. Flesh dark red, firm, very juicy, vinous, with a rich pine Havor.

\section{HigmLAND Mary.}

An English variety; an abundant bearer.

Fruit above medium, conical, inelining to cock's-eomb shape, dark red. Flesh white, hollow at core. (Hogg.)

\section{Hooker.}

Raised by H. E. Hooker, Rochester, N. Y. Plant vigorous, hardy, and procluctive. Hermaphrodite.

Fruit large, broadly conical, regular, very large, specimens sometimes cock's-comb-shaped or depressed. Color deep crimson, almost maroon, with a polished surface, which is rather soft. Flesh deep crim. son, rather tender, juicy, with a fine rich flavor. 


\section{JOOPER'S SEEDLING.}

An English variety. Hermaphrodite. Medium, conical, deep glossy crimson, rich and sweet, not productive.

\section{Hovey's Seedlixg.}

Young's Seedling.

Germantown.

This splendid Strawberry was raised in 1834, by Messrs. Hovey, seedsmen, of Boston, and is undoubtedly one of the finest of all varieties. The vines are vigorous and hardy, prodncing moderately large crops, and the fruit is always of the largest size, and finely flavored. It is well known at the present monent throughout all the States. The leaves are large, rather light green, and the fruit-stalk long and erect. Pistillate.

Fruit very large, roundish oval or slightly conical, deep shining scarlet. Seeds slightly embedded. Flesh firm, with a rich, agreeable flavor. It ripens about the medium season, or a few days after it.

\section{Hudsov.}

Hudson's Bay. Late Scarlet.
American Scarlet.

Tork River Scrilet.

An old American variety, formerly much cultivated for the markets, bnt other and larger kinds are taking its place. Pistillate.

Fruit medium, conical, sometimes with a neck. Color rich, dark shining red. Seeds deeply embedded. Flesh firm, of a high, but brisk acid flavor. Good for preserving.

\section{Huntsuan.}

American. Pistillate. Large roundish, light scarlet, poor flavor, very productive.

IDA.

Miss Ida.

Raised by E. H. Cocklin. Plants vigorous, and when fertilized very productive. Pistillate. Foot-stalks long, holding the fruit well up.

Fruit medium, roundish conical, dark rich red. Flesh moderately firm, juicy, sprightly, rich, a little acid. Fipens among the earliest, and continues late.

Tupératrice EUgé.ite.

Fruit large, conical, bright glossy rosette, handsome, firm, sweet, perfumed.

\section{IMperial Crimson.}

Raised by W. R. Prince. Plant vigorous, productive. Pistillate.

Fruit large, short cone, or rounded. Color dark scirlet or crimson. Flesh firm, sweet, and fine flavor. (Pr.) 


\section{IMperial Scarlet.}

Raised by Wm. R. Prince. Plant vigorous, productive. Pistillate. ly flavor.

Fruit very large, obtuse cone or rounded, scarlet, juicy, and spright-

\section{Ingran's Prince Arther.}

Raised at the Royal Gardens, Frogmore, England.

Fruit medium, conical, regular, with a glossy neck, brilliant scarlet. Flesh white, sólid, juicy, brisk, rich and fine flavor.

\section{IowA.}

Early Washington. Washington. Brook's Prolific.

A seedling of the Western prairies. Hermaphrorite. Plant hardy vigorous, and very productive.

Fruit mediun to large, roundish, light orange scarlet. Flesh tender, juics, very acid; an early variety.

\section{JENNY LIND.}

Raised by Isaac Fay, Cambridgeport, Mass. Hermaphrodite. Vines hardy, vigorous, and productive; an early variety.

Fruit medium, conical. Color rich crimson, glossy. Flesh rather firm, juicy, rich, sprightly subacid.

\section{JenNy's SEedling.}

An American variety, hardy, vigorons, and productive. Pistillate.

Fruit large, roundish conical. Color rich dark red. Flesh firm, rich, sprightly subacid.

\section{Jessie Read.}

Raised by W. H. Read, Port Dallousie, C. W. Hermaphrodite. Moderately productive.

Fruit large, roundish conical, light scarlet. Flesh soft, sweet, rich.

\section{Johx Powell.}

Fruit above medium size, long ovate, with a neck, bright shining red. Flesh white, firm, juicy, sugary, rich. (Hogg.)

\section{JUCUNDA.}

Knox's 700 .

A foreign variety, that, like some other's of its class, does extremely well in some few localities, under ligh cultivation. Plants moderately vigorous. Hermaphrodite.

Fruit large to very large, obtuse conical or coxcomb flattened, bright light scarlet. Seeds mostly yellow. Flesh light pink, moderately firm, sweet, not high flavor, often hollow.

\section{JULIEN.}

Originated with W. F. Kramer, Dubuque, Iowa. Said to be from seed of the Peabody. 
Fruit medium, roundish, rich scarlet, glossy. Flesh moderately firm, sweet, well flavored.

\section{Keen's Seedlixg.}

Keen's Black Pine.

IIurphy's Child.

An old well-known English sort of the tinest quality, but does not generally succeed here. Hermaphrodite.

Fruit larce, roundish, often coxcomb-shaped, dark purplish scarlet. Surface polished. Flesh firm, with a rich high Havor.

\section{Kextucky.}

Raised by J. S. Downer, of Fairview, Todd Co., Ky. We have not seen the fruit, and give Wm. Parry's description. Plant strong, vigorous, very productive, with long fruit-stalks, bear-ing the berries well up from the ground, and the foliage standing the heat of summer and cold of winter, and is a week later than most varieties. Hermaphrodite.

Fruit large to very large, roundish conical, bright scarlet. Flesh white, firm, juicy, rich, sweet, and of excellent quality. (Wm. Parry's MS.)

\section{Kimberly Piye.}

Fruit large, irregular oval, bright crimson scarlet. Flesh firm, juicy, subacid.

\section{Kramer.}

Origin, near Dubuque, Iowa. Plant vigorous, hardy. Hermaphrodite. Productive.

Fruit medium, roundish conical, rich dlark red, moderately firm, juicy, a little acid, but pretty rich and good.

\section{La Ciiallonaise.} (Hogg.)

Fruit large, conical, bright pale searlet. Flesh white, juicy, sweet.

\section{La Cosstaxte.}

A foreign variety that occasionally sueceeds, but generally it burns and dies out. In quality it is excellent, and for some amateur gardens a desirable variety. Hermaphodite.

Fruit large, romulish conical, bright lively crimson. Flesh white, tinged with rose-color, firm, juiç, rich, and delicions.

\section{Tha Délicieutse.}

Of foreign origin.

Fruit large, roundish oblate, pale red. Flesh whitish, sweet.

\section{LADIES' PINE.}

Originated with W. H. Read, Canada. Unproductive. Pistillate.

Fruit small, roundish, light searlet. Flesh soft, sweet, rich, and delicious.

\section{LADY.}

This is comparatively a new variety from England. It is described 
as large in size, bright salmon-color, tinged with crimson. Flesh juicy, and delicious flavor.

\section{LADY FINGER.}

\section{Ladies' Finger.}

Originated in Burlington, N. J. Plants vigorous, moderately productive. Hermaphrodite.

Eruit medium, oblong conical, dark rich clear scarlet or red. Flesh firm, juicy, rich, sprightly subacil. Very good.

\section{LADY OF THE LAKE.}

Raised by John C. Scott, Brighton, Mass. Plants vigorous, hardy, productive. Pistillate.

Fruit large, rather uneven, dark red. Flesh furm. (Jour. of Hort.)

\section{T/A Fertille.}

Fruit large, conical, bright red. Flesh white, with a rosy tinge, firm, juicy, sweet. (Hogg.)

\section{La Grosse Sucree.}

A German variety. Hermaphrodite.

Fruit large, oblong, dark crimson. Flesh white, solid, sweet, pleasant.

\section{LA Liegeoise.}

French. Hermaphrodite. Large, bright scarlet, medium quality, unproductive.

- Foreign.

\section{La Perle.}

Fruit medium, conical, bright red.

LA Reine.

A foreign sort. It is described as of large size, conical, or coxcomb shape. Flesh white, juicy, sweet, rich, not productive.

\section{Large Early Scarlet.}

Early Virginia.

An American variety, one of the earliest, an abundant bearer ; popular in many sections. Hermaphrodite.

Fruit medium or below, roundish ovate, regularly formed, light scarlet. Seeds deeply embedded. Flesh tender, of a rich, excellent flavor.

\section{La Sultane.}

This is a French variety, of large size, conical in form, light clear red. Flesh white, firm, juicy, sweet, perfumed.

\section{LAURELLA.}

Origin unknown. Plant vigorous, productive. Pistillate.

Fruit large, broadly conical, scarlet. Seeds yellow brown. Flesb rather soft, pink, rather acid, not rich. 


\section{La Versalllaise.}

A Freuch variety.

Fruit very laige, oblong, bright scarlet. Flesh shaded with red, firm, juicy, rich, sweet.

\section{LE Baron.}

Raised by Wm. R. Prince. Hermaphrodite

Fruit early, very large, obtuse cone, dark scarlet, not showy, sweet, rich, melting.

\section{Lexnig's White.}

White Pineapple. Albino.
Albion White.

White Albany.

Origin, supposed Germantown, Pa. This is one of the very finestflavored sorts grown; but unfortunately it does not produce but very moderate crops, and is therefore unsuited to any but ainateurs. Plants vigorous. Hermaphrodite.

Fruit large, roundish obtuse conical. Seeds reddish, not deep. Color whitish, tinged with red. Flesh soft, tender, juicy, sweet, rich, delicious pineapple tlavor.

\section{Léonce de Lambertye.}

Fruit very large, conical. Skin bright shining red, as if varnished. Seets shightly embedded. Flesh firm, rosy white, very juicy, rich and sweet. (Hogg.)

\section{LÉopold I.}

This is a Belgian variety.

Fruit large, roundish conical, rich deep red. Seels yellow, prominent. Flesh tinted with rose, juicy, sweet, delicious. (An. Pom.)

\section{Little MIonitor.}

Originated with W. A. Burgess. sweet.

Fruit small, roundish obtuse conical, light scarlet. Flesh soft, rich,

\section{Lizzie RaNDolpir.}

American. Pistillate. Medium, roundish, light crimson, poor flavor, productive.

\section{Losgworti's Prolific.}

Originated at Cincinnati, on the lands of Mr. Longworth, in the Garden of Eden, by Mr. Schneicke. Mermaphrodite. Tines vigorous and very productive. Footstalks long, stout. Leaves large, not very thick. considerably ruffled.

Fruit large, roundish, broad at base, sometimes oblate. Color light crimson. Flesh firm, scarlet, with numerous rays (the remains of the filaments). Flavor rich, briskly acict. Taluable for preserving.

\section{LORENZ BOOTH.}

Fruit large, oval, bright glossy reu. Flesh dark crimson, firm, sweet. 


\section{Lorio.}

A new German variety.

Fruit large, obtuse conical, rich clear dark red. Flesh reddish tinged, juicy, vinous, sweet.

\section{Lucas.}

Fruit large, roundish oval, glossy crimson. Flesh firm, rich. Good.

\section{Lucida Perfecta.}

Fruit medium to large, light clear crimson, conical or obtuse conical, occasionally coxcomb shape. Flesh white, juicy, sweet.

\section{McAroy's Extra Red.}

McAroy's No. 1.

Same origin as Superior. Pistillate. Vines hardy, vigorous, and very productive.

Fruit large, irregularly oblate, generally necked. Color deep scarlet. Flesh tender, juicy. Flavor exceedingly acid. Excellent for preserving.

\section{McAvoy's Superior.}

McAroy's No. 12. General MeLellan. Buffalo.

Origin, Cincinnati, on the lands of Mr. Longworth. Pistillate. Vigorous and productive.

Fruit large, roundish irregularly oblate, more or less necked. Color light crimson, becoming deep crimson at full matuity. Flesh deep scarlet, tender, very juicy, with an exceedingly rich vinous flavor. surface of the fruit rather tender, and will not bear long carriage.

\section{Mead's Seedling.}

Raised by Peter B. Mead, Tenafly, Bergen Co., N. J. Plant a good grower, moderately productive. Pistillate.

Fruit medium size, long conical, inclining to a neck, light scarlet. Seeds brown yellow. Flesh pinkish, rather firm, sweet, and rich.

\section{Marguerite.}

A French variety.

Fruit large, elongated conical, bright shining red. Flesh whitish pinkish, sweet, coarse, hollow, poor.

\section{Mам⿻оте}

Myatt's Mammoth.

English. Hermaphrodits. Large, roundish, dark crimson, poor flavor, unproductive.

\section{Melon.}

Scotch, medium, roundish, dark color; not of much vaiue. 


\section{Metcalf's Early.}

Urigin, Niles, Mich. Plant hardy, vigorous, moderately productive.

Fruit small, rouudish, inclining to oval, light searlet. Flesh rather soft, mild acid. Not very early.

\section{Methven Scartet.}

Methven Castlę.

Warren's Seedling.

Southampton Scarlet.
Keen's Seedling of some.

Higgins' Seedling.

British Queen of some.

An English variety, of large size, roundish or coxcomb-shaped, rather dull searlet. Flesh soft, and of indifferent flavor. Pistillate.

\section{Monitor.}

Raised by A. S. Fuller. Hermaphrodite.

Fruit medium to large, roundish conical, with a neck, bright scarlet. Flesh dry, coarse, firm. Poor. Carries well to market.

\section{Monroe Scarlet.}

Raised by Ellwanger \& Barry, Rochester, N. Y. Pistillate. Plant vigorous and productive.

Fruit rather large, roundish, light scarlet. Flesh tender, juicy, and of very good flavor.

\section{Montevideo Pine.}

Raised by $W^{r}$ m. R. Prince. Hermaphrodite. Hort.) .

Fruit large, conical, pineapple flavor, xipening late. (W. R. P. in

\section{- Moyamessing.}

Raised by Gerhaid Sclımitz, of Philadelphia. Pistillate. Moderately vigorous and productive.

Fruit medium to large, broadly conical, deep crimson. Seeds numerous, deeply embedded. Flesh red, rather firm, pretty briskly acid, much like Hudson.

\section{Mratt's Eliza.}

Omer Pacha.

Rival Queen.

An English variety, of fine flaror; but, like most of its class, a poor bearer. Hermaphrodite.

Fruit medium to large, roundish conical, with a glossy neck, light g! ossy scarlet. Flesh rich, sweet, delicious.

\section{Naomi.}

An accidental Amcrican seedling.

Fruit medium, roundish, inclining to oval, quite deep scarlet. Flesh white, sweet; soft, not high-flavored. 
NAPOLEON.

This variety originated with M. Lorio, of Liege, Belgium. Herma phrodite. sweet.

Fruit large, roundish, light clear red or scarlet. Flesh firm, juicy,

\title{
NAPOE.EOY III.
} phrodite.

Fruit large" to very large, conical, irregular, sometimes coxcombshaped, light scarlet. Seerls yellow, reddish near the surface. Flesh white, rather firm, juicy, sweet, rich.

\section{Necked Pine.}

\author{
Unique Prairie. $\quad$ Pine Apple.
}

An American variety, rather early. Pistillate. Medium size; conical, with a neck, light scarlet. Flesh tender, sprightly, rather acid.

\section{New Jersey Scarlet.}

Originated near Burlington, N. J. Plants vigorous, moderately productive. Hermaphrodite. Early.

Fruit medium, conical, with a neck, light clear scarlet. Flesh mode. rately firn, juicy, sprightly, mild subacid.

\section{NicANor.}

Raised by Messrs. Ellwanger \& Barry, Rochester, N. Y. Plants vigorous, productive. Hermaphrodite. Footstalks tall, upright.

Fruit medium or above, roundish obtuse conical, bright scarlet, somewhat glossy. Seeds brown yellow, not deeply embedded. Flesh juicy, reddish, rather firm, rich, sweet.

\section{Old Black.}

Black.

Black Pine.

Black Beacon.
Mulberry.

Black Canterbury.

Turkey Pine.

A very old variety, described by Lindley, as :-

"Fruit middle-size, conical elongated and pointed, with a neck, hairy, very dark purplish red. Flesh scarlet, firm, with a buttery core, very rich and high-flarored."

\section{OLd JoHN Brown.}

Raised by Dr. H. Schroeder, of Bloomington, Ill. lex.)

Fruit very large, broadly conic, pointed, light crimson, sweet. (Ful. 


\section{Old Pine, or Carolina.}

\section{Pine Apple.}

Carolina.

Old Scarlet Pine.
Old Scarlet.

Blood Pine.

Grandiflora.

American. Hermaphrodite. Medium, conical, with a neck, sonetimes coxcomb-shaped, bright scarlet. Flesh solid, juicy, and rich.

\section{Oraxge Prolific.}

Raised by Ellwanger \& Barry, Rochester, N. Y. Pistillate. Vines hardy, vigorous, very productive.

Fruit large, roundish, sometimes oblate, often necked, deep crimson. Seeds deeply embedded. Flesh somewhat firm, with a brisk, rather acid flavor.

\section{Oscar.}

An English variety. Hermaphrodite.

Fruit large, irregular in form, from ovate to coxcomb, rich deep crimson. Flesh red, melting, firm, juicy, rich, and sweet.

\section{Peabody.}

Peabody's Seedling.

New Hautbois.

This variety originated with Charles A. Peabody, Columbus, Ga.

Fruit of large size, form irregular. Flesh firm, sweet, melting, juicy, with a pineapple flavor. When fully ripe the color is a rich deep crimson.

\section{Peak's Emperor.}

Originated by E. Peak, South Bend, Ind.

Fruit large, oblong conical, dark crimson. Flesh firm, juicy, mild, subacid.

\section{Pennstivania.}

Raised by Gerhard Schmitz, of Philadelphia. Pistillate. Plant moderately vigorous, not productive.

Fruit medium to large, broadly conical, deep crimson. Flesh red, very similar to Moyamensing.

\section{Premier.}

\section{British Green Seedling.}

An English variety.

Fruit large, roundish or roundish ovate, bright red, shining. Flesb white, firm, juicy, rich. (Hogg.)

\section{President Wilder.}

Raised in 1860 by Hon. Marslaall P. Wilder, of Dorchester, Mass., from seed of Hovey's Seedling impregnated with La Constante, and dedicated to him by the Massachusetts Horticultural Society. This new variety, as grown on the originator's gromuls, promises to be valuable, and if it succeeds as well in other soils and localities it will be an acquisition. Hiant healthy, hardy, vigorous, and very productive. Fruit-stalk short, 
stout, erect. It is said to stand the heat of summer and cold of winter uninjured.

Fruit large to very large, roundish obtuse conical, very regular, bright crimson scarlet. Sceds mostly yellow, near the surface. Flesh rosy white, quite firm, juicy, sweet, and rich.

There is another President Wilder, originated in Europe, that is described as large, ovate conical, with a neck, bright rich deep crimson. Flesh rose-color, moderately firm, juicy, rich, and excellent.

\section{Primondian.}

Raised by Wm. R. Prince. Pistillate.

Fruit large, conical, leep scarlet. (W. R. P., in Hort.)

\section{Prince Albert.}

English. Hermaphrodite. Large, oblong cone, deep scarlet, not ligh flavor, moderately productive.

\section{Reine des Belges.}

A new Belgian variety.

Fruit large. Form variable, from long conical to obtuse conical, bright rich scarlet. Flesh firm, juicy, sweet. Agreeable. (An. Pom.)

\section{Prixce Frederick William.}

An English variety. Hermaphrodite.

Fruit large, roundish, pale red. Flesh with a rosy tint, sweet, and good flavor.

\section{Prince of Orleans.}

Hermaphrodite. Medium. Roundish, dark color, poor bearer.

\section{Prince of Wales.}

An Euglish fruit of large size, with a bright deep red glossy surface, and a delicate solid flesh, somewhat acid.

\section{Prince's Climax.}

Raised by Wm. R. Prince, Flushing, T. I. Pistillate. Productive. Eruit large, conical, bright scarlet. Flesh sweet, good flavor.

\section{Prince's Excelsior.}

liaised by Win. R. Prince. Pistillate.

Fruit large, obtuse conical or rounded, deep scarlet. Flesh sweet, fine flavor.

\section{Prince's Magnate. \\ Scarlet Magnate.}

Originated with Wm. R. Prince. Pistillate.

Fruit large, roundish obtuse conical, bright scarlet. Flesh rather soft, pinkish, hullow, not rich. 


\section{Princess Royal.}

Ingram's Princess Royal.

This is an English variety. Pistillate.

Fruit medium, roundish conical, bright deep scarlet. Flesh firm, juicy, rich, perfumed.

\section{Princess Royal.}

Originated in France, by M. Pelvilian.

Fruit large, oblong obtuse conical in form. Skin very bright rich scarlet. Flesh half firm, juicy, melting, sweet. (An. Pom.)

\section{Princess Royal of Exgland.}

Cuthill's Princess Royal.

An English variety. Hermaphrodite.

Fruit mediun size, roundish ovate or conical, with a neck. Seeds teeply embedded. Skin deep scarlet. Flesh pale red at the surface, whitish at the core, rich, high flavor. (Hogg.)

\section{Prolific.}

English. Hermaphrodite. Large, conical, light glossy scarlet, rich flavor, unproductive.

\section{Profuse Scarlet.}

American. Pistillate. Medium, a little improvement on the old Early Scarlet, which it much resembles. Productive.

\section{Raxdolpit Pine.}

Raised by O. T. Hobbs, Randolph, Pa.

Fruit medium, long conical, bright scarlet. Flesh sweet, whitish, not rich.

\section{Richardson's Early.}

American. Hermaphrodite. Medium, conical, clark crimson, early, good flavor. Not productive.

\section{Ricilardson's Late.}

American. Hermaphrodite. Large, roundish, light scarlet, good sprightly flavor, moderately productive.

\section{Riflemax.}

An English variety.

Fruit large, ovate or coxcomb shape. Skin bright salmon-colored. Flosh solid, white, firm, juicy, rich. (Hogg.)

\section{Ripawam.}

Faulkner's King.

Faulkner's Seedling.

Raised by J. W. Faulkner, Stamford, Conn. Plant moderately vigorous and productive. 
Fruit large, roundish obtuse conical, sometimes coxcomb shape, scarlet. Flesh whitish, rather firm, juicy, sweet.

\section{Rival Hudson.}

Raised by Mr. Burr, Columbus, O. An improvement on the old Hudson. Plant hardy and productive. Pistillate.

Fruit medium, conical. Color deep crimson. Flesh firm, with a brisk subacid flavor.

\section{Rivers' Eliza.}

Seedling Eliza.

Rased by Thomas Rivers, England. Hermaphrodite.

Fruit large, ovate conical, glossy scarlet. Flesh moderately firm, good flavor.

\section{Robinson's Defiance.}

Raised in Ohio. Plant vigorous, not productive.

Fruit medium, roundish conical, necked, dull red. Flesh quite firm, acid.

\section{Rosebeliry.}
Aberdeen.
Scotch Scarlet.
Prolific Pine.
Aberdeen Seedling.
Rose.
Brickley Scarlet.

Foreign. Pistillate. Rather small, ovate, dark scarlet, tolerable flavor. Poor bearer.

\section{Rosegud.}

Fruit large, orate, coxcomb shape, with a neck. Skin fine bright rerl. Flesh rich. (Hogg.)

\section{Roșs's Phonent.}

Raised by Alexander Ross, Hudson, N. Y. Hẹrmap̣hrodite; does not sncceed unless with deep, rich soil, and good cuitivation.

Fruit large, generally coxcomb-shaped. Color very dark red. Flesh firm, and high-flavored.

\section{Runy.}

Fnglish. Medium size. Bright-colored berry of a long orate form, similar in shape to Scott's Seedling. Flesh juicy, rich, and excellent. Not very larrly.

\section{Russelís Prolific.}

Originated with H. Russell, Seneca Falls, N. Y. Vines vigorous, productive. Pistillate.

Fruit large, conic, compressed, ribbed, scarlet, clanging to crimson. Seeds small, pretty deepiy embedded. Flesh mild, moderately rich, rather soft, pleasant. 
SABREUR.

A foreign variety, productive.

Fruit inedium, conical, bright orange scarlet. Seeds prominent Flesh solid, white, sweet, and of high flavor. (Fuller.)

\section{Salter's Versailiaise.}

An English variety. Hermaphrodite.

Fruit large, ovate, sometimes flattened or coxcomb-shaped, darks red. Flesh pale, juicy, and rich. (Thomp.)

\section{Scarlet Cone.}

Raised by Ellwanger \& Barry, Rochester, N. Y. Pistillate. Plant vigorous and very productive.

Fruit large, perfectly conical, bright scarlet, beautiful.

\section{Scarlet Melting.}

American. Pistillate. Medium, conical, light scarlet, showy, very tender, not rich. Very productive.

\section{Scarlet Nonpareil.}

English. Large, pretty regularly forned, roundish conical, bright glossy red, saccharine, and rich.

\section{ScotT's SEedLiNG.}

Raised by Mr. J. Scott, of Brighton, Mass. Hermaphrodite.

Fruit rather large, elongated conic, regular, light crimson or scarlet. Flesh pale red, not very juicy, nor high-1lavored.

\section{Sir Charles Napier.}

An English variety. Plant tender.

Fruit large, roundish, flattened or coxcomb-shaped, light scarlet. Flesh whitish pink, juicy, not high-flavored.

\section{Sir HARRY,}

A seedling of the British Queen, impregnated with Kieen's Seedling. The berries are large, of a thick coxcomb form, large calyx, and stout fruit stems. Color deep dark red, or mulberry, glossy. Flesh red, solid, fine grained, very juicy, and of delicious flavor.

\section{Sir Josephi Paxton.}

A fine early variety.

Fruit large, roundish, bright shining crinson. Seerls frominent. Elesh salmon-colored, firm, and rich. (Hogg.) 


\section{Southborougir.}

Southborough Seedling.

Marshall's Seedling.

English. Pistillate.

Fruit medium, ovate conical, rich deep scarlet. Flesh firm, mild. rich flavor. (Elliott.)

\section{SOUVENiR.}

\section{Souvenir de Kieff?}

Raised by M. de Jonghe, of Brussels.

Fruit large, roundish ovate to long conical, irregular and corrugated, bright shining red. Seeds large, even with the surface. Flesh white, firm, juicy, rich.

\section{Stinger.}

\section{Union. Stinger's Seedling.}

Raised by Wm. H. Stinger, near Philadelphia. Hermaphrodite.

Fruit large, roundish, sometimes coxcomb shape, brilliant glossy scarlet. Flesh firm, juicy, rich, pleasant

\section{Stirling Castle Pine.}

Fivit large, ovate or conical, bright deep scarlet. Flesh pale scarlet, brisk. (Hogg.)

\section{Swainstone's Seedling.}

English. Hermaphrodite. Large, ovate, beautiful light glossy scarlet, and good flavor. Bears only very moderate crops.

The Pralrie Farder.

Originated on the grounds of Wm. D. Neff, of Ottawa, Ill. Plant strong and vigorons. Foot-stalks large and tall, and promise well as a market variety. Hermaphrodite.

Fruit very large, oblong compressed or ovate, occasionally coxcombshape, irregular, deep scarlet; texture firm; subacid. (Prairie Farmer.)

\section{TOPSY.}

One of De Jonghe's seellings, not valuable.

Fruit medium, oblong conical, light scarlet. Flesh firm, sweet.

\section{Trionphe de Gand.}

The Triomphe de Gand is a Belgian variety, which appears to stand our climate, and produce more crops in more localities than any other foreign sort. 'The vines are vigorous, hardy, moderately productive, and well suited to strong clayey soils, requires high eultivation and to be grown in hills. Hermaphrodite.

Fruit large, roundish obtuse, sometimes coxcomb shape, bright rich red next the calyx, almost greenish white at point, glossy as if varnisher. Seeds light yellow lrown, near the surface. Flesh firm, white, a littlo hollow at core, juicy, with a peculiar rich and agreeable flavor. 
Romeyn Seedling so closely resembles this that we are unable to see any difference; but the originator clains that it is a seedling of more vigor in foliage and roots, more productive, and less number of coxcomb berries.

\section{Trionphe DE LIEGE.}

A Belgian variety, raised by M. Lorio.

Fruit large, oval, with a slight neck, bright deep scarlet. Seeds few, long-pointed. Flesh ratler soft, juicy, rich, aromatic. (An. Pom.)

\section{Vicontesse Héricart de Thury.}

Duchesse de Trévisse.

Marquise de la Torz Maubourg.

A French variety, of finc quality, but the foliage does not stand our climate wcll. Hermaphrodite. Moderately produetive.

Fruit large, roundish, broadly conical, sometimes coxcomb-shaped, deep scarlet, somewhat glossy. Flesh rich, sweet, and high-flavored.

\section{VICTORIA.}

Trollope's Victoria. Union.
Golden Queen.

Trembly's Union.

An English variety, moderately productive, quite handsome. Hermaphrodite.

Fruit very large, nearly globular, regular. Calyx very large, in 'a depression. Color light crimson. Flesh light scarlet, tender, juicy, sweet, rich, with a somewhat peculiar aromatic flavor.

\section{VICTORY OF BATH.}

Fruit large, ovate, bright red. Flesh white, firm, juicy, rich. (Hogg.)

\section{Vineuse de NaNTES.}

Fruit medium to large, flattened, bright slossy crimson. Flesh red, solid, sweet, peculiar vinous flavor. (Fuller.)

\section{WALKER'S SEEILLING。}

Raised by Samuel Walker, Roxbury, Mass. Hermaphrodite.

Fruit medium to large, regular, generally conic. Color very deep crimson, becoming maroon at maiurity, glossy. Flesh deep crimson, tender, juicy, with a fine, rich, brisk acid Hlavor.

\section{WARD'S FAYORITE.}

Fruit medium to large, roundish, deep crimson. Fl sh sweet, rich.

\section{Western Queen.}

Raised by Prof. Kirtland, Cleveland, O. Pistillate. Vines hardy and productive.

Fruit medium to large, roundish conical. Color rich gloss dark red. Flesh firm, juicy, subacid, sprightly and agreeable flavor. (Elliott.) 


\section{WILLEY.}

American. Pistillate. Vigorous, hardy, and very prc-inctive.

Fruit medium, roundish. Color deep crimson. Flesh firm, with a sprightly acid flavor. A good sort for preserving.

Wilmot's Prinee Arthur.

Fruit medium size, conical. Skin deep red and glossy. Flesh scar. let, firm, hollow at core. (Hogg.)

\section{Wilson's Albany.}

Raised by the late James Wilson, Albany, N. Y. Althougin not of high quality, because of its superabundance of acid, yet no variety has become so generally cultivated as the Wilson's Albany. The vine is very hardy and vigorous, very productive, commencing to ripen its fruit early, and continuing to the latest. Hermaphrodite.

Fruit large, broadly conic, pointed. Color deep crimson. Flesh crimson, tender, with a brisk acid flavor.

\section{Wizard of the Nortir.}

A Scottish variety. Hermaphrodite.

Fruit medium to large, roundish obtuse, dull red. Flesh red, soft, juicy, not rich.

\section{WONDERFUL.}

Jeyes' Wonderful.

Myatt's Prolific.

Fruit large, conical, frequently coxcomb-shaped and fingered. Skin pale red, whitish at apex. Seeds numerous. Flesh white, tender, melting, juicy, sweet, with a fine aroma. (Hogg.)

\section{ALPINE AND WOOD STRAWBERRIES.}

\section{Brune de Gilbert.}

A variety of the Alpine, with larger fruit than the common, and remarkable for its reddish-brown color. It is well flavored, and an abuudant bearer. (Hogg.)

\section{GaLLAND.}

This is a variety of the Alpine, of a dark red color.

\section{Red Alpine.}

Red Nonthly Strawberry.

Des Alpes à Fruit Rouge.

Des Alpes de Tous les Mrois it Fruit Ronge, dic.

The common Red Alpine, or monthly-bearing Strawberry, is a native of the Alps, and succeeds well with very trifling care in this country. The Alpines always continue bearing from June till November; but a 
very fine antumnal crop is secured by cutting off all the spring blossoms The plant resembles the Red Wood, and the fruit is sinilar in flavor and color, but long conical in form. Flowers always perfect.

\section{Red-Bush Alpine.}

\section{Ruisson. \\ Monthly, without Runners. \\ Des Alpes sans Filets. \\ Commun sans Filets.}

The Bush Alpines are remarkable among Strawberries for their total destitution of runners. Hence they always grow in neat, compact bunches, and are preferred by many persons for edging beds in the kitchen garden. The fruit is conical, and the whole plant, otherwise, is quite similar to common Alpines. We think it one of the most desirable sorts, and it bears abundantly through the whole season. The Bush Alpines were first introduced into the United States by the late Andrew Parmentier, of Brooklyn. To propagate them the roots are divided. Flowers always perfect.

\section{RED WOOD.}

\section{English Red Wood.}

Des Bois à Fruit Rouge.

Common Rouge.
Newland's Mammoth. Stoddard's Alpine.

Washingtorı Alpine.

This is the wild Strawberry of Europe (F. vesca), long more com monly cultivated in om garclens than any other sort, and still, perhups, the easiest of cultivation, and one of the most desirable kinds. It always bear's abundantly; and though the fruit is small, yet it is produced for a much longer time than that of the other classes of strawberries, and is very sweet and delicate in flavor. Flowers always perfect.

Fruit red, small, roundish ovate. Seeds set even with the surface of the fruit. It ripens at medium season.

\section{Trionphe D'Holdande.}

Triumph of Holland Alpine.

Des Quatre Saisons.

This new variety of the Alpine comes from the Netherlands, where it is said to have been raised by MI. J. Verkroost, Utrecht. The habit of growth is very vigorons, compact, and the plant very productive. The fruit is large for its class, regular, roundish conical, light scarlet red, Seeds light yellow. Flesh juicy, sweet, rich, aromatic, delicious.

\section{VHITE AlPINE.}

White Monthly. Des Alpes à Fruit Blanc. Des Alpes de Tous les Mois ì Fruit Blanc, dc.

Precisely similar to the Red Alpine, except in color. Frnit conical, white.

\section{White-Bush Alpine.}

White Monthly, without Runners.

Buisson des Alpes Blanc, \&c.

This differs from the Red-Bush Alpine only in the color of the fruit, which is conical and white. 


\section{WHITE WOOD.}

This is precisely similar in all respects to the Red Wood, except in its solor, which is white. It ripens at the same time.

\section{HAUTBOIS * STRAWBERRIES.}

\section{Belle de Bordelaise.}

A new variety. Plants very vigorous and productive.

Fruit meclium or large, ovate, deep rich crimson. Fleslı firm and high-flavored.

\section{Prolific or Coxical.}

Musk Hautbois.

French Mrusk Hautbois.

Sacombe.
Double Bearing. Caperon Royal.

Regent's Dwarf.
Sir Joseph Banks.

Caperon Hermaphrodite.

This is a capital variety. Its strong habit and very large, usually perfect flowers, borne high above the leaves, distinguish it. The frut is very large and fine, dark-colored, with a peculiarly rich, slightly musky flavor. It bears most abundant crops. Hermaphrodite.

Fruit large, conical, light purple in the shade, dark blackish purylo in the sun. Seeds prominent. Flesh rather firm, siveet, and excellent. It ripens tolerably early, and sometimes gives a second crop.

The Cominon Hautbois, Globe, Lakif Flat, \&c., are scarcely worthy of cultivation liere.

\section{Royal Hautbors.}

This is one of the largest, most vigorous, and prolific of the Hautbois family.

Fruit medium to large, roundish conical, regular. Seeds yellow, on the surface, rich dark crimson. Flesh whitish, soft, sweet, rich.

\section{CHILI STRAWBERRIES.}

\section{True Chili.}

Patagonian, Greenwell's New Giant. Greenwell's French.

Fruit very large, bluntly conical or ovate, dull red. Seeds dark brown, projecting. Flesh very firm, hollow-cored, of a rather indifferent sweet flavor. Ripens late.

\section{Wilmot's Superb.}

An Fnglish seedling, raised from the foregoing, rery showy in size, but indifferent fruit and a poor bearer.

Fruit roundish, sometimes coxcomb-shaped; surface pale scarlet, polished; seeds projecting. Flesh hollow, and of only tolerable flaror. Medium season.

* Inut-bois, literally high-zoood, that is, wood strawberries with high leaves and fruit-stalks. 


\section{Yellow CHILI.}

Fruit very large, irregular in form, yellow, with a brown cheer, Seeds slightly embedded. Flesh very firm, rather rich.

\section{GREEN STRAWBERRIES.}

Little valued or cultivated, being more curious than good. 'They resemble, in general appearance, the Wood Strawberries. Leaves light green, much plaited. Flesh solid. There are several sorts grown by the French, but the following is the only one of any value, and it is a shy bearer.

\section{Green Strawberry.}

Green Pine.

Green Wood.

\author{
Fraisier Vert. \\ Powdered Pine.
}

Green Alpine.

Fruit small, roundish or depressed, whitish green, and at maturity tinged with reddish brown on the sunny side. Flesh solid, greenish, very juicy, with a peculiar rich, pineapple flavor. Rijens late.

\section{SELECTION OF VARIETIES.}

The Strawberry is so variable in soils and climates that it is very difficult to select such as will always give satisfaction. We present the following as a list embracing varieties that have proved satisfactory with us :-

Agriculturist, Charles Downing, Downer's Prolific, French, Green Prolific, Hovey's Seedling, Jucundi, Longworth's Prolific, Napoleon III., Royal Hautbois, Triomphe de Gand, Wilson's Albany.

Fey to French standard names of Fruit.-To meet the wants of some of our farming friends in various parts of the country who are zealous collectors of fruit, but at the same time are more familiar with plough-handles than with the sound of Monsieur Crapaud's polite vernacular, we have prepared the following little key to the pronunciation of such French names as are necessarily retained among the standard varieties.

So long as these sorts must retain their foreign names, it is very desirable that they should be correctly pronounced. To give to these French terms what appears to merely English rearlers the proper sonnd is often as far as possible from the true pronunciation. A skilful Hibernian gardener puzzled his employer, a friend of ours, during the whole m nth of September with some pear's that he persisted in calling the "Lucy Bony," until, after a careful comparison of notes, the latter found he meant the Louise Bonne.

We have therefore, in the following, eschewed all letters with signs, and given, as neariy us types alone will permit us, the exact pronunciation of the French names. 


\section{KEY TO FRENCII NAMES.}

\section{APPLES.}

Court Pendu Plat.-- Coor Pahn du Plah. Drap d'Or-Drah dor. Fenouillet Gris.-Fen-nool-yai Gree. Male Carle.-Mal Carl.

Pomme de Neige.-Pum de Naije.

Reinette Blanche d'Espagne.-Ren-ett-Blansh d'Espagne.

Reinette Triomphante--Ren-ett Tre-ome-fant.

\section{APRICOTS.}

Albergier. - Al-bare-je-ai.

Brialiçon.-Bre-ahn-sohn.

Belle de Clroisy._-Bel de Shwoi-sey.

Belle Magnifique.-Bel Man-gne-feek.

Bigarreau.-Be-gar-ro.

Bigarreau Rouge.-Be-gar-ro Rooje.

Bigarreau Conleur de Chair.-Be-gar-ro Coo-lur de Shair.

Bigarreau Gros Cœuret.-Be-gar-ro Gro Keur-ai.

Bigarreau Tardif de Hildesheim - Be-gar-ro Tar-deef de Hildesheim.

Gros Bigarreau Rouge,-Gro Be-gar-ro Rooje.

Griotte d'Espagne.-Gre-ote Des-pan.

\section{GRAPES.}

Chasselas Musqu6.-Shah-slah Meuskay.

Chasselas de Fontainebleau.-Shah-slah de Fone-tane-blo.

Ciotat.-Se-o-tah.

Lenoir.-Lun-war.

NECTARINES.

Brugnon Violet Musqué.-Brune-yon Ve-o-lay Meus-kaj.

Brugnon Musqué.-Brune-yon Meus-kay.

D'Angleterre.--Dahn-glet-are.

Duc du Tellier.-Deuk du Tel-yay.

\section{PEACHES.}

Abricotée.-Ab-re-co-tay.

Belle de Vitry.-Bell de Ve-tree.

Grosse Mignonne.-Groce Mene-yon.

Madeleine de Courson.-Mad-lane de Coor-son.

Pavie de Pompone.-Pah-vee de Pom-none.

Pourprée Hâtive.-Poor-pray Hat-eve.

Sanguinole à Chair adhérente.-Sahn-gwe-nole ah Shair Ad-hay-reat 
PEARS.

Amiré Joannet,-Am-e-ray Jo-ahn-nay.

Ananas.-An-an-ah.

Ananas d'Été.-An-an-ah Da-tay.

Angleterre.-Ahn-glet-are.

Beurré.-Bur-ray.

Belle de Bruxelles.-Bel-de Broos-ell.

Belle et Bonne.-Bel-a-Bun.

Belle-Lucrative.-Bel-iu-crah-teve.

Beurré de Capiumont.-Bur-ray de Cap-u-mohn.

Beurré d'Amalis.-Bur-ray Dah-mah-lee.

Beurré Gris d'Hiver Nouveau.-Bur-ray Gree Dee-vair Noo-vo.

Benrré Diel._Bur-ray De-ell.

Beurré Bronzée.-Bur-ray Brone-zay.

Bezi d'Heri.-Ba-zee Daree.

Bezi Vaet,-Bazee Vah-ai.

Beurré Crapaud.-Bur-ray Crah-po.

Bezi de Montigny.-Bay-zee de Mon-teen-gnee.

Bon Chrétien Fondante.-Bone Cray-te-an Fone-donte.

Boucquia.-Boo-kiah.

Calebasse Grosse.-Cal-bass Groce.

Capucin.-Cap-u-san.

Chaumontel très Gros.-Sho-mone-tell tray Gro.

Compte de Lamay.-Conte de Lah-me.

Colnar Épine.-Cole-mar A-peen.

Crassane.-Cras-sahn.

Cuisse Madame.-Kuees Mah-dam.

D'Amour.-Dam-oor.

De Louvain.-Dul-oo-van.

Délices d'Hardenpont.-Day-lece Dar-dahn-pone.

Doyenné d'Été.-Dwoy-on-nay Day-tay.

Doyenné Panaché.-Dwoy-on-nay Pan-ah-Shay.

Dumortier. -Du-mor-te-ay.

Duchesse d'Angoulême.-Du-shess Dong-goo-lame.

-Duchesse d'Orléans.-Du-shess Dor-lay-un.

Enfant Prodige.-On-font Pro-deeje.

Épine d'Été.-A-peen day-tay.

Figne de Naples,-Feeg de Nah-pl.

Fondante d'Automne.-Fone-donte do-tonn.

Forme de Délices.-Form de Day-lece.

Forelle.-Fo-rel.

Fondante du Bois.-Fone-dont du Bwoi.

Fortunée.-For-tu-nay.

Franc Réal d'Hiver.-Fronk Ray-ahl Dee-vair.

Glout Morceau.-Gloo Mor-so.

Héricart.-Hay-re-car.

Jalousie-Jal-oo-zee.

Jalousie de Fontenay Vendée.-Jal-oo-zee de Fone-ten-ai Von-day.

Léon le Clerc.-Lay-on le Clair.

Limou.-Lee-mohn.

Louise Bonne-Loo-eze Bun.

Madeleine, or Citron des Carmes.-Mad-lane, or Cee-trone day Carn.

Marie Louise.-Mah-re Loo-eze.

Michaux.-Me-sho.

Passans de Portugal.-Pah-sahn de Por-tu-gal.

Pailleau.-Pahl-yo.

Paradise d'Automne - Par-ah-deze do-tonn.

Passe Colmar.-Pass Col-mar.

Quilletette.-Keel-tet. 
Reine Caroline.--Rane Car-o-lene.

Reine des Poires.-Rane day Pwore.

Rousselet Ifâtif--Roos-lay Hat-eef.

Sanspeau.-Salin-po.

Sieulle.-See-ull.

Sucrée de Hoyerswarda.-Seu-cray de Hoyersworda

Surpasse Virgalieu,--Seur-pass Vere-gal-yu.

St. Germain.-San Jare-man.

Sylrange.-Seel-ronje.

Vallée Franche,-Vol-lay Fronsh.

Terte Longne.-Y Trirt Longh.

Verte Longue Panachée.-Vairt Longh Pan-ah-shay.

Virgouleuse.-Tere-goo-leuz.

Wilhelmine.-Wil-el-meen.

\section{PITNS.}

Abricotée Rouge.-Ab-re-co-tay Rooje.

Diaprée Rouge.-De-ah-pray Rooje.

Drap d'Or.-Drah-dor.

Jame Hâtive.-Jaun Hat-eve.

Mirabelle.-Me-rah-bell.

Précoee de Tours.-Pray-cose de Toor.

Prune Suisse.-Prune Su-ece.

Royale Hâtive.-Rwoy-al Hat-ere. 



\section{INDEX TO TIIE DIFFERENT FRUTTS.}

[The standard names are in Roman letters. The synonymous names in Itrlac.]

ALMONDS.

A. c. Dulcis.

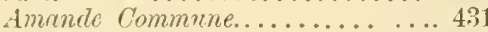

Amunde Pistache............. 4:31

Amande Prinesse.............. 431

Amunde Sultrine............. 4:32

Amandier a Coque Tendre....... 4:31

Amandier à Gros Fruit. .......... 432

Amandier à Gros Fruit Dur...... 4.32

Amandirr ì Petit Fruit.......... $4: 31$

1manclier Commun...........4 4:31

Amandier des Dames........... 43 !

Amandier-P'cher.............. 431

Amrndier Pistuche............. 481

Amundier Sultune............. 432

Bitter Almord

Common Almond.

Common Sucet.

Doux r Coque Tendre... . . . . . . 4.31 Dwarf Double Flowering Almond... 4:3;

\section{Lradies' Thin Shell.}

Large Double Flowering Almond... 4:32

Long Hard-Shell Almond ....... 4:32

Peach Almond. .............. 431

I'rach Almond .............. 4:31

Pcher.... . ............ 4:31

Pistachia Sweet Almond. . . . . . . 4:31

Soft-Shell Sweet Almond . . . . . . . 4. 4. . . .

Siltrun................. 4:32

Sultrin ì Coque Tenilre ......... . 4:31

Sultana Sweet Almond. . . . . . . . 432

\section{APPLES.}

Abbott.

Abbott's Fire-Sided Spice........ Abbott's Sweet................ Abe Lincoln ..................

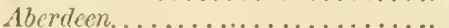

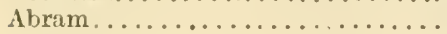
Accidental. .
PAGT

Acklam's Russet. .............

Aclemy Russet................

Adams ..................

Adams Pearmain..............

Fisopus Spitzenherg............. 164

Exopus Spitzenburg.............. 164

Agate D'Enckhuysen...........

Agathe................... \%

Agnes's.................. i4

Ailes...................... 74

Akin's vinter................. 422

Alabrma Pearmain............ . 26i5

Alant. . . . . . . . . . . . . . . . . .

Albernarle Pippin............. 419

Alexander.................

Alfriston.................. 74

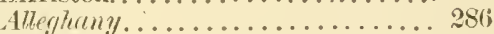

Allemand ...............

Allen's Choice............... \%

Allen's Pippin............... n. \%

All-Hallows................ T.

All-Sunmer................ 75

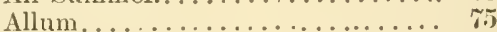

Alsace..................

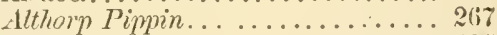

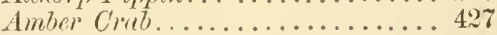

Amelia...................

American Beauty............

American Golden Pippin........ 76

American Golden Russet........ 76

Americun Wrammoth ... ......... 191

American Nezctoren Pippin........ 201

American Tonpareil........... 77

American Peach.......... . . . . . 304

American Pippin............ 77

American Plate. ............ \%7

American Red Junerting........ 157

American Summer Pearmain..... 78

Ananas................... 78

Ananas de Liege.............. 79

Angle..................

72 Anglo-American. ............ 79

2 Annaberger. ................ 341

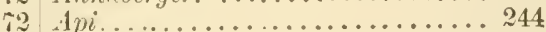

323 Api Petit................... 244

286 Aporta.................... 74

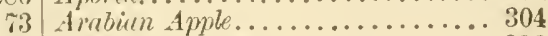

286 Arbroath Pippin............. 296 
Archiduc Antoine............ 79

Arley....................... 417

Aromatic Carolina................ 79

Aromatic Russet.............. 79

Arundel Pearmain............... 222

Ashland.................. 79

Ashmead's Kernel..............

Ashmore.........................

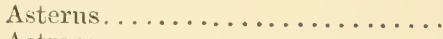

Astracan. ...................... 492

- Istruentischer commerapfel....... 401

Astrachanr. .............. 422

Astruchan Piouge................... 328

-August Apple..............155, 181

August Siret................ 250

Angustine......................

Angustus Pearmain..............

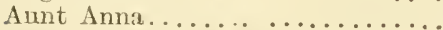

Aunt Anne's Seedling...............

Aunt Doreas. ................... 199

Aunt Hamnah.

Aunt Susan's Favorite...........

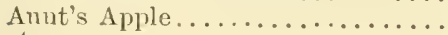

Aurover..................

Arrore....................... 19

Austin Sweet.

Autumn Golden Pippin...........

Autumn Pearmain.............

1utumn Piquin............... 4

Autumn Romanite............

Autumn Rose.................

Autiunn Seek-No-Farther.......

Autumn Strouderry........... 2.

Autumn Sweet Bough... .......

Autumnal Swar.

Autumnal Sweet Swaar........ . Averill.

Avery Suect.

Jaecolinus

Buch's liernel.

Brachelor

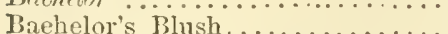

Bachelor's Glorr..............

Backhouse's Lord Nelson. . . . . . 83 .

Baddow Pijpin................

Ji(t)................... 215

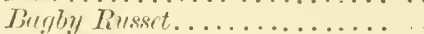

Bailey's Golden............. . .

Bailey's Spice.

Bailey's Sweet. . . . . . . . . . . . . . . . . . .

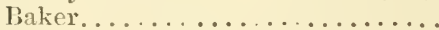

Baker's Sweet................

Baldwin. . . . . . . . . . . . .

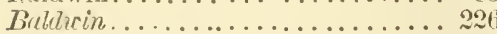

Baldwin Sweet............... . . so

Balgone Pippin................ 19t

Pall Apple................. 2n!

Balm................ 84

Baltimore................ 80

Bultimere............. 167, 191

Baltimore Greening............ St

Baltimone Pippin.
Baltimore Red............ 93,98

Baltimore Red Strant.......... 9:3, 98

Baltzby.................. $\delta 7$

Bar................... 87

Barbour................... 87

Bareelona Pearmain.......... 87

Barehard's Seedling........... 87

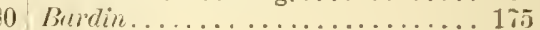

Bark Apple................. 88

Bartovo................. 135

Bamhan's Sweet............ 8

Barnhilt................ 87

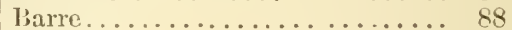

Barrett....................... 88

Burrett's Sprtzenburgh.......... 285

80 Bars.... .................. 88

80 Bartlett................... ss

so Burtlett................... 111

so Barton ........................ 88

99 Barton's Incomparable......... 88

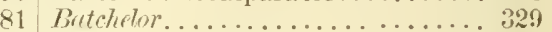

81 Bariman's Reinette........... 88

81 Baxter's Pearmain............. 89

89 Briy Amle.................. 149

9.5 Ruyfondbury Golden Pippin....... 194

81 Beachemwell Seedling......... \$?

81 Beadell.................. \&9

81 Bean Swirt............... 8?

413 Bear sweet................ .9

81 Berred Burden.............. 152

s? Rean................. s9

82 Bertel Ponige............... 219

Brreuty................ . . .3:3

82 Reruty of imerica. . ......... i5

82 Beauty of Kent ... ........ s?

82 Bermty Red............... 1332

8. Beauty of the West.......... \&9

163 Bedfor d Sirert.............. 89:3

Bedfordshire Foundling ....... 90

83 Beefsteak............................ 90

96 Beeler's Russet.............. 90

109 Belden..................... 90

8:3 Belden Sweet.............. 90

89 Brbl Dulunis . . . . . . . . . . 38.9

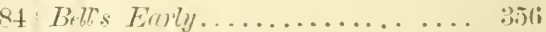

si) Bell's sentet Pectrmain.......... 347

15 Bell Bonde................. 90

159 Belle d'Angers............... . .1

8:3 Belle Bonne................ 91

84 Belle et Bonne.............. 91

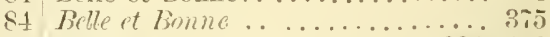

s4 Bille Fille.............201, 112

84 Belle-Flewr. . . . . . . . . . . 324, 418

j Brlle.Flem Ronge............. 324

Belle Grideline............... 91

Thelle Grisdeline.............. 91

Belle Josephine............... 191

Belledge................... 91

Bellodye Pipmin.............. 91

Belltower Pippin .............. 91

1 Belmont................. 92

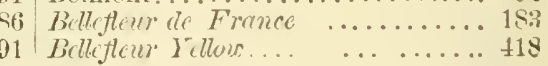




\begin{tabular}{|c|c|}
\hline & \\
\hline 7 y Bmonder................ & \\
\hline$\ldots \ldots \ldots \ldots \ldots$ & Blentecim On \\
\hline$\ldots \ldots \ldots \ldots .342$ & $\mathrm{Pi}$ \\
\hline$n \ldots \ldots \ldots \ldots \ldots$ & \\
\hline$\ldots \ldots$ & $g \ldots \ldots \ldots \ldots$ \\
\hline$\ldots \ldots \ldots \ldots 165$ & \\
\hline$\ldots \ldots .9 \%$ & ley Pippin. \\
\hline ..... 210 & \\
\hline$\ldots \ldots \ldots \ldots \ldots$ & \\
\hline$\ldots \ldots \ldots \ldots \ldots$ & . \\
\hline$\ldots \ldots \ldots \ldots \ldots \ldots \ldots$ & t. ........ \\
\hline$\because \cdots \ldots \ldots \ldots$ & $\ldots \ldots \ldots \ldots$ \\
\hline in . . . . . . . . . & \\
\hline$n \ldots \ldots \ldots \ldots \ldots$ & $\ldots \ldots \ldots \ldots \ldots$ \\
\hline$\ldots \ldots$ & \\
\hline ........ 841 & \\
\hline & \\
\hline$\ldots \ldots \ldots 3$ & ilicimes \\
\hline 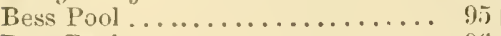 & \\
\hline$\ldots \ldots \ldots \ldots \ldots$ & $\ldots \ldots \ldots \ldots$ \\
\hline$\ldots \ldots \ldots \ldots \ldots$ & Enge $\ldots \ldots \ldots \ldots \ldots \ldots$ \\
\hline$\ldots \ldots \ldots \ldots \ldots$ & rginie. . \\
\hline$\ldots \ldots \ldots \ldots$ & \\
\hline F: & $l h$ \\
\hline tha & s Ear \\
\hline . & $\mathrm{ky}$. \\
\hline$\ldots \ldots \ldots \ldots \ldots$ & $\mathrm{f} O \mathrm{gr}$ \\
\hline . . . . . . 286 & \\
\hline$\ldots \ldots \ldots \ldots \ldots \ldots$ & \\
\hline$\ldots \ldots \ldots \ldots \ldots$ & Russet \\
\hline .. & $e$. \\
\hline & $\mathrm{G}$ \\
\hline . & - \\
\hline$\ldots \ldots \ldots$ & \\
\hline$\ldots \ldots \ldots \ldots$ & \\
\hline$\ldots \ldots \ldots \ldots$ & 's \\
\hline te $\ldots \ldots \ldots \ldots$ & \\
\hline$\ldots \ldots \ldots \ldots \ldots$ & e \\
\hline Seoti & \\
\hline$\ldots \ldots \ldots \ldots \ldots$ & \\
\hline pin........ & il. ... \\
\hline$\ldots \ldots \ldots \ldots$ & \\
\hline$\ldots \ldots \ldots \ldots$ & $\ldots \ldots \ldots$ \\
\hline$\ldots \ldots \ldots \ldots \ldots$ & $\ldots \ldots \ldots$ \\
\hline$\ldots \ldots \ldots$ & \\
\hline$\ldots \ldots \ldots \ldots$ & \\
\hline$\ldots 14$ & \\
\hline$\ldots$ & like:h. \\
\hline & orse Apple.... \\
\hline . . 245 & \\
\hline$\cdots$ & \\
\hline$\ldots \ldots$ & $\cdots$ \\
\hline .. 11 & \\
\hline ley Sweet. . & \\
\hline$\ldots$. & $\ldots \ldots \ldots$ \\
\hline & pin....... \\
\hline & \\
\hline 26 & 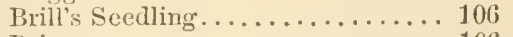 \\
\hline$\ldots$ & \\
\hline 21 & eel. \\
\hline 10 & in \\
\hline & \\
\hline & in . . . . . . . . . . \\
\hline
\end{tabular}


PAGT

Brittle Sweet............. 107

Broad-End................. 107

Broad-Eye Pippin.............. 107

Broved River............... 389

Brouding................. 107

Broadwell.................... 107

Broadecll Sweet.............. 107

Bromelia Anamas.............. 78

Bronson Sweet............... 108

Brmlie's Pippin................ 201

Brookes................... 108

Broughton................ 109

Brown.................... 108

Broun Cockle................ 129

Brown Kenting............. 108

Brow's Golden Sneet........... 379

Brown's Summer Beanty......... 108

Brown's Winter............... 108

Brownite.................... 108

Brownlee's Russet............ 108

Bmovele's Sectling Russet........ 108

Brubucker.................. 167

Brummage Pipin ............. 97

Buchenan................... 101

Buchanan's Pippin. . . . . . . . . . 109

Buehrenan's Seedling............ 109

Buck Meadow................... 110

Buckinum................2 215

Buckingham................ 109

Buclitry................. 121

Bucks County Pippin........... 109

Bnel's Favorite............... 110

Buel's Sweet............... 110

Buff..................... 111

Buffington's Early............ 110

Bull's Golden Reinette......... 111

Bnllett................... 111

Bullock's Pippin.............76, 166

Bullripe.................. 152

Buncombe .................. 329

Bunkurn................ 329

Burlington...................285

Burlington Greening............ 332

Burr Knott................... 193

Burr's Seedling ................... 111

Burr's Winter Sweet........... 111

Burrell's Red.................. 111

Burroughs Greening............ 112

Burstorff.................... 103

Bursdorifer..................... 103

Burst Open................. 112

Bush..................... 112

Bush's Beauty............... 112

Bushwhacker............... 112

Butter..................... 11"

Butter...................... 355

Butter Pippin.............. 195

Butters.................... 85

Byam's Sweet................. 113

Byer's. ........................ 109

Byer's Red.................. 109

Byson Wood ................. 113

Byson Wood Russet.............. 113
CABGE

Cars...................... 134

Cabashea.................. 113

Cabbage Head. ................ 113

Cable's Gilliflower................ 80

Cache ..................... 113

Cadeau du General. ................ 392

Crillot Rosat................ 328

Cuin............................... 2305

Cake Apple.................. 11?

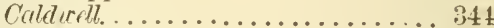

Caleb Sweet................. 11:

Calef's Sweet................. 114

Crilf Presture........................ 123

Crilkin's Pippin................. 368

Calville Ananas de Liege........ 79

Calcitle Blenc................. 372

Calville Blanche à Cote's........... 114

Culville Blrnehe d'Eté........... 372

Calvithe Blanche of IFicer. .............. 401

Cabille de Angleterre............ 133

Calcille ditomne.............. 324

Cribille de Eté. ................. 371

Calcille d'Hirer de Monsfidd. . . . . . 272

Culville des Prairics. ............. 312

Culcill Etrite ............. 165, 360

Calville Malingre................ 114

Calcille Ronige... ........ 324. 328

Calcille Rouge of Anjou........... 328

Calcille Roruge ot Automne.....182, 32t

Calville Ronge de Mlicoud......... 114

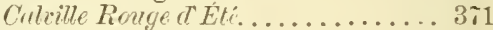

Culville Rouge d Hiver................. 328

Culcille Ronge Normande........ 328

Calcitle Royale d'Hiver. .............. 328

Culcille Suint Sancour........... 345

Corleille Tulipee................ 387

Calillle vare des Allemands ........ 328

Camack's Sweet................. 114

Crumele's Winter Sicect........... 114

Crembridge Pipmin............... 90

Cambusnethan Pippin.......... 115

Camnesar. .................. $40 t$

Campbell.................... 114

Camplutlite................... 405

Campfield......................... 115

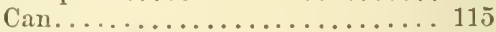

Canuda Pippin................ 402

Canada Reinette.................. 115

Canadir himette Gris............ 204

Canada Reinette Grise............. 116

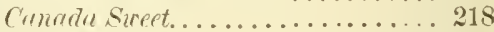

Cumadian Reinctte............ 115

Crrne......................... 235

Cane Creek Sweet............ 116

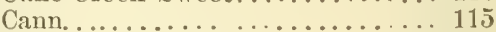

Camnon Pearmain............ 116

Canterbury Reinette........... $110^{\circ}$

Capendu.......................... 134

Capital ................... 117

Capron's Pleasant............. 117

Caraway Russet.............. 117

Carbage.................. 117

Cardinal Red........................ 11 ? 


\begin{tabular}{|c|c|}
\hline & \\
\hline$\ldots \ldots \ldots \ldots$ & \\
\hline .. 117 & $\sin \ldots . . . \ldots$. \\
\hline$\ldots \ldots \ldots \ldots \ldots 117$ & 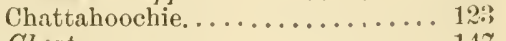 \\
\hline ite. . . . . . . . & \\
\hline$\ldots \ldots \ldots \ldots \ldots$ & Thertan Pippin. \\
\hline$\ldots \ldots \ldots \ldots \ldots$ & Theritaio ........ \\
\hline .. 118 & he \\
\hline .. 201 & . \\
\hline$\ldots \ldots \ldots \ldots \ldots 119$ & $13 x+2 y$ \\
\hline$\ldots \ldots \ldots \ldots$ & $\ldots \ldots \ldots \ldots \ldots$ \\
\hline$k \ldots \ldots \ldots \ldots$ & Russet......... \\
\hline ipe............ 328 & $-x^{2}+2$ \\
\hline$\ldots \ldots \ldots \ldots \ldots 280$ & 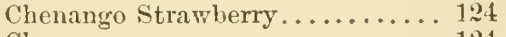 \\
\hline$\ldots \ldots 119$ & \\
\hline$\ldots \ldots \ldots \ldots \ldots 1$ & $\ldots \ldots \ldots \ldots \ldots$ \\
\hline$\ldots \ldots \ldots \ldots \ldots 1$ & $\ldots \ldots \ldots \ldots \ldots$ \\
\hline$\ldots \ldots \ldots \ldots 1$ & \\
\hline$\ldots \ldots \ldots \ldots 286,4$ & $\ldots \ldots \ldots$ \\
\hline$\ldots \ldots \ldots \ldots \ldots 11$ & $k \ldots \ldots \ldots \ldots \ldots$ \\
\hline$\ldots \ldots \ldots \ldots \ldots 1$ & 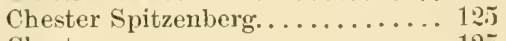 \\
\hline$\ldots \ldots \ldots 1$ & $\ldots \ldots \ldots \ldots$ \\
\hline$\ldots \ldots 30$ & \\
\hline . sis & $\cdots$ \\
\hline ... & 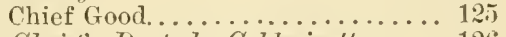 \\
\hline$\ldots 21$ & . \\
\hline$\ldots \ldots \ldots \ldots \ldots 120$ & te... \\
\hline$\ldots \ldots \ldots 2(i)$ & . \\
\hline$\ldots \ldots \ldots \ldots \ldots$ & $\cdots$ \\
\hline$\ldots \ldots \ldots \ldots \ldots \ldots \ldots$ & $\ldots \ldots \ldots$ \\
\hline .. & $\ldots \ldots$ \\
\hline . & t. . \\
\hline . & $\ldots$. \\
\hline . & $\cdots$ \\
\hline . 121 & $\ldots \ldots \ldots$ \\
\hline$\ldots \ldots \ldots \ldots \ldots .28 j$ & $\ldots \ldots \ldots$ \\
\hline$\ldots \ldots \ldots \ldots \ldots \ldots 1$ & \\
\hline$\ldots \ldots \ldots \ldots 169,324$ & \\
\hline$\ldots \ldots \ldots \ldots 1$ & Now \\
\hline$\ldots \ldots \ldots \ldots \ldots 1$ & \\
\hline ... & $\cdots \cdots$ \\
\hline$\ldots \ldots \ldots$ & $\ldots \ldots$ \\
\hline$\ldots \ldots \ldots \ldots \ldots \ldots \ldots \ldots 121$ & $\ldots \ldots \ldots$ \\
\hline$\therefore 121$ & n...... \\
\hline Berufin..... & \\
\hline . . 291 & \\
\hline$\ldots \ldots$ & \\
\hline direak. . .......... & m \\
\hline & \\
\hline$\ldots .$. & alling ...... \\
\hline$\ldots \ldots \ldots$ & ard Apile.. . . \\
\hline$\ldots \ldots \ldots \ldots 122$ & \\
\hline . 122 & pin. \\
\hline .. . & \\
\hline $281 i$ & \\
\hline nette & $\mathrm{C}$ \\
\hline 3 & \\
\hline$\ldots 122$ & \\
\hline$\ldots 12$ & Fall Pippin... \\
\hline 15 & \\
\hline $26: 3$ & \\
\hline 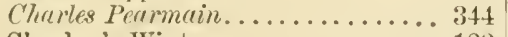 & \\
\hline (1) & \\
\hline & ite. ... \\
\hline
\end{tabular}


Coclin Gee................. 129 Conert-pendu Doré............ 19:

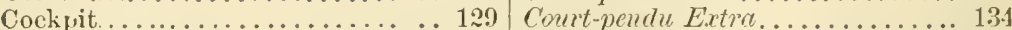

Coe's Golden Drop............. 129 Court-pendu Giv............. 175

Goés Spice................. 152 Court-pendu Musqué.......... 1:34

Coner de Pigcon................ 304 Court Pendu Plat............. 134

Cogswell.................. 130 Court-pendu plnt rougeâtre....... 1:34

Congrell Pearmain............. 1:30 Court-pendu Roud Gros......... 134

Cole.................... 130 Court Pendu Resat........... 135j

Crdeman................. 38. Court Pendu Rose........... 193i

Coles Quince .............. 319 Court-prnedu Ponse........... 1:34

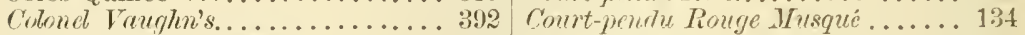

Colored Harbord's Pippin. . . . . . . . 209 Cowarne Ped. . . . . . . . . . . . . . 13.j

Columbian. ................ 1:11 Cowarne's Queening.. ........ 13\%

Culumbiren Pusset............ 127 Cox's Orange Pippin........... 13.j

Colvert ................. 1:31 Cox's Pomona............. 135̃

Colville Bure.............. ss Cracking................ 135

Compote................ 298 Cram................. 1:36

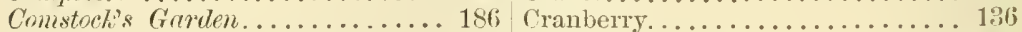

Conant's Red ... . .......... 131 Cranberry Pippin............. 1:36

Concmibre des Chartrcux....... 345 Cranberry Russet............ 136;

Condit stoect ................ 181 Crane's Pippin................ 296;

Congress..................131 Crawford ............... 136

Connecticut Calip............ 113 Crawford's Keeper........... 131;

Connecticut Seck-no-Futher...... 399 Cray Pippin............... 1:36;

Comnecticnt Summer Sweet. .... 1:31: Crayton ................137

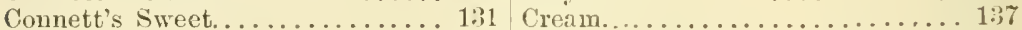

Contin Reinette............ 1:31 Crede's Quittenreinette........ 13\%

Conway.................. 132 Credo's Gutten Reinette. ....... 1:3i

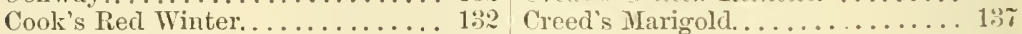

Coolie's Greening.............416 Creek................. 13i

Cooledge's Favorite.......... 192 Creeper................. 1:37

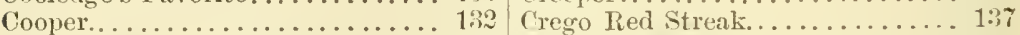

Cooper's Early White.......... 192 Crimsm Pippin............ 144

Cooper's Market............. 1:32 Crimson Queening........... 1:37

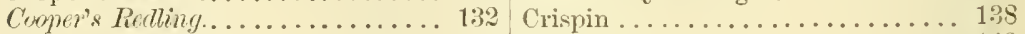

Cooper's Russeting........... 132 Crittenden ............... 1:38

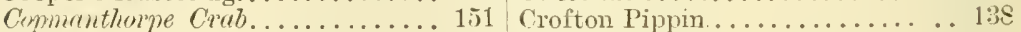

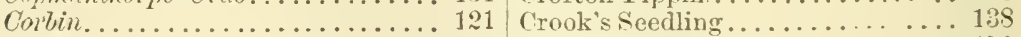

Coral. . . . . ................ 423 Crooled Limb Pimin........... 151

Coral Blish................. 1:34 Cropsey's Farorite........... 1:38

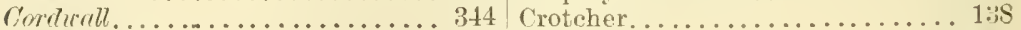

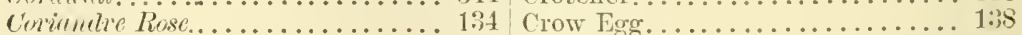

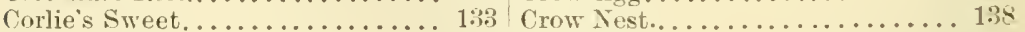

Cornell's Faney. . . . . . . . . . . . 133| Cullasaga . . . . . . . . . . . . . . 1:39

Cornelis Fuwrite ............ 1333 Cullawhee................ 139

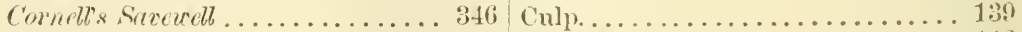

Comfield.................. 1:33 Cumbetind Binck............... 140

Comish Aromatic. . . . . . . . . .... 133 Cumberland Seedling.......... 189

Cornish Gilliflower. ........... 1:38 Cumberland Spice........... 139

Comixh July Flower. . . . . . . . . . . 139 Curant Crab. . . . . . . . . . . 42:3

Comish Spice ............. 138 Curry's Red Winter.......... 133?

Corse's Favorite............... 133 Curtis Errly sitripe............ 363

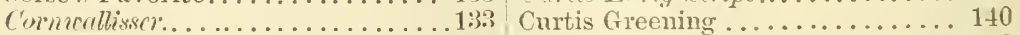

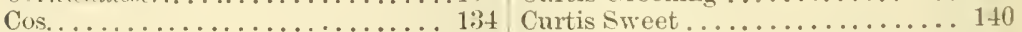

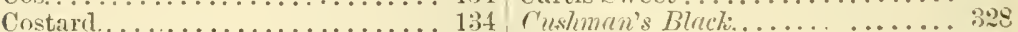

Cotsville Spitzenberg........... 134 Custard................ 140

Cotton Apple............... 126 Cut Pippin................ 140

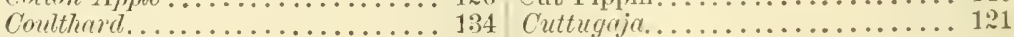

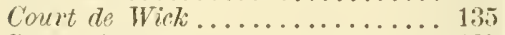

Court of Wick................ 135

Court of Wick Pippin.............. 135

Conert-pendu................ 134

Court Pendu de Tournay.......... 134

Daddy. . . . ............. 322

Dahlongea...................... 14

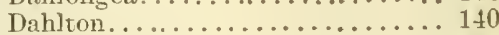

Dahlton Pipjin................ 140 
PATR

Drinty Amle.................218 Doctor Fulcher..............14i

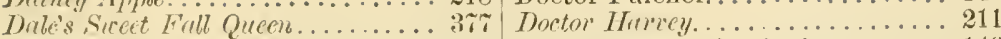

Dame Jeamette ........... 140 Doctor Helsham's Pippin....... 146

Din Peamain.............. 141 H. Hitson.............. 82

I)

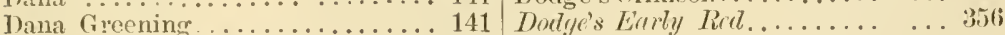

Dana's Striped Sweet......... 141 Domine................ 147

I) aniel .................... 141 Donnelan's Seedling......... 148

1)aniel's Apple................ 141 Double bellefleur............. 183

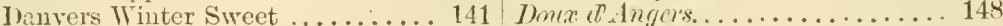

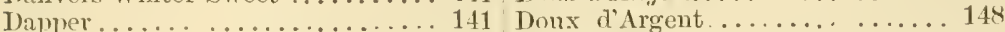

1)arling Pippin... . ... . . . . 142 Dow's Winter Pippin.......... 148

Darlington ........ 142 Dowell's Pippin............ 148

Darlingfon Rusact............. 142 Downing's P'aragon........... 148

Dartmonth Sweet............ 142 Downton Grden I'imin........ 148

J) listerus. . . .............. 80 Downton Pippin.............. 148

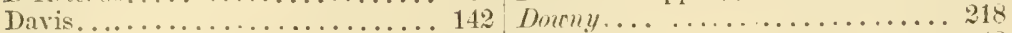

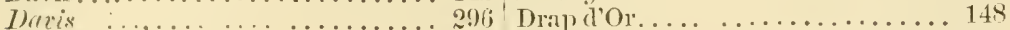

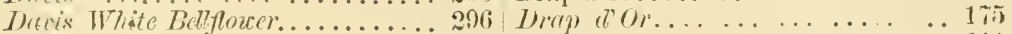

Daris's Sweet.............. 142 Drotge's Bemty of Iritis.........21\}

Dawson's Cluster.............. 142 Dredge's Fair Maid of Wishford... 14!

Dar................... 142 Drerlge's Fame............ 14!

Daiton.................. 142 Drerlge's Folden Pippin......... 14!

J) Jimutigne................ 10; Diedge's White Lily. . . . . . . 144

De. Britugne... . . . . . . . . . 11. . Du Halker. . . . . . . . . . . . 150

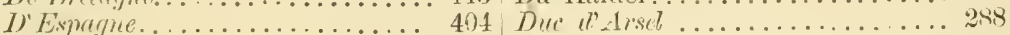

If Ect ................ 148 Duchess of Oldenburgh........ 14!)

De Gint.Jutien. . ............ 34.) Dnehesse de Brabant . . . . . . . 149

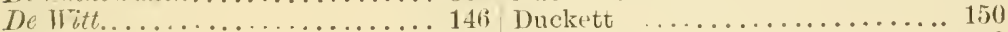

Defiance................ 14: Diffiell Pippin............. 150

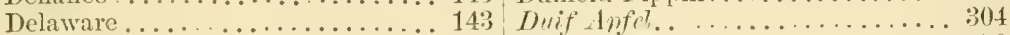

Delencre ................ 319 Duke of Beaufort's Pippin. . . . . 150

Delicht............... 14.) Duke of Devonshire ........ 150

Democrat................143, 144 Dulce Doman ............ 151

Der cumentin............... 120 Duling... . ............. 1:30

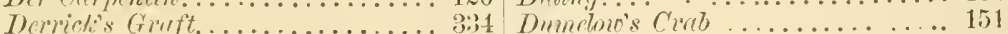

I)

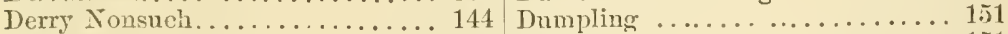

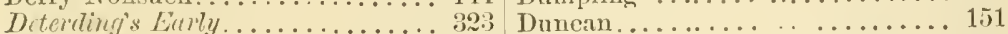

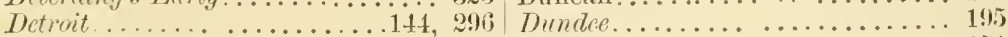

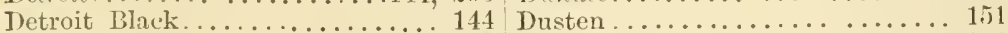

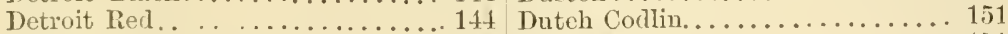

Deronshire Puckland ......... 144 Duteh Nignonne............. 151

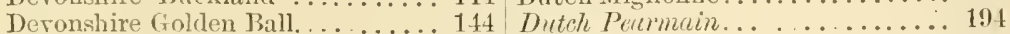

Devolshire Quarrenten......... 145 Duteh Tulip ............... 387

Devonshive Queen............ 14.5 Dutches County Siceet... ..... 417

Devonshire Red Streak ........ 145 Dnzenbury .............. 152

Deronshire Wilding.......... 145 Dyer or Pomme Royale....... 15:

Dickskill $\ldots . . .14 \pi$

Dickson's Einperor. ... . . . . . . 145 Earl of Farmontlis Pearmain.... 297

Diel firmolst. . . . . . . . . . . 145 Erly Chandler . . . . . . . . . 15:3

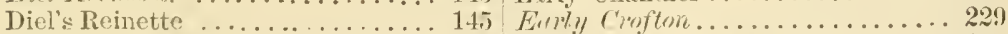

Dietzer Rothe itandel Reinette... . 145 Emly Frruch Reinctte...... . . . 15:3

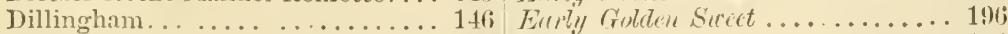

Jrinsmore. . . . . . . . . . . 144 Early Harvest.............. 15:;

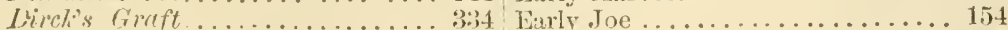

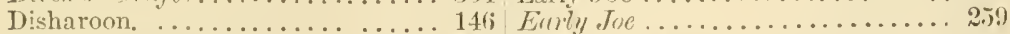

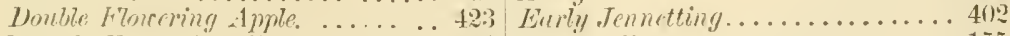

Double Flowering Chinese Crab. . . 42:3 Early Julien. . . . . . . . . . . . 15.

Double White Siberian Crab. . . . 42:3 Early Long Stem . . . . . . . . . . 155

Dobb's Kernel Golden Pippin. .... 146 Early IIarrow ... . . . . . . . . . 15is

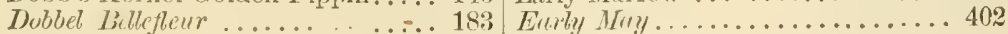

Doctor................. 146 Early Nonjareil............. 15i 


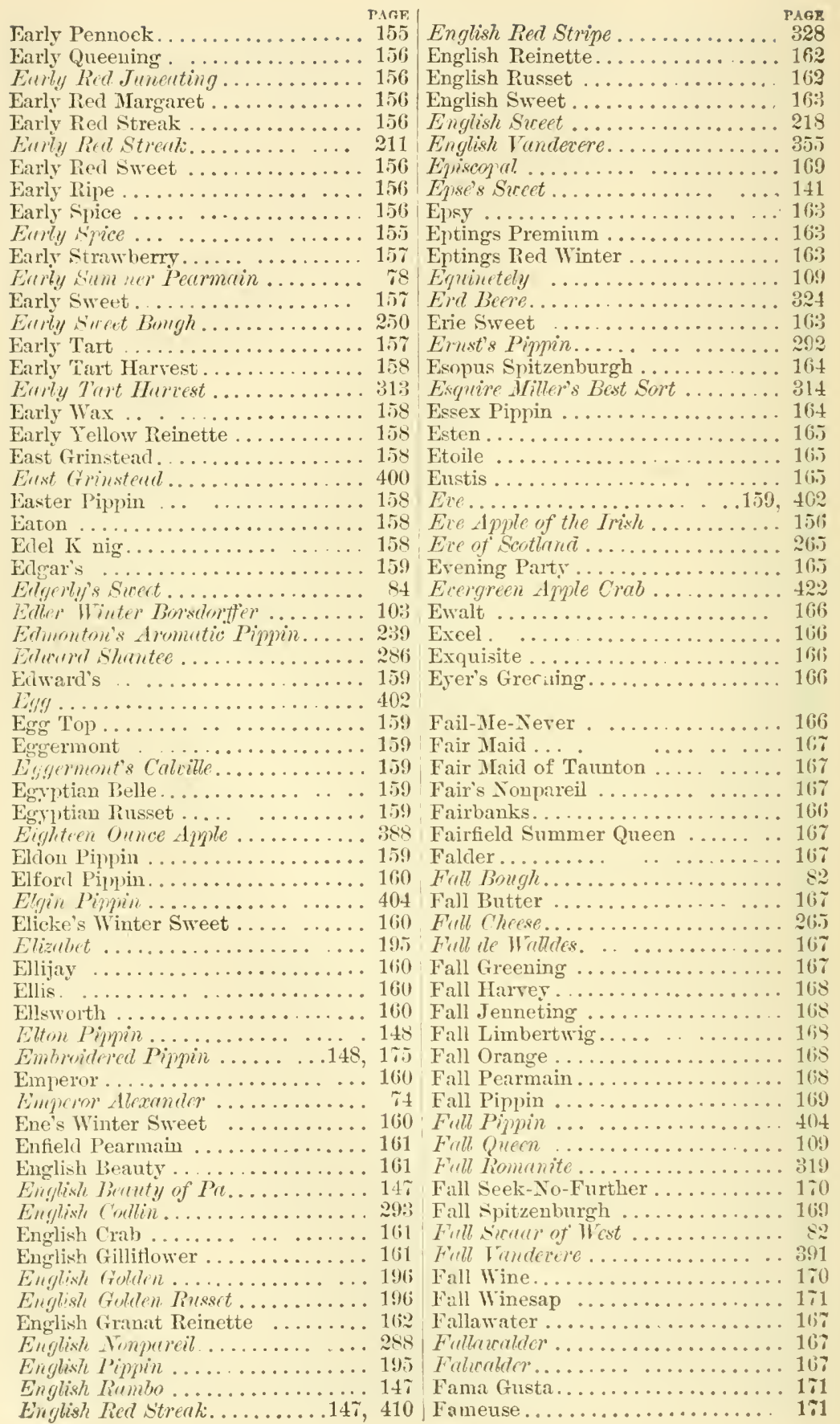




\begin{tabular}{|c|c|}
\hline & \\
\hline$\ldots \ldots \ldots \ldots \ldots 172$ & orest Styre \\
\hline$\ldots 172$ & .......... 3(i.j \\
\hline$\ldots \ldots \ldots \ldots \ldots 173$ & Fonecer Pippin \\
\hline arleigh Pippin............... 173 & $\ldots \ldots \ldots \ldots \ldots, \quad 180$ \\
\hline Farley Pipquin . . . . . . . . . . . 173 & Forman's Crew. . . . . . . . . . . . 180 \\
\hline Farley's Red .............. 173 & Formosa Pippin............... . 33:3 \\
\hline Furos .................. 205 & Fonnerrilder ............... 167 \\
\hline Farrar's Summer............. 337 & Forsyth (not of Coxc) ......... 158 \\
\hline$\ldots \ldots \ldots \ldots 170$ & Forsythe's Secdling............. \\
\hline Father ................. 174 & $\ldots \ldots \ldots \ldots \ldots$ \\
\hline Futher Apple................. 306 & 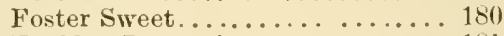 \\
\hline Faust ................ 174 & Fouldon Pearmain ............. \\
\hline Faust's Winter............... 174 & Foundling. \\
\hline avorite ............... 174 & Fourth of July............. \\
\hline Russet .............. 174 & 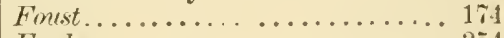 \\
\hline ns Pippin ............ 174 & 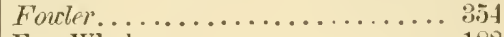 \\
\hline Federal Pearmain... & 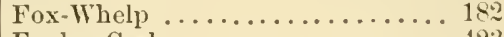 \\
\hline Feleh ............. & Crab ............... \\
\hline Fell's Winter Sweet & $n t \ldots \ldots \ldots \ldots$ \\
\hline Fenley. . . . . . . . . . . . . . . 175 & $\ldots \ldots \ldots \ldots \ldots \ldots \ldots$ \\
\hline movillet Jaune... & boise ............... \\
\hline uillet Gris............. 175 & Framboos... \\
\hline uillet Jaume .......... 175 & chot. \\
\hline illet Rouge............ 175 & 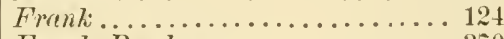 \\
\hline$\ldots \ldots \ldots 386$ & 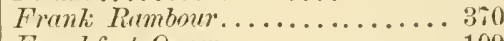 \\
\hline$\ldots \ldots \ldots \ldots 175$ & fort Queen ..... \\
\hline$\ldots \ldots 175,176$ & in's Golden Pippin........ \\
\hline is Pippin .............. 174 & 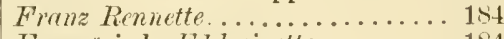 \\
\hline Fett.................. 170 & sche Elelreinette......... \\
\hline$\ldots \ldots \ldots \ldots \ldots 176$ & $\ldots \ldots \ldots \ldots$ \\
\hline Findlicy Apple..... & ud Thaw..... \\
\hline Findley................ 175 & nt Pippin ...... \\
\hline$\ldots \ldots \ldots \ldots \ldots \ldots 176$ & $\ldots \ldots \ldots \ldots$. \\
\hline$l_{i}$ s Seedling ............. 176 & h Belltlower ........... \\
\hline$y \ldots \ldots \ldots$ & ch Crab .............. 189 \\
\hline Last. . . . . . & ch Crreb...........158, 27:3 \\
\hline$\ldots \ldots \ldots 176$ & Conpareil............. \\
\hline hkill Beanty .... & h Pippin............. \\
\hline$\ldots \ldots \ldots 17$ & French Pippin ..............184, \\
\hline Five Crmoned Pippin .......... 255 & h Pippin of Indiana ........ \\
\hline Flake's Fall ................ 177 & nette............. \\
\hline$\ldots \ldots \ldots \ldots 177$ & set $\ldots \ldots \ldots \ldots \ldots \ldots 184$ \\
\hline einette ......... 178 & I's Sweet. ............. 184 \\
\hline . . . . . 127 & $\cdots \cdots$ \\
\hline ... 178 & ind Reinette.......... \\
\hline .. 306 & Pippin ................ $26 . j$ \\
\hline ... 178 & itcher.............. \\
\hline t's Nompareil .. & $n \ldots \ldots \ldots \ldots . . . .$. \\
\hline . 178 & Door ............... 18 \\
\hline int Russct ....... & 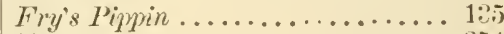 \\
\hline a............ & Fuller. \\
\hline 'ence Pippin .... & Fullerton Sweet... \\
\hline .. 179 & 185 \\
\hline . . 179 & Strawl \\
\hline .. 179 & \\
\hline$e t-\Lambda o-F u r t h e r$. & Funklk \\
\hline ing Spitzenburgh. & \\
\hline . 179 & \\
\hline e's Nonpare & onker Gold Reinette........ \\
\hline . 179 & $\ldots \ldots \ldots \ldots$ \\
\hline .179 & - 186 \\
\hline 101 & Gerden Alple.. \\
\hline & Garden Royal. . \\
\hline
\end{tabular}


Garden Stripe............... 187

Garden Sweet

Gurdiner's Apple.

Gardne1 Sweet.

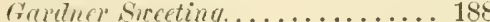

Gardner's Sweet Pearmain. . . . . . . 188

Ginnoie Apple.............. 134

Gartet Pipmin ............... 108

Garrettson's Early............. 188

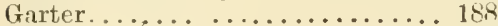

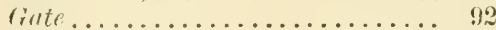

Gault's Bellflower............ 188

Gaumont ................. 188

Gay'x Romanite............. 302

General Grant. . . . . . . . . . . . . 42;

General Haskell. . . . . . . . . . . 188

Generule ................... 298

Genesee Chief................ 188

Gencm Pearmain. . . . . . . . . . . . . 368

Geneva Pippin.............. 18!

Gonntting............... 402

(ientle's Rarge Red............ 189

George..................... 18!

Genrgit June . . . . . . . . . . . . . 11

Gestreifter Sommer Zimmetapfèl. . 19

Gewiss Good .................. 19

Gewiss Guth................. 190

Giant...................... 190

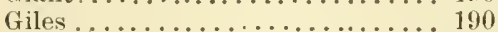

Gillett's Secdling.............. : \$40

Gilpin. .................. 191

Ginetting ............... 402

Gipson's Kentucky. . . . . . . . . . . 191

Gipson's Kentucky Scedling........ 191

Girkin Pippin .............. 417

Gibere lionge................. 87

Glacé de Ĺélande................. 401

Gladney's Red................ 191

Glammis Crstle................ 381

Glanz Reinette............... 191

rzezenwood Gloriv Munuli. . . . . . . . 191

Gleason Sweet................... 191

Glendale................... 191

Gloria Mundi. . . . . . . . . . . . . . . 191

Glory of England............. 19?

(ilory of the West............. 192

Ghory of Tork................. 383

Glowester Prormain.......... 127

Gloucester White............. 192

Goble Russet. . . . . . . . . . . . 192

Gogar Pippin............... 192

Golay ....................... 192

Gold Reinette von Bordeaux. . . . . 197

Golden.................192, 424

Gollen Apple................. т т

folden Ball. . . . . . . . . . . . 192

Golden Burr. ............... 198

Golden Drop............... 135

Grolden Goss................... 193

Grolden Harvey. . . . . . . . . . . . . . 193

Folden Knob. . . . . . . . . . . . . . 198

Golden Lustre. ................... 19:

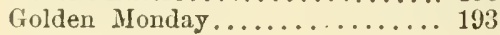

Golden Noble .................... PAs:

Golden Noble................ 193

Golden Nonpareil. . . . . . . . . . . . 194

Golden Pearmain. .............. 194

Golten Prormain............. 12i

Golden Pippin.............194, 19.3

Golden Pippin... .76, 92, 109, 258, 294

Golden Red................ 19.j

Golden Reinette.... . . . . . . . . 19. 19.

Golden Reinette of Tanderlaans.. 19:j

Golden Russet. ................ 196

Golden Russet.................. \%6,

Golden Russet of Massachusetts... 196;

Golden Seedling.............. 196;

Golden Svice................. 152

Golden Streak . . . . . . . . . . . . 194

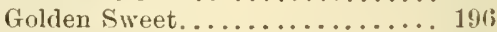

Golden Sircet. . . . . . . . . . . . . . 290

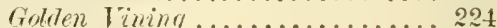

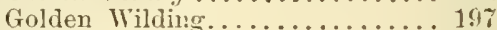

Golden Worcester............ 197

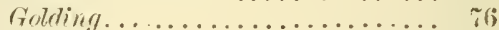

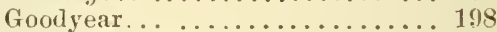

Goodyen's Sectling............. 198

Gooseberry.................. 198

Gooseberry Pippin............. 198

Gould's sweet................ 198

Governor.................. 198

frovernor Charter.............. 198

Govermen Clanter's Sedibig......... 198

Gouden .................. 286

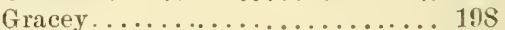

Graftom Srcet. . . . . . . . . . . . . 349

Gruhamis Rel Warrior. . . . . . . . . 28 28

Grand Suchem................. 144

Grondfather................. 129

Grandmother.............361, 414

Grandmother's Apple............ 199

Grange... . . . . . . . . . . . . . 198

Grange's Pearmain. . . . . . . . . . . 199

Ginnge's Pippin.............. 199

Granjte Beauty............... 199

Graniwinkle ................ 199

Givnny But.................. 111

Granny Earle................. 199

Crupe Time................... 114

Grau Osnabrucker Reinctte...... 2910

rrome Perturiesivelue lieinette..... 310

Gramue Franse Remnett......... 412

Grove slije................. 199

Grarenstein. . . . . . . . . . . . 199

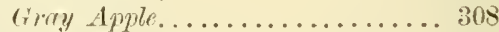

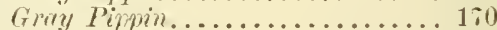

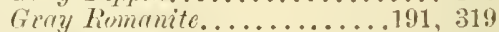

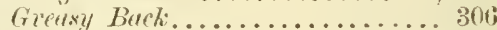

Greasy Piptin..................

Great Pearmain............... 413

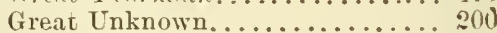

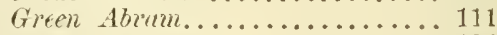

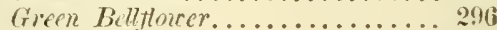

Green Cheese..................... ?01

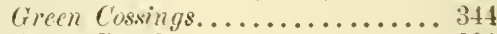

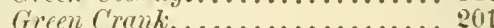

Green Domine................ 201 


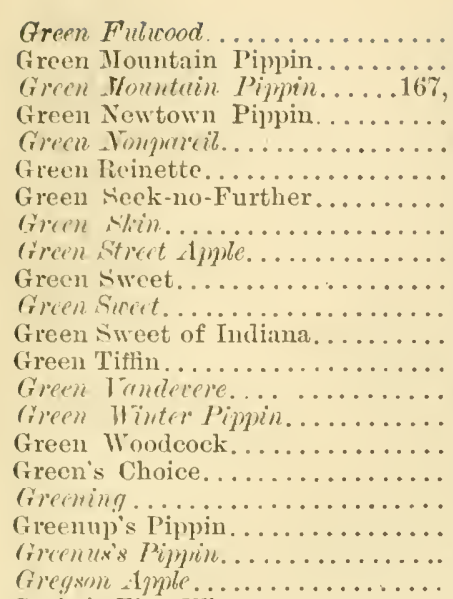

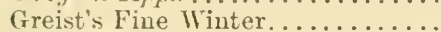
Grey Canada Reinette...

Grey French Reinette...........

Grey Leadington................ . . . . . .

Grey Leadington Pippin.......... Gres Reinette................

Greyhouse .

Griffith...................... 204

Grimes Goldcn................. 205

Grimes' Golden Pippin......... 20.5

Grindstone................

Grise....................308

Groene Franse Renette......... 202

Groene Renet...............202

Grooveland Sweet............206

Gros Api Roune............... 241

Gros C'aur de Pigeon............ 304

Gros Faros................... 205

Grosh ...................20. 20.

Grosse lisincte de ingleterre...... 115

Grossr) Cossclar Reinette........ 151

Grosster Edller Prinzessinapfel. . . . . 314

Givoton .................... 181

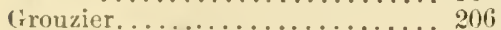

Grumen. Pippin.............. 9

Grummane Pippin.................. 97

Grume Reinette...........202, 288

Griüuling wn lihode Island....... 332

Gruver's Early. . . . . . . . . . . . . 206

Guernsey Pippin............. 206

Gullett..................... 200

Gully....................206

Gully....................2(in)

Gntivy....................20

ITar.s. . . . . . . . . . . 223, 259

Habersham's Pearmain. . . . . . . . 206

Hagloe. .................. 3107

Hagloe Crab. . . . . . . . . . . . . 206

Hague l'ippin. . . . . . . . . . . 207

Hain..................... 207

Haley................... 142
PAGR

Hall...................207

Hall Door. . . . . . . . . . . . . . . $\approx 07$

Hall's Red.................... 207

Ihell's Scedling. . .............. 207

Hall's Sweet.................. 208

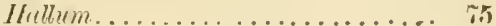

Jambleton Deux Ans. ........... 208

Himilton. . . . . . . . . . 208, 305

Hammond . . . . . . . . . . . . 208

Hompslive Girening........... 350

Hampstave Yellon............. 240

Hampton Bellflower. . . . . . . . . . 2 208

Hampton's Fall Sweet.... . . . . . 208

Hampton's Honey Sweet. . . . . . . . 208

Hampton's Late Sweet. . . . . . . . . . 209

Hampton's Russet. . . . . . . . . . . 2099

Hampton's Siberian Crab. ....... 424

Hancock. . . . . . . . . . . . . . . 209

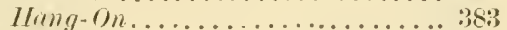

Hannah. . . . . . . . . . . . . 209

Ilanover Sodling............. 89

Ifanwell Souring. . . . . . . . . . . 209

Harbord's Pippin. . . . . . . . . . 209

IIandingham's Russct. ............ 305

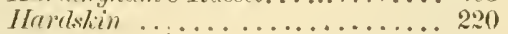

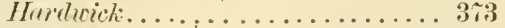

Hare ........................... 209

Hargreave's Green Sweet. ....... 210

Urikness Nero Facorite.......... 326

IInmony. ............... 155

Harnish .................. 210

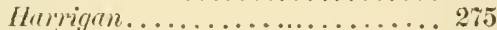

Harris................... 210

Harrison. .................. 210

Harry Sweet .............. 210

IIurtford. . ............... 220

Hartford Sweet.............. 210

Harvest Red Streak. .............211

Harvey .................... 211

Harvey's Pippin ................. 211

Harvey's Wiltshire Defiance....... 2!1

Haskell Sweet. . . . . . . . . . . . 211

Haute Bonte............... 212

Haverstrano Pimpin............ 368

Ilawberry Pippin.............. 219

Hawley................. 25

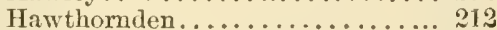

Hay Bors.................. 213

IIry's Ii inter................4 410

Hriymaker...................... 140

Heaster. .................. 215

II ector ...................213

Heivle's Winter Succet.......... 255

Ileidrlocher. ................ 224

Ilitige Juliaves Apfol........... 345

Itrister . . . . . . .......... 215

Helen's Favorite ............. 213

Hemphill ................ 213

II

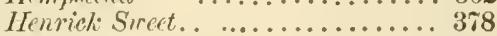

Henry Apple................ 213

Henry Sirect................. 378

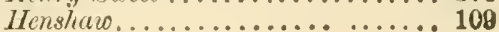


Henrood ................... 213

Hepler .................... 213

Herbstrich Apfel............... 298

Herefordatire Golden Pippin...... 194

Herefordshire Pearmain......... 214

Iterfordshive Qucening............ 137

IIerefordshire Red Streak........ 328

Herman .................. 214

IItrmann................. 214

Hess...................... 214

Hetterich................. 214

Hewe's Virginia Crab............ 214

Hewitt's Sweet............... 215

Hick's .................... 215

Hick's Funcy...................... 155

Hiester.................. 215

Higby Sweet................ 215

Highlander . . . . . . . . . . . . 216

Hightop .................. 216

Hightop Sweet.............. 216

Hill's Farorite ............. 217

Hill's Sweet................ 217

Hilton..................... 217

Hinekman ................... 284

Hinnersley................. 217

Hoary Morning. . . . . . . . . . . 218

Hobb's Sweet................ 218

Hockett's Sweet...................... 218

Hocking ....................... 384

Hodge's Limber 'Twig............ 218

Hog Island Sweet.............. 218

Hogan................... 14\%

Hogpen....................... 168

Holbert's Victoria............ 218

Holcomb.................. 218

Holden........................ 168

Ilokden Pippin .................. 16 s

Hollady .................... 219

Holland Pippin............... 219

Holland Sweet............... 219

Hollandbury...................... 219

II

Hollow Core ............... 219

Hollow Core..................... 321

Hollow-Cored Pippin.............. 296

Hollow Crown................ 220

Holluno Crown Pearmain........... 25.

Hollow Crown Pippin.............

Hollow-Eyed Pippin............ 220

Holly .......................

Holmes. .....................

Holmes's Sweet.................

Holsten Sweet............... 2:20

liominy ................... 350

Hommucher Apfel............... 140

Ilomemaker Pippin............... 140

Honey Greening ............... 2:1

Homey Greening............... . 20

Honey Sweet................ 221

IIoncy Siccet...............221, 404

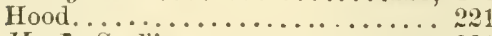

Howets Seedling .................. 221

Iooker....................21

Hoopes.................. 201

Hoover ....................221

Hopkins . . . . . . . . . . . . . . 222

Hopper................... 222

Hopsey. . . . . . . . . . . . . . . . 20

Hormead Pearmain.......... 222

ITormead Pippin. . . . . . . . . . . . 222

Horn. . . . . . . . . . . . . . . 223

Herrrex's Pearmain.............. 181

Horse. . . . . . . . . . . . . . . 175

Horse Apple................ 22:3

Horse Block. . . .............. 265

Horsham Russet............. 223

Itor:sley Pippin. . . . . . . . . . . . . 219

Hoskreiger ................ 224

IImse. .................. 170

Housum's Red............... 224

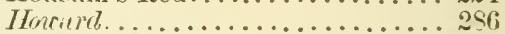

Hencrird Pusset. .............. 123

Howard's Edgemont............ 224

Howrerds Sicet............... 84

Howburry Pippin................ 219

Houce Apple ................ 415

Hove's Russet................. 342

Honcer................... 170

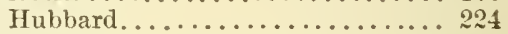

Hubburd................. 286

Hubbard's Pearmain .......... 22.1

Hubburd's Russet Pcarmain....... 224

Hubbard's Sugar............. 224

Hubbridaton .................. 224

Hubbardston Nonsuch.......... 224

Hubbardton Pippin ........... 225

Hudson Red Streak ............. 235

Hughes.................. 225

Hughes' Golden Pippin. . . . . . . . 225

Hughes' Tirginin C'rab........... 214

Hull Blossom............... 226

Hull Sweet. . . . . . . . . . . . . . 220

Hunge. . . . . . . . . . . . . . . 226

Hunger. . . . . . . . . . . . . . 226

Hunt.................... 226

Hunt's Connecticut ............ 226

Hunt's Derx Ans. . . . . . . . . . . 220

Hunt's Duke of Gloucester. . . . . . 227

Hunt:s Fine Green Pipmin........ 201

Hunt's Green Vertocr Pippin ..... 201

Hunt. Nomperteil. . . . . . . . 22\%. 298

Hunt's Russet............... 227

Hunthouse. . . . . . . . . . . . . 226

Hurlbut . . . . . . . . . . . . . 2.

Hurlbut stripe. . . . . . . . . . . . . . .

Hurlbut sireet............... 163

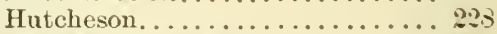

Hutching's Scedling................ 340

Hutchison's Winter Sweet....... . 4:1

Hutton Square.............. 2.28

Hyde's Sicet. . .............. 416

Hyslop . . . . . . . . . . . . . 4. 421

Imperial. ............... 224

Imperial Tandevere................ 391

Indeed Good.................. 190 


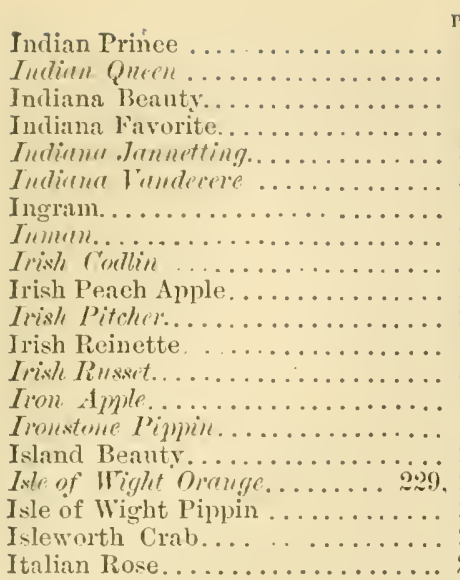

Jabe

Jahez Sweet .

Juck A imple.

Jackson

Jurlesum ipple ............121, Jackisone Ried. . . . . . . . . . . . . 2

Juchermis Red .............. 920

Jacques Lebel . . . . . . . . . . . . . . . . 2: 2:30

James River . . . . . . . . . . . . . . 40y

Jumes lierer. . . . . . . . . . . . . . 25:3

Jane... . . . . . . . . . . . . . . . 2:230

Jenuaren ................ 115

Jarminite . . . . . . . . . . . . . . 2:30

Jefferis . .................2: 0

Jefferson County ............ 2:31

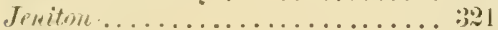

Jenkins. . . . . . . . . . . . . . . 2:31

dennett .....................21

Jenutting ................ 40.2

Jenning's Sweet. . . . . . . . . . . 2:31

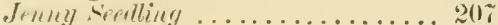

Jizery blenti. ............... (1!)

Jersey Grefning. . . . . . . . . 2906, 3:32

. Tersey Pippin .............. 2:31

.Jersey Sweeting............. 2:31

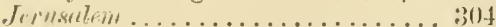

Jewett's Best. . . . . . . . . . . . 23:2

Jewett's Fine Red . . . . . . . . . . 232

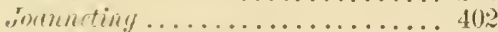

frommettries Prinette ........... 140

Swe Berry ................. 28.j

Joel .................... 2:3:

John Carter................. 2:3

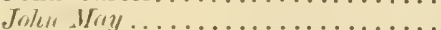

Jun. Sinr $q) x^{\prime} \ldots \ldots \ldots \ldots \ldots \ldots \ldots \ldots$

John's Swect..................

Johuson . . . . . . . . . . . . . .

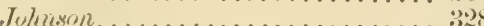

Johnson Russet .................. 23:

Johnson's Fine Winter ......... 490

Jolenstem's Fiverite............. 2jis

Jolly Beggar ................
PAFF

Jonathan .............. 232

Jomes' Pimin................ 168

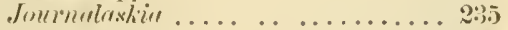

Jubilee Tippin . . . . . . . . . . . 2. 2:4

Judge Andrews. . . . . . . . . . . . . . 2:34

Juicy Bite . . . . . . . . . . . 2: 2:4

Julian . . . . . . . . . . . . . . .

Julirn . . . . . . . . . . . . . 2:34

Suling ................... 2:14

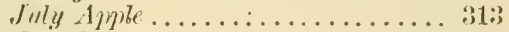

Suly l'ippin ................ 15:3

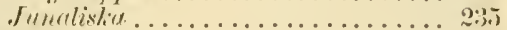

Junaluskee. . . . . . . . . . . . . 23, 23,

June sirecting ................ 320

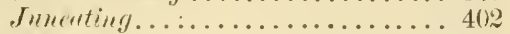

Jemerting . . . . . . . . . . . . . . 402

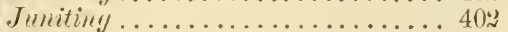

Kaighn's Spitzenburgh. . . . . . . 23.

Kane..................... 28.5

Keddleston I'ippin.......... 23.

Keeping Red Streak. . . . . . . . . . 23.5

Keeping Russet.............. 2:36

Keim................... 2:30

Keiser. . . . . . . . . . . . . $2: 0$

filley White.............. 92

Kelsey................. $2: 30$

helsey ................... 220

Kelsey Sweet. . . . . . . . . . . . . 2:30

hielte . . ............... 101

Krmpster's Pipin ............. 100

Keneys sicret................ 210

Kennebec Russet . . . . . . . . . 2:36

Kemmedy's Red Winter. . . . . . . . . 2: 2:36

Kenney. . ................

Kenrick................ 2:3

Irovicli's futumn. . . . . . . . . . 2:37

Findiclis Ped Autrmun .......... 2:37

Kent ................... 2:38

Kentish Froaking........... 2:37

Krutish Brondinf. . . . . . . . . . 109

Kentish Fill-Bitsket...........2:77

Kentish Pippin............ 2:;

Kentucky................2:

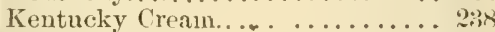

Kentucky King.............. 2:3s

Kétucley Piqniu. . . . . . . . . . . . 9.

fientucliy preon. . . . . . . . . . . . 109,

Kentueky Red Streak.......... 2:34

Kentucky siweet............. 2:38

Kerry Pippin. . . . . . . . . . . . . $2: 39$

Keswick Corllin. . . . . . . . . . . . . . 2:3!)

Ketchum's Favorite. . . . . . . . . . . . : $: !$

Kikita... . . . . . . . . . . . . . 2t0

Kilham Hill. . . . . . . . . . . . . . . 240

3.)(; Kinellan .................240

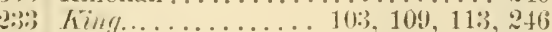

hing $1 p^{2} e \ldots \ldots \ldots \ldots \ldots \ldots \ldots \ldots 241$

liveg Gerrge the Thiml.......... 103

king Philip..........................

0 King of the Pippins...........240

j) King Tom .................. 241

234 King of Tompkins County......... 241 


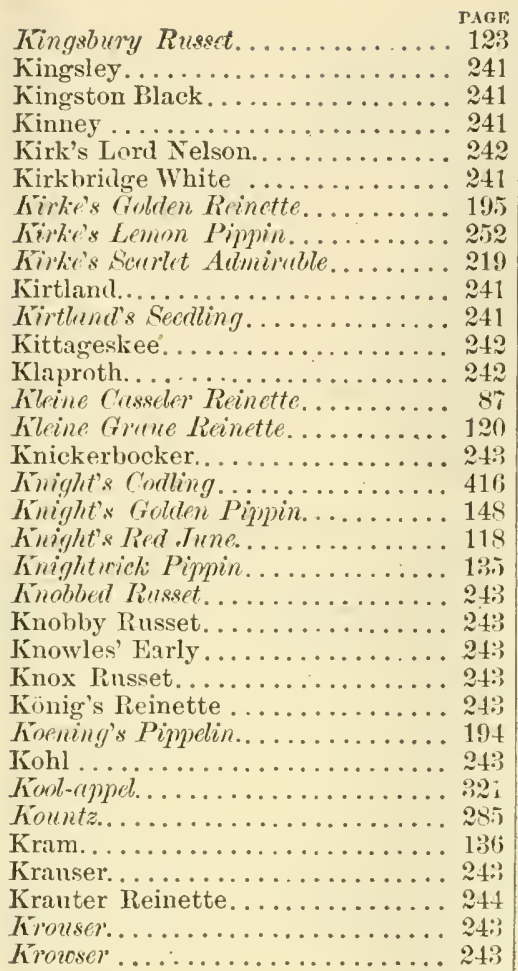

La Canelle.................... 190

La Mire des Pommes............ 321

Iabute................... 244

Lacker.................244

Lacy's Nompureib. . . . . . . . . . . 155

Ladies Blush.............186, 215

Inthes' Fivorite. . . . . . . . . . . 109

Ladies' Sreet...............246, 378

Lady Apple............... 244

Lady Blush................. 245

Lady Cheek Siceet.............. 215

Lady Crab............... 424

Lady Finger. . . . . . . . . . . . . 24.

Lady Finger. ............... 2:3.;

Lady Fitzpatrick.............. 120

Lady de Grey's............... 237

Lady Haley's Nonsuch.......... 246

Lady Wrakington.......132, 257,418

Lady of the Wemyss........... 246

Lady's Delight............. 2 240

Lady's Fancy. . . . . . . . . . . . . 24k

Lady's Finger............... 402

Lady's Seerling............ 24's

Lady's Sweet. ................ 24;

Lady's sicesting............. 246

Lady's White. ................. 247

Lafayctte................. 247

Lake
Lamb Abbey Pearmain

Lamb Abbey Pearmain... ........ 248

Lancastive Crab............ 276

Lancaster Crab................... $2 \pi$

Lancaster Greening. ........... 248

Lancrester Pippin.............. 248

Lamerester Queen...................

Lancaster Sweet............. 248

Landon...................... 248

Lane's Red Streak............. 249

Lane's Sweet. ................ 249

Lansingburgh ................ 219

Laquier....................... 244

Large Black ...................... 144

Large Eurbly Red.................. $32: 3$

Large Full Pippin............. 404

Large Golden Pimpin..........195, 368

Large Rambo................ 319

Large Red Siberian Crab........ 424

Large Rommenite............... 302

Large Striped II inter Perrmain... 363

Large. White Incomparable Crab... 402

Lange White Junenting. .......... 15:3

Large Yellow Bough........... 250

Large Yellow Siberian Crab...... 42j

Large Follow Summer........... 259

Larue's Big Green. . . . . . . . . . 250

Lesting Vandervere........................... 391

Late Bough............... \&2

Late Carse of Gourrie. ............ 384

Late Char.uiter.................. 122

Late Golden Sireet............ \&t

Late Strawberry.................... 250

Late Sreet................ 251

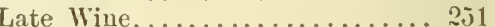

Latham......................... 251

Lauren's Greening............. 2.51

Lawver................... 251

Le Grond Bohemian Borstentfer... 103

Leadington's Grouer Pippin....... 204

Lerenhem ................... 286

Lenther Apple. . ............. 308

Lerither Cout Russet...........293, 349

Leaver.................... 251

Lodge Sweet............... 2...

Lecelis. Red Winter................. 2.2:3

Leicester Sweet..............25

Leithemer Streifling.......... 25:3

Lelend Pippin................ 25:

Leland spice............... 25,

Lemon........................ 338

Lemon Pippin. . . . . . . . . . . 252

Lesher...................... 252

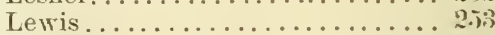

Lewis's Incomparable. . . . . . . . 25:3

Lexington Queen.................. 109

Liberty. . . . . . . . . . . . . . 25:

Libhart................... 28:3

Ligoz..........................

Lily Bucktend.............. 144

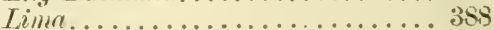

Limber Twig............... . 253

Lincoln Pippin................ $41 \bar{\Sigma}$ 
Lineolnshire lIolland Pipluin ..... P.. 253

Lindenwald. . . . . . . . . . . 254

Lindley's Nonpareil. . . . . . . . . . 254

isppincott Sweet. . . . . . . . . 254

Liprineott's Early. ............ 3\%1

Iitchficld Pimpin.............. 254

Little Beauty.............. 254

Little Pearmain.............. $\%$

Iittle Remanite............. 191

Jittle Tinule rere.............. 391

Loan's Pearmain............. 254

Locy . . . . . . . . . . . . . . 2. 25

Lodgemore Nonpareil. . . . . . . . . 254

Immeton Grulden Pippin.......... 194

London Pippin.............. 25.

London Sweet .............. 25in

Imudon. Winter Siceet........... 25.5

Londonderry................ 144

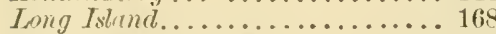

Long Island Pearmain. . . . . . . 2ij.

Iong Island Pippin............ 2i)

Long Island Russet. . . . . . . . . 25.

Long John. . . . . . . . . . . . . . 25.

Long John. . . . . . . . . . . . . . 2:35

Long May. . . . . . . . . . . . . 402

Jong Pertmain................ 235

Long's Red Winter. . . . . . . . . . 256

Long Start. . . . . . . . . . . . . . 25

Long Stem ................ 256

Long Stem Sirect............ 81

Longrille's Kernel. . . . . . . . . . 256

Imp-Sinled Pertmain. ......... 270

Lord Burghtey. . . . . . . . . . . . . 257

Lord Burleigh............... 257

Lorel Guydr's Vextson Pipmin.... 74

Lord Suffield................ 257

Lorick Cluster............... 25\%

Loring Sweet..............2.257

Louton Pippin.............. 257

Louise Renard...............257

Loure Oufen................ 258

Lovalen's Piprin................ 288

Lovett's Sweet.............. 258

Lowell. . . . . . . . . . . . . . . . 258

Jowre Queen............... 258

Luce's Larly Joe . . . . . . . . . . . . . 2599

Lucombe's Pine-Apple. . . . . . . . . 259

Lucombe's Seedling. . . . . . . . . . 259)

Ludwig . . . . . . . . . . . . . . . . . 25 259

Lutticher Ananas Calville....... 79

Lyman's Large Snmmer. . . . . . . . . 25:9

Lyman's Pumplivin sirect. . . . . . . 317

Lyon's Sweet. . . . . . . . . . . . . . 259

Lyscom . . . . . . . . . . . . . 259

McAders's . Tune................ 181

McAfee's Nonsuch. . . . . . . . . . . 260

Mc.1fee's Red................. 260

MLCoy's Pippin................ 260

MIcDaniel .................. 260

MicDowell's Sweet.............260

McHenry ................... 260

McIntire's Suceting.............
MeKin's Vandervere............ 261

McKinley................. 261

II Lellaw. .................. 261

Ke Loueds Fiamily............... 17?

Mackiny sweet................. 260

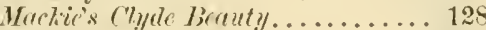

Maclean's Favorite............. 261

ILamber.

Wuddeino.................. 371

Mrege's Johnny. . . . . . . . . . . . . 20:3

Yrignifique ................ 228

Magnolia................... 20.2

Vrignmm Bommm............. 102

Wignoun 1 ipple.................. 114

Wridon's Apple............... 2683

Maiden's Blnsh. ........... 262, 42\%

Muiden's Bosom. . . . . . . . . . . . . 283

Maiden's Favorite. . . . . . . . . . . 26i:

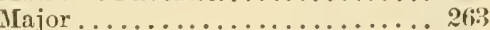

Mala Carle................. 263

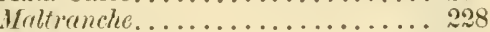

Mamma. . . . . . . . . . . . . . . 2(i:)

Mirmma Beam.............. 92

Ifammoth .................. 195

Mammoth June. . . . . . . . . . . . 2 264

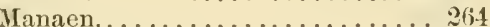

Mangum................. 26.5

Mank's Codlin. ................ 20.5

Mannington's Pearmain . . . . . . . 26.

Manomet . . . . . . . . . . . . . 2 26.

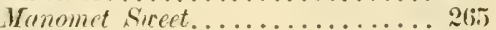

Mansfield Russet ............. . 2(j5)

Marble sweet . 260

Mrtreh's Red Scedling. ............ 266

March's Red Winter. . . . . . . . . . 266

Marengo. . . . . . . . . . . . . . . . . . 425

Margaret . . . . . . . . . . . . . 156

Margarethe Anfel. ............. 15ti

Marril ........................ 266i

Maria Bush .................. 26ti

Muriette Russet. ............. 342

Wrevigold I'immin ................ 294

Marks ................... 2677

Marmalade Pippin............. 267

Jumovo Jippin............... 296;

Marshall ............... 2677

Marshall's Sweet ................ . . . . . . . . . . . .

Marston's Red Winter .......... 20.77

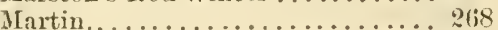

Mrertu . . . . . . . . . . . . . . 26 61

M[artin Nonpareil............... 268

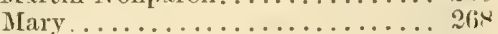

Maryland Beauty............ 268

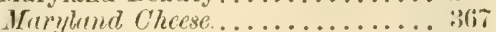

Masten ................. 26.

IFrsten's Secdling............... 26s

Master's . . . . . . . . . . . . . . 268

Master's Scedling. . . . . . . . . . . 268

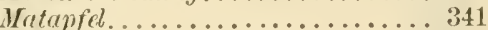

Mutchiless ............... 73, 285

Matlock's Summer. . . . . . . . . . . 2 259

Matson ................... 2fin

Mattamusket. . . . . . . . . . . . 269 


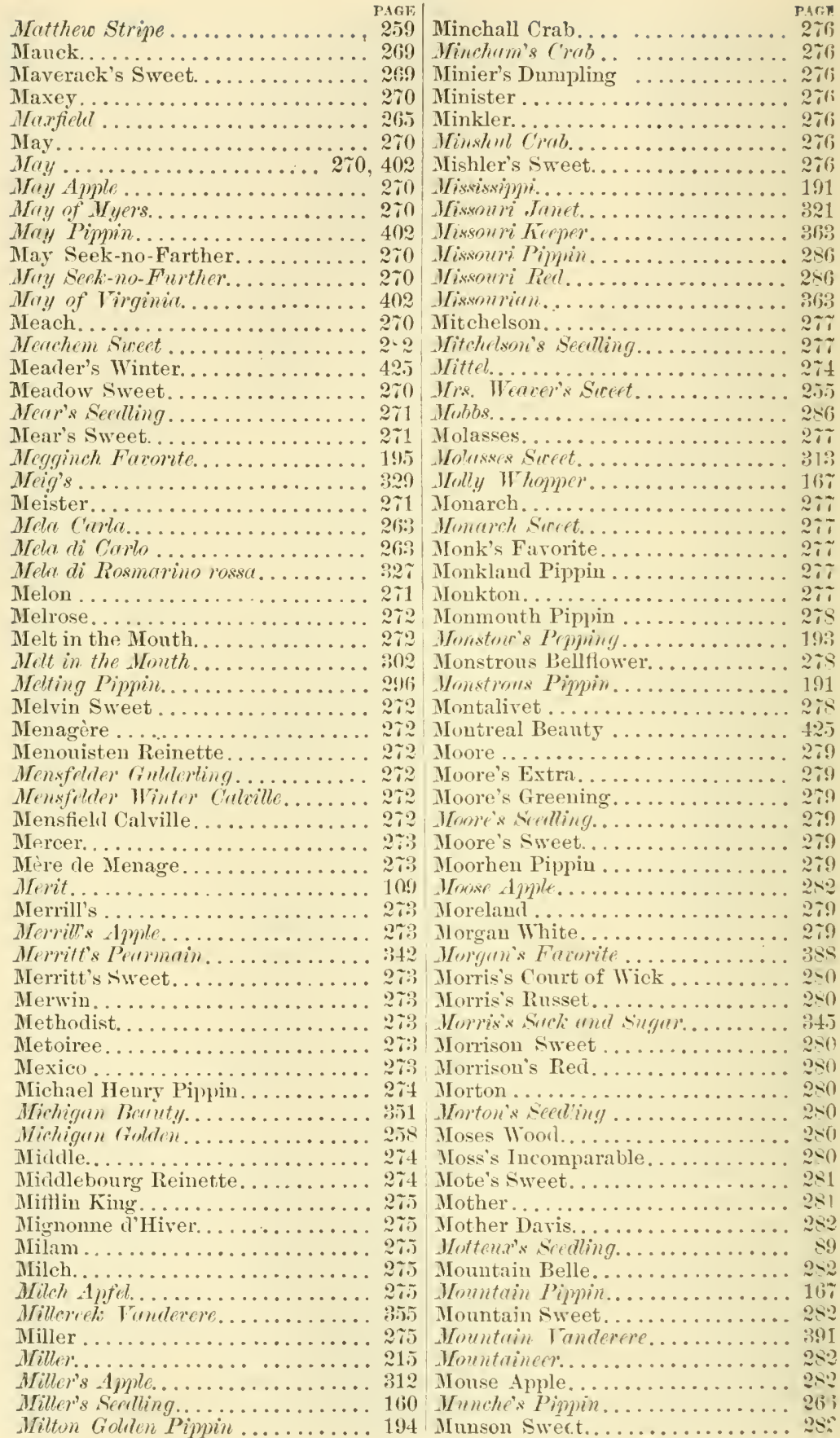


ring

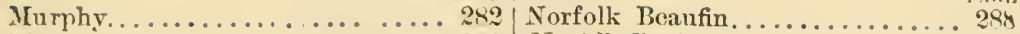

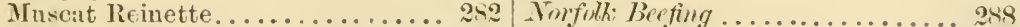

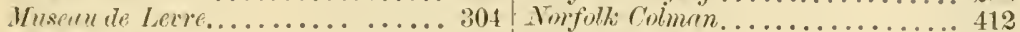

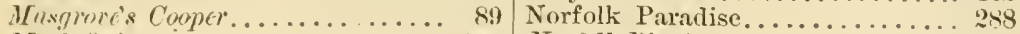

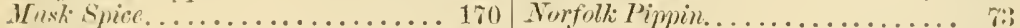

Mustuclom................88:3 Norfolk Stone Pippin........... 289

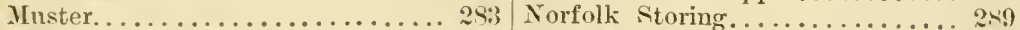

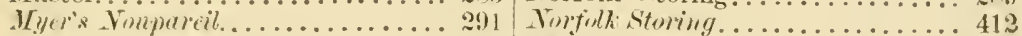

Uy!ntt: Bergumot............ 152 Surth Americun Best.......... 313

Worth Carolina Grening........ 111

Naigle's Winter.............283 Worthein Golden Sireet........ 290

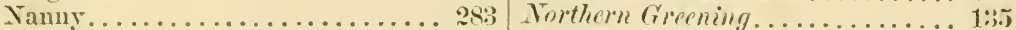

Nantahalee ............... 28: Northern Hurdskin............. 220

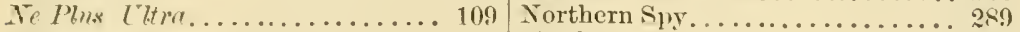

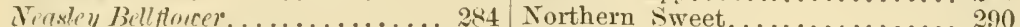

Vectar. . . ............... 28. Northfield Beauty. . . . . . . . . . . 290

Ted..................... 24:3 Nopthoick Pimin........... 100

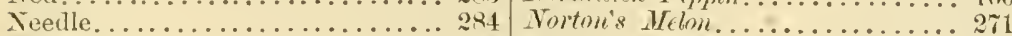

Teedle................ 1is Nottingham Pippin........... 2!)0

Teisley Bellflower............. 284 Nursery.................. 290

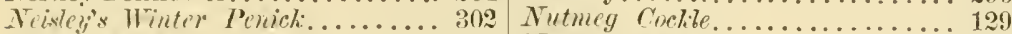

Velken Apfel............... 1:33 Tutmeg Pippin.............. 129

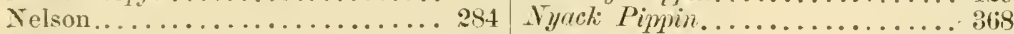

Telson's Codliu. .............. 284

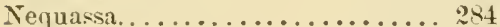

Tequnswi siceet.............. 28t

Teverfail ................. 266

Teverfirl................166. 321

Terersink................ 294

Wex Brmusiciel. . . . . . . . . . . . 14!

Ter Jerxey Red Strocrk.......... 15.j

New Late Reinette. ............ 28.j

Tre London Pimpin............ 2.j.j

Ner Trenparacil.............. 15is

New Rock Pippin............. 28

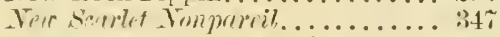

Tew Small Lemon Pipin........ 28.j

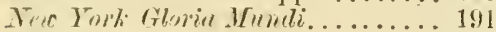

Tic Irirk Greening. ............

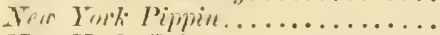

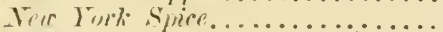

Newark King................

Newark Pippin................

Tiermo sirfeting............ 115

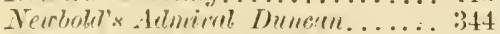

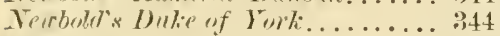

Newlury ................ 24.5

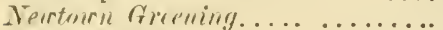

Nertonn Pippin...............

Sewtown Spitzenlourgh...........

Tichols Sweet. . . . . . . . . . . . .

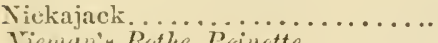

Viemenis Refle Reincte............

Tieman's Red Reinette.......... . . . . . . .

Nix Green................. 248

Toblesse de Gand............. 28s

Frotherd. . . . . . . . . . . . 2:2

Tompareil.................. 248

Vuicparcil d ingleterve........... 288

Nonpareil Pusset............. 288

Yousuch.................. 28k

Nonsuch .................. 288

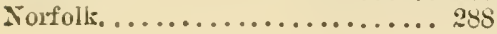

Oakes................... 290

Ont Irimest. . . . . . . . . . . .

Oblong-Fruited Siberian Crab .... 425

Oconee Greening . ............. 291

Ofine. ...................... 291

Ogdensburg................ 291

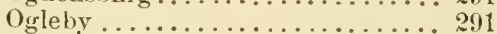

Ohin Beruty.................. 89

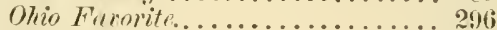

Ohio Nonpareil. . . . . . . . . . . . . 291

Ohio Pippin . . . . . . . . . . . . . . 29)?

Ohio Red Streak. . . . . . . . . . . 202

Ohio Wine.................. 170

Ohlinger.................. 29:3

old English Codlin............. 2993

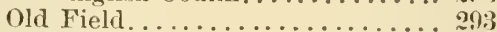

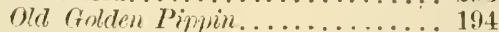

Old House . . . . . . . . . . . . . 29:3

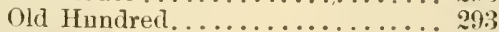

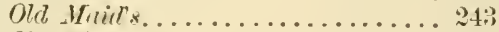

Old Nimpareil. . ............. 288

Old Nomsmeh................ 324

Old Pirrmain. ............ 214, 413

; Old Royal Russet.............. 298

201 Old Town Crab.............. 293

ol.1 Town Pippin............. 29:3

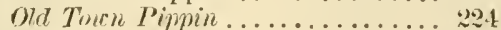

Oldaker's Vear...............

Oline. . . . . . . . . . . . . . . . . 291

Olive ......................

Omar Pasha. . . . . . . . . . . . . . 294

Oristive................... 416

Osceola................... 296;

Oxgoods Farorite. . . . . . . . . . 259

O.kaloosa............................ 296

Oslin .................... 296

Osnabrucker Reiuette.......... 2!

Osterley ................... 297

Osterbey Pippin............... 297 


\begin{tabular}{|c|c|}
\hline & \\
\hline ............297 & Pearmain d Hiver. \\
\hline ............. & Pearsall's Sweet. . \\
\hline ..........294,425 & Pearson's Early... \\
\hline$\ldots \ldots \ldots \ldots 168,258,369$ & ......... 301 \\
\hline Orange Pippin. . . . . . . . . . . 294 & $\ldots \ldots \ldots 301$ \\
\hline Orrenge Pippin.............. 22? & Pecker... \\
\hline Orange Sweet. . . . . . . . . . 295 & $\ldots \ldots \ldots .302$ \\
\hline$\ldots \ldots \ldots \ldots \ldots 282$ & Pelican..... \\
\hline Orrtuge Sireeting.............. 196 & $\ldots \ldots \ldots$ \\
\hline$\ldots \ldots \ldots \ldots \ldots 295$ & Pennock .... \\
\hline$\ldots \ldots \ldots \ldots \ldots 295$ & Pennock's Red Winter............ 30:2 \\
\hline Original Fongareit............. 2ss & Pentusyleariut Cider. \\
\hline Orleans Reinette............ 295 & Pennsybeanirs Red sitreak ........ 410 \\
\hline Orndorf................. 295 & Pennsylvania Sweet. . . . . . . . . . 302 \\
\hline Orne's Early . . . . . . . . . . . . . . . 295 & Prnnsybundue Sireeting........... 302 \\
\hline$\ldots \ldots \ldots \ldots \ldots 296$ & Penusylurnim Vunderere.......... \\
\hline$\ldots \ldots \ldots . \ldots 296$ & Pennsylvania Wine Sap.... \\
\hline Overman's Sweet............. 297 & Peoples' Choice. . \\
\hline$\ldots \ldots \ldots \ldots \ldots 29 \tau$ & Prpin Limon te Gulles. . . . . . . . . 25: \\
\hline Orevi's Golden Beunty........... 402 & Pepin dor........ \\
\hline$\ldots \ldots \ldots \ldots \ldots 297$ & Pequin or Allemena ............ \\
\hline$\ldots \ldots \ldots \ldots \ldots 191$ & Pepin Parminin o Angleterre . . . . 413 \\
\hline Or-Eye............... 109, 25i & Pepin Pamain d Hicer........... 413 \\
\hline Ox Sweet.................... 297 & Pepin Riusse............. \\
\hline Ox Sireet................... 417 & Peremenes... \\
\hline$\ldots \ldots \ldots 347$ & Perry Russet. . \\
\hline Oxnerd l'earmain... & 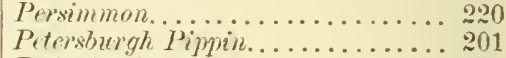 \\
\hline Padley's Pippin. . . . . . . . . . . . . . . 298 & Prit Api Rouge............... 211 \\
\hline I'rulley's Royal George Pippin ..... 2.9s & Petit Jean. \\
\hline Palmer Greening............... 396 & areil......... \\
\hline ........ 298 & Pfirrrer Whalter.............. \\
\hline$\ldots \ldots \ldots 346$ & Pfeifir ......... \\
\hline$\ldots \ldots \ldots 368$ & I'Tiluelelplive Pigmin . . . . . . . . . 169 \\
\hline Paradise Pipmin............. 402 & Philundelplina Serert ............. \\
\hline Parredise Winter Sireet ..........444 & Plilip Kick............... \\
\hline Park Apple ................. . 29s & Phitip's Reinette.............. 1355 \\
\hline$\ldots \ldots \ldots 298$ & Phillippi................. 303 \\
\hline$\ldots \ldots \ldots 298$ & Phillips' Swcet............. \\
\hline$\ldots \ldots \ldots 214$ & .. 304 \\
\hline Parmin Royal............... 214 & Pickarl's Reserve......... \\
\hline Parrot Reinette . . . . . . . . . . 2! & Pickman... \\
\hline Parry's Peammain... & Piclinarn Pipquin........... \\
\hline Passe Pmmme...............314 & 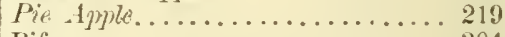 \\
\hline Passe Pomme d'Antomne........ 2. & $\ldots \ldots \ldots \ldots$ \\
\hline Pusse Pomme de C'unade......... 348) & $\ldots \ldots \ldots \ldots$ \\
\hline$\ldots \ldots \ldots 298$ & Pigeon Ronge............ \\
\hline ae Ronge. . . . . . . . 299 & Pigronet Blane........... \\
\hline 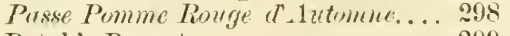 & Pigeonett \\
\hline Patch's Russet & Pigeonette Blene dEt ...... \\
\hline Paternoster Apfel... & Pigeonette Gries de lienest... \\
\hline Paterson's Sweet. & Pigeonette de Ronen.... \\
\hline Paterson's Sirect. & Piketon Russet. . \\
\hline$\ldots \ldots \ldots 26.5$ & Piles Russet. \\
\hline . . . 299 & Pillikin \\
\hline . . 299 & 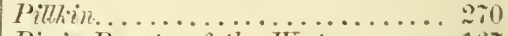 \\
\hline ‥ 299 & Pimis Bianty of the Wist... \\
\hline Peach-Pond sweet & $\ldots \ldots \ldots$ \\
\hline$\ldots \ldots \ldots 300$ & Pine-limple Pipmin..... \\
\hline$\ldots .300,319$ & Pine-Apple Russet...... \\
\hline Pear Lot....... & Pine Creek sweet.. \\
\hline Peur-Tree Lot... & Pine Strawberry... \\
\hline & \\
\hline
\end{tabular}


Pith

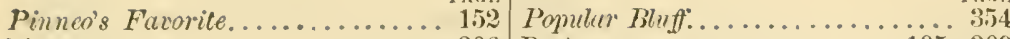

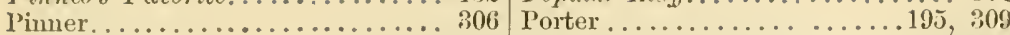

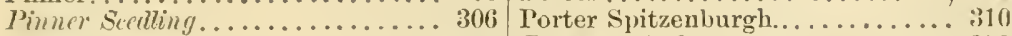

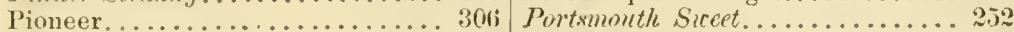

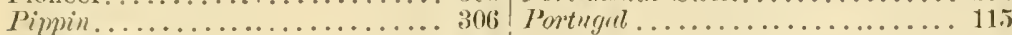

Pitmastm................ 306 Portmgal Gray Reinette........ 310

Pitmaston Golden Pippin........ 306 Posey's Red............... 310

Pitmaston Nonpareil.......... 306 Pnsey's Red Winter Sicet........ 310

Pitmaston Pine-Apple.......... 306 Posteley..................... 310

Pittsburgh Pippin........... 306 P'osteley's Sectling ............ 310

Pittstown Pippin.............. 194 Potpie 1 . . . .............. 411

Pitzer IIIl ................ 316 Potter's Large.............. 310

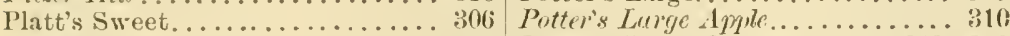

Pleasant Valley Pippin.........307 Pntter's Lmige Seedling.......23\%, 310

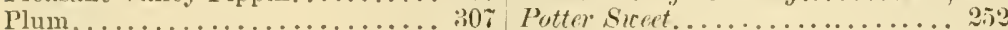

Plymonith Greening............ 270 Pottinger................. 310

Poland.................. 324 Poughkepsie Rulswet........... 162

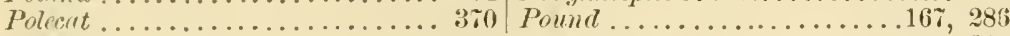

Polheinus................ 979 Pound Cake............... 311

Polivice Peumuin............... 87 Pound Pippin ............... 169

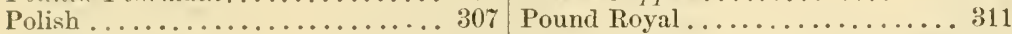

Polly Bright................ 307 Ponmel Royul. . . . . . 169, 195, 369

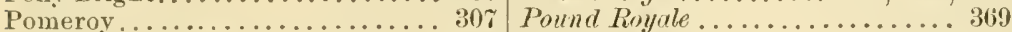

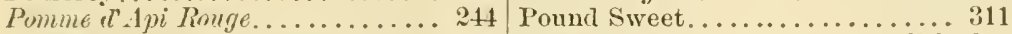

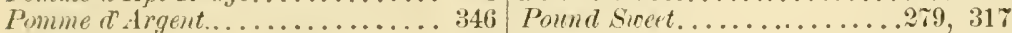

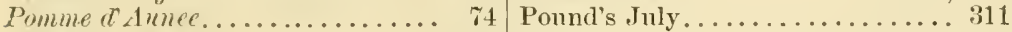

Pomme de Berlin............. 134 Poveshon ................ 311

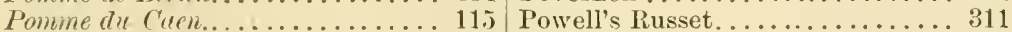

Pomme de Carotive........148. 175 Powers ................. 312

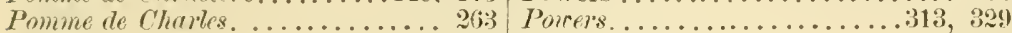

Pomme de Codillae.............. 341 Powers Large................ 426

Ponume de Cuiv.............. 308 Pownal Spitzenburgh ......... 312

Pomme Dorble Agathe.......... 73 Prager...............204, 412

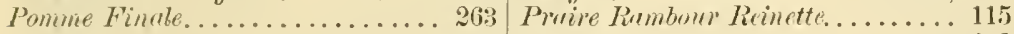

Pomme Gronate............. 162 Prairie Calville.............\$12

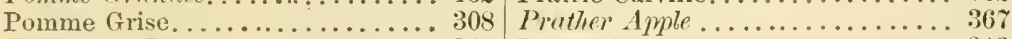

Pomme de funne............ 346 Pratt's Sweet ............. 312

Pomme de Jaune de lo Sitrtha .... 346 President................. 312

Pomme de Lark. ............. 15i President De Fay's Dumorcean ... 31:3

Pommine dle Wulingre.......... 114 Press................... 31:3

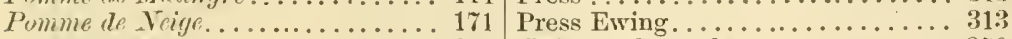

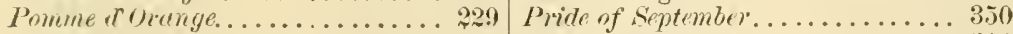

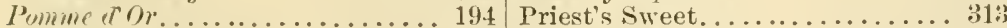

Pomme d Outre Puxse .......... 298 Prisstley's American........... 31:3

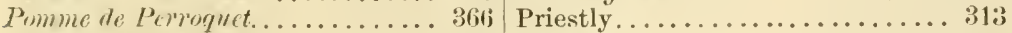

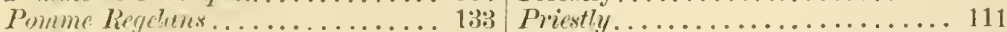

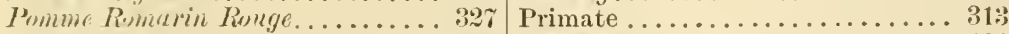

Pomme liose................244 Primiting............... 402

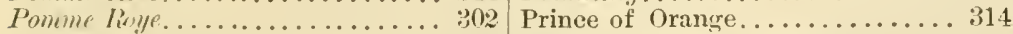

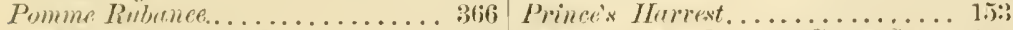

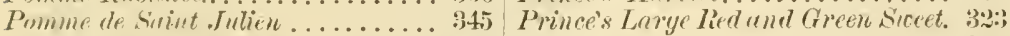

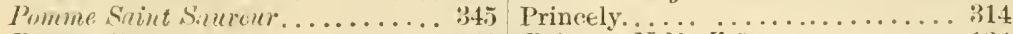

Prmme sivisse. ............. 360 Princess Woble Zuëte.......... 134

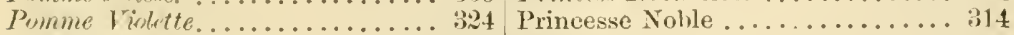

Pomme Water. . ............. 308 Prinesse Woble . . . . . . . . . . . 19.5

Ponme Witer Secct............ 30s Princesse Noble des Chartreaux... 315

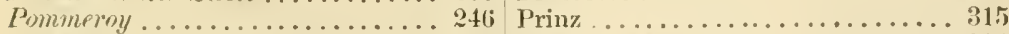

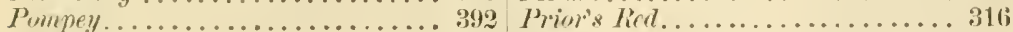

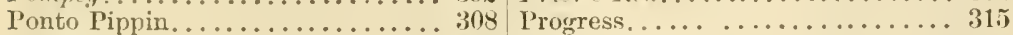

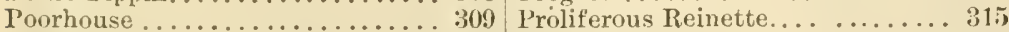

Pope ................... 309 Prolific Beauty ............. 315

Pope's Apple................. 309 Prolific Benuty . . . . . . . . . . 302

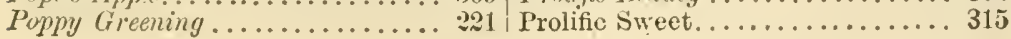


Prop ........................ PAl6

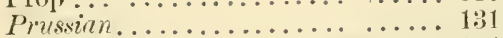

Prussinn Pippin............ 1:34

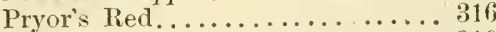

Pucker End................. 31

Pumplin Russet.

Pumpkin Sweet

Pumplin Sireet.

…317

Purple Siberian Crab.

Pushmataha..

Putuan Harrey.

Putnam Keeper.

Puturm Risset.

Putuam Sweet. .

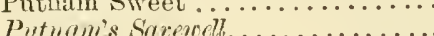

Putneyite.

Pylè: lỉuset.

T)

Quaker...................... 318

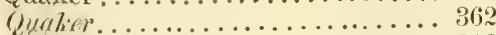

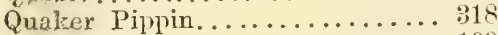

Quern ..................... 10?

Quren Anne..............258, 281

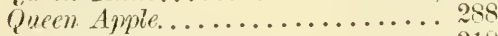

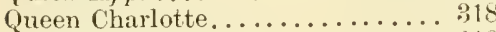

Queen of the Pippins.......... \$18

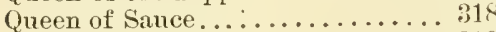

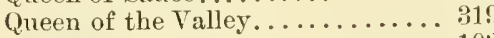

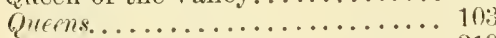

Quince.................... 31!

Tubbit's Hend............... 12i

Pabine.................. 319

Ragan .................... ... . . . . . . . . . .

Rerguris Red. . . . . . . . . . . . . 319

Ram's Homs............... 32

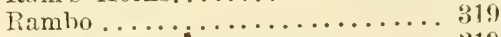

Pombonizht ............... 319

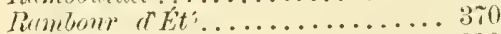

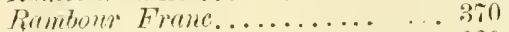

liambour Gros .............. 320

Rrmbonr Gro.............. 370

Riambour Papeleu, . . . . . . . . . 320

Ramboux Rose. . . . . . . . . . . . 321

Rumbour Rouge.............. 321

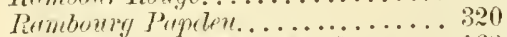

Lumbalelis Red Pumpkin Siecet.... 16:3

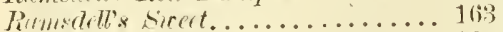

Romsdeb's sireting............ 16:

Rumdril's Red Winter............. 16:3

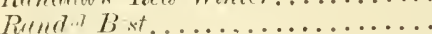

Randel's Best................ 321

Sinritul Sireet............... 274

Rasche .................. 321

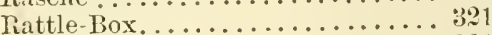

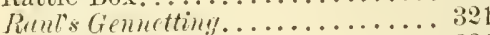

Rumlis Junucting............ 321

Ravelston Pippin.............21

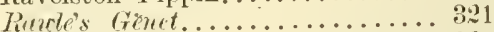

Rawle's Janet............... 321

Racte's Junnet ................ 321

Parcling's Fine Red streak....... rate

$32 \%$

282

288

บ22

$3 \div * 3$

Red Autumn Calville........... 324

Red Balducin.................. 8.

Rerl Belle-Fleur.............. 324

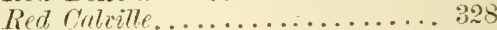

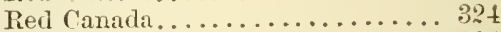

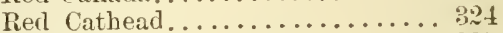

Red Cedar............................

Red Cheek...............90, 325

Red theet. ........................... 16

hed Chpel Pipqin............. 278

Red Codmin .................. 180

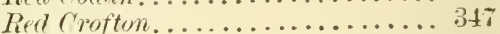

Red Doctor................... 146

Red Frell Piprin. . . . . . . . . . . . 32!

Red Favorite...................

Ped Gilliflower............... 326

Led Gillitloret .............. 1:33

Red Glonin Mindi............. 109

Red and Green Sweet.......... 323

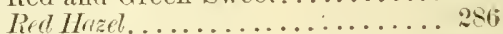

Red Horse.................. 326

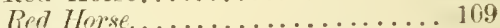

Red Ingestrie. . . . . . . . . . . . . 326

Red Jewell.................. 3206

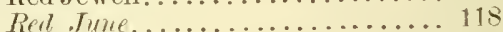

Red June Sireet.............. 986

Red. Junenting..............156. 157

Ped hentish Pipmin............ 2:3i

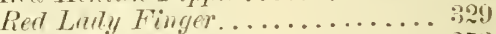

Red Limber Tirig............. 2tis

Red Mormon............... 827

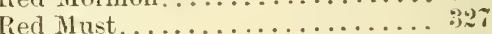

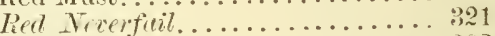

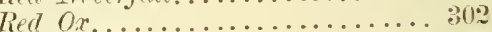

Tied Permmain..............2:5, 414

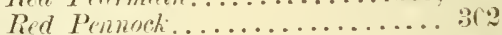

Red Phamix.................. 23.5

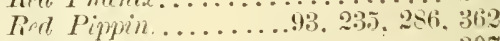

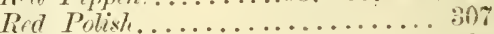

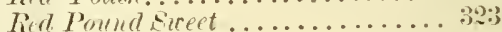

Rird Primplin Sireet............ 16:3

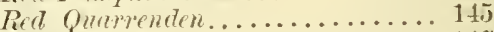

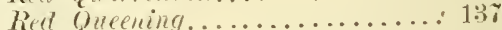

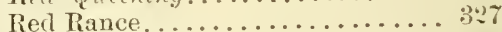

Red Republican............... 327

Red Romarin .......................

Red Russet.............................

Rel Rusist................... 191

Red Seek-no-Farther........... 3.

Fed Secti-nu-Finther............3?

Red sech-nn-Further............ 2:

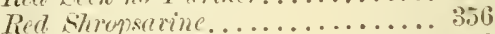

Red Siberian Crab............. 426

Red Spitzenbuvg............... 2:3,

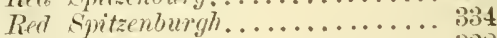

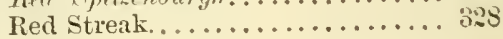


PIGE PAFE

Rell streated Rarding..........

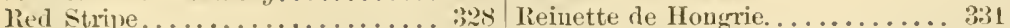

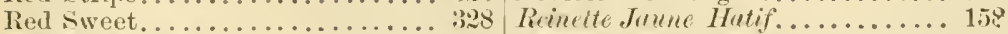

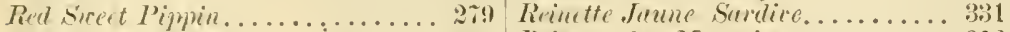

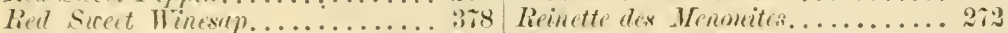

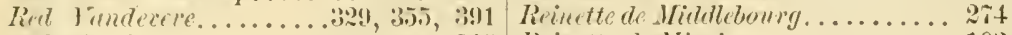

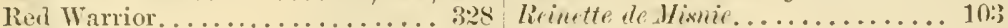

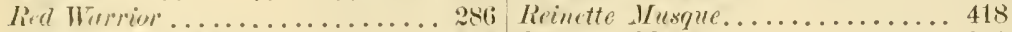

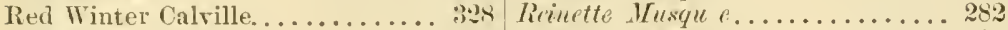

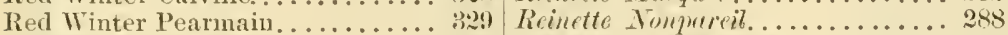

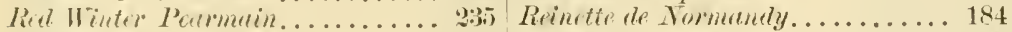

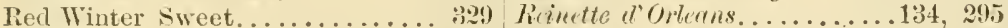

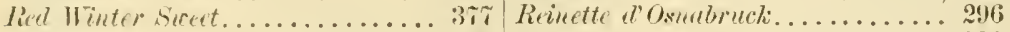

Redick ................. 320 Reinette Pippin............332

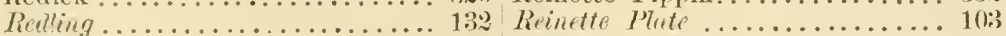

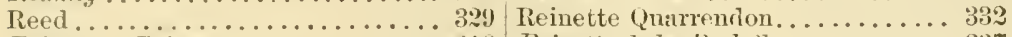

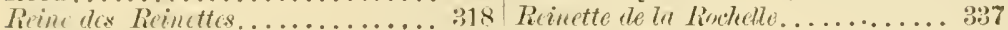

Reinete d. Aix.............. 1!.j Reinette lu Roi............243

Rinctte $d^{*}$ Lugletere.......162, 194 Reinette Rouge............ 87

Reinette d'Anjou............. 3:30| Reinete Rouge de Vitmun........ 287

Reinctte Buturde............. 10: Reinctte Rumare...........8\%, 331

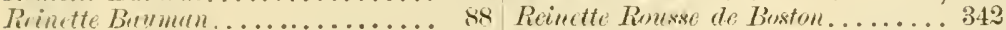

Reinette de Bayeux. .......... 3:30 Reinette St. Lambert. . . . . . . . 332

Reincte Blanche............. 184 Reinctte Snisse.............. 378

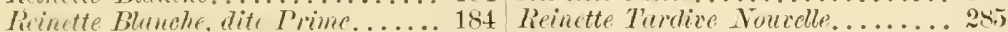

Rinette Blonche of Exymgne...... 404 Reinette de Thorn............ 331

lieinette de Breda............ 3:30 Reinette Triomphante..........3:32

Reinette Calville............. 330 Reinette der Tyrol. . . . . . . . . 389

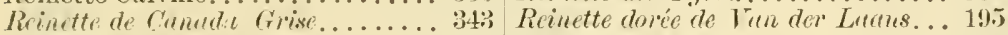

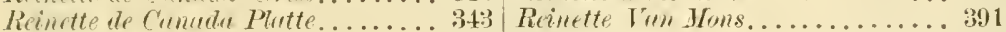

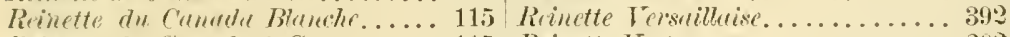

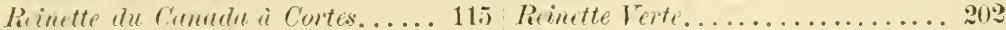

Pirinctte de Cunturbery.......... 116 Reinette Tervane............ 332

Rintte des Curmes............ si Reinette du Vigan.............3.31

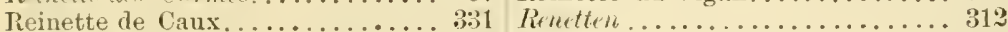

Reintte do Chrmprigue.......... 12:2 Republican Pippin........... 33:2

Rrinette de Citmol............ 126 Revelstone Pippin...........321

lieinette de Clareval. .......... 3:31 Rhenish La.y............. 270

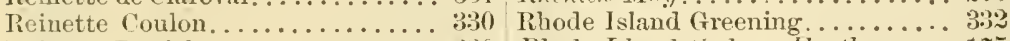

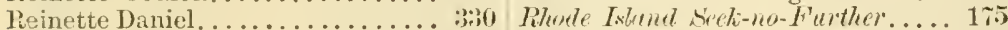

$R$ incte Diel................. 14j Rhode's Orange.................;

Reinette Dor...............331|Ribed Piprin.............

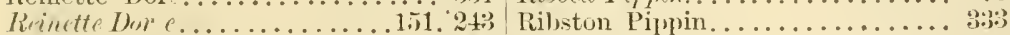

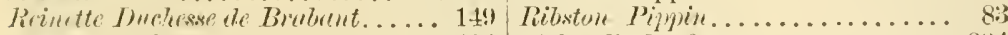

Reincte d Expugne............ 404 Richard's Graft..............3:4

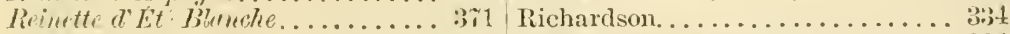

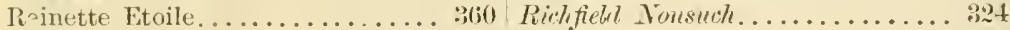

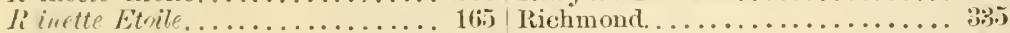

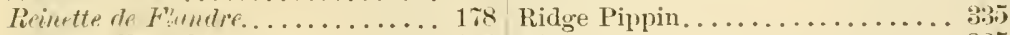

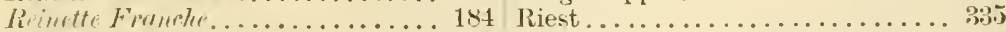

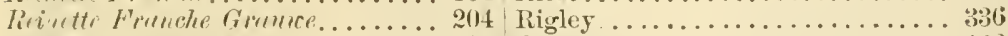

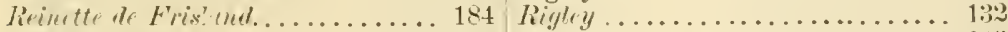

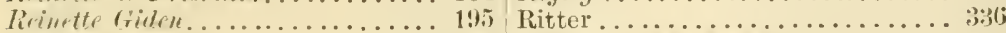

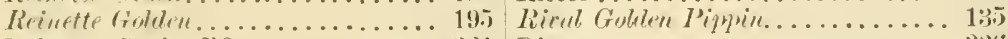

Reinette Grain dOr. ..........

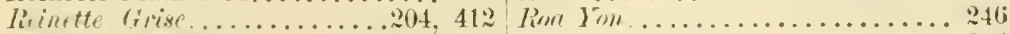

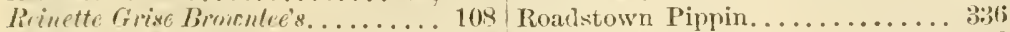

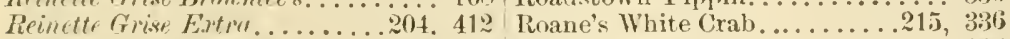

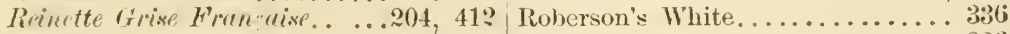

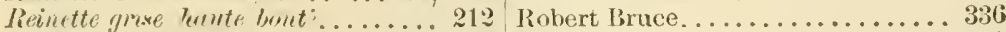

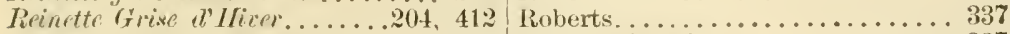

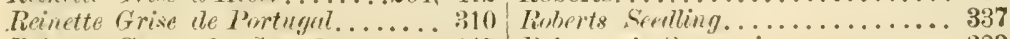

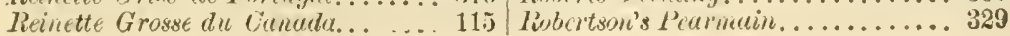




\begin{tabular}{|c|c|}
\hline & \\
\hline$\ldots \ldots \ldots \ldots$ & al \\
\hline .......... 3387 & al $\mathrm{P}$ \\
\hline$\ldots \ldots \ldots .3$ & al $P e$ \\
\hline$\ldots \ldots \ldots$. & lal Pi \\
\hline b............ 3 & $\ldots \ldots \ldots \ldots$ \\
\hline$\ldots \ldots \ldots \ldots \ldots$ & \\
\hline$\ldots \ldots \ldots \ldots$ & $\ldots \ldots$ \\
\hline$\ldots \ldots \ldots . .3$ & \\
\hline$\ldots \ldots \ldots \ldots$ & Hoyal so \\
\hline$\ldots \ldots \ldots \ldots$ & Bomyale... \\
\hline ock Rimmon & Rignale d's \\
\hline ...: & Ruticon. \\
\hline hill's Russ & $n \ldots \ldots \ldots$ \\
\hline hill's Sum & m's Ped. \\
\hline ingham $R$ & te.......... \\
\hline$\ldots$ : & $\ldots \ldots \ldots$ \\
\hline$\ldots$ & \\
\hline 's Keepe & \\
\hline & \\
\hline$n d \ldots .$. & t Ginden............ \\
\hline$\ldots \ldots 3$ & $\therefore$ Gollen Pignin........ \\
\hline .191 , & Sompareit........... \\
\hline$\ldots \ldots:$ & $\mathrm{I}$ \\
\hline$\ldots \ldots:$ & $\ldots \ldots$ \\
\hline$\ldots \ldots \ldots$. & $n$. \\
\hline amite of the West............ & Emper \\
\hline anin Blunche....... & n Transp \\
\hline .. & ne........ \\
\hline . & C'ont Milc \\
\hline .. & $y$ Core.... \\
\hline$\ldots$ & ene \\
\hline$\ldots$ & \\
\hline$\ldots$ & weet \\
\hline$\ldots$ & \\
\hline ... & \\
\hline . & \\
\hline . & il. \\
\hline$\ldots \ldots$ & $n$. \\
\hline ... 341 & \\
\hline mary Russ & $\ldots \ldots \ldots \ldots$ \\
\hline$\ldots 3$ & ex \\
\hline$\ldots \ldots$ & 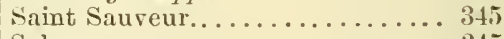 \\
\hline & \\
\hline & $\cdots$ \\
\hline & $\ldots$ \\
\hline . & in ..... \\
\hline es & lings.......... \\
\hline$S t$ & l......... \\
\hline . & $\ldots \ldots$ \\
\hline$\ldots 3$ & \\
\hline$e r .1$ & $\ldots \ldots \ldots \ldots \ldots$ \\
\hline & ..... \\
\hline . : & $\ldots \ldots$ \\
\hline . & \\
\hline $\mathrm{ab}$ & \\
\hline . : & w. \\
\hline (d) & \\
\hline . & \\
\hline - & \\
\hline & $\ldots \ldots \ldots \ldots$ \\
\hline & $\ldots \ldots \ldots \ldots$ \\
\hline & 1, \\
\hline & \\
\hline
\end{tabular}




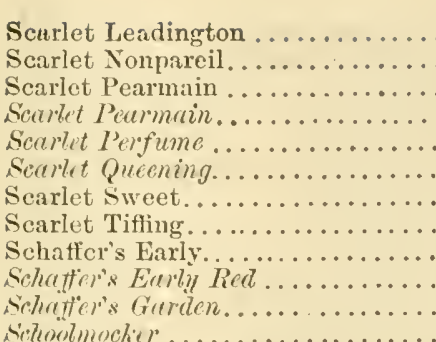

PACF:

347

347

347

2:3 3

130

$13 i$

$3+7$

Schoonmaker.

Schrewton Gothen Pipinin........ 348

Selucitzer Apple............... 306

Sciota Beanty.............. 348

Scollop Gillitlower............. 348

Sicolloped Gillifloser ............ 348

Scotch Bridget............... 349

Scotel Trirgin. ............... 40.

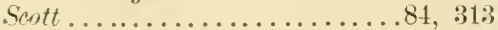

Scott's Best. . . . . . . . . . . . . 34!

Scrivener's Red............... 349

Seudamore's Crab.............. 328

Seaconk Sweet.............. 349

Seuger..................... 384

Seago................... 2(in

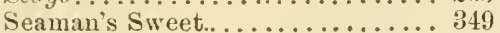

Seaver Sweet ............... 349

Seedless................... 349

Sectsvilbe Secet ................ 417

Seek-No-Further. . . 202, 319, 390, 399

Seever....................... 350

Secver's Red Streak. . . . . . . . . . 350

Stignemr dOrsay. . . . . . . . . . . 345

Selby Bellffower.............. 350

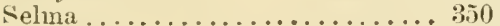

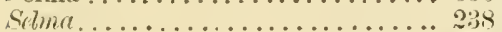

Selwood's Rein tte........... 3.j0)

Senecu Spice................. 319

September. ................ . 350

Sergeant's Sweet............ 850

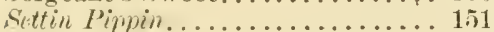

Shaker Geeening ............. 3jo

slurliet Pimin. .............. 350

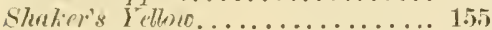

Shakespeare................ 351

Shamnun. . . . . . . . . . . . . . 292

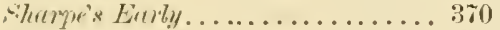

sharpe's Greening............. 3.31

- Tererpe's sprict... . . . . . . . . . . 170

Shlieepnose ................. 3in

Sheep trse............66, 159, 2:35

Shetp shire................. 17!

Shell . .

Shepherd's Fame............

Sheplerds Piprin............ T.t

Sheppard's Sweet. ........... 3.j1

Sherinod's Finmite........... 12t

Shiawassee Beauty........... 351

Shipley Green .............. 3.5.

Shippen's Russet ............ . 352

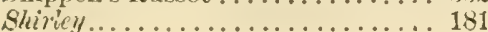

PAST

... 352

(20)

Siberian Aug?st............. 181

Sigler's Red................ 347

Simmon.................... 2:20

Simpson's P'ippin.............. 29:

Simpron's secelling... . . . . . . . . . . 29.

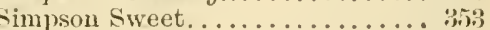

Sincluirs's Yellow............... 153

Sine-qua-non. ................ 35:3

Sink ................. 3in:3

Sir William Gibbons... . . . . . . . . 35;

Skunk. . . . . . . . . . . . . . . 35:3

slunk.................. 362

sleeper..................... 35:3

Sleeping Beauty. . . . . . . . . . 35;

Sleight's Lady Apple. . . . . . . . . . . 35:3

Slingerland pippin. ............ 354

Shoun's Sealling.............. 317

Small Bbtred. ................... 99

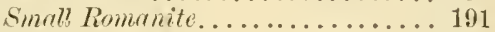

Simall's Admiral)le. ............. $35 t$

Simalley ........................ 351

Smitlis.................... 354

Smitl's Bertuty of Neworl . . . . . . . 14!

Sinith's Cidler................ 3int

Smitlifich Spice............... 152

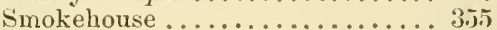

Smyrua.................. 12t

Snediker. . . . . . . . . . . . . . 35.j

Snepps'................... 350

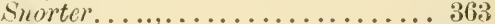

Snow . . . . . . . . . . . . . . . . . 171

Snow Climney .............. 171

Sol. Carter.................. 109

Somerset.................. 356

Somerset Irariest. . . . . . . . . . . . 188

Sommerset Lasting. . . . . . . . . . 356

Sops of Wine............... 356

Soskrieger.................. 122

Sonisson Russet.............. 350

Soulard................... 426

Sour Bough................... 357

Sour Bongh...............368, 380

sour Harrest. . . . . . . . . . . . . . 313

Southern Fall Pipmin............ 329

Southern Golelen Pippin .......... 201

Southern Greening............ 201

Southern Lady ............... 357

Sinthern Romunite............. 839

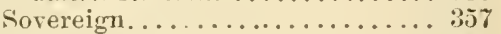

Spafford Russet. . . . . . . . . . 357

Spark's......................57

Spark's Late . . . . . . . . . . . . 3it

Sipeckled ................. 357

Spectiled Golden Iieinctte........ 87

Speckled Oley.............. 357

sineclled Pearnain............. 87

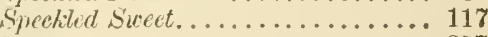

Spectator.................. 357

Speneer Siceeting............... 210

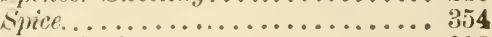

Spice ipple . . . . . . . . . . . . . 293 
PAfF

Spice Russet............... 358

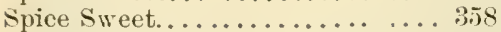

spiecd ox Eye................ 25j

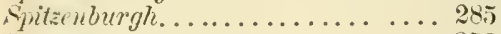

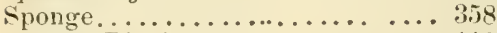

4potted Pipmin................. 110

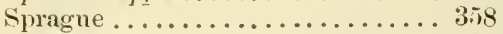

Spring ...................

Spring Grove Codlin............ 3is

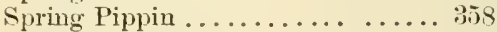

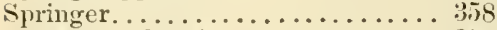

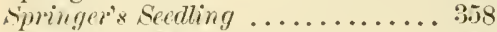

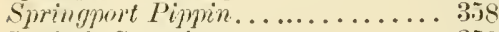

Squire's Greening. . . . . . . . . . . 3.j9

Staats' Sweet................ 3is?

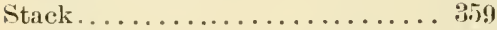

Stackyard................. 3. . 39

Stryg's Nonpureil............ 15i5

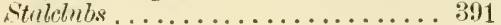

Stamford Pippin. . . . . . . . . . . . . 35

Stanari. . . . . . . . . . . . . . . 3i)

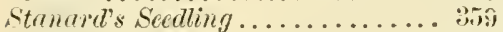

Stanley................... . ;60

Sturnley's Seedling............. 360

Stanley's Winter Sweet. . ........ 360

Stansill.................... 360

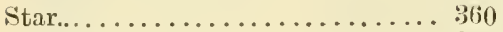

Star Lady Apple.............. 245

Star Reinette................ 300

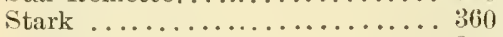

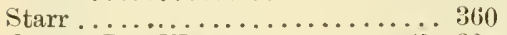

Stede's Rud Winter........... 85, 32-1

Steele's Sweet................ 361

Stehly .................. 215

Stephenson's Winter............ 361

Stoving Bunty.............

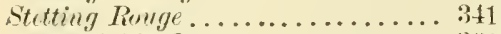

Stevens' Gillitlower ........... 36i1

Stearrit's Vonpurib............ 181

Stillman's Early.............. . 361

Stillwater Sweet.............. 361

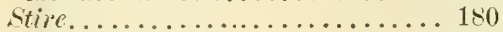

Stirzaker's Early Square......... 361

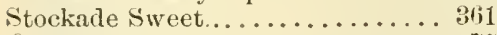

Stome................... \%

Stone Pippin. . . . . . . . . . . . . 362

Sitone Pipmin..........97, 192,

Stonewall Jackson ............ 3

Stonor Park. . ............. $36 \%$

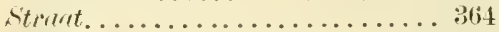

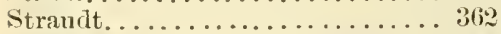

Struwberiy ........121, 324, 3:34

Strawn ................ 36:

Strurn's Secdling.............. 360

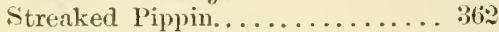

strifling ofliver.............. 80

Striped Ashmore............... 80

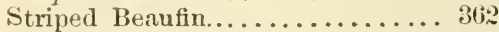

Striped Belle et Bonne.......... 36:3

Stripad Bobl-Fleur............ 32t

Striped Fumedse............. 172

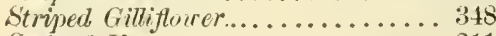

Striped Harvest ................. 211
PAGK

Striped IIolland Pimin ............ 2,:

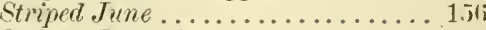

stived Juneating.............. 15r

Striped Mohawk............... 363

Striped Monstrous Reinette. . . . . 36:3

Striped Perrmain............... $30 ;$

Striped Porter. . . . . . . . . . . . 36;

Striped Rambo................. 19:3

Striped R. I. Grening.......... 14i

Striped Shropsavine........... 8(;:3

Striped Siberian Crab. . . . . . . . 42

Striped sueet Pippin. . . . . . . . . . 8 8 :

Stiped Trandercere............ 391

Striped Wister Pearmain......... 36:3

Stroat...................... 36t

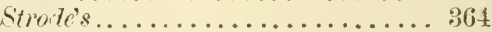

Strole's Birmingham. .......... 364

Strubel ......................... 36 .

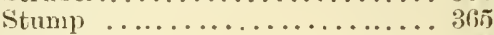

Sturmer Pippin .............. 36.j

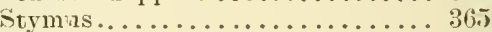

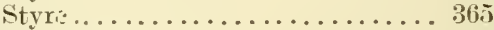

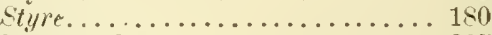

Sudbury sweet..................... 36.

Surlore's Frall Pippin............ 182

Suffolk Beauty........................

Sugar and Brandy............. S66

Sugar Loaf Pippin............. 966

Sugar Sweet ................ 36ti

Suisse .......................... 360

Summer Bellflower. . . .......... 366

Summer Bellflower of Pennsylvania 360

Summer Broaden............ 36i

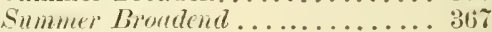

Summer Cheese...........................

Summet Cobman.........................

Summer Golden Pippin. . . . . . . . . 367

Summer Hagloe .............. 36i

Summer Harvey................ 367

Summer Hoive.............. 22:3

Summer Janet ...........................

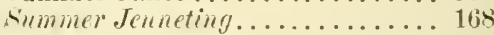

Summer Limbertwig....................

Sunmer Marigold............ 36is

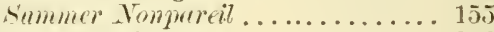

Simmer l'ippin.............. 368

Summet Pipgin............... 219

Summer Pound Royal........... 369

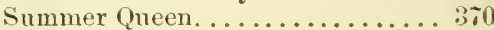

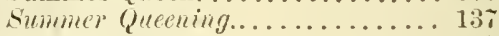

Summer Rambo............. 370

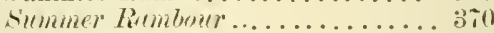

Summer Red Calville. . . . . . . . . 371

Sumner Red Streak. .......... 3i1

siummer Reinette............. 371

Silumer R. I. Greenmg......... 369

Summer Rose................. 371

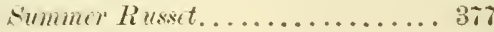

Simmer Sweet.............. \$๐:

Simmer Sicct ............... 210

Summer Siweet Paradise......... 373

Summer Terchat Egg ........... 353 


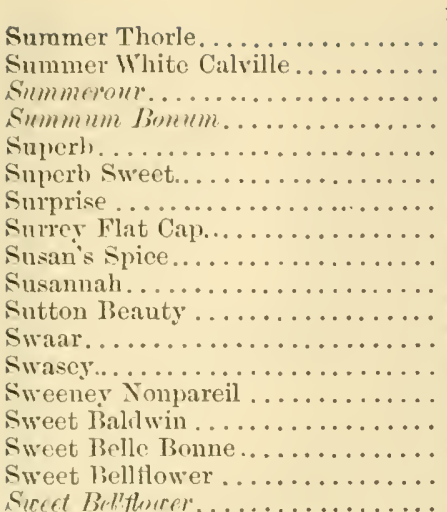

Sweet Bellflower of Wyandot Co.

Sirect Bungh.

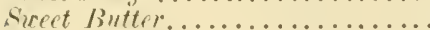

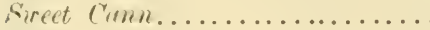

Sweet Doetor . . . . . . . . . . .

Sweet Fall Pippin............ 375

Sircet Ciolden Jippin........... 82

Sweet Greening............... . . . . . . . . . . . .

Sireet llawest................. 250

Sirpet /larery ................. 378

Sispet Ifrme... . . . . . . . . . . . 151

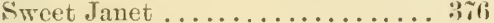

Siret .Jersey. . . . . . . . . . . . . . 209

Siret Jirne.................216

sweet King. ...................375

Sirect Mrriden's Blush.........115, 204

Sweet Marr................ $3 \pi 6$

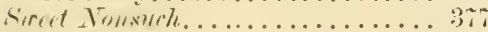

Sweet Pear. . . . . . . . . . . . . . 376

Sweet Pearmain. . . . . . . . . . . 376

Sizrot Prommen ............. 378

Sweet Pippin................ 876

Sirert I'ipplin.............218, 2i!

Siveet Queen............... 37\%

Sweet Rambo ................ :

Sicert Rirdstrorli............... 3is

Sweet Ribberl Gillillower... . . . . . 379

Swect Romanite. . . . . . . . . . . 377

Sweet Russet.............. 37\%

Sirfet linsaxt ..........123, :317, 358

Sweet Seek-no-Farther......... 3:8

Sirect Serli-mo-Finther............ 1912

Sweet and four................. 34

Sweet Sponge ............. 378

sirret sirmeri................ \$2

Sweet Vandervere.................

Sweet Willie............... 378

sireet $17 i n e . . \ldots \ldots \ldots \ldots \ldots \ldots \ldots . . \ldots 170$

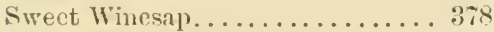

Sweet Winter Pennock.......... 378

Sirerting, Wills.............. . 399

Siriss Apnile. . . . . . . . . . . . . . . . 3060

Siriss Jippin .........................

Swiss Reinette................. 978

Syke-House Russet............. 379

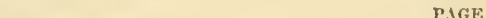

Sylean Russet............... 342

Sylvester................... 379

Table Greening. . . . . . . . . . . . . 9\%

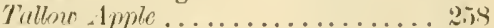

Tallmaris Simpeting............. 37?

Talınau's sweet ............... . . .

Taudive de Joneret. . . . . . . . . . :

Tart Bough .................. 3s0

Thert liomill. .............158, :308

Tarvey Corllin............... \$80

Tienbenfurbige $1 p f a \ldots \ldots \ldots . .304$

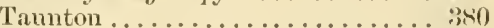

Tauntem................. 30

Taunton Golden Pippin.......... 380

Teigmmonth ............... 38:3

Ten Shillings................381

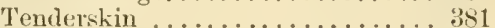

Trnor Kill.................. 91

Tenterden Park ......................

Terral's Late . . . . . . . . . . . . . . . . . . . . . . . . . . .

Terry's lied sitreak............. 319

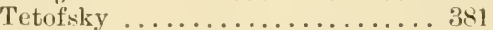

Tetofisky .................. 181

Teuchint's Egg............... 382

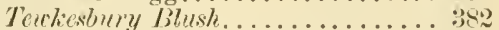

Tewkesburs Winter Blush . . . . . . 38\%

Them's Red Streak ........... 3-2

Thickiset ................. 12k

Thomas ..............................

Thomers. . . . . . . . . . . . . 27.

Thoral Pippin.............. 372

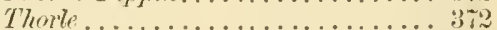

Tift's Sweet. . . . . . . . . . . . 38:3

Tillaqua .................. 38:;

Timenthy ...........................

Timothy Titus Sort ........... 38:;

Tinmouth................ $38: 3$

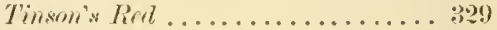

Titus Pippin . . . . . . . . . . . . 38:3

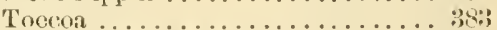

Tod's fidden Pippin............ 296

Toker's Ineomparable ... . . . . . . . 384

Tolbert................... 384

Tolmum's Sirpeting ............. 3is

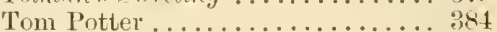

Tom IVomlarame I'impin .......... 296;

Timmzy Ríft. . . .............. 241

Tommitin . . . . . . . . . . . 152

Toole's Indian Rareripe. . . . . . . 3 384

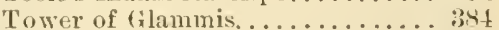

Tower's Glory . . . . . . . . . . . . 394

Tormsend. .................... 344

Townsend's Smiling Beauty. . . . . . .

'T'rader's Faney ............... . 3ै4.5

Transeendent............... 420

Transpuarent Codlin .......... . 38.j

Tirmsparent de Woscorie.........401

Tiumspirtent Jippin........... 1:35

Trimsparent de Zurich . . . . . . . . . 38.

Tramsport. . . .............

Truters' ................. 3:3:

Treudle jiole ................... 386 
Trenham

Trenton Early

Trenton Eamly

Trescott Russet

Tront Apple.

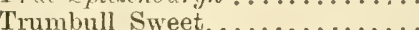

Trumbulb Scceting ................

Trumpeter.................. 38

Trumpington .............143, 319

Tucker.................... 386

Tuebner's Cider. . . . . . . . . . . . . 386

Tuebner's Golden ................ 386

Tnft's ..................... 386

Tuft's Bulducin ............... 386;

Tulip.................... 387

Tulipen Caloille............... 387

Tulp ................... 38

Tulpehoeken ................. 167

Tulpen .................... 388

Turk's Cap.................. 387

Turkey Greening .............. 387

Turn-off Lane ................ 387

Turner's Cheese................. 201

Tuscaloosa .................. 387

Tuserelonost Seedling................. 387

Tuscaloosa Sweet............. 38 ;

Tuttle ................... 388

Twenty Onnce................. 388

Ticenty Ounce Apple ............ 388

20-Ounce Pippin.............. 118

Twin ....................... 388

Thin Cluster Pippin........... 12s

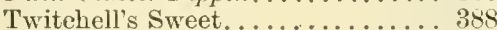

Tyler.................... 220

Tylor Apple ................. 131

Tyre Beanty . . . . . . . . . . . . . 388

Tyroler Glanz-reinette ........... 191

Tyroler Pippin ............... 389

Uncle John

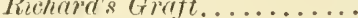

Tnete Sam's Best............... 170

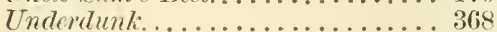

Union .................. . 389

Uniqne ...................... 389

Updegraff. ................. 389

Utter. . . . . . . . . . . . . . . . . . 389

Vale Maseal Pearmain .......... 390

Van Buren. . . . . . . . . . . . . . . 390

Tan Dyne ..................... . . . . . . . . .

Van Mons Reinette............ 391

Vance's Early. . . . . . . . . . . . . . 390

Vanee's IIarvest. . . . . . . . . . . . . 390

Vandenabeele................ 390

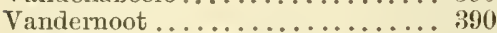

Vanderspiegel............... 390

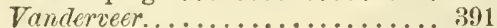

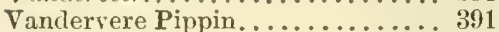

Vandevere................... 391

Varidereme...................
PAgn

Tandevere of $P a \ldots \ldots . . . . . .391$

Vundiver .................. 391

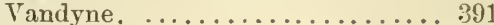

Varick. . ................. 14

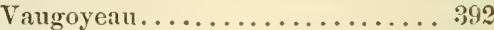

Vaughn's Pippin................ 392

Vaughu's Winter............... 392

Traun's Pimpin................237

T'ermillon d lite. . . . . . . . . . . . 328

Vermillon Reyée............. 392

Termont Pippin.............. 383

Vermont Pwmpkin Succet......... 317

Versaillaise Reinette........... 382

Tictoria ....................

Tietoria Pipmin.............. 03

Tietoria Red .................. 93

Victorious Reinctte.............. . . . . . . . . . .

Victuals and Drink. ........... 392

Violette.................... 993

Virginia Greening ............ 393

Tiryinia Pippin............... $39 ;$

Virginia Quaker............... 393

Virginia Spice............... 393

Tirginirt Suceet............... 26r

Voss' Winter. ................ 39:3

Irai Drap d Or.............. 148

Wabash . . . . . . . . . . . . . . . 393

Wrbash Bellflower. . . . . . . . . . . . . 39:3

Waddell Hall . . . . . . . . . . . . . . 394

Wadhurst Pippin. ............ 394

Wagrener..................... 394

Wahr Reinette............... 115

Whher Weiser Sommer-crlville .... 3i2

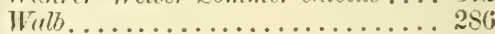

Wruther's Winter................. 39.

Walker's Yellow .............. 39.5

Wnll. . . . . . ............... 280

Wulnut Stem................ 338

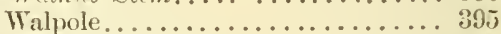

Waltham Abbey ............. 395

Waltham Abbey Scedling. . . . . . . . . 395

Wultz ilpile................ 301

Hislerorth ................. 368

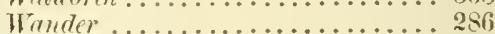

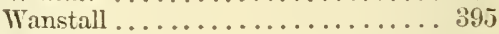

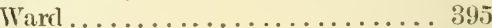

Warfel Crab............... 427

Warfield ..................... 395

Wroner Russet .................. 342

Warner's King. . . . . . . . . . . 396

Warraschke de Guben .......... 396

Werren Pennock.................. 155

Warren Pippin ............296, 418

H"urter.s Golden Pippin........... 194

Hirrickshire Pipmin........... 41 \%

Wrshington. .............250, 356

Wreshington Peamain.............. 144

Washington Rocal. ............ 396

Washington Strawberry. . . . . . . . . 396

Washington Sweet............ 397

Watch ilpple ............... 115

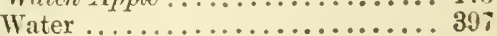




\begin{tabular}{|c|c|}
\hline & \\
\hline $\begin{array}{ll}\ldots \ldots 9 & 398 \\
209 & 271\end{array}$ & Thite \\
\hline $\begin{array}{l}\ldots \ldots \ldots .209, \\
\ldots \ldots \ldots \ldots .271 \\
271\end{array}$ & $\mathrm{~m}$ \\
\hline Diminting................ 15 & 7 \\
\hline pling . . . . . . . . . 398 . & $\ldots, \ldots, \ldots$ \\
\hline … . . . 398 & $\ldots \ldots \ldots$ \\
\hline$\ldots \ldots 372$ & bo. \\
\hline$\ldots \ldots \ldots \ldots$ & Ment \\
\hline$\ldots \ldots \ldots 2$ & 0 \\
\hline (2) 3 & thier ...... \\
\hline$\ldots \ldots \ldots \ldots \ldots$ & nette......... \\
\hline$\ldots \ldots \ldots \ldots \ldots$ & 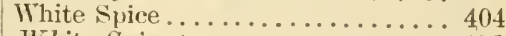 \\
\hline ...92, & $11 \%$ \\
\hline ....398 & perg. \\
\hline$\ldots$. & Pippin \\
\hline$\ldots$ & Whi \\
\hline 皮 & WI \\
\hline$\therefore 414$ & \\
\hline pfil. . 22!) & $e$ \\
\hline$\ldots$ & \\
\hline$\therefore$ & \\
\hline . & \\
\hline & . \\
\hline & earmant \\
\hline .... & $W 7$ \\
\hline .. 383 & Wh \\
\hline . 39 & $\because \cdots$ \\
\hline 6 & e \\
\hline - 1 & \\
\hline & III. \\
\hline e & \\
\hline & $P$ \\
\hline & $\mathrm{Wi}$ \\
\hline 77 & main. \\
\hline 1 & cet \\
\hline$\cdots \cdots$ & n... \\
\hline . 89 & \\
\hline$\cdots:$ & Ipfel \\
\hline . & 10 \\
\hline in & Pen \\
\hline & Tell. \\
\hline$\therefore$ & $\ldots \ldots$ \\
\hline & ite ... \\
\hline . & a.... \\
\hline & 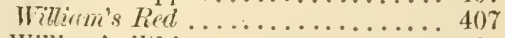 \\
\hline 4 & $\ldots$ \\
\hline$\ldots \ldots 92$ & $\cdots$ \\
\hline$\ldots \ldots \ldots$ & - \\
\hline & \\
\hline & Lenf 1 \\
\hline - . 296 & wig \\
\hline$\ldots 4$ & 0 \\
\hline 372 & $\cdots \cdots$ \\
\hline . $1:$ & Seerling \\
\hline 2 . 2 ? & \\
\hline 41 & Fune ... \\
\hline$\because$ & Summer . \\
\hline . & Yol \\
\hline 2 & $\mathrm{~S} \mathrm{~S}$ \\
\hline$\tilde{2}$ & n Russet. . \\
\hline 419 & \\
\hline . & 11 \\
\hline & \\
\hline
\end{tabular}


PAGF

Winesap. ...........................411

IVing Sweet. ................... 411

Winn's Russet ...............4 41

Winslow ...................

Winter Belle and Bonne..........

Winter Belle bo m..............

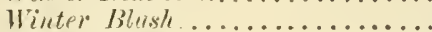

llinter $B$ ugh..................

Winter Bronding..............

Winter (here..................201

Winter Citr nenapfel...........

Winter Codlin ...............

Winter Colman...............

Wint=r Ciolden Siceet.............

Winter Gray Reimette..............

- Winter Greening...............

Winter Harvey............

Winter Hog Island Sweet........

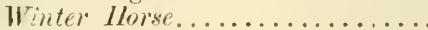

Winter Jomnetting...................

Winter IIaiden's Blush. ...........

IVinter Majettin................

Winter Muy..................

Vinter P'earmain..............

Winter Perrmain. . ....81, 27\%,

Wirter Pipmin ..................

Winter Pimin of Gereve..........

Winter Pippin of Vermont........

Winter I'sud Roysel.............

Winter Queen...................

Winter Rad streuti..............115,

Winter lieinette..................

Winter livinette..............

Winter Rose .....................

Wirter liksset...............

Winter Secelling ................

Winter Seek-no-Further. . ........

Winter Sleeping Benuty..... ....

Winter Strawberry.............

Winter Struwbiry.............

$1{ }^{\top}$ neter siceet Brough............

Winter Sweet Paradise.............

Wint W $^{r}$ ne.................. 410

Winthrop Greening........... 41.j

Winthrop Pearmain............ 415

Wisner.................. 415

Witherills Whits sioe t......... 404

Wolf"s Den ................ 8;

W llutent Pippin.............. 1:34

Womler...................20

Wood's Greening ............ 416

Wrod's IJutingdon............ 133i

Wool's Sweet................ 416

Woodland................... 41is

Woorlpecker................ 85

Woodring................. 41t;

Wordistock ................. 150

Wood tock jippin............... 100

Wo derer i's P'ippine.............. 296

Woolfolks.................. 416

Wrodmun's Ilarvest............ . 371
Worge PAg

TH

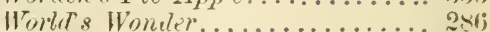

Wormsley Pippin.............446,

Wright .................. 41ti

91 IVright's Janet............. 417

1 Wygers.................... 19.

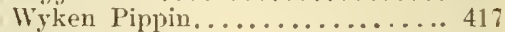

Wylier Piprin.............. 19.j

Wythe ................. 30 .

Yacht ................ 417

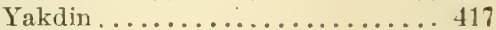

Yaboola .................. 417

Yankee Spy................. 413

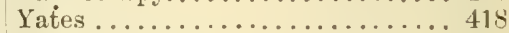

Ielluc................... 19.j

Yellow Bellflower............. 418

Yellow Crunk.............. 201

Yellow Foster................4 419

Yellow Geman Peinettc. . . . . . . . 19.

Iellow Hervest. . . . . . . . . . . 1ij:

Yelloin Hos. . . . . . . . . . . . . . 22:3

Yellow Ingestrie............. 419

Iellow . Jutt............... 321

Yellow June ................. 419

; Yellow . I \%.............. 102

:3 Yellow Meadow .............. 419)

Yellow Newtown Pippin.........4 41!

Íllewo P'ertmatio.............. 127

Jiloo Pimin............255. 2!)(j

$09 \mid$ Tellow Siberian Crab.......... 4:3

Yellow sweet...............41!

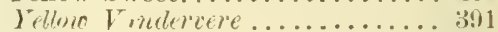

Toder..................... 106

Yoplis Favorite............. 420

Tork...................... 420

York Imperial. . . . . . . . . . . . 4 4 20

Jork: Piprinin..............169, 19.5

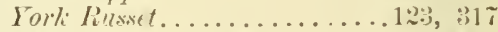

Jorkxhe frome sinuce .......... 421

Torkshire Greenirg. ........... 4:1

Yost .................... 421

Joung Long feepring... . . . . . . 1, is

Zane ................... 421

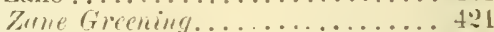

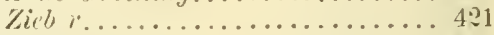

Zoar Greening............... 421

Zrmi Brongh............... 313

Zoceibel Apfel . . . . . . . . . 10:

APRICOTS.

1briont Blume...............4 42

1bricot Commun ................ $4 t(1$

Ihricut de l'rocence............ 4:3:)

Abr cot heitit Jusquée. . . . . . . 440

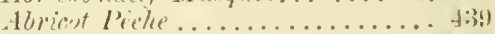

Abri t Précues............... 440

Abrirotier................... 440

Abricutier Blarec.............. 14 ? 


\begin{tabular}{|c|c|}
\hline$\ldots \ldots \ldots \ldots 40$ & $\begin{aligned} \text { P.ARB } \\
4: 34\end{aligned}$ \\
\hline 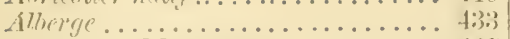 & Jemskirke. . . . . . . . . \\
\hline rige ile Wromitrumet. . . . . . . . . 4i3i & Hunt's Hoorparls.......... \\
\hline 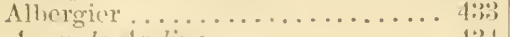 & \\
\hline 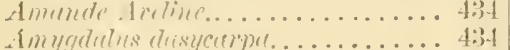 & $\ldots \ldots \ldots \ldots \ldots \ldots 4$ \\
\hline 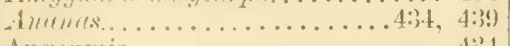 & Kaisha. \\
\hline Ingoumis. . . . . . . . . . . . . $4: 1$ & \\
\hline$\ldots \ldots \ldots \ldots \ldots 4: 34$ & Lafayctte.................. 130 \\
\hline Ansmu's............... & Large Early. . . . . . . . . . . 4:37 \\
\hline dusmen's 7 mperiel. . . . . . . . . . . . 4:39 & 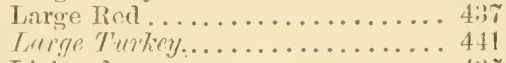 \\
\hline cauge.................... $4:{ }_{1}$ & 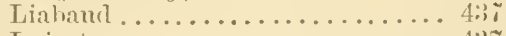 \\
\hline lack................... 4:34 & Luizet.................. . $4: 37$ \\
\hline$\ldots \ldots \ldots \ldots \ldots .42$ & \\
\hline . 411 & Irribe. . \\
\hline 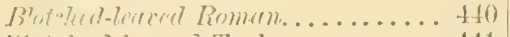 & $\ldots \ldots \ldots \ldots \ldots \ldots \ldots+4 ; \pi$ \\
\hline lotched-leaved Turker.......... 441 & MLontgamet............... 4:37 \\
\hline $12 \ldots \ldots \ldots \ldots \ldots \ldots \ldots \ldots \ldots \ldots \ldots \ldots$ & Moorpark ............... 4:38 \\
\hline (on 1 pricot............ 442 & Musch-Musch............... $4: 38$ \\
\hline P7иm........... 442 & \\
\hline Irisculine........ & Newhall's Early. . . . . . . . . . . . . 4:3 \\
\hline n's Earty........... & Toir.......................... \\
\hline iels.............. & \\
\hline urlington ................. 4.35 & 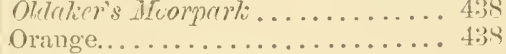 \\
\hline inino (rrosso............. 4:3 & Oullins Harly Peach............ 4.3!) \\
\hline .......... 43;5 & \\
\hline e de Toulon............. 4:3i & Peach \\
\hline Crotti............. & 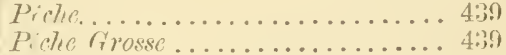 \\
\hline l.xandrie.............. 4:38 & $\ldots \ldots \ldots \ldots \ldots \ldots 484$ \\
\hline Des Farges.......... & ........... 4::4 \\
\hline 1) Mrollinde........ & $\ldots \ldots \ldots \ldots \ldots \ldots$ \\
\hline De tincel............ & $\ldots \ldots \ldots \ldots \ldots \ldots$ \\
\hline 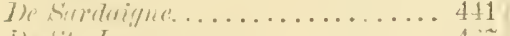 & Portugal. \\
\hline 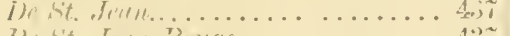 & Prience er Psporin .............. 4:ii \\
\hline 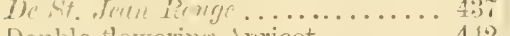 & 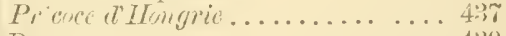 \\
\hline cring Apricot.. & Provence......... \\
\hline 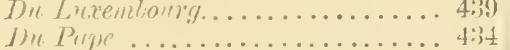 & Purple Apricot............... 4: \\
\hline Inubis' birly Gisliten. & $\ldots, 41$ \\
\hline .. $4: 3$ & Ringold................. . 440 \\
\hline .. 438 & Roman................. 440 \\
\hline ... $4: 30$ & \\
\hline .... 410 & 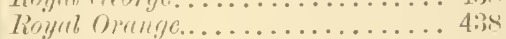 \\
\hline Eury 1100 & Réplyul P'cuch. . . . . . . . . . . . . 439? \\
\hline 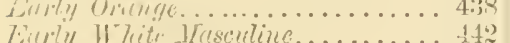 & Rerygul Persian............... 438 \\
\hline & $R$ \\
\hline Frühe Mirseretoler ... & $\ldots \ldots$ \\
\hline .. 440 & - \\
\hline . 441 & S \\
\hline .. 436 & Shiqule y's Large... \\
\hline . . $4 \pm 1$ & 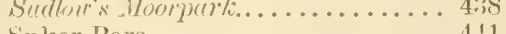 \\
\hline$\ldots .4: 37$ & Suker Para... . \\
\hline Giros Frute...... & \\
\hline 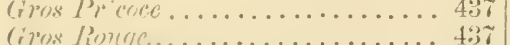 & $\begin{array}{l}\text { Trmp } \\
\text { Texas }\end{array}$ \\
\hline $\begin{array}{l}437 \\
\cdots 4: 37\end{array}$ & $\begin{array}{l}\text { Texas } \\
\text { Trom }\end{array}$ \\
\hline inosece Giemine... & Tuxkey. \\
\hline
\end{tabular}


riolet...

Wulton Monrpurk.

White Algiers............... 442

White 1 priest............... 442

Thite Masculine. . . . . . . . . . 442

Wivtemburg.............. 4399

\section{BERBERRIES \& BLACKBERRIES.}

THE BERBERRY.

Common Red.

\section{BLACKRERRIES.}

Arlair's Claret

Albion

Cane Mray.

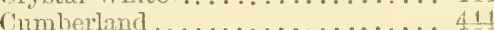

Cht-Lenved ............... 441

Cutter's Mulberry............. 444

Denberry ................. 44i

Doctor Warder............... 414

Dorchester.............. 414

Double Pink Blossomed .......... 416

Double White Blossomed.......... 440

Durean's Falls............. 44j

Farley.................. 44,

Felton ................... 445

Holcomb. ................. 445

Kentucky White ............. 445

Kittatinny ................ 445

Craston ....................446

Low Blackberry. . . . . . . . . . . 4t;

Mrason's Mountain. . .......... 44i

Missouri Mrmmoth . . . . . . . 4 44.)

New Rochelle............... 446

Newmon's Thornless ............ 446

Orange's Crystat...............44

Prerstey Leaced............... 44

Rose Flóvering Bramble........ 447

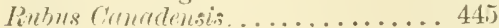

Rubus oidoratus............. 447

Sable Queen.

Seucor's Hummoth............. 446

Trailing Blackbrry ...... .... 44
Trashington ............... 44t

Wilson's Early ............. . 446

\section{CHERRIES.}

A Courte Quene de Provence...... 480

Arlam's Crown.............. 4:0

Admirable de Soissons. ......... 4iti

All-Saints.................. 4s

Allon's Sireet Montmoreniy. . . . . . 4i.

Allorleiligen hipsche........... 4s

Amber.................. 4.

Amber....................... 4ij3

Amber Gean................. 45t

Amber Ilernt.............. 46 .

Amber ci petit finit.............. 4io

Ambree.................. 451

Imbrie de rhoixy.............. 4ia

Ambre iो frros Fruit................ 4ii

American Amber.............. 451

American Heart. ............... 4ii

Angluise Turdice............... 48.2

Anne.................. 4ir

Lusells Fine Black . . . . . . . . . 4. 45

A prle Chrmy............... 46-t

Arch Dnke................ 47

1rderis Emly White IIernt...... 46.2

Argental's Late.............. 4.51

dutume Bigarreceu........... 45;

Barametam.................. 45.

Baumann's May ................. 45.

Belle Agrathe............... 45?

Brlte Aruthe de Tormbre........ 4,52

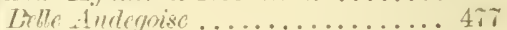

Bolle de bievey................ 45,

Bello de Chutenry................. 4ĩ

Belle de Choisy............. 477

belle Mrgnifique ........... 4i

Belle et 1/urnitique.............. tii

Belle d'Orleans .... ......... 452

Gille Prtmonise................ ti?

bitle de livemant ...........463, 46r

Belle de Sceaux ............. 47

Belle de sealux .............. 47

Brlle to suisonu.............. 4iti

Bentarmes Fine Earty Dute ....... 48;

Bigarrean ............... 4.3

Bigrerrean Coun de Pigon ........ 453

Bigarreme Comberer de Chuir....... 4ti:?

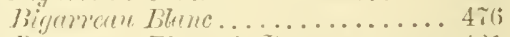

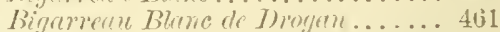

Bignerene Btane Turdij de Hitdes-

heim ................... 465

Bigarmene te Esperin ........... 4(3i)

Bigamerne Cimbulais ............ 454

Bigarrenu Gros.............. 453

Bigarreau Gros Couret ............ 4.53

Bigarrean it Gros Fruit Blane ... 4 46i3

Bigarreru iो Gros Fruit Pouge .... 4tio

Bigarrenu Gros Monstrueux.......453 
Bigarrenu Gros Noir ........... P.4\%

Bigarreau . Taboulay ... . . . . . . . . 45:;

Bigurecau Jaune de Drogirre . . . . . 4til

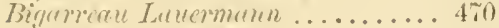

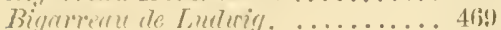

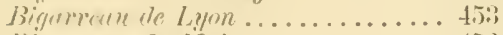

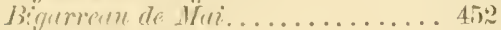

Bigareatu . Rurcelli. . . . . . . . . . . 45:3

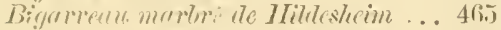

Tigarreau of Mezcl ........... 45t

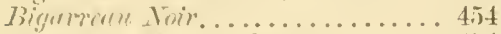

Bigurmeren . Vurr de Sarri. . . . . . . 4. 451

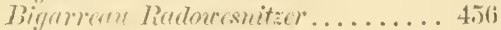

IBigarreau liverchon . . . . . . . . . 4. it

Bigurv"enu de Rocmont. . . . . . . . . 4(i?)

Bigumene Rouge de Crouben. . . . . . 462

Bigarreau Royal . . . . . . . . . . 45.

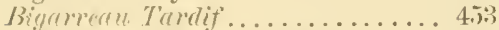

Bigurean Turdif de Hildesheim ... 40.5

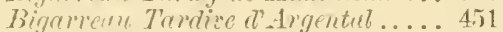

Bigarrean des Figmes..........4 46:3

Binenverention is Fienilles de Tabue . . 474

Bignreantier i Grandes Fuilles. . 4.4

Bill and $\mathrm{C}_{00} \ldots \ldots \ldots \ldots \ldots \ldots \ldots . . . .4 .4 .4$

Biskojis Large . . . . . . . . . . . . . . . . . 456

Black Bigarreau of Saroy ....... 454

Black (rnmon................... 45.)

Bluck Cincassiun .............. 456

Black Eagle. . . . . . . . . . . . . . 45.

Black Hawk ............... 4.5.5

Black Heart ............... 45 45

Bliect: Honey . . . . . . . . . . . . 4 45.j

Black Jazzari . . . . . . . . . . . . 4.j

Iluck Pussinn . . . . . . . . .455, 45(j)

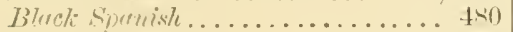

Black fiartarian .............. 456

Black Wild (herry .............486

Bleuting Hewt . . . . . . . . . . . 4tit

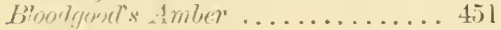

b'ondyouts Itoncy. . . . . . . . . . . . . 451

Blondgond ser Itwrey . . . . . . . . 451

Bohemian Tlack Bigarreau ...... 4.5

Bouquet Aluere!le ............ 478

Bowyer's Early Ileart .......... 4.75

Brandywine . . .............t5

Brant ................. 4.57

Bremmemalix Litry............ 47is

Bristed Clewry ............... 4.j.j

Brown's heedling . . . . . . . . . . 45

Buclermun's Lurby Dulie . . . . . . . 44:;

Bullocles Iterert . . . . . . . . . . . 4it

Burr's s.sedling. . . . . . . . . 4 4i

Buselh Wicherl................. 4is

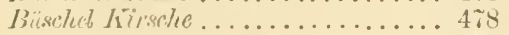

Buttner's Black Heart. . . . . . . . . 45\%

IButtner's October Morello....... 478

Buttner's Iellow ............. 4ir

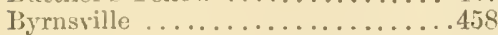

Carmine Stripe............. 457

Carmation ................. 478

Caroline.................. 457

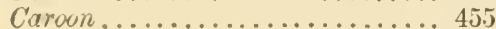

rigip

creinus a rium . . . . . . . . . . . 4 45.

Corasus servelrita.............440

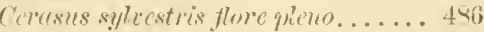

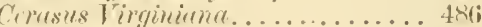

C. vulgaris semperflorerus. . . . . . 44.

Cerise Ambrie............451, 45:

Cerise is lionquet............... 4is

Cerise à Courte (Dneue............ 480

Crise Doncette. ............... 4i.

Crise ruigne............... 48:

Cerise Indulle .................. 479

Cerise du. Turd ................... 484

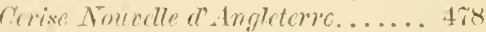

Grrise a truman Tendie......... ti.

rerixn de li Pulembre. . . . . . . . . . 478

Cerise de Portugul ............4 48

Crrise de st. Jurtin............ 48 .

Cerise Tumtire................. 487

Crpise de la Toussuinte .......... 487

Cevixire a Flems Dumbles.......... 486i

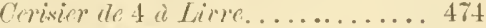

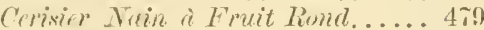

Cerisier . Trim Precoce ..........4 470

Cerisier 17eurant............. 48т

Cerivier is Trochet................ 478

Cenisier de Tirginie ............ 48i

Champagne.................... 45

Chertenaty ................ 47\%

Chervy Cluster.................. 481

Clemry Dule.................481, 483

chrevense................ 45

China Bigarreau............. tij

Chinese Double Flowering. . . . . . . 4\$ 4 (j

Chiverse Herert. . . . . . . . . . . . . 4is

Choke Cherry ......................... 48

Circessirem............... 450

Clurle's Bignurersu. . . . . . . . . . 470

C7rlie's Supperb............. . 470

Cleveland ..................... 45

chedend Bigarienu............. 458

Cluster................. 478

Cocklin's Favorite........... 45. 4

Coe's Late Carnation. . . . . . . . . . . . . 478

Coe's Trimsparent........... 4. 4 is

C'nur de Pigenn. . . . . . . . . . . . 4ti:

Columbia................ . 45 !)

Cerimmome English . . . . . . . . . . 45. 45

Crmmonn Red.............481, 482

C'mmmo sour Clecry.......... 482

Commmne.................. 481

Commentac i Trocket............448

Conestnga . . . . . . . . . . . . 4 45?

Cornelia.................... 4.9

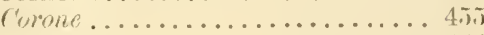

Coularte................ 48:

Comronne...................... 4isis

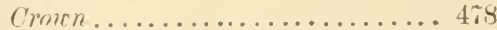

Cumberlerid Scouling........... 4ij

Dacotah ................. 459

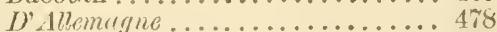

Dauphine................4 4 78

Davenport ................... 459 
TAGF

Drenenport's Enrly. . . . . . . . . . 4 4iq

Dremport's Early Black. . . . . . . . 4is?

The Chaux................. 478

D'Exprrme................ 4 4 .

De Ilollamde. . . . . . . . . . . . . . 4k:

De linlh ................. 4kt

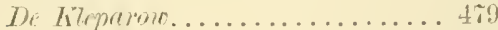

De sinisenus................. 45

De la Toussaint. . . . . . . . . . . 47s

Delicate ................... 460

Dochenaut................448

Doctor. .................. $41 ; 0$

Domma Maria................ 479

Deipgulte Fitte.............. 4 . .

Dimlin Flowering Kintish........ 480

Donde Fiench Cherry. . . . . . . . 486

Doneble (these . . . . . . . . . . . . 480

Domble Ilont ..............4. 4ti

Doulle Natte............... 479

Double Tolgers............... 440

Donlin Bigarrean............. 400

Downer. .................. . 46i

Downer's Late. ................. 4 (bi

Donemer's Late Red............. 4tio

Downing's Ped Cheek. . . . . . . . . 441

Downton.................. 4 . . .

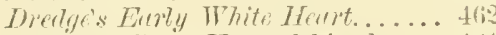

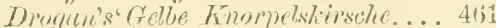

Drogan's White Bigarreau . . . . . . 461

Drogan's Yellow Bigarreau . . . . . . 461

Duchesse de Palluau. .......... 4i?

Dutch Worello .............. 484

Dwarf Double-Flowering....... $480^{\circ}$

Eremly Plack. ................ 45 5

Early Black Bigarreau............ 4ti

Eurly Dulie. . . . . . . . . . . . . 489

Early Lamanrie. . . . . . . . . . . . . 461

Early Lyons. . . . . . . . . . . . . . . $40^{\circ}$

Early iray. ............479, 480

Early Prolific. .............. 44\%

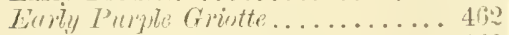

Emly Pumple Guigne... . . . . . . 4 46?

Early Red Bisarreat . . . . . . . . . 46?

Eully Pichmond . . . . . . . . . . . 4\$1

Errly White Heart. . . . . . . . . $4 t^{2}$

Elizibeth... . . . . . . . . . . . . . 4 40 . . . .

Jitidum. . . . ........... $4 \pi$

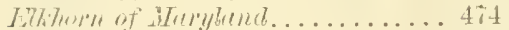

Julictis ficourte. . . . . . . . . . . 46.3

Elton..................... 4ti

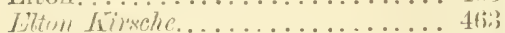

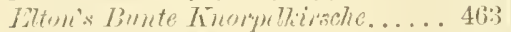

Timpress Eugemue......... . . . . . 480

Eugliwa Horelho.. . . . . . . . . . . . . 484

English Weicherl..............480

Esperen Bigarrean. . . . . . . . . 4 463

Ever-Flowering Chr. . . . . . . 4.4

Excellente Douce Tardive........ 480

Farorite................ 468

Flumdrische Weichael. ............. 4is

Flemish ................. 480

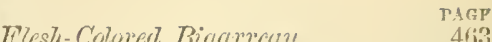

llorence.

Fiver to the Ponnd............. 4is

Franlische ITncher firisule. . . . . . 484 481

Fraser's Blriel. ................ 4;

Fraser's Blecti Ilerert. . . . . . . . . . 4.jo

Fraser's Blucie Turteriun. . . . . . . 4. 4

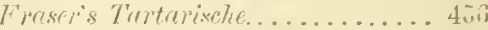

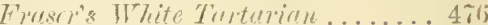

Furesci's White Transjurent....... 470

Frogmore Early Bigarreau. . . . . . . 464t

Frïle Kleine Pumile............ 4i!

triule Zeerg Weichsel............ 479

Gascoigne's Heart. ............ 464

Gian Amber................. 4j1

Griman Haydutie. . . . . . . . . 46. 46

Gifford's Seedling. . . . . . . . . . 4tit

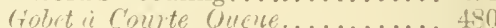

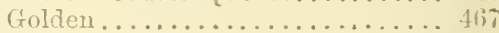

Governor Wood. .............. Ait

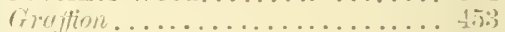

Grent Bigarpeau............. 4. 4

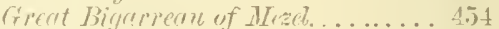

Great Comelian. .............4 480

Gridler ................. $415 t$

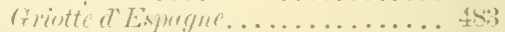

Griotte Grosse linir............. 44;

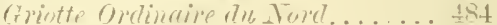

Friotte de Portugat. . ........... 47

Griotte Precence................ 4y:3

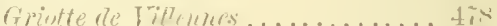

Giviticer is Bunguet........... 4in

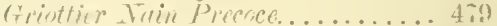

Grintier Remge Pale............. 4is

Grinote Princess . . . . . . . . . . tio.;

Gros Bigaroman Blante........... 46i:3

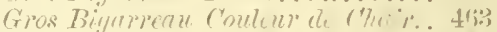

fros Bigaperan Ponge.......... $410 \%$

Gios remet. ......................

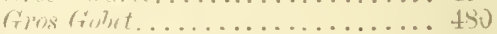

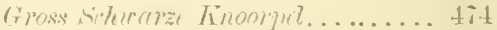

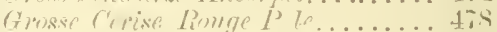

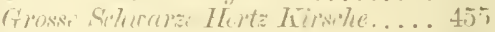

Grosse de Waguellee. .......... 46.5

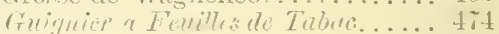

quigne grose renin............ tis

Fuigne Joir Lnisante. . . . . . . . . . 480

Gruigne Vrip Turdive........... 4it

Gnigne Rinnge Ihative. . . . . . . . 40.4

Guigne Tres Precoce. . . . . . . . . . . 4tij

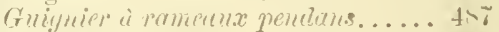

Guiner it fruit noir............. $45 j$

Javition Heat. .............. 470

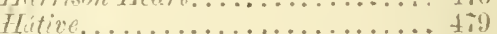

Hative Mnlgre Tout. . . . . . . . . 4 $4>0$

Hensel's Early .............. 405

ITerefordstive Heart. . . . . . . . . . . 4 tit

Her forktslive Tllite. . . . . . . . . 162

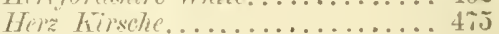

Hildeshein Bigarreau. . . . . . . 160 
P.IGE P.igi

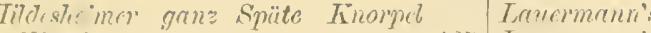

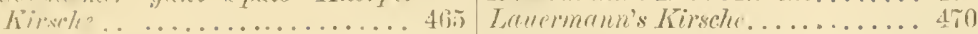

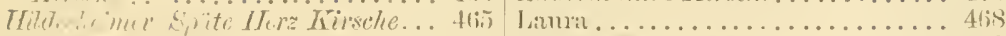

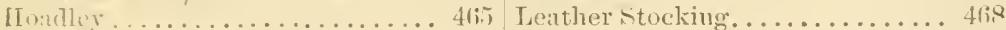

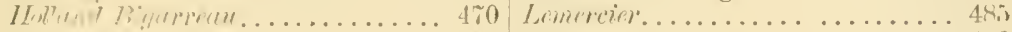

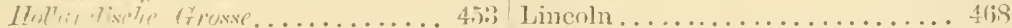

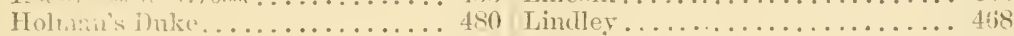

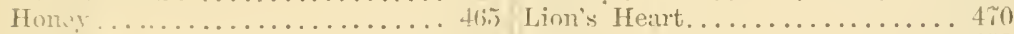

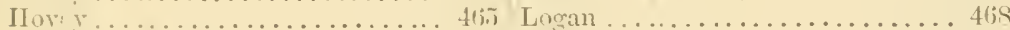

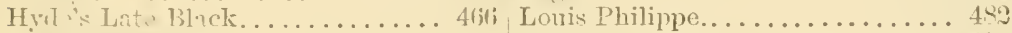

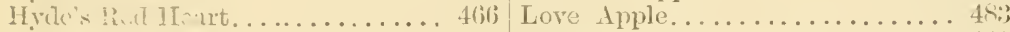

Ludwig. . . . . . . . . . . . 469

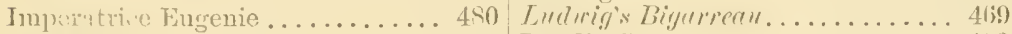

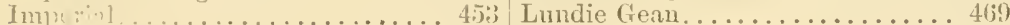

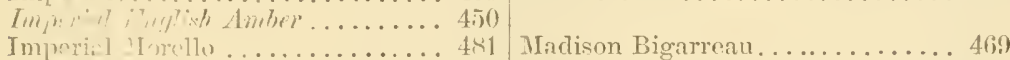

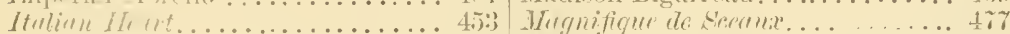

Mauning's Early Black IIeart. . . . . 469

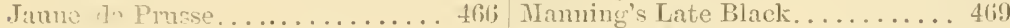

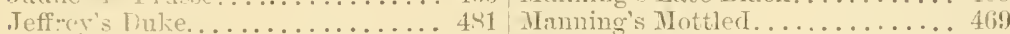

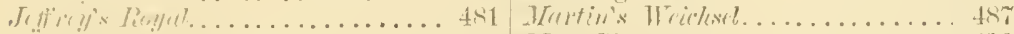

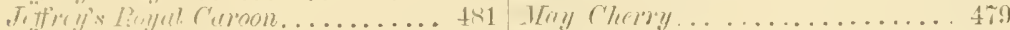

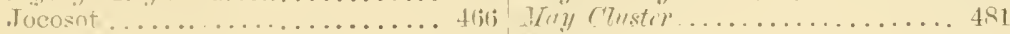

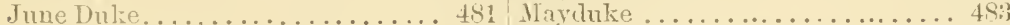

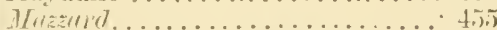

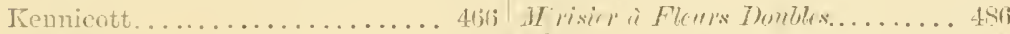

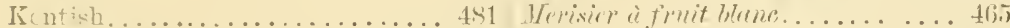

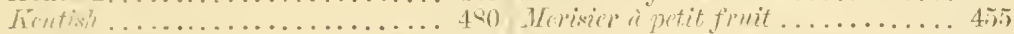

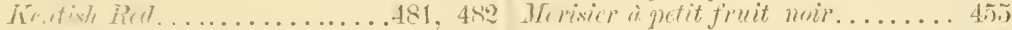

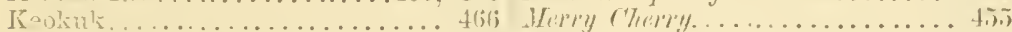

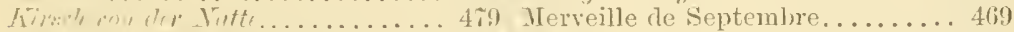

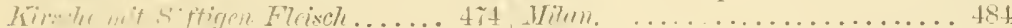

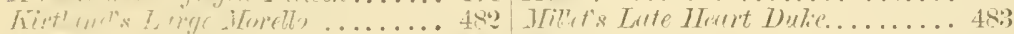

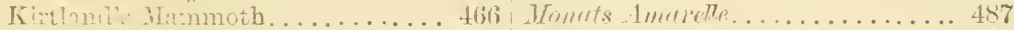

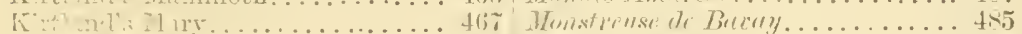

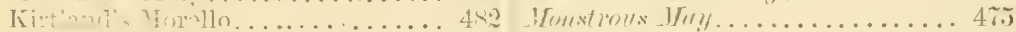

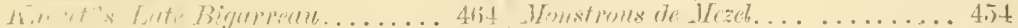

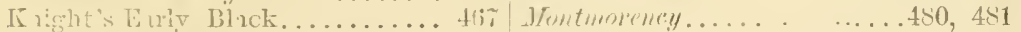

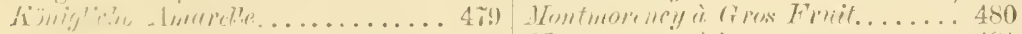

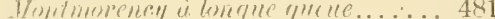

Lali

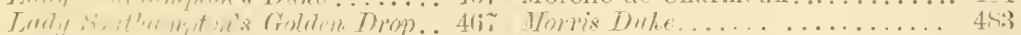

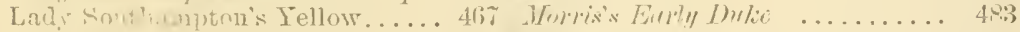

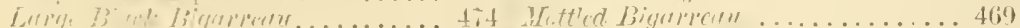

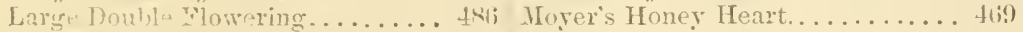

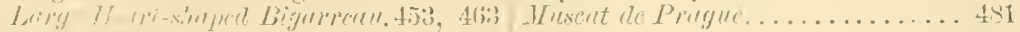

l,

j,

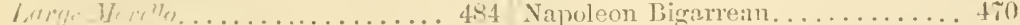

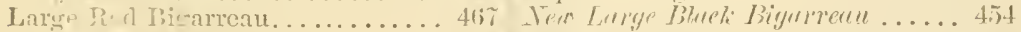

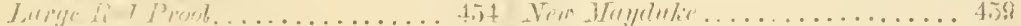

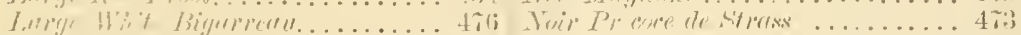

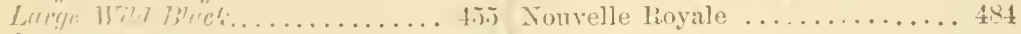

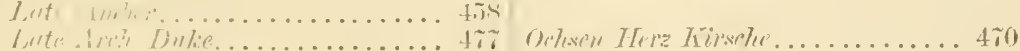

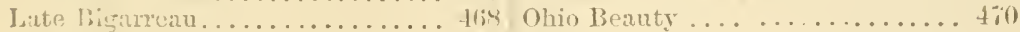

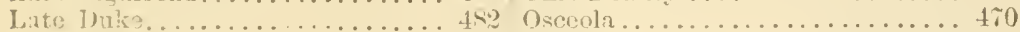

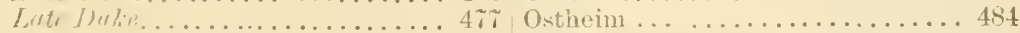

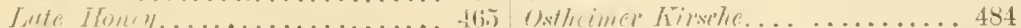

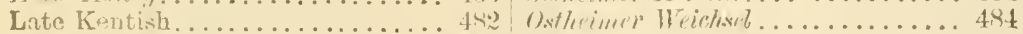

Late I'nrple Guigne .......... 16in Ox-Heart ............... 470

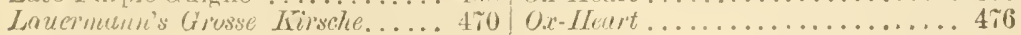




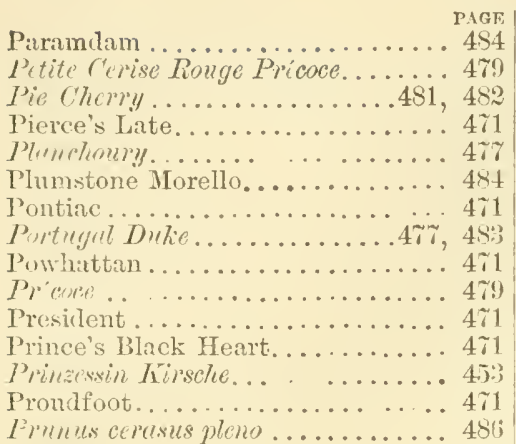

Rert. IIeart.

lied Jacket ..................... 479

Reine Hortense............. 4

Remington............... $4 i_{2}$

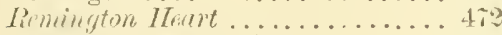

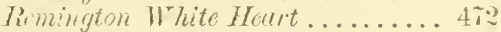

Tichardson ................. 4iv

Riral ................. 4i2

Rivers's Farly Amber.......... 472

Rivers's Early IIeart.......... 4i?

Roberts' Red Heart........... 4i:

Rockport ............... 4 $4 \pi ;$

Indiport Bigareate.......... 4i:3

Romulel's Hewrt . ...............45ti

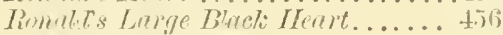

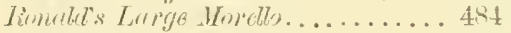

Rese te Lyous . . . . . . . . . . . 46.2

Royal Dnke .............. 45.

Puigrele .................. 4s1

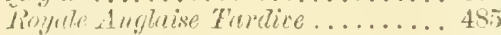

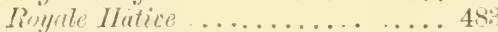

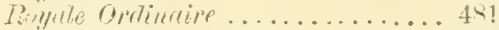

Rumsey's Late Morello......... ts;

St. Wortinis Amerelle......... 487

Segrine con Choisy. .............. 4ir

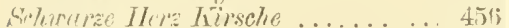

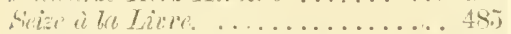

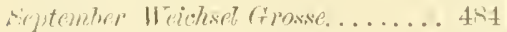

Sermulated Letered Cherry........ $480^{\circ}$

Shammon...................... th5

stipmen................ $4 \$ 1$

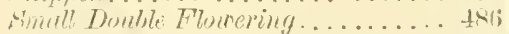

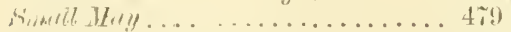

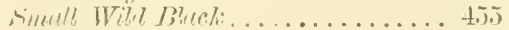

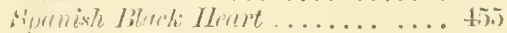

simmish Jom ............. 4it

Sparhawk's Ioney........... 47:;

sparrowhawk's Honey ......... 473

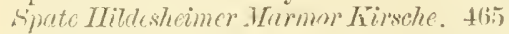

Strass's Early Black............ 47:3

sitrere's 1ley.............. 4 4i.j

Sumner's Honey. . . . . . . . . . . 4 4r:

Sinperb Circessiun............ 450

sussex ................... 481

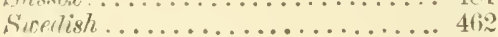

Sweet Montmorency.......... 4it
Thur dive de JTho. PAst:

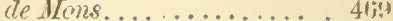

Turtarirn.................... 4519

Tecumseh ............... 4i4

The Doctor. . ............... 460

Thompsenis Dutie............. 4\$;

Tobacco-Leaved.............. 4it

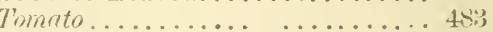

Townsend ............... 4it

Trudescunt's.............. 4it.t

Tradescant's Black Heart ....... 4it

Trankpurent................ 4h...

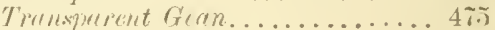

Trausparent Guigne.......... 4..5

Tramben Anuretle............ 4 .

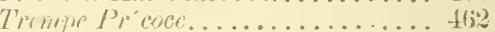

Tres-Furtile .............. 4 48

Trimmph of Cumberland........ 4i.

T'urlis Bigurretu. . . . . . . . 4j3, 4 i6

Vail's Anrust Dnke............ 48.j

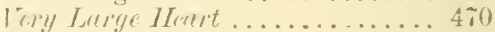

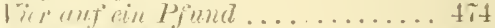

Tirginiun Hrey ............... 4s1

Virginian Wild Cherry ......... ts

Tirjinische Tirsche ............ $4 \$ 8$

Warren's Transparent......... 4 4.j

Waterloo .................. 4i.j

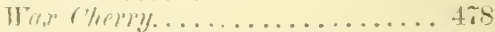

Veeping. ................ twi

Weiches imit yunzkurzen stid. ..... 480

Wellington ............... 4iij

W'endell's Mottled Bigarrean .... 4. 4i.

Werder's Errty Black Heart. ..... 4i.

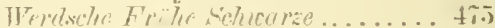

West's White /furt ............. t.

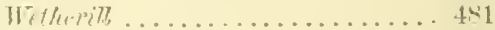

White Bigarrean ............ . $4 \pi i^{\circ}$

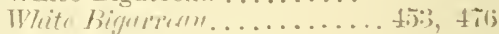

White French Guigne ......... 4iti

White Hont . . . . . . . . . . . 4 4i?

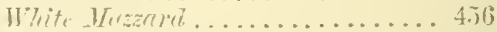

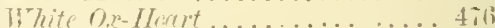

White Tartariam .... . . ....... 4io

White Trmesperent ............ Hi:

Whirle bluck. .............. 4.5.

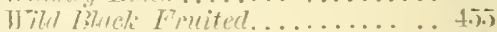

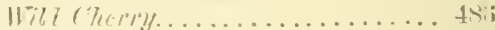

IItk Engpish Cherry ............ 45.

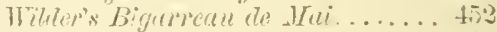

Wilkinson.................. titi

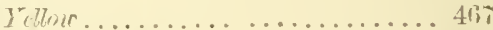

Yello: IItomé........................ 4t.

Tellen spuniath ............. 45:3

Fung to .................... 48

Zwerg Firsche............. 484

\section{CRAYBERRIES.}

Bell-Shaped............... 493 
P.IGE

Bugle, Oval, or Egr-shaped ...... 49: Cherry. . . . . . ............ 493

\section{CURRANTS.}

Attractor.

Bang Up . .

Black Naples. . . . . . . . . . . . . 4!2

Black Glape ................ 49.2

Bhane Tiunsparent..... . . . . . . 4!)1

Inuist's Loug-Bunched. . . . . . . . . 1s')

(118:.................... 492

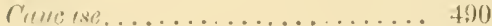

Chammane . . . . . . . . . . . . . 489

Cherry. . . . . . ............. 489

Common Blitek.............492

Danc's tow White............ 492

Fertibe it Angers.... ........ . 490

Fertile de Palluan. . . . . . . . . . 489

Vivinth ...................491

Gondouin Red ..............44!)0

Gondoniu White.............. 4!90

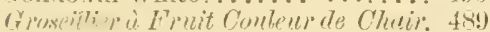
Frosseller Rouge is Gros Fruit. ... 4.91

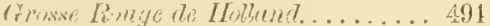

Gimsse Jliss und Rothigestreifie Jo-

leituresbere ..............4491

II ivire de Bertin ............. 490

IInughton Cistbe..............491

Im) rivl $B^{\prime}(n) \ldots \ldots \ldots \ldots \ldots \ldots \ldots .492$

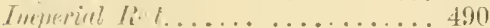

IIIij) (i.ll Hite ...........492

Knight's Ewly Rerl. . . . . . . . . . 490

linig'st's Large Red . . . . . . . . 490

Knight's swe fred. . . . . . . . . . 490

L.t Fiertile. . . . . . ... . . . . . 490

L2 H itive ................ 490

La Tel'villaise ............. 490

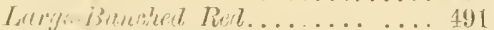

Laty ?.d Dut:it . . . . . . . . . . 491

Loing-linnched Red........... 491

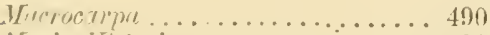

Way's bictorie .............. 491

Wissomri Currant. . . . . . . . . . . . 49):3

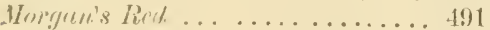

Iorgruis White.............. 49.3

Tero Red Dutch............... 491

Feo White Dutch. . . . . . . . . . 492

Ogalen's Blact Grape. 492 rian

Plicasant's Eye .............. 489

Prince 1 lboct...............491

Raby Castlo................ 491

Red Dutch . . . . . . . . . . . . . . 491

Rerl Flowering Currant........449:3

lied trrepe... . . . . . . . . . . . 491

livel Propens. . . . . . . . . . . . . . 490

Reeve's White............... 49:3

Short-Binched Tieil .......... 491

silver-strigml. . . . . . . . . . . . 4. 491

Striped-Fruited.............. 491

Transparent.................491

Victoria .................491

White Antwerp. . . . . . . . . . . 492

I17ite Clinton. . .............. 452

White rystul. . . . . . . . . . . 492

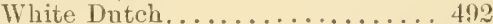

White Grape................ 492

White Leghorn. . . . . . . . . . . . . . 492

White Provence. . . . . . . . . . . . 49:

Wilmot's Iicd Grape............ 491

\section{FIGS,}

Angुelique ............... 498

Bulyswater ................4.497

Black Grenoa ................ 49ti

Black Ischia ................. 49)

Blicek Virples .............. 497

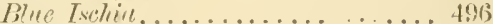

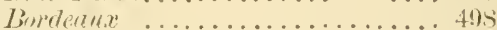

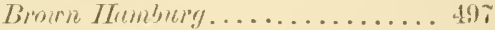

Brown Ischia. . . . . . . . . . . . . . 4! 4)

Brovon fintion ............... 498

Broenn virples ................ 498

Brown Turkey ............... 497

Brunswick ..............498

Chestnut................497

Chestmut-colored Sschire.......... 49?

Clementine................ 497

Conemede Blunche...........498

Eirly Forcing . .............. 490

Firue Binche . . . . . . . . . . . 498

Fort's sectling.............. 498

Green Ischin ............... 499

Hrenoecr . . . . .............497

Italinn . . . . ............. 497

Lrurge lilue ................ 497

Large II hitc Genoa............. 498 


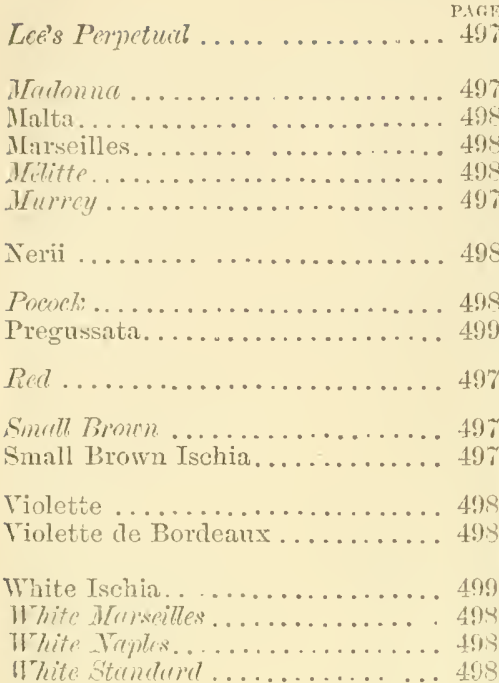

\section{GOOSEBERRIES.}

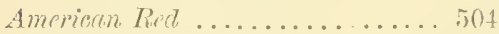

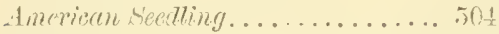

Atlas .................. .503

Banks Dublin . . . . . . . . . . . . . . 50:3

Berry's Greenwood. . . . . . . . . . . 50?

Boarfman's British Crown . ....... jol

Briton. . . . . . . . . . . . . 50:3

Brom Girl . . . . . . . . . . . . 50:?

Buerdsill's Duckwing.......... . 50

Capper's Bonny Lass. . . . . . . . 50:

('apper's liumker Hill . . . . . . . . . . (1)

('apmer"s: Top sawrel .......... .01

Champague.............. . .

('leworth's White Lion......... J)

Gluster ................. त0

('ollier's Jolly Angler. . . . . . . . . 50.2

('onquering Lero . . . . . . . . ti):?

Cook's White Eagle........... 5(j;)

rrompton Sheha Quesn ........ . 50?

Downing. . . . . . . . . . . . 5ns

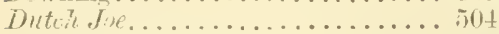

Early Green Hairy. .......... 50)

Echo ................. 50,

Elwarl's Tolly Tar. .......... 50..

Elijah . . . . . . . . . . . . . jo:

Farrow's laturing Lion. . . . . . . . . 501

Favorite . . . . . . . . . . . . . . 50:3

Freedon.................. 50:3

Glenton Green . . . . . . . . . . . . 502

Gorton's Viper . . . . . . . . . . . 502
Paris

Green Grascoigne............. 511?

Green River. ....................

Green Walnut................. 5(

Guido ................... 50;

Hapley's Lady of the IInnor. . . . . is):

Hartshorn's Laneashire Lad. . . . . . 5.)

Heplurn Green Prolific.......... . $(:)$

Hill's Golklen Gourd. . . . . . . . . 5 5( $)_{2}$

Hoblus' Seedling. . . . . . . . . . . . j(1)

Hopley's Companion. ... ....... j(i.)

Houghton's seedling. . . . . . . . jo jut

Huntsman . . . . . . . . . . . J j(i:?

Kusbandman.............. 50:3

Independent. ............. 50:;

Jolly Cutter. .............. 50;

Keen's Seediing.............. 501

Keepsake ... . . . . . . . . . . 50:3

Ladt Delamere. ...... . . . . . 50)3

Leigh's liitleman. . . . . . . . . . . . ju1

Marigoll . . . . . . . . . . . . . . . 50:;

ilassey's Heart of Oak. . . . . . . if

Idelling's (rown Bob......... . j(1

Miss Bold................. . 501

Momtain Seedling. . . . . . . . . . jo

Ohio Prelific................. 50t

Ohio ferding. ...............504

Ostrich.................. . j(i:)

Orerall ............ .... 50

Pale Red................. 504

Parkinson's Lamrel. . . . . . . . . . . 5:1?

Part's Golden Fleece... . . . . . . . . 502

Pilot . . . . . . . . . . . . . . . . jo

Pitmaston Green Gage ....... . 00

Prince Albert .......... . . 50;

Prince Regent. . . . . . . . . . . 5 $\left(i i^{3}\right.$

Profit ................. 503

Prophet's Rockwcod......... 50

Queen Caroline............. 50.3

Red IIarrington............

Riler's ... ............. sofis

Riley Tall who ............. . $(0)$

Robirts sicect Huter..... . . . . . 50t

st. (linir.................... . . . .

Sinunders' Cheshire Lass. . . . . . . 51:3

Scorpion ..................

smiling Beanty ............ 50 .

Simith's Inprored ........... 504

Smitlis siculling.............. 504

Sorereign . . . . . . . . . . . . 593

Taylor's Bright Tenus. . . . . . . . 503

Teazer. .................. 503 
Thumper . . . . . . . . . . .

Waimman's Green Gcean ....... 502

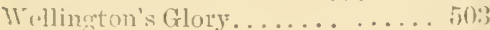

Irbite Jomer

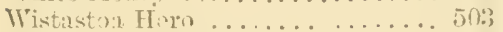

Woolward's White Smith........ 50.;

Yellow Pall

502

Yellow Champarlie........... 502

Founer Wonderful............ 50;:

\section{GPIPES.}

Adirondac .

A gitwam.

diken

Albino

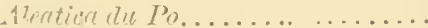

1leppo

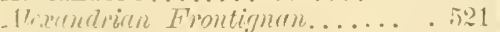

Alicante.................. is:;

dicintenivein.............. il:;

Allair ....................... ij

Alver... . ............ .

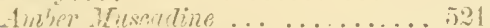

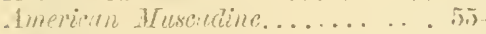

1mims .............. 5. 5.

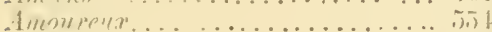

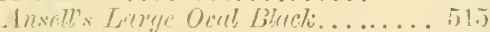

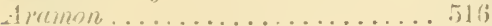

Archer................. 5. 50

Areott . . . . . . . . . . . .

Arkensas ... . ..........

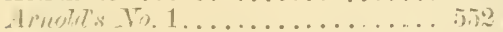

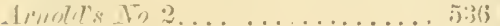

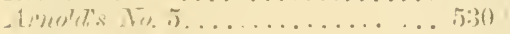

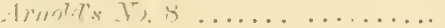

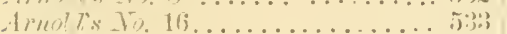

Anetuwick . . . . . . . . . . 5 5,0

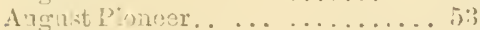

Lliejust. Tranbe............ 517

Artuchou .................. 5:?

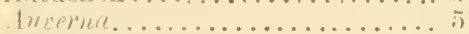

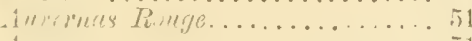

Alutrue....................

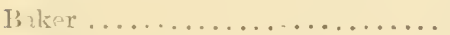

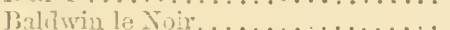

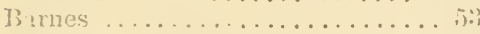

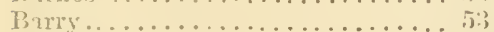

Baxtor.............. . . 5.;

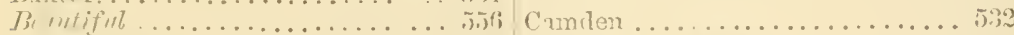

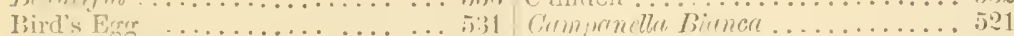

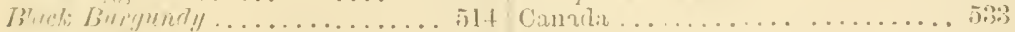

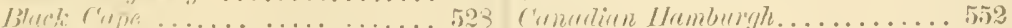

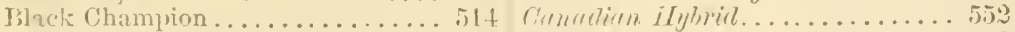

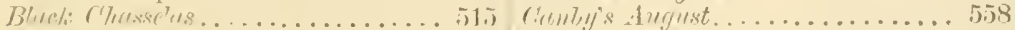

Black Clust: r............. $51+$ Canon Hall Huscat . . . . . . . . 516

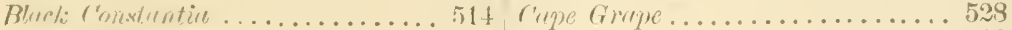

Bucti Franhenthull .......... $51+$ Curter ............... 533

511

514

Tili

$51+$

531

i.: $1: 3$

$51 \overline{5}$

511

15

(i)

513

\section{$1: 3$}

1.;

513

ก.5 1

$11 ;$

Black Tripoli............... . . . . .

Plun te 7 mom

$5: 31$

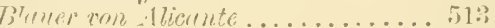

S

Blue Favorite . . . . . ..... 5:32

Blue Imperial . . . . . . . . . . . . . $5: 32$

511

$5+5$

511

16

32

5i:30

5) 1 -1

$5 i 5$

16

5)

302

32

19

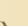

1
8

6
3

3




\begin{tabular}{|c|c|}
\hline$\ldots \ldots \ldots \ldots \ldots .556$ & Dutch Succetuater... \\
\hline Cassady . . . . . . . . . . . . 5938 & \\
\hline Catawba.............. 539 & Early Blacti. \\
\hline Cntancbre Tokay .............. 53:) & Early Black Bordeaux... \\
\hline 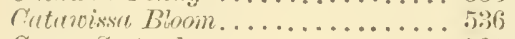 & Early Black July........... \\
\hline Cerese Siptembro ............ 521 & Early Chasselns. .............. \\
\hline Thallenge. .............. 5:33 & n Frontignan......... \\
\hline$\ldots \ldots \ldots 516$ & $\ldots \ldots \ldots \ldots$ \\
\hline Th Tokay & Ëroly Kienzheim................ \\
\hline rth Tokay Malaga. . & ur Frontignan......... \\
\hline$a \ldots \ldots \ldots \ldots \ldots \ldots \ldots$ & Early Silver Frontignan........... \\
\hline dits blienc ............. 5 & a Frontignan.......... \\
\hline$\ldots \ldots \ldots 5$ & recticriter............... \\
\hline 6. Fontainebseare.......5 & Gite Teneriftic...... \\
\hline las Hizsque. . . . . . . . . . . 516; & Early White Mlalvasia........... \\
\hline (1ts $N\left(0 i r^{2}\right.$. & Eurily White Muscadine.......... \\
\hline las younrelte? & 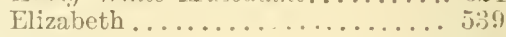 \\
\hline Chasselus Précoce... & 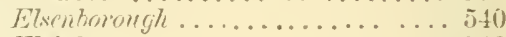 \\
\hline Chatssehes lionge ............... & $\ldots \ldots \ldots \ldots \ldots$ \\
\hline Ures Ronige Foncie.......... & ghburgh . . . . . . . . . . . \\
\hline Rcyal ............ 517 & Emily . . . . . . . . . . . . \\
\hline Y Remall & $\ldots \ldots \ldots$. \\
\hline las Vibert.... & Espugnin Lir............... \\
\hline$\ldots 534$ & 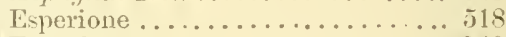 \\
\hline Christie's Improced Isubclle.. & Enmelan.................. \\
\hline Christine................ is & \\
\hline Figar-Box Grope ............ . & $\ldots \ldots \ldots \ldots \ldots \ldots$ \\
\hline$\ldots \ldots \ldots \ldots \ldots \ldots \ldots \ldots$ & F'arineux noir. \\
\hline$\ldots \ldots \ldots \ldots \ldots$ & $\ldots \ldots \ldots \ldots$ \\
\hline$\ldots \ldots$ & Filume-Coloned Toliny............ \\
\hline 's Constuntire... & Fleisch Traube.............. \\
\hline$n \ldots \ldots \ldots \ldots$ & Flora $\ldots \ldots \ldots \ldots \ldots$ \\
\hline $1 \mathrm{e} \ldots \ldots \ldots \ldots$ & te Seedling . . . . . . . . \\
\hline treet Black........... & 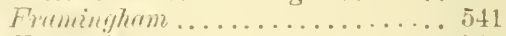 \\
\hline reet Red ..... & c Pinenu................ \\
\hline$a \ldots \ldots \ldots \ldots$ & Tirnelule. ............. \\
\hline bive Gounty ...... & elienthuler.............. \\
\hline Concord ................ 5830 & Frunlienthaler Gros Loir ...... . \\
\hline$o r \ldots \ldots \ldots \ldots \ldots \ldots \ldots \ldots \ldots$ & $\ldots \ldots \ldots \ldots \ldots \ldots$ \\
\hline ntir ............... 528 & $\ldots \ldots \ldots \ldots \ldots$ \\
\hline$(a \ldots \ldots \ldots \ldots \ldots \ldots \ldots 50.56$ & \\
\hline$\ldots \ldots \ldots \ldots \ldots \ldots \ldots$ & Garluer's 1 \\
\hline$\ldots \ldots \ldots \ldots \ldots$ & G: \\
\hline $\operatorname{lli} \lg \ldots \ldots \ldots \ldots$ & e Tolity. \\
\hline$\ldots \ldots \ldots$ & n Wine.......... \\
\hline net Lortge .... & eltar. \\
\hline lam ......... & $\ldots \ldots \ldots$ \\
\hline$\ldots \ldots \ldots$ & gion ....... \\
\hline Cyuthiama ..... & $n+\ldots \ldots \ldots \ldots \ldots$ \\
\hline$\ldots \ldots \ldots \ldots \ldots \ldots \ldots$ & $\operatorname{mgh} \ldots \ldots \ldots \ldots$ \\
\hline$\ldots \ldots$ & $\mathrm{G}$ \\
\hline$\ldots$. & $\operatorname{ctl} c r \ldots . .$. \\
\hline Seren $\ldots$ & Toliary \\
\hline Detroit . . . . . . & Green's Prolifie........ \\
\hline Deverentex & Givianly Froutignule..... \\
\hline Diamant......... & aly Froutigman .... \\
\hline int Traube.. & aro \\
\hline . . 5:29 & $r$ Riending........ \\
\hline .. $5: 39$ & uet II iter. \\
\hline Dex.......... & \\
\hline ss of Bucelengh. & II \\
\hline burght... & \\
\hline
\end{tabular}




\begin{tabular}{|c|c|}
\hline & \\
\hline ine............ & $\ldots \ldots \ldots \ldots$ \\
\hline Iy Blue Windsor........... 518 & $\ldots \ldots \ldots \ldots \ldots$ \\
\hline$\ldots \ldots \ldots \ldots$ & ir dEspagne. ......... \\
\hline rd Prolific........... & th's Ohiw................ \\
\hline$\ldots \ldots \ldots \ldots$ & . \\
\hline$\ldots \ldots \ldots$ & \\
\hline$\ldots \ldots \ldots$ & $\ldots \ldots \ldots \ldots \ldots$ \\
\hline emont's Mfedeira.......... & 列 \\
\hline e $\ldots \ldots \ldots \ldots \ldots \ldots$ & \\
\hline$\ldots \ldots \ldots \ldots \ldots$ & 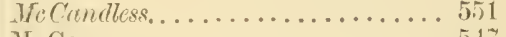 \\
\hline iss Lecrly Red....... & $\ldots \ldots \ldots \ldots \ldots$ \\
\hline$\ldots \ldots \ldots \ldots \ldots \ldots$ & $\ldots \ldots \ldots \ldots \ldots \ldots$ \\
\hline$\ldots \ldots \ldots$ & $\ldots \ldots \ldots \ldots \ldots$ \\
\hline$\ldots$ & $\ldots \ldots \ldots \ldots \ldots$ \\
\hline .. & rape............ \\
\hline . & $I^{\prime}, \ldots \ldots \ldots \ldots$ \\
\hline & de $C^{\prime} u$ \\
\hline incimb? & $\ldots \ldots \ldots$ \\
\hline 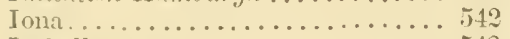 & $\ldots \ldots \ldots \ldots$ \\
\hline . & $\ldots \ldots \ldots \ldots \ldots$ \\
\hline Dili & $\ldots \ldots \ldots \ldots \ldots \ldots$ \\
\hline . & t. . . . . . . . \\
\hline n & .. \\
\hline . & . \\
\hline pes indeir & $\cdots$ \\
\hline S pllina & \\
\hline & ho.... \\
\hline & $\ldots \ldots \ldots$ \\
\hline . & $\ldots \ldots \ldots \ldots$ \\
\hline ng. & $\cdots \ldots \ldots$ \\
\hline . & \\
\hline$\ldots$ & inte \\
\hline & . . \\
\hline & $\ldots \ldots \ldots$ \\
\hline .. & \\
\hline . & - \\
\hline . & dy. \\
\hline ... & $\ldots$ \\
\hline$\ldots$ & - \\
\hline$n g \ldots \ldots$ & 1... \\
\hline egated $\mathrm{Cl}$ & $\ldots$ \\
\hline & \\
\hline$\cdots$ & \\
\hline & \\
\hline . & $t i f{ }^{\prime}$. \\
\hline * scentlin! & \\
\hline & ......... \\
\hline & $\ldots \ldots \ldots$ \\
\hline ". & \\
\hline$\ldots$ & cii). . \\
\hline$\pi, 7$ & , \\
\hline . & 1 \\
\hline . & Bhen \\
\hline & 1 \\
\hline & \\
\hline & 1.... \\
\hline & \\
\hline & \\
\hline & $-e^{-}$ \\
\hline
\end{tabular}




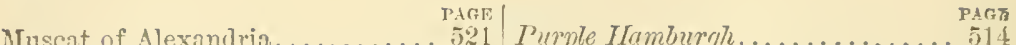

Wuscert Blami ............. 52:3 Pulvorulenta.............. 52C

Museat Blizne le Jura......... 52:3

Wuscut Eschuluta........... 521 Raabe ............... 5.52

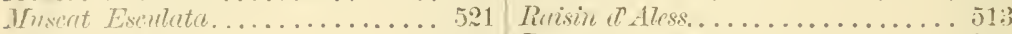

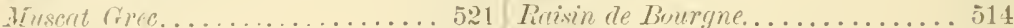

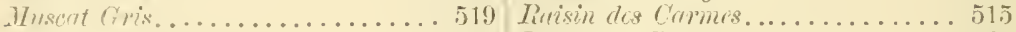

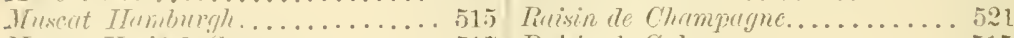

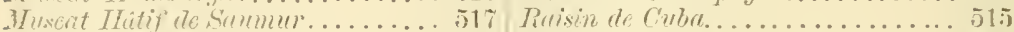

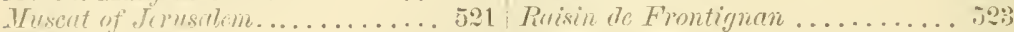

Wusent if Lmed. ........... 521 Ruisin Prierece.............517

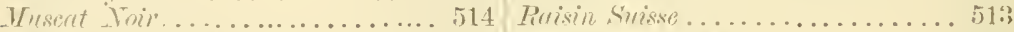

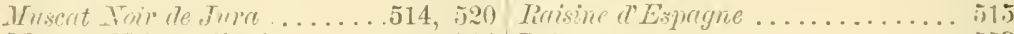

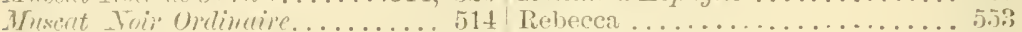

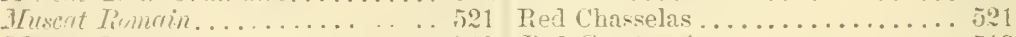

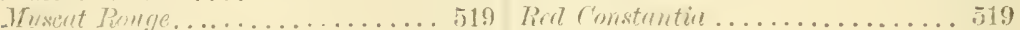

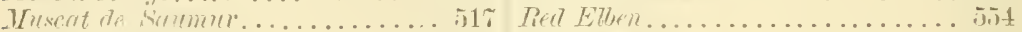

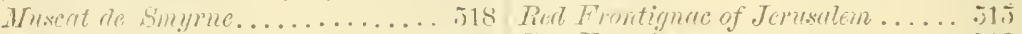

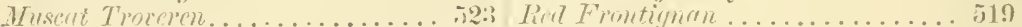

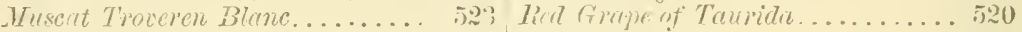

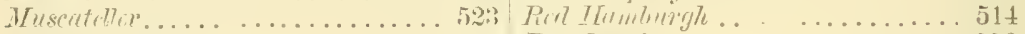

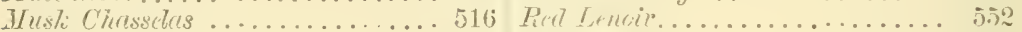

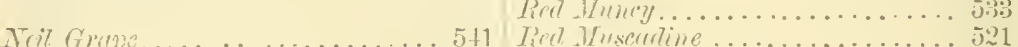

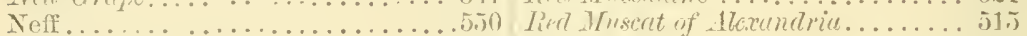

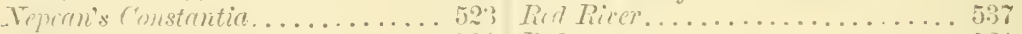

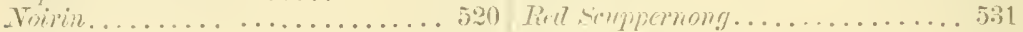

Tonantum ............... 5iso Tieeres' Muscadine...........

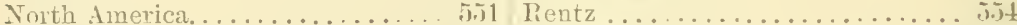

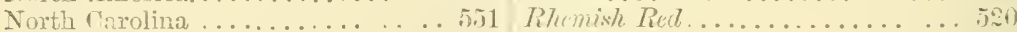

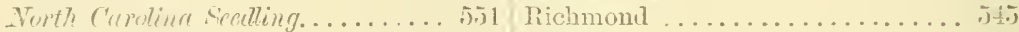

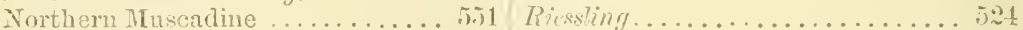

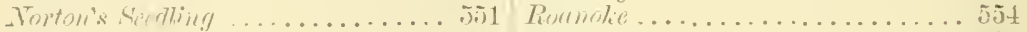

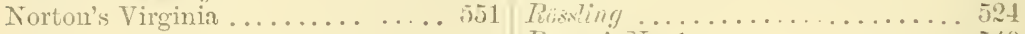

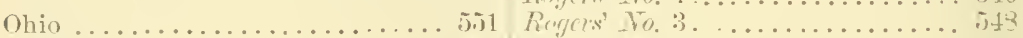

Ontario.................

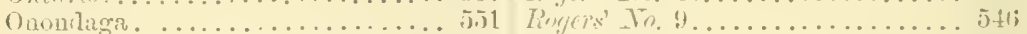

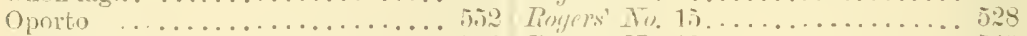

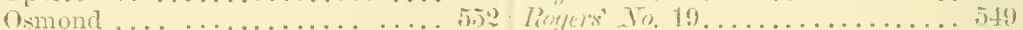

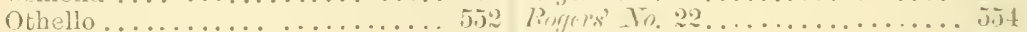

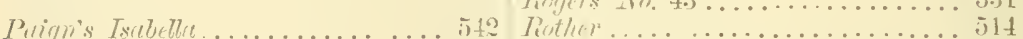

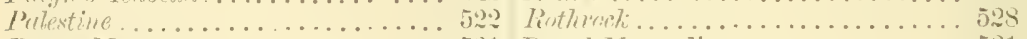

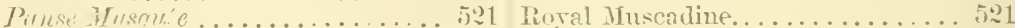

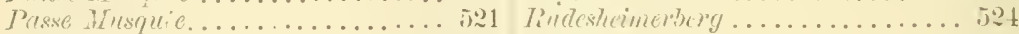

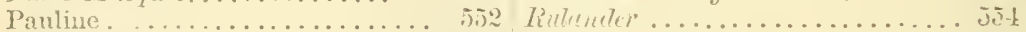

Prymis Entis ...............

Perlins................. 5.j

Pitit lidewting ............... int

Pinean ................... 514

Pitmaston White Cluster ....... . isl

Punte Ricke................516

Poenelis Dumusens ............ isij

Poeschel's IIammoth . . . . . . . 5: i:?

Pollock ..................... ne

Pond's Seedling . . . . . . . . . . 5:3;3

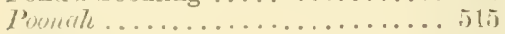

Pнireld ................... . $5: 1$

Précore Husqué . . . . . . . . . . . 517

Primavis Frontignan......... 521

Purple Comstentia ............ sit

Punie Fiontigniln ............ 511

St. thums ................ 16

St. Catherime.............. jist

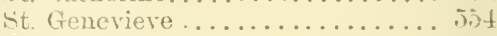

sit. Peters .... ......... jlis

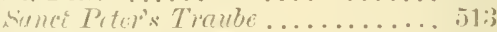

salem .................. 万.j.

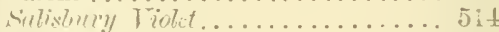

Simborniton ............... itis

simbortutom..................

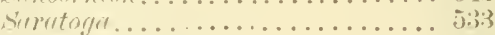

Sintignien nosir. . . . . . . . 5. 501

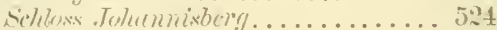

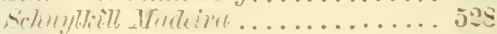

sihuyllinl Kusende............ 528

sibuyllitl s Juscudine . . . . . . . . 528 


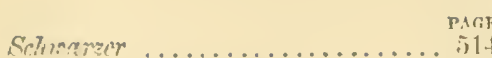

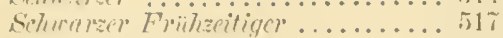

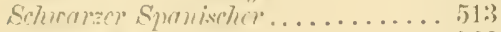

Seotch White Cluster.... . . . . . 5. $)^{20}$

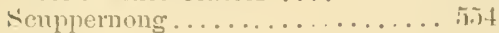

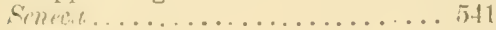

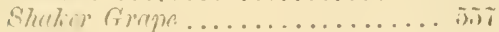

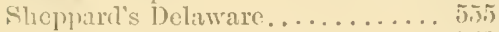

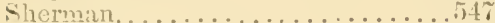

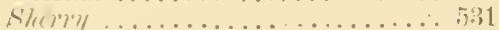

Sluntlelf's Seelling........... 5isli

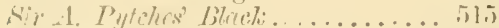

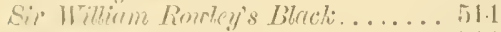

Sumall Bluch: Cluster............ 51t

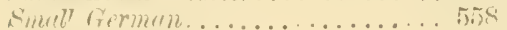

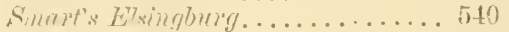

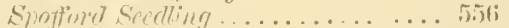

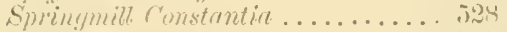

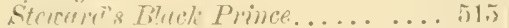

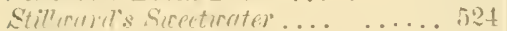

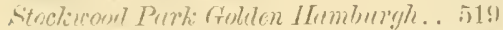

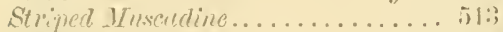

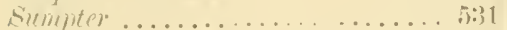

Siritarlumel Grape ........... int:3

Sirrian ................. 522

Tirslinis Frome.............. 528

Taylor's Bullet ... . . . . . . . . 5. 50

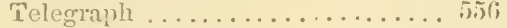

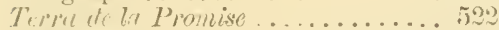

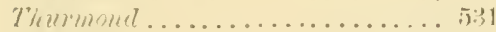

Tu Kalon ................... 5. 5iti

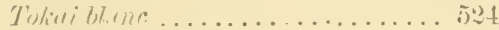

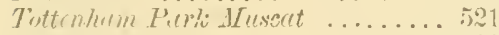

Treblinun................. 522

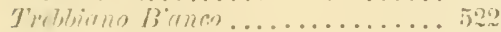

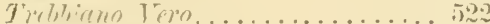

Trentham Black...........

Trullet.................. 5 . $31 \frac{1}{1}$

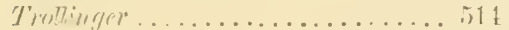

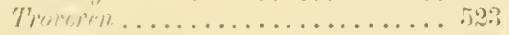

'Trovareil Froiltiman. . . . . . . . 5.):;

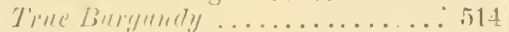

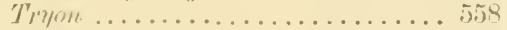

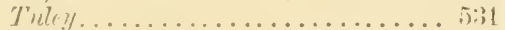

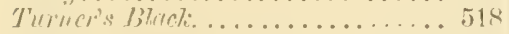

'I'vingham IIuscat . . . . . . . 5.2.

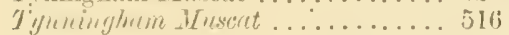

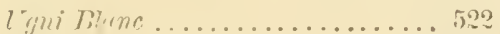

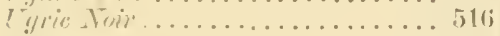

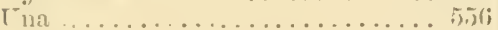

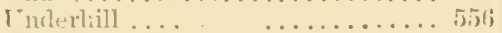

T'nolerhill's Celestial........... nijli

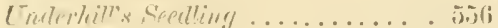

Enion Villagre .............. 5. . .

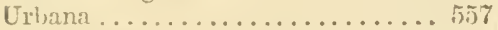

Uva Sildimana ................... 521

Yrelentine. ...................511

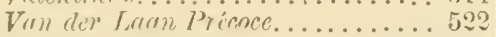

Tarviegutel Chassdus .......513, 520

Venango...............................
PAar

Trvtal ................ . . 52:

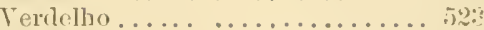

Trutilhio.................. 5. 5.

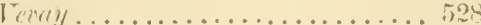

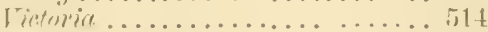

I itis rotundifoliu............. 5ist

Fitis Tulpina ............... 5.t

Frai lucemana............51t

Walter.................. 5it

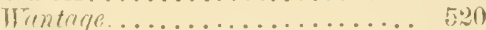

Wrimer's Bluck IIrmburgh . . . . . 514

Warren .................. $5+1$

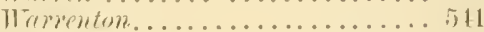

Wruter Znet Nir...............515

Tilt, Znete Blunc............. 5) 21

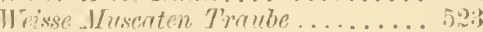

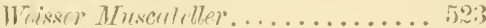

Trissholaigro J'ollinger ..........511

Wracher ................. 511

Wem

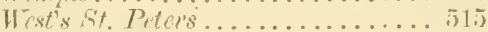

White Cape................. 528

White Catawba.............. . . ...:

White Cherswhes. . . . . . . . . . . 521

White Consturtiue ... . . . . . . . . 5:3:3

White Frontignan ............. is);

White Frontnile............. . 52:3

White Hamburgh . . . . . . . . . . 5:3

White Lisbm . . . . . . . . . . . 5:?:?

Ithite Mtipl ............... 51s

Wlite Muscrdine ........... 5. 5t

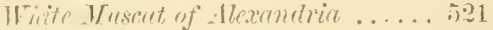

Thite Nice ................ 521

White Iice................. 5. 521

IVlite Pintugul .............. 5?:3

Wlite Ritrivin.............. 583

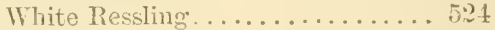

White Swentwatel. . . . . . . . . . 5. 5t

White Tokay................ 5. Tt

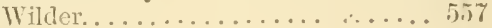

Wilmington. . . . . . . . . . . . . 5.57

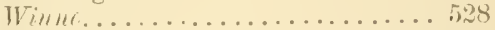

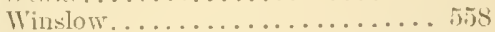

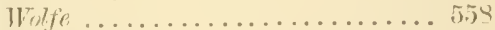

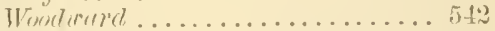

IInthingtrin ............... 5ist

Vright's Isilbella ............. 51;

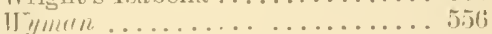

Wyoming Red .............. j.js

Xeres...................... 521

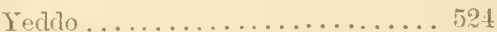

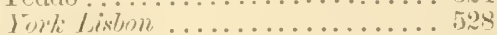

York Madeira ... ........... . . . . . . . . . . .

Zane...................... 533

\section{MELON FAMHL.}

1. MELONS.

Allen's Superb. 
PME | PACF

Alvord's Hybrid............. 560 Irick's Everbearing. . ... ...... 564

Beechwool. ................ 560

Johnson. ................. 504

Christiana................. 560

Red Mulberry. ............ 50.5

Dampsha................. 561

White Mrulberry ............ 56

Green Citron............... 560

Green \relon............... 51;1

Ispahan. . . . . . . . . . .. 560

Jenny Lind. .............. 560

Albert ......................

4 nderson's. . . . . . . . . . . .56\%, 570

Andepsnie's Renind. ............. 5i0

Large Irusk Cantelope. . . . . . . . 5 561

Nutmeg ................. 561

Persion. ................ 561

Pine-Apple................. 56

Skillman's Fine Netted ........ 501

Taiencia...............561

White Japan............... $5 \wp 1$

Winter Melon............... 561

2. WATER-MEIONS.

Apple-Seeded j62

Baugh 562

Black Spanish............. . 562

Bradford ................ 562

Carolina ................ 509

Citron Water Melon........... 5is?

Clarendon ...............

Ice Cream ............... $50 ;$

Imperial . . . . . . . . . . . . 563

Mountain Spront . . . . . . . . . . . 56?

Mountain Srreet. . . . . . . . . . 563

Odell's Large White .......... 563

Orange ................ $56 \%$

Ravenscroft. ........... $56 \%$

Souter.................. 561

\section{MULBERRIES.}

Black MIulberry.

English MIulberry.

Everbearing.......

Galopin................... 568

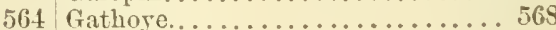

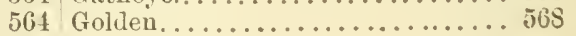

Bulgone................ 560

Balgowan. . . . . . . . . . . . $566^{4}$

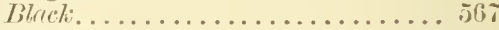

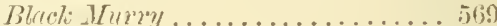

Boston. ................... 566;

Broomfield ... 56 i

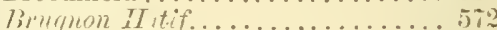

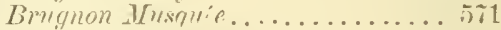

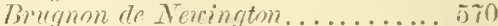

Brugnom Red at the Sitrne........ $5 \% 2$

Brugnan Tiolette Musqu'c....... 5i1

Chaurière................ 50 (n

Clareniont.............. j6i

Comisom Elruge.............. ific

Condray White............... 570

D' 1ngleterre................

De Bulqone. ................. 560

De Filign?.................. jo

Downton.................. $56 \%$

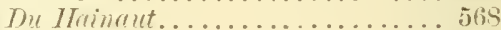

Dn Tilly's .................. 567

Duc du Tellier's ............ 5fir

Duc de Thllo .................... 56 .

Dnc Tidiets................ 5067

Dule de Tilly................. joti

Eurly Black . . . . . . . . . . . . 56i

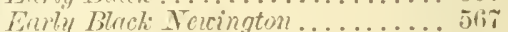

Exrly Brugnon. . . . . . . . . . . 572

Early Newington ............ 56:

Eraty Tiolt................ 5\%:

EIruge ................... 5(i⿱

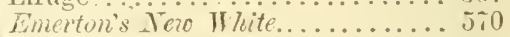

Fairchild's................50s

Frivchilds Earby. . . . . . . . . . . . 56s

Feligny................... 56s

Fine Gold-fleshed ............... 56s

Flendirs................. 5\%0

French Teuington ........... 578

68 


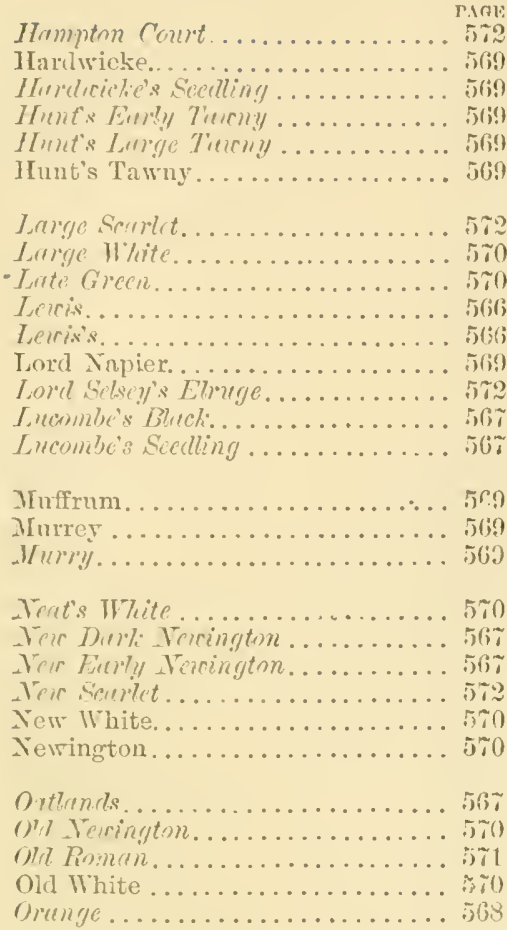

Perlings Seeding.............5\%

Peterhorough.............. 5 .

Prtirborongh.............. $5(59$

P.tit Tinlette Ilutice. . . . . . . . . . . . . ?

Pine-Apple................ לो

Pitmaston Orange........... 5\%

Tied Roman ............... $5 \tau 1$

Rivers Orange............... 5)

Rivers' White ............... 5\%1

Rmman ...............

lion.gh Romun.............. 5\%0

sitet . ................. $5 \pi 0$

Serrlet Vencington............ 5\%0

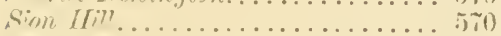

simitlis Werington ........... 5. 580

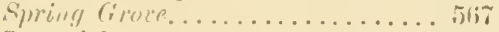

Stanwick................. 5 51

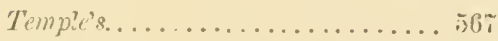

Trrmash................ 5\%

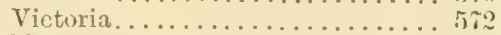

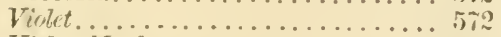

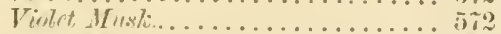

Violet Reel ut the Stone.......... 5\%2

Violette Angercillives........... 5\%

Violette Grosse............. 5\%?
Violette Hatire.............. $5 \%$

Tiolette Musquie............. 572

Willimms' Orange............. 571

Hillinms' Scedling....................571

\section{NUTS.}

1. CHESTYTTS

Chestm $\ldots \ldots \ldots \ldots \ldots \ldots \ldots \ldots . \ldots 72$

Chinquapin.............. 573

Dwarf Chestmut............. 573

Spanish Chestnut............ $5 \pi 3$

2. FILIBETS

Cosford................ 5 57t

Dicarf Prolific............. 5\%t

Fithert $C o b \ldots \ldots \ldots \ldots \ldots \ldots \ldots, 5, \ldots \ldots$

Frizzled................ 5\%

lintish $C o b \ldots \ldots \ldots \ldots \ldots \ldots \ldots 5 r 4$

Lambert. . . . . . . . . . . . . 574

Northamptonshire Prolific........574

Tottingliam Prolific............ 5it

Penrson's Prolific............. 57t

Puple Filbert............. $57 t$

Purple-Leared. .............. 5\%t

Red Filbert............... 5rt

White Filbert............. 5\%t

‥ IICKORY NUTS, IDTTERNUTS.

Hickory Nat.............. 5\%t

Shell Bark................ 5it

The Butternut............ 5\%4

4. WALNUTS

A Coque Tenulre.............. $5 \% 4$

Black..................5 5it

De.Tange................... 579

Donlle.................. 573

Dwarf Prolific............... 573

Early-Berring. . . . . . . . . . . 573

European. ................ 573 


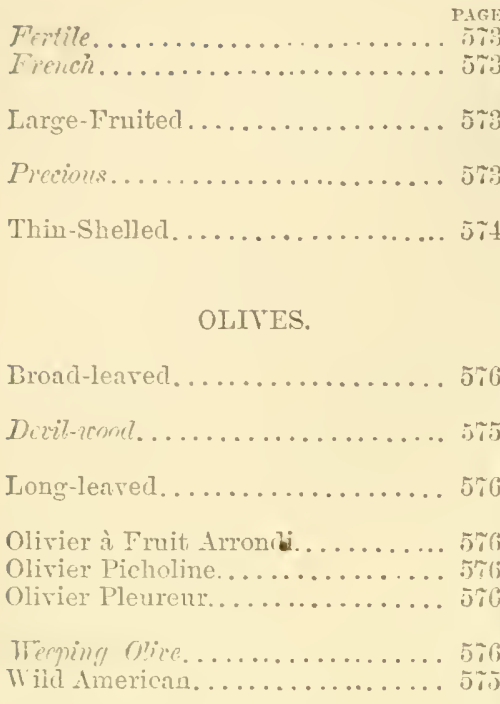

\section{ORANGE FAMILY.}

1. ORAXEES

Bergamot.

Jitte. Opane ............... nats

Blood Red................. dis

Common sweet.$\ldots \ldots \ldots \ldots \ldots$. 5

Donble Bigarade.............. is

Fingered................. $5 \%$

Harana.

Maltese.

Mandarin

Tolice Orange.

Perte-slupert.

Iivoured.

St. Ancustine.

st. 7richael's.

Serille.

Sharldock.

sicat stiviner.

\section{LEMTONS}

Common.

Sweet.
3. LIMES

PAGB

Common............... . 579

Pomo de Adamo......... ..... $5 \pi$

4. CITROXS.

Common................. $5 \pi$

Madras.................. 57

\section{PEACHES}

A Bec....................

Abricotee................... 598

Aeton Sentt................ 597

Admiralle ................. bios

Atmirable Jienne. . . . . ......... 597

Admirable Tardire ............ 600

Alberge Jarme............... (ii:i

Albert's L:te Rareripc.......... j! i

Alexaudra ................. 597

Alexender Tnliesse........... 59.

Algices Winter.................6.6.1

Algiers Tellorr............... 621

Alida.................... 597

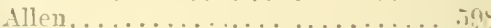

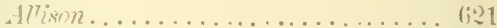

Amelia ...... 50

Anne....................... tint!

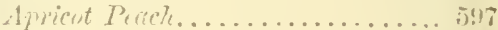

Aremie................ is

Astor.................. n!

Atwool ..................

Austin's Late Red ............ $5 ! 19$

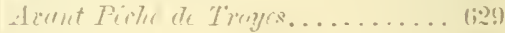
Ateant Rounge.................. bi:

Baldwin's Late. ............... jng

Barnael's Farly. ................ . tiri i

Bamard's Yellow Monest John. .... ti:

is Barington.

5 is Batchelder................... je.19

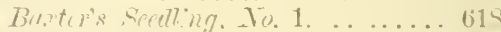

Bilf Bunce -................. is

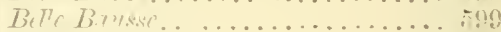

5.9 Belle de Beancaire.............. bing

Belle et Bonme................ (000

Belle Chevreuse . . ........... 509

Belle de la Crois. .

Bame de Domati.................. (ino

Belle de Doné .............. 600

Balle de Fill mañ. .............. 600

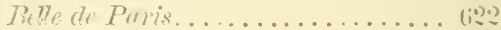

Belle de TitrT................. lico

Bille de Titry ................60 608

Bellegarde.................60 60

Bullis.............................600 600

Bergen’s Tellor................ 601

Blanton Cling.................601 601

5\%9. Bloul Cling.................. 801 
PIGE! PArF

Blood Clingstone.............601 Donble Montagne............607

Bonne (iros de Noisette......... (i01 Double Jlomutuin.............60\%

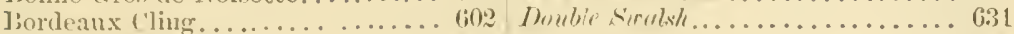

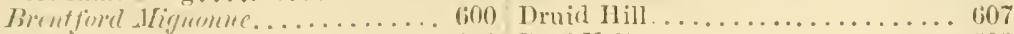

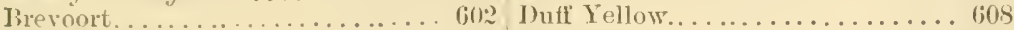

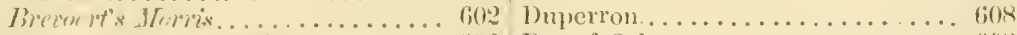

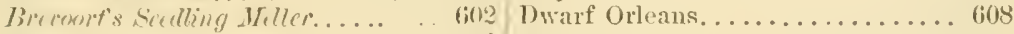

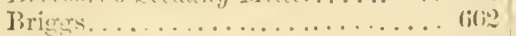

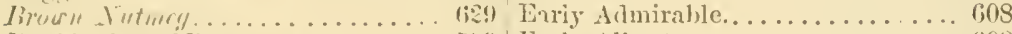

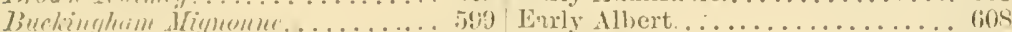

Errly Alfred............... (i09

Cable's Late . . . . . . . . . . . . .

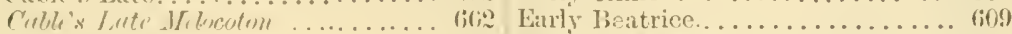

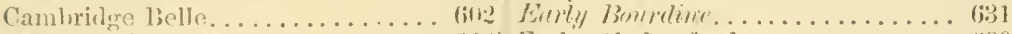

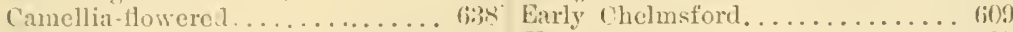

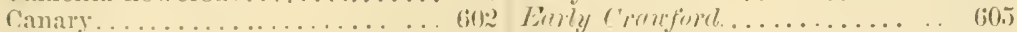

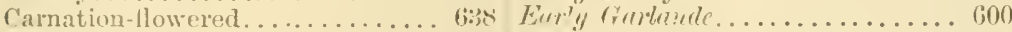

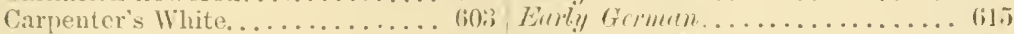

(atherine. . . . . . . . . . . . . 6. 60:3 Early Grosse Mignonme......... 60)

Chancellor . . . . . . . . . . . . . . . . (i0:3 Early Lonise. . . . . . . . . . . . . . (io!)

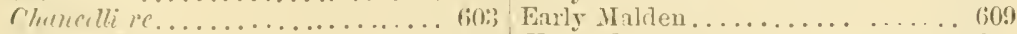

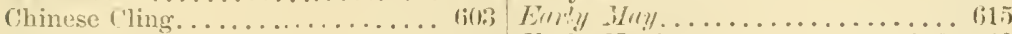

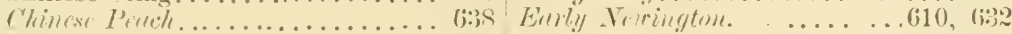

Christiana. . ............. 6(0;) Enrly Newington Freestone...... (ilo

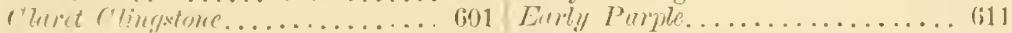

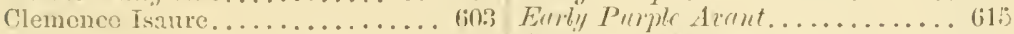

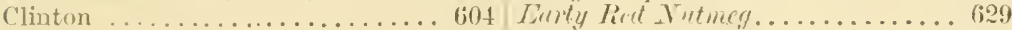

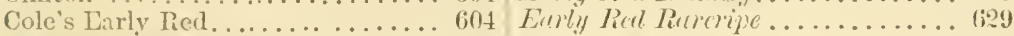

Cole's II hit Medectom.........624 Early Rivers. . ...........610

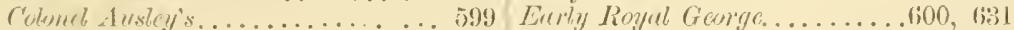

Columbia................ 604 Early Silver............... 610

Columbus, June..............60.4 Early Sireet Water........... (i10)

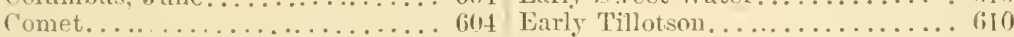

Comtesse de Hainant..........605 E. Erly Victoria...... . . ..... (i11

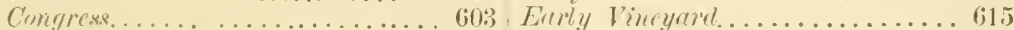

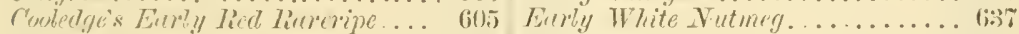

Cooledge's Favorite........... (60) Early Tork...............611

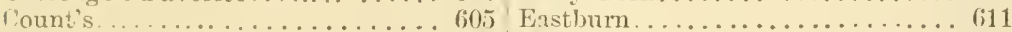

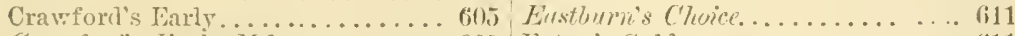

C'reirforel"s Émily Mclocoton........ 60.j Eaton's Golden................ (i11

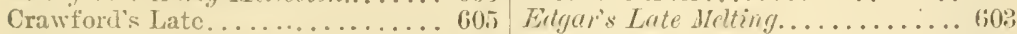

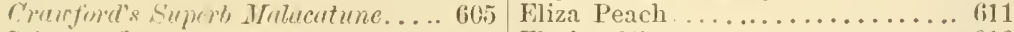

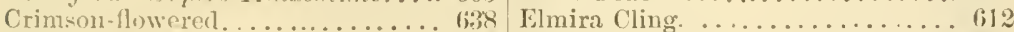

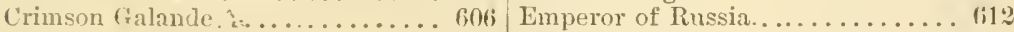

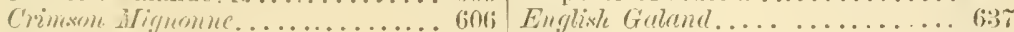

Crockett's Late White.......... 606 Ernoult.................. 612

'ut-Lorwal. ..............612 Exqnisite................612

Cuttris lillow .............. 6.38

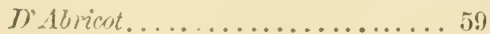

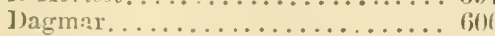

De Beurre................ (i0)

De lionlez.................. 60

1). Joutign! . . . . . . . . . . 51

Desse Tardive. . . . . . . . . . . . . 6

De $Z$ lhern.................. 600

Doctor Hoger. . . . . . . . . . . . . 60

D'Oignes. . . . . . . . . . . . . $80 \%$

Jonaboo Cling................ (60)

Jy Oringe...................... 597

Jorsetshire. . ................. 625

Double-13lossomed..............638

Farorite...............612

Favnite Red................ (112

Five II wth..................616

Flat Peach of China.......... (6:38

Flater's st. John............ 61:

Flewellen Cling . . . . . . . . . 6 61:3

Fox's Seerlling ............. 6!:?

Freeman .............. 613

Frectome Herith. . . . . . . . .619, 624

French Burdine.............6\%0

French Chancellor.............. (i:31

Fronoh Hugdalen............. 622

Freneh Jignonne...........6.615

French língal George............600

Double Flockering Perch......... Giss Fruitland................613 


\begin{tabular}{|c|c|}
\hline friutuand seedlum & \\
\hline 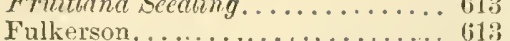 & Jane....... \\
\hline Fulkerson's $\mathrm{E}$ & $\begin{array}{l}\text { Jutra Perieh. } \\
\text {. ohnson's Ear }\end{array}$ \\
\hline & Jones' Early... \\
\hline alande. & Jones' Large Early. . . . . . . . . . . . 618 \\
\hline . 614 & Jose Sweet. . ............ . 018 \\
\hline se the Fourth. & Fudd's Meiting. . . . . . . . . . . . 620 \\
\hline Golel-Flesterd ..... & Julia.......... \\
\hline Golden Mignumue.. & \\
\hline oode's October... & I'pnnedy's Carolina ............621 \\
\hline$\ldots \ldots \ldots$ & Kennedy's Lemm Clingstone... . . . . (i21 \\
\hline stern. . . . & Kenrick's Heath............... 619 \\
\hline Catharinc $\ldots \ldots \ldots \ldots \ldots \ldots \ldots$ & \\
\hline arg $\ldots \ldots \ldots$ & I'Adminable \\
\hline regory's Late. . . . . & La Grange. ............. . . \\
\hline G'riftin's Mignonne. & La Royule .... . . . . . . . 615, \\
\hline Griffith... & Lady Amn sterored............. \\
\hline riffith Whe & Laty Parham............. \\
\hline riffich $\mathrm{J}$ I:1 & Lally Palmerston........... \\
\hline rimuood's Nean lion? & Larige Anerienu Vutneg..... \\
\hline$a d ' s$ liongel $C$ & Large Early Iork. ......... \\
\hline is le'iyal Ge & Laige French Wignonne......... \\
\hline 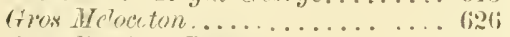 & 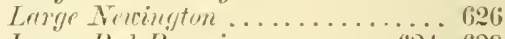 \\
\hline (rios 1 & 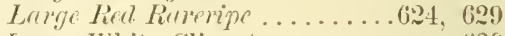 \\
\hline Grosise Jumbe Tardice. & e White Clingstone ......... \\
\hline Grosse Mignonne... & Ie Yillow Rereripe....... \\
\hline Grosise Mignou. & $n \ldots \ldots \ldots \ldots \ldots \ldots$ \\
\hline & Late Admirable $\ldots . \cdots \cdot \cdots \cdot \ldots 20$ \\
\hline aines' Early Red.............. (615 & $l_{14 y^{2}}$ \\
\hline$\ldots \ldots 615$ & $\cdots \ldots \ldots$ \\
\hline Hardy Gat & Red Raieripe.... \\
\hline$\therefore \ldots(615$ & Alberge... \\
\hline$\ldots 1$ & gstone......... \\
\hline & $\ldots$ \\
\hline$\ldots \ldots \ldots t$ & $\cdots$ \\
\hline$\ldots \ldots \ldots 1$ & $n+\ldots$ \\
\hline Herth & 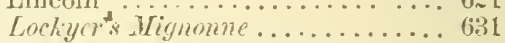 \\
\hline Hruth Free... & Icllore Pine-Apile \\
\hline$\ldots($ & onberg's llignonne. \\
\hline$\cdots \cdot 1$ & unucis Ioblesise.... \\
\hline$\cdots 6$ & 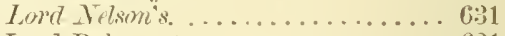 \\
\hline . 61 & $\operatorname{ton}$. \\
\hline . 6:9 & Lill \\
\hline . 619 & Lyo \\
\hline . $61 \%$ & Mas \\
\hline . 61 & Mardeleine Blanche........ . \\
\hline & Nudeleine Blanche he loisel. . \\
\hline$\therefore$ & ... \\
\hline . & i Prtite Ilcur.... \\
\hline & Ronucie r \\
\hline .. & ue i Mitite s'leur' \\
\hline & Ronge T'urdize... \\
\hline . 604 & $\ldots \ldots$ \\
\hline $\operatorname{Ir}$ & . 60 \\
\hline Italium & \\
\hline Italial & . \\
\hline . & . \\
\hline Jar & $\mathrm{MI}$ \\
\hline Taca & ite. . \\
\hline
\end{tabular}


Middleton's Tmperial ............. (jog

Mignome ...............6. 615

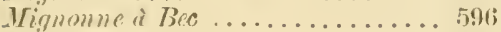

Miguonne Dubarle. . . . . . . . . . (i22

Jignomne liutive. . . . . . . . . . (60)

Milletis Mignonne .............6.31

Mrolden's White........... . . (i2:3

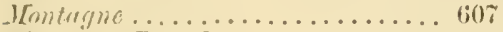

Wemtigne Biandie.............. (i:36

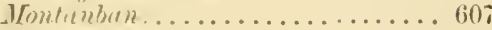

Montgomerț's Late . . . . . . . . . . 62:3

Moore's Favorite . . . . . . . . . 62:3

Mnore's .June................ 6. 62:

Monistions Pilvie .............. li?6

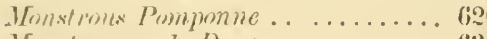

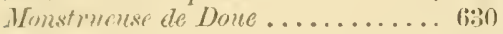

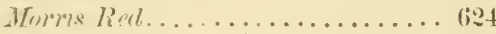

Morris's Rel Rareripe.......... 624

Womris's Wlite............... 6924

Worriss White Freestome........ 62t

Jorris's White Rareripe........ 691

Morrisania Pound. . . . . . . . . . 62:

Morvison's Tound... . . . . . . . . 6293

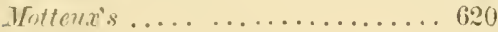

M[rs. Hunley. . . . . . . . . . . . . . . 62:

Mrs. Poinsette ............ 62:3

Mubutto ..................6. 601

Napoleon.

Nectarine Peach

ITil's Errvy P'urple.

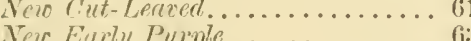

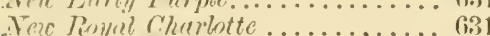

Stex Fink Rardipe........... 61?

Wero Jorle White Clingstone...... 620

Veroington .................. 626

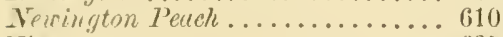

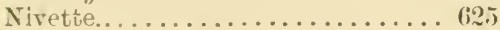

Wiutte Velout e............ 62.)

Noblesse... . . . . . . . . . . . . 625

Woir de Wontreuil ............. 600

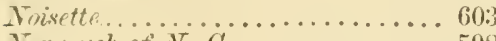

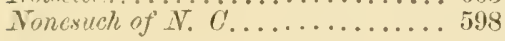

Oetober Jello10..............6.621

Old Newington............... 626

Olelmirnen Clectistone........... 625

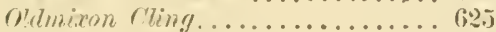

Oldmixon Clingstone........... 69.

Oldmixon Freestone .......... (625)

Orange Clingstone ............ (i2ti

Orunge Perelk. . . . . . . . . . . . 597

Orangeburg................. . . . . . . . . . . .

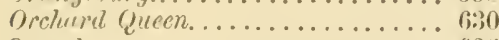

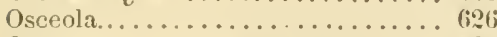

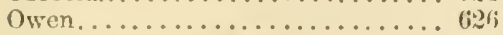

Ouch's Lemon Rareripe.......... 6iqu

Pace......................60 601

Parie Admirable..............6.618

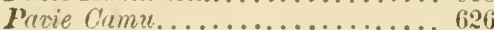

Puvie Monstrueux.
Pavie de Pompone............... PAan

Pavie de l'omponne Grosse.......... (i20

Puxie liuuge de Pomponne........ 6*6

Pivhe Jamne................6.6:37

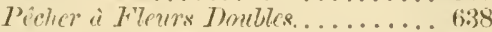

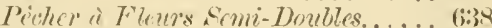

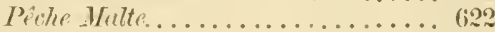

Picke Riogule................620

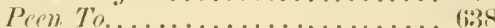

Pettit's Imperial. . . . . . . . . . . . . (i29

Picquet's Juate................ 2ri

Pine-rpple. Climgstone........... (i2l

Pool.'s Large Tellow. . . . . . . . . . . 6 627

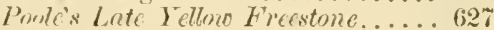

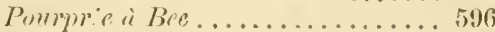

Pumpris Ilitire.............611, 615

Ponrmie Ilatice Tineuse......... 599

Pmorprie de Tommandie.........61j

Pentrpr.e Turdive................ (i20

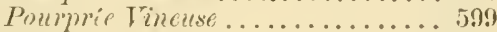

President ................... 627

President Church ........... 6\%

Prince of IVales..............6. 67

Prince's Climax. ................ 628

Prince's Excelsior............... (928

Prince's Paragon. .................. 62s

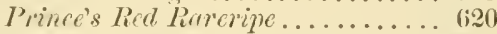

Princess of 11 ales. . . . . . . . . . . . . . . . . .

Pucelle de Malines.............. 6.

Purple Alberge.............. (6:37

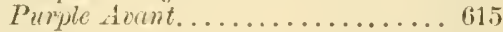

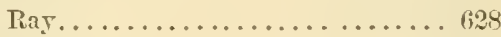

Riaymackers................. 6...

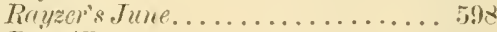

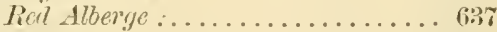

lied 1 vanit . . . . . . . . . . . . . . (ias

Rid Check IFribcuton .......... 6i2n

Red-Cheek Melocoton.......... 629

Ped Heath ................... (i16

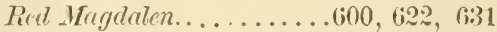

Red Nutmeg .................. (529)

Red Rareripe................ 699

Red Raveripe............... 62.

Red and Iellozo Rirreripe......... 60.38

Reeves' Favorite............... $6: 30$

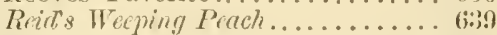

Reiue Des Tergers ............. (j:30

Rivers' Early York.............. (;:30)

Rodman's Cling ............... 630

Podman's Red................ (;:;0)

Ronaldes Miquomine.............. 600

Romald's Seedling Grabande ....... 615

Rosanna................... (;:37

Rose.................... (;:3:\})

Rose Aromatic . . . . . . . . . . . . (i:3)

Rose-f'bnering ............... (i:38

Rosebank .................. 6: 6:30

Rough l'aysrinne.............622

Royal Charlotte ............. $6: 31$

Royal George................6. 631

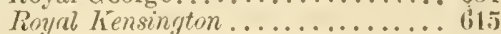

626 Royal Sovereign.............. 615 


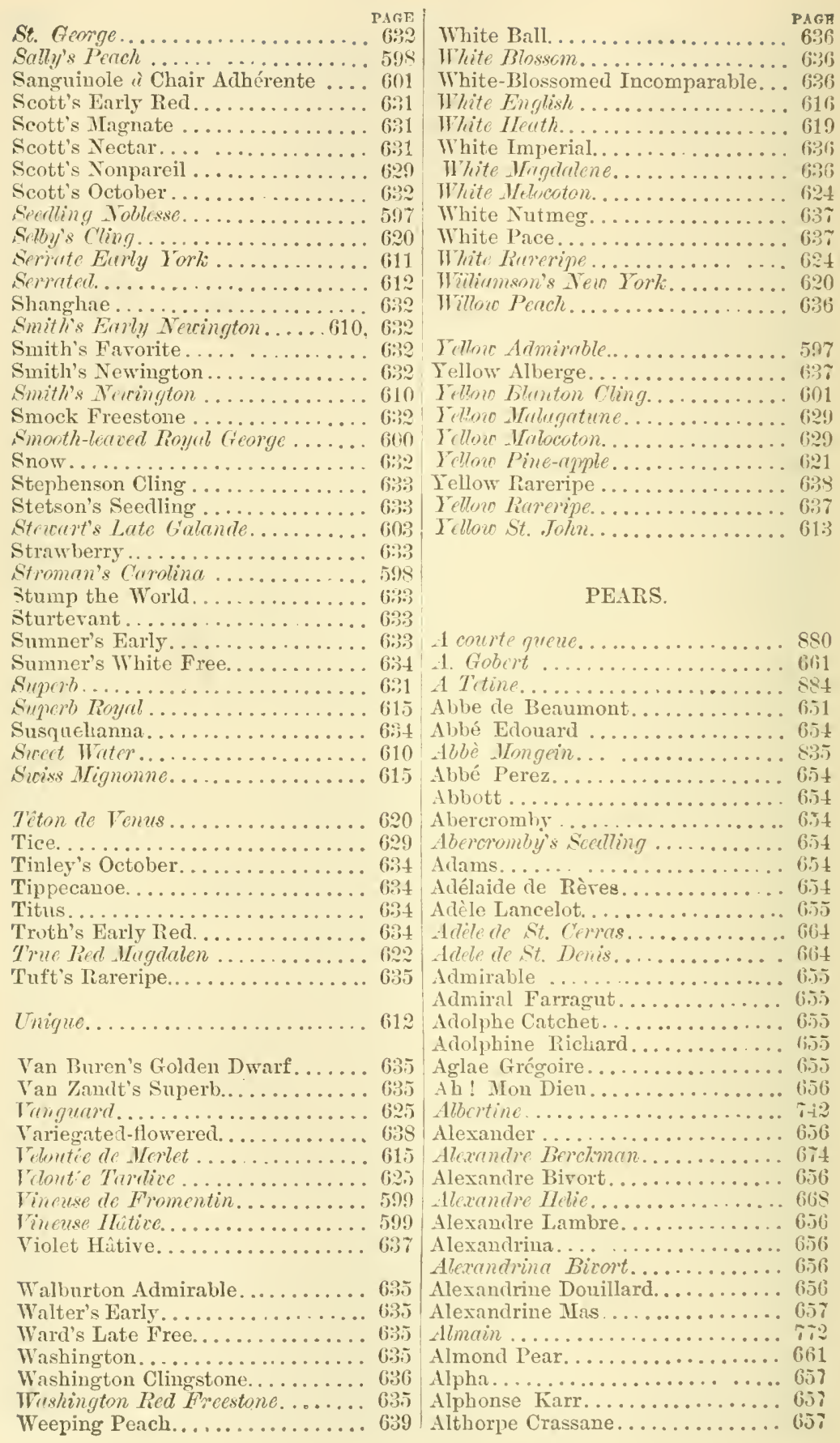


Amadotte................. Piji

Amanule Dimble............... (ioi

Amandine the liouen............ (6iñ

Ambre bris............... . bis

Ambet. . . . ............... 6ins

Ambrette .................. (6.58

Ambitte arec iquines........... (358

. 1 mbrette ignimense............. (i.5)

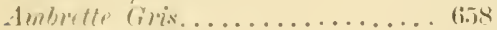

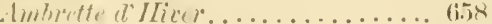

Ambrosia .................. (iins

Sumelie Leclerc............... (i.is

America .................... (i.j.

Amerima Branty............. . 740

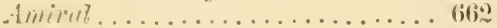

Amiral Cecil .............. (i.)

Amire Joamnet. . . . . . . . . . . (6ĩe

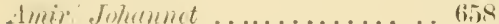

Limire mur. . ............. 862

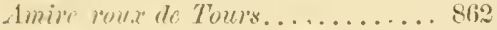

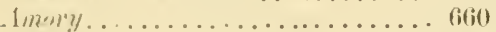

1moxile ................. ist

Ainomx..................... (i.i)

Anumus.............660, \%82

Ananas ile Courtray............ (i59?

Anamas diété. . . . . . . . . . . . . (ivio

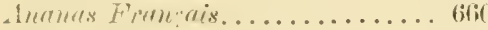

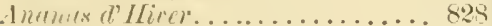

Anele

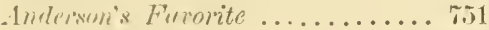

Antré Desiportes ............. $\mathbf{6 6 0}$

Andrews. . ...............6ito

Andrers' hingsesxing........... 594

Angúlin̨ue de Bordeanx. . . . . . . . 660

Anģ̉lique Leclere............. (ibi

Angleterre................... (itil

Angleterre d'Hiver. . . . . . . . . . 6 6il

Angletere Nain.............6(i1

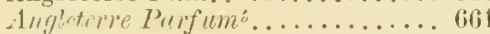

Angobert ................6.6il

Ingoisse blanche.............661

Angorve .................. 835

Anna Audisson .............661

Apple Pear. ............... 662

Arbre Courbé. ............... 60.61

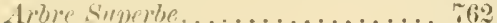

Arelululis Cleavies............. 7333

Archelul: of Summer........... 862

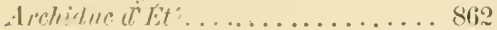

Arlequin Musqué. ...........66 $66^{3}$

1rtateive ................. 8.5

Arthur Bivort................ litis

Aston Town. . . . . . . . . . . fiti?

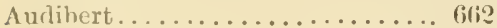

dutibert.................. (iss

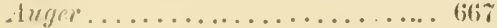

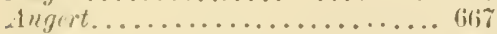

Alugive...................667

August l'erfume..............8.8

Auguste Jurie. . . . . . . . . . . 66 692

Auguste Lelieur............... (6iti)

Auguste de Maraise............. $\mathbf{6 8 4}$

Auguste Royer.............6603

Auguste Van Krans............. 850

Angustine Jelieur. . . . . . . . . . (60)

Angustus Dana................ 66:3

Amate................... . biis

furvere. . . . .

Antumn Bergamot. .......... $66 ; 3$

Lutumn Bon Chritien.......... $8 \pi 8$

dutumu Butter................ 880

Autumn Cotherine............ 846

Antumu Colmar.............. fifi.)

1utumn Colmar................... 21

Intumn Jolting............

Iutumin Nonthurater........... 804

Antumn Nelis............... 1364

Autumn superb..............6. 6ir

A vril . . .................... 664

3. O. de la Cour.............. 811

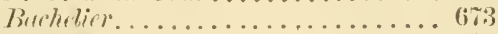

Budlatun's ................. $\$ 10$

Bugpipe of iviou .............. Trio

Brmerist . . . . . . . . . . . . .

Bund de le Cour............... \$11

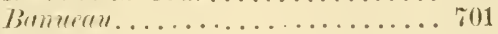

Barbancinet...............664

Barbe Nelis................ 664

Burnott's Hillium.............6660

Baron Deman De Lennick . . . . . . . 664

Baronne de Mello.............. (664

Bary .................. 66.j

Burflett ..................... 6(i6

Bartlett Bonchrétien ...........66ti

Bartram ................... 60\%

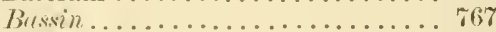

Bromomnaise. ............... 861

Beadnell ...................6667

Bendmoll's Scedling . . . . . . . .... 667

Berm Présent................. . 58

Beau Present d'Artois .......... 1667

Benuchemps............... $6 \%$.

Buruelene................. 863

Bearets de Terwuen .......... 835

Berruty of Brussels ............. filis

Beauralot. ...............

Brdminster Gratioli........... 791

Briu Ammdi .............. .

liklt Tongue. . . . . . . . . . . . . 88?

belle devienne............. 85.5

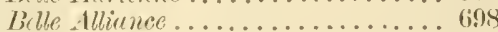

bille Indreane. ............ 8\%

Bille Angerine ............... 8:35

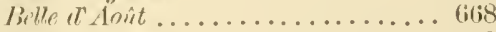

br lle Audibert................. (6602

lille d Azstrasio .............. 790

Brlle de Berry. . . . . . . . . . . . 85

Belle de Bruxelles............. (i6s

Bille te Bruxelles ............. T78

Bulle des beris ..............

brlle et Brmme................ т78

Balle at bonne di trate........... 70.5

liblle et Bonne dlliver.......... 723

13elle Canrise................. 819

Belle Comelic.................. 767 
PAGE

Belle dT Esruermes.

Jolle deté

Belle Frellento.

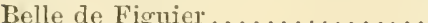

liclle the Thisic

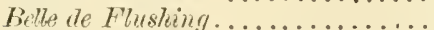

Belle de Forêts .................

Brlle Gubrielle .................

Bulle Ileloise . ......................

Belle Honrirtte . . . . . . . . . . $78 \%$

Bolte de Jersey. . . . . . . . . . 668, 8:8

lielle Julie . . . . . . . . . . . . . . . . 60

Brthe Lncrution .............. 76 ;

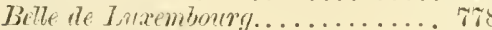

Brlle de Mrive ................ 69

Belle Moulinoise . . . . . . . . . . 6 6(i9)

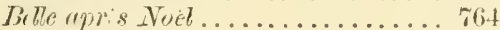

Brlie de Noël. . . . . . . . . . . . r r

Brble Wrixptte ................. (i6s?

Belle de l'Orient . . . . . . . . . . . . 668

Belle sans Pepins.............. Th

Belle de Prague..............668

Belle Rouennaise . . . . . . . . . . 6669

Belle de Thomas..... . . .......668

Brble tle Thomar..................668

Brbe de Troyes............... 66

Belle Terge................... Tis

Belle du Tremie............... Tisi

Belle du Terwis ............. T31

Belle Williams................6 $6(6 !)$

Bellegrarde................ Tis

Bellisime d'Automne . . . . . . . . . . 66is

Bellisime du Bur . . . . . . . . . . . . 66

Bellinime tle Provence ............ 847

Bellissime................ 85:

Bellissime di Eté. . . . . . . . . . . .

Bellissime d'Hiver. ............. 669

Bellissime of Hicer a

Bollissime Jargonelle. . . . . . . . . . . ifir

Bellissime Suprime............. T67

Belmont . . . . . . . . . . . . . 669

Benoist. . . ............6.674

Bergrmot Ruyje............. 805

Bergamot Seckel............. if

Bergomot sylumehe . . . . . . . . . . . 860

Bergamotte $l$ Alencon............ T84

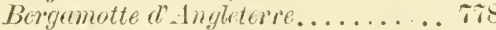

Bergrmotte d' - Irranches.......... soi

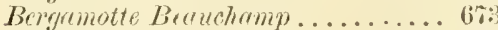

Bergamotte Bouissière... . . . . . . $66^{\circ}$

Berganotte de Bruxelles......... is

Bergamotte Bufo............. 670

Bergamotte de buri. . . . . . . . . . T51

Bergamotte Cadet............6\%0

Bergamotte Caqmand ...........670

Bergrimotte de Curéme.......... 751

Bergumotte Cheminette............ 590

Eeryamotte Crassinie........... T29

Bergamotte Crassane d' Automine. . . 529

Bergamotte Crassane de Brumean... 6iri

Bergumotte Crassane d'Hiver....... 676

Bergamatte Dorie.............. \$ 841
Bergamotte Dussart..........6770

Bergamotte d'Esperin........6\%0

Bergamotte de Eté...........862, 869

Bergamotte d' Eté Grosse ..... ... T.78

Berentmote Fiivie. ............ \%62

Bergamotte de Flandre.......... 760

Bergumotte Fortmie............ $\% 66$

Jergamote ale Fongère............ T84

Brigramotte Geerard............ 7\%2

7irgamotte de the Grillive......... in1

Bergamotte Gandry.............. 6ro

Bergamotte Heimbourg.........671

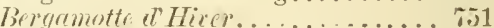

Bergame tte a' Hiver d'Holland. . . . . T84

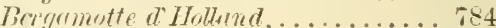

Bergamotte Leseble. . . . . . . . . . 6 671

Brrgumette Lowise. . . . . . . . . . . ع 82

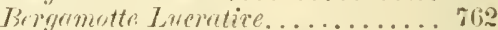

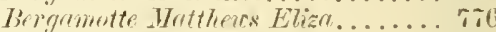

Jergamotte de Millipieds ......... (ific

Brigrmente Mtisquí............ 841

linvifumotte de Púques. . . . . . . . . . 551

Bergamotte Parthena .......... 671

Bergamotte de Prerthenay. ........ 6ri

Birgamotte de Prysans.. . . . . . . 7 78

Birgamotte de la Pentecite....... Tij]

Bergamotte Piquot. ...........6.671

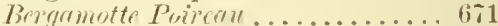

Bergimutte Quessong d' Et ......... . T00

Brigamette Ronde d'Hixer ........ 51

Bergamotte Rouge .............. 841

Bergomette Ponerge Tardif ........ T82

liergamotte Risyat d'Hicer. . . . . . . i2:3

Bergamotte Sageret............. (iii

Bergamotte Sinexpareit.......... ;02

Beromurte siculle.............. iti

Bergumotte Soldut-Tabours........ $\$ 51$

Bergamotte de Eouler's. . . . . . . . . T06

Brrgamotte Stotfits............ 6.1

Bergammite Sulsise. . . . . . . . . . . 8 8(i)

Beryemontte sylearige........... S6ti

Bergremette Tirdice........... T29

Brrgumotte Thermin............ \&\$4

Bergamette de Tonlonse. .......... 501

Bergen. ................. 6ir1

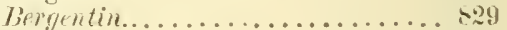

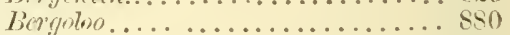

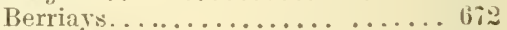

Berthebirn ................. \&55

Bwi diry. ............... 500

Besi de Bretagne................ 500

Bewi Esperen ................... ;01

Best Fondinte...............

Besi Incomparable............. T0\%

Besi Humon.................. . it

Brat de Mri.................

Besi de Wurcise.................... 716

Besi de la Pierre ...............

Besi de Qurseoy................ 700

Best Qufssoy di Et .............. 700

Besi de St. Waast. .............. 502

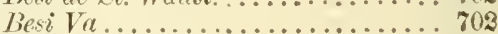

Besi Tuat..................703 


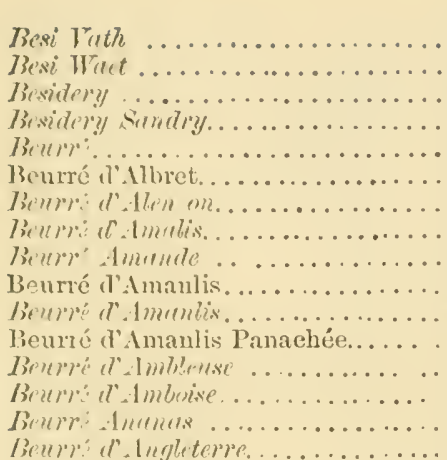

Beurré ḋ lnjon. . . . . . . . . . . . .

Benry inmen iledissem........... lieurré Antoine.

lieuré Antoinctte. . . . . . . . . .

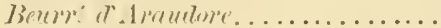

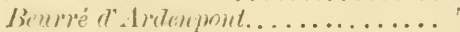

Beuré d'Aremberg. . . . . . . . . . . fiso

benred dremberg............ T\%

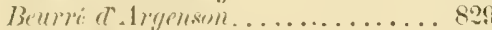

Beurcé Assomption............ (in'?

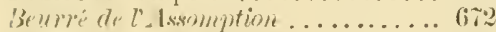

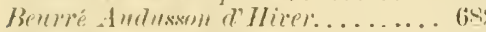

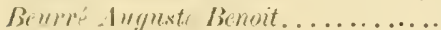

Beurré Ameniere.............

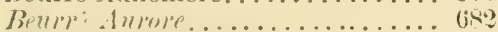

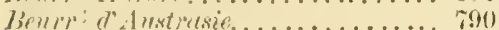

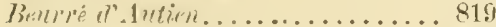

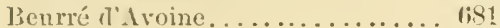

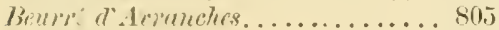

Beurré Baehelier.............. (j7\%

Beuró Bailey. ................ (;7:3

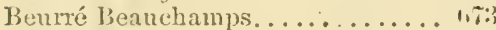

Benrré lieaulien. ............6.67:

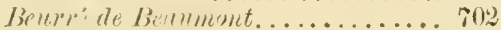

Beurré liegnines.............673

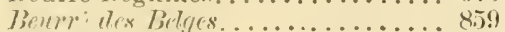

Bewré Bennert. .............67t

Beurré lienoist. ..............674

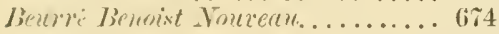

Beurré Berrkmuns. . . . . . . ..... bit

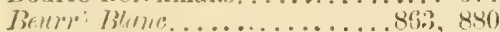

Buner Blundes Cupucins. . . . . . 6. 6is

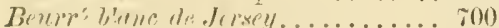

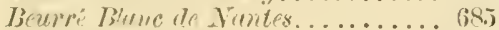

lieurrá lBoislunel. ............. bizt

Beurré loollwiller.............. (irt

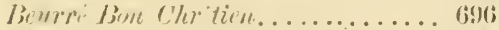

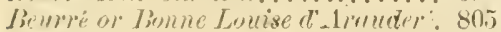

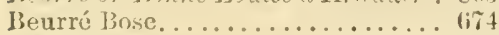

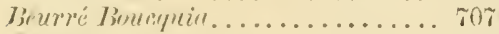

Beurr de Inomigngne............ Tor

Beurit Jimssock.............. 742

Jeurré Brettonneau. ................ (iff;

Beurré de Rrignais............. lis1

Beurv Bimzzé.............. \%60

Beurré Bruneau ................ (jitj

Beurré de Bruxelles.

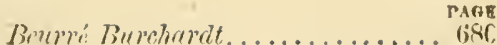

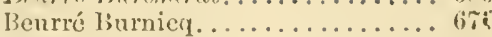

Brumé de Chen................ 710

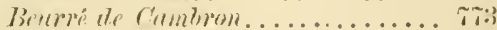

Beurré de Capiaumont. . . . . . . . . 6.

Beurré rlu Cerele............... (ik7

Bente te reme.............. 6ist

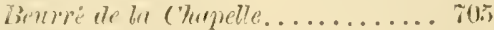

betrive

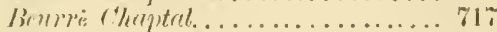

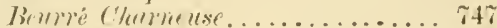

Benrs: ('barron. . ............. (ifit

Benré Chatenay. . . . . . . . . . . Bifi;

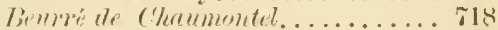

Beurré Citron. . . . . . . . . . . . tiriti

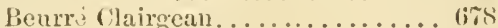

Bonr. Coit...............

Beurré Colmar............... (izes

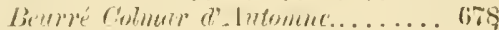

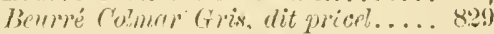

Beurré Coloma................. firs

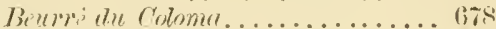

bentré de Conick............... (is4

Benre roming................ (88)

Búuré (vellem............... 万(01

Bemps ruvet................. 72 \%

Billré Cufter........................ \%

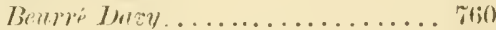

Beurré Detais............... (6x:

Bнию. Drfilys................ (is:

Benrovede Deftinge............

Bempr. Deftingherr...............

Beurré Delannoy............. (684

Beurré Delhecq. . . . . . . . . . . . 6 \$ . . . . . . . .

Binpe Delbery.............. (6S4

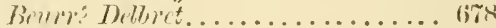

Beurré Delfosse.................... (is4

Bemré Derouineau. . . . . . . . . . . 68.;

Be ur. Descheumps............... (isol

Beurré Diel. ................. (j) fi

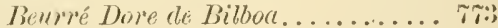

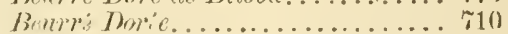

Benrpe Drmpiez.............. 87

Beuré Duhaume..............687

Betré Dumon................ (is7

]Beurre Dumont................ 688 .

Benré Dumortien.................. (\$8

Beurré Durand................ (iss

Beurré Duval................... 684

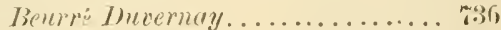

Beurré Juvivier. . . . . . . . . . . . . . (;Ss

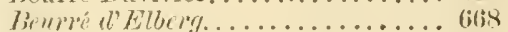

Beurre d'Enghien of Frunce...... (6is

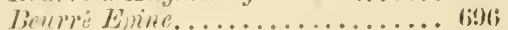

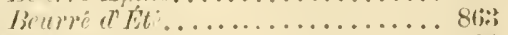

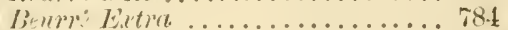

Bering be fevre................ 790

Jeurr de Fevrier. . . . . . . . . . 68:2

Bemry de Fitundre.............. 699

Peuriú Flon................ 688

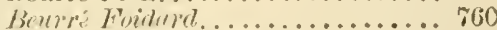

Berrivé de Fontenail................690

$668 \mid$ beuré Fougiere...............688 


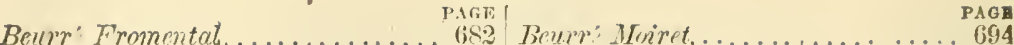

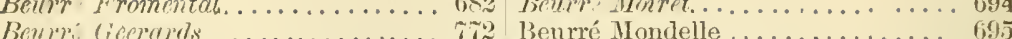

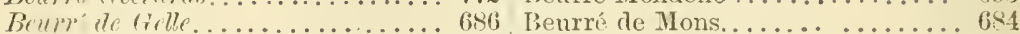

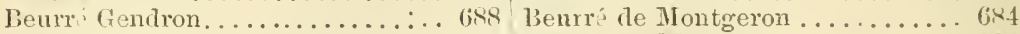

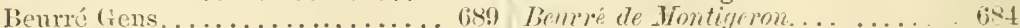

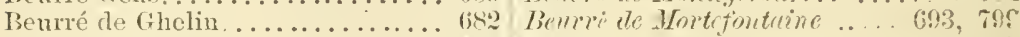

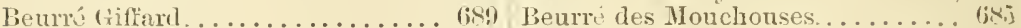

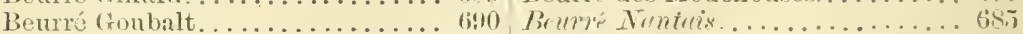

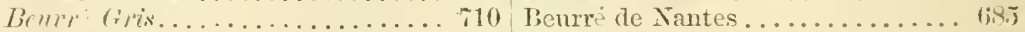

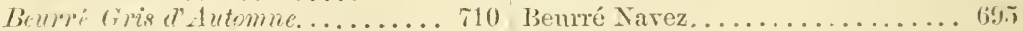

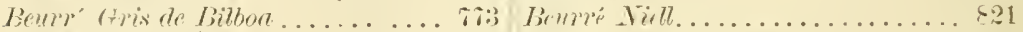

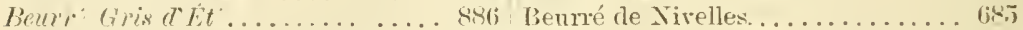

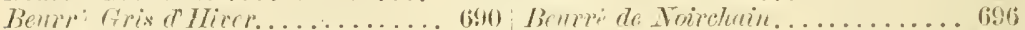

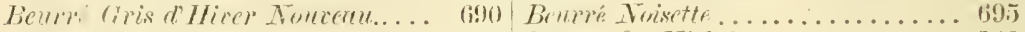

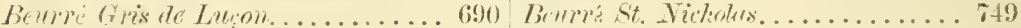

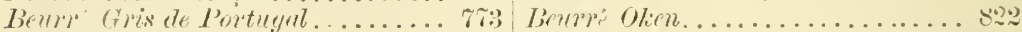

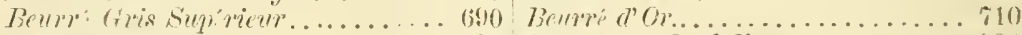

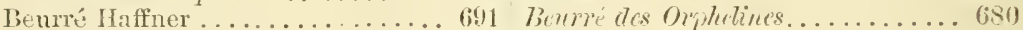

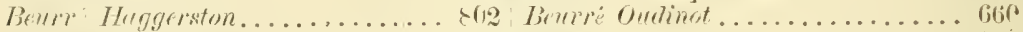

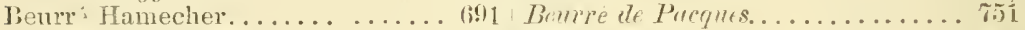

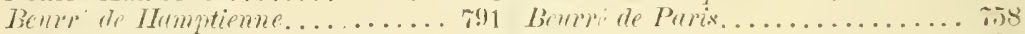

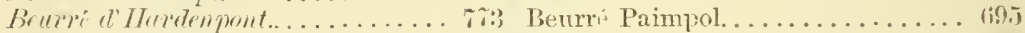

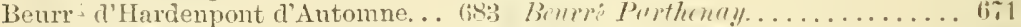

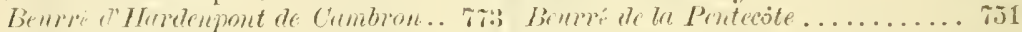

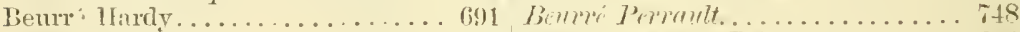

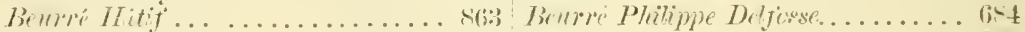

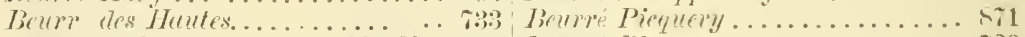

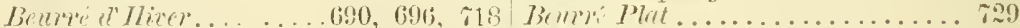

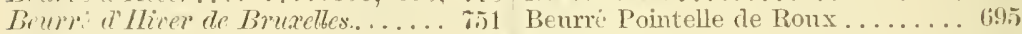

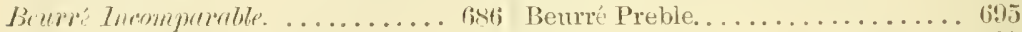

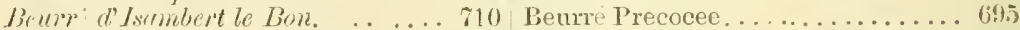

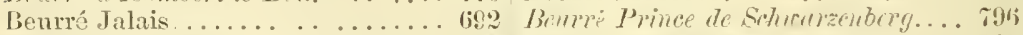

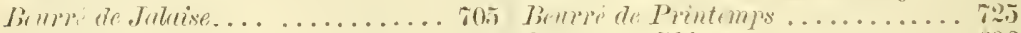

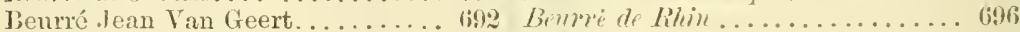

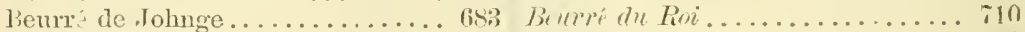

Bewro Indes

Bemr: Kenues.............. (992 Beurre de Quenast........... 68.j

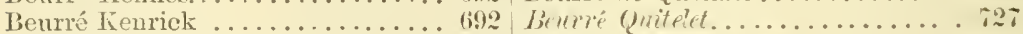

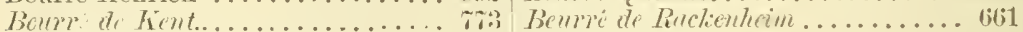

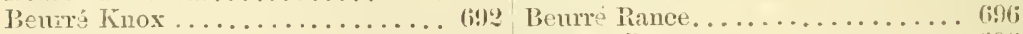

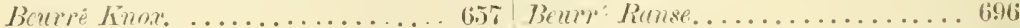

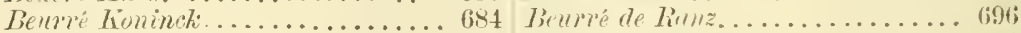

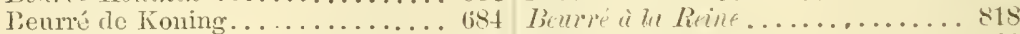

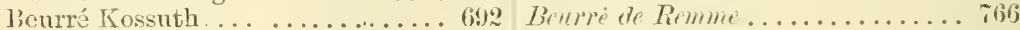

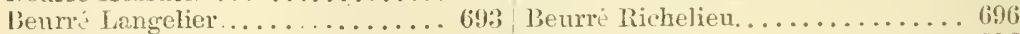

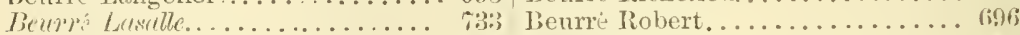

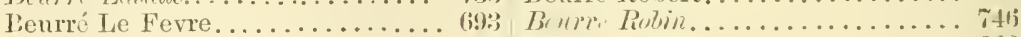

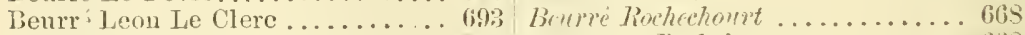

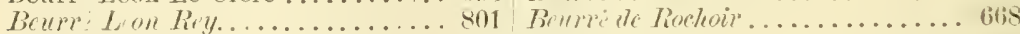

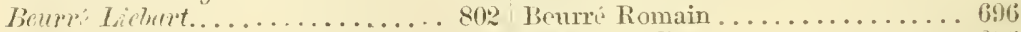

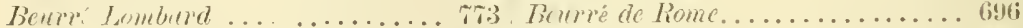

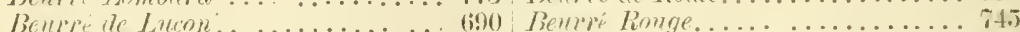

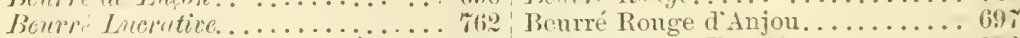

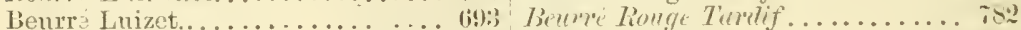

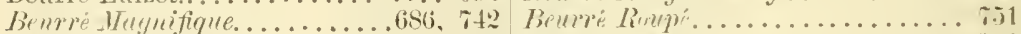

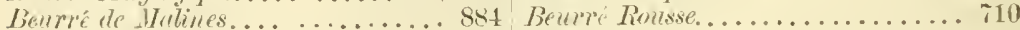

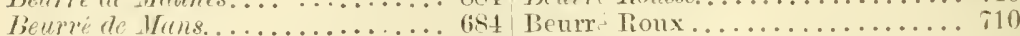

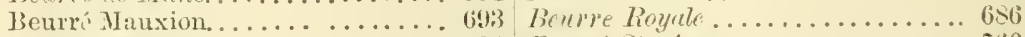

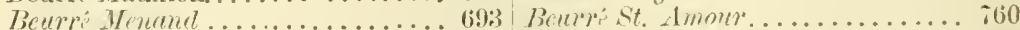

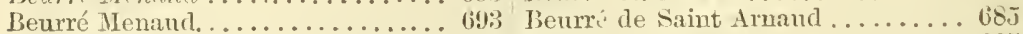

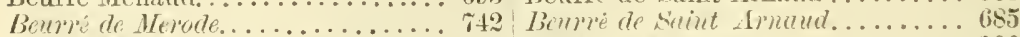

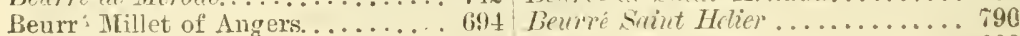

Beurré Hoire ............. 694 beuré st. Louls.............66s 


\begin{tabular}{|c|c|}
\hline & \\
\hline Benrre Seheidweiller . . . . . . . . . . $69 \%$ & Blunquet innasterque... \\
\hline Benrvi de semur.............. liti1 & Blunquet al Anstrusin. \\
\hline 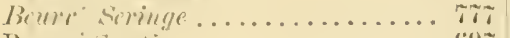 & Munquet de likmenee ........ \\
\hline Beurese Seutiu................ lis & l'munuet l'tit. \\
\hline brutre sieulle............... Ttti & Blienquetts is (s) \\
\hline leurr six................ big & B'uluquette ì bongue quemen....... \\
\hline nurre somlange ............ 6917 & Blecelier's Mea \\
\hline Brurve simle $\ldots \ldots \ldots \ldots \ldots \ldots$ ith & liloodgoon \\
\hline Benre do soulers............. ros & lilendy. \\
\hline enir spae............... (i9) & l"нmirnibuel .. \\
\hline emr s spence. . . . . . . . . . . (in) & Bris Sirpoleon. \\
\hline linir sipenes.............. Trio & bolinur ...... \\
\hline 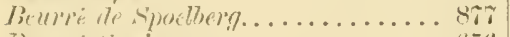 & bulienr allie \\
\hline 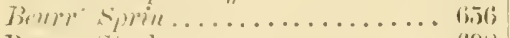 & Bun riretion... \\
\hline r. sterkmans. . . . . . . . . (99s & Bun cloretion el Amions C'burtreuse. \\
\hline . . . . . . . . bets & lion elur tien et'dueh . . . . . . . . . . \\
\hline Tlendiuctir ............. ven & Bon Chrotien al Lutomine........ \\
\hline Benm Van Driessche ........... (ion & bonche tien burmett. \\
\hline 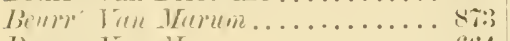 & 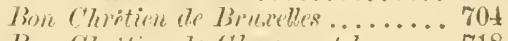 \\
\hline 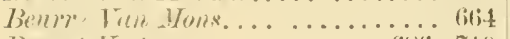 & Bon Chrition ale ('hrummmtel...... \\
\hline 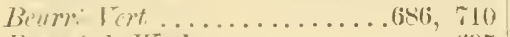 & Bon Cluitirn ale comstrutinogle.... \\
\hline b'tum ale Wired & time Deri: \\
\hline lisurv de II & Bon $C h$ \\
\hline Benro de llistcrloo... & Bom $(\%)$ \\
\hline mé ile Wetteren... & Bon chrtion at Et ...... \\
\hline Brum dr teble............... biso & Bon Chritien al Etr $\dot{J} a$ \\
\hline 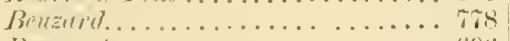 & Bom Chrétion d' Etre J Hesque... \\
\hline$\ldots \ldots \ldots \ldots+6 b^{2}$ & Bun Che tien Fomdunte.......... \\
\hline i le Caen ....... & Bom rhestirn Fondunte Buxque.... \\
\hline de Caissoy . .. & Bon Chretion Grotioly....... \\
\hline i de Caissoy d'Ét: & Bon Cletetien of Hiers..... \\
\hline de Chusseruy..... & didutomne... \\
\hline ite: Clirumontste... & ien . Toseph lemmarque. . \\
\hline Circumontelle tres-gl & Bon Chrition Wusqu Fondunte. \\
\hline ilErhusserie ............... & Bom Cler tien de Rerens.......... \\
\hline Bezi a Eelurusey . . . . . . . . & Bon Cibretien Spinn ............. \\
\hline i Esperen....... & Bon Chretion de Tomis. .......... \\
\hline ult...... & cn Turc...... \\
\hline dHeri......... & Bunch \\
\hline di $I I+r y \ldots \ldots \ldots$ & ien de Timon.... \\
\hline ai. ........... & Bon Gu \\
\hline e Montigny ....... & Bun P'tput.. \\
\hline la Motte........ & Bon Pul \\
\hline la Pierre ...... & Bonuly \\
\hline Jinzi jiccocece........ & $\ldots \ldots \ldots$ \\
\hline liczi liryul......... & hes........ \\
\hline$\ldots \ldots \ldots$ & pelle........ \\
\hline T. tians... & rlotte.......... \\
\hline isperill..... & $\ldots \ldots \ldots$ \\
\hline Lourvin..... & $\ldots \ldots \ldots \ldots$ \\
\hline $9 ! \ldots \ldots$ & $\ldots \ldots \ldots \ldots$ \\
\hline reil. .... & Jial: \\
\hline . $17 \div 3$ & iim......... \\
\hline .. $8(i ;)$ & siral......... roj, \\
\hline$t+\ldots \ldots \ldots$ & e lomise a'draculore.... \\
\hline Thumb.... & e de Mulines.......... \\
\hline $.8 \pi j$ & 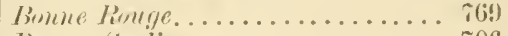 \\
\hline int of Woreest & lomene śriplirs. \\
\hline oreester.... & Iomme Sophia \\
\hline 800 & e de Soulers ........ \\
\hline 8. & e Thérése......... \\
\hline 8.5 & de lips. \\
\hline & \\
\hline
\end{tabular}




\begin{tabular}{|c|c|}
\hline & \\
\hline 13onneserre de Saint Denis....... 705 & Calebasse.. \\
\hline 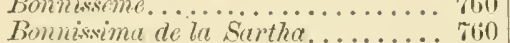 & 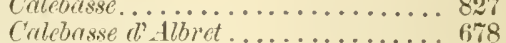 \\
\hline Busc sire. . . . . . . . . . . & Culcbasse Bosc... \\
\hline Bnsc's Fluschentione. & Calebasse Currafon. \\
\hline Brosech ................... & Calebasse Delvigne ....... \\
\hline 7rewell Toncelle................. Tilo & Gulebraser Double Eatrie . . . . . . . . \\
\hline$\ldots \ldots \ldots \ldots 7(0)$ & Calebasse d'Ét \\
\hline ... 742 & 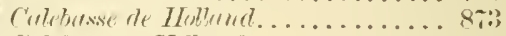 \\
\hline .. $8 ; ;: 3$ & Cialebase di Hollumale... \\
\hline . 779 & Culdelesse Impiriste... \\
\hline mia. & Calebasse Honstre.............. \\
\hline ........ 707 & Caleluesse Wonstruense ........... \\
\hline mestre Delfosse........... 6st & Culebuase Womstruezese du troid .... \\
\hline$\ldots \ldots \ldots \ldots 8$ & Colubusse Masquie.............. \\
\hline Bonticr..... & 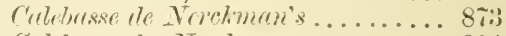 \\
\hline .. 507 & 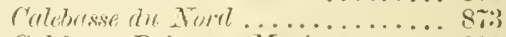 \\
\hline . 798 & 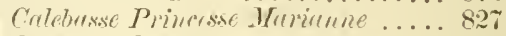 \\
\hline $0 \%$ & Culdousse Pongule.............. \\
\hline licks Field Stendard........ & ralebusse sterkmans............ ( \\
\hline de St. Germain........... 507 & Calebasse Tougard............. \\
\hline$e^{\prime} s \ldots \ldots \ldots \ldots \ldots \ldots$ & C'alebusse I'usse................. \\
\hline s Saint Germain..... & $\ldots \ldots \ldots \ldots \ldots$ \\
\hline wine .............. & Culure Roset.................. \\
\hline ne le Gour............ & Crambrialge Sugar Penr ... \\
\hline илесии............ & rling $\ldots \ldots \ldots \ldots$ \\
\hline ........... 708 & Camerling id illemagne ........ T14 \\
\hline$\ldots \ldots \ldots \ldots$ 708 & tingne.............. 714 \\
\hline ........ & $\ldots \ldots$ \\
\hline$\ldots \ldots \ldots \ldots \ldots+500$ & e Rohan............. \\
\hline .. 760 & grta.............. \\
\hline$\ldots \ldots \ldots$ & ditie ............... 863 \\
\hline$\ldots \ldots \ldots \ldots \ldots \% 709$ & Commlie.... \\
\hline h Queen................ & $\ldots \ldots 751$ \\
\hline Brocas Bergamot.............. T69 & chicer............. 751 \\
\hline$\ldots \ldots \ldots \ldots \ldots+10$ & c............. \\
\hline ham .............. 710 & $y \ldots \ldots \ldots \ldots$ \\
\hline Admired............ & $\ldots \ldots$ \\
\hline$\ldots$. & Car \\
\hline ermain....... & Criptif de Sainte II lène... \\
\hline Bunne d'Automne... & Cupuction ............. \\
\hline Buchunan's Spring Beurve. & Capucin \\
\hline Buffurm........ & in I I Won . W. . . . . . . \\
\hline Buffum... & Cromeine d'Automme Crlona ..... 6rs \\
\hline$d x \ldots \ldots \ldots \ldots$ & $\ldots \ldots \ldots \ldots \ldots \ldots \ldots$ s \\
\hline Mela des Itraliens. . . . . . & $\ldots .$. \\
\hline euf .......... & de Mars..... \\
\hline . 711 & e......... \\
\hline . 712 & $\ldots \ldots \ldots \ldots \ldots$ \\
\hline Butler's Herrest......... & Gardette.. \\
\hline Butter of Micliegren.. & $\ldots \ldots \ldots$ \\
\hline 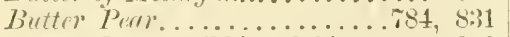 & Lambre . \\
\hline Butter I'ur of Plizulelphia. & $\ldots$. \\
\hline .712 & C \\
\hline de Vaux. & st $118 \ldots$ \\
\hline$\ldots 716$ & C'ellite \\
\hline de France. & Cint Co \\
\hline . $8(i ;)$ & a d'Été \\
\hline r'cilllorozar & ure Wulum ...... \\
\hline Caillot Rosiet & Centeru Musqui d Hiver. \\
\hline t Rosat $\overrightarrow{\mathrm{V}} \mathrm{F}$ & Chriv i Dame......... \\
\hline Gaillou $R_{0}$ sat. . ............. 863 & Chamber's Large............... \\
\hline
\end{tabular}


PAGF

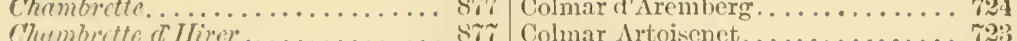

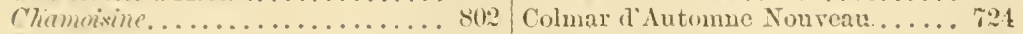

Chancellor ............... $\$ 1 \%$ Colmar limisr.............. 7\%?

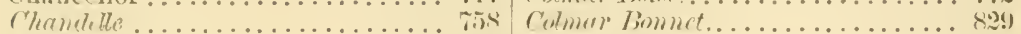

Chituman...............

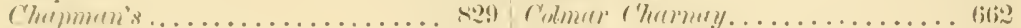

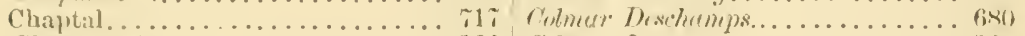

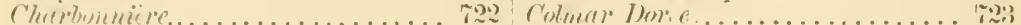

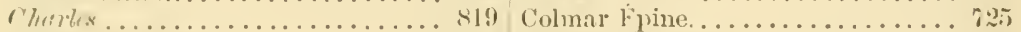

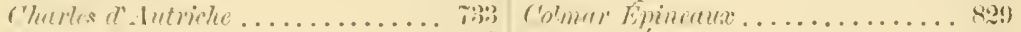

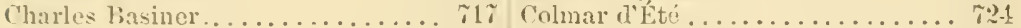

Charles Bivort .............. ร

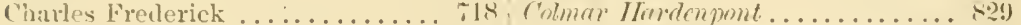

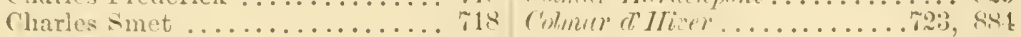

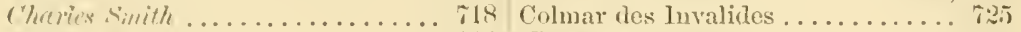

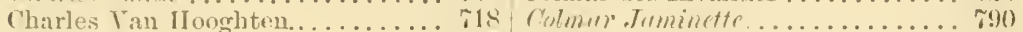

Cliarlotte de Brower.......... ;18 Colmar de Jonghe............. i2t

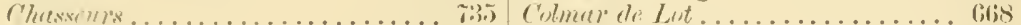

rhutix................. 815 Colmar de Meester.......... \%2.

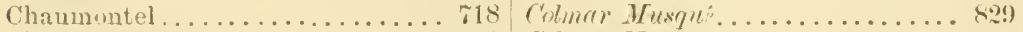

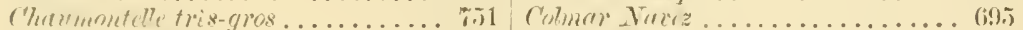

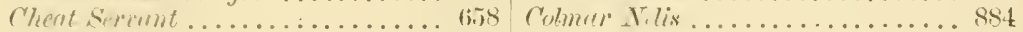

Chelmsfort ............... 71! C'sher Tiet.............. 821

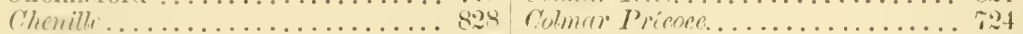

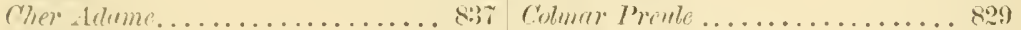

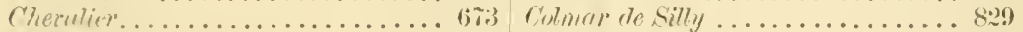

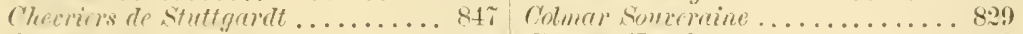

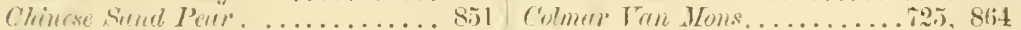

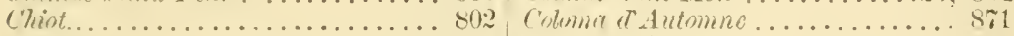

Choisnard............... 719 Crtor ed toit............. 717

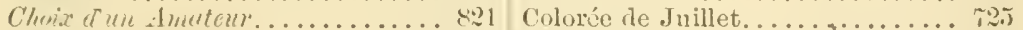

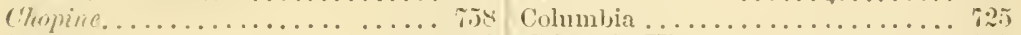

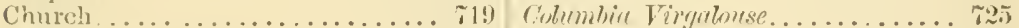

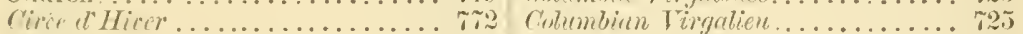

Citrina...................

Citron ................. F⿻ Commissaire Delmotte ........ э26

Citron des Carmes............ sog Commodorf............... r.2;

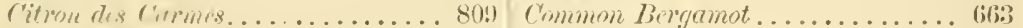

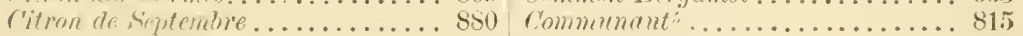

Citmolime Bumiscle grosse punc- Comprignis d'Ostende........... sis

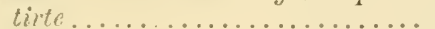

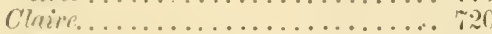

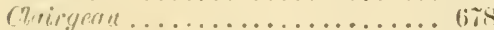

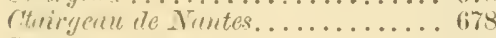

Clap....................

Clapp is Favorite .............. \%

Clara ...................

rlerled................... 71!

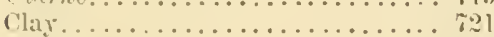

Clemence .............. 1:2

Clement Birort ............ 72.2

Clement Duyguré............... ditit;

Clemrntine .............. 722

Clinton ................. 洆

Cirm................... 8in

Clustrr. ................. 720

Cluster Pril)............... Tis

Coit's leurri .............. 729

Colin Voir..................

Collins. . . . . . . . . . . . . . . . .

Colmar d'Alost.

Comptese de Lunuty. . . . . . . . . . . 01

Comstock ....................

Comstock Wilding............

Comte d'Egmont. . . . . . . . . . . .

Comte de Flandre............ r $27^{2}$

Comte Lrumiy .............. 727

Comte de Lamy. ............. 727

Comte Lelieur. . . . . . . . . . . . 727

Comte de Limoges............. 6688

Cembete Michure............. 816

Comte de Paris.............. $72 \%$

Comtesse d'Alost............. T28

Comtesse de Chambord......... 728

Commtesse de Irenot............. ric

Comtesse de Limeny. ........... T4?

Fomitesse de Terrention......... S:3i.

Congress Pomologique.........

Conklin..................... 728

Consciller de lic Cour........... 811

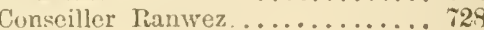

729 


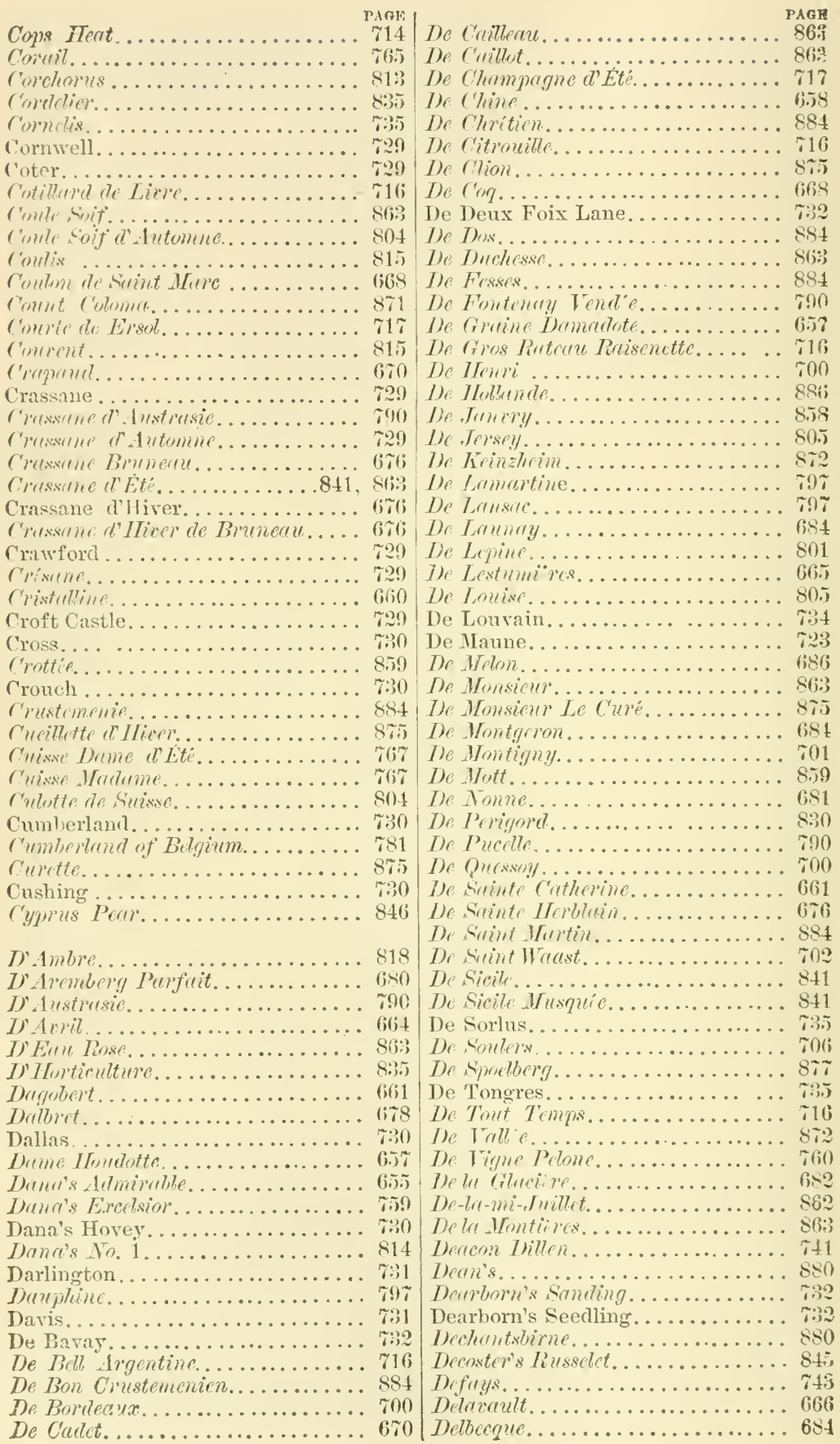


PISE

Delequine..................... s01

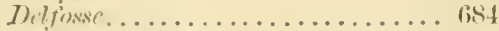

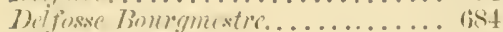

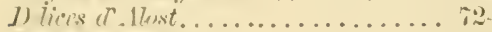

7) lices if lnger............... i:3:\}

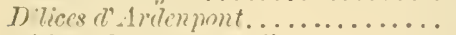

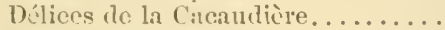

1)ílices rle Charles.

Dilices d'llarderument of Aligers...

D liec's d'Hardenjont of Belgim.

Dilices de Froyenues............

Diliees de Joilnigne. . . . . . . . . .

Dilices de Lomrenjal. . . . . . . . . .

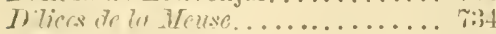

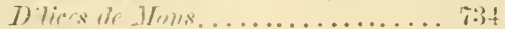

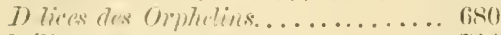

D. ilices Vin Mous..............

J) meester. . . . . . . . . . . . 7.

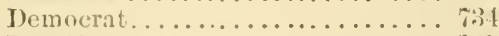

Des Chrsseurs.............. (u.j

$U_{1} \times$ Dhmes................... (ibis

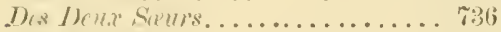

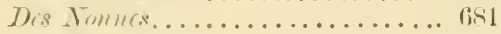

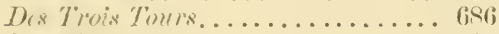

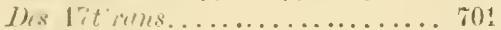

D. xclemmp................. (j80

$D$ sir e Cornolis.............

Desiré $\operatorname{Tan}$ MIons. . . . . . . . . . ri:j

Dr.muiber?............... 8.

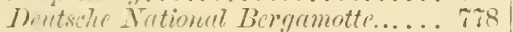

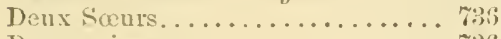

Devergnies.................

Jivl. ....................

Dinmant. . . . . . . . . . . . . .

Dicknтman................

Jir sommer Chrixtebirne........ 81;3

Dirl. . . . . ................ 6s 6

Jict. linttribirme............. lis6;

Dienctonnú Anthoine. . . . . . . . . .

J)ithm.................... bisti

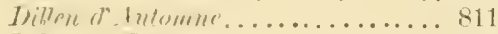

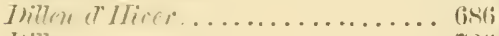

Irith . .................

Itinglen................... .

1)ix.................... 1:39

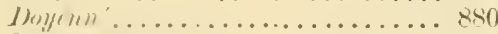

J)

Doy̆enn d'Alençon.......... it?

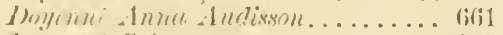

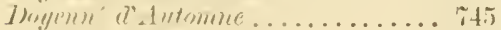

I)

J)ing nué blunc............... 840

Joycuni: Ibunssock........... . 742

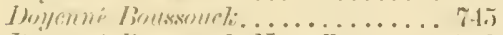

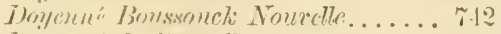

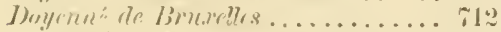

Doyenn. de rercle............ it?

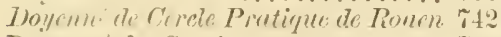

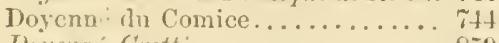

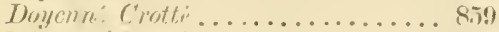

Dojeuné Defais. ............ r.

Dovenn: Downing ........... 144

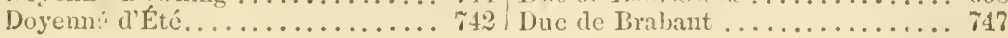

Doyenné Cutent............74i, 8.73

Doyenué Goubault........... 745

Joyeme Gray .............. T. . .

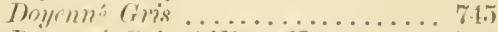

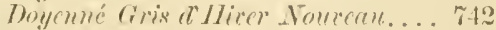

7)

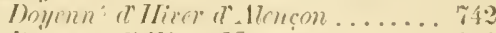

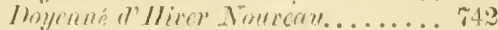

Heingme Hoiry ..............

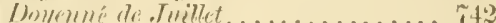

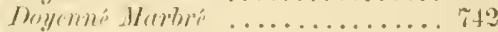

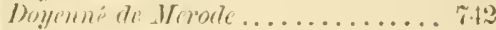

Driyrmié. Wusque. . . . . . . . . . . 701

Doyemé Panache............. 881

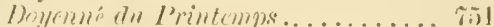

Doyenné Robin .............. 7. . . . . . . . . .

Doyenn liose .............

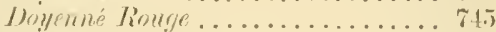

Doyenue Jinna............ \%4

Doyemé siantellet ........... 746

Doyenné de Sanum . . . . . . . . . 748

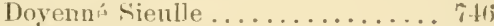

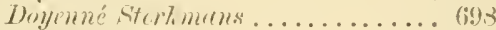

bingenn. Iflite............... 880

Doctenr Bouvier. . . . . . . . . . . . . 7:38

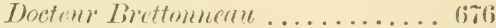

Docteur Capron.............. r... r.

Docteur Tientier......................

Docteur Troussean. . . . . . . . . . . 7:;

Doctor Dillen................. 7.11

Dnetor Lentling. . ............

1)octor Nelis ................. 7.38

Doctor Reedter. . . . . . . . . . . . . 7.

Doctor Turner............... ito

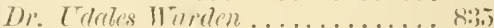

Dorothic Roynte............... (sivti

Dorothe Royale Nouvelle ... . . . . ito

Dorsoris ................. 740

Domble Mrinsuntte............. (661

Domble Pritipule............. T4:

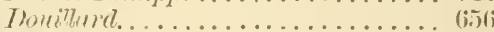

Dow..................... \%

Jourlin. . . . . . . . . . . . . 8 87t3

7)orntarm. Spestling ...........

Doyen Dillen............... it1

Dricer.................. . .

1) Murtin ............... 814

Diy Torm ................. (689

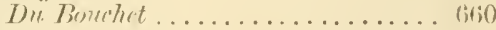

Du Brenil Pire............. itli

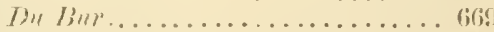

I) Colmbirs............. 841

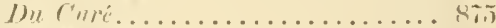

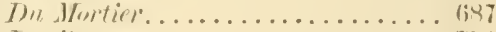

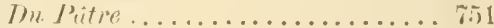

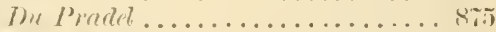

Dn, Srigueur..............

D)" Timnemu ................. Sï.

Due Alfred de Cruy . . . . . . . . . 747

Duc: d'.1 remberg. .............. \$80

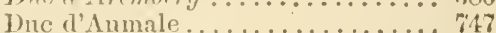




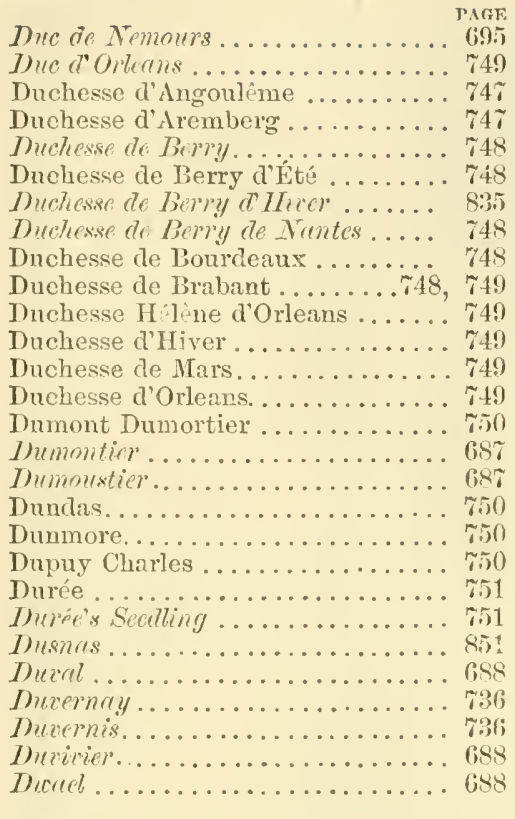

Evrrl Penr.

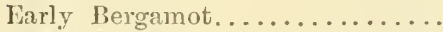
Erriby Berrmé.............6.58,

Early Butter of Cincinnati.......

Eurly Cothurine...............

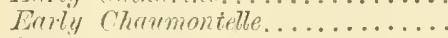

Farly Denztona................ 8:

Early Oneen ................. 818

Enoly Romsselct.................. 849

Eraly suger. . . . . . . . . . . . .

Early Summor Buiter . . . . . . . . .

Easter Bergamot...............

Easter Beurré. . . . . . . . . . . . . . 7ij1

Eroster Stint Gormain........... 800

Eastnor Castle............... 752

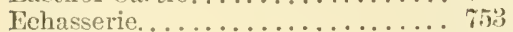

Echasery .................. 75:3

Filmonds................. 75:

Bdward Morren. . . . . . . . . . . . .jt

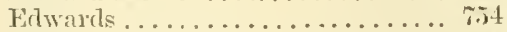

Edwards' Elizabetl............. . . . 4

Edwards' Seedling St. Germain. . . . T.j

Edirige..................880

Exsendurt ................... 710

Eleonie Bonvier............... 74

Elivtt Dumders..............

Eliza d'Heyst. ................ Ti 4

Elizalueth Fien Hons............. 810

Ellanrioch..................... 778

Elliott's ILelting. . . . . . . . . . . .

Ellis ................... .

Ellsworth.......................... 756

Elton.................... 750

Emerald.
Emerance .................. PAGR

Emerance Bivort............. 755

Emile d'Herst ............... 757

Eimile de Rochois................. 668

Emilie Bivort. . . . . . . . . . . . .

Emily Bivort. ...............

Emminnued.................

Enmilaconer ................. 815

Endientt .................... $86(3)$

Enfrnt Prodigue............ 840

Evisleliert lott ............... . .

Englisk Bergamot.............. (663)

English - Lutumn Bergamot......... (6939

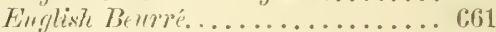

English Jargonelle............ ijs

English Red rheeli.............. Tfis

Evintrgne................. 758

Equice Immars................ (6fis

Épine d'Et ................ 758

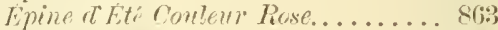

Fine d' llirer. . . . . . . . . . . . . . 88.

Equine de Limoges............... 668

Epline de Poeherir.............. Glis

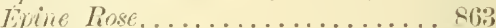

Equine Rosi Giris.............. s.51

Enine Rose al Hiver. . . . . . . . . . . 885

Epine Rorale................. \%

Epriseopal.................. Ttit

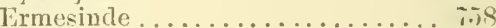

Frnestine Auzolle............ i.js

Exhlman . ................ ist

E*marme................ is

Esperin's Ilorpenlime.........

Esperine................... Ting

Eisperine .................... (i.jo

Essex . . . . . . . . . . . . . . . . is

Esturion .................

Etommearie................. 8st

European IInney............ T84

Excelsior. . . . . . . . . . . . . 759

Eyewood................

Frllse sprecierc............... 827

Famenga. . . . . . . . . . . . . . тin

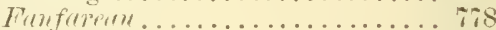

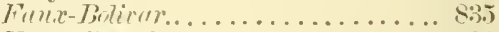

Finn spmecien.............. 827

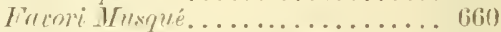

Fucme Musqué du Consciller. . . . . . T82

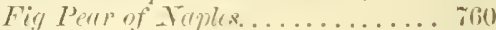

Figue . . . . .............. 760

Figlie dithenenn.............. itio

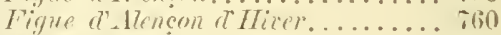

Tigne driver. . . . . . . . . . . . . . $\$ 60$

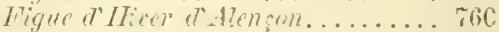

Figue te Vaples.............. T6r;

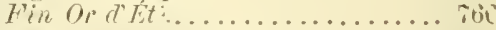

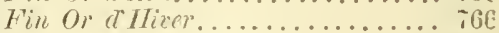

Fine Goic of Summer. . . . . . . . 7 (100

Fine Gold of Irinter.............. 766

Fingabs.................. Tis

Feast................... 759

Fenst's Seedling.................... T. T9 
PAez

Feaster................ ro:3 Frederick de Wurtemburg...... 76 ?

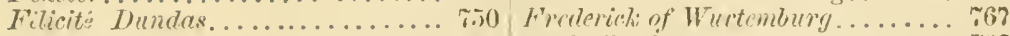

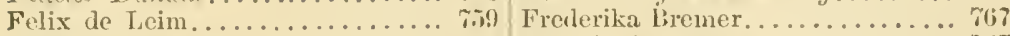

Ferdinomd Demcester........... 84it Freneh .Jargonelle........... 767

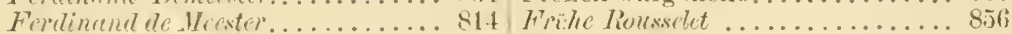

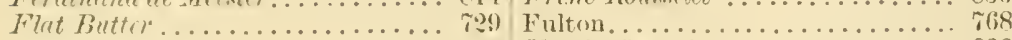

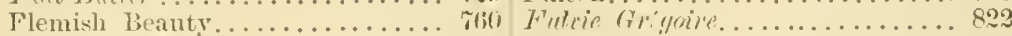

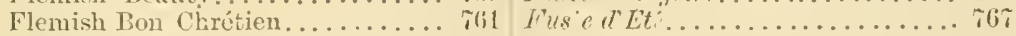

Flende drmignes............ sint

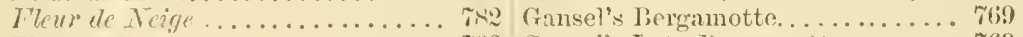

Florent Scomman. . . . . . . . . . . .

Florimond Parent............ Ttid Gansel's Seckel............... $7 \% 0$

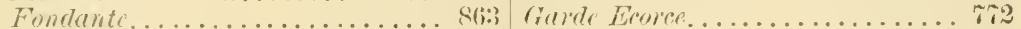

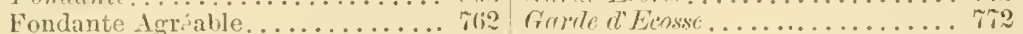

Fondante dilbret............ itis Garden Pear................ iin

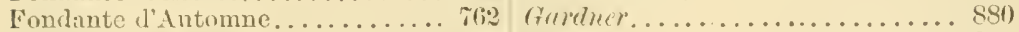

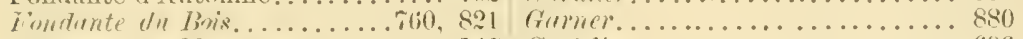

Tondunte de Clumene......... 74 frostelier.................696

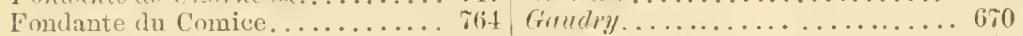

Fondante re Cueme........... For: Gideon Pilvidme............ 747

Fondente Delbeg............. (i.t) Gendebien................ \%70

Fondante d'Ingendal. . ........

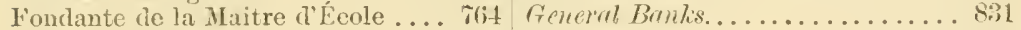

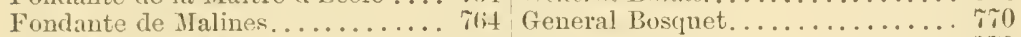

Fondunte de Wumbege............

Fondunte de Miblet. ............. 8.jt General Dutilleul.............. .70

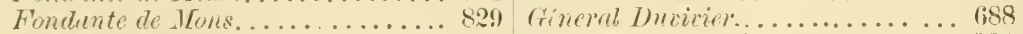

Fondunte Kusqué............ Tos General Lamorieièe........... 7 ir

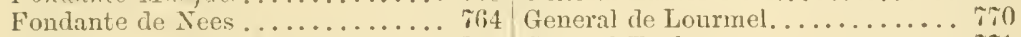

Fondante de Noe]............ rit General Taylor..............

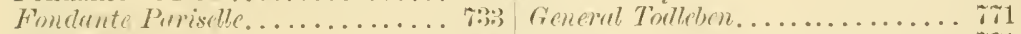

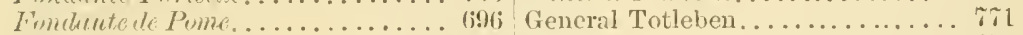

Fondante des Près.......... 704 Genrse................. 85̃

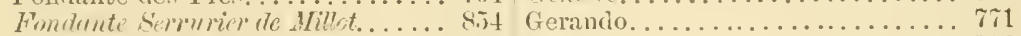

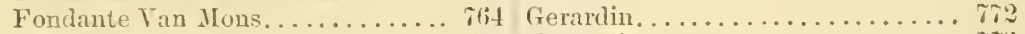

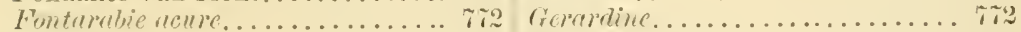

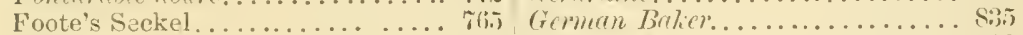

Forelle ................ tij German Muscat.............

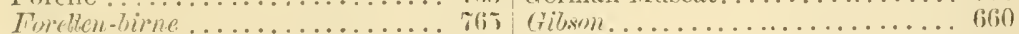

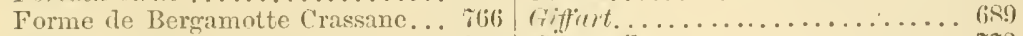

Forme de Jilices.............

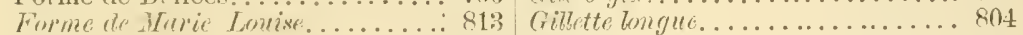

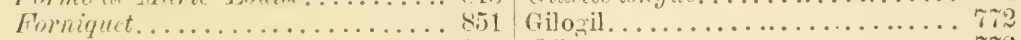

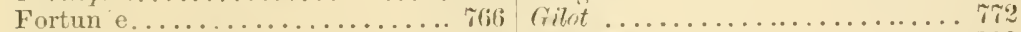

Fintun e de limme........... Trif Girartin...............

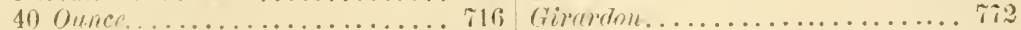

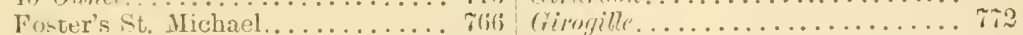

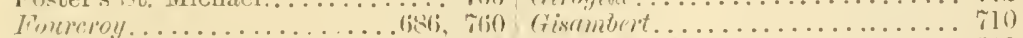

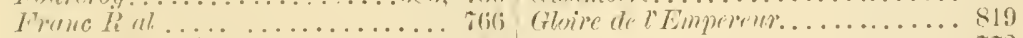

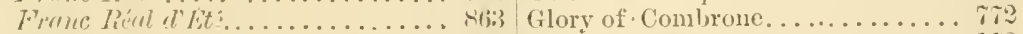

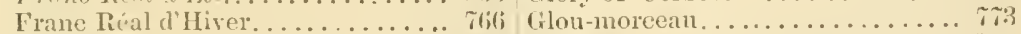

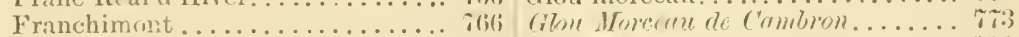

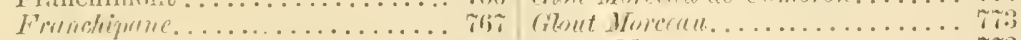

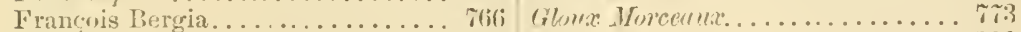

Frangipane ............... tif Golwt................

Frurelifored ..... ..........

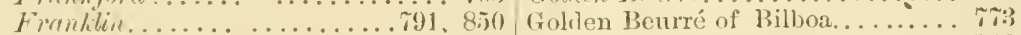

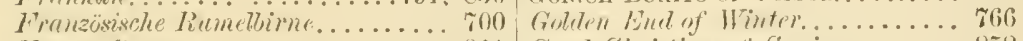

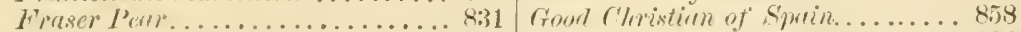

Fravenschentiel ............................... 884

Frederick Leclerc.............

Frederick Letiour.............. 
PAGE

Got

Goulu Worecre................

Goulue Morcenu de Chimbron..... 77.3 Gros Mouille Bouche............. 8ti.3

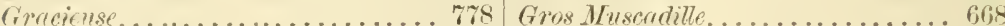

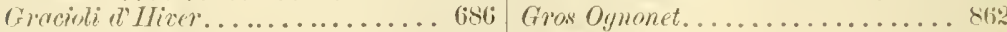

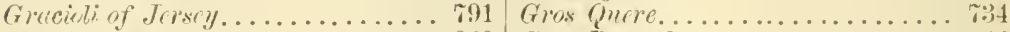

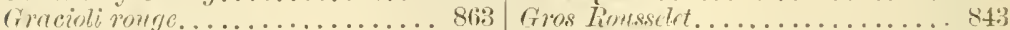

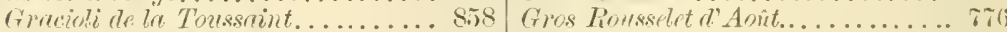

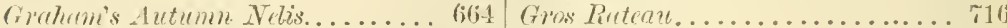

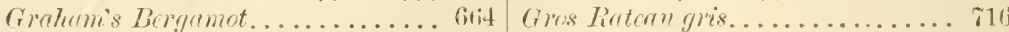

Grand Bretagne............ Tr. Gres Themas............ \%10

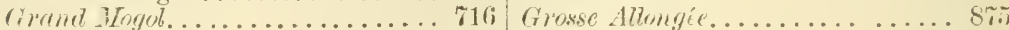

Grend Irmuerque..............

Grand Soleil............... 755 Grosie Blunqutte............ itj

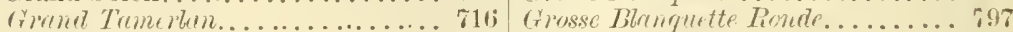

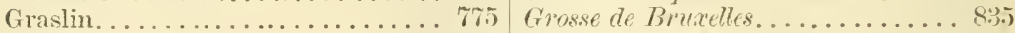

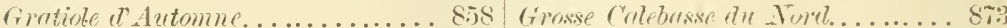

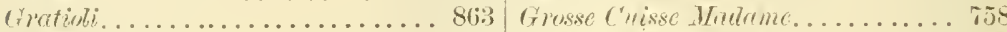

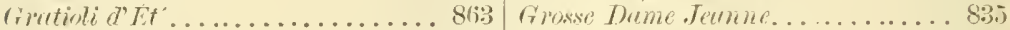

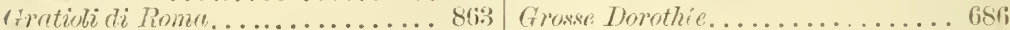

Fraue Sommer Butterbirne....... 880 Grosse Figut............... Tin

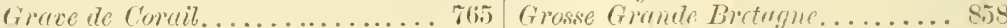

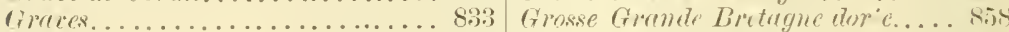

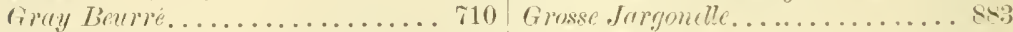

Gray Butter Perr............... 745 Grosse Waric ................ s11

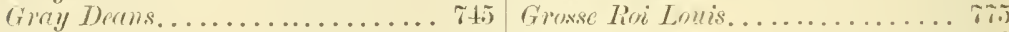

Gruy Doyeme............... Thi Grosse Sucre................ (i!t

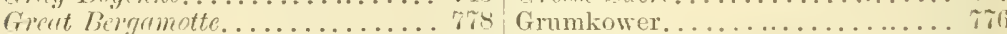

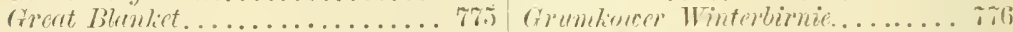

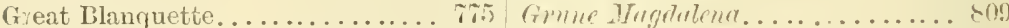

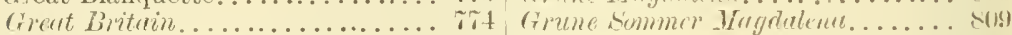

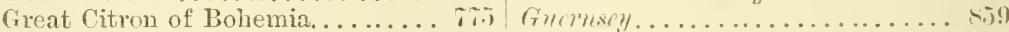

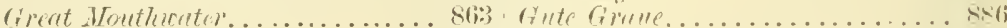

Grent Musl: Perr of Cone....... 818 Guenrte................ in

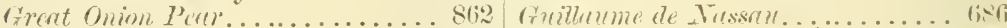

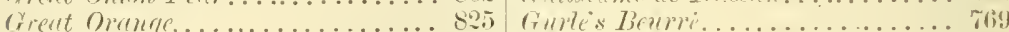

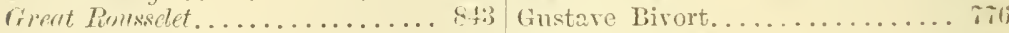

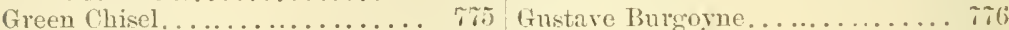

Green Mountain Boy......... \% . .j Gustin's Summer............ $\%$

Green Pear of Yair.............

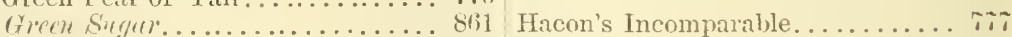

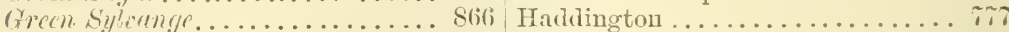

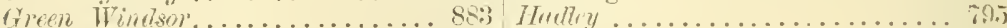

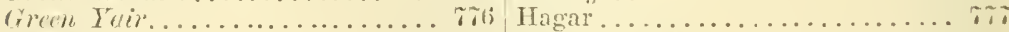

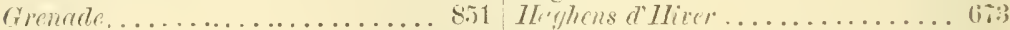

Gresillier................

Givis de Chine................ 861 Hamilton.................

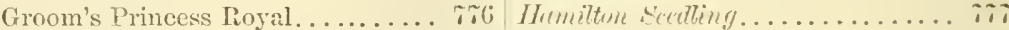

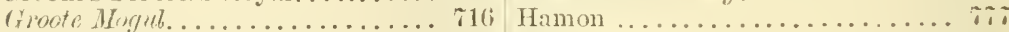

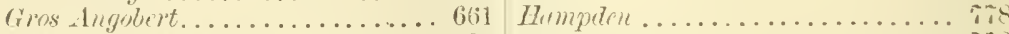

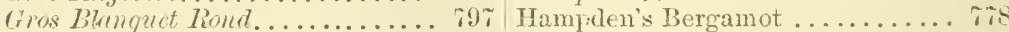

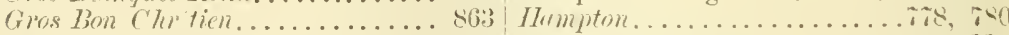

Gros Bem Clurition Bernelere...... S6:3 Hampton's Bergamot .......... iis

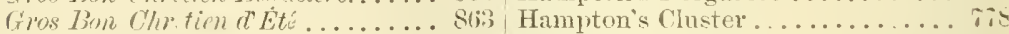

Gros Certeru tit. ............ iti Hampton's Tirgalieu .......... its

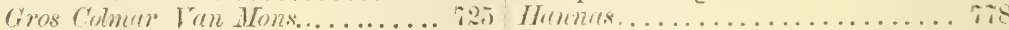

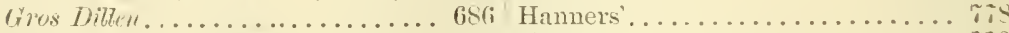

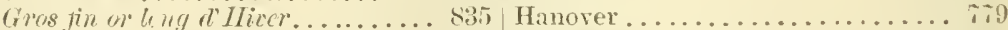

Gros Franc $R$ al . ...........

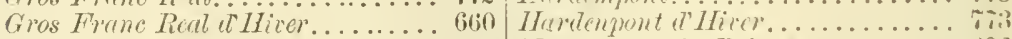

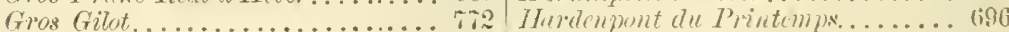

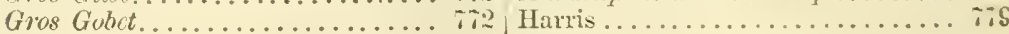




\begin{tabular}{|c|c|}
\hline & \\
\hline Harrisnn's Large Fall. . . . . . . . . . . 779 & Inyshe's Prince of Wales.......... \\
\hline Harvard . . . . . . . . . . . . . . 799 & IIuyshe's Princess of Wales....... \\
\hline Harvest............... & Huyshe's Victoria .............. \\
\hline Iluswelinirn................ & \\
\hline$\ldots \ldots \ldots \ldots \ldots \ldots 75$ & Tee Perer. \\
\hline ILuticenn Blane ............... sfi:3 & Timprotrice. \\
\hline Hawes Winter. . . . . . . . . . . . . . 780 & Impiratrice tle Ifrence............ \\
\hline 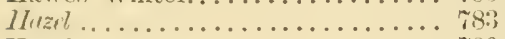 & 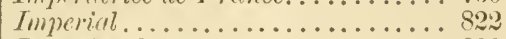 \\
\hline Ireathcot ............... & Timperial Oak-lerred......... \\
\hline IIebe . . . . . . . . . . . . . & Inug) viale à fenilles de chêne...... \\
\hline Hlcbron ................... 883:3 & It :nmunicable............. \\
\hline ILegentan . . . . . . . . . . . . . . . Tiso & 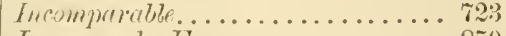 \\
\hline Megrmman............. 780 & $\ln$ Fure................ \\
\hline ILegrgmaren .............. 780 & e Van Mons............. \\
\hline ......... & tant $\ldots \ldots \ldots \ldots \ldots \ldots \ldots$ \\
\hline Hinline Grégoire ........... 780 & Iris Gregoire ................. \\
\hline Henkel .................. . †1 & $\ldots \ldots \ldots \ldots$ \\
\hline Ilentiel dilized . . . . . . . . & $\ldots \ldots \ldots \ldots$ \\
\hline IIenri Bivort . . . . . . . . . . . . 781 & $\ldots \ldots \ldots$ \\
\hline Iemi (Bicort) .............. 781 & abert le Bon........... \\
\hline Henri Desportes............. & $a \ldots \ldots \ldots \ldots \ldots \ldots$ \\
\hline Henry the Fourth............ T82 & Ives' August . . . . . . . . . . . . . . \\
\hline guntre.............. & gatmot.......... \\
\hline Henri Tinn Mons ........ & amotte ......... \\
\hline Hemi Tinn Bons.............. 727 & Ives' Pear............... \\
\hline Henrietta ............... 782 & Ives' Seedling . . . . . . . . . . . . \\
\hline Henriette .............. Ts2 & Ives' Virgalien................ \\
\hline the Bmrrier............. 782 & Ives' Winter .................. \\
\hline Menriette dorlestns ............ Ti2 & Ives' Iale...$\ldots \ldots \ldots \ldots \ldots \ldots$ \\
\hline th .............. & \\
\hline cart . . . . . . . . . & Juckman's Melting .............. \\
\hline Hericart de Thury............ & Jac \\
\hline 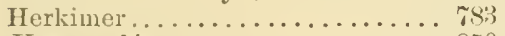 & J110 \\
\hline usbirne ............. & on's Elizabeth .......... \\
\hline$\ldots \ldots \ldots \ldots \ldots \ldots .789$ & 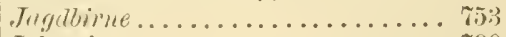 \\
\hline Herres' Winter............... 780 & $\ldots \ldots \ldots \ldots$ \\
\hline ham ........ & Julousie de Frmtenay .......... \\
\hline te. $\ldots \ldots \ldots \ldots$ & le de Fontenay Tendée.. \\
\hline .. 814 & $\ldots \ldots \ldots \ldots \ldots \ldots$ \\
\hline IIne-Lunger IIor-Liever... & $\ldots \ldots \ldots$. \\
\hline Ilothend İergumot. . . . . . . & $\ldots \ldots \ldots \ldots$ \\
\hline Hollind Green ......... & $\ldots \ldots \ldots \ldots$ \\
\hline le Rergamotte .... & Juqmin \\
\hline HInlundixche B̈erganotle. . & Jrerdin de Jourgrrs......... \\
\hline Ifrmerend ............ & nelle de finomp........... \\
\hline . 784 & welle des Proven aux.... \\
\hline Bilboa .......... & Baptiste Bivort....... \\
\hline lienck... & de Witte ............. \\
\hline ehenck.... & Jefterson ................ \\
\hline$\ldots-78 t$ & $\ldots \ldots \ldots \ldots \ldots$ \\
\hline .. 78.5 & tioli .......... \\
\hline ..785 & Jent \\
\hline . fifs & .Tilengil \\
\hline$\ldots 7 \mathrm{TH}$ & 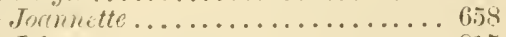 \\
\hline$\therefore 780$ & $\ldots \ldots \ldots . .$. \\
\hline Oswego. & vifith ........... \\
\hline is Comnecticut... & Johomnot ............. \\
\hline . . & Juli-mont \\
\hline ITuntiugdene. & Jolie Fille de Gust........ \\
\hline . . 786 & 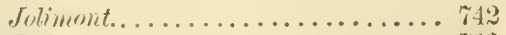 \\
\hline . $8.5 \%$ & Jolivet \\
\hline 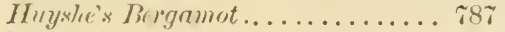 & Jolliemont. \\
\hline Huyshe's Prince Consort . . . . . . . 786 & Joly de Honneau .............. \\
\hline
\end{tabular}




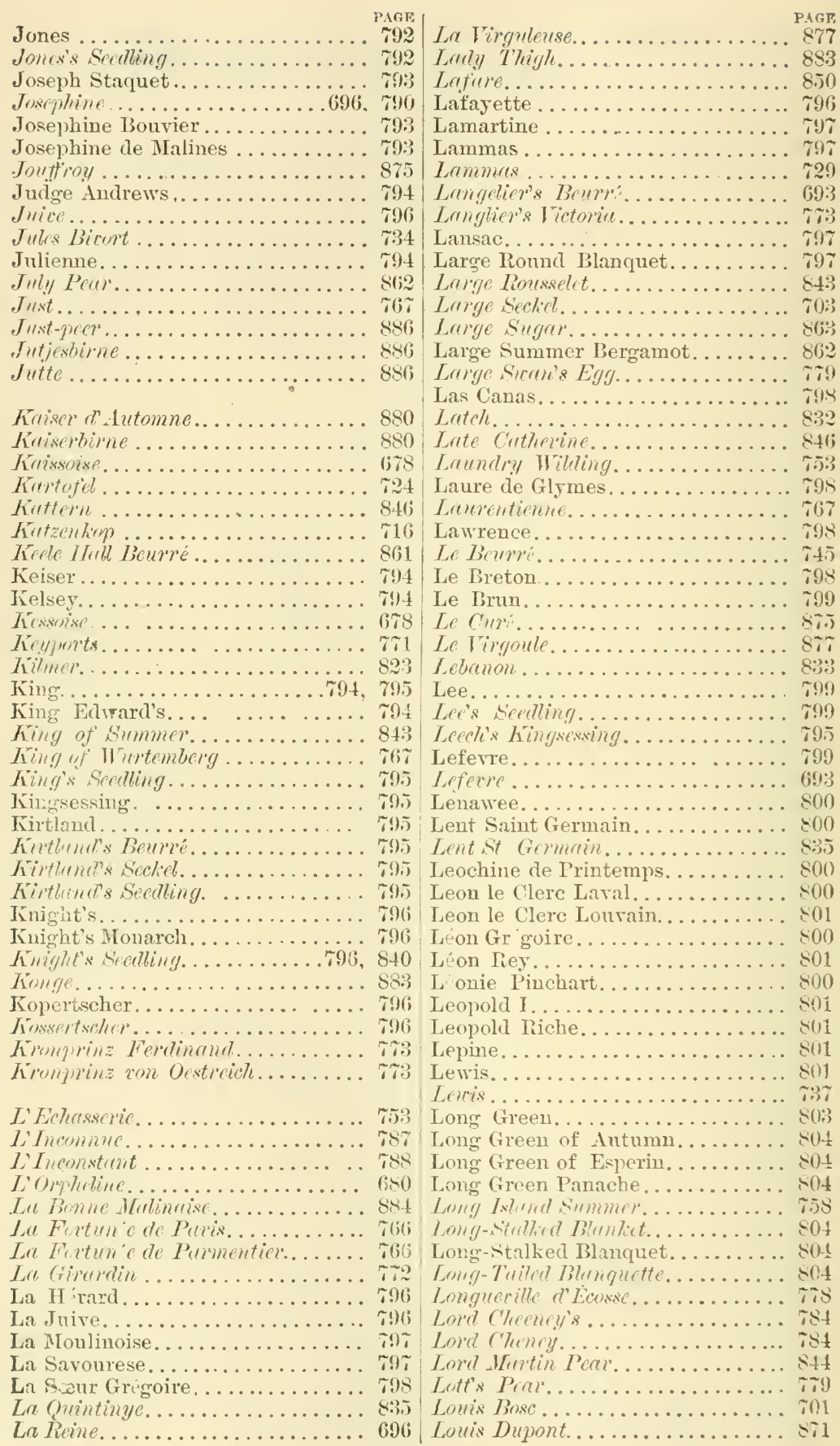


TAGP

Lon is Grégoire............... 8... 806

Lonise Konme.................. \& 8.4

Jomise lionne of livanches....... 80.)

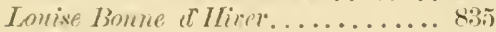

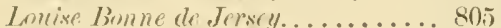

Louise Bonne of Jersey. . . . . . . . . 8. 805

Lomise Bonne de Printemps. . . . . . 804

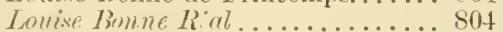

Lomise of Boulogne............. 806

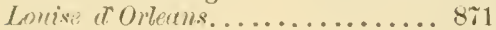

Comise te Prusse. . . . . . . . . . . 8.j,

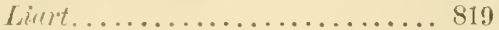

Liberale .................. 801

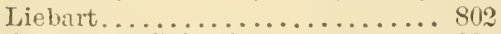

I. ientenunt Poidevin ............ 802

1 ientenant Poitevin. . . . . . . . . . . . . . . . . . . . .

Limon. ..................... 802

Linden r. lutrimme............. 7r3

Little Blunlict.............. 802

Little Blanquet............... $80 ?$

Jittle Muscat ............... 802

Little Mush................ 802

Livingston Tirgalieu . . . . . . . . . . 80:3

livre de Burgoyne.......... ... $7 \%$ ?

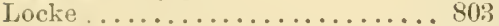

Lochis Jew Beurv............ 803

Lodge ..................... . . 803

London Sugar................ 803

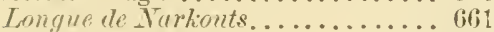

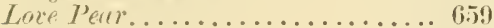

Lucien Leclercq. . . . . . . . . . . . . so 806

Lncrite................. т .

Lyeurgus ..................... 806

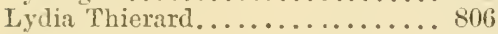

Iyon . . . . . . . . . . . . . . . . . 807

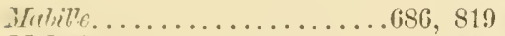

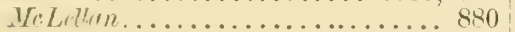

MlcLaughlin. .............. 807

McVean.................. 807

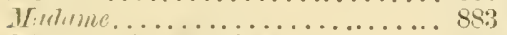

Fretheme Ad luide $R$ res......... 6.5t

Martame Ducar. ................. 808

Marlame Durienx. ............. 808

Madame Eliza. . . . . . . . . . . . . . . 809

Wredime de France............. 8893

MLidame Grúgoire........... 809

Madame Hemri Desportes. . . . . . . 8 80?

Madame Millet. . . . . . . . . . . . . 809

Madame 'Treyre. . . . . . . . . . . . . . . 80!

Madeleine. . . . . . . . . . . . . . son

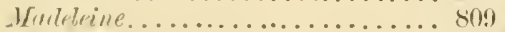

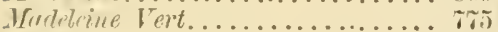

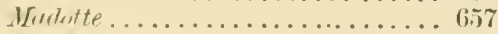

Erigulden ................. 809

Wrielen of Flunders............ 818

Ifrinten of Jrintonge............ 818

Whilanderin Grosse Grune...... . \$ \$1!

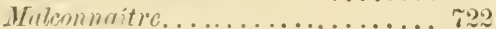

Malconnaitre d'Haspin.......... 810

Manchester................ 810

Manchester Lrite. ............... 810

Marchester Octwber.

810

PAGH

6...656

Ilanuing's Elizabeth............ 810

Mansficle................... 811

Wansurtte.................. 601

MLarasquine. ................ 811

Morenlis................. 81i

March Bergamotte............ 811

Maréchal de la Cour............. 811

Merichul Decours.............. 811

Maréchal Dillen.............. 811

Margaret.................... 811

Murin Soucclle............... 8:2

Muriunne.................... 827

Marianne de Nancy............ 81:

Wurie Chritionue.............. 81:

Marie Guisse................ 81:3

Marie Jonise. . . . . . . . . . . . . . 819

Jurie Lonise Delncomrt. . . . . . . . . . . . 813

Mrrie Lonise Donkelur. . . . . . . . . . 81:

Worie Louise (I Elcourt. . . . . . . . . . . 81?

Waric Lomise de Jersey. . . . . . . . . . 813

Murie Lonise Nouvelle. . . . . . . . . 81:3

Marie Louise Nova. . . . . . . . . . . . . . 81:

Marie Lonise d'Uccle........... . 813

Marie de Nantes............... 812

Marie Parent................. 814

Jarion.................... 815

Marmion. . . . .............. 814

Ifrette Sucrie Juune. . . . . . . . . . 829

Marquise de Bedman...........814

Nartha Amr.................. 814

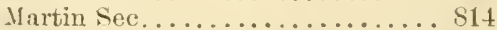

Wurtin See de Champagne........ 814

Martin sec dliver.............. 814

MIartin Sire................ 814

Wurtin sire...................... 814

Marulis.................. 815

Mary ...................... 815

Mather................... 815

Mutthers Elizu. ............. 7 \%6

Maynard................. 81,

Mivedoro Feaster. ............... 50:3

Wert's Summer Butter............. 5.51

If conmaitre................ T22

II dritle. . .................. 819

IV drille $\mathrm{l}$ Or.....................

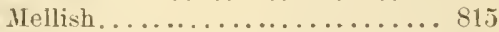

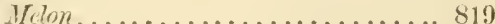

Ifelon de liops...............686

Merriam............... 81,j

Mervirecither............... 860

Werveille de lie Nicture........... 751

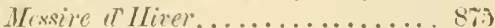

Messire Jean. .............. 81j

Mrsxipe Jean Blunc............ 81.

Wexsire Jran Doré. . . . . . . . . . 81.

Ifexire Jeun Gris............ 815

Michaux................... $\$ 16$

Wirl il Iriterloo............... 747

Mignonne d'Hiver. ........... 816

IIilan Blanc. . . . . . . . . . . . . 8 8

Ifitan Blanc. . . . . . . . . . . . . . . . sij:)

Vilan de la Beurri re........... s'i3 
Mitan de Bourdeanx.

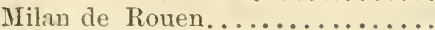

Milun Vert..................

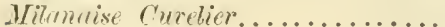

Willer's Early. .

Nillot de Nancy.

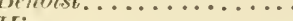

Vitchell's Russet......................

Moccas . . . . . . . . . . . . . . . . .

Wogul Summer. . . . . . . . . . . . .

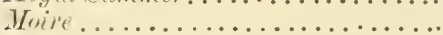

Wrille Bouche W'Itiver.

Wolle Bonche Touvelle.

Wruldet's Gremusy Chammontelle.

Ion Dien.

Homaricl

Vomlioztly

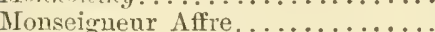

Monseigneur des Hons.

Monseirneur Sibour. . . . . . . . . . . .

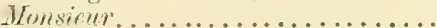

Wrnsiem le Curé..............

Honsiener Jean...................

Womstreuse de Lamilers.

Monestruense due Nord.

1

Morel.

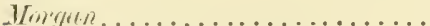

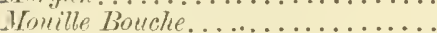

Wrille bonche d'A Litome .........

Monnt Teruon...................

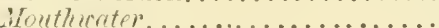

Moyamensing.

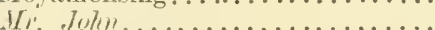

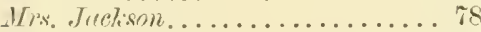

Wresemet el' Et .............. $\gamma_{67}$

Irusentille . . . . . . . . . . . 668

Muscudine ............... 818

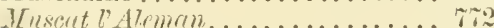

Wircat of Allemagne............

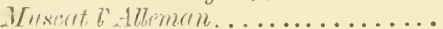

Wusont All mermul. . ...............

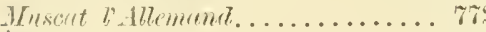

Yusent ambre............... 8]

Wuseut of gremany......... . 7.2

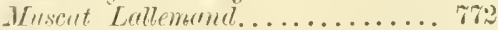

1.11seret Petit. ................. 802

IInscat Robert............... 818

Yuseat liobije............... 818

Whsent Remge.............668

Wuscte d'Anjom............... 755

Wusli: Blampuet, or Blanquette. . . . 802

Wusk: Oramge.

Wusk l'eur. .................

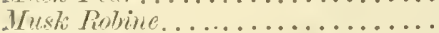

Wust: Summer Bon Chritien.......

Muskingum

Musquine de Bretagne...........

My-God Pear.
PAGE

Nareman's Creet............... 878

Namm's Creel................878

Napoleon. . . . .............. 819

Nupoteon di Hiver. . . . . . . . . . . . . 819

Napoleon Sarinien............ 819

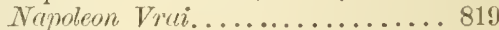

Naumkeag. . ................ 819

Navez Peintre.............. 819

Ne Plus Meuris. . . . . . . . . . . . . 820

Ve Plus Meuris................ 679

Nottrine................. 84

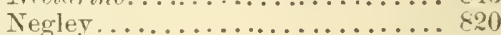

Telis d'Hiver. . . . . . . . . . . . . . . $8 \$ 4$

Vene Crassane.............. 829

New Bridge.................. 820

New Frederick of Wurtemberg. . . . 6.84

Tew St. Gemmuin............. 8.37

Sewo Sming Beurré............. 87.5

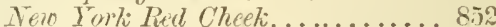

Newhall.................. 820

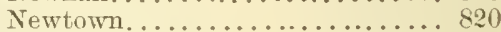

Nentorn Scenling............... 820

Nickerson ................. $\$ 20$

Niell. .......................... 821

Niles.................. 821

No. 10 Tran irons............... 802

No. 135 Vim Vons............. 8.7

No. 1599 of T'an Mons. . . . . . . . . 692

Nrivehwin................. 690

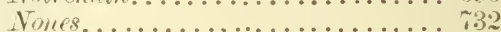

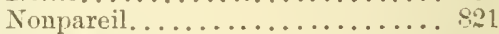

Vomparaille...................

Nortis Perr. ................. $\tau_{91}$

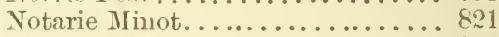

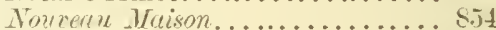

Toucear Wruxion................. s.

Touveau Poiteau.............. \&21

Nomvelle Fnlvie. ................ \$ \$2

Sourdle rouef. ............... 880

Num's Perr....................681

Nutmeg Patr............... 700

Oak-Leared Imperial. ............ \$ $\$ 22$

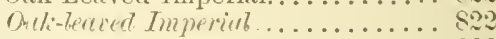

Oakley Park Bergamotte ......... \& \&?

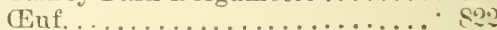

Ognon de Ttintonge............ 80:3

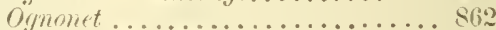

Ognonet irusqué............. 862

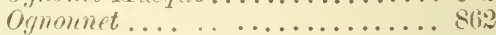

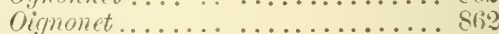

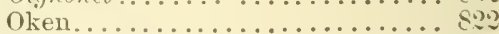

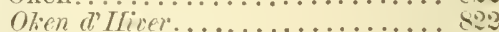

Oliver's Russet ............... sing

Olivier de Serres.............. \$ \$ 22

Omer Pacha................. 8.50

Oneida .................. 82:

Onondaga................... s?

Ontario................... $\$ 2 t$

Orange ................... $\$ 24$

Orange di iutomne............... 824

Orange Bergamot................ 832

Orange Bergamotte............. \$2t 


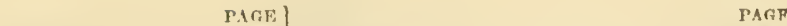

Orange teté.............. 82t Pennsylvania.............. 8.32

Orange d'Hiver............ 824 Pequini................ .7.

Orange Mandarine............. s24 Peral del Campo.............. \&(i;)

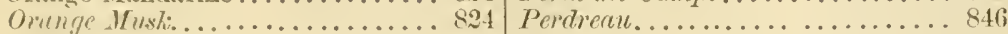

Orange Insquée........... 8.4 Perfumed.............828, 851

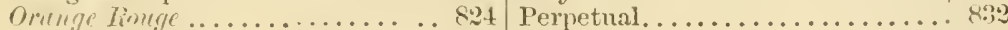

Orange Tulipie............. \$25 Pctaless.................

Orpheline Colmar............ siz Peters.................. 8.;2

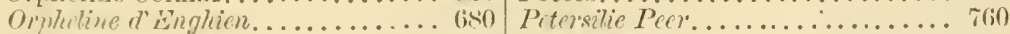

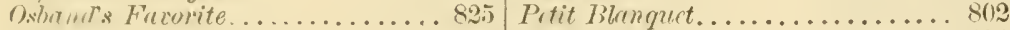

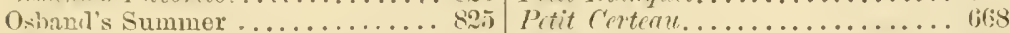

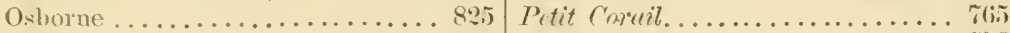

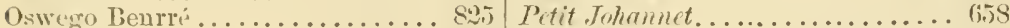

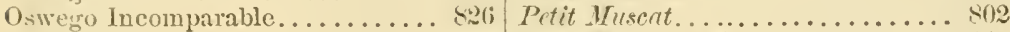

Ott ................... \&26 Petit Nusent i Autmme........ \&41

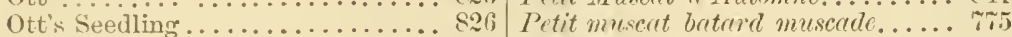

Owev ................. 826 Petit Wusqu.............. 04

Orfurel Chumonted ........... 718 Prtit Rousselt................ 846

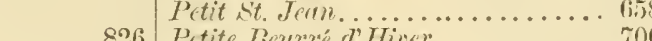

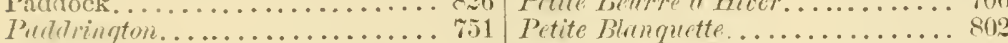

Paillean.................... 826 Petite Epine d'Ete.............

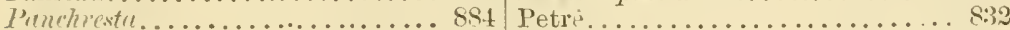

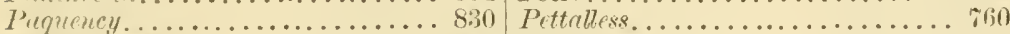

Pumbelle Iusqué............ Tist Pfirsichbirne.............. 831

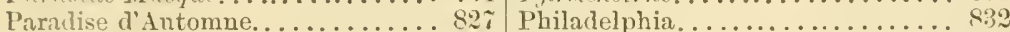

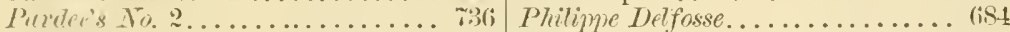

Pardee's Seedling............ 82 i Philippe Goes.............. 83:

Parfum d'Asit............... sqg Plitigpe de Preques..............

Parfum de Rose............. 82s Philippe Strie.............. 859

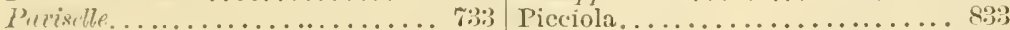

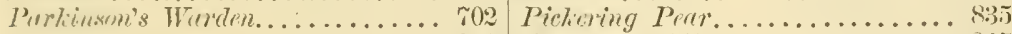

Parsonage. ............... 828 Piclering's ITarden........... 8.3.

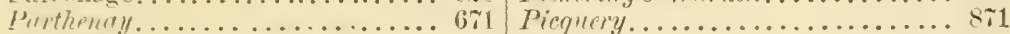

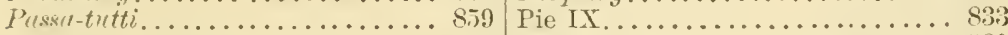

Passans du Portigal.............. s28 Pine Peri....................... s80

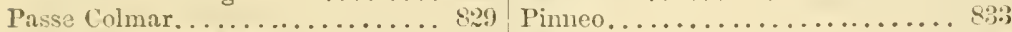

Prisse Colmar Equinerax.......... 829 Pionlice.................... 04

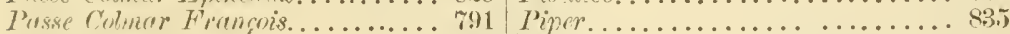

P'rsse Colmer Grix............829 Pixtolette............... 760

Passe-Colmar Musqué........... 829 Pitmaston Duchesse d'Angouleme. 8.3:

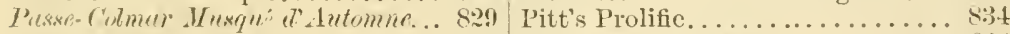

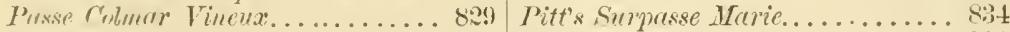

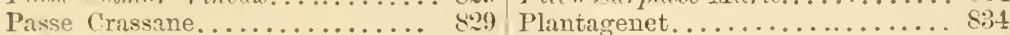

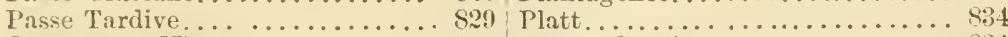

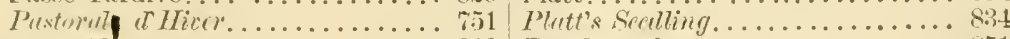

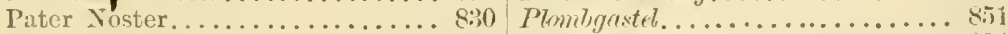

Paul Ambre. . ............. $8: 30$ Pocahontas ............... 8.34

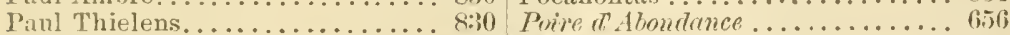

Penl Thidens................ 8:30 Prive t 1 .

Payenche................ 830 Prive $r$ Imboise.............. 110

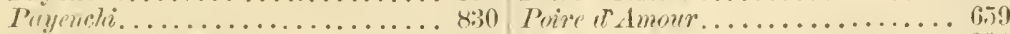

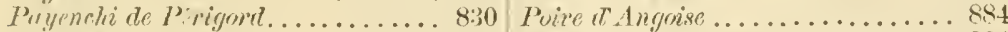

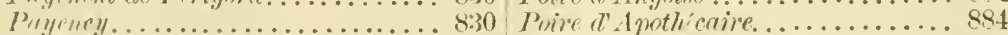

Pruch.................... 8331 Prive d divil...............664

Peach l'ear................ 8:31 Prire de Butay............ .9.2

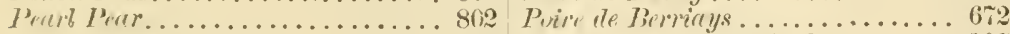

P'ele's Seedling.............. 847 Pive Bruennot d'Epinal........ .07

Pemberton................ $8: 31$ Prive de lunville ........... 844

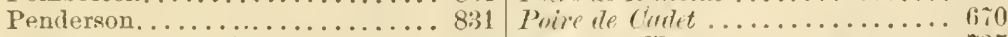

Pendleton's Early York........... 831 Poive des Chusseurs............ 73.1

Pengethly.................. 831 Prive (honille............. 828

Penn.................... 831 P'ire de Chypre ............ 846 
PAGE PAGB

Poire Davy ................ r60 Prisent Royal de Nantes........667

Poive du Doyen...............880 President................ 836

Pmive Durandeau ...............

Poire Gendron ..............688 President Felton............. 836

Poire Ferando ............. 771 President Mas............. 836

Prive Gutfird...............689 Pretty Girl of Gust...........

Poire-glabe................ 8it Preul.................... 829

Prire de Glnce ...............8 877 Prevost.................. 8.36

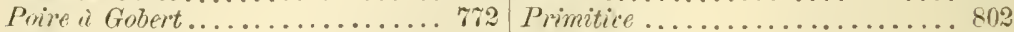

Poire Goubalt ..............690 Prince Albert .... .........8:36

Poire Guillevme.................666 Prince Camille de Roluan ......... 114

Prive His . . . . . . . . . . . . . 8. 0 Prince Imperial de France ...... 8.37

Poire des Invalides ... . . . . . . . . i.j Prince de Joinville . . . . . . . . . \&37

Prive du .Jardin . . . . . . . . . . 750 Prince Napoleon. . . . . . . . . . . 8.5i

Poire de Lepine. . . . . . . . . . . . . . 801 Prince's Hartest... . . . . . . . . . . 83.

Prine Liaril. . . . . . . . . . . . 819 Prince's Pear............... 8:4

Poire de Limon.............. 880 Prince's St. Germain........... 89.

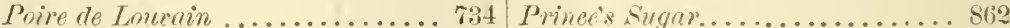

Poire anx Houches............ 825 Prince's Sugar Top ........... 862

Poire Nugrobon ............. 819 Prineess................. 818

Poire Nicll................ 821 Princess Charlotte........... 8.8

Poire des Tonnes ............. (is1 Prinews Helen d Onleans........ 549

Prive de Puyency ............. 8.30 Princess Maria . . . . . . . . . . . 8:38

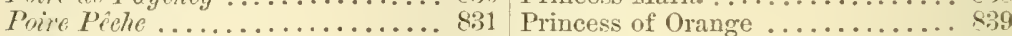

Poire ì ln Perle............. 802 Prineess Penyal.............. Tr5

Poire de Persil. ............... т60 Prinersse Conquête............ sỉy

Poire-Pomme .............66\% Princese Warianne .......... 82?

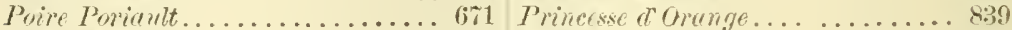

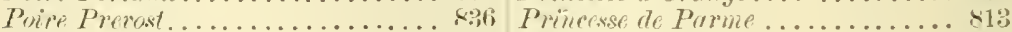

Poire de Prince.............. s:3 Prineire de Kimertsh ......... 596

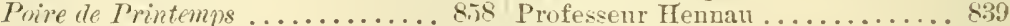

Poirc ì la Reine ............. 818 Predle Cont sienne........... \$29

Poire Ritelle............... 842 Pulsifer .................8.89

Prive de hose............... s6.; Puvis St. Germain ............ 839

Prive arms Peau. ............. 8.5

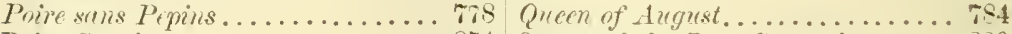

Poire Sentin ............... 8. 4 . Qneen of the Low Countries...... 8.39

Prive six .................. 6it queeris Amber.............. 81s

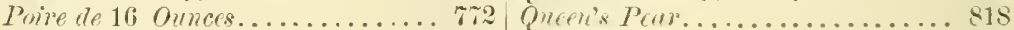

Prire de Stnttgard. .........84i Qnilletette............ . 840

Poive de tubles des prines ....... ins Quinn ................. \& 40

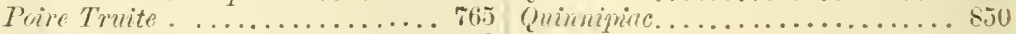

Prive Tiun Barume........... 873

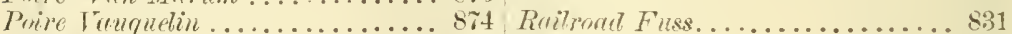

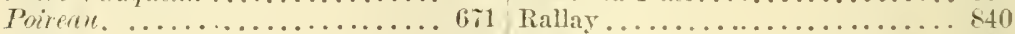

Pollan ................. $8: 4$ Rapelje................. 8

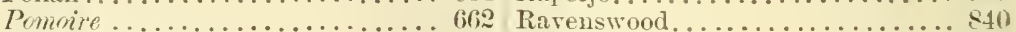

Pope's Quaker.............. 8.34 Raymond ................ \&4:

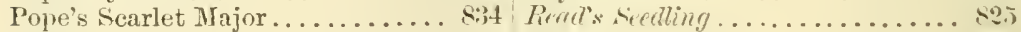

Potts .................. 7 . Reading ................ 841

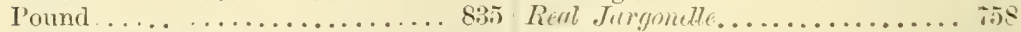

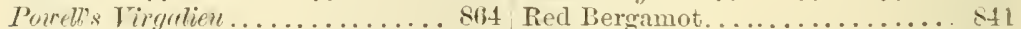

Pradtle de Cutulogne ......... 875 Red Berme.............710. 745

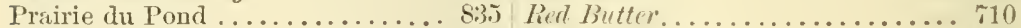

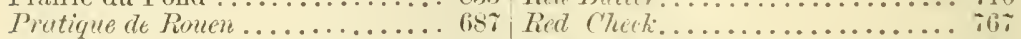

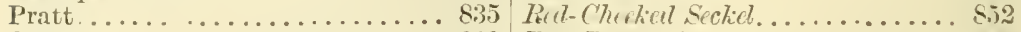

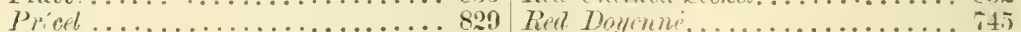

Precilly................. 8в. Fed Garden............... 841

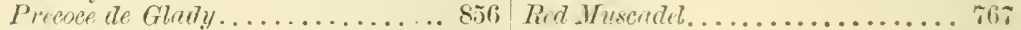

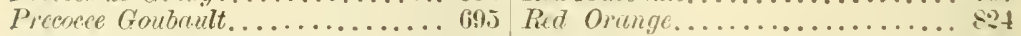

Pr mices de Wagelwater . . . . . . 8.30 Reeder's Sectling. . . . . . . . . . . . .39?

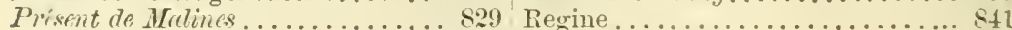

Present lioyal de Siples........ 66. Regintin................ s. 
PAGE PAGP

Re................. 880 Rousselet Vanderwecken.. ....847

Reine Caroline............. 841 Rousseline................ 347

Reine dHiver............ 841 Rousselon............... 847

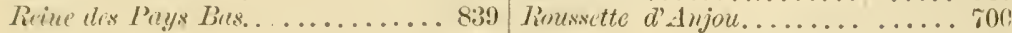

Reine des Poires. . . . . . . . . . 842 Royal ................... 847

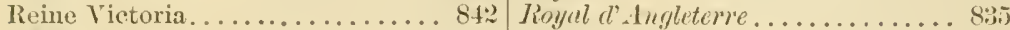

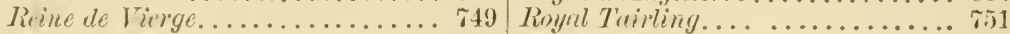

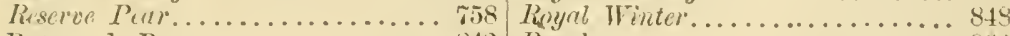

Retour de Rome............ 842 Royrle ................. 8ti:

Reymaer Beermaert.......... 842 Royale d'Hiver............. 848

Richarels................ 842 Joyule Nouvelle............84!

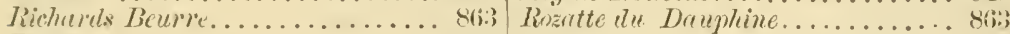

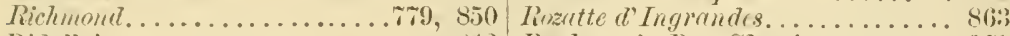

Ridelle's................. 842 Rushnene's Bon Chritien........ . .

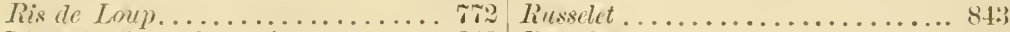

Rivers' Winter Beurré. ........ 843 Russelin ..................47

lishert's ficening............ T51 Rutter................. 848

Robert's Mushiteller............ 818

Timbertson............... 878

holvine............... 818

Rotrinson................. 858

Rue's Bergamot............. 843

Roi l'Eté. . . . . . . . . . . . . . . 8 84:

Rini Jelimont. . . . . . . . . . . . 942

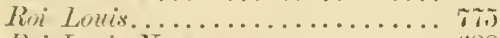

IRi Lnmis Wonveau. ............ (is8

Rei de Louvain. . . . . . . . . . . . . . 16

Roi de Rome............... St:3

lirvi de liome............... 819

Rei de Ilurtendero............. 50 \%

Roitelet. ............... 84:3

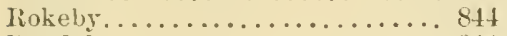

liondelet................. $\$ 4 t$

Ronville .................. 844

Ropes................... 844

T'se Epine Rese............... 863

Perse Perer................ . Sti3

Resenbirne ................ s6.3

Roslyn................... 844

Rostiezer................. 845

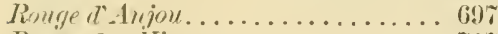

Pinnge des Irerges............. 117

Ranud Top................. 8\%2

Romsullet de ileester. . . . . . . . . . 814

Rousse Lench.............. 84.5

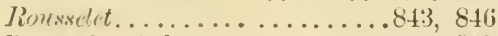

Rousselet Aclens... . . . . . . . . . 845

Rousselet Bivort............. 84.5

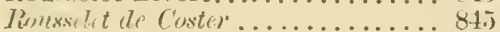

Rousselet Deeoster........... 84.5

Rumsictit Drmble............. 8tij

Rousselet Enfante Prodigue. . . . . . 8ti

Rionsselet Esperen........... 846

liousselet Hatif............. 840

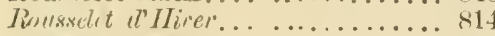

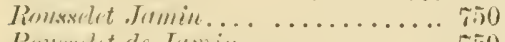

Pronsadet de Jumin. . . . . . . . . 750

Rousselet de Janrier .......... 84,

Rousselet de Jonghe .......... 846

Rouxwelet Husenti............ 840

Rousselet te Rheims.......... 846

Rousselet St. Nicholas.......... 847

Rousselet Stuttgart.

Sabine.................... 590

Sabine el tete. . . . . . . . . . . . . 767

Sabine Van Jons.............. . 790

Saeandaga................. 8.1!

Sucanduga Seckel.............. 849

Saco..................... . . . . . . . . . . . . .

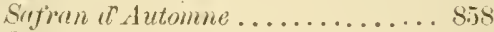

Srifinan l' Eité. ............. sti:3

Siffren rosat el'Automine........ s. so

Sigeret .................... $6{ }^{2} 1$

Saint André. . . . . . . . . . . . . . . . 84?

St. Cerpan ..................... . . 664

Saint Crispin.............. 849

Saint Denis. . . . . . . . . . . . . . . 8t!

Saint Dorothée............. 849

Saint Germain. . . . . . . . . . . . . 851

Saint Germain blane... . . . . . 804, 8.50

Sclint Germain brun........... 8. 8

St. Gemmin Dom............. ह.jo

St. Germuin Dutilleul........... (ifis

Saint Germain de Eté........... stit

Saint Germaii Fondant......... 6i:?

St. Germain de Gruines.......... (66s

\$\$. Germain Gris............. 8. 50

St. Gemerin Janne. . . . . . . . . . 850

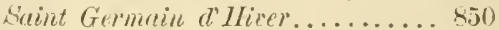

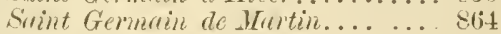

St. Germain Touverne......... Sit

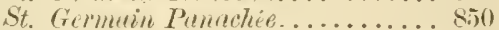

Saint Germain de Pepins. . . . . . . . 850

Suint-Germuin-1"uris........... 8.3!

St. Germuin du Tillay............. (968

St. Gemerein du Tilloy... ........ Gobs

Surint Germain I'ueuquelin......... 8.4

Saint Gemain rert............ sin

Saint Ghisiain.............. 8,

St. Merblain of Jicer.............. 551

St. Jenn................ 6.jo

S\%. Jeren Briptiste............. .

St. Jean Brytiste illiver........ 727

St. Jenn Jusquic Gres.... . . . . 818

St. John's l'eut . ............ 6.58

Saint Lambert.............. . . . . . . . . . . . .

saint Lamrent. . . . . . . . . . . . 767

Saint Lezin. . . . . . . . . . . . 850 


\begin{tabular}{|c|c|}
\hline & \\
\hline$\ldots \ldots \ldots \ldots 850$ & Sire Martin.... \\
\hline$\ldots \quad \therefore \ldots .668,871$ & Skinless.... \\
\hline$\ldots \ldots \ldots \ldots 60$ & Small Blonquet. \\
\hline St. Mirliatel Archange........... ssi & Sincell Winter Beurré........ \\
\hline Saint Michael Archangel. . . . . . . . 851 & Sinitl's Borelenare.... \\
\hline St. Mirknel of Boston............. 880 & Smith's Early Butter.... \\
\hline 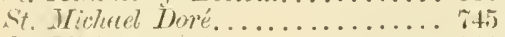 & Smitl's Pennsyliania.... \\
\hline St. Michad d lits. & Smokichouse........... \\
\hline 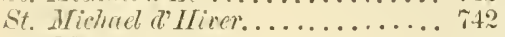 & Srow Flower......... \\
\hline st. Michel. ................. 8sso & 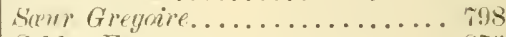 \\
\hline Swint Wiehel Crotté............ Est? & Soldut Esperen....... \\
\hline t. Nicholas. ................ 749 & Soldat Laboureur. . . . . . . . . . . . \\
\hline Suint sumpon............... 558 & 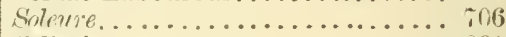 \\
\hline Saint Viucent de Paul......... 8.51 & solitrire. . \\
\hline srinte-Wadelaine ............. son & Sommer Gute Christenbirne....... \\
\hline alishmry Seedling............ 851 & Sophiou Beekmans............. \\
\hline alviata............... 851 & ress. ........... \\
\hline$\ldots \ldots \ldots \ldots \ldots \ldots 851$ & $n \ldots \ldots \ldots \ldots$ \\
\hline Sengmine di Itulie......... & nir Fay \\
\hline Sanguinole... . ..... & Souvenir of Madame Treyie. \\
\hline Sanguinole de Belgique........ 852 & nir de la Reine des Belges... \\
\hline Sinus Pair ............ & Souvenir de Simon Bourier........ \\
\hline Sums Prereille.............. ron & Sourproine. \\
\hline Sune Prinins................. grits & eraine d'Été.............. \\
\hline Sirnspeerü.................. Sisi & "rine d'Hicer. . . . . . . . . . . . . \\
\hline Sarah........ & Printemps........ \\
\hline$\ldots \ldots \ldots$ & ish Bon Chr tien..... \\
\hline Satin... & Sprrnish Wurden............ \\
\hline Satin Tert. & Sparbirme............ \\
\hline Sohclis.... & sperliled Hurris.... \\
\hline Sehöre and Gute......... & Sprice Butter. \\
\hline Schumau............. & Sivic Pent. . \\
\hline Sicotel Bergamot .......... & Simina..... \\
\hline Seal ....... & Sprinu di Curpi....... \\
\hline Sebastopol............ & viponge... \\
\hline Sirluestopol dl Et .......... & Sportsman. \\
\hline Seckel............... & 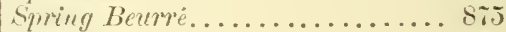 \\
\hline Eipelile.... & 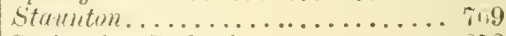 \\
\hline Singnemr... & Steinmitz Catherine......... \\
\hline$\gamma$ desplerin . . . . . . & ........... \\
\hline Seigneur el Hiver....... & Stophen's Gencsee..... \\
\hline Selleck. . . . . . . . . . . & ng... \\
\hline eur Mosselman.... . & Sterens' Genesee.... \\
\hline un-guenle........... & Stor \\
\hline Seria jhine Ovin.......... & Striped Bergomot..... \\
\hline vier. . . . . . . . . . . & Stripuel Dean \\
\hline ver lidutomne. & in...... \\
\hline$\ldots \ldots \ldots \ldots$ & striphed Oirtnge............. \\
\hline esperite. & stuttgarter Geishirtel. . \\
\hline mitel....... & Stuyerersent. . \\
\hline Woutel........... & styer \\
\hline$\ldots \ldots \ldots$ & Styriau. . \\
\hline .855 & Siblime Gramotte........... \\
\hline Chentis... & suere d'Antumne de Tertolen. \\
\hline .85 .5 & Worr el kt . . . . . . . . \\
\hline silnort's Suint Germain.... & e de Tertolan..... \\
\hline 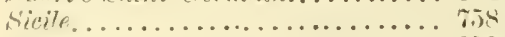 & Simere Tert. \\
\hline$\ldots 852$ & Suere Tert ilutomne de Tolstuyn. s61 \\
\hline Sirulle... & Sucre-vert di Hoyersucorda......... s si1 \\
\hline Silliman's lilts & Sincris blanche....... \\
\hline Siluanbirne. & Sncrée du Comice... . \\
\hline P Pierard. & Sucrée de Hoyerswerda \\
\hline Bo1 & 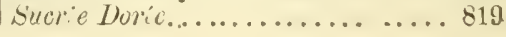 \\
\hline
\end{tabular}




\begin{tabular}{|c|c|}
\hline & \\
\hline uehrin blane at fité. & Prom \\
\hline affolk 'Thom..... & howin. . \\
\hline igul of Hinyersicorda. . . . . . . . . 8 $81 ; 1$ & \\
\hline igar Peill.................. iา9 & \\
\hline & $20(0) y)$. \\
\hline$\ldots \ldots \ldots$ & Tilton \\
\hline$\ldots \ldots \ldots \ldots$ & matenr............ \\
\hline piprine............ & liiner $\ldots \ldots \ldots \ldots \ldots$ \\
\hline ke............ & 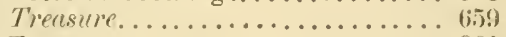 \\
\hline . & \\
\hline$\ldots \ldots \ldots \ldots$ & \\
\hline$\ldots \ldots \ldots \ldots$ & $\ldots \ldots \ldots \ldots$ \\
\hline$g \ldots$ & \\
\hline$\ldots \ldots$ & alt $\ldots \ldots \ldots \ldots \ldots$ \\
\hline$\ldots \ldots \ldots \ldots$ & gne .......... \\
\hline$\ldots \ldots \ldots . .$. & 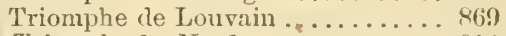 \\
\hline léal. & the din $\mathrm{I}$ \\
\hline Iristich. & iplue de Pomologique \\
\hline elle........... & Martin.......... \\
\hline ple...... & bevalet.. \\
\hline$\ldots$ c & $T ?$ \\
\hline . & $\ldots \ldots$ \\
\hline main. . & .... \\
\hline$\ldots \ldots$ & $T$ \\
\hline 1...... & \\
\hline 825 & or Fly Perror. \\
\hline$\ldots \ldots$ & Boneliritien.. \\
\hline$\ldots$ & $\ldots \ldots \ldots$ \\
\hline ... & Anniversaire de Leo- \\
\hline & $\ldots \ldots \ldots \ldots \ldots \ldots \ldots$ \\
\hline & tone \\
\hline . . & \\
\hline$\cdots$ & oró \\
\hline . & $T y$ \\
\hline .. & \\
\hline .. & \\
\hline$\ldots$. & $T d n$ \\
\hline & $C_{i}$ \\
\hline . & \\
\hline & \\
\hline . : & ecllin \\
\hline . & \\
\hline .. & St. Ger \\
\hline . & $\ldots \ldots \ldots$ \\
\hline .. & \\
\hline$x^{\circ}$ & \\
\hline & \\
\hline & \\
\hline 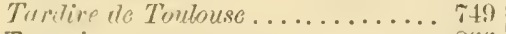 & \\
\hline & \\
\hline . & .. \\
\hline . 8 & V \\
\hline$\ldots 8$ & \\
\hline . & \\
\hline . & . \\
\hline . & \\
\hline & . \\
\hline & Bates.. \\
\hline & ter. . \\
\hline & slerer. . \\
\hline . 8 & I'in In! \\
\hline . & $\operatorname{Tan} \mathrm{M}$ \\
\hline ett & te..... \\
\hline
\end{tabular}




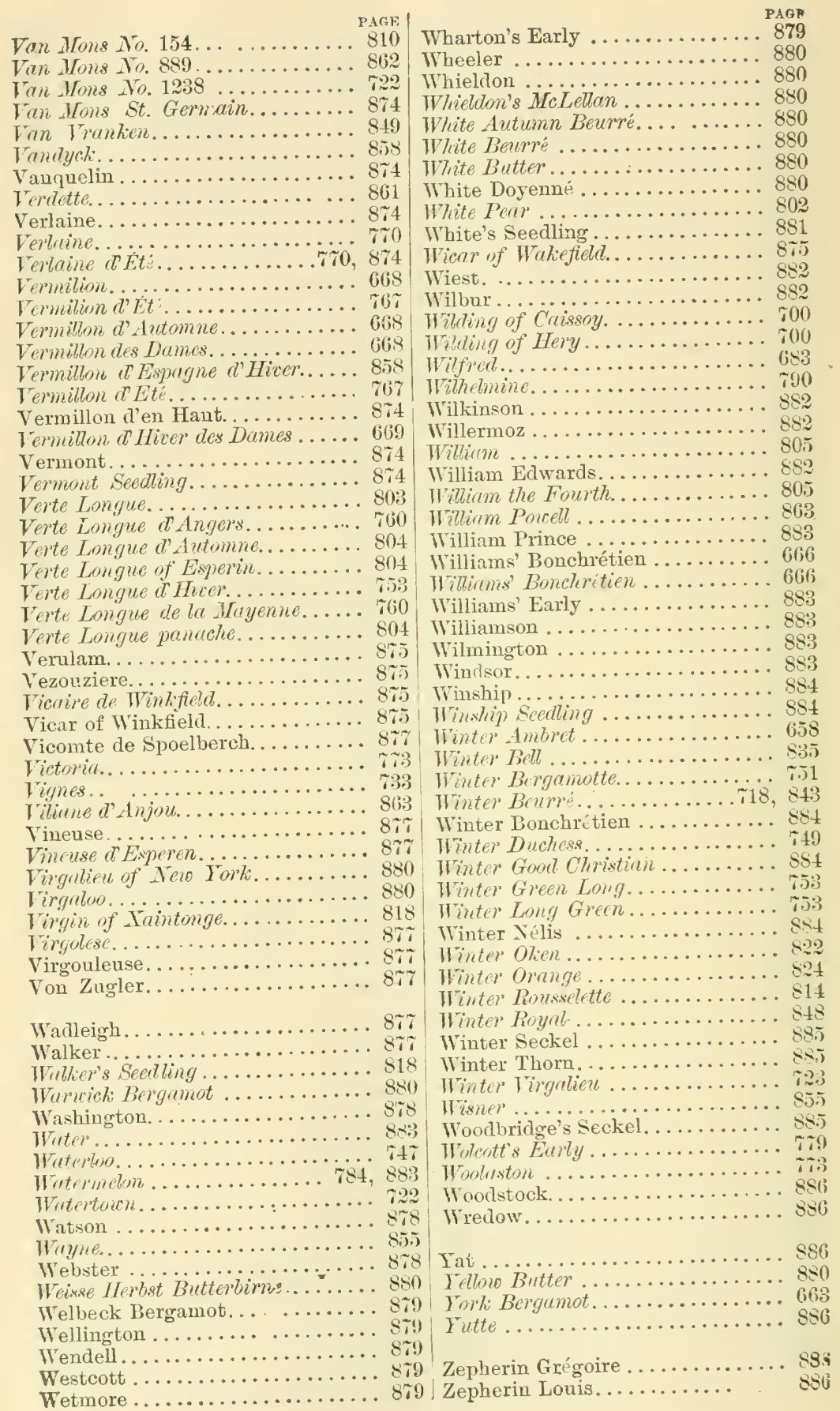


Zepherin Lowis Grégoire . . . . . . . . $8 S$

Zoar Beauty ............... 887

Zour Scedling................ S87

\section{PLUMIS.}

Abrient Tert.

Abriente Ilatif. . . . ...........911

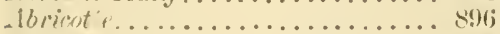

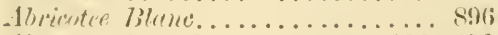

.16rient e blumche..........896, 9592

Alricotée de Braunau........... 8!)

Alrientie de Brounau Nuncelle... 9?9

Ibrient e Hitive..............911

Ihrintie Ronge.............. . 942

-1bricot sigert.............917

Abrient $e$ de Tours. . . . . . . . . . . . 896

Arlmirul de lignny. . . . . . . . . . 92:3

Igen Dutte. . ................ 9:99

Albany Beanty............... 8 8

dblerton.................... 9.4

Ilense's Given Grige.............. 917

Altexse Blanche.............. 9ist

Itrase Donble................ 924

Ameriean Mrgnum Bonum. . . . . . 896

American Wheat. . . . . . . . . . . . 896

Americru. Yellor Gage........... 9:39

Amber I'rimontirn............. 92.j

Angrelina Burdett. . . . . . . . . . . 896

Angluive Voir ............... (1:3.j

Anna Mrria.............. \$ 96

Apple [lum. . . . . . . . . . . . .

Apricot ................... s9t;

Amicot Plum of Tours. . . . . . . . . 89)

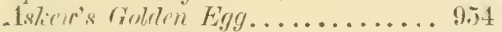

Askirir'x Purple Egy. . . . . . . . . 9. 94:?

Auburn .................... 897

Alunt dim.................... 18

Austrian Quetsche............916

Automne de Schamali.......... 89t

dutumen Beccuty............. 898

Autumn Compote............ 898

Antumn Gage.............. 8 897

Aermt Prome blunche.......... 925

. Izure Hitive. . . . . . . . . . . . s99

lhavay's Green Gage............. \$97

Beacli Plum. . . . . . . . . . . . . 8.9

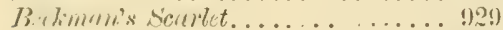

Bejomières ............... 89

Belgrian Purple.............. s!

Jiclle rle Louvain. . . . . . . . . . . . 8. s!

Belle de Septembre........... s!n

Benedict. . . . . . . . . . . . . . . . . \$ $\$ 99$

Iillbure ..................

Bincham . . . . . . . . . . . . 8!!)

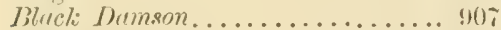

Blacle Imperial. . . . . ............ 901

Blierli Horrece............... 982

Blucli Perdrigon................ s99

Blackthorn............... 95j
TAGrin

Bleecker's Gagc.............. 89?

Bhectier's Scurlet. . . . . . . . . . . 920

Bleceler's Tdlow................ 8!)

Blectier's Tillono Gage........... 849

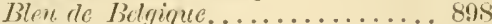

blen de Perque. . . . . . . . . . . . . 89s

Blue Gage. . . . . . . . . . . . . . . 899

Blue Itollamel. ................ 921

Blue Impératrice. . . . . . . . . . . . .. 900

b? ue limpératrice.............. 947

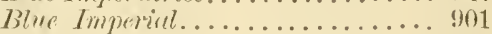

Blue Pertlrigon............... 900

Blue Perdition................ 9:3\%

Blue Plum. . . . . . . . . . . . .

Bilum . . . . . . . . . . . . . . . 900

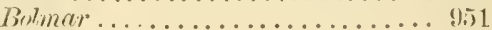

Bolmer..................... 951

Bolmer's Wirshington............ 951

Bonnet d'Eveque............... 900

Boulouf..................... 901

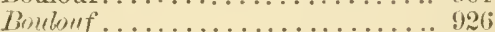

Brartford Gage.................917

Bradshaw ..................

Brahy's Green Gage.............. . 901

Brundy Guge................ 9:31

Bremen Prume.

Brevoort's Purple............... 901

Brevoort's Purple Bolmar........ 901

Brevoort's l'urple Wastimgton..... 901

Bricet ................... 901

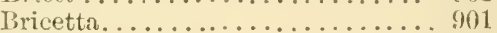

Brigrole ................. 45:3

Brimude Violette ............... 900

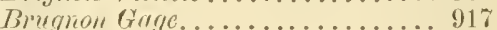

Briygu Grage..................917

Bryanston's Gage. . . . . . . . . . . . 902

Buel's Favorite. . . . . . . . . . . . . 902

Burettes .................. 902

Burgmandy Prume.....................

Burlington Gage.............. 90.

Bury Seculling............... 901

Byfield ................. 902

Caldwell's Golden Drop......... 902

Caldwell's White Gage. ......... !10:3

r'aledonian.............917, 9:33

Cambell. . . . . . . . . . . . . . . 90:3

('rmbell's Sredling............. 90:3

C'int's bite Green Gage........... 917

Gituloniun................ 92i

Cerisette Blunche..............

Chapin ...................

Cherpin's Emly.............. 921

Cherimmen's Prince of Wules........ (1:)

Chuthotte................. nis

Cherry................... . 90:3

Chester County Prune.......... (0:3

Cheston ..................... 00.

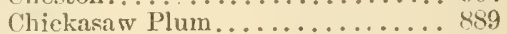

Cleavinger.................. 004

Cloth of Gold Experen........... 916

rysth of Guld llum............ 910

Coe's Golden Drop ............ 904 


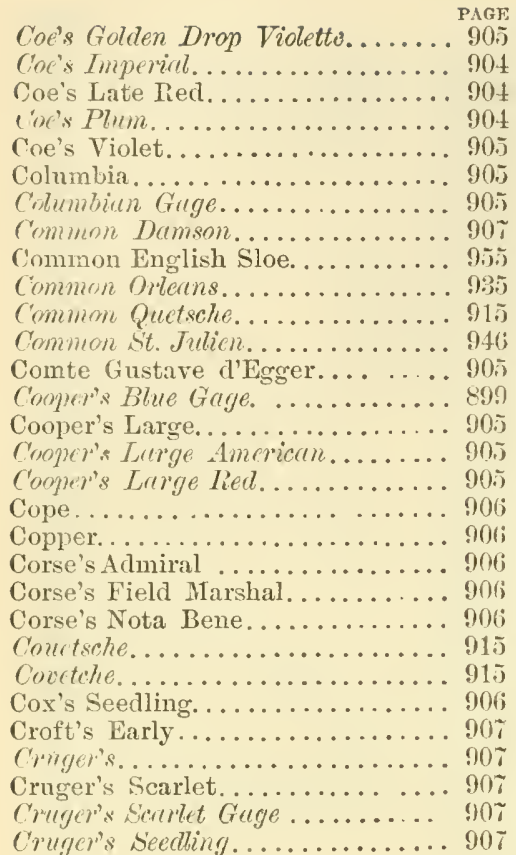

I Agen .................. 939

L' Amerique Romigo. . . . . . . . . . . . . 903

7) Automne de Schamal. . . . . . . . 897

D'Antriche.................908

J'Arine. . . . . . . . . . . . 92J

Domus Blunc. .... . . ... . . . 952

Diemus Blane Gios. .......... 95̃

Dumes Blene Hâtij Gros. . . . . . . 952

Jimes Dionet. ............... 910

Hemes in Espagne. . . . . . . . . . . 949

Dimmes Gins............... 915

Dremas of Itulie. . . . . . . . . . . . . . . 924

Damas Jaune. . . . . . . . . . . . . 95:3

Derners. Latrowon . . . . . . . . . . 928

Damas de Diangeron. . . . . . . . . 9:31

Dumas Musque. . . . . . . . . . 9 93:3

Damas te Provence.............. 9.9!)

Damas de Piovence Ilütif. . . . . . . . 9:39

Detmas de Septembre........... 947

Demas de Toure.............. 932

Damas de Tours gros. .......... 917

Damas Tert..................91\%

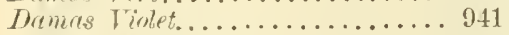

Dimas Irolet Gros............ . 915

Damasema schamali............ s:

Damascene Mrugeron............ 931

Damasti ...................915

Dame Aubert. . . . . . . . . . . . 954

Dane Aubert blanche............954

Dame Aubert Jicune. . . . . . . . . . . 9. 9.5

Dume Aubert Violette...........94;3

Damson.
PAGR

Dana's Yeli эw Gage............. 908

Date Plum.................. 908

Dittelzicetsche ................ 909

Danplin .................. 918

Jorupline................... 917

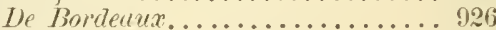

De cliypre................. 933

De Dílice.................. 909

De Montfort. . ............... 908

De Tirginie................. 90:3

Demixton's Albany Beauty....... 896

Denniston's Red.............. 908

Denuiston's Superb............ 908

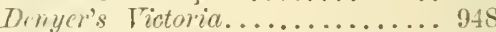

Diamond................... 9r?

Dictator ..................... gr g

Direpleane.................. 950

Jireplerane Laffiry. . . . . . . . . . . . 9.50

Diapmé Blunc............... 9.52

Dirmpie Blonche. . . . . . . . . . . 952

Direprie Thonge............... 94?

Thaprie Tinlste............... 904

Die Pothe Eigirfarme.......... 943

Die Tialette Kürigin Claudie...... 940

Dolphin....................948

Domine Dull................ 909

Dorellys Vuce Grosse Zicetsche..... 9.3t

Dorelle's New Purnle Prune. . . . . . 934

Dorr's Favorite. ............... 909

Double-blossomed Plum......... 9.5

Double-flowering Sloe. . . . . . . . 9.j

Downing's Early ..............9.910

Downton Impiratrice............ 910

Drap d'Or................... 910

Drelp dor Experen................ 910

Dronet Damask. ............. 910

Duane's Purple................ 910

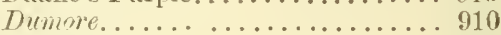

Dunmore. . . . ............ 910

Duteh Prune................ 909

Dutch Ouetzen................. 909

Dwarf Texas Plum.............. 889

Early Amber............... 911

Early Apricot................ 911

Early Bavay................. 920

Early Black Horocco........... 932

Early Cross. . . . . . . . . . . . . . . 911

Early Damaxk................ 932

Early Dumask of Procence........ 939

Early Dumenn ................. 907

Early Favorite............... 911

Early Genexee.................. 020

Early Green Gage. . . . . . . . . . . . 911

Early Jolin................. 925

Early Hurwientr. . . . . . . . . . . 911

Ererly Worocen. . . . . . . . . . . . . 932

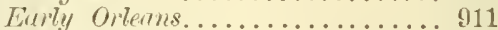

Early Prolific............... 912

Eamly Pumple................ 921

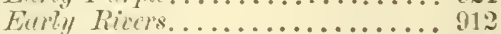

Errily Royml................ 945

Early Royul of Nikita ......... 912 
PIGF

Enrly Ruseian............. 915

Early St. Johu. ............. 112

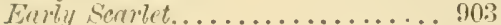

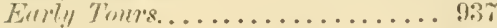

Enerly lintet............... 9.37

Einty I thom.................925

Early Iellow Prune........... 912

Frlonar] Seneclauze............ 912

Figl l'lıाн. ............... 951

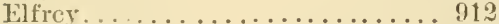

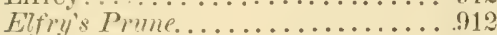

Emerald Drop.............. 91:

Emmess. .................. 900

Englixh Orleans.............. 9:.

English Wheat................ 91?

Euglish Yellow Gage........... 91

Eugene Furst. ............... 91;

Firip's Golden Drop............ 904

Frntenberg............... 924

Fine Bonte..............913

Florence .................. 949

Flusling Gage............. 92;

Fonthill. ................... 983

Funte's Early Orlerins...........913

Foote's Golden Gage............. \$14

Futheringry............... 914

Fotheringham.............914

Firmlitin................. 9. 1

Fiench ropper...............906

French Royal. ................945

Finench St. Jutien........... 940

Frost Gage............... 914

Frost Plum.............914, 952

Fulton................. 914

Tras

017

Grose Lisisante

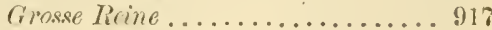

Grosse lieine Claude ............917

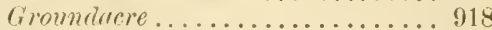

Grove House Purple........... 914

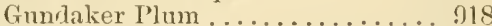

Gundaker Prune... . . . . . . . . . . 918

Guthrie's Apricot.............. 918

Guthrie's Aunt Ann............918

Guthrie's Golden..............918

Guthrie's Late Green ............. !1!

Futhrie's Russet.............. 91!

Guthrie's Taybank............. 91!

Guthrie's Topaz . . . . . . . . . . . . . 919

Gwalsh. .............. 919

Hallenbeck ................ 920

IIrimpton Comrt .............. 911

Hartwiss' Yellow Prune ......... 920

Hemrietta Gage............. 920

Henry Clay ................. 920

Highlander . . . . . . . . . . . . 920

Hinchley................. 9:31

Holland .................. 921

Iloblarad Prane ............... 921

Horse Plum.............. 921

How's Amber . . ............. 921

Howard's Favorite. . . . . . . . . 921

Howell's Early .............. 921

Ihomell's Large. . . . . . . . . . . . . . 93:)

Hudson Gage................ 922

Hwling's Rine Claudia......... 917

Huling's Superb. . . . . . . . . . 922

Galbraith ................. 914

Grelbe Mirabelle ............... 932

Gem .................. 915

Genl. Hand ................ 91.5

Gipman Gage................ 899

German Prnme ................ 915

German () betwehe............915

Ghiston's Eurly. ............. 916

Giffort's Lafayette .............916

frillett ................. 931

Gisborne's. ...............916

Gisborne's Early.............. 916

Grive de Ter York............. 922

Goliten Cherry Plum........... 916

Golden Esperen ..............916

Gointen finge ................ 904

Golden Grege Lazeson ........... 928

Goliath ................... 917

Gonne ................. 917

Gounes Green Grage ............ 913

Goving's Golden Guge........... 917

Goutte ror ................... 004

Great Damask Violet of Tours . . . . 917

Grent Freen Drmask. . . . . . . . . 917

Green Gage.................917

Grimernels Ererly Orleans ........ 911

Gros Damas Vert.............917

Ickworth Impératrice .. . . . . . . 9. 922

Iila Gage ................... 917

Idir Green Gage ................ 917

Impératrice................ $\$ 00$

Imp ratrice Blanche........... 9.2

Inip patrice Tiolet.............. 900

Timpiratrice Tioldte ............ 915

Impl',ritrice T'iolette Grosse........ 915

Timperiab.................. 943

Impevial Diadem. . . ........... 942

Imperial Gage. . . . . . . . . . . . 1923

Imperial Ottoman. . . . . . . . . . 19:3

Imperial Purple. . . . . . . . . . . . . . . . 923

Imp rial de Sharp. . . . . . . . . . . . 948

Imp'rive Violet ............... 94;3

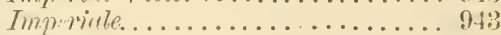

Imperinle blanche............. 95.t

Imp riale de Milan. . . . . . . . . . . 92.

Impirivle Rouge.............. \$1:3

Imp'viale Violette........... 942

Incomparable .............. 924

Incomprarable Prune. . ......... 924

Irving's Bolmar.............. 951

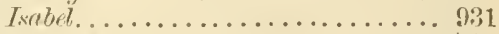

Isabella. . . . . . . . . . . . . . . 924

Islenorth Given Gage............. 917

Italian Damask. ........... 924 
PAGF

Italian Prune............... 924

Itrlian Quetsche................ 924

Ires.................... 924

Ires' scellding............... 924

Ires' Hashington.............. 924

Jackison. . . . . . . . . . . . 951

Jacob. ................... 925

Janne de Catalogne............ 925

Janue Hâtive............... 925

, Term Hâtive................ 925

Jefferson................. 925

. Tentines' Tmperial............. 933

Jerusalem. . . . . . . . . . . . . . 920

Jolioigne Green Gage. . . . . . . . . 020

Judson................... 926

July Green Gage.............. 926

Kester's Green Gage............ 020

Kester's Yellow Gage........... .926

Keyser's Plum............... 922

Kirke's................. 920

Kirke's Stondess............. 949

Kinewtt's Lute Orleans.......... . 9833

Tinight's Large Drying. ......... 927

Knight's No. 6............. 922

Kuetsshe.................. 915

Kolenkamp.............. 92

La Dilicieuse................ 905

Iar Roynle............... 94i

Lady Plum................... . 927

Langdon................ 92

Langdon's Seerling........... 927

Large Early Damson........... 921

Large Geman Prune.......... 915

Large Green Drying........... $92 \pi$

Larye Long Blue.............. 990

Large Perch................. 936

Large White Damson........... $90 \%$

Lurgest Dumush of Tours........ 917

Late Black Damson........... 907

Late Black Orlenns............ 927

Late Bolmer................ 928

Late Chuster............... 952

Lite Green Gage.............. 933

Late Monsienr............... 935

Late Purple Damson........... 907

Late Rivers............... 928

Late Yoblow Damson........... 9.2?

Lawrence's Favorite............ 928

Latrenee's Gage............... 928

'Lawrence's Early............. 928

Lawson's Golden...............

Leipzic .................. .15

Lewiston $\operatorname{Lgg} . \ldots \ldots \ldots \ldots \ldots . . . .929$

Tiegel's Apricot.............. 929

Little Blue Gage.............. 899

Little Lirabelle.............. 939

Little Queen Claude............. 913

Livinyston Munor.............. 917

Lombard................. 929

Long Scarlet................. 929

PAGE

Lomis Brmn................ . 917

Lonis Plitippe. . . . . . . . . . . . . 933

Lonisn. . . . . . . . . . . . . . . . . 9830

Lucombe's Nonesuch. . . . . . . . . 930

MeCrulry's Seerlling............ 903

McLanghlin. . . . . . . . . . . . . . . . $9: 30$

Indison ................... 908

Wrignum. Bonum............. 95t

Mrititip Clande. . . . . . . . . . . . 9.5:3

Wrimelor Sageret.............. 930

Mamelonnée ............... 930

Kangeron................. 931

Irann's Brandy Gage . . . . . . . . . 9. 9:1

MIann's Imperial. . . . . . . . . . . . . 9:31

Mamming's Long Bine ............ 930

MIanuing's Long Blue Prune ...... 9:30

Yanning's Prume.............. 930

Mrtian . . . . . ............. 945

Marten .................... 9:931

Jurrten's Scolling.............. 981

Writchless .................... 904

Maugeron ................. $9: 1$

Manderon Damask............. 9:31

Meciterranean .............. $9: 31$

Meigs .................. 9:

Mimms ................. 94:

Miner ................... 931

Jinette................. 919

Mirabelle ................. 982

Wirrubelle Blanche. . . . . . . . . . 932

Wirabrlle Donble............. 910

Wirreblle Grosse............... 910

Mirabelle.Janne. . . . . . . . . . . 9:32

Mirabelle de Nancy ............ 932

Wirabdle d'octubre .............. 901

Wivrludle Prile ............. 932

Wirabche Petite................. 932

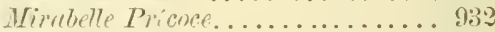

Mirmbelle Tardine.............. 901

Mirrluelle Firt Doulde...........91\%

Vimbelle de Tienne........... 9:32

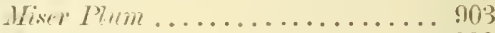

Mitchelson. . . . . . . . . . . . . 932

Witchelson's . . . . . . . . . . . 9:9?

Monroe . . . . . . . . . . . . . . . 9: 9:3

Wmmo Egg . . . . . . . . . . . . 932

Worisiem ............... 93.5

Ifonsient à fruits Jamne . . . . . . . . . 95t

Wonsicur Heitif . . . . . . . . . . . 911

Womxicur Thutif do Honetmonency ... 911

Yonsiemr Mutie. . . ........... 911

Monsienr Ortinuire........... 985

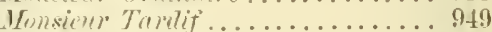

Monsiemr Tamtior. . . . . . . . . . . 9. 49

Monatmense de Buray. . . . . . . 897

Monstrueuse de Oullins . . . . . . . . . 935

Tontgomery Prune............ 929

Horoceco .................. 932

Moyret's Gage ................9933

Mulbeny . . .............. 933

Vurvoy's lieine Clicutic........... 917 
rifi

Muscle

Musk Damask....

Musquó de Multre

Iyruboten

Nectarine.

Telson's Tictory

I'ero Eirrly Oiberins.

Nere Gimelen Diop.

Tel0 Th

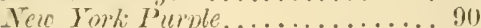

Newman.................. 9:3

Toire Jlutice................ (9:3

Tinker Plom................. 9.

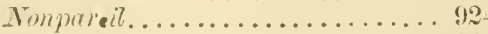

Norbert.

Norman Perdrigon. . . . . . . . . . 9:3

Yorth..................... 9...

Worth's Scerling............... 9.3t

Tonvelle de Dorelle........... 9:3t

Iitmeg ....................91:3

Oberley.................... 9...

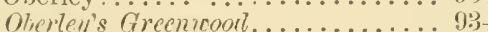

October Green Gage. .......... 9:3;

(Eil le Bomf ................. 926;

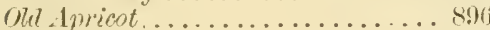

Olel Or.jerms................. 9:3:)

Orange .................... . . . . . . . . . . . . . . .

Urange Grige............... 9:3ì

Orleans .................

Ouilin's Groge................. 9:35

Oullin's Golden ............. 9:3i)

Dullin's Golden Gage............ 9...

Pulver's Wammoth.

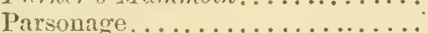

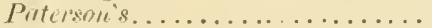

Peach Plum.................

Pereh Plum. . . . . . . . . . . . 9:3

F'enobscot.................. 9:30

Peoly's Exrlv Blize.............. ! 130

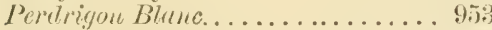

Perdrigm Vomand............ 9. . .

Pevdivignn Romge..............94:

I'erelrigon rivbt...............9:3r

Perlrigon Violet Hitif. . . . . . . . . $9: 3($

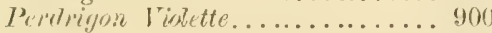

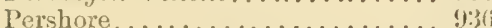

Peter's Yellow Gage.............. $9: 37$

Petit Bricette.................... (1)

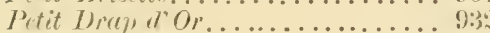

Pitit . St. Jubien. . . . . . . . . . . 9 40

I'tite Reine Clande.............. !) 1:

Philipge $I \ldots \ldots \ldots \ldots \ldots \ldots \ldots \ldots \ldots$ g.

Piclertt's.July. . . . . . . . . . . . !)

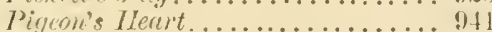

Pitbes.................... 94!!

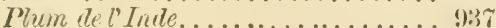

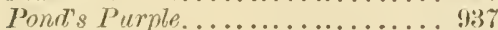

Pond's Seedling.............. 9:37

Pourprie Duane.
Précoce de Relorthcld ....... 038

Précoce de 'Tours.............. 9:37

Prilice 1 llurt............... 938

Prince Englebert. . . . . . . . . . . 938

Prince of Wales..............9:38

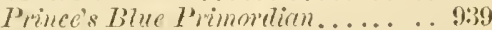

Prince's livrly Daunson. . . . . . . . . 907

Jrime's tratge................ 923

Prince's Inigerial. .............. 923

Irincers Implial Gruge.......... 92:3

Prince's Orange Ero............. 9. 938

Prince's Orange Gage... . . . . . . . . 988

Prince's Primordian. . . . . . . . . . . 989

I'rince's White Gurfe............. 92:3

Prince's Yellow Gage.............. 989

Provence Jamask. . . . . . . . . . . . 939

Prume 1 Aren................ 989

Prune dillemargme............ 915

Prume dilltese............... 949

Prune diltesse blanche......... 925

Pindie d' ist................. 989

Pr.une d' tutomne de Sclumiti..... 897

Prune d'sutriche.............. 908

Pinne res Bejonnieres........... 898

Prine de Binergogne............ 902

l'rune de Briginde............. 9:39

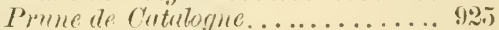

Prune de Chymo.............. 9:3:3

Prune Damson................ 907

Prune Dutte.................. 908

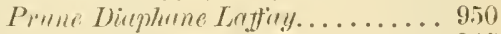

Pinne de Gritlon .............99:37

Prune Gonne................. 917

Prune Goulte d' Or............. 004

Prone Fronser Ontsche Fonvelle... 9:4

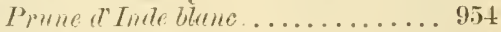

1 Prune ditublis............... 924

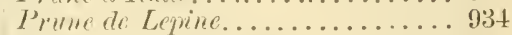

l'inne ale Lonvain.............. 898

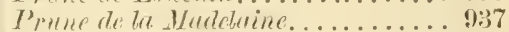

Prwne ale Writhe.............. 98:3

Prume ale IVitum............. 922

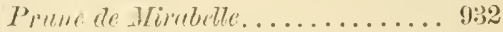

Prune de Alonsieur. . . . . . . . . 9: 9:35)

Prume Homesient Jimme......... 925)

Prine Tomirlbe te Doriel. ....... 9:34

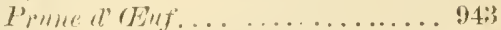

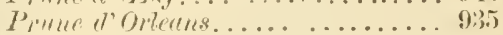

Pinue Prahe..............9:33, $9: 36$

I'vnlle ale Prince.............. 934

Prune du Rut............... 9:39

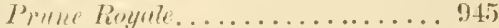

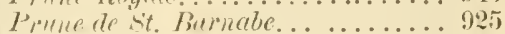

I'rmer de sit. Jeen..............912

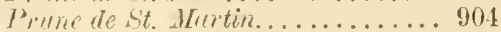

Pronne sinisise................ y 49

Prunc de Tiecrnec............. 947

Prume I iolet de Jerusulema....... 926

Prumier de Jerusulem.......... 926

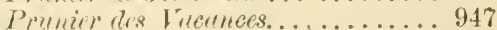

Prunus Cerrsiffru............ 903

Prumns Myrubulena.......... 903

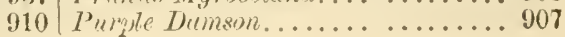


PAGF

Privile Egg...............943 Reizenstein's Yellow Prune......943

Purple Farorite..............9940 Rensielrer Gruge..............917

Purple Gage................940 Rhinebeck Yellow Gage......... 944

Punple Hagnum Bonum.....910,943 Rhue.................944

Rline's Seedling................. 944

Quackenboss ..............941 Richland ...............944

Oner.m Clumedir................ 917 Rivers' No. 1............. 911

Queen Mother................... 941 Pivers' Early Wo. 2.......... 912

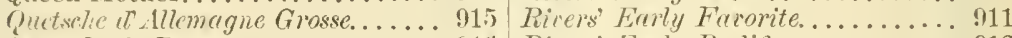

vluctectue de Breme ............. g16 Rivers' Errly Prolific........... 913

Gurtivhe Dutte............... nos Rube de Sergent............. 939

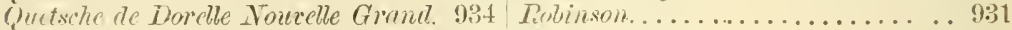

Chetsche Growse.............915 Rohr's Yellow.............. 944

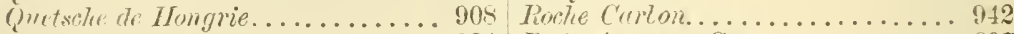

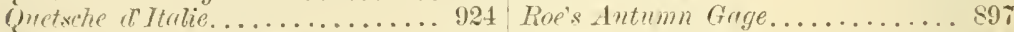

(juetsece Precuce de Furst........ 91:3 Rollande Galloppi.............944

Quetzen.................995 Ronald's Fancy............. 94.

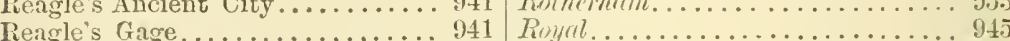

Reagle's Union Purple............ 942 Royni Dianphine................. 949

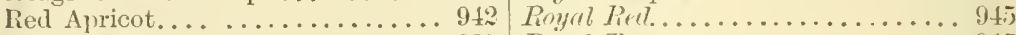

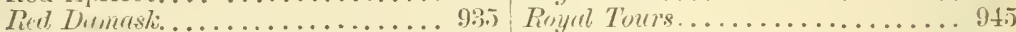

Red Diaper...............942 Rryyl de Tilvonde........... \$26

Red Ey!.................94: Royale..................947

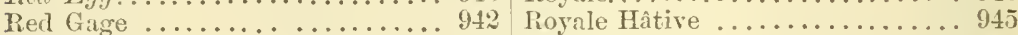

Ped frige................. 92! Royale de Tours............955

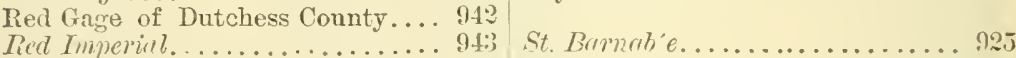

Red Magnnm Bonnm. . . . . . . 94:3 Saint Catherine.............946

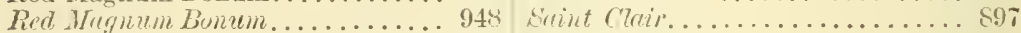

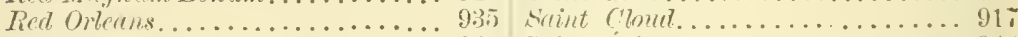

Red Perdrigon.............943 Saint Etienne ............ 941

Red Primordian............. 94; | St. James' Quetsche..........916

Red Qucen Wrther........... 9t1 St. Jesn.................912

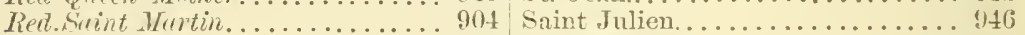

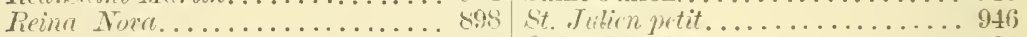

Peine Clunde.............. $91 \%$ Srint Murtin............... 904

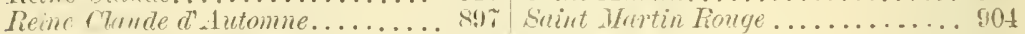

Reine Clumle de Burry......... 897 Saint Martin's Quetsche........ 947

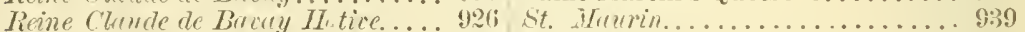

Reine Clame Berger.......... 9:66 Sand Plum............... s-g

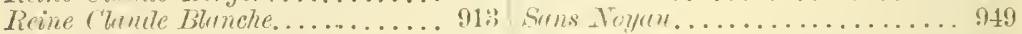

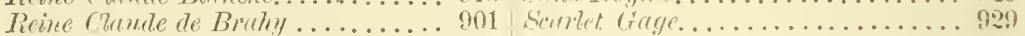

Pine (1/unde Dirqhane........ 950 Schenectady Catherine........947

Reine Chude Uorie...........917 Schnyier Gage.............94i

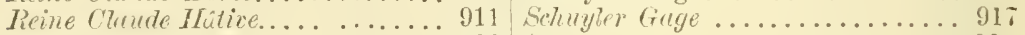

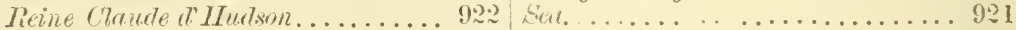

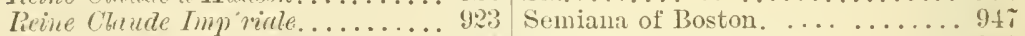

Ticine Chude de Judrigne......... 9:0; September Damask........... 947

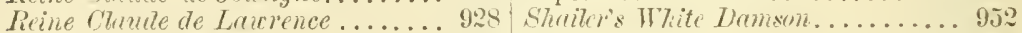

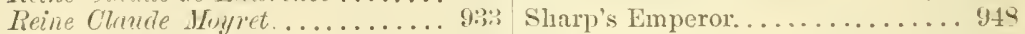

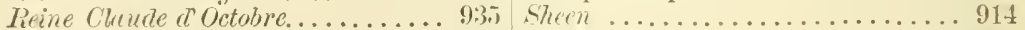

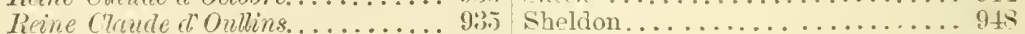

Reine Chude Pricoce........... 9:35 shequer.................. 943

Reine Clrunde Rouge de Scptembre. s9s Shropshire Damson............997

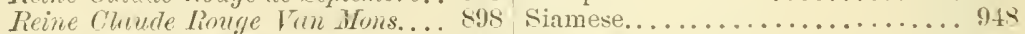

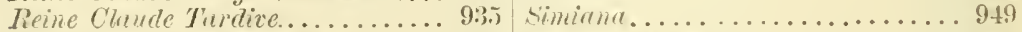

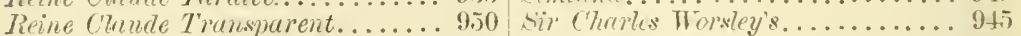

Reine Clrude Violette........... 940 Swell Green Gage............ 918

lieine Clnutin blanehe lie grosse.... 917 Small Mimblle.............. 932

Reine petite esj ce........... 91: Small Red Damson...........907

Reine Vietoria..............943 I Small White Damson.......... 907 


\begin{tabular}{|c|c|}
\hline & \\
\hline$\ldots \ldots \ldots \ldots \ldots .948$ & White Dimarascene. \\
\hline k. . . . . . . 9. 9 & hite Dimmask... \\
\hline Grage............ 949 & $\mathrm{Di}_{\mathrm{i}}$ \\
\hline of England. ........ & White Diaper. \\
\hline Empleror........... & White Egg. .. \\
\hline,$\ldots \ldots \ldots \ldots \ldots$ & White Einpress. . . . \\
\hline$r t \ldots \ldots \ldots \ldots \ldots \ldots \ldots$ & White rage . . . . . .9913, 923, \\
\hline$\ldots \ldots \ldots \ldots \ldots \ldots$ & White Ilolland................. \\
\hline - Gipen Grege............ & ratrice............. \\
\hline arneomn..........913, 9; & White Imperial. . \\
\hline .......... (915 & White Hugnum Bonum .... \\
\hline .. $9+9$ & White Mirubelle. . . . . . . . . . . . \\
\hline .. 94 & White Wogm!. . . . . . . . . . . . \\
\hline & \\
\hline ...... 91 & $\operatorname{Pr}$ \\
\hline$\ldots . ?$ & White Pro \\
\hline tte. . & $c \ldots \ldots$ \\
\hline .. ! & $\mathrm{W} \%$ \\
\hline$\ldots 95$ & 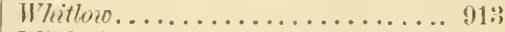 \\
\hline ...9 & .. \\
\hline$\ldots \ldots 91$ & $\ldots \ldots \ldots \ldots \ldots$ \\
\hline che ........9. & esere \\
\hline an Prune...... ? & son \\
\hline 然 & $\begin{array}{l}\text { Wil } \\
\text { Wil }\end{array}$ \\
\hline (2) & 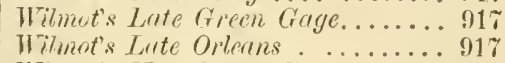 \\
\hline ... & s Nero Green Gage.... \\
\hline s' lier & Orleans............. \\
\hline ......... & IV \\
\hline$\ldots \ldots \ldots \ldots \ldots$ & Bol \\
\hline Imperatrice............. & $1 \ldots \ldots \ldots \ldots$ \\
\hline$\ldots \ldots \ldots$ & on's Black Gage. . . . . . . . . \\
\hline .... & \\
\hline & 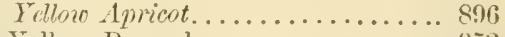 \\
\hline . & . \\
\hline$\ldots 9$ & $\mathrm{Eg}$ \\
\hline$\ldots .9$ & rice. . \\
\hline 900,91 & Bonum. \\
\hline$\ldots 9:$ & $16 \ldots \ldots$ \\
\hline .90 & $\ldots \ldots \ldots \ldots$ \\
\hline .. $9:$ & ............... \\
\hline . . 926 & $\ldots \ldots \ldots \ldots \ldots$ \\
\hline clucude.. & aling............ \\
\hline$\cdots$ & \\
\hline & \\
\hline
\end{tabular}

\section{PONEGRANATES.}

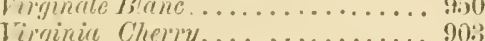

Hinger. ................ 9:3

Wangenhoim.............. 9.51

Washington. ............. 9.

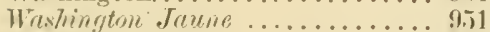

Wriskington Purple.......... . 001

W'utrvloo...................904

Wax............... 9.

Werutecorth................ 951

Whent Pirm. . . . . . . . . . . . . 913

Wheaton.................. 91:

White Apricot ............ 952

White Bullace ............. 952

Acid-Fruited............. 95'7

Double Red....................57

Double White ............. 957

Grenadier à Frmit Doux......... 957

Subacid-Fruited............. 957

Sweet-Fruited .............. 957

Variegated Flowered.......... 957

Wild Pomegranate............ 957 
Yellow Flowered

PAGE

957

\section{QUINCES.}

Angers

Apple-shaped Quince........... 95

Blush Japan Quince. . . . . . . . . . . . 960

Chinese Quince .............9960

Cyclonia Japonica. . . . . . . . . . . . 960

Japan Quince ..............9960

New Upright ............. 959

Oblong Quince................. 9. 9.9

Orange Quince,.............. 959

Paris de Tontenay .............. 959

Pear-shaped Quince ........... 959

Portugal Quince............... 959

Pyrus Japonica. . . . . . . . . . . . . . . 960

Rea's Seedling .............. 959

Van Slyle................. 959

White Quince .............. 960

\section{RASPBERRIES.}

Abet.

Allen.

Allen.

Allen's Antioe

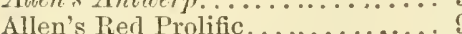

American Black .............. 969

Anerican Inmproved. .............966

American Red................ 963

American White. ............. 96:3

Arnold's Orange. . . . . . . . . . . . 963

Arnold's Red................ 96:3

August Black. ................ 969

Antumn Black. ............... 963

Autumen Black Raspberry. . . . . . . 969

Bagley's Perpetnal.............994

barnet.

Brenit Cane......................964

Belle de lontenay..... .........994

Belle al' Orlecm. ................ 964

Belle de Paluan............... 96t

Black. .................... 964

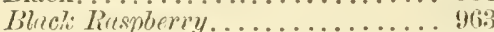

Brentford Cane...............961

Brinclile's Orange .. ...........971

Burley. ................. 972

Burlington................ 964

Canada Black Cap............... 964

Carter's Prolific.
Catawissa................ 96.96

Cincinnati Red............... 969

Clarke ..............................

Col. Wilder................. 96.5

Collinsville Mriami............... 069

Common Black-Cap............ 963

Common Red.................963

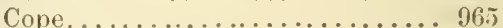

Connucrles Prolific............... 964

Connwall's Seedling.............964

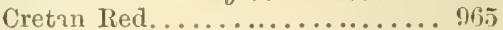

Cushing. ................ 9(i.j

Cutbush's Prince of Wales........ 971

Davison's Thornless............ $9 f f i$

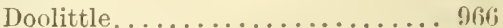

Doolittle's Black Cap............. 96it;

Doulittle's Red Flarored Black Cap. 96; Double-Bearing. ................ 966

Double-Bearing Tellow.......... 97t

Duhring................. 966

Ellisdale ................. 960

Elm City. ................ 9601

Elsie ................... $966^{\circ}$

Emily .................. . 0606

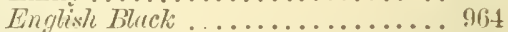

English Globe .............. 960

English Purple................. 9ז1

English Red. .................. 971

English Red Cane.............. 962

False Red Antrcerp ............ 962

Fastollf .................. 967

Filby ......................................... 967

Frrmboisier iो Gros Fruit......... 972

Franconia................................

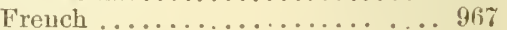

Fulton.................. 96r

Garden .................. 967

Gen. Patterson ............... 96.

Golden Cap ................. 96:3

Golden Thornless............ 967

Hildreth ................... 968

Hornet ....... 968

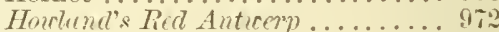

Hudson River Antwerp.... . . . . . 968

Huntsman's Giant .............998

Huntsville................. 9;1

Imperial .................. 968

Imperial Red............... 96is

Improved Miami. . . . . . . . . . . 969

Joslyn's Black Cap ............. 960

Jostyn's Imeroved .............. 960

Jostyn's Improved Black Cap ...... 960

Jouet................... 965

Kirtland .................. 969

Knevet's Gjant. . . . . . . . . . . . . 969 


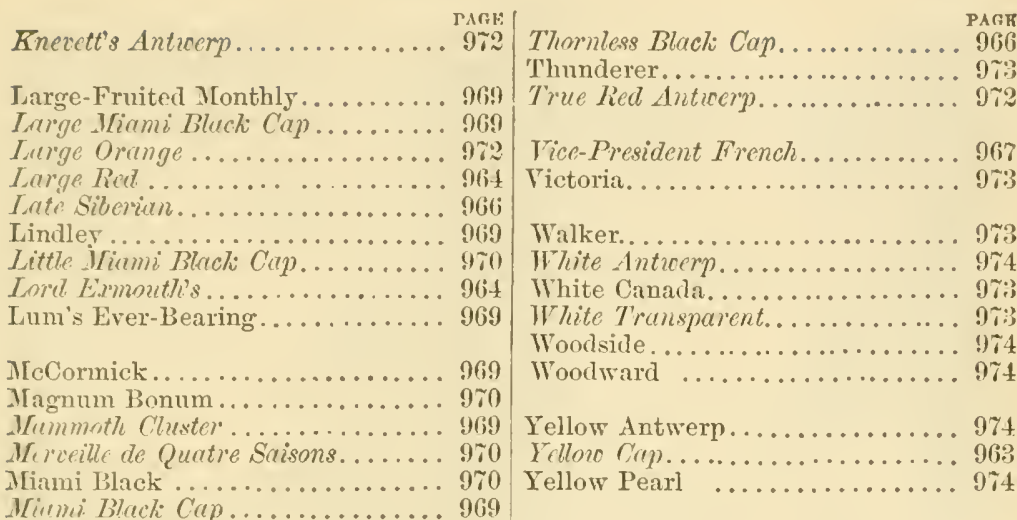

Mote's Ever-Bearing. . . . . . . . . . 970

Mrs. Wood ................. 970

Nero Red Anticerp............. 968

Northumberland Fill-Basket ...... 970

Jottingham Scarlet.......... 9r0

October Red.................9 970

Octoher Yellow............... 9т

Ohio Erer-Bearing ............. 971

Ohio Ruspberry ...............9 9r1

Old Red Anticerp ............. 972

Orange .................971

Perpetual Bearing .............966

Philadelphia............... 971

Pilate .................9\%1

Prince of Wales.............. 9\%1

Prince's Globose............... . 971

Prolifor (C'iter's) . . . . . . . . . . 96.)

Prosiser . . .................964

Purple Cane............... 971

Purple Prolific .............. 9\%

Red Antwerp ..............9\%2

Red Imperial ................. 968

Red Pearl ................ 97:

Red Prolific ................ 971

Riley's Early .............. 972

Rivers' Nero Large Monthly . . . . . . 969

Rivers' Orauge .............. 972

Inger's Fictoria.............99:3

I ubus Occidentatis ........... 96i:

Russell's Red............. 9:2

Semper Fidelis.............. 972

Seneca Black Cap............. 972

Souchetti............... 979

Sitneter................ 96i:

Summit. . . . . . . . . . . . . 9 9:3

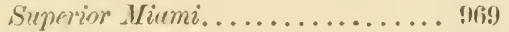

Surprise................. g. 9.

Sweet Yellow Antwerp.........973

Thimbleberry. 963

Aberdeen....................1001

Aberdeen Beclive.............. 988

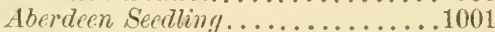

Abraham Lincoln............... 97s

Adair......................978

Admiral Dundas................ 978

Agriculturist ............... 978

Ajax.................... 978

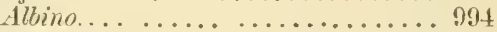

Albion White .................. 994

Alice Mand. . . . . . . . . . . . . . . . . . . . . . . . . . .

Ambrosia. . . . . . . . . . . . . . . 978

America ................... 978

American Scarlet............... 990

Ariadne................... 978

Athinsmis Surlet............. . 988

Austin. . . . . . . . . . . . . . . 979

Anstin Seedling...............979

Austin Shuker................. 979

Austrian Sourlet............. 985

Barnes' Mammoth . . . . . . . . . 979

Burnes' llthite. . . . . . . . . . . . . . 97?

Baron Deman de Lemick. . . . . . . 979

Burtlett. ................... 980

Belle de Bordelaise.............1007

Bicolor. . . . . . . . . . . . . . . 979

Bicton Pine . . . . . . . . . . . . 979

Bijou ................. 9

Bistepp's Tern ............... 979

Bishop's Orange............ 979

Blrceli.................... 997

Blacle Bertenn ................ 999

Blncl: Crenterbury............. 997

Black Imperial. . . . . . . . . . . . 979

Blact Pine. . . . . . . . . . . . . . 997

Black Prince............... 979

Black Roseberry............... 980

Blood Pine................... 998

Boixsetnt..................980

Bonté de St. Julian............. . 980

Boston Pine ............... 9s0 
Boudinot................ 980

Boule d'Or.................. 9so

Boyden's Mammoth. . . . . . . . . . 980

Bosden's No. $30 \ldots . . . . . . . . . .9980$

Brewer's Emperor. . . . . . . . . . . . .980

Bricliley scarlet. ................1001

Brighton Pine................ 980

Brilliaut .................. 981

British Green Secdling........... 998

British Queen................ 981

British Queen.................. 996

Brook's Prolific................. 991

Brooklyn Scarlet. . . . . . . . . . . . 981

Brume de Gilbert...............1005

Bryan's Satisfaction. . . . . . . . . . 981

Buffalo .................. 995

Buisson des Alpes Blanc, etc.......100n

Bunce...................... 984

Burr's New Pine................ 981

Burr's Old Seedling ..............981

Burr's Seedling. . . . . . . . . . . . . 9s1

Burr's Staminate.............. 981

Caleb Cope.................. 981

Caperon Hermaphrodite. . . . . . . . 1007

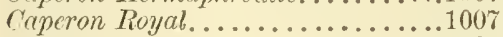

Capt. Cook.................. 981

Carolina .................. 998

Carolina.................. 998

Carolina Superba............ 981

Champion................. 982

Charles Downing........... 982

Charles Favorite ..............9982

Charlotte................ 982

Charton Prolific............... 982

Chorlton................... 982

Chillian................ 982

Clintou.................. 9s2

Cockscomb................ 942

Colfax.................. 9s?

Colonel Ellsworth............. 98:3

Colmmbus. ................. 9\$:3

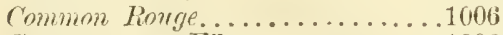

Gommon sans Filets...... . . . . 1006

Comte de Flandre.............983

Comte de Paris................ 94:

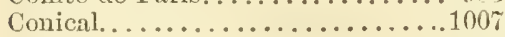

Cornucopia ................. 983

Crimson Cluster..............983

Crimson Cone............... 983

Crimson Favorite............. 98:

Crimson Queen............... 983

Crystal Palace............... 95.

Culverwell's Seedling. .......... 9st

Cushing....................984

C'uthill's Black Prince...........979

Guthill's Princess Royal............1000

Cutter's Seedling............. 984

De Bath .................9..981

Délices d'Automne............. 984

Deptford Pine.

Des Alpes à Fruit Blanc..........1006
Des Alpes a Fruit Ronige. . . . . . . 1005 Des Alpes de Tous les Hois a Fruit Blane, cto..................1006 Des Alpes de Tous les Iois a Fruit Rouge.....................100. Des Alpes scins Filets. . . . . . . . . . 1006 Des Bois a Fruit Rouge. . . . . . . . . . 1006 Des Quatre Saisons..............1006 Diadem ................... 984 Doctor Hogg ................ 984 Doctor Nicaise................ 9s4 Double-Bearing...............1007 Doubleday's 1\%. 2. . . . . . . . . . . 983

Downer's Prolific.............. 984

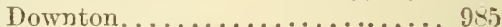
Duc de Brabant............... 985

Duc de Malakoff............... 985

Duchesse de Trivisse................ 1004

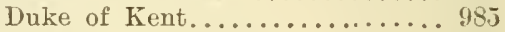
Duke of Tork Scarlet............. 9s5 Dundee.................... 985 Durand ..................... 985 Durand's Scedling.............. 985 Dutchberry................ 983

Early Prolific Scarlet............ 985

Early Firginirt................ 99:

Early Wastington............... 991

Eclipse................... 9\$

Elton................... 956

Elton Improved. . ..............

Elton Pine.................... 986

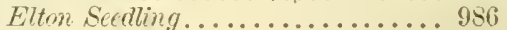

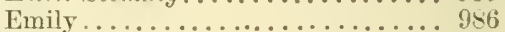

Emma..................... 986

Empress Engénie............. 986

English Lady Finger. . . . . . . . . . . . 9\$16

English Red Wood..............1006

Fairy Queen.................. 986

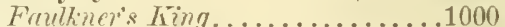

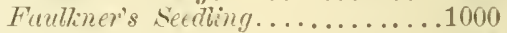

Ferdinande................. 9\$6

Filbert Pine.................. 986

Fill-Basket................ 987

Fillmore................... 98.

Fleming................... 9s

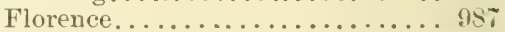

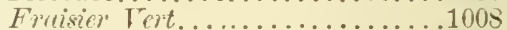

French.................. 9s

French Wusk Hautbois. . . . . . . . . 1007

French's Secdling................ 9s:

Frogmore Late Pine............ 987

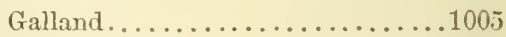

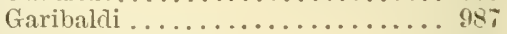

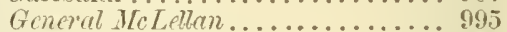

General Scott................ 9s

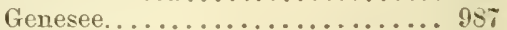

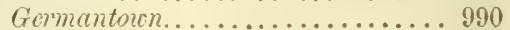

Globe...................... $98 s$

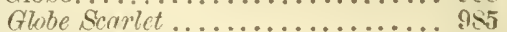

Globose Scarlet.............. 98s 


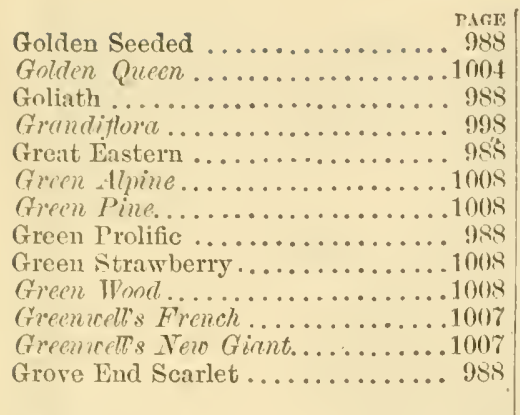

Haquin .................., 9, 9

II rlem Orange ............. 9s?

Hathaway................. 9s!

Ihthrecriy's Seedling............ 9\$9

Hendry . . . . . . . . . . . . . . . 989

Hero . . . . . . . . . . . . . . . 9 989

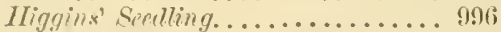

Highland Chief .............. 9s9

Highland Mary . . . . . . . . . . . . 999

Hooker.................... 989

Hooper's Seedling............. 990

Hovey's Seedling . . . . . . . . . . . . . 990

Hudson. . . . . . . . . . . . . . .

Iludsou's $B a y . . . . . . . . . . . . .990$

Huntsman . . . . . . . . . . . . . . 990

Icla .

Inpératrice Eugcnie . . . . . . . . . . 990

Imperial Crimson . . . . . . . . . . . . 990

Imperial Scarlet . . . . . . . . . . 991

Ingram's Prince Arthur . . . . . . . . . 991

Ingram's Prisecess Royal. . . . . . . . 1000

Iowa ...................... 991

Jenny Lind.

991

Jenny's Seedling.

991

............... 991

Jessie Read. . . . . . . . . . . . . . . . 991

Jeyes' Wonderful . . . . . . . . . . . 100.

John Powell ................. 991

Jucunda .................... 9!1

Julien . . ................ 991

Fien's Blucti Pine. . . . . . . . . . . . 992

Kcen's Seedling. . . . . . . . . . . 992

Tien's Seedling.............. 99t;

Kentucky . . . . . . . . . . . . $99 ?$

Kimberly Pine............... 9!

Kitley's Grolinth ............. $98 \mathrm{.}$

Knight's Seedling. ........... 9..;

Kinsx's 700

9!1

Kramer................ 992

La Challonaise. ............ 99.

La Constante. . . . . . . . . . . . 9 992

La Délicieuse............... 992

I.a Fertile. . . . . . . . . . . . $9 ! 9:$

I Aa Grosse Sucrée............ 998

La Liegeoise . . . . . . . . . . . . 999

PAAR

La Reine. . . . . . . . . . . . . . . . 998

Ta Sultane. . . . . . . . . . . . . . 993

La Versaillaise................ 994

Ladles' Finger. . . . . . . . . . . . . 99:3

Ladies' Pine. . . . . . . . . . . . . . . . 992

Lady . . . . . . . . . . . . . . . 99 92

Lady Finger. . . . . . . . . . . . . . 99:3

Lady of the Lake.............. 993

Large Early Scarlet. . . . . . . . . . 9 9!:3

Late Scarlet. . . . . . . . . . . . . . . 990

Lanrella . . . . . . . . . . . . . . 99:3

Le Baron.................. 994

Lemnig's White . . . . . . . . . . . . 994

Lonoe de Lambertye........... 994

Leopold I .................. 994

Little Monitor. . . . . . . . . . . . 994

Lizzie Randolph ............. 994

Longworth's Prolific............. 994

Lorenz Booth. . . . . . . . . . . . . .. 994

Lorio. . . . . . . . . . . . . . . . . 99.

Lucas. . . . . . . . . . . . . . . . . . 99. 995

Lucida Perfecta............. 990

McAroy's Extra Red........... 995

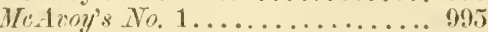

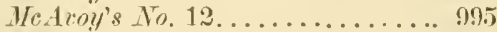

MeAvoy's Superior. ............. 995

Wrelcolin's Aberdeen Scedling. . . . . . 979

Mammoth. . . . . . . . . . . . . 99. 995

Narguerite ................. 995

Marqmise de la Tono Mrubourg. . . 1004

Warshall's Srealling.............. 100:3

Mead's Seedling.............. 995

Melon .................. 995

Metcalf's Early................ 996

Wethere Custle................ 996

Methren Scarlet.............. 996

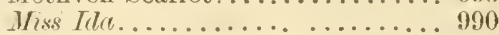

Monitor. . . . ............. 996

Ionroe Scarlet. . . . . . . . . . . . $99 t^{\circ}$

Monterideo Pine. . . . ........ 996

Wonthly, withont muners........1006

Moyamensing. . . . . . . . . . . . 996

Wilberry................. 997

Wrimpliy's Child............... 992

Husk: Ilontboix................ 1007

Hyutt's British Quecn............981

Myatt's Dentford Pine.......... 984

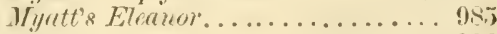

IIratt's Eliza. . . . . . . . . . . . . 996

Migattis Giebe.................. 985

Wurtt's Mrrmmoth............ (9).

Myatt's Protific.................. 100.5

Wyutt's Seculing............. 980

Naomi ................... 998

Napoleon. ................. 997

Napoleon III. ............... 997

Neckert Pine............... 997

Nero Iluutbois. . . . . . . . . . . . . 999

New Jersey Scarlet............ 997

Shoorth Prolific............... 988

La Perle................. 993 Nerdund.................982 


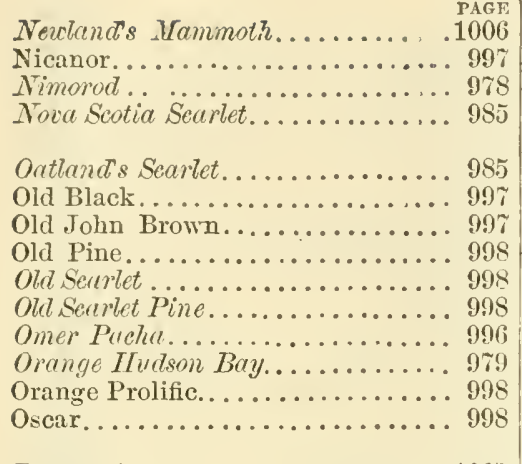

Patagonian.................1007

Peabody .................... 998

Peabody's Scudling.............. 998

Peak's Emperor................ 998

Pennsylvania. ................. 998

Pine Apple................997, 998

Pordered Pine..................100s

Prainie Farmer ...............1008

Premier................... 998

President................. 978

President Wilder.............. 998

Primordian................. 999

Prince Albert. . . . . . . . . . . . 999

Prince Frederick William........ 999

Prince of Orleans. .............. 999

Prince of Wales............... 999

Prince's Climax. . . . . . . . . . . . . 999

Prince's Excelsior . . . . . . . . . . . . . 999

Prince's Magnate................ 999

Princess Alice Mand. . . . . . . . . 978

Princess Royal. ....................1000

Princess Royal of England........1000

Profuse Scarlet..................1000

Prolific................1000, 100\%

Prolific Pine...................1001

Pyramidal Critlian.............. 982

Randolph Pine................... 1000

Red Alpine..................... 100

Red-Bnsh Alpine...............1006

Red Monthly Strauberry...........1005

Red Wood....................1006;

Peeve's Eelipse.................. 98.

Regent's Dwarf...............1007

Reine des Belges ............ 999

lichardson's Early ...................1000

liichardson's Late.................. 1000

Rifleman ......................1000

Ripawam ......................1000

Rival Hndson............... 1001

Rival Queen........................ 996

Rivers' Eliza ..................... 1001

Robinson's Defiance ..............1001

Romeyn Seedling ...................1004

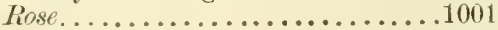

Roseberry .......................1001

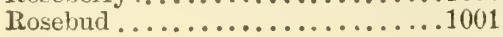

P.GE

Ross's Phønix................1001

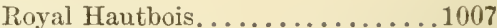

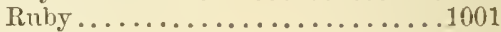

Ruisson ......................1006

Pússell's Prolific .................... 1001

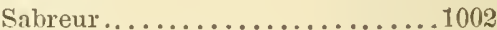

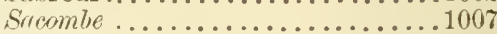

Salter's Versaillaise..............1002

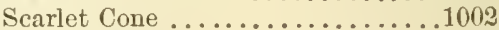

Scarlet Magmate ................. 999

Scarlet Melting................... 1002

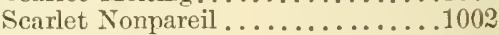

Scotch Pineripule ............... 98:3

Seoteh Runner .................. 98:

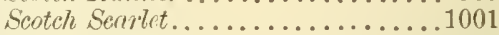

Scott's Seedling................. 1002

Seeding Eliza ...................1001

Shaker's Scedling.............. 979

Sir Charles Napier .............. 1002

Sir Harry . . . . . . . . . . . . . . . . . 1002

Sir Joseph Banks . . . . ............1007

Sir Joseph Paxton ............................

Southempton Searlet.............. 996

Sonthborough ................. 1003

Southborough secaling...............1003

Souvenir.................... 1003

Sonvenir de hicti................ 1003

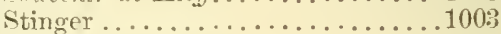

Stinger's Sedling................1003

Stirling Castle Pine ................ 1003

Stoddard's Alpine...............1006

Swainstone's Seedling. ...........1003

Topsy.................................

Tremblys Trim............... 1004

Triomphe de Gand..............100:3

Triomphe d'Hollande............. . . 1006

Triomphe de Liege............ 1004

Triamph of Hollind Alpine.......1006

Trollope's Tietoria.................1004

True Chili..........................

Turkey Pine................. 997

Tnion..................1003, 1004

Unique Prairie.................... 997

Vicomtesse Héricart de Thury....1004

Victoria ........................

Victory of Bath... ............... $100 t$

Vineuse de Nantes................ 1004

Virgin Queen.................. 979

Walker's Seedling..............1004

Warl's Farorite....................

Warren's Stadling............... 996

Washington .....................991

Wrshington Alpine..............1006

White Abbomy. . . .................... 994

White Alpine........................ 1006

White Bush Alpine... ...........1006

White Uonthly. . . . . . . . . . . . . 1006

White Monthly, without muners ...1006 


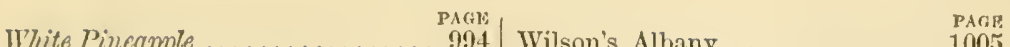

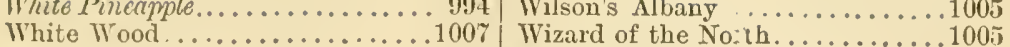

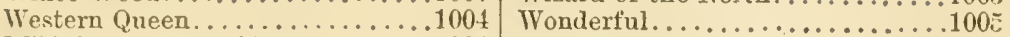

Wild Strawberry of Europe......1006

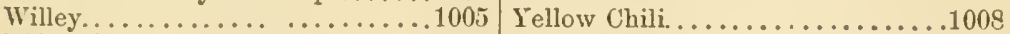

IVilmot's Superb.... .......1007 York River Scarlet............ 99C

Wilmot's Prince Arthur... . . . . . . 1005 Yonung's Scedling. . . . . . . . . . . . . . 990 


\section{GENERAL INDEX.}

ALMOND, its nativity, 430 ; uses of, ib.; its cultivation, ib.; varieties, 431 ; ornamental, 432.

American Blight, 66.

Annual proning of peach trees, 585 (note).

Aphis, the Woolly, 60 .

Apple, its history, is ; where best naturalized. 59 ; its uses, ib. ; its quality, (60; propagation, ib ; grafting, 21; soil and situation for, 61 ; planting and cultivation of apple orchards. 122 ; the bearing year. 6is; pruning, ib.; insects destructive to, ib. ; how to destroy, 64; gathering and keeping. 67 ; varieties of. 72 ; Siberian crabs and improved Siberian apples, 421; selections for different latitudes, and for table use, inarketing, cooking, and keeping, $42 \%$.

Apple bark beetle, 6\%.

Apple Borer, 6:3.

Apple Worm, fi(j.

Apricot, uses and cultivation of, 433 ; liable to disease, ib. ; curculio fatal to fruit, ib. ; rarieties of tree, ib. ; ornamental varieties, $44^{\circ}$; varieties adapted for small gardens, and for cold climates, ib.

$\Lambda$ shes, a cure for peach borer, 586 .

Aspect of fruit trees, $5 \%$.

BARK Louse, the, 66.

Bats, useful as destroyers of insects, 58.

Bending down limbs, to produce fruitfulness, :37.

Berberry, description of, 442 ; its use and culture, 443 ; varieties of, ib.

Birds, as destroyers of insects, $5 \%$.

Black Gum, fatal to plum trees, 894 .

Black Walnut, 5\%t.

Blackberry, culture and varieties of, 443 ; ornamental varieties, 446.

Blight on Apple Trees, 67.

Budding, 2:; proper season for, 24; shield and American shield budding, 25 ; reversed shield budding, 26 ; annular budding, 27 .
Butternut, 574.

CANKer Worm, the, 6.5.

Caterpillar, 64; to destroy, ib.

Chamomile to destroy insects, 56 .

Cherry, its history. 447 ; uses of, ib. ; gum of the, 418 ; as shade trees, ib. ; soil and sitnation for. ib.; propagation and cultivation, 449 ; classes of, 4io); ormamental varieties, $4 s 6$; selections of. for family use, to ripeu in succession. $48 \%$.

Chestnut, 5\%2.

Cider, how to make, (69).

Citron, the, 5\%9

Coal Tar, a remedy for grubs, 56 .

Codling Moth, 66.

Composition for wounds in pruning, 35.

Crab, wild species of, 58 .

Cranberry, description of and value, 493 ; its cnlture protitable, 494.

Cross-breeding, $\%$.

Cncumber Bug, the, 559 .

Curculio, E9?; habits of, ib.; how to destrox, s!?

Curl, the, in peach trees, 592 .

Currant, its history and nse, $45 \tau$; propagation and culture, 488 ; insects destructive to, $488,4=9$; varieties of, 489 ; ornainental, 493

Cuttings, to propagate br, 29 .

DE CAxDorite, remarks on decay of varieties, 11.

Deep planting to be aroided, 48.

Disbarking and ringing. 37 .

Duration of varieties, 10 .

Eres, or Buds, to propagate by, 23.

FIG, its history, 494 ; its secret blossom, 494,495 ; propagation, $495 \bar{j}$; soil and culture, ib.; oiling the fruit, 496 ; ra. rieties, ib.

Filbert, varieties of, 574 .

Fire Blight, 64 .

French Standard Names, key to, 1009,

Frozen-Sap Blight, $6 \pm 6$.

Fruit, production of new rarieties, 1. 
Fruitfulness increased by root-pruning, 36 ; by bending the limbs, 37.

Graxns of the Pench, 593.

Gooseberry, description and uses of, 409,500 ; propugation and culture, 500 ; rarietics, 501 ; sclection of, 503 ; American varictics, ib.

Graft. its influence on the stock. $2 \%$.

Grafting, uses of, 16; proper time for, ib. ; seions selected, 1\%; stock for, il. ; theory of, ib. ; confined to certain limits, ib.; its manual operation, 18 ; splice and tongue grafting, 18,19 ; Anerican Whip-tongue grafting, 19 ; cleft grafting, 21 ; gratting the rine. $2 \cdot 3$; saddle grafting, ib.; side grafting, $2: 3$

Grafting Cley, 23

Grafting Wax, 2:3.

Grame, history of. 504 ; nses and soil. 50.5 ; proplagation, 506 ; culture of foreign, ib.; renewal system, $50 \%$; culture under glass, without heat, 508 ; soil for vinery. 509 ; pruning, ib. ; routine of culture, 510; thinning the fruit, ib.; culture under glass. with fire-heat, ib. ; construction of vinery, 511; the border, 512; the Epur system of pruning, 512 ; insects and diseases peculiar to, 513 ; varieties, ib. ; pruning, training. and culture of American grapes, 525; diseases and insects, 52\%; grafting, ib. ; keeping, ib. ; rarieties, 528; selection of varieties, 558 .

Grape Beetle, 52\%.

Hickory Nut, $5 \% 4$.

Hylridising, $\tilde{\imath}$; limits of, 8 .

[xocrlatixg Fruit Trees, 23.

Insect Blight, $64 \mathrm{~J}$.

Insects, remarks on, 5t; to destroy by hand-picking, 5i); larve, or grubs, ib. ; salt, a remedy for, ib. ; to destroy in the winged state, 56 .

KxigIr, his mode of raising new varieties, 10; his theory on the decay of varicties, ib.

Knots Disease, fatal to plum, 894.

[AYERS, propagating by, 31 .

Laying in by the heels, 50 .

Leinons and Limes, 5\%.

Lime, a cure for peach-borer, 586 .

Loams, best adapted for plantations, 51 .

Longevity of Peach Trees, 585 (note).

MADEIRA Nut, $5 \%$.

Janure for fruit trees, $48,49$.
Melon, its history and culture, 559 ; in seets attacking, ił. ; varicties, 560 .

Mice, to prevent girdling trees, 35.

Mildew in grapes, 527.

Moths, how to destroy, 56 .

Mulberry, habits and varieties, 564 ; the ever-bearing, ib. ; the red mulbery, 5 (i).

IItlching, 48 .

NectariNe, its history and culture, itis; curculio an enems to, ib. ; varietics, 566 .

Toyes, Darling, remarks on the yellows in Peach iss (note).

Nuts: Chestuut, $5 \% 2$; the Chinquapin and European Walnut, 5\%3; Filbert, Hickory nut, 5\%t.

OLIVE, history and uses, 575 ; propagation and culture, ib. ; rarieties, 576.

Orange, history, $576,57 \%$; soil and culture, 577 ; insects on, ib.; specific against, $5 i 8$; varieties, ib.

PEACI, its history, 5\&0; nses, 5\&1; propagation, 582; soil and situation, ib. ; pruning, 58.3 ; training, 585 ; insects and diseases, 586 ; ycllows in, 587 ; symptoms. ib ; canse, 588 ; remedy for, 591 ; the curl. 592 ; classification of freestones and rlingstones, ib. ; raising peaches in pots, 594 ; rarieties, 596 ; curious or ornamental varieties, (i) s: selection of choice sorts, 639 ; selection for the South. ib.

Peach Borer, 586; remedy for, ib.

Pear, history of, $6: 39$; its nativity, 640 ; extraordinary specimen of tree, 611 ; uses of. ib. ; gathering and keeping, ib. ; propagating, 6.42 ; soil, situation, and culuure, $64: 3$; diceases of, (itt; insect blight, etc., (64.); varieties, (i.) 0 ; select list for table use, market ing. and cooking, 8si.

Planting deep, bad effects of. 48 .

Plum, history and use, \&s! ; propagation and culture, $\$ 90$; soil, $\$ 91$; inseets and diseases, ib. ; curculio or plum-weevil. 8!) ; how to destroy, 89:3 the knots or black gum, 894 ; varieties, 8!5; ornamental varieties, (1).5; selection of raricties for table, market, and cooking, ib.

Plum Weevil, 8!).

Pomegramate, history and uses, 956; propagation and culture, $95 \%$; varie. ties, ib.

Position of fruit trees, 51.

Potash Wash for fruit trees, 3ก.

Preparing soil for frnit trees, 47

Propagation of Varictics, $16 ;$ by cut. tings, 29); by layers and suckers, 31. 
Prunes, to make, 890.

Pruning, to promote growth, 33 ; to induce fruitfulness, 36 ; annual, produces longevity in peach trees, 585 (note).

QUENOUILLE training, 39.

Quince, its history and use, 957, 958; propagation, culture, and varieties, 958 ; ornamental varieties, 960.

Quince Stocks to dwarf pears, 643 .

RAmBITs, to prevent girdling trees, 35.

Raspberry, its habits, uses, propagation, and culture, 900,961 ; varieties, 962.

Remedies for Blight, 646 .

Renewal Training of vines, 507.

Ringing and Disbarking, 37.

Rivers, Mr., on Root-pruning, 36.

Root-pruning, 36 .

SADDLE-GRAFTNIG, 22.

Salt, used to destroy insects, 55 .

Scale Insect on Orange, $5 \%$ S.

Scions, to select, 17.

Seedlings, to raise, 4,5 .

Shadduck. the, 579 .

Shellac, for wounds in trees, 35.

Shortening-in, mode oi pruning the peach, 3\%.

Siberian Crabs, 421

Slug-worm, 6:0.

Smells will drive away winged insects, 56.

Soft-Soap, for stems of trees, 36 .

soil, best for fruit trees, 51 .

Species of Frnit Trees, 2.

Spurring-in, training the vine, 507 .

Stocks, for graftiug, 17 ; their influence on graft, 27 .

Stopping the bearing shoots of the vine, 50 s.

Strawberry, history and uses, 974; propagation and soil, 975 ; modes of culture, 976; fertile and barren plants, $976,9 \%$; varieties, $97 \%$; Alpine and wood strawberries, 1005 ; hautbois strawberries, 100\%; Chili strawberries, ib. ; green strawberries, 10018 ; seleo tion of varieties. 1008.

Suckers, propagating by, 32 .

TAkixg up Trees, 46.

Thom, the, good stocks for pear trees, 643.

Toads destroy insects, 58 .

'Tobacco-Water, remedy for insects, 56 .

Training, remarks on, 28 ; its objects, 39 ; conical standards and quenouille training, 39, 40 ; prramids and bushes, 40 ; cordon-training, 41 ; fan-train ing, 42 ; horizontal training, 14.

Transplanting, remaris on, 4.j; best season for, 45, 46; preparing the places, 47 ; proper size for, 49 ; lay. ing in by the heels, 50 .

Trellis, use of, for the vine, 508 .

Trenching, to improve soil, 53.

VALLEYS, objectionable for fruit trees, 53.

Tan Mons' Theory. 5.

Varieties, to produce new, 1; tendency to change, 3 ; influence of grafting oll. 4; Tan Mons' method of raising new, 5 ; cross-breeding. 7 ; propagation of, 16 ; remarks on the duration of, 10 ; Knight's theory on the decay of. ib.; effects of climate on, 12 ; tc restore decared. 15

Vine. grafting the, 22 ; culture of, 506.

Vinery, cheap mode of building, 508; for fire-heat, j10.

Finerard Culture, 526.

IVAsH for stems of fruit trees, 3.

Water Melon, its uses, culture, and rarieties, $\tilde{j} 61$.

Weeril, attacks plun:s, 892.

Whale-oil Soap, to destror insects, 56

Wild Plnm, varieties indigenous, $8 \$ 9$.

Woolly Aphis, the, 66 .

Wounds made in pruning, compositior for, 35 .

Yellows, disease of, in Peach, 587 symptoms, ib. ; cause, 5SS; remedy 591. 
$\mathrm{THH}$

\section{FRUITS AND FRUIT-TREES}

OF

\section{A M E R I A ;}

$O R$

THE CULTURE, PROPAGATION, AND MANAGENENT, IN THE GARDEN AND ORCHARD, OF FRUIT-TREES GENERALLY;

WITI

DESCRIPTIONS OF ALL THE FINEST VARIETIES OF FRUIT, NATIVE AND FOREIGN, CULTIVATED IN THIS COUNTRY.

\section{BY A. J. DOWNINir.}

CORRESPONDING MEMBER OF TIE ROYAL BOTANIC SOCIETX OF LONION; AND OF TILE HOITTITL TURAL 8OCLETIES OF BERLIN, THE LOW COUNTRIF,, MASSACUUSETTS,

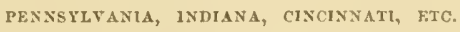

A PPENDIXES-I., II., AXD III.

NEW YORK :

JOHA WILEY \& SONS, 15 ASTOR PLACE.

1881. 
Copyright,

$$
1851,
$$

BY JOIIN WILEY \& SONS. 


\section{GLVER L L I N DE I}

To

\section{A P PEN DIXES I, II, and III.}

\section{APPLES.}

[Standard names are in Roman letters. The synonymons names in Italic.]

Adrem's White

Allerson's Early................. American Golien liesset of Wero Englinnd.

American Beruty

Amsterdam Sweet............

Aulrew's Favorite .............

Andrew's Sweet..............

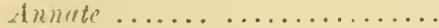

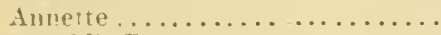

Arnold's Beauty.

Austin Apple...............

Autumn Pomme Gris.... ......

Bajley's Crimson Crab ..........

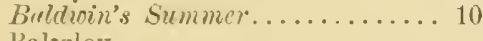

Baltzley. .................

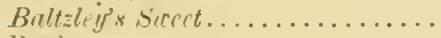

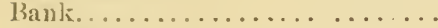

Baptist. . . . . . . . . . . .

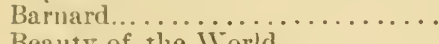

Beauty of the World..........

Belle de Boskool .............

Belle du Havre ...............

Belle Donce du llavre..........

Bell's Serdling .............

Bruder....................

Bergen ..................

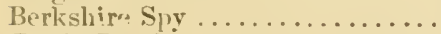

Brttip Grom lis . . . . . . . . . .

Big loper.................

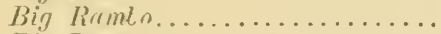

Big Rommanite...............

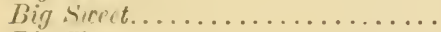

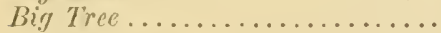

l3lack Ilawk................

Blesh Juct . . . . . . . . . . . . .

Blick Pennork................

Black Twiq...............

Black Vunderere.............

Black's Aur,ette.............

Blenheim Pspin.............

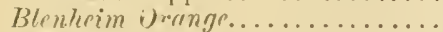

Blonming Grenge.............

blentisim.

Blue Bloon.
PArit ! PAgE

67 Blue Spitsenber........... 4.

\%j Bower's Nonpareil ............ 45

Bord.................... 3

53 Breckemidlge............... is

10.j Brewington Pippin..........

4:3 Brevington..............

75 Briers sweet Crab............ 39

\%.) Brilliant................. 46

43 Brondwater.................. 46

$4: 3$ Bromen Fill.................. 8.5

43 Bucks Councy ............. 46

\%6 Buclis Connty Seclling......... \%

1 Bullorle's Pippin .............. 53

Bunker Hill ................. 4

39 Burlington Pippin............ 4

10 73ushnell. .............. 8

2 Busby's Earir.............. 4

2

7i) Cruane dn (7irm............ 103

44 Cadwallader's Golden .......... 5

76 Calkin's Pipin ............ 5

76. Canarla Baldwin.............

i⿱ Carpenter's Sweet............

2 Carpentin................. 79

2 Carpentin Rimutte...........

3 Centennial.................. 80

$10 \pm$ r'hecse spple................ 48

44 Chese.................. 35

44 Chester County ............

49 Child's................. 4 i

45 Clark's Prolific............... 48

37 Clark .................. 80

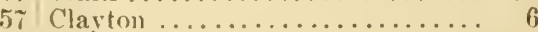

4.j Clermont................. 48

9i Cline's Coullin.............. 6

4.) Columbia................. 81

5i Columbire IIydi.............. 81

5 i Connertirut Perl Clieek......... 6

Ts romnretient Red Strenk......... 6

57 Conncrtient Rerl side.......... 6

4 (i) Cons.....................

3 Conper's Pert............... 51

3 Cornell's Enily............... 45

3 Curnell's Furmite........... 4.5

3 Cornwall's (iolden sweet ........ 81

7 Crain's Spice............. 7 
Cross

Curtis' Grecning ................ 109

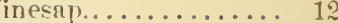

Dale's Seedling .............

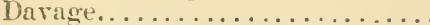

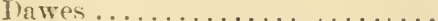

Dures Portri...............

Dueres' Donsurk..............

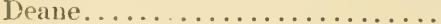

Decarie....................

De $\mathrm{Hogg}_{\mathrm{n}} \ldots \ldots \ldots \ldots \ldots \ldots \ldots \ldots$

De Long... . . . . . . . . . . . . .

Dr. Fulcher................

Dr. Walker.

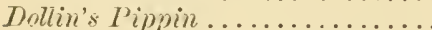

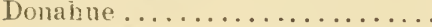

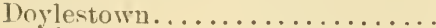

Dutfield . . .

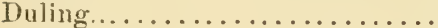

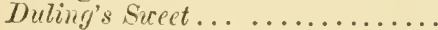

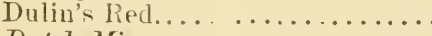

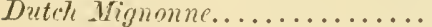

Drciglt Apple................

Ertrly Russt

Gloucester White.............6. 67

Goff................... 51

49 Golden Dixie.............. 52- 6

7 Golden Pippin.............. 87

81 Golden Russet............... 5:

81 Golden Russet of Mrassactiuertt... 53

81 Golden liusut if $\mathrm{Y}$ (ue Engltind... 53

49 Golden Siy............... 87

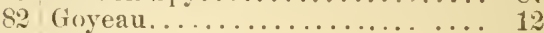

83. Gianny Hyde.............. 81

82 Grattan.................. 12

\% Gray's leeper............... 21

83 Grey's Apple............... 21

64 Gruy Romanite............. 5 \%

7 Gryhonse................ 57

81 Gros Pigeonnet.............. 12

8 Gros Vert................... 13

8 Gios Pommiv................ 10

8 Gros Pomicr................ 10

9 Guilford Red............... 8 \%

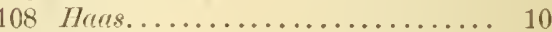

Hames..................... 88

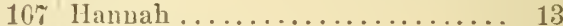

Edelkonig Reinette.......... \&t Hard Red............... 57

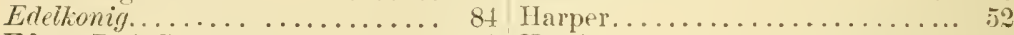

Edgar Red Streak........... j0 Hateher................. 13

Egyptian Queen.............. 84 Hateher's Secding............. 13

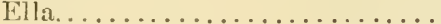

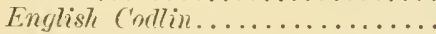

English Peamain.............

Esperens Reinette.............

Etowalı..................

Eurcki..................

Fairy

Fall.

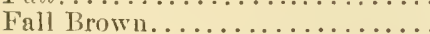

Fall Queen, or Haas............

Fall Stripe.................

Fameuse Baldwiu............

Fameuse Sucıée...............

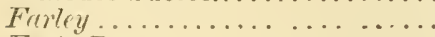

Fuy's Russet. . . . . . . . . . . .

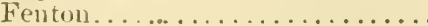

Fïe-Quartercd Gillifourer .......

Fletcher Russet...............

Fleming

Foote's Nonsuch ...............

Forney

Fomtain

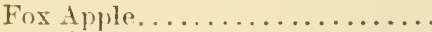

Fox Sherpnose...............

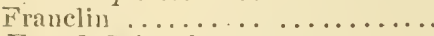

Frenrte Syitenberg ............

French Wine...............

General Iron.

50 Haven... ...................

67 Hawkin's Clief............... 14

55 Mreyasele Gold Reimette......... 14

9) Hex's Hhite .................. 67

51 Hich's Tilite............... 67

81 Highland Beauty............. 88 IIigh Top sizet. . . . . . . . $43, \overline{54}, 91$

9 Hiram.................. 14

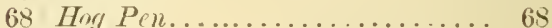

85 Hocpe.

10 Thrope's licmain............. 5i

11 Hopsey .................. 5i

102 Hopson................. 5 .

8.j Horse .................... 10

69 Hows. . . . . . . . . . . . . . . . . . . . . . .

5:3 Hottenstein............... 5.3

51 Hova Golden Peinette.......... 14

70 IIriburidstom's Sonsuch.......... 21

51 Mudson Red sitreut............. 55

86 Hunt Russet Apple.... ....... 53

51 Hunt Russet .............. 53

86 Hunter Pippiu............. it

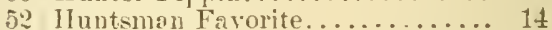

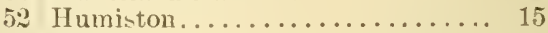

52 Ilycle................. 81

36 Illinois freening ............ 15

86 Illinois Pippin...............

Imperial Ram? o........... 89

11 Imperial White.............. 25

11 Improved Red Spitsenberg....... 4. 4.

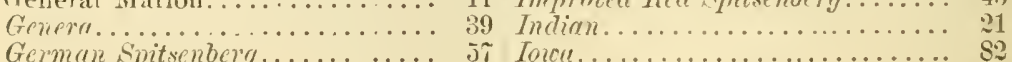

German Spitsenberg......... 


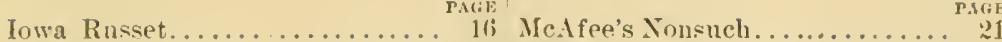

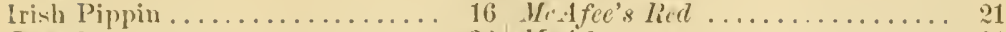

Izztrd................. $2: 3$ KeAfee ................

Jucleson's $R_{0}$ min

Jelly Flozce

Johinson................ 16 Mann ................ .1

Jolmson ................. 89 Merengo Siberiun, In. 4.......39

Jomes .................. 68 Marquis of Lorne........... .

July Queen................. 90 Wary Wornack .............. 9.

Murylund Queen .................. 10

...) Mrtion's Stranger............. 2.

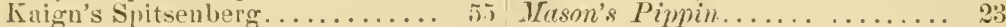

Jiansas Queen.............. 17 Massarhust ts Golden Russet..... 53

Kansas Sweet............. 17 Mathews.............. 57

Kersbey's Facolite.......... 19 Nay Seek-no-Farther........ 57

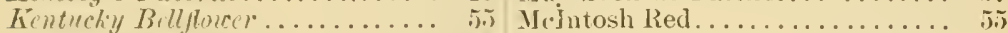

hentuchy filitower......... 5j NeKinney............. 56

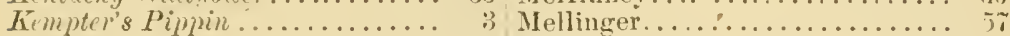

Tiestner................ gn Mercer................ $90^{\circ}$

Kiev's Red............... 91 Vilden ............... 53

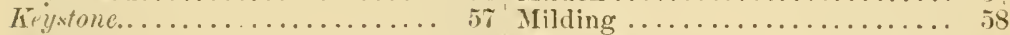

Fidd ................ (is Misouri Kerper........... 2:

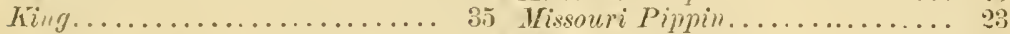

Kinkead................ 91 Missouri Superior.......... 21

Kinnaird's Choice .. . ...... 18 Monte Bello............... 24

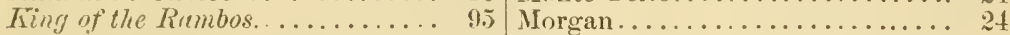

King Solomon.............. 18 Morton's Red............. 59

King Sweet. . . . . . . . . . . 5t, 91 Moser's Sweet............. 96

King of Sxcets............ it Mosher Bweet............ 97

Kirkland ............... 92 Mother's Favorite.......... 97

Knapl's Harrey............ 92 Mountain Beauty.......... 97

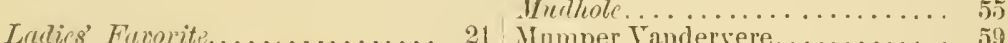

Lady El Ein.............. 39 Musgrove's Cnoper........... 37

Luily Finger. ............ j. . Mystic...............

Lady Hentiker.............. . . . . . . . . .

Lallier's Prolific Red......... 19 Nansemond Beanty.......... 60

Lambert. . . . ............. 19 Nelson Rock.............. 60

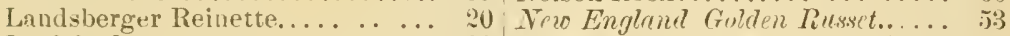

Lankford ............... 99 Nero England Resset......... 53

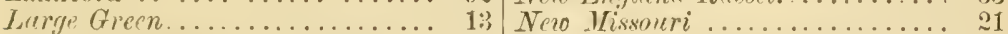

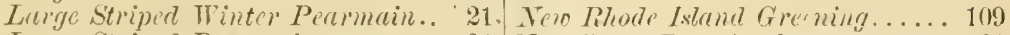

Large Striper Pearminile....... 21 New River Buat Apple........ 61

Large Summer Qneen........ 93 Vine Ounce.............. 49

Lelieur................ 20 Nomsuch.............. 21

likis.................. 80 Sorton's Pippin.............. 97

Liveri................. 5.3 Northampton............ 61

Lincoln Pippin............. 93 Northfield Beauty ('rab........ 61

Jipkin's Swect............ 51 Sortheick Pippin.......... 3

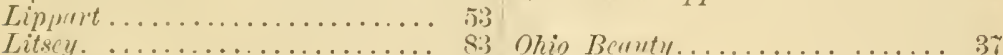

Long ................... 6i old Bittic............... 43

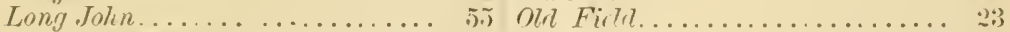

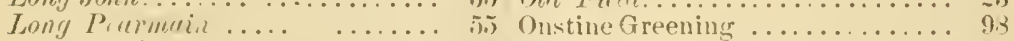

Long Red Pearmain ......... i.j Ontario................

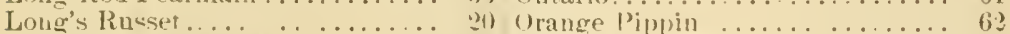

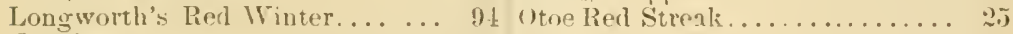

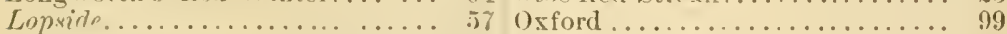

Lucy Sweet. ............ ij

Mackie's Beauty Siberian... . . 39 Prik (Not of Kiansis) .......... ... 


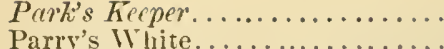

Peach Blow.

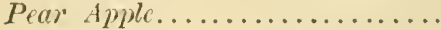

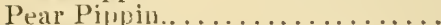

Perle d'Angleterre.

Pearl of Eurglenel.

Pearmain.

Peasuood's Nonsuch............

Perkins.

Perry Red Streal.

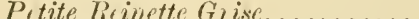

Pewankee...................

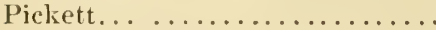

Piedmont Pippin..............

Pilot.

Pine Apple.

Plumb's Cider.

Ponme Gise d'Or.

Porter.

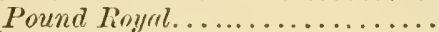

Presh's Winter.

Prewit

$\ldots \ldots \ldots \ldots$

Prolific Blush...............

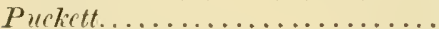

Prehettis Summer.............

Pyle's Red Winter.

Races Red

Randolph Sweet............. 100

Ransom ................... 101

Red Streak................ 101

Reed's Golden Pippin ......... $66^{\circ}$

Red Bellflurer .............. 5. 5.

Pied Bietigheimer............. 101

Red Erorlasting. . . . . . . . . . 5i-10

Riel Gilliflower.............69, 70

Red Peamain............... 5.)

Red Plumix .............. 万. 万.

Red Pippin................ 5. 5.

Ped spitsenbero.............. 55

Red Winter Peremain ........ 5is

Red Winter Sweet ............. 101

Reinctte d'Esperen..............

Reinutte de Ilaygr.............. Rimutte de Lrindsbery ..........

Reinette Edellonig.............

Reinette Onts................

Reliance.

Pibbed Gilliflorer .............

Riplev ....................

Piptry's Claret ...............

Poljinson ................. 101

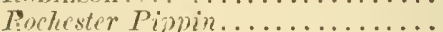

Roct: Apple.

Rockwood.

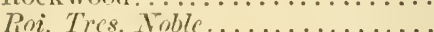

Pomanite.

Rose Bee.

Rose Bud.

Rose Red.

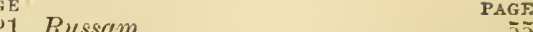

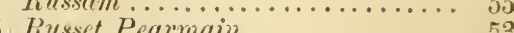

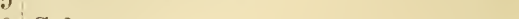

Salome................... 10

9 Sanderson ................... 103

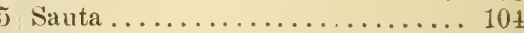

5 Sarah .................... 67

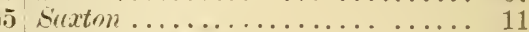

00 Sirimlet Pcarmain ............. 55

86 Scluffer................... 104

63. Sclsurler's Sweet............. 31

99. Scollop Gilliflow er...........

26 Scollop Gilliflower............... 69

83. Scriluner's Spitsenbers........ 31

64 Seager.................... 30

26 Settle Pippin.............. 67

61 sottles superd.............. 67

65 Shaffer..................... 104

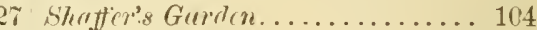

68 Shannon Pippiu............... 104

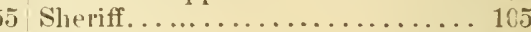

27 Sheepnose........... 5?, 58-55

(i) Shermanis Futuite............ 31

28 Sthermentis siret............... 31

5) Sirlney Sucect............... $5 t$

35 Sillix................... 31

35. Simmons' Red................ 10

6.) Sisk................... 6 .

Suith's Favorite.............. 68

Simith's Furoite. ............ is

Sneplis................... 100

sucppis Sonsuch;.............. 101

Snorter................. 21

Sonserset ................... 8

Soulard................

Southern Portar............. 68

st. Hitaire. . .............. 10 !

Stalkey................. 69

Starr....................

Stayman's Sunmer........... 31

Stayman's Winesaj........... 10k

Stearns' Greening............ 16

Stearn's Winter Greening....... 10.

Stere Baldwin.............. 107

9 Stevenson Pippin...................... 108

14 Stonewall Jackison............. 108

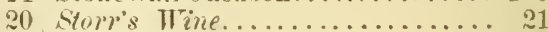

St Stribling.................... 31

60 Strinestown Pippin...........

28 striped Bellftoret..............

70 Striped Gilliflower........... 69

28. Striped Pearmain...........21, 5j

28 strined l! inter Peamein ......... 21

101 Striped Pippin............... 35

2s Striped Sweet Piplin.......... 35

60) Stuart's Golden ............... 10

6i Stump................... . 110

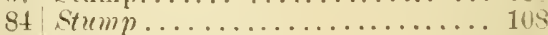

5i Strmer Chese................ 3i

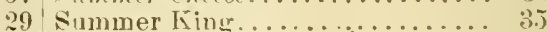

29 Summer Sirert.................. 11

30 Summer Spitsenberg......... $30^{2}$ 
PMGE! PAGE

Superb White.............

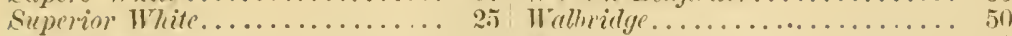

Sutton s Early ............ in watwool................ i1

Shrosie Pomme Grise ......... 27 Wealthy ................ 37

Sweet IRhode Islaud Gieening ... 10 9 Westeri Beauty ........... 37

Sweet Winter spitsenberg. ..... 109 Westmoreland Rambo... . . . 112

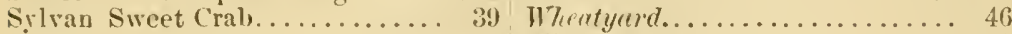

Tanner's Winter ............ 110 Whitescarser............ 39

Thmas Secet............. $54-91$ White Crow ................ 21

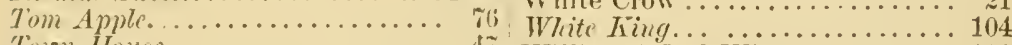

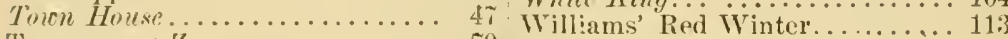

Transparent Zoar. .......... 70 Wilson's Summer........... 111

Tuttle ................ 36 Vinter Peamuin...........

Ticin Apple............... 5i

Tncle Zeelie............... 21 Wyrndotte................ 21

Valley...................... 111

Vulabilingham Wine......... 21 Yardley ..............

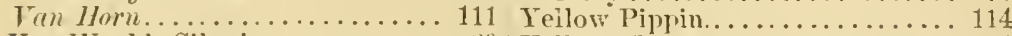

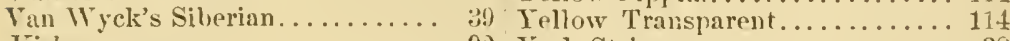

Tirkers................ 9 Tork Stripe.............. 3 S $^{3}$

Victoria Pippin...................... 111

Yictoria Sweet............. 111 Zachary Pippin........... $\approx 2$

Volney................ $\% 1$, Zolotereff.................... 114

Additional Synonyms to Apples, $x, x i$, xii.

\section{CHERRIES.}

Barrhart. ................ 161 I Large Montmorency.......... 163

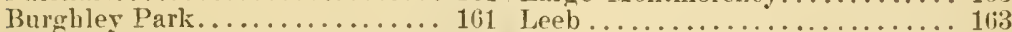

Dyehouse. . . . . . . . . . . . . 161 Love Apple................ 16:3

Early Lyons. . . . . . . . . . . . . 16. Marie Theres . . . . . . . . . . . 16.4

Early Rivers .............. 162 Montmorency, Large Fruitch..... 163

Flagg ................... 11it Jontmoveney a Limgue Quenc.... 163

Galusha, or No. 11.......... 16.5 Northwest, or No. 29........ 16.j

Gloire de France........... 16: Olivet ............... 164

Guigne llative de Lyon. . . . . . . 16: Rase Hative de Lyon. . . . . . . . . 162

Iila .................. 16: Tomato............... 16:3

Lancaster................. 163 . Weir's Early Kentish.......... 164

\section{GRAPES.}

Allen's IIybrid. ............ 119. Lady Washington........... 167

Beauty................. 165 Niagara.............. 16

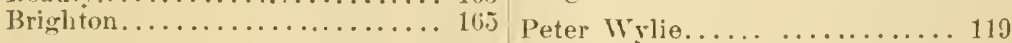

Duchess. . 166 Pocklington............... 168

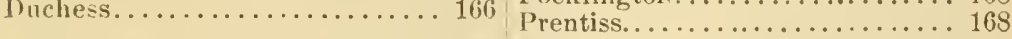

Early Dawn.............. 16 .

Eiarly Victor............... 166 Quassajck............... 168

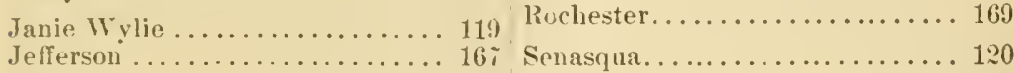

Iialamazoo.............. 119 , Triumph .............169

PEIC'HFS.

Alexander's Early........... 141 Crss................. 142

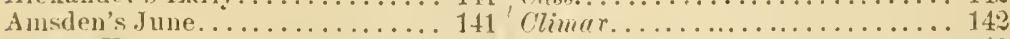

Annir Wylie.............. 169 Conneticut............. 14:3

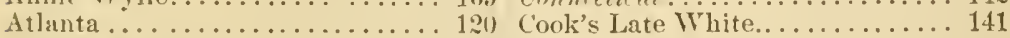

Black's Extra Early Peach. . . . . 1:0 Early Ascot . . . . . . . . . . . . 142 
Farly Rivers $\ldots \ldots \ldots$

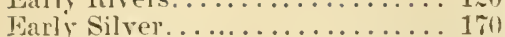

Earjy Victoria ............... 170

Family Favorite.............. 170

Fipters .................. 142

Foster................... 1:1

Freemason................. 121

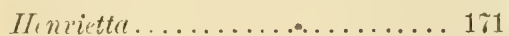

High's Early Canada........... 142

Ilill's Chili Peach............. 142

Honeywell. . . . . . . . . . . . . . 119

Hopkinsville................ 170

Imperial I r lioro............... 141

Jenny Lind................. 14?

Lajorte ................... 121

Lcopold................... 142

Lery's Late.................. 171

Intrdison................. 142

Mountain Rose................ 1:1

Mrs. Brett................. 14:

Inscogee. . . . . . . . . . . . . . 149

Nectarine Peach. ............. 1;1

Nix's Late IV'hite.............. 143

PEARS

Buerre Delpierre............ 121

Buerre Ladie... . . . . . . . . . . 12

Bonne du Puita Ansault... . . . 12:3

Brockworth............ . . . 12:

Bronze d'Er!rlien... . . . . . . . . . 124

Calebass d'Octoinre........... 14

Chanbers ................. 174

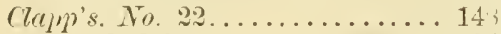

Colmal Dela

Colomel IVilrier .............. 146;

C'onrte Quene d'Automme....... 146

Curqan................... 15:

Dertn. . . . . . . . . . . . . 1:;

Delpierre.................. 1:

Doctor Howe ................ 1+6

Doctor Kích................ 12t

Doctor Lindley .............. 146

Duc de Mlorny . . . . . . . . . . . . . 12t

Duchesse de Uonchy.......... 12.

Duchesse Plícoce............ 12i

Dulıamel du Monceau .......... 146

Eastern Belle............... 126

Egerie ................. 127

Eliot's Early . . . . . . . . . . . . . 12

Elizabeth IIanry............ 117

Eugene Appert............. 175

Fall Beurre D'Artuberg........ 175

Fox B. S .................. 1.14

Frederick ('lapp.............. 148

General De Bouchamp......... 176

Grand Isle.
Park's Cling ............... PAGE

Petit, Imperial............... 144

Queen of Stuclua............... 142

Quisenberg................... 170

Raisin.................... 171

Richmond .................. 122

Sallie Worrell... ............ 171

Salway ................... 122

Seagrove...................... 142

Scagrove's Simock ... .......... 14

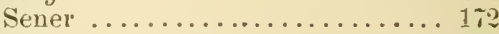

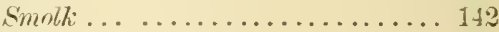

Southwick, Late ............. 12:

Strinley's Late................ 142

Sitedly.................... 112

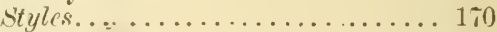

sugar........................ 14

Thurber. .................... 144

Tuskena.................. 172

IVager.................... 113

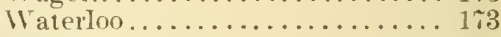

IVheatland................. 1\%

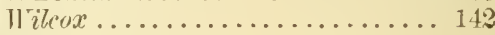

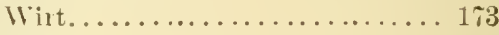

ITarris. . . . . . . . . . . . . . . . . . . 149

Homestead ................ . . 150

Hoosic.................... 17

Iorace Greeley ............... 150

Housatonic ................ 151

Indiau Queen.............. 127

Jacques Chamaret........... 127

Josephine de Binche........... 12i

Jules D'Airoles (De Lion Lec!eic). 178

Jules D'Airoles (De X. Gregoire). 17s

Keiffer................. 179

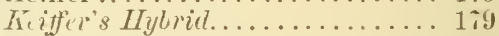

Longue dn Bosquet............. 151

Ioriol de Barny............. 1:8

I.onis Vilmorin............... 128

Lncie Andus:son . . . . . . . . . 1.51

lucy Grieve................ 151

Madame Andre Leroy......... 129

Nadame Appert............. 151

Marlame Bantiste Desportes. . . . . 15:2

Marlame Cuissard............ 129

Nadame Fa vre. . . . . . . . . . . 129

Marlame Loriol de Barmer ...... 129

Maunington ............. 1:9

Marechal Vaillant............... 1:0

Maria ................ 15:

Mal's]all ... ............... . 179

Maurice Desportes ............ 130

Forthfield Seckit............ 15t

P. Barry................. 15 ? 


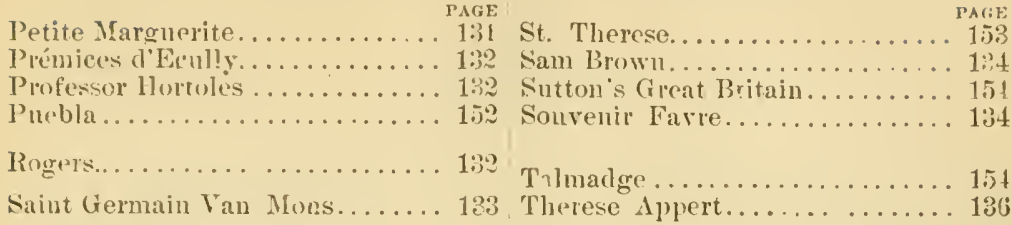

\section{PLUIIS.}

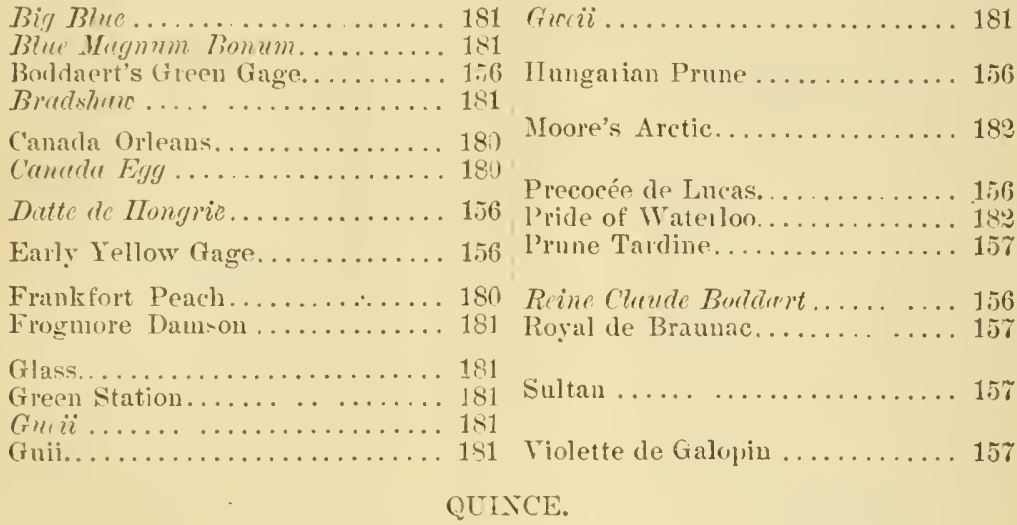

Sweet Quince............. 136 |

\section{RASPBERRIES.}

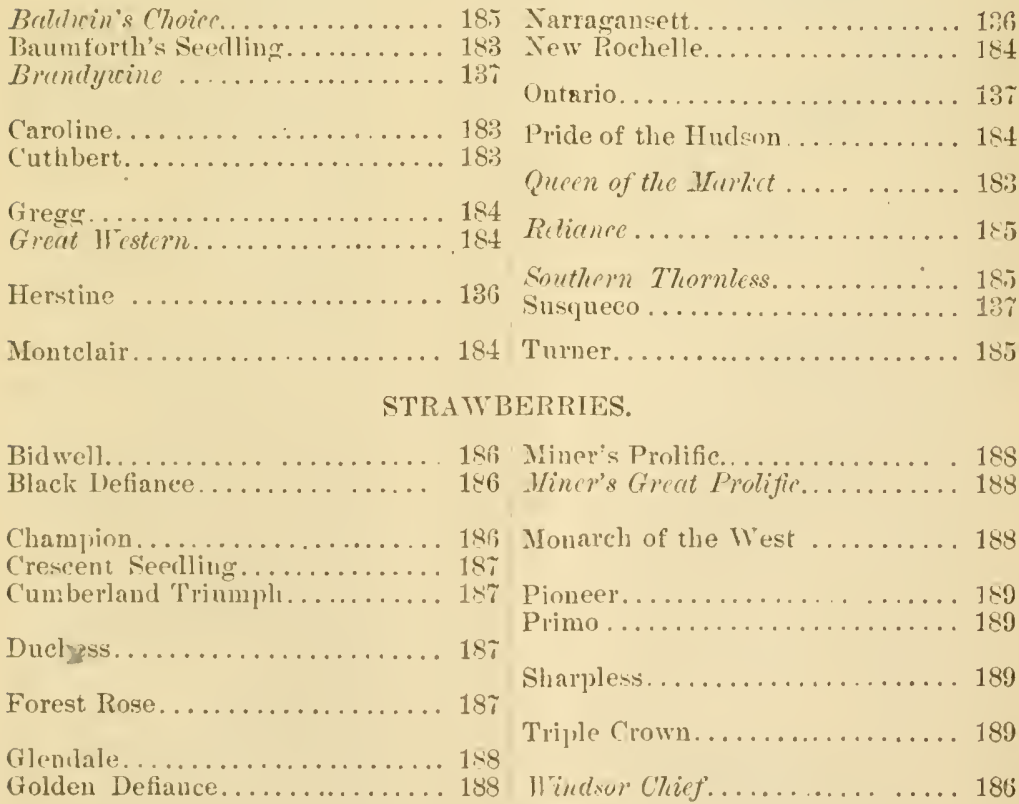




\title{
ADDITIONAL SYNONYIS
}

\author{
TO THE
}

\section{A P PLE.}

Alpian

Anderson

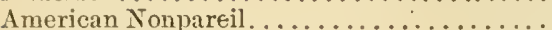

August Pippin. ...................

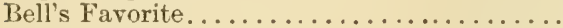

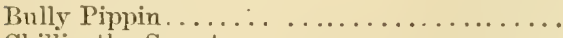

Chillicothe Sweet................

Crutchfield Greening. . . . . . . . . . . . . .

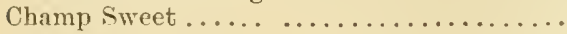

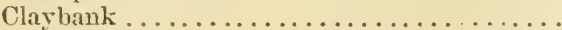

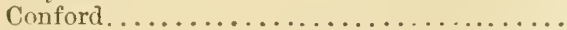

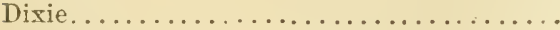

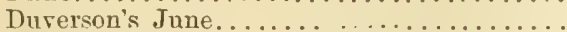

Early White

Early July Pippin.

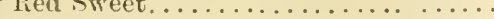

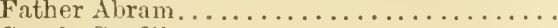

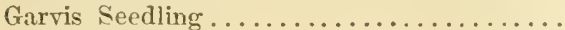

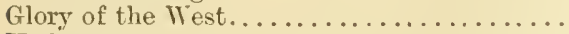

Hollman ......................

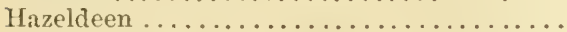

Herr's June . . . . . . . . . . . . . . .

Holland's Red Winter................

Hutchinson's Pippin. ...............

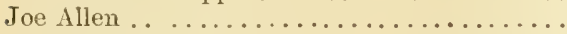

Jones's Early Harvest. . . . . . . . . . . . . . .

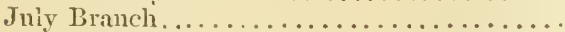

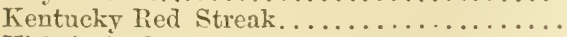

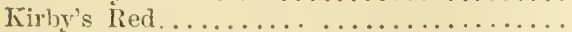

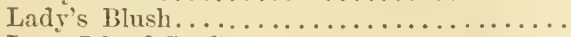

Long Island Graft. . . . . . . . . . . . . . . .

Normanton Wonder.

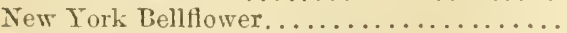

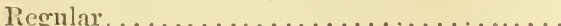

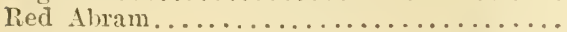

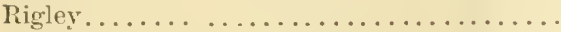

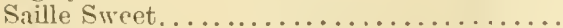

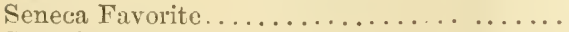

Speckled

Striped Quarendon...................

Striped Sweet Harvest . . . . . . . . . . . . . .

Striped Red Harrest. . . . . . . . . . . . . .

Susy Clark.

Summer Traveller.

Tenan Red

Texan Red

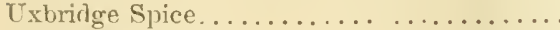

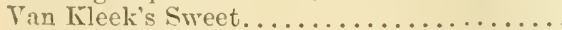

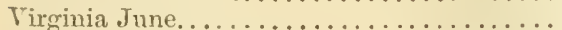

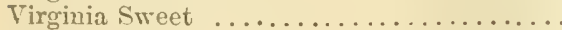

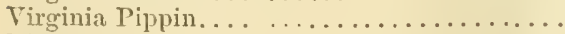

Westbrook

White Codlin

White, or Tellow June of sonue...........

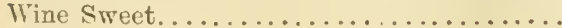

Wrigler
Syn. of Cannon Pearmain.

Domine.

Summer Sweet Paradise Sons of Wine.

Ewalt

Bailey's Sweet.

Bullet.

Hartford Sweet.

Griffith.

Pryor's Red.

Shockler.

Eärly Red Margaret.

Cooper's Early White.

Early Harrest.

Red June Sweet.

Abram.

Buckingham.

Duteh Codlin.

Nickajack.

Princely.

Early Red Margaret.

Winesan.

Ben Daris.

Carolina Red June.

Jersey Sweet.

Ben Daris.

Red Vinter Pearmain.

Ewalt.

Fall Orange.

Dumelow's Seedling.

Fall Orange.

Cooper's Market.

Abran.

Cooper's Market.

Red and Green Swee!

Quince.

Fall Orange.

Early Red Margaret.

Red June Sweet.

Carolina Red June.

Early Red Margaret.

Summer Sweet Parsdise

Ben Davis.

Winesan.

Capron's Pleasant.

Hog Island Sweet.

Early Red Margaret.

Red and Green sweet.

Ben Daris.

Fall Orauge.

Dutch Codlin.

Fall Orange.

Kirkbridge White.

Tinter Swreet Paradise.

Cooper's Market.

St. Lawrence. 


\section{ADDITIONAL SINONYMS}

TO TIIE

\section{A P PLE.}

American Beauty (incorectly).

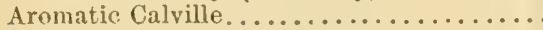

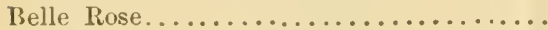

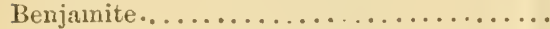

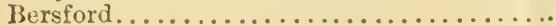

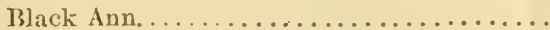

Black Spitzenberg.................

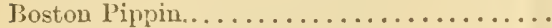

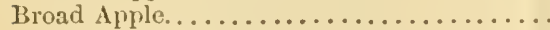

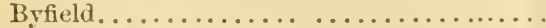

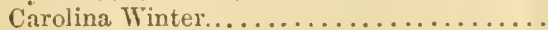

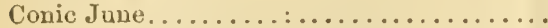

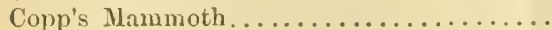

Cranberry Pippin (incorrectly)..........

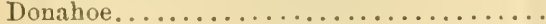

Early Baldwin.....................

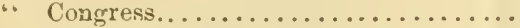

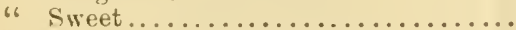

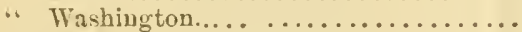

English King..................

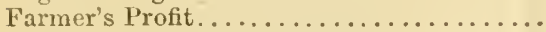

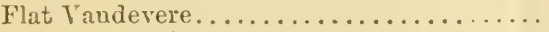

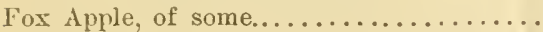
Franklin.

French Pearmain..................

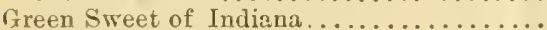

"Winter Pearmain..............

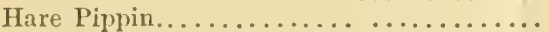

Harris White Hall....................

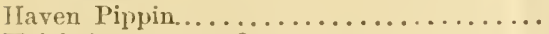

Heicke's summer Queen...............

Highland l'ippin..................

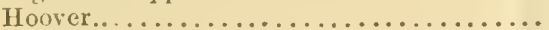

June....................

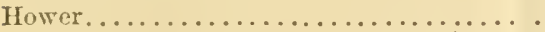

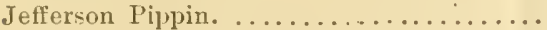

Jenkins' Summer Pipuin.............. Jennings. . . . . . . . . . . . . . . . . . . . Jersey Pearmain. . . . . . . . . . . . . . .

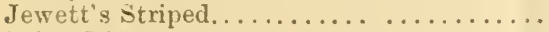
Juicy Bite......................

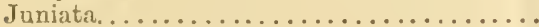

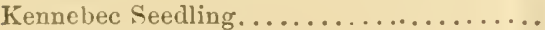
Kingsbury Russet.................... Large Summer Pearmain.............. Limber Twig Russet..................

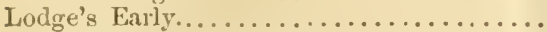
Logan's Northern Pippin..............

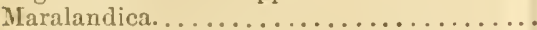
Montgomery Sweet................

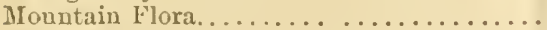

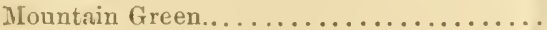
North Carolina Vaudevere.............

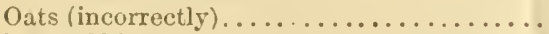

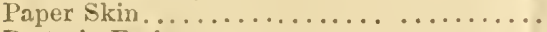

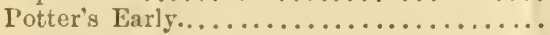
Pound's July....................
Syn. to Baltimore. Arounatic Carolina.

Primate.

" Fallawater.

66 Pryor's Red.

"Black Coal.

" Flushing Spitzenberg.

"Golden Pippin.

"6 Pennock.

" Rock Sweet.

" Nix Green.

"6 Kirkbridge White.

i6 Gloria Mlundi.

" Black Coal.

" Red Canada.

6) Primate.

" Gravenstien.

"6 High Top Sweet.

$\therefore$ Sops of Wine.

" Alexauder.

"6 Hubbardston Nonsuch.

" American Pippin.

" American Golden Russet.

"6 Fronclin.

" Autumn Pearmair.

" Victnals aud Drink.

"Antumu Pearmain.

" Summer Sweet Paradise.

" Dyer.

"6 Ledge Sweet.

"Early Pennock.

" Primate.

"Black Conl.

"6 Yellow Jume.

" Freuch Pippin.

"6 Rawles' Genet.

“ Primate.

"6 Porter.

- Autumn Pearmain.

"Jewett's Best.

"Better than Good.

6. Washington Strawberry.

"Winthrop Greening.

" Pumpkin Russet.

" Buckingham.

"Goldeu Russet of N. Y.

6. Summer Rose.

" Minkler.

"6 Early IIarvest.

"6 Autumn Sweet Bough.

6" Gloria Muudi.

" Fallawater.

"6 Horn.

-6 Early Harvest.

" Summer P'ippin.

"Knowles' Eirrly.

" Large Yellow Bough. 
Pound Royal (incorrectly).............. Syn. to Lowell.

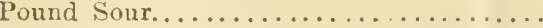

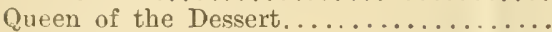
Rock Apple........................ Red Cheek Bellflower................. Red Gilliflower, of some.............. Red Harvest, of some................

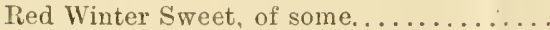

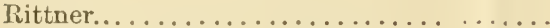

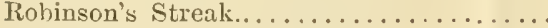

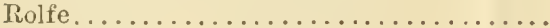
Royal Red of Kentucky............... Russian Hagloe................... Ryerson.

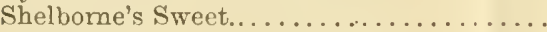
Shropshirevine.

St. John Strawberry

Striped Shronshire.

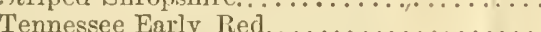

Vestal.

Virginia May.

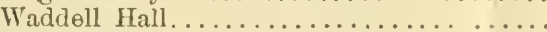

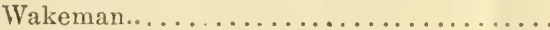

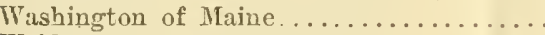

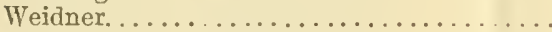

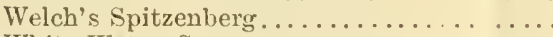

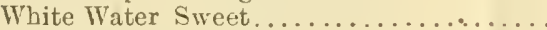

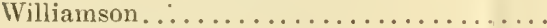

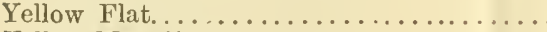

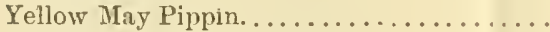

Yellow Summer Pearmain

"Golden Pirpin.

6. Newtown Spitzenberg.

“ Lansingburgh.

"6 Ewalt.

" Tied Winter Pearınain.

" Carolina Red June.

"Moore's Sweet.

" Jackson.

" Ben Davis.

" Macomber.

"Winesap.

" Summer Hagloe.

Primate.

$\therefore$ Spice Sweet.

"6 Sops of IVine.

" Early Strawberry.

" Early Strawberry.

' Maiden's Blush.

66 White Juneating.

Shockley.

: Baltimore.

"Washington Strawbery.

" Early Ripe.

" Red Cauada.

66 Wells' Sweet.

" Domine.

“ Kirkbridge White.

" White Juneating.

" Porter. 


\section{APPENDIX.}

For specimens of Fruit, and information relating to many of the varieties in this Appendix, I am indehted to many of the leading Pomologists in many parti of the country, who will please accept my cordial thanks.

Charles Domnixg. 
Fintered 2000rding to Act of Congress, in the year 1872, by JOHN WILEY \& SON,

the Office of the Librarian of Congress, at Washingtoe

Trow's

Printing and Bookbinding Cang 205-213 First i 2 th St., NEW YORk. 


\section{THE APPLE.}

\section{Autuma J'omse Gris.}

OrJgivated in the orchard of William Reynolds, Markham, Ontario. T'ree a strong upright grower, very productive. Fruit small, oblate, is jining to conic; skin yellow, nearly covered with thin 'nettings of russet, sometimes a shade of rich red in the sun; stalk long, slender, inserted in a medium cavity; calyx closed; basin broad, shallow, chis

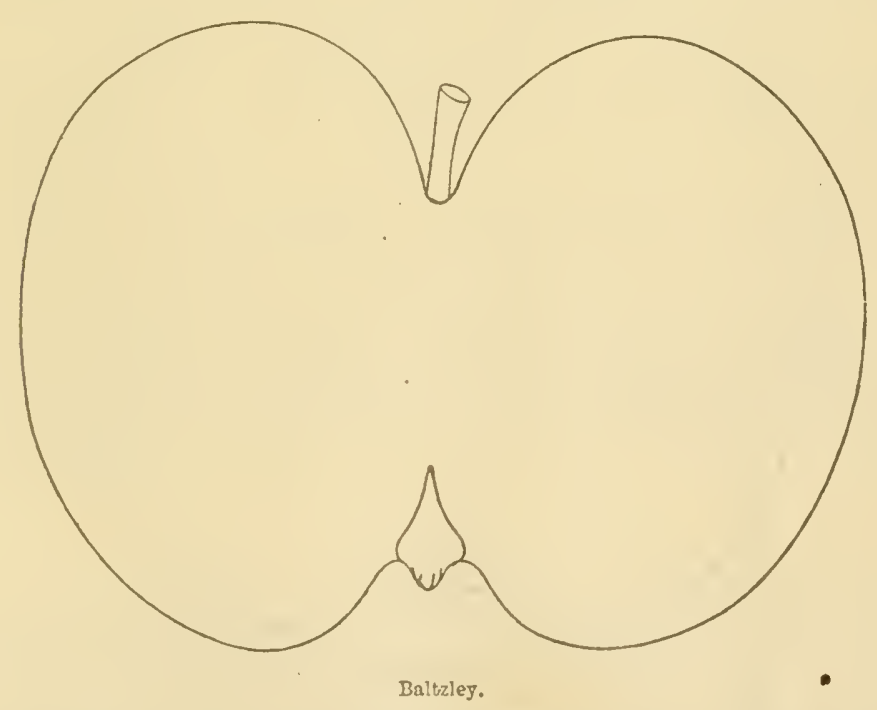

tinctly and peculiarly corrugated; flesh fine, yellowish, tender, moderately juicr, rich, sprightly sulacid and aromatic; very good; core small. October and November. 


\section{BALTZLEY.}

Baltzley's Sweet.

Originated on the farm of John Baitzley, Manellan Townslip, Pa, Tree moderately vigorous, spreading, an early bearer, very productive erery other year, and a small crop alternate ones; an old apple, but a farorite where known; youug shoots light reddish brown, many. russet dots.

Fruit rather large, oblate or roundish oblate, nearly regular; skin pale yellow, often with a shade of light pale red in the sun, and a few grayish dots; stalk rather short, small; cavity large, deep; calyx closed; basin large, deep, slightly corrugated; flesh white, half tine, tender, moderately juicy, rather rich, sweet; good to very good. September, October.

\section{Belle du HAtre.}

Belle Donce du Harre.

A promising French variety. Tree hardy, vigorous, upright. an early and abundant bearer annually; a good table firut, and excellent for culinary uses; young shoots reddish brown, slightly dowuy at the eud.

Fruit medium to large, roundish oblate, conical; angular or slightly

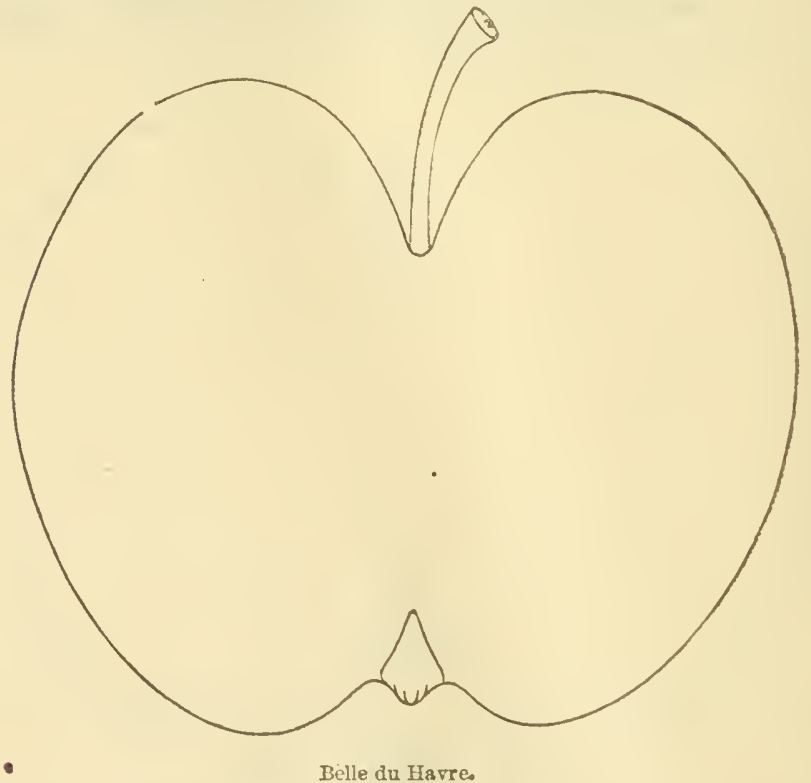

ribbed; skin pale greenish ycllow, shaded and rather obscurely striped and splashed with light and dark rich red over most of the surfice, and many light brown dots; stalk medium, slender; carity large, deep: 
calyx closed; basin rather large, corrugated; flesh quite white, fune, tender, moderately juicy, with a brisk, peculiar, quince-like flavor ; good to very grood; core suall. Ripe last of August to last of September.

\section{Belis SeEdlixg.}

Originated with the late Z. Bell, near Adairville, Kentucky. Tree a vigorous grower, making a large, handsome round head; comes into bearing tolerably carly, and rarcly fails to produce a crop of fair fruit, and is pepular where known.

Frnit medium or above, roundish, inclining to roundish oblong, slightly angular; skin entirely covered with light red, striped and splashed with dark red and a few light dots; stalk short, slender; cavity deep', acute, musseted; culyx dosed or partially open; basin rather decl', medium size; flesh whitish, half fine, tender, juiey, sprightly subacid; good to rery good; core medium. September; October.

\section{Blenifein Pippin.}

Blenheim Orange. Woodstock Pippin.

\section{Blooming Orange.}

Northwick Piplin.

Dutch Timuonne, erroneously.
Blenheim.

Kempter's Pippin.

An error having been made in the second revised edition of this work with this rariety, Dutch Mignonne and Blooming Orange,-the last being a syn.,-we give a corrected description.

An old variety which originated in Oxfordshire, England. Tree very strong, vigorous, spreading, somewhat drooping when in full bearing,

1 makes a large handsome tree in the orchard. It is late coming into beuring, but when fully established is a good regular bearer. This apple is a furorite in England, and succeeds in most localities here in the Midclle and Northern States, especially the latter. Young wood stout, reddish brown.

Frnit large, often reuy large, xoundish oblate, regular, skin dull orange, half corered or more with rich dull red, often mixed with russet, dotted and wottled with large yellow russet specks, some of which are areole; stalk rather short, slender, curved; cavity large, deep', russuted, the russet sometimes extencling in rays out on the finit; calyx large, open; basin broad, large, rather deep, slightly corrugated; flesh white, a little coarse-at first firm-- but becoming erisp, tender, juier, rich, lrisk sulacid, slightly aromatic; core small, very good. Novenber, Felsuary.

Bord.

Origin supposed to be on the MrePherson farm, Monroe County, Kentucky, and introduced by Alfred and Thomas Boyd. Tree a strong, spreading, rather straggling grower, and productive.

Fmit large, oblate, slightly conic; skin yellow, shaded with light und dark rol, deep rich red in the sun, sometimes olsscure splashes and stripes and moderately sprinkled with light and brown dots; stalk very Eliort; carity large, broad, deen, often slightly russeted; calyx closed 
or. half open; basin rather large and smooth; flesh yellowish, a littl coarse, rather firm, moderately juicy, rather rich subacid, slightly aro matic; good to very good; core small. January to April.

\section{BUNKer HiLu。}

Originated in the orchard of the late Dr. Paige, of Dryden, New Iork. Tree a healthy, rapid grower, an early and abundant bearer, and valued where known.

Fruit medium, roundish conical, regular; skin pale whitish yellow, shaded, mottled, striped and splashed with two shades of red, rather thinly over two-thirds the surface, and moderately sprinkled with light dots, a

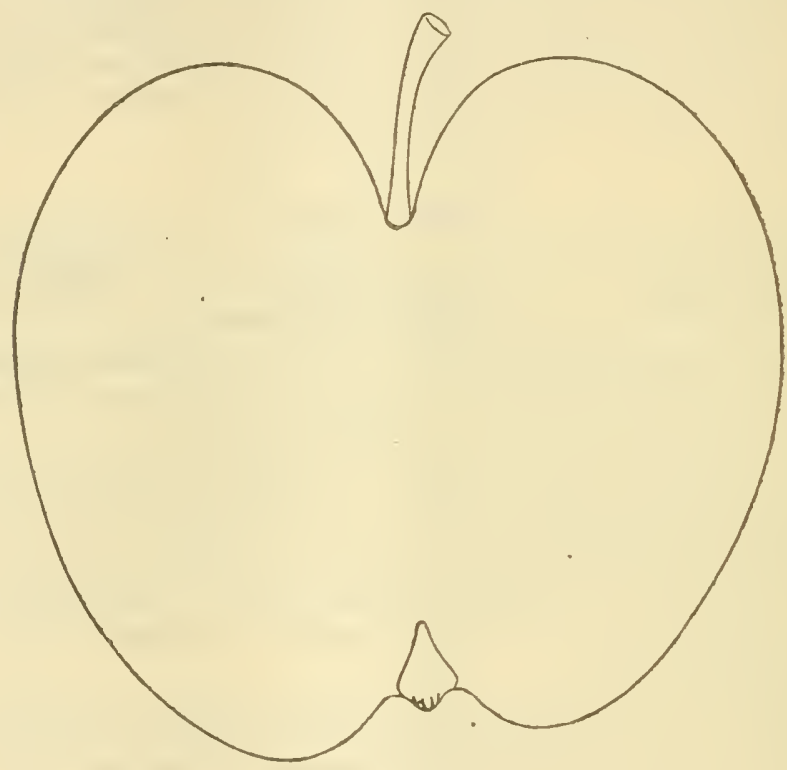

Bunker Hill.

few being areole; stalk short, slender; cavity medium or large, a little greenish; calyx closed; basin medium, shightly corrugated; flesh quite white, sometimes a little stained next the skin, fine, tender, juicy, subacid, vinous, slight quince-like flavor; very good; core rather small. October.

\section{.Buzby's Early.}

Origin uncertain, supposed to be Moorestawn, New Jersey. Tree a moderate grower, rather spreading, very productive alternate years.

Fruit below medium, roundish oblate; skin pale yellow, thinly shaded, striped and splashed with light red over half the surface; stalk short, small; cavity large, deep; calyx closed ; basin quite deep, slightly corrugated; flesh whitish, fine, crisp, tender, juiry, mild subacid; good to very good; core small. Last of August and September. 


\section{Cadwallader's Golden.}

Originated on the farm of James Simmons, near Greenbush, Warren County, Illinois, and introdneed by E. F. Cadwallader, Paola, Kansis, who states that the tree is hardy, a strong, vigorous grower, spreading, an early and prolifie bearer, and valuable for market and culinary uses.

Fruit medium, oblate or roundish oblate; skin bright yellow, sometimes with a slight blush, moderately spriukled with dark grayish dots;

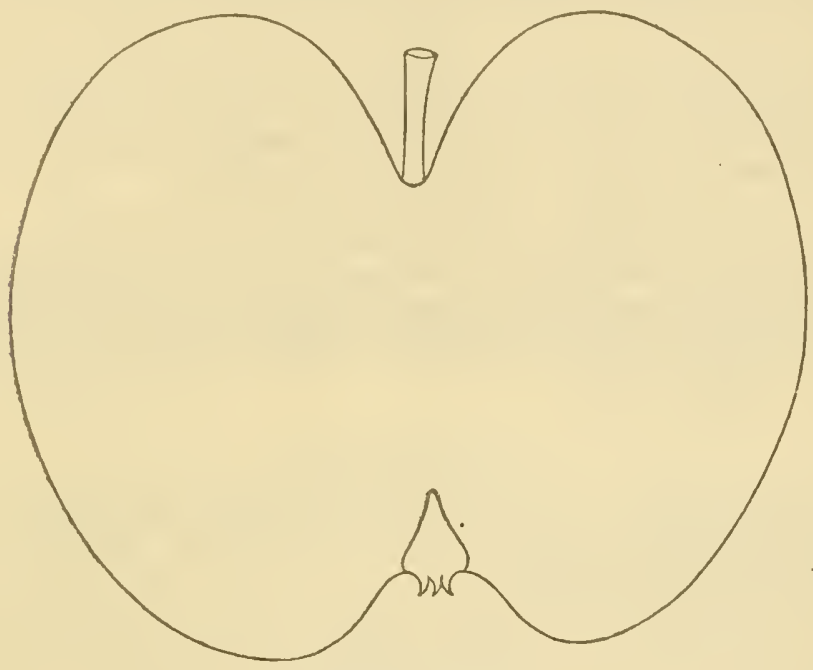

Cadwallader's Golden.

stalk rather short, slender; cavity quite large, deep, sometimes slight russet; calyx closed or laalf open; basin large, deep, slightly corrugated; flesh yellowish white, half fine, tender, juicy, mild, pleasant subacid; good to very good; core small. October, February.

\section{Calikins' Pippin.}

Originated with the late Elias Calkins, of West Cornwallis, Nova Scotia. Tree vigorous; forms a large round head, with drooping branches; an early and henvy bearer alternate years; is valuable for market and culinary uses.

Fruit large, roundish conical, sometimes oblong, slightly angular; skin whitish, thinly shader and mottled on the sunny side, sometimes a few nettings of russet and a few grayish dots; stalk of medium lengtl, slender; cavity large, deep; calyx closed; basin rather narrow, dec ', much corrugated; flesh white, rather coarse, tender, juicy, brisk subacid; good; core large. November, February.

\section{Ciiester County.}

Origin uncertain; found on the farm of Dr. J. C. Brosins, Cochranville, Pennsylvania. Tree vigorous, spreading, inclining to droop; very 
productive nearly every year; a late keeper, and considered valuable in its locality.

Fruit medium to large, roundish oblate, very slightly conic; skin yellow, shaded, splashed and strijed with light and dark red in the sun and faintly on the shaded side, moderately sprinkled with large and small light dots, a few being areole; stalk short; cavity medium, sometimes slightly russeted; calyx small, closed; basin deep, large, slightly corrugated; flesh yellowish, half fine, crisp, tender, juicy, subacid; good to very good; core small. January, March.

\section{Clayton.}

Originated with Richard Worrell, near Clayton, Indiana, and is valued as a late keeper. Tree vigorous, upright, a regular and abundant bearer, but only moderate crop alternate rears.

Fruit rather large, roundish oblate, regular; skin smooth, yellow, nearly covered with light and dark rich red, and moderately sprinkled with light dots; stalk short; cavity rather large, thinly russeted; calyx small, nearly closed; basin medium, slightly corrugated; flesh yellowish, rather coarse, compact, moderately juicy, mild subacid; good; core small. January, May.

\section{Oline's Codlin.}

Origin unknown; introduced by Daniel Cline, of Fairview Township, York County, Pennsylvania. Tree vigorous, upright, an early bearer, and very prodnctive.

Fruit medium, oblate, nearly regular; skin pale whitish yellow, almost waxen, sometimes a light shade of red in the sun; stalk short, small; cavity large; calyx closed; basin medium, slightly corrugated; flesh whitish yellow, fine, crisp, juicy, lively subacid; good to very good; core medium. Middle of August to middle of September.

\section{Connecticut Red Cheek.}

\section{Connecticut Red Streak. Connecticut Red Side.}

An old variety, which originated in Hartford County, Conn. Iree vigorous, upright spreading; very productive alternate years.

Fruit ratler large, roundish oblate; skin pale, with a bright red cheek, sometimes a few obscure splashes and stripes, and a few scattering brown dots; stalk short, small; cavity large, deep; calyx closed; basin large, deep, slightly corrugated; flesh white, half fine, crisp, tender, juicy, mild subacid; good to very good; core medium. October, November.

\section{Coxs.}

An old variety of uncertain origin, grown in Lancastel and Tork countjes, Pa., where it is esteemed as a dessert apple. Tree moderately vigorous, rather upright, very productive.

Fruit quite small, roundish, slightly conic; skin whitish, mottled and striped with rather dull red, and spinkled with a few light dots; stalk long, slender; cavity medium; calyx half closed; basin medimu. 
corrugated; flesh white, tender, juicy, mild, pleasant subacid; good tc very good; core medium. Ripe last of July and August.

\section{Crats's Spice.}

Originated with Dr. James H. Crain, Undulation, Illinois. Tree vigorous, forming a round liead; an early, ammal, and abundant bearer.

Fruit below medium, oblate, slightly conic, slightly angular; skin entirely corered with cleepr rich red, and a few light dots; stalk very short, small; cavity small or medium; calyx small, closed; basin somewhat narrow, deep, sliglitly plaited; flesh quite white, a little stainer next the skin, fine, tender, cuite acid at first, but when fully ripe a peculiar subacid, quiuce-like ilavor; good; core rather small. October, January.

\section{DAFAGE.}

Origin unknown; introlneed by Judge James Davage, of Caledonia, Illinois. Tree moderately vigorons, forming a round head, an early and annual bearer, suid to be a fine apple, retaining its juice and Havor remarkably well.

Fruit nearly of medium size, oblate; skin whitish, nearly covered with light and dark red, many large yellowish and some brown, irregular, and star-shaped dots, it few being areole; stall short, smill; cavity medium, often slightly russeted; calyx open; basin quite broul, not deep, slightly plaited; flesh whitish, tine, rather firm, juicy, mild subacid, inclining to sweet; good to very good; core small. February, May.

\section{- Dr. Fulcher.}

Received from J. S. Downer, of Fairview, Kentucky, who informs me that it was a cliance seedling found on the farm of the late Dr. Fulcher, of that town, and is very popular there. Tree thrifty, upright, inclining to spread in the orchard; an early, annual, and abundiut bearer; young shoots light reddish brown.

Fruit helow merlium, roundish oblate, a little flattened at the ends, sometines slightly oblique; skin whitish yellow, slialed, mottled, striped, and splashed over two-thirds its surface with light and dark red, a thin grayish bloom, and a few liwht dots; stalk short, small; cavity rather large, sometines slightly russeted; calyx olven or half closed; basin medium, slightly plaited; nesh white, half fine, sometines a little stainet next the skin, tencler, juicy, refieshing, subacid; very good; core small. November, January.

\section{DOXAITCE.}

Originated with P. Donahne, near Cumberland, Mr. Tree moderately vigorous, spreading, prorluctive.

Fruit medium or below, oblate, very slightly conic, regular; skin deep rich red or purplish in the sun, moderately spuinkled with light dots; stalk short, small; cavity broad, sometimes a little greenish; 
calyx small, closed; basin large, slightly uneven; flesh white, fine, ten der, moderately juicy, mild, pleasant subacid; very good; core small. October, January.

\section{DUFFIELD.}

Originated with James Duffield, Jr., Van Buren, Iowa. Tree moderately vigorous, spreading; an early and abundant bearer.

Fruit medium, oblate, sides unequal, skin yellow, shaded, splashed and striped with light and dark red over the whole surface, and moderately sprinkled with light and brown dots; stalk short, small; cavity

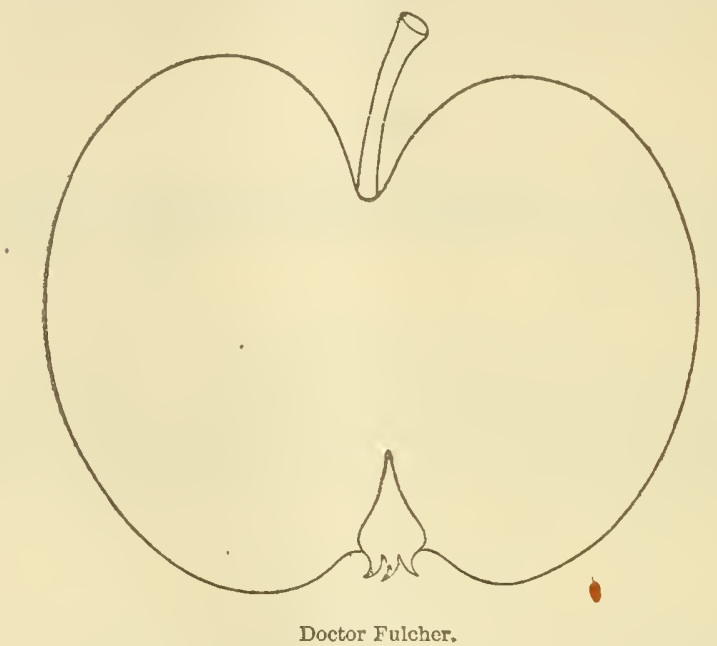

large, deep, slightly russeted; calyx closed, basin medium, corrugated; Alesh yellowish, half fine, tender, juicy, pleasant mild subacid, rather rich; good to very good; core small. November, February.

\section{DuLris.}

Duling's Sweet.

Originated with Edmund Duling, Linton Township, Coshocton Co., Ohio. Tree healthy, vigorous, rather spreading; begins to bear quite early; a regular bearer, some seasons very heary crops; young shoots, grayish brown, smootl.

Fruit roundish, inclining to conic, regular; skin vellow, shaded, striped and splashed witl deep rich red nearly orer the whole surfacethe splashes sometimes in broad bands,--pale red in the shade; stalk of medium length, slender, curved; cavity rather narrow, deep; calyx closed; basin medium, regular; flesh whitish, tender, juicr, pleasant, rild subacid, almost sweet; very good; core small. Middle of August to middle of September. 


\section{Dulin's Red.}

Raisod by Lodd Dulin, of Hopkinsville, Christian County, $\mathrm{Ky}$., where it is considered a valuable and popular winter fruit. Tree moderately vigorous, rather upright, and makes a handsome orchard tree, very productive alternate years; young shoots brownish red, grayish.

Fruit medium, oblate, very little conic, sides sometimes unequal; skin entirely covered with light red, striped and splashed with dark red, and many light and brown dots; stalk short; cuvity large, dee' 1 ; calyx half closed; basin medium, regular; flesh yellowish, a little coarse, breaking, tender, moderately juicy, subacid, slightly aromatic; good to very good; core medium. December, February.

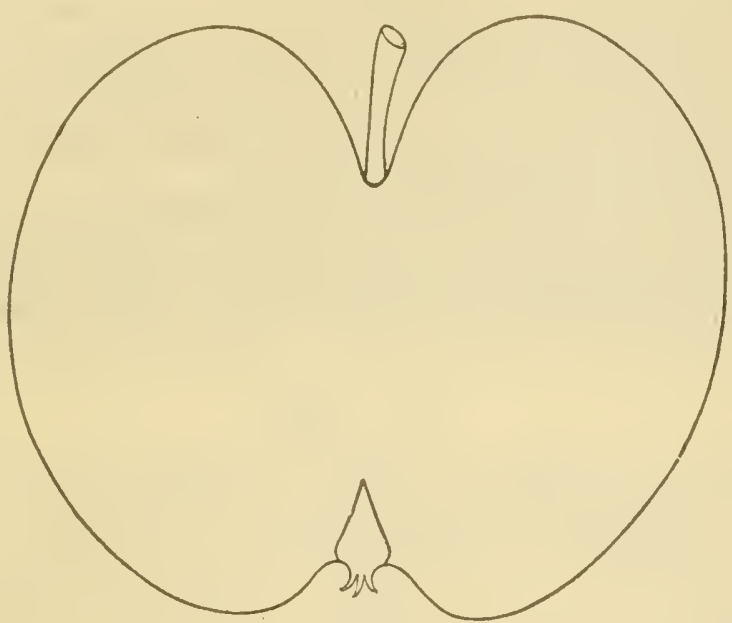

Dulin's Red.

\section{Esperex's ReINetTe.}

\section{Reinette d'Esperen.}

A foreign variety; tree strong and vigorous, spreading, very productive.

Fruit large oblate, or roundish oblate, slightly conic; skin light golden rellow, a shade of pale light red in the sun, and a few browis dots; stalk rather short, small; cavity large, broad, regular, thinly russeted; calyx closed; basin medium, corrugated; flesh whitish yellow: rather coarse, tender, juicy, pleasant subacid; good to very good; core small. December, Felsuary.

\section{FAIRY.}

A new English dessert apple, which is spoken of as very handsome: and of fine quality, and it is thought will rival in size and color the celebrated Lady apple. Tree moderately vigorous, upright, hardy, and prolific. 
Fruit small, oblate, slightly conical; skin lemon yellow, covereu with bright lively crimson, shaded with streaks of a deeper tinge; stalk of medium length, slender; cavity small, russety; calyx closed; basin small, plaited; flesh deep yellow, firm, crisp, very juicy, with a rich brisk flavor, and a fine delicate aroma. December, February. (Florist and Pomologist.)

\section{Fall Queen, or HaAs.}

\section{Gros Pommier. \\ Haas. Gros Pomier. \\ Maryland Queen. \\ Horse of some. Hossీ.}

Originated on the grounds of Gabriel Cerré many years since, adjoining the then village of St. Louis (now city), MIo. It was at first called Gros Pommier, but now generally Fall Queen or Haas, and we retain this, as it is most commonly used. It is very popular through most of the West and Southwest as a profitable market fruit, and for family use. Tree hardy, very vigorons, upright, forming a beantiful symmetric head; an early, annual, and abuulant bearer.

Eruit medium to large, oblate, slightly conical, angular or slightly ribbed; skin smooth, pale greenish yellow, shaded nearly over the whole surface with light and dark red, some rather obscure splashes and stripes, and a few light dots ; stalk short, small; cavity medium, a little greenish; calyx closed; basin small or medium, slightly corrugated;

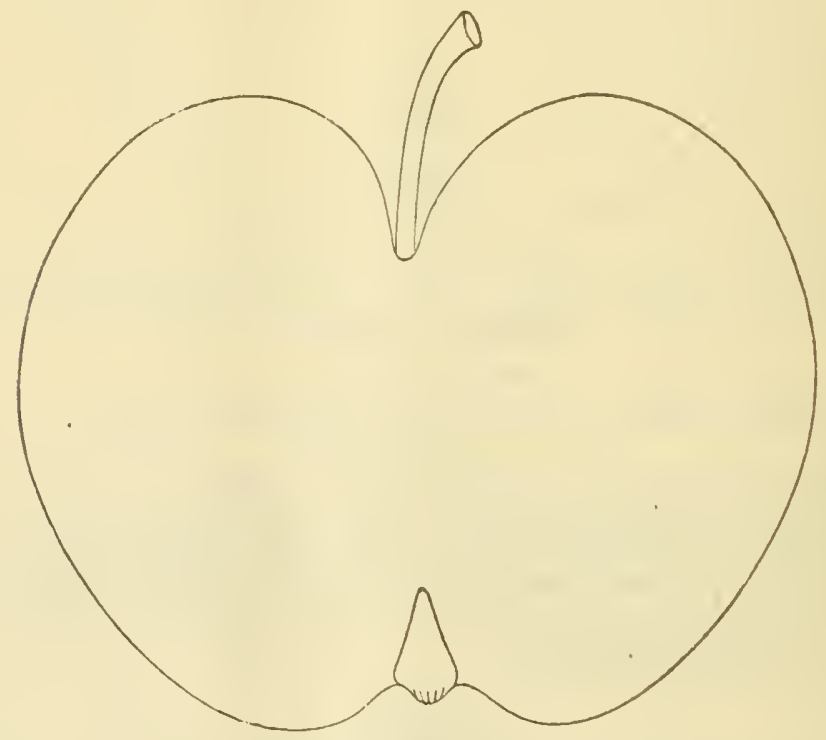

Fall Queen, or Haas.

flesh quite white, fine, often stained next the skin, and sometimes through the flesh, tender, very juicy, vinous, brisk subacid; good to very good; core medium or large. September, October. 


\section{Fall Stripe.}

Saxton.

An old variety which originated in Massachusetts or Connecticut. Tree vigorous, forming a handsome round head; very productive alternate years ; an early bearer.

- Fruit medium, roundish oblate, regular; skin yellow, shaded, strije: and splashed with light and dark red over the whole surface, liaving a few light and brown dots; stalk short, small; cavity merium, slightly russeted: calyx closed; basin medium, slightly corrugated; skin yellowish, a little coarse, juicy, tender, subacid, slightly aromatic; good to very good; core small. September.

\section{Fraxclis.}

Origin, Lancaster County, Pa. Tree moderately vigorous, with at round head, very productive alternate years, and a few the intervening olles.

Frnit nearly of medium size, oblate; skin pale grecnish white, covered with pale red, often deep red in the sum, sometimes obsemre splashes and strijes, and a few light and gray dots; stalk short, small; cavity rather large, sometimes a little russeted; calyx closed; basin medium, rery slightly corrugated; flesh whitish yellow, half fine, tender, juicy, pleasant subacid; very good; core small. September, Uctober.

\section{Gexeral Lyon.}

A new variety, received from George S. Park, who writes that it was raised from seed of Ben Davis by the late Elias Peck, of Parksville, Missouri, and that the trec is hardy, and resembles its parent in growth; very productive amnually, a long keeper, and at good warket fruit ; youn:s shoots smooth, brownish red.

Fruit medium or below, roundish conical, flattened at the ends, sometimes a little oblique; skin bright yellow, shaded with light and lark red nearly over the whole surface; sometimes a few faint stripes and a few light and brown dots; stalk short, small; cavity medium, often slight green russet; calyx open; basin broal, not very deep, corl'ugated ; Hesh yellowish, fine, compact, moderately juicy, mild subacid, rather rich; good to very good; core small. January, April.

\section{Geveral Mariox.}

Originated with Henry Iyons, Columbia, S. C. Tree a strong, vigorous grower, quite sprealing, not early coming into learing, but uniformly productive when it attains sufficient age, valuable for its late kecping and productiveness; young shoots reddish brown.

Fruit medium or below; roundish oblate conic, slightly angular' skin pale yellow, shaded, and rather obscurely striped with light and dark red nearly over the whole surface, and moderately sprinkled with light and gray dots; stalk short; cavity merlium or small; calyx half closed; basin rather narrow, decp, slightly plaited; flesh whitish, lialf fine, compact, molerately juicy, mild subacid; good to very good; core nedium. January to April. 


\section{Gillette's Winesap.}

Origin unknown, but supposed to have originated with the late $\mathbf{H}_{\text {. }}$ N. Gillette, of Quaker Bottom, Ohio. Tree vigorous, rather spreading, a good and valuable apple, quite productive alternate years.

Fruit rather large, roundish oblate, a little oblique, sides sometimes .mequal; skin whitish, shaded and mottled with light red, rather thinly striped and splasshed with darker'red, and moderately sprinkled with light and brown dots; some specimens have a mixed red and russet on the exposed side; stalk short; cavity medium, much russeted; calyx open, or half closed; basin rather large, regular; flesh white, a little coarse, crisp, juicy, tender, mild subacid; very good; core small. December, January.

\section{Goyeau.}

A chance seedling on the farm of - Goyean, Windsor, Ontario. Tree a vigorous grower, rather straggling and crooked; cowes rather early into bearing, and produces good crops annually.

Fruit rather large, roundish, angular or slightly ribbed, and somewhat irregular; skin light pale yellow, many rather obscure light dots; stalk of medium length, slender; cavity rather large, uneven; calyx closed; basin quite large, furrowed; flesh yellowish, fine, very tender, juicy, brisk subacid, excellent for culinary uses, and a fair table fruit. August, September.

\section{Grattan.}

This new large apple was grown from seed by Nehemiah Smith, of Grattan, but while quite young, before fruiting, was removed to the farm of Solomon Deal, of Oakfield, Mich. It is highly prized in that section for culinary purposes as well as for the table. Tree vigorous, upright, forming a round open head, producing good crops annually, and larger ones alternate year's.

Fruit large to very large, roundish oblate, slightly conic, regular; skin smooth, bright yellow, moderately sprinkled with grayish dots; stalk very short, small; cavity large, deep, sometimes slightly russeted; calyx open, or partially closect ; basin larce, deep, nearly smooth ; tlesh yellowish, a little coarse, tender, juicy, brisk, subacid; good to very good; core small. September, December.

\section{Gros Pigeonnet.}

Of foreign origin. Tree strong, but a slow grower ; productive.

Fruit medium, roundish oblate; skin pale yellow, shaded, mottled, and rather obscurely striped and splashed, with light and dark rich red over most of the surface, and moderately sprinkled with small light dots ; stalk short, small ; cavity medium, russet; calyx closed ; basin medium, furrowed; flesh whitish yellow, a little coarse, juicy, subacid; good December, February. 


\section{Gros Vert.}

\section{Large Green.}

Of foreign origin. Tree vigorous, spreacling, productive.

Fruit medium, oblate; skin greenish yellow, covered with a fow rather obscure green and grayish dots; stalk rather short, moderately stont; cavity quite large, russet; calyx closed; basin medium, slightly corrugated ; tlesh pale yellow, half fine, tender, juicy, pleasant subacid; good to very good; core small. January, March.

\section{HANAMIr.}

Originated with Joseph Curtis, of Manchester, O. Tree hardy, vigorous, upright at first, but sjureading when in bearing; an annual, morlerate bearer.

Fruit roundish oblate conic, slightly angular; skin pale dull greenish yellow, striped, splashed and mottled over half the surface with light recl, and moderately sprinkled with large and small white dots, a few being areole; stalk short, small; cavity large, deep; calyx small, closed; basin small, corrugated; flesh greenish white, frne, tender, juicy, mild subacil, almost sweet; good to very good; core small. November, December.

\section{HATcher.}

\section{Hatcher's Seedling.}

Originated on the farm of the late O. C. Hatcher, near Franklin, Tenn. Tree an upright thrifty grower, not an early bearer, but pro-

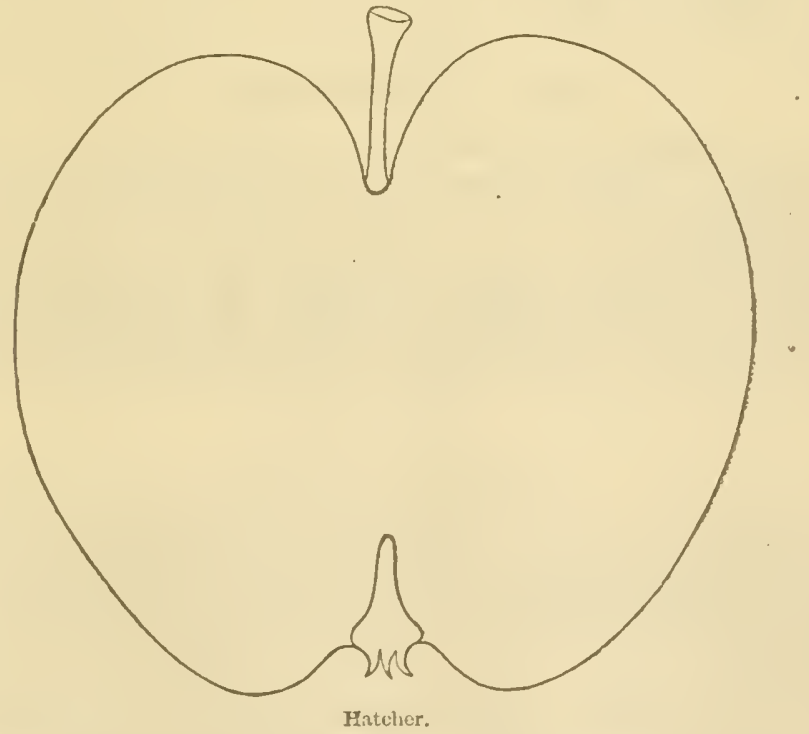

duces gond crops annually; a late kecper, and one of the most popular aproles in Hidule Tennessee. 
Fruit medium, roundish inclining to conic, slightly angular; skin very dark rich red, sometimes almost purplish, a few light dots; stalk short, small; cavity medium, often slight russet; calyx open; basin medium, slightly plaited; Hesh yellow, fine, rather compact, juicy, mild. pleasiant rich subacid, almost sweet; rery good; core small. January, March.

\section{Hawhiss' Chief.}

Originated with S. Hawkins, Maple Grove, Minn. Tree hardy, bealthy and rigorous, and aclapted for a northeru latitude.

Fruit medium, oblate, slightly conic; skin pale yellow, clear of the slightest blush or tinge; stalk short, stout; eavity shallow; calyx closed; basin broad, leep; flesh rather coarse, brittle, acid; good; core small. October. (Western Pomologist.)

\section{HIRAM.}

Origin, orchard of General Isaac Sandford, of Vermillion, Ill. Tree a moderate grower, forming a rouncl head; a moderate bearer at first, but when the tree has attained some age is very productive; raluable in its locality for late keeping and market.

Frnit medium, roundish oblate, sometimes a little oblique; skin entirely covered with dark red, sometimes obscure splashes and molerately sprinkled with light dots; stalk short, small; cavity medium, much russet; calyx closed; basin broad, rather shallow, courugated; flesh whitish, half fine, rather compact, mild subacid; good to rery good; core small. January to Miay.

\section{Hoya Golden Reinette.}

Hayasche Gold Reinette.

Reinette de Hoya.

Of German origin. Tree strong, vigorous, spreading; an early and abundant bearer.

Fruit medium, oblate, regular; skin golden yellow, shaded with dark red, faintly striped and splashed with light red, and sprinkled with a few light and gray dots; stalk short, small; cavity large, slight russet; calyx closed; basin medium; flesh yellowish, half fine, juicy, tender, subacid; good; core small. November, Narch.

\section{Huntsuan's Fayorite.}

A seedling on the farm of John Huntsman, of Fayette, Mo. Tree vigorous, not a very early bearer, but is very productive annually when the tree has attained sufficient age; it is said to be a valuable and profitable fruit in the locality where it originated; young shoots smooth, reddish brown.

Fruit large, oblate, slightly conic, often a little oblique; skiri smooth, pale yellow, sometimes a shade of pale red or deep rellow in the sun, and a few scattering grayish dots; stalk short, suall; carity broad, deep, sometimes slight russet; calyx closed, or nearly so; basi: 
large, deep, slightly corrugated; flesh pale yellow, a little coarse, crisp', tenter, juicy, mild rich subacicl, slightly aromatic; very good; core rather small. December, Mareh.

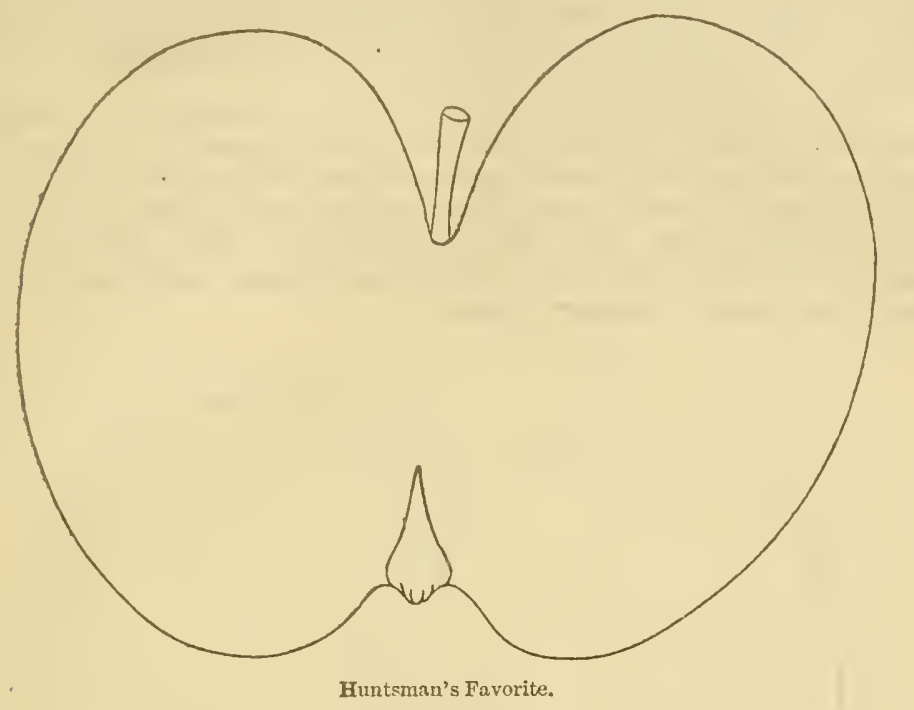

Humiston.

Origin Plymouth, Conn. Tree vigorous, upright, with long branclies, forming a spreading head when in fruit, very productive every other year, hangs late on the tree, cooks well, but only second quality for eating.

Fruit medium, oblate to xomdish oblate, slightly conie, sides sometimes nnequal; skin yellow, a little greenish, shaded and rather obscurely striped and splashed with light and dark red over half or twothirds its surface, a few light and gray dots; stalk rather short, small ; cavity quite large, slightly russeted; calyx closed; basin medium, slightly corrugated; flesh white, half fine, tender, moderately juicy, subacid; good; core small. Febrnary, Miarch.

\section{ItLinots Greening.}

Originated with Joseph Curtis, of Paris, Ill. Tree hardy, vigorous, upright, somewhat spreading, prorluces large crops annually, valuable as a latt keeping market apple in its locality.

Fruit large oblate, to roundish ollate, sometimes a little oblique; skin greenish yellow, often a shade of dull red in the sun, and a few light and brown dots; stalk slort; cavity medium, slight russet; calyx half open; basin large, decp, nearly smooth; flesh yellowish; hilf fine, rather compact, moderately juicy, subacid; good; core suall. January, April. 


\section{Iowa Russet.}

This new apple originated with Joseph L. Budd, Shellsburg, Iowa, who informs us that the tree is very luardy, vigorous, making a cornuact round head, an early, amnual, and abundant bearer; fruit even in size, of good quality, and a valuable acquisition for the prairie country; young shoots light reddish yellow brown.

Fruit medium, oblate to roundish oblate, sometimes slightly oblique : skin deep yellow, a shade of pale red when exposed to the sun, moderately sprinkled with grayish dots, and partially covered with patches and nettings of russet; stalk short, small; cavity quite large; calyx closed; basin round, quite deep, nearly smooth; flesh yellowish, half fine, tender, moderately juicy, mild subacid, rather rich; good to very good; core small. Jamuary, March.

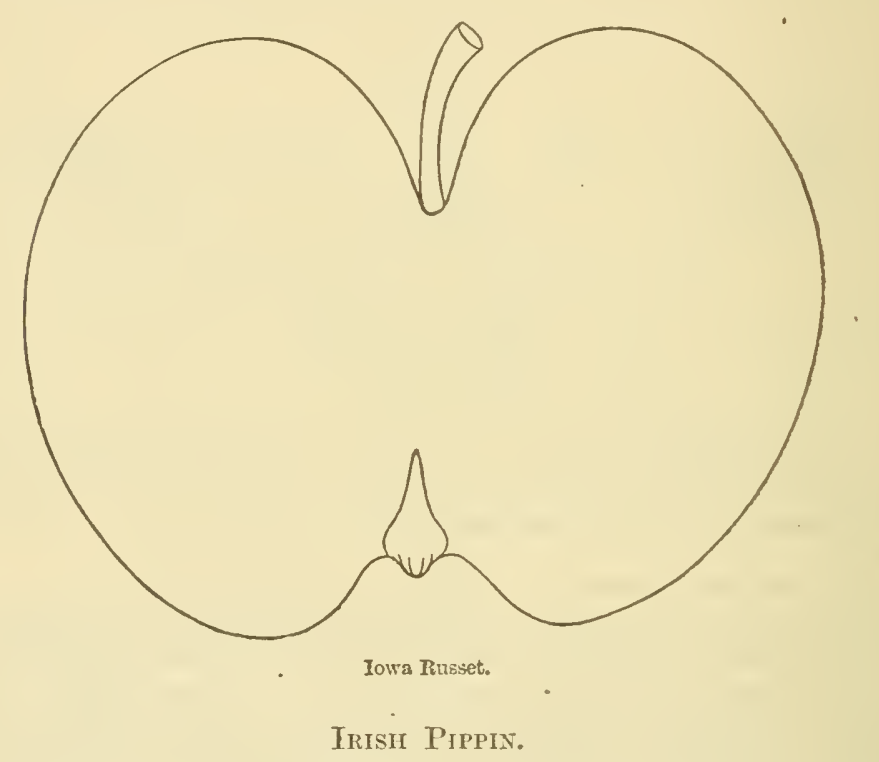

Originated with Stephen A. Porter, Norristown, Pa. Tree a fiee upright grower, forming a handsome head, very productive alternate years; young shoots smooth, reddish brown.

Fruit melium to large, roundish oblate, sometimes roundish, slightly conical; skin whitish, shaded with light bright red, striped and broken splashes of dark red, and a few light and brown dots : stalk very short, small; cavity medium, sometimes a little russeted; basin small, corrugaterl; flesh white, tender, juicy, mild subacid, slightly vinous; very good; core rather small. October, November.

\section{JoHrsox.}

Originater with Thomas Johnson, Ash Rillge, III. Tree rigorous, upright, an anmual and good bearer; it is highly prized where it originated. 
Fruit medium to large, oblate, sometimes slightly oblique skin pale greenish yellow, almost entirely corered wikh dirk rich red, inclining to marom, and moderately sprinkled with light and gray dots; stalk very short, small ; cavity medium, russet; calyx open; basin medimm, slightly plaited; llesh yellowish, fine, juicy, mild rich subacid, inclining to sweet; rery good; core small. December, March.

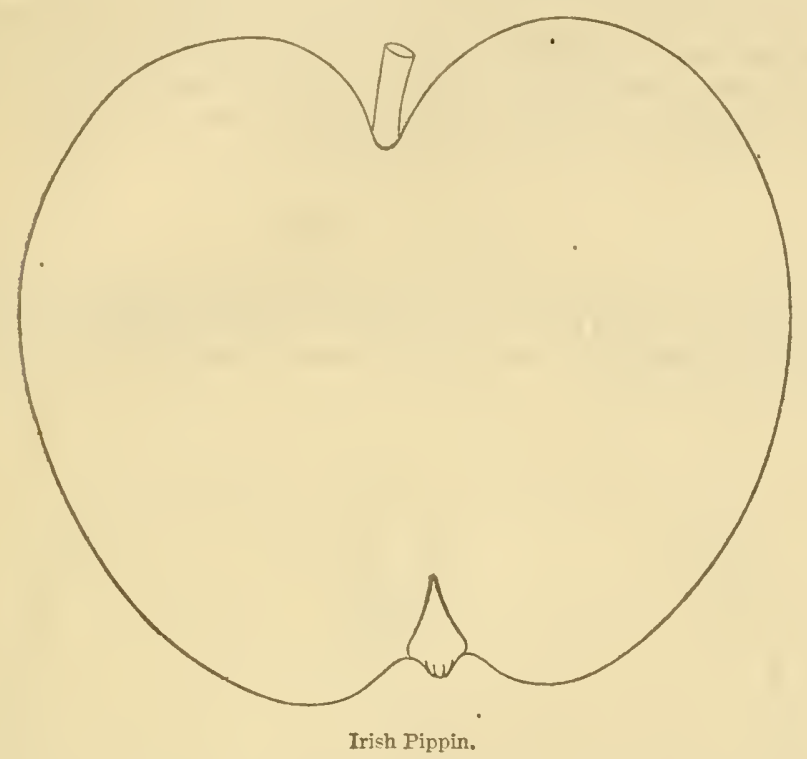

Kansas QueEn.

Kaised by Burrell Atkinson, Leavenworth, Kan. Tree hardy, vigorous, forming a landsome open head; rery productive.

Fruit medium, roundish, slightly conical, slightly angular; skin entirely corered with light and clark red, sometimes almost purplish in the sum, moderately sprinkled with small light and gray dots; stalk short, slender; cavity deep, rather narrow; calyx closed or nearly so ; basin medium, corrugated; Hesh quite white, rather firm, juicy, brisk subacid; good; core rather large. August, September.

\section{Kaxsas Sweet.}

A seedling raised by B. Atkinson, of Leavenworth, Kansas. Tree erect, compact, vigorous, prodictive.

Fruit ratlier large, oblate, shightly conical; skin greenish yellow, covered with broken stripes of light red and crimson; dots small, black, scatterecl; stalk short, rather thick; cavity regular, wide, deep; calyx small, closed; basin shallow; flesh yellowish white, fine, juicy, crisp, breaking, very tender and pleasant, sugar sweet; quality excellent; core nedium, November to January. 


\section{Kixg Solonion.}

Origin unknown; received from J. S. Downer \& Son, of Fairview. Kry., who write me that it came from Georgia. Tree a strong, vigorons grower, spreading, not an early bearer, but rery prodnctive alternate years; a haudsome and good apple of its season; young shoots dark reddish brown; buds large.

Fruit medium or above, oblate to roundish oblate, slightly angular; skin orange yellow, a few seattered stripes and splashes of light red over the surface, and moderately sprinkied with brown dots; stalk short: carity medimm; calyx large, open; basin rather large or medium; fles. yellow, a little coarse, moderately juicy, mild subacid, slightly aromatir; good to very good; core small. September.

\section{Kistardis Chotce.}

Originated on the farm of the Iate ITichael Kinnaird, of Franklin, Teun. Tree a thrifty, vigorous grower, not very upright or regular, similar to Winesap; an early and ammal bearer, producing hearies crops alternate years.

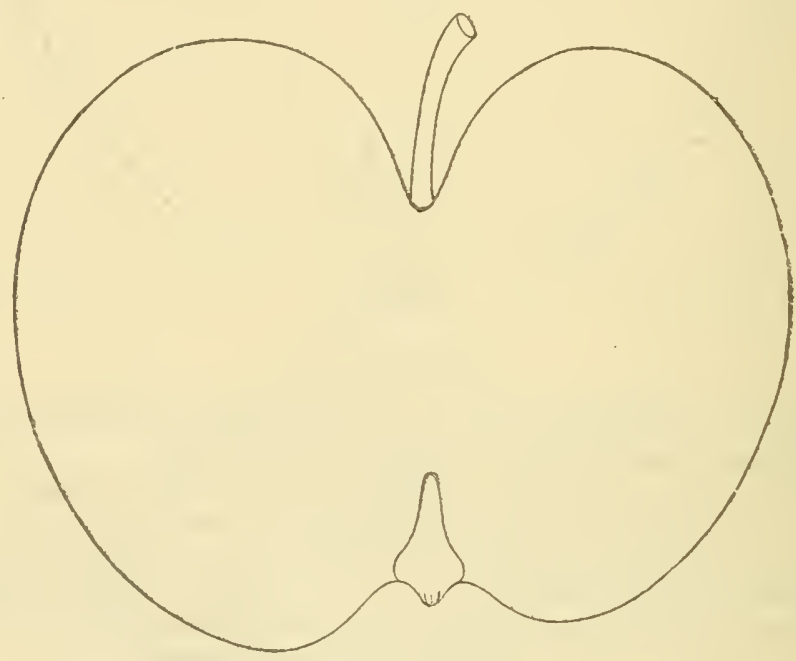

Kinnaird's Choice.

Fruit medium, oblate, inclining to conic, slightly angular, or ob scrirely ribbed, sides sometimes unequal; skin yellow, almost covereo with dark rich red, many small light lots near the erown, and larger ones and less number near the base; stalk short, small, sometimes by a lip; carity wide, deep, russeted; calyx closed; basin large, deel', fur. rowed; flesh yellowish, half fine, crisp, tender, juicy, mild, rich sub acicl, slightly aromatic; very good; core small. January. 


\section{Lallien's Prolific Red.}

A new variety raised by Eugene Lallier, of Leavenworth, Fiansas. Specimens received from Dr.J. Stayman, who wites that the tree is moderately vigorous, forming a round head, unusually productive on rich bottom land, where nearly all others fitil, and has shown no symptow of blight or disease of any kind ; use, table and market.

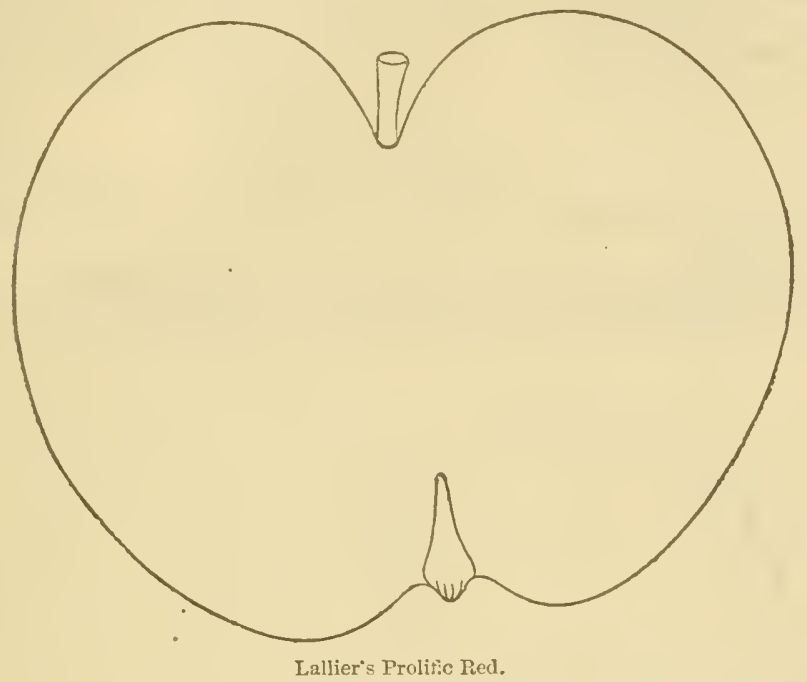

Fruit medium, oblate, slightly conical; skin pale greenish yellow, shaded with rather bright red, more or less faint stripes and splashes of rather dull red over most of the surface, and eovered with numerons light dots in the sun and grayish ones in the shade; stalk short; cavity medium to large, sometimes thinly russeted ; calyx closed, or nearly so; basin small or medium, slightly corrugated; flesh yellowish, half fine, crisp, teuder, juicy, milk, pleasant subacid; very good; core small. Octolber, February.

\section{L.AMBERT.}

Keasbey's Favorite.

Origin near Salem, N. J., on the premises of Jolnn H. Lambert. Tree very vigorous, rather upright, inclining to spread; a good bearer, and keepis well.

Fruit large, roundish, inclining to oblong, sliglitly conical; skin whitish yellow, nearly covered with pale light red and obscurely striped aud splashed with darker red and munerous light dots; stalk very short, small; cavity large, deep, russeterl; calyx large, closed; basin large, derp, corrugated; flesh whitish, half fine, rather firm, juicy, pleasant subacid, slightly aromatic; very good; core small. December to February. 


\section{Landsberger Reinette.}

\section{Reinette de Landsberg.}

Originated with Justrigrath Burchardt, Hanorer, Germany. Tree stroug, vigorous, spreading, very productive.

Fruit medinm to large, oblate, regular; skin smooth, golden yellow, sometimes a sliade of light red in the sun, and many light and brown dots; stalk long, slender; cavity medium, russet; calyx closed; basin medium, corrugated; flesh yellowish, fine, crisp, tender, juicr, lively subacid, rather rich; good to very good; core small. Novemher, Jairuary.

\section{LELIEUR.}

Of foreign origin and a promising variety. Tree vigorous, upright, very productive.

Fruit medium or above, roundish oblate, slightly angular; skin yellow, shaded, splashed, and striped with light and dark red over the eur-

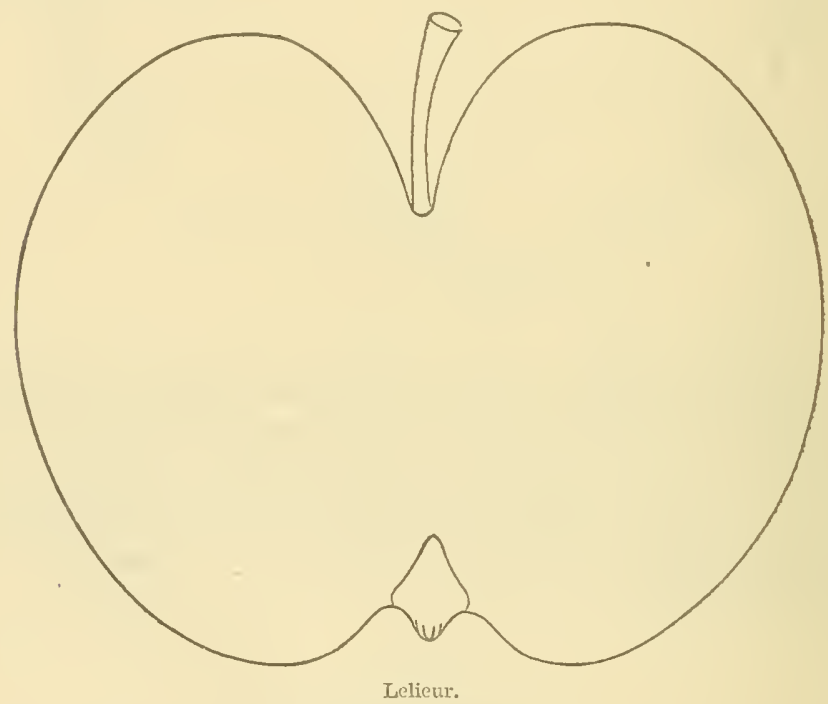

tire surface, and a few scattering light dots; stalk short, slencier; carity large, deep, a little greenish; calyx closed: basin qnite large, moilerateIy deep, slightly corrugated; flesh white, fine, tender, juicy, mild sub acil; good to rery good; core small. November, February.

\section{ToNG's Russet.}

Originated with the late J. S. Long, of Fairview, $K$ r.. and is consiclered one of the best late keeping apples for that locality. Tree vigo rous, upright, but spreading when in fruit, and makes a large liantsome tree; very productive annually; Joung shoots resldish brom, grayish. 
Fruit medium to large, oblate, slightly oblique; skin greenish, nt:t1Iy covered with rough dull russet; stalk very short; cavity rather lroal, decu; calyx open; basin malium, regular; flesh white, green tinge, half tine, moderately juicy, half tender, pleasant subacid; good; core suall March, April.

\section{MCAfEe's Nonsuchr}

IieAfee.

Mc.lfee's Red.

striped Peurmain.

Snorter.

Nonsuch

Zeeke.

Gray's Keeper.

Park's liceper.

Wyandotte.
Gray Aprle.
Indian.
Uncle Zeeke.
Winter Pearmain.
Large Striped Winter Pear-
main.
Striped Winter Pearmain.

Large Striped Pearmain.

Sitorr's Wine.

Missouri Superior.

New Missouri.

Talandingham's Wine.

White Crow.

Ladies' Favorite of some.

Hubbardston Nonsuch, erroneously.

As this and Striped Winter Pearmain in the second rerised edition have proved to be identical, we give a new description with the adulitional syus. An old rariety, which originated in the orchard of Cieorge Mcitee, near Harodshurg, Mencer Connty, Ky. We are indebted to Dị. William Howsley, of Leavenworth, Kansis, for its listory, origin, etc. Tree very vigorous, forming a round spreading head. It cloes not come early into bearing, but is rery productive when it attains some age. It is considerably grown through the West and South-west under the name of striped Winter Pearmain, also more or less by the syns. as given above. It is ralued in many localities as one of the best of its season; in others of but little value.

Fruit medium to lange, roundish oblate, inclining to conic; skin yellow, striped, splashed and marbled with light and dank bight reil nearly over the surface, yet showing the yellow ground nearly all though, thickly splinkled with large and small light dots, some areole; stalk short to l.my, slentex; carity large, deep, often thinly russeted; calyx snall, closed; basin rather smin], slightly plaited; Hesh yellowish, half tine, ('risp), tender, juicy, rich mild subacil, inclining to sweet, slightly aromatic; very good; core medium. October, February.

\section{Maxv.}

A chance seedling in the orchard of Julge Mooney, of Granby, $\mathrm{X} . \mathrm{Y}$. "Tree hardy, an upright grower, with rather slender branches, fuming a. romud heal; an early and annual bearer, a late keeper, valuable for market and cooking, and a fair table fruit.

Fruit medium to large, roundish oblate, nearly regular:; skin llece. yellow when fully ripe, often with a shate of brownish red where exposerl, and thickly sprinkled with hinht and gray dots, a few beingrg areole; stalk short, rather small; cavity medium or quite large, smmstimes slightly russeted; calyx generally closed; basin rather laroe, slightly corrugated; flesh yellowish, half tine, half tender, juicy, mild Ileasint subacid; good to very good; core medium. January, April, 


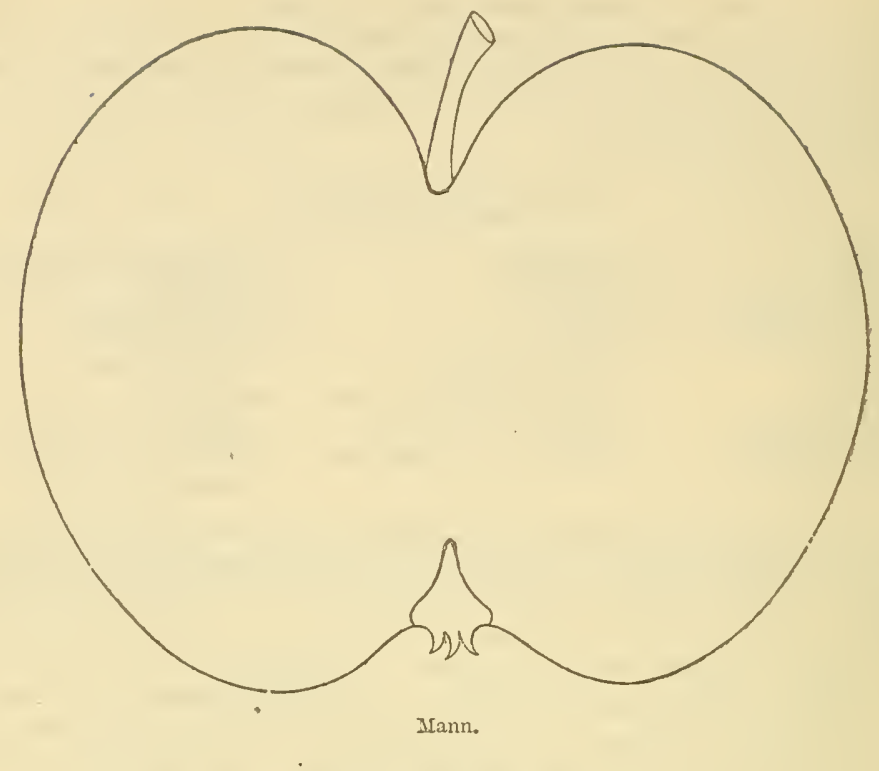

Marquis of Lorne.

Raised from seed of the Gravenstien by William Sutton, of Port

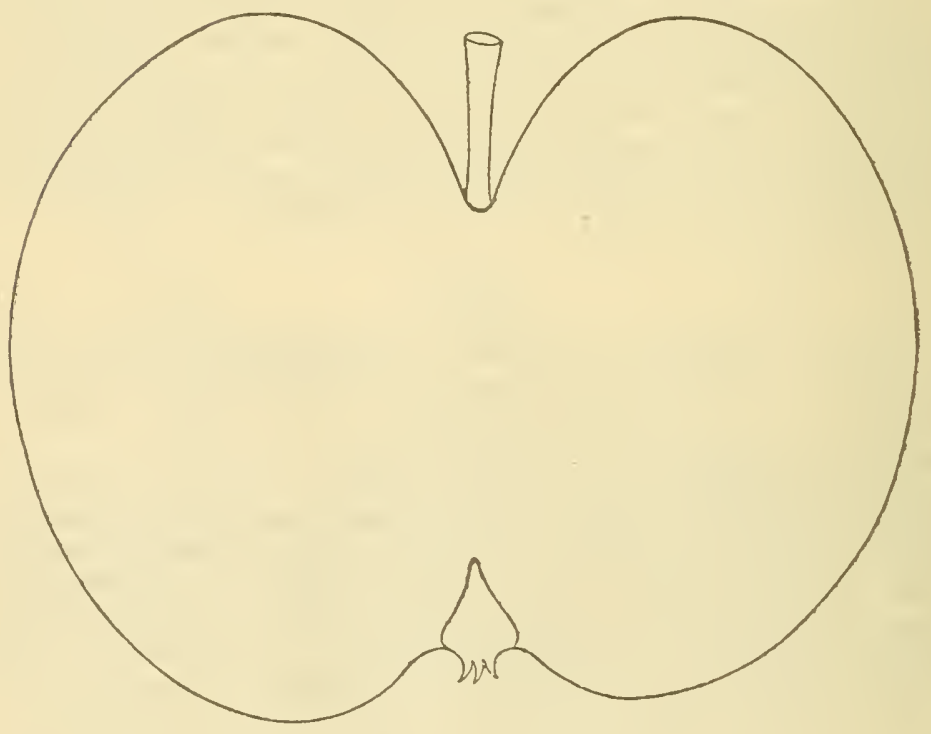

Marquis of Lorne.

Tilliams, Nova Scotia. Tree very rigorous, making a large spreading 
arear, it is rather late coming into hearing, but produces good crops anmaally when established; valuable for market and culinary uses.

Fruit large to very large, romblish oblate; skin smooth, whitish yellow, shaded, mottled, and a few broken splashes aurd stripes of light and lank bright red orer most of the surfice, with a few light and brown lots; stalk short; cavity large, deep, russeted; calyx large, open ; balsin large, inregnlar or ribbed; flesh white, rather coarse, breaking, tenker, juicy, lively subacid; good to very good; core medium. Norember:

\section{Masox's Stranǵer. \\ Mason's Pippin. Old Field. Izzard.}

A chance seedling found on the farn of Dr. George Mason, Virginia. Tree of vigorous growth, forming a large symmetric head, very productive amnually; a popular and favorite apple where it originater; young shoots brownish red.

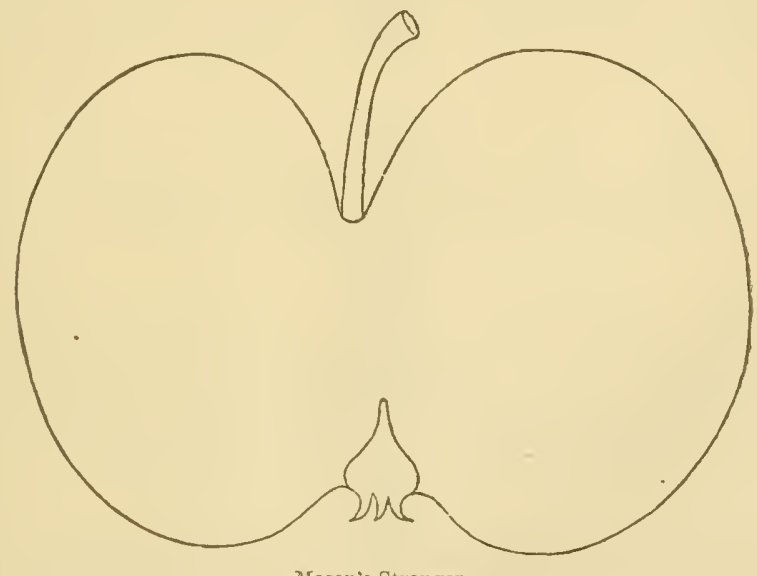

Mason's Stranger.

Fruit medium, oblate, somewhat depressed; skin light bright yellow, sometimes a sharle of light red where exposed to the sum, and a few brownish dots; stalk short, small; cavity large, slight russet; calyx open; basin large, deep, smooth; flesh whitish, fine, rather compact, crisp, juicy, mild subacid, inclining to sweet, somewhat spicy and rich; very good; core small. December, February.

\section{Missouri Pippin.}

\section{Missouri Keeper.}

It is said to have originated in the orchard of Brink Hornsby, Johnson County, iIo. Tree hardy, a strong upright, rather spreacling grower, an early and abundant annual bearer.

Fruit medium to large, rounclish oblate, slightly oblique, somewhar flattened at the ends; skin pale whitish yellow, shaded, striped anci 
splashed with light and dark ret, often quite dark in the sun, l aving ma1y large and small light and gray dots; stalk short, small; cavity large, deep ; calyx closed, or half open; basin rather abrupt, deep; slightly corrugated; Hesh whitish, a little coarse, crisp or breaking, moderately juicy, subacid; good; core small. January, April.

\section{Monte Bello.}

Originated with Natthew Gray, Riverside, Monte Bello Township: Ill. Tree rather upright, hardy, healthy, moderately vigorous, an early bearer, very productive annually, a new variety, and A. C. Hammond, from whom specimens were received, writes that he considers it an apple of great promise.

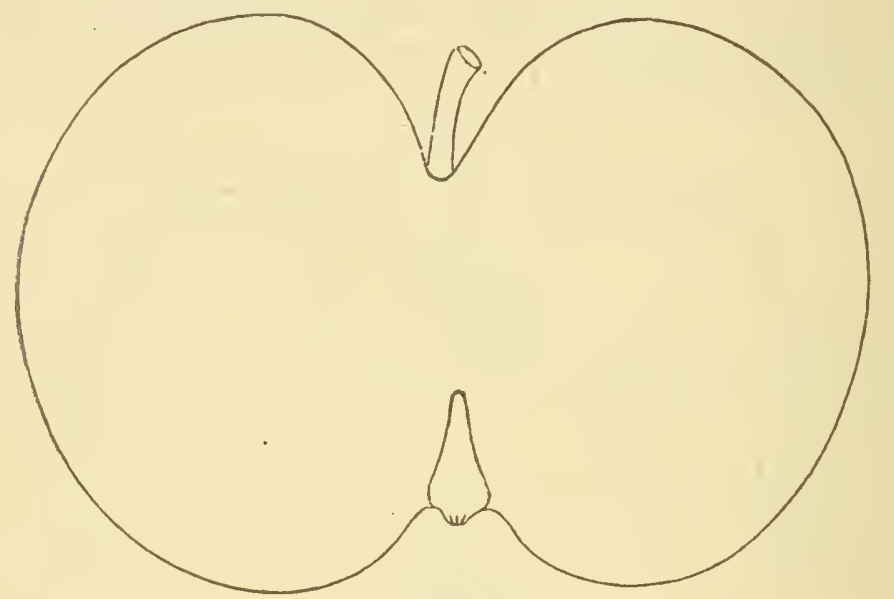

Sonte Bello.

Fruit above medium, oblate, regular; skin pale yellow, shaded and mottled with light red, striped and splashed with dark rich red orer the whole surface, and a few large light dots; stalk very short, small: cavity large, broad, russeted; calyx small, nearly closed; basin large, deep, smooth; flesh quite white, fine, sometimes a little stained next the skin, very tender, juicy, mild subacid, vinous; very good; core small or medium. September, Norember.

\section{MORGAN.}

Originated with Benjamin Morgan, Gloucester County, N. J., many years since. Tree a healthy moderate grower, not an early bearer, but produces good crops alternate years when the tree attains some age.

Fruit medium, roundish; skin pale greenish yellow, sometimes a shade of pale red in the sun, and many brown dots; stalk short, small; cavity small, often a little russeted; basin rather small, slightly corrugated; Hesh white, fine, tender, moderately juicy, pleasant, mild sub. acid; good; core.small. October, January. 


\section{Otoe Ren Streak.}

Originated with James H. Masters, Nebraska City, Otoe Counly, Nebraska. 'Tree an upright sprealing grower, forming a round heal; un carly and abmudant bearer anmually.

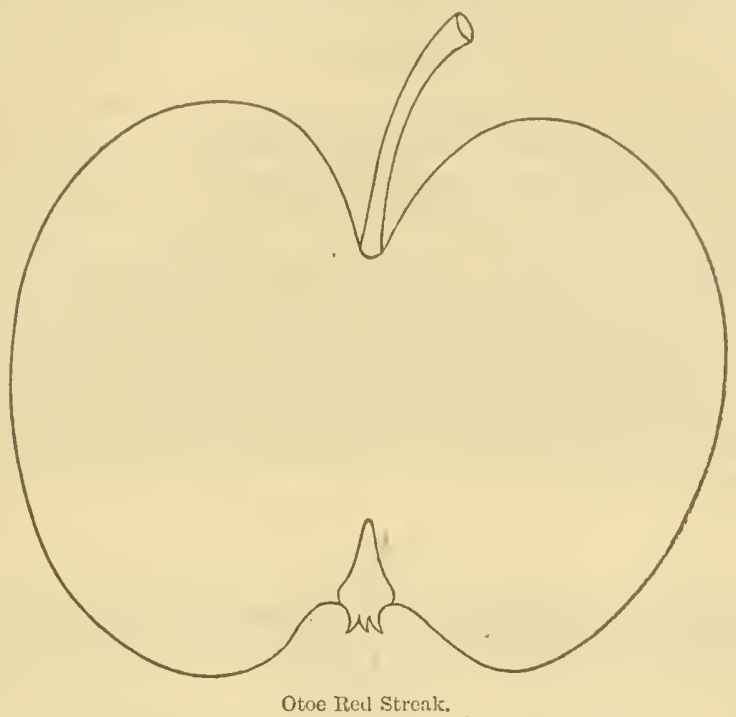

Fruit medium, roundish oblate, sides sometimes unequal; skin whitish yellow, nearly eovered with light red, many stripes and broken splashes of dark rich red, moderately sprinkled with light and grayish dots; stalk rather short, slender' ; cavity large, deep, russeted ; calvx closed; basin large, deep, very slightly corrugated; flesh quite white, sonetimes a little stained next the skin, crisp, tender, juiey, mild, sprrightly subacid; good to very good; core small. November, May.

\section{Parry's Winte.}

Inperial White. Superior White. White Apple.

Of unknown origin, sulposed to be Pennsylvania. Tree vigorous, upriglit, compact head, a regular bearer, and very produetive; use, talsle; cooking, anil market.

Fruit mediun or below, roundish oblate, slightly conie; skin smootl, whitish, sometimes a slight tinge of red in the sun; stalk short, suall; cavity large, deep; ealyx rlosed; basin rather shallow, a little uneven; Hesh fine, white, crisp, ver'y tender, juicy, subacid; good. August.

\section{Perle D'Axgleterre.}

Tearl of Fugland.

Of foreign origin. Tree a strong grower, productive.

Fruit medium or below, sides sometimes unequal; skin yellow; thiu!y 
shaded with light red, some rather obscure stripes and splashes, and many brown dots; stalk of medimm length, slender; cavity quite large, russetel; calyx large, open; basin large, broad, slightly corrugated; tlesh whitish, half fine, half tender, juicy, brisk subacid, rather rich; good to very good; core small. November, December.

\section{Pewauke.}

Raised from seed of Duchess of Oldenburg by George P. Pepper, of Pewankee, Wis., who sends us specimens, and writes that the tree is strong and vigorous, centre upright, very spreading, an anmual bearer, and one of the hardiest and best for the Northwest; young shoots dark brownish red.

Frnit medium to large, roundish oblate; skin bright yellow, striped, splashed and mottled with light and dark red over most of the surface, covered with a thin grayish bloom, and many large and small light clots, a few being areole; stalk short, small; cavity small ; calyx closed; basin medium, slightly corrugated; tlesh white, a little coarse, breaking, half tender, juicy, subacid, slightly aromatic; good; core small. Jauuary to May.

\section{Pilot.}

An accidental seedling, found on the premises of John Robbins, at the foot of Pilot Mountain, Nelson County, Va. Tree liarly, of mod-

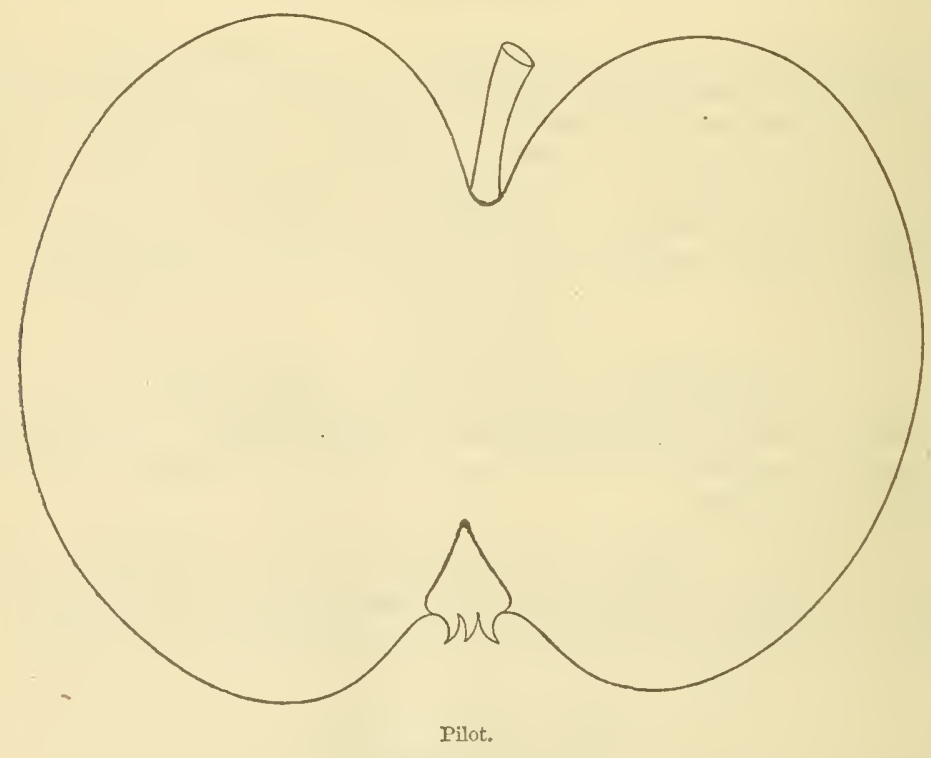

erate growth, forming a round head, rather slow coming into bearing, but when establishel pioduces large crops alternate years, ant a few the 
intervening ones, and is considerer a valuable variety in its locality; young shoots recldish brown.

Fruit large, roundish oblate, slightly angular; skin pale yellowish green, shaded, splashed and striped with pale dull red nearly over the surfuce, and thickly sprinkled with large areole dots; stalk short, small; cavity rather large; calyx half closed; basin large, deep, smootl, ; Hesh yellowish white, fine, rather firm, tender, juicy, rich subacid, slightly aromatic; very good; core small. December, January.

\section{Pomme Grise D'Or.}

\section{Swazie Pomme Grise.}

An old variety of unknown origin. I am informed it is consider. ably grown in Canada and some portions of Western New York, and there were trees of it near Niagara on the Colonel Swazie farm-wher it probably originated-two feet in diameter. Tree harly, upright, moderately vigorous, and a good bearer every other year. The firuit is more oblong, more golden in color, and more aromatic than the lomme Grise, and is considered superior to it.

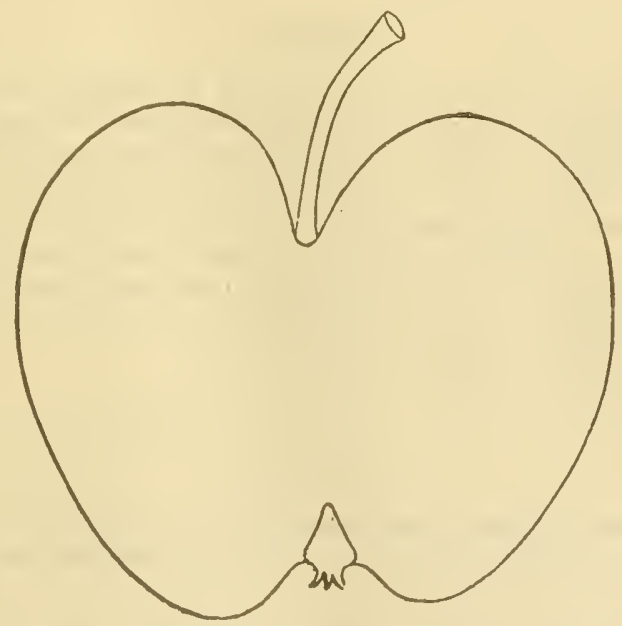

Pomme Grise d'Or.

Fruit small, oblate, or roundish ol)late, conical; skin deep rellow, covered with a thin light cinnamon grayish russet, and many rather obscure light dots; stalk short to long, slender; cavity rather broat, deep; calyx closed; basin quite large, deep, slightly corrugated; fleshl whitish, fine, tender, juicy, mild subacid, rich and aromatic; very good or best; core rather small. January to March or April.

\section{Presh's Wixter.}

Originated at the Forest Nursery of J. S. Downer \& Son, of Fail. view, Todd County, Ky., who write tliat the tree is a good grower, "1. 
right, rather irregular, very productive alternate seasons, and an excellent winter apple; young shoots reeldish brown.

Fruit medium to large roundish, slightly conic; skin pale yellow, shauled with dark red in the sun, thinly shaded and rather obscurely and faintly splashed and striped in the shade, moderately sprinkled with liglit dots; stalk short, small; cavity medium, considerably russeted; calyx open; basin quite large, deep, smooth ; flesh yellowish, fine, a li:tle firm, crisp, juicy, pleasant subacid, vinous; very good; core small. December, March.

\section{Princeton.}

Origin, Massachusetts. Tree a vigorous grower, spreading; a good bearer alteruate years.

Fruit medium, oblate, slightly angular; skin pale yellow, shaded, striped and splashed with light and dark red over most of the surface, a few light and gray dots; stalk short, small; cavity medium, smooth, sometimes thinly russeted; calyx closed; basin large, deep, a little uneven; flesh white, fine, tender, juicy, pleasant subacid; good to very good; core medium. October, January.

\section{Reliance.}

Origin, Berlin, Wis.; received from G. N. Snith, who writes that it is valuable for that locality for its hardiness, vigor, and productiveness.

Fruit conical, or oblong conical, slightly ribbed, or with broad shallow furrows; skin pale light yellow with broken stripes and shades of leep red where fully exposed; stalk short; cavity deep, open, slight greenish russet; calyx nearly closed; basin deep, broad, open, with many small sharp furrows; flesh white, half fine, tender, moderately juicy, mild subacid; good to very good; core rather open at centre. Jawuary to Mirch.-(Rural New-Yorker.)

\section{Ripley.}

Ripley's Claret.

This is said to have been raised by N. I. Riples, of Collinsville, Madison Connty, Tll. Tree said to be thrifty, well shaped and tolerably productive.

Fruit medium to large, oblate, somewhat conical, sicles nuequal; skin smooth and shining, greenish gromul, nearly covered with a brilliant crimson and marked with numerous white dots: stem medium length, slender; calyx large, closed; flesh white, tim, moderately juicy, subacid; very good; core rather small and closed. Septem. ber. (IV. C. Flagg, in Journal of ITorticulture.)

\section{Rochester Pippin.}

A hybrid raised by Jacob MLore, of Rochester, N. Y., and judging from the specimens received, being of large size and excellent quality, is a very promising winter variety.

Fruit large, roundish oblate, nearly regular; skin smooth, pale greenish yellow, shaded with light brownish red in the sun, and a few 
grecnish dots; stalk short, sma.l; cavity large, smooth, a littie greernish; calyx closed; basin medimm or rather large, smooth; flesh whitish, fine, crisp, tender, juicy, vinous refreshing flavor, slightly aromatic and rich ; rery good or best; core small. danuary, March.

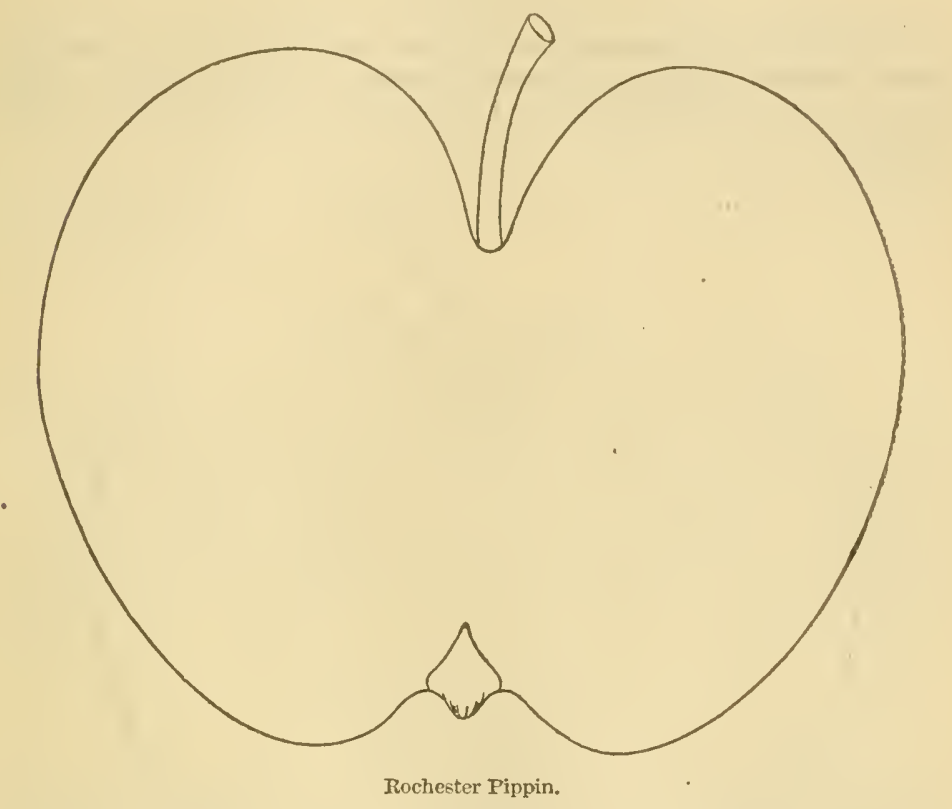

Rose-Bud.

Origin unknown, supposed to be New Castle County, Del. Tree a strong, vigorous grower, forming a round, rather spreading top, very productive : fruit hangs firmly to the tree, keeps well, and is useful for the table and kitchen.

Fruit medium, roundish oblate, slightly angular; skin yellowish, shaded and rather obscurely splashed and striped with light and dark red nearly over the surface, and moderately sprinkled with quite large light dots : stalk of medium length, slender; cavity rather large, often slightly russeted; calyx closed; basin broad, moderately deep; Hesh. whitish yellow, half fine, breaking, juicy, mild subacid; good; core small. Iecember, March.

\section{Tiose BeE.}

Originated with John Rose, Toudon, Mercer County, Pr. Tree rigorous, upright, a good bearer altelnate years, and some the intervening ones.

Fruit medium, roundish oblate, inclining to conic, slightly angular; skin pale whitish yellow, sharled with light red, stripert and splashed with dark red, sometimes almost purplish, and a few light dots; stalk sluort, rather stout; cavity rather small, often russeted; calyx closed; 
basin small, slightly comugated; flesh quite white, sometimes a littlo stained next the skin, half fine, tender, moderately juicy, brisk subacirl: good ; core medium. October, Jamury.

\section{Rose Red.}

Of unknown origin, supposed to be on the farm formerly owned by Gideon Ramsdell, Egypt, Monroe County, N. Y. Tree a tly ifty, strong grower, upright, inclining to spread; very productive and regrtlar bearer.

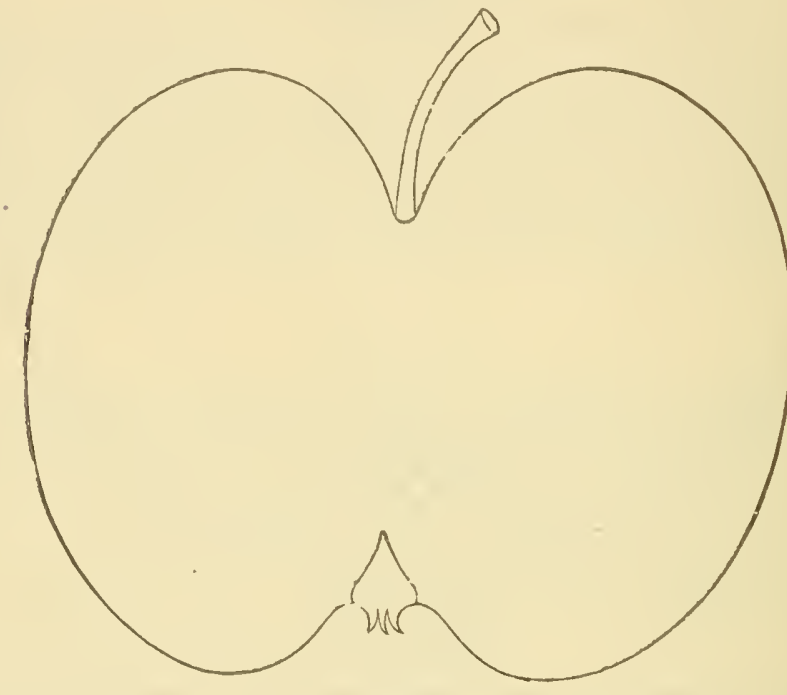

Rose Red.

Fruit medium, oblate, or roundish oblate; skin whitish, shaded, striped and splashed with light and dark red, sometimes quite lark, nearly over the whole surface, many light dots, a portion being areole; stalk short, small; cavity large, deep, smooth, a little greenish; calyx half closed; basin large, deep ; flesh yellowish, fine, very tender, juicy, vinous, lively subacid; rery good; core small. Niddle of September and November.

\section{Seáger.}

The original tree grows on land owned by the Indians near Lumberville, Bncks Countr, Pa. Tree vigorous, upright, productive; roung shoots dark brown, burls large, long. prominent.

Fruit medium, oblate, inclining to conic, slightly angular; skin pale jellow, shaded, striped and splashed with light and dark rich red, some of the splashes quite broad and broken, and a few light dots; stalk rather long, slender, curved; cavity large, deep; calyx closed: hasin aredium, corrugated; flesh white, tender, juicy, rather rich, mild sulm 
acid; good to very good; eore rather small. Last of August and september.

\section{Scirurler's SWEet.}

Originated on the farm of Rensseluer Sehuyler, Seneca Falls, N. I. Tree vigorous, spreading, open hearl, a regular bearer, and productive.

Fruit large, rommlish or loundish oluate, shightly conic, slightly angular; skin jale yellow, a few seattering brown dots; stalk rather short, slender; carity large, deep; calyx closed; basin large, deep, slightly corngatel; flesh white, half tine, teucler, morlerately juicy, mild, pleasant sweet, slightly aromatic; good to very good; core smail. September, October.

\section{Scribner Spitzenburgh.}

Originated on the farm of Elijah Seribner, Plattsburgh, N. Y. Tree vigorons, spreacling, very productive alternate years.

Fruit medium, roundish conical, angular; skin pale yellow, shaded with bright deep red in the sum, sometimes obseme stripes and splashes and pretty thickly sprinkled with light dots; stalk short, moderately stout; cavity rather narrow, deep; calyx half elosed; basin medium, furrowed; flesh whitish yellow, half fine, crisp, tender, juiey, subacid, slightly aromatic; good to rery good; core small. Deember; February

\section{Shermax's Favorite.}

Sherman's Sreet.

Originated on the farm now owned by E. C. Slerman, of Wyoming, N. Y. Tree vigorous, rather spreading, very productive alternate years.

Fxuit medium or above, oblate, angular or slightly ribbed; skin greenish yellow, sometimes brownish red in the sum, moderately sprinkled with light and gray dots; stalk rather long, sleniler; eavity broad, not rery deep, a little greenish ; calyx closed ; basin broad, rather deep; flesh a little coarse, half tender, crisp, juicy, mild, rather lieh sweet; good to very good; core medium. November, January.

\section{Sillix.}

Oriminated on the farm of Thomas Sillix, Manellan Township, Pa. Tree moderately vigorous, upuight, somewhat spreading, not an early harex, but very productive alternate years when the tree has attained some age.

Fruit below medium, roundish, regular; skin pale rellow, sharied with light and dark rich red orer half or more of the surface, obsemrely splashed and striped, and eovered with numerous smáll light and gray dots; stalk short, small ; carity small, smooth ; calyx half elosed ; basin medium, slightly corrugated; flesh yellow, fine, compact, moderately juiey, mild subacid, almost sweet, quite rieh; very good; core small December, Narch. 


\section{SOMERSET.}

Of uncertain origin; supposed to have originated in the torn of Somerset, N. Y. Tree vigorous, spreading; an annual bearer, but

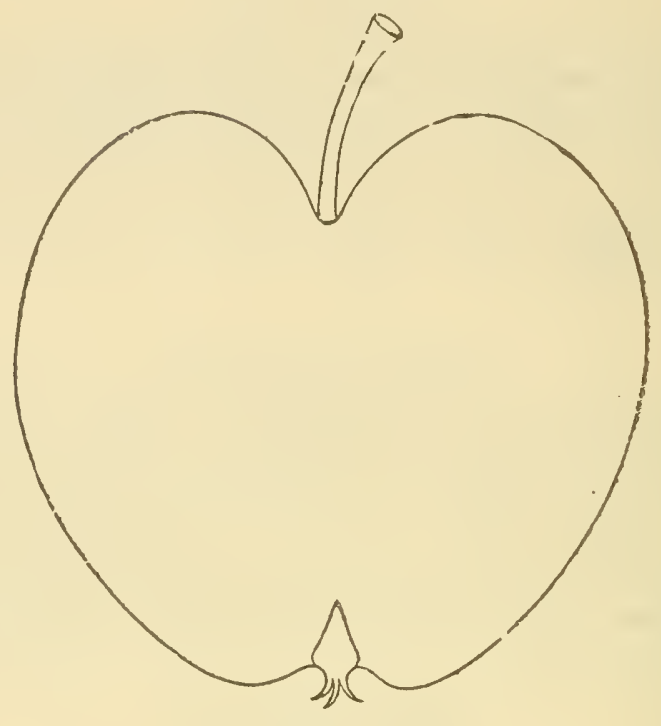

Somerset.

heavier crops every ather year; a rich, high-flavored apple, desirable for family use.

Fruit below medium, roundish conical, much narrowed towards the calyx; skin whitish yellow, some nettings and patches of russet, and a few brown dots; stalk of medium length, slender; cavity medium; calyx closed; basin small, corrugated; flesh quite white, fine, very tender, juicy, rich, highly aromatic; very goad or best; core medium, October.

\section{SOULARD,}

Raised by Antoine Lessieur, of Portage des Sioux, a few miles above St. Louis, Mo. Tree very vigorous, ripright, slightly spreading when in fruit; an early and abundant bearer. This is highly prized in the neigliborhood of its origin.

Fruit medium to large, oblate, slightly conic, slightly angular, or obscurely ribled; skin whitish, shaded, striped and splashed with light and dark bright red over most of the surface, with a few light and brown dots; stalk short, small; eavity quite large, slight russet; basin mediun, corrugated; flesh quite white, very tender, rery juics, spriglitly subacid, vinous; very good; core rather large. October, Norember.

\section{STARR。}

This large early apple was an accidental seedling on the premises of the late John Starr, of Woodbury, N. J. The tree is said to bre of 
rigorous grower, forming a round, somewhat spreading head; branches malher slender; a regular and abundant bearer; valuable as an early

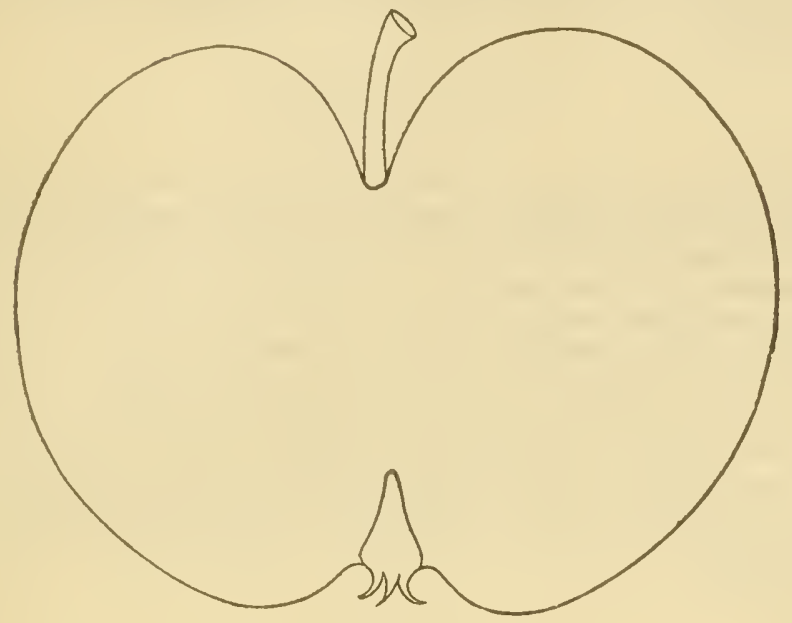

Soulard.

market sort, and for culinary uses; young wood light reddish yellow brorra, buds prominent.

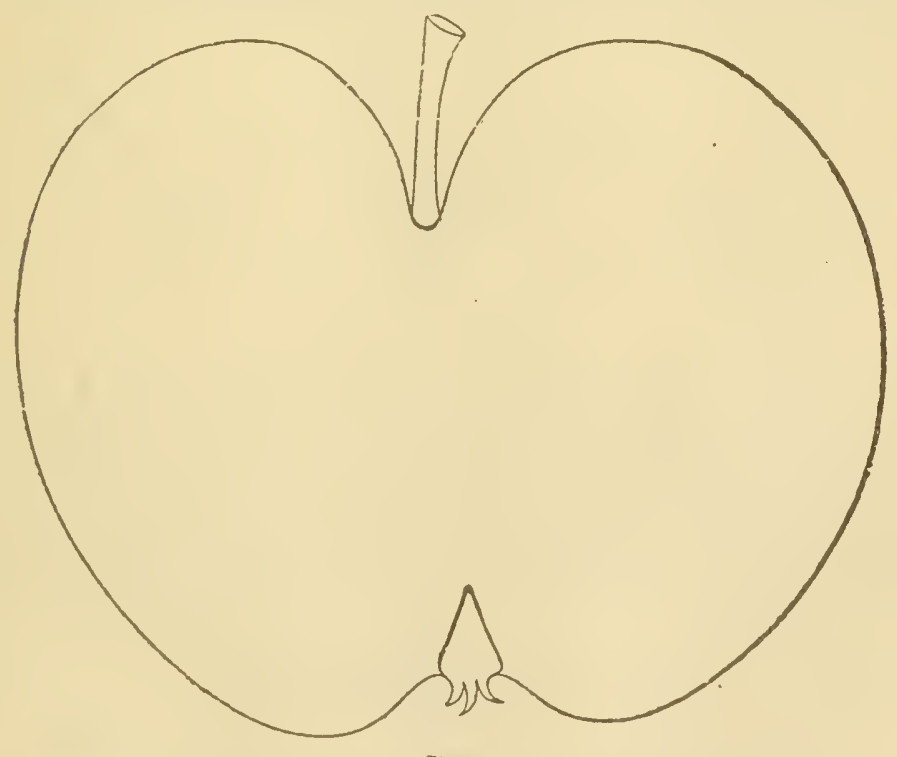

Starr.

Fmit large, roundish oblate, obscurely ribbed ; skin greenish white, or pale yellow at full maturity, sometimes a shade of light red in the sun; 
moderately sprinkled with light and gray dots; stalk short; cavit large, deep; calyx closed; basin of medium size. slightly cormugated, flesh whitish, half fine, crisp, tender, juicy, sprightly subacid; good to very good; core medinm; ripens from the middle of July to the middle of september.

\section{Stamiay's Summer.}

Originated on the grounds of Dr. J. Stayman, Leavenworth, Kansas. Tree hardy, vigorous, spreading, irregular, tough, wiry, droops like a weeping willow with ropes of fuit, never breaking a limb; an early bearer and very productive, very nearly equal to Benoni and Sum. mer Pearmain, and handsomer.

Fruit medium, round, regular, approaching conic; skin smooth, greenish yellow, splashed and striped with red and jurple, covered with a white bloom; dots small, gl'ay, scattered; stem medium, rather slender; cavity narrow, deep, inregular, russeted; eye very small, closed; basin narrow, shallow, furrowed; core small, slightiy open ; flesl greenish white, very. juicy, brittle, sprightly, high flavored, mild acid; very good; use, kitchen, table, and market. August, September.--(W'estern Pomologist.)

\section{STRIBLING。}

Originated with the late William Stribling, Medon, Tenn. Tree a good grower, rather upriglit, forming a regular round liead; an early amulal and abundant bearer; young shoots reddish brown.

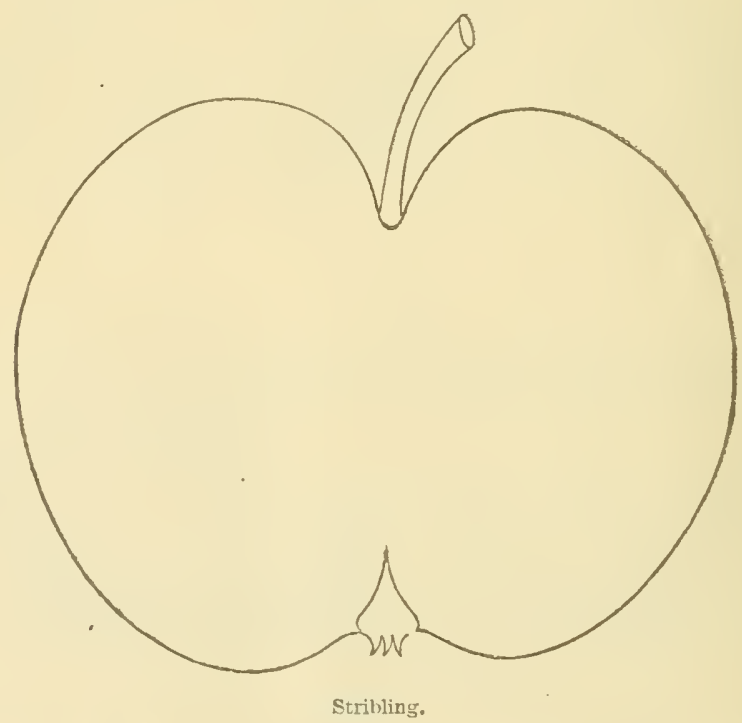

Fruit medium, oblate, slightly angular; skin whitish, neadly corered with stripes and splashes of light and dark rich red-sone of the 
splashes almost purplish with rather conspicuous yellow dots; stalk short, small; cavity medium; calrx half open; basin rather small, slightly corrugated; flesh white, tricletr, molerately juicy, mild pleasant subacid; grood to very good. July at the South.

\section{Striped Siweet Pippix.}

\section{Striped Pippin.}

An old variety of nuknown origin, and was given as a syn. in formen editions of this work to Striped Winter Pearmain, but has proved distinct. Tree vigorous, forming a rouml, rather low head; an eurly and abundint bearer, but more hearily alternate years; valuable for table or market; young shoots olive brown, slightly downy at the end.

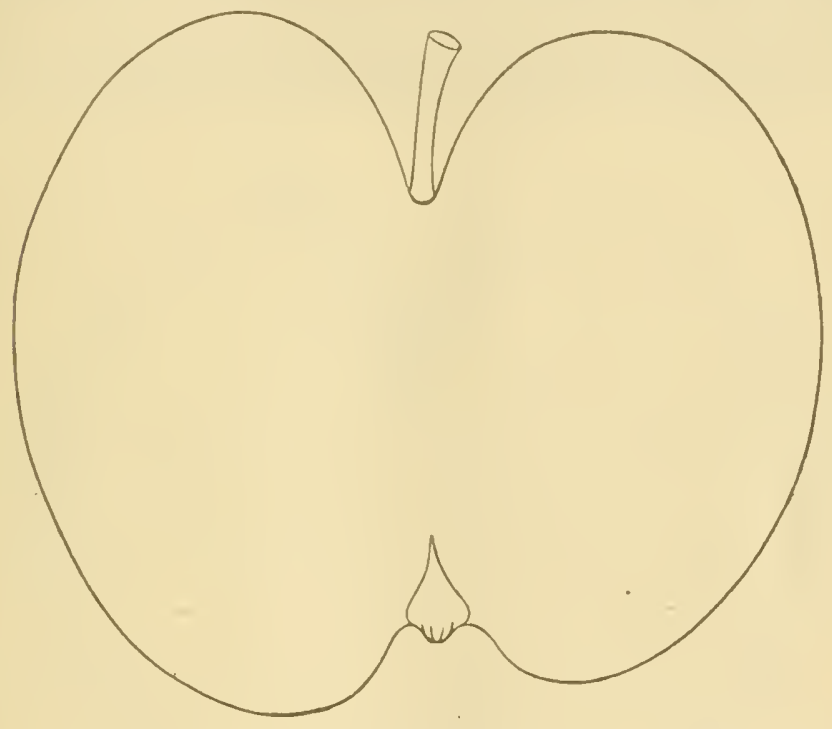

Striped Sweet Pippin.

Fruit rather large, roundish oblate, shightly angular; skin bright vellow, sharled with dark rich red in the sun, striped, sulashed and inottled with lighter red on the shaded side, and many light and gray rlots; stalk sliort, small; cavity rather large, deep; calyx closed; basin (juite deep, rather abrupt, a little uneven; flesh white, fine, tender, juicy, mili, pleasant rich.sweet, or very mild subacid; very good; core lather large. November, February.

\section{Sumer Kíng.}

King.

Puchett's Summex.
Puckett.

An old variety supposed to have originated in North Carolina, and has been cultivated in Warren and Torld Counties, hy., for many year's, 
where it is highly prized as one of their best and liandsomest apples of its scason. Tree upright, moderate grower, and productive alternate. years: young shoots reddish brown, grayish.

Fruit medium to large, roundish oblate; skin yellowish green, striped with crimson, red and orange; stalk short; cavity large, deep, russeted; calyx closed; basin medium, regular; flesh whitish, yellow, fine, brittle, juicy, mild agreeable subacid flavor; core small. August, September. (Western Gardener.)

\section{Summer Spitzenburgh.}

French Spitzenburgh.

Originated with Woolsey Ostrander, Plattekill, N. Y. Tree moderately vigorous, forming a round head; an early and abundant bearer anmually.

Fruit medium, roundish conical, slightly angular; skin whitish, almost entirely covered with two shades of red in stripes and splashes,

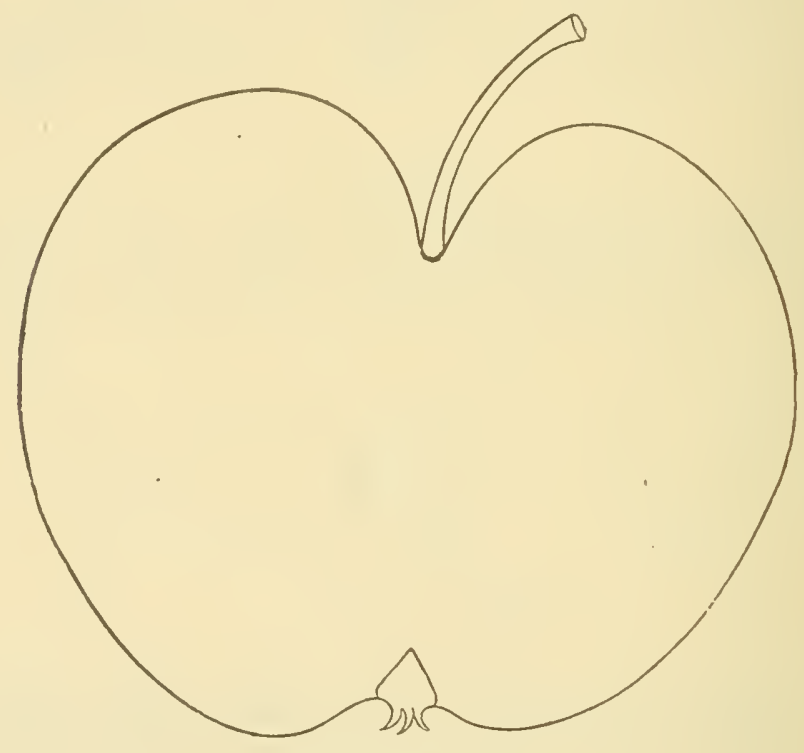

Summer Spitzenburgh.

some of which are quite dark, and covered with a thin hloom; stalk short; cavity mẻdium, sometimes slightly russeted; calyx closed; bitrin nedium, slightly corrugated; flesh yellowish white, half tender, mocler. sately juicy, subacid, and a little aromatic; good to very goou. August, September.

\section{TUTTLE.}

Originated on the farm, of Lyman Tuttle, Hamden, Comn. Tree upright, vigorous, an early and abundant bearer erery other year of fair 
fruit, and ralued in its locality for market and family use; yourg shoots dark brown, miny light grayish dots.

Fruit medium, roundish oblate eonie, sides sometimes umequal ; skin pale yellow, shaded, striped and splashed with light and dark red, nearly corering the fruit, and moderately sprinkled with light russet and gray dots; stalk medium, slender; cavity large, russeter, sometimes extending in rays on the base; calyx closed; basin small, slightly cor'ugated; tlesh whitish, fine, tender, juicy, mild pleasant subacid; very good; core medium. December, March.

\section{WVEATHIY.}

A new variety, raised by Peter M. Gideon, of Excelsior, near St. Paul, Iinn. So far the tree has proved hardy, healthy, vigorous, spreading, very productive; a beantiful and excellent fruit.

Fruit medium, oblate, or roundish oblate; skin smooth, whitish rellow, shaded with deep rich red in the sun, obscure broken strijes,

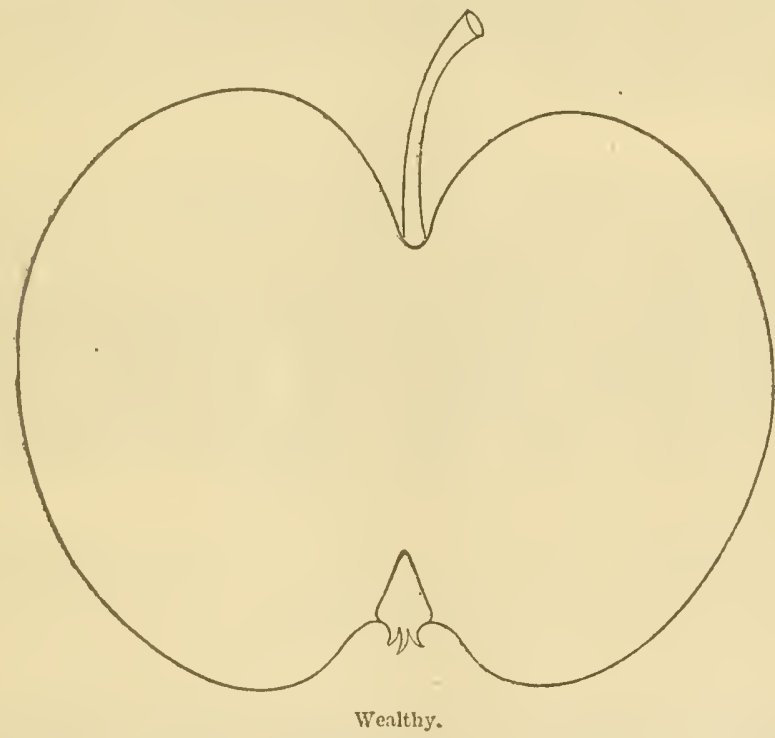

splashes and mottlings in the shade, sometimes entirely covererl with crimson, and many light dots; stalk short to medium, slender; cavity large, green russet; calyx partially closed; basin deep, abruj, uneren; flesh white, fine, sometimes stained with red, tender, juicy, vinous, lively subacid; very good; core small. December, February.

\section{Western Beauty.}

Musgrove's Cooper. Big Rambo. Ohio Benuty.

Origin unknown. William T. English, of Rlinehart, O., seens to have brought it into notice, and furrished us specimens. Tree very 
vigurons, making a large, spreating, open head; an early and good bearer.

Fruit large to very large, roundish oblate, regular; skin pale yellow, shalded with bright red in the sum, some rather obscure splashes and stripes of light red in the shade, thickly sprinkled with large light and gray dots, the light oues being areole; stalk of medium lengtli, slenrler; carvity large, sometimes light russet; calyx large, closed; basin large, broul, slightly corrugated; flesh whitish yellow, coarse, crisp, tender, juicy, mild subacid; good to very good; core rather small. October, February.

\section{WHITESCARVER.}

Originated with R. A. Whitescarver, of Lawrel Mills, Ta., who informs me that the tree is vicorous, rather spreading or round head, in early and good bearer ammually, but more so alternate years.

Fruit medium, roundish oblate; skin pale vellowish green, a few light dots, a portion being areole; stalk short; cavity narlow; calyx small; basin broad, moderately deep; flesh yellowish white, half fine, crisp; tender, juicy, pleasant subacid; very good; core large, open. November, December.

\section{YORK STRIPE.}

Origin York County, Pa. Tree morlerately rigorous, spreading, an early bearer, and rery productive alternate years.

Fruit rather large, roundish, slightly conic, slightly angular; skin pale whitish yellow, shaded and rather thinly striped and splashed with light bright red over the whole surface, but quite faintly on the side least exposed to the sun; stalk short, small; cavity large, deep, a.little - greenish; calyx open or half closed; basin large, deep, slightly corrugated; flesh white, rather coarse, breaking, moderately juicy, wild subacid; good; core small. January, February.

\section{SIBFRIAN CRABS AND IMPROYED SIBERIAN APPLES.}

\section{Batuey"s Crumsox Crab.}

Raised by Tilliam H. Bailey, of Plattsburgh, N. Y. Tree vigor. ous, upright; vers productive.

Fruit large for a silherian, roundish, very slightly conie: skin vellow, shaded over the whole surface with deep rich cimsci. almosi fmplish in the sun, and covered with a light bloom; stalk short to lons, slender, in a medium or small eavity; basin rather shallow, corrugated; Hlesh yellow, juicy, subacid and astringent. September. 


\section{Brier's s'll Eet Crab.}

Originated with B. B. Brier, of Barabon, Wis. Is the result of a fertilizition of the Siberian ('rab with the Bailey apple. T'ree perfectly hatrly, vigorous and productive.

Fruit as large as the "1ranseenlent; shaped like the Bailey Sweet; solor pale yellow, heantifully pencilled and splasherl with carmine; Hesh yellowish, crisp, juiey, very sweet and rich; quality best for dessert or presterves. (A. G. Tuttle, Minuscript.)

\section{LADY ELGIN. \\ Genera. \\ Marengo Siberian, No. 4.}

This beantiful new Siberian apple originated on the farm of James Forbes, of Rililott Township, Ill. 'T'ree hardy, vigorous, upright, slemder' branches, very productive, a pleasant dessert fruit, and said to be excellent for emning; the slight acid or vinons flavor being preferred by some to the rich sweet of the peach.

Frnit large for a siberian, roundish oblate, regular; skin smooth, whitish vellow, nearly covered with bright rich red, a few light and graly dots; stalk medium, slender ; cavity small; calyx closed; basin sliallow, corrugated; flesh white, fine, tender, juicy, mild subacid, slightly vinous; very good. September, December.

\section{Mackie's Beacty Siberian.}

Originated with Mattlew Mackie, Clycle, N. Y. Tree vigorous; very productive.

Fruit large of its class, roundish oblate; skin whitish, nearly covered with deep rich real, a light grayish bloom, and a few light dots; stalk rather long, slender; cavity quite large; ealyx elosed; basin broad, rather shallow, corrugated; flesh white, crisp', tender, moderately juicy, subacid, a little astringent. September.

\section{Syluar Slieet Cirab.}

Raised by Mrs. C. P. Alling, Sylvan, Richland County, Wis., from seed of siberian Cral, and A. L. Hateh, of that town, describes the tree as vigorous, handsome, and suited to a northern latitude; he says the fish is tender, juicy, and sweet, and thinks it would make good eider.

Fruit large, two inclies or more in cliameter, ronmelish oblate; skin smooth, light yellow, nearly covered with bright red; stalk long, slender ; cavity medium; basin ratlıcr small; flesh yellowish, tender, juicy, mile, pleasant sweet; core rather large; rijens last of August and first of september. (Pomologist and Gurdener.)

\section{Vay Wrok's SibertaN.}

A chance seedling on the farm of Miss Caroline Van Wyek, Fishkill, Thutchess County, N. Y. 'Jree vigorous, upright, productive.

Fruit lange for at Siberian, roundisl, slightly conie; skin smootl, whitich, sharled amb nottlerl with light bright red, and covered with a thin blomm: stalk rather long, slender" cavity rather narow, deep); ealyx closed ; basin medimm, smooth; flesh whitish. fine, rather firm, moderately juicy, lather rich, honeyed sweet; good; core small and elosen sieptember. 



\section{SECOND APPENDIX TO}

SECOND REVISED EDITION.

The publishers of Downing's Fruit and Fruit-Trees have requested me to give them a short Appendix containing some of the new fruits, with the additional synonyms, corrections, etc. Further corrections, with at more complete list of new fruits, must airait a complete: rerision of the whole work; and this I hope to be abse to accomplish if my life and health are spared, at it future day.

I again thank the many Pomologists and Fruit Growers in various parts of the country for information and specimens of fruit relating to many of the varietic: in this $\Lambda$ ppendix; their names will be duly acknowledged when the third revision of the work is issued.

Cifarles Downisia.

NEWBUrga, March, 1876. 



\section{THE APPLE.}

Amsterday Sweet.

High Top Sweet, incorrectly.

Origix, Amsterdam, N. Y., on the farm of Joseph Britten. Tree hardy ; a vigorous, stout, upright grower; an early and moderate bearer minually.

Fruit medium, roundish oblate, a little flattened at the ends; skin pale greenish yellow, striped and splashed with light and dark bright red; stalk short, small; cavity meelium; basin large, deep, sliglitly plaited; flesh white, half fine, tender, juicy, rather rich sweet, slightly aromatic; core medium. October, November.

\section{Annette.}

\section{Annate. Old Bettie. Bettie Brooks.}

Of unknown origin, received from John Dollins, Greenwood, Virginia, who informs us that it was found in that locality in the late Nicholas Merritt's orchard a half a century ago; tree vigorous, with an up,right, round, compact head, requiring but little pruning-one of the most valuable of its season for its locality.

Fruit medium, oblate, sides sometines unequal, slightly angular; skin pale greenish yellow, rarely with a blush; stalk very short, small; cavity large, deep, slight russet; lasin, broad, deen, a little meven; flesli white, half fine, brittle, tender, moderately juicy, mild, pleasant, subacid. September, October.

\section{Arsold's BeAutY.}

This fine new apple was raised from seed of the Northern Spy, crossed with the Wagener and Spitzenberg, by Charles A rnold, of Paris, 
Ontario. Mrr. Arnold states that the tree is hardy, an excellent "u' right grower, forming maturally a symmetric head, and bearing alun. diuntly.

Fruit medium, oblate, slightly angular; skin bright yellow, occasion ally a shade of bright red, and a few brown dots; stalk medium, slender; cavity large, deep, sometimes slight russet; calyx closed; basin, deep, ronnd, slightly plaited; flesh pale yellow, fine, rather firm, juicy, rick subacid, and slightly aromatic; core small. January, May.

\section{BAptist.}

Origin, Clinton, Kentucky, but by whom is not known; tree vigorous, spreading, and an abundant bearer alternate years; not a good market variety, but valuable as a table.and family apple.

Fruit medium, oblate, somewhat depressed; sides sometimes unequal; skin yellow, entirely covered with dark red, a few faint splashes on the shaded side, and many yellowish and brown dots; stalk very short, rather stout; cavity broad, deep, russeted ; calyx half open ; basin large, broal, deep, slightly wrinkled; flesh whitish, half fine, tender, moderately juicy, very mild subacid, inclining to sweet; core suall. Decem ber, February.

\section{BERGEN.}

Origin, on the farm of Jessie Griswold, Bergen, N. Y.; tree hardy, vigolous, with an open spreading head, requiring but little pruning; a full beaser alternate years, and a light crop the intervening ones; a good table apple, but more valued for culinary uses.

Fruit medium, roundish; a little angular; skin greenish white, shaded, silashed anıl marbled with light and clark red over half the snrface; stalk short, slender; cavity small; calyx small, closed; basin rather small, corrugated; flesh white, fine, tender, juicy, mild subacid, slightly aromatic; core medium. January, February.

\section{Berkshire Spt.}

A new variety, raised by Asahel Foote, of Williaustown, Mass., from seed of Northern Suy; tree of modlerate rigor, spreading, wood of great solidity; a moderate annual bearer. Mr. Foote has raised several promising apples, pears and plums which are worthy of trial.

Fruit medium, roundish conical, sides sometimes mequal: skin pale yellow, shadec on one sicle with light bright red, sometimes a few rather olsscure strijes and splashes of a darker hne, and a few light dots: stalk short, small; cavity medium, greenish russet; calyx open with short and livided seguments; basin medium, slightly corrugated; flesh whitish yellow, fine, tender, juicy, sprightly subacid, slightly aromatic and rich; core small. December, February. 
BLACK's ANNETTE.

Cornell's Early. Cornell's Farorite.

Of unknown origin, supposed to be Virginia; tree vigorous, spreading, rery productive alternate years.

Fruit medium or below, romdish oblate conical; skin whitish yellow; sialk slıort to long, slender; "avity large, dee r; calyx small, closed; busin rather small, slightly corrugated; Hesh white, fine, tender, modciatuly juicy, sprightly subacid; core small. August.

\section{Black Hawk.}

Originated in the orchard of William Brooks, Rock Island, Illinois; tree moderately vigorous, with a round rather spreading head; blooms lite; an annual bearer of good crops, some seasons very large ones; viluable as a late keejer.

Fruit rather large, oblate; skin greenish yellow, nearly covered with dull red or purplish red in the sun, a few rather obscure stripes and splashes, and a few light dots ; flesh whitish, rather coarse, firm, morlerately juicy, mild subacid; core small. Jamuary, April.

\section{Blue Spitzendurg.}

\section{Improved Red Spitzenberg.}

Origin, Oley Township, Pa.; tree moderately vigorous, making a round head; not an early bearer, but produces good erojs altemate yeurs when a little advancer.

Fruit medium or above, romulish oblate, slightly conic, sometimes a little oblique; skin pale whitish yellow, nearly covered with light and dark red, sometimes a few rather obscure stripes and splaslies, and many large and small light dots; stalk short, small; cavity medium, slight russet; calyx closed or nearly so; basin medium, corrugated; flesh whitish yellow, half fine, tender, moderately juicy, mild subacid, slightly aromatic; core medium. Jantary, Harch.

\section{Bower's Nowpareit.}

Big Sweet. Big Green。

Origin supposed to be Harrisonburg, Tirginia; tree vigorons, uprighe, somewhat spleading; an early and good bearer ammilly, but larger crops alternate years; a large fruit, and highly valned where known.

Fruit large, oblate, regular; skin pale yellow, often a shade of red and numerous russet and brown dots; stalk short, small; cavity rather large, sometimes slight russet; calyx closed; basiu linge, deep, corru- 
gatud; flesh white, half fine, tender, juicy, rery mild subacid, o1 ahmost sweet, slightly aromatic; core small. October, March.

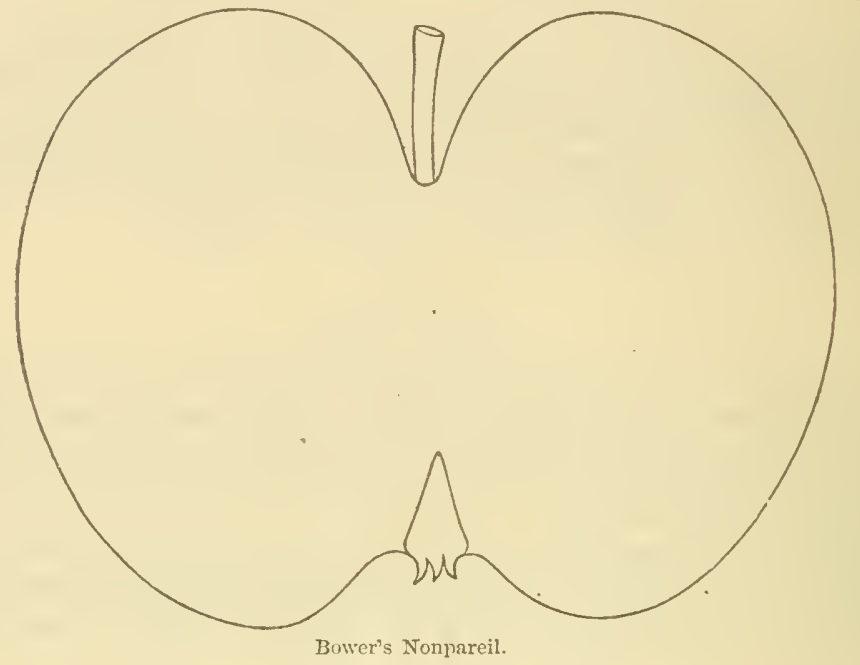

Brilliant.

Originated with Lindsay F. Thomas, near Portsmouth, Ohio; tree vigorous, rather spreading; an early and good bearer annually; much esteemed in the neighborhood of its origin.

Fruit merlinm to large, oblate, slightly angular, sometimes a little oblique; skin paie vellow, somewhat waxen, a shade of jrale rerl where exposed, and a fer grayish dots; stalk short, rather sulll; cavity large, deep, often slightly russeted; calyx large, open; basin lirce, broad, deep, slightly corrugated; thesh white, i little coarse, tender, juicy, - leasant subacid; core small. October, Janiary.

\section{BroAdWATER.}

\section{Wheatyard.}

Origin, on the farm of Col. Charles Broadwater, near Vienna, Tirginia ; tree bealthy, vigorous ; an early and good bearer; a firorite for the table and market in its season where it originated.

Fruit below nedium, oblate; skin smooth, pule yellowish white, pale red in the sun; stalk short, small ; cavity medium, slightly corrugated ; flesh whitish, fine, tender, juicy, mild rich subacid; core snall. September.

\section{Bucks County.}

Originated on the farm of Thomas Head, Iardleyville, Pa.; tree vigorous; long slender branches, spreading head; an annual bearer of good crop's, some seasons large crops. 
Fruit melium, rounclish ohlate, or nearly so; skin greenish yellow, shated, and rather obscurely strijed and splashed with dull red; stalk short; cavity small; callyx closed; basin medium, corrugated; tlesh whitish, half time, half firm, moderately juicy, mild subacid; core small. Jaunary, May.

\section{Burlington Pippin.}

\section{Town Ilouse.}

Origin unknown, supposed to be Burlington, Vermont; tree hardy, rigorous, forming a round rather spreading head; a grood bearer annially of feir fruit of uniform size and excellent quality.

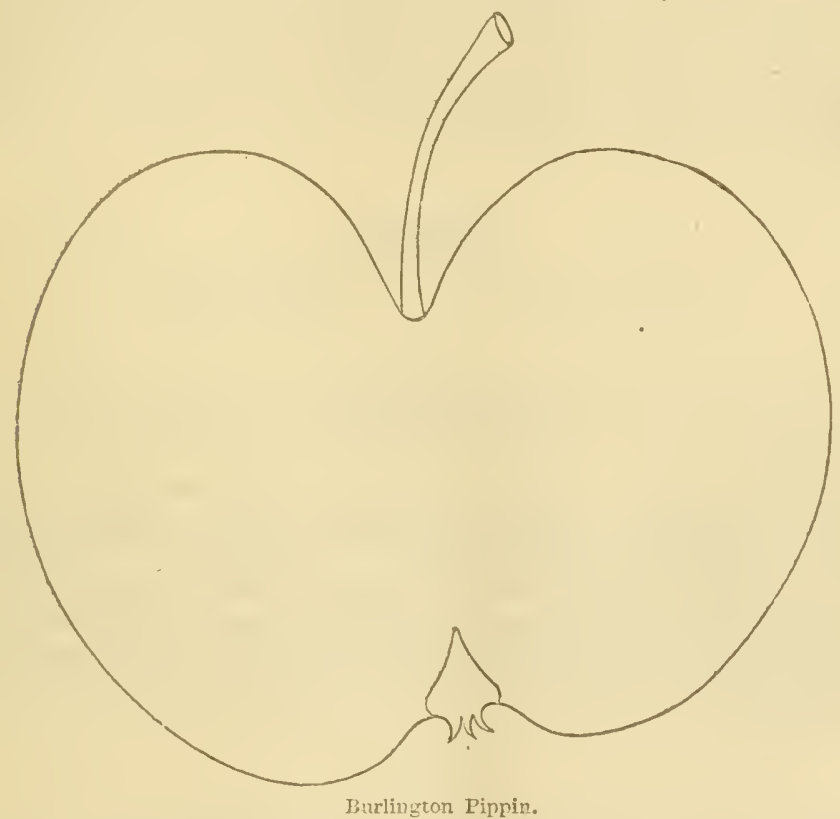

Fruit medium or abore, oblate, slightly conic, slightly angular; skin pale whitish yellow, sharled and mottled with light red, with stripes and broken splashes of dark red, and a few light and grayish dots; stalk medium, slender; cavity broad, deep, slight russet; calyx elosed; basin medium, slightly plaited; flesh quite white, sometimes a little stained next the skin, half fine, tender, juicy, pleasant mild sulacil, aurl a little vinous; core medium. Oetober, January.

\section{CHILDS.}

Paised by the late Ezekiel Page, Belgrade, Maine; tree vigorous, spreacling, and very svmetric in form; a good bearer annually. 
Fruit mellium, oblate to roundish oblate; skin whitish, shaded, striped and splashed with light and dark red over most of the surface; stallk short, small; cavity rather large; calyx open; basin broad, not rery deep, slightly corlugated; flesh white, fine; half tender, juicy, sprightly subacid; core medium. December, January.

\section{Clark:s Prolific.}

Raised by W. G. Clark, Albia, Iowa ; tree hardy, vigorous; an early and abundant bearer, and is highly esteemed in the neighborhood of its origin.

Fruit medium to large, oblate conic, slightly angular; skin pale whitish yellow, a shade of light red, a few gray and many inclistinct light dots; stalk short, small; cavity broad, deep, uneven, sometimes slight russet; ealynx small, closed; basin rather small, slightly furrowed; flesh white, fine, very tender, juicy, lively subacid, slightly aromatic; core suall. November, February.

\section{Clervont.}

Jackson's Roman Stem.

Cheese Apple.

The Clermont is said to be a seedling raised by Sammel Medary, near Batavia, Ohio. Tree a moderate grower, an early and good bearer, and a. late keeper.

Fruit medium oblate, depressed, sides sometimes unequal; skin rellow, deep orange yellow in the snn, sometimes a shade of bright red. and sonetimes nettings of russet, and a few gray dots; stalk very short; cavity rather large, russeted, which sometimes extentls ont on the fruit; calyx elosed; basin rather large, slightly corrugated; flesh rellow, half fine, quite firm, moderately juicy, rich subacid; core close and small. Jaunuary, Miay.

\section{Cross.}

Originated with Robert Cross of Fair Play, Maryland; tree vig. orous, making a large spreading head; an early bearer, producing large crops alternate years, and a light one the intervening ones; its large size and fine appearance renders it one of the most valuable of its season for market and culinary uses.

Fruit large to very large, roundish oblate, nearly regular; skin whit. ish, or greenish white, rather thinly striped, splashed and mottled with light and dark reel, and a few light and grayish dots; stalt vers short: cavity large, ileep; basin large, deep, broad, slightly plaited; flesh white, half fine, tender, juicy, mild subacid; core small. Middle of August tc middle of September. 


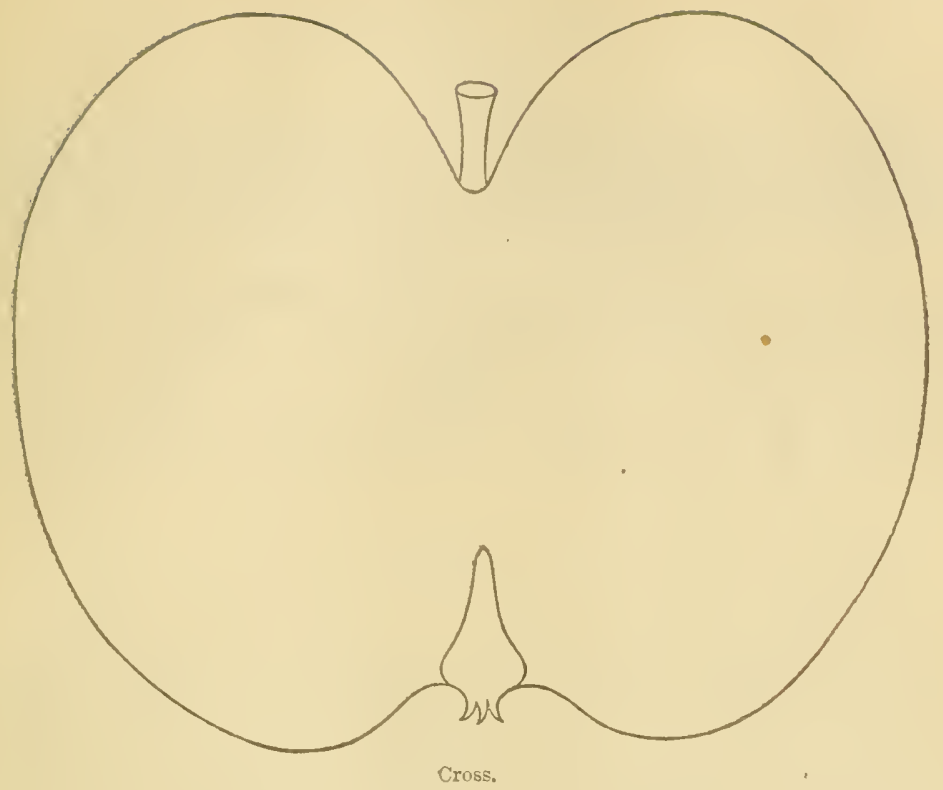

Dale's SeEdling.

Drigin, farm of Christian Dale, near Boalsburg, Pa.; tree of upright morlerate growth; great bearer alternate years, and valuable for making apple butter.

Fruit medium, roundish oblate conic, sides often unequal; skin white, shaded, striped and splashed with light and dark rich red, and many whitish clots; stalk short, small ; cavity medium; calyx closed; basin rather small, slightly corrugated; flesh white, fine, tender, mild subacid, or almost sweet; core small. September, October.

\section{DEANE。}

Nine Ounce.

Origin unknown, supposed to be Fast Wilton, Maine, where it is consiclered the best apple of its scason ; tree vigorous, spreading, bear: ing abundantly alternate years, and a light crop the intervening ones.

Fruit medium, oblate to romelish oblate conic, angular, sliglitly oblique, and flattened at the base ; skin whitish, sharted and rather olscurely splashed and mottled with liglit rerl, and molerately sprinkled with yellowish dots, a few being areole; stalk short, small; cavity rather large, a little greenish ; ealyx closed ; basin medium, slightly corrugated; Hesh quite white, fine, tender, juiey, sprightly subacid or vinous; core nedium. September, October. 


\section{Edgar Red Streak.}

Walbringe.

1) rigin, in the orchard of Joseph Curtis, Paris, Edgur County, Illinois; this apple has been grown in the Vest and Northwest for many years under the name of Walbridge, its true name being unknown until lately;

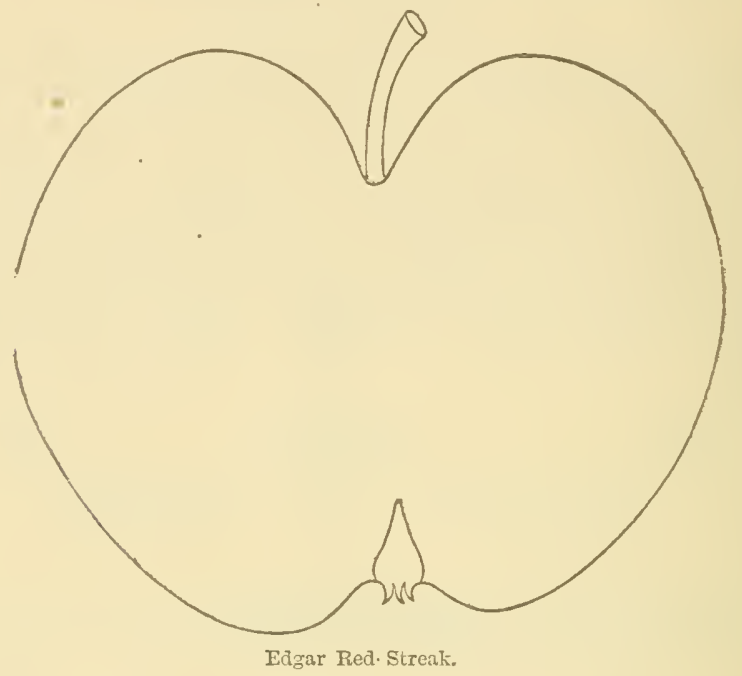

tree very hardy, vigorous, mpright at first, but spreading with age and weight of fiuit; very productive alternate vears, and a light crop the intervening ones; not of the best quality, but raluable for its hardiness, prorluctiveness, and late keeping in a cold climate.

Fruit medium, oblate, very slightly conic, regular; skin pale whitish yellow when fully mature, shaded with pale red in the sun, narrow stripes and a few splashes of bright red over most of the surface where fully exposed; stalk rather short, small; cavity medimm, sometimes slight russet; calyx small, closed; basin small; sliglitly plaited ; flesli white, fine, crisp, tender, $j u i c y$, mild sulacid ; core small or mediun. Juml. ary, May.

\section{ELLA.}

Another of Charles Arnold's seedlings, raised from seed of Nortliern. Spy, crossed with $\mathrm{W}_{\mathrm{T}}$ agener and Spitzenburg; tree moderately vigorous, swreading, young wood dark brown; bears heavy crops alternate rears.

Fruit medium, roundish oblate conic, aides sometimes a little nnequal: skin pale yellow, nearly covered with light and dark dull reel. some rather obscure stripes and splashes, and a few light dots; staik short, small ; cavity rather large, deep, slight russet; calyx small, closed; basis: medium, slightly plaited; flesh whitish, with a greenish tinge, half fine, tender, juicr, with an agreeable aromatic flaror, inclining to sweet; core rather small. December, February. 


\section{ETowaIr.}

Cooper's Red.

Origin, in the garden of Major MI. A. Cooper, Glen Holly, Georgia; twe healthy, moderately vigorous; upright, compact, rather round head; luaring abundantly nearly every year; it is esteemed in the neighborhood of its origin as one of their best late-keeping aplyles.

Fruit nearly of medium size, oblate conic, slightly oblique; skin pale vellow, almost entirely covered with bright red, some obsure stripes and splasherl, a few large light dots, areole; stalk very short, small; cavity linge, dee1, sometimes slight russet; calyx half ojen; basin lurge, very 'lee'); flesh whitish, half fine, tender, moderately juicy, mild pleasant subicid, inclining to sweet; core small. January, March.

\section{Fextoy.}

Origin, Cheltenluam Township, Pa., on the grounds of Samuel Fenton; tree thrifty, spreading; an abmdant bearer alternate years, and valued in $\mathrm{jts}$ locality for the table and cooking.

Fruit rather large, oblate, angular; skin pale whitish yellow, shaded, striped and splashed on the sumy side with light and dark red; flesh white, a little tirm, moderately juicy, pleasant subacid; core small. October, November.

\section{Fletcher Russet.}

Origin, on the farm of James Fletcluer, Acton, MIass.; tree thrifty, upuight, with a round rather s]ureading head; a good bearer alternate rears, and much pized as a table apple where known.

Frut medimm, oblate couic; skin greenish yellow, or pale yellow when fully ripe, nearly covered with dull russet, often mixed with brownish red in the sun; stalk short, slender; cavity medium; calyx closed; basin merlium, slightly corrugated; flesh whitish, fin', tender, juicy, fliasunt subacid and quite rich; core rather small. December, Fobruary.

\section{Foote's Nonsucir.}

This fine new apple was raised by Asahel Eoote, of Willianstown, Mass., from seed of Red Canada or Nonsuch. Mr. Foote writes that the tree is hardy, vigorons, upright, with bright reddish wood, remarkably morluctive alteruate years, and keeps well.

Frnit medimm, oblate, regulau; skin very nearly covered with dark rich red, and many conspicnons light dots, a few being areola; stalk rather short, slender; cuvity rather large, often thinly russeted; calyx minall, closed; basin medium, sliglitly plaited; flesh white, sometimes a littlestained next the skin, fine, tenter, juicy, mild, rich suluacicl, slightly uromatic; core small and close. Jamuary, April. 


\section{Fountais Hill.}

Raised by Suel Foster, Museatine, Iowa, which he vaInes as a good table apple, and for continuing long in use; tree vigorous, rather spreading; an early and good beares, evenly through the tree.

Fruit medium or below oblate, regular; skin pale green, shader, striped and splashed, with dull red nearly over the surface, and many light dots; stalk very short; cavity medium; calyx closed or nearly so. basin large; flesh whitish, fine, crisp, tender, juicy, mild subacid; core small. September, November.

\section{Fox APple.}

Sheepnose.

Fox Sheepnose.

Originated with Eli Fox, near Coshoeton, Ohio; tree strong, rigorous, mpright, rather spreading; an abundant bearer, and is esteemed as an imatenr fruit.

Fruit medium to large, oblate to roundish oblate, slightly conical, angular, or slightly ribbed; skin whitish, nearly covered with light and dark red, striped and splashed rather obscmely with a darker hne, and many light dots; Hesh white, a little coarse, tender, juicy, pleasant subacid, slightly aromatic and rich; core rather large. October, No vember.

\section{GOFF.}

Originated with J. S. Goff, near Bellefontaine, Ohio; tree hardy, vigoruus, spreading; an abundant bearer alternate rears of fair fruit of miform size, and valuable as a market and cooking apple.

Fruit medium to large, oblate; skin whitish, a few light and gray dots; stalk short, small; cavity rather lasge; basin large, deep, slightly con'ugated; Hesh white, half tine, tender, brisk subacid; core medinm.

Pipe the last of Angust and first of September.

\section{Gouden Dixie.}

Originated on the farm of James Fitz, township of Rivama, Tirginia; tree thrifty, vigorous, mpright, forming a lrandsome pramidal head, reauiring but little pruming; an early and abundint learer alternute yeitrs, and much esteemed in its locality.

Fruit merlinm, oblate to roundish oblate, slightly conic: skin light yellow, deep yellow where exposed; stalk short, small; carity medinm, ofteu slight russet; calyx small, closed; basin medium, slightly corrugated; Hesh whitish yellow, half fine, lather firm, crisp, juiç, lively rich subacid, slightly aromatic; core small. August.

\section{HARPER.}

Of unknown origin, supposed to lse Tenuessee; tree vigorons, round nead; bears moderate crop's ammally, and popular where known.

Fruit medium to large, oblate, slightly conic; stin whitish velluw; 
shaded, striped and splashed with light and dark bright red nearly over the whole surface, with inany large and small light dots, a portion being areola; stalk rather short, slender; eavity large, deep, yellowish; basin rather large, slightly wrinkled; flesh whitish, half fine, tender, juisy, mild, pleasant subacid; core small. October, January.

\section{HAVEN.}

An old variety of unkuown origin, but supposed to have been imported by the Haven fumily of Portsmonth, New Hamplsire, many years since; tree vigonous, iather spreading; not an enrly brarer, but bearing abundantly alternate years when established; fruit fair of uniform size, which is highly esteemed where known for jts excellent quality; the tree repuires good enltivation.

Frnit mediun, wiblate conie, slightly angular; skin smooth, whitish yellow, often a shade of pale red on the sumny side, and a few grayish dots; stalk short, small; cavity large, deel; calvx closed; basin rather large, slightly corrugated; flesh whitish yellow, fine, very tender, juicy, rich, sprightly pleasant subacid; core small. January, Harch.

\section{Hottenstien.}

\section{Libert. Lippart.}

Origin, Kutztown, Pa., on the lands of Frederick Libert; tree vig orous, spreading; an abundant bearer annually; valuable for enlinary uses and for market.

Fruit large, roundish oblate, slightly angular ; skin greenish yellow, covered with stripes and splashes of ligit and dark red, moderately sjuinkled with large light dots, a portion being areole; stalk short, small; eavity medium; calyx closed; basin rather shallow, corrugated; flesh whitish, half fine, tender, juicy, mild subacid. October, December:

\section{Hunt Russet Apple.}

This favorite old apple is claimed, by those knowing it hest, to lave originated witl the Hunt fimily, at Concord, Mass., nearly 201 years sinc and, being of excellent quality, has been cultivited and disseminated widely under different names; and I an satisfied, from experience ani examiuation, that Colden Rusisset of Masss., Fay's Russet, and Russet Jeamain are identical with the Hunt Russet, and that the latter is tho original nane, with the symonyms as stated below.

\section{IIust Russet.}

Golden Russet (not of N. Y.)

Golien Russet of Mass. IIass. Golden Russet. Golden Russet of New England.
New England Russet. . Fay's Russet.

New England Golden Insset Peamain. Russet.

Bullock's Pippix, or Shecpnose. Incorrectly.
Americun Gollen Russet of New England.

There is said to be a distinct liusset l'earmain; but those that I re- 
wived as such from Connecticut, many years since, proved to be the Inut Russet.

The Golden Russet of New York, or Western New York, is quite distinct, and is incorrectly cilled by some, at the West, English Golden liusset.

\section{Hunter Pippin.}

A chance seedling on the land of William Gray Hunter, Westport, N. Y.; tree moderately vigorous, hardy, spreading; a good bearer amulally.

Fruit medium, roundish conical, angular or slightly ribbed; skin lale whitish yellow, a few scattered gray dots; stalk short, small; cavity medium, often russeted; calyx small, closed; basin rather narrow, (leej) furrowed; flesh whitish, crisj, tender, juicy, brisk subacid, slightly al omatic; core rather large. August.

\section{KING SWEET.}

Summer Sweet. Thomas Sweet.

Sidney Sweet. King of Sweets.

High 'Top Sweet, incorrectly.

Origin, on the farm of Ichabod Thomas, Sidney, Maine; tree lrardy, thrifty, upright, compact, and requires much inside In'uning; not a very early bearer, but produces large crojs of fair fruit altermate years, and is highly esteemed where known.

Fruit below medium, roundish conical, inclining to oblong; skin greenish yellow, or pate yellow at full maturity, a shade of pale red where exposed; stalk short, small; cavity medium; calyx closed ; basin rather deep; flesh whitish, half fine, tender, juicy, rich honey sweet. core rather small. September, Norember.

\section{Lady Hexiker.}

This new English apple was raised by John Perkins, Thornham Hall, Suffolk, England; tree healthy, and a great bearer; chiefly valuable as a cooking variety, but useful also in the dessert.

Fruit vel'y litrge, roundish, slightly conic, angular, with prominent ridges arouncl the rye; skin yellow, shated witl pale red, aud broken streaks of erimson on the sunny side; staik very short; cavity wide, deel, resssety ; calyx large, open; basin very deep, angular; flesh very tencler in the grain, well flavored, and with a pleasant perfume. October, February. (Jourial of Horticulture.)

\section{Liptĩs SWEET.}

Origin unknown, supposed to be near Philadelphia; tree nocleritely vigorous, muight at first, but spreading with age and bearing; a good arnual bearer:

Fruit medium, or nearly so, oblate or slightly conic; skin pale whitish yellow, shaded with light red, many large and small light and brownish 
lots, sone star-shaped; stalk short, small; cavity rather small; calyx s:mall, closed; basin unedium; flesh white, fine, rather compact, moderatcly juicy, mild sweet, rather rich; core small. December, March.

\section{Kaigis's Sipitzexiburg axd Long Red Pearmain.}

Iror many years these have been considered identical, and Downing so makes it in the second revised edition, but experienee and examination liave proven them distinct, both in the growth and form of the tree, and of the fint.t. 'The Long lied Permmin is sail to have originated on the property of the Economites at New Harmony, Indiana, many years since; The name and synonyms by which it is known in different localities are given below.

\section{Losg Red Pearmain.}

Rerl Pearmain.

Kaign's Spitzenburg, incurectly.

Iong John.

Red Spitzenberg.

Striper Pearmain.

Lady' Finger, incorrectly.

Winter I'earmain.

Long Pearmain.
Red Tinter Pearmain, in- Red Phnenix. correctly.

Scarlet Pearmain, incorrectly

English Pearmain, incor. rectly.

Red Bellflower, incorrectly.

Red Pippin.
Pearmain.

Kentucky Gillitiower. Kentucky Belltlower. Hudson Red, Streak. Sheepnose, of some. Wabash Belltlower.

Russam.

Park (not of Kansas). Mudhole.

Pound Roy al, incorrectly

The true Kaign's Spitzenberg, so far as I know, has no synonyms, and was first described by William Coxe, in his work on Fruits, in 1817, as liuving originated in Gloucester county, New Jersey.

Neither of these apples are much enltivated now, as we have better kinds, the object being to correct the mistake.

\section{LUCY SWEET.}

\section{Twin Apple.}

Originated on the farm of Simnel Jewett, Weybridge, Vermont; tree vigorous, of a pyramid form, producing moderate mops annually.

Fruit medium rounchish oblate; skin pale greenish yellow, a shade of lale red where exposed; stalk short, small; carvity deer, sometimes light 'usset; basin large, deep; flesh whitish, half fine, moderately juicy, mild, rather rich sweet; core small. October, November.

\section{Mutxtosh Red.}

Originated with John MeIntosh, Dundela, Ontario, some seventy years since, but is not willely known; the tree is sard to be very hardy, loug-lived, vigorous, with a spreading head; a good ammal bener of firir, handsome fruit of exeellent quality, and valuable for home use and market.

Fruit merlium or above, roundish oblate, regular; skin whitish ye! low, very nearly covered with dark rich red or crimson, almost purplist 
in the sun, moderately sprinkled with light dots; stalk short, rather small; cavity medium; calyx closed; basin rather small, slightly

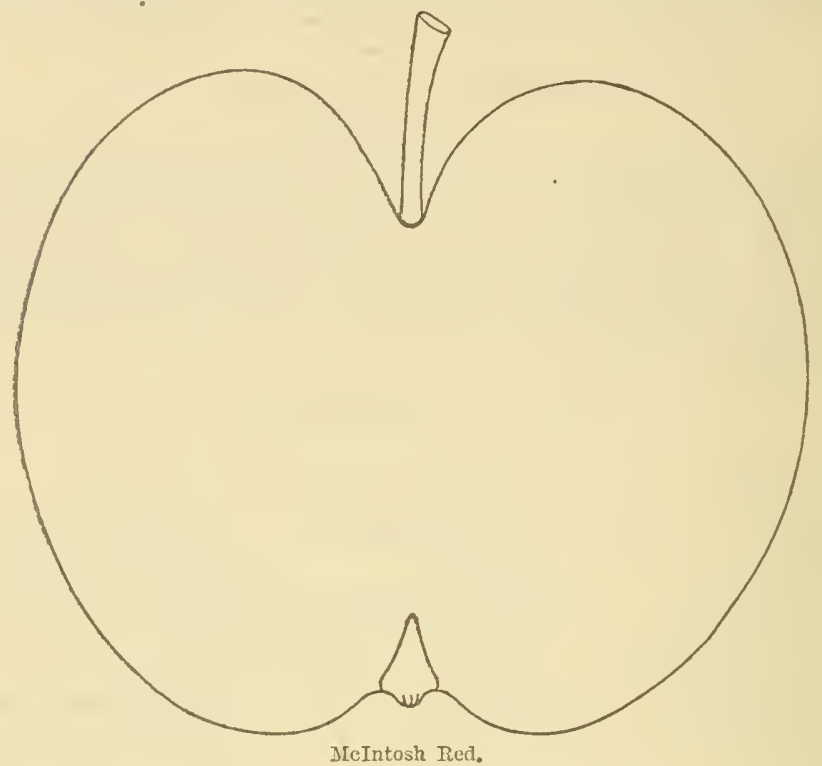

plaited; flesh white, fine, very tender, juicy, mild subacid, refreshing, peculiar slight quince-like flavor; core medium. November, February.

\section{McKixvey.}

Origin, on the fam of Luther M[cKinney, Crawford, N. Y. ; tree vigorous, forming a round head; an early and abundant bearer alternate rears, and a light crop the intervening ones; fruit fair of uniform size, and valuable as a late keeper.

Fruit medium to large, oblate; skin deep yellow, sluaded with pille brownish red where exposed, a few grayish dots; stalk very slıort; cavity broad, deep', sometimes slight russet; calyx open, or half closed; basin broad, deep; flesh whitish yellow, lialf fine, lather tim, molerately juicy, mikl subacid; core close and small. January, April.

\section{Migog PeD STrEAK.}

Raised from seed by WVilliam Warren, Newport, Vermont; tree very lrardy, thrifty and vigorous, an upright spreating head; bears every year, but large crops in eren years; valued for its extreme hardiucss: vicor, productiveness, and long keeping.

Fivit medium or nearly so, roumlish inclining to oblong; skin light reliow, shaded and faintly striped and splashed with light red orer lialf the fruit; stalls short, small; calyx closed; basin medium, corrugizied ; 
Alesh yellowish, a little coarse, morlerately juicy, mild subacid; coro meilium. Ducember, March.

\section{Mathews.}

Origin, on the furm of Hugh Foster, near Alton Depot, Nelson Co., Tirginia; tree vigorois, with an open spreading liead; an carly aut abundant bearer alternate years, and a partial crop the intervening yeatls.

Fruit medinm, roundish oblate, slightly conic, regular; skin smooth, whitish almost waxen, shaded with pale dull red where exposed, many large light dots, a portion almost obscure, a few areole; stalk short, small; cavity medimn, regular; calyx small, closed; basin lather abmpt, deep, slightly plaited; Hesh white, fine, tender, juicy, mild, pleasant, sprightly subacid; core medium. October, January.

\section{MAY SEEK-NO-FARTHER.}

An old variety of unknown origin, and the original name also unknown, and was described in Downing's second revised edition, page 270; it was once valuable as a long keeper and a profitable market variety, but now nerrly out of use ; tree hardy, vigorous, upright and very productive alternate years; it has been grown in clifferent sections of the commtry, under the following names, in addition to those namod in the secolicl revision.

Lopside.

Hoopes.

Hopson.

Holisey.

Hoopes Pearmain.
Romanite, incorrectly. Big Romanite, of somè. Black Pennock.

Black Vandervere.

German Spitzenberg.
Greyhouse, incorrectly.

Black Jack.

Red Everlasting.

Hard Red.

Keystone.

Gray Romanite, of some.

\section{MELLINGer.}

An old variety of late introduction, found on the Mellinger projerty, now owned by Dr. Nellinger, Manor Township, Pa., and considered in that neighborhood one of the most valuable and showy ajples of its sealson; tree healthy, vigorous, sprealing, bearing large erops alternate years, and a light one the intervening ones.

Funit medium to large, rom dish, or romulish conical; skin smooth, white, mostly covered with stripes and broken splashes of light and dark bright red, sone of the splashes of a purplish real, and moderately sprinkled with light ints; stalk short; eavity mediun, slight russert; cilyx small, closed; basin mectinn, rather abrupt, deep, sigghtly corra. gated; thesh quite white, half fine, tender, juicy, sprightly subacid an vinous; core medium. September, November. 
THE APPLE.

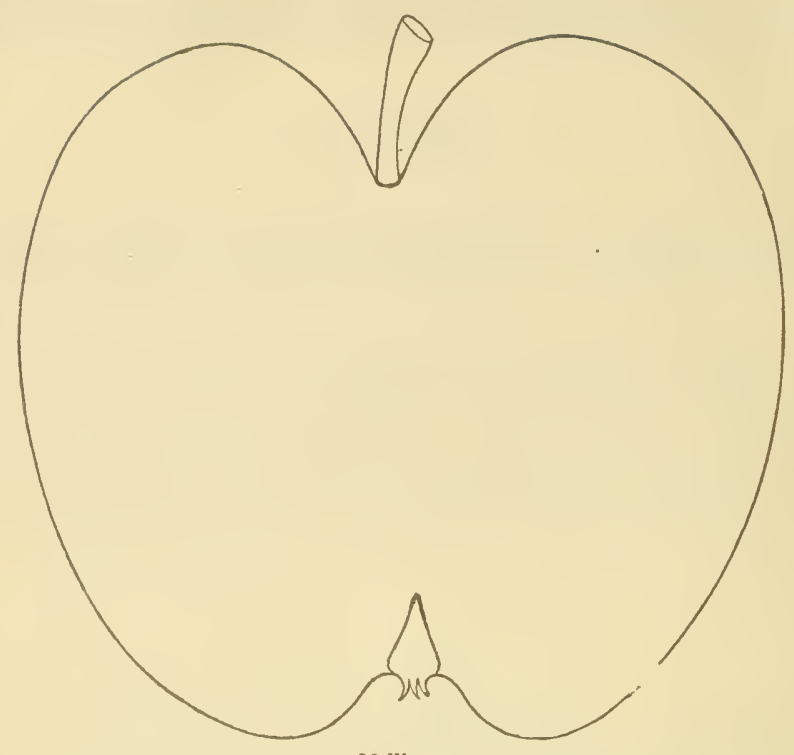

Mcllinger.

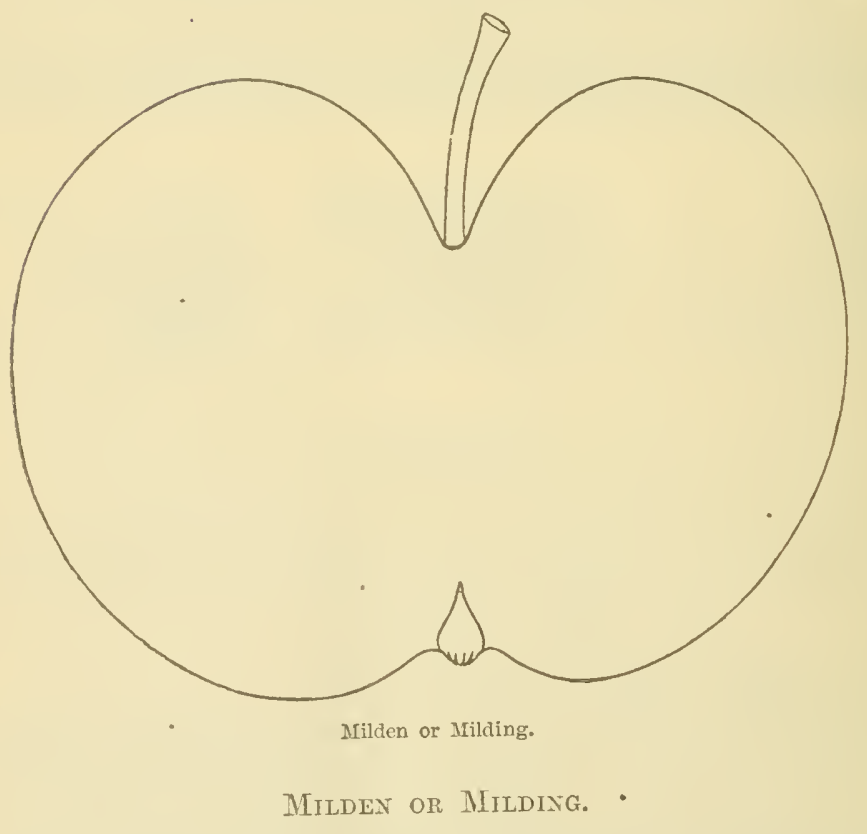

Orimin, Alton, New Hampshire; tree hardy, a strong, rigorows, apright grower, forming a large round head; very productive alterrats 
years, of large fair fruit, which is highly estecmed where known for market and family use.

Fruit large, oblate, slightly conie, slightly angular; skin su,ooth, whitish yellow, shaded, stripred, splashed and mottled with light aurl clark bright rich red nearly over the whole surface, and a few light dots; stalk rather short, slender; cavity broad, deep, sometimes thinly russeted; calyx slosed or nearly so; basin broat, moderately deerl, fur rowed ; Hesh whitish yellow, rather coarse, brittle, tender, juicy, sprightly suluacid, slightly aromatic; core medium. December, January.

\section{Mortox's Red.}

Origin, supposed to be on the farm of the late Elkannal Morton, IBill Town, Nova Scotia; tree noderately vigorous, forming a round rather spueading head; an early and good bearer ammally, and a favorite aplule for market and home use.

Fruit medium, regular, roundisì oblate, slightly conic; skin whitish, nealy covered with light and dark rich red, quite dark in the sum, sometimes a few obscure stripes and splashes, and sometimes nettings of russet; stalk medium, slender; eavity medium, slight russet; calyx closed or nearly so; basin small, slightly corrugated; flesh quite white, half fine, tender, juicy, brisk subacid; core large. December, January.

\section{Mumper Vandevere.}

Origin, on the farm of John Mumper, near Dillsbury, Pa.; tree strong and vigorous, making a round, rather spreading open head; in abundant bearer alternate years of fair fruit of uniform size; valued chiefly for its late keeping, market, and kitchen use.

Fruit medium, oblate or roundish oblate, regular, flattened at the ends; skin pale greenish yellow, rather faintly shaded, striped and splashed with light red, and moderately sprinkled with large light and gray clots; stalk rather short, small; cavity medium, often a little greenish; calyx large, open; basin broad, rather deep, corrugated; Hesh whitish, coarse, compact, moderately juicy, brisk subacid; core close and small. December, April.

\section{Mrstic.}

Origin, Mystic Valley, Conn., on the farm of Alden Fish; tree vigorous, rather late coming into bearing, but prorluces large crops alternate year's when of sufficient age.

Fruit medium, roundish, flattened at the ends; skin pale yellow, shaded and mottlerl with light red, and some rather obscme stripes and broken splaslies of a darker hue, with a few russet dots; stalk long, slencler; cavity medium, modcrately deep; calyx small, closed; basin large, deep, slightly plaited; flesh white, fine, tender, juicy, pleas?nt nild subacid; core rather small. Oetober, November. 


\section{Naxsemond Beauty.}

Origin, somewhat uncertain, supposed to be Suffolk, Virginia; tree vigorous, rather spreading, bearing good crops annually of fair fruit of uniform size, and a good keeper.

Fruit medium, roundish oblate, slightly conic; skin pale yellow, nearly coverad with light and dark rich red, sometimes rather obscure stripes and splashes of a darker hue; stalk short, small; cavity quito lange, slight russet; calyx half open; basin large, deep, slightly corrugated; Hesh quite white, half fine, crisp, tender, juicy, vinous subacid; core sinall. January, April.

\section{Nelson Rock.}

\section{Rock Apple.}

A chance seedling on the farm of the late Henry G. Roberts, near Greenfield, Virginia; tree moderately vigorous, upright at first, but spreading with weight of fruit; an abundant bearer alternate years, and a light crop the odd years; valuable in its locality for its good qualities and lite keeping.

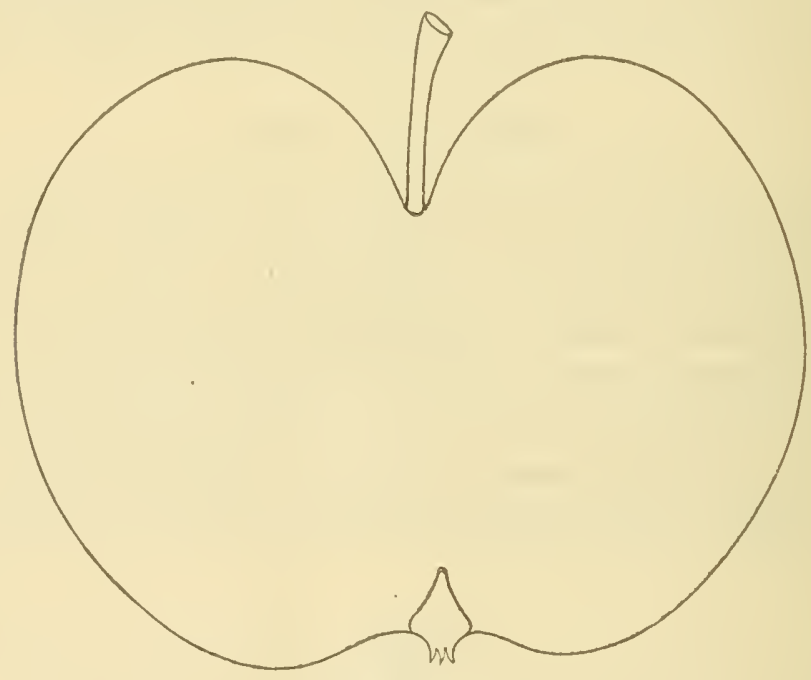

Nelson Rock.

Fruit medium to large, oblate, slightly conic; skiu pale greenish white, shaded, striped and splashed with light and dark red over most of the surface, and moderately sprinkled with light and gray dots: stalk short, snrall; cavity large, deep, sometimes slight russet; caly: closed; basin rather broad, shallow, slightly colrugated; flesh whitish yellow, half fine, tender, juicy, rich, mild subacid; core small. December, March. 


\section{New Rrver BoAt Apple.}

Origin, on the premises of Robert Porter, Sr., Porter's Ferry, Virginia; tree astrong vigorous grower, spreading; an early and great bearer alternate vears, and highly prized where known.

Fruit medinm, oblate, thattened at the base, sometimes a little oblique; skin bright yellow, rarely with a blush; stalk very short; cavity wather large; calyx closerl; basin medium, slightly corrugated; flesh whitish, half fine, tender, moderately juicy, mild, pleasaut, peculiar subacid, almost sweet; core small. October, December.

\section{Northasipton.}

A Pennsylvania apple from Northampton Connty, but exact origin unknown; tree vigorous, upright, spreading, an early bearer, and very productive; it is saicl the lower half of the tree bears one year and the upper part the next year, and this is more characteristic with trees of some age; valned especially as a table fruit where krown.

Fruit medinm, oblate, often depressed; skin smooth, pale whitest yellow, shaded, striped and splashed rather thinly over most of the surface with light and dark red, and many large and small light dots, a few areole; stalk short, slender; cavity rather large, deep, regular; cajyx closed or nearly so; basin medimm, slightly plaited; tlesh white, fine, tender, juicy, pleasant mild subacid and very good; core small. Octoler, Febuary.

\section{Northfield Beauty Crab.}

Raised hy I Leonard D. Cady, Northfield, Vermont, from seed of yellow Siberian Crab; tree vigorous, hardy, forming a compact symmetrical head; a handsome apple of good size, good quality, and rromises to be valuable in cold localities.

Fruit medim, roundish oblate; skin smooth, whitish, shaded with light red, rather obscurely striped and splashed with two shades of rich red and a few light dots; stalk short; cavity medium; calyx closed; basin rather small, slightly corrugated; flesh whito, half fine, tender, juicy, sprightly subacid; core small. September, Decembes.

\section{ONTARIO.}

'This handsome and excellent apple' was raised by Claries Arnold, Paris, Ontario, from seed of Northern Spy crossed with the Wagener; tree vigorous, somewhat spreading, bears qnite young and abundantly.

Fruit large, oblate, slightly conic, slightly angular; skin whitish yellow, nearly covered with bright rich reel, some rather obseures stripes and splashles, and morkrately sprinkled with light dots; stalk short, rather stont; carity broad, deep, sometimes slight russet; calyx closer or nearly so; basin large, decl, slightly corrugated; flesh whitish yellrw, fine, tender, juicy, subacid, refieshiug, slightly aromatic; core small. January, April. 


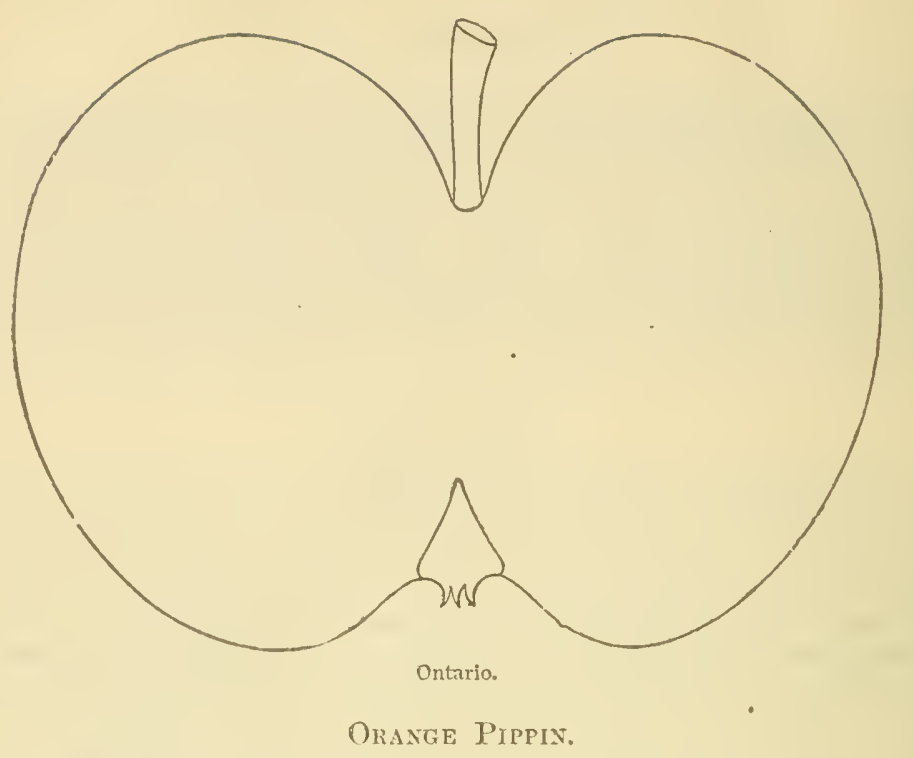

Origin unknown, considerably grown in some parts of New Jerser, where it is valued as a profitable summer marknt apple; tree vigorons, upright at first, but spreading with age and bearing; good and sure bearers alteruate years.

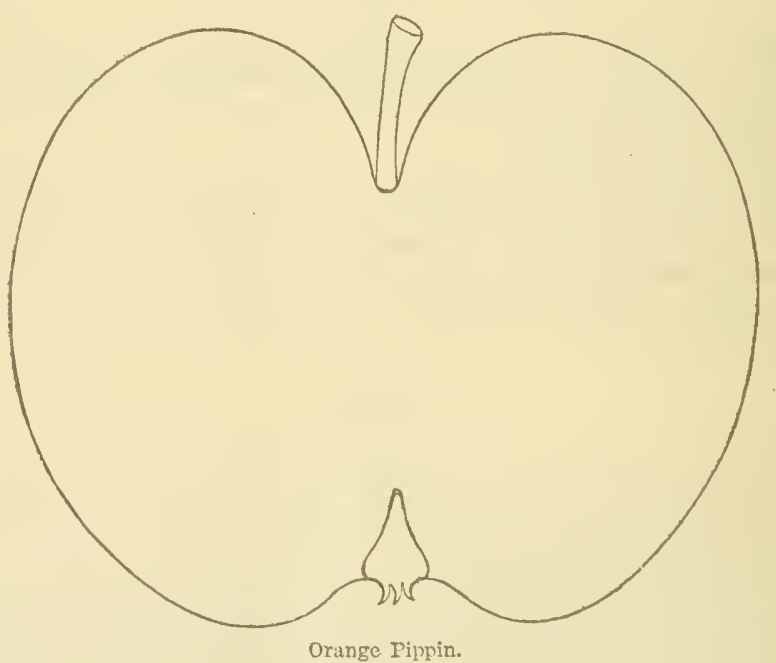

Fruit medium or above, oblate or roundish oblate; skin smootl, pale yellow, orange red or fawn in the sum, a few gray dots; stalk short, small; cavity large, sometimes slight russet; calyx lurge, open ; basin 
large, deep, siightly ylaited; flesh white, lualf fina, tender, juiey, pleas ant subacid, slightly aromatic; core small. September.

\section{PERTX Red Streak.}

Origin, Lowville, N. Y., on the premises of Dr. David Perry; tree hardy, vigorous, spreading, forming an open head; an ahundant hetrer alternate years, and a light crop the intervening ones; it does not contimue loug in use.

Fruit merlium, oblate, slightly angular; skin light yellow, shader, striped and splashed with light and dark rich red, and moderately sprinkled with light and gray dots; stalk short, small; cavity large, sometimes slight russet; calyx elosed or nearly so ; basin large, derp, slightly corrugated; flesh whitish, fine, crisp, teuder, juicy, mild subacid, slightly aromatic; core medium. October.

\section{Picket.}

Origin, near Arlington, Kentucky, on the farm of William I'icket; tree a strong, vigorous, mpright grower; an early and abundant bearer annually, and is considered an acquisition in its locality.

Fruit rather large, oblate or roundish oblate, often slightly oblinue, somewlat flattened at the ends; skin yellow, nearly covered with lighlit and clark red, some rather obsemre stripes and splashes of a darker hine,

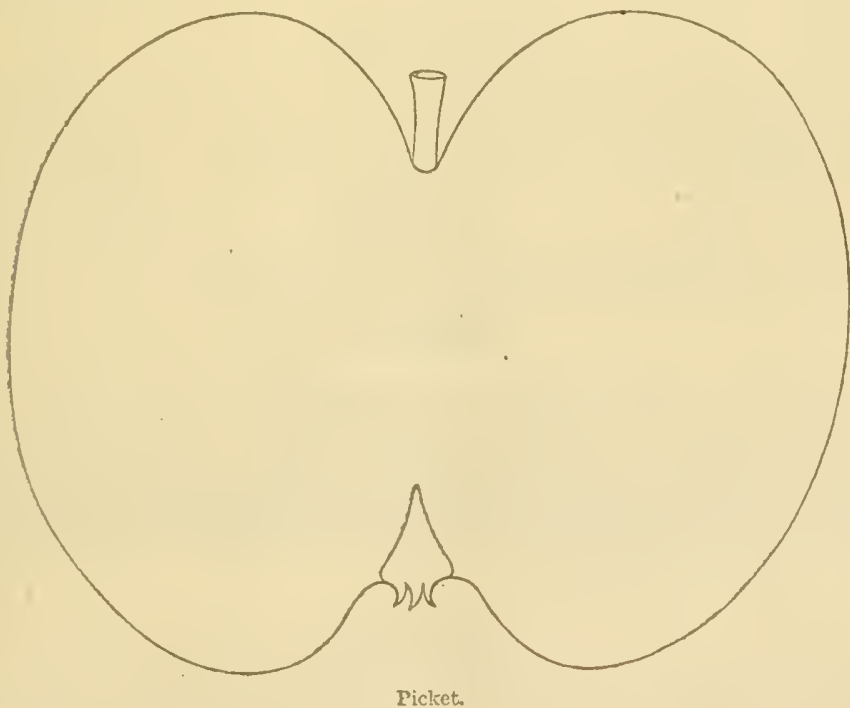

nometimes with a grayish bloom, a shade of light purple, and moderately sprinkled with light and brown dots; stalk very short; cavity large, deep, slight russet; ca $\mathrm{yx}$ open ; basin decp, round, slightly wrinkled; 
fleslı whitish yellow, fine, tender, juicy, rich, mild subacid, and verg good; core small. December, February.

\section{Piednont Pippin.}

\section{Dollins Pippin.}

Origin, on the farm of the late James Woods, Rockford I'ownship, Virginia, and is supposed to be a seedling of the Albemarle Pippin; tree quite vigorous, upright at first, but spreading with age; not a very early bearer, but giving large crops alternate years when of sufficient age, and promises to be valuable.

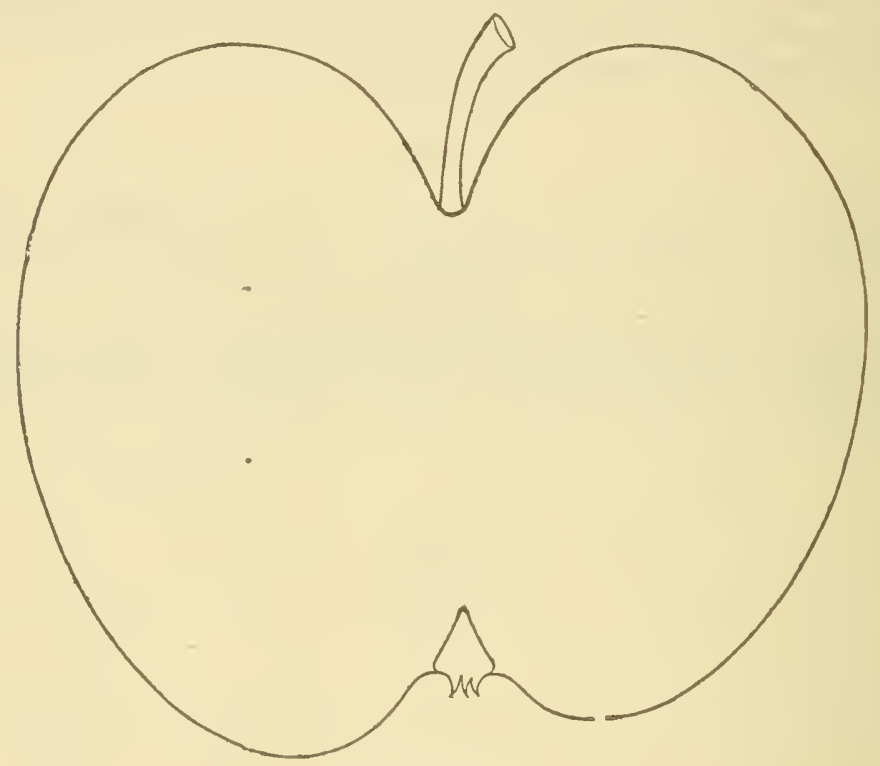

Piedmont Pippin.

Fruit large, rounclish oblate, conic, angular, sometimes oblique; skin greenish yellow, a few nettings of russet and some brown dots; stalk short, rather small; cavity large, deep, sometimes slight russet; calyx nearly closed; basin large, deep, slightly corrugated; flesh pale yellow, half tine, crisp, tender, juicy, rich subacid, slightly aromatic; core medium. November, March.

\section{Pine Apple.}

Origin uncertain, supposed to be Mit. Laurel, New Jersey; tree of moderate growth, upright, rather spreading, producing good crops alternate rears.

Fruit medium or below, oblate; skin pale yeilow, shaded and somewhat obscurely striped and splatshed with bright red, a few light dots; 
stalk short, small; cavity medium; calyx closed; basin medium; slinhtly corrugated; Hesh whitish, half fine, tender, juicy, pleasant mild subacil, slightly aromatic; core smill. October, November.

\section{Plumis's Cider.}

Origin uncertain, introduced by J. C. Plumb, Milton, Wisconsin tree hardy, vigorous, round headed; an early bearer, and very produetive alternate years.

Fruit medimm, rommlish, slightly conic; skin greenish yellow, sharled and rather obseurely stipiped and splisshed with dull red, some light dots; stalk short, small ; cavity small; calyx small, closed; basin small, corrugated; tlesh whitish, lialf fine, tender, juicy, mild subacid ; cor'e small. September, January.

\section{Prewit.}

Origin, farm of William l'rewit, Rock Spring Church, Kentucky, tree vigorous, upright, an anmual bearer; chiefly valuable for its long keeping.

Fruit medium, oblate, conic, sides unequal ; skin yellow, shaded, and rather faintly striped and splashed with light and dark red; stalk very short ; cavity large, deep, slight russet; calyx closed; basin deep; flesh yellowish, half tender, moderately juicy, mild subacid; core small. Jamuary, May.

\section{Prolific BuUsh.}

Origin, on the farm of E. H. Cocklin, Shepherdstown, Pa.; tree a slow stout grower, forming a low head; an early and great bearer alternate years; blooms late; valuable for home use, and a profitable early market variety.

Fruit medium, oblate, slightly conic; skin smooth, white, a blush of bright red ; stalk short, small; carity large, deep, slight russet; calyx closerl; basin rather shallow, corrugated; flesh quite white, crisp, juicy, brisk subacid; core medium. August.

\section{Pyle's Red IVinter.}

A cliance seerlling on the farm of Baynard Pyle, Thornbury Township, I'it.; tree vigorous, spreading; an early and good bearer ammually of large tuir fruit of uniform size, of excellent quality, and keeping well.

Fruit large, roundish, ohlate, slightly conie, sometimes slightly oblicine; skin greenish yellow, or pale yellow at full maturity, shaded with palce red over two-thirls its surface, with some rather obseme stripes und splashes of a darker color, and moderately spninkied with light and brown dots; stalk short, small; cavity rather large; calyx small, closed; basin large, deep, slightly wrinkled; flesh whitish yellow, half fine, crisp, rencler, juicy, pleasant lively subacid; core rather small. January. March. 


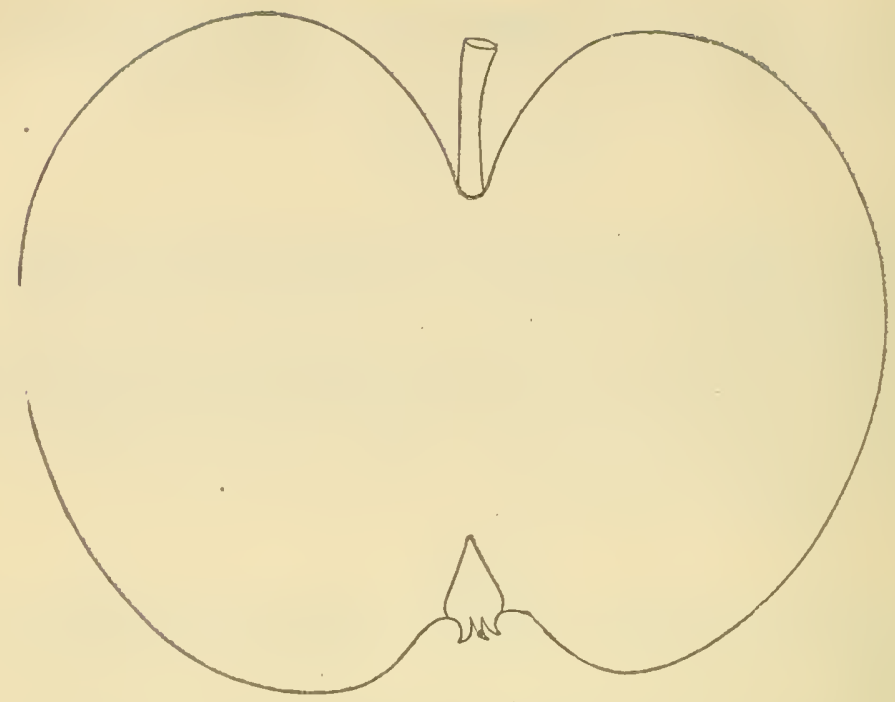

Pyle's Red Winter.

\section{RaCE's Red.}

A chance seeding on the farm of Stephen Race, Claverack, Y. I.; tree strong, vigorous, forming a round rather spreading bead, learing large crops alternate years.

Fruit medium, nearly globular, regular; skin smooth, light yellow, nearly covered with light scarlet crimson, many light dots, some rather obscure; stalk short, small; cavity somewhat nimow, deep; clarx closed; basin medium; flesh white, fine, sometimes stained next the skin, tender, juicy, pleasant subacid; core small. Angust, September.

\section{Reed's Goldex Pippix.}

Origin unknown, from Central New Jersey ; tree vigorons, making a large round head, bearing good crops ammally, and evenly through the tree.

Fruit medium, roundish, oblate, slightly angular; skin golden rellow, shaded with light bright red where exposed, a few nettings of russet and a few grayish clots; stalk short, small; cavity medium, often russeted: calyx closed; basin medium, slightly corrugated; flesh yellow, fine. a little firm, juicy, rich mild subacid, slightly aromatic; coip small. Jan uary, March.

\section{ReinetTe Ostz.}

Origin, supposed to be Iuxemberg, Belgium; tree vigorous, spread. ing; a good learer alternate years.

Fruit medium, oblate, slightly conic; skin pale greenish rellow, or pale yellow at full maturity, many grayish dots; stalk short, small. 
cavity medium; calyx closed; hasin rather shallow, slightly corrugated; tlesh yellowish, a little coarse, moderately juicy, subacid; core small. December, March.

\section{RockWOoD.}

Origgin, Belgrade, Maine, on the farm of John Rockwood; tree hardy, healthy, vigorous, upright; an early and full bearer alternate years, and a lirht crop the intervening ones; it is popular and profitable where known.

Fruit medium, roundish, inclining to oblong, flattened at the ends, angular; skin greenish yellow, nearly covered with light and dark Inll red, brownish red in the sun, and numerous yellowish dots, a few :lreole; stalk rather short; cavity medium; ealyx closed; basin medium, corrugated; Hesh whitish, lıalf fine, tender, moderately juicy, mild subacid, inclining to sweet; core small. December, February.

\section{SARAH.}

Origin, farm of John Tufts, East Wilton, Maine; tree very vigorous, forming a broad spreading top; an early and good bearer, annually, with very large crops alternate yeurs; a valuable and profitable apple for market and home use.

Fruit large to very large, oblate conic; skin yellow shaded and mottled with light red, striped and splashed with dark red, some splashes almost furplish, a few light dots; stalk short, small; cavity broad, deep; calyx closed, or half open; basin medimm, slightly corrugater; Hesh whitish, coarse, tender, juicy, brisk subacid; core medium. October.

\section{Settle Pippin.}

Superb White.

Adams White.

Euglish Codlin, incorrectly.
Hex's White.

Settle's superb.
Hick's White.

Gloucester White, incorrect]s.

An old apple of unknown origin, supposed to be Marvand or Virginia ; it is a popular apple in Winchester and the lower part of the Shenandoah Valley of its season; tree thrifty and rigorous, making a tine head; an early and annual hearer.

Fruit nnedium or nearly so, romudish oblate conic; skin white, sladed with light red, and sprinkled with a few brown dots; stalk short, small; carity rather large, deep; calyx small, closed; basin rather shallow, broal, corrugated; flesh quite white, fine, crisp, tender, juicy, mild subacid, refreshing; core small. September, November.

\section{SISK.}

Origin, on the the farm of Joseph Sisk, near Preston, Maryland; tree vigorons, "lpright; not an early bealrer, but with age bears good crops, amnually; some seasons less alternate years.

Fruit rather large, oblite, som what depressed; skin pale yellow, sladrd, and rather obscurely striped and splashed with lightit and dark 
red, a few brown dots; stalk short, small; cavity broad, deep; calvs linge, open; basin broad, deep, slightly col'ungated: flesh whitish yel. low, half tine, tender, juicy, pleasant subacid, slightly aromatic. October Jamualy.

\section{SMith's Favorite.}

Origin, on the farm of Isaac Smith, Winthrop, Maine; tree vigorous, upright at first, forming a large round sead; an amnual bearer, but more abundantly alternate years; valuable in its locality for family use and market.

Fruit medium, roundish, sometimes inclining to oblong, slightly angular'; 'skin pale yellow; thinly shaded, striped, splashed, and mottled with light red over half or more of the surface, and moderately sprinkled with light dots; stalk rather long, slender; cavity medium; calyx closed; basin small, corrugated; flesh pale yellow, half fine, half tender, juicy, subacid, slightly aromatic; core medium. October, November.

\section{Southern Porter.}

$\begin{array}{lll}\text { Porter. } & \text { Kidd. } & \text { Jones. } \\ \text { Fall. } & \text { Hog Pen. } & \text { Long. }\end{array}$

An old and valuable apple, which originate l about ten miles east of Chesterville, South Carolina; tree hardy, a strong grower, young woorl

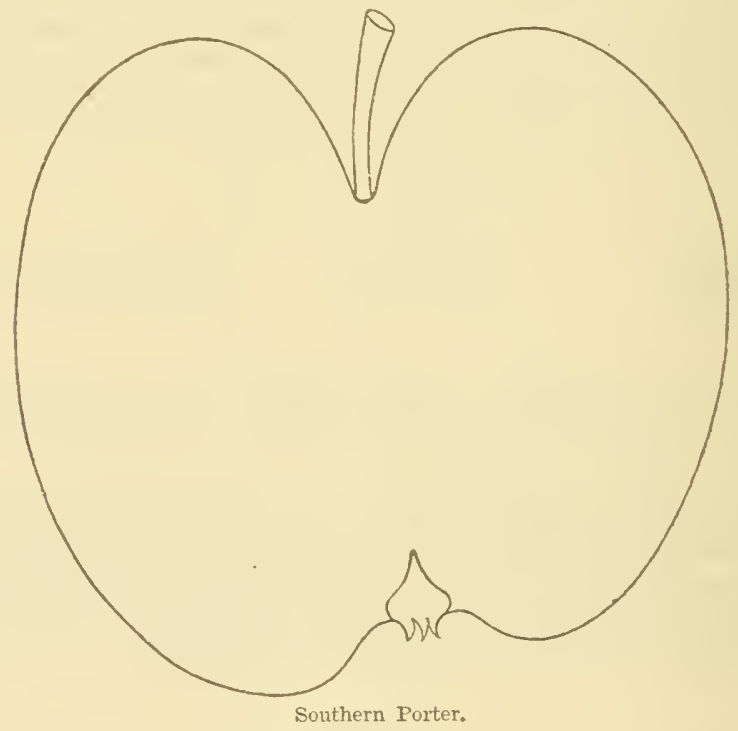

hard and tongh, rather sprearling; very productive alteruate sears, and a moderate crop the intervening one; one of the most popular apples of its locality and season, ripening near two months later than the Porter.

Fruit mediur, roundish conical, regular; skin bright golden sellow, 
and a few gray dots; stalk short, small; cavity medium, decp; calyx open; hasin lange, slightly cornugated; flesh whitish, fine, half tender; juicy, rich mild subacid, slightly arouatic; core small. September at the south.

\section{STARKEY.}

Origin, town of North Vassalboro, Maine, on the filrm of Moses Starkey; tree hardy, vigorous, sprealing; a regular goou bearer, and highly esteemed in its locality as a profitable market variety as well as for home use.

Fruit medium, oblate, slightly conic, regular; skin pale yellow, slialed, striped and splashed with light and dark bright red, and noderatcly sprinkled with light and gray dots; stalk short, small; cavity medimm, sometimes slight russet; calyx closed or nearly so; basin medium, sliglitly corrugated; fiesh whitish, half fine, tender, juicy, mild pleasint subacid; core small. October, January.

\section{Strinestown Pippin.}

Origin, near Strinestown, Pa., on the farm formerly ownel by Clnisto. pher IIiller; tree hardy, upright at first, but forms a ronnd open head; an early and good bearer alternate years; valued mostly as a late keeping market rariety and for culinary uses.

Finit medium, roundish, conical; skin yellow, a shade of bright reor in the sun; stalk short, small; cavity rather narrow; calyx closeci; basin large, broad, deep, furrowed; Hesh whitish, rather coarse, compact, moderately juicy, brisk subacid; core close and small. Jan uary, April.

\section{Striped Gildiflowek-Furley--Scollop Gilliflower.}

These apples were formerly considered identical, but time and experience have proven them distinct. The striped variety is a vigorons grower, with long shoots, and generally bears good crops amually. It is a showy fruit, and in some localities, thonght much of for market and culinary uses; the fruit is variable in form and size, nsmally romelish conical, angular, or more or less ribbed; skin white, strijed and mottled with bright lively red; flesh whitish, erisp, juicy, with a brisk, subacid flavor. The scollop variety is a moderate, or poor grower, the young shoots much darker colored, the tree more spreading, a poor bearer, and has nearly gone ont of use; the fruit is roumdish oblate conic, more vilbed, the color much darker, rather dull red, with broader stripes and splashes, the flesh more yellow, of a mild, subacid aromatic, richer in quality, and a month or more later in ripening, than the striped valiety; they are known by the following names and synonyms.

\section{Striped Gilliflower.}

Striped Bellflower. Scollop Gilliflower, incorrectly. $\quad$ Red Gilliflowe:. 


\section{SCOLLOP TriLlifLOWER.}

Ribbed Gilliflower. Five-Quartered Gilli- Jellyflower.

Red Gilliflower, of some. flower.

\section{Sutton's Early.}

Raised by William Sutton, Port Williams, Nova Scotia; tree vigor ous, spreading, productive; young shoots stout, dark, downy; promis. ing as an early apple for culinary uses.

Fruit medium or above, oblate to roundish oblate, slightly conic, slightly angular; skin whitish yellow; stalk short, small; carity medium, slightly russeted; calyx closed; basin medium, corrugated ; tlesh white, tender, juicy, brisk subacid; care rather large. September.

\section{TraNsparext ZOAR.}

A beautiful and very good apple, which originated with the Zoar Society, at Zoar, Ohio : tree vigorous, making a round rather spreading head; an early and abmudant bearer nearly every year.

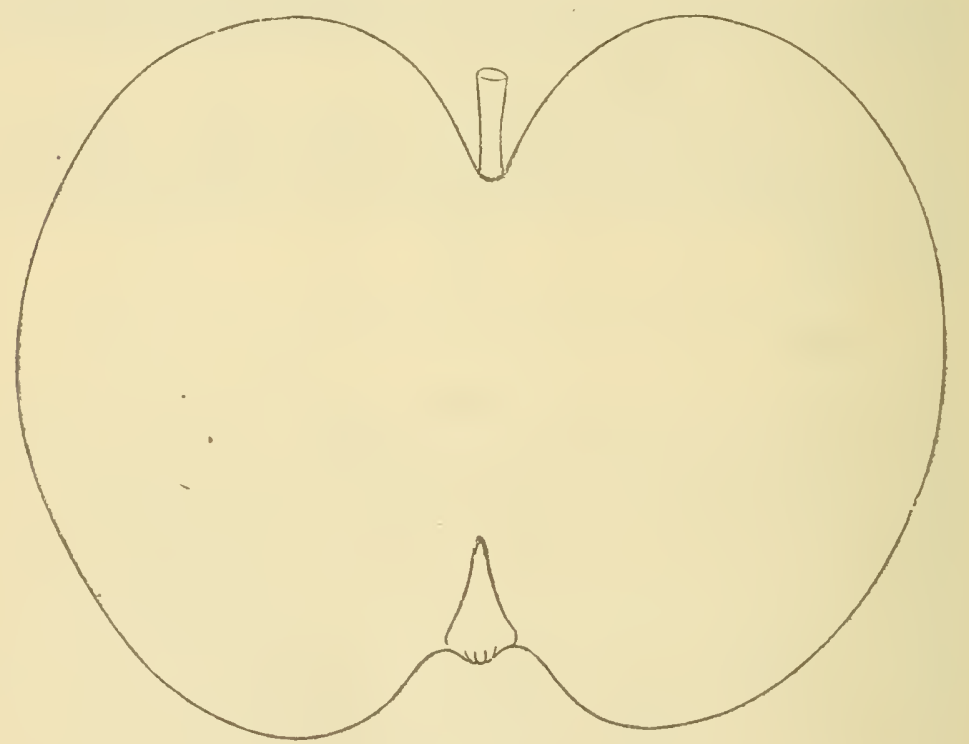

Transparent Zoar.

Fruit large, oblate, regular; skin smooth, a beautiful waxen white: shaded with light pink or carmine where exposed to the sun, a fow rather obscure light dots; stalk very short, small; cavity lal:ge, deep; calyx small, elosed; basin large, round, slightly plaited; flesh white, fine, rery tender, juicy, mild subacid, refreshing; core medium. Octoher, Novernber. 


\section{VOLNEY.}

Origin, orchart of William MLunson, near Astoria, Illinois; tree vig. orons, with an upright rather spreading head; a good bearer annually, and highly esteemed where knowi.

Fruit inedim, oblate, regular; skin smooth, bright yellow, shaded with light bright red in the sm, many light brown dots, some irregular or star-shirped; stalk short, slender; cavity medium, slight rnsset; culyx closed or nearly so; basin large, deep, a little wrinkled; flesb whitish yellow, half fine, cris], tender, juicy, rich subacid; core small. Jamuary, April.

\section{WATWOOD.}

Origin; on the furm of Nithan Rose, near Blandville, Kentucky; tree vigorous, inuight, forming a round head; a good bearer annually, and esteemed in its locality for its quality and long keeping.

Fruit mediun, oblate, depressed and flattened at the ends; skin whitisl yellow, shaded with pale red over two-thirds its surface, and a few light and gray dots; stalk rery short; carity broad, deep, slight russet; calyx closed; basin lather shallow, slightly corrugated; Hesh pale yellow, half fine, rather firm, juicy, pleasant subacid; core small. January, March.

\section{WYTHE.}

Illinois Pippin.

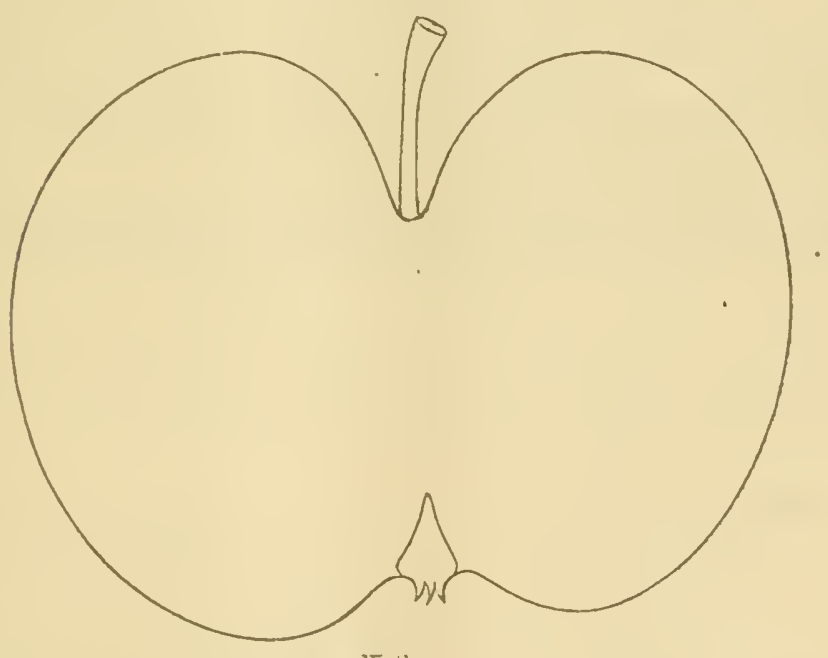

Wythe.

(1risin, on the farm of Podolphus Chandler, Wythe, Illinois; tree is satid to lue hards, vigorons, round head, blooms rather late, bears good crop's annua ly of fair fruit of uniform size, and keeps well. 
Fruit medium, oblate, slightly conic, nearly resular; skin white, shacked, striped and splashed over more than half the surface with bright red and a few light and gray dots; stalk short, small; cavity rather linge, deep; calyx small, closed; basin medium, slightly plaited; flesh whitish, fine, tenter, juicy, sprightly subacid, slightly aromatic; core medium. Jauuary, March.

\section{YARDLEY.}

\section{Bucks County Seedling of Some.}

Origin, on the farm of Thomas Yardley, Lower Makefield Township, $\mathrm{Pa}$; tree vigorous, spreading; an abundant bearer alternate years, and a light crop the odd years; a large apple, valuable as an early market variety, and for home use.

Fruit large, roundish oblate, slightly angular'; skin greenish white, thinly striped and splashed with pale dull red, and moderately sprinkled with quite large irregular brown dots; stalk short, rather stout; cavity large, deep, slight russet; calyx closed or nearly so; basin broad, moderately deep, corrugated; flesh whitish, rather coarse, tender, juicy, brisk subacid; core small. Angust and half of September.

\section{Zachary Pippin.}

A chance seedling on the land of John Burbank, Belgrade, Maine, and was introduced the year Zachary Taylor was inangurated; tree vigorous, sprearling; not an eurly bearer, but when established prorluces good crops amnually of large fair fruit, and esteemed in its locality.

Frnit large to very larrge, oblate, angular; skin greenish yellow, or yellow at matmity, shaded, striped, splashed and mottled with light and dark red, some of the splashes quite dark; stalk short, rather smail; cavity large, quite broad, deep, slight russet; calyx closed; basin medium, slightly corrugated; flesh whitish, a little coarse, tender, mou. erately juicy, subacid, rather rich; core medium. November, December. 


\title{
TIIRD APPENDIX
}

$\mathrm{T}()$

\author{
SECOND IREISEI EUTPION.
}

PREFACE.

Wrex the second Appendix to "Downing's Fruits and Fritit Tirees of Anerica" was published it was ny intention to revise the whole rork, correct the errors in the descriptions of fruits, describe fully the new frnits, and make the whole complete to the fresent time; but the publishers do not feel warranted in doine? so at present, and I am obliged, therefore, to defer the rerision : , I have, however, at their ment recpuest, prepared this third I1.penclix.

To the numerous friends of Pomolngy to whom I an indebter? for specinens of fruit, and for information relating to them, I offer many thanks, and their names wonkd have been acknow:edged if the third revised elition hat been required by the snlslishers.

Cilarles Dofictaci.

Newbligh, 1881. 



\section{TIE APPLE.}

\section{Alersox's Eamix.}

Origin uncertain, supposed by some to he Ohio, and it may prore to be the Enrly George or August Tart. 'Tree said to be hardy, uyright, moderately rigorous; an early and good bearer.

Fruit merium, oblate, angular, ribbed or meren: skin pale yellow; stalk short, rather stout; eavity rather broad, slightly russeted: ealyx closed; basin medium, slightly corrugaterl; flesh white, tender. juicy, sprohty subacid; core rather small. Ripens about the time of the Early Harvest, to which it is inferior as an eating-apple, but stuperior for cooking.

\section{AxDrews' Favorite.}

Origin on the Andrews farm, Berlin, Vt.; the original tree is said to be seventy years old, healthy, rigorous, spreading and irregular; a good bearer anumally of handsome fruit, and of good quality.

Fruit medinm, roundish, inclining to oblong, slightly angular: skin whitish, shaded, and mottled with light red, with stripes and broken splashes of dark red or erimson, and many light dots, a fow being areole; stalk short, sinall; cavity small, sometimes slight russet; calyx small, closeri; basin medium, corrugated; flesh white, half fine, tender, juiey, pleasant subacid; very good; core large and open. December, January.

\section{AXDREW'S SWEFT.}

\section{Mrajor Sweet.}

Of Nova Scotia origin, on the grounds of Major Andrew, of Yarmouth, am it is sairl to be a very hardy tree for that locality. Tree a free upright grower; an early and anmal bearer, but larger erops (o) altrinate yerrs.

Fruit below meciium size, round oblate conic, slightly ancular; skin whitish or pale yellow; stalk short, small; carity medium; 
"alyx closed or nearly so; basin large, deep, slightly corrugated; Hesh white, half fine, tender, moderateiy juicy, mild, pleasant, sweet, rather rich, and very good; core medium. Novenber, December.

\section{Austix Arple.}

Tom Apple.

(Higinated on the farm of Thomas Austin, of Suffield, Conn., many years since. Tree a good grower, spreading, and produces groor crops annually. Its size and color make it valuable as a market apple, and also for home use: the tree requipes grood cultivation.

Fruit large, roundish oblate conic, regular; skin pale whitish vellow, shaded with light red, splashed with crimson over most of the surface, and thickly sprinkled with large and small yellowish dots; stalk short; cavity medium; flesh white, half fine, tender, juicy, sprightly subacid; cood; core medium. Season middle of August to the midalle of September.

\section{Baxk.}

Care.

This is an old varicty, but little known out of its locality, and originated in the orchard of James Hadsell, on the west bank of the Gusquehanna River, opposite Ransom, Pa., and is a farorite-apple in that neighborhood. The tree is a vigorous grower, with a roundish spreading head; an abundant bearer on alternate years, and a light crop interrening.

Fruit medium, or rather large, oblate, slightly conic, slightly angular, sides sometimes a little mequal; skin whitish yellow, shided with light red stripes and broken splashes of dark red or crimson, and morlerately sprinkled with light and brown dots; stalk short, small; cavity ratlier large, deep; calyx closert; basin medium, nearly smooth; flesh whitish, half fine, tender, juicy, refreshing, pleasant subacid; core small. Season Eeptember, January.

\section{Baring.}

Its origin is said to be on the farm of John Barnard, near IIus. catine, Iowa. Tree very hardr, rigomus, healthr, upright, somewhat sprealing, roundish top, rather long, slender bianches, valuable for its harliness, productireness, long-keeping, and quality; an abunclant bearer on alternate years.

Fruit medium, oblate to roundish oblate, slightly oblique; slin whitish yellow, shaded with pale red (dark red where fully exposed to the sun), a few gray (lots; stalk short, moderately stout; carity medium, deep, sometimes light russet; calyx closed; basin rathei large, broad, saucer-like shape, corrugated; flesh whitish, ratlic: conse, crisp, juicy, with a peculiarly mill subacil flavor; core incdium. Devember to May.

\section{Be.LTY OF THE TORID.}

A new variety, raised by John Mace, of Morganton, X. C., or found in an old field of his at the foot of South Mountain-a 
spur of the Blue Ridge-a few miles from Morganton. Tree at vigorous grower, rather tall and spreading; bears morierate crop's anumlly; keeps well, and is said to be a valuable variety for that locality.

Fruit medium, oblate, regular: skin yellowish, entirely covered wh pale red and yellow, thekly striped and splashed with erimsun, purplish crinson in the sun, moderately sprinkled with light, rellowish dots; stalk slort, rather small; caviuy small or mediun, thin russet: calyx closed; basin rather large and broad; flesh white, half fine, rather firm, mild subacid; very good; core small. Ripens in November, and keeps till March.

\section{BElle dE BOSKOOP'}

A new varietr, trees of which I received from France; it is said to be of Russian origin. Tree vigorous, spreading, comes into bearing moderately early, and produces abundantly aiternate years of fair fruit, grood size, very good quality; leeps well, and is a promising variety.

Fruit medium to large, oblate to roundish oblate, sometimes a

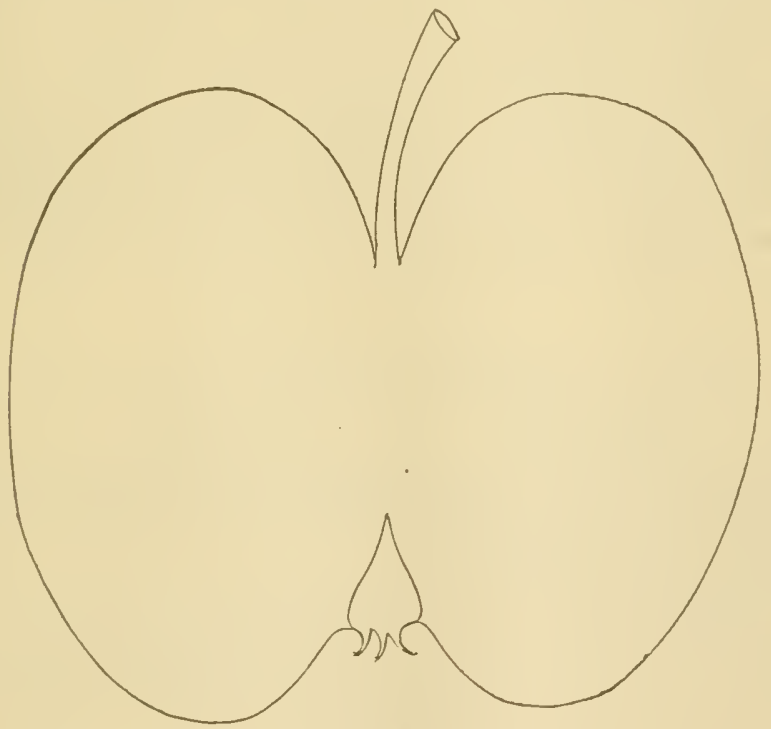

Bcile de To:koop.

little oblique; skin rellow, sharled with light and dark red over nearly the whole surface, with some rather obscure stripes aut splashes on the shaded side, some specimens more or less mixed with russet, and many small and large yellowish-brown dots, with some irregular ones; stalk short, small; cavity rather large, often russeted, sometimes extending in rays ont on the fruit; calyx closed, or partially open; basin large, round, deep, slightly corrugated; 
flesl a little coarse, crisp, tender, juicy, brisk subacid, rich, and of very gool quality; core small and close. Season February to April.

\section{BLACix TWIs.}

The exact origin of this apple is unknown, but supposed to be i. the northern portion of Lincoln County, 'Tenn. It is said to be (me of the most valuable and profitable apples grown in that section. 'Tree very rigorous, spreading, rather an open head, not an eariy bearer, but giving good regular crops annually.

Fruit medium, oblate, very little conical, slightly angular; skin bright yellow, shaded with light red (lark crimson in the sun), some cbscure stripes and splashes on the shaded side, and rather thickly sprinkled with yellowish and brown dots; stalk short, rather stout; cavity medium, slight russet; calyx closed; basin medium, roundish, regular; flesh pale rellow, half finc, tender, juicy, mili subacid, rich; very good; core rather small. October to February.

\section{Blue Bloom.}

This apple originated in an orchard of seedlings planted by the Rer. Daniel G. Cartwight, in Lnion, Iowa, alout 1st0. 'Iree vigorous, making a round head; a good bearer in alteruate years, and a moderate intervening crop.

Fruit ratier large, oblate or roundis! oblate, slightly angular; skin white, striped, splashed and mottled with light and dark red over most of the surfice, with a light grayish bloom, often mixed with russet, and moderately sprinkled with light dots: stalk short, small; cavity large, deep, slight russet; calyx small, closel; basin rather smali, slightly plaited; flesh white, lialf fine, tencler, juicy, sprightly subacid, good flavor and rich; core large. Septenber, Cotober.

\section{Brewixgton Pispix.}

\section{Breckenridge.}

Brewington.

This new apple originated with James Brewington, Carfield, Ky, about $18 \% 0$. Tree a vigorous grower, upright, becomes spreacling with age and bearing; an eariy and abundant beurer on alternate years, anul blooms quite late.

Fruit large, roundish oblate conic, slightly angular; skin rellow, shaded with pale red, striped and splasined with rich crimson over most of the surface, and pretty thiekly sprinkled with rather large yellowish dots, a portion being areole; stall short, small; carity medium, lusseted, sometimes extanding out on the fruit; calyx closed; basin rather abrupt, quite deep, slightly plaited; flesh white, half fine, tender, juicy, mild subacid, inclining to sweet: quality very good; core small. Ripe February, March.

\section{BLFHNELL.}

Origiuated in the garden of General Andrew Bushnell. ITartford, rhio, many years sinee. Tree hardy, a moderate grower, spreading; an early and prolific bearer on alteriate years. 
Fruit rather helow merlium, ol)late, slightly angular; skin whitish rellow, having a few small wray stots; stalk short, small; cavity meklum; calyx opum; hasin ral her small, slighty platited; flesh white, fanc, tencler, juicy, milel, jleasant subacid; very good; core rather small. Season dugust and sejetember.

\section{CANAI)A THIMWIN.}

This beautiful apple is said to hare oricinated, some years since,

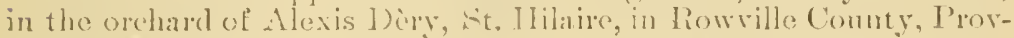
ince of (umbee, and is pobably of the Famense tye. Tree hardy, vigorous, thrily arower, upright at first, grachalily spreacling wih age and bearing; it begins to bear rather any. giving heary and light crops on alternate years; it is a handsome fruit, of very good yuality; it is considered one of the most raluable, long-keeping apples of its locality, both for market and family use; it is saicl to succeed hest on heary soils, while on light, wam soils, and sudden changes of temperature, the trunk is apt to sun-scalil, which often caises premature decri:

Fruit medium or below, oblate, slightly angular; slin quite white, thickly striped and splashed with rich red! and erimssn, purpish erimson where fully exposel, laving a slight bloom, anci many white dots; stalk short to medium, slender; cavity rather large, decp, regular; calyx small, closed; hasin linge, deep, slightly corrugated; flesh very white, fine, sometimes a little stained next the skin, and sonetimes reined in the flesh, tender, juicy, refreshing, with a mild subacid, preculiar slight quince-like flavor; very good; core small. Season January, April.

\section{Campextan'; Shet.}

An old rariety which originated on the lands of Ephraim Carpenter, of Woolstock, Com. 'Tree a thifty grower, upright; comes rather early into bearing, and produces large crops alternate years; its size, color, and flaror make it valuable for home use or market.

Fruit medium or abore, roundisti oblate conic; skin pale yellow, striped with light and dark red neasly over the whole surtace, but quite thinly, with a few brown clots; stalk short, small; carity medium or rather large, sometimes slight russet; calyx closed; basin medium, stightly corrugated; flesh white, fine, tender, juicy, with a mild, pleasant, rich, sweet flavor; rery good; core medium. Lipe in September, and continues in use till Norember.

\section{Carpintix.}

\section{Carpentin Reinette.}

Petite Reinette Grise.

Of German oricin. Tree a morlerate grower, forming a round, open heal, producing molerate crops anmully, often growing in clusters; fruit of small size, but regular, liendsome, and of tiuc quai ity; raluahle as an amatenr fruit, and when well known will, w doubt, be in demand for the market.

Fruit small, oblate, slightly angular, nearly regular, entirely cov- 
ered with a peculiar light red russet, more or less mixed with crimsois and russet where exposed, and a few brown dots; stalk short to medium, slender; cavity mediun; or rather large, regnilar; calyx

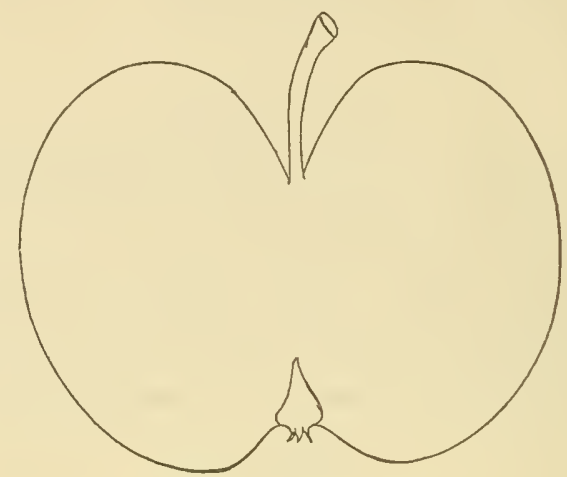

Carpentin.

elosed; basin round, rather deep, slightly plaited: flesh white, fine, erisp, tender, juicy, with a rich, sprightly subacid flavor; very grood; core small. November, February.

\section{Cextexial.}

An old variety which originated on the farm of Stephen Child, East Woodstock, Conn, but was not brought into notice till quite recently. Tree a thrilty upright grower, somewhat spreading, an abundaut bearer on alteruate years; fruit always fair, handsome, and desirable for home use or market.

Fruit medium, roundish oblate, slightly conic, slightly angular; skin yellow, shaded with light and dark red, striped and splashed with erimson over the entire surface, and purplish crimson in the sun, with a few light dots; stalls rather short, small; carity medium, much russeted, sometimes extending its rays ont on the fruit; calyx elosed; hasin rather large, deep, corrugated; flesh white, sometimes a little stained next the skin, half fine, tender, juicr, subacid, with a pleasint, refreshing flavor; rery good; eore large. 'Season Novem. bcr, Necember.

There is another Centennial which originated with J. Z. Schuman, of Unper Berne, Pa., which he states is a new apple, and produeed its first fruit in 18.5 . Tree is rigorous, healthy, and a good bearer; the fruit is large, handsome, striped with red, of an aromatic flavor, and. lieeps through the winter.

\section{Chatr.}

Lewis.

An old variety, but little known out of the neighhorhood of its origgin; it was raised from seed by Deacon William Clark, of Clark's Green, Pa. Tree a vigoruus grower, spreading, and inclining to 
droop with orer-bearing; an early and profuse hearer on alteruate Years: it is sail to be uniformly fair, very pouluetive, alapted to all purposes, and lor a long tine, which makes it a farorite and popular fruit where known.

Fruit medium, oblate, slighty angular, slinhty conic; skin whitish. often with a blush, and molerately sprinkled with grayish duts; stalk short: eavity suall or medium, rather deep, light russet; calyx clused; basin medium, slightly corrugated; flesh white, half fine, crisp, temiler, juicy. sprichtly subacul, with a pleasant, slightuty aronatic llavor: core rather large. lijpening in succession from sceptember to January, and can be kept nuch longer.

\section{Collimia.}

Hyde. Columbia Iyde. Granny Iyde.

() liginated on the farm of Nathaniel Hyde, Columbia, Conn., about fifty rears since. Tree a vigorous grower, upright, with a round top; and long, pendent, rather slender branches: a good low) on alternate vears, with a molemte crop the intervening ones, and is considered, in its locality, valuable for home use and for market.

Fruit medium, oblate, regular; skiu light rellow, shaded, striped and splashed with light and dark reat over the whole surface, some of the splashes are of a purplish crimson, and a few light dots; stalk quite slort, sinall; carity medium; calyx closed; basin medium, slimlity corrugated; flesh white, half fine, rather firm, moderately juicy, mill subacid; good or very good in quality; core medimm. January to March.

\section{Cornwall Goldew Sivent.}

This is supposed to have originated in Cornwall, Tt., with a Mr. Bartholomew, one of the old settlers, many years since. Tree very hardy, a vigorous grower, round head, somewhat spreading, an abumdant bearer on alternate years; a late fall and carly winter apple. fair, nuiform in size, and very valuable for eulinary purposes.

Fruit rather below medium, ovate, or roundish conical; skin (leep vellow, a slade of reil in the sun, and a few seattering brown dots; stalk short, small; carity smail, slight russet; calyx small, closerl; lasin medium, slightly plaited; flesh white, half finc, half tender, moderately juicy, mild rich swect; rery good; core medium. October, December.

\section{DAWES.}

\section{Dawes Porter. Dawes Nonsuch.}

The Tawes apple is an old variety, originated on the farm of Francis If, T)awes, of ('ummington, MIass., where it is much cultivatul, and is considered by some superior to the Porter. Tree barly, a vigorous grower, making a larere round head; not an early hearer, hut, when fruting, bears profusely on alternate years.

Fruit merlium, romolish oblate conical; skin light yellow, a slado of light purplish red, and sometimes a few rather obscure splashed 
and a few scattering gray dots; stalk rather short, slender; cavity medium, slight russet; calyx small, closed; basin small, slightly corrugated; flesh whitish yellow, half fune, half tender, juicy, sprichty subacid, and of very good quality; core medium. October, November.

\section{DeCATIE.}

A rery handsome and very good apple, said to have originated in the orchard of Jérémie Decarie, in Coteau, St. Pierre, Province of Quebec, and is more than one hundred years old. Tree hardy, vigorous, healthy, forming an erect head, which spreads out gradmally, and bears heary and light crops alternately; it is thought by some to be the same as the Red Antumn Calville, but I believe it to be distinct.

Fruit medium, or nearly so, oblate, slightly conical, flattened at the base; skin white, nearly corered with light and dark rich red,

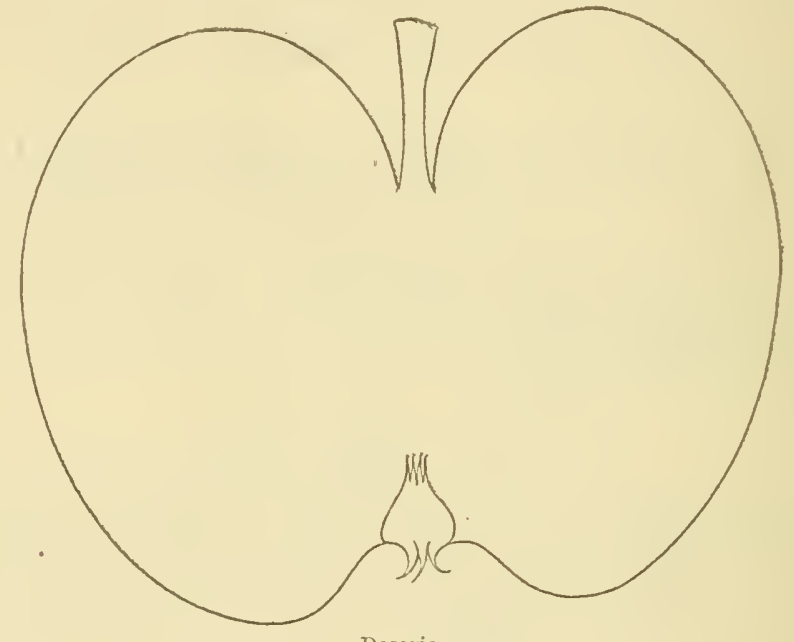

Decarie.

dark crimson in the sun, moderately. sprinkled with light and brown dots, and covered with a thin grayish bloom; stalk short, rather stout; cavity large, deep, slightly russeted; calyx closed; basin round, deep, slightly corrugated; flesh quite white, often stained next the skin, and sometimes in the flesh, fine, tender, juicy, sprightly subacid, having a slight peculiar, quince-Iike, agreeable flavor; core small. September, October.

\section{DE Loxg.}

\section{Iowa.}

The original tree of this variety was grown by Trilliam De L.ong, near Lexington, Jowa. It is said to be hardy, thrifty and vigorous. forming a roundish regular head; an early and productire bearer, a good dessert apple, and fine for culinary uses. 
Fruit rather large, roundish ublate, slightly conical; skin whitish, thickly covered with hroken splashes and stripes of bright red, somewhat mottled; stalli medinu; earity rather laree, deen; calyx elosed; hasin unedium, slightly eorrugated; flesh white, half fine, tender, juicy, sprightly subacid; core mediun. liipens the last of Septenber and tirst of October.

\section{Dr. Hocir.}

A new apple raised from seed by Sidney Ford, of Leonardslee, ncar Horsham, England, and is supposed to be a seedling of Thite IIuter Calville, as the resemblance is close. It is said to be hardy, healthy, and should be in any litehen garden, as a constant and heary cropper, being a large and handsome fruit of the finest quality for culinary purposes.

Fruit nealinu, roundish conical, angular or ribbed; skin whitish or pale yellow, sometimes a sharle of red where exposed; stalk merlim, slender, in a rather large, deep cavity; flesh white, tender, juicy, sprighty subacid, rich, a first-rate baking apple. Septenuluer to Iiarch. (Filo. \& Pon.)

\section{DR. WALKER.}

\section{Litsey.}

This is a seedling of Rawles' Genet, and originated on the farm of John Litsey, near Springfield. Ky. It is said to be superior in quality to its parent, and an acquisition for its locality. Tree

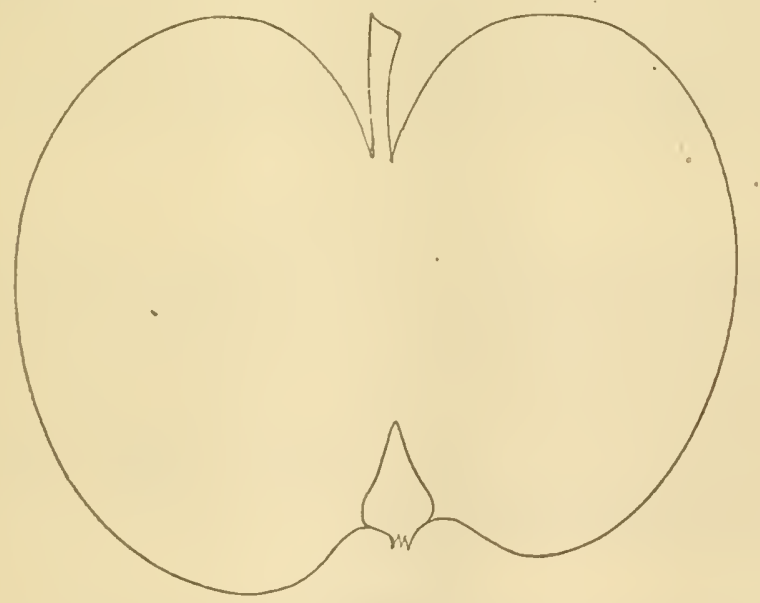

Dr. Walker.

hardy, vigorons, an early and good bearer annually. It blooms late, and keeps well.

Fruit maljum, oblate, inclining to conical, sometimes a litrle obligue; skin pale yellow; shadod, striped and splasherl with light and dark red nearly over the whole surface, and moderately sprinkled 
with light dots; stalk short, small; eavity medium; calyx closed; basin rather large, moderately deep, slightly eormgated; flesh whitish, half tine, tender, juicy, quite rich, with a,pleasant, mild subacid flaror; core rather small. February to May.

\section{DOYLESTOWN.}

Origin somewhat uncertain, but supposed to be on the farm of Elisha Lynn, Otsego, near Doylestown, Wis. The tree is said to be very hardy, moderately vigorous, with long, mather slender, tough branches, upright at first, but spreads out with age and heuring, requiring but little pruning; an early and good bearer ammually.

Fruit medium, roundish oblate conical, nearly regunlar; skin whitish, shaded, striped and splashed with light and dark red over most of the surface, and moderately sprinkled with laroe and small rellowish dots, some irregular; stalk short to medium, slender: cuvity medium, much russeted, and sometimes extending out on the fini!; calyx small, closed; basin medium, slightly plaited; flesh fue, quite white, tender, juicy, sprightly subacid, with a peculiar slight cranberry flavor; core large. October, February.

\section{Edelionig Reinetete.}

\section{Reinette Edelkonig. Edelkonis. \\ Roi Tris Foble.}

A German apple much valined for eulinary uses. Tree very vigorous, upright, productive.

Fruit large, roundish oblate conic, hroadly ribbed; skin rellow, nearly covered with dark rich red, sometimes almost purplish in the sun, moderately sprinkled with light dots; stalk rather short; cavicy larce, deep. slight russet; calyx closed; basin meelium, furrowed; flesh quite white, a little stined next the skin, tender, juicy, brish subacid; gool to very good; core large. Oetober, November.

\section{Egrptian Queex.}

Origin unknown, supposed to be Kentucky. Tree rignroas, nipright, a good amual bearer, and esteened valuable where known.

Fruit large, oblate, slightly conical, sometimes a little oblicine, angular, or slightly ribbed; slin smooth, bright lemon yellow, somewhat waxen, sometimes with a shade of bright red, and a few wrat dots; stalk very short, sinall; carity large, deep, often russered: ealyx elosed or nearly so; basin laree, deep, slightly plaitci: fles! white, a little course, erisp, juiey. pleasant subacid; goal to rery good; core sinall. January to May.

\section{Eurekl.}

Origin somewhat uneertain, but supposed to be Cheshire, Conn. Tree thifty, uright, rather slender branches, forming a handsome Jouncl heait; an early and prolific benter on alternate yea.s, and estemed in its locality for market or home use.

Fruit merlium, roundish ohlate, slightly conical: skin whitish, shaded, striped, and splashed with pale and dark red; stalk short, 
small; cavity small; calyx closed; basin small, corrugated; flesh white, fine, temler, juicy, mild subacid, and of very grood llaver: core nnedium. September, Oetober.

\section{Fal, Brow:}

Brown Fall.

Of mknown origin, considerably grown in southem New Jersey, and is prized as a family fruit. 'Tre moderately vigorous, with a roumd spreading heat, very productive biemnially, and griving a moderate crop the intervening years.

Frut below medium, ohlate; skin whitish, nearly eovered with dull rerl, sometimes nettings of gravish russet, some obseure stripes and splashes, and a few yellow russet clots; stalk medim, slender; carity medium, olten slight russet; calyx small, closed; basin rather small, slightly corrugated; flesh whitish, fine, tender, mocterately juicy, mild, pleasant subacid; good to very good. September, Novenber.

\section{Fametse Stcrée.}

This beautiful and excellent dessert apule is said to have originated on the premises of Maurice Gongen, near Montreal, Canalia, and its appearance indicates Famense furentage. Tree quite harly,

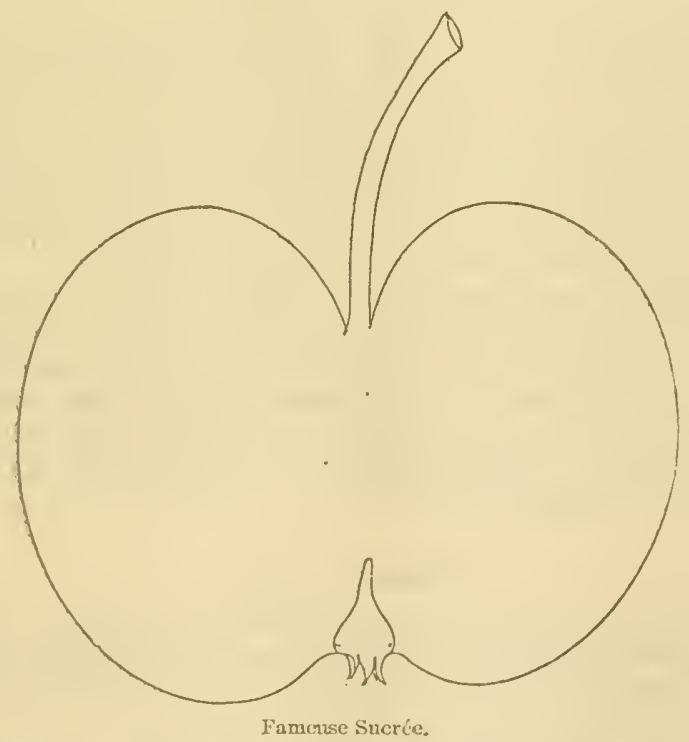

healthy, growth of moderate vigor, upright, spreads a little with age and hearing: a good but not a profuse bearer, and is highly esteemed as a table fruit where known.

Fruit rather below mediun, oblate, somewhat depresserl, slimbty angrular; skin almost entirely covered with light and dark red anil 
crimson, often striped and splashed with deep purplish red on the exposed side, and sometimes almost obscure; stalk medium to long, slender: eavity medium; calyx suall, closed; basin medinu, slightly corrugited: flesh rery white, stained next the skin, sometimes a little in the flesh, which is fune, tender, moderately juicy, with a deilicate, lively, slight quince-like flavor; of very good quality; core rather small. Ripens from the midclle of September to the last of Oetober.

\section{Fonter.}

Perkins.

Fleming.

In old variety, which has not been much disseminated, and is said to have originated in Bulke County, N. C., but the particular localits is unknown. Tree vigorous, upright, and bears alundantly nearly every year. It is much esteemed where known for its appeurance, excellent flavor, and market value.

Fruit rather large, rounclish, inclining to oblong, slightly conical, a little oblique; skin whitish, shaded, striped and splashed with light an 1 dark red, corered with many small ani large light dots, a few ieing areole; stalk short, rather small; carity mecium, rather narrow, (leep); calyx elosed; basin quite large, romid, slightly plaited; flesh white, half fine, tender, moderatery juier, mild, pleasant subacid; quality very good; core medium. October, November.

\section{Frexcil Wine.}

This large apple was bronght to notice by Darid H. Merritt, of Highlant, N. F., who informs me that the erafts were brought from Gomany, where it was called "French Wine," by a man namert Elicknof, living in the northern part of New Jersey. Tree a strong, visorons grower, makinz a round head; an early and abumlant bearer o: altemate vears; the fruit is large, fair, uniform $\mathrm{jn}$ size, and a profia! s: apple for culinaly purposes and market.

Fruit lire to verv large, oblate, slightly angular: skin smooth, whitish, shated with light and dark red, striped and splashed with crimson over a large portion of the surface, with many light dots; sialk short, rather small; carity broad, deep, slight rinsset; calyx closud; basin broad, deep, slightly corrugated; flesh white, a little co:ırse, crisp, juicy, sprightly subacid; of good quality, but uot rich; core medium. September, October.

\section{Golnex Disie.}

Originated on the farm of Janes Fitz, Township of Rivanna, Wa. Tree thrifty, vigorous, unright, forming a haudsome prramidal head, requiring but little pruning; an early and abumdant bearer on ilternite vears.

Fruit medium, oblate to roundish oblate, slightly conical: shin light groldin yellow, deep yellow on the sunny side; stalk short, small; carity inerlium, often with slight russet; calyx small, choser; basin lather abrupt, deep, sliently comgated; flesh whit ish rellow, half fine, a little firm, juicr, brisk, rich subacid, slightly aromatic; goout to very good; core sinall. Ripe about the time of Summer (queen. 


\section{(ivis)ist l'ipirs.}

A variety of the Golden Pippin which originated with Moses (ason, of Kenusville, la., many rears sinee. It is said to be one of the kiuds that suceed well in that locality, and is esteemed there for its good quality and productiveness. T'rees a vigorous, lealthy mower, making a large round liead; an arly and prolific bearè wn alternate years.

Fruit small, oblate, slightly eonieal, a little oblique; skia golien rellow, molerately sprinkled with rrigy dots; stalk short, small; cavity rather large, deep, often a little russet; (alyx smati, closed; basin large, deep, corrugated; flesh pale vellow, lialf fine, tember, juicy, sprightly subacid, (1!nte rich, slightly aromatic a:al of rery grood quality; core small. ()etober, January.

\section{Goth Siv.}

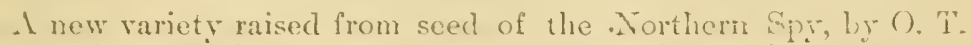
Fioblus, of liandolph, Pa. Mr. IIobbs says that the trec is a very stout aud rery upright grower; it is late coming into bearing, but bears molierate crops anmully when the tree has attained some age; the fruit is of very grood quality, and a late liceper.

Fruit medium, roundisli oblate, slightly conical, sightly angular; skin pale yellow, orange yellow in the sum, and a few small graysh dots; stalk rery short; cavity rather large, deep; calyx open; basin medim, rather deen, a littlo neven; flesh whitish, half fine, crisl', tenler, juicy, mild subacicl, rich, and of very gool quality; core medium. February, April.

\section{Guthond Fiè.}

Origin near Greenshorought, Guilford Couniy, $\because$. (', , (m thes

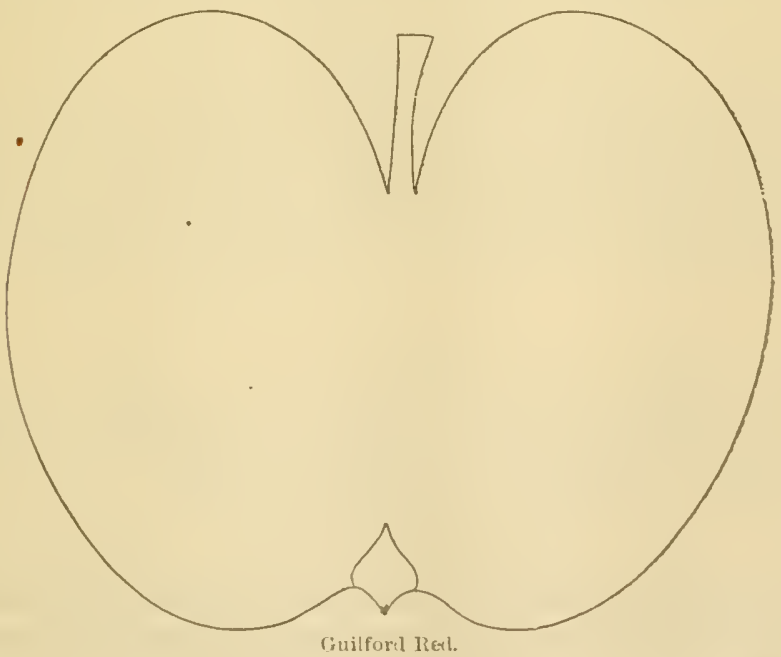

Edwaris plantation. Tree a thrifty, strong, upright grower, some- 
what sprealing, not a very early bearer, but produces grood crops ammally after it comes into bearing; it is ralued for its good quaiity aml late lieeping.

Fruit medium, cblate, slightly conical, slightly angular; skin pale yellow, entirely covered with light and dark rich red and erimson (purplish crimson where fully exposed), and moderately sprinlikel with yellowish dots; stalk short, rather small; cavity rither large, deep, sometimes slightly rusefted; calyx closed; bisin mealium, corrugated; flesh pale yellow, half fine, rather firm, juicy, subacid, rich, a little aromatic; core medium. January, March.

\section{Himes.}

A seedling raised by Henry S. Hames, Mest Point, Ga., anrl is suid to be a valuable variety of its season for its locality, especially for the market and all hinds of culinary uses. Tree a vigorous srower, unright, making a round head with age; an eary and good barer annually, ripening about the season of Red Astrachan.

Fruit large, roundish, or roundish oblate; shin whitish, striped, splashed and mottled with light and dark red over most of the surm face in well-colorol specimens (purplish red where fully exposed), and moderately sprinted with relluwish and brown dots; stalls short, small; carity rather largé; calyx elosed; basin mediun, sligutly corrugated; flesh white, half fine, rather firm, juicr, brish subacid; quality good; core medium. Pipens in Georgia from 15th of June to 1öth of July.

\section{Hiantaxi BeAtTy.}

A new variety which originated in the garden of the late Tilliam Poe, Newbursh, N. Y.; it is a beartiful apple, of very good quality,

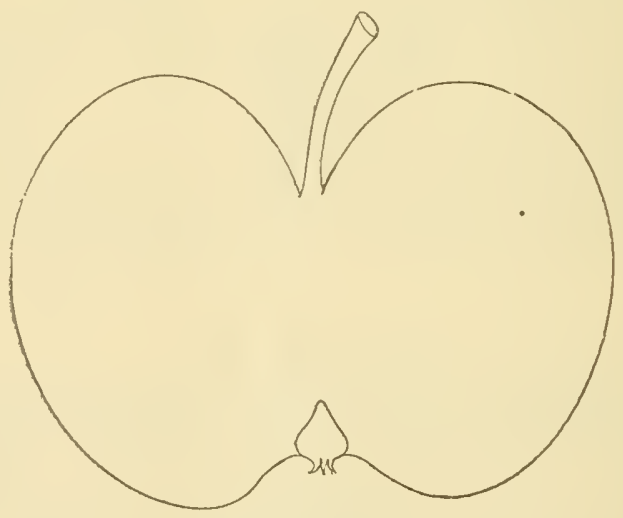

Highland Ieauty.

keeps well, and is a promising addition for the dessert. Tree thrifty, moderately vigorous, formine a round head; an abundant hearer on alternate rears, with a light orop the non-bearing season.

Fruit small to medium, oblate, slighty conical, somewhat angrth- 
Jar: shin smooth, almost waxen white, often a siliale of brielu wr (1) cambe in the sum, amel a few scattering eraysh dots; stall. slowt

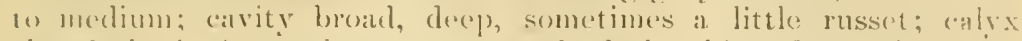

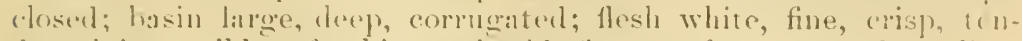
(ier, juicy, mild, refreshing subacid thavor, of very grool qualits; core rather small. Season Jannary, March.

\section{lametida, Rismio.}

A new variets raised hy C. T. Toblos, of Randolpli, Pa. Tire a strong grower, spreading; a reowlar and moderate bearer: is late fall and early winter apple of fine quality.

Fruit medimin, ob]ate, oblique, slightly angular; skin smooth,

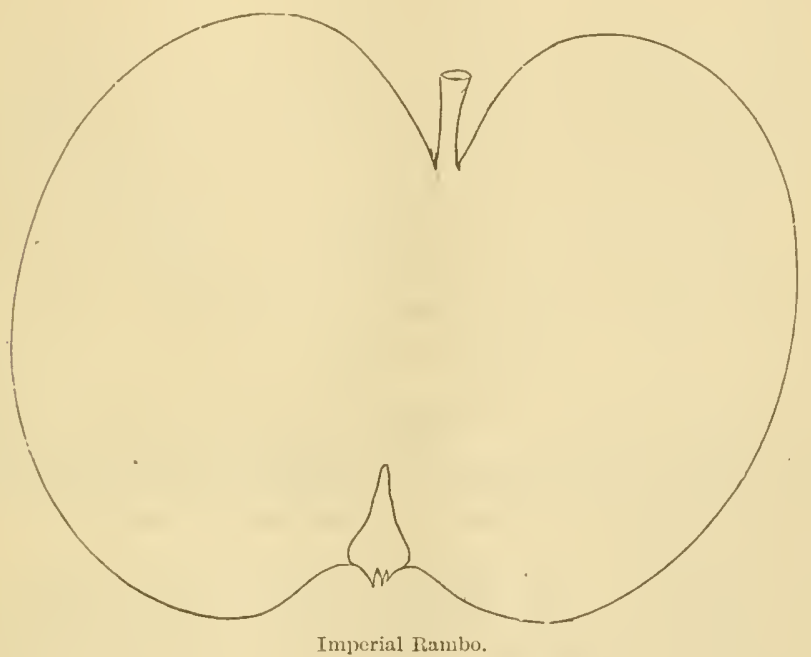

whitish yellow, rather thinly striped and splashed with light rest over most of the surface, with a few scattering light and gravish dots: stalk very short, small; cavity rather laroge, deep; calyx suall, closed; hasin la ree, deep, slightly plaited; flesl white, half fine, ver: tender, juicy, mild subacid, refreshing and excellent flavon; coro small. Cetober, February.

\section{JoHNSON.}

This fune winter apple was raised from seed by Thomas Johnson, Ash Ridge, Ill., and is said to be equal to any apple of its season for cuality, and for the locality of its origin. Tree a vigorons, n]right grower, an early and good bearer annually, and valuable for. table and miaket.

Fruit medium, oblate, sometines slightly olslique, regular; skin pale yellow at maturity, nearly covered with deep rich rerl or rirk crimson, somewhat puiplish in the sun, and moderately sprinklent with light and eray dots; stalk short, small; carity medium o: rather large, russeted; calyx closed; basin broad, not very ceen, 
slichly plaite 7 ; fiesh yellowish, half fine, a little firm, morlerately juicr, mild subacid, rich, and of excellent quality; core small. 1)ccomber to Narch.

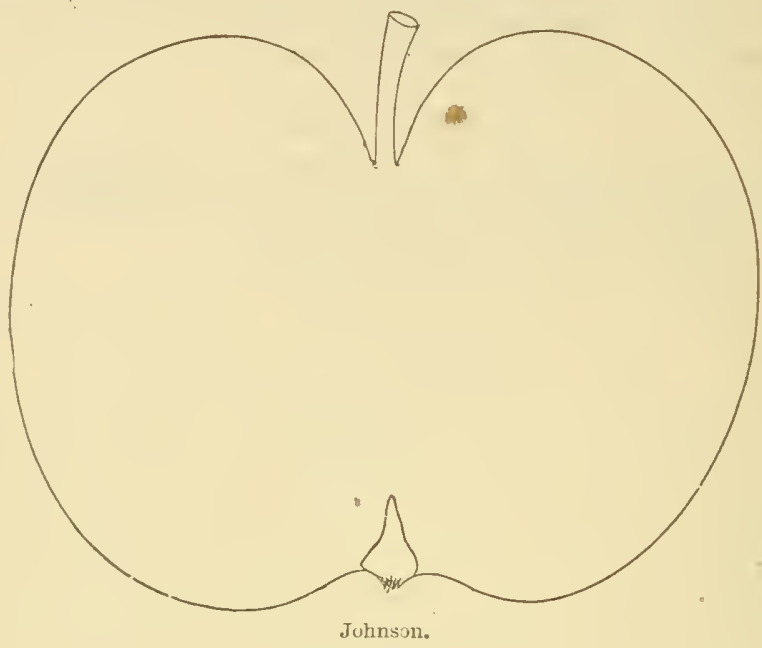

JULT QTEEx.

A new variety which originated in the nursery of Newman Taunton, near Ophelia, Ga. Tree a rigorous grower, somewhat spreading, not a very cally, but a good bearer every year; it ripens soon after the Gravenstein, and is cunsidered an acquisition in the locality of its origiu.

Fruit medium, roundish, slightly conical; skin pale yellow. a little giecnish, striped and splashed ratlier thinly and faintly over balf the surface in exposed specimens, and but little color where grown in the shade, with a few light and brown dots; stalk short, small, sometims by a lip; cavity rather small, russeted; calyx closed, or nearly so; basin rather small, slightly plaited: flesh whitish, half tine. tender, juicy, mild, pleasunt subacid, slightly aromatic, and of rerv good quality, core small. Ripens in Georgia from the midclle of July till the 20th of August.

\section{KestNer.}

A new apple originated with Marcus Kestner, Hickman, Ky. Tree thrifty, rigorous, upright, tall, but spreading and irregular; an early and good bearer anmually, and is considered a raluable accuisition for the locality of its origin.

Fruit medium, oblate, somewhat flattened at the ends, slightr oblique; skin whitish rellow, nenly corered with pale earmine red, many rather obscure stripes and sulashes of a darker hue, and a few light and gray dots; stalk very short, small; cavity medium. slight russet; calyx closed or nearly so: basin rather large, slightly corru. guted; flesh yellow, half fire, tenfler, juicy, rich subacid; quality very good; core smill. Season December to March. 


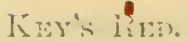

I new raricty which originated with the late Martin Key, of Clar libook, 'T'mn, and is saicl to he an accinisition for the locality of its orierin. Tree hardy, a stronger, vigrorous grower, sprealing, and beats good crops anmually.

Fruit medium, romblish oblate, slightly conical, sometimes a lit te oblique; skin pale greenish yellow, nearly covered with dark red, and many rather large rellowish areole dots; stalk short, small; eavity medium, rather deep, russeted; calyx open; basin rather large, dere, slight?y plaited; flesh whitish, a little coarse, juicy, sul)acid, slightity aromatic; core small. Ripens from October to Februa) ry.

\section{HNA SWEET.}

Summer Sweet, of some.

Thomas Sweet.

IIirh Top Sweet, of some.

Originated on the farm of Ichabod Thomas, Sirney, IIc. Tree a harily, thrifty errower, upright, compact, and recuires mnch inside pruning, bears abundanty on alternate years; esteemed in its locality as an early family fruit.

Frnit below medium, roundish conical, inclining to oblong; skin greenish rellow, often a shade of pate red; stalk short, small; cavity medium; calyx closed; basin rather deen; flesh half fine, whitisli, juicy, half tender, rich honey sweet; core rather small. Scptember, November.

\section{Kinkeat.}

This large, beantiful, and fune summer apple originated on the

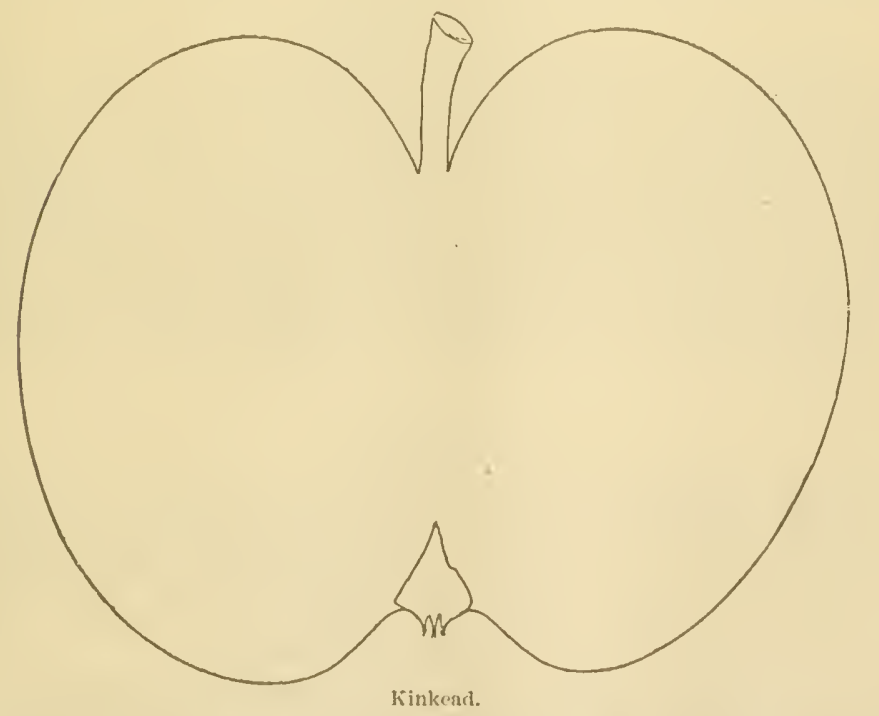

grounds of J. C. Kinkead, Lancaster, Ohio. Tree a vigorous, stout, upright grower, producieg good crops annually. This apple was ar 
first sipposed to be the Testern Beauty, or Big Rambo, but it has proved to be distinet, being of better quality, brighter in color, and earlier in ripening.

Fruit large, oblate to round oblate; skin whitisl, striped, splashed and mottled with light and dark rich red orer nearly the whole surface, and moderately sprinkled with light dots; stalk short, moderately stont; carity large, sometimes with slight russet: calyx closed or nearly so; basin large, deep, nearly smooth; flesh white, half fine, tender, juicy, mild subacid, refreshing; quality very good; core small. Season all the montl of September.

\section{KIRKLAND.}

An old variety, but little disseminated out of its locality: it originated on the Kirkland farm, and was named after Doninie Kirkland, a missionary to the Oneida Indians. Tree hardy, a rigorous grower, witl a round, rather spreading head; an early and good bearer annually, but more abundantly on alternate year's: fruit not of the best quality, but valuable for its hardiness, productiveness, late keeping, market and culinary uses.

Fruit medium or above, roundish, inclining to oblong, angular, or alinost ribbed; skin smooth, bright straw color, a shade of pale red where exposed to the sum, and a few small brownish dots; stalk short, small; cavity medium, a little uneren: calyx closerl: basin medium, somewhat furrowed or angled; flesh whitish yelow, 'lalte fine, crisp, half tender, juiey, with a brisk subaeid flavor; core large. January to May.

Finpr's HaRvex.

Originated on the farm of Capt. Rufus Knapp, Sutton, Iiass. Tree vigorous, spreading, inclining to droop; a rood bearer amminlly.

Fruit large to very large, oblate to round oblate, very slirhty conical; skin pale yellow, or light straw color, a slade of male reil in the sun, and many gravish dots; stalk short, molerately stout; cavity large, deep, often five angled, and a little greenish: calyx open; basin medium, slightly plaited: flesh whitish yeliow, rather coarse, moderately juicy, pleasant, mild subacid, slightly aromatic, and of good qualit:; core medium, or rather large. September, Uetober.

\section{LAXKTORD.}

\section{Tickers.}

A chance seedling on the land of Thomas J. Tieliers. Lankford. MI., and is much rished in that locality for its rigor, harlines. productiveness, good quality, and adiptedness to that latitude. 'íree vigorons, upright, with rather slender, firm branches, forming a round heat, and bearing gool crops annully.

Fruit medium, oblate to roundish oblate, sides sometimes nuequal, or a little oblique, often fiattened at the ends: skin male green, shaded with pale and dark red over half or more of its surface, and moderately sprinkled with large light and grayish dots- 
many areole: stalk rather short, slencler; cavity large, deep, sreen. isli; calyx closed, or pirtially open; hasin large, rather deep, sliglitly

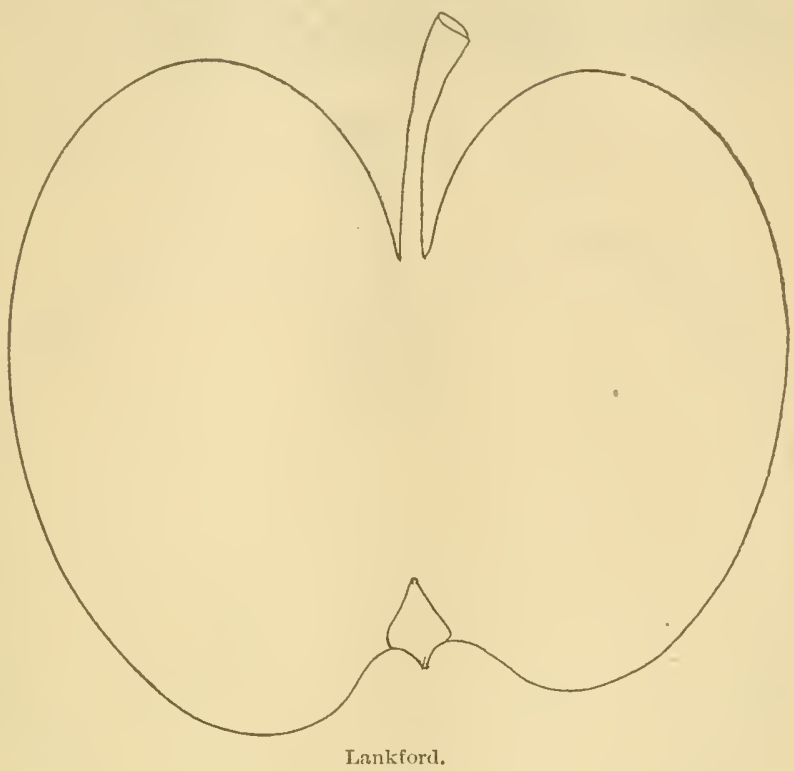

corrugated; flesh whitish, a little coarse, tender, moderately juicy, milel subacid, inclining to sweet; core sumall. December, May.

\section{Lamge Suman Queex.}

This fine large summer apple is supposed to be of Nopth Carolina origin, but the exact locality is not known. The tree is saicl to be very vigorous, upright at first, but, with age, spreacling and irregular; in the orchard an early and abmond anmul bearer, and valuable in its locality for its time of ripening, which is abont the time of the American Summer l'earmain.

Fruit large to very large, roundish oblate, nearly regular; skin pale greenish yellow, shaded, splashed and mottled with pale red, and moderately sprinkled with large, light, yellowish dots, a few being areole; stalk verr short, morlerately stout; cavity rather large, deep, smooth; ealyx closed; basin quite large, deep, nearly smooth; flesh whitish, fire, tenter, juicy, rich, mild subacicl, slightly aromatic; very good; core medium. Tipens in Nortl Carolina from the last of July till the first of September.

\section{Lixcolis Piprex.}

An old variety, said to have been bronght from Connecticut, many rears since, to Syracuse, $\mathrm{N}$. Y., by a . Ir. Knapp, and lately brought into notice by the late Reuben Lincoln, whose name it bears, the original wame being lost. Tree a tall vigorous grower, making a 
large, open, spreading head; an early and good bearer annunily, hut large crops on alternate vears: and being hardy, healthy, long-lived, and the fruit of good appearance, large, fair, and uniform in size, makes it valuable for market or fumily use.

Fruit medium to large, roundish oblate, slightly conical, slightly

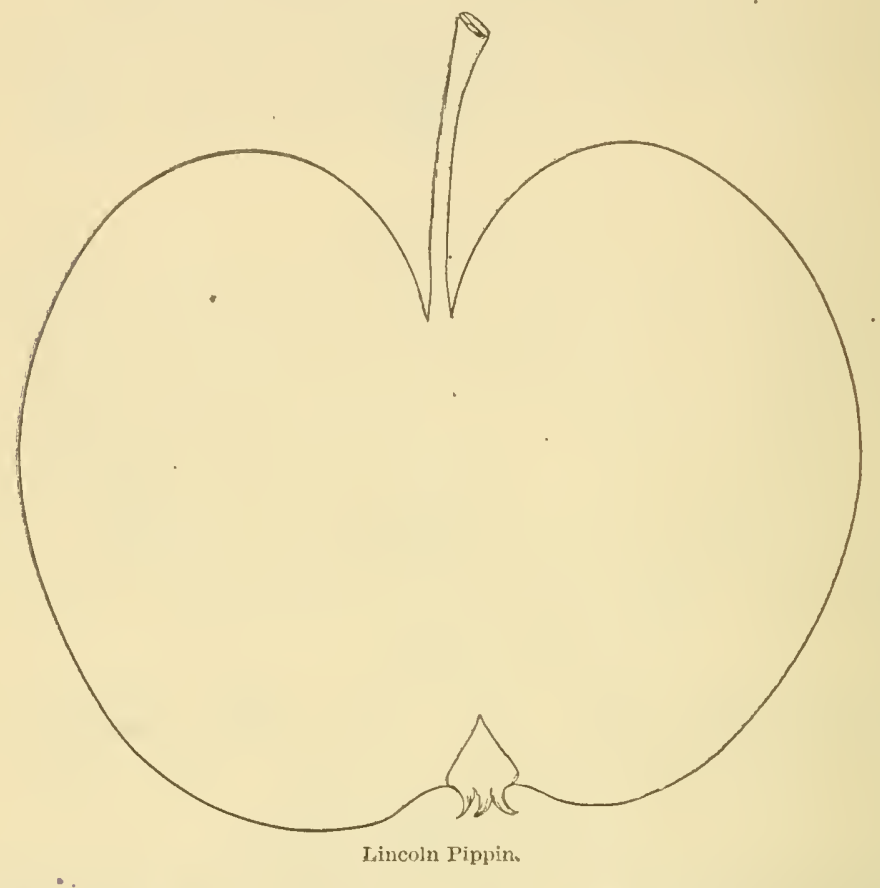

angular, sides sometimes a little unequal; skin pale grecnish yellow, moderately sprinkled with grayish dots; stalk short to long, slender; ruvity large, decp; calyx small, closed; basin small or medimm, slightly corrugaterl; flesh half fine, pale whitish yellow, tender, juicy, subacid, slightly aromatic; very good; core rather large. October, December.

\section{Longmorti's ReD Writer.}

Oriminated with William Longworth, Dubuque, Towa, who writes that the tree is hardy, a vigorous grower, with a roundish head, inclining to he upright; an early and good bearer annually, but larger crops on alternate years.

Fruit medium, roundish oblate conical, regular; skin whitish yollow, shaded, striped and splashed with light and dark rich red prer most of the surface, and thickly sprinkled with light dots: stalk mediun, slender; cavity rather large, smooth; calyx closed or nearly so; basin medium, slightly corrugatex: Hesh white, fine, sometimes reins of red around the core, tender, juicy, mill subacid, harig a slight peculiar quince-like flaror; very grood. Norember, February. 


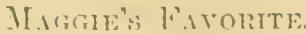

Fing of the liambos.

An old varicty originatimg on the farm of Anson Purple, W' astfield, P'enn., and although a first-class summer and fall apple, it anpears not to have been widely disseminated out of the neighborhood of its orignin. 'l'ree a vigorons grower, making a large spreading. hear, bearing very full eropis on alturnate yours.

Fruit medium or ahove, roundish oblate, nearly regrular; skin

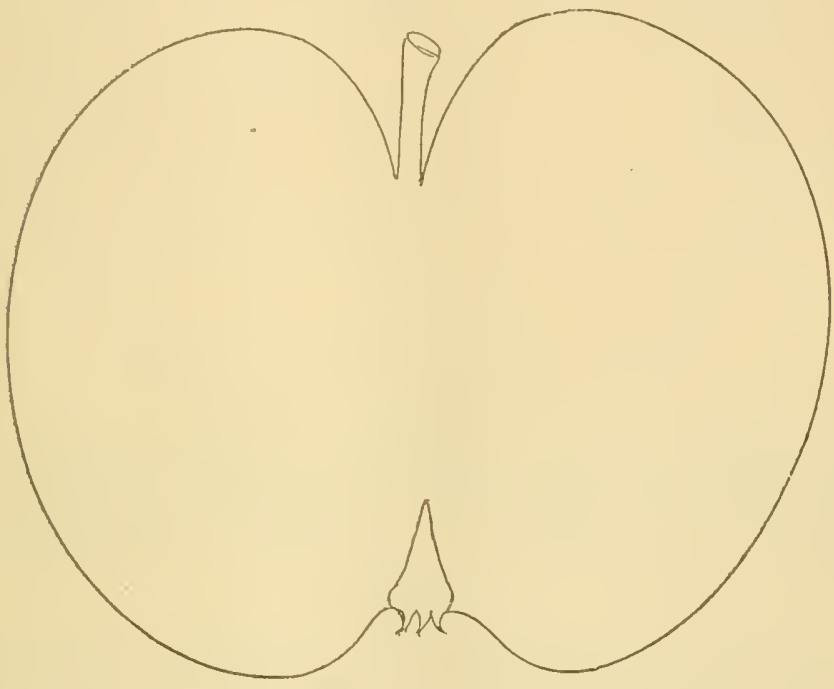

Maggie's Favorite.

pale yellow at full maturity, shaded with light red, having short stripes and splashes of dark red over half or more of the surface, and many large vellowish and brown dots, a portion heing areole; stalk short, lather stout; cavity nedium, regular, slight greenish russet; calyx open; basin medium, roundish, deep; flesh whitish, fine, +ender, juicy, very pleasant subacid, slightly aromatic and very good quality; core sinall or medium. Ripens in September and keeps well.

\section{MARY WOMACK.}

John W. Walker, of Anchorage, Ky., who sends specimens of this apple, writes that it is a chance seedling on the farm of Giorge Womack, near Middletown, Ky., and named for his wife by the Kentucky Horticultural Society. It is evilently a seedling of the Rambo, the color, form of fritit, and habit of the tree indieate it, yet it is a mild sweet apple of first quality; it ripens in Kentucky in Ausust and feptember. or just after the Porter and Gravenstein. Tree a thrifty grower, bears full crops on altemate years, and a morlerate erop intervenimer.

Fruit medium, oblate, somewhat depressed, nearly regular; skir. 
whitish, faintly sipiped and splashed with pale and bright red where exposed to the sum, and thickly sprinkled with small and large Irregular brown dots; stalk short, rather small; cavity large, deep, is

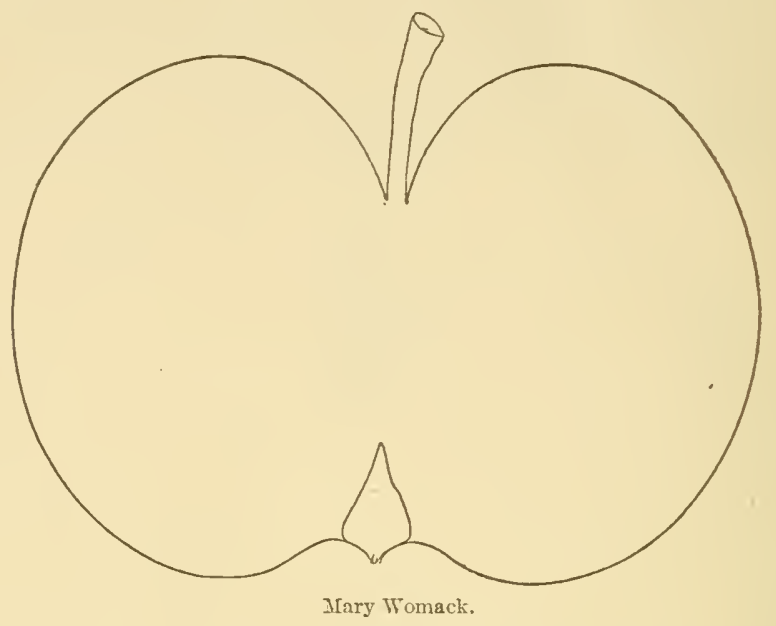

little uneren; calyx small, closed; basin large, saucer-like form, slightly corrugated; flesh whitish yellow, haif fine. tender, moderately juicy, mild rich sweet; quality very good; core medium.

\section{MERCER.}

The origin of this apple appears to be unknown. W. H. Lewis, of Pike County, Miss, writes that it was obtained by the late Jeremiah Smith, a successful fruit-grower on Bogue ('hitto Piver, from a Baptist minister by the name of Mereer, many years ago. but where he procured the grafts is not known. It is nore hichly esteemed where known than any apple ripening at the sime season. Tree a thrifty, strong, upright grower, forming a round head; an early and abundant bearer nearly everv rear.

Fruit medium, oblate, nearly regular; skin whitish, shaded and streaked with light and dark red rather thinly over half or more of the surface, and a few light dots; stalk short. small: cavity rather large, slightly russetted; calyx large, open; basin large, deep, partially plaited; flesh whitish, fine. tender, juicy, mild, rich subacid: quality very goort; core small and close. Ripening all the month of July in Mississippi, or at the sime time with the Horse apple.

\section{Moser's SWEET.}

Originated on the farm of Michael Moser. Cloverdale. Int., the tree having been obtained as a seedling from the nursery of $\mathrm{Mr}$. Juncan. 'The tree is said to be a vigorous grower, with rather slender branches, making a round sprealing head, and producing good crops on altermate years; it is much ralued by those who linow it for its uniform size, fine appearance, home use, and for market. 
Fruit medium, olblate, a little oblique; skin smooth, bright yellow, with al lew seattering brown dots; stalk short, rather suiall; (avity laree, deep); caly nearly closeri; basin quite laree, a little. nneven: Ilesh whitish, half fine, half tencler, moderately juiey, sweet and rich; core small. December to March.

\section{MosIlER SWEET.}

Originated in the orchard of Ephraim Mosher, Washington, N. Y., many years since. 'lee very hardy, thrifty, vigorous, making a laree sproading head; a good, but not jrolifie bearer; not a raluable market frut, hut desirable for those who like a good sweet apple either for eating or cooking.

Frut melium, oblate conical, angular, often considerably ribbed; skin pale yellow; stalk medium, rather stout; carity large, deep; calrx clusei; basin narrow, dern, nuch corrugated or ribbed; flesin white. half tine, moderately juicy, mild, rich, sweet, aromatic; core medium. Season all of October.

\section{MoTHER'S FAroRITE.}

Smith's Favorite.

Big Tree.

A large, showr summer apple, raised by Patrick W. Smith, Hanoverton, ()hio; and his son, L. L. smith. Brooklyn, Iowa, writes that the tree is hardy, a vigorous grower, making a large round-headed tree: requires very little pruning, and prodiseing full crops on alternate years,

Fruit large to very large, roundish oblate, slightly angular; skin bright rellow, sometimes pale red in the sun. a few brown dots, and many (ibscure liwht ones; stalk short, small; cavity large, deep, a littie uneven; calyx small, closerl; basin large, deep, slighty plaiterl; flesh pale vellow, half fine, rather firm, juiry, sprightly subacid, aromatic: of very cood quality, and one of the best for culinary uses; core small. Sceason september.

\section{Morxtais Beattr.}

Originated with the late Stephen Ferguson, near Keswick Depot, Ta. Tree vigorons, with stout shoots, sureading, hearing abundanty on altermate rears: it is a beantiful apple, and said to be much esteemer in the localits of its oricin.

Fruit medium or below, oblate, somewhat depressed; skin smooth, whitish, shaded with light and lark rich red (purplish red where (xposerl), with sone ohseure stripes and splashes on the shaded side. and uany light dots, a few being arenle; stalk very short, moderately stont: "avity hroal, morlerately deep, russetted; basin broad, not verr leon. smonth; flesh white, half fine, tenrler, juicy, mill subacid, inclining to sweet; quality ve:y good; core small. December, January.

\section{Nortox Pipris.}

The Norton Pippin originated witl James Brewington, of Freedom, Ky. Tree thrifty, a moderate grower, making a round, rather 
close head; an early and prolific bearer on alternate years, and a light crop, intervening.

Fruit medium or ahore, roundish, flattened at the ends, sides sonetimes a little unequal, nearly regular; skin whitish rellow, shaded with light and dark red over neariy the whole surface, with some obscure stripes and splashes, and moderately sprinkled with

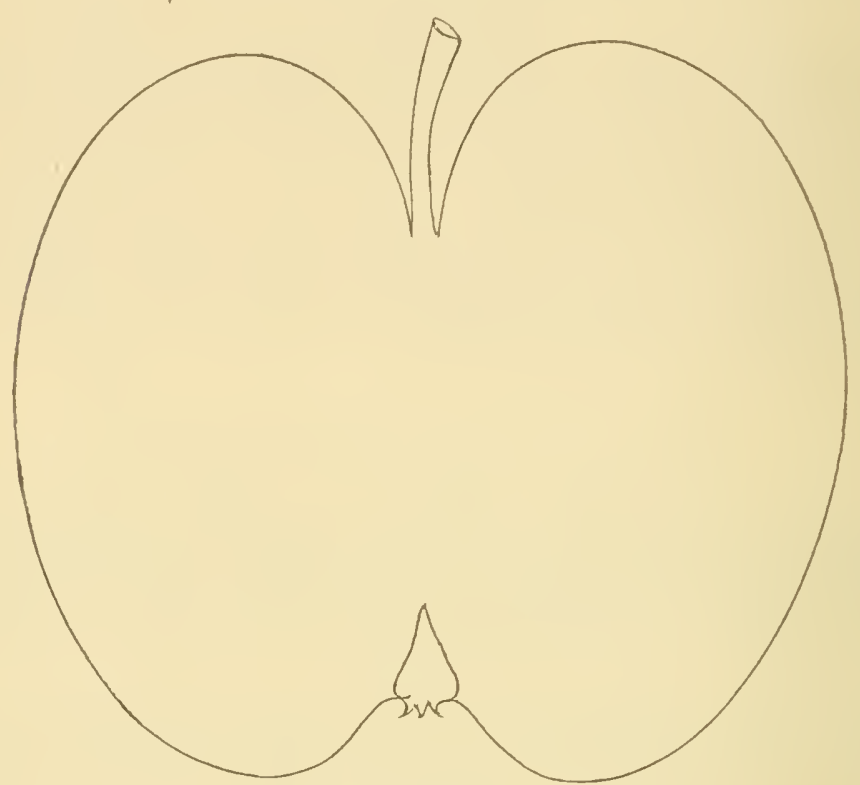

Norton's Pippin.

light dots-a few areole; stalk short to medium, small; carity medium, often slight russet or greenish; calyx closed, or nearly so: basin large, round, deep, slightly plaited; flesh white, half fine. tender, juicy, pleasant subacid, rich; very good; core rather small. November, December.

\section{Onstine Greening.}

Of uncertain origin, supposed to be Ohin; introduced br Seth A. Bushnell, of Oberlin, Ohio, who states that the tree is a vigorons grower, somewhat irregular, spreading open head, bearing gnod crops annualiy, and although not a first class table apple. it is of good quality; being a very late keeper, retaining its firmness ant freshness to the last, makes it valuable for market and culinary purposes.

Fruit medium, oblate to round oblate, slightly conical, a little angular, often slightly ribbed; skin greenish yellow, molerately sprinkled with grayish and greenish dots: stalk short, small: cavity rather large, sometimes slight russet; calyx open; basin rather shallow, corrugated, or with small ribs; flesh whitish yellow, quite firm, moderately juicy, mild subacid; core medim. January to June. 


\section{Oxrorn.}

Originated in an old garlen on the farm of Joln F. Morgan, of Oxford, lut. Tree harty, vignous, upreght, spreading with age:

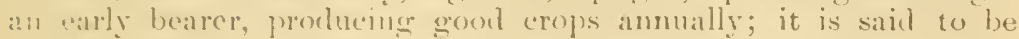
valuable for its hardiness, keening, and guality of the fruit.

Fruit merlium, romulish oblate, slighty conial, sometimes sides uncenal; skin pale rellow, covered with light red on the sharted side, dark crimson in the sun, mixed and spotted with grav, and many vellowish, conspicuons dots-a few being areole; stalls very short, small, often by a lip); "avity large, deep, thin russet; calyx small, closed, or nearly so; basin rather large, slighty corrugated; flesh whitish rellow, hall line, rather fim, juicy, mild subacid, a litthe aromatic, and quite rich; core rather small. January, March.

\section{Palmer Apple.}

Pear Apple.

An old variety, of uncertain origin, but supposed to have originated in Tashington ('onnty, Ga., and said to be little known out of its lucality, where it is much estermed for its quality, market value, and home ase in its season, which is a week or two later than Pied Astrachan. Tree moderately vigorois, spreading, producing molerate crops anmulis.

Fruit medium to large, roundish oblate, slightly conical; skin light yellow, streaked and splashed with pale red rather thinly over most of the surface, and sprinkled with numerous rather large light duts; stalk of medium length, slender; cavity medium, slight russet; calyx closerl, or nearly so; basin large, deep, slightly plaited; flesh whitish vellow, half finc, a little firm. juicy, pleasant subacid, slighty aromatic; core medium. Ripens the middle of June in Central Georgia.

\section{Pencil Brow.}

Crigiuated on the farm of Davis Iumper, Dexter, Me. Tree harily, lealthy, and vigorous, foming a wide, rather low-spreading liearl. Learing large crops on alternate years, with a light one interrening: use, culinary and market.

Finit large, roundish oblate, slightly conical, nearly regular; some specimens angular; skin smooth, deep rellow at maturity, a sharde of pale brownish red where exposed, moderately sprinlibed with rray dots, and sometimes nettings of russet: stalk short to melium, slender: cavity rather large, russetted: calyx open; hasin rather large, deep, slightly corrugated; tlesh pale whitish yellow, half line, half tender, moderatrely juicy, subacid, slightly aromatic, and of good ruality; core medimm. Jipqens from the middle of Oetober to the midalle of November.

\section{Peir Pappix.}

The origin of this apple is somewhat meertain, but it is said to have originated on the farm of the late Thomas Baldwin, near Hightstown, X.J., and considered, where known, a valuable fall 
a)ple for its faimess, large size, and sood houring qualities, either for market or family use. 'lree a healthr, iree grower, nakirg a rombl head; an early and abundant hearer nearly every rear.

Fruit large, rounctish conical, inclining to oblune, shintly angular; skin pale, greenish yellow, or pale yellow at full maturity, with

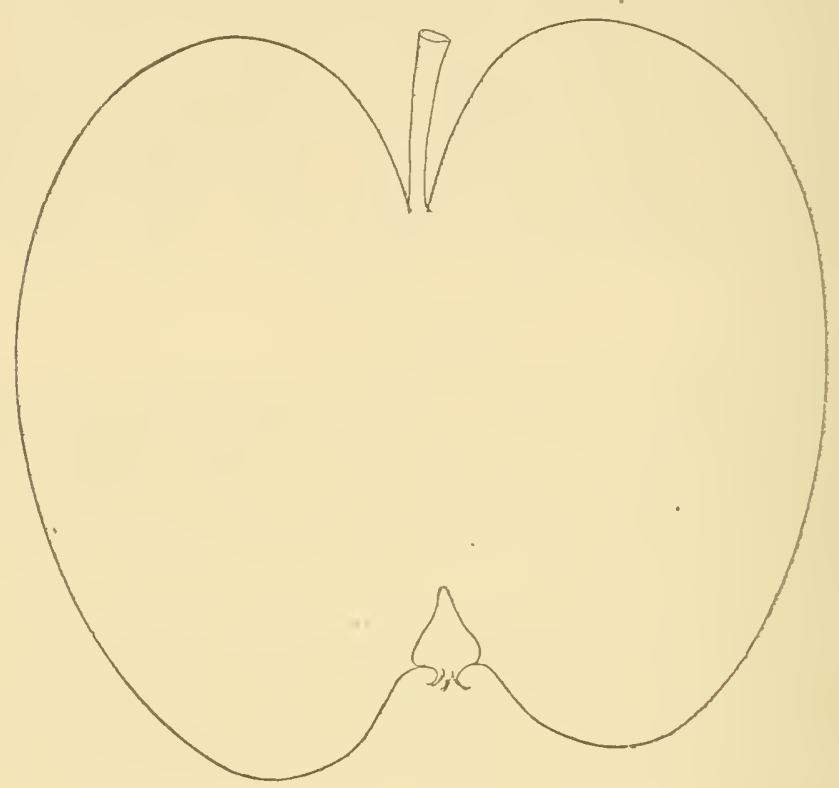

Tear Pippin.

many rather obseure light and gireen dots: stalli short to long, slenler; cavity large, deep, sometimes slight russet; caly closest: bisin large, deep, slightly corrugated; tlesh whitish, half fine, temler. juicy, sprightly subacid, and good quality; core rather large. September.

\section{Peasgoon's Noxescrir.}

This heautiful apple was raised by Mr. Peasgood, of Etamfert, Englum, and is a fune culinary or dessert apple, and is like a hun?some and highly-colored Blentreim Pippin.

Frut large, roundish oblate; skiu rellow, orersnrear on the sunny sicle with red, and copiously streaked with bricht tatker crimson streaks; stalk short, deeply inserted: eve repr laree ant onen, set in a deep, rouml, and even basin: flesh reilowish. tender, very juicy, with an agreeable acid flavor. September, October (1)

\section{RANTOLPH SWEeT.}

An accidental seedling on the farm of O. T. Hobbs. Ramiolph, Pa. The tree is said to be rigorous, spreacling; not an early, but a good bearer annually, when it has attained sufficient age; it is a late keeper. 
Fruit medium or above, roundish oblate, slightly angular; skin pale greenish yellow, a shade of rod where exposed, some rather obseure splashes. and a few erayish dots; stalk short, small; cavity deep, rather narrow, slightly russetted; ealyx small, elosed; hasin small, slightly cormerated: flesh whitish, half fine, tender, juicy, mild, rich, sweet; very good; core large. February, April.

\section{Raxsom or lien Strwik.}

In old variety, which is said to have originated in Columbia, Comn, on the l'inneo farm. It is not widely known, but is valued by :hose who enltivate it; tree moderately vigorous, uprisht, some. what spreading, bears abundantly on alternate years, with light erops intervening.

Fruit rather large, roundish oblate, slightly angular; slin pale rellow, shaded, strijed. splashed and mottled with light and dark ired, with a few licht and brown dots; stalk short, small; cavity linre, deep, often russeied, and sometimes extending cut on the frnit; calyx elosed; basin medium, slightly corrmgated; flesh rellowish white, lualf tine, tender, juicy, pleasant subacid, slightly aromatic; very good; core medium. Season September.

\section{Red Bietighenater.}

Of German origin, a large and handsome early autumn apple, valuable for market and culinary purposes. T'ree a free grower, having large shining leaves, spreading; an abundant bearer on alternate vears.

Fruit large to very large, oblate, slightly conical, regular; skin smonth, whitish or whitish yellow, shaded with light and lark red, (mumlish crimson where fully exposed to the sun,) sometim(s obscure stripes and splashes, a few grayish and many rather indi-tinct light dots; stalk short, rather stout; eavity broad, deep, regular, often russeterl; calyx closed, basin large, deep, slightly (orrugated; flesh white, half fine, quite irm. juicy, with a brisk subacid flaror; core medium or rather large. Season september.

\section{Red Winter Sweet.}

Originated in the orehard of Gen. Isaae Sandford, Yermillion, Ili. 'Tree vigorous, spreading, not an early hearer, but abundant on alternate vears, and a partial crop the intervenimg rears; a late ketper.

Finit medium or below, oblate, sometimes sliglitly oblique; skin pale rellow, shaded with light and dark dull brownish red, quite thickiy sprinkled with larese vellowish dots-many of them areole: stalk short, snall; eavity large, slight russet; calyx ojen; hasin laree, deep, round; tlesh rellowish, rather eoarse, moderately juier, rich, sweet, grood; core small. January, April.

\section{Romixson.}

Originated on the farm of Moses Wr. Pohinson, near Burliugton, Iowa. 'Tree hardy, thrifty, vigorous, forming a handsome romd top, 
a little spreading, producing good crops annually; it is ralued in its locality for hardiness, lieeping, and good quality as a table apple.

Fruit nedium or below, roundish oblate, conical, sides sometimes a little mequal, slightly oblique, a little flattened at the base; skin pale greenish yellow, shaded with pale brownish red over one-third of its surface, and moderately sprinkled with light and brown dots: stalk short, slender; cavity medim, narow, thinly russetted; calyx elosed or nearly so; basin large, deep, slightly corruqated; flesh whitish yeliow, half frne, tender, juicy, very mild subacil, or almost sweet, rather rich; quality very good; core rather small. January to March.

\section{St. Hilatre.}

Cabane du Chien.

Fameuse Baldwin (of some).

This apple is said to have originated in the orchard of Alexis Diry, Province of Quebee, and is supposed to be a seeding of the Famense, which it much resembles in the color and form of the fruit, but is a little larger, more variable in size, bears nearly as early, and quite as heavily, keeps longer, will carry better, and is a favor-

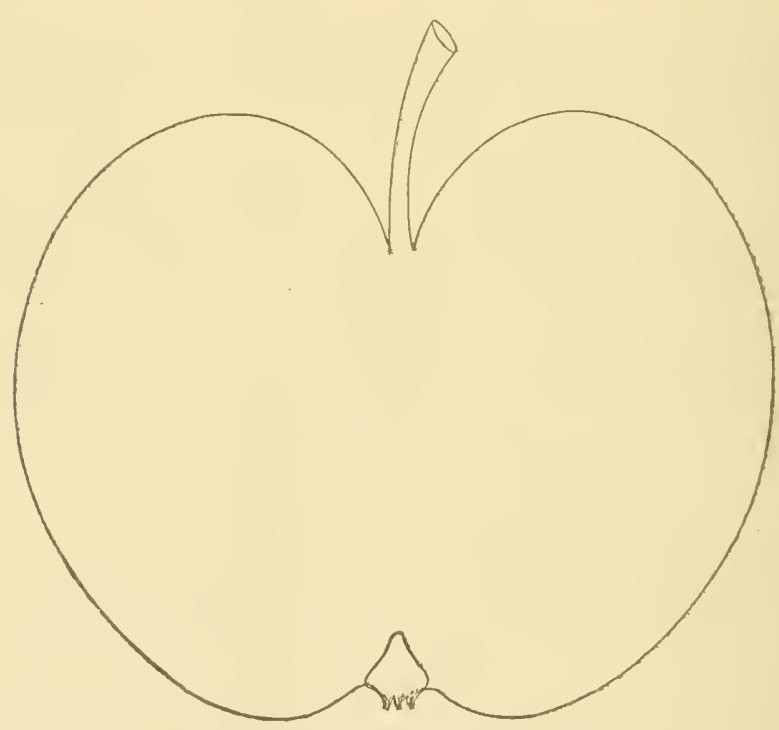

st. Hilaire.

ite in the neighborhood of its origin : tree as luardy as the Famense, and similar to it in growth and bearing.

Fruit medium or below, oblate or round oblate, very slightly conical, skin smooth, white, shaded with light and dark red and crimson (pmplish erimson in the smu), sometimes obscure splasles. and s!rinkilen with a few lioht and brown dots, more and minnte ones near the basin; stalk short to medium, slender; cavity medium, regular ; 
calyx closeri; basin rather small, shoghty corrugated ; flesh puite white, fine, tender, juicy, sprightly subacid, possessing a slight eranherry flaror ; core small. November, January.

\section{SALOME.}

1 new variety, which originated on the grounds of Elias C. Hatha. way, ()ttawa, Tli. 'Tree said to be very hatrly, healthy, vigorous; leaves laree, thick and firm: roumg wood very dark, havel, and finearaned; an upright grower, forming a round head with awe; an early and good hearer anmally, but more abundantly on altemate years; the fruit adheres fimly until gathering time. Its hardiness, long

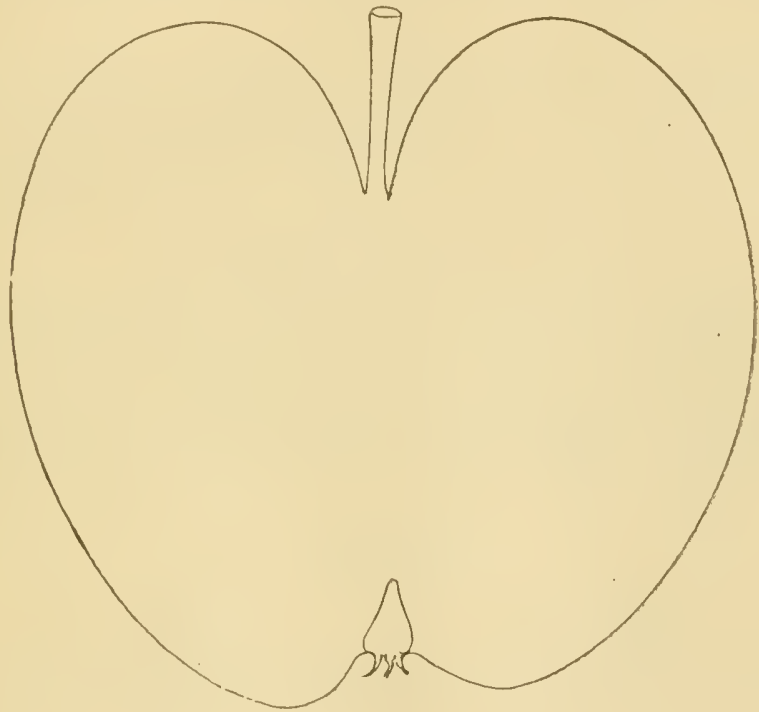

Sa ome.

keeping, good quality, uniform size, retaining its flaror quite late, rven into summer, will no doubt make it valuable for the 11 est and Northwest.

Fruit rather helow medium, rounciish eonical, slightly angular; skin pale vellow, shaded with pale red, striped anci splashed with rark red over most of the surface, and thickly sprinkled with large ami small light rellowish riots-a portion aroole; stalk short, rather small ; cavity quite large, deep, a little greenish ; calyx closed ; hasin rather small, slightly plaited; fiesh whit ish yellow, half fine, temder, juicy, mild subacil, slightly aromatic; very good; core rather. large. January, May.

\section{SATIERSON.}

This handsome apple was foumd in an old field owned hy Miss Filli. II. (rap, near Holly Girings, Miss., ant was iutroduced by (Col. 1). 1). sanders. 'Tree a moderate grower, somewhat spreading; a good au- 
mual bearer, ripens just after the Red istrachan, continues a lon cine in use, and is considered a valuable market variety for the 1 . cality of its orioniu.

Fruit medium to large, roundish, inclining to oblong, slighi?: ancular ; skin whitish, shaded, striped, and mottled, with ligit a:1il alith red, some specimens entirely corered with deep red or crinso:i, ancl purplish red where fully exposech, having a light bloom, an l many light dots - a few areole; stalk rather short, moderately stou:: cavity medium, deep, sometimes slight russet; calyx elosed; basin rather snall, slightly corrugated; flesh white, sometimes a littlo staned next the slin, half fine, tenler, juicr, pleasant subacid; core rather small. Season list of July to the ioth of Angust.

\section{SALTA.}

This apple is supposed to have originated in White Comn:, Ga., on the banks of the Santa liver or ('reek, and is said to bo popular in its locality, and also in Nississippi and Alabama, for iis long-kepeping, where only a few rarietics are finown possessing this quality. Thee thrity, moderately rigorous, branches rather slender, spreading, a regular and moderate bearer anmually.

Fruit nedian to large, oblate, a little oblique, sometimos siclos mequal, angular; skin smooth, liwht yellow or straw color, a few scattering gray dots; stalk very short, moderately stont; carity anedium, dull insset; calyx closed; hasin rather large, round, quite deep, slighty corrugateil; flesh whitish vellow, half fine, tender, juicr, sprightly subicicl, and of good, but not high quality; core small. February, April.

\section{SHMFER.}

Sehaeffre.

Bencler.

Shaffer"s Garden.

White King

A rery old viliety, which is saicl to have originatei with a lir. Benter, near Philatelphia. Some forty years since, the late fieorece Shaffer, of Allentown, Pa., obtained grafts and introduced it. Tleces thrifty, very vigorous, maling a large snreading top; an early ant abundint bearer on alternate vears; the fruit is large, fair of mniform size, and although not a first class table apple, is lighly esteemed, where known, as profitable for maket and for eulinar. purposes.

Fruit medium to larore, or very large, oblate, very slighty conical: skin smooth, pale greenish yellow, or whitish vellow, sometimes a blush in the sun, ant a few gray dots; stalk short, small; carit: broal, heep, sometimes slight russet; calyx closed or nearly so: hasin rather large, deep, sliwhty cormeated: flesh white, half fine, temler, juicy, sprightly subacid, and of good quality; core ne lium. September, November.

\section{Shaxiox Prpix.}

The origin of this apple is disputer, some asserting that it is the Ohio I'ipplin, taken from Indiana to Arliansas by a Mr. Rector in 1833 ; 


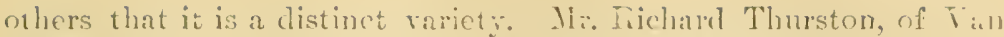
Buren, Ark. writes that he has lived in that state over thirty years, is well acyuainted with the aly)le, and that it is distinet from the ()hice

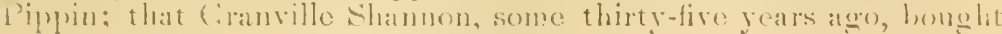
of a tree-pedeller near Evansville, Irk, a number of apple trees of various limk, and when they fruitert, the labels being lost, they were namet shamon l'ippin, and there were several of this kinil. The tree is said to be astrong, rimorous grower, of a sine:aliug habit;

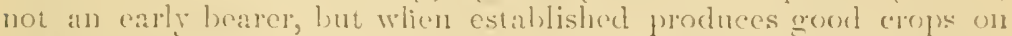
aliemate rears, ripening in suecession from feptember to J)ecemlere and is a popular and valuable apple in that locality.

Frut laree to very large, oblate, slighty eonieal; skin male rellow, leep yellow in the smn, and a iew gray dots; stalk very shom, moderately stout; eavity loroal, dere?), sometimes slight russet; cally closed of nearl: so; basin loroad, moderately deel', slighty corvilgatert: flesh whitish yollow, rather coarse, juicy, tencter, milu stuacicl; good to rery good; core small.

\section{Silitifif.}

\section{American Benuty (incorrectly).}

This was brought from Penusylrania, many years since, hy James Sheriff-bunce its nume, the true or original one having heen lost. 'The tree is said to be vigorous and very hardy, one of the iron-chats; this with its crops of fair lruit, although not rich, makes it of value for a cold climate; the tree grows tall, with few branches, forming :m open, somewhat spreacing, symmetrical top; it comes carly into bearine, and hears regular annual crops.

Fruit rather below medium, roundish obiate, flattened at the ends, nearly rewalar; skin pale vellow, nearly covered with liwht and dalk rell, with obseure stripes anel splashes, and many small liglit dots: stalk short: cavity small, russetted; calyx closed; basin laregen dorp, slimhty corrugated; flesh whitish, fine, tender, juicy, milk sul)acid; pleasant flavor, but not rich; core small. December, February.

\section{Sunuoxis' lien.}

\section{Red Everlasting.}

The Simmons' Reel originated with the late Jolnn IV. Davis, noar

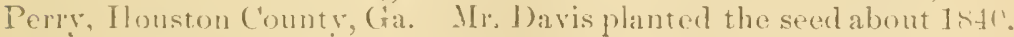
T'ree a thrifty, upright, compact grower; an early bearer, and gives good copls nearly every year. It ripens in Georgia the ent of June, continuing in use two or three months, and is considered on:o of tlecir best summer atumles.

Fruit molium to larere, oblate, slightly conical, sirles somotimes a little un'rual, slightly oblique; skin pale vellow, sharked with dauk rimson where exposerl to the smn, and on the opposite side ratlus olsenrely striped and splashed with light and dark red, and juetiv thickly sprinkled with yellowish russet dots, small, large, and irreslar in form; stalk short, small; cavity broad, deep, al little ulim, with light russet, sometimes extending ont on tle froit in rays : 1 il blotches; calyx closed, or nearly so; basin round, deep, nearly sinvor!; 
fiesh pale yellow, lualf fine, tender, juicy, mild subacid, slightly aromatic; quality very good; core rather small.

\section{Syeprs.}

\section{Sneprs' Nonesuch.}

This fine apple is said to have originated near Edinburgh, Ind. Tree molerately vigorous, with short-jointed shoots, forming a round head, producing good erops of fair frut of uniform size, which is highly prized by those who have grown it, both for the table and for culiniar purposes:

Frui medium, oblate, angular, slichtly ohlique, or sicles a little unequal; skin pale yellow to deep yellow, aluost grolden yellow in the sun, moderately sprinkled with gray and brown dots; stalk very short, quite small; cavity large, deep, sometimes with slight russet; calyx small, closed, or nearly so; basin medium, corrugated; flesh whitish yellow, fine, tender, juicy, mild subacid, rich. a little aromatic, and inclinime to saccharine; quality very good, at least; core small. December, February.

\section{STATMAX's WIXESAP.}

A seeding of the Winesap, oricinated witl Dr. J. Starman, Leavenworth, Kansas. We give his clescription: "Tree very vigorous, open, irregular, spreadiug; wood very dark; dark heary foliage; an

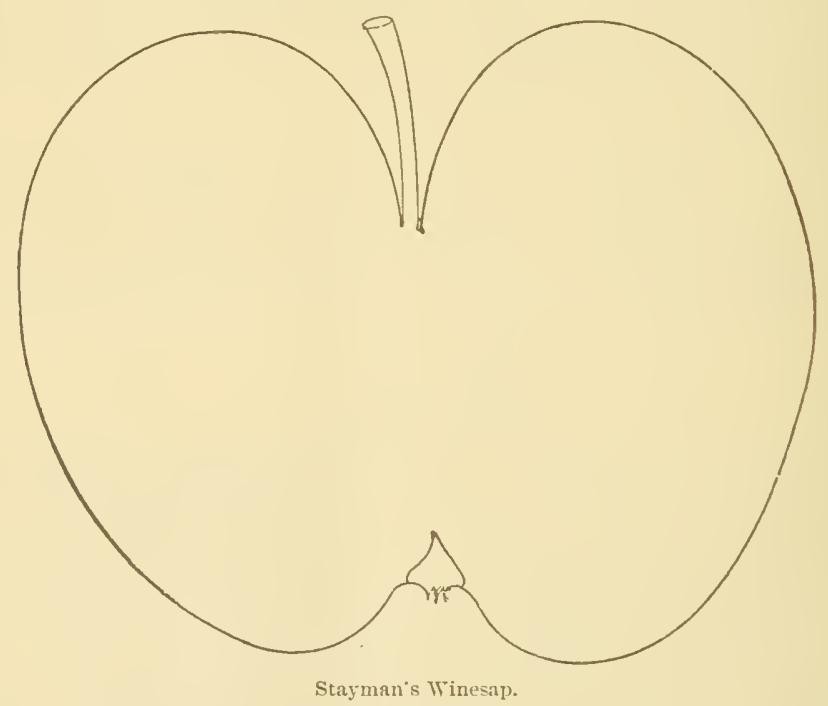

early and very abundaut hearer; tree much in appearance like Winesap; fruit hangs well on the tree.

"Fruit medium to large, heary, oblate conical, regular: greenish yellow, mostly covered aud indistinctly splashed. mixed and striped with dark cull red; dots medium, numerous, distinct gray; stem of 
medium length, slender; cavity wide, deep, much russetted, extending, regular; caly x larene, open, or half open, erect. large; basin ratler narrow, abrupt, deep, furroweri; core medium; flesh vellow, firm, tender, juicy, rich, mild subacid, aromatic; quality best. Season finmary to May."

\section{Stentras' Greestít.}

\section{Stearns' Winter Greening.}

This fine winter apple originated with Thomas Stearns, Jackson, Ind. 'Tree said to he very hardy, a strong, vigorous grower, mals ing around symmetrical head; an early, ammal, and abundant bearer, and is lighly estemed where kuown.

Fruit medium, oblate, slightly flattened at the ends, slightly an-

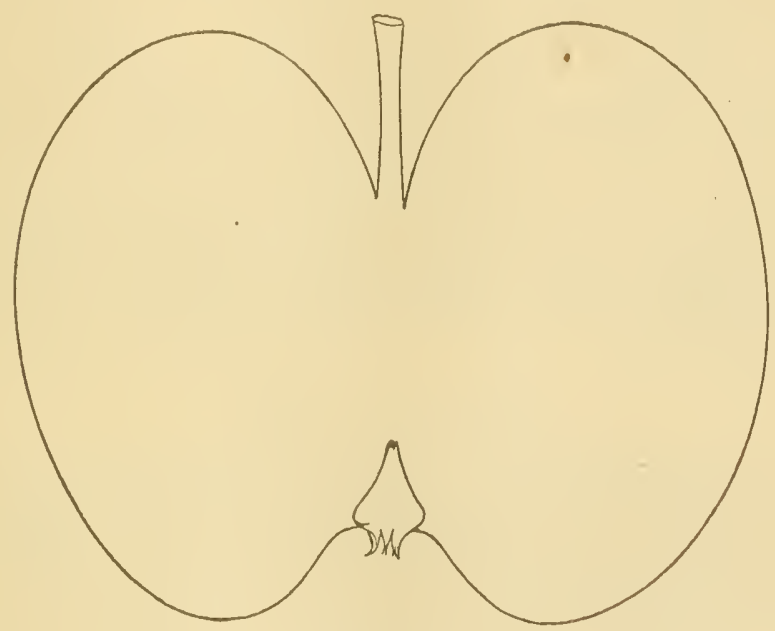

Stearns' Greening.

gular; skin pale green, witl a pale blush of brown in the sun, and a few scattering brown dots; stalk short, small; cavity rather large, deep; calyx closed; basin large, deep, corrugated; flesh fine, palc vellow, tender, juicy, with a mild subacid, rich flavor; quality very good; corc small or medium. Decenber, April.

\section{Stete Batumin.}

Baldwin's Summer.

Early Russet.

A chance seelling found in the wonds on the farm of Stephen Baldwin, town of Seymour, Com. Tree a strong, vigorous, upright grower, rather an early'bearer, producing lare crops on alternate vears; it is saict to be valuable for home use, is highly esteemed where known, and worthy of a place in every orehard.

Fruit medium or below, oblate, very slightly angular; skin whitish, more or less covered with a peculiar net-rork of russet; stall; 
short, small; cavity rather large, deep, slight russet; ealrx closed; basin medium, slightly eorugated; flesh quite white, fine, tencler, moderately juies, mild, rich subacid flaror; very good; core rather smail. Season from the last of August and continues five or six weeks, and with care till Deeember.

\section{Stevexsox Pippis.}

\section{Dwight Apple.}

An Arkansas apple, which originated with the Cherokee Indians in what is now Pope County, and was first brought to notiee by a Mr. Dwiglut, of the Dwight Mission, as it was known for a long time. James $G$. Stevenson, of Crawford County, Ark., ohtained trees of the variety, propagated and lisseminated them, and they are highly esteemed where known. Tree a vigorous, upright grower, somewhat spreading with age and bearing; not an early bearer, but produces heary and light erops alternately.

Fruit medium to large, roundish oblate, a little flattened at the ends, nearly regular; slin yellow, shaded with light red, striped and splashed witl clark red and erimson rather thickly over the whole sirfice, and large and small yellowish dots-a portion areole: stalk short, small; cavity rather large, deep, much russetted, sometines extending out on the fruit; calyx small, closed; basin rather large, slightly plaited; flesh pale yellow, a little eoarse, half tender, juicy, J) leasant subacid and aromatie; quality very good; core mediun. October, February.

\section{STOXEWAL JACKSOA.}

A ehance seedling found growing in a stone wall on Silas Jackson's farm, in (larence, innapolis County, Nowa Seotia, hence the nane. 'The tree is said to be a strong, upright grower at first, but becomes spreading and somewhat drooping with ane and bearing: it has qiate a local reputation, but is not much known elsewhere; is a very good bearer, and liceps well.

Fruit medium or above. roundish, or roundish oblate, slightly eonical, angular, or slightly ribbed; skin rellow, sharted with light and dark rich red, with a still darker hue in the sun, amb moibrately sprinkled with light and brown dots: stalk rather short, morierately stout; cavity deen, rather narrow; calyx small, elosed; basin rather small, corrugated; flesh whitish yellow, half fine, tender, juicy, subacik, slightly aromatic, rich, snd of very good quality; core large. Jamuary, March.

This is distinet from the Stonewall Jackson of Southern Alabama.

\section{STlart's Golnex.}

Stump (incorrectly). .

Originated on the farm of the late William Stuart, Rush Creek, O., where it grew near a stump many years since. It is sald to he very popular, where known, for home use and a near market. Tree harily, healthy, moderately vigorous, spreading, making a tree of 
merlimu size, with tongh, close-grained shoots; an eariy and prolific: bearer, altermate rears, of lair fruit of miform size, and lice ps well.

Fruit below medium, oblate, sometimes a little oblique, noarly regular; stin bright yellow, deep orange reci in the sun, with a few

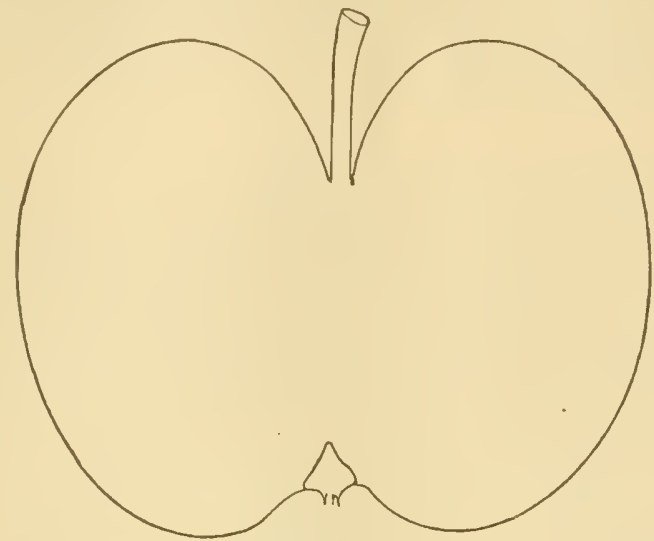

Stuart's Gollen.

brown dots; stalk short, small; cavity medium, sometimes slight russet; calyx small, closed; basin rather large, moderately deep, sancer-like shape, smootl, flesh whitish yellow, half fine, tender, juicy, pleasant subacil, rich, and of excellent quality; core smali. Season, December to April.

\section{Sweet Ruode Islayd Greevixg.}

\section{New Rhode Island Greening. Curtis' Greening.}

The place of origin of this apple appears to be unknown, but is supposed to be Ohio; it was first introduced into Illinois by Joseph Curtis, many years since. Tree rery vigorous, spueading; it begins to bear rather early, and produces full erops the even rears, and moderate crops odd years; the fruit is of large size, excelient quality, and is said to be the best sweet apple, where known, for December and Jannary, for culinary purposes and inarket.

Fruit large to very large, oblate, often oblique, sides sometimes unecual; skin greenish vellow, often a shade of pale brown in the sun, and sometimes spotted with red, a few brown and cray dots; stalk vory short, small; cavity rather large; calyx closed; basin laroe, decp; slightly plaited; flesh rellowish, half fine, tender, juicy, sweet, rich, slightly aromatic; very good quality; core small. December, January.

\section{Sweet Wixter Spitzexperg.}

An old variety, supposed to have been raised hy the late Samuel Bartholomew, of Cornwall, Vt., and is considered one of the most useful and profital) we winter sweet apples of that locality; fruit always fair, smooth, and keeps well. 'Tree a vigorous, upright grower, and an early and abundant bearer nearly erery year. 
Fruit medium, roundish, or roundish oblate, conical, smooth and regular; skin golilen vellow at full maturity, some rather obscure light and green dots; stalk short to medium, rather siender: can rity brond, not very deep; calyx small, closed; hasin rather smail, corrugated; flesh deep yellow, half fine, tender, moderately juicy, rich homey-sweet, slightly aromatic; very grood; core medium. I)ecen:ber to February.

\section{STUMP.}

A chance seedling found in an old stump on the grounds of John Prue, Chili, N. I. Thee a thrifty, vigorous, upright grower, forming a symmetrical, roundish conical head; rather an early and rery abundant bearer, on alternate years, of fair, handsome fruit of good quality.

Fruit medium or below, roundish conjcal, inclining to ohlong conical, sometimes sides a little unequal; skin smooth, white, shaded

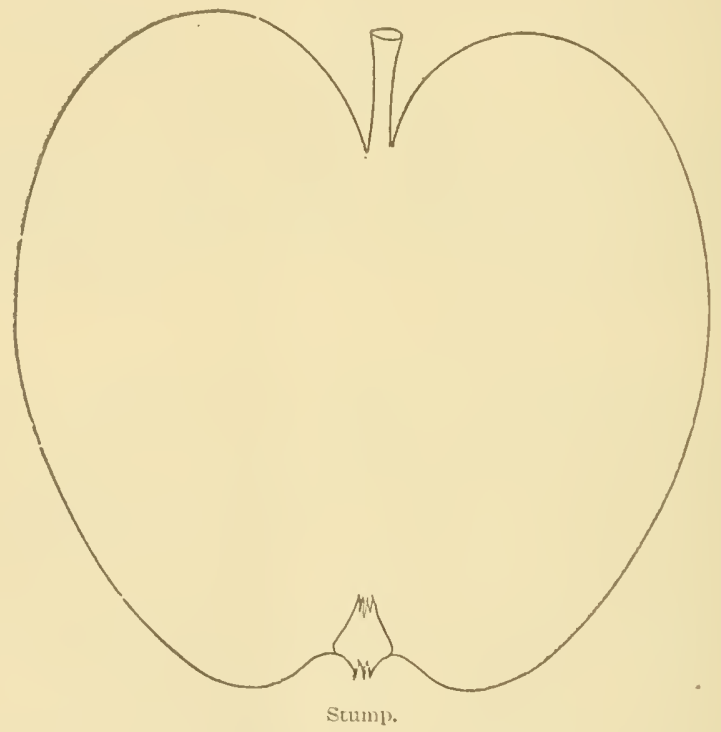

with bright red, moderately striped and splashed with crimson orer most of the surface, a few large and small light dots-a portion areole; stalk very short, rather small; cavity medium, often russetted; calyx small, closed; basin medium, slightly plaited; flesh white, half fine, tender, juicy, pleasantly subacid; quality good to very good; core rather large. September, October.

\section{TAXYER'S W'TATER.}

An old rariety of unknown origin. It is considerably gromn in Granville Connty, (ra., where it suceeds and is prized is a winter fruit for general use. The history and original name are unknown. 
Tree a good thrifty grower, with slender hranches, upright, inchinesl to spread with age; a good bearer nearly every year.

Frut medium, oblate, slightly conieal, slightly angular; shin whitish rellow, shaded, rather obsenrely striped and splashed with pale umrplish red; stalk short, small; eavity broad, deep, sometimes thin russet; calyx small, half open; hasin large, very deep, nearly smooth; flesh whitish yellow, a little coarse, morlerately juicy, mild subacid; good to rery good; core small. October, February.

\section{TALLET.}

Yan Horn.

Originated with George C. Stanforl, Boston, O. The tree is said to he vigorous, healthy, of a roundish, rather spreading top, and has borue abundant crops hiennially for sixty rears, of smooth fair fruit, and comes early in to bearing.

Fruit rather below medium, oblate, sides sometimes unequal, a little flattened at the ends; skin smooth, pale whitish yellow, occalsionally a shade of pale red, a few small brown or russet dots, and sometimes a few obscure stripes and snlashes on the sump side: stalk short, small; cavity rather large, deep; calyx elosed; basiu large, corrugated; flesh whitish, half tine, tender, juicy; mild subacid; core small. December, March.

\section{Victoria Piprix.}

A chance seedling on the farm of John Benge, near Elkton, Cecil County, Md., and being an Englisiman, named it in honor of his Queen. T'ree a healthy, vigorous grower, making a round, rather spreading head; an early and moderate bearer every year, but full crops on alternate years; it is not a rich, high-flavored tahle apple, but is lighly valued in its locality for culinary purposes and for market.

Fruit medium to large, oblate to roundish oblate; skin rellow, shaded, striped and splashed rather thinly over most of the surface with light and dark red, and pretty thickly sprinkled with gravish and brown dots; stalk short, small; cavity rather large, sonetimes slight russet; calyx closed; basin broad, moderately deep, a little uneven; Hesh whitish yellow, rather coarse, juicy, sprightly subacid, and of good quality. September, October.

\section{Victorla Sweet.}

This is quite an old variety, the origin of which is uncertain, although claimed for Chenango Countr, N. Y.; it may have an older and prior name. Tree a moderate grower, spreadiug, very productive. on alternate years; a beautiful and very grood sweet apple of its seasoll.

Fruit medium, oblate, regular; skin entirely covered with light and dark red and crimson, sometimes obscure stripes and splashes of a darker hue, and many rather conspicuous yellowish dots; stalk rather small; cavity medium, regular, sometimes slight russet; calyx 
small, closed; basin rather large, moderately deep, slightly plaited: flesh whitish, half fine, tender, juicy, sweet, rich; very good; core small. October, Norember.

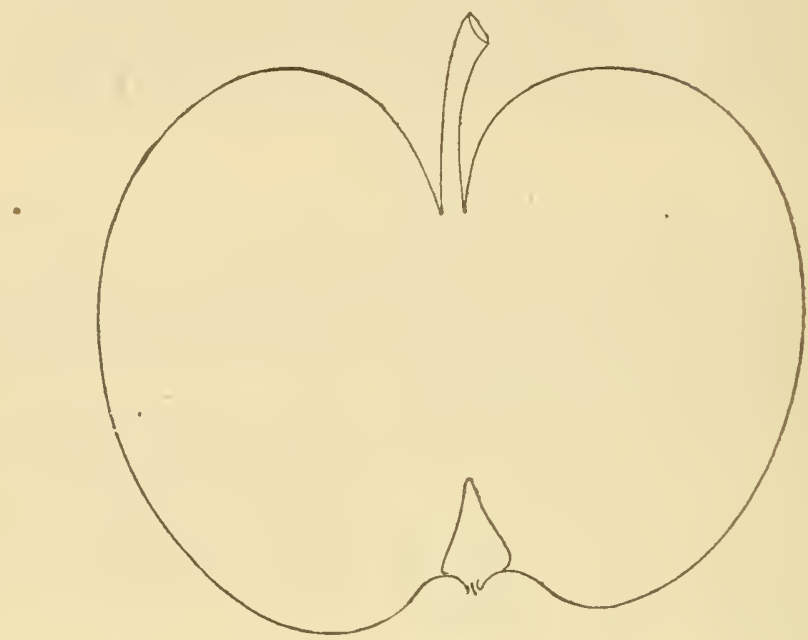

Victoria Swect.

Westaroreland Rambo.

Grown from seed of the Common Rambo, by Joseph Kern, Greensburg, Tenn. Tree vigorous and a rapid grower, makes a large, spreading, open head, requiring very little pruning; it bears annually fair crops of large fruit of very good quality, and evenly distributed over the tree. There are several varieties of the Large Rambo raised from seed of the Old Rambo, which are nuch larger in size, more vigorous in growth; most of them ripen earlier, but do not quite equal it in quality.

Fruit large to very large, oblate, somewhat flattened at the ends; skin pale greenish yellow, shaded, striped and splashed with light and dark red over nearly the whole surface, with a few brown dots; stalk short, rather small; cavity large, deep, a little greenish; calyx closed, or nearly so; basin large, deep, slightly corrugated; Hlesh whitish, a little coarse, juicy, tender, pleasant subacid; quality good or very good; core small. September, October.

\section{Wilsox's Sumer.}

Origin unknown, but supposed to be near Salem, N. C. Tree a thrifty, upright grower, with rather sleuder wood, making a mediumsized tree when fully grown. It bears young and abundintly on alternate rears, and is valued, where known, for its fine quality for summer use.

Fruit rather below merlium, oblate, slimhtly conical, sicle sometimes a little unequal; skin smooth, whitish yellow, nearly covered with rich bright red, more or less striped and splashed with erimson, 
and moderately snrinkled with light dots; stalk short, small; cavity medinm, regular, often a little russet; calyx closed; basin mediun,

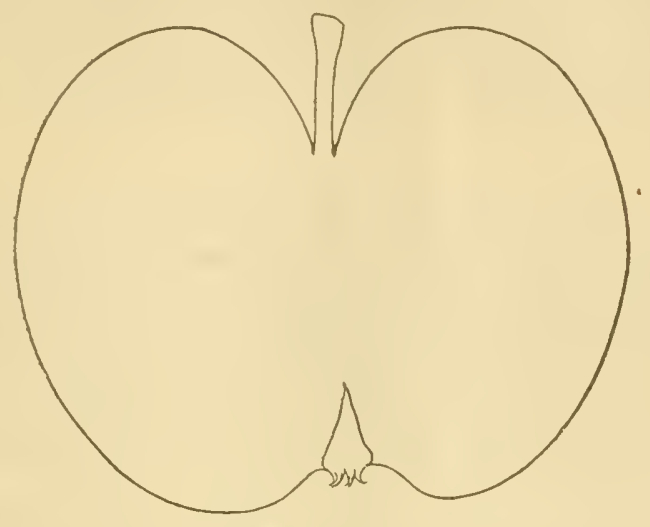

Wilson's Summer.

nearly smonth; flesh white, fine, tender, juicr, mild subacid, rich, and of excellent quality; core small. Season about the time of American Summer l'earmain.

\section{Willials' Red WiNTER.}

Originated on the farm of the elder Abraham Williams, Fast Hartford, Conn., many years since, and is but little known out of its $11 \cdot j$ hhorhood. Tree a strong, vigorous grower, forming a very large, spreading head; not a very early bearer, but bearing moderately annnally; it is highly esteemed by those who know it best.

Fruit medimn, oblate, slightly conical, slightly angular; skin whitish, nearly covered with light and dark red (kark crimson in the suin), somewhat obscurely striped and splashed, and moderately sprinkled with vellow russet dots; stalk rery short, small; carity medium, slight russet; calyx closed; basin large, moderately deep, slightly corrugated; flesh white, fine, tender, juicy, sprightly subacil, not rich, hut pleasant and of good quality; core rather small. 1) cember, February.

\section{WolF Riter.}

A new, large, handsome apple, the tree of which was grown br II. 1. Sprincere, and disposed of before fruiting to the late Henriv liflen, near the rast bank of Wolf liver, Fremont, $1 \mathrm{Tis.}$; smpposed to lea seedling of the Alexander. which it somewhat resembles; not usinaly so large nor so regular in form, darker in color, and rather better in quality. The tree is said to be very harly; a strong, vigorous grower, spreading, with large thick leaves; not an early bearer, hut proflucing full crops oin alternate years.

Fuit lare to very laree, oblate to roundish oblate. slightly anwnlar, some of the larger specinens uneven and irregular. but those of average size are regular; slin pale greenish yollow; but becomes 
whitish when mature, shaded with light and dark red or crimson where fully exposed, having a thin whitish bloom, and a few light dots; stalli very short, quite small; cavity rather litre, greenish, sometimes much russetted; calyx open, or nearly so; basin larere, verv deep, a little uneven; flesh white, rather coarse, half tencler, juicy, pleasant, mild subacid, with a peculiar spicy, slight quinecIilie flavor; core medium. Season, October, Novenber.

\section{Teltow Pirtix.}

Origin unknown; specimens under this name were received from 13. O. Curtis, Edgar County, Ill., whose father brought it from Adlams County, Ohio, some sixty years ago; it is distinet from either the Green or Iellow Newtow Pippin in tree and fruit, and nat prove to be the Newtown Pippin of Lewis sanclers, of Kentucky. 'Tree hardy, a very thrifty upliyht grower, rather late coming into bearing, but then bears abundant crops nearly every year. Conmences to ripen in January and continues in use till April, and longer with eare.

Fruit medium, roundish oblate, slightly angular, often slightly oblique, somewhat flattened at the ends; skin deep yellow, sometimes a shade of light red, and many brown dots; stalk short, small; eavit medium, deep, slight russet; calyx open, or nearly so; basin medium, quite deep, a little wrinliled; flesh pale yellow, half fine, half firm, crisp, juicy, rich, subacid, slightly aromatic, and very good; corc small. Jainuary to April.

\section{ZOLOTOREFE.}

One of the new Russian apples lately introduced, which promises to be valuable for a cold climate; it is said to be quite as harly as the Duchess of Oldenburg; a good upright grower, an early and abundant bearer of linge, showr fruit, lipening about a month later than the I) uchess.

Fruit large, roundish, very shightly conical, slightly angular; skin pale greenish yellow, or light yellow at full maturity, shaded, sp lashed and mottled with light and dark red orer most of the surface; stalk short, rather stout; cavity rather narrow, deep; calvx elosed or half open; basin large, deep, corrugated; flesh whitish, half fine, tencler, juicy, sprightly subacid, and of good quality; core rather large. Season middle to the last of September.

\section{TELLOW THATSTAENT.}

A new Russian variety, which was imported from St. Petershurg in $18 \% 0$ by the Department of Agriculture, Washington. 1). ( promises to be valuable for a eold climate as an early iruit of good quality, ripening before the Tetofsky, with more terder and delicate thesh, but does contimue long in use. It is said that the tree so far lias provel to he very harly, moderately vigorous, upright, an early and oond bearer annually.

Fruit medium, roundish oblate, slightly conical, slightly angular: skin clear white at first, becoming pale yellow when fully mature. 
moderately sprinkled with light and greenish dots, somewhat obsicure; stalk short to medium, rather slender; cavity rather large, sometimes a little greenish; calyx closerl; hasin medium, slightly eorugated, sometines small protuberances; flesh white, half fine,

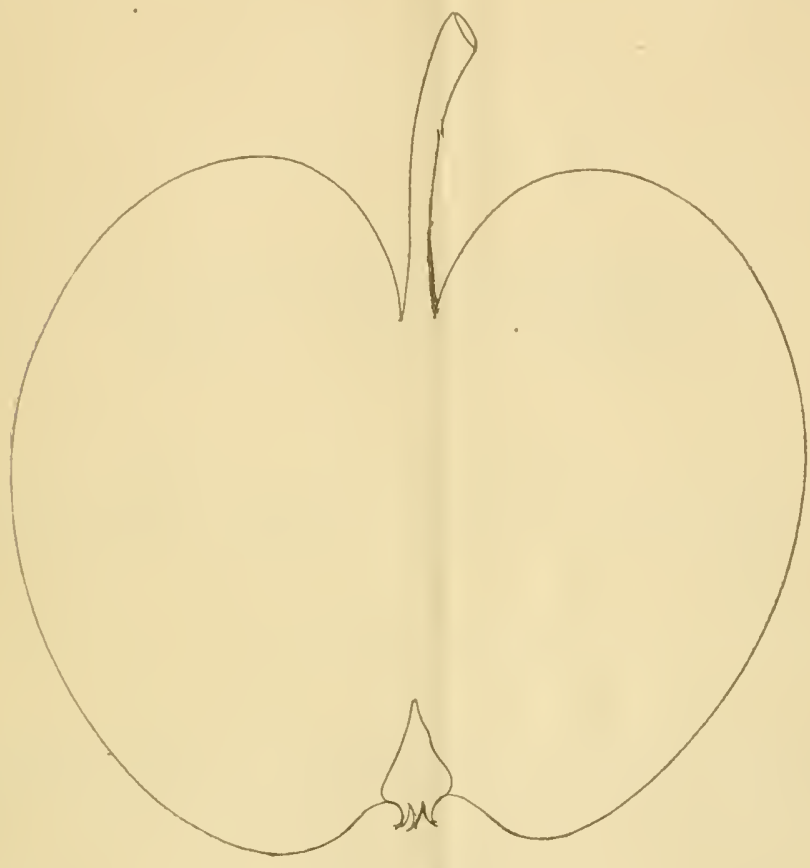

Yellow Transparent.

tender, juicy, sprightly subacid; quality good to very good; core mediun. Season early in August, and a week or two betore Tetofsky.

There appears to be some confusion regarling some of the new liussian apples, a few not being true to name, and others having proved synonymous with older varieties; some of the new varieties are large and handsome, and if the trees prove as hardy as is claimed for them, they will be valuable acquisitions for the North and Northwest. 



\section{APPENDIX.}

GRAPES, PEACHES, PEARS, \&c.

For specimens of Fruit, and information relating tc many of the varieties in this Appendix, I. am indebted to many of the leading Pomologists in many parts of the comntry, who will please accept my cordial thanks.

Chlarles Downing. 



\section{GRAPES.}

\section{Allex's Ifybrid.}

Originated with J. Fisk Allen, Salem, Mass. It is a hybrid be tween the native and foreign, and is one of the best in quality, and has peculiar erumpled leaves. The vine is not hardy, and requires winter protection, but is vigorous and productive, ripentfy quite early, and in sheltered situations is a desirable variety.

Bunch medium to large, shouldered, compact; berry medium to large, round, sometimes depressed; skin thin, white, changing to pale yellow when fully ripe; flesh tender, juicy, sweet, rich, with a delicate slightly vinous flavor, and one of the best in quality.

\section{JANIE IVYLIE.}

A new hybrid between Clinton and foreign, raised by Dr. A. P. Wylie, of Chester, S. C., who kinclly sent us specimens, and writes that the vine is vigorous and has a pretty large, thick, deep green foliage, and so far free from mildew; an early and productive variety, hangs well and late. It may require protection at the north during winter.

Bunch large, shouldered; berry varying from medium to large, roundish oval; some of the larger ones are nearly globular; color dark red, with'a thick grayish bloom; Hesh rather firm and meaty, juicy, sweet, rich, slightly vinous, refreshing; skin thick yet tender; very good.

\section{Kalamazoo.}

Said to have originated with__Dixon, of Steubenville, O., from seed of Catawba, which it somewhat resembles in color, but the bunch and berry are larger, and it ripens a week or ten days earlier, and is a showy grape.

Bunch large, long, often shouldered, compact; berry large, round; skin rather light dull red, with a lila bloom; flesh soft, but not quite tender, and adheres a little to the seeds, juicy, sweet, vinous.

\section{Peter IVyuie.}

This fine new early grape was raised by Dr. A. P. Wylie, of Chester, s. C., from a seevlling of a hybrid. The Doctor inforns us when. sending the specimens of fruit that the vine is one of the most rapicl growers, free from millew and rot, entirely native in its appearance; wood short jointed; leaves not large, but thick and leathery, hold well and late, and the fruit one of the first to ripen. 
Bunch medium; berry medium to small, round, transparent, yellow, with a rather tiick whitish bloom; flesh soft, juicy, sweet, rich, slightly vinous, with a Frontignan flavor; skin thin but tough; very good os best.

\section{Senasqua.}

This new grape was raised by Stephen Underhill, of Croton Point, N. Y., and is a hybrid between Concord and Black Prince. The vine is vigorons and hardy, and the fruit similar to Black Prince, and of fine quality; but in consequence of its thin skin and compactness of bunch the fruit is sometimes apt to crack, especially in wet weather.

Bunch large, often shouldered, very compact; berry large, round; skin deep black, with a thick blue bloom; flesh quite firm, but tender, breaking, juicy, sweet, rich, slightly vinous; ripens about the time of Concord, or soon after.

\section{PEACTIES.}

\section{AtLanta.}

Raised by Dr. E. W. Sylvester, Lyons, N. Y. Tree vigorous, productive; reniform glands.

Fruit medium, roundish, slightly compressed, regular, suture large, distinct, extending nearly round the fruit; carity quite deep; skin whitish, shaded, and mottled with deep red, almost purplish in "the sun; flesh white, a little red at the stone, juicy, melting, sweet, rich, adheres partially to the stone. Ripe last of september.

\section{Black's Extra Early Peach.}

An accidental seedling found on the farm of Dr. J. Stayman, Leavenworth, Kansas. Tree a good grower, hardy, and productive.

Fruit large, round with a slight point, suture distinct, shallow all around; color clear rose pink, shaded maroon, and slightly mottled with light yellow, very handsome; flesh stained red to the seed, to which it slightly alheres; juicy, teuder, with rich subacid ; excellent.

This is the earliest peach we are acquainted with, ripening this season (1871) before the 4th of July, being ten days before Hale's Early, and it is of larger size and better quality.-Pomologist and Grardener.

\section{EARly Rivers.}

Raised by Thomas Rivers, Sawbridgeworth, England. It ripens a few days earlier than the Albert or Alfied, and quite equal to them in flavor. The tree is thrifty, healthy, and productive; glands reniform, flowers large. 
Fruit medium, roundish oblong, slightly compressed, sutur slight, ending at the ajex, which is a little sunk, and has a very small nipple; skin creamy white, shaded with light red in the sun, cavity deep; flesh white to the stone; juicy, melting, sweet, rich, refreshiug, slightly vinous; rery good; separates fieely fiom the stonc. Ripe middle of September.

\section{Foster.}

Originated with J. T. Foster, Medford, Mass. Tree said to be hardy, vigorous, and produetive; a good market variety.

Fruit large, slightly flatteued, with a slight suture, stem moderately depressed; flesh yellow, very rich and juicy, with a pleasant subacid flaror: freestone of medium size; color a decp orange red, becoming very dark red on the exposed side. Ripe from the middle to the last of September.-Jour. of Hort.

\section{Free Mason.}

This new late peach originated with Nathan Todd, Denton, Caroline County, Md. Tree a vigorous grower, rather spreading; leaves serrated, without glands; flowers small.

Fruit medium, roundish inclining to oblong, a little compressed, suture slight, apex small; skin white, shaded with red where exposed to the sun; flesh white, deep red at the storie, juicy and good. Ripens just after the Smoek.-Hecrth and Home.

\section{LAPORTE.}

Raised by M. Laporte at Ecully, near Lyons, France. Tree moderate vigorous, productive, a curious resemblanee to the blood peach.

Fruit medium to large, a little oval, tapering to the apex; suture large, extending a little beyond the apex, which is a little swollen; skin rellow, covered and washed and strongly striped and splashed with clark red; flesh white, reddish, or rose tint, but darker towarls the pit, tine, juicy, sugary, melting, delicate and agreeable; very good.-T'he Terger.

\section{Mountain Rose.}

This new peach is said to have originated in Morris County, N. I Tree vigorous and very productive. It ripens about the same time as Large Early York, is more highly eolored, but not quite as rich. Glands globose. Flowers small.

Fruit large, roundish, slightly eompressed; suture distiuct, extending a little beyond the apex; skin whitish, nearly eovered with light and dark rich red; flesh white, slightly stained at the stone, juicy, sweet, slightly vinous; very good; separates freely from the stone.

\section{Parks' Cling.}

A chance seedling on the grounds of A. L. Parks, Alton, Ill. Tree vigorons, produetive, leaves witl globose glands, ripens eight or ten days later than Heath Cling. 
Fruit very large, broader than deep; suture deep, extending quite around the fruit; skin slightly downy, light creany yellow, inostly covered with red; flesh also of a light creamy color, stained with red, but leeper red at the stone, very juicy, but not of the highest flaror; adheres to the stone.-Prairie Furmer.

\section{RichuoND.}

Raised by Dr. E. W. Sylvester, Lyons, N. Y., who writes that the tree is vigorous and very productive, and ripens a few days later than Crawford's Early, is less acid, and a promising market variety. Glands reniform.

Eruit medium to large, roundish, slightly compressed; suture slight but distinct, ending at the apex, which is a little swollen; skin fine yellow, shaded and mottled with dark rich red; flesh yellow, a little red at the stone, juicy, melting, sweet, vinous; very good; separates from the stone, which is of medium size. Ripe last of September.

\section{SALWAY.}

Originated with Thomas Rivers, Sawbridgeworth, England. Tree vigorous, very productive, ripens soon after the Smock. Flowers small. Glands reniform.

Fruit large, roundish oblate; suture broad, deep, extending beyond the apex; skin downy, creamy yellow, with a warm, rich, clear crimson red cheek in the sun; flesh deep yellow, stained with red at the stone, which is free, juicy, melting, rich, sweet, slightly vinous; rery good. -R. N. Yorlier.

\section{Southwick's Late.}

An accidental seedling on the grounds of T. T. Southwick, Dansville. N. Y., and is said by those who have it to be very juicy and rich. Tree vigorous and productive. Flower's small.

Fruit large, roundish, a little depressed at the summit; suture quite distirct, mamelon small, sunken nearly to a level with the parts around; skin yellowish white, sprinkled with minute red dots in the shade, and streaked and clouded with red towards the sun; Hesh white, parting fieely from the stone, very juicy, melting, with a fine delicate flaror; stone very small. Last of September.-Jour. of Hort.

\section{PEARS.}

\section{Beurre Lade.}

Originated by M. Gregoire-Nelis, of Jodoigne, Belgium, and dedicated to MI. le Consul Lade. Tree vigorous, an abundant bearer, and fruit bolds well to the tree. 
Fruit rather large, oblong obtuse prriform; skin fine yellow, shaded with camine in the sun; stalk long, curved, inserted in a slight depres sion; calyx and basin rather small, surromded somewhat by pointer kuols; flesh white, almost fine, melting, juicy, sugary, with a delicate aroma. October, November,-Iievue Ilorticole.

\section{Bonxe du Puits Ansault.}

Originated at Angers, France, in the nursery of Andre Leroy; for specimens of this and several other new varieties, we are indebted to Messrs. Ellwanger \& Barry, Rochester, N. Y. Tree moderately vigor* ous, very productive.

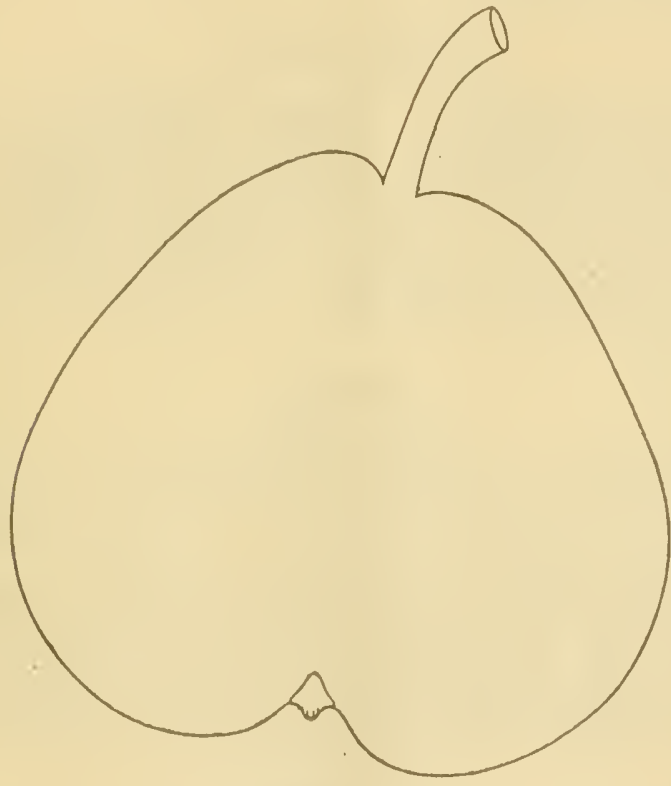

Bonne du Puits Ansault.

Fruit medium or below, roundish oblate, inclining to obtuse pyi $\mathrm{i}$ form, surface a little rough, uneven; skin light greenish yellow, mostly covered with a thin light russet; stalk short; cavity mediun, uneven; calyx small, closed; basin deep, rather narrow; flesh white, fine, juicy, melting, sweet, vinous, and rich; very good. September.

\section{BROCKWORTIL.}

A now Fnglish variety raised by Mr. Lawrence, Brockworth Park, and the English journals say it is of excellent quality.

Fruit large, oblong obtuse pyriform; skin smooth pale rellow, slightly flushed and streaked with red on the exposed side; stalk an 
inch long, rather stout, obliquely inserted without any depression; calyx small, closed; basin shallow; flesh white, buttery, melting, very juicy, vinous, and rich.-Lon. Jour. of Hort.

\section{Bronzé D'EnghieMr.}

Originated by M. Paternoster, in the province of Hainaut, Belgium. Tree moderately vigorous, productive.

Frnit medium, oblong ovate pyriform, regular; skin rough, deep yellow, nearly covered with brown russet and slightly bronzed in the sun; stalk long, slender, curved, cavity shallow; basin small, uneven ; flesh yellowish, a little coarse, juicy, half melting, vinous, slightly astringent; good. November, January.

\section{Colmar Delahaut.}

Raised by M. Gregoire, of Jodoigne, Belgium. Tree vigorous, spreading, moderately productive; young shoots olive brown.

Fruit medium, roundish acute pyriform; skin pale yellow, partially netted and patched with russet and many russet dots; stalk long, curved, slender, joined to the fruit without depression; calyx half closed; basin small, uneven, russeted; flesh white, juicy, half melting, sweet; good. November, December.

\section{DelpierRe.}

Beurre Delpierre.

A chance seedling in the garden of MI. Delpierre, of Jodoigne, Belgium. Tree very vigorous, very productive; young shoots dark olive brown.

Frnit large, roundish obtuse pyriform; skin pale yellow, partially blotched and netted with russet and thickly sprinkled with small russet dots; stalk rather long, generally curved; cavity medium; calyx closed ; basin medium, nearly smooth ; flesh white, a little coarse, juicy, melting, sweet, slightly vinous; good to very good. September.

\section{Doctor Косн.}

Originated in the nurseries of Andre Leroy, Angers, France. Tree moderately vigorous, very productive.

Fruit medium, roundish pyriform: skin pale yellow, a shade of red when fully exposed, a few traces of russet and many small russet dots; stalk long, rather slender, curved; cavity shallow; calyx half closed; basin rather small, uneven; Hesh whitish yellow, half fine, juicy, mclting, slightly vinous; good. October.

\section{Dú DE MORNY.}

A seedling of M. Boisbunel, Rouen, France. Tree vigorous, pro ductive; young shoots dark olive brown, many grayish specks.

Fruit medium, roundish pyriform, a little obtuse; skin pale rellow, sometimes a shade of red in the sun, a few traces of russet, and many 
small russet dots; stalk of medium length, inclined, curved, cavity very small; calyx open; basin medium, a little uneven; flesh yellowish; half fine, juicy, half melting, vinous; good. November, December.

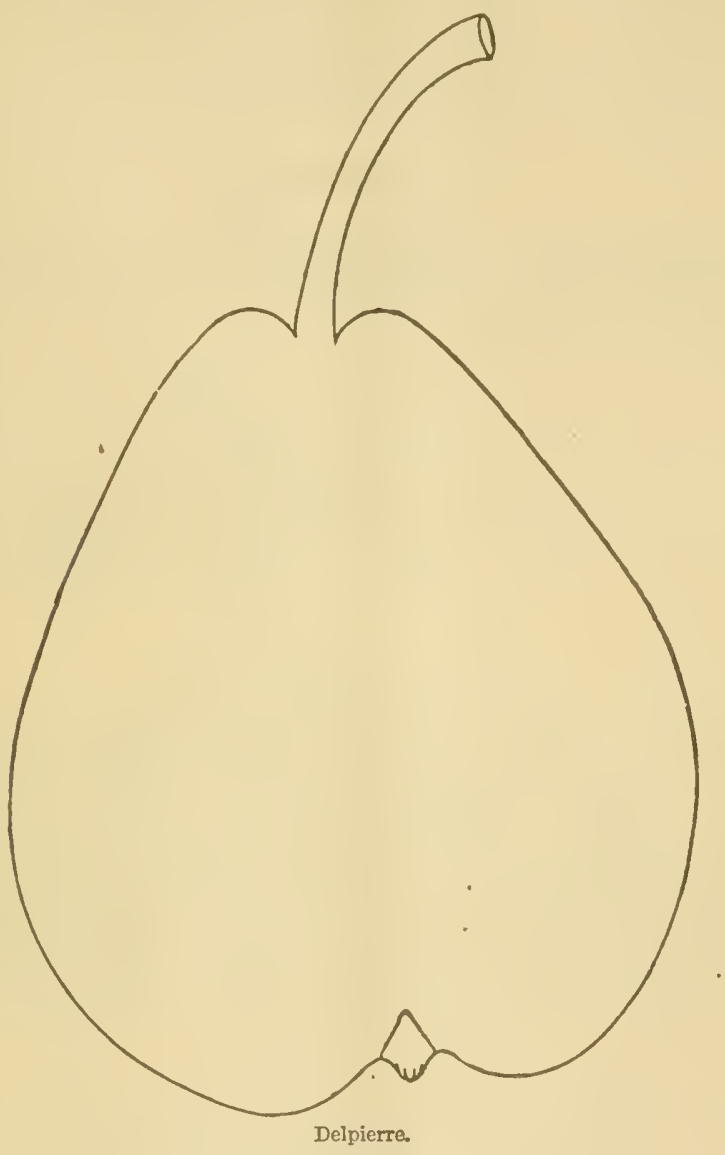

DUCHESSE DE MOUCHY.

A chance seedling discovered by Florentin Delavier, of Beauvaise, in a garden at Breteuil, France. Tree vigorous, upright, moderately productive.

Fruit medium roundish, inclining to obtuse pyriform; skin deep yellow, shaded with light orange red in the sun, slight nettings of russet and small russet dots; stalk rather short, stout; cavity small; calyx half open; basin medium, a little uneven; flesh white, half fine, half melting, moderately juicy, sweet; good. April, May.

\section{Duchesse Precoce.}

Originated in the nurseries of Andre Leroy, Angers, France. Tree strong and vigorous, moderately productive. 
Fruit medium to large, long pyriform, a little obtuse; skin palc yellow, shaded and mottled with pale red where exposed to the sun, and covered with many small russet dots; stalk of medium length, rather stont, inclined, inserted in a slight depression, sometimes small carity; calyx large, open; basin shallow, uneven; flesh whitish, a little coarse, juicy, half melting, sweet, slightly vinous, and a littlo astringent; good. Ripe first of September.

\section{Eastern Belle.}

Raised by Henry McLaughlin, Bangor, Me., from whom we received specimens, which were of excellent quality. Tree hardy, vigorous, and a regular bearer; young shoots yellow brown.

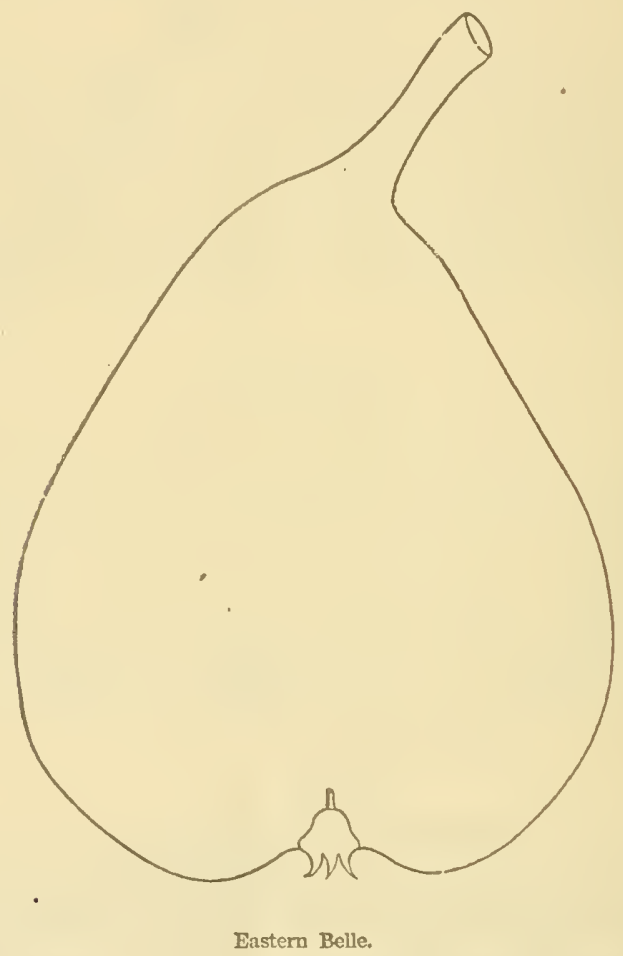

Fruit medium, oborate pyriform, somewhat obtuse; skin pale jellow, often shaded with light red in the sun, a few nettings and patches of russet, and many russet dots; stalk short, stout, inclined, and sometimes Heshy at its insertion in a slight depression, much russeted: calyx open; basin medium, nearly smooth, slight russet; flesh whitish yellow, a little coarse at the core, juicy, half melting, very sweet, rich, slightly aromatic, and a peculiar slight musky perfume; very good. September 


\section{Egerie.}

A chance seedling in the grounds of M. Tavenier de Boullongue at Anger's, France. 'Tree moderately vigorous, rather upright, a good bearer.

Fruit medium, roundish pyriform, slightly obtuse; skin pale yellow, partially netted and patched with russet, and many russet dots; stalk rather long, slightly eurved; cavity small; ealyx open; basin medium, regular, russet; llesh white, lıalf tine, juicy, half melting, sweet, slightly vinous; good to very good. October.

\section{Eiliot's Early.}

A new early pear, raised by Charles Eliot, of Windsor, Ontario. Specimens received from James Dougall, who writes that the tree is very hardy, a strong, vigorous grower, an early beurex, very productive, and ripens a week or more before the Madeline.

Fruit small pyriform, regular; skin pale greenish yellow, brownish red when exposed to the sun; stalk long, slender, curved; cavity small, russeted ; calyx closed or partially open; basin small; slightly plaited; flesh whitish, half fine, juicy, melting, sweet, slight perfume; good to very good. July.

\section{INDIAN QUEEN.}

Raised by Menry McLaughlin, Bangor, Me., who writes that the tree is perfectly hardy, a vigorous grower, productive, and a good market variety, although not of the best quality.

Fruit rather large, long pyriform, somewhat acute, surface a little uneven; skin pale yellow, often shaded with light red where exposed to the sun, slight nettings of russet, and many russet and brown dots; stalk of medium length, rather stout, set in a slight depression; calyx open; basin medium, uneven; flesh whitish yellow, a little coarse, moderately juicy, half melting, sweet, but not rich. September.

\section{Jacques Chamaret.}

A seedling of the late Leon Leclerc, at Laval, France, Tree strong, vigorons, erect, moderately productive; joung shoots light reddish brown.

Fruit medium, roundish, inclining to acute pyriform; skin pale yellow, sometimes thinly sharled and marbled with light red in the sun; stalk rather long, curved, a little swollen at its insertion, sometimes by a lip; calyx open; basin shallow, uneven; flesh whitish, fine, juicy, half melting, sweet, slightly vinous; good to very good. October.

\section{Joserhine DE Binche.}

Raised at Binche, Belgitum, fiom seed of Josephine de Malines Tree very vigorous and very productive, branches smooth, of a yellow. ish brown, with grayish dots.

Fruit medium, roundish obtuse pyriform; skin smooth, clear yellow, nettrd with browz and russet; stalk of medium length, small, inserted 
in a moderate cavity; eye large, deeply sunk; flesh half fine, half melt ing, very juicy, sugary, of an exquisite perfumed flavor. October, De cember.-Illus. Horticole.

\section{LORIOL DE BARNY.}

Originated in the nurseries of Andre Leroy, Angers, France. Tree vigorous, upright, "very productive.

Fruit medium to large, oblong pyriform, slightly obtuse; skin pale yellow, a few nettings and patches of russet, and numerous russet dots; stalk of medium length; cavity small; calyx closed; basin medium, slightly corrugated; tlesh whitish, half fine, juicy, melting, sweet, pleasant; good to very good. September.

\section{LOUIS VILMORIN.}

Originated with Andre Leroy, Angers, France. Tree vigorous, rather spreading, very productive.

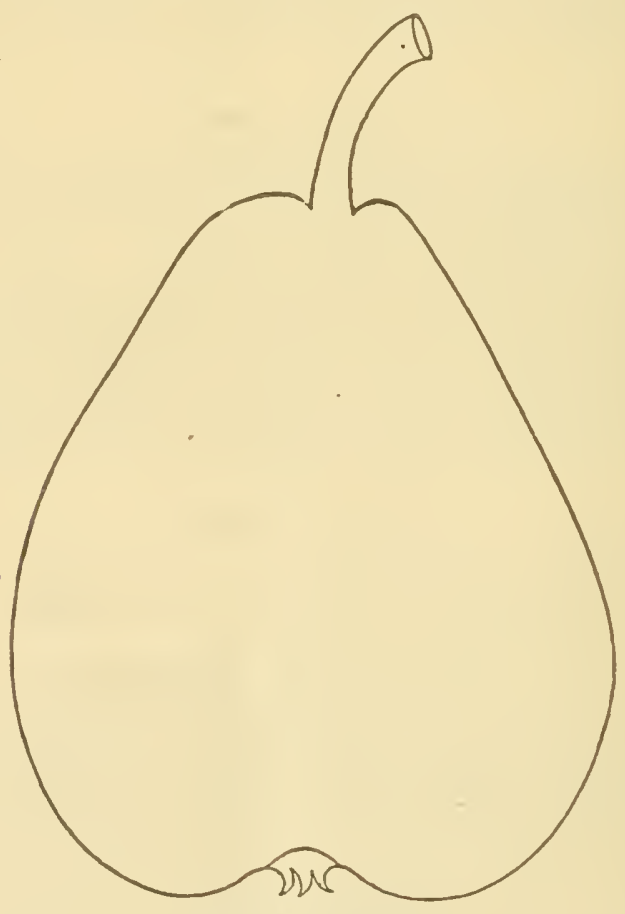

Lonis Vilmorin.

Fruit medium, pyriform, a little obtuse; skin deep yellow, considerably nctted with russet, many russet dots, and sometimes a sliade of red where exposed; stalk short, curved; carvity small, sometnmes broud and 
shallow; calyx large, open; basin medium, nneven, russet; flesh white, half tine, juicy, melting, sweet, slightly perfumed; good to very good. December.

\section{Madane Andre Leroy.}

Raised by Andre Leroy, Angers, France. Tree moderately vigorous, but lealthy, with long shoots, productive.

Fruit rather large, oblong pyriform, somewhat obtuse, inclined or sides unequal; skin pale whitish yellow, sometimes a shade of red in the sun, and many brown dots; stalk rather long, set at an inclination in a small cavity, sometimes by a lip; calyx closed or half open; basin medium, meven; flesh whitish yellow, a little coarse, juicy, melting, vimous, a little astringent; good to very good. Last of September and first of October.

\section{Madame Cuissard.}

A seedling of M. Cuissard, of Ecully, near Lyons, France. Tree moderately vigorous, productive.

Fruit medium, roundish obtuse pyriform; skin pale greenish yellow, with many green and brown dots; stalk rather long, curved; cavity small; calyx closed or mearly so; basin medium, slightly corrugated; flesh white, a little coarse, juicy, melting, sweet, very slight acid or vinous; good. Last of August and first of September.

\section{Madaine Favre.}

A chance seedling discovered by M. Favre, of Chalons, France. T'ree very strong, upright, pyramid, an early and abundant bearer.

Fruit large, roundish obovate, a little obtuse; skin pale greenish yellow, with numerous traces and splashes of russet; stalk rather long, quite strong, set in a slight depression; calyx large, open; basin quite deep, and rather abrupt; flesh whitish, fine, melting, juicy, sweet, and of a delicate flavor. October, November.-Illustrated IIonthly.

\section{MLADAure Loriol de Barny.}

Originated in the nurseries of Andre Leroy, Angers, France. Tree vigorous, upright, productive.

Fruit medium, oblong pyriform, a little obtuse; skin greenish yellow at first, changing to a deep yellow, slightly bronzed, sometimes a shade of red in the sun; stalk short; cavity small, or slight depression; calyx closed, or nearly so ; basin rather shallow, a little uneven; flesh yellowish, a little conrse, melting, juicy, slightly vinous; good to very good. October, November.

\section{Manningtox.}

Originated in the garden of James M. Hannah, of Salem, Manning. ton Township, N.J., who writes that the tree is rather a slow grower, forming a compact symmetric head; branches strong, short jointed; 
ripens two or three weeks later than Seckel, of the best quality, and keeping remarkably well.

Fruit rather small, ovate acute pyriform; skin pale greenish yellow, a shade of brownish red in the sun, slight nettings of russet and many russet dots; stalk short, slightly curved, joined to the fruit without depression; calyx open; basin shallow, uneren; flesh white, juicy, melt. ing, sugary, rich, aromatic; very good or best. September, October.

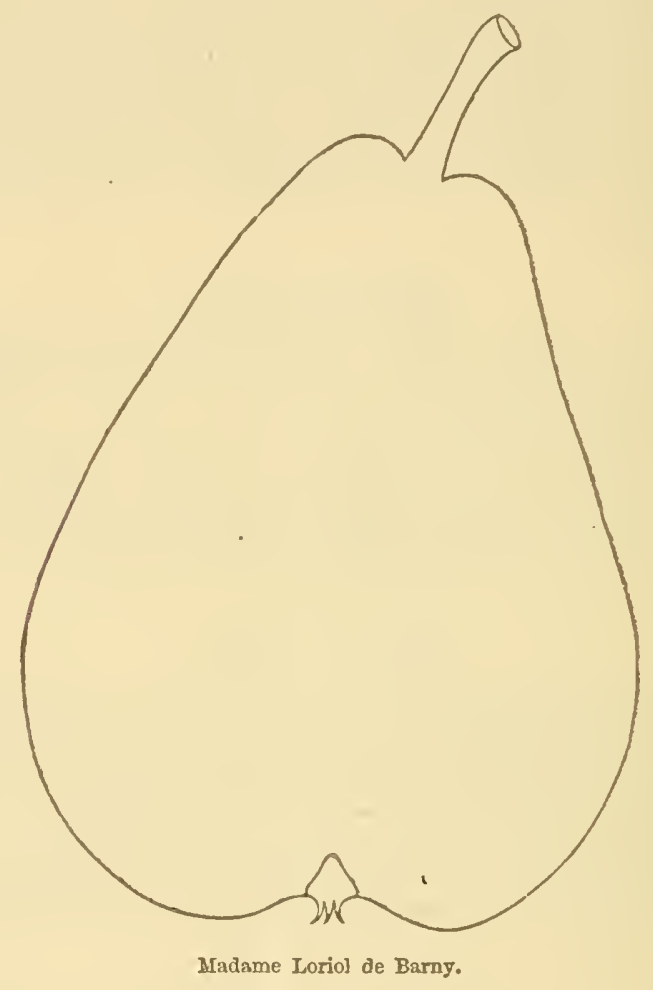

Maréchal Vaillant.

Originated with M. Boisbunel, of Rouen, France. Tree vigorous, upright, very productive.

Fruit large, broad obtuse pyriform; skin greenish jellow, a fer nettings of russet and many russet and brown dots; stalk rather short, moderately stout, curved; cavity broad, not very deep; calyx open; basin large, deep, uneven; flesh whitish, half fine, melting, sweet, slightly vinous; very good. November, December.

\section{Maurice Desportes.}

Originated in the nurseries of Andre Leroy, Angers, France. Tree vigorous, moderately productive; young shoots yellow brown.

Fruit medium to large, long acute pyriform; surface somewhat uo 
even; skin pale yellow, nearly covered with thin light russet, often a shade of red in the sun; stalk long, rather slender, curved, joined to the fruit acutely without cavity, sometimes by a ring or lip; calyx open; basin medium, slightly corrugated; flesh white, fine, juicy, melting, sweet, slightly perfumed; very good. September, Oetober.

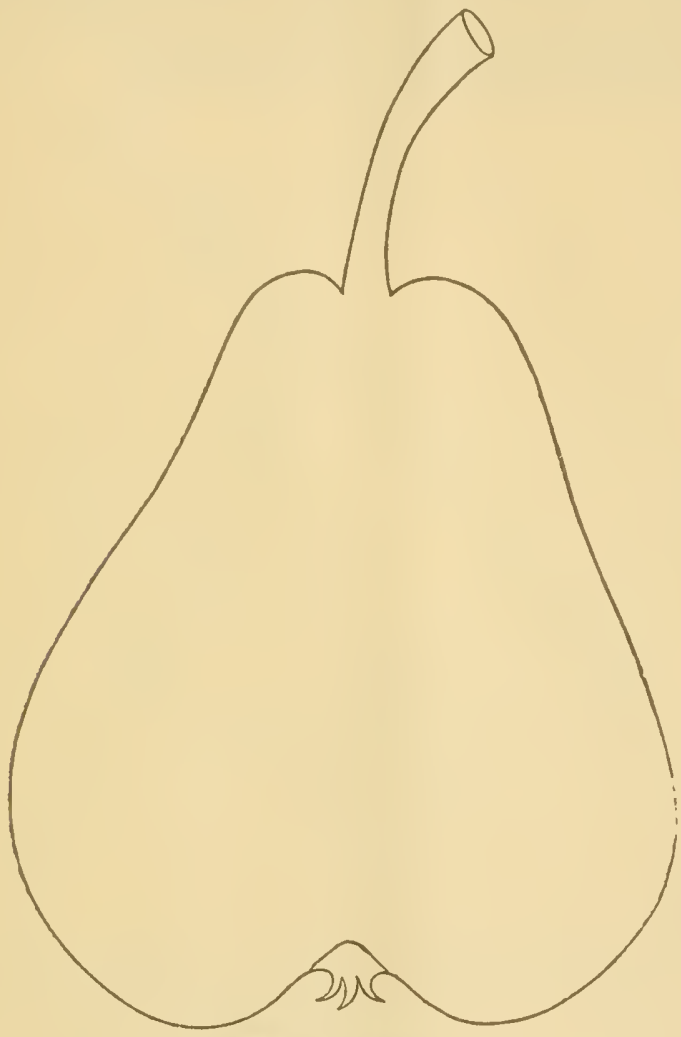

Maréchal Vaillant.

\section{Petite Marguerite.}

Originated in the nurseries of Andre Leroy, Angers, France. Tree moderately vigorous, very productive; young shoots olive brown.

Fruit nearly of medium size, oblate obtuse pyriform, surface slightly uneven; skin greenish yellow, or pale yellow when mature, sharled with brownish red on the sunny side, and many greenish dots; stalk long, slightly curved, set in a narrow, rather deep eavity; calyx half open; basin quite large, slightly corrugated; flesh white, half fine, buttery, juicy, melting, sweet, slight perfume flavor; very good. Ripens last of Augrust. 


\section{Prémices D'Ecully.}

Originated with M. Luizet, at Ecully, near Lyons, France. Tree moderately vigorous, very productive.

Fruit nearly of medium size, obtuse pyriform; skin pale yellow, a few nettings of russet, and many russet dots; stalk of medium length, a little inclined; cavity broad, shallow; calyx closed or half open; basin rather shallow, russet; flesh whitish, a little coarse, juicy, half melting, sweet, slightly aromatic; good. September.

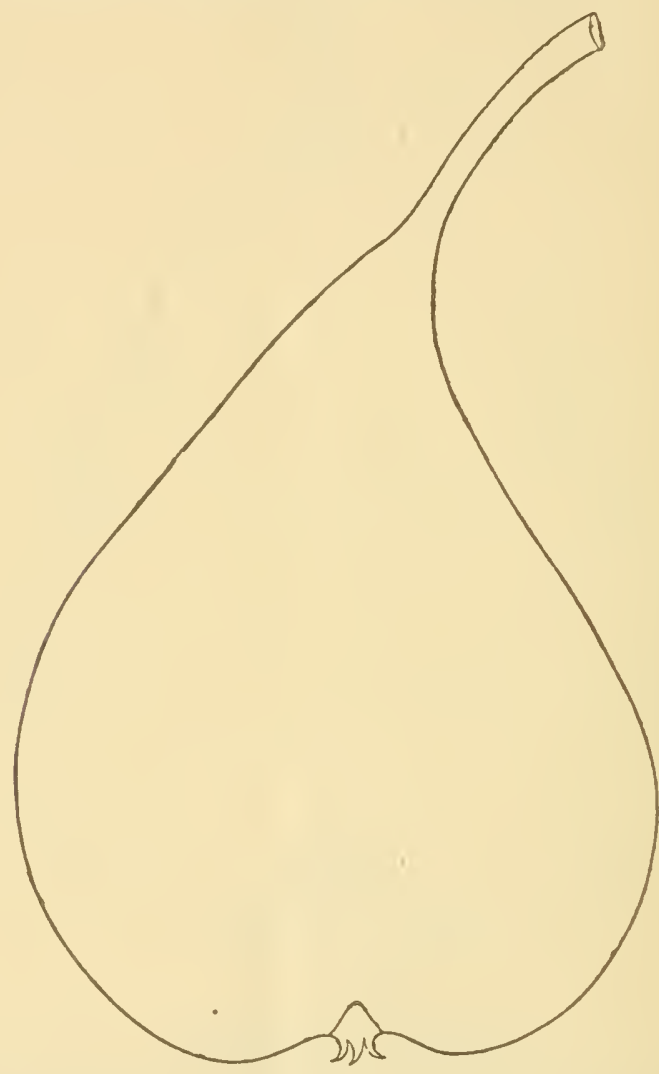

Maurice Desportes.

\section{Professor Hortoles.}

This new pear originated with M. MTorel, at Lyons, France. Tree very strong and vigorous, and a very good bearer.

Fruit medium to large, roundish oblate, inclining to pyriform, slight ly obtuse; skin deep yellow, slight nettings of russet, and many lar re dark brownish red dots, and often brownish red in the sun; stalk short, stout; cavity medium; calyx large, open; basin rather wide, quite deep; flesh fine, juicy, melting, sugary, vinous, and of the highest qual ity. September, October.-Illustrated Monthly. 


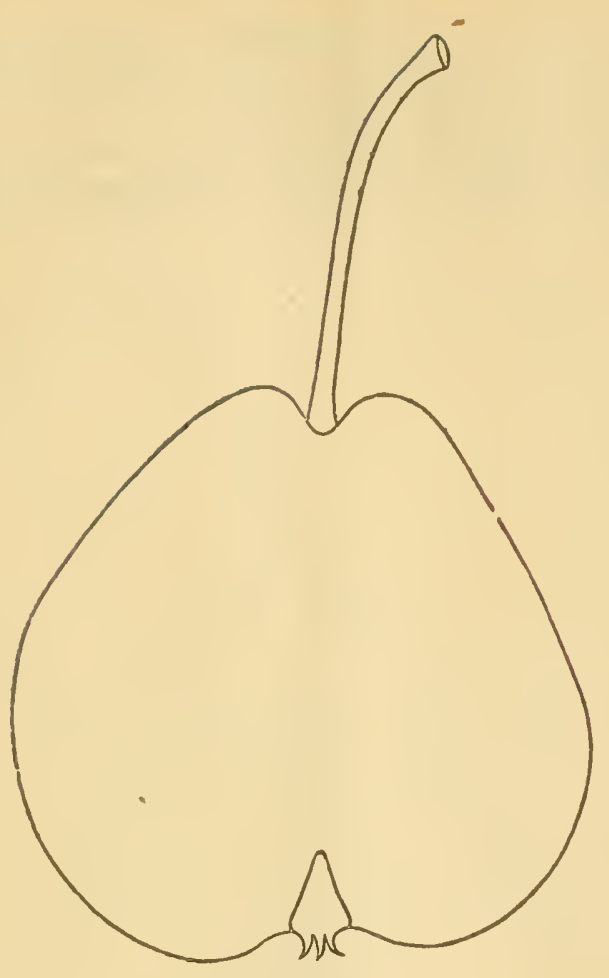

Petite Marguerite.

\section{ROGERS.}

Dean.

A chance seedling in the garden of the late Capt. Rogers, of Boston, Mass, and introduced by A.J. Dean, of the same place. Tree vigorous, somewhat spreading, productive.

Fruit medium, oblong ovate obtuse pyriform; skin yellowish green, sometimes a shade of dull red in the sun, and many green and russet dots; stalk long, curved, inserted in a slight depression or small cavity ; calyx half open; basin rather small, slightly corrugated; flesh whitish yellow, a little coarse, juicy, half meiting, sweet, slightly vinous, and slightly aromatic; good to very good. September.

\section{Saint Germain Van Mons.}

Origin Belgium, one of Van Mons' seedlings. Tree moderately vigorous, moderately productive.

Fruit medium or nearly so, roundish obovate pyriform; skin light greenish yellow, many brown dots; stalk long, curved; cavity very smitll; calyx open; basin small, russet; flesh whitish, buttery, molting, juicy, sweet; good. October. 


\section{SAMI BROWN.}

Originated with Samuel Brown, Jr., at Walnut Hills, MId. Tree a free grower, an early and regular bearer.

Fruit nearly of medium size, roundish oblate, a little uneren; skin pale yellow, partially corered with thin russet, sometimes a little

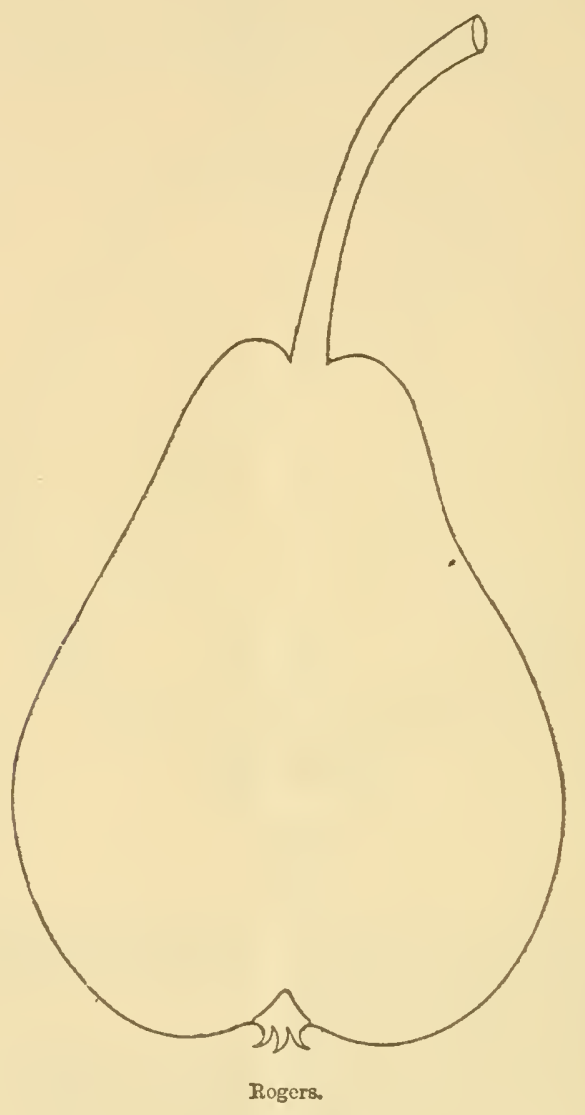

brownish in the sun; stalk short, rather stout, inserted in a large cavity; calyx open or partially closed; basin large, deep; flesh white, a little coarse, juicy, melting, vinous, and rich; rery good. September.

\section{Souvenir Fatre.}

A variety raised by II Favre, of Chalons, France. Tree vigorous, moderately productive.

Fruit unedium, obovate pyriform; skin greenish yellow, sometimes a sharde of red in the sun, many brown and green dots; stalk short, inserted at an inclination in a slight depression by a lip; calyx ojen; 
PEARS.

basin small or medium, uneven, slightly russeted; flesh whitish, half tine, juicy, melting, sweet, slightly perfumed; good to very good. (1).tober.

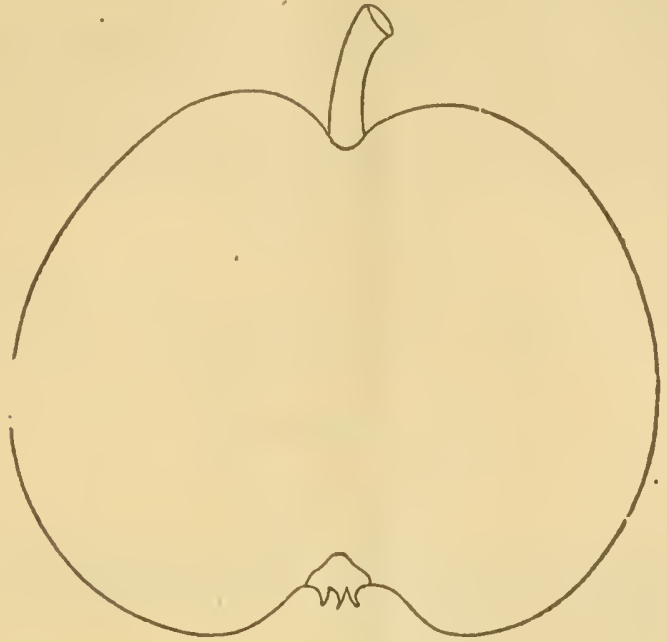

Sam Brown.

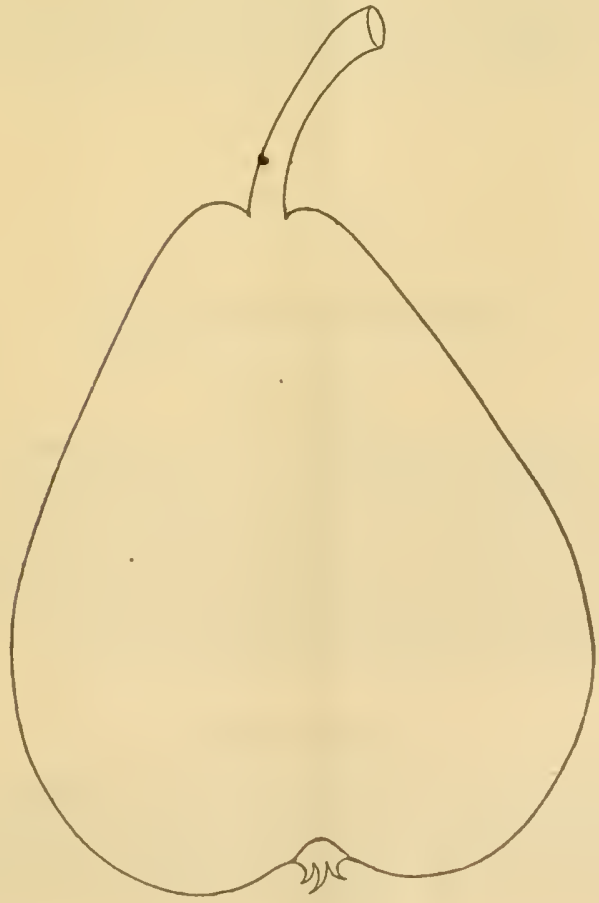

Therese Appert. 


\section{Therese Appert.}

A new variety raised by Andre Leroy, Angers, France. Trec strong, vigorous, an abundant bearer. .

Fruit medium, rather long pyriform to roundish obovate pyriform, a little obtuse; skin deep yellow, partially netted, dotted, and patched with russet, sometimes a shade of rich brownish red in the sun; stalk short, a little inclined; cavity small, often without; calyx open; basin rather shallow, smooth; flesh whitish yellow, half fine, juicy, melting, sweet, slightly vinous; very good. September.

\section{QUINCE.}

\section{Sweet Quince.}

Origin said to be Chambersburg, Pa., many years since. Tree a good grower and an abundant bearer. The fruit is less acid than other kinds, keeps late, and cooks tender.

Fruit medium to large, roundish oblate, angular or somewhat ribbed; skin deep yellow; stalk short, set on a swollen projection in a broad, shallow depression; calyx open, with long, broad segments; basin large, deep, corrugated; flesh firm, deep yellow, with the same juice and acid astringency of the apple-quince, but much less of it.

\section{RASPBERRY.}

\section{Herstine.}

Tris new raspberry originated with D. W. Herstine, Branchtown, Ta. The plant is said to be hardy, is very vigorous, and very productive, and is a promising market variety, except for carrying long distances I fear it will not be quite firm enough; canes strong, erect; spines short, strong, scattering, greenish white, slightly purple.

Fruit large, roundish obtuse conical, bright scarlet; flesh moderately firm, juicy, sweet, rich, separates freely from the core.

\section{Narraganset.}

A new variety raised by John F. Jolls, of Providence, R. I., which is said to be very large, very productive, and a promising variety for market, being large and keeping in good coudition for a long time; the berry is scarlet, of a conical form and fine flavor. We have not seen the firuit. 


\section{Ostario.}

A variety of the Black Cap found on the grounds of F. E. Lorrl, Fairport, N.I. Plant hardy, rigorous, and very productive, and, being firm, it will bear carriage to a distant market. The fruit is quite larow of its class, deep black, with a very thick bluish bloom, juicy, sweet, and very good.

\section{Susqueco. \\ Brandywine.}

Of unknown origin, but said to be a good market sort for Delaware and Maryland.

Fruit medium, roundish obtuse conical, bright red; flesh quite firu, moderately juicy, sprightly subacid. 



\section{SECOND APPENDIX \\ TO}

SECOND REVISED EDITION.

PEACHES, PEARS, \&C. 



\section{PEACHES.}

\section{Alexander's EARly.}

A chance seerlling on the farm of $O$. A. Alexander, near Mount Pulaski, Illinois. This new peach ripened liere last season, towards the last of July, two weeks before Hale's Early; tree vigorous, productive; tho fruit showy, of good flavor, and promises to be an acquisition as an early market variety and for home use; leaves with globose glands; flowers Jarge.

Fruit medium, nearly globular, slightly depressed; suture shallow, ending at the apex, which is slightly sunk; skin greenish white, nearly covered with deep rich red, almost purplish in the sun; flesh whitish, with a tinge of green, sometimes a little stained next the skin; a little firn, or half melting, juicy, sweet, slightly vinous, white at the stone, to which it adheres slightly, and which is small.

\section{Ausden's JuNe.}

A chance seedling on the grounds of L. C. Amsclen, near Carthago, Missonri; tree vigorons, productive, and it is said to ripen two or three weeks earlier than Hale's Early, but not having fruited it here, cannot say as to time. Fruit received July 13 from the originator, where the season is earlier; leaves with globose glands; flowers large.

Fruit medium, roundish, slightly depressed; suture rather broad, shallow, extending a little beyond the apex, which is slightly sunk; skin greenish white, nearly covered with light and dark red, almost purplish in the sun, and somewhat mottled in the shade; flesh greenish white, while at the stone, to which it slightly adheres, and which is small; flesh half melting, juicy, sweet, slightly vinous and very good.

\section{CoOK's LATE White.}

A chance seedling in the garden of an unknown person in Philadel. phia, but was introduced by Joseph Cook of Salen, New Jersey; it is a large peach, highly esteemed and popular, where known, for market and family use; tree vigorous, an abundant bearer; flower's small.

Fruit large, roundish, a little inclining to oblong; skin pale whitish vellow, a sliade of pale red where exposed; suture small, extending a little beyond the apex, which is a small point; flesh white, a little stained with red next the stone, juicy, melting, sweet, rich and delicious; free stone. Ripe last of September. 


\section{EARLY Ascot.}

Raised a few years since by Mr. Standish, of the Royal Ascot Nursery, England, and is considered a choice peach; leavts with small roundish reniform glands; flowers smatl.

Eruit medium, roundish, somewhat dejressed; suture shallow; skin flushed with bright red on nearly all parts, suffused on the sharly with crimson and on the exposed side with deeper blood red; flesh shight red at the stone, from which it parts freely, pale greenish straw color, with abundant juice, and an excellent flavor. Ripe first of September. (Florist and Pomologist.)

\section{FetTers.}

A new variety, raised by Jolın Fetter's, near Lancaster, Ohio; trce vigorous, a good and regular bearer and fine quality; glands globuse; flowers small.

Fruit medium to large, roundish, inclining to oblong; suture distinct but not deep, extending a little berond the apex, which is a small point; skin creamy white, with a slight b! ush where exposed; flesh white, a slight tinge of red at the stone, juicy, melting, sweet, rich and excellent; freestone. Ripens the first of September.

\section{Higir's Early Canada.}

A seedling raised by Abraham High, Jordan, Ontario, who claims that it is as early or a few clays earlier than Early Beatrice, larger and better quality: and the fruit he sent me was rery similar in size, form, color and quality to Alexander's Early, Amsden's Jume and Honeywell, and I am inclined to think they are all seedlings, varying slightly, of one kind-probably Hale's Early.

\section{Hill's Chili Pfach.}

\section{Synonyms :}

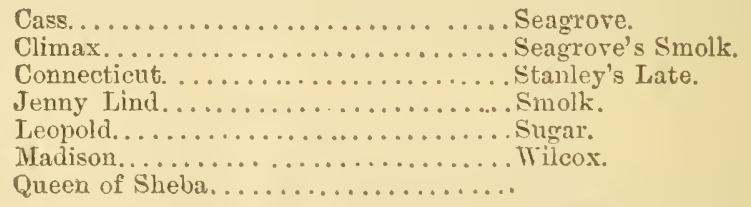

It is now pretty well ascertained that this peach originated on the farm of Deacon I'itmann Wilcox, of Riga, Monroe County, N. I., more than sixty years since, and is still healthy and bearing fruit; it wus first called Connecticut Peach. The tree is hardy, vigorous, very productive, and is considered a valuable market variety. It is also said to reproduce itself from seed, and the many names by which it is called in different localities is no doubt the result of its reproduction. 
Fruit medium oval; suture slight, ending a little beyond the apex; which is a small point; skin derp yellow, shaded with ilark red, often dark spots or blotches of brownish renl where exposed; flesh deep yellow, red at the stone, moderately juicy, half melting, sweet, vinous; separates freely from tịe stone, which is rather small; ripens the last of September and first of October.

\section{HoneTWelL.}

A new variety, raised hy John Honeywell, Randolph, Ohio ; a handsome early peach, ripening a week or two before Hale's Early, and growing here last season side by side with Alexander's Farly was two or three days earlier; tree is vigorous and productive, and promises to he valuable; leaves without glands, flowers large.

Fruit medinm, neally globular, a little flattened; suture slight, rather shallow, extending a little beyond the apex, which is small; skin green. ish white, nearly covered with light and dark rich red; redrish purple where fully exposed; flesh whitish, juicy, half melting, sweet, slightly vinous and rery good; adheres slightly to the stone, which is small and not stained.

\section{Mrs. Bretr.}

A ehance seedling in the garden of Mrs. Maria Brett, Newburgh, N. Y.; tree vigorous, productive; glands reniform; flowers small; glands globose.

Fruit medium, roundish; suture broad and shallow, extending a little beyond the apex, which is a small swollen point; skin whitish, shaded with lark rich red where fully exposed; Hesh white, red at the stone; juicy, melting, sweet and ricls; free stone.

\section{Muscugee.}

A variety of the Columbia, raised by J. C. Cook, Columbia, Georgia; the tree much resembles the Columbia in all its parts; Howers small.

Fruit large, roundish, slightly depressed; suture rather broad and distinct, extending a little beyond the apex, which is a small point; skin downy, dull yellow, more or less striped, splashed or mottled with dull or brownish red; the splashes rary in form and size; flesh whitish, a little coarse, sometimes a little stained and veined with red; juicy, sweet, slightly vinous; free stone, which is nearly romd and of medium size. Riperes at the South the first of August, and a month later at the Nortl.

\section{Nix's Jate White.}

Origin said to be Newtown County, Georgia; tree vigorons, produetive, and ripens a week or two later than Ileatheling; leaves with reniform glands; flowers large.

Fruit large, roundish, inclining to oblong; suture medium, extending 
to the apex, which is slightly sunk ; skin white, downy, a shade of red in the sun; flesh white to the stone, to which it adheres; rather firm, juicy, sweet, vinous and rich. Ripe middle and end of October.

\section{Peitit's Imperial.}

\section{Imperial Yellow.}

This was raised by David Petit, Salem, N. J.; it is a large, handsome late peach, one of the richest of the yellow-fleshed varieties, and continues in use longer than most kinds; tree vigorous, a moderate bearer gencrally, but some seasons produces good crops; flowers small.

Fruit large to very large, roundish, slightly depressed; suture shallow, extending a little beyond the apex, which is small; skin deep orange yellow, sharled and mottled with dark rich red; flesh yellow; red at the stone, juicy, melting, rich, sweet and high flavored; free stone. Ripe last of September.

\section{Thurber.}

A new variety, raised from the seed of Chinese Cling, by Dr. L. E. Berckmans, Rome, Georgia, and named after his friend, Dr. George Thurber ; it is a handsome and very promising variety, and as it is said to carry well, and being of good size, it will be an acquisition for market and general use; tree very healthy, vigorous and symmetric in form; Hower's small.

Fruit large, roundish, inclining to oblong; suture slight, extending to the apex, which is slightly sunk; skin slightly downy, creamy white, shaded and mottled with pale red and carmine where fully exposed; flesh white, a little red at the stone, which is tree; fine grained, very juicy, melting, slightly vinous, rich and delicious. Ripe from middle to the end of July in Georgia. 


\section{PEARS.}

\section{Calebasse d'Octobre.}

Of Belgian origiu; tree vigorous, upright; promises to be an abundant bearer.

Fruit large, elongated pyriform, a little obtuse, some specimens acute, when the stalk is inserted by a lip, without cavity; skin smooth, pale yellow, a shade of rich crimson where fully exposed; stalk long, inclined, curved ; cavity small; calyx closed; basin shallow, slightly cor"ugated; flesh white, fine, jucy, melting, with a pleasant, rather rich Havor. Ripens in October.

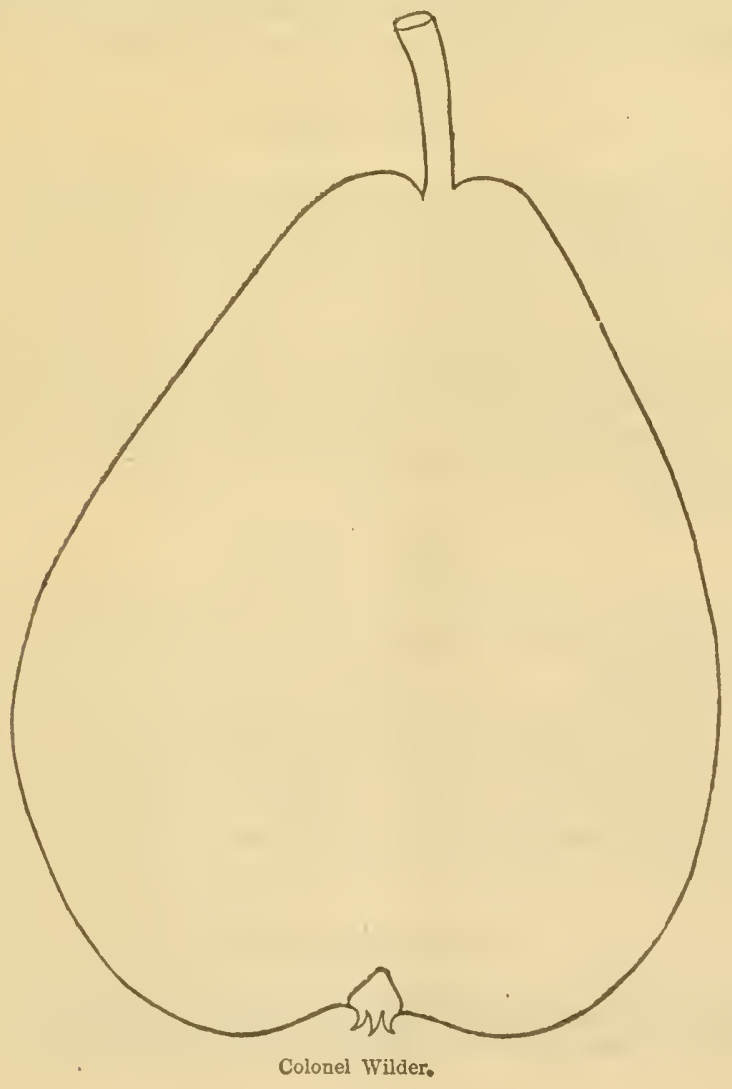




\section{Colonel Wilder.}

A new seerlling raised by B. S. Fox, San Jose, California, and is said to be a valuable late variety.

Fruit medium to large, round sh obtuse pyriform; skin light yellow, a sharle of light orange red in the sun, slight nettings of russet, anr numerous small russet and brown dots; stalk rather short; cavity small; calyx small, open, or wearly so; basin rather shallow, slightly 1)aited; flesh whitish yellow, a little coarse around the core, juicy, melting, very sweet, with a peculiar slight musky and slightly aromatic flavor. December, January.

\section{Courte Queue D'Autowne.}

Originated with Andre Leroy; Angers, France; tree vigorous, some. what spreading, very productive.

Fruit medium, oblate to roundish oblate, slightly elevated, surface rough, uneven and irregular; skin pale whitish yellow, sometimes a shacle of pale red in the sun, and many russet dots; stalk short, stout, a little inclined ; cavity medinm ; calyx closed ; basin broad, corrugated; Hesh whitish, fine, melting, sweet, slightly vinous, and a slight cinud mon perfume. Last of September and first of October.

\section{Doctor Howe.}

Origin, in the garden of Dr. John J. Howe, Birmingham, Conn.; tree healthy, vigorous, spreading, with mumerous branches of firm textmre and persistent foliage; very productive; a new promising variety of its season.

Fruit medium, roundish, inclining to pyriform, slightly obtuse ; skin greenish, but becoming light yellow at maturity; slightly netted and patched with russet, and many russet dots ; stalk medium ; carity small ; calyx ojen; basin medium, a little uneven; flesh whitish, half fine, juicy, melting, with a sweet, rich, slightly vinous flavor. Ripens the last half of October.

\section{DOCTOR LINDLEY.}

Origin unknown; tree vigorous; an abundant bearer of handsome, high-flavored fruit.

Frnit nearly medium, oblate pyriform, or broadly turbinate; skin pale yellow, a shade of bright red where exposed, thinly netterl and tracui with russet, and many russet dots; stalk rather long, inclined, set in is suall cavity, sometimes by a lip; calyx open; basin medium, sligltty plaited; flesh whitish, fine, juicy, melting, sweet, rich and excellcut. November.

\section{Duhamel du Moxcenu.}

Raised by Andre Leroy, Angers, France, and dedicated to Duhame] du Monceau; tree vigorous, spreading, and a good bearer. 
Fruit medium, roundish pyriform; skin pale whitish yellow, a shade of brown in the smm, partially netted and patched with rnsset, and sprinkled with many russet and brown dots; stalk long, inclined, set in a slight de.

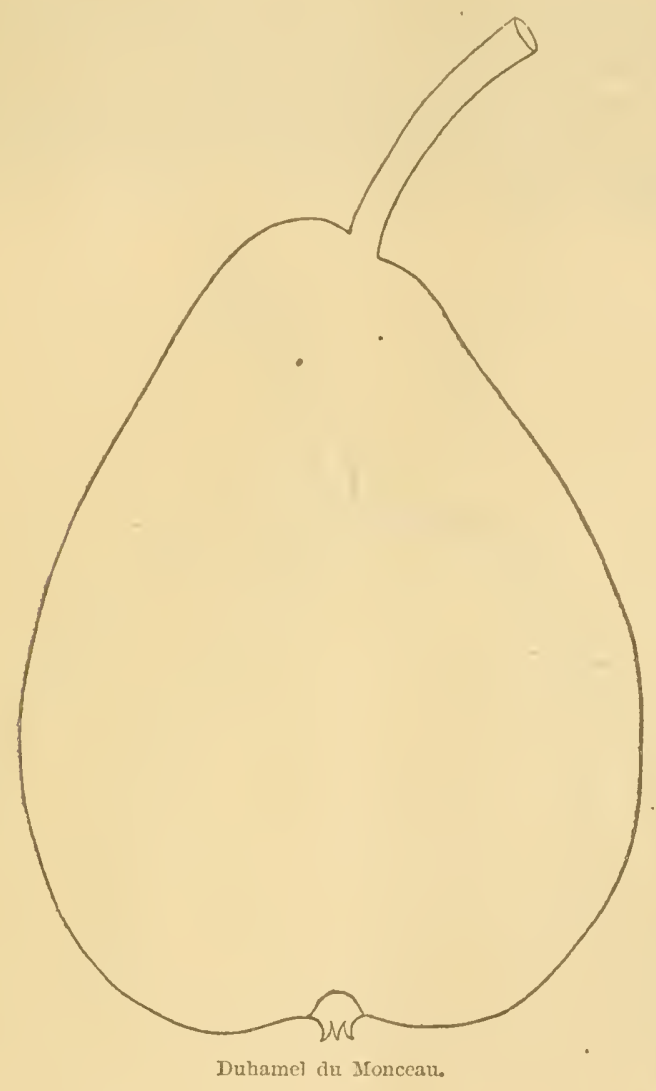

pression, sometimes by a lip; calyx open, or half closer ; basin shallow, a little meven; flesh whitish, half fine, buttery, juicy, melting, sweet, sliglitly vinous, and very good. November.

\section{Elizabetil Maury.}

A cliance seedling on the ground of Reuben Maury, Charlottsville Virginia, and namod after lis granci-danghter, Elizabeth Maury; tree vigorous ; in abundant bearer.

Fruit small, olylate, sliwhtly elevated; skin pale greenish yellow, sonetimes a sharle of brown in the smu, and many greenish dots; stalk short to medium; cavity small; calyx small, open or half open; basin lather small, shightly plaited; flesh whitish, half tine, tender, juicy: uelting, sweet, slightly vinous. August. 


\section{Frederick Clapr.}

Clapp's No. 22.

This fine new pear was raised by Lamuel Clapp, (brother of the late Frederick and Thaddeus Clapp, who produced Clapp's favorite pear, anc? upon the same farm) Dorchester, Mass., from seed of Urbaniste crossed with Beurre Superfin, which it much resembles in flavor, only a little more vinous. Mr. Clapp writes that the tree is vigorous, with rather slender branches, somewhat inclined to spread; a good bearer, anc keeps remarkably well.

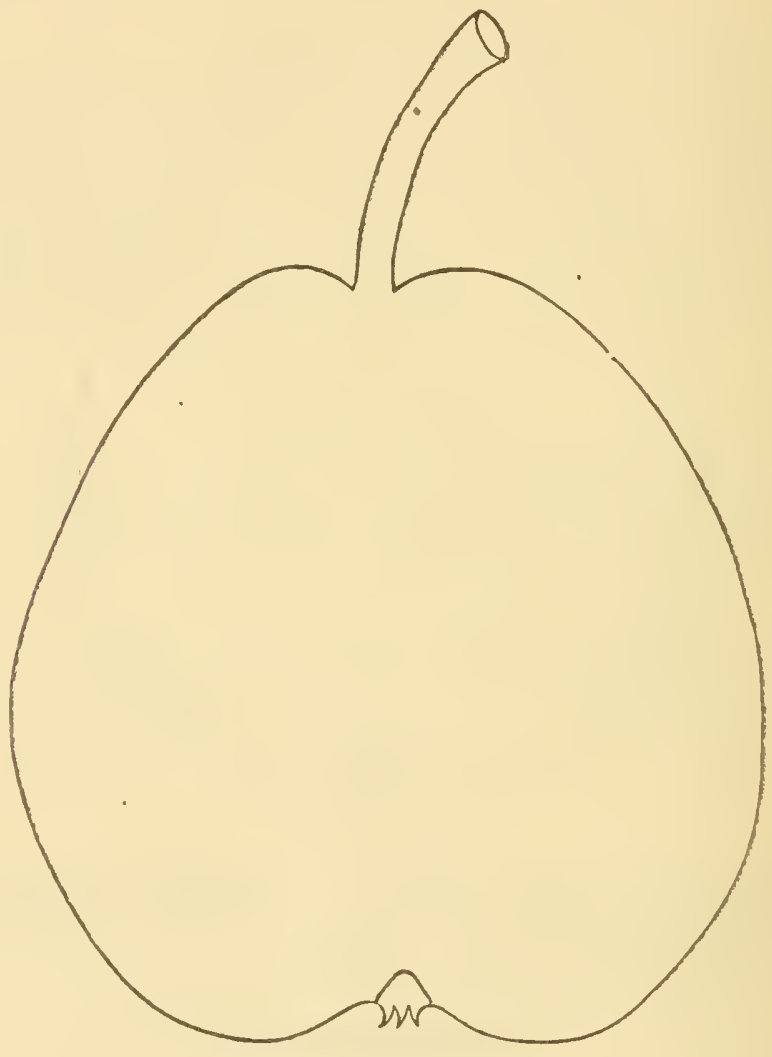

Frederick Clapp.

Fruit medinm to large, roundish, inclining to obovate pyriform, but often variable and irregular in form; skin smooth, bright yellow, witiout blush or russet, but many minute brown dots; stalk of medinm length and thickness, sometimes a little fleshy inclined, set in a slight depression or small cavity; calyx nearly closed ; basin medium, regular ; flesh whitish yellow, fine, very juicy, melting, rich, highly vinous aud slightly aromatic. Ripens from the middle to the last of October. 


\section{Harris.}

This is another of the fine pears raised by Lemuel Clapp, of Dor. cliester, Mass., from seed of Urbaniste, supposed to be crossed with Beurre Bose. Mr. Clapp states that the tree is moderately vigorous, short-jointed wood, and naturally inclined to make a compact yyramid, and very produetive.

Fruit medium, oblong, obtuse pyriform; skin smooth, thin pale yellow, nearly covered with light cimmamon russet, sometimes a shide

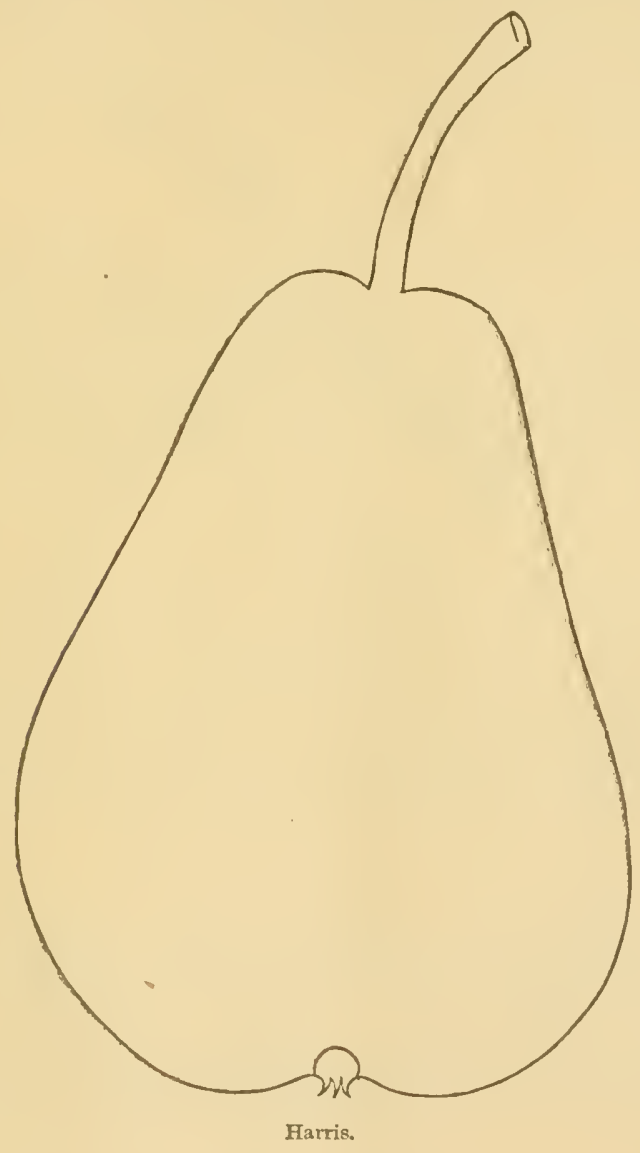

of crimson where fully exposed; stalk medium, or rather long; curverl, set in a slight depression; calyx open or nearly so; basin shallow, regular; flesh white, fine, buttery, juicy, melting, sweet, rich, slightly aromatic and vinous. Pipens from the middle to the last of September 


\section{MOMESTEAD.}

A new pear, raised by Asahel Foote, of Williamstown, Mass., from seed of the Virgalieu or White Doyemne; tree vigorons, upright, a srool beal'er, annully. Mr. Foote has raised many seedling pears which promise well, and when fully tested will be noticed, if worthy.

Fruit merlium or above, oblong abtuse pyriform; skin gy'eenish yellow, often pale yellow when fully matured, sometimes a shacle of bicwnish red where exposed, slightly netted and patched with l'usset, and uniny r'usset dots; stalk long, curved; cavity small; calyx large, open ; bissin shallow, regular; flesh whitish, a little coarse around the core; half fine, juicy, melting, sweet, slightly vinous and slightly aromatic. liipens from the first week in Norember to the middle of December.

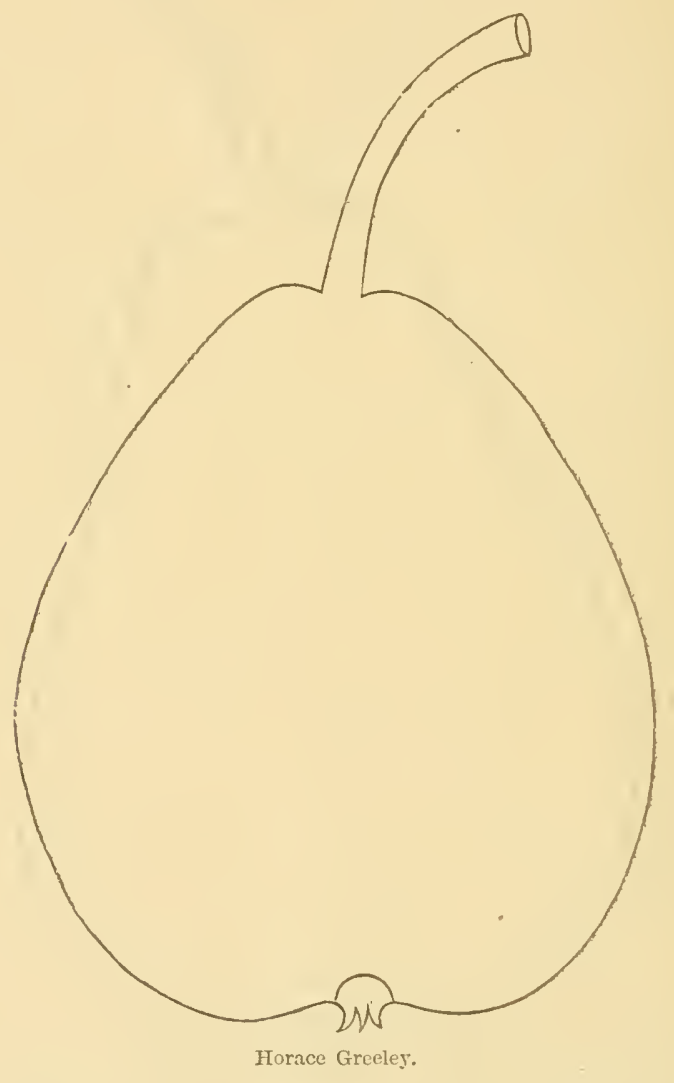

Horace Greeley.

Origin, in the garden of Dr. John J. Howe, Birmingham, Comm.; tree a strong, vigorous grower, holding its foliage well; rery productie and promising. 
Frut melium or above, roundish, inclining to obtuse pyriform ; skin pale yellow at maturity, partially netted and blotehed with russet, and many russet dots; stalk rather long, inclined, curved, set in a slight rlefression or small ravity; calyx open; basin medium, rather shallow, atul a little uneven; flesh a little coarse, juicy, melting, sweet, rich and slightly ruinous. Ripe last lialf of October.

\section{IIOUSATONIC.}

Origin, in the garden of Dr. John .J. Howe, of Birmingham, Conn.; ree healthy and vigorous, rather upright; a good bearer, and a good late varicty.

Fruit rather large, roundish pyriform; surface a litile uneven; skin greenish yellow, many green and brown dots; stalk rather long, curverl; (avity small; calyx small, closed; basin mither shallow, slightly plaited; tlesh white, half tine, juicy, melting, rich and vinous. Novenber.

\section{LoNgue DU Bosquet.}

Grigin, in the nurseries of Andre Leroy, Angers, France; tree moderately vigorous; an early and good bearer.

Fruit medium, roundish acute pyriform; skin bright straw color, shaded and mottled with pale red or carmine, a few traces of russet and many small russet dots; stalk long, slender, curved, joined to the fruit acutely ; calyx closer or half open; hasin shallow, a little uneven; fiesh whitish, fine, melting, juicy, sprightly, with a slight musky perfume. September.

\section{LCCIE ANDUsson.}

Raised by Alexis Andusson, Angers, France; tree vigorous, npright, somewhat spreading, moderately productive.

Fruit medium or above, roundish pyriform, obtuse; skin pale yellow, much netted and patched with russet, and many snall russet dots, stalk mediun, inclined; cavity small; calyx open; basin rather shallow, slightly corrugaterl ; flesh white, fine, jricy, melting, sweet, rich, slightly aromatic. Ripens the last of October and first of November.

\section{Lucy Grieve.}

A new pear raised from seed by Lucy Grieve, Gnilford, England.

Eruit mediun, oblong obtuse jyriform; skin clear, deep lemon-yellow, thinly marked with russet dots, and slight russet aromul the stem and calyx; stalk of mediun length and thickness, set at an inclination in a shallow, uneven cavity; calyx closed; basiu slatlow, regular; flest molerately firm, fine grained, tencler, melting: very juicy, rich, sliggtly inous. Uctober. (F'lorist and l'omologist.)

\section{Madane APpert.}

Laised by Andre Leroy, and dedicated to his oldest danghter; tres vigorvins, "pright, pyramilal; a gorm bearer.

Fruit medium or above, roundish acute pyriform; skin pale green, 
sprinkled with many brown dots; stalk long, curved, slender, joined to the fruit acutely, sometimes by a lip; calyx half open; basin small, slightly plaited; flesh whitish yellow, fine, juicy, melting, sweet, slightly perfumed, and quite rich. Last of September and first of October.

\section{Madane Baptiste Desportes.}

Origin, in the nurseries of Andre Leroy, Angers, France; tree moder ately vigorous; an abundant bearer.

Fruit medium, roundish oval; skin pale yellow, sometimes a shade of brownish red, partially patched and netted with russet, and many russet dots; stalk long, rather stout, inclined, set in a small earity; calyx open; basin large, deep, slightly corrugated; Hesh white, fine, juicy, melting, sweet, rich, slightly aromatic. October.

\section{Maria.}

\section{Curran.}

Origin, in the garden of the late Cuthbert M. Curran, Windsor, Nova Scotid, and was brought to notice by the late Hon. C. R. Prescott, and named by him in honor to his wife; tree hardy, moderately vigorous, or of slow growth; a good bearer.

Fruit below medium, roundish, a little elevated around the stalk; skin pale yeliow, often shaded with light bright red; stalk long, curved; cavity small; calyx open; basin rather small, slightly corrugated; flesh white, fine, buttery, juicy, melting, sweet, vinous, rich. Ripens a week or two earlier than the Bartlett.

\section{P. BakrY.}

A very promising new variety, raised by S. B. Fox, San José, California. Mr. Fox has raised several seedling pears of great merit, at least as grown with him; how they will succeed elsewhere has yet to be tested. We give descriptions of Colonel Wilder, P. Barry and s. B. Fox, from specimens received from Ellwanger \& Barry and IIarshall P. Wilder.

Fruit large, elongater pyriform, a little obtuse; skin deep rellow, nearly covered with rich golden russet; stalk of medium length and thickness, inclined, set rather cbliquely in a medium cavity, sometimes by a lip; calyx small, open; basin small, regular; thesh whitish, fine, juicy, melting, sweet, slightly vinous and rich. December.

\section{Puebla.}

Origin, in the nurseries of Audre Leroy, Angers, France; tree strong, vigorous, rather upright; a good bearer.

Fruit large, roundish pyriform, a little obtuse; surface rough, meven; skin pale greenish yellow, sprinkled with many brown and green 
dots; stalk medium, stout; cavity small; calyx closed or nearly so); basin medium or broad, corrugated ; flesh white, a little coarse, buttery half melting, juicy, slightly vinous. Last of September and first or October.

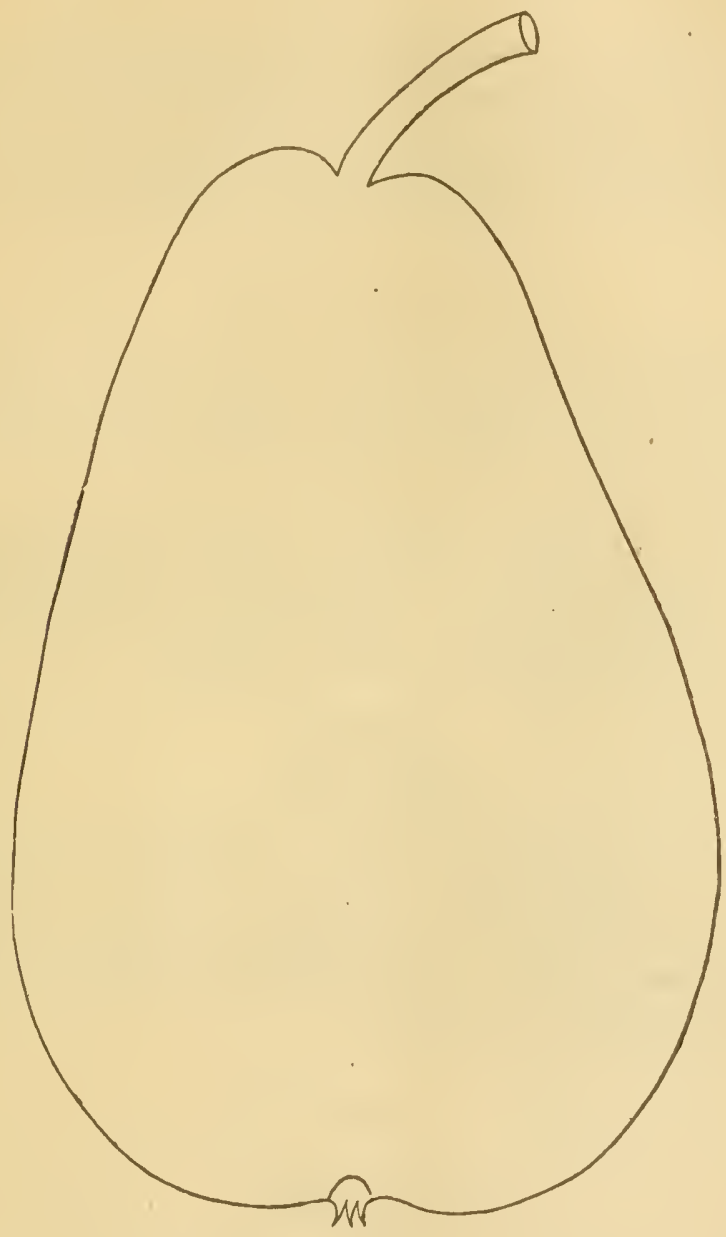

P. Barry.

St. Therese.

Originated in the nurseries of Andre Leroy, Angers, France; tree s good grower, upright, somewhat spreading.

Fruit medium, oblong pyriform, slightly obtuse; skin whitish yellow, shaded with bright red, slight nettings of russet, and many russet and brown dots; stalk of medium length and thickness, inserted in a slight depression, or small eavity; calyx open; basin medium, a littlo uneveu; 
tlesh whitish yellow, a little coarse, juicy, melting, buttery, sweet, and very good. October.

\section{B. S. Fox.}

This is thought loy some to be one of Fox's best late fall varieties.

Fruit large, oblong, obtuse pyriform; skin clear bright yellow, nearly covered with rich golden russet; stalk rather short, stout, inserted obliguely by a lip, in a slight depression; calyx small, open; basin medium, uneven; flesh whitish, fine, juicy, melting, sweet, rich and excellent.

\section{Sutton's Great Britain.}

I seedling of the Bartlett, raised by William Sutton, Cornwallis, Nova Scotia; the tree is said to be hardy, with stout short-jointed, dark colored young wood; fruit large, showy, very productive, and is becoming popular as a market fruit.

Fruit large, pyriform, a little obtuse; skin greenish yellow or pale yellow, often with a shade of red where exposed, slight nettings and patches of l'usset, and manv l'usset dots; stalk long, rather stont, a little inclined, set in a sunall cavity; calyx open; basin shallow, a little nneven; flesh whitish, a little coarse, half melting, juicy, sweet and pleasant. Ripeus about ten days later than the Bartlett.

\section{Talmadge.}

\section{Northford Seckel.}

A chance seedling in the garden of Levi Talmadge, N srtliford, Conn. Tree hardy, vigorous, symetric; an early and abundant bearer.

Fruit rather small, obovate; skin yellow, more or less netted and patched with russet; stalk long, inclined ; carity medium; calyx small, open; basin small, regular; Hesh whitish, half fine, juicy, melting, sweet, slightly aromatic. September.

\section{CORRECTIONS.}

\section{Afaxas or Axaxas d'Ètè Pear.}

There is much confusion in regard to the pears Ananas, Ananas d'Ètè Ananas de Courtrai, and Henry the Fourth. The three first hrving proved identical with. me, and the latter distinct, I have receivel trees and grafts of Ananas de Courtrai fiom many sources, both in Enrope and this country, and when in bearing have proved to be Ananas l'ete. From all I can learn of its history, it is a very old variety, and was first called De Bonchet, but wils afterward named Ananas, which is still retained, with the sys onyms annexed: 
Ananas.

De Bouchet...................... Pouchet.

Auanas d'Ltì........................ Comperette.

Ananas de Courtrai................. Beurre Amanas.

Summer Pine Apple..................... Auanas Française.

Favori .Musque..................

Farori Musque du Conseiller, V. MI....

Henry IV., ineorreetly............

The Henry the Fourth pear las but two synonyms, v'z., Heury Otiatre and Jacquin, and as we received it from Europe, and as it is generally known in this country, is a small pear of very good quality; but Andre Leroy, in his Dictomuare de Pomologie, describes Henry tre? Fourth as a large pear of second quality; which of the two is correct, I am unable to decide.

Additional Synonyms.

\section{Pears.}

Abbe le Berriays.................... Syn. to Berriays.

Anmande regenerie....................

Barou de Geer.......................

Belleville Baking.....................

Beurre d'Apremont....................

Benre Dilly .......................

Beurre de Paques.....................

Beure Robert......................

Beurre Seeringe....................

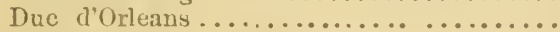

Early Bergamont of Wisconsin...........

Eunes of Kentucky .......................

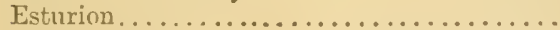

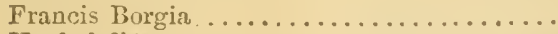

Henkel d'Automne ...................

Humboldt's Butterbirm................

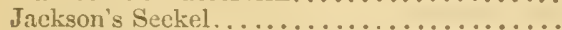

Josephine Bourier. ...................

Lauren's Summer...................

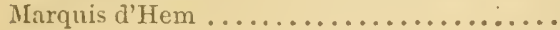

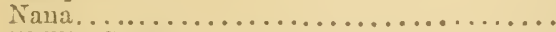

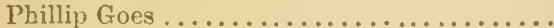

Petour de Rome.

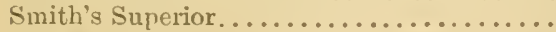

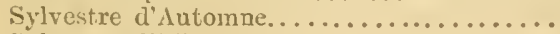

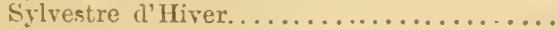

Turner's Early of Illinois...............

Wredow

\begin{tabular}{|c|c|}
\hline 66 & \\
\hline "6 & Hemri Tan Mons. \\
\hline 16 & Haxuison's Fall. \\
\hline 6 & Beurre Bosc. \\
\hline 66 & Beume Dellannoy. \\
\hline “ & Boune de Souler.. \\
\hline 66 & Doyenne du Comice. \\
\hline "6 & Doyenne de Saumur. \\
\hline 66 & Marechal de la Cour. \\
\hline "6 & Passans du Portugal. \\
\hline 6 & Windsor. \\
\hline .6 & Winter Nelis. \\
\hline "6 & Onondaga. \\
\hline "6 & Henkel. \\
\hline 66 & Beurre Bose. \\
\hline “ & Jacksou's Elizabeth. \\
\hline “6 & Beurre Navez. \\
\hline 66 & English Jargorelle. \\
\hline 66 & Hampdeu's Bercamotte. \\
\hline 6 & Manning's Elizabetb. \\
\hline 66 & Barromme de Mello. \\
\hline “ & Nouveau Poiteiul. \\
\hline 16 & Windsor. \\
\hline 66 & Frederick de Wurteniberg. \\
\hline "6 & $66 \quad 66 \quad 06$ \\
\hline 6 & Rousselet Hatif. \\
\hline "6 & Delices de Charles. \\
\hline
\end{tabular}




\section{PLUMS.}

\section{Boddaert's Green Gage.}

\section{Reine Claude Boddaert.}

Of foreign origin; tree vigorous, rather upright; branches smooth, brownish; productive.

Fruit large, roundish, inclining to oblong; suture slight, apex a dot; skin pale greenish yellow, with broad splashes of green, and covered with a thin whitish bloom; stalk medium, rather stout; cavity small; Hesh light yellow, melting, juicy, sugary and delicious. Ripens the end of August.

\section{Early Yellow Gage.}

A new early plum, raised by Asahel Foots, Williamstown, Mass., tree a strong, upright grower; an early and abundant bearer; branches smooth, dark brown.

Fruit medium, roundish oval, narrowing a little towards the stalk; suture broad, shallow, extending to the apex; skin greenish yellow or pale yellow at maturity, covered with a whitish bloom; stalk medium, slender; cavity small; flesh greenish yellow, a little coarse, juicy, sugary and rich; adheres slightly to the stone.

\section{Hungarian Prune.}

Datte de Hongrie.

Of Belgian origin; tree vigorous, spreading; branches smooth, ģravish brown; a good bearer.

Fruit medium, elongated oval, slight neck, sides compressed, one edge considerably flattened, and the other much rounded; suture shallow, apex a pointed dot; skin dark purplish black, with a thick blue bloom; stalk long, slender, curved at the end; cavity small; flesh greenish yellow, juicy, sugary, rich, separates freely from the stone. Ripens the first of September.

\section{Precocée de Lucas.}

Of foreign origin; tree vigorous, upright; branches smooth, grayish; very productive.

Fruit medium, oval, narrowing a little towards the apex; suture a line; stalk rather long, slender; cavity very small; skin deep blick, thick blue bloom ; flesh greenish, juicy, sweet, slightly vinous; separates from the stone. Ripens the last of August. 


\section{Prune Tardine.}

Origin unknown; tree vigorous, upright; branches smooth, light reddish brown; very productive.

Fruit below medium, oval, narrowing a little at the ends, one sile a little enlarged; suture a line, apex a point; skin black, with a thick blue bloom; stalk rather long, slender; cavity small; flesh greenish yellow, juicy, sweet, slightly vinous; separates from the stone. Ripens the middle of October.

\section{Royal de Braunac.}

Of foreign origin ; tree vigorous, upright; branches smooth, grayish, slightly downy at the ends; a good bearer.

Fruit medium, roundish oval, regular, almost without suture; skin light reddish in the shade, pmplish black in the sme thickly dotted with brown dots, and covered with a thick lilac bloom; flesh greenish yellow, a little coarse, rather firm, juicy, rich; adheres to the stone. Ripens the first of September.

\section{Sultan.}

Raised by Thomas Rivers, Sawbrilgeworth, England; tree vigorons; very productive.

Fruit medium, round; suture rather shallow; skin dark, purplish red, dotted with minute brown specks, and covered with a thin bluish bloom; stalk medium; cavity large; flesh greenish yellow, firm, hrisk, sweet, pleasant flavor; adheres partially to the pit. Ripe middle of August. (Florist and Pomologist.)

\section{Violette DE.Galopin.}

Origin unknown; tree vigorous, upright; branches smooth, brownish, short-jointed; an abundant bearer.

Fruit medium, nearly globular, shightly oval at the apex; almost without suture; apex slightly sunk; stalk of medium length, rather stout; cavity small, deep; skin dark purple, almost black, thick blue bloom; flesh deep yellow, juicy, sugary, rich; adheres slightly to the pit on one side. Ripens the last of August.

\section{NOTE.}

There have been many new grapes, strawberries and raspberries introduced during the past few years, some of which are very promising, but further experience and examination is necessary before deciding ully as to their merits. 

THIRD APPENDIX To

SECOND REVISED EDITION.

CHERRIES, GRAPES, PEARS, dre 



\section{CHERRIES.}

\section{Batimatit.}

This new chepry originated on the farm of Louis Shepler, of Belle Ternon, P'i., and is much grown by the Shepler Brothers, who have a linge collection of cherries and other fruits, which are prown in quantities for the market, and it is said this cherry commams a ligher price than any other variety. The fruit is large, handsome, firm flesh, and of excellent quality; the tree is healthy, rigorous, and an ahundant bearer.

Fruit large, obtuse heart-shaped, a little compressed; suture slicht: arity large, deep: stalk rather lons, slender; skin whitish re]low, shaded and nottled with liyght and dark rich red; flesh firm, juicy, sweet, with a sprightly, rich flavor. Ripens the last of June and the first of July.

\section{Betgilley Parte.}

Origin Burghley Park, Stamford, England; a Duke cherry of moderately vigorous growth; a shy bearer at first, but abundantly productive in a few years.

Fruit large, usually round, with an obscure suture, but occasionally compressed or flattened; skin very thin, transparent, the color deej rich reil, with shades of maroon: the flesh is of a tawny color, juicy, melting, a little astringent at first, hut very pleasant, refreshing, subacid flavor when fully ripe. It belongs to the Red Duke class, and, in general characteristics, nearest to Reine Hortense, though it appears to combine the best qualities of both. - Gurcleners Hélily.

\section{DYEIIOUSE.}

Orimin unknown; was introduced by H. T. Harris, of Stanford, Fy, and was found erowing in an old Ilorello orchard, on the farm of a In. Dychonse, in Linculn County, orer thirty years sinee; it is still grown there from suckers, and is clamed to be hardy, moderately vigorous, somewhat spreading, of the Morello type, but partakes both of the Ioreilo and ])uke in srowth, wood, and fruit; a very rarly and sure bearer; ripens a week hefore Early Richmond, is abont the same size, of better quality, and quite as prorluctive.

Eruit mecium, ohlate or romdish oblate, slightly depresserl, without suture; apex sliglitly depressed; skin bright red, dark red 
in the sun; stalk of medium length, slender; cavity rather large, smooth; flesh soft, juicy, tender, sprightly subacid, rather rich; pit rery small; sometimes the stalk adheres to the pit.

\section{EAmLY Lions.}

\section{Rose Hative de Lyon. Guigne Hative de Lron.}

A rery large and handsome cherry of excellent quality. The fruit is roundish, obtuse heart-shape, with a faint depression or suture on the flattened side, and having the stalk, which is an inch and three-quarters long, set in a rather shallow cavity; the skin is blackish crimson-purple, or glossy blackish mahogany color: the flesh is of a very clark brownish-red, sweet, tender, juicy, and wellflarorel. It is an early variety, ripening about the end of June. (11) \& Pom.)

\section{EARLy Riters.}

A new early cherry raised from seed of Early Purple Guigne, by Thomas Rivers, Sawbridgeworth, England. Tree Juxuriant, healthy, and an abundant bearer; fruit as large as its parent, very rich and good, and a trifle later.

Fruit medium to larcre, roundish heart-shape, and somewhat ineven on the surface, slightly pitted on the apex, with a distinct strle point; suture not well defined; slin deep blick; stalk long. rather slender; cavity small, rather deep; flesh very tender, sweet, and anreably perfumed; stone very small; a very excellent cherry. Ripe the end of June. (Lon. Jour. of Hort.)

\section{Glolre de Frixce.}

This heautiful cherry originated with Auguste Bonnemain, Etamps (Eeine-et-Oise), France, and is of the livinlie type. Tree moderately vigorous, erect, with rather slender branclres, making a regular, lumdish, conical head, moderately productire.

Fruit rather large, roundish oblate, somewhat depressed; suture broad, shallow, often very slight; apex rather large, a lirtle sunk; skin bright scarlet or crimson, almost transparent; flesh pile red, tender, very juicy, sprightly, and when fully ripe of a rich, refresh. ing acid flavor. Season the first of July.

\section{IDA.}

A new and promising variety, raised by E. II. Cocklin, of Shepherdstown, Pa., who says that it is a seedling of the Cocklin's F:trorite, and has borne good crops for fifteen rears; it is consiclerch worthy of general cultivation; it is named after his daughter Iha. lree vigorous, upright, an abundant bearer.

Fruit medium, or rather large, obtuse conical, slightly compressed: suture slight; skin pale whitish yellow, nearly corereil with hright red, more or less mottled; stalk of medium length, slender, inserted in a rather large, deep cavity; flesh very tender, juicy, rich: rery mood, if not best quality; pit very small. Season about the time of the Mayclulic. 


\section{J.ANCASTER.}

An aceidental secelling in the proumls of J)aniol Smereh, I,ananter, l'at. The troe is salid to he a rignous, mpright, complact srower, a prolific bearer, and the fruit continnes in ase a long time.

Fruit melimm, heart-shape, regular; stume very slight; apex very snall; slin bright red; stali long, slender; cavit y medium, smootl; livsh half teruler, juicy, sweet with a sprighty good flavor; the ilesh adheres slightly to the pit, which is of medium size. IRjpens turing the month of Jume.

\section{LARGE MOATMORHACY.}

Montmorency, Large Fruited. Montmorency à Longue Queue.

Aceming to Andre Leroy, this is a rey old variety, and is supposed to hate oricinated near I'anis or Montmoreney, Finee, more than :00 years since. Tree larrly, a viggorous grower of its class, and bearing abumelantly.

Fruit medium to large, romdish oblate, slightiy flattened at the 1) ase, rexular, almost without suture; apex small; skin dark, rich rea? stak of menlum length, moderately stum; cavity medium, or rather lirre, smoroth; flesh solt, tender, juicy, rich acid, becoming subacid when lully mature. Season a week or ten days later than Early Tíchmonil.

The Morellu cherries appear to have been neglected of late rears, probably on accomt of the introduction of so many choice varieties of sweet cherries. The Morellos are now becoming more popuiar, as they are more hardy, more certain bearers, less suljject to rot, continue a longer time in use, are more valuable for cambing, drying, and for various enlinary purposes; atso many of the kincls when fully ripe are good table fruits.

\section{LEIT.}

This fine Morello cherry is sail to have been brought from. (ac:many thirty rears ago and planted in the garden of a Mr. Leib, in the city of (ialena, lil., where it still stands and is over thirtr feet high; it is said to be very hardy, thrifty. halthy, upright in growth, baring abuncianty annually. The fruit is as large or larger than Early Richmond, a littlo later, much less acid, of better quality, and coimmands a better price in market.

\section{Lore Aliplis.}

Tomato.

A vigorous erowing variety of the Tuke cherry, which is sait to have orierinaterl in spain; it has borne abunclantly here, and is a promising kind of its class.

Fruit rather larere, romdish oblate, often depresserl, or tomatoshope; suture shallow; apex a dot; shin rollowish, shaded with light resl. brierlit rich red in the sun; stalk rather loner, slencler; cavity

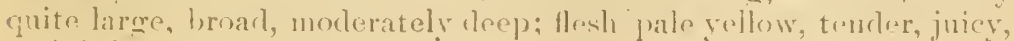
s!rightly subacid, rich; rery good. Lipens the first half of July. 


\section{Minie Thimente}

A new seedling of MI. le Luigne, near Chateaugontier (Iiaycume), Fince, and was declicated to his laughter liarie Therese. The strong, vigorous, with rather long slender branches, forming a bea:tiful head; molerately productive, of excellent quality, and wis. worthy of cultivation.

Fruit medium or above, roundish, flattened at. the ends; suture broad, shallow; apex small, a little sunken; stalk long, slender; cavity very small; skin fine, strong, transparent, ciear red in the slade, a cornelian red in the sun, slightly dotted with whitish gray; flesh yellow, complact, melting, very juicy, sugary, deliciously acii and perfuned; first quality. 'Ripens the last of August. (Leroy.)

\section{Otrret.}

A new French cherry, with the following description from the catulogue of Transou Zrothers, of Orleans, l rance:

"This sort takes a place not occupied up to the present among the list of early cherries. Nearly all the early sorts that we possess are sweet, amber, or red varieties, with a limited fruiting season. 'The Olivet cherry is a large, globular, very shining deep red sort. The flesh is red, with a rose-colored juice, tender, rich, and rinous. with a very sweet subacidulous flaror. It ripens in the beginning of iune, and continues till July without losing its quality. It possesses the fertility of the best of the Duke tribe, and is perhaps the larrest of that class."

A friend writes that it fruited rith him the past season, but being very ary the fruit was small, otherwise it sustained its foreign reputation.

Daniel B. Wier, of Lacon, lil.. has been engaged for many years in growing and testing seedling cherries of the Norello class, in larce numbers, for the purpose of oltaining varieties suited to a cold climate, and of equal if not superior quality to thase now in nse. Ile states that he has been successful beyoud his expectations, an! is offering some of the most valuable of them to the public. The following are his descriptions of three which he values lighly:

\section{Flaga, on Wietis Earty Hextish.}

"Fruit medium, heart-shaped: black; ten days earlicr than Ear?y Pichmond; in quality when fill $\because$ ripe equaling the finest of the darkcolored sweet cherries, combining all the desirable qualities for litchen or tabie; flesh firm; shin strong; at first rich subacin, but becoming very rich and sweet, an so strong that it has hun upon the tis for a fill month after being fully ripe withont decaring or drop! ing; pit small. Tree a slender, short-jointed, recularly conical, an? rate grower, entirely lardy, and enorinously prouluctive; shculd l.are high, dry, light soil, and an airy sitution."

Mr. Wier sent me specimens of this variety in $15: 6$. which were of medium size, hlack color, with p?mplish-red flesh, tender, juicy, liaving a rich subacid flavor, of very gool quality. 
Gausui, or No. 11.

"One of the finest of cherries; fruit above medium; light and subacid at first, rery good, but as it matures, growing darker, firmer, richer, sweeter, until at last a very dark bright red, and one of the sweetest and most delicious of cherries; three days carlier that Early Richmond; hangs on the tree for a long periol after being iully ripe without any rot. Tree hardy, foliage entirely free from disciase, a vigorous and strong grower in the orehard, a very abundint bearer."

\section{NortuWest, or No. ฉ9.}

"This is undoubtedly the most valuable of all cherries for the Northwest for market and hone use. Fruit dark bright red, a little larerer and six dars earlier than Early Richnond, and the tree almost exacty similar in general appearance. 'This variety in time will supersede all other sour cherries of its season. Its fue size, color, richness, earliness, firmuess, and great produetiveness, with entire hardihood of tree and fruit-bud, and perfect health of foliage, will make it the cherry both for North and South. 'T'le fruit is a brisk, pleasant acid, entirely without the intense sonruess of the English Horello. Pit small; fruit globular; stem long, adheriug quite firmly to the fruit; and ripening very evenly and quickly after coloring, and hang's on the tree for weeks without beeoming soft or rotting.

"I have found all cherries ripening earlier than Early Richmond free from the attacks of the plum curculio."

\section{GRAPES.}

\section{BEALTY.}

" Oxw of the seedlings of Jacob Rommel, of Morrison, Mo., and is a cross between Delaware and Maxatawney; has been vigorons and healthy so far; a strong grower and very productive; bunch full medium, compact, shouldered; berry about the size and eolor of C'atawba, oblong, eovered with lilac bloom; ripens here the last werk in August; sweet exquisite flavor; thin but rather tough skin; tender pulp; this promises to keep well, and as the bunches áre very even and attractive in appearance, it mar be a very valuable market grape, as it is superior in quality to Dolaware; and as it execls the Catawba in fine and delicate flavor, is withont its loarshness and austerity in pulp. I eonsirler it the most promising of all our varieties of the Labrusea class." (Husmann.)

\section{Brimintox.}

This liandsome and fine grape was raiser by Jacoh MInore, of Brighton, N. Y., being a eross of the Coneord and Diana Hambure: vine hardy, a rapid vigorous grower, with medium to long-jointed 
shnots, which ripen carly; leares large, thick, dark green, coarsely seriated, occasionally lobed; very productive, and if the small bunches were talien off early in the season it would be a great benefit to the others.

Bunch medium to large, shouldered, occasionally domble shoulders, moderately compact; berries medium to largre, round, light bright led at first, changing to a dark crimson, or maroon when fully mature, sometimes almost black, and corered with a thick lilac blcom; the berries adhere weli to the peduncle; skin thin but tough; flesh tender, very slight pulp, sweet, juiey, slightly aromatic, very slightly vinous, and of very good quality for an early grape. It has its best flavor when it is first ripe, but becomes pasty and loses its sprightly flavor when fully ripe. Pipens nearly as early as Hartford Prolific and before the Delaware.

\section{I) LCHESS.}

This fine grape was raised by A. J. Caysood, Modena, N. Y., who states that "it was produced by crossing a White Concord seerling with Delaware or ITalter, the pollen of both being applied at the same time." The vine is a vigorous grower, with moderately shortjointed shoots; leaves large, light green, rather thick, coarsely serrated, adhere to the vine very late in the season; vine abundantly productive.

Bunch medium to large, shoulkered, occasionally double shouldered, compact; berries medim, roundish, inclining to oral; skin rather thick, light green at first, but pale greenish yellow when mature, sometimes a golden vellow where fully exposed and gathcred late, and covered with a thin whitish bloom: flesh tender, free from pulp, juicy, sweet, sjicy, rich, and of excellent qualitr; the berries adhere strongly to the peduncle, and the fruit lieeps a longtime after being gathered. Ripens soon after the Concord.

\section{EAILY D. DWx.}

An early black grape of fine quality, which originated witl Dr. Tru. A. M. Culbert, of Newburgh, N. Y., being a cross of Muscat. Hamburg and Israella; vine healthy, vigorous, and rery productire: wood moderately short jointed; leaves linge, thick, and firm, roundish, broadly, but not deeply serrated, sometimes slightly lobed.

Bunch melium to large, long, shoultered, occisionally double shouldered; berry medium, round, black, with a thick blue bloom; skin thin but firm; flesh tender, juicy, sweet, slightly vinous, rich, and of very good quality; the fruit adheres well to the peduncle, keeps well, and is a valuable addition to the early grapes, either for the table or market. Ripens a week or more before the Hartford Prolific.

\section{Earty Victor.}

"A cliance seediing that originated with John Burr, of Learenworth. Kansas, about ten years ago, of the Labrusca class. Vine very harly, healthy, vigorons, and very poductive: rood dark gray, rather long jointed; foliage thick, nedium, dark green, deeply 
Whed, partaking somewhat of the character of the Telaware and llartford l'rolific-not as pubescent as the latter. 'The original vune has not been injured by the severe cold and sudrlent changes of onclimate, and has showi no rot or cliscase; it is not only the rery hest carly market, but also the best wine grape that we know of i:1 eultivation, making a rieh, high bonquet, eliset wine.

"Bunch ahove medium, (ompact, often shouldered, and sometimes romble shouldered; berry merlinm, round, black, with a heary blus

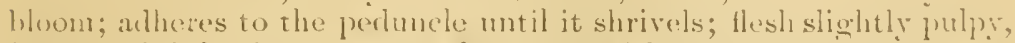
juicy, sprightly vinous, anceably sweet, without any foxiness. sinason at least a week earlier than Hartford P'rolific." (Dr.J. Stayman.)

\section{JEFFRSON.}

This new, handsome, and excellent grape was raised by James H. Ricketts, Newburyli, N. Y., and is a cross of the ('oneord and lona; it is healthy, very vigorous: wood rather short jointed; leaves larere, thick and downy; very productive.

Bunch lare, shouldered, often double shoultered, compact; berry meitim to linge, roundish oval; skin rather thick, light red. with a thin like bloom; flesh meaty, ret tender, juies, sweet, slightly vinous, aromatic and rich; the berries acthere strongly to the peclumcle, and the fruit maintains its freshness for a long time after being rathered; it is of finc quality, and very promising either for market or home use. It ripens about the time of the Comeord, or soon alter.

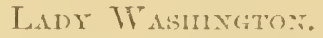

This beautiful and rery good grape was raised by Tames II.

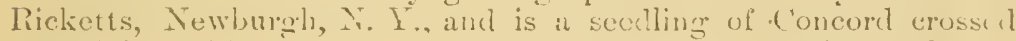
with Allen's Irbrici; vine healthy, vigorons, short jointed; leares larre, roundisli, coarsely seratei, occasionally lober, thick and downy.

Bunch large to very large, compact, shouldered, often double shonlders; berry medium to larese, being very nearly uniform in size, rounel; slin pale yellow. with a tinge of dolicate pink where riposed to the sun, having a thin whitish bleom; flesh soft, tenri:r, julicy, sweet, rery sighthly vinous, and of rery gooi quality; tho ierries adhere weil to the peduncle, and the fruit continues a long time in use. lipens about the time of the Concord, or soon after, and is a rery promising variety for the table or for marliet.

\section{Nisgara.}

This new grape originated with Hoar \& Clark, of Tockport, $N$. Y.; not having seen the vine in its growing and bearing state,

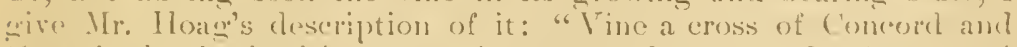
C'assacly, hardy, healthy. very vieroroms, and very productive: wored rather long jouted; laves very large, thick, leathery, down, loberi, sometimes dumble lobed."

I3molı mediun to large, eompact, occasionally with small shon!ders; berry large, roundish, slightly inclining to oval, quite unifor:u 
iil size; skin pale green at first, but changing to pale rellow when fully ripe, with a thin whitish bloom; flesh soft, tender, sweet, pleasant, and in quality about the same as (oncord, and ripening with it or soon after; it lias quite a foxy orlor when first gathered, but loses much of this when fully rije.

\section{Pocklimetox.}

This large showy grape was raised from seer of the Concord by John Pocklington, Sandy Hill, N. I., and as 1 have not seen tlie vine in a growing and bearing condition, I give lir. Pucklington's description: "Vine very hardy, healthy, very vigorous, with shortjointed shoots; wood close and firm; leaves large, thick, tough, and downy; very productive."

Bunch medium to large, or very large, generally shouldered, compact; berry large to very large, roundish, whitish yellow, pale yellow when fully mature, covered with a thin light bloom; flesh with co:1siclerable pulp, juicy, sprightly, but not rich; perhaps not fully rije when tested. The originator claims that when fully ripe the $\therefore$ flesh is not hard, but tender, juicy, sweet, rich, and superior to Concord, and ripens at the same time."

\section{Prentiss.}

This promising grape is a seedling of the Isabella, raiserl by J. IT. Prentiss, Pultuer, N. I. Not laving seen the vine dungr its srowth and bearing, 1 give Mr. Prentiss" description of it, riz.: "A hardy, healthy and good grower; wood rather short jointed: leares quite large, thick, slightly dowy; very productive and inclined to overbear. It ripens with Concord, except when overloaded, when it is a little later."

Bnnch medium, occasionally with small shoulders, compact; ber: medium, round, inclining to oral; slin thick, greenish white, pa! e rellow when fully mature, with a thin whitish bloom; flesh with a slight pulp, toncler, juicy, sweet and pleasant: the berries adhere well to the perluncle, and keep well in good condition; its firm skin makes it raluable for market, where it has so far commanded a high price.

\section{QUASSAICK.}

This fune black grape originated with James H. Ricketts, of Newbureh, N. Y., and is a seedling of the Clinton fertilized with Muscat Hamburg; vine vigorous, short jointed; leaves large, roundish. morlerately thick, lobel. coarsely serrated: bunch large to very linge, shoulitered, sometimes double shouldered. compact; berry mediun to large, roundish oval; skin thin, but firm, black, with thick blus blorm; flesh meaty, crisp, tender, juicy, very slightly rinous, rich and refreshing; the fruit adheres well to the perlunele, and continues a long time in use; very productive, and is a valuable tabie or market errape. It ripens about the midalle of September, or soon after the Concord. 


\section{linchestese.}

One of Ellwanger and balry's sectlings; I give taceir 1?dseription of it: "Vine a remarkibly vigorons arower; wout sho:" jointed and harly; foliage large, thick, healthy; the hahits of th. iine are similar to those of the l)iana, and it requires ample roos.t ant rather long praning.

"Bunch lange to very large, shouldered, frequently double shouldered, very compact; berries merlium to large size, roume, diar'pupple or purplish lilac, peculiar, with thin white blocun; thesh very sweet, vinous, rich and aromatic. lípens ustully the first week it soptember; has never falled to ripen well in the worst of seitsoitis since it first bore."

\section{Trituris.}

'This new hybrid of the Coneord and Chasselas Musque was laibot hy Geore 11 . ('ampbell, J elaware, O., and considered hy him to. late for that locality, and waning in character. Georese litsmam, in his new work on gratpes, etc., saly"s that "it ripens in pertection i:l Iissouri, and is certannly one of the most attractive white wapes for the table I have ret seen.

"Bunc!l large and heavy, shouldered, moderately compact: herrs very lan"golden yellow, transparent, with delicate blonm; skin thin; pulp tencier, swect, juicy, and excellent. Ripens abont with ('atawba; it seems to be harly and tolerably liealthy."

samnel Miller, of Iluffiton, Mo., writes me that "it is the finest table grape I lave for open air cultivation."

'T. I. IIunson, of Demnison, Texas, has frnited the Trimmb for six years, and pronontinces it a creat acquisition to the erapes for thr: South. "Had bunches weighing one and a half pound each, fine as Golden Chasselas in quality, vigorous, and very produetive."

\section{PEACHES.}

\section{Axre Mrte.}

A new seedling raised by the late Dr. A. P. Wylie, Chestrer, $\therefore$ (C. It is of the Heath Cling trpe, raluable for the couth, but ripros too late here, excrpt in very fatromble seasons. Tree health: vignoms, and a good bearer; leaves without glands, but fincly sorrated; flower's smail.

Fruit large, nearly glolular; suture shallow, extendiug a little

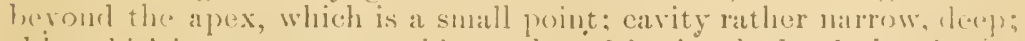
skin whitish, or a creamy white, pale reel in the shate, dark crimser rerl in the sum; flesh white, rather firm, juicy, melting, vimens, rich, and of excellent quality; adheres to the pit, which is a linte stainex?. Ripensi at the South from the first to the 10th of September; here the middle of Uctober. 


\section{EARI Silter.}

This fine peach was raised from seed of the White Nectarine ly Thomas livers, of Sawbridgeworth, England. Tree vigonous and roluctive; one of the best for family and home use, but too delicate for market purposes; leaves with reniform glands; flowers large.

Fruit mediun, roundish, inclinin to oral; sutnre sinall, extenciiar a little beyond the apex, which i:s a littie sumken, witi a small loint: cavity rather small, deep; skin thin, of a deicate cream color, Donetimes with a marbled blush; flesh white, juicy, melting, sweet, rich, with the vinous flavor of its parent; flesh white at the stone, from which it separates freely. It ripens the last of August.

\section{EArix Victoris.}

A new peach raised from seed of the Large Early Tork by Thomas Rivers, of Sawbridgeworth, England; rather carlier in its time of ripening; a healthy and productive sort; named in lionor of (ueen Victoria; leares withont glands; flowers lirge.

Fritit medinm, roundish, marked on one sile with a shullow suture shin very thin, pale yellow on the shated sile, and dart dimll maroon on the side next the smo flesh yellowish white, very tencler, nelting, very juicy, with a sweet and Juscious flarow. A first-rate carly peach, ripening the beginning of August.-IIngy's Irnit Henerect.

\section{FAMTH FAVORTE.}

A new seedling peach of Texas, which is said to be of superior quality, hut not having scen the fruit, by request. T. T. Munson, of I)ennison, Texas, has fumished the following description: "The Family Favorite originated with $\mathrm{W}$. H. Locke, of Bonham, Famin Countr, Texas, and is a seedling of the Chinese Cling, but a freestene, two weeks carlier, of finer color and quality, firmer, not as liable to rot, very la rece. Tree exceedingly vigorons, with very large leaves; the original tree has borne six successive crops, yet is in good health; very productive; flowers small; leaves with reniform ginuds.

"Fruit large, inclining to oblong; but not as much so as its parent; suture shallow; apex mediun: skin cream color, with a blush on the smmny side; flesh with red streaks next the stone, firm, yet juicy, high aromatic flavor, but not very sweet, resembling the ('hinesc Cling in this respect, and it possesses that sime peculiarly agreeable perfume when thoromghly ripened."

\section{HopiNixiLI.:.}

\section{Quisenburg. Stṛles.}

Raised from scel by James ( ¿usenburg, near Hopkinsville, Ky. ancl it is said to be the numst popular of any peach in that seetion of the eomntry for family use. Tree modematy vigoroms, rery monlintive, and is remarkable for reprolneing itself from seed: fluwers small; leaves serrate, without glands.

Fruit rather large, inclining to oblong; suture small, with a 
swollen point at the apex; slin duil white, quite downy, shaded and motted with red and crimson; 1trsh white, slighty red at the stone, juicy, melting. swect, rich, and of excellent flavor; separates freely from the stone. Season abont the first of September.

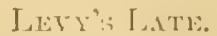

\section{Henrietta.}

A new late Clingstone, which originated in the garlen of 11 . 17 . Lery, Washington, 1). (C., and it is said to be a valuable and profi:able variety for the market at the South; leaves with globose gilands; flowers small.

Frnit large, roundish, slightly depressed; suture large, extending a little beyond the apex, which is a very small point; cavity medium, deep; skin deep yellow, a shacke of rich brownish red in the sun: thesh leep rellow, rather firm, juicr, half melting, sweet, a little vinons, and very good. Ripens in Kentnekr the inidule of ()etober. and continues into November, and will seldom ripen in this latitude.

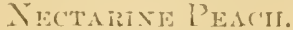

A new prach, which was raised by Thomas Rivera, of Sawbridgeworth, Enclind, from the seed of a Xectarine; a very fine and hanisome peach, which ripens just after the Royal Georoge it may he carricil almost any distance, on aceonnt of its firm substance; flowers large; leaves witi reniform glands.

Fruit litge, ovate, terminating at the apex in a pointerl nipple; suture well marked, particularly near the nipple; skin nearly quite smooth, like a Nectarine, yellow, with a bright mottled red cheek next the sun: flesh semi-transparent, with a brilliant red next the stone, from which it separates freely; very richly flavored, and with a fiue refreshing briskness. Season middle of September.-IToyg's Frout Hunuel.

\section{RAISIX.}

A Southern peach, of uncertain origin, but supposed to have originated in Correta County, Cra., and is probably a cross between the Columbia and Heatl Cling; it often reproduces itself from seed, except that it raries in its time of ripening. Tree healthy, very prolific, and lives to a good age; glands reniform; flowers large.

Fruit large, roundish; suture distinct, but small, encling at the apex, which is a small point; cavity rather deep); skin whitish, nearly corered with pale red, purplish red in the sun, with more or less narrow stripes and a few splashes of purplish red on the shaded sids; flesh white, stained next the skin, and sometimes throngh tho tlesh, rather firm, juicy, sweet, slightly vinous, and rich; arlheres to the pit. liprens the first of September at the South, and the first week in Oetober at the North.

\section{SAtite WronRet,}

Originater on the farm of C. WT. Westbrook, Wilson, X. C., and was raised from seed by an old lady named Sallie Worre!l; 
it is regarded in that locality as one of the largest and best peaches they cultivate, either for market or family use. Tree healthy, vigorous, and an abundant bearer; leaves serrate, without glands; flowers sillall.

Fruit large, roundish, one side a little enlarged; suture shallow, but distinct, extending a little beyond the apex, which is a small swollen point; carity rather narrow, deep; skin creamy white, shaded and mottled orer half the surface with light red; flesh white, juicy, melting, slightly vinous, rich, and of excellent quality; the flesh is red at the stone, from which it separates readily. It ripens with the Stump of the World, or the last of September.

\section{SENER.}

A handsome yellow peach, which originated with Gottlcib Sener, many rears since, and it is said that it reproduces itself from seed with scarcely any variation since its first introduction. Tree healthy, rigorous, and bears full and regular crops; glands reniform; flowers small.

Fruit large to very large, nearly globular, regular; suture shallow; cavity medium; skin deep' yellow, with a dark red check; flesh vellow. juicy, melting, sweet, with a rich aroma, and is one of the verr best of the vellow-fleshed peaches; red at the stone (from which it separates freely), which is rather flat and small in proportion to the size of the fruit. Season September.

\section{STEAIITY.}

This new late peach originated with .John Steadly, Bluffton, Mo. 'Tree healthy, rigorous, and hears abundantly; it is a rery promising late rariety, of good size, handsome, and of excellent quality; leaves with globose glands; flowers small.

Fruit medium, roundish, inclining to oblong; suture rather shallow, extenciing a little beyond the apex, which is a small swollen point; skin whitish, or creamy white, shaded and mottled with light and dark red where fully exposed to the sun; carity medium; rather narrow, deep; flesh white, juicy, melting, sweet, slightly vinous, with a little of the Rareripe flavor; flesh white at the stone, from which it separates frecly. Season first lialf of October.

\section{Tusisena.}

Origin uncertain, but it is sail to have originated in South Mississippi, while others say in Alabama: it is a beautiful early Clingstone, ripening at the South soon after the Early Tillotson, and is esteemed in its locality the best of its season, either for home nse or market. Tree rigorous and a gool bearer; leares with globose glands; flowers large.

Fruit medium, roundish, inclining to oblong; suture distinct, but small, ending a little berond the apex, which is a small or medium sharp point; cavity rather large, deep; shin deep yellow, nearly corcred with light and dark rich red and crimson, sometimes mottled and splashed with brownish red in the sun; flesh rather firm, deep 
yeliow, juicy, vinous, subacid, rich, and of very good quality. liipens the last of August.

\section{WAGER.}

Originated with the lite Bonjamin Wagrer, West Bloomfieli, N. Y., many years since, and is considered in that section valuable as a market fruit, and for camming purposes. The tree is hardy, healthy, very productive, and bears good crops in unfavorahle seasons when many other kinds fail; it is claimed that it. often reproduces itself from seed, or nearly so.

Fruit mediun, oblong oval, varying in form, one side often enlarged; suture medium, extending to the apex, which is a small point, or a little beyond; cavity medium, rather narrow; slin quite downy, of a light golden vellow when fully mature; flesh bright yellow, ratler firm, moderately juiey, sweet, slightly vinous, not very melting or ricli; separates freely from the stone. Season the first of September or a little later than Crawford's Early.

\section{TITARELOO.}

A new early peach raised by Itenry Lisk, Waterloo, N. T., who says that the tree is a healthy, vigorous grower, a prolifie bearer, and the fruit uniform in size; flowers large; glands reniform.

Fruit medium, roundish; suture mather large, distinet, extending a little beyoud the apex, which is a small point ; carity of medium depth; skin greenish white, dark purplish red in the sun, pale red in the shade, where it is mottled with some short splashes of a darker hue; flesh greenish-white, juicy, melting, sweet, slightly vinous; quality very good; adheres partially to the pit, where the flesh is white. Ripens the last week in July.

\section{TIIEATLAXD.}

This fine new peach is a chance seedling on the grounds of Daniel E. Rogers, Scottsville, N. I. The tree is said to be remarkably vigorous, healthy, and somewhat resembles C'rawford's Inte, but more sturdy and strong, more sprealing in its growth, and with larger foliage; it bears la rere crops of fruit of large size, showy, and ripens nearly at the same time; it is a very promising late variety for market, being quite firm, will endure distant shipment, and is valuable for all purposes in the fanily; the leaves have reniform glands; flowers large.

Fruit large to very large, roundish; a distinet suture on one side, but not large; cavity medium; shin deep golden rellow, shaded with dark red or crimson on the sumny side; flesh vellow, rather firm, juier, sweet, and of fine quality; the flesh is light red around the stone, which is small, and from which it separates easily. It ripens between the Early and Late C'rawford.

\section{TIIIT.}

A chance seedling in the garden of William Wirt Smith, Newhurgh, X. Y. Tree thrifty, vigorous, an abundant bearer of fair fruit, of fine quality. 
Fruit rather large, nearly globular, suture rery slight, ending at the apex, which is i small point; cavity of medium size; skin shaded and mottled with light and dark red, purplish red where fully exposed; flesh white, juicy, melting, sweet, rich, slightly vinous and of excellent quality; flesh white to the stone, from which it separates freely. Ripens the second week in August.

Iany ney varicties of peaches, much earlier than those hefore known to the public, hare been introduced within the last ten or twelve years. The Alexander was exhibited in $18 \%$ by J. Capp \& Son, of Mt. Pulaski, Ill., and found to be nearly two weeks earlier than Hale's Early, or any of the older varieties; this mas followed the next season by Amsden's June, grown by L. C. Amsien, near Carthage, Mo.; these are so nearly alike in size, form, color, flesh, and quality, that good judges are seldom able to find any marks of distinction between them. The Honeywell, Higlis Early Canalla, and many other early varieties, clamed attention about the same time, or soon after, but while all of them are noted for earliness in ripening, they are so nearly alike in all respects, that the planter of one named sort can have no adrantage over another.

It is supposed that most of these early kinds are reproductions of Hale's Early and Alexinder, an so nearly ailic that the distinction of name is not worth retaining. It is probable that after a few years of fruiting, many of the new seedlings will show the same failing as Hale's Early_ "soon ripe, soon rotten.". 'iher adhere, more or less, to the pit, and our effort should he directed to correcting this fault, and ohtaining a fruit as early as the Alexinder and of as good color, size and quality, free from jot. 'That this desirable result will be ultimately secured, we have no reason to cloult, and the originator will be giving the country a valuable contribution, and bring honor and credit to himself.

\section{PEARS.}

\section{Cinmmers.}

Origin uncertain, but report says was brought from Maryland by Julge Wiiliam Chamber's to Nicldletown, Kentucky, many years since, where it has the reputation of being the most profitable early market pear in that locality; it ripens a week after the Madeleine, but is not equal in quality to many of the later varieties. Tree a moderate grower, spreading, and said to be perfectly hardy, free from blight; a good and regular, but not an early bearer.

Fruit medium, or nearly so, roundish obovate, regular; skin smooth, pale yellow, shaded and mottled with light red where fully exposed, and many greenish dots; stalk medimm, moderately stout: cavity medium; calyx open; basin rather shallow, slightly plaited; 
flesh white, a little coarse, moderately juicy, half melting, swect and pleasant, but not rich. Ripens in Kentucky the first half of July, here the last of July.

\section{EUGEXT: ATPERT.}

Origin in the mursery of Andre Leroy, Angers, France. Tree moderitely vigorous, with slender shoots, somewhat spreadug and irregular; moderately productive.

Fruit melium of below, roundish oblate, inelining to obtuse pyriform; skin greenish yelluw, considerably netted and patelied

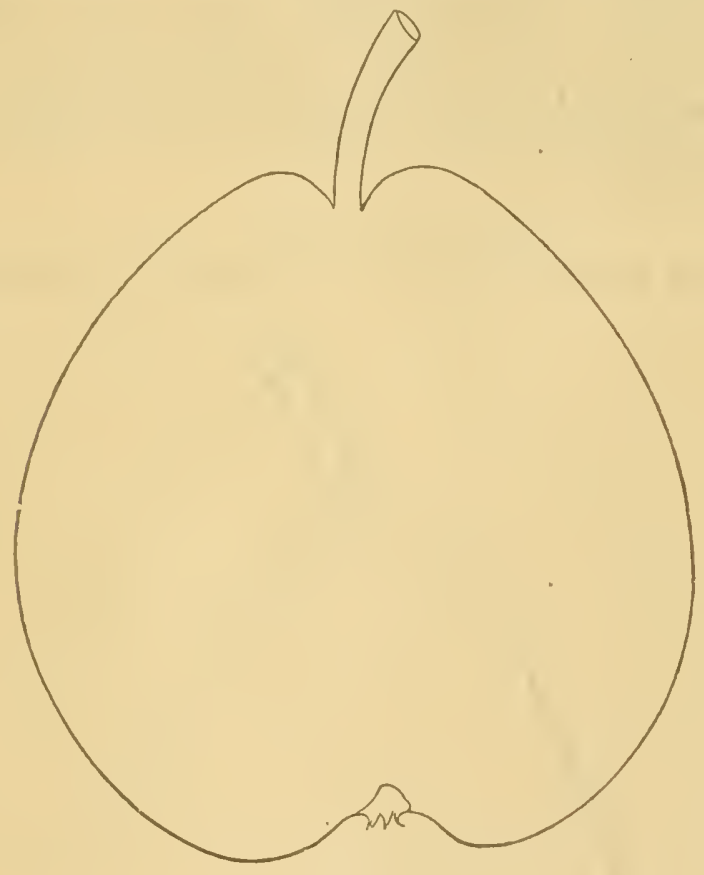

Eugene Appert.

witl russet, and thickly sprinkled with russet dots; stalk short to long. rather slender; cavity medium, smooth; calyx quite large, opren; hasin small or medium, nearly smooth; flesh white, half fine, juicy, melting, sweet, rich, with a slight aroma; quality very good. liipens the midule of September.

\section{- Falt Beutre 1'Arembira.}

A seedling of the Beurre d'Aremberg, raised by Asahel Foote, Willianstown, Mass., and is a promising variety. 'Tree moderately vignrous, an early and good bearer.

Fruit medium, roundish oblate, inclining to obtuse pyriform; skin pile greenish yellow, orange yellow where fully exposed, some- 
times a blush in the sun, slight mettings and patches of russet, esjecially around the stalk and ealyx, and thickly sprinkled with russet dots: stalk short to medium, ser at an inclination in a shallow cavits: calyx open, or partially closed: hasin shallow, slightly, corrugated; flesh whitish, a little coarse, juicy, melting, sweet, vinous, with a peculiar slight musky flavor; quality very good. Uctober.

\section{Grieral DE Butchine.}

A chance seedling in the garden of II. Penneton, Saint-Florentle-Tieil (IInine-et-Loire), France. 'Tree molerately vigorous, thrifty, rather upright, moderately productive.

Frnit medium, roundish pyriform, a little obtuse, regular; skin greenish yellow, a shade of red where exposed to the sun, a few nettings and traces of russet, and many russet dots; stalk short, small, inclined, sometimes obliquely set in a shallow carity; flesh white. fine, juicy, buttery, melting, sweet, slightly vinous, and slightly aronatic. Season November.

\section{Grand IsLe.}

A chance seedling in the garden of Benjamin Macomber, Grand

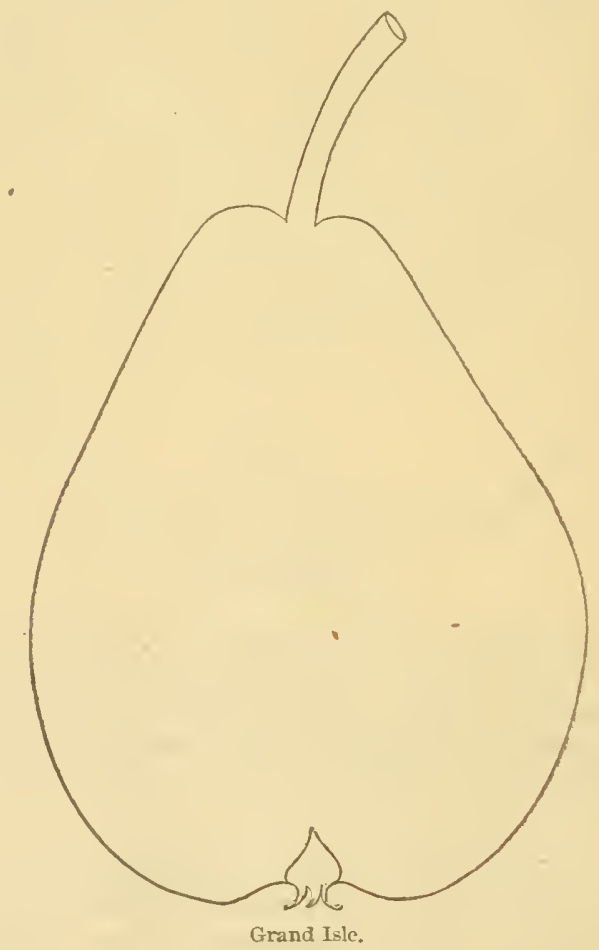

Isle, Irt. Tree vigorous, upright, somewhat spreading with age and bearing; it has proved quite hardy so far, and bids fair to be 
valuable for a cold locality; a good and regular bearer anuually, but more abmulant on alternate years.

Fruit medim, romelish ohlong, ohtuse pyriform; skin smooth, bright straw color, covered with many small russet dots; stalk of moilimm lengrth, rather slender, a little inclined, set in a small eavity; alyx small, open; basin small, nearly smonth; flesh whitish, half fint, juicy, melting, sweet, slightly vinous, and of very groor quality. It ripens from the last of September to the middle of Uctober.

\section{Honsic.}

A promising new variety, raised from seed of Hacon's Incomparable by Asaled Foote, of Williamstown, IIass. Tree vigorous, upright, very productive.

Fruit large, roundish, inclining to obtuse pyiform; skin green-

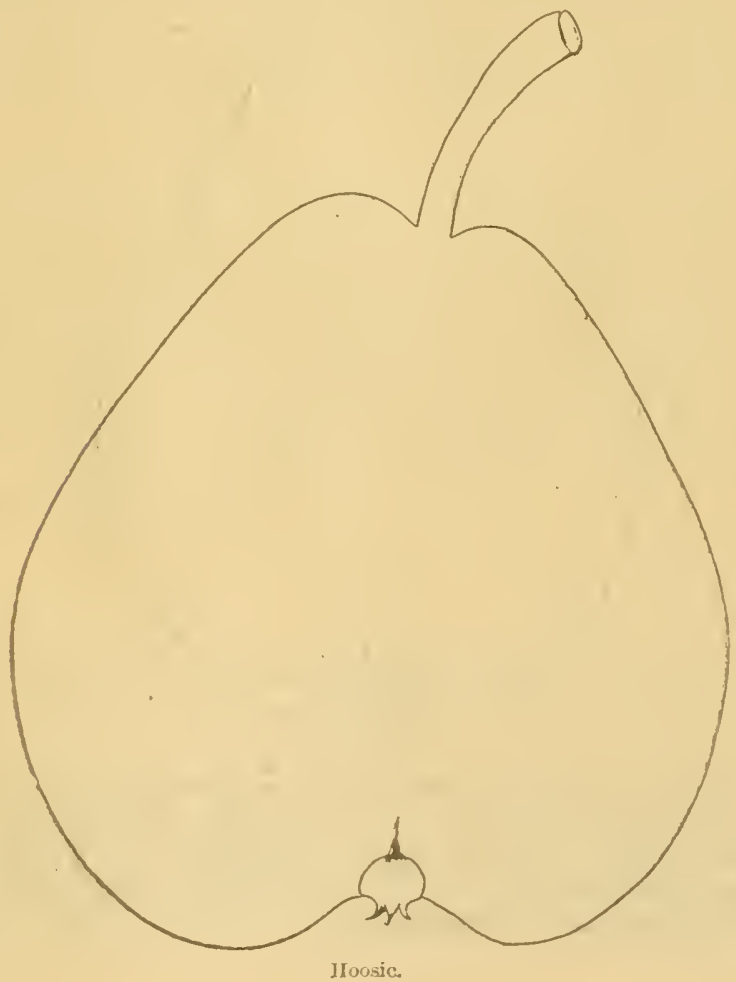

ish yellow, deep yellow where exposed and iully mature, some traces and nettings of russet, and many russet dots; stalk long, curred, set at an inclination in a small cavity; calyx open; basin rather broal, moderately deep, a little meven; flesh whitish, half fine, juicy, melting, quite rich and aromatic; very good. Scason October. 


\section{Jules D'Arrolis (De Leon Leclerc).}

A seerlling of Leon Leclerc, raised at Laval, France, and derlicated to his friend, M. cle Liron d'Airoles. Tree moderately vigorous, rather upright, a good but not rery prolific bearer.

Fruit medium, roundish pyriform, a little elongated, and slightly obtuse, regular; skin pale greenish yellow, often shaded witl crim-

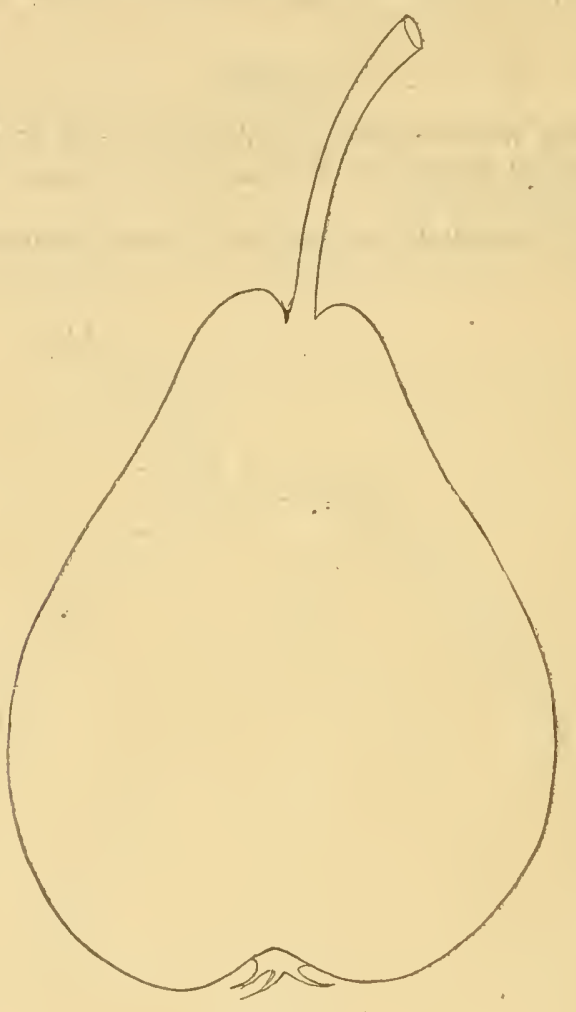

Jules d'Airoles.

son in the sun, partially netted and iraced with russet, and many russet dots; stalk long, slencler, curved; carity small, nearly regular; flesh whitish yellow, half fine, juicy, melting, sweet, a little vinous, slightly aromatic, and of very good quality. Ripening the last of Norember and the first of Decenber.

\section{Jutes D'Airotes (De X. Gregoire).}

This pear was produced at Jodoigne (Belgium), in 185\%, by Xavier Gregoire, a distinguished pomologist. Tree quite vigorous, with rather long, stout branches, making an upright, regular head; moderately productive. 
Fruit above medium, slightly inclining to turbinate; stru long, slender, eurved at the upper end: cavity suall; hasin shallow; skin a little ro!ght, thick, hright vellow, party covered with large slots, marbled, and streaked with hrownish red; thesh yollowish white, fine, melting. a little coarse at the core, juicy, sugary, slightly vinous, and pleasantly perfumed. Season last of October to the last of November. (Teroy.)

M. de Jiron d'Airoles having aecepted the dedication of these two pears, it is necessary to be careful that the two be not confounded.

\section{KEIFER.}

\section{Keiffer's Hybril.}

This new and unique pear was raised by Peter Keifer, Roxbury, near Philadelphia, l'rom seed of the Chinese sind pear, accidentalls erossed with Beurre d'Anjou, or some other kind grown near $i$. 'Tree remarkably vigorous, having large, dark green, whossy leaves, and is an early and rery prolific beatrer; the fruit is of cool size, grood color, gool quality, and is a promising variefy for the zable ol inarket.

Fruit medium, roundish oval, narrowing at both ends, with the largest dimeter near the centre, some sperimens roundish, inclining to oblong obtuse prriform; skin decp yellow, orange yellow in the sun, a few patches and nettings of russet, and many brown russet dots; stalk short to medium, moderately stont; cavity meilum; calyx open; basin medium, a little uneven; "flesh whitish, a little coarse, juicy, half melting, sweet: quality very good, partaking slightly of the Chinese sand pears. "Ripens all of Oetober and a part of November. To have it in perfection, it should be gathered when fully grown, and ripened in the house.

\section{MARSHALL.}

This pear is said to have originated on the farm of William Marshall, Cambridge, N. I., some rears since. Tree a molerate grower, making a romdish. rather spreading head, and bearing abundantly.

Fruit medium, roundish, inclining to obtuse pyriform; skin yellow, netted and patehed with russet orer nearly the whole surfice, and thickly sprinkled with russet dots; stalk long, curverl, rather slender; carity small; calyx open; hasin rather shallow, a little uneven; flesh white, half fine, juicy, half melting, slightly vinous, and slightly aromatic; very good. Ripens the last of September. 


\section{PLUMS.}

\section{Caxada Orleats.}

\section{Canada Egg?}

The origin of this fine plum is obscure; it has been grown in and around Hamilton, Ontario, for many years as the German Prune, but bears no resemblance to it, and is believed to have originated with the old settlers, and is grown by them from suckers. Tree grows strong, vigorous, and makes short-jointed wood, with prominent huds, and is very productive; it is highly esteemed where known for its handsome appearance, fine quality, market ralue and family purposes, branches smooth, brownish gray.

Fruit medium to large, nearly globular; suture broad, shallow,

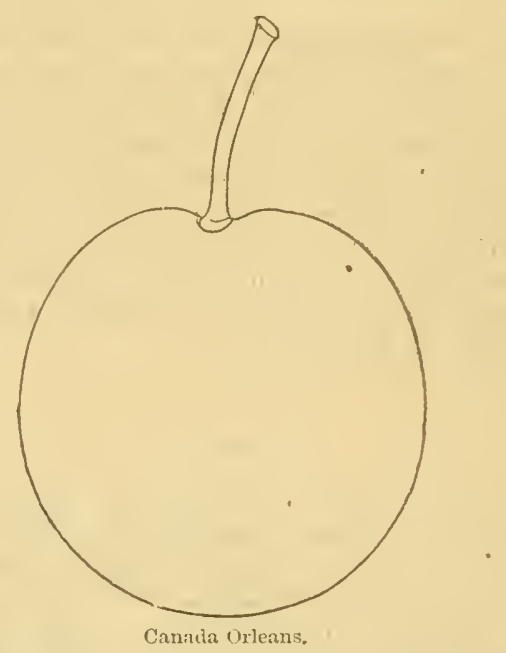

ending at the apex, which is a little depressed; stalk long, stender; cavity small; skin dark reddish purple, corered with a thick blue bloon; flesh pale yellow, juicy, nelting, very sweet and rich; adhering to the stone, which is small. Ripens early in August and keeps well.

The Canada Egg, highly valued in some localities in Michigan, is no doubt this variety.

\section{Frankfort Peich.}

Of German origin: tree moderately vigorons, spreading, very jroductire; branches rather slender, slightly downy, grayish brown. 
Fruit medium or above, oral, narrowing a little toward the apex: sides a little unequal; suture shallow; skin black, covered wih a thiek blue bloom; stalk medium, rather stout; cavity small; He:sh orange rellow, a little coarse, juicy, sweet, vinous, and of good quality; separates freely from the pit, which is oval and thin. Seasun first half of September.

\section{Frogarem ] hason.}

This plum originated, as its name implies, in the Roral Gardens at Frognore, England, and although a few years have elapsed since it was raised and distributed, it is not as well known as it deserves to be; the habit of the tree is lifferent from that of the usual tyle, sinee it has broader leaves, is of spreading growth, and has its shoots less thorny; it is an enormous bearer.

The fruit is a trifle larger than that of its class, of a purplish black color, and inclining to obtuse oval in shape; the flesh is tender and richly flavored; it is suitable for all purposes to which I)amsons are applicd.-(Flo. \& Pom.)

\section{Grass.}

Raised by Alexander Glass, Guelph, Ontario. Tree hardy, very vighorous, uyright, with thick dark green foliage; very productive; a showy fruit of second-rate quality, but valuable for narket and culinarr parposes; branches smooth, brownish gray.

Fruit large, oval; suture large and broal, one side often enlarged; stalk of medium length, slender; cavity large; skin dark purple, almost black, with a thin blue bloom; flesh greenish yellow, a little coarse, moderately juicy, sweet, good; separates freely from the stone. Ripens in September.

\section{Green Ttalian.}

Of German origin; tree moderately vigorous, fairly productive; branches slightly downy, browrish, short-jointed.

Fruit medium, oval; suture very shallow or a distinct green line; apex a dot: skin pale greenish yellow, streaked and blotched with green; covered with a thin grayish bloom; stalli long, slender; carity small; flesh green, a little coarse, juicr, sweet, quite rich, and very grond: adheres partially to the pit, which is long and thin. Season first half of September.

\section{Gurr.}

Gweii-Gueii-Blue Magnum Bonum-Big Blve-Bradshaw, incorrectly.

'Phis plum is sail to have originated with a Mr. Hagaman, I Aansinghurgh, N. Y., about fifty years sines; it was cultivated largely hy John Gueway (Guii), and was generally called by this name, but was not mol disseminated until quite reently; it is now quite extensively grown for market, having provel to be one of the most profitable for that purpose; tree liadr, a rery strong, viegorous up right errower, spreating with acre and bearingr; an early and very abundant bearer; branches smooth, light brown, grayish. 
Fruit large, roundish oral, narrowing a little at the apex, which is a dot or small point; suture slight, often without any; skin dark purple, covered with a thick blue bloom: stalk long, slender; carity lirwe, deep; flesh pale yellow, a little coarse, rather firm, juicy, sweet, sprightly subacid; not a rich table fruit, but valuable for culinary purposes and market; free stone, but often adheres slightly to the pit; season last of August and first of September.

\section{Moore's Arctic.}

A new hardy plum which originated on the Highlands of Aroostook County, Me., about forty miles north of Bangor, on the grounds of A. T. Moore, Ashlanil, Me., where, unprotected and exposed to Arctic colds, it has for many years borne enormous crops, and is claimed to be the hardiest plum known, and so far free from hlack knots; tree healthy, vigorons, an early and abundant bearer; branches smooth, olive brown, grayish.

Fruit below medium, roundish, slightly inclining to oral; suture nearly obscure, apex a dot; skin purplish black, thin blue bloom; stalk medium, rather slender; carity small; flesh greenish yellow, a little coarse, juicy, sweet, pleasant flavor, but not rich, adheres a little to the stone; season first half of September.

\section{Pride of Thaterloo.}

A new variety raised by $\Lambda$. H. Doles, Wraterloo, N. Y., from

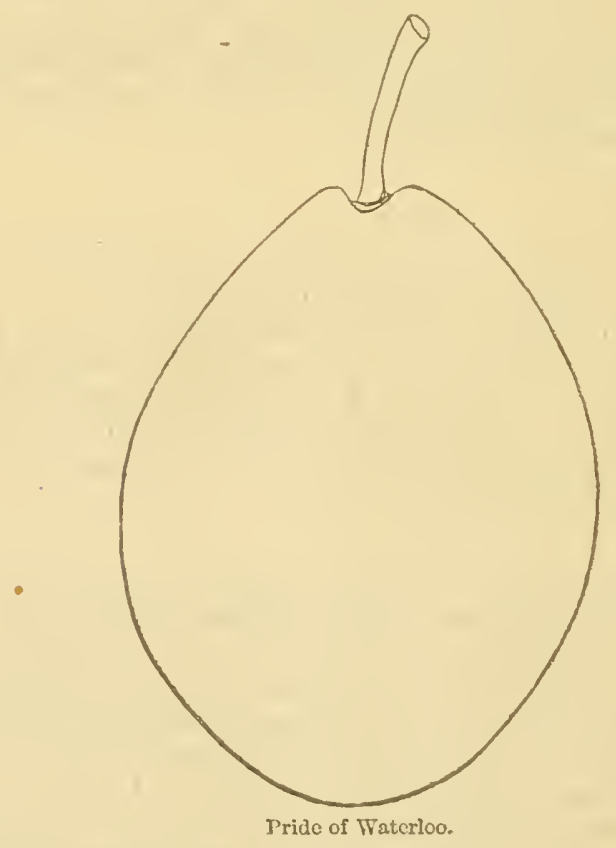

seed of Smith's Orleans; a vigorous upright grower, very productive. 
and promises to be valuable for market and eulinary uses: branches susouth, rechlish brown.

Fruit laroe, oval, narrowing a little towarel the stalk, regular; suture seareely risible, apex a clot, skin light redctish purple, with a thin blue bloom and many brown dots; stak of meelium length and thickness; cavity rather large; thesh cheep yellow, rather coarse, juicy, sweet, sprightly, but not rich; it acliseres slightly to the pit; ripens the micldle of september.

\section{RASPBERRIES.}

\section{3А TMFORTI'S SEEDLIN.}

A new raricty raised from the seed of the Nortlumberlaus Fillbasket by John Batumforth, of Pontefract, England; the plant is of a stronger" constitution than its parent, and more prolific; the fruit is large and handsome, beine remarkable for their broad, roundish, rather than eonical outline; it is about ten days eariier, and at least one-thiri larger-that is, broacter, more uniform in shape and size, anct of a deeper and richer crimson color, while the separite sucenlent carpel or drupes; of which the fruit is composed, are large anrl prominent; the color of the drupes, which are of large size, and rerry juicy, is of a dee p lake crimson, and the flaror is rich and full, with a tine aroma. The plant frequently bears fruit in the autumn from the current season's growth. (Fło. \& Pom.)

\section{Carolise.}

This fine new raspberry was raised by S. P. Carpenter, New Rochelle, $X^{\text {. }} \mathrm{I}_{\text {. }}$, and is supposed to be a seedling of Brinckle's ()range and a Golden Cap. Mr. Carpenter informs me that it has proved very hardy, and the plant is an Antwerp in nearly all its characteristies; suckers quite freely and can with care be propagated irom the tips; canes very strong, vigorous, sometimes branching, light red in the sum, having a thin whitish bloom, and a few slender green spines. It is a very prolific bearer and is an acquisition worthy of a place in the home garden, but is too soft for shipping.

Fruit quite large, rounclish oblite, deep orange yellow, or salmon color, with a slight blnom, grains of meelinm size; flesh soft, juicy, sweet, rich, and of very good quality; it continues a long time in use.

\section{Cuthisert.}

Queen of the Market.

A chance seedling in the garden of the late Thomas Cuthbert, Riverdale, $\mathbf{N}$. Y. It is said to be harly, and is generally so, but 1 have seen it more or less killed in severi and changeable winters, or when the canes were not well ripened; it has so far proved a valuar 
ble market variety, also one of the hest for family use; it is very productive; canes strong, vigorous, upright, sometimes branching: spines short, stout, purplish, rather numerous; it suckers freely, too much so for the benefit of the plant and fruit.

Fruit medium to large, scarlet crimson, roundish, obtuse-conical: grains rather small, compact, separates freely from the stalk; flesh yuite firm, juicy, sweet, sprightly, luaring a slight flaror of the common Red, which is probably one of its parents.

\section{Gregre}

\section{Great Western.}

This is one of the largest, if not the largest of the Black Cap family; it originated with R. \& P. Gregg, Pandolph, Ind. It is a hardy, strong grower, with round, heart-shaped, coarsely serrated leares; canes strong, branching, with a few sharp greenish spines.

Fruit large, oblate or roundish oblate, black, with a sliglit bloom; rrains large, compact; flesh quite firm, morlerately juicy, sweet, and rich; the fruit ripens evenly, making the picking season short; it is much like the McComick or Mammoth Cluster in growth, bearing, etc.; the fruit is a little larger, clarker in color, and firmer, but not quite as sweet, nor quite as juicy.

\section{Montchatir.}

This new rariety is a chance seedling on the grounds of $\mathrm{E} . \& \mathrm{~J}$. C. Williams, Montelair, N. .J.; canes strong, rigorous, light red, often branching, spines quite numerous at the base, rather slender. purplish; leaves thick, roundish, deeply reined or crumpled; rery productive; it promises to be valuable as a market variety, and for family use; it proparates moderately by suckers.

Fruit mediun to large, roundish or roundish oblate, dark red or crimson, grains rather small, compact; flesh quite firm, juicy, sweet, and sprightly, and of very good quality; separates readily from the stalk in picking.

\section{NEW RocheLte.}

A seedling of the Catawissa, raised by S. P. Carpenter, New Rochelle, IT. I.; plant hardy, or nearly so, a very strong, upright, stocky grower, short-jointed and much branched, spines rather mumerous, short, stiff, green and light red; it is very productive, firm, and bears carriace well, but lacks the bright color so attractive to the popular taste; propagated by tips.

Fruit mediun to large. roundish, obtuse-conical, brownish rerl, or lark maroon, with a slight bloom; Hesh quite firm, juicr, with a rich subacirl flaror, making it valuable for camniug and all" culinary purposes, as well as for the table; it continues a long time in use.

\section{Prine of the Hunsox.}

A chance seedling in the garden of the late William Roe, Nerrburgh, . Y. : canes rather strong, vigorous, a fer short purplish spines; leaves large, deeply veined or corrugated; very productive; 
one of the best varieties for family use, lut not firm enough for distant market; it requires good cultivation, which well repays the labor bestowed.

Fruit large, roundisl conieal, a little olutuse, grains rather large: color searlet crinson; flesh mokleratoly firm, juicy, sweet, rich, and of fine flawor; separates freely from thic stem.

\section{IiEIIATCl:}

A seedling of the Philadely)hia, raiserl by (). I. Felton, Merchatrille, X. J.; it is hardy, lealthy, and vigorous, véry produclive, one of the largest of its class; ('anes strong, branching, with a few small 'oreenish spines.

Fruit lare, nearly globular, or romolish oblate, chark red or crimson; grains large; flesh quite firm, juicy. sweet and sprightly, but not of high flavor; separates freely from the stem.

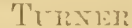

\section{Southern Thornless. Baluwin's Choice.}

A hardy variety which originated in the garden of Prof. J. B. Turner, Jacksonville, Ill.; it appears to succeed in more localities than any of the red rarieties, and less subject to changes of heat and colit; the canes, foliage, and fruit possess many characteristics of the native red berry, and it suckers quite as freely; canes vigorous, light recldish on the sunny sicke; npright, seldom with hranches; very few short purplish spines; foliage quite large and abundant; very prochuctive.

Fruit medium or alove, roundish conical, brimt searlet; grains of medimm size, compact; Hesh rather soft, sweet, pleasant, but not rich; a good berry for home use, but not quite firm enough for a distant market.

The Black Cap family is now numerous, and of larese size and good quality; Creag, Ifcormick, or Manmoth (luster among the best, vet there are growers who claim to have produed varietices as largo and of better quality. The sweet Home is sald to be equal in size, rather more productive, and, repert says, of better quality, although the distinction is hady perecptible. The Surprise and klsie aro nearly or quite as large more comiual in form, of a brighter color, and Pieher. Duncan's Plack (ap, or Lentucky Prolifie is highly extollerl in its locality as the best anfl largest of J3lack Caps. The IIanilion Blate (a) of Shelby Comnty. 'lemn, lats the reputation of being a very lare berry of the finest quality.

There are many other varieties before the jublic not named above, for the reason that they are so near alike in egrowth, color, cuality, amd season of ripenine as to regure moseparate deseription.

Eifort las been made to obtain a periectly hardy, bright-colored red raspburry, of higr quality, an!l flesh sufficiently firm to bear transportation for a long distance, and many think they have it in the Cubbert, hut it will require the test of time and experience to clecide upon these points. The cultivator who is so fortunate as to produce a variety to meet all the requirements of the grower and marketman ought to be, and I think would be, richty rewarded. 
But while continuing the work of seed-planting for this desirable result, it is to he regretted that the foreign tender varieties of such delicions flavor as the Antwerps-Franconia, Brinckle's Orange, Fistolff, and Belle de Palluau-are being neglected. 'The little extra care and labor of covering in the fall is more than reuaid by the livge size and luscious fruit. For family use they are much superior.

\section{STRA WBERRTES.}

BMWTET.t.

This fine variety is a Michigan seedling, receiving its name from a Mr. Bidwell, althongh its origin is a matter of uncertainty and somewhat in dispute. It has receiver favorable notice from the Michigan Pomological Society; it has receiverl considerable attention on account of its rery ponising character, especially on light soils; it is very rigorous, with light green leaves; rery productive, and continues long in bearing. An carly berry; with hill culture or the narrow row system, rich soil, and remoral of rumers, it makes large stools and fine fruit; staminate.

Fruit medium to large, the first berpies sometimes irregular in form, being round conical and long conical, often with an uneven surface, and a slight neck, somewhat glossy; color bright erimson; flesh light red, quite firm, juicy, sprightly subacid, quite rich, and very promising for family use and market.

\section{Buack Defiance.}

One of the seedlings of E. W. Durand, Irvington, N. J.; plant vigorous, with dark green foliage, productive in heary soils: requiring high culture in hills or narrow rows and removal of runners to obtain the fruit in quantity and perfection; staminate.

Fruit large, roundish obtuse conical, regular; color dark crimson; flesh dark red, firm, juicy, sprightly and rich; rather early, fine for the amateur, and gives promise of being a good variety for shipment to a listant market.

\section{CHAMTIOA.}

Windsor Chief.

These were sent out as two distinct varieties, and this claim is still made by some, while others who have grown them near each other and examined them carefully, have been unable to detect any difference. It originated with Dr. J. C. Neff, Carlisle, Pa.; it requires high cultivation to produce good crops; it is a vigorous grower, with healthy deep green foliage; very productive: pistillate.

Fruit large, conical, or roundish obtuse conical, regular, exeept a few of the first berries, which are a little meven;" color cleep scarlet 
or erimson, flesh dark red, rather soft, sprightly, rich acid, and of good quality; it holds its size well to the end, and is a fine variety for the amatemr and a near market.

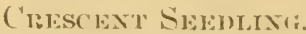

The Crescent originated with William l'armulee, New ITaven, Comn. It is a hardy, strong, vigorous grower and very productive; leates of medium size, dark green; the plant requires much room to grive good results; it ripens alrly and continues late, holrling its size tolerably well, and althonghi not of high flavor, its fair size, grood color, and moderately firm flesh has given it a near market value; pistilliate.

Fruit medium to large, roundish conical, the first berries a little irregular or uneven; brimht scarlet; seeds vellow and brown, near the surface; it requires less time and attention than most varieties, and is well calculated for those who camot and will not give the necessary labor to produce the better kinds.

\section{Cumeriant Trumpir.}

The Cumberland Triumpl is a fine large strawberry, originatert by Amos Miller, Carlisle, Pa.; the plant is a vigorous grower, with dark green foliage; a good but not prolific bearer; when grown in hills and the rumers clipped, it makes heavy stools, giving large, handsome, regular fruit; staninate.

Fruit large, oblate, broarly conical, very regular, light scarlet; seeds yullow and brown, near the surface; flesh pale red, rather soft, juicy, sweet: very good, but not of high quality; a fue variety for the anteur and family use, but too soit and light-colored for market.

\section{Duritess.}

This excellent early strawberry was first fomm in the garden of D. H. Barnes, Poughkeepsie, N. $i$. The plant is very vigorons, foliage of medium size, lark green and healthy; very produetive; when grown in hills or narrow rows it stools and makes large plants, thus saving the labor of replanting: staminate.

Fruit medium to large, roundish, obtuse-conical, regular in form, might scarlet or crimson; flesh light rexl, quite firm, juicy, sprightly subacist, and of fine quality; one of the carliest to ripen, and continues a long time for an early variety; it retains its size quite well to the last; is valuable for early market, also for general use in tho family.

\section{Forest liosi:}

Originated in the garden of John A. Fetters, Iancaster, O.: it is a vigorous grower and grool bearer, snceeding woll with grool culture; the foliage sometimes a little affected with unfavomble and changeable seasons of heat and cold; a grood variety for home use aud a fance market; staminate.

Fruit inedium to large, roundish conical, a little obtuse, sometimes oval, and some of the first berries a little uneven; bright 
scarlet; flesh light red, moderatcly: firm, juicy, sweet, sprightly and rich; rather early, and retains its size well through the season.

\section{Glandille.}

The Glenclate is an accidental seedling, found by $\mathbb{T}$. B. Storer in the Glendale Cemetery, Akron, O. Plant hardy, healthy, vigorous, with large, dark green leaves; very productive; it promises to be a valuable market variety, as it hlooms late, has quite a firm flesh and a large calyx, which is favorable for carriage; rather late in ripening, and of fair quality; staminate.

Fruit medium to large, Jong conical, regular in form, sometimes with a slight neck; color light scarlet; flesh firm, sprightly, of gool but not best flaror; it holls its size well to the end; it separates readily from the stalk, making it easy to gather.

\section{Gomiden Defuace.}

The Golden Defiance originated with Amos Miller, Carlisle, Pa. Plant very rigorous, with large, thick, dark green leaves when mature, deeply reined, and moderately serrated; rery prodnetive; it is said to be hardy, stands the drought, and the lares endure the sun well; it is a handsome berry of excellent quality, and worthy of a general trial; it succeeds either in hills or narrow rows; pistillate.

Fruit large, roundish obtuse-conical, regular, sometimes with a slight neck; color dark scarlet or crimson; seeds yellow, near the surface; flesh scarlet, quite firm, juicy, subacid, rich, and of very gool quality. Season rather late. It is a good variety for the market or family usc.

\section{Miraeris Prolific. \\ Miner's Great Prolific.}

This originated with the late T'. 13. Miner, Linden, N. J. Plant hardy, vigorous, and healthy, with.light green foliage; rery prolific hearer, and gives the groatest snceess under the hill and nalrow row system of culture; a promising variety for family use and near ma:ket: staminate.

Fruit medium to large, roundish conical; surface somewhat irregular or uneven; color dark scarlet or crimson; flesh light red, mocierately firm, juicy, subacid and of fair quality. Ripens medium to late and holds out well in size to the end.

\section{Moxaren of the West.}

This highly praised strawerry was raised by Jesse Brady, of Plano, Ill. Plant very vigorous, with large, pale green leaves, moderately productive; a good variety for home use and a near market; it requires high cultivation and a rich soil to produce large fruit abundantly and of good quality; it should be grown in hills or narrow rows.

Fruit large, sometimes very large, roundish conical, nearly regulin; a few of the first berries are cuxeomb shape, and a little irregn- 
latr; light searlet; flesh light red, rather solt, juicy, sprightly sulacoil, rieh; quality very groocl.

\section{Pioxier.}

The Pioneer, raised by F. W. Lurand, of Irvington, N. ... is siat to he one of the best of the struberres grown by him. I'lant hall and rigorous, although the foliage is salich to burn in some locialisis. oecasionally; leaves large, light green; ripens rather early, and main -

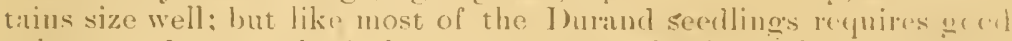
culture and removal of the rumers to make it fairly production; vielis best under the narrow row system; very grom for home use: and near inarket; staminate.

Fruit medium to large; romulish oval, with a slight neck; se exls mostly dirk, a little below the surface; color light scarlet; fhesh light red, moderately firm, juiey, sweet, rich, with a delicate flavor.

\section{Primo.}

A new seediling raised by Daniel Smith, Newburgh, X. I.; 1, lant rery vigorous, with large, roundish dark green leaves, deeply reinen: foot-stalks stout and heary; berries larote and handsome; productio, and promising good returins for home use and a near market; a new varietr not extensively tested; staminate.

Fruit large, roundish oblate, obtuse-conical, regular; color tark scarlet; flesh white, morlerately firm, juicy, sweet and pleasant; ripening with the early varieties.

\section{SILARPIASS.}

This large, showy strawberry originated with J. K. Sharpless, of ('atawissa, Pa, it is very vigorons, with latrge dark green, coasely serrated, and teeply veined leaves very productive, and is best. adapted to the hill system, making large stools; it also succetus when eultivated in uarrow rows; staminate.

Fruit large to verv larese, variable in form, from irrogular coxcomb shape to romdish conical and oval; bright scarlet, somewhat glossy; thesh light rel, quite firm, moderately juiey, sweet, rich, and of very grood flaror; merlium to late in ripening." "The Sharpless is very promising, either for market or family purposes.

\section{Thime ( ROW:.}

This excellent strawberry was raised by William Hunt, of

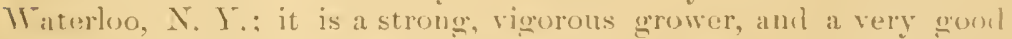
bearer: it should be grown in lills or narrow rows to have it in perfection; staminate.

Fruit medium to large, oral conieal, often with a neck; a few of tha first berries are of werloge or ecoxemb shatpe, the surface somewhat uneven and irreurular; crimson; llesh light red, quite tirm, juicy, surightly, rich and of high flavor; sebarates readily from the ealy: one of the most promising varieties for narket, also for any use in the family; it holds its size very well through the stason. 






\section{$F^{5}$}

A.

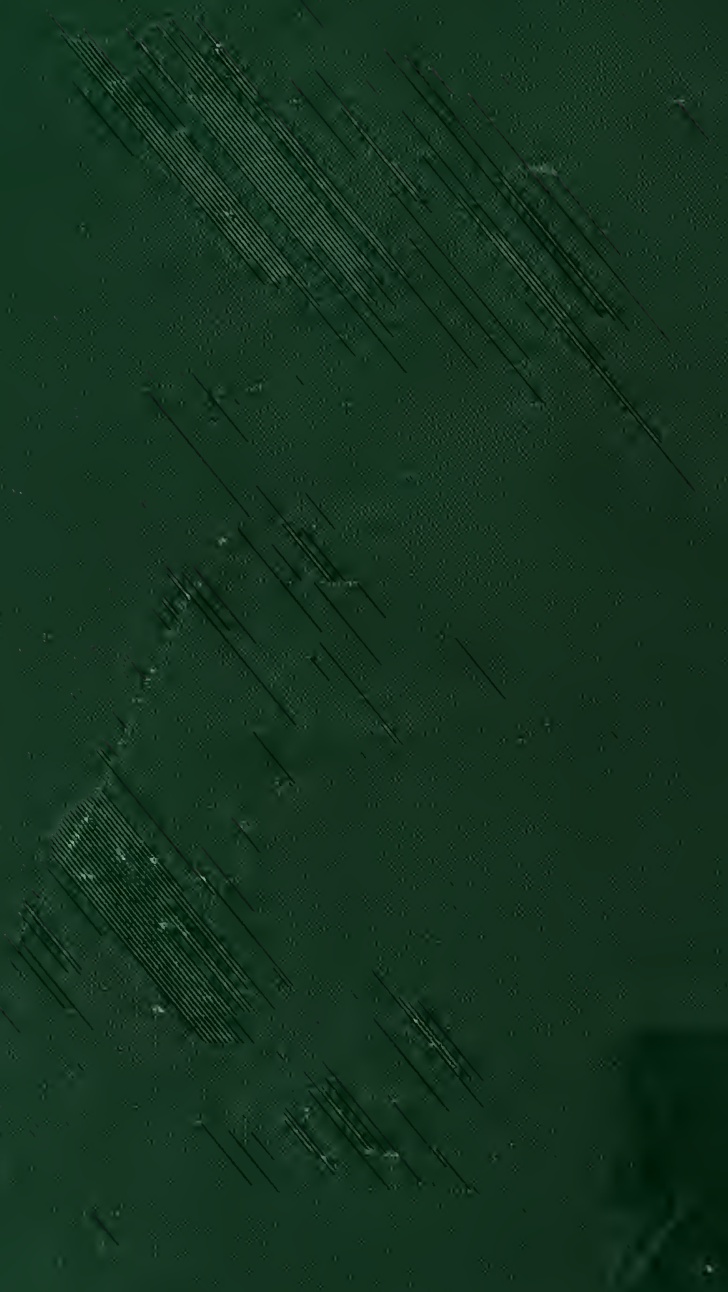

